\title{
A STATISTICAL REVIEW OF DWPF LABORATORY MEASUREMENTS GENERATED DURING THE PROCESSING OF BATCHES 300 THROUGH 356
}

Thomas B. Edwards

August 2006

Statistical Consulting Section

Savannah River National Laboratory

Aiken, SC 29808

Prepared for the U.S. Department of Energy Under Contract Number DEAC09-96SR18500

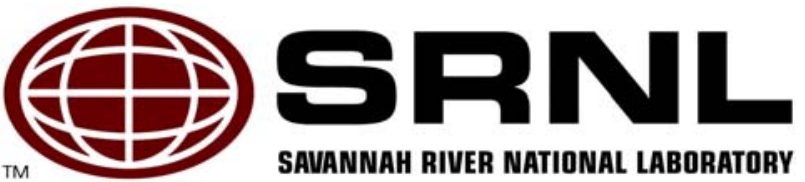




\section{DISCLAIMER}

This report was prepared by Washington Savannah River Company (WSRC) for the United States Department of Energy under Contract No. DE-AC09-96SR18500 and is an account of work performed under that contract. Neither the United States Department of Energy, nor WSRC, nor any of their employees makes any warranty, expressed or implied, or assumes any legal liability or responsibility for the accuracy, completeness, or usefulness, of any information, apparatus, or product or process disclosed herein or represents that its use will not infringe privately owned rights. Reference herein to any specific commercial product, process, or service by trademark, name, manufacturer or otherwise does not necessarily constitute or imply endorsement, recommendation, or favoring of same by WSRC or by the United States Government or any agency thereof. The views and opinions of the authors expressed herein do not necessarily state or reflect those of the United States Government or any agency thereof.

\section{Printed in the United States of America \\ Prepared For \\ U.S. Department of Energy}

The Savannah River National Laboratory is operated for the U.S. Department of Energy by Washington Savannah River Company. 
Key Words: statistics, uncertainty, SRAT, SME, Fusion, Mixed Acid, Cold Chem

Retention: Permanent

\section{A STATISTICAL REVIEW OF DWPF LABORATORY MEASUREMENTS GENERATED DURING THE PROCESSING OF BATCHES 300 THROUGH 356}

Thomas B. Edwards

August 2006

Statistical Consulting Section Savannah River National Laboratory Aiken, SC 29808
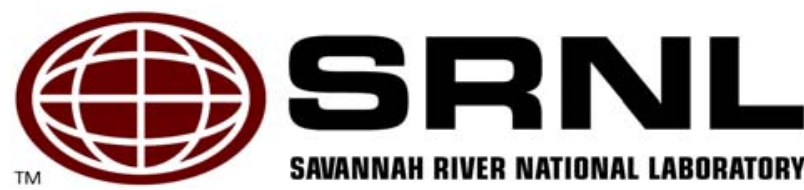


\section{REVIEWS AND APPROVALS}

\section{AUTHOR:}

$\frac{9-20-06}{\text { T. B. Edwards, S'tatistical Consulting Section }}$

\section{TECHNICAL REVIEWER:}

S. P. Harris, Statisticall Consulting Section

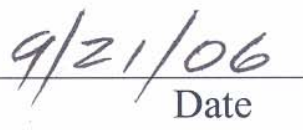

\section{APPROVERS:}
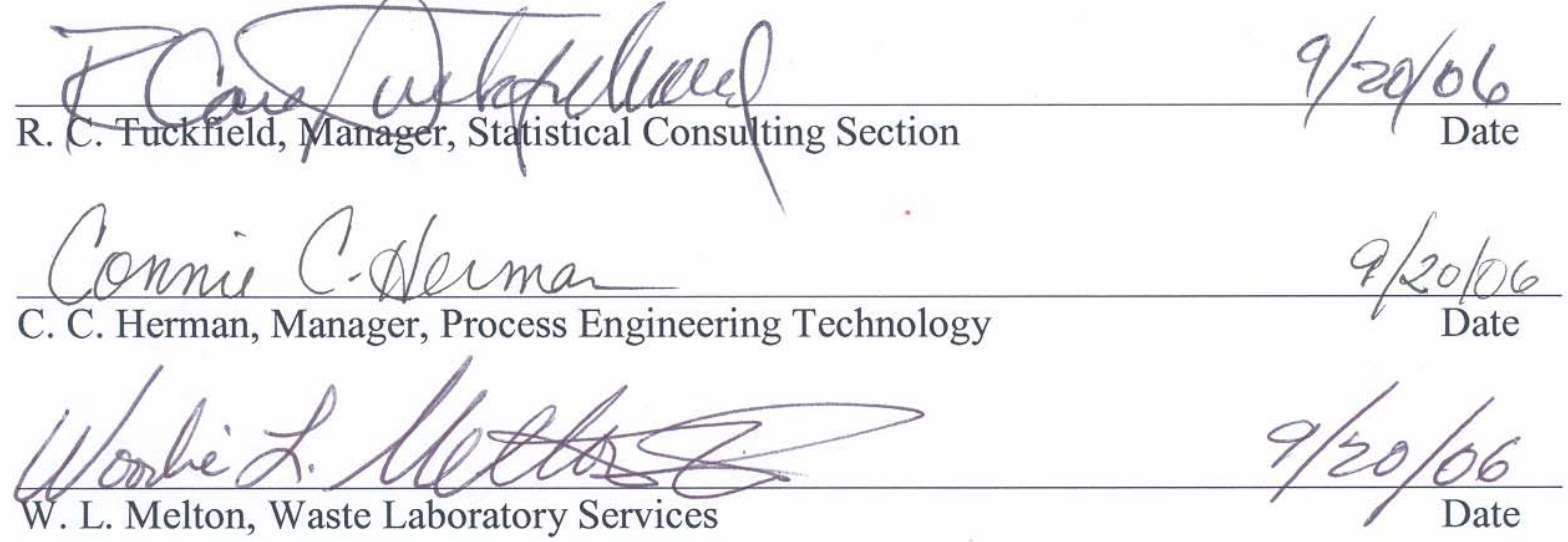

$$
9-20-06
$$

J.E. Occhipinti, Waste Solidification Engineering 


\section{EXECUTIVE SUMMARY}

In this report, the Statistical Consulting Section (SCS) of the Savannah River National Laboratory (SRNL) provides summaries and comparisons of composition measurements for glass samples that were generated during the processing of batches 300 through 356 at the Defense Waste Processing Facility (DWPF). These analyses, which include measurements of samples from the Sludge Receipt and Adjustment Tank (SRAT) and the Slurry Mix Evaporator (SME) as well as samples of glass standards, were provided to SCS by the DWPF Laboratory (DWPF Lab) of Waste Laboratory Services. The comparisons made by SCS were extensive given that these data allowed for contrasts between preparation methods and between the two spectrometers that are currently in use at the DWPF Lab. In addition to general comparisons, specific questions that were posed in the Technical Task Request (TTR) behind this effort were addressed in this report. 
WSRC-STI-2006-00068

Revision 0

This page intentionally left blank. 


\section{TABLE OF CONTENTS}

EXECUTIVE SUMMARY iii

List of Tables $\quad$ vi

List of Figures $\quad$ vi

List of Acronyms vii

1.0 INTRODUCTION AND BACKGROUND 1

2.0 OVERVIEW OF DATA 1

3.0 RESULTS 2

3.1 Initial Assessment of Standard and Process Measurements 2

3.2 Comparisons of ARG-1 Measurements 3

3.3 ICP Comparisons Using Cold Chem Process Samples 4

3.4 Preparation Comparisons by ICP Using SME Sample Measurements 4

3.5 Comparisons of Elemental Ratios for PRocess samples by Preparation method and ICP

3.6 Analysis of Variance by Preparation Method, ICP, and Analyte 5

3.7 Comparisons against the Variances of PCCS 18

3.8 Specific Issues Outlined in the TTR 18

4.0 CONCLUSIONS 36

5.0 REFERENCES $\quad 36$ 


\section{LIST OF TABLES}

Table 2-1 Reference Composition of the ARG-1 Standard ................................................ 2

Table 3-1 Estimated Components of Variance, Mean Confidence Intervals, and Overall Uncertainty for ARG-1 Measurements 6

Table 3-2 Estimated Components of Variance and Mean Confidence Intervals for Process Samples 12

Table 3-3 Current Average Measurements and Relative Standard Deviations and the Historical Values Used in PCCS. 18

Table 3-4 Percent Relation Standard Deviations for Some Key Sludge and Frit Ratios........ 19

Table 3-5 Sum of Oxides (wt\%) for ARG-1 by Preparation Method and ICP ..................... 21

Table 3-6 ICP Comparisons for ARG-1 Measurements by Preparation Method .................. 22

Table 3-7 ICP Comparisons for SRAT Product Measurements ........................................... 23

Table 3-8 Current Protocol for Representing the SME Measurements ................................. 24

Table 3-9 Fusion versus Mixed Acid Comparisons for ARG-1 Measurements.................... 25

Table 3-10 Comparisons Between Fusion and Mixed Acid for the SME Measurements ...... 26 Table 3-11 Target WLs at Blending with Error Propagations (95\% confidence) for M-13 and M-14 ICPs 29

Table 3-12 Estimated WLs at the SME with Error Propagations (95\% confidence) for M-13 and M-14 ICPs 32

Table 3-13 Target WLs at Blending and Estimated WLs at the SME. 33

Table 3-14 Average U Measurement by Preparation Method and ICP and Target WLs at

Blending and Estimated WLs at the SME 35

\section{LIST OF FIGURES}

Figure 3-1. Measurements (over all analytes) Flagged as Potential Outliers 3

Figure 3-2. SME Sum of Oxides versus ARG-1 Sum of Oxides by Preparation Method/ICP

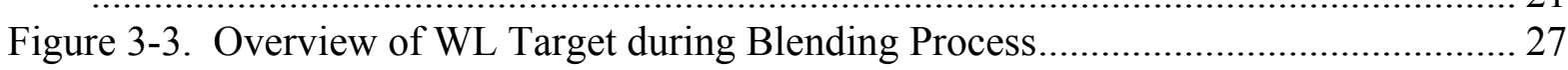

Figure 3-4. 95\% Uncertainty Bands around Targeted WLs for M-13 and M-14 ICPs ........ 28

Figure 3-5. Overview of WL Estimation at the SME .................................................. 30

Figure 3-6. Overview of WL Estimation at the SME .................................................... 31

Figure 3-7. Sum of Oxides versus WLs........................................................................... 34

Figure 3-8. Mixed Acid Average U Concentration (wt $\%$ ) by Batch ............................... 35 


\section{LIST OF ACRONYMS}

DWPF Defense Waste Processing Facility

ICP-AES Inductively-Coupled Plasma - Atomic Emission Spectroscopy

JMP Pronounced "jump." It's a statistical software package, a registered trademark of SAS Institute, Inc.

MAR Measurement Acceptability Region

MFT Melter Feed Tank

PCCS Product Composition Control System

PET Process Engineering Technology

RSD Relative Standard Deviation

SCS Statistical Consulting Section

SME Slurry Mix Evaporator

SRAT Sludge Receipt and Adjustment Tank

SRNL Savannah River National Laboratory

SRS Savannah River Site

TT\&QA Task Technical and Quality Assurance (plan)

TTR Technical Task Request

WL Waste Loading 
WSRC-STI-2006-00068

Revision 0

This page intentionally left blank. 


\subsection{INTRODUCTION AND BACKGROUND}

The Defense Waste Processing Facility (DWPF) at the Savannah River Site (SRS) in Aiken, South Carolina, has been immobilizing high level radioactive waste (HLW) in borosilicate glass since 1996. Chemical composition analyses of the material being processed at the facility are among the measurements used by the DWPF to manage and control their operation and to ensure that they meet product specifications. These analyses, which include measurements of samples from the Sludge Receipt and Adjustment Tank (SRAT), the Slurry Mix Evaporator (SME), and (on a less frequent basis) the Melter Feed Tank (MFT), are provided by the DWPF Laboratory (DWPF Lab) of Waste Laboratory Services. As part of its conduct of operations (ConOps), the DWPF Lab employs standards to establish and monitor the comprehensive quality control program under which the process sample analyses are conducted.

Statistical reviews of measurement data generated by this program have been conducted in the past by the Statistical Consulting Section (SCS) of the Savannah River National Laboratory (SRNL). Measurements of process samples have been reviewed by Edwards ([1], [2], and [3]) as well as Harris [4] with the latest review by Edwards [3] covering data through process batch 263. The purpose of this report, which was initiated in response to a Technical Task Request (TTR) issued by DWPF Process Engineering [5], is to provide a statistical review of the measurements of standards and process samples generated by the DWPF Lab during the processing of batches 300 through 356. During this processing, the two Leeman spectrometers used by the DWPF Lab generated the measurements for samples prepared by the three methods routinely used by the DWPF Lab [5]. In addition to providing a general assessment of these measurements, the TTR requested that the statistical review address several specific areas of inquiry. These areas, which were identified and discussed in the Task Technical and Quality Assurance Plan (TT\&QA plan) [6] that was prepared in response to DWPF's TTR, are highlighted as they are addressed in the sections that follow.

\subsection{OVERVIEW OF DATA}

The DWPF Lab, through their WG17 server on the SRS computer network, provided SCS the measurement data for this analysis. The measurements were generated by Inductively Coupled Plasma (ICP) - Atomic Emission Spectroscopy (AES) and were grouped into three datasets, each related to the preparation method utilized for the samples being measured. The preparation/dissolution method(s) used was determined by the vessel being sampled: for the SRAT product samples, there was only one preparation/dissolution method used and it was denoted as "Cold Chem;" and for the SME, two different dissolution methods were used, and these were denoted as "Mixed Acid" and "Fusion." Thus, the data were organized into three datasets corresponding to these three preparation or "prep" methods: Cold Chem, Fusion and Mixed Acid. Tables A1, A2, and A3 in Appendix A provide the listings of these data sets. For each, the process batch number corresponding to the measurements is indicated as well as the instrument (the ICP spectrometer or ICP for short) used to generate the data. Two ICPs were used by the DWPF Lab, and they are denoted as M-13 and M-14. The statistical analyses of this study were initiated using all of the data of Tables A1 - A3.

One of the standards utilized in each of the three datasets was the Analytical Reference Glass One (ARG-1). This was the standard of primary interest in this study. It was labeled as Type of Sample "ARGB" in the Cold Chem dataset, "ARGG" in the Fusion dataset, and "ARGC" in the Mixed Acid dataset. ARG-1 is a powered glass that was prepared by Corning Glass and characterized by the

Material Characterization Center (MCC) at Pacific Northwest National Laboratory (PNNL). Its reference composition is provided in Table 2-1 in both elemental and oxide weight percents (wt\%'s). 
Table 2-1 Reference Composition of the ARG-1 Standard

\begin{tabular}{|c|c|c|c|c|}
\hline Element & $\begin{array}{c}\text { Weight Percent } \\
\text { (wt \%) }\end{array}$ & $\begin{array}{c}\text { Gravimetric } \\
\text { Factor }\end{array}$ & Oxide & $\begin{array}{c}\text { Weight Percent } \\
\text { (wt \%) }\end{array}$ \\
\hline Aluminum (Al) & 2.5 & 1.8895 & $\mathrm{Al}_{2} \mathrm{O}_{3}$ & 4.7238 \\
\hline Boron $(\mathrm{B})$ & 2.69 & 3.2199 & $\mathrm{~B}_{2} \mathrm{O}_{3}$ & 8.6615 \\
\hline Calcium $(\mathrm{Ca})$ & 1.02 & 1.3992 & $\mathrm{CaO}$ & 1.4272 \\
\hline Chromium $(\mathrm{Cr})$ & 0.06 & 1.4616 & $\mathrm{Cr}_{2} \mathrm{O}_{3}$ & 0.0877 \\
\hline Copper $(\mathrm{Cu})$ & 0.0001 & 1.2518 & $\mathrm{CuO}$ & 0.0001 \\
\hline Iron $(\mathrm{Fe})$ & 9.79 & 1.4297 & $\mathrm{Fe}_{2} \mathrm{O}_{3}$ & 13.9968 \\
\hline Potassium (K) & 2.25 & 1.2046 & $\mathrm{~K}_{2} \mathrm{O}$ & 2.7104 \\
\hline Lithium (Li) & 1.49 & 2.1529 & $\mathrm{Li}_{2} \mathrm{O}$ & 3.2078 \\
\hline Magnesium (Mg) & 0.52 & 1.6581 & $\mathrm{MgO}$ & 0.8622 \\
\hline Manganese (Mn) & 1.46 & 1.2912 & $\mathrm{MnO}$ & 1.8852 \\
\hline Sodium $(\mathrm{Na})$ & 8.53 & 1.3480 & $\mathrm{Na}_{2} \mathrm{O}$ & 11.4984 \\
\hline Nickel (Ni) & 0.83 & 1.2725 & $\mathrm{NiO}$ & 1.0562 \\
\hline Silicon $(\mathrm{Si})$ & 22.39 & 2.1393 & $\mathrm{SiO}_{2}$ & 47.8989 \\
\hline Titanium (Ti) & 0.69 & 1.6680 & $\mathrm{TiO}_{2}$ & 1.1509 \\
\hline Uranium $(\mathrm{U})$ & 0 & 1.1792 & $\mathrm{U}_{3} \mathrm{O}_{8}$ & 0.0000 \\
\hline Zirconium ( $\mathrm{ZrO})$ & 0.1 & 1.3508 & $\mathrm{ZrO}_{2}$ & 0.1351 \\
\hline
\end{tabular}

The other standard included as a Type of Sample in the three datasets is a (reagent) blank: IN32 for Cold Chem, SM55 for Fusion and SM32 for Mixed Acid. The other data listed in the tables correspond to measurements of process samples (SR04 for SRAT product samples prepared by Cold Chem and SM01 for SME samples prepared by either Fusion or Mixed Acid).

\subsection{RESULTS}

The information in Section 2 provides the framework for the data that are reviewed in this report. Most, but not all, of the measurement data were generated along with measurements that were reported for SRAT, SME, and MFT samples. A review of the measurements provides an opportunity to investigate and estimate the components or sources of variation in these data. There also are opportunities to estimate bias in the elemental measurements of the standards. All of these aspects of the comparisons of the measurement data are discussed in this section. The specific issues identified in the TT\&QA Plan [6] are also addressed in this section.

The statistical analyses were conducted using JMP Version 5.1.2 [7].

\subsection{INITIAL ASSESSMENT OF STANDARD AND PROCESS MEASUREMENTS}

Tables A1 through A3 list all of the data that were provided to SCS. As a preliminary step in the evaluation of these data, an attempt was made to identify measurements that were potential outliers. Such a need was deemed necessary since some of the measurements provided by the DWPF Lab had been prelabeled by the Lab as not acceptable. While the exclusion of the more extreme instances of outlying data is seen as having merit, there was an effort made not to be overly aggressive in excluding data from these analyses. Exhibit A1 in Appendix A provides plots of all of the data: sequenced by analyte by type of sample (ARG-1, process sample (either SRAT product or SME), and blank) and grouped by ICP within preparation method. Note that the analytes cover ratios of elements in addition to the 16 elements listed in Tables A1 through A3. The symbols used in these plots identify those data flagged as potential outliers $(\times)$ from the other data $(\diamond)$. Also shown in the exhibit are box plots for each set of data. 
The box plot summarizes the distribution of each group of points. The ends of each box mark the 25 th and 75th quantiles (i.e., the first and third quartiles). The difference between these quartiles is called the interquartile range. The line across the middle of the box identifies the median of the set of measurements. Each box has lines, sometimes called whiskers, that extend from each end. The whiskers extend from the upper end of the box to the largest measurement that is no more than $1.5 \times$ (interquartile range) above the upper quartile and from the lower end of the box to the smallest measurement that is no less than $1.5 \times$ (interquartile range) below the lower quartile. Measurements that fall beyond the whiskers are potential outliers. If there is no indication of a potential outlier in the group of measurements (based upon this approach), then the endpoints of the box plot are the minimum and maximum values in the group of measurements.

To be slightly more conservative in the approach used to flag potential outliers, a multiplier of 2 was used instead of the 1.5 value. In addition, the measurements were grouped in two different ways: one way was as illustrated in Exhibit A1 and the other (not shown) was to not distinguish between the two ICPs. If a measurement was identified as an outlier by both of these groupings (as indicated in Figure 1) it was flagged using the $\times$ symbol and it was excluded from the analyses that follow.

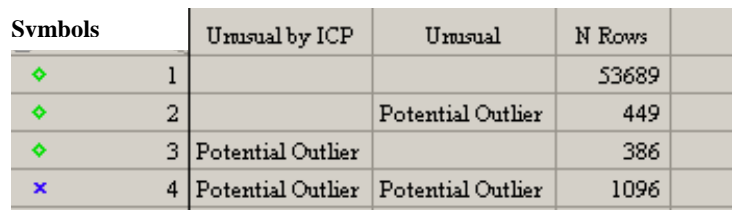

Figure 3-1. Measurements (over all analytes) Flagged as Potential Outliers

Exhibit A2 in Appendix A provides plots of the data by batch within ICP for each preparation method and sample type and analyte with the potential outlying data excluded. A horizontal line is also shown as part of each of these plots indicating the average measurement over the batches for each ICP. In addition to the 16 elements and the numerous ratios, a sum of oxides plot is also provided as part of this exhibit. The results are presented by analyte grouping in alphabetical order.

\subsection{COMPARISONS OF ARG-1 MEASUREMENTS}

ARG-1 measurements provide the opportunity for the most comprehensive set of comparisons across the three preparation methods and the two ICPs (i.e., M-13 and M-14). Exhibit A3 in Appendix A provides comparisons of the average of the ARG-1 measurements by batch (for those batches with two ARG-1 measurements for the given analyte) across the preparation and ICP combinations for each analyte. In this exhibit the horizontal line represents the "known" ARG-1 value of the analyte. Once again, a box plot is superimposed over each set of measurement data. For this exhibit, tabulated information is provided below each plot. Included in this information is an Analysis of Variance (ANOVA) that tests for a significant difference in underlying average values of the sets of measurements for each analyte. A significant difference (at a 5\% significance level) is indicated by the "Prob $>$ F" value's being less than or equal to 0.05 in this information. If such a difference is indicated, the "Means Comparisons" portion of the information may be scanned to identify (based upon a lettering scheme) those means that differ.

For example, consider the first plot and corresponding information of Exhibit A3, ARG-1 Al comparisons. Note that almost all of the measurements fall below the reference value for $\mathrm{Al}$ (the horizontal line of the plot). Also, note that the average Al concentrations range from a low of $2.299 \mathrm{wt} \%$ for Mixed Acid/M-13 to a high of $2.401 \mathrm{wt} \%$ for Fusion/M-13. Thus, the Mixed Acid/M-13 average is 
$\sim 4.2 \%$ below the average for Fusion/M-13. The ANOVA's "Prob $>$ F" value is given as " $<.0001$ " indicating a statistically significant difference among the underlying means for these data. The lower portion of the information provides the "Means Comparisons" which lists the average of the sets of measurements in descending order. The lettering scheme indicates that the Fusion/M-13 average differs (statistically, at the 5\% significance level) from the Cold Chem/M-14 average and the other preparation/ICP combinations that yielded smaller averages. Also, it may be noted that the Mixed Acid/M-13 average differed from the Mixed Acid/M-14 average and the other preparation/ICP combinations that yielded larger averages. Thus, statistically significant differences in the underlying mean measurements for the Al concentrations are indicated in these results in spite of all of the differences for the sample averages being no greater than $4.2 \%$. The information for the other analytes may be interpreted in a similar fashion.

\subsection{ICP COMPARISONS USING COLD CHEM PROCESS SAMPLES}

Comparisons of the M-13 versus M-14 ICPs may be conducted using all of the SRAT product measurement data since the compositions of these process batches remain relatively stable during the processing of the sludge batch. Specifically, waste loading targets and other processing decisions do not affect the compositions of the SRAT. Exhibit A4 in Appendix A provides "head-to-head" comparisons between the two ICPs using the average measurements by batch of the process samples prepared using Cold Chem.

For each analyte covered in the exhibit, there is a plot of the batch averages for each ICP. Superimposed on the data are "mean diamonds" generated by JMP. Each of these diamonds graphically represents a $95 \%$ confidence interval for the mean of the data (using a pooled estimate of the standard deviation). The information provided below the plot shows the results of statistical tests for differences between the two sets of data. Under the "t Test" heading, a value for "Prob $>|t|$ " of 0.05 or less indicates a statistical difference between the two underlying means for the ICPs at a significance level of 0.05. Identical results are also provided through the "Prob $>$ F" value of the "Analysis of Variance" portion of the information, which is also provided by JMP. A set of "Tests that the Variances are Equal" is also provided as part of the JMP output. One may use the line of results corresponding to the "Levene" test and the rule that a value for "Prob $>$ F" less than or equal to 0.05 implies a statistically significant difference to check for a difference between the two underlying variances for the ICPs at a significance level of 0.05 .

The information of Exhibit A4 may be summarized as: there is an indication of a significant difference in the means for $\mathrm{Cr}, \mathrm{Cu}, \mathrm{Fe} / \mathrm{Al}, \mathrm{K}, \mathrm{Li}$, and $\mathrm{Sum}$ of Oxides and in the variances for $\mathrm{Al} / \mathrm{Ca}, \mathrm{Fe} / \mathrm{Ni}, \mathrm{K}$, and $\mathrm{Na}$. Note that for the Sum of Oxides, the M-14 yields, on average, about a $1.6 \mathrm{wt} \%$ lower sum than the M-13 for the SRAT product samples.

\subsection{PREPARATION COMPARISONS BY ICP USING SME SAMPLE MEASUREMENTS}

Exhibit A5 in Appendix A provides comparisons between Fusion and Mixed Acid using the averages of SME measurements by batch for each analyte and each ICP. The information provided in this exhibit parallels that that was provided in Exhibit A4 except that for Exhibit A5 the differences being investigated are between the two preparations methods (Fusion and Mixed Acid). The information in Exhibit A5 may be summarized as follows: there is an indication of a significant difference in the Fusion and Mixed Acid means for $\mathrm{Al} / \mathrm{Ca}, \mathrm{Cu}, \mathrm{Fe}, \mathrm{Fe} / \mathrm{Ca}, \mathrm{Fe} / \mathrm{Li}, \mathrm{Fe} / \mathrm{Ni}, \mathrm{Fe} / \mathrm{U}, \mathrm{K}, \mathrm{Mn} / \mathrm{Mg}, \mathrm{Si}, \mathrm{Ti}, \mathrm{U}$, and U/Ca and in the variances for $\mathrm{Al} / \mathrm{Ca}, \mathrm{Ca}, \mathrm{Cu}, \mathrm{Fe}, \mathrm{K}$, and $\mathrm{U} / \mathrm{Ca}$ for $\mathrm{M}-13$. There is an indication of a significant difference in the Fusion and Mixed Acid means for $\mathrm{Al}, \mathrm{Al} / \mathrm{Ca}, \mathrm{Ca}, \mathrm{Fe} / \mathrm{Al}, \mathrm{Fe} / \mathrm{Ca}, \mathrm{Fe} / \mathrm{Mg}, \mathrm{Fe} / \mathrm{Mn}, \mathrm{Fe} / \mathrm{Ni}$, $\mathrm{Fe} / \mathrm{U}, \mathrm{Li}, \mathrm{Mg}, \mathrm{Mn} / \mathrm{Mg}, \mathrm{Ni}, \mathrm{Si}, \mathrm{U}$, and $\mathrm{U} / \mathrm{Ca}$ and in the variances for $\mathrm{Fe} / \mathrm{Mn}$ and $\mathrm{Li}$ for the M-14. 
WSRC-STI-2006-00068

Revision 0

\subsection{COMPARISONS OF ELEMENTAL RATIOS FOR PROCESS SAMPLES BY PREPARATION METHOD AND ICP}

Exhibit A6 in Appendix A provides comparisons of elemental ratios for the batch averages by preparation method and ICP. By restricting the investigation to the analytes that represent ratios of the elements comparisons can be made across all preparations and ICPs. The plots and information in this exhibit parallel those of Exhibit A3.

\subsection{ANALYSIS OF VARIANCE BY PREPARATION METHOD, ICP, AND ANALYTE}

Exhibit A7 in Appendix A provides an analysis of variance (ANOVA) for the measurements by type of sample (for this analysis, ARG-1 and the process samples, either SME or SRAT product), preparation method, ICP, and analyte. For each of these categories of measurements, the data used for this analysis were all of the batches for which a complete set of measurements were available for that type of measurement. Thus, for ARG-1 Al determined by Cold Chem and using the M-13 ICP, if two measurements were available for a batch, those measurements were included in the analysis, and similarly for the other preparation/ICP combinations and using 6 measurements to identify a qualifying batch of process samples. The purpose of the ANOVA was to estimate the sources of variation in the data: the within batch variation and the between batch variation. These estimates provide the components of variance for each of these categories of measurements.

In Exhibit 7, the estimated components of variance are provided: the between batch variance is designated as the "Batch" component and the within batch variance is designated as the "Residual" component. In addition to these estimated variances, the percentages of the total variance attributed to the two components are also given in the exhibit.

For the ARG-1 measurements, the information in the exhibit provides an opportunity to look at the potential for bias as well as to estimate the overall uncertainty (bias and precision errors) for a single measurement at a confidence level of 95\%. Table 3-1 summarizes information from Exhibit A7, provides the reference composition for ARG-1, determines a 95\% confidence interval for the mean measurement value, and estimates the uncertainty of a single measurement at $95 \%$ confidence. As an example, consider a single Al measurement by Cold Chem with the M-13 ICP. The lower bound on the uncertainty interval is $7.91 \%$ and the upper bound is $11.39 \%$. Thus, based upon the ARG-1 data, the true Al value could be $7.91 \%$ lower than the measurement or $11.39 \%$ higher, with $95 \%$ confidence.

ANOVA's were also conducted for the measurements of the process samples (SRAT product and SME). The results from these analyses are also presented in Exhibit A7 and all of the batches for which 6 measurements were available for an analyte were used in the analysis of that analyte. No bias estimates can be developed for these results since the "true" values are not known. However, the components of variance are estimated as part of the ANOVA results. These estimates are summarized in Table 3-2. 
Table 3-1 Estimated Components of Variance, Mean Confidence Intervals, and Overall Uncertainty for ARG-1 Measurements

Cold Chem/M-13

\begin{tabular}{|c|c|c|c|c|c|c|c|c|c|c|c|c|c|}
\hline \multirow[b]{2}{*}{ Analyte } & \multirow{2}{*}{$\begin{array}{c}\text { Reference } \\
\text { Value } \\
(\mathrm{wt} \%) \\
\end{array}$} & \multirow{2}{*}{$\begin{array}{l}\text { Average } \\
(\mathrm{wt} \%)\end{array}$} & \multirow[b]{2}{*}{$\%$ Bias } & \multirow{2}{*}{$\begin{array}{c}\text { Estimate of } \\
\text { Between } \\
\text { Var }\end{array}$} & \multirow{2}{*}{$\begin{array}{l}\text { Estimate of } \\
\text { Within Var }\end{array}$} & \multirow{2}{*}{$\begin{array}{c}\text { Estimate of } \\
\text { Total } \\
\text { Variance } \\
\end{array}$} & \multirow{2}{*}{$\begin{array}{l}\text { Estimate of } \\
\% \text { RSD (B) }\end{array}$} & \multirow{2}{*}{$\begin{array}{l}\text { Estimate of } \\
\% \mathrm{RSD}(\mathrm{W})\end{array}$} & \multirow{2}{*}{$\begin{array}{l}\text { Estimate of } \\
\% \operatorname{RSD}(\mathrm{T}) \\
\end{array}$} & \multicolumn{2}{|c|}{$95 \%$ Confidence Interval for Mean } & \multicolumn{2}{|c|}{ 95\% Measurement Uncertainty } \\
\hline & & & & & & & & & & Lower & Upper & $\%$ Lower & $\%$ Upper \\
\hline $\mathrm{Al}$ & 2.5 & 2.338 & $-6.49 \%$ & 0.002726 & 0.005365 & 0.008091 & $2.23 \%$ & $3.13 \%$ & $3.85 \%$ & 2.309 & 2.367 & $7.91 \%$ & $11.38 \%$ \\
\hline $\mathrm{Al} / \mathrm{Ca}$ & 2.451 & 2.417 & $-1.38 \%$ & 0.003266 & 0.002203 & 0.005469 & $2.36 \%$ & $1.94 \%$ & $3.06 \%$ & 2.390 & 2.444 & $6.30 \%$ & $6.78 \%$ \\
\hline $\mathrm{Al} / \mathrm{Mg}$ & 4.808 & 4.708 & $-2.08 \%$ & 0.008766 & 0.010288 & 0.019054 & $1.99 \%$ & $2.15 \%$ & $2.93 \%$ & 4.661 & 4.755 & $6.03 \%$ & $6.78 \%$ \\
\hline $\mathrm{Al} / \mathrm{Mn}$ & 1.712 & 1.652 & $-3.53 \%$ & 0.000178 & 0.002487 & 0.002665 & $0.81 \%$ & $3.02 \%$ & $3.13 \%$ & 1.637 & 1.666 & $6.43 \%$ & $7.88 \%$ \\
\hline $\mathrm{B}$ & 2.69 & 2.613 & $-2.88 \%$ & 0.00188 & 0.00403 & 0.00591 & $1.66 \%$ & $2.43 \%$ & $2.94 \%$ & 2.588 & 2.637 & $6.05 \%$ & $7.20 \%$ \\
\hline $\mathrm{B} / \mathrm{Li}$ & 1.805 & 1.816 & $0.60 \%$ & 0.002027 & 0.002878 & 0.004905 & $2.48 \%$ & $2.95 \%$ & $3.86 \%$ & 1.793 & 1.839 & $8.15 \%$ & $7.93 \%$ \\
\hline $\mathrm{Ca}$ & 1.02 & 0.968 & $-5.11 \%$ & 0.001529 & 0.001472 & 0.003001 & $4.04 \%$ & $3.96 \%$ & $5.66 \%$ & 0.949 & 0.987 & $11.66 \%$ & $13.79 \%$ \\
\hline $\mathrm{Cr}$ & 0.06 & 0.065 & $8.86 \%$ & 0.000032 & 0.000014 & 0.000046 & $8.66 \%$ & $5.73 \%$ & $10.38 \%$ & 0.063 & 0.068 & $24.47 \%$ & $21.34 \%$ \\
\hline $\mathrm{Cu}$ & 0.0001 & 0.004 & $3659.00 \%$ & 0 & 0.000019 & 0.000019 & $0.00 \%$ & $115.96 \%$ & $115.96 \%$ & 0.003 & 0.005 & $271.80 \%$ & $238.36 \%$ \\
\hline $\mathrm{Fe}$ & 9.79 & 9.723 & $-0.68 \%$ & 0.02523 & 0.058054 & 0.083284 & $1.63 \%$ & $2.48 \%$ & $2.97 \%$ & 9.631 & 9.815 & $6.11 \%$ & $6.10 \%$ \\
\hline $\mathrm{Fe} / \mathrm{Al}$ & 3.916 & 4.162 & $6.28 \%$ & 0.004437 & 0.010178 & 0.014615 & $1.60 \%$ & $2.42 \%$ & $2.90 \%$ & 4.123 & 4.201 & $9.08 \%$ & $5.97 \%$ \\
\hline $\mathrm{Fe} / \mathrm{Ca}$ & 9.598 & 9.980 & $3.98 \%$ & 0.019172 & 0.136476 & 0.155648 & $1.39 \%$ & $3.70 \%$ & $3.95 \%$ & 9.855 & 10.105 & $9.63 \%$ & $8.18 \%$ \\
\hline $\mathrm{Fe} / \mathrm{Li}$ & 6.57 & 6.758 & $2.86 \%$ & 0.034139 & 0.03079 & 0.064929 & $2.73 \%$ & $2.60 \%$ & $3.77 \%$ & 6.670 & 6.846 & $8.76 \%$ & $7.75 \%$ \\
\hline $\mathrm{Fe} / \mathrm{Mg}$ & 18.827 & 19.543 & $3.80 \%$ & 0.137021 & 0.099314 & 0.236335 & $1.89 \%$ & $1.61 \%$ & $2.49 \%$ & 19.361 & 19.726 & $6.90 \%$ & $5.15 \%$ \\
\hline $\mathrm{Fe} / \mathrm{Mn}$ & 6.705 & 6.884 & $2.67 \%$ & 0 & 0.011197 & 0.011197 & $0.00 \%$ & $1.54 \%$ & $1.54 \%$ & 6.855 & 6.913 & $4.38 \%$ & $3.17 \%$ \\
\hline $\mathrm{Fe} / \mathrm{Ni}$ & 11.795 & 12.030 & $2.00 \%$ & 0.011033 & 0.047533 & 0.058566 & $0.87 \%$ & $1.81 \%$ & $2.01 \%$ & 11.955 & 12.106 & $4.88 \%$ & $4.14 \%$ \\
\hline $\mathrm{Fe} / \mathrm{U}$ & - & & & & & & & & & & & & \\
\hline $\mathrm{K}$ & 2.25 & 2.333 & $3.69 \%$ & 0.007457 & 0.041245 & 0.048702 & $3.70 \%$ & $8.70 \%$ & $9.46 \%$ & 2.267 & 2.399 & $20.47 \%$ & $19.44 \%$ \\
\hline $\mathrm{Li}$ & 1.49 & 1.444 & $-3.11 \%$ & 0.001485 & 0.001213 & 0.002698 & $2.67 \%$ & $2.41 \%$ & $3.60 \%$ & 1.425 & 1.462 & $7.41 \%$ & $8.67 \%$ \\
\hline $\mathrm{Mg}$ & 0.52 & 0.497 & $-4.43 \%$ & 0.000424 & 0.000186 & 0.00061 & $4.14 \%$ & $2.74 \%$ & $4.97 \%$ & 0.488 & 0.506 & $10.22 \%$ & $12.07 \%$ \\
\hline $\mathrm{Mn}$ & 1.46 & 1.416 & $-3.03 \%$ & 0.000145 & 0.001545 & 0.00169 & $0.85 \%$ & $2.78 \%$ & $2.90 \%$ & 1.404 & 1.428 & $5.97 \%$ & $7.17 \%$ \\
\hline $\mathrm{Mn} / \mathrm{Mg}$ & 2.808 & 2.849 & $1.45 \%$ & 0.00575 & 0.002821 & 0.008571 & $2.66 \%$ & $1.86 \%$ & $3.25 \%$ & 2.814 & 2.884 & $7.21 \%$ & $6.71 \%$ \\
\hline $\mathrm{Na}$ & 8.53 & 8.340 & $-2.23 \%$ & 0.0058 & 0.016258 & 0.022058 & $0.91 \%$ & $1.53 \%$ & $1.78 \%$ & 8.290 & 8.390 & $3.68 \%$ & $4.67 \%$ \\
\hline $\mathrm{Ni}$ & 0.83 & 0.808 & $-2.62 \%$ & 0.000068 & 0.000236 & 0.000304 & $1.02 \%$ & $1.90 \%$ & $2.16 \%$ & 0.803 & 0.814 & $4.44 \%$ & $5.57 \%$ \\
\hline $\mathrm{Si}$ & 22.39 & 21.860 & $-2.37 \%$ & 0.102924 & 0.263944 & 0.366868 & $1.47 \%$ & $2.35 \%$ & $2.77 \%$ & 21.664 & 22.055 & $5.71 \%$ & $6.60 \%$ \\
\hline $\mathrm{Ti}$ & 0.69 & 0.672 & $-2.55 \%$ & 0.000118 & 0.000114 & 0.000232 & $1.62 \%$ & $1.59 \%$ & $2.27 \%$ & 0.667 & 0.678 & $4.67 \%$ & $5.78 \%$ \\
\hline \multicolumn{14}{|l|}{$\mathrm{U}$} \\
\hline $\mathrm{U} / \mathrm{Ca}$ & 0 & 0.096 & - & 0 & 0.013895 & 0.013895 & $0.00 \%$ & $122.79 \%$ & $122.79 \%$ & 0.068 & 0.124 & $283.45 \%$ & $252.40 \%$ \\
\hline $\mathrm{Zr}$ & 0.1 & 0.102 & $2.17 \%$ & 0.000022 & 0.000009 & 0.000031 & $4.59 \%$ & $2.94 \%$ & $5.45 \%$ & 0.100 & 0.104 & $11.95 \%$ & $11.22 \%$ \\
\hline $\begin{array}{c}\text { Sum } \\
\mathrm{Ox}\end{array}$ & 99.3 & 97.413 & $-1.90 \%$ & 2.987575 & 8.206505 & 11.19408 & $1.77 \%$ & $2.94 \%$ & $3.43 \%$ & 96.359 & 98.466 & $7.06 \%$ & $7.68 \%$ \\
\hline
\end{tabular}


WSRC-STI-2006-00068

Revision 0

Table 3-1 Estimated Components of Variance, Mean Confidence Intervals, and Overall Uncertainty for ARG-1 Measurements (continued)

Cold Chem/M-14

\begin{tabular}{|c|c|c|c|c|c|c|c|c|c|c|c|c|c|}
\hline & Reference & Average & & Estimate of & Estimate of & Estimate of & $\begin{array}{c}\text { Estimate } \\
\text { of }\end{array}$ & Estimate of & $\begin{array}{c}\text { Estimate } \\
\text { of }\end{array}$ & $95 \%$ Confiden & val for Mean & 95\% Measur & t Uncertainty \\
\hline Analyte & $\begin{array}{l}\text { Value } \\
(\text { wt } \%)\end{array}$ & $(\mathrm{wt} \%)$ & $\%$ Bias & $\begin{array}{c}\text { Between } \\
\text { (B) Batch } \\
\text { Variance } \\
\end{array}$ & $\begin{array}{c}\text { Within } \\
\text { (W) Batch } \\
\text { Variance } \\
\end{array}$ & $\begin{array}{l}\text { Total }(\mathrm{T}) \\
\text { Variance } \\
\end{array}$ & $\begin{array}{c}\text { \%RSD } \\
\text { (B) }\end{array}$ & $\% \mathrm{RSD}(\mathrm{W})$ & $\% \operatorname{RSD}(\mathrm{T})$ & Lower & Upper & $\%$ Lower & $\%$ Upper \\
\hline $\mathrm{Al}$ & 2.5 & 2.340 & $-6.39 \%$ & 0.001847 & 0.003672 & 0.005519 & $1.84 \%$ & $2.59 \%$ & $3.17 \%$ & 2.316 & 2.364 & $6.52 \%$ & $10.21 \%$ \\
\hline $\mathrm{Al} / \mathrm{Ca}$ & 2.451 & 2.407 & $-1.80 \%$ & 0.001484 & 0.003563 & 0.005047 & $1.60 \%$ & $2.48 \%$ & $2.95 \%$ & 2.385 & 2.429 & $6.06 \%$ & $6.65 \%$ \\
\hline $\mathrm{Al} / \mathrm{Mg}$ & 4.808 & 4.839 & $0.64 \%$ & 0.016171 & 0.013193 & 0.029364 & $2.63 \%$ & $2.37 \%$ & $3.54 \%$ & 4.783 & 4.895 & $7.46 \%$ & $7.24 \%$ \\
\hline $\mathrm{Al} / \mathrm{Mn}$ & 1.712 & 1.673 & $-2.28 \%$ & 0.001188 & 0.001052 & 0.00224 & $2.06 \%$ & $1.94 \%$ & $2.83 \%$ & 1.657 & 1.689 & $5.80 \%$ & $6.68 \%$ \\
\hline $\mathrm{B}$ & 2.69 & 2.595 & $-3.53 \%$ & 0.000315 & 0.003639 & 0.003954 & $0.68 \%$ & $2.32 \%$ & $2.42 \%$ & 2.577 & 2.613 & $4.97 \%$ & $6.60 \%$ \\
\hline $\mathrm{B} / \mathrm{Li}$ & 1.805 & 1.786 & $-1.07 \%$ & 0.001349 & 0.001218 & 0.002567 & $2.06 \%$ & $1.95 \%$ & $2.84 \%$ & 1.769 & 1.802 & $5.80 \%$ & $6.14 \%$ \\
\hline $\mathrm{Ca}$ & 1.02 & 0.971 & $-4.85 \%$ & 0.000314 & 0.001546 & 0.00186 & $1.83 \%$ & $4.05 \%$ & $4.44 \%$ & 0.958 & 0.983 & $9.10 \%$ & $11.12 \%$ \\
\hline $\mathrm{Cr}$ & 0.06 & 0.068 & $13.97 \%$ & 0.00003 & 0.000011 & 0.000041 & $8.01 \%$ & $4.85 \%$ & $9.36 \%$ & 0.066 & 0.071 & $24.63 \%$ & $19.15 \%$ \\
\hline $\mathrm{Cu}$ & 0.0001 & 0.002 & $1693.00 \%$ & 0.000004 & 0.000006 & 0.00001 & $111.54 \%$ & $136.61 \%$ & $176.37 \%$ & 0.001 & 0.003 & $388.13 \%$ & $361.27 \%$ \\
\hline $\mathrm{Fe}$ & 9.79 & 9.517 & $-2.79 \%$ & 0.027879 & 0.016305 & 0.044184 & $1.75 \%$ & $1.34 \%$ & $2.21 \%$ & 9.442 & 9.592 & $4.54 \%$ & $5.83 \%$ \\
\hline $\mathrm{Fe} / \mathrm{Al}$ & 3.916 & 4.085 & $4.32 \%$ & 0.013204 & 0.004398 & 0.017602 & $2.81 \%$ & $1.62 \%$ & $3.25 \%$ & 4.038 & 4.133 & $8.51 \%$ & $6.65 \%$ \\
\hline $\mathrm{Fe} / \mathrm{Ca}$ & 9.598 & 9.764 & $1.73 \%$ & 0.03374 & 0.100665 & 0.134405 & $1.88 \%$ & $3.25 \%$ & $3.75 \%$ & 9.651 & 9.876 & $8.21 \%$ & $7.70 \%$ \\
\hline $\mathrm{Fe} / \mathrm{Li}$ & 6.57 & 6.548 & $-0.34 \%$ & 0.01457 & 0.016193 & 0.030763 & $1.84 \%$ & $1.94 \%$ & $2.68 \%$ & 6.492 & 6.604 & $5.50 \%$ & $5.48 \%$ \\
\hline $\mathrm{Fe} / \mathrm{Mg}$ & 18.827 & 19.622 & $4.22 \%$ & 0.141571 & 0.069632 & 0.211203 & $1.92 \%$ & $1.34 \%$ & $2.34 \%$ & 19.452 & 19.792 & $6.89 \%$ & $4.82 \%$ \\
\hline $\mathrm{Fe} / \mathrm{Mn}$ & 6.705 & 6.853 & $2.21 \%$ & 0.001497 & 0.005917 & 0.007414 & $0.56 \%$ & $1.12 \%$ & $1.26 \%$ & 6.828 & 6.878 & $3.60 \%$ & $2.57 \%$ \\
\hline $\mathrm{Fe} / \mathrm{Ni}$ & 11.795 & 11.937 & $1.21 \%$ & 0.014555 & 0.028419 & 0.042974 & $1.01 \%$ & $1.41 \%$ & $1.74 \%$ & 11.874 & 12.001 & $3.95 \%$ & $3.55 \%$ \\
\hline $\mathrm{Fe} / \mathrm{U}$ & - & & & & & & & & & & & & \\
\hline $\mathrm{K}$ & 2.25 & 2.308 & $2.59 \%$ & 0 & 0.018742 & 0.018742 & $0.00 \%$ & $5.93 \%$ & $5.93 \%$ & 2.273 & 2.344 & $12.79 \%$ & $12.13 \%$ \\
\hline $\mathrm{Li}$ & 1.49 & 1.455 & $-2.35 \%$ & 0.000574 & 0.001668 & 0.002242 & $1.65 \%$ & $2.81 \%$ & $3.25 \%$ & 1.440 & 1.470 & $6.68 \%$ & $7.49 \%$ \\
\hline $\mathrm{Mg}$ & 0.52 & 0.484 & $-6.93 \%$ & 0.000092 & 0.00022 & 0.000312 & $1.98 \%$ & $3.06 \%$ & $3.65 \%$ & 0.478 & 0.490 & $7.50 \%$ & $11.43 \%$ \\
\hline $\mathrm{Mn}$ & 1.46 & 1.389 & $-4.85 \%$ & 0.000286 & 0.001045 & 0.001331 & $1.22 \%$ & $2.33 \%$ & $2.63 \%$ & 1.378 & 1.400 & $5.39 \%$ & $7.99 \%$ \\
\hline $\mathrm{Mn} / \mathrm{Mg}$ & 2.808 & 2.870 & $2.22 \%$ & 0.002568 & 0.002346 & 0.004914 & $1.77 \%$ & $1.69 \%$ & $2.44 \%$ & 2.846 & 2.895 & $5.86 \%$ & $5.02 \%$ \\
\hline $\mathrm{Na}$ & 8.53 & 8.300 & $-2.70 \%$ & 0.009452 & 0.02236 & 0.031812 & $1.17 \%$ & $1.80 \%$ & $2.15 \%$ & 8.243 & 8.356 & $4.42 \%$ & $5.61 \%$ \\
\hline $\mathrm{Ni}$ & 0.83 & 0.798 & $-3.88 \%$ & 0.000176 & 0.000347 & 0.000523 & $1.66 \%$ & $2.33 \%$ & $2.87 \%$ & 0.791 & 0.805 & $5.88 \%$ & $7.68 \%$ \\
\hline $\mathrm{Si}$ & 22.39 & 21.885 & $-2.26 \%$ & 0.043324 & 0.313542 & 0.356866 & $0.95 \%$ & $2.56 \%$ & $2.73 \%$ & 21.708 & 22.062 & $5.61 \%$ & $6.42 \%$ \\
\hline $\mathrm{Ti}$ & 0.69 & 0.671 & $-2.81 \%$ & 0.000015 & 0.000203 & 0.000218 & $0.58 \%$ & $2.12 \%$ & $2.20 \%$ & 0.666 & 0.675 & $4.53 \%$ & $5.75 \%$ \\
\hline $\mathrm{U}$ & 0 & 0.030 & & 0.000849 & 0.005408 & 0.006257 & $97.40 \%$ & $245.84 \%$ & $264.43 \%$ & 0.007 & 0.053 & $569.48 \%$ & $541.66 \%$ \\
\hline $\mathrm{U} / \mathrm{Ca}$ & 0 & 0.030 & & 0.001195 & 0.006067 & 0.007262 & $115.11 \%$ & $259.37 \%$ & $283.76 \%$ & 0.005 & 0.055 & $609.21 \%$ & $581.27 \%$ \\
\hline $\mathrm{Zr}$ & 0.1 & 0.103 & $2.68 \%$ & 0.000022 & 0.000017 & 0.000039 & $4.57 \%$ & $4.02 \%$ & $6.08 \%$ & 0.101 & 0.105 & $13.33 \%$ & $12.48 \%$ \\
\hline $\begin{array}{l}\text { Sum } \\
\text { Ox }\end{array}$ & 99.3 & 96.179 & $-3.14 \%$ & 0 & 14.10631 & 14.10631 & $0.00 \%$ & $3.91 \%$ & $3.91 \%$ & 95.178 & 97.180 & $8.00 \%$ & $9.07 \%$ \\
\hline
\end{tabular}


WSRC-STI-2006-00068

Revision 0

Table 3-1 Estimated Components of Variance, Mean Confidence Intervals, and Overall Uncertainty for ARG-1 Measurements (continued)

Fusion/M-13

\begin{tabular}{|c|c|c|c|c|c|c|c|c|c|c|c|c|c|}
\hline \multirow[b]{2}{*}{ Analyte } & \multirow{2}{*}{$\begin{array}{c}\text { Reference } \\
\text { Value } \\
(\mathrm{wt} \%)\end{array}$} & \multirow{2}{*}{$\frac{\text { Average }}{(\mathrm{wt} \%)}$} & \multirow[b]{2}{*}{$\%$ Bias } & \multirow{2}{*}{$\begin{array}{c}\text { Estimate of } \\
\text { Between } \\
\text { Var }\end{array}$} & \multirow{2}{*}{$\begin{array}{l}\text { Estimate of } \\
\text { Within Var }\end{array}$} & \multirow{2}{*}{$\begin{array}{c}\text { Estimate of } \\
\text { Total } \\
\text { Variance }\end{array}$} & \multirow{2}{*}{$\begin{array}{c}\begin{array}{c}\text { Estimate } \\
\text { of }\end{array} \\
\% \text { RSD } \\
\text { (B) } \\
\end{array}$} & \multirow{2}{*}{$\begin{array}{l}\text { Estimate of } \\
\% \operatorname{RSD}(\mathrm{W})\end{array}$} & \multirow{2}{*}{$\begin{array}{c}\begin{array}{c}\text { Estimate } \\
\text { of }\end{array} \\
\text { \%RSD(T) }\end{array}$} & \multicolumn{2}{|c|}{$95 \%$ Confidence Interval for Mean } & \multicolumn{2}{|c|}{ 95\% Measurement Uncertainty } \\
\hline & & & & & & & & & & Lower & Upper & $\%$ Lower & $\%$ Upper \\
\hline $\mathrm{Al}$ & 2.5 & 2.401 & $-3.96 \%$ & 0.002892 & 0.006025 & 0.008917 & $2.24 \%$ & $3.23 \%$ & $3.93 \%$ & 2.376 & 2.426 & $7.96 \%$ & $9.49 \%$ \\
\hline $\mathrm{Al} / \mathrm{Ca}$ & 2.451 & 2.438 & $-0.53 \%$ & 0.001788 & 0.001601 & 0.003389 & $1.73 \%$ & $1.64 \%$ & $2.39 \%$ & 2.421 & 2.455 & $4.84 \%$ & $4.84 \%$ \\
\hline $\mathrm{Al} / \mathrm{Mg}$ & 4.808 & 4.764 & $-0.91 \%$ & 0.008971 & 0.006851 & 0.015822 & $1.99 \%$ & $1.74 \%$ & $2.64 \%$ & 4.728 & 4.801 & $5.35 \%$ & $5.61 \%$ \\
\hline $\mathrm{Al} / \mathrm{Mn}$ & 1.712 & 1.706 & $-0.35 \%$ & 0.000779 & 0.000791 & 0.00157 & $1.64 \%$ & $1.65 \%$ & $2.32 \%$ & 1.695 & 1.717 & $4.72 \%$ & $4.71 \%$ \\
\hline $\mathrm{B}$ & 2.69 & 2.617 & $-2.72 \%$ & 0.001922 & 0.006052 & 0.007974 & $1.68 \%$ & $2.97 \%$ & $3.41 \%$ & 2.594 & 2.640 & $6.91 \%$ & $7.83 \%$ \\
\hline $\mathrm{B} / \mathrm{Li}$ & 1.805 & 1.784 & $-1.16 \%$ & 0.000324 & 0.001958 & 0.002282 & $1.01 \%$ & $2.48 \%$ & $2.68 \%$ & 1.772 & 1.796 & $5.42 \%$ & $5.72 \%$ \\
\hline $\mathrm{Ca}$ & 1.02 & 0.983 & $-3.59 \%$ & 0.000736 & 0.001132 & 0.001868 & $2.76 \%$ & $3.42 \%$ & $4.40 \%$ & 0.971 & 0.995 & $8.91 \%$ & $10.20 \%$ \\
\hline $\mathrm{Cr}$ & 0.06 & 0.068 & $13.27 \%$ & 0.000023 & 0.000016 & 0.000039 & $7.06 \%$ & $5.89 \%$ & $9.19 \%$ & 0.066 & 0.070 & $23.52 \%$ & $18.62 \%$ \\
\hline $\mathrm{Cu}$ & 0.0001 & 0.002 & $1746.00 \%$ & 0.000012 & 0.000008 & 0.00002 & $187.65 \%$ & $153.22 \%$ & $242.26 \%$ & 0.001 & 0.003 & $516.68 \%$ & $490.43 \%$ \\
\hline $\mathrm{Fe}$ & 9.79 & 9.709 & $-0.83 \%$ & 0.040073 & 0.083086 & 0.123159 & $2.06 \%$ & $2.97 \%$ & $3.61 \%$ & 9.614 & 9.804 & $7.33 \%$ & $7.33 \%$ \\
\hline $\mathrm{Fe} / \mathrm{Al}$ & 3.916 & 4.032 & $2.95 \%$ & 0.005055 & 0.005306 & 0.010361 & $1.76 \%$ & $1.81 \%$ & $2.52 \%$ & 4.003 & 4.061 & $6.25 \%$ & $5.12 \%$ \\
\hline $\mathrm{Fe} / \mathrm{Ca}$ & 9.598 & 9.807 & $2.18 \%$ & 0.024542 & 0.070248 & 0.09479 & $1.60 \%$ & $2.70 \%$ & $3.14 \%$ & 9.727 & 9.887 & $7.01 \%$ & $6.36 \%$ \\
\hline $\mathrm{Fe} / \mathrm{Li}$ & 6.57 & 6.614 & $0.67 \%$ & 0.012297 & 0.028217 & 0.040514 & $1.68 \%$ & $2.54 \%$ & $3.04 \%$ & 6.561 & 6.667 & $6.34 \%$ & $6.17 \%$ \\
\hline $\mathrm{Fe} / \mathrm{Mg}$ & 18.827 & 19.166 & $1.80 \%$ & 0.005845 & 0.11381 & 0.119655 & $0.40 \%$ & $1.76 \%$ & $1.80 \%$ & 19.083 & 19.250 & $4.27 \%$ & $3.66 \%$ \\
\hline $\mathrm{Fe} / \mathrm{Mn}$ & 6.705 & 6.868 & $2.43 \%$ & 0.003799 & 0.007128 & 0.010927 & $0.90 \%$ & $1.23 \%$ & $1.52 \%$ & 6.839 & 6.896 & $4.16 \%$ & $3.09 \%$ \\
\hline $\mathrm{Fe} / \mathrm{Ni}$ & 11.795 & 12.052 & $2.18 \%$ & 0 & 0.087972 & 0.087972 & $0.00 \%$ & $2.46 \%$ & $2.46 \%$ & 11.983 & 12.121 & $5.67 \%$ & $4.99 \%$ \\
\hline $\mathrm{Fe} / \mathrm{U}$ & - & & & & & & & & & & & & \\
\hline $\mathrm{K}$ & 2.25 & 2.198 & $-2.33 \%$ & 0.005032 & 0.012719 & 0.017751 & $3.23 \%$ & $5.13 \%$ & $6.06 \%$ & 2.163 & 2.232 & $12.27 \%$ & $12.90 \%$ \\
\hline $\mathrm{Li}$ & 1.49 & 1.467 & $-1.54 \%$ & 0.000445 & 0.002301 & 0.002746 & $1.44 \%$ & $3.27 \%$ & $3.57 \%$ & 1.454 & 1.480 & $7.24 \%$ & $7.64 \%$ \\
\hline $\mathrm{Mg}$ & 0.52 & 0.506 & $-2.69 \%$ & 0.000123 & 0.000256 & 0.000379 & $2.19 \%$ & $3.16 \%$ & $3.85 \%$ & 0.501 & 0.511 & $7.80 \%$ & $8.68 \%$ \\
\hline $\mathrm{Mn}$ & 1.46 & 1.414 & $-3.13 \%$ & 0.000749 & 0.0023 & 0.003049 & $1.94 \%$ & $3.39 \%$ & $3.90 \%$ & 1.400 & 1.429 & $7.91 \%$ & $8.98 \%$ \\
\hline $\mathrm{Mn} / \mathrm{Mg}$ & 2.808 & 2.793 & $-0.54 \%$ & 0.000661 & 0.002691 & 0.003352 & $0.92 \%$ & $1.86 \%$ & $2.07 \%$ & 2.778 & 2.808 & $4.20 \%$ & $4.33 \%$ \\
\hline $\mathrm{Na}$ & 8.53 & & & & & & & & & & & & \\
\hline $\mathrm{Ni}$ & 0.83 & 0.803 & $-3.29 \%$ & 0.0004 & 0.000528 & 0.000928 & $2.49 \%$ & $2.86 \%$ & $3.80 \%$ & 0.794 & 0.811 & $7.69 \%$ & $8.89 \%$ \\
\hline $\mathrm{Si}$ & 22.39 & 22.586 & $0.87 \%$ & 0.213535 & 0.420774 & 0.634309 & $2.05 \%$ & $2.87 \%$ & $3.53 \%$ & 22.372 & 22.800 & $7.37 \%$ & $7.14 \%$ \\
\hline $\mathrm{Ti}$ & 0.69 & 0.671 & $-2.76 \%$ & 0.000115 & 0.000545 & 0.00066 & $1.60 \%$ & $3.48 \%$ & $3.83 \%$ & 0.665 & 0.677 & $7.75 \%$ & $8.63 \%$ \\
\hline $\mathrm{U}$ & 0 & 0.021 & & 0.00284 & 0.000899 & 0.003739 & $251.01 \%$ & $141.22 \%$ & $288.01 \%$ & 0.003 & 0.040 & $612.48 \%$ & $583.05 \%$ \\
\hline $\mathrm{U} / \mathrm{Ca}$ & 0 & 0.022 & & 0.002989 & 0.000987 & 0.003976 & $247.24 \%$ & $142.07 \%$ & $285.15 \%$ & 0.003 & 0.041 & $606.65 \%$ & $577.26 \%$ \\
\hline $\mathrm{Zr}$ & 0.1 & & & & & & & & & & & & \\
\hline $\begin{array}{l}\text { Sum } \\
\text { Ox }\end{array}$ & 87.7 & 87.103 & $-0.68 \%$ & 2.020595 & 9.161029 & 11.181624 & $1.63 \%$ & $3.47 \%$ & $3.84 \%$ & 86.270 & 87.935 & $7.78 \%$ & $7.77 \%$ \\
\hline
\end{tabular}


WSRC-STI-2006-00068

Revision 0

Table 3-1 Estimated Components of Variance, Mean Confidence Intervals, and Overall Uncertainty for ARG-1 Measurements (continued)

Fusion/M-14

\begin{tabular}{|c|c|c|c|c|c|c|c|c|c|c|c|c|c|}
\hline \multirow[b]{2}{*}{ Analyte } & \multirow{2}{*}{$\begin{array}{c}\text { Reference } \\
\begin{array}{c}\text { Value } \\
\text { (wt } \%)\end{array}\end{array}$} & \multirow{2}{*}{$\begin{array}{c}\text { Average } \\
(\mathrm{wt} \%) \\
\end{array}$} & \multirow[b]{2}{*}{$\%$ Bias } & \multirow{2}{*}{$\begin{array}{c}\text { Estimate of } \\
\text { Between } \\
\text { Var }\end{array}$} & \multirow{2}{*}{$\begin{array}{l}\text { Estimate of } \\
\text { Within Var }\end{array}$} & \multirow{2}{*}{$\begin{array}{c}\text { Estimate of } \\
\text { Total } \\
\text { Variance }\end{array}$} & \multirow{2}{*}{$\begin{array}{c}\begin{array}{c}\text { Estimate } \\
\text { of }\end{array} \\
\% \text { RSD } \\
\text { (B) } \\
\end{array}$} & \multirow{2}{*}{$\begin{array}{l}\text { Estimate of } \\
\text { \%RSD (W) }\end{array}$} & \multirow{2}{*}{$\begin{array}{c}\begin{array}{c}\text { Estimate } \\
\text { of }\end{array} \\
\% \operatorname{RSD}(\mathrm{T}) \\
\end{array}$} & \multicolumn{2}{|c|}{$95 \%$ Confidence Interval for Mean } & \multicolumn{2}{|c|}{ 95\% Measurement Uncertainty } \\
\hline & & & & & & & & & & Lower & Upper & $\%$ Lower & $\%$ Upper \\
\hline $\mathrm{Al}$ & 2.5 & 2.392 & $-4.31 \%$ & 0.001287 & 0.004373 & 0.00566 & $1.50 \%$ & $2.76 \%$ & $3.14 \%$ & 2.358 & 2.426 & $6.79 \%$ & $9.01 \%$ \\
\hline $\mathrm{Al} / \mathrm{Ca}$ & 2.451 & 2.475 & $0.99 \%$ & 0.001819 & 0.001839 & 0.003658 & $1.72 \%$ & $1.73 \%$ & $2.44 \%$ & 2.442 & 2.509 & $5.86 \%$ & $5.38 \%$ \\
\hline $\mathrm{Al} / \mathrm{Mg}$ & 4.808 & 4.821 & $0.27 \%$ & 0.000327 & 0.007693 & 0.00802 & $0.38 \%$ & $1.82 \%$ & $1.86 \%$ & 4.784 & 4.858 & $4.15 \%$ & $4.01 \%$ \\
\hline $\mathrm{Al} / \mathrm{Mn}$ & 1.712 & 1.721 & $0.52 \%$ & 0.000333 & 0.000967 & 0.0013 & $1.06 \%$ & $1.81 \%$ & $2.10 \%$ & 1.704 & 1.737 & $4.76 \%$ & $4.53 \%$ \\
\hline $\mathrm{B}$ & 2.69 & 2.555 & $-5.01 \%$ & 0.000335 & 0.004066 & 0.004401 & $0.72 \%$ & $2.50 \%$ & $2.60 \%$ & 2.526 & 2.585 & $5.66 \%$ & $8.56 \%$ \\
\hline $\mathrm{B} / \mathrm{Li}$ & 1.805 & 1.744 & $-3.36 \%$ & 0.000598 & 0.000387 & 0.000985 & $1.40 \%$ & $1.13 \%$ & $1.80 \%$ & 1.728 & 1.761 & $3.89 \%$ & $5.88 \%$ \\
\hline $\mathrm{Ca}$ & 1.02 & 0.971 & $-4.80 \%$ & 0.000008 & 0.000565 & 0.000573 & $0.29 \%$ & $2.45 \%$ & $2.47 \%$ & 0.960 & 0.982 & $5.43 \%$ & $8.20 \%$ \\
\hline $\mathrm{Cr}$ & 0.06 & 0.066 & $10.06 \%$ & 0.000026 & 0.000023 & 0.000049 & $7.72 \%$ & $7.26 \%$ & $10.60 \%$ & 0.062 & 0.070 & $27.50 \%$ & $23.10 \%$ \\
\hline $\mathrm{Cu}$ & 0.0001 & -0.001 & $810.00 \%$ & 0.000009 & 0.000013 & 0.000022 & $422.54 \%$ & $507.82 \%$ & $660.62 \%$ & -0.003 & 0.002 & $-1441.25 \%$ & $-1427.19 \%$ \\
\hline $\mathrm{Fe}$ & 9.79 & 9.550 & $-2.46 \%$ & 0.030727 & 0.029682 & 0.060409 & $1.84 \%$ & $1.80 \%$ & $2.57 \%$ & 9.426 & 9.673 & $5.56 \%$ & $6.74 \%$ \\
\hline $\mathrm{Fe} / \mathrm{Al}$ & 3.916 & 3.994 & $1.98 \%$ & 0.002222 & 0.008155 & 0.010377 & $1.18 \%$ & $2.26 \%$ & $2.55 \%$ & 3.948 & 4.040 & $6.32 \%$ & $5.51 \%$ \\
\hline $\mathrm{Fe} / \mathrm{Ca}$ & 9.598 & 9.883 & $2.97 \%$ & 0.030124 & 0.078915 & 0.109039 & $1.76 \%$ & $2.84 \%$ & $3.34 \%$ & 9.724 & 10.042 & $8.56 \%$ & $7.28 \%$ \\
\hline $\mathrm{Fe} / \mathrm{Li}$ & 6.57 & 6.552 & $-0.28 \%$ & 0.010526 & 0.009968 & 0.020494 & $1.57 \%$ & $1.52 \%$ & $2.18 \%$ & 6.480 & 6.624 & $4.79 \%$ & $4.72 \%$ \\
\hline $\mathrm{Fe} / \mathrm{Mg}$ & 18.827 & 19.143 & $1.68 \%$ & 0.024027 & 0.025567 & 0.049594 & $0.81 \%$ & $0.84 \%$ & $1.16 \%$ & 19.027 & 19.259 & $3.39 \%$ & $2.53 \%$ \\
\hline $\mathrm{Fe} / \mathrm{Mn}$ & 6.705 & 6.838 & $1.99 \%$ & 0.002191 & 0.003606 & 0.005797 & $0.68 \%$ & $0.88 \%$ & $1.11 \%$ & 6.800 & 6.877 & $3.49 \%$ & $2.43 \%$ \\
\hline $\mathrm{Fe} / \mathrm{Ni}$ & 11.795 & 12.191 & $3.36 \%$ & 0.027218 & 0.047318 & 0.074536 & $1.35 \%$ & $1.78 \%$ & $2.24 \%$ & 12.061 & 12.322 & $6.49 \%$ & $4.84 \%$ \\
\hline $\mathrm{Fe} / \mathrm{U}$ & - & 6.546 & & 0.001865 & 0.005893 & 0.007758 & $0.66 \%$ & $1.17 \%$ & $1.35 \%$ & 6.502 & 6.590 & & \\
\hline $\mathrm{K}$ & 2.25 & 2.165 & $-3.78 \%$ & 0.020849 & 0.032443 & 0.053292 & $6.67 \%$ & $8.32 \%$ & $10.66 \%$ & 2.054 & 2.276 & $23.07 \%$ & $23.04 \%$ \\
\hline $\mathrm{Li}$ & 1.49 & 1.458 & $-2.14 \%$ & 0.000877 & 0.001119 & 0.001996 & $2.03 \%$ & $2.29 \%$ & $3.06 \%$ & 1.436 & 1.480 & $6.62 \%$ & $7.58 \%$ \\
\hline $\mathrm{Mg}$ & 0.52 & 0.496 & $-4.55 \%$ & 0.000114 & 0.000167 & 0.000281 & $2.15 \%$ & $2.60 \%$ & $3.38 \%$ & 0.488 & 0.505 & $7.30 \%$ & $9.71 \%$ \\
\hline $\mathrm{Mn}$ & 1.46 & 1.397 & $-4.30 \%$ & 0.000399 & 0.000898 & 0.001297 & $1.43 \%$ & $2.14 \%$ & $2.58 \%$ & 1.380 & 1.415 & $5.62 \%$ & $8.04 \%$ \\
\hline $\mathrm{Mn} / \mathrm{Mg}$ & 2.808 & 2.802 & $-0.23 \%$ & 0.00092 & 0.000842 & 0.001762 & $1.08 \%$ & $1.04 \%$ & $1.50 \%$ & 2.781 & 2.823 & $3.28 \%$ & $3.24 \%$ \\
\hline $\mathrm{Na}$ & 8.53 & & & & & & & & & & & & \\
\hline $\mathrm{Ni}$ & 0.83 & 0.784 & $-5.59 \%$ & 0.000021 & 0.000564 & 0.000585 & $0.58 \%$ & $3.03 \%$ & $3.09 \%$ & 0.774 & 0.794 & $6.67 \%$ & $9.82 \%$ \\
\hline $\mathrm{Si}$ & 22.39 & 22.414 & $0.11 \%$ & 0.084419 & 0.263206 & 0.347625 & $1.30 \%$ & $2.29 \%$ & $2.63 \%$ & 22.145 & 22.682 & $5.83 \%$ & $5.68 \%$ \\
\hline $\mathrm{Ti}$ & 0.69 & 0.672 & $-2.66 \%$ & 0.000064 & 0.000174 & 0.000238 & $1.19 \%$ & $1.96 \%$ & $2.30 \%$ & 0.664 & 0.679 & $5.00 \%$ & $6.30 \%$ \\
\hline $\mathrm{U}$ & 0 & -0.045 & & 0.003833 & 0.003878 & 0.007711 & $138.01 \%$ & $138.82 \%$ & $195.75 \%$ & -0.089 & -0.001 & $-422.89 \%$ & $-466.85 \%$ \\
\hline $\mathrm{U} / \mathrm{Ca}$ & 0 & -0.049 & & 0.003646 & 0.005307 & 0.008953 & $123.23 \%$ & $148.67 \%$ & $193.10 \%$ & -0.095 & -0.003 & $-417.17 \%$ & $-459.88 \%$ \\
\hline $\mathrm{Zr}$ & 0.1 & & & & & & & & & & & & \\
\hline $\begin{array}{c}\text { Sum } \\
\text { Ox }\end{array}$ & 87.7 & 86.176 & $-1.74 \%$ & 0.780452 & 3.27123 & 4.051682 & $1.03 \%$ & $2.10 \%$ & $2.34 \%$ & 85.278 & 87.073 & $5.05 \%$ & $5.78 \%$ \\
\hline
\end{tabular}


WSRC-STI-2006-00068

Revision 0

Table 3-1 Estimated Components of Variance, Mean Confidence Intervals, and Overall Uncertainty for ARG-1 Measurements (continued)

Mixed Acid/M-13

\begin{tabular}{|c|c|c|c|c|c|c|c|c|c|c|c|c|c|}
\hline \multirow[b]{2}{*}{ Analyte } & \multirow{2}{*}{$\begin{array}{c}\text { Reference } \\
\text { Value } \\
(\mathrm{wt} \%)\end{array}$} & \multirow{2}{*}{$\begin{array}{c}\text { Average } \\
(\mathrm{wt} \%)\end{array}$} & \multirow[b]{2}{*}{$\%$ Bias } & \multirow{2}{*}{$\begin{array}{c}\text { Estimate of } \\
\text { Between } \\
\text { Var }\end{array}$} & \multirow{2}{*}{$\begin{array}{l}\text { Estimate of } \\
\text { Within Var }\end{array}$} & \multirow{2}{*}{$\begin{array}{c}\text { Estimate of } \\
\text { Total } \\
\text { Variance }\end{array}$} & \multirow{2}{*}{$\begin{array}{c}\begin{array}{c}\text { Estimate } \\
\text { of }\end{array} \\
\% \text { RSD } \\
\text { (B) }\end{array}$} & \multirow{2}{*}{$\begin{array}{l}\text { Estimate of } \\
\text { \%RSD(W) }\end{array}$} & \multirow{2}{*}{$\begin{array}{c}\begin{array}{c}\text { Estimate } \\
\text { of }\end{array} \\
\% \operatorname{RSD}(\mathrm{T})\end{array}$} & \multicolumn{2}{|c|}{$95 \%$ Confidence Interval for Mean } & \multicolumn{2}{|c|}{$95 \%$ Measurement Uncertainty } \\
\hline & & & & & & & & & & Lower & Upper & $\%$ Lower & $\%$ Upper \\
\hline $\mathrm{Al}$ & 2.5 & 2.299 & $-8.04 \%$ & 0.000939 & 0.001763 & 0.002702 & $1.33 \%$ & $1.83 \%$ & $2.26 \%$ & 2.283 & 2.315 & $4.62 \%$ & $10.51 \%$ \\
\hline $\mathrm{Al} / \mathrm{Ca}$ & 2.451 & 2.313 & $-5.64 \%$ & 0.000606 & 0.001116 & 0.001722 & $1.06 \%$ & $1.44 \%$ & $1.79 \%$ & 2.300 & 2.325 & $3.66 \%$ & $7.48 \%$ \\
\hline $\mathrm{Al} / \mathrm{Mg}$ & 4.808 & 4.519 & $-6.02 \%$ & 0.007425 & 0.008062 & 0.015487 & $1.91 \%$ & $1.99 \%$ & $2.75 \%$ & 4.479 & 4.558 & $5.62 \%$ & $9.19 \%$ \\
\hline $\mathrm{Al} / \mathrm{Mn}$ & 1.712 & 1.654 & $-3.39 \%$ & 0.00058 & 0.000749 & 0.001329 & $1.46 \%$ & $1.65 \%$ & $2.20 \%$ & 1.643 & 1.665 & $4.50 \%$ & $6.15 \%$ \\
\hline $\mathrm{B}$ & 2.69 & & & & & & & & & & & & \\
\hline $\mathrm{B} / \mathrm{Li}$ & 1.805 & & & & & & & & & & & & \\
\hline $\mathrm{Ca}$ & 1.02 & 0.994 & $-2.57 \%$ & 0.000229 & 0.000282 & 0.000511 & $1.52 \%$ & $1.69 \%$ & $2.27 \%$ & 0.987 & 1.001 & $4.65 \%$ & $5.74 \%$ \\
\hline $\mathrm{Cr}$ & 0.06 & 0.067 & $11.34 \%$ & 0.000041 & 0.000026 & 0.000067 & $9.58 \%$ & $7.63 \%$ & $12.25 \%$ & 0.064 & 0.070 & $28.80 \%$ & $25.02 \%$ \\
\hline $\mathrm{Cu}$ & 0.0001 & -0.003 & $3480.00 \%$ & 0.00006 & 0.000006 & 0.000066 & $229.17 \%$ & $72.47 \%$ & $240.36 \%$ & -0.006 & 0.000 & $-491.58 \%$ & $-527.76 \%$ \\
\hline $\mathrm{Fe}$ & 9.79 & 9.524 & $-2.72 \%$ & 0.002008 & 0.039176 & 0.041184 & $0.47 \%$ & $2.08 \%$ & $2.13 \%$ & 9.469 & 9.579 & $4.36 \%$ & $5.51 \%$ \\
\hline $\mathrm{Fe} / \mathrm{Al}$ & 3.916 & 4.149 & $5.95 \%$ & 0.005276 & 0.006361 & 0.011637 & $1.75 \%$ & $1.92 \%$ & $2.60 \%$ & 4.115 & 4.183 & $8.34 \%$ & $5.31 \%$ \\
\hline $\mathrm{Fe} / \mathrm{Ca}$ & 9.598 & 9.593 & $-0.05 \%$ & 0.023985 & 0.024037 & 0.048022 & $1.61 \%$ & $1.62 \%$ & $2.28 \%$ & 9.524 & 9.663 & $4.71 \%$ & $4.67 \%$ \\
\hline $\mathrm{Fe} / \mathrm{Li}$ & 6.57 & 6.500 & $-1.07 \%$ & 0.030624 & 0.009195 & 0.039819 & $2.69 \%$ & $1.48 \%$ & $3.07 \%$ & 6.430 & 6.570 & $6.28 \%$ & $6.28 \%$ \\
\hline $\mathrm{Fe} / \mathrm{Mg}$ & 18.827 & 18.737 & $-0.48 \%$ & 0.041043 & 0.041294 & 0.082337 & $1.08 \%$ & $1.08 \%$ & $1.53 \%$ & 18.646 & 18.828 & $3.13 \%$ & $3.13 \%$ \\
\hline $\mathrm{Fe} / \mathrm{Mn}$ & 6.705 & 6.859 & $2.30 \%$ & 0.004794 & 0.005737 & 0.010531 & $1.01 \%$ & $1.10 \%$ & $1.50 \%$ & 6.827 & 6.891 & $4.09 \%$ & $3.06 \%$ \\
\hline $\mathrm{Fe} / \mathrm{Ni}$ & 11.795 & 11.829 & $0.29 \%$ & 0.031055 & 0.050373 & 0.081428 & $1.49 \%$ & $1.90 \%$ & $2.41 \%$ & 11.740 & 11.917 & $5.04 \%$ & $4.93 \%$ \\
\hline $\mathrm{Fe} / \mathrm{U}$ & - & & & & & & & & & & & & \\
\hline $\mathrm{K}$ & 2.25 & 2.007 & $-10.80 \%$ & 0.107098 & 0.059314 & 0.166412 & $16.31 \%$ & $12.13 \%$ & $20.32 \%$ & 1.869 & 2.145 & $41.57 \%$ & $45.70 \%$ \\
\hline $\mathrm{Li}$ & 1.49 & 1.465 & $-1.65 \%$ & 0.001682 & 0.00638 & 0.008062 & $2.80 \%$ & $5.45 \%$ & $6.13 \%$ & 1.448 & 1.482 & $12.55 \%$ & $12.87 \%$ \\
\hline $\mathrm{Mg}$ & 0.52 & 0.509 & $-2.20 \%$ & 0.000034 & 0.000116 & 0.00015 & $1.15 \%$ & $2.12 \%$ & $2.41 \%$ & 0.505 & 0.512 & $4.93 \%$ & $5.74 \%$ \\
\hline $\mathrm{Mn}$ & 1.46 & 1.389 & $-4.86 \%$ & 0.000041 & 0.000735 & 0.000776 & $0.46 \%$ & $1.95 \%$ & $2.01 \%$ & 1.381 & 1.397 & $4.10 \%$ & $6.99 \%$ \\
\hline $\mathrm{Mn} / \mathrm{Mg}$ & 2.808 & 2.732 & $-2.71 \%$ & 0.001394 & 0.001132 & 0.002526 & $1.37 \%$ & $1.23 \%$ & $1.84 \%$ & 2.716 & 2.748 & $3.76 \%$ & $5.05 \%$ \\
\hline $\mathrm{Na}$ & 8.53 & 8.328 & $-2.37 \%$ & 0.003996 & 0.008399 & 0.012395 & $0.76 \%$ & $1.10 \%$ & $1.34 \%$ & 8.290 & 8.365 & $2.76 \%$ & $3.99 \%$ \\
\hline $\mathrm{Ni}$ & 0.83 & 0.804 & $-3.17 \%$ & 0.000299 & 0.000341 & 0.00064 & $2.15 \%$ & $2.30 \%$ & $3.15 \%$ & 0.796 & 0.812 & $6.44 \%$ & $7.73 \%$ \\
\hline $\mathrm{Si}$ & 22.39 & 21.306 & $-4.84 \%$ & 0.082177 & 0.141992 & 0.224169 & $1.35 \%$ & $1.77 \%$ & $2.22 \%$ & 21.160 & 21.453 & $4.54 \%$ & $7.35 \%$ \\
\hline $\mathrm{Ti}$ & 0.69 & 0.671 & $-2.69 \%$ & 0.000163 & 0.000171 & 0.000334 & $1.90 \%$ & $1.95 \%$ & $2.72 \%$ & 0.666 & 0.677 & $5.57 \%$ & $6.65 \%$ \\
\hline $\mathrm{U}$ & 0 & -0.127 & & 0.006857 & 0.002756 & 0.009613 & $65.04 \%$ & $41.24 \%$ & $77.01 \%$ & -0.161 & -0.094 & $-157.28 \%$ & $-201.62 \%$ \\
\hline $\mathrm{U} / \mathrm{Ca}$ & 0 & -0.122 & & 0.006006 & 0.002659 & 0.008665 & $63.45 \%$ & $42.22 \%$ & $76.21 \%$ & -0.154 & -0.090 & $-155.87 \%$ & $-200.55 \%$ \\
\hline $\mathrm{Zr}$ & 0.1 & 0.093 & $-6.53 \%$ & 0.000044 & 0.000011 & 0.000055 & $7.10 \%$ & $3.55 \%$ & $7.93 \%$ & 0.091 & 0.096 & $16.23 \%$ & $18.97 \%$ \\
\hline $\begin{array}{c}\text { Sum } \\
\mathrm{Ox}\end{array}$ & 90.6 & 86.570 & $-4.45 \%$ & 0.78431 & 2.122052 & 2.906362 & $1.02 \%$ & $1.68 \%$ & $1.97 \%$ & 86.063 & 87.077 & $4.03 \%$ & $6.61 \%$ \\
\hline
\end{tabular}


WSRC-STI-2006-00068

Revision 0

Table 3-1 Estimated Components of Variance, Mean Confidence Intervals, and Overall Uncertainty for ARG-1 Measurements (continued)

Mixed Acid/M-14

\begin{tabular}{|c|c|c|c|c|c|c|c|c|c|c|c|c|c|}
\hline \multirow[b]{2}{*}{ Analyte } & \multirow{2}{*}{$\begin{array}{c}\text { Reference } \\
\begin{array}{c}\text { Value } \\
\text { (wt } \%)\end{array}\end{array}$} & \multirow{2}{*}{$\begin{array}{c}\text { Average } \\
(\mathrm{wt} \%) \\
\end{array}$} & \multirow[b]{2}{*}{$\%$ Bias } & \multirow{2}{*}{$\begin{array}{c}\text { Estimate of } \\
\text { Between } \\
\text { Var }\end{array}$} & \multirow{2}{*}{$\begin{array}{l}\text { Estimate of } \\
\text { Within Var }\end{array}$} & \multirow{2}{*}{$\begin{array}{c}\text { Estimate of } \\
\text { Total } \\
\text { Variance }\end{array}$} & \multirow{2}{*}{$\begin{array}{c}\begin{array}{c}\text { Estimate } \\
\text { of }\end{array} \\
\% \text { RSD } \\
\text { (B) } \\
\end{array}$} & \multirow{2}{*}{$\begin{array}{l}\text { Estimate of } \\
\% \operatorname{RSD}(\mathrm{W})\end{array}$} & \multirow{2}{*}{$\begin{array}{c}\begin{array}{c}\text { Estimate } \\
\text { of }\end{array} \\
\% \operatorname{RSD}(\mathrm{T}) \\
\end{array}$} & \multicolumn{2}{|c|}{$95 \%$ Confidence Interval for Mean } & \multicolumn{2}{|c|}{ 95\% Measurement Uncertainty } \\
\hline & & & & & & & & & & Lower & Upper & $\%$ Lower & $\%$ Upper \\
\hline $\mathrm{Al}$ & 2.5 & 2.366 & $-5.37 \%$ & 0.000705 & 0.001819 & 0.002524 & $1.12 \%$ & $1.80 \%$ & $2.12 \%$ & 2.348 & 2.384 & $4.42 \%$ & $7.80 \%$ \\
\hline $\mathrm{Al} / \mathrm{Ca}$ & 2.451 & 2.365 & $-3.50 \%$ & 0.000316 & 0.000886 & 0.001202 & $0.75 \%$ & $1.26 \%$ & $1.47 \%$ & 2.353 & 2.377 & $3.05 \%$ & $5.14 \%$ \\
\hline $\mathrm{Al} / \mathrm{Mg}$ & 4.808 & 4.657 & $-3.14 \%$ & 0.005154 & 0.003236 & 0.00839 & $1.54 \%$ & $1.22 \%$ & $1.97 \%$ & 4.620 & 4.693 & $4.09 \%$ & $5.74 \%$ \\
\hline $\mathrm{Al} / \mathrm{Mn}$ & 1.712 & 1.691 & $-1.20 \%$ & 0.00059 & 0.000321 & 0.000911 & $1.44 \%$ & $1.06 \%$ & $1.78 \%$ & 1.679 & 1.704 & $3.71 \%$ & $4.18 \%$ \\
\hline $\mathrm{B}$ & 2.69 & & & & & & & & & & & & \\
\hline $\mathrm{B} / \mathrm{Li}$ & 1.805 & & & & & & & & & & & & \\
\hline $\mathrm{Ca}$ & 1.02 & 1.000 & $-1.92 \%$ & 0.000083 & 0.000419 & 0.000502 & $0.91 \%$ & $2.05 \%$ & $2.24 \%$ & 0.993 & 1.008 & $4.66 \%$ & $5.39 \%$ \\
\hline $\mathrm{Cr}$ & 0.06 & 0.059 & $-1.18 \%$ & 0.000022 & 0.000006 & 0.000028 & $7.91 \%$ & $4.13 \%$ & $8.92 \%$ & 0.057 & 0.062 & $18.73 \%$ & $18.56 \%$ \\
\hline $\mathrm{Cu}$ & 0.0001 & -0.005 & $5460.00 \%$ & 0.000028 & 0.000002 & 0.00003 & $98.72 \%$ & $26.38 \%$ & $102.19 \%$ & -0.008 & -0.003 & $-212.51 \%$ & $-258.50 \%$ \\
\hline $\mathrm{Fe}$ & 9.79 & 9.492 & $-3.05 \%$ & 0.037323 & 0.019055 & 0.056378 & $2.04 \%$ & $1.45 \%$ & $2.50 \%$ & 9.396 & 9.588 & $5.20 \%$ & $6.66 \%$ \\
\hline $\mathrm{Fe} / \mathrm{Al}$ & 3.916 & 4.012 & $2.46 \%$ & 0.003916 & 0.002344 & 0.00626 & $1.56 \%$ & $1.21 \%$ & $1.97 \%$ & 3.981 & 4.044 & $5.20 \%$ & $4.10 \%$ \\
\hline $\mathrm{Fe} / \mathrm{Ca}$ & 9.598 & 9.489 & $-1.13 \%$ & 0.01237 & 0.023461 & 0.035831 & $1.17 \%$ & $1.61 \%$ & $1.99 \%$ & 9.421 & 9.558 & $4.15 \%$ & $4.55 \%$ \\
\hline $\mathrm{Fe} / \mathrm{Li}$ & 6.57 & 6.338 & $-3.54 \%$ & 0.014416 & 0.004065 & 0.018481 & $1.89 \%$ & $1.01 \%$ & $2.15 \%$ & 6.281 & 6.394 & $4.46 \%$ & $6.38 \%$ \\
\hline $\mathrm{Fe} / \mathrm{Mg}$ & 18.827 & 18.682 & $-0.77 \%$ & 0.087733 & 0.038321 & 0.126054 & $1.59 \%$ & $1.05 \%$ & $1.90 \%$ & 18.537 & 18.827 & $3.95 \%$ & $4.25 \%$ \\
\hline $\mathrm{Fe} / \mathrm{Mn}$ & 6.705 & 6.767 & $0.92 \%$ & 0.00921 & 0.004629 & 0.013839 & $1.42 \%$ & $1.01 \%$ & $1.74 \%$ & 6.718 & 6.815 & $3.98 \%$ & $3.63 \%$ \\
\hline $\mathrm{Fe} / \mathrm{Ni}$ & 11.795 & 11.820 & $0.21 \%$ & 0.027135 & 0.03584 & 0.062975 & $1.39 \%$ & $1.60 \%$ & $2.12 \%$ & 11.726 & 11.914 & $4.53 \%$ & $4.42 \%$ \\
\hline $\mathrm{Fe} / \mathrm{U}$ & - & & & & & & & & & & & & \\
\hline $\mathrm{K}$ & 2.25 & 2.227 & $-1.03 \%$ & 0.007624 & 0.017962 & 0.025586 & $3.92 \%$ & $6.02 \%$ & $7.18 \%$ & 2.170 & 2.284 & $15.02 \%$ & $14.94 \%$ \\
\hline $\mathrm{Li}$ & 1.49 & 1.498 & $0.53 \%$ & 0.000399 & 0.000564 & 0.000963 & $1.33 \%$ & $1.59 \%$ & $2.07 \%$ & 1.486 & 1.509 & $4.50 \%$ & $4.31 \%$ \\
\hline $\mathrm{Mg}$ & 0.52 & 0.508 & $-2.27 \%$ & 0.000096 & 0.000081 & 0.000177 & $1.93 \%$ & $1.77 \%$ & $2.62 \%$ & 0.503 & 0.513 & $5.44 \%$ & $6.39 \%$ \\
\hline $\mathrm{Mn}$ & 1.46 & 1.399 & $-4.18 \%$ & 0.000519 & 0.000601 & 0.00112 & $1.63 \%$ & $1.75 \%$ & $2.39 \%$ & 1.386 & 1.412 & $4.97 \%$ & $7.25 \%$ \\
\hline $\mathrm{Mn} / \mathrm{Mg}$ & 2.808 & 2.753 & $-1.94 \%$ & 0.001205 & 0.000851 & 0.002056 & $1.26 \%$ & $1.06 \%$ & $1.65 \%$ & 2.736 & 2.771 & $3.42 \%$ & $4.32 \%$ \\
\hline $\mathrm{Na}$ & 8.53 & 8.400 & $-1.52 \%$ & 0.005383 & 0.016489 & 0.021872 & $0.87 \%$ & $1.53 \%$ & $1.76 \%$ & 8.344 & 8.457 & $3.70 \%$ & $4.31 \%$ \\
\hline $\mathrm{Ni}$ & 0.83 & 0.803 & $-3.24 \%$ & 0.000061 & 0.00024 & 0.000301 & $0.97 \%$ & $1.93 \%$ & $2.16 \%$ & 0.797 & 0.809 & $4.49 \%$ & $6.07 \%$ \\
\hline $\mathrm{Si}$ & 22.39 & 20.985 & $-6.27 \%$ & 0.210354 & 0.289058 & 0.499412 & $2.19 \%$ & $2.56 \%$ & $3.37 \%$ & 20.706 & 21.264 & $7.05 \%$ & $10.68 \%$ \\
\hline $\mathrm{Ti}$ & 0.69 & 0.688 & $-0.29 \%$ & 0.000024 & 0.000179 & 0.000203 & $0.71 \%$ & $1.94 \%$ & $2.07 \%$ & 0.683 & 0.693 & $4.33 \%$ & $4.31 \%$ \\
\hline $\mathrm{U}$ & 0 & $\begin{array}{l}-0.092 \\
\end{array}$ & & 0.004201 & 0.001916 & 0.006117 & $70.78 \%$ & $47.80 \%$ & $85.41 \%$ & -0.123 & -0.060 & $-177.62 \%$ & $-222.97 \%$ \\
\hline $\mathrm{U} / \mathrm{Ca}$ & 0 & -0.092 & & 0.004171 & 0.002093 & 0.006264 & $70.15 \%$ & $49.70 \%$ & $85.97 \%$ & -0.124 & -0.060 & $-178.79 \%$ & $-223.91 \%$ \\
\hline $\mathrm{Zr}$ & 0.1 & 0.094 & $-5.80 \%$ & 0.000017 & 0.000007 & 0.000024 & $4.38 \%$ & $2.81 \%$ & $5.20 \%$ & 0.092 & 0.096 & $10.81 \%$ & $13.61 \%$ \\
\hline $\begin{array}{c}\text { Sum } \\
\text { Ox }\end{array}$ & 90.6 & 85.974 & $-5.11 \%$ & 2.183376 & 4.211222 & 6.394598 & $1.72 \%$ & $2.39 \%$ & $2.94 \%$ & 85.055 & 86.892 & $6.12 \%$ & $8.89 \%$ \\
\hline
\end{tabular}


WSRC-STI-2006-00068

Revision 0

Table 3-2 Estimated Components of Variance and Mean Confidence Intervals for Process Samples

Cold Chem/M-13

\begin{tabular}{|c|c|c|c|c|c|c|c|c|c|c|c|c|c|}
\hline & & & & Estimate of & Estimate of & Estimate of & Estimate of & Estimate of & Estimate of & & & \multicolumn{2}{|c|}{$95 \%$ Confidence Interval for Mean } \\
\hline Analyte & Process & $\begin{array}{c}\text { Average } \\
(\mathrm{wt} \%)\end{array}$ & $\mathrm{n}$ & $\begin{array}{l}\text { Between } \\
\text { Variance } \\
\end{array}$ & $\begin{array}{c}\text { Within } \\
\text { Variance }\end{array}$ & $\begin{array}{c}\text { Total } \\
\text { Variance } \\
\end{array}$ & $\% \mathrm{RSD}(\mathrm{B})$ & $\% \mathrm{RSD}(\mathrm{W})$ & $\% \operatorname{RSD}(\mathrm{T})$ & $\begin{array}{c}\text { MS } \\
\text { Between }\end{array}$ & DoF & Lower & Upper \\
\hline $\mathrm{Al}$ & SRAT & 5.142316 & 114 & 0.019759 & 0.037367 & 0.057126 & $2.73 \%$ & $3.76 \%$ & $4.65 \%$ & 0.15592 & 18 & 5.065 & 5.220 \\
\hline $\mathrm{Al} / \mathrm{Ca}$ & SRAT & 3.837108 & 150 & 0.001677 & 0.005061 & 0.006738 & $1.07 \%$ & $1.85 \%$ & $2.14 \%$ & 0.01512 & 24 & 3.816 & 3.858 \\
\hline $\mathrm{Al} / \mathrm{Mg}$ & SRAT & 3.841868 & 150 & 0.008873 & 0.009367 & 0.01824 & $2.45 \%$ & $2.52 \%$ & $3.52 \%$ & 0.0626 & 24 & 3.800 & 3.884 \\
\hline $\mathrm{Al} / \mathrm{Mn}$ & SRAT & 1.619489 & 144 & 0.000031 & 0.000024 & 0.000055 & $0.34 \%$ & $0.30 \%$ & $0.46 \%$ & 0.00664 & 23 & 1.605 & 1.634 \\
\hline B & SRAT & 0.011891 & 156 & 0.000588 & 0.000032 & 0.00062 & $203.92 \%$ & $47.57 \%$ & $209.40 \%$ & 0.00356 & 25 & 0.002 & 0.022 \\
\hline $\mathrm{B} / \mathrm{Li}$ & SRAT & 0.253943 & 107 & 1.371449 & 0.833412 & 2.204861 & $461.16 \%$ & $359.50 \%$ & $584.73 \%$ & 8.9852 & 17 & -0.357 & 0.865 \\
\hline $\mathrm{Ca}$ & SRAT & 1.342026 & 114 & 0.001739 & 0.001177 & 0.002916 & $3.11 \%$ & $2.56 \%$ & $4.02 \%$ & 0.01161 & 18 & 1.321 & 1.363 \\
\hline $\mathrm{Cr}$ & SRAT & 0.084246 & 138 & 0.000036 & 0.00003 & 0.000066 & $7.12 \%$ & $6.50 \%$ & $9.64 \%$ & 0.00025 & 22 & 0.081 & 0.087 \\
\hline $\mathrm{Cu}$ & SRAT & 0.032562 & 144 & 0.000009 & 0.000008 & 0.000017 & $9.21 \%$ & $8.69 \%$ & $12.66 \%$ & 0.00006 & 23 & 0.031 & 0.034 \\
\hline $\mathrm{Fe}$ & SRAT & 15.06258 & 126 & 0.35166 & 0.589908 & 0.941568 & $3.94 \%$ & $5.10 \%$ & $6.44 \%$ & 2.69987 & 20 & 14.757 & 15.368 \\
\hline $\mathrm{Fe} / \mathrm{Al}$ & SRAT & 2.923278 & 132 & 0.002235 & 0.001743 & 0.003978 & $1.62 \%$ & $1.43 \%$ & $2.16 \%$ & 0.01515 & 21 & 2.901 & 2.946 \\
\hline $\mathrm{Fe} / \mathrm{Ca}$ & SRAT & 11.15218 & 138 & 0.057839 & 0.058253 & 0.116092 & $2.16 \%$ & $2.16 \%$ & $3.06 \%$ & 0.40528 & 22 & 11.040 & 11.265 \\
\hline $\mathrm{Fe} / \mathrm{Li}$ & SRAT & - & & & & & & & & & & & \\
\hline $\mathrm{Fe} / \mathrm{Mg}$ & SRAT & 11.16104 & 138 & 0.058619 & 0.072505 & 0.131124 & $2.17 \%$ & $2.41 \%$ & $3.24 \%$ & 0.42422 & 22 & 11.046 & 11.276 \\
\hline $\mathrm{Fe} / \mathrm{Mn}$ & SRAT & 4.720936 & 144 & 0.010697 & 0.008329 & 0.019026 & $2.19 \%$ & $1.93 \%$ & $2.92 \%$ & 0.07251 & 23 & 4.675 & 4.767 \\
\hline $\mathrm{Fe} / \mathrm{Ni}$ & SRAT & 17.38547 & 132 & 0.071776 & 0.048859 & 0.120635 & $1.54 \%$ & $1.27 \%$ & $2.00 \%$ & 0.47951 & 21 & 17.260 & 17.511 \\
\hline $\mathrm{Fe} / \mathrm{U}$ & SRAT & 2.701894 & 144 & 0.013955 & 0.004535 & 0.01849 & $4.37 \%$ & $2.49 \%$ & $5.03 \%$ & 0.08827 & 23 & 2.651 & 2.753 \\
\hline $\mathrm{K}$ & SRAT & 0.251314 & 156 & 0.032657 & 0.011443 & 0.0441 & $71.91 \%$ & $42.57 \%$ & $83.56 \%$ & 0.020738 & 25 & 0.228 & 0.275 \\
\hline $\mathrm{Li}$ & SRAT & 0.007727 & 150 & 0.000639 & 0.000034 & 0.000673 & $327.14 \%$ & $75.46 \%$ & $335.74 \%$ & 0.00387 & 24 & -0.003 & 0.018 \\
\hline $\mathrm{Mg}$ & SRAT & 1.340317 & 126 & 0.002395 & 0.002757 & 0.005152 & $3.65 \%$ & $3.92 \%$ & $5.36 \%$ & 0.01713 & 20 & 1.316 & 1.365 \\
\hline $\mathrm{Mn}$ & SRAT & 3.184317 & 120 & 0.014961 & 0.011639 & 0.0266 & $3.84 \%$ & $3.39 \%$ & $5.12 \%$ & 0.10141 & 19 & 3.123 & 3.245 \\
\hline $\mathrm{Mn} / \mathrm{Mg}$ & SRAT & 2.371366 & 156 & 0.00105 & 0.002084 & 0.003134 & $1.37 \%$ & $1.93 \%$ & $2.36 \%$ & 0.00839 & 25 & 2.356 & 2.386 \\
\hline $\mathrm{Na}$ & SRAT & 10.63782 & 114 & 0.029301 & 0.075806 & 0.105107 & $1.61 \%$ & $2.59 \%$ & $3.05 \%$ & 0.25161 & 18 & 10.539 & 10.737 \\
\hline $\mathrm{Ni}$ & SRAT & 0.866895 & 114 & 0.001063 & 0.001277 & 0.00234 & $3.76 \%$ & $4.12 \%$ & $5.58 \%$ & 0.00766 & 18 & 0.850 & 0.884 \\
\hline $\mathrm{Si}$ & SRAT & 1.162522 & 138 & 0.012658 & 0.005145 & 0.017803 & $9.68 \%$ & $6.17 \%$ & $11.48 \%$ & 0.08109 & 22 & 1.112 & 1.213 \\
\hline $\mathrm{Ti}$ & SRAT & 0.014567 & 150 & 0.000011 & 0.000003 & 0.000014 & $22.77 \%$ & $11.89 \%$ & $25.69 \%$ & 0.00007 & 24 & 0.013 & 0.016 \\
\hline $\mathrm{U}$ & SRAT & 5.57614 & 114 & 0.042396 & 0.029745 & 0.072141 & $3.69 \%$ & $3.09 \%$ & $4.82 \%$ & 0.28412 & 18 & 5.471 & 5.681 \\
\hline $\mathrm{U} / \mathrm{Ca}$ & SRAT & 4.132033 & 156 & 0.0154 & 0.003869 & 0.019269 & $3.00 \%$ & $1.51 \%$ & $3.36 \%$ & 0.09627 & 25 & 4.081 & 4.183 \\
\hline $\mathrm{Zr}$ & SRAT & 0.077667 & 144 & 0.000037 & 0.000026 & 0.000063 & $7.83 \%$ & $6.57 \%$ & $10.22 \%$ & 0.00025 & 23 & 0.075 & 0.080 \\
\hline Sum Ox & SRAT & 64.68359 & 114 & 3.840858 & 3.673771 & 7.514629 & $3.03 \%$ & $2.96 \%$ & $4.24 \%$ & 26.7189 & 18 & 63.666 & 65.701 \\
\hline
\end{tabular}


WSRC-STI-2006-00068

Revision 0

Table 3-2 Estimated Components of Variance and Mean Confidence Intervals for Process Samples (continued)

Cold Chem/M-14

\begin{tabular}{|c|c|c|c|c|c|c|c|c|c|c|c|c|c|}
\hline & & & & Estimate of & Estimate of & Estimate of & $\begin{array}{c}\text { Estimate } \\
\text { of }\end{array}$ & Estimate of & $\begin{array}{c}\text { Estimate } \\
\text { of }\end{array}$ & & & \multicolumn{2}{|c|}{$95 \%$ Confidence Interval for Mear } \\
\hline Analyte & Process & Average $(\mathrm{wt} \%)$ & $\mathrm{n}$ & $\begin{array}{l}\text { Between } \\
\text { Variance }\end{array}$ & $\begin{array}{c}\text { Within } \\
\text { Variance }\end{array}$ & $\begin{array}{c}\text { Total } \\
\text { Variance } \\
\end{array}$ & $\begin{array}{c}\text { \%RSD } \\
\text { (B) }\end{array}$ & $\% \operatorname{RSD}(\mathrm{W})$ & $\% \operatorname{RSD}(\mathrm{T})$ & $\begin{array}{c}\text { MS } \\
\text { Between }\end{array}$ & DoF & Lower & Upper \\
\hline $\mathrm{Al}$ & SRAT & 5.092173 & 168 & 0.040134 & 0.071265 & 0.111399 & $3.93 \%$ & $5.24 \%$ & $6.55 \%$ & 0.31207 & 27 & 5.004 & 5.181 \\
\hline $\mathrm{Al} / \mathrm{Ca}$ & SRAT & 3.808229 & 162 & 0.004894 & 0.00954 & 0.014434 & $1.84 \%$ & $2.56 \%$ & $3.15 \%$ & 0.0389 & 26 & 3.776 & 3.840 \\
\hline $\mathrm{Al} / \mathrm{Mg}$ & SRAT & 3.881657 & 156 & 0.005158 & 0.0176 & 0.022758 & $1.85 \%$ & $3.42 \%$ & $3.89 \%$ & 0.04855 & 25 & 3.845 & 3.918 \\
\hline $\mathrm{Al} / \mathrm{Mn}$ & SRAT & 1.623093 & 150 & 0.000463 & 0.000963 & 0.001426 & $1.33 \%$ & $1.91 \%$ & $2.33 \%$ & 0.00374 & 24 & 1.613 & 1.633 \\
\hline $\mathrm{B}$ & SRAT & 0.007577 & 168 & 0.000248 & 0.000015 & 0.000263 & $207.84 \%$ & $51.11 \%$ & $214.03 \%$ & 0.0015 & 27 & 0.001 & 0.014 \\
\hline $\mathrm{B} / \mathrm{Li}$ & SRAT & & & & & & & & & & & & \\
\hline $\mathrm{Ca}$ & SRAT & 1.336208 & 144 & 0.001371 & 0.001742 & 0.003113 & $2.77 \%$ & $3.12 \%$ & $4.18 \%$ & 0.00997 & 23 & 1.319 & 1.353 \\
\hline $\mathrm{Cr}$ & SRAT & 0.08831 & 168 & 0.000046 & 0.000029 & 0.000075 & $7.68 \%$ & $6.10 \%$ & $9.81 \%$ & 0.0003 & 27 & 0.086 & 0.091 \\
\hline $\mathrm{Cu}$ & SRAT & 0.028247 & 174 & 0.000011 & 0.000005 & 0.000016 & $11.74 \%$ & $7.92 \%$ & $14.16 \%$ & 0.00007 & 28 & 0.027 & 0.030 \\
\hline $\mathrm{Fe}$ & SRAT & 14.66683 & 162 & 0.467665 & 0.596778 & 1.064443 & $4.66 \%$ & $5.27 \%$ & $7.03 \%$ & 3.40277 & 26 & 14.369 & 14.965 \\
\hline $\mathrm{Fe} / \mathrm{Al}$ & SRAT & 2.88557 & 162 & 0.001274 & 0.002085 & 0.003359 & $1.24 \%$ & $1.58 \%$ & $2.01 \%$ & 0.00973 & 26 & 2.870 & 2.902 \\
\hline $\mathrm{Fe} / \mathrm{Ca}$ & SRAT & 10.99948 & 162 & 0.084765 & 0.100118 & 0.184883 & $2.65 \%$ & $2.88 \%$ & $3.91 \%$ & 0.60871 & 26 & 10.873 & 11.125 \\
\hline $\mathrm{Fe} / \mathrm{Li}$ & SRAT & - & & & & & & & & & & & \\
\hline $\mathrm{Fe} / \mathrm{Mg}$ & SRAT & 11.20593 & 168 & 0.083785 & 0.128779 & 0.212564 & $2.58 \%$ & $3.20 \%$ & $4.11 \%$ & 0.63149 & 27 & 11.080 & 11.332 \\
\hline $\mathrm{Fe} / \mathrm{Mn}$ & SRAT & 4.686563 & 168 & 0.008628 & 0.006665 & 0.015293 & $1.98 \%$ & $1.74 \%$ & $2.64 \%$ & 0.05843 & 27 & 4.648 & 4.725 \\
\hline $\mathrm{Fe} / \mathrm{Ni}$ & SRAT & 17.21092 & 162 & 0.017063 & 0.062958 & 0.080021 & $0.76 \%$ & $1.46 \%$ & $1.64 \%$ & 0.16533 & 26 & 17.145 & 17.277 \\
\hline $\mathrm{Fe} / \mathrm{U}$ & SRAT & 2.648256 & 156 & 0.005284 & 0.006448 & 0.011732 & $2.74 \%$ & $3.03 \%$ & $4.09 \%$ & 0.03815 & 25 & 2.616 & 2.680 \\
\hline $\mathrm{K}$ & SRAT & 0.159494 & 180 & 0.01001 & 0.005298 & 0.015308 & $62.73 \%$ & $45.64 \%$ & $77.57 \%$ & 0.06536 & 29 & 0.121 & 0.198 \\
\hline $\mathrm{Li}$ & SRAT & -0.01106 & 162 & 0.000398 & 0.000059 & 0.000457 & $180.38 \%$ & $69.45 \%$ & $193.29 \%$ & 0.00245 & 26 & -0.019 & -0.003 \\
\hline $\mathrm{Mg}$ & SRAT & 1.316891 & 138 & 0.001809 & 0.001484 & 0.003293 & $3.23 \%$ & $2.93 \%$ & $4.36 \%$ & 0.01234 & 22 & 1.297 & 1.337 \\
\hline $\mathrm{Mn}$ & SRAT & 3.12864 & 150 & 0.014734 & 0.013496 & 0.02823 & $3.88 \%$ & $3.71 \%$ & $5.37 \%$ & 0.1019 & 24 & 3.075 & 3.182 \\
\hline $\mathrm{Mn} / \mathrm{Mg}$ & SRAT & 2.388462 & 174 & 0.000532 & 0.002697 & 0.003229 & $0.97 \%$ & $2.17 \%$ & $2.38 \%$ & 0.00589 & 28 & 2.377 & 2.400 \\
\hline $\mathrm{Na}$ & SRAT & 10.48891 & 132 & 0.122829 & 0.059293 & 0.182122 & $3.34 \%$ & $2.32 \%$ & $4.07 \%$ & 0.79627 & 21 & 10.327 & 10.650 \\
\hline $\mathrm{Ni}$ & SRAT & 0.852729 & 144 & 0.001682 & 0.001337 & 0.003019 & $4.81 \%$ & $4.29 \%$ & $6.44 \%$ & 0.01143 & 23 & 0.834 & 0.871 \\
\hline $\mathrm{Si}$ & SRAT & 1.078161 & 174 & 0.033962 & 0.00363 & 0.037592 & $17.09 \%$ & $5.59 \%$ & $17.98 \%$ & 0.2074 & 28 & 1.007 & 1.149 \\
\hline $\mathrm{Ti}$ & SRAT & 0.016476 & 168 & 0.000013 & 0.000002 & 0.000015 & $21.88 \%$ & $8.58 \%$ & $23.51 \%$ & 0.00008 & 27 & 0.015 & 0.018 \\
\hline $\mathrm{U}$ & SRAT & 5.506865 & 156 & 0.037274 & 0.048697 & 0.085971 & $3.51 \%$ & $4.01 \%$ & $5.32 \%$ & 0.27234 & 25 & 5.421 & 5.593 \\
\hline $\mathrm{U} / \mathrm{Ca}$ & SRAT & 4.141391 & 168 & 0.015488 & 0.008133 & 0.023621 & $3.01 \%$ & $2.18 \%$ & $3.71 \%$ & 0.10106 & 27 & 4.091 & 4.192 \\
\hline $\mathrm{Zr}$ & SRAT & 0.07804 & 174 & 0.000033 & 0.000019 & 0.000052 & $7.36 \%$ & $5.59 \%$ & $9.24 \%$ & 0.00022 & 28 & 0.076 & 0.080 \\
\hline Sum Ox & SRAT & 62.99344 & 150 & 3.657759 & 6.040064 & 9.697823 & $3.04 \%$ & $3.90 \%$ & $4.94 \%$ & 27.9866 & 24 & 62.102 & 63.885 \\
\hline
\end{tabular}


WSRC-STI-2006-00068

Revision 0

Table 3-2 Estimated Components of Variance and Mean Confidence Intervals for Process Samples (continued)

Fusion/M-13

\begin{tabular}{|c|c|c|c|c|c|c|c|c|c|c|c|c|c|}
\hline & & & & Estimate of & Estimate of & Estimate of & $\begin{array}{c}\text { Estimate } \\
\text { of }\end{array}$ & Estimate of & $\begin{array}{c}\text { Estimate } \\
\text { of }\end{array}$ & & & $95 \%$ Confidenc & val for Mean \\
\hline Analyte & Process & Average (wt $\%$ ) & $\mathrm{n}$ & $\begin{array}{l}\text { Between } \\
\text { Variance }\end{array}$ & $\begin{array}{c}\text { Within } \\
\text { Variance }\end{array}$ & $\begin{array}{c}\text { Total } \\
\text { Variance } \\
\end{array}$ & $\begin{array}{c}\text { RSD } \\
(\mathrm{B})\end{array}$ & $\% \mathrm{RSD}(\mathrm{W})$ & $\% \operatorname{RSD}(\mathrm{T})$ & $\begin{array}{c}\text { MS } \\
\text { Between }\end{array}$ & DoF & Lower & Upper \\
\hline $\mathrm{Al}$ & SME & 2.956626 & 198 & 0.036541 & 0.015696 & 0.052237 & $6.47 \%$ & $4.24 \%$ & $7.73 \%$ & 0.23494 & 32 & 2.886 & 3.027 \\
\hline $\mathrm{Al} / \mathrm{Ca}$ & SME & 4.109778 & 192 & 0.014504 & 0.017205 & 0.031709 & $2.93 \%$ & $3.19 \%$ & $4.33 \%$ & 0.10423 & 31 & 4.062 & 4.157 \\
\hline $\mathrm{Al} / \mathrm{Mg}$ & SME & 4.314932 & 198 & 0.028375 & 0.027778 & 0.056153 & $3.90 \%$ & $3.86 \%$ & $5.49 \%$ & 0.19803 & 32 & 4.251 & 4.379 \\
\hline $\mathrm{Al} / \mathrm{Mn}$ & SME & 1.878336 & 198 & 0.004903 & 0.002835 & 0.007738 & $3.73 \%$ & $2.83 \%$ & $4.68 \%$ & 0.03225 & 32 & 1.852 & 1.904 \\
\hline $\mathrm{B}$ & SME & 1.448972 & 180 & 0.00227 & 0.002645 & 0.004915 & $3.29 \%$ & $3.55 \%$ & $4.84 \%$ & 0.01627 & 29 & 1.430 & 1.468 \\
\hline $\mathrm{B} / \mathrm{Li}$ & SME & 0.658095 & 204 & 0.000136 & 0.000189 & 0.000325 & $1.77 \%$ & $2.09 \%$ & $2.74 \%$ & 0.001 & 33 & 0.654 & 0.663 \\
\hline $\mathrm{Ca}$ & SME & 0.71798 & 204 & 0.002711 & 0.001807 & 0.004518 & $7.25 \%$ & $5.92 \%$ & $9.36 \%$ & 0.01807 & 33 & 0.699 & 0.737 \\
\hline $\mathrm{Cr}$ & SME & 0.055045 & 198 & 0.000038 & 0.000014 & 0.000052 & $11.20 \%$ & $6.80 \%$ & $13.10 \%$ & 0.00024 & 32 & 0.053 & 0.057 \\
\hline $\mathrm{Cu}$ & SME & 0.014146 & 192 & 0.000017 & 0.000001 & 0.000018 & $29.15 \%$ & $7.07 \%$ & $29.99 \%$ & 0.00011 & 31 & 0.013 & 0.016 \\
\hline $\mathrm{Fe}$ & SME & 7.96904 & 198 & 0.154136 & 0.113598 & 0.267734 & $4.93 \%$ & $4.23 \%$ & $6.49 \%$ & 1.03841 & 32 & 7.822 & 8.117 \\
\hline $\mathrm{Fe} / \mathrm{Al}$ & SME & 2.692412 & 204 & 0.008046 & 0.002192 & 0.010238 & $3.33 \%$ & $1.74 \%$ & $3.76 \%$ & 0.05047 & 33 & 2.660 & 2.724 \\
\hline $\mathrm{Fe} / \mathrm{Ca}$ & SME & 11.08334 & 192 & 0.176172 & 0.12507 & 0.301242 & $3.79 \%$ & $3.19 \%$ & $4.95 \%$ & 1.1821 & 31 & 10.923 & 11.243 \\
\hline $\mathrm{Fe} / \mathrm{Li}$ & SME & 3.622828 & 204 & 0.065614 & 0.014899 & 0.080513 & $7.07 \%$ & $3.37 \%$ & $7.83 \%$ & 0.40858 & 33 & 3.532 & 3.714 \\
\hline $\mathrm{Fe} / \mathrm{Mg}$ & SME & 11.58352 & 192 & 0.179584 & 0.109651 & 0.289235 & $3.66 \%$ & $2.86 \%$ & $4.64 \%$ & 1.18716 & 31 & 11.423 & 11.744 \\
\hline $\mathrm{Fe} / \mathrm{Mn}$ & SME & 5.048998 & 204 & 0.020213 & 0.014434 & 0.034647 & $2.82 \%$ & $2.38 \%$ & $3.69 \%$ & 0.13571 & 33 & 4.997 & 5.101 \\
\hline $\mathrm{Fe} / \mathrm{Ni}$ & SME & 17.50425 & 210 & 0.160614 & 0.11932 & 0.279934 & $2.29 \%$ & $1.97 \%$ & $3.02 \%$ & 1.083 & 34 & 17.358 & 17.650 \\
\hline $\mathrm{Fe} / \mathrm{U}$ & SME & 3.087834 & 210 & 0.019898 & 0.002703 & 0.022601 & $4.57 \%$ & $1.68 \%$ & $4.87 \%$ & 0.12209 & 34 & 3.039 & 3.137 \\
\hline $\mathrm{K}$ & SME & 0.101844 & 192 & 0.01181 & 0.01163 & 0.02344 & $106.71 \%$ & $105.89 \%$ & $150.33 \%$ & 0.08249 & 31 & 0.060 & 0.144 \\
\hline $\mathrm{Li}$ & SME & 2.202906 & 180 & 0.003417 & 0.005659 & 0.009076 & $2.65 \%$ & $3.41 \%$ & $4.32 \%$ & 0.02616 & 29 & 2.178 & 2.228 \\
\hline $\mathrm{Mg}$ & SME & 0.685966 & 204 & 0.00233 & 0.001461 & 0.003791 & $7.04 \%$ & $5.57 \%$ & $8.98 \%$ & 0.01544 & 33 & 0.668 & 0.704 \\
\hline $\mathrm{Mn}$ & SME & 1.57525 & 204 & 0.011374 & 0.006361 & 0.017735 & $6.77 \%$ & $5.06 \%$ & $8.45 \%$ & 0.0746 & 33 & 1.536 & 1.614 \\
\hline $\mathrm{Mn} / \mathrm{Mg}$ & SME & 2.296603 & 198 & 0.002186 & 0.001738 & 0.003924 & $2.04 \%$ & $1.82 \%$ & $2.73 \%$ & 0.01485 & 32 & 2.279 & 2.314 \\
\hline $\mathrm{Na}$ & SME & & & & & & & & & & & & \\
\hline $\mathrm{Ni}$ & SME & 0.456263 & 198 & 0.000668 & 0.000531 & 0.001199 & $5.66 \%$ & $5.05 \%$ & $7.59 \%$ & 0.00454 & 32 & 0.447 & 0.466 \\
\hline $\mathrm{Si}$ & SME & 23.80898 & 198 & 0.47517 & 1.26271 & 1.73788 & $2.90 \%$ & $4.72 \%$ & $5.54 \%$ & 4.11373 & 32 & 23.515 & 24.103 \\
\hline $\mathrm{Ti}$ & SME & 0.038603 & 204 & 0.000059 & 0.000004 & 0.000063 & $19.90 \%$ & $5.18 \%$ & $20.56 \%$ & 0.00036 & 33 & 0.036 & 0.041 \\
\hline $\mathrm{U}$ & SME & 2.601328 & 192 & 0.026761 & 0.010782 & 0.037543 & $6.29 \%$ & $3.99 \%$ & $7.45 \%$ & 0.17135 & 31 & 2.540 & 2.662 \\
\hline $\mathrm{U} / \mathrm{Ca}$ & SME & 3.611818 & 210 & 0.053232 & 0.017015 & 0.070247 & $6.39 \%$ & $3.61 \%$ & $7.34 \%$ & 0.33641 & 34 & 3.530 & 3.693 \\
\hline $\mathrm{Zr}$ & SME & & & & & & & & & & & & \\
\hline Sum Ox & SME & 85.72756 & 192 & 1.203131 & 8.418976 & 9.622107 & $1.28 \%$ & $3.38 \%$ & $3.62 \%$ & 15.6378 & 31 & 85.146 & 86.310 \\
\hline
\end{tabular}


WSRC-STI-2006-00068

Revision 0

Table 3-2 Estimated Components of Variance and Mean Confidence Intervals for Process Samples (continued)

Fusion/M-14

\begin{tabular}{|c|c|c|c|c|c|c|c|c|c|c|c|c|c|}
\hline & & & & Estimate of & Estimate of & Estimate of & Estimate of & Estimate of & Estimate of & & & \multicolumn{2}{|c|}{$95 \%$ Confidence Interval for Mea } \\
\hline Analyte & Process & Average (wt $\%)$ & $\mathrm{n}$ & $\begin{array}{l}\text { Between } \\
\text { Variance }\end{array}$ & $\begin{array}{c}\text { Within } \\
\text { Variance }\end{array}$ & $\begin{array}{c}\text { Total } \\
\text { Variance } \\
\end{array}$ & \%RSD (B) & $\% \mathrm{RSD}(\mathrm{W})$ & $\% \operatorname{RSD}(\mathrm{T})$ & $\begin{array}{c}\text { MS } \\
\text { Between }\end{array}$ & DoF & Lower & Upper \\
\hline $\mathrm{Al}$ & SME & 2.885389 & 54 & 0.02575 & 0.033926 & 0.059676 & $5.56 \%$ & $6.38 \%$ & $8.47 \%$ & 0.18842 & 8 & 2.749 & 3.022 \\
\hline $\mathrm{Al} / \mathrm{Ca}$ & SME & 4.178395 & 60 & 0.016479 & 0.013636 & 0.030115 & $3.07 \%$ & $2.79 \%$ & $4.15 \%$ & 0.11251 & 9 & 4.080 & 4.276 \\
\hline $\mathrm{Al} / \mathrm{Mg}$ & SME & 4.307171 & 60 & 0.007653 & 0.008472 & 0.016125 & $2.03 \%$ & $2.14 \%$ & $2.95 \%$ & 0.05439 & 9 & 4.239 & 4.375 \\
\hline $\mathrm{Al} / \mathrm{Mn}$ & SME & 1.873531 & 60 & 0.001112 & 0.001611 & 0.002723 & $1.78 \%$ & $2.14 \%$ & $2.79 \%$ & 0.00828 & 9 & 1.847 & 1.900 \\
\hline $\mathrm{B}$ & SME & 1.390241 & 54 & 0.004578 & 0.007651 & 0.012229 & $4.87 \%$ & $6.29 \%$ & $7.95 \%$ & 0.03512 & 8 & 1.331 & 1.449 \\
\hline $\mathrm{B} / \mathrm{Li}$ & SME & 0.640935 & 60 & 0.000115 & 0.00009 & 0.000205 & $1.67 \%$ & $1.48 \%$ & $2.23 \%$ & 0.00078 & 9 & 0.633 & 0.649 \\
\hline $\mathrm{Ca}$ & SME & 0.687037 & 54 & 0.002227 & 0.002413 & 0.00464 & $6.87 \%$ & $7.15 \%$ & $9.91 \%$ & 0.01578 & 8 & 0.648 & 0.726 \\
\hline $\mathrm{Cr}$ & SME & 0.051067 & 60 & 0.000072 & 0.00005 & 0.000122 & $16.62 \%$ & $13.85 \%$ & $21.63 \%$ & 0.00048 & 9 & 0.045 & 0.057 \\
\hline $\mathrm{Cu}$ & SME & 0.011241 & 54 & 0.000017 & 0.000005 & 0.000022 & $36.68 \%$ & $19.89 \%$ & $41.73 \%$ & 0.00011 & 8 & 0.008 & 0.015 \\
\hline $\mathrm{Fe}$ & SME & 7.678778 & 54 & 0.165535 & 0.277684 & 0.443219 & $5.30 \%$ & $6.86 \%$ & $8.67 \%$ & 1.2709 & 8 & 7.325 & 8.033 \\
\hline $\mathrm{Fe} / \mathrm{Al}$ & SME & 2.668255 & 60 & 0.002619 & 0.002124 & 0.004743 & $1.92 \%$ & $1.73 \%$ & $2.58 \%$ & 0.01784 & 9 & 2.629 & 2.707 \\
\hline $\mathrm{Fe} / \mathrm{Ca}$ & SME & 11.14501 & 60 & 0.106763 & 0.09468 & 0.201443 & $2.93 \%$ & $2.76 \%$ & $4.03 \%$ & 0.73526 & 9 & 10.895 & 11.395 \\
\hline $\mathrm{Fe} / \mathrm{Li}$ & SME & 3.543268 & 60 & 0.07665 & 0.010987 & 0.087637 & $7.81 \%$ & $2.96 \%$ & $8.35 \%$ & 0.47089 & 9 & 3.343 & 3.744 \\
\hline $\mathrm{Fe} / \mathrm{Mg}$ & SME & 11.4888 & 60 & 0.048626 & 0.059122 & 0.107748 & $1.92 \%$ & $2.12 \%$ & $2.86 \%$ & 0.35088 & 9 & 11.316 & 11.662 \\
\hline $\mathrm{Fe} / \mathrm{Mn}$ & SME & 4.996603 & 60 & 0.002514 & 0.007029 & 0.009543 & $1.00 \%$ & $1.68 \%$ & $1.96 \%$ & 0.02211 & 9 & 4.953 & 5.040 \\
\hline $\mathrm{Fe} / \mathrm{Ni}$ & SME & 17.70708 & 60 & 0.086331 & 0.123647 & 0.209978 & $1.66 \%$ & $1.99 \%$ & $2.59 \%$ & 0.64163 & 9 & 17.473 & 17.941 \\
\hline $\mathrm{Fe} / \mathrm{U}$ & SME & 2.829664 & 60 & 0.010778 & 0.004097 & 0.014875 & $3.67 \%$ & $2.26 \%$ & $4.31 \%$ & 0.06876 & 9 & 2.753 & 2.906 \\
\hline $\mathrm{K}$ & SME & 0.1152 & 60 & 0.014837 & 0.016934 & 0.031771 & $105.74 \%$ & $112.96 \%$ & $154.73 \%$ & 0.10596 & 9 & 0.020 & 0.210 \\
\hline $\mathrm{Li}$ & SME & 2.169796 & 54 & 0.007419 & 0.019375 & 0.026794 & $3.97 \%$ & $6.42 \%$ & $7.54 \%$ & 0.06389 & 8 & 2.090 & 2.249 \\
\hline $\mathrm{Mg}$ & SME & 0.668833 & 54 & 0.00162 & 0.001889 & 0.003509 & $6.02 \%$ & $6.50 \%$ & $8.86 \%$ & 0.01161 & 8 & 0.635 & 0.703 \\
\hline $\mathrm{Mn}$ & SME & 1.536222 & 54 & 0.008833 & 0.009772 & 0.018605 & $6.12 \%$ & $6.43 \%$ & $8.88 \%$ & 0.06277 & 8 & 1.458 & 1.615 \\
\hline $\mathrm{Mn} / \mathrm{Mg}$ & SME & 2.299459 & 60 & 0.001116 & 0.001733 & 0.002849 & $1.45 \%$ & $1.81 \%$ & $2.32 \%$ & 0.00843 & 9 & 2.273 & 2.326 \\
\hline $\mathrm{Na}$ & SME & & & & & & & & & & & & \\
\hline $\mathrm{Ni}$ & SME & 0.432926 & 54 & 0.000665 & 0.000904 & 0.001569 & $5.96 \%$ & $6.94 \%$ & $9.15 \%$ & 0.00489 & 8 & 0.411 & 0.455 \\
\hline $\mathrm{Si}$ & SME & 23.2878 & 54 & 0.809927 & 2.376999 & 3.186926 & $3.86 \%$ & $6.62 \%$ & $7.67 \%$ & 7.23656 & 8 & 22.444 & 24.132 \\
\hline $\mathrm{Ti}$ & SME & 0.040967 & 60 & 0.000022 & 0.000012 & 0.000034 & $11.45 \%$ & $8.46 \%$ & $14.23 \%$ & 0.00014 & 9 & 0.038 & 0.044 \\
\hline $\mathrm{U}$ & SME & 2.709963 & 54 & 0.033204 & 0.031864 & 0.065068 & $6.72 \%$ & $6.59 \%$ & $9.41 \%$ & 0.23109 & 8 & 2.559 & 2.861 \\
\hline $\mathrm{U} / \mathrm{Ca}$ & SME & 3.94113 & 60 & 0.006785 & 0.011638 & 0.018423 & $2.09 \%$ & $2.74 \%$ & $3.44 \%$ & 0.05235 & 9 & 3.874 & 4.008 \\
\hline $\mathrm{Zr}$ & SME & & & & & & & & & & & & \\
\hline Sum Ox & SME & 83.3977 & 48 & 3.167982 & 26.89557 & 30.063552 & $2.13 \%$ & $6.22 \%$ & $6.57 \%$ & 45.9035 & 7 & 81.085 & 85.710 \\
\hline
\end{tabular}


WSRC-STI-2006-00068

Revision 0

Table 3-2 Estimated Components of Variance and Mean Confidence Intervals for Process Samples (continued) Mixed Acid/M-13

\begin{tabular}{|c|c|c|c|c|c|c|c|c|c|c|c|c|c|}
\hline & & & & Estimate of & Estimate of & Estimate of & Estimate of & Estimate of & Estimate of & & & \multicolumn{2}{|c|}{$95 \%$ Confidence Interval for Mean } \\
\hline Analyte & Process & Average $(\mathrm{wt} \%)$ & $\mathrm{n}$ & $\begin{array}{c}\text { Between } \\
\text { Variance } \\
\end{array}$ & $\begin{array}{c}\text { Within } \\
\text { Variance } \\
\end{array}$ & $\begin{array}{c}\text { Total } \\
\text { Variance } \\
\end{array}$ & \%RSD (B) & $\% \mathrm{RSD}(\mathrm{W})$ & $\% \operatorname{RSD}(\mathrm{T})$ & $\begin{array}{c}\text { MS } \\
\text { Between }\end{array}$ & DoF & Lower & Upper \\
\hline $\mathrm{Al}$ & SME & 2.884844 & 180 & 0.024775 & 0.012151 & 0.036926 & $5.46 \%$ & $3.82 \%$ & $6.66 \%$ & 0.1608 & 29 & 2.824 & 2.946 \\
\hline $\mathrm{Al} / \mathrm{Ca}$ & SME & 4.021323 & 162 & 0.003973 & 0.010935 & 0.014908 & $1.57 \%$ & $2.60 \%$ & $3.04 \%$ & 0.03477 & 26 & 3.991 & 4.051 \\
\hline $\mathrm{Al} / \mathrm{Mg}$ & SME & 4.26423 & 186 & 0.040041 & 0.027564 & 0.067605 & $4.69 \%$ & $3.89 \%$ & $6.10 \%$ & 0.26781 & 30 & 4.187 & 4.342 \\
\hline $\mathrm{Al} / \mathrm{Mn}$ & SME & 1.879144 & 186 & 0.005235 & 0.00279 & 0.008025 & $3.85 \%$ & $2.81 \%$ & $4.77 \%$ & 0.0342 & 30 & 1.851 & 1.907 \\
\hline B & SME & & & & & & & & & & & & \\
\hline $\mathrm{B} / \mathrm{Li}$ & SME & & & & & & & & & & & & \\
\hline $\mathrm{Ca}$ & SME & 0.716852 & 162 & 0.000895 & 0.001145 & 0.00204 & $4.17 \%$ & $4.72 \%$ & $6.30 \%$ & 0.00651 & 26 & 0.704 & 0.730 \\
\hline $\mathrm{Cr}$ & SME & 0.054339 & 192 & 0.00043 & 0.0002 & 0.00063 & $38.16 \%$ & $26.03 \%$ & $46.19 \%$ & 0.00028 & 31 & 0.052 & 0.057 \\
\hline $\mathrm{Cu}$ & SME & 0.008978 & 186 & 0.000054 & 0.000006 & 0.00006 & $81.85 \%$ & $27.28 \%$ & $86.28 \%$ & 0.00033 & 30 & 0.006 & 0.012 \\
\hline $\mathrm{Fe}$ & SME & 7.782 & 162 & 0.066965 & 0.052832 & 0.119797 & $3.33 \%$ & $2.95 \%$ & $4.45 \%$ & 0.45462 & 26 & 7.673 & 7.891 \\
\hline $\mathrm{Fe} / \mathrm{Al}$ & SME & 2.688102 & 192 & 0.008565 & 0.00195 & 0.010515 & $3.44 \%$ & $1.64 \%$ & $3.81 \%$ & 0.05334 & 31 & 2.654 & 2.722 \\
\hline $\mathrm{Fe} / \mathrm{Ca}$ & SME & 10.85282 & 180 & 0.082547 & 0.117632 & 0.200179 & $2.65 \%$ & $3.16 \%$ & $4.12 \%$ & 0.61292 & 29 & 10.733 & 10.972 \\
\hline $\mathrm{Fe} / \mathrm{Li}$ & SME & 3.489506 & 174 & 0.058608 & 0.012259 & 0.070867 & $6.94 \%$ & $3.17 \%$ & $7.63 \%$ & 0.36391 & 28 & 3.396 & 3.583 \\
\hline $\mathrm{Fe} / \mathrm{Mg}$ & SME & 11.44492 & 180 & 0.18887 & 0.13889 & 0.32776 & $3.80 \%$ & $3.26 \%$ & $5.00 \%$ & 1.27211 & 29 & 11.273 & 11.617 \\
\hline $\mathrm{Fe} / \mathrm{Mn}$ & SME & 5.046693 & 186 & 0.019645 & 0.012828 & 0.032473 & $2.78 \%$ & $2.24 \%$ & $3.57 \%$ & 0.1307 & 30 & 4.993 & 5.101 \\
\hline $\mathrm{Fe} / \mathrm{Ni}$ & SME & 17.14521 & 180 & 0.158684 & 0.123879 & 0.282563 & $2.32 \%$ & $2.05 \%$ & $3.10 \%$ & 1.07598 & 29 & 16.987 & 17.303 \\
\hline $\mathrm{Fe} / \mathrm{U}$ & SME & 2.828548 & 186 & 0.010644 & 0.005588 & 0.016232 & $3.65 \%$ & $2.64 \%$ & $4.50 \%$ & 0.06945 & 30 & 2.789 & 2.868 \\
\hline $\mathrm{K}$ & SME & -0.06115 & 162 & 0.061792 & 0.058618 & 0.12041 & $406.51 \%$ & $395.93 \%$ & $567.46 \%$ & 0.42937 & 26 & -0.167 & 0.045 \\
\hline $\mathrm{Li}$ & SME & 2.213846 & 156 & 0.009231 & 0.002982 & 0.012213 & $4.34 \%$ & $2.47 \%$ & $4.99 \%$ & 0.05837 & 25 & 2.174 & 2.254 \\
\hline $\mathrm{Mg}$ & SME & 0.674586 & 174 & 0.001661 & 0.001076 & 0.002737 & $6.04 \%$ & $4.86 \%$ & $7.76 \%$ & 0.01104 & 28 & 0.658 & 0.691 \\
\hline $\mathrm{Mn}$ & SME & 1.541925 & 174 & 0.005946 & 0.004723 & 0.010669 & $5.00 \%$ & $4.46 \%$ & $6.70 \%$ & 0.0404 & 28 & 1.511 & 1.573 \\
\hline $\mathrm{Mn} / \mathrm{Mg}$ & SME & 2.268349 & 186 & 0.001377 & 0.001867 & 0.003244 & $1.64 \%$ & $1.90 \%$ & $2.51 \%$ & 0.01013 & 30 & 2.253 & 2.283 \\
\hline $\mathrm{Na}$ & SME & 8.807543 & 162 & 0.073645 & 0.085691 & 0.159336 & $3.08 \%$ & $3.32 \%$ & $4.53 \%$ & 0.52756 & 26 & 8.690 & 8.925 \\
\hline $\mathrm{Ni}$ & SME & 0.450274 & 168 & 0.000366 & 0.000342 & 0.000708 & $4.25 \%$ & $4.11 \%$ & $5.91 \%$ & 0.00254 & 27 & 0.442 & 0.458 \\
\hline $\mathrm{Si}$ & SME & 22.46066 & 174 & 0.361926 & 0.51073 & 0.872656 & $2.68 \%$ & $3.18 \%$ & $4.16 \%$ & 2.68229 & 28 & 22.206 & 22.715 \\
\hline $\mathrm{Ti}$ & SME & 0.031952 & 186 & 0.000049 & 0.000011 & 0.00006 & $21.91 \%$ & $10.38 \%$ & $24.24 \%$ & 0.0003 & 30 & 0.029 & 0.035 \\
\hline $\mathrm{U}$ & SME & 2.754569 & 174 & 0.024752 & 0.01534 & 0.040092 & $5.71 \%$ & $4.50 \%$ & $7.27 \%$ & 0.16385 & 28 & 2.692 & 2.817 \\
\hline $\mathrm{U} / \mathrm{Ca}$ & SME & 3.838824 & 174 & 0.020452 & 0.018778 & 0.03923 & $3.73 \%$ & $3.57 \%$ & $5.16 \%$ & 0.14149 & 28 & 3.780 & 3.897 \\
\hline $\mathrm{Zr}$ & SME & 0.049783 & 180 & 0.000102 & 0.000011 & 0.000113 & $20.29 \%$ & $6.66 \%$ & $21.35 \%$ & 0.00062 & 29 & 0.046 & 0.054 \\
\hline Sum Ox & SME & 89.09756 & 180 & 1.756465 & 4.898024 & 6.654489 & $1.49 \%$ & $2.48 \%$ & $2.90 \%$ & 15.4368 & 29 & 88.499 & 89.697 \\
\hline
\end{tabular}


WSRC-STI-2006-00068

Revision 0

Table 3-2 Estimated Components of Variance and Mean Confidence Intervals for Process Samples (continued)

Mixed Acid/M-14

\begin{tabular}{|c|c|c|c|c|c|c|c|c|c|c|c|c|c|}
\hline & & & & Estimate of & Estimate of & Estimate of & Estimate of & Estimate of & Estimate of & & & \multicolumn{2}{|c|}{$95 \%$ Confidence Interval for Mear } \\
\hline Analyte & Process & Average $(\mathrm{wt} \%)$ & $\mathrm{n}$ & $\begin{array}{c}\text { Between } \\
\text { Variance } \\
\end{array}$ & $\begin{array}{c}\text { Within } \\
\text { Variance } \\
\end{array}$ & $\begin{array}{c}\text { Total } \\
\text { Variance } \\
\end{array}$ & \%RSD (B) & $\% \operatorname{RSD}(\mathrm{W})$ & $\% \operatorname{RSD}(\mathrm{T})$ & $\begin{array}{c}\text { MS } \\
\text { Between } \\
\end{array}$ & DoF & Lower & Upper \\
\hline $\mathrm{Al}$ & SME & 3.050817 & 120 & 0.033572 & 0.007754 & 0.041326 & $6.01 \%$ & $2.89 \%$ & $6.66 \%$ & 0.20919 & 19 & 2.963 & 3.138 \\
\hline $\mathrm{Al} / \mathrm{Ca}$ & SME & 4.041221 & 114 & 0.009753 & 0.007037 & 0.01679 & $2.44 \%$ & $2.08 \%$ & $3.21 \%$ & 0.06556 & 18 & 3.991 & 4.092 \\
\hline $\mathrm{Al} / \mathrm{Mg}$ & SME & 4.246526 & 120 & 0.030268 & 0.011988 & 0.042256 & $4.10 \%$ & $2.58 \%$ & $4.84 \%$ & 0.1936 & 19 & 4.162 & 4.331 \\
\hline $\mathrm{Al} / \mathrm{Mn}$ & SME & 1.886865 & 120 & 0.00545 & 0.001464 & 0.006914 & $3.91 \%$ & $2.03 \%$ & $4.41 \%$ & 0.03416 & 19 & 1.852 & 1.922 \\
\hline $\mathrm{B}$ & SME & & & & & & & & & & & & \\
\hline $\mathrm{B} / \mathrm{Li}$ & SME & & & & & & & & & & & & \\
\hline $\mathrm{Ca}$ & SME & 0.755316 & 114 & 0.001695 & 0.000684 & 0.002379 & $5.45 \%$ & $3.46 \%$ & $6.46 \%$ & 0.01086 & 18 & 0.735 & 0.776 \\
\hline $\mathrm{Cr}$ & SME & 0.046758 & 120 & 0.000022 & 0.000009 & 0.000031 & $10.03 \%$ & $6.42 \%$ & $11.91 \%$ & 0.00014 & 19 & 0.044 & 0.049 \\
\hline $\mathrm{Cu}$ & SME & 0.007517 & 120 & 0.000024 & 0.000005 & 0.000029 & $65.17 \%$ & $29.75 \%$ & $71.64 \%$ & 0.00015 & 19 & 0.005 & 0.010 \\
\hline $\mathrm{Fe}$ & SME & 7.880575 & 120 & 0.179052 & 0.054942 & 0.233994 & $5.37 \%$ & $2.97 \%$ & $6.14 \%$ & 1.12926 & 19 & 7.678 & 8.084 \\
\hline $\mathrm{Fe} / \mathrm{Al}$ & SME & 2.585362 & 120 & 0.006636 & 0.001543 & 0.008179 & $3.15 \%$ & $1.52 \%$ & $3.50 \%$ & 0.04136 & 19 & 2.547 & 2.624 \\
\hline $\mathrm{Fe} / \mathrm{Ca}$ & SME & 10.41888 & 114 & 0.030141 & 0.05384 & 0.083981 & $1.67 \%$ & $2.23 \%$ & $2.78 \%$ & 0.23468 & 18 & 10.324 & 10.514 \\
\hline $\mathrm{Fe} / \mathrm{Li}$ & SME & 3.516826 & 120 & 0.081383 & 0.007765 & 0.089148 & $8.11 \%$ & $2.51 \%$ & $8.49 \%$ & 0.49607 & 19 & 3.382 & 3.651 \\
\hline $\mathrm{Fe} / \mathrm{Mg}$ & SME & 10.96896 & 120 & 0.119542 & 0.087915 & 0.207457 & $3.15 \%$ & $2.70 \%$ & $4.15 \%$ & 0.80516 & 19 & 10.798 & 11.140 \\
\hline $\mathrm{Fe} / \mathrm{Mn}$ & SME & 4.872926 & 120 & 0.012976 & 0.008529 & 0.021505 & $2.34 \%$ & $1.90 \%$ & $3.01 \%$ & 0.08639 & 19 & 4.817 & 4.929 \\
\hline $\mathrm{Fe} / \mathrm{Ni}$ & SME & 17.13264 & 120 & 0.125898 & 0.137845 & 0.263743 & $2.07 \%$ & $2.17 \%$ & $3.00 \%$ & 0.89323 & 19 & 16.952 & 17.313 \\
\hline $\mathrm{Fe} / \mathrm{U}$ & SME & 2.728421 & 120 & 0.00591 & 0.003465 & 0.009375 & $2.82 \%$ & $2.16 \%$ & $3.55 \%$ & 0.03893 & 19 & 2.691 & 2.766 \\
\hline $\mathrm{K}$ & SME & 0.166454 & 108 & 0.0526 & 0.017961 & 0.070561 & $137.78 \%$ & $80.51 \%$ & $159.58 \%$ & 0.33356 & 17 & 0.049 & 0.284 \\
\hline $\mathrm{Li}$ & SME & 2.243683 & 126 & 0.004938 & 0.00292 & 0.007858 & $3.13 \%$ & $2.41 \%$ & $3.95 \%$ & 0.03255 & 20 & 2.210 & 2.277 \\
\hline $\mathrm{Mg}$ & SME & 0.719683 & 120 & 0.002339 & 0.000601 & 0.00294 & $6.72 \%$ & $3.41 \%$ & $7.53 \%$ & 0.01464 & 19 & 0.697 & 0.743 \\
\hline $\mathrm{Mn}$ & SME & 1.6196 & 120 & 0.013257 & 0.002431 & 0.015688 & $7.11 \%$ & $3.04 \%$ & $7.73 \%$ & 0.08198 & 19 & 1.565 & 1.674 \\
\hline $\mathrm{Mn} / \mathrm{Mg}$ & SME & 2.243634 & 114 & 0.001556 & 0.000993 & 0.002549 & $1.76 \%$ & $1.40 \%$ & $2.25 \%$ & 0.01033 & 18 & 2.224 & 2.264 \\
\hline $\mathrm{Na}$ & SME & 9.053983 & 120 & 0.087393 & 0.057395 & 0.144788 & $3.27 \%$ & $2.65 \%$ & $4.20 \%$ & 0.58175 & 19 & 8.908 & 9.200 \\
\hline $\mathrm{Ni}$ & SME & 0.460142 & 120 & 0.000492 & 0.000288 & 0.00078 & $4.82 \%$ & $3.69 \%$ & $6.07 \%$ & 0.00324 & 19 & 0.449 & 0.471 \\
\hline $\mathrm{Si}$ & SME & 21.66863 & 120 & 0.32832 & 0.936661 & 1.264981 & $2.64 \%$ & $4.47 \%$ & $5.19 \%$ & 2.90658 & 19 & 21.343 & 21.994 \\
\hline $\mathrm{Ti}$ & SME & 0.04 & 120 & 0.000038 & 0.000005 & 0.000043 & $15.41 \%$ & $5.59 \%$ & $16.39 \%$ & 0.00024 & 19 & 0.037 & 0.043 \\
\hline $\mathrm{U}$ & SME & 2.890975 & 120 & 0.026328 & 0.009988 & 0.036316 & $5.61 \%$ & $3.46 \%$ & $6.59 \%$ & 0.16796 & 19 & 2.813 & 2.969 \\
\hline $\mathrm{U} / \mathrm{Ca}$ & SME & 3.822947 & 114 & 0.011573 & 0.01171 & 0.023283 & $2.81 \%$ & $2.83 \%$ & $3.99 \%$ & 0.08115 & 18 & 3.767 & 3.879 \\
\hline $\mathrm{Zr}$ & SME & 0.060383 & 120 & 0.000197 & 0.000003 & 0.0002 & $23.24 \%$ & $2.87 \%$ & $23.42 \%$ & 0.00119 & 19 & 0.054 & 0.067 \\
\hline $\begin{array}{c}\text { Sum } \\
\mathrm{Ox}\end{array}$ & SME & 89.2959 & 114 & 1.453049 & 4.539041 & 5.99209 & $1.35 \%$ & $2.39 \%$ & $2.74 \%$ & 13.2573 & 18 & 88.579 & 90.012 \\
\hline
\end{tabular}




\subsection{COMPARISONS AGAINST THE VARIANCES OF PCCS}

The estimated components of variance provided in Table 3-3 offer an opportunity for comparisons against the estimated variances that are used as part of the assessment of measurement uncertainty of the Product Composition Control System (PCCS). The assessment of this uncertainty as well as estimates of the variances is described in [8]. For those elements present in the recent SME batches at concentrations of $0.5 \mathrm{wt} \%$ and greater, the current \%RSD's for both fusion and mixed acid preparation methods for both ICPs are comparable to the \%RSD's in PCCS.

Table 3-3 Current Average Measurements and Relative Standard Deviations and the Historical Values Used in PCCS

\begin{tabular}{|c|c|c|c|c|c|c|c|c|c|c||}
\hline & Historical & Historical & Fusion & Fusion & Fusion & Fusion & Mixed Acid & Mixed Acid & Mixed Acid & Mixed Acid \\
\hline & Composition & Relative Standard & M-13 & M-13 & M-14 & M-14 & M-13 & M-13 & M-14 & M-14 \\
\hline Element & $(\mathrm{wt} \%)$ & Deviation (\%RSD) & mean & \%RSD & mean & \%RSD & mean & \%RSD & mean & \%RSD \\
\hline $\mathrm{Al}$ & 2.222 & 5.1 & 2.957 & 4.2 & 2.885 & 6.4 & 2.885 & 3.8 & 3.051 & 2.9 \\
\hline $\mathrm{B}$ & 2.093 & 7.2 & 1.45 & 3.3 & 1.39 & 6.3 & & & & \\
\hline $\mathrm{Ca}$ & 1.077 & 5.9 & 0.718 & 5.9 & 0.687 & 7.2 & 0.717 & 4.7 & 0.755 & 3.5 \\
\hline $\mathrm{Cr}$ & 0.064 & 33.5 & 0.055 & 6.8 & 0.051 & 13.8 & 0.054 & 26.0 & 0.047 & 6.4 \\
\hline $\mathrm{Cu}$ & 0.25 & 5.8 & 0.014 & 7.1 & 0.011 & 19.9 & 0.009 & 27.3 & 0.008 & 29.8 \\
\hline $\mathrm{Fe}$ & 6.235 & 4.8 & 7.97 & 4.2 & 7.679 & 6.9 & 7.782 & 3.0 & 7.881 & 3.0 \\
\hline $\mathrm{K}$ & 2.455 & 6.5 & 0.102 & 105.9 & 0.115 & 113.0 & & & 0.166 & 80.5 \\
\hline $\mathrm{Li}$ & 1.963 & 4.1 & 2.203 & 3.4 & 2.17 & 6.4 & 2.214 & 2.5 & 2.244 & 2.4 \\
\hline $\mathrm{Mg}$ & 0.842 & 4.8 & 0.686 & 5.6 & 0.669 & 6.5 & 0.675 & 4.9 & 0.72 & 3.4 \\
\hline $\mathrm{Mn}$ & 2.11 & 5.2 & 1.575 & 5.1 & 1.536 & 6.4 & 1.542 & 4.5 & 1.62 & 3.0 \\
\hline $\mathrm{Na}$ & 7.463 & 4.5 & & & & & 8.808 & 3.3 & 9.054 & 2.6 \\
\hline $\mathrm{Ni}$ & 0.643 & 13.2 & 0.456 & 5.1 & 0.433 & 6.9 & 0.45 & 4.1 & 0.46 & 3.7 \\
\hline $\mathrm{Si}$ & 23.31 & 5.7 & 23.81 & 4.7 & 23.29 & 6.6 & 22.46 & 3.2 & 21.67 & 4.5 \\
\hline $\mathrm{Ti}$ & 0.256 & 4.5 & 0.039 & 4.7 & 0.04 & 8.5 & 0.032 & 10.4 & 0.04 & 5.6 \\
\hline $\mathrm{U}$ & 0 & 0 & 2.6 & 4.0 & 2.71 & 6.6 & 2.755 & 4.5 & 2.891 & 3.5 \\
\hline $\mathrm{Zr}$ & 0.029 & 9.0 & & & & & 0.05 & 6.7 & 0.06 & 2.9 \\
\hline
\end{tabular}

\subsection{SPECIFIC ISSUES OUTLINED IN THE TTR}

Several specific issues were identified in the TTR for this work [5], and they were discussed in more detail as part of the planning for this effort [6]. Each of these issues is identified and then addressed in this section.

- Evaluate elemental ratios for pairs of frit-only and pairs of sludge-only elements for ARG-1 and process sample data to better understand the sources of uncertainty.

As discussed in [6], the percent relative standard deviations (also called the percent coefficients of variation) for the pairs of elements and for their ratios serve as the input for this evaluation. Information for several of the ratios from Table 3-1 for ARG-1 samples and from Table 3-2 for SME samples is provided in Table 3-4 to facilitate this discussion. 
Table 3-4 Percent Relation Standard Deviations for Some Key Sludge and Frit Ratios

\begin{tabular}{|c|c|c|c|c|c|}
\hline & Type of & M-13 & M-14 & M-13 & $\mathrm{M}-14$ \\
\hline Analyte & Sample & Fusion & Fusion & $\begin{array}{c}\text { Mixed } \\
\text { Acid }\end{array}$ & $\begin{array}{c}\text { Mixed } \\
\text { Acid }\end{array}$ \\
\hline $\mathrm{Al}$ & ARG-1 & $3.23 \%$ & $2.76 \%$ & $1.83 \%$ & $1.80 \%$ \\
\hline $\mathrm{Fe}$ & ARG-1 & $2.97 \%$ & $1.80 \%$ & $2.08 \%$ & $1.45 \%$ \\
\hline $\mathrm{Fe} / \mathrm{Al}$ (variance propagation) & ARG-1 & $4.39 \%$ & $3.30 \%$ & $2.77 \%$ & $2.31 \%$ \\
\hline $\mathrm{Fe} / \mathrm{Al}$ & ARG-1 & $1.81 \%$ & $1.18 \%$ & $1.92 \%$ & $1.21 \%$ \\
\hline Ratio of Variances & ARG-1 & 5.877 & 7.798 & 2.082 & 3.649 \\
\hline $\mathrm{Al}$ & SME & $4.24 \%$ & $6.38 \%$ & $3.82 \%$ & $6.66 \%$ \\
\hline $\mathrm{Fe}$ & SME & $4.23 \%$ & $6.86 \%$ & $4.45 \%$ & $6.14 \%$ \\
\hline $\mathrm{Fe} / \mathrm{Al}$ (variance propagation) & SME & $5.99 \%$ & $9.37 \%$ & $5.86 \%$ & $9.06 \%$ \\
\hline $\mathrm{Fe} / \mathrm{Al}$ & SME & $1.74 \%$ & $1.73 \%$ & $3.81 \%$ & $3.50 \%$ \\
\hline Ratio of Variances & SME & 11.848 & 29.324 & 2.369 & 6.698 \\
\hline $\mathrm{Al}$ & ARG-1 & $3.23 \%$ & $2.76 \%$ & $1.83 \%$ & $1.80 \%$ \\
\hline $\mathrm{Mn}$ & ARG-1 & $3.39 \%$ & $2.14 \%$ & $1.95 \%$ & $1.75 \%$ \\
\hline $\mathrm{Al} / \mathrm{Mn}$ (variance propagation) & ARG-1 & $4.68 \%$ & $3.49 \%$ & $2.67 \%$ & $2.51 \%$ \\
\hline $\mathrm{Al} / \mathrm{Mn}$ & ARG-1 & $1.65 \%$ & $1.81 \%$ & $1.65 \%$ & $1.06 \%$ \\
\hline Ratio of Variances & ARG-1 & 8.053 & 3.723 & 2.627 & 5.609 \\
\hline $\mathrm{Al}$ & SME & $4.24 \%$ & $6.38 \%$ & $3.82 \%$ & $6.66 \%$ \\
\hline $\mathrm{Mn}$ & SME & $5.06 \%$ & $6.43 \%$ & $4.46 \%$ & $7.73 \%$ \\
\hline $\mathrm{Al} / \mathrm{Mn}$ (variance propagation) & SME & $6.60 \%$ & $9.06 \%$ & $5.87 \%$ & $10.20 \%$ \\
\hline $\mathrm{Al} / \mathrm{Mn}$ & SME & $2.83 \%$ & $2.14 \%$ & $2.81 \%$ & $2.03 \%$ \\
\hline Ratio of Variances & SME & 5.442 & 17.916 & 4.367 & 25.264 \\
\hline $\mathrm{Fe}$ & ARG-1 & $2.97 \%$ & $1.80 \%$ & $2.08 \%$ & $1.45 \%$ \\
\hline $\mathrm{U}$ & ARG-1 & NA & NA & NA & NA \\
\hline $\mathrm{Fe} / \mathrm{U}$ (variance propagation) & ARG-1 & NA & NA & NA & NA \\
\hline $\mathrm{Fe} / \mathrm{U}$ & ARG-1 & NA & NA & NA & NA \\
\hline Ratio of Variances & ARG-1 & NA & NA & NA & NA \\
\hline $\mathrm{Fe}$ & SME & $4.23 \%$ & $6.86 \%$ & $4.45 \%$ & $6.14 \%$ \\
\hline $\mathrm{U}$ & SME & $3.99 \%$ & $6.59 \%$ & $4.50 \%$ & $3.46 \%$ \\
\hline $\mathrm{Fe} / \mathrm{U}$ (variance propagation) & SME & $5.81 \%$ & $9.51 \%$ & $6.33 \%$ & $7.05 \%$ \\
\hline $\mathrm{Fe} / \mathrm{U}$ & SME & $1.68 \%$ & $2.26 \%$ & $2.64 \%$ & $2.16 \%$ \\
\hline Ratio of Variances & SME & 11.980 & 17.716 & 5.747 & 10.646 \\
\hline $\mathrm{B}$ & ARG-1 & $2.97 \%$ & $2.50 \%$ & NA & NA \\
\hline $\mathrm{Li}$ & ARG-1 & $3.27 \%$ & $2.29 \%$ & $5.45 \%$ & $1.59 \%$ \\
\hline $\mathrm{B} / \mathrm{Li}$ (variance propagation) & ARG-1 & $4.42 \%$ & $3.39 \%$ & NA & NA \\
\hline $\mathrm{B} / \mathrm{Li}$ & ARG-1 & $2.48 \%$ & $1.13 \%$ & NA & NA \\
\hline Ratio of Variances & ARG-1 & 3.173 & 9.002 & NA & NA \\
\hline $\mathrm{B}$ & SME & $3.55 \%$ & $6.29 \%$ & NA & NA \\
\hline $\mathrm{Li}$ & SME & $3.41 \%$ & $6.42 \%$ & $2.47 \%$ & $2.41 \%$ \\
\hline $\mathrm{B} / \mathrm{Li}$ (variance propagation) & SME & $4.92 \%$ & $8.99 \%$ & NA & NA \\
\hline $\mathrm{B} / \mathrm{Li}$ & SME & $2.09 \%$ & $1.48 \%$ & NA & NA \\
\hline Ratio of Variances & SME & 5.547 & 36.879 & NA & NA \\
\hline
\end{tabular}


Consider a pair of sludge elements: $\mathrm{Al}$ and $\mathrm{Fe}$. If both of the elements go into solution for a sample to the same extent (specifically, at the same ratio as they are in the glass) as a dissolution is conducted, then the variation in the values of the $\mathrm{Fe}$ to $\mathrm{Al}$ ratio $(\mathrm{Fe} / \mathrm{Al})$ generated for the replicates of a single SME batch/ICP calibration block is primarily related to the variation due to the instrument (i.e., the ICP) in measuring Fe. Specifically, if the Al and Fe measurements by the ICP are uncorrelated, then the \% $\mathrm{cv}$ of the ratio would be expected to equal the \%cv's of $\mathrm{Al}$ and $\mathrm{Fe}$ summed in quadrature as defined by

$$
\% \mathrm{cv}_{\frac{\mathrm{Al}}{\mathrm{Fe}}}=\sqrt{\% \mathrm{cv}_{\mathrm{Al}}^{2}+\% \mathrm{cv}_{\mathrm{Fe}}^{2}}
$$

Note that the percent coefficient of variation of the replicate Al values, $\% \mathrm{cv}_{\mathrm{Al}}$, would reflect contributions to the variation of the Al measurements from both the dissolution and the instrument (as well as sample to sample variation for the process samples). This is also true for the Fe measurements used to derive $\% \mathrm{cv}_{\mathrm{Fe}}$.

If it is determined that

$$
\% \mathrm{cv}_{\frac{\mathrm{Al}}{\mathrm{Fe}}}<<\sqrt{\% \mathrm{cv}_{\mathrm{Al}}^{2}+\% \mathrm{cv}_{\mathrm{Fe}}^{2}}
$$

for the ARG-1 samples, then the data would be suggesting that the dissolution process is contributing substantially to the variation in the measurements for these elements.

There is row in Table 3-4, with the heading ratio of variances, that provides the ratio of the variances for each pair of elements considered in the table. From these ratios, it appears that the M-14 ICP yields larger ratios of variances than the M-13 over both preparation methods and both types of samples (ARG-1 and SME) and that the Fusion preparation method yields larger ratios of variances than the Mixed Acid method, in general.

- Investigate the sums of oxides for SME samples to include the target range of 95 to $105 \%$ and a possible relationship between the sums of oxides for the ARG-1 samples and the sums of oxides for the process samples over the process batches studied.

Currently, the protocol for determining the overall sum of oxides for a sample of the SME uses the results for both Mixed Acid (Mg, Na, and $\mathrm{Zr}$ ) and Fusion (other elements). The sum of oxides results from Table 3-1 provide some insight into this issue, and these values are repeated in Table 3-5. The measurements used to represent the concentrations of most of the elements are from the Fusion method, and the sum of oxides in Table 3-5 for this method correspond very closely to the reference value for ARG-1. For Mixed Acid the overall sum of oxides is 4 to $5 \%$ below the ARG-1 reference value, but the measurements of $\mathrm{Si}$ are the dominant cause of the poor overall sum of oxides values. If one uses the current protocol for combining the Fusion and Mixed Acid results to represent the ARG1 composition, the resulting sum of oxides for the M-13 and M-14 measurements are 98.6 and 97.7 $\mathrm{wt} \%$, respectively, as indicated in Table 3-5. Two conclusions are suggested by these results: the dissolution methods and the ICPs do an excellent job, in general, of obtaining a representative and acceptable sum of oxides (at least for the ARG-1 samples) but the M-14 ICP seems to yield, on average, about a $1 \mathrm{wt} \%$ smaller sum of oxides. 
WSRC-STI-2006-00068

Revision 0

Table 3-5 Sum of Oxides (wt \%) for ARG-1 by Preparation Method and ICP

\begin{tabular}{|c|c|c|c|c|c||}
\hline \hline Method & ICP & $\begin{array}{c}\text { Type of } \\
\text { Sample }\end{array}$ & $\begin{array}{c}\text { Reference } \\
\text { Value (wt\%) }\end{array}$ & $\begin{array}{c}\text { Measured } \\
\text { (wt\%) }\end{array}$ & $\begin{array}{c}\text { \% } \\
\text { Difference }\end{array}$ \\
\hline Fusion & M-13 & ARG-1 & 87.7 & 87.1 & $-0.68 \%$ \\
\hline Fusion & M-14 & ARG-1 & 87.7 & 86.2 & $-1.74 \%$ \\
\hline Mixed Acid & M-13 & ARG-1 & 90.6 & 86.6 & $-4.45 \%$ \\
\hline Mixed Acid & M-14 & ARG-1 & 90.6 & 86.0 & $-5.11 \%$ \\
\hline Protocol & M-13 & ARG-1 & 99.3 & 98.6 & $-0.70 \%$ \\
\hline Protocol & M-14 & ARG-1 & 99.3 & 97.7 & $-1.61 \%$ \\
\hline
\end{tabular}

Figure 3-2 provides plots of the sum of oxides values of the ARG-1 samples versus the values of the SME samples for each preparation method and ICP combination. Superimposed on the data of these plots are fitted lines produced by the regression of the SME sums on the ARG-1 sums. None of these lines are statistically significant at a 5\% significance level. Thus, there is no indication of a relationship between the ARG-1 sum of oxides values and the sum of oxides values determined from the SME samples.
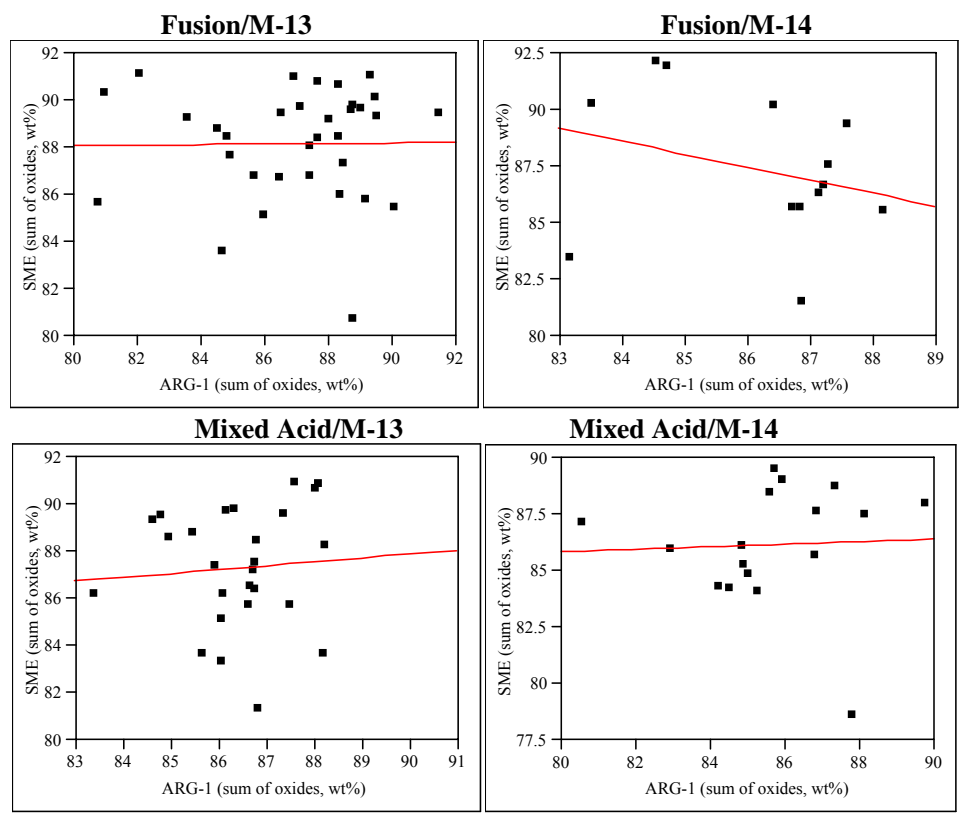

Figure 3-2. SME Sum of Oxides versus ARG-1 Sum of Oxides by Preparation Method/ICP

- Using primarily the ARG-1 data, compare the performance of the two ICPs (M-13 versus M-14).

Comparisons between the two ICPs have been made in several of the earlier discussions. Table 3-5 summarizes the ARG-1 comparisons on the two ICPS by preparation method for the 16 primary elements monitored by the DWPF Lab. Averages and standard deviations are provided along with the percent relative difference between the averages (based on the M-13 values) and variance ratios (with the maximum variance of the two being in the numerator). The information of Exhibit A3 in the Appendix also may be used to provide insight into this issue. 
WSRC-STI-2006-00068

Revision 0

Table 3-6 ICP Comparisons for ARG-1 Measurements by Preparation Method

\begin{tabular}{|c|c|c|c|c|c|c|c|c|c|c|}
\hline & & Cold Chem/M-13 & Cold Chem/M-14 & \% Rel Diff & Fusion/M-13 & Fusion/M-14 & \% Rel Diff & Mixed Acid/ M-13 & Mixed Acid/M-14 & \% Rel Diff \\
\hline Analyte & Ref. Value & Average & Average & (Based on M-13) & Average & Average & (Based on M-13) & Average & Average & (Based on M-13) \\
\hline $\mathrm{Al}$ & 2.5 & 2.338 & 2.340 & $0.11 \%$ & 2.401 & 2.392 & $-0.37 \%$ & 2.299 & 2.366 & $2.91 \%$ \\
\hline $\mathrm{B}$ & 2.69 & 2.613 & 2.595 & $-0.67 \%$ & 2.617 & 2.555 & $-2.35 \%$ & & & \\
\hline $\mathrm{Ca}$ & 1.02 & 0.968 & 0.971 & $0.28 \%$ & 0.983 & 0.971 & $-1.25 \%$ & 0.994 & 1.000 & $0.66 \%$ \\
\hline $\mathrm{Cr}$ & 0.06 & 0.065 & 0.068 & $4.70 \%$ & 0.068 & 0.066 & $-2.83 \%$ & 0.067 & 0.059 & $-11.24 \%$ \\
\hline $\mathrm{Cu}$ & 0.0001 & 0.004 & 0.002 & $-52.30 \%$ & 0.002 & -0.001 & $-138.46 \%$ & -0.003 & -0.005 & $58.58 \%$ \\
\hline $\mathrm{Fe}$ & 9.79 & 9.723 & 9.517 & $-2.12 \%$ & 9.709 & 9.550 & $-1.64 \%$ & 9.524 & 9.492 & $-0.34 \%$ \\
\hline $\mathrm{K}$ & 2.25 & 2.333 & 2.308 & $-1.06 \%$ & 2.198 & 2.165 & $-1.48 \%$ & 2.007 & 2.227 & $10.95 \%$ \\
\hline $\mathrm{Li}$ & 1.49 & 1.444 & 1.455 & $0.79 \%$ & 1.467 & 1.458 & $-0.61 \%$ & 1.465 & 1.498 & $2.21 \%$ \\
\hline $\mathrm{Mg}$ & 0.52 & 0.497 & 0.484 & $-2.62 \%$ & 0.506 & 0.496 & $-1.91 \%$ & 0.509 & 0.508 & $-0.08 \%$ \\
\hline $\mathrm{Mn}$ & 1.46 & 1.416 & 1.389 & $-1.88 \%$ & 1.414 & 1.397 & $-1.21 \%$ & 1.389 & 1.399 & $0.72 \%$ \\
\hline $\mathrm{Na}$ & 8.53 & 8.340 & 8.300 & $-0.49 \%$ & & & & 8.328 & 8.400 & $0.87 \%$ \\
\hline $\mathrm{Ni}$ & 0.83 & 0.808 & 0.798 & $-1.29 \%$ & 0.803 & 0.784 & $-2.38 \%$ & 0.804 & 0.803 & $-0.07 \%$ \\
\hline $\mathrm{Si}$ & 22.39 & 21.860 & 21.885 & $0.12 \%$ & 22.586 & 22.414 & $-0.76 \%$ & 21.306 & 20.985 & $-1.51 \%$ \\
\hline $\mathrm{Ti}$ & 0.69 & 0.672 & 0.671 & $-0.27 \%$ & 0.671 & 0.672 & $0.11 \%$ & 0.671 & 0.688 & $2.46 \%$ \\
\hline \multicolumn{11}{|l|}{$\mathrm{U}$} \\
\hline $\mathrm{Zr}$ & 0.1 & 0.102 & 0.103 & $0.50 \%$ & & & & 0.093 & 0.094 & $0.79 \%$ \\
\hline \multirow[t]{19}{*}{ Sum Ox } & 99.3 & 97.413 & 96.179 & $-1.27 \%$ & 87.103 & 86.176 & $-1.06 \%$ & 86.570 & 85.974 & $-0.69 \%$ \\
\hline & Analyte & $\% \mathrm{RSD}(\mathrm{T})$ & $\% \operatorname{RSD}(\mathrm{T})$ & Variance Ratio & $\% \operatorname{RSD}(\mathrm{T})$ & $\% \mathrm{RSD}(\mathrm{T})$ & Variance Ratio & $\% \mathrm{RSD}(\mathrm{T})$ & $\% \operatorname{RSD}(\mathrm{T})$ & Variance Ratio \\
\hline & $\mathrm{Al}$ & $3.85 \%$ & $3.17 \%$ & 1.47 & $3.93 \%$ & $3.14 \%$ & 1.58 & $2.26 \%$ & $2.12 \%$ & 1.07 \\
\hline & $\mathrm{B}$ & $2.94 \%$ & $2.42 \%$ & 1.49 & $3.41 \%$ & $2.60 \%$ & 1.81 & & & \\
\hline & $\mathrm{Ca}$ & $5.66 \%$ & $4.44 \%$ & 1.61 & $4.40 \%$ & $2.47 \%$ & 3.26 & $2.27 \%$ & $2.24 \%$ & 1.02 \\
\hline & $\mathrm{Cr}$ & $10.38 \%$ & $9.36 \%$ & 1.12 & $9.19 \%$ & $10.60 \%$ & 1.26 & $12.25 \%$ & $8.92 \%$ & 2.39 \\
\hline & $\mathrm{Cu}$ & $115.96 \%$ & $176.37 \%$ & 1.90 & $242.26 \%$ & $-660.62 \%$ & 1.10 & $-240.36 \%$ & $-102.19 \%$ & 2.20 \\
\hline & $\mathrm{Fe}$ & $2.97 \%$ & $2.21 \%$ & 1.88 & $3.61 \%$ & $2.57 \%$ & 2.04 & $2.13 \%$ & $2.50 \%$ & 1.37 \\
\hline & $\mathrm{K}$ & $9.46 \%$ & $5.93 \%$ & 2.60 & $6.06 \%$ & $10.66 \%$ & 3.00 & $20.32 \%$ & $7.18 \%$ & 6.50 \\
\hline & $\mathrm{Li}$ & $3.60 \%$ & $3.25 \%$ & 1.20 & $3.57 \%$ & $3.06 \%$ & 1.38 & $6.13 \%$ & $2.07 \%$ & 8.37 \\
\hline & $\mathrm{Mg}$ & $4.97 \%$ & $3.65 \%$ & 1.96 & $3.85 \%$ & $3.38 \%$ & 1.35 & $2.41 \%$ & $2.62 \%$ & 1.18 \\
\hline & $\mathrm{Mn}$ & $2.90 \%$ & $2.63 \%$ & 1.27 & $3.90 \%$ & $2.58 \%$ & 2.35 & $2.01 \%$ & $2.39 \%$ & 1.44 \\
\hline & $\mathrm{Na}$ & $1.78 \%$ & $2.15 \%$ & 1.44 & & & & $1.34 \%$ & $1.76 \%$ & 1.76 \\
\hline & $\mathrm{Ni}$ & $2.16 \%$ & $2.87 \%$ & 1.72 & $3.80 \%$ & $3.09 \%$ & 1.59 & $3.15 \%$ & $2.16 \%$ & 2.13 \\
\hline & $\mathrm{Si}$ & $2.77 \%$ & $2.73 \%$ & 1.03 & $3.53 \%$ & $2.63 \%$ & 1.82 & $2.22 \%$ & $3.37 \%$ & 2.23 \\
\hline & $\mathrm{Ti}$ & $2.27 \%$ & $2.20 \%$ & 1.06 & $3.83 \%$ & $2.30 \%$ & 2.77 & $2.72 \%$ & $2.07 \%$ & 1.65 \\
\hline & $\mathrm{U}$ & & & & & & & & & \\
\hline & $\mathrm{Zr}$ & $5.45 \%$ & $6.08 \%$ & 1.26 & & & & $7.93 \%$ & $5.20 \%$ & 2.29 \\
\hline & Sum Ox & $3.43 \%$ & $3.91 \%$ & 1.26 & $3.84 \%$ & $2.34 \%$ & 2.76 & $1.97 \%$ & $2.94 \%$ & 2.20 \\
\hline
\end{tabular}


A review of the results for the Cold Chem preparations of ARG-1 indicates that for the "major" elements the largest average difference between M-13 and M-14 is for Mg with the M-14 values being $2.62 \%$ (on average) below the M-13 values. A review of the results for the Fusion preparations of ARG-1 indicates that for the "major" elements the largest average difference between M-13 and $\mathrm{M}-14$ is for $\mathrm{B}$ and $\mathrm{Ni}$ with the M-14 values being $2.4 \%$ (on average) below the M-13 values. A review of the results for the Mixed Acid preparations of ARG-1 indicates that for the "major" elements the largest average differences between M-13 and M-14 are for $\mathrm{Al}$ (2.91\%)and $\mathrm{Li}(2.21 \%)$ with the M-14 values being, on average, above the M-13 values. The shading of the entries in Table 3-5 is derived from the results for the ARG-1 samples presented in Exhibit A3. If the statistical comparisons of the means of the measurements for an element indicate that the averages for the two ICPs differ (at a 5\% significance level) for a given preparation method, then the $\%$ relative difference entry in Table 3-5 is shaded.

Another area of comparisons for the ICPs is the SRAT product results from the Cold Chem preparation method. Table 3-6 provides and modifies information from Table 3-3 to help provide insight into this aspect of the ICP comparison. Exhibit A4 in the Appendix is also used to help address this issue. The results from the statistical tests in that exhibit for differences in the means of the measurements and in the variances from the two ICPs have been used to shade entries in Table 36. If the results of the exhibit indicate a statistically significant (at the 5\% significance level) difference in means, the $\%$ difference entry is shaded. If the results of the exhibit indicate a statistically significant (at the 5\% significance level) difference in the variance (using the 2-sided Ftest), the variance ratio entry is shaded.

Table 3-7 ICP Comparisons for SRAT Product Measurements

\begin{tabular}{||c|c|c|c|c|c|c||}
\hline & Cold Chem/M-13 & Cold Chem/M-14 & $\%$ & M-13 & M-14 & Variance \\
\hline Analyte & Average & Average & Difference & $\%$ RSD(T) & $\%$ RSD(T) & Ratio \\
\hline $\mathrm{Al}$ & 5.142 & 5.092 & $-0.98 \%$ & $4.65 \%$ & $6.55 \%$ & 1.95 \\
\hline $\mathrm{B}$ & 0.012 & 0.008 & $-36.28 \%$ & $209.40 \%$ & $214.03 \%$ & 2.36 \\
\hline $\mathrm{Ca}$ & 1.342 & 1.336 & $-0.43 \%$ & $4.02 \%$ & $4.18 \%$ & 1.07 \\
\hline $\mathrm{Cr}$ & 0.084 & 0.088 & $4.82 \%$ & $9.64 \%$ & $9.81 \%$ & 1.14 \\
\hline $\mathrm{Cu}$ & 0.033 & 0.028 & $-13.25 \%$ & $12.66 \%$ & $14.16 \%$ & 1.06 \\
\hline $\mathrm{Fe}$ & 15.063 & 14.667 & $-2.63 \%$ & $6.44 \%$ & $7.03 \%$ & 1.13 \\
\hline $\mathrm{K}$ & 0.251 & 0.159 & $-36.54 \%$ & $83.56 \%$ & $77.57 \%$ & 2.88 \\
\hline $\mathrm{Li}$ & 0.008 & -0.011 & $-243.13 \%$ & $335.74 \%$ & $-193.29 \%$ & 1.47 \\
\hline $\mathrm{Mg}$ & 1.340 & 1.317 & $-1.75 \%$ & $5.36 \%$ & $4.36 \%$ & 1.56 \\
\hline $\mathrm{Mn}$ & 3.184 & 3.129 & $-1.75 \%$ & $5.12 \%$ & $5.37 \%$ & 1.06 \\
\hline $\mathrm{Na}$ & 10.638 & 10.489 & $-1.40 \%$ & $3.05 \%$ & $4.07 \%$ & 1.73 \\
\hline $\mathrm{Ni}$ & 0.867 & 0.853 & $-1.63 \%$ & $5.58 \%$ & $6.44 \%$ & 1.29 \\
\hline $\mathrm{Si}$ & 1.163 & 1.078 & $-7.26 \%$ & $11.48 \%$ & $17.98 \%$ & 2.11 \\
\hline $\mathrm{Ti}$ & 0.015 & 0.016 & $13.10 \%$ & $25.69 \%$ & $23.51 \%$ & 1.07 \\
\hline $\mathrm{U}$ & 5.576 & 5.507 & $-1.24 \%$ & $4.82 \%$ & $5.32 \%$ & 1.19 \\
\hline $\mathrm{Zr}$ & 0.078 & 0.078 & $0.48 \%$ & $10.22 \%$ & $9.24 \%$ & 1.21 \\
\hline $\mathrm{Sum} \mathrm{Ox}$ & 64.684 & 62.993 & $-2.61 \%$ & $4.24 \%$ & $4.94 \%$ & 1.29 \\
\hline
\end{tabular}

These results do suggest some differences between the two ICPs. While most of the statistically significant differences involve relatively minor SRAT product components, the fact that the M-14 yields, on average, a lower sum of oxides may be somewhat of concern since it suggests a lower recovery of the composition of the SRAT product. 
- Using primarily the ARG-1 data, review the protocol that defines the preferred analytical method (Fusion versus Mixed acid) for each of the elements reported by DWPF Lab for SME samples.

Although the protocol has already been described and used above, it is detailed in Table 3-8 for completeness. The table shows that all of the elements are obtained from the Fusion preparation method except $\mathrm{Mg}$, $\mathrm{Na}$ and $\mathrm{Zr}$, which are taken from the Mixed Acid method.

Table 3-8 Current Protocol for Representing the SME Measurements

\begin{tabular}{||c|c||}
\hline Element & Represented by \\
\hline aluminum $(\mathrm{Al})$ & Fusion \\
\hline boron $(\mathrm{B})$ & Fusion \\
\hline calcium $(\mathrm{Ca})$ & Fusion \\
\hline chromium $(\mathrm{Cr})$ & Fusion \\
\hline copper $(\mathrm{Cu})$ & Fusion \\
\hline iron $(\mathrm{Fe})$ & Fusion \\
\hline potassium $(\mathrm{K})$ & Fusion \\
\hline lithium $(\mathrm{Li})$ & Fusion \\
\hline magnesium $(\mathrm{Mg})$ & Mixed Acid \\
\hline manganese $(\mathrm{Mn})$ & Fusion \\
\hline sodium $(\mathrm{Na})$ & Mixed Acid \\
\hline nickel $(\mathrm{Ni})$ & Fusion \\
\hline silicon $(\mathrm{Si})$ & Fusion \\
\hline titanium $(\mathrm{Ti})$ & Fusion \\
\hline uranium $(\mathrm{U})$ & Fusion \\
\hline zirconium $(\mathrm{Zr})$ & Mixed Acid \\
\hline
\end{tabular}

The information in Table 3-5 provides the basis for relevant comparisons based upon the ARG-1 measurements. Statistical tests for significant differences in the mean concentrations are provided by the ARG-1 results in Exhibit A3. Table 3-9 provides a summary of this information by ICP from the ARG-1 measurements for the two preparation methods. Those averages that indicate statistically different underlying mean concentrations for the two preparation methods have the $\%$ relative difference (\% Rel Diff) entries shaded in Table 3-9. The lower portion of the table provides the \% relative standard deviation of the total variation $(\% \mathrm{RSD}(\mathrm{T}))$ for the measurements. The table also includes the ratio of the (total) variances of the two methods with the larger of the two variances in the numerator of the ratio. 
WSRC-STI-2006-00068

Revision 0

Table 3-9 Fusion versus Mixed Acid Comparisons for ARG-1 Measurements

\begin{tabular}{|c|c|c|c|c|c|c|c|}
\hline & & $\begin{array}{c}\text { Fusion/ } \\
\text { M-13 }\end{array}$ & $\begin{array}{l}\text { Mixed Acid/ } \\
\text { M-13 }\end{array}$ & $\%$ Rel Diff & $\begin{array}{c}\text { Fusion/ } \\
\text { M-14 }\end{array}$ & $\begin{array}{c}\text { Mixed Acid/ } \\
\text { M-14 }\end{array}$ & $\%$ Rel Diff \\
\hline Analyte & $\begin{array}{c}\text { Ref. } \\
\text { Value }\end{array}$ & Average & Average & $\begin{array}{c}\text { (Based on } \\
\text { Mixed Acid) }\end{array}$ & Average & Average & $\begin{array}{c}\text { (Based on } \\
\text { Mixed Acid) }\end{array}$ \\
\hline $\mathrm{Al}$ & 2.5 & 2.401 & 2.299 & $4.44 \%$ & 2.392 & 2.366 & $1.12 \%$ \\
\hline $\mathrm{B}$ & 2.69 & 2.617 & & & 2.555 & & \\
\hline $\mathrm{Ca}$ & 1.02 & 0.983 & 0.994 & $-1.06 \%$ & 0.971 & 1.000 & $-2.93 \%$ \\
\hline $\mathrm{Cr}$ & 0.06 & 0.068 & 0.067 & $1.73 \%$ & 0.066 & 0.059 & $11.37 \%$ \\
\hline $\mathrm{Cu}$ & 0.0001 & 0.002 & -0.003 & $-154.62 \%$ & -0.001 & -0.005 & $-86.75 \%$ \\
\hline $\mathrm{Fe}$ & 9.79 & 9.709 & 9.524 & $1.94 \%$ & 9.550 & 9.492 & $0.61 \%$ \\
\hline $\mathrm{K}$ & 2.25 & 2.198 & 2.007 & $9.49 \%$ & 2.165 & 2.227 & $-2.77 \%$ \\
\hline $\mathrm{Li}$ & 1.49 & 1.467 & 1.465 & $0.11 \%$ & 1.458 & 1.498 & $-2.66 \%$ \\
\hline $\mathrm{Mg}$ & 0.52 & 0.506 & 0.509 & $-0.50 \%$ & 0.496 & 0.508 & $-2.33 \%$ \\
\hline $\mathrm{Mn}$ & 1.46 & 1.414 & 1.389 & $1.82 \%$ & 1.397 & 1.399 & $-0.13 \%$ \\
\hline $\mathrm{Na}$ & 8.53 & & 8.328 & & & 8.400 & $-100.00 \%$ \\
\hline $\mathrm{Ni}$ & 0.83 & 0.803 & 0.804 & $-0.13 \%$ & 0.784 & 0.803 & $-2.43 \%$ \\
\hline $\mathrm{Si}$ & 22.39 & 22.586 & 21.306 & $6.00 \%$ & 22.414 & 20.985 & $6.81 \%$ \\
\hline $\mathrm{Ti}$ & 0.69 & 0.671 & 0.671 & $-0.08 \%$ & 0.672 & 0.688 & $-2.37 \%$ \\
\hline \multicolumn{8}{|l|}{$\mathrm{U}$} \\
\hline $\mathrm{Zr}$ & 0.1 & & 0.093 & & & 0.094 & \\
\hline Sum Ox & 99.3 & 87.103 & 86.570 & NA & 86.176 & 85.974 & NA \\
\hline Analyte & & $\%$ RSD(T) & $\% \operatorname{RSD}(\mathrm{T})$ & Variance Ratio & $\% \operatorname{RSD}(\mathrm{T})$ & $\% \operatorname{RSD}(\mathrm{T})$ & Variance Ratio \\
\hline $\mathrm{Al}$ & & $3.93 \%$ & $2.26 \%$ & 3.30 & $3.14 \%$ & $2.12 \%$ & 2.24 \\
\hline $\mathrm{B}$ & & $3.41 \%$ & & & $2.60 \%$ & & \\
\hline $\mathrm{Ca}$ & & $4.40 \%$ & $2.27 \%$ & 3.66 & $2.47 \%$ & $2.24 \%$ & 1.14 \\
\hline $\mathrm{Cr}$ & & $9.19 \%$ & $12.25 \%$ & 1.72 & $10.60 \%$ & $8.92 \%$ & 1.75 \\
\hline $\mathrm{Cu}$ & & $242.26 \%$ & $240.36 \%$ & 3.30 & $660.62 \%$ & $102.19 \%$ & 1.36 \\
\hline $\mathrm{Fe}$ & & $3.61 \%$ & $2.13 \%$ & 2.99 & $2.57 \%$ & $2.50 \%$ & 1.07 \\
\hline $\mathrm{K}$ & & $6.06 \%$ & $20.32 \%$ & 9.37 & $10.66 \%$ & $7.18 \%$ & 2.08 \\
\hline $\mathrm{Li}$ & & $3.57 \%$ & $6.13 \%$ & 2.94 & $3.06 \%$ & $2.07 \%$ & 2.07 \\
\hline $\mathrm{Mg}$ & & $3.85 \%$ & $2.41 \%$ & 2.53 & $3.38 \%$ & $2.62 \%$ & 1.59 \\
\hline $\mathrm{Mn}$ & & $3.90 \%$ & $2.01 \%$ & 3.93 & $2.58 \%$ & $2.39 \%$ & 1.16 \\
\hline $\mathrm{Na}$ & & & $1.34 \%$ & & & $1.76 \%$ & \\
\hline $\mathrm{Ni}$ & & $3.80 \%$ & $3.15 \%$ & 1.45 & $3.09 \%$ & $2.16 \%$ & 1.94 \\
\hline $\mathrm{Si}$ & & $3.53 \%$ & $2.22 \%$ & 2.83 & $2.63 \%$ & $3.37 \%$ & 1.44 \\
\hline $\mathrm{Ti}$ & & $3.83 \%$ & $2.72 \%$ & 1.98 & $2.30 \%$ & $2.07 \%$ & 1.17 \\
\hline \multicolumn{8}{|l|}{$\mathrm{U}$} \\
\hline $\mathrm{Zr}$ & & & $7.93 \%$ & & & $5.20 \%$ & \\
\hline Sum Ox & & $3.84 \%$ & $1.97 \%$ & 3.85 & $2.34 \%$ & $2.94 \%$ & 1.58 \\
\hline
\end{tabular}

Another area of comparisons for the two preparation methods is the SME sample results from each of the two ICPs. Table 3-10 provides and modifies information from Table 3-3 to help provide insight into the comparisons between the prep methods. Exhibit A5 is also available to investigate for statistical differences. Shading is used in Table 3-10 in the same manner as was used in Table 3-9. 
Table 3-10 Comparisons Between Fusion and Mixed Acid for the SME Measurements

\begin{tabular}{|c|c|c|c|c|c|c|c|}
\hline & & Fusion/M-13 & Mixed Acid/M-13 & $\%$ Rel Diff & Fusion/M-14 & Mixed Acid/M-14 & \% Rel Diff \\
\hline Analyte & Process & Average & Average & (Based on MA) & Average & Average & (Based on MA) \\
\hline $\mathrm{Al}$ & SME & 2.957 & 2.885 & $2.49 \%$ & 2.885 & 3.051 & $-5.42 \%$ \\
\hline $\mathrm{B}$ & SME & 1.449 & & & 1.390 & & \\
\hline $\mathrm{Ca}$ & SME & 0.718 & 0.717 & $0.16 \%$ & 0.687 & 0.755 & $-9.04 \%$ \\
\hline $\mathrm{Cr}$ & SME & 0.055 & 0.054 & $1.30 \%$ & 0.051 & 0.047 & $9.22 \%$ \\
\hline $\mathrm{Cu}$ & SME & 0.014 & 0.009 & $57.56 \%$ & 0.011 & 0.008 & $49.54 \%$ \\
\hline $\mathrm{Fe}$ & SME & 7.969 & 7.782 & $2.40 \%$ & 7.679 & 7.881 & $-2.56 \%$ \\
\hline $\mathrm{K}$ & SME & 0.102 & -0.061 & $-266.55 \%$ & 0.115 & 0.166 & $-30.79 \%$ \\
\hline $\mathrm{Li}$ & SME & 2.203 & 2.214 & $-0.49 \%$ & 2.170 & 2.244 & $-3.29 \%$ \\
\hline $\mathrm{Mg}$ & SME & 0.686 & 0.675 & $1.69 \%$ & 0.669 & 0.720 & $-7.07 \%$ \\
\hline $\mathrm{Mn}$ & SME & 1.575 & 1.542 & $2.16 \%$ & 1.536 & 1.620 & $-5.15 \%$ \\
\hline $\mathrm{Na}$ & SME & & 8.808 & & & 9.054 & \\
\hline $\mathrm{Ni}$ & SME & 0.456 & 0.450 & $1.33 \%$ & 0.433 & 0.460 & $-5.91 \%$ \\
\hline $\mathrm{Si}$ & SME & 23.809 & 22.461 & $6.00 \%$ & 23.288 & 21.669 & $7.47 \%$ \\
\hline $\mathrm{Ti}$ & SME & 0.039 & 0.032 & $20.82 \%$ & 0.041 & 0.040 & $2.42 \%$ \\
\hline $\mathrm{U}$ & SME & 2.601 & 2.755 & $-5.56 \%$ & 2.710 & 2.891 & $-6.26 \%$ \\
\hline $\mathrm{Zr}$ & SME & & 0.050 & & & 0.060 & \\
\hline Sum Ox & SME & 85.728 & 89.098 & NA & 83.398 & 89.296 & NA \\
\hline & & Fusion/M-13 & Mixed Acid/M-13 & Variance & Fusion/M-14 & Mixed Acid/M-14 & Variance \\
\hline Analyte & Process & $\%$ RSD $(\mathrm{T})$ & $\% \mathrm{RSD}(\mathrm{T})$ & Ratio & $\% \mathrm{RSD}(\mathrm{T})$ & $\% \operatorname{RSD}(\mathrm{T})$ & Ratio \\
\hline $\mathrm{Al}$ & SME & $7.73 \%$ & $6.66 \%$ & 1.415 & $8.47 \%$ & $6.66 \%$ & 1.444 \\
\hline $\mathrm{B}$ & SME & $4.84 \%$ & & & $7.95 \%$ & & \\
\hline $\mathrm{Ca}$ & SME & $9.36 \%$ & $6.30 \%$ & 2.215 & $9.91 \%$ & $6.46 \%$ & 1.950 \\
\hline $\mathrm{Cr}$ & SME & $13.10 \%$ & $46.19 \%$ & 12.115 & $21.63 \%$ & $11.91 \%$ & 3.935 \\
\hline $\mathrm{Cu}$ & SME & $29.99 \%$ & $86.28 \%$ & 3.333 & $41.73 \%$ & $71.64 \%$ & 1.318 \\
\hline $\mathrm{Fe}$ & SME & $6.49 \%$ & $4.45 \%$ & 2.235 & $8.67 \%$ & $6.14 \%$ & 1.894 \\
\hline $\mathrm{K}$ & SME & $150.33 \%$ & $567.46 \%$ & 5.137 & $154.73 \%$ & $159.58 \%$ & 2.221 \\
\hline $\mathrm{Li}$ & SME & $4.32 \%$ & $4.99 \%$ & 1.346 & $7.54 \%$ & $3.95 \%$ & 3.410 \\
\hline $\mathrm{Mg}$ & SME & $8.98 \%$ & $7.76 \%$ & 1.385 & $8.86 \%$ & $7.53 \%$ & 1.194 \\
\hline $\mathrm{Mn}$ & SME & $8.45 \%$ & $6.70 \%$ & 1.662 & $8.88 \%$ & $7.73 \%$ & 1.186 \\
\hline $\mathrm{Na}$ & SME & & $4.53 \%$ & & & $4.20 \%$ & \\
\hline $\mathrm{Ni}$ & SME & $7.59 \%$ & $5.91 \%$ & 1.694 & $9.15 \%$ & $6.07 \%$ & 2.012 \\
\hline $\mathrm{Si}$ & SME & $5.54 \%$ & $4.16 \%$ & 1.991 & $7.67 \%$ & $5.19 \%$ & 2.519 \\
\hline $\mathrm{Ti}$ & SME & $20.56 \%$ & $24.24 \%$ & 1.050 & $14.23 \%$ & $16.39 \%$ & 1.265 \\
\hline $\mathrm{U}$ & SME & $7.45 \%$ & $7.27 \%$ & 1.068 & $9.41 \%$ & $6.59 \%$ & 1.792 \\
\hline $\mathrm{Zr}$ & SME & & $21.35 \%$ & & & $23.42 \%$ & \\
\hline Sum Ox & SME & $3.62 \%$ & $2.90 \%$ & 1.446 & $6.57 \%$ & $2.74 \%$ & 5.017 \\
\hline
\end{tabular}

When it was established, the protocol for how to use the Fusion and Mixed Acid results to report the chemical compositions of the SME samples relied on the method that provided the better recovery of the particular element of interest. A review of the results presented in Table 3-9 and Table 3-10 suggests the following: For Al, the Fusion method provides a higher recovery, on average, than the Mixed Acid method for this element for ARG-1 samples as well as for SME samples when the M-13 ICP is used but the advantage is not seen when the M-14 is used. Also, note that the precision of the Fusion method is not as good as that of the Mixed Acid for both ICPs. For Ca, the Fusion method leads to poorer average recovery and to poorer precision than the Mixed Acid method. For Cr, the Fusion method provides, on average, better recoveries than Mixed Acid regardless of the ICP used and better precision than the Mixed Acid for the M-13 but worse precision for the M-14. For $\mathrm{Cu}$, the Fusion method appears to provide a higher recovery than and as good precision as the Mixed Acid method regardless of ICP used. For Fe, the Fusion method appears to provide a higher recovery than the Mixed Acid when the M-13 ICP is used but this is not seen when the M-14 ICP is used.

However, the Fusion method appears to lead to less precise Fe measurements than does the Mixed Acid method, in general. For Li, while the M-13 results suggest little difference in average recovery or precision between the two preparation methods, the M-14 results suggest that Mixed Acid yields higher Li recoveries and more precise Li measurements. For Mg, the Mixed Acid method appears to 
yield more precise measurements regardless of ICP and the average recovery for Mixed Acid is better than that for Fusion when the M-14 ICP is used. For Mn, while the Fusion method yields a better average recovery than the Mixed Acid method when the M-13 ICP is used, the Mixed Acid may yield a higher recovery when the M-14 ICP is used. For both ICPs, the Fusion method yields less precise Mn measurements than the Mixed Acid method. For Ni, the Fusion method appears to be less precise than the Mixed Acid method regardless of ICP while the Mixed Acid method appears to yield a higher average Ni recovery when the M-14 ICP is used. For Si, the Fusion method yields a higher recovery than Mixed Acid regardless of ICP but is less precise for the M-13 ICP than the M-14 for the ARG-1 samples. For Ti, there appears to be little difference between the results from the two preparation methods.

These results indicate the protocol may be sensitive to the ICP used, which would suggest that there may be a need to assess the benefits of aligning both ICPs in the same manner to establish a single protocol for selecting between the Fusion and Mixed Acid results to represent the chemical composition of the SME samples.

- Evaluate the uncertainty of a waste loading target determined during the SME blending process using actual variation of the measurements for the specific batches.

Figure 3-3 provides an overview of the blending process and the associated targeting of WL. For the sixteen elements of interest, the total mass of these elements is tracked during the blending process so that the fraction of this mass attributable to $\mathrm{Li}$ oxide $\left(\mathrm{Li}_{2} \mathrm{O}\right)$ can be ratioed to the $\mathrm{Li}_{2} \mathrm{O}$ in the frit to determine a target for WL as given by

$\mathrm{WL}=100 \times\left(1-\left(\mathrm{Li}_{2} \mathrm{O}\right.\right.$ weight percent in the $\mathrm{SME} / \mathrm{Li}_{2} \mathrm{O}$ weight percent in the frit $\left.)\right)$

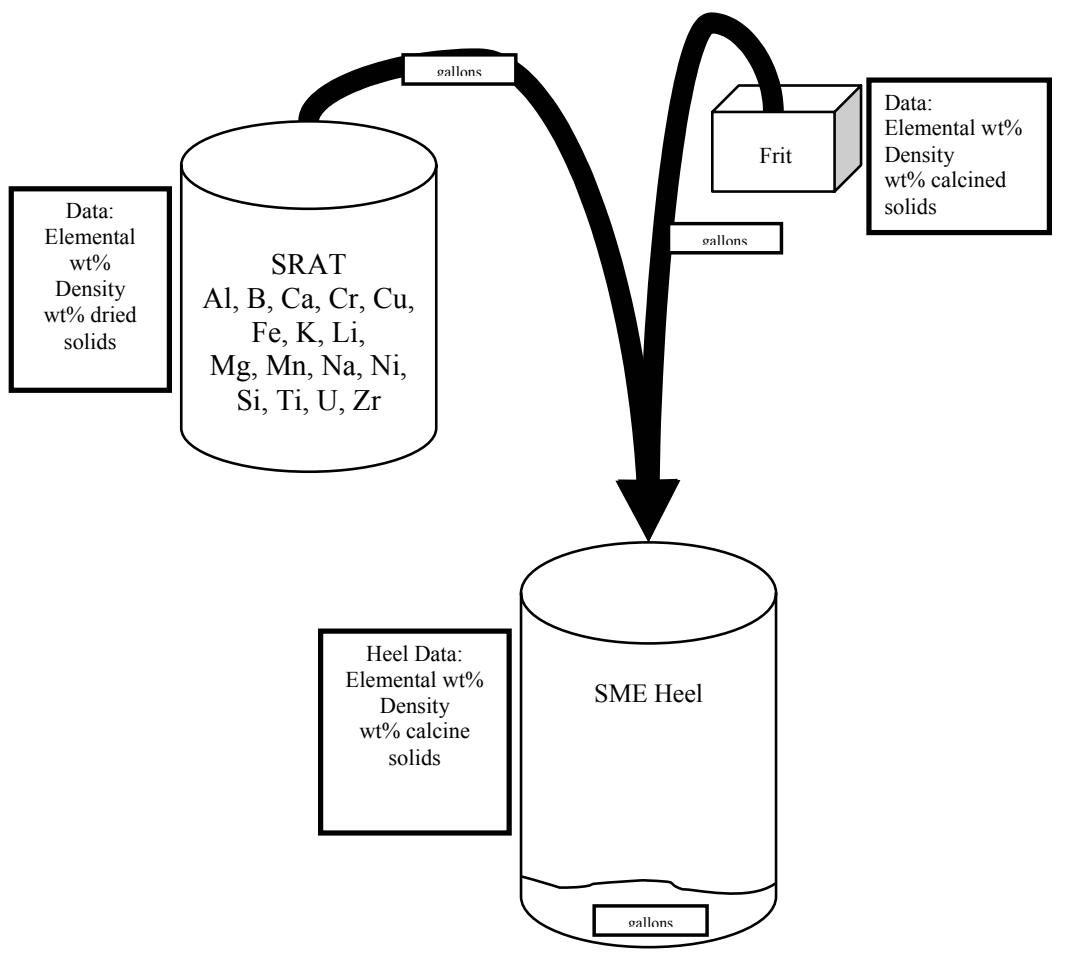

Figure 3-3. Overview of WL Target during Blending Process 
The details associated with the calculation of a targeted WL involve two sets of measurements that are directly related to this study: the SME heel composition determined from the Fusion and Mixed Acid results from the SME samples and the composition of the material transferred from the SRAT into the SME determined by the Cold Chem results of the SRAT product. What do the results of the ARG-1 samples and the comparisons of the ICPs suggest regarding the impact of the uncertainties in these measurements on the targeting of a WL for the SME?

Table A4 in Appendix A provides a point of reference for information on the targeted waste loadings (WLs) for the batches being investigated in this study. The table provides the WL value targeted during the blending process and the information associated with this process. Exhibit A8 in Appendix A provides the JMP formulas that were used to capture the estimates of bias and variance components from Tables 3-1 through 3.4 to investigate the sensitivity of the targeted WLs to the uncertainty of the measured quantities used in the associated calculations. A formula is provided for each ICP (M-13 and M-14). The inputs to the WL target calculation for each of the batch from 300 through 356 are subjected to the uncertainties of Exhibit A8 for 10,000 iterations with a target WL calculated for each iteration. Exhibit A9 in Appendix A provides a histogram and other information on the distribution of the resulting 10,000 targeted WLs for the M-13 ICP and the 10,000 for the M14 ICP for each batch. Figure 3-4 provides a plot of uncertainty bands (at 95\% confidence) around the targeted WLs by batch for the M-13 and M-14 ICPs. Table 3-11 summarizes the information that was used in developing this plot. These results suggest that, on average, the uncertainty in the targeted WLs at blending are $(-1.1,1.4)$ percentage points for the M-13 ICP and $(-1.3,2.1)$ percentage points for the M-14 ICP.

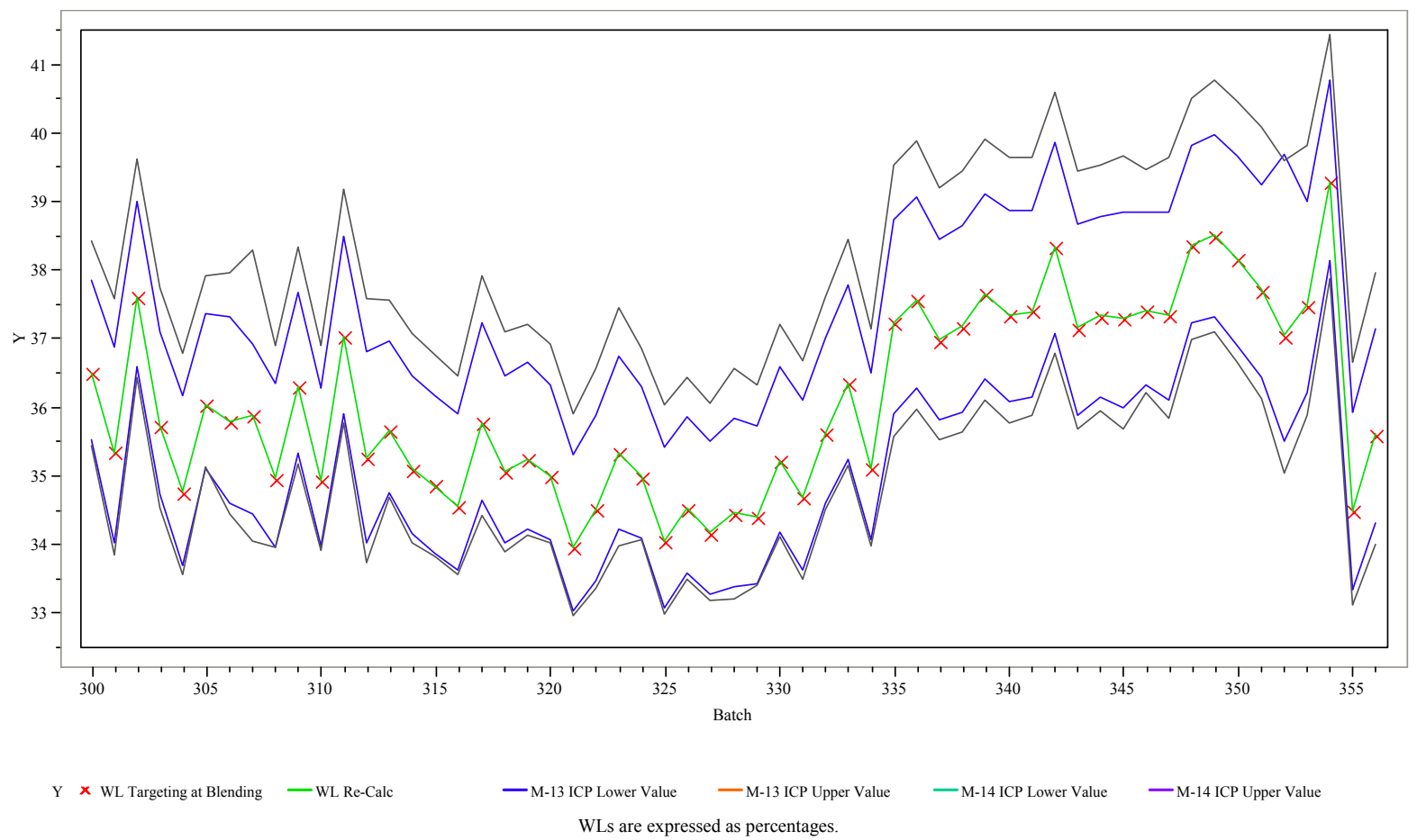

Figure 3-4. 95\% Uncertainty Bands around Targeted WLs for M-13 and M-14 ICPs 
WSRC-STI-2006-00068 Revision 0

Table 3-11 Target WLs at Blending with Error Propagations (95\% confidence) for M-13 and M-14 ICPs

\begin{tabular}{|c|c|c|c|c|c|c|}
\hline \multirow[b]{2}{*}{ Batch } & \multirow{2}{*}{$\begin{array}{c}\text { WL Targeted } \\
\text { At Blending }\end{array}$} & \multirow{2}{*}{$\begin{array}{c}\text { Re-Calculation } \\
\text { Of Targeted WL }\end{array}$} & \multicolumn{2}{|c|}{ 95\% Uncertainty Band for M-13 } & \multicolumn{2}{|c|}{ 95\% Uncertainty Band for M-14 } \\
\hline & & & Lower Value & Upper Value & Lower Value & Upper Value \\
\hline 300 & 36.47 & 36.51 & 35.544 & 37.855 & 35.452 & 38.446 \\
\hline 301 & 35.31 & 35.35 & 34.038 & 36.894 & 33.856 & 37.599 \\
\hline 302 & 37.57 & 37.61 & 36.593 & 39.010 & 36.456 & 39.628 \\
\hline 303 & 35.70 & 35.74 & 34.736 & 37.109 & 34.548 & 37.751 \\
\hline 304 & 34.73 & 34.78 & 33.712 & 36.178 & 33.583 & 36.811 \\
\hline 305 & 36.00 & 36.05 & 35.127 & 37.384 & 35.149 & 37.918 \\
\hline 306 & 35.76 & 35.81 & 34.616 & 37.326 & 34.461 & 37.964 \\
\hline 307 & 35.84 & 35.90 & 34.464 & 36.935 & 34.065 & 38.296 \\
\hline 308 & 34.92 & 34.98 & 33.974 & 36.359 & 33.964 & 36.922 \\
\hline 309 & 36.26 & 36.32 & 35.348 & 37.690 & 35.196 & 38.339 \\
\hline 310 & 34.89 & 34.94 & 33.989 & 36.292 & 33.928 & 36.917 \\
\hline 311 & 37.00 & 37.04 & 35.907 & 38.503 & 35.793 & 39.192 \\
\hline 312 & 35.24 & 35.28 & 34.045 & 36.816 & 33.751 & 37.602 \\
\hline 313 & 35.63 & 35.67 & 34.770 & 36.982 & 34.710 & 37.579 \\
\hline 314 & 35.06 & 35.11 & 34.170 & 36.477 & 34.036 & 37.090 \\
\hline 315 & 34.83 & 34.85 & 33.885 & 36.183 & 33.845 & 36.776 \\
\hline 316 & 34.53 & 34.57 & 33.645 & 35.906 & 33.565 & 36.472 \\
\hline 317 & 35.75 & 35.79 & 34.659 & 37.241 & 34.431 & 37.918 \\
\hline 318 & 35.03 & 35.07 & 34.029 & 36.466 & 33.895 & 37.112 \\
\hline 319 & 35.21 & 35.26 & 34.229 & 36.677 & 34.154 & 37.213 \\
\hline 320 & 34.96 & 35.01 & 34.078 & 36.338 & 34.028 & 36.936 \\
\hline 321 & 33.93 & 33.98 & 33.039 & 35.330 & 32.970 & 35.906 \\
\hline 322 & 34.47 & 34.52 & 33.489 & 35.886 & 33.365 & 36.570 \\
\hline 323 & 35.30 & 35.35 & 34.225 & 36.751 & 33.997 & 37.474 \\
\hline 324 & 34.95 & 35.00 & 34.097 & 36.315 & 34.092 & 36.866 \\
\hline 325 & 34.01 & 34.06 & 33.077 & 35.434 & 33.000 & 36.043 \\
\hline 326 & 34.49 & 34.54 & 33.599 & 35.878 & 33.517 & 36.447 \\
\hline 327 & 34.13 & 34.19 & 33.290 & 35.522 & 33.205 & 36.071 \\
\hline 328 & 34.42 & 34.47 & 33.392 & 35.841 & 33.217 & 36.583 \\
\hline 329 & 34.36 & 34.41 & 33.442 & 35.743 & 33.417 & 36.326 \\
\hline 330 & 35.18 & 35.23 & 34.197 & 36.601 & 34.121 & 37.212 \\
\hline 331 & 34.65 & 34.70 & 33.649 & 36.108 & 33.516 & 36.695 \\
\hline 332 & 35.58 & 35.63 & 34.622 & 37.023 & 34.529 & 37.616 \\
\hline 333 & 36.31 & 36.36 & 35.263 & 37.800 & 35.157 & 38.468 \\
\hline 334 & 35.07 & 35.12 & 34.080 & 36.515 & 33.996 & 37.151 \\
\hline 335 & 37.19 & 37.24 & 35.919 & 38.736 & 35.593 & 39.551 \\
\hline 336 & 37.52 & 37.57 & 36.298 & 39.082 & 35.991 & 39.892 \\
\hline 337 & 36.94 & 37.00 & 35.826 & 38.465 & 35.531 & 39.206 \\
\hline 338 & 37.13 & 37.19 & 35.943 & 38.669 & 35.642 & 39.455 \\
\hline 339 & 37.63 & 37.66 & 36.418 & 39.121 & 36.109 & 39.928 \\
\hline 340 & 37.32 & 37.35 & 36.102 & 38.875 & 35.792 & 39.648 \\
\hline 341 & 37.37 & 37.40 & 36.149 & 38.885 & 35.895 & 39.659 \\
\hline 342 & 38.31 & 38.34 & 37.090 & 39.874 & 36.812 & 40.612 \\
\hline 343 & 37.11 & 37.17 & 35.894 & 38.673 & 35.686 & 39.454 \\
\hline 344 & 37.29 & 37.35 & 36.163 & 38.799 & 35.963 & 39.553 \\
\hline 345 & 37.26 & 37.32 & 36.008 & 38.847 & 35.703 & 39.671 \\
\hline 346 & 37.37 & 37.43 & 36.345 & 38.861 & 36.220 & 39.471 \\
\hline 347 & 37.30 & 37.36 & 36.122 & 38.855 & 35.851 & 39.649 \\
\hline 348 & 38.32 & 38.38 & 37.241 & 39.831 & 37.005 & 40.527 \\
\hline 349 & 38.46 & 38.52 & 37.324 & 39.994 & 37.104 & 40.778 \\
\hline 350 & 38.12 & 38.17 & 36.919 & 39.668 & 36.671 & 40.471 \\
\hline 351 & 37.67 & 37.73 & 36.446 & 39.264 & 36.129 & 40.098 \\
\hline 352 & 37.00 & 37.06 & 35.528 & 39.687 & 35.051 & 39.600 \\
\hline 353 & 37.44 & 37.50 & 36.234 & 39.006 & 35.901 & 39.821 \\
\hline 354 & 39.25 & 39.30 & 38.141 & 40.777 & 37.889 & 41.455 \\
\hline 355 & 34.45 & 34.50 & 33.354 & 35.939 & 33.131 & 36.675 \\
\hline 356 & 35.57 & 35.63 & 34.330 & 37.163 & 34.017 & 37.969 \\
\hline
\end{tabular}


For comparison purposes, the estimation of WLs at the SME was also investigated as part of this study. A graphical overview of this estimation is provided in Figure 3-5. As indicated in this figure, there are 4 estimates of WL provided at the SME (one for each of the samples recorded in PCCS). The estimated WL for each of the four samples for each SME batch is determined using the formula given by this equation:

$$
\mathrm{WL}=100 \cdot\left(1-\frac{\mathrm{Li}_{2} \mathrm{O} /(\text { Sum of Oxides })}{\text { Frit }_{\mathrm{Li}_{2} \mathrm{O}} / 100}\right)
$$

Table A5 in Appendix A provides the information used in the computation of the estimated WLs for batches 300 through 356 .

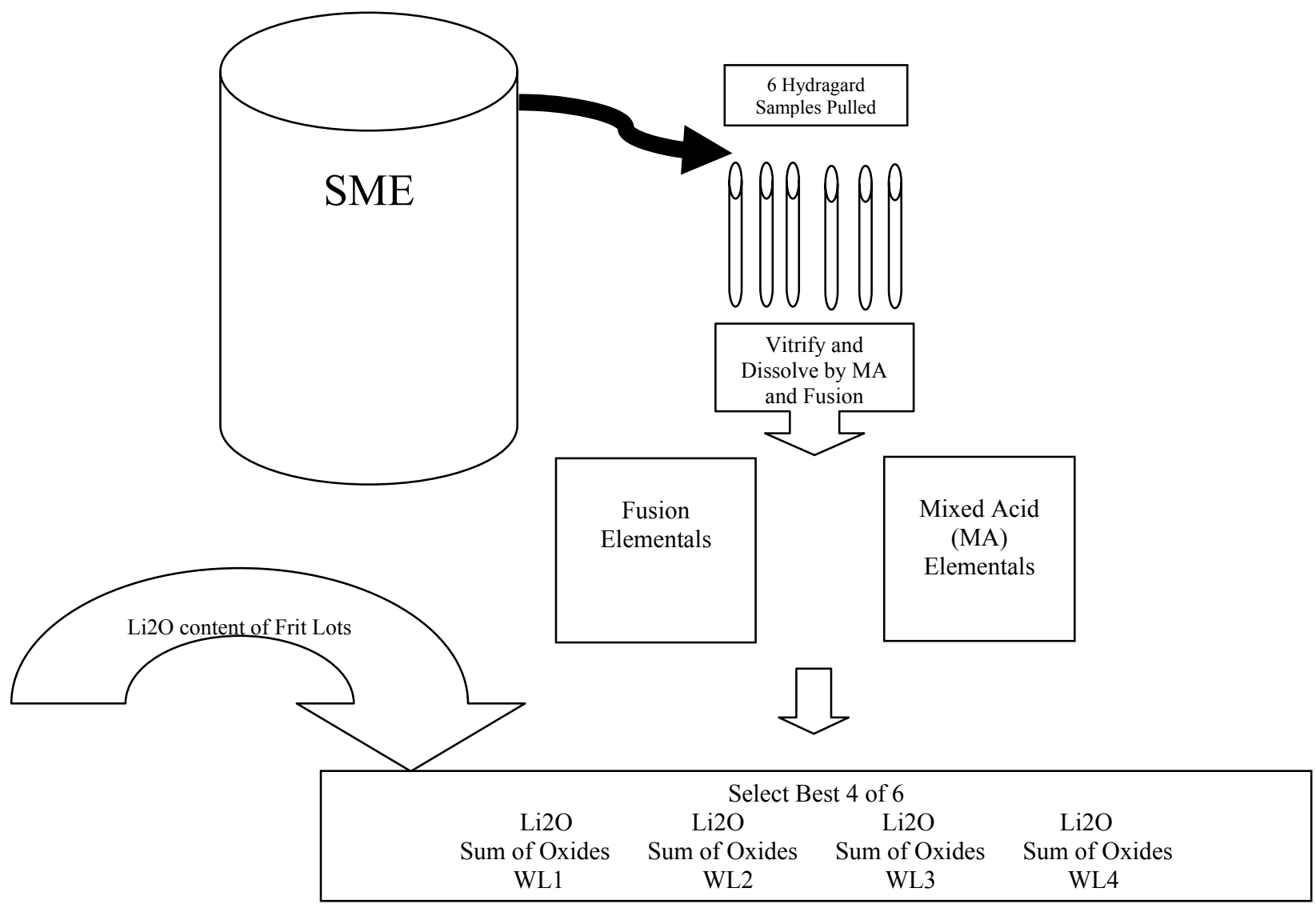

Figure 3-5. Overview of WL Estimation at the SME

Exhibit A10 in Appendix A provides the JMP formulas that were used to capture the estimates of bias and batch-to-batch variance components from Tables 3-1 through 3.4 to investigate the sensitivity of the estimated WLs to the uncertainty of the measured quantities used in the associated calculations. A formula is provided for each ICP (M-13 and M-14). The inputs to the WL target 
calculation for each of the batches from 300 through 356 are subjected to the uncertainties of Exhibit A10 for 10,000 iterations with a target WL calculated for each iteration. Exhibit A11 in Appendix A provides a histogram and other information on the distribution of the resulting 10,000 targeted WLs for the M-13 ICP and the 10,000 for the M-14 ICP for each batch. Figure 3-6 provides a plot of uncertainty bands (at $95 \%$ confidence) around the estimated WLs by batch for the M-13 and M-14 ICPs. Table 3-12 summarizes the information that was used in developing this plot. These results suggest that, on average, the uncertainty in the estimated WLs at the SME are $(-3.2,2.0)$ percentage points for the M-13 ICP and $(-3.0,2.3)$ percentage points for the M-14 ICP.

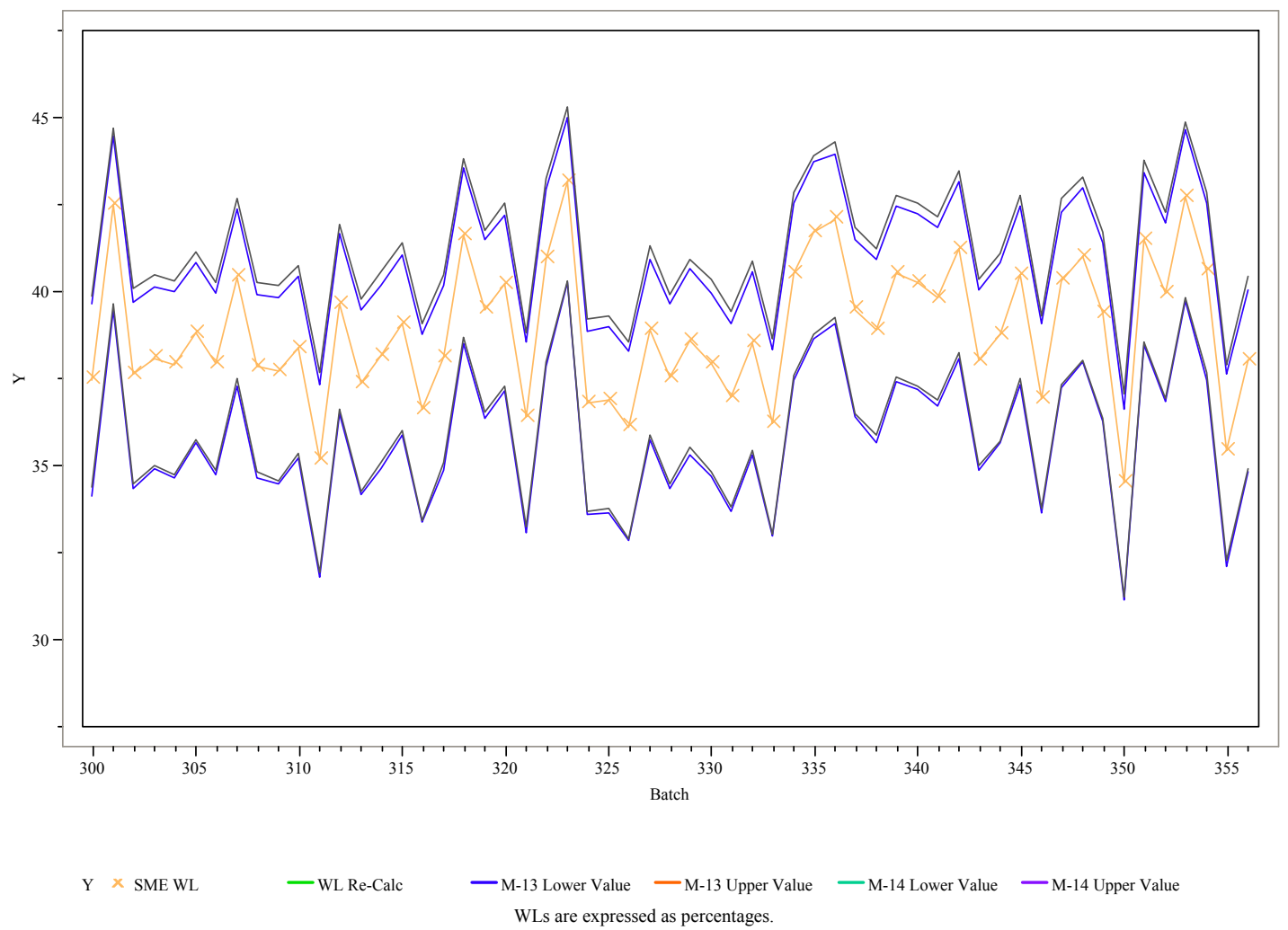

Figure 3-6. Overview of WL Estimation at the SME 
WSRC-STI-2006-00068

Revision 0

Table 3-12 Estimated WLs at the SME with Error Propagations (95\% confidence) for M-13 and M-14 ICPs

\begin{tabular}{|c|c|c|c|c|c|c|}
\hline \multirow[b]{2}{*}{ Batch } & \multirow{2}{*}{$\begin{array}{c}\text { WL Estimated } \\
\text { At the SME }\end{array}$} & \multirow{2}{*}{$\begin{array}{c}\text { Re-Calculation } \\
\text { Of Estimated WL }\end{array}$} & \multicolumn{2}{|c|}{ 95\% Uncertainty Band for M-13 } & \multicolumn{2}{|c|}{ 95\% Uncertainty Band for M-14 } \\
\hline & & & Lower Value & Upper Value & Lower Value & Upper Value \\
\hline 300 & 37.54 & 37.50 & 34.137 & 39.661 & 34.422 & 39.911 \\
\hline 301 & 42.54 & 42.53 & 39.491 & 44.482 & 39.668 & 44.727 \\
\hline 302 & 37.66 & 37.65 & 34.384 & 39.733 & 34.509 & 40.092 \\
\hline 303 & 38.12 & 38.11 & 34.947 & 40.159 & 35.042 & 40.498 \\
\hline 304 & 37.95 & 37.94 & 34.689 & 40.015 & 34.774 & 40.345 \\
\hline 305 & 38.85 & 38.84 & 35.693 & 40.854 & 35.785 & 41.166 \\
\hline 306 & 37.96 & 37.95 & 34.777 & 39.994 & 34.890 & 40.295 \\
\hline 307 & 40.44 & 40.43 & 37.298 & 42.396 & 37.502 & 42.715 \\
\hline 308 & 37.89 & 37.88 & 34.682 & 39.939 & 34.839 & 40.273 \\
\hline 309 & 37.75 & 37.74 & 34.515 & 39.835 & 34.604 & 40.184 \\
\hline 310 & 38.41 & 38.40 & 35.222 & 40.476 & 35.354 & 40.753 \\
\hline 311 & 35.19 & 35.18 & 31.823 & 37.325 & 31.970 & 37.697 \\
\hline 312 & 39.68 & 39.67 & 36.529 & 41.702 & 36.654 & 41.970 \\
\hline 313 & 37.40 & 37.39 & 34.167 & 39.490 & 34.294 & 39.784 \\
\hline 314 & 38.19 & 38.18 & 34.945 & 40.215 & 35.130 & 40.587 \\
\hline 315 & 39.11 & 39.10 & 35.901 & 41.066 & 36.032 & 41.418 \\
\hline 316 & 36.66 & 36.65 & 33.413 & 38.809 & 33.459 & 39.116 \\
\hline 317 & 38.14 & 38.12 & 34.906 & 40.189 & 35.098 & 40.490 \\
\hline 318 & 41.64 & 41.63 & 38.549 & 43.585 & 38.721 & 43.819 \\
\hline 319 & 39.53 & 39.52 & 36.368 & 41.511 & 36.550 & 41.783 \\
\hline 320 & 40.26 & 40.25 & 37.177 & 42.223 & 37.285 & 42.550 \\
\hline 321 & 36.44 & 36.43 & 33.110 & 38.576 & 33.271 & 38.831 \\
\hline 322 & 40.97 & 40.96 & 37.888 & 42.954 & 38.001 & 43.246 \\
\hline 323 & 43.18 & 43.17 & 40.267 & 45.013 & 40.342 & 45.350 \\
\hline 324 & 36.82 & 36.80 & 33.599 & 38.883 & 33.714 & 39.219 \\
\hline 325 & 36.91 & 36.90 & 33.652 & 38.996 & 33.777 & 39.310 \\
\hline 326 & 36.15 & 36.13 & 32.873 & 38.315 & 32.938 & 38.556 \\
\hline 327 & 38.92 & 38.91 & 35.774 & 40.941 & 35.884 & 41.322 \\
\hline 328 & 37.58 & 37.57 & 34.359 & 39.657 & 34.482 & 39.936 \\
\hline 329 & 38.62 & 38.61 & 35.326 & 40.682 & 35.553 & 40.943 \\
\hline 330 & 37.96 & 37.94 & 34.727 & 39.988 & 34.855 & 40.357 \\
\hline 331 & 37.01 & 37.00 & 33.705 & 39.112 & 33.825 & 39.473 \\
\hline 332 & 38.56 & 38.54 & 35.329 & 40.575 & 35.465 & 40.902 \\
\hline 333 & 36.25 & 36.24 & 33.026 & 38.361 & 33.068 & 38.666 \\
\hline 334 & 40.56 & 40.55 & 37.500 & 42.558 & 37.617 & 42.874 \\
\hline 335 & 41.73 & 41.72 & 38.669 & 43.746 & 38.811 & 43.922 \\
\hline 336 & 42.11 & 42.10 & 39.088 & 43.964 & 39.256 & 44.333 \\
\hline 337 & 39.53 & 39.52 & 36.414 & 41.515 & 36.507 & 41.858 \\
\hline 338 & 38.92 & 38.91 & 35.679 & 40.948 & 35.878 & 41.251 \\
\hline 339 & 40.55 & 40.53 & 37.432 & 42.468 & 37.556 & 42.798 \\
\hline 340 & 40.28 & 40.27 & 37.205 & 42.239 & 37.309 & 42.559 \\
\hline 341 & 39.86 & 39.85 & 36.721 & 41.855 & 36.890 & 42.176 \\
\hline 342 & 41.24 & 41.23 & 38.099 & 43.190 & 38.272 & 43.479 \\
\hline 343 & 38.04 & 38.03 & 34.875 & 40.084 & 35.042 & 40.381 \\
\hline 344 & 38.79 & 38.78 & 35.668 & 40.839 & 35.724 & 41.127 \\
\hline 345 & 40.50 & 40.48 & 37.367 & 42.486 & 37.502 & 42.785 \\
\hline 346 & 36.96 & 36.95 & 33.668 & 39.085 & 33.790 & 39.332 \\
\hline 347 & 40.35 & 40.34 & 37.277 & 42.323 & 37.348 & 42.681 \\
\hline 348 & 41.02 & 41.01 & 38.004 & 42.986 & 38.052 & 43.301 \\
\hline 349 & 39.43 & 39.41 & 36.315 & 41.433 & 36.403 & 41.711 \\
\hline 350 & 34.55 & 34.53 & 31.158 & 36.650 & 31.266 & 37.067 \\
\hline 351 & 41.51 & 41.50 & 38.485 & 43.425 & 38.560 & 43.776 \\
\hline 352 & 39.99 & 39.98 & 36.849 & 41.983 & 36.964 & 42.305 \\
\hline 353 & 42.76 & 42.75 & 39.737 & 44.683 & 39.847 & 44.908 \\
\hline 354 & 40.62 & 40.61 & 37.484 & 42.567 & 37.718 & 42.884 \\
\hline 355 & 35.47 & 35.46 & 32.110 & 37.668 & 32.312 & 37.918 \\
\hline 356 & 38.05 & 38.04 & 34.848 & 40.077 & 34.946 & 40.477 \\
\hline
\end{tabular}


- Using the ARG-1 lithium (Li) data, investigate for a Li bias in the DWPF Lab's analytical protocol and, if present, assess its impact on the determination of WL.

Table 3-1 provides the information necessary to investigate this issue. Since Mixed Acid is the current method that is used to yield a Li value for the SME samples, the results from this prep method for the ARG-1 samples in Table 3-1 are of interest. For the M-13 ICP, the average of Li measurements $(1.465 \mathrm{wt} \%)$ for the ARG-1 samples are $1.65 \%$ below the reference value $(1.49 \mathrm{wt} \%)$ for this element. The $95 \%$ confidence interval for the mean Li measurement (in wt $\%$ ) for $\mathrm{M}-13$ is $(1.448,1.482)$ suggesting that there is a slight bias $(1.65 \%)$ in the Mixed Acid Li measurement through the M-13 ICP. For the M-14 ICP, the average Li measurement is $1.498 \mathrm{wt} \%$ and the $95 \%$ confidence interval for the mean in wt $\%$ is $(1.486,1.509)$. Thus, there is not an indication of a bias for the Mixed Acid method when the M-14 ICP is used.

What is the impact on the estimated WL at the SME if a 1.65\% low bias is present in the Li measurements?

Once again, the estimated WL for each of the four samples for each SME batch is determined using the formula given by this equation:

$$
\mathrm{WL}=100 \cdot\left(1-\frac{\mathrm{Li}_{2} \mathrm{O} /(\text { Sum of Oxides })}{\text { Frit }_{\mathrm{Li}_{2} \mathrm{O}} / 100}\right)
$$

Table 3-13 provides insight into the potential impact of a measurement bias in the $\mathrm{Li}_{2} \mathrm{O}$ content of the SME samples using a blending target of $38 \%$. The effect of the sum of oxides values on the calculation is also explored.

Table 3-13 Target WLs at Blending and Estimated WLs at the SME

\begin{tabular}{||c|c|c|c|c|c|c||}
\hline & & $\mathrm{Li}_{2} \mathrm{O}$ & & Sum of & & Targeted WL \\
\hline & $\mathrm{WL}$ & $\mathrm{Bias}$ & $\mathrm{Li}_{2} \mathrm{O}$ & Oxides & Frit $\mathrm{Li}_{2} \mathrm{O}$ & at Blending \\
\hline Ideal Situation & 38.00 & 0.00 & 4.96 & 100 & 8 & 38 \\
\hline Low Sum of Oxides (1) & 37.37 & 0.00 & 4.96 & 99 & 8 & 38 \\
\hline Low Sum of Oxides (2) & 36.73 & 0.00 & 4.96 & 98 & 8 & 38 \\
\hline Low Sum of Oxides (3) & 36.08 & 0.00 & 4.96 & 97 & 8 & 38 \\
\hline Low Sum of Oxides (4) & 35.42 & 0.00 & 4.96 & 96 & 8 & 38 \\
\hline Bias in $\mathrm{Li}_{2} \mathrm{O}$ values (1) & 38.62 & 1.00 & 4.96 & 100 & 8 & 38 \\
\hline Bias in $\mathrm{Li}_{2} \mathrm{O}$ values (2) & 39.24 & 2.00 & 4.96 & 100 & 8 & 38 \\
\hline Bias/Low Sum of Oxides & 36.48 & 1.65 & 4.96 & 96 & 8 & 38 \\
\hline \hline
\end{tabular}

- Evaluate process sample measurements from both dissolution methods to determine if there is a relationship between the recent increase in targeted WLs and the increase in recent sum of oxide failures.

As a reference point, recall that the targeted and estimated WLs for the batches of interest in this study are provided above in Table 3-11 and Table 3-12. Exhibit A12 in Appendix A provides a set of trend analyses (i.e., linear regressions) for various analytes of interest versus estimated WLs over 
process batches of this study. These plots (one for the targeted WL at blending and one for the estimated WL at the SME) are grouped by preparation method and by ICP. In general, what one expects to see in these plots are increasing trends for measurements of the sludge-only elements, decreasing trends for measurements of frit-only elements, and no appreciable trends for ratios of measurements (for pairs of sludge-only or pairs of frit-only elements). And, in general, these patterns of behavior are demonstrated in this exhibit.

The specific question here, however, is the behavior of the sum of oxides versus these WL values. While the plots for sum of oxides values versus WLs are provided in Exhibit A12, portions of these results are repeated here as Figure 3-7 to facilitate this discussion. There is no indication of a downward trend for the Mixed Acid sum of oxides as WLs increase; in fact, the upward trends for the sums versus the SME average WL values are statistically significant. However, there is a slight downward trend in the Fusion sum of oxides as WL increases (for both ICPs), but the trends are not statistically significant at the $5 \%$ level.
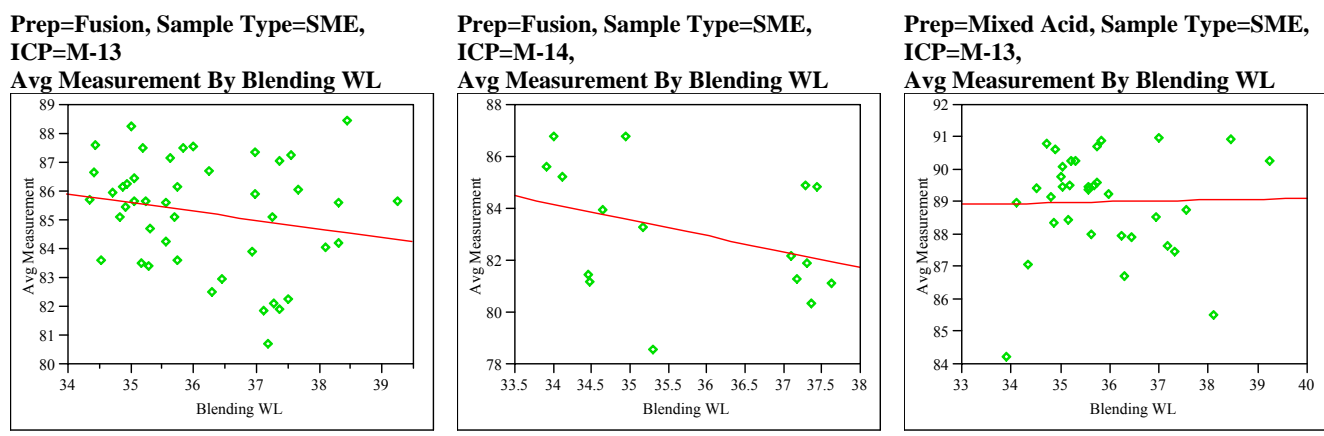

Prep=Mixed Acid, Sample Type=SME, ICP=M-14

ICP $=$ M-13 ICP=M-14, Avg Measurement By Blending W
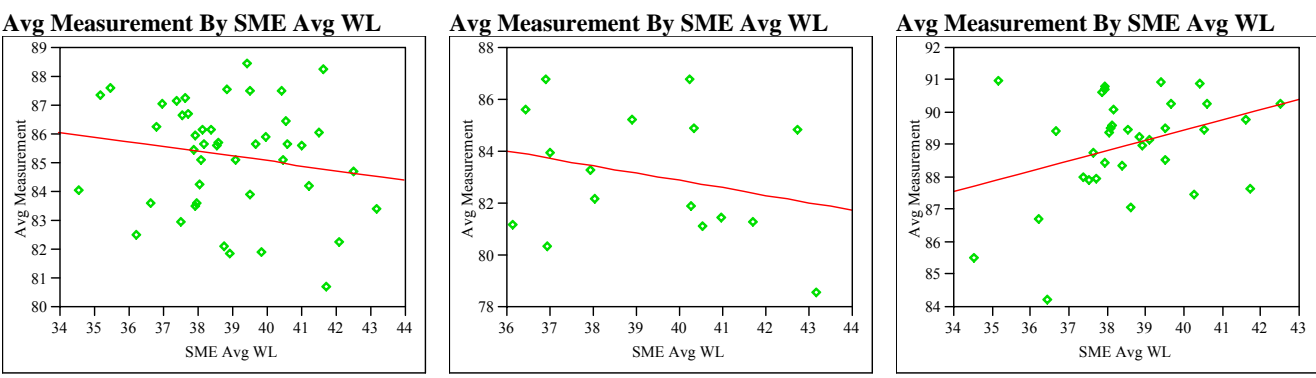
Avg Measurement By Blending WL
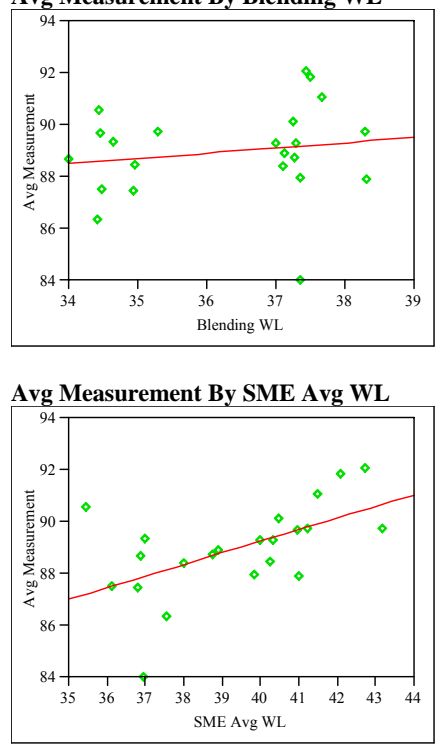

Figure 3-7. Sum of Oxides versus WLs

- Evaluate the uranium measurements generated for the process samples to determine whether or not there are shifts in these measurements as the DWPF Lab switches between the two ICPs.

Table 3-2 provides some of the information that is necessary to address this issue. This information is compiled in Table 3-14 to facilitate its review. It suggests that the M-14 U concentration measurements for Mixed Acid (used for reporting) and for Fusion are, on average, larger than the measurements provided by the M-13 ICP. The individual batch values are plotted in Figure 3-8 along with mean (horizontal) lines for each ICP (M-13 shown as • and M-14 shown as $\square$ ). 
Unfortunately, there are no "head-to-head" comparisons between the ICPs for U since the measurements for a given SME batch are generated by a single ICP. Note that while the batches measured using the M-14 yielded larger U concentrations on average, they also yielded higher WLs on average than the batches measured using the M-13.

Table 3-14 Average U Measurement by Preparation Method and ICP and Target WLs at Blending and Estimated WLs at the SME

\begin{tabular}{|c|c|c|c|c|c||}
\hline & & & Average U & Average & Average Estimated \\
\hline Prep & ICP & N Rows & Measurement (wt\%) & Blending WL & SME WL \\
\hline Fusion & M-13 & 32 & 2.601 & 35.92 & 38.84 \\
\hline Fusion & M-14 & 9 & 2.710 & 35.18 & 39.90 \\
\hline Mixed Acid & M-13 & 29 & 2.755 & 35.87 & 38.53 \\
\hline Mixed Acid & M-14 & 20 & 2.891 & 36.21 & 39.52 \\
\hline
\end{tabular}

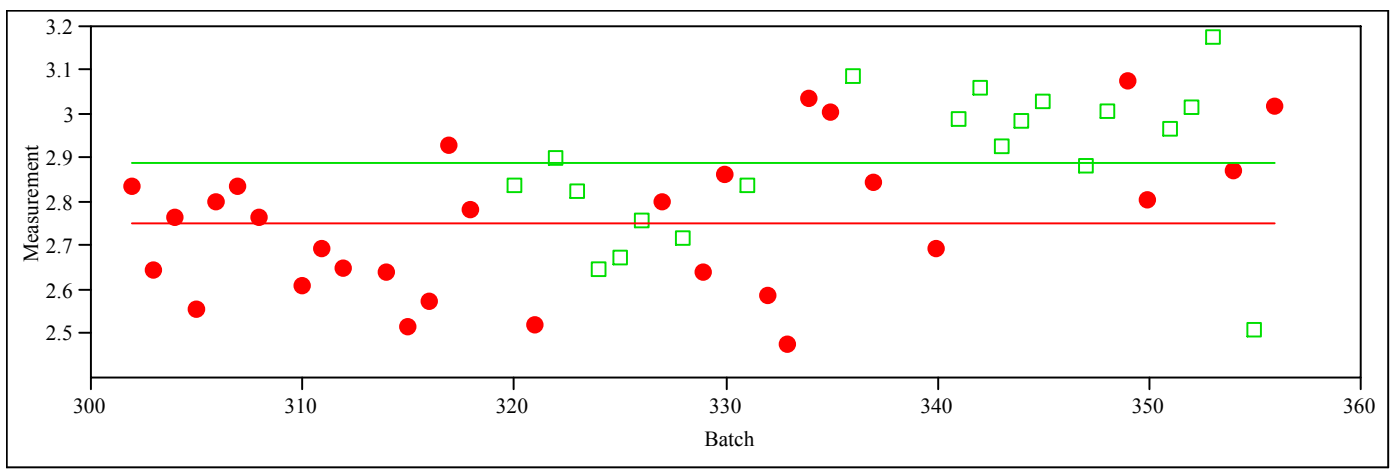

Fit Mean ICP=="M-13"

Fit Mean ICP=="M-14"

Figure 3-8. Mixed Acid Average U Concentration (wt\%) by Batch

- Based upon the results from this statistical review, recommend metrics that may be monitored by DWPF Lab to provide a set of sensitive and reliable indicators of performance of the Lab's analytical protocols.

One of the metrics that may be of value for the Lab to monitor is the average of the measurements of the ARG-1 samples per analytical block. The information of Table 3-1 would allow the Lab to establish appropriate control charts for this average for each of the major elements being tracked by the Lab. This approach would allow the flagging of situations for which the preparation of the samples or the calibration of the ICP (or combinations of both) has led to errors that are reflected in the measurements of the ARG-1 samples but which may also affect the process samples. It may be necessary, however, to set up separate control charts for each of the two ICPs since differences between the two instruments have been revealed by the analyses presented in this report. 


\subsection{CONCLUSIONS}

In this report, SCS provided summaries and comparisons of DWPF Lab data covering ICP-AES measurements that were generated for the SRAT product and SME samples for batches 300 through 356 . The comparisons were extensive given that these data allowed for contrasts between preparation methods and between the two ICPs. In addition to general comparisons, specific questions that were posed by the TTR behind this effort were addressed in this report.

\subsection{REFERENCES}

[1] Edwards, TB, "Statistical Review of Composition Data from DWPF's Process Samples for Macro-Batch 1 (U),” WSRC-RP-2000-00174, Revision 0, February 15, 2000.

[2] Edwards, TB, "A Statistical Review of Analytical Laboratory Measurements from DWPF's Macrobatch 1and Macrobatch 2 (U)," WSRC-TR-2003-00045, Revision 0, January 22, 2003.

[3] Edwards, TB, "A Statistical Review of DWPF Laboratory Data Including Measurements of the ARG-1 Standard for Batches 94 - 263,” WSRC-TR-2004-00576, Revision 0, November, 2004.

[4] Harris, SP, “Statistical Analysis of DWPF ARG-1 Data (U),” WSRC-TR-2000-00070, May 24, 2000 .

[5] Mahannah, RN, "Statistical Analysis of ARG-1/DWPF Sample Results From the Leeman ICP (U)," HLW/DWPF/TTR-2005-0025, Revision 1, January 23, 2006.

[6] Edwards, TB, "Task Technical and Quality Assurance Plan: Statistical Analysis of ARG-1/DWPF Sample Results from Leeman ICPs," WSRC-RP-2006-00460, Revision 0, February 3, 2006.

[7] SAS Institute, Inc., JMP Statistics and Graphics Guide, SAS Institute, Inc., Cary, NC, 2002.

[8] Brown, KG, RL Postles, and TB Edwards, "SME Acceptability Determination for DWPF Process Control (U)," WSRC-TR-95-00364, Revision 4, August 30, 2002. 


\subsection{APPENDIX A}

Supplemental Tables and Exhibits 
WSRC-STI-2006-00068

Table A1. Cold Chem Measurement Data Set

Revision 0

\begin{tabular}{|c|c|c|c|c|c|c|c|c|c|c|c|c|c|c|c|c|c|c|}
\hline Batch & Type of Sample & ICP/ID & Al & B & $\begin{array}{l}\mathbf{C a} \\
\end{array}$ & $\mathrm{Cr}$ & $\mathbf{C u}$ & $\mathbf{F e}$ & $\mathbf{K}$ & Li & $\mathrm{Mg}$ & Mn & $\mathrm{Na}$ & $\mathrm{Ni}$ & $\mathrm{Si}$ & Ti & $\mathbf{U}$ & $\mathrm{Zr}$ \\
\hline 300 & ARGC & M-13/S2133 & 2.259 & 2.595 & 0.926 & 0.071 & 0.000 & 9.566 & 2.349 & 1.340 & 0.478 & 1.386 & 8.111 & $\begin{array}{ll}0.788 \\
\end{array}$ & 21.531 & 0.664 & 0.080 & 0.092 \\
\hline 300 & ARGC & M-13/S2133 & 2.306 & 2.626 & 0.959 & 0.070 & 0.006 & 9.919 & 2.653 & 1.343 & 0.499 & 1.444 & 8.457 & 0.837 & 22.587 & 0.673 & 0.297 & 0.099 \\
\hline 300 & $\begin{array}{l}\text { SR04 } \\
\end{array}$ & M-13/S2133 & 5.025 & -0.004 & 1.319 & 0.088 & 0.029 & 14.760 & 0.561 & -0.023 & 1.339 & 3.103 & 10.671 & 0.842 & 1.121 & 0.013 & 5.395 & 0.067 \\
\hline 300 & SR04 & M-13/S2133 & 5.215 & -0.012 & 1.335 & 0.094 & 0.032 & 15.512 & 0.604 & -0.024 & 1.338 & 3.216 & 10.634 & 0.887 & 1.122 & 0.013 & 5.662 & 0.068 \\
\hline 300 & SR04 & M-13/S2133 & 5.351 & -0.009 & 1.378 & 0.099 & 0.035 & 15.749 & 0.596 & -0.027 & 1.354 & 3.250 & 10.666 & 0.906 & 1.123 & 0.014 & 5.705 & 0.070 \\
\hline 300 & SR04 & M-13/S2133 & 5.330 & -0.002 & 1.385 & 0.094 & 0.037 & 16.223 & 0.524 & -0.025 & 1.388 & 3.330 & 10.596 & 0.953 & 1.174 & 0.015 & 5.733 & 0.072 \\
\hline 300 & $\begin{array}{l}\text { SR04 } \\
\end{array}$ & M-13/S2133 & 5.197 & -0.011 & 1.365 & 0.094 & 0.033 & 15.901 & 0.594 & -0.034 & 1.372 & 3.256 & 10.634 & 0.936 & 1.162 & 0.012 & 5.532 & 0.068 \\
\hline 300 & SR04 & M-13/S2133 & 5.542 & -0.009 & 1.392 & 0.096 & 0.033 & 16.997 & 0.557 & -0.033 & 1.376 & 3.370 & 10.661 & 0.986 & 1.216 & 0.013 & 5.812 & 0.074 \\
\hline 300 & IN32 & M-13/S2133 & 0.009 & -0.012 & 0.002 & 0.001 & 0.000 & 0.003 & 0.196 & -0.016 & 0.000 & 0.002 & 0.003 & 0.006 & 0.029 & -0.001 & 0.030 & -0.003 \\
\hline 300 & IN32 & M-13/S2133 & -0.009 & -0.010 & 0.000 & 0.001 & -0.004 & -0.001 & 0.183 & -0.014 & 0.000 & 0.001 & -0.003 & 0.003 & 0.026 & -0.002 & -0.055 & -0.004 \\
\hline 301 & ARGC & $\mathrm{M}-13 / \mathrm{S} 2133$ & 2.344 & 2.560 & 0.980 & 0.067 & -0.001 & 9.655 & 2.267 & 1.553 & 0.511 & 1.416 & 8.373 & 0.796 & 21.746 & 0.664 & 0.001 & 0.091 \\
\hline 301 & ARGC & M-13/S2133 & 2.409 & 2.577 & 0.998 & 0.067 & 0.002 & 9.664 & 2.695 & 1.471 & 0.516 & 1.422 & 8.518 & 0.814 & 22.264 & 0.656 & 0.103 & 0.094 \\
\hline 301 & $\begin{array}{l}\text { SR04 } \\
\end{array}$ & M-13/S2133 & 5.170 & -0.023 & 1.375 & 0.085 & 0.028 & 15.001 & 0.066 & 0.074 & 1.383 & 3.197 & 11.088 & 0.883 & 1.033 & 0.012 & 5.647 & 0.068 \\
\hline 301 & SR04 & M-13/S2133 & 5.096 & -0.026 & 1.390 & 0.089 & 0.027 & 14.795 & 0.075 & 0.074 & 1.366 & 3.159 & 10.877 & 0.865 & 1.024 & 0.012 & 5.652 & 0.066 \\
\hline 301 & SR04 & M-13/S2133 & 5.163 & -0.024 & 1.369 & 0.084 & 0.031 & 15.172 & 0.373 & 0.074 & 1.406 & 3.294 & 11.030 & 0.895 & 1.053 & 0.012 & 5.716 & 0.066 \\
\hline 301 & $\begin{array}{l}\text { SR04 } \\
\end{array}$ & M-13/S2133 & 5.111 & -0.033 & 1.364 & 0.088 & 0.028 & 15.181 & 0.270 & 0.073 & 1.380 & 3.238 & 10.771 & 0.895 & 0.974 & 0.011 & 5.758 & 0.066 \\
\hline 301 & SR04 & M-13/S2133 & 5.379 & -0.039 & 1.392 & 0.090 & 0.029 & 15.673 & 0.500 & 0.081 & 1.403 & 3.286 & 10.933 & 0.909 & 1.043 & 0.012 & 5.834 & 0.068 \\
\hline 301 & SR04 & M-13/S2133 & 5.244 & -0.031 & 1.373 & 0.094 & 0.028 & 15.429 & 0.232 & 0.070 & 1.376 & 3.253 & 10.840 & 0.912 & 1.056 & 0.013 & 5.781 & 0.069 \\
\hline 301 & IN32 & M-13/S2133 & -0.002 & -0.014 & -0.001 & 0.000 & -0.002 & 0.013 & 0.032 & 0.017 & 0.000 & 0.000 & 0.015 & 0.002 & 0.030 & -0.002 & -0.032 & -0.003 \\
\hline 301 & IN32 & M-13/S2133 & 0.007 & -0.020 & 0.003 & 0.000 & -0.001 & 0.020 & 0.189 & 0.017 & 0.001 & 0.001 & 0.009 & 0.005 & 0.050 & -0.001 & 0.011 & -0.003 \\
\hline 302 & ARGC & M-13/S2133 & 2.321 & 2.656 & 0.976 & 0.069 & 0.001 & 9.836 & 2.248 & 1.459 & 0.520 & 1.448 & 8.258 & 0.812 & 22.195 & 0.668 & 0.075 & 0.103 \\
\hline 302 & ARGC & M-13/S2133 & 2.389 & 2.614 & 1.028 & 0.071 & 0.012 & 9.795 & 2.264 & 1.410 & 0.512 & 1.424 & 8.454 & 0.835 & 22.154 & 0.677 & 0.289 & 0.108 \\
\hline 302 & SR04 & M-13/S2133 & 5.121 & 0.019 & 1.334 & 0.086 & 0.033 & 15.301 & 0.241 & 0.011 & 1.373 & 3.231 & 10.826 & 0.885 & 1.186 & 0.015 & 5.853 & 0.077 \\
\hline 302 & SR04 & M-13/S2133 & 5.272 & 0.011 & 1.387 & 0.092 & 0.033 & 15.575 & 0.247 & -0.005 & 1.420 & 3.305 & 10.936 & 0.909 & 1.201 & 0.014 & 5.985 & 0.079 \\
\hline 302 & $\begin{array}{l}\text { SR04 } \\
\end{array}$ & M-13/S2133 & 5.359 & 0.013 & 1.404 & 0.089 & 0.035 & 16.148 & 0.330 & 0.006 & 1.387 & 3.374 & 10.736 & 0.942 & 1.266 & 0.014 & 6.014 & 0.079 \\
\hline 302 & SR04 & M-13/S2133 & 5.581 & 0.014 & 1.449 & 0.096 & 0.040 & 16.388 & 0.216 & 0.001 & 1.428 & 3.439 & 10.904 & 0.982 & 1.311 & 0.016 & 6.236 & 0.084 \\
\hline 302 & $\begin{array}{l}\text { SR04 } \\
\end{array}$ & M-13/S2133 & 5.406 & 0.010 & 1.432 & 0.096 & 0.040 & 15.982 & 0.236 & 0.003 & 1.382 & 3.373 & 10.748 & 0.951 & 1.259 & 0.018 & 6.202 & 0.085 \\
\hline 302 & SR04 & M-13/S2133 & 5.224 & 0.013 & 1.368 & 0.088 & 0.036 & 15.492 & 0.312 & 0.002 & 1.370 & 3.240 & 10.685 & 0.907 & 1.175 & 0.015 & 5.783 & 0.078 \\
\hline 302 & IN32 & M-13/S2133 & 0.016 & -0.007 & 0.004 & 0.002 & 0.002 & 0.008 & 0.026 & -0.012 & 0.000 & 0.002 & 0.013 & 0.005 & 0.069 & 0.000 & 0.042 & 0.001 \\
\hline 302 & IN32 & M-13/S2133 & -0.011 & -0.006 & -0.002 & 0.000 & -0.001 & 0.002 & 0.053 & -0.012 & -0.001 & 0.000 & 0.017 & 0.002 & 0.062 & -0.002 & -0.025 & 0.001 \\
\hline 303 & ARGC & M-13/S2133 & 2.517 & 2.824 & 1.005 & 0.081 & 0.002 & 10.262 & 2.563 & 1.539 & 0.529 & 1.463 & 8.987 & 0.839 & 27.852 & 0.708 & -0.010 & 0.123 \\
\hline 303 & ARGC & M-13/S2133 & 2.411 & 2.650 & 0.995 & 0.070 & 0.011 & 9.794 & 2.308 & 1.439 & 0.513 & 1.412 & $\begin{array}{ll}8.514 \\
\end{array}$ & 0.815 & 22.740 & 0.656 & 0.247 & 0.116 \\
\hline 303 & $\begin{array}{l}\text { SR04 } \\
\end{array}$ & M-13/S2133 & 4.953 & -0.038 & 1.303 & 0.090 & 0.031 & 14.264 & 0.171 & -0.039 & 1.275 & 2.998 & 10.424 & 0.803 & 1.930 & 0.019 & 5.678 & 0.085 \\
\hline 303 & SR04 & M-13/S2133 & 4.825 & -0.041 & 1.291 & 0.088 & 0.032 & 14.192 & 0.425 & -0.043 & 1.267 & 2.932 & 10.342 & 0.779 & 1.956 & 0.019 & 5.535 & 0.088 \\
\hline 303 & SR04 & M-13/S2133 & 5.121 & -0.023 & 1.312 & 0.088 & 0.036 & 15.241 & 0.401 & -0.035 & 1.351 & 3.158 & 10.737 & 0.864 & 2.270 & 0.021 & 5.808 & 0.093 \\
\hline 303 & $\begin{array}{l}\text { SR04 } \\
\end{array}$ & M-13/S2133 & 4.891 & -0.038 & 1.317 & 0.084 & 0.034 & 14.608 & 0.189 & -0.041 & 1.312 & 3.096 & 10.428 & 0.828 & 1.403 & 0.020 & 5.623 & 0.087 \\
\hline 303 & SR04 & M-13/S2133 & 5.135 & -0.023 & 1.344 & 0.092 & 0.032 & 14.813 & 0.404 & -0.017 & 1.307 & 3.124 & 10.676 & 0.829 & 3.173 & 0.019 & 5.849 & 0.087 \\
\hline 303 & $\begin{array}{l}\text { SR04 } \\
\end{array}$ & M-13/S2133 & 5.004 & -0.036 & 1.291 & 0.097 & 0.030 & 14.478 & 0.305 & -0.035 & 1.311 & 3.074 & 10.501 & 0.823 & 2.451 & 0.023 & 5.635 & 0.088 \\
\hline 303 & IN32 & M-13/S2133 & 0.014 & -0.016 & 0.003 & 0.003 & 0.001 & 0.010 & 0.028 & -0.023 & 0.003 & 0.000 & 0.025 & 0.005 & 0.175 & 0.002 & 0.022 & 0.006 \\
\hline 303 & IN32 & M-13/S2133 & 0.001 & -0.011 & 0.001 & 0.003 & -0.001 & 0.004 & 0.101 & -0.017 & 0.002 & -0.001 & 0.023 & 0.002 & 0.791 & 0.001 & -0.031 & 0.006 \\
\hline 304 & ARGC & M-13/S2133 & 2.318 & 2.620 & 0.966 & 0.070 & -0.002 & 9.769 & 2.411 & 1.383 & 0.486 & 1.455 & 8.341 & 0.794 & 21.788 & 0.677 & -0.030 & 0.094 \\
\hline 304 & ARGC & M-13/S2133 & 2.239 & 2.621 & 0.905 & 0.063 & 0.001 & 9.800 & 2.498 & 1.365 & 0.479 & 1.396 & 8.028 & 0.821 & 22.223 & 0.664 & 0.109 & 0.097 \\
\hline 304 & SR04 & M-13/S2133 & 5.072 & -0.006 & 1.307 & 0.089 & 0.024 & 14.339 & 0.400 & -0.066 & 1.324 & 3.149 & 10.655 & 0.827 & 1.003 & 0.006 & 5.401 & 0.066 \\
\hline 304 & SR04 & M-13/S2133 & 5.118 & -0.009 & 1.319 & 0.090 & 0.024 & 14.698 & 0.443 & -0.068 & 1.318 & 3.181 & 10.555 & 0.845 & 0.982 & 0.007 & 5.318 & 0.066 \\
\hline 304 & $\begin{array}{l}\text { SR04 } \\
\end{array}$ & M-13/S2133 & 4.998 & -0.006 & 1.307 & 0.082 & 0.026 & 14.860 & 0.401 & -0.073 & 1.368 & 3.099 & 10.509 & 0.856 & 0.990 & 0.006 & 5.381 & 0.065 \\
\hline 304 & SR04 & M-13/S2133 & 4.850 & -0.011 & 1.267 & 0.083 & 0.025 & 14.251 & 0.417 & -0.085 & 1.319 & 3.031 & 10.077 & 0.850 & 0.980 & 0.004 & 5.173 & 0.063 \\
\hline 304 & SR04 & M-13/S2133 & 3.424 & 0.003 & 0.834 & 0.056 & 0.019 & 11.494 & 0.298 & -0.044 & 0.843 & 2.025 & 6.317 & 0.559 & 0.683 & 0.004 & 3.395 & 0.045 \\
\hline 304 & SR04 & M-13/S2133 & 10.642 & -0.003 & 2.693 & 0.167 & 0.055 & 31.044 & 0.603 & -0.119 & 2.767 & 6.422 & 21.025 & 1.804 & 2.060 & 0.016 & 11.243 & 0.139 \\
\hline 304 & IN32 & M-13/S2133 & -0.009 & -0.010 & -0.001 & 0.001 & -0.001 & -0.025 & 0.069 & -0.029 & 0.000 & -0.002 & -0.009 & -0.002 & -0.002 & -0.002 & -0.022 & -0.002 \\
\hline 304 & IN32 & M-13/S2133 & -0.019 & -0.007 & -0.002 & 0.002 & -0.003 & -0.026 & 0.122 & -0.025 & 0.000 & -0.003 & 0.001 & -0.002 & -0.022 & -0.003 & -0.042 & -0.003 \\
\hline
\end{tabular}


WSRC-STI-2006-00068

Table A1. Cold Chem Measurement Data Set (continued)

Revision 0

\begin{tabular}{|c|c|c|c|c|c|c|c|c|c|c|c|c|c|c|c|c|c|c|}
\hline Batch & Type of Sample & ICP/ID & Al & B & $\mathbf{C a}$ & $\mathrm{Cr}$ & $\mathbf{C u}$ & $\mathbf{F e}$ & $\mathbf{K}$ & $\mathbf{L i}$ & $\mathbf{M g}$ & Mn & $\mathrm{Na}$ & $\mathrm{Ni}$ & $\mathrm{Si}$ & Ti & $\mathbf{U}$ & $\mathrm{Zr}$ \\
\hline 305 & ARGC & M-13/S2133 & 2.418 & 2.660 & 1.012 & 0.065 & 0.009 & 9.966 & 2.404 & 1.421 & 0.517 & 1.435 & 8.205 & 0.810 & 22.385 & 0.670 & 0.225 & 0.103 \\
\hline 305 & ARGC & M-13/S2133 & 2.328 & 2.685 & 0.978 & 0.064 & 0.002 & 9.620 & 2.406 & 1.439 & 0.507 & 1.406 & 8.369 & 0.794 & 21.740 & 0.661 & -0.041 & 0.096 \\
\hline 305 & $\begin{array}{l}\text { SR04 } \\
\end{array}$ & M-13/S2133 & 5.049 & 0.070 & 1.342 & 0.084 & 0.032 & 14.701 & 0.479 & 0.015 & 1.371 & 3.194 & 10.829 & 0.846 & 1.238 & 0.010 & 5.408 & 0.069 \\
\hline 305 & SR04 & M-13/S2133 & 5.049 & 0.065 & 1.360 & 0.087 & 0.032 & 15.132 & 0.410 & 0.008 & 1.415 & 3.261 & 10.828 & 0.853 & 1.166 & 0.010 & 5.594 & 0.071 \\
\hline 305 & SR04 & M-13/S2133 & 5.173 & 0.067 & 1.367 & 0.085 & 0.035 & 15.167 & 0.463 & 0.006 & 1.393 & 3.220 & 10.651 & 0.868 & 1.193 & 0.012 & 5.451 & 0.072 \\
\hline 305 & SR04 & M-13/S2133 & 5.166 & 0.064 & 1.386 & 0.084 & 0.034 & 15.048 & 0.474 & 0.011 & 1.404 & 3.254 & 10.720 & 0.854 & 1.184 & 0.011 & 5.481 & 0.073 \\
\hline 305 & $\begin{array}{l}\text { SR04 } \\
\end{array}$ & M-13/S2133 & 5.357 & 0.071 & 1.403 & 0.091 & 0.036 & 15.612 & 0.572 & 0.006 & 1.412 & 3.321 & 10.894 & 0.872 & 1.233 & 0.012 & 5.683 & 0.074 \\
\hline 305 & SR04 & M-13/S2133 & 5.297 & 0.072 & 1.380 & 0.087 & 0.037 & 15.629 & 0.440 & 0.010 & 1.395 & 3.281 & 10.615 & 0.882 & 1.228 & 0.011 & 5.794 & 0.076 \\
\hline 305 & IN32 & M-13/S2133 & 0.008 & 0.013 & 0.003 & 0.000 & 0.001 & -0.011 & 0.121 & -0.008 & 0.000 & -0.001 & -0.001 & -0.004 & 0.082 & -0.001 & 0.015 & -0.002 \\
\hline 305 & IN32 & M-13/S2133 & -0.014 & 0.013 & 0.001 & -0.001 & -0.001 & -0.015 & 0.155 & -0.005 & -0.001 & -0.002 & 0.003 & -0.003 & 0.066 & -0.002 & -0.051 & -0.002 \\
\hline 306 & ARGC & M-13/S2133 & 2.279 & 2.590 & 0.883 & 0.068 & 0.000 & 9.772 & 2.397 & 1.543 & 0.462 & 1.420 & 8.426 & 0.788 & 22.143 & 0.672 & -0.065 & 0.108 \\
\hline 306 & ARGC & M-13/S2133 & 2.248 & 2.658 & 0.878 & 0.060 & 0.006 & 9.946 & 2.395 & 1.478 & 0.464 & 1.435 & 8.391 & 0.835 & 22.459 & 0.685 & 0.137 & 0.115 \\
\hline 306 & SR04 & M-13/S2133 & 5.279 & -0.020 & 1.390 & 0.081 & 0.032 & 15.701 & 0.340 & 0.052 & 1.410 & 3.243 & 10.918 & 0.909 & 1.180 & 0.009 & 5.486 & 0.086 \\
\hline 306 & SR04 & M-13/S2133 & 5.195 & -0.018 & 1.359 & 0.079 & 0.032 & 15.462 & 0.231 & 0.047 & 1.412 & 3.258 & 10.901 & 0.880 & 1.122 & 0.010 & 5.456 & 0.085 \\
\hline 306 & SR04 & M-13/S2133 & 5.241 & -0.019 & 1.388 & 0.081 & 0.035 & 15.229 & 0.162 & 0.046 & 1.412 & 3.286 & 10.892 & 0.882 & 1.077 & 0.011 & 5.430 & 0.087 \\
\hline 306 & $\begin{array}{l}\text { SR04 } \\
\end{array}$ & M-13/S2133 & 5.329 & -0.017 & 1.367 & 0.081 & 0.030 & 15.213 & 0.282 & 0.057 & 1.363 & 3.311 & 11.008 & 0.862 & 1.190 & 0.010 & 5.332 & 0.087 \\
\hline 306 & SR04 & M-13/S2133 & 5.272 & -0.013 & 1.369 & 0.081 & 0.032 & 15.668 & 0.093 & 0.048 & 1.411 & 3.273 & 10.915 & 0.894 & 1.119 & 0.009 & 5.426 & 0.086 \\
\hline 306 & $\begin{array}{l}\text { SR04 } \\
\end{array}$ & M-13/S2133 & 5.437 & -0.022 & 1.421 & 0.085 & 0.034 & 16.177 & 0.285 & 0.052 & 1.434 & 3.344 & 10.992 & 0.925 & 1.144 & 0.010 & 5.628 & 0.089 \\
\hline 306 & IN32 & M-13/S2133 & -0.012 & -0.013 & -0.001 & -0.001 & -0.002 & 0.001 & 0.059 & 0.007 & -0.002 & -0.006 & 0.007 & -0.004 & 0.017 & -0.002 & -0.027 & 0.002 \\
\hline 306 & IN32 & M-13/S2133 & -0.002 & -0.015 & 0.000 & 0.000 & -0.001 & -0.001 & 0.045 & 0.007 & -0.001 & -0.005 & 0.009 & -0.003 & 0.027 & -0.002 & -0.001 & 0.003 \\
\hline 307 & ARGC & M-13/S2133 & 2.322 & 2.698 & 0.977 & 0.061 & -0.001 & 9.715 & 2.477 & 1.483 & 0.499 & 1.428 & 8.413 & 0.800 & 22.360 & 0.677 & -0.044 & 0.103 \\
\hline 307 & ARGC & M-13/S2133 & 2.429 & 2.639 & 1.024 & 0.052 & 0.010 & 9.535 & 1.990 & 1.446 & 0.493 & 1.383 & 8.100 & 0.797 & 22.127 & 0.681 & 0.281 & 0.110 \\
\hline 307 & SR04 & M-13/S2133 & 5.163 & 0.019 & 1.313 & 0.079 & 0.030 & 15.107 & 0.318 & 0.018 & 1.318 & 3.143 & 10.306 & 0.852 & 1.090 & 0.009 & 5.147 & 0.077 \\
\hline 307 & SR04 & M-13/S2133 & 5.187 & 0.014 & 1.317 & 0.079 & 0.031 & 15.024 & 0.103 & 0.018 & 1.313 & 3.162 & 10.242 & 0.859 & 1.078 & 0.009 & 5.144 & 0.079 \\
\hline 307 & SR04 & M-13/S2133 & 5.295 & 0.014 & 1.335 & 0.078 & 0.034 & 15.608 & 0.293 & 0.014 & 1.304 & 3.186 & 10.237 & 0.872 & 1.097 & 0.010 & 5.419 & 0.082 \\
\hline 307 & SR04 & M-13/S2133 & 5.308 & 0.013 & 1.340 & 0.078 & 0.033 & 15.445 & 0.086 & 0.013 & 1.267 & 3.148 & 9.820 & 0.862 & 1.063 & 0.010 & 5.234 & 0.079 \\
\hline 307 & SR04 & M-13/S2133 & 5.287 & 0.012 & 1.335 & 0.091 & 0.036 & 15.256 & 0.054 & 0.015 & 1.287 & 3.122 & 9.921 & 0.863 & 1.097 & 0.011 & 5.341 & 0.083 \\
\hline 307 & SR04 & M-13/S2133 & 5.016 & 0.010 & 1.316 & 0.075 & 0.034 & 17.327 & 0.130 & 0.013 & 1.255 & 3.088 & 9.976 & 0.814 & 1.026 & 0.012 & 5.211 & 0.079 \\
\hline 307 & IN32 & M-13/S2133 & -0.008 & -0.002 & -0.001 & -0.020 & -0.012 & -0.017 & 0.076 & -0.005 & -0.002 & -0.004 & 0.037 & -0.007 & 0.045 & -0.003 & -0.039 & 0.000 \\
\hline 307 & IN32 & M-13/S2133 & 0.014 & -0.003 & 0.003 & -0.002 & 0.002 & -0.016 & -0.041 & -0.005 & -0.002 & -0.003 & 0.022 & -0.005 & 0.073 & -0.001 & 0.037 & 0.001 \\
\hline 308 & ARGC & M-13/S2133 & 2.354 & 2.596 & 0.981 & 0.074 & -0.001 & 9.782 & 2.086 & 1.496 & 0.496 & 1.437 & 8.164 & 0.826 & 21.713 & 0.670 & 0.005 & 0.100 \\
\hline 308 & ARGC & M-13/S2133 & 2.402 & 2.594 & 1.016 & 0.064 & 0.007 & 9.931 & 2.270 & 1.454 & 0.504 & 1.414 & $\begin{array}{l}8.331 \\
\end{array}$ & 0.823 & 21.634 & 0.683 & 0.177 & 0.103 \\
\hline 308 & SR04 & M-13/S2133 & 5.170 & 0.019 & 1.364 & 0.082 & 0.030 & 14.718 & 0.044 & 0.036 & 1.363 & 3.208 & 10.489 & 0.850 & 1.155 & 0.017 & 5.682 & 0.074 \\
\hline 308 & SR04 & M-13/S2133 & 5.153 & 0.013 & 1.348 & 0.080 & 0.033 & 14.538 & 0.008 & 0.032 & 1.351 & 3.170 & 10.632 & 0.849 & 1.192 & 0.015 & 5.616 & 0.074 \\
\hline 308 & SR04 & M-13/S2133 & 5.030 & 0.011 & 1.341 & 0.079 & 0.030 & 14.366 & -0.076 & 0.027 & 1.338 & 3.045 & 10.358 & 0.847 & 1.143 & 0.015 & 5.580 & 0.074 \\
\hline 308 & SR04 & M-13/S2133 & 5.152 & 0.015 & 1.347 & 0.076 & 0.032 & 14.691 & -0.011 & 0.030 & 1.367 & 3.134 & 10.703 & 0.843 & 1.186 & 0.015 & 5.780 & 0.076 \\
\hline 308 & SR04 & M-13/S2133 & 4.986 & 0.012 & 1.339 & 0.076 & 0.031 & 14.269 & 0.039 & 0.028 & 1.322 & 3.078 & 10.600 & 0.845 & 1.217 & 0.016 & 5.523 & 0.073 \\
\hline 308 & SR04 & M-13/S2133 & 4.981 & 0.018 & 1.327 & 0.080 & 0.035 & 14.496 & 0.061 & 0.025 & 1.354 & 3.130 & 10.502 & 0.862 & 1.206 & 0.017 & 5.690 & 0.075 \\
\hline 308 & IN32 & M-13/S2133 & 0.012 & -0.005 & 0.002 & -0.001 & 0.000 & -0.022 & 0.015 & 0.002 & -0.001 & -0.001 & -0.005 & 0.003 & 0.101 & 0.000 & 0.007 & 0.000 \\
\hline 308 & IN32 & M-13/S2133 & -0.005 & -0.004 & -0.002 & -0.001 & -0.002 & -0.024 & -0.010 & 0.003 & -0.001 & -0.002 & -0.011 & 0.001 & 0.078 & -0.001 & -0.035 & -0.001 \\
\hline 309 & ARGC & M-13/S2133 & 2.080 & 2.334 & 0.868 & 0.064 & 0.008 & 8.920 & 1.913 & 1.221 & 0.457 & 1.270 & 7.417 & 0.704 & 19.671 & 0.593 & 0.219 & 0.091 \\
\hline 309 & ARGC & M-13/S2133 & 2.425 & 2.659 & 1.011 & 0.069 & 0.001 & 10.169 & 2.401 & 1.495 & 0.521 & 1.476 & 8.777 & 0.817 & 22.373 & 0.697 & 0.009 & 0.101 \\
\hline 309 & SR04 & M-13/S2133 & 3.887 & 0.023 & 1.041 & 0.066 & 0.022 & 11.530 & 0.280 & -0.006 & 1.061 & 2.466 & 8.563 & 0.649 & 0.876 & 0.013 & 4.256 & 0.055 \\
\hline 309 & SR04 & M-13/S2133 & 5.194 & 0.027 & 1.382 & 0.089 & 0.030 & 15.582 & 0.295 & -0.008 & 1.398 & 3.328 & 11.119 & 0.851 & 1.105 & 0.017 & 5.627 & 0.075 \\
\hline 309 & SR04 & M-13/S2133 & 5.259 & 0.027 & 1.381 & 0.087 & 0.033 & 15.662 & 0.301 & -0.002 & 1.411 & 3.365 & 11.008 & 0.855 & 1.126 & 0.017 & 5.695 & 0.077 \\
\hline 309 & SR04 & M-13/S2133 & 5.319 & 0.033 & 1.430 & 0.092 & 0.035 & 16.328 & 0.402 & -0.009 & 1.449 & 3.417 & 11.124 & 0.887 & 1.153 & 0.019 & 5.792 & 0.079 \\
\hline 309 & SR04 & M-13/S2133 & 5.179 & 0.029 & 1.385 & 0.092 & 0.034 & 15.826 & 0.149 & -0.007 & 1.419 & 3.343 & 11.046 & 0.874 & 1.125 & 0.018 & 5.674 & 0.077 \\
\hline 309 & SR04 & M-13/S2133 & 5.368 & 0.032 & 1.423 & 0.092 & 0.036 & 16.172 & 0.256 & -0.012 & 1.465 & 3.418 & 11.315 & 0.895 & 1.172 & 0.019 & 5.839 & 0.078 \\
\hline 309 & IN32 & M-13/S2133 & -0.003 & -0.001 & -0.001 & 0.001 & -0.002 & $\begin{array}{l}-0.016 \\
\end{array}$ & 0.104 & -0.010 & 0.000 & -0.004 & 0.039 & -0.004 & 0.021 & 0.000 & -0.034 & 0.000 \\
\hline 309 & IN32 & M-13/S2133 & 0.017 & 0.004 & 0.002 & 0.002 & 0.001 & -0.012 & 0.110 & -0.013 & 0.000 & -0.003 & 0.035 & -0.002 & 0.046 & 0.001 & 0.029 & 0.001 \\
\hline
\end{tabular}


WSRC-STI-2006-00068

Table A1. Cold Chem Measurement Data Set (continued)

Revision 0

\begin{tabular}{|c|c|c|c|c|c|c|c|c|c|c|c|c|c|c|c|c|c|c|}
\hline Batch & Type of Sample & ICP/ID & Al & B & $\mathbf{C a}$ & $\mathrm{Cr}$ & $\mathbf{C u}$ & $\mathbf{F e}$ & $\mathbf{K}$ & $\mathbf{L i}$ & $\mathbf{M g}$ & Mn & $\mathrm{Na}$ & $\mathrm{Ni}$ & $\mathrm{Si}$ & Ti & $\mathbf{U}$ & $\mathrm{Zr}$ \\
\hline 310 & ARGC & M-13/S2133 & 2.432 & 2.690 & 1.037 & 0.060 & 0.009 & 10.108 & 2.815 & 1.440 & 0.508 & 1.438 & 8.367 & 0.826 & 22.789 & 0.675 & 0.289 & 0.108 \\
\hline 310 & ARGC & M-13/S2133 & 2.328 & 2.616 & 0.963 & 0.055 & -0.001 & 9.643 & 2.557 & 1.468 & 0.513 & 1.415 & 8.479 & 0.802 & 21.821 & 0.675 & 0.024 & 0.103 \\
\hline 310 & $\begin{array}{l}\text { SR04 } \\
\end{array}$ & M-13/S2133 & 5.303 & -0.053 & 1.331 & 0.078 & 0.030 & 15.393 & 0.486 & 0.006 & 1.318 & 3.163 & 10.276 & 0.895 & 1.161 & 0.016 & 5.375 & 0.078 \\
\hline 310 & SR04 & M-13/S2133 & 4.951 & -0.045 & 1.286 & 0.076 & 0.029 & 14.190 & 0.378 & 0.007 & 1.297 & 3.037 & 10.512 & 0.849 & 1.020 & 0.016 & 5.356 & 0.074 \\
\hline 310 & SR04 & M-13/S2133 & 5.098 & -0.023 & 1.309 & 0.072 & 0.033 & 14.939 & 0.332 & 0.013 & 1.292 & 3.071 & 10.120 & 0.872 & 1.047 & 0.017 & 5.363 & 0.078 \\
\hline 310 & SR04 & M-13/S2133 & 5.254 & -0.014 & 1.382 & 0.078 & 0.035 & 15.340 & 0.606 & 0.023 & 1.377 & 3.209 & 10.794 & 0.887 & 1.095 & 0.019 & 5.760 & 0.081 \\
\hline 310 & $\begin{array}{l}\text { SR04 } \\
\end{array}$ & M-13/S2133 & 4.658 & -0.050 & 1.261 & 0.065 & 0.029 & 13.885 & 0.362 & 0.002 & 1.234 & 2.848 & 9.716 & 0.770 & 1.036 & 0.015 & 5.076 & 0.070 \\
\hline 310 & SR04 & M-13/S2133 & 4.940 & -0.023 & 1.316 & 0.075 & 0.034 & 14.786 & 0.706 & 0.014 & 1.302 & 3.053 & 10.391 & 0.846 & 1.074 & 0.018 & 5.466 & 0.077 \\
\hline 310 & IN32 & M-13/S2133 & -0.010 & -0.017 & -0.003 & -0.002 & -0.002 & -0.022 & 0.114 & -0.006 & 0.000 & -0.003 & -0.002 & -0.004 & 0.022 & 0.000 & -0.027 & 0.000 \\
\hline 310 & IN32 & M-13/S2133 & 0.010 & -0.020 & 0.001 & -0.001 & 0.001 & -0.020 & 0.265 & -0.003 & 0.000 & -0.003 & -0.015 & -0.002 & 0.034 & 0.001 & 0.064 & 0.002 \\
\hline 311 & ARGC & M-13/S2133 & 2.355 & 2.638 & 0.970 & 0.054 & -0.001 & 9.931 & 2.089 & 1.456 & 0.523 & 1.385 & 8.587 & 0.831 & 22.021 & 0.685 & 0.036 & 0.097 \\
\hline 311 & ARGC & M-13/S2133 & 2.332 & 2.572 & 0.962 & 0.060 & 0.007 & 9.800 & 2.776 & 1.447 & 0.509 & 1.480 & 8.442 & 0.827 & 21.610 & 0.690 & 0.135 & 0.099 \\
\hline 311 & SR04 & M-13/S2133 & 5.563 & 0.018 & 1.404 & 0.073 & 0.034 & 16.514 & 0.126 & 0.003 & 1.452 & 3.237 & 10.889 & 0.950 & 1.514 & 0.014 & 5.538 & 0.074 \\
\hline 311 & SR04 & M-13/S2133 & 5.516 & 0.011 & 1.403 & 0.074 & 0.033 & 16.725 & 0.196 & -0.001 & 1.445 & 3.291 & 11.098 & 0.948 & 1.394 & 0.013 & 5.466 & 0.076 \\
\hline 311 & SR04 & M-13/S2133 & 4.202 & -0.006 & 1.109 & 0.056 & 0.028 & 12.708 & 0.086 & -0.009 & 1.112 & 2.598 & 8.680 & 0.731 & 1.080 & 0.010 & 4.362 & 0.057 \\
\hline 311 & SR04 & M-13/S2133 & 4.890 & -0.005 & 1.257 & 0.067 & 0.033 & 14.333 & 0.424 & -0.010 & 1.252 & 2.932 & 9.633 & 0.819 & 1.367 & 0.012 & 4.783 & 0.063 \\
\hline 311 & SR04 & M-13/S2133 & 6.344 & 0.012 & 1.594 & 0.089 & 0.043 & 18.476 & 0.334 & 0.003 & 1.589 & 3.814 & 12.471 & 1.066 & 1.507 & 0.018 & 6.306 & 0.090 \\
\hline 311 & $\begin{array}{l}\text { SR04 } \\
\end{array}$ & M-13/S2133 & 5.043 & 0.004 & 1.354 & 0.070 & 0.037 & 14.904 & 0.082 & -0.003 & 1.380 & 3.182 & 10.953 & 0.845 & 1.276 & 0.014 & 5.276 & 0.071 \\
\hline 311 & IN32 & M-13/S2133 & -0.014 & -0.008 & -0.002 & -0.004 & -0.001 & -0.023 & 0.034 & -0.008 & -0.002 & -0.015 & $\begin{array}{l}-0.011 \\
\end{array}$ & -0.002 & 0.115 & -0.001 & -0.026 & -0.003 \\
\hline 311 & IN32 & M-13/S2133 & 0.005 & -0.006 & 0.000 & -0.003 & 0.001 & -0.020 & 0.190 & -0.008 & -0.002 & -0.015 & -0.022 & -0.002 & 0.114 & 0.000 & 0.014 & -0.002 \\
\hline 313 & ARGC & M-13/S2133 & 2.148 & 2.547 & 0.830 & 0.066 & -0.002 & 9.583 & 2.322 & 1.381 & 0.442 & 1.389 & 8.308 & 0.822 & 21.347 & 0.658 & -0.026 & 0.093 \\
\hline 313 & ARGC & M-13/S2133 & 2.245 & 2.596 & 0.863 & 0.057 & 0.005 & 9.663 & 2.675 & 1.371 & 0.466 & 1.426 & 8.359 & 0.819 & 21.376 & 0.664 & 0.156 & 0.093 \\
\hline 313 & SR04 & M-13/S2133 & 4.868 & 0.020 & 1.305 & 0.079 & 0.026 & 14.397 & 0.668 & -0.034 & 1.301 & 3.066 & 10.434 & 0.823 & 1.266 & 0.011 & 5.295 & 0.065 \\
\hline 313 & SR04 & M-13/S2133 & 4.997 & 0.014 & 1.302 & 0.078 & 0.027 & 14.245 & 0.704 & -0.039 & 1.309 & 3.110 & 10.773 & 0.819 & 1.225 & 0.012 & 5.465 & 0.067 \\
\hline 313 & SR04 & M-13/S2133 & 5.196 & 0.019 & 1.350 & 0.082 & 0.030 & 14.909 & 0.441 & -0.014 & 1.349 & 3.175 & 10.952 & 0.858 & 1.168 & 0.014 & 5.653 & 0.072 \\
\hline 313 & SR04 & M-13/S2133 & 5.069 & 0.017 & 1.329 & 0.074 & 0.030 & 14.549 & 0.419 & -0.017 & 1.310 & 3.135 & 10.725 & 0.869 & 1.111 & 0.012 & 5.549 & 0.069 \\
\hline 313 & SR04 & M-13/S2133 & 4.959 & 0.017 & 1.303 & 0.074 & 0.028 & 14.667 & 0.701 & -0.017 & 1.342 & 3.168 & 10.708 & 0.866 & 1.189 & 0.014 & 5.452 & 0.067 \\
\hline 313 & SR04 & M-13/S2133 & 4.840 & 0.016 & 1.277 & 0.071 & 0.030 & 14.113 & 0.512 & -0.026 & 1.294 & 2.983 & 10.576 & 0.810 & 1.116 & 0.011 & 5.276 & 0.067 \\
\hline 313 & IN32 & M-13/S2133 & 0.003 & -0.001 & 0.000 & 0.001 & -0.001 & -0.004 & 0.188 & -0.013 & -0.001 & 0.001 & 0.013 & 0.000 & 0.047 & -0.001 & -0.001 & -0.001 \\
\hline 313 & IN32 & M-13/S2133 & -0.005 & 0.001 & -0.001 & 0.001 & -0.001 & -0.005 & 0.082 & -0.009 & 0.000 & 0.001 & 0.013 & 0.001 & 0.039 & -0.001 & -0.018 & -0.001 \\
\hline 314 & ARGC & M-14/S2150 & 2.407 & 2.597 & 0.989 & 0.075 & 0.007 & 9.729 & 2.234 & 1.510 & 0.491 & 1.409 & 8.547 & 0.807 & 21.335 & 0.688 & 0.026 & 0.103 \\
\hline 314 & ARGC & M-14/S2150 & 2.269 & 2.464 & 0.926 & 0.072 & 0.006 & 9.314 & 2.335 & 1.441 & 0.471 & 1.360 & $\begin{array}{l}8.149 \\
\end{array}$ & 0.788 & 20.891 & 0.646 & 0.022 & 0.098 \\
\hline 314 & SR04 & M-14/S2150 & 5.075 & -0.040 & 1.336 & 0.092 & 0.033 & 14.389 & 0.083 & -0.004 & 1.291 & 3.142 & 10.596 & 0.846 & 0.896 & 0.021 & 5.648 & 0.076 \\
\hline 314 & SR04 & M-14/S2150 & 5.177 & -0.057 & 1.311 & 0.097 & 0.032 & 15.183 & -0.062 & -0.010 & 1.307 & 3.156 & 10.426 & 0.857 & 0.846 & 0.019 & 5.690 & 0.078 \\
\hline 314 & SR04 & $\mathrm{M}-14 / \mathrm{S} 2150$ & 5.768 & -0.063 & 1.373 & 0.106 & 0.036 & 16.312 & -0.011 & -0.004 & 1.340 & 3.323 & 10.598 & 0.948 & 0.940 & 0.021 & 5.919 & 0.088 \\
\hline 314 & SR04 & M-14/S2150 & 4.915 & -0.058 & 1.280 & 0.091 & 0.031 & 14.051 & 0.090 & -0.007 & 1.276 & 3.049 & 10.375 & 0.821 & 0.801 & 0.019 & 5.499 & 0.074 \\
\hline 314 & SR04 & M-14/S2150 & 4.150 & -0.361 & 1.078 & 0.120 & 0.031 & 12.849 & 0.151 & -0.173 & 1.065 & 2.560 & 8.872 & 0.664 & 0.173 & 0.031 & 4.265 & 0.074 \\
\hline 314 & SR04 & M-14/S2150 & 5.015 & -0.052 & 1.282 & 0.092 & 0.035 & 14.911 & 0.154 & 0.001 & 1.320 & 3.118 & 10.604 & 0.854 & 0.855 & 0.019 & 5.648 & 0.078 \\
\hline 314 & IN32 & M-14/S2150 & 0.002 & -0.018 & 0.000 & 0.003 & 0.001 & -0.001 & -0.008 & -0.011 & 0.000 & -0.003 & 0.004 & -0.003 & -0.017 & 0.001 & -0.010 & 0.001 \\
\hline 314 & IN32 & M-14/S2150 & 0.008 & -0.026 & 0.001 & 0.004 & 0.001 & 0.009 & 0.004 & -0.013 & 0.001 & 0.000 & 0.007 & -0.003 & -0.028 & 0.002 & 0.013 & 0.001 \\
\hline 315 & ARGC & M-13/S2133 & 2.366 & 2.589 & 1.003 & 0.085 & 0.005 & 9.900 & 1.989 & 1.498 & 0.516 & 1.443 & 8.539 & 0.818 & 22.095 & 0.684 & -0.050 & 0.102 \\
\hline 315 & ARGC & M-13/S2133 & 2.442 & 2.631 & 1.034 & 0.083 & 0.014 & 9.660 & 2.154 & 1.440 & 0.512 & 1.425 & 8.538 & 0.816 & 21.857 & 0.684 & 0.053 & 0.106 \\
\hline 315 & SR04 & M-13/S2133 & 4.975 & 0.033 & 1.282 & 0.097 & 0.035 & 14.379 & -0.070 & 0.017 & 1.325 & 3.115 & 10.732 & 0.836 & 1.070 & 0.016 & 5.486 & 0.074 \\
\hline 315 & SR04 & M-13/S2133 & 6.110 & 0.036 & 1.591 & 0.120 & 0.046 & 17.540 & 0.012 & 0.016 & 1.582 & 3.713 & 13.101 & 1.028 & 1.316 & 0.019 & 6.606 & 0.092 \\
\hline 315 & SR04 & M-13/S2133 & 4.987 & 0.024 & 1.325 & 0.101 & 0.037 & 14.363 & -0.086 & 0.014 & 1.317 & 3.090 & 10.944 & 0.808 & 1.073 & 0.016 & 5.447 & 0.073 \\
\hline 315 & SR04 & M-13/S2133 & 5.007 & 0.024 & 1.320 & 0.100 & 0.038 & 14.188 & 0.031 & 0.013 & 1.298 & 3.048 & 10.561 & 0.817 & 1.099 & 0.016 & 5.395 & 0.072 \\
\hline 315 & SR04 & M-13/S2133 & 5.087 & 0.028 & 1.310 & 0.101 & 0.034 & 14.428 & -0.092 & 0.013 & 1.304 & 3.106 & 10.639 & 0.842 & 1.106 & 0.014 & 5.527 & 0.072 \\
\hline 315 & SR04 & M-13/S2133 & 5.165 & 0.025 & 1.336 & 0.098 & 0.037 & 14.737 & -0.092 & 0.006 & 1.328 & 3.210 & 11.015 & 0.854 & 1.112 & 0.017 & 5.609 & 0.076 \\
\hline 315 & IN32 & M-13/S2133 & -0.004 & 0.001 & 0.000 & 0.006 & 0.000 & -0.009 & -0.142 & -0.007 & 0.001 & 0.000 & -0.001 & 0.001 & 0.055 & 0.000 & -0.026 & 0.000 \\
\hline 315 & IN32 & M-13/S2133 & -0.012 & 0.001 & 0.000 & 0.005 & -0.001 & -0.010 & -0.093 & -0.004 & 0.001 & -0.001 & -0.001 & -0.001 & 0.054 & -0.001 & -0.050 & 0.000 \\
\hline
\end{tabular}


WSRC-STI-2006-00068

Table A1. Cold Chem Measurement Data Set (continued)

Revision 0

\begin{tabular}{|c|c|c|c|c|c|c|c|c|c|c|c|c|c|c|c|c|c|c|}
\hline Batch & Type of Sample & ICP/ID & Al & B & $\mathbf{C a}$ & $\mathrm{Cr}$ & $\mathbf{C u}$ & $\mathbf{F e}$ & $\mathbf{K}$ & $\mathbf{L i}$ & $\mathbf{M g}$ & Mn & $\mathrm{Na}$ & $\mathrm{Ni}$ & Si & Ti & $\mathbf{U}$ & $\mathrm{Zr}$ \\
\hline 316 & ARGC & M-13/S2133 & 2.295 & 2.608 & 0.957 & 0.073 & 0.000 & 9.668 & 2.391 & 1.488 & 0.492 & 1.383 & 8.361 & 0.793 & 21.334 & 0.653 & -0.065 & 0.100 \\
\hline 316 & ARGC & M-13/S2133 & 2.213 & 2.540 & 0.915 & 0.067 & 0.001 & 9.356 & 2.148 & 1.391 & 0.468 & 1.350 & 8.037 & 0.785 & 21.089 & 0.645 & -0.031 & 0.098 \\
\hline 316 & $\begin{array}{l}\text { SR04 } \\
\end{array}$ & M-13/S2133 & 4.860 & 0.017 & 1.270 & 0.085 & 0.027 & 14.384 & 0.087 & 0.008 & 1.299 & 3.021 & 10.597 & 0.838 & 1.058 & 0.017 & 5.255 & 0.072 \\
\hline 316 & SR04 & M-13/S2133 & 4.775 & 0.015 & 1.236 & 0.082 & 0.026 & 14.105 & 0.052 & 0.008 & 1.268 & 2.951 & 10.388 & 0.815 & 0.969 & 0.016 & 5.080 & 0.071 \\
\hline 316 & SR04 & M-13/S2133 & 4.924 & 0.013 & 1.261 & 0.088 & 0.026 & 14.929 & 0.104 & 0.009 & 1.287 & 3.085 & 10.654 & 0.849 & 1.045 & 0.016 & 5.294 & 0.073 \\
\hline 316 & SR04 & M-13/S2133 & 4.705 & 0.020 & 1.238 & 0.085 & 0.026 & 14.023 & -0.001 & 0.008 & 1.300 & 3.023 & 10.609 & 0.808 & 1.004 & 0.016 & 5.119 & 0.071 \\
\hline 316 & $\begin{array}{l}\text { SR04 } \\
\end{array}$ & M-13/S2133 & 4.686 & 0.012 & 1.253 & 0.084 & 0.026 & 14.090 & 0.079 & 0.010 & 1.287 & 3.030 & 10.855 & 0.817 & 0.994 & 0.016 & 5.182 & 0.072 \\
\hline 316 & SR04 & M-13/S2133 & 4.482 & 0.010 & 1.186 & 0.083 & 0.023 & 13.204 & 0.143 & 0.012 & 1.231 & 2.893 & 10.362 & 0.778 & 0.936 & 0.015 & 4.970 & 0.068 \\
\hline 316 & IN32 & M-13/S2133 & -0.006 & 0.000 & -0.001 & 0.002 & -0.001 & -0.006 & -0.021 & -0.006 & 0.000 & -0.001 & -0.029 & -0.004 & 0.039 & 0.001 & -0.018 & 0.001 \\
\hline 316 & IN32 & M-13/S2133 & -0.007 & -0.003 & -0.001 & 0.002 & -0.001 & -0.005 & 0.020 & -0.006 & 0.000 & -0.001 & -0.031 & -0.003 & 0.047 & 0.001 & -0.021 & 0.001 \\
\hline 317 & ARGC & M-13/S2133 & 2.387 & 2.661 & 1.004 & 0.064 & 0.004 & 10.278 & 2.257 & 1.492 & 0.524 & 1.496 & 8.550 & 0.792 & 22.192 & 0.702 & 0.077 & 0.107 \\
\hline 317 & ARGC & M-13/S2133 & 2.487 & 2.604 & 1.038 & 0.067 & 0.011 & 10.129 & 2.474 & 1.454 & 0.518 & 1.474 & 8.384 & 0.805 & 22.234 & 0.685 & 0.172 & 0.108 \\
\hline 317 & SR04 & M-13/S2133 & 5.360 & 0.024 & 1.416 & 0.084 & 0.036 & 16.209 & 0.315 & -0.001 & 1.413 & 3.336 & 10.730 & 0.862 & 1.212 & 0.015 & 5.522 & 0.080 \\
\hline 317 & SR04 & M-13/S2133 & 5.472 & 0.025 & 1.419 & 0.088 & 0.036 & 16.056 & 0.289 & 0.008 & 1.436 & 3.414 & 10.627 & 0.882 & 1.199 & 0.015 & 5.634 & 0.082 \\
\hline 317 & SR04 & M-13/S2133 & 5.266 & 0.022 & 1.388 & 0.086 & 0.032 & 15.831 & 0.434 & 0.001 & 1.399 & 3.390 & 10.614 & 0.882 & 1.229 & 0.014 & 5.452 & 0.077 \\
\hline 317 & SR04 & M-13/S2133 & 5.251 & 0.026 & 1.365 & 0.085 & 0.034 & 16.006 & 0.338 & 0.004 & 1.400 & 3.375 & 10.560 & 0.870 & 1.231 & 0.014 & 5.396 & 0.078 \\
\hline 317 & SR04 & M-13/S2133 & 5.472 & 0.030 & 1.425 & 0.088 & 0.037 & 16.064 & 0.273 & 0.007 & 1.439 & 3.497 & 11.024 & 0.890 & 1.212 & 0.015 & 5.671 & 0.082 \\
\hline 317 & $\begin{array}{l}\text { SR04 } \\
\end{array}$ & M-13/S2133 & 5.439 & 0.029 & 1.432 & 0.088 & 0.037 & 15.564 & 0.331 & 0.009 & 1.380 & 3.411 & 10.598 & 0.883 & 1.182 & 0.017 & 5.657 & 0.082 \\
\hline 317 & IN32 & M-13/S2133 & -0.002 & -0.002 & 0.001 & 0.000 & -0.001 & -0.016 & 0.024 & -0.008 & 0.000 & -0.001 & 0.005 & -0.003 & 0.046 & -0.001 & -0.032 & 0.001 \\
\hline 317 & IN32 & M-13/S2133 & 0.016 & -0.002 & 0.003 & 0.000 & 0.001 & -0.012 & 0.057 & -0.008 & 0.000 & 0.000 & 0.003 & -0.001 & 0.059 & 0.000 & 0.017 & 0.001 \\
\hline 318 & ARGC & M-14/S2150 & 2.277 & 2.538 & 0.956 & 0.064 & 0.001 & 9.254 & 2.400 & 1.541 & 0.491 & 1.369 & 8.259 & 0.774 & 21.161 & 0.658 & -0.013 & 0.098 \\
\hline 318 & ARGC & M-14/S2150 & 2.348 & 2.660 & 0.983 & 0.062 & 0.002 & 9.646 & 2.213 & 1.598 & 0.501 & 1.409 & 8.312 & 0.799 & 22.076 & 0.684 & -0.073 & 0.102 \\
\hline 318 & SR04 & M-14/S2150 & 5.071 & 0.008 & 1.325 & 0.084 & 0.028 & 14.607 & -0.141 & -0.073 & 1.353 & 3.154 & 10.481 & 0.835 & 1.014 & 0.023 & 5.234 & 0.075 \\
\hline 318 & SR04 & M-14/S2150 & 4.910 & 0.009 & 1.310 & 0.079 & 0.028 & 14.201 & -0.105 & -0.063 & 1.303 & 3.091 & 10.422 & 0.830 & 0.943 & 0.021 & 5.174 & 0.073 \\
\hline 318 & SR04 & M-14/S2150 & 5.021 & 0.013 & 1.326 & 0.082 & 0.029 & 14.570 & 0.007 & -0.056 & 1.346 & 3.162 & 10.583 & 0.855 & 0.999 & 0.021 & 5.296 & 0.076 \\
\hline 318 & SR04 & M-14/S2150 & 5.004 & 0.008 & 1.338 & 0.082 & 0.027 & 14.197 & -0.023 & -0.058 & 1.333 & 3.168 & 10.680 & 0.839 & 0.993 & 0.021 & 5.255 & 0.076 \\
\hline 318 & SR04 & M-14/S2150 & 5.082 & 0.007 & 1.325 & 0.082 & 0.029 & 14.395 & -0.024 & -0.057 & 1.331 & 3.154 & 10.648 & 0.838 & 1.005 & 0.022 & 5.347 & 0.077 \\
\hline 318 & SR04 & M-14/S2150 & 4.894 & 0.009 & 1.329 & 0.081 & 0.026 & 13.920 & 0.031 & -0.050 & 1.335 & 3.082 & 10.640 & 0.835 & 0.969 & 0.022 & 5.290 & 0.074 \\
\hline 318 & IN32 & M-14/S2150 & -0.005 & -0.002 & 0.001 & 0.001 & -0.001 & -0.001 & -0.035 & $\begin{array}{l}-0.018 \\
\end{array}$ & 0.001 & -0.003 & 0.001 & -0.003 & 0.006 & 0.002 & -0.040 & 0.000 \\
\hline 318 & IN32 & M-14/S2150 & -0.008 & -0.003 & 0.001 & 0.001 & -0.001 & -0.001 & -0.031 & -0.018 & 0.001 & -0.003 & 0.001 & -0.001 & 0.014 & 0.002 & -0.057 & 0.000 \\
\hline 319 & ARGC & M-13/S2133 & 2.447 & 2.520 & 0.996 & 0.059 & 0.015 & 9.565 & 2.282 & 1.519 & 0.484 & 1.399 & 8.480 & 0.815 & 21.532 & 0.665 & 0.443 & 0.110 \\
\hline 319 & ARGC & M-13/S2133 & 2.251 & 2.588 & 0.856 & 0.059 & 0.006 & 9.513 & 2.319 & 1.458 & 0.456 & 1.390 & $\begin{array}{l}8.328 \\
\end{array}$ & 0.812 & 21.346 & 0.681 & 0.133 & 0.107 \\
\hline 319 & SR04 & M-13/S2133 & 5.140 & 0.034 & 1.296 & 0.075 & 0.031 & 14.707 & 0.256 & 0.041 & 1.300 & 3.100 & 10.490 & 0.858 & 1.134 & 0.011 & 5.494 & 0.078 \\
\hline 319 & SR04 & M-13/S2133 & 5.229 & 0.033 & 1.339 & 0.080 & 0.033 & 15.058 & 0.277 & 0.040 & 1.322 & 3.104 & 10.869 & 0.874 & 1.155 & 0.012 & 5.710 & 0.082 \\
\hline 319 & SR04 & M-13/S2133 & 4.987 & 0.036 & 1.308 & 0.075 & 0.035 & 14.250 & 0.167 & 0.043 & 1.297 & 2.994 & 10.689 & 0.835 & 1.129 & 0.012 & 5.430 & 0.079 \\
\hline 319 & SR04 & M-13/S2133 & 5.182 & 0.031 & 1.309 & 0.080 & 0.038 & 14.671 & 0.101 & 0.046 & 1.283 & 3.098 & 10.461 & 0.873 & 1.168 & 0.014 & 5.696 & 0.081 \\
\hline 319 & SR04 & M-13/S2133 & 5.146 & 0.029 & 1.324 & 0.079 & 0.037 & 15.009 & 0.098 & 0.044 & 1.309 & 3.172 & 10.469 & 0.867 & 1.104 & 0.015 & 5.676 & 0.084 \\
\hline 319 & SR04 & M-13/S2133 & 5.068 & 0.028 & 1.352 & 0.083 & 0.039 & 14.346 & 0.186 & 0.047 & 1.294 & 3.066 & 10.567 & 0.844 & 1.110 & 0.014 & 5.634 & 0.083 \\
\hline 319 & IN32 & M-13/S2133 & -0.005 & 0.000 & 0.000 & -0.002 & -0.001 & -0.011 & 0.047 & 0.009 & 0.001 & -0.003 & 0.009 & 0.001 & 0.058 & -0.002 & -0.012 & 0.002 \\
\hline 319 & IN32 & M-13/S2133 & 0.022 & 0.001 & 0.005 & -0.001 & 0.002 & -0.006 & 0.024 & 0.005 & 0.001 & -0.001 & 0.008 & 0.002 & 0.059 & 0.000 & 0.075 & 0.003 \\
\hline 320 & ARGC & M-13/S2133 & 2.362 & 2.710 & 0.977 & 0.066 & -0.001 & 9.997 & 2.531 & 1.424 & 0.515 & 1.442 & 8.497 & 0.799 & 22.531 & 0.676 & -0.006 & 0.099 \\
\hline 320 & ARGC & M-13/S2133 & 2.471 & 2.651 & 1.030 & 0.066 & 0.009 & 10.009 & 2.425 & 1.414 & 0.512 & 1.438 & 8.462 & 0.834 & 22.095 & 0.692 & 0.252 & 0.104 \\
\hline 320 & SR04 & M-13/S2133 & 5.041 & 0.017 & 1.300 & 0.084 & 0.029 & 14.663 & 0.171 & -0.007 & 1.295 & 3.058 & 10.110 & 0.832 & 1.119 & 0.010 & 5.210 & 0.070 \\
\hline 320 & SR04 & M-13/S2133 & 5.207 & 0.016 & 1.331 & 0.082 & 0.031 & 15.042 & 0.330 & -0.006 & 1.333 & 3.128 & 10.383 & 0.847 & 1.142 & 0.011 & 5.329 & 0.073 \\
\hline 320 & SR04 & M-13/S2133 & 5.188 & 0.015 & 1.340 & 0.084 & 0.031 & 14.777 & 0.259 & -0.006 & 1.358 & 3.160 & 10.715 & 0.844 & 1.100 & 0.011 & 5.314 & 0.072 \\
\hline 320 & SR04 & M-13/S2133 & 5.193 & 0.015 & 1.329 & 0.086 & 0.032 & 14.857 & 0.205 & -0.009 & 1.343 & 3.077 & 10.287 & 0.850 & 1.134 & 0.011 & 5.182 & 0.072 \\
\hline 320 & SR04 & M-13/S2133 & 5.229 & 0.019 & 1.344 & 0.089 & 0.034 & 14.930 & 0.941 & -0.013 & 1.358 & 3.152 & 10.405 & 0.855 & 1.170 & 0.013 & 5.256 & 0.072 \\
\hline 320 & SR04 & M-13/S2133 & 6.944 & 0.028 & 1.774 & 0.111 & 0.041 & 20.203 & 0.610 & 0.007 & 1.761 & 4.247 & 13.926 & 1.158 & 1.500 & 0.017 & 7.134 & 0.099 \\
\hline 320 & IN32 & M-13/S2133 & -0.019 & -0.002 & -0.001 & 0.000 & -0.003 & -0.020 & 0.197 & -0.016 & -0.001 & -0.001 & 0.026 & -0.002 & 0.050 & -0.002 & -0.059 & -0.002 \\
\hline 320 & IN32 & M-13/S2133 & 0.002 & -0.004 & 0.003 & 0.001 & 0.000 & -0.016 & -0.042 & -0.015 & 0.000 & 0.000 & 0.007 & -0.001 & 0.057 & -0.001 & 0.011 & -0.001 \\
\hline
\end{tabular}


WSRC-STI-2006-00068

Table A1. Cold Chem Measurement Data Set (continued)

Revision 0

\begin{tabular}{|c|c|c|c|c|c|c|c|c|c|c|c|c|c|c|c|c|c|c|}
\hline Batch & Type of Sample & ICP/ID & Al & B & $\mathbf{C a}$ & $\mathrm{Cr}$ & $\mathbf{C u}$ & $\mathbf{F e}$ & $\mathbf{K}$ & $\mathbf{L i}$ & Mg & Mn & $\mathrm{Na}$ & $\mathrm{Ni}$ & $\mathrm{Si}$ & Ti & $\mathbf{U}$ & $\mathrm{Zr}$ \\
\hline 321 & ARGC & $\mathrm{M}-14 / \mathrm{S} 2150$ & 2.561 & 2.553 & 1.014 & 0.075 & 0.033 & 9.465 & 2.197 & 1.503 & 0.490 & 1.383 & 8.603 & 0.806 & 21.868 & 0.673 & 0.764 & 0.122 \\
\hline 321 & ARGC & M-14/S2150 & 2.576 & 2.557 & 1.047 & 0.076 & 0.032 & 9.645 & 2.290 & 1.551 & 0.502 & 1.405 & 8.845 & 0.831 & 21.852 & 0.697 & 0.775 & 0.121 \\
\hline 321 & $\begin{array}{l}\text { SR04 } \\
\end{array}$ & M-14/S2150 & 5.004 & -0.019 & 1.343 & 0.095 & 0.057 & 14.370 & 0.013 & 0.027 & 1.303 & 3.041 & 10.959 & 0.849 & 0.960 & 0.028 & 5.467 & 0.092 \\
\hline 321 & SR04 & M-14/S2150 & 5.528 & -0.016 & 1.385 & 0.101 & 0.058 & 15.632 & 0.000 & 0.031 & 1.337 & 3.217 & 10.941 & 0.922 & 1.018 & 0.029 & 5.785 & 0.100 \\
\hline 321 & SR04 & M-14/S2150 & 5.095 & -0.020 & 1.362 & 0.093 & 0.057 & 14.707 & -0.047 & 0.028 & 1.289 & 3.071 & 10.861 & 0.854 & 0.918 & 0.029 & 5.517 & 0.096 \\
\hline 321 & SR04 & M-14/S2150 & 4.780 & -0.016 & 1.318 & 0.088 & 0.055 & 13.681 & 0.052 & 0.024 & 1.279 & 2.942 & 10.769 & 0.806 & 0.902 & 0.027 & 5.418 & 0.090 \\
\hline 321 & SR04 & M-14/S2150 & 4.740 & -0.015 & 1.313 & 0.084 & 0.052 & 13.397 & 0.007 & 0.023 & 1.281 & 2.888 & 10.897 & 0.792 & 0.857 & 0.027 & 5.287 & 0.085 \\
\hline 321 & SR04 & M-14/S2150 & 4.985 & -0.015 & 1.351 & 0.091 & 0.056 & 14.295 & 0.097 & 0.032 & 1.318 & 3.036 & 10.866 & 0.825 & 0.963 & 0.027 & 5.353 & 0.091 \\
\hline 321 & IN32 & M-14/S2150 & 0.081 & -0.012 & 0.020 & 0.005 & 0.010 & -0.003 & 0.015 & -0.001 & 0.002 & 0.003 & 0.126 & 0.005 & 0.014 & 0.005 & 0.235 & 0.008 \\
\hline 321 & IN32 & M-14/S2150 & 0.090 & -0.013 & 0.020 & 0.004 & 0.010 & -0.003 & 0.002 & -0.001 & 0.002 & 0.003 & 0.121 & 0.006 & 0.021 & 0.005 & 0.249 & 0.009 \\
\hline 322 & ARGC & M-14/S2150 & 2.268 & 2.564 & 0.928 & 0.067 & -0.003 & 9.353 & 2.089 & 1.448 & 0.464 & 1.355 & 8.097 & 0.789 & 21.486 & 0.653 & -0.010 & 0.102 \\
\hline 322 & ARGC & M-14/S2150 & 2.268 & 2.647 & 0.937 & 0.066 & 0.005 & 9.477 & 2.136 & 1.436 & 0.471 & 1.382 & 8.103 & 0.821 & 21.131 & 0.661 & 0.201 & 0.105 \\
\hline 322 & $\begin{array}{l}\text { SR04 } \\
\end{array}$ & M-14/S2150 & 4.969 & 0.042 & 1.347 & 0.087 & 0.024 & 14.734 & 0.157 & -0.007 & 1.294 & 3.090 & 10.542 & 0.837 & 1.029 & 0.015 & 5.385 & 0.080 \\
\hline 322 & SR04 & M-14/S2150 & 5.333 & 0.037 & 1.349 & 0.092 & 0.027 & 15.738 & 0.023 & 0.008 & 1.324 & 3.248 & 10.363 & 0.903 & 1.072 & 0.017 & 5.787 & 0.083 \\
\hline 322 & SR04 & M-14/S2150 & 4.668 & 0.037 & 1.256 & 0.084 & 0.029 & 14.371 & -0.037 & -0.003 & 1.309 & 3.062 & 8.366 & 0.837 & 1.005 & 0.012 & 3.842 & 0.053 \\
\hline 322 & SR04 & M-14/S2150 & 4.832 & 0.036 & 1.301 & 0.083 & 0.030 & 14.225 & -0.091 & 0.001 & 1.263 & 3.043 & 10.451 & 0.840 & 0.991 & 0.018 & 5.406 & 0.079 \\
\hline 322 & SR04 & M-14/S2150 & 4.972 & 0.037 & 1.336 & 0.087 & 0.030 & 14.640 & -0.063 & -0.001 & 1.303 & 3.104 & 10.713 & 0.876 & 0.970 & 0.018 & 5.509 & 0.082 \\
\hline 322 & SR04 & M-14/S2150 & 4.946 & 0.038 & 1.324 & 0.086 & 0.032 & 14.414 & -0.036 & 0.006 & 1.321 & 3.094 & 10.637 & 0.882 & 1.045 & 0.018 & 5.468 & 0.079 \\
\hline 322 & IN32 & M-14/S2150 & -0.010 & 0.006 & -0.001 & 0.001 & -0.002 & -0.012 & -0.010 & -0.008 & 0.002 & 0.000 & 0.015 & -0.003 & 0.016 & 0.000 & -0.022 & 0.003 \\
\hline 322 & IN32 & M-14/S2150 & 0.016 & 0.006 & 0.003 & 0.002 & 0.001 & -0.011 & -0.039 & -0.011 & 0.002 & 0.000 & 0.005 & -0.004 & 0.047 & 0.001 & 0.058 & 0.004 \\
\hline 323 & ARGC & M-13/S2133 & 2.366 & 2.643 & 1.002 & 0.060 & -0.003 & 9.546 & 2.202 & 1.471 & 0.490 & 1.397 & 8.384 & 0.797 & 21.778 & 0.672 & 0.049 & 0.102 \\
\hline 323 & ARGC & M-13/S2133 & 2.353 & 2.581 & 1.005 & 0.059 & 0.001 & 9.717 & 2.469 & 1.470 & 0.490 & 1.408 & 8.461 & 0.794 & 21.812 & 0.681 & 0.139 & 0.105 \\
\hline 323 & SR04 & M-14/S2150 & 5.077 & -0.005 & 1.334 & 0.080 & 0.025 & 14.639 & 0.104 & 0.002 & 1.325 & 3.098 & 10.801 & 0.843 & 1.072 & 0.012 & 5.322 & 0.075 \\
\hline 323 & SR04 & M-14/S2150 & 5.071 & -0.007 & 1.368 & 0.078 & 0.026 & 14.602 & 0.169 & 0.006 & 1.314 & 3.131 & 10.857 & 0.839 & 1.027 & 0.013 & 5.398 & 0.077 \\
\hline 323 & SR04 & M-14/S2150 & 5.007 & -0.010 & 1.338 & 0.078 & 0.022 & 14.375 & 0.227 & 0.004 & 1.313 & 3.107 & 10.641 & 0.827 & 0.999 & 0.012 & 5.294 & 0.075 \\
\hline 323 & SR04 & M-14/S2150 & 4.964 & -0.006 & 1.347 & 0.077 & 0.028 & 14.282 & 0.209 & 0.010 & 1.311 & 3.090 & 10.906 & 0.826 & 1.009 & 0.013 & 5.262 & 0.074 \\
\hline 323 & SR04 & M-14/S2150 & 5.339 & -0.006 & 1.394 & 0.082 & 0.029 & 15.590 & 0.204 & 0.011 & 1.320 & 3.244 & 10.789 & 0.883 & 1.067 & 0.014 & 5.528 & 0.079 \\
\hline 323 & SR04 & M-14/S2150 & 4.895 & -0.012 & 1.322 & 0.075 & 0.027 & 14.027 & 0.212 & 0.003 & 1.272 & 3.039 & 10.649 & 0.805 & 0.974 & 0.013 & 5.143 & 0.075 \\
\hline 323 & IN32 & M-13/S2133 & -0.013 & -0.010 & -0.001 & -0.002 & -0.002 & -0.021 & -0.020 & -0.010 & -0.003 & -0.004 & -0.017 & -0.005 & 0.020 & -0.001 & 0.014 & 0.001 \\
\hline 323 & IN32 & M-13/S2133 & -0.003 & -0.012 & 0.000 & -0.001 & -0.001 & -0.019 & 0.084 & -0.010 & -0.003 & -0.004 & -0.020 & -0.005 & 0.021 & -0.001 & 0.039 & 0.001 \\
\hline 324 & ARGC & M-14/S2150 & 2.386 & 2.574 & 0.989 & 0.064 & -0.004 & 9.536 & 2.233 & 1.475 & 0.491 & 1.396 & 8.499 & 0.781 & 21.750 & 0.678 & 0.002 & 0.096 \\
\hline 324 & ARGC & M-14/S2150 & 2.297 & 2.525 & 0.973 & 0.066 & -0.003 & 9.337 & 2.133 & 1.444 & 0.487 & 1.335 & 8.331 & 0.773 & 21.443 & 0.661 & 0.045 & 0.096 \\
\hline 324 & SR04 & M-14/S2150 & 4.860 & 0.001 & 1.288 & 0.078 & 0.024 & 13.645 & 0.196 & 0.000 & 1.274 & 2.916 & 10.573 & 0.778 & 0.944 & 0.011 & 5.485 & 0.067 \\
\hline 324 & SR04 & M-14/S2150 & 5.006 & -0.001 & 1.269 & 0.082 & 0.023 & 14.203 & 0.088 & 0.006 & 1.262 & 2.989 & 10.227 & 0.798 & 0.956 & 0.012 & 5.413 & 0.070 \\
\hline 324 & SR04 & M-14/S2150 & 4.914 & 0.000 & 1.289 & 0.082 & 0.025 & 14.254 & 0.079 & 0.006 & 1.274 & 2.998 & 10.652 & 0.807 & 0.942 & 0.013 & 5.500 & 0.069 \\
\hline 324 & SR04 & M-14/S2150 & 4.960 & -0.002 & 1.279 & 0.083 & 0.023 & 14.183 & 0.046 & 0.007 & 1.277 & 2.997 & 10.377 & 0.828 & 0.941 & 0.013 & 5.489 & 0.068 \\
\hline 324 & SR04 & M-14/S2150 & 5.153 & -0.004 & 1.300 & 0.085 & 0.024 & 14.665 & 0.076 & 0.002 & 1.274 & 3.070 & 10.419 & 0.839 & 0.970 & 0.013 & 5.563 & 0.071 \\
\hline 324 & SR04 & M-14/S2150 & 5.386 & 0.001 & 1.329 & 0.090 & 0.025 & 15.152 & 0.119 & 0.006 & 1.298 & 3.157 & 10.305 & 0.875 & 1.044 & 0.013 & 5.726 & 0.074 \\
\hline 324 & IN32 & M-14/S2150 & -0.025 & -0.005 & -0.003 & 0.000 & -0.003 & -0.003 & 0.030 & -0.008 & -0.001 & -0.002 & -0.016 & -0.004 & 0.011 & -0.001 & -0.011 & -0.001 \\
\hline 324 & IN32 & M-14/S2150 & -0.017 & -0.009 & -0.002 & 0.000 & -0.003 & -0.004 & -0.001 & -0.010 & -0.001 & -0.002 & -0.019 & -0.004 & 0.015 & -0.001 & 0.000 & -0.001 \\
\hline 325 & ARGC & M-14/S2150 & 2.339 & 2.671 & 0.979 & 0.071 & -0.001 & 9.875 & 2.272 & 1.521 & 0.499 & 1.430 & 8.661 & 0.824 & 22.687 & 0.696 & 0.022 & 0.105 \\
\hline 325 & ARGC & M-14/S2150 & 2.286 & 2.605 & 0.877 & 0.070 & 0.002 & 9.937 & 2.466 & 1.447 & 0.478 & 1.442 & 8.509 & 0.818 & 22.398 & 0.684 & 0.132 & 0.105 \\
\hline 325 & SR04 & M-14/S2150 & 4.874 & -0.170 & 1.298 & 0.090 & 0.024 & 14.501 & 0.042 & 0.003 & 1.305 & 3.080 & 11.009 & 0.839 & 1.085 & 0.015 & 5.359 & 0.075 \\
\hline 325 & SR04 & M-14/S2150 & 4.786 & -0.013 & 1.275 & 0.068 & 0.025 & 10.886 & 0.069 & 0.009 & 0.979 & 2.312 & 10.649 & 0.629 & 1.020 & 0.016 & 5.394 & 0.074 \\
\hline 325 & SR04 & M-14/S2150 & 4.862 & \begin{tabular}{c|}
-0.009 \\
\end{tabular} & 1.308 & 0.085 & 0.028 & 14.168 & 0.223 & 0.016 & 1.318 & 3.054 & 10.825 & 0.834 & 0.998 & 0.017 & 5.509 & 0.077 \\
\hline 325 & SR04 & M-14/S2150 & 4.913 & -0.014 & 1.306 & 0.085 & 0.026 & 14.310 & 0.174 & 0.010 & 1.287 & 3.045 & 11.056 & 0.846 & 1.030 & 0.016 & 5.512 & 0.077 \\
\hline 325 & SR04 & M-14/S2150 & 4.868 & -0.010 & 1.291 & 0.096 & 0.028 & 15.895 & 0.136 & 0.010 & 1.479 & 3.426 & 11.101 & 0.935 & 1.003 & 0.016 & 5.516 & 0.077 \\
\hline 325 & SR04 & $\mathrm{M}-14 / \mathrm{S} 2150$ & 5.087 & -0.009 & 1.310 & 0.086 & 0.029 & 14.813 & 0.228 & 0.013 & 1.301 & 3.119 & 10.932 & 0.855 & 1.034 & 0.016 & 5.564 & 0.077 \\
\hline 325 & IN32 & M-14/S2150 & -0.007 & -0.008 & -0.002 & 0.002 & -0.002 & -0.004 & -0.040 & -0.008 & 0.001 & 0.001 & -0.015 & -0.001 & 0.022 & 0.000 & -0.005 & 0.001 \\
\hline 325 & IN32 & M-14/S2150 & 0.004 & -0.011 & 0.000 & 0.002 & 0.000 & -0.002 & 0.067 & -0.005 & 0.001 & 0.001 & -0.004 & -0.001 & 0.030 & 0.001 & 0.025 & 0.002 \\
\hline
\end{tabular}


WSRC-STI-2006-00068

Table A1. Cold Chem Measurement Data Set (continued)

Revision 0

\begin{tabular}{|c|c|c|c|c|c|c|c|c|c|c|c|c|c|c|c|c|c|c|}
\hline Batch & Type of Sample & ICP/ID & Al & B & $\mathbf{C a}$ & $\mathrm{Cr}$ & $\mathbf{C u}$ & $\mathbf{F e}$ & $\mathbf{K}$ & $\mathbf{L i}$ & Mg & Mn & Na & $\mathrm{Ni}$ & $\mathrm{Si}$ & Ti & $\mathbf{U}$ & $\mathrm{Zr}$ \\
\hline 326 & ARGC & $\mathrm{M}-14 / \mathrm{S} 2150$ & 2.332 & 2.522 & 1.004 & 0.065 & 0.006 & 9.368 & 2.421 & 1.424 & 0.480 & 1.382 & 8.249 & 0.803 & 21.362 & 0.654 & 0.207 & 0.103 \\
\hline 326 & ARGC & M-14/S2150 & 2.362 & 2.635 & 0.993 & 0.065 & -0.001 & 9.541 & 2.299 & 1.491 & 0.485 & 1.404 & 8.396 & 0.787 & 21.625 & 0.677 & 0.008 & 0.101 \\
\hline 326 & $\begin{array}{l}\text { SR04 } \\
\end{array}$ & M-14/S2150 & 5.472 & 0.004 & 1.442 & 0.091 & 0.031 & 15.799 & 0.060 & -0.018 & 1.457 & 3.386 & 11.548 & 0.911 & 1.246 & 0.016 & 5.992 & 0.083 \\
\hline 326 & SR04 & M-14/S2150 & 4.702 & 0.001 & 1.231 & 0.079 & 0.026 & 13.467 & 0.236 & -0.021 & 1.183 & 2.878 & 9.377 & 0.791 & 1.055 & 0.013 & 5.221 & 0.071 \\
\hline 326 & SR04 & M-14/S2150 & 4.896 & 0.002 & 1.335 & 0.083 & 0.029 & 13.967 & 0.147 & -0.022 & 1.305 & 3.074 & 10.485 & 0.837 & 1.120 & 0.015 & 5.621 & 0.074 \\
\hline 326 & SR04 & M-14/S2150 & 4.974 & 0.001 & 1.321 & 0.083 & 0.028 & 14.074 & 0.162 & -0.021 & 1.315 & 3.054 & 10.538 & 0.843 & 1.114 & 0.014 & 5.591 & 0.074 \\
\hline 326 & SR04 & M-14/S2150 & 5.051 & 0.004 & 1.344 & 0.087 & 0.031 & 14.079 & 0.217 & -0.020 & 1.286 & 3.116 & 10.483 & 0.845 & 1.145 & 0.016 & 5.721 & 0.075 \\
\hline 326 & SR04 & M-14/S2150 & 5.095 & 0.000 & 1.359 & 0.090 & 0.033 & 14.603 & 0.144 & -0.023 & 1.276 & 3.119 & 10.421 & 0.878 & 1.170 & 0.015 & 5.733 & 0.079 \\
\hline 326 & IN32 & M-14/S2150 & -0.015 & -0.005 & -0.001 & 0.000 & -0.002 & -0.015 & -0.009 & -0.020 & 0.000 & -0.002 & -0.017 & -0.003 & 0.061 & -0.001 & -0.003 & 0.000 \\
\hline 326 & IN32 & M-14/S2150 & 0.005 & -0.006 & 0.002 & 0.002 & 0.000 & -0.012 & 0.017 & -0.017 & 0.000 & -0.002 & -0.002 & -0.002 & 0.068 & 0.000 & 0.048 & 0.001 \\
\hline 327 & ARGC & M-14/S2150 & 2.268 & 2.540 & 0.978 & 0.059 & 0.004 & 9.386 & 2.154 & 1.409 & 0.486 & 1.353 & 8.226 & 0.751 & 21.618 & 0.656 & 0.034 & 0.103 \\
\hline 327 & ARGC & M-14/S2150 & 2.015 & 2.571 & 0.993 & 0.063 & 0.009 & 9.478 & 2.352 & 1.413 & 0.476 & 1.381 & 8.284 & 0.784 & 21.592 & 0.644 & 0.132 & 0.103 \\
\hline 327 & $\begin{array}{l}\text { SR04 } \\
\end{array}$ & M-14/S2150 & 4.875 & 0.013 & 1.298 & 0.089 & 0.031 & 13.778 & 0.172 & -0.011 & 1.286 & 2.938 & 10.422 & 0.804 & 1.282 & 0.018 & 5.514 & 0.076 \\
\hline 327 & SR04 & M-14/S2150 & 4.909 & 0.007 & 1.300 & 0.078 & 0.030 & 13.602 & 0.166 & -0.014 & 1.277 & 3.022 & 10.522 & 0.780 & 1.312 & 0.018 & 5.500 & 0.077 \\
\hline 327 & SR04 & M-14/S2150 & 4.739 & 0.008 & 1.299 & 0.077 & 0.032 & 13.656 & 0.091 & -0.014 & 1.289 & 3.016 & 10.347 & 0.795 & 1.317 & 0.018 & 5.444 & 0.076 \\
\hline 327 & SR04 & M-14/S2150 & 4.849 & 0.006 & 1.305 & 0.079 & 0.032 & 13.887 & 0.071 & -0.017 & 1.300 & 2.980 & 10.672 & 0.803 & 1.318 & 0.019 & 5.504 & 0.077 \\
\hline 327 & SR04 & M-14/S2150 & 4.701 & 0.005 & 1.259 & 0.078 & 0.032 & 13.545 & 0.124 & -0.017 & 1.270 & 3.035 & 10.450 & 0.799 & 1.305 & 0.018 & 5.387 & 0.075 \\
\hline 327 & SR04 & M-14/S2150 & 4.884 & 0.006 & 1.312 & 0.084 & 0.034 & 13.943 & 0.159 & -0.013 & 1.322 & 3.082 & 10.791 & 0.819 & 1.354 & 0.019 & 5.531 & 0.077 \\
\hline 327 & IN32 & M-14/S2150 & -0.001 & -0.002 & 0.001 & 0.000 & 0.000 & -0.016 & -0.006 & -0.017 & 0.000 & 0.000 & 0.016 & -0.003 & 0.095 & 0.001 & -0.004 & 0.002 \\
\hline 327 & IN32 & M-14/S2150 & 0.009 & -0.005 & 0.003 & 0.000 & 0.001 & -0.011 & 0.094 & -0.017 & 0.001 & 0.001 & 0.041 & -0.003 & 0.110 & 0.002 & 0.034 & 0.003 \\
\hline 328 & ARGC & M-14/S2150 & 2.352 & 2.638 & 0.985 & 0.067 & 0.001 & 9.597 & 2.219 & 1.473 & 0.486 & 1.387 & 8.548 & 0.788 & 22.161 & 0.691 & -0.010 & 0.104 \\
\hline 328 & ARGC & M-14/S2150 & 2.242 & 2.555 & 0.877 & 0.067 & 0.006 & 9.371 & 2.390 & 1.393 & 0.429 & 1.351 & 8.390 & 0.781 & 21.514 & 0.678 & 0.124 & 0.104 \\
\hline 328 & SR04 & M-14/S2150 & 4.830 & 0.013 & 1.300 & 0.083 & 0.027 & 14.064 & 0.150 & -0.017 & 1.285 & 2.982 & 10.826 & 0.802 & 1.165 & 0.016 & 5.348 & 0.074 \\
\hline 328 & SR04 & M-14/S2150 & 4.773 & 0.011 & 1.291 & 0.080 & 0.026 & 13.518 & 0.175 & -0.017 & 1.259 & 2.956 & 10.593 & 0.790 & 1.100 & 0.016 & 5.062 & 0.073 \\
\hline 328 & SR04 & M-14/S2150 & 4.886 & 0.008 & 1.314 & 0.083 & 0.027 & 13.725 & 0.085 & -0.021 & 1.279 & 3.006 & 10.891 & 0.800 & 1.111 & 0.016 & 5.330 & 0.076 \\
\hline 328 & SR04 & M-14/S2150 & 4.915 & 0.007 & 1.352 & 0.081 & 0.030 & 14.301 & 0.280 & -0.014 & 1.317 & 3.065 & 10.993 & 0.804 & 1.070 & 0.017 & 5.384 & 0.078 \\
\hline 328 & SR04 & M-14/S2150 & 4.904 & 0.010 & 1.346 & 0.082 & 0.030 & 14.074 & 0.240 & -0.014 & 1.277 & 3.028 & 10.766 & 0.814 & 1.133 & 0.018 & 5.458 & 0.078 \\
\hline 328 & SR04 & M-14/S2150 & 4.834 & 0.009 & 1.294 & 0.080 & 0.028 & 13.804 & 0.240 & -0.016 & 1.258 & 2.954 & 10.770 & 0.816 & 1.117 & 0.017 & 5.212 & 0.076 \\
\hline 328 & IN32 & M-14/S2150 & -0.002 & 0.000 & -0.001 & 0.001 & -0.001 & 0.004 & 0.007 & -0.014 & 0.000 & -0.001 & -0.012 & -0.005 & 0.055 & 0.000 & -0.031 & 0.001 \\
\hline 328 & IN32 & M-14/S2150 & 0.017 & -0.004 & 0.001 & 0.001 & 0.000 & 0.000 & 0.067 & -0.014 & 0.000 & -0.001 & -0.007 & -0.003 & 0.051 & 0.001 & 0.035 & 0.002 \\
\hline 329 & ARGC & M-14/S2150 & 2.260 & 2.600 & 0.957 & 0.070 & -0.003 & 9.460 & 2.355 & 1.468 & 0.489 & 1.396 & 8.261 & 0.796 & 21.678 & 0.664 & -0.041 & 0.100 \\
\hline 329 & ARGC & M-14/S2150 & 2.364 & 2.580 & 1.012 & 0.071 & 0.001 & 9.526 & 2.325 & 1.461 & 0.486 & 1.393 & 8.448 & 0.803 & 21.206 & 0.668 & -0.021 & 0.101 \\
\hline 329 & SR04 & M-14/S2150 & 5.157 & -0.009 & 1.304 & 0.106 & 0.026 & 14.954 & 0.167 & -0.008 & 1.305 & 3.131 & 10.830 & 0.860 & 0.748 & 0.015 & 5.486 & 0.074 \\
\hline 329 & SR04 & M-14/S2150 & 5.209 & -0.010 & 1.315 & 0.090 & 0.026 & 14.813 & 0.176 & -0.006 & 1.299 & 3.166 & 11.056 & 0.863 & 0.723 & 0.015 & 5.648 & 0.075 \\
\hline 329 & SR04 & M-14/S2150 & 5.014 & -0.011 & 1.293 & 0.087 & 0.027 & 14.735 & 0.154 & -0.011 & 1.295 & 3.062 & 10.718 & 0.834 & 0.698 & 0.014 & 5.490 & 0.074 \\
\hline 329 & SR04 & M-14/S2150 & 4.368 & -0.013 & 1.223 & 0.075 & 0.023 & 12.487 & 0.080 & -0.010 & 1.252 & 2.780 & 10.452 & 0.723 & 0.543 & 0.013 & 5.055 & 0.065 \\
\hline 329 & SR04 & M-14/S2150 & 4.997 & -0.012 & 1.285 & 0.086 & 0.026 & 14.191 & 0.161 & -0.007 & 1.286 & 3.041 & 10.790 & 0.831 & 0.670 & 0.015 & 5.481 & 0.075 \\
\hline 329 & SR04 & M-14/S2150 & 4.915 & -0.012 & 1.298 & 0.087 & 0.026 & 13.980 & 0.148 & -0.006 & 1.256 & 2.981 & 10.392 & 0.815 & 0.709 & 0.015 & 5.278 & 0.075 \\
\hline 329 & IN32 & M-14/S2150 & -0.002 & -0.014 & 0.002 & 0.002 & -0.001 & -0.009 & 0.013 & -0.015 & 0.001 & -0.001 & -0.003 & -0.005 & -0.109 & 0.000 & 0.005 & 0.001 \\
\hline 329 & IN32 & M-14/S2150 & -0.005 & -0.009 & 0.000 & 0.002 & -0.002 & -0.012 & 0.032 & -0.014 & 0.001 & -0.001 & -0.020 & -0.004 & -0.082 & 0.000 & -0.023 & 0.000 \\
\hline 330 & ARGC & M-13/S2133 & 2.370 & 2.544 & 1.013 & 0.066 & 0.004 & 9.514 & 2.551 & 1.482 & 0.491 & 1.366 & 8.352 & 0.805 & 21.679 & 0.678 & 0.119 & 0.104 \\
\hline 330 & ARGC & M-13/S2133 & 2.318 & 2.661 & 0.967 & 0.072 & 0.002 & 9.707 & 2.316 & 1.455 & 0.497 & 1.371 & 8.257 & 0.798 & 22.005 & 0.663 & -0.017 & 0.101 \\
\hline 330 & SR04 & M-13/S2133 & 5.492 & 0.022 & 1.339 & 0.097 & 0.030 & 15.876 & 0.168 & 0.004 & 1.301 & 3.285 & 10.849 & 0.893 & 1.244 & 0.014 & 5.979 & 0.082 \\
\hline 330 & SR04 & M-13/S2133 & 5.053 & 0.015 & 1.290 & 0.085 & 0.029 & 14.709 & 0.071 & -0.005 & 1.254 & 3.035 & 10.356 & 0.848 & 1.122 & 0.013 & 5.498 & 0.077 \\
\hline 330 & SR04 & M-13/S2133 & 5.026 & 0.015 & 1.309 & 0.083 & 0.028 & 14.647 & 0.041 & -0.002 & 1.313 & 3.051 & 10.919 & 0.839 & 1.085 & 0.015 & 5.588 & 0.078 \\
\hline 330 & SR04 & M-13/S2133 & 4.675 & 0.012 & 1.204 & 0.079 & 0.028 & 13.479 & 0.052 & -0.007 & 1.176 & 2.809 & 9.852 & 0.774 & 1.015 & 0.012 & 5.134 & 0.073 \\
\hline 330 & SR04 & M-13/S2133 & 5.015 & 0.015 & 1.299 & 0.084 & 0.031 & 14.373 & 0.114 & -0.006 & 1.266 & 3.054 & 10.690 & 0.826 & 1.100 & 0.014 & 5.559 & 0.079 \\
\hline 330 & SR04 & $\mathrm{M}-13 / \mathrm{S} 2133$ & 5.139 & 0.017 & 1.328 & 0.090 & 0.032 & 15.110 & 0.063 & -0.006 & 1.334 & 3.084 & 11.007 & 0.865 & 1.139 & 0.014 & 5.834 & 0.080 \\
\hline 330 & IN32 & M-13/S2133 & -0.007 & 0.000 & 0.004 & 0.001 & -0.001 & -0.007 & 0.035 & -0.011 & 0.006 & 0.001 & 0.017 & 0.000 & 0.070 & -0.001 & -0.039 & 0.002 \\
\hline 330 & IN32 & M-13/S2133 & 0.002 & -0.002 & 0.000 & 0.001 & 0.000 & -0.012 & 0.068 & -0.010 & 0.001 & 0.000 & 0.023 & -0.001 & 0.048 & 0.000 & 0.013 & 0.002 \\
\hline
\end{tabular}


WSRC-STI-2006-00068

Table A1. Cold Chem Measurement Data Set (continued)

Revision 0

\begin{tabular}{|c|c|c|c|c|c|c|c|c|c|c|c|c|c|c|c|c|c|c|}
\hline Batch & Type of Sample & ICP/ID & Al & B & $\mathbf{C a}$ & $\mathrm{Cr}$ & $\mathbf{C u}$ & $\mathbf{F e}$ & $\mathbf{K}$ & $\mathbf{L i}$ & $\mathbf{M g}$ & Mn & $\mathrm{Na}$ & $\mathrm{Ni}$ & $\mathrm{Si}$ & Ti & $\mathbf{U}$ & $\mathrm{Zr}$ \\
\hline 331 & ARGC & M-14/S2150 & 2.248 & 2.645 & 0.882 & 0.072 & -0.001 & 9.953 & 2.381 & 1.526 & 0.459 & 1.440 & 8.598 & 0.818 & 22.451 & 0.675 & -0.058 & 0.100 \\
\hline 331 & ARGC & M-14/S2150 & 1.772 & 2.180 & 0.638 & 0.058 & -0.003 & 7.818 & 1.859 & 1.206 & 0.347 & 1.149 & 6.930 & 0.658 & 18.184 & 0.546 & -0.107 & 0.083 \\
\hline 331 & $\begin{array}{l}\text { SR04 } \\
\end{array}$ & M-14/S2150 & 4.989 & -0.003 & 1.246 & 0.087 & 0.020 & 14.357 & 0.063 & -0.008 & 1.268 & 3.041 & 10.440 & 0.803 & 1.060 & 0.014 & 5.259 & 0.069 \\
\hline 331 & SR04 & M-14/S2150 & 4.858 & 0.000 & 1.254 & 0.087 & 0.020 & 14.111 & 0.084 & 0.002 & 1.285 & 2.977 & 10.467 & 0.800 & 0.976 & 0.013 & 5.300 & 0.070 \\
\hline 331 & SR04 & M-14/S2150 & 4.250 & -0.012 & 1.081 & 0.078 & 0.015 & 12.451 & -0.029 & -0.009 & 1.103 & 2.664 & 9.047 & 0.715 & 0.847 & 0.012 & 4.603 & 0.061 \\
\hline 331 & SR04 & M-14/S2150 & 4.920 & -0.003 & 1.248 & 0.090 & 0.023 & 14.255 & 0.084 & 0.004 & 1.240 & 3.006 & 9.953 & 0.829 & 1.010 & 0.015 & 5.419 & 0.072 \\
\hline 331 & $\begin{array}{l}\text { SR04 } \\
\end{array}$ & M-14/S2150 & 4.978 & -0.003 & 1.274 & 0.094 & 0.024 & 14.576 & 0.027 & 0.007 & 1.253 & 3.067 & 10.138 & 0.859 & 1.041 & 0.014 & 5.508 & 0.072 \\
\hline 331 & SR04 & M-14/S2150 & 4.738 & -0.005 & 1.215 & 0.086 & 0.021 & 13.726 & 0.126 & 0.002 & 1.229 & 2.929 & 10.215 & 0.801 & 0.983 & 0.014 & 5.190 & 0.069 \\
\hline 331 & IN32 & M-14/S2150 & -0.003 & -0.005 & -0.001 & 0.003 & -0.002 & -0.013 & -0.021 & -0.010 & 0.000 & 0.000 & 0.003 & -0.003 & 0.029 & 0.000 & -0.050 & 0.000 \\
\hline 331 & IN32 & M-14/S2150 & 0.000 & -0.007 & -0.001 & 0.003 & -0.002 & -0.009 & -0.001 & -0.008 & 0.000 & 0.000 & 0.007 & -0.001 & 0.040 & 0.000 & -0.029 & 0.000 \\
\hline 332 & ARGC & M-14/S2150 & 2.314 & 2.499 & 0.954 & 0.065 & 0.001 & 9.168 & 2.300 & 1.405 & 0.481 & 1.345 & 8.072 & 0.764 & 21.123 & 0.647 & -0.016 & 0.099 \\
\hline 332 & ARGC & M-14/S2150 & 2.357 & 2.544 & 1.002 & 0.061 & 0.003 & 9.222 & 2.230 & 1.432 & 0.483 & 1.344 & 8.146 & 0.767 & 21.257 & 0.663 & 0.108 & 0.106 \\
\hline 332 & SR04 & M-14/S2150 & 5.590 & 0.009 & 1.364 & 0.094 & 0.032 & 16.184 & 0.137 & 0.004 & 1.281 & 3.183 & 9.992 & 0.931 & 1.205 & 0.017 & 6.047 & 0.084 \\
\hline 332 & SR04 & M-14/S2150 & 4.704 & 0.001 & 1.265 & 0.084 & 0.027 & 13.490 & 0.176 & -0.010 & 1.292 & 2.960 & 10.458 & 0.795 & 0.994 & 0.014 & 5.248 & 0.074 \\
\hline 332 & SR04 & M-14/S2150 & 4.921 & 0.001 & 1.302 & 0.081 & 0.028 & 14.169 & 0.136 & -0.004 & 1.282 & 3.081 & 10.313 & 0.825 & 1.020 & 0.015 & 5.544 & 0.075 \\
\hline 332 & SR04 & M-14/S2150 & 4.063 & -0.001 & 1.193 & 0.069 & 0.023 & 11.660 & 0.170 & -0.013 & 1.247 & 2.760 & 10.630 & 0.673 & 0.930 & 0.012 & 4.777 & 0.064 \\
\hline 332 & SR04 & M-14/S2150 & 5.105 & -0.001 & 1.345 & 0.084 & 0.029 & 14.672 & 0.120 & -0.002 & 1.284 & 3.081 & 10.490 & 0.829 & 1.028 & 0.016 & 5.561 & 0.078 \\
\hline 332 & $\begin{array}{l}\text { SR04 } \\
\end{array}$ & M-14/S2150 & 5.334 & -0.003 & 1.390 & 0.085 & 0.032 & 15.747 & 0.139 & -0.009 & 1.288 & 3.191 & 10.451 & 0.876 & 1.080 & 0.016 & 5.960 & 0.083 \\
\hline 332 & IN32 & M-14/S2150 & 0.002 & -0.004 & 0.001 & 0.000 & -0.001 & -0.052 & 0.026 & -0.012 & 0.002 & -0.002 & -0.008 & -0.001 & -0.015 & 0.000 & -0.011 & 0.001 \\
\hline 332 & IN32 & M-14/S2150 & 0.007 & -0.008 & 0.002 & 0.000 & 0.000 & -0.060 & 0.039 & -0.014 & 0.002 & -0.002 & -0.015 & -0.002 & -0.032 & 0.001 & 0.015 & 0.002 \\
\hline 333 & ARGC & M-13/S2133 & 2.443 & 2.625 & 1.146 & 0.056 & 0.001 & 9.597 & 1.893 & 1.452 & 0.563 & 1.422 & 8.305 & 0.801 & 21.578 & 0.671 & -0.018 & 0.103 \\
\hline 333 & ARGC & M-13/S2133 & 2.305 & 2.711 & 0.958 & 0.053 & 0.001 & 9.356 & 2.127 & 1.385 & 0.521 & 1.508 & 8.011 & 0.772 & 20.763 & 0.653 & 0.091 & 0.100 \\
\hline 333 & SR04 & M-13/S2133 & 5.159 & 0.037 & 1.358 & 0.078 & 0.029 & 15.386 & 0.263 & 0.028 & 1.373 & 3.320 & 10.762 & 0.871 & 1.120 & 0.015 & 5.462 & 0.079 \\
\hline 333 & SR04 & M-13/S2133 & 5.110 & 0.034 & 1.319 & 0.074 & 0.029 & 14.693 & 0.196 & 0.027 & 1.399 & 3.329 & 10.488 & 0.831 & 1.050 & 0.015 & 5.408 & 0.077 \\
\hline 333 & SR04 & M-13/S2133 & 5.242 & 0.038 & 1.383 & 0.076 & 0.030 & 15.154 & -0.058 & 0.022 & 1.473 & 3.444 & 11.127 & 0.875 & 1.104 & 0.014 & 5.630 & 0.078 \\
\hline 333 & SR04 & M-13/S2133 & 5.644 & 0.036 & 1.378 & 0.078 & 0.033 & 16.037 & 0.256 & 0.026 & 1.451 & 3.608 & 10.896 & 0.913 & 1.176 & 0.017 & 5.607 & 0.084 \\
\hline 333 & SR04 & M-13/S2133 & 5.236 & 0.043 & 1.342 & 0.077 & 0.031 & 15.146 & 0.036 & 0.022 & 1.450 & 3.500 & 11.014 & 0.864 & 1.137 & 0.015 & 5.642 & 0.078 \\
\hline 333 & SR04 & M-13/S2133 & 5.329 & 0.035 & 1.360 & 0.077 & 0.029 & 15.528 & 0.101 & 0.024 & 1.388 & 3.362 & 10.929 & $\begin{array}{ll}0.898 \\
\end{array}$ & 1.159 & 0.016 & 5.624 & 0.081 \\
\hline 333 & IN32 & M-13/S2133 & -0.009 & 0.002 & -0.001 & -0.001 & -0.003 & -0.031 & 0.009 & 0.001 & 0.001 & -0.002 & 0.025 & 0.000 & 0.028 & -0.001 & -0.056 & 0.000 \\
\hline 333 & IN32 & M-13/S2133 & 0.000 & 0.004 & 0.000 & -0.002 & -0.003 & -0.031 & 0.082 & -0.004 & 0.001 & -0.001 & 0.025 & 0.000 & 0.031 & 0.000 & -0.041 & 0.000 \\
\hline 334 & ARGC & M-13/S2133 & 2.201 & 2.567 & 0.893 & 0.069 & -0.002 & 9.491 & 2.384 & 1.455 & 0.464 & 1.399 & 8.291 & 0.796 & 21.542 & 0.674 & -0.072 & 0.101 \\
\hline 334 & ARGC & M-13/S2133 & 2.224 & 2.531 & 0.919 & 0.065 & 0.003 & 9.263 & 2.018 & 1.416 & 0.457 & 1.365 & 8.263 & 0.779 & 21.165 & 0.658 & 0.052 & 0.102 \\
\hline 334 & SR04 & M-13/S2133 & 4.775 & -0.003 & 1.245 & 0.081 & 0.025 & 13.747 & 0.370 & 0.025 & 1.269 & 2.961 & 10.453 & 0.788 & 0.952 & 0.015 & 5.026 & 0.070 \\
\hline 334 & SR04 & M-13/S2133 & 4.838 & 0.003 & 1.265 & 0.080 & 0.032 & 13.787 & 0.478 & 0.023 & 1.242 & 2.951 & 10.412 & 0.803 & 0.933 & 0.016 & 5.183 & 0.073 \\
\hline 334 & SR04 & M-13/S2133 & 5.252 & 0.002 & 1.359 & 0.092 & 0.030 & 14.949 & 0.422 & 0.031 & 1.306 & 3.169 & 10.816 & 0.864 & 1.082 & 0.017 & 5.653 & 0.079 \\
\hline 334 & SR04 & M-13/S2133 & 4.776 & -0.001 & 1.253 & 0.081 & 0.028 & 13.304 & 0.604 & 0.021 & 1.214 & 2.900 & 10.385 & 0.784 & 0.913 & 0.015 & 5.192 & 0.071 \\
\hline 334 & SR04 & M-13/S2133 & 4.792 & -0.005 & 1.275 & 0.080 & 0.028 & 13.242 & 0.505 & 0.028 & 1.189 & 2.890 & 10.226 & 0.774 & 0.918 & 0.015 & 5.058 & 0.073 \\
\hline 334 & SR04 & M-13/S2133 & 5.009 & -0.004 & 1.296 & 0.084 & 0.029 & 14.149 & 0.301 & 0.031 & 1.260 & 3.045 & 10.827 & 0.812 & 0.979 & 0.016 & 5.359 & 0.075 \\
\hline 334 & IN32 & M-13/S2133 & -0.014 & -0.007 & -0.002 & 0.001 & -0.003 & -0.041 & 0.086 & -0.001 & 0.007 & -0.003 & 0.032 & 0.001 & 0.013 & 0.000 & -0.071 & 0.000 \\
\hline 334 & IN32 & M-13/S2133 & 0.001 & -0.008 & 0.000 & 0.000 & -0.001 & -0.037 & 0.023 & -0.004 & 0.000 & -0.002 & 0.000 & 0.002 & -0.004 & 0.001 & -0.024 & 0.001 \\
\hline 335 & ARGC & M-14/S2150 & 2.236 & 2.629 & 0.869 & 0.057 & 0.003 & 9.417 & 2.372 & 1.379 & 0.438 & 1.383 & 8.233 & 0.787 & 21.864 & 0.671 & 0.144 & 0.107 \\
\hline 335 & ARGC & M-14/S2150 & 2.387 & 2.591 & 1.000 & 0.054 & 0.000 & 9.501 & 2.292 & 1.472 & 0.491 & 1.393 & 8.338 & 0.787 & 2.887 & 0.493 & 0.049 & 0.040 \\
\hline 335 & SR04 & M-14/S2150 & 5.218 & 0.029 & 1.358 & 0.083 & 0.026 & 15.131 & 0.254 & -0.042 & 1.400 & 3.270 & 11.763 & 0.876 & 1.056 & 0.013 & 5.732 & 0.084 \\
\hline 335 & SR04 & M-14/S2150 & 4.934 & 0.019 & 1.313 & 0.074 & 0.024 & 14.710 & 0.227 & -0.086 & 1.293 & 3.158 & 10.866 & 0.846 & 0.949 & 0.011 & 5.624 & 0.083 \\
\hline 335 & SR04 & M-14/S2150 & $\begin{array}{ll}4.846 \\
\end{array}$ & 0.016 & 1.262 & 0.071 & 0.024 & 13.660 & 0.167 & -0.068 & 1.253 & 2.952 & 10.467 & 0.812 & 0.881 & 0.010 & 5.237 & 0.078 \\
\hline 335 & SR04 & M-14/S2150 & 5.306 & 0.017 & 1.336 & 0.081 & 0.030 & 15.030 & 0.189 & -0.047 & 1.323 & 3.224 & 11.149 & 0.885 & 0.992 & 0.014 & 5.699 & 0.085 \\
\hline 335 & SR04 & M-14/S2150 & 4.965 & 0.018 & 1.278 & 0.073 & 0.027 & 14.257 & 0.220 & -0.057 & 1.287 & 3.106 & 10.858 & 0.841 & 0.944 & 0.013 & 5.558 & 0.082 \\
\hline 335 & SR04 & M-14/S2150 & 5.472 & 0.016 & 1.362 & 0.085 & 0.030 & 15.494 & 0.242 & -0.048 & 1.302 & 3.275 & 10.886 & 0.903 & 1.003 & 0.014 & 5.784 & 0.087 \\
\hline 335 & IN32 & M-14/S2150 & -0.003 & 0.006 & -0.001 & -0.002 & -0.001 & -0.047 & 0.023 & -0.023 & 0.000 & -0.001 & 0.021 & -0.004 & 0.036 & -0.001 & -0.004 & 0.001 \\
\hline 335 & IN32 & M-14/S2150 & 0.008 & 0.001 & 0.001 & -0.002 & 0.000 & -0.043 & 0.056 & -0.021 & 0.000 & -0.001 & 0.021 & -0.003 & 0.010 & 0.000 & 0.024 & 0.002 \\
\hline
\end{tabular}


WSRC-STI-2006-00068

Table A1. Cold Chem Measurement Data Set (continued)

Revision 0

\begin{tabular}{|c|c|c|c|c|c|c|c|c|c|c|c|c|c|c|c|c|c|c|}
\hline Batch & Type of Sample & ICP/ID & Al & B & $\mathbf{C a}$ & $\mathrm{Cr}$ & $\mathbf{C u}$ & $\mathbf{F e}$ & $\mathbf{K}$ & $\mathbf{L i}$ & $\mathbf{M g}$ & Mn & $\mathrm{Na}$ & $\mathrm{Ni}$ & $\mathrm{Si}$ & Ti & $\mathbf{U}$ & $\mathrm{Zr}$ \\
\hline 336 & ARGC & M-14/S2150 & 2.333 & 2.614 & 0.981 & 0.065 & 0.002 & 9.354 & 2.245 & 1.482 & 0.484 & 1.386 & 8.299 & 0.776 & 21.943 & 0.674 & -0.054 & 0.100 \\
\hline 336 & ARGC & M-14/S2150 & 2.364 & 2.586 & 1.024 & 0.066 & 0.008 & 9.417 & 2.375 & 1.428 & 0.479 & 1.362 & 7.796 & 0.778 & 21.418 & 0.670 & 0.107 & 0.106 \\
\hline 336 & $\begin{array}{l}\text { SR04 } \\
\end{array}$ & M-14/S2150 & 5.061 & 0.014 & 1.313 & 0.085 & 0.027 & 14.468 & 0.287 & 0.004 & 1.291 & 3.073 & 10.840 & 0.839 & 1.012 & 0.014 & 5.507 & 0.076 \\
\hline 336 & SR04 & M-14/S2150 & 4.968 & 0.010 & 1.314 & 0.083 & 0.028 & 14.134 & 0.178 & -0.003 & 1.218 & 2.987 & 10.192 & 0.821 & 0.903 & 0.014 & 5.464 & 0.076 \\
\hline 336 & SR04 & M-14/S2150 & 5.265 & 0.011 & 1.396 & 0.086 & 0.032 & 14.866 & 0.159 & -0.006 & 1.265 & 3.148 & 10.730 & 0.860 & 0.966 & 0.016 & 5.662 & 0.083 \\
\hline 336 & SR04 & M-14/S2150 & 5.216 & 0.012 & 1.399 & 0.086 & 0.031 & 15.083 & 0.242 & 0.004 & 1.292 & 3.141 & 10.781 & 0.873 & 0.966 & 0.015 & 5.739 & 0.083 \\
\hline 336 & $\begin{array}{l}\text { SR04 } \\
\end{array}$ & M-14/S2150 & 5.418 & 0.012 & 1.392 & 0.089 & 0.031 & 15.519 & 0.195 & -0.001 & 1.288 & 3.232 & 10.889 & 0.885 & 1.011 & 0.015 & 5.884 & 0.083 \\
\hline 336 & IN32 & M-14/S2150 & -0.003 & 0.000 & -0.002 & 0.001 & -0.001 & -0.040 & 0.012 & -0.009 & 0.000 & -0.002 & 0.002 & -0.002 & 0.019 & -0.001 & -0.029 & 0.001 \\
\hline 336 & IN32 & M-14/S2150 & 0.009 & -0.002 & 0.002 & 0.000 & 0.001 & -0.040 & 0.092 & -0.008 & 0.000 & -0.002 & 0.013 & -0.001 & 0.003 & 0.000 & 0.025 & 0.002 \\
\hline 337 & ARGC & M-14/S2150 & 2.268 & 2.584 & 0.921 & 0.065 & -0.002 & 9.347 & 2.265 & 1.425 & 0.470 & 1.371 & 8.076 & 0.780 & 21.468 & 0.668 & 0.023 & 0.101 \\
\hline 337 & ARGC & M-14/S2150 & 1.995 & 2.265 & 0.872 & 0.057 & 0.001 & 7.955 & 2.090 & 1.228 & 0.417 & 1.202 & 6.868 & 0.696 & 18.155 & 0.559 & 0.110 & 0.088 \\
\hline 337 & SR04 & M-14/S2150 & 4.771 & 0.001 & 1.301 & 0.084 & 0.023 & 13.309 & 0.243 & -0.017 & 1.273 & 2.983 & 10.575 & 0.792 & 0.859 & 0.016 & 5.408 & 0.075 \\
\hline 337 & SR04 & M-14/S2150 & 4.579 & -0.006 & 1.224 & 0.076 & 0.020 & 12.658 & 0.233 & -0.025 & 1.179 & 2.881 & 10.104 & 0.779 & 0.755 & 0.013 & 5.144 & 0.074 \\
\hline 337 & SR04 & M-14/S2150 & 4.864 & -0.001 & 1.254 & 0.079 & 0.024 & 13.263 & 0.269 & -0.019 & 1.221 & 3.028 & 10.369 & 0.822 & 0.802 & 0.015 & 5.396 & 0.075 \\
\hline 337 & SR04 & M-14/S2150 & 4.792 & -0.009 & 1.288 & 0.080 & 0.025 & 13.183 & 0.180 & -0.025 & 1.261 & 3.002 & 10.647 & 0.823 & 0.742 & 0.015 & 5.397 & 0.074 \\
\hline 337 & SR04 & M-14/S2150 & 4.810 & 0.004 & 1.266 & 0.081 & 0.026 & 13.538 & 0.183 & -0.018 & 1.253 & 3.032 & 10.612 & 0.844 & 0.859 & 0.015 & 5.503 & 0.075 \\
\hline 337 & SR04 & M-14/S2150 & 4.836 & 0.000 & 1.308 & 0.087 & 0.025 & 13.631 & 0.318 & -0.022 & 1.300 & 3.121 & 10.829 & 0.858 & 0.835 & 0.016 & 5.420 & 0.076 \\
\hline 337 & IN32 & M-14/S2150 & -0.012 & -0.004 & -0.002 & 0.001 & -0.002 & -0.042 & 0.047 & -0.013 & 0.000 & -0.001 & 0.006 & -0.003 & -0.009 & 0.000 & -0.017 & 0.001 \\
\hline 337 & IN32 & M-14/S2150 & -0.003 & -0.006 & 0.000 & 0.002 & -0.001 & -0.040 & 0.048 & -0.013 & 0.000 & -0.001 & 0.007 & -0.003 & -0.046 & 0.000 & 0.015 & 0.001 \\
\hline 338 & ARGC & M-14/S2150 & 2.320 & 2.574 & 0.982 & 0.065 & 0.001 & 9.281 & 2.316 & 1.449 & 0.473 & 1.359 & 8.207 & 0.785 & 22.169 & 0.676 & 0.007 & 0.102 \\
\hline 338 & ARGC & M-14/S2150 & 2.337 & 2.538 & 0.998 & 0.066 & 0.002 & 9.241 & 2.494 & 1.394 & 0.474 & 1.328 & 8.190 & 0.780 & 21.291 & 0.660 & 0.167 & 0.100 \\
\hline 338 & SR04 & M-14/S2150 & 4.933 & 0.008 & 1.321 & 0.085 & 0.029 & 14.307 & 0.271 & -0.010 & 1.314 & 3.094 & 10.980 & 0.834 & 0.651 & 0.019 & 5.482 & 0.077 \\
\hline 338 & SR04 & M-14/S2150 & 4.959 & 0.012 & 1.318 & 0.084 & 0.028 & 14.298 & 0.326 & 0.000 & 1.278 & 3.045 & 10.680 & 0.824 & 0.702 & 0.019 & 5.456 & 0.078 \\
\hline 338 & SR04 & M-14/S2150 & 5.003 & 0.015 & 1.308 & 0.087 & 0.028 & 14.464 & 0.340 & -0.008 & 1.276 & 3.040 & 10.804 & 0.841 & 0.564 & 0.020 & 5.665 & 0.078 \\
\hline 338 & SR04 & M-14/S2150 & 5.157 & 0.011 & 1.352 & 0.086 & 0.030 & 15.087 & 0.447 & -0.005 & 1.332 & 3.197 & 11.233 & 0.872 & 0.665 & 0.021 & 5.770 & 0.081 \\
\hline 338 & SR04 & M-14/S2150 & 4.963 & 0.009 & 1.319 & 0.084 & 0.028 & 14.399 & 0.420 & -0.006 & 1.281 & 3.066 & 10.744 & 0.830 & 0.602 & 0.022 & 5.506 & 0.079 \\
\hline 338 & SR04 & M-14/S2150 & 4.930 & 0.011 & 1.298 & 0.082 & 0.028 & 14.232 & 0.178 & -0.016 & 1.268 & 3.004 & 10.717 & 0.813 & 0.734 & 0.018 & 5.420 & 0.076 \\
\hline 338 & IN32 & M-14/S2150 & -0.008 & -0.003 & -0.001 & 0.001 & -0.001 & -0.026 & 0.019 & -0.014 & 0.000 & 0.000 & -0.002 & -0.002 & 0.071 & 0.001 & -0.024 & 0.001 \\
\hline 338 & IN32 & M-14/S2150 & 0.010 & -0.004 & 0.002 & 0.001 & -0.001 & -0.025 & 0.155 & -0.011 & 0.000 & 0.000 & 0.017 & -0.001 & -0.116 & 0.002 & 0.041 & 0.002 \\
\hline 339 & ARGC & M-13/S2133 & 2.349 & 2.609 & 1.027 & 0.067 & 0.005 & 9.551 & 2.693 & 1.434 & 0.488 & 1.413 & 8.168 & 0.797 & 21.732 & 0.658 & 0.160 & 0.101 \\
\hline 339 & ARGC & M-13/S2133 & 2.314 & 2.602 & 0.979 & 0.064 & -0.001 & 9.426 & 2.442 & 1.429 & 0.495 & 1.388 & 8.155 & 0.790 & 21.832 & 0.649 & 0.001 & 0.102 \\
\hline 339 & $\begin{array}{l}\text { SR04 } \\
\end{array}$ & M-13/S2133 & 5.332 & -0.007 & 1.386 & 0.091 & $\begin{array}{l}0.029 \\
\end{array}$ & 15.700 & 0.308 & -0.017 & 1.326 & 3.251 & 10.745 & 0.926 & 1.073 & 0.013 & 5.868 & 0.083 \\
\hline 339 & SR04 & M-13/S2133 & 4.969 & -0.018 & 1.336 & 0.084 & 0.026 & 14.542 & 0.291 & -0.038 & 1.314 & 3.121 & 10.894 & 0.838 & 1.055 & 0.011 & 5.643 & 0.077 \\
\hline 339 & SR04 & M-13/S2133 & 5.180 & -0.009 & 1.330 & 0.086 & 0.028 & 14.837 & 0.395 & $\begin{array}{l}-0.018 \\
\end{array}$ & 1.279 & 3.108 & 10.553 & 0.869 & 1.017 & 0.013 & 5.554 & 0.078 \\
\hline 339 & SR04 & M-13/S2133 & 5.327 & -0.008 & 1.371 & 0.092 & 0.031 & 15.840 & 0.354 & -0.017 & 1.319 & 3.194 & 10.800 & 0.902 & 1.076 & 0.013 & 5.792 & 0.082 \\
\hline 339 & SR04 & M-13/S2133 & 5.543 & -0.010 & 1.411 & 0.093 & 0.032 & 16.571 & 0.411 & -0.022 & 1.326 & 3.307 & 10.666 & 0.962 & 1.173 & 0.015 & 5.917 & 0.088 \\
\hline 339 & SR04 & M-13/S2133 & 5.229 & -0.007 & 1.370 & 0.091 & 0.030 & 15.604 & 0.371 & -0.013 & 1.315 & 3.201 & 10.717 & 0.891 & 1.060 & 0.015 & 5.655 & 0.079 \\
\hline 339 & IN32 & M-13/S2133 & -0.004 & -0.010 & 0.000 & 0.000 & -0.001 & -0.034 & 0.043 & -0.021 & 0.001 & 0.001 & 0.010 & -0.002 & 0.046 & -0.002 & -0.010 & 0.001 \\
\hline 339 & IN32 & M-13/S2133 & 0.016 & -0.010 & 0.002 & 0.000 & 0.000 & -0.033 & 0.099 & -0.016 & 0.001 & 0.001 & 0.026 & -0.002 & 0.031 & 0.000 & 0.046 & 0.002 \\
\hline 340 & ARGC & M-13/S2133 & 2.286 & 2.593 & 0.955 & 0.065 & 0.003 & 9.453 & 2.340 & 1.453 & 0.484 & 1.395 & 8.277 & 0.780 & 21.498 & 0.670 & -0.001 & 0.105 \\
\hline 340 & ARGC & M-13/S2133 & 2.266 & 2.578 & 0.944 & 0.067 & 0.008 & 9.401 & 2.347 & 1.411 & 0.477 & 1.377 & 8.110 & 0.820 & 21.870 & 0.654 & 0.196 & 0.106 \\
\hline 340 & $\begin{array}{l}\text { SR04 } \\
\end{array}$ & M-13/S2133 & 4.979 & 0.022 & 1.334 & 0.085 & 0.028 & 14.455 & 0.223 & -0.007 & 1.320 & 3.176 & 10.804 & 0.848 & 1.097 & 0.020 & 5.517 & 0.080 \\
\hline 340 & SR04 & M-13/S2133 & 5.146 & 0.019 & 1.348 & 0.086 & 0.031 & 14.841 & 0.173 & -0.007 & 1.313 & 3.187 & 10.804 & 0.865 & 1.102 & 0.021 & 5.597 & 0.082 \\
\hline 340 & SR04 & M-13/S2133 & 5.038 & 0.020 & 1.323 & 0.093 & 0.030 & 14.259 & 0.215 & -0.006 & 1.339 & 3.163 & 10.639 & 0.838 & 1.067 & 0.021 & 5.582 & 0.081 \\
\hline 340 & SR04 & M-13/S2133 & 4.971 & 0.018 & 1.320 & 0.083 & 0.031 & 14.130 & 0.156 & -0.005 & 1.294 & 3.103 & 10.570 & 0.823 & 1.043 & 0.021 & 5.466 & 0.081 \\
\hline 340 & SR04 & $\mathrm{M}-13 / \mathrm{S} 2133$ & 13.515 & 0.046 & 3.642 & 0.234 & 0.082 & 39.004 & 0.336 & -0.019 & 3.625 & 8.489 & 29.818 & 2.282 & 2.926 & 0.057 & 15.256 & 0.222 \\
\hline 340 & SR04 & M-13/S2133 & 6.356 & 0.028 & 1.722 & 0.110 & 0.040 & 18.409 & 0.353 & 0.012 & 1.718 & 4.083 & 13.940 & 1.105 & 1.341 & 0.026 & 7.048 & 0.101 \\
\hline 340 & IN32 & M-13/S2133 & -0.003 & 0.000 & 0.001 & 0.001 & -0.001 & -0.032 & 0.030 & -0.013 & 0.001 & 0.000 & 0.027 & -0.001 & 0.034 & 0.002 & -0.020 & 0.001 \\
\hline 340 & IN32 & M-13/S2133 & 0.013 & 0.000 & 0.003 & 0.002 & 0.002 & -0.024 & 0.065 & -0.012 & 0.002 & 0.001 & 0.028 & 0.000 & 0.042 & 0.003 & 0.043 & 0.003 \\
\hline 341 & ARGC & M-14/S2150 & 2.314 & 2.548 & 0.954 & 0.062 & 0.002 & 9.299 & 2.336 & 1.422 & 0.465 & 1.336 & 8.301 & 0.760 & 21.788 & 0.680 & -0.001 & 0.108 \\
\hline
\end{tabular}


WSRC-STI-2006-00068

Table A1. Cold Chem Measurement Data Set (continued)

Revision 0

\begin{tabular}{|c|c|c|c|c|c|c|c|c|c|c|c|c|c|c|c|c|c|c|}
\hline Batch & Type of Sample & ICP/ID & Al & B & $\mathbf{C a}$ & $\mathrm{Cr}$ & $\mathbf{C u}$ & $\mathbf{F e}$ & $\mathbf{K}$ & $\mathbf{L i}$ & Mg & Mn & Na & $\mathrm{Ni}$ & $\mathrm{Si}$ & Ti & $\mathbf{U}$ & $\mathrm{Zr}$ \\
\hline 341 & ARGC & $\mathrm{M}-14 / \mathrm{S} 2150$ & 2.224 & 2.484 & 0.935 & 0.061 & 0.003 & 8.968 & 2.342 & 1.384 & 0.441 & 1.328 & 8.202 & 0.757 & 21.264 & 0.648 & 0.089 & 0.105 \\
\hline 341 & $\begin{array}{l}\text { SR04 } \\
\end{array}$ & M-14/S2150 & 5.009 & -0.008 & 1.314 & 0.082 & 0.027 & 13.714 & 0.169 & -0.055 & 1.217 & 2.967 & 10.326 & 0.802 & 1.031 & 0.015 & 5.312 & 0.082 \\
\hline 341 & SR04 & M-14/S2150 & 5.187 & -0.011 & 1.363 & 0.081 & 0.028 & 14.617 & 0.151 & -0.058 & 1.281 & 3.059 & 10.468 & 0.837 & 1.057 & 0.016 & 5.475 & 0.087 \\
\hline 341 & SR04 & M-14/S2150 & 5.452 & -0.017 & 1.418 & 0.056 & 0.031 & 9.594 & 0.154 & -0.056 & 0.881 & 2.071 & 10.534 & 0.551 & 1.105 & 0.017 & 5.668 & 0.091 \\
\hline 341 & SR04 & M-14/S2150 & 5.661 & -0.022 & 1.432 & 0.089 & 0.031 & 15.702 & 0.230 & -0.099 & 1.281 & 3.245 & 10.423 & 0.904 & 1.182 & 0.018 & 5.952 & 0.098 \\
\hline 341 & SR04 & M-14/S2150 & 5.539 & -0.012 & 1.433 & 0.083 & 0.032 & 14.932 & 0.184 & -0.056 & 1.308 & 3.125 & 11.305 & 0.855 & 1.124 & 0.019 & 5.889 & 0.094 \\
\hline 341 & SR04 & M-14/S2150 & 5.036 & -0.016 & 1.376 & 0.144 & 0.027 & 22.390 & 0.251 & -0.103 & 1.851 & 4.573 & 10.887 & 1.261 & 1.054 & 0.016 & 5.515 & 0.089 \\
\hline 341 & IN32 & M-14/S2150 & -0.007 & -0.008 & -0.001 & 0.001 & -0.001 & -0.034 & 0.047 & -0.027 & 0.001 & -0.001 & 0.010 & -0.004 & 0.014 & 0.000 & -0.013 & 0.003 \\
\hline 341 & IN32 & M-14/S2150 & -0.003 & -0.009 & -0.001 & 0.000 & 0.000 & -0.041 & 0.094 & -0.025 & 0.001 & -0.002 & 0.019 & -0.004 & 0.008 & 0.000 & 0.030 & 0.004 \\
\hline 342 & ARGC & M-14/S2150 & 2.290 & 2.539 & 0.963 & 0.069 & 0.004 & 9.594 & 2.341 & 1.454 & 0.490 & 1.396 & 8.178 & 0.790 & 22.398 & 0.662 & 0.085 & 0.108 \\
\hline 342 & ARGC & M-14/S2150 & 2.281 & 2.541 & 0.962 & 0.064 & 0.000 & 9.432 & 2.348 & 1.448 & 0.487 & 1.370 & 8.149 & 0.791 & 21.853 & 0.658 & -0.044 & 0.103 \\
\hline 342 & SR04 & M-14/S2150 & 5.136 & 0.032 & 1.317 & 0.087 & 0.029 & 14.855 & 0.148 & 0.008 & 1.266 & 3.113 & 10.064 & 0.866 & 0.987 & 0.017 & 5.834 & 0.080 \\
\hline 342 & SR04 & M-14/S2150 & 5.390 & 0.034 & 1.386 & 0.089 & 0.030 & 15.779 & 0.146 & 0.013 & 1.310 & 3.233 & 10.507 & 0.923 & 1.046 & 0.018 & 6.165 & 0.086 \\
\hline 342 & SR04 & M-14/S2150 & 5.172 & 0.055 & 1.347 & 0.088 & 0.030 & 15.279 & 0.201 & 0.041 & 1.303 & 3.134 & 10.342 & 0.878 & 1.302 & 0.019 & 5.889 & 0.085 \\
\hline 342 & SR04 & M-14/S2150 & 6.489 & 0.041 & 1.682 & 0.108 & 0.041 & 18.592 & 0.147 & 0.008 & 1.641 & 3.954 & 13.300 & 1.095 & 1.189 & 0.023 & 7.201 & 0.106 \\
\hline 342 & SR04 & M-14/S2150 & 5.116 & 0.030 & 1.342 & 0.091 & 0.031 & 15.271 & 0.232 & 0.009 & 1.301 & 3.143 & 10.186 & 0.855 & 0.988 & 0.018 & 5.789 & 0.082 \\
\hline 342 & SR04 & M-14/S2150 & 5.504 & 0.033 & 1.387 & 0.098 & 0.034 & 16.289 & 0.241 & 0.008 & 1.343 & 3.323 & 10.156 & 0.920 & 1.069 & 0.020 & 6.225 & 0.089 \\
\hline 342 & IN32 & M-14/S2150 & 0.041 & 0.004 & 0.009 & 0.002 & -0.001 & 0.104 & 0.025 & -0.007 & 0.012 & 0.027 & 0.102 & 0.005 & 0.016 & 0.001 & 0.015 & 0.002 \\
\hline 342 & IN32 & M-14/S2150 & 0.001 & 0.003 & 0.000 & 0.001 & 0.001 & -0.033 & 0.033 & -0.008 & 0.002 & 0.000 & 0.013 & -0.002 & -0.017 & 0.001 & 0.025 & 0.003 \\
\hline 343 & ARGC & M-14/S2150 & 2.349 & 2.660 & 0.998 & 0.072 & -0.002 & 9.470 & 2.691 & 1.457 & 0.488 & 1.416 & 8.293 & 0.800 & 21.949 & 0.685 & -0.020 & 0.110 \\
\hline 343 & ARGC & M-14/S2150 & 2.303 & 2.605 & 0.972 & 0.080 & 0.001 & 9.683 & 2.385 & 1.412 & 0.506 & 1.422 & 8.126 & 0.838 & 22.835 & 0.644 & 0.013 & 0.111 \\
\hline 343 & $\begin{array}{l}\text { SR04 } \\
\end{array}$ & M-14/S2150 & 4.828 & 0.011 & 1.323 & 0.088 & 0.022 & 13.903 & 0.671 & -0.020 & 1.293 & 3.068 & 10.388 & 0.804 & 0.877 & 0.018 & 5.381 & 0.083 \\
\hline 343 & SR04 & M-14/S2150 & 4.788 & 0.009 & 1.297 & 0.087 & 0.024 & 13.417 & 0.257 & -0.010 & 1.276 & 3.003 & 10.397 & 0.793 & 0.888 & 0.017 & 5.518 & 0.080 \\
\hline 343 & SR04 & M-14/S2150 & 4.847 & 0.011 & 1.328 & 0.087 & 0.026 & 13.783 & 0.131 & -0.009 & 1.291 & 3.060 & 10.081 & 0.822 & 0.902 & 0.018 & 5.462 & 0.083 \\
\hline 343 & SR04 & M-14/S2150 & 4.839 & 0.008 & 1.286 & 0.096 & 0.026 & 13.857 & 0.304 & -0.011 & 1.349 & 3.127 & 10.424 & 0.809 & 0.948 & 0.018 & 4.936 & 0.083 \\
\hline 343 & SR04 & M-14/S2150 & 4.840 & 0.007 & 1.327 & 0.102 & 0.026 & 14.130 & 0.532 & -0.026 & 1.348 & 3.185 & 10.469 & 0.821 & 0.934 & 0.019 & 4.879 & 0.085 \\
\hline 343 & SR04 & M-14/S2150 & 4.777 & 0.006 & 1.302 & 0.097 & 0.024 & 14.096 & 0.212 & -0.027 & 1.356 & 3.086 & 10.219 & 0.832 & 0.911 & 0.019 & 4.736 & 0.085 \\
\hline 343 & IN32 & M-14/S2150 & -0.017 & -0.001 & -0.002 & 0.003 & -0.002 & -0.045 & 0.010 & -0.013 & -0.001 & -0.001 & 0.003 & 0.001 & -0.016 & 0.001 & -0.024 & 0.003 \\
\hline 343 & IN32 & M-14/S2150 & -0.002 & -0.004 & 0.000 & 0.003 & 0.000 & -0.042 & 0.082 & -0.011 & -0.001 & -0.001 & 0.013 & 0.001 & 0.003 & 0.002 & 0.013 & 0.003 \\
\hline 344 & ARGC & M-13/S2133 & 2.228 & 2.433 & 0.866 & 0.062 & 0.004 & 9.470 & 2.115 & 1.394 & 0.458 & 1.366 & 8.084 & 0.800 & 21.236 & 0.650 & 0.123 & 0.102 \\
\hline 344 & ARGC & M-13/S2133 & 2.193 & 2.441 & 0.925 & 0.057 & 0.005 & 9.166 & 1.889 & 1.307 & 0.467 & 1.357 & 7.662 & 0.790 & 20.763 & 0.639 & 0.200 & 0.100 \\
\hline 344 & $\begin{array}{l}\text { SR04 } \\
\end{array}$ & M-13/S2133 & 5.177 & 0.031 & 1.380 & 0.081 & 0.036 & 14.378 & -0.034 & -0.011 & 1.296 & 3.183 & 10.550 & 0.869 & 1.301 & 0.022 & 5.972 & 0.084 \\
\hline 344 & SR04 & M-13/S2133 & 4.941 & 0.026 & 1.289 & 0.078 & 0.034 & 13.140 & -0.027 & -0.002 & 1.229 & 2.914 & 9.776 & 0.797 & 1.154 & 0.018 & 5.638 & 0.078 \\
\hline 344 & SR04 & M-13/S2133 & 4.739 & 0.024 & 1.203 & 0.079 & 0.029 & 13.298 & -0.131 & -0.008 & 1.197 & 2.903 & 9.097 & 0.811 & 1.178 & 0.017 & 5.373 & 0.073 \\
\hline 344 & SR04 & M-13/S2133 & 5.058 & 0.026 & 1.337 & 0.080 & 0.034 & 13.829 & -0.065 & 0.001 & 1.299 & 3.094 & 10.185 & 0.849 & 1.235 & 0.020 & 5.771 & 0.080 \\
\hline 344 & SR04 & M-13/S2133 & 5.354 & 0.027 & 1.379 & 0.081 & 0.036 & 14.221 & -0.075 & -0.004 & 1.305 & 3.229 & 10.166 & 0.884 & 1.262 & 0.020 & 6.216 & 0.084 \\
\hline 344 & SR04 & M-13/S2133 & 5.618 & 0.028 & 1.426 & 0.083 & 0.036 & 15.628 & -0.106 & -0.020 & 1.333 & 3.353 & 9.983 & 0.955 & 1.358 & 0.020 & 6.307 & 0.087 \\
\hline 344 & IN32 & M-13/S2133 & -0.001 & 0.001 & 0.002 & 0.000 & -0.001 & -0.015 & -0.054 & -0.008 & 0.000 & -0.002 & 0.023 & 0.001 & 0.088 & 0.001 & 0.011 & 0.002 \\
\hline 344 & IN32 & M-13/S2133 & 0.008 & 0.001 & 0.001 & -0.003 & 0.000 & -0.017 & -0.027 & -0.010 & -0.001 & -0.001 & -0.021 & 0.001 & 0.084 & 0.001 & 0.017 & 0.002 \\
\hline 345 & ARGC & M-14/S2150 & 2.294 & 2.614 & 0.947 & 0.072 & 0.003 & 9.416 & 2.576 & 1.456 & 0.455 & 1.382 & 8.348 & 0.800 & 22.252 & 0.676 & 0.006 & 0.098 \\
\hline 345 & ARGC & M-14/S2150 & 2.293 & 2.581 & 0.911 & 0.069 & 0.003 & 9.416 & 2.101 & 1.451 & 0.453 & 1.389 & 8.350 & 0.801 & 22.072 & 0.663 & 0.018 & 0.098 \\
\hline 345 & SR04 & M-14/S2150 & 5.152 & 0.032 & 1.428 & 0.091 & 0.028 & 14.509 & 0.243 & 0.024 & 1.323 & 3.174 & 11.094 & 0.848 & 1.452 & 0.012 & 5.676 & 0.073 \\
\hline 345 & SR04 & M-14/S2150 & 5.241 & 0.037 & 1.417 & 0.098 & 0.030 & 15.014 & 0.090 & 0.018 & 1.352 & 3.249 & 11.099 & 0.879 & 1.638 & 0.012 & 5.866 & 0.071 \\
\hline 345 & SR04 & M-14/S2150 & 5.011 & 0.029 & 1.348 & 0.089 & 0.028 & 14.320 & 0.121 & 0.022 & 1.324 & 3.184 & 10.815 & 0.848 & 1.368 & 0.012 & 5.638 & 0.072 \\
\hline 345 & SR04 & $\mathrm{M}-14 / \mathrm{S} 2150$ & 5.189 & 0.031 & 1.343 & 0.092 & 0.031 & 14.589 & 0.265 & 0.021 & 1.333 & 3.198 & 10.766 & 0.863 & 1.419 & 0.013 & 5.658 & 0.073 \\
\hline 345 & SR04 & M-14/S2150 & 5.041 & 0.030 & 1.340 & 0.091 & 0.030 & 14.260 & 0.030 & 0.019 & 1.292 & 3.116 & 10.369 & 0.850 & 1.392 & 0.013 & 5.493 & 0.073 \\
\hline 345 & SR04 & M-14/S2150 & 5.147 & 0.036 & 1.367 & 0.091 & 0.029 & 14.842 & 0.164 & 0.022 & 1.346 & 3.205 & 10.951 & 0.857 & 1.454 & 0.013 & 5.644 & 0.073 \\
\hline 345 & IN32 & M-14/S2150 & 0.006 & 0.004 & 0.006 & 0.002 & 0.000 & 0.007 & -0.019 & -0.005 & 0.003 & 0.000 & 0.019 & 0.001 & 0.141 & -0.001 & -0.004 & 0.000 \\
\hline 345 & IN32 & M-14/S2150 & 0.004 & 0.003 & 0.006 & 0.003 & 0.000 & 0.004 & -0.027 & -0.003 & 0.002 & 0.000 & 0.017 & 0.003 & 0.133 & 0.000 & -0.002 & -0.001 \\
\hline 346 & ARGC & M-14/S2150 & 2.329 & 2.562 & 0.969 & 0.067 & 0.000 & 9.649 & 2.220 & 1.406 & 0.476 & 1.364 & 8.076 & 0.799 & 21.779 & 0.657 & 0.033 & 0.095 \\
\hline
\end{tabular}


WSRC-STI-2006-00068

Table A1. Cold Chem Measurement Data Set (continued)

Revision 0

\begin{tabular}{|c|c|c|c|c|c|c|c|c|c|c|c|c|c|c|c|c|c|c|}
\hline Batch & Type of Sample & ICP/ID & Al & B & $\mathbf{C a}$ & $\mathrm{Cr}$ & $\mathbf{C u}$ & $\mathbf{F e}$ & $\mathbf{K}$ & $\mathbf{L i}$ & $\mathbf{M g}$ & Mn & $\mathrm{Na}$ & $\mathrm{Ni}$ & $\mathrm{Si}$ & Ti & $\mathbf{U}$ & $\mathrm{Zr}$ \\
\hline 346 & ARGC & M-14/S2150 & 2.306 & 2.640 & 0.940 & 0.066 & 0.002 & $\begin{array}{l}9.846 \\
\end{array}$ & 2.414 & 1.464 & 0.461 & 1.389 & $\begin{array}{l}8.419 \\
\end{array}$ & 0.809 & 21.895 & 0.685 & 0.093 & 0.101 \\
\hline 346 & SR04 & M-14/S2150 & 5.124 & 0.008 & 1.328 & 0.089 & 0.027 & 14.762 & 0.156 & -0.037 & 1.273 & 3.139 & 10.482 & 0.873 & 1.044 & 0.016 & 5.458 & 0.072 \\
\hline 346 & SR04 & M-14/S2150 & 4.923 & 0.004 & 1.320 & 0.082 & 0.024 & 14.356 & 0.110 & -0.041 & 1.294 & $\begin{array}{l}3.027 \\
\end{array}$ & 10.361 & 0.811 & 0.957 & 0.014 & 5.262 & 0.068 \\
\hline 346 & SR04 & M-14/S2150 & 5.076 & 0.005 & 1.313 & 0.088 & 0.026 & 14.206 & 0.073 & -0.038 & 1.269 & 3.056 & 10.187 & 0.810 & 0.993 & 0.014 & 5.311 & 0.070 \\
\hline 346 & SR04 & M-14/S2150 & 5.120 & 0.003 & 1.339 & 0.085 & 0.026 & 14.608 & 0.144 & -0.042 & 1.261 & 3.138 & 10.361 & 0.841 & 1.013 & 0.015 & 5.337 & 0.073 \\
\hline 346 & SR04 & M-14/S2150 & 5.080 & 0.001 & 1.345 & 0.086 & 0.026 & 14.658 & 0.040 & -0.052 & 1.275 & 3.089 & 10.425 & 0.825 & 0.967 & 0.014 & 5.454 & 0.072 \\
\hline 346 & $\begin{array}{l}\text { SR04 } \\
\end{array}$ & M-14/S2150 & 5.489 & 0.006 & 1.318 & 0.084 & 0.028 & 15.698 & 0.044 & -0.042 & 1.260 & 3.060 & 10.375 & 0.816 & 1.057 & 0.015 & 5.449 & 0.075 \\
\hline 346 & IN32 & M-14/S2150 & -0.003 & -0.006 & -0.002 & 0.000 & -0.001 & -0.006 & 0.029 & -0.023 & 0.000 & -0.002 & -0.004 & -0.004 & -0.003 & 0.000 & -0.017 & -0.001 \\
\hline 346 & IN32 & M-14/S2150 & 0.002 & -0.005 & -0.001 & 0.002 & -0.001 & -0.004 & 0.045 & -0.022 & 0.000 & -0.002 & 0.001 & -0.004 & 0.003 & 0.000 & 0.009 & 0.000 \\
\hline 347 & ARGC & M-14/S2150 & 2.444 & 2.586 & 0.979 & 0.068 & 0.004 & 9.521 & 2.277 & 1.447 & 0.477 & 1.368 & 8.317 & 0.798 & 21.437 & 0.669 & 0.062 & 0.129 \\
\hline 347 & ARGC & M-14/S2150 & 2.384 & 2.610 & 0.968 & 0.069 & 0.002 & 9.379 & 2.248 & 1.458 & 0.486 & 1.376 & 8.376 & 0.801 & 21.471 & 0.670 & -0.024 & 0.143 \\
\hline 347 & SR04 & M-14/S2150 & 5.133 & 0.009 & 1.330 & 0.086 & 0.029 & 14.980 & 0.124 & -0.031 & 1.291 & 3.068 & 11.030 & 0.856 & 1.126 & 0.018 & 5.698 & 0.070 \\
\hline 347 & SR04 & M-14/S2150 & 5.313 & 0.008 & 1.356 & 0.090 & 0.029 & 15.425 & 0.036 & -0.025 & 1.312 & 3.194 & 10.601 & 0.886 & 1.167 & 0.018 & 5.860 & 0.073 \\
\hline 347 & SR04 & M-14/S2150 & 5.377 & 0.008 & 1.321 & 0.090 & 0.029 & 15.456 & 0.123 & -0.029 & 1.293 & 3.169 & 10.435 & 0.885 & 1.155 & 0.019 & 5.851 & 0.076 \\
\hline 347 & SR04 & M-14/S2150 & 5.200 & 0.010 & 1.319 & 0.085 & 0.030 & 14.735 & 0.062 & -0.021 & 1.305 & 3.112 & 10.907 & 0.851 & 1.137 & 0.018 & 5.740 & 0.073 \\
\hline 347 & SR04 & M-14/S2150 & 5.075 & 0.009 & 1.312 & 0.084 & 0.029 & 14.537 & 0.037 & -0.025 & 1.311 & 3.111 & 10.690 & 0.854 & 1.112 & 0.017 & 5.634 & 0.072 \\
\hline 347 & SR04 & M-14/S2150 & 5.226 & 0.010 & 1.339 & 0.090 & 0.031 & 14.780 & -0.062 & -0.027 & 1.312 & 3.247 & 10.664 & 0.861 & 1.149 & 0.019 & 5.909 & 0.074 \\
\hline 347 & IN32 & M-14/S2150 & -0.002 & -0.003 & 0.001 & 0.002 & -0.001 & -0.014 & 0.006 & -0.018 & 0.001 & 0.000 & $\begin{array}{l}-0.013 \\
\end{array}$ & -0.001 & 0.052 & 0.001 & -0.011 & -0.001 \\
\hline 347 & IN32 & M-14/S2150 & 0.004 & -0.005 & 0.001 & 0.001 & 0.000 & -0.015 & -0.005 & -0.019 & 0.002 & 0.000 & -0.015 & -0.001 & 0.050 & 0.001 & 0.009 & -0.001 \\
\hline 348 & ARGC & M-14/S2150 & 2.331 & 2.637 & 0.969 & 0.064 & 0.000 & 9.478 & 2.296 & 1.409 & 0.485 & 1.396 & 8.193 & 0.800 & 21.962 & 0.666 & -0.021 & 0.100 \\
\hline 348 & ARGC & M-14/S2150 & 2.352 & 2.618 & 0.995 & 0.066 & 0.002 & 9.671 & 2.235 & 1.450 & 0.496 & 1.405 & 8.238 & 0.818 & 22.262 & 0.667 & -0.010 & 0.102 \\
\hline 348 & SR04 & M-14/S2150 & 5.338 & 0.026 & 1.418 & 0.088 & 0.030 & 15.119 & 0.126 & -0.015 & 1.367 & 3.240 & 10.167 & 0.881 & 1.287 & 0.019 & 5.640 & 0.078 \\
\hline 348 & SR04 & M-14/S2150 & 5.157 & 0.026 & 1.373 & 0.082 & 0.029 & 14.974 & 0.099 & -0.009 & 1.338 & 3.171 & 9.734 & 0.873 & 1.236 & 0.018 & 5.501 & 0.078 \\
\hline 348 & SR04 & M-14/S2150 & 5.216 & 0.026 & 1.400 & 0.085 & 0.031 & 15.345 & 0.037 & -0.011 & 1.362 & 3.238 & 9.957 & 0.889 & 1.298 & 0.019 & 5.601 & 0.078 \\
\hline 348 & SR04 & M-14/S2150 & 5.404 & 0.025 & 1.412 & 0.087 & 0.031 & 15.529 & 0.117 & -0.004 & 1.371 & 3.260 & 9.873 & 0.902 & 1.246 & 0.018 & 5.764 & 0.080 \\
\hline 348 & SR04 & M-14/S2150 & 5.337 & 0.025 & 1.417 & 0.085 & 0.033 & 15.253 & 0.174 & -0.005 & 1.358 & 3.246 & 9.931 & 0.890 & 1.225 & 0.020 & 5.682 & 0.080 \\
\hline 348 & SR04 & M-14/S2150 & 5.328 & 0.024 & 1.417 & 0.087 & 0.033 & 15.628 & 0.103 & -0.001 & 1.365 & 3.251 & 9.708 & 0.908 & 1.234 & 0.019 & 5.792 & 0.081 \\
\hline 348 & IN32 & M-14/S2150 & -0.006 & 0.003 & -0.002 & 0.001 & -0.001 & -0.018 & 0.012 & -0.012 & 0.001 & 0.000 & -0.001 & -0.001 & 0.067 & 0.001 & -0.031 & 0.000 \\
\hline 348 & IN32 & M-14/S2150 & 0.003 & 0.001 & -0.001 & 0.001 & 0.000 & -0.017 & 0.017 & -0.012 & 0.001 & 0.000 & -0.012 & 0.000 & 0.066 & 0.001 & -0.010 & 0.000 \\
\hline 349 & ARGC & M-14/S2150 & 2.395 & 2.712 & 1.002 & 0.076 & 0.001 & 9.944 & 2.542 & 1.531 & 0.507 & 1.476 & 8.408 & 0.845 & 22.857 & 0.689 & 0.137 & 0.106 \\
\hline 349 & ARGC & M-14/S2150 & 2.399 & 2.741 & 1.001 & 0.071 & -0.002 & 9.849 & 2.480 & 1.512 & 0.503 & 1.434 & 8.240 & 0.822 & 22.890 & 0.690 & 0.029 & 0.103 \\
\hline 349 & $\begin{array}{l}\text { SR04 } \\
\end{array}$ & M-14/S2150 & 5.558 & -0.004 & 1.397 & 0.099 & 0.024 & 16.089 & 0.440 & -0.040 & 1.341 & 3.304 & 10.161 & 0.922 & 1.209 & 0.015 & 5.370 & 0.083 \\
\hline 349 & SR04 & M-14/S2150 & 5.471 & 0.001 & 1.346 & 0.095 & 0.027 & 16.348 & 0.362 & -0.020 & 1.366 & 3.275 & 9.954 & 0.927 & 1.154 & 0.014 & 5.260 & 0.083 \\
\hline 349 & SR04 & M-14/S2150 & 5.048 & -0.011 & 1.343 & 0.096 & 0.020 & 15.140 & 0.367 & -0.060 & 1.358 & 3.159 & 10.272 & 0.875 & 1.189 & 0.011 & 5.309 & 0.075 \\
\hline 349 & SR04 & $\mathrm{M}-14 / \mathrm{S} 2150$ & 4.755 & -0.008 & 1.277 & 0.089 & 0.021 & 13.876 & 0.275 & -0.043 & 1.282 & 2.966 & 9.580 & 0.822 & 1.076 & 0.012 & 4.936 & 0.071 \\
\hline 349 & SR04 & M-14/S2150 & 5.256 & 0.000 & 1.344 & 0.095 & 0.027 & 15.577 & 0.316 & -0.020 & 1.342 & 3.258 & 10.248 & 0.915 & 1.167 & 0.015 & 5.291 & 0.080 \\
\hline 349 & SR04 & M-14/S2150 & 5.028 & 0.003 & 1.317 & 0.091 & 0.027 & 15.061 & 0.271 & -0.016 & 1.362 & 3.189 & 10.265 & 0.871 & 1.098 & 0.014 & 5.180 & 0.076 \\
\hline 349 & IN32 & M-14/S2150 & -0.007 & -0.006 & 0.001 & 0.003 & -0.002 & -0.024 & 0.049 & -0.016 & -0.001 & -0.003 & 0.017 & -0.003 & 0.034 & -0.001 & -0.016 & 0.000 \\
\hline 349 & IN32 & M-14/S2150 & -0.002 & -0.006 & 0.000 & 0.003 & -0.001 & -0.025 & 0.095 & -0.018 & 0.000 & -0.003 & 0.020 & 0.000 & 0.053 & 0.000 & 0.011 & 0.001 \\
\hline 350 & ARGC & M-14/S2150 & 2.351 & 2.551 & 1.015 & 0.068 & 0.007 & 9.406 & 2.269 & 1.430 & 0.492 & 1.374 & 8.234 & 0.801 & 21.770 & 0.666 & 0.127 & 0.104 \\
\hline 350 & ARGC & M-14/S2150 & 2.357 & 2.652 & 0.994 & 0.069 & 0.003 & 9.531 & 2.360 & 1.452 & 0.495 & 1.396 & 8.217 & 0.800 & 22.173 & 0.678 & -0.015 & 0.102 \\
\hline 350 & $\begin{array}{l}\text { SR04 } \\
\end{array}$ & M-14/S2150 & 5.459 & 0.021 & 1.334 & 0.089 & 0.032 & 15.860 & 0.224 & -0.021 & 1.320 & 3.209 & 10.607 & 0.900 & 1.331 & 0.021 & 5.659 & 0.081 \\
\hline 350 & SR04 & M-14/S2150 & 5.543 & 0.018 & 1.389 & 0.095 & 0.031 & 16.275 & 0.093 & -0.020 & 1.337 & 3.298 & 10.545 & 0.931 & 1.394 & 0.022 & 5.763 & 0.085 \\
\hline 350 & SR04 & M-14/S2150 & 4.934 & 0.017 & 1.287 & 0.086 & 0.028 & 14.171 & 0.186 & -0.020 & 1.297 & 3.032 & 10.243 & 0.833 & 1.230 & 0.020 & 5.386 & 0.075 \\
\hline 350 & SR04 & M-14/S2150 & 5.221 & 0.016 & 1.359 & 0.107 & 0.031 & 15.063 & 0.179 & -0.026 & 1.328 & 3.170 & 10.703 & 0.886 & 1.332 & 0.021 & 5.704 & 0.080 \\
\hline 350 & SR04 & M-14/S2150 & 5.192 & 0.018 & 1.333 & 0.089 & 0.030 & 15.305 & 0.134 & -0.016 & 1.304 & 3.133 & 10.568 & 0.874 & 1.269 & 0.021 & 5.586 & 0.079 \\
\hline 350 & SR04 & M-14/S2150 & 6.188 & 0.024 & 1.562 & 0.104 & 0.037 & 18.248 & 0.201 & 0.005 & 1.609 & 3.799 & 12.601 & 1.057 & 1.425 & 0.023 & 6.652 & 0.094 \\
\hline 350 & IN32 & M-14/S2150 & 0.000 & -0.002 & 0.003 & 0.002 & 0.000 & -0.023 & 0.021 & -0.015 & 0.000 & -0.001 & 0.009 & -0.003 & 0.049 & 0.001 & -0.019 & 0.002 \\
\hline 350 & IN32 & M-14/S2150 & 0.009 & -0.001 & 0.002 & 0.002 & 0.001 & -0.021 & 0.025 & -0.015 & 0.000 & -0.001 & -0.001 & -0.001 & 0.045 & 0.002 & 0.026 & 0.002 \\
\hline 351 & ARGC & M-13/S2133 & 2.413 & 2.632 & 0.998 & 0.065 & 0.003 & 9.597 & 2.136 & 1.435 & 0.504 & 1.410 & 8.311 & 0.809 & 22.221 & 0.688 & -0.010 & 0.106 \\
\hline
\end{tabular}


WSRC-STI-2006-00068

Table A1. Cold Chem Measurement Data Set (continued)

Revision 0

\begin{tabular}{|c|c|c|c|c|c|c|c|c|c|c|c|c|c|c|c|c|c|c|}
\hline Batch & Type of Sample & ICP/ID & Al & B & $\mathbf{C a}$ & $\mathrm{Cr}$ & $\mathbf{C u}$ & $\mathbf{F e}$ & $\mathbf{K}$ & $\mathbf{L i}$ & $\mathbf{M g}$ & Mn & $\mathrm{Na}$ & $\mathrm{Ni}$ & $\mathrm{Si}$ & Ti & $\mathbf{U}$ & $\mathrm{Zr}$ \\
\hline 351 & ARGC & M-13/S2133 & 2.432 & 2.737 & 1.042 & 0.064 & 0.006 & 10.129 & 2.246 & 1.406 & 0.528 & 1.473 & $\begin{array}{l}8.338 \\
\end{array}$ & 0.810 & 23.392 & 0.698 & 0.188 & 0.110 \\
\hline 351 & SR04 & M-13/S2133 & 6.170 & 0.022 & 1.461 & 0.100 & 0.037 & 17.750 & 0.234 & 0.000 & 1.378 & 3.486 & 10.623 & 1.012 & 1.466 & 0.019 & 6.036 & 0.090 \\
\hline 351 & SR04 & M-13/S2133 & 6.070 & 0.016 & 1.408 & 0.096 & 0.038 & 17.625 & 0.238 & -0.005 & 1.378 & 3.452 & 10.594 & 0.989 & 1.450 & 0.018 & 5.898 & 0.089 \\
\hline 351 & SR04 & M-13/S2133 & 5.463 & 0.016 & 1.361 & 0.088 & 0.035 & 16.146 & 0.143 & -0.004 & 1.368 & 3.326 & 10.639 & 0.913 & 1.330 & 0.017 & 5.754 & 0.083 \\
\hline 351 & SR04 & M-13/S2133 & 5.073 & 0.016 & 1.381 & 0.081 & 0.034 & 14.773 & 0.171 & -0.017 & 1.385 & 3.176 & 10.918 & 0.853 & 1.329 & 0.017 & 5.654 & 0.078 \\
\hline 351 & SR04 & M-13/S2133 & 4.946 & 0.019 & 1.349 & 0.082 & 0.034 & 14.577 & 0.194 & -0.014 & 1.385 & 3.164 & 10.806 & 0.820 & 1.322 & 0.016 & 5.548 & 0.076 \\
\hline 351 & $\begin{array}{l}\text { SR04 } \\
\end{array}$ & M-13/S2133 & 5.694 & 0.013 & 1.420 & 0.093 & 0.036 & 16.997 & 0.139 & -0.016 & 1.402 & 3.443 & 10.773 & 0.959 & 1.410 & 0.017 & 5.726 & 0.087 \\
\hline 351 & IN32 & M-13/S2133 & 0.001 & -0.001 & 0.000 & 0.000 & -0.002 & -0.015 & 0.003 & -0.015 & -0.001 & -0.002 & 0.019 & -0.002 & 0.108 & -0.001 & -0.048 & 0.002 \\
\hline 351 & IN32 & M-13/S2133 & 0.014 & -0.003 & 0.003 & 0.000 & 0.000 & -0.010 & -0.084 & -0.018 & -0.001 & 0.000 & 0.032 & -0.003 & 0.120 & 0.000 & 0.005 & 0.001 \\
\hline 352 & ARGC & M-14/S2150 & 2.348 & 2.576 & 0.926 & 0.067 & 0.002 & 9.644 & 2.225 & 1.468 & 0.468 & 1.387 & 8.418 & 0.791 & 21.983 & 0.670 & 0.074 & 0.103 \\
\hline 352 & ARGC & M-14/S2150 & 2.344 & 2.624 & 0.939 & 0.069 & -0.001 & 9.564 & 2.372 & 1.433 & 0.479 & 1.416 & 8.226 & 0.802 & 22.076 & 0.674 & -0.004 & 0.101 \\
\hline 352 & SR04 & M-14/S2150 & 4.735 & -0.020 & 1.245 & 0.084 & 0.023 & 13.515 & 0.358 & -0.077 & 1.226 & 2.957 & 9.933 & 0.792 & 1.156 & 0.013 & 4.988 & 0.072 \\
\hline 352 & SR04 & M-14/S2150 & 4.657 & -0.010 & 1.130 & 0.087 & 0.025 & 14.702 & 0.185 & -0.043 & 0.926 & 3.176 & 10.622 & 0.858 & 1.164 & 0.014 & 5.345 & 0.073 \\
\hline 352 & SR04 & M-14/S2150 & 3.887 & -0.009 & 0.887 & 0.082 & 0.023 & 13.143 & 0.172 & -0.037 & 0.595 & 2.825 & 9.318 & 0.770 & 1.016 & 0.013 & 4.907 & 0.067 \\
\hline 352 & SR04 & M-14/S2150 & 4.475 & -0.007 & 0.997 & 0.087 & 0.027 & 14.761 & 0.115 & -0.035 & 0.698 & 3.124 & 10.420 & 0.843 & 1.151 & 0.014 & 5.551 & 0.076 \\
\hline 352 & SR04 & M-14/S2150 & 5.069 & -0.010 & 1.327 & 0.084 & 0.026 & 14.626 & 0.151 & -0.038 & 1.329 & 3.103 & 10.676 & 0.840 & 1.113 & 0.015 & 5.277 & 0.076 \\
\hline 352 & SR04 & M-14/S2150 & 4.411 & -0.008 & 1.005 & 0.087 & 0.027 & 14.701 & 0.105 & -0.041 & 0.683 & 3.093 & 10.549 & 0.841 & 1.123 & 0.014 & 5.500 & 0.074 \\
\hline 352 & IN32 & M-14/S2150 & -0.006 & -0.007 & 0.001 & 0.001 & -0.002 & -0.010 & 0.026 & -0.022 & 0.001 & 0.000 & 0.018 & -0.003 & 0.083 & 0.000 & -0.009 & 0.001 \\
\hline 352 & IN32 & M-14/S2150 & -0.004 & -0.010 & 0.002 & 0.002 & -0.001 & -0.014 & 0.020 & -0.023 & 0.001 & -0.001 & 0.004 & -0.002 & 0.057 & 0.000 & -0.001 & 0.001 \\
\hline 353 & ARGC & M-14/S2150 & 2.367 & 2.607 & 1.017 & 0.079 & 0.002 & 9.802 & 2.327 & 1.460 & 0.491 & 1.407 & 8.253 & 0.806 & 22.349 & 0.688 & -0.005 & 0.102 \\
\hline 353 & ARGC & M-14/S2150 & 2.335 & 2.681 & 1.037 & 0.081 & 0.002 & 9.967 & 2.491 & 1.500 & 0.499 & 1.440 & 8.579 & 0.824 & 22.659 & 0.695 & 0.056 & 0.105 \\
\hline 353 & SR04 & M-14/S2150 & 5.568 & 0.002 & 1.469 & 0.105 & 0.031 & 15.919 & 0.223 & -0.011 & 1.397 & 3.444 & 10.459 & 0.935 & 1.279 & 0.014 & 6.089 & 0.083 \\
\hline 353 & SR04 & M-14/S2150 & 5.405 & 0.000 & 1.446 & 0.105 & 0.031 & 15.648 & 0.249 & -0.009 & 1.435 & 3.395 & 10.762 & 0.917 & 1.247 & 0.013 & 6.000 & 0.080 \\
\hline 353 & SR04 & M-14/S2150 & 4.701 & -0.020 & 1.257 & 0.099 & 0.024 & 13.495 & 0.224 & -0.050 & 1.212 & 2.894 & 9.271 & 0.789 & 1.204 & 0.008 & 5.133 & 0.070 \\
\hline 353 & SR04 & M-14/S2150 & 4.599 & -0.014 & 1.214 & 0.093 & 0.022 & 13.330 & 0.190 & -0.038 & 1.171 & 2.837 & 8.860 & 0.761 & 1.189 & 0.008 & 4.929 & 0.066 \\
\hline 353 & SR04 & M-14/S2150 & 5.378 & -0.008 & 1.433 & 0.105 & 0.030 & 15.757 & 0.236 & -0.025 & 1.384 & 3.349 & 10.617 & 0.907 & 1.384 & 0.012 & 5.945 & 0.080 \\
\hline 353 & SR04 & M-14/S2150 & 5.028 & -0.003 & 1.437 & 0.101 & 0.029 & 15.368 & 0.315 & -0.018 & 1.367 & 3.267 & 10.416 & 0.889 & 1.242 & 0.013 & 5.615 & 0.077 \\
\hline 353 & IN32 & M-14/S2150 & 0.001 & -0.006 & 0.002 & 0.005 & -0.001 & 0.014 & 0.020 & -0.014 & 0.002 & 0.000 & -0.020 & -0.001 & 0.131 & -0.001 & -0.015 & 0.000 \\
\hline 353 & IN32 & M-14/S2150 & 0.002 & -0.007 & 0.002 & 0.005 & 0.000 & 0.007 & 0.052 & -0.013 & -0.001 & 0.000 & -0.017 & 0.000 & 0.083 & 0.000 & 0.011 & 0.000 \\
\hline 354 & ARGC & M-14/S2150 & 2.218 & 2.600 & 0.913 & 0.082 & -0.004 & 9.440 & 2.150 & 1.357 & 0.478 & 1.403 & 7.948 & 0.823 & 22.000 & 0.642 & -0.231 & 0.095 \\
\hline 354 & ARGC & $\mathrm{M}-14 / \mathrm{S} 2150$ & 2.329 & 2.631 & 0.980 & 0.073 & -0.001 & 9.567 & 2.329 & 1.458 & 0.488 & 1.395 & 8.446 & 0.816 & 22.426 & 0.684 & -0.107 & 0.102 \\
\hline 354 & $\begin{array}{l}\text { SR04 } \\
\end{array}$ & M-14/S2150 & 5.910 & 0.037 & 1.446 & 0.100 & 0.031 & 17.049 & 0.118 & -0.014 & 1.399 & 3.462 & 9.851 & 0.979 & 1.273 & 0.016 & 6.041 & 0.086 \\
\hline 354 & SR04 & M-14/S2150 & 5.877 & 0.037 & 1.433 & 0.103 & 0.031 & 16.717 & 0.152 & -0.015 & 1.408 & 3.502 & 9.622 & 0.993 & 1.288 & 0.014 & 5.939 & 0.085 \\
\hline 354 & SR04 & M-14/S2150 & 5.396 & 0.034 & 1.410 & 0.093 & 0.029 & 15.277 & 0.119 & -0.021 & 1.387 & 3.268 & 9.776 & 0.905 & 1.192 & 0.014 & 5.825 & 0.080 \\
\hline 354 & SR04 & $\mathrm{M}-14 / \mathrm{S} 2150$ & 5.879 & 0.036 & 1.443 & 0.104 & 0.030 & 16.543 & 0.172 & -0.022 & 1.397 & 3.534 & 9.699 & 0.996 & 1.292 & 0.015 & 6.138 & 0.083 \\
\hline 354 & SR04 & M-14/S2150 & 5.607 & 0.034 & 1.390 & 0.102 & 0.028 & 16.504 & 0.114 & -0.019 & 1.405 & 3.528 & 9.848 & 0.985 & 1.257 & 0.014 & 5.924 & 0.083 \\
\hline 354 & SR04 & M-14/S2150 & 4.606 & 0.032 & 1.308 & 0.081 & 0.025 & 13.621 & 0.164 & -0.022 & 1.330 & 3.028 & 9.584 & 0.806 & 1.066 & 0.012 & 5.354 & 0.068 \\
\hline 354 & IN32 & M-14/S2150 & -0.020 & 0.005 & -0.001 & 0.003 & 0.000 & -0.013 & 0.048 & -0.018 & 0.002 & 0.000 & -0.015 & -0.002 & 0.068 & -0.001 & -0.049 & 0.001 \\
\hline 354 & IN32 & M-14/S2150 & -0.020 & 0.003 & -0.002 & 0.003 & -0.002 & -0.015 & 0.005 & -0.020 & 0.002 & 0.000 & -0.025 & -0.001 & 0.073 & -0.001 & -0.061 & 0.000 \\
\hline 355 & ARGC & M-13/S2133 & 2.415 & 2.661 & 0.996 & 0.067 & 0.002 & 10.127 & 2.137 & 1.504 & 0.516 & 1.433 & 8.414 & 0.829 & 22.535 & 0.698 & 0.061 & 0.110 \\
\hline 355 & ARGC & M-13/S2133 & 2.404 & 2.710 & 0.997 & 0.068 & 0.007 & 10.311 & 2.482 & 1.505 & 0.526 & 1.459 & 8.573 & 0.844 & 22.943 & 0.692 & 0.158 & 0.111 \\
\hline 355 & $\begin{array}{l}\text { SR04 } \\
\end{array}$ & M-13/S2133 & 6.448 & 0.047 & 1.652 & 0.093 & 0.040 & 16.909 & 0.033 & 0.036 & 1.612 & 3.640 & 11.591 & 0.950 & 1.467 & 0.024 & 6.844 & 0.101 \\
\hline 355 & SR04 & M-13/S2133 & 5.461 & 0.046 & 1.432 & 0.089 & 0.035 & 15.738 & -0.104 & 0.025 & 1.418 & 3.326 & 9.895 & 0.900 & 1.368 & 0.021 & 5.739 & 0.085 \\
\hline 355 & SR04 & M-13/S2133 & 6.085 & 0.046 & 1.580 & 0.098 & 0.039 & 17.589 & -0.017 & 0.031 & 1.573 & 3.696 & 10.970 & 1.009 & 1.452 & 0.023 & 6.474 & 0.096 \\
\hline 355 & SR04 & M-13/S2133 & 6.459 & 0.046 & 1.648 & 0.102 & 0.041 & 18.497 & -0.065 & 0.030 & 1.613 & $\begin{array}{l}3.816 \\
\end{array}$ & 11.462 & 1.029 & 1.519 & 0.023 & 6.857 & 0.102 \\
\hline 355 & SR04 & M-13/S2133 & 5.481 & 0.044 & 1.418 & 0.086 & 0.035 & 15.393 & -0.056 & 0.023 & 1.379 & 3.200 & 10.004 & 0.875 & 1.331 & 0.020 & 5.836 & 0.085 \\
\hline 355 & SR04 & M-13/S2133 & 5.745 & 0.047 & 1.601 & 0.100 & 0.038 & 17.883 & -0.101 & 0.024 & 1.600 & 3.758 & 9.620 & 1.026 & 1.476 & 0.022 & 6.293 & 0.091 \\
\hline 355 & IN32 & M-13/S2133 & 0.004 & 0.008 & 0.000 & 0.000 & -0.001 & -0.019 & -0.027 & 0.001 & 0.000 & -0.001 & 0.026 & -0.001 & 0.101 & 0.001 & -0.015 & 0.001 \\
\hline 355 & IN32 & M-13/S2133 & 0.008 & 0.007 & 0.002 & 0.001 & 0.000 & $\begin{array}{l}-0.016 \\
\end{array}$ & 0.093 & -0.002 & 0.000 & -0.001 & 0.033 & -0.002 & 0.134 & 0.001 & 0.021 & 0.001 \\
\hline 356 & ARGC & M-14/S2150 & 2.428 & 2.661 & 1.002 & 0.079 & 0.003 & 9.715 & 2.336 & 1.488 & 0.506 & 1.404 & 8.332 & 0.811 & 22.252 & 0.685 & -0.004 & 0.106 \\
\hline
\end{tabular}


WSRC-STI-2006-00068

Table A1. Cold Chem Measurement Data Set (continued)

Revision 0

\begin{tabular}{|c|c|c|c|c|c|c|c|c|c|c|c|c|c|c|c|c|c|c|}
\hline Batch & Type of Sample & ICP/ID & Al & B & $\mathbf{C a}$ & $\mathrm{Cr}$ & $\mathbf{C u}$ & $\mathbf{F e}$ & $\mathbf{K}$ & $\mathbf{L i}$ & Mg & Mn & $\mathrm{Na}$ & $\mathrm{Ni}$ & $\mathrm{Si}$ & $\mathrm{Ti}$ & $\mathbf{U}$ & $\mathrm{Zr}$ \\
\hline 356 & ARGC & M-14/S2150 & 2.427 & 2.694 & 0.996 & 0.079 & 0.003 & 9.762 & 2.245 & 1.476 & 0.512 & 1.446 & 8.316 & 0.832 & 22.712 & 0.680 & -0.024 & 0.106 \\
\hline 356 & SR04 & M-14/S2150 & 5.546 & 0.024 & 1.452 & 0.102 & 0.033 & 16.299 & 0.051 & -0.004 & 1.421 & 3.424 & 9.825 & 0.926 & 1.376 & 0.025 & 5.944 & 0.087 \\
\hline 356 & SR04 & M-14/S2150 & 5.175 & 0.021 & 1.357 & 0.095 & 0.030 & 15.107 & 0.040 & -0.012 & 1.336 & 3.168 & 9.443 & 0.875 & 1.308 & 0.025 & 5.693 & 0.082 \\
\hline 356 & SR04 & M-14/S2150 & 5.792 & 0.022 & 1.482 & 0.108 & 0.034 & 16.935 & 0.063 & -0.006 & 1.420 & 3.487 & 9.781 & 1.001 & 1.433 & 0.027 & 6.075 & 0.090 \\
\hline 356 & SR04 & M-14/S2150 & 5.324 & 0.020 & 1.385 & 0.097 & 0.031 & 15.378 & 0.094 & -0.003 & 1.386 & 3.256 & 9.600 & 0.908 & 1.273 & 0.024 & 5.798 & 0.084 \\
\hline 356 & SR04 & M-14/S2150 & 5.502 & 0.023 & 1.443 & 0.103 & 0.031 & 16.440 & 0.152 & -0.003 & 1.423 & 3.429 & 9.669 & 0.962 & 1.348 & 0.026 & 5.671 & 0.086 \\
\hline 356 & SR04 & M-14/S2150 & 5.625 & 0.021 & 1.438 & 0.104 & 0.031 & 16.602 & 0.068 & -0.004 & 1.413 & 3.487 & 9.637 & 0.969 & 1.376 & 0.025 & 5.833 & 0.088 \\
\hline 356 & IN32 & M-14/S2150 & 0.008 & 0.000 & 0.001 & 0.005 & 0.000 & 0.004 & 0.024 & -0.014 & 0.004 & 0.006 & 0.002 & 0.002 & 0.134 & 0.003 & -0.032 & 0.002 \\
\hline 356 & IN32 & M-14/S2150 & 0.008 & 0.000 & 0.001 & 0.005 & -0.001 & 0.005 & 0.044 & -0.013 & 0.004 & 0.006 & 0.006 & 0.002 & 0.097 & 0.003 & -0.014 & 0.002 \\
\hline 357 & ARGC & M-14/S2150 & 2.227 & 2.447 & 0.925 & 0.072 & 0.006 & 9.027 & 2.217 & 1.373 & 0.465 & 1.331 & 7.956 & 0.753 & 20.486 & 0.639 & 0.048 & 0.102 \\
\hline 357 & ARGC & M-14/S2150 & 2.519 & 2.755 & 1.082 & 0.083 & 0.009 & 10.527 & 2.611 & 1.539 & 0.543 & 1.525 & 8.925 & 0.862 & 23.901 & 0.735 & 0.108 & 0.117 \\
\hline 357 & SR04 & M-14/S2150 & 5.859 & 0.003 & 1.480 & 0.108 & 0.040 & 16.824 & 0.334 & 0.009 & 1.401 & 3.528 & 10.336 & 0.956 & 1.207 & 0.025 & 6.103 & 0.095 \\
\hline 357 & SR04 & M-14/S2150 & 5.467 & -0.006 & 1.477 & 0.103 & 0.036 & 15.861 & 0.632 & 0.000 & 1.439 & 3.371 & 10.763 & 0.924 & 1.164 & 0.024 & 5.753 & 0.090 \\
\hline 357 & SR04 & M-14/S2150 & 5.773 & 0.002 & 1.513 & 0.108 & 0.038 & 16.879 & 0.423 & 0.014 & 1.454 & 3.571 & 10.747 & 0.988 & 1.286 & 0.024 & 6.079 & 0.093 \\
\hline 357 & SR04 & M-14/S2150 & 5.628 & -0.001 & 1.453 & 0.104 & 0.037 & 16.065 & 0.388 & 0.005 & 1.441 & 3.440 & 10.419 & 0.947 & 1.182 & 0.022 & 5.973 & 0.090 \\
\hline 357 & SR04 & M-14/S2150 & 5.406 & -0.005 & 1.448 & 0.102 & 0.036 & 15.907 & 0.362 & 0.008 & 1.420 & 3.385 & 10.356 & 0.927 & 1.172 & 0.024 & 5.830 & 0.089 \\
\hline 357 & SR04 & M-14/S2150 & 5.588 & 0.005 & 1.550 & 0.102 & 0.037 & 16.770 & 0.304 & 0.011 & 1.496 & 3.589 & 10.921 & 0.972 & 1.183 & 0.024 & 5.824 & 0.091 \\
\hline 357 & IN32 & M-14/S2150 & 0.007 & -0.006 & 0.005 & 0.005 & 0.001 & 0.008 & 0.067 & -0.010 & 0.003 & 0.003 & 0.009 & 0.001 & 0.024 & 0.002 & 0.000 & 0.002 \\
\hline 357 & IN32 & M-14/S2150 & 0.024 & -0.008 & 0.007 & 0.005 & 0.002 & 0.013 & 0.055 & -0.008 & 0.003 & 0.004 & 0.022 & 0.002 & 0.035 & 0.002 & 0.032 & 0.003 \\
\hline
\end{tabular}




\section{Table A2. Fusion Measurement Data Set}

\section{Revision 0}

\begin{tabular}{|c|c|c|c|c|c|c|c|c|c|c|c|c|c|c|c|c|c|c|}
\hline Batch & Type of Sample & ICP/ID & Al & B & $\begin{array}{l}\mathbf{C a} \\
\end{array}$ & Cr & $\mathbf{C u}$ & $\mathrm{Fe}$ & $\mathbf{K}$ & $\mathbf{L i}$ & Mg & Mn & $\mathrm{Na}$ & $\mathrm{Ni}$ & $\mathrm{Si}$ & Ti & $\mathbf{U}$ & $\overline{Z r r}$ \\
\hline 300 & ARGG & M-13/S2133 & 2.242 & 2.489 & 0.918 & 0.067 & 0.002 & 9.136 & 2.044 & 1.362 & 0.471 & 1.329 & & 0.766 & 21.628 & 0.633 & 0.028 & \\
\hline 300 & ARGG & M-13/S2133 & 1.818 & 1.950 & 0.732 & 0.520 & 0.001 & 7.361 & 1.588 & 1.094 & 0.375 & 1.050 & . & 0.618 & 17.147 & 0.501 & 0.022 & \\
\hline 300 & ARGG & M-13/S2133 & 2.277 & 2.502 & 0.931 & 0.060 & 0.000 & 9.248 & 2.054 & 1.384 & 0.472 & 1.344 & . & 0.756 & 21.428 & 0.650 & 0.041 & \\
\hline 300 & ARGG & M-13/S2133 & 2.277 & 2.530 & 0.922 & 0.062 & -0.001 & 9.333 & 2.074 & 1.400 & 0.486 & 1.405 & & 0.786 & 21.662 & 0.643 & 0.035 & \\
\hline 300 & SM01 & M-13/S2133 & 2.936 & 1.446 & 0.650 & 0.053 & 0.008 & 7.563 & 0.020 & 2.207 & 0.645 & 1.413 & . & 0.430 & 24.180 & 0.019 & 2.638 & \\
\hline 300 & SM01 & M-13/S2133 & 2.920 & 1.399 & 0.661 & 0.055 & 0.009 & 7.598 & 0.016 & 2.111 & 0.651 & 1.418 & & 0.424 & 23.330 & 0.019 & 2.702 & \\
\hline 300 & SM01 & M-13/S2133 & 2.619 & 1.267 & 0.611 & 0.047 & 0.008 & 6.657 & 0.005 & 1.931 & 0.587 & 1.251 & . & 0.386 & 21.496 & 0.017 & 2.404 & \\
\hline 300 & SM01 & M-13/S2133 & 2.844 & 1.397 & 0.669 & 0.053 & 0.008 & 7.502 & 0.064 & 2.112 & 0.656 & 1.435 & 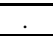 & 0.432 & 23.017 & 0.018 & 2.661 & \\
\hline 300 & SM01 & M-13/S2133 & 3.220 & 1.579 & 0.785 & 0.061 & 0.010 & 8.335 & 0.027 & 2.389 & 0.711 & 1.563 & & 0.474 & 26.310 & 0.022 & 2.885 & \\
\hline 300 & SM01 & M-13/S2133 & 2.740 & 1.303 & 0.591 & 0.051 & 0.009 & 7.121 & 0.061 & 2.007 & 0.622 & 1.356 & . & 0.400 & 21.739 & 0.018 & 2.453 & \\
\hline 300 & SM01 & M-13/S2133 & 2.912 & 1.454 & 0.667 & 0.055 & 0.011 & 7.543 & 0.068 & 2.137 & 0.641 & 1.470 & & 0.431 & 22.974 & 0.029 & 2.606 & \\
\hline 300 & SM01 & M-13/S2133 & 2.774 & 1.424 & 0.640 & 0.049 & 0.011 & 7.307 & 0.013 & 2.106 & 0.618 & 1.450 & . & 0.414 & 22.767 & 0.027 & 2.476 & \\
\hline 300 & SM01 & M-13/S2133 & 2.764 & 1.492 & 0.630 & 0.048 & 0.010 & 7.281 & -0.010 & 2.151 & 0.629 & 1.464 & 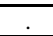 & 0.419 & 23.579 & 0.028 & 2.481 & \\
\hline 300 & SM01 & M-13/S2133 & 2.898 & 1.437 & 0.640 & 0.049 & 0.011 & 7.540 & 0.004 & 2.086 & 0.633 & 1.465 & 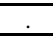 & 0.418 & 23.067 & 0.029 & 2.617 & \\
\hline 300 & SM01 & M-13/S2133 & 2.923 & 1.502 & 0.661 & 0.049 & 0.012 & 7.481 & 0.028 & 2.256 & 0.620 & 1.465 & & 0.416 & 24.058 & 0.029 & 2.594 & \\
\hline 300 & SM01 & M-13/S2133 & 2.850 & 1.494 & 0.644 & 0.050 & 0.010 & 7.506 & -0.012 & 2.205 & 0.643 & 1.513 & . & 0.430 & 24.635 & 0.036 & 2.521 & \\
\hline 300 & SM55 & M-13/S2133 & -0.056 & 0.001 & 0.048 & 0.001 & -0.003 & -0.087 & -0.061 & -0.061 & -0.008 & -0.041 & 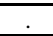 & -0.004 & 0.089 & -0.009 & -0.008 & \\
\hline 300 & SM55 & M-13/S2133 & -0.082 & 0.039 & -0.018 & -0.001 & -0.003 & -0.090 & -0.087 & -0.066 & -0.010 & -0.045 & . & -0.006 & 0.109 & -0.008 & -0.008 & \\
\hline 300 & SM55 & M-13/S2133 & 0.003 & 0.017 & -0.024 & -0.005 & -0.005 & -0.102 & -0.051 & -0.032 & -0.009 & -0.005 & . & -0.013 & 0.066 & 0.004 & 0.015 & \\
\hline 300 & SM55 & M-13/S2133 & -0.003 & 0.021 & -0.026 & -0.007 & -0.005 & -0.116 & -0.071 & -0.036 & -0.008 & -0.007 & - & -0.005 & 0.125 & 0.004 & -0.010 & \\
\hline 301 & ARGG & M-13/S2133 & 2.473 & 2.567 & 1.066 & 0.059 & 0.000 & 9.640 & 2.270 & 1.453 & 0.496 & 1.405 & . & 0.789 & 22.503 & 0.655 & 0.061 & \\
\hline 301 & ARGG & M-13/S2133 & 2.272 & 2.541 & 0.968 & 0.057 & 0.000 & 9.381 & 2.099 & 1.395 & 0.494 & 1.344 & & 0.810 & 21.667 & 0.613 & 0.044 & \\
\hline 301 & ARGG & M-13/S2133 & 2.230 & 2.441 & 0.908 & 0.050 & 0.003 & 8.627 & 2.025 & 1.376 & 0.461 & 1.338 & . & 0.752 & 20.676 & 0.637 & -0.167 & \\
\hline 301 & SM01 & M-13/S2133 & 2.709 & 1.196 & 0.696 & 0.042 & 0.011 & 6.958 & 0.050 & 1.770 & 0.622 & 1.439 & . & 0.391 & 19.411 & 0.014 & 2.515 & \\
\hline 301 & SM01 & M-13/S2133 & 3.181 & 1.442 & 0.783 & 0.052 & 0.012 & 8.551 & 0.039 & 2.120 & 0.765 & 1.714 & . & 0.493 & 23.180 & 0.016 & 2.919 & \\
\hline 301 & SM01 & M-13/S2133 & 2.912 & 1.361 & 0.752 & 0.045 & 0.011 & 7.738 & 0.058 & 2.063 & 0.714 & 1.562 & . & 0.439 & 21.762 & 0.014 & 2.693 & \\
\hline 301 & SM01 & M-13/S2133 & 3.209 & 1.432 & 0.798 & 0.057 & 0.013 & 8.459 & 0.059 & 2.070 & 0.779 & 1.748 & . & 0.499 & 23.164 & 0.016 & 2.969 & \\
\hline 301 & SM01 & M-13/S2133 & 3.066 & 1.421 & 0.756 & 0.048 & 0.012 & 8.196 & 0.042 & 2.018 & 0.738 & 1.625 & 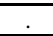 & 0.471 & 23.042 & 0.017 & 2.847 & \\
\hline 301 & SM01 & M-13/S2133 & 3.236 & 1.456 & 0.816 & 0.055 & 0.014 & 8.646 & 0.046 & 2.136 & 0.780 & 1.735 & . & 0.507 & 23.743 & 0.018 & 2.992 & \\
\hline 301 & SM55 & M-13/S2133 & -0.070 & 0.004 & -0.054 & -0.013 & -0.003 & -0.239 & -0.040 & -0.036 & -0.017 & -0.047 & . & -0.025 & -0.152 & -0.011 & 0.024 & \\
\hline 301 & SM55 & M-13/S2133 & -0.061 & 0.019 & $\begin{array}{l}-0.018 \\
\end{array}$ & -0.011 & -0.004 & -0.197 & -0.025 & -0.040 & -0.010 & -0.042 & - & -0.018 & -0.043 & -0.011 & 0.004 & \\
\hline 301 & SM55 & M-13/S2133 & -0.036 & 0.017 & -0.043 & -0.008 & -0.003 & 0.019 & -0.061 & 0.001 & -0.004 & -0.010 & . & -0.011 & 0.142 & -0.006 & -0.277 & \\
\hline 301 & SM55 & M-13/S2133 & -0.010 & 0.024 & -0.022 & -0.006 & -0.007 & 0.040 & -0.168 & -0.004 & 0.003 & -0.007 & & -0.008 & 0.213 & -0.007 & -0.180 & \\
\hline 302 & ARGG & M-13/S2133 & 2.407 & 2.654 & 1.010 & 0.073 & 0.016 & 9.760 & 2.230 & 1.404 & 0.500 & 1.423 & . & 0.797 & 22.687 & 0.635 & -0.020 & \\
\hline 302 & ARGG & M-13/S2133 & 2.428 & 2.717 & 1.083 & 0.075 & -0.004 & 9.866 & 2.483 & 1.565 & 0.519 & 1.443 & & 0.785 & 22.937 & 0.719 & -0.031 & \\
\hline 302 & SM01 & M-13/S2133 & 3.030 & 1.443 & 0.654 & 0.058 & 0.018 & 7.813 & -0.013 & 2.161 & 0.661 & 1.566 & & 0.444 & 23.675 & 0.035 & 2.597 & \\
\hline 302 & SM01 & M-13/S2133 & 3.007 & 1.454 & 0.689 & 0.061 & 0.007 & 8.153 & -0.022 & 2.209 & 0.715 & 1.660 & . & 0.434 & 23.774 & 0.038 & 2.654 & \\
\hline 302 & SM01 & M-13/S2133 & 3.006 & 1.494 & 0.770 & 0.062 & 0.034 & 8.261 & -0.021 & 2.329 & 0.696 & 1.608 & & 0.443 & 24.210 & 0.037 & 2.687 & \\
\hline 302 & SM01 & M-13/S2133 & 3.880 & 1.420 & 0.664 & 0.062 & 0.017 & 7.939 & -0.024 & 2.181 & 0.698 & 1.645 & . & 0.441 & 27.169 & 0.041 & 2.631 & \\
\hline 302 & SM01 & M-13/S2133 & 3.079 & 1.482 & 0.709 & 0.062 & 0.018 & 8.182 & -0.026 & 2.336 & 0.689 & 1.599 & . & 0.442 & 24.346 & 0.037 & 2.641 & \\
\hline 302 & SM01 & M-13/S2133 & 2.853 & 1.435 & 0.796 & 0.058 & 0.020 & 7.867 & -0.009 & 2.156 & 0.693 & 1.603 & & 0.435 & 23.572 & 0.039 & 2.563 & \\
\hline 302 & SM55 & M-13/S2133 & 0.020 & 0.020 & -0.007 & 0.005 & -0.005 & -0.001 & -0.107 & -0.053 & 0.004 & 0.003 & . & -0.007 & 0.106 & 0.018 & -0.042 & \\
\hline 302 & SM55 & M-13/S2133 & -0.010 & 0.023 & -0.033 & 0.006 & -0.004 & 0.000 & -0.095 & -0.058 & 0.006 & 0.006 & 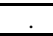 & -0.016 & 0.120 & 0.014 & -0.088 & \\
\hline 303 & ARGG & M-13/S2133 & 2.376 & 2.541 & 0.952 & 0.065 & 0.006 & 9.455 & 2.230 & 1.473 & 0.493 & 1.373 & & 0.787 & 22.085 & 0.670 & 0.002 & \\
\hline 303 & ARGG & M-13/S2133 & 2.360 & 2.612 & 0.964 & 0.089 & 0.006 & 9.636 & 2.211 & 1.467 & 0.501 & 1.355 & & 0.822 & 22.363 & 0.665 & 0.005 & \\
\hline 303 & SM01 & M-13/S2133 & 2.866 & 1.443 & 0.667 & 0.052 & 0.018 & 7.555 & 0.017 & 2.221 & 0.626 & 1.513 & & 0.429 & 24.124 & 0.035 & 2.464 & \\
\hline 303 & SM01 & M-13/S2133 & 2.874 & 1.458 & 0.648 & 0.069 & 0.019 & 7.813 & -0.006 & 2.205 & 0.654 & 1.514 & & 0.467 & 24.385 & 0.030 & 2.492 & \\
\hline 303 & SM01 & M-13/S2133 & 2.829 & 1.501 & 0.658 & 0.067 & 0.019 & 7.639 & 0.037 & 2.334 & 0.656 & 1.476 & & 0.447 & 25.088 & 0.030 & 2.377 & \\
\hline 303 & SM01 & M-13/S2133 & 2.735 & 1.432 & 0.652 & 0.053 & 0.018 & 7.421 & 0.011 & 2.150 & 0.638 & 1.472 & & 0.438 & 24.105 & 0.028 & 2.393 & \\
\hline 303 & SM01 & M-13/S2133 & 2.919 & 1.440 & 0.692 & 0.065 & 0.020 & 7.704 & 0.011 & 2.239 & 0.638 & 1.541 & & 0.443 & 23.783 & 0.030 & 2.550 & \\
\hline
\end{tabular}


Table A2. Fusion Measurement Data Set (continued)

\section{Revision 0}

\begin{tabular}{|c|c|c|c|c|c|c|c|c|c|c|c|c|c|c|c|c|c|c|}
\hline Batch & Type of Sample & ICP/ID & Al & B & $\begin{array}{l}\mathbf{C a} \\
\end{array}$ & $\mathrm{Cr}$ & $\begin{array}{l}\mathbf{C u} \\
\end{array}$ & Fe & $\mathbf{K}$ & $\mathrm{Li}$ & Mg & Mn & $\mathrm{Na}$ & $\mathrm{Ni}$ & Si & Ti & $\mathbf{U}$ & $\overline{Z \mathbf{Z r}}$ \\
\hline 303 & SM01 & M-13/S2133 & 2.883 & 1.439 & 0.663 & 0.053 & 0.018 & 7.568 & 0.001 & 2.196 & 0.631 & 1.530 & & 0.428 & 23.785 & 0.029 & 2.499 & \\
\hline 303 & SM55 & M-13/S2133 & 0.066 & 0.074 & -0.047 & 0.035 & 0.003 & 0.239 & -0.034 & 0.009 & 0.015 & 0.029 & & 0.032 & 0.987 & 0.022 & -0.046 & \\
\hline 303 & SM55 & M-13/S2133 & 0.062 & 0.094 & 0.010 & 0.034 & 0.003 & 0.119 & -0.006 & 0.000 & 0.041 & 0.038 & & 0.027 & 0.789 & 0.007 & -0.001 & . \\
\hline 304 & ARGG & M-13/S2133 & 2.381 & 2.697 & 0.724 & 0.066 & 0.005 & 9.826 & 2.109 & 1.418 & 0.470 & 1.351 & & 0.836 & 23.058 & 0.671 & 0.075 & \\
\hline 304 & ARGG & M-13/S2133 & 2.449 & 2.677 & 0.864 & 0.074 & 0.005 & 9.758 & 2.290 & 1.534 & 0.490 & 1.429 & & 0.811 & 23.011 & 0.693 & 0.059 & \\
\hline 304 & SM01 & M-13/S2133 & 2.825 & 1.554 & 0.555 & 0.062 & 0.020 & 7.752 & 0.136 & 2.293 & 0.620 & 1.381 & & 0.442 & 25.632 & 0.039 & 2.487 & \\
\hline 304 & SM01 & M-13/S2133 & 2.800 & 1.504 & 0.641 & 0.052 & 0.016 & 7.651 & 0.021 & 2.279 & 0.631 & 1.415 & & 0.437 & 24.802 & 0.036 & 2.544 & \\
\hline 304 & SM01 & M-13/S2133 & 2.772 & 1.463 & 0.607 & 0.053 & 0.016 & 7.559 & 0.072 & 2.176 & 0.622 & 1.401 & & 0.452 & 24.333 & 0.037 & 2.520 & \\
\hline 304 & SM01 & M-13/S2133 & 2.796 & 1.487 & 0.611 & 0.050 & 0.016 & 7.540 & 0.768 & 2.250 & 0.637 & 1.433 & & 0.429 & 24.634 & 0.037 & 2.500 & \\
\hline 304 & SM01 & M-13/S2133 & 2.768 & 1.532 & 0.660 & 0.052 & 0.017 & 7.606 & 0.176 & 2.313 & 0.609 & 1.355 & & 0.445 & 24.825 & 0.037 & 2.531 & \\
\hline 304 & SM01 & M-13/S2133 & 2.650 & 1.379 & 0.658 & 0.048 & 0.015 & 7.174 & 1.144 & 2.114 & 0.640 & 1.380 & & 0.414 & 23.014 & 0.034 & 2.417 & \\
\hline 304 & SM55 & M-13/S2133 & 0.012 & 0.027 & -0.138 & 0.003 & 0.001 & 0.014 & -0.191 & -0.044 & 0.014 & 0.017 & & -0.004 & 0.020 & 0.012 & 0.047 & . \\
\hline 304 & SM55 & M-13/S2133 & 0.005 & 0.021 & -0.159 & 0.001 & 0.000 & 0.001 & -0.183 & -0.040 & 0.003 & 0.014 & & -0.009 & 0.138 & 0.010 & 0.020 & \\
\hline 305 & ARGG & M-13/S2133 & 2.251 & 2.456 & 0.908 & 0.066 & 0.004 & 9.292 & 2.044 & 1.378 & 0.481 & 1.336 & & 0.740 & 21.358 & 0.632 & 0.013 & \\
\hline 305 & ARGG & M-13/S2133 & 2.280 & 2.565 & 0.913 & 0.070 & 0.004 & 8.087 & 2.136 & 1.423 & 0.713 & 1.605 & & 0.733 & 22.560 & 0.642 & 0.001 & \\
\hline 305 & SM01 & M-13/S2133 & 2.772 & 1.412 & 0.675 & 0.057 & 0.017 & 7.591 & 0.730 & 2.130 & 0.685 & 1.530 & i & 0.427 & 23.357 & 0.023 & 2.363 & . \\
\hline 305 & SM01 & M-13/S2133 & 2.813 & 1.475 & 0.693 & 0.058 & 0.016 & 7.841 & -0.001 & 2.220 & 0.692 & 1.587 & & 0.438 & 24.707 & 0.022 & 2.401 & \\
\hline 305 & SM01 & $\mathrm{M}-13 / \mathrm{S} 2133$ & 2.917 & 1.495 & 0.691 & 0.059 & 0.016 & 8.028 & 0.048 & 2.290 & 0.701 & 1.575 & & 0.447 & 25.082 & 0.022 & 2.459 & \\
\hline 305 & SM01 & M-13/S2133 & 2.230 & 1.073 & 0.527 & 0.043 & 0.013 & 6.000 & 3.942 & 1.750 & 0.542 & 1.183 & & 0.331 & 16.889 & 0.016 & 1.897 & \\
\hline 305 & SM01 & M-13/S2133 & 2.812 & 1.405 & 0.684 & 0.062 & 0.017 & 8.001 & 4.992 & 2.189 & 0.700 & 1.542 & & 0.429 & 23.801 & 0.021 & 2.392 & \\
\hline 305 & SM01 & M-13/S2133 & 2.699 & 1.380 & 0.647 & 0.060 & 0.017 & 7.774 & 4.831 & 2.139 & 0.686 & 1.543 & & 0.416 & 23.511 & 0.021 & 2.313 & . \\
\hline 305 & SM55 & M-13/S2133 & -0.020 & 0.019 & -0.187 & 0.000 & 0.000 & -0.096 & -0.164 & -0.024 & 0.006 & -0.007 & & 0.001 & 0.316 & -0.005 & -0.031 & \\
\hline 305 & SM55 & M-13/S2133 & -0.018 & 0.025 & -0.173 & 0.007 & -0.001 & -0.053 & -0.159 & -0.025 & 0.008 & -0.005 & & 0.001 & 0.322 & -0.005 & -0.050 & 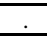 \\
\hline 306 & ARGG & M-13/S2133 & 2.383 & 2.625 & 0.999 & 0.065 & 0.005 & 9.616 & 2.266 & 1.503 & 0.500 & 1.403 & & 0.782 & 22.728 & 0.670 & 0.026 & \\
\hline 306 & ARGG & M-13/S2133 & 2.369 & 2.648 & 0.999 & 0.073 & 0.006 & 9.567 & 2.550 & 1.499 & 0.509 & 1.356 & & 0.818 & 22.649 & 0.666 & 0.057 & \\
\hline 306 & SM01 & M-13/S2133 & 2.800 & 1.388 & 0.735 & 0.050 & 0.017 & 7.778 & 0.004 & 2.144 & 0.694 & 1.605 & & 0.436 & 23.121 & 0.042 & 2.540 & \\
\hline 306 & SM01 & M-13/S2133 & 2.856 & 1.396 & 0.747 & 0.053 & 0.017 & 7.892 & 0.131 & 2.229 & 0.713 & 1.644 & & 0.453 & 23.355 & 0.041 & 2.612 & \\
\hline 306 & SM01 & M-13/S2133 & 2.890 & 1.383 & 0.746 & 0.058 & 0.017 & 8.013 & 0.068 & 2.141 & 0.703 & 1.628 & & 0.457 & 23.319 & 0.041 & 2.614 & \\
\hline 306 & SM01 & M-13/S2133 & 2.868 & 1.398 & 0.733 & 0.054 & 0.018 & 8.051 & 0.058 & 2.141 & 0.720 & 1.567 & & 0.477 & 23.572 & 0.041 & 2.608 & \\
\hline 306 & SM01 & M-13/S2133 & 2.896 & 1.407 & 0.736 & 0.063 & 0.017 & 8.082 & 0.036 & 2.177 & 0.716 & 1.557 & & 0.467 & 24.489 & 0.042 & 2.637 & \\
\hline 306 & SM01 & M-13/S2133 & 2.656 & 1.285 & 0.685 & 0.056 & 0.015 & 7.540 & -0.033 & 1.984 & 0.665 & 1.546 & & 0.425 & 22.071 & 0.041 & 2.497 & \\
\hline 306 & SM55 & M-13/S2133 & 0.001 & 0.008 & -0.015 & 0.004 & 0.000 & 0.011 & 0.222 & -0.015 & 0.004 & 0.039 & & -0.003 & 0.462 & 0.011 & -0.003 & . \\
\hline 306 & SM55 & M-13/S2133 & 0.038 & 0.000 & 0.000 & 0.000 & 0.001 & -0.005 & 0.316 & -0.017 & 0.007 & 0.036 & & 0.004 & 0.367 & 0.012 & 0.032 & \\
\hline 307 & ARGG & M-13/S2133 & 2.460 & 2.645 & 0.998 & 0.067 & -0.002 & 9.939 & 2.200 & 1.497 & 0.521 & 1.427 & & 0.822 & 23.033 & 0.684 & 0.016 & 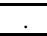 \\
\hline 307 & ARGG & M-13/S2133 & 2.491 & 2.742 & 1.048 & 0.071 & -0.002 & 10.140 & 2.123 & 1.469 & 0.532 & 1.463 & & 0.833 & 23.797 & 0.667 & 0.015 & \\
\hline 307 & SM01 & M-13/S2133 & 2.516 & 1.156 & 0.578 & 0.046 & 0.009 & 6.758 & -0.022 & 1.854 & 0.592 & 1.353 & & 0.381 & 19.707 & 0.024 & 2.261 & \\
\hline 307 & SM01 & M-13/S2133 & 3.071 & 1.561 & 0.721 & 0.056 & 0.010 & 8.333 & -0.054 & 2.358 & 0.707 & 1.632 & & 0.479 & 26.158 & 0.030 & 2.757 & \\
\hline 307 & SM01 & M-13/S2133 & 2.863 & 1.460 & 0.680 & 0.055 & 0.010 & 7.894 & -0.036 & 2.202 & 0.665 & 1.561 & & 0.458 & 24.827 & 0.027 & 2.607 & \\
\hline 307 & SM01 & M-13/S2133 & 2.912 & 1.464 & 0.699 & 0.056 & 0.011 & 7.999 & -0.042 & 2.214 & 0.680 & 1.580 & & 0.472 & 24.479 & 0.027 & 2.634 & \\
\hline 307 & SM01 & M-13/S2133 & 2.869 & 1.498 & 0.690 & 0.054 & 0.009 & 7.799 & -0.072 & 2.203 & 0.675 & 1.567 & & 0.448 & 24.968 & 0.028 & 2.564 & \\
\hline 307 & SM01 & M-13/S2133 & 2.818 & 1.403 & 0.681 & 0.052 & 0.010 & 7.787 & -0.044 & 2.126 & 0.676 & 1.548 & & 0.451 & 23.941 & 0.029 & 2.541 & \\
\hline 307 & SM55 & M-13/S2133 & -0.026 & -0.018 & -0.027 & -0.003 & -0.007 & -0.166 & -0.145 & -0.038 & -0.007 & -0.015 & & 0.003 & 0.191 & -0.008 & -0.005 & \\
\hline 307 & SM55 & M-13/S2133 & -0.015 & -0.013 & -0.011 & 0.005 & 0.004 & -0.050 & -0.125 & -0.033 & -0.005 & -0.013 & & 0.008 & 0.283 & -0.008 & -0.008 & \\
\hline 308 & ARGG & M-13/S2133 & 2.421 & 2.652 & 0.979 & 0.061 & 0.000 & 9.719 & 2.138 & 1.485 & 0.504 & 1.418 & & 0.799 & 22.660 & 0.677 & 0.019 & \\
\hline 308 & ARGG & M-13/S2133 & 2.456 & 2.678 & 0.998 & 0.062 & -0.001 & 9.657 & 2.165 & 1.475 & 0.494 & 1.396 & & 0.815 & 22.472 & 0.706 & 0.030 & \\
\hline 308 & SM01 & M-13/S2133 & 2.778 & 1.412 & 0.682 & 0.050 & 0.012 & 7.637 & 0.543 & 2.115 & 0.695 & 1.564 & & 0.438 & 23.601 & 0.035 & 2.653 & \\
\hline 308 & SM01 & M-13/S2133 & 2.833 & 1.494 & 0.674 & 0.049 & 0.011 & 7.842 & -0.035 & 2.210 & 0.665 & 1.535 & & 0.453 & 24.132 & 0.035 & 2.762 & \\
\hline 308 & SM01 & M-13/S2133 & 2.917 & 1.465 & 0.692 & 0.050 & 0.013 & 7.848 & 0.259 & 2.221 & 0.666 & 1.551 & & 0.443 & 24.209 & 0.038 & 2.752 & \\
\hline 308 & SM01 & $\mathrm{M}-13 / \mathrm{S} 2133$ & 2.847 & 1.459 & 0.689 & 0.047 & 0.011 & 7.652 & 0.257 & 2.145 & 0.679 & 1.547 & & 0.449 & 24.202 & 0.037 & 2.767 & \\
\hline 308 & SM01 & M-13/S2133 & 2.812 & 1.452 & 0.695 & 0.053 & 0.013 & 7.662 & -0.032 & 2.217 & 0.669 & 1.538 & & 0.434 & 23.782 & 0.035 & 2.682 & \\
\hline
\end{tabular}


Table A2. Fusion Measurement Data Set (continued)

\section{Revision 0}

\begin{tabular}{|c|c|c|c|c|c|c|c|c|c|c|c|c|c|c|c|c|c|c|}
\hline Batch & Type of Sample & ICP/ID & Al & B & $\begin{array}{l}\mathbf{C a} \\
\end{array}$ & $\mathrm{Cr}$ & $\mathbf{C u}$ & $\mathrm{Fe}$ & $\mathbf{K}$ & $\mathrm{Li}$ & Mg & Mn & $\mathrm{Na}$ & $\mathrm{Ni}$ & Si & Ti & $\mathbf{U}$ & $\overline{Z \mathbf{Z r}}$ \\
\hline 308 & SM01 & M-13/S2133 & 2.852 & 1.452 & 0.684 & 0.052 & 0.013 & 7.813 & 0.199 & 2.188 & 0.675 & 1.561 & & 0.443 & 24.221 & 0.036 & 2.688 & \\
\hline 308 & SM55 & M-13/S2133 & -0.071 & -0.012 & -0.037 & -0.008 & -0.004 & -0.150 & -0.122 & -0.037 & -0.010 & -0.016 & & -0.015 & 0.151 & -0.007 & -0.015 & \\
\hline 308 & SM55 & M-13/S2133 & 0.020 & -0.010 & -0.034 & -0.009 & -0.006 & -0.132 & -0.142 & -0.029 & -0.004 & -0.007 & & -0.011 & 0.330 & -0.004 & 0.001 & . \\
\hline 309 & ARGG & M-13/S2133 & 2.361 & 2.570 & 0.979 & 0.071 & -0.001 & 9.535 & 2.163 & 1.460 & 0.509 & 1.378 & & 0.818 & 22.412 & 0.661 & 0.053 & \\
\hline 309 & ARGG & M-13/S2133 & 2.446 & 2.645 & 0.993 & 0.071 & -0.002 & 9.905 & 2.169 & 1.463 & 0.519 & 1.422 & & 0.835 & 23.131 & 0.679 & 0.053 & \\
\hline 309 & SM01 & M-13/S2133 & 2.948 & 1.436 & 0.730 & 0.058 & 0.013 & 8.070 & 0.008 & 2.204 & 0.703 & 1.609 & & 0.476 & 24.081 & 0.029 & 2.786 & \\
\hline 309 & SM01 & M-13/S2133 & 2.902 & 1.436 & 0.720 & 0.059 & 0.010 & 8.059 & -0.014 & 2.164 & 0.697 & 1.599 & & 0.478 & 24.321 & 0.028 & 2.777 & \\
\hline 309 & SM01 & M-13/S2133 & 2.947 & 1.440 & 0.719 & 0.060 & 0.011 & 8.215 & -0.007 & 2.255 & 0.681 & 1.594 & & 0.490 & 24.634 & 0.029 & 2.786 & \\
\hline 309 & SM01 & M-13/S2133 & 2.877 & 1.454 & 0.689 & 0.059 & 0.010 & 7.987 & 0.051 & 2.228 & 0.666 & 1.525 & & 0.458 & 24.934 & 0.028 & 2.754 & \\
\hline 309 & SM01 & M-13/S2133 & 2.863 & 1.430 & 0.698 & 0.059 & 0.011 & 7.960 & 0.001 & 2.203 & 0.663 & 1.539 & & 0.459 & 24.166 & 0.028 & 2.722 & \\
\hline 309 & SM01 & M-13/S2133 & 2.870 & 1.434 & 0.696 & 0.060 & 0.010 & 8.154 & 0.017 & 2.177 & 0.682 & 1.569 & & 0.483 & 24.160 & 0.027 & 2.788 & \\
\hline 309 & SM55 & M-13/S2133 & -0.101 & -0.035 & -0.031 & 0.003 & -0.007 & -0.179 & -0.089 & -0.044 & -0.005 & -0.015 & & 0.005 & 0.104 & -0.009 & 0.020 & . \\
\hline 309 & SM55 & M-13/S2133 & -0.099 & -0.044 & -0.027 & 0.004 & -0.006 & -0.148 & -0.095 & -0.047 & -0.003 & -0.016 & & 0.008 & 0.136 & -0.009 & 0.013 & \\
\hline 310 & ARGG & M-13/S2133 & 2.360 & 2.562 & 0.972 & 0.070 & 0.001 & 9.559 & 2.149 & 1.421 & 0.508 & 1.382 & & 0.802 & 22.323 & 0.663 & 0.072 & \\
\hline 310 & ARGG & M-13/S2133 & 2.514 & 2.769 & 1.041 & 0.077 & 0.003 & 10.086 & 2.273 & 1.506 & 0.541 & 1.479 & & 0.860 & 24.207 & 0.696 & 0.087 & \\
\hline 310 & SM01 & M-13/S2133 & 2.902 & 1.551 & 0.711 & 0.059 & 0.015 & 7.903 & -0.036 & 2.254 & 0.653 & 1.512 & & 0.451 & 25.062 & 0.038 & 2.538 & - \\
\hline 310 & SM01 & M-13/S2133 & 2.724 & 1.474 & 0.665 & 0.058 & 0.014 & 7.416 & -0.026 & 2.154 & 0.610 & 1.425 & & 0.442 & 23.641 & 0.035 & 2.373 & \\
\hline 310 & SM01 & $\mathrm{M}-13 / \mathrm{S} 2133$ & 2.812 & 1.507 & 0.672 & 0.056 & 0.014 & 7.805 & -0.040 & 2.199 & 0.597 & 1.434 & & 0.461 & 24.256 & 0.035 & 2.440 & \\
\hline 310 & SM01 & M-13/S2133 & 2.927 & 1.575 & 0.697 & 0.060 & 0.015 & 8.224 & -0.046 & 2.250 & 0.638 & 1.543 & & 0.488 & 25.410 & 0.037 & 2.575 & 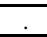 \\
\hline 310 & SM01 & M-13/S2133 & 2.866 & 1.609 & 0.671 & 0.061 & 0.015 & 7.859 & -0.040 & 2.255 & 0.624 & 1.498 & & 0.469 & 25.676 & 0.037 & 2.478 & \\
\hline 310 & SM01 & M-13/S2133 & 2.622 & 1.458 & 0.598 & 0.055 & 0.013 & 7.242 & -0.066 & 2.099 & 0.557 & 1.331 & & 0.420 & 23.861 & 0.034 & 2.280 & . \\
\hline 310 & SM55 & M-13/S2133 & -0.006 & 0.024 & -0.019 & 0.000 & -0.002 & -0.052 & -0.080 & -0.032 & 0.004 & 0.010 & & 0.006 & 0.044 & 0.005 & 0.037 & \\
\hline 310 & SM55 & M-13/S2133 & 0.033 & 0.029 & -0.010 & 0.001 & -0.001 & -0.016 & -0.111 & -0.036 & 0.005 & 0.014 & & 0.012 & 0.081 & 0.007 & 0.077 & \\
\hline 311 & ARGG & M-13/S2133 & 2.293 & 2.501 & 0.943 & 0.065 & 0.001 & 9.241 & 2.073 & 1.429 & 0.478 & 1.351 & & 0.783 & 21.595 & 0.643 & 0.040 & \\
\hline 311 & ARGG & M-13/S2133 & 2.129 & 2.356 & 0.885 & 0.061 & 0.002 & 8.584 & 1.949 & 1.328 & 0.448 & 1.255 & & 0.733 & 20.443 & 0.610 & 0.057 & \\
\hline 311 & SM01 & M-13/S2133 & 2.747 & 1.543 & 0.635 & 0.054 & 0.013 & 7.408 & -0.065 & 2.266 & 0.580 & 1.374 & & 0.423 & 25.385 & 0.032 & 2.551 & \\
\hline 311 & SM01 & M-13/S2133 & 2.742 & 1.536 & 0.630 & 0.052 & 0.015 & 7.264 & -0.044 & 2.318 & 0.578 & 1.370 & & 0.424 & 24.461 & 0.032 & 2.562 & \\
\hline 311 & SM01 & M-13/S2133 & 2.784 & 1.591 & 0.636 & 0.053 & 0.015 & 7.285 & -0.039 & 2.435 & 0.582 & 1.374 & & 0.432 & 25.296 & 0.033 & 2.601 & \\
\hline 311 & SM01 & M-13/S2133 & 2.810 & 1.539 & 0.659 & 0.058 & 0.015 & 7.574 & 0.034 & 2.340 & 0.622 & 1.440 & & 0.448 & 24.592 & 0.031 & 2.625 & \\
\hline 311 & SM01 & M-13/S2133 & 2.940 & 1.567 & 0.672 & 0.054 & 0.015 & 7.575 & -0.057 & 2.358 & 0.626 & 1.465 & & 0.447 & 25.656 & 0.032 & 2.629 & \\
\hline 311 & SM01 & M-13/S2133 & 2.843 & 1.577 & 0.646 & 0.053 & 0.015 & 7.608 & -0.067 & 2.376 & 0.593 & 1.423 & & 0.444 & 25.738 & 0.034 & 2.651 & \\
\hline 311 & SM55 & M-13/S2133 & 0.001 & -0.018 & -0.039 & 0.000 & -0.003 & -0.187 & -0.129 & -0.045 & -0.007 & -0.014 & & -0.004 & 0.035 & 0.000 & 0.016 & . \\
\hline 311 & SM55 & M-13/S2133 & 0.080 & -0.008 & -0.022 & 0.003 & -0.001 & 0.117 & -0.145 & -0.046 & -0.005 & -0.008 & & -0.003 & 0.130 & 0.001 & 0.060 & \\
\hline 312 & ARGG & M-13/S2133 & 2.336 & 2.543 & 0.963 & 0.065 & -0.002 & 9.697 & 2.084 & 1.473 & 0.506 & 1.401 & & 0.788 & 22.557 & 0.669 & 0.081 & 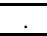 \\
\hline 312 & ARGG & M-13/S2133 & 2.380 & 2.674 & 0.989 & 0.066 & -0.001 & 9.959 & 2.057 & 1.463 & 0.506 & 1.428 & & 0.838 & 22.764 & 0.672 & 0.089 & \\
\hline 312 & SM01 & M-13/S2133 & 2.828 & 1.469 & 0.680 & 0.052 & 0.010 & 7.979 & -0.074 & 2.168 & 0.653 & 1.537 & & 0.446 & 24.700 & 0.033 & 2.691 & \\
\hline 312 & SM01 & M-13/S2133 & 2.762 & 1.411 & 0.699 & 0.051 & 0.011 & 7.887 & 0.371 & 2.137 & 0.691 & 1.539 & & 0.447 & 23.733 & 0.032 & 2.643 & \\
\hline 312 & SM01 & M-13/S2133 & 2.778 & 1.446 & 0.690 & 0.059 & 0.012 & 8.217 & -0.068 & 2.143 & 0.670 & 1.558 & & 0.462 & 24.297 & 0.032 & 2.659 & \\
\hline 312 & SM01 & M-13/S2133 & 2.859 & 1.419 & 0.701 & 0.054 & 0.037 & 8.182 & 0.387 & 2.049 & 0.655 & 1.561 & & 0.501 & 23.443 & 0.033 & 2.733 & \\
\hline 312 & SM01 & M-13/S2133 & 2.920 & 1.424 & 0.714 & 0.059 & 0.012 & 8.282 & 0.203 & 2.154 & 0.702 & 1.610 & & 0.478 & 24.245 & 0.033 & 2.783 & \\
\hline 312 & SM01 & M-13/S2133 & 2.785 & 1.402 & 0.686 & 0.052 & 0.012 & 7.973 & 0.057 & 2.167 & 0.668 & 1.546 & & 0.454 & 23.761 & 0.032 & 2.662 & \\
\hline 312 & SM55 & M-13/S2133 & -0.077 & 0.000 & -0.062 & 0.000 & -0.006 & 0.162 & -0.170 & -0.021 & -0.012 & 0.015 & & -0.012 & 0.300 & -0.008 & 0.027 & \\
\hline 312 & SM55 & M-13/S2133 & -0.065 & -0.019 & -0.043 & -0.006 & -0.004 & 0.077 & -0.183 & -0.032 & -0.013 & 0.009 & & -0.010 & 0.085 & -0.007 & 0.069 & \\
\hline 313 & ARGG & M-13/S2133 & 2.497 & 2.695 & 1.000 & 0.069 & 0.005 & 10.100 & 2.269 & 1.529 & 0.527 & 1.463 & & 0.851 & 23.419 & 0.697 & 0.031 & \\
\hline 313 & ARGG & M-13/S2133 & 2.493 & 2.612 & 0.994 & 0.067 & 0.006 & 9.911 & 2.113 & 1.449 & 0.509 & 1.426 & & 0.826 & 22.926 & 0.679 & 0.049 & \\
\hline 313 & SM01 & M-13/S2133 & 2.782 & 1.542 & 0.613 & 0.050 & 0.015 & 7.545 & 0.025 & 2.273 & 0.593 & 1.415 & & 0.437 & 25.319 & 0.040 & 2.395 & \\
\hline 313 & SM01 & M-13/S2133 & 2.854 & 1.490 & 0.667 & 0.050 & 0.017 & 7.756 & 0.525 & 2.320 & 0.657 & 1.502 & & 0.449 & 25.124 & 0.040 & 2.467 & \\
\hline 313 & SM01 & M-13/S2133 & 2.735 & 1.454 & 0.637 & 0.049 & 0.016 & 7.493 & 0.140 & 2.207 & 0.618 & 1.434 & & 0.437 & 24.466 & 0.039 & 2.350 & \\
\hline 313 & SM01 & $\mathrm{M}-13 / \mathrm{S} 2133$ & 2.875 & 1.467 & 0.622 & 0.049 & 0.016 & 7.665 & 0.271 & 2.270 & 0.589 & 1.395 & & 0.436 & 25.161 & 0.040 & 2.439 & \\
\hline 313 & SM01 & M-13/S2133 & 2.329 & 1.658 & 0.455 & 0.048 & 0.013 & 6.252 & 0.027 & 2.467 & 0.410 & 1.041 & & 0.354 & 27.801 & 0.042 & 1.886 & \\
\hline
\end{tabular}


Table A2. Fusion Measurement Data Set (continued)

\section{Revision 0}

\begin{tabular}{|c|c|c|c|c|c|c|c|c|c|c|c|c|c|c|c|c|c|c|}
\hline Batch & Type of Sample & ICP/ID & Al & B & $\mathbf{C a}$ & $\mathrm{Cr}$ & $\mathrm{Cu}$ & $\mathbf{F e}$ & $\mathbf{K}$ & $\mathbf{L i}$ & Mg & Mn & $\mathrm{Na}$ & $\mathrm{Ni}$ & $\mathrm{Si}$ & Ti & $\mathbf{U}$ & $\mathbf{Z r}$ \\
\hline 313 & SM01 & M-13/S2133 & 2.782 & 1.480 & 0.644 & 0.051 & 0.017 & 7.531 & -0.014 & 2.223 & 0.610 & 1.431 & & 0.438 & 24.793 & 0.039 & 2.420 & \\
\hline 313 & SM55 & M-13/S2133 & -0.028 & -0.032 & -0.036 & -0.005 & 0.001 & -0.054 & -0.120 & -0.043 & -0.009 & -0.021 & & -0.007 & -0.001 & 0.004 & -0.012 & . \\
\hline 313 & SM55 & $\mathrm{M}-13 / \mathrm{S} 2133$ & 0.038 & -0.011 & -0.026 & -0.003 & 0.003 & -0.018 & -0.151 & -0.045 & -0.010 & -0.018 & & 0.006 & 0.224 & 0.006 & 0.030 & \\
\hline 314 & ARGG & M-13/S2133 & 2.450 & 2.603 & 0.985 & 0.066 & 0.013 & 9.695 & 2.153 & 1.465 & 0.510 & 1.432 & & 0.812 & 22.513 & 0.689 & 0.063 & \\
\hline 314 & ARGG & M-13/S2133 & 2.437 & 2.625 & 0.955 & 0.068 & 0.000 & 9.866 & 2.047 & 1.428 & 0.522 & 1.458 & & 0.841 & 23.107 & 0.678 & 0.273 & 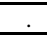 \\
\hline 314 & SM01 & M-13/S2133 & 2.563 & 1.262 & 0.619 & 0.046 & 0.011 & 6.949 & -0.044 & 1.994 & 0.609 & 1.370 & & 0.393 & 21.483 & 0.028 & 2.461 & \\
\hline 314 & SM01 & M-13/S2133 & 2.881 & 1.466 & 0.685 & 0.054 & 0.014 & 7.934 & 0.262 & 2.293 & 0.662 & 1.554 & & 0.449 & 24.954 & 0.031 & 2.755 & \\
\hline 314 & SM01 & M-13/S2133 & 2.799 & 1.483 & 0.669 & 0.058 & 0.013 & 7.866 & 0.014 & 2.272 & 0.662 & 1.538 & & 0.447 & 24.705 & 0.030 & 2.743 & \\
\hline 314 & SM01 & M-13/S2133 & 2.878 & 1.463 & 0.689 & 0.054 & 0.014 & 7.890 & 0.040 & 2.232 & 0.686 & 1.582 & & 0.457 & 24.615 & 0.031 & 2.845 & \\
\hline 314 & SM01 & M-13/S2133 & 2.996 & 1.457 & 0.699 & 0.057 & 0.015 & 8.241 & 0.098 & 2.186 & 0.683 & 1.604 & & 0.481 & 24.303 & 0.031 & 3.007 & \\
\hline 314 & SM01 & M-13/S2133 & 2.898 & 1.465 & 0.678 & 0.056 & 0.015 & 7.974 & 0.182 & 2.257 & 0.686 & 1.595 & & 0.461 & 24.866 & 0.032 & 2.881 & \\
\hline 314 & SM55 & $\mathrm{M}-13 / \mathrm{S} 2133$ & -0.024 & -0.019 & -0.034 & -0.003 & -0.004 & -0.075 & -0.091 & -0.016 & 0.000 & -0.003 & & -0.012 & 0.102 & -0.003 & 0.011 & \\
\hline 314 & SM55 & M-13/S2133 & 0.014 & -0.026 & -0.030 & 0.000 & -0.001 & -0.126 & -0.091 & -0.020 & 0.000 & -0.004 & & -0.004 & 0.050 & -0.004 & 0.303 & \\
\hline 315 & ARGG & M-13/S2133 & 2.330 & 2.484 & 0.981 & 0.059 & 0.001 & 9.320 & 2.086 & 1.439 & 0.485 & 1.352 & & 0.793 & 21.646 & 0.671 & -0.081 & \\
\hline 315 & SM01 & M-13/S2133 & 2.851 & 1.458 & 0.731 & 0.054 & 0.013 & 7.748 & -0.033 & 2.234 & 0.675 & 1.549 & & 0.449 & 23.961 & 0.040 & 2.490 &. \\
\hline 315 & SM01 & M-13/S2133 & 2.816 & 1.448 & 0.722 & 0.051 & 0.013 & 7.536 & -0.043 & 2.214 & 0.670 & 1.519 & & 0.440 & 24.264 & 0.041 & 2.415 & . \\
\hline 315 & SM01 & M-13/S2133 & 2.889 & 1.495 & 0.726 & 0.052 & 0.014 & 7.697 & $\begin{array}{ll}-0.029 \\
\end{array}$ & 2.253 & 0.657 & 1.526 & & 0.457 & 24.815 & 0.042 & 2.446 & . \\
\hline 315 & SM01 & M-13/S2133 & 2.954 & 1.446 & 0.768 & 0.057 & 0.013 & 7.902 & -0.045 & 2.244 & 0.694 & 1.607 & & 0.459 & 24.425 & 0.041 & 2.509 & \\
\hline 315 & SM01 & M-13/S2133 & 2.838 & 1.392 & 0.729 & 0.051 & 0.013 & 7.565 & -0.012 & 2.146 & 0.644 & 1.499 & & 0.437 & 23.151 & 0.038 & 2.433 & . \\
\hline 315 & SM01 & M-13/S2133 & 2.834 & 1.462 & 0.730 & 0.051 & 0.013 & 7.571 & -0.006 & 2.252 & 0.668 & 1.526 & & 0.448 & 24.021 & 0.039 & 2.449 & \\
\hline 315 & SM55 & $\mathrm{M}-13 / \mathrm{S} 2133$ & 0.006 & \begin{tabular}{l|l|}
-0.041 \\
\end{tabular} & -0.028 & -0.007 & -0.004 & -0.059 & -0.120 & -0.034 & -0.003 & 0.004 & & -0.004 & 0.097 & 0.003 & -0.186 &. \\
\hline 315 & SM55 & M-13/S2133 & 0.068 & -0.030 & -0.032 & -0.002 & -0.005 & -0.039 & -0.133 & -0.036 & -0.005 & 0.008 & & 0.003 & 0.134 & 0.005 & -0.157 & \\
\hline 316 & ARGG & $\mathrm{M}-13 / \mathrm{S} 2133$ & 2.351 & 2.582 & 0.966 & 0.055 & -0.003 & 9.795 & 2.112 & 1.457 & 0.499 & 1.401 & & 0.783 & 21.863 & 0.670 & -0.085 & \\
\hline 316 & ARGG & M-13/S2133 & 2.397 & 2.635 & 0.992 & 0.057 & -0.003 & 10.300 & 2.114 & 1.451 & 0.508 & 1.456 & & 0.830 & 22.501 & 0.671 & -0.106 & \\
\hline 316 & SM01 & M-13/S2133 & 2.746 & 1.434 & 0.690 & 0.041 & 0.009 & 7.770 & 0.409 & 2.233 & 0.672 & 1.532 & & 0.419 & 22.711 & 0.033 & 2.272 & \\
\hline 316 & SM01 & M-13/S2133 & 2.817 & 1.458 & 0.685 & 0.039 & 0.009 & 7.789 & -0.065 & 2.215 & 0.686 & 1.562 & & 0.425 & 23.709 & 0.036 & 2.315 & \\
\hline 316 & SM01 & M-13/S2133 & 2.755 & 1.486 & 0.666 & 0.040 & 0.008 & 7.941 & -0.066 & 2.284 & 0.650 & 1.519 & & 0.424 & 23.839 & 0.035 & 2.263 &. \\
\hline 316 & SM01 & M-13/S2133 & 2.805 & 1.435 & 0.686 & 0.041 & 0.008 & 7.915 & -0.067 & 2.201 & 0.663 & 1.567 & & 0.436 & 22.825 & 0.035 & 2.294 & \\
\hline 316 & SM01 & M-13/S2133 & 2.776 & 1.432 & 0.655 & 0.044 & 0.008 & 7.859 & -0.028 & 2.204 & 0.664 & 1.535 & & 0.442 & 23.209 & 0.034 & 2.268 & \\
\hline 316 & SM01 & M-13/S2133 & 2.819 & 1.504 & 0.620 & 0.041 & 0.008 & 7.864 & 0.421 & 2.283 & 0.558 & 1.418 & & 0.435 & 24.419 & 0.036 & 2.302 & \\
\hline 316 & SM55 & M-13/S2133 & -0.007 & -0.023 & -0.048 & -0.017 & -0.008 & -0.054 & -0.187 & -0.051 & -0.015 & -0.010 & & -0.021 & -0.243 & -0.004 & -0.168 & \\
\hline 316 & SM55 & $\mathrm{M}-13 / \mathrm{S} 2133$ & -0.015 & -0.022 & -0.060 & -0.018 & -0.010 & 0.004 & -0.178 & -0.043 & -0.014 & -0.006 & & -0.024 & -0.292 & -0.006 & -0.195 &. \\
\hline 317 & ARGG & M-13/S2133 & 2.459 & 2.622 & 1.015 & 0.065 & 0.000 & 9.913 & 2.280 & 1.477 & 0.518 & 1.441 & & 0.817 & 22.907 & 0.677 & 0.008 & \\
\hline 317 & ARGG & $\mathrm{M}-13 / \mathrm{S} 2133$ & 2.495 & 2.679 & 1.044 & 0.066 & 0.000 & 10.085 & 2.224 & 1.478 & 0.528 & 1.446 & & 0.819 & 23.054 & 0.699 & 0.018 & \\
\hline 317 & SM01 & M-13/S2133 & 2.870 & 1.394 & 0.735 & 0.052 & 0.013 & 7.895 & 0.005 & 2.141 & 0.700 & 1.606 & & 0.442 & 23.079 & 0.042 & 2.566 & \\
\hline 317 & SM01 & M-13/S2133 & 3.011 & 1.459 & 0.775 & 0.055 & 0.013 & 8.390 & -0.009 & 2.209 & 0.722 & 1.708 & & 0.472 & 24.009 & 0.044 & 2.731 & \\
\hline 317 & SM01 & M-13/S2133 & 3.047 & 1.440 & 0.779 & 0.055 & 0.014 & 8.361 & 0.019 & 2.213 & 0.721 & 1.650 & & 0.461 & 24.041 & 0.044 & 2.718 & \\
\hline 317 & SM01 & M-13/S2133 & 2.955 & 1.451 & 0.751 & 0.053 & 0.012 & 8.172 & 0.012 & 2.193 & 0.712 & 1.649 & & 0.454 & 23.625 & 0.044 & 2.642 & \\
\hline 317 & SM01 & M-13/S2133 & 3.047 & 1.444 & 0.798 & 0.056 & 0.014 & 8.366 & -0.002 & 2.212 & 0.745 & 1.684 & & 0.485 & 24.078 & 0.044 & 2.700 & \\
\hline 317 & SM01 & M-13/S2133 & 2.955 & 1.467 & 0.758 & 0.058 & 0.012 & 8.574 & 0.000 & 2.288 & 0.747 & 1.698 & & 0.469 & 24.066 & 0.043 & 2.686 & \\
\hline $\begin{array}{ll}317 \\
\end{array}$ & SM55 & $\mathrm{M}-13 / \mathrm{S} 2133$ & -0.010 & 0.007 & 0.019 & -0.004 & -0.004 & -0.037 & -0.049 & -0.034 & -0.008 & 0.000 & & -0.013 & -0.040 & 0.003 & -0.035 & \\
\hline 317 & SM55 & M-13/S2133 & 0.003 & 0.008 & -0.001 & -0.004 & -0.004 & -0.050 & -0.087 & -0.040 & -0.008 & 0.003 & & -0.012 & -0.008 & 0.005 & -0.013 & \\
\hline 318 & ARGG & $\mathrm{M}-13 / \mathrm{S} 2133$ & 2.416 & 2.608 & 0.986 & 0.060 & -0.005 & 9.817 & 2.162 & 1.455 & 0.508 & 1.425 & & 0.832 & 22.882 & 0.682 & 0.039 & 5 \\
\hline 318 & ARGG & M-13/S2133 & 2.444 & 2.659 & 0.993 & 0.060 & -0.005 & 9.851 & 2.145 & 1.456 & 0.515 & 1.445 & & 0.850 & 23.391 & 0.680 & 0.038 & \\
\hline 318 & SM01 & M-13/S2133 & 3.124 & 1.463 & 0.788 & 0.050 & 0.007 & 8.604 & 0.328 & 2.139 & 0.815 & 1.796 & & 0.511 & 24.558 & 0.044 & 2.694 & \\
\hline 318 & SM01 & M-13/S2133 & 3.050 & 1.491 & 0.739 & 0.054 & 0.007 & 8.446 & 0.185 & 2.172 & 0.771 & 1.739 & & 0.505 & 24.504 & 0.045 & 2.634 & \\
\hline 318 & SM01 & M-13/S2133 & 2.987 & 1.526 & 0.740 & 0.050 & 0.007 & 8.339 & 0.039 & 2.257 & 0.731 & 1.670 & & 0.485 & 24.946 & 0.048 & 2.514 & \\
\hline 318 & SM01 & M-13/S2133 & 2.990 & 1.444 & 0.724 & 0.047 & 0.006 & 8.058 & 0.439 & 2.167 & 0.748 & 1.658 & & 0.475 & 24.021 & 0.046 & 2.487 & \\
\hline 318 & SM01 & M-13/S2133 & 3.041 & 1.470 & 0.773 & 0.055 & 0.006 & 8.505 & 0.561 & 2.183 & 0.782 & 1.730 & & 0.508 & 24.385 & 0.046 & 2.582 & \\
\hline 318 & SM01 & M-13/S2133 & 3.075 & 1.461 & 0.735 & 0.051 & 0.007 & 8.410 & 0.655 & 2.188 & 0.736 & 1.659 & & 0.497 & 24.113 & 0.046 & 2.579 & \\
\hline
\end{tabular}


Table A2. Fusion Measurement Data Set (continued)

\section{Revision 0}

\begin{tabular}{|c|c|c|c|c|c|c|c|c|c|c|c|c|c|c|c|c|c|c|}
\hline Batch & Type of Sample & ICP/ID & Al & B & $\begin{array}{l}\mathbf{C a} \\
\end{array}$ & $\mathrm{Cr}$ & $\begin{array}{l}\mathbf{C u} \\
\end{array}$ & $\mathrm{Fe}$ & $\mathbf{K}$ & $\mathrm{Li}$ & $\mathrm{Mg}$ & Mn & $\mathrm{Na}$ & $\mathrm{Ni}$ & Si & Ti & $\mathbf{U}$ & $\overline{Z \mathbf{Z r}}$ \\
\hline 318 & SM55 & M-13/S2133 & 0.031 & 0.017 & -0.049 & -0.014 & -0.014 & 0.084 & -0.013 & -0.006 & -0.004 & 0.025 & & -0.001 & 0.794 & 0.008 & 0.001 & \\
\hline 318 & SM55 & M-13/S2133 & 0.051 & 0.014 & -0.030 & -0.014 & -0.011 & 0.086 & -0.037 & -0.016 & -0.003 & 0.025 & & 0.000 & 0.776 & 0.010 & 0.003 & \\
\hline 319 & ARGG & M-13/S2133 & 2.392 & 2.575 & 0.947 & 0.061 & 0.005 & 9.658 & 2.097 & 1.451 & 0.503 & 1.400 & & 0.792 & 23.378 & 0.674 & 0.040 & . \\
\hline 319 & ARGG & M-13/S2133 & 2.396 & 2.590 & 0.949 & 0.074 & 0.007 & 9.718 & 2.096 & 1.464 & 0.501 & 1.413 & & 0.814 & 23.433 & 0.670 & 0.055 & \\
\hline 319 & SM01 & M-13/S2133 & 2.775 & 1.518 & 0.631 & 0.043 & 0.017 & 7.313 & -0.023 & 2.262 & 0.588 & 1.372 & & 0.400 & 26.150 & 0.041 & 2.309 & \\
\hline 319 & SM01 & M-13/S2133 & 2.083 & 1.100 & 0.510 & 0.030 & 0.013 & 5.520 & 18.768 & 1.659 & 0.533 & 1.187 & & 0.315 & 19.320 & 0.032 & 1.696 & \\
\hline 319 & SM01 & M-13/S2133 & 2.728 & 1.545 & 0.630 & 0.043 & 0.018 & 7.346 & 0.115 & 2.302 & 0.557 & 1.350 & & 0.425 & 26.070 & 0.042 & 2.276 & \\
\hline 319 & SM01 & M-13/S2133 & 2.352 & 1.221 & 0.588 & 0.039 & 0.016 & 6.226 & 12.266 & 1.847 & 0.568 & 1.275 & & 0.361 & 20.882 & 0.035 & 1.975 & \\
\hline 319 & SM01 & M-13/S2133 & 2.759 & 1.457 & 0.675 & 0.043 & 0.018 & 7.142 & 1.800 & 2.186 & 0.620 & 1.416 & & 0.428 & 23.923 & 0.039 & 2.273 & \\
\hline 319 & SM01 & M-13/S2133 & 2.797 & 1.545 & 0.658 & 0.045 & 0.017 & 7.443 & -0.025 & 2.245 & 0.619 & 1.440 & & 0.426 & 25.434 & 0.042 & 2.369 & \\
\hline 319 & SM55 & M-13/S2133 & 0.009 & 0.000 & -0.050 & -0.009 & 0.004 & -0.082 & -0.092 & -0.004 & 0.000 & 0.007 & & -0.007 & 0.273 & 0.006 & 0.019 & \\
\hline 319 & SM55 & M-13/S2133 & -0.007 & 0.006 & -0.060 & -0.009 & 0.001 & -0.048 & -0.078 & 0.004 & 0.001 & 0.006 & & -0.011 & 0.232 & 0.006 & 0.006 & . \\
\hline 320 & ARGG & M-14/S2150 & 2.394 & 2.462 & 0.973 & 0.064 & -0.013 & 9.337 & 1.952 & 1.462 & 0.485 & 1.375 & & 0.760 & 22.602 & 0.669 & 0.031 & \\
\hline 320 & ARGG & M-14/S2150 & 2.370 & 2.510 & 0.954 & 0.065 & 0.000 & 9.556 & 1.922 & 1.458 & 0.502 & 1.391 & & 0.767 & 23.380 & 0.668 & 0.031 & \\
\hline 320 & SM01 & M-14/S2150 & 2.971 & 1.393 & 0.699 & 0.051 & 0.016 & 7.713 & -0.087 & 2.188 & 0.699 & 1.552 & & 0.448 & 24.496 & 0.044 & 2.876 & \\
\hline 320 & SM01 & M-14/S2150 & 3.010 & 1.404 & 0.695 & 0.051 & -0.050 & 7.820 & 0.012 & 2.190 & 0.686 & 1.561 & . & 0.441 & 24.080 & 0.042 & 2.904 & . \\
\hline 320 & SM01 & M-14/S2150 & 3.044 & 1.406 & 0.692 & 0.054 & 0.014 & 7.911 & 0.022 & 2.210 & 0.698 & 1.560 & & 0.442 & 24.734 & 0.043 & 2.889 & \\
\hline 320 & SM01 & $\mathrm{M}-14 / \mathrm{S} 2150$ & 3.001 & 1.438 & 0.695 & 0.053 & 0.015 & 7.993 & -0.081 & 2.241 & 0.689 & 1.573 & & 0.452 & 24.764 & 0.044 & 2.862 & \\
\hline 320 & SM01 & M-14/S2150 & 2.942 & 1.418 & 0.698 & 0.052 & 0.012 & 7.778 & -0.049 & 2.212 & 0.699 & 1.570 & & 0.432 & 24.397 & 0.045 & 2.867 & 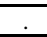 \\
\hline 320 & SM01 & M-14/S2150 & 2.405 & 1.135 & 0.582 & 0.043 & 0.011 & 6.317 & -0.092 & 1.766 & 0.563 & 1.281 & & 0.346 & 19.767 & 0.035 & 2.282 & \\
\hline 320 & SM55 & M-14/S2150 & 0.049 & -0.008 & -0.063 & -0.001 & -0.019 & 0.058 & -0.119 & 0.032 & 0.005 & 0.015 & & -0.016 & 0.242 & 0.009 & -0.061 & . \\
\hline 320 & SM55 & M-14/S2150 & 0.060 & -0.007 & -0.058 & 0.000 & -0.003 & 0.057 & -0.128 & 0.024 & 0.006 & 0.014 & & -0.011 & 0.259 & 0.010 & -0.061 & \\
\hline 321 & ARGG & M-14/S2150 & 2.416 & 2.570 & 0.956 & 0.064 & -0.004 & 9.603 & 2.303 & 1.490 & 0.503 & 1.402 & & 0.793 & 22.846 & 0.667 & -0.019 & 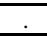 \\
\hline 321 & ARGG & M-14/S2150 & 2.332 & 2.441 & 0.945 & 0.066 & -0.005 & 9.306 & 2.324 & 1.420 & 0.488 & 1.347 & & 0.750 & 22.762 & 0.647 & -0.009 & \\
\hline 321 & SM01 & M-14/S2150 & 2.778 & 1.474 & 0.672 & 0.052 & 0.005 & 7.466 & 0.214 & 2.348 & 0.652 & 1.506 & & 0.438 & 25.409 & 0.038 & 2.633 & \\
\hline 321 & SM01 & M-14/S2150 & 2.749 & 1.450 & 0.687 & 0.053 & 0.005 & 7.212 & 0.282 & 2.236 & 0.646 & 1.491 & & 0.426 & 24.480 & 0.037 & 2.638 & \\
\hline 321 & SM01 & M-14/S2150 & 2.735 & 1.408 & 0.597 & 0.046 & 0.005 & 6.864 & 0.263 & 2.327 & 0.585 & 1.326 & & 0.383 & 24.063 & 0.033 & 2.489 & \\
\hline 321 & SM01 & M-14/S2150 & 2.677 & 1.356 & 0.645 & 0.049 & 0.007 & 7.017 & 0.329 & 2.142 & 0.605 & 1.393 & & 0.412 & 22.711 & 0.037 & 2.489 & \\
\hline 321 & SM01 & M-14/S2150 & 2.917 & 1.495 & 0.696 & 0.049 & 0.008 & 7.525 & 0.249 & 2.361 & 0.653 & 1.512 & & 0.426 & 25.786 & 0.038 & 2.734 & \\
\hline 321 & SM01 & M-14/S2150 & 2.751 & 1.478 & 0.670 & 0.047 & 0.006 & 7.314 & 0.374 & 2.308 & 0.645 & 1.477 & & 0.425 & 25.018 & 0.039 & 2.532 & \\
\hline 321 & SM55 & M-14/S2150 & 0.007 & 0.008 & -0.010 & 0.003 & -0.010 & -0.035 & 0.173 & 0.017 & 0.016 & 0.020 & & 0.003 & 0.029 & 0.004 & -0.058 & \\
\hline 321 & SM55 & M-14/S2150 & 0.028 & 0.003 & -0.027 & -0.003 & -0.012 & -0.065 & 0.515 & 0.016 & 0.013 & 0.018 & & 0.003 & 0.006 & 0.003 & 0.037 & . \\
\hline 322 & ARGG & M-14/S2150 & 2.335 & 2.455 & 0.926 & 0.081 & 0.009 & 9.528 & 2.056 & 1.411 & 0.478 & 1.346 & & 0.778 & 22.446 & 0.658 & 0.016 & \\
\hline 322 & ARGG & M-14/S2150 & 2.185 & 2.315 & 0.754 & 0.077 & 0.001 & 9.451 & 1.754 & 1.358 & 0.443 & 1.258 & & 0.733 & 21.237 & 0.598 & -0.185 & 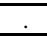 \\
\hline 322 & SM01 & M-14/S2150 & 2.540 & 1.248 & 0.588 & 0.031 & 0.010 & 6.784 & -0.063 & 1.887 & 0.599 & 1.356 & & 0.366 & 21.183 & 0.034 & 2.302 & \\
\hline 322 & SM01 & M-14/S2150 & 2.878 & 1.442 & 0.693 & 0.065 & 0.015 & 8.252 & -0.079 & 2.232 & 0.709 & 1.612 & & 0.442 & 24.447 & 0.039 & 2.549 & \\
\hline 322 & SM01 & M-14/S2150 & 2.502 & 1.207 & 0.533 & 0.032 & 0.014 & 6.676 & -0.108 & 1.889 & 0.585 & 1.328 & & 0.370 & 21.156 & 0.033 & 2.136 & \\
\hline 322 & SM01 & M-14/S2150 & 2.920 & 1.415 & 0.675 & 0.071 & 0.018 & 8.236 & -0.134 & 2.210 & 0.691 & 1.584 & & 0.447 & 24.209 & 0.042 & 2.542 & \\
\hline 322 & SM01 & M-14/S2150 & 2.628 & 1.247 & 0.635 & 0.040 & 0.012 & 6.966 & 0.094 & 1.957 & 0.627 & 1.419 & & 0.391 & 21.826 & 0.034 & 2.336 & \\
\hline 322 & SM01 & $\mathrm{M}-14 / \mathrm{S} 2150$ & 2.948 & 1.498 & 0.693 & 0.050 & 0.014 & 7.975 & -0.047 & 2.328 & 0.703 & 1.627 & & 0.457 & 25.829 & 0.040 & 2.652 & \\
\hline 322 & SM55 & M-14/S2150 & -0.007 & 0.011 & -0.082 & -0.017 & -0.001 & 0.036 & -0.125 & -0.003 & 0.004 & 0.026 & & 0.000 & -0.047 & 0.007 & -0.053 & \\
\hline 322 & SM55 & M-14/S2150 & -0.060 & 0.015 & -0.172 & -0.014 & -0.006 & -0.018 & -0.365 & -0.015 & 0.004 & 0.022 & & -0.014 & -0.049 & 0.003 & -0.234 & \\
\hline 323 & ARGG & M-14/S2150 & 2.414 & 2.540 & 0.946 & 0.054 & 0.000 & 9.492 & 2.202 & 1.467 & 0.497 & 1.402 & & 0.771 & 22.621 & 0.671 & -0.060 & \\
\hline 323 & ARGG & $\mathrm{M}-14 / \mathrm{S} 2150$ & 2.406 & 2.571 & 0.990 & 0.063 & 0.001 & 9.571 & 2.224 & 1.502 & 0.496 & 1.387 & & 0.765 & 23.004 & 0.675 & -0.099 & \\
\hline 323 & ARGG & M-13/S2133 & 2.432 & 2.632 & 1.027 & 0.056 & 0.008 & 9.777 & 2.102 & 1.457 & 0.499 & 1.431 & & 0.773 & 22.787 & 0.688 & -0.026 & \\
\hline 323 & ARGG & M-13/S2133 & 2.406 & 2.697 & 0.990 & 0.063 & 0.010 & 9.567 & 2.220 & 1.468 & 0.491 & 1.407 & & 0.807 & 22.186 & 0.682 & 0.016 & \\
\hline 323 & SM01 & M-14/S2150 & 2.786 & 1.339 & 0.647 & 0.037 & 0.010 & 7.272 & 0.127 & 2.097 & 0.639 & 1.470 & & 0.418 & 22.810 & 0.039 & 2.601 & \\
\hline 323 & SM01 & M-14/S2150 & 2.648 & 1.248 & 0.606 & 0.033 & 0.013 & 6.818 & 0.090 & 2.039 & 0.618 & 1.320 & & 0.373 & 20.414 & 0.034 & 2.530 & \\
\hline 323 & SM01 & $\mathrm{M}-14 / \mathrm{S} 2150$ & 2.701 & 1.256 & 0.613 & 0.031 & 0.011 & 6.965 & 0.000 & 1.991 & 0.615 & 1.425 & & 0.390 & 22.055 & 0.038 & 2.600 & \\
\hline 323 & SM01 & M-14/S2150 & 2.763 & 1.271 & 0.634 & 0.031 & 0.010 & 7.057 & 0.034 & 2.017 & 0.618 & 1.442 & & 0.398 & 22.185 & 0.037 & 2.621 & \\
\hline
\end{tabular}


Table A2. Fusion Measurement Data Set (continued)

\section{Revision 0}

\begin{tabular}{|c|c|c|c|c|c|c|c|c|c|c|c|c|c|c|c|c|c|c|}
\hline Batch & Type of Sample & ICP/ID & Al & B & $\mathbf{C a}$ & $\mathrm{Cr}$ & $\mathbf{C u}$ & $\mathbf{F e}$ & $\mathbf{K}$ & $\mathbf{L i}$ & Mg & Mn & $\mathrm{Na}$ & $\mathrm{Ni}$ & $\mathrm{Si}$ & Ti & $\mathbf{U}$ & $\overline{Z \mathbf{Z r}}$ \\
\hline 323 & SM01 & M-14/S2150 & 2.625 & 1.212 & 0.610 & 0.031 & 0.009 & 6.836 & 0.020 & 1.914 & 0.596 & 1.387 & & 0.376 & 21.338 & 0.036 & 2.485 & \\
\hline 323 & SM01 & M-14/S2150 & 2.898 & 1.383 & 0.714 & 0.037 & 0.013 & 7.481 & 0.081 & 2.153 & 0.666 & 1.507 & & 0.422 & 23.715 & 0.039 & 2.685 & . \\
\hline 323 & SM01 & M-13/S2133 & 2.673 & 1.456 & 0.655 & 0.056 & 0.018 & 7.546 & 0.075 & 2.033 & 0.642 & 1.531 & & 0.429 & 23.700 & 0.039 & 2.205 & \\
\hline 323 & SM01 & M-13/S2133 & 2.897 & 1.354 & 0.835 & 0.048 & 0.022 & 7.402 & 0.183 & 2.209 & 0.666 & 1.535 & & 0.414 & 22.182 & 0.039 & 2.370 & \\
\hline 323 & SM01 & M-13/S2133 & 2.729 & 1.389 & 0.684 & 0.050 & 0.022 & 7.287 & 0.074 & 2.168 & 0.637 & 1.498 & & 0.408 & 25.025 & 0.042 & 2.320 & 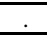 \\
\hline 323 & SM01 & M-13/S2133 & 2.758 & 1.428 & 0.671 & 0.053 & 0.022 & 7.351 & 0.065 & 2.074 & 0.650 & 1.525 & & 0.409 & 24.991 & 0.041 & 2.350 & \\
\hline 323 & SM01 & M-13/S2133 & 2.848 & 1.383 & 0.796 & 0.046 & 0.020 & 7.484 & 0.169 & 2.178 & 0.662 & 1.546 & & 0.410 & 22.340 & 0.038 & 2.290 & \\
\hline 323 & SM01 & M-13/S2133 & 2.734 & 1.410 & 0.661 & 0.051 & 0.020 & 7.399 & 0.076 & 2.114 & 0.624 & 1.517 & & 0.410 & 24.543 & 0.041 & 2.340 & \\
\hline 323 & SM55 & M-14/S2150 & -0.047 & 0.012 & -0.129 & -0.004 & -0.003 & -0.069 & 0.124 & 0.008 & 0.004 & 0.022 & & -0.010 & 0.073 & 0.001 & -0.107 & \\
\hline 323 & SM55 & $\mathrm{M}-14 / \mathrm{S} 2150$ & -0.050 & 0.010 & -0.090 & -0.012 & -0.006 & -0.080 & 0.360 & 0.011 & 0.004 & 0.022 & & -0.017 & 0.090 & 0.001 & -0.181 & \\
\hline 323 & SM55 & M-13/S2133 & -0.023 & -0.007 & -0.031 & -0.004 & 0.004 & -0.239 & 0.043 & -0.012 & 0.000 & -0.007 & & -0.012 & -0.453 & 0.000 & -0.085 & \\
\hline 323 & SM55 & M-13/S2133 & 0.006 & -0.008 & -0.028 & 0.006 & 0.007 & -0.175 & 0.025 & -0.017 & -0.001 & -0.006 & & -0.004 & -0.350 & 0.001 & -0.055 & \\
\hline 324 & ARGG & M-13/S2133 & 2.334 & 2.516 & 0.901 & 0.058 & -0.002 & 9.036 & 2.079 & 1.390 & 0.472 & 1.337 & & 0.765 & 22.632 & 0.664 & 0.065 & \\
\hline 324 & ARGG & M-13/S2133 & 2.325 & 2.497 & 0.913 & 0.059 & -0.003 & 9.409 & 2.131 & 1.433 & 0.486 & 1.372 & & 0.763 & 22.677 & 0.648 & -0.003 & \\
\hline 324 & SM01 & M-13/S2133 & 2.766 & 1.500 & 0.612 & 0.043 & 0.008 & 7.054 & 0.084 & 2.360 & 0.621 & 1.408 & & 0.401 & 24.093 & 0.045 & 2.387 &. \\
\hline 324 & SM01 & M-13/S2133 & 2.563 & 1.474 & 0.615 & 0.041 & 0.007 & 6.862 & 0.297 & 2.243 & 0.595 & 1.372 & & 0.364 & 22.912 & 0.042 & 2.319 & \\
\hline 324 & SM01 & M-13/S2133 & 2.730 & 1.558 & 0.669 & 0.041 & 0.007 & 7.275 & 0.022 & 2.336 & 0.615 & 1.438 & & 0.411 & 24.661 & 0.044 & 2.414 & \\
\hline 324 & SM01 & M-13/S2133 & 2.761 & 1.516 & 0.688 & 0.042 & 0.009 & 7.353 & 0.040 & 2.284 & 0.650 & 1.468 & & 0.413 & 24.879 & 0.045 & 2.499 & \\
\hline 324 & SM01 & M-13/S2133 & 2.944 & 1.634 & 0.689 & 0.045 & 0.011 & 7.596 & 0.045 & 2.326 & 0.662 & 1.556 & & 0.431 & 27.039 & 0.046 & 2.551 & . \\
\hline 324 & SM01 & M-13/S2133 & 2.792 & 1.615 & 0.682 & 0.047 & 0.012 & 7.568 & 0.042 & 2.385 & 0.653 & 1.513 & & 0.431 & 25.446 & 0.046 & 2.545 & \\
\hline 324 & SM55 & $\mathrm{M}-13 / \mathrm{S} 2133$ & 0.006 & 0.008 & -0.022 & -0.010 & -0.009 & -0.162 & -0.027 & 0.000 & -0.009 & -0.003 & & -0.016 & -0.095 & 0.011 & -0.042 &. \\
\hline 324 & SM55 & M-13/S2133 & 0.031 & 0.007 & -0.048 & 0.003 & -0.007 & -0.092 & -0.056 & 0.001 & -0.009 & 0.001 & & -0.003 & 0.044 & 0.013 & 0.017 & \\
\hline 325 & ARGG & $\mathrm{M}-14 / \mathrm{S} 2150$ & 2.323 & 2.616 & 0.941 & 0.122 & 0.001 & 9.728 & 2.160 & 1.461 & 0.504 & 1.446 & & 0.817 & 22.622 & 0.664 & -0.111 & \\
\hline 325 & ARGG & M-14/S2150 & 2.409 & 2.570 & 0.961 & 0.069 & 0.002 & 9.592 & 2.233 & 1.468 & 0.504 & 1.407 & & 0.777 & 22.957 & 0.672 & -0.180 & \\
\hline 325 & SM01 & M-14/S2150 & 2.681 & 1.496 & 0.646 & 0.061 & 0.011 & 7.136 & 0.096 & 2.253 & 0.618 & 1.388 & & 0.409 & 24.472 & 0.044 & 2.557 & \\
\hline 325 & SM01 & M-14/S2150 & 2.982 & 1.557 & 0.713 & 0.066 & 0.013 & 8.104 & 0.329 & 2.315 & 0.681 & 1.547 & & 0.448 & 25.457 & 0.046 & 2.752 & \\
\hline 325 & SM01 & M-14/S2150 & 2.823 & 1.570 & 0.689 & 0.054 & 0.013 & 7.626 & 0.437 & 2.391 & 0.684 & 1.488 & & 0.428 & 26.309 & 0.046 & 2.669 & 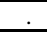 \\
\hline 325 & SM01 & M-14/S2150 & 2.772 & 1.537 & 0.648 & 0.055 & 0.011 & 7.586 & -0.057 & 2.326 & 0.633 & 1.463 & & 0.427 & 25.207 & 0.044 & 2.676 & \\
\hline 325 & SM01 & $\mathrm{M}-14 / \mathrm{S} 2150$ & 2.646 & 1.547 & 0.639 & 0.051 & 0.011 & 7.184 & -0.026 & 2.245 & 0.627 & 1.441 & & 0.406 & 23.875 & 0.044 & 2.434 & \\
\hline 325 & SM01 & $\mathrm{M}-14 / \mathrm{S} 2150$ & 2.717 & 1.493 & 0.664 & 0.052 & 0.012 & 7.293 & -0.031 & 2.231 & 0.628 & 1.446 & & 0.418 & 23.733 & 0.042 & 2.559 & \\
\hline 325 & SM55 & M-14/S2150 & -0.001 & 0.007 & 0.017 & 0.018 & -0.001 & 0.253 & 0.029 & 0.022 & 0.018 & 0.016 & & 0.012 & 0.089 & 0.005 & -0.147 & \\
\hline 325 & SM55 & $\mathrm{M}-14 / \mathrm{S} 2150$ & -0.044 & 0.007 & -0.090 & -0.003 & -0.005 & 0.126 & -0.220 & 0.018 & 0.003 & 0.000 & & -0.014 & 0.072 & 0.005 & -0.340 &. \\
\hline 326 & ARGG & M-14/S2150 & 2.264 & 2.382 & 0.921 & 0.056 & -0.002 & 9.120 & 2.069 & 1.390 & 0.470 & 1.322 & & 0.742 & 22.466 & 0.639 & -0.061 & \\
\hline 326 & ARGG & $\mathrm{M}-14 / \mathrm{S} 2150$ & 2.324 & 2.557 & 0.967 & 0.052 & -0.005 & 9.067 & 2.435 & 1.431 & 0.473 & 1.364 & & 0.763 & 21.455 & 0.647 & -0.071 & \\
\hline 326 & ARGG & M-14/S2150 & 2.312 & 2.354 & 0.930 & 0.054 & -0.008 & 8.956 & 2.069 & 1.390 & 0.469 & 1.286 & & 0.723 & 21.628 & 0.635 & -0.019 & \\
\hline 326 & ARGG & $\mathrm{M}-14 / \mathrm{S} 2150$ & 2.373 & 2.484 & 0.972 & 0.056 & 0.003 & 9.475 & 2.435 & 1.431 & 0.485 & 1.374 & & 0.772 & 22.235 & 0.661 & 0.094 & \\
\hline 326 & SM01 & M-14/S2150 & 2.740 & 1.413 & 0.694 & 0.038 & 0.007 & 7.316 & 0.215 & 2.240 & 0.645 & 1.468 & & 0.403 & 23.249 & 0.038 & 2.671 & \\
\hline 326 & SM01 & M-14/S2150 & 2.746 & 1.454 & 0.650 & 0.039 & 0.007 & 7.172 & 0.012 & 2.278 & 0.621 & 1.444 & & 0.412 & 23.314 & 0.038 & 2.568 & \\
\hline 326 & SM01 & M-14/S2150 & 2.776 & 1.390 & 0.672 & 0.037 & 0.006 & 7.154 & 0.206 & 2.148 & 0.642 & 1.468 & & 0.421 & 22.841 & 0.036 & 2.599 & \\
\hline 326 & SM01 & M-14/S2150 & 2.496 & 1.270 & 0.597 & 0.032 & 0.003 & 6.460 & 0.166 & 1.966 & 0.595 & 1.356 & & 0.369 & 20.704 & 0.032 & 2.352 & \\
\hline 326 & SM01 & $\mathrm{M}-14 / \mathrm{S} 2150$ & 3.033 & 1.543 & 0.766 & 0.044 & 0.007 & 7.949 & $\begin{array}{ll}0.349 \\
\end{array}$ & 2.474 & 0.726 & 1.614 & & 0.455 & 24.446 & 0.043 & 2.923 & \\
\hline 326 & SM01 & & 2.396 & 1.229 & 0.571 & 0.032 & 0.008 & 6.097 & -0.028 & 1.903 & 0.564 & 1.296 & & 0.355 & 19.870 & 0.032 & 2.219 & \\
\hline 326 & SM01 & $\mathrm{M}-14 / \mathrm{S} 2150$ & 2.787 & 1.429 & 0.711 & 0.040 & 0.013 & 7.369 & 0.215 & 2.240 & 0.657 & 1.486 & & 0.407 & 24.384 & 0.042 & 2.694 & 5 \\
\hline 326 & SM01 & M-14/S2150 & 3.025 & 1.508 & 0.779 & 0.049 & 0.016 & 8.188 & 0.349 & 2.474 & 0.729 & 1.614 & & 0.447 & 25.821 & 0.046 & 3.001 & \\
\hline 326 & SM01 & $\mathrm{M}-14 / \mathrm{S} 2150$ & 2.367 & 1.211 & 0.586 & 0.033 & 0.017 & 6.378 & -0.028 & 1.903 & 0.575 & 1.321 & & 0.360 & 20.699 & 0.037 & 2.353 & \\
\hline 326 & SM01 & M-14/S2150 & 2.762 & 1.468 & 0.675 & 0.042 & 0.015 & 7.404 & 0.012 & 2.278 & 0.622 & 1.431 & & 0.425 & 24.058 & 0.043 & 2.644 & \\
\hline 326 & SM01 & M-14/S2150 & 2.764 & 1.378 & 0.684 & 0.040 & 0.014 & 7.498 & 0.206 & 2.148 & 0.651 & 1.459 & & 0.413 & 23.673 & 0.042 & 2.720 & \\
\hline 326 & SM01 & M-14/S2150 & 2.533 & 1.271 & 0.638 & 0.036 & 0.013 & 6.686 & 0.166 & 1.966 & 0.601 & 1.335 & & 0.377 & 21.733 & 0.037 & 2.505 & \\
\hline 326 & SM55 & M-14/S2150 & 0.004 & -0.014 & -0.017 & -0.009 & -0.009 & 0.089 & 0.056 & -0.004 & 0.004 & 0.010 & & -0.013 & 0.062 & 0.001 & -0.053 & \\
\hline 326 & SM55 & M-14/S2150 & -0.024 & $\begin{array}{ll}-0.016 \\
\end{array}$ & $\begin{array}{ll}-0.038 \\
\end{array}$ & -0.015 & -0.011 & 0.050 & 0.138 & -0.007 & 0.004 & 0.009 & & -0.024 & 0.073 & 0.001 & -0.194 & \\
\hline
\end{tabular}


Table A2. Fusion Measurement Data Set (continued)

\section{Revision 0}

\begin{tabular}{|c|c|c|c|c|c|c|c|c|c|c|c|c|c|c|c|c|c|c|}
\hline Batch & Type of Sample & ICP/ID & Al & B & $\mathbf{C a}$ & $\mathrm{Cr}$ & $\mathbf{C u}$ & $\mathbf{F e}$ & $\mathbf{K}$ & $\mathbf{L i}$ & Mg & Mn & $\mathrm{Na}$ & $\mathrm{Ni}$ & $\mathrm{Si}$ & Ti & $\mathbf{U}$ & $\overline{Z \mathbf{Z r}}$ \\
\hline 327 & ARGG & M-14/S2150 & 2.422 & 2.501 & 0.951 & 0.061 & -0.001 & 9.463 & 2.334 & 1.434 & 0.484 & 1.393 & & 0.783 & 22.514 & 0.672 & -0.092 & \\
\hline 327 & ARGG & M-14/S2150 & 2.393 & 2.503 & 0.944 & 0.061 & -0.001 & 9.685 & 2.161 & 1.474 & 0.501 & 1.405 & & 0.796 & 23.305 & 0.686 & -0.101 & . \\
\hline 327 & SM01 & $\mathrm{M}-14 / \mathrm{S} 2150$ & 2.759 & 1.424 & 0.674 & 0.046 & 0.012 & 7.415 & -0.016 & 2.224 & 0.642 & 1.528 & & 0.434 & 23.825 & 0.040 & 2.667 & \\
\hline 327 & SM01 & M-14/S2150 & 3.160 & 1.583 & 0.769 & 0.050 & 0.014 & 8.561 & -0.035 & 2.586 & 0.741 & 1.690 & & 0.469 & 27.044 & 0.045 & 2.994 & \\
\hline 327 & SM01 & M-14/S2150 & 2.875 & 1.498 & 0.708 & 0.047 & 0.017 & 7.914 & -0.035 & 2.346 & 0.682 & 1.585 & & 0.440 & 24.897 & 0.041 & 2.793 & 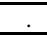 \\
\hline 327 & SM01 & M-14/S2150 & 2.751 & 1.439 & 0.686 & 0.046 & 0.011 & 7.638 & 0.127 & 2.219 & 0.667 & 1.537 & & 0.429 & 24.010 & 0.038 & 2.672 & \\
\hline 327 & SM01 & M-14/S2150 & 2.361 & 1.222 & 0.564 & 0.038 & 0.008 & 6.448 & 0.007 & 1.906 & 0.551 & 1.304 & & 0.356 & 20.138 & 0.032 & 2.210 & \\
\hline 327 & SM01 & M-14/S2150 & 2.934 & 1.482 & 0.709 & 0.049 & 0.012 & 7.941 & 0.007 & 2.314 & 0.682 & 1.587 & & 0.454 & 24.802 & 0.042 & 2.737 & \\
\hline 327 & SM55 & M-14/S2150 & -0.028 & 0.000 & -0.057 & -0.003 & 0.000 & 0.085 & 0.107 & -0.009 & 0.005 & 0.013 & & -0.009 & 0.175 & 0.004 & -0.076 & \\
\hline 327 & SM55 & $\mathrm{M}-14 / \mathrm{S} 2150$ & -0.033 & 0.012 & -0.118 & -0.003 & -0.008 & 0.128 & -0.133 & -0.014 & 0.003 & 0.011 & & -0.004 & 0.278 & 0.003 & -0.175 & \\
\hline 328 & ARGG & M-13/S2133 & 2.336 & 2.704 & 0.991 & 0.072 & 0.001 & 10.257 & 2.245 & 1.483 & 0.529 & 1.479 & & 0.784 & 23.263 & 0.664 & -0.006 & \\
\hline 328 & ARGG & M-13/S2133 & 2.325 & 2.673 & 0.974 & 0.073 & -0.001 & 9.847 & 2.197 & 1.457 & 0.533 & 1.449 & & 0.778 & 23.088 & 0.658 & -0.031 & \\
\hline 328 & SM01 & M-13/S2133 & 2.794 & 1.527 & 0.718 & 0.058 & 0.011 & 8.096 & 0.062 & 2.334 & 0.664 & 1.574 & & 0.434 & 24.780 & 0.043 & 2.567 & \\
\hline 328 & SM01 & M-13/S2133 & 2.802 & 1.522 & 0.689 & 0.059 & 0.012 & 8.201 & 0.083 & 2.328 & 0.673 & 1.594 & & 0.446 & 24.757 & 0.043 & 2.617 & \\
\hline 328 & SM01 & M-13/S2133 & 2.707 & 1.624 & 0.686 & 0.057 & 0.010 & 7.983 & 0.037 & 2.339 & 0.655 & 1.560 & & 0.423 & 25.417 & 0.047 & 2.439 &. \\
\hline 328 & SM01 & M-13/S2133 & 2.645 & 1.542 & 0.673 & 0.055 & 0.010 & 7.482 & 0.049 & 2.328 & 0.648 & 1.480 & & 0.412 & 24.722 & 0.042 & 2.406 & \\
\hline 328 & SM01 & M-13/S2133 & 2.730 & 1.525 & 0.679 & 0.059 & 0.010 & 8.217 & 0.038 & 2.263 & 0.690 & 1.601 & & 0.436 & 23.791 & 0.041 & 2.537 & \\
\hline 328 & SM01 & M-13/S2133 & 2.716 & 1.539 & 0.647 & 0.056 & 0.010 & 7.941 & 0.035 & 2.234 & 0.657 & 1.544 & & 0.423 & 23.335 & 0.041 & 2.469 & \\
\hline 328 & SM55 & M-13/S2133 & -0.031 & 0.011 & -0.032 & 0.004 & -0.003 & 0.051 & -0.013 & -0.024 & 0.010 & 0.005 & & -0.008 & 0.025 & 0.006 & -0.103 & . \\
\hline 328 & SM55 & M-13/S2133 & 0.003 & 0.005 & -0.024 & 0.003 & -0.006 & 0.021 & -0.008 & -0.021 & 0.009 & 0.010 & & -0.009 & 0.078 & 0.008 & $\begin{array}{ll}-0.081 \\
\end{array}$ & \\
\hline 329 & ARGG & $\mathrm{M}-13 / \mathrm{S} 2133$ & 2.308 & 2.631 & 0.953 & 0.078 & 0.003 & 9.799 & 2.173 & 1.399 & 0.512 & 1.373 & & 0.806 & 22.399 & 0.631 & -0.016 &. \\
\hline 329 & ARGG & M-13/S2133 & 2.219 & 2.409 & 0.896 & 0.072 & 0.002 & 9.145 & 2.015 & 1.354 & 0.488 & 1.334 & & 0.760 & 21.779 & 0.621 & -0.033 & \\
\hline 329 & SM01 & M-13/S2133 & 2.824 & 1.454 & 0.726 & 0.064 & 0.016 & 7.868 & 0.085 & 2.231 & 0.694 & 1.569 & & 0.465 & 23.278 & 0.033 & 2.447 & \\
\hline 329 & SM01 & M-13/S2133 & 2.884 & 1.536 & 0.710 & 0.067 & 0.015 & 8.022 & -0.006 & 2.297 & 0.679 & 1.521 & & 0.467 & 24.520 & 0.034 & 2.468 & \\
\hline 329 & SM01 & M-13/S2133 & 2.882 & 1.460 & 0.679 & 0.065 & 0.016 & 7.656 & 0.065 & 2.211 & 0.649 & 1.467 & & 0.446 & 23.873 & 0.034 & 2.379 & \\
\hline 329 & SM01 & M-13/S2133 & 2.907 & 1.565 & 0.697 & 0.074 & 0.015 & 8.262 & -0.004 & 2.324 & 0.714 & 1.561 & & 0.478 & 25.314 & 0.036 & 2.530 & \\
\hline 329 & SM01 & M-13/S2133 & 2.718 & 1.388 & 0.638 & 0.061 & 0.014 & 7.384 & 0.019 & 2.179 & 0.632 & 1.395 & & 0.435 & 25.244 & 0.065 & 2.247 & \\
\hline 329 & SM01 & M-13/S2133 & 2.869 & 1.465 & 0.706 & 0.063 & 0.015 & 7.601 & 0.041 & 2.265 & 0.645 & 1.466 & & 0.443 & 23.498 & 0.033 & 2.356 & \\
\hline 329 & SM55 & M-13/S2133 & -0.077 & 0.010 & -0.027 & 0.009 & -0.001 & -0.050 & -0.048 & -0.005 & 0.007 & -0.012 & & 0.000 & 0.303 & -0.001 & -0.099 & \\
\hline 329 & SM55 & $\mathrm{M}-13 / \mathrm{S} 2133$ & -0.075 & 0.021 & -0.021 & 0.016 & -0.001 & -0.045 & -0.076 & -0.009 & 0.011 & -0.007 & & 0.016 & 0.351 & 0.001 & -0.058 & \\
\hline 330 & ARGG & M-14/S2150 & 2.544 & 2.698 & 1.027 & 0.063 & -0.008 & 10.055 & 2.195 & 1.556 & 0.527 & 1.477 & & 0.827 & 23.382 & 0.712 & -0.165 & \\
\hline 330 & ARGG & $\mathrm{M}-14 / \mathrm{S} 2150$ & 2.350 & 2.547 & 0.936 & 0.058 & -0.006 & 9.556 & 2.227 & 1.468 & 0.496 & 1.391 & & 0.784 & 21.922 & 0.675 & -0.182 &. \\
\hline 330 & ARGG & M-13/S2133 & 2.598 & 2.667 & 1.048 & 0.067 & 0.000 & 10.038 & 2.261 & 1.564 & 0.526 & 1.497 & & 0.814 & 23.536 & 0.716 & -0.065 & \\
\hline 330 & ARGG & $\mathrm{M}-13 / \mathrm{S} 2133$ & 2.412 & 2.589 & 0.959 & 0.061 & 0.002 & 9.521 & 2.158 & 1.466 & 0.503 & 1.434 & & 0.810 & 22.114 & 0.675 & 0.008 & \\
\hline 330 & SM01 & M-14/S2150 & 2.630 & 1.247 & 0.594 & 0.039 & 0.004 & 6.953 & 0.094 & 2.024 & 0.585 & 1.391 & & 0.386 & 20.086 & 0.033 & 2.430 & \\
\hline 330 & SM01 & M-14/S2150 & 3.320 & 1.591 & 0.773 & 0.049 & 0.005 & 8.873 & 0.086 & 2.498 & 0.728 & 1.736 & & 0.471 & 25.365 & 0.044 & 3.048 & \\
\hline 330 & SM01 & M-14/S2150 & 2.970 & 1.449 & 0.692 & 0.045 & 0.000 & 7.937 & 0.128 & 2.305 & 0.681 & 1.588 & & 0.430 & 23.284 & 0.037 & 2.721 & \\
\hline 330 & SM01 & M-14/S2150 & 2.908 & 1.410 & 0.668 & 0.045 & 0.004 & 7.782 & 0.324 & 2.192 & 0.624 & 1.515 & & 0.420 & 22.612 & 0.037 & 2.664 & \\
\hline 330 & SM01 & M-14/S2150 & 2.943 & 1.443 & 0.687 & 0.043 & 0.003 & 7.949 & 0.174 & 2.280 & 0.674 & 1.596 & & 0.452 & 23.269 & 0.040 & 2.823 & \\
\hline 330 & SM01 & M-14/S2150 & 2.910 & 1.413 & 0.656 & 0.046 & 0.002 & 7.854 & 0.389 & 2.211 & 0.630 & 1.527 & & 0.438 & 22.324 & 0.037 & 2.707 & \\
\hline 330 & SM01 & M-13/S2133 & 2.994 & 1.441 & 0.756 & 0.051 & 0.013 & 7.846 & 0.134 & 2.225 & 0.690 & 1.638 & & 0.462 & 22.418 & 0.046 & 2.806 & \\
\hline 330 & SM01 & & 3.008 & 1.459 & 0.735 & 0.055 & 0.012 & 8.011 & 0.142 & 2.231 & 0.691 & 1.631 & & 0.479 & 22.825 & 0.044 & 2.832 & \\
\hline 330 & SM01 & M-13/S2133 & 2.982 & 1.431 & 0.760 & 0.052 & 0.015 & 7.927 & 0.090 & 2.229 & 0.687 & 1.605 & & 0.473 & 23.047 & 0.047 & 2.803 & 5 \\
\hline 330 & SM01 & M-13/S2133 & 2.938 & 1.360 & 0.713 & 0.052 & 0.013 & 7.780 & 0.099 & 2.234 & 0.654 & 1.551 & & 0.428 & 22.002 & 0.044 & 2.835 & \\
\hline 330 & SM01 & M-13/S2133 & 3.023 & 1.473 & 0.749 & 0.054 & 0.013 & 8.018 & 0.116 & 2.249 & 0.683 & 1.625 & & 0.473 & 23.059 & 0.045 & 2.833 & \\
\hline 330 & SM01 & M-13/S2133 & 2.972 & 1.448 & 0.753 & 0.052 & 0.014 & 7.983 & 0.124 & 2.247 & 0.690 & 1.640 & & 0.469 & 23.065 & 0.046 & 2.837 & \\
\hline 330 & SM55 & $\mathrm{M}-14 / \mathrm{S} 2150$ & -0.064 & 0.026 & -0.035 & -0.005 & -0.010 & -0.121 & 0.026 & -0.018 & 0.001 & -0.004 & & -0.016 & -0.019 & 0.000 & -0.259 & \\
\hline 330 & SM55 & M-14/S2150 & -0.065 & 0.017 & -0.065 & -0.013 & -0.013 & -0.110 & 0.137 & -0.020 & 0.001 & -0.003 & & -0.020 & -0.091 & 0.000 & -0.194 & \\
\hline 330 & SM55 & M-13/S2133 & -0.017 & -0.050 & -0.034 & -0.003 & -0.004 & -0.134 & -0.057 & -0.003 & 0.001 & -0.001 & & -0.021 & 0.086 & 0.007 & -0.047 & \\
\hline 330 & SM55 & M-13/S2133 & -0.021 & $\begin{array}{ll}-0.043 \\
\end{array}$ & -0.030 & -0.003 & -0.003 & -0.095 & -0.035 & 0.009 & 0.003 & 0.000 & & -0.012 & 0.093 & 0.009 & $\begin{array}{ll}-0.062 \\
\end{array}$ & \\
\hline
\end{tabular}


Table A2. Fusion Measurement Data Set (continued)

\section{Revision 0}

\begin{tabular}{|c|c|c|c|c|c|c|c|c|c|c|c|c|c|c|c|c|c|c|}
\hline Batch & Type of Sample & ICP/ID & Al & B & $\mathbf{C a}$ & $\mathrm{Cr}$ & $\mathrm{Cu}$ & $\mathbf{F e}$ & $\mathbf{K}$ & $\mathbf{L i}$ & Mg & Mn & $\mathrm{Na}$ & $\mathrm{Ni}$ & $\mathrm{Si}$ & Ti & $\mathbf{U}$ & $\overline{Z \mathbf{Z r}}$ \\
\hline 331 & ARGG & M-14/S2150 & 2.421 & 2.583 & 1.012 & 0.067 & 0.001 & 9.580 & 2.579 & 1.479 & 0.507 & 1.408 & & 0.806 & 22.351 & 0.684 & 0.059 & \\
\hline 331 & ARGG & M-14/S2150 & 2.435 & 2.560 & 0.981 & 0.066 & 0.001 & 9.527 & 2.491 & 1.465 & 0.500 & 1.408 & & 0.792 & 22.175 & 0.672 & 0.014 & . \\
\hline 331 & SM01 & $\mathrm{M}-14 / \mathrm{S} 2150$ & 2.959 & 1.509 & 0.760 & 0.054 & 0.012 & 7.822 & 0.324 & 2.328 & 0.713 & 1.587 & & 0.447 & 23.386 & 0.042 & 2.903 & \\
\hline 331 & SM01 & M-14/S2150 & 2.808 & 1.414 & 0.719 & 0.053 & 0.011 & 7.786 & 0.310 & 2.173 & 0.659 & 1.555 & & 0.447 & 21.869 & 0.052 & 2.821 & \\
\hline 331 & SM01 & M-14/S2150 & 2.981 & 1.494 & 0.753 & 0.057 & 0.016 & 8.269 & 0.335 & 2.361 & 0.706 & 1.647 & & 0.475 & 23.642 & 0.041 & 2.954 & 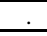 \\
\hline 331 & SM01 & M-14/S2150 & 4.062 & 2.066 & 1.060 & 0.075 & 0.021 & 11.185 & 0.451 & 3.220 & 0.966 & 2.235 & & 0.665 & 32.615 & 0.054 & 4.054 & \\
\hline 331 & SM01 & M-14/S2150 & 2.838 & 1.409 & 0.728 & 0.054 & 0.014 & 7.760 & 0.268 & 2.199 & 0.680 & 1.568 & & 0.444 & 22.038 & 0.038 & 2.789 & \\
\hline 331 & SM01 & M-14/S2150 & 3.028 & 1.480 & 0.757 & 0.055 & 0.011 & 8.164 & 0.358 & 2.297 & 0.706 & 1.672 & & 0.472 & 22.774 & 0.040 & 2.971 & \\
\hline 331 & SM55 & M-14/S2150 & 0.049 & 0.007 & -0.004 & 0.004 & -0.007 & -0.060 & 0.433 & 0.021 & 0.007 & 0.010 & & 0.000 & 0.206 & 0.008 & 0.093 & \\
\hline 331 & SM55 & $\mathrm{M}-14 / \mathrm{S} 2150$ & 0.004 & 0.007 & -0.023 & -0.004 & -0.004 & -0.086 & 0.495 & 0.018 & 0.011 & 0.008 & & -0.001 & 0.169 & 0.007 & -0.003 & \\
\hline 332 & ARGG & M-13/S2133 & 2.465 & 2.665 & 0.986 & 0.069 & -0.004 & 9.586 & 2.336 & 1.483 & 0.497 & 1.390 & & 0.807 & 22.075 & 0.671 & -0.078 & \\
\hline 332 & ARGG & M-13/S2133 & 2.401 & 2.617 & 0.988 & 0.066 & -0.004 & 9.716 & 2.258 & 1.469 & 0.508 & 1.400 & & 0.806 & 22.316 & 0.662 & -0.074 & \\
\hline 332 & SM01 & M-13/S2133 & 2.879 & 1.432 & 0.717 & 0.052 & 0.009 & 7.604 & 0.531 & 2.195 & 0.672 & 1.482 & & 0.434 & 23.069 & 0.038 & 2.418 & \\
\hline 332 & SM01 & M-13/S2133 & 2.701 & 1.376 & 0.608 & 0.055 & 0.008 & 7.309 & 0.186 & 2.117 & 0.630 & 1.432 & & 0.413 & 21.595 & 0.036 & 2.206 & \\
\hline 332 & SM01 & M-13/S2133 & 2.847 & 1.474 & 0.713 & 0.050 & 0.008 & 7.704 & 0.133 & 2.279 & 0.693 & 1.534 & & 0.440 & 23.790 & 0.037 & 2.445 &. \\
\hline 332 & SM01 & M-13/S2133 & 3.405 & 1.771 & 0.856 & 0.066 & 0.012 & 9.173 & 0.222 & 2.700 & 0.805 & 1.828 & & 0.524 & 27.737 & 0.044 & 2.826 & \\
\hline 332 & SM01 & M-13/S2133 & 2.888 & 1.432 & 0.693 & 0.058 & 0.010 & 7.600 & 0.181 & 2.207 & 0.658 & 1.501 & & 0.434 & 22.906 & 0.039 & 2.443 & \\
\hline 332 & SM01 & M-13/S2133 & 2.950 & 1.451 & 0.731 & 0.056 & 0.008 & 7.687 & 0.156 & 2.267 & 0.685 & 1.542 & & 0.432 & 24.064 & 0.039 & 2.453 & \\
\hline 332 & SM55 & M-13/S2133 & -0.033 & -0.040 & -0.097 & -0.006 & -0.012 & -0.185 & -0.055 & -0.012 & 0.000 & -0.009 & & -0.013 & 0.229 & 0.003 & -0.166 & . \\
\hline 332 & SM55 & M-13/S2133 & 0.000 & -0.015 & -0.032 & 0.007 & -0.011 & -0.104 & -0.005 & -0.010 & 0.008 & -0.003 & & -0.001 & 0.423 & 0.003 & -0.143 & \\
\hline 333 & ARGG & $\mathrm{M}-13 / \mathrm{S} 2133$ & 2.442 & 2.619 & 0.986 & 0.067 & 0.004 & 9.898 & 2.132 & 1.457 & 0.523 & 1.384 & & 0.805 & 22.186 & 0.670 & -0.021 &. \\
\hline 333 & ARGG & M-13/S2133 & 2.360 & 2.586 & 0.960 & 0.067 & 0.004 & 9.800 & 2.156 & 1.481 & 0.516 & 1.396 & & 0.804 & 21.538 & 0.664 & -0.016 & \\
\hline 333 & ARGG & $\mathrm{M}-13 / \mathrm{S} 2133$ & 2.322 & 2.598 & 0.969 & 0.097 & -0.001 & 9.658 & 2.248 & 1.482 & 0.515 & 1.403 & & 0.821 & 21.852 & 0.649 & -0.051 & \\
\hline 333 & ARGG & M-13/S2133 & 2.403 & 2.625 & 0.997 & 0.071 & 0.000 & 9.628 & 2.213 & 1.499 & 0.518 & 1.440 & & 0.844 & 22.312 & 0.678 & -0.039 & \\
\hline 333 & SM01 & M-13/S2133 & 2.910 & 1.522 & 0.627 & 0.057 & 0.016 & 7.730 & -0.035 & 2.237 & 0.610 & 1.412 & & 0.445 & 24.152 & 0.043 & 2.347 & \\
\hline 333 & SM01 & M-13/S2133 & 2.370 & 1.197 & 0.508 & 0.040 & 0.013 & 6.271 & -0.062 & 1.885 & 0.498 & 1.119 & & 0.348 & 19.369 & 0.035 & 1.902 & \\
\hline 333 & SM01 & M-13/S2133 & 2.925 & 1.387 & 0.668 & 0.056 & 0.017 & 7.883 & -0.026 & 2.188 & 0.645 & 1.462 & & 0.466 & 23.192 & 0.041 & 2.381 &. \\
\hline 333 & SM01 & M-13/S2133 & 2.943 & 1.402 & 0.680 & 0.053 & 0.016 & 7.879 & -0.012 & 2.309 & 0.683 & 1.466 & & 0.445 & 22.660 & 0.040 & 2.419 & \\
\hline 333 & SM01 & M-13/S2133 & 2.908 & 1.428 & 0.688 & 0.052 & 0.017 & 7.893 & -0.026 & 2.120 & 0.671 & 1.520 & & 0.455 & 22.552 & 0.040 & 2.408 & \\
\hline 333 & SM01 & M-13/S2133 & 2.685 & 1.287 & 0.638 & 0.046 & 0.015 & 7.164 & 0.069 & 2.033 & 0.617 & 1.357 & & 0.406 & 21.191 & 0.038 & 2.190 & \\
\hline 333 & SM01 & M-13/S2133 & 2.648 & 1.382 & 0.651 & 0.052 & 0.012 & 7.283 & 0.132 & 2.167 & 0.618 & 1.408 & & 0.419 & 22.389 & 0.039 & 2.210 & \\
\hline 333 & SM01 & M-13/S2133 & 2.973 & 1.453 & 0.729 & 0.059 & 0.013 & 7.869 & 0.021 & 2.298 & 0.679 & 1.546 & & 0.475 & 23.646 & 0.042 & 2.397 &. \\
\hline 333 & SM01 & M-13/S2133 & 2.818 & 1.532 & 0.661 & 0.055 & 0.011 & 7.509 & 0.025 & 2.352 & 0.592 & 1.410 & & 0.435 & 24.695 & 0.042 & 2.280 & \\
\hline 333 & SM01 & M-13/S2133 & 2.929 & 1.448 & 0.723 & 0.058 & 0.012 & 7.979 & 0.020 & 2.261 & 0.687 & 1.556 & & 0.461 & 23.783 & 0.040 & 2.399 & \\
\hline 333 & SM01 & M-13/S2133 & 2.874 & 1.421 & 0.721 & 0.059 & 0.011 & 7.945 & 0.029 & 2.251 & 0.682 & 1.574 & & 0.471 & 23.124 & 0.038 & 2.355 & \\
\hline 333 & SM01 & M-13/S2133 & 2.703 & 1.383 & 0.651 & 0.053 & 0.012 & 7.278 & 0.044 & 2.185 & 0.626 & 1.415 & & 0.429 & 22.675 & 0.038 & 2.206 & \\
\hline 333 & SM55 & M-13/S2133 & 0.022 & 0.003 & -0.052 & -0.006 & 0.000 & -0.040 & -0.136 & -0.027 & 0.013 & 0.003 & & -0.004 & -0.224 & 0.001 & -0.116 & \\
\hline 333 & SM55 & M-13/S2133 & 0.058 & -0.074 & -0.023 & 0.009 & 0.003 & 0.064 & -0.085 & -0.020 & 0.022 & 0.039 & & 0.026 & -0.762 & 0.004 & -0.065 & \\
\hline 333 & SM55 & M-13/S2133 & -0.009 & -0.050 & -0.023 & 0.001 & -0.005 & -0.081 & -0.045 & -0.035 & 0.012 & 0.007 & & 0.002 & $\begin{array}{ll}-0.191 \\
\end{array}$ & 0.001 & -0.130 & \\
\hline 333 & SM55 & M-13/S2133 & 0.018 & -0.024 & -0.020 & 0.004 & -0.006 & -0.074 & $\begin{array}{ll}-0.069 \\
\end{array}$ & -0.038 & 0.011 & 0.008 & & 0.010 & 0.005 & 0.003 & -0.119 & \\
\hline 334 & ARGG & $\mathrm{M}-13 / \mathrm{S} 2133$ & 2.486 & 2.667 & 1.041 & 0.072 & 0.001 & 10.109 & 2.246 & 1.469 & 0.526 & 1.446 & & 0.835 & 23.040 & 0.706 & 0.069 & \\
\hline 334 & ARGG & M-13/S2133 & 2.491 & 2.632 & 1.042 & 0.072 & 0.004 & 9.917 & 2.203 & 1.436 & 0.516 & 1.446 & & 0.819 & 22.597 & 0.688 & 0.085 & \\
\hline 334 & SM01 & $\mathrm{M}-13 / \mathrm{S} 2133$ & 3.590 & 1.600 & 0.855 & 0.069 & 0.017 & 9.389 & -0.006 & 2.274 & 0.770 & 1.795 & & 0.540 & 25.401 & 0.048 & 2.962 & 5 \\
\hline 334 & SM01 & M-13/S2133 & 3.310 & 1.544 & 0.824 & 0.064 & 0.018 & 8.715 & 0.032 & 2.314 & 0.730 & 1.697 & & 0.497 & 24.710 & 0.045 & 2.777 & \\
\hline 334 & SM01 & M-13/S2133 & 3.240 & 1.470 & 0.786 & 0.061 & 0.016 & 8.400 & 0.012 & 2.202 & 0.677 & 1.592 & & 0.480 & 23.452 & 0.045 & 2.677 & \\
\hline 334 & SM01 & M-13/S2133 & 3.150 & 1.457 & 0.748 & 0.061 & 0.016 & 8.329 & -0.001 & 2.154 & 0.645 & 1.556 & & 0.467 & 23.113 & 0.043 & 2.645 & \\
\hline 334 & SM01 & M-13/S2133 & 2.969 & 1.305 & 0.741 & 0.056 & 0.015 & 7.842 & 0.022 & 1.964 & 0.663 & 1.520 & & 0.446 & 21.236 & 0.038 & 2.481 & \\
\hline 334 & SM01 & M-13/S2133 & 3.089 & 1.455 & 0.763 & 0.062 & 0.016 & 8.181 & -0.008 & 2.179 & 0.702 & 1.621 & & 0.469 & 23.734 & 0.043 & 2.607 & \\
\hline 334 & SM55 & M-13/S2133 & 0.017 & 0.017 & -0.001 & 0.005 & -0.003 & 0.059 & -0.056 & -0.032 & 0.005 & 0.008 & & 0.003 & 0.174 & 0.001 & 0.054 & \\
\hline 334 & SM55 & M-13/S2133 & 0.001 & 0.048 & $\begin{array}{ll}-0.016 \\
\end{array}$ & 0.005 & -0.001 & -0.030 & -0.070 & -0.027 & 0.004 & 0.003 & & 0.003 & 0.273 & 0.003 & 0.084 & \\
\hline
\end{tabular}


Table A2. Fusion Measurement Data Set (continued)

\section{Revision 0}

\begin{tabular}{|c|c|c|c|c|c|c|c|c|c|c|c|c|c|c|c|c|c|c|}
\hline Batch & Type of Sample & ICP/ID & Al & B & $\begin{array}{l}\mathbf{C a} \\
\end{array}$ & $\mathrm{Cr}$ & $\begin{array}{l}\mathbf{C u} \\
\end{array}$ & $\mathrm{Fe}$ & $\mathbf{K}$ & $\mathrm{Li}$ & Mg & Mn & $\mathrm{Na}$ & $\mathrm{Ni}$ & $\mathrm{Si}$ & Ti & $\mathbf{U}$ & $\overline{Z \mathbf{Z r}}$ \\
\hline 335 & ARGG & M-13/S2133 & 2.396 & 2.559 & 0.968 & 0.064 & 0.001 & 9.513 & 2.247 & 1.479 & 0.490 & 1.362 & & 0.794 & 21.649 & 0.671 & 0.032 & \\
\hline 335 & ARGG & M-13/S2133 & 2.452 & 2.580 & 0.990 & 0.065 & 0.002 & 9.474 & 2.328 & 1.476 & 0.498 & 1.385 & & 0.794 & 21.713 & 0.655 & 0.018 & \\
\hline 335 & ARGG & M-14/S2150 & 2.370 & 2.497 & 0.970 & 0.077 & 0.002 & 9.394 & 2.260 & 1.441 & 0.498 & 1.379 & & 0.784 & 21.942 & 0.657 & -0.083 & . \\
\hline 335 & ARGG & M-14/S2150 & 2.338 & 2.524 & 0.968 & 0.069 & 0.004 & 9.486 & 2.194 & 1.431 & 0.498 & 1.378 & & 0.794 & 21.795 & 0.651 & 0.023 & \\
\hline 335 & SM01 & M-13/S2133 & 2.970 & 1.351 & 0.724 & 0.055 & 0.013 & 7.864 & 0.145 & 2.052 & 0.682 & 1.552 & & 0.453 & 20.830 & 0.041 & 2.464 & \\
\hline 335 & SM01 & M-13/S2133 & 3.180 & 1.398 & 0.777 & 0.058 & 0.014 & 8.366 & 0.106 & 2.106 & 0.733 & 1.637 & & 0.474 & 21.977 & 0.041 & 2.611 & \\
\hline 335 & SM01 & M-13/S2133 & 3.178 & 1.368 & 0.794 & 0.057 & 0.014 & 8.258 & 0.104 & 2.089 & 0.734 & 1.642 & & 0.472 & 21.827 & 0.042 & 2.632 & \\
\hline 335 & SM01 & M-13/S2133 & 3.150 & 1.335 & 0.771 & 0.057 & 0.015 & 8.148 & 0.433 & 2.052 & 0.718 & 1.605 & & 0.464 & 20.484 & 0.041 & 2.621 & \\
\hline 335 & SM01 & M-13/S2133 & 3.197 & 1.341 & 0.815 & 0.054 & 0.015 & 8.414 & 0.180 & 1.986 & 0.744 & 1.703 & & 0.481 & 21.136 & 0.043 & 2.681 & \\
\hline 335 & SM01 & M-13/S2133 & 3.062 & 1.438 & 0.766 & 0.056 & 0.013 & 8.019 & 0.110 & 2.090 & 0.713 & 1.630 & & 0.454 & 22.320 & 0.043 & 2.559 & \\
\hline 335 & SM01 & M-14/S2150 & 2.879 & 1.322 & 0.725 & 0.059 & 0.015 & 7.640 & 0.085 & 2.100 & 0.689 & 1.532 & & 0.441 & 21.591 & 0.037 & 2.783 & \\
\hline 335 & SM01 & M-14/S2150 & 2.961 & 1.307 & 0.752 & 0.058 & 0.016 & 7.995 & 0.089 & 2.081 & 0.694 & 1.622 & & 0.455 & 21.098 & 0.038 & 2.804 & . \\
\hline 335 & SM01 & M-14/S2150 & 2.822 & 1.241 & 0.689 & 0.056 & 0.015 & 7.592 & -0.009 & 1.986 & 0.672 & 1.544 & & 0.432 & 20.027 & 0.036 & 2.729 & \\
\hline 335 & SM01 & M-14/S2150 & 2.955 & 1.306 & 0.718 & 0.062 & 0.017 & 7.979 & 0.157 & 2.056 & 0.696 & 1.591 & & 0.465 & 21.628 & 0.037 & 2.846 & \\
\hline 335 & SM01 & M-14/S2150 & 3.208 & 1.347 & 0.801 & 0.057 & 0.016 & 8.439 & 0.142 & 2.094 & 0.763 & 1.722 & & 0.486 & 21.765 & 0.039 & 3.131 & \\
\hline 335 & SM01 & M-14/S2150 & 3.430 & 1.450 & 0.837 & 0.073 & 0.019 & 9.160 & 0.442 & 2.271 & 0.785 & 1.822 & . & 0.528 & 23.928 & 0.040 & 3.299 & . \\
\hline 335 & SM55 & M-13/S2133 & 0.014 & 0.034 & -0.012 & 0.006 & -0.005 & 0.080 & 0.036 & -0.004 & -0.002 & 0.002 & & 0.001 & -0.112 & 0.010 & -0.039 & \\
\hline 335 & SM55 & $\mathrm{M}-13 / \mathrm{S} 2133$ & -0.058 & 0.005 & -0.016 & -0.003 & -0.004 & -0.089 & 0.026 & -0.017 & -0.003 & 0.000 & & 0.008 & -0.221 & 0.011 & -0.001 & \\
\hline 335 & SM55 & M-14/S2150 & 0.005 & 0.014 & -0.025 & 0.006 & 0.001 & 0.034 & -0.250 & -0.001 & 0.010 & 0.010 & & 0.005 & 0.125 & 0.006 & 0.029 & 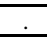 \\
\hline 335 & SM55 & M-14/S2150 & 0.001 & 0.014 & -0.015 & 0.003 & -0.003 & 0.024 & -0.067 & 0.003 & 0.006 & 0.010 & & 0.004 & 0.082 & 0.005 & -0.107 & \\
\hline 336 & ARGG & M-13/S2133 & 2.426 & 2.572 & 0.984 & 0.062 & 0.014 & 9.663 & 2.184 & 1.483 & 0.491 & 1.406 & & 0.788 & 21.725 & 0.679 & 0.009 & . \\
\hline 336 & ARGG & M-13/S2133 & 2.459 & 2.682 & 1.069 & 0.069 & 0.014 & 9.976 & 2.210 & 1.444 & 0.534 & 1.455 & & 0.855 & 22.663 & 0.685 & 0.009 & \\
\hline 336 & ARGG & M-13/S2133 & 2.493 & 2.618 & 1.019 & 0.073 & 0.002 & 9.783 & 2.193 & 1.477 & 0.508 & 1.440 & & 0.810 & 22.807 & 0.694 & 0.023 & 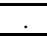 \\
\hline 336 & ARGG & M-13/S2133 & 2.503 & 2.578 & 1.014 & 0.078 & 0.007 & 9.908 & 2.233 & 1.477 & 0.519 & 1.457 & & 0.832 & 22.915 & 0.691 & 0.011 & \\
\hline 336 & SM01 & M-13/S2133 & 3.120 & 1.355 & 0.740 & 0.058 & 0.023 & 8.191 & 0.859 & 2.114 & 0.730 & 1.657 & & 0.481 & 21.922 & 0.036 & 2.454 & \\
\hline 336 & SM01 & M-13/S2133 & 3.098 & 1.389 & 0.808 & 0.058 & 0.026 & 8.484 & 0.009 & 2.077 & 0.766 & 1.725 & & 0.478 & 21.777 & 0.036 & 2.607 & \\
\hline 336 & SM01 & M-13/S2133 & 2.819 & 1.301 & 0.691 & 0.056 & 0.024 & 7.640 & 0.113 & 1.952 & 0.666 & 1.524 & & 0.435 & 19.985 & 0.033 & 2.334 & \\
\hline 336 & SM01 & M-13/S2133 & 2.781 & 1.219 & 0.701 & 0.053 & 0.024 & 7.561 & 9.191 & 1.842 & 0.674 & 1.515 & & 0.435 & 18.775 & 0.033 & 2.331 & \\
\hline 336 & SM01 & M-13/S2133 & 3.150 & 1.348 & 0.750 & 0.064 & 0.025 & 8.206 & 0.018 & 2.045 & 0.738 & 1.675 & & 0.479 & 21.409 & 0.036 & 2.549 & \\
\hline 336 & SM01 & M-13/S2133 & 3.024 & 1.379 & 0.810 & 0.059 & 0.026 & 8.339 & 0.059 & 2.142 & 0.740 & 1.717 & & 0.484 & 21.913 & 0.038 & 2.590 & \\
\hline 336 & SM01 & M-13/S2133 & 3.105 & 1.376 & 0.862 & 0.060 & 0.016 & 7.987 & 0.238 & 2.098 & 0.708 & 1.641 & & 0.468 & 22.302 & 0.044 & 3.013 & \\
\hline 336 & SM01 & M-13/S2133 & 3.146 & 1.328 & 0.906 & 0.063 & 0.020 & 8.255 & 0.213 & 2.088 & 0.723 & 1.686 & & 0.491 & 22.462 & 0.044 & 3.044 &. \\
\hline 336 & SM01 & M-13/S2133 & 3.198 & 1.355 & 0.885 & 0.064 & 0.017 & 8.315 & 0.190 & 2.055 & 0.744 & 1.737 & & 0.473 & 22.514 & 0.045 & 3.153 & \\
\hline 336 & SM01 & M-13/S2133 & 3.187 & 1.333 & 0.913 & 0.067 & 0.018 & 8.266 & 0.960 & 2.117 & 0.743 & 1.708 & & 0.519 & 22.469 & 0.045 & 3.055 & \\
\hline 336 & SM01 & M-13/S2133 & 3.141 & 1.328 & 0.888 & 0.062 & 0.017 & 8.221 & 0.211 & 2.057 & 0.749 & 1.648 & & 0.464 & 22.057 & 0.043 & 3.101 & \\
\hline 336 & SM01 & M-13/S2133 & 2.730 & 1.151 & 0.798 & 0.058 & 0.014 & 7.246 & 9.356 & 1.779 & 0.650 & 1.532 & & 0.421 & 19.175 & 0.039 & 2.568 & \\
\hline 336 & SM55 & M-13/S2133 & 0.038 & 0.049 & -0.011 & 0.005 & 0.009 & 0.103 & -0.081 & 0.001 & 0.004 & -0.004 & & 0.010 & 0.400 & -0.004 & -0.034 & \\
\hline 336 & SM55 & M-13/S2133 & -0.026 & 0.005 & -0.012 & -0.007 & 0.009 & -0.044 & -0.081 & -0.029 & -0.007 & -0.008 & & -0.013 & -0.106 & -0.004 & -0.015 & \\
\hline 336 & SM55 & M-13/S2133 & 0.043 & 0.046 & -0.030 & 0.014 & -0.003 & 0.251 & -0.200 & 0.026 & 0.011 & 0.019 & & 0.004 & 0.469 & 0.008 & -0.060 & \\
\hline 336 & SM55 & M-13/S2133 & 0.015 & 0.014 & -0.020 & 0.012 & 0.002 & 0.100 & -0.047 & -0.006 & 0.000 & 0.016 & & 0.011 & 0.084 & 0.007 & 0.083 & \\
\hline 337 & ARGG & M-13/S2133 & 2.355 & 2.496 & 1.114 & 0.060 & 0.016 & 9.146 & 2.561 & 1.497 & 0.480 & 1.399 & & 0.768 & 21.785 & 0.629 & 0.093 & \\
\hline 337 & ARGG & M-13/S2133 & 2.295 & 2.505 & 1.076 & 0.061 & 0.007 & 9.189 & 2.590 & 1.511 & 0.467 & 1.384 & & 0.774 & 21.731 & 0.634 & 0.046 & \\
\hline 337 & ARGG & M-13/S2133 & 2.430 & 2.538 & 0.994 & 0.064 & -0.005 & 9.238 & 2.180 & 1.417 & 0.486 & 1.359 & & 0.782 & 21.658 & 0.679 & 0.043 & \\
\hline 337 & ARGG & M-13/S2133 & 2.493 & 2.629 & 1.052 & 0.070 & -0.005 & 9.722 & 2.206 & 1.454 & 0.512 & 1.422 & & 0.815 & 22.739 & 0.699 & 0.053 & \\
\hline 337 & SM01 & M-13/S2133 & 2.782 & 1.448 & 0.801 & 0.046 & 0.019 & 7.422 & 0.243 & 2.269 & 0.627 & 1.490 & & 0.438 & 22.469 & 0.041 & 2.357 & \\
\hline 337 & SM01 & M-13/S2133 & 2.992 & 1.407 & 0.851 & 0.054 & 0.022 & 8.134 & 0.322 & 2.266 & 0.679 & 1.616 & & 0.468 & 22.659 & 0.040 & 2.563 & \\
\hline 337 & SM01 & M-13/S2133 & 3.059 & 1.509 & 0.900 & 0.054 & 0.022 & 8.059 & 0.227 & 2.441 & 0.707 & 1.664 & & 0.473 & 23.982 & 0.043 & 2.576 & \\
\hline 337 & SM01 & M-13/S2133 & 2.866 & 1.372 & 0.820 & 0.049 & 0.024 & 7.653 & 0.580 & 2.294 & 0.639 & 1.518 & & 0.450 & 21.583 & 0.042 & 2.450 & \\
\hline 337 & SM01 & M-13/S2133 & 3.043 & 1.375 & 0.849 & 0.052 & 0.026 & 8.129 & 0.589 & 2.175 & 0.666 & 1.585 & & 0.460 & 21.637 & 0.042 & 2.555 & \\
\hline 337 & SM01 & M-13/S2133 & 2.968 & 1.446 & 0.854 & 0.051 & 0.024 & 7.882 & 0.492 & 2.283 & 0.648 & 1.534 & & 0.458 & 23.310 & 0.042 & 2.534 & \\
\hline
\end{tabular}


Table A2. Fusion Measurement Data Set (continued)

\section{Revision 0}

\begin{tabular}{|c|c|c|c|c|c|c|c|c|c|c|c|c|c|c|c|c|c|c|}
\hline Batch & Type of Sample & ICP/ID & Al & B & $\mathbf{C a}$ & $\mathrm{Cr}$ & $\mathbf{C u}$ & $\mathbf{F e}$ & $\mathbf{K}$ & $\mathbf{L i}$ & Mg & Mn & $\mathrm{Na}$ & $\mathrm{Ni}$ & $\mathrm{Si}$ & Ti & $\mathbf{U}$ & $\overline{Z \mathbf{Z r}}$ \\
\hline 337 & SM01 & M-13/S2133 & 2.997 & 1.441 & 0.717 & 0.050 & 0.007 & 7.459 & 0.044 & 2.176 & 0.637 & 1.463 & & 0.412 & 22.436 & 0.047 & 2.462 & \\
\hline 337 & SM01 & M-13/S2133 & 3.083 & 1.485 & 0.706 & 0.059 & 0.007 & 8.175 & 0.209 & 2.140 & 0.674 & 1.563 & & 0.473 & 23.397 & 0.049 & 2.590 & . \\
\hline 337 & SM01 & M-13/S2133 & 3.149 & 1.497 & 0.770 & 0.060 & 0.007 & 8.384 & 0.300 & 2.202 & 0.711 & 1.620 & & 0.495 & 23.587 & 0.052 & 2.684 & \\
\hline 337 & SM01 & M-13/S2133 & 3.289 & 1.437 & 0.768 & 0.060 & 0.009 & 8.543 & 0.351 & 2.143 & 0.723 & 1.631 & & 0.503 & 23.193 & 0.050 & 2.785 & \\
\hline 337 & SM01 & M-13/S2133 & 3.164 & 1.434 & 0.752 & 0.057 & 0.007 & 8.122 & 0.095 & 2.160 & 0.699 & 1.603 & & 0.472 & 22.549 & 0.050 & 2.700 & 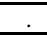 \\
\hline 337 & SM01 & M-13/S2133 & 3.028 & 1.502 & 0.746 & 0.057 & 0.007 & 7.919 & 0.010 & 2.220 & 0.693 & 1.609 & & 0.468 & 23.390 & 0.049 & 2.557 & \\
\hline 337 & SM55 & M-13/S2133 & 0.037 & 0.013 & 0.148 & -0.006 & 0.004 & 0.020 & 0.191 & -0.005 & 0.000 & 0.042 & & -0.009 & -0.104 & 0.003 & -0.006 & \\
\hline 337 & SM55 & M-13/S2133 & 0.138 & 0.010 & 0.148 & -0.004 & 0.017 & 0.016 & 0.153 & -0.003 & 0.000 & 0.049 & & -0.003 & -0.004 & 0.007 & 0.073 & \\
\hline 337 & SM55 & M-13/S2133 & 0.009 & 0.007 & -0.046 & -0.001 & -0.016 & -0.003 & -0.117 & -0.024 & 0.007 & 0.006 & & -0.004 & 0.204 & 0.011 & 0.011 & \\
\hline 337 & SM55 & $\mathrm{M}-13 / \mathrm{S} 2133$ & 0.045 & 0.018 & -0.018 & 0.001 & -0.013 & 0.010 & -0.124 & -0.034 & 0.008 & 0.001 & & 0.011 & 0.202 & 0.013 & 0.052 & \\
\hline 338 & ARGG & M-13/S2133 & 2.319 & 2.536 & 0.950 & 0.062 & 0.002 & 9.574 & 2.163 & 1.432 & 0.482 & 1.359 & & 0.771 & 21.496 & 0.654 & 0.103 & \\
\hline 338 & ARGG & M-13/S2133 & 2.358 & 2.616 & 0.972 & 0.063 & 0.001 & 9.046 & 2.219 & 1.439 & 0.503 & 1.337 & & 0.803 & 22.354 & 0.641 & 0.085 & \\
\hline 338 & SM01 & M-13/S2133 & 3.025 & 1.354 & 0.750 & 0.054 & 0.013 & 7.894 & 0.595 & 2.121 & 0.728 & 1.645 & & 0.456 & 21.524 & 0.024 & 2.551 & \\
\hline 338 & SM01 & M-13/S2133 & 3.032 & 1.371 & 0.761 & 0.054 & 0.013 & 7.985 & 0.293 & 2.127 & 0.727 & 1.651 & & 0.448 & 21.807 & 0.021 & 2.631 & \\
\hline 338 & SM01 & M-13/S2133 & 2.979 & 1.413 & 0.743 & 0.050 & 0.011 & 7.615 & 0.095 & 2.089 & 0.718 & 1.563 & & 0.463 & 22.287 & 0.019 & 2.680 &. \\
\hline 338 & SM01 & M-13/S2133 & 2.897 & 1.347 & 0.698 & 0.049 & 0.011 & 6.777 & 0.349 & 1.994 & 0.688 & 1.519 & & 0.438 & 21.411 & 0.022 & 2.519 & \\
\hline 338 & SM01 & M-13/S2133 & 3.071 & 1.424 & 0.766 & 0.053 & 0.012 & 7.894 & 0.496 & 2.192 & 0.727 & 1.673 & & 0.457 & 22.717 & 0.022 & 2.713 & . \\
\hline 338 & SM01 & M-13/S2133 & 3.089 & 1.383 & 0.755 & 0.053 & 0.013 & 8.180 & 0.370 & 2.190 & 0.730 & 1.675 & & 0.462 & 22.356 & 0.021 & 2.708 & \\
\hline 338 & SM01 & M-13/S2133 & 3.061 & 1.364 & 0.802 & 0.058 & 0.014 & 8.233 & 0.616 & 2.139 & 0.754 & 1.661 & & 0.470 & 22.211 & 0.025 & 2.661 & . \\
\hline 338 & SM01 & M-13/S2133 & 3.020 & 1.384 & 0.772 & 0.057 & 0.015 & 8.070 & 0.104 & 2.126 & 0.718 & 1.614 & & 0.459 & 22.230 & 0.026 & 2.660 & \\
\hline 338 & SM01 & M-13/S2133 & 3.099 & 1.380 & 0.789 & 0.058 & 0.015 & 8.228 & 0.348 & 2.218 & 0.729 & 1.625 & & 0.460 & 22.543 & 0.023 & 2.679 &. \\
\hline 338 & SM01 & M-13/S2133 & 2.977 & 1.361 & 0.753 & 0.057 & 0.014 & 8.094 & 0.316 & 2.137 & 0.718 & 1.579 & & 0.450 & 22.024 & 0.023 & 2.614 & \\
\hline 338 & SM01 & M-13/S2133 & 3.056 & 1.384 & 0.774 & 0.056 & 0.014 & 8.225 & 0.475 & 2.201 & 0.723 & 1.607 & & 0.450 & 22.487 & 0.025 & 2.662 & \\
\hline 338 & SM01 & M-13/S2133 & 2.944 & 1.295 & 0.762 & 0.054 & 0.015 & 7.746 & 0.301 & 2.065 & 0.713 & 1.545 & & 0.437 & 21.257 & 0.024 & 2.587 & \\
\hline 338 & SM55 & M-13/S2133 & -0.059 & -0.031 & -0.021 & -0.005 & -0.005 & -0.057 & -0.016 & -0.017 & 0.004 & 0.006 & & -0.012 & 0.168 & -0.021 & 0.110 & \\
\hline 338 & SM55 & M-13/S2133 & -0.052 & -0.021 & -0.006 & -0.001 & -0.005 & -0.021 & -0.004 & -0.010 & 0.006 & 0.014 & & 0.004 & 0.203 & -0.019 & 0.102 & \\
\hline 339 & ARGG & M-13/S2133 & 2.293 & 2.503 & 0.949 & 0.060 & -0.006 & 9.392 & 2.095 & 1.416 & 0.489 & 1.359 & & 0.772 & 21.453 & 0.649 & -0.132 &. \\
\hline 339 & ARGG & M-13/S2133 & 2.359 & 2.600 & 0.975 & 0.062 & -0.007 & 9.650 & 2.065 & 1.487 & 0.508 & 1.411 & & 0.793 & 22.232 & 0.669 & -0.177 & \\
\hline 339 & SM01 & M-14/S2150 & 3.046 & 1.261 & 0.736 & 0.058 & 0.009 & 7.946 & 0.095 & 1.981 & 0.694 & 1.546 & & 0.466 & 20.893 & 0.038 & 2.735 & \\
\hline 339 & SM01 & $\mathrm{M}-14 / \mathrm{S} 2150$ & 3.196 & 1.349 & 0.740 & 0.048 & 0.006 & 8.304 & -0.020 & 2.113 & 0.737 & 1.665 & & 0.474 & 22.087 & 0.037 & 2.837 & \\
\hline 339 & SM01 & M-14/S2150 & 3.085 & 1.419 & 0.701 & 0.057 & 0.006 & 8.042 & 0.128 & 2.213 & 0.687 & 1.560 & & 0.452 & 23.251 & 0.040 & 2.720 & \\
\hline 339 & SM01 & $\mathrm{M}-14 / \mathrm{S} 2150$ & 3.357 & 1.316 & 0.755 & 0.052 & 0.010 & 8.792 & -0.045 & 2.081 & 0.744 & 1.701 & & 0.484 & 21.771 & 0.040 & 3.091 & . \\
\hline 339 & SM01 & M-14/S2150 & 3.119 & 1.319 & 0.734 & 0.053 & 0.008 & 8.090 & 0.022 & 2.078 & 0.719 & 1.603 & & 0.473 & 21.922 & 0.039 & 2.755 & \\
\hline 339 & SM01 & M-14/S2150 & 3.245 & 1.344 & 0.780 & 0.055 & 0.005 & 8.354 & 0.103 & 2.084 & 0.743 & 1.657 & & 0.471 & 21.985 & 0.041 & 2.939 & \\
\hline 339 & SM01 & M-14/S2150 & 3.145 & 1.362 & 0.748 & 0.053 & 0.007 & 8.210 & -0.017 & 2.119 & 0.737 & 1.682 & & 0.465 & 21.842 & 0.037 & 2.719 & \\
\hline 339 & SM01 & M-14/S2150 & 2.796 & 1.180 & 0.648 & 0.045 & 0.005 & 7.442 & 0.070 & 1.935 & 0.643 & 1.441 & & 0.427 & 19.443 & 0.035 & 2.532 & \\
\hline 339 & SM01 & M-14/S2150 & 3.089 & 1.308 & 0.748 & 0.048 & 0.003 & 8.299 & 0.083 & 2.111 & 0.738 & 1.700 & & 0.473 & 21.451 & 0.038 & 2.651 & \\
\hline 339 & SM01 & M-14/S2150 & 3.152 & 1.343 & 0.753 & 0.054 & 0.008 & 8.328 & 0.321 & 2.111 & 0.739 & 1.654 & & 0.468 & 22.173 & 0.039 & 2.775 & \\
\hline 339 & SM55 & M-13/S2133 & -0.040 & -0.028 & -0.049 & -0.003 & -0.013 & -0.082 & 0.172 & -0.017 & 0.011 & -0.003 & & -0.008 & 0.021 & -0.005 & -0.357 & \\
\hline 339 & SM55 & M-13/S2133 & -0.029 & -0.023 & -0.047 & -0.001 & -0.013 & -0.100 & 0.023 & -0.022 & 0.012 & -0.003 & & -0.004 & 0.075 & -0.003 & -0.227 & \\
\hline 340 & ARGG & $\mathrm{M}-14 / \mathrm{S} 2150$ & 2.406 & 2.521 & 0.954 & 0.066 & -0.003 & 9.617 & 2.345 & 1.438 & 0.496 & 1.392 & & 0.771 & 21.962 & 0.677 & -0.033 & \\
\hline 340 & ARGG & $\mathrm{M}-14 / \mathrm{S} 2150$ & 2.536 & 2.665 & 0.975 & 0.068 & -0.004 & 9.877 & 2.202 & 1.512 & 0.523 & 1.455 & & 0.822 & 22.286 & 0.687 & -0.058 & \\
\hline 340 & SM01 & $\mathrm{M}-14 / \mathrm{S} 2150$ & 3.108 & 1.345 & 0.714 & 0.054 & 0.014 & 8.119 & 0.318 & 2.130 & 0.707 & 1.623 & & 0.457 & 21.052 & 0.038 & 2.831 & 5 \\
\hline 340 & SM01 & M-14/S2150 & 3.164 & 1.326 & 0.778 & 0.060 & 0.012 & 8.326 & 0.700 & 2.100 & 0.800 & 1.766 & & 0.459 & 20.741 & 0.037 & 2.937 & \\
\hline 340 & SM01 & $\mathrm{M}-14 / \mathrm{S} 2150$ & 3.177 & 1.377 & 0.755 & 0.064 & $\begin{array}{ll}0.014 \\
\end{array}$ & 8.552 & 0.315 & 2.152 & 0.729 & 1.703 & & 0.481 & 21.834 & 0.039 & 2.974 & \\
\hline 340 & SM01 & M-14/S2150 & 3.072 & 1.355 & 0.739 & 0.058 & 0.013 & 8.219 & -0.002 & 2.116 & 0.744 & 1.700 & & 0.467 & 21.375 & 0.038 & 2.901 & \\
\hline 340 & SM01 & M-14/S2150 & 3.155 & 1.439 & 0.747 & 0.062 & 0.010 & 8.480 & 0.861 & 2.215 & 0.782 & 1.782 & & 0.465 & 22.754 & 0.038 & 2.840 & \\
\hline 340 & SM01 & M-14/S2150 & 3.172 & 1.372 & 0.714 & 0.058 & 0.005 & 8.435 & 0.441 & 2.105 & 0.740 & 1.699 & & 0.494 & 21.769 & 0.036 & 2.845 & \\
\hline 340 & SM01 & M-14/S2150 & 3.192 & 1.375 & 0.706 & 0.070 & 0.007 & 8.584 & 0.305 & 2.136 & 0.746 & 1.707 & & 0.485 & 21.965 & 0.036 & 2.869 & \\
\hline 340 & SM01 & M-14/S2150 & 3.169 & 1.388 & 0.733 & 0.047 & 0.010 & 8.001 & 0.437 & 2.159 & 0.738 & 1.643 & & 0.437 & 18.860 & 0.038 & 2.850 & \\
\hline
\end{tabular}


Table A2. Fusion Measurement Data Set (continued)

\section{Revision 0}

\begin{tabular}{|c|c|c|c|c|c|c|c|c|c|c|c|c|c|c|c|c|c|c|}
\hline Batch & Type of Sample & ICP/ID & Al & B & $\begin{array}{l}\mathbf{C a} \\
\end{array}$ & $\mathrm{Cr}$ & $\begin{array}{l}\mathbf{C u} \\
\end{array}$ & $\mathrm{Fe}$ & $\mathbf{K}$ & $\mathrm{Li}$ & Mg & Mn & $\mathrm{Na}$ & $\mathrm{Ni}$ & $\mathrm{Si}$ & Ti & $\mathbf{U}$ & $\overline{Z \mathbf{Z r}}$ \\
\hline 340 & SM01 & M-14/S2150 & 3.144 & 1.321 & 0.747 & 0.055 & 0.008 & 8.317 & 0.457 & 2.132 & 0.754 & 1.714 & & 0.456 & 21.176 & 0.039 & 2.878 & \\
\hline 340 & SM01 & M-14/S2150 & 3.163 & 1.432 & 0.739 & 0.063 & 0.008 & 8.557 & 0.015 & 2.216 & 0.781 & 1.788 & & 0.485 & 22.821 & 0.037 & 2.894 & \\
\hline 340 & SM55 & M-14/S2150 & -0.056 & -0.006 & -0.057 & 0.020 & -0.008 & 0.248 & -0.096 & 0.005 & 0.017 & 0.029 & & 0.005 & 0.227 & 0.002 & -0.219 & . \\
\hline 340 & SM55 & M-14/S2150 & -0.047 & -0.007 & -0.061 & -0.001 & -0.009 & 0.110 & -0.104 & 0.000 & 0.009 & 0.019 & & 0.004 & 0.189 & 0.000 & -0.163 & \\
\hline 341 & ARGG & M-13/S2133 & 2.465 & 2.650 & 1.012 & 0.070 & -0.004 & 10.103 & 2.217 & 1.509 & 0.513 & 1.452 & & 0.807 & 23.086 & 0.703 & 0.011 & \\
\hline 341 & ARGG & M-13/S2133 & 2.091 & 2.180 & 0.862 & 0.071 & -0.002 & 8.078 & 1.756 & 1.218 & 0.421 & 1.165 & & 0.660 & 18.490 & 0.602 & -0.009 & \\
\hline 341 & SM01 & M-13/S2133 & 3.108 & 1.440 & 0.798 & 0.070 & 0.012 & 8.529 & 0.265 & 2.188 & 0.753 & 1.729 & & 0.480 & 22.329 & 0.046 & 2.585 & \\
\hline 341 & SM01 & M-13/S2133 & 3.363 & 1.526 & 0.880 & 0.063 & 0.012 & 8.945 & 0.264 & 2.425 & 0.823 & 1.869 & & 0.508 & 24.207 & 0.040 & 2.835 & \\
\hline 341 & SM01 & M-13/S2133 & 2.741 & 1.227 & 0.729 & 0.049 & 0.008 & 7.148 & 0.219 & 1.929 & 0.653 & 1.486 & & 0.402 & 19.209 & 0.033 & 2.220 & \\
\hline 341 & SM01 & M-13/S2133 & 3.120 & 1.363 & 0.811 & 0.059 & 0.012 & 8.037 & 0.176 & 2.129 & 0.742 & 1.715 & & 0.465 & 21.215 & 0.039 & 2.545 & \\
\hline 341 & SM01 & M-13/S2133 & 2.836 & 1.234 & 0.733 & 0.058 & 0.010 & 7.404 & 0.142 & 1.878 & 0.671 & 1.539 & & 0.420 & 19.219 & 0.036 & 2.357 & \\
\hline 341 & SM01 & M-13/S2133 & 3.127 & 1.370 & 0.800 & 0.054 & 0.012 & 8.050 & 0.123 & 2.107 & 0.716 & 1.672 & & 0.467 & 21.329 & 0.039 & 2.608 & . \\
\hline 341 & SM01 & M-13/S2133 & 3.143 & 1.354 & 0.796 & 0.076 & 0.012 & 7.973 & 0.142 & 2.204 & 0.731 & 1.661 & & 0.455 & 21.253 & 0.037 & 2.593 & \\
\hline 341 & SM01 & M-13/S2133 & 3.302 & 1.484 & 0.808 & 0.059 & 0.010 & 8.973 & 0.216 & 2.237 & 0.804 & 1.863 & & 0.508 & 23.037 & 0.039 & 2.772 & \\
\hline 341 & SM01 & M-13/S2133 & 3.075 & 1.399 & 0.777 & 0.076 & 0.011 & 8.283 & 0.100 & 2.139 & 0.736 & 1.712 & & 0.478 & 21.504 & 0.037 & 2.676 & \\
\hline 341 & SM01 & M-13/S2133 & 3.127 & 1.370 & 0.800 & 0.054 & 0.012 & 8.050 & 0.123 & 2.124 & 0.716 & 1.672 &. & 0.467 & 21.329 & 0.039 & 2.608 & . \\
\hline 341 & SM55 & M-13/S2133 & -0.010 & -0.015 & -0.023 & -0.003 & -0.009 & -0.053 & -0.047 & -0.009 & -0.003 & 0.000 & & -0.015 & 0.027 & -0.005 & -0.034 & \\
\hline 341 & SM55 & M-13/S2133 & 0.108 & -0.018 & 0.063 & 0.017 & -0.006 & 0.144 & -0.031 & -0.006 & 0.021 & 0.026 & & 0.012 & 0.813 & 0.014 & -0.040 & \\
\hline 342 & ARGG & M-13/S2133 & 2.661 & 2.784 & 1.078 & 0.078 & 0.001 & 10.604 & 2.365 & 1.587 & 0.561 & 1.545 & & 0.862 & 24.190 & 0.739 & -0.007 & \\
\hline 342 & ARGG & M-13/S2133 & 2.278 & 2.370 & 0.958 & 0.078 & 0.004 & 9.019 & 2.012 & 1.340 & 0.459 & 1.352 & & 0.754 & 20.431 & 0.625 & 0.040 & \\
\hline 342 & SM01 & M-13/S2133 & 3.044 & 1.392 & 0.760 & 0.064 & 0.014 & 8.476 & 0.196 & 2.106 & 0.771 & 1.765 & & 0.497 & 21.904 & 0.037 & 2.721 &. \\
\hline 342 & SM01 & M-13/S2133 & 3.044 & 1.392 & 0.760 & 0.064 & 0.014 & 8.476 & 0.196 & 2.106 & 0.771 & 1.765 & & 0.497 & 21.904 & 0.037 & 2.721 & \\
\hline 342 & SM01 & M-13/S2133 & 3.044 & 1.392 & 0.760 & 0.064 & 0.014 & 8.476 & 0.196 & 2.106 & 0.771 & 1.765 & & 0.497 & 21.904 & 0.037 & 2.721 & 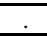 \\
\hline 342 & SM01 & M-13/S2133 & 3.067 & 1.401 & 0.764 & 0.060 & 0.015 & 8.276 & 0.199 & 2.087 & 0.752 & 1.759 & & 0.482 & 21.815 & 0.035 & 2.712 & \\
\hline 342 & SM01 & M-13/S2133 & 3.005 & 1.380 & 0.753 & 0.067 & 0.015 & 8.385 & 0.087 & 2.075 & 0.725 & 1.715 & & 0.486 & 22.300 & 0.035 & 2.609 & \\
\hline 342 & SM01 & M-13/S2133 & 3.005 & 1.380 & 0.753 & 0.067 & 0.015 & 8.385 & 0.087 & 2.075 & 0.725 & 1.715 & & 0.486 & 22.300 & 0.035 & 2.609 & \\
\hline 342 & SM01 & M-13/S2133 & 3.051 & 1.430 & 0.787 & 0.071 & 0.017 & 8.527 & 0.183 & 2.165 & 0.744 & 1.763 & & 0.491 & 23.761 & 0.035 & 2.761 & \\
\hline 342 & SM01 & M-13/S2133 & 3.051 & 1.430 & 0.787 & 0.071 & 0.017 & 8.527 & 0.183 & 2.165 & 0.744 & 1.763 & & 0.491 & 23.761 & 0.035 & 2.761 & \\
\hline 342 & SM01 & M-13/S2133 & 3.219 & 1.513 & 0.806 & 0.084 & 0.018 & 9.100 & 0.033 & 2.137 & 0.763 & 1.876 & & 0.530 & 23.052 & 0.038 & 2.830 & \\
\hline 342 & SM01 & M-13/S2133 & 3.219 & 1.513 & 0.806 & 0.084 & 0.018 & 9.100 & 0.033 & 2.137 & 0.763 & 1.876 & & 0.530 & 23.052 & 0.038 & 2.830 & \\
\hline 342 & SM01 & M-13/S2133 & 3.219 & 1.513 & 0.806 & 0.084 & 0.018 & 9.100 & 0.033 & 2.137 & 0.763 & 1.876 & & 0.530 & 23.052 & 0.038 & 2.830 & \\
\hline 342 & SM01 & M-13/S2133 & 2.864 & 1.391 & 0.737 & 0.070 & 0.017 & 8.319 & 0.029 & 2.021 & 0.737 & 1.754 & & 0.474 & 21.553 & 0.035 & 2.695 &. \\
\hline 342 & SM01 & M-13/S2133 & 2.864 & 1.391 & 0.737 & 0.070 & 0.017 & 8.319 & 0.029 & 2.021 & 0.737 & 1.754 & & 0.474 & 21.553 & 0.035 & 2.695 & \\
\hline 342 & SM01 & M-13/S2133 & 3.121 & 1.396 & 0.782 & 0.062 & 0.015 & 8.285 & 0.345 & 2.240 & 0.755 & 1.696 & & 0.474 & 22.857 & 0.036 & 2.687 & \\
\hline 342 & SM01 & M-13/S2133 & 3.121 & 1.396 & 0.782 & 0.062 & 0.015 & 8.285 & 0.345 & 2.240 & 0.755 & 1.696 & & 0.474 & 22.857 & 0.036 & 2.687 & \\
\hline 342 & SM01 & M-13/S2133 & 3.359 & 1.427 & 0.845 & 0.069 & 0.018 & 9.141 & 0.209 & 2.154 & 0.830 & 1.916 & & 0.515 & 22.252 & 0.036 & 2.986 & \\
\hline 342 & SM55 & M-13/S2133 & -0.021 & -0.013 & -0.031 & 0.025 & 0.000 & 0.132 & -0.035 & -0.004 & 0.017 & 0.026 & & 0.004 & 0.209 & 0.000 & -0.053 & \\
\hline 342 & SM55 & M-13/S2133 & 0.025 & -0.010 & -0.021 & 0.008 & -0.001 & -0.007 & -0.051 & -0.012 & 0.009 & 0.005 & & 0.005 & 0.536 & 0.003 & -0.014 & \\
\hline 343 & ARGG & M-14/S2150 & 2.536 & 2.709 & 1.007 & 0.067 & -0.002 & 10.245 & 2.375 & 1.534 & 0.527 & 1.486 & & 0.839 & 23.288 & 0.702 & -0.104 & \\
\hline 343 & ARGG & M-14/S2150 & 2.396 & 2.560 & 0.979 & 0.062 & -0.003 & 9.803 & 2.191 & 1.483 & 0.502 & 1.413 & & 0.772 & 22.019 & 0.672 & -0.139 & \\
\hline 343 & SM01 & M-14/S2150 & 3.072 & 1.392 & 0.774 & 0.050 & 0.012 & 8.321 & 0.201 & 2.208 & 0.779 & 1.791 & & 0.474 & 22.722 & 0.042 & 3.113 & \\
\hline 343 & SM01 & M-14/S2150 & 3.200 & 1.388 & 0.788 & 0.053 & 0.011 & 8.422 & 0.487 & 2.166 & 0.786 & 1.743 & & 0.485 & 22.552 & 0.042 & 3.124 & \\
\hline 343 & SM01 & M-14/S2150 & 3.219 & 1.377 & 0.767 & 0.053 & 0.012 & 8.459 & 0.059 & 2.174 & 0.734 & 1.722 & & 0.476 & 22.466 & 0.041 & 3.048 & \\
\hline 343 & SM01 & M-14/S2150 & 3.223 & 1.509 & 0.759 & 0.049 & 0.013 & 8.730 & 0.245 & 2.250 & 0.753 & 1.724 & & 0.465 & 23.118 & 0.052 & 3.075 & \\
\hline 343 & SM01 & M-14/S2150 & 3.212 & 1.396 & 0.788 & 0.052 & 0.014 & 8.480 & 0.073 & 2.149 & 0.744 & 1.731 & & 0.468 & 22.501 & 0.042 & 3.238 & \\
\hline 343 & SM01 & M-14/S2150 & 2.832 & 1.240 & 0.665 & 0.041 & 0.006 & 7.516 & 0.085 & 1.981 & 0.650 & 1.526 & & 0.422 & 20.518 & 0.035 & 2.686 & \\
\hline 343 & SM01 & M-14/S2150 & 2.996 & 1.302 & 0.720 & 0.047 & 0.012 & 7.863 & 0.322 & 2.044 & 0.697 & 1.608 & & 0.440 & 21.048 & 0.039 & 2.805 & \\
\hline 343 & SM01 & M-14/S2150 & 2.881 & 1.255 & 0.678 & 0.047 & 0.010 & 7.622 & 0.068 & 2.008 & 0.663 & 1.563 & & 0.426 & 20.311 & 0.036 & 2.868 & \\
\hline 343 & SM55 & M-14/S2150 & -0.059 & -0.019 & -0.056 & -0.009 & -0.008 & 0.087 & -0.071 & 0.011 & 0.003 & 0.004 & & -0.009 & 0.020 & -0.007 & -0.017 & \\
\hline 343 & SM55 & M-14/S2150 & -0.063 & -0.029 & -0.032 & -0.013 & -0.008 & 0.086 & -0.047 & 0.015 & 0.003 & 0.005 & & -0.018 & 0.019 & -0.008 & -0.340 & \\
\hline
\end{tabular}


Table A2. Fusion Measurement Data Set (continued)

\section{Revision 0}

\begin{tabular}{|c|c|c|c|c|c|c|c|c|c|c|c|c|c|c|c|c|c|c|}
\hline Batch & Type of Sample & ICP/ID & Al & B & $\begin{array}{l}\mathbf{C a} \\
\end{array}$ & $\mathrm{Cr}$ & $\begin{array}{l}\mathbf{C u} \\
\end{array}$ & $\mathrm{Fe}$ & $\mathbf{K}$ & $\mathrm{Li}$ & Mg & Mn & $\mathrm{Na}$ & $\mathrm{Ni}$ & $\mathrm{Si}$ & Ti & $\mathbf{U}$ & $\overline{Z \mathbf{Z r}}$ \\
\hline 344 & ARGG & M-13/S2133 & 2.269 & 2.419 & 0.952 & 0.065 & 0.003 & 9.027 & 2.264 & 1.448 & 0.469 & 1.293 & & 0.722 & 20.711 & 0.619 & 0.000 & \\
\hline 344 & ARGG & M-13/S2133 & 2.300 & 2.518 & 0.948 & 0.066 & 0.002 & 9.158 & 2.113 & 1.404 & 0.480 & 1.353 & & 0.748 & 21.526 & 0.642 & -0.004 & \\
\hline 344 & SM01 & M-13/S2133 & 3.054 & 1.426 & 0.690 & 0.057 & 0.012 & 7.715 & 0.090 & 2.188 & 0.654 & 1.527 & & 0.431 & 22.930 & 0.047 & 2.474 & . \\
\hline 344 & SM01 & M-13/S2133 & 3.109 & 1.368 & 0.707 & 0.061 & 0.013 & 7.976 & 0.112 & 2.144 & 0.672 & 1.551 & & 0.453 & 22.098 & 0.046 & 2.521 & \\
\hline 344 & SM01 & M-13/S2133 & 3.115 & 1.380 & 0.767 & 0.060 & 0.015 & 8.087 & 0.191 & 2.166 & 0.715 & 1.616 & & 0.468 & 22.465 & 0.045 & 2.567 & \\
\hline 344 & SM01 & M-13/S2133 & 3.080 & 1.400 & 0.721 & 0.060 & 0.014 & 7.972 & 0.092 & 2.183 & 0.681 & 1.550 & & 0.462 & 23.000 & 0.045 & 2.544 & \\
\hline 344 & SM01 & M-13/S2133 & 3.130 & 1.426 & 0.744 & 0.061 & 0.015 & 8.109 & 0.081 & 2.181 & 0.714 & 1.611 & & 0.469 & 23.187 & 0.045 & 2.560 & \\
\hline 344 & SM01 & M-13/S2133 & 3.033 & 1.364 & 0.746 & 0.059 & 0.014 & 7.782 & 0.340 & 2.096 & 0.686 & 1.548 & & 0.441 & 22.202 & 0.046 & 2.516 & \\
\hline 344 & SM01 & M-13/S2133 & 2.858 & 1.313 & 0.676 & 0.055 & 0.013 & 7.285 & 0.077 & 2.050 & 0.642 & 1.448 & & 0.408 & 21.083 & 0.042 & 2.376 & \\
\hline 344 & SM01 & M-13/S2133 & 3.109 & 1.412 & 0.772 & 0.059 & 0.016 & 8.005 & 0.111 & 2.192 & 0.715 & 1.616 & & 0.454 & 22.354 & 0.045 & 2.598 & \\
\hline 344 & SM55 & M-13/S2133 & 0.001 & 0.001 & -0.016 & 0.004 & -0.002 & 0.011 & 0.009 & -0.015 & 0.006 & 0.015 & & -0.002 & -0.015 & 0.002 & -0.043 & \\
\hline 344 & SM55 & M-13/S2133 & 0.001 & -0.009 & -0.019 & 0.008 & -0.003 & -0.047 & -0.004 & -0.021 & 0.004 & 0.006 & & 0.004 & -0.054 & 0.003 & -0.048 & . \\
\hline 345 & ARGG & M-13/S2133 & 2.391 & 2.634 & 0.985 & 0.067 & 0.001 & 9.743 & 2.102 & 1.427 & 0.505 & 1.411 & & 0.789 & 22.568 & 0.676 & 0.087 & \\
\hline 345 & ARGG & M-13/S2133 & 2.534 & 2.818 & 1.069 & 0.074 & 0.001 & 10.190 & 2.264 & 1.497 & 0.533 & 1.500 & & 0.847 & 23.666 & 0.711 & 0.111 & \\
\hline 345 & SM01 & M-13/S2133 & 3.083 & 1.424 & 0.746 & 0.054 & 0.013 & 7.901 & 0.809 & 2.148 & 0.700 & 1.568 & & 0.447 & 23.099 & 0.042 & 2.563 & \\
\hline 345 & SM01 & M-13/S2133 & 3.107 & 1.438 & 0.762 & 0.059 & 0.012 & 8.100 & 0.952 & 2.173 & 0.711 & 1.626 & . & 0.463 & 23.732 & 0.043 & 2.590 & . \\
\hline 345 & SM01 & M-13/S2133 & 2.901 & 1.254 & 0.736 & 0.055 & 0.013 & 7.607 & 0.470 & 2.012 & 0.673 & 1.531 & & 0.425 & 20.581 & 0.037 & 2.458 & \\
\hline 345 & SM01 & $\mathrm{M}-13 / \mathrm{S} 2133$ & 3.162 & 1.356 & 0.763 & 0.056 & 0.013 & 8.060 & 0.463 & 2.029 & 0.708 & 1.656 & & 0.456 & 22.059 & 0.041 & 2.623 & \\
\hline 345 & SM01 & M-13/S2133 & 3.657 & 1.603 & 0.862 & 0.066 & 0.016 & 9.313 & 0.768 & 2.409 & 0.795 & 1.817 & & 0.539 & 25.834 & 0.049 & 3.060 & \\
\hline 345 & SM01 & M-13/S2133 & 3.309 & 1.384 & 0.834 & 0.064 & 0.015 & 8.732 & 0.389 & 2.129 & 0.781 & 1.811 & & 0.520 & 22.415 & 0.044 & 2.848 & \\
\hline 345 & SM01 & M-13/S2133 & 3.203 & 1.375 & 0.794 & 0.058 & 0.012 & 8.067 & 0.697 & 2.093 & 0.685 & 1.553 & & 0.466 & 22.527 & 0.043 & 2.644 & . \\
\hline 345 & SM01 & M-13/S2133 & 2.538 & 1.114 & 0.605 & 0.044 & 0.011 & 6.542 & 0.191 & 1.604 & 0.555 & 1.290 & & 0.362 & 18.007 & 0.033 & 2.180 & \\
\hline 345 & SM55 & M-13/S2133 & -0.034 & 0.000 & -0.007 & 0.002 & -0.003 & 0.019 & 0.041 & 0.012 & -0.001 & -0.002 & & -0.003 & 0.217 & -0.003 & 0.043 & 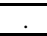 \\
\hline 345 & SM55 & M-13/S2133 & 0.011 & 0.000 & 0.011 & 0.005 & -0.004 & 0.005 & 0.017 & 0.001 & -0.001 & 0.001 & & 0.002 & 0.218 & -0.001 & 0.073 & \\
\hline 346 & ARGG & M-14/S2150 & 2.421 & 2.560 & 0.999 & 0.058 & -0.004 & 9.584 & 1.671 & 1.432 & 0.497 & 1.373 & & 0.773 & 21.950 & 0.678 & 0.025 & \\
\hline 346 & ARGG & M-14/S2150 & 2.432 & 2.529 & 0.985 & 0.057 & -0.001 & 9.349 & 1.879 & 1.435 & 0.489 & 1.365 & & 0.767 & 21.808 & 0.670 & 0.055 & \\
\hline 346 & ARGG & M-13/S2133 & 2.365 & 2.715 & 0.984 & 0.063 & 0.012 & 9.419 & 2.279 & 1.490 & 0.491 & 1.359 & & 0.777 & 22.207 & 0.661 & 0.021 & \\
\hline 346 & SM01 & M-14/S2150 & 3.016 & 1.336 & 0.702 & 0.046 & 0.007 & 7.842 & 0.500 & 2.057 & 0.653 & 1.535 & & 0.430 & 21.608 & 0.048 & 2.759 & \\
\hline 346 & SM01 & $\mathrm{M}-14 / \mathrm{S} 2150$ & 2.927 & 1.314 & 0.718 & 0.042 & 0.009 & 7.629 & -0.306 & 2.031 & 0.628 & 1.482 & & 0.414 & 21.718 & 0.049 & 2.621 & \\
\hline 346 & SM01 & M-14/S2150 & 3.153 & 1.338 & 0.741 & 0.046 & 0.011 & 8.196 & 0.057 & 2.114 & 0.664 & 1.534 & & 0.452 & 22.253 & 0.050 & 2.869 & \\
\hline 346 & SM01 & M-14/S2150 & 3.147 & 1.376 & 0.728 & 0.047 & 0.014 & 8.177 & 0.080 & 2.165 & 0.657 & 1.543 & & 0.447 & 22.878 & 0.051 & 2.984 & \\
\hline 346 & SM01 & M-14/S2150 & 3.105 & 1.311 & 0.709 & 0.047 & 0.012 & 7.905 & 0.326 & 2.055 & 0.652 & 1.527 & & 0.435 & 21.581 & 0.048 & 2.842 &. \\
\hline 346 & SM01 & M-14/S2150 & 3.105 & 1.341 & 0.721 & 0.048 & 0.012 & 7.884 & 0.290 & 2.126 & 0.643 & 1.495 & & 0.437 & 22.627 & 0.049 & 2.849 & \\
\hline 346 & SM01 & M-14/S2150 & 2.827 & 1.252 & 0.661 & 0.041 & 0.006 & 7.232 & -0.100 & 1.941 & 0.604 & 1.398 & & 0.407 & 20.643 & 0.046 & 2.556 & 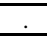 \\
\hline 346 & SM01 & M-14/S2150 & 2.957 & 1.291 & 0.674 & 0.045 & 0.011 & 7.648 & 0.136 & 2.008 & 0.626 & 1.479 & & 0.430 & 21.132 & 0.047 & 2.737 & \\
\hline 346 & SM01 & M-13/S2133 & 3.184 & 1.397 & 0.721 & 0.053 & 0.023 & 8.090 & 0.530 & 2.105 & 0.645 & 1.515 & & 0.452 & 25.357 & 0.054 & 2.684 & \\
\hline 346 & SM01 & M-13/S2133 & 3.065 & 1.336 & 0.710 & 0.059 & 0.022 & 8.038 & 0.201 & 2.031 & 0.649 & 1.535 & & 0.446 & 21.752 & 0.049 & 2.612 & \\
\hline 346 & SM01 & $\mathrm{M}-13 / \mathrm{S} 2133$ & 3.011 & 1.422 & 0.685 & 0.052 & 0.022 & 7.758 & 0.118 & 2.200 & 0.646 & 1.540 & & 0.429 & 22.785 & 0.051 & 2.581 & \\
\hline 346 & SM01 & M-13/S2133 & 3.013 & 1.385 & 0.686 & 0.049 & 0.022 & 7.836 & 0.542 & 2.104 & 0.628 & 1.457 & & 0.445 & 22.466 & 0.049 & 2.574 & \\
\hline 346 & SM01 & M-13/S2133 & 3.966 & 1.778 & 0.872 & 0.062 & 0.027 & 9.884 & 0.570 & 2.761 & 0.831 & 1.894 & & 0.549 & 24.908 & 0.058 & 3.380 & \\
\hline 346 & SM01 & M-13/S2133 & 3.132 & 1.448 & 0.747 & 0.057 & 0.022 & 8.169 & 0.483 & 2.219 & 0.687 & 1.586 & & 0.472 & 23.249 & 0.053 & 2.727 & \\
\hline 346 & SM01 & M-13/S2133 & 3.100 & 1.440 & 0.732 & 0.053 & 0.023 & 8.041 & 0.211 & 2.278 & 0.675 & 1.546 & & 0.458 & 23.653 & 0.051 & 2.696 & \\
\hline 346 & SM01 & M-13/S2133 & 3.505 & 1.550 & 0.854 & 0.070 & 0.027 & 9.193 & 0.295 & 2.414 & 0.801 & 1.847 & & 0.551 & 24.774 & 0.062 & 3.068 & \\
\hline 346 & SM55 & M-14/S2150 & 0.004 & -0.005 & -0.036 & -0.007 & -0.013 & -0.005 & -0.480 & -0.015 & 0.005 & 0.009 & & -0.005 & 0.075 & 0.000 & -0.068 & \\
\hline 346 & SM55 & M-14/S2150 & 0.035 & -0.007 & -0.028 & -0.011 & -0.010 & -0.011 & -0.545 & -0.021 & 0.006 & 0.006 & & -0.018 & 0.090 & 0.001 & 0.087 & \\
\hline 346 & SM55 & M-13/S2133 & -0.015 & 0.015 & -0.032 & -0.003 & 0.008 & -0.212 & -0.047 & 0.001 & 0.008 & -0.008 & & -0.005 & 0.015 & 0.004 & -0.045 & \\
\hline 347 & ARGG & $\mathrm{M}-14 / \mathrm{S} 2150$ & 2.310 & 2.526 & 0.974 & 0.079 & 0.006 & 9.219 & 2.061 & 1.404 & 0.484 & 1.380 & & 0.776 & 21.868 & 0.659 & 0.085 & \\
\hline 347 & ARGG & M-14/S2150 & 2.302 & 2.507 & 0.978 & 0.063 & 0.005 & 9.042 & 2.153 & 1.374 & 0.469 & 1.351 & & 0.751 & 21.387 & 0.659 & 0.078 & \\
\hline 347 & SM01 & $\mathrm{M}-14 / \mathrm{S} 2150$ & 3.078 & 1.389 & 0.783 & 0.065 & 0.019 & 8.510 & 0.039 & 2.177 & 0.732 & 1.707 & & 0.502 & 28.454 & 0.061 & 3.010 & \\
\hline 347 & SM01 & M-14/S2150 & 2.988 & 1.331 & 0.786 & 0.059 & 0.019 & 8.073 & 0.178 & 2.066 & 0.725 & 1.635 & & 0.449 & 22.340 & 0.054 & 3.019 & \\
\hline
\end{tabular}


Table A2. Fusion Measurement Data Set (continued)

\section{Revision 0}

\begin{tabular}{|c|c|c|c|c|c|c|c|c|c|c|c|c|c|c|c|c|c|c|}
\hline Batch & Type of Sample & ICP/ID & Al & B & $\begin{array}{l}\mathbf{C a} \\
\end{array}$ & $\mathrm{Cr}$ & $\mathbf{C u}$ & $\mathrm{Fe}$ & $\mathbf{K}$ & $\mathrm{Li}$ & Mg & Mn & $\mathrm{Na}$ & $\mathrm{Ni}$ & $\mathrm{Si}$ & Ti & $\mathbf{U}$ & $\overline{Z \mathbf{Z r}}$ \\
\hline 347 & SM01 & M-14/S2150 & 3.083 & 1.341 & 0.756 & 0.061 & 0.017 & 8.031 & 0.092 & 2.072 & 0.695 & 1.621 & & 0.457 & 22.452 & 0.054 & 2.993 & \\
\hline 347 & SM01 & M-14/S2150 & 2.986 & 1.354 & 0.755 & 0.052 & 0.017 & 7.740 & 0.322 & 2.082 & 0.699 & 1.569 & & 0.439 & 22.796 & 0.056 & 2.924 & \\
\hline 347 & SM01 & M-14/S2150 & 2.459 & 1.044 & 0.601 & 0.040 & 0.014 & 6.242 & 0.376 & 1.830 & 0.552 & 1.231 & & 0.346 & 17.315 & 0.043 & 2.430 & . \\
\hline 347 & SM01 & M-14/S2150 & 2.999 & 1.329 & 0.734 & 0.053 & 0.016 & 7.655 & 0.430 & 2.056 & 0.691 & 1.587 & & 0.454 & 22.262 & 0.053 & 2.843 & \\
\hline 347 & SM01 & M-14/S2150 & 3.059 & 1.360 & 0.804 & 0.055 & 0.018 & 7.852 & 0.568 & 2.103 & 0.744 & 1.684 & & 0.444 & 22.827 & 0.056 & 2.945 & \\
\hline 347 & SM01 & M-14/S2150 & 3.049 & 1.337 & 0.803 & 0.056 & 0.016 & 8.012 & 0.408 & 2.028 & 0.724 & 1.685 & & 0.469 & 22.275 & 0.052 & 3.012 & \\
\hline 347 & SM55 & M-14/S2150 & 0.007 & 0.010 & 0.035 & 0.008 & 0.003 & -0.075 & -0.170 & 0.004 & 0.006 & 0.006 & & 0.000 & -0.028 & 0.001 & 0.027 & \\
\hline 347 & SM55 & M-14/S2150 & 0.019 & 0.036 & 0.014 & 0.006 & 0.003 & -0.064 & 0.195 & 0.058 & 0.004 & 0.004 & & 0.004 & 0.538 & 0.003 & 0.041 & \\
\hline 348 & ARGG & M-13/S2133 & 2.431 & 2.660 & 0.980 & 0.072 & 0.007 & 9.705 & 2.113 & 1.451 & 0.510 & 1.440 & & 0.819 & 23.024 & 0.670 & 0.028 & \\
\hline 348 & ARGG & M-13/S2133 & 2.489 & 2.679 & 1.015 & 0.072 & 0.005 & 9.933 & 2.286 & 1.507 & 0.508 & 1.460 & & 0.814 & 22.576 & 0.700 & -0.009 & \\
\hline 348 & SM01 & M-13/S2133 & 3.341 & 1.362 & 0.829 & 0.068 & 0.020 & 8.832 & 0.104 & 2.133 & 0.806 & 1.854 & & 0.531 & 22.181 & 0.048 & 2.859 & \\
\hline 348 & SM01 & M-13/S2133 & 3.263 & 1.393 & 0.811 & 0.062 & 0.020 & 8.675 & 0.151 & 2.144 & 0.775 & 1.772 & & 0.480 & 23.030 & 0.048 & 2.894 & . \\
\hline 348 & SM01 & M-13/S2133 & 3.376 & 1.387 & 0.825 & 0.071 & 0.019 & 8.978 & 0.208 & 2.095 & 0.822 & 1.861 & & 0.536 & 22.362 & 0.047 & 2.933 & \\
\hline 348 & SM01 & M-13/S2133 & 3.376 & 1.392 & 0.846 & 0.070 & 0.021 & 9.202 & 0.277 & 2.088 & 0.846 & 1.992 & & 0.549 & 22.492 & 0.049 & 2.894 & \\
\hline 348 & SM01 & M-13/S2133 & 3.319 & 1.371 & 0.820 & 0.070 & 0.019 & 8.811 & 0.082 & 2.122 & 0.794 & 1.838 & & 0.524 & 22.486 & 0.047 & 2.869 & \\
\hline 348 & SM01 & M-13/S2133 & 3.365 & 1.392 & 0.800 & 0.068 & 0.021 & 8.690 & 0.133 & 2.184 & 0.803 & 1.818 &. & 0.492 & 22.799 & 0.047 & 2.859 & . \\
\hline 348 & SM55 & M-13/S2133 & -0.012 & 0.006 & -0.027 & 0.003 & 0.003 & -0.129 & -0.039 & 0.000 & 0.000 & 0.010 & & -0.014 & 0.035 & 0.001 & -0.060 & \\
\hline 348 & SM55 & M-13/S2133 & 0.016 & 0.010 & -0.033 & 0.003 & 0.004 & -0.148 & -0.055 & -0.007 & 0.004 & 0.011 & & -0.010 & 0.096 & 0.003 & -0.018 & \\
\hline 349 & ARGG & M-13/S2133 & 2.514 & 2.692 & 1.958 & 0.069 & 0.003 & 10.040 & 2.744 & 1.557 & 0.534 & 1.479 & & 0.833 & 23.354 & 0.718 & -0.012 & \\
\hline 349 & ARGG & M-13/S2133 & 2.552 & 2.716 & 1.040 & 0.066 & 0.003 & 9.948 & 2.326 & 1.552 & 0.521 & 1.485 & & 0.828 & 23.468 & 0.702 & -0.018 & \\
\hline 349 & SM01 & M-13/S2133 & 3.548 & 1.487 & 0.872 & 0.066 & 0.019 & 9.436 & 0.270 & 2.372 & 0.817 & 1.853 & . & 0.558 & 24.554 & 0.053 & 3.082 & . \\
\hline 349 & SM01 & M-13/S2133 & 3.355 & 1.483 & 0.792 & 0.059 & 0.017 & 8.821 & 0.145 & 2.269 & 0.755 & 1.733 & & 0.505 & 24.242 & 0.047 & 2.888 & \\
\hline 349 & SM01 & M-13/S2133 & 3.314 & 1.450 & 0.725 & 0.062 & 0.016 & 8.595 & 0.123 & 2.169 & 0.693 & 1.654 & & 0.507 & 23.801 & 0.047 & 2.840 & 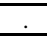 \\
\hline 349 & SM01 & M-13/S2133 & 3.447 & 1.497 & 0.794 & 0.067 & 0.017 & 9.172 & 0.146 & 2.277 & 0.763 & 1.798 & & 0.547 & 24.011 & 0.049 & 3.029 & \\
\hline 349 & SM01 & M-13/S2133 & 3.171 & 1.485 & 0.732 & 0.056 & 0.016 & 8.178 & 0.247 & 2.253 & 0.695 & 1.635 & & 0.476 & 23.834 & 0.046 & 2.688 & \\
\hline 349 & SM01 & M-13/S2133 & 3.439 & 1.296 & 0.897 & 0.064 & 0.018 & 9.050 & 0.278 & 2.066 & 0.880 & 1.963 & & 0.543 & 21.720 & 0.044 & 3.014 & \\
\hline 349 & SM55 & M-13/S2133 & 0.103 & 0.017 & -0.023 & 0.002 & -0.002 & -0.132 & 0.056 & 0.030 & 0.003 & 0.003 & & -0.007 & 0.232 & 0.002 & -0.065 & \\
\hline 349 & SM55 & M-13/S2133 & -0.004 & 0.028 & -0.024 & -0.004 & -0.003 & -0.161 & -0.001 & 0.026 & 0.004 & 0.003 & & -0.007 & 0.053 & 0.003 & -0.066 & \\
\hline 350 & ARGG & $\mathrm{M}-13 / \mathrm{S} 2133$ & 2.417 & 2.625 & 1.003 & 0.070 & 0.006 & 9.576 & 2.437 & 1.582 & 0.495 & 1.410 & & 0.791 & 22.581 & 0.665 & -0.010 & \\
\hline 350 & ARGG & M-13/S2133 & 2.339 & 2.596 & 0.960 & 0.068 & 0.004 & 9.651 & 2.221 & 1.538 & 0.500 & 1.407 & & 0.808 & 22.029 & 0.659 & -0.032 & \\
\hline 350 & SM01 & M-13/S2133 & 3.068 & 1.393 & 0.741 & 0.053 & 0.018 & 7.928 & 0.041 & 2.141 & 0.690 & 1.589 & & 0.429 & 22.502 & 0.043 & 2.589 & \\
\hline 350 & SM01 & M-13/S2133 & 3.156 & 1.399 & 0.788 & 0.055 & 0.019 & 8.104 & 0.023 & 2.169 & 0.732 & 1.683 & & 0.443 & 22.020 & 0.044 & 2.683 &. \\
\hline 350 & SM01 & M-13/S2133 & 2.943 & 1.525 & 0.645 & 0.052 & 0.015 & 7.326 & 0.018 & 2.392 & 0.597 & 1.382 & & 0.410 & 25.058 & 0.046 & 2.334 & \\
\hline 350 & SM01 & M-13/S2133 & 3.027 & 1.513 & 0.657 & 0.054 & 0.016 & 7.571 & 0.007 & 2.382 & 0.611 & 1.442 & & 0.423 & 24.324 & 0.047 & 2.405 & \\
\hline 350 & SM01 & M-13/S2133 & 3.188 & 1.404 & 0.768 & 0.059 & 0.019 & 8.321 & 0.017 & 2.215 & 0.727 & 1.673 & & 0.467 & 22.578 & 0.044 & 2.728 & \\
\hline 350 & SM01 & M-13/S2133 & 3.091 & 1.407 & 0.737 & 0.058 & 0.017 & 8.230 & 0.064 & 2.221 & 0.715 & 1.661 & & 0.478 & 22.327 & 0.044 & 2.621 & \\
\hline 350 & SM55 & M-13/S2133 & -0.010 & 0.011 & 0.009 & 0.000 & 0.001 & -0.056 & -0.078 & -0.035 & 0.006 & 0.005 & & -0.005 & 0.157 & 0.005 & -0.057 & \\
\hline 350 & SM55 & M-13/S2133 & -0.009 & 0.009 & 0.008 & 0.000 & 0.001 & -0.060 & -0.066 & -0.029 & 0.006 & -0.001 & & -0.003 & 0.213 & 0.005 & -0.077 & \\
\hline 351 & ARGG & M-13/S2133 & 2.459 & 2.664 & 1.057 & 0.100 & 0.014 & 9.925 & 2.342 & 1.503 & 0.523 & 1.440 & & 0.841 & 23.028 & 0.683 & 0.046 & \\
\hline 351 & ARGG & M-13/S2133 & 2.505 & 2.616 & 1.027 & 0.069 & 0.013 & 9.793 & 2.331 & 1.492 & 0.520 & 1.421 & & 0.822 & 22.807 & 0.700 & 0.081 & \\
\hline 351 & SM01 & M-13/S2133 & 3.306 & 1.389 & 0.828 & 0.088 & 0.028 & 8.673 & 0.118 & 2.157 & 0.748 & 1.753 & & 0.505 & 22.806 & 0.042 & 2.717 & \\
\hline 351 & SM01 & M-13/S2133 & 3.369 & 1.388 & 0.832 & 0.063 & 0.026 & 8.739 & 0.097 & 2.108 & 0.769 & 1.769 & & 0.501 & 23.181 & 0.043 & 2.755 & \\
\hline 351 & SM01 & M-13/S2133 & 3.268 & 1.389 & 0.792 & 0.062 & 0.027 & 8.433 & 0.289 & 2.204 & 0.778 & 1.725 & & 0.499 & 22.879 & 0.042 & 2.695 & \\
\hline 351 & SM01 & M-13/S2133 & 3.283 & 1.397 & 0.792 & 0.069 & 0.027 & 8.592 & 0.344 & 2.263 & 0.741 & 1.719 & & 0.498 & 23.280 & 0.043 & 2.715 & \\
\hline 351 & SM01 & M-13/S2133 & 3.320 & 1.452 & 0.802 & 0.069 & 0.027 & 8.438 & 0.108 & 2.233 & 0.713 & 1.651 & & 0.487 & 23.804 & 0.044 & 2.677 & \\
\hline 351 & SM01 & M-13/S2133 & 3.396 & 1.415 & 0.827 & 0.064 & 0.028 & 8.578 & 0.103 & 2.154 & 0.752 & 1.742 & & 0.508 & 22.698 & 0.046 & 2.764 & \\
\hline 351 & SM55 & M-13/S2133 & 0.020 & 0.000 & 0.003 & 0.006 & 0.010 & 0.008 & 0.014 & 0.018 & 0.005 & 0.001 & & 0.003 & 0.085 & 0.000 & -0.001 & \\
\hline 351 & SM55 & M-13/S2133 & 0.072 & 0.000 & 0.036 & 0.009 & 0.012 & 0.054 & 0.039 & 0.020 & 0.005 & 0.002 & & 0.010 & 0.203 & 0.002 & 0.039 & \\
\hline 352 & ARGG & $\mathrm{M}-13 / \mathrm{S} 2133$ & 2.379 & 2.673 & 1.002 & 0.073 & -0.003 & 9.980 & 2.306 & 1.557 & 0.519 & 1.462 & & 0.811 & 23.407 & 0.667 & 0.027 & \\
\hline 352 & ARGG & M-13/S2133 & 2.374 & 2.631 & 1.008 & 0.073 & -0.003 & 9.956 & 2.248 & 1.493 & 0.509 & 1.490 & & 0.807 & 22.602 & 0.670 & 0.040 & \\
\hline
\end{tabular}


Table A2. Fusion Measurement Data Set (continued)

\section{Revision 0}

\begin{tabular}{|c|c|c|c|c|c|c|c|c|c|c|c|c|c|c|c|c|c|c|}
\hline Batch & Type of Sample & ICP/ID & Al & B & $\begin{array}{l}\mathbf{C a} \\
\end{array}$ & Cr & $\mathbf{C u}$ & $\mathrm{Fe}$ & $\mathbf{K}$ & $\mathbf{L i}$ & Mg & Mn & $\mathrm{Na}$ & $\mathrm{Ni}$ & $\mathrm{Si}$ & Ti & $\mathbf{U}$ & $\overline{Z r r}$ \\
\hline 352 & SM01 & M-13/S2133 & 3.186 & 1.386 & 0.811 & 0.065 & 0.009 & 8.565 & 0.106 & 2.199 & 0.766 & 1.750 & & 0.476 & 22.666 & 0.047 & 2.787 & \\
\hline 352 & SM01 & M-13/S2133 & 3.257 & 1.442 & 0.785 & 0.064 & 0.009 & 8.724 & 0.411 & 2.192 & 0.754 & 1.737 & & 0.483 & 23.913 & 0.047 & 2.842 & \\
\hline 352 & SM01 & M-13/S2133 & 3.297 & 1.421 & 0.820 & 0.067 & 0.010 & 8.786 & 0.385 & 2.210 & 0.781 & 1.836 & . & 0.490 & 23.158 & 0.047 & 2.847 & \\
\hline 352 & SM01 & M-13/S2133 & 3.143 & 1.389 & 0.778 & 0.065 & 0.009 & 8.444 & 0.359 & 2.085 & 0.753 & 1.763 & & 0.483 & 22.381 & 0.045 & 2.717 & \\
\hline 352 & SM01 & M-13/S2133 & 3.252 & 1.432 & 0.814 & 0.064 & 0.009 & 8.694 & 0.092 & 2.288 & 0.774 & 1.771 & . & 0.498 & 23.620 & 0.047 & 2.837 & \\
\hline 352 & SM01 & M-13/S2133 & 3.224 & 1.344 & 0.763 & 0.066 & 0.008 & 8.512 & 0.436 & 2.001 & 0.767 & 1.750 & & 0.497 & 22.209 & 0.046 & 2.810 & \\
\hline 352 & SM55 & M-13/S2133 & -0.052 & 0.013 & -0.011 & 0.005 & -0.008 & -0.137 & -0.023 & -0.007 & -0.002 & 0.004 & . & -0.007 & 0.013 & 0.000 & 0.001 & \\
\hline 352 & SM55 & M-13/S2133 & -0.037 & 0.018 & 0.030 & 0.008 & -0.006 & -0.111 & -0.019 & -0.007 & -0.001 & 0.002 & . & -0.006 & 0.031 & 0.001 & 0.012 & \\
\hline 353 & ARGG & M-14/S2150 & 2.440 & 2.645 & 0.871 & 0.065 & -0.004 & 9.335 & 1.680 & 1.515 & 0.500 & 1.346 & & 0.790 & 22.833 & 0.676 & -0.133 & \\
\hline 353 & ARGG & M-14/S2150 & 2.348 & 2.521 & 0.975 & 0.076 & 0.006 & 9.407 & 2.493 & 1.454 & 0.500 & 1.370 & . & 0.803 & 22.323 & 0.641 & 0.080 & \\
\hline 353 & SM01 & M-14/S2150 & 3.272 & 1.417 & 0.774 & 0.063 & 0.011 & 8.452 & -0.209 & 2.197 & 0.754 & 1.701 & & 0.489 & 23.767 & 0.055 & 3.060 & \\
\hline 353 & SM01 & M-14/S2150 & 3.281 & 1.336 & 0.815 & 0.061 & 0.013 & 8.460 & -0.090 & 2.069 & 0.749 & 1.742 & . & 0.494 & 21.635 & 0.052 & 3.039 & \\
\hline 353 & SM01 & M-14/S2150 & 3.282 & 1.350 & 0.786 & 0.062 & 0.015 & 8.816 & 0.006 & 2.073 & 0.773 & 1.784 & 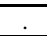 & 0.505 & 22.922 & 0.052 & 3.051 & \\
\hline 353 & SM01 & M-14/S2150 & 3.304 & 1.329 & 0.817 & 0.066 & 0.012 & 8.765 & 0.031 & 2.045 & 0.772 & 1.770 & 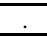 & 0.494 & 22.695 & 0.051 & 3.138 & \\
\hline 353 & SM01 & M-14/S2150 & 3.172 & 1.311 & 0.764 & 0.061 & 0.012 & 8.189 & 0.323 & 2.038 & 0.752 & 1.706 & 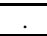 & 0.463 & 22.304 & 0.052 & 3.023 & \\
\hline 353 & SM01 & M-14/S2150 & 3.286 & 1.335 & 0.774 & 0.067 & 0.013 & 8.725 & 0.450 & 2.050 & 0.774 & 1.784 & . & 0.490 & 22.600 & 0.050 & 3.088 & \\
\hline 353 & SM55 & M-14/S2150 & -0.037 & -0.001 & -0.029 & 0.001 & -0.018 & -0.173 & -0.917 & -0.024 & 0.007 & -0.010 & 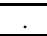 & -0.011 & 0.158 & 0.006 & -0.447 & \\
\hline 353 & SM55 & M-14/S2150 & 0.095 & 0.019 & -0.001 & 0.018 & 0.000 & -0.183 & 0.528 & 0.054 & 0.006 & -0.013 & . & 0.014 & 0.487 & 0.015 & 0.170 & \\
\hline 354 & ARGG & M-13/S2133 & 2.409 & 2.607 & 0.998 & 0.065 & 0.002 & 9.492 & 2.268 & 1.527 & 0.522 & 1.411 & . & 0.803 & 22.463 & 0.665 & 0.081 & \\
\hline 354 & ARGG & M-13/S2133 & 2.469 & 2.615 & 0.964 & 0.067 & 0.000 & 9.612 & 2.152 & 1.436 & 0.509 & 1.448 & 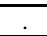 & 0.809 & 22.922 & 0.663 & 0.078 & \\
\hline 354 & SM01 & M-13/S2133 & 3.332 & 1.375 & 0.755 & 0.063 & 0.013 & 8.610 & 0.097 & 2.129 & 0.730 & 1.711 & . & 0.498 & 23.058 & 0.044 & 2.785 & \\
\hline 354 & SM01 & M-13/S2133 & 3.296 & 1.396 & 0.763 & 0.058 & 0.013 & 8.487 & 0.017 & 2.237 & 0.696 & 1.647 & & 0.478 & 23.120 & 0.044 & 2.732 & \\
\hline 354 & SM01 & M-13/S2133 & 3.198 & 1.403 & 0.733 & 0.056 & 0.013 & 8.128 & -0.002 & 2.052 & 0.668 & 1.577 & . & 0.454 & 23.319 & 0.043 & 2.583 & \\
\hline 354 & SM01 & M-13/S2133 & 3.316 & 1.417 & 0.734 & 0.062 & 0.012 & 8.330 & 0.003 & 2.074 & 0.688 & 1.615 & . & 0.462 & 24.097 & 0.044 & 2.682 & \\
\hline 354 & SM01 & M-13/S2133 & 3.446 & 1.356 & 0.840 & 0.064 & 0.014 & 9.035 & 0.138 & 2.109 & 0.885 & 1.947 & & 0.529 & 22.828 & 0.044 & 2.923 & \\
\hline 354 & SM01 & M-13/S2133 & 3.208 & 1.421 & 0.738 & 0.057 & 0.013 & 8.146 & 0.000 & 2.072 & 0.679 & 1.611 & . & 0.454 & 23.321 & 0.042 & 2.662 & \\
\hline 354 & SM55 & M-13/S2133 & 0.004 & 0.018 & -0.042 & 0.006 & -0.004 & -0.177 & -0.054 & -0.001 & 0.004 & 0.020 & . & 0.003 & 0.250 & -0.001 & 0.049 & \\
\hline 354 & SM55 & M-13/S2133 & 0.108 & 0.007 & -0.039 & 0.001 & -0.004 & -0.278 & -0.089 & -0.020 & 0.001 & 0.015 & . & 0.003 & 0.185 & 0.000 & 0.051 & \\
\hline 355 & ARGG & M-13/S2133 & 2.319 & 2.523 & 0.965 & 0.081 & 0.004 & 9.141 & 2.153 & 1.402 & 0.482 & 1.351 & . & 0.764 & 21.237 & 0.658 & 0.055 & \\
\hline 355 & ARGG & M-13/S2133 & 2.363 & 2.542 & 0.965 & 0.081 & 0.002 & 9.269 & 2.181 & 1.418 & 0.491 & 1.373 & . & 0.769 & 21.019 & 0.651 & 0.050 & \\
\hline 355 & SM01 & M-13/S2133 & 3.447 & 1.710 & 0.889 & 0.064 & 0.047 & 8.601 & 0.495 & 2.690 & 0.817 & 1.799 & - & 0.488 & 28.164 & 0.051 & 2.742 & \\
\hline 355 & SM01 & M-13/S2133 & 3.103 & 1.507 & 0.774 & 0.056 & 0.040 & 7.269 & 0.434 & 2.337 & 0.733 & 1.592 & . & 0.438 & 25.191 & 0.046 & 2.445 & \\
\hline 355 & SM01 & M-13/S2133 & 3.057 & 1.532 & 0.807 & 0.143 & 0.012 & 7.937 & 0.417 & 2.391 & 0.776 & 1.699 & & 0.470 & 24.978 & 0.045 & 2.477 & \\
\hline 355 & SM01 & M-13/S2133 & 2.824 & 1.406 & 0.749 & 0.136 & 0.013 & 7.373 & 0.397 & 2.265 & 0.729 & 1.582 & . & 0.428 & 23.338 & 0.042 & 2.308 & \\
\hline 355 & SM01 & M-13/S2133 & 2.765 & 1.415 & 0.663 & 0.048 & 0.009 & 6.948 & 0.463 & 2.232 & 0.646 & 1.433 & & 0.398 & 23.421 & 0.043 & 2.275 & \\
\hline 355 & SM01 & M-13/S2133 & 2.804 & 1.378 & 0.705 & 0.049 & 0.008 & 7.055 & 0.373 & 2.183 & 0.669 & 1.476 & & 0.400 & 23.112 & 0.042 & 2.289 & \\
\hline 355 & SM55 & M-13/S2133 & -0.015 & -0.026 & -0.032 & 0.018 & -0.008 & -0.255 & 0.053 & 0.001 & -0.007 & -0.032 & . & 0.009 & 0.016 & 0.000 & 0.026 & \\
\hline 355 & SM55 & M-13/S2133 & 0.011 & -0.011 & -0.014 & 0.014 & -0.007 & -0.220 & 0.029 & -0.006 & -0.006 & -0.025 & & 0.005 & 0.041 & 0.001 & 0.025 & \\
\hline 356 & ARGG & M-13/S2133 & 2.441 & 2.668 & 0.996 & 0.064 & 0.000 & 9.704 & 2.293 & 1.501 & 0.509 & 1.444 & . & 0.781 & 23.116 & 0.678 & -0.034 & \\
\hline 356 & ARGG & M-13/S2133 & 2.560 & 2.820 & 1.008 & 0.070 & 0.002 & 10.406 & 2.272 & 1.527 & 0.535 & 1.422 & . & 0.823 & 24.197 & 0.699 & -0.006 & \\
\hline 356 & SM01 & M-13/S2133 & 3.137 & 1.474 & 0.729 & 0.055 & 0.012 & 8.000 & 0.109 & 2.212 & 0.686 & 1.477 & 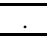 & 0.448 & 25.005 & 0.049 & 2.402 & \\
\hline 356 & SM01 & M-13/S2133 & 3.193 & 1.476 & 0.799 & 0.055 & 0.013 & 8.259 & 0.081 & 2.182 & 0.751 & 1.585 & . & 0.468 & 25.007 & 0.050 & 2.472 & \\
\hline 356 & SM01 & M-13/S2133 & 3.038 & 1.385 & 0.713 & 0.053 & 0.010 & 7.786 & 0.094 & 2.055 & 0.670 & 1.467 & . & 0.433 & 23.245 & 0.049 & 2.346 & \\
\hline 356 & SM01 & M-13/S2133 & 3.043 & 1.387 & 0.690 & 0.053 & 0.011 & 7.581 & 0.137 & 2.138 & 0.648 & 1.456 & & 0.416 & 23.543 & 0.048 & 2.345 & \\
\hline 356 & SM01 & M-13/S2133 & 3.131 & 1.350 & 0.753 & 0.056 & 0.013 & 7.894 & 0.062 & 2.089 & 0.697 & 1.545 & & 0.430 & 22.806 & 0.050 & 2.476 & \\
\hline 356 & SM01 & M-13/S2133 & 2.832 & 1.323 & 0.651 & 0.049 & 0.011 & 7.250 & 0.069 & 1.985 & 0.618 & 1.344 & & 0.399 & 22.412 & 0.045 & 2.207 & \\
\hline 356 & SM55 & M-13/S2133 & 0.084 & 0.022 & -0.026 & -0.001 & -0.005 & -0.211 & 0.053 & -0.015 & -0.011 & -0.009 & . & -0.016 & 0.324 & 0.003 & -0.079 & \\
\hline 356 & SM55 & M-13/S2133 & 0.101 & 0.019 & -0.004 & 0.003 & -0.004 & -0.150 & 0.118 & -0.016 & -0.009 & -0.007 & & -0.004 & 0.243 & 0.004 & -0.058 & \\
\hline
\end{tabular}


Table A3. Mixed Acid Measurement Data Set

\section{Revision 0}

\begin{tabular}{|c|c|c|c|c|c|c|c|c|c|c|c|c|c|c|c|c|c|c|}
\hline Batch & Гype of Sample & ICP/ID & Al & B & $\mathbf{C a}$ & $\mathrm{Cr}$ & $\mathbf{C u}$ & $\mathbf{F e}$ & $\mathbf{K}$ & $\mathbf{L i}$ & Mg & Mn & $\mathrm{Na}$ & $\mathrm{Ni}$ & $\mathrm{Si}$ & $\mathbf{T i}$ & $\mathbf{U}$ & $\mathbf{Z r}$ \\
\hline 300 & ARGB & M-13/S2133 & 2.257 & & 0.993 & 0.061 & 0.002 & 9.472 & 1.914 & 1.465 & 0.515 & 1.375 & 8.206 & 0.795 & 21.277 & 0.652 & -0.124 & 0.083 \\
\hline 300 & ARGB & M-13/S2133 & 2.280 & & 0.997 & 0.066 & 0.006 & 9.821 & 1.954 & 1.517 & 0.535 & 1.428 & 8.302 & 0.833 & 21.481 & 0.673 & -0.089 & 0.085 \\
\hline 300 & ARGB & M-13/S2133 & 2.298 & & 1.005 & 0.064 & 0.003 & 9.514 & 2.415 & 1.485 & 0.501 & 1.385 & 8.323 & 0.796 & 20.835 & 0.678 & 0.065 & 0.102 \\
\hline 300 & ARGB & M-13/S2133 & 2.274 & & 1.000 & 0.063 & 0.006 & 9.561 & 2.272 & 1.470 & 0.503 & 1.407 & 8.207 & 0.792 & 21.475 & 0.676 & -0.047 & 0.101 \\
\hline 300 & SM01 & M-13/S2133 & 2.842 & & 0.703 & 0.047 & 0.014 & 7.394 & -0.208 & 2.288 & 0.667 & 1.463 & 8.581 & 0.433 & 23.223 & 0.023 & 2.665 & 0.032 \\
\hline 300 & SM01 & M-13/S2133 & 2.845 & & 0.699 & 0.048 & 0.015 & 7.466 & -0.034 & 2.213 & 0.668 & 1.466 & 8.552 & 0.420 & 22.130 & 0.022 & 2.674 & 0.036 \\
\hline 300 & SM01 & M-13/S2133 & 2.847 & & 0.686 & 0.049 & 0.015 & 7.446 & 0.078 & 2.286 & 0.651 & 1.446 & 8.344 & 0.431 & 22.801 & 0.023 & 2.642 & 0.036 \\
\hline 300 & SM01 & M-13/S2133 & 2.911 & & 0.706 & 0.052 & 0.021 & 7.571 & -0.092 & 2.240 & 0.661 & 1.479 & 8.566 & 0.433 & 22.690 & 0.024 & 2.740 & 0.039 \\
\hline 300 & SM01 & M-13/S2133 & 2.860 & & 0.701 & 0.051 & 0.019 & 7.577 & -0.021 & 2.297 & 0.680 & 1.495 & 8.638 & 0.436 & 22.687 & 0.024 & 2.716 & 0.041 \\
\hline 300 & SM01 & M-13/S2133 & 2.450 & & 0.584 & 0.045 & 0.017 & 6.317 & -0.146 & 1.959 & 0.576 & 1.251 & 7.159 & 0.366 & 19.458 & 0.020 & 2.295 & 0.032 \\
\hline 300 & SM01 & M-13/S2133 & 2.975 & & 0.719 & 0.049 & 0.012 & 7.745 & -0.058 & 2.247 & 0.662 & 1.499 & 8.781 & 0.431 & 22.924 & 0.027 & 2.812 & 0.053 \\
\hline 300 & SM01 & M-13/S2133 & 2.900 & & 0.690 & 0.050 & 0.011 & 7.530 & -0.228 & 2.211 & 0.656 & 1.491 & 8.738 & 0.435 & 23.022 & 0.028 & 2.741 & 0.054 \\
\hline 300 & SM01 & M-13/S2133 & 2.906 & & 0.697 & 0.047 & 0.010 & 7.436 & -0.195 & 2.320 & 0.641 & 1.465 & 8.628 & 0.430 & 23.709 & 0.028 & 2.689 & 0.052 \\
\hline 300 & SM01 & M-13/S2133 & 2.837 & & 0.685 & 0.050 & 0.010 & 7.367 & 0.030 & 2.259 & 0.641 & 1.436 & 8.497 & 0.409 & 22.990 & 0.028 & 2.677 & 0.051 \\
\hline 300 & SM01 & M-13/S2133 & 2.840 & & 0.669 & 0.045 & 0.012 & 7.274 & 0.050 & 2.226 & 0.629 & 1.413 & 8.315 & 0.411 & 22.603 & 0.027 & 2.707 & 0.050 \\
\hline 300 & SM01 & M-13/S2133 & 2.805 & & 0.674 & 0.047 & 0.011 & 7.264 & 0.080 & 2.174 & 0.637 & 1.437 & 8.427 & 0.407 & 22.159 & 0.027 & 2.650 & 0.049 \\
\hline 300 & SM32 & M-13/S2133 & -0.082 & & 0.020 & -0.011 & 0.000 & -0.036 & -0.221 & -0.002 & -0.003 & 0.005 & -0.158 & -0.014 & 0.265 & -0.005 & -0.233 & -0.020 \\
\hline 300 & SM32 & M-13/S2133 & -0.087 & & -0.001 & -0.006 & -0.001 & -0.025 & -0.303 & 0.006 & -0.003 & 0.006 & -0.175 & -0.017 & 0.095 & -0.006 & -0.250 & -0.022 \\
\hline 300 & SM32 & M-13/S2133 & 0.039 & & -0.020 & -0.009 & -0.003 & -0.058 & -0.004 & -0.013 & -0.004 & 0.016 & -0.110 & -0.013 & -0.031 & 0.003 & -0.148 & 0.001 \\
\hline 300 & SM32 & M-13/S2133 & -0.042 & & -0.017 & -0.008 & 0.095 & -0.064 & -0.266 & -0.017 & -0.003 & 0.014 & -0.100 & -0.011 & -0.056 & 0.000 & -0.147 & 0.001 \\
\hline 301 & ARGB & M-13/S2133 & 2.283 & & 0.955 & 0.061 & 0.009 & 9.568 & 2.074 & 1.478 & 0.497 & 1.383 & 8.285 & 0.769 & 21.106 & 0.669 & -0.001 & 0.098 \\
\hline 301 & ARGB & M-13/S2133 & 2.242 & & 0.948 & 0.059 & 0.004 & 9.420 & 2.143 & 1.454 & 0.487 & 1.364 & 8.155 & 0.757 & 20.777 & 0.648 & -0.048 & 0.095 \\
\hline 301 & ARGB & M-13/S2133 & 2.337 & & 0.983 & 0.058 & -0.007 & 9.470 & 2.174 & 1.450 & 0.499 & 1.382 & 8.089 & 0.775 & 20.857 & 0.671 & -0.019 & 0.090 \\
\hline 301 & ARGB & M-13/S2133 & 2.314 & & 0.985 & 0.056 & -0.006 & 9.411 & 2.252 & 1.470 & 0.495 & 1.366 & 8.300 & 0.776 & 20.525 & 0.682 & -0.080 & 0.089 \\
\hline 301 & SM01 & M-13/S2133 & 3.085 & & 0.754 & 0.053 & 0.017 & 8.271 & 0.042 & 2.124 & 0.731 & 1.634 & 8.984 & 0.450 & 21.956 & 0.028 & 2.892 & 0.049 \\
\hline 301 & SM01 & M-13/S2133 & 3.272 & & 0.820 & 0.053 & 0.023 & 8.507 & 0.147 & 2.171 & 0.773 & 1.734 & 9.274 & 0.494 & 22.205 & 0.027 & 3.130 & 0.055 \\
\hline 301 & SM01 & M-13/S2133 & 3.201 & & 0.802 & 0.057 & 0.022 & 8.529 & -0.090 & 2.082 & 0.757 & 1.694 & 9.065 & 0.489 & 21.167 & 0.027 & 3.044 & 0.055 \\
\hline 301 & SM01 & M-13/S2133 & 3.179 & & 0.781 & 0.050 & 0.022 & 8.195 & -0.124 & 2.145 & 0.755 & 1.689 & 9.296 & 0.462 & 21.579 & 0.026 & 2.982 & 0.052 \\
\hline 301 & SM32 & M-13/S2133 & -0.026 & & -0.015 & -0.009 & -0.001 & -0.018 & -0.322 & -0.006 & -0.009 & 0.012 & -0.111 & -0.005 & -0.001 & -0.001 & -0.145 & -0.002 \\
\hline 301 & SM32 & M-13/S2133 & -0.052 & & -0.016 & -0.012 & -0.018 & 0.021 & -0.412 & -0.011 & -0.006 & 0.009 & -0.087 & -0.022 & -0.054 & 0.001 & -0.112 & -0.008 \\
\hline 301 & M32 & $-13 / \mathrm{S} 2133$ & -0.047 & & -0.015 & -0.012 & -0.015 & 0.018 & -0.293 & -0.013 & -0.005 & 0.010 & -0.170 & -0.017 & 0.045 & 0.001 & -0.123 & $-0.00 \mathrm{~s}$ \\
\hline 302 & RGB & M-13/S2133 & $\begin{array}{l}2.249 \\
\end{array}$ & . & 0.971 & $\begin{array}{ll}0.068 \\
\end{array}$ & 0.001 & 9.535 & 2.194 & 1.491 & 0.506 & 1.384 & 8.179 & 0.785 & 20.686 & 0.661 & -0.136 & 0.094 \\
\hline 302 & ARGB & M-13/S2133 & 2.303 & & 0.994 & 0.069 & -0.002 & 9.506 & 1.744 & 1.457 & 0.504 & 1.398 & 8.162 & 0.798 & 21.200 & 0.658 & -0.138 & 0.094 \\
\hline 302 & SM01 & $1-13 / \mathrm{S} 2133$ & 2.938 & & 0.732 & 0.056 & 0.011 & 7.922 & 0.133 & 2.193 & 0.707 & 1.596 & 8.613 & 0.449 & 22.068 & 0.023 & 2.890 & 0.048 \\
\hline 302 & SM01 & M-13/S2133 & 2.885 & & 0.690 & 0.052 & 0.013 & 7.836 & -0.057 & 2.195 & 0.686 & 1.520 & 8.536 & 0.435 & 22.144 & 0.022 & 2.839 & 0.047 \\
\hline 302 & SM01 & M-13/S2133 & 2.875 & & 0.723 & 0.052 & 0.013 & 7.674 & -0.271 & 2.194 & 0.703 & 1.529 & 8.911 & 0.430 & 22.353 & 0.022 & 2.762 & 0.047 \\
\hline 302 & SM01 & -13/S2133 & 2.959 & & 0.740 & 0.063 & 0.012 & 7.931 & -0.426 & 2.205 & 0.697 & 1.550 & 8.377 & 0.465 & 22.453 & 0.024 & 2.877 & 0.051 \\
\hline 302 & SM01 & M-13/S2133 & 2.878 & & 0.698 & 0.057 & 0.012 & 7.643 & -0.131 & 2.210 & 0.677 & 1.521 & 8.599 & 0.439 & 22.589 & 0.023 & 2.759 & 0.046 \\
\hline 302 & SM01 & & $\begin{array}{l}2.918 \\
\end{array}$ & & 0.721 & 0.057 & 0.014 & 7.898 & -0.126 & 2.196 & 0.711 & 1.561 & 8.776 & 0.445 & 21.972 & 0.022 & 2.899 & 0.048 \\
\hline 302 & SM32 & M-13/S2133 & -0.075 & & -0.012 & 0.004 & -0.007 & -0.032 & -0.955 & -0.034 & -0.001 & 0.000 & -0.095 & -0.005 & 0.044 & -0.003 & -0.279 & -0.005 \\
\hline 302 & SM32 & M-13/S2133 & -0.028 & & -0.015 & 0.001 & -0.004 & -0.024 & $\begin{array}{l}-0.130 \\
\end{array}$ & -0.028 & -0.003 & -0.003 & -0.073 & -0.009 & -0.086 & -0.001 & -0.194 & -0.001 \\
\hline 303 & & & 2.302 & & 1.010 & 0.061 & 0.001 & 9.484 & 2.535 & 1.502 & 0.519 & 1.370 & 8.303 & 0.804 & 21.314 & 0.673 & -0.115 & 0.098 \\
\hline 303 & ARGB & M-13/S2133 & 2.275 & . & 1.014 & 0.063 & 0.006 & 9.509 & 2.329 & 1.482 & 0.505 & 1.375 & 8.259 & 0.824 & 21.548 & 0.666 & -0.116 & 0.098 \\
\hline 303 & SM01 & M-13/S2133 & 2.809 & & 0.689 & 0.045 & 0.013 & 7.449 & 0.069 & 2.261 & 0.649 & 1.471 & 8.644 & 0.426 & 22.562 & 0.023 & 2.693 & 0.046 \\
\hline 303 & & & 2.809 & & 0.694 & 0.049 & 0.012 & 7.680 & -0.143 & 2.241 & 0.656 & 1.544 & 8.708 & 0.450 & 23.089 & 0.023 & 2.647 & 0.048 \\
\hline 303 & SM01 & M-13/S2133 & 2.790 & & 0.706 & 0.049 & 0.020 & 7.475 & -0.119 & 2.290 & 0.647 & 1.510 & 8.560 & 0.430 & 23.099 & 0.025 & 2.750 & 0.049 \\
\hline 303 & SM01 & M-13/S2133 & 2.701 & & 1.094 & 0.052 & 0.013 & 7.312 & 0.220 & 2.296 & 0.640 & 1.457 & 8.626 & 0.427 & 23.542 & 0.024 & 2.631 & 0.049 \\
\hline 303 & SM01 & M-13/S2133 & 2.731 & & 0.688 & 0.049 & 0.011 & 7.449 & -0.039 & 2.282 & 0.655 & 1.500 & 8.754 & 0.438 & 23.020 & 0.024 & 2.524 & 0.047 \\
\hline 303 & SM01 & M-13/S2133 & 2.772 & & 0.701 & 0.048 & 0.015 & 7.480 & -0.115 & 2.275 & 0.650 & 1.496 & 8.582 & 0.435 & 22.588 & 0.022 & 2.644 & 0.046 \\
\hline 303 & SM32 & $\mathrm{M}-13 / \mathrm{S} 2133$ & -0.051 & & -0.003 & $\begin{array}{ll}-0.008 \\
\end{array}$ & 0.000 & 0.023 & 0.031 & 0.008 & 0.004 & 0.023 & 0.019 & -0.012 & 0.226 & -0.004 & -0.274 & -0.001 \\
\hline
\end{tabular}


Table A3. Mixed Acid Measurement Data Set (continued)

\section{Revision 0}

\begin{tabular}{|c|c|c|c|c|c|c|c|c|c|c|c|c|c|c|c|c|c|c|}
\hline Batch & Cype of Sample & ICP/ID & Al & B & Ca & $\mathrm{Cr}$ & $\mathbf{C u}$ & $\mathbf{F e}$ & $\mathbf{K}$ & $\mathbf{L i}$ & Mg & Mn & $\mathrm{Na}$ & $\mathrm{Ni}$ & Si & $\mathbf{T i}$ & $\mathbf{U}$ & $\mathrm{Zr}$ \\
\hline 303 & SM32 & M-13/S2133 & -0.086 & & -0.011 & -0.006 & -0.008 & 0.010 & -0.275 & -0.001 & 0.004 & 0.022 & -0.003 & -0.006 & 0.384 & -0.006 & -0.267 & -0.003 \\
\hline 304 & ARGB & M-13/S2133 & 2.361 & & 1.039 & 0.079 & 0.011 & 9.710 & 2.863 & 1.540 & 0.515 & 1.363 & 8.301 & 0.833 & 21.884 & 0.681 & 0.041 & 0.101 \\
\hline 304 & ARGB & M-13/S2133 & 2.296 & & 1.006 & 0.073 & 0.005 & 9.450 & 2.057 & 1.501 & 0.507 & 1.380 & 8.246 & 0.804 & 21.264 & 0.685 & -0.095 & 0.095 \\
\hline 304 & SM01 & M-13/S2133 & 2.735 & & 0.660 & 0.063 & 0.016 & 7.364 & 0.410 & 2.331 & 0.589 & 1.383 & 8.252 & 0.427 & 23.543 & 0.031 & 2.637 & 0.046 \\
\hline 304 & SM01 & M-13/S2133 & 2.697 & & 0.675 & 0.056 & 0.023 & 7.292 & 0.749 & 2.257 & 0.583 & 1.356 & 8.115 & 0.432 & 23.184 & 0.031 & 2.686 & 0.048 \\
\hline 304 & SM01 & M-13/S2133 & 2.713 & & 0.690 & 0.057 & 0.023 & 7.266 & 0.649 & 2.337 & 0.610 & 1.413 & 8.416 & 0.424 & 23.163 & 0.032 & 2.790 & 0.049 \\
\hline 304 & SM01 & M-13/S2133 & 2.763 & & 0.689 & 0.065 & 0.025 & 7.608 & 0.557 & 2.261 & 0.632 & 1.423 & 8.519 & 0.470 & 23.133 & 0.032 & 2.790 & 0.049 \\
\hline 304 & SM01 & M-13/S2133 & 2.774 & & 0.691 & 0.058 & 0.022 & 7.380 & 0.720 & 2.360 & 0.647 & 1.424 & 8.494 & 0.426 & 23.849 & 0.033 & 2.811 & 0.050 \\
\hline 304 & SM01 & M-13/S2133 & 2.803 & & 0.702 & 0.069 & 0.023 & 7.810 & 0.536 & 2.271 & 0.646 & 1.455 & 8.679 & 0.477 & 23.570 & 0.032 & 2.899 & 0.051 \\
\hline 304 & SM32 & M-13/S2133 & -0.003 & & 0.031 & 0.011 & 0.006 & -0.013 & -0.319 & -0.004 & -0.001 & 0.018 & 0.082 & 0.000 & -0.023 & 0.004 & -0.089 & -0.003 \\
\hline 304 & SM32 & M-13/S2133 & -0.011 & & -0.003 & 0.007 & 0.001 & -0.042 & 0.383 & 0.015 & -0.003 & 0.016 & 0.062 & 0.011 & 0.155 & 0.004 & -0.159 & -0.001 \\
\hline 305 & ARGB & M-13/S2133 & 2.199 & & 0.960 & 0.079 & -0.003 & 9.560 & 2.037 & 1.464 & 0.512 & 1.371 & 8.258 & 0.801 & 21.061 & 0.645 & -0.224 & 0.085 \\
\hline 305 & ARGB & M-13/S2133 & 2.235 & & 0.952 & 0.080 & -0.004 & 9.196 & 2.042 & 1.496 & 0.492 & 1.357 & 8.365 & 0.784 & 21.197 & 0.646 & -0.197 & 0.087 \\
\hline 305 & SM01 & M-13/S2133 & 2.793 & & 0.705 & 0.066 & 0.009 & 7.757 & 1.419 & 2.218 & 0.732 & 1.573 & 8.651 & 0.459 & 22.603 & 0.018 & 2.662 & 0.042 \\
\hline 305 & SM01 & M-13/S2133 & 2.716 & & 0.683 & 0.066 & 0.008 & 7.683 & 0.836 & 2.204 & 0.692 & 1.533 & 8.636 & 0.457 & 22.507 & 0.015 & 2.549 & 0.039 \\
\hline 305 & SM01 & M-13/S2133 & 2.702 & & 0.681 & 0.066 & 0.009 & 7.383 & -0.065 & 2.243 & 0.669 & 1.513 & 8.899 & 0.439 & 22.284 & 0.015 & 2.611 & 0.040 \\
\hline 305 & SM01 & M-13/S2133 & 2.672 & & 0.676 & 0.065 & 0.007 & 7.448 & 0.049 & 2.237 & 0.668 & 1.483 & 8.824 & 0.430 & 22.932 & 0.017 & 2.552 & 0.040 \\
\hline 305 & SM01 & M-13/S2133 & 2.507 & & 0.639 & 0.066 & 0.007 & 7.194 & 4.357 & 2.094 & 0.637 & 1.442 & 8.187 & 0.428 & 21.160 & 0.014 & 2.343 & 0.035 \\
\hline 305 & SM01 & M-13/S2133 & 2.743 & & 0.667 & 0.066 & 0.009 & 7.548 & 0.124 & 2.219 & 0.655 & 1.483 & 8.866 & 0.458 & 22.825 & 0.016 & 2.631 & 0.041 \\
\hline 305 & SM32 & M-13/S2133 & -0.063 & & -0.018 & 0.010 & -0.009 & -0.029 & -0.090 & -0.013 & -0.004 & 0.006 & -0.122 & -0.012 & -0.263 & -0.010 & -0.283 & -0.010 \\
\hline 305 & SM32 & M-13/S2133 & -0.122 & & -0.017 & 0.011 & -0.015 & -0.008 & -0.749 & -0.026 & -0.004 & 0.009 & -0.114 & -0.001 & -0.083 & -0.012 & -0.460 & -0.012 \\
\hline 306 & ARGB & M-13/S2133 & 2.281 & & 1.009 & 0.071 & -0.002 & 9.501 & 1.688 & 1.517 & 0.507 & 1.358 & 8.583 & 0.816 & 21.642 & 0.680 & -0.143 & 0.097 \\
\hline 306 & ARGB & M-13/S2133 & 2.305 & & 0.998 & 0.072 & -0.003 & 9.672 & 2.315 & 1.509 & 0.510 & 1.400 & 8.416 & 0.823 & 21.518 & 0.672 & -0.151 & 0.093 \\
\hline 306 & SM01 & M-13/S2133 & 2.880 & & 0.733 & 0.063 & 0.013 & 8.027 & -0.250 & 2.151 & 0.731 & 1.618 & 8.982 & 0.481 & 22.279 & 0.029 & 2.663 & 0.050 \\
\hline 306 & SM01 & M-13/S2133 & 2.902 & & 0.747 & 0.060 & 0.014 & 7.901 & 0.106 & 2.206 & 0.743 & 1.630 & 9.121 & 0.465 & 22.619 & 0.030 & 2.835 & 0.050 \\
\hline 306 & SM01 & M-13/S2133 & 2.946 & & 0.750 & 0.059 & 0.013 & 8.038 & -0.096 & 2.181 & 0.718 & 1.599 & 9.241 & 0.475 & 22.528 & 0.030 & 2.868 & 0.053 \\
\hline 306 & SM01 & M-13/S2133 & 2.901 & & 0.737 & 0.064 & 0.013 & 8.079 & -0.471 & 2.180 & 0.732 & 1.627 & 9.308 & 0.475 & 22.705 & 0.028 & 2.723 & 0.049 \\
\hline 306 & SM01 & -113/S2133 & 2.864 & & 0.740 & 0.061 & 0.012 & 7.935 & -0.285 & 2.226 & 0.733 & 1.620 & 9.255 & 0.481 & 23.073 & 0.031 & 2.769 & 0.050 \\
\hline 306 & SM01 & M-13 & 2.917 & & 0.758 & 0.062 & 0.015 & 8.050 & -0.110 & 2.233 & 0.728 & 1.616 & 8.915 & 0.471 & 22.867 & 0.058 & 2.943 & 0.052 \\
\hline 306 & SM32 & M-13/S2133 & -0.051 & & -0.010 & 0.003 & -0.006 & 0.010 & -0.619 & 0.003 & -0.004 & 0.025 & 0.050 & -0.003 & -0.236 & -0.006 & -0.281 & -0.008 \\
\hline 306 & M32 & $1-13 / \mathrm{S} 2133$ & -0.060 & & -0.012 & -0.004 & -0.010 & 0.010 & -0.357 & 0.002 & -0.004 & 0.025 & 0.080 & -0.002 & -0.064 & -0.009 & -0.328 & -0.011 \\
\hline 307 & ARGB & M-13/S2133 & $\begin{array}{l}2.246 \\
\end{array}$ & . & $\begin{array}{l}0.980 \\
\end{array}$ & 0.062 & -0.007 & 9.374 & 1.752 & 1.494 & 0.515 & 1.363 & 8.321 & 0.797 & 21.445 & 0.666 & -0.139 & 0.095 \\
\hline 307 & ARGB & M-13/S2133 & 2.383 & & 1.017 & 0.073 & 0.000 & 9.910 & 2.168 & 1.540 & 0.541 & 1.441 & 8.560 & 0.833 & 22.030 & 0.703 & -0.085 & 0.098 \\
\hline 307 & SM01 & M-13/S2133 & 2.835 & & 0.734 & 0.058 & 0.010 & 7.923 & -0.047 & 2.268 & 0.713 & 1.580 & 9.211 & 0.466 & 22.493 & 0.034 & 2.896 & 0.049 \\
\hline 307 & SM01 & M-13/S2133 & 2.816 & & 0.701 & 0.054 & 0.007 & 7.510 & -0.507 & 2.244 & 0.660 & 1.494 & 8.823 & 0.443 & 22.600 & 0.033 & 2.754 & 0.047 \\
\hline 307 & SM01 & M-13/S2133 & 2.895 & & 0.695 & 0.061 & 0.009 & 7.964 & -0.230 & 2.349 & 0.703 & 1.545 & 9.058 & 0.478 & 24.182 & 0.035 & 2.860 & 0.052 \\
\hline 307 & SM01 & $1-13 / \mathrm{S} 2133$ & 2.907 & & 0.711 & 0.060 & 0.011 & 8.153 & -0.243 & 2.331 & 0.708 & 1.557 & 8.912 & 0.483 & 24.017 & 0.036 & 2.968 & 0.050 \\
\hline 307 & SM01 & M-13/S2133 & 2.722 & & 0.672 & 0.052 & 0.010 & 7.417 & -0.135 & 2.155 & 0.667 & 1.448 & 8.488 & 0.432 & 22.422 & 0.033 & 2.680 & 0.047 \\
\hline 307 & SM01 & & $\begin{array}{l}2.832 \\
\end{array}$ & & 0.719 & 0.057 & 0.009 & 7.878 & -0.282 & 2.269 & 0.706 & 1.543 & 8.917 & 0.452 & 23.222 & 0.033 & 2.873 & 0.049 \\
\hline 307 & SM32 & M-13/S2133 & -0.035 & & -0.018 & -0.001 & -0.008 & -0.104 & -0.307 & -0.007 & -0.005 & 0.022 & -0.080 & -0.008 & -0.173 & -0.003 & -0.144 & -0.005 \\
\hline 307 & SM32 & M-13/S2133 & -0.054 & & -0.020 & 0.000 & -0.007 & -0.108 & $\begin{array}{l}-0.438 \\
\end{array}$ & -0.004 & -0.004 & 0.023 & -0.080 & 0.003 & -0.068 & -0.001 & -0.227 & -0.005 \\
\hline 308 & & & 2.274 & & 0.986 & 0.065 & -0.002 & 9.513 & 2.048 & 1.489 & 0.512 & 1.385 & 8.349 & 0.802 & 21.146 & 0.634 & -0.088 & 0.092 \\
\hline 308 & ARGB & M-13/S2133 & 2.300 & & 0.986 & 0.074 & -0.003 & 9.529 & 2.087 & 1.502 & 0.502 & 1.376 & 8.321 & 0.821 & 20.946 & 0.636 & -0.135 & 0.091 \\
\hline 308 & SM01 & M-13/S2133 & 2.745 & & 0.693 & 0.051 & 0.011 & 7.602 & 0.267 & 2.243 & 0.673 & 1.508 & 8.626 & 0.440 & 22.740 & 0.038 & 2.775 & 0.047 \\
\hline 308 & & & 2.670 & & 0.803 & 0.059 & 0.008 & 7.532 & -0.018 & 2.261 & 0.669 & 1.489 & 8.575 & 0.457 & 23.203 & 0.036 & 2.675 & 0.047 \\
\hline 308 & SM01 & M-13/S2133 & 2.766 & & 0.703 & 0.059 & 0.008 & 7.705 & 0.623 & 2.229 & 0.675 & 1.535 & 8.666 & 0.460 & 23.074 & 0.038 & 2.755 & 0.048 \\
\hline 308 & SM01 & M-13/S2133 & 2.831 & & 0.704 & 0.056 & 0.011 & 8.010 & 0.086 & 2.343 & 0.688 & 1.550 & 9.033 & 0.476 & 23.652 & 0.040 & 2.941 & 0.048 \\
\hline 308 & SM01 & M-13/S2133 & 2.698 & & 0.675 & 0.056 & 0.008 & 7.528 & 0.168 & 2.202 & 0.649 & 1.483 & 8.393 & 0.466 & 22.843 & 0.038 & 2.676 & 0.045 \\
\hline 308 & SM01 & M-13/S2133 & 2.723 & & 0.695 & 0.057 & 0.010 & 7.741 & 0.435 & 2.252 & 0.679 & 1.528 & 8.795 & 0.461 & 23.285 & 0.038 & 2.769 & 0.045 \\
\hline 308 & SM32 & $\mathrm{M}-13 / \mathrm{S} 2133$ & -0.082 & & $\begin{array}{l}-0.026 \\
\end{array}$ & -0.001 & -0.014 & -0.007 & -0.090 & 0.008 & -0.011 & 0.021 & -0.071 & 0.005 & $\begin{array}{l}-0.007 \\
\end{array}$ & -0.001 & -0.193 & -0.010 \\
\hline
\end{tabular}


Table A3. Mixed Acid Measurement Data Set (continued)

\section{Revision 0}

\begin{tabular}{|c|c|c|c|c|c|c|c|c|c|c|c|c|c|c|c|c|c|c|}
\hline Batch & Гуре of Sample & ICP/ID & Al & B & Ca & $\mathrm{Cr}$ & $\mathbf{C u}$ & $\mathbf{F e}$ & $\mathbf{K}$ & $\mathbf{L i}$ & Mg & Mn & $\mathrm{Na}$ & $\mathrm{Ni}$ & $\mathrm{Si}$ & $\mathbf{T i}$ & $\mathbf{U}$ & $\mathrm{Zr}$ \\
\hline 308 & SM32 & M-13/S2133 & -0.075 & & -0.019 & -0.007 & -0.010 & -0.012 & 0.300 & 0.005 & -0.011 & 0.022 & -0.079 & -0.010 & -0.131 & 0.000 & -0.262 & -0.008 \\
\hline 309 & ARGB & M-13/S2133 & 2.233 & & 0.977 & 0.076 & 0.002 & 9.769 & 1.884 & 1.473 & 0.509 & 1.391 & 8.211 & 0.818 & 21.142 & 0.648 & -0.221 & 0.100 \\
\hline 309 & ARGB & M-13/S2133 & 2.310 & & 0.969 & 0.071 & 0.003 & 9.485 & 1.878 & 1.459 & 0.498 & 1.350 & 8.392 & 0.812 & 21.105 & 0.646 & -0.207 & 0.100 \\
\hline 309 & SM01 & M-13/S2133 & 2.790 & & 0.675 & 0.059 & 0.012 & 7.886 & -0.176 & 2.194 & 0.660 & 1.566 & 8.670 & 0.465 & 22.632 & 0.032 & 2.702 & 0.059 \\
\hline 309 & SM01 & M-13/S2133 & 2.755 & & 0.667 & 0.066 & 0.013 & 7.888 & -0.111 & 2.218 & 0.651 & 1.510 & 8.746 & 0.469 & 22.616 & 0.031 & 2.636 & 0.058 \\
\hline 309 & SM01 & M-13/S2133 & 2.851 & & 0.719 & 0.067 & 0.012 & 8.228 & -0.528 & 2.141 & 0.699 & 1.616 & 8.945 & 0.485 & 21.578 & 0.032 & 2.827 & 0.060 \\
\hline 309 & SM01 & M-13/S2133 & 2.839 & & 0.690 & 0.063 & 0.013 & 7.827 & -0.545 & 2.197 & 0.682 & 1.548 & 8.706 & 0.486 & 22.422 & 0.033 & 2.715 & 0.060 \\
\hline 309 & SM01 & M-13/S2133 & 2.624 & & 0.645 & 0.052 & 0.012 & 7.518 & -0.259 & 2.138 & 0.633 & 1.510 & 8.165 & 0.451 & 21.626 & 0.031 & 2.671 & 0.056 \\
\hline 309 & SM01 & M-13/S2133 & 1.619 & & 0.440 & 0.040 & 0.006 & 4.389 & -0.599 & 1.270 & 0.402 & 0.870 & 4.935 & 0.265 & 13.185 & 0.016 & 1.403 & 0.035 \\
\hline 309 & SM32 & M-13/S2133 & -0.101 & & -0.027 & 0.001 & -0.003 & -0.044 & -0.299 & -0.013 & 0.000 & 0.021 & -0.053 & 0.010 & -0.214 & -0.001 & -0.348 & 0.006 \\
\hline 309 & SM32 & M-13/S2133 & -0.075 & & -0.027 & 0.000 & -0.005 & -0.046 & -0.875 & -0.016 & 0.000 & 0.021 & -0.004 & 0.015 & -0.088 & -0.001 & -0.391 & 0.008 \\
\hline 310 & ARGB & M-13/S2133 & 2.309 & & 0.997 & 0.072 & -0.001 & 9.411 & 2.306 & 1.480 & 0.506 & 1.408 & 8.230 & 0.806 & 21.252 & 0.667 & -0.071 & 0.103 \\
\hline 310 & ARGB & M-13/S2133 & 2.268 & & 0.996 & 0.079 & 0.004 & 9.622 & 1.630 & 1.495 & 0.511 & 1.387 & 8.305 & 0.846 & 21.389 & 0.684 & -0.093 & 0.103 \\
\hline 310 & SM01 & M-13/S2133 & 2.722 & & 0.695 & 0.058 & 0.014 & 7.534 & -0.147 & 2.290 & 0.634 & 1.466 & 8.941 & 0.441 & 23.001 & 0.032 & 2.682 & 0.056 \\
\hline 310 & SM01 & M-13/S2133 & 2.683 & & 0.671 & 0.058 & 0.012 & 7.462 & -0.484 & 2.313 & 0.627 & 1.457 & 8.798 & 0.431 & 23.020 & 0.033 & 2.676 & 0.054 \\
\hline 310 & SM01 & M-13/S2133 & 2.755 & & 0.666 & 0.066 & 0.011 & 7.700 & -0.490 & 2.323 & 0.603 & 1.403 & 8.424 & 0.459 & 22.986 & 0.033 & 2.652 & 0.056 \\
\hline 310 & SM01 & M-13/S2133 & 2.653 & & 0.650 & 0.064 & 0.011 & 7.532 & -0.280 & 2.245 & 0.588 & 1.390 & 8.385 & 0.454 & 23.266 & 0.031 & 2.618 & 0.054 \\
\hline 310 & SM01 & M-13/S2133 & 2.679 & & 0.646 & 0.062 & 0.014 & 7.397 & -0.140 & 2.350 & 0.581 & 1.365 & 8.465 & 0.443 & 23.603 & 0.033 & 2.502 & 0.055 \\
\hline 310 & SM01 & M-13/S2133 & 2.642 & & 0.638 & 0.063 & 0.011 & 7.399 & -0.585 & 2.131 & 0.587 & 1.364 & 8.164 & 0.441 & 21.511 & 0.030 & 2.525 & 0.053 \\
\hline 310 & SM32 & M-13/S2133 & -0.019 & & -0.014 & 0.011 & -0.007 & -0.068 & -0.722 & 0.008 & 0.006 & 0.030 & 0.011 & 0.003 & -0.003 & -0.001 & -0.248 & 0.003 \\
\hline 310 & SM32 & M-13/S2133 & -0.063 & & -0.011 & 0.007 & -0.008 & -0.055 & -0.513 & 0.014 & 0.010 & 0.033 & 0.023 & -0.022 & -0.199 & 0.000 & -0.255 & 0.003 \\
\hline 311 & ARGB & M-13/S2133 & 2.233 & & 1.006 & 0.063 & -0.012 & 9.718 & 1.647 & 1.473 & 0.510 & 1.394 & 8.517 & 0.794 & 21.152 & 0.657 & -0.028 & 0.097 \\
\hline 311 & ARGB & M-13/S2133 & 2.215 & & 0.987 & 0.061 & -0.010 & 9.651 & 1.707 & 1.450 & 0.519 & 1.382 & 8.401 & 0.811 & 21.606 & 0.653 & 0.029 & 0.095 \\
\hline 311 & SM01 & M-13/S2133 & 2.674 & & 0.672 & 0.050 & 0.006 & 7.779 & -0.686 & 2.307 & 0.651 & 1.426 & 8.705 & 0.443 & 23.773 & 0.028 & 2.726 & 0.054 \\
\hline 311 & SM01 & M-13/S2133 & 2.749 & & 0.660 & 0.052 & 0.006 & 7.694 & 0.014 & 2.381 & 0.618 & 1.400 & 8.628 & 0.435 & 24.397 & 0.030 & 2.758 & 0.054 \\
\hline 311 & SM01 & M-13/S2133 & 2.676 & & 0.681 & 0.054 & 0.001 & 7.790 & -0.577 & 2.302 & 0.647 & 1.449 & 8.851 & 0.443 & 23.787 & 0.028 & 2.753 & 0.051 \\
\hline 311 & SM01 & M-13/S2133 & 2.644 & & 0.648 & 0.048 & -0.001 & 7.333 & -0.432 & 2.357 & 0.582 & 1.358 & 8.517 & 0.417 & 23.546 & 0.028 & 2.542 & 0.052 \\
\hline 311 & SM01 & -113/S2133 & 2.804 & & 0.682 & 0.052 & 0.003 & 7.828 & -0.996 & 2.438 & 0.617 & 1.451 & 8.843 & 0.437 & 24.905 & 0.029 & 2.776 & 0.054 \\
\hline 311 & SM01 & M-13 & 2.648 & & 0.670 & 0.060 & 0.003 & 7.597 & -0.345 & 2.253 & 0.635 & 1.401 & 8.573 & 0.453 & 22.859 & 0.029 & 2.622 & 0.051 \\
\hline 311 & SM32 & M-13/S2133 & -0.108 & & -0.007 & -0.013 & -0.013 & -0.016 & -0.490 & -0.028 & -0.004 & 0.005 & -0.125 & -0.013 & -0.219 & -0.003 & -0.054 & 0.001 \\
\hline 311 & SM32 & M-13/S2133 & -0.127 & & 0.000 & -0.016 & -0.013 & -0.019 & -0.029 & -0.030 & -0.004 & 0.007 & -0.049 & -0.019 & 0.056 & -0.003 & -0.042 & 0.003 \\
\hline 312 & ARGB & M-13/S2133 & $\begin{array}{l}2.284 \\
\end{array}$ & . & 0.981 & 0.063 & -0.003 & 9.630 & 2.283 & 1.481 & 0.494 & 1.404 & 8.474 & 0.790 & 21.317 & 0.652 & -0.106 & 0.087 \\
\hline 312 & ARGB & M-13/S2133 & 2.290 & & 0.984 & 0.071 & -0.004 & 9.408 & 1.957 & 1.473 & 0.495 & 1.400 & 8.676 & 0.812 & 21.734 & 0.664 & -0.133 & 0.090 \\
\hline 312 & SM01 & $1-13 / \mathrm{S} 2133$ & 2.803 & & 0.687 & 0.054 & 0.008 & 7.511 & -0.057 & 2.224 & 0.645 & 1.482 & 9.051 & 0.441 & 23.111 & 0.034 & 2.587 & 0.048 \\
\hline 312 & SM01 & M-13/S2133 & 2.909 & & 0.710 & 0.054 & 0.007 & 7.971 & 0.473 & 2.254 & 0.666 & 1.527 & 8.795 & 0.464 & 22.958 & 0.033 & 2.700 & 0.047 \\
\hline 312 & SM01 & M-13/S2133 & 2.807 & & 0.707 & 0.054 & 0.007 & 7.614 & 0.281 & 2.183 & 0.691 & 1.536 & 9.151 & 0.444 & 22.461 & 0.032 & 2.645 & 0.045 \\
\hline 312 & SM01 & M-13/S2133 & 2.839 & & 0.712 & 0.058 & 0.008 & 7.920 & 0.593 & 2.173 & 0.683 & 1.597 & 9.058 & 0.466 & 22.352 & 0.033 & 2.663 & 0.046 \\
\hline 312 & SM01 & M-13/S2133 & 2.802 & & 0.681 & 0.056 & 0.006 & 7.639 & -0.115 & 2.244 & 0.640 & 1.516 & 8.912 & 0.452 & 23.317 & 0.031 & 2.641 & 0.046 \\
\hline 312 & SM01 & & $\begin{array}{l}2.801 \\
\end{array}$ & & 0.714 & 0.055 & 0.010 & 7.725 & $\begin{array}{l}-0.042 \\
\end{array}$ & 2.220 & 0.665 & 1.542 & 9.210 & 0.453 & 22.535 & 0.034 & 2.667 & 0.048 \\
\hline 312 & SM32 & M-13/S2133 & -0.116 & & -0.012 & -0.003 & -0.007 & -0.099 & -0.338 & -0.012 & -0.004 & -0.019 & 0.087 & -0.011 & -0.010 & -0.007 & -0.238 & -0.015 \\
\hline 312 & SM32 & M-13/S2133 & -0.119 & & -0.012 & -0.003 & -0.011 & -0.095 & 0.169 & -0.009 & -0.003 & -0.019 & 0.087 & 0.005 & -0.037 & -0.008 & -0.266 & -0.014 \\
\hline 313 & & & 2.277 & & 0.972 & 0.058 & -0.040 & 9.393 & 2.049 & 1.478 & 0.500 & 1.359 & & 0.788 & 21.046 & 0.657 & -0.071 & 0.083 \\
\hline 313 & ARGB & M-13/S2133 & 2.332 & & 0.985 & 0.069 & -0.039 & 9.543 & 2.022 & 1.496 & 0.509 & 1.395 & 8.428 & 0.813 & 21.134 & 0.653 & 0.007 & 0.083 \\
\hline 313 & SM01 & M-13/S2133 & 2.702 & & 0.674 & 0.048 & -0.034 & 7.228 & 0.591 & 2.246 & 0.633 & 1.406 & 8.333 & 0.421 & 22.146 & 0.028 & 2.592 & 0.037 \\
\hline 313 & & & 2.643 & & 0.620 & 0.045 & -0.024 & 7.070 & -0.538 & 2.271 & 0.578 & 1.336 & 8.327 & 0.408 & 23.515 & 0.026 & $\begin{array}{l}2.501 \\
\end{array}$ & 0.033 \\
\hline 313 & SM01 & M-13/S2133 & 2.631 & & 0.635 & 0.049 & -0.034 & 7.195 & -0.028 & 2.265 & 0.614 & 1.395 & 8.588 & 0.435 & 23.052 & 0.021 & 2.449 & 0.031 \\
\hline 313 & SM01 & M-13/S2133 & 2.251 & & 0.461 & 0.032 & -0.017 & 5.835 & -0.504 & 2.573 & 0.397 & 1.004 & 7.373 & 0.332 & 24.759 & 0.030 & 1.033 & 0.030 \\
\hline 313 & SM01 & M-13/S2133 & 2.727 & & 0.626 & 0.048 & -0.010 & 7.281 & 0.191 & 2.328 & 0.579 & 1.390 & 8.293 & 0.421 & 23.774 & 0.027 & 2.599 & 0.036 \\
\hline 313 & SM01 & M-13/S2133 & 2.795 & & 0.662 & 0.047 & -0.027 & 7.375 & -0.286 & 2.304 & 0.613 & 1.424 & 8.429 & 0.425 & 23.478 & 0.029 & 2.691 & 0.038 \\
\hline 313 & SM32 & $\mathrm{M}-13 / \mathrm{S} 2133$ & -0.093 & & -0.015 & -0.010 & $\begin{array}{l}-0.032 \\
\end{array}$ & -0.051 & -0.577 & -0.016 & -0.005 & -0.012 & -0.027 & -0.010 & -0.345 & -0.008 & -0.053 & -0.016 \\
\hline
\end{tabular}


Table A3. Mixed Acid Measurement Data Set (continued)

\section{Revision 0}

\begin{tabular}{|c|c|c|c|c|c|c|c|c|c|c|c|c|c|c|c|c|c|c|}
\hline Batch & Cype of Sample & ICP/ID & Al & B & Ca & $\mathrm{Cr}$ & $\mathrm{Cu}$ & $\mathrm{Fe}$ & $\mathbf{K}$ & $\mathbf{L i}$ & Mg & Mn & $\mathrm{Na}$ & $\mathrm{Ni}$ & $\mathrm{Si}$ & $\mathrm{Ti}$ & $\mathbf{U}$ & $\mathrm{Zr}$ \\
\hline 313 & SM32 & M-13/S2133 & -0.148 & & 0.007 & -0.007 & -0.045 & -0.057 & -0.233 & -0.026 & -0.006 & -0.013 & -0.059 & -0.009 & -0.226 & -0.010 & 0.016 & -0.021 \\
\hline 314 & ARGB & $\mathrm{M}-13 / \mathrm{S} 2133$ & 2.333 & & 1.002 & 0.079 & -0.002 & 9.653 & 1.955 & 1.496 & 0.509 & 1.372 & 8.321 & 0.803 & 21.895 & 0.672 & -0.077 & 0.087 \\
\hline 314 & ARGB & M-13/S2133 & 2.287 & & 0.979 & 0.074 & -0.004 & 9.743 & 2.080 & 1.498 & 0.509 & 1.388 & 8.324 & 0.807 & 21.937 & 0.661 & -0.225 & 0.084 \\
\hline 314 & SM01 & M-13/S2133 & 2.777 & & 0.695 & 0.062 & 0.007 & 7.586 & -0.323 & 2.265 & 0.673 & 1.511 & 8.878 & 0.441 & 23.256 & 0.025 & 2.634 & 0.038 \\
\hline 314 & SM01 & M-13/S2133 & 2.761 & & 0.676 & 0.060 & 0.019 & 7.554 & -0.191 & 2.229 & 0.644 & 1.473 & 8.388 & 0.438 & 23.065 & 0.025 & 2.659 & 0.039 \\
\hline 314 & SM01 & M-13/S2133 & 2.801 & & 0.696 & 0.067 & 0.021 & 7.515 & -0.402 & 2.296 & 0.656 & 1.472 & 8.705 & 0.453 & 23.553 & 0.025 & 2.567 & 0.036 \\
\hline 314 & SM01 & $\mathrm{M}-13 / \mathrm{S} 2133$ & 2.871 & & 0.706 & 0.063 & 0.017 & 7.866 & -0.139 & 2.191 & 0.640 & 1.496 & 8.550 & 0.464 & 22.904 & 0.025 & 2.643 & 0.042 \\
\hline 314 & SM01 & M-13/S2133 & 2.823 & & 0.690 & 0.063 & 0.018 & 7.580 & -0.155 & 2.245 & 0.655 & 1.493 & 8.667 & 0.460 & 23.278 & 0.026 & 2.662 & 0.041 \\
\hline 314 & SM01 & $\mathrm{M}-13 / \mathrm{S} 2133$ & 2.820 & & 0.704 & 0.065 & 0.017 & 7.599 & -0.171 & 2.283 & 0.662 & 1.505 & 8.926 & 0.436 & 23.498 & 0.026 & 2.693 & 0.042 \\
\hline 314 & SM32 & $\mathrm{M}-13 / \mathrm{S} 2133$ & -0.070 & & 0.001 & 0.010 & -0.006 & -0.035 & 0.731 & -0.005 & 0.002 & -0.022 & -0.005 & -0.013 & -0.046 & -0.012 & -0.309 & -0.016 \\
\hline 314 & SM32 & $\mathrm{M}-13 / \mathrm{S} 2133$ & -0.080 & & -0.004 & 0.013 & -0.008 & -0.035 & -0.609 & -0.006 & 0.002 & -0.019 & -0.018 & 0.004 & 0.218 & -0.012 & -0.418 & -0.017 \\
\hline 315 & ARGB & M-13/S2133 & 1.576 & & 0.689 & 0.044 & 0.001 & 6.838 & 1.499 & 1.070 & 0.361 & 0.995 & 5.902 & 0.582 & 14.671 & 0.472 & -0.385 & 0.055 \\
\hline 315 & ARGB & M-13/S2133 & 2.520 & & 1.100 & 0.071 & 0.004 & 10.703 & 1.999 & 1.661 & 0.566 & 1.535 & 9.237 & 0.880 & 23.897 & 0.761 & -0.271 & 0.096 \\
\hline 315 & SM01 & $\mathrm{M}-13 / \mathrm{S} 2133$ & 2.746 & & 0.694 & 0.049 & 0.013 & 7.480 & -0.043 & 2.286 & 0.639 & 1.483 & 8.740 & 0.443 & 23.171 & 0.031 & 2.451 & 0.037 \\
\hline 315 & SM01 & M-13/S2133 & 3.046 & & 0.763 & 0.055 & 0.015 & 8.180 & -0.044 & 2.397 & 0.719 & 1.634 & 9.705 & 0.476 & 23.562 & 0.034 & 2.805 & 0.045 \\
\hline 315 & SM01 & M-13/S2133 & 2.745 & & 0.692 & 0.051 & 0.013 & 7.510 & -0.269 & 2.274 & 0.657 & 1.515 & 8.732 & 0.426 & 22.395 & 0.030 & 2.397 & 0.027 \\
\hline 315 & SM01 & M-13/S2133 & 2.740 & & 0.704 & 0.049 & 0.018 & 7.338 & -0.332 & 2.179 & 0.667 & 1.534 & 8.690 & 0.435 & 21.385 & 0.031 & 2.532 & 0.039 \\
\hline 315 & SM01 & $\mathrm{M}-13 / \mathrm{S} 2133$ & 2.751 & & 0.725 & 0.051 & 0.016 & 7.386 & -0.248 & 2.259 & 0.675 & 1.541 & 8.912 & 0.443 & 22.748 & 0.033 & 2.525 & 0.037 \\
\hline 315 & SM01 & M-13/S2133 & 2.825 & & 0.717 & 0.049 & 0.012 & 7.565 & -0.265 & 2.292 & 0.680 & 1.551 & 8.934 & 0.454 & 22.593 & 0.031 & 2.407 & 0.036 \\
\hline 315 & SM32 & M-13/S2133 & 0.078 & & -0.008 & -0.013 & 0.003 & -0.117 & -0.394 & -0.007 & -0.004 & -0.018 & -0.078 & -0.008 & 0.071 & -0.007 & -0.478 & -0.021 \\
\hline 315 & SM32 & 2133 & -0.075 & & -0.004 & -0.012 & 0.000 & -0.066 & -0.239 & 0.000 & -0.003 & -0.011 & 0.001 & -0.011 & 0.042 & -0.003 & -0.356 & -0.025 \\
\hline 316 & ARGB & M-13/S2133 & 2.109 & & 0.920 & 0.063 & 0.005 & 8.764 & 2.126 & 1.358 & 0.470 & 1.279 & 7.661 & 0.718 & 19.283 & 0.618 & -0.227 & 0.080 \\
\hline 316 & ARGB & M-13/S2133 & 2.311 & & 1.004 & 0.072 & 0.011 & 9.770 & 2.388 & 1.481 & 0.522 & 1.430 & 8.393 & 0.771 & 21.299 & 0.690 & $\begin{array}{l}-0.169 \\
\end{array}$ & 0.091 \\
\hline 316 & SM01 & M-13/S2133 & 2.797 & & 0.702 & 0.055 & 0.017 & 7.590 & 0.533 & 2.238 & 0.680 & 1.544 & 8.947 & 0.435 & 22.187 & 0.036 & 2.576 & 0.042 \\
\hline 316 & SM01 & M-13/S2133 & 2.756 & & 0.685 & 0.058 & 0.017 & 7.647 & 0.107 & 2.291 & 0.660 & 1.522 & 8.919 & 0.435 & 23.007 & 0.036 & 2.487 & 0.040 \\
\hline 316 & SM01 & $\mathrm{M}-13$ & 2.759 & & 0.726 & 0.059 & 0.015 & 7.729 & 0.198 & 2.256 & 0.698 & 1.558 & 9.350 & 0.411 & 22.351 & 0.036 & 2.499 & 0.041 \\
\hline 316 & SM01 & /S2133 & 2.769 & & 0.727 & 0.061 & 0.021 & 7.799 & 0.147 & 2.292 & 0.689 & 1.571 & 9.136 & 0.426 & 22.399 & 0.038 & 2.576 & 0.044 \\
\hline 316 & SM01 & -113/S2133 & 2.794 & & 0.657 & 0.057 & 0.021 & 7.610 & 0.450 & 2.336 & 0.573 & 1.404 & 7.949 & 0.409 & 22.937 & 0.038 & 2.606 & 0.043 \\
\hline 316 & SM01 & $\mathrm{M}-13$ & 2.850 & & 0.731 & 0.059 & 0.022 & 7.917 & 0.228 & 2.242 & 0.692 & 1.604 & 8.890 & 0.435 & 22.005 & 0.039 & 2.698 & 0.045 \\
\hline 316 & SM32 & $\mathrm{M}-13 / \mathrm{S} 2133$ & -0.038 & & 0.003 & -0.004 & 0.001 & -0.068 & -0.095 & 0.009 & 0.001 & -0.005 & 0.000 & -0.011 & 0.286 & -0.004 & -0.392 & -0.015 \\
\hline 316 & SM32 & M-13/S2133 & -0.049 & & -0.004 & -0.001 & 0.001 & -0.082 & -0.278 & -0.003 & 0.003 & -0.003 & -0.023 & -0.013 & 0.142 & -0.003 & -0.418 & -0.013 \\
\hline 317 & RGB & $\mathrm{M}-13 / \mathrm{S} 2133$ & 2.272 & 5 & 0.977 & 0.069 & -0.003 & 9.784 & 1.993 & 1.402 & 0.512 & 1.394 & 8.388 & 0.784 & 21.762 & 0.684 & -0.021 & 0.085 \\
\hline 317 & RGB & M-13/S2133 & 2.297 & & 0.966 & 0.079 & -0.004 & 9.986 & 2.070 & 1.418 & 0.537 & 1.450 & 8.234 & 0.756 & 21.902 & 0.675 & -0.008 & 0.090 \\
\hline 317 & M01 & M-13/S2133 & 2.862 & & 0.717 & 0.062 & 0.013 & 8.018 & 0.040 & 2.045 & 0.719 & 1.603 & 8.917 & 0.438 & 22.982 & 0.036 & 2.989 & 0.041 \\
\hline 317 & SM01 & M-13/S2133 & 2.766 & & 0.709 & 0.064 & 0.009 & 8.121 & 0.091 & 2.012 & 0.741 & 1.659 & 9.134 & 0.419 & 21.738 & 0.034 & 2.913 & 0.040 \\
\hline 317 & SM01 & -113/S2133 & 2.865 & & 0.774 & 0.069 & 0.008 & 8.486 & -0.365 & 2.039 & 0.750 & 1.678 & 9.189 & 0.439 & 20.682 & 0.034 & 2.968 & 0.040 \\
\hline 317 & SM01 & $-13 / 52133$ & 2.735 & & 0.682 & 0.071 & 0.007 & 8.069 & -0.351 & 2.020 & 0.712 & 1.601 & 8.635 & 0.403 & 21.793 & 0.031 & 2.831 & 0.035 \\
\hline 317 & SM01 & $\mathrm{M}-13 / \mathrm{S} 2133$ & 2.837 & & 0.724 & 0.068 & 0.007 & 8.353 & -0.143 & 2.048 & 0.746 & 1.668 & 9.070 & 0.429 & 22.630 & 0.034 & 2.937 & 0.039 \\
\hline 317 & & & 2.868 & & 0.734 & 0.068 & 0.009 & 8.220 & -0.504 & 2.167 & 0.753 & 1.689 & 9.379 & 0.425 & 23.645 & 0.033 & 2.946 & 0.040 \\
\hline 317 & SM32 & M-13/S2133 & -0.118 & & -0.029 & -0.001 & -0.011 & -0.064 & -0.470 & -0.015 & 0.001 & -0.028 & -0.143 & -0.027 & 0.044 & -0.011 & -0.122 & -0.017 \\
\hline 317 & SM32 & $\mathrm{M}-13 / \mathrm{S} 2133$ & -0.092 & & -0.026 & 0.007 & -0.012 & -0.053 & -0.652 & 0.001 & 0.003 & -0.026 & -0.107 & -0.038 & 0.285 & -0.010 & -0.145 & -0.019 \\
\hline 318 & & & 2.336 & & 0.995 & 0.076 & 0.008 & 9.808 & 1.895 & 1.494 & 0.511 & 1.414 & 8.302 & 0.802 & 21.097 & 0.678 & -0.194 & 0.088 \\
\hline 318 & ARGB & M-13/S2133 & 2.313 & & 1.019 & 0.076 & 0.010 & 9.549 & 1.924 & 1.481 & 0.513 & 1.395 & 8.400 & 0.843 & 21.357 & 0.679 & $\begin{array}{ll}-0.041 \\
\end{array}$ & 0.094 \\
\hline 318 & SM01 & M-13/S2133 & 3.092 & & 0.777 & 0.065 & 0.023 & 8.086 & 0.197 & 2.182 & 0.778 & 1.692 & 8.945 & 0.463 & 21.462 & 0.030 & 2.726 & 0.041 \\
\hline 318 & & & 3.007 & & 0.784 & 0.061 & 0.016 & 8.162 & 0.253 & 2.159 & 0.783 & 1.700 & 9.083 & 0.467 & 21.459 & 0.028 & 2.797 & 0.042 \\
\hline 318 & SM01 & M-13/S2133 & 2.946 & & 0.738 & 0.062 & 0.018 & 7.949 & -0.255 & 2.130 & 0.736 & 1.628 & 8.909 & 0.467 & 21.388 & 0.028 & 2.697 & 0.044 \\
\hline 318 & SM01 & M-13/S2133 & 2.962 & & 0.718 & 0.066 & 0.018 & 8.209 & 0.658 & 2.239 & 0.740 & 1.625 & 8.425 & 0.495 & 22.660 & 0.035 & 2.753 & 0.042 \\
\hline 318 & SM01 & M-13/S2133 & 3.007 & & 0.769 & 0.065 & 0.021 & 8.034 & 0.466 & 2.244 & 0.755 & 1.636 & 8.768 & 0.471 & 22.741 & 0.033 & 2.859 & 0.046 \\
\hline 318 & SM01 & $\mathrm{M}-13 / \mathrm{S} 2133$ & 3.031 & & 0.768 & 0.067 & 0.025 & 7.978 & -0.211 & 2.228 & 0.735 & 1.612 & 8.873 & 0.479 & 22.526 & 0.031 & 2.865 & 0.044 \\
\hline 318 & SM32 & $\mathrm{M}-13 / \mathrm{S} 2133$ & -0.103 & & -0.005 & 0.003 & 0.002 & -0.071 & $\begin{array}{ll}-0.143 \\
\end{array}$ & -0.011 & 0.000 & -0.008 & -0.114 & -0.018 & -0.040 & -0.016 & -0.132 & -0.016 \\
\hline
\end{tabular}


Table A3. Mixed Acid Measurement Data Set (continued)

\section{Revision 0}

\begin{tabular}{|c|c|c|c|c|c|c|c|c|c|c|c|c|c|c|c|c|c|c|}
\hline Batch & Cype of Sample & ICP/ID & Al & B & $\mathbf{C a}$ & $\mathrm{Cr}$ & $\mathbf{C u}$ & $\mathbf{F e}$ & $\mathbf{K}$ & $\mathbf{L i}$ & Mg & Mn & $\mathrm{Na}$ & $\mathrm{Ni}$ & Si & $\mathbf{T i}$ & $\mathbf{U}$ & $\mathbf{Z r}$ \\
\hline 318 & SM32 & M-13/S2133 & -0.066 & & 0.009 & 0.009 & 0.003 & -0.077 & $\begin{array}{l}-0.136 \\
\end{array}$ & -0.012 & 0.002 & -0.006 & -0.101 & 0.012 & 0.210 & -0.012 & -0.195 & -0.012 \\
\hline 319 & ARGB & M-13/S2133 & 2.288 & & 0.994 & 0.071 & 0.006 & 9.642 & 1.619 & 1.483 & 0.514 & 1.382 & 8.269 & 0.815 & 21.624 & 0.671 & -0.078 & 0.091 \\
\hline 319 & ARGB & M-13/S2133 & 2.283 & & 1.012 & 0.074 & 0.012 & 9.446 & 2.184 & 1.489 & 0.504 & 1.380 & 8.252 & 0.837 & 21.153 & 0.690 & 0.035 & 0.095 \\
\hline 319 & SM01 & M-13/S2133 & 2.730 & & 0.681 & 0.056 & 0.023 & 7.264 & -0.252 & 2.392 & 0.599 & 1.363 & 8.333 & 0.422 & 23.177 & 0.041 & 2.536 & 0.045 \\
\hline 319 & SM01 & M-13/S2133 & 2.752 & & 0.663 & 0.057 & 0.022 & 7.394 & -0.498 & 2.433 & 0.582 & 1.361 & 8.280 & 0.441 & 24.187 & 0.034 & 2.578 & 0.045 \\
\hline 319 & SM01 & M-13/S2133 & 2.696 & & 0.678 & 0.052 & 0.019 & 7.128 & 0.299 & 2.387 & 0.602 & 1.346 & 8.228 & 0.424 & 24.045 & 0.033 & $\begin{array}{l}2.567 \\
\end{array}$ & 0.044 \\
\hline 319 & SM01 & M-13/S2133 & 2.723 & & 0.687 & 0.057 & 0.022 & 7.276 & -0.098 & 2.412 & 0.604 & 1.349 & 8.365 & 0.428 & 24.215 & 0.034 & 2.575 & 0.047 \\
\hline 319 & SM01 & M-13/S2133 & 2.740 & & 0.684 & 0.052 & 0.022 & 7.276 & -0.138 & 2.400 & $\begin{array}{ll}0.611 \\
\end{array}$ & 1.385 & 8.373 & 0.424 & 23.685 & 0.032 & 2.500 & 0.043 \\
\hline 319 & SM01 & M-13/S2133 & 1.879 & & 0.513 & 0.041 & 0.018 & 5.113 & 18.675 & 1.619 & 0.517 & 1.080 & 5.917 & 0.315 & 16.555 & 0.021 & 1.702 & 0.028 \\
\hline 319 & SM32 & M-13/S2133 & -0.038 & & -0.004 & 0.007 & 0.003 & -0.035 & $\begin{array}{l}-0.694 \\
\end{array}$ & -0.019 & 0.004 & -0.019 & -0.026 & 0.000 & $\begin{array}{l}0.028 \\
\end{array}$ & -0.007 & -0.135 & -0.010 \\
\hline 319 & SM32 & M-13/S2133 & -0.078 & & -0.013 & 0.000 & 0.001 & -0.089 & -0.558 & -0.022 & 0.003 & -0.016 & -0.031 & 0.009 & 0.173 & -0.009 & -0.251 & -0.012 \\
\hline 320 & ARGB & M-14/S2150 & 2.352 & & 1.016 & 0.063 & 0.001 & 9.398 & 2.121 & 1.497 & 0.509 & 1.404 & 8.499 & 0.821 & 20.490 & 0.703 & -0.111 & 0.095 \\
\hline 320 & ARGB & M-14/S2150 & 2.308 & & 0.980 & 0.061 & 0.000 & 9.233 & 2.013 & 1.479 & 0.488 & 1.357 & 8.160 & 0.781 & 20.279 & 0.677 & -0.112 & 0.092 \\
\hline 320 & SM01 & M-14/S2150 & 2.993 & & 0.763 & 0.050 & 0.011 & 7.699 & $\begin{array}{l}-0.040 \\
\end{array}$ & 2.284 & 0.715 & 1.549 & 9.026 & 0.450 & 22.528 & 0.035 & 2.872 & 0.049 \\
\hline 320 & SM01 & M-14/S2150 & 3.065 & & 0.765 & 0.053 & 0.017 & 7.612 & -0.115 & 2.202 & 0.714 & 1.556 & 8.997 & 0.455 & 20.120 & 0.037 & 2.837 & 0.047 \\
\hline 320 & SM01 & M-14/S2150 & 2.982 & & 0.744 & 0.051 & 0.010 & 7.554 & -0.085 & 2.205 & 0.702 & 1.542 & 9.049 & 0.460 & 22.044 & 0.035 & 2.817 & 0.049 \\
\hline 320 & SM01 & M-14/S2150 & 2.989 & & 0.744 & 0.049 & 0.012 & 7.741 & -0.116 & 2.242 & 0.689 & 1.536 & 8.640 & 0.465 & 22.377 & 0.036 & 2.894 & 0.051 \\
\hline 320 & SM01 & M-14/S2150 & 3.018 & & 0.766 & 0.055 & 0.013 & 7.734 & -0.011 & 2.182 & 0.727 & 1.590 & 8.849 & 0.455 & 21.253 & 0.038 & 2.810 & 0.048 \\
\hline 320 & SM01 & M-14/S2150 & 2.965 & & $\begin{array}{ll}0.748 \\
\end{array}$ & 0.051 & 0.014 & 7.615 & 0.067 & 2.286 & 0.720 & 1.559 & 8.869 & 0.445 & 22.652 & 0.036 & 2.797 & 0.050 \\
\hline 320 & SM32 & M-14/S2150 & -0.044 & & 0.007 & -0.001 & -0.004 & -0.030 & -0.079 & -0.005 & 0.004 & 0.004 & -0.138 & -0.005 & 0.168 & -0.001 & -0.192 & $-0.00 \varepsilon$ \\
\hline 320 & SM32 & M-14/S2150 & -0.055 & & 0.008 & -0.001 & -0.004 & -0.030 & -0.269 & -0.008 & 0.004 & 0.003 & -0.111 & 0.013 & 0.136 & -0.001 & -0.176 & -0.005 \\
\hline 321 & ARGB & M-13/S2133 & 2.317 & & 1.014 & 0.064 & 0.003 & 9.586 & 2.430 & 1.430 & 0.519 & 1.394 & 8.167 & 0.812 & 20.743 & 0.667 & -0.234 & 0.088 \\
\hline 321 & ARGB & M-13/S2133 & 2.366 & & 0.989 & 0.069 & -0.001 & 9.702 & 2.275 & 1.475 & 0.523 & 1.396 & 8.250 & 0.829 & 20.979 & 0.689 & -0.087 & 0.093 \\
\hline 321 & SM01 & $1-13 / \mathrm{S} 2133$ & 2.826 & & 0.702 & 0.055 & 0.008 & 7.468 & 0.402 & 2.294 & 0.674 & 1.496 & 8.642 & 0.436 & 22.656 & 0.029 & 2.653 & 0.041 \\
\hline 321 & SM01 & M-13/S2133 & 2.463 & & 0.613 & 0.050 & 0.006 & 6.571 & -0.217 & 1.970 & 0.596 & 1.333 & 7.712 & 0.392 & 19.899 & 0.025 & 2.332 & 0.039 \\
\hline 321 & SM01 & M-13/S2133 & 2.319 & & 0.570 & 0.043 & 0.009 & $\begin{array}{ll}6.149 \\
\end{array}$ & -0.067 & 1.853 & 0.532 & 1.222 & 6.918 & 0.366 & 18.797 & 0.025 & 2.255 & 0.037 \\
\hline 321 & SM01 & M-13/S2133 & 2.799 & & 0.702 & 0.052 & 0.007 & 7.442 & 0.333 & 2.227 & 0.667 & 1.472 & 8.539 & 0.439 & 21.385 & 0.029 & 2.702 & 0.042 \\
\hline 321 & SM01 & -113/S2133 & 2.814 & & 0.682 & 0.053 & 0.008 & 7.530 & -0.167 & 2.249 & 0.659 & 1.483 & 8.500 & 0.454 & 22.792 & 0.028 & 2.637 & 0.043 \\
\hline 321 & SM01 & M-13 & 2.755 & & 0.690 & 0.053 & 0.006 & 7.201 & 0.219 & 2.289 & 0.670 & 1.462 & 8.643 & 0.454 & 23.165 & 0.024 & 2.556 & 0.038 \\
\hline 321 & SM32 & M-13/S2133 & -0.094 & & -0.033 & -0.003 & -0.011 & -0.183 & 0.325 & -0.025 & -0.004 & -0.017 & -0.235 & -0.006 & 0.039 & -0.012 & -0.379 & -0.014 \\
\hline 321 & SM32 & $1-13 / \mathrm{S} 2133$ & -0.113 & & -0.028 & -0.010 & -0.017 & -0.239 & 0.334 & -0.037 & -0.004 & -0.020 & -0.236 & -0.010 & 0.125 & -0.014 & -0.472 & -0.016 \\
\hline 322 & ARGB & M-14/S2150 & $\begin{array}{l}2.399 \\
\end{array}$ & . & 1.034 & 0.060 & 0.001 & 9.714 & 2.294 & 1.491 & $\begin{array}{ll}0.521 \\
\end{array}$ & 1.441 & 8.549 & 0.820 & 21.420 & 0.721 & -0.008 & 0.103 \\
\hline 322 & ARGB & M-14/S2150 & 2.370 & & 1.031 & 0.058 & 0.001 & 9.506 & 2.272 & 1.472 & 0.518 & 1.380 & 8.403 & 0.798 & 21.281 & 0.704 & -0.046 & 0.102 \\
\hline 322 & SM01 & M-14/S2150 & 2.718 & & 0.705 & 0.040 & 0.011 & 7.019 & -0.008 & 2.119 & 0.659 & 1.468 & 8.429 & 0.410 & 21.618 & 0.036 & 2.633 & 0.050 \\
\hline 322 & SM01 & M-14/S2150 & 2.893 & & $\begin{array}{ll}0.748 \\
\end{array}$ & 0.043 & 0.013 & 7.300 & 0.006 & 2.145 & 0.701 & 1.529 & 8.945 & 0.432 & 21.997 & 0.034 & 2.863 & 0.054 \\
\hline 322 & SM01 & M-14/S2150 & 3.179 & & 0.846 & 0.051 & 0.016 & 8.433 & 0.046 & 2.355 & 0.765 & 1.665 & 9.414 & 0.474 & 23.365 & 0.035 & 3.082 & 0.059 \\
\hline 322 & SM01 & M-14/S2150 & 2.981 & & $\begin{array}{ll}0.738 \\
\end{array}$ & 0.042 & 0.013 & 7.618 & 0.195 & 2.237 & 0.699 & 1.556 & 8.715 & 0.433 & 22.384 & 0.039 & 3.005 & 0.055 \\
\hline 322 & SM01 & M-14/S2150 & 3.018 & & 0.772 & 0.041 & 0.015 & 7.569 & -0.058 & 2.260 & 0.713 & 1.572 & 9.140 & 0.438 & 22.872 & 0.033 & 2.938 & 0.056 \\
\hline 322 & SM01 & & 2.932 & & 0.734 & 0.052 & 0.013 & 7.583 & 0.068 & 2.237 & 0.704 & 1.580 & 8.771 & 0.466 & 22.262 & 0.033 & 2.876 & 0.056 \\
\hline 322 & SM32 & M-14/S2150 & -0.024 & & 0.009 & -0.013 & -0.004 & -0.212 & -0.203 & -0.032 & 0.004 & -0.021 & -0.120 & -0.011 & -0.008 & -0.003 & -0.124 & 0.003 \\
\hline 322 & SM32 & M-14/S2150 & -0.026 & & 0.012 & -0.009 & -0.001 & -0.218 & -0.041 & -0.036 & 0.004 & -0.022 & -0.115 & 0.007 & -0.095 & 0.000 & -0.023 & 0.004 \\
\hline 323 & & & 2.427 & & 1.030 & 0.064 & -0.001 & 9.604 & 2.331 & 1.521 & 0.522 & 1.418 & 8.616 & 0.819 & 21.705 & 0.699 & -0.038 & 0.097 \\
\hline 323 & ARGB & M-14/S2150 & 2.377 & 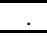 & 0.993 & 0.064 & -0.003 & 9.591 & 2.300 & 1.502 & 0.510 & 1.396 & 8.407 & 0.804 & 21.216 & 0.693 & -0.046 & 0.094 \\
\hline 323 & SM01 & M-14/S2150 & 3.005 & & 0.744 & 0.050 & 0.013 & 7.747 & 0.037 & 2.253 & 0.710 & 1.583 & 8.991 & 0.450 & 22.500 & 0.044 & 2.855 & 0.048 \\
\hline 323 & & & 3.000 & & 0.742 & 0.051 & 0.011 & 7.532 & 0.115 & 2.232 & 0.698 & 1.565 & 9.020 & 0.446 & 22.181 & 0.041 & $\begin{array}{l}2.883 \\
\end{array}$ & 0.049 \\
\hline 323 & SM01 & M-14/S2150 & 2.955 & & 0.739 & 0.053 & 0.010 & 7.632 & 0.092 & 2.224 & 0.709 & 1.614 & 9.134 & 0.446 & 22.097 & 0.045 & 2.653 & 0.048 \\
\hline 323 & SM01 & M-14/S2150 & 2.994 & & 0.749 & 0.050 & 0.012 & 7.742 & 0.182 & 2.225 & 0.718 & 1.608 & 8.946 & 0.453 & 22.191 & 0.040 & 2.876 & 0.049 \\
\hline 323 & SM01 & M-14/S2150 & 2.908 & & 0.716 & 0.048 & 0.012 & 7.416 & 0.080 & 2.304 & 0.677 & 1.542 & 8.941 & 0.429 & 22.537 & 0.042 & 2.758 & 0.047 \\
\hline 323 & SM01 & M-14/S2150 & 2.979 & & 0.743 & 0.050 & 0.012 & 7.770 & 0.112 & 2.214 & 0.702 & 1.571 & 9.116 & 0.443 & 22.321 & 0.041 & 2.910 & 0.048 \\
\hline 323 & SM32 & M-14/S2150 & -0.085 & & 0.019 & -0.001 & -0.008 & -0.240 & 0.139 & -0.011 & 0.008 & -0.016 & -0.122 & -0.014 & 0.010 & -0.001 & -0.124 & -0.006 \\
\hline
\end{tabular}


Table A3. Mixed Acid Measurement Data Set (continued)

\section{Revision 0}

\begin{tabular}{|c|c|c|c|c|c|c|c|c|c|c|c|c|c|c|c|c|c|c|}
\hline Batch & yype of Sample & ICP/ID & Al & B & Ca & $\mathrm{Cr}$ & $\mathbf{C u}$ & $\mathbf{F e}$ & $\mathbf{K}$ & $\mathbf{L i}$ & Mg & Mn & $\mathrm{Na}$ & $\mathrm{Ni}$ & Si & $\mathbf{T i}$ & $\mathbf{U}$ & $\mathbf{Z r}$ \\
\hline 323 & SM32 & M-14/S2150 & -0.078 & & -0.005 & -0.003 & -0.006 & -0.223 & 0.108 & -0.006 & 0.007 & -0.016 & -0.105 & -0.012 & 0.177 & 0.000 & -0.290 & -0.007 \\
\hline 324 & ARGB & M-14/S2150 & $\begin{array}{l}2.366 \\
\end{array}$ & & 0.989 & 0.064 & -0.012 & 9.589 & 2.414 & 1.496 & 0.511 & 1.397 & 8.545 & 0.818 & 20.647 & 0.673 & -0.229 & 0.089 \\
\hline 324 & ARGB & M-14/S2150 & 2.476 & & 1.058 & 0.072 & -0.009 & 10.043 & 2.029 & 1.576 & 0.536 & 1.461 & 8.985 & 0.840 & 21.022 & 0.719 & -0.099 & 0.095 \\
\hline 324 & SM01 & M-14/S2150 & 2.790 & & 0.694 & 0.051 & 0.001 & 7.197 & 0.168 & 2.402 & 0.651 & 1.454 & 9.072 & 0.440 & 22.897 & 0.030 & 2.782 & 0.043 \\
\hline 324 & SM01 & M-14/S2150 & 2.742 & . & 0.681 & 0.044 & 0.005 & 7.237 & -0.119 & 2.342 & 0.634 & 1.467 & 8.694 & 0.433 & 22.206 & 0.030 & 2.700 & 0.043 \\
\hline 324 & SM01 & M-14/S2150 & 2.807 &. & 0.704 & 0.048 & 0.002 & 7.339 & -0.170 & 2.336 & 0.658 & 1.486 & 9.066 & 0.433 & 21.605 & 0.028 & 2.722 & 0.040 \\
\hline 324 & SM01 & M-14/S2150 & 2.705 & & 0.686 & 0.037 & -0.007 & 7.037 & -0.169 & 2.418 & 0.640 & 1.440 & 8.810 & 0.418 & 22.510 & 0.025 & 2.406 & 0.039 \\
\hline 324 & SM01 & M-14/S2150 & 2.769 & & 0.708 & 0.042 & 0.004 & 7.292 & 0.321 & 2.322 & 0.668 & 1.491 & 8.994 & 0.453 & 21.250 & 0.028 & 2.659 & 0.042 \\
\hline 324 & SM01 & M-14/S2150 & 2.668 & & 0.677 & 0.050 & -0.001 & 7.129 & -0.123 & 2.349 & 0.636 & 1.446 & 8.833 & 0.445 & 21.684 & 0.026 & 2.608 & 0.040 \\
\hline 324 & SM32 & M-14/S2150 & -0.058 & & 0.003 & 0.009 & -0.016 & -0.053 & -0.391 & -0.013 & 0.003 & 0.000 & -0.018 & 0.011 & 0.175 & -0.010 & -0.125 & -0.013 \\
\hline 324 & SM32 & M-14/S2150 & -0.108 & & -0.018 & -0.010 & -0.018 & -0.166 & 0.117 & -0.004 & -0.003 & -0.006 & -0.015 & -0.006 & 0.188 & -0.010 & -0.236 & -0.014 \\
\hline 325 & ARGB & M-14/S2150 & 2.325 & & 0.978 & 0.057 & -0.009 & 9.350 & 2.250 & 1.475 & 0.499 & 1.370 & 8.325 & 0.789 & 20.269 & 0.690 & -0.030 & 0.092 \\
\hline 325 & ARGB & M-14/S2150 & 2.347 & & 0.977 & 0.056 & -0.008 & 9.329 & 2.139 & 1.459 & 0.503 & 1.363 & 8.192 & 0.800 & 20.798 & 0.687 & -0.025 & 0.093 \\
\hline 325 & SM01 & M-14/S2150 & 2.767 & & 0.678 & 0.038 & 0.003 & 7.150 & -0.001 & 2.328 & 0.639 & 1.405 & 8.698 & 0.424 & 23.186 & 0.037 & 2.698 & 0.048 \\
\hline 325 & SM01 & M-14/S2150 & 2.927 & & 0.709 & 0.040 & 0.003 & 7.342 & 0.392 & 2.263 & 0.670 & 1.460 & 8.967 & 0.425 & 22.315 & 0.041 & 2.820 & 0.051 \\
\hline 325 & SM01 & M-14/S2150 & 2.816 & & 0.680 & 0.038 & 0.001 & 7.234 & -0.023 & 2.327 & 0.648 & 1.407 & 8.797 & 0.430 & 22.992 & 0.037 & 2.726 & 0.047 \\
\hline 325 & SM01 & M-14/S2150 & 2.681 & & 0.660 & 0.043 & 0.000 & 6.935 & 0.320 & 2.276 & 0.635 & 1.354 & 8.611 & 0.433 & 22.007 & 0.036 & 2.536 & 0.045 \\
\hline 325 & SM01 & M-14/S2150 & 2.743 & & 0.690 & 0.042 & 0.001 & 7.245 & 0.023 & 2.301 & 0.671 & 1.428 & 8.778 & 0.446 & 22.778 & 0.037 & 2.728 & 0.048 \\
\hline 325 & SM01 & M-14/S2150 & 2.698 & & 0.668 & 0.038 & 0.002 & 6.956 & 0.033 & 2.342 & 0.646 & 1.382 & 8.857 & 0.409 & 22.949 & 0.038 & 2.520 & 0.050 \\
\hline 325 & SM32 & M-14/S2150 & -0.055 & & 0.009 & -0.007 & -0.015 & -0.155 & -0.165 & -0.014 & 0.010 & -0.012 & -0.106 & -0.001 & -0.072 & 0.000 & -0.121 & -0.006 \\
\hline 325 & SM32 & M-14/S2150 & -0.061 & & 0.001 & -0.002 & -0.017 & -0.175 & 0.135 & -0.009 & 0.009 & -0.011 & -0.045 & 0.043 & 0.102 & -0.002 & -0.131 & -0.007 \\
\hline 326 & ARGB & M-14/S2150 & 2.463 & & 1.024 & 0.054 & -0.005 & 9.502 & 2.098 & 1.512 & 0.512 & 1.441 & 8.519 & 0.810 & 21.212 & 0.700 & -0.024 & 0.093 \\
\hline 326 & ARGB & M-14/S2150 & 2.313 & & 0.997 & 0.056 & -0.008 & 9.384 & 2.092 & 1.448 & 0.501 & 1.380 & 8.329 & 0.786 & 20.408 & 0.685 & -0.111 & 0.089 \\
\hline 326 & SM01 & $\mathrm{I}-14 / \mathrm{S} 2150$ & 2.840 & & 0.719 & 0.036 & 0.000 & 7.242 & -0.123 & 2.279 & 0.695 & 1.557 & 8.883 & 0.423 & 21.446 & 0.038 & 2.677 & 0.044 \\
\hline 326 & SM01 & M-14/S2150 & 2.873 & & 0.746 & 0.040 & 0.005 & 7.441 & -0.142 & 2.300 & 0.703 & 1.538 & 8.877 & 0.431 & 22.089 & 0.041 & 2.812 & 0.044 \\
\hline 326 & SM01 & M-14/S2150 & 2.864 & & 0.712 & 0.037 & 0.004 & 7.247 & -0.159 & 2.300 & 0.680 & 1.490 & 8.672 & 0.434 & 21.412 & 0.036 & 2.689 & 0.043 \\
\hline 326 & SM01 & M-14/S2150 & 2.890 & & 0.721 & 0.040 & 0.005 & 7.501 & $\begin{array}{l}-0.199 \\
\end{array}$ & 2.302 & 0.687 & 1.546 & 8.844 & 0.452 & 22.129 & 0.037 & 2.859 & 0.045 \\
\hline 326 & SM01 & -14/S2150 & 2.918 & & 0.711 & 0.038 & 0.008 & 7.441 & -0.085 & 2.336 & 0.664 & 1.495 & 8.622 & 0.436 & 22.255 & 0.040 & 2.758 & 0.045 \\
\hline 326 & SM01 & M-14 & 2.856 & & 0.707 & 0.040 & 0.008 & 7.402 & -0.147 & 2.332 & 0.658 & 1.501 & 8.489 & 0.435 & 22.102 & 0.040 & 2.759 & 0.045 \\
\hline 326 & SM32 & M-14/S2150 & -0.029 & & -0.003 & -0.017 & -0.012 & -0.181 & -0.277 & -0.021 & -0.008 & -0.004 & -0.145 & -0.017 & -0.162 & -0.004 & -0.140 & -0.011 \\
\hline 326 & SM32 & $1-14 / \mathrm{S} 2150$ & -0.018 & & 0.001 & -0.014 & -0.014 & -0.177 & -0.056 & -0.014 & -0.007 & -0.004 & -0.093 & -0.013 & -0.042 & 0.003 & -0.155 & $-0.00 \mathrm{~s}$ \\
\hline 327 & RGB & M-13/S2133 & $\begin{array}{l}2.390 \\
\end{array}$ & . & 1.016 & $\begin{array}{ll}0.058 \\
\end{array}$ & -0.007 & 9.510 & 2.331 & 1.527 & 0.500 & 1.417 & 8.475 & 0.798 & 20.903 & 0.710 & -0.130 & 0.094 \\
\hline 327 & ARGB & M-13/S2133 & 2.386 & & 1.025 & 0.060 & -0.003 & 9.609 & 2.156 & 1.495 & 0.505 & 1.410 & 8.413 & 0.799 & 20.999 & 0.711 & -0.027 & 0.098 \\
\hline 327 & SM01 & M-13/S2133 & 2.831 & & 0.750 & 0.044 & 0.009 & 7.556 & 0.066 & 2.310 & 0.697 & 1.582 & 9.513 & 0.435 & 21.836 & 0.041 & 2.806 & 0.048 \\
\hline 327 & SM01 & M-13/S2133 & 2.911 & & 0.731 & 0.045 & 0.007 & 7.494 & -0.035 & 2.334 & 0.692 & 1.606 & 9.105 & 0.457 & 22.423 & 0.043 & 2.885 & 0.049 \\
\hline 327 & SM01 & M-13/S2133 & 2.859 & & 0.727 & 0.043 & 0.006 & 7.613 & -0.050 & 2.305 & 0.699 & 1.578 & 9.348 & 0.442 & 22.063 & 0.045 & 2.749 & 0.047 \\
\hline 327 & SM01 & -13/S2133 & 2.904 & & 0.736 & 0.042 & 0.007 & 7.586 & -0.074 & 2.338 & 0.699 & 1.601 & 9.172 & 0.453 & 22.058 & 0.043 & 2.837 & 0.046 \\
\hline 327 & SM01 & M-13/S2133 & 2.891 & & 0.712 & 0.042 & 0.006 & 7.521 & 0.024 & 2.354 & 0.653 & 1.534 & 9.024 & 0.444 & 22.400 & 0.043 & 2.785 & 0.048 \\
\hline 327 & SM01 & & $\begin{array}{l}2.858 \\
\end{array}$ & & 0.745 & 0.043 & 0.005 & 7.503 & $\begin{array}{l}-0.049 \\
\end{array}$ & 2.267 & 0.684 & 1.561 & 9.021 & 0.439 & 21.395 & 0.048 & 2.758 & 0.048 \\
\hline 327 & SM32 & M-13/S2133 & -0.035 & & -0.022 & -0.007 & -0.012 & -0.209 & -0.041 & -0.017 & -0.005 & -0.013 & -0.136 & -0.019 & -0.136 & 0.002 & -0.125 & -0.002 \\
\hline 327 & SM32 & M-13/S2133 & -0.017 & & -0.025 & -0.011 & -0.012 & -0.209 & $\begin{array}{l}-0.089 \\
\end{array}$ & -0.022 & -0.005 & -0.013 & -0.185 & -0.022 & $\begin{array}{ll}0.028 \\
\end{array}$ & 0.007 & -0.168 & -0.004 \\
\hline 328 & & & 2.351 & & 1.013 & 0.057 & 0.003 & 9.239 & 1.951 & 1.470 & 0.490 & 1.370 & 8.347 & 0.806 & 19.233 & 0.681 & -0.029 & 0.091 \\
\hline 328 & ARGB & M-14/S2150 & 2.360 & & 0.998 & 0.055 & 0.001 & 9.449 & 2.160 & 1.490 & 0.497 & 1.405 & 8.466 & 0.800 & 17.622 & 0.695 & -0.033 & 0.090 \\
\hline 328 & SM01 & M-14/S2150 & 2.853 & & 0.677 & 0.045 & 0.013 & 7.415 & -0.105 & 2.432 & 0.605 & 1.425 & 8.978 & 0.442 & 19.225 & 0.037 & 2.635 & 0.046 \\
\hline 328 & & & 2.862 & & 0.690 & 0.048 & 0.013 & 7.296 & $\begin{array}{l}-0.118 \\
\end{array}$ & 2.433 & 0.625 & 1.461 & 9.141 & 0.428 & 22.527 & 0.037 & 2.663 & 0.043 \\
\hline 328 & SM01 & M-14/S2150 & 2.971 & & 0.714 & 0.046 & 0.014 & 7.712 & -0.035 & 2.401 & 0.658 & 1.537 & 9.261 & 0.456 & 21.990 & 0.034 & 2.796 & 0.048 \\
\hline 328 & SM01 & M-14/S2150 & 2.904 & & 0.707 & 0.045 & 0.014 & 7.452 & -0.101 & 2.300 & 0.658 & 1.494 & 9.112 & 0.430 & 20.745 & 0.032 & 2.706 & 0.044 \\
\hline 328 & SM01 & M-14/S2150 & 2.928 & & 0.704 & 0.043 & 0.009 & 7.542 & $\begin{array}{l}-0.142 \\
\end{array}$ & 2.365 & 0.650 & 1.529 & 9.301 & 0.454 & 21.218 & 0.031 & 2.774 & 0.044 \\
\hline 328 & SM01 & M-14/S2150 & 2.922 & & 0.704 & 0.043 & 0.014 & 7.358 & -0.186 & 2.354 & 0.644 & 1.495 & 9.048 & 0.447 & 20.410 & 0.032 & 2.725 & 0.043 \\
\hline 328 & SM32 & $\mathrm{M}-14 / \mathrm{S} 2150$ & -0.069 & & -0.012 & $\begin{array}{ll}-0.008 \\
\end{array}$ & -0.003 & -0.312 & $\begin{array}{l}-0.213 \\
\end{array}$ & -0.016 & -0.008 & -0.011 & 0.042 & -0.020 & $\begin{array}{l}-0.048 \\
\end{array}$ & -0.008 & -0.124 & -0.016 \\
\hline
\end{tabular}


Table A3. Mixed Acid Measurement Data Set (continued)

\section{Revision 0}

\begin{tabular}{|c|c|c|c|c|c|c|c|c|c|c|c|c|c|c|c|c|c|c|}
\hline Batch & Cype of Sample & ICP/ID & Al & B & Ca & $\mathrm{Cr}$ & $\mathrm{Cu}$ & $\mathrm{Fe}$ & $\mathbf{K}$ & $\mathbf{L i}$ & Mg & Mn & $\mathrm{Na}$ & $\mathrm{Ni}$ & $\mathrm{Si}$ & Ti & $\mathbf{U}$ & $\mathbf{Z r}$ \\
\hline 328 & SM32 & $\mathrm{M}-14 / \mathrm{S} 2150$ & -0.077 & & -0.003 & -0.010 & -0.001 & -0.302 & -0.392 & -0.026 & -0.005 & -0.010 & 0.180 & -0.021 & 0.065 & -0.010 & -0.110 & -0.014 \\
\hline 329 & ARGB & $\mathrm{M}-13 / \mathrm{S} 2133$ & 2.364 & & 1.010 & 0.066 & -0.006 & 9.528 & 2.092 & 1.484 & 0.505 & 1.411 & 8.347 & 0.822 & 21.433 & 0.681 & -0.181 & 0.089 \\
\hline 329 & ARGB & M-13/S2133 & 2.288 & & 0.990 & 0.067 & -0.009 & 9.565 & 1.970 & 1.464 & 0.509 & 1.408 & 8.549 & 0.803 & 20.475 & 0.659 & -0.212 & 0.085 \\
\hline 329 & SM01 & M-13/S2133 & 2.918 & & 0.727 & 0.055 & 0.004 & 7.978 & -0.151 & 2.259 & 0.695 & 1.597 & 9.286 & 0.470 & 21.671 & 0.029 & 2.695 & 0.046 \\
\hline 329 & SM01 & M-13/S2133 & 2.827 & & 0.677 & 0.071 & 0.001 & 7.544 & -0.057 & 2.231 & 0.639 & 1.481 & 8.773 & 0.449 & 21.804 & 0.027 & 2.659 & 0.042 \\
\hline 329 & SM01 & M-13/S2133 & 2.991 & & 0.688 & 0.053 & 0.005 & 7.679 & 0.044 & 2.286 & 0.642 & 1.510 & 8.803 & 0.449 & 22.423 & 0.029 & 2.663 & 0.102 \\
\hline 329 & SM01 & $\mathrm{M}-13 / \mathrm{S} 2133$ & 2.825 & & 0.695 & 0.061 & 0.003 & 7.533 & -0.148 & 2.282 & 0.643 & 1.463 & 8.846 & 0.468 & 21.331 & 0.026 & 2.589 & 0.044 \\
\hline 329 & SM01 & M-13/S2133 & 2.882 & & 0.688 & 0.053 & 0.004 & 7.544 & -0.127 & 2.301 & 0.649 & 1.485 & 8.815 & 0.435 & 21.724 & 0.029 & 2.665 & 0.044 \\
\hline 329 & SM01 & $\mathrm{M}-13 / \mathrm{S} 2133$ & 2.890 & & 0.688 & 0.049 & 0.001 & 7.435 & -0.132 & 2.355 & 0.635 & 1.472 & 8.928 & 0.436 & 20.201 & 0.028 & 2.586 & 0.042 \\
\hline 329 & SM32 & $\mathrm{M}-13 / \mathrm{S} 2133$ & -0.118 & & -0.017 & -0.009 & -0.016 & -0.231 & -0.069 & -0.004 & -0.007 & -0.015 & -0.009 & -0.015 & -0.096 & -0.009 & -0.397 & -0.017 \\
\hline 329 & SM32 & $\mathrm{M}-13 / \mathrm{S} 2133$ & -0.092 & & -0.017 & -0.007 & -0.023 & -0.200 & -0.282 & -0.017 & -0.006 & -0.010 & -0.029 & 0.004 & 0.083 & -0.010 & -0.359 & -0.017 \\
\hline 330 & ARGB & M-13/S2133 & 2.248 & & 0.976 & 0.056 & -0.010 & 9.265 & 2.120 & 1.473 & 0.502 & 1.359 & 8.326 & 0.763 & 20.324 & 0.658 & -0.073 & 0.091 \\
\hline 330 & RGB & M-13/S2133 & 2.246 & & 0.983 & 0.055 & -0.015 & 9.290 & 2.196 & 1.460 & 0.498 & 1.354 & 8.453 & 0.768 & 21.109 & 0.670 & -0.112 & 0.090 \\
\hline 330 & ARGB & $\mathrm{M}-13 / \mathrm{S} 2133$ & 2.353 & & 0.997 & 0.058 & -0.007 & 9.196 & 2.400 & 1.457 & 0.490 & 1.366 & 8.323 & 0.805 & 20.039 & 0.677 & -0.027 & 0.093 \\
\hline 330 & ARGB & M-13/S2133 & 2.267 & & 0.978 & 0.052 & -0.013 & 9.134 & 2.493 & 1.436 & 0.489 & 1.386 & 8.493 & 0.817 & 20.840 & 0.667 & 0.003 & 0.093 \\
\hline 330 & SM01 & M-13/S2133 & 2.967 & & 0.717 & 0.051 & -0.001 & 8.033 & 0.121 & 2.282 & 0.657 & 1.514 & 8.789 & 0.455 & 21.765 & 0.029 & 2.856 & 0.049 \\
\hline 330 & SM01 & M-13/S2133 & 2.915 & & 0.738 & 0.044 & -0.001 & 7.716 & -0.106 & 2.292 & 0.676 & 1.533 & 9.197 & 0.444 & 21.620 & 0.028 & 2.843 & 0.047 \\
\hline 330 & SM01 & $\mathrm{M}-13 / \mathrm{S} 2133$ & 2.873 & & 0.704 & 0.044 & -0.001 & 7.834 & 0.262 & 2.246 & 0.649 & 1.527 & 8.674 & 0.448 & 21.541 & 0.034 & 2.826 & 0.049 \\
\hline 330 & SM01 & M-13/S2133 & 2.920 & & 0.718 & 0.044 & 0.000 & 7.672 & -0.022 & 2.258 & 0.664 & 1.529 & 9.165 & 0.435 & 21.303 & 0.029 & 2.864 & 0.048 \\
\hline 330 & SM01 & M-13/S2133 & 2.903 & & 0.747 & 0.041 & 0.000 & 7.729 & 0.261 & 2.185 & 0.697 & 1.573 & 9.162 & 0.431 & 21.299 & 0.027 & 2.883 & 0.047 \\
\hline 330 & SM01 & 2133 & 3.022 & & 0.763 & 0.049 & 0.001 & 8.150 & 0.466 & 2.251 & 0.719 & 1.656 & 9.460 & 0.450 & 21.828 & 0.029 & 2.924 & 0.048 \\
\hline 330 & SM32 & -13/S2133 & -0.064 & & -0.015 & -0.008 & -0.019 & -0.181 & -0.007 & -0.011 & 0.000 & -0.018 & -0.066 & -0.019 & -0.220 & -0.013 & -0.157 & -0.011 \\
\hline 330 & SM32 & M-13/S2133 & -0.083 & & -0.017 & -0.013 & -0.020 & -0.197 & 0.032 & -0.005 & 0.000 & -0.019 & -0.055 & -0.019 & -0.141 & -0.014 & -0.182 & -0.012 \\
\hline 331 & ARGB & M-14/S2150 & 2.375 & & 0.994 & 0.063 & -0.015 & 9.664 & 2.032 & 1.484 & 0.501 & 1.366 & 8.323 & 0.788 & 20.837 & 0.684 & -0.201 & 0.090 \\
\hline 331 & $\overline{\mathrm{RGB}}$ & M-14/S2150 & 2.362 & & 1.023 & 0.068 & -0.010 & 9.715 & 2.274 & 1.484 & 0.505 & 1.328 & 8.384 & 0.774 & 20.520 & 0.683 & -0.155 & 0.092 \\
\hline 331 & SM01 & M-14 & 2.999 & & 0.782 & 0.055 & 0.000 & 8.175 & 0.149 & 2.315 & 0.722 & 1.611 & 9.544 & 0.452 & 21.847 & 0.031 & 2.944 & 0.046 \\
\hline 331 & SM01 & 1/S2150 & 2.916 & & 0.753 & 0.054 & 0.002 & 7.934 & 0.107 & 2.341 & 0.674 & 1.535 & 9.478 & 0.438 & 21.700 & 0.042 & 2.845 & 0.044 \\
\hline 331 & SM01 & -14/S2150 & 2.962 & & 0.739 & 0.052 & -0.001 & 8.117 & -0.028 & 2.333 & 0.678 & 1.547 & 9.316 & 0.439 & 21.736 & 0.037 & 2.838 & 0.044 \\
\hline 331 & SM01 & $\mathrm{M}-14$ & 2.828 & & 0.749 & 0.051 & 0.000 & 7.717 & 0.024 & 2.342 & 0.692 & 1.530 & 9.427 & 0.413 & 21.523 & 0.033 & 2.707 & 0.043 \\
\hline 331 & SM01 & M-14/S2150 & 3.047 & & 0.796 & 0.056 & 0.000 & 8.163 & -0.140 & 2.354 & 0.714 & 1.588 & 9.423 & 0.452 & 21.611 & 0.039 & 2.825 & 0.045 \\
\hline 331 & SM01 & M-14/S2150 & 2.911 & & 0.743 & 0.054 & 0.002 & 7.954 & 0.000 & 2.303 & 0.685 & 1.567 & 9.305 & 0.439 & 21.400 & 0.030 & 2.869 & 0.045 \\
\hline 331 & SM32 & M-14/S2150 & -0.053 & & -0.004 & 0.002 & -0.017 & 0.051 & -0.007 & -0.004 & 0.009 & -0.021 & -0.017 & -0.006 & -0.198 & 0.002 & -0.157 & -0.009 \\
\hline 331 & SM32 & $\mathrm{M}-14 / \mathrm{S} 2150$ & -0.050 & & -0.009 & -0.001 & -0.021 & 0.014 & -0.135 & -0.009 & 0.005 & -0.026 & 0.036 & -0.010 & -0.058 & -0.005 & -0.137 & -0.010 \\
\hline 332 & RGB & $\mathrm{M}-13 /$ & 2.324 & & 0.980 & 0.059 & -0.017 & 9.338 & 1.067 & 1.456 & 0.505 & 1.366 & 8.264 & 0.765 & 21.672 & 0.690 & -0.249 & 0.095 \\
\hline 332 & ARGB & M-13/S2133 & 2.268 & & 0.978 & 0.059 & -0.018 & 9.535 & 1.180 & 1.453 & 0.534 & 1.388 & 8.525 & 0.804 & 22.219 & 0.685 & -0.212 & 0.093 \\
\hline 332 & SM01 & M-13/S2133 & 2.796 & & 0.696 & 0.048 & -0.008 & 7.568 & -0.329 & 2.232 & 0.694 & 1.552 & 9.000 & 0.441 & 22.457 & 0.021 & 2.565 & 0.054 \\
\hline 332 & SM01 & $-13 / 52133$ & 2.907 & & 0.740 & 0.044 & -0.002 & 7.600 & -0.839 & 2.296 & 0.713 & 1.579 & 9.130 & 0.441 & 22.803 & 0.028 & 2.680 & 0.053 \\
\hline 332 & SM01 & $\mathrm{M}-13 / \mathrm{S} 2133$ & 2.872 & & 0.745 & 0.046 & -0.003 & 7.677 & -0.220 & 2.327 & 0.703 & 1.566 & 9.136 & 0.438 & 23.167 & 0.022 & 2.627 & 0.052 \\
\hline 332 & & & 2.834 & & 0.731 & 0.046 & -0.003 & 7.596 & -0.612 & 2.317 & 0.680 & 1.539 & 9.071 & 0.430 & 23.095 & 0.022 & 2.637 & 0.053 \\
\hline 332 & SM01 & $\mathrm{M}-13 / \mathrm{S}$ & 2.878 & & 0.723 & 0.044 & -0.004 & 7.608 & -0.762 & 2.328 & 0.683 & 1.548 & 9.067 & 0.432 & 23.079 & 0.021 & 2.472 & 0.053 \\
\hline 332 & SM01 & M-13/S2133 & 2.783 & & 0.695 & 0.044 & -0.002 & 7.401 & -0.122 & 2.275 & 0.694 & 1.577 & 8.791 & 0.438 & 22.289 & 0.022 & 2.555 & 0.052 \\
\hline 332 & & & -0.114 & & -0.001 & -0.013 & -0.026 & -0.184 & -1.021 & -0.058 & 0.002 & -0.001 & -0.087 & -0.001 & 0.337 & -0.011 & -0.341 & -0.008 \\
\hline 332 & SM32 & $\mathrm{M}-13 / \mathrm{S} 2133$ & -0.105 & & 0.012 & -0.012 & -0.026 & -0.208 & $\begin{array}{ll}-0.641 \\
\end{array}$ & -0.102 & 0.001 & -0.006 & -0.275 & 0.001 & 0.608 & -0.018 & -0.502 & -0.009 \\
\hline 333 & ARGB & M-13/S2133 & 2.271 & & 0.977 & 0.059 & -0.008 & 9.409 & 1.631 & 1.430 & 0.497 & 1.388 & 8.062 & 0.773 & 21.227 & 0.670 & -0.306 & 0.083 \\
\hline 333 & & & 2.249 & & 0.977 & 0.057 & $\begin{array}{ll}-0.008 \\
\end{array}$ & 9.288 & 1.742 & 1.409 & $\begin{array}{ll}0.489 \\
\end{array}$ & 1.365 & 7.970 & 0.762 & 21.179 & 0.676 & -0.301 & 0.082 \\
\hline 333 & SM01 & M-13/S2133 & 2.907 & & 0.728 & 0.051 & 0.007 & 7.608 & -0.691 & 2.181 & 0.656 & 1.508 & 8.609 & 0.430 & 21.870 & 0.033 & 2.550 & 0.044 \\
\hline 333 & SM01 & M-13/S2133 & 2.884 & & 0.704 & 0.047 & 0.007 & 7.587 & -0.474 & 2.257 & 0.645 & 1.483 & 8.775 & 0.427 & 22.412 & 0.032 & 2.600 & 0.046 \\
\hline 333 & SM01 & M-13/S2133 & 2.755 & & 0.668 & 0.044 & 0.006 & 7.228 & -0.367 & 2.166 & 0.612 & 1.412 & 8.210 & 0.398 & 21.733 & 0.032 & 2.392 & 0.042 \\
\hline 333 & SM01 & M-13/S2133 & 2.817 & & 0.670 & 0.045 & 0.006 & 7.310 & -0.152 & 2.233 & 0.580 & 1.379 & 8.143 & 0.407 & 22.834 & 0.035 & 2.440 & 0.047 \\
\hline 333 & SM01 & M-13/S2133 & 2.772 & & 0.648 & 0.044 & 0.007 & 7.138 & -0.291 & 2.286 & 0.569 & 1.327 & 8.310 & 0.375 & $\begin{array}{l}23.120 \\
2\end{array}$ & 0.035 & 2.380 & 0.047 \\
\hline
\end{tabular}


Table A3. Mixed Acid Measurement Data Set (continued)

\section{Revision 0}

\begin{tabular}{|c|c|c|c|c|c|c|c|c|c|c|c|c|c|c|c|c|c|c|}
\hline Batch & Type of Sample & ICP/ID & Al & B & $\begin{array}{l}\mathbf{C a} \\
\end{array}$ & Cr & $\mathbf{C u}$ & $\mathrm{Fe}$ & $\mathbf{K}$ & $\mathbf{L i}$ & Mg & Mn & Na & $\mathrm{Ni}$ & $\mathrm{Si}$ & Ti & $\mathbf{U}$ & $\mathrm{Zr}$ \\
\hline 333 & SM01 & M-13/S2133 & 2.862 & & 0.695 & 0.048 & 0.010 & 7.502 & -0.500 & 2.133 & 0.604 & 1.421 & 8.174 & 0.414 & 22.108 & 0.034 & 2.505 & 0.047 \\
\hline 333 & SM32 & M-13/S2133 & -0.129 & & -0.012 & -0.010 & -0.017 & -0.112 & -0.661 & -0.007 & -0.007 & -0.026 & -0.205 & -0.024 & -0.003 & -0.009 & -0.474 & -0.021 \\
\hline 333 & SM32 & M-13/S2133 & -0.126 & & -0.010 & -0.014 & -0.016 & -0.113 & -0.540 & 0.017 & -0.005 & -0.030 & -0.301 & -0.026 & 0.157 & -0.009 & -0.472 & -0.016 \\
\hline 334 & ARGB & M-13/S2133 & 2.354 & & 0.993 & 0.051 & -0.005 & 9.337 & 2.180 & 1.518 & 0.489 & 1.370 & 8.366 & 0.772 & 21.653 & 0.675 & 0.039 & 0.088 \\
\hline 334 & ARGB & M-13/S2133 & 2.351 & & 0.996 & 0.047 & -0.004 & 9.114 & 2.309 & 1.481 & 0.482 & 1.353 & 8.384 & 0.741 & 21.053 & 0.672 & 0.043 & 0.088 \\
\hline 334 & SM01 & M-13/S2133 & 3.119 & & 0.731 & 0.037 & 0.008 & 8.030 & -0.019 & 2.233 & 0.640 & 1.522 & 8.915 & 0.432 & 21.913 & 0.037 & 3.050 & 0.056 \\
\hline 334 & SM01 & M-13/S2133 & 3.068 & & 0.716 & 0.038 & 0.010 & 7.746 & -0.002 & 2.247 & 0.617 & 1.476 & 8.540 & 0.422 & 22.148 & 0.033 & 2.958 & 0.055 \\
\hline 334 & SM01 & M-13/S2133 & 3.150 & & 0.753 & 0.041 & 0.009 & 7.930 & 0.106 & 2.181 & 0.649 & 1.513 & 9.090 & 0.434 & 21.500 & 0.033 & 3.067 & 0.056 \\
\hline 334 & SM01 & M-13/S2133 & 3.103 & & 0.762 & 0.037 & 0.009 & 7.775 & 0.040 & 2.263 & 0.668 & 1.553 & 9.085 & 0.428 & 21.888 & 0.039 & 2.982 & 0.056 \\
\hline 334 & SM01 & M-13/S2133 & 2.995 & & 0.728 & 0.048 & 0.008 & 7.719 & 0.104 & 2.246 & 0.650 & 1.493 & 9.059 & 0.430 & 21.922 & 0.034 & 2.963 & 0.054 \\
\hline 334 & SM01 & M-13/S2133 & 3.208 & & 0.786 & 0.043 & 0.011 & 8.210 & 0.125 & 2.238 & 0.698 & 1.606 & 9.485 & 0.466 & 21.934 & 0.033 & 3.198 & 0.056 \\
\hline 334 & SM32 & M-13/S2133 & -0.048 & & -0.006 & -0.015 & -0.010 & -0.144 & -0.021 & -0.026 & -0.007 & -0.017 & -0.028 & -0.022 & 0.548 & -0.007 & 0.005 & -0.012 \\
\hline 334 & SM32 & I-13/S2133 & -0.051 & & -0.010 & -0.018 & -0.008 & -0.149 & -0.075 & -0.024 & -0.007 & -0.017 & -0.091 & -0.024 & 0.511 & -0.010 & -0.002 & -0.012 \\
\hline 335 & ARGB & M-13/S2133 & 2.286 & & 0.981 & 0.067 & -0.016 & 9.314 & 0.841 & 1.335 & 0.496 & 1.357 & 8.355 & 0.785 & 20.859 & 0.658 & -0.103 & 0.091 \\
\hline 335 & ARGB & M-13/S2133 & 2.332 & & 0.994 & 0.068 & -0.018 & 9.339 & 2.261 & 1.352 & 0.501 & 1.382 & 8.398 & 0.800 & 21.226 & 0.675 & -0.089 & 0.090 \\
\hline 335 & SM01 & M-13/S2133 & 3.022 & & 0.762 & 0.057 & -0.004 & 7.774 & -1.197 & 2.049 & 0.724 & 1.607 & 9.345 & 0.457 & 21.912 & 0.033 & 2.940 & 0.053 \\
\hline 335 & SM01 & M-13/S2133 & 3.145 & & 0.753 & 0.058 & -0.004 & 8.050 & -0.336 & 1.942 & 0.714 & 1.617 & 9.171 & 0.470 & 21.531 & 0.030 & 2.987 & 0.055 \\
\hline 335 & SM01 & M-13/S2133 & 3.181 & & 0.780 & 0.058 & 0.001 & 8.098 & -1.004 & 2.008 & 0.741 & 1.684 & 9.423 & 0.480 & 21.061 & 0.040 & 3.066 & 0.053 \\
\hline 335 & SM01 & M-13/S2133 & 3.093 & & 0.770 & 0.059 & -0.003 & 8.000 & -0.743 & 1.973 & 0.728 & 1.643 & 9.270 & 0.480 & 21.031 & 0.029 & 2.923 & 0.053 \\
\hline 335 & SM01 & M-13/S2133 & 3.199 & & 0.789 & 0.061 & 0.000 & 8.230 & -0.829 & 1.975 & 0.746 & 1.669 & 9.467 & 0.484 & 20.900 & 0.030 & 3.091 & 0.054 \\
\hline 335 & SM01 & M-13/S2133 & 3.204 & & 0.804 & 0.063 & -0.004 & 8.221 & -0.369 & 1.924 & 0.754 & 1.685 & 9.626 & 0.493 & 20.873 & 0.027 & 3.022 & 0.054 \\
\hline 335 & SM32 & M-13/S2133 & -0.140 & & -0.006 & -0.001 & -0.027 & -0.068 & -0.561 & 0.004 & -0.001 & -0.012 & 0.244 & -0.006 & 0.032 & -0.008 & -0.133 & -0.011 \\
\hline 335 & SM32 & M-13/S2133 & -0.170 & & -0.036 & -0.006 & -0.031 & -0.089 & -1.166 & -0.014 & -0.005 & -0.018 & 0.021 & -0.003 & 0.004 & -0.009 & -0.302 & -0.015 \\
\hline 336 & ARGB & M-14/S2150 & 2.391 & & 1.029 & 0.063 & -0.002 & 9.823 & 2.426 & 1.499 & 0.541 & 1.467 & 9.990 & 0.829 & 21.716 & 0.691 & 0.059 & 0.091 \\
\hline 336 & ARGB & M-14/S2150 & 2.399 & & 1.013 & 0.064 & 0.000 & 9.736 & 2.436 & 1.477 & 0.529 & 1.438 & 8.480 & 0.820 & 21.308 & 0.680 & 0.051 & 0.089 \\
\hline 336 & SM01 & M-14/S2150 & 3.143 & & 0.810 & 0.051 & 0.010 & 8.448 & 0.087 & 2.146 & 0.803 & 1.782 & 9.830 & 0.471 & 21.208 & 0.034 & 3.142 & 0.051 \\
\hline 336 & M01 & M-14/S2150 & 3.138 & & 0.794 & 0.054 & 0.011 & 8.443 & 0.996 & 2.206 & 0.793 & 1.782 & 9.772 & 0.497 & 21.714 & 0.035 & 3.127 & 0.052 \\
\hline 336 & SM01 & S2150 & 3.236 & & 0.807 & 0.053 & 0.009 & 8.515 & 0.271 & 2.183 & 0.794 & 1.844 & 9.349 & 0.481 & 21.339 & 0.033 & 3.140 & 0.052 \\
\hline 336 & SM01 & M-14/S2150 & 3.132 & & 0.780 & 0.055 & 0.009 & 8.465 & 0.502 & 2.219 & 0.773 & 1.754 & 9.240 & 0.473 & 21.990 & 0.035 & 3.126 & 0.054 \\
\hline 336 & SM01 & -14/S2150 & 3.193 & & 0.794 & 0.056 & 0.012 & 8.420 & 0.365 & 2.206 & 0.788 & 1.776 & 9.539 & 0.495 & 21.905 & 0.035 & 3.109 & 0.052 \\
\hline 336 & SM01 & M-14 & 2.853 & & 0.720 & 0.047 & 0.009 & 7.664 & 9.960 & 1.916 & 0.724 & 1.658 & 8.558 & 0.442 & 18.755 & 0.030 & 2.871 & 0.046 \\
\hline 336 & SM32 & M-14/S2150 & 0.022 & & 0.044 & -0.001 & -0.011 & -0.127 & 0.042 & -0.004 & 0.000 & -0.007 & 1.741 & -0.001 & 0.042 & -0.009 & -0.074 & -0.011 \\
\hline 336 & SM32 & -14/S2150 & 0.022 & & 0.004 & -0.002 & -0.008 & -0.115 & 0.362 & 0.005 & 0.002 & -0.006 & 1.724 & 0.006 & 0.123 & -0.006 & 0.049 & -0.009 \\
\hline 337 & ARGB & M-13/S2133 & 2.330 & & 0.999 & 0.070 & 0.003 & 9.516 & 2.277 & 1.415 & 0.514 & 1.388 & 8.221 & 0.811 & 21.193 & 0.677 & -0.080 & 0.099 \\
\hline 337 & ARGB & M-13/S2133 & 2.379 & & 1.006 & 0.069 & 0.002 & 9.396 & 2.478 & 1.372 & 0.512 & 1.377 & 8.116 & 0.798 & 21.012 & 0.681 & -0.097 & 0.116 \\
\hline 337 & & & 3.084 & & 0.756 & 0.058 & 0.016 & 8.084 & 0.170 & 2.123 & 0.706 & 1.607 & 8.921 & 0.469 & 21.490 & 0.036 & 2.902 & 0.060 \\
\hline 337 & SM01 & M-13/S2133 & 2.956 & & 0.738 & 0.056 & 0.015 & 7.712 & 0.001 & 2.142 & 0.699 & 1.564 & 9.128 & 0.466 & 21.841 & 0.036 & 2.741 & 0.066 \\
\hline 337 & SM01 & M-13/S2133 & 3.045 & & 0.721 & 0.056 & 0.012 & 7.854 & 0.381 & 2.107 & 0.664 & 1.506 & 8.692 & 0.461 & 22.236 & 0.034 & 2.830 & 0.056 \\
\hline 337 & SM01 & $1-13 / S 2133$ & 2.980 & & 0.723 & 0.057 & 0.016 & 7.676 & 0.586 & 1.977 & 0.673 & 1.506 & 8.130 & 0.457 & 20.864 & 0.034 & 2.821 & 0.057 \\
\hline 337 & SM01 & M-13/S2133 & 3.265 & & 0.808 & 0.060 & 0.018 & 8.481 & 0.390 & 2.333 & 0.754 & 1.706 & 9.426 & 0.505 & 24.094 & 0.040 & 3.168 & 0.065 \\
\hline 337 & SM01 & M-13/S2133 & 2.792 & & 0.696 & 0.052 & 0.013 & 7.235 & 0.546 & 1.960 & 0.633 & 1.435 & 7.968 & 0.429 & 20.086 & 0.034 & 2.607 & 0.057 \\
\hline 337 & SM32 & I-13/S2133 & -0.072 & & -0.014 & -0.005 & -0.008 & -0.169 & 0.271 & -0.015 & -0.007 & -0.025 & -0.164 & -0.005 & -0.058 & -0.007 & -0.173 & 0.000 \\
\hline 337 & SM32 & M-13/S2133 & -0.037 & & -0.007 & -0.001 & -0.003 & -0.133 & -0.794 & -0.046 & -0.005 & -0.023 & -0.220 & -0.001 & 0.109 & -0.007 & -0.226 & 0.000 \\
\hline 338 & ARGB & & 2.359 & & 1.010 & 0.053 & -0.002 & 9.404 & 1.984 & 1.514 & 0.517 & 1.418 & 8.322 & 0.842 & 21.359 & 0.678 & -0.164 & 0.082 \\
\hline 338 & ARGB & M-14/S2150 & 2.314 & & 0.992 & 0.055 & -0.004 & 9.349 & 1.958 & 1.512 & 0.519 & 1.376 & 8.277 & 0.799 & 21.588 & 0.677 & -0.155 & 0.085 \\
\hline 338 & ARGB & M-14/S2150 & 2.285 & & 0.966 & 0.066 & -0.009 & 9.444 & 2.348 & 1.470 & 0.505 & 1.382 & 8.299 & 0.800 & 20.494 & 0.676 & -0.089 & 0.092 \\
\hline 338 & ARGB & M-14/S2150 & 2.390 & & 0.989 & 0.061 & -0.005 & 9.304 & 2.415 & 1.483 & 0.497 & 1.346 & 8.371 & 0.778 & 20.582 & 0.676 & -0.086 & 0.093 \\
\hline 338 & SM01 & M-14/S2150 & 3.007 & & 0.755 & 0.045 & 0.011 & 7.647 & 0.166 & 2.130 & 0.738 & 1.608 & 9.191 & 0.446 & 20.910 & 0.034 & 2.714 & 0.043 \\
\hline 338 & SM01 & M-14/S2150 & 3.023 & & 0.770 & 0.044 & 0.011 & 7.813 & 0.144 & 2.271 & 0.758 & 1.660 & 9.481 & 0.471 & 22.112 & 0.035 & 2.908 & 0.045 \\
\hline 338 & SM01 & M-14/S2150 & 3.068 & & 0.769 & 0.045 & 0.012 & 7.980 & 0.109 & 2.237 & 0.753 & 1.673 & 9.162 & 0.472 & 22.070 & 0.034 & 2.885 & 0.044 \\
\hline
\end{tabular}


Table A3. Mixed Acid Measurement Data Set (continued)

\section{Revision 0}

\begin{tabular}{|c|c|c|c|c|c|c|c|c|c|c|c|c|c|c|c|c|c|c|}
\hline Batch & Гype of Sample & ICP/ID & Al & B & $\mathbf{C a}$ & $\mathrm{Cr}$ & $\mathbf{C u}$ & $\mathbf{F e}$ & $\mathbf{K}$ & $\mathbf{L i}$ & Mg & Mn & $\mathrm{Na}$ & $\mathrm{Ni}$ & Si & $\mathbf{T i}$ & $\mathbf{U}$ & $\mathbf{Z r}$ \\
\hline 338 & SM01 & M-14/S2150 & 3.068 & & 0.875 & 0.046 & 0.012 & 7.968 & 0.369 & 2.247 & 0.787 & 1.702 & 9.423 & 0.485 & 21.641 & 0.035 & 2.920 & 0.045 \\
\hline 338 & SM01 & M-14/S2150 & 3.056 & & 0.774 & 0.047 & 0.012 & 7.837 & -0.160 & 2.198 & 0.742 & 1.655 & 9.398 & 0.468 & 21.876 & 0.034 & 2.893 & 0.045 \\
\hline 338 & SM01 & M-14/S2150 & 3.107 & & 0.768 & 0.044 & 0.013 & 7.886 & -0.282 & 2.245 & 0.745 & 1.655 & 9.657 & 0.479 & 22.040 & 0.035 & 2.921 & 0.045 \\
\hline 338 & SM01 & M-14/S2150 & 3.192 & & 0.775 & 0.050 & 0.007 & 8.067 & 0.411 & 2.120 & 0.723 & 1.589 & 9.269 & 0.444 & 20.647 & 0.041 & 3.024 & 0.062 \\
\hline 338 & SM01 & M-14/S2150 & 3.309 & & 0.786 & 0.057 & 0.002 & 8.592 & 0.242 & 2.115 & 0.734 & 1.682 & 9.209 & 0.489 & 20.418 & 0.040 & 3.269 & 0.062 \\
\hline 338 & SM01 & M-14/S2150 & 3.195 & & 0.771 & 0.053 & 0.005 & 8.018 & 0.229 & 2.132 & 0.726 & 1.603 & 9.222 & 0.457 & 20.575 & 0.042 & 3.019 & 0.059 \\
\hline 338 & SM01 & M-14/S2150 & 3.069 & & 0.716 & 0.050 & 0.003 & 7.622 & 0.321 & 2.284 & 0.671 & 1.508 & 8.704 & 0.442 & 21.761 & 0.043 & 2.807 & 0.058 \\
\hline 338 & SM01 & M-14/S2150 & 3.163 & & 0.777 & 0.052 & 0.006 & 8.055 & 0.389 & 2.167 & $\begin{array}{ll}0.748 \\
\end{array}$ & 1.645 & 9.191 & 0.465 & 20.941 & 0.042 & 2.987 & 0.060 \\
\hline 338 & SM01 & $\mathrm{M}-14 / \mathrm{S} 2150$ & 3.159 & & 0.743 & 0.051 & 0.005 & 7.831 & 0.294 & 2.113 & 0.708 & 1.584 & 9.144 & 0.457 & 20.681 & 0.041 & 2.967 & 0.058 \\
\hline 338 & SM32 & M-14/S2150 & -0.063 & & -0.008 & -0.008 & -0.004 & -0.114 & -0.261 & -0.012 & -0.001 & 0.000 & -0.240 & -0.004 & 0.297 & -0.009 & -0.143 & -0.016 \\
\hline 338 & SM32 & M-14/S2150 & -0.054 & & -0.006 & -0.013 & -0.004 & -0.119 & -0.433 & -0.022 & -0.003 & 0.000 & -0.281 & -0.001 & 0.381 & -0.009 & -0.222 & -0.016 \\
\hline 338 & SM32 & M-14/S2150 & -0.057 & & -0.013 & -0.001 & -0.012 & 0.025 & 0.092 & 0.001 & 0.004 & -0.006 & -0.024 & -0.007 & -0.089 & -0.001 & -0.117 & -0.007 \\
\hline 338 & SM32 & M-14/S2150 & -0.038 & & -0.017 & -0.001 & -0.015 & 0.029 & 0.423 & 0.004 & 0.004 & -0.005 & -0.037 & -0.023 & 0.231 & -0.001 & -0.084 & -0.006 \\
\hline 340 & ARGB & M-13/S2133 & 2.286 & & 1.012 & 0.071 & -0.012 & 9.602 & 1.224 & 1.444 & 0.518 & 1.410 & 8.236 & 0.840 & 21.236 & 0.675 & -0.255 & 0.095 \\
\hline 340 & ARGB & M-13/S2133 & 2.267 & & 0.968 & 0.061 & -0.007 & 9.162 & 1.342 & 1.403 & 0.497 & 1.359 & 8.159 & 0.781 & 20.899 & 0.666 & -0.101 & 0.093 \\
\hline 340 & SM01 & M-13/S2133 & 3.058 & & 0.780 & 0.070 & -0.008 & 8.230 & -0.682 & 2.163 & 0.764 & 1.709 & 9.494 & 0.572 & 20.312 & 0.031 & 2.718 & 0.051 \\
\hline 340 & SM01 & M-13/S2133 & 3.076 & & 0.768 & 0.059 & 0.008 & 8.296 & 0.291 & 2.174 & 0.750 & 1.660 & 9.339 & 0.500 & 20.692 & 0.034 & 2.927 & 0.059 \\
\hline 340 & SM01 & M-13/S2133 & 3.124 & & 0.774 & 0.054 & 0.005 & 8.307 & 0.051 & 2.203 & 0.750 & 1.691 & 9.205 & 0.485 & 20.996 & 0.034 & 2.980 & 0.057 \\
\hline 340 & SM01 & M-13/S2133 & 2.208 & & 0.587 & 0.041 & -0.001 & 5.812 & 0.040 & 1.466 & 0.581 & 1.262 & 6.595 & 0.355 & 11.138 & 0.022 & 2.070 & 0.040 \\
\hline 340 & SM01 & M-13/S2133 & 3.079 & & 0.775 & 0.049 & -0.001 & 8.145 & -0.832 & 1.973 & 0.772 & 1.714 & 8.867 & 0.470 & 20.697 & 0.030 & 2.713 & 0.055 \\
\hline 340 & SM01 & M-13/S2133 & 3.142 & & 0.779 & 0.057 & -0.006 & 8.274 & -0.067 & 2.115 & 0.774 & 1.703 & 9.137 & 0.504 & 21.133 & 0.031 & 2.753 & 0.057 \\
\hline 340 & SM32 & M-13/S2133 & -0.076 & & -0.014 & -0.007 & -0.018 & 0.018 & -0.495 & -0.014 & -0.002 & 0.004 & -0.145 & -0.012 & -0.129 & -0.005 & -0.239 & -0.006 \\
\hline 340 & SM32 & M-13/S2133 & -0.050 & & -0.008 & -0.009 & -0.017 & 0.016 & -0.704 & -0.046 & -0.001 & 0.003 & -0.203 & -0.011 & $\begin{array}{l}-0.051 \\
\end{array}$ & -0.006 & -0.266 & -0.008 \\
\hline 341 & ARGB & M-14/S2150 & 2.323 & & 0.983 & 0.053 & -0.008 & 9.424 & 2.270 & 1.476 & 0.498 & 1.385 & 8.320 & 0.788 & 20.272 & 0.674 & -0.202 & 0.092 \\
\hline 341 & ARGB & M-14/S2150 & 2.402 & & 1.017 & 0.058 & -0.005 & 9.673 & 2.156 & 1.522 & 0.509 & 1.407 & 8.587 & 0.826 & 20.868 & 0.689 & -0.137 & 0.095 \\
\hline 341 & SM01 & M-14/S2150 & 3.042 & & 0.801 & 0.045 & 0.008 & 8.274 & 0.193 & 2.235 & 0.769 & 1.718 & 9.495 & 0.487 & 20.846 & 0.041 & 2.998 & 0.054 \\
\hline 341 & SM01 & M-14/S2150 & 3.059 & & 0.806 & 0.047 & 0.005 & 8.270 & 0.310 & 2.198 & 0.790 & 1.731 & 9.650 & 0.490 & 20.678 & 0.041 & 3.082 & 0.056 \\
\hline 341 & SM01 & -14/S2150 & 3.095 & & 0.790 & 0.046 & 0.005 & 8.289 & 0.299 & 2.210 & 0.767 & 1.743 & 9.456 & 0.481 & 20.887 & 0.040 & 3.053 & 0.054 \\
\hline 341 & SM01 & M-14 & 2.845 & & 2.528 & 0.041 & 0.004 & 7.561 & 0.240 & 2.047 & 0.758 & 1.599 & 8.848 & 0.431 & 18.933 & 0.048 & 2.751 & 0.048 \\
\hline 341 & SM01 & M-14/S2150 & $\begin{array}{l}3.079 \\
\end{array}$ & & 0.785 & 0.049 & 0.005 & 8.297 & 0.160 & 2.217 & 0.757 & 1.750 & 9.507 & 0.486 & 20.062 & 0.041 & 3.021 & 0.054 \\
\hline 341 & SM01 & M-14/S2150 & 3.115 & & 0.791 & 0.045 & 0.009 & 8.333 & 0.200 & 2.215 & 0.771 & 1.730 & 9.614 & 0.484 & 20.528 & 0.041 & 3.031 & 0.053 \\
\hline 341 & SM32 & M-14/S2150 & -0.056 & & -0.008 & -0.008 & -0.013 & -0.028 & -0.064 & -0.015 & -0.001 & -0.005 & -0.083 & -0.001 & 0.009 & 0.009 & -0.181 & -0.003 \\
\hline 341 & SM32 & M-14/S2150 & -0.080 & & -0.014 & -0.016 & -0.015 & -0.050 & 0.331 & -0.007 & -0.003 & -0.007 & -0.083 & -0.012 & 0.084 & 0.000 & -0.326 & -0.005 \\
\hline 342 & RGB & M-14/S2150 & $\begin{array}{l}2.381 \\
\end{array}$ & & 1.010 & 0.063 & -0.004 & 9.821 & 2.013 & 1.497 & $\begin{array}{l}0.509 \\
\end{array}$ & 1.413 & 5.615 & $\begin{array}{l}0.818 \\
\end{array}$ & 21.732 & 0.692 & -0.060 & 0.096 \\
\hline 342 & ARGB & M-14/S2150 & 2.384 & & 1.008 & 0.061 & -0.003 & 9.929 & 2.293 & 1.543 & 0.517 & 1.410 & 5.234 & 0.798 & 22.326 & 0.687 & -0.185 & 0.094 \\
\hline 342 & SM01 & M-14/S2150 & 2.887 & & 0.726 & 0.046 & 0.006 & 7.742 & 0.069 & 2.123 & 0.694 & 1.584 & 8.918 & 0.443 & 20.051 & 0.032 & 2.902 & 0.057 \\
\hline 342 & SM01 & M-14/S2150 & 3.163 & & 0.806 & 0.047 & 0.008 & 8.444 & 0.084 & 2.213 & 0.790 & 1.804 & 9.605 & 0.493 & 20.700 & 0.034 & 3.152 & 0.061 \\
\hline 342 & SM01 & M-14/S2150 & 3.102 & & 0.789 & 0.048 & 0.009 & 8.276 & 0.057 & 2.255 & 0.750 & 1.699 & 9.736 & 0.473 & 21.288 & 0.035 & 3.085 & 0.061 \\
\hline 342 & SM01 & & 3.073 & & 0.789 & 0.050 & 0.007 & 8.380 & 0.167 & 2.277 & 0.767 & 1.761 & 9.843 & 0.500 & 21.218 & 0.035 & 3.139 & 0.062 \\
\hline 342 & SM01 & M-14/S2150 & 3.278 & & 0.836 & 0.048 & 0.011 & 8.699 & 0.324 & 2.381 & 0.808 & 1.841 & 10.351 & 0.496 & 22.600 & 0.035 & 3.199 & 0.066 \\
\hline 342 & SM01 & M-14/S2150 & 2.943 & & 0.740 & 0.046 & 0.009 & 7.762 & 0.507 & 2.223 & 0.710 & 1.624 & 9.202 & 0.445 & 20.828 & 0.034 & 2.896 & 0.059 \\
\hline 342 & & & -0.081 & & -0.013 & -0.009 & -0.008 & -0.024 & -0.392 & -0.012 & -0.007 & 0.001 & -0.976 & -0.021 & -0.172 & -0.003 & -0.141 & -0.007 \\
\hline 342 & SM32 & M-14/S2150 & -0.069 & & -0.010 & -0.010 & -0.016 & -0.023 & -0.037 & 0.000 & -0.007 & -0.001 & -0.750 & -0.014 & -0.049 & -0.003 & -0.289 & -0.007 \\
\hline 343 & ARGB & M-14/S2150 & 2.312 & & 0.978 & 0.049 & -0.008 & 9.583 & 2.154 & 1.491 & 0.499 & 1.383 & 8.280 & 0.771 & 20.568 & 0.673 & -0.087 & 0.093 \\
\hline 343 & & & $\begin{array}{l}2.366 \\
\end{array}$ & & 1.000 & 0.051 & -0.007 & 9.561 & 2.200 & 1.480 & 0.509 & 1.406 & 8.327 & 0.803 & 20.104 & 0.689 & -0.090 & 0.094 \\
\hline 343 & SM01 & M-14/S2150 & 2.959 & & 0.774 & 0.044 & 0.004 & 8.139 & 0.040 & 2.228 & 0.774 & 1.780 & 9.266 & 0.478 & 21.162 & 0.044 & 2.867 & 0.083 \\
\hline 343 & SM01 & M-14/S2150 & 3.109 & & 0.771 & 0.042 & 0.008 & 8.375 & 0.146 & 2.157 & 0.749 & 1.692 & 9.193 & 0.470 & 20.544 & 0.057 & 2.904 & 0.085 \\
\hline 343 & SM01 & M-14/S2150 & 3.068 & & 0.766 & 0.043 & 0.008 & 8.334 & -0.034 & 2.197 & 0.743 & 1.694 & 9.207 & 0.477 & 21.122 & 0.044 & 2.943 & 0.086 \\
\hline 343 & SM01 & M-14/S2150 & 3.100 & & 0.803 & 0.043 & 0.008 & 8.260 & -0.036 & 2.183 & 0.768 & 1.744 & 9.330 & 0.474 & 21.164 & 0.043 & 3.100 & 0.089 \\
\hline 343 & SM01 & M-14/S2150 & 3.067 & & 0.790 & 0.039 & 0.006 & 8.200 & 0.489 & 2.199 & 0.772 & 1.747 & 9.483 & 0.479 & 20.425 & 0.045 & 2.857 & 0.086 \\
\hline
\end{tabular}


Table A3. Mixed Acid Measurement Data Set (continued)

\section{Revision 0}

\begin{tabular}{|c|c|c|c|c|c|c|c|c|c|c|c|c|c|c|c|c|c|c|}
\hline Batch & Cype of Sample & ICP/ID & Al & B & $\mathbf{C a}$ & $\mathrm{Cr}$ & $\mathbf{C u}$ & $\mathbf{F e}$ & $\mathbf{K}$ & $\mathbf{L i}$ & Mg & Mn & $\mathrm{Na}$ & $\mathrm{Ni}$ & Si & $\mathbf{T i}$ & $\mathbf{U}$ & $\mathrm{Zr}$ \\
\hline 343 & SM01 & M-14/S2150 & 3.102 & & 0.782 & 0.039 & 0.007 & 8.196 & -0.024 & 2.201 & 0.735 & 1.685 & 9.255 & 0.486 & 20.640 & 0.043 & 2.896 & 0.085 \\
\hline 343 & SM32 & M-14/S2150 & -0.041 & & -0.004 & -0.016 & -0.012 & -0.046 & -0.067 & -0.007 & -0.012 & -0.001 & -0.045 & -0.028 & -0.351 & -0.001 & -0.334 & -0.006 \\
\hline 343 & SM32 & M-14/S2150 & -0.050 & & -0.009 & -0.020 & -0.011 & -0.055 & $\begin{array}{l}-0.044 \\
\end{array}$ & -0.005 & -0.012 & -0.002 & -0.030 & -0.026 & -0.266 & -0.001 & -0.278 & -0.006 \\
\hline 344 & ARGB & M-14/S2150 & 2.337 & & 0.983 & 0.065 & -0.007 & 9.229 & 2.395 & 1.486 & 0.507 & 1.373 & 8.441 & 0.798 & 20.836 & 0.689 & -0.099 & 0.085 \\
\hline 344 & ARGB & M-14/S2150 & 2.198 & & 0.941 & 0.060 & -0.006 & 8.739 & 2.184 & 1.432 & 0.484 & 1.311 & 8.008 & 0.751 & 19.093 & 0.649 & -0.077 & 0.079 \\
\hline 344 & SM01 & M-14/S2150 & 3.076 & & 0.744 & 0.054 & 0.006 & 7.864 & -0.027 & 2.230 & 0.705 & 1.578 & 9.089 & 0.451 & 22.199 & 0.042 & 3.016 & 0.070 \\
\hline 344 & SM01 & M-14/S2150 & 3.014 & & 0.775 & 0.055 & 0.006 & 7.903 & 1.115 & 2.208 & 0.718 & 1.654 & 8.915 & 0.462 & 21.661 & 0.041 & 2.993 & 0.069 \\
\hline 344 & SM01 & M-14/S2150 & 2.999 & & 0.744 & 0.054 & 0.008 & 7.907 & 0.126 & 2.221 & $\begin{array}{ll}0.671 \\
\end{array}$ & 1.618 & 9.010 & 0.462 & 21.752 & 0.042 & 3.078 & 0.072 \\
\hline 344 & SM01 & M-14/S2150 & 3.015 & & 0.726 & 0.056 & 0.006 & 8.113 & 0.005 & 2.229 & 0.661 & 1.585 & 8.570 & 0.468 & 21.137 & 0.042 & 2.953 & 0.072 \\
\hline 344 & SM01 & M-14/S2150 & 2.870 & & 0.666 & 0.054 & 0.007 & 7.797 & 0.157 & 2.250 & 0.600 & 1.574 & 8.570 & 0.460 & 22.017 & 0.042 & 3.016 & 0.071 \\
\hline 344 & SM01 & M-14/S2150 & 2.930 & & 0.727 & 0.050 & 0.006 & 7.917 & 0.255 & 2.177 & 0.656 & 1.559 & 8.689 & 0.453 & 20.988 & 0.042 & 2.847 & 0.068 \\
\hline 344 & SM32 & M-14/S2150 & -0.055 & & -0.014 & 0.000 & -0.011 & -0.188 & 0.095 & -0.023 & 0.004 & -0.009 & 0.001 & -0.023 & -0.698 & -0.005 & -0.125 & -0.019 \\
\hline 344 & SM32 & M-14/S2150 & -0.048 & & -0.001 & -0.001 & -0.013 & -0.164 & 0.079 & -0.023 & 0.004 & -0.006 & -0.003 & -0.023 & -0.595 & -0.005 & -0.098 & -0.018 \\
\hline 345 & ARGB & M-14/S2150 & 2.398 & & 1.004 & 0.055 & 0.000 & 9.397 & 2.321 & 1.496 & 0.499 & 1.373 & 8.367 & 0.788 & 21.021 & 0.682 & 0.015 & 0.100 \\
\hline 345 & ARGB & M-14/S2150 & 2.388 & 5 & 0.996 & 0.055 & -0.001 & 9.221 & 2.202 & 1.472 & 0.490 & 1.362 & 8.233 & 0.790 & 19.838 & 0.679 & 0.064 & 0.097 \\
\hline 345 & SM01 & M-14/S2150 & 3.096 & & 0.745 & 0.043 & 0.013 & 7.689 & 0.652 & 2.265 & 0.689 & 1.561 & 8.655 & 0.457 & 22.143 & 0.047 & 2.937 & 0.076 \\
\hline 345 & SM01 & M-14/S2150 & 3.158 & & 0.765 & 0.042 & 0.013 & 7.701 & 0.875 & 2.239 & 0.696 & 1.560 & 8.776 & 0.448 & 21.847 & 0.047 & 2.953 & 0.076 \\
\hline 345 & SM01 & M-14/S2150 & 3.113 & & 0.762 & 0.038 & 0.013 & 7.674 & 0.859 & 2.250 & 0.705 & 1.565 & 8.695 & 0.451 & 22.091 & 0.050 & 2.961 & 0.076 \\
\hline 345 & SM01 & M-14/S2150 & 3.308 & & 0.792 & 0.041 & 0.014 & $\begin{array}{ll}8.147 \\
\end{array}$ & 0.476 & 2.207 & 0.734 & 1.653 & 9.187 & 0.461 & 21.439 & 0.049 & 3.052 & 0.076 \\
\hline 345 & SM01 & M-14/S2150 & 3.296 & & 0.794 & 0.044 & 0.015 & 8.184 & 0.782 & 2.228 & 0.713 & 1.590 & 8.801 & 0.483 & 21.149 & 0.049 & 3.128 & 0.076 \\
\hline 345 & SM01 & M-14/S2150 & 3.313 & & 0.799 & 0.046 & 0.015 & 8.251 & 0.729 & 2.277 & 0.718 & 1.582 & 8.915 & 0.467 & 21.379 & 0.049 & 3.133 & 0.077 \\
\hline 345 & SM32 & M-14/S2150 & -0.020 & & -0.004 & -0.015 & -0.004 & -0.208 & -0.312 & -0.039 & -0.001 & -0.006 & -0.074 & -0.025 & -0.066 & 0.004 & 0.046 & -0.002 \\
\hline 345 & SM32 & M-14/S2150 & -0.004 & & -0.001 & -0.013 & -0.001 & -0.191 & 0.070 & -0.030 & 0.000 & -0.005 & -0.021 & -0.018 & -0.044 & 0.004 & 0.040 & -0.001 \\
\hline 346 & ARGB & M-14/S2150 & 2.357 & & 0.988 & 0.059 & -0.013 & 9.463 & 2.142 & 1.506 & 0.504 & 1.393 & 8.380 & 0.822 & 21.352 & 0.682 & -0.057 & 0.103 \\
\hline 346 & ARGB & M-14/S2150 & 2.361 & & 0.978 & 0.055 & -0.012 & 9.578 & 2.090 & 1.482 & 0.503 & 1.385 & 8.267 & 0.807 & 21.129 & 0.670 & -0.003 & 0.092 \\
\hline 346 & SM01 & M-14/S2150 & 3.179 & & 0.760 & 0.059 & -0.004 & 9.894 & 0.230 & 2.193 & 0.782 & 1.834 & 8.949 & 0.563 & 26.402 & 0.058 & 2.843 & 0.074 \\
\hline 346 & SM01 & M-14/S2150 & 2.319 & & 0.552 & 0.038 & -0.002 & 6.788 & 0.100 & 2.207 & 0.590 & 1.346 & 9.031 & 0.406 & 18.585 & 0.034 & 2.084 & 0.054 \\
\hline 346 & SM01 & $1-14 / \mathrm{S} 2150$ & 2.465 & & 0.586 & 0.029 & -0.002 & 6.180 & 0.228 & 1.784 & 0.527 & 1.194 & 7.119 & 0.350 & 16.133 & 0.036 & 2.214 & 0.058 \\
\hline 346 & SM01 & M-14 & 3.125 & & 0.755 & 0.043 & -0.003 & 7.824 & 0.018 & 2.202 & 0.679 & 1.552 & 9.115 & 0.467 & 21.421 & 0.047 & 2.752 & 0.075 \\
\hline 346 & SM01 & M-14/S2150 & 3.065 & & 0.732 & 0.045 & -0.001 & 8.053 & 0.112 & 2.193 & 0.666 & 1.549 & 8.914 & 0.458 & 21.530 & 0.047 & 2.807 & 0.076 \\
\hline 346 & SM01 & M-14/S2150 & 2.319 & & 0.552 & 0.038 & -0.002 & 6.788 & 0.100 & 2.207 & 0.590 & 1.346 & 9.031 & 0.406 & 18.585 & 0.034 & 2.084 & 0.054 \\
\hline 346 & SM01 & M-14/S2150 & 2.465 & . & 0.586 & 0.029 & -0.002 & 6.180 & 0.228 & 1.784 & 0.527 & 1.194 & 7.119 & 0.350 & 16.133 & 0.036 & 2.214 & 0.058 \\
\hline 346 & SM01 & M-14/S2150 & 3.016 & & 0.711 & 0.048 & 0.001 & 8.111 & 0.491 & 2.140 & 0.641 & 1.504 & 8.410 & 0.462 & 21.644 & 0.046 & 2.808 & 0.076 \\
\hline 346 & M32 & M-14/S2150 & -0.024 & & -0.009 & -0.009 & -0.020 & -0.214 & -0.109 & -0.009 & 0.001 & -0.008 & -0.001 & -0.006 & 0.018 & -0.004 & -0.021 & -0.008 \\
\hline 346 & SM32 & M-14/S2150 & 0.025 & & 0.005 & -0.013 & -0.018 & 0.031 & -0.228 & -0.004 & 0.001 & -0.009 & 0.083 & -0.011 & 0.034 & -0.004 & -0.093 & -0.005 \\
\hline 347 & ARGB & M-14/S2150 & 2.333 & & 1.000 & 0.065 & -0.004 & 9.538 & 2.042 & 1.507 & 0.518 & 1.407 & 8.415 & 0.811 & 20.988 & 0.686 & -0.087 & 0.095 \\
\hline 347 & ARGB & M-14/S2150 & 2.330 & & 0.988 & 0.070 & -0.004 & 9.524 & 2.129 & 1.492 & 0.517 & 1.408 & 8.306 & 0.823 & 21.517 & $\begin{array}{ll}0.681 \\
\end{array}$ & -0.137 & 0.094 \\
\hline 347 & SM01 & M-14/S2150 & 3.024 & & 0.744 & 0.051 & 0.007 & 7.840 & 0.104 & 2.205 & 0.739 & 1.610 & 8.736 & 0.445 & 21.797 & 0.056 & 2.787 & 0.072 \\
\hline 347 & SM01 & & 3.031 & & 0.783 & 0.054 & 0.010 & 8.070 & 0.107 & 2.113 & 0.770 & 1.705 & 9.195 & 0.467 & 21.930 & 0.055 & 2.844 & 0.072 \\
\hline 347 & SM01 & M-14/S2150 & 3.104 & & 0.794 & 0.056 & 0.011 & 8.266 & -0.083 & 2.192 & 0.775 & 1.703 & 9.218 & 0.471 & 21.338 & 0.056 & 2.934 & 0.073 \\
\hline 347 & SM01 & M-14/S2150 & 3.085 & & 0.763 & 0.052 & 0.009 & 8.167 & 0.164 & 2.180 & 0.754 & 1.688 & 9.322 & 0.472 & 22.057 & 0.055 & 2.890 & 0.072 \\
\hline 347 & & & 3.114 & & 0.768 & 0.056 & 0.005 & 8.161 & -0.108 & 2.184 & 0.743 & 1.673 & 9.306 & 0.479 & 21.247 & 0.056 & 2.964 & 0.070 \\
\hline 347 & SM01 & M-14/S2150 & 3.099 & . & 0.787 & 0.056 & 0.012 & 8.059 & -0.089 & 2.174 & 0.755 & 1.690 & 9.226 & 0.481 & 20.946 & 0.055 & 2.877 & 0.071 \\
\hline 347 & SM32 & M-14/S2150 & -0.055 & & -0.015 & -0.001 & -0.012 & -0.238 & -0.022 & -0.026 & 0.001 & -0.001 & -0.056 & -0.012 & -0.075 & 0.003 & -0.210 & -0.008 \\
\hline 347 & & & -0.032 & & -0.017 & -0.001 & -0.007 & -0.232 & 0.041 & -0.030 & 0.001 & -0.002 & -0.041 & -0.010 & -0.053 & 0.001 & -0.197 & -0.006 \\
\hline 348 & ARGB & M-14/S2150 & 2.463 & & 1.010 & 0.050 & -0.020 & 9.700 & 2.505 & 1.571 & 0.525 & 1.454 & 8.584 & 0.802 & 17.399 & 0.715 & -0.103 & 0.103 \\
\hline 348 & ARGB & M-14/S2150 & 2.447 & & 1.011 & 0.053 & -0.019 & 9.604 & 2.284 & 1.578 & 0.520 & 1.444 & 8.560 & 0.824 & 21.459 & 0.703 & -0.174 & 0.101 \\
\hline 348 & SM01 & M-14/S2150 & $\begin{array}{l}3.319 \\
\end{array}$ & & 0.864 & 0.053 & 0.004 & 8.730 & 0.104 & 2.204 & 0.837 & 1.870 & 9.442 & 0.545 & 20.809 & 0.047 & 3.129 & 0.077 \\
\hline 348 & SM01 & M-14/S2150 & 3.393 & & 0.830 & 0.046 & -0.005 & 8.639 & 0.299 & 2.202 & 0.834 & 1.902 & 9.075 & 0.535 & -0.466 & 0.047 & 3.083 & 0.076 \\
\hline 348 & SM01 & M-14/S2150 & 3.262 & & 0.815 & 0.041 & $\begin{array}{l}-0.006 \\
\end{array}$ & 8.643 & 0.370 & 2.164 & 0.813 & 1.801 & 9.410 & 0.512 & 20.302 & 0.045 & 2.967 & 0.075 \\
\hline
\end{tabular}


Table A3. Mixed Acid Measurement Data Set (continued)

\section{Revision 0}

\begin{tabular}{|c|c|c|c|c|c|c|c|c|c|c|c|c|c|c|c|c|c|c|}
\hline Batch & Type of Sample & ICP/ID & Al & B & $\mathbf{C a}$ & Cr & $\mathbf{C u}$ & $\mathrm{Fe}$ & K & $\mathbf{L i}$ & Mg & Mn & Na & $\mathrm{Ni}$ & $\mathrm{Si}$ & Ti & $\mathbf{U}$ & $\mathrm{Zr}$ \\
\hline 348 & SM01 & M-14/S2150 & 3.367 & & 0.801 & 0.040 & -0.006 & 8.398 & 0.271 & 2.237 & 0.777 & 1.750 & 9.034 & 0.469 & 21.500 & 0.047 & 2.948 & 0.074 \\
\hline 348 & SM01 & M-14/S2150 & 3.277 & & 0.813 & 0.047 & -0.004 & 8.607 & 0.248 & 2.178 & 0.800 & 1.813 & 9.162 & 0.550 & 15.967 & 0.047 & 2.990 & 0.076 \\
\hline 348 & SM01 & M-14/S2150 & 3.339 & & 0.816 & 0.040 & -0.008 & 8.295 & 0.082 & 2.205 & 0.810 & 1.811 & 9.306 & 0.489 & 21.242 & 0.044 & 2.922 & 0.074 \\
\hline 348 & SM32 & M-14/S2150 & -0.084 & & -0.019 & -0.024 & -0.028 & -0.330 & 0.147 & -0.018 & 0.001 & 0.015 & -0.097 & -0.022 & -0.012 & -0.003 & -0.238 & 0.000 \\
\hline 348 & SM32 & M-14/S2150 & -0.057 & & -0.020 & -0.020 & -0.026 & -0.296 & 0.165 & -0.016 & 0.001 & 0.014 & -0.133 & -0.026 & -0.318 & -0.003 & -0.207 & -0.001 \\
\hline 349 & ARGB & M-13/S2133 & 2.263 & & 1.004 & 0.053 & -0.011 & 9.433 & 3.034 & 1.344 & 0.512 & 1.405 & 8.457 & 0.803 & 21.610 & 0.674 & -0.240 & 0.094 \\
\hline 349 & ARGB & M-13/S2133 & 2.257 & & 1.018 & 0.050 & -0.013 & 9.707 & 2.794 & 1.304 & 0.516 & 1.428 & 8.306 & 0.805 & 22.046 & 0.666 & -0.277 & 0.095 \\
\hline 349 & SM01 & M-13/S2133 & 3.380 & & 0.914 & 0.050 & 0.008 & 8.977 & 0.271 & 1.880 & 0.906 & 1.968 & 10.146 & 0.541 & 20.631 & 0.038 & 3.335 & 0.074 \\
\hline 349 & SM01 & M-13/S2133 & 3.358 & & 0.813 & 0.055 & 0.006 & 9.014 & 1.019 & 1.939 & 0.812 & 1.806 & 9.091 & 0.545 & 20.793 & 0.039 & 3.225 & 0.072 \\
\hline 349 & SM01 & M-13/S2133 & 3.198 & & 0.773 & 0.043 & 0.005 & 8.420 & 0.951 & 1.941 & 0.744 & 1.687 & 8.679 & 0.485 & 21.310 & 0.036 & 3.022 & 0.074 \\
\hline 349 & SM01 & M-13/S2133 & 3.015 & & 0.715 & 0.050 & 0.007 & 8.037 & 0.845 & 1.938 & 0.693 & 1.609 & 8.506 & 0.470 & 22.751 & 0.039 & 2.922 & 0.072 \\
\hline 349 & SM01 & M-13/S2133 & 3.091 & & 0.737 & 0.051 & 0.007 & 8.015 & 0.848 & 1.968 & 0.697 & 1.598 & 8.666 & 0.476 & 22.887 & 0.039 & 2.936 & 0.072 \\
\hline 349 & SM01 & $1-13 / \mathrm{S} 2133$ & 3.159 & & 0.737 & 0.048 & 0.005 & 8.375 & 0.471 & 1.973 & 0.703 & 1.644 & 8.560 & 0.495 & 22.268 & 0.038 & 3.036 & 0.075 \\
\hline 349 & SM32 & M-13/S2133 & -0.146 & & -0.024 & -0.020 & -0.017 & -0.236 & 0.610 & 0.012 & -0.007 & 0.007 & -0.282 & -0.035 & 0.087 & -0.007 & -0.311 & -0.002 \\
\hline 349 & SM32 & M-13/S2133 & -0.142 & & -0.023 & -0.021 & -0.017 & -0.237 & 0.830 & 0.008 & -0.006 & 0.009 & -0.317 & -0.025 & 0.137 & -0.010 & -0.326 & -0.003 \\
\hline 350 & ARGB & M-13/S2133 & 2.357 & & 0.998 & 0.071 & -0.025 & 9.361 & 1.108 & 1.412 & 0.512 & 1.390 & 8.353 & 0.840 & 21.507 & 0.690 & -0.190 & 0.096 \\
\hline 350 & ARGB & M-13/S2133 & 2.296 & & 0.986 & 0.072 & -0.022 & 9.389 & 1.640 & 1.397 & 0.511 & 1.382 & 8.273 & 0.834 & 21.284 & 0.687 & -0.178 & 0.095 \\
\hline 350 & SM01 & M-13/S2133 & 3.212 & & 0.763 & 0.054 & -0.010 & 8.079 & -3.884 & 1.681 & 0.768 & 1.680 & 9.296 & 0.475 & 22.089 & 0.040 & 2.974 & 0.078 \\
\hline 350 & SM01 & M-13/S2133 & 3.225 & & 0.768 & 0.059 & -0.011 & 8.155 & -3.746 & 1.709 & 0.756 & 1.682 & 8.912 & 0.506 & 22.336 & 0.041 & 2.991 & 0.078 \\
\hline 350 & SM01 & M-13/S2133 & 3.009 & & 0.648 & 0.043 & -0.010 & 7.139 & -2.491 & 1.884 & 0.615 & 1.387 & 8.105 & 0.407 & 23.750 & 0.041 & 2.540 & 0.076 \\
\hline 350 & SM01 & M-13/S2133 & 3.127 & & 0.753 & 0.049 & -0.009 & 7.948 & -3.642 & 1.600 & 0.744 & 1.648 & 9.028 & 0.472 & 21.948 & 0.040 & 2.866 & 0.076 \\
\hline 350 & SM01 & M-13/S2133 & 3.064 & & 0.650 & 0.045 & -0.006 & 7.317 & -2.471 & 1.817 & 0.633 & 1.428 & 8.176 & 0.424 & 23.747 & 0.041 & 2.598 & 0.077 \\
\hline 350 & SM01 & M-13/S2133 & 3.129 & & 0.745 & 0.048 & -0.009 & 7.907 & -3.488 & 1.742 & 0.733 & 1.641 & 8.985 & 0.466 & 22.495 & 0.041 & 2.884 & 0.079 \\
\hline 350 & SM32 & M-13/S2133 & -0.085 & & -0.047 & 0.001 & -0.031 & -0.283 & -0.769 & -0.027 & -0.015 & -0.013 & -0.065 & 0.013 & 0.026 & 0.000 & -0.300 & 0.000 \\
\hline 350 & SM32 & M-13/S2133 & -0.160 & & -0.062 & -0.007 & -0.044 & -0.321 & -6.793 & -0.162 & -0.017 & -0.014 & -0.007 & 0.000 & 0.162 & -0.004 & -0.479 & -0.007 \\
\hline 351 & ARGB & M-14/S2150 & 2.372 & & 1.023 & 0.055 & -0.002 & 9.565 & 2.615 & 1.541 & 0.516 & 1.418 & 8.659 & 0.808 & 20.703 & 0.693 & -0.105 & 0.102 \\
\hline 351 & RGB & M-14/S2150 & 2.372 & & 1.015 & 0.051 & -0.005 & 9.395 & 2.586 & 1.535 & 0.500 & 1.395 & 8.778 & 0.796 & 21.405 & 0.700 & -0.106 & 0.100 \\
\hline 351 & SM01 & M-14/S2150 & 3.394 & & 0.759 & 0.039 & 0.008 & 7.977 & 0.563 & 2.346 & 0.696 & 1.618 & 9.426 & 0.462 & 22.489 & 0.040 & 2.815 & 0.072 \\
\hline 351 & SM01 & M-14/S2150 & 3.372 & & 0.813 & 0.040 & 0.011 & 8.166 & 0.561 & 2.240 & 0.763 & 1.706 & 9.713 & 0.464 & 21.716 & 0.039 & 3.005 & 0.074 \\
\hline 351 & SM01 & -14/S2150 & 3.349 & & 0.782 & 0.038 & 0.010 & 8.225 & 0.797 & 2.250 & 0.725 & 1.656 & 9.136 & 0.480 & 21.435 & 0.039 & 2.998 & 0.073 \\
\hline 351 & M01 & M-14 & 3.312 & & 0.800 & 0.039 & 0.010 & 8.028 & 0.816 & 2.241 & 0.748 & 1.683 & 9.597 & 0.459 & 20.070 & 0.040 & 2.946 & 0.071 \\
\hline 351 & SM01 & M-14/S2150 & 3.401 & . & 0.819 & 0.045 & 0.012 & 8.420 & 0.515 & 2.239 & 0.761 & 1.720 & 9.643 & 0.485 & 21.031 & 0.040 & 3.007 & 0.074 \\
\hline 351 & SM01 & -14/S2150 & 3.436 & & 0.821 & 0.043 & 0.012 & 8.500 & 0.593 & 2.248 & 0.756 & 1.747 & 9.651 & 0.486 & 21.176 & 0.041 & 3.027 & 0.073 \\
\hline 351 & SM32 & M-14/S2150 & -0.039 & & -0.020 & -0.016 & -0.010 & -0.251 & 0.651 & 0.011 & -0.009 & 0.004 & 0.268 & -0.020 & -0.103 & -0.002 & -0.186 & -0.004 \\
\hline 351 & SM32 & M-14/S2150 & -0.086 & & -0.021 & -0.020 & -0.010 & -0.264 & 0.580 & 0.020 & -0.009 & 0.003 & 0.301 & -0.029 & -0.094 & -0.004 & -0.189 & -0.004 \\
\hline 352 & $\overline{\mathrm{A}}$ & M-14/S2150 & 2.381 & & 1.005 & 0.060 & -0.005 & 9.292 & 2.278 & 1.515 & 0.522 & 1.439 & 8.398 & 0.806 & 21.609 & 0.700 & -0.066 & 0.099 \\
\hline 352 & ARGB & M-14/S2150 & 2.414 & & 0.994 & 0.062 & -0.006 & 9.345 & 2.206 & 1.513 & 0.517 & 1.424 & 8.328 & 0.806 & 23.157 & 0.691 & -0.085 & 0.096 \\
\hline 352 & SM01 & M-14/S2150 & 2.881 & & 0.695 & 0.042 & 0.006 & 7.138 & 0.052 & 1.932 & 0.676 & 1.502 & 8.276 & 0.421 & 18.812 & 0.040 & 2.702 & 0.067 \\
\hline 352 & SM01 & $1-14 / \mathrm{S} 2150$ & 3.326 & & 0.808 & 0.056 & 0.008 & 8.335 & 0.511 & 2.186 & 0.788 & 1.768 & 9.219 & 0.514 & 21.967 & 0.045 & 3.143 & 0.074 \\
\hline 352 & SM01 & M-14/S2150 & 3.389 & & 0.799 & 0.051 & 0.009 & 8.014 & 0.380 & 2.202 & 0.771 & 1.721 & 9.172 & 0.476 & 22.057 & 0.045 & 3.020 & 0.072 \\
\hline 352 & SM01 & & 3.334 & & 0.815 & 0.053 & 0.008 & 8.146 & 0.054 & 2.248 & 0.780 & 1.745 & 9.673 & 0.492 & 21.900 & 0.046 & 3.172 & 0.073 \\
\hline 352 & SM01 & -14/S2150 & 3.239 & & 0.762 & 0.047 & 0.005 & 7.976 & 0.164 & 2.162 & 0.749 & 1.674 & 9.020 & 0.465 & 21.794 & 0.043 & 3.026 & 0.069 \\
\hline 352 & SM01 & M-14/S2150 & 3.288 & & 0.779 & 0.050 & 0.010 & 8.093 & 0.400 & 2.139 & 0.762 & 1.665 & 9.141 & 0.478 & 21.746 & 0.045 & 3.017 & 0.073 \\
\hline 352 & & & -0.106 & & -0.006 & -0.014 & -0.012 & -0.343 & -0.155 & -0.022 & 0.014 & 0.018 & 0.101 & -0.018 & 0.335 & -0.005 & -0.071 & -0.005 \\
\hline 352 & SM32 & M-14/S2150 & -0.130 & & -0.017 & -0.019 & -0.014 & -0.356 & -0.098 & -0.020 & 0.011 & 0.014 & 0.006 & -0.028 & 0.424 & -0.005 & -0.189 & -0.008 \\
\hline 353 & ARGB & M-14/S2150 & 2.329 & & 0.961 & 0.061 & -0.010 & 9.204 & 2.418 & 1.464 & 0.487 & 1.363 & 8.253 & 0.799 & 21.141 & 0.659 & -0.263 & 0.091 \\
\hline 353 & ARGB & M-14/S2150 & 2.373 & & 1.003 & 0.057 & -0.010 & 9.185 & 2.102 & 1.505 & 0.507 & 1.390 & 8.441 & 0.781 & 20.991 & 0.682 & -0.206 & 0.093 \\
\hline 353 & SM01 & M-14/S2150 & 3.361 & & 0.819 & 0.050 & 0.006 & 8.424 & 0.117 & 2.124 & 0.775 & 1.778 & 9.189 & 0.486 & 21.049 & 0.041 & 3.197 & 0.063 \\
\hline 353 & SM01 & M-14/S2150 & 3.424 & & 0.832 & 0.047 & 0.004 & 8.530 & 0.235 & 2.175 & 0.780 & 1.794 & 9.266 & 0.491 & 22.021 & 0.042 & 3.119 & 0.063 \\
\hline 353 & SM01 & M-14/S2150 & 3.419 & & 0.826 & 0.049 & 0.007 & 8.710 & 0.090 & 2.178 & 0.793 & 1.795 & 9.564 & 0.490 & 21.829 & 0.042 & 3.306 & 0.064 \\
\hline
\end{tabular}


WSRC-STI-2006-00068

Table A3. Mixed Acid Measurement Data Set (continued)

\begin{tabular}{|c|c|c|c|c|c|c|c|c|c|c|c|c|c|c|c|c|c|c|}
\hline Batch & Type of Sample & ICP/ID & $\mathbf{A l}$ & B & $\begin{array}{l}\mathbf{C a} \\
\end{array}$ & $\mathrm{Cr}$ & $\mathbf{C u}$ & $\mathbf{F e}$ & $\mathbf{K}$ & $\mathbf{L i}$ & Mg & Mn & Na & $\mathrm{Ni}$ & $\mathrm{Si}$ & Ti & $\mathbf{U}$ & $\mathbf{Z r}$ \\
\hline 353 & SM01 & M-14/S2150 & 3.429 & & 0.815 & 0.048 & 0.005 & 8.516 & 0.223 & 2.155 & 0.765 & 1.795 & 9.300 & 0.494 & 22.065 & 0.042 & 3.123 & 0.061 \\
\hline 353 & SM01 & M-14/S2150 & 3.468 & & 0.834 & 0.048 & 0.007 & 8.713 & 0.222 & 2.160 & 0.783 & 1.790 & 9.599 & 0.489 & 21.942 & 0.040 & 3.168 & 0.064 \\
\hline 353 & SM01 & M-14/S2150 & 3.405 & & 0.818 & 0.051 & 0.006 & 8.514 & 0.424 & 2.129 & 0.772 & 1.779 & 9.228 & 0.503 & 21.569 & 0.041 & 3.132 & 0.064 \\
\hline 353 & SM32 & M-14/S2150 & -0.067 & & 0.004 & -0.008 & -0.014 & -0.261 & -0.084 & -0.033 & 0.008 & 0.007 & -0.039 & -0.033 & 0.092 & -0.004 & -0.296 & -0.005 \\
\hline 353 & SM32 & M-14/S2150 & -0.069 & & -0.018 & -0.008 & -0.015 & -0.285 & 0.334 & -0.026 & 0.006 & 0.004 & -0.008 & -0.026 & 0.142 & -0.005 & -0.360 & -0.008 \\
\hline 354 & ARGB & M-13/S2133 & 2.282 & & 0.992 & 0.063 & -0.011 & 9.513 & 1.384 & 1.394 & 0.507 & 1.424 & 8.664 & 0.816 & 20.892 & 0.676 & -0.097 & 0.096 \\
\hline 354 & ARGB & M-13/S2133 & 2.314 & & 0.978 & 0.060 & -0.010 & 9.429 & 1.978 & 1.443 & 0.512 & 1.420 & 8.363 & 0.816 & 20.914 & 0.681 & -0.069 & 0.099 \\
\hline 354 & SM01 & M-13/S2133 & 3.148 & & 0.760 & 0.051 & 0.001 & 8.135 & -0.306 & 2.140 & 0.702 & 1.648 & 8.678 & 0.469 & 21.381 & 0.041 & 2.894 & 0.069 \\
\hline 354 & SM01 & M-13/S2133 & 3.122 & & 0.752 & 0.048 & 0.001 & 7.906 & 0.048 & 2.181 & 0.676 & 1.583 & 8.733 & 0.465 & 22.488 & 0.043 & 2.725 & 0.069 \\
\hline 354 & SM01 & M-13/S2133 & 3.314 & & 0.810 & 0.053 & 0.007 & 8.537 & 0.186 & 2.163 & 0.737 & 1.718 & 8.768 & 0.505 & 22.047 & 0.044 & 3.010 & 0.071 \\
\hline 354 & SM01 & M-13/S2133 & 3.224 & & 0.787 & 0.055 & 0.006 & 8.486 & 0.144 & 2.172 & 0.701 & 1.643 & 8.698 & 0.483 & 22.305 & 0.042 & 2.932 & 0.071 \\
\hline 354 & SM01 & M-13/S2133 & 3.304 & & 1.097 & 0.061 & 0.003 & 8.998 & 0.402 & 2.050 & 0.805 & 1.783 & 8.841 & 0.550 & 21.558 & 0.086 & 2.874 & 0.074 \\
\hline 354 & SM01 & M-13/S2133 & 3.109 & & 0.765 & 0.051 & 0.005 & 8.063 & -0.673 & 2.168 & 0.689 & 1.593 & 8.856 & 0.471 & 22.366 & 0.043 & 2.804 & 0.068 \\
\hline 354 & SM32 & M-13/S2133 & -0.130 & & -0.011 & -0.004 & -0.019 & -0.250 & -0.219 & 0.018 & -0.006 & 0.003 & -0.018 & -0.018 & -0.652 & -0.003 & -0.153 & 0.001 \\
\hline 354 & SM32 & M-13/S2133 & -0.115 & & -0.016 & -0.004 & -0.023 & -0.274 & -0.546 & -0.047 & -0.006 & 0.001 & 0.042 & -0.004 & -0.593 & -0.004 & -0.246 & 0.000 \\
\hline 355 & ARGB & M-14/S2150 & 2.349 & & 1.008 & 0.061 & 0.002 & 9.362 & 2.144 & 1.503 & 0.497 & 1.429 & 8.518 & 0.808 & 20.766 & 0.694 & -0.058 & 0.096 \\
\hline 355 & ARGB & M-14/S2150 & 2.265 & & 0.951 & 0.059 & -0.002 & 9.204 & 2.242 & 1.471 & 0.484 & 1.388 & 8.390 & 0.791 & 20.346 & 0.667 & -0.196 & 0.090 \\
\hline 355 & SM01 & M-14/S2150 & 2.970 & & 0.741 & 0.046 & 0.014 & 7.561 & 0.199 & 2.376 & 0.709 & 1.546 & 8.580 & 0.449 & 23.976 & 0.042 & 2.565 & 0.082 \\
\hline 355 & SM01 & M-14/S2150 & 2.857 & & 0.697 & 0.042 & 0.010 & 7.228 & 0.573 & 2.369 & 0.682 & 1.479 & 8.199 & 0.417 & 23.485 & 0.039 & 2.445 & 0.080 \\
\hline 355 & SM01 & M-14/S2150 & 2.909 & . & 0.668 & 0.044 & 0.008 & 7.334 & 0.380 & 2.407 & 0.656 & 1.450 & 7.953 & 0.433 & 24.646 & 0.040 & 2.554 & 0.082 \\
\hline 355 & SM01 & M-14/S2150 & 2.882 & & 0.697 & 0.045 & 0.013 & 7.304 & 0.535 & 2.335 & 0.685 & 1.494 & 8.398 & 0.434 & 23.161 & 0.041 & 2.466 & 0.081 \\
\hline 355 & SM01 & M-14/S2150 & 2.916 & & 0.724 & 0.047 & 0.013 & 7.132 & 0.297 & 2.332 & 0.704 & 1.516 & 8.432 & 0.412 & 21.465 & 0.041 & 2.580 & 0.079 \\
\hline 355 & SM01 & M-14/S2150 & 2.923 & & 0.674 & 0.044 & 0.010 & 7.359 & 0.454 & 2.401 & 0.653 & 1.463 & 7.867 & 0.427 & 23.920 & 0.039 & 2.446 & 0.081 \\
\hline 355 & SM32 & M-14/S2150 & -0.110 & & 0.003 & -0.004 & -0.003 & -0.126 & -0.338 & -0.012 & -0.005 & -0.006 & 0.035 & -0.006 & -0.498 & -0.004 & -0.117 & -0.004 \\
\hline 355 & SM32 & M-14/S2150 & -0.101 & & 0.007 & -0.005 & -0.007 & -0.124 & 0.099 & -0.007 & -0.005 & -0.008 & 0.023 & -0.016 & -0.465 & -0.003 & -0.226 & -0.007 \\
\hline 356 & ARGB & M-13/S2133 & 2.383 & & 1.066 & 0.066 & 0.000 & 9.871 & 2.474 & 1.555 & 0.533 & 1.438 & 8.719 & 0.847 & 22.388 & 0.712 & 0.008 & 0.117 \\
\hline 356 & RGB & M-13/S2133 & 2.389 & & 1.039 & 0.065 & -0.001 & 9.659 & 2.376 & 1.511 & 0.517 & 1.440 & 8.407 & 0.814 & 21.716 & 0.680 & 0.008 & 0.112 \\
\hline 356 & ARGB & M-14/S2150 & 2.360 & & 0.990 & 0.062 & -0.002 & 9.746 & 2.405 & 1.511 & 0.522 & 1.416 & 8.431 & 0.814 & 21.792 & 0.700 & -0.177 & 0.094 \\
\hline 356 & ARGB & M-14/S2150 & 2.340 & & 0.995 & 0.060 & 0.000 & 9.485 & 1.972 & 1.485 & 0.507 & 1.398 & 8.426 & 0.805 & 20.721 & 0.680 & -0.161 & 0.094 \\
\hline 356 & SM01 & M-13/S2133 & 3.169 & & 0.771 & 0.051 & 0.013 & 7.927 & -0.011 & 2.272 & 0.683 & 1.579 & 8.103 & 0.445 & 23.924 & 0.057 & 3.123 & 0.131 \\
\hline 356 & SM01 & M-13/S2133 & 2.983 & & 0.732 & 0.048 & 0.014 & 7.991 & 0.047 & 2.111 & 0.660 & 1.574 & 7.834 & 0.465 & 21.732 & 0.056 & 3.037 & 0.128 \\
\hline 356 & SM01 & M-13/S2133 & 2.990 & & 0.720 & 0.049 & 0.012 & 7.677 & -0.143 & 2.175 & 0.649 & 1.473 & 7.717 & 0.448 & 22.269 & 0.055 & 2.602 & 0.108 \\
\hline 356 & SM01 & M-13/S2133 & 3.102 & & 0.751 & 0.049 & 0.014 & 7.649 & 0.106 & 2.125 & 0.666 & 1.500 & 7.769 & 0.448 & 21.532 & 0.052 & 3.036 & 0.122 \\
\hline 356 & SM01 & M-13/S2133 & 3.230 & & 0.799 & 0.056 & 0.014 & 8.221 & -0.026 & 2.280 & 0.724 & 1.592 & 8.272 & 0.470 & 23.229 & 0.054 & 3.222 & 0.133 \\
\hline 356 & SM01 & M-13/S2133 & 3.103 & & 0.743 & 0.055 & 0.012 & 7.907 & -0.124 & 2.251 & 0.673 & 1.501 & 7.806 & 0.460 & 22.601 & 0.053 & 3.087 & 0.126 \\
\hline 356 & SM32 & M-13/S2133 & -0.037 & & -0.004 & -0.006 & -0.006 & -0.099 & -0.064 & -0.006 & -0.012 & 0.015 & -0.031 & -0.013 & -0.748 & 0.008 & -0.145 & 0.018 \\
\hline 356 & SM32 & M-13/S2133 & -0.032 & & -0.005 & -0.012 & -0.008 & -0.113 & -0.165 & -0.005 & -0.013 & 0.012 & -0.074 & -0.019 & $\begin{array}{l}-0.674 \\
\end{array}$ & 0.009 & -0.035 & 0.018 \\
\hline
\end{tabular}


WSRC-STI-2006-00068 Revision 0

Table A4. Targeting WLs at Blending

\begin{tabular}{|c|c|c|c|c|c|c|c|}
\hline Batch & $\begin{array}{l}\mathrm{Li}_{2} \mathrm{O} \text { lbs in } \\
\text { SME Heel }\end{array}$ & $\begin{array}{l}\text { Oxide lbs in } \\
\text { SME Heel }\end{array}$ & $\begin{array}{c}\text { Oxide lbs } \\
\text { SRAT Transfer. }\end{array}$ & $\begin{array}{c}\mathbf{L i}_{2} \mathbf{O} \text { lbs in } \\
\text { SRAT Transfer }\end{array}$ & $\begin{array}{c}\text { Oxide lbs in } \\
\text { Frit }\end{array}$ & $\begin{array}{c}\mathrm{Li}_{2} \mathrm{O} \text { lbs in } \\
\text { Frit }\end{array}$ & $\begin{array}{c}\text { WL Targeting } \\
\text { at Blending }\end{array}$ \\
\hline 300 & 6503.159 & 314.014 & 7482.471 & 0.000 & 13491.564 & 1071.173 & 36.47 \\
\hline 301 & 8550.541 & 420.021 & 7787.828 & 19.015 & 14241.095 & 1130.683 & 35.31 \\
\hline 302 & 7664.272 & 350.264 & 7914.455 & 0.758 & 14091.189 & 1118.781 & 37.57 \\
\hline 303 & 6918.459 & 343.210 & 7480.173 & 0.000 & 13791.376 & 1094.977 & 35.70 \\
\hline 304 & 6655.614 & 330.911 & 6833.539 & 0.000 & 13240.955 & 1044.813 & 34.73 \\
\hline 305 & 6145.347 & 305.068 & 8399.647 & 2.564 & 14989.761 & 1182.808 & 36.00 \\
\hline 306 & 8575.352 & 410.450 & 8036.572 & 13.150 & 14789.897 & 1167.037 & 35.76 \\
\hline 307 & 10662.923 & 512.057 & 7047.691 & 3.597 & 13487.804 & 1068.139 & 35.84 \\
\hline 308 & 7111.860 & 338.931 & 8230.561 & 8.291 & 15985.546 & 1265.943 & 34.92 \\
\hline 309 & 7217.491 & 347.646 & 7939.544 & 0.000 & 14486.901 & 1147.261 & 36.26 \\
\hline 310 & 6251.095 & 299.916 & 7134.861 & 2.638 & 13987.352 & 1107.700 & 34.89 \\
\hline 311 & 8478.505 & 410.171 & 8271.574 & 0.127 & 14490.193 & 1148.309 & 37.00 \\
\hline 312 & 9033.594 & 461.755 & 7596.495 & 0.000 & 13990.531 & 1108.713 & 35.24 \\
\hline 313 & 6890.516 & 324.557 & 8341.960 & 0.000 & 15989.179 & 1267.100 & 35.63 \\
\hline 314 & 6730.292 & 332.305 & 7816.075 & -1.272 & 14989.855 & 1187.906 & 35.06 \\
\hline 315 & 6565.085 & 318.720 & 7691.114 & 3.310 & 14989.855 & 1187.906 & 34.83 \\
\hline 316 & 6685.912 & 327.712 & 8132.780 & 2.638 & 15989.179 & 1267.100 & 34.53 \\
\hline 317 & 8672.657 & 433.541 & 8226.900 & 1.231 & 14989.855 & 1187.906 & 35.75 \\
\hline 318 & 7631.922 & 368.349 & 7893.112 & 0.000 & 15489.517 & 1227.503 & 35.03 \\
\hline 319 & 6913.973 & 324.890 & 7497.755 & 11.010 & 14489.723 & 1152.750 & 35.21 \\
\hline 320 & 6344.207 & 311.253 & 7750.735 & 0.000 & 14989.368 & 1192.500 & 34.96 \\
\hline 321 & 6308.906 & 302.924 & 7199.656 & 6.807 & 14789.510 & 1176.600 & 33.93 \\
\hline 322 & 6829.448 & 348.178 & 7363.588 & 0.171 & 14239.900 & 1132.875 & 34.47 \\
\hline 323 & 8531.548 & 412.209 & 7534.234 & 1.543 & 14688.526 & 1169.986 & 35.30 \\
\hline 324 & 6459.813 & 300.286 & 7704.002 & 1.204 & 15487.901 & 1233.659 & 34.95 \\
\hline 325 & 6658.953 & 341.501 & 7688.623 & 2.708 & 15088.214 & 1201.823 & 34.01 \\
\hline 326 & 6744.068 & 336.723 & 8149.556 & 0.000 & 15987.511 & 1273.455 & 34.49 \\
\hline 327 & 7145.570 & 357.769 & 8813.887 & 0.000 & 17586.262 & 1400.800 & 34.13 \\
\hline 328 & 7372.587 & 366.144 & 7132.176 & 0.000 & 14238.877 & 1134.170 & 34.42 \\
\hline 329 & 6527.696 & 327.465 & 7655.552 & 0.000 & 15088.214 & 1201.823 & 34.36 \\
\hline 330 & 6800.313 & 334.981 & 7354.763 & 0.000 & 14088.994 & 1122.232 & 35.18 \\
\hline 331 & 7135.224 & 355.571 & 7352.586 & 0.364 & 14388.760 & 1146.109 & 34.65 \\
\hline 332 & 7196.821 & 364.972 & 8248.868 & -1.177 & 15088.214 & 1201.823 & 35.58 \\
\hline 333 & 7258.898 & 362.632 & 7637.003 & 6.192 & 13339.580 & 1062.539 & 36.31 \\
\hline 334 & 6151.657 & 315.124 & 6997.400 & 6.529 & 12790.009 & 1018.764 & 35.07 \\
\hline 335 & 8938.933 & 429.798 & 6771.970 & 0.000 & 11990.633 & 955.091 & 37.19 \\
\hline 336 & 10200.451 & 483.301 & 7826.763 & 0.422 & 13789.228 & 1098.355 & 37.52 \\
\hline 337 & 9739.944 & 451.610 & 7567.579 & 0.000 & 14286.246 & 1148.550 & 36.94 \\
\hline 338 & 9867.620 & 471.809 & 7699.541 & 0.000 & 13886.631 & 1116.423 & 37.13 \\
\hline 339 & 9893.539 & 481.511 & 8234.258 & 0.000 & 13993.560 & 1117.200 & 37.63 \\
\hline 340 & 10130.444 & 483.703 & 7884.211 & 0.000 & 13993.560 & 1117.200 & 37.32 \\
\hline 341 & 9855.149 & 476.771 & 8164.994 & 0.000 & 14193.468 & 1133.160 & 37.37 \\
\hline 342 & 10606.308 & 515.349 & 8748.489 & 0.000 & 14293.422 & 1141.140 & 38.31 \\
\hline 343 & 10212.800 & 479.935 & 7677.895 & 0.000 & 14036.840 & 1118.661 & 37.11 \\
\hline 344 & 9403.646 & 452.504 & 8114.956 & 0.000 & 14186.699 & 1130.604 & 37.29 \\
\hline 345 & 9669.703 & 474.526 & 7728.999 & 5.382 & 13087.730 & 1043.022 & 37.26 \\
\hline 346 & 7415.997 & 350.951 & 7271.204 & 0.000 & 12788.011 & 1019.136 & 37.37 \\
\hline 347 & 8843.523 & 435.365 & 7475.029 & 0.000 & 12688.421 & 1007.857 & 37.30 \\
\hline 348 & 8859.665 & 411.814 & 7985.664 & 0.000 & 13537.646 & 1075.312 & 38.32 \\
\hline 349 & 9250.034 & 429.603 & 7682.394 & 0.000 & 12988.147 & 1031.665 & 38.46 \\
\hline 350 & 9421.403 & 446.307 & 7684.914 & 0.000 & 12988.147 & 1031.665 & 38.12 \\
\hline 351 & 9363.207 & 480.908 & 8047.999 & 0.000 & 12688.421 & 1007.857 & 37.67 \\
\hline 352 & 11256.130 & 533.351 & 6531.105 & 0.000 & 12088.968 & 960.242 & 37.00 \\
\hline 353 & 9550.308 & 458.522 & 7482.829 & 0.000 & 12988.615 & 1031.174 & 37.44 \\
\hline 354 & 9506.534 & 433.498 & 8222.673 & 0.000 & 13488.177 & 1070.834 & 39.25 \\
\hline 355 & 9853.231 & 462.115 & 8114.465 & 6.882 & 16985.112 & 1348.458 & 34.45 \\
\hline 356 & 9876.498 & 505.313 & 7862.769 & 0.000 & 14187.564 & 1126.359 & 35.57 \\
\hline
\end{tabular}


WSRC-STI-2006-00068

Revision 0

Exhibit A1. Standard and Process Measurements by Analyte for

Standard/Process=ARG-1, Analyte $=$ A

Variability Chart for Measurement

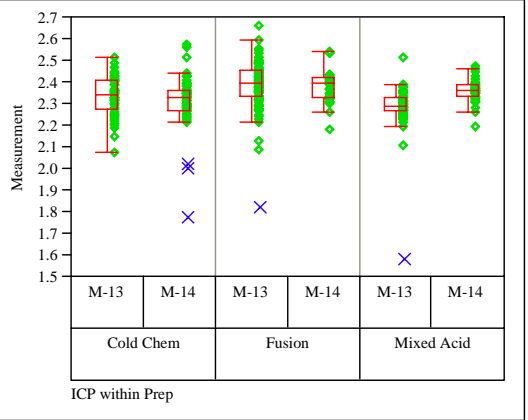

Standard/Process $=$ ARG -1 , Analyte $=$ Al $/$ Ca

Variability Chart for Measurement

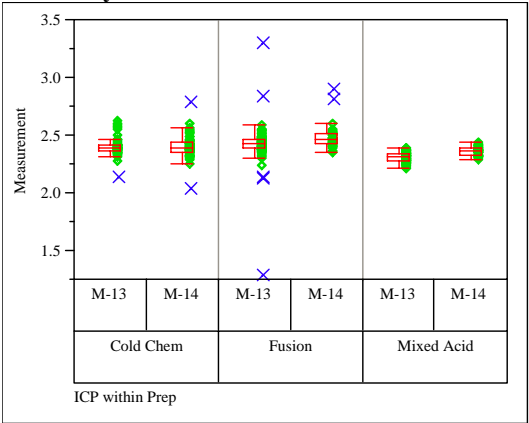

Standard/Process=ARG-1, Analyte=Al/Mg

Variability Chart for Measurement

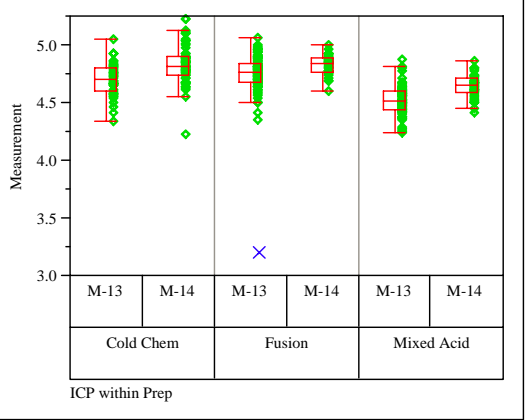

Standard/Process=ARG-1, Analyte=Al/Mn

Variability Chart for Measurement

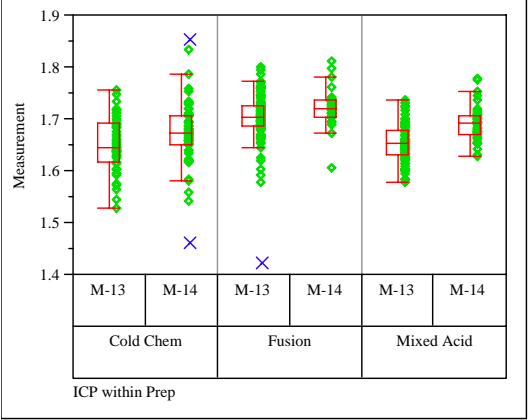

Standard/Process=ARG-1, Analyte $=$ B

Variability Chart for Measurement

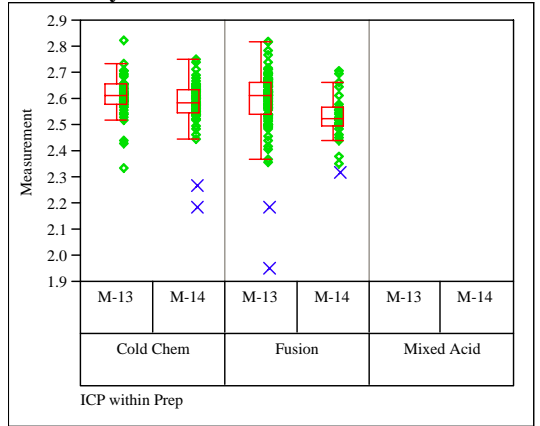

Standard/Process=ARG-1, Analyte=B/Li

Variability Chart for Measurement

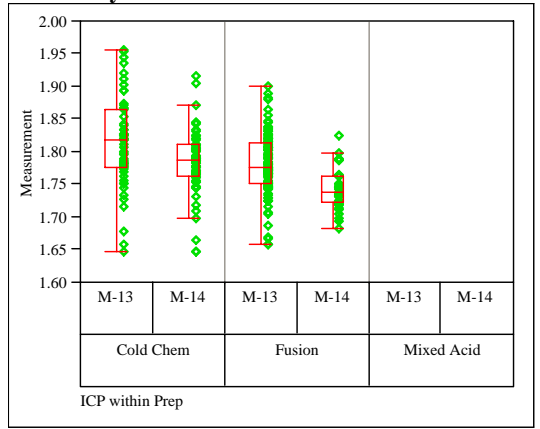

Standard/Process $=$ ARG-1, Analyte $=\mathrm{Ca}$

Variability Chart for Measurement

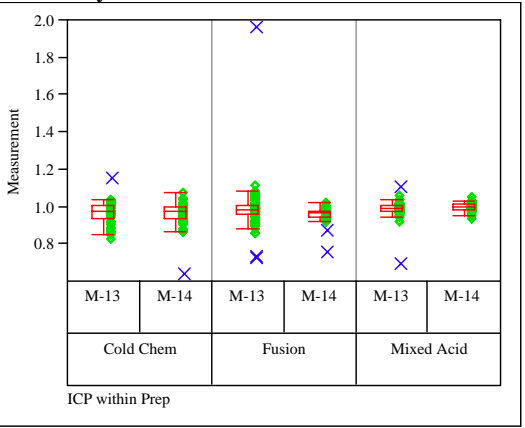

Standard $/$ Process $=$ ARG-1, Analyte $=\mathbf{C r}$ Variability Chart for Measurement

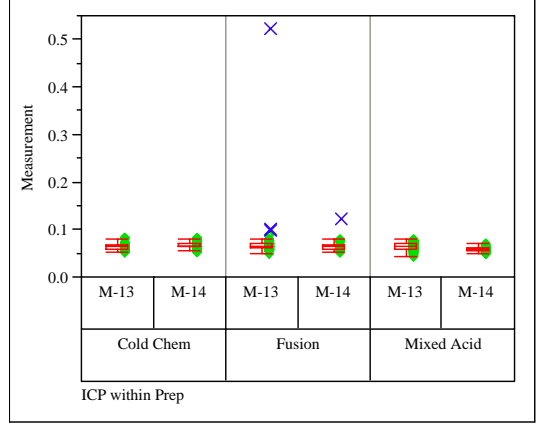

Standard/Process=ARG-1, Analyte $=\mathbf{C u}$

Variability Chart for Measurement

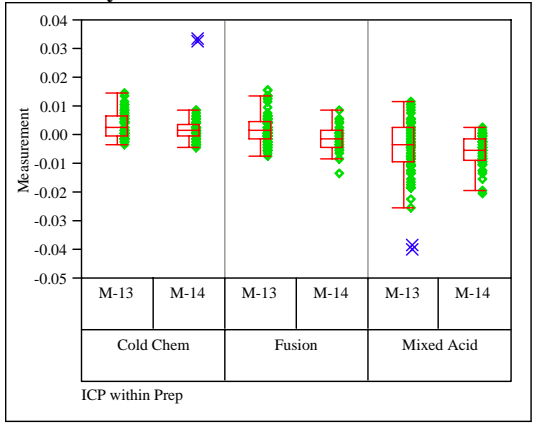

Standard/Process=ARG-1, Analyte $=$ Fe

Variability Chart for Measurement

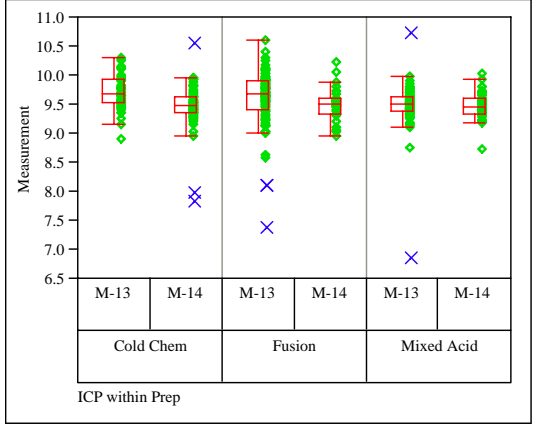

Standard/Process=ARG-1, Analyte=Fe/Al Variability Chart for Measurement

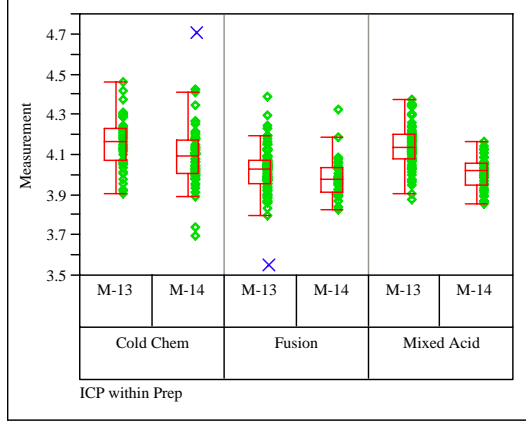

Standard/Process=ARG-1, Analyte $=\mathbf{F e} / \mathbf{C a}$

Variability Chart for Measurement

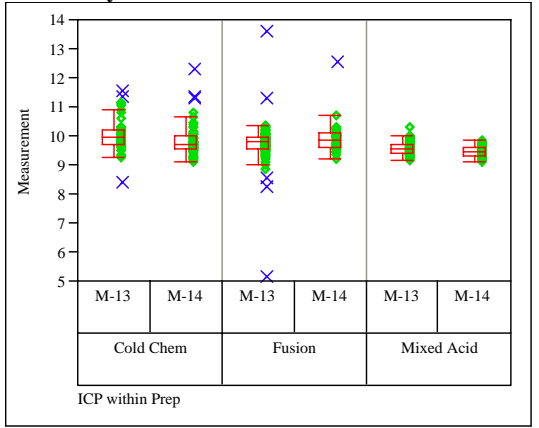


Exhibit A1. Standard and Process Measurements by Analyte for

Standard/Process=ARG-1, Analyte $=\mathrm{Fe} / \mathrm{Li}$

Variability Chart for Measurement

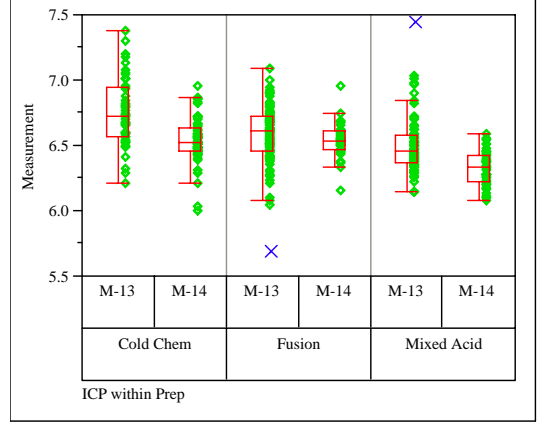

Standard/Process=ARG-1, Analyte=Fe/Mg

Variability Chart for Measurement

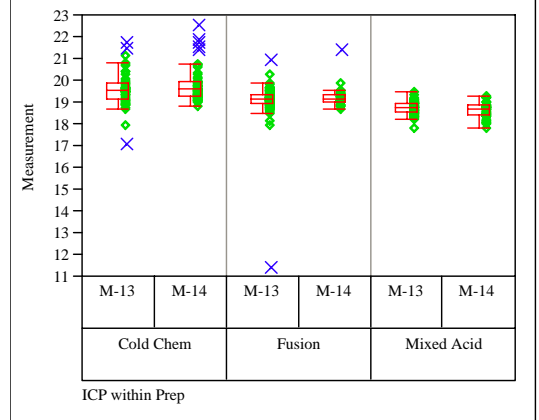

Standard/Process=ARG-1, Analyte $=$ Fe/Mn

Variability Chart for Measurement

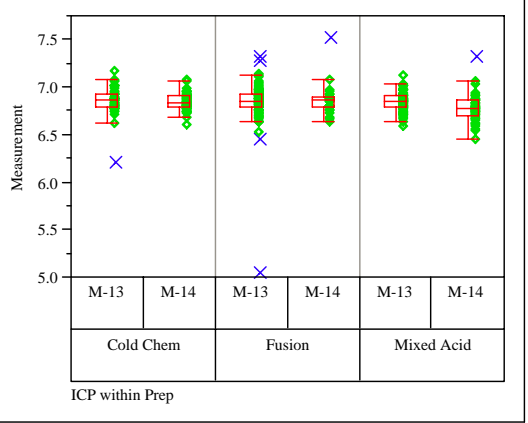

Standard/Process $=$ ARG -1 , Analyte $=\mathbf{F e} / \mathbf{N i}$

Variability Chart for Measurement

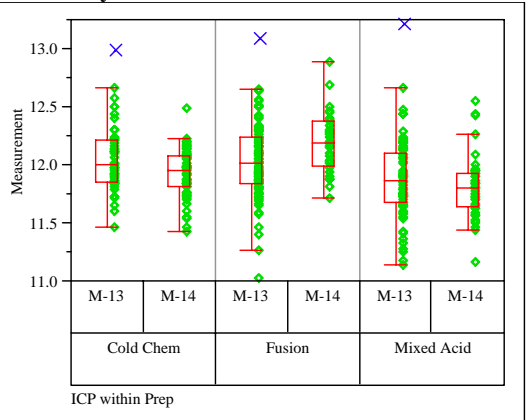

Standard/Process=ARG-1, Analyte $=$ Fe/U

Variability Chart for Measurement

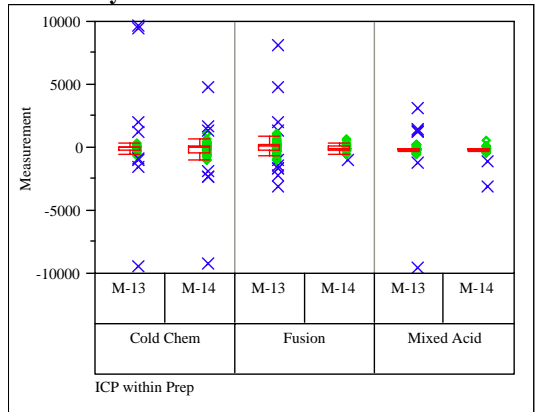

Standard/Process=ARG-1, Analyte $=$ K

Variability Chart for Measurement

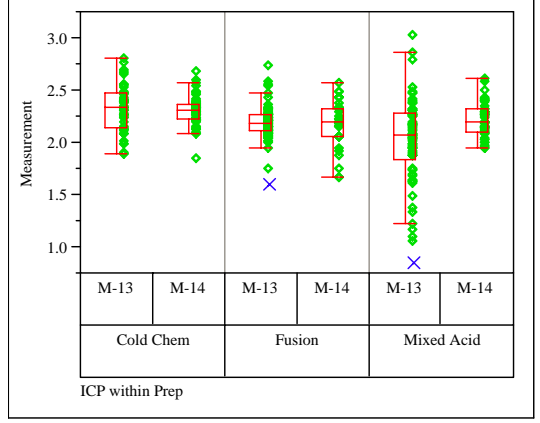

Standard/Process $=$ ARG-1, Analyte $=\mathrm{L}$

Variability Chart for Measurement

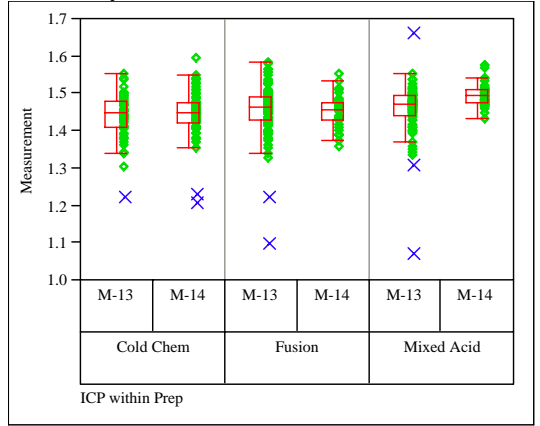

Standard/Process=ARG-1, Analyte=Mg

Variability Chart for Measurement

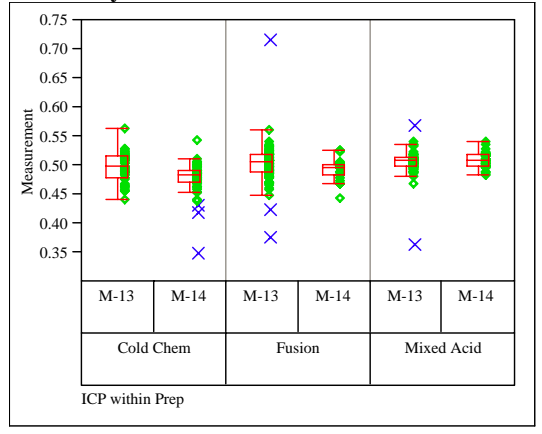

Standard/Process=ARG-1, Analyte $=$ Mn

Variability Chart for Measurement

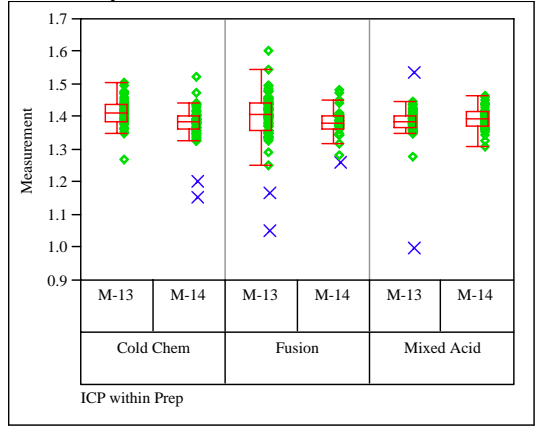

Standard/Process=ARG-1, Analyte $=\mathrm{Mn} / \mathrm{Mg}$

Variability Chart for Measurement

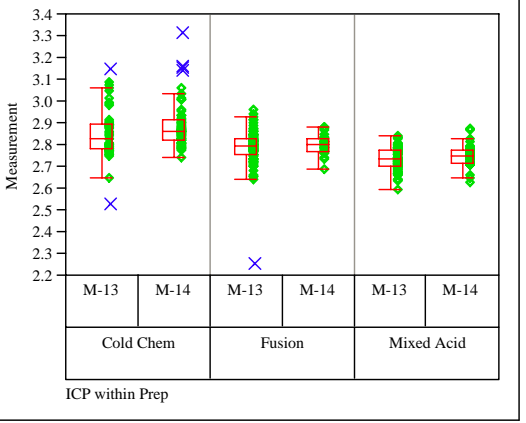

Standard/Process $=$ ARG-1, Analyte $=\mathrm{Na}$

Variability Chart for Measurement

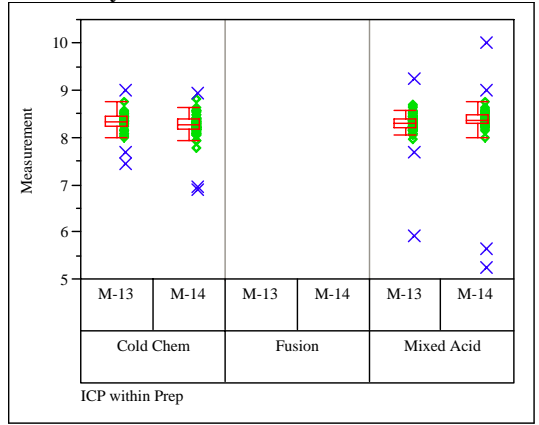

Standard/Process=ARG-1, Analyte $=\mathrm{Ni}$

Variability Chart for Measurement

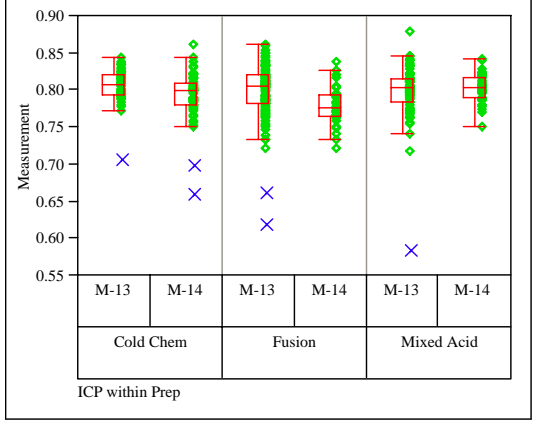


Exhibit A1. Standard and Process Measurements by Analyte for

Standard/Process $=$ ARG-1, Analyte $=\mathrm{Si}$

Variability Chart for Measurement

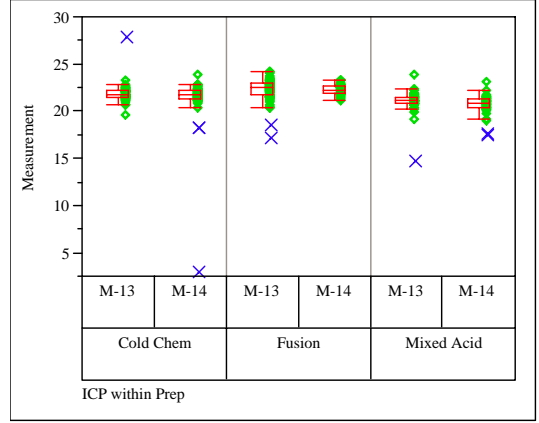

Standard/Process=ARG-1, Analyte=Sum of

Oxides

Variability Chart for Measurement

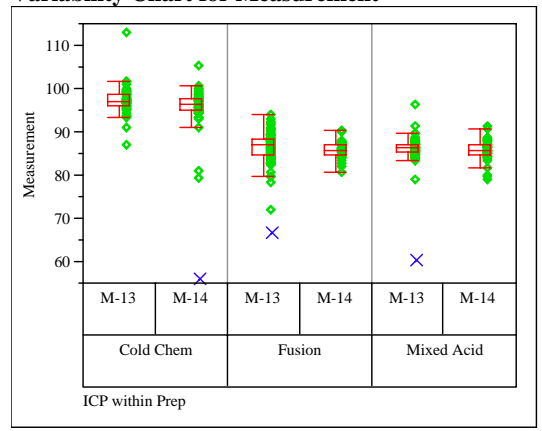

Standard/Process=ARG-1, Analyte=Ti

Variability Chart for Measurement

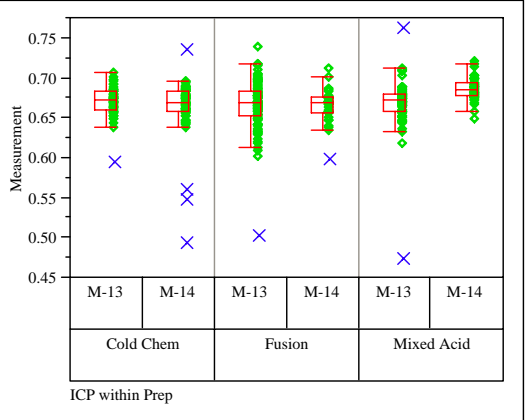

Standard/Process=ARG-1, Analyte $=\mathbf{U}$

Variability Chart for Measurement

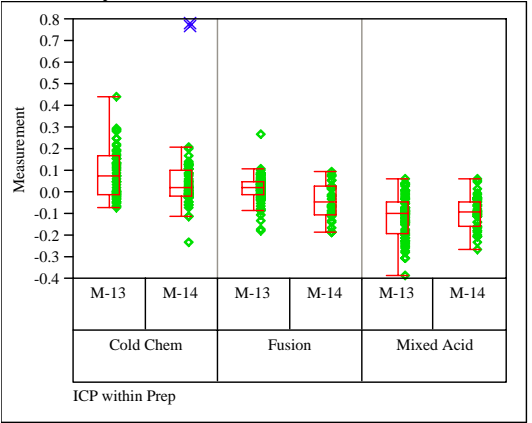

Standard/Process $=$ ARG-1, Analyte $=$ U/Ca

Variability Chart for Measurement

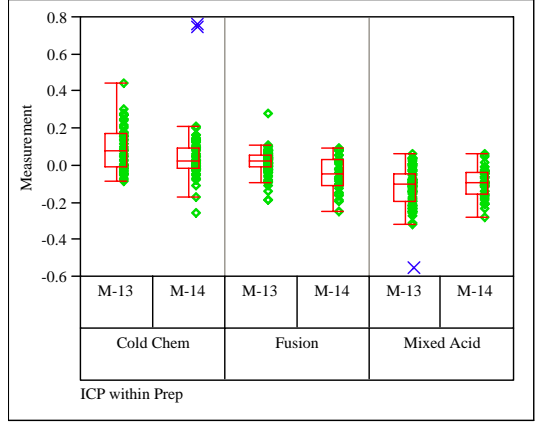

Standard/Process=ARG-1, Analyte $=\mathrm{Zr}$

Variability Chart for Measurement

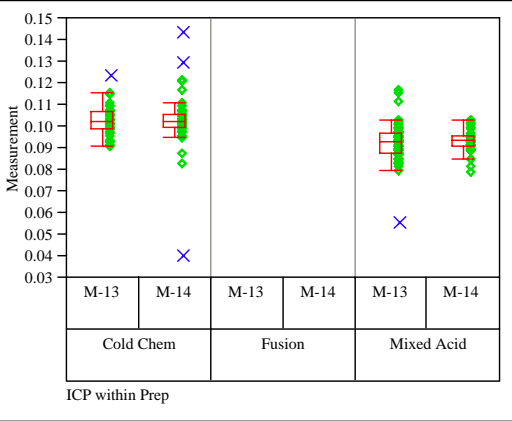

Standard/Process $=$ Process, Analyte $=\mathbf{A l}$

Variability Chart for Measurement

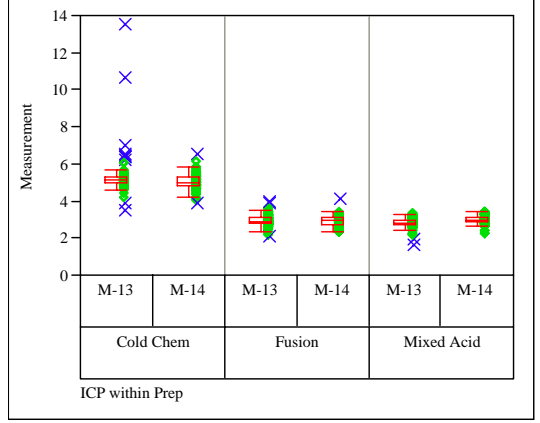

Standard/Process $=$ Process, Analyte $=\mathrm{Al} / \mathrm{Ca}$

Variability Chart for Measurement

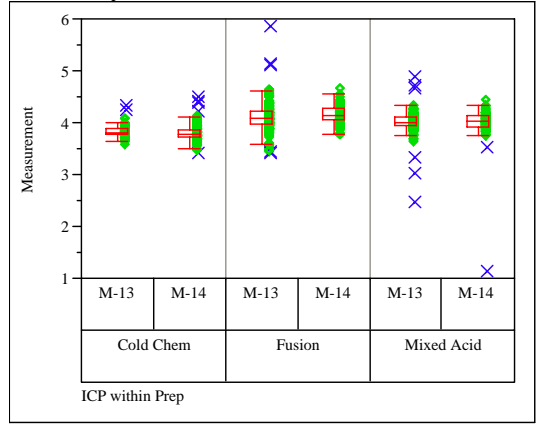

Standard/Process $=$ Process, Analyte $=\mathrm{Al} / \mathrm{Mg}$

Variability Chart for Measurement

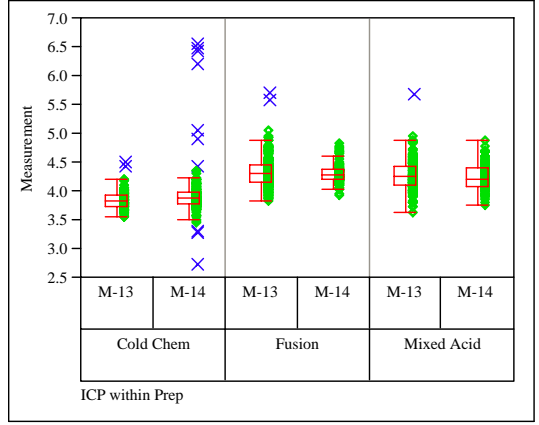

Standard/Process $=$ Process, Analyte $=\mathrm{Al} / \mathrm{Mn}$

Variability Chart for Measurement

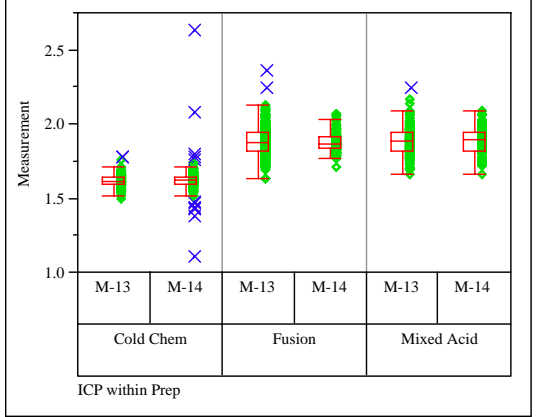

Standard/Process $=$ Process, Analyte $=B$

Variability Chart for Measurement

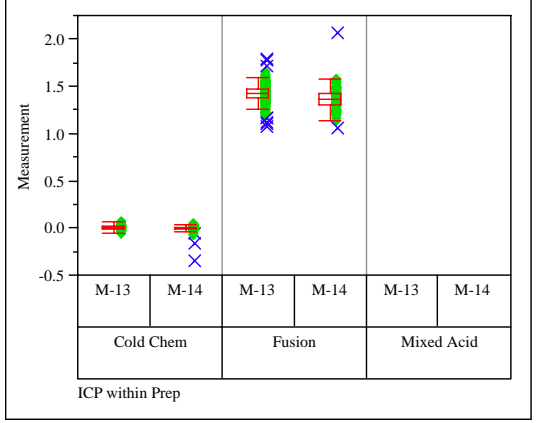

Standard/Process $=$ Process, Analyte $=\mathbf{B} / \mathbf{L i}$

Variability Chart for Measurement

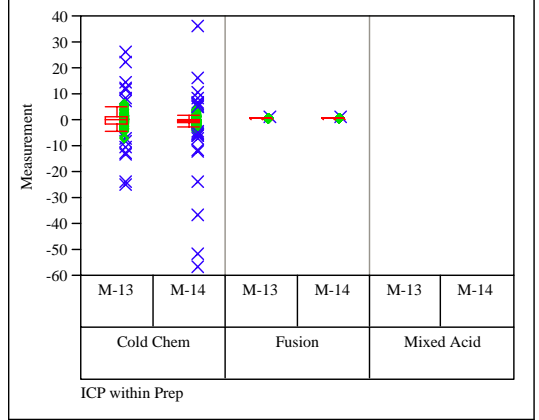


Exhibit A1. Standard and Process Measurements by Analyte for

Standard/Process $=$ Process, Analyte $=$ Ca

Variability Chart for Measurement

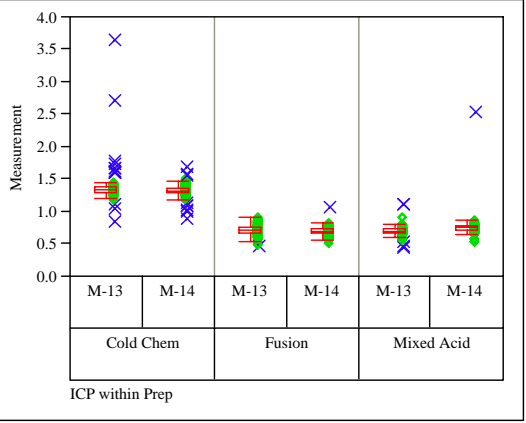

Standard $/$ Process $=$ Process, Analyte $=\mathrm{Cr}$

Variability Chart for Measurement

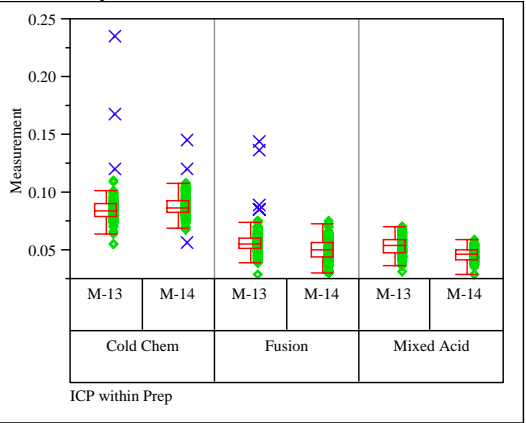

Standard/Process $=$ Process, Analyte $=\mathrm{Cu}$

Variability Chart for Measurement

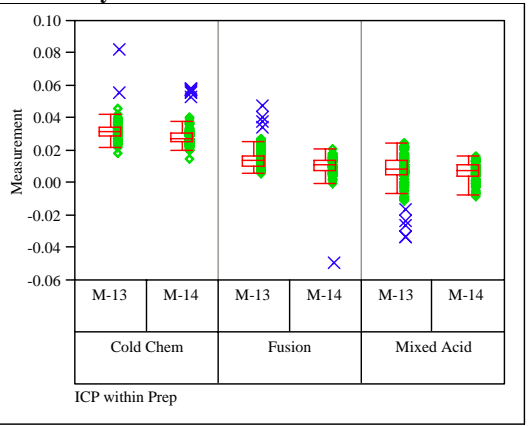

Standard/Process $=$ Process, Analyte $=$ Fe

Variability Chart for Measurement

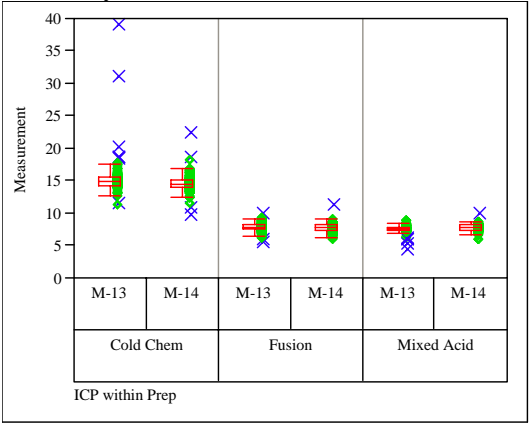

Standard/Process $=$ Process, Analyte $=\mathrm{Fe} / \mathrm{Al}$

Variability Chart for Measurement

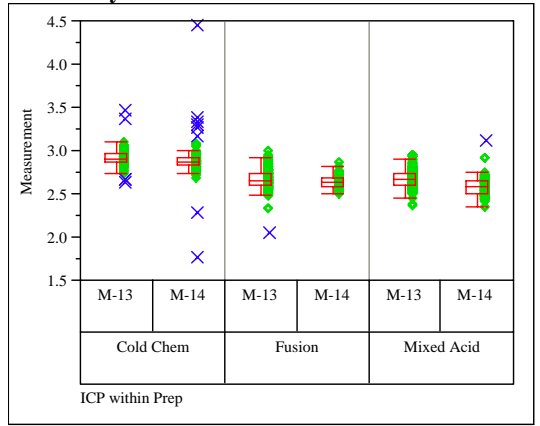

Standard/Process $=$ Process, Analyte $=\mathrm{Fe} / \mathrm{Ca}$

Variability Chart for Measurement

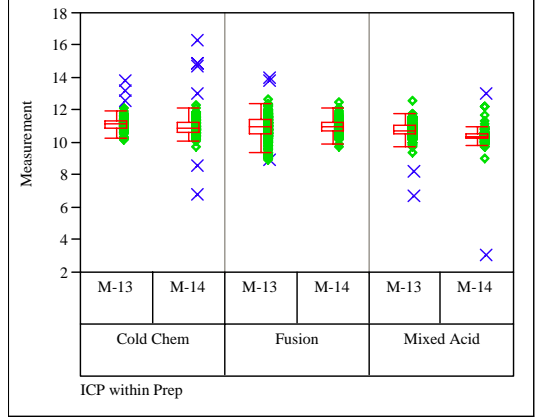

Standard/Process $=$ Process, Analyte $=\mathrm{Fe} / \mathrm{Li}$

Variability Chart for Measurement

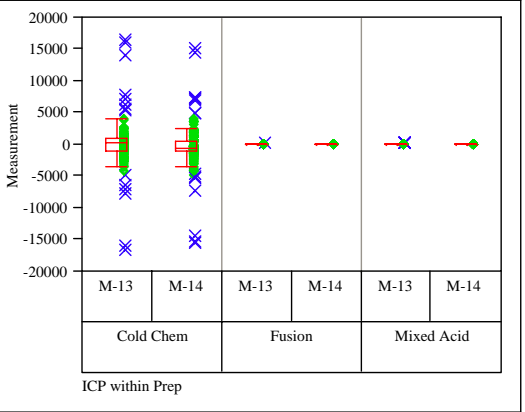

Standard/Process=Process, Analyte $=\mathrm{Fe} / \mathrm{Mg}$ Variability Chart for Measurement

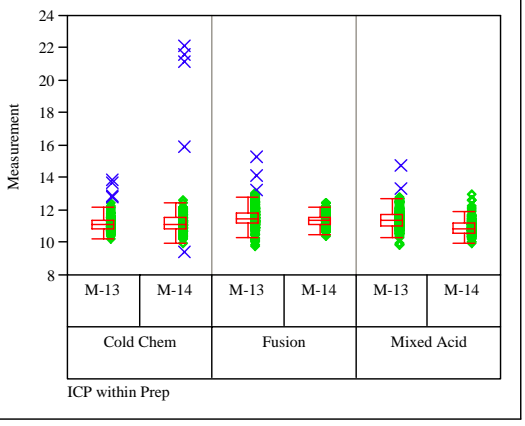

Standard/Process=Process, Analyte $=$ Fe/Mn Variability Chart for Measurement

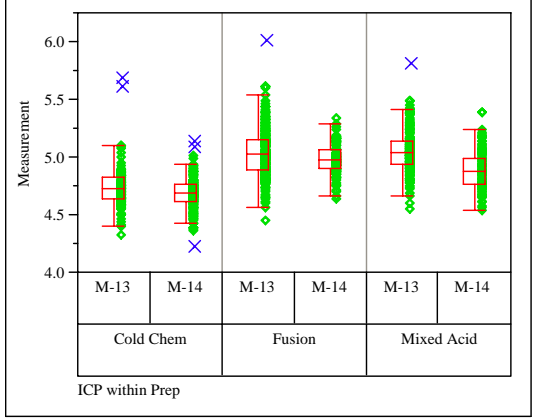

Standard $/$ Process $=$ Process, Analyte $=\mathrm{Fe} / \mathrm{Ni}$

Variability Chart for Measurement

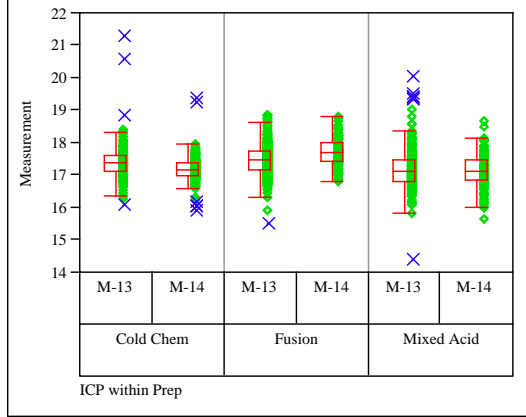

Standard/Process $=$ Process, Analyte $=$ Fe $/ U$ Variability Chart for Measurement

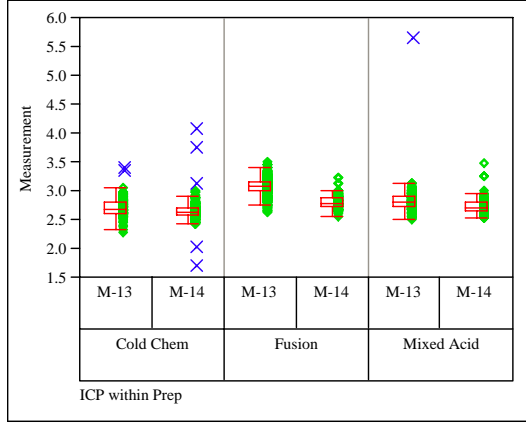

Standard/Process $=$ Process, Analyte $=K$

Variability Chart for Measurement

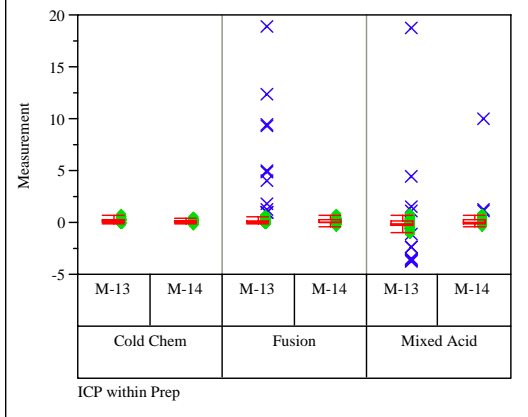


Exhibit A1. Standard and Process Measurements by Analyte for

Standard/Process $=$ Process, Analyte $=\mathrm{Li}$

Variability Chart for Measurement

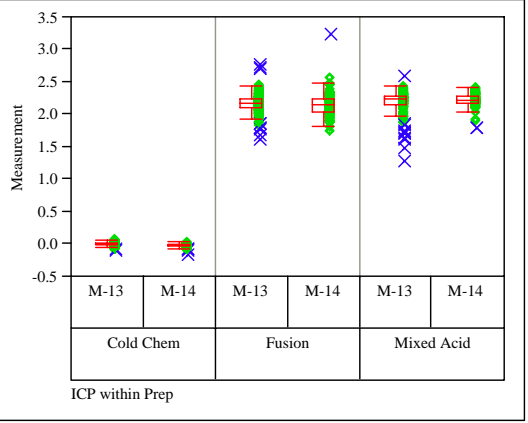

Standard $/$ Process $=$ Process, Analyte $=\mathbf{M g}$

Variability Chart for Measurement

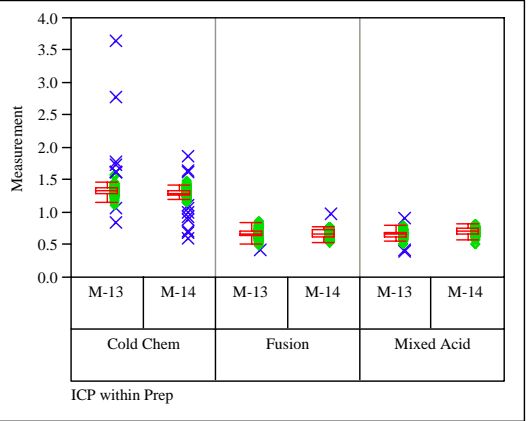

Standard/Process $=$ Process, Analyte $=\mathbf{M n}$ Variability Chart for Measurement

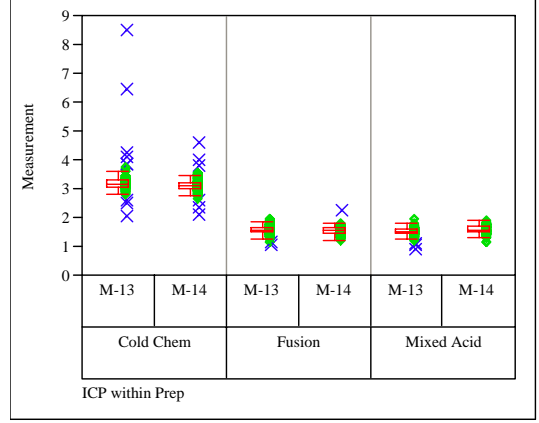

Standard/Process $=$ Process,

Analyte $=\mathbf{M n} / \mathbf{M g}$

Variability Chart for Measurement

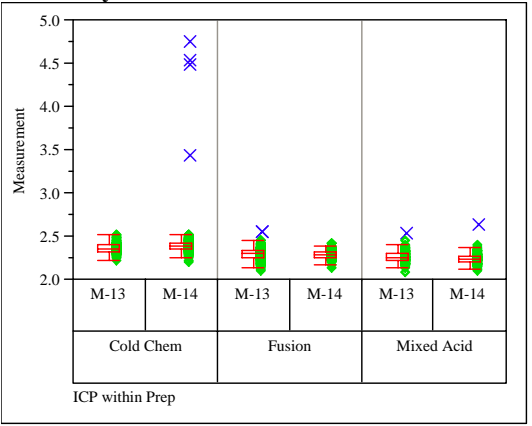

Standard/Process $=$ Process, Analyte $=\mathrm{Na}$

Variability Chart for Measurement

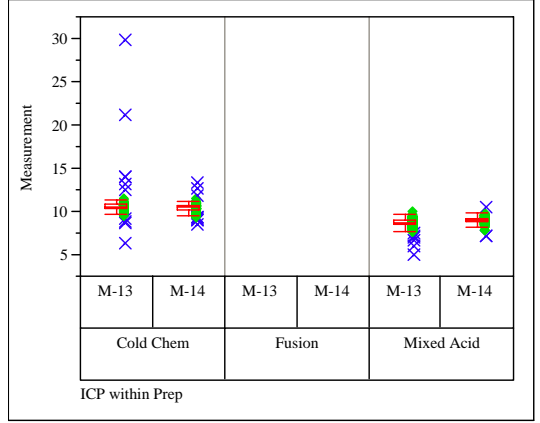

Standard $/$ Process $=$ Process, Analyte $=\mathrm{Ni}$

Variability Chart for Measurement

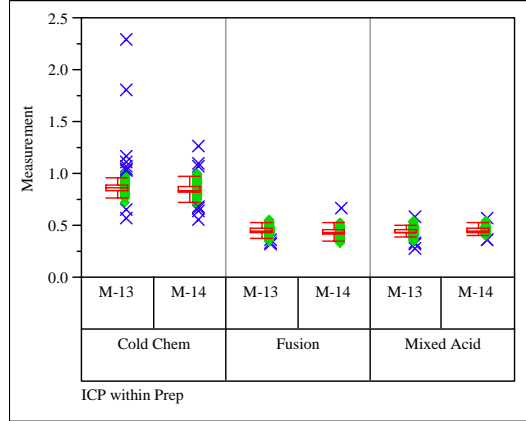

Standard/Process $=$ Process, Analyte $=\mathrm{Si}$

Variability Chart for Measurement

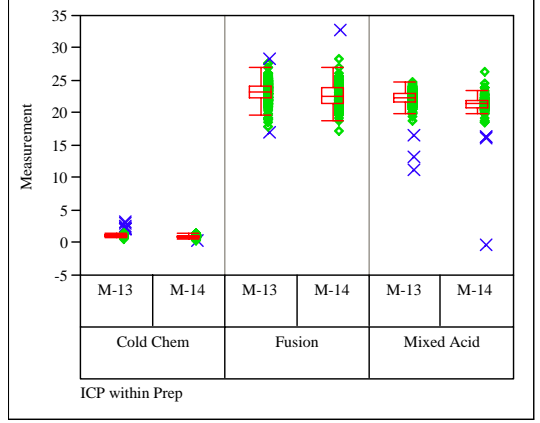

Standard/Process $=$ Process, Analyte $=$ Sum of

Oxides

Variability Chart for Measurement

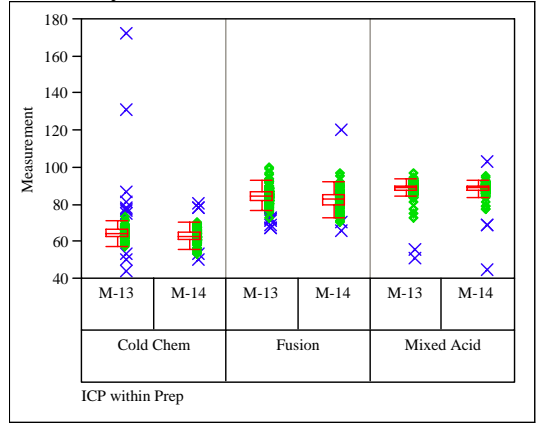

Standard/Process $=$ Process, Analyte $=\mathrm{Ti}$

Variability Chart for Measurement

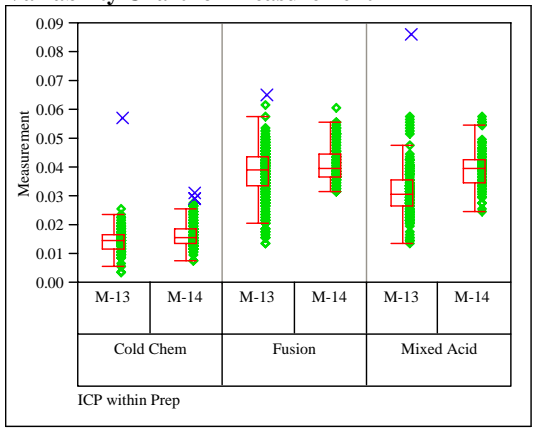

Standard/Process $=$ Process, Analyte $=\mathrm{U}$

Variability Chart for Measurement

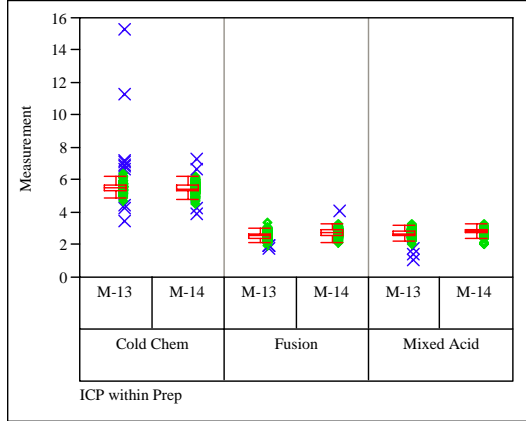

Standard/Process $=$ Process, Analyte $=U / C a$ Variability Chart for Measurement

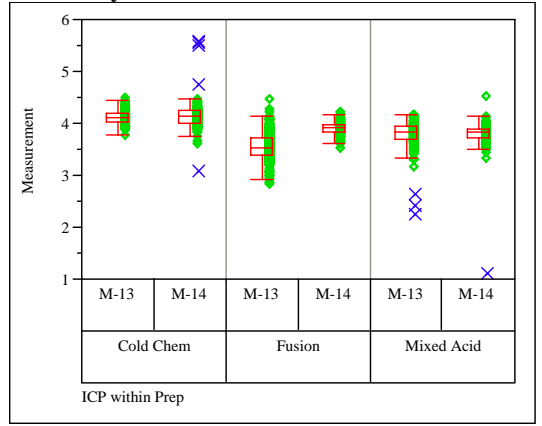

Standard/Process $=$ Process, Analyte $=\mathrm{Zr}$

Variability Chart for Measurement

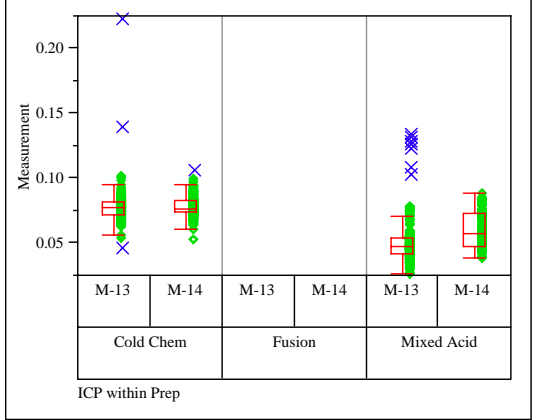


Exhibit A1. Standard and Process Measurements by Analyte for

Standard/Process $=$ blank, Analyte $=$ A

Variability Chart for Measurement

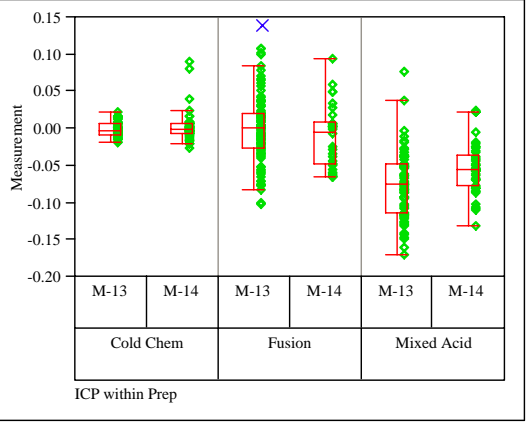

Standard/Process $=$ blank, Analyte $=\mathrm{Al} / \mathrm{Ca}$

Variability Chart for Measurement

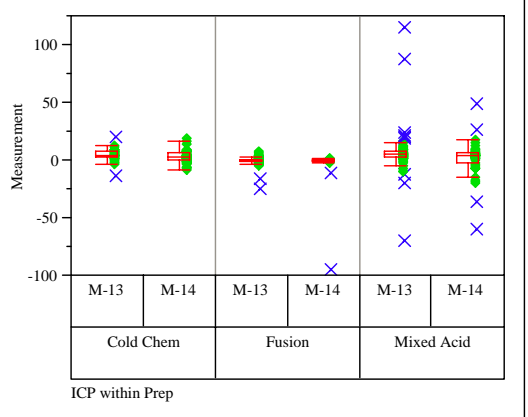

Standard/Process=blank, Analyte $=\mathrm{Al} / \mathrm{Mg}$

Variability Chart for Measurement

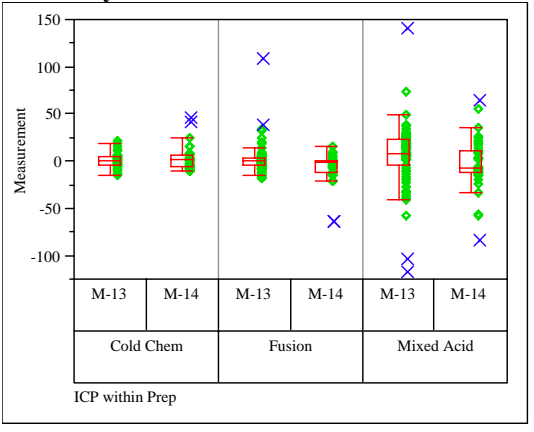

Standard $/$ Process $=$ blank, Analyte $=\mathbf{A l} / \mathbf{M n}$

Variability Chart for Measurement

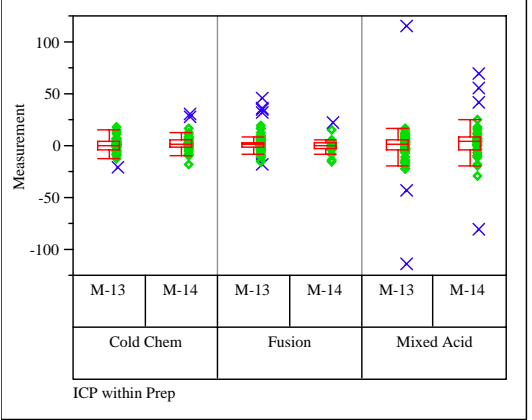

Standard/Process $=$ blank, Analyte $=\mathbf{B}$

Variability Chart for Measurement

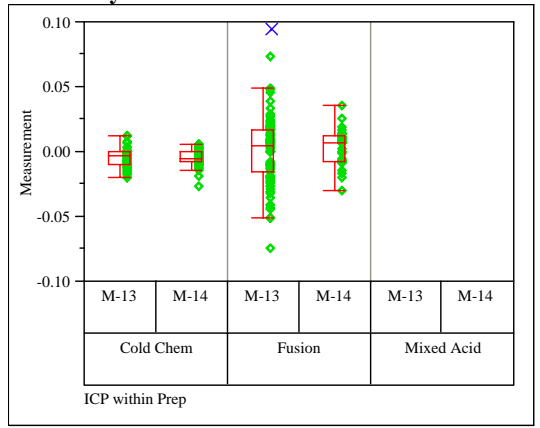

Standard/Process $=$ blank, Analyte $=\mathbf{B} / \mathbf{L i}$

Variability Chart for Measurement

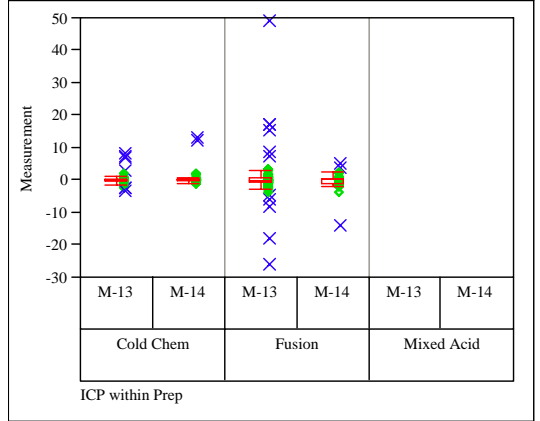

Standard/Process $=$ blank, Analyte $=$ Ca

Variability Chart for Measurement

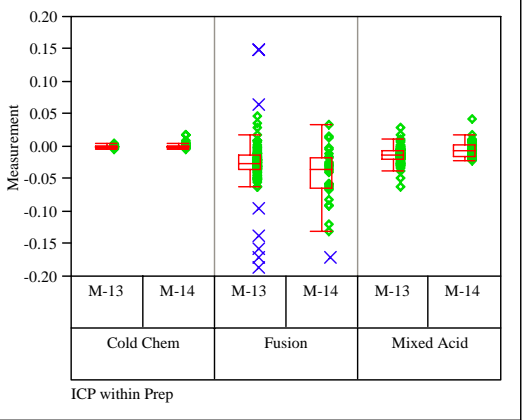

Standard/Process $=$ blank, Analyte $=\mathbf{C r}$

Variability Chart for Measurement

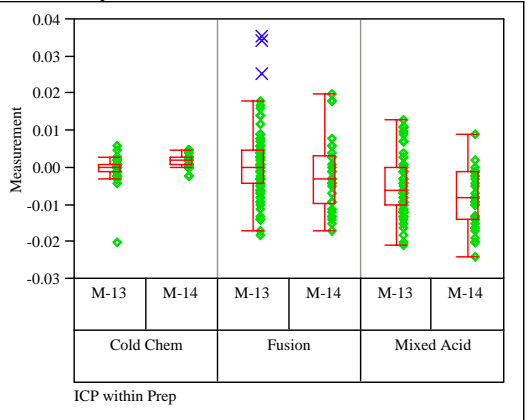

Standard/Process=blank, Analyte $=\mathrm{Cu}$

Variability Chart for Measurement

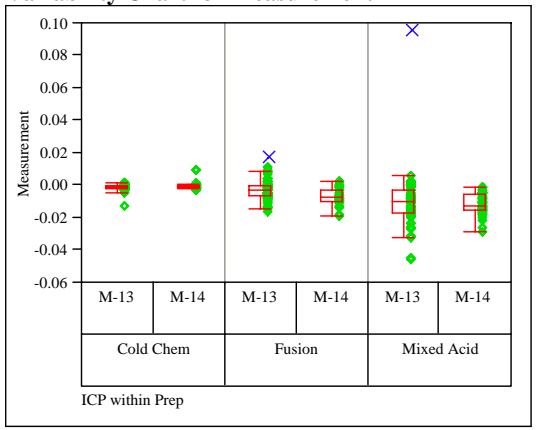

Standard/Process $=$ blank, Analyte $=$ Fe

Variability Chart for Measurement

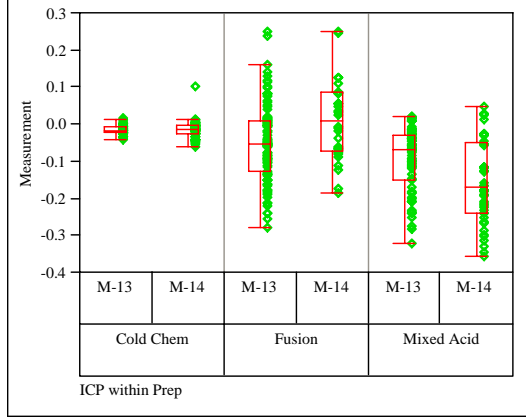

Standard/Process=blank, Analyte=Fe/Al

Variability Chart for Measurement

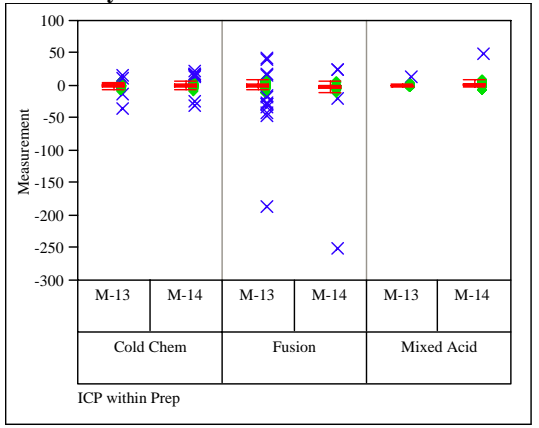

Standard/Process $=$ blank, Analyte $=\mathrm{Fe} / \mathrm{Ca}$

Variability Chart for Measurement

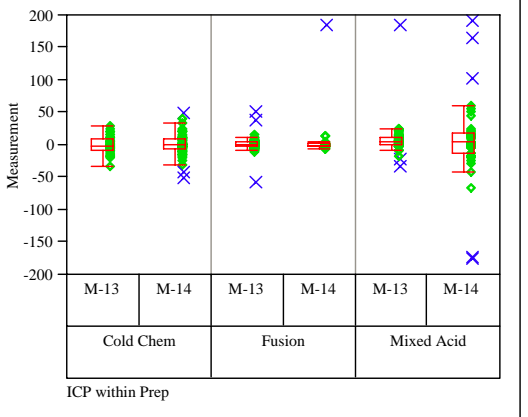


Exhibit A1. Standard and Process Measurements by Analyte for

Standard/Process=blank, Analyte $=\mathrm{Fe} / \mathrm{Li}$

Variability Chart for Measurement

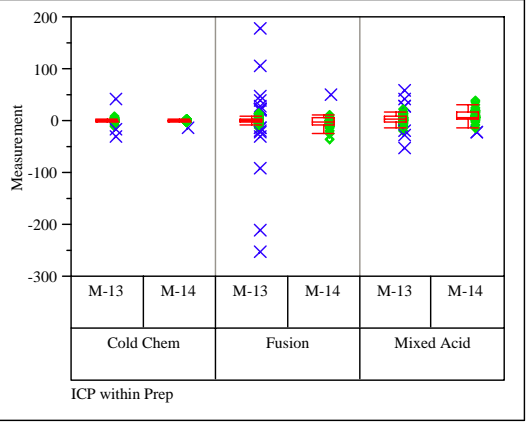

Standard/Process=blank, Analyte $=\mathbf{F e} / \mathbf{M g}$

Variability Chart for Measurement

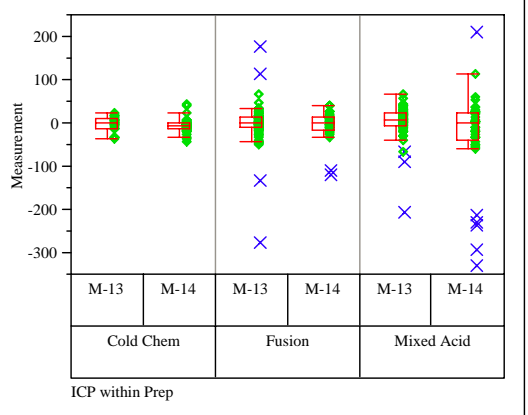

Standard/Process=blank, Analyte $=$ Fe/Mn

Variability Chart for Measurement

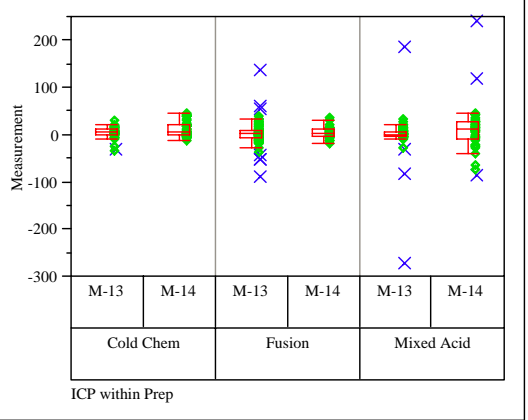

Standard $/$ Process $=$ blank, Analyte $=\mathbf{F e} / \mathrm{N}$

Variability Chart for Measurement

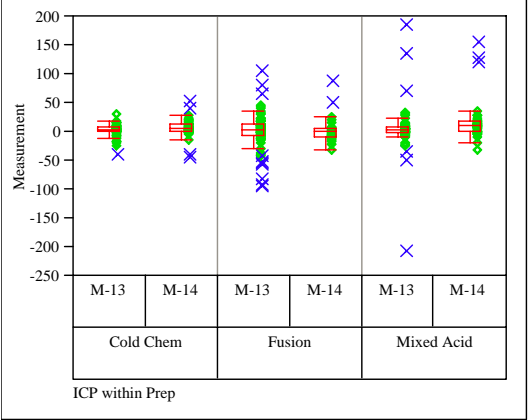

Standard/Process=blank, Analyte $=\mathrm{Fe} / \mathrm{U}$

Variability Chart for Measurement

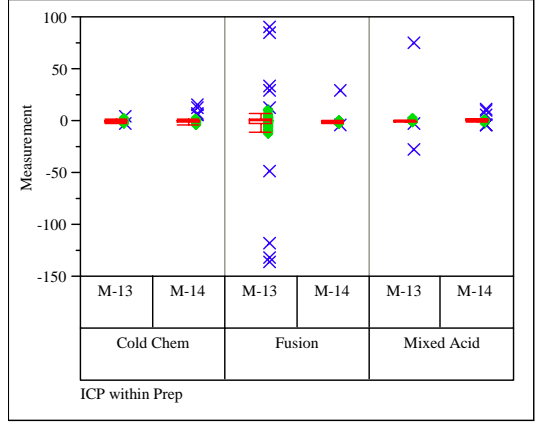

Standard/Process $=$ blank, Analyte $=K$

Variability Chart for Measurement

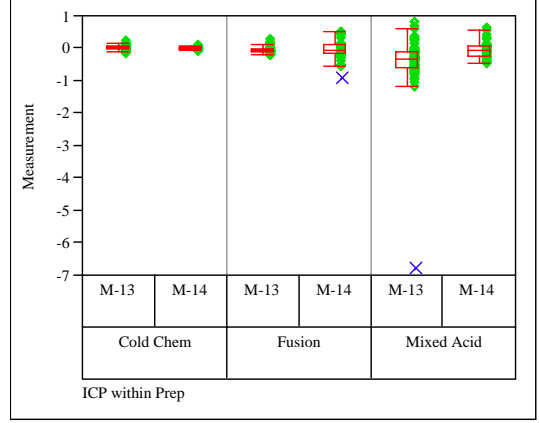

Standard/Process $=$ blank, Analyte $=\mathbf{L i}$

Variability Chart for Measurement

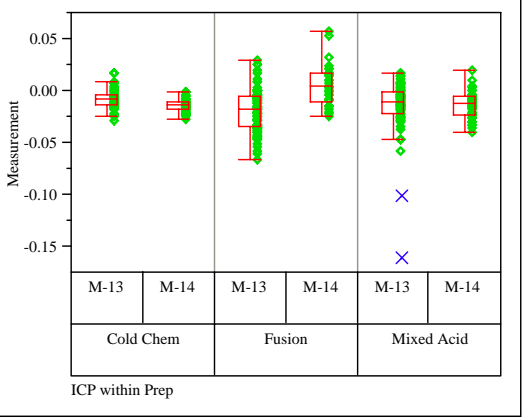

Standard/Process=blank, Analyte $=\mathbf{M g}$

Variability Chart for Measurement

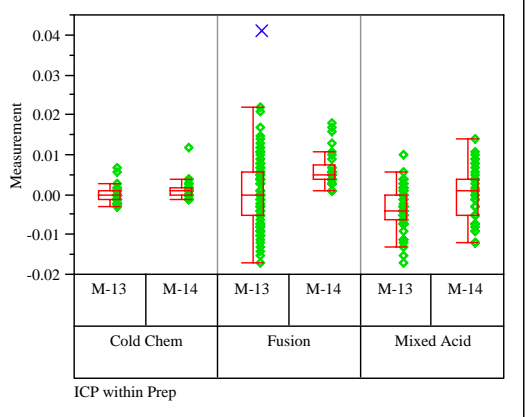

Standard/Process=blank, Analyte=Mn

Variability Chart for Measurement

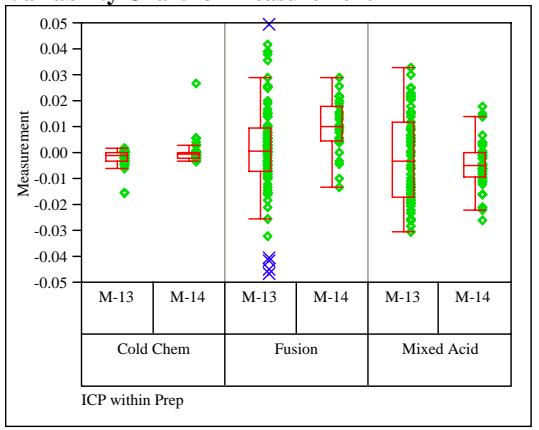

Standard/Process=blank, Analyte $=\mathbf{M n} / \mathbf{M g}$

Variability Chart for Measurement

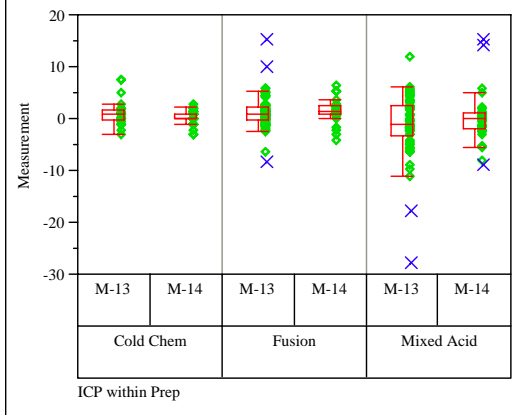

Standard/Process $=$ blank, Analyte $=\mathrm{Na}$

Variability Chart for Measurement

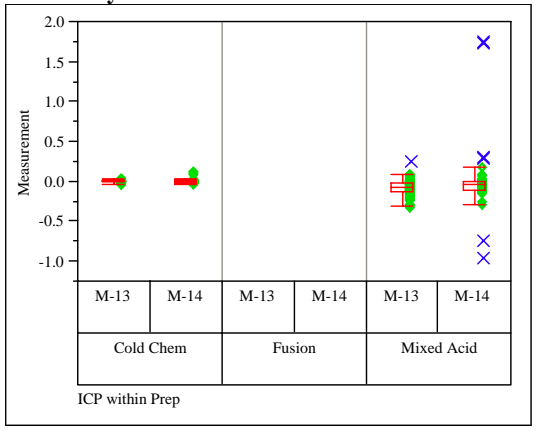

Standard/Process=blank, Analyte $=\mathbf{N}$

Variability Chart for Measurement

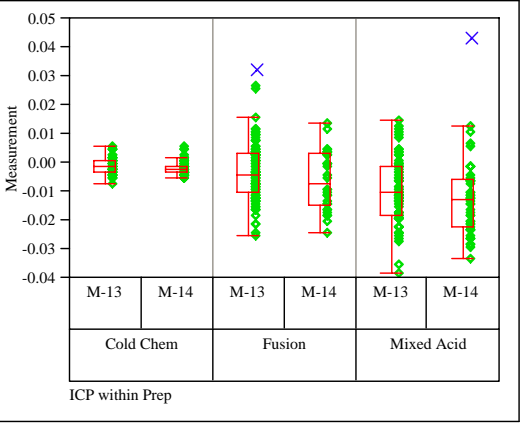


Exhibit A1. Standard and Process Measurements by Analyte for

Standard/Process $=$ blank, Analyte $=\mathrm{Si}$

Variability Chart for Measurement

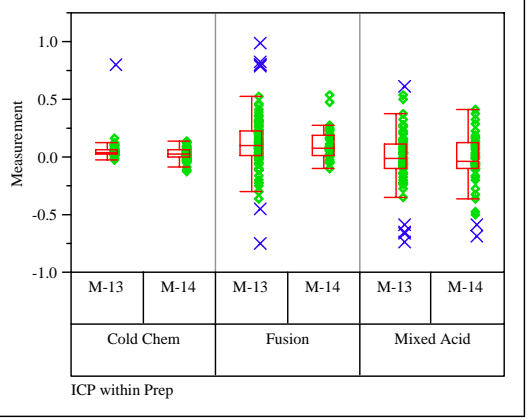

Standard/Process=blank, Analyte=Sum of Oxides

Variability Chart for Measurement

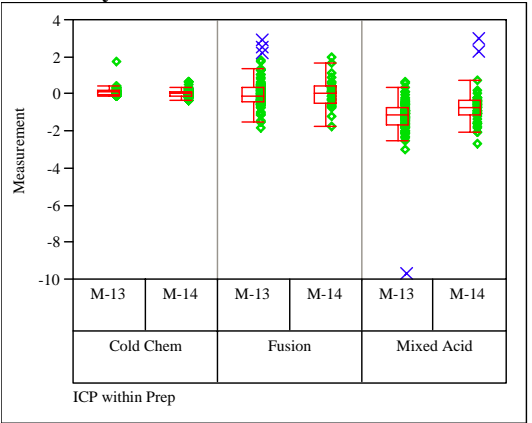

Standard/Process=blank, Analyte $=\mathbf{T i}$

Variability Chart for Measurement

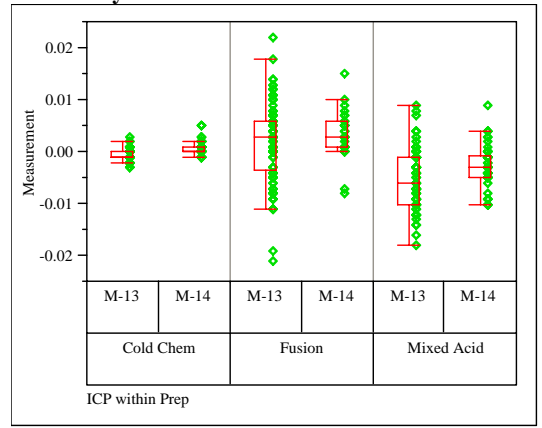

Standard/Process=blank, Analyte $=\mathbf{U}$ Variability Chart for Measurement

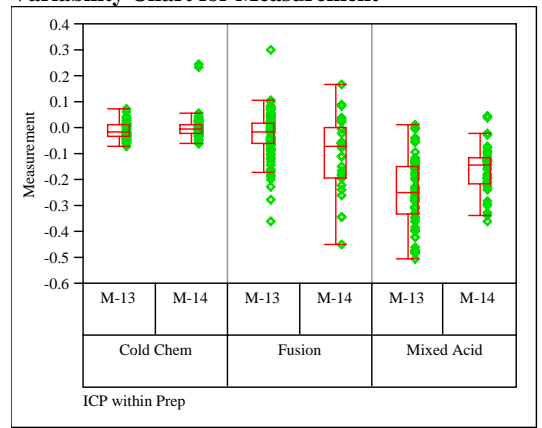

Standard/Process=blank, Analyte=U/Ca

Variability Chart for Measurement

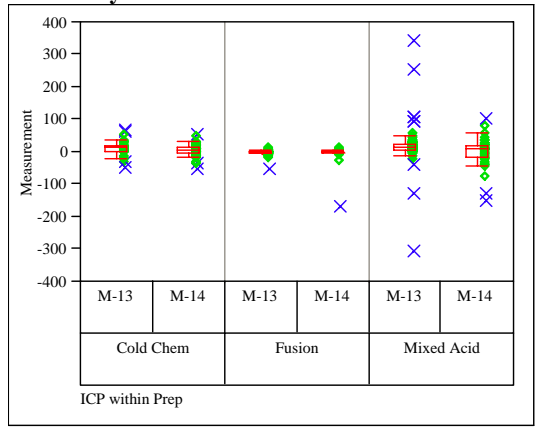

Standard/Process $=$ blank, Analyte $=\mathbf{Z r}$

Variability Chart for Measurement

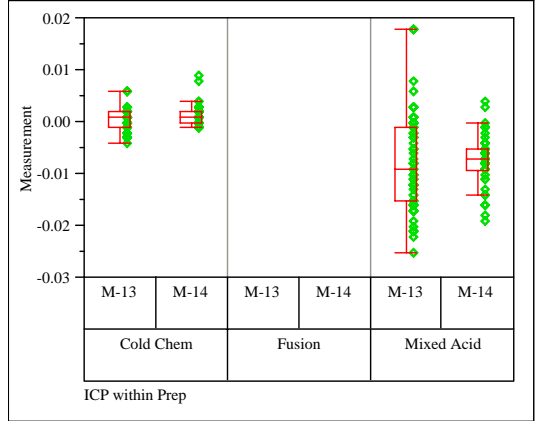


WSRC-STI-2006-00068

Revision 0

Exhibit A2. Measurement Data by Batch by ICP for Prep Method, Sample Type, and Analyte Prep=Cold Chem, Sample Type=ARG-1, Analyte=Al Variability Chart for Measurement

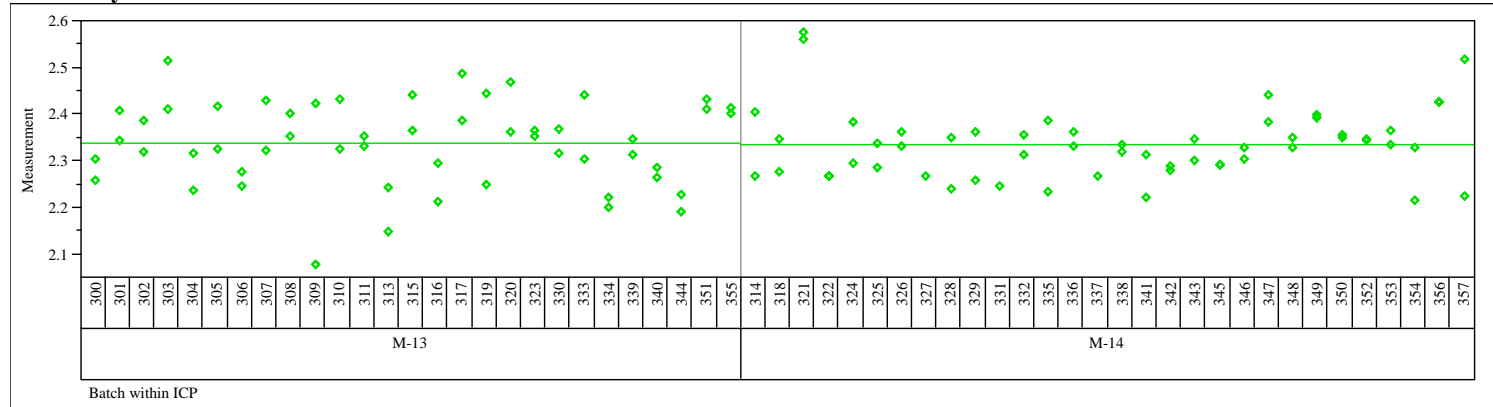

Prep $=$ Cold Chem, Sample Type $=$ ARG-1, Analyte $=$ Al $/$ Ca

Variability Chart for Measurement

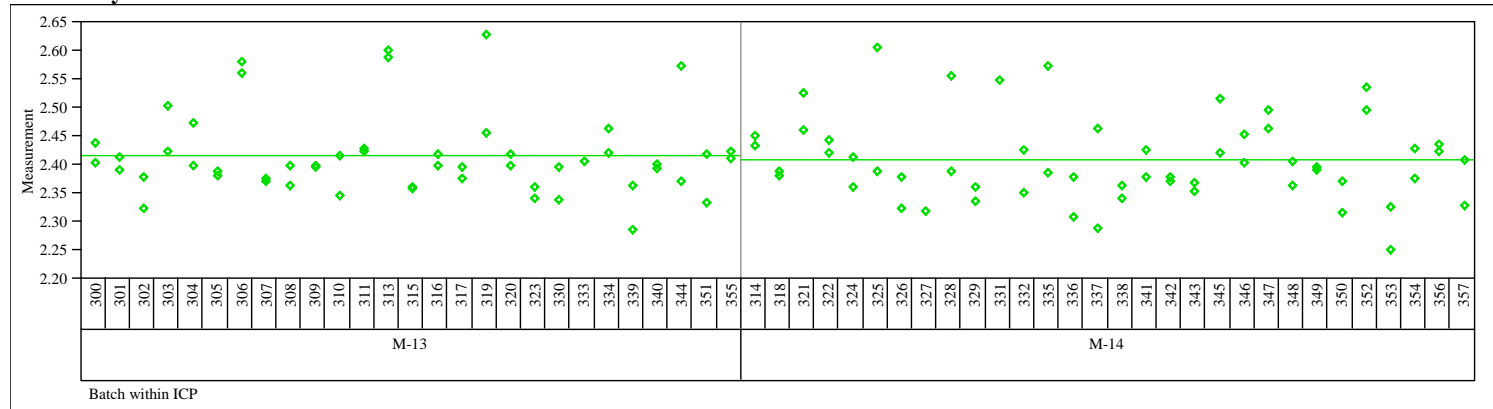

Prep=Cold Chem, Sample Type=ARG-1, Analyte=Al/Mg

Variability Chart for Measurement

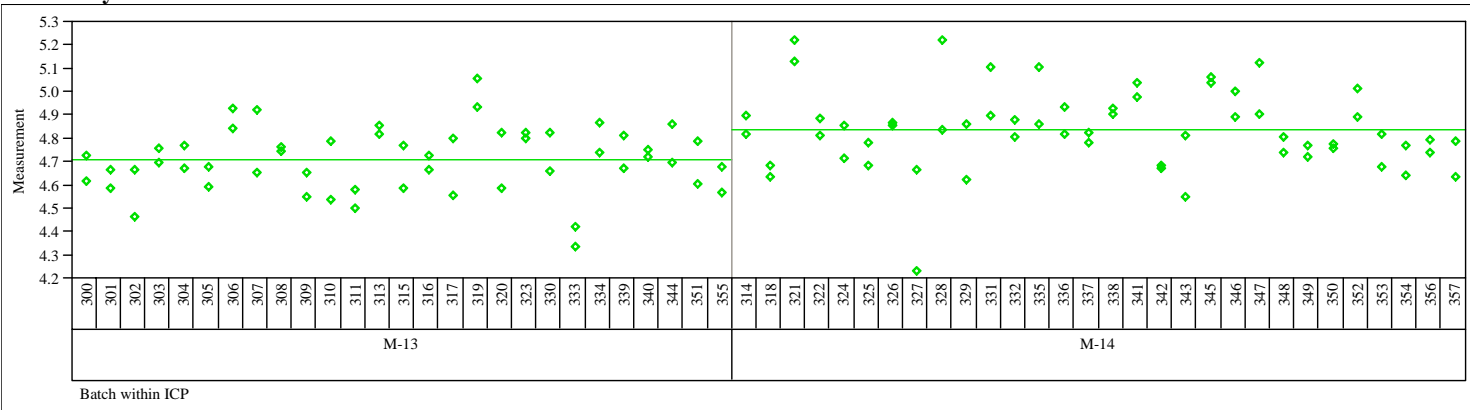

Prep $=$ Cold Chem, Sample Type $=$ ARG-1, Analyte $=$ Al/Mn

Variability Chart for Measurement

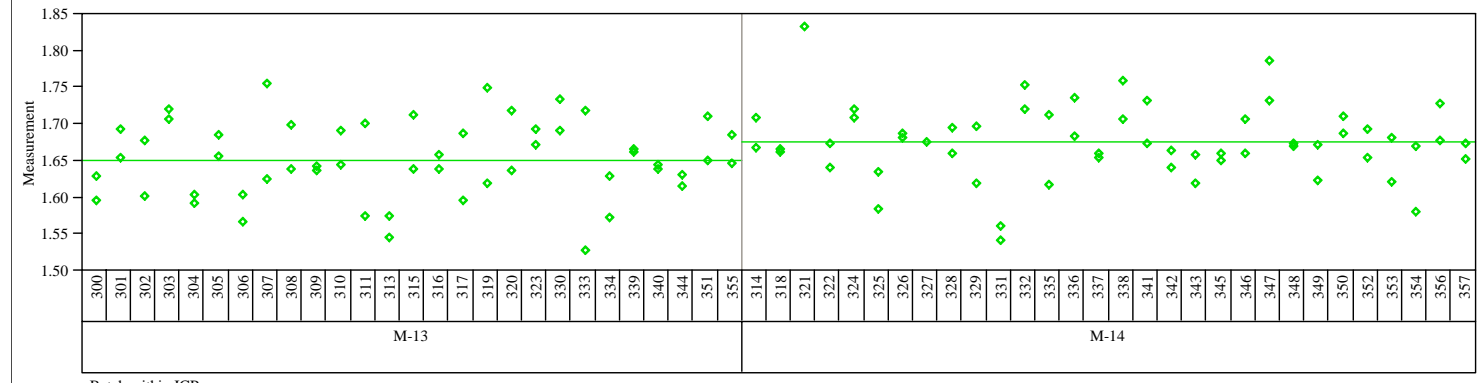


WSRC-STI-2006-00068

Revision 0

Exhibit A2. Measurement Data by Batch by ICP for Prep Method, Sample Type, and Analyte

Prep=Cold Chem, Sample Type=ARG-1, Analyte $=$ =B

(continued)

Variability Chart for Measurement

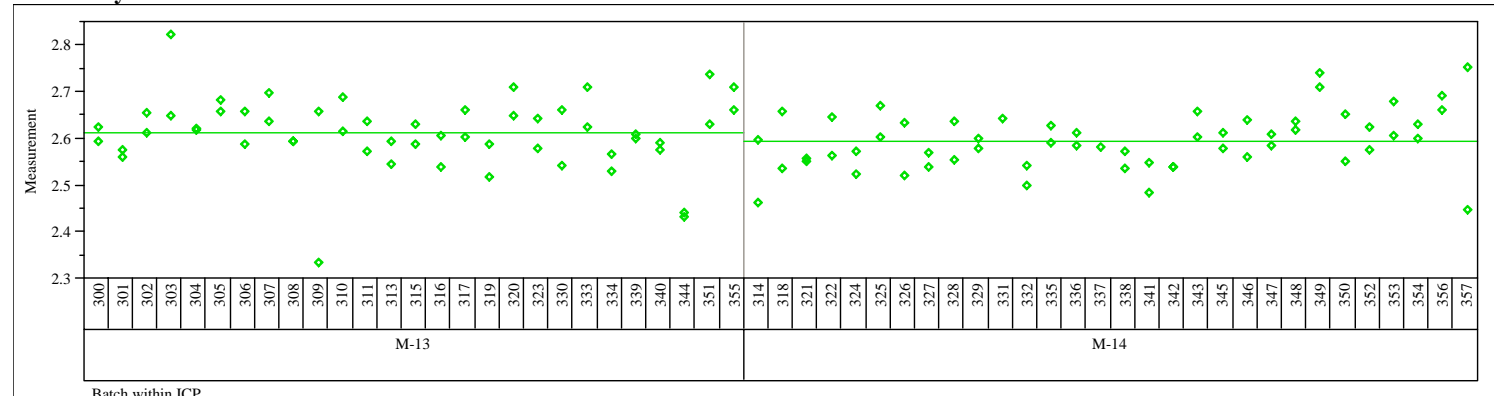

Prep $=$ Cold Chem, Sample Type $=$ ARG-1, Analyte $=\mathrm{B} / \mathrm{Li}$

Variability Chart for Measurement

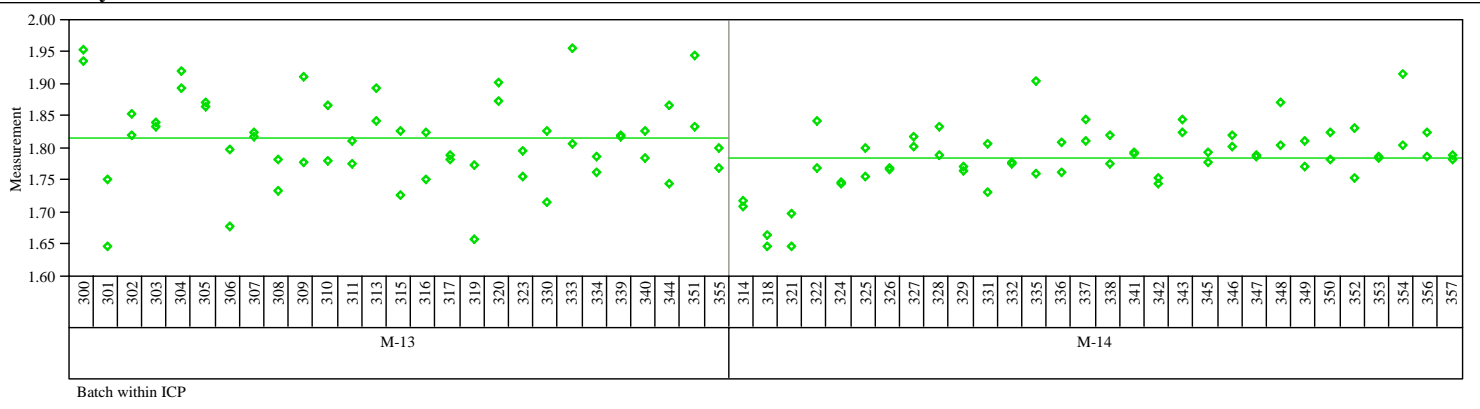

Prep=Cold Chem, Sample Type $=$ ARG-1, Analyte $=$ Ca

Variability Chart for Measurement

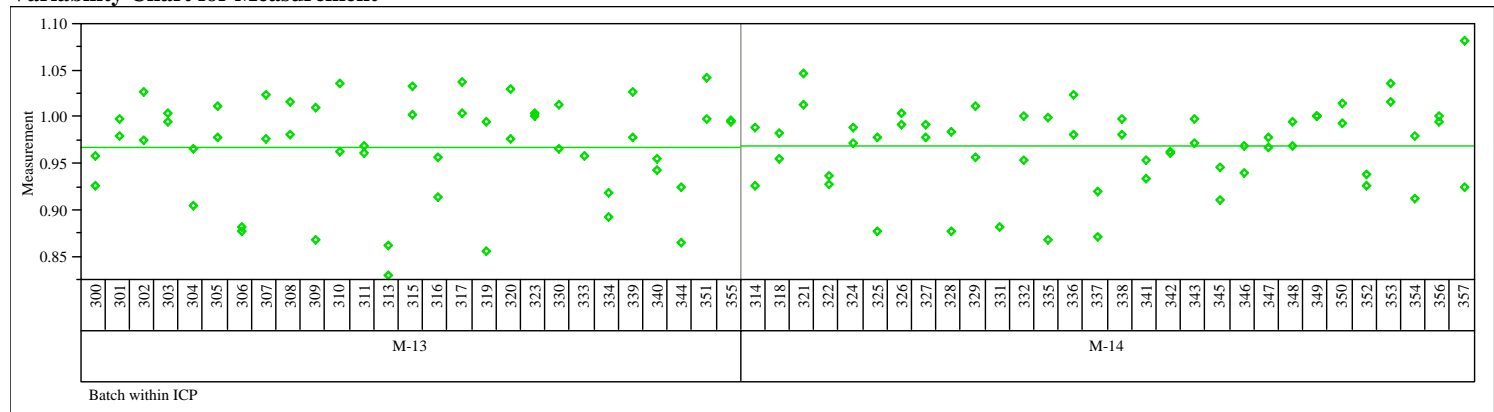

Prep $=$ Cold Chem, Sample Type $=$ ARG-1, Analyte $=$ Cr

Variability Chart for Measurement

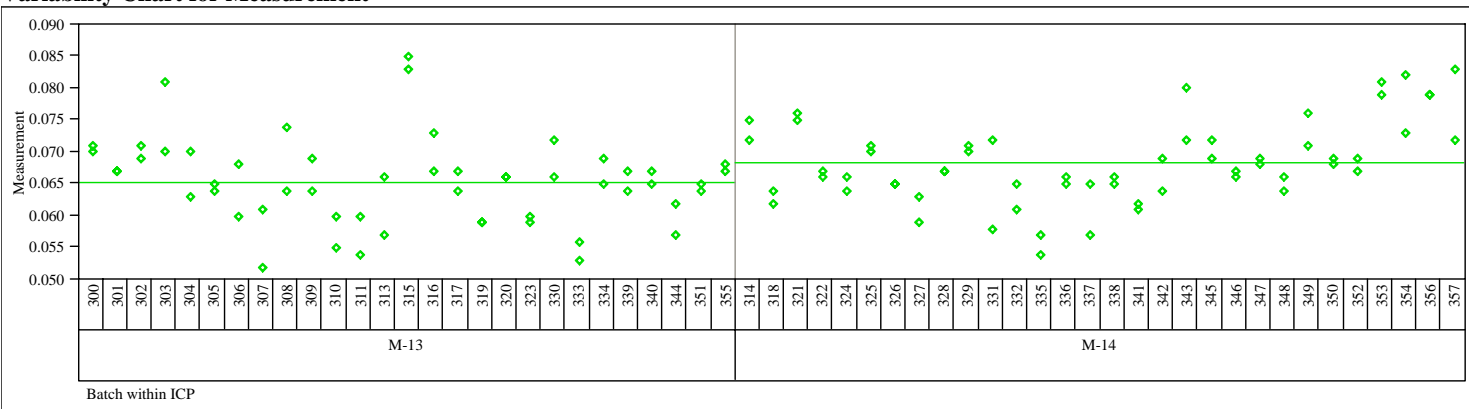


WSRC-STI-2006-00068

Revision 0

Exhibit A2. Measurement Data by Batch by ICP for Prep Method, Sample Type, and Analyte

Prep $=$ Cold Chem, Sample Type $=$ ARG -1 , Analyte $=$ Cu

(continued)

Variability Chart for Measuremen

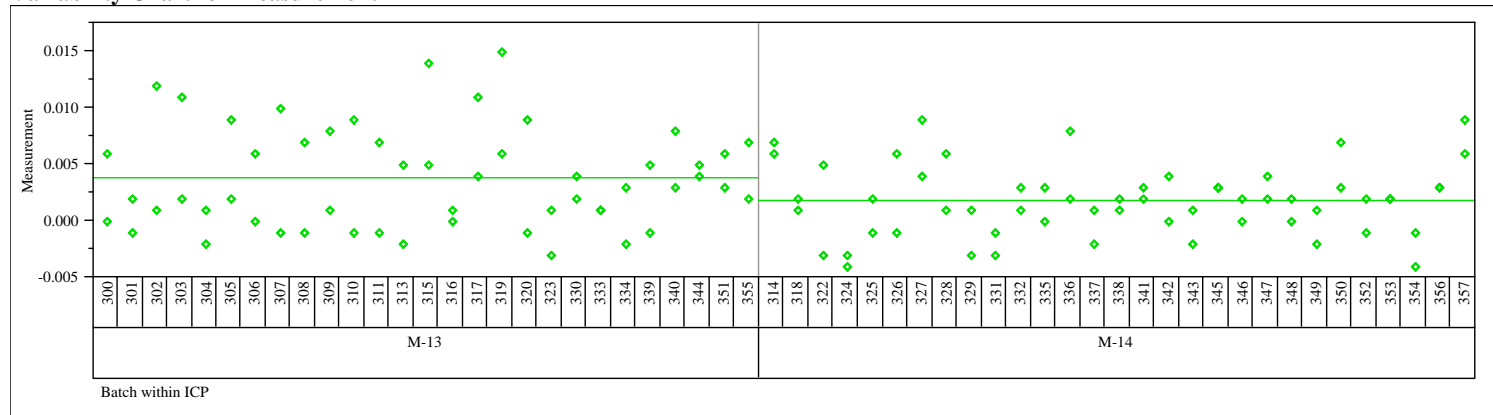

Prep $=$ Cold Chem, Sample Type $=$ ARG -1 , Analyte $=F e$

Variability Chart for Measurement

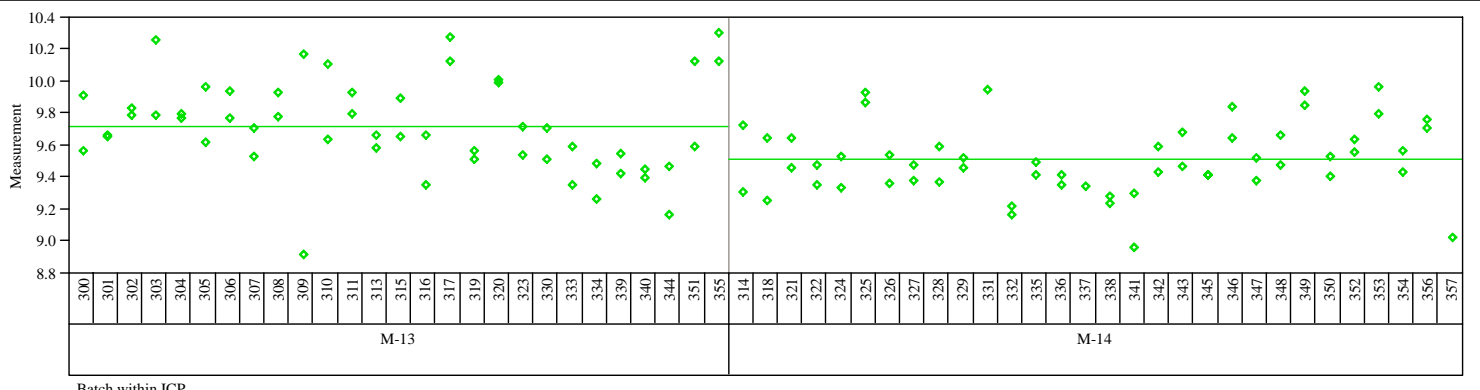

Prep $=$ Cold Chem, Sample Type $=$ ARG-1, Analyte $=$ Fe/Al

Variability Chart for Measurement

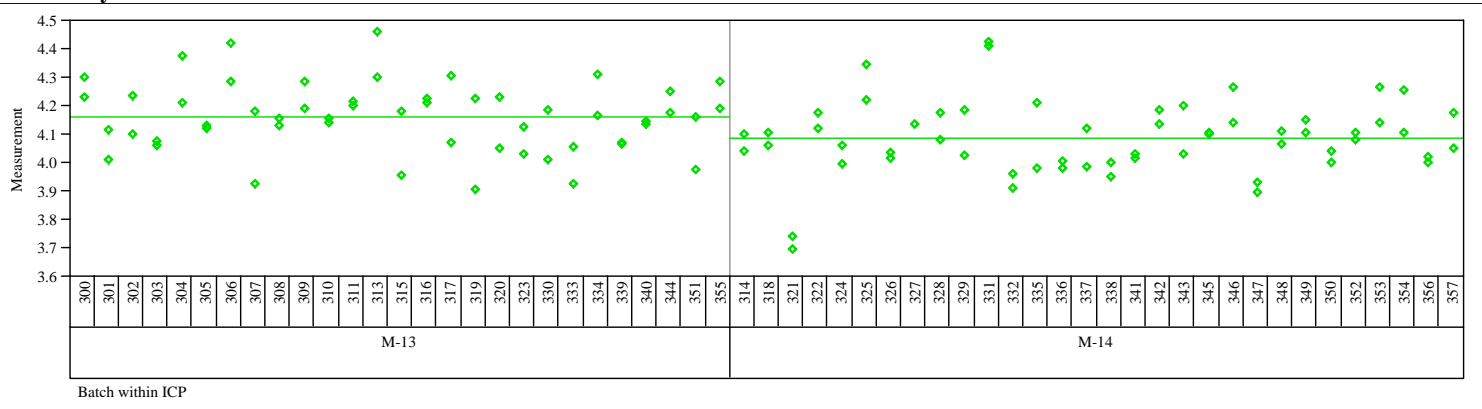

Prep $=$ Cold Chem, Sample Type=ARG-1, Analyte $=$ Fe $/$ Ca

Variability Chart for Measurement

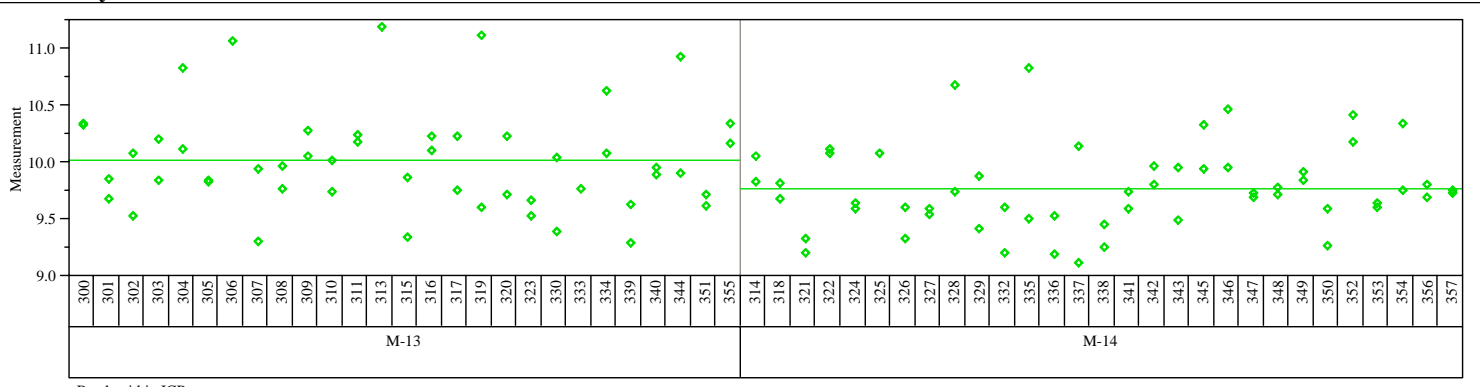


WSRC-STI-2006-00068

Revision 0

Exhibit A2. Measurement Data by Batch by ICP for Prep Method, Sample Type, and Analyte

Prep $=$ Cold Chem, Sample Type $=$ ARG -1 , Analyte $=\mathrm{Fe} / \mathrm{Li}$

(continued)

Variability Chart for Measurement

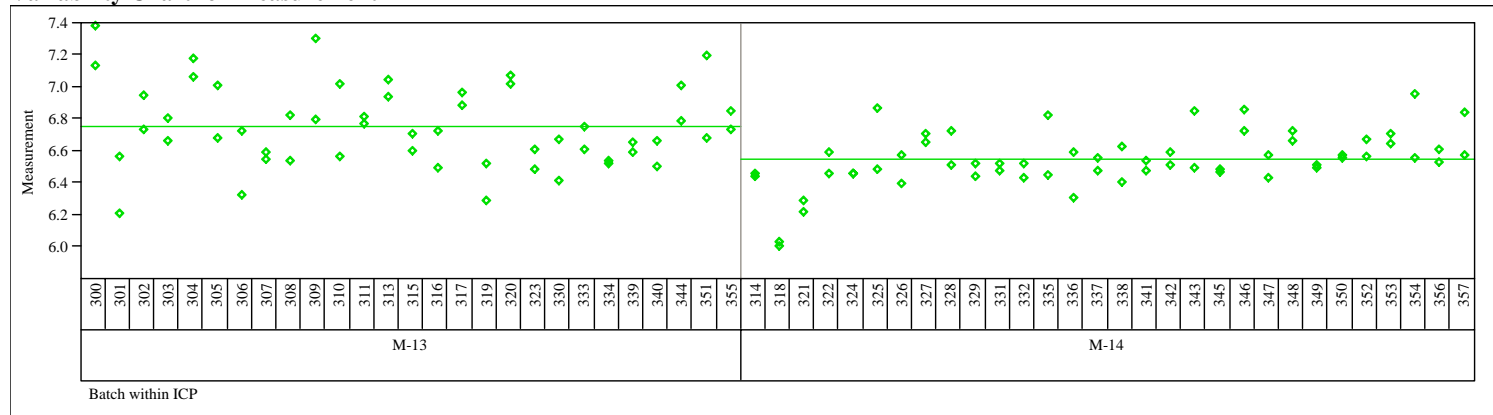

Prep=Cold Chem, Sample Type $=$ ARG-1, Analyte $=$ Fe $/ M g$

Variability Chart for Measurement

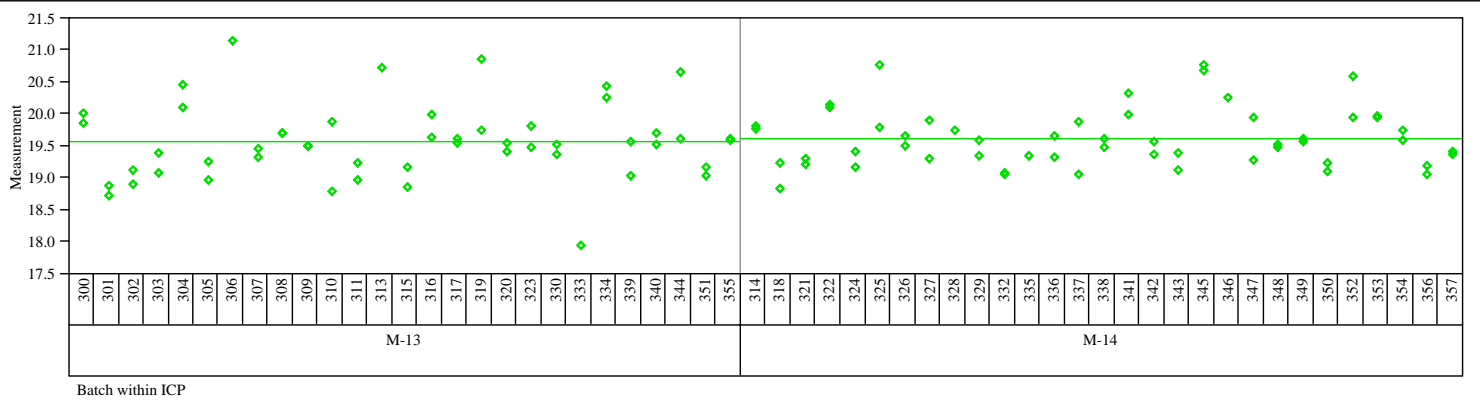

Prep=Cold Chem, Sample Type=ARG-1, Analyte $=$ Fe/Mn

Variability Chart for Measurement

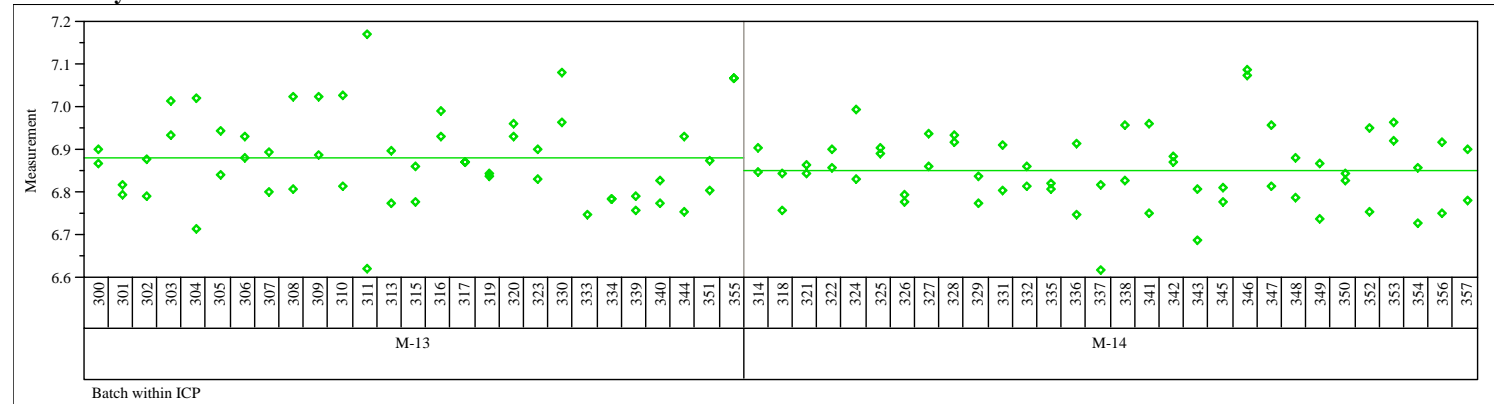

Prep $=$ Cold Chem, Sample Type $=$ ARG -1 , Analyte $=$ Fe $/$ Ni

Variability Chart for Measurement

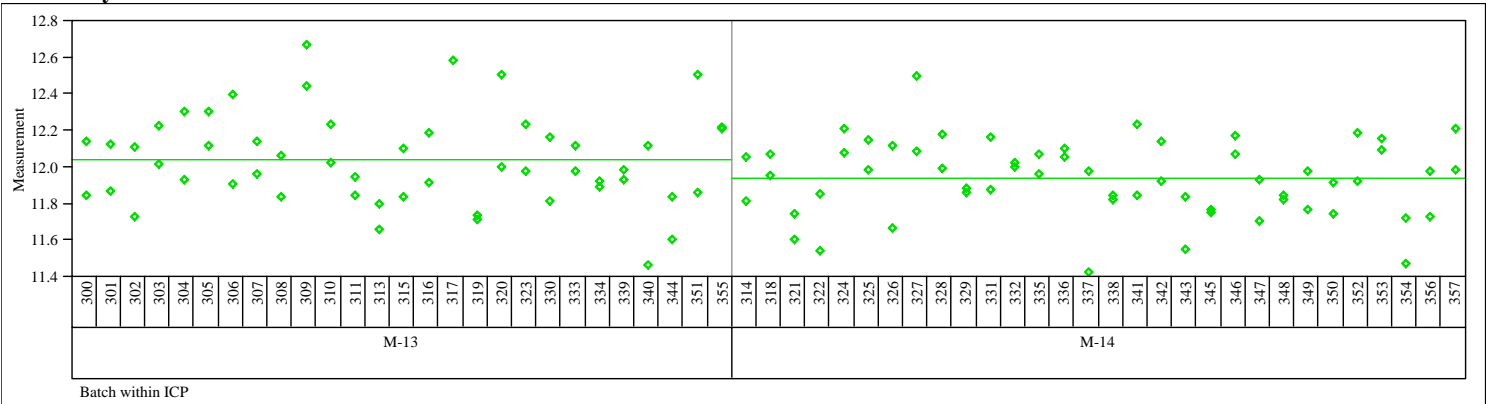


WSRC-STI-2006-00068

Revision 0

Exhibit A2. Measurement Data by Batch by ICP for Prep Method, Sample Type, and Analyte

Prep=Cold Chem, Sample Type=ARG-1, Analyte=Fe/U

(continued)

Variability Chart for Measurement

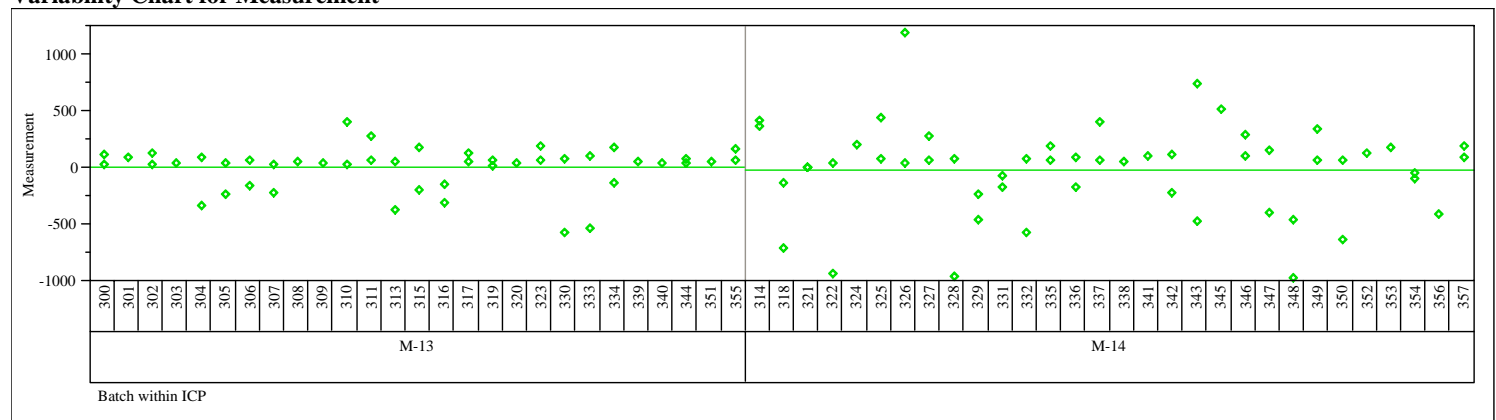

Prep $=$ Cold Chem, Sample Type $=$ ARG-1, Analyte $=K$

Variability Chart for Measurement

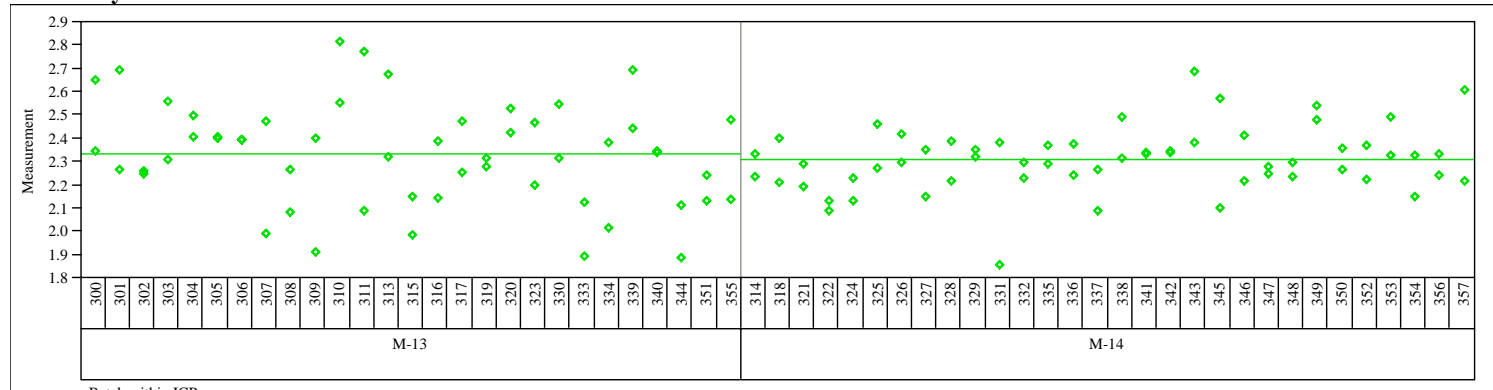

Batch within ICP

Prep $=$ Cold Chem, Sample Type $=$ ARG-1, Analyte $=$ Li

Variability Chart for Measurement

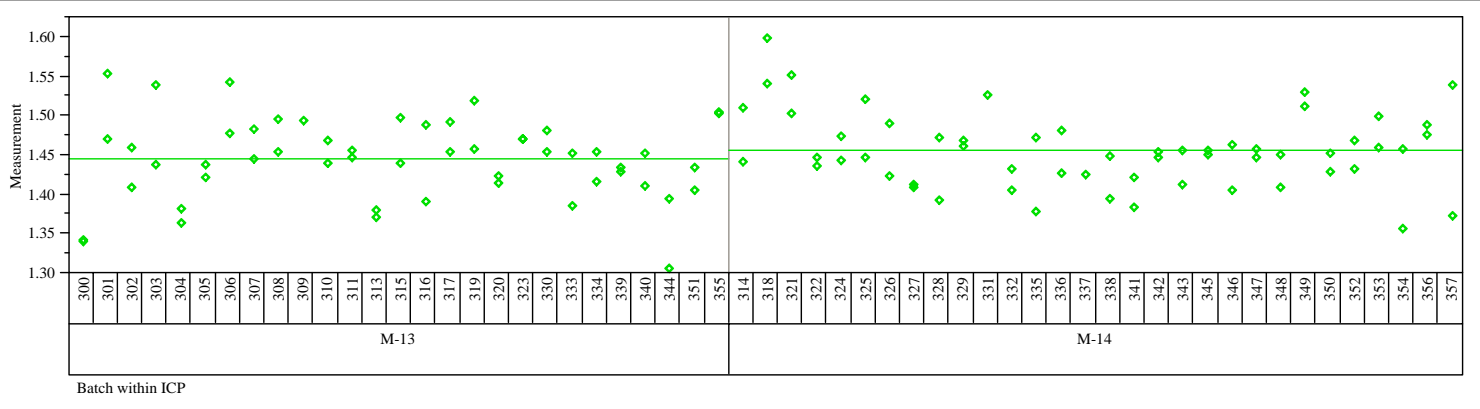

Prep $=$ Cold Chem, Sample Type=ARG-1, Analyte $=$ Mg

Variability Chart for Measurement

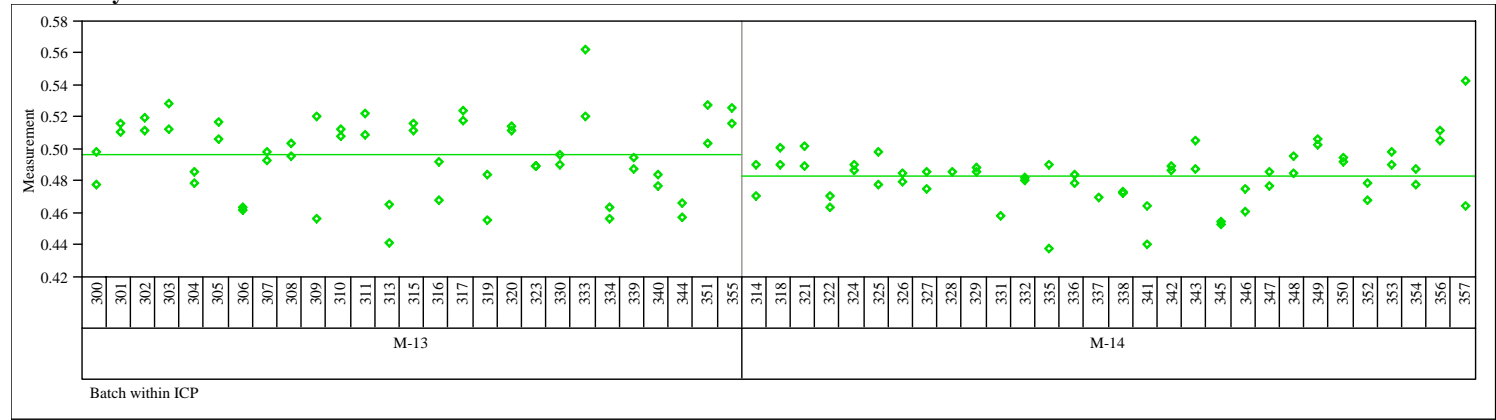


WSRC-STI-2006-00068

Revision 0

Exhibit A2. Measurement Data by Batch by ICP for Prep Method, Sample Type, and Analyte

Prep $=$ Cold Chem, Sample Type $=$ ARG -1 , Analyte $=$ Mn

(continued)

Variability Chart for Measurement

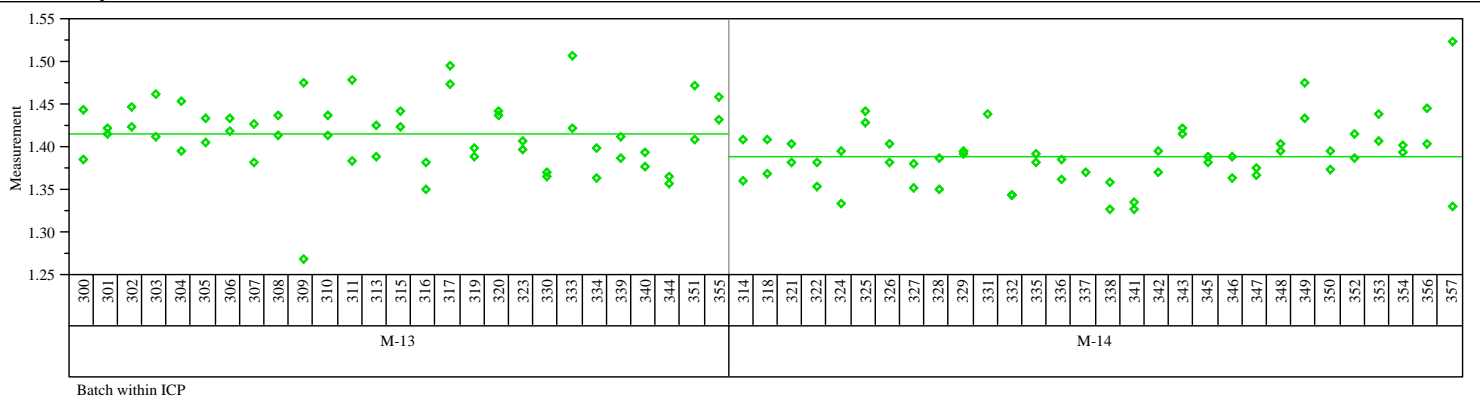

Prep=Cold Chem, Sample Type=ARG-1, Analyte $=$ Mn $/ \mathbf{M g}$

Variability Chart for Measurement

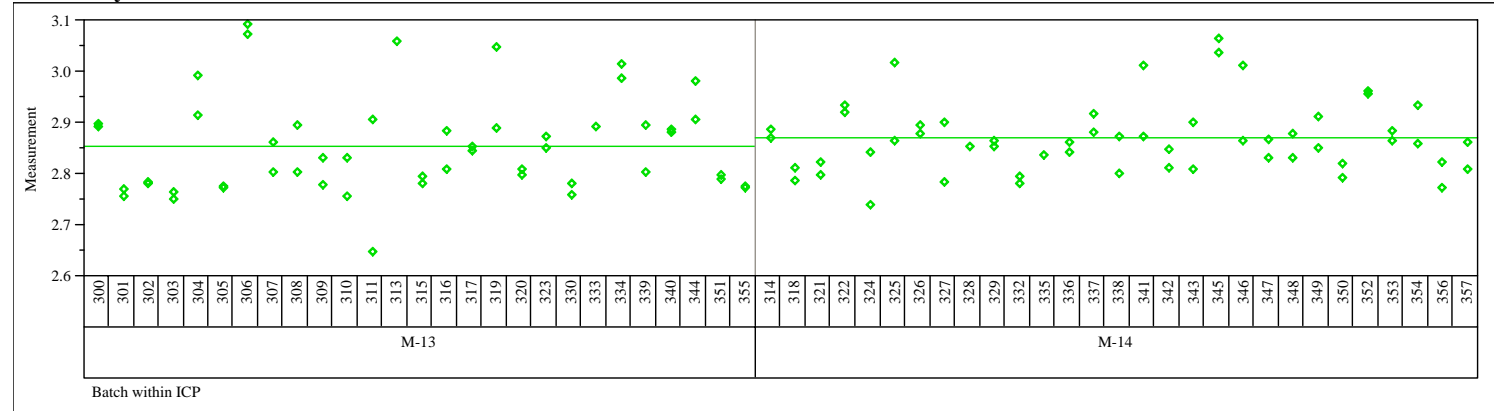

Prep $=$ Cold Chem, Sample Type $=$ ARG-1, Analyte $=$ Na

Variability Chart for Measurement

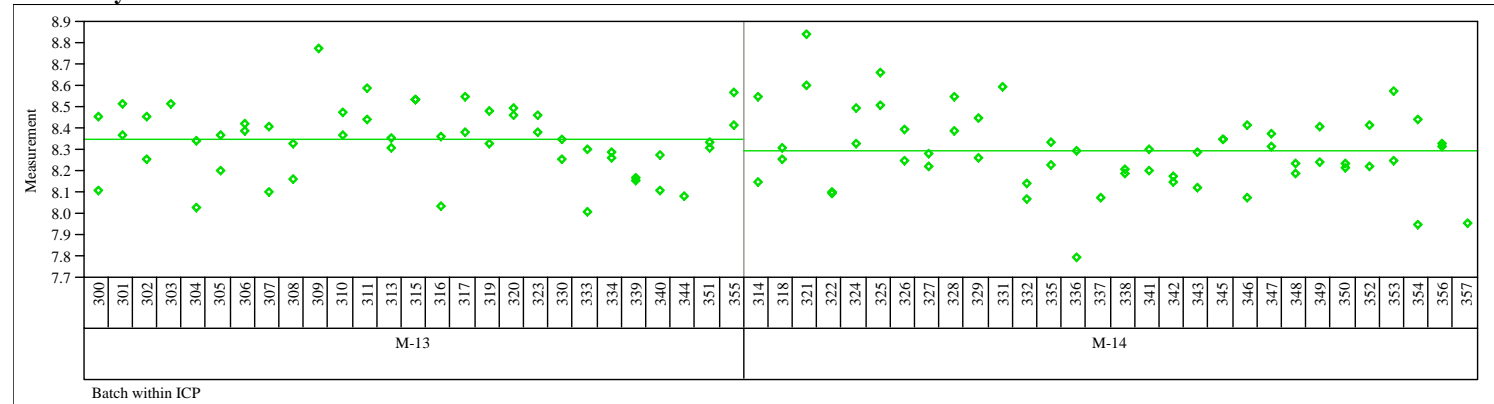

Prep $=$ Cold Chem, Sample Type $=$ ARG -1 , Analyte $=\mathrm{Ni}$

Variability Chart for Measurement

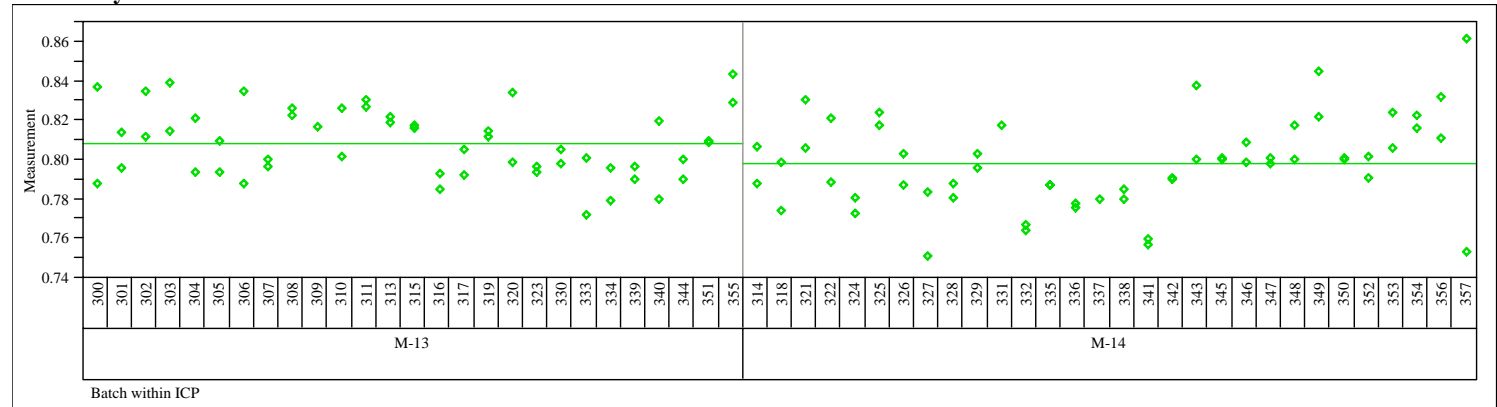


WSRC-STI-2006-00068

Revision 0

Exhibit A2. Measurement Data by Batch by ICP for Prep Method, Sample Type, and Analyte

Prep=Cold Chem, Sample Type=ARG-1, Analyte $=$ Si

(continued)

Variability Chart for Measurement

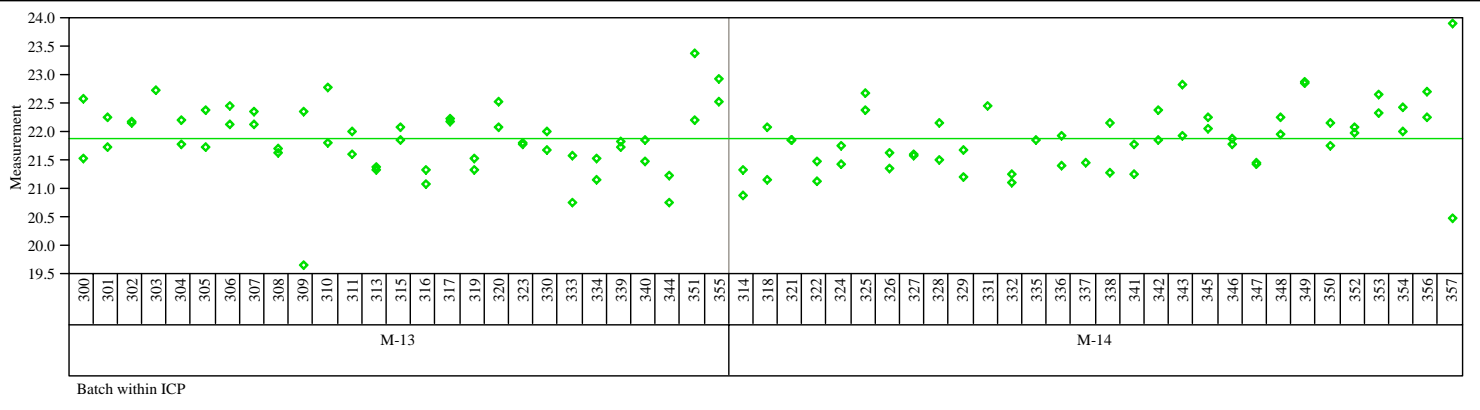

Prep=Cold Chem, Sample Type=ARG-1, Analyte $=$ Sum of Oxides

Variability Chart for Measurement

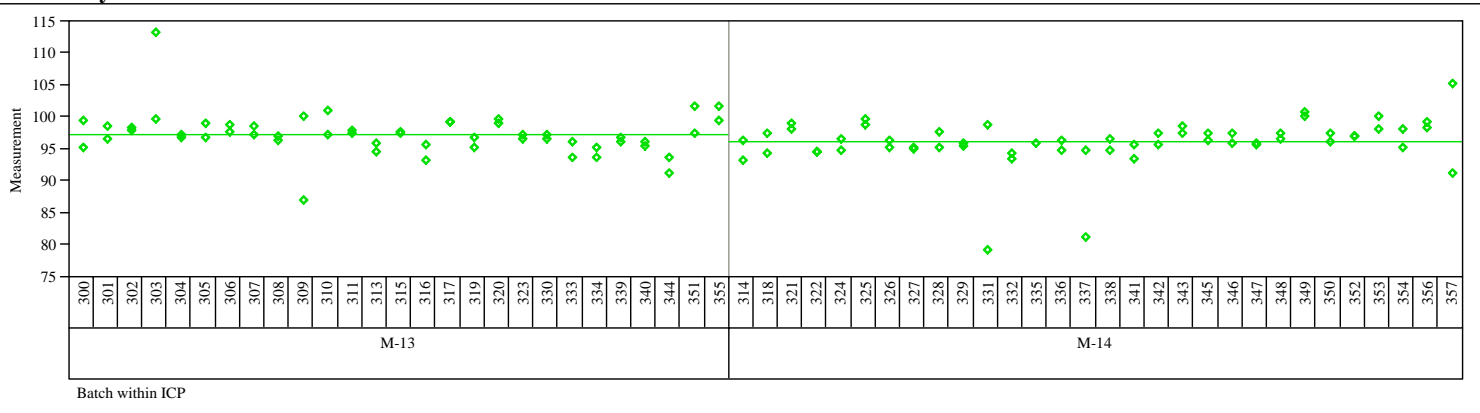

Prep $=$ Cold Chem, Sample Type $=$ ARG-1, Analyte $=$ Ti

Variability Chart for Measurement

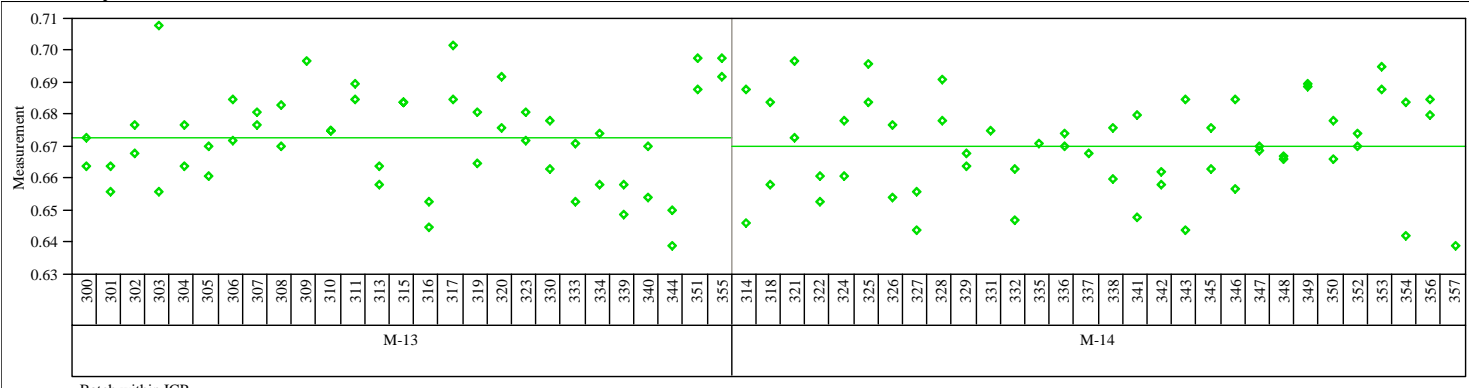

Prep $=$ Cold Chem, Sample Type $=$ ARG -1 , Analyte $=\mathbf{U}$

Variability Chart for Measurement

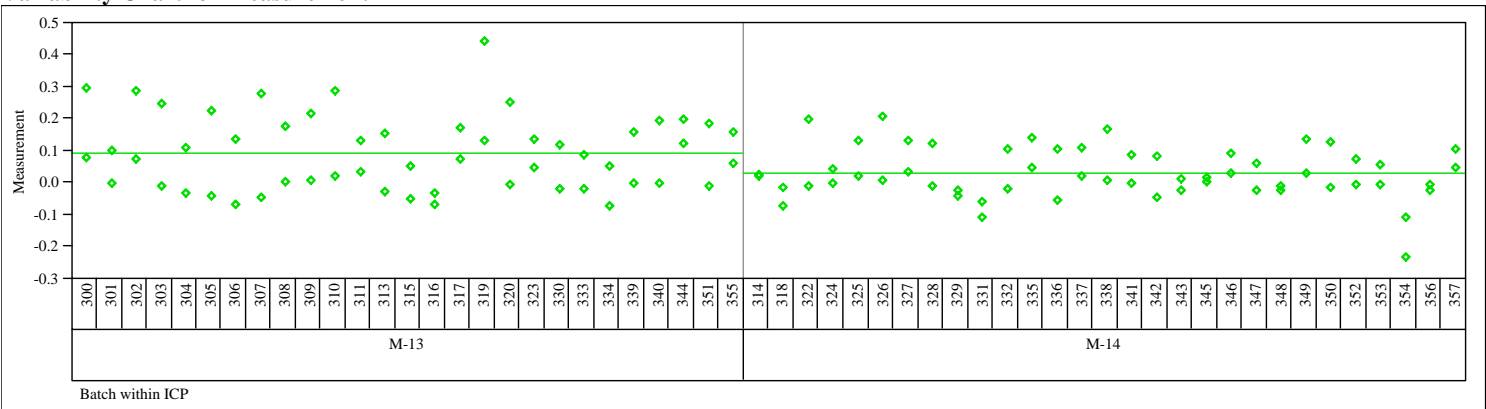


WSRC-STI-2006-00068

Revision 0

Exhibit A2. Measurement Data by Batch by ICP for Prep Method, Sample Type, and Analyte

Prep $=$ Cold Chem, Sample Type $=$ ARG -1 , Analyte $=U / C$

(continued)

Variability Chart for Measurement

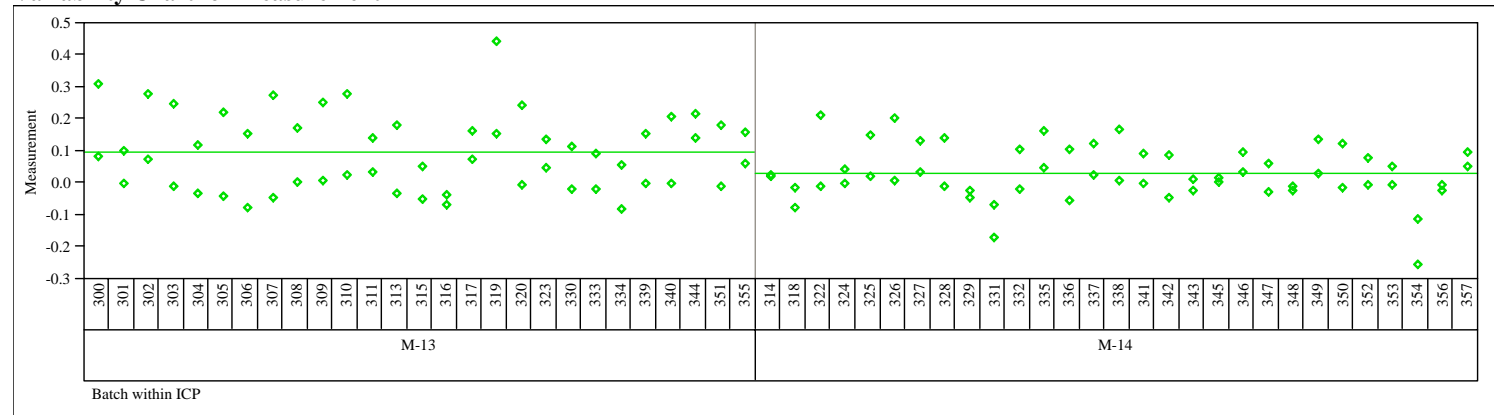

Prep=Cold Chem, Sample Type $=$ ARG-1, Analyte $=\mathrm{Zr}$

Variability Chart for Measurement

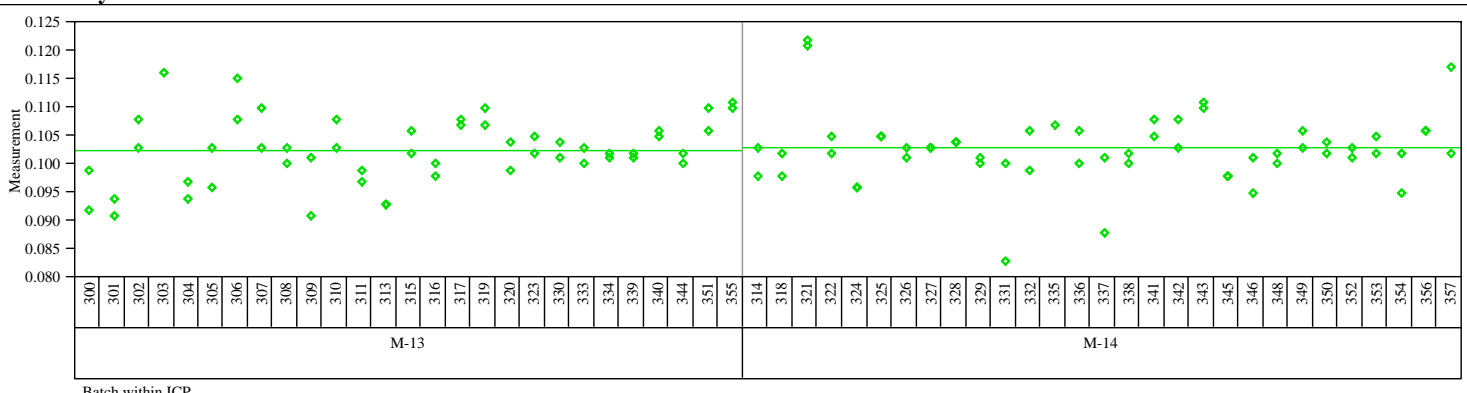

Prep $=$ Cold Chem, Sample Type $=$ SRAT, Analyte $=$ Al

Variability Chart for Measurement

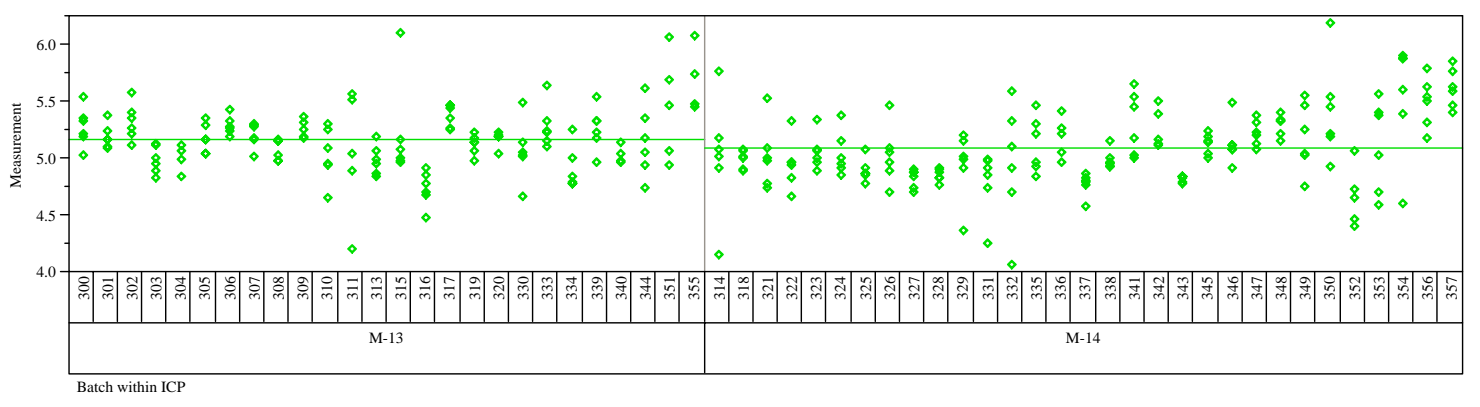

Prep $=$ Cold Chem, Sample Type $=$ SRAT, Analyte $=$ Al $/$ Ca

Variability Chart for Measurement

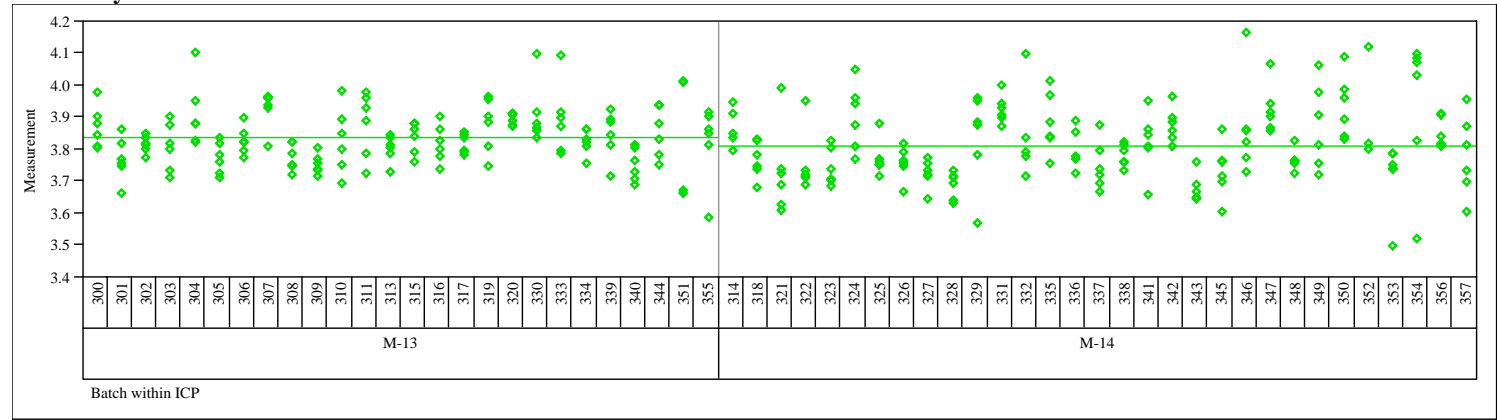


WSRC-STI-2006-00068

Revision 0

Exhibit A2. Measurement Data by Batch by ICP for Prep Method, Sample Type, and Analyte

Prep $=$ Cold Chem, Sample Type $=$ SRAT, Analyte $=A l / M g$

(continued)

Variability Chart for Measurement

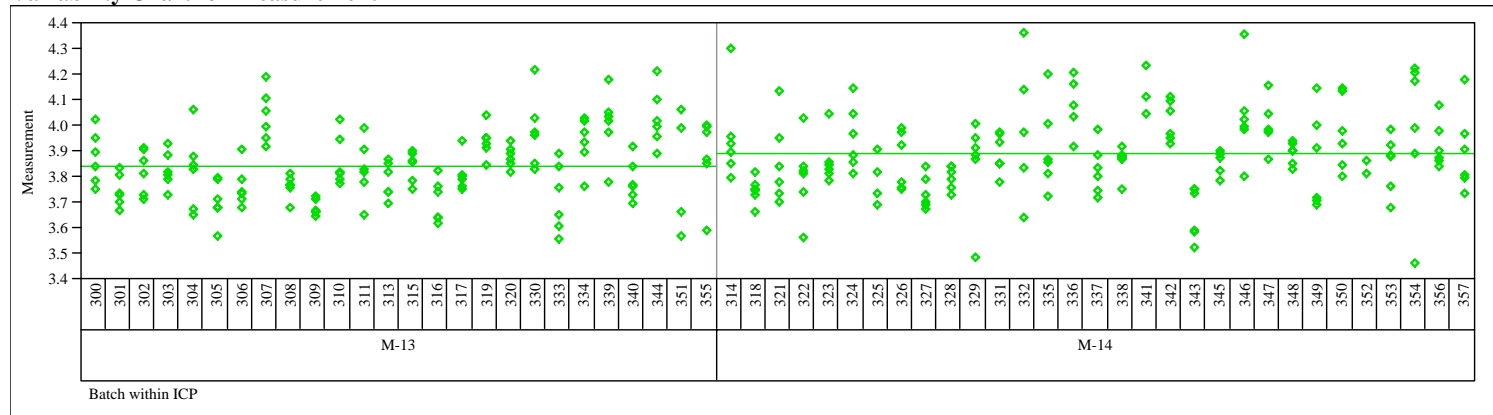

Prep=Cold Chem, Sample Type $=$ SRAT, Analyte $=A \mathrm{I} / \mathrm{Mn}$

Variability Chart for Measurement

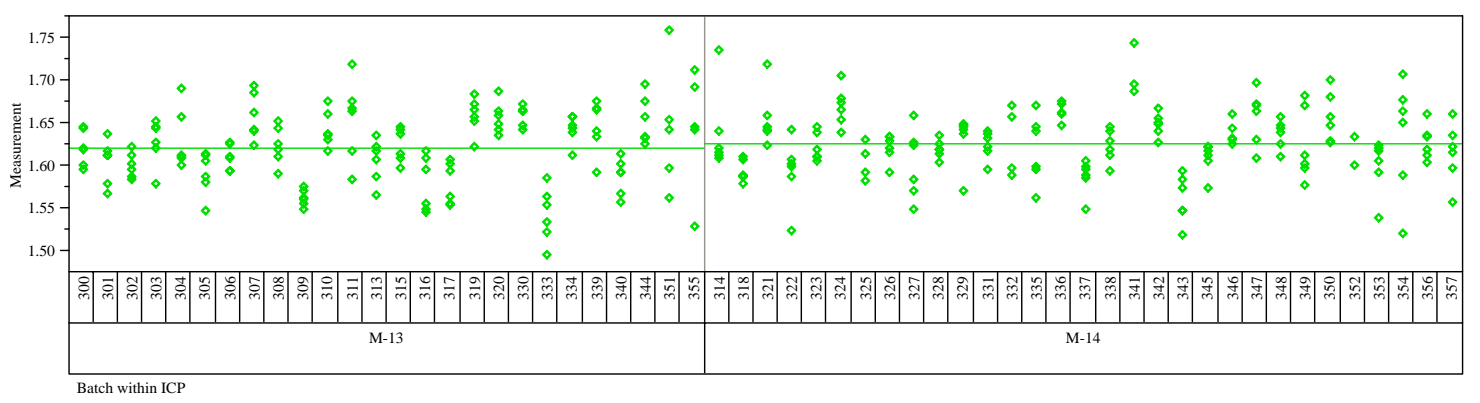

Prep $=$ Cold Chem, Sample Type $=$ SRAT, Analyte $=B$

Variability Chart for Measurement

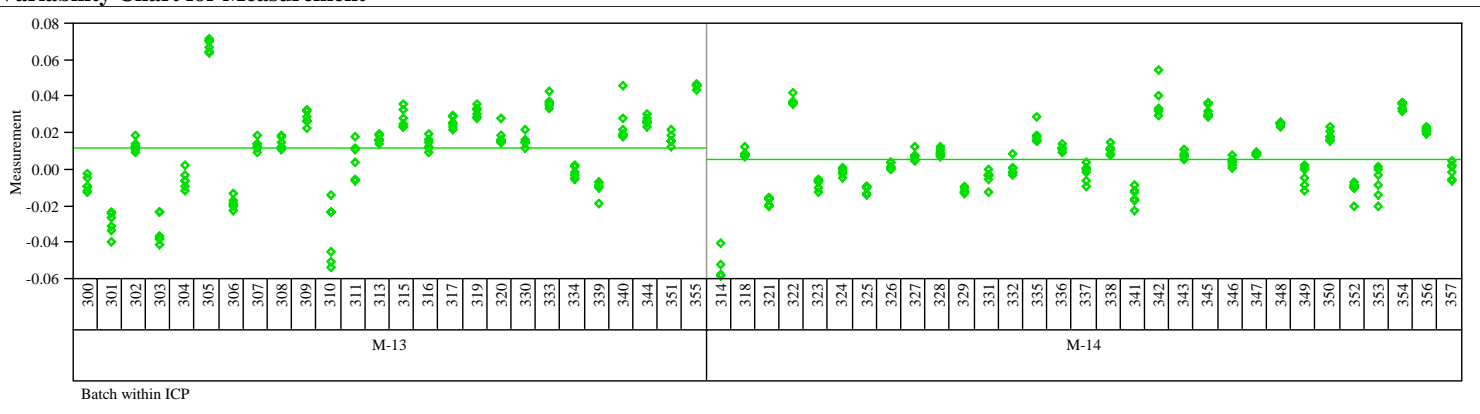

Prep $=$ Cold Chem, Sample Type $=$ SRAT, Analyte $=B / L i$

Variability Chart for Measurement

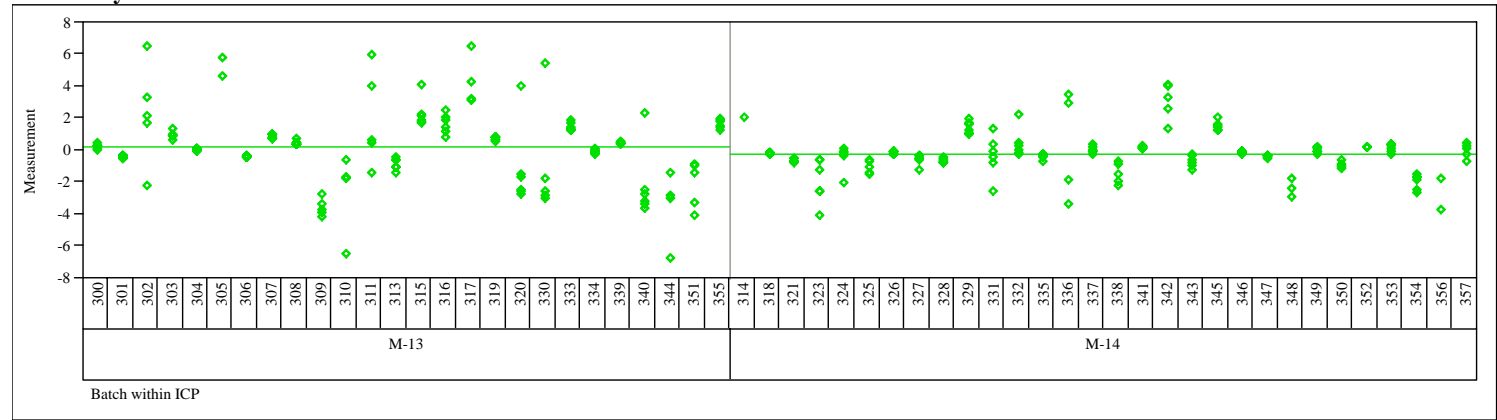


WSRC-STI-2006-00068

Revision 0

Exhibit A2. Measurement Data by Batch by ICP for Prep Method, Sample Type, and Analyte

Prep $=$ Cold Chem, Sample Type $=$ SRAT, Analyte $=$ Ca

(continued)

Variability Chart for Measurement

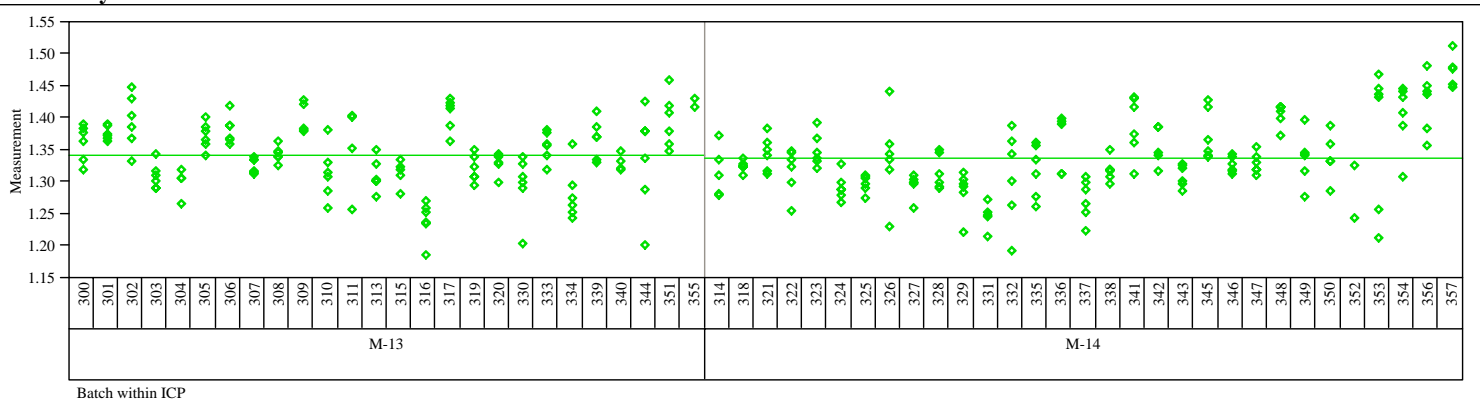

Prep $=$ Cold Chem, Sample Type $=$ SRAT, Analyte $=\mathrm{Cr}$

Variability Chart for Measurement

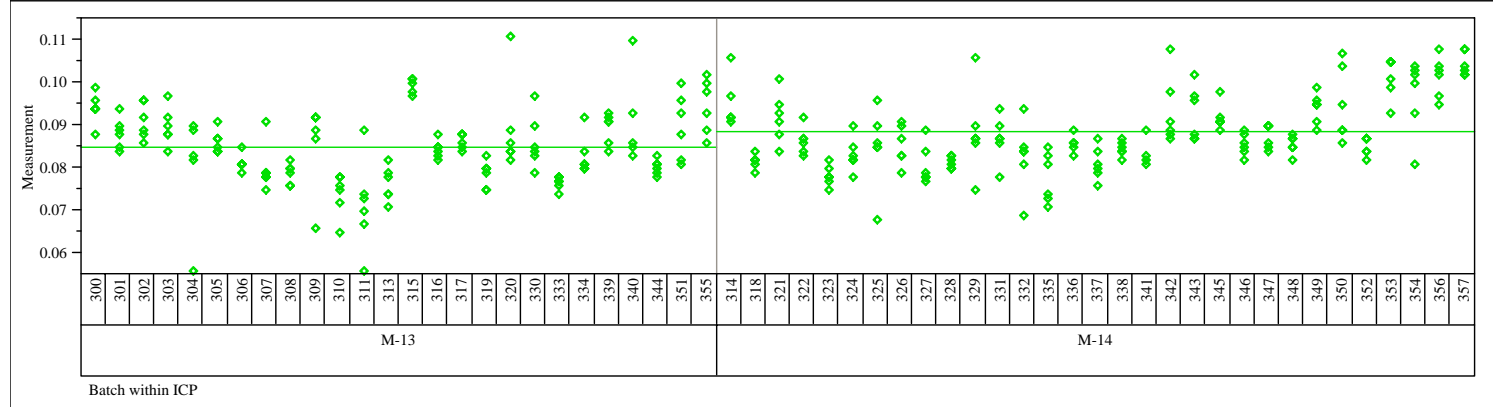

Prep $=$ Cold Chem, Sample Type $=$ SRAT, Analyte $=\mathrm{Cu}$

Variability Chart for Measurement

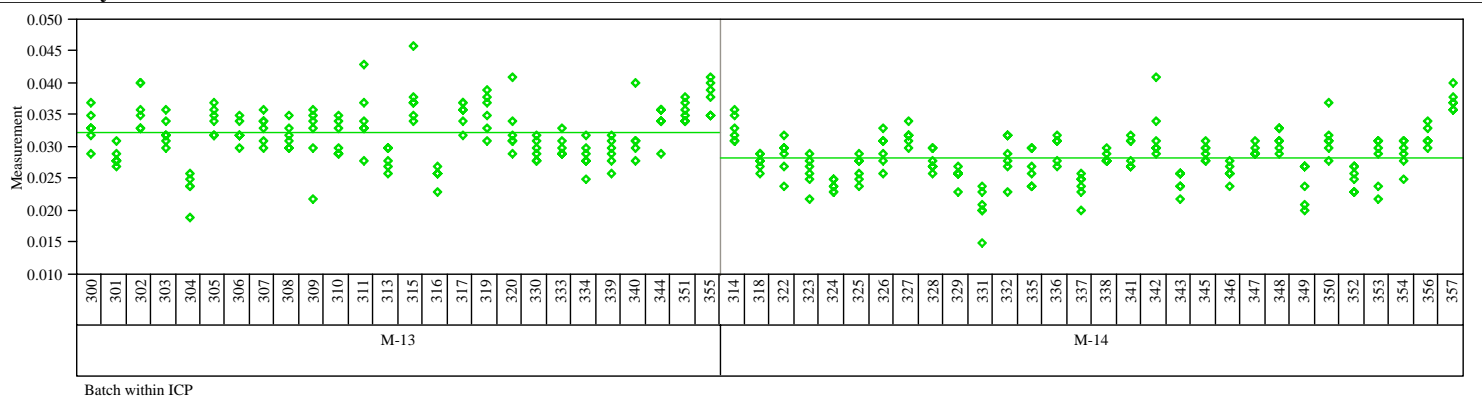

Prep $=$ Cold Chem, Sample Type $=$ SRAT, Analyte $=$ Fe

Variability Chart for Measurement

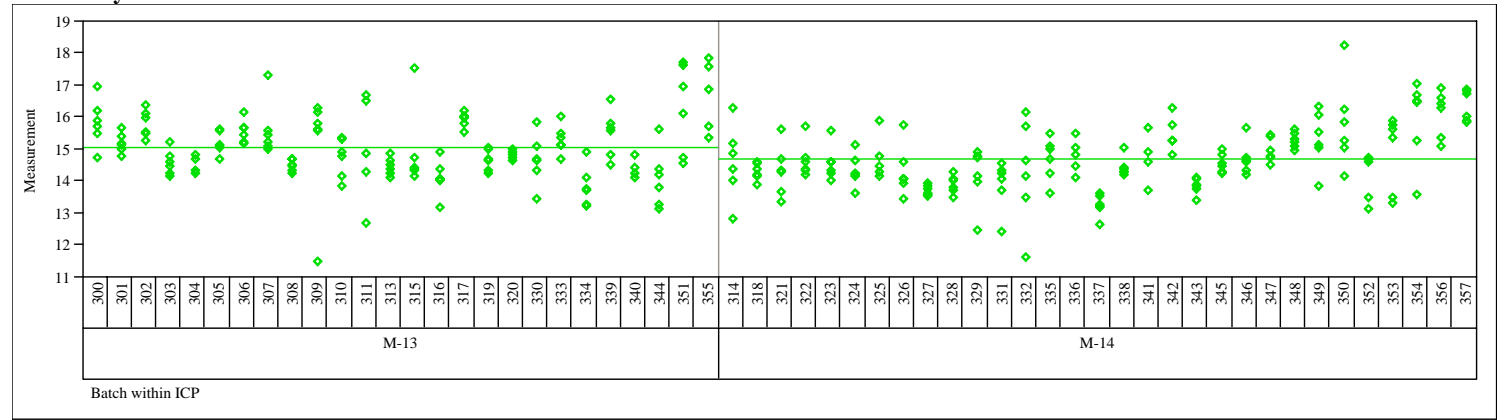


WSRC-STI-2006-00068

Revision 0

Exhibit A2. Measurement Data by Batch by ICP for Prep Method, Sample Type, and Analyte

Prep $=$ Cold Chem, Sample Type $=$ SRAT, Analyte $=\mathrm{Fe} / \mathrm{Al}$

(continued)

Variability Chart for Measurement

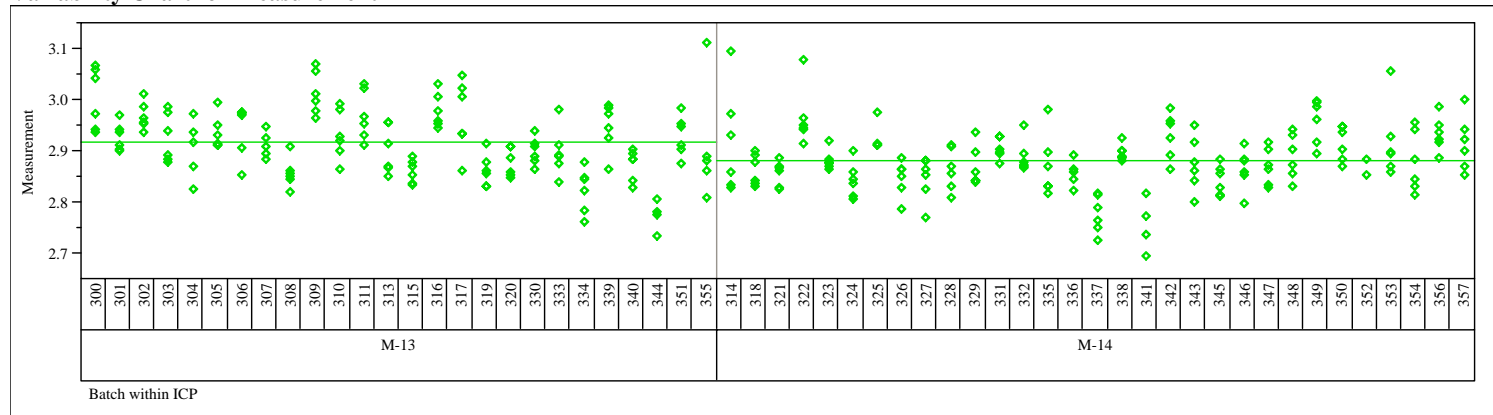

Prep=Cold Chem, Sample Type=SRAT, Analyte $=$ Fe $/$ Ca

Variability Chart for Measurement

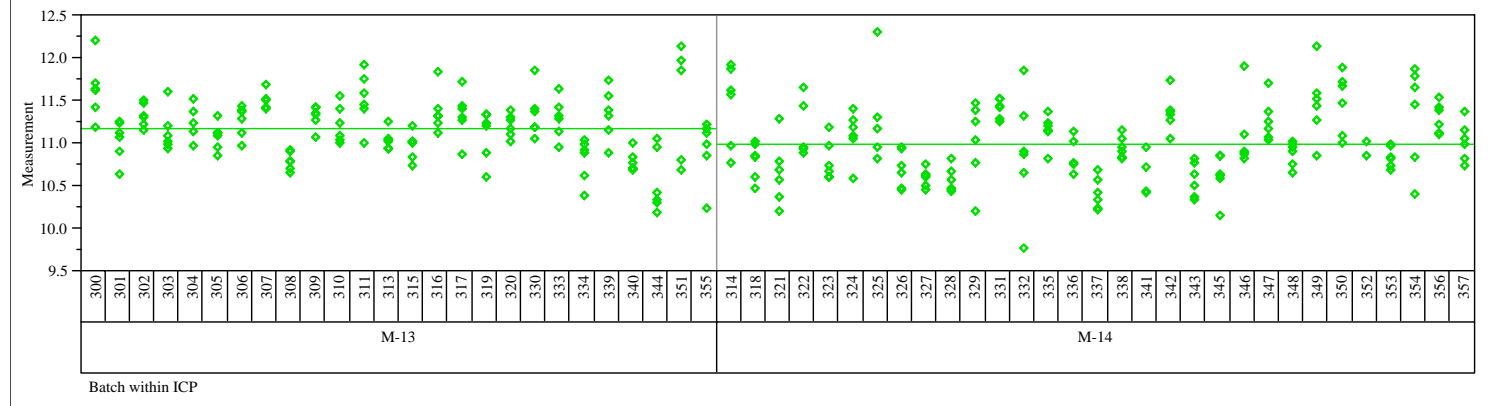

Prep $=$ Cold Chem, Sample Type $=$ SRAT, Analyte $=\mathrm{Fe} / \mathrm{Li}$

Variability Chart for Measurement

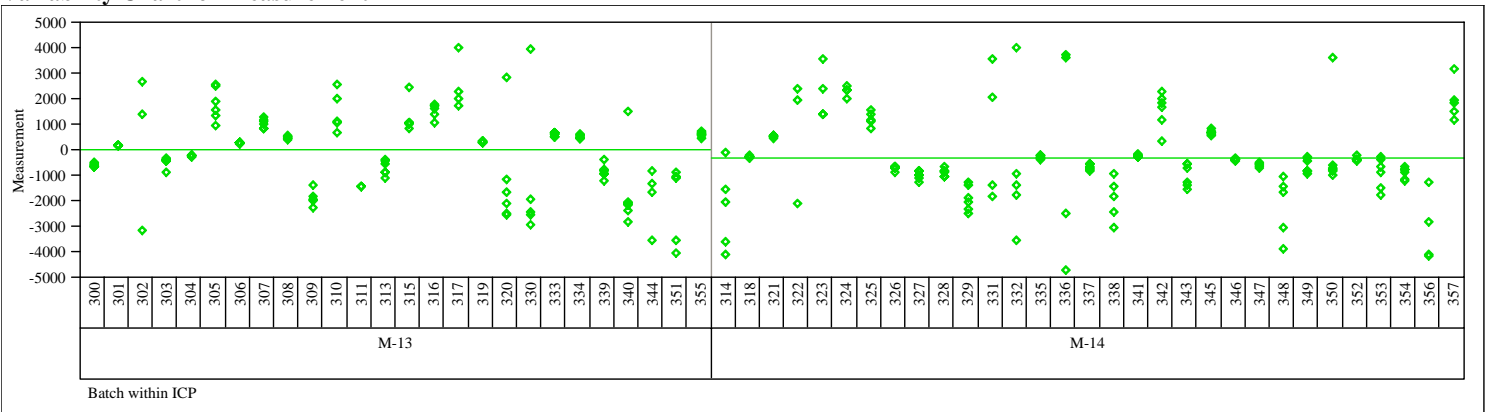

Prep $=$ Cold Chem, Sample Type $=$ SRAT, Analyte $=$ Fe $/ \mathrm{Mg}$

Variability Chart for Measurement

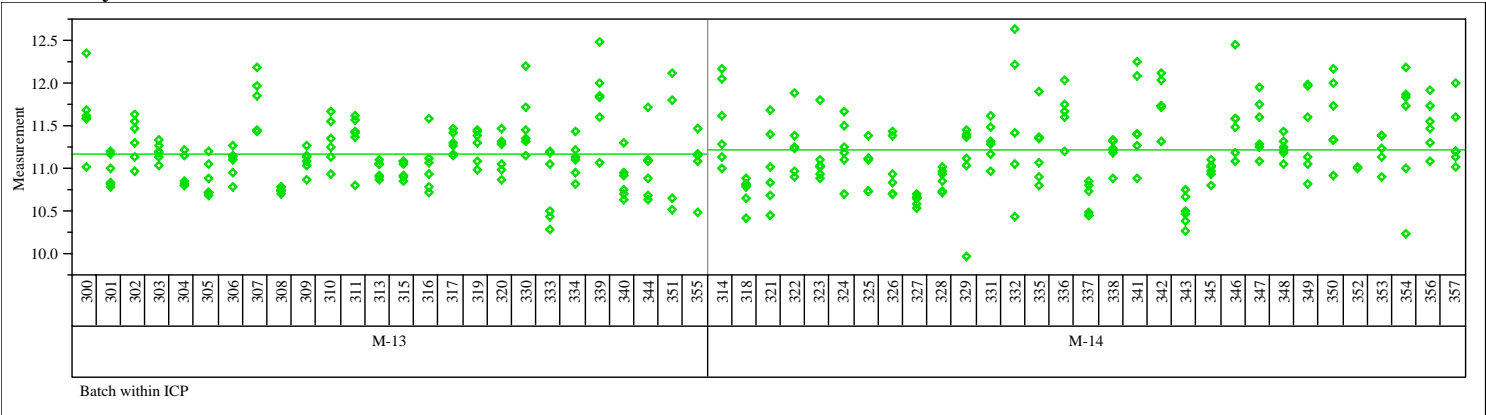


WSRC-STI-2006-00068

Revision 0

Exhibit A2. Measurement Data by Batch by ICP for Prep Method, Sample Type, and Analyte

Prep $=$ Cold Chem, Sample Type $=$ SRAT, Analyte $=F e / M n$

(continued)

Variability Chart for Measurement

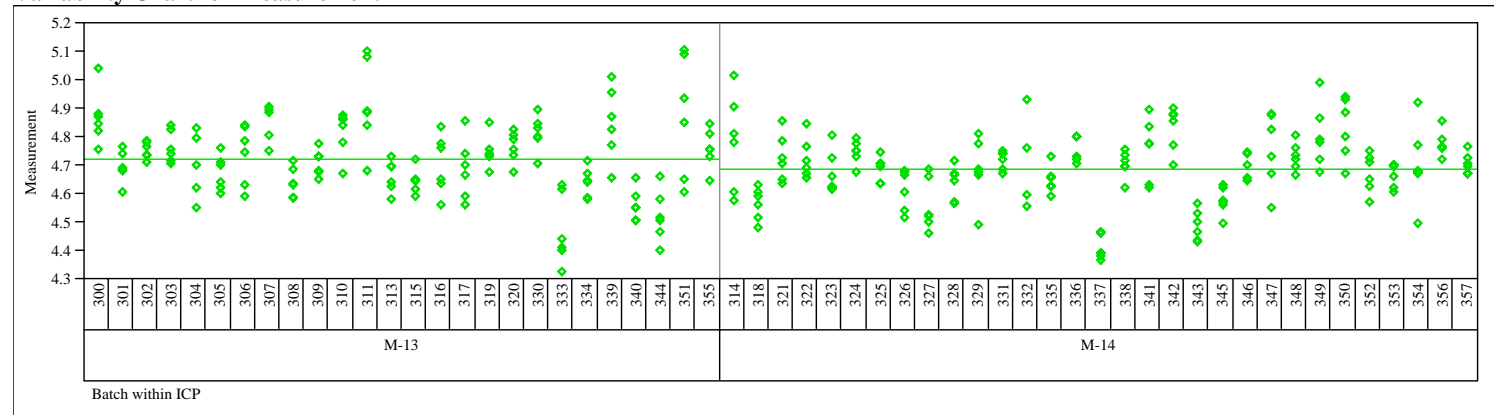

Prep $=$ Cold Chem, Sample Type $=$ SRAT, Analyte $=\mathrm{Fe} / \mathrm{Ni}$

Variability Chart for Measurement

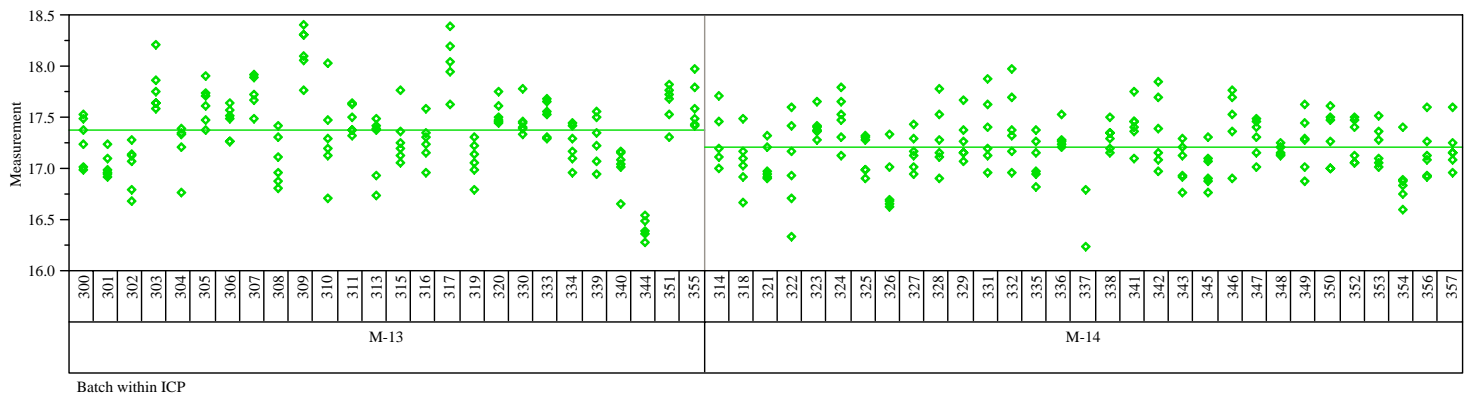

Prep=Cold Chem, Sample Type $=$ SRAT, Analyte $=F e / U$

Variability Chart for Measurement

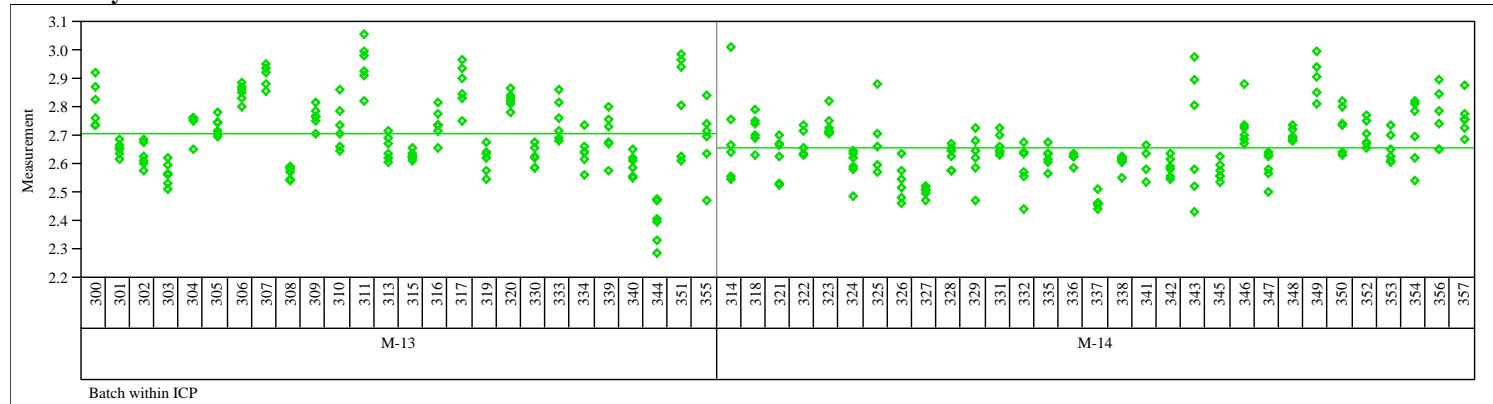

Prep $=$ Cold Chem, Sample Type $=$ SRAT, Analyte $=K$

Variability Chart for Measurement

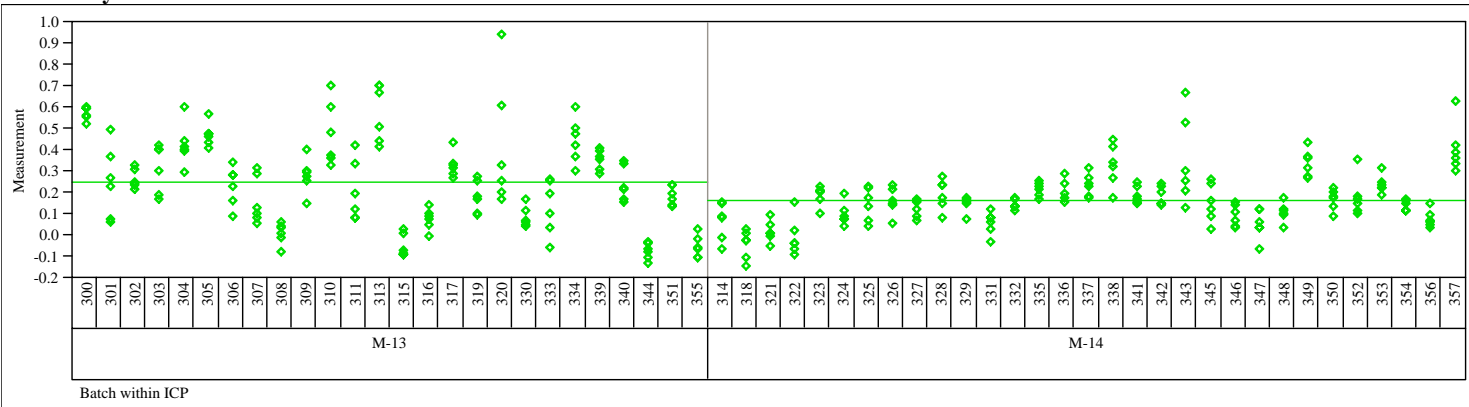


WSRC-STI-2006-00068

Revision 0

Exhibit A2. Measurement Data by Batch by ICP for Prep Method, Sample Type, and Analyte

Prep $=$ Cold Chem, Sample Type $=$ SRAT, Analyte $=\mathrm{Li}$

(continued)

Variability Chart for Measurement

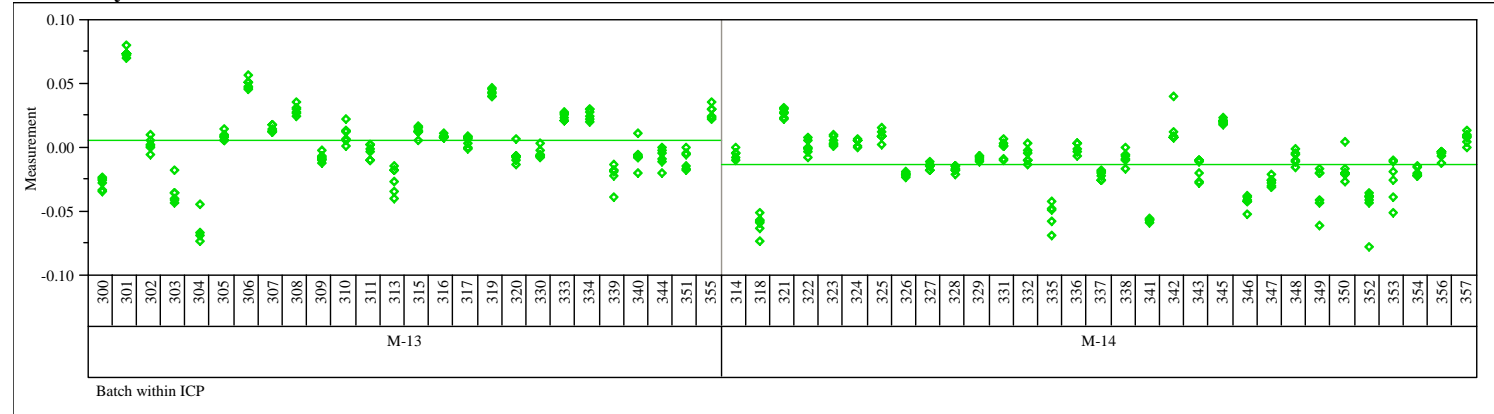

Prep=Cold Chem, Sample Type $=$ SRAT, Analyte $=\mathrm{Mg}$

Variability Chart for Measurement

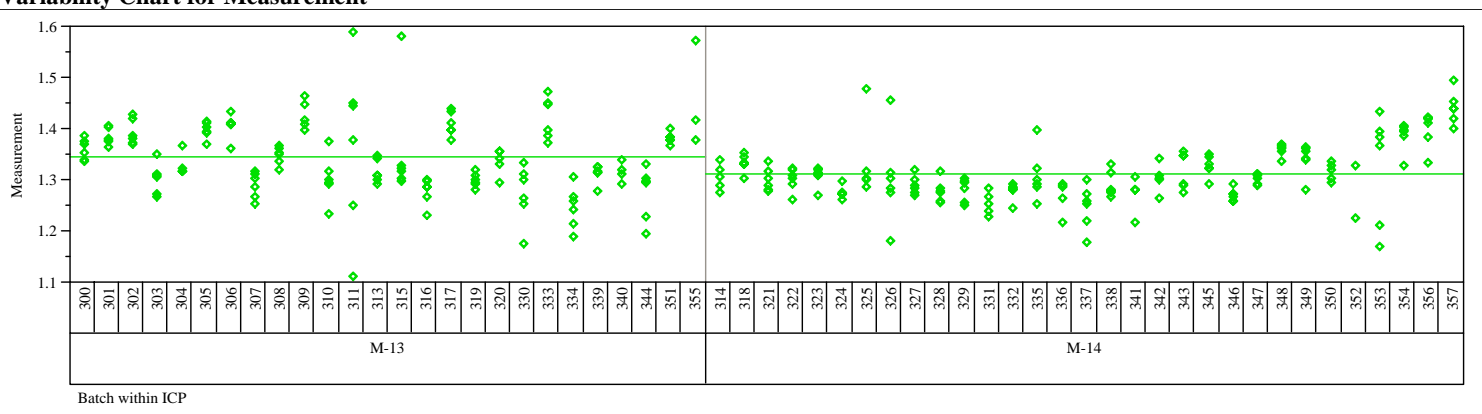

Prep $=$ Cold Chem, Sample Type $=$ SRAT, Analyte $=M n$

Variability Chart for Measurement

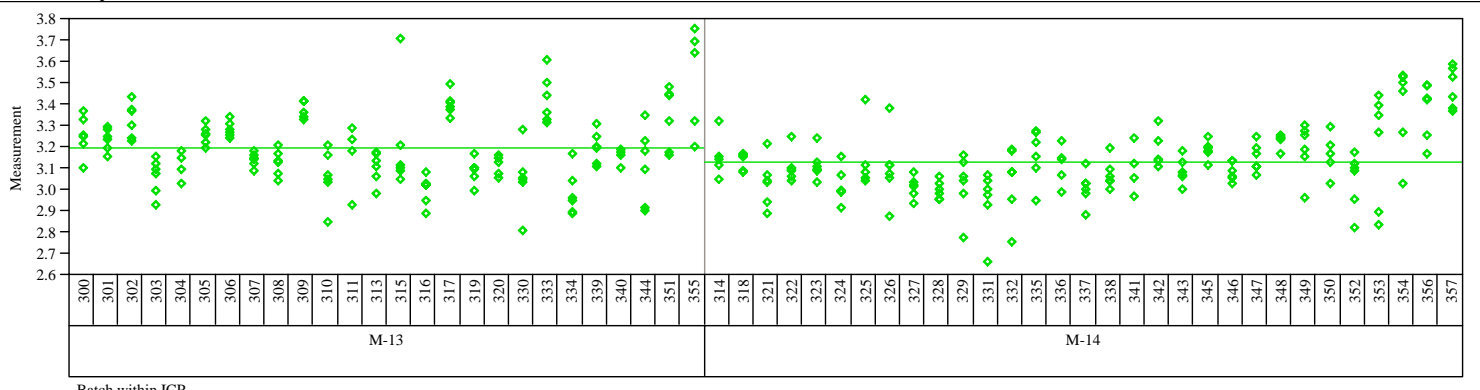

Prep $=$ Cold Chem, Sample Type $=$ SRAT, Analyte $=M n / M g$

Variability Chart for Measurement

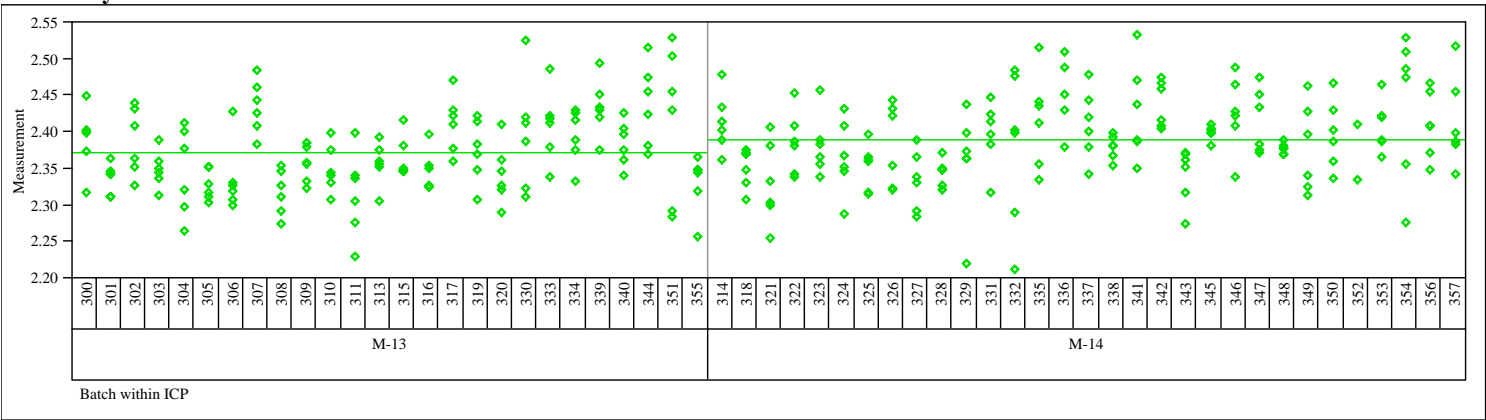


WSRC-STI-2006-00068

Revision 0

Exhibit A2. Measurement Data by Batch by ICP for Prep Method, Sample Type, and Analyte

Prep $=$ Cold Chem, Sample Type $=$ SRAT, Analyte $=\mathrm{Na}$

(continued)

Variability Chart for Measurement

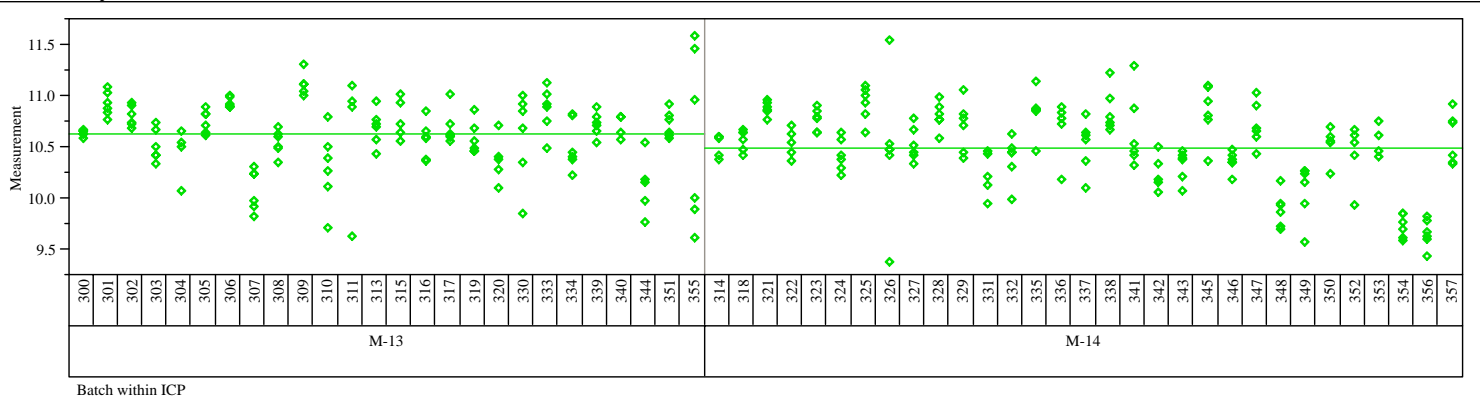

Prep $=$ Cold Chem, Sample Type $=$ SRAT, Analyte $=$ Ni

Variability Chart for Measurement

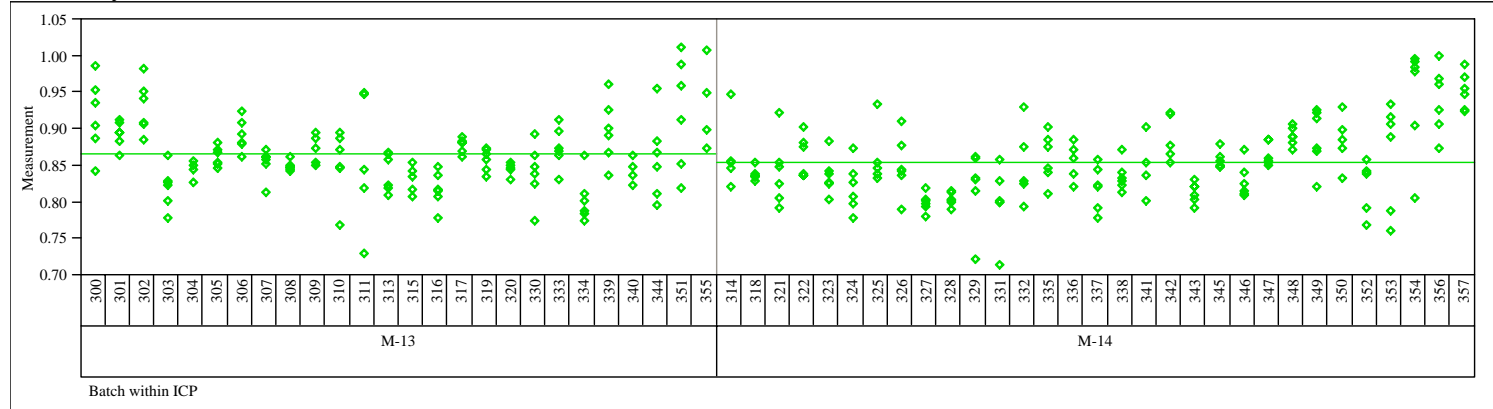

Prep $=$ Cold Chem, Sample Type $=$ SRAT, Analyte $=S i$

Variability Chart for Measurement

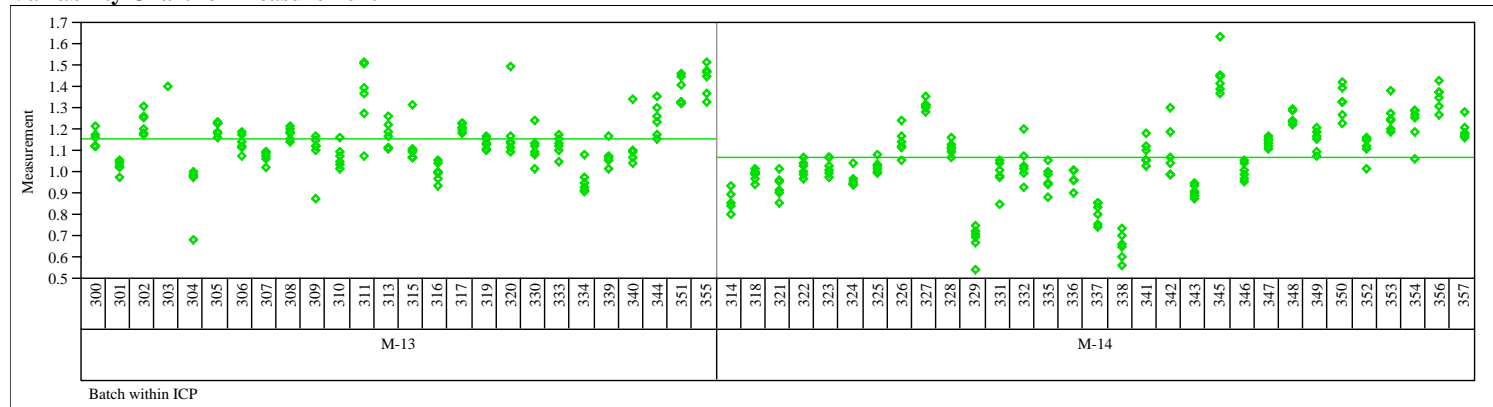

Prep $=$ Cold Chem, Sample Type $=$ SRAT, Analyte $=$ Sum of Oxides

Variability Chart for Measurement

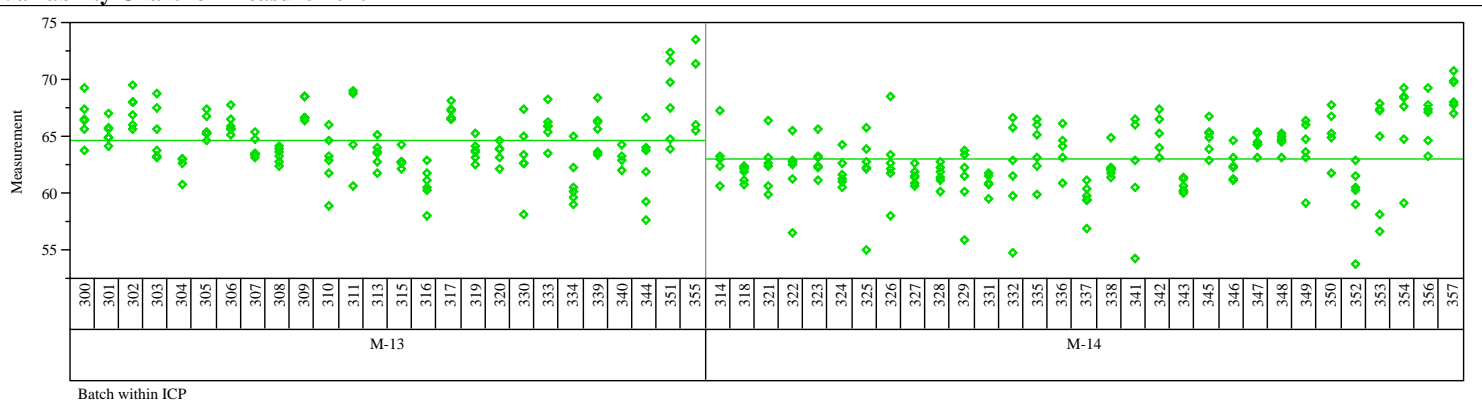


WSRC-STI-2006-00068

Revision 0

Exhibit A2. Measurement Data by Batch by ICP for Prep Method, Sample Type, and Analyte

Prep $=$ Cold Chem, Sample Type $=$ SRAT, Analyte $=T i$

(continued)

Variability Chart for Measurement

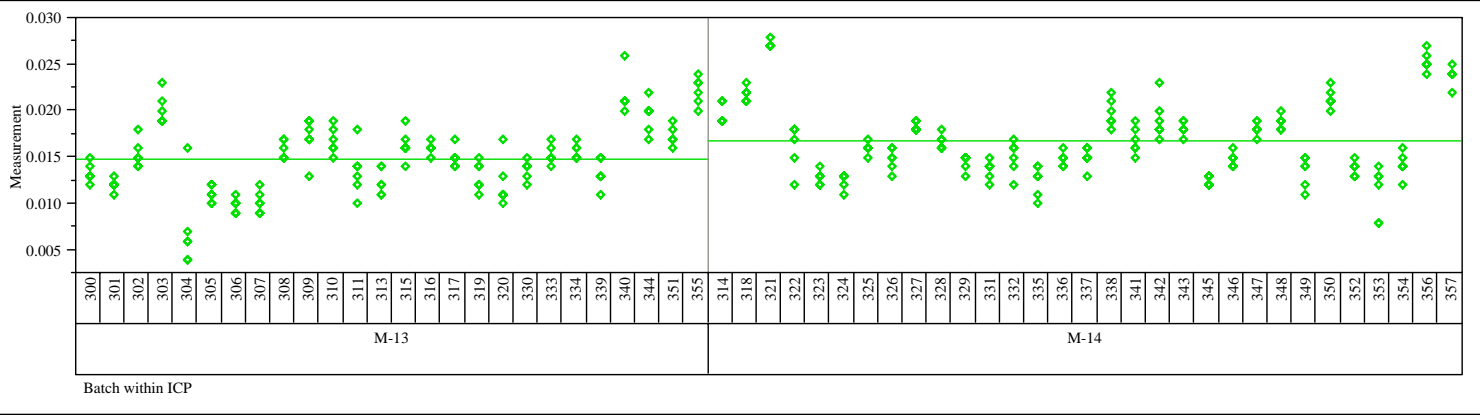

Prep $=$ Cold Chem, Sample Type $=$ SRAT, Analyte $=U$

Variability Chart for Measurement

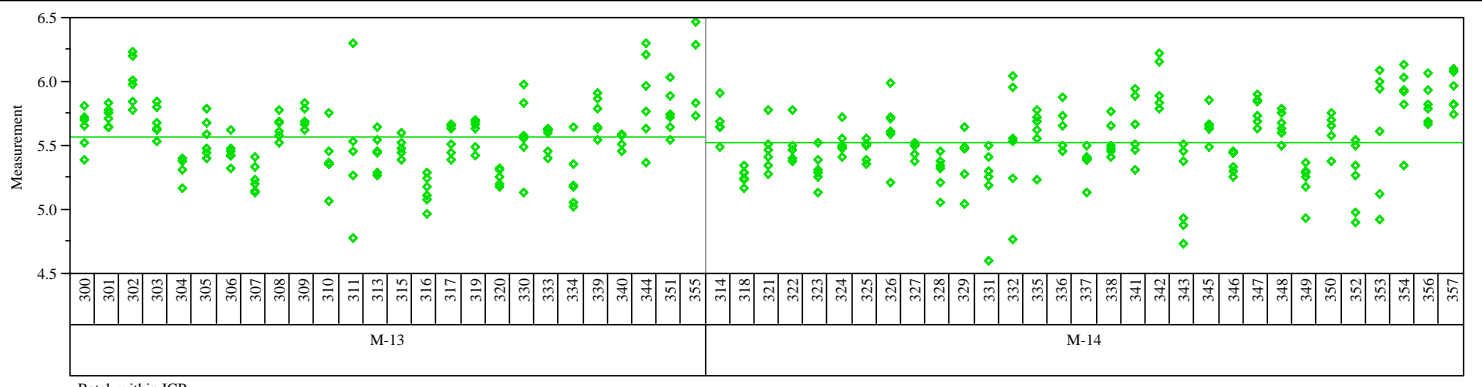

Batch within ICP

Prep $=$ Cold Chem, Sample Type $=$ SRAT, Analyte $=U / C a$

Variability Chart for Measurement

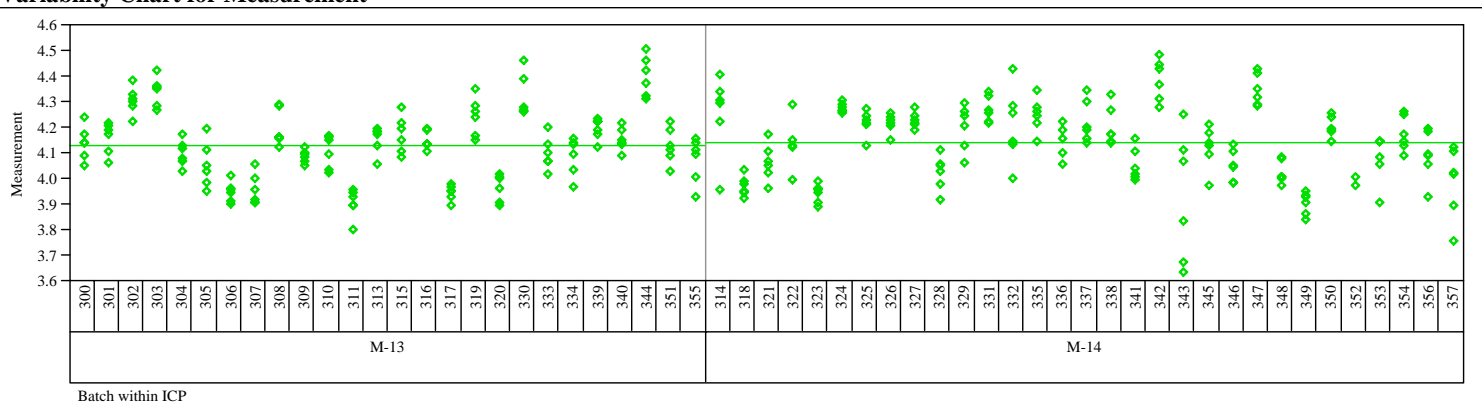

Prep $=$ Cold Chem, Sample Type $=$ SRAT, Analyte $=\mathrm{Zr}$

Variability Chart for Measurement

\begin{tabular}{ll}
\hline \\
Batch within ICP
\end{tabular}


Exhibit A2. Measurement Data by Batch by ICP for Prep Method, Sample Type, and Analyte

Prep $=$ Cold Chem, Sample Type $=$ blank, Analyte $=A$

(continued)

Variability Chart for Measurement

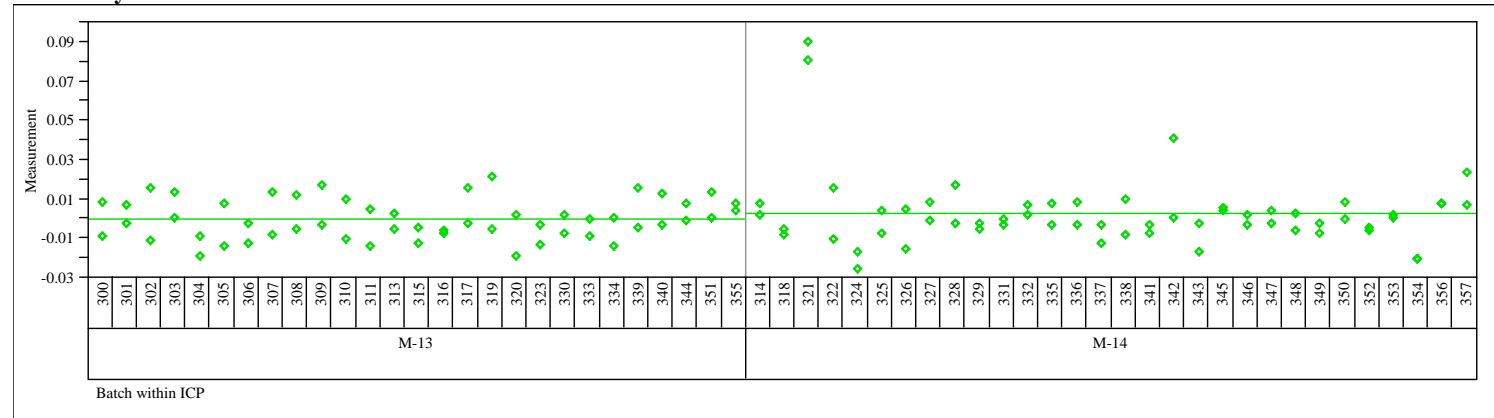

Prep $=$ Cold Chem, Sample Type $=$ blank, Analyte $=$ Al $/$ Ca

Variability Chart for Measurement

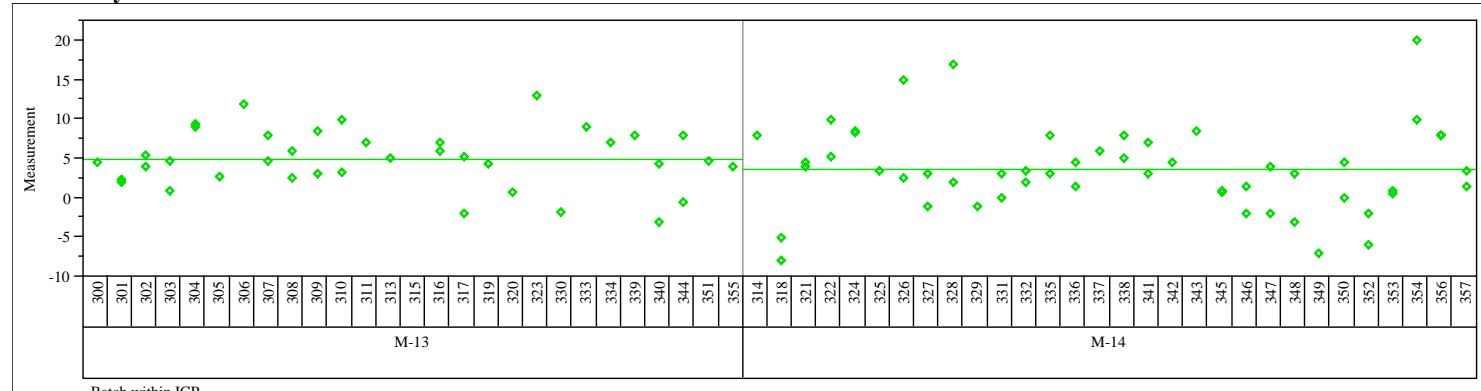

Prep $=$ Cold Chem, Sample Type $=$ blank, Analyte $=$ Al/Mg

Variability Chart for Measurement

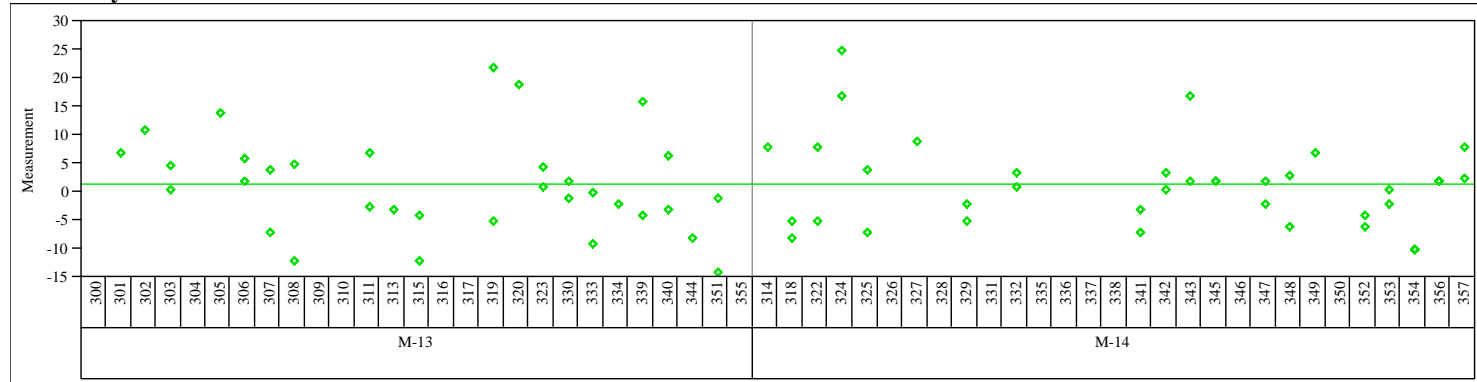

Batch within ICP

Prep $=$ Cold Chem, Sample Type $=$ blank, Analyte $=\mathbf{A l} / \mathbf{M n}$

Variability Chart for Measurement

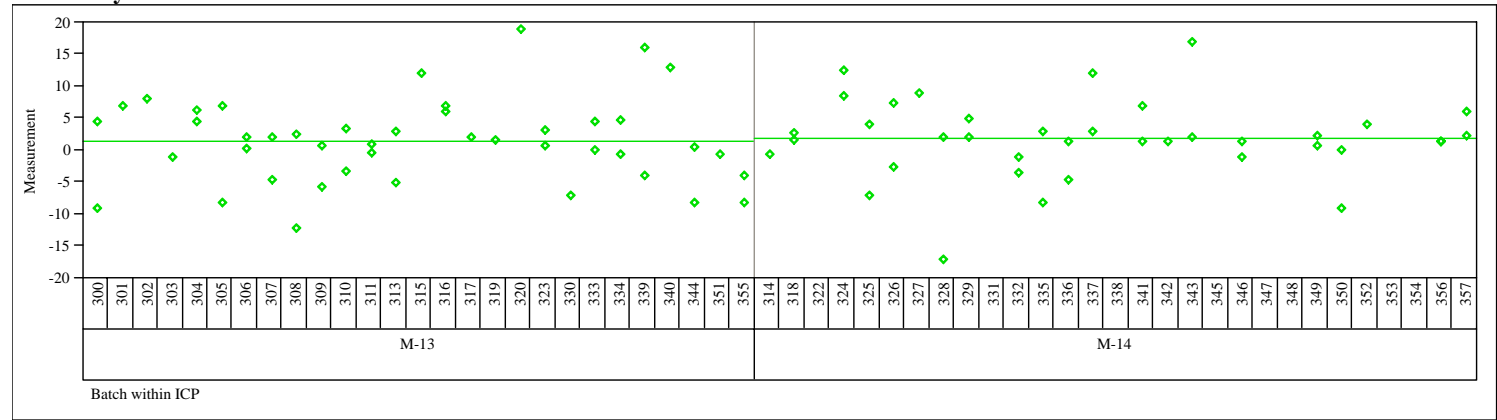


WSRC-STI-2006-00068

Revision 0

Exhibit A2. Measurement Data by Batch by ICP for Prep Method, Sample Type, and Analyte

Prep $=$ Cold Chem, Sample Type $=$ blank, Analyte $=B$

(continued)

Variability Chart for Measurement

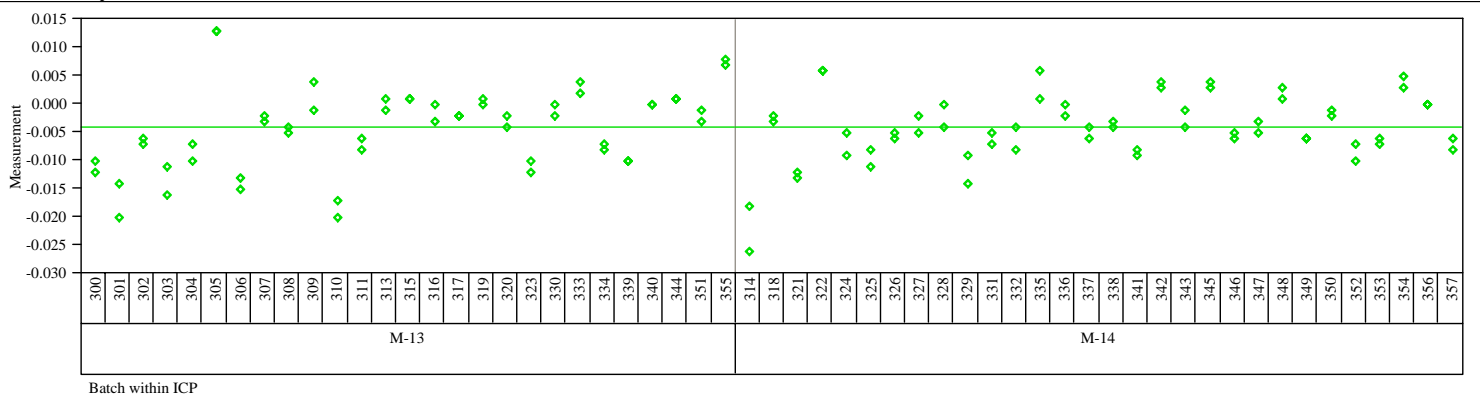

Prep $=$ Cold Chem, Sample Type $=$ blank, Analyte $=\mathrm{B} / \mathrm{Li}$

Variability Chart for Measurement

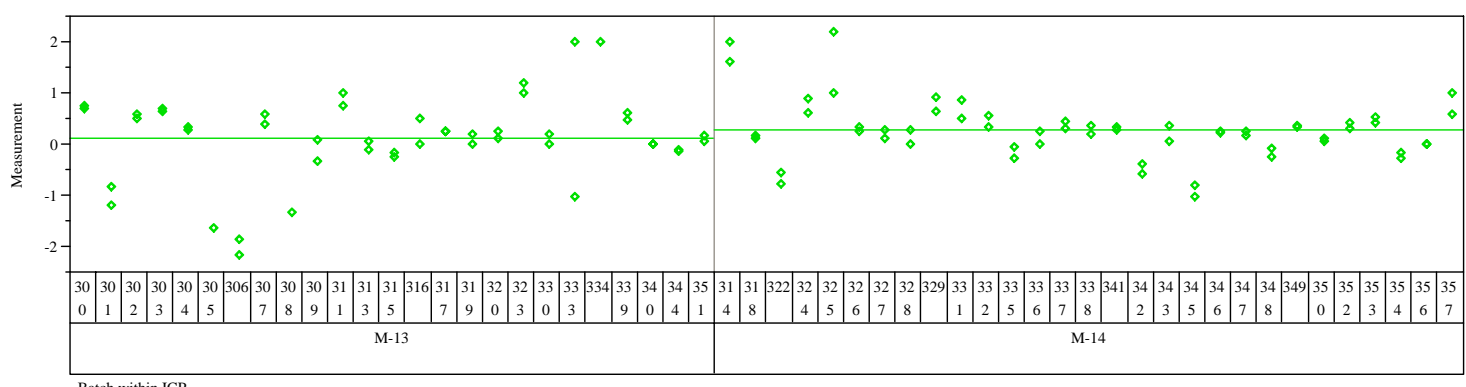

Prep=Cold Chem, Sample Type=blank, Analyte $=$ Ca

Variability Chart for Measurement

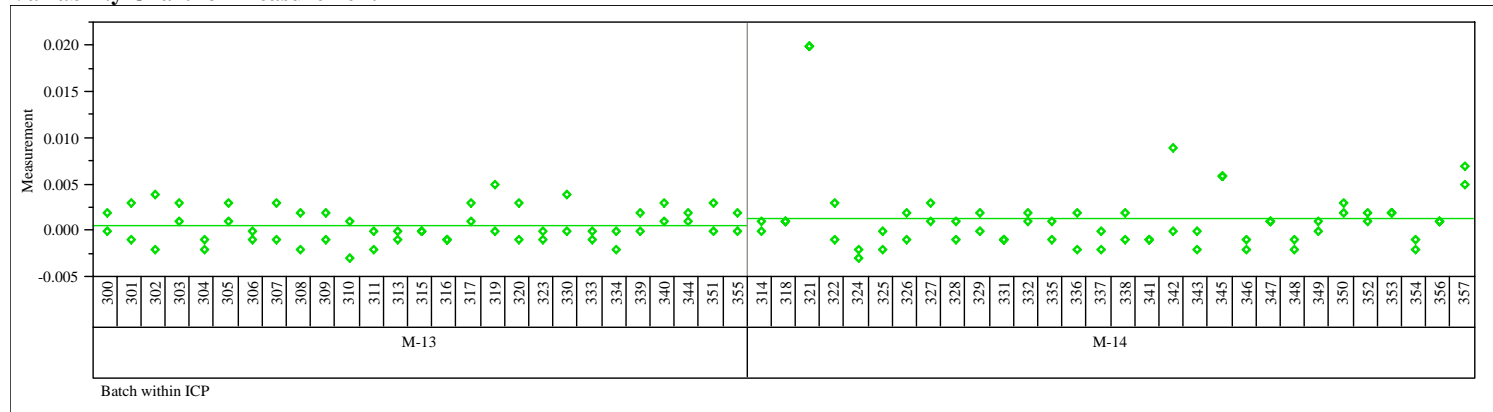

Prep $=$ Cold Chem, Sample Type $=$ blank, Analyte $=\mathrm{Cr}$

Variability Chart for Measurement

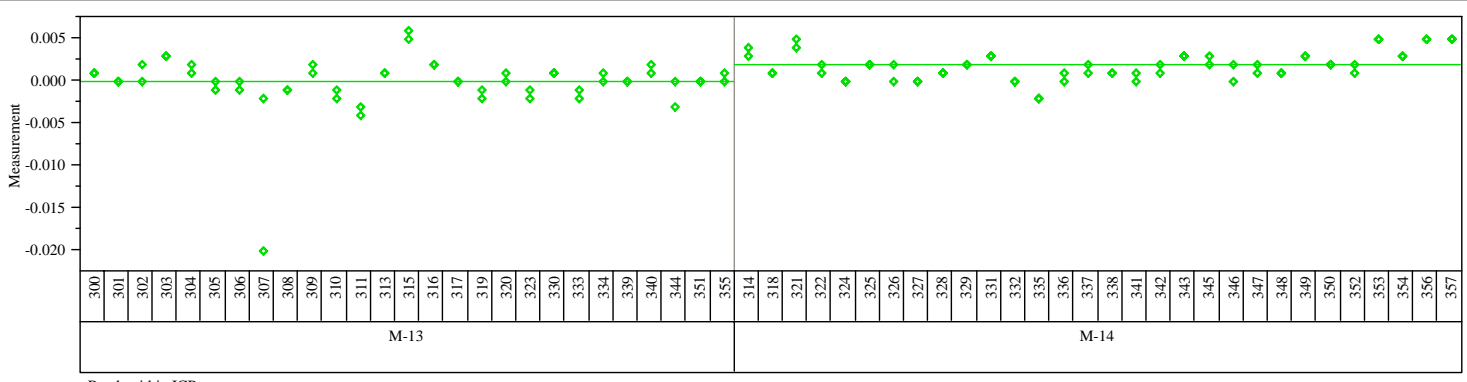


WSRC-STI-2006-00068

Revision 0

Exhibit A2. Measurement Data by Batch by ICP for Prep Method, Sample Type, and Analyte

Prep $=$ Cold Chem, Sample Type $=$ blank, Analyte $=\mathrm{Cu}$

(continued)

Variability Chart for Measurement

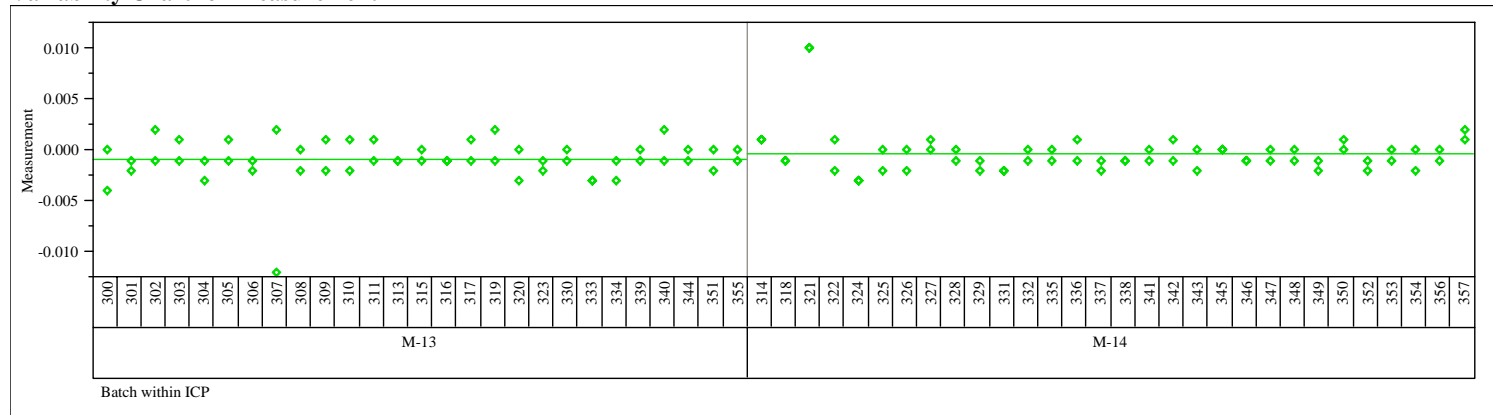

Prep $=$ Cold Chem, Sample Type $=$ blank, Analyte $=$ Fe

Variability Chart for Measurement

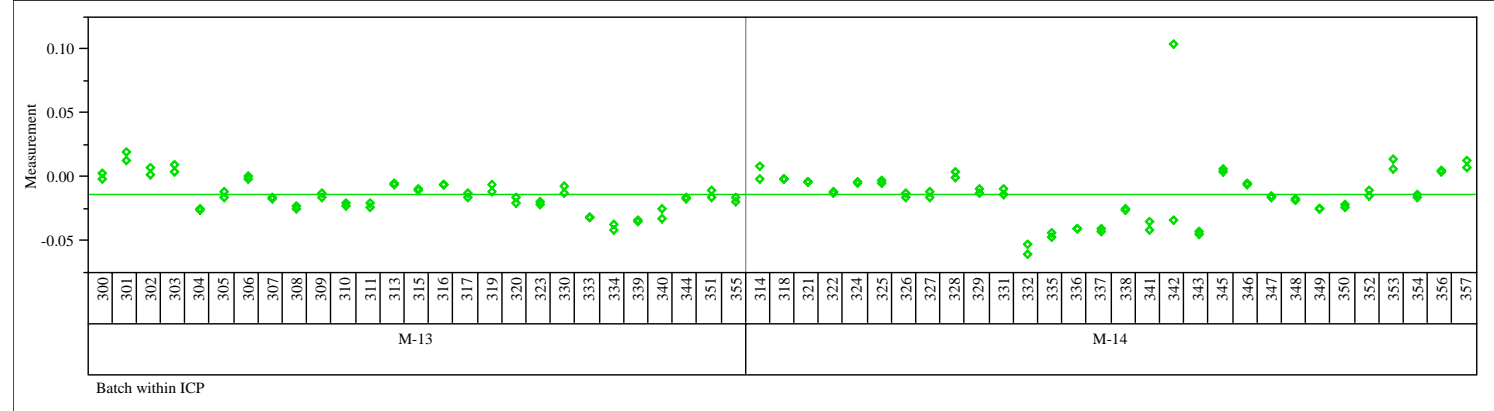

Prep=Cold Chem, Sample Type=blank, Analyte $=$ Fe/Al

Variability Chart for Measurement

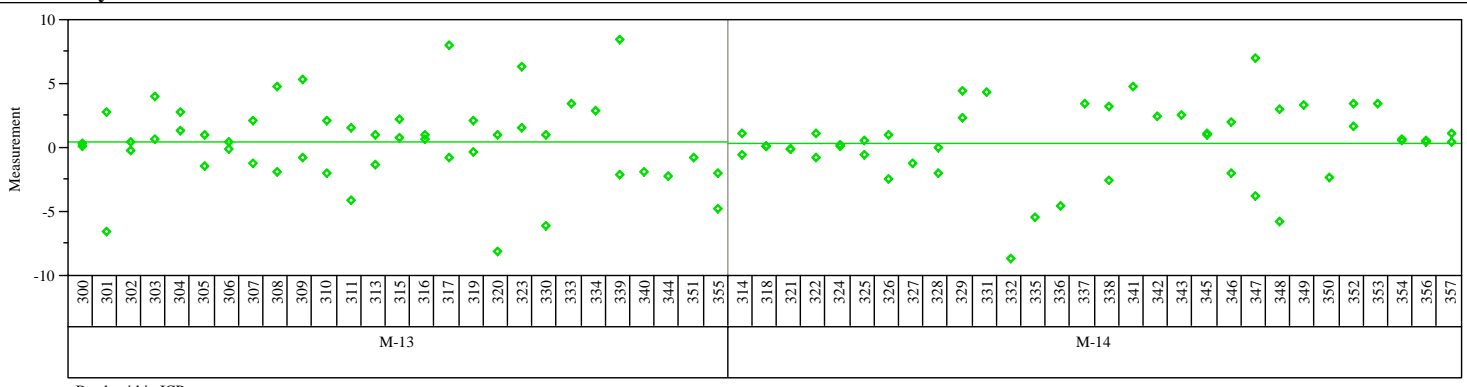

Batch within ICP

Prep=Cold Chem, Sample Type $=$ blank, Analyte $=$ Fe $/$ Ca

Variability Chart for Measurement

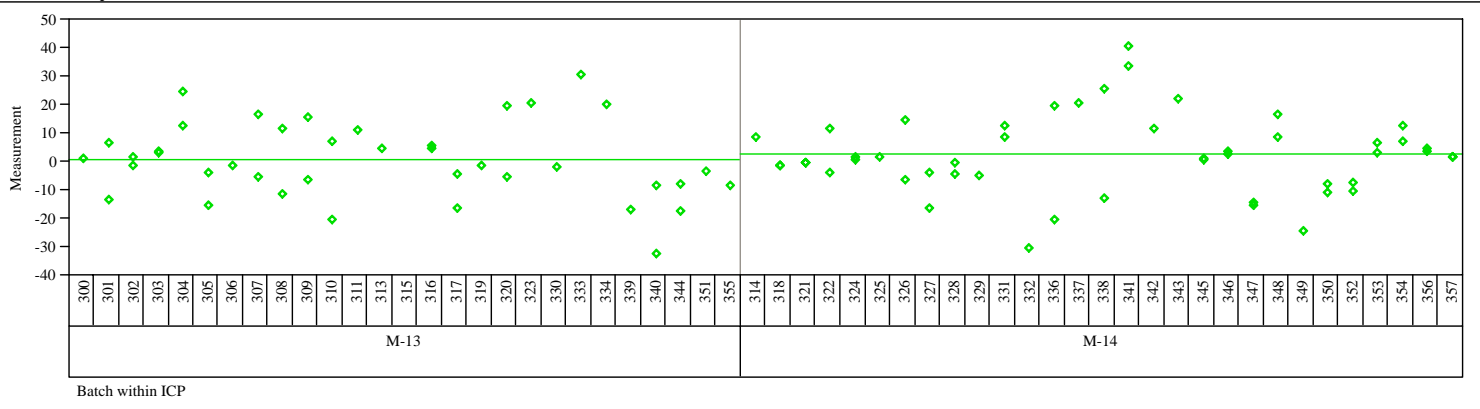


WSRC-STI-2006-00068

Revision 0

Exhibit A2. Measurement Data by Batch by ICP for Prep Method, Sample Type, and Analyte

Prep $=$ Cold Chem, Sample Type $=$ blank, Analyte $=\mathrm{Fe} / \mathrm{Li}$

(continued)

Variability Chart for Measurement

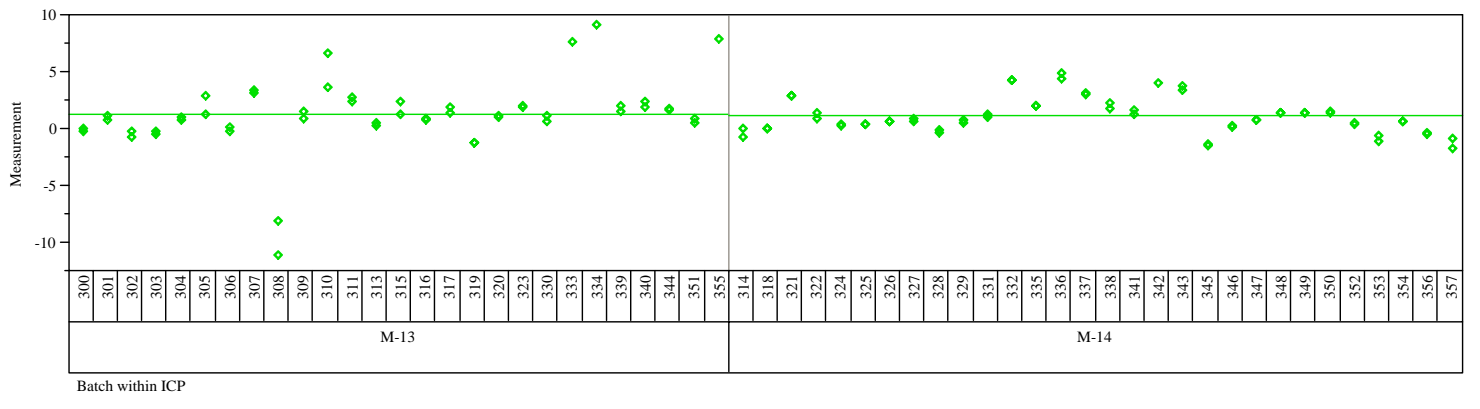

Prep $=$ Cold Chem, Sample Type $=$ blank, Analyte $=$ Fe $/ \mathrm{Mg}$

Variability Chart for Measurement

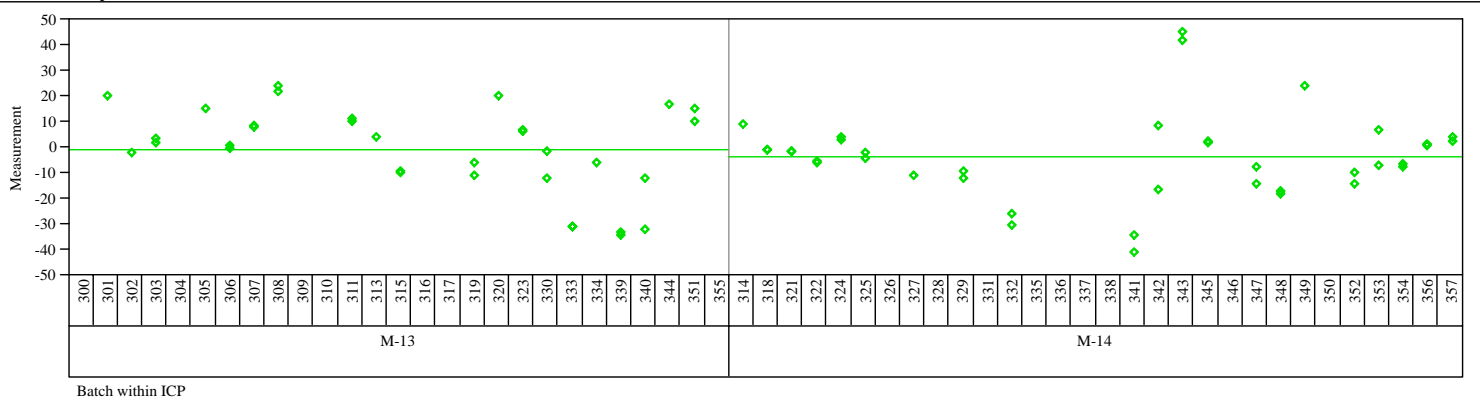

Prep $=$ Cold Chem, Sample Type $=$ blank, Analyte $=F e / M n$

Variability Chart for Measurement

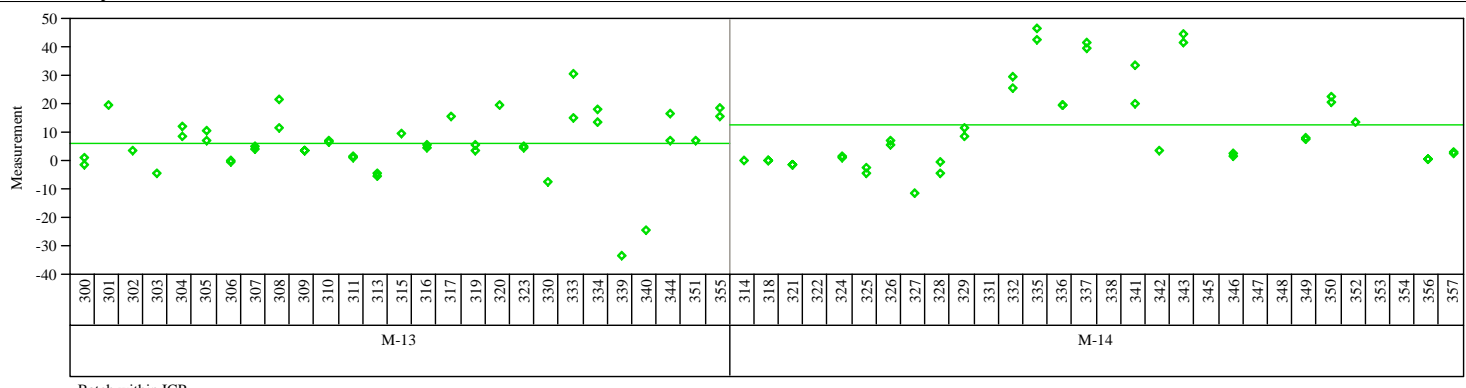

Prep $=$ Cold Chem, Sample Type=blank, Analyte $=\mathrm{Fe} / \mathrm{Ni}$

Variability Chart for Measurement

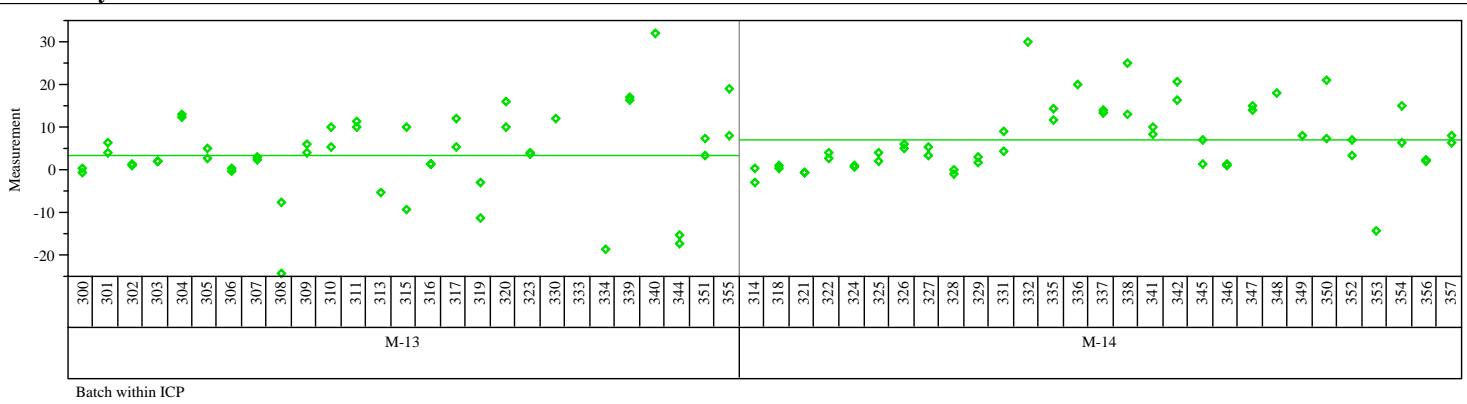


WSRC-STI-2006-00068

Revision 0

Exhibit A2. Measurement Data by Batch by ICP for Prep Method, Sample Type, and Analyte

Prep $=$ Cold Chem, Sample Type $=$ blank, Analyte $=F e / U$

(continued)

Variability Chart for Measurement

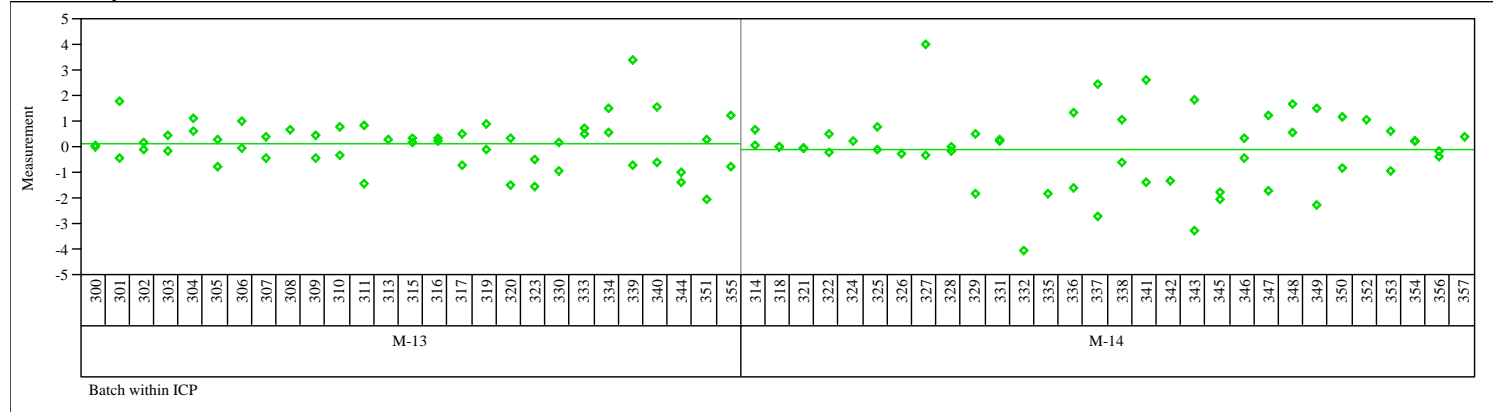

Prep $=$ Cold Chem, Sample Type $=$ blank, Analyte $=K$

Variability Chart for Measurement

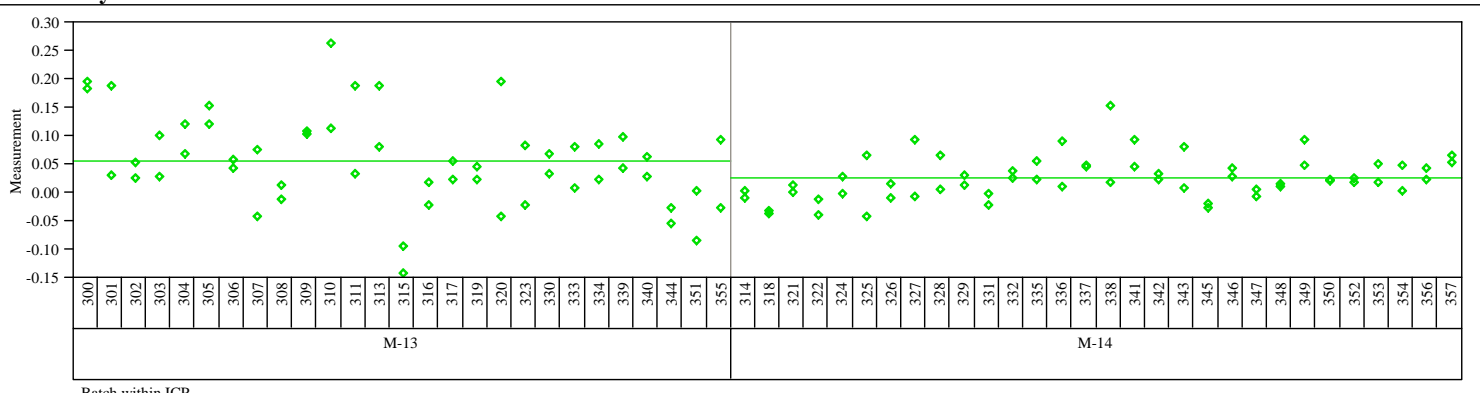

Prep $=$ Cold Chem, Sample Type $=$ blank, Analyte $=$ Li

Variability Chart for Measurement

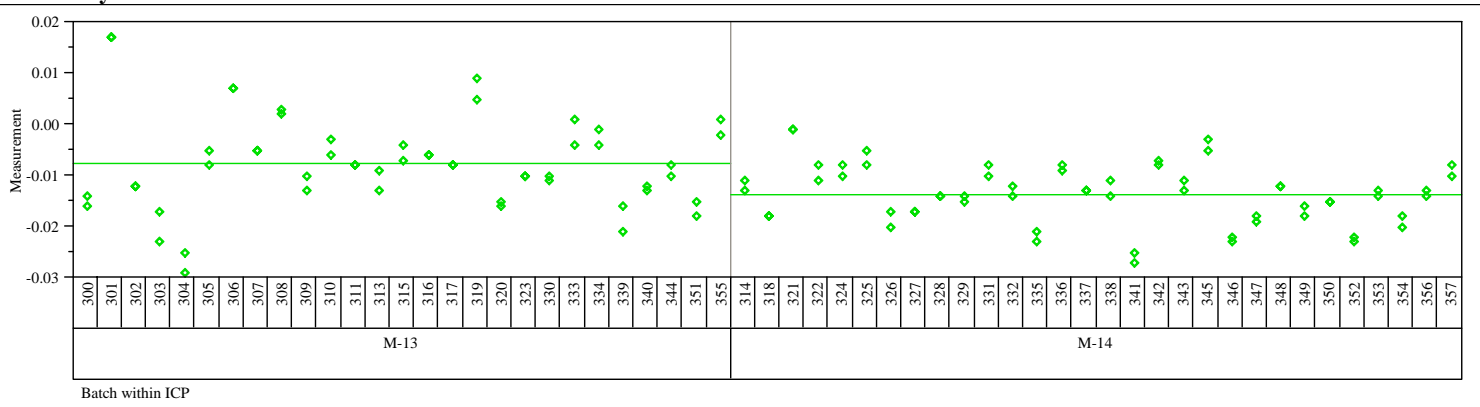

Prep $=$ Cold Chem, Sample Type $=$ blank, Analyte $=M g$

Variability Chart for Measurement

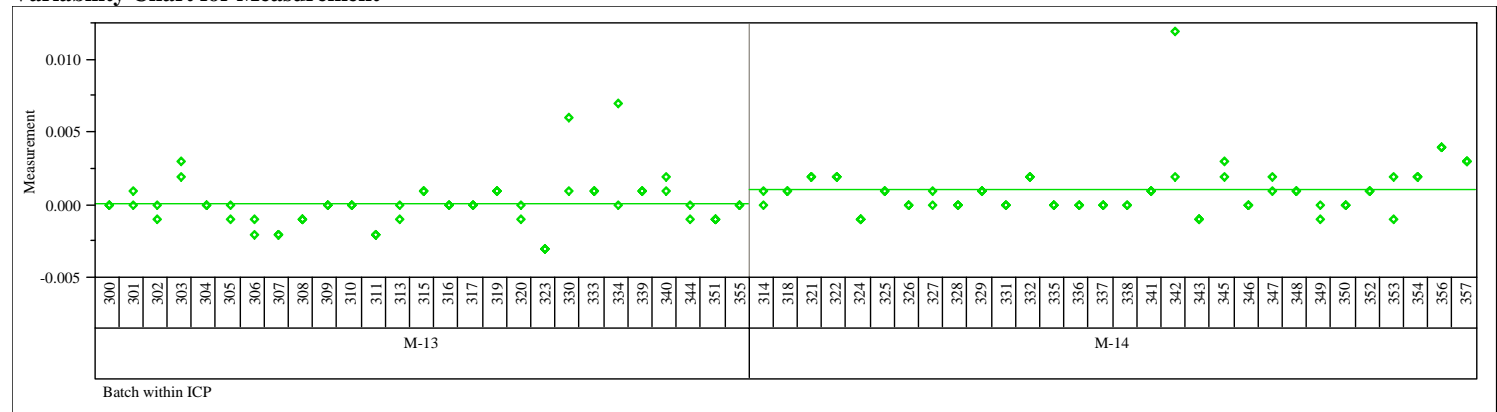


WSRC-STI-2006-00068

Revision 0

Exhibit A2. Measurement Data by Batch by ICP for Prep Method, Sample Type, and Analyte

Prep $=$ Cold Chem, Sample Type $=$ blank, Analyte $=M n$

(continued)

Variability Chart for Measurement

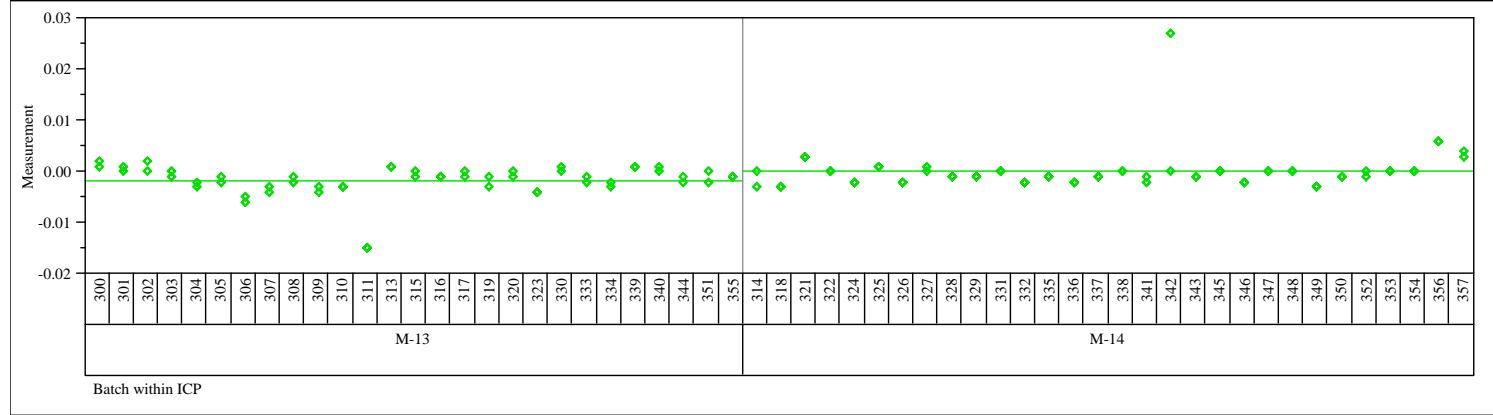

Prep $=$ Cold Chem, Sample Type $=$ blank, Analyte $=\mathrm{Mn} / \mathrm{Mg}$

Variability Chart for Measurement

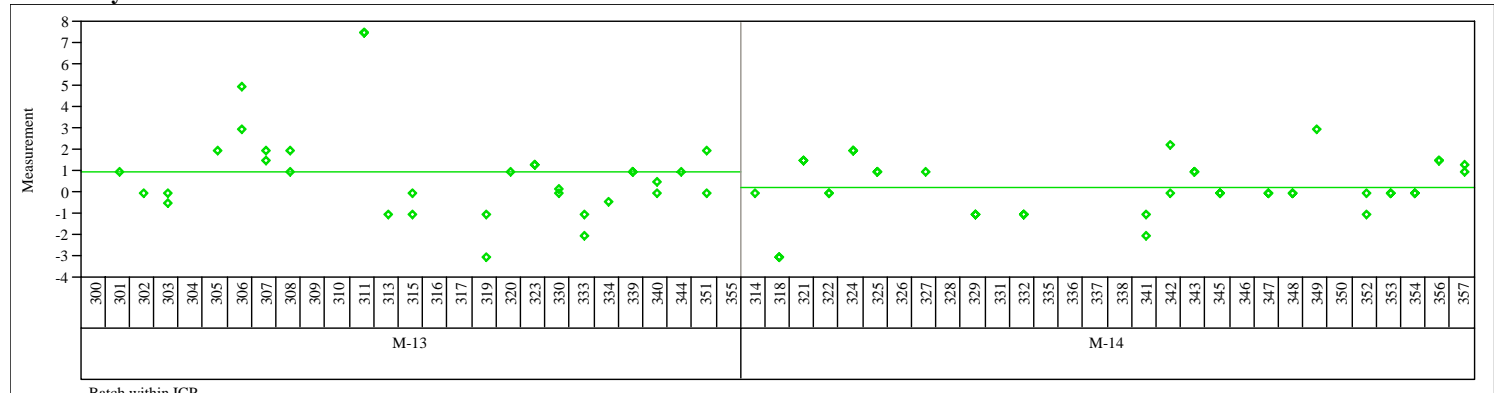

Prep $=$ Cold Chem, Sample Type $=$ blank, Analyte $=\mathrm{Na}$

Variability Chart for Measurement

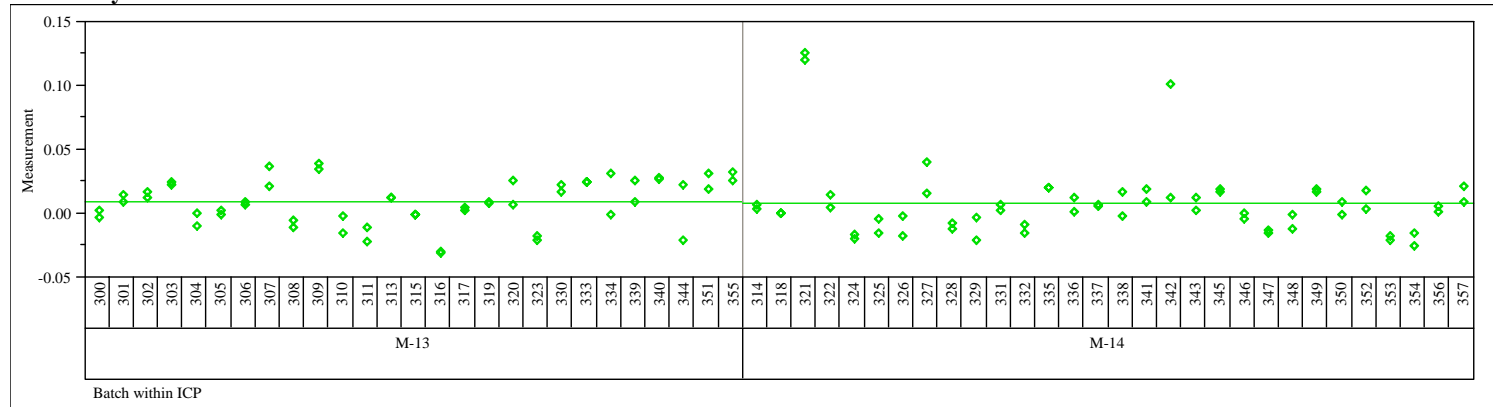

Prep=Cold Chem, Sample Type=blank, Analyte=Ni

Variability Chart for Measurement

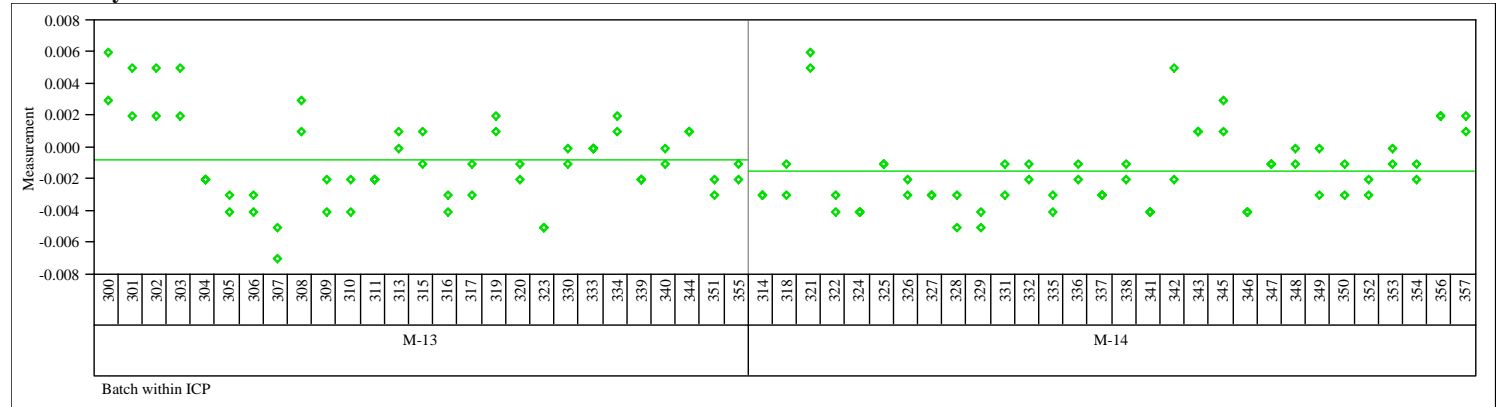


WSRC-STI-2006-00068

Revision 0

Exhibit A2. Measurement Data by Batch by ICP for Prep Method, Sample Type, and Analyte

Prep $=$ Cold Chem, Sample Type $=$ blank, Analyte $=\mathrm{Si}$

(continued)

Variability Chart for Measurement

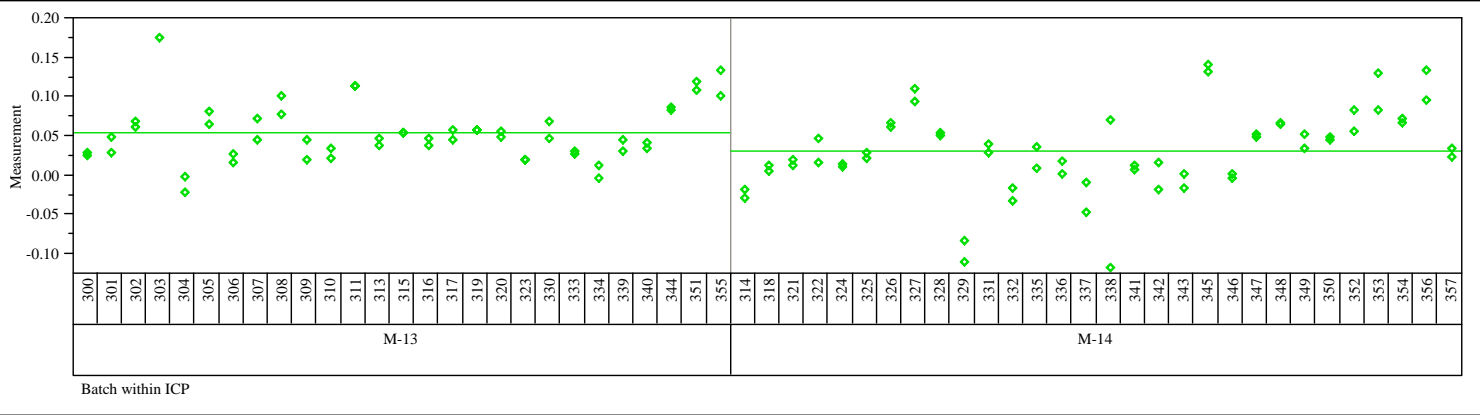

Prep $=$ Cold Chem, Sample Type $=$ blank, Analyte $=$ Sum of Oxides

Variability Chart for Measurement

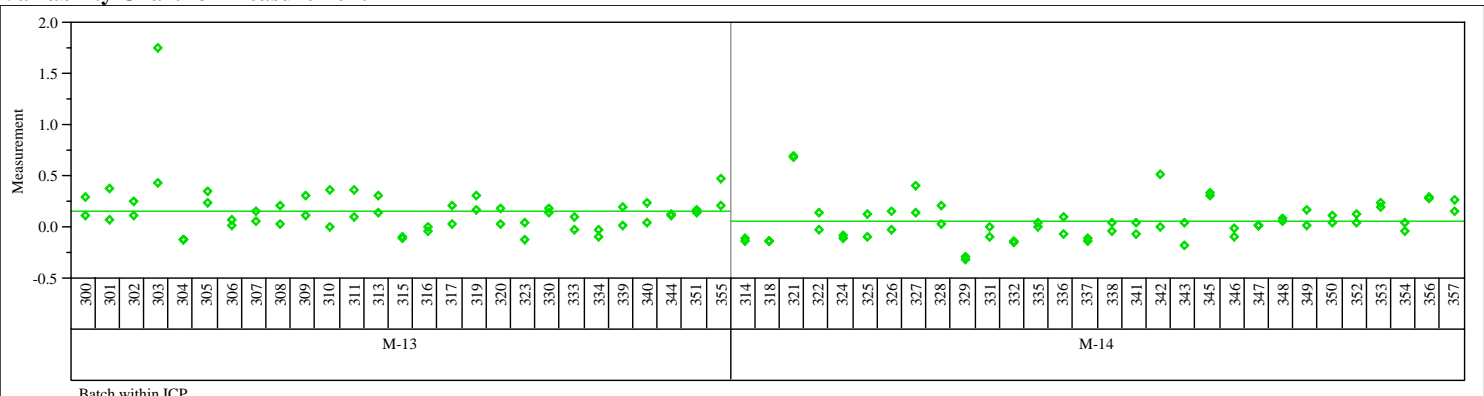

Prep $=$ Cold Chem, Sample Type $=$ blank, Analyte $=T i$

Variability Chart for Measurement

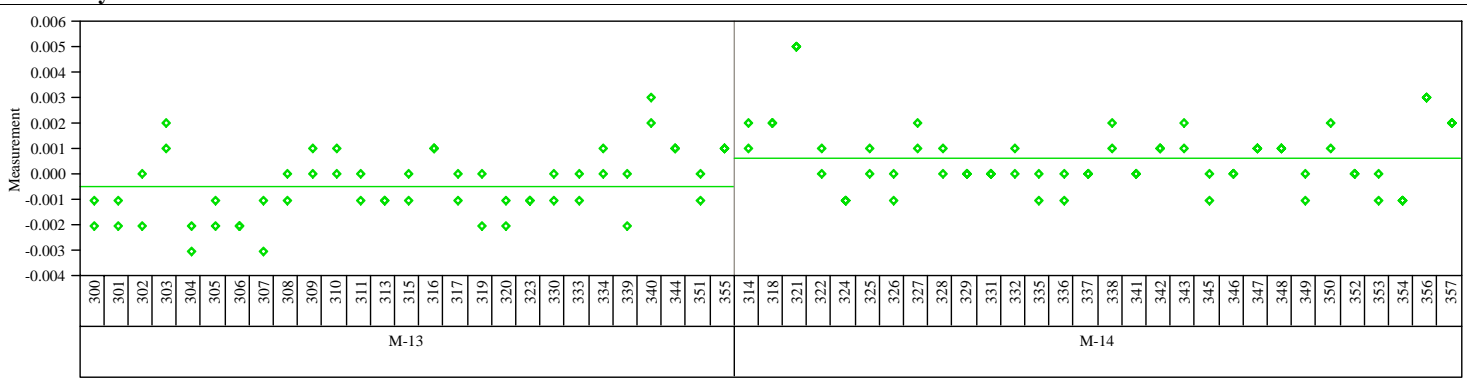

Prep=Cold Chem, Sample Type $=$ blank, Analyte $=U$

Variability Chart for Measurement

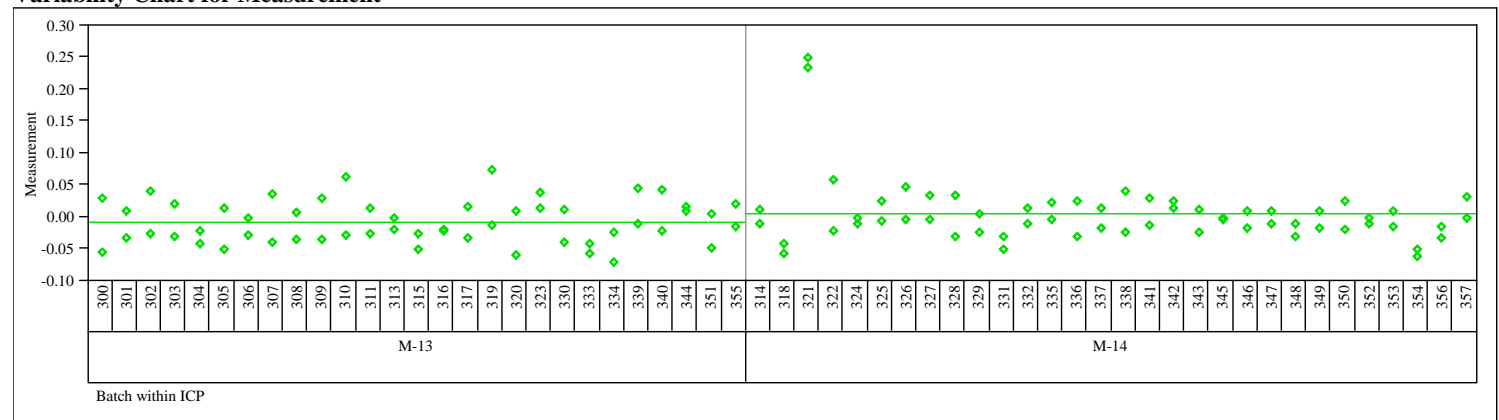


WSRC-STI-2006-00068

Revision 0

Exhibit A2. Measurement Data by Batch by ICP for Prep Method, Sample Type, and Analyte

Prep $=$ Cold Chem, Sample Type $=$ blank, Analyte $=U / C a$

(continued)

Variability Chart for Measurement

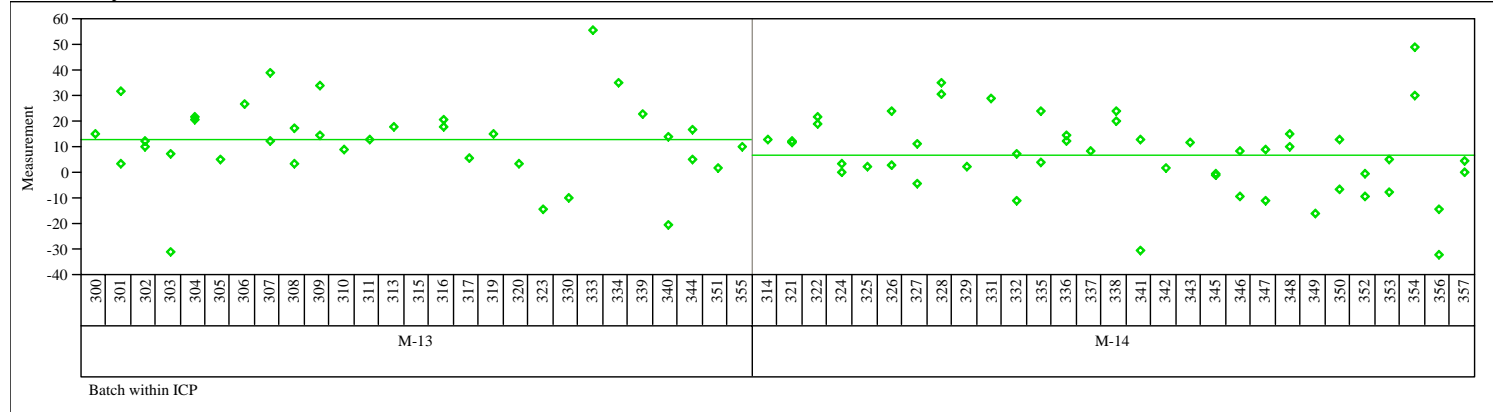

Prep $=$ Cold Chem, Sample Type $=$ blank, Analyte $=\mathrm{Zr}$

Variability Chart for Measurement

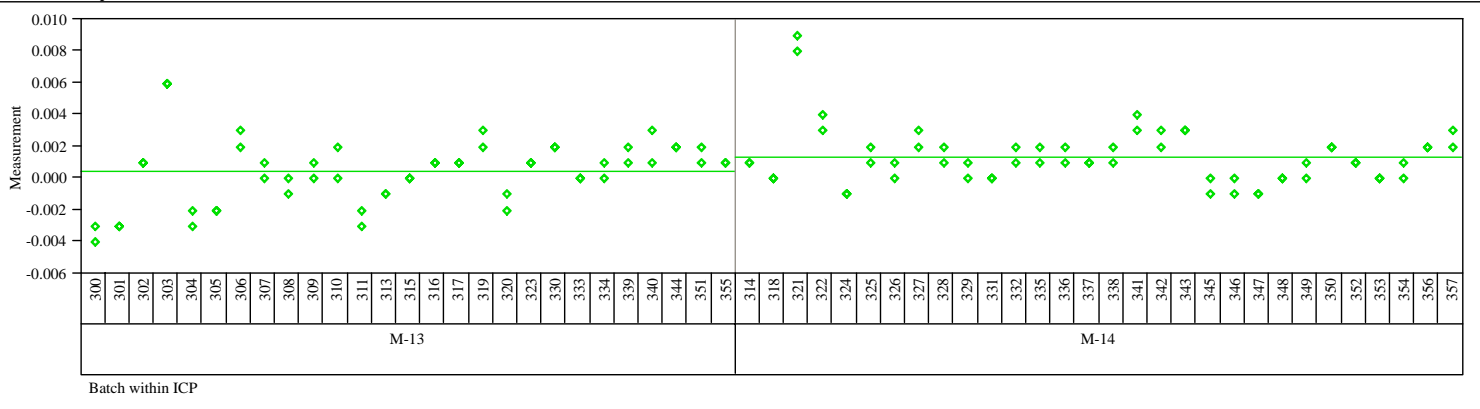

Prep=Fusion, Sample Type=ARG-1, Analyte=Al

Variability Chart for Measurement

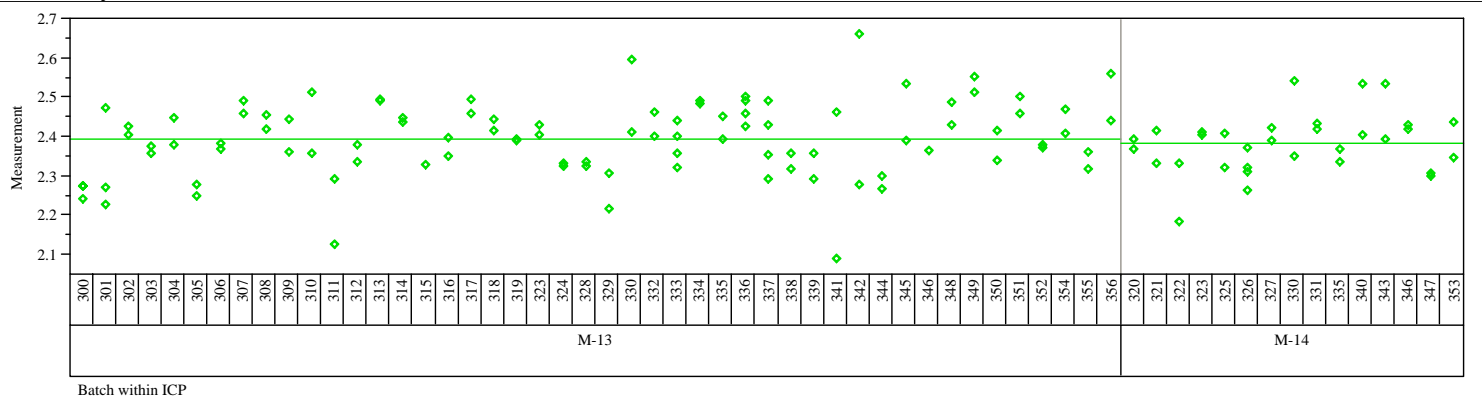

Prep=Fusion, Sample Type=ARG-1, Analyte=Al/Ca

Variability Chart for Measurement

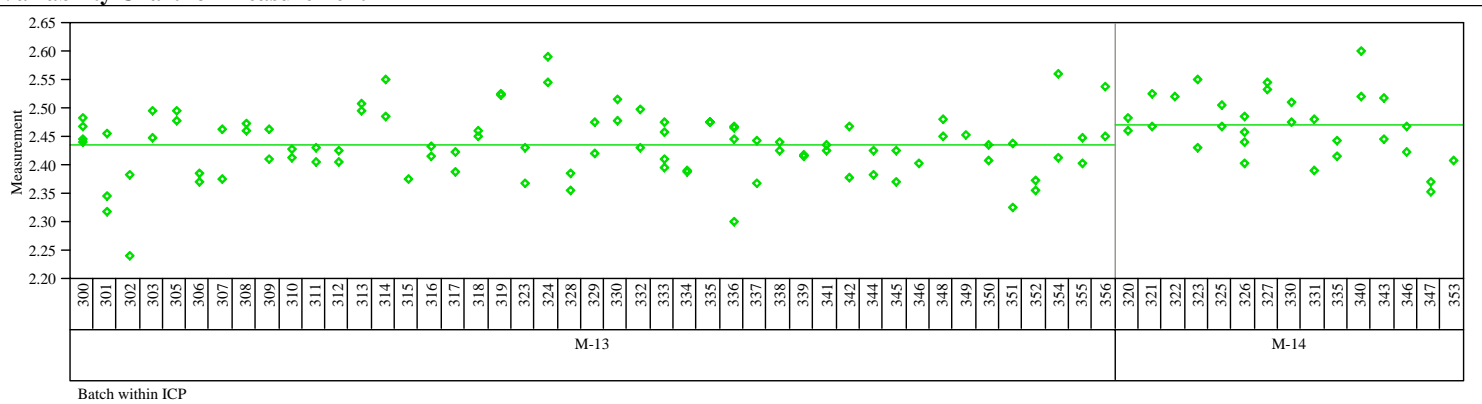


WSRC-STI-2006-00068

Revision 0

Exhibit A2. Measurement Data by Batch by ICP for Prep Method, Sample Type, and Analyte

Prep=Fusion, Sample Type=ARG-1, Analyte $=$ Al/Mg

(continued)

Variability Chart for Measurement

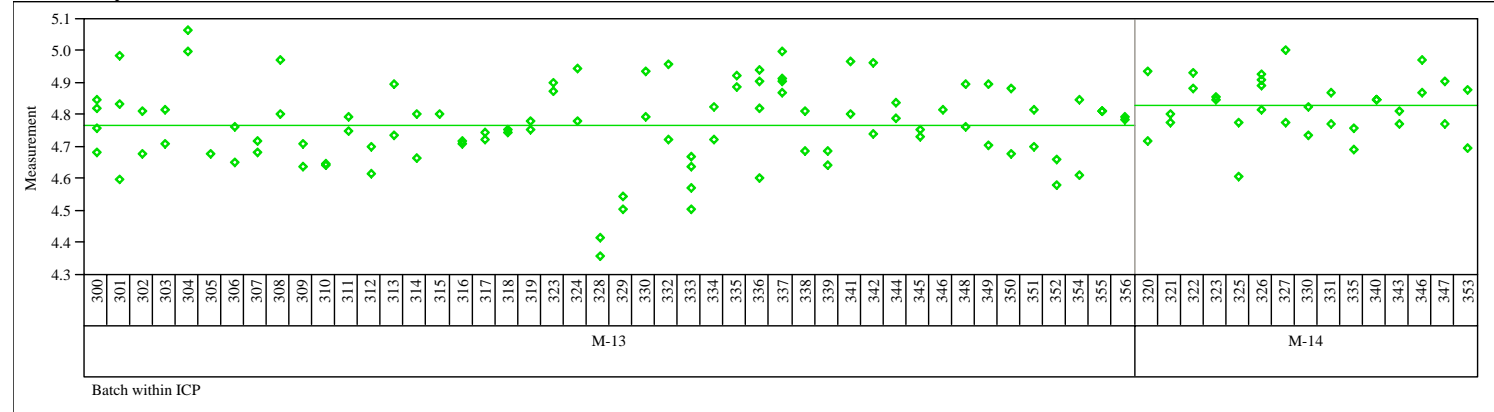

Prep $=$ Fusion, Sample Type $=$ ARG-1, Analyte $=A 1 /$ Mn

Variability Chart for Measurement

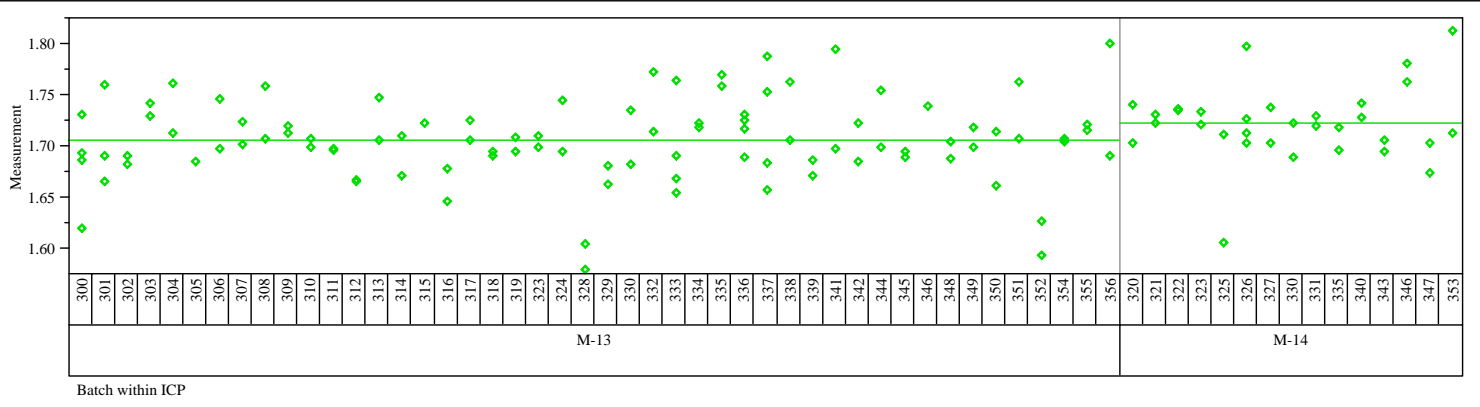

Prep=Fusion, Sample Type $=$ ARG-1, Analyte $=$ B

Variability Chart for Measurement

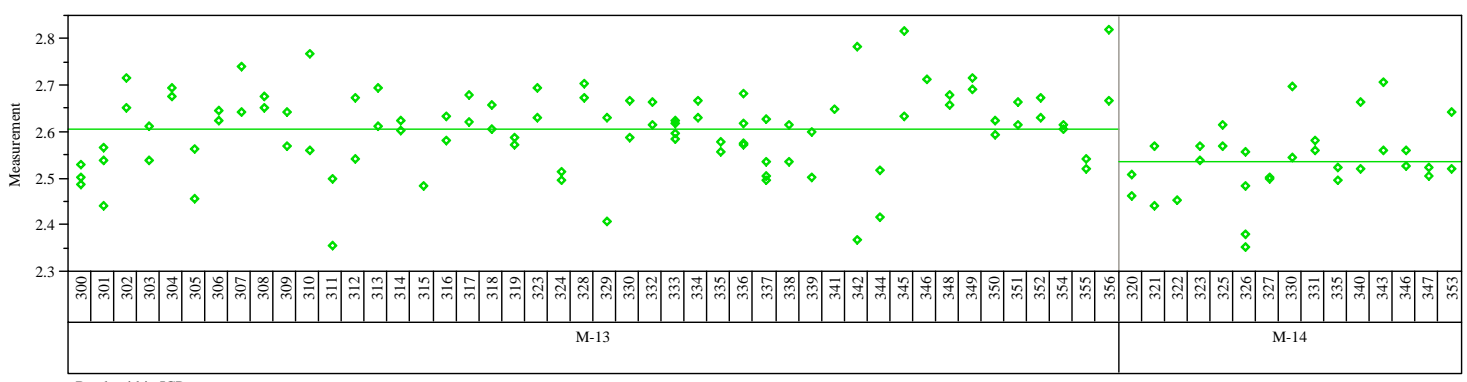

Batch within ICP

Prep=Fusion, Sample Type=ARG-1, Analyte $=$ B $/ \mathrm{Li}$

Variability Chart for Measurement

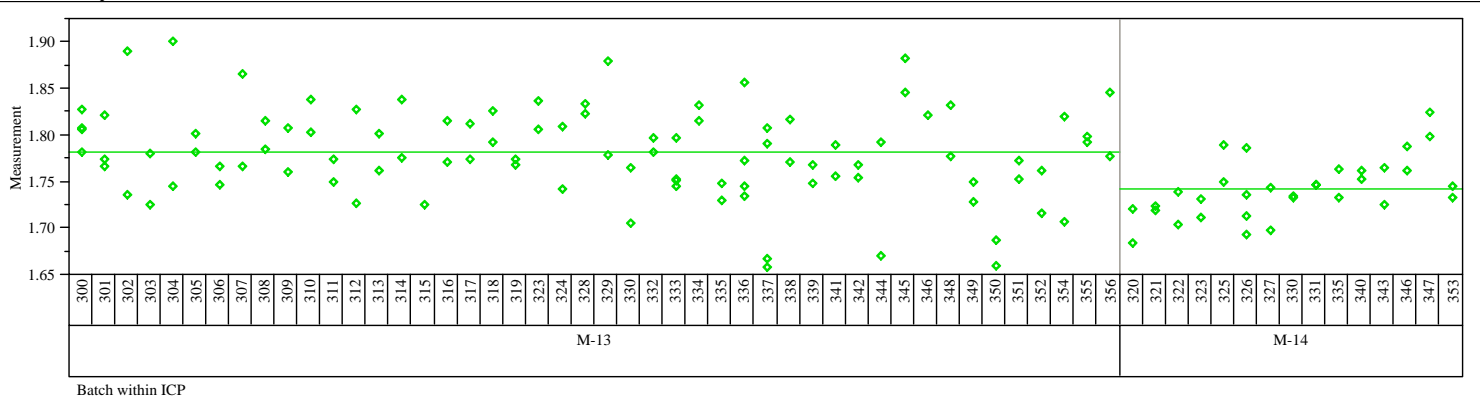


WSRC-STI-2006-00068

Revision 0

Exhibit A2. Measurement Data by Batch by ICP for Prep Method, Sample Type, and Analyte

Prep=Fusion, Sample Type=ARG-1, Analyte $=$ Ca

(continued)

Variability Chart for Measurement

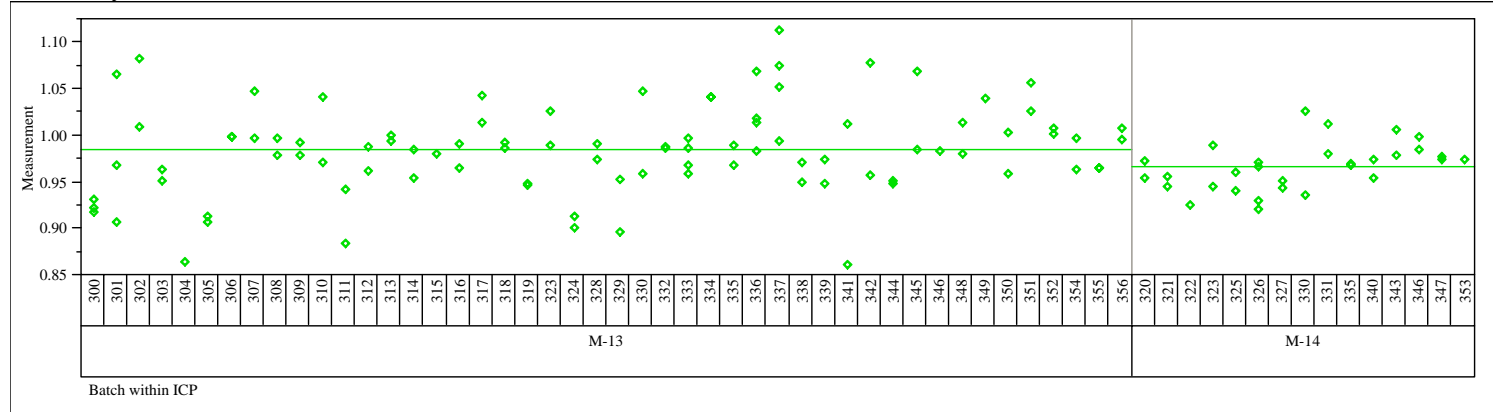

Prep $=$ Fusion, Sample Type $=$ ARG-1, Analyte $=$ Cr

Variability Chart for Measurement

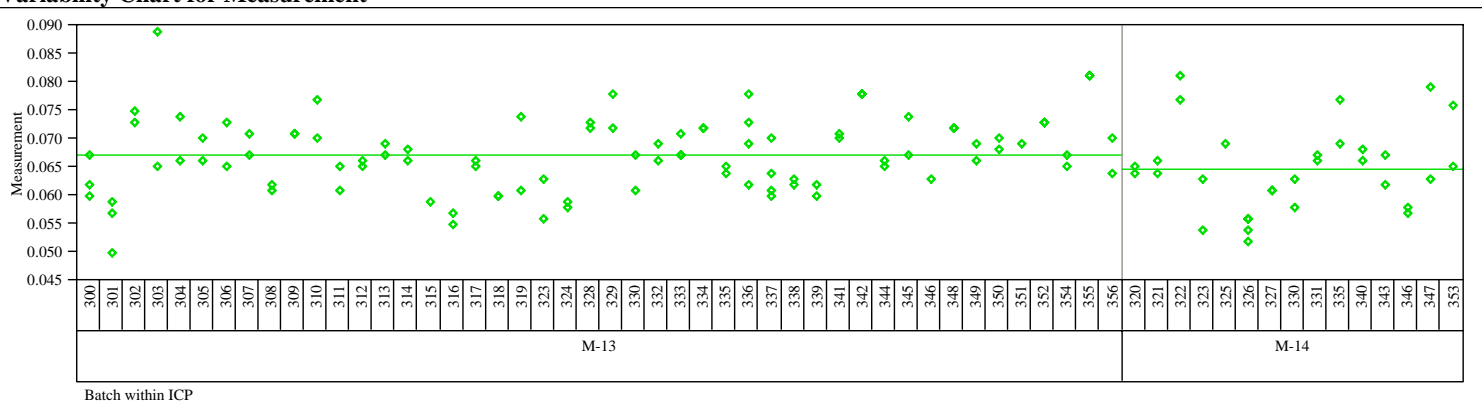

Prep $=$ Fusion, Sample Type $=$ ARG-1, Analyte $=$ Cu

Variability Chart for Measurement

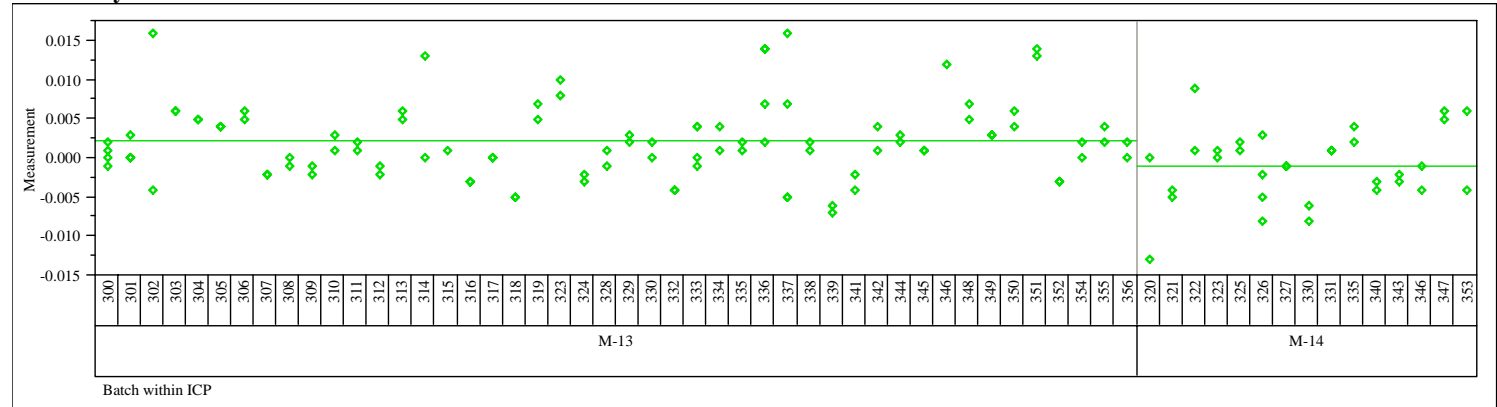

Prep=Fusion, Sample Type $=$ ARG-1, Analyte $=$ Fe

Variability Chart for Measurement

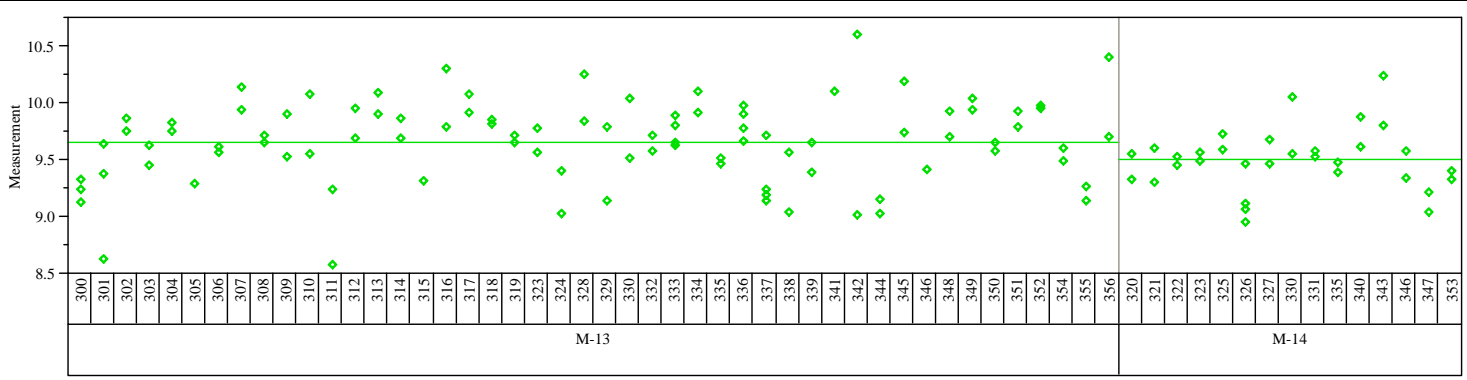


WSRC-STI-2006-00068

Revision 0

Exhibit A2. Measurement Data by Batch by ICP for Prep Method, Sample Type, and Analyte

Prep=Fusion, Sample Type=ARG-1, Analyte=Fe/Al

(continued)

Variability Chart for Measurement

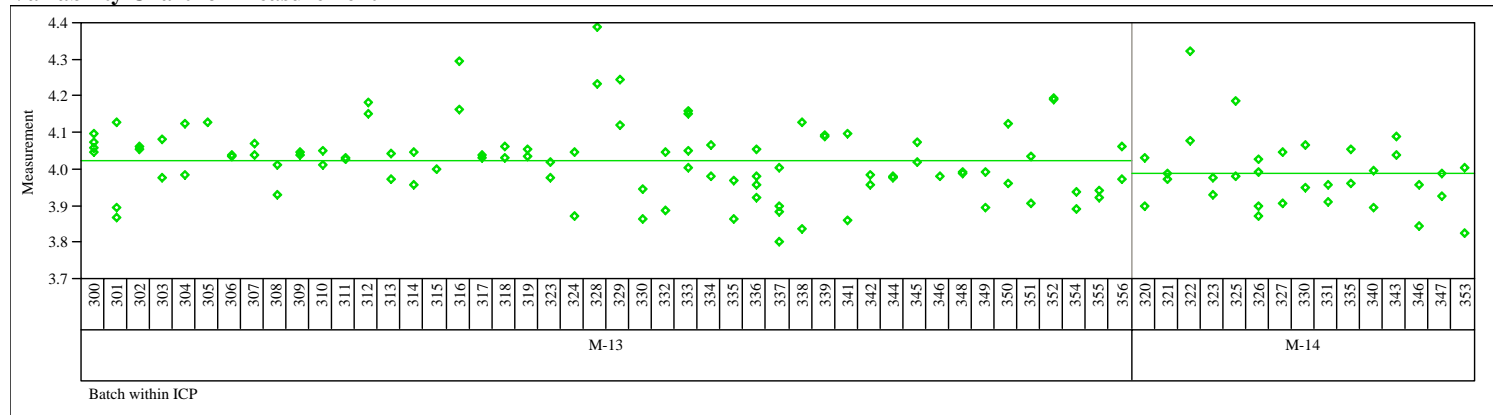

Prep=Fusion, Sample Type $=$ ARG-1, Analyte $=$ Fe $/$ Ca

Variability Chart for Measurement

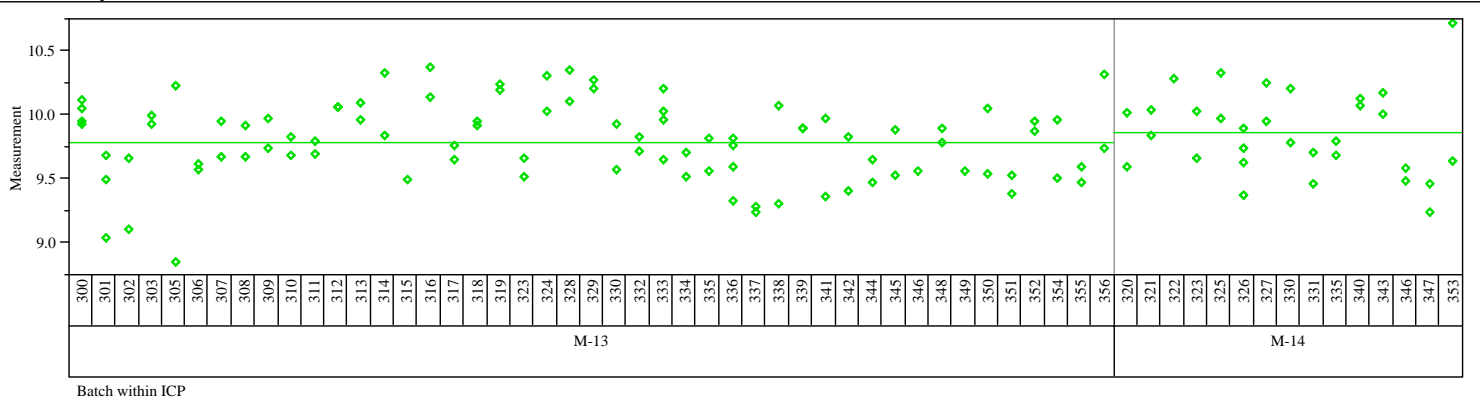

Prep $=$ Fusion, Sample Type $=$ ARG-1, Analyte $=$ Fe $/$ Li

Variability Chart for Measurement

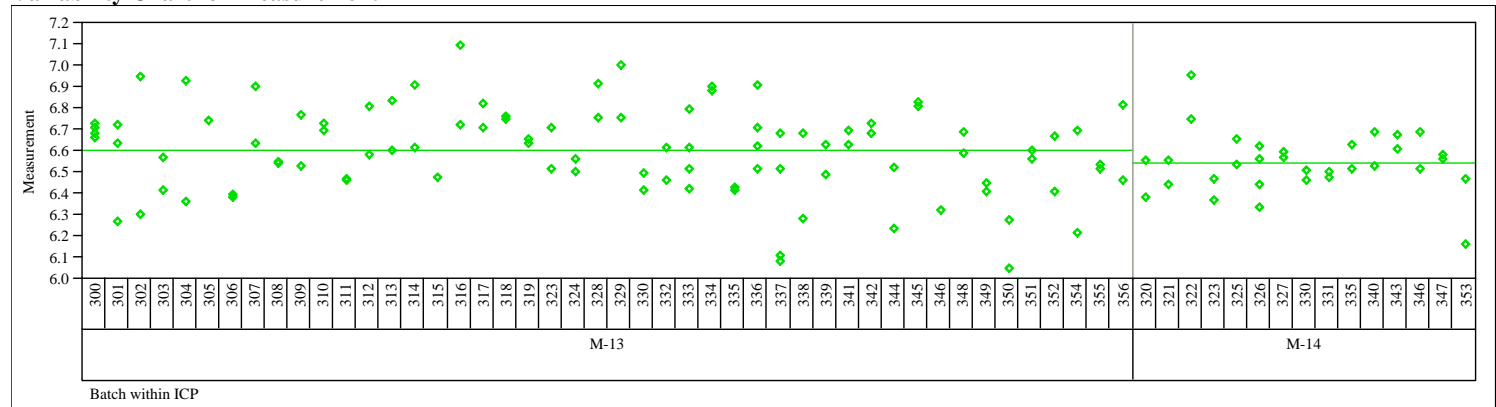

Prep=Fusion, Sample Type=ARG-1, Analyte $=$ Fe $/ \mathbf{M g}$

Variability Chart for Measurement

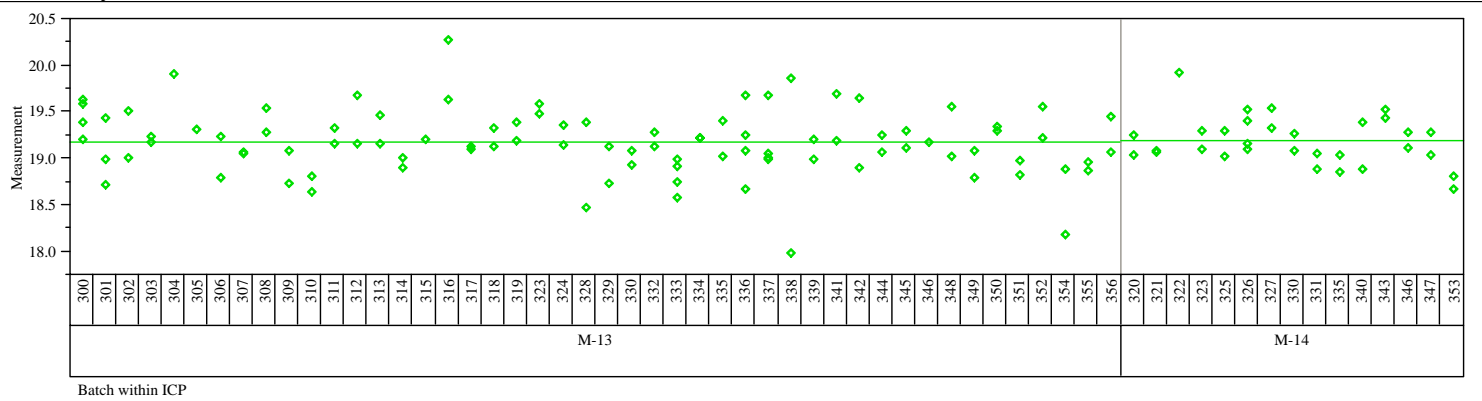


WSRC-STI-2006-00068

Revision 0

Exhibit A2. Measurement Data by Batch by ICP for Prep Method, Sample Type, and Analyte

Prep $=$ Fusion, Sample Type $=$ ARG -1 , Analyte $=$ Fe $/$ Mn

(continued)

Variability Chart for Measurement

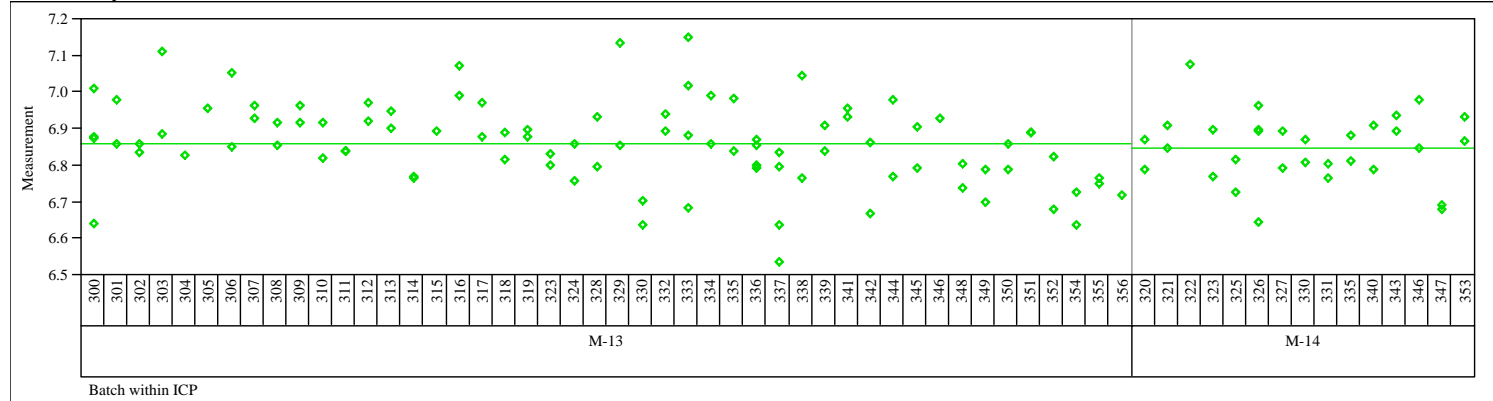

Prep=Fusion, Sample Type=ARG-1, Analyte $=$ Fe/Ni

Variability Chart for Measurement

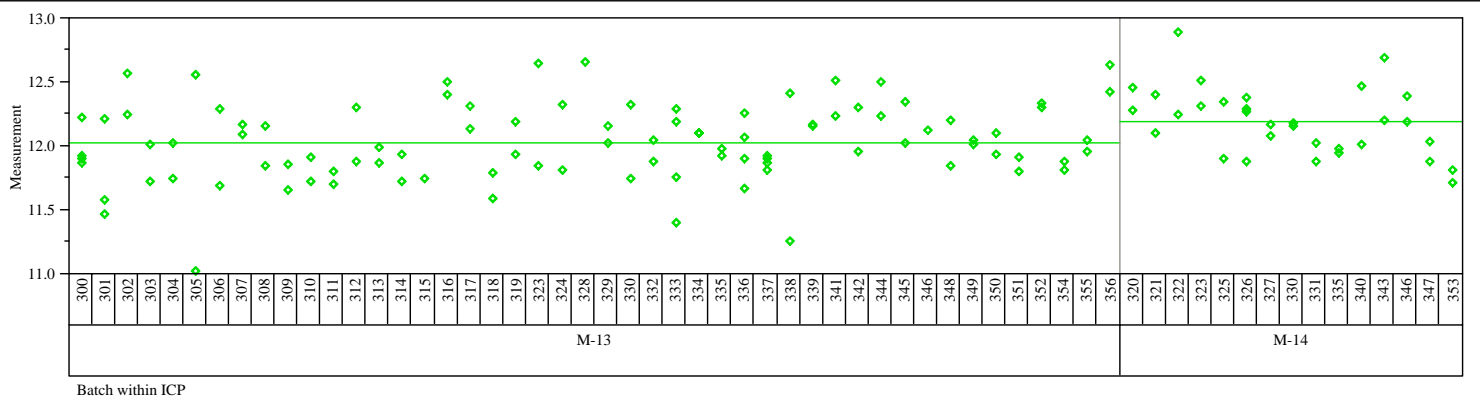

Prep=Fusion, Sample Type $=$ ARG-1, Analyte $=$ Fe $/ U$

Variability Chart for Measurement

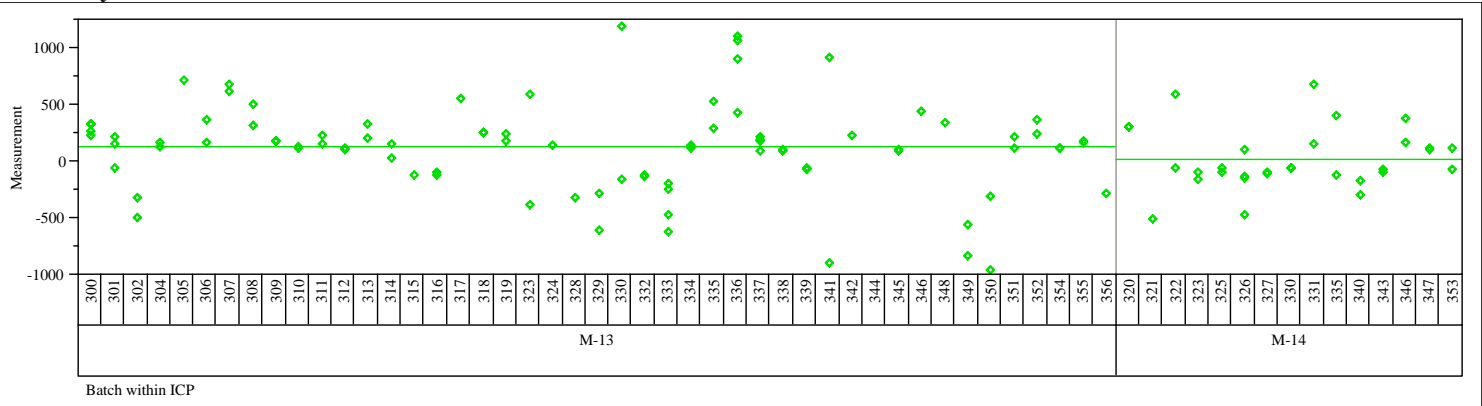

Prep=Fusion, Sample Type=ARG-1, Analyte $=$ K

Variability Chart for Measurement

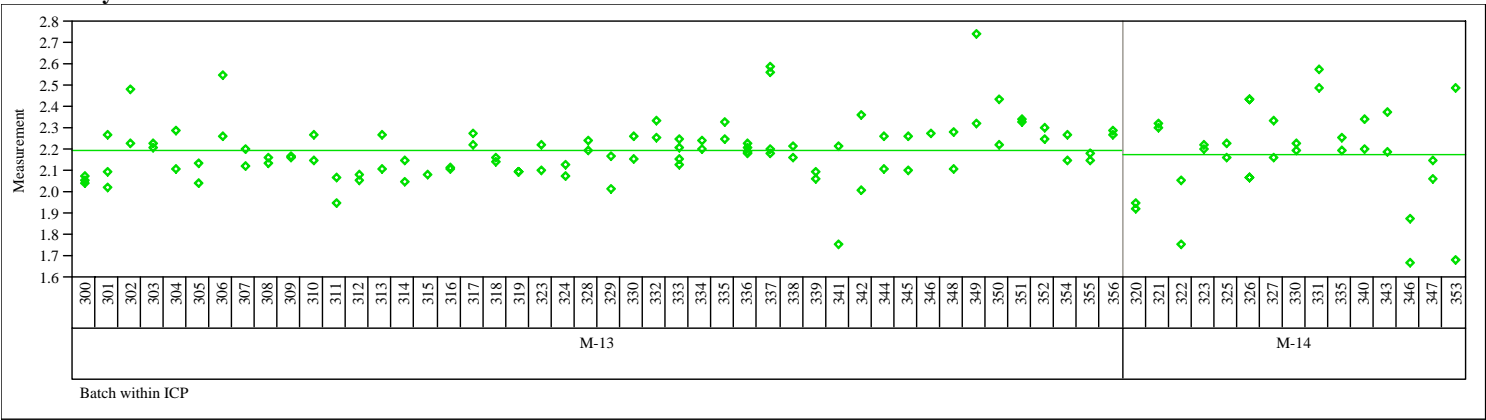


WSRC-STI-2006-00068

Revision 0

Exhibit A2. Measurement Data by Batch by ICP for Prep Method, Sample Type, and Analyte

Prep=Fusion, Sample Type=ARG-1, Analyte $=\mathbf{L i}$

(continued)

Variability Chart for Measurement

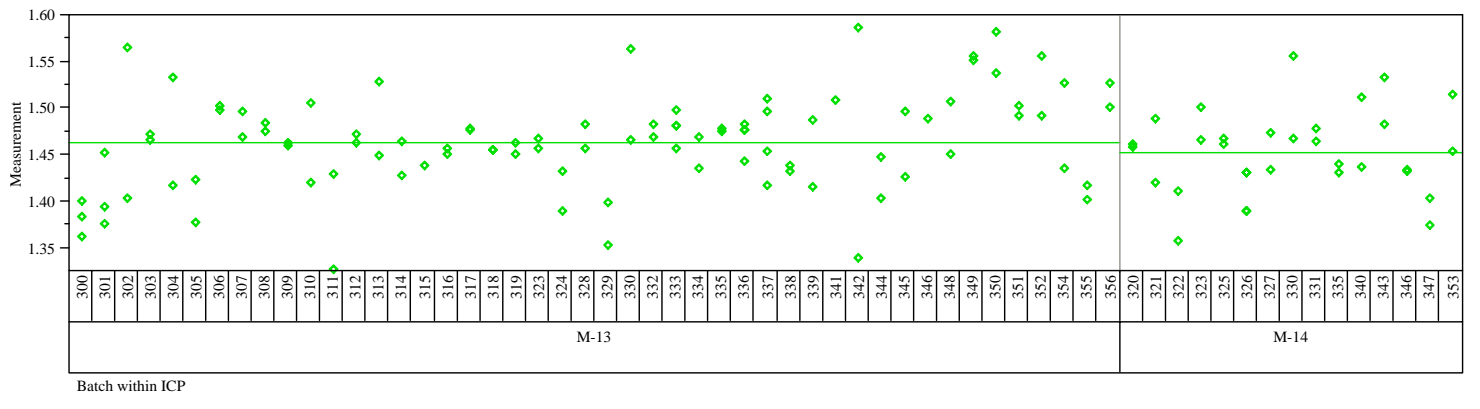

Prep=Fusion, Sample Type $=$ ARG-1, Analyte $=$ Mg

Variability Chart for Measurement

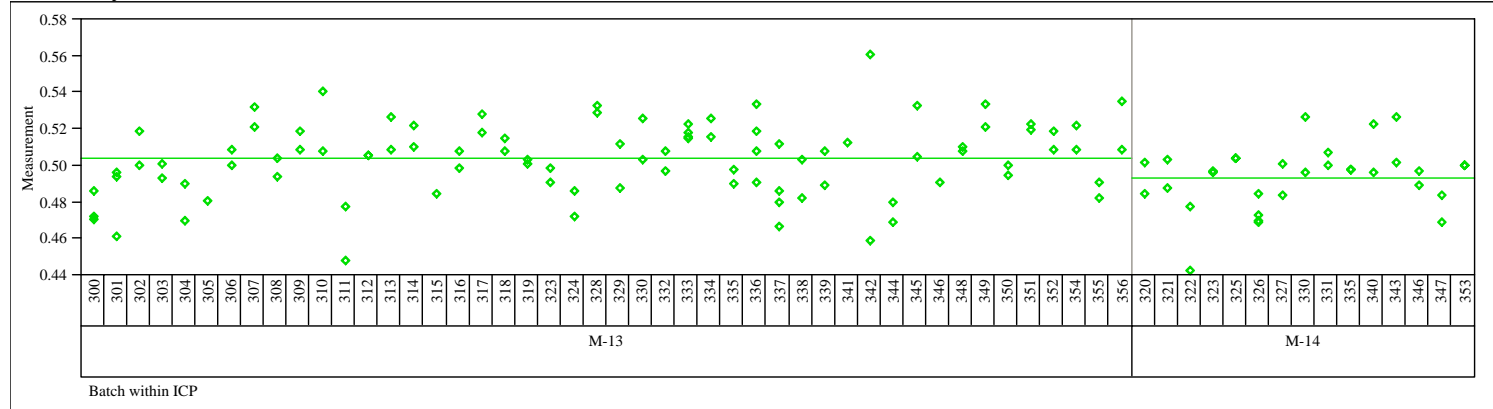

Prep $=$ Fusion, Sample Type $=$ ARG-1, Analyte $=M n$

Variability Chart for Measurement

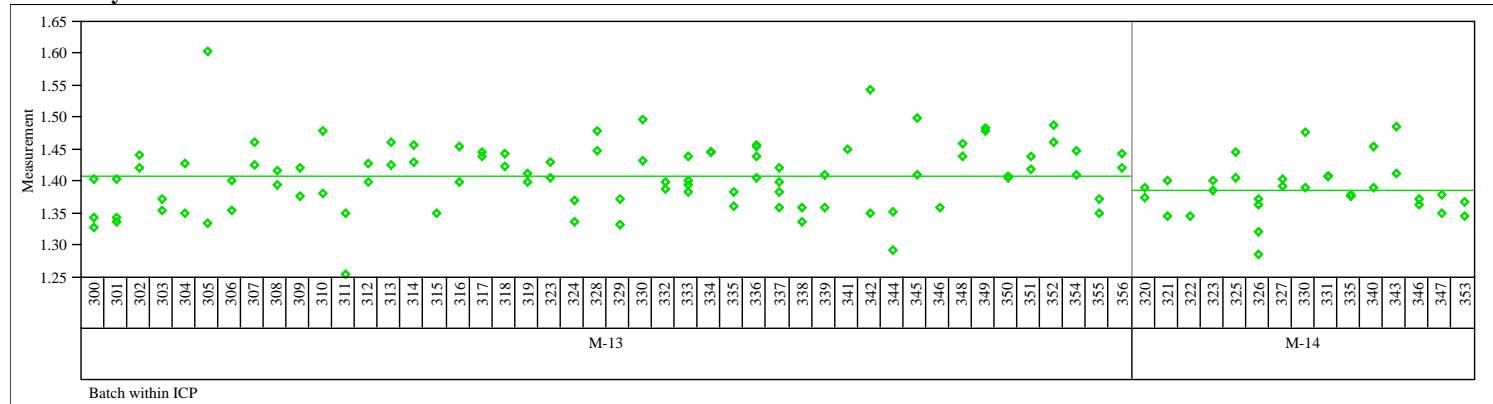

Prep=Fusion, Sample Type $=$ ARG-1, Analyte $=\mathbf{M n} / \mathbf{M g}$

Variability Chart for Measurement

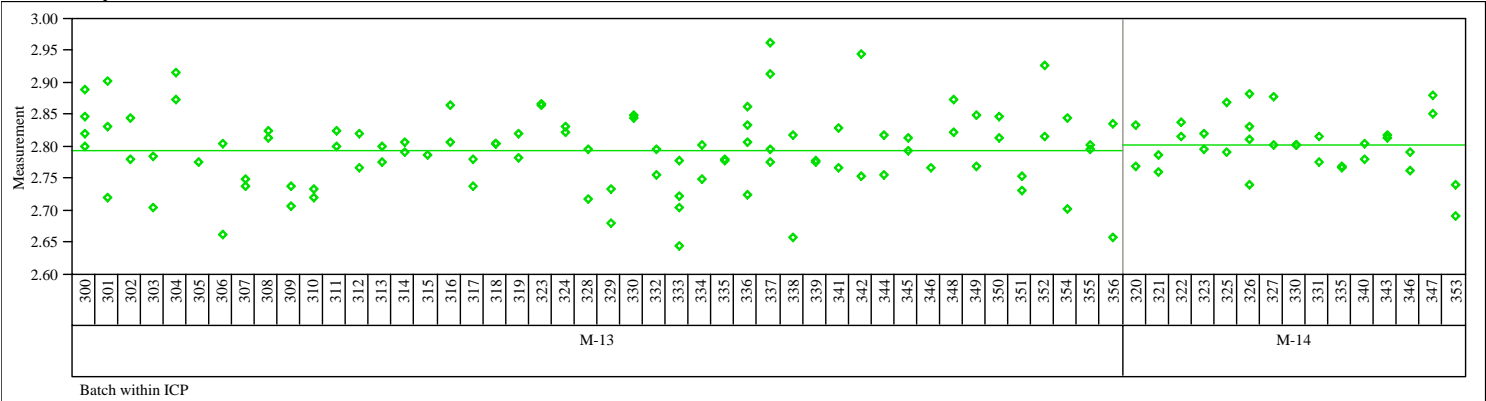


WSRC-STI-2006-00068

Revision 0

Exhibit A2. Measurement Data by Batch by ICP for Prep Method, Sample Type, and Analyte

Prep=Fusion, Sample Type $=$ ARG-1, Analyte $=\mathrm{Na}$

(continued)

Variability Chart for Measurement
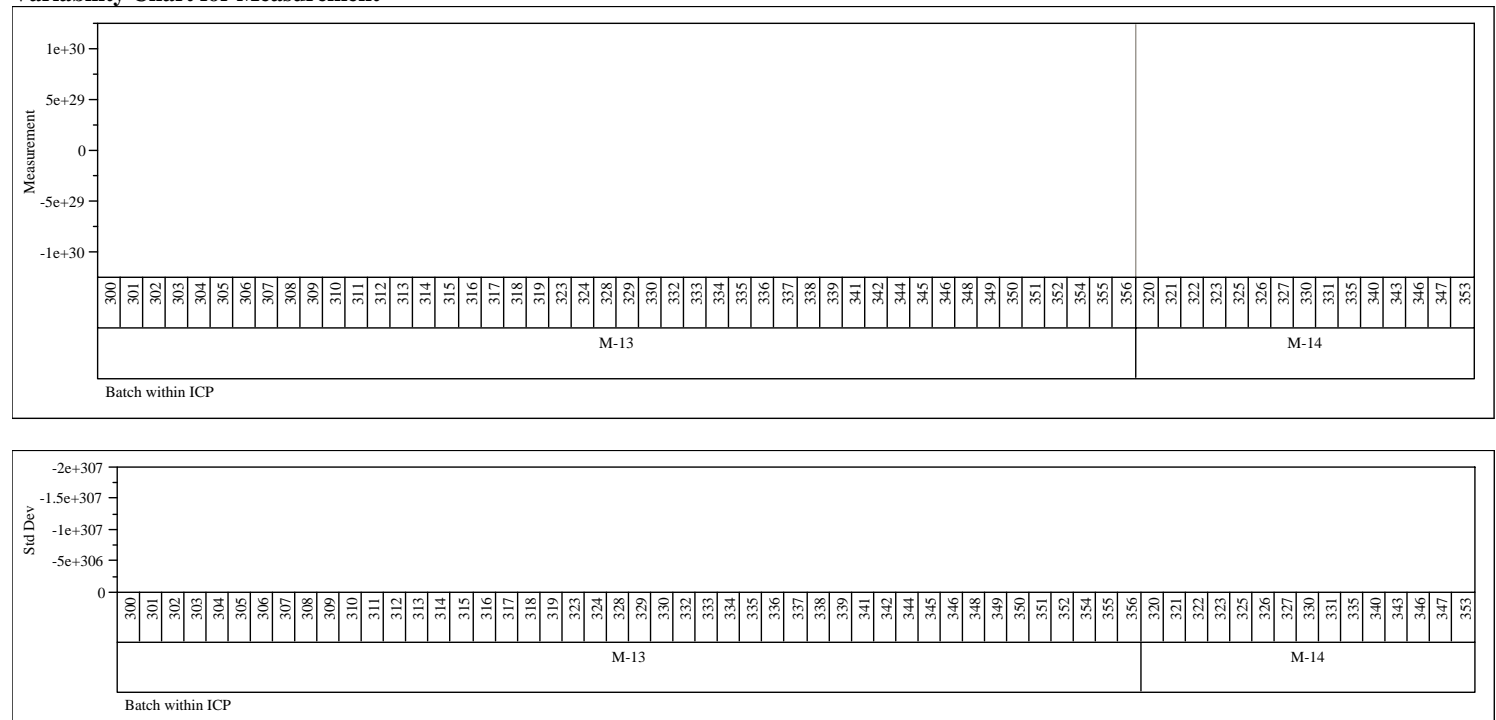

Prep $=$ Fusion, Sample Type $=$ ARG-1, Analyte $=$ Ni

Variability Chart for Measurement

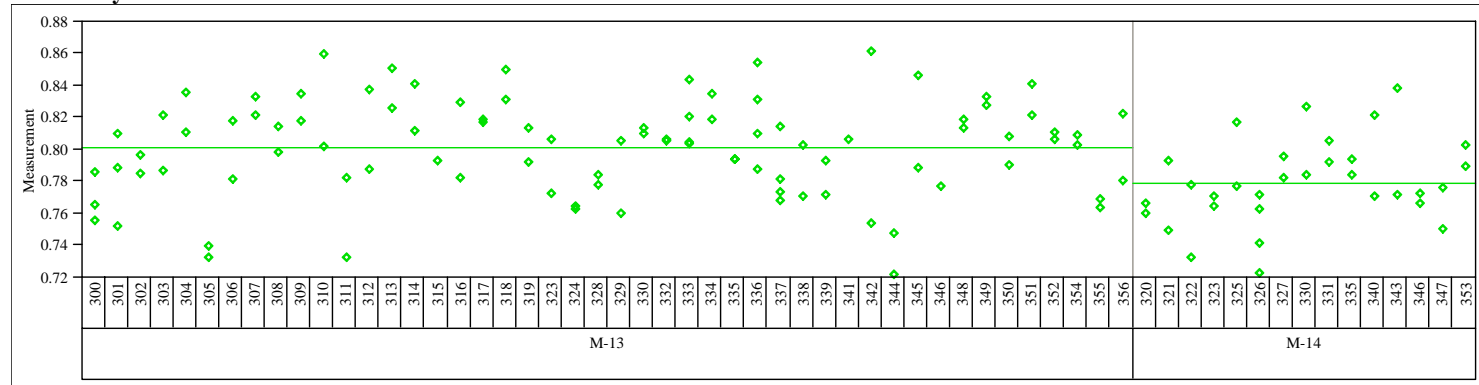

Prep $=$ Fusion, Sample Type $=$ ARG-1, Analyte $=$ Si

Variability Chart for Measurement

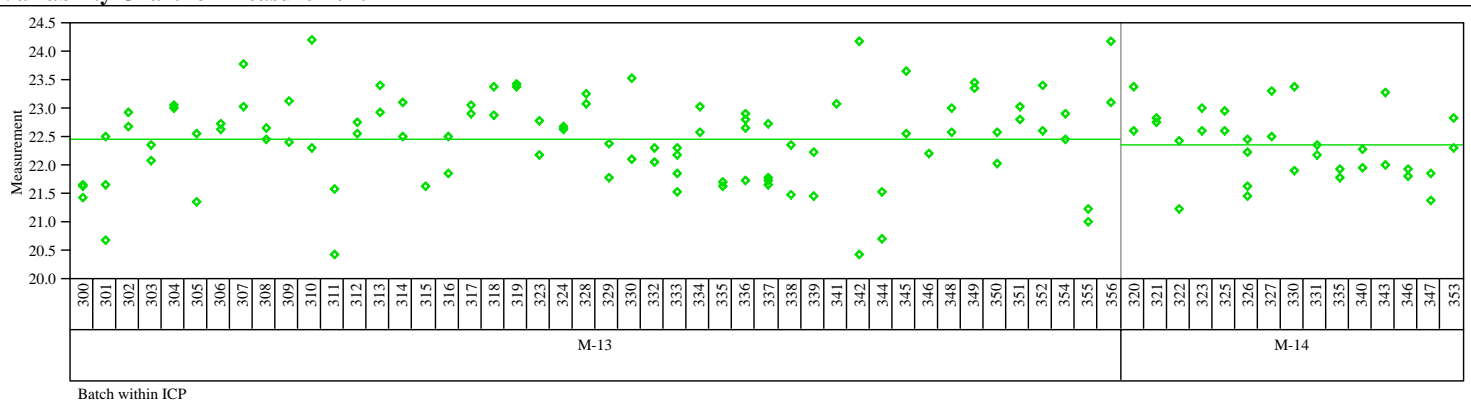


WSRC-STI-2006-00068

Revision 0

Exhibit A2. Measurement Data by Batch by ICP for Prep Method, Sample Type, and Analyte

Prep=Fusion, Sample Type $=$ ARG -1 , Analyte $=$ Sum of Oxides

(continued)

Variability Chart for Measurement

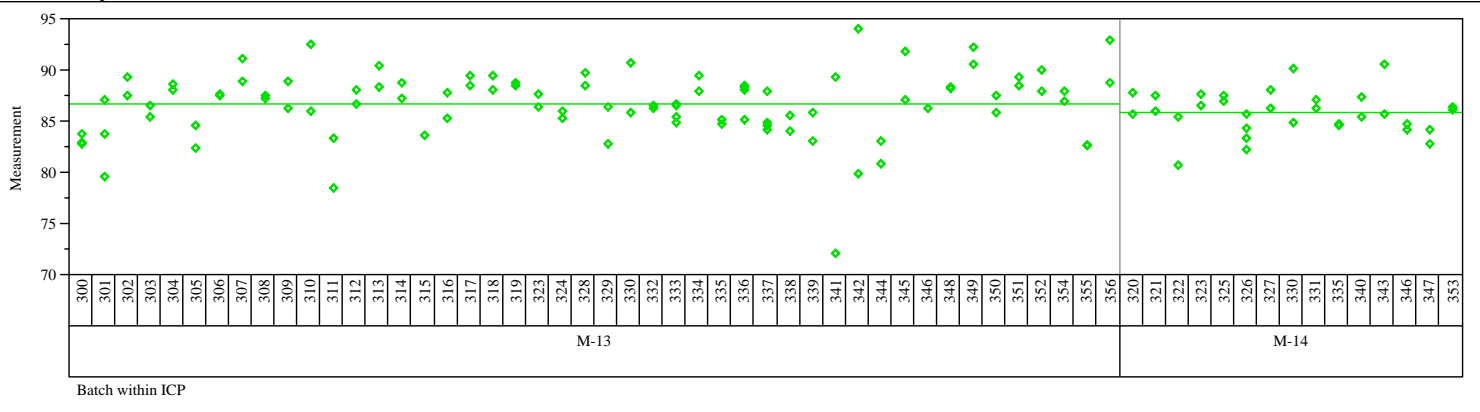

Prep $=$ Fusion, Sample Type $=$ ARG-1, Analyte $=$ Ti

Variability Chart for Measurement

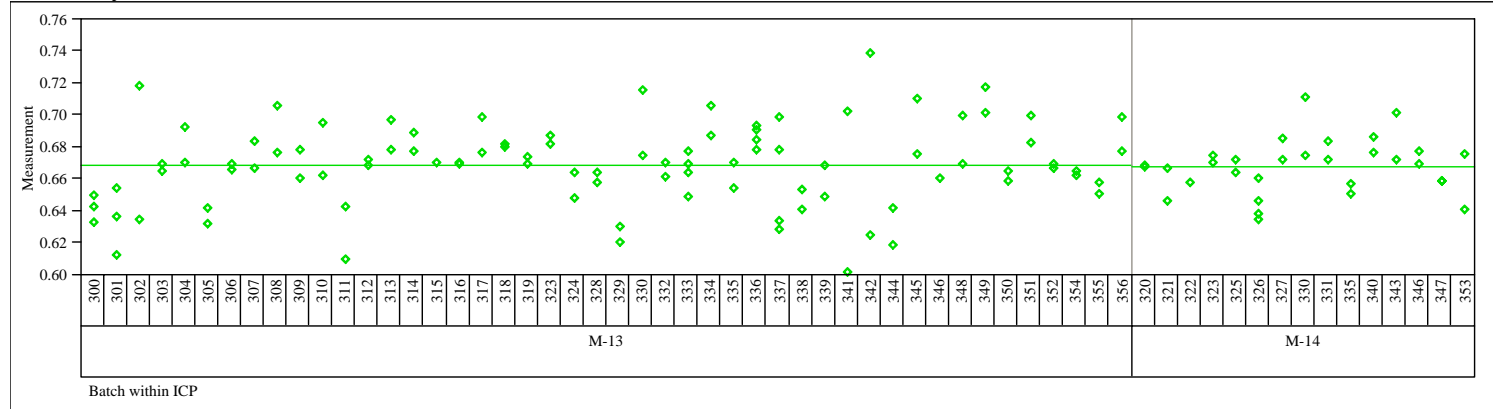

Prep $=$ Fusion, Sample Type $=$ ARG -1 , Analyte $=U$

Variability Chart for Measurement

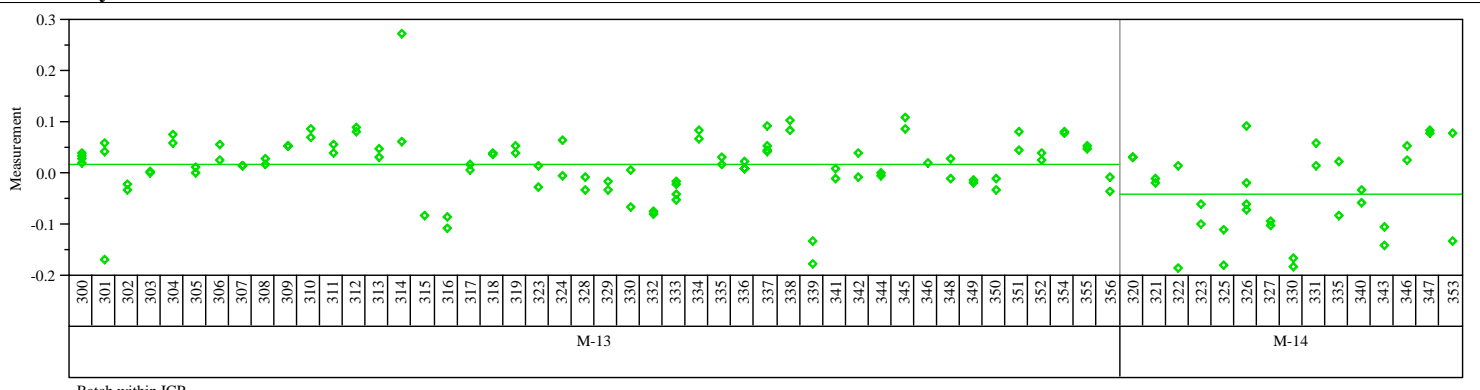

Prep $=$ Fusion, Sample Type $=$ ARG-1, Analyte $=U / C a$

Variability Chart for Measurement

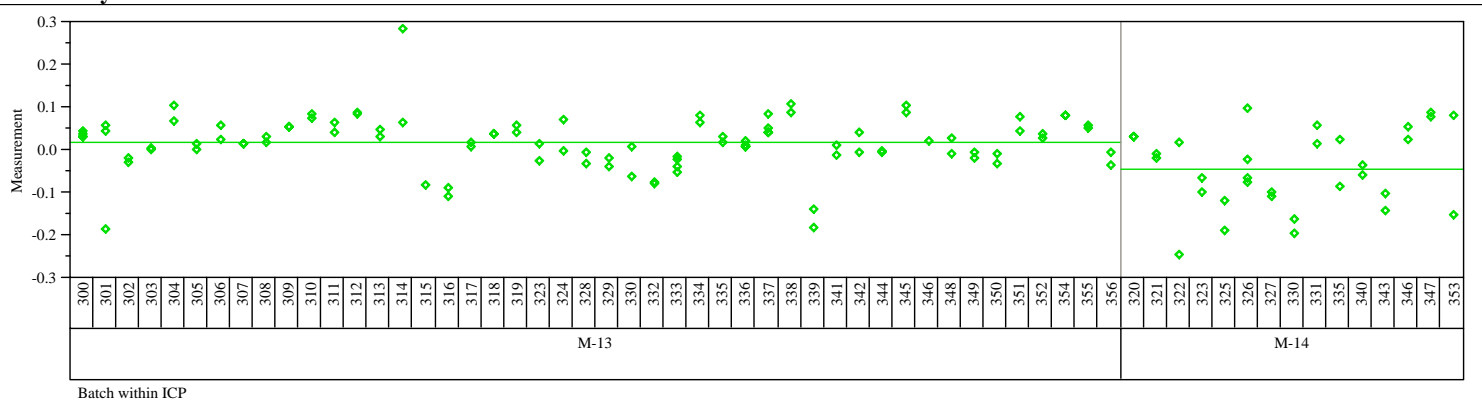


WSRC-STI-2006-00068

Revision 0

Exhibit A2. Measurement Data by Batch by ICP for Prep Method, Sample Type, and Analyte

Prep $=$ Fusion, Sample Type $=$ ARG-1, Analyte $=\mathrm{Zr}$

(continued)

Variability Chart for Measurement
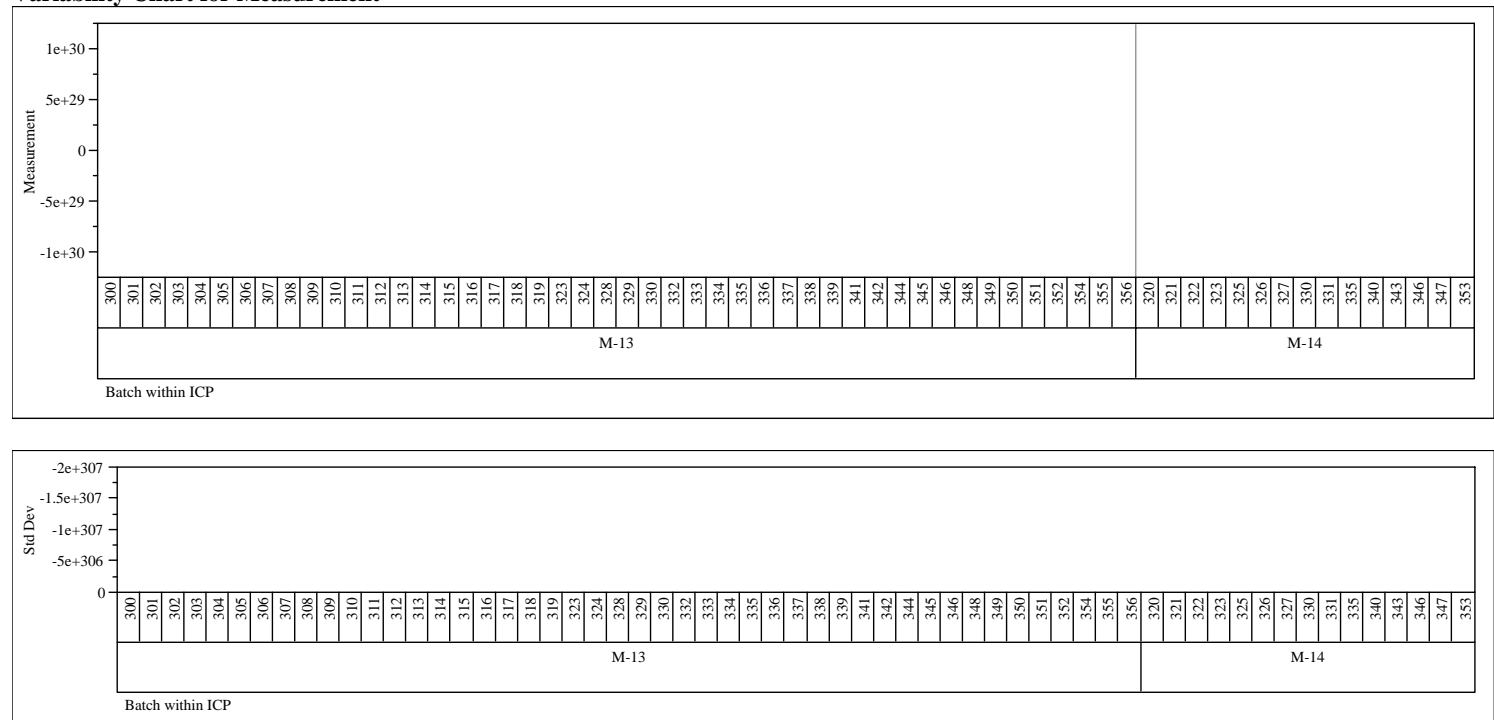

Prep $=$ Fusion, Sample Type $=$ SME, Analyte $=$ Al

Variability Chart for Measurement

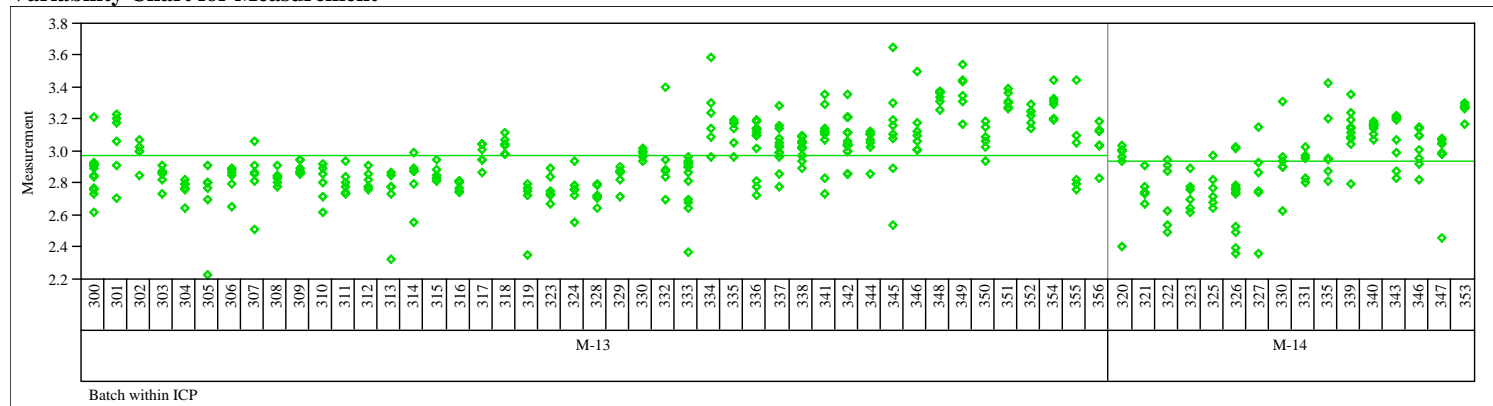

Prep $=$ Fusion, Sample Type $=$ SME, Analyte $=\mathrm{Al} / \mathrm{C}$

Variability Chart for Measurement

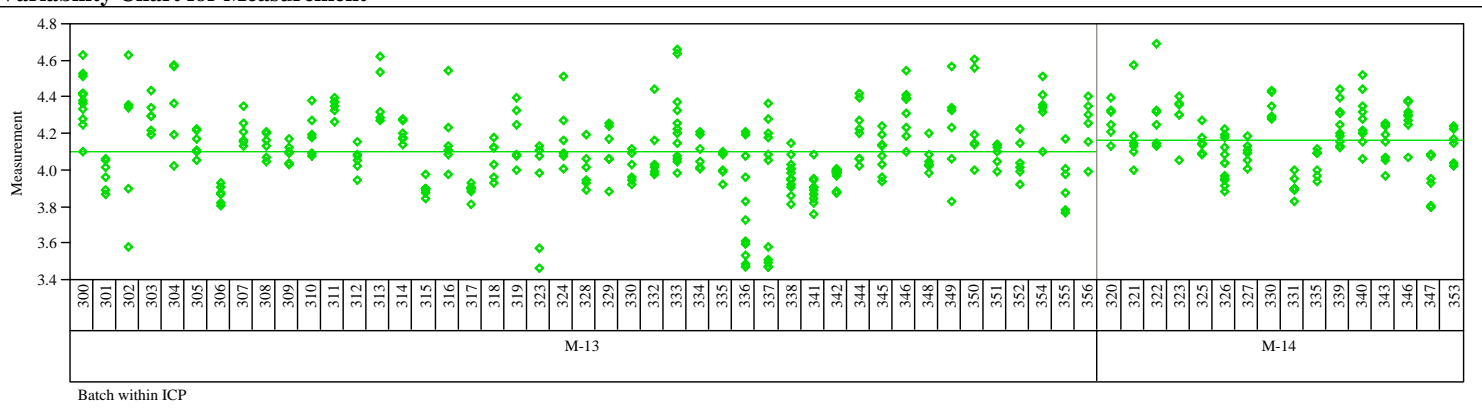


WSRC-STI-2006-00068

Revision 0

Exhibit A2. Measurement Data by Batch by ICP for Prep Method, Sample Type, and Analyte

Prep $=$ Fusion, Sample Type $=$ SME, Analyte $=\mathrm{Al} / \mathrm{Mg}$

(continued)

Variability Chart for Measurement

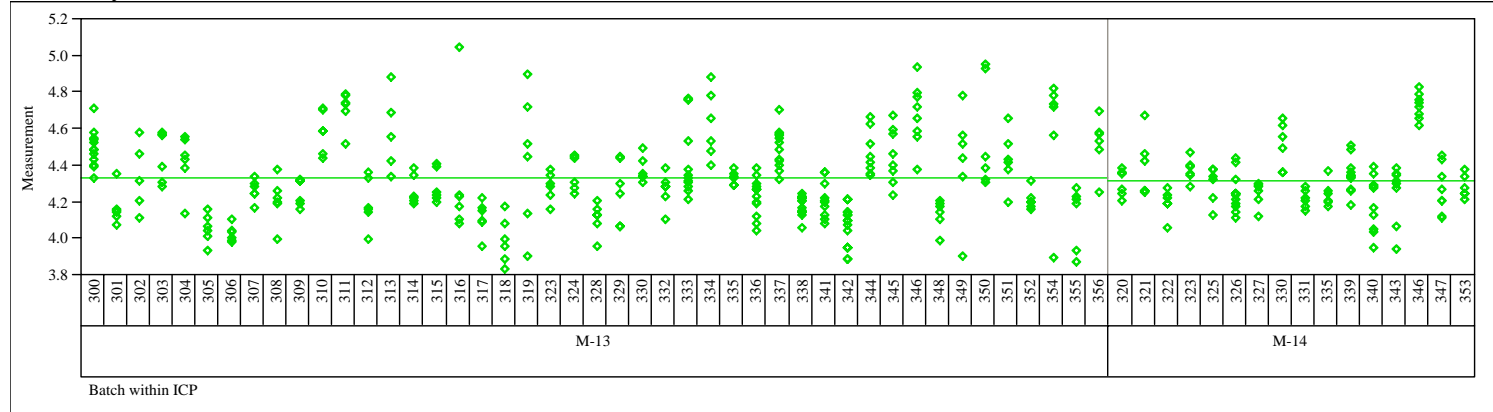

Prep $=$ Fusion, Sample Type $=$ SME, Analyte $=\mathrm{Al} / \mathrm{Mn}$

Variability Chart for Measurement

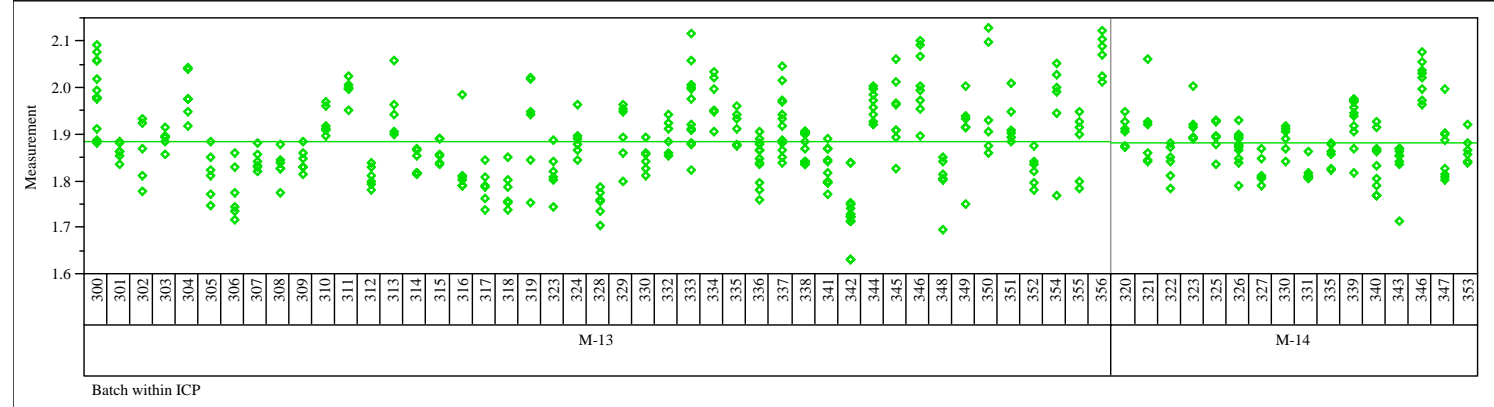

Prep=Fusion, Sample Type=SME, Analyte $=B$

Variability Chart for Measurement

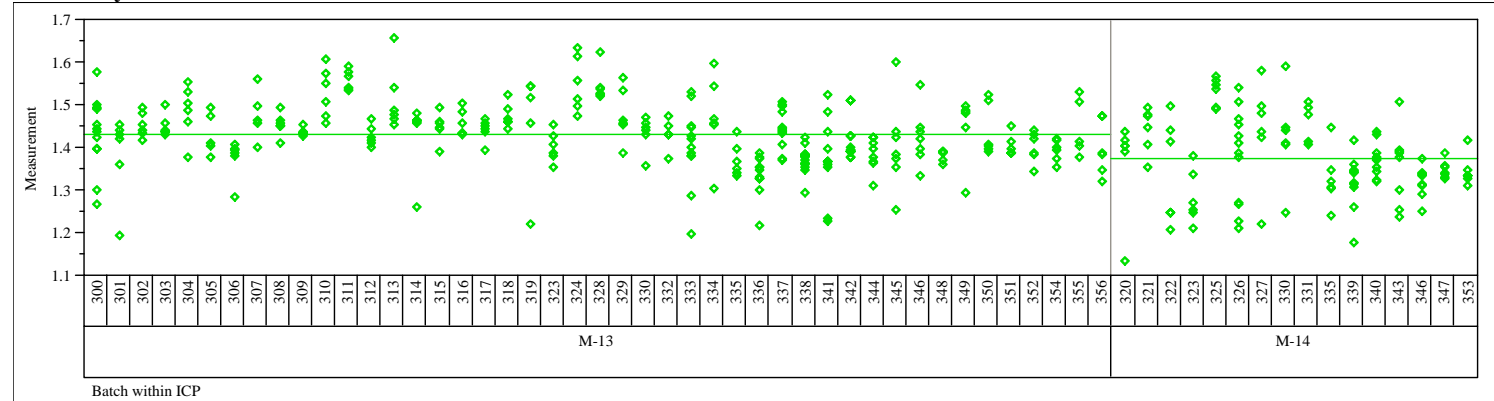

Prep $=$ Fusion, Sample Type $=$ SME, Analyte $=B / L i$

Variability Chart for Measurement

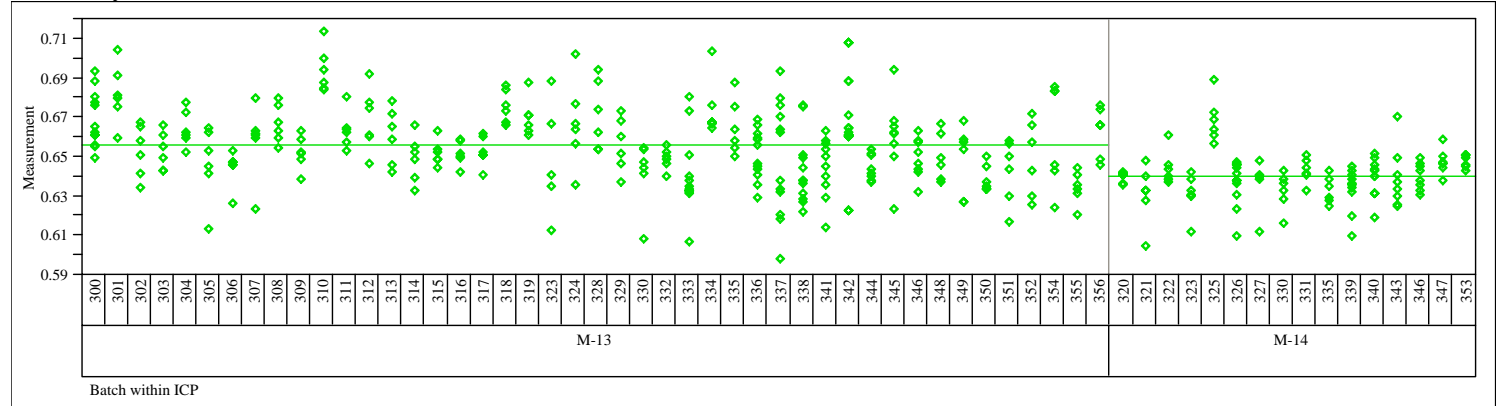


WSRC-STI-2006-00068

Revision 0

Exhibit A2. Measurement Data by Batch by ICP for Prep Method, Sample Type, and Analyte

Prep $=$ Fusion, Sample Type $=$ SME, Analyte $=\mathrm{Ca}$

(continued)

Variability Chart for Measurement

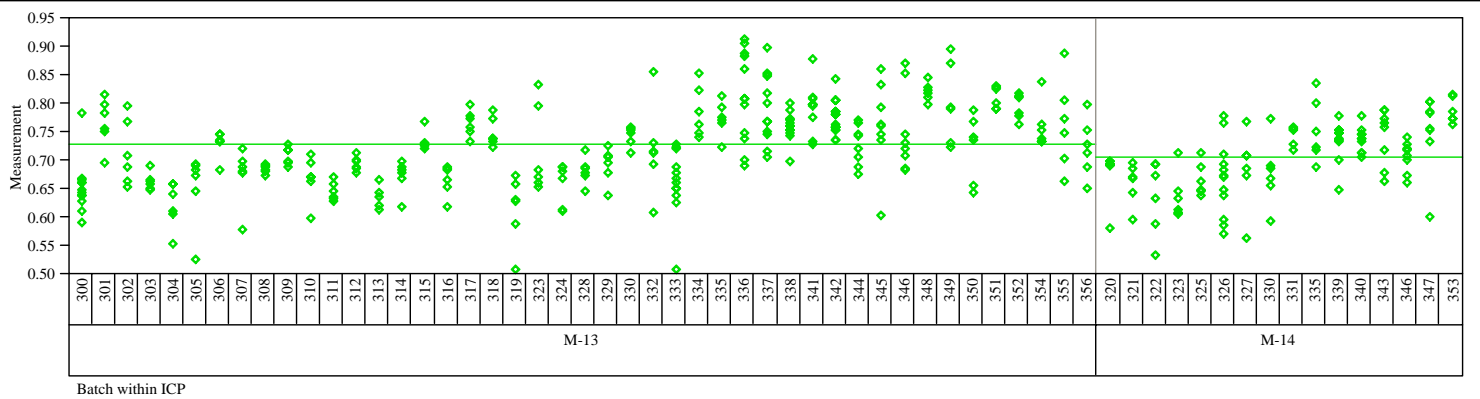

Prep $=$ Fusion, Sample Type $=$ SME, Analyte $=\mathrm{Cr}$

Variability Chart for Measurement

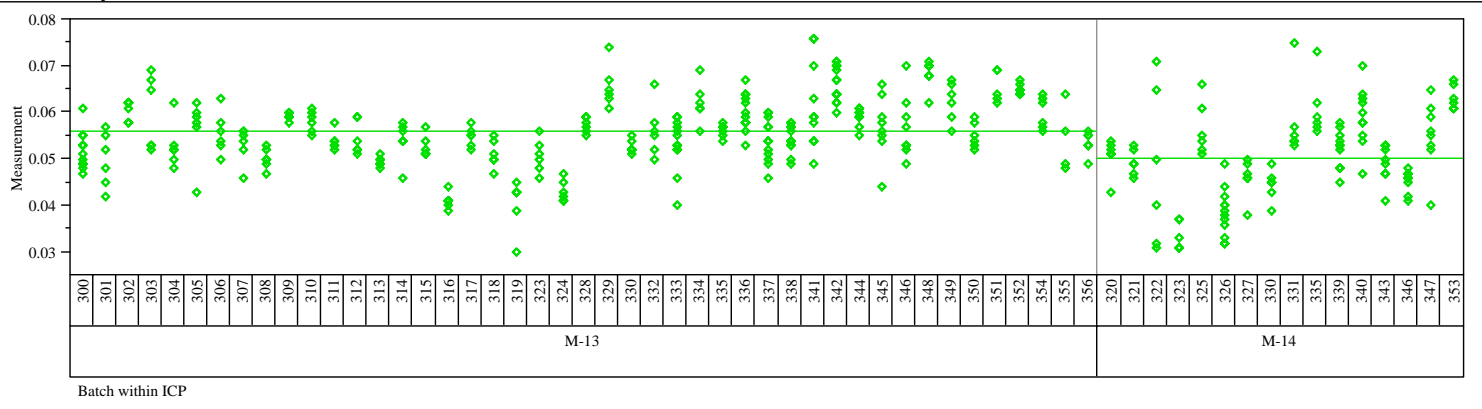

Prep $=$ Fusion, Sample Type $=$ SME, Analyte $=\mathrm{Cu}$

Variability Chart for Measurement

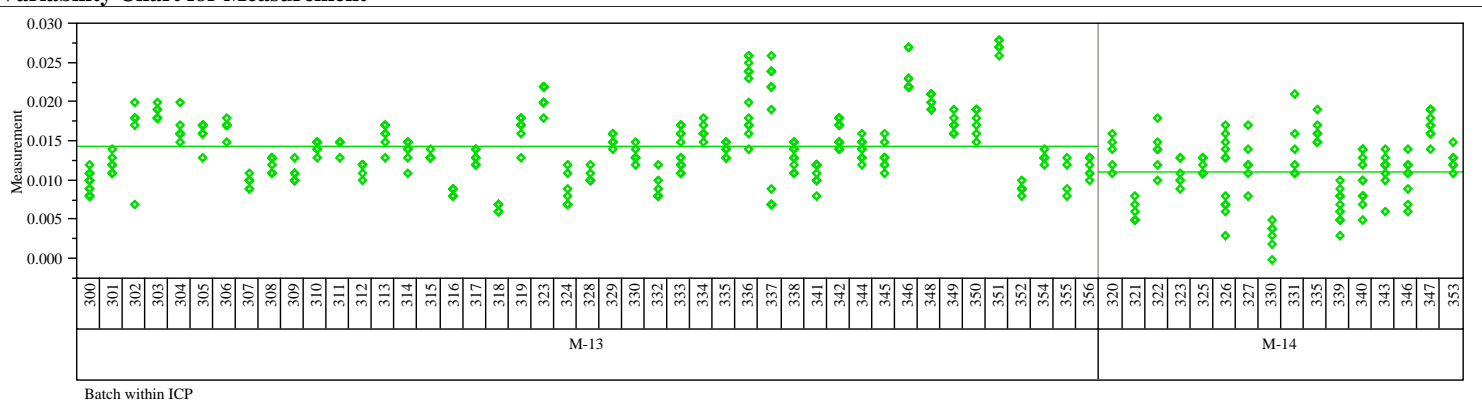

Prep $=$ Fusion, Sample Type $=$ SME, Analyte $=F e$

Variability Chart for Measurement

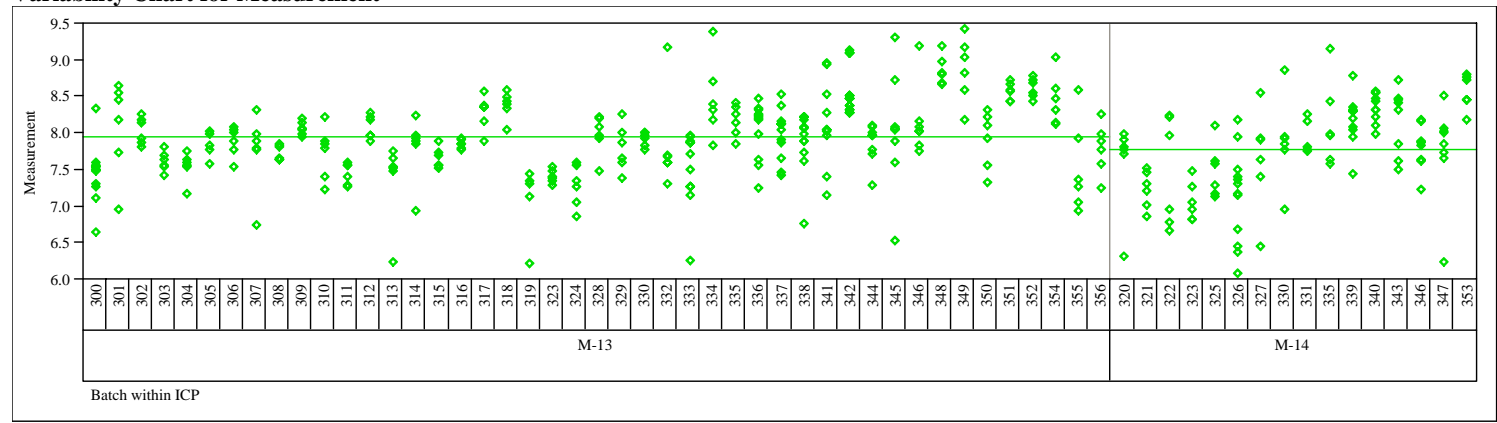


WSRC-STI-2006-00068

Revision 0

Exhibit A2. Measurement Data by Batch by ICP for Prep Method, Sample Type, and Analyte

Prep=Fusion, Sample Type $=$ SME, Analyte $=$ Fe/Al

(continued)

Variability Chart for Measurement

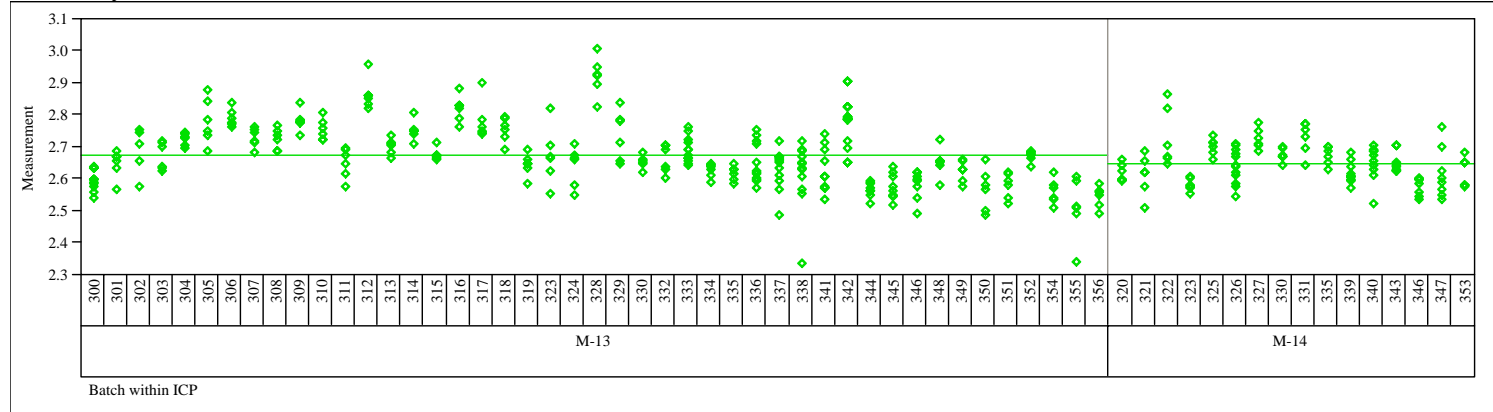

Prep $=$ Fusion, Sample Type $=$ SME, Analyte $=$ Fe $/$ Ca

Variability Chart for Measurement

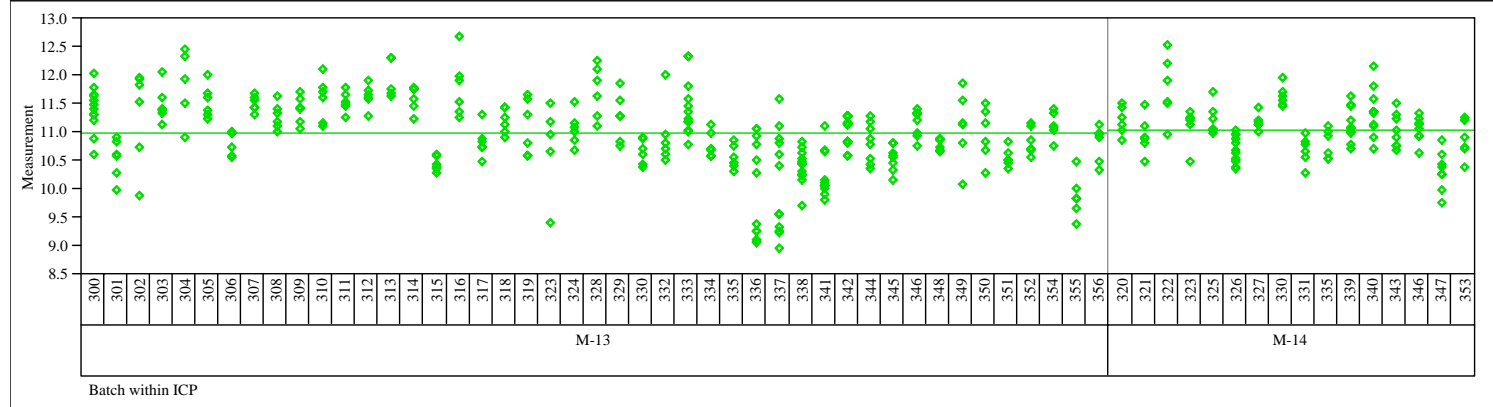

Prep $=$ Fusion, Sample Type $=\mathrm{SME}$, Analyte $=\mathrm{Fe} / \mathrm{Li}$

Variability Chart for Measurement

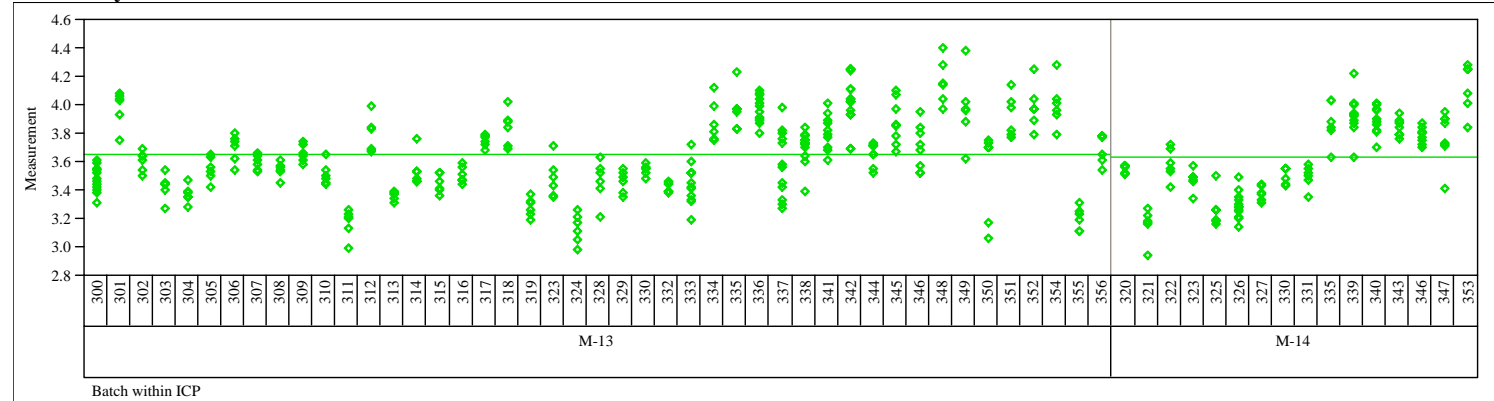

Prep $=$ Fusion, Sample Type $=\mathrm{SME}$, Analyte $=\mathrm{Fe} / \mathrm{Mg}$

Variability Chart for Measurement

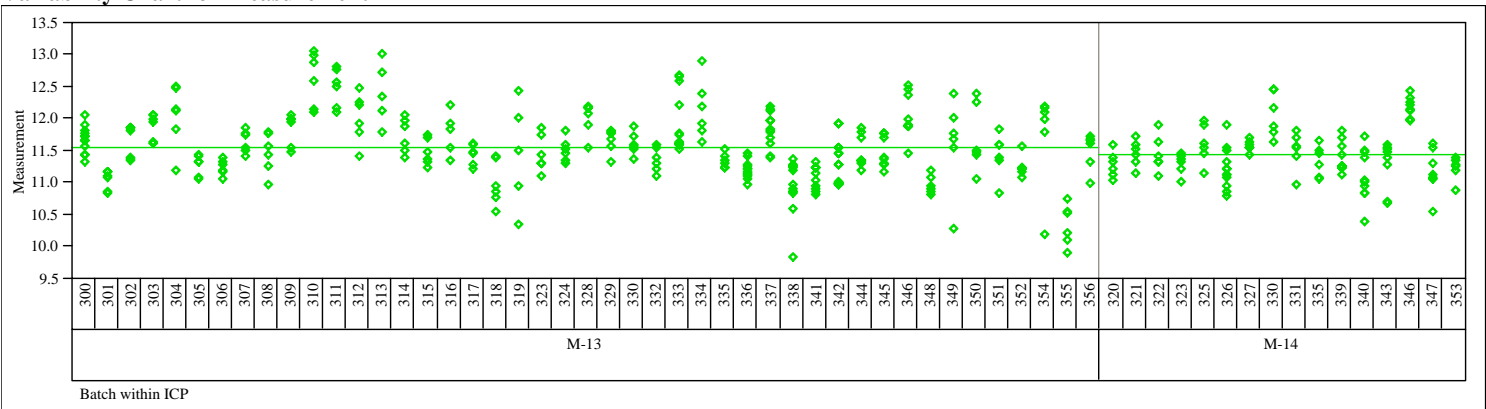


WSRC-STI-2006-00068

Revision 0

Exhibit A2. Measurement Data by Batch by ICP for Prep Method, Sample Type, and Analyte

Prep $=$ Fusion, Sample Type $=$ SME, Analyte $=\mathrm{Fe} / \mathrm{Mn}$

(continued)

Variability Chart for Measurement

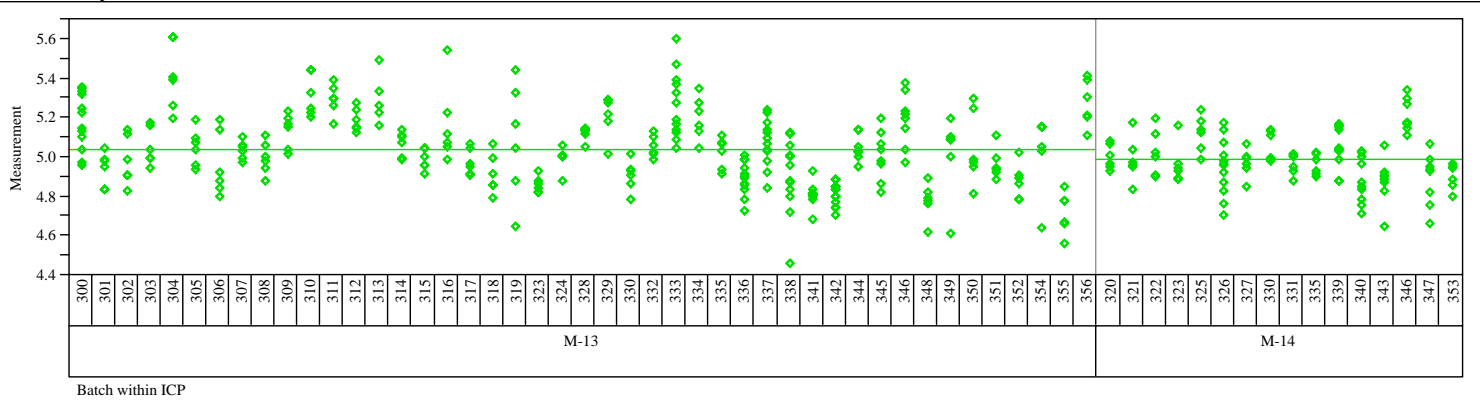

Prep $=$ Fusion, Sample Type $=$ SME, Analyte $=\mathrm{Fe} / \mathrm{Ni}$

Variability Chart for Measurement

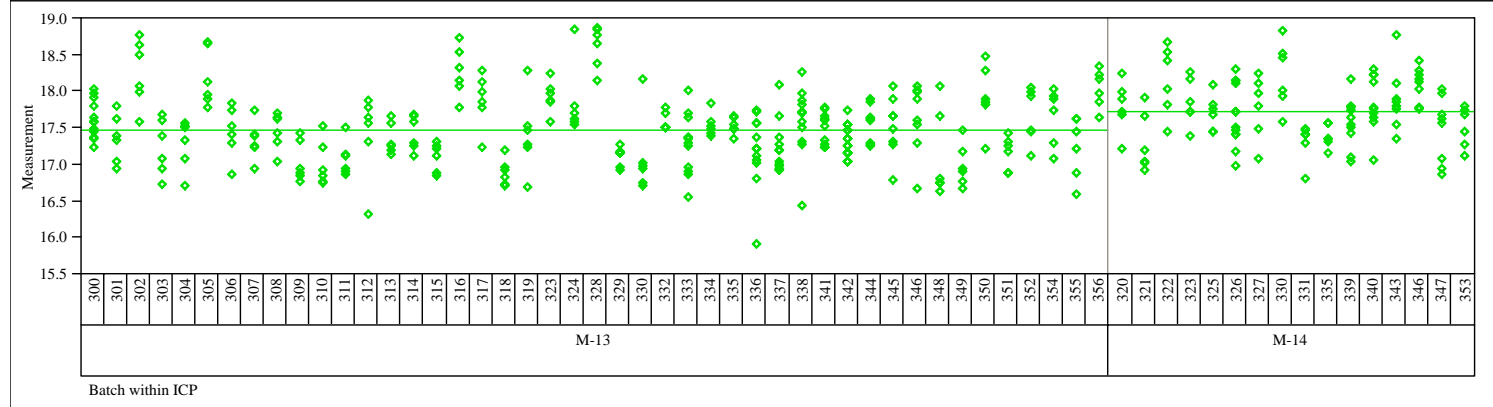

Prep $=$ Fusion, Sample Type $=$ SME, Analyte $=\mathrm{Fe} / \mathrm{U}$

Variability Chart for Measurement

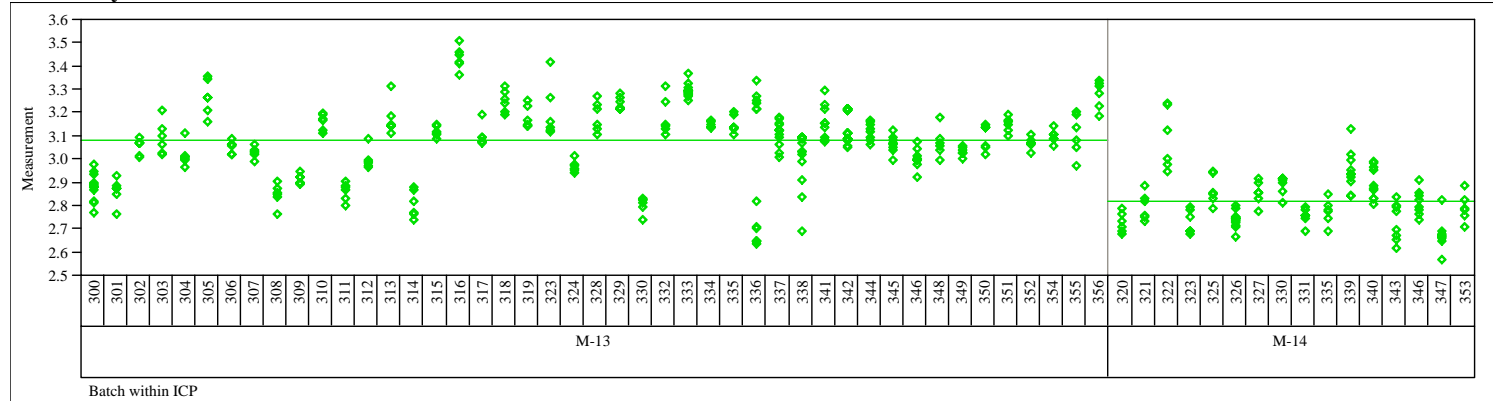

Prep=Fusion, Sample Type $=$ SME, Analyte $=K$

Variability Chart for Measurement

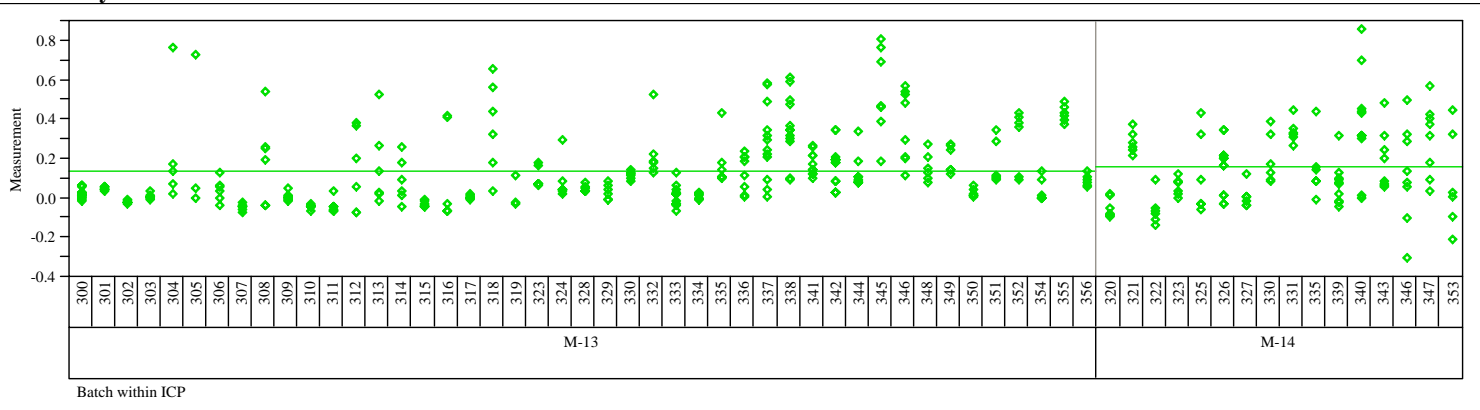


WSRC-STI-2006-00068

Revision 0

Exhibit A2. Measurement Data by Batch by ICP for Prep Method, Sample Type, and Analyte

Prep $=$ Fusion, Sample Type $=$ SME, Analyte $=\mathrm{Li}$

(continued)

Variability Chart for Measurement

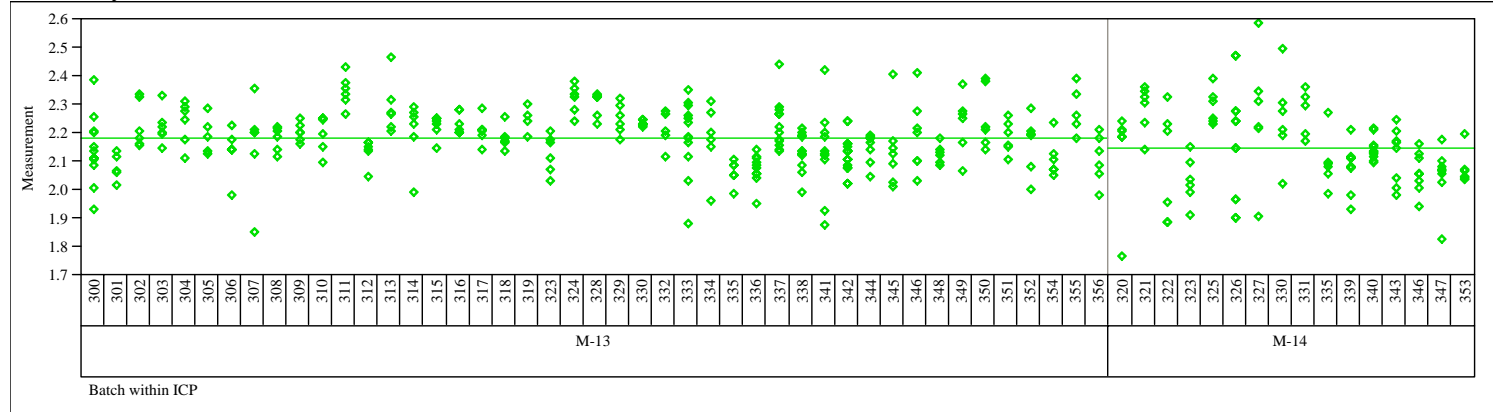

Prep $=$ Fusion, Sample Type $=$ SME, Analyte $=M g$

Variability Chart for Measurement

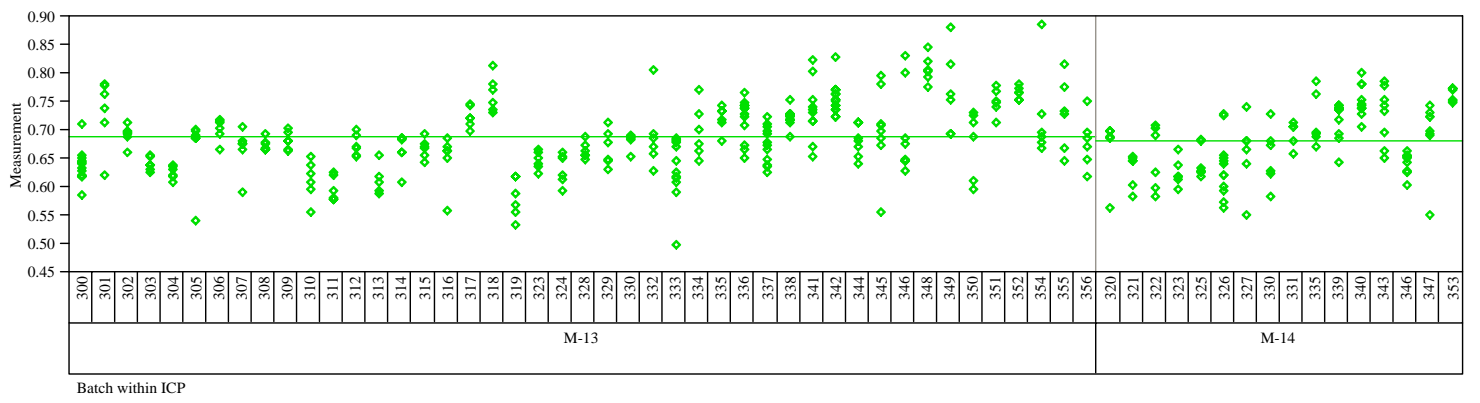

Prep $=$ Fusion, Sample Type $=$ SME, Analyte $=M n$

Variability Chart for Measurement

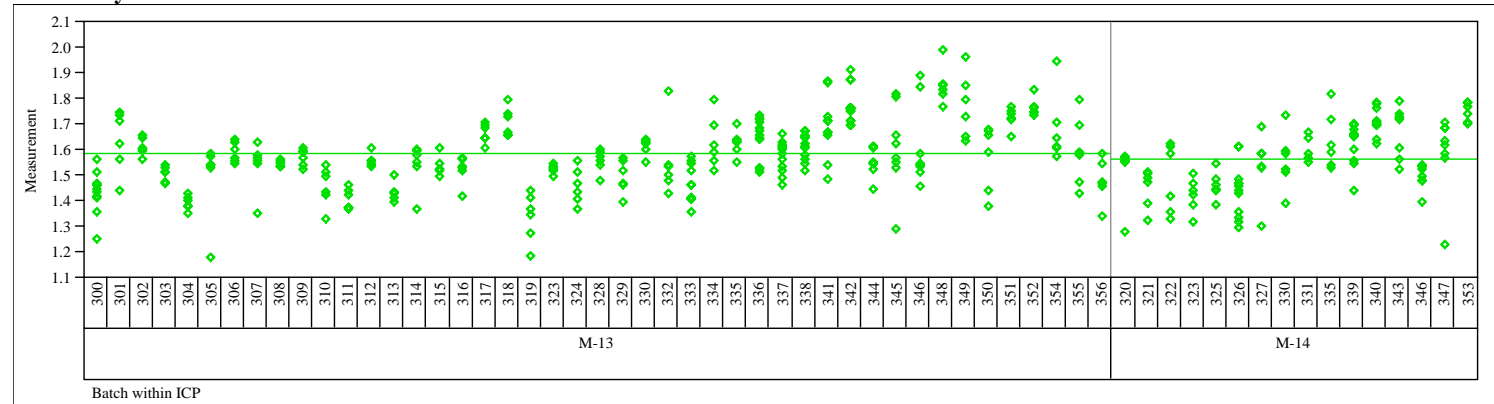

Prep $=$ Fusion, Sample Type $=$ SME, Analyte $=M n / M g$

Variability Chart for Measurement

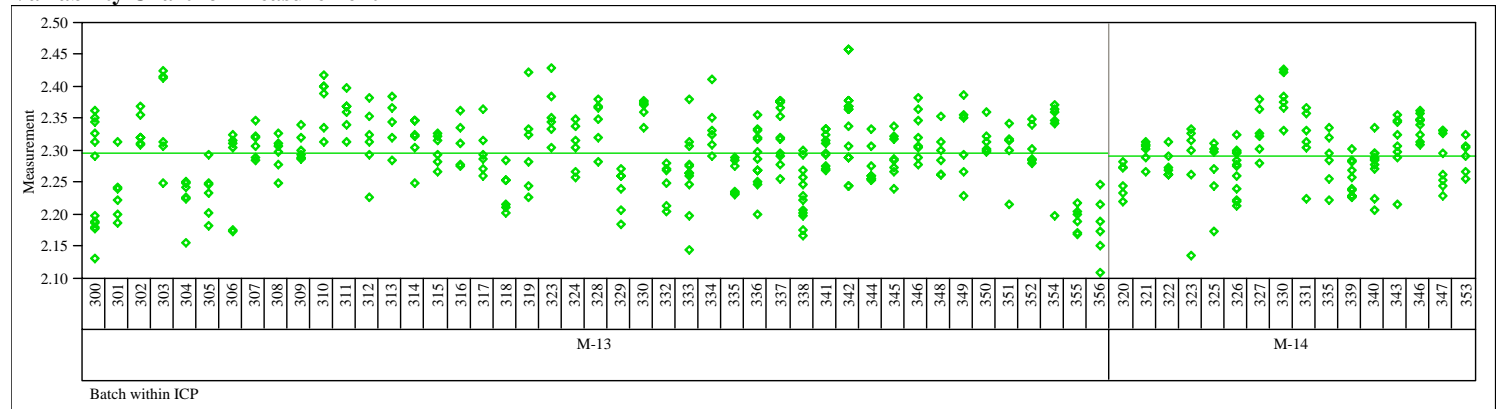


WSRC-STI-2006-00068

Revision 0

Exhibit A2. Measurement Data by Batch by ICP for Prep Method, Sample Type, and Analyte

Prep $=$ Fusion, Sample Type $=$ SME, Analyte $=\mathrm{Na}$

(continued)

Variability Chart for Measurement
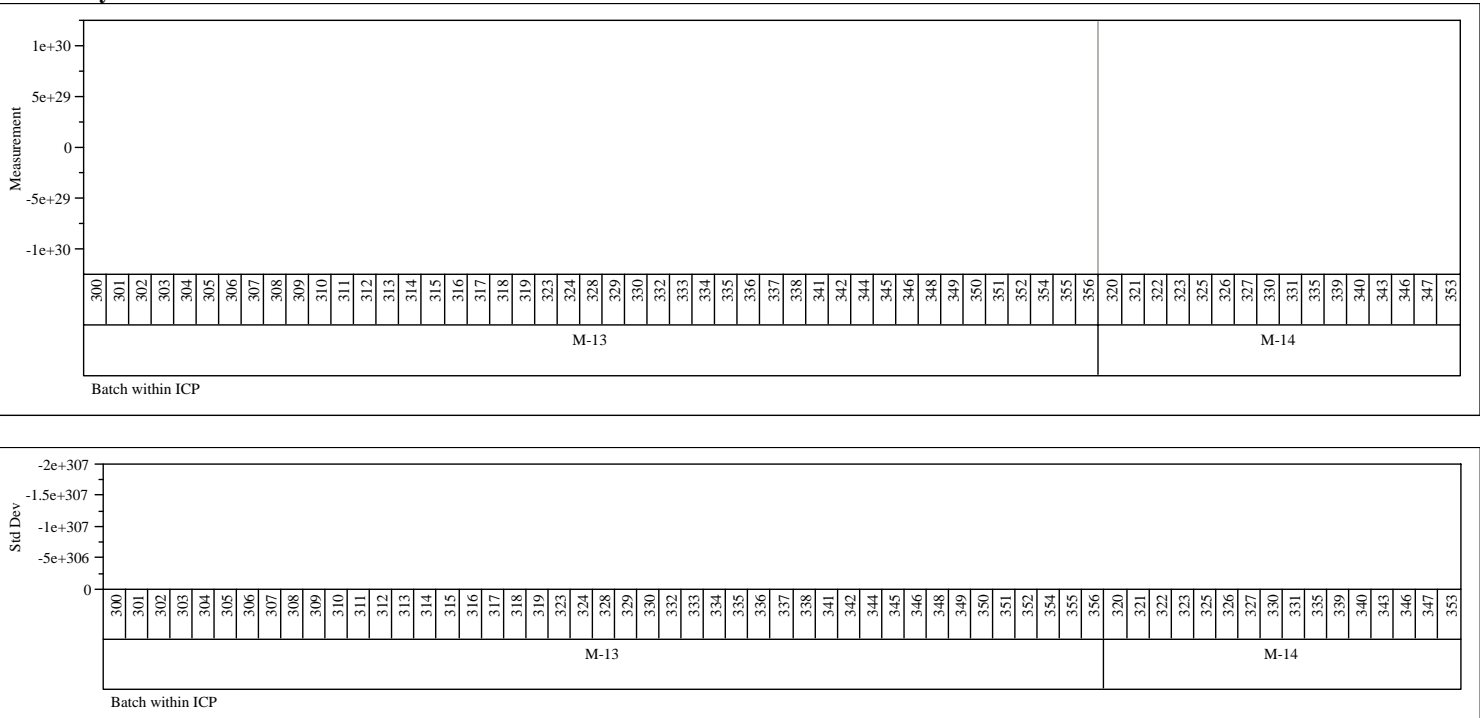

Prep $=$ Fusion, Sample Type $=$ SME, Analyte $=\mathrm{Ni}$

Variability Chart for Measurement

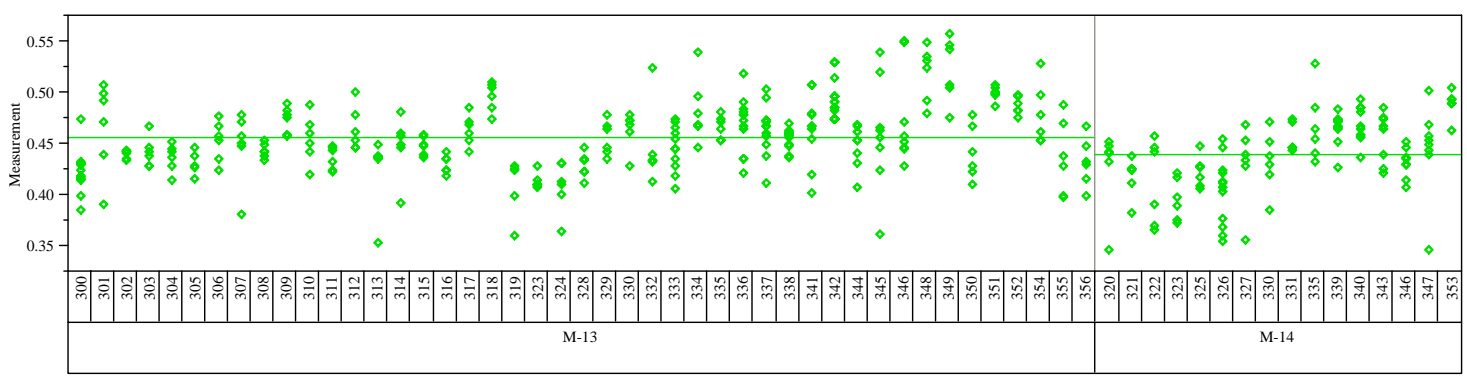

Prep $=$ Fusion, Sample Type $=$ SME, Analyte $=S i$

Variability Chart for Measurement

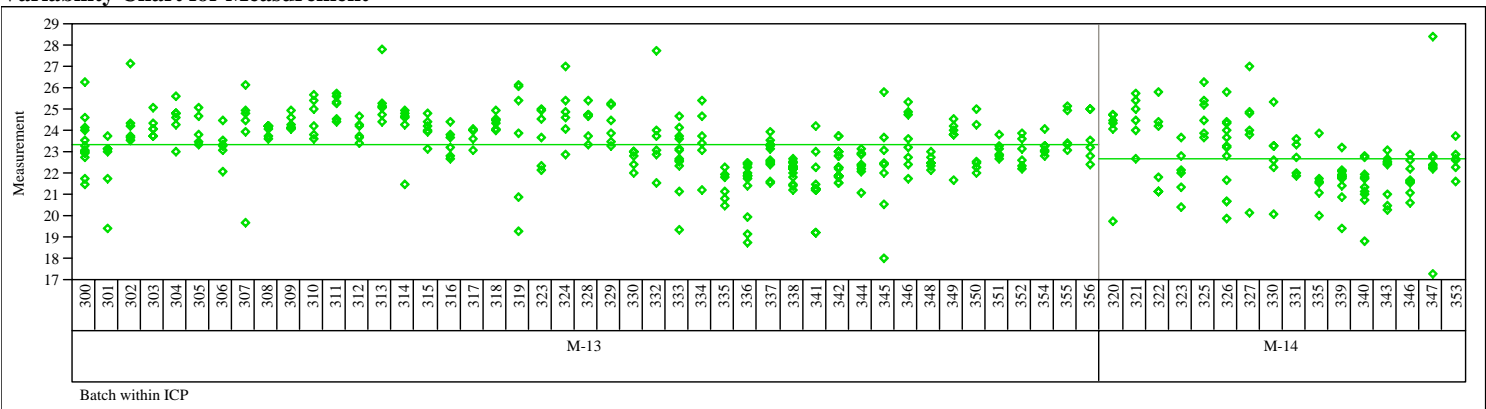


WSRC-STI-2006-00068

Revision 0

Exhibit A2. Measurement Data by Batch by ICP for Prep Method, Sample Type, and Analyte

Prep $=$ Fusion, Sample Type $=$ SME, Analyte $=$ Sum of Oxides

(continued)

Variability Chart for Measurement

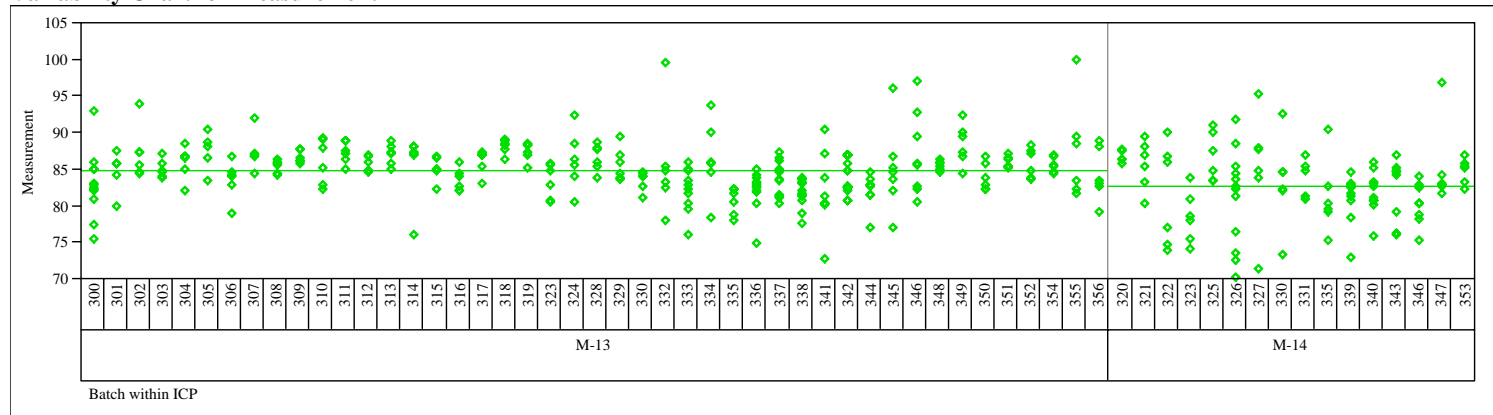

Prep $=$ Fusion, Sample Type $=$ SME, Analyte $=$ Ti

Variability Chart for Measurement

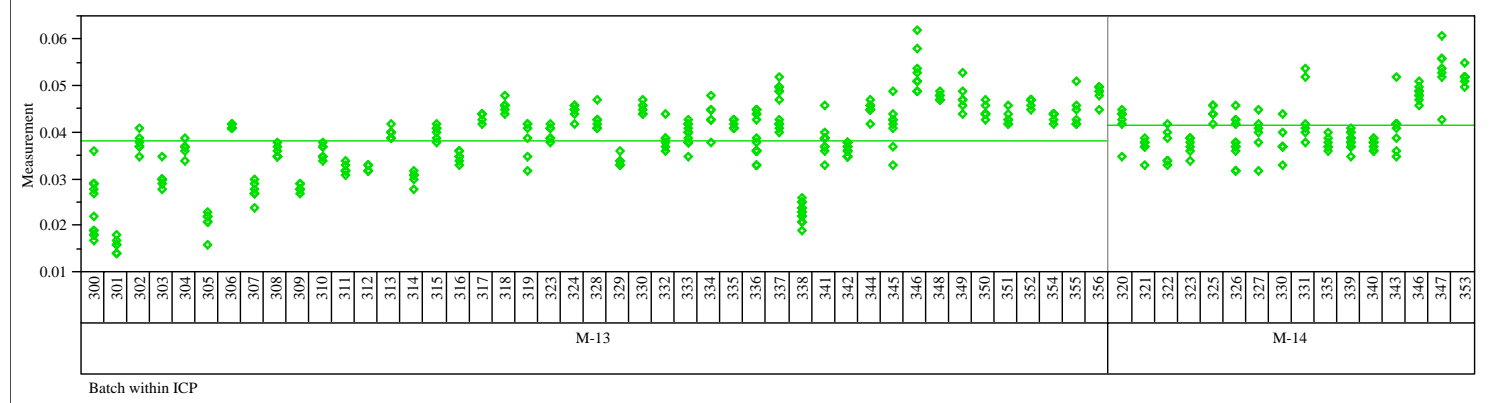

Prep=Fusion, Sample Type $=$ SME, Analyte $=U$

Variability Chart for Measurement

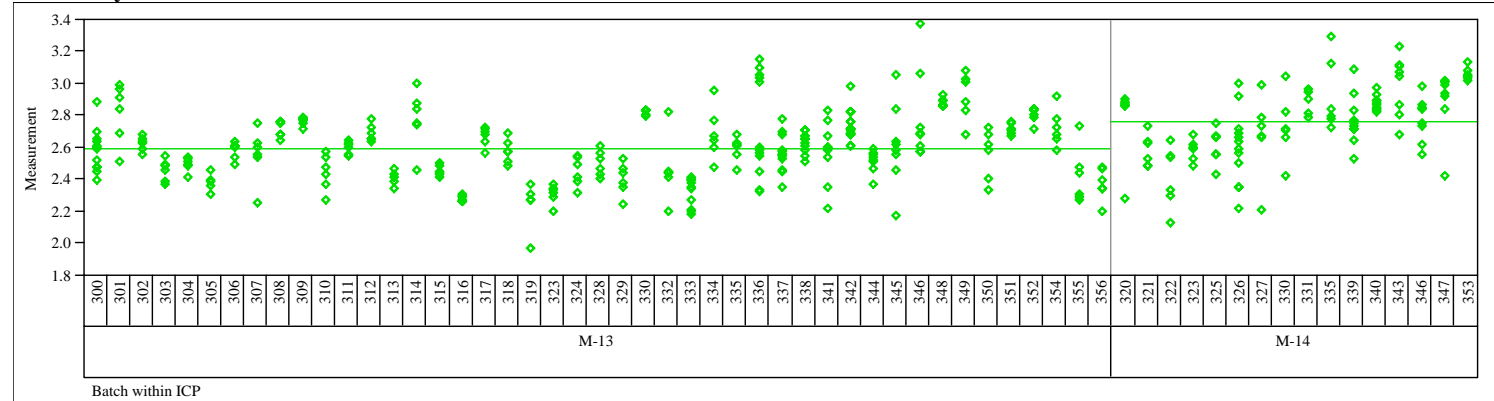

Prep=Fusion, Sample Type=SME, Analyte $=$ U/Ca

Variability Chart for Measurement

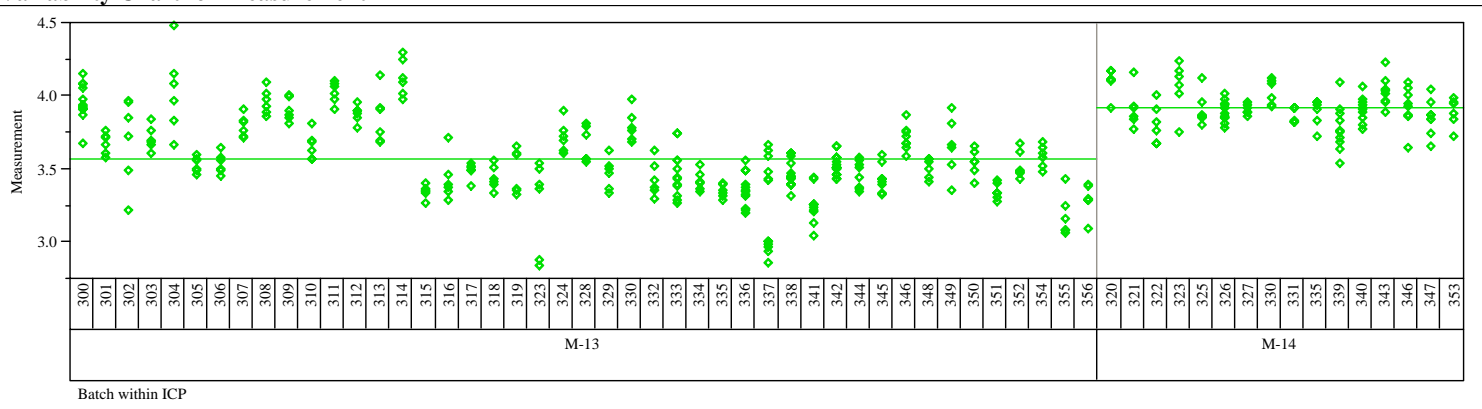


WSRC-STI-2006-00068

Revision 0

Exhibit A2. Measurement Data by Batch by ICP for Prep Method, Sample Type, and Analyte

Prep $=$ Fusion, Sample Type $=$ SME, Analyte $=\mathrm{Zr}$

(continued)

Variability Chart for Measurement
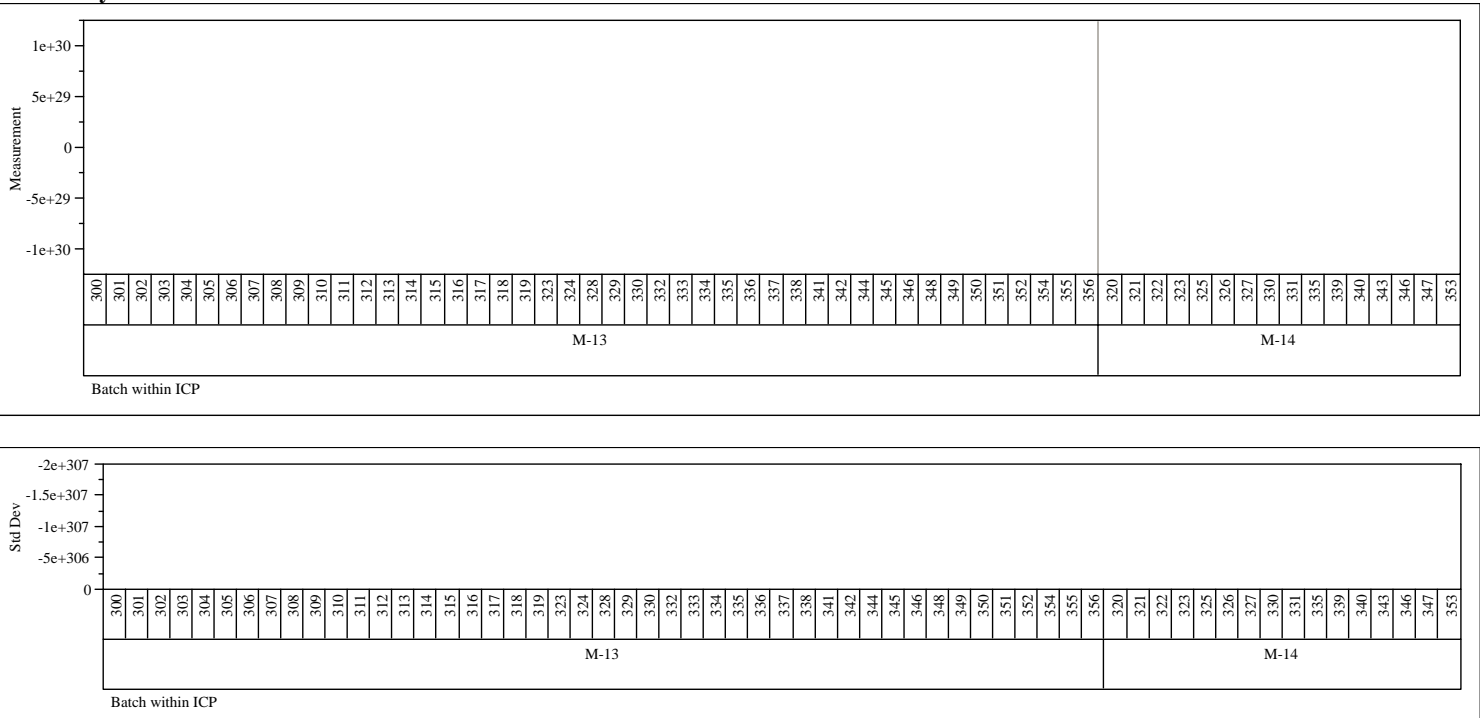

Prep=Fusion, Sample Type=blank, Analyte $=$ Al

Variability Chart for Measurement

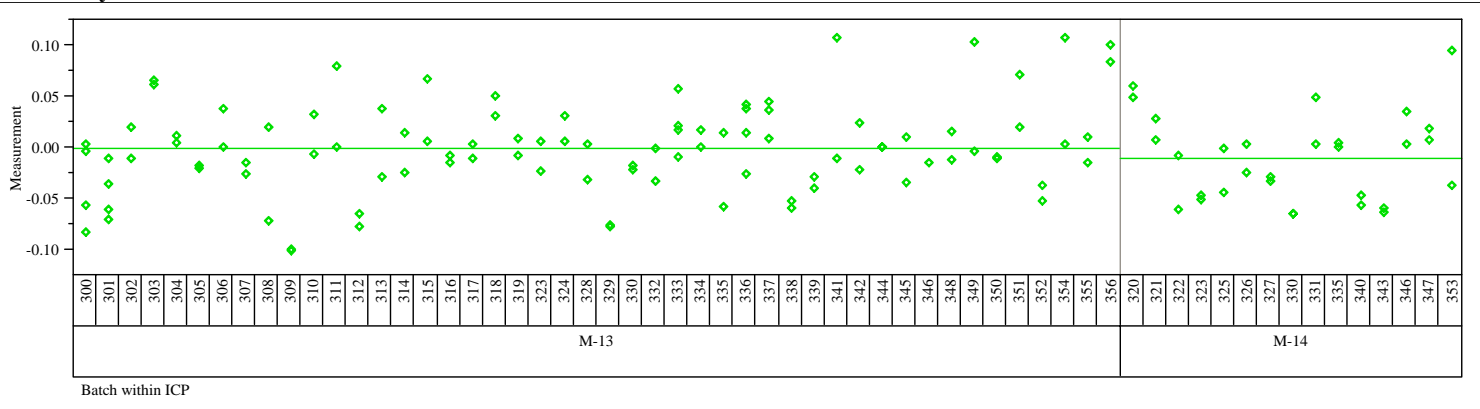

Prep $=$ Fusion, Sample Type $=$ blank, Analyte $=\mathrm{Al} / \mathrm{Ca}$

Variability Chart for Measurement

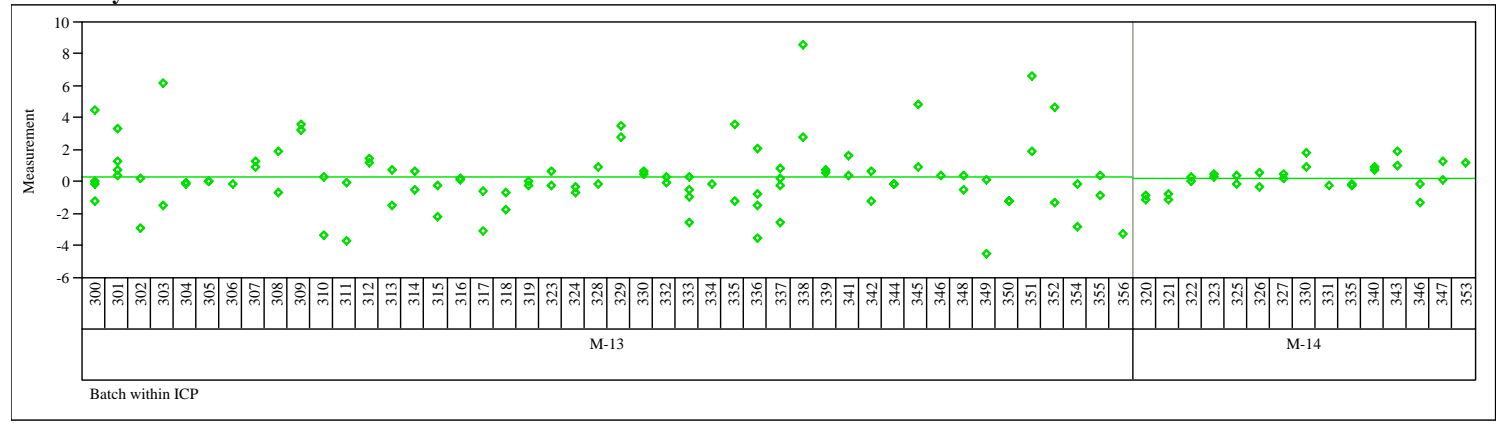


WSRC-STI-2006-00068

Revision 0

Exhibit A2. Measurement Data by Batch by ICP for Prep Method, Sample Type, and Analyte

Prep=Fusion, Sample Type $=$ blank, Analyte $=A \mathrm{I} / \mathrm{Mg}$

(continued)

Variability Chart for Measurement

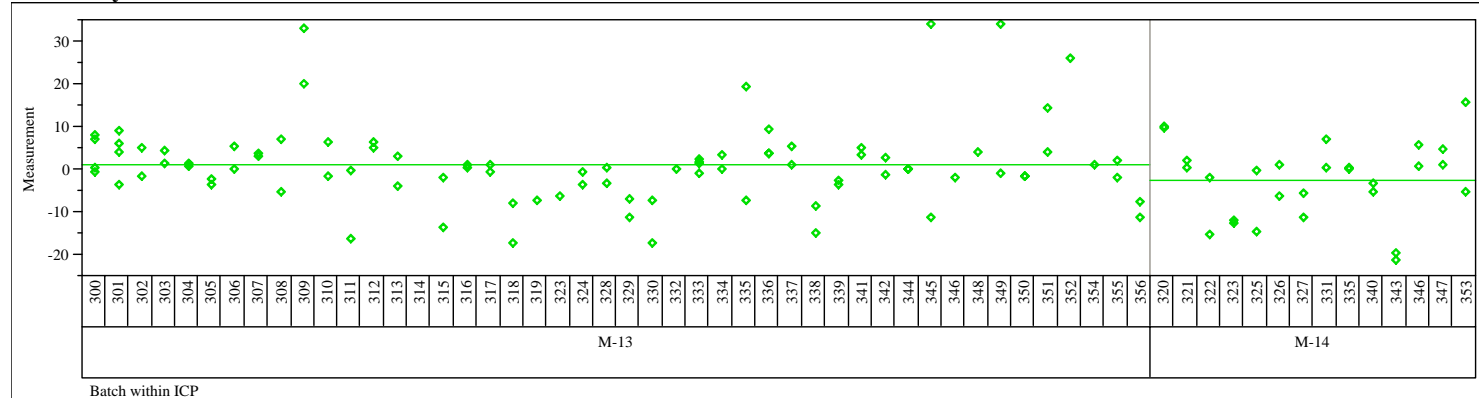

Prep $=$ Fusion, Sample Type $=$ blank, Analyte $=\mathrm{Al} / \mathrm{Mn}$

Variability Chart for Measurement

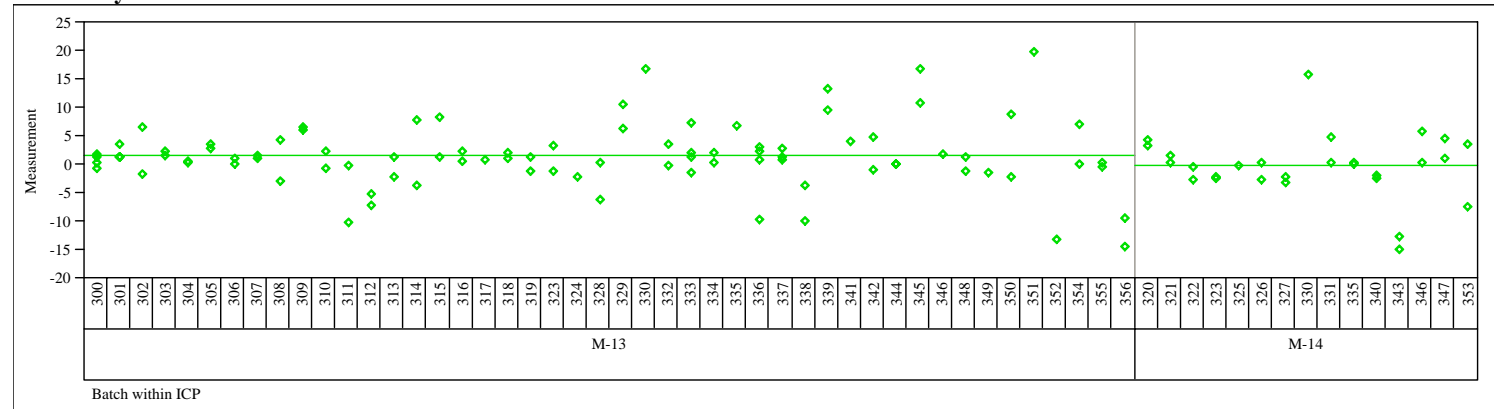

Prep=Fusion, Sample Type $=$ blank, Analyte $=B$

Variability Chart for Measurement

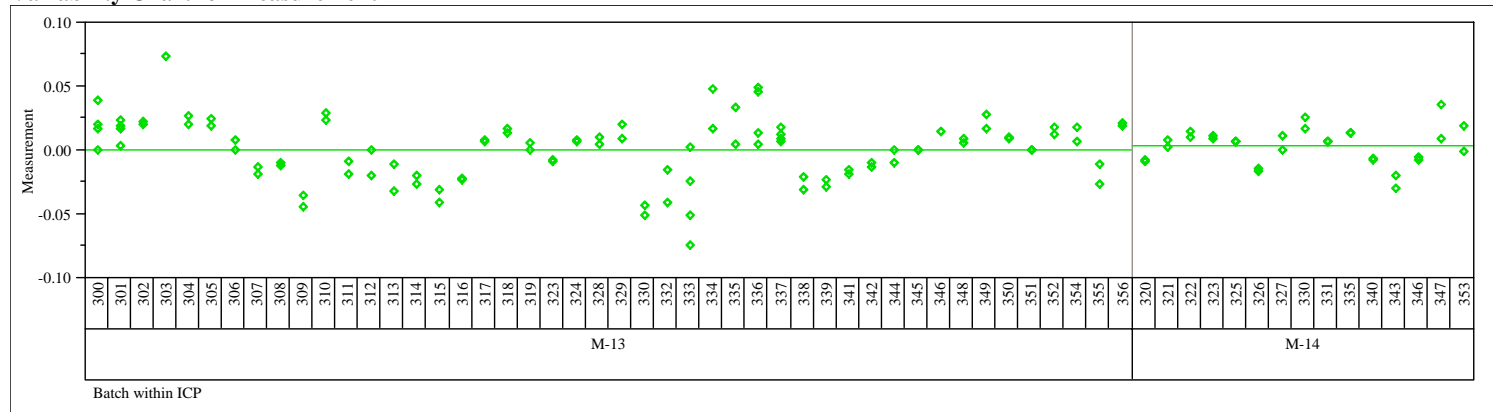

Prep=Fusion, Sample Type=blank, Analyte $=\mathbf{B} / \mathrm{Li}$

Variability Chart for Measurement

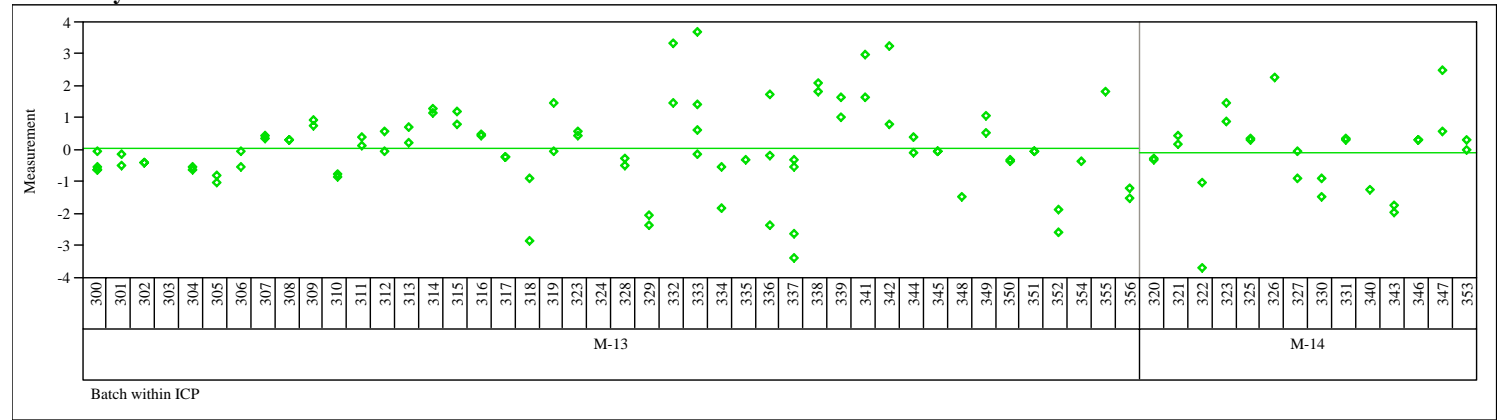


WSRC-STI-2006-00068

Revision 0

Exhibit A2. Measurement Data by Batch by ICP for Prep Method, Sample Type, and Analyte

Prep $=$ Fusion, Sample Type $=$ blank, Analyte $=\mathrm{Ca}$

(continued)

Variability Chart for Measurement

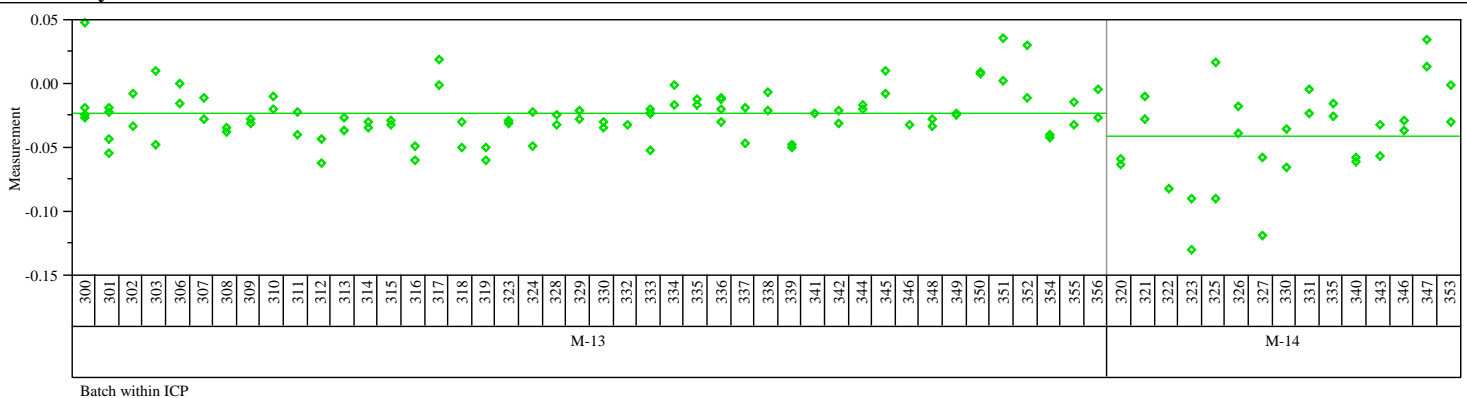

Prep $=$ Fusion, Sample Type $=$ blank, Analyte $=\mathrm{Cr}$

Variability Chart for Measurement

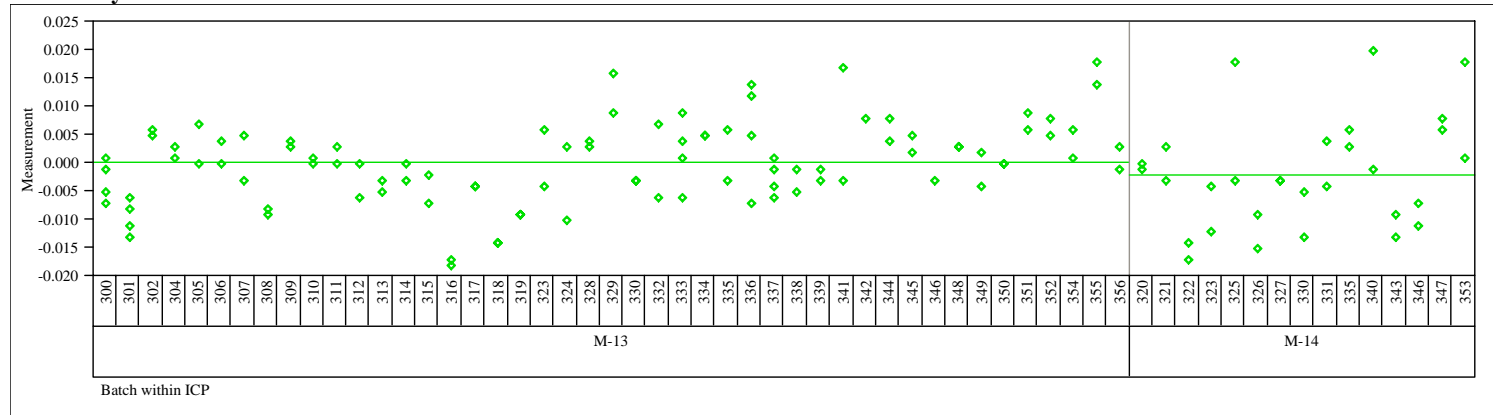

Prep=Fusion, Sample Type $=$ blank, Analyte $=\mathrm{Cu}$

Variability Chart for Measurement

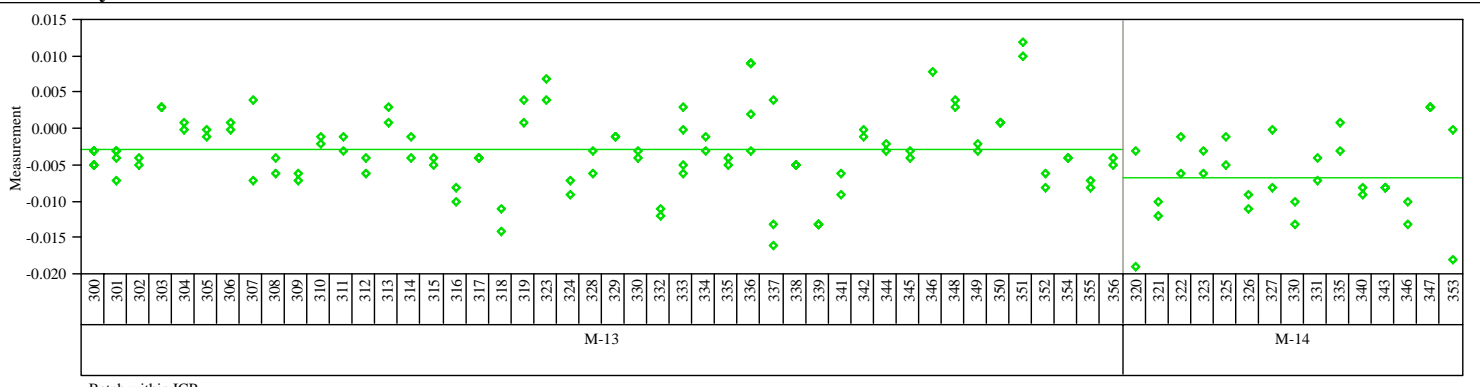

Prep $=$ Fusion, Sample Type $=$ blank, Analyte $=$ Fe

Variability Chart for Measurement

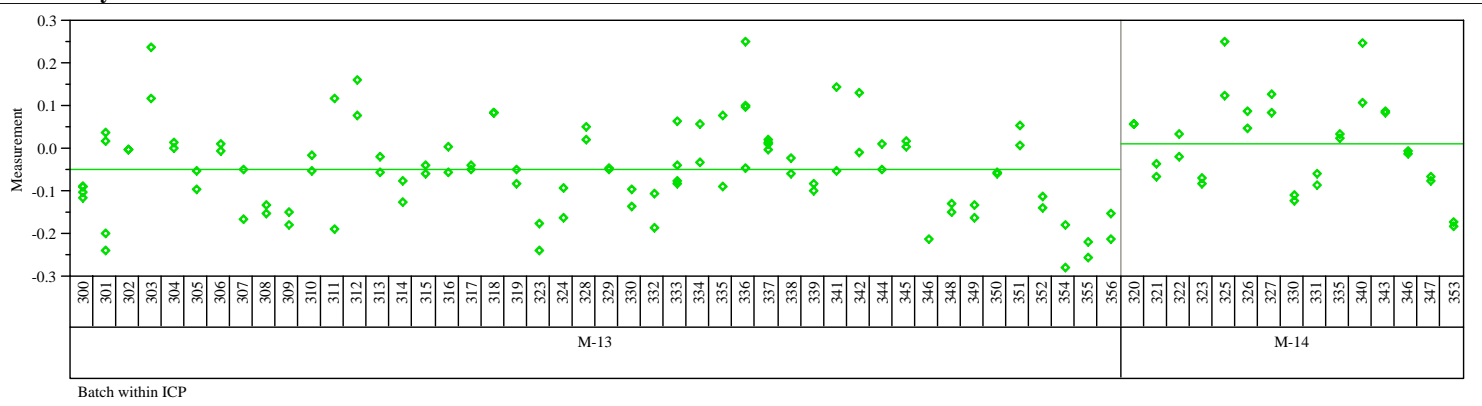


WSRC-STI-2006-00068

Revision 0

Exhibit A2. Measurement Data by Batch by ICP for Prep Method, Sample Type, and Analyte

Prep $=$ Fusion, Sample Type $=$ blank, Analyte $=\mathrm{Fe} / \mathrm{Al}$

(continued)

Variability Chart for Measurement

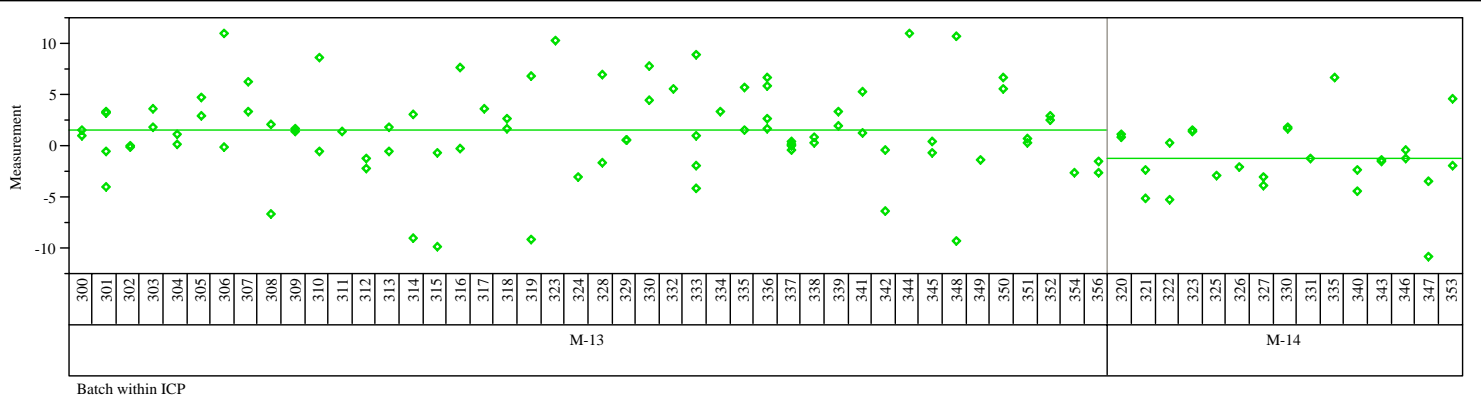

Prep=Fusion, Sample Type=blank, Analyte $=\mathrm{Fe} / \mathrm{Ca}$

Variability Chart for Measurement

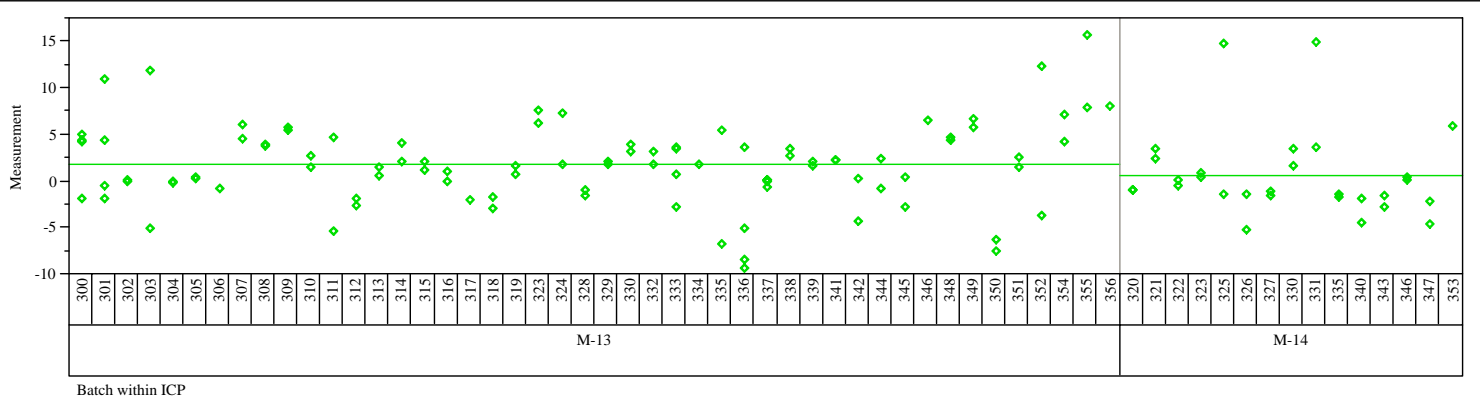

Prep=Fusion, Sample Type=blank, Analyte $=\mathrm{Fe} / \mathrm{Li}$

Variability Chart for Measurement

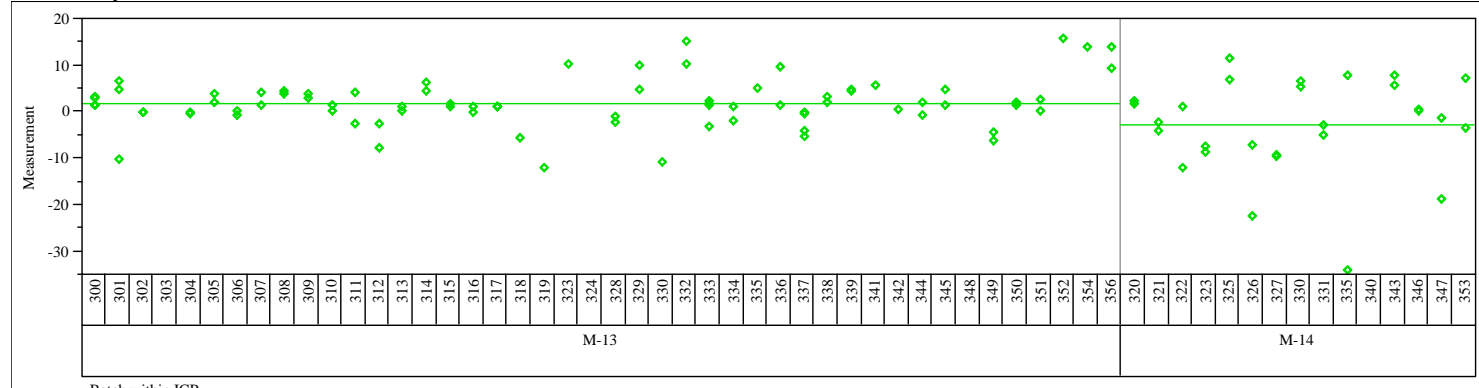

Prep=Fusion, Sample Type $=$ blank, Analyte $=\mathrm{Fe} / \mathrm{Mg}$

Variability Chart for Measurement

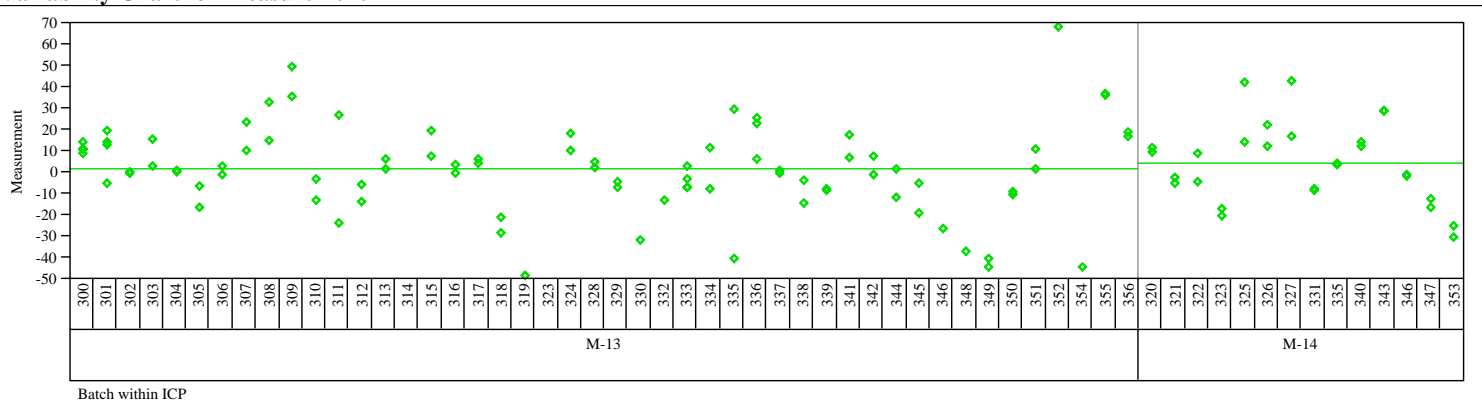


WSRC-STI-2006-00068

Revision 0

Exhibit A2. Measurement Data by Batch by ICP for Prep Method, Sample Type, and Analyte

Prep=Fusion, Sample Type=blank, Analyte $=\mathrm{Fe} / \mathrm{Mn}$

(continued)

Variability Chart for Measurement

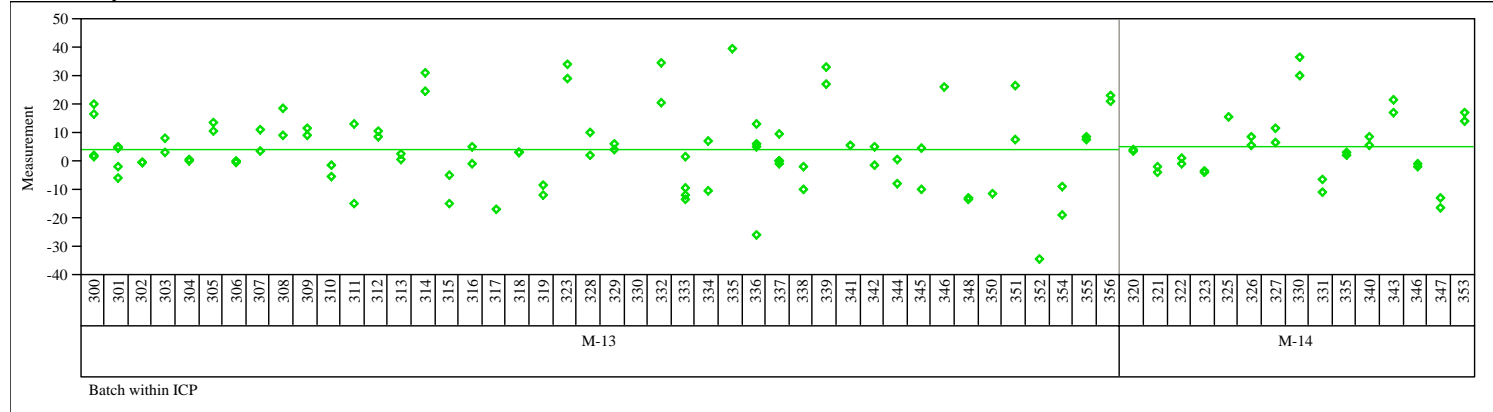

Prep=Fusion, Sample Type=blank, Analyte $=\mathrm{Fe} / \mathrm{Ni}$

Variability Chart for Measurement

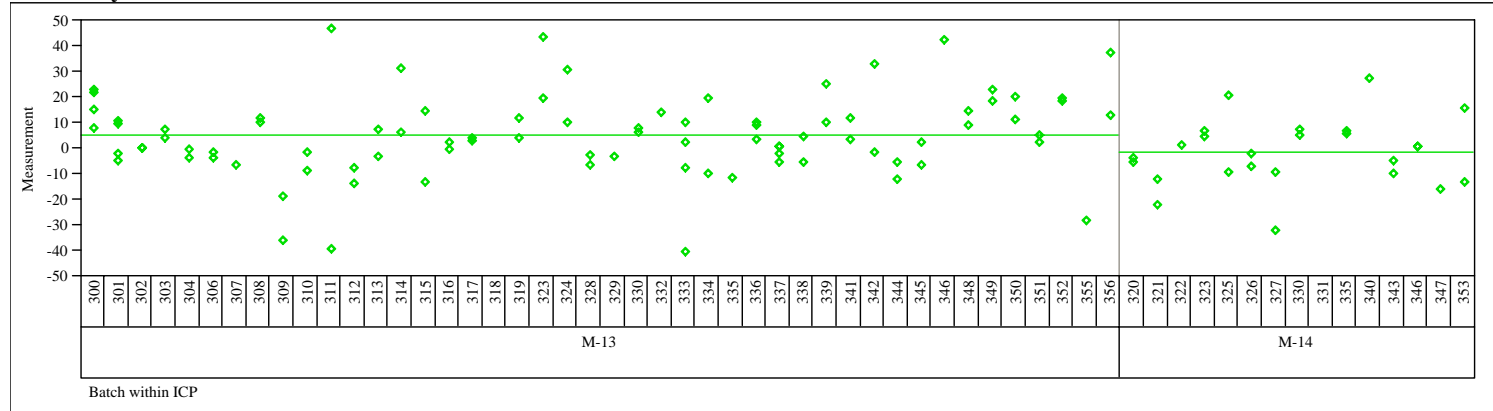

Prep=Fusion, Sample Type $=$ blank, Analyte $=\mathrm{Fe} / \mathrm{U}$

Variability Chart for Measurement

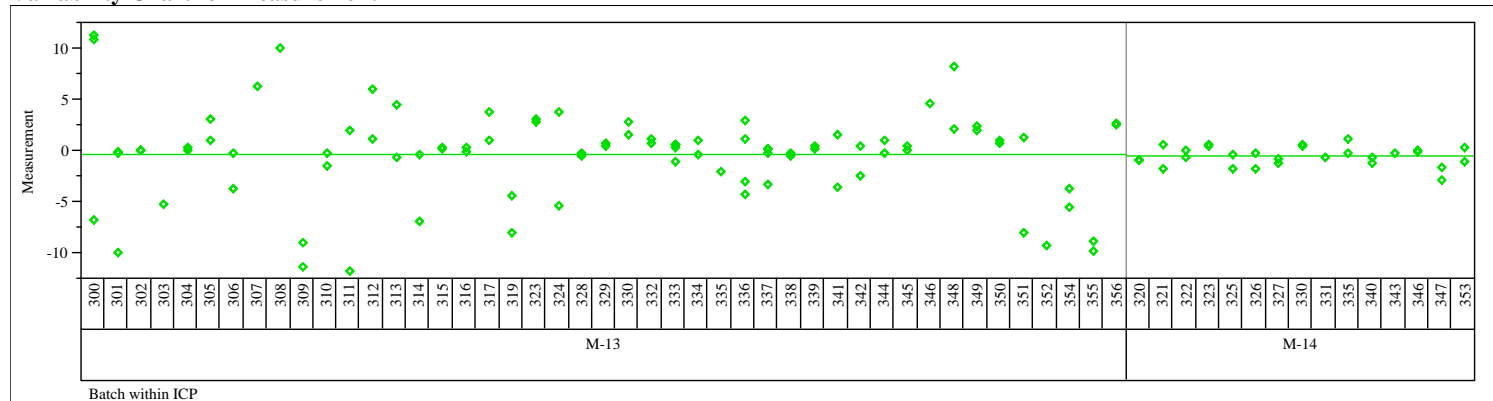

Prep=Fusion, Sample Type $=$ blank, Analyte $=K$

Variability Chart for Measurement

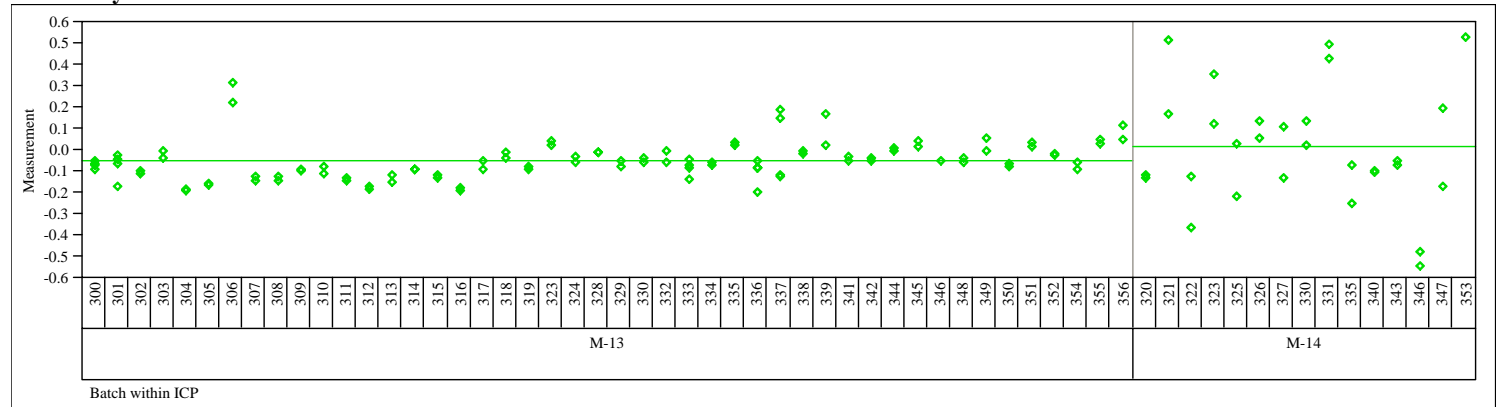


WSRC-STI-2006-00068

Revision 0

Exhibit A2. Measurement Data by Batch by ICP for Prep Method, Sample Type, and Analyte

Prep=Fusion, Sample Type=blank, Analyte $=\mathrm{Li}$

(continued)

Variability Chart for Measurement

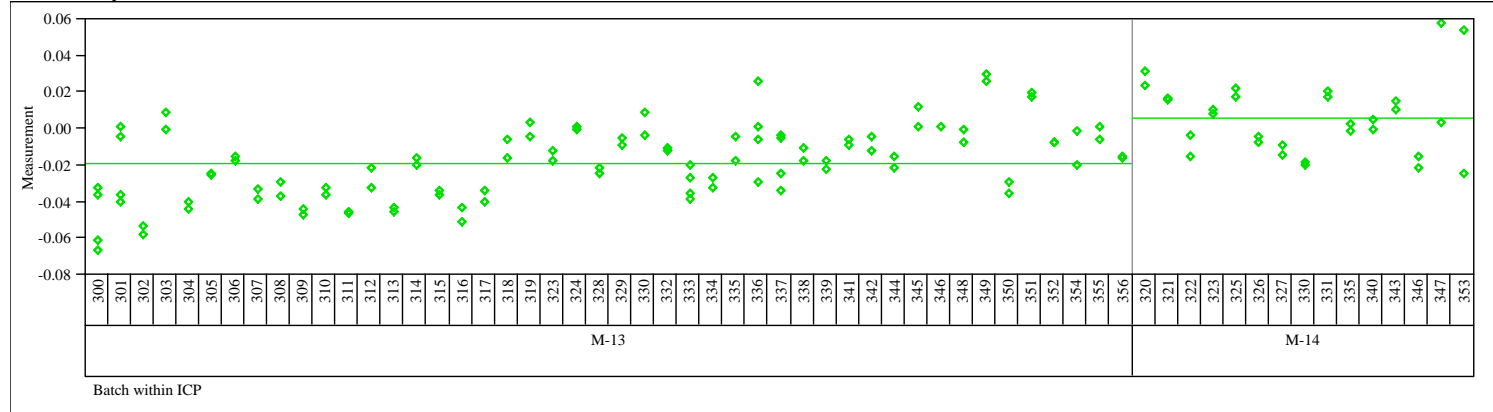

Prep=Fusion, Sample Type $=$ blank, Analyte $=M g$

Variability Chart for Measurement

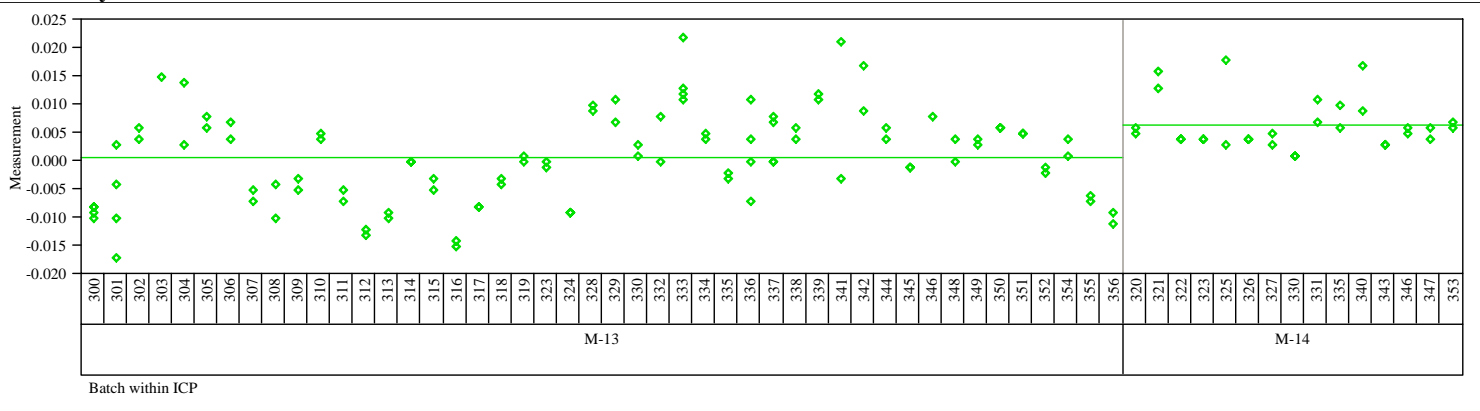

Prep=Fusion, Sample Type $=$ blank, Analyte $=M n$

Variability Chart for Measurement

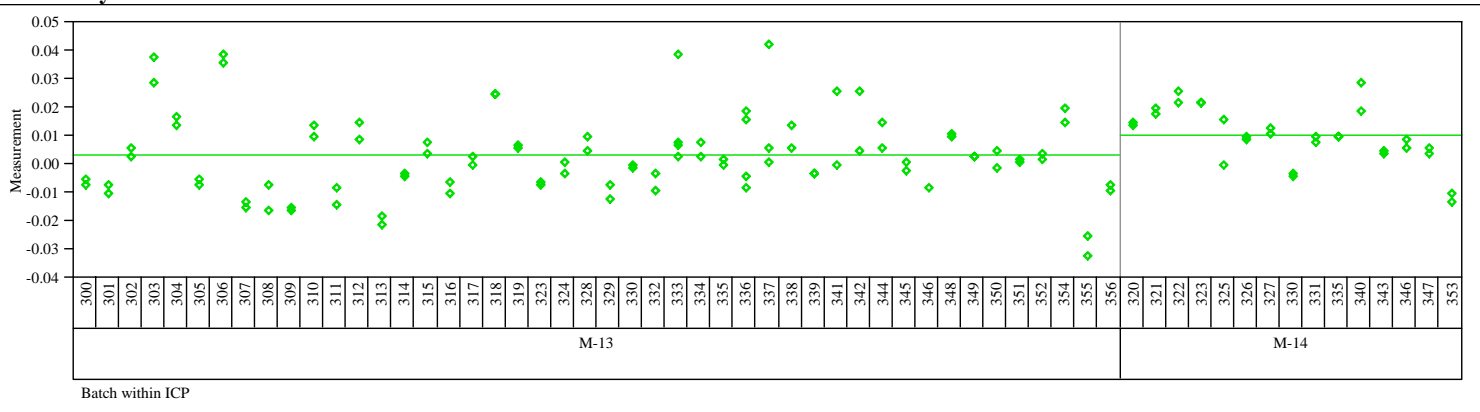

Prep=Fusion, Sample Type $=$ blank, Analyte $=\mathbf{M n} / \mathbf{M g}$

Variability Chart for Measurement

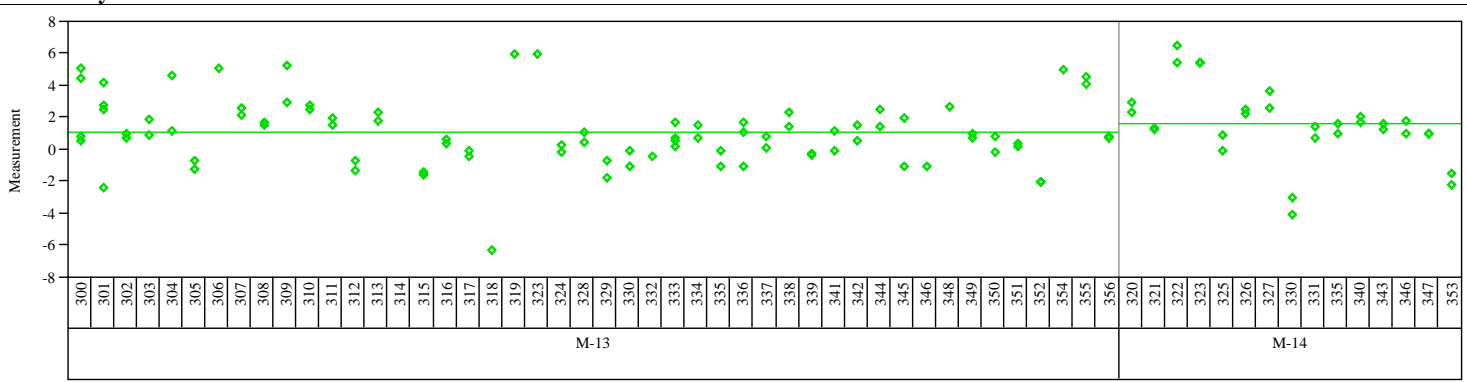

Batch within ICP 
WSRC-STI-2006-00068

Revision 0

Exhibit A2. Measurement Data by Batch by ICP for Prep Method, Sample Type, and Analyte

Prep $=$ Fusion, Sample Type $=$ blank, Analyte $=\mathrm{Na}$

(continued)

Variability Chart for Measurement
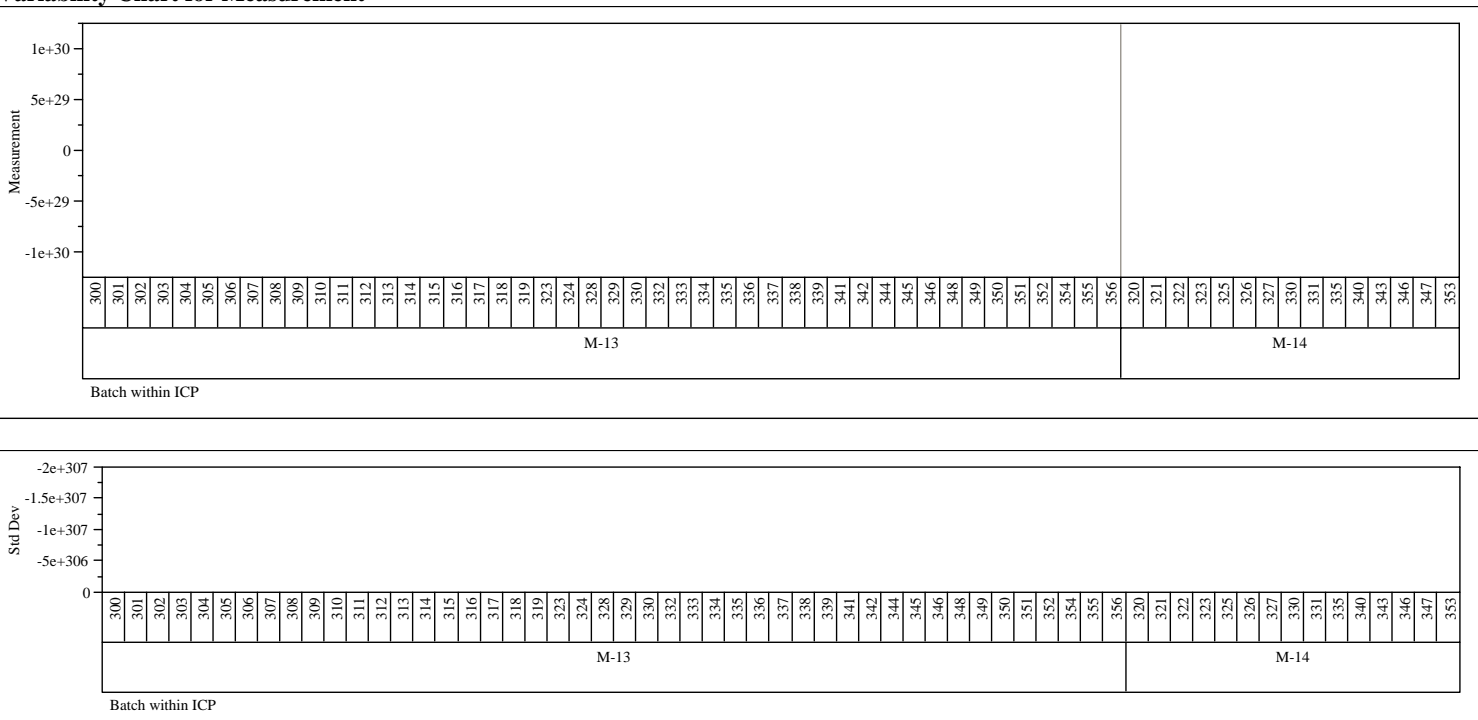

Prep=Fusion, Sample Type=blank, Analyte $=\mathrm{Ni}$

Variability Chart for Measurement

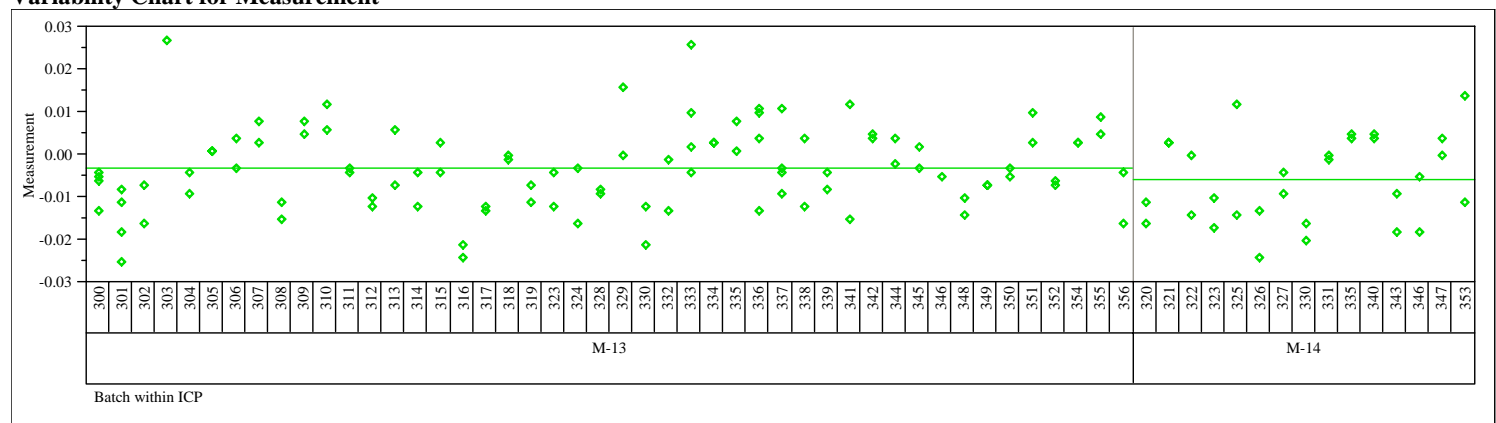

Prep $=$ Fusion, Sample Type $=$ blank, Analyte $=\mathrm{Si}$

Variability Chart for Measurement

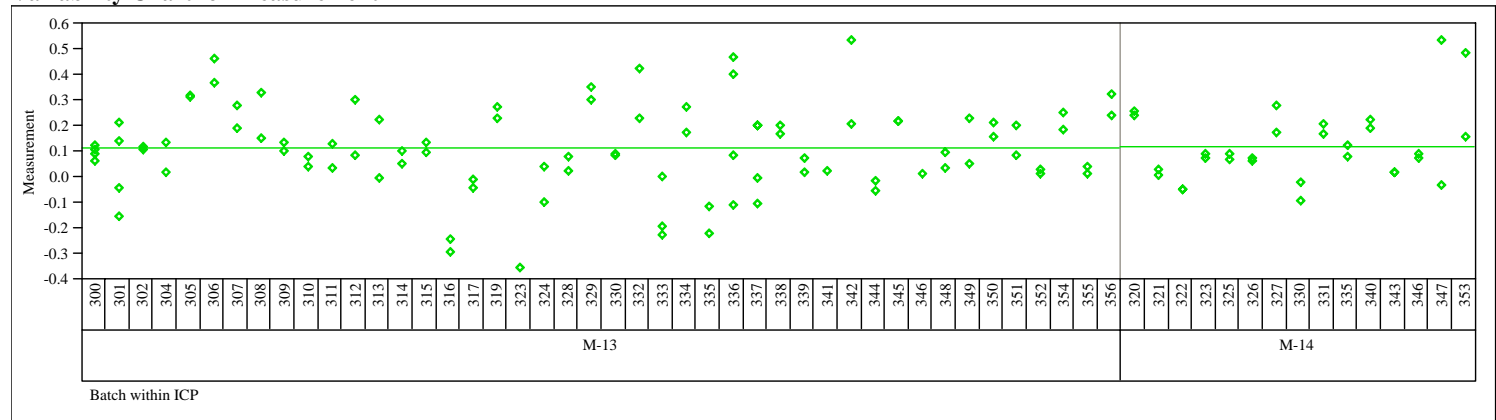


WSRC-STI-2006-00068

Revision 0

Exhibit A2. Measurement Data by Batch by ICP for Prep Method, Sample Type, and Analyte

Prep=Fusion, Sample Type=blank, Analyte $=$ Sum of Oxides

(continued)

Variability Chart for Measurement

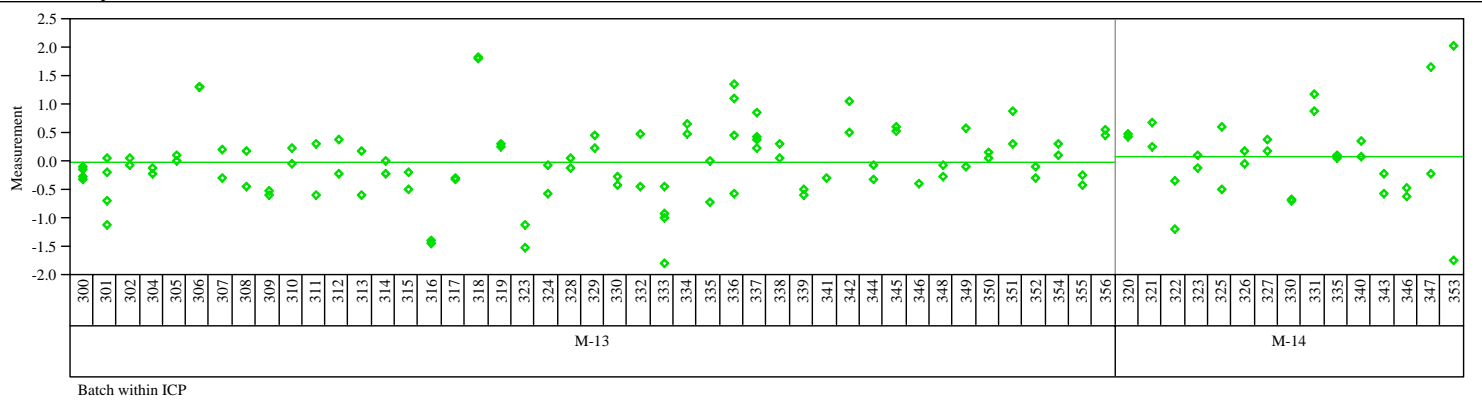

Prep $=$ Fusion, Sample Type $=$ blank, Analyte $=T i$

Variability Chart for Measurement

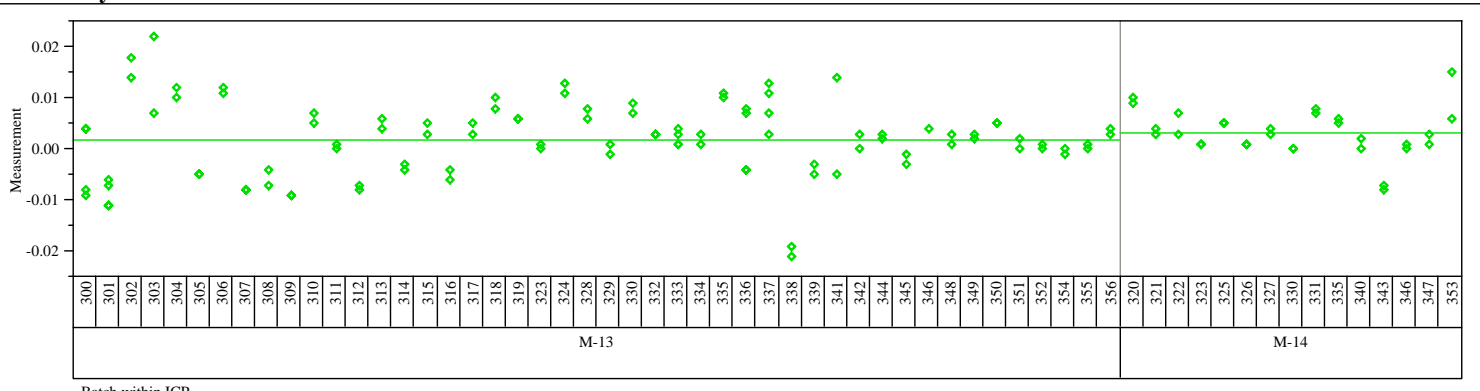

Prep=Fusion, Sample Type $=$ blank, Analyte $=U$

Variability Chart for Measurement

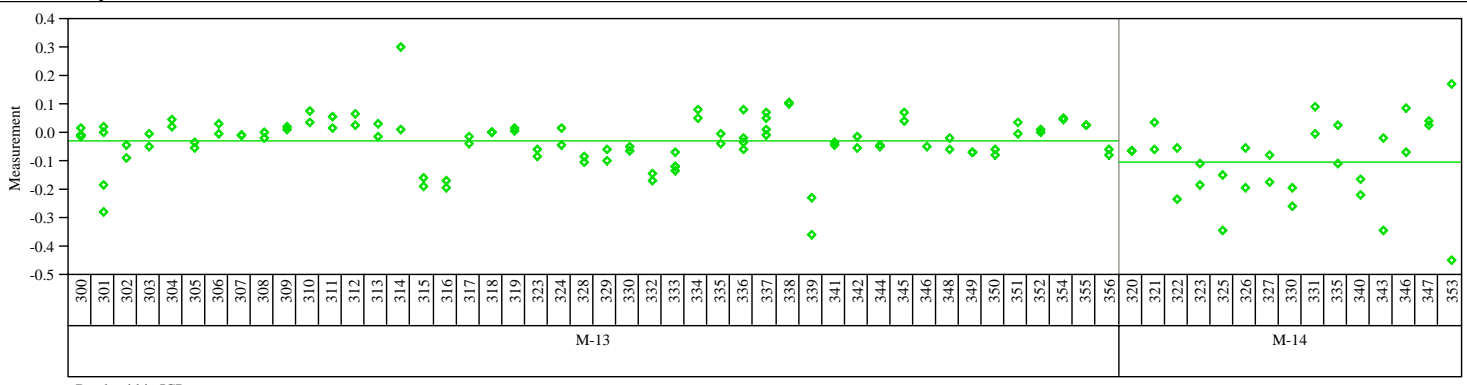

Batch within ICP

Prep=Fusion, Sample Type=blank, Analyte $=$ U/Ca

Variability Chart for Measurement

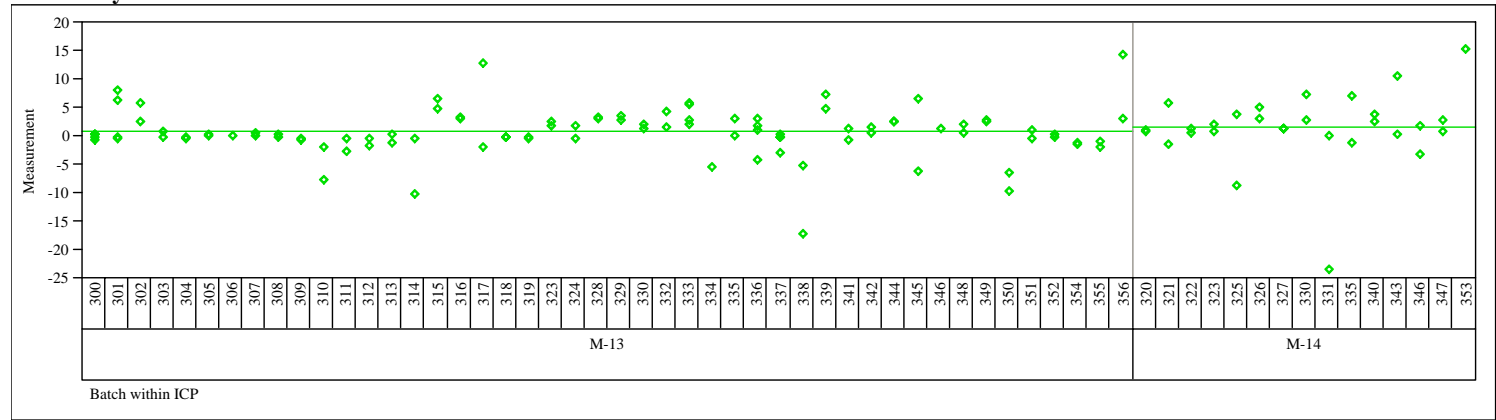


Exhibit A2. Measurement Data by Batch by ICP for Prep Method, Sample Type, and Analyte

Prep $=$ Fusion, Sample Type $=$ blank, Analyte $=\mathrm{Zr}$

(continued)

Variability Chart for Measurement
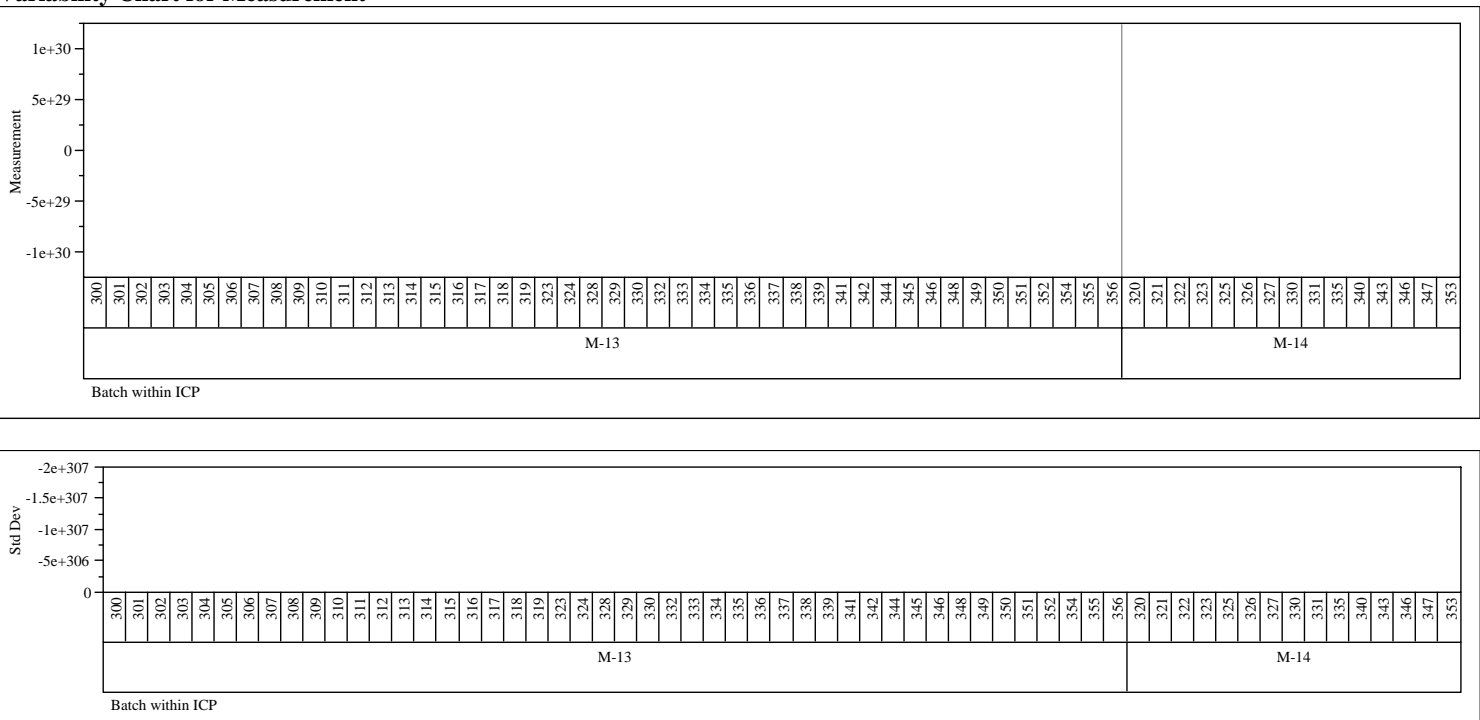

Prep=Mixed Acid, Sample Type=ARG-1, Analyte=Al

Variability Chart for Measurement

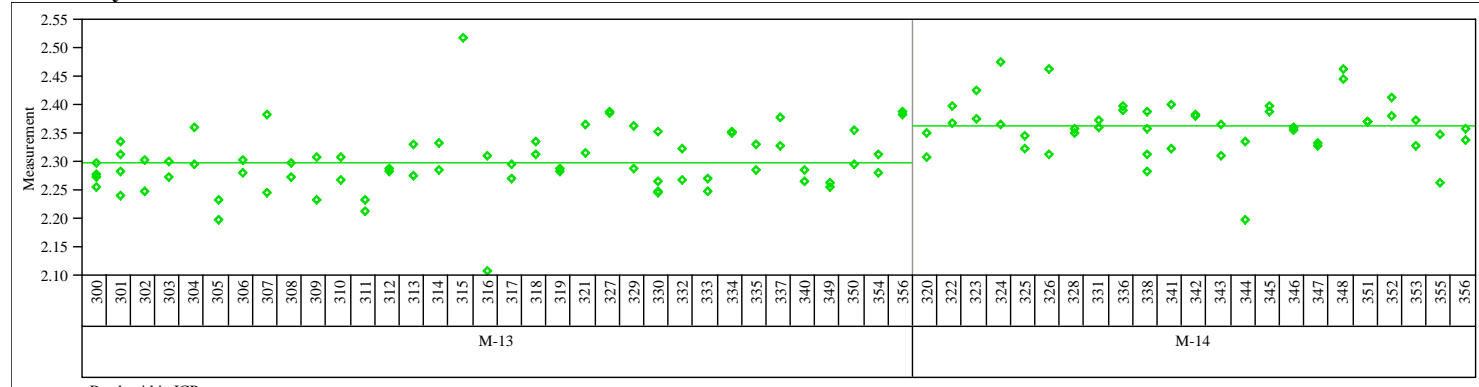

Prep=Mixed Acid, Sample Type=ARG-1, Analyte=Al/Ca

Variability Chart for Measurement

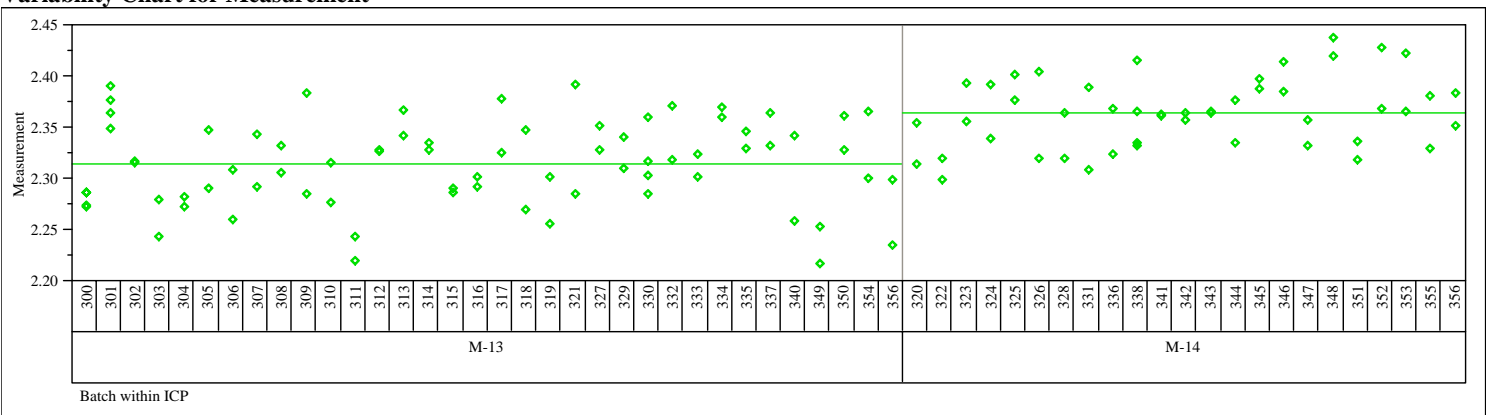


WSRC-STI-2006-00068

Revision 0

Exhibit A2. Measurement Data by Batch by ICP for Prep Method, Sample Type, and Analyte

Prep=Mixed Acid, Sample Type=ARG-1, Analyte=Al/Mg

(continued)

Variability Chart for Measurement

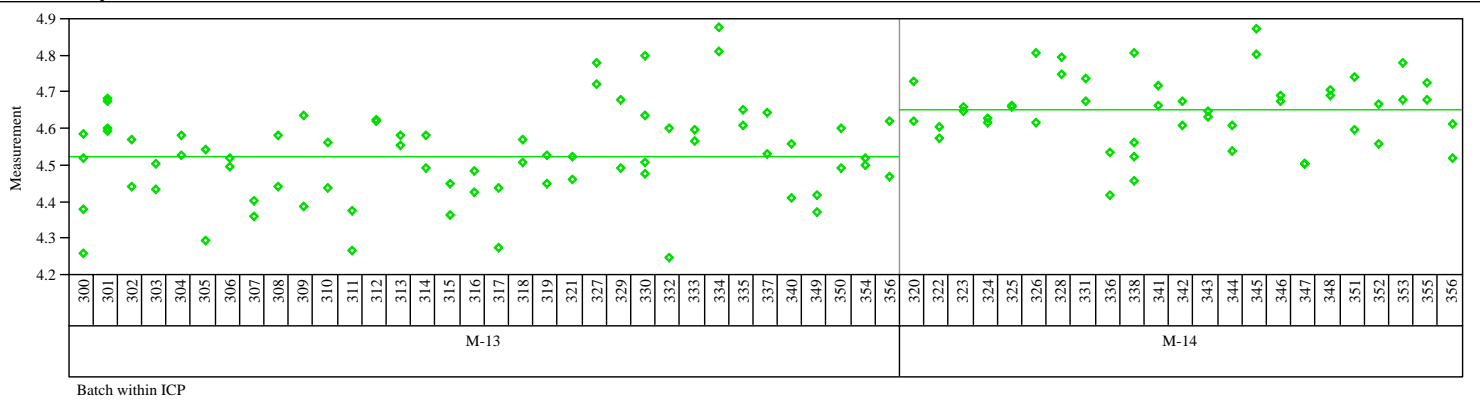

Prep=Mixed Acid, Sample Type=ARG-1, Analyte $=$ Al/Mn

Variability Chart for Measurement

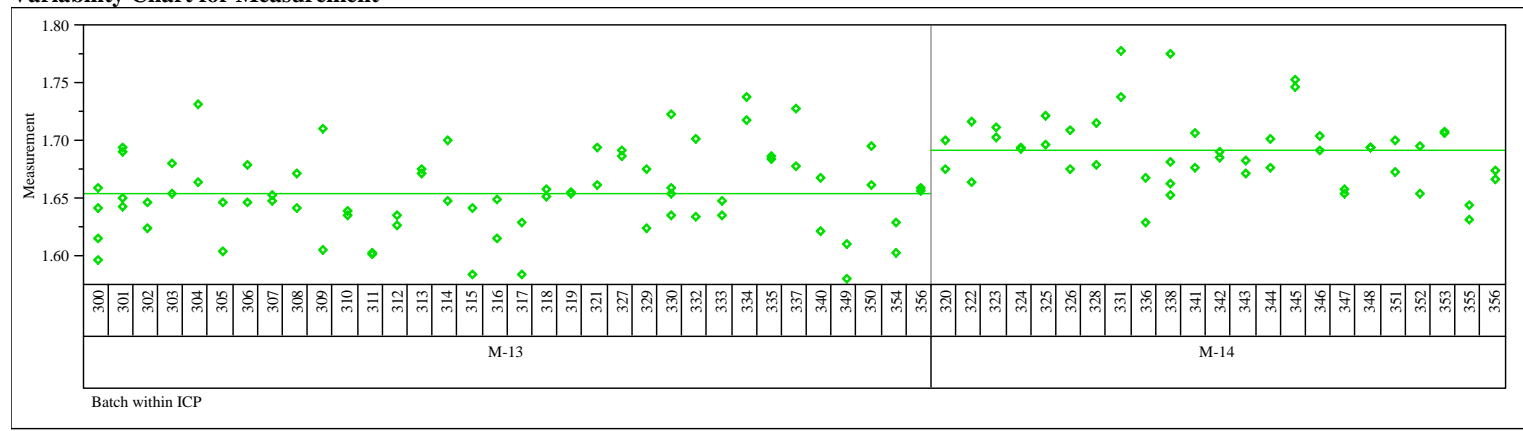

Prep=Mixed Acid, Sample Type=ARG-1, Analyte $=$ =B

Variability Chart for Measurement
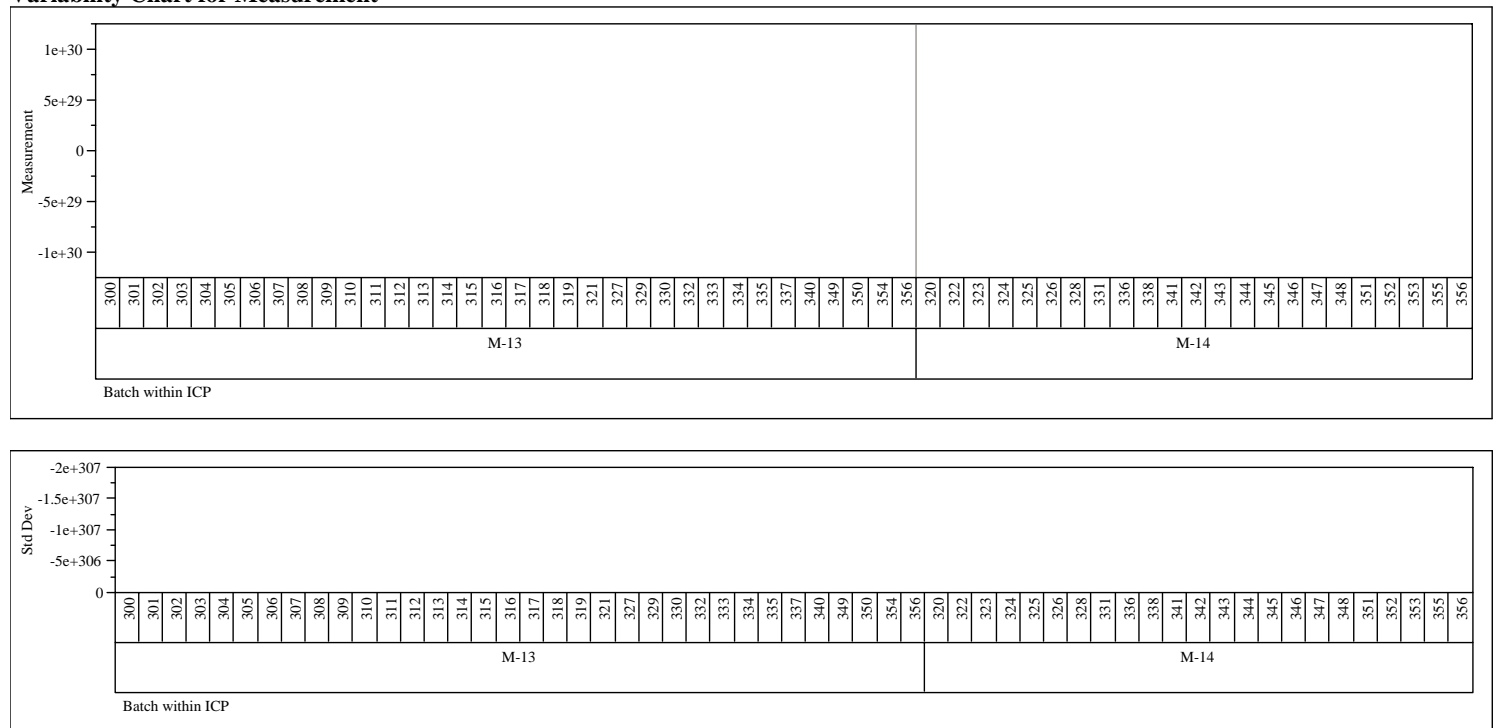
WSRC-STI-2006-00068

Revision 0

Exhibit A2. Measurement Data by Batch by ICP for Prep Method, Sample Type, and Analyte

Prep=Mixed Acid, Sample Type=ARG-1, Analyte $=\mathrm{B} / \mathrm{Li}$

(continued)

Variability Chart for Measurement
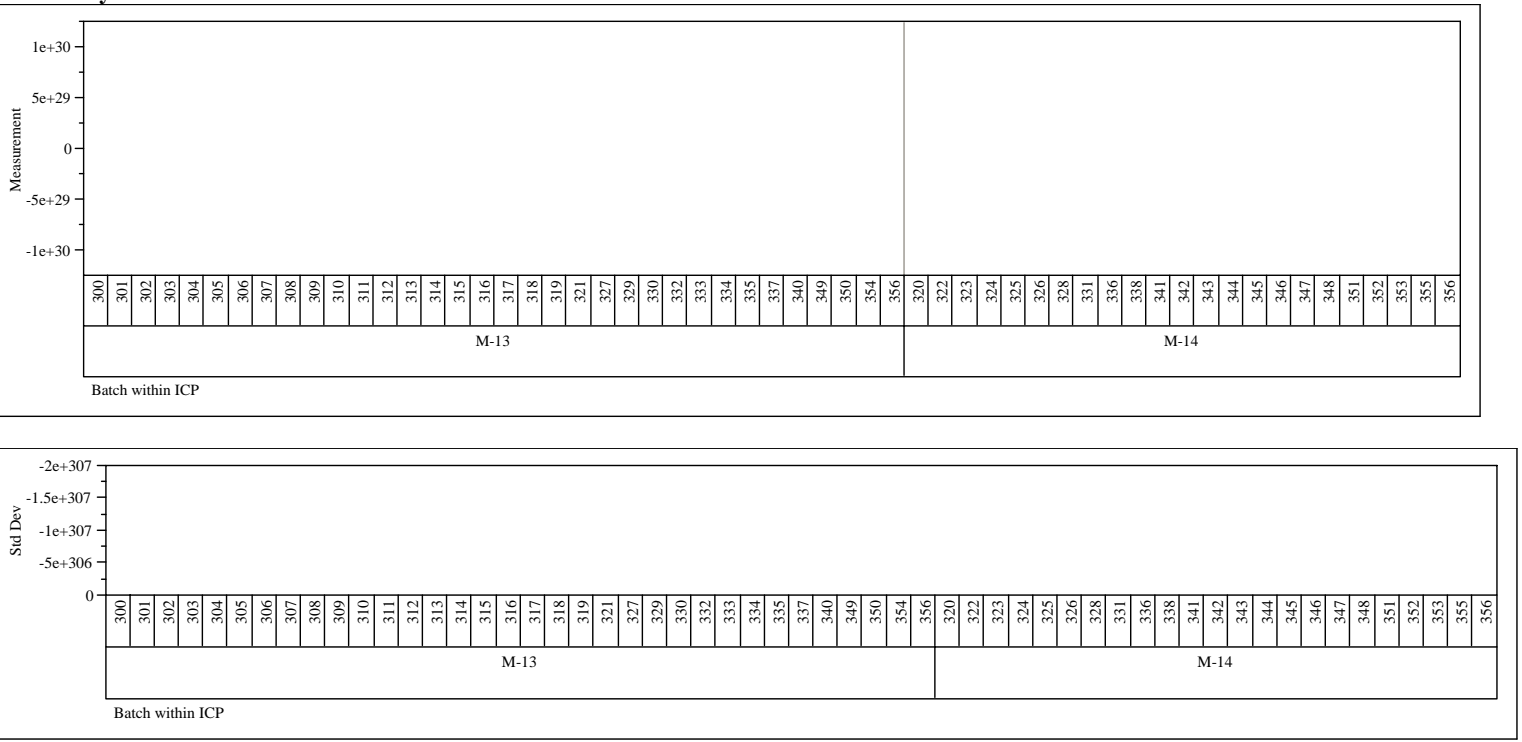

Prep=Mixed Acid, Sample Type=ARG-1, Analyte $=$ Ca

Variability Chart for Measurement

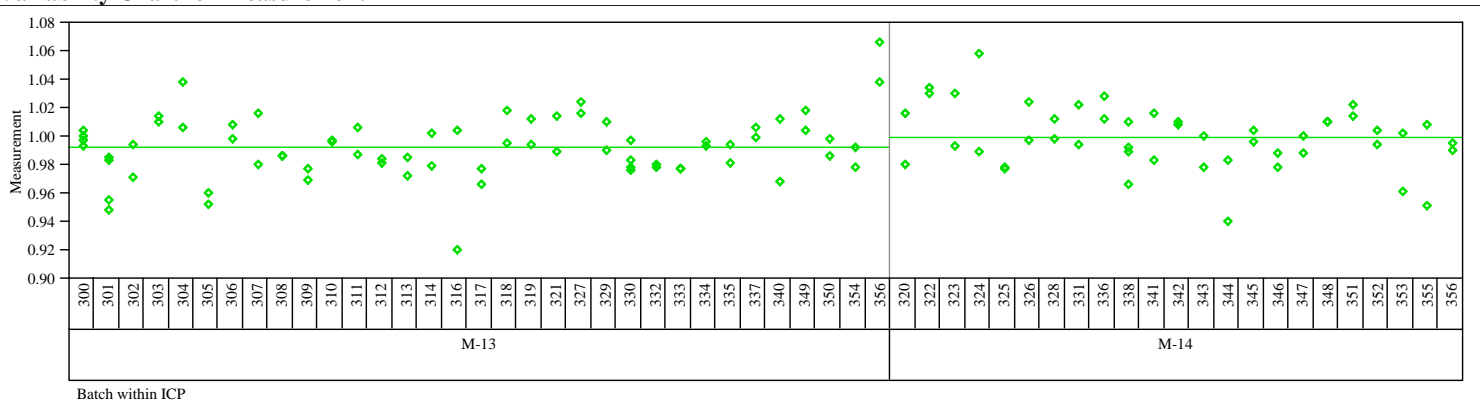

Prep=Mixed Acid, Sample Type $=$ ARG-1, Analyte $=\mathbf{C r}$

Variability Chart for Measurement

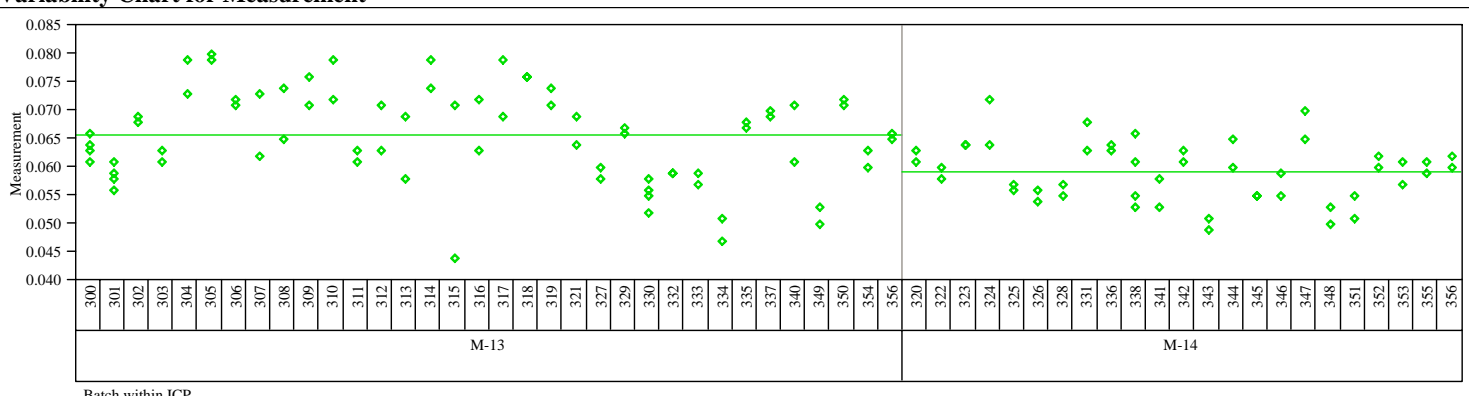


WSRC-STI-2006-00068

Revision 0

Exhibit A2. Measurement Data by Batch by ICP for Prep Method, Sample Type, and Analyte

Prep=Mixed Acid, Sample Type=ARG-1, Analyte $=\mathbf{C u}$

(continued)

Variability Chart for Measurement

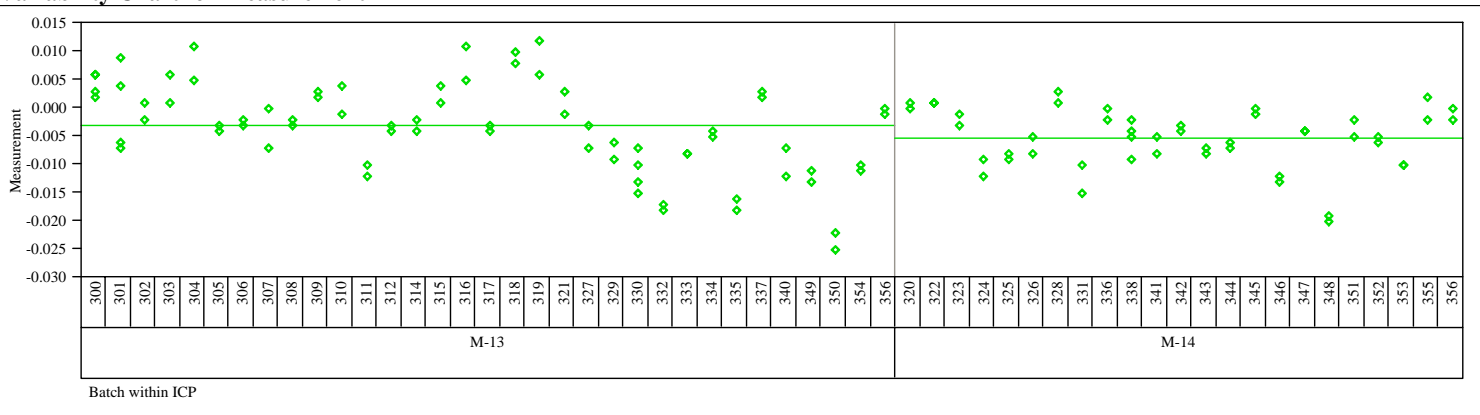

Prep=Mixed Acid, Sample Type=ARG-1, Analyte $=$ Fe

Variability Chart for Measurement

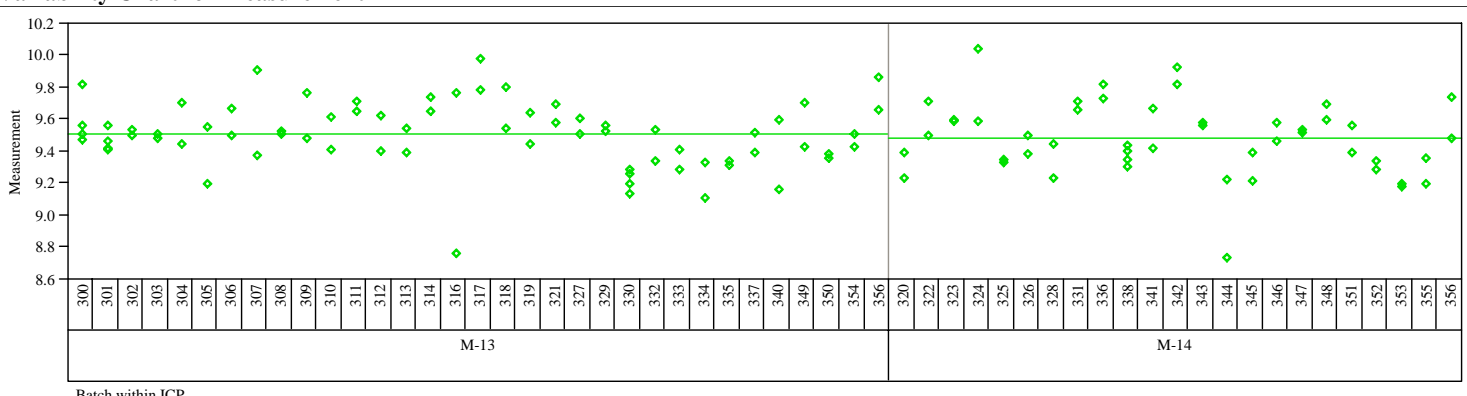

Prep=Mixed Acid, Sample Type=ARG-1, Analyte=Fe/Al

Variability Chart for Measurement

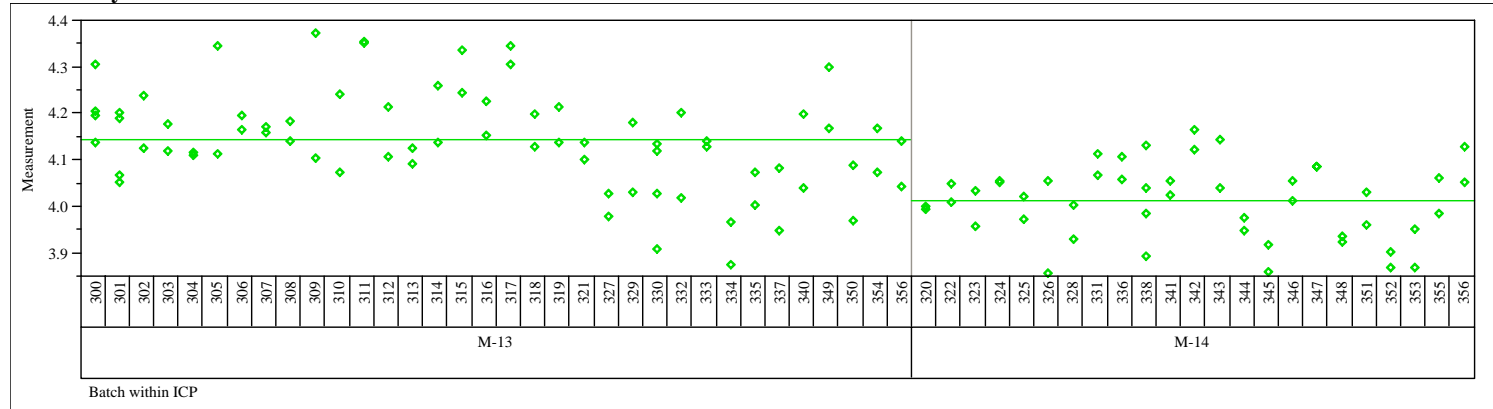

Prep=Mixed Acid, Sample Type=ARG-1, Analyte=Fe/Ca

Variability Chart for Measurement

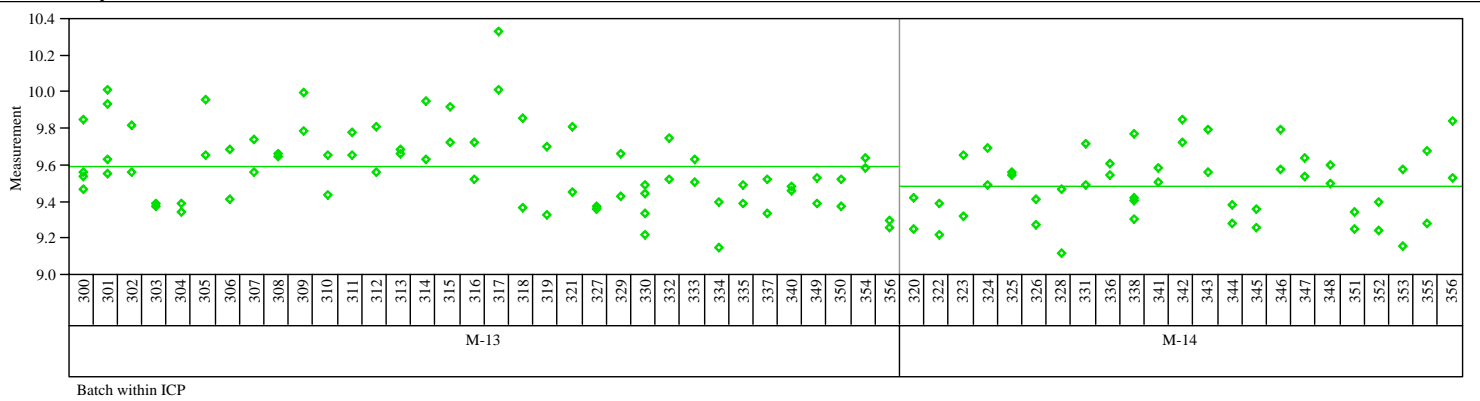


WSRC-STI-2006-00068

Revision 0

Exhibit A2. Measurement Data by Batch by ICP for Prep Method, Sample Type, and Analyte

Prep=Mixed Acid, Sample Type=ARG-1, Analyte=Fe/Li

(continued)

Variability Chart for Measurement

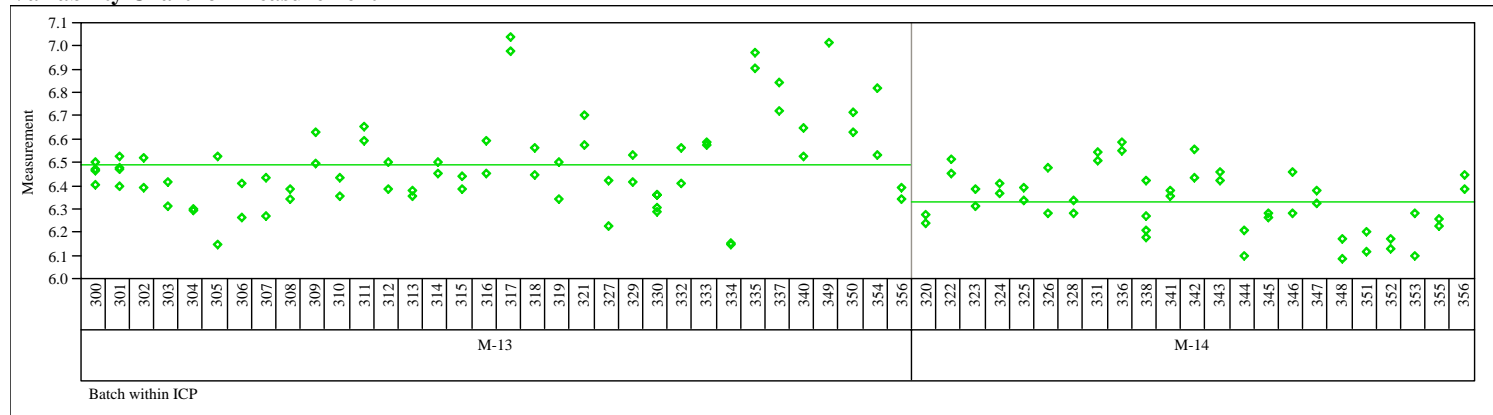

Prep=Mixed Acid, Sample Type=ARG-1, Analyte $=$ Fe/Mg

Variability Chart for Measurement

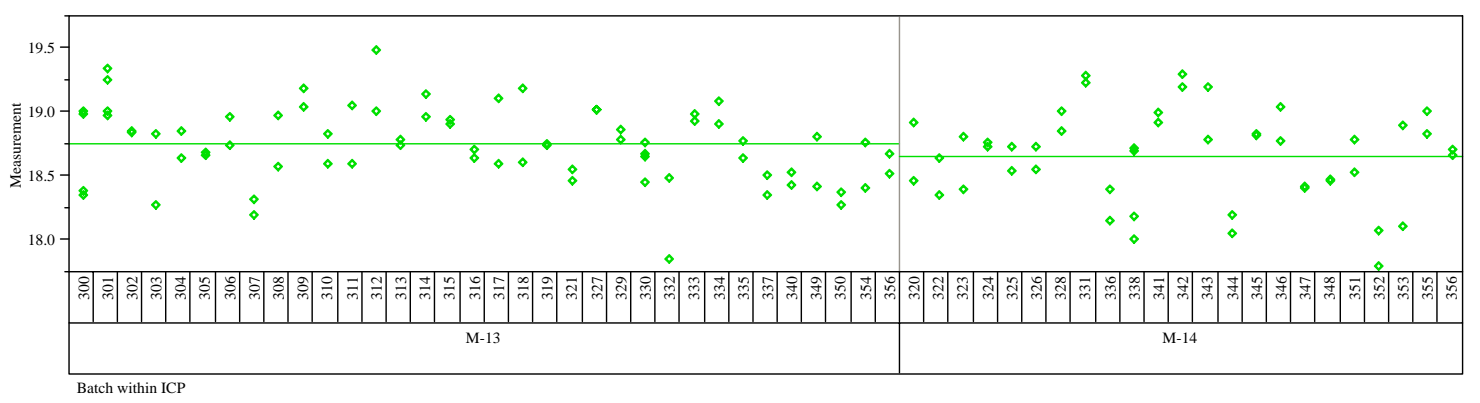

Prep=Mixed Acid, Sample Type=ARG-1, Analyte $=$ Fe/Mn

Variability Chart for Measurement

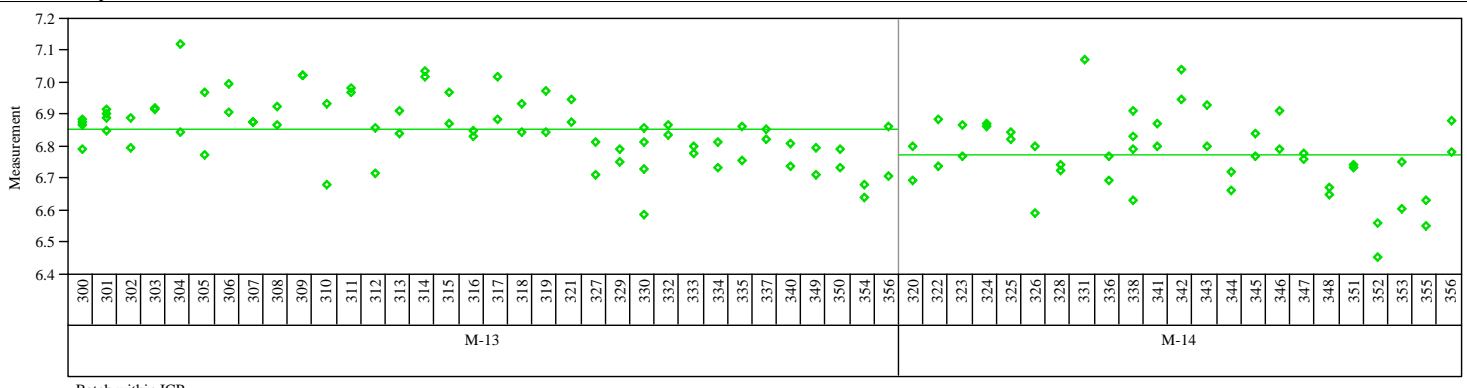

Prep=Mixed Acid, Sample Type $=$ ARG-1, Analyte $=\mathrm{Fe} / \mathrm{Ni}$

Variability Chart for Measurement

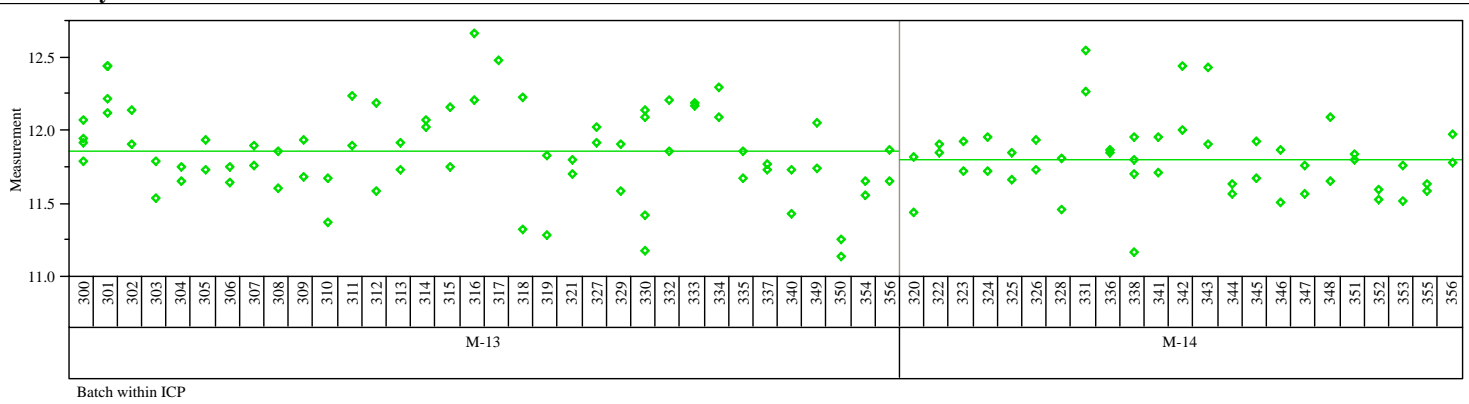


WSRC-STI-2006-00068

Revision 0

Exhibit A2. Measurement Data by Batch by ICP for Prep Method, Sample Type, and Analyte

Prep=Mixed Acid, Sample Type=ARG-1, Analyte $=$ Fe/U

(continued)

Variability Chart for Measurement

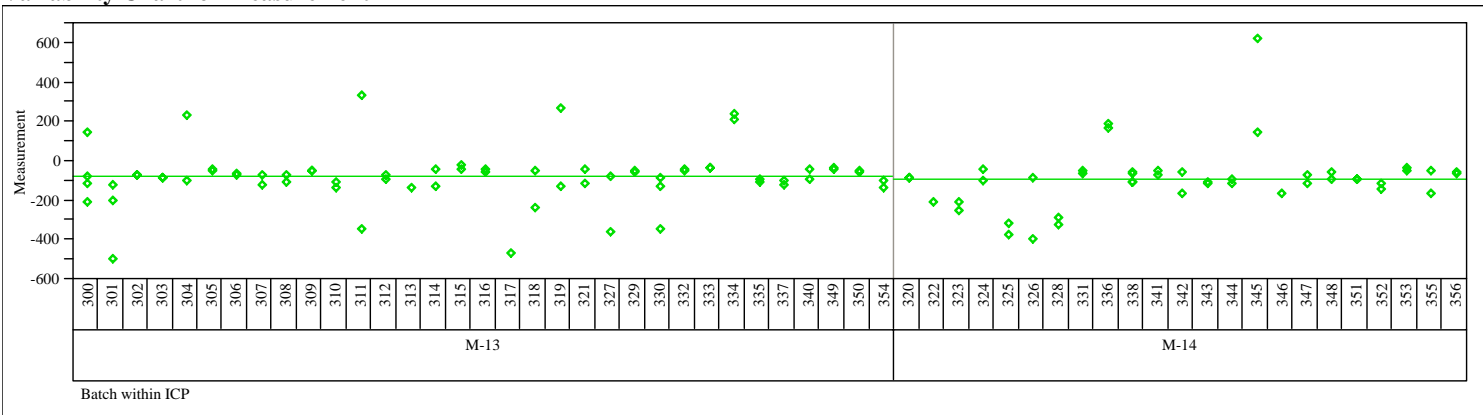

Prep=Mixed Acid, Sample Type=ARG-1, Analyte $=$ K

Variability Chart for Measurement

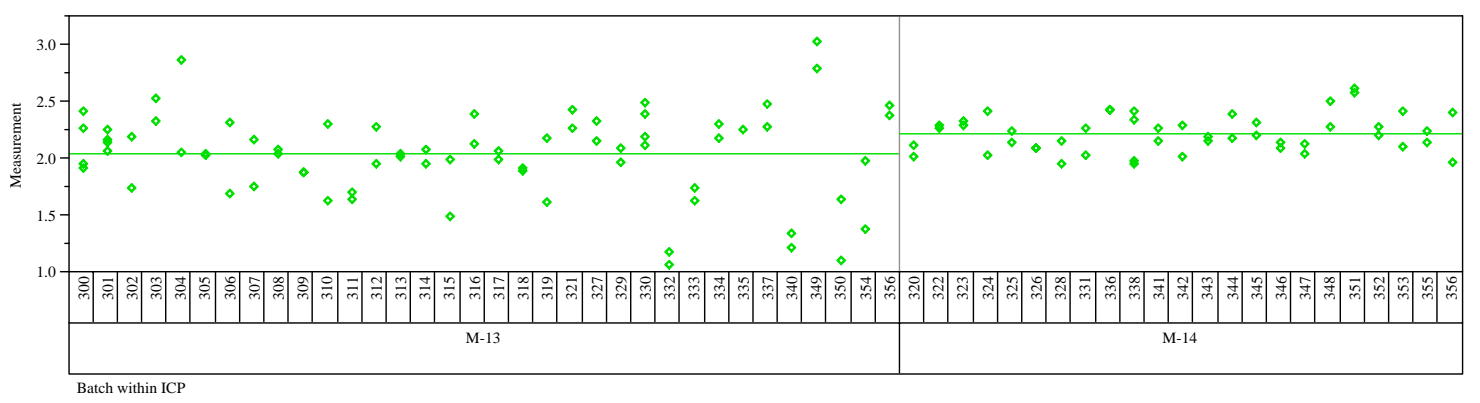

Prep=Mixed Acid, Sample Type=ARG-1, Analyte $=$ Li

Variability Chart for Measurement

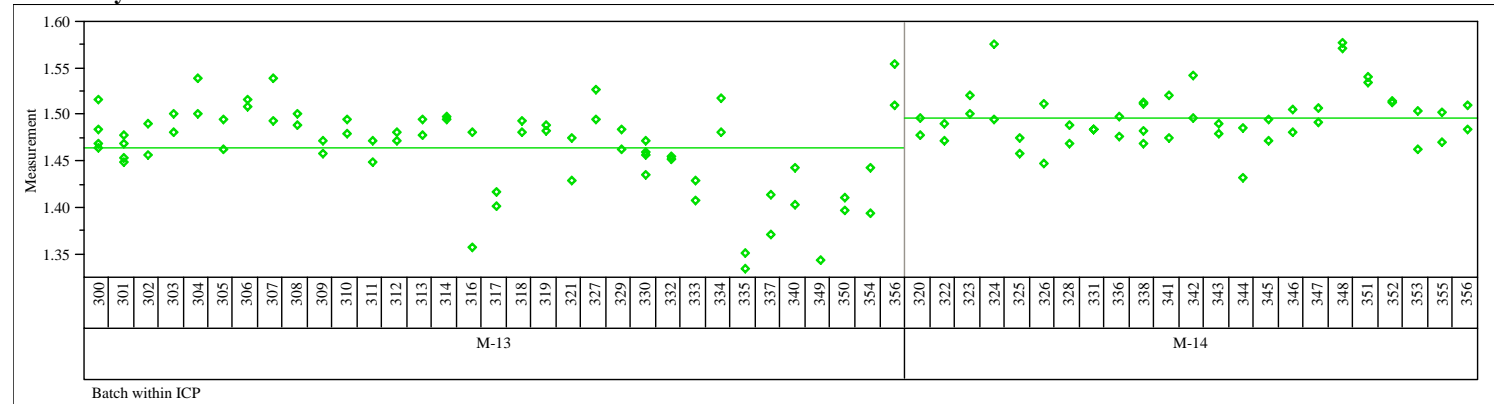

Prep=Mixed Acid, Sample Type=ARG-1, Analyte=Mg

Variability Chart for Measurement

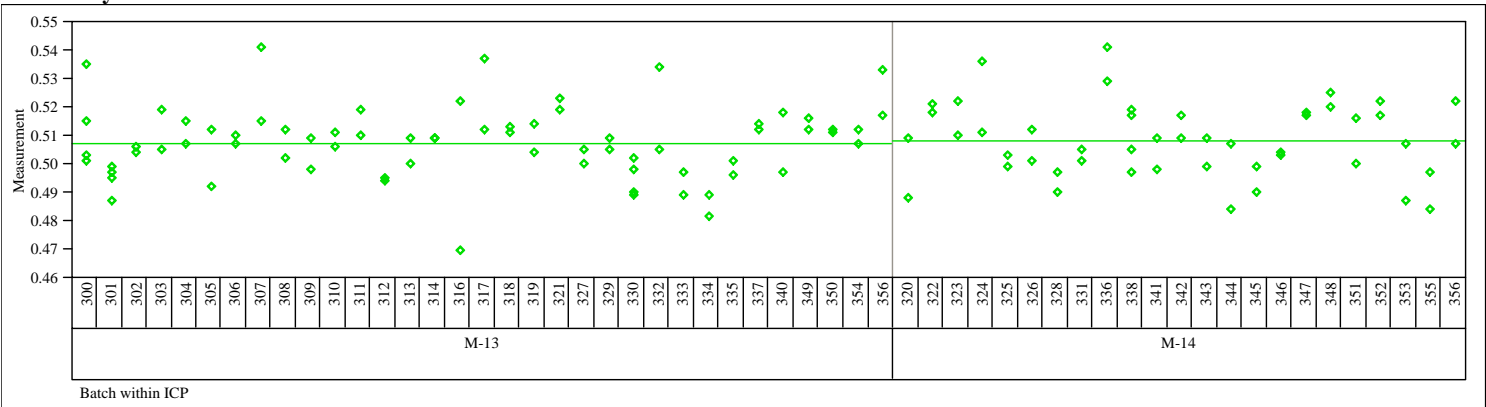


WSRC-STI-2006-00068

Revision 0

Exhibit A2. Measurement Data by Batch by ICP for Prep Method, Sample Type, and Analyte

Prep=Mixed Acid, Sample Type=ARG-1, Analyte $=$ Mn

(continued)

Variability Chart for Measurement

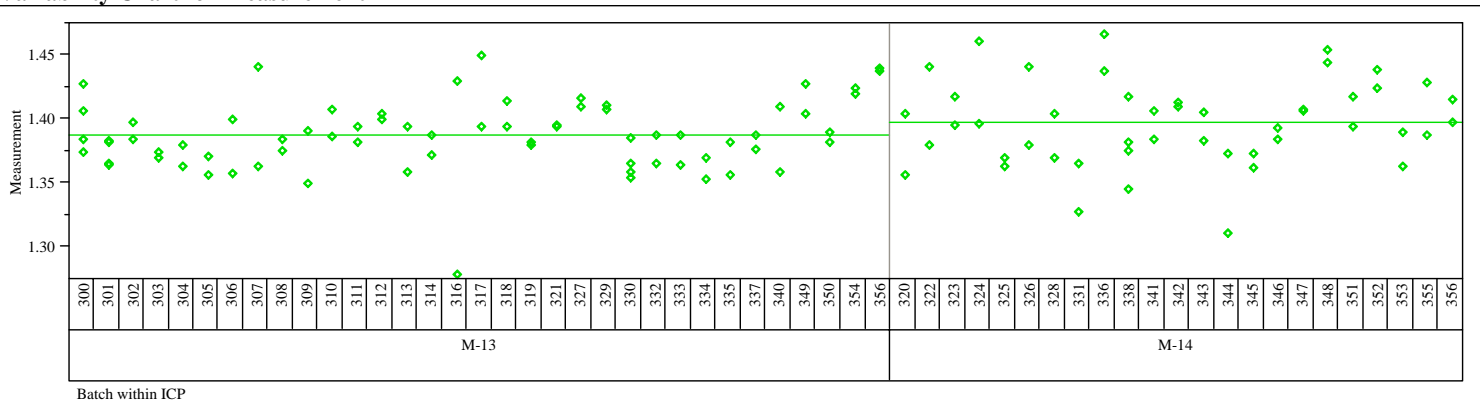

Prep=Mixed Acid, Sample Type $=$ ARG-1, Analyte $=M n / M g$

Variability Chart for Measurement

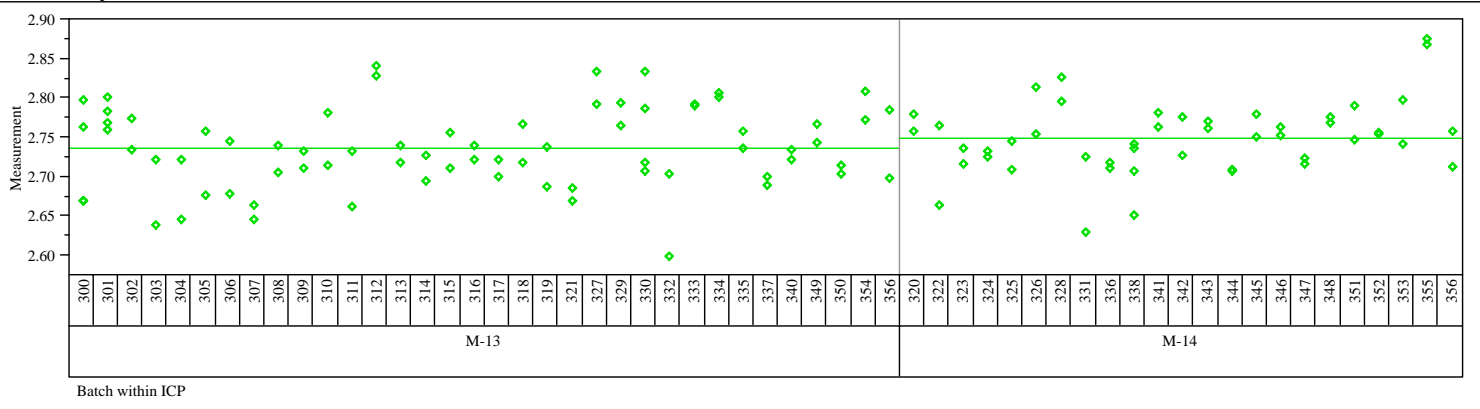

Prep=Mixed Acid, Sample Type $=$ ARG-1, Analyte $=$ Na

Variability Chart for Measurement

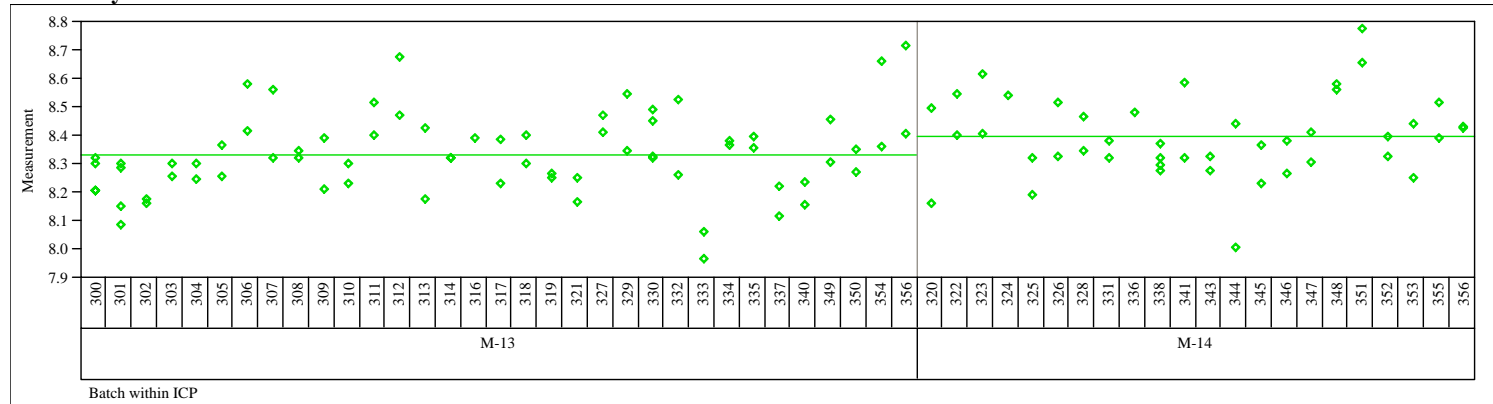

Prep=Mixed Acid, Sample Type=ARG-1, Analyte=Ni

Variability Chart for Measurement

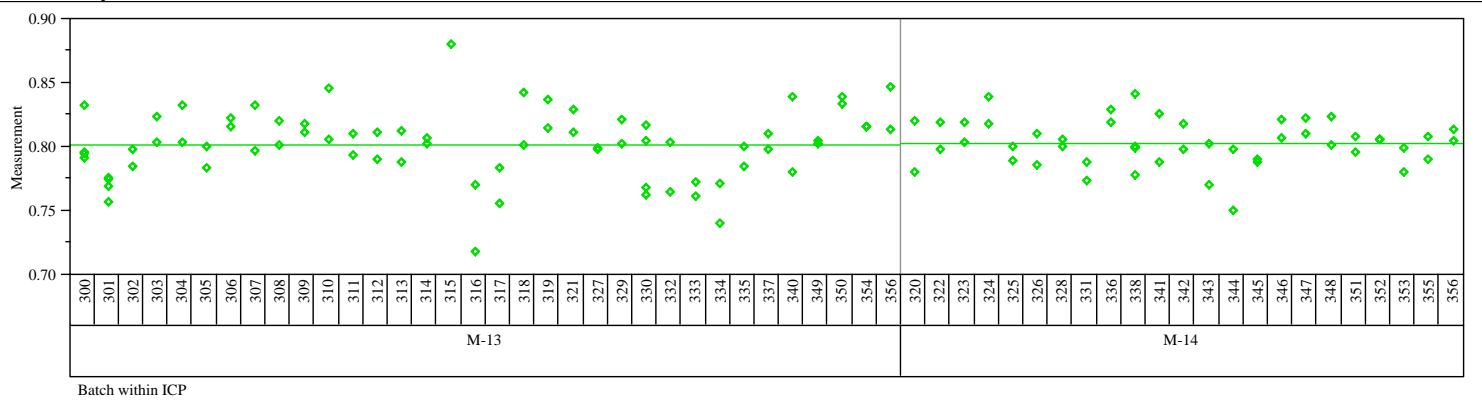


WSRC-STI-2006-00068

Revision 0

Exhibit A2. Measurement Data by Batch by ICP for Prep Method, Sample Type, and Analyte

Prep=Mixed Acid, Sample Type=ARG-1, Analyte $=$ Si

(continued)

Variability Chart for Measurement

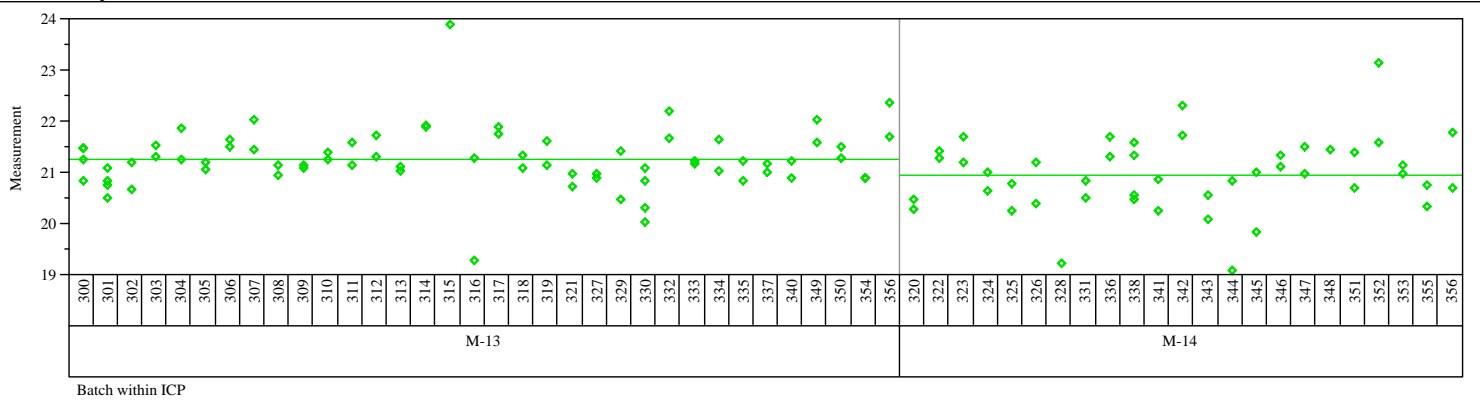

Prep=Mixed Acid, Sample Type=ARG-1, Analyte=Sum of Oxides

Variability Chart for Measurement

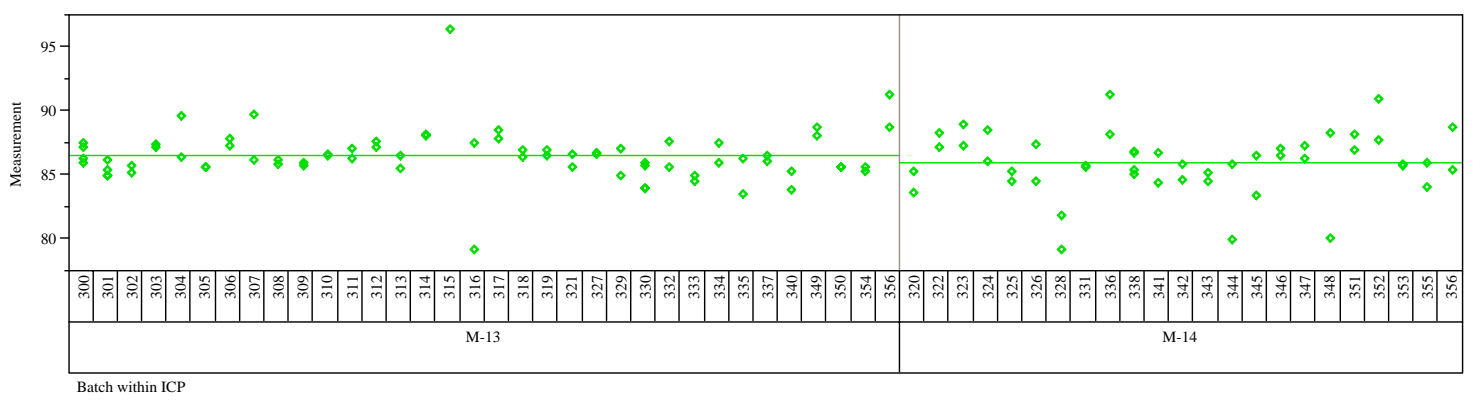

Prep=Mixed Acid, Sample Type=ARG-1, Analyte=Ti

Variability Chart for Measurement

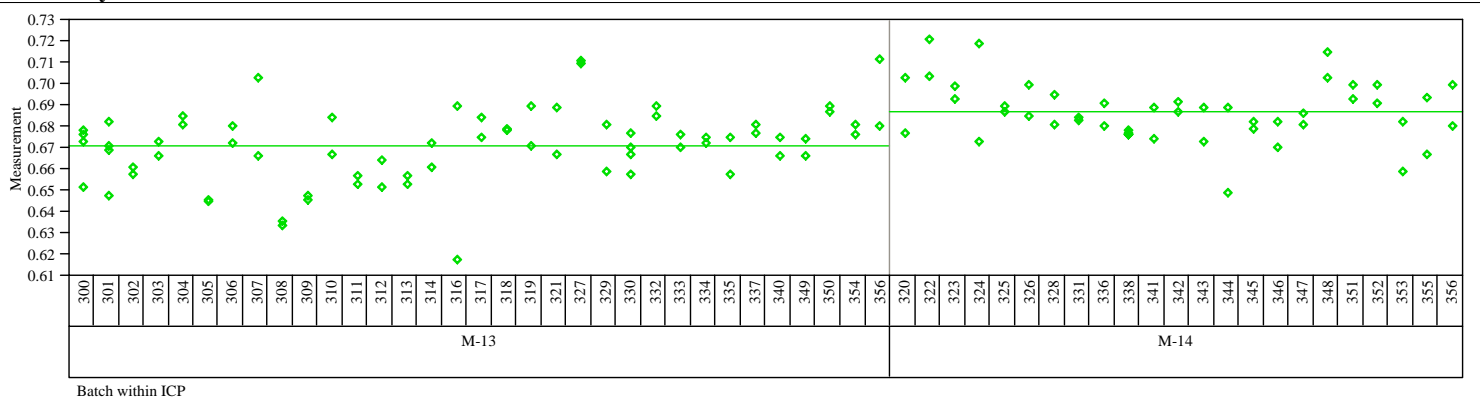

Prep=Mixed Acid, Sample Type=ARG-1, Analyte=U

Variability Chart for Measurement

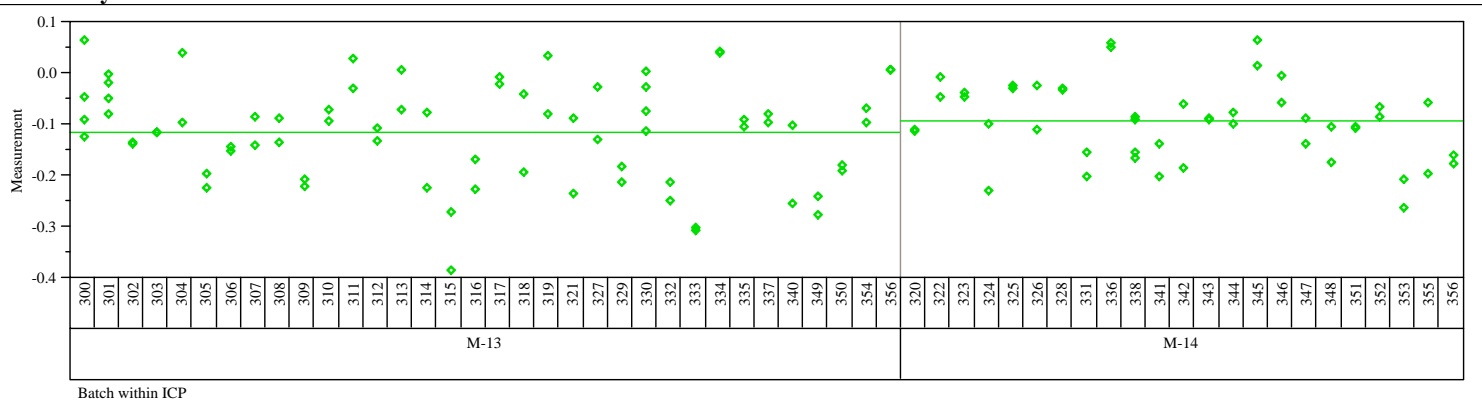


WSRC-STI-2006-00068

Revision 0

Exhibit A2. Measurement Data by Batch by ICP for Prep Method, Sample Type, and Analyte

Prep=Mixed Acid, Sample Type=ARG-1, Analyte=U/Ca

(continued)

Variability Chart for Measurement

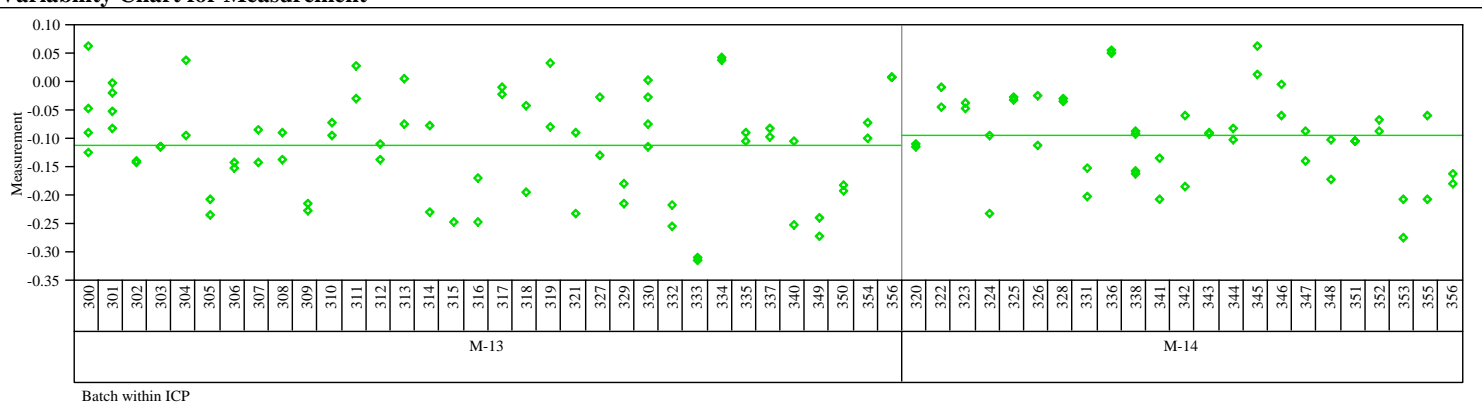

Prep=Mixed Acid, Sample Type=ARG-1, Analyte $=\mathbf{Z r}$

Variability Chart for Measurement

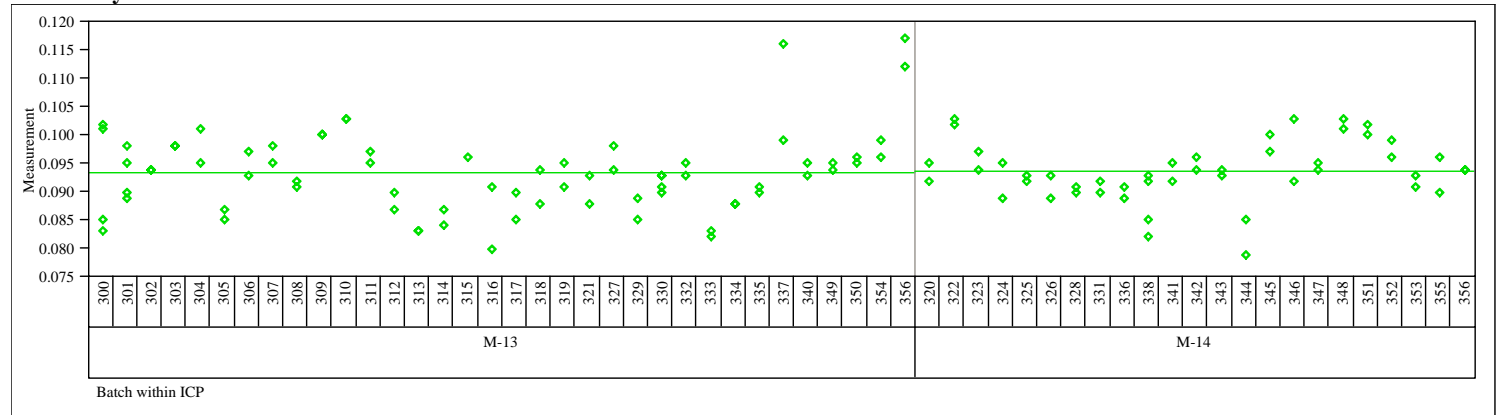

Prep=Mixed Acid, Sample Type=SME, Analyte $=$ Al

Variability Chart for Measurement

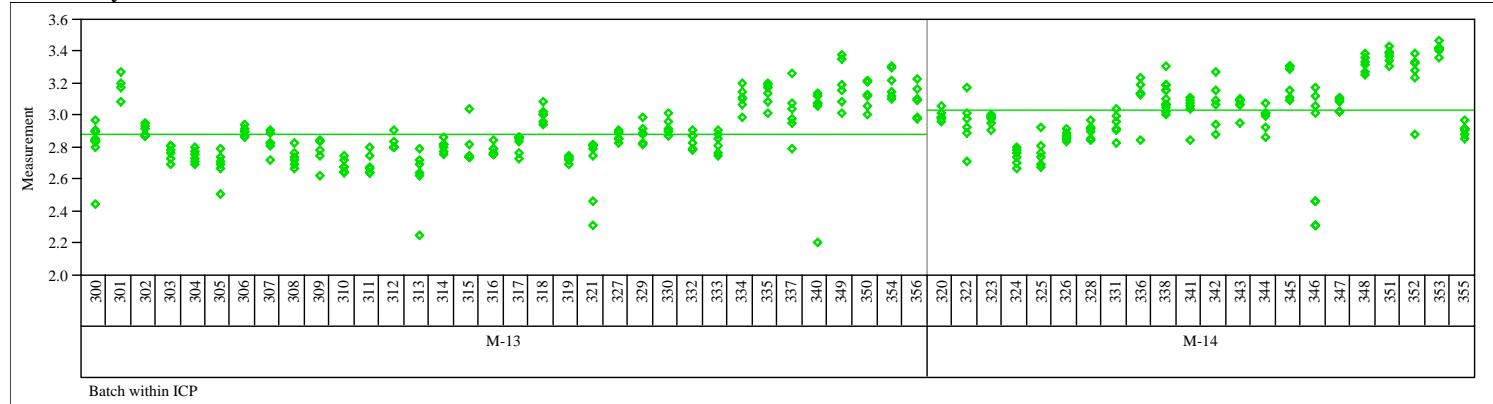

Prep=Mixed Acid, Sample Type $=$ SME, Analyte $=$ Al $/$ Ca

Variability Chart for Measurement

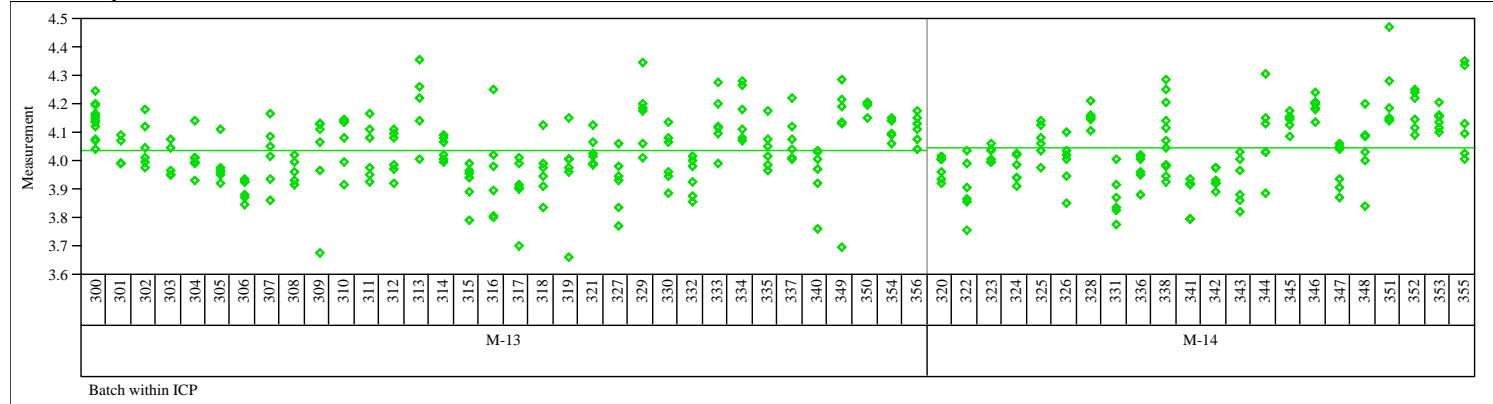


WSRC-STI-2006-00068

Revision 0

Exhibit A2. Measurement Data by Batch by ICP for Prep Method, Sample Type, and Analyte

Prep=Mixed Acid, Sample Type=SME, Analyte $=$ Al $/$ Mg

(continued)

Variability Chart for Measurement

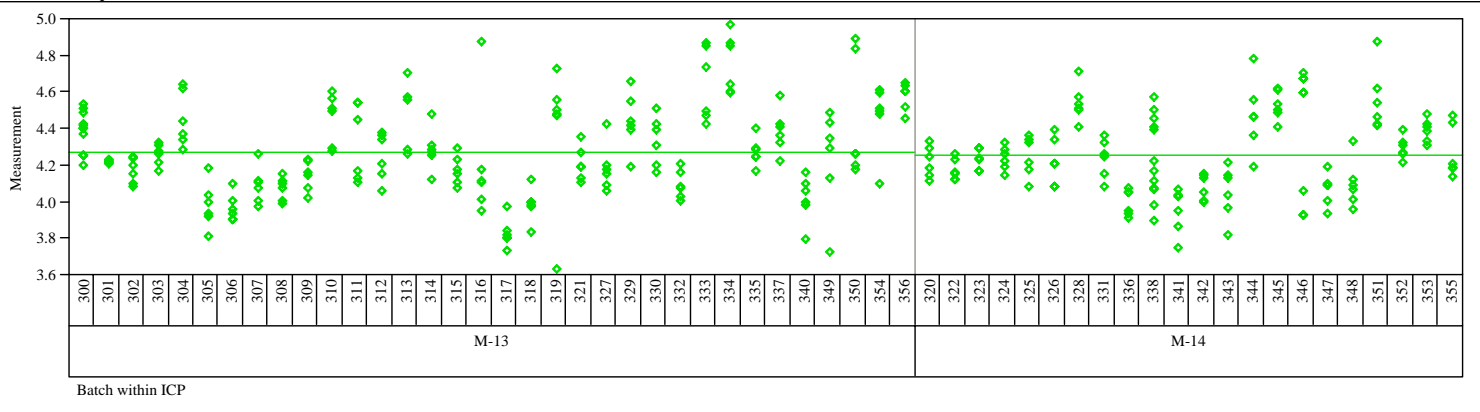

Prep $=$ Mixed Acid, Sample Type $=$ SME, Analyte $=A \mathbf{A} /$ Mn

Variability Chart for Measurement

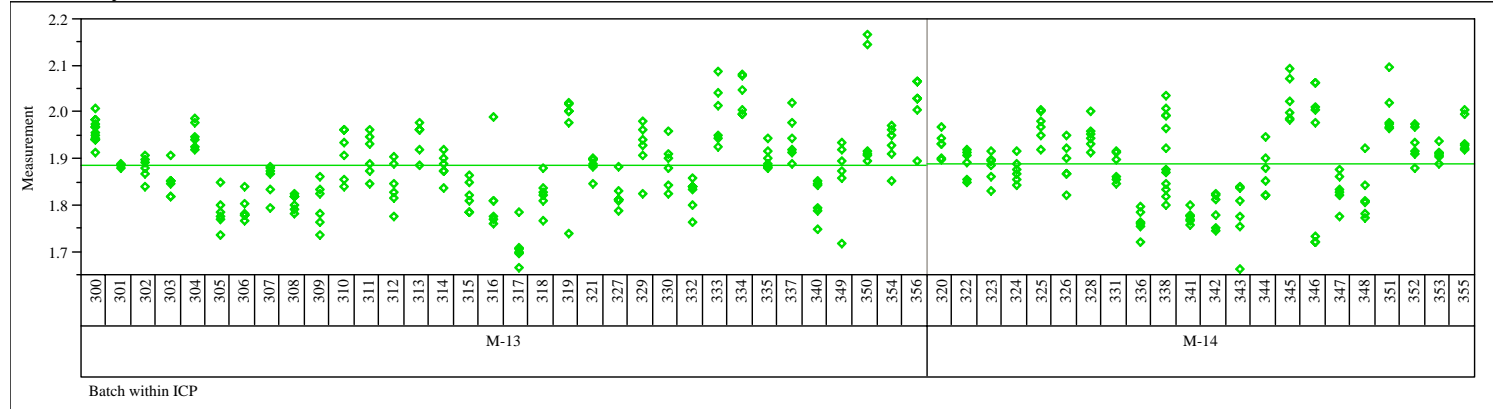

Prep=Mixed Acid, Sample Type=SME, Analyte $=B$

Variability Chart for Measurement

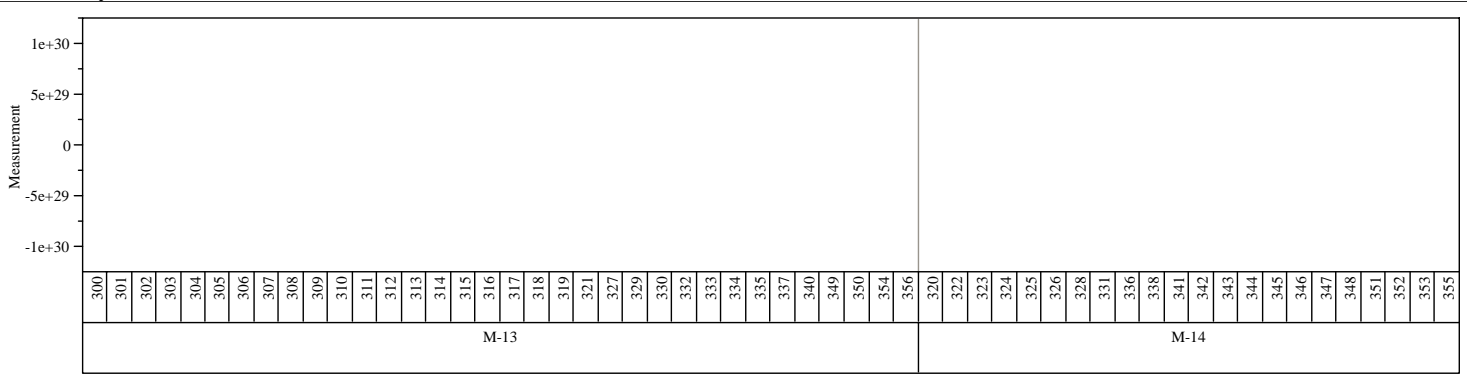

Batch within ICP

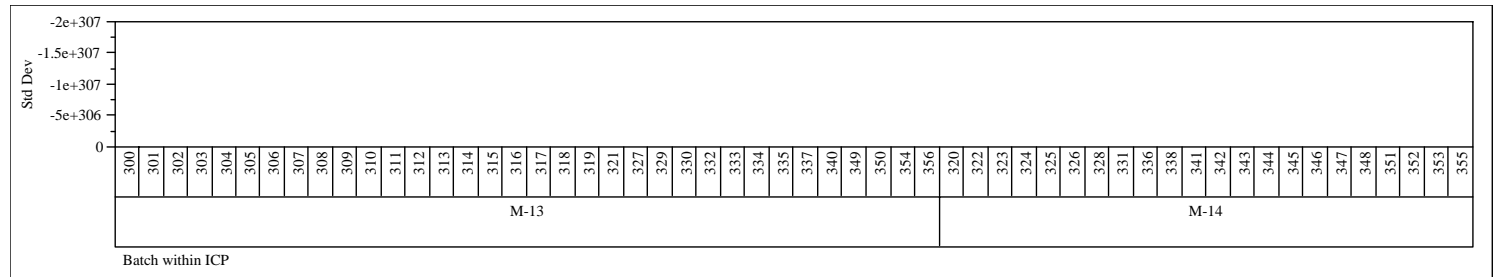


WSRC-STI-2006-00068

Revision 0

Exhibit A2. Measurement Data by Batch by ICP for Prep Method, Sample Type, and Analyte

Prep=Mixed Acid, Sample Type=SME, Analyte $=\mathrm{B} / \mathrm{Li}$

(continued)

Variability Chart for Measurement
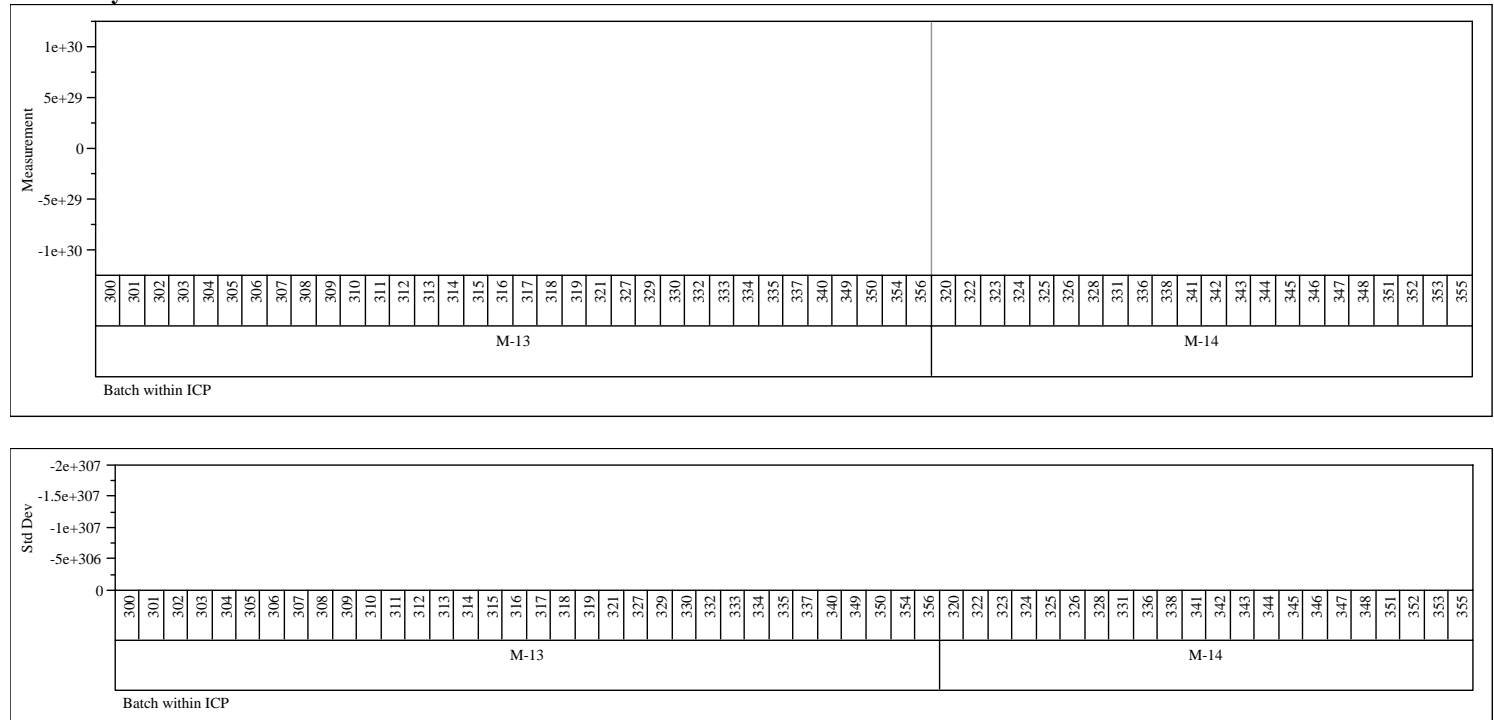

Prep=Mixed Acid, Sample Type=SME, Analyte $=$ Ca

Variability Chart for Measurement

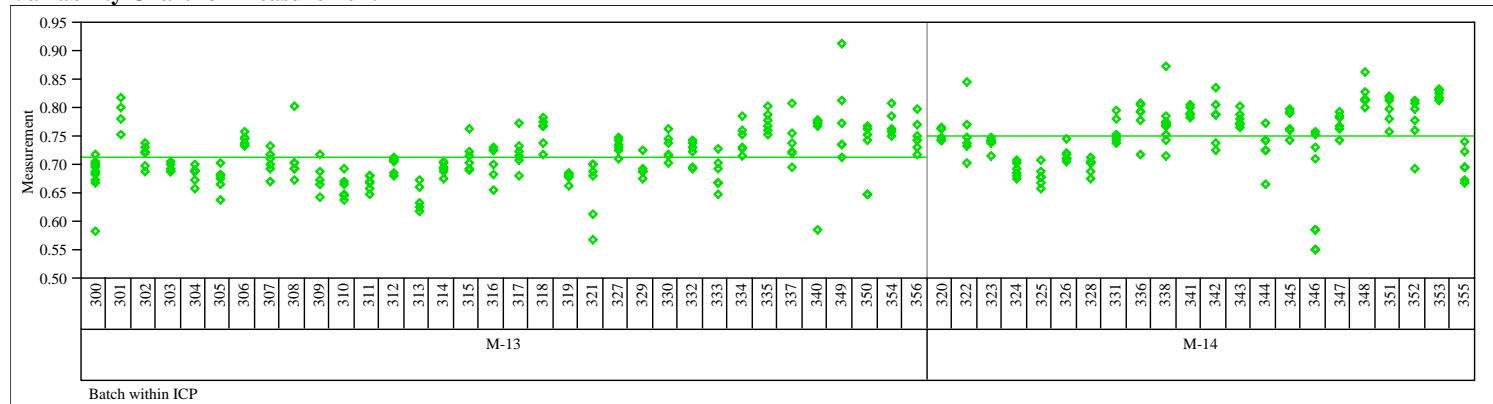

Prep=Mixed Acid, Sample Type $=$ SME, Analyte $=\mathrm{Cr}$

Variability Chart for Measurement

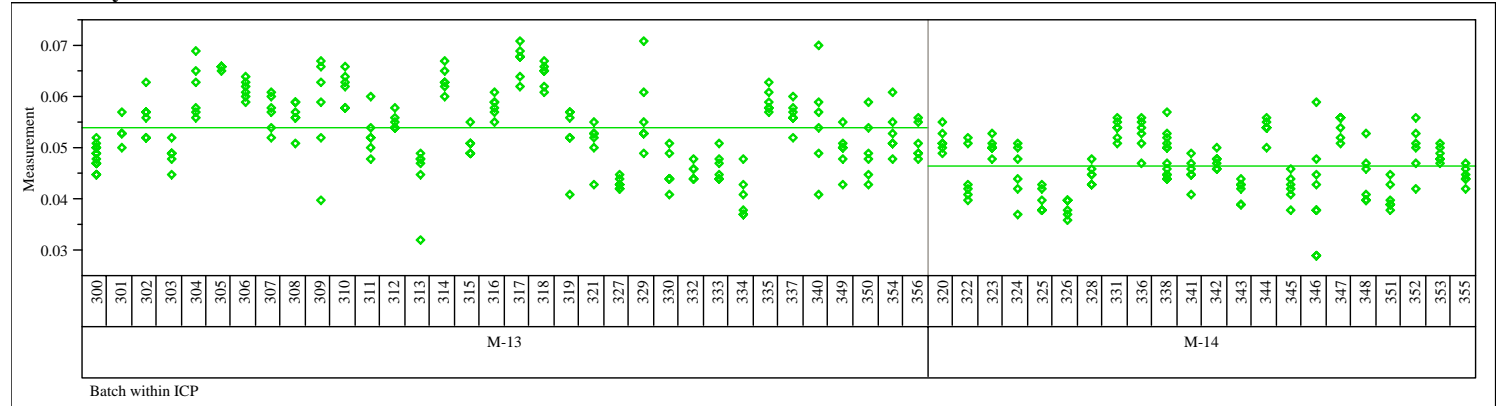


WSRC-STI-2006-00068

Revision 0

Exhibit A2. Measurement Data by Batch by ICP for Prep Method, Sample Type, and Analyte

Prep=Mixed Acid, Sample Type $=$ SME, Analyte $=\mathrm{Cu}$

(continued)

Variability Chart for Measurement

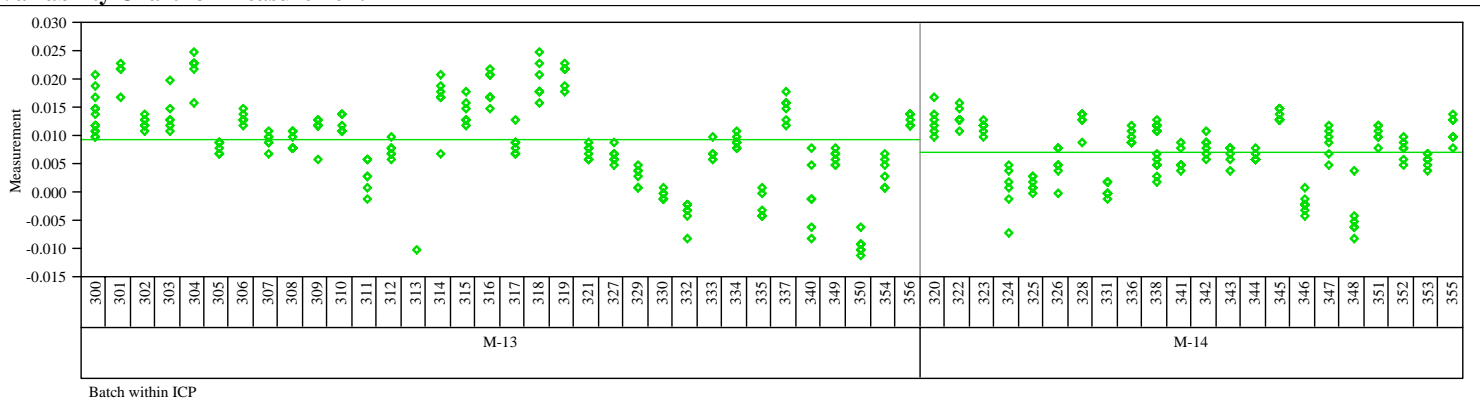

Prep $=$ Mixed Acid, Sample Type $=$ SME, Analyte $=F e$

Variability Chart for Measurement

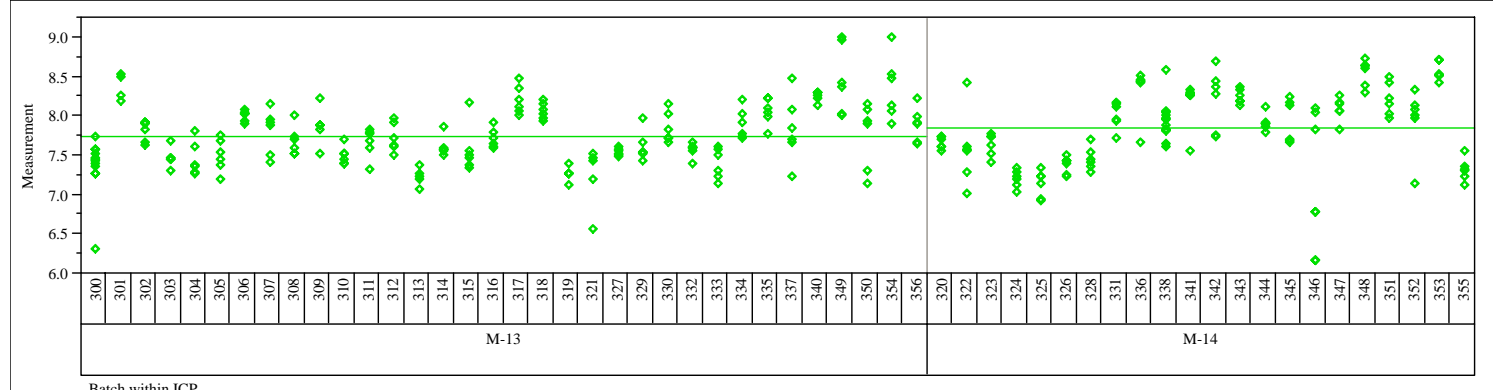

Prep=Mixed Acid, Sample Type=SME, Analyte=Fe/Al

Variability Chart for Measurement

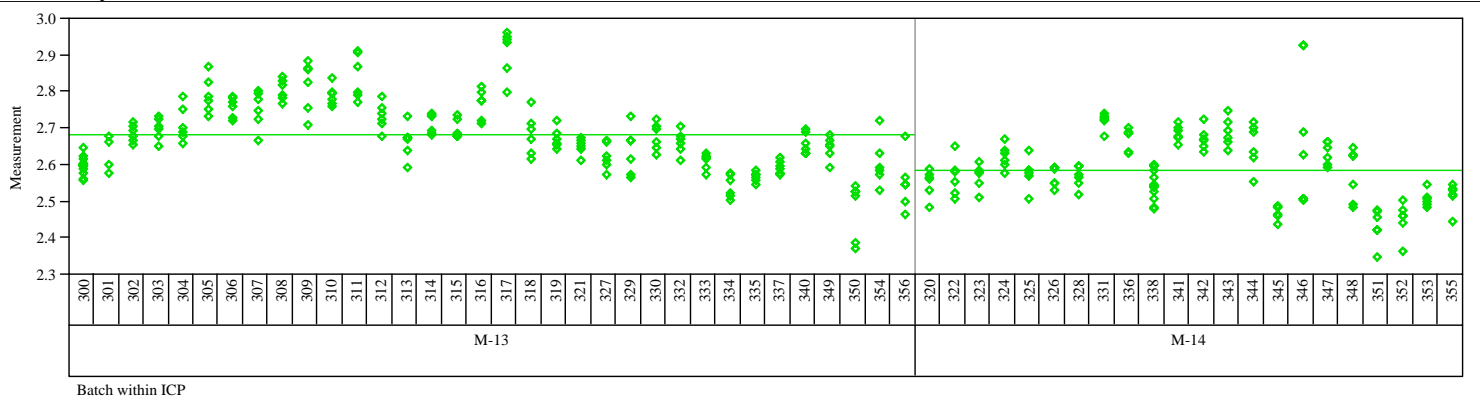

Prep=Mixed Acid, Sample Type=SME, Analyte=Fe/Ca

Variability Chart for Measurement

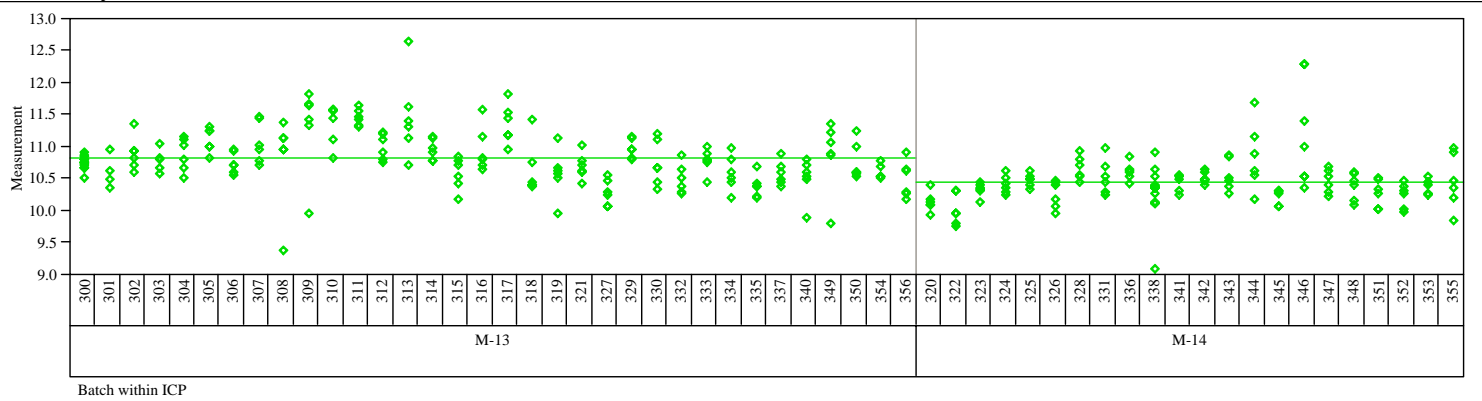


WSRC-STI-2006-00068

Revision 0

Exhibit A2. Measurement Data by Batch by ICP for Prep Method, Sample Type, and Analyte

Prep=Mixed Acid, Sample Type $=\mathrm{SME}$, Analyte $=\mathrm{Fe} / \mathrm{Li}$

(continued)

Variability Chart for Measurement

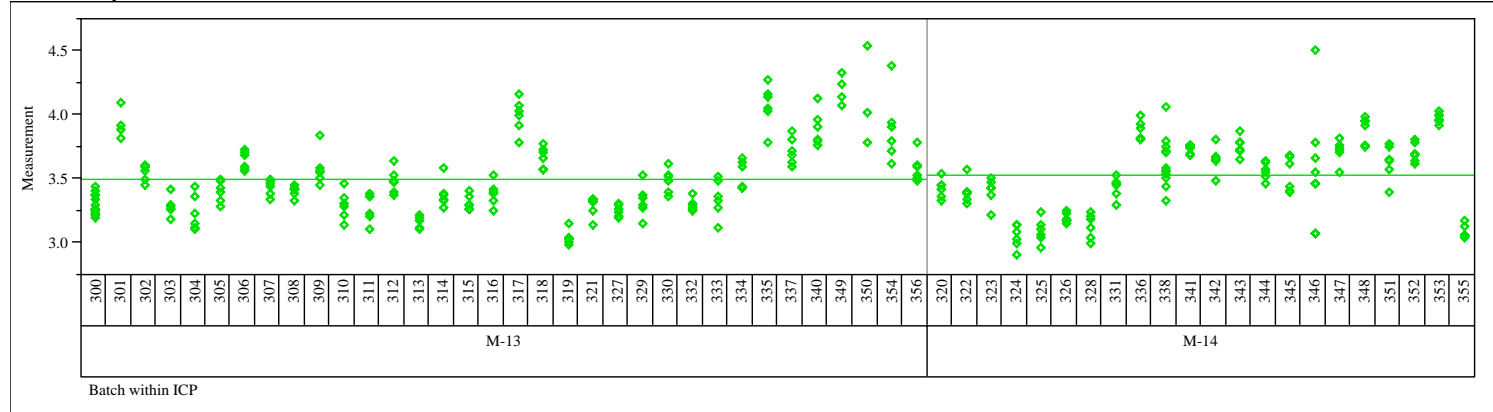

Prep=Mixed Acid, Sample Type $=$ SME, Analyte $=\mathrm{Fe} / \mathrm{Mg}$

Variability Chart for Measurement

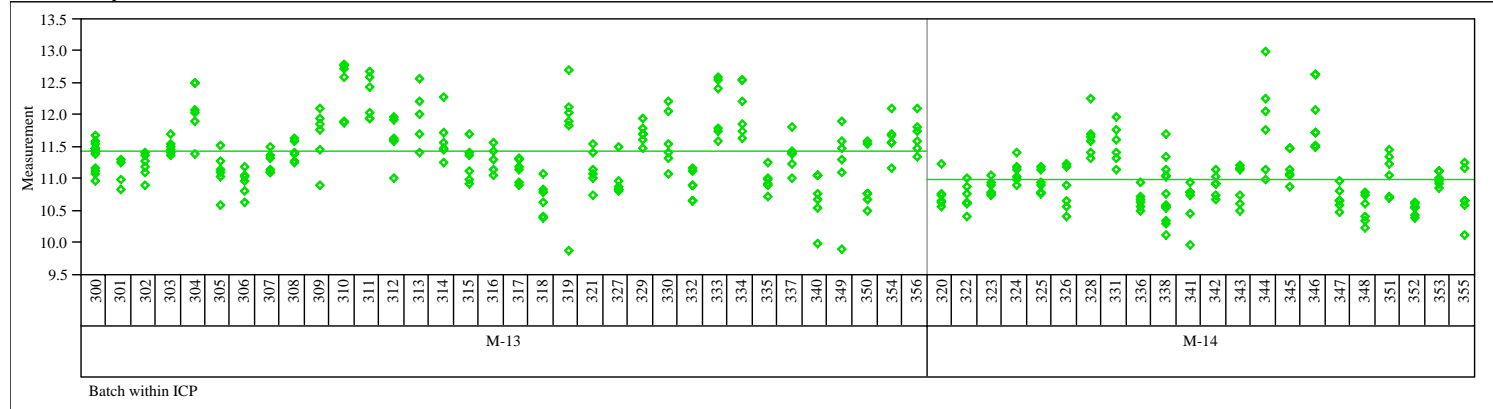

Prep=Mixed Acid, Sample Type $=$ SME, Analyte $=$ Fe $/$ Mn

Variability Chart for Measurement

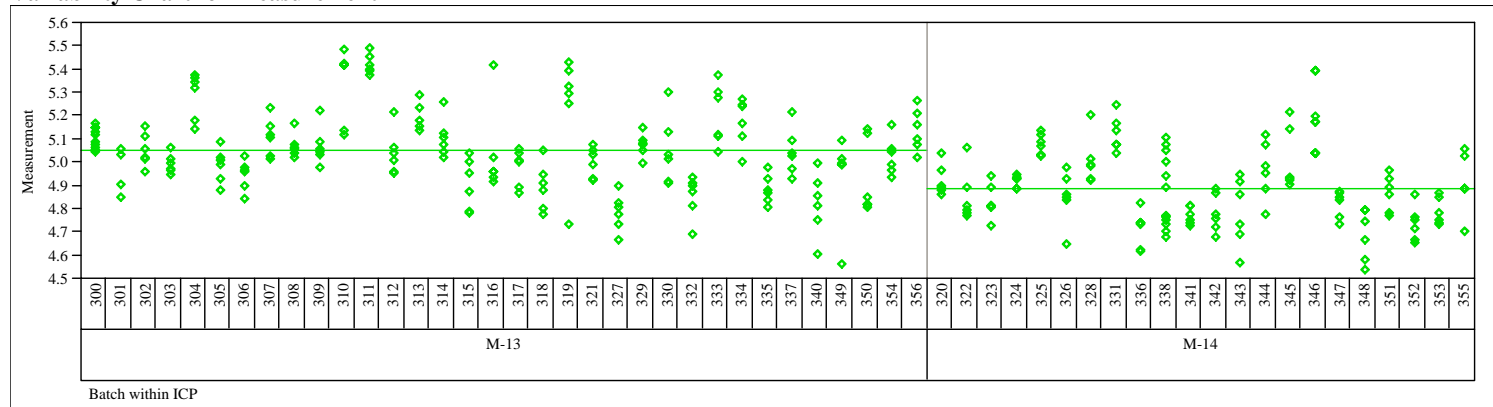

Prep=Mixed Acid, Sample Type=SME, Analyte $=\mathrm{Fe} / \mathrm{Ni}$

Variability Chart for Measurement

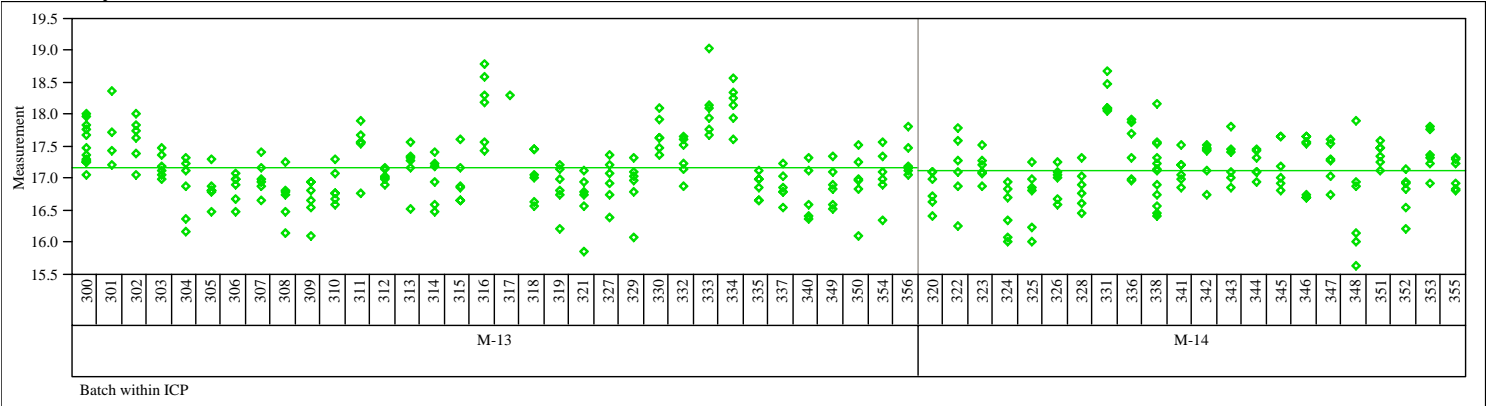


WSRC-STI-2006-00068

Revision 0

Exhibit A2. Measurement Data by Batch by ICP for Prep Method, Sample Type, and Analyte

Prep=Mixed Acid, Sample Type=SME, Analyte=Fe/U

(continued)

Variability Chart for Measurement

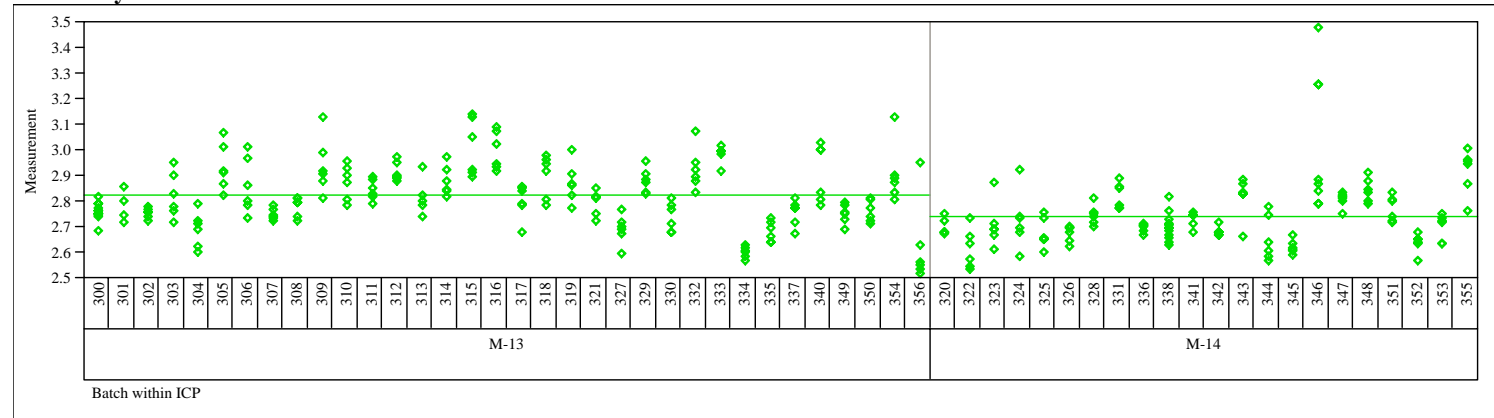

Prep=Mixed Acid, Sample Type $=$ SME, Analyte $=K$

Variability Chart for Measurement

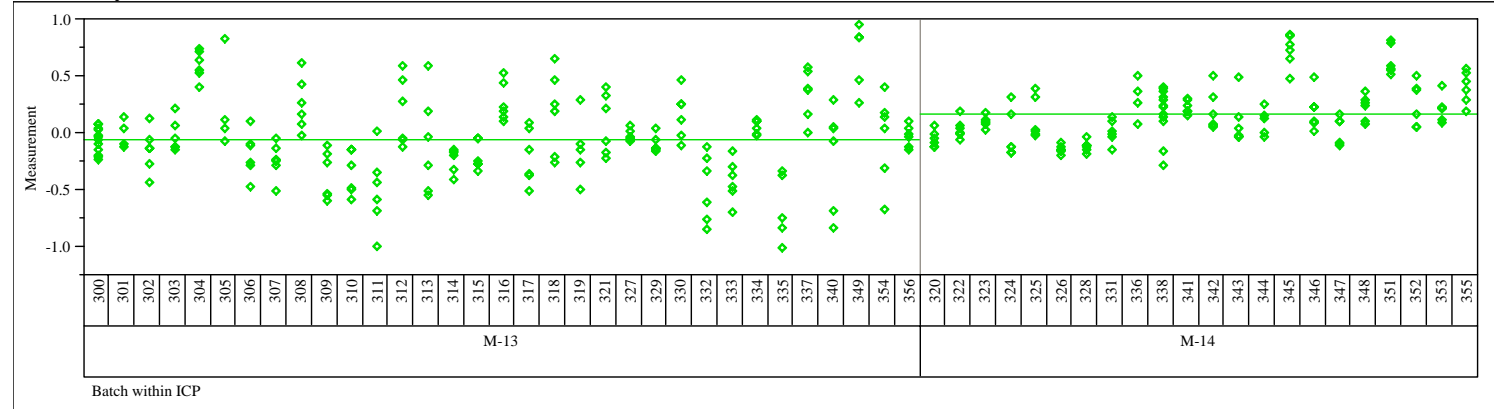

Prep=Mixed Acid, Sample Type=SME, Analyte $=$ Li

Variability Chart for Measurement

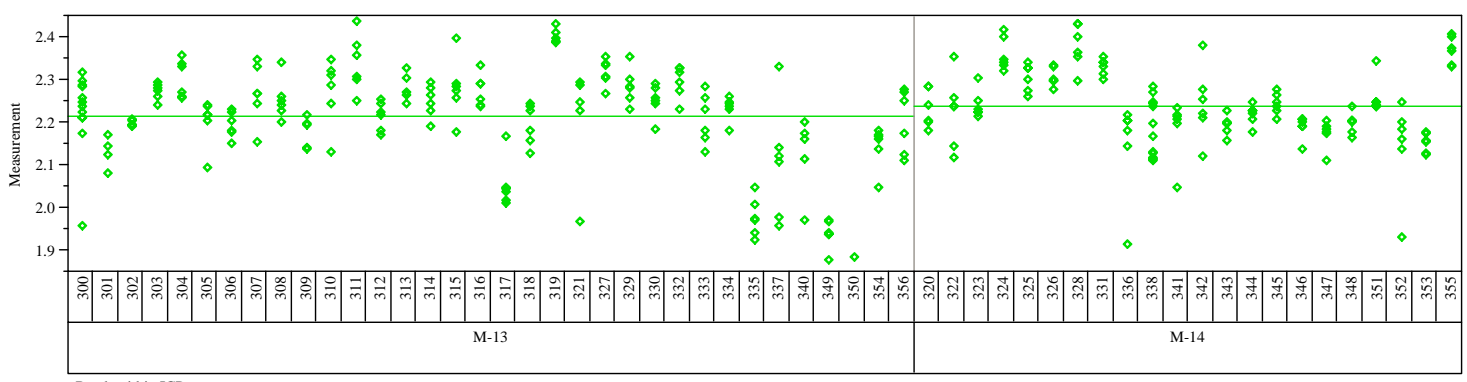

Prep=Mixed Acid, Sample Type=SME, Analyte $=\mathbf{M g}$

Variability Chart for Measurement

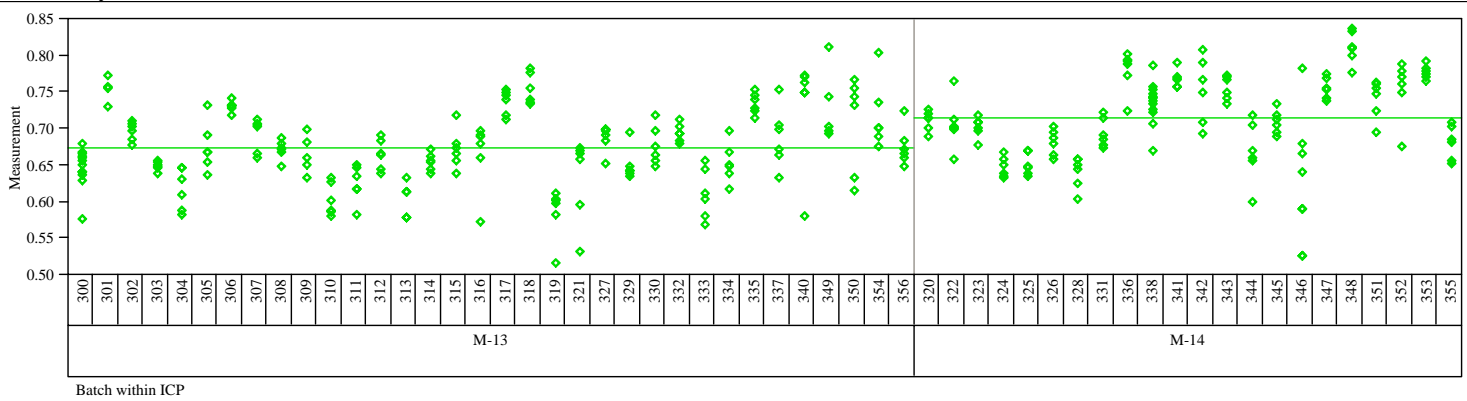


WSRC-STI-2006-00068

Revision 0

Exhibit A2. Measurement Data by Batch by ICP for Prep Method, Sample Type, and Analyte

Prep $=$ Mixed Acid, Sample Type $=$ SME, Analyte $=$ Mn

(continued)

Variability Chart for Measurement

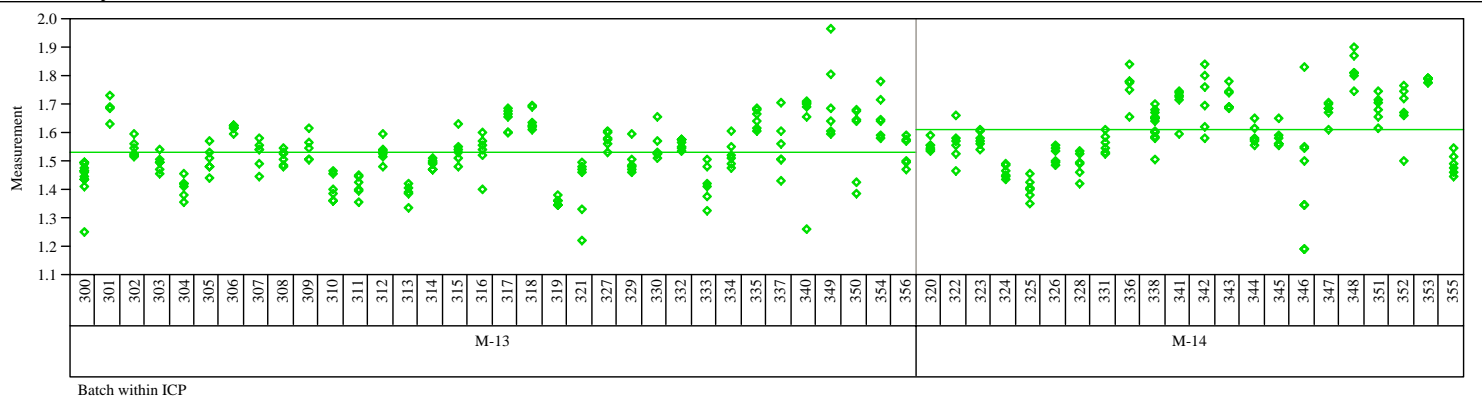

Prep=Mixed Acid, Sample Type=SME, Analyte $=\mathrm{Mn} / \mathrm{Mg}$

Variability Chart for Measurement

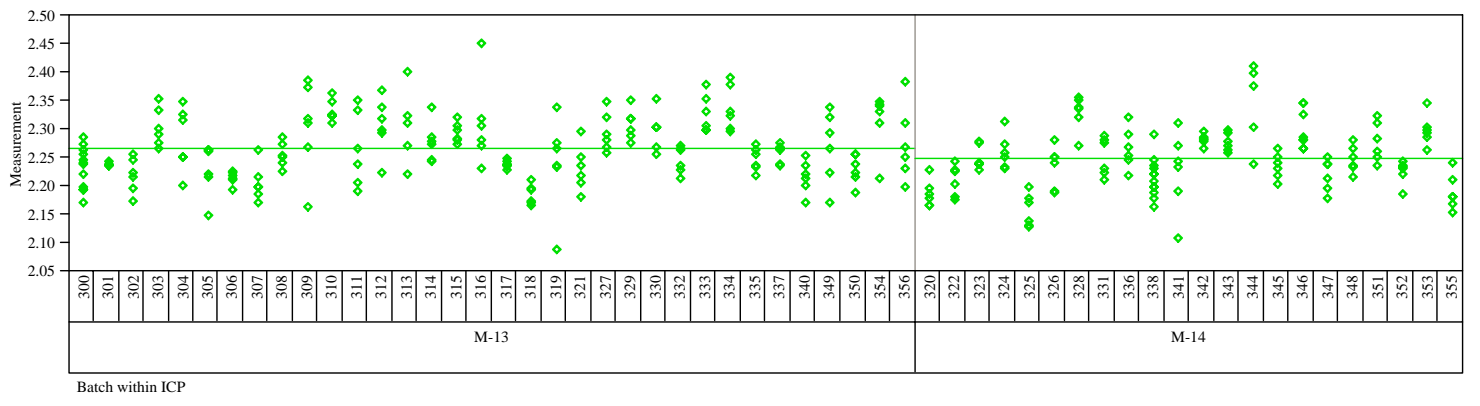

Prep=Mixed Acid, Sample Type $=$ SME, Analyte $=$ Na

Variability Chart for Measurement

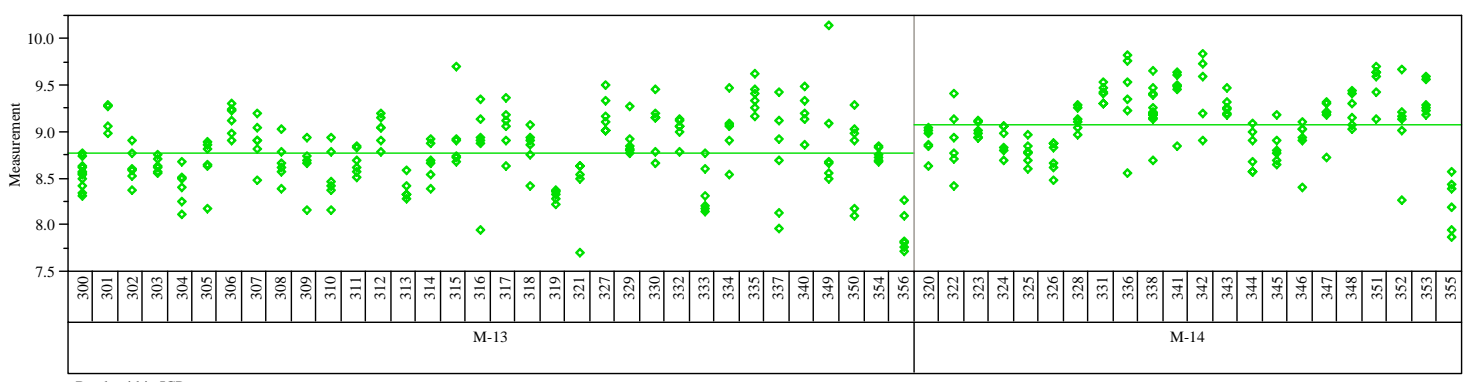

Prep=Mixed Acid, Sample Type $=$ SME, Analyte $=\mathrm{N} i$

Variability Chart for Measurement

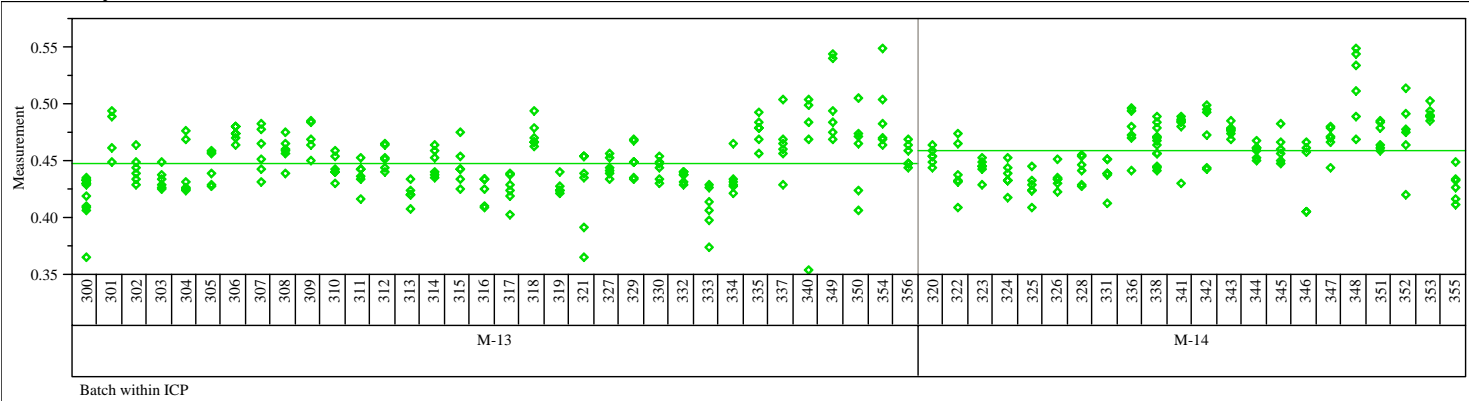


WSRC-STI-2006-00068

Revision 0

Exhibit A2. Measurement Data by Batch by ICP for Prep Method, Sample Type, and Analyte

Prep=Mixed Acid, Sample Type=SME, Analyte=Si

(continued)

Variability Chart for Measurement

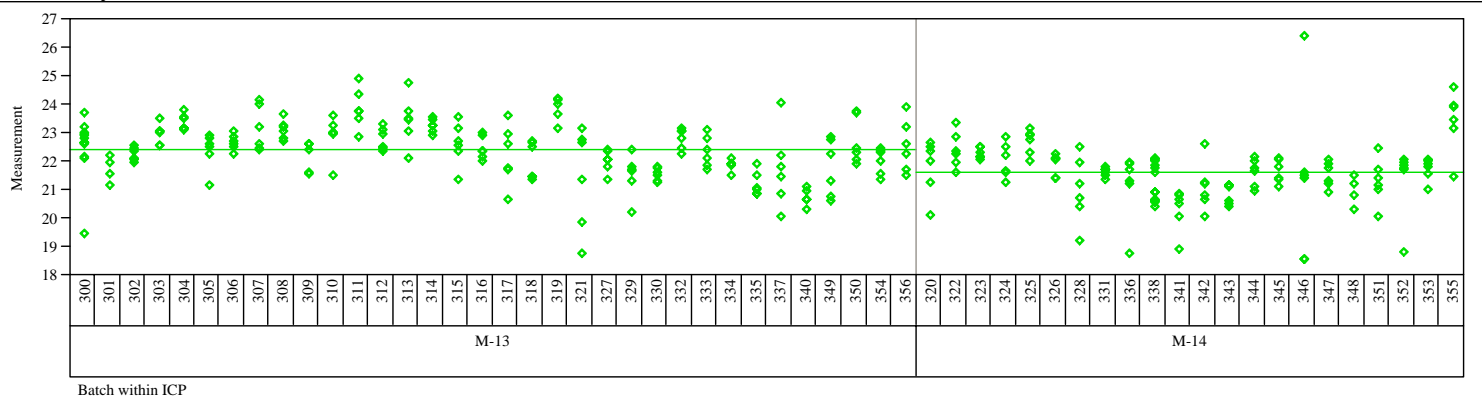

Prep=Mixed Acid, Sample Type=SME, Analyte=Sum of Oxides

Variability Chart for Measurement

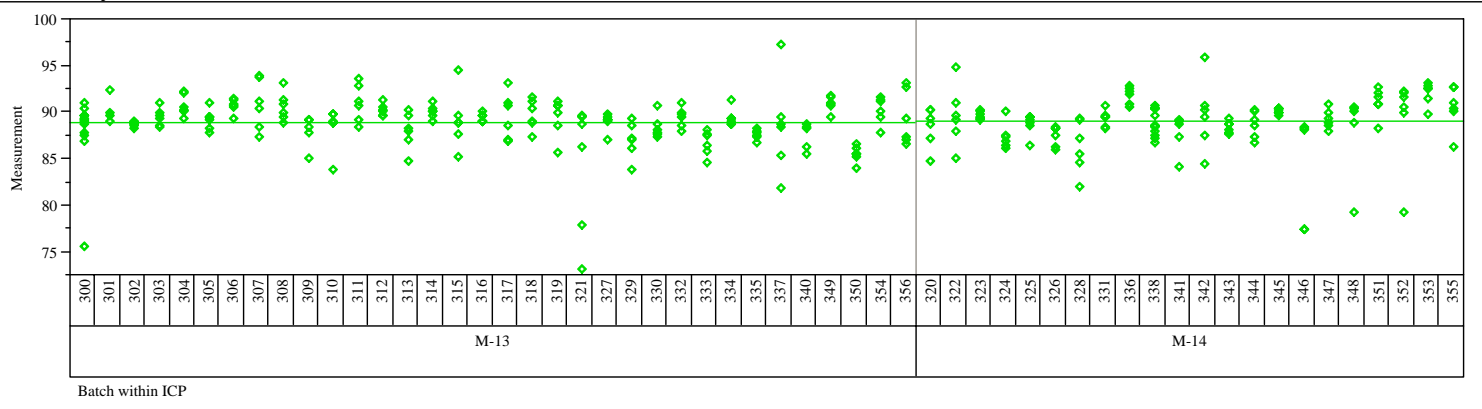

Prep=Mixed Acid, Sample Type=SME, Analyte $=$ Ti

Variability Chart for Measurement

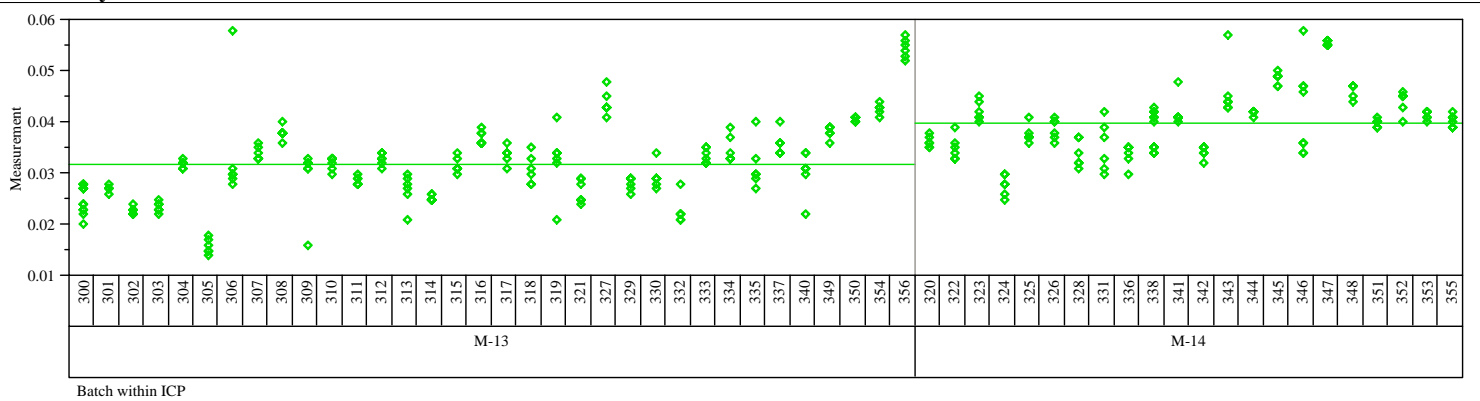

Prep=Mixed Acid, Sample Type $=$ SME, Analyte $=U$

Variability Chart for Measurement

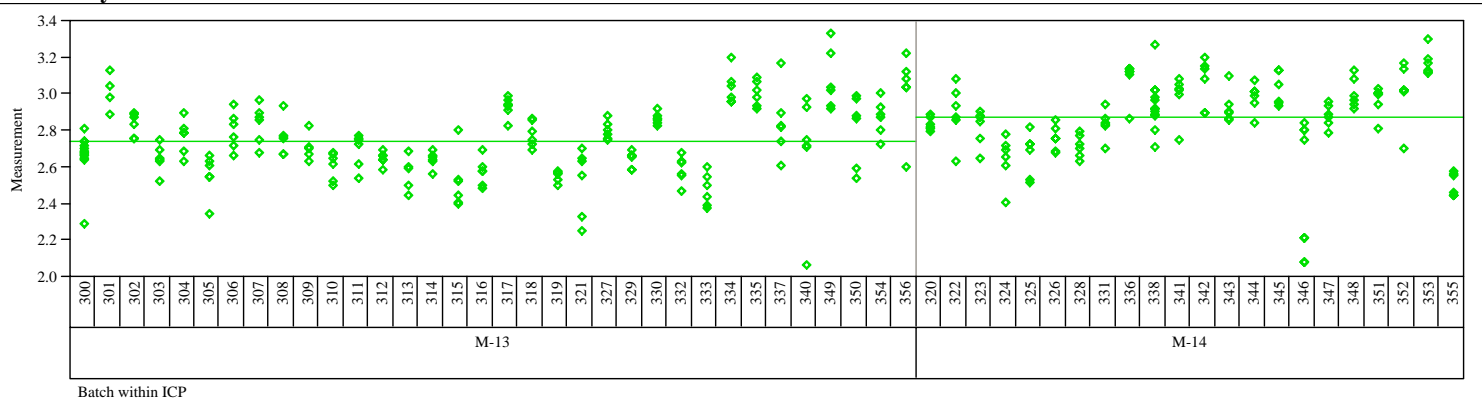


WSRC-STI-2006-00068

Revision 0

Exhibit A2. Measurement Data by Batch by ICP for Prep Method, Sample Type, and Analyte

Prep=Mixed Acid, Sample Type $=$ SME, Analyte $=$ U/Ca

(continued)

Variability Chart for Measurement

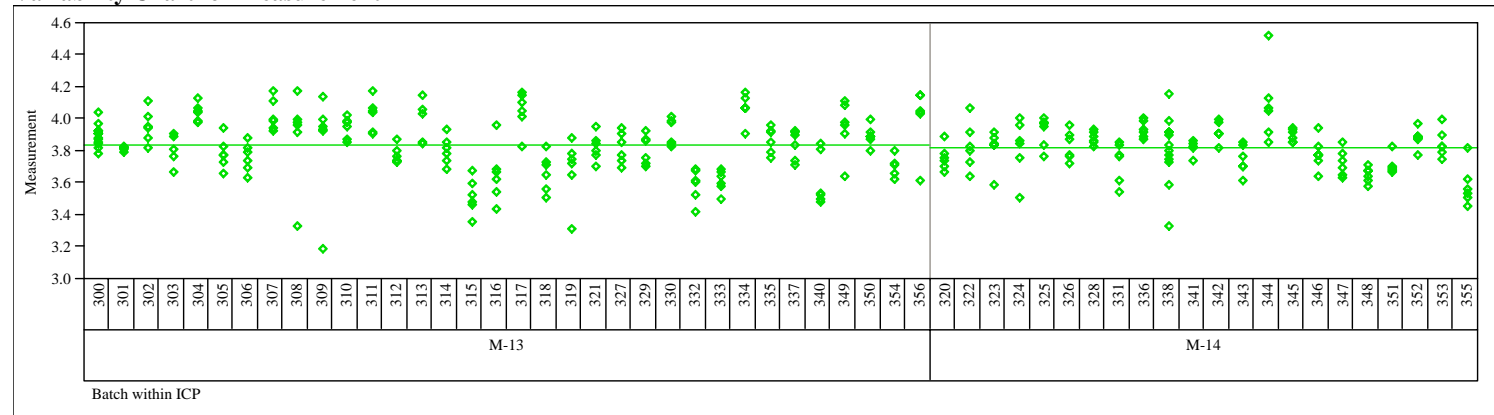

Prep=Mixed Acid, Sample Type $=$ SME, Analyte $=\mathrm{Zr}$

Variability Chart for Measurement

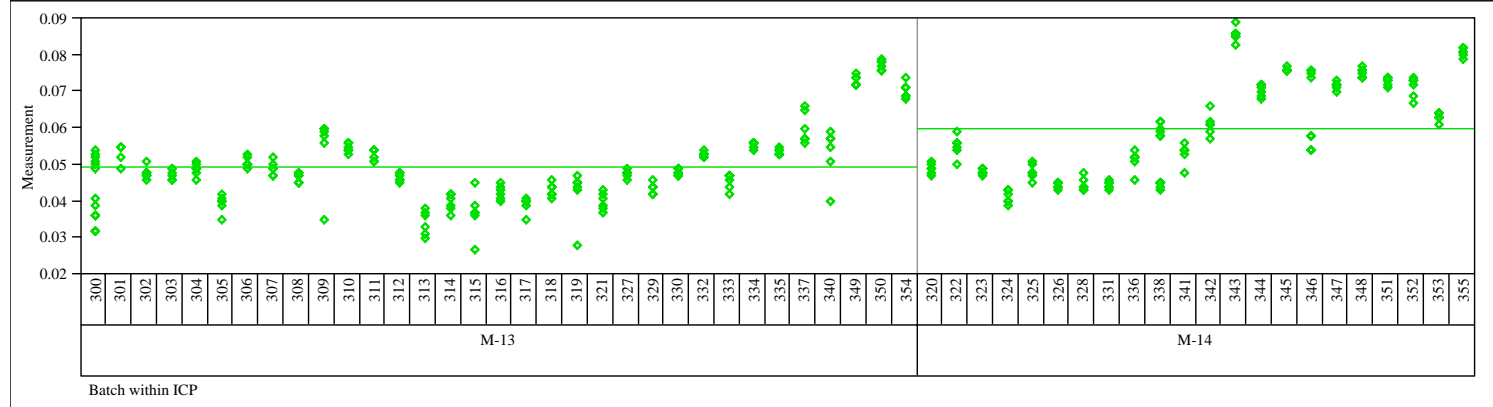

Prep=Mixed Acid, Sample Type=blank, Analyte $=$ Al

Variability Chart for Measurement

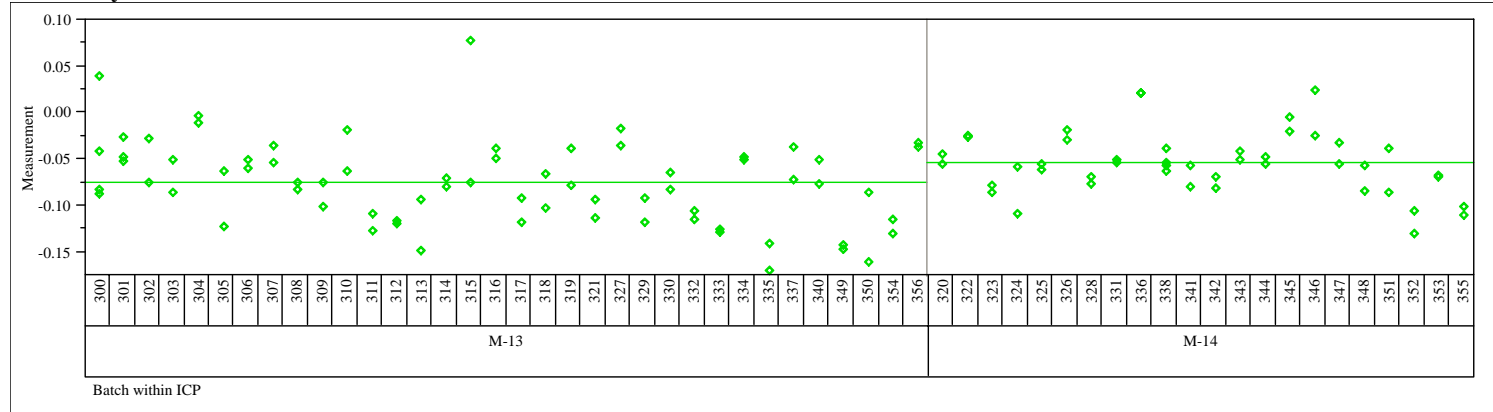

Prep=Mixed Acid, Sample Type=blank, Analyte $=$ Al/Ca

Variability Chart for Measurement

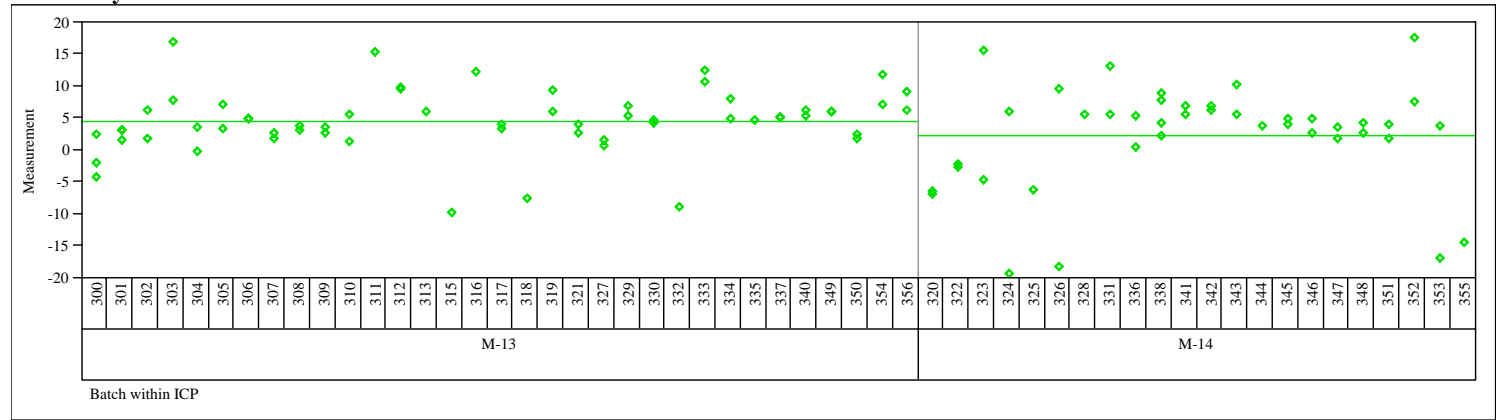


WSRC-STI-2006-00068

Revision 0

Exhibit A2. Measurement Data by Batch by ICP for Prep Method, Sample Type, and Analyte

Prep=Mixed Acid, Sample Type=blank, Analyte=Al/Mg

(continued)

Variability Chart for Measurement

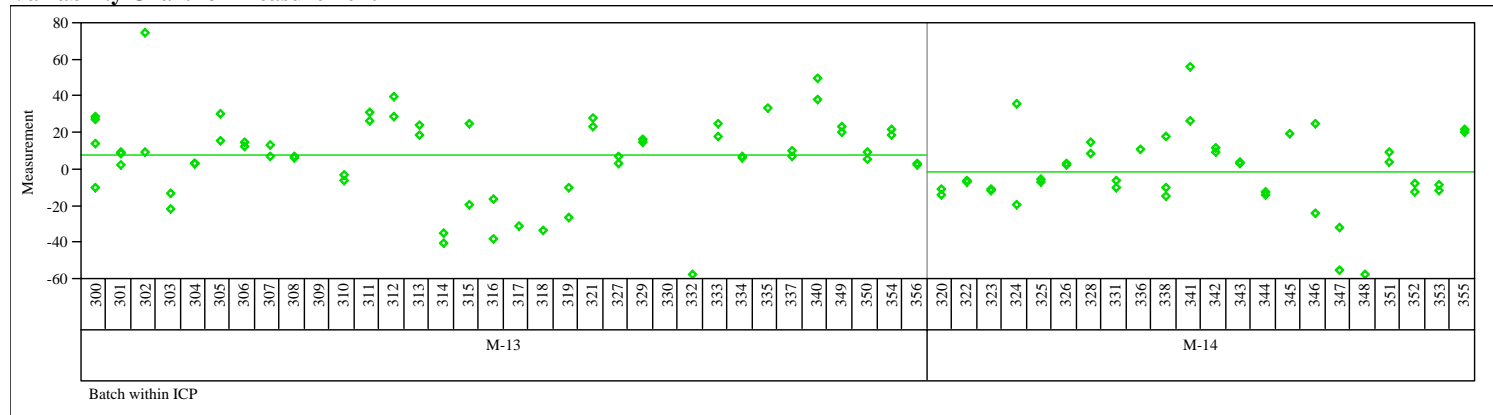

Prep $=$ Mixed Acid, Sample Type $=$ blank, Analyte $=A \mathbf{A} /$ Mn

Variability Chart for Measurement

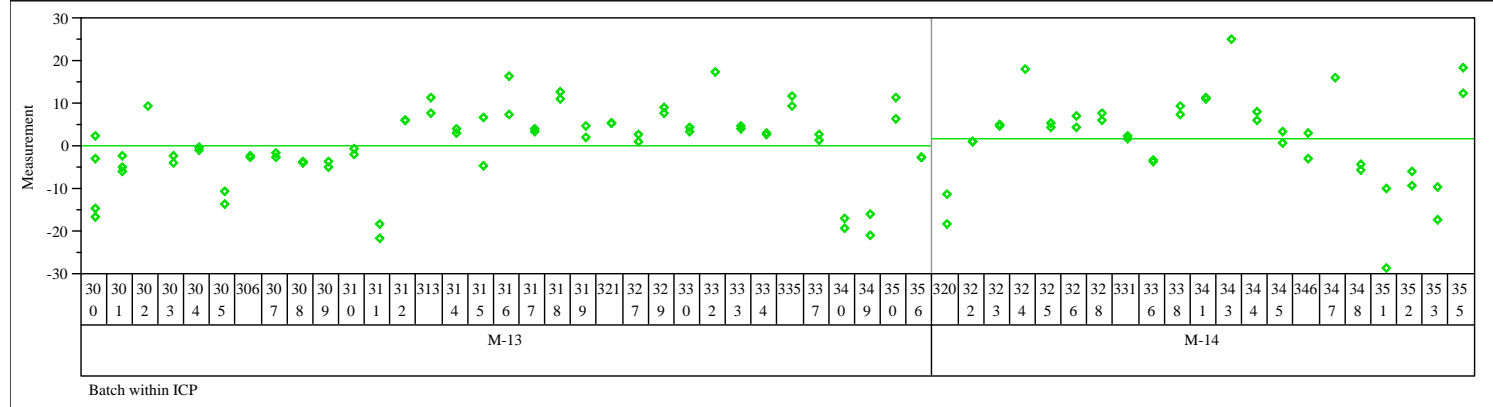

Prep=Mixed Acid, Sample Type=blank, Analyte=B

Variability Chart for Measurement

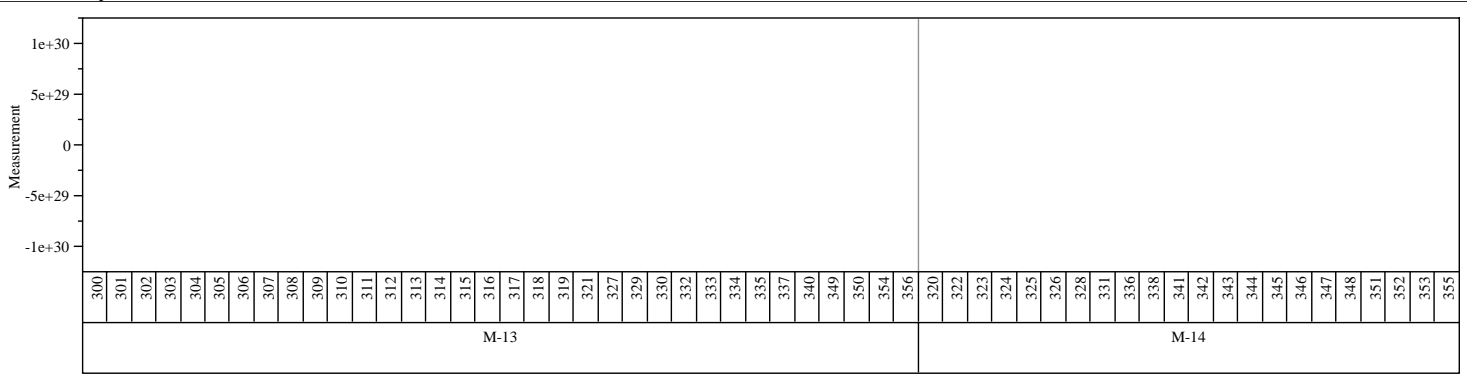

Batch within ICP

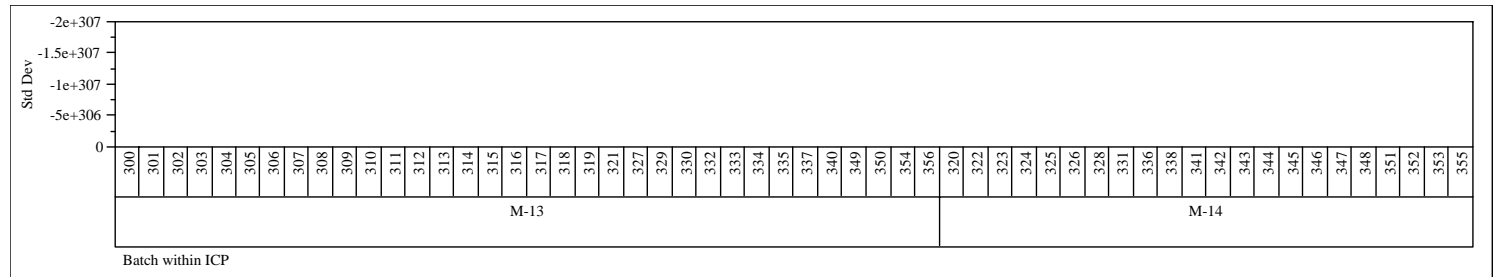


WSRC-STI-2006-00068

Revision 0

Exhibit A2. Measurement Data by Batch by ICP for Prep Method, Sample Type, and Analyte

Prep=Mixed Acid, Sample Type=blank, Analyte $=\mathrm{B} / \mathrm{Li}$

(continued)

Variability Chart for Measurement
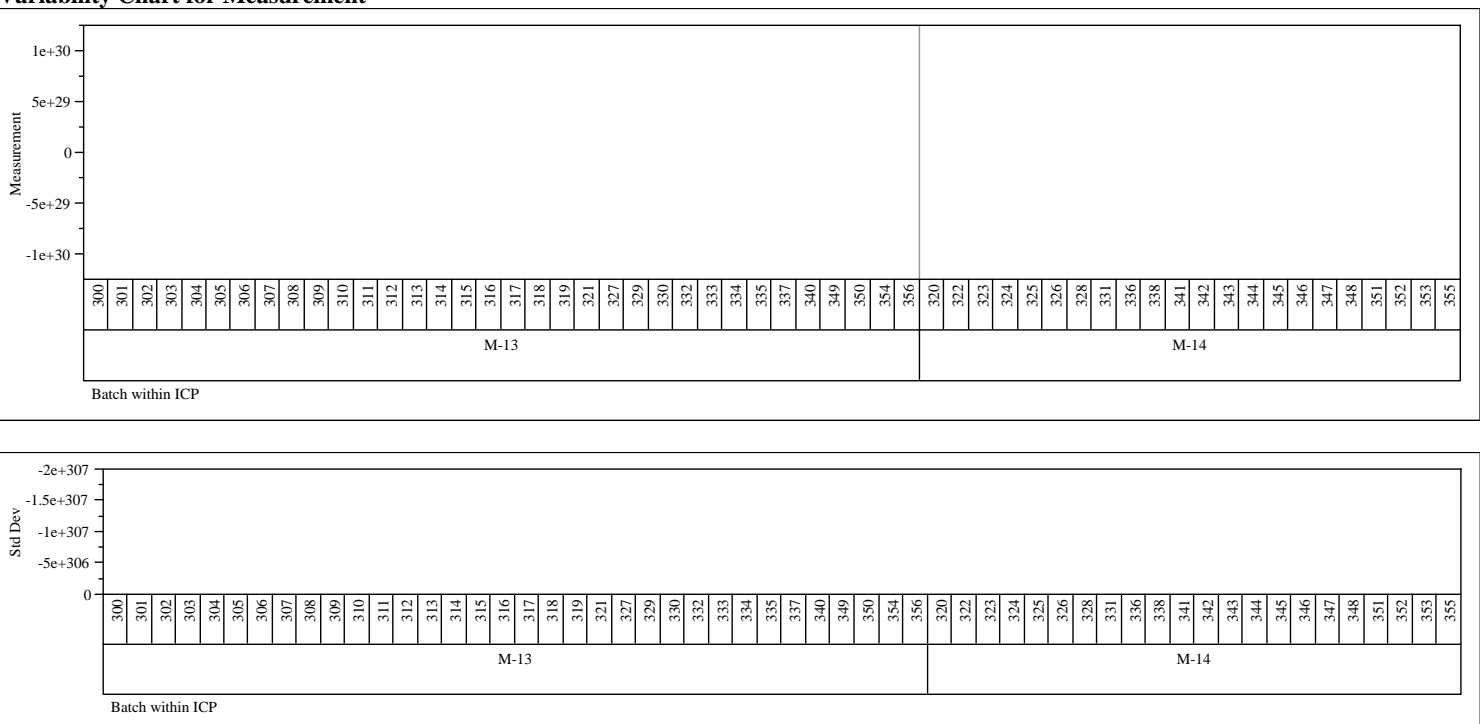

Prep=Mixed Acid, Sample Type=blank, Analyte $=$ Ca

Variability Chart for Measurement

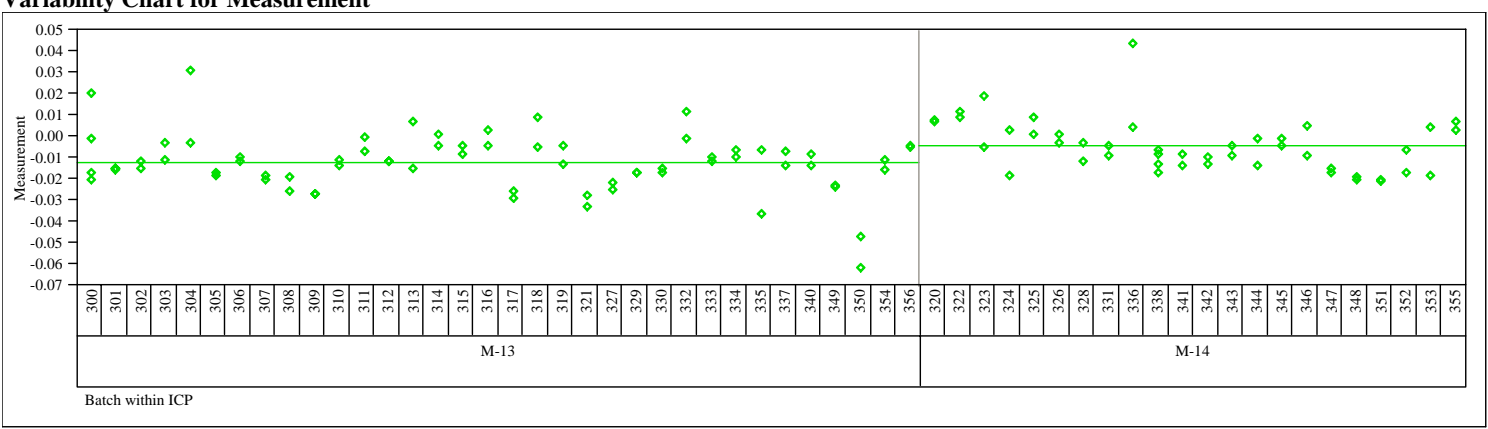

Prep=Mixed Acid, Sample Type $=$ blank, Analyte $=\mathrm{Cr}$

Variability Chart for Measurement

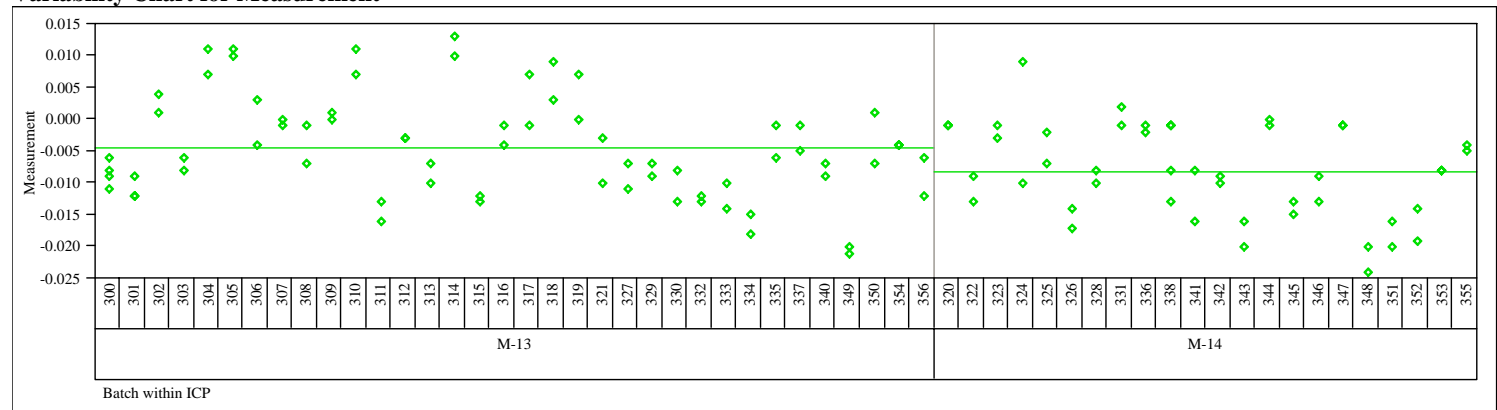


WSRC-STI-2006-00068

Revision 0

Exhibit A2. Measurement Data by Batch by ICP for Prep Method, Sample Type, and Analyte

Prep=Mixed Acid, Sample Type $=$ blank, Analyte $=\mathrm{Cu}$

(continued)

Variability Chart for Measurement

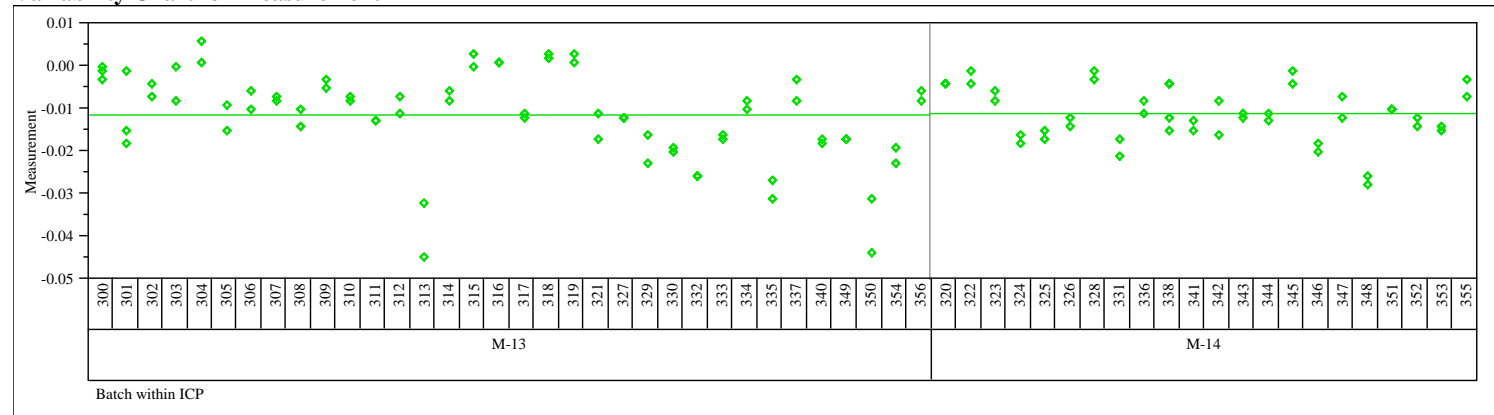

Prep=Mixed Acid, Sample Type=blank, Analyte $=$ Fe

Variability Chart for Measurement

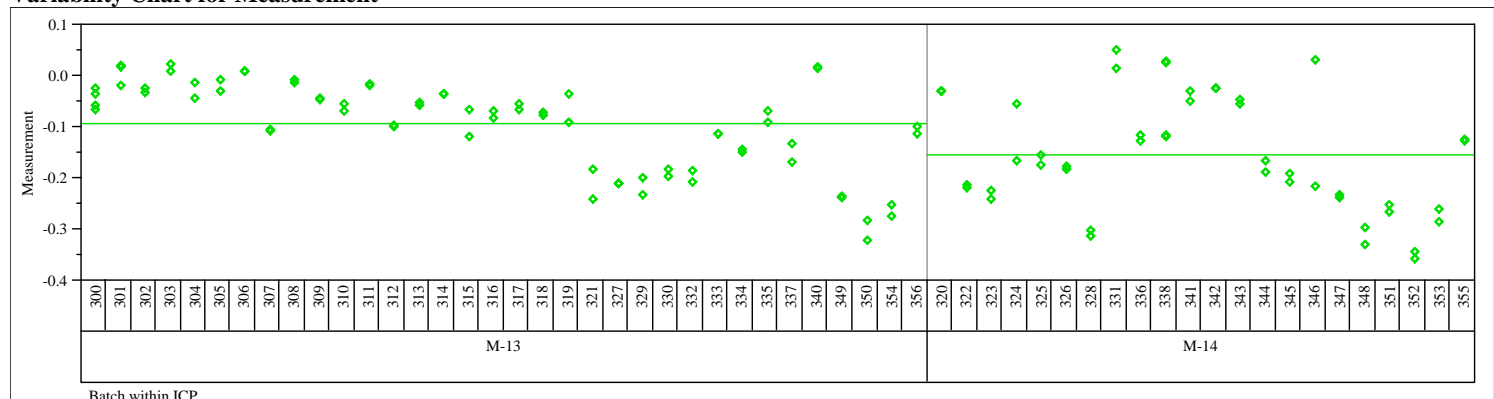

Prep=Mixed Acid, Sample Type=blank, Analyte=Fe/Al

Variability Chart for Measurement

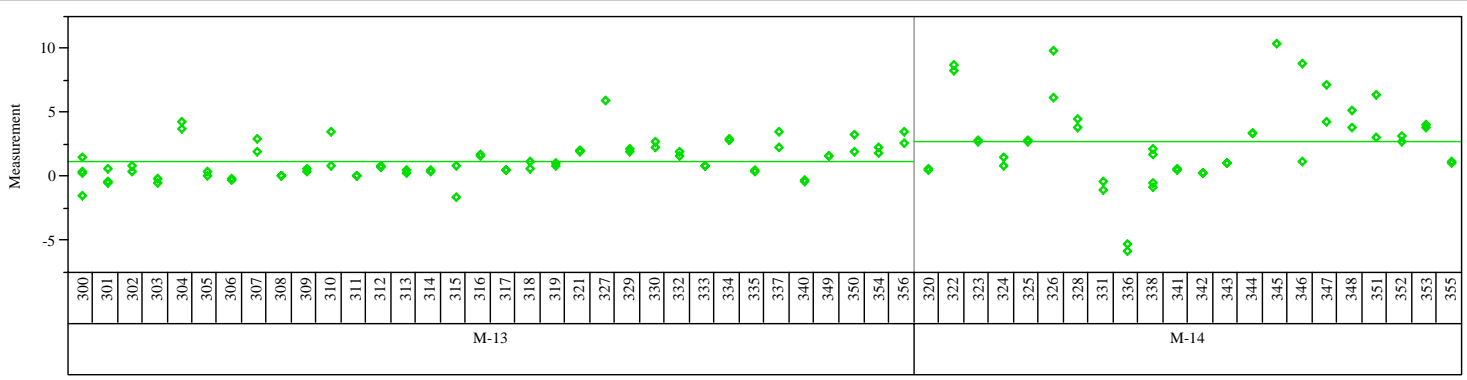

Batch within ICP

Prep=Mixed Acid, Sample Type=blank, Analyte $=\mathrm{Fe} / \mathrm{Ca}$

Variability Chart for Measurement

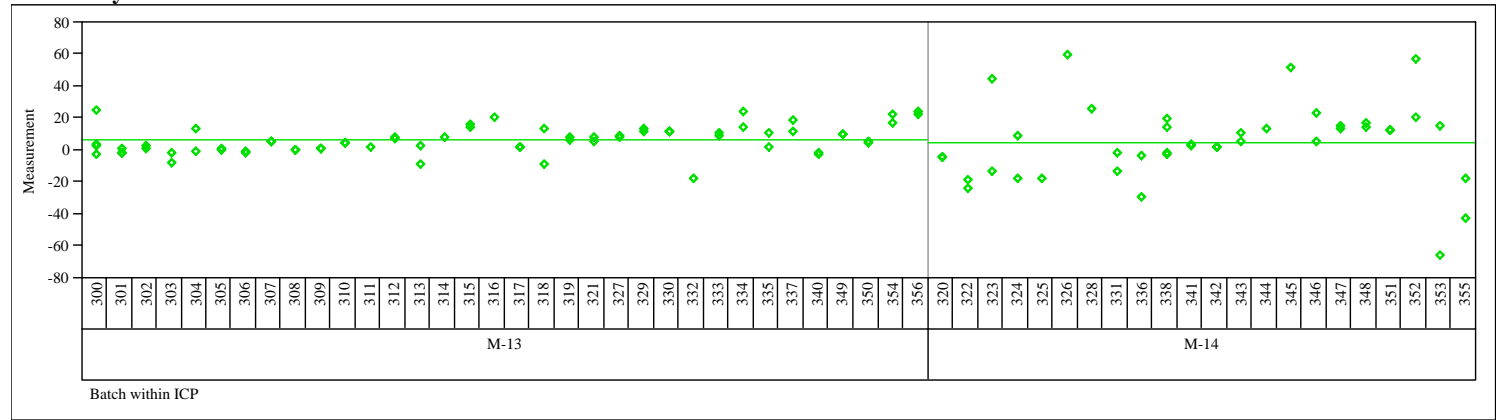


WSRC-STI-2006-00068

Revision 0

Exhibit A2. Measurement Data by Batch by ICP for Prep Method, Sample Type, and Analyte

Prep=Mixed Acid, Sample Type $=$ blank, Analyte $=\mathrm{Fe} / \mathrm{Li}$

(continued)

Variability Chart for Measurement

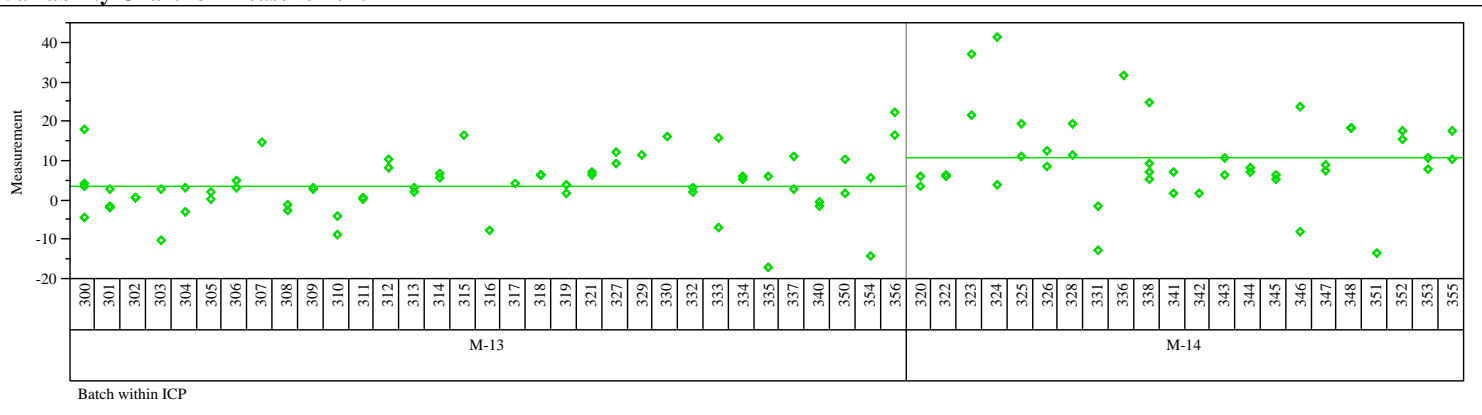

Prep=Mixed Acid, Sample Type=blank, Analyte $=$ Fe/Mg

Variability Chart for Measurement

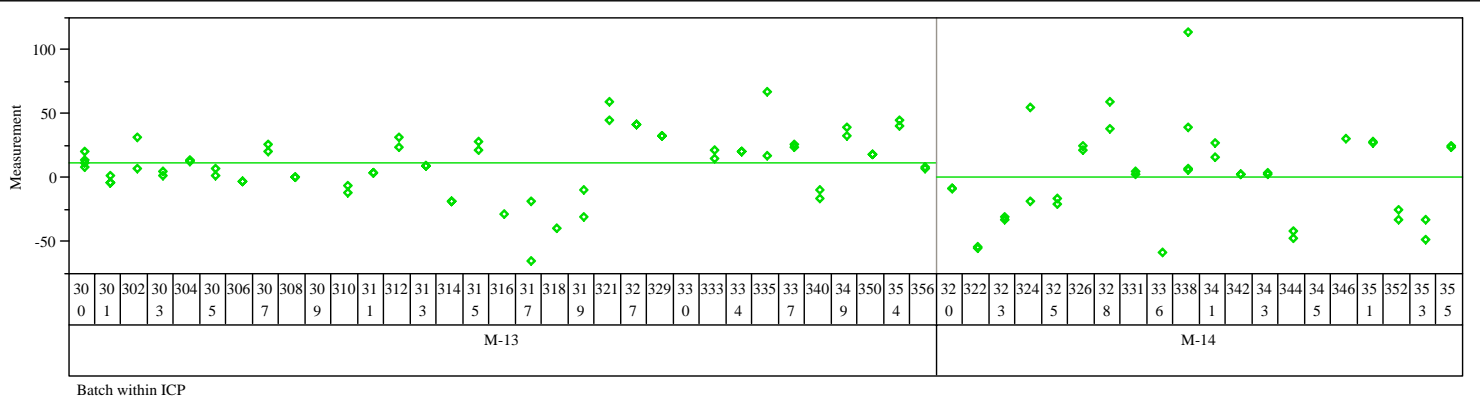

Prep=Mixed Acid, Sample Type=blank, Analyte $=\mathrm{Fe} / \mathrm{Mn}$

Variability Chart for Measurement

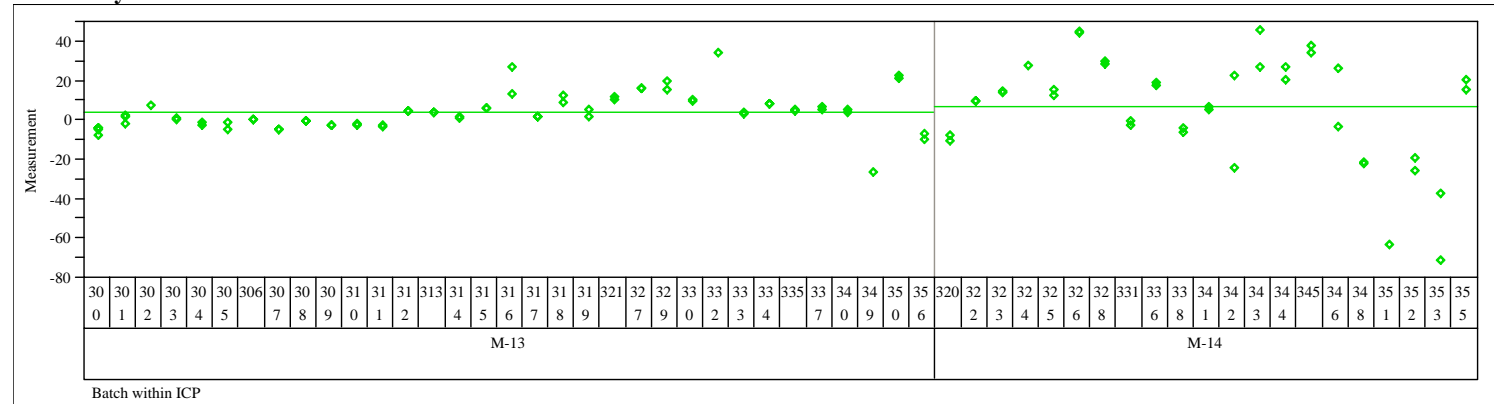

Prep=Mixed Acid, Sample Type=blank, Analyte=Fe/Ni

Variability Chart for Measurement

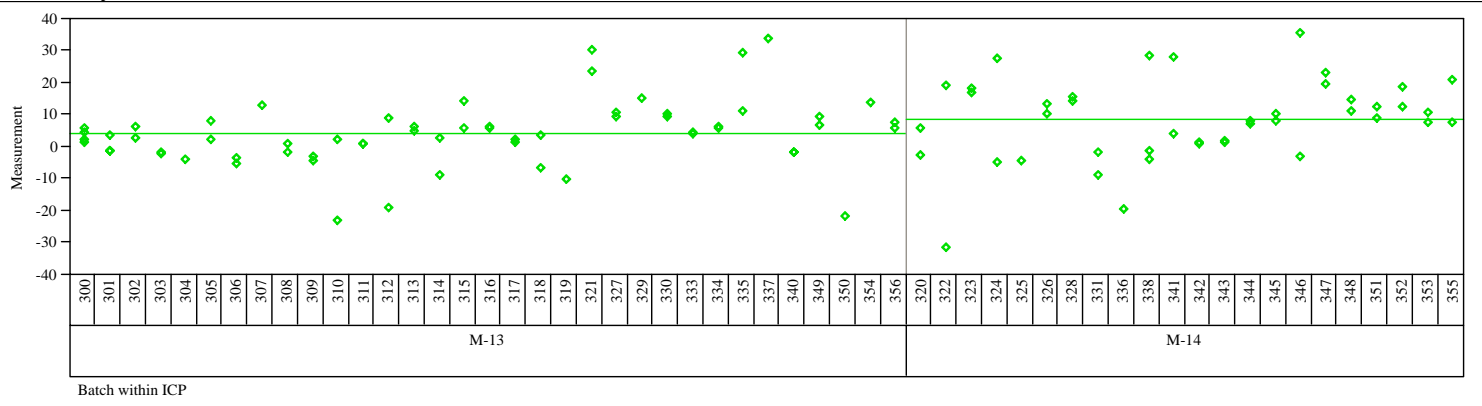


WSRC-STI-2006-00068

Revision 0

Exhibit A2. Measurement Data by Batch by ICP for Prep Method, Sample Type, and Analyte

Prep=Mixed Acid, Sample Type $=$ blank, Analyte $=\mathrm{Fe} / \mathrm{U}$

(continued)

Variability Chart for Measurement

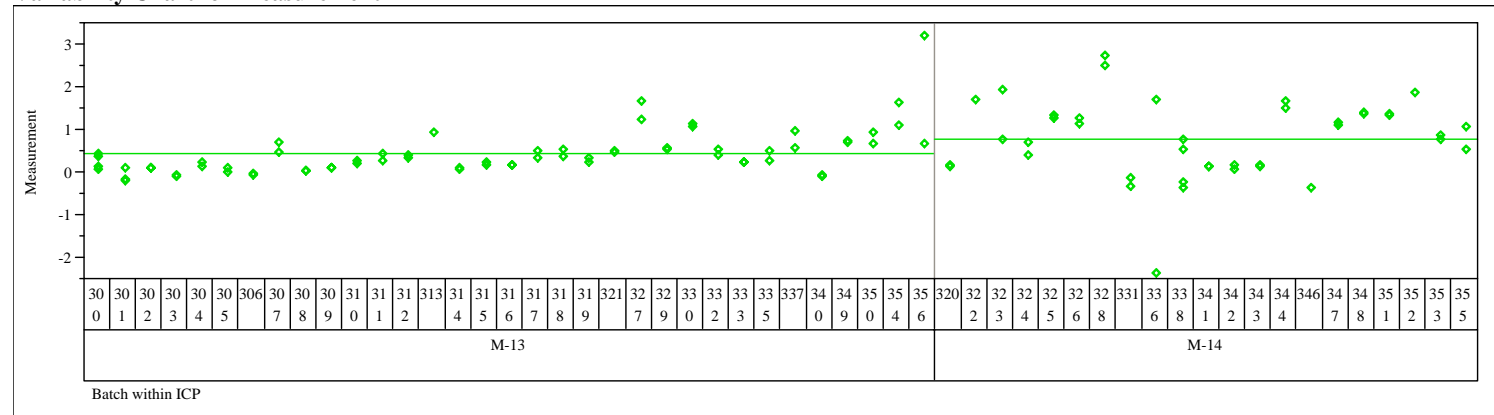

Prep=Mixed Acid, Sample Type $=$ blank, Analyte $=K$

Variability Chart for Measurement

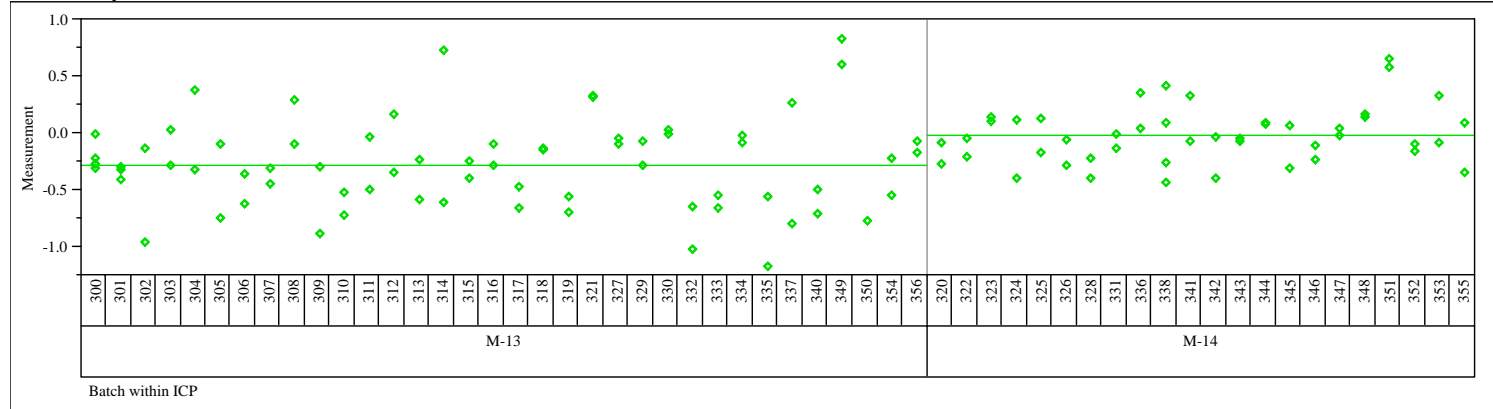

Prep=Mixed Acid, Sample Type=blank, Analyte $=\mathbf{L i}$

Variability Chart for Measurement

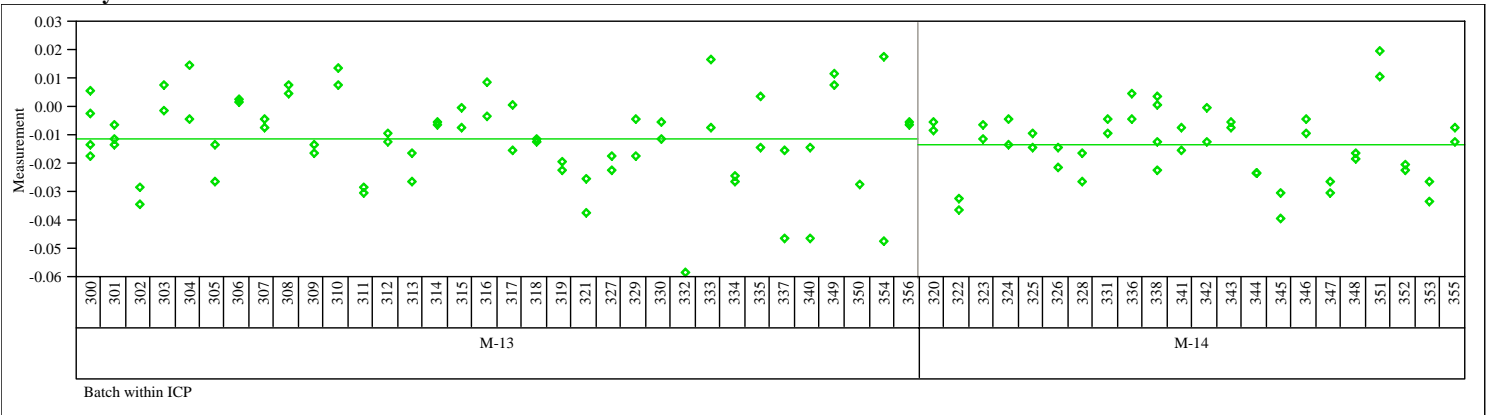

Prep=Mixed Acid, Sample Type=blank, Analyte $=\mathbf{M g}$

Variability Chart for Measurement

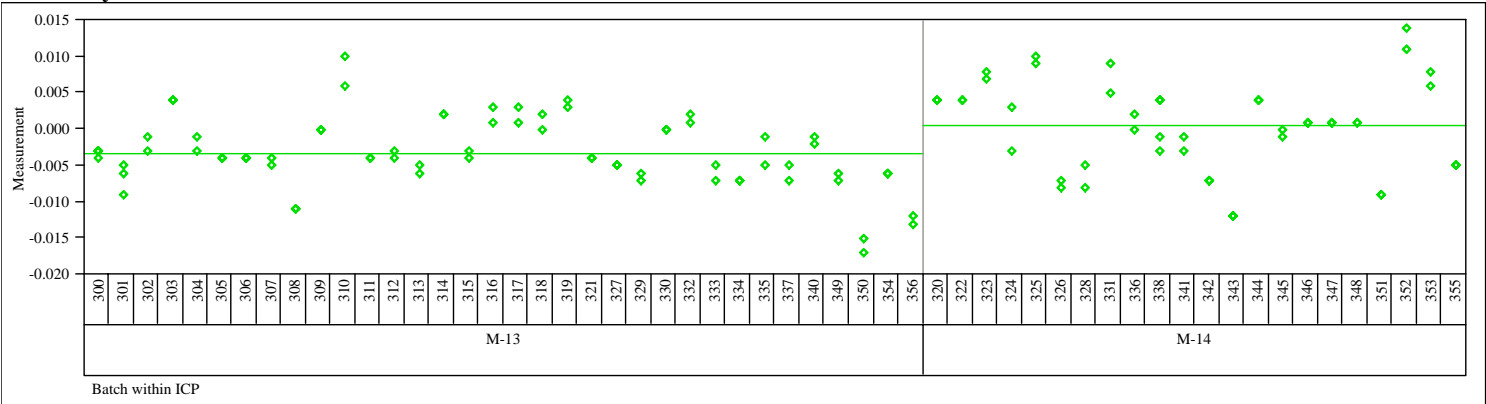


WSRC-STI-2006-00068

Revision 0

Exhibit A2. Measurement Data by Batch by ICP for Prep Method, Sample Type, and Analyte

Prep=Mixed Acid, Sample Type=blank, Analyte $=M n$

(continued)

Variability Chart for Measurement

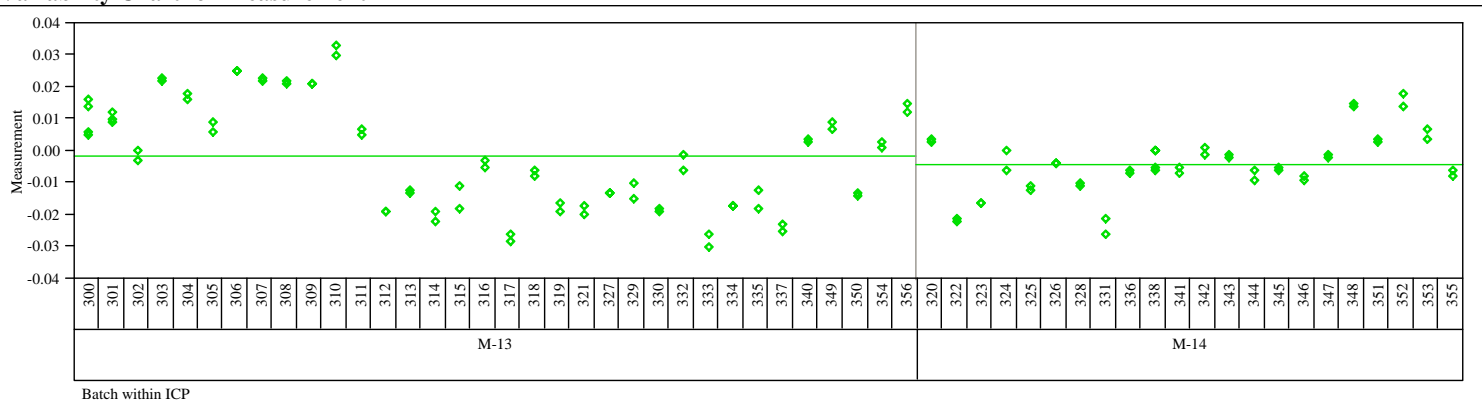

Prep=Mixed Acid, Sample Type=blank, Analyte $=\mathrm{Mn} / \mathrm{Mg}$

Variability Chart for Measurement

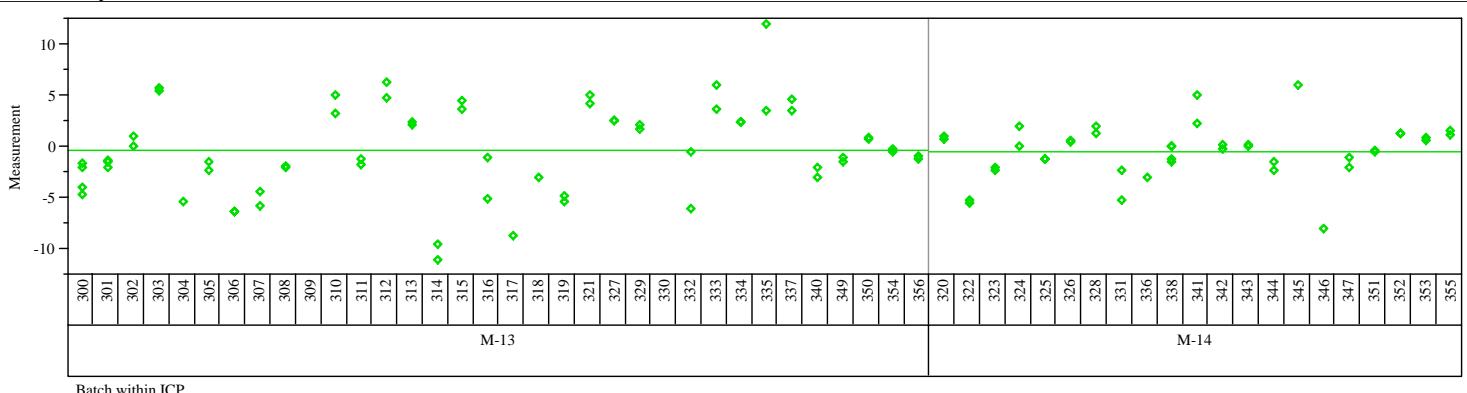

Prep=Mixed Acid, Sample Type $=$ blank, Analyte $=\mathrm{Na}$

Variability Chart for Measurement

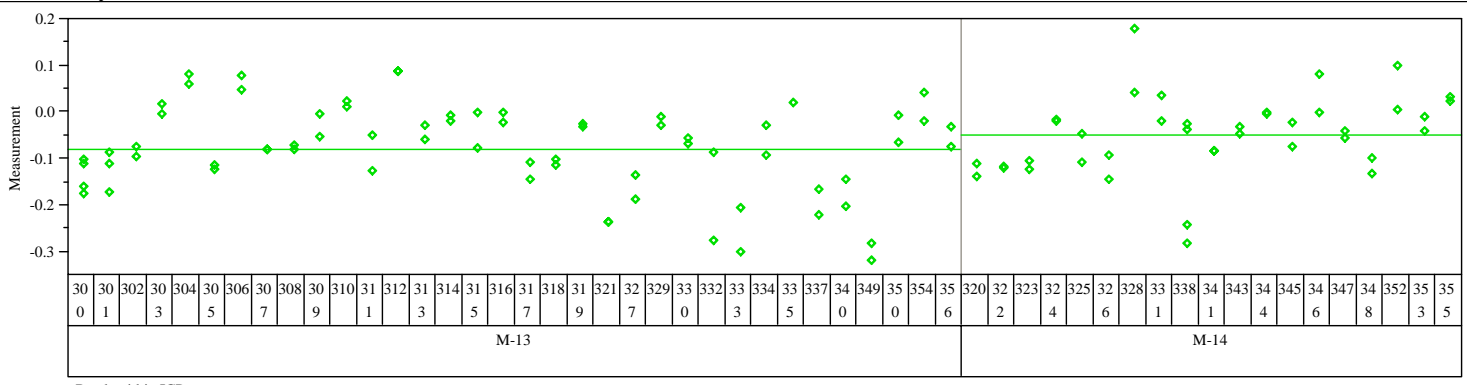

Prep=Mixed Acid, Sample Type=blank, Analyte=Ni

Variability Chart for Measurement

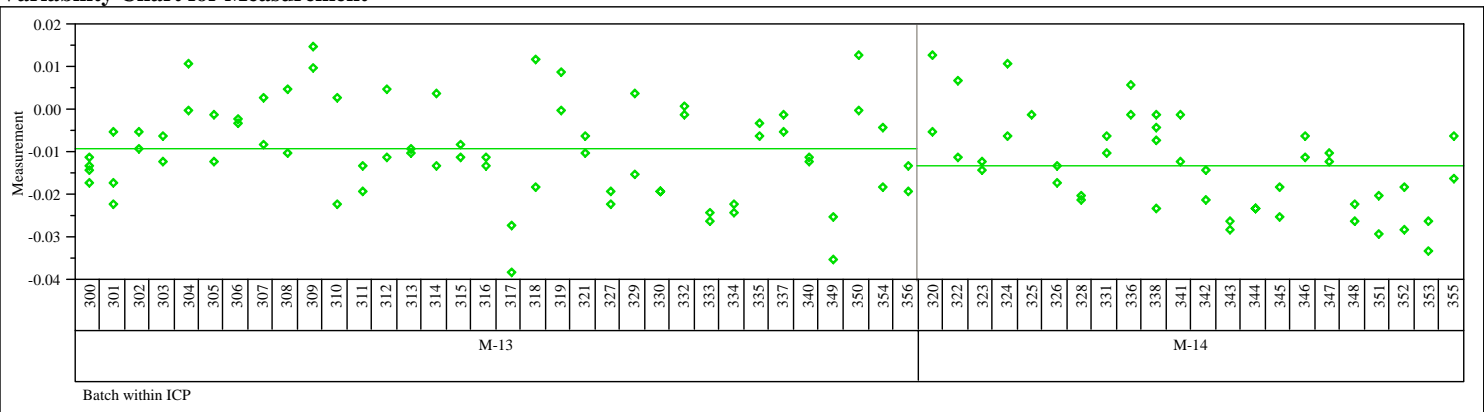


WSRC-STI-2006-00068

Revision 0

Exhibit A2. Measurement Data by Batch by ICP for Prep Method, Sample Type, and Analyte

Prep=Mixed Acid, Sample Type=blank, Analyte=Si

(continued)

Variability Chart for Measurement

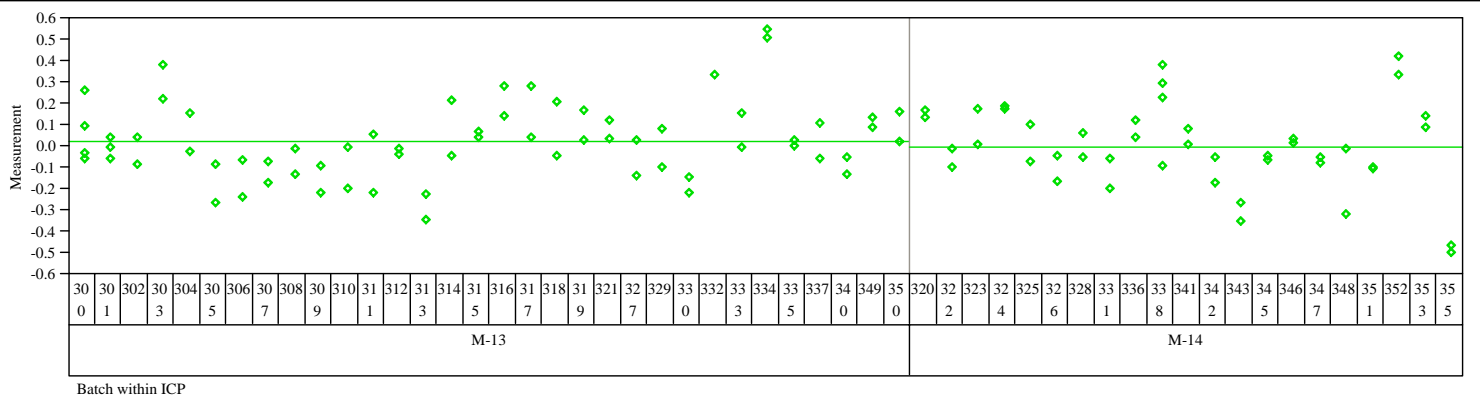

Prep=Mixed Acid, Sample Type=blank, Analyte=Sum of Oxides

Variability Chart for Measurement

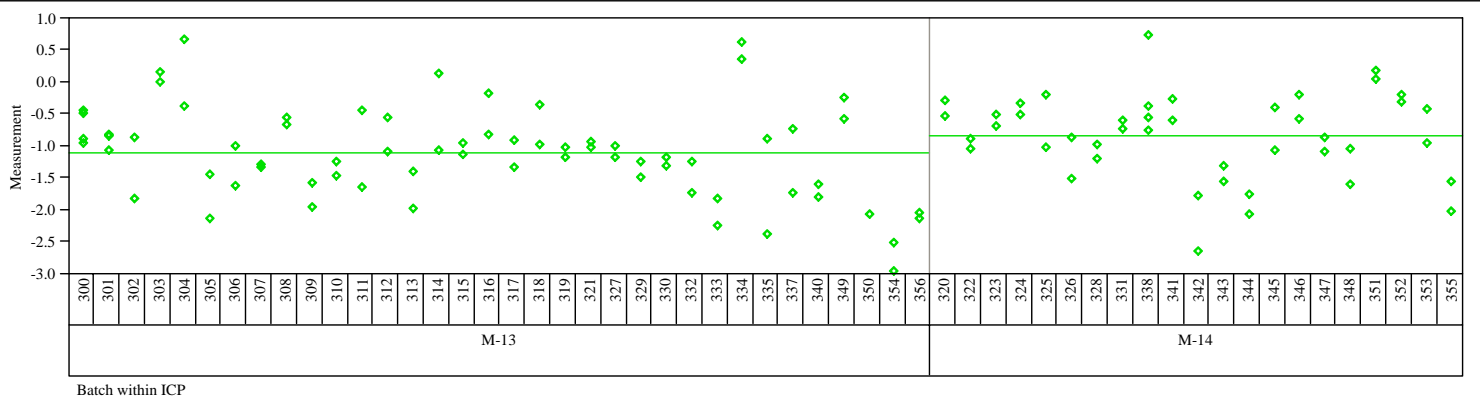

Prep=Mixed Acid, Sample Type=blank, Analyte $=$ Ti

Variability Chart for Measurement

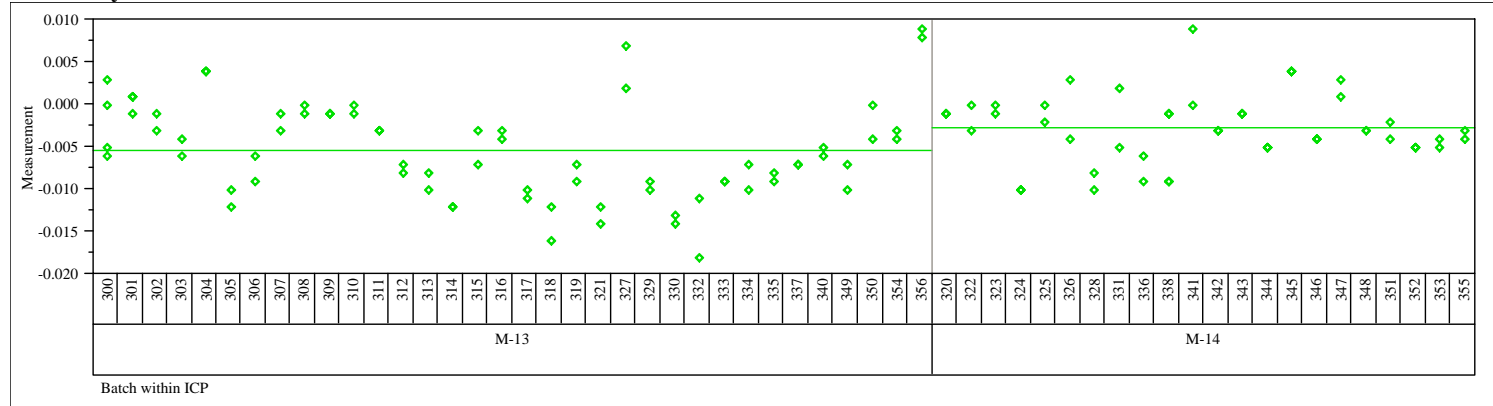

Prep=Mixed Acid, Sample Type=blank, Analyte=U

Variability Chart for Measurement

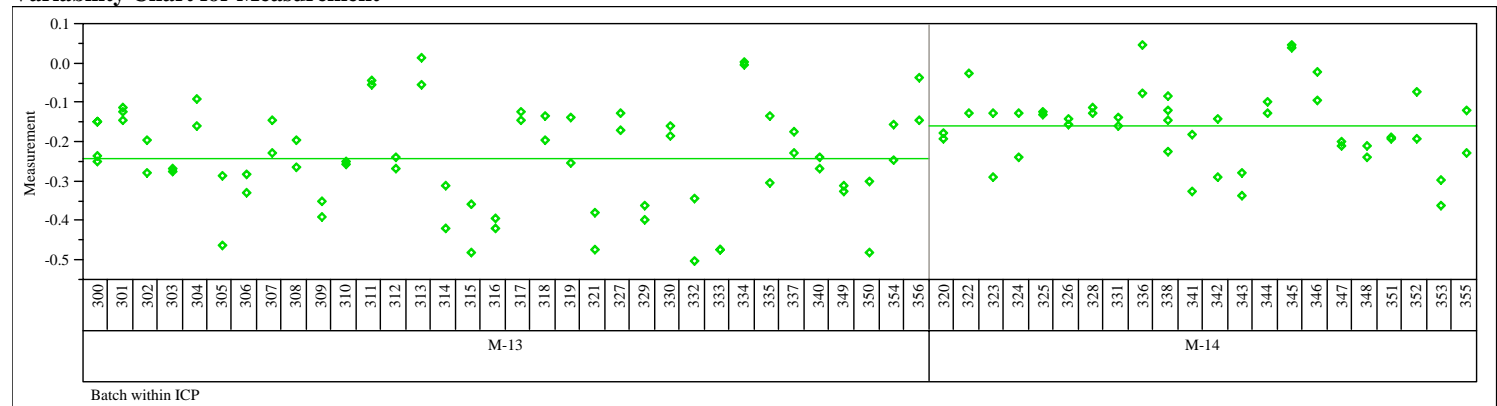


WSRC-STI-2006-00068

Revision 0

Exhibit A2. Measurement Data by Batch by ICP for Prep Method, Sample Type, and Analyte

Prep=Mixed Acid, Sample Type=blank, Analyte=U/Ca

(continued)

Variability Chart for Measurement

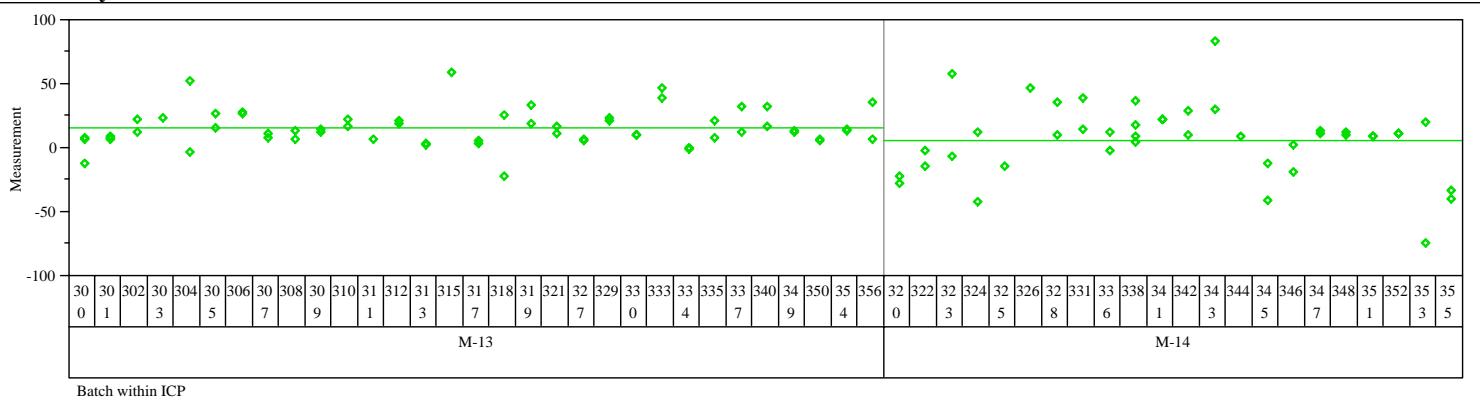

Prep=Mixed Acid, Sample Type=blank, Analyte $=\mathbf{Z r}$

Variability Chart for Measurement

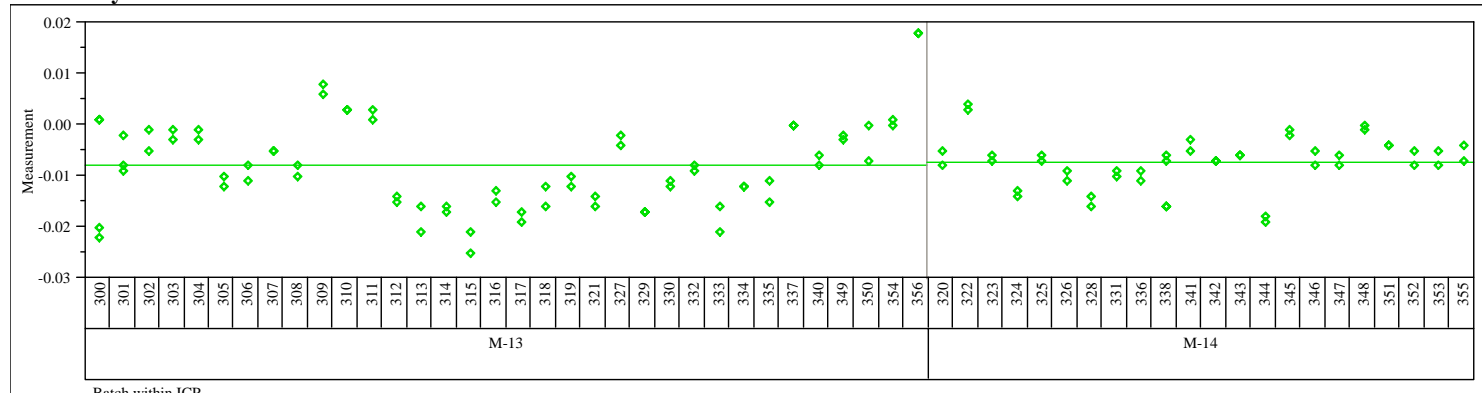




\section{Exhibit A3. Measurement Comparisons Using Batch Averages of Prep Method/ICP Combination for ARG-1 by Analyte}

Sample Type=ARG-1, Analyte $=$ Al

Oneway Analysis of Batch Average Value By Prep/ICP

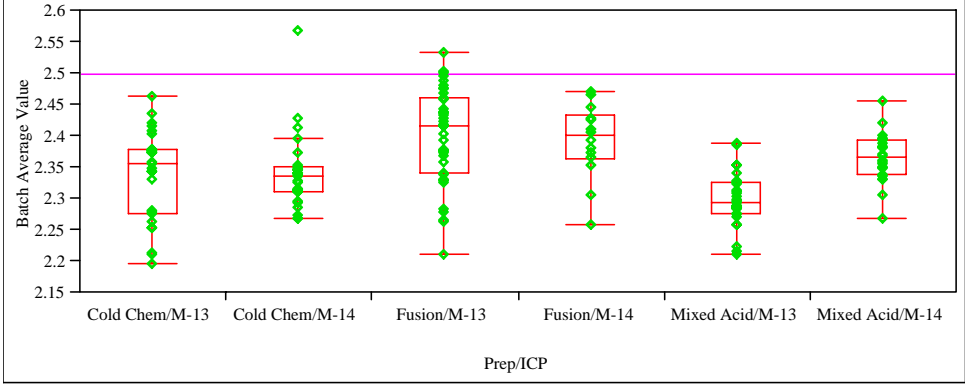

\section{Oneway Anova}

$\begin{array}{lr}\text { Rsquare } & 0.26417 \\ \text { Adj Rsquare } & 0.240123\end{array}$

\begin{tabular}{ll}
0.240123 \\
\hline
\end{tabular}

Mean of Response 2.355091

Observations (or Sum Wgts)

Analysis of Variance

Source DF Sum of Squares Mean Square F Ratio Prob > F

$\begin{array}{lllllll}\text { Prep/ICP } & 5 & 0.21274095 & 0.042548 & 10.9857 & <.0001\end{array}$

$\begin{array}{llll}\text { Error } & 153 & 0.59257698 & 0.003873\end{array}$

C. Total $158 \quad 0.80531793$

Level Number Mean Std Error Lower 95\% Upper 95\%

$\begin{array}{llllll}\text { Cold Chem/M-13 } & 27 & 2.33776 & 0.01198 & 2.3141 & 2.3614\end{array}$

$\begin{array}{llllll}\text { Cold Chem/M-14 } & 27 & 2.34037 & 0.01198 & 2.3167 & 2.3640\end{array}$

$\begin{array}{llllll}\text { Fusion/M-13 } & 39 & 2.40105 & 0.00997 & 2.3814 & 2.4207\end{array}$

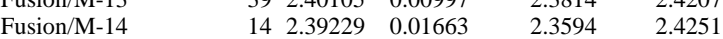

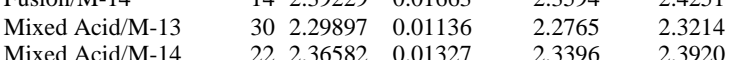

Std Error uses a pooled estimate of error variance

Means and Std Deviations

Level Number Mean Std Dev Std Err Mean Lower 95\% Upper 95\%

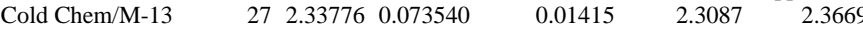

$\begin{array}{lllllll}\text { Cold Chem/M-14 } & 27 & 2.34037 & 0.060686 & 0.01168 & 2.3164 & 2.3644\end{array}$

$\begin{array}{lllllll}\text { Fusion/M-13 } & 39 & 2.40105 & 0.076841 & 0.01230 & 2.3761 & 2.4260\end{array}$

$\begin{array}{lllllll}\text { Fusion/M-14 } & 14 & 2.39229 & 0.058939 & 0.01575 & 2.3583 & 2.4263 \\ \end{array}$

$\begin{array}{lllllll}\text { Mixed Acid/M-13 } & 30 & 2.29897 & 0.042664 & 0.00779 & 2.2830 & 2.3149 \\ \text { Mixed Acid/M-14 } & 22 & 2.36582 & 0.040175 & 0.00857 & 2.3480 & 2.3836\end{array}$

Comparisons for all pairs using Tukey-Kramer HSD

Level

Mean

Fusion/M-13 A $\quad 2.4010513$

$\begin{array}{llll}\text { Fusion/M-14 } & \text { A B } & 2.3922857\end{array}$

Mixed Acid/M-14 A B 2.3658182

Cold Chem/M-14 B C 2.3403704

Cold Chem/M-13 $\quad$ B C 2.3377593

Mixed Acid/M-13 $\quad$ C 2.2989667

Levels not connected by same letter are significantly different
Sample Type $=$ ARG-1, Analyte $=$ Al/Ca

Oneway Analysis of Batch Average Value By Prep/ICP

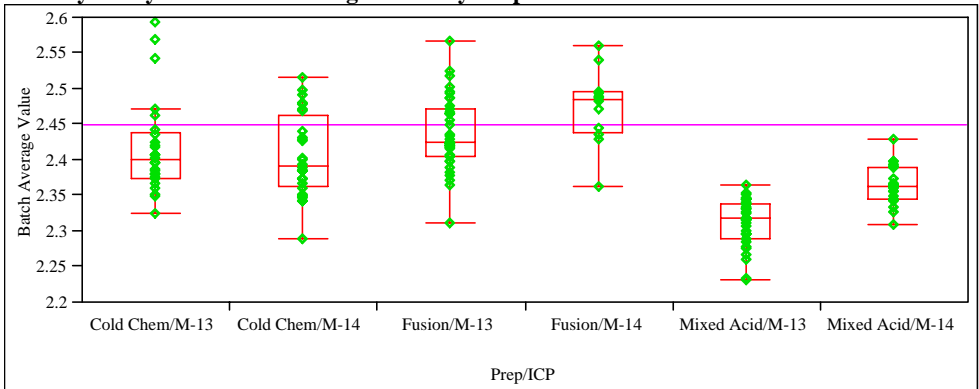

\section{Oneway Anova}

Rsquare

Adj Rsquare

0.512073

0.495917

$\begin{array}{ll}\text { Root Mean Square Error } & 0.049778 \\ \text { Mean of Response } & 2.396927\end{array}$

Mean of Response $\quad 2.396927$

Analysis of Variance

Source DF Sum of Squares Mean Square F Ratio Prob $>$ F

$\begin{array}{lrrrrr}\text { Prep/ICP } & 5 & 0.39266484 & 0.078533 & 31.6946 & <.0001\end{array}$

$\begin{array}{lrrr}\text { Error } & 151 & 0.37414881 & 0.002478\end{array}$

C. Total $156 \quad 0.76681365$

Means for Oneway Anova

Level $\quad$ Number Mean Std Error Lower 95\% Upper 95\%

$\begin{array}{lrrrrr}\text { Cold Chem/M-13 } & 26 & 2.41711 & 0.00976 & 2.3978 & 2.4364\end{array}$

$\begin{array}{llllll}\text { Cold Chem/M-14 } & 28 & 2.40686 & 0.00941 & 2.388 & 2.4364 \\ & 38 & 2.4385 & 0.4254\end{array}$

$\begin{array}{llllll}\text { Fusion/M-13 } & 38 & 2.43804 & 0.00807 & 2.4221 & 2.4540\end{array}$

$\begin{array}{llllll}\text { Fusion/M-14 } & 12 & 2.47527 & 0.01437 & 2.4469 & 2.5037\end{array}$

$\begin{array}{llllll}\text { Mixed Acid/M-13 } & 31 & 2.31282 & 0.00894 & 2.2952 & 2.3305 \\ \text { Mixed Acid/M-14 } & 22 & 2.36521 & 0.01061 & 2.3442 & 2.3862\end{array}$

Std Error uses a pooled estimate of error variance

Number Mean Std Dev Std Err Mean Lower 95\% Upper 95\%

Cold Chem/M-13 $\quad 262.417110 .066086 \quad 0.01296 \quad 2.3904 \quad 2.4438$

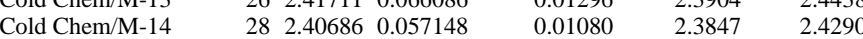

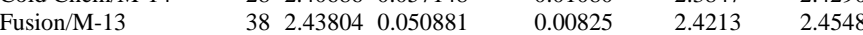

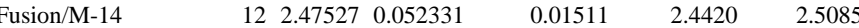

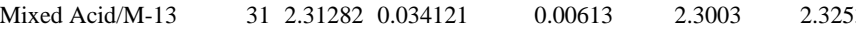

Mixed Acid/M-14

22 2.36521 0.02755

0.00587

2.3774

Level Mean

$\begin{array}{lll} & \text { A } & 2.4752687 \\ \text { Fusion/M-13 } & \text { A B } & 2.4380369\end{array}$

$\begin{array}{lll}\text { Cold Chem/M-13 } & \text { B } & 2.4171087\end{array}$

Cold Chem/M-14 B $\quad 2.4068627$

Mixed Acid/M-14 C 2.3652095

Mixed Acid/M-13 D 2.3128171

Levels not connected by same letter are significantly different 
WSRC-STI-2006-00068

Revision 0

\section{Exhibit A3. Measurement Comparisons Using Batch Averages of Prep Method/ICP Combination for ARG-1 by Analyte}

(continued)

Sample Type=ARG-1, Analyte=Al/Mg

Oneway Analysis of Batch Average Value By Prep/ICP

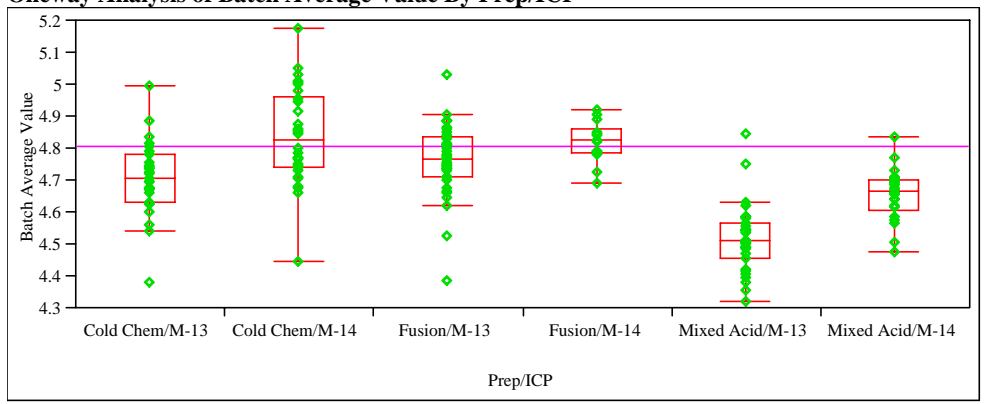

Oneway Anova

$\begin{array}{ll}\text { Rsquare } & 0.494721 \\ \text { Adj Rsquare } & 0.478526\end{array}$

Root Mean Square Error $\quad 0.113813$

Mean of Response 4.711986

Observations (or Sum W

Analysis of Variance
Source DF Sum of Squares Mean Square F Ratio Prob > F

$\begin{array}{llllll}\text { Prep/ICP } & 5 & 1.9785104 & 0.395702 & 30.5481 & <.0001\end{array}$

$\begin{array}{lrrr}\text { Error } & 156 & 2.0207352 & 0.012953\end{array}$

C. Total $161 \quad 3.9992456$

Means for Oneway Anova $\quad$ Mean Std Error Lower 95\% Upper 95\%

$\begin{array}{llllll}\text { Cold Chem/M-13 } & 27 & 4.70809 & 0.02190 & 4.6648 & 4.7514\end{array}$

$\begin{array}{llllll}\text { Cold Chem/M-14 } & 30 & 4.83889 & 0.02078 & 4.7978 & 4.8799\end{array}$

$\begin{array}{llllll}\text { Fusion/M-13 } & 38 & 4.76410 & 0.01846 & 4.7276 & 4.8006\end{array}$

$\begin{array}{llllll}\text { Fusion/M-14 } & 14 & 4.82087 & 0.03042 & 4.7608 & 4.8810\end{array}$

$\begin{array}{llllll}\text { Mixed Acid/M-13 } & 31 & 4.51864 & 0.02044 & 4.4783 & 4.5590 \\ \text { Mixed Acid/M-14 } & 22 & 4.65683 & 0.02427 & 4.6089 & 4.7048\end{array}$

Std Error uses a pooled estimate of error variance

Means and Std Deviations

Level Number Mean Std Dev Std Err Mean Lower 95\% Upper 95\%

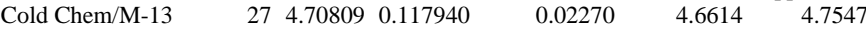

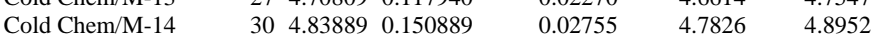

$\begin{array}{lllllll}\text { Fusion/M-13 } & 38 & 4.76410 & 0.111341 & 0.01806 & 4.7275 & 4.8007\end{array}$

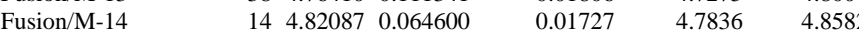

$\begin{array}{lllllll}\text { Mixed Acid/M-13 } & 31 & 4.51864 & 0.107032 & 0.01922 & 4.4794 & 4.5579 \\ \text { Mixed Acid/M-14 } & 22 & 4.65683 & 0.082293 & 0.01754 & 4.6203 & 4.6933\end{array}$

Mixed Acid/M-14

Comparisons for all pairs using Tukey-Kramer HSD

Level

Mean

$\begin{array}{lll} & & \\ \text { Cold Chem/M-14 A } & 4.8388949 \\ & \text { A } & 4.8208709\end{array}$

\begin{tabular}{lll} 
Cusion/M-14 & A & 4.8208709 \\
\hline
\end{tabular}

$\begin{array}{llll}\text { Cold Chem/M-13 } & \text { A B } & & 4.7641034 \\ \text { B C } & 4.7080893\end{array}$

Mixed Acid/M-14 C 4.6568332

Mixed Acid/M-13 D 4.5186449

Levels not connected by same letter are significantly different
Sample Type=ARG-1, Analyte=Al/Mn

Oneway Analysis of Batch Average Value By Prep/ICP

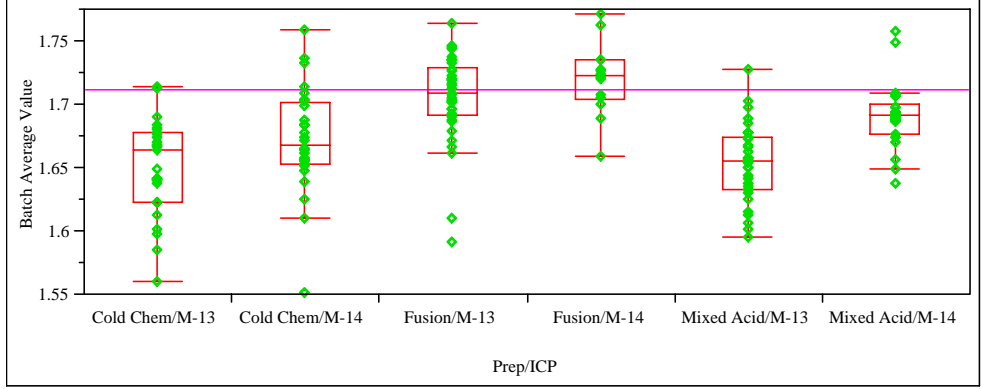

Oneway Anova

Summary of Fit

Rsquare

0.346403

Adj Rsquare

0.346403

Root Mean Square Error $\quad 0.03434$

$\begin{array}{lr}\text { Mean of Response } & 1.680259 \\ \text { Observations (or Sum Wgts) } & 160\end{array}$

Analysis of Variance

Source DF Sum of Squares Mean Square F Ratio Prob > F

$\begin{array}{lllllll}\text { Prep/ICP } & 5 & 0.09629528 & 0.019259 & 16.3238 & <.0001\end{array}$

$\begin{array}{llll}\text { Error } & 154 & 0.18169095 & 0.001180\end{array}$

C. Total $159 \quad 0.27798623$

Means for Oneway Anov

Level Number Mean Std Error Lower 95\% Upper 95\%

$\begin{array}{llllll}\text { Cold Chem/M-13 } & 27 & 1.65154 & 0.00661 & 1.6385 & 1.6646\end{array}$

$\begin{array}{llllll}\text { Cold Chem/M-14 } & 28 & 1.67291 & 0.00649 & 1.6601 & 1.6857\end{array}$

$\begin{array}{llllll}\text { Fusion/M-13 } & 38 & 1.70602 & 0.00557 & 1.6950 & 1.7170\end{array}$

$\begin{array}{llllll}\text { Fusion/M-14 } & 14 & 1.72097 & 0.00918 & 1.7028 & 1.7391\end{array}$

$\begin{array}{llllll}\text { Mixed Acid/M-13 } & 31 & 1.65402 & 0.00617 & 1.6418 & 1.6662\end{array}$

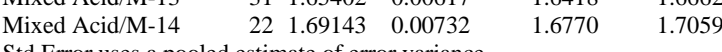

Std Error uses a pooled estimate of error variance

Means and Std Deviations

Level Number Mean Std Dev Std Err Mean Lower 95\% Upper 95\%

$\begin{array}{llllll}\text { Cold Chem/M-13 } & 27 & 1.65154 & 0.037711 & 0.00726 & 1.6366\end{array}$

$\begin{array}{lllllll}\text { Cold Chem/M-14 } & 28 & 1.67291 & 0.041396 & 0.00782 & 1.6569 & 1.6890\end{array}$

$\begin{array}{lllllll}\text { Fusion/M-13 } & 38 & 1.70602 & 0.034261 & 0.00556 & 1.6948 & 1.7173\end{array}$

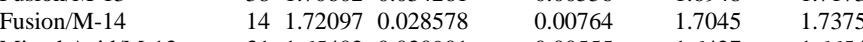

Mixed Acid/M-13 311.654020 .030901

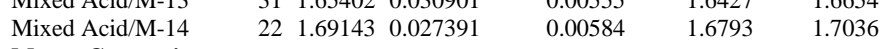

Means Comparisons

Comparisons for all pairs using Tukey-Kramer HSD

Level Mean

$\begin{array}{lll}\text { Fusion/M-14 } & \text { A } & 1.7209737 \\ \text { Fusion/M-13 } & \text { A } & 1.7060178\end{array}$

$\begin{array}{llll}\text { Fusion/M-13 } & \text { A } & 1.7060178 \\ \text { Mixed Acid/M-14 } & \text { A B } & 1.6914323\end{array}$

$\begin{array}{llll}\text { Mixed Acid/M-14 } & \text { A } & \text { B } & 1.6914323 \\ \text { Cold Chem/M-14 } & \text { B C } 1.6729072\end{array}$

Mixed Acid/M-13 C 1.6540209

Cold Chem/M-13 C 1.6515377

Levels not connected by same letter are significantly different 
Sample Type=ARG-1, Analyte=B

Oneway Analysis of Batch Average Value By Prep/ICP

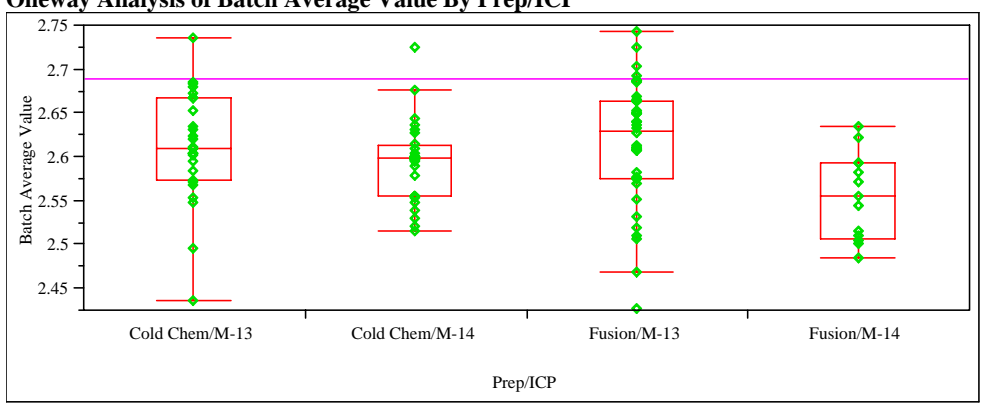

Missing Rows 53

Oneway Anova

Adj Rsquare

\subsection{7}

$\begin{array}{lr}0.06026 \\ \text { Mean of Response } & 2.602425\end{array}$

Observations (or Sum Wgts) $\quad 106$

Analysis of Variance

Source DF Sum of Squares Mean Square F Ratio Prob > F

$\begin{array}{llllll}\text { Prep/ICP } & 3 & 0.04100255 & 0.013668 & 3.7638 & 0.0131\end{array}$

$\begin{array}{lllll}\text { Error } & 102 & 0.37039435 & 0.003631\end{array}$

C. Total $105 \quad 0.41139690$

Means for Oneway Anova

Level Number Mean Std Error Lower 95\% Upper 95\%

$\begin{array}{llllll}\text { Cold Chem/M-13 } & 27 & 2.61252 & 0.01160 & 2.5895 & 2.6355\end{array}$

$\begin{array}{llllll}\text { Cold Chem/M-14 } & 28 & 2.59514 & 0.01139 & 2.5726 & 2.6177\end{array}$

$\begin{array}{llllll}\text { Fusion/M-13 } & 38 & 2.61676 & 0.00978 & 2.5974 & 2.6362\end{array}$

$\begin{array}{llllll}\text { Fusion/M-14 } & 13 & 2.55523 & 0.01671 & 2.5221 & 2.5884\end{array}$

Std Error uses a pooled estimate of error variance

Means and Std Deviations

Level Number Mean Std Dev Std Err Mean Lower 95\% Upper 95\%

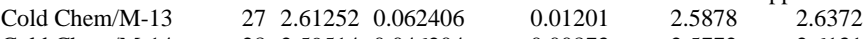

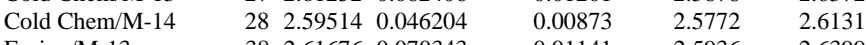

$\begin{array}{lllllll}\text { Fusion/M-13 } & 38 & 2.61676 & 0.070343 & 0.01141 & 2.5936 & 2.6399 \\ \text { Fusion/M-14 } & 13 & 2.55523 & 0.048660 & 0.01350 & 2.5258 & 2.5846\end{array}$

Means Comparisons

Comparisons for all pairs using Tukey-Kramer HSD

Level

Mean
.6167632

$\begin{array}{llr}\text { Fusion/M-13 } & \text { A } & 2.6167632 \\ \text { Cold Chem/M-13 } & \text { A } & 2.6125185\end{array}$

$\begin{array}{llr}\text { Cold Chem/M-13 A } & 2.6125185 \\ \text { Co } & 2.5951429\end{array}$

$\begin{array}{llll}\text { Cold Chem/M-14 } & \text { A } & \text { B } & 2.5951429 \\ \text { Fusion/M-14 } & \text { B } & 2.5552308\end{array}$

Levels not connected by same letter are significantly different
Sample Type=ARG-1, Analyte $=\mathbf{B} / \mathrm{Li}$

Oneway Analysis of Batch Average Value By Prep/ICP

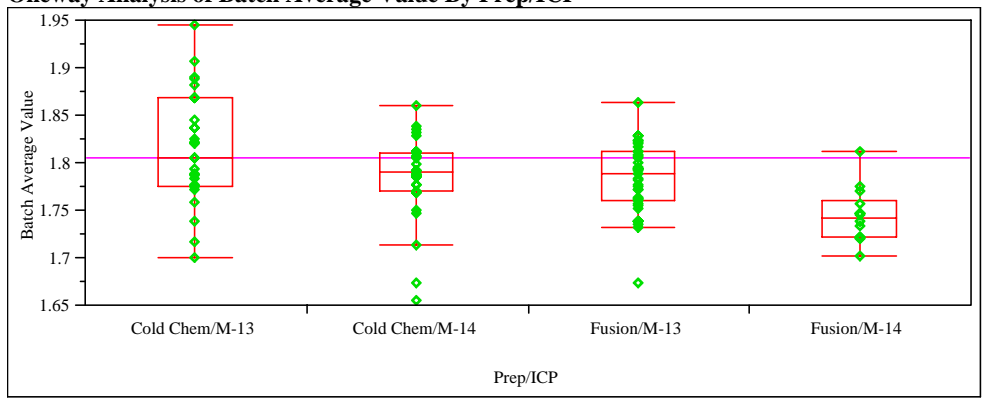

Missing Rows 53

Oneway Anova

Summary of Fit

Rsquare

0.18932

Adj Rsquare

0.166377

Root Mean Square Error $\quad 0.044162$
Mean of Response

Observations (or Sum Wgts) 110

Analysis of Variance

Source DF Sum of Squares Mean Square F Ratio Prob $>F$

$\begin{array}{lllllll}\text { Prep/ICP } & 3 & 0.04827758 & 0.016093 & 8.2515 & <.0001\end{array}$

$\begin{array}{llll}\text { Error } & 106 & 0.20672720 & 0.001950\end{array}$

C. Total $109 \quad 0.25500478$

Means for Oneway Anova

Level Number Mean Std Error Lower 95\% Upper 95\%

$\begin{array}{llllll}\text { Cold Chem/M-13 } & 27 & 1.81582 & 0.00850 & 1.7990 & 1.8327\end{array}$

$\begin{array}{llllll}\text { Cold Chem/M-14 } & 30 & 1.78566 & 0.00806 & 1.7697 & 1.8016\end{array}$

$\begin{array}{llllll}\text { Fusion/M-13 } & 39 & 1.78413 & 0.00707 & 1.7701 & 1.7981\end{array}$

$\begin{array}{llllll}\text { Fusion/M-14 } & 14 & 1.74434 & 0.01180 & 1.7209 & 1.7677\end{array}$

Std Error uses a pooled estimate of error variance

Level Number Mean Std Dev Std Err Mean Lower 95\% Upper 95\%

$\begin{array}{lllllll}\text { Cold Chem/M-13 } & 27 & 1.81582 & 0.058877 & 0.01133 & 1.7925 & 1.8391\end{array}$

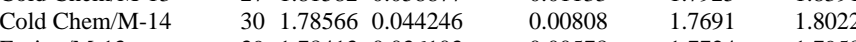

$\begin{array}{lllllll}\text { Fusion/M-13 } & 39 & 1.78413 & 0.036103 & 0.00578 & 1.7724 & 1.7958\end{array}$

$\begin{array}{lllllll}\text { Fusion/M-14 } & 14 & 1.74434 & 0.028141 & 0.00752 & 1.7281 & 1.7606\end{array}$

Means Comparisons

Comparisons for all pairs using Tukey-Kramer HSD

Level Mean

Cold Chem/M-13 A 1.8158208

Cold Chem/M-14 A B 1.7856610

Fusion/M-13 $\quad$ B 1.7841253

Fusion/M-14 C 1.7443371

Levels not connected by same letter are significantly different 
Sample Type $=$ ARG-1, Analyte $=$ Ca

Oneway Analysis of Batch Average Value By Prep/ICP

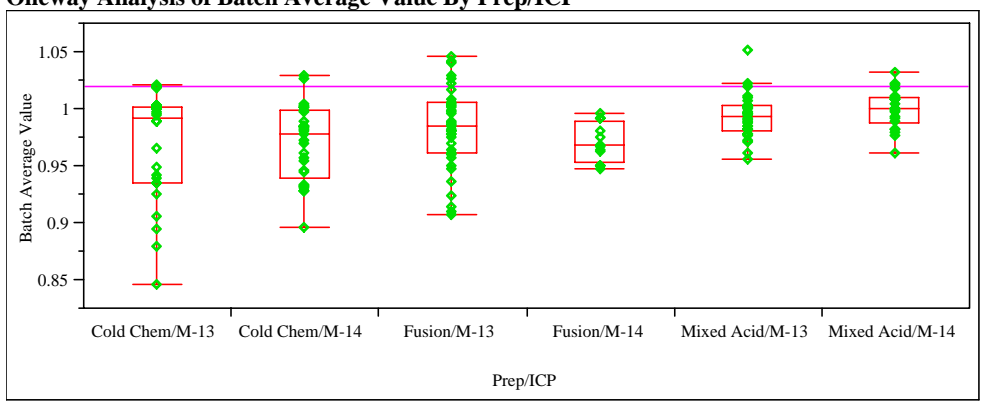

Oneway Anova

Summary of Fit

$\begin{array}{lr}\text { Rsquare } & 0.125684 \\ \text { Adj Rsquare } & 0.09654 \\ \text { Root Mean Square Error } & 0.032042 \\ \text { Mean of Response } & 0.981859 \\ \text { Observations (or Sum Wgts) } & 156\end{array}$

Observations (or Sum w

Analysis of Variance

Source DF Sum of Squares Mean Square F Ratio Prob > F

$\begin{array}{llllll}\text { Prep/ICP } & 5 & 0.02213808 & 0.004428 & 4.3125 & 0.0011\end{array}$

$\begin{array}{llll}\text { Error } & 150 & 0.15400232 & 0.001027\end{array}$

C. Total $155 \quad 0.17614040$

Means for Oneway Anova

Level Number Mean Std Error Lower 95\% Upper 95\%

$\begin{array}{llllll}\text { Cold Chem/M-13 } & 26 & 0.96787 & 0.00628 & 0.95545 & 0.9803\end{array}$

$\begin{array}{llllll}\text { Cold Chem/M-14 } & 29 & 0.97053 & 0.00595 & 0.95878 & 0.9823\end{array}$

$\begin{array}{llllll}\text { Fusion/M-13 } & 37 & 0.98334 & 0.00527 & 0.97293 & 0.9937\end{array}$

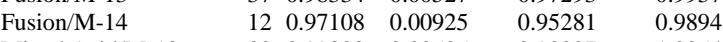

$\begin{array}{lllll}\text { Mixed Acid/M-13 } 30 & 0.99383 & 0.00585 & 0.98227 & 1.0054\end{array}$

$\begin{array}{llllll}\text { Mixed Acid/M-14 } & 22 & 1.00039 & 0.00683 & 0.98689 & 1.0139\end{array}$

Std Error uses a pooled estimate of error variance

(1)

Level Number Mean Std Dev Std Err Mean Lower 95\% Upper 95\%

$\begin{array}{lllllll}\text { Cold Chem/M-13 } & 26 & 0.96787 & 0.047597 & 0.00933 & 0.94864 & 0.9871\end{array}$

$\begin{array}{lllllll}\text { Cold Chem/M-14 } & 29 & 0.97053 & 0.032966 & 0.00612 & 0.95800 & 0.9831\end{array}$

$\begin{array}{lllllll}\text { Fusion/M-13 } & 37 & 0.98334 & 0.036078 & 0.00593 & 0.97131 & 0.9954\end{array}$

$\begin{array}{lllllll}\text { Fusion/M-14 } & 12 & 0.97108 & 0.017041 & 0.00492 & 0.96026 & 0.9819\end{array}$

$\begin{array}{lllllll}\text { Mixed Acid/M-13 } & 30 & 0.99383 & 0.019244 & 0.00351 & 0.98665 & 1.0010 \\ \text { Mixed Acid/M-14 } & 22 & 1.00039 & 0.017105 & 0.00365 & 0.99280 & 1.0080\end{array}$

Means Comparison

Comparisons for all pairs using Tukey-Kramer HSD

Level

Mean

$\begin{array}{lll} & & \\ \text { Mixed Acid/M-14 A } & 1.0003864 \\ \text { Mixed Acid/M-13 A в } & 0.9938333\end{array}$

$\begin{array}{lllll}\text { Fusion/M-13 } & \text { A } & \text { B } & \text { C } & 0.9833378\end{array}$

Fusion/M-14 A $\quad$ B $C$ C 0.9710833

Cold Chem/M-14 B C 0.9705345

Cold Chem/M-13 C 0.9678654

Levels not connected by same letter are significantly different
Sample Type $=$ ARG -1 , Analyte $=\mathbf{C r}$

Oneway Analysis of Batch Average Value By Prep/ICP

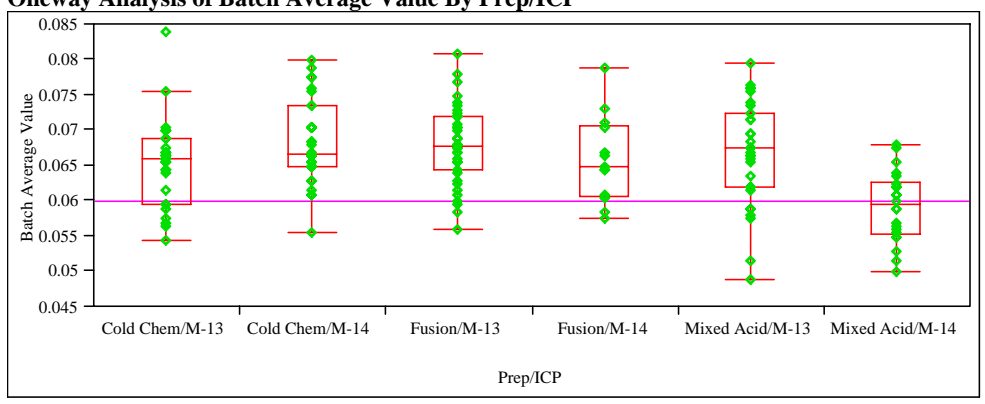

\section{Oneway Anova}

Rsquare

Adj Rsquare

0.187822

Root Mean Square Error $\quad \begin{array}{rr}0.161623 \\ 0.00611\end{array}$

Mean of Response $\quad 0.066034$

Observations (or Sum Wgts) $\quad 16$

Analysis of Variance

Source DF Sum of Squares Mean Square F Ratio Prob $>$ F

$\begin{array}{lrlllll}\text { Prep/ICP } & 5 & 0.00133806 & 0.000268 & 7.1690 & <.0001\end{array}$

$\begin{array}{llll}\text { Error } & 155 & 0.00578601 & 0.000037\end{array}$

C. Total $160 \quad 0.00712406$

Means for Oneway Anova

Level Number Mean Std Error Lower 95\% Upper 95\%

$\begin{array}{llllll}\text { Cold Chem/M-13 } & 27 & 0.065315 & 0.00118 & 0.06299 & 0.06764\end{array}$

$\begin{array}{llllll}\text { Cold Chem/M-14 } & 30 & 0.068383 & 0.00112 & 0.06618 & 0.07059\end{array}$

$\begin{array}{llllll}\text { Fusion/M-13 } & 38 & 0.067961 & 0.00099 & 0.06600 & 0.06992\end{array}$

$\begin{array}{llllll}\text { Fusion/M-14 } & 13 & 0.066038 & 0.00169 & 0.06269 & 0.06939\end{array}$

$\begin{array}{llllll}\text { Mixed Acid/M-13 } & 31 & 0.066806 & 0.00110 & 0.06464 & 0.06897\end{array}$

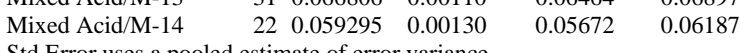

Std Error uses a pooled estimate of error variance

Means and Std Deviations

Level Number Mean Std Dev Std Err Mean Lower 95\% Upper 95\%

$\begin{array}{lllllll}\text { Cold Chem/M-13 } & 27 & 0.065315 & 0.006248 & 0.00120 & 0.06284 & 0.06779\end{array}$

$\begin{array}{lllllll}\text { Cold Chem/M-14 } & 30 & 0.068383 & 0.006000 & 0.00110 & 0.06614 & 0.07062\end{array}$

$\begin{array}{lllllll}\text { Fusion/M-13 } & 38 & 0.067961 & 0.005555 & 0.00090 & 0.06613 & 0.06979\end{array}$

$\begin{array}{lllllll}\text { Fusion/M-14 } & 13 & 0.066038 & 0.006149 & 0.00171 & 0.06232 & 0.06975\end{array}$

$\begin{array}{lllllll}\text { Mixed Acid/M-13 } & 31 & 0.066806 & 0.007341 & 0.00132 & 0.06411 & 0.06950\end{array}$

Mixed Acid/M-14

Means Comparisons

$0.00106 \quad 0.0571$

0.06149

$\begin{array}{lr}\text { Level } & \text { Mean } \\ \text { Cold Chem/M-14 A } 0.06838333\end{array}$

Cold Chem/M-14 A 0.06838333

$\begin{array}{lll}\text { Fusion/M-13 A } & 0.06796053 \\ \text { Mixed Acid/M-13 A } & 0.066806456\end{array}$

Mixed Acid/M-13 A 0.06680645

Fusion/M-14 A 0.06603846

$\begin{array}{lrr}\text { Cold Chem/M-13 } & \text { A } & 0.06531481 \\ \text { Mixed Acid/M-14 } & \text { B } 0.05929545\end{array}$

Levels not connected by same letter are significantly different 
Sample Type $=$ ARG-1, Analyte $=\mathbf{C u}$

Oneway Analysis of Batch Average Value By Prep/ICP

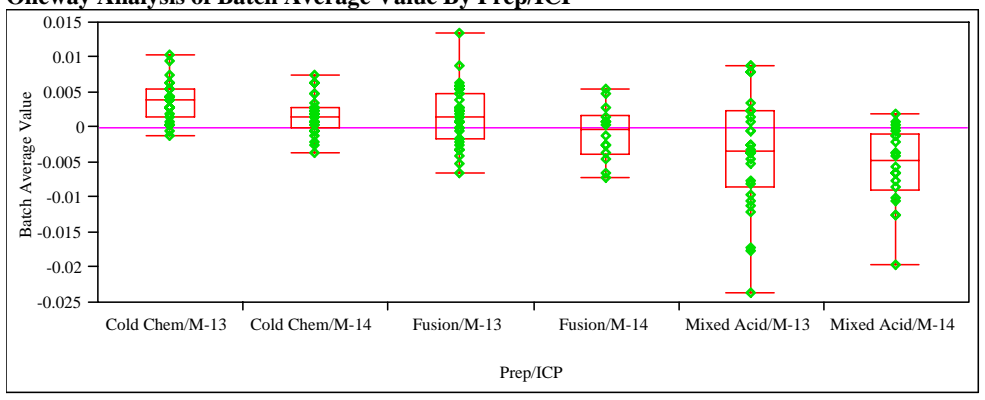

\section{Oneway Anova
Summary of Fit}

Adj Rsquare

0.302638

Root Mean Square Error $\quad 0.280143$

Eror 0.004863

\begin{tabular}{lr} 
Observations (or Sum Wgts) & -0.00002 \\
\hline
\end{tabular}

Analysis of Variance

Source DF Sum of Squares Mean Square F Ratio Prob > F

$\begin{array}{llllll}\text { Prep/ICP } & 5 & 0.00159109 & 0.000318 & 13.4533 & <.0001\end{array}$

$\begin{array}{llll}\text { Error } & 155 & 0.00366631 & 0.000024\end{array}$

C. Total $160 \quad 0.00525740$

Means for Oneway Anova

Level Number Mean Std Error Lower 95\% Upper 95\%

$\begin{array}{llllll}\text { Cold Chem/M-13 } & 27 & 0.00376 & 0.00094 & 0.0019 & 0.0056\end{array}$

$\begin{array}{llllll}\text { Cold Chem/M-14 } & 29 & 0.00179 & 0.00090 & 9.07 \mathrm{e}-6 & 0.0036\end{array}$

$\begin{array}{llllll}\text { Fusion/M-13 } & 39 & 0.00185 & 0.00078 & 0.00031 & 0.0034\end{array}$

$\begin{array}{llllll}\text { Fusion/M-14 } & 14 & -0.00071 & 0.00130 & -0.0033 & 0.0019\end{array}$

$\begin{array}{llllll}\text { Mixed Acid/M-13 } & 30 & -0.00338 & 0.00089 & -0.0051 & -0.0016\end{array}$

$\begin{array}{llllll}\text { Mixed Acid/M-14 } & 22 & -0.00536 & 0.00104 & -0.0074 & -0.0033\end{array}$

Std Error uses a pooled estimate of error variance

Means and Std Deviations

Level Number Mean Std Dev Std Err Mean Lower 95\% Upper 95\%

$\begin{array}{lllllll}\text { Cold Chem/M-13 } & 27 & 0.00376 & 0.002826 & 0.00054 & 0.0026 & 0.0049\end{array}$

$\begin{array}{lllllll}\text { Cold Chem/M-14 } & 29 & 0.00179 & 0.002644 & 0.00049 & 0.00079 & 0.0028\end{array}$

$\begin{array}{lllllll}\text { Fusion/M-13 } & 39 & 0.00185 & 0.004059 & 0.00065 & 0.00053 & 0.0032\end{array}$

$\begin{array}{lllllll}\text { Fusion/M-14 } & 14 & -0.00071 & 0.003911 & 0.00105 & -0.0030 & 0.0015\end{array}$

$\begin{array}{lllllll}\text { Mixed Acid/M-13 } & 30 & -0.00338 & 0.007945 & 0.00145 & -0.0063 & -0.0004 \\ \text { Mixed Acid/M-14 } & 22 & -0.00536 & 0.005379 & 0.00115 & -0.0077 & -0.0030\end{array}$

Means Comparisons

Comparisons for all pairs using Tukey-Kramer HSD

Level Mean
Lel

Cold Chem/M-13 A 0.0037593

Fusion/M-13 $\quad$ A $\quad 0.0018462$

Cold Chem/M-14 A 0.0017931

Fusion/M-14 A B -0.0007143

Mixed Acid/M-13 $\quad$ B -0.0033833

Levels not connected by same letter are significantly different
Sample Type=ARG-1, Analyte $=\mathbf{F e}$

Oneway Analysis of Batch Average Value By Prep/ICP

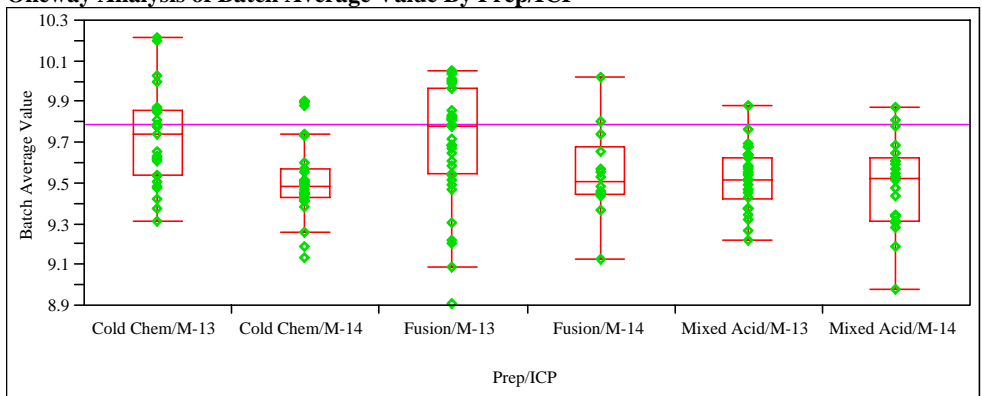

Oneway Anova

Summary of Fi

Rsquare

0.16694

Adj Rsquare

0.139355

Root Mean Square Error $\quad 0.22269$

Mean of Response

9.598309

Observations (or Sum

Analysis of Variance

Source DF Sum of Squares Mean Square F Ratio Prob > F

$\begin{array}{lllllll}\text { Prep/ICP } & 5 & 1.5005884 & 0.300118 & 6.0519 & <.0001\end{array}$

$\begin{array}{llll}\text { Error } & 151 & 7.4881973 & 0.049591\end{array}$

C. Total $156 \quad 8.9887858$

Means for Oneway Anova

Level Number Mean Std Error Lower 95\% Upper 95\%

$\begin{array}{llllll}\text { Cold Chem/M-13 } & 27 & 9.72298 & 0.04286 & 9.6383 & 9.8077\end{array}$

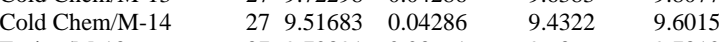

$\begin{array}{llllll}\text { Fusion/M-13 } & 37 & 9.70891 & 0.03661 & 9.6366 & 9.7812\end{array}$

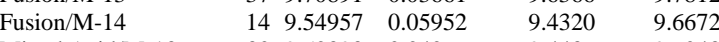

$\begin{array}{lllll}\text { Mixed Acid/M-13 } 309.52393 & 0.04066 & 9.4436 & 9.6043\end{array}$

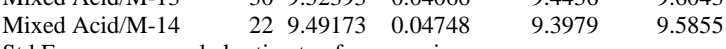

Std Error uses a pooled estimate of error variance

Means and Std Deviations

Level Number Mean Std Dev Std Err Mean Lower 95\% Upper 95\%

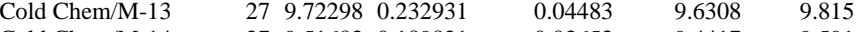

$\begin{array}{lllllll}\text { Cold Chem/M-14 } & 27 & 9.51683 & 0.189821 & 0.03653 & 9.4417 & 9.5919\end{array}$

$\begin{array}{lllllll}\text { Fusion/M-13 } & 37 & 9.70891 & 0.285684 & 0.04697 & 9.6137 & 9.8042\end{array}$

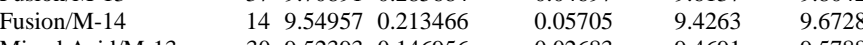

$\begin{array}{lllllll}\text { Mixed Acid/M-13 } & 30 & 9.52393 & 0.146956 & 0.02683 & 9.4691 & 9.5788\end{array}$

$\begin{array}{lllllll}\text { Mixed Acid/M-14 } & 22 & 9.49173 & 0.216449 & 0.04615 & 9.3958 & 9.5877\end{array}$

Means Comparisons

Comparisons for all pairs using Tukey-Kramer HSD

Level

Cold Chem/M-13 A 9.7229815

Fusion/M-13 A 9.7089054

Fusion/M-14 A B 9.5495714

Mixed Acid/M-13 $\quad$ B 9.5239333

Cold Chem/M-14 B 9.5168333

Mixed Acid/M-14 $\quad$ B 9.4917273

Levels not connected by same letter are significantly different 
WSRC-STI-2006-00068

Revision 0

\section{Exhibit A3. Measurement Comparisons Using Batch Averages of Prep Method/ICP Combination for ARG-1 by Analyte}

(continued)

Sample Type=ARG-1, Analyte=Fe/Al

Oneway Analysis of Batch Average Value By Prep/ICP

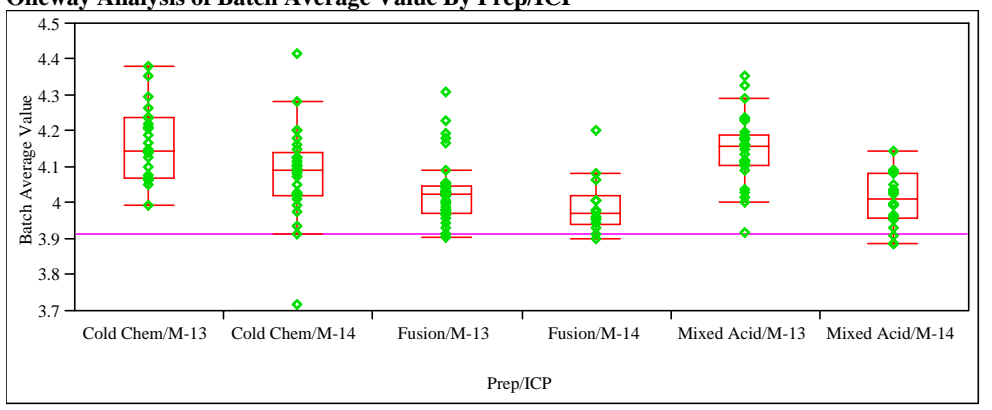

\section{Oneway Anova}

$\begin{array}{lr}\text { Summary of Fit } & 0.307108 \\ \text { Rsquare } & 0.284757 \\ \text { Adj Rsquare } & 0.095263 \\ \text { Root Mean Square Error } & 4.079849 \\ \text { Mean of Response } & 161\end{array}$

Observations (or Sum

Analysis of Variance
Source DF Sum of Squares Mean Square F Ratio Prob > F

$\begin{array}{lllllll}\text { Prep/ICP } & 5 & 0.6234506 & 0.124690 & 13.7400 & <.0001\end{array}$

$\begin{array}{llll}\text { Error } & 155 & 1.4066189 & 0.009075\end{array}$

C. Total $160 \quad 2.0300695$

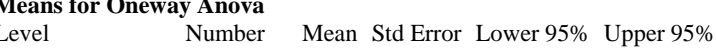

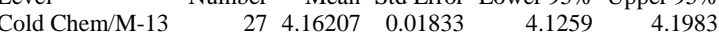

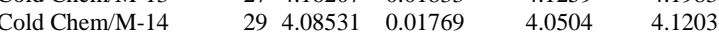

$\begin{array}{llllll}\text { Fusion/M-13 } & 38 & 4.03166 & 0.01545 & 4.0011 & 4.0622\end{array}$

$\begin{array}{llllll}\text { Fusion/M-14 } & 14 & 3.99370 & 0.02546 & 3.9434 & 4.0440\end{array}$

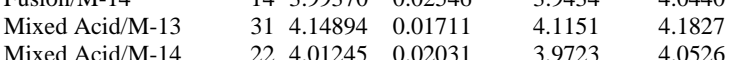

Std Error uses a pooled estimate of error variance

Means and Std Deviations

Level Number Mean Std Dev Std Err Mean Lower 95\% Upper 95\%

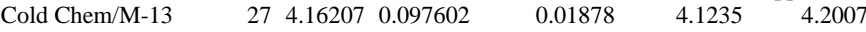

$\begin{array}{lllllll}\text { Cold Chem/M-14 } & 29 & 4.08531 & 0.124108 & 0.02305 & 4.0381 & 4.1325\end{array}$

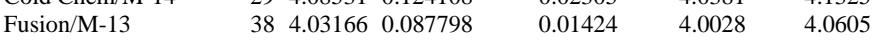

$\begin{array}{lllllll}\text { Fusion/M-14 } & 14 & 3.99370 & 0.079369 & 0.02121 & 3.9479 & 4.0395\end{array}$

$\begin{array}{lllllll}\text { Mixed Acid/M-13 } & 31 & 4.14894 & 0.091960 & 0.01652 & 4.1152 & 4.1827 \\ \text { Mixed Acid/M-14 } & 22 & 4.01245 & 0.071334 & 0.01521 & 3.9808 & 4.0441\end{array}$

Mixed Acid/M-14

Comparisons for all pairs using Tukey-Kramer HSD

Mean

Cold Chem/M-13 A 4.1620697

Mixed Acid/M-13 A B 4.1489365

Cold Chem/M-14 B C 4.0853122

Fusion/M-13 $\quad$ C D 4.0316589

Mixed Acid/M-14 C D 4.0124493

Fusion/M-14 D 3.9936986

Levels not connected by same letter are significantly different
Sample Type=ARG-1, Analyte=Fe/Ca

Oneway Analysis of Batch Average Value By Prep/ICP

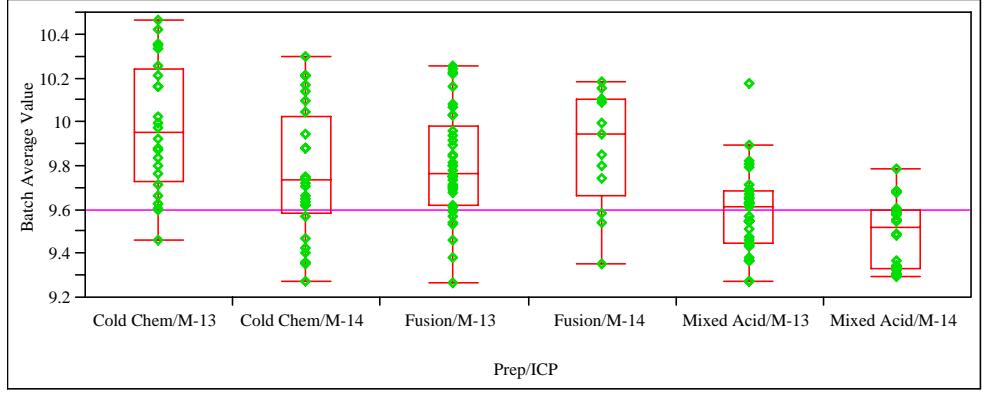

Oneway Anova

Summary of Fit

Rsquare

0.303185

Adj Rsquare

0.279958

Root Mean Square Error $\quad 0.24371$

$\begin{array}{lr}\text { Mean of Response } & 9.74495 \\ \text { Observations (or Sum Wgts) } & 156\end{array}$

Analysis of Variance

Source DF Sum of Squares Mean Square F Ratio Prob > F

$\begin{array}{lllllll}\text { Prep/ICP } & 5 & 3.876414 & 0.775283 & 13.0530 & <.000\end{array}$

$\begin{array}{lrrr}\text { Error } & 150 & 8.909233 & 0.059395\end{array}$

C. Total $155 \quad 12.785646$

Means for Oneway Anov

Level Number Mean Std Error Lower 95\% Upper 95\%

$\begin{array}{llllll}\text { Cold Chem/M-13 } & 24 & 9.97977 & 0.04975 & 9.8815 & 10.078\end{array}$

$\begin{array}{llllll}\text { Cold Chem/M-14 } & 28 & 9.76386 & 0.04606 & 9.6729 & 9.855\end{array}$

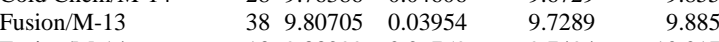

$\begin{array}{lllllr}\text { Fusion/M-14 } & 13 & 9.88299 & 0.06759 & 9.7494 & 10.017\end{array}$

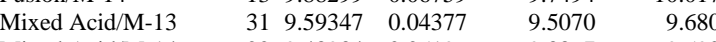

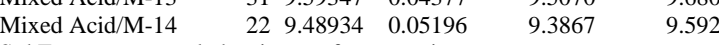

Std Error uses a pooled estimate of error variance

Means and Std Deviations

Level Number Mean Std Dev Std Err Mean Lower 95\% Upper 95\%

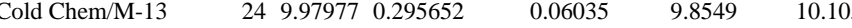

$\begin{array}{lllllll}\text { Cold Chem/M-14 } & 28 & 9.76386 & 0.289952 & 0.05480 & 9.6514 & 9.876\end{array}$

$\begin{array}{lllllll}\text { Fusion/M-13 } & 38 & 9.80705 & 0.244267 & 0.03963 & 9.7268 & 9.887\end{array}$

$\begin{array}{llllllr}\text { Fusion/M-14 } & 13 & 9.88299 & 0.263783 & 0.07316 & 9.7236 & 10.042\end{array}$

$\begin{array}{lllllll}\text { Mixed Acid/M-13 } & 31 & 9.59347 & 0.189746 & 0.03408 & 9.5239 & 9.663 \\ \text { Mixed Acid/M-14 } & 22 & 9.48934 & 0.155243 & 0.03310 & 9.4205 & 9.558\end{array}$

Means Compariso

Comparisons for all pairs using Tukey-Kramer HSD

Level

Cold Chem/M-13 A 9.979773

Fusion/M-14 A B 9.8829863

Fusion/M-13 A B 9.8070497

Cold Chem/M-14 B C 9.7638569

Mixed Acid/M-13 C D 9.5934669

Mixed Acid/M-14 D 9.4893408

Levels not connected by same letter are significantly different 
Sample Type=ARG-1, Analyte=Fe/Li

Oneway Analysis of Batch Average Value By Prep/ICP

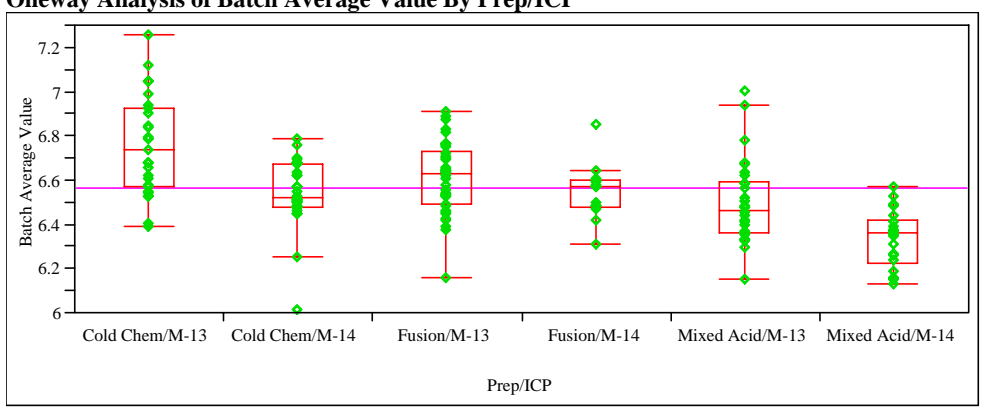

\section{Oneway Anova}

$\begin{array}{lr}\text { Summary of Fit } & \\ \text { Rsquare } & 0.345144 \\ \text { Adj Rsquare } & 0.324019 \\ \text { Root Mean Square Error } & 0.170212 \\ \text { Mean of Response } & 6.561351 \\ \text { Observations (or Sum Wgts) } & 161\end{array}$

Observations (or Sum

Analysis of Variance
Source DF Sum of Squares Mean Square F Ratio Prob > F

$\begin{array}{lllllll}\text { Prep/ICP } & 5 & 2.3668145 & 0.473363 & 16.3386 & <.0001\end{array}$

Error $\quad 155 \quad 4.4906613 \quad 0.028972$

C. Total $160 \quad 6.8574758$

Mevel for Oneway Anova $\quad$ Mean Std Error Lower 95\% Upper 95\%

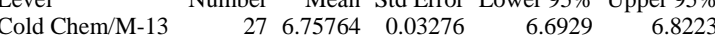

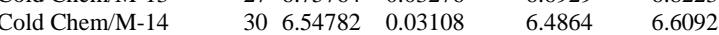

$\begin{array}{llllll}\text { Fusion/M-13 } & 38 & 6.61406 & 0.02761 & 6.5595 & 6.6686\end{array}$

\begin{tabular}{llllll} 
Fusion/M-14 & 14 & 6.55183 & 0.04549 & 6.4620 & 6.6417 \\
\hline
\end{tabular}

$\begin{array}{llllll}\text { Mixed Acid/M-13 } & 30 & 6.49997 & 0.03108 & 6.4386 & 6.5614 \\ \text { Mixed Acid/M-14 } & 22 & 6.33763 & 0.03629 & 6.2659 & 6.4093\end{array}$

Std Error uses a pooled estimate of error variance

Means and Std Deviations

Level Number Mean Std Dev Std Err Mean Lower 95\% Upper 95\%

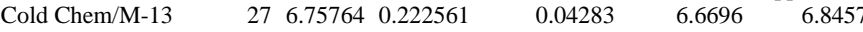

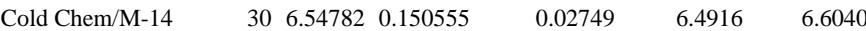

$\begin{array}{lllllll}\text { Fusion/M-13 } & 38 & 6.61406 & 0.162496 & 0.02636 & 6.5606 & 6.6675\end{array}$

$\begin{array}{lllllll}\text { Fusion/M-14 } & 14 & 6.55183 & 0.124537 & 0.03328 & 6.4799 & 6.6237\end{array}$

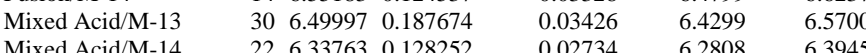

Mixed Acid/M-14

Comparisons for all pairs using Tukey-Kramer HSD

Level

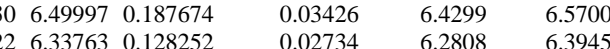

B 6.6140599

Fusion/M-14 B $\quad$ B 6.5518281

Cold Chem/M-14 $\quad$ B $\quad 6.5478214$

$\begin{array}{lrr}\text { Mixed Acid/M-13 } & \text { B } \quad 6.4999683 \\ \text { Mixed Acid/M-14 } & \text { C } 6.3376251\end{array}$

Levels not connected by same letter are significantly different
Sample Type=ARG-1, Analyte $=\mathrm{Fe} / \mathrm{Mg}$

Oneway Analysis of Batch Average Value By Prep/ICP

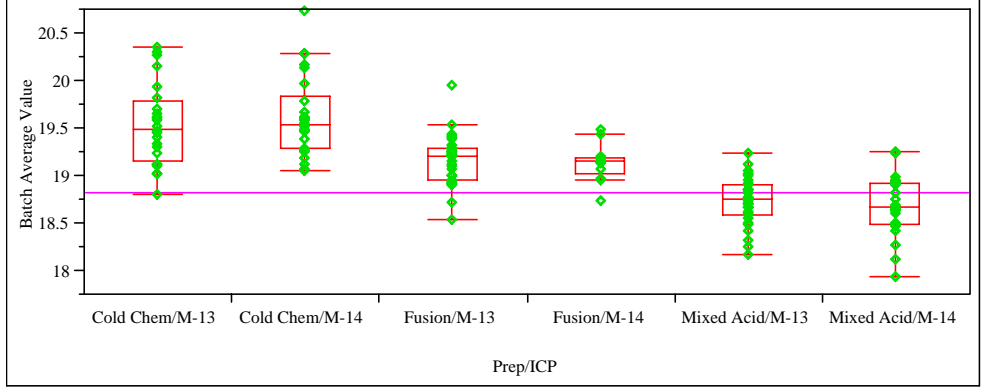

Oneway Anova

Summary of Fit

Rsquare

0.558861

Adj Rsquare

0.543856

Root Mean Square Error $\quad 0.324713$

Mean of Response 19.14412

Observations (or Sum Wgts) 153

Analysis of Variance

Source DF Sum of Squares Mean Square F Ratio Prob > F

$\begin{array}{lllllll}\text { Prep/ICP } & 5 & 19.635617 & 3.92712 & 37.2457 & <.000\end{array}$

$\begin{array}{llll}\text { Error } & 147 & 15.499451 & 0.10544\end{array}$

C. Total $152 \quad 35.135068$

Means for Oneway Anov

Level Number Mean Std Error Lower 95\% Upper 95\%

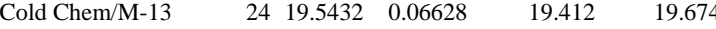

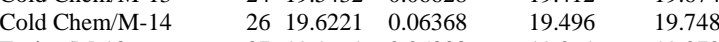

$\begin{array}{llllll}\text { Fusion/M-13 } & 37 & 19.1661 & 0.05338 & 19.061 & 19.272\end{array}$

$\begin{array}{llllll}\text { Fusion/M-14 } & 13 & 19.1432 & 0.09006 & 18.965 & 19.321\end{array}$

$\begin{array}{llllll}\text { Mixed Acid/M-13 } & 31 & 18.7366 & 0.05832 & 18.621 & 18.852\end{array}$

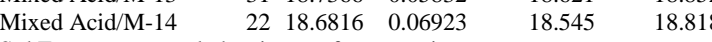

Std Error uses a pooled estimate of error variance

Means and Std Deviations

Level Number Mean Std Dev Std Err Mean Lower 95\% Upper 95\%

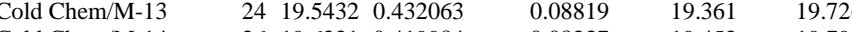

$\begin{array}{lllllll}\text { Cold Chem/M-14 } & 26 & 19.6221 & 0.419984 & 0.08237 & 19.452 & 19.792\end{array}$

$\begin{array}{lllllll}\text { Fusion/M-13 } & 37 & 19.1661 & 0.250499 & 0.04118 & 19.083 & 19.250\end{array}$

$\begin{array}{lllllll}\text { Fusion/M-14 } & 13 & 19.1432 & 0.191860 & 0.05321 & 19.027 & 19.259\end{array}$

Mixed Acid/M-13 $\quad 31 \quad 18.73660 .248374$

$\begin{array}{lllllll}\text { Mixed Acid/M-14 } & 22 & 18.6816 & 0.326946 & 0.06971 & 18.537 & 18.827\end{array}$

Means Comparisons

Comparisons for all pairs using Tukey-Kramer HSD

Level

SD

Cold Chem/M-14 A $\quad 19.622102$

Cold Chem/M-13 A 19.543232

$\begin{array}{lll}\text { Fusion/M-13 } & \text { B } & 19.166117 \\ \text { Fusion/M-14 } & \text { B } & 19.143169\end{array}$

Fusion/M-14 B $\quad 19.143169$

Mixed Acid/M-13 C 18.736626

Mixed Acid/M-14 C 18.681567

Levels not connected by same letter are significantly different 
WSRC-STI-2006-00068

Revision 0

\section{Exhibit A3. Measurement Comparisons Using Batch Averages of Prep Method/ICP Combination for ARG-1 by Analyte}

(continued)

Sample Type=ARG-1, Analyte=Fe/Mn

Oneway Analysis of Batch Average Value By Prep/ICP

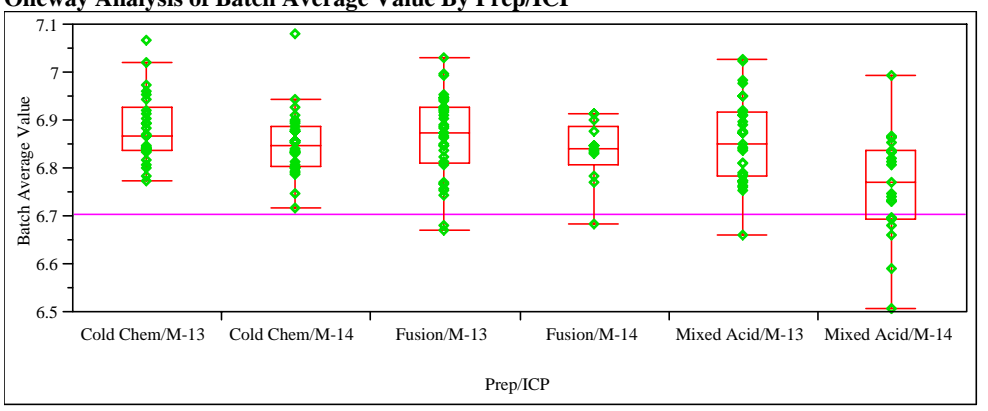

Oneway Anova

Rsquare of Fit $\quad 0.157656$

Adj Rsquare $\quad 0.129947$

Root Mean Square Error $\quad 0.082399$

Mean of Response $\quad 6.850188$

Observations (or Su

Analysis of Variance

Source DF Sum of Squares Mean Square F Ratio Prob > F

$\begin{array}{lllllll}\text { Prep/ICP } & 5 & 0.1931565 & 0.038631 & 5.6897 & <.0001\end{array}$

Error $\quad 152-1.0320238$

0.006790

Total $157 \quad 1.2251802$

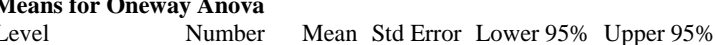

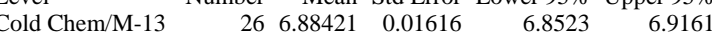

$\begin{array}{llllll}\text { Cold Chem/M-14 } & 30 & 6.85320 & 0.01504 & 6.8235 & 6.8829\end{array}$

$\begin{array}{llllll}\text { Fusion/M-13 } & 37 & 6.86782 & 0.01355 & 6.8411 & 6.8946\end{array}$

$\begin{array}{llllll}\text { Fusion/M-14 } & 13 & 6.83840 & 0.02285 & 6.7932 & 6.8836\end{array}$

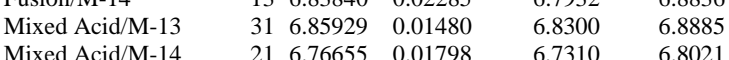

Std Error uses a pooled estimate of error variance

Means and Std Deviations

Level Number Mean Std Dev Std Err Mean Lower 95\% Upper 95\%

$\begin{array}{lllllll}\text { Cold Chem/M-13 } & 26 & 6.88421 & 0.071948 & 0.01411 & 6.8552 & 6.9133\end{array}$

$\begin{array}{lllllll}\text { Cold Chem/M-14 } & 30 & 6.85320 & 0.066750 & 0.01219 & 6.8283 & 6.8781 \\ & 37 & 6.86782 & 0.085809 & 0.01411 & 6.8392 & 6.8964\end{array}$

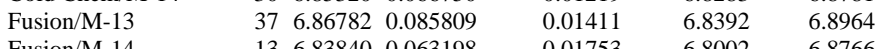

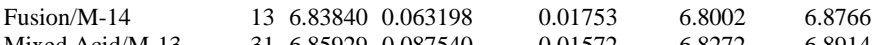

$\begin{array}{lllllll}\text { Mixed Acid/M-13 } & 31 & 6.85929 & 0.087540 & 0.01572 & 6.8272 & 6.8914 \\ \text { Mixed Acid/M-14 } & 21 & 6.76655 & 0.107354 & 0.02343 & 6.7177 & 6.8154\end{array}$

Mixed Acid/M-14

Comparisons for all pairs using Tukey-Kramer HSD

Level

Mean
Men

Cold Chem/M-13 A 6.8842136

Fusion/M-13 A 6.8678229

Mixed Acid/M-13 A 6.8592873

Cold Chem/M-14 A 6.8532001

Fusion/M-14 A B 6.8383996

Mixed Acid/M-14 B 6.7665496

Levels not connected by same letter are significantly different
Sample Type=ARG-1, Analyte=Fe/Ni

Oneway Analysis of Batch Average Value By Prep/ICP

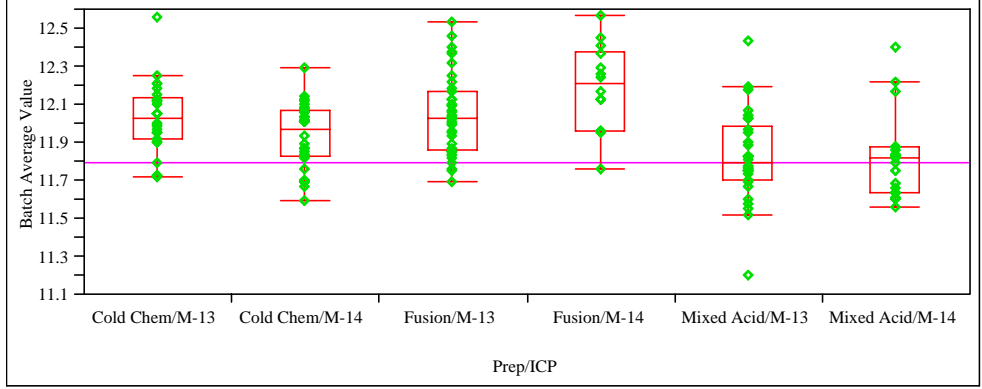

Oneway Anova

Summary of Fit

$\begin{array}{lr}\text { Rsquare } & 0.247477 \\ \text { Adj Rsquare } & 0.223044 \\ \text { Root Mean Square Error } & 0.206381 \\ \text { Mean of Response } & 11.96546 \\ \text { Observations (or Sum Wgts) } & 160\end{array}$

Observations (or Sum Wgts) $\quad 160$

Analysis of Variance

Source DF Sum of Squares Mean Square F Ratio Prob > F

$\begin{array}{lllllll}\text { Prep/ICP } & 5 & 2.1571261 & 0.431425 & 10.1290 & <.000\end{array}$

$\begin{array}{llll}\text { Error } & 154 & 6.5593437 & 0.042593\end{array}$

C. Total $159 \quad 8.7164698$

Means for Oneway Anov

Level Number Mean Std Error Lower 95\% Upper 95\%

$\begin{array}{llllll}\text { Cold Chem/M-13 } & 26 & 12.0303 & 0.04047 & 11.950 & 12.110\end{array}$

$\begin{array}{llllll}\text { Cold Chem/M-14 } & 30 & 11.9373 & 0.03768 & 11.863 & 12.012\end{array}$

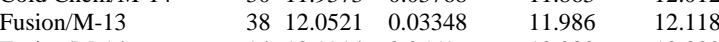

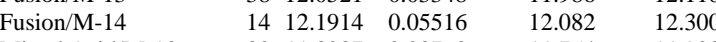

$\begin{array}{lllll}\text { Mixed Acid/M-13 } 30 & 11.8287 & 0.03768 & 11.754 & 11.903\end{array}$

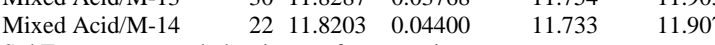

Std Error uses a pooled estimate of error variance

Means and Std Deviation

Level Number Mean Std Dev Std Err Mean Lower 95\% Upper 95\%

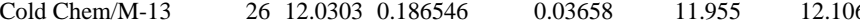

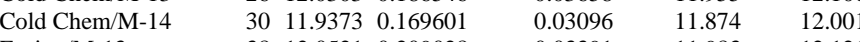

$\begin{array}{lllllll}\text { Fusion/M-13 } & 38 & 12.0521 & 0.209028 & 0.03391 & 11.983 & 12.121\end{array}$

$\begin{array}{lllllll}\text { Fusion/M-14 } & 14 & 12.1914 & 0.225559 & 0.06028 & 12.061 & 12.322\end{array}$

$\begin{array}{llll}\text { Mixed Acid/M-13 } 30 & 11.8287 & 0.237153\end{array}$

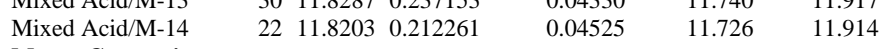

Means Comparisons

Comparisons for all pairs using Tukey-Kramer HSD

Level Mean

$\begin{array}{lll}\text { Fusion/M-14 } & \text { A } & 12.191359 \\ \text { Fusion/M-13 } & \text { A B } & 12.052060\end{array}$

Fusion/M-13 A B 12.052060

Cold Chem/M-13 A B 12.030331

Cold Chem/M-14 B C 11.937335

Mixed Acid/M-13 C 11.82869

Mixed Acid/M-14 C 11.820322

Levels not connected by same letter are significantly different 
Sample Type=ARG-1, Analyte=Fe/U

Oneway Analysis of Batch Average Value By Prep/ICP

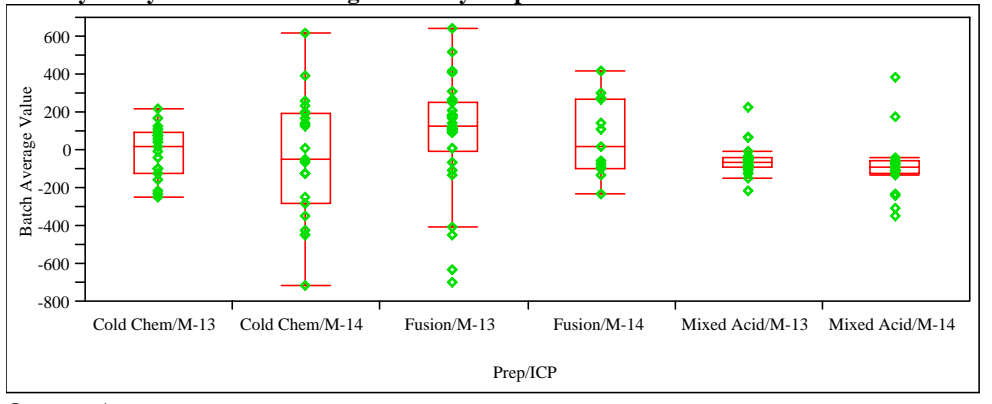

Oneway Anova

Summary of $F$

$\begin{array}{lr}\text { Rsquare } & 0.079012 \\ \text { Adj Rsquare } & 0.042753 \\ \text { Root Mean Square Error } & 223.0314 \\ \text { Mean of Response } & -5.01646 \\ \text { Observations (or Sum Wgts) } & 133\end{array}$

Observations (or Sum Wgts)

Analysis of Variance

Source DF Sum of Squares Mean Square F Ratio Prob $>$ F

$\begin{array}{llllll}\text { Prep/ICP } & 5 & 541970.4 & 108394 & 2.1791 & 0.0605\end{array}$

Error $\quad 127 \quad 6317359.6 \quad 49743$

C. Total $132 \quad 6859330.1$

Means for Oneway Anova

Level Number Mean Std Error Lower 95\% Upper 95\%

$\begin{array}{llllll}\text { Cold Chem/M-13 } & 19 & -8.714 & 51.167 & -110.0 & 92.54\end{array}$

$\begin{array}{llllll}\text { Cold Chem/M-14 } & 23 & -33.244 & 46.505 & -125.3 & 58.78\end{array}$

$\begin{array}{llllrr}\text { Fusion/M-13 } & 30 & 86.994 & 40.720 & 6.4 & 167.57\end{array}$

$\begin{array}{llllrr}\text { Fusion/M-14 } & 13 & 68.552 & 61.858 & -53.9 & 190.96\end{array}$

$\begin{array}{lrrrrr}\text { Mixed Acid/M-13 } & 28 & -54.156 & 42.149 & -137.6 & 29.25 \\ \text { Mixed Acid/M-14 } & 20 & -86.083 & 49.871 & -184.8 & 12.60\end{array}$

Std Error uses a pooled estimate of error variance

Means and Std Deviations

Number Mean Std Dev Std Err Mean Lower 95\% Upper 95\%

$\begin{array}{lllllll}\text { Cold Chem/M-13 } & 19 & -8.714 & 139.437 & 31.989 & -75.9 & 58.5\end{array}$

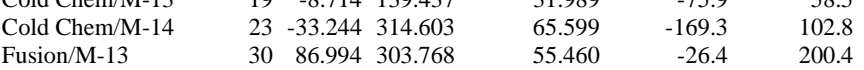

Fusion/M-14

Mixed Acid/M-13

$\begin{array}{lll}13 & 68.552 & 202.133\end{array}$

55.460

Mixed Acid/M-14

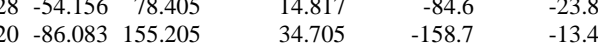

56.062
14.817

$-26.4$

$-53.6-190.7$

Means Comparisons

Comparisons for all pairs using Tukey-Kramer HSD

Level

Mean

Fusion/M-13 A 86.99412

Fusion/M-14 A 68.55243

Cold Chem/M-13 A -8.71399

Cold Chem/M-14 A -33.24439

Mixed Acid/M-13 A -54.15562

Mixed Acid/M-14 A -86.08253

Levels not connected by same letter are significantly different
Sample Type=ARG-1, Analyte $=K$

Oneway Analysis of Batch Average Value By Prep/ICP

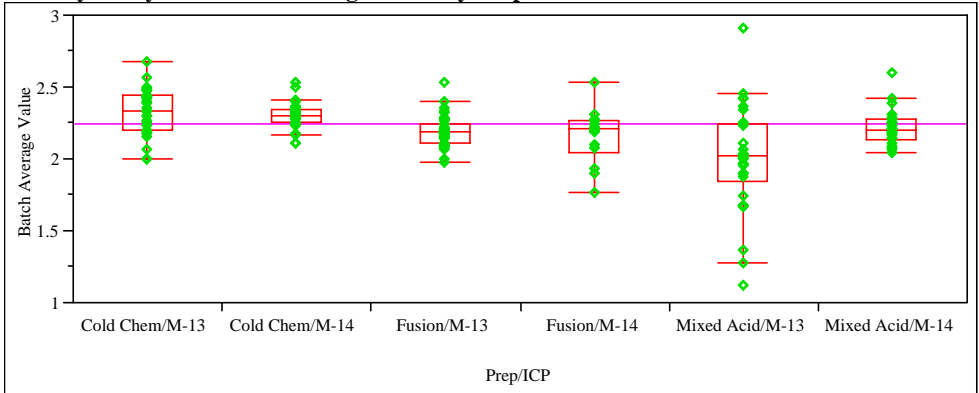

Oneway Anova

Summary of Fit

Rsquare

Root Mean Square Error $\quad 0.199689$

Mean of Response 2.206543

Analysis of Variance

Source DF Sum of Squares Mean Square F Ratio Prob $>$ F

$\begin{array}{lllllll}\text { Prep/ICP } & 5 & 1.9723285 & 0.394466 & 9.8924 & <.0001\end{array}$

$\begin{array}{llll}\text { Error } & 156 & 6.2205902 & 0.039876\end{array}$

C. Total $161 \quad 8.1929187$

Level Number Mean Std Error Lower 95\% Upper 95\%

$\begin{array}{llllll}\text { Cold Chem/M-13 } & 27 & 2.33307 & 0.03843 & 2.2572 & 2.4090\end{array}$

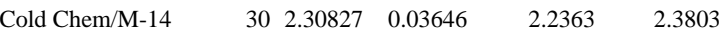

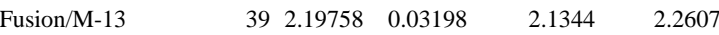

$\begin{array}{llllll}\text { Fusion/M-14 } & 14 & 2.16504 & 0.05337 & 2.0596 & 2.2705\end{array}$

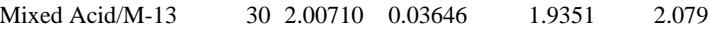

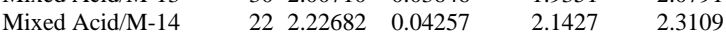

Std Error uses a pooled estimate of error variance

Level Number Mean Std Dev Std Err Mean Lower 95\% Upper 95\%

$\begin{array}{lllllll}\text { Cold Chem/M-13 } & 27 & 2.33307 & 0.167570 & 0.03225 & 2.2668 & 2.3994\end{array}$

$\begin{array}{lllllll}\text { Cold Chem/M-14 } & 30 & 2.30827 & 0.094889 & 0.01732 & 2.2728 & 2.3437\end{array}$

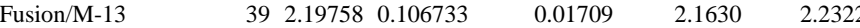

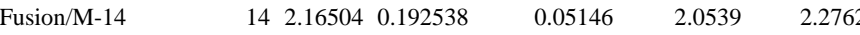

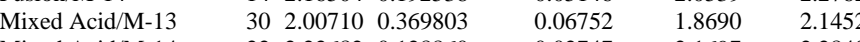

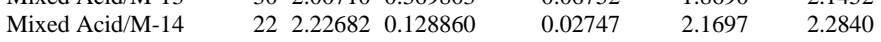

Comparisons for all pairs using Tukey-Kramer HSD

Level

Cold Chem/M-13 A 2.3330741

Cold Chem/M-14 A 2.3082667

Mixed Acid/M-14 A 2.226818

Fusion/M-13 A 2.1975769

Fusion/M-14 A B 2.165035

Mixed Acid/M-13 $\quad$ B 2.0071000

Levels not connected by same letter are significantly different 
WSRC-STI-2006-00068

Revision 0

\section{Exhibit A3. Measurement Comparisons Using Batch Averages of Prep Method/ICP Combination for ARG-1 by Analyte}

(continued)

Sample Type=ARG-1, Analyte=Li

Oneway Analysis of Batch Average Value By Prep/ICP

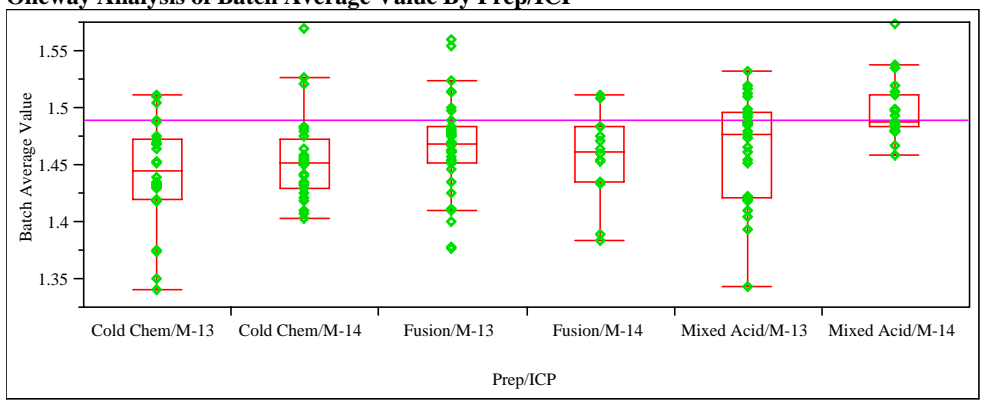

Oneway Anova

Summary of Fit

Adj Rsquare

0.141202

0.112765
Root Mean Square Error $\quad 0.039732$

Mean of Response 1.464252

Observations (or Sum

1.464252
157

Analysis of Variance

Source DF Sum of Squares Mean Square F Ratio Prob > F

$\begin{array}{lllllll}\text { Prep/ICP } & 5 & 0.03919225 & 0.007838 & 4.9654 & 0.0003\end{array}$

$\begin{array}{llll}\text { Error } & 151 & 0.23837006 & 0.001579\end{array}$

C. Total $156 \quad 0.27756231$

Means for Oneway Anova

Level Number Mean Std Error Lower 95\% Upper 95\%

$\begin{array}{llllll}\text { Cold Chem/M-13 } & 26 & 1.44360 & 0.00779 & 1.4282 & 1.4590\end{array}$

$\begin{array}{llllll}\text { Cold Chem/M-14 } & 28 & 1.45505 & 0.00751 & 1.4402 & 1.4699\end{array}$

$\begin{array}{llllll}\text { Fusion/M-13 } & 38 & 1.46705 & 0.00645 & 1.4543 & 1.4798\end{array}$

$\begin{array}{llllll}\text { Fusion/M-14 } & 14 & 1.45807 & 0.01062 & 1.4371 & 1.4791 \\ & 29 & 1.46547 & 0.00738 & 1.4509 & 1.4800\end{array}$

$\begin{array}{llllll}\text { Mixed Acid/M-13 } & 29 & 1.46547 & 0.00738 & 1.4509 & 1.4800 \\ \text { Mixed Acid/M-14 } & 22 & 1.49786 & 0.00847 & 1.4811 & 1.5146\end{array}$

Std Error uses a pooled estimate of error variance

Level and Std Dev Std Err Mean Lower 95\% Upper 95\%

$\begin{array}{lrrrrrr}\text { Cold Chem/M-13 } & 26 & 1.44360 & 0.045735 & 0.00897 & 1.4251 & 1.4621\end{array}$

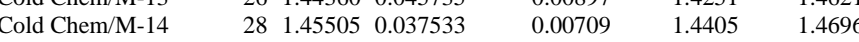

$\begin{array}{lllllll}\text { Fusion/M-13 } & 38 & 1.46705 & 0.039949 & 0.00648 & 1.4539 & 1.4802\end{array}$

$\begin{array}{lllllll}\text { Fusion/M-14 } & 14 & 1.45807 & 0.037901 & 0.01013 & 1.4362 & 1.4800\end{array}$

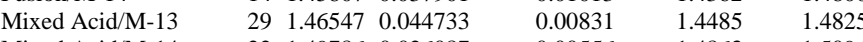

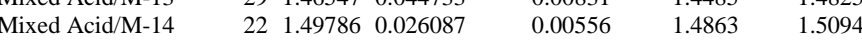

Means Comparisons

Comparisons for all pairs using Tukey-Kramer HSD

Level

Mixed Acid/M-14 A 1.4978636

Fusion/M-13 B 1.4670526

Mixed Acid/M-13 A B 1.4654655

Fusion/M-14 B 1.4580714

Cold Chem/M-14 B 1.4550536

Cold Chem/M-13 $\quad$ B 1.4435962

Levels not connected by same letter are significantly different
Sample Type $=$ ARG-1, Analyte $=\mathbf{M g}$

Oneway Analysis of Batch Average Value By Prep/ICP

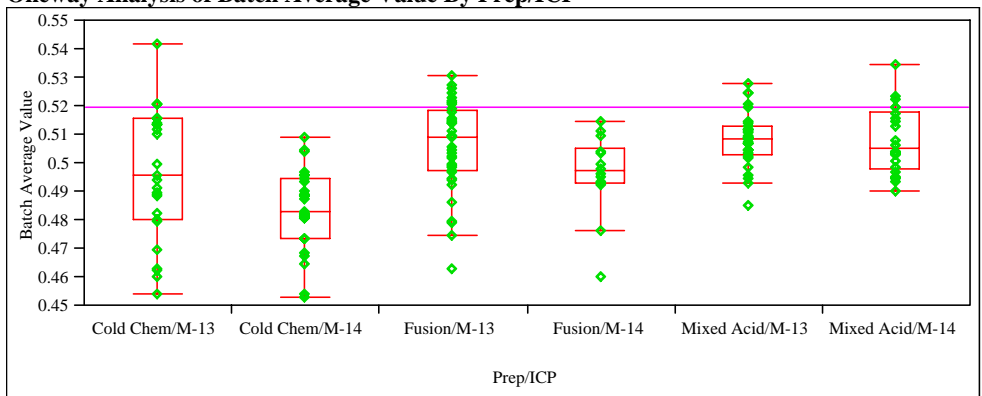

Oneway Anova

Summary of Fit

Rsquare

0.256825

Adj Rsquare

0.232217

Root Mean Square Error $\quad 0.015387$

Mean of Response

0.500599
157

Observations (or Sum

Source DF Sum of Squares Mean Square F Ratio Prob > F

$\begin{array}{lllllll}\text { Prep/ICP } & 5 & 0.01235399 & 0.002471 & 10.4365 & <.0001\end{array}$

$\begin{array}{llll}\text { Error } & 151 & 0.03574873 & 0.000237\end{array}$

C. Total $156 \quad 0.04810272$

Means for Oneway Anova

Level Number Mean Std Error Lower 95\% Upper 95\%

$\begin{array}{llllll}\text { Cold Chem/M-13 } & 27 & 0.496981 & 0.00296 & 0.49113 & 0.50283\end{array}$

$\begin{array}{llllll}\text { Cold Chem/M-14 } & 27 & 0.483944 & 0.00296 & 0.47809 & 0.48980\end{array}$

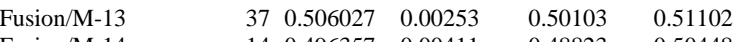

$\begin{array}{llllll}\text { Fusion/M-14 } & 14 & 0.496357 & 0.00411 & 0.48823 & 0.50448\end{array}$

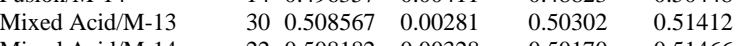

$\begin{array}{llllll}\text { Mixed Acid/M-14 } & 22 & 0.508182 & 0.00328 & 0.50170 & 0.51466\end{array}$

Std Error uses a pooled estimate of error variance

Means and Std Deviations

Level Number Mean Std Dev Std Err Mean Lower 95\% Upper 95\%

$\begin{array}{lllllll}\text { Cold Chem/M-13 } & 27 & 0.496981 & 0.022651 & 0.00436 & 0.48802 & 0.50594\end{array}$

$\begin{array}{lllllll}\text { Cold Chem/M-14 } & 27 & 0.483944 & 0.014232 & 0.00274 & 0.47831 & 0.48957\end{array}$

$\begin{array}{lllllll}\text { Fusion/M-13 } & 37 & 0.506027 & 0.015843 & 0.00260 & 0.50074 & 0.51131\end{array}$

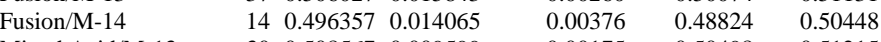

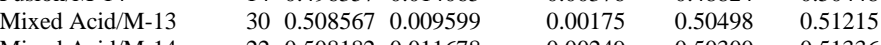

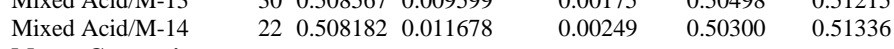

Means Comparison

Comparisons for all pairs using Tukey-Kramer HSD

$\begin{array}{rr}\text { Mean } & \text { Mevel } \\ \text { Mixed Acid/M-13 A } & 0.50856667\end{array}$

Mixed Acid/M-14 A 0.50818182

Fusion/M-13 A 0.50602703

Cold Chem/M-13 A 0.49698148

Fusion/M-14 A B 0.49635714

Cold Chem/M-14 B 0.48394444

Levels not connected by same letter are significantly different 
WSRC-STI-2006-00068

Revision 0

\section{Exhibit A3. Measurement Comparisons Using Batch Averages of Prep Method/ICP Combination for ARG-1 by Analyte}

(continued)

Sample Type=ARG-1, Analyte $=M n$

Oneway Analysis of Batch Average Value By Prep/ICP

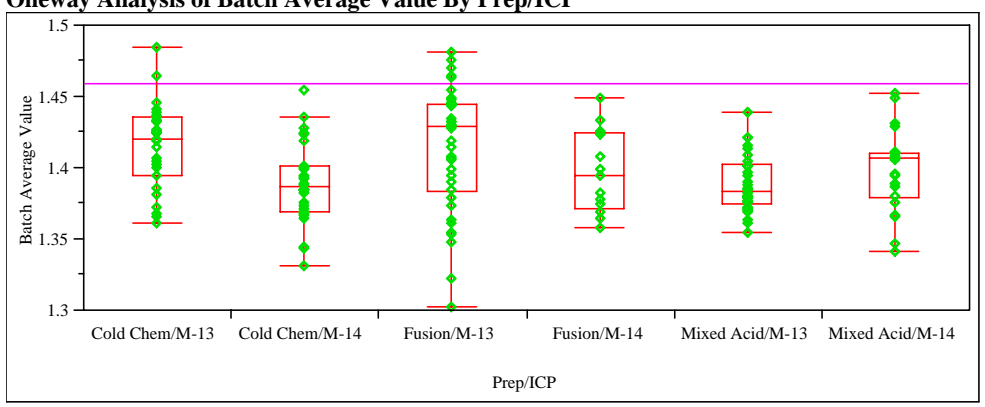

Oneway Anova

Summary of Fit

Adj Rsquare

0.119139

0.090163
Root Mean Square Error $\quad 0.03195$

Mean of Response $\quad 1.401747$

Observations (or Sum Wgts) 158

Analysis of Variance

Source DF Sum of Squares Mean Square F Ratio Prob $>$ F

$\begin{array}{llllll}\text { Prep/ICP } & 5 & 0.02098580 & 0.004197 & 4.1117 & 0.0016\end{array}$

$\begin{array}{llll}\text { Error } & 152 & 0.15516007 & 0.001021\end{array}$

C. Total $157 \quad 0.17614587$

Means for Oneway Anova

Level Number Mean Std Error Lower 95\% Upper 95\%

$\begin{array}{llllll}\text { Cold Chem/M-13 } & 27 & 1.41574 & 0.00615 & 1.4036 & 1.4279\end{array}$

$\begin{array}{llllll}\text { Cold Chem/M-14 } & 28 & 1.38916 & 0.00604 & 1.3772 & 1.4011\end{array}$

$\begin{array}{llllll}\text { Fusion/M-13 } & 38 & 1.41428 & 0.00518 & 1.4040 & 1.4245\end{array}$

$\begin{array}{llllll}\text { Fusion/M-14 } & 13 & 1.39719 & 0.00886 & 1.3797 & 1.4147 \\ \text { Mixed Acid/M-13 } & 30 & 1.38902 & 0.00583 & 1.3775 & 1.4005\end{array}$

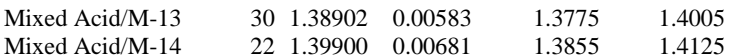

Std Error uses a pooled estimate of error variance

Means and Std Deviations

Level Number Mean Std Dev Std Err Mean Lower 95\% Upper 95\%

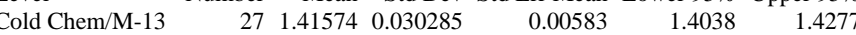

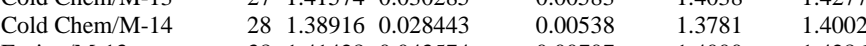

$\begin{array}{lllllll}\text { Fusion/M-13 } & 38 & 1.41428 & 0.043574 & 0.00707 & 1.4000 & 1.4286\end{array}$

$\begin{array}{lllllll}\text { Fusion/M-14 } & 13 & 1.39719 & 0.029112 & 0.00807 & 1.3796 & 1.4148\end{array}$

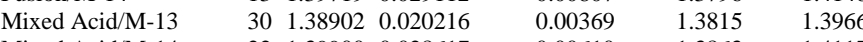

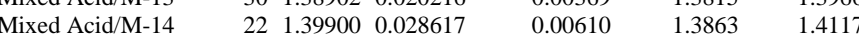

Means Comparisons

irs using Tukey-Kramer HSD

Level

Mean

$\begin{array}{rrr}\text { Mean } & \\ \text { Cold Chem/M-13 A } 1.4157407\end{array}$

Fusion/M-13 A 1.4142763

Mixed Acid/M-14 A B 1.3990000

Fusion/M-14 A B 1.3971923

Cold Chem/M-14 B 1.3891607

Mixed Acid/M-13 $\quad$ B 1.3890167

Levels not connected by same letter are significantly different
Sample Type=ARG-1, Analyte $=\mathrm{Mn} / \mathrm{Mg}$

Oneway Analysis of Batch Average Value By Prep/ICP

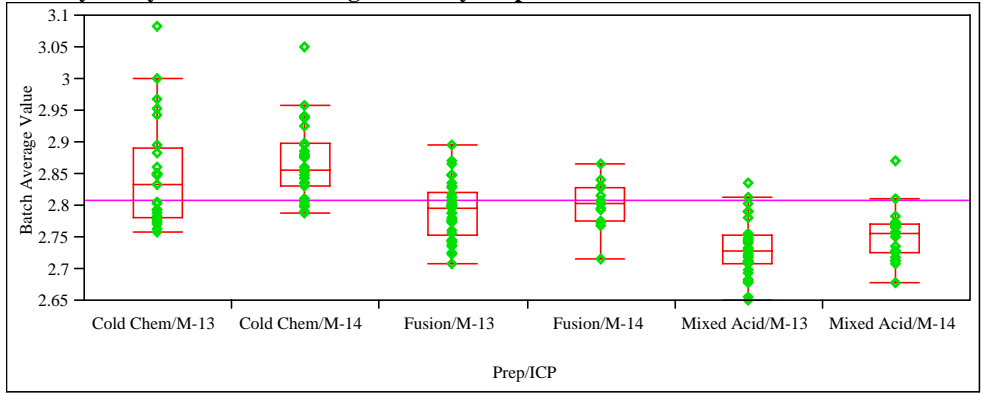

Oneway Anova

Summary of Fit

Rsquare

.459497

Adj Rsquare

0.459497

Root Mean Square Error $\quad 0.054823$

$\begin{array}{lr}\text { Mean of Response } & 2.798359 \\ \text { Observations (or Sum Wgts) } & 157\end{array}$

Analysis of Variance

Source DF Sum of Squares Mean Square F Ratio Prob > F

$\begin{array}{lllllll}\text { Prep/ICP } & 5 & 0.38582232 & 0.077164 & 25.6738 & <.000\end{array}$

$\begin{array}{llll}\text { Error } & 151 & 0.45384078 & 0.003006\end{array}$

C. Total $156 \quad 0.83966310$

Means for Oneway Anova

Level Number Mean Std Error Lower 95\% Upper 95\%

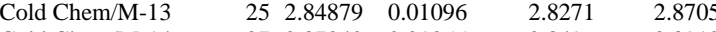

$\begin{array}{llllll}\text { Cold Chem/M-14 } & 27 & 2.87040 & 0.01055 & 2.8496 & 2.8912 \\ \text { Fusion } & 38 & 2.79290 & 0.00889 & 2.7753 & 2.8105\end{array}$

$\begin{array}{llllll}\text { Fusion/M-13 } & 38 & 2.79290 & 0.00889 & 2.7753 & 2.8105 \\ \text { Fusion/M-14 } & 14 & 2.80167 & 0.01465 & 2.7727 & 2.8306\end{array}$

$\begin{array}{llllll}\text { Fusion/M-14 } & 14 & 2.80167 & 0.01465 & 2.7727 & 2.8306 \\ \text { Mixed Acid/M-13 } & 31 & 2.73201 & 0.00985 & 2.7126 & 2.7515\end{array}$

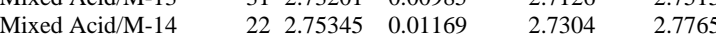

Std Error uses a pooled estimate of error variance

Means and Std Deviation

Level Number Mean Std Dev Std Err Mean Lower 95\% Upper 95\%

$\begin{array}{llllll}\text { Cold Chem/M-13 } & 25 & 2.84879 & 0.084618 & 0.01692 & 2.8139\end{array} 2.8837$

$\begin{array}{lllllll}\text { Cold Chem/M-14 } & 27 & 2.87040 & 0.061165 & 0.01177 & 2.8462 & 2.8946\end{array}$

$\begin{array}{lllllll}\text { Fusion/M-13 } & 38 & 2.79290 & 0.044792 & 0.00727 & 2.7782 & 2.8076\end{array}$

$\begin{array}{lllllll}\text { Fusion/M-14 } & 14 & 2.80167 & 0.036621 & 0.00979 & 2.7805 & 2.8228\end{array}$

Mixed Acid/M-13 $\quad 312.732010 .044279$

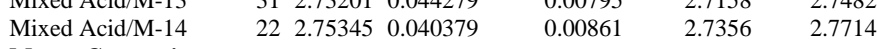

Means Comparisons

Comparisons for all pairs using Tukey-Kramer HSD

Level Mean

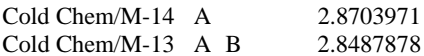

$\begin{array}{llll}\text { Fusion/M-14 } & \text { B C } 2.8016698\end{array}$

$\begin{array}{llll}\text { Fusion/M-13 } & \text { C } & 2.7929036\end{array}$

Mixed Acid/M-14 C D 2.7534543

Mixed Acid/M-13 $\quad$ D 2.7320062

Levels not connected by same letter are significantly different 
WSRC-STI-2006-00068

Revision 0

\section{Exhibit A3. Measurement Comparisons Using Batch Averages of Prep Method/ICP Combination for ARG-1 by Analyte}

(continued)

Sample Type=ARG-1, Analyte=Na

Oneway Analysis of Batch Average Value By Prep/ICP

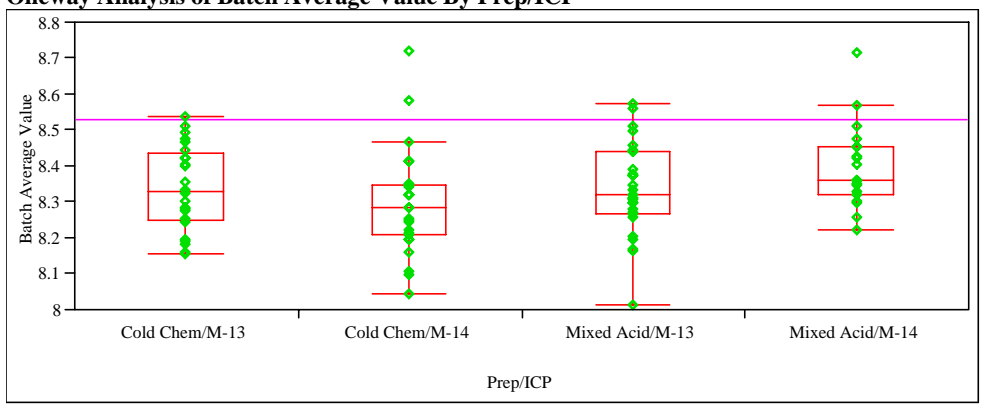

Missing Rows 53

Oneway Anova

Summary of Fit

0.068416

Adj Rsquare

0.068416

Root Mean Square Error $\quad 0.127427$

\begin{tabular}{lr} 
Mean of Response & 8.340631 \\
\hline & $99{ }^{2}$
\end{tabular}

Analysis of Variance

Source DF Sum of Squares Mean Square F Ratio Prob $>$ F

$\begin{array}{llllll}\text { Prep/ICP } & 3 & 0.1132878 & 0.037763 & 2.3256 & 0.0797\end{array}$

$\begin{array}{llll}\text { Error } & 95 & 1.5425840 & 0.016238\end{array}$

C. Total $98 \quad 1.6558718$

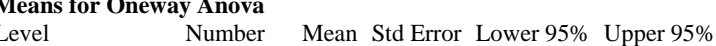

$\begin{array}{llllll}\text { Cold Chem/M-13 } & 24 & 8.34015 & 0.02601 & 8.2885 & 8.3918\end{array}$

$\begin{array}{llllll}\text { Cold Chem/M-14 } & 27 & 8.29965 & 0.02452 & 8.2510 & 8.3483\end{array}$

$\begin{array}{lllll}\text { Mixed Acid/M-13 } 29 & 8.34002 & 0.02366 & 8.2930 & 8.3870\end{array}$

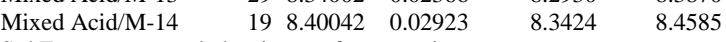

Std Error uses a pooled estimate of error variance

Level Number Mean Std Dev Std Err Mean Lower 95\% Upper 95\%

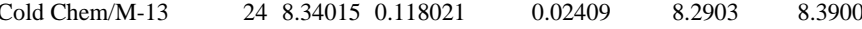

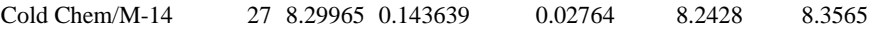

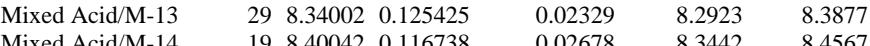

Means Comparisons

Comparisons for all pairs using Tukey-Kramer HSD

Level

Mixed Acid/M-14 A 8.4004211

Cold Chem/M-13 A B 8.3401458

Mixed Acid/M-13 A B 8.3400172

Cold Chem/M-14 $\quad$ B 8.2996481

Levels not connected by same letter are significantly different
Sample Type $=$ ARG-1, Analyte $=\mathrm{Ni}$

Oneway Analysis of Batch Average Value By Prep/ICP

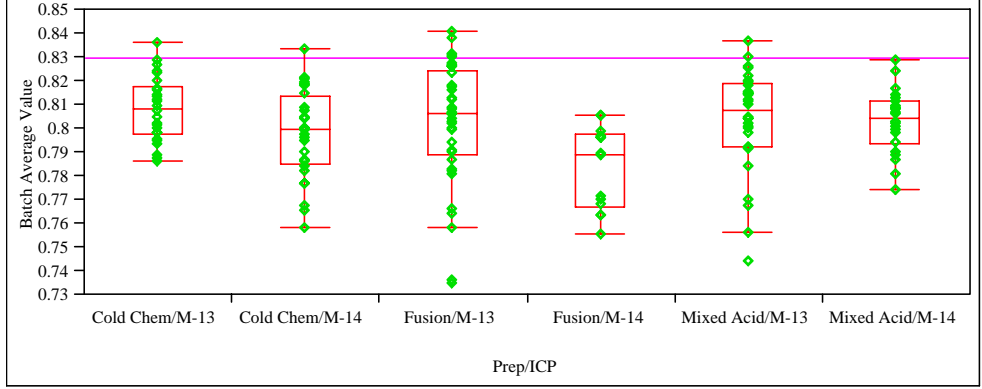

Oneway Anova

Summary of Fit

Rsquare

0.095056

Adj Rsquare

0.065288

Root Mean Square Error $\quad 0.019873$

Mean of Response

0.801301
158

Observations (or Sum

Source DF Sum of Squares Mean Square F Ratio Prob > F

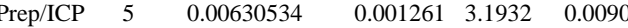

$\begin{array}{llll}\text { Error } & 152 & 0.06002763 & 0.000395\end{array}$

C. Total $157 \quad 0.06633297$

Means for Oneway Anova

Level Number Mean Std Error Lower 95\% Upper 95\%

$\begin{array}{llllll}\text { Cold Chem/M-13 } & 26 & 0.808288 & 0.00390 & 0.80059 & 0.81599\end{array}$

Cold Chem/M-14 $280.797821 \quad 0.00376 \quad 0.79040 \quad 0.80524$

$\begin{array}{llllll}\text { Fusion/M-13 } & 38 & 0.802671 & 0.00322 & 0.79630 & 0.80904\end{array}$

$\begin{array}{llllll}\text { Fusion/M-14 } & 14 & 0.783607 & 0.00531 & 0.77311 & 0.79410\end{array}$

$\begin{array}{llllll}\text { Mixed Acid/M-13 } & 30 & 0.803683 & 0.00363 & 0.79652 & 0.81085\end{array}$

$\begin{array}{lrrrrr}\text { Mixed Acid/M-14 } \quad 22 & 0.803114 & 0.00424 & 0.79474 & 0.81148\end{array}$

Std Error uses a pooled estimate of error variance

Means and Std Deviations

Level Number Mean Std Dev Std Err Mean Lower 95\% Upper 95\%

$\begin{array}{lllllll}\text { Cold Chem/M-13 } & 26 & 0.808288 & 0.013632 & 0.00267 & 0.80278 & 0.81379\end{array}$

$\begin{array}{lllllll}\text { Cold Chem/M-14 } & 28 & 0.797821 & 0.018697 & 0.00353 & 0.79057 & 0.80507\end{array}$

$\begin{array}{lllllll}\text { Fusion/M-13 } & 38 & 0.802671 & 0.025775 & 0.00418 & 0.79420 & 0.81114\end{array}$

$\begin{array}{lllllll}\text { Fusion/M-14 } & 14 & 0.783607 & 0.017420 & 0.00466 & 0.77355 & 0.79367\end{array}$

$\begin{array}{lllllll}\text { Mixed Acid/M-13 } & 30 & 0.803683 & 0.021671 & 0.00396 & 0.79559 & 0.81178\end{array}$

$\begin{array}{lllllll}\text { Mixed Acid/M-14 } & 22 & 0.803114 & 0.013449 & 0.00287 & 0.79715 & 0.80908\end{array}$

Means Comparisons

Comparisons for all pairs using Tukey-Kramer HSD

Level

Mixed Acid/M-13 A $\quad 0.80368333$

Mixed Acid/M-14 A в 0.80311364

Fusion/M-13 A 0.80267105

Cold Chem/M-14 A B 0.79782143

Fusion/M-14

B 0.78360714

Levels not connected by same letter are significantly different 
Sample Type=ARG-1, Analyte=Si

Oneway Analysis of Batch Average Value By Prep/ICP

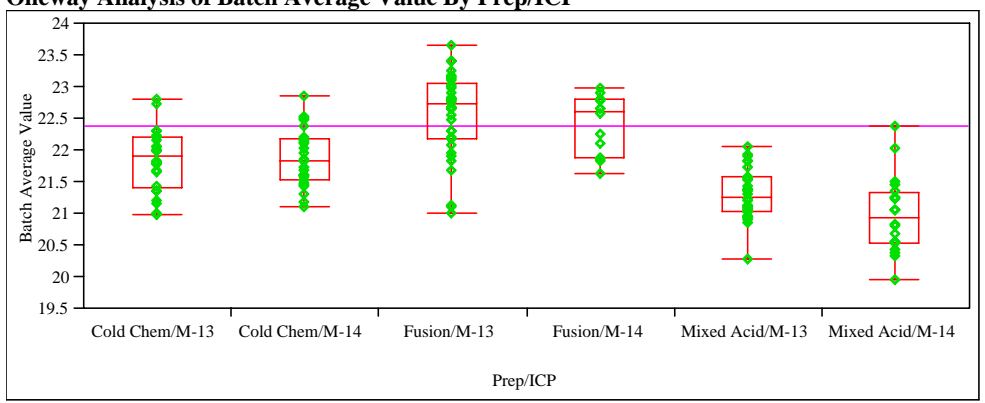

Oneway Anova

Summary of Fit

Rsquare

Adj Rsquare

0.544945

0.522982

\begin{tabular}{lr}
21.87219 \\
\hline Observations (or Sum Wgts) & 155
\end{tabular}

Source DF Sum of Squares Mean Square F Ratio Prob $>$ F

$\begin{array}{lllllll}\text { Prep/ICP } & 5 & 48.803342 & 9.76067 & 35.6866 & <.0001\end{array}$

Error $\quad 149 \quad 40.753045 \quad 0.27351$

C. Total $154 \quad 89.556387$

Means for Oneway Anova

Level Number Mean Std Error Lower 95\% Upper 95\%

$\begin{array}{lllllr}\text { Cold Chem/M-13 } & 26 & 21.8597 & 0.10257 & 21.657 & 22.062\end{array}$

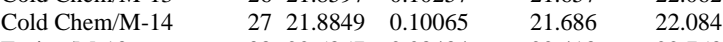

$\begin{array}{llllll}\text { Fusion/M-13 } & 38 & 22.5857 & 0.08484 & 22.418 & 22.753\end{array}$

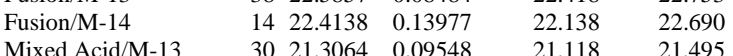

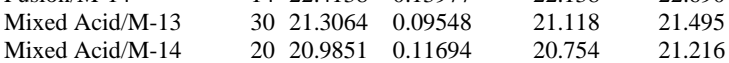

Std Error uses a pooled estimate of error variance

Means and Std Deviations

Level Number Mean Std Dev Std Err Mean Lower 95\% Upper 95\%

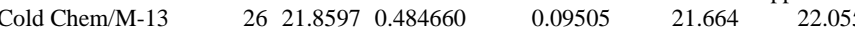

$\begin{array}{lllllll}\text { Cold Chem/M-14 } & 27 & 21.8849 & 0.447320 & 0.08609 & 21.708 & 22.062\end{array}$

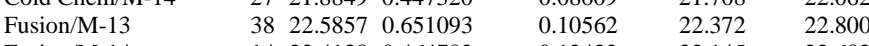

$\begin{array}{lllllll}\text { Fusion/M-14 } & 14 & 22.4138 & 0.464782 & 0.12422 & 22.145 & 22.682\end{array}$

$\begin{array}{lllllll}\text { Mixed Acid/M-13 } & 30 & 21.3064 & 0.391373 & 0.07145 & 21.160 & 21.453 \\ \text { Mixed Acid/M-14 } & 20 & 20.9851 & 0.595720 & 0.13321 & 20.706 & 21.264\end{array}$

Comparisons for all pairs using Tukey-Kramer HSD

Comparis

Mean
A 22.585684

Fusion/M-13 A $\quad 22.585684$

Fusion/M-14 A 22.413821

Cold Chem/M-14 B 21.884926

Cold Chem/M-13 $\quad$ B 21.859731

Mixed Acid/M-13 C 21.306400

Mixed Acid/M-14 C 20.985075

Levels not connected by same letter are significantly different
Sample Type=ARG-1, Analyte=Sum of Oxides

Oneway Analysis of Batch Average Value By Prep/ICP

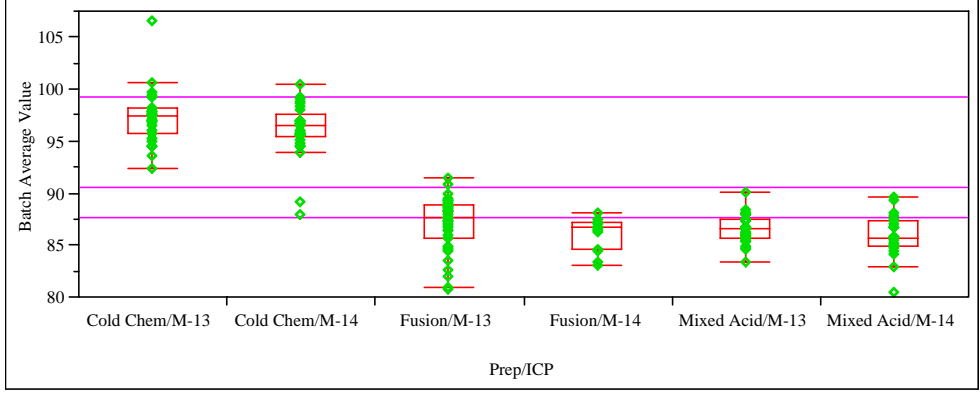

Oneway Anova

Summary of Fit

Rsquare

.826472

Adj Rsquare

0.826472

Root Mean Square Error $\quad 2.277669$

Mean of Response

90.13247

Observations (or Sum

Source DF Sum of Squares Mean Square F Ratio Prob > F

$\begin{array}{lllllll}\text { Prep/ICP } & 5 & 3829.7578 & 765.952 & 147.6454 & <.0001\end{array}$

Error $\quad \begin{array}{lll}155 & 804.1056 & 5.188\end{array}$

C. Total $160 \quad 4633.8634$

Means for Oneway Anova

Level Number Mean Std Error Lower 95\% Upper 95\%

Cold Chem/M-13 $\quad 2797.4129 \quad 0.43834 \quad 96.547 \quad 98.279$

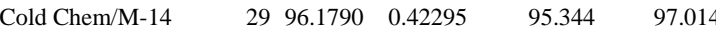

$\begin{array}{llllll}\text { Fusion/M-13 } & 39 & 87.1026 & 0.36472 & 86.382 & 87.823\end{array}$

$\begin{array}{lllll}\text { Fusion/M-14 } & 1486.1759 & 0.60873 & 84.973 & 87.378\end{array}$

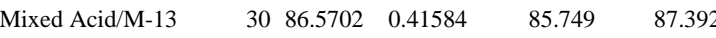

$\begin{array}{llllll}\text { Mixed Acid/M-14 } & 22 & 85.9735 & 0.48560 & 85.014 & 86.933\end{array}$

Std Error uses a pooled estimate of error variance

Means and Std Deviations

Level Number Mean Std Dev Std Err Mean Lower 95\% Upper 95\%

$\begin{array}{llllll}\text { Cold Chem/M-13 } & 2797.4129 & 2.66286 & 0.51247 & 96.359 & 98.466\end{array}$

$\begin{array}{lllllll}\text { Cold Chem/M-14 } & 29 & 96.1790 & 2.63160 & 0.48868 & 95.178 & 97.180\end{array}$

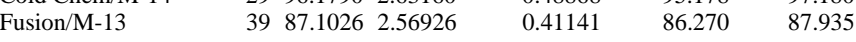

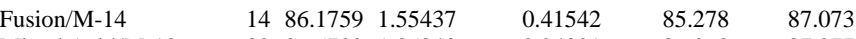

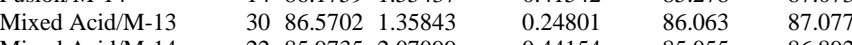

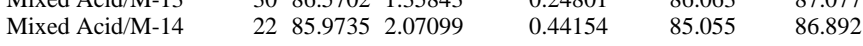

Means Comparisons

Comparisons for all pairs using Tukey-Kramer HSD

Level

Mean
Cold Chem/M-13 A 97.412860

Cold Chem/M-14 A 96.179002

Fusion/M-13 $\quad$ B 87.102613

Mixed Acid/M-13 B 86.570229

Fusion/M-14 B 86.175937

Mixed Acid/M-14 $\quad$ B 85.973550

Levels not connected by same letter are significantly different 
WSRC-STI-2006-00068

Revision 0

\section{Exhibit A3. Measurement Comparisons Using Batch Averages of Prep Method/ICP Combination for ARG-1 by Analyte}

(continued)

Sample Type=ARG-1, Analyte=Ti

Oneway Analysis of Batch Average Value By Prep/ICP

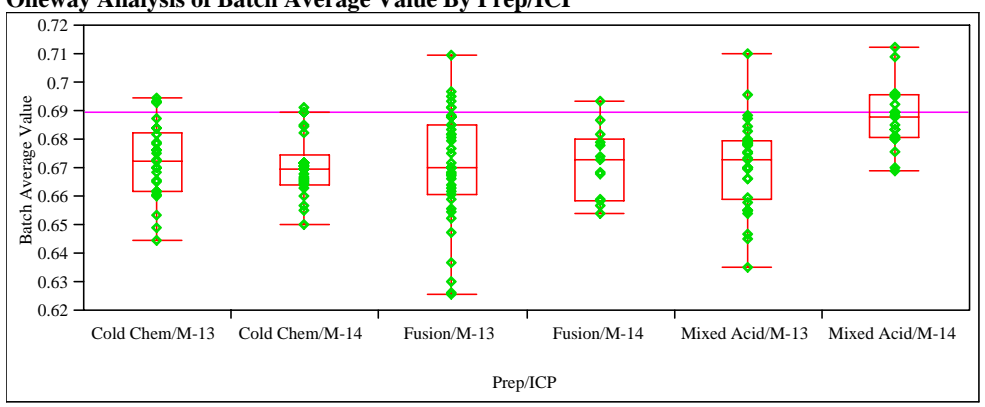

Oneway Anova

Summary of Fit

$\begin{array}{lr}\text { Rsquare } & 0.13631 \\ \text { Adj Rsquare } & 0.10752 \\ \text { Root Mean Square Error } & 0.014925 \\ \text { Mean of Response } & 0.673699 \\ \text { Observations (or Sum Wgts) } & 156\end{array}$

Observations (or Sum w

Analysis of Variance

Source DF Sum of Squares Mean Square F Ratio Prob $>F$

$\begin{array}{lllllll}\text { Prep/ICP } & 5 & 0.00527354 & 0.001055 & 4.7347 & 0.0005\end{array}$

$\begin{array}{llll}\text { Error } & 150 & 0.03341430 & 0.000223\end{array}$

C. Total $155 \quad 0.03868784$

Means for Oneway Anova

Level Number Mean Std Error Lower 95\% Upper 95\%

$\begin{array}{llllll}\text { Cold Chem/M-13 } & 26 & 0.672423 & 0.00293 & 0.66664 & 0.6782\end{array}$

$\begin{array}{llllll}\text { Cold Chem/M-14 } & 26 & 0.670615 & 0.00293 & 0.66483 & 0.67640\end{array}$

$\begin{array}{llllll}\text { Fusion/M-13 } & 39 & 0.670949 & 0.00239 & 0.66623 & 0.67567\end{array}$

$\begin{array}{llllll}\text { Fusion/M-14 } & 13 & 0.671654 & 0.00414 & 0.66347 & 0.67983\end{array}$

$\begin{array}{llllll}\text { Mixed Acid/M-13 } & 30 & 0.671467 & 0.00272 & 0.66608 & 0.67685\end{array}$

$\begin{array}{llllll}\text { Mixed Acid/M-14 } & 22 & 0.687977 & 0.00318 & 0.68169 & 0.69426\end{array}$

Std Error uses a pooled estimate of error variance

Means and Std Deviations

Level Number Mean Std Dev Std Err Mean Lower 95\% Upper 95\%

$\begin{array}{lllllll}\text { Cold Chem/M-13 } & 26 & 0.672423 & 0.013244 & 0.00260 & 0.66707 & 0.67777\end{array}$

$\begin{array}{lllllll}\text { Cold Chem/M-14 } & 26 & 0.670615 & 0.010788 & 0.00212 & 0.66626 & 0.67497\end{array}$

$\begin{array}{lllllll}\text { Fusion/M-13 } & 39 & 0.670949 & 0.019687 & 0.00315 & 0.66457 & 0.67733\end{array}$

$\begin{array}{lllllll}\text { Fusion/M-14 } & 13 & 0.671654 & 0.012262 & 0.00340 & 0.66424 & 0.67906\end{array}$

Mixed Acid/M-13 $30 \quad 0.671467 \quad 0.015753$

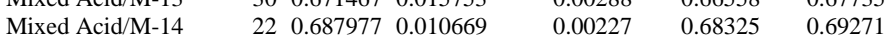

Means Comparisons

Comparisons for all pairs using Tukey-Kramer HSD

Level

Mixed Acid/M-14 A 0.68797727

Cold Chem/M-13 B 0.67242308

Fusion/M-14

B 0.67165385

Mixed Acid/M-13 $\quad$ B 0.6714666

Fusion/M-13

B 0.6709487

Cold Chem/M-14 B 0.67061538

Levels not connected by same letter are significantly different
Sample Type $=$ ARG-1, Analyte $=U$

Oneway Analysis of Batch Average Value By Prep/ICP

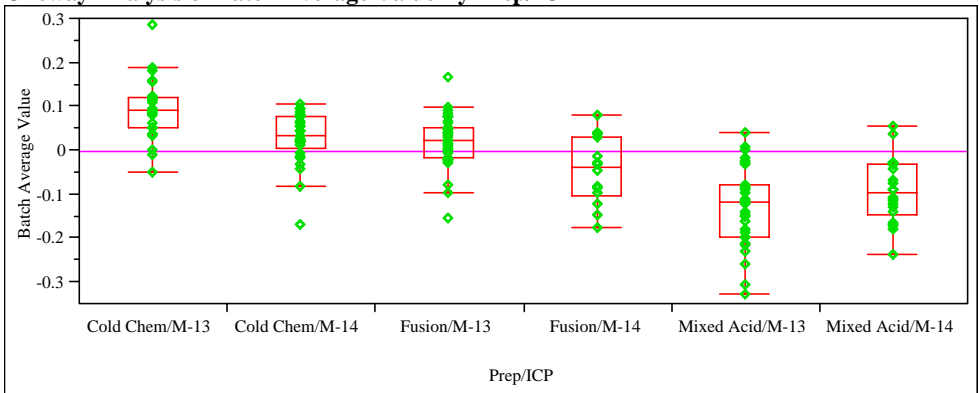

Oneway Anova

Summary of Fit

Rsquare

0.553964

Adj Rsquare

0.539668

Root Mean Square Error $\quad 0.070493$

Mean of Response $\quad-0.0145$

Observations (or Sum

Source DF Sum of Squares Mean Square F Ratio Prob > F

$\begin{array}{lllllll}\text { Prep/ICP } & 5 & 0.9627928 & 0.192559 & 38.7496 & <.000\end{array}$

$\begin{array}{llll}\text { Error } & 156 & 0.7752124 & 0.004969\end{array}$

C. Total $161 \quad 1.7380052$

Means for Oneway Anova

Level Number Mean Std Error Lower 95\% Upper 95\%

$\begin{array}{llllll}\text { Cold Chem/M-13 } & 27 & 0.09398 & 0.01357 & 0.0672 & 0.1208\end{array}$

$\begin{array}{llllll}\text { Cold Chem/M-14 } & 29 & 0.02991 & 0.01309 & 0.0041 & 0.0558\end{array}$

$\begin{array}{llllll}\text { Fusion/M-13 } & 39 & 0.02123 & 0.01129 & -0.0011 & 0.0435\end{array}$

$\begin{array}{llllll}\text { Fusion/M-14 } & 14 & -0.04486 & 0.01884 & -0.0821 & -0.0076\end{array}$

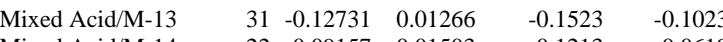

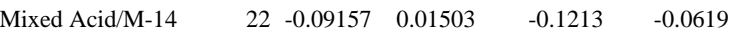

Std Error uses a pooled estimate of error variance

Means and Std Deviations

Level Number Mean Std Dev Std Err Mean Lower 95\% Upper 95\%

$\begin{array}{lllllll}\text { Cold Chem/M-13 } & 27 & 0.09398 & 0.068027 & 0.01309 & 0.0671 & 0.1209 \\ \text { Cold Chem/M-14 } & 29 & 0.02991 & 0.059607 & 0.01107 & 0.0072 & 0.0526\end{array}$

$\begin{array}{lllllll}\text { Cold Chem/M-14 } & 29 & 0.02991 & 0.059607 & 0.01107 & 0.0072 & 0.0526 \\ \text { Fus } & 39 & 0.02123 & 0.057350 & 0.00918 & 0.0026 & 0.0398\end{array}$

$\begin{array}{lrrrrrr}\text { Fusion/M-13 } & 39 & 0.02123 & 0.057350 & 0.00918 & 0.0026 & 0.0398 \\ \text { Fusion/M-14 } & 14 & -0.04486 & 0.075976 & 0.02031 & -0.0887 & -0.001\end{array}$

$\begin{array}{llllll}\text { Mixed Acid/M-13 } & 14 & -0.04486 & 0.075976 & 0.02031 & -0.0887 \\ & 31 & -0.12731 & 0.090744 & 0.01630 & -0.1606\end{array}$

$\begin{array}{lllllll}\text { Mixed Acid/M-14 } & 22 & -0.09157 & 0.071830 & 0.01531 & -0.1234 & -0.0597\end{array}$

Means Comparisons

Comparisons for all pairs using Tukey-Kramer HSD

Level

$\begin{array}{lr}\text { Mean } \\ \text { Cold Chem/M-13 A } & 0.0939815\end{array}$

Cold Chem/M-14 B $\quad 0.0299138$

Fusion/M-13 B $\quad 0.0212308$

Fusion/M-14 B C -0.0448571

$\begin{array}{lr}\text { Mixed Acid/M-14 } & \text { C } \text { D }-0.0915682 \\ \text { Mixed Acid/M-13 } & \text { D }-0.1273065\end{array}$

Levels not connected by same letter are significantly different 
Sample Type $=$ ARG-1, Analyte $=\mathrm{U} / \mathrm{Ca}$

Oneway Analysis of Batch Average Value By Prep/ICP

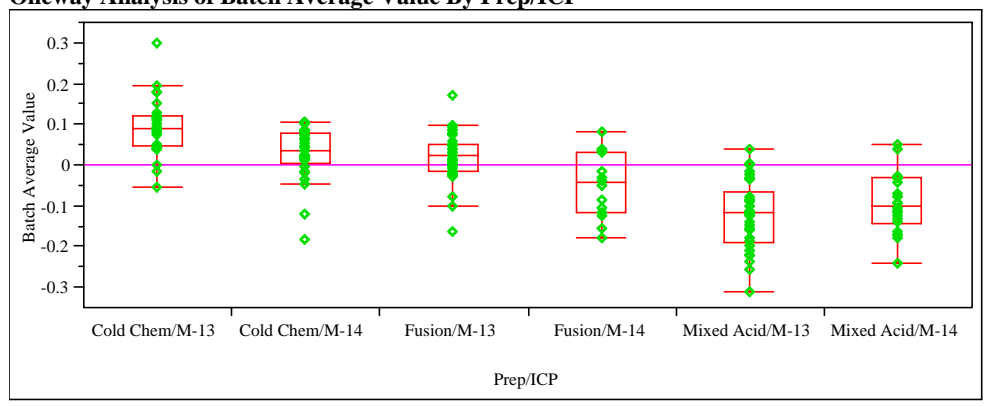

\section{Oneway Anova
Summary of Fit}

Rsquare

0.544187

0.529483

$\begin{array}{ll}\text { Root Mean Square Error } & 0.071102 \\ \text { Mean of Response } & -0.01273\end{array}$

Observations (or Sum Wgts) $\quad 161$

Analysis of Variance

Source DF Sum of Squares Mean Square F Ratio Prob $>$ F

$\begin{array}{llllll}\text { Prep/ICP } & 5 & 0.9355274 & 0.187105 & 37.0103 & <.0001\end{array}$

$\begin{array}{llll}\text { Error } & 155 & 0.7836018 & 0.005055\end{array}$

C. Total $160 \quad 1.7191292$

Means for Oneway Anova

Level Number Mean Std Error Lower 95\% Upper 95\%

$\begin{array}{llllll}\text { Cold Chem/M-13 } & 27 & 0.09600 & 0.01368 & 0.0690 & 0.1230\end{array}$

$\begin{array}{llllll}\text { Cold Chem/M-14 } & 29 & 0.03003 & 0.01320 & 0.0039 & 0.0561\end{array}$

$\begin{array}{llllll}\text { Fusion/M-13 } & 39 & 0.02211 & 0.01139 & -0.0004 & 0.0446\end{array}$

$\begin{array}{llllll}\text { Fusion/M-14 } & 14 & -0.04900 & 0.01900 & -0.0865 & -0.0115\end{array}$

$\begin{array}{llllll}\text { Mixed Acid/M-13 } & 30 & -0.12214 & 0.01298 & -0.1478 & -0.0965\end{array}$

Mixed Acid/M-14 $22-0.09206 \quad 0.01516 \quad-0.1220 \quad-0.0621$

Std Error uses a pooled estimate of error variance

Means and Std Deviations

Level Number Mean Std Dev Std Err Mean Lower 95\% Upper 95\%

$\begin{array}{lllllll}\text { Cold Chem/M-13 } & 27 & 0.09600 & 0.070349 & 0.01354 & 0.0682 & 0.1238\end{array}$

$\begin{array}{lllllll}\text { Cold Chem/M-14 } & 29 & 0.03003 & 0.065022 & 0.01207 & 0.0053 & 0.0548\end{array}$

$\begin{array}{lllllll}\text { Fusion/M-13 } & 39 & 0.02211 & 0.059013 & 0.00945 & 0.0030 & 0.0412\end{array}$

$\begin{array}{lllllll}\text { Fusion/M-14 } & 14 & -0.04900 & 0.079371 & 0.02121 & -0.0948 & -0.0032\end{array}$

Mixed Acid/M-13 $\quad 30-0.122140 .085650 \quad 0.01564 \quad-0.1541 \quad-0.0902$

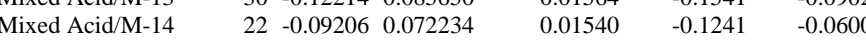

Means Comparison

Comparisons for all pairs using Tukey-Kramer HSD

Level Mean

Cold Chem/M-13 A $\quad 0.0959995$

Cold Chem/M-14 B $\quad 0.030031$

$\begin{array}{lll}\text { Fusion/M-13 } & \text { B } & 0.0221128\end{array}$

Fusion/M-14 C $\quad-0.0489994$

Mixed Acid/M-14 C D -0.0920569

Mixed Acid/M-13 D $\quad$ D -0.1221373

Levels not connected by same letter are significantly different
Sample Type=ARG-1, Analyte $=\mathbf{Z r}$

Oneway Analysis of Batch Average Value By Prep/ICP

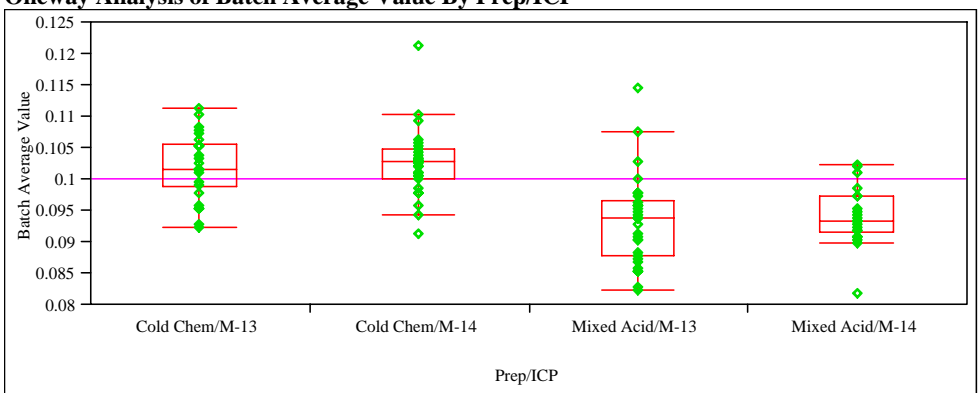

\section{Missing Rows 53}

Oneway Anova

Summary of Fit

Rsquare

0.372912

Adj Rsquare $\quad 0.354469$

Root Mean Square Error $\quad 0.005735$

Mean of Response 0.098189

Observations (or Sum

Analysis of Variance

Source DF Sum of Squares Mean Square F Ratio Prob $>$ F

$\begin{array}{lllllll}\text { Prep/ICP } & 3 & 0.00199535 & 0.000665 & 20.2189 & <.0001\end{array}$

$\begin{array}{llll}\text { Error } & 102 & 0.00335537 & 0.000033\end{array}$

C. Total $105 \quad 0.00535073$

Means for Oneway

Level Number Mean Std Error Lower 95\% Upper 95\%

$\begin{array}{llllll}\text { Cold Chem/M-13 } & 26 & 0.102173 & 0.00112 & 0.09994 & 0.10440\end{array}$

$\begin{array}{llllll}\text { Cold Chem/M-14 } & 28 & 0.102679 & 0.00108 & 0.10053 & 0.10483\end{array}$

$\begin{array}{llllll}\text { Mixed Acid/M-13 } & 30 & 0.093467 & 0.00105 & 0.09139 & 0.09554\end{array}$

$\begin{array}{llllll}\text { Mixed Acid/M-14 } & 22 & 0.094205 & 0.00122 & 0.09178 & 0.09663\end{array}$

Std Error uses a pooled estimate of error variance

Means and Std Deviations

Number Mean Std Dev Std Err Mean Lower 95\% Upper 95\%

$\begin{array}{lllllll}\text { Cold Chem/M-13 } & 26 & 0.102173 & 0.005134 & 0.00101 & 0.10010 & 0.10425\end{array}$

$\begin{array}{lllllll}\text { Cold Chem/M-14 } & 28 & 0.102679 & 0.005540 & 0.00105 & 0.10053 & 0.10483\end{array}$

$\begin{array}{llllll}\text { Mixed Acid/M-13 } 30 & 0.093467 & 0.007029 & 0.00128 & 0.09084 & 0.09609\end{array}$

Means Comparison

Comparisons for all pairs using Tukey-Kramer HSD

$\begin{array}{ll}\text { Level } & \text { Mean } \\ \text { Cold Chem/M-14 A } & 0.10267857\end{array}$

Cold Chem/M-14 A 0.10267857

Cold Chem/M-13 A 0.10217308

Mixed Acid/M-14 $\quad$ B 0.09420455

Mixed Acid/M-13 $\quad$ B 0.09346667

Levels not connected by same letter are significantly different 
WSRC-STI-2006-00068

Revision 0

Exhibit A4. ICP Comparisons Using Cold Chem Batch Averages of Process Samples by Analyte

Prep=Cold Chem, Sample Type $=$ SRAT, Analyte $=$ Al

Oneway Analysis of Batch Average Value By ICP

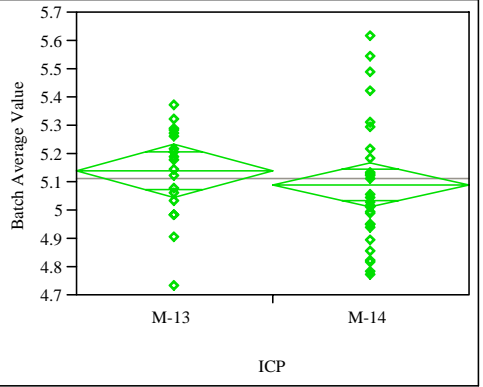

\section{Oneway Anova}

Summary of Fit

Adj Rsquare

Root Mean Square Error $\quad 0.203965$

Mean of Response 5.112443

Observations (or Sum Wgts)

47

t Test

M-13-M-14

Assuming equal variances

Difference $\quad 0.05014$ t Ratio 0.827108

Std Err Dif $\quad 0.06062$ DF 45

Upper CL Dif 0.17225 Prob $>|t| \quad 0.4125$

Lower CL Dif -0.07196 Prob $>t \quad 0.2063$

Confidence $\quad 0.95$ Prob $<\mathrm{t} \quad 0.7937$

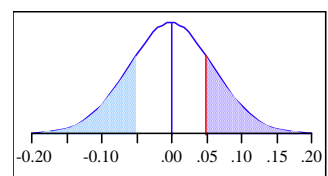

Analysis of Variance

Source DF Sum of Squares Mean Square F Ratio Prob $>$ F

$\begin{array}{llllll}\text { ICP } & 1 & 0.0284602 & 0.028460 & 0.6841 & 0.4125\end{array}$

$\begin{array}{llll}\text { Error } \quad 45 & 1.8720846 & 0.041602\end{array}$

C. Total $46 \quad 1.9005448$

Means for Oneway Anova

Level Number Mean Std Error Lower 95\% Upper 95\%

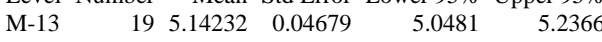

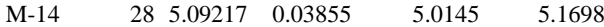

Std Error uses a pooled estimate of error variance

Means and Std Deviations

Level Number Mean Std Dev Std Err Mean Lower 95\% Upper 95\%

$\begin{array}{lllllll}\text { M-13 } & 19 & 5.14232 & 0.161204 & 0.03698 & 5.0646 & 5.2200\end{array}$

$\begin{array}{lllllll}\text { M-14 } & 28 & 5.09217 & 0.228061 & 0.04310 & 5.0037 & 5.1806\end{array}$

Tests that the Variances are Equal

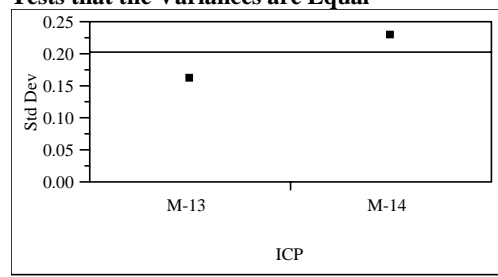

Level Count Std Dev MeanAbsDif to Mean MeanAbs Dif

$\begin{array}{lrrrr}\text { M-13 } & 19 & 0.1612044 & 0.1275642 & 0.1255351\end{array}$

$\begin{array}{lrrrr}M-14 & 28 & 0.2280612 & 0.1783044 & 0.1726607\end{array}$

Test F Ratio DFNum $\quad$ DFDen $\quad$ Prob $>$ F

$\begin{array}{lllll}\text { O'Brien[.5] } & 2.0079 & 1 & 45 & 0.1634 \\ & 1.3361 & 1 & 45 & 0.2538\end{array}$

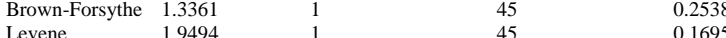

Levene

Bartlett $\quad 2.3842$

F Test 2-sided 2.0015

18

0.1695

Welch Anova testing Means Equal, allowing Std Devs Not Equal

F Ratio DFNum DFDen Prob $>$ F

$\begin{array}{llll}0.7796 & 1 & 44.892 & 0.3820\end{array}$

t Test

0.8829
Prep $=$ Cold Chem, Sample Type $=$ SRAT, Analyte $=$ Al $/$ Ca

Oneway Analysis of Batch Average Value By ICP

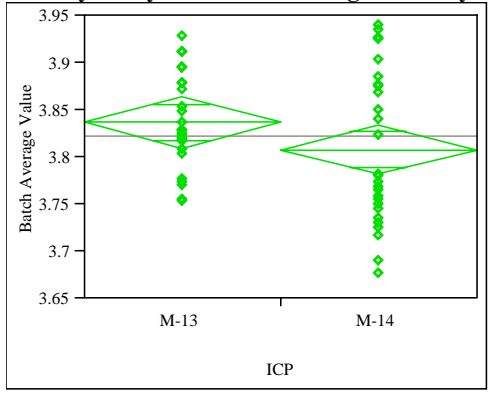

Oneway Anova

Summary of Fit

Rsquare

0.045126

Adj Rsquare

0.026029

Root Mean Square Error $\quad 0.067688$

$\begin{array}{lr}\text { Mean of Response } & 3.822113 \\ \text { Observations (or Sum Wgts) } & 52\end{array}$

52

t Test

M-13-M-14

Assuming equal variances

Difference $\quad 0.02888$ t Ratio $\quad 1.537186$

Std Err Dif $\quad 0.01879$ DF

Upper CL Dif 0.06661 Prob $>|t| \quad 0.1306$

Lower CL Dif -0.00886 Prob $>\mathrm{t} \quad 0.0653$

Confidence $\quad 0.95$ Prob $<\mathrm{t} \quad 0.9347$

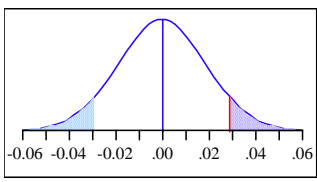

Analysis of Variance

Source DF Sum of Squares Mean Square F Ratio Prob $>$ F

$\begin{array}{llllll}\text { ICP } & 1 & 0.01082608 & 0.010826 & 2.3629 & 0.1306\end{array}$

$\begin{array}{llll}\text { Error } & 50 & 0.22908069 & 0.004582\end{array}$

C. Total $51 \quad 0.23990677$

Means for Oneway Anova

Level Number Mean Std Error Lower 95\% Upper 95\%

$\begin{array}{lllllr}\text { M-13 } & 25 & 3.83711 & 0.01354 & 3.8099 & 3.8643\end{array}$

$\begin{array}{llllll}M-14 & 27 & 3.80823 & 0.01303 & 3.7821 & 3.8344\end{array}$

Std Error uses a pooled estimate of error variance

Means and Std Deviations

Level Number Mean Std Dev Std Err Mean Lower 95\% Upper 95\%

$\begin{array}{lllllll}\text { M-13 } & 25 & 3.83711 & 0.050205 & 0.01004 & 3.8164 & 3.8578\end{array}$

$\begin{array}{lllllll}\text { M-14 } & 27 & 3.80823 & 0.080524 & 0.01550 & 3.7764 & 3.8401\end{array}$

Tests that the Variances are Equal

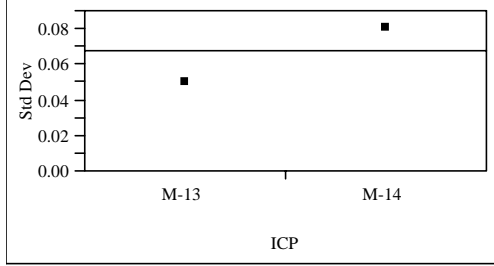

Level Count Std Dev MeanAbsDif to Mean MeanAbsDif to Median

$\begin{array}{lrrrr}\text { M-13 } & 25 & 0.0502048 & 0.0407387 & 0.0398488\end{array}$

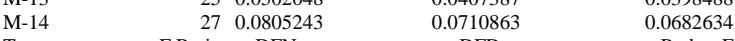

$\begin{array}{lllll}\text { Test } & \text { F Ratio } & \text { DFNum } & \text { DFDen } & \text { Prob }>\text { F }\end{array}$

$\begin{array}{lllll}\text { O'Brien[.5] } & 9.4852 & 1 & 50 & 0.0034 \\ & 6.1690 & 1 & 50 & 0.0164\end{array}$

$\begin{array}{lrrrr}\text { Brown-Forsythe } & 6.1690 & 1 & 50 & 0.0164 \\ & 11.6858 & 1 & 50 & 0.0013\end{array}$

$\begin{array}{lrl}11.6858 & 1 \\ \text { Levene } & 5.2076 & 1\end{array}$

$\begin{array}{lllll}\text { F Test 2-sided } & 2.5725 & 26 & 24 & 0.0228\end{array}$

Welch Anova testing Means Equal, allowing Std Devs Not Equal

F Ratio DFNum DFDen Prob $>$ F

$\begin{array}{llll}2.4460 & 1 & 44.01 & 0.1250\end{array}$

t Test

1.5640 
WSRC-STI-2006-00068

Revision 0

Exhibit A4. ICP Comparisons Using Cold Chem Batch Averages of Process Samples by Analyte

Prep $=$ Cold Chem, Sample Type $=$ SRAT, Analyte $=\mathrm{Al} / \mathrm{Mg}$ Oneway Analysis of Batch Average Value By ICP

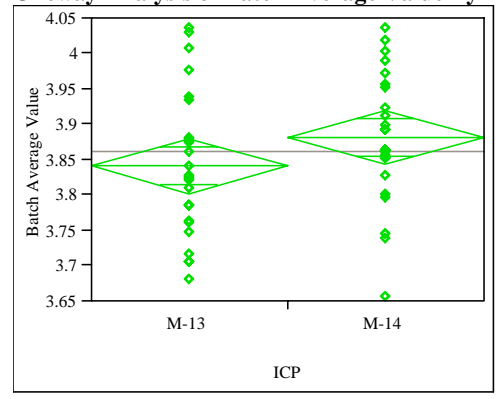

Oneway Anova

Summary of Fit

Rsquare

0.042669

Adj Rsquare

0.023131

Root Mean Square Error $\quad 0.096119$

Mean of Response 3.862152

Observations (or Sum Wgts) 51

t Test

M-13-M-14

Assuming equal variances

Difference $\quad-0.03979$ t Ratio $\quad-1.47782$

Std Err Dif $\quad 0.02692$ DF 49

Upper CL Dif 0.01432 Prob $>|\mathrm{t}| \quad 0.1459$

Lower CL Dif -0.09389 Prob $>\mathrm{t} \quad 0.9271$

$\begin{array}{lll}\text { Confidence } & 0.95 \text { Prob }<\mathrm{t} & 0.0729\end{array}$

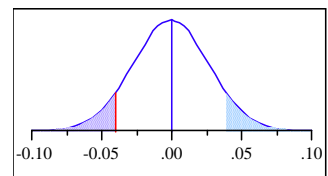

Analysis of Variance

Source DF Sum of Squares Mean Square F Ratio Prob $>$ F

$\begin{array}{llllll}\text { ICP } & 1 & 0.02017722 & 0.020177 & 2.1840 & 0.1459\end{array}$

$\begin{array}{llll}\text { Error } \quad 49 & 0.45270307 & 0.009239\end{array}$

C. Total $50 \quad 0.47288029$

Means for Oneway Anova

Level Number Mean Std Error Lower 95\% Upper 95\%

$\begin{array}{lllllr}\text { M-13 } & 25 & 3.84187 & 0.01922 & 3.8032 & 3.8805\end{array}$

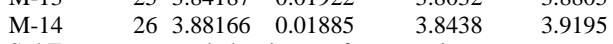

Std Error uses a pooled estimate of error variance

Means and Std Deviations

Level Number Mean Std Dev Std Err Mean Lower 95\% Upper 95\%

$\begin{array}{lllllll}\text { M-13 } & 25 & 3.84187 & 0.102146 & 0.02043 & 3.7997 & 3.8840\end{array}$

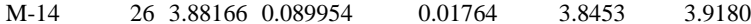

Tests that the Variances are Equal

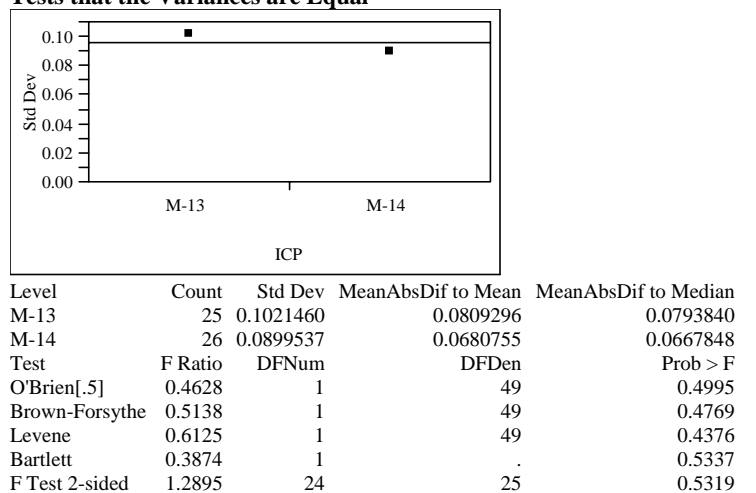

Welch Anova testing Means Equal, allowing Std Devs Not Equal

F Ratio DFNum DFDen Prob $>$ F

$\begin{array}{lrrr}2.1729 & 1 & 47.684 & 0.1470\end{array}$

$\mathrm{t}$ Test

1.4741
Prep $=$ Cold Chem, Sample Type $=$ SRAT, Analyte $=A \mathrm{I} / \mathrm{Mn}$

Oneway Analysis of Batch Average Value By ICP

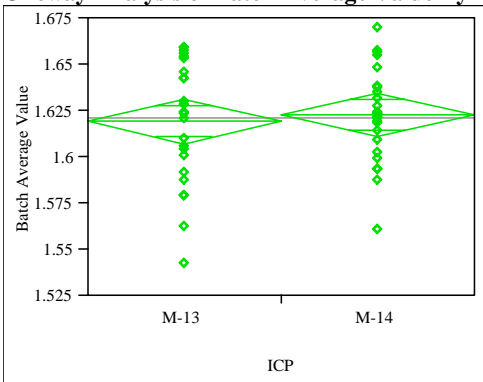

Oneway Anova

Summary of Fit

Rsquare

0.003919

Adj Rsquare

$-0.01727$

Root Mean Square Error $\quad 0.029323$

Mean of Response

Observations (or Sum Wgts)

1.621328

t Test

M-13-M-14

Assuming equal variances

Difference $\quad-0.00360$ t Ratio $\quad-0.43002$

Std Err Dif $\quad 0.00838$ DF

Upper CL Dif 0.01325 Prob $>|t| \quad 0.6691$

Lower CL Dif -0.02046 Prob $>t$

Confidence $\quad 0.95$ Prob $<\mathrm{t} \quad 0.3346$

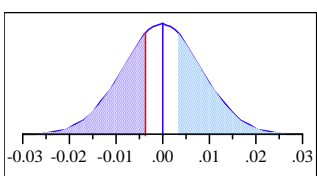

Analysis of Variance

Source DF Sum of Squares Mean Square F Ratio Prob $>$ F

$\begin{array}{llllll}\text { ICP } & 1 & 0.00015900 & 0.000159 & 0.1849 & 0.6691\end{array}$

Error $\quad 47 \quad 0.04041296 \quad 0.000860$

C. Total $48 \quad 0.04057196$

Means for Oneway Anova

Level Number Mean Std Error Lower 95\% Upper 95\%

$\begin{array}{llllll}\text { M-13 } & 24 & 1.61949 & 0.00599 & 1.6074 & 1.6315\end{array}$

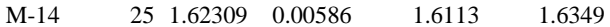

Std Error uses a pooled estimate of error variance

Means and Std Deviations

Level Number Mean Std Dev Std Err Mean Lower 95\% Upper 95\%

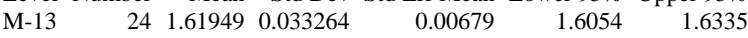

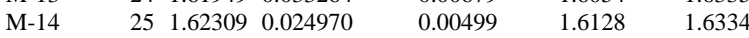

Tests that the Variances are Equal

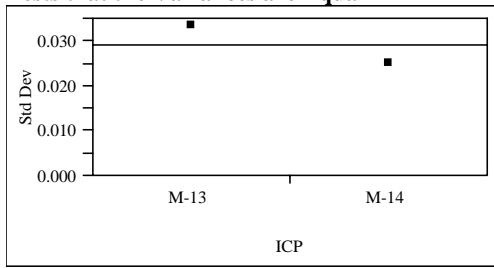

Level Count Std Dev MeanAbsDif to Mean MeanAbsDif to Median

$\begin{array}{lllll}\text { M-13 } & 24 & 0.0332639 & 0.0274485 & 0.0269067\end{array}$

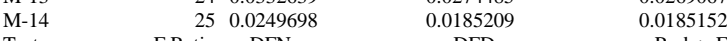

$\begin{array}{llll}\text { Test } & \text { F Ratio DFNum } & \text { DFDen } & \text { Prob }>\text { F }\end{array}$

$\begin{array}{lllll}\text { O'Brien[.5] } & 2.0808 & 1 & 47 & 0.1558 \\ & & 1 & 47 & 0.1070\end{array}$

$\begin{array}{lllll}\text { Brown-Forsythe } & 2.7008 & 1 & 47 & 0.1070\end{array}$

Levene $\quad 3.3347 \quad 11$

$\begin{array}{lrrrr}\text { Bartlett } & 1.8740 & 1 & \dot{3} & 0.1710 \\ \text { F Test 2-sided } & 1.7747 & 23 & 24 & 0.1701\end{array}$

Welch Anova testing Means Equal, allowing Std Devs Not Equal

F Ratio DFNum DFDen Prob $>$ F

$\begin{array}{llll}0.1828 & 1 & 42.653 & 0.6711\end{array}$

t Test

0.4275 
WSRC-STI-2006-00068

Revision 0

Exhibit A4. ICP Comparisons Using Cold Chem Batch Averages of Process Samples by Analyte

(continued)

Prep $=$ Cold Chem, Sample Type $=$ SRAT, Analyte $=B$ Oneway Analysis of Batch Average Value By ICP

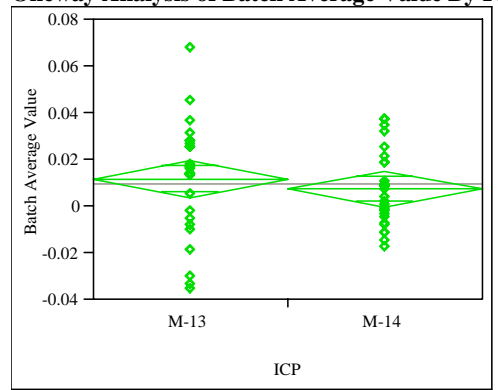

Oneway Anova

Summary of Fit

Rsquare

Adj Rsquare

0.011485

Root Mean Squ

Mean of Response

t Test

M-13-M-14

Assuming equal variances

Difference $\quad 0.00431$ t Ratio 0.777277

Std Err Dif 0.00555 DF

Upper CL Dif 0.01545 Prob $>|t| \quad 0.4405$

Lower CL Dif -0.00682 Prob $>t \quad 0.2203$

$\begin{array}{lll}\text { Confidence } & 0.95 \text { Prob }<\mathrm{t} \quad 0.7797\end{array}$

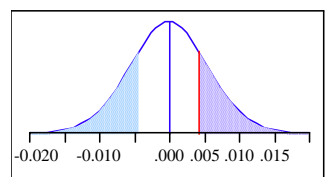

Analysis of Variance

Source DF Sum of Squares Mean Square F Ratio Prob $>$ F

$\begin{array}{lrrrrr}\text { ICP } & 1 & 0.00025086 & 0.000251 & 0.6042 & 0.4405\end{array}$

$\begin{array}{llll}\text { Error } & 52 & 0.02159125 & 0.000415\end{array}$

C. Total $53 \quad 0.02184210$

Means for Oneway Anova

Level Number Mean Std Error Lower 95\% Upper 95\%

$\begin{array}{llllll}\text { M-13 } & 26 & 0.011891 & 0.00400 & 0.0039 & 0.01991\end{array}$

$\begin{array}{llllll}\mathrm{M}-14 & 28 & 0.007577 & 0.00385 & -0.0001 & 0.01530\end{array}$

Std Error uses a pooled estimate of error variance

Means and Std Deviations

Level Number Mean Std Dev Std Err Mean Lower 95\% Upper 95\%

$\begin{array}{lllllrr}\mathrm{M}-13 & 26 & 0.011891 & 0.024356 & 0.00478 & 0.00205 & 0.02173\end{array}$

$\begin{array}{lllllll}\mathrm{M}-14 & 28 & 0.007577 & 0.015825 & 0.00299 & 0.00144 & 0.01371\end{array}$

Tests that the Variances are Equal

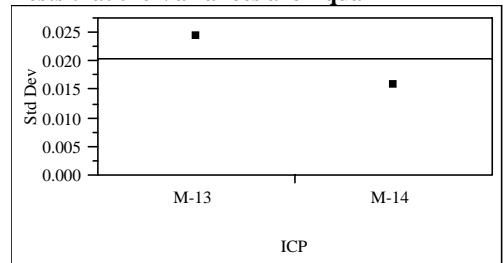

Level Count Std Dev MeanAbsDif to Mean MeanAbsDif to Median

$\begin{array}{lllll}\text { M-13 } & 26 & 0.0243555 & 0.0185399 & \text { Mear }\end{array}$

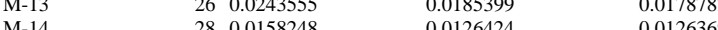

$\begin{array}{lrrrr}\text { M-14 } & \text { F Ratio } & \text { DFNum } & 0.0126424 & 0.0126369 \\ \text { Test } & 3.8708 & \text { DFDen } & \text { Prob }>\text { F }\end{array}$

$\begin{array}{lrrrr}\text { O'Brien[.5] } & 3.8708 & 1 & 52 & 0.0545\end{array}$

$\begin{array}{lllll}\text { Brown-Forsythe } & 2.0962 & 1 & 52 & 0.1537 \\ \text { Levene } & 2.9811 & 1 & 52 & 0.0902\end{array}$

$\begin{array}{lllll}\text { Levene } & 2.9811 & 1 & 52 & 0.0902 \\ \text { Bartlett } & 4.6449 & 1 & & 0.0311\end{array}$

$\begin{array}{lllll}\text { F Test 2-sided } & 2.3687 & 25 & 27 & 0.0307\end{array}$

Welch Anova testing Means Equal, allowing Std Devs Not Equal

F Ratio DFNum DFDen Prob $>$ F

$\begin{array}{llll}0.5859 & 1 & 42.408 & 0.4482\end{array}$

$\mathrm{t}$ Test

0.7654
Prep=Cold Chem, Sample Type $=$ SRAT, Analyte $=B / L i$ Oneway Analysis of Batch Average Value By ICP

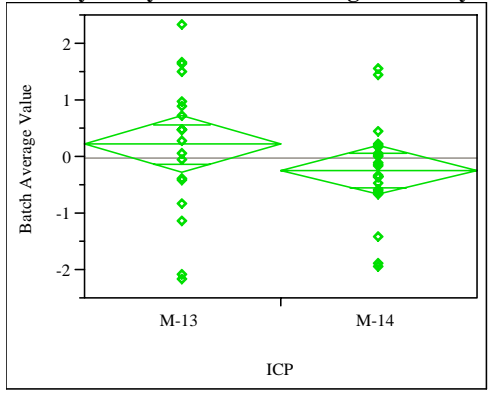

Oneway Anova

Summary of Fit

Rsquare

0.049402

Adj Rsquare

0.025028

Root Mean Square Error $\quad 1.031233$

Mean of Response $\quad-0.02668$

Observations (or Sum Wgts) 41

t Test

M-13-M-14

Assuming equal variances

Difference $\quad 0.4620$ t Ratio 1.423662

Std Err Dif $\quad 0.3245$ DF 39

Upper CL Dif 1.1184 Prob $>|t| \quad 0.1625$

Lower CL Dif -0.1944 Prob $>\mathrm{t} \quad 0.0812$

$\begin{array}{lll}\text { Confidence } & 0.95 \text { Prob }<\mathrm{t} \quad 0.9188\end{array}$

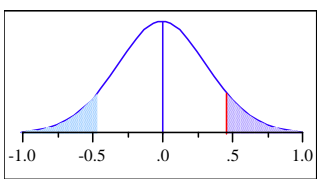

Analysis of Variance

Source DF Sum of Squares Mean Square F Ratio Prob > F

$\begin{array}{llllll}\text { ICP } & 1 & 2.155397 & 2.15540 & 2.0268 & 0.1625\end{array}$

$\begin{array}{llll}\text { Error } & 39 & 41.474222 & 1.06344\end{array}$

C. Total $40 \quad 43.629618$

Means for Oneway Anova

Level Number Mean Std Error Lower 95\% Upper 95\%

$\begin{array}{llllll}\text { M-13 } & 18 & 0.23250 & 0.24306 & -0.2591 & 0.72414\end{array}$

$\begin{array}{llllll}\mathrm{M}-14 & 23 & -0.22952 & 0.21503 & -0.6644 & 0.20542\end{array}$

Std Error uses a pooled estimate of error variance

Means and Std Deviations

Level Number Mean Std Dev Std Err Mean Lower 95\% Upper 95\%

$\begin{array}{lllllll}\text { M-13 } & 18 & 0.23250 & 1.24484 & 0.29341 & -0.3865 & 0.85154\end{array}$

$\begin{array}{lllllll}\text { M-14 } & 23 & -0.22952 & 0.82930 & 0.17292 & -0.5881 & 0.12910\end{array}$

Tests that the Variances are Equal

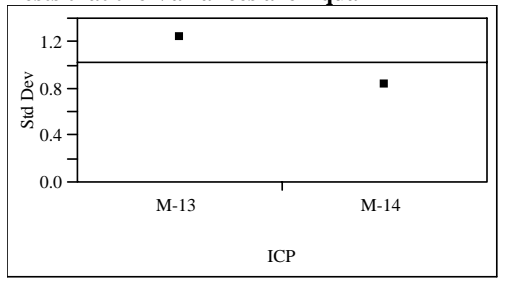

Level Count Std Dev MeanAbsDif to Mean MeanAbsDif to Median

$\begin{array}{lrrrr}\text { M-13 } & 18 & 1.244845 & 0.9718205 & 0.9664776\end{array}$

$\begin{array}{lllll}\mathrm{M}-14 & 23 & 0.829303 & 0.9718205 & 0.9664776 \\ \mathrm{~T} & \mathrm{~F} & & 0.5761647 & \end{array}$

$\begin{array}{lllr}\text { Test } & \text { F Ratio DFNum } & \text { DFDen } & \text { Prob }>\text { F }\end{array}$

$\begin{array}{lllll}\text { O'Brien[.5] } & 2.9260 & 1 & 39 & 0.0951\end{array}$

$\begin{array}{lllll}\text { Brown-Forsythe } & 3.4393 & 1 & 39 & 0.0712 \\ \text { Levene } & 3.6610 & 1 & 39 & 0.0631\end{array}$

Bartlett $\quad 3.1066 \quad 1$

F Test 2-sided $2.2532 \quad 17 \quad 22$

Welch Anova testing Means Equal, allowing Std Devs Not Equal

F Ratio DFNum DFDen Prob $>$ F

$\begin{array}{llll}1.8403 & 1 & 28.229 & 0.1857\end{array}$

t Test

1.3566 
WSRC-STI-2006-00068

Revision 0

Exhibit A4. ICP Comparisons Using Cold Chem Batch Averages of Process Samples by Analyte

(continued)

Prep $=$ Cold Chem, Sample Type $=$ SRAT, Analyte $=$ Ca Oneway Analysis of Batch Average Value By ICP

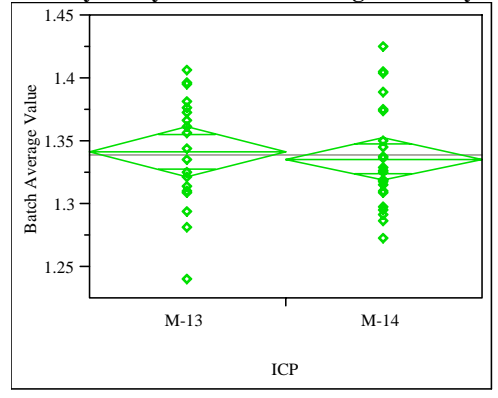

Oneway Anova

Summary of Fit

Rsquare

Adj Rsquare

0.00489

Root Mean Square

Mean of Response

$-0.01938$

0.042209

1.338779

Observations (or Sum Wgts) 43

t Test

M-13-M-14

Assuming equal variances

Difference $\quad 0.00582$ t Ratio 0.448865

Std Err Dif 0.01296 DF 41

Upper CL Dif 0.03199 Prob $>|t| \quad 0.6559$

Lower CL Dif -0.02036 Prob $>t \quad 0.3279$

$\begin{array}{lll}\text { Confidence } & 0.95 \text { Prob }<\mathrm{t} & 0.6721\end{array}$

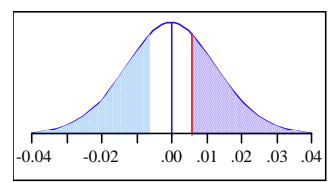

Analysis of Variance

Source DF Sum of Squares Mean Square F Ratio Prob $>$ F

$\begin{array}{llllll}\text { ICP } & 1 & 0.00035896 & 0.000359 & 0.2015 & 0.6559\end{array}$

$\begin{array}{llll}\text { Error } \quad 41 & 0.07304536 & 0.001782\end{array}$

C. Total $42 \quad 0.07340432$

Means for Oneway Anova

Level Number Mean Std Error Lower 95\% Upper 95\%

$\begin{array}{llllll}\text { M-13 } & 19 & 1.34203 & 0.00968 & 1.3225 & 1.3616\end{array}$

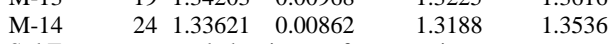

Std Error uses a pooled estimate of error variance

Means and Std Deviations

Level Number Mean Std Dev Std Err Mean Lower 95\% Upper 95\%

$\begin{array}{lllllll}\text { M-13 } & 19 & 1.34203 & 0.043993 & 0.01009 & 1.3208 & 1.3632\end{array}$

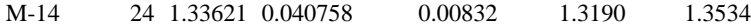

Tests that the Variances are Equal

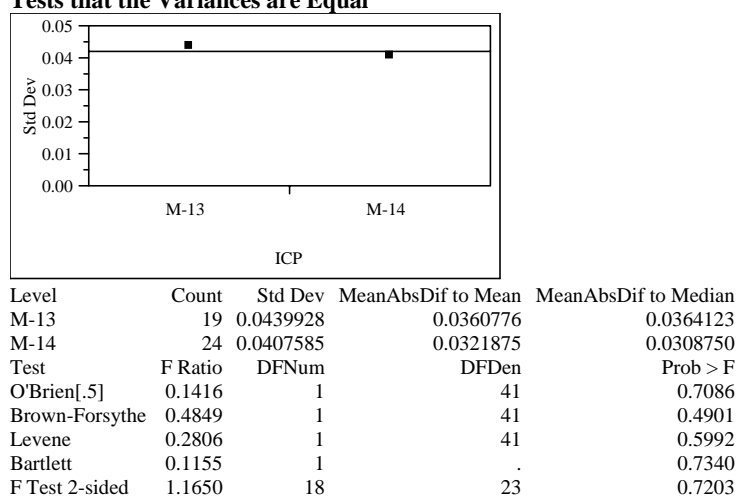

Welch Anova testing Means Equal, allowing Std Devs Not Equal

F Ratio DFNum DFDen Prob $>$ F

$\begin{array}{lllr}0.1979 & 1 & 37.297 & 0.6590\end{array}$

t Test

0.4448
Prep $=$ Cold Chem, Sample Type $=$ SRAT, Analyte $=\mathrm{Cr}$ Oneway Analysis of Batch Average Value By ICP

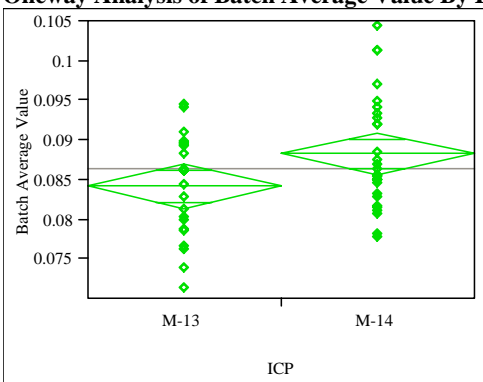

Oneway Anova

Summary of Fit

Rsquare

0.084455

Adj Rsquare

0.065771

Root Mean Square Error $\quad 0.006791$

Mean of Response

0.086477

Observations (or Sum Wgts)

t Test

M-13-M-14

Assuming equal variances

Difference $\quad-0.00406$ t Ratio $\quad-2.12604$

Std Err Dif $\quad 0.00191$ DF

Upper CL Dif -0.00022 Prob $>|t| \quad 0.0386$

Lower CL Dif -0.00790 Prob $>t \quad 0.9807$

Confidence $\quad 0.95$ Prob $<\mathrm{t} \quad 0.0193$

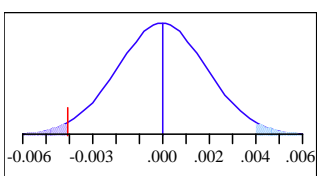

Analysis of Variance

Source DF Sum of Squares Mean Square F Ratio Prob $>$ F

$\begin{array}{lrrrrr}\text { ICP } & 1 & 0.00020847 & 0.000208 & 4.5201 & 0.0386\end{array}$

Error $49 \quad 0.00225992 \quad 0.000046$

C. Total $50 \quad 0.00246839$

Means for Oneway Anova

Level Number Mean Std Error Lower 95\% Upper 95\%

$\begin{array}{llllll}\text { M-13 } & 23 & 0.084246 & 0.00142 & 0.08140 & 0.08709\end{array}$

$\begin{array}{llllll}\text { M-14 } & 28 & 0.088310 & 0.00128 & 0.08573 & 0.09089\end{array}$

Std Error uses a pooled estimate of error variance

Means and Std Deviations

Level Number Mean Std Dev Std Err Mean Lower 95\% Upper 95\%

$\begin{array}{lllllll}\mathrm{M}-13 & 23 & 0.084246 & 0.006392 & 0.00133 & 0.08148 & 0.08701\end{array}$

$\begin{array}{lllllll}\mathrm{M}-13 & 28 & 0.088310 & 0.007100 & 0.00134 & 0.08556 & 0.09106\end{array}$

Tests that the Variances are Equal

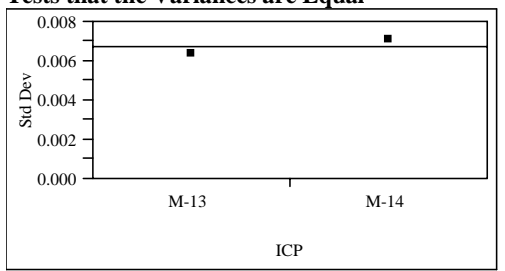

Level Count Std Dev MeanAbsDif to Mean MeanAbsDif to Median

$\begin{array}{lllll}\text { M-13 } 23 & 0.0063922 & 0.0053737 & 0.0052609\end{array}$

$\begin{array}{lrrrr}\text { M-14 } & 28 & 0.0070998 & 0.0057925 & 0.0055119\end{array}$

$\begin{array}{llll}\text { Test } & \text { F Ratio DFNum } & \text { DFDen }>\text { F }\end{array}$

$\begin{array}{lrrrr}\text { O'Brien[.5] } & 0.3435 & 1 & \text { DFDen } & \text { Prob }>\text { F } \\ & & 1 & 49 & 0.5605\end{array}$

$\begin{array}{lllll}\text { Brown-Forsythe } & 0.0385 & 1 & 49 & 0.8452\end{array}$

$\begin{array}{lllll}\text { Levene } & 0.1654 & 1 & 49 & 0.6860\end{array}$

$\begin{array}{lrrrr}\text { Bartlett } & 0.2594 & 1 & 0 . & 0.6105 \\ \text { F Test 2-sided } & 1.2336 & 27 & 22 & 0.6203\end{array}$

Welch Anova testing Means Equal, allowing Std Devs Not Equa

F Ratio DFNum DFDen Prob $>$ F

$\begin{array}{lrrr}4.6156 & 1 & 48.553 & 0.0367\end{array}$

t Test

2.1484 
WSRC-STI-2006-00068

Revision 0

Exhibit A4. ICP Comparisons Using Cold Chem Batch Averages of Process Samples by Analyte

(continued)

Prep $=$ Cold Chem, Sample Type $=$ SRAT, Analyte $=\mathrm{Cu}$

Oneway Analysis of Batch Average Value By ICP

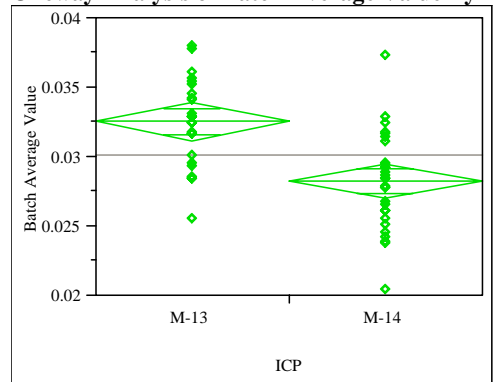

Oneway Anova

Summary of Fit

Rsquare

Adj Rsquare

0.304455

0.290817

Root Mean Square Error $\quad 0.00331$

Mean of Response

Observations (or Sum Wgts) 53

t Test

M-13-M-14

Assuming equal variances

Difference $\quad 0.004315$ t Ratio 4.724811

Std Err Dif $\quad 0.000913$ DF

51
$<.0001$

Lower CL Dif 0.002482 Prob $>t<.0001$

Confidence $\quad 0.95$ Prob $<\mathrm{t} \quad 1.0000$

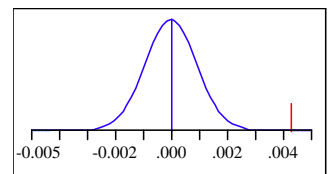

Analysis of Variance

Source DF Sum of Squares Mean Square F Ratio Prob $>$ F

$\begin{array}{llllll}\text { ICP } & 1 & 0.00024455 & 0.000245 & 22.3238 & <.0001\end{array}$

Error $51 \quad 0.00055869$

C. Total $52 \quad 0.00080324$

Means for Oneway Anova

Level Number Mean Std Error Lower 95\% Upper 95\%

$\begin{array}{llllll}\text { M-13 } & 24 & 0.032563 & 0.00068 & 0.03121 & 0.03392\end{array}$

$\begin{array}{llllll}\text { M-14 } & 29 & 0.028247 & 0.00061 & 0.02701 & 0.02948\end{array}$

Std Error uses a pooled estimate of error variance

Means and Std Deviations

Level Number Mean Std Dev Std Err Mean Lower 95\% Upper 95\%

$\begin{array}{lrrrrrr}\mathrm{M}-13 & 24 & 0.032563 & 0.003160 & 0.00064 & 0.03123 & 0.03390\end{array}$

$\begin{array}{lllllll}\mathrm{M}-13 & 24 & 0.032563 & 0.003160 & 0.00064 & 0.03123 & 0.03390 \\ \mathrm{M}-14 & 29 & 0.028247 & 0.003428 & 0.00064 & 0.02694 & 0.02955\end{array}$

Tests that the Variances are Equal

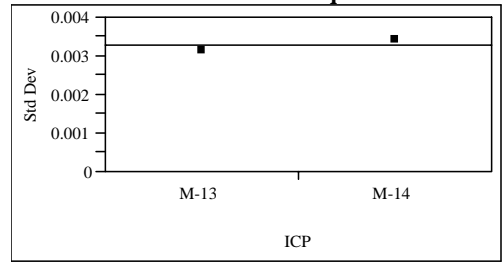

Level Count Std Dev MeanAbsDif to Mean MeanAbsDif to Median

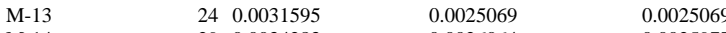

$\begin{array}{lrrrr}\text { M-14 } & 29 & 0.0034283 & 0.0026064 & 0.0025977\end{array}$

$\begin{array}{llll}\text { Test } & \text { F Ratio DFNum } & \text { DFDen } & \text { Prob }>\text { F }\end{array}$

$\begin{array}{lllll}\text { O'Brien[.5] } & 0.1508 & 1 & 51 & 0.6993\end{array}$

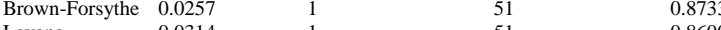

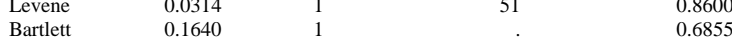

$\begin{array}{llll}\text { F Test 2-sided } & 1.1774 & 28 & 23\end{array}$

Welch Anova testing Means Equal, allowing Std Devs Not Equal

F Ratio DFNum DFDen Prob $>$ F

$22.6764 \quad 1 \quad 50.373<.0001$

t Test

4.7620
Prep $=$ Cold Chem, Sample Type $=$ SRAT, Analyte $=F e$ Oneway Analysis of Batch Average Value By ICP

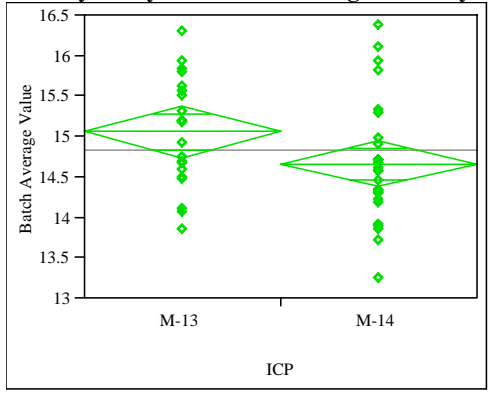

Oneway Anova

Summary of Fit

Rsquare

0.072283

Adj Rsquare

0.052115

Root Mean Square Error $\quad 0.718466$

Mean of Response

14.83997

Observations (or Sum Wgts) $\quad 48$

t Test

M-13-M-14

Assuming equal variances

Difference $\quad 0.39575$ t Ratio $\quad 1.893164$

Std Err Dif $\quad 0.20904$ DF 46

Upper CL Dif 0.81653 Prob $>|\mathrm{t}| \quad 0.0646$

Lower CL Dif -0.02503 Prob $>\mathrm{t} \quad 0.0323$

$\begin{array}{lll}\text { Confidence } & 0.95 \text { Prob }<\mathrm{t} \quad 0.9677\end{array}$

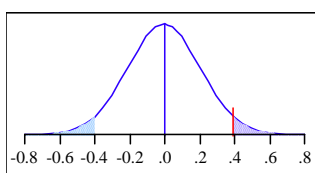

Analysis of Variance

Source DF Sum of Squares Mean Square F Ratio Prob > F

$\begin{array}{llllll}\text { ICP } & 1 & 1.850071 & 1.85007 & 3.5841 & 0.0646\end{array}$

$\begin{array}{llll}\text { Error } & 46 & 23.744885 & 0.51619\end{array}$

C. Total $47 \quad 25.594957$

Means for Oneway Anova

Level Number Mean Std Error Lower 95\% Upper 95\%

$\begin{array}{lllllr}\text { M-13 } & 21 & 15.0626 & 0.15678 & 14.747 & 15.378\end{array}$

$\begin{array}{llllll}\mathrm{M}-14 & 27 & 14.6668 & 0.13827 & 14.389 & 14.945\end{array}$

Std Error uses a pooled estimate of error variance

Means and Std Deviations

Level Number Mean Std Dev Std Err Mean Lower 95\% Upper 95\%

$\begin{array}{lllllll}\text { M-13 } & 21 & 15.0626 & 0.670804 & 0.14638 & 14.757 & 15.368\end{array}$

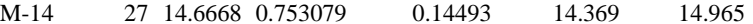

Tests that the Variances are Equal

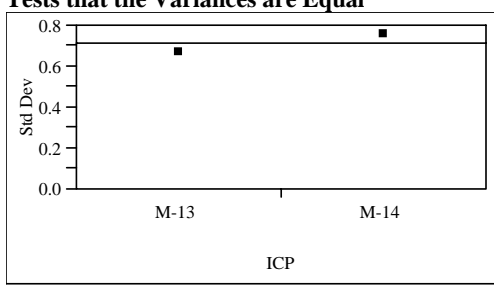

Level Count Std Dev MeanAbsDif to Mean MeanAbsDif to Median

$\begin{array}{lllll}\text { M-13 } & 21 & 0.6708043 & 0.5617581 & 0.5572063\end{array}$

$\begin{array}{lllll}\text { M-14 } & 27 & 0.7530788 & 0.5648198 & 0.5523951\end{array}$

$\begin{array}{lrrrr}\text { Test } & \text { F Ratio } & \text { DFNum } & \text { DFDen } & \text { Prob }>\text { F }\end{array}$

$\begin{array}{lllll}\text { O'Brien[.5] } & 0.3275 & 1 & 46 & 0.5699 \\ \text { Brown-Forsythe } & 0.0013 & 1 & 46 & 0.9711\end{array}$

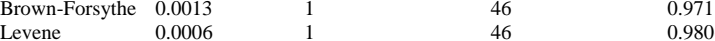

$\begin{array}{llll}\text { Bartlett } & 0.2924 & 1 & 0.98067\end{array}$

$\begin{array}{lllll}\text { F Test 2-sided } & 1.2603 & 26 & 20 & 0.6014\end{array}$

Welch Anova testing Means Equal, allowing Std Devs Not Equal

F Ratio DFNum DFDen Prob $>$ F

$\begin{array}{llll}3.6911 & 1 & 45.096 & 0.0610\end{array}$

t Test

1.9212 
WSRC-STI-2006-00068

Revision 0

Exhibit A4. ICP Comparisons Using Cold Chem Batch Averages of Process Samples by Analyte

(continued)

Prep $=$ Cold Chem, Sample Type $=$ SRAT, Analyte $=$ Fe $/ A$

Oneway Analysis of Batch Average Value By ICP

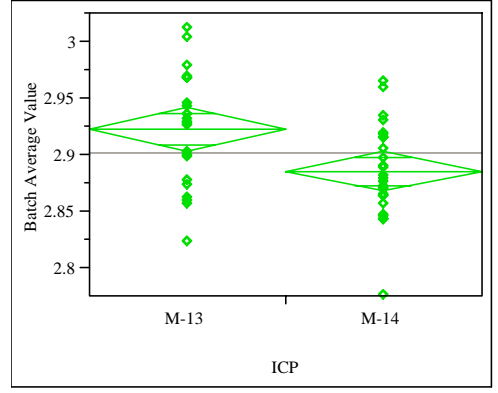

Oneway Anova

Summary of Fit

Rsquare

0.153284

Adj Rsquare

0.135269

Root Mean Square Error $\quad 0.045009$

Mean of Response

2.9025

Observations (or Sum Wgts)

t Test

M-13-M-14

Assuming equal variances

Difference 0.037708 t Ratio 2.916949

Std Err Dif $\quad 0.012927$ DF

47

Upper CL Dif 0.063714 Prob > |t 0.0054

Lower CL Dif 0.011702 Prob $>t \quad 0.0027$

$\begin{array}{lll}\text { Confidence } & 0.95 \text { Prob }<\mathrm{t} \quad 0.9973\end{array}$

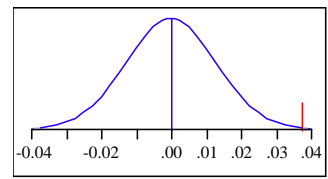

Analysis of Variance

Source DF Sum of Squares Mean Square F Ratio Prob $>$ F

$\begin{array}{llllll}\text { ICP } & 1 & 0.01723669 & 0.017237 & 8.5086 & 0.0054\end{array}$

$\begin{array}{llll}\text { Error } \quad 47 & 0.09521258 & 0.002026\end{array}$

C. Total $48 \quad 0.11244927$

Means for Oneway Anova

Level Number Mean Std Error Lower 95\% Upper 95\%

$\begin{array}{llllll}\text { M-13 } & 22 & 2.92328 & 0.00960 & 2.9040 & 2.9426\end{array}$

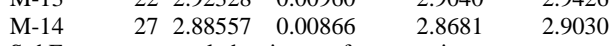

Std Error uses a pooled estimate of error variance

Means and Std Deviations

Level Number Mean Std Dev Std Err Mean Lower 95\% Upper 95\%

$\begin{array}{lllllll}\text { M-13 } & 22 & 2.92328 & 0.050257 & 0.01071 & 2.9010 & 2.9456\end{array}$

$\begin{array}{lllllll}M-14 & 27 & 2.88557 & 0.040274 & 0.00775 & 2.8696 & 2.9015\end{array}$

Tests that the Variances are Equal

\begin{tabular}{|c|c|c|c|c|}
\hline $0.05-$ & 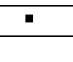 & & & \\
\hline & M-13 & ICP & M-14 & \\
\hline Level & Count & Std Dev & MeanAbsDif to Mea & n MeanAbsDif to Median \\
\hline $\mathrm{M}-13$ & 22 & 0.0502566 & 0.040645 & $2 \quad 0.0398514$ \\
\hline M-14 & 27 & 0.0402742 & 0.031069 & 0.0307220 \\
\hline Test & F Ratio & DFNum & DFDe & Prob $>$ F \\
\hline O'Brien[.5] & 1.2481 & 1 & & 0.2696 \\
\hline Brown-Forsythe & 1.2952 & 1 & & 0.2609 \\
\hline Levene & 1.5925 & 1 & & 0.2132 \\
\hline Bartlett & 1.1236 & 1 & & 0.2891 \\
\hline Test 2-sided & 1.5572 & 21 & & 0.2825 \\
\hline
\end{tabular}

Welch Anova testing Means Equal, allowing Std Devs Not Equal

F Ratio DFNum DFDen Prob $>$ F

$\begin{array}{lllr}8.1306 & 1 & 39.903 & 0.0069\end{array}$

t Test

2.8514
Prep $=$ Cold Chem, Sample Type $=$ SRAT, Analyte $=\mathrm{Fe} / \mathrm{Ca}$ Oneway Analysis of Batch Average Value By ICP

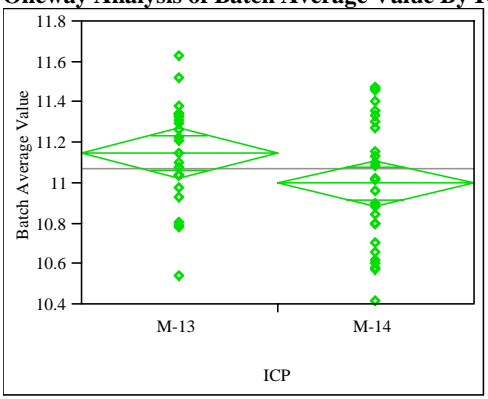

Oneway Anova

Summary of Fit

Rsquare

0.065618

Adj Rsquare

0.046152

Root Mean Square Error $\quad 0.293108$

Mean of Response

11.06972

Observations (or Sum Wgts) 50

t Test

M-13-M-14

Assuming equal variances

Difference $\quad 0.15270$ t Ratio 1.835994

Std Err Dif $\quad 0.08317$ DF 48

Upper CL Dif 0.31992 Prob $>|\mathrm{t}| \quad 0.0726$

Lower CL Dif -0.01452 Prob $>\mathrm{t} \quad 0.0363$

$\begin{array}{lll}\text { Confidence } & 0.95 \text { Prob }<\mathrm{t} \quad 0.9637\end{array}$

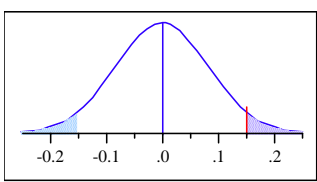

Analysis of Variance

Source DF Sum of Squares Mean Square F Ratio Prob > F

$\begin{array}{llllll}\text { ICP } & 1 & 0.2895996 & 0.289600 & 3.3709 & 0.0726\end{array}$

$\begin{array}{llll}\text { Error } & 48 & 4.1237918 & 0.085912\end{array}$

C. Total $49 \quad 4.4133913$

Means for Oneway Anova

Level Number Mean Std Error Lower 95\% Upper 95\%

$\begin{array}{lllllr}\text { M-13 } & 23 & 11.1522 & 0.06112 & 11.029 & 11.275\end{array}$

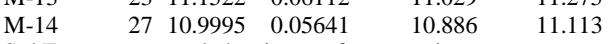

Std Error uses a pooled estimate of error variance

Means and Std Deviations

Level Number Mean Std Dev Std Err Mean Lower 95\% Upper 95\%

$\begin{array}{lllllll}\text { M-13 } & 23 & 11.1522 & 0.259899 & 0.05419 & 11.040 & 11.265\end{array}$

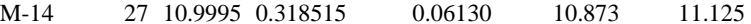

Tests that the Variances are Equal

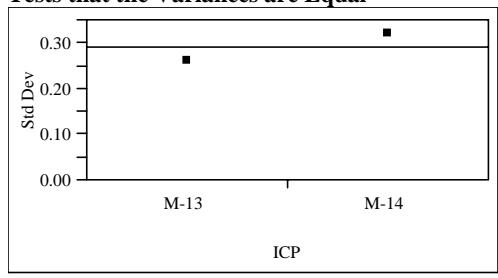

Level Count Std Dev MeanAbsDif to Mean MeanAbsDif to Median

$\begin{array}{lllll}\text { M-13 } & 23 & 0.2598989 & 0.2082312 & 0.2060782\end{array}$

$\begin{array}{llll}23 & 0.259889 & 0.2082312 & -2060782\end{array}$

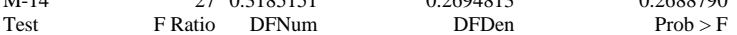

$\begin{array}{lrrrr}\text { O'Brien[.5] } & 1.5729 & 1 & 48 & 0.2159\end{array}$

$\begin{array}{lllll}\text { Brown-Forsythe } & 1.8153 & 1 & 48 & 0.1842\end{array}$

$\begin{array}{lllll}\text { Levene } & 1.9185 & 1 & 48 & 0.1724\end{array}$

$\begin{array}{lrrrr}\text { Bartlett } & 0.9483 & 1 & . & 0.3301 \\ \text { F Test 2-sided } & 1.5019 & 26 & 22 & 0.3359\end{array}$

Welch Anova testing Means Equal, allowing Std Devs Not Equal

F Ratio DFNum DFDen Prob $>$ F

$\begin{array}{rrrr}3.4831 & 1 & 47.926 & 0.0681\end{array}$

t Test

1.8663 
WSRC-STI-2006-00068

Revision 0

Exhibit A4. ICP Comparisons Using Cold Chem Batch Averages of Process Samples by Analyte

Prep $=$ Cold Chem, Sample Type=SRAT, Analyte $=\mathrm{Fe} / \mathrm{Li}$

Oneway Analysis of Batch Average Value By ICP

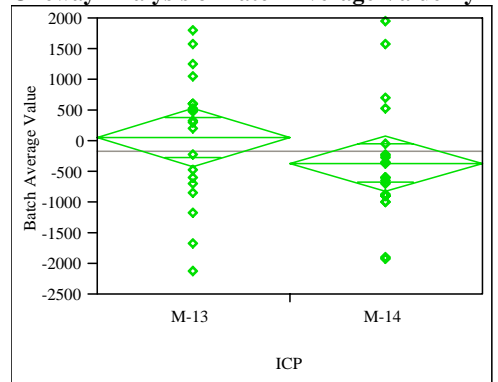

Oneway Anova

Summary of Fit

Rsquare

Adj Rsquare

0.044185

Root Mean S

Mean of Response

0.019032

1001.517

t Test

M-13-M-14

Assuming equal variances

Difference $\quad 420.3$ t Ratio 1.325388

Std Err Dif $\quad 317.1$ DF

$\begin{array}{lll}317.1 \mathrm{DF} & 38\end{array}$

Upper CL Dif 1062.2 Prob $>|t| \quad 0.1930$

Lower CL Dif -221.7 Prob $>t \quad 0.0965$

Confidence $\quad 0.95$ Prob $<\mathrm{t} \quad 0.9035$

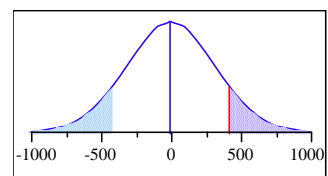

Analysis of Variance

Source DF Sum of Squares Mean Square F Ratio Prob $>$ F

$\begin{array}{llllll}\text { ICP } & 1 & 1761988 & 1761988 & 1.7567 & 0.1930\end{array}$

$\begin{array}{llll}\text { Error } & 38 & 38115389 & 1003037\end{array}$

C. Total $39 \quad 39877377$

Means for Oneway Anova

Level Number Mean Std Error Lower 95\% Upper 95\%

$\begin{array}{llllll}\text { M-13 } & 19 & 59.98 & 229.76 & -405.2 & 525.11\end{array}$

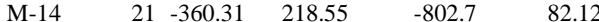

Std Error uses a pooled estimate of error variance

Means and Std Deviations

Level Number Mean Std Dev Std Err Mean Lower 95\% Upper 95\%

$\begin{array}{lllllll}\text { M-13 } & 19 & 59.98 & 1062.38 & 243.73 & -452.1 & 572.03\end{array}$

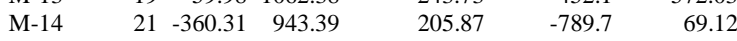

Tests that the Variances are Equal

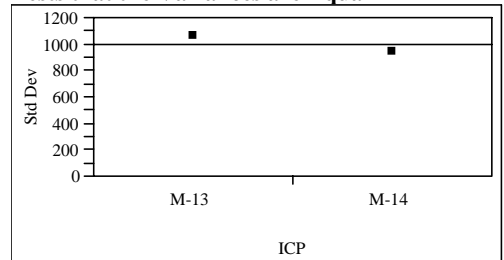

Level Count Std Dev MeanAbsDif to Mean MeanAbsDif to Median

$\begin{array}{rrrrr}\text { M-13 } & 19 & 1062.376 & 862.0514 & 835.0301\end{array}$

\begin{tabular}{lrrrr} 
M-14 & 21 & 943.394 & 659.0551 & 649.1279 \\
\hline & & & Prob $>$ F
\end{tabular}

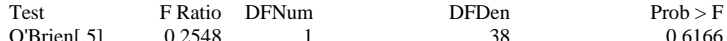

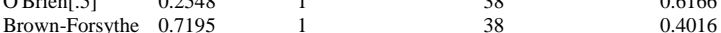

$\begin{array}{lllll}\text { Levene } & 1.0501 & 1 & 38 & 0.3120\end{array}$

$\begin{array}{llrll}\text { Bartlett } & 0.2609 & 1 & 0.6095\end{array}$

Welch Anova testing Means Equal, allowing Std Devs Not Equal

F Ratio DFNum DFDen Prob > F

$\begin{array}{llll}1.7355 & 1 & 36.243 & 0.1960\end{array}$

t Test

1.3174
Prep=Cold Chem, Sample Type $=$ SRAT, Analyte $=\mathrm{Fe} / \mathrm{Mg}$ Oneway Analysis of Batch Average Value By ICP

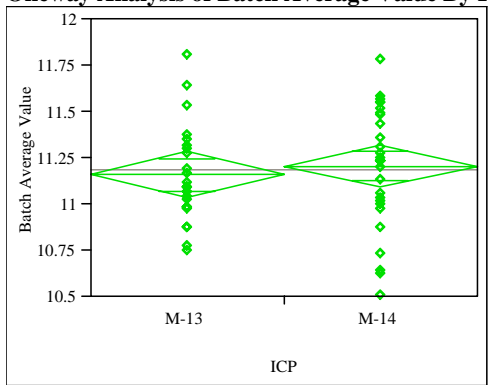

Oneway Anova

Summary of Fit

Rsquare

0.005753

Adj Rsquare

$-0.01454$

Root Mean Square Error $\quad 0.299563$

Mean of Response

11.18569

Observations (or Sum Wgts)

t Test

M-13-M-14

Assuming equal variances

Difference -0.04489 t Ratio -0.53246

Std Err Dif $\quad 0.08430$ DF 49

Upper CL Dif 0.12452 Prob $>|t| \quad 0.5968$

Lower CL Dif -0.21430 Prob $>t \quad 0.7016$

Confidence $\quad 0.95$ Prob $<\mathrm{t} \quad 0.2984$

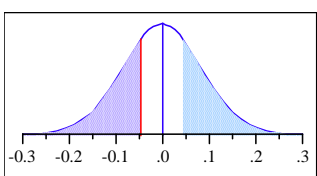

Analysis of Variance

Source DF Sum of Squares Mean Square F Ratio Prob $>$ F

$\begin{array}{llllll}\text { ICP } & 1 & 0.0254423 & 0.025442 & 0.2835 & 0.5968\end{array}$

$\begin{array}{llll}\text { Error } \quad 49 \quad 4.3971711 & 0.089738\end{array}$

C. Total $50 \quad 4.4226135$

Means for Oneway Anova

Level Number Mean Std Error Lower 95\% Upper 95\%

$\begin{array}{llllll}\text { M-13 } & 23 & 11.1610 & 0.06246 & 11.036 & 11.287\end{array}$

$\begin{array}{llllll}\text { M-14 } & 28 & 11.2059 & 0.05661 & 11.092 & 11.320\end{array}$

Std Error uses a pooled estimate of error variance

Means and Std Deviations

Level Number Mean Std Dev Std Err Mean Lower 95\% Upper 95\%

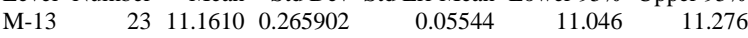

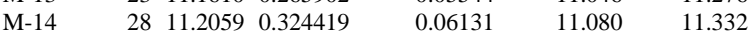

Tests that the Variances are Equal

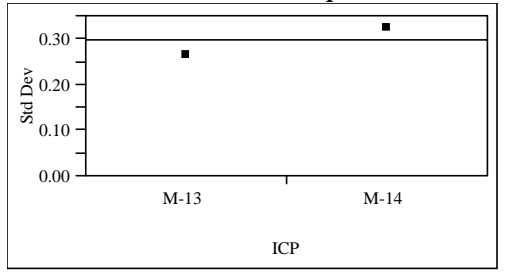

Level Count Std Dev MeanAbsDif to Mean MeanAbsDif to Median $\begin{array}{lllll}\text { M-13 } & 23 & 0.2659017 & 0.2076847 & 0.2011053 \\ \text { M-14 } & 28 & 0.3244191 & 0.2582882 & 0.2535557\end{array}$

$\begin{array}{llrr}\text { Test } & \text { F Ratio DFNum } & \text { DFDen } & \text { Prob }>\text { F }\end{array}$

$\begin{array}{lllll}\text { O'Brien[.5] } & 1.0239 & 1 & 49 & 0.3166\end{array}$

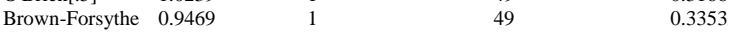

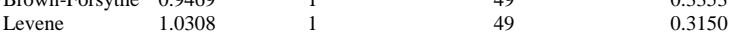

$\begin{array}{llll}\text { Levene } & 1.0308 & 1 & 40.3150 \\ \text { Bartlett } & 0.9213 & 1 & 0.3371\end{array}$

$\begin{array}{lllll}\text { F Test 2-sided } & 1.4886 & 27 & 22 & 0.3441\end{array}$

Welch Anova testing Means Equal, allowing Std Devs Not Equal

F Ratio DFNum DFDen Prob > F

$\begin{array}{llll}0.2949 & 1 & 49 & 0.5896\end{array}$

t Test

0.5430 
WSRC-STI-2006-00068

Revision 0

Exhibit A4. ICP Comparisons Using Cold Chem Batch Averages of Process Samples by Analyte

(continued)

Prep $=$ Cold Chem, Sample Type $=$ SRAT, Analyte $=\mathrm{Fe} / \mathrm{Mn}$ Oneway Analysis of Batch Average Value By ICP

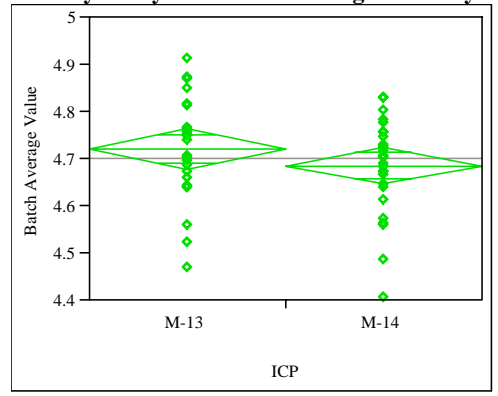

Oneway Anova

Summary of Fit

Rsquare

0.027454

Adj Rsquare

0.008003

Root Mean Square

Mean of Response

0.10401

Observations (or Sum Wgts) 52

t Test

M-13-M-14

Assuming equal variances

Difference $\quad 0.03437$ t Ratio 1.188046

Std Err Dif $\quad 0.02893$ DF

50

Upper CL Dif 0.09249 Prob $>|t| \quad 0.2404$

Lower CL Dif -0.02374 Prob $>t \quad 0.1202$

$\begin{array}{lll}\text { Confidence } & 0.95 \text { Prob }<\mathrm{t} & 0.8798\end{array}$

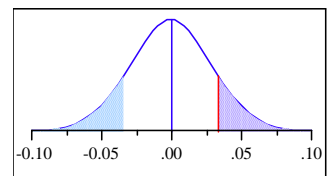

Analysis of Variance

Source DF Sum of Squares Mean Square F Ratio Prob $>$ F

$\begin{array}{llllll}\text { ICP } & 1 & 0.01526911 & 0.015269 & 1.4115 & 0.2404\end{array}$

$\begin{array}{llll}\text { Error } \quad 50 & 0.54090018 & 0.010818\end{array}$

C. Total $51 \quad 0.55616929$

Means for Oneway Anova

Level Number Mean Std Error Lower 95\% Upper 95\%

$\begin{array}{llllll}\text { M-13 } & 24 & 4.72094 & 0.02123 & 4.6783 & 4.7636\end{array}$

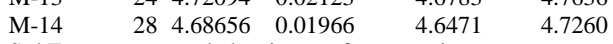

Std Error uses a pooled estimate of error variance

Means and Std Deviations

Level Number Mean Std Dev Std Err Mean Lower 95\% Upper 95\%

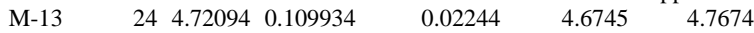

$\begin{array}{lllllll}M-14 & 28 & 4.68656 & 0.098683 & 0.01865 & 4.6483 & 4.7248\end{array}$

Tests that the Variances are Equal

\begin{tabular}{|c|c|c|c|c|}
\hline $\begin{array}{l}0.12 \\
0.10\end{array}$ & - & & & \\
\hline & M-13 & & M-14 & \\
\hline Level & Count & Std Dev & MeanAbsDif to Me & an MeanAbsDif to Median \\
\hline M-13 & 24 & 0.1099338 & 0.08556 & $\begin{array}{ll}79 & 0.0855679\end{array}$ \\
\hline M-14 & 28 & 0.0986830 & 0.07332 & 0.0717078 \\
\hline Test & F Ratio & DFNum & DFD & Prob $>F$ \\
\hline D'Brien[.5] & 0.2499 & 1 & & 0.6194 \\
\hline Brown-Forsythe & 0.5370 & 1 & & 0.4671 \\
\hline Levene & 0.4514 & 1 & & 0.5048 \\
\hline Bartlett & 0.2849 & 1 & & 0.5935 \\
\hline Test 2-sided & 1.2410 & 23 & & 0.5861 \\
\hline
\end{tabular}

Welch Anova testing Means Equal, allowing Std Devs Not Equal

F Ratio DFNum DFDen Prob $>$ F

$\begin{array}{rrrr}1.3878 & 1 & 46.747 & 0.2447\end{array}$

t Test

1.1781
Prep $=$ Cold Chem, Sample Type $=$ SRAT, Analyte $=\mathrm{Fe} / \mathrm{Ni}$

Oneway Analysis of Batch Average Value By ICP

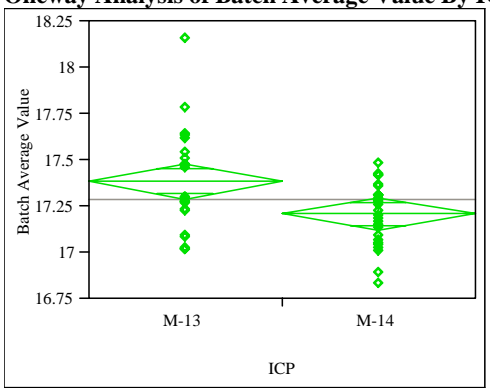

Oneway Anova

Summary of Fit

Rsquare

0.133626

Adj Rsquare $\quad 0.115193$

Root Mean Square Error $\quad 0.225726$

Mean of Response $\quad 17.28929$

Observations (or Sum Wgts)

49

t Test

M-13-M-14

Assuming equal variances

Difference $\quad 0.174553$ t Ratio 2.692414

Std Err Dif 0.064831 DF 47

Upper CL Dif 0.304977 Prob $>|t| \quad 0.0098$

Lower CL Dif 0.044129 Prob $>t \quad 0.0049$

Confidence $\quad 0.95$ Prob $<\mathrm{t} \quad 0.9951$

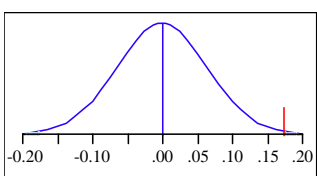

Analysis of Variance

Source DF Sum of Squares Mean Square F Ratio Prob $>$ F

$\begin{array}{lrrrrr}\text { ICP } & 1 & 0.3693558 & 0.369356 & 7.2491 & 0.0098\end{array}$

$\begin{array}{llll}\text { Error } \quad 47 & 2.3947441 & 0.050952\end{array}$

C. Total $48 \quad 2.7640999$

Means for Oneway Anova

Level Number Mean Std Error Lower 95\% Upper 95\%

$\begin{array}{llllll}\text { M-13 } & 22 & 17.3855 & 0.04812 & 17.289 & 17.482\end{array}$

$\begin{array}{llllll}\text { M-14 } & 27 & 17.2109 & 0.04344 & 17.124 & 17.298\end{array}$

Std Error uses a pooled estimate of error variance

Means and Std Deviations

Level Number Mean Std Dev Std Err Mean Lower 95\% Upper 95\%

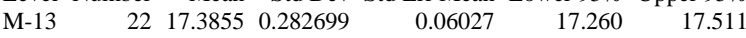
$\begin{array}{lllllll}\text { M-14 } & 27 & 17.2109 & 0.165999 & 0.03195 & 17.145 & 17.277\end{array}$

Tests that the Variances are Equal

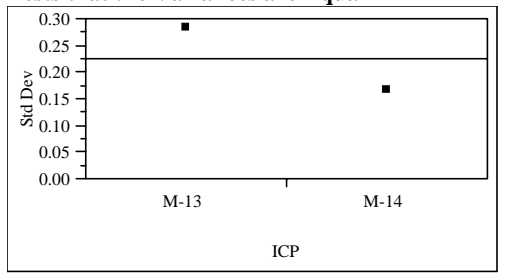

Level Count Std Dev MeanAbsDif to Mean MeanAbsDif to Median $\begin{array}{lllll}\text { M-13 } & 22 & 0.2826992 & 0.2248208 & 0.2177904 \\ \text { M-14 } & 27 & 0.1659991 & 0.1361127 & 0.1363641\end{array}$

$\begin{array}{llll}\text { Test } & \text { F Ratio DFNum } & \text { DFDen } & \text { Prob }>\text { F }\end{array}$

$\begin{array}{lllll}\text { O'Brien[.5] } & 3.6519 & 1 & 47 & 0.0621\end{array}$

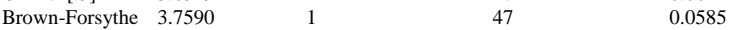

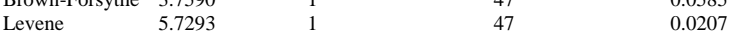

$\begin{array}{llll}\text { Levene } & 5.7293 & 1 & 0.0207 \\ \text { Bartlett } & 6.3908 & 1 & 0.0115\end{array}$

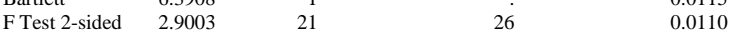

Welch Anova testing Means Equal, allowing Std Devs Not Equal

F Ratio DFNum DFDen Prob > F

$\begin{array}{llll}6.5478 & 1 & 32.392 & 0.0154\end{array}$

t Test

2.5589 
WSRC-STI-2006-00068

Revision 0

Exhibit A4. ICP Comparisons Using Cold Chem Batch Averages of Process Samples by Analyte

(continued)

Prep $=$ Cold Chem, Sample Type=SRAT, Analyte $=\mathrm{Fe} / \mathrm{U}$ Oneway Analysis of Batch Average Value By ICP

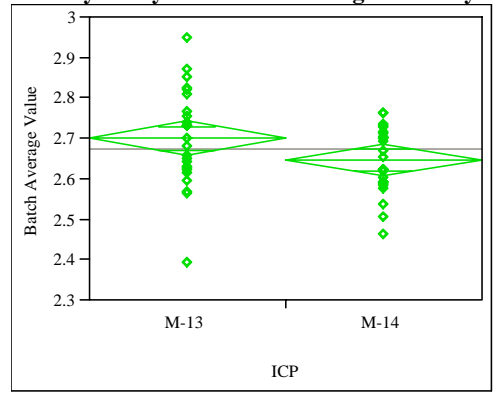

Oneway Anova

Summary of Fit

Rsquare

0.067336

Adj Rsquare

0.047906

Root Mean Square

Mean of Response

0.101789

2.674002

Observations (or Sum Wgts)

50

M-13-M-14

Assuming equal variances

Difference $\quad 0.05364$ t Ratio 1.861582

Std Err Dif $\quad 0.02881$ DF

Upper CL Dif 0.11157 Prob $>|\mathrm{t}| \quad 0.0688$

Lower CL Dif -0.00429 Prob $>\mathrm{t} \quad 0.0344$

Confidence $\quad 0.95$ Prob $<\mathrm{t} \quad 0.9656$

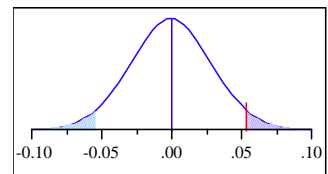

Analysis of Variance

Source DF Sum of Squares Mean Square F Ratio Prob $>$ F

$\begin{array}{llllll}\text { ICP } & 1 & 0.03590563 & 0.035906 & 3.4655 & 0.0688\end{array}$

$\begin{array}{llll}\text { Error } \quad 48 & 0.49732409 & 0.010361\end{array}$

C. Total $49 \quad 0.53322972$

Means for Oneway Anova

Level Number Mean Std Error Lower 95\% Upper 95\%

$\begin{array}{lllllr}\text { M-13 } & 24 & 2.70189 & 0.02078 & 2.6601 & 2.7437\end{array}$

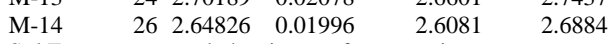

Std Error uses a pooled estimate of error variance

Means and Std Deviations

Level Number Mean Std Dev Std Err Mean Lower 95\% Upper 95\%

$\begin{array}{lllllll}\text { M-13 } & 24 & 2.70189 & 0.121289 & 0.02476 & 2.6507 & 2.7531\end{array}$

$\begin{array}{lllllll}M-14 & 26 & 2.64826 & 0.079742 & 0.01564 & 2.6160 & 2.6805\end{array}$

Tests that the Variances are Equal

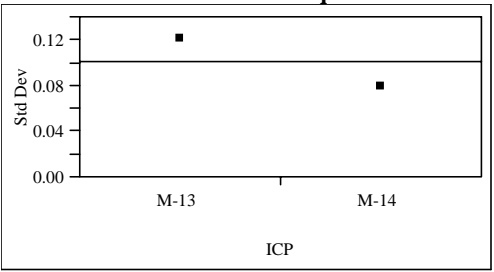

Level Count Std Dev MeanAbsDif to Mean MeanAbsDif to Median

$\begin{array}{lllll}\text { M-13 } & 24 & 0.1212890 & 0.0957519 & 0.0957519\end{array}$

$\begin{array}{llll}24 & 0.1212850 & 0.0957519 & -13\end{array}$

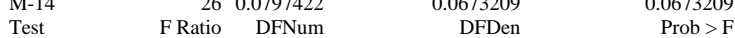

$\begin{array}{lrrrr}\text { O'Brien[.5] } & 3.0260 & 1 & 48 & 0.0883\end{array}$

Brown-Forsythe 2.987

Levene 3.036

Bartlett 4.0574

F Test 2-sided 2.3135

1
1
23

48

25

0.0904

0.0878

列

F Ratio DFNum DFDen Prob $>$ F

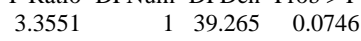

t Test

1.8317
Prep $=$ Cold Chem, Sample Type $=$ SRAT, Analyte $=K$ Oneway Analysis of Batch Average Value By ICP

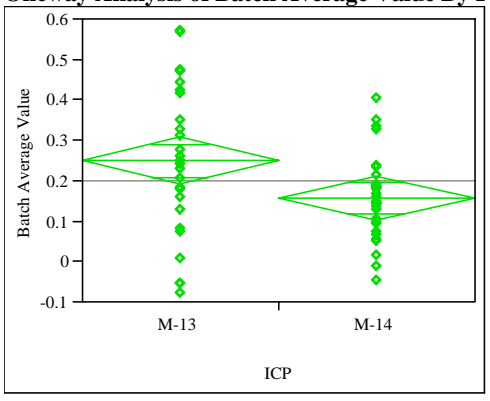

Oneway Anova

Summary of Fit

Rsquare

0.09051

Adj Rsquare

0.073667

Root Mean Square Error $\quad 0.147824$

Mean of Response $\quad 0.202125$

Observations (or Sum Wgts) 56

t Test

M-13-M-14

Assuming equal variances

Difference $\quad 0.091820$ t Ratio 2.31817

Std Err Dif $\quad 0.039609$ DF 54

Upper CL Dif 0.171230 Prob $>|\mathrm{t}| \quad 0.0243$

Lower CL Dif 0.012409 Prob $>t \quad 0.0121$

$\begin{array}{lll}\text { Confidence } & 0.95 \text { Prob }<\mathrm{t} \quad 0.9879\end{array}$

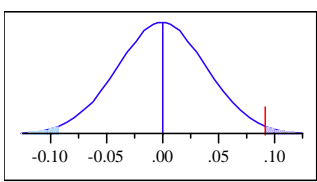

Analysis of Variance

Source DF Sum of Squares Mean Square F Ratio Prob > F

$\begin{array}{llllll}\text { ICP } & 1 & 0.1174297 & 0.117430 & 5.3739 & 0.0243\end{array}$

$\begin{array}{llll}\text { Error } & 54 & 1.1799979 & 0.021852\end{array}$

C. Total $55 \quad 1.2974276$

Means for Oneway Anova

Level Number Mean Std Error Lower 95\% Upper 95\%

$\begin{array}{llllll}\text { M-13 } & 26 & 0.251314 & 0.02899 & 0.19319 & 0.30944\end{array}$

$\begin{array}{llllll}\mathrm{M}-14 & 30 & 0.159494 & 0.02699 & 0.10539 & 0.21360\end{array}$

Std Error uses a pooled estimate of error variance

Means and Std Deviations

Level Number Mean Std Dev Std Err Mean Lower 95\% Upper 95\%

$\begin{array}{llllrrr}\text { M-13 } & 26 & 0.251314 & 0.185914 & 0.03646 & 0.17622 & 0.32641\end{array}$

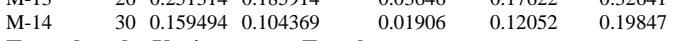

Tests that the Variances are Equal

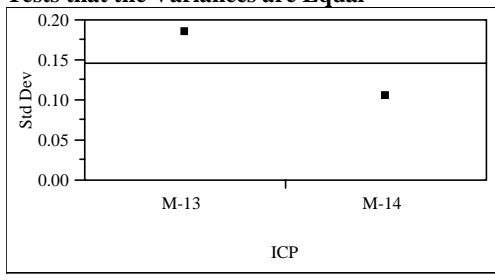

Level Count Std Dev MeanAbsDif to Mean MeanAbsDif to Median

$\begin{array}{lrrrr}\text { M-13 } & 26 & 0.1859142 & 0.1478269 & 0.1478269\end{array}$

$\begin{array}{lrrrr}\mathrm{M}-14 & 30 & 0.1043694 & 0.0771719 & 0.0766833\end{array}$

$\begin{array}{lrrrr}\text { Test } & \text { F Ratio } & \text { DFNum } & \text { DFDen } & \text { Prob }>\text { F } \\ \text { O'Brien[.5] } & 9.0931 & 1 & 54 & 0.0039\end{array}$

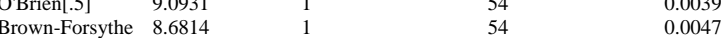

$\begin{array}{lllll}\text { Levene } & 8.6684 & 1 & 54 & 0.0047 \\ & 8.5658 & 1 & 0.0048\end{array}$

$\begin{array}{lll}\text { Levene } & 8.6684 & 1 \\ \text { Bartlett } & 8.5658 & 1\end{array}$

$\begin{array}{lrrrr}\text { Bartlett } & 8.5658 & 1 & \cdot & 0.0034 \\ \text { F Test 2-sided } & 3.1731 & 25 & 29 & 0.0033\end{array}$

Welch Anova testing Means Equal, allowing Std Devs Not Equal

F Ratio DFNum DFDen Prob $>$ F

$\begin{array}{llll}4.9813 & 1 & 38.073 & 0.0316\end{array}$

t Test

2.2319 
WSRC-STI-2006-00068

Revision 0

Exhibit A4. ICP Comparisons Using Cold Chem Batch Averages of Process Samples by Analyte

(continued)

Prep $=$ Cold Chem, Sample Type $=$ SRAT, Analyte $=\mathbf{L i}$

Oneway Analysis of Batch Average Value By ICP

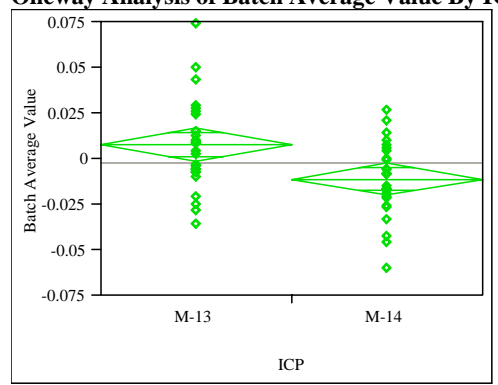

Oneway Anova

Summary of Fit

Adj Rsquare

0.149354

Root Mean Squar

Mean of Response

Observations (or Sum Wgts)

0.132341

0.022839

$-0.00203$

t Test

M-13-M-14

Assuming equal variances

Difference $\quad 0.018782$ t Ratio 2.962915

Std Err Dif 0.006339 DF

Upper CL Dif 0.031515 Prob $>|\mathrm{t}| \quad 0.0047$

Lower CL Dif 0.006050 Prob $>t \quad 0.0023$

Confidence $\quad 0.95$ Prob $<\mathrm{t} \quad 0.9977$

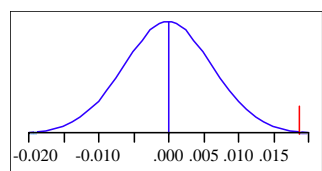

Analysis of Variance

Source DF Sum of Squares Mean Square F Ratio Prob $>$ F

$\begin{array}{lrrrrr}\text { ICP } & 1 & 0.00457925 & 0.004579 & 8.7789 & 0.0047\end{array}$

$\begin{array}{llll}\text { Error } & 50 & 0.02608110 & 0.000522\end{array}$

C. Total $51 \quad 0.03066035$

Means for Oneway Anova

Level Number Mean Std Error Lower 95\% Upper 95\%

$\begin{array}{llllll}\text { M-13 } & 25 & 0.00773 & 0.00457 & -0.0014 & 0.0169\end{array}$

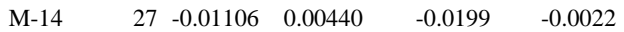

Std Error uses a pooled estimate of error variance

Means and Std Deviations

Level Number Mean Std Dev Std Err Mean Lower 95\% Upper 95\%

$\begin{array}{llllllr}\mathrm{M}-13 & 25 & 0.00773 & 0.025393 & 0.00508 & -0.0028 & 0.0182\end{array}$

$\begin{array}{lrrrrrr}\text { M-13 } & 25 & 0.00773 & 0.025393 & 0.00508 & -0.0028 & 0.0182 \\ \text { M-14 } & 27 & -0.01106 & 0.020197 & 0.00389 & -0.0190 & -0.0031\end{array}$

Tests that the Variances are Equal

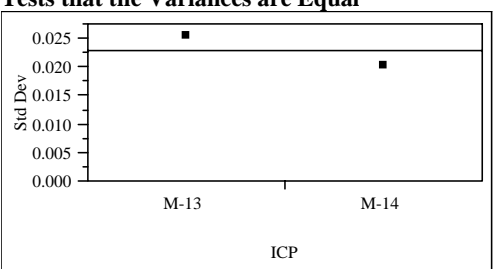

Level Count Std Dev MeanAbsDif to Mean MeanAbsDif to Median

$\begin{array}{lllll}\text { M-13 } & 25 & 0.0253928 & 0.0193824 & 0.0193267\end{array}$

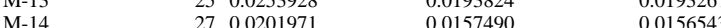

$\begin{array}{lll}\mathrm{M}-14 & \text { F Ratio DFNum } & 0.0156543 \\ \mathrm{Test} & & 0.0103\end{array}$

$\begin{array}{lrrrr}\text { O'Brien[.5] } & 1.0481 & 1 & 50 & \text { Prob }>\text { F } \\ \text { O's } & 1 & 50 & 0.3109\end{array}$

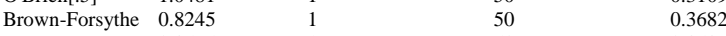

$\begin{array}{lllll}\text { Levene } & 0.8575 & 1 & 50 & 0.3589\end{array}$

$\begin{array}{lrrrr}\text { Bartlett } & 1.2791 & 1 & \dot{3} & 0.2581\end{array}$

Welch Anova testing Means Equal, allowing Std Devs Not Equal

F Ratio DFNum DFDen Prob $>$ F

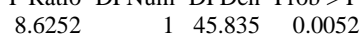

t Test

2.9369
Prep $=$ Cold Chem, Sample Type $=$ SRAT, Analyte $=M g$

Oneway Analysis of Batch Average Value By ICP

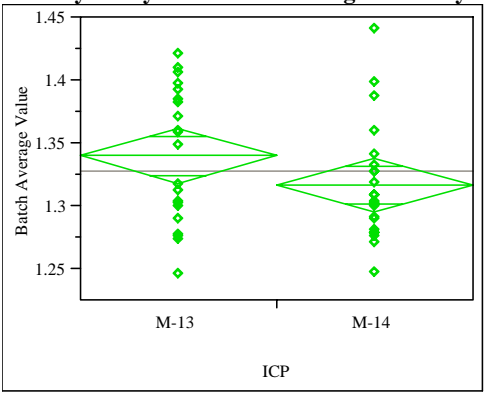

Oneway Anova

Summary of Fit

Rsquare

0.055596

Adj Rsquare

0.03311

Root Mean Square Error $\quad 0.049361$

Mean of Response

1.328072

Observations (or Sum Wgts)

t Test

M-13-M-14

Assuming equal variances

Difference $\quad 0.02343$ t Ratio 1.572411

Std Err Dif $\quad 0.01490$ DF

Upper CL Dif 0.05349 Prob > |t 0.1234

Lower CL Dif -0.00664 Prob $>\mathrm{t} \quad 0.0617$

$\begin{array}{lll}\text { Confidence } & 0.95 \text { Prob }<\mathrm{t} \quad 0.9383\end{array}$

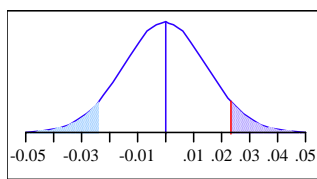

Analysis of Variance

Source DF Sum of Squares Mean Square F Ratio Prob > F

$\begin{array}{llllll}\text { ICP } & 1 & 0.00602416 & 0.006024 & 2.4725 & 0.1234\end{array}$

$\begin{array}{llll}\text { Error } & 42 & 0.10233253 & 0.002436\end{array}$

C. Total $43 \quad 0.10835669$

Means for Oneway Anova

Level Number Mean Std Error Lower 95\% Upper 95\%

$\begin{array}{lllllr}\text { M-13 } & 21 & 1.34032 & 0.01077 & 1.3186 & 1.3621\end{array}$

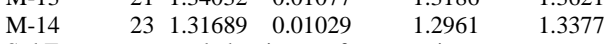

Std Error uses a pooled estimate of error variance

Means and Std Deviations

Level Number Mean Std Dev Std Err Mean Lower 95\% Upper 95\%

$\begin{array}{lllllll}\text { M-13 } & 21 & 1.34032 & 0.053426 & 0.01166 & 1.3160 & 1.3646\end{array}$

$\begin{array}{lllllll}\text { M-14 } & 23 & 1.31689 & 0.045350 & 0.00946 & 1.2973 & 1.3365\end{array}$

Tests that the Variances are Equal

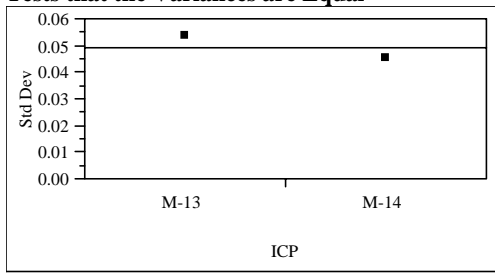

Level Count Std Dev MeanAbsDif to Mean MeanAbsDif to Median

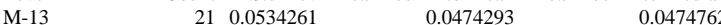

$230.0453499=0.0337083$

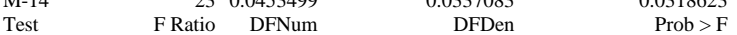

$\begin{array}{lrrrr}\text { O'Brien[.5] } & 0.6888 & 1 & \text { DFDen } & \text { Prob }>\text { F } \\ & 3.0205 & 1 & 42 & 0.4113\end{array}$

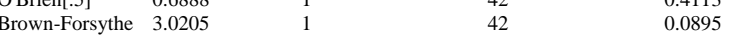

$\begin{array}{lllll}\text { Levene } & 2.9974 & 1 & 42 & 0.0907\end{array}$

$\begin{array}{lrrrr}\text { Bartlett } & 0.5501 & 1 & 2 & 0.4583\end{array}$

Fest 2-sided 1.387 Means Equal, allowing Std Devs Not Equal

F Ratio DFNum DFDen Prob $>$ F

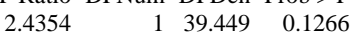

t Test

1.5606 
WSRC-STI-2006-00068

Revision 0

Exhibit A4. ICP Comparisons Using Cold Chem Batch Averages of Process Samples by Analyte

(continued)

Prep $=$ Cold Chem, Sample Type $=$ SRAT, Analyte $=M n$ Oneway Analysis of Batch Average Value By ICP

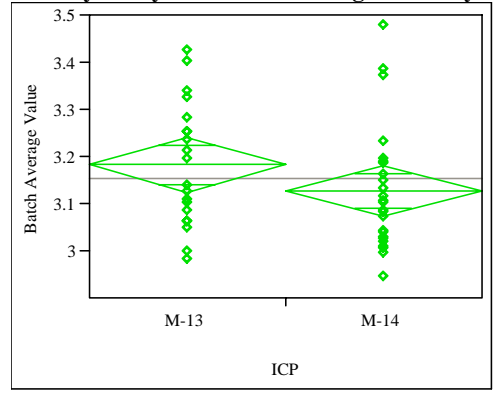

Oneway Anova

Summary of Fit

Rsquare

0.045133

Adj Rsquare

0.022926

Root Mean Square Error $\quad 0.13018$

Mean of Response

Observations (or Sum Wgts) $\quad 45$

t Test

M-13-M-14

Assuming equal variances

Difference 0.05568 t Ratio 1.425632

Std Err Dif 0.03905 DF 43

Upper CL Dif 0.13444 Prob $>|t| \quad 0.1612$

Lower CL Dif -0.02308 Prob $>t \quad 0.0806$

$\begin{array}{lll}\text { Confidence } & 0.95 \text { Prob }<\mathrm{t} \quad 0.9194\end{array}$

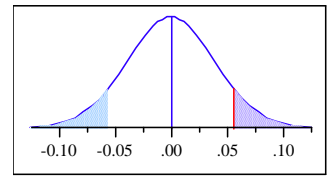

Analysis of Variance

Source DF Sum of Squares Mean Square F Ratio Prob $>$ F

$\begin{array}{llllll}\text { ICP } & 1 & 0.03444324 & 0.034443 & 2.0324 & 0.1612\end{array}$

$\begin{array}{llll}\text { Error } \quad 43 & 0.72871431 & 0.016947\end{array}$

C. Total $44 \quad 0.76315755$

Means for Oneway Anova

Level Number Mean Std Error Lower 95\% Upper 95\%

$\begin{array}{llllll}\text { M-13 } & 20 & 3.18432 & 0.02911 & 3.1256 & 3.2430\end{array}$

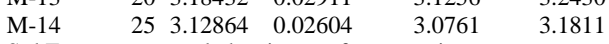

Std Error uses a pooled estimate of error variance

Means and Std Deviations

Level Number Mean Std Dev Std Err Mean Lower 95\% Upper 95\%

$\begin{array}{lllllll}\text { M-13 } & 20 & 3.18432 & 0.130004 & 0.02907 & 3.1235 & 3.2452\end{array}$

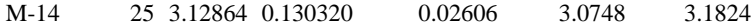

Tests that the Variances are Equal

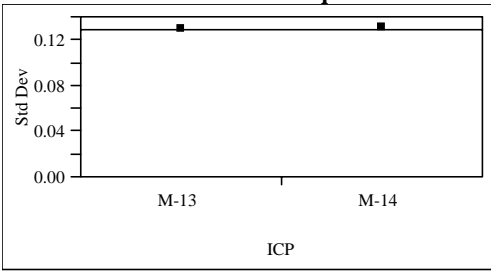

Level Count Std Dev MeanAbsDif to Mean MeanAbsDif to Median

$\begin{array}{lllll}\text { M-13 } & 20 & 0.1300036 & 0.1099667 & 0.1099667\end{array}$

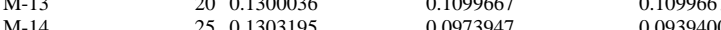

$\begin{array}{lrrrr}\text { M-14 } & \text { F Ratio } & \text { DFNum } & \text { DFDen } & 0.0939400 \\ \text { Test } & \text { Prob }>\text { F }\end{array}$

$\begin{array}{lrrrr}\text { Test } & \text { F Ratio } & \text { DFNum } & \text { Drob }>\text { F } \\ \text { O'Brien[.5] } & 0.0001 & 1 & 43 & 0.9915\end{array}$

Brown-Forsythe 0.430

Levene $\quad 0.302$

Bartlett

0.0001

F Test 2-sided 1.0049

0.5155

0.5155

0.9912

列

F Ratio DFNum DFDen Prob $>$ F

$\begin{array}{lrrr}2.0335 & 1 & 40.901 & 0.1614\end{array}$

t Test

1.4260
Prep $=$ Cold Chem, Sample Type $=$ SRAT, Analyte $=M n / M g$

Oneway Analysis of Batch Average Value By ICP

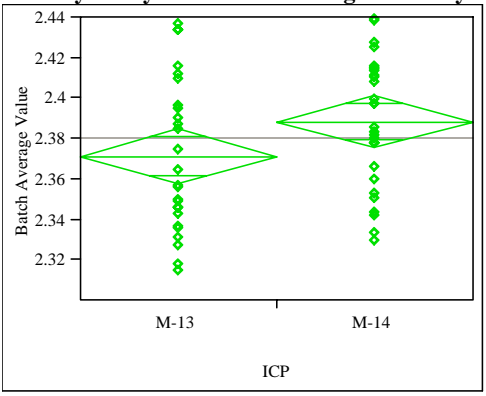

Oneway Anova

Summary of Fit

Rsquare

0.060316

Adj Rsquare

0.042586

Root Mean Square Error $\quad 0.034319$

Mean of Response 2.38038

Observations (or Sum Wgts) 55

t Test

M-13-M-14

Assuming equal variances

Difference $\quad-0.01710$ t Ratio $\quad-1.84443$

Std Err Dif $\quad 0.00927$ DF 53

Upper CL Dif 0.00150 Prob $>|\mathrm{t}| \quad 0.0707$

Lower CL Dif -0.03569 Prob $>\mathrm{t} \quad 0.9646$

$\begin{array}{lll}\text { Confidence } & 0.95 \text { Prob }<\mathrm{t} \quad 0.0354\end{array}$

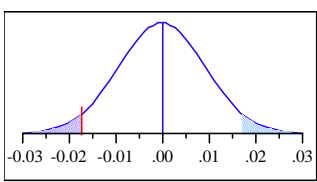

Analysis of Variance

Source DF Sum of Squares Mean Square F Ratio Prob > F

$\begin{array}{llllll}\text { ICP } & 1 & 0.00400668 & 0.004007 & 3.4019 & 0.0707\end{array}$

$\begin{array}{llll}\text { Error } & 53 & 0.06242151 & 0.001178\end{array}$

C. Total $54 \quad 0.06642818$

Means for Oneway Anova

Level Number Mean Std Error Lower 95\% Upper 95\%

$\begin{array}{lllllr}\text { M-13 } & 26 & 2.37137 & 0.00673 & 2.3579 & 2.3849\end{array}$

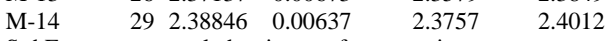

Std Error uses a pooled estimate of error variance

Means and Std Deviations

Level Number Mean Std Dev Std Err Mean Lower 95\% Upper 95\%

$\begin{array}{llllllr}\text { M-13 } & 26 & 2.37137 & 0.037387 & 0.00733 & 2.3563 & 2.3865\end{array}$

$\begin{array}{lllllll}\text { M-14 } & 29 & 2.38846 & 0.031326 & 0.00582 & 2.3765 & 2.4004\end{array}$

Tests that the Variances are Equal

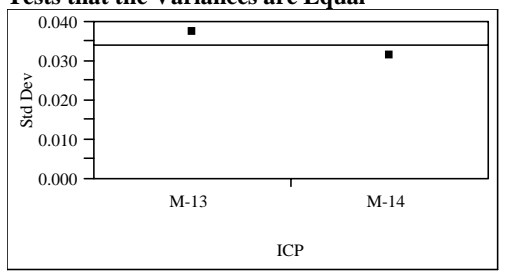

Level Count Std Dev MeanAbsDif to Mean MeanAbsDif to Median

$\begin{array}{lllll}\text { M-13 } & 26 & 0.0373868 & 0.0322418 & 0.0317715\end{array}$

$\begin{array}{lllll}\text { M-14 } & 29 & 0.0313261 & 0.0261697 & 0.0261417\end{array}$

$\begin{array}{llll}\text { Test } & \text { F Ratio DFNum } & \text { DFDen } & \text { Prob }>\text { F }\end{array}$

$\begin{array}{lrrrr}\text { O'Brien[.5] } & 1.5992 & 1 & 53 & 0.2116\end{array}$

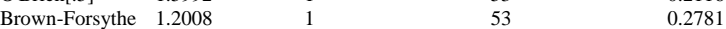

$\begin{array}{lllll}\text { Levene } & 1.7247 & 1 & 53 & 0.1948\end{array}$

$\begin{array}{lrrrr}\text { Bartlett } & 0.8121 & 1 & . & 0.3675\end{array}$

W Test 2-sided $1.4244 \quad 25$ Anova testing Means Equal, allowing Std Devs Not Equal

F Ratio DFNum DFDen Prob $>$ F

$\begin{array}{llll}3.3364 & 1 & 49.032 & 0.0739\end{array}$

t Test

1.8266 
WSRC-STI-2006-00068

Revision 0

Exhibit A4. ICP Comparisons Using Cold Chem Batch Averages of Process Samples by Analyte

(continued)

Prep $=$ Cold Chem, Sample Type $=$ SRAT, Analyte $=\mathrm{Na}$ Oneway Analysis of Batch Average Value By ICP

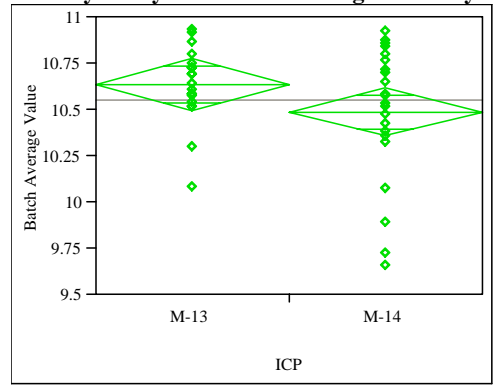

Oneway Anova

Summary of Fit

Rsquare

Adj Rsquare

0.059997

Root Mean S

Mean of Response

0.55791

Observations (or Sum Wgts)

t Test

M-13-M-14

Assuming equal variances

Difference $\quad 0.14891$ t Ratio 1.57773

$\begin{array}{lll}\text { Std Err Dif } & 0.09438 \text { DF } & 39\end{array}$

Upper CL Dif 0.33981 Prob $>|t| \quad 0.1227$

Lower CL Dif -0.04200 Prob $>\mathrm{t} \quad 0.0614$

Confidence $\quad 0.95$ Prob $<\mathrm{t} \quad 0.9386$

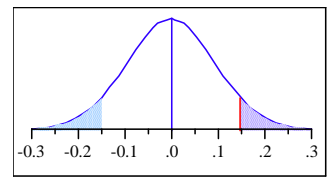

Analysis of Variance

Source DF Sum of Squares Mean Square F Ratio Prob $>$ F

$\begin{array}{llllll}\text { ICP } & 1 & 0.2260585 & 0.226059 & 2.4892 & 0.1227\end{array}$

$\begin{array}{llll}\text { Error } & 39 & 3.5417688 & 0.090815\end{array}$

C. Total $40 \quad 3.7678273$

Means for Oneway Anova

Level Number Mean Std Error Lower 95\% Upper 95\%

$\begin{array}{llllll}\text { M-13 } & 19 & 10.6378 & 0.06914 & 10.498 & 10.778\end{array}$

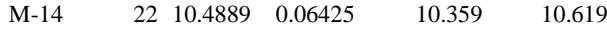

Std Error uses a pooled estimate of error variance

Means and Std Deviations

Level Number Mean Std Dev Std Err Mean Lower 95\% Upper 95\%

$\begin{array}{lllllrr}\text { M-13 } & 19 & 10.6378 & 0.204781 & 0.04698 & 10.539 & 10.737\end{array}$

$\begin{array}{lllllll}\text { M-14 } & 22 & 10.4889 & 0.364295 & 0.07767 & 10.327 & 10.650\end{array}$

Tests that the Variances are Equal

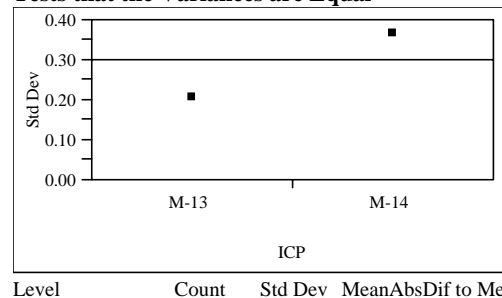

Level Count Std Dev MeanAbsDif to Mean MeanAbsDif to Median

$\begin{array}{lllll}\text { M-13 } & 19 & 0.2047813 & 0.1472816 & 0.1486316\end{array}$

$\begin{array}{lrrrr}\text { M-14 } & 22 & 0.3642953 & 0.2773953 & 0.2702273\end{array}$

$\begin{array}{llll}\text { Test } & \text { F Ratio DFNum } & \text { DFDen } & \text { F }\end{array}$

$\begin{array}{lllll}\text { O'Brien[.5] } & 3.4460 & 1 & 39 & 0.0710\end{array}$

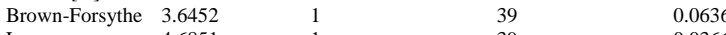

5.7923

F Test 2-sided $3.1647 \quad 2$

21

0.0366

0.0161

Welch Anova testing Means Equal, allowing Std Devs Not Equal

F Ratio DFNum DFDen Prob $>$ F

$\begin{array}{llll}2.6911 & 1 & 33.886 & 0.1102\end{array}$

t Test

1.6405
Prep $=$ Cold Chem, Sample Type $=$ SRAT, Analyte $=\mathrm{Ni}$

Oneway Analysis of Batch Average Value By ICP

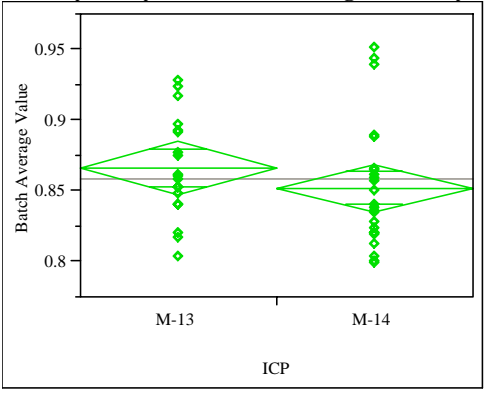

Oneway Anova

Summary of Fit

Rsquare

0.030879

Adj Rsquare

0.007242

Root Mean Square Error $\quad 0.040359$

Mean of Response $\quad 0.858988$

Observations (or Sum Wgts)

43

t Test

M-13-M-14

Assuming equal variances

Difference $\quad 0.01417$ t Ratio $\quad 1.142979$

Std Err Dif $\quad 0.01239$ DF

Upper CL Dif 0.03919 Prob > |t $\mid 0.2597$

Lower CL Dif -0.01086 Prob $>\mathrm{t} \quad 0.1298$

$\begin{array}{lll}\text { Confidence } & 0.95 \text { Prob }<\mathrm{t} \quad 0.8702\end{array}$

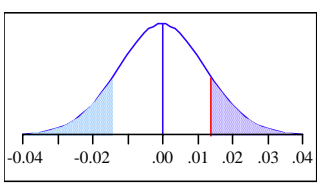

Analysis of Variance

Source DF Sum of Squares Mean Square F Ratio Prob > F

$\begin{array}{llllll}\text { ICP } & 1 & 0.00212797 & 0.002128 & 1.3064 & 0.2597\end{array}$

$\begin{array}{llll}\text { Error } & 41 & 0.06678395 & 0.001629\end{array}$

C. Total $42 \quad 0.06891191$

Means for Oneway Anova

Level Number Mean Std Error Lower 95\% Upper 95\%

$\begin{array}{llllll}\text { M-13 } & 19 & 0.866895 & 0.00926 & 0.84820 & 0.88559\end{array}$

$\begin{array}{llllll}\mathrm{M}-14 & 24 & 0.852729 & 0.00824 & 0.83609 & 0.86937\end{array}$

Std Error uses a pooled estimate of error variance

Means and Std Deviations

Level Number Mean Std Dev Std Err Mean Lower 95\% Upper 95\%

$\begin{array}{lrrrrrr}\text { M-13 } & 19 & 0.866895 & 0.035721 & 0.00819 & 0.84968 & 0.88411\end{array}$

$\begin{array}{lllllll}\mathrm{M}-14 & 24 & 0.852729 & 0.043647 & 0.00891 & 0.83430 & 0.87116\end{array}$

Tests that the Variances are Equal

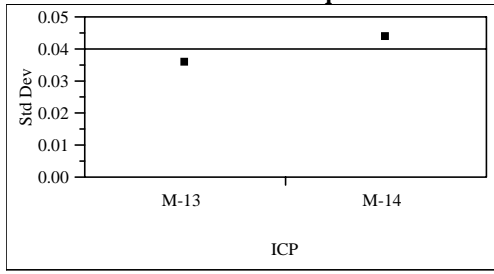

Level Count Std Dev MeanAbsDif to Mean MeanAbsDif to Media

$\begin{array}{lllll}\text { M-13 } & 19 & 0.0357209 & 0.0287904 & 0.0280965\end{array}$

$\begin{array}{lrrrr}\text { M-14 } & 24 & 0.0436469 & 0.0333924 & 0.0322847 \\ \text { Test } & \text { F Ratio } & \text { DFNum } & \text { Prob }>\text { F }\end{array}$

$\begin{array}{lrrrr}\text { Test } & \text { F Ratio } & \text { DFNum } & \text { DFDen } & \text { Prob > F } \\ \text { O'Brien[.5] } & 0.7109 & 1 & 41 & 0.4040\end{array}$

$\begin{array}{lllll}\text { Brown-Forsythe } & 0.2432 & 1 & 41 & 0.6245\end{array}$

$\begin{array}{lllll}\text { Levene } & 0.3793 & 1 & 41 & 0.5414\end{array}$

$\begin{array}{lllll}\text { Bartlett } & 0.7736 & 1 & 0.3791\end{array}$

Welch Anova testing Means Equal, allowing Std Devs Not Equal

F Ratio DFNum DFDen Prob $>$ F

$\begin{array}{llll}1.3694 & 1 & 40.938 & 0.2487\end{array}$

t Test

1.1702 
WSRC-STI-2006-00068

Revision 0

Exhibit A4. ICP Comparisons Using Cold Chem Batch Averages of Process Samples by Analyte

(continued)

Prep $=$ Cold Chem, Sample Type $=$ SRAT, Analyte $=S i$ Oneway Analysis of Batch Average Value By ICP

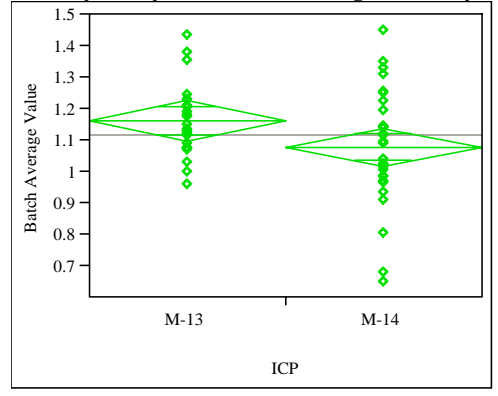

Oneway Anova

Summary of Fit

Rsquare

0.067296

Adj Rsquare

0.048642

Root Mean Square Error $\quad 0.159072$

Mean of Response $\quad 1.115474$

Observations (or Sum Wgts) 52

t Test

M-13-M-14

Assuming equal variances

Difference 0.08436 t Ratio 1.899363

Std Err Dif $\quad 0.04442$ DF 50

Upper CL Dif 0.17357 Prob $>|t| \quad 0.0633$

Lower CL Dif -0.00485 Prob $>\mathrm{t} \quad 0.0316$

$\begin{array}{lll}\text { Confidence } & 0.95 \text { Prob }<\mathrm{t} & 0.9684\end{array}$

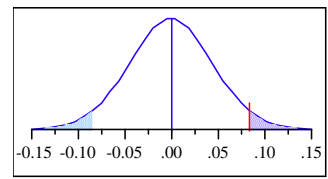

Analysis of Variance

Source DF Sum of Squares Mean Square F Ratio Prob $>$ F

$\begin{array}{llllll}\text { ICP } & 1 & 0.0912860 & 0.091286 & 3.6076 & 0.0633\end{array}$

$\begin{array}{llll}\text { Error } \quad 50 & 1.2651967 & 0.025304\end{array}$

C. Total $51 \quad 1.3564827$

Means for Oneway Anova

Level Number Mean Std Error Lower 95\% Upper 95\%

$\begin{array}{lllllr}\text { M-13 } & 23 & 1.16252 & 0.03317 & 1.0959 & 1.2291\end{array}$

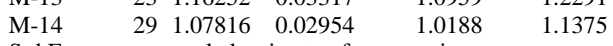

Std Error uses a pooled estimate of error variance

Means and Std Deviations

Level Number Mean Std Dev Std Err Mean Lower 95\% Upper 95\%

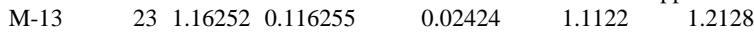

$\begin{array}{lllllll}\text { M-14 } & 29 & 1.07816 & 0.185921 & 0.03452 & 1.0074 & 1.1489\end{array}$

Tests that the Variances are Equal

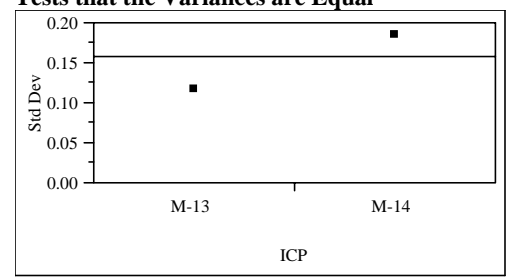

Level Count Std Dev MeanAbsDif to Mean MeanAbsDif to Median

$\begin{array}{lllll}M-13 & 23 & 0.1162547 & 0.0875173 & 0.085884\end{array}$

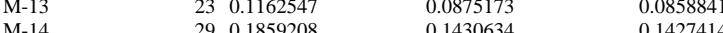

$\begin{array}{lrrrr}\text { M-14 } & \text { F Ratio } & \text { DFNum } & \text { DFDen } & 0.1427414 \\ \text { Test } & 3.3522 & & \text { Prob }>\text { F }\end{array}$

$\begin{array}{lrrrr}\text { Test } & \text { F Ratio } & \text { DFNum } & \text { DFDen } & \text { Prob }>\text { F } \\ \text { O'Brien[.5] } & 3.3522 & 1 & 50 & 0.0731\end{array}$

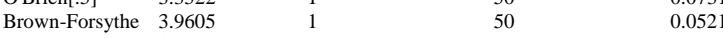

Levene $\quad 3.9936$

Bartlett $\quad 4.962$

F Test 2-sided 2.5576

50

Welch Anova testing Means Equal, allowing Std Devs Not Equal

F Ratio DFNum DFDen Prob $>$ F

$\begin{array}{rrrr}3.9991 & 1 & 47.668 & 0.0512\end{array}$

t Test

1.9998
Prep $=$ Cold Chem, Sample Type $=$ SRAT, Analyte $=$ Sum of Oxides Oneway Analysis of Batch Average Value By ICP

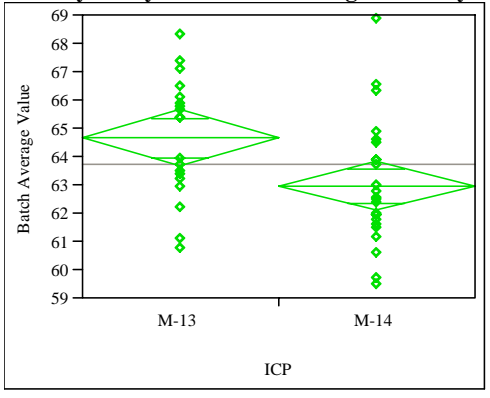

Oneway Anova

Summary of Fit

Rsquare

0.138324

Adj Rsquare

0.117808

Root Mean Square Error $\quad 2.138665$

Mean of Response 63.72328

Observations (or Sum Wgts) 44

t Test

M-13-M-14

Assuming equal variances

Difference $\quad 1.69015$ t Ratio 2.596583

Std Err Dif $\quad 0.65091$ DF 42

Upper CL Dif 3.00374 Prob > |t 0.0129

Lower CL Dif 0.37655 Prob $>\mathrm{t} \quad 0.0065$

$\begin{array}{lll}\text { Confidence } & 0.95 \text { Prob }<\mathrm{t} & 0.9935\end{array}$

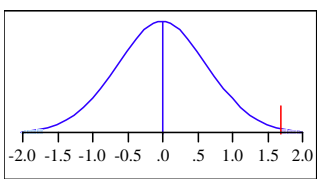

Analysis of Variance

Source DF Sum of Squares Mean Square F Ratio Prob > F

$\begin{array}{llllll}\text { ICP } & 1 & 30.83826 & 30.8383 & 6.7422 & 0.0129\end{array}$

$\begin{array}{llll}\text { Error } \quad 42 & 192.10323 & 4.5739\end{array}$

C. Total $43 \quad 222.94149$

Means for Oneway Anova

Level Number Mean Std Error Lower 95\% Upper 95\%

$\begin{array}{llllll}\text { M-13 } & 19 & 64.6836 & 0.49064 & 63.693 & 65.674\end{array}$

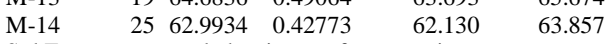

Std Error uses a pooled estimate of error variance

Means and Std Deviations

Level Number Mean Std Dev Std Err Mean Lower 95\% Upper 95\%

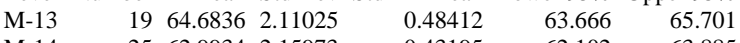

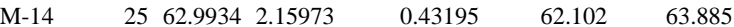

Tests that the Variances are Equal

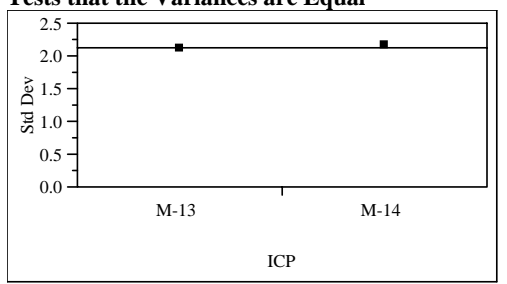

Level Count Std Dev MeanAbsDif to Mean MeanAbsDif to Median

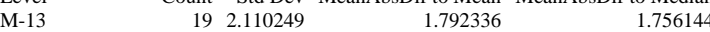

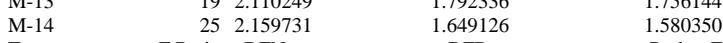

$\begin{array}{llll}\text { Test } & \text { F Ratio DFNum } & \text { DFDen } & \text { Prob }>\text { F }\end{array}$

$\begin{array}{lllll}\text { O'Brien[.5] } & 0.0101 & 1 & 42 & 0.9206 \\ & 0.1624 & 1 & 42 & 0.6890\end{array}$

$\begin{array}{lllll}\text { Brown-Forsythe } & 0.1624 & 1 & 42 & 0.6890 \\ \text { Levene } & 0.1474 & 1 & 42 & 0.7029\end{array}$

$\begin{array}{lll}\text { Bartlett } & 0.0108 & 1\end{array}$

F Test 2-sided $1.0474 \quad 24 \quad 18$

Welch Anova testing Means Equal, allowing Std Devs Not Equal

F Ratio DFNum DFDen Prob $>$ F

$\begin{array}{llll}6.7860 & 1 & 39.358 & 0.0129\end{array}$

t Test

2.6050 
WSRC-STI-2006-00068

Revision 0

Exhibit A4. ICP Comparisons Using Cold Chem Batch Averages of Process Samples by Analyte

(continued)

Prep $=$ Cold Chem, Sample Type $=$ SRAT, Analyte $=T$ Oneway Analysis of Batch Average Value By ICP

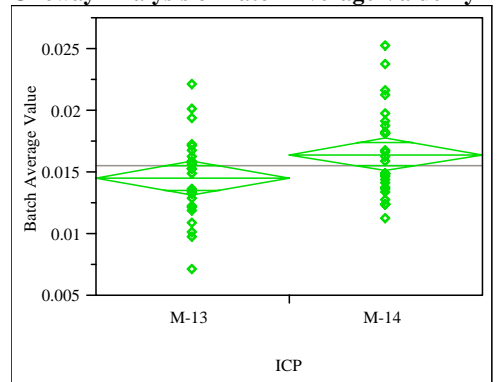

Oneway Anova

Summary of Fit

Rsquare

Adj Rsquare 0.053488

Root Mean Square Error $\quad 0.003497$

Mean of Response $\quad 0.015575$

Observations (or Sum Wgts) 53

t Test

M-13-M-14

Assuming equal variances

Difference $\quad-0.00191$ t Ratio $\quad-1.98459$

$\begin{array}{lll}\text { Std Err Dif } \quad 0.00096 \text { DF } & 51\end{array}$

Upper CL Dif 0.000022 Prob $>|t| 0.0526$

Lower CL Dif -0.00384 Prob $>t \quad 0.9737$

Confidence $\quad 0.95$ Prob $<\mathrm{t} \quad 0.0263$

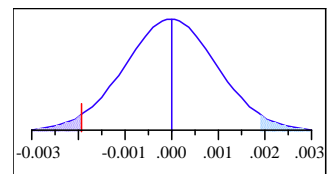

Analysis of Variance

Source DF Sum of Squares Mean Square F Ratio Prob > F

$\begin{array}{lrrrrr}\text { ICP } & 1 & 0.00004816 & 0.000048 & 3.9386 & 0.0526\end{array}$

$\begin{array}{llll}\text { Error } & 51 & 0.00062360 & 0.000012\end{array}$

C. Total $52 \quad 0.00067175$

Means for Oneway Anova

Level Number Mean Std Error Lower 95\% Upper 95\%

$\begin{array}{llllll}\text { M-13 } & 25 & 0.014567 & 0.00070 & 0.01316 & 0.01597\end{array}$

$\begin{array}{llllll}\text { M-14 } & 28 & 0.016476 & 0.00066 & 0.01515 & 0.01780\end{array}$

Std Error uses a pooled estimate of error variance

Means and Std Deviations

Level Number Mean Std Dev Std Err Lower Upper

$\begin{array}{lll}0.00068 & 0.01317 & 0.01597 \\ -0.01509 & 0.01787\end{array}$

Tests that the Variances are Equal

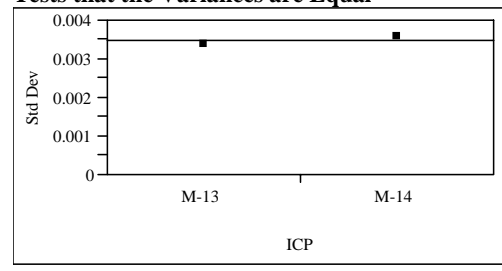

Level Count Std Dev MeanAbsDif to Mean MeanAbsDif to Median

$\begin{array}{lrrrr}\text { M-13 } & 25 & 0.0033936 & 0.0026640 & 0.0026600\end{array}$

$\begin{array}{lllll}\mathrm{M}-14 & 28 & 0.0035860 & 0.0028895 & 0.0028452\end{array}$

$\begin{array}{lllll}\text { Test } & \text { F Ratio } & \text { DFNum } & \text { DFDen } & \text { Prob }>\text { F }\end{array}$

$\begin{array}{lllll}\text { O'Brien[.5] } & 0.0754 & 1 & 51 & 0.7847\end{array}$

Levene $0.1612 \quad 11$

Levene $\quad 0.1612 \quad 12$

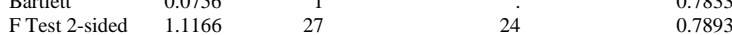

Welch Anova testing Means Equal, allowing Std Devs Not Equal

F Ratio DFNum DFDen Prob $>$ F

$\begin{array}{llll}3.9637 & 1 & 50.814 & 0.0519\end{array}$

t Test

1.9909
Prep $=$ Cold Chem, Sample Type $=$ SRAT, Analyte $=U$ Oneway Analysis of Batch Average Value By ICP

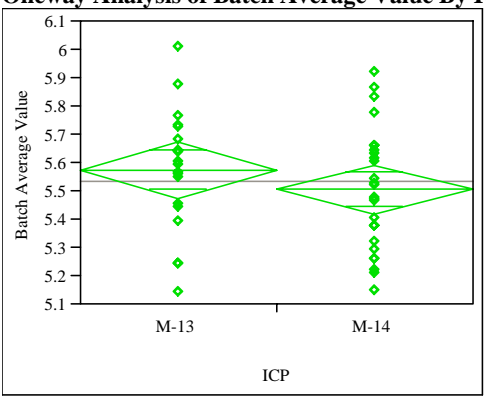

Oneway Anova

Summary of Fit

Rsquare

0.025827

Adj Rsquare

0.003172

Root Mean Square Error $\quad 0.21497$

Mean of Response

5.536115

Observations (or Sum Wgts) $\quad 45$

t Test

M-13-M-14

Assuming equal variances

Difference $\quad 0.06927$ t Ratio $\quad 1.067718$

Std Err Dif 0.06488 DF 43

Upper CL Dif 0.20012 Prob $>|\mathrm{t}| \quad 0.2916$

Lower CL Dif -0.06157 Prob $>\mathrm{t} \quad 0.1458$

$\begin{array}{lll}\text { Confidence } & 0.95 \text { Prob }<\mathrm{t} \quad 0.8542\end{array}$

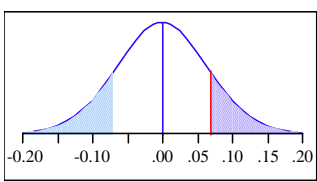

Analysis of Variance

Source DF Sum of Squares Mean Square F Ratio Prob > F

$\begin{array}{llllll}\text { ICP } & 1 & 0.0526826 & 0.052683 & 1.1400 & 0.2916\end{array}$

$\begin{array}{llll}\text { Error } & 43 & 1.9871141 & 0.046212\end{array}$

C. Total $44 \quad 2.0397967$

Means for Oneway Anova

Level Number Mean Std Error Lower 95\% Upper 95\%

$\begin{array}{lllllr}\text { M-13 } & 19 & 5.57614 & 0.04932 & 5.4767 & 5.6756\end{array}$

M-14 $\quad 265.50687 \quad 0.04216 \quad 5.4218 \quad 5.5919$

Std Error uses a pooled estimate of error variance

Means and Std Deviations

Level Number Mean Std Dev Std Err Mean Lower 95\% Upper 95\%

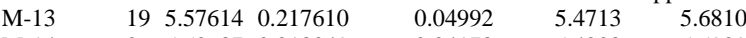

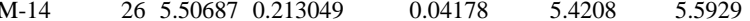

Tests that the Variances are Equal

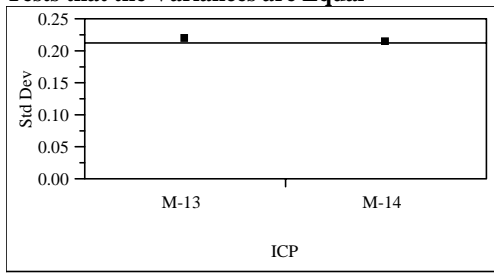

Level Count Std Dev MeanAbsDif to Mean MeanAbsDif to Median

M-13 $19 \quad 0.2176095 \quad 0.1628873 \quad 0.173785$

$\begin{array}{llll}19 & 0.2176095 & 0.1628873 & 0.1621228\end{array}$

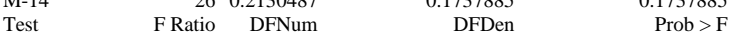

$\begin{array}{lrrrr}\text { O'Brien[.5] } & 0.0125 & 1 & 43 & 0.9114\end{array}$

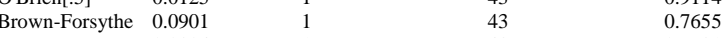

$\begin{array}{lllll}\text { Levene } & 0.0804 & 1 & 43 & 0.7781\end{array}$

$\begin{array}{lrrrr}\text { Bartlett } & 0.0092 & 1 & . & 0.9236 \\ \text { F Test 2-sided } & 1.0433 & 18 & 25 & 0.9047\end{array}$

Welch Anova testing Means Equal, allowing Std Devs Not Equal

F Ratio DFNum DFDen Prob > F

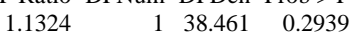

t Test

1.0641 
WSRC-STI-2006-00068

Revision 0

Exhibit A4. ICP Comparisons Using Cold Chem Batch Averages of Process Samples by Analyte

(continued)

Prep $=$ Cold Chem, Sample Type $=$ SRAT, Analyte $=$ U $/$ Ca Oneway Analysis of Batch Average Value By ICP

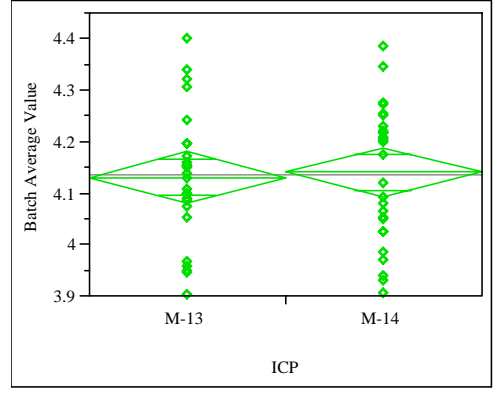

Oneway Anova

Summary of Fit

Rsquare

0.001377

Adj Rsquare

Root Mean Square

Mean of Response

0.128295

4.136885

Observations (or Sum Wgts) 54

t Test

M-13-M-14

Assuming equal variances

Difference $\quad-0.00936$ t Ratio $\quad-0.26782$

Std Err Dif $\quad 0.03494$ DF

Upper CL Dif 0.06076 Prob $>|t| \quad 0.7899$

Lower CL Dif -0.07947 Prob $>t \quad 0.6051$

Confidence $\quad 0.95$ Prob $<\mathrm{t} \quad 0.3949$

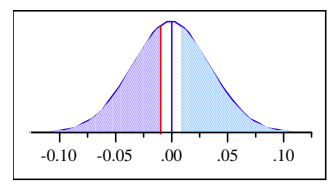

Analysis of Variance

Source DF Sum of Squares Mean Square F Ratio Prob $>$ F

$\begin{array}{llllll}\text { ICP } & 1 & 0.00118060 & 0.001181 & 0.0717 & 0.7899\end{array}$

$\begin{array}{llll}\text { Error } \quad 52 & 0.85589310 & 0.016459\end{array}$

C. Total $53 \quad 0.85707370$

Means for Oneway Anova

Level Number Mean Std Error Lower 95\% Upper 95\%

$\begin{array}{llllll}\text { M-13 } & 26 & 4.13203 & 0.02516 & 4.0815 & 4.1825\end{array}$

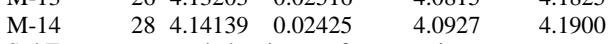

Std Error uses a pooled estimate of error variance

Means and Std Deviations

Level Number Mean Std Dev Std Err Mean Lower 95\% Upper 95\%

$\begin{array}{lllllll}\text { M-13 } & 26 & 4.13203 & 0.126668 & 0.02484 & 4.0809 & 4.1832\end{array}$

$\begin{array}{lllllll}\text { M-14 } & 28 & 4.14139 & 0.129782 & 0.02453 & 4.0911 & 4.1917\end{array}$

Tests that the Variances are Equal

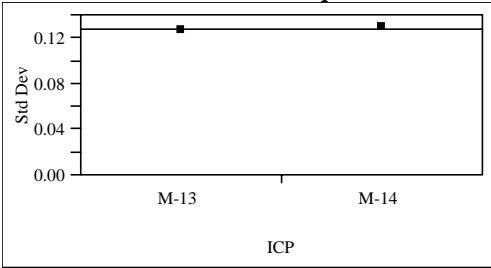

Level Count Std Dev MeanAbsDif to Mean MeanAbsDif to Median

M-13 $26 \quad 0.1266682 \quad 0.0951156$

M-14 280.12666820 .1121464

$\begin{array}{lrrrr}\text { M-14 } & \text { F Ratio } & \text { DFNum } & 0.1121464 & 0.1096008 \\ \text { Test } & \text { DFDen } & \text { Prob }>\text { F }\end{array}$

$\begin{array}{lrrrr}\text { O'Brien[.5] } & 0.0220 & 1 & 52 & 0.8826\end{array}$

Brown-Forsythe 0.4206

Levene $\quad 0.7572$

Bartlett $\quad 0.0150$

F Test 2-sided 1.0498

1
1
27

0.5195

0.3882

列

F Ratio DFNum DFDen Prob $>$ F

$\begin{array}{rrrr}0.0719 & 1 & 51.864 & 0.7897\end{array}$

t Test

0.2681
Prep=Cold Chem, Sample Type $=$ SRAT, Analyte $=\mathrm{Zr}$ Oneway Analysis of Batch Average Value By ICP

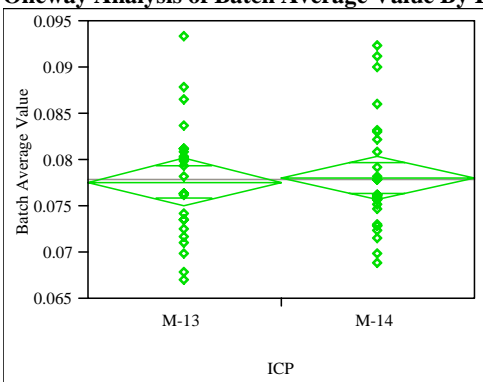

Oneway Anova

Summary of Fit

Rsquare

0.000927

Adj Rsquare

$-0.01866$

Root Mean Square Error $\quad 0.006222$

Mean of Response

0.077871

Observations (or Sum Wgts)

t Test

M-13-M-14

Assuming equal variances

Difference $\quad-0.00037$ t Ratio $\quad-0.21757$

Std Err Dif $\quad 0.00172$ DF 51

Upper CL Dif 0.00307 Prob $>|t| \quad 0.8286$

Lower CL Dif -0.00382 Prob $>t \quad 0.5857$

Confidence $\quad 0.95$ Prob $<\mathrm{t} \quad 0.4143$

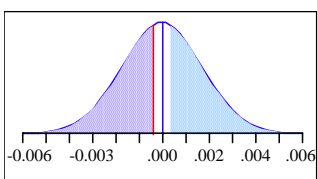

Analysis of Variance

Source DF Sum of Squares Mean Square F Ratio Prob $>$ F

$\begin{array}{llllll}\text { ICP } & 1 & 0.00000183 & 0.000002 & 0.0473 & 0.8286\end{array}$

$\begin{array}{llll}\text { Error } & 51 & 0.00197448 & 0.000039\end{array}$

C. Total $52 \quad 0.00197631$

Means for Oneway Anova

Level Number Mean Std Error Lower 95\% Upper 95\%

$\begin{array}{llllll}\text { M-13 } & 24 & 0.077667 & 0.00127 & 0.07512 & 0.08022\end{array}$

$\begin{array}{llllll}\text { M-14 } & 29 & 0.078040 & 0.00116 & 0.07572 & 0.08036\end{array}$

Std Error uses a pooled estimate of error variance

Means and Std Deviations

Level Number Mean Std Dev Std Err Mean Lower 95\% Upper 95\%

$\begin{array}{lllllll}\mathrm{M}-13 & 24 & 0.077667 & 0.006429 & 0.00131 & 0.07495 & 0.08038\end{array}$

$\begin{array}{lllllll}\text { M-13 } & 24 & 0.077667 & 0.006429 & 0.00131 & 0.07495 & 0.08038 \\ \text { M-14 } & 29 & 0.078040 & 0.006047 & 0.00112 & 0.07574 & 0.08034\end{array}$

Tests that the Variances are Equal

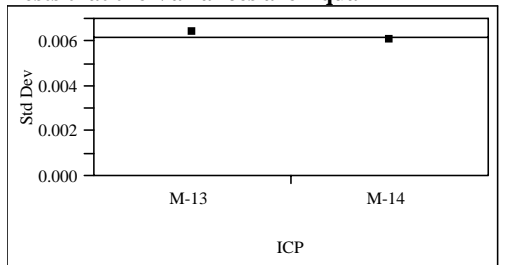

Level Count Std Dev MeanAbsDif to Mean MeanAbsDif to Median

$\begin{array}{lllll}\text { M-13 } & 24 & 0.0064287 & 0.0050972 & 0.0050972\end{array}$

$\begin{array}{lrrrr}\text { M-14 } & 29 & 0.0060472 & 0.0045815 & 0.0042816\end{array}$

$\begin{array}{llll}\text { Test } & \text { F Ratio DFNum } & \text { DFDen } & \text { Prob }>\text { F }\end{array}$

$\begin{array}{lrrrr}\text { O'Brien[.5] } & 0.0879 & 1 & 51 & 0.7680\end{array}$

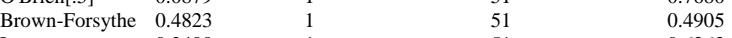

F Test 2-sided 1.1302

51

0.6263
0.7604

Welch Anova testing Means Equal, allowing Std Devs Not Equal

F Ratio DFNum DFDen Prob $>$ F

$\begin{array}{llll}0.0468 & 1 & 47.913 & 0.8297\end{array}$

t Test

0.2163 
WSRC-STI-2006-00068

Revision 0

Exhibit A5. Prep Comparisons Using SME Batch Averages by Analyte for each ICP

Sample Type $=$ SME, Analyte $=\mathrm{Al}, \mathrm{ICP}=\mathrm{M}-13$

Oneway Analysis of Batch Average Value By Prep/ICP

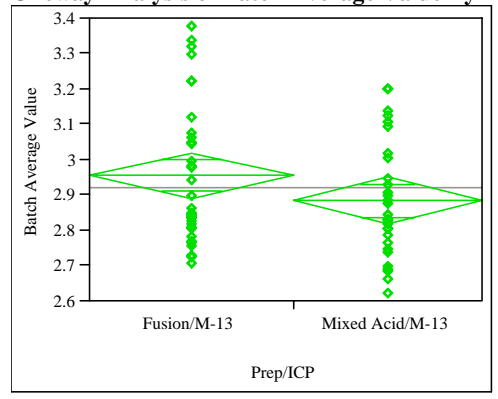

Oneway Anova

Summary of Fit

Root Mean Square Error $\quad 0.182434$

Mean of Response 2.922444

Observations (or Sum Wgts) 63

t Test

Fusion/M-13-Mixed Acid/M-13

Assuming equal variances

Difference $\quad 0.07178$ t Ratio 1.559757

Std Err Dif $\quad 0.04602$ DF 61

Upper CL Dif 0.16381 Prob $>|t| \quad 0.1240$

Lower CL Dif -0.02024 Prob $>t \quad 0.0620$

Confidence $\quad 0.95$ Prob $<\mathrm{t} \quad 0.9380$

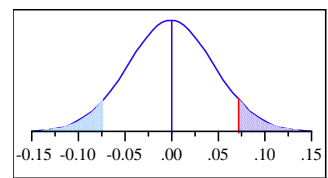

Analysis of Variance

Source DF Sum of Squares Mean Square F Ratio Prob $>$ F

$\begin{array}{llllll}\text { Prep/ICP } & 1 & 0.0809699 & 0.080970 & 2.4328 & 0.1240\end{array}$

$\begin{array}{llll}\text { Error } & 61 & 2.0302020 & 0.033282\end{array}$

C. Total $62 \quad 2.1111719$

Means for Oneway Anova

Level Number Mean Std Error Lower 95\% Upper 95\%

$\begin{array}{lrrrrr}\text { Fusion/M-13 } & 33 & 2.95663 & 0.03176 & 2.8931 & 3.0201\end{array}$

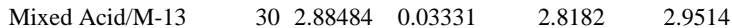

Std Error uses a pooled estimate of error variance

Tests that the Variances are Equal

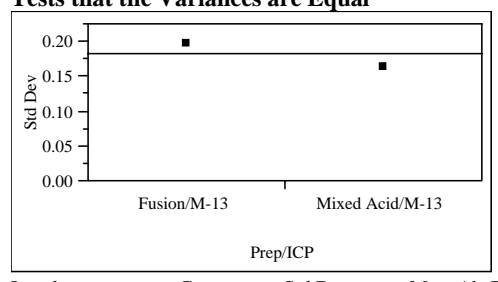

\begin{tabular}{|c|c|c|c|c|c|}
\hline Level & Count & Std Dev & & MeanAbsDif to Mean & $\begin{array}{r}\text { MeanAbsDif to } \\
\text { Median }\end{array}$ \\
\hline Fusion/M-13 & 33 & 0.1978801 & & 0.1653373 & 0.1588384 \\
\hline $\begin{array}{l}\text { Mixed Acid/M- } \\
13\end{array}$ & 30 & 0.1637063 & & 0.1320459 & 0.1287778 \\
\hline & $\begin{array}{r}F \\
\text { Ratio }\end{array}$ & DFNum & DFDen & Prob $>F$ & \\
\hline O'Brien[.5] & 1.4589 & 1 & 61 & 0.2318 & \\
\hline Brown-Forsythe & 0.8278 & 1 & 61 & 0.3665 & \\
\hline Levene & 1.7560 & 1 & 61 & 0.1901 & \\
\hline Bartlett & 1.0630 & 1 & & 0.3025 & \\
\hline F Test 2-sided & 1.4611 & 32 & 29 & $9 \quad 0.3053$ & \\
\hline \multicolumn{6}{|c|}{ Welch Anova testing Means Equal, allowing Std Devs Not Equal } \\
\hline F Ratio DFNu & m DFDen & n Prob > & & & \\
\hline 2.4774 & 160.489 & $9 \quad 0.120$ & & & \\
\hline
\end{tabular}

Sample Type=SME, Analyte=Al, ICP=M-14

Oneway Analysis of Batch Average Value By Prep/ICP

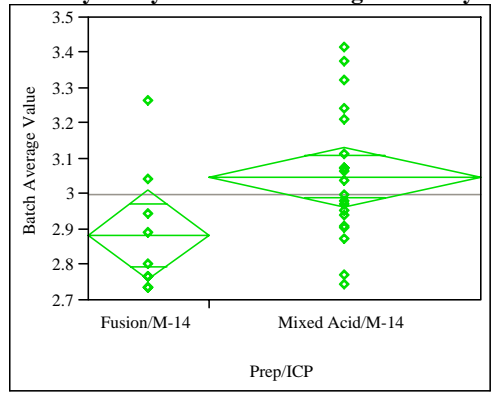

Oneway Anova

Summary of Fit

Rsquare $\quad 0.156768$

Adj Rsquare $\quad 0.125537$

Root Mean Square Error $\quad 0.183954$

Mean of Response 2.999477

Observations (or Sum Wgts) 29

t Test

Fusion/M-14-Mixed Acid/M-14

Assuming equal variances

Difference $\quad-0.16543$ t Ratio $\quad-2.24046$

Std Err Dif $\quad 0.07384$ DF 27

Upper CL Dif -0.01393 Prob $>|t| \quad 0.0335$

Lower CL Dif -0.31693 Prob $>t \quad 0.9833$

Confidence $\quad 0.95$ Prob $<\mathrm{t} \quad 0.0167$

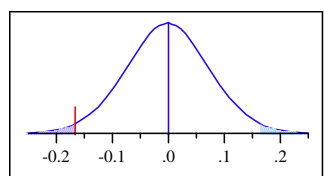

Analysis of Variance

Source DF Sum of Squares Mean Square F Ratio Prob $>$ F

$\begin{array}{llllll}\text { Prep/ICP } & 1 & 0.1698601 & 0.169860 & 5.0196 & 0.0335\end{array}$

$\begin{array}{llll}\text { Error } & 27 & 0.9136543 & 0.033839\end{array}$

C. Total $28 \quad 1.0835144$

Means for Oneway Anova

Level Number Mean Std Error Lower 95\% Upper 95\%

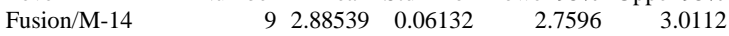

Mixed Acid/M-14 $203.05082 \quad 0.04113 \quad 2.9664 \quad 3.1352$

Std Error uses a pooled estimate of error variance

Tests that the Variances are Equal

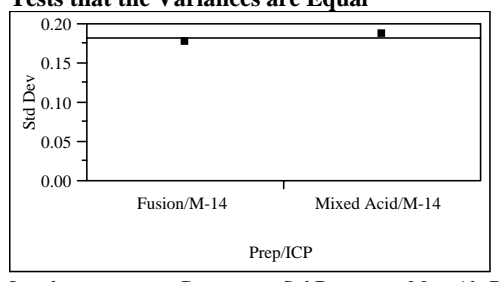

\begin{tabular}{|c|c|c|c|c|c|}
\hline Level & Count & Std De & & MeanAbsDif to Mean & $\begin{array}{r}\text { MeanAbsDif to } \\
\text { Median }\end{array}$ \\
\hline Fusion/M-14 & 9 & 0.177211 & & 0.1354321 & 0.1307407 \\
\hline $\begin{array}{l}\text { Mixed Acid/M- } \\
14\end{array}$ & 20 & 0.186720 & & 0.1454483 & 0.1442833 \\
\hline Test & $\begin{array}{r}\mathrm{F} \\
\text { Ratio }\end{array}$ & DFNum & DFDen & Prob $>$ F & \\
\hline O'Brien[.5] & 0.0330 & 1 & 27 & 0.8572 & \\
\hline Brown-Forsythe & 0.0734 & 1 & 27 & 0.7885 & \\
\hline Levene & 0.0517 & 1 & 27 & 0.8219 & \\
\hline Bartlett & 0.0290 & 1 & & 0.8649 & \\
\hline F Test 2-sided & 1.1102 & 19 & 8 & 0.9292 & \\
\hline \multicolumn{6}{|c|}{ Welch Anova testing Means Equal, allowing Std Devs Not Equal } \\
\hline F Ratio DFNur & m DFDe & n Prob > & & & \\
\hline 5.2300 & 116.27 & $9 \quad 0.03$ & & & \\
\hline
\end{tabular}


WSRC-STI-2006-00068

Revision 0

Exhibit A5. Prep Comparisons Using SME Batch Averages by Analyte for each ICP

Sample Type $=$ SME, Analyte $=\mathrm{Al} / \mathrm{Ca}, \mathrm{ICP}=\mathrm{M}-13$

Oneway Analysis of Batch Average Value By Prep/ICP

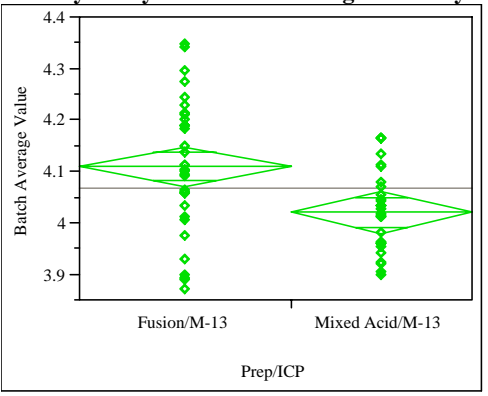

Oneway Anova

Summary of Fit

Rsquare

0.14255

Adj Rsquare

0.127507

Root Mean Square Error $\quad 0.109961$

Mean of Response

4.069299

Observations (or Sum Wgts) 59

t Test

Fusion/M-13-Mixed Acid/M-13

Assuming equal variances

Difference $\quad 0.088455$ t Ratio $\quad 3.078339$

Std Err Dif 0.028735 DF

Upper CL Dif 0.145995 Prob $>|\mathrm{t}|>0.03$

Lower CL Dif 0.030915 Prob $>\mathrm{t} \quad 0.0016$

$\begin{array}{lll}\text { Confidence } & 0.95 \text { Prob }<\mathrm{t} \quad 0.9984\end{array}$

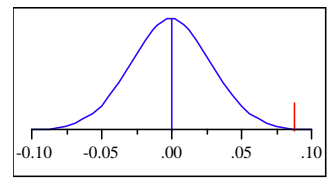

Analysis of Variance

Source DF Sum of Squares Mean Square F Ratio Prob $>$ F

$\begin{array}{llllll}\text { Prep/ICP } & 1 & 0.11457950 & 0.114580 & 9.4762 & 0.0032\end{array}$

$\begin{array}{llll}\text { Error } & 57 & 0.68920584 & 0.012091\end{array}$

C. Total $58 \quad 0.80378534$

Means for Oneway Anova

Level Number Mean Std Error Lower 95\% Upper 95\%

$\begin{array}{lrrrrr}\text { Fusion/M-13 } & 32 & 4.10978 & 0.01944 & 4.0709 & 4.1487\end{array}$

$\begin{array}{llllll}\text { Mixed Acid/M-13 } & 27 & 4.02132 & 0.02116 & 3.9789 & 4.0637\end{array}$

Std Error uses a pooled estimate of error variance

Tests that the Variances are Equal

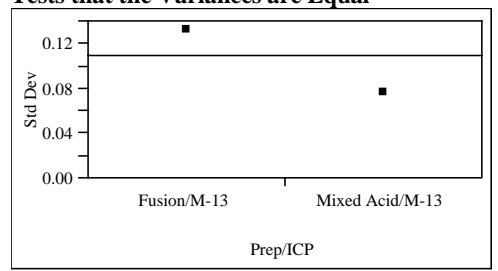

\begin{tabular}{|c|c|c|c|c|}
\hline Level & Count & Std De & & MeanAbsDif to Mean \\
\hline Fusion/M-13 & 32 & 0.131801 & & 0.10621 \\
\hline $\begin{array}{l}\text { Mixed Acid/M- } \\
13\end{array}$ & 27 & 0.076129 & & $0.0603 s$ \\
\hline Test & $\begin{array}{r}F \\
\text { Ratio }\end{array}$ & DFNum & DFDen & Prob $>$ \\
\hline O'Brien[.5] & 8.1784 & 1 & 57 & \\
\hline Brown-Forsythe & 7.3850 & 1 & 57 & 0.00 \\
\hline Levene & 7.6267 & 1 & 57 & \\
\hline Bartlett & 7.7496 & 1 & & \\
\hline F Test 2-sided & 2.9973 & 31 & 26 & 0.0 \\
\hline
\end{tabular}

Welch Anova testing Means Equal, allowing Std Devs Not Equal

F Ratio DFNum DFDen Prob $>$ F

$\begin{array}{llll}10.3289 & 1 & 50.878 & 0.0023\end{array}$

t Test

3.2139
Sample Type $=$ SME, Analyte $=$ Al $/$ Ca, ICP $=$ M-14

(continued)

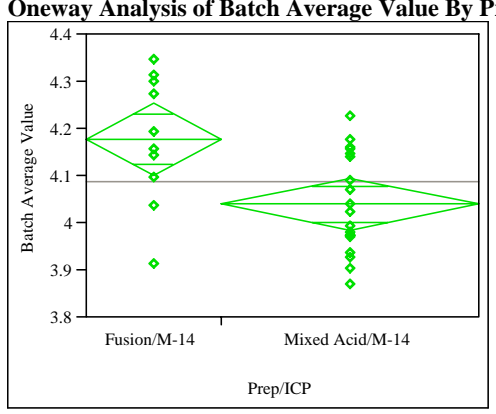

Oneway Anova

Summary of Fit

Rsquare

0.252257

Adj Rsquare

0.224562

Root Mean Square Error $\quad 0.116338$

Mean of Response 4.088522

Observations (or Sum Wgts) 29

t Test

Fusion/M-14-Mixed Acid/M-14

Assuming equal variances

Difference $\quad 0.137174$ t Ratio 3.018052

Std Err Dif 0.045451 DF 27

Upper CL Dif 0.230432 Prob $>|t| \quad 0.0055$

Lower CL Dif 0.043916 Prob $>$ t 0.0027

$\begin{array}{lll}\text { Confidence } & 0.95 \text { Prob }<\mathrm{t} \quad 0.9973\end{array}$

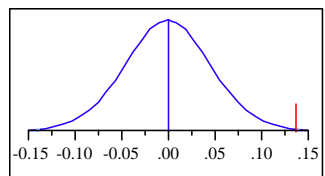

Analysis of Variance

Source DF Sum of Squares Mean Square F Ratio Prob $>$ F

$\begin{array}{llllll}\text { Prep/ICP } & 1 & 0.12328212 & 0.123282 & 9.1086 & 0.0055\end{array}$

$\begin{array}{llll}\text { Error } & 27 & 0.36543517 & 0.013535\end{array}$

C. Total $28 \quad 0.48871729$

Means for Oneway Anova

Level Number Mean Std Error Lower 95\% Upper 95\%

$\begin{array}{lllllr}\text { Fusion/M-14 } & 10 & 4.17839 & 0.03679 & 4.1029 & 4.2539\end{array}$

$\begin{array}{lllll}\text { Mixed Acid/M-14 } & 194.04122 & 0.02669 & 3.9865 & 4.0960\end{array}$

Std Error uses a pooled estimate of error variance

Tests that the Variances are Equal
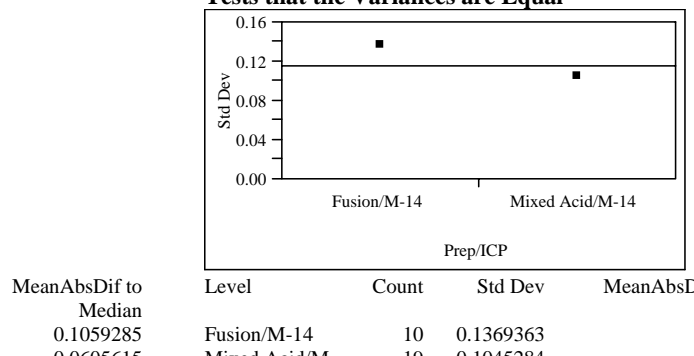

0.0605615

$\begin{array}{lllrr}\text { Fusion/M-14 } & 10 & 0.1369363 & 0.1077499 & 0.1077499 \\ \text { Mixed Acid/M- } & 19 & 0.1045284 & 0.0891671 & 0.0892608\end{array}$

Test F DFNum DFDen Prob $>$

$\begin{array}{lrlll} & \text { Ratio } & & & \\ \text { O'Brien[.5] } & 1.4545 & 1 & 27 & 0.2383\end{array}$

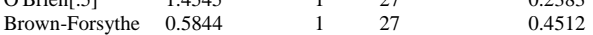

$\begin{array}{lllll}\text { Levene } & 0.6216 & 1 & 27 & 0.4373\end{array}$

$\begin{array}{lrrrr}\text { Bartlett } & 0.8813 & 1 & . & 0.3478 \\ \text { F Test 2-sided } & 1.7162 & 9 & 18 & 0.3149\end{array}$

Welch Anova testing Means Equal, allowing Std Devs Not Equal

F Ratio DFNum DFDen Prob > F

$\begin{array}{llll}7.6796 & 1 & 14.676 & 0.0145\end{array}$

t Test

2.7712 
WSRC-STI-2006-00068

Revision 0

Exhibit A5. Prep Comparisons Using SME Batch Averages by Analyte for each ICP

Sample Type $=$ SME, Analyte $=\mathrm{Al} / \mathrm{Mg}$, ICP $=\mathrm{M}-13$ Oneway Analysis of Batch Average Value By Prep/ICP

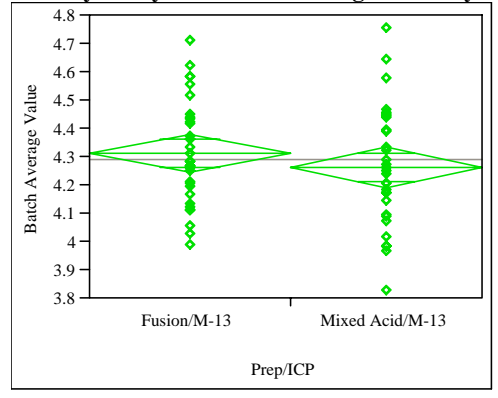

Oneway Anova

Summary of Fit

Rsquare

Adj Rsquare

Root Mean Square Error

Mean of Response

0.016866

0.001009

0.196551

4.290373

Observations (or Sum Wgts) 64

t Test

Fusion/M-13-Mixed Acid/M-13

Assuming equal variances

Difference $\quad 0.05070$ t Ratio 1.031333

Std Err Dif $\quad 0.04916$ DF

Upper CL Dif 0.14897 Prob $>|\mathrm{t}| \quad 0.3064$

Lower CL Dif -0.04757 Prob $>\mathrm{t} \quad 0.1532$

Confidence $\quad 0.95$ Prob $<\mathrm{t} \quad 0.8468$

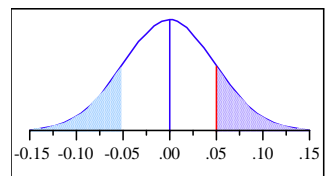

Analysis of Variance

Source DF Sum of Squares Mean Square F Ratio Prob $>$ F

$\begin{array}{llllll}\text { Prep/ICP } & 1 & 0.0410911 & 0.041091 & 1.0636 & 0.3064\end{array}$

$\begin{array}{llll}\text { Error } & 62 & 2.3951995 & 0.038632\end{array}$

C. Total $63 \quad 2.4362906$

Means for Oneway Anova

Level Number Mean Std Error Lower 95\% Upper 95\%

$\begin{array}{lllllr}\text { Fusion/M-13 } & 33 & 4.31493 & 0.03422 & 4.2465 & 4.3833\end{array}$

$\begin{array}{lllll}\text { Mixed Acid/M-13 } & 31 & 4.26423 & 0.03530 & 4.1937\end{array} 4.3348$

Std Error uses a pooled estimate of error variance

Tests that the Variances are Equal
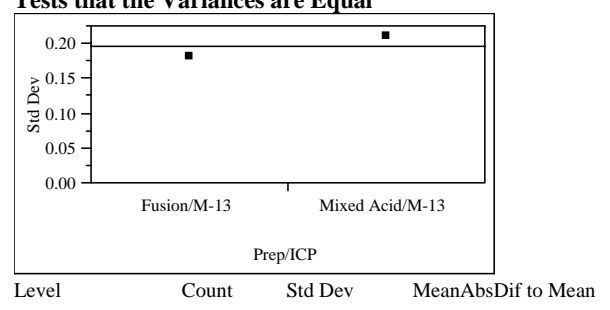

Fusion/M-13

Mixed Acid/M-

Conter

MeanAbsDif to Mean

13

Test

$31 \quad 0.2112706$

0.1469595

F DFNum DFD

0.1660928

O'Brien[.5]

Ratio
0.8213

Brown-Forsythe 0.5162

Levene $\quad 0.4385$

Bartlett

0.6940

1.3524

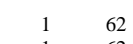

$\begin{array}{ll}1 & 62 \\ 1 & 62 \\ 1 & 62\end{array}$

$\begin{array}{rr}1 & 62 \\ 1 & 32 \\ 30 & 32\end{array}$

0.3683

0.4752

0.5103

0.4027

Welch Anova testing Means Equal, allowing Std Devs Not Equal

MeanAbsDif to Median 0.1445382 0.1659547

F Ratio DFNum DFDen Prob > F

$\begin{array}{lrrr}1.0536 & 1 & 59.319 & 0.3089\end{array}$

t Test

1.0264
Sample Type=SME, Analyte=Al/Mg, ICP=M-14

(continued)
Oneway Analysis of Batch Average Value By Prep/ICP

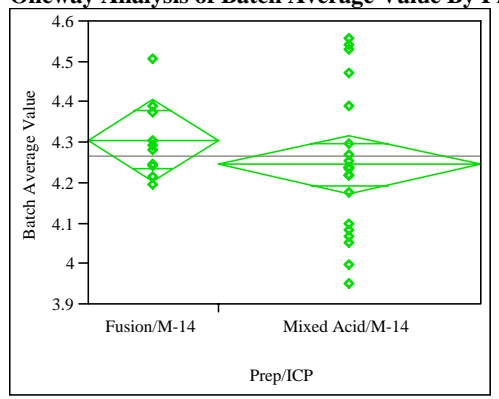

Oneway Anova

Summary of Fit

Rsquare

0.034094

Adj Rsquare

$-0.0004$

Root Mean Square Error $\quad 0.157508$

Mean of Response $\quad 4.266741$

Observations (or Sum Wgts) 30

t Test

Fusion/M-14-Mixed Acid/M-14

Assuming equal variances

Difference $\quad 0.06065$ t Ratio 0.994144

Std Err Dif $\quad 0.06100$ DF 28

Upper CL Dif 0.18560 Prob $>|t| \quad 0.3287$

Lower CL Dif -0.06431 Prob $>\mathrm{t} \quad 0.1643$

$\begin{array}{lll}\text { Confidence } & 0.95 \text { Prob }<\mathrm{t} \quad 0.8357\end{array}$

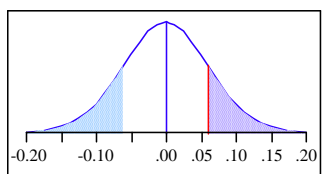

Analysis of Variance

Source DF Sum of Squares Mean Square F Ratio Prob $>$ F

$\begin{array}{llllll}\text { Prep/ICP } & 1 & 0.02451898 & 0.024519 & 0.9883 & 0.3287\end{array}$

$\begin{array}{llll}\text { Error } & 28 & 0.69464311 & 0.024809\end{array}$

C. Total $29 \quad 0.71916210$

Means for Oneway Anova

Level Number Mean Std Error Lower 95\% Upper 95\%

$\begin{array}{lllllr}\text { Fusion/M-14 } & 10 & 4.30717 & 0.04981 & 4.2051 & 4.4092\end{array}$

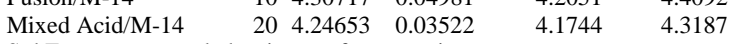

Std Error uses a pooled estimate of error variance

Tests that the Variances are Equal

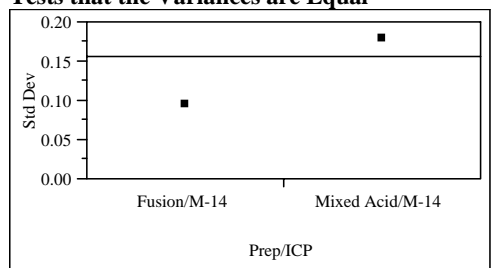

$\begin{array}{lrrrr}\text { Level } & \text { Count } & \text { Std Dev } & \text { MeanAbsDif to Mean } & \begin{array}{r}\text { MeanAbsDif to } \\ \text { Median }\end{array} \\ \text { Fusion/M-14 } & 10 & 0.0952088 & 0.0715208 & 0.0688280 \\ \text { Mixed Acid/M- } & 20 & 0.1796284 & 0.1356999 & 0.1346623\end{array}$

14

F DFNum DFDen Prob $>$ F

$\begin{array}{lllll}\text { O'Brien[.5] } & 3.4905 & 1 & 28 & 0.0722\end{array}$

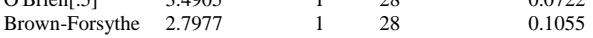

$\begin{array}{lllll}\text { Levene } & 2.7938 & 1 & 28 & 0.1058\end{array}$

$\begin{array}{lrrrr}\text { Bartlett } & 3.9010 & 1 & . & 0.0483 \\ \text { F Test 2-sided } & 3.5596 & 19 & 9 & 0.0558\end{array}$

Welch Anova testing Means Equal, allowing Std Devs Not Equal

F Ratio DFNum DFDen Prob $>$ F

$\begin{array}{llll}1.4596 & 1 & 27.813 & 0.2372\end{array}$

t Test

1.2081 
WSRC-STI-2006-00068

Revision 0

Exhibit A5. Prep Comparisons Using SME Batch Averages by Analyte for each ICP

Sample Type $=$ SME, Analyte $=\mathrm{Al} / \mathrm{Mn}, \mathrm{ICP}=\mathrm{M}-13$ Oneway Analysis of Batch Average Value By Prep/ICP

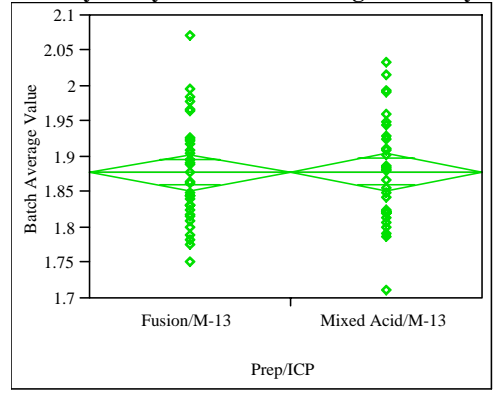

Oneway Anova

Summary of Fit

Rsquare

0.00003

Adj Rsquare

$-0.0161$

Root Mean Square Erro

Mean of Response

0.074381

Observations (or Sum Wgts) 64

t Test

Fusion/M-13-Mixed Acid/M-13

Assuming equal variances

Difference $\quad-0.00081$ t Ratio -0.04343

Std Err Dif $\quad 0.01860$ DF

Upper CL Dif 0.03638 Prob $>|\mathrm{t}| \quad 0.9655$

Lower CL Dif -0.03800 Prob $>\mathrm{t} \quad 0.5173$

Confidence

0.95 Prob $<\mathrm{t}$

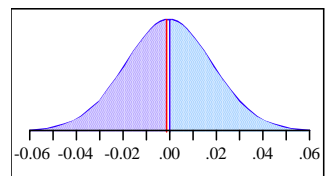

Analysis of Variance

Source DF Sum of Squares Mean Square F Ratio Prob $>$ F $\begin{array}{lllllll}\text { Prep/ICP } & 1 & 0.00001044 & 0.000010 & 0.0019 & 0.9655\end{array}$

$\begin{array}{llll}\text { Error } & 62 & 0.34301569 & 0.005533\end{array}$

C. Total $63 \quad 0.34302612$

Means for Oneway Anova

Level Number Mean Std Error Lower 95\% Upper 95\%

$\begin{array}{lrrrrr}\text { Fusion/M-13 } & 33 & 1.87834 & 0.01295 & 1.8525 & 1.9042\end{array}$

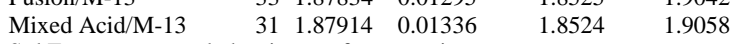

Std Error uses a pooled estimate of error variance

Tests that the Variances are Equal

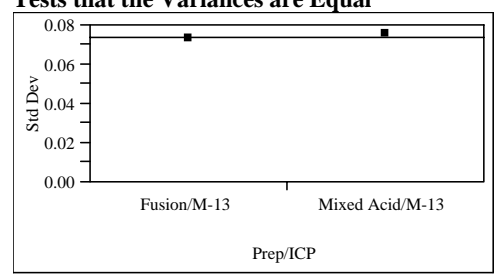

\begin{tabular}{lrrrr} 
Level & Count & Std Dev & \multicolumn{2}{r}{ MeanAbsDif to Mean } \\
Fusion/M-13 & 33 & 0.0733151 & & 0.0595393 \\
$\begin{array}{l}\text { Mixed Acid/M- } \\
13\end{array}$ & 31 & 0.0755010 & 0.0609041 \\
Test & F & DFNum & DFDen & Prob > F \\
& Ratio & & & \\
O'Brien[.5] & 0.0299 & 1 & 62 & 0.8633 \\
Brown-Forsythe & 0.0232 & 1 & 62 & 0.8795 \\
Levene & 0.0166 & 1 & 62 & 0.8978 \\
Bartlett & 0.0263 & 1 &. & 0.8711 \\
F Test 2-sided & 1.0605 & 30 & 32 & 0.8681
\end{tabular}

Welch Anova testing Means Equal, allowing Std Devs Not Equal

F Ratio DFNum DFDen Prob $>$ F

$\begin{array}{llll}0.0019 & 1 & 61.47 & 0.9655\end{array}$

$\mathrm{t}$ Test

0.0434
Sample Type $=$ SME, Analyte $=$ Al/Mn, ICP=M-14

(continued)

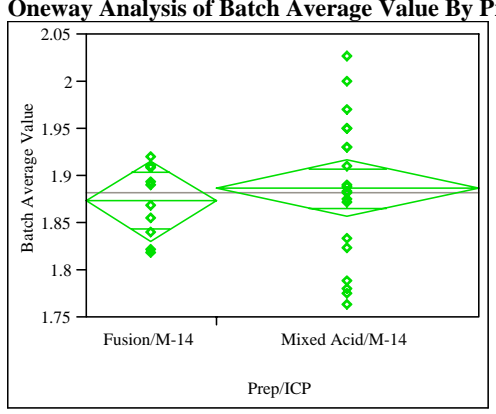

Oneway Anova

Summary of Fit

Rsquare 0.009733

Adj Rsquare

Root Mean Square Error $\quad 0.06563$

Mean of Response 1.88242

Observations (or Sum Wgts) $\quad 30$

t Test

Fusion/M-14-Mixed Acid/M-14

Assuming equal variances

Difference $\quad-0.01333$ t Ratio -0.52459

Std Err Dif $\quad 0.02542$ DF 28

Upper CL Dif 0.03873 Prob $>|t| \quad 0.6040$

Lower CL Dif -0.06540 Prob $>\mathrm{t} \quad 0.6980$

$\begin{array}{lll}\text { Confidence } & 0.95 \text { Prob }<\mathrm{t} \quad 0.3020\end{array}$

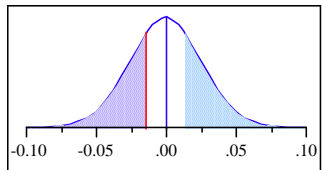

Analysis of Variance

Source DF Sum of Squares Mean Square F Ratio Prob > F

$\begin{array}{llllll}\text { Prep/ICP } & 1 & 0.00118536 & 0.001185 & 0.2752 & 0.6040\end{array}$

$\begin{array}{llll}\text { Error } & 28 & 0.12060597 & 0.004307\end{array}$

C. Total $29 \quad 0.12179133$

Means for Oneway Anova

Level Number Mean Std Error Lower 95\% Upper 95\%

$\begin{array}{llllrr}\text { Fusion/M-14 } & 10 & 1.87353 & 0.02075 & 1.8310 & 1.9160\end{array}$

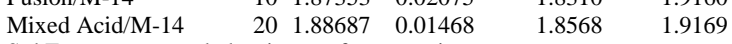

Std Error uses a pooled estimate of error variance

Tests that the Variances are Equal
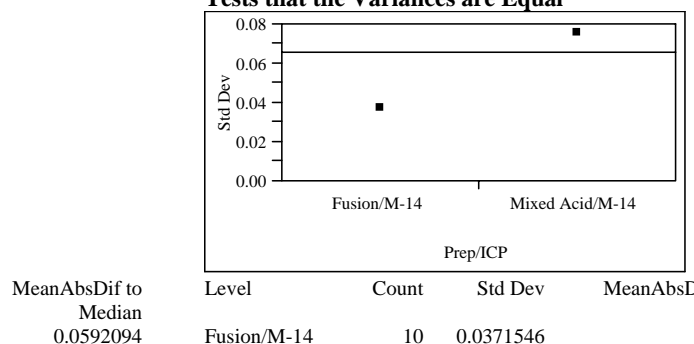

0.0592094

0.0608731

$\begin{array}{lrrrr}\text { Level } & \text { Count } & \text { Std Dev } & \text { MeanAbsDif to Mean } & \begin{array}{r}\text { MeanAbsDif to } \\ \text { Median }\end{array} \\ \text { Fusion/M-14 } & 10 & 0.0371546 & 0.0316282 & 0.0316282 \\ \text { Mixed Acid/M- } & 20 & 0.0754571 & 0.0587624 & 0.0587624\end{array}$

14

$\begin{array}{llll}\text { Test } & \text { F } & \text { DFNum DFDen } & \text { Prob }\end{array}$

$\begin{array}{lrlll} & \text { Ratio } & & & \\ \text { O'Brien[.5] } & 4.2135 & 1 & 28 & 0.0496\end{array}$

Brown-Forsythe $\begin{array}{llll}3.2775 & 1 & 28 & 0.0810\end{array}$

$\begin{array}{lllll}\text { Levene } & 3.3084 & 1 & 28 & 0.0810 \\ \end{array}$

$\begin{array}{lrrrr}\text { Bartlett } & 4.7370 & 1 & . & 0.0295 \\ \text { F Test 2-sided } & 4.1245 & 19 & 9 & 0.0344\end{array}$

Welch Anova testing Means Equal, allowing Std Devs Not Equal

F Ratio DFNum DFDen Prob $>$ F

$\begin{array}{llll}0.4206 & 1 & 27.997 & 0.5219\end{array}$

t Test

0.6485 
WSRC-STI-2006-00068

Revision 0

Exhibit A5. Prep Comparisons Using SME Batch Averages by Analyte for each ICP

Sample Type $=$ SME, Analyte $=B$, ICP $=M-13$ Oneway Analysis of Batch Average Value By Prep/ICP

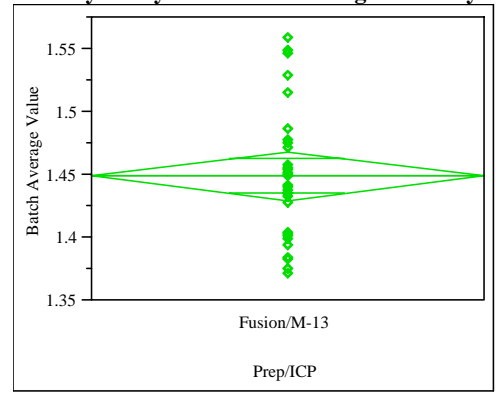

Missing Rows

32Oneway Anova

Summary of Fit

Rsquare

Adj Rsquare

0
0
0.05207
1.448972

$\begin{array}{lr}\text { Root Mean Square Error } & 0.05207 \\ \text { Mean of Response } & 1.448972\end{array}$

Observations (or Sum

Analysis of Variance

Source DF Sum of Squares Mean Square F Ratio Prob $>$ F

Prep/ICP 00.00000000

Error $\quad 29-0.07862767$

C. Total $29 \quad 0.07862767$

Means for Oneway Anova

Level Number Mean Std Error Lower 95\% Upper 95\%

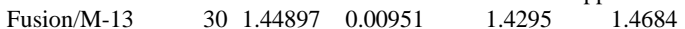

Std Error uses a pooled estimate of error variance

Sample Type $=$ SME, Analyte $=B$, ICP $=$ M-14

Oneway Analysis of Batch Average Value By Prep/ICP

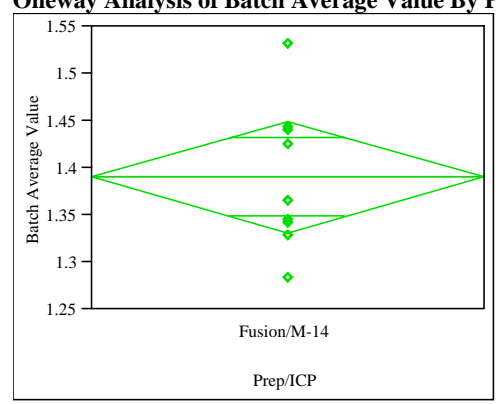

Missing Rows

20Oneway Anova

Summary of Fit

Adj Rsquare

Root Mean Square Error $\quad 0.076507$

Mean of Response $\quad 1.390241$

Observations (or Sum Wgts)

Analysis of Variance

Source DF Sum of Squares Mean Square F Ratio Prob $>$ F

Prep/ICP 00.00000000

$\begin{array}{llll}\text { Error } & 8 & 0.04682651 & 0.005853\end{array}$

C. Total $8 \quad 0.04682651$

Means for Oneway Anova

Level Number Mean Std Error Lower 95\% Upper 95\%

$\begin{array}{lrrrr}\text { Fusion/M-14 } & 9 & 1.39024 & 0.02550 & 1.3314\end{array}$

Std Error uses a pooled estimate of error variance
Sample Type $=$ SME, Analyte $=\mathrm{B} / \mathrm{Li}$, ICP $=M-13$

(continued)
Oneway Analysis of Batch Average Value By Prep/ICP

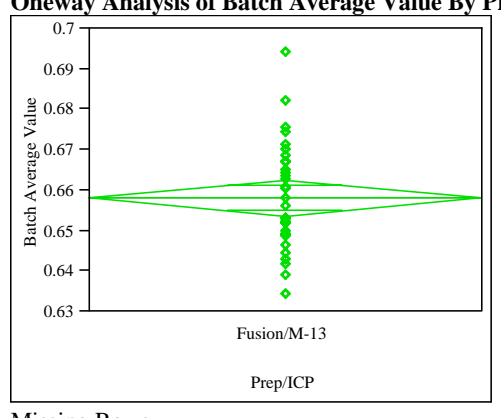

Missing Rows

32Oneway Anova

Summary of Fit

Rsquare

Adj Rsquare

$\begin{array}{ll}\text { Root Mean Square Error } & 0.012936 \\ \text { Mean of Response } & 0.658095\end{array}$

Observations (or Sum Wgts) 34

Analysis of Variance

Source DF Sum of Squares Mean Square F Ratio Prob > F

Prep/ICP 00.00000000

$\begin{array}{llll}\text { Error } & 33 & 0.00552209 & 0.000167\end{array}$

C. Total $33 \quad 0.00552209$

Means for Oneway Anova

Level Number Mean Std Error Lower 95\% Upper 95\% $\begin{array}{llllll}\text { Fusion/M-13 } & 34 & 0.658095 & 0.00222 & 0.65358 & 0.66261\end{array}$ Std Error uses a pooled estimate of error variance

Sample Type $=$ SME, Analyte $=\mathrm{B} / \mathrm{Li}$, ICP $=\mathrm{M}-14$

Oneway Analysis of Batch Average Value By Prep/ICP

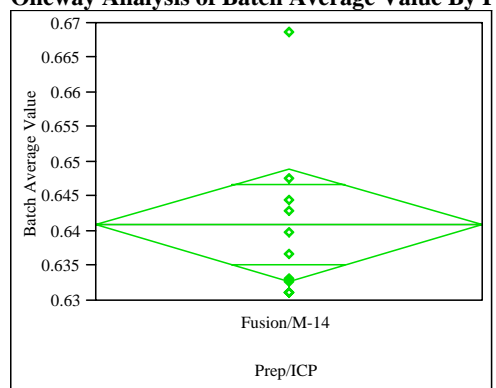

Missing Rows

20Oneway Anova

Summary of Fit

Rsquare

Adj Rsquare

Root Mean Square Error

Mean of Response 0.640935

Observations (or Sum Wgts) 10

Analysis of Variance

Source DF Sum of Squares Mean Square F Ratio Prob > F

Prep/ICP 00.00000000

$\begin{array}{llll}\text { Error } & 9 & 0.00116561 & 0.000130\end{array}$

C. Total $9 \quad 0.00116561$

Means for Oneway Anova

Level Number Mean Std Error Lower 95\% Upper 95\%

$\begin{array}{llllll}\text { Fusion/M-14 } & 10 & 0.640935 & 0.00360 & 0.63279 & 0.64908\end{array}$

Std Error uses a pooled estimate of error variance 
WSRC-STI-2006-00068

Revision 0

Exhibit A5. Prep Comparisons Using SME Batch Averages by Analyte for each ICP

Sample Type $=$ SME, Analyte $=$ Ca, ICP $=$ M-13

Oneway Analysis of Batch Average Value By Prep/ICP

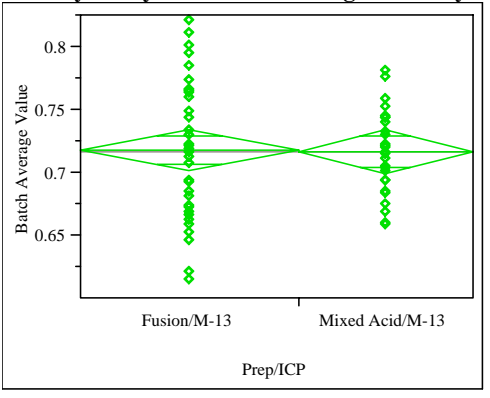

Oneway Anova

Summary of Fit

Rsquare

0.00015

Adj Rsquare

$-0.0168$

Root Mean Square Error $\quad 0.046507$

Mean of Response

0.717481

Observations (or Sum Wgts)

t Test

Fusion/M-13-Mixed Acid/M-13

Assuming equal variances

Difference 0.00113 t Ratio 0.094137

Std Err Dif $\quad 0.01199$ DF

Upper CL Dif 0.02512 Prob $>|t| \quad 0.9253$

Lower CL Dif -0.02286 Prob $>t \quad 0.4627$

$\begin{array}{lll}\text { Confidence } & 0.95 \text { Prob }<\mathrm{t} \quad 0.5373\end{array}$

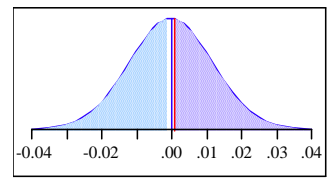

Analysis of Variance

Source DF Sum of Squares Mean Square F Ratio Prob $>$ F

$\begin{array}{llllll}\text { Prep/ICP } & 1 & 0.00001917 & 0.000019 & 0.0089 & 0.9253\end{array}$

$\begin{array}{llll}\text { Error } & 59 & 0.12760867 & 0.002163\end{array}$

C. Total $60 \quad 0.12762784$

Means for Oneway Anova

Level Number Mean Std Error Lower 95\% Upper 95\%

$\begin{array}{lllllr}\text { Fusion/M-13 } & 34 & 0.717980 & 0.00798 & 0.70202 & 0.73394\end{array}$

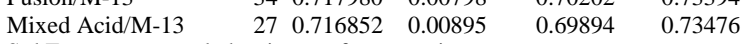

Std Error uses a pooled estimate of error variance

Tests that the Variances are Equal

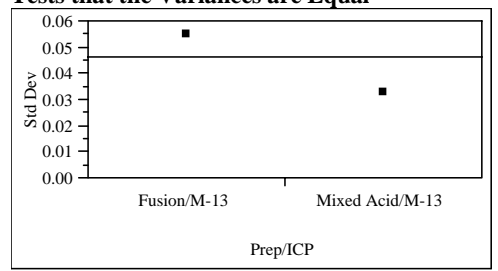

\begin{tabular}{lrrrr} 
Level & Count & Std Dev & \multicolumn{2}{r}{ MeanAbsDif to Mean } \\
Fusion/M-13 & 34 & 0.0548795 & & 0.0451569 \\
Mixed Acid/M- & 27 & 0.0329455 & & 0.0263759 \\
13 & & & & \\
Test & F & DFNum & DFDen & Prob > F \\
& Ratio & & & \\
O'Brien[.5] & 8.2089 & 1 & 59 & 0.0058 \\
Brown-Forsythe & 7.9063 & 1 & 59 & 0.0067 \\
Levene & 7.9299 & 1 & 59 & 0.0066 \\
Bartlett & 6.8815 & 1 &. & 0.0087 \\
F Test 2-sided & 2.7748 & 33 & 26 & 0.0091
\end{tabular}

Welch Anova testing Means Equal, allowing Std Devs Not Equal

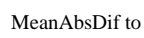
Median
0.0451569

0.0264136

F Ratio DFNum DFDen Prob $>$ F

$\begin{array}{llll}0.0099 & 1 & 55.295 & 0.9211\end{array}$

$\mathrm{t}$ Test

0.0994
Sample Type=SME, Analyte $=\mathrm{Ca}, \mathrm{ICP}=\mathrm{M}-14$

(continued)

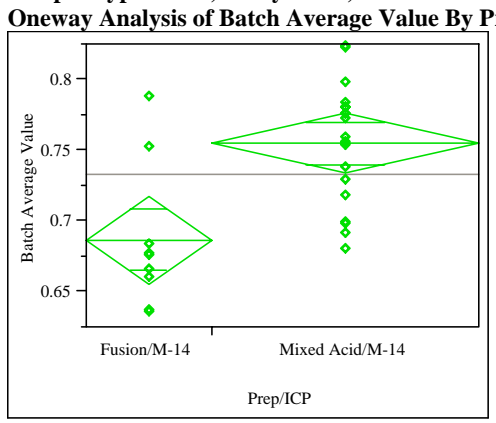

Oneway Anova

Summary of Fit

Rsquare

Adj Rsquare

Error $\quad 0.045406$

Mean of Response 0.733369

Observations (or Sum Wgts) 28

t Test

Fusion/M-14-Mixed Acid/M-14

Assuming equal variances

Difference $\quad-0.06828$ t Ratio $\quad-3.71615$

Std Err Dif $\quad 0.01837$ DF 26

Upper CL Dif -0.03051 Prob $>|t| \quad 0.0010$

Lower CL Dif -0.10605 Prob $>$ t 0.9995

$\begin{array}{lll}\text { Confidence } & 0.95 \text { Prob }<\mathrm{t} & 0.0005\end{array}$

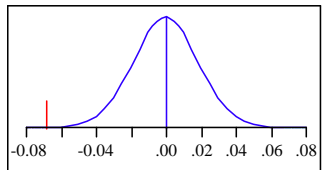

Analysis of Variance

Source DF Sum of Squares Mean Square F Ratio Prob $>$ F

$\begin{array}{llllll}\text { Prep/ICP } & 1 & 0.02847143 & 0.028471 & 13.8098 & 0.0010\end{array}$

Error $\quad 26 \quad 0.05360376 \quad 0.002062$

C. Total $27 \quad 0.08207519$

Means for Oneway Anova

Level Number Mean Std Error Lower 95\% Upper 95\%

$\begin{array}{llllrr}\text { Fusion/M-14 } & 9 & 0.687037 & 0.01514 & 0.65593 & 0.71815\end{array}$

$\begin{array}{lrllll}\text { Mixed Acid/M-14 } & 19 & 0.755316 & 0.01042 & 0.73390 & 0.77673\end{array}$

Std Error uses a pooled estimate of error variance

Tests that the Variances are Equal

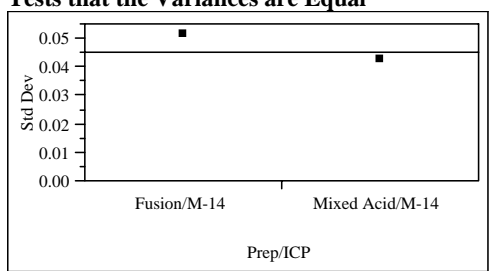

$\begin{array}{lrrrr}\text { Level } & \text { Count } & \text { Std Dev } & \text { MeanAbsDif to Mean } & \begin{array}{r}\text { MeanAbsDif to } \\ \text { Median }\end{array} \\ \text { Fusion/M-14 } & 9 & 0.0512759 & 0.0373169 & 0.0339630 \\ \text { Mixed Acid/M- } & 19 & 0.0425376 & 0.0344238 & 0.0341316\end{array}$

$\begin{array}{lll}\text { Test } & \text { F DFNum DFDen } & \text { Prob }>\text { F }\end{array}$

$\begin{array}{lrlll} & \text { Ratio } & & & \\ \text { O'Brien[.5] } & 0.5268 & 1 & 26 & 0.4745\end{array}$

Brown-Forsythe $\begin{array}{llll}0.0002 & 1 & 26 & 0.9888\end{array}$

$\begin{array}{lllll}\text { Levene } & 0.0716 & 1 & 26 & 0.7911\end{array}$

$\begin{array}{lllll}\text { Bartlett } & 0.3855 & 1 & . & 0.5347\end{array}$

$\begin{array}{lllll}\text { F Test 2-sided } & 1.4531 & 8 & 18 & 0.4838\end{array}$

Welch Anova testing Means Equal, allowing Std Devs Not Equal

F Ratio DFNum DFDen Prob $>$ F

$\begin{array}{llll}12.0350 & 1 & 13.432 & 0.0040\end{array}$

t Test

3.4691 
WSRC-STI-2006-00068

Revision 0

Exhibit A5. Prep Comparisons Using SME Batch Averages by Analyte for each ICP

Sample Type $=$ SME, Analyte $=\mathrm{Cr}, \mathrm{ICP}=\mathrm{M}-13$

Oneway Analysis of Batch Average Value By Prep/ICP

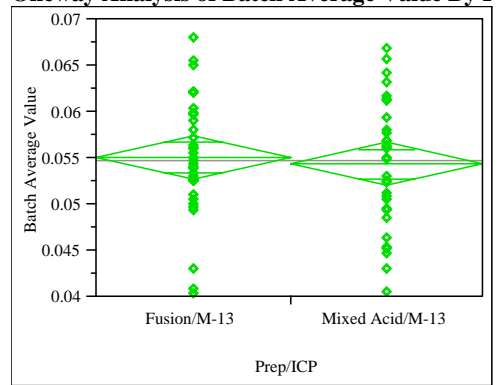

Oneway Anova

Summary of Fit

Rsquare

Adj Rsquare $\quad-0.01288$

Root Mean Square Error $\quad 0.006602$

Mean of Response $\quad 0.054697$

Observations (or Sum Wgts) 65

t Test

Fusion/M-13-Mixed Acid/M-13

Assuming equal variances

Difference $\quad 0.00071$ t Ratio 0.431598

Std Err Dif $\quad 0.00164$ DF

Upper CL Dif 0.00398 Prob $>|t| 0.6675$

Lower CL Dif -0.00257 Prob $>t$

Confidence $\quad 0.95$ Prob $<\mathrm{t} \quad 0.6662$

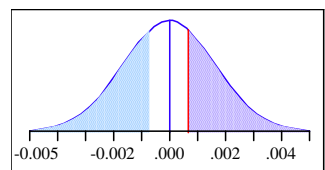

Analysis of Variance

Source DF Sum of Squares Mean Square F Ratio Prob $>$ F

$\begin{array}{lrrrrr}\text { Prep/ICP } & 1 & 0.00000812 & 0.000008 & 0.1863 & 0.6675\end{array}$

$\begin{array}{llll}\text { Error } & 63 & 0.00274576 & 0.000044\end{array}$

C. Total $64 \quad 0.00275388$

Means for Oneway Anova

Level Number Mean Std Error Lower 95\% Upper 95\%

$\begin{array}{llllll}\text { Fusion/M-13 } & 33 & 0.055045 & 0.00115 & 0.05275 & 0.05734\end{array}$

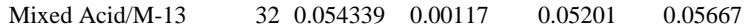

Std Error uses a pooled estimate of error variance

Tests that the Variances are Equal

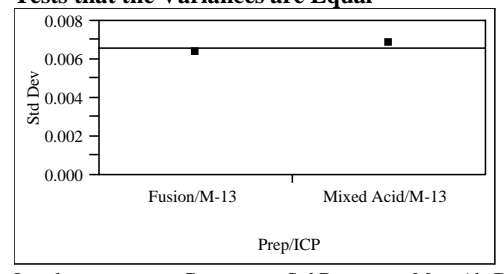

\begin{tabular}{lrrrr}
\hline Level & Count & Std Dev & MeanAbsDif to Mean & $\begin{array}{r}\text { MeanAbsDif to } \\
\text { Median }\end{array}$ \\
Fusion/M-13 & 33 & 0.0063632 & 0.0046933 & 0.0046970 \\
Mixed Acid/M- & 32 & 0.0068394 & 0.0056195 & 0.0055781
\end{tabular}

13

Test F DFNum DFDen Prob $>$ F

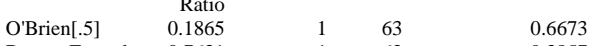

$\begin{array}{lllll}\text { Brown-Forsythe } & 0.7631 & 1 & 63 & 0.3857\end{array}$

$\begin{array}{lllll}\text { Levene } & 0.8707 & 1 & 63 & 0.3543\end{array}$

$\begin{array}{llrrr}\text { Bartlett } & 0.1614 & 1 & . & 0.6878\end{array}$

Welch Anova testing Means Equal, allowing Std Devs Not Equal

F Ratio DFNum DFDen Prob $>$ F

$\begin{array}{llll}0.1859 & 1 & 62.336 & 0.6679\end{array}$

$\mathrm{t}$ Test

0.4311
Sample Type $=$ SME, Analyte $=\mathrm{Cr}$, ICP $=\mathrm{M}-14$

(continued)
Oneway Analysis of Batch Average Value By Prep/ICP

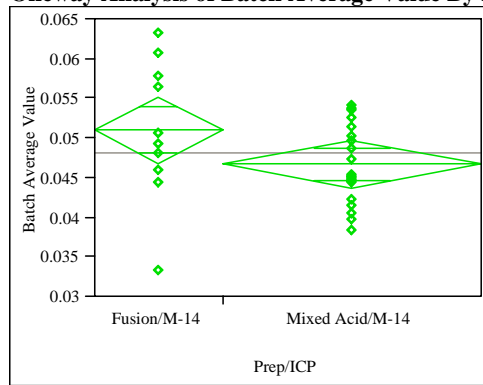

Oneway Anova

Summary of Fit

Rsquare

Adj Rsquare $\quad 0.063038$

Root Mean Square Error $\quad 0.006475$

Mean of Response $\quad 0.048194$

Observations (or Sum Wgts)

30

t Test

Fusion/M-14-Mixed Acid/M-14

Assuming equal variances

Difference $\quad 0.00431$ t Ratio 1.717874

Std Err Dif $\quad 0.00251$ D

Upper CL Dif 0.00945 Prob $>|t| \quad 0.0969$

Lower CL Dif -0.00083 Prob $>t \quad 0.0484$

Confidence $\quad 0.95$ Prob $<\mathrm{t} \quad 0.9516$

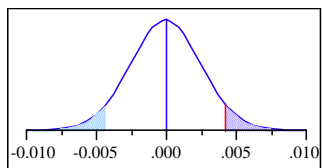

Analysis of Variance

Source DF Sum of Squares Mean Square F Ratio Prob > F

$\begin{array}{lrrrrr}\text { Prep/ICP } & 1 & 0.00012374 & 0.000124 & 2.9511 & 0.0969\end{array}$

$\begin{array}{llll}\text { Error } & 28 & 0.00117409 & 0.000042\end{array}$

C. Total $29 \quad 0.00129784$

Means for Oneway Anova

Level Number Mean Std Error Lower 95\% Upper 95\%

$\begin{array}{llllll}\text { Fusion/M-14 } & 10 & 0.051067 & 0.00205 & 0.04687 & 0.05526\end{array}$

$\begin{array}{llllll}\text { Mixed Acid/M-14 } & 20 & 0.046758 & 0.00145 & 0.04379 & 0.04972\end{array}$

Std Error uses a pooled estimate of error variance

Tests that the Variances are Equal

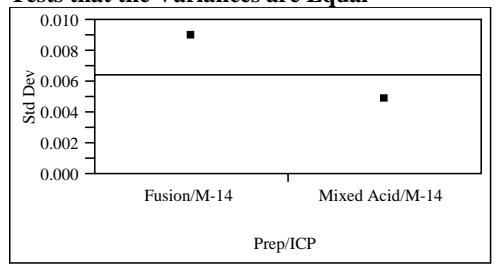

$\begin{array}{lrrrr}\text { Level } & \text { Count } & \text { Std Dev } & \text { MeanAbsDif to Mean } & \begin{array}{r}\text { MeanAbsDif to } \\ \text { Median }\end{array} \\ \text { Fusion/M-14 } & 10 & 0.0089336 & 0.0068800 & 0.0068000 \\ \text { Mixed Acid/M- } & 20 & 0.0048979 & 0.0041508 & 0.0040250\end{array}$

Mixed Acid/M- $\quad 20 \quad 0.0048979 \quad 0.0041508$

14

Test F DFNum DFDen Prob $>$ F

$\begin{array}{lrlll}\text { O'Brien[.5] } & \text { Ratio } & & & \\ & 4.5233 & 1 & 28 & 0.0424\end{array}$

$\begin{array}{lllll}\text { Brown-Forsythe } & 3.3040 & 1 & 28 & 0.0798\end{array}$

$\begin{array}{lllll}\text { Levene } & 3.9037 & 1 & 28 & 0.0581\end{array}$

$\begin{array}{llrrr}\text { Bartlett } & 4.6204 & 1 & . & 0.0316 \\ \text { F Test 2-sided } & 3.3268 & 9 & 19 & 0.0262\end{array}$

Welch Anova testing Means Equal, allowing Std Devs Not Equal

F Ratio DFNum DFDen Prob $>$ F

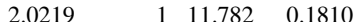

t Test

1.4219 
WSRC-STI-2006-00068

Revision 0

Exhibit A5. Prep Comparisons Using SME Batch Averages by Analyte for each ICP

Sample Type $=$ SME, Analyte $=\mathrm{Cu}, \mathrm{ICP}=\mathrm{M}-13$

Oneway Analysis of Batch Average Value By Prep/ICP

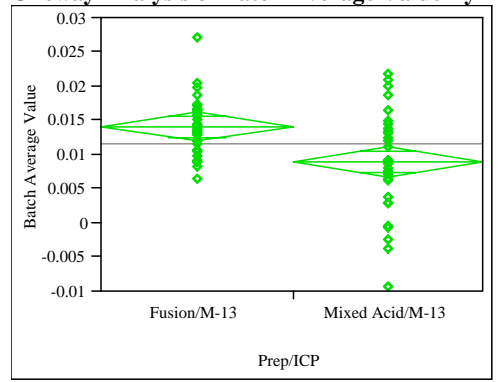

Oneway Anova

Summary of Fit

Adj Rsquare

0.159957

Root Mean Squar

Mean of Response

0.146185

0.006016 0.011603

Observations (or Sum Wgts)

63

t Test

Fusion/M-13-Mixed Acid/M-13

Assuming equal variances

Difference $\quad 0.005167$ t Ratio 3.408122

Std Err Dif $\quad 0.001516$ DF

Upper CL Dif $0.008199 \operatorname{Prob}>|\mathrm{t}| \quad 0.0012$

Lower CL Dif 0.002136 Prob $>t \quad 0.0006$

Confidence $\quad 0.95$ Prob $<\mathrm{t} \quad 0.9994$

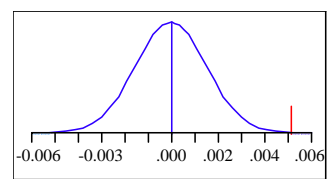

Analysis of Variance

Source DF Sum of Squares Mean Square F Ratio Prob > F

$\begin{array}{llllll}\text { Prep/ICP } & 1 & 0.00042044 & 0.000420 & 11.6153 & 0.0012\end{array}$

$\begin{array}{llll}\text { Error } & 61 & 0.00220803 & 0.000036\end{array}$

C. Total $62 \quad 0.00262847$

Means for Oneway Anova

Level Number Mean Std Error Lower 95\% Upper 95\%

$\begin{array}{llllll}\text { Fusion/M-13 } & 32 & 0.014146 & 0.00106 & 0.01202 & 0.01627\end{array}$

$\begin{array}{lllll}\text { Mixed Acid/M-13 } 31 & 0.008978 & 0.00108 & 0.00682 & 0.01114\end{array}$

Std Error uses a pooled estimate of error variance

Tests that the Variances are Equal

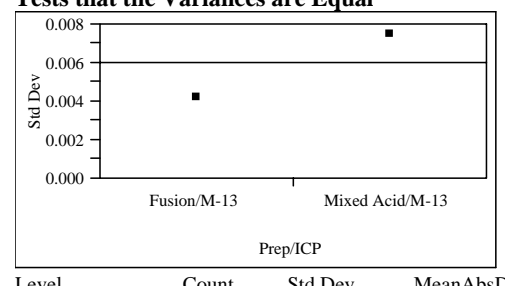

\begin{tabular}{|c|c|c|c|c|c|}
\hline Level & Count & Std Dev & & MeanAbsDif to Mean & $\begin{array}{r}\text { MeanAbsDif to } \\
\text { Median }\end{array}$ \\
\hline Fusion/M-13 & 32 & 0.0041963 & & 0.0031862 & 0.0031771 \\
\hline $\begin{array}{l}\text { Mixed Acid/M- } \\
13\end{array}$ & 31 & 0.0074435 & & 0.0057211 & 0.0057204 \\
\hline Test & $\begin{array}{r}\mathrm{F} \\
\text { Ratio }\end{array}$ & DFNum & DFDen & Prob $>F$ & \\
\hline O'Brien[.5] & 6.4669 & 1 & 61 & 0.0135 & \\
\hline Brown-Forsythe & 7.1020 & 1 & 61 & 0.0098 & \\
\hline Levene & 7.1066 & 1 & 61 & 0.0098 & \\
\hline Bartlett & 9.4128 & 1 & & 0.0022 & \\
\hline F Test 2-sided & 3.1464 & 30 & 31 & 0.0021 & \\
\hline \multicolumn{6}{|c|}{ Welch Anova testing Means Equal, allowing Std Devs Not Equal } \\
\hline F Ratio DFN & um DFD & en Prob > & & & \\
\hline 11.4229 & 147.0 & $05 \quad 0.00$ & 15 & & \\
\hline
\end{tabular}

Sample Type=SME, Analyte $=\mathrm{Cu}$, ICP $=$ M-14

(continued)

Oneway Analysis of Batch Average Value By Prep/ICP

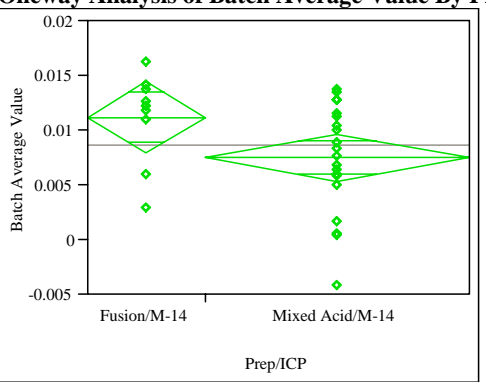

Oneway Anova

Summary of Fit

Rsquare 0.125094

Adj Rsquare 0.09269

Root Mean Square Error $\quad 0.004722$

Mean of Response $\quad 0.008672$

Observations (or Sum Wgts)

29

t Test

Fusion/M-14-Mixed Acid/M-14

Assuming equal variances

Difference $\quad 0.00372$ t Ratio 1.964803

Std Err Dif $\quad 0.00190$ DF 27

Upper CL Dif 0.00761 Prob $>|t| \quad 0.0598$

Lower CL Dif -0.00016 Prob $>t \quad 0.0299$

Confidence $\quad 0.95$ Prob $<\mathrm{t} \quad 0.9701$

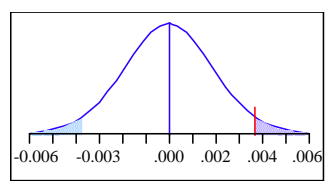

Analysis of Variance

Source DF Sum of Squares Mean Square F Ratio Prob $>$ F

$\begin{array}{llllll}\text { Prep/ICP } & 1 & 0.00008608 & 0.000086 & 3.8604 & 0.0598\end{array}$

$\begin{array}{llll}\text { Error } & 27 & 0.00060206 & 0.000022\end{array}$

C. Total $28 \quad 0.00068814$

Means for Oneway Anova

Level Number Mean Std Error Lower 95\% Upper 95\%

$\begin{array}{llllll}\text { Fusion/M-14 } & 9 & 0.011241 & 0.00157 & 0.00801 & 0.01447\end{array}$

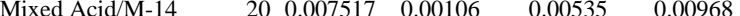

Std Error uses a pooled estimate of error variance

Tests that the Variances are Equal

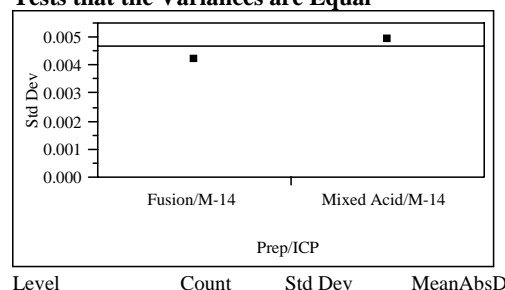

\begin{tabular}{|c|c|c|c|c|c|}
\hline Level & Count & Std De & & MeanAbsDif to Mean & $\begin{array}{r}\text { MeanAbsDif to } \\
\text { Median }\end{array}$ \\
\hline Fusion/M-14 & 9 & 0.004186 & & 0.0030494 & 0.0028333 \\
\hline $\begin{array}{l}\text { Mixed Acid/M- } \\
14\end{array}$ & 20 & 0.004930 & & 0.0038817 & 0.0038667 \\
\hline Test & $\begin{array}{r}F \\
\text { Ratio }\end{array}$ & DFNum & DFDen & Prob $>$ F & \\
\hline O'Brien[.5] & 0.2757 & 1 & 27 & 0.6038 & \\
\hline Brown-Forsythe & 0.7265 & 1 & 27 & 0.4015 & \\
\hline Levene & 0.5349 & 1 & 27 & 0.4709 & \\
\hline Bartlett & 0.2741 & 1 & & 0.6006 & \\
\hline F Test 2-sided & 1.3867 & 19 & 8 & 0.6575 & \\
\hline
\end{tabular}

F Ratio DFNum DFDen Prob > F

$\begin{array}{llll}4.3847 & 1 & 18.127 & 0.0506\end{array}$

$\mathrm{t}$ Test

2.0940 
WSRC-STI-2006-00068

Revision 0

Exhibit A5. Prep Comparisons Using SME Batch Averages by Analyte for each ICP

Sample Type $=$ SME, Analyte $=$ Fe, ICP $=$ M-13

Oneway Analysis of Batch Average Value By Prep/ICP

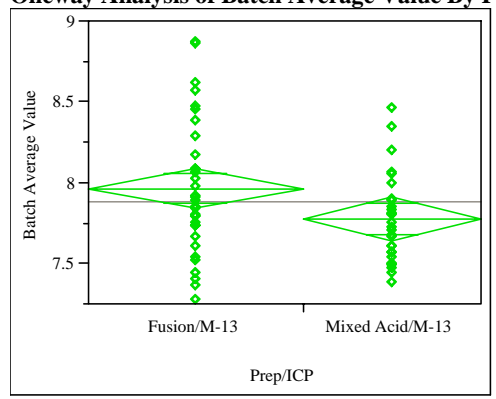

Oneway Anova

Summary of Fit

Rsquare

0.064715

Adj Rsquare

Root Mean Square Error $\quad 0.359795$

Mean of Response $\quad 7.884872$

Observations (or Sum Wgts) 60

t Test

Fusion/M-13-Mixed Acid/M-13

Assuming equal variances

Difference $\quad 0.187040$ t Ratio 2.003289

Std Err Dif $\quad 0.093367$ DF 58

Upper CL Dif 0.373934 Prob $>|\mathrm{t}| \quad 0.0498$

Lower CL Dif 0.000147 Prob $>t \quad 0.0249$

Confidence $\quad 0.95$ Prob $<\mathrm{t} \quad 0.9751$

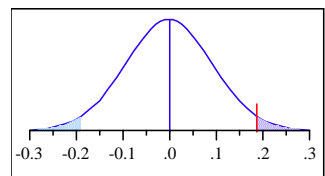

Analysis of Variance

Source DF Sum of Squares Mean Square F Ratio Prob $>$ F

$\begin{array}{llllll}\text { Prep/ICP } & 1 & 0.5195141 & 0.519514 & 4.0132 & 0.0498\end{array}$

$\begin{array}{llll}\text { Error } & 58 & 7.5082383 & 0.129452\end{array}$

C. Total $59 \quad 8.0277524$

Means for Oneway Anova

Level Number Mean Std Error Lower 95\% Upper 95\%

$\begin{array}{lrrrrr}\text { Fusion/M-13 } & 33 & 7.96904 & 0.06263 & 7.8437 & 8.0944\end{array}$

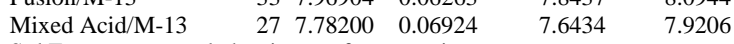

Std Error uses a pooled estimate of error variance

Tests that the Variances are Equal
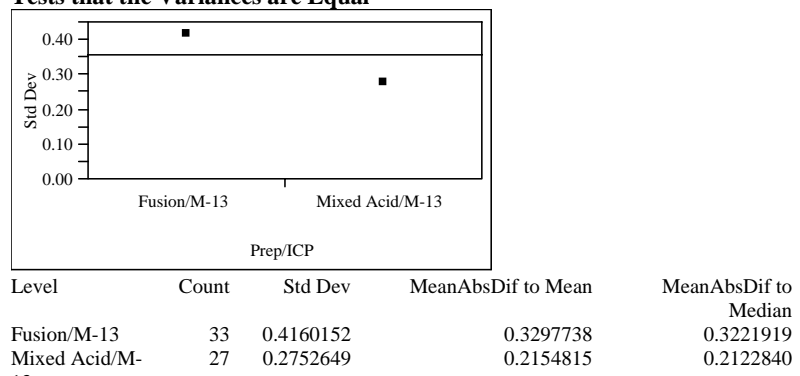

$27 \quad 0.2752649$

0.2154815

13

Test

F DFNum DFDen

Prob $>$ F

O'Brien[.5]

Levene 3.3220

Levene

4.5539
2.2841

$\begin{array}{ll}1 & 58 \\ 1 & 58\end{array}$

$\begin{array}{ll}1 & 58 \\ 1 & 58 \\ 1 & \end{array}$

0.0468

0.0735

0.0445

0.0328

Welch Anova testing Means Equal, allowing Std Devs Not Equal

F Ratio DFNum DFDen Prob $>$ F

$\begin{array}{llll}4.3454 & 1 & 55.759 & 0.0417\end{array}$

t Test

2.0846
Sample Type=SME, Analyte=Fe, ICP=M-14

(continued)
Oneway Analysis of Batch Average Value By Prep/ICP

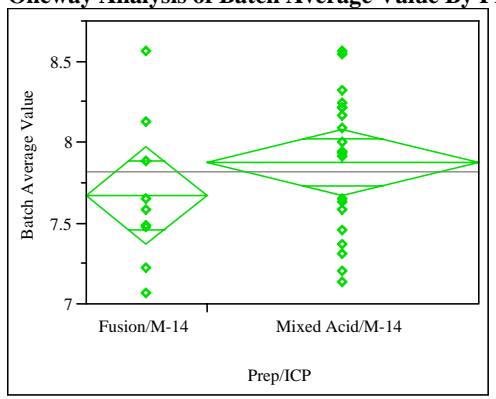

Oneway Anova

Summary of Fit

Rsquare

0.045762

Adj Rsquare

0.01042

Root Mean Square Error $\quad 0.441819$

Mean of Response $\quad 7.817948$

Observations (or Sum Wgts) 29

t Test

Fusion/M-14-Mixed Acid/M-14

Assuming equal variances

Difference $\quad-0.20180$ t Ratio $\quad-1.13791$

Std Err Dif $\quad 0.17734$ DF 27

Upper CL Dif 0.16207 Prob $>|t| \quad 0.2652$

Lower CL Dif -0.56567 Prob $>\mathrm{t} \quad 0.8674$

$\begin{array}{lll}\text { Confidence } & 0.95 \text { Prob }<\mathrm{t} \quad 0.1326\end{array}$

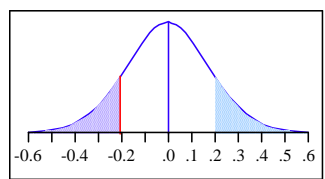

Analysis of Variance

Source DF Sum of Squares Mean Square F Ratio Prob $>$ F

$\begin{array}{llllll}\text { Prep/ICP } & 1 & 0.2527580 & 0.252758 & 1.2948 & 0.2652\end{array}$

$\begin{array}{llll}\text { Error } & 27 & 5.2705089 & 0.195204\end{array}$

C. Total $28 \quad 5.5232669$

Means for Oneway Anova

Level Number Mean Std Error Lower 95\% Upper 95\%

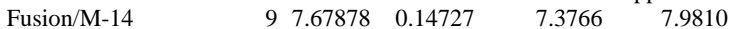

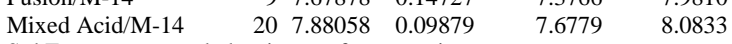

Std Error uses a pooled estimate of error variance

Tests that the Variances are Equal

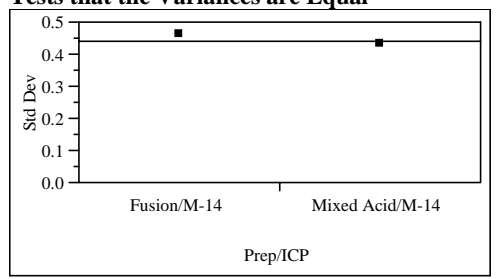

$\begin{array}{lrrrr}\text { Level } & \text { Count } & \text { Std Dev } & \text { MeanAbsDif to Mean } & \begin{array}{r}\text { MeanAbsDif to } \\ \text { Median }\end{array} \\ \text { Fusion/M-14 } & 9 & 0.4602346 & 0.3460000 & 0.3373519 \\ \text { Mixed Acid/M- } & 20 & 0.4338313 & 0.3648600 & 0.3551917 \\ 14 & & & & \end{array}$

14

Test F DFNum DFDen $\quad$ Prob $>$ F

$\begin{array}{lrlll}\text { O'Brien[.5] } & 0.0640 & 1 & 27 & 0.8022\end{array}$

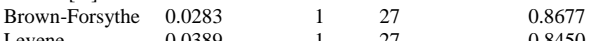

$\begin{array}{lllll}\text { Levene } & 0.0389 & 1 & 27 & 0.8450\end{array}$

$\begin{array}{lllll}\text { Bartlett } & 0.0381 & 1 & . & 0.8452 \\ & & 1 & \end{array}$

Welch Anova testing Means Equal, allowing Std Devs Not Equal

F Ratio DFNum DFDen Prob > F

$\begin{array}{llll}1.2360 & 1 & 14.688 & 0.2841\end{array}$

t Test

1.1118 
WSRC-STI-2006-00068

Revision 0

Exhibit A5. Prep Comparisons Using SME Batch Averages by Analyte for each ICP

Sample Type $=$ SME, Analyte $=$ Fe/Al, ICP $=$ M-13

Oneway Analysis of Batch Average Value By Prep/ICP

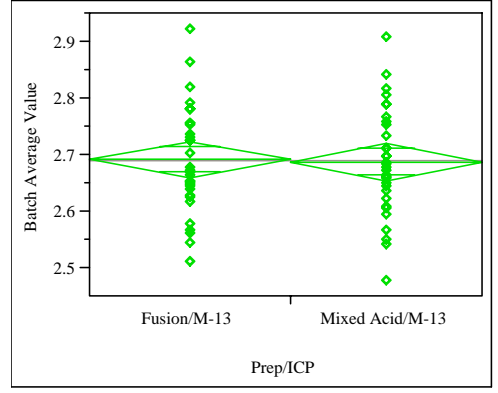

Oneway Anova

Summary of Fit

Rsquare

0.000553

Adj Rsquare

Root Mean Square Erro

0.092969

Mean of Response

2690322

Observations (or Sum Wgts) 66

t Test

Fusion/M-13-Mixed Acid/M-13

Assuming equal variances

Difference $\quad 0.00431$ t Ratio 0.188212

Std Err Dif $\quad 0.02290$ D

64

Upper CL Dif 0.05005 Prob $>|\mathrm{t}| \quad 0.8513$

Lower CL Dif -0.04143 Prob $>t \quad 0.4257$

Confidence $\quad 0.95$ Prob $<\mathrm{t} \quad 0.5743$

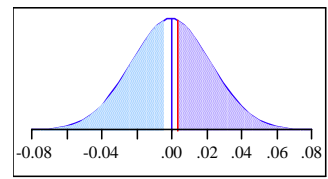

Analysis of Variance

Source DF Sum of Squares Mean Square F Ratio Prob $>$ F $\begin{array}{llllll}\text { Prep/ICP } & 1 & 0.00030617 & 0.000306 & 0.0354 & 0.8513\end{array}$

$\begin{array}{llll}\text { Error } & 64 & 0.55316229 & 0.008643\end{array}$

C. Total $65 \quad 0.55346846$

Means for Oneway Anova

Level Number Mean Std Error Lower 95\% Upper 95\%

$\begin{array}{lrrrrr}\text { Fusion/M-13 } & 34 & 2.69241 & 0.01594 & 2.6606 & 2.7243\end{array}$

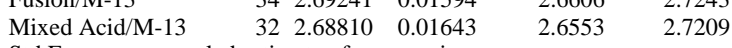

Std Error uses a pooled estimate of error variance

Tests that the Variances are Equal

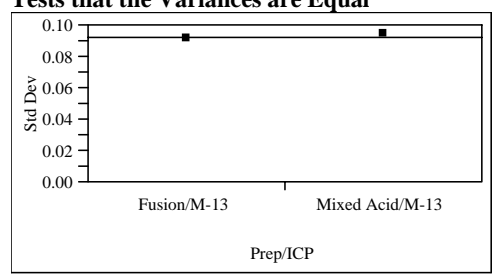

\begin{tabular}{|c|c|c|c|c|}
\hline Level & Count & Std De & & MeanAbsDif to Mean \\
\hline Fusion/M-13 & 34 & 0.091713 & & 0.07380 \\
\hline $\begin{array}{l}\text { Mixed Acid/M- } \\
13\end{array}$ & 32 & 0.094286 & & 0.07262 \\
\hline Test & $\begin{array}{r}F \\
\text { Ratio }\end{array}$ & DFNum & DFDen & Prob > \\
\hline O'Brien[.5] & 0.0248 & 1 & 64 & \\
\hline Brown-Forsythe & 0.0007 & 1 & 64 & \\
\hline Levene & 0.0073 & 1 & 64 & \\
\hline Bartlett & 0.0241 & 1 & & \\
\hline F Test 2-sided & 1.0569 & 31 & 33 & 0.8 \\
\hline
\end{tabular}

Welch Anova testing Means Equal, allowing Std Devs Not Equal

F Ratio DFNum DFDen Prob $>$ F

$\begin{array}{llll}0.0354 & 1 & 63.495 & 0.8514\end{array}$

t Test

0.1881
Sample Type $=\mathrm{SME}$, Analyte $=\mathrm{Fe} / \mathrm{Al}$, ICP $=\mathrm{M}-14$

(continued)

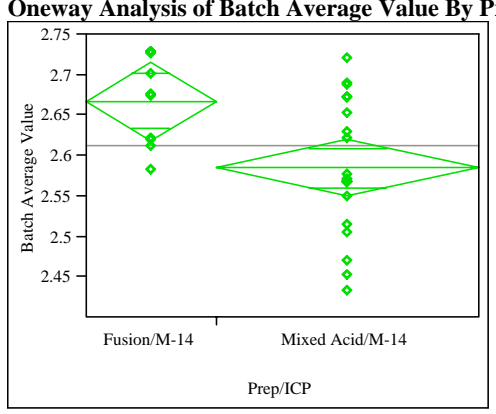

Oneway Anova

Summary of Fit

Rsquare

Adj Rsquare

0.225063

Root Mean Square Error $\quad 0.075054$

Mean of Response 2.612993

Observations (or Sum Wgts) 30

t Test

Fusion/M-14-Mixed Acid/M-14

Assuming equal variances

Difference $\quad 0.082893$ t Ratio 2.85166

Std Err Dif $\quad 0.029068$ DF 28

Upper CL Dif 0.142437 Prob $>|\mathrm{t}| \quad 0.0081$

Lower CL Dif 0.023349 Prob $>$ t 0.0040

Confidence $\quad 0.95$ Prob $<\mathrm{t} \quad 0.9960$

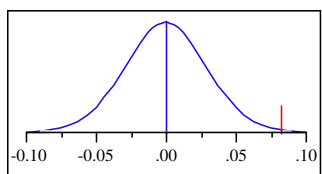

Analysis of Variance

Source DF Sum of Squares Mean Square F Ratio Prob > F

$\begin{array}{llllll}\text { Prep/ICP } & 1 & 0.04580872 & 0.045809 & 8.1320 & 0.0081\end{array}$

$\begin{array}{llll}\text { Error } & 28 & 0.15772869 & 0.005633\end{array}$

C. Total $29 \quad 0.20353740$

Means for Oneway Anova

Level Number Mean Std Error Lower 95\% Upper 95\%

$\begin{array}{lllllr}\text { Fusion/M-14 } & 10 & 2.66826 & 0.02373 & 2.6196 & 2.7169\end{array}$

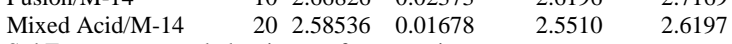

Std Error uses a pooled estimate of error variance

Tests that the Variances are Equal

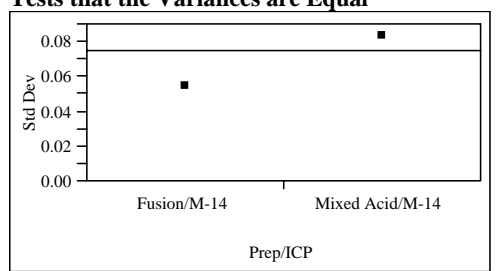

MeanAbsDif to Median 0.0719316 0.0723163

$\begin{array}{lrrrr}\text { Level } & \text { Count } & \text { Std Dev } & \text { MeanAbsDif to Mean } & \begin{array}{r}\text { MeanAbsDif to } \\ \text { Median }\end{array} \\ \text { Fusion/M-14 } & 10 & 0.0545285 & 0.0463375 & 0.0451411 \\ \text { Mixed Acid/M- } & 20 & 0.0830246 & 0.0670892 & 0.0649917\end{array}$

14

$\begin{array}{lll}\text { Test } & \text { F } \text { DFNum DFDen } & \text { Prob }>\end{array}$

$\begin{array}{lrlll} & \text { Ratio } & & & \\ \text { O'Brien[.5] } & 2.4845 & 1 & 28 & 0.1262\end{array}$

Brown-Forsythe $\begin{array}{rlll}1.2719 & 1 & 28 & 0.1262 \\ & 1.7385 & 1 & 28\end{array}$

$\begin{array}{lllll}\text { Levene } & 1.7385 & 1 & 28 & 0.1980\end{array}$

$\begin{array}{lrrrr}\text { Bartlett } & 1.8373 & 1 & . & 0.1753 \\ \text { F Test 2-sided } & 2.3183 & 19 & 9 & 0.1970\end{array}$

Welch Anova testing Means Equal, allowing Std Devs Not Equal

F Ratio DFNum DFDen Prob $>$ F

$\begin{array}{llll}10.7031 & 1 & 25.639 & 0.0031\end{array}$

t Test

3.2716 
WSRC-STI-2006-00068

Revision 0

Exhibit A5. Prep Comparisons Using SME Batch Averages by Analyte for each ICP

Sample Type $=$ SME, Analyte $=\mathrm{Fe} / \mathrm{Ca}, \mathrm{ICP}=\mathrm{M}-13$ Oneway Analysis of Batch Average Value By Prep/ICP

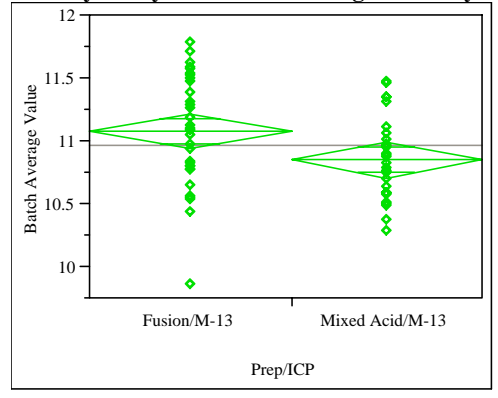

Oneway Anova

Summary of Fit

Rsquare

Adj Rsquare

0.083176

0.067895

Root Mean Square Error $\quad 0.388801$

Mean of Response 10.9718

Observations (or Sum Wgts) 62

t Test

Fusion/M-13-Mixed Acid/M-13

Assuming equal variances

Difference $\quad 0.230525$ t Ratio 2.333087

Std Err Dif $\quad 0.098807$ DF

Upper CL Dif 0.428169 Prob $>|t|-0.02$

Lower CL Dif 0.032882 Prob $>t \quad 0.0115$

$\begin{array}{lll}\text { Confidence } & 0.95 \text { Prob }<\mathrm{t} \quad 0.9885\end{array}$

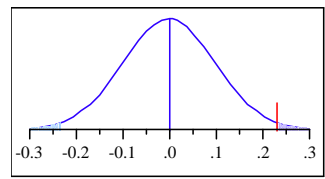

Analysis of Variance

Source DF Sum of Squares Mean Square F Ratio Prob $>$ F

$\begin{array}{llllll}\text { Prep/ICP } & 1 & 0.8228422 & 0.822842 & 5.4433 & 0.0230\end{array}$

$\begin{array}{llll}\text { Error } & 60 & 9.0699714 & 0.151166\end{array}$

C. Total $61 \quad 9.8928136$

Means for Oneway Anova

Level Number Mean Std Error Lower 95\% Upper 95\%

$\begin{array}{llllll}\text { Fusion/M-13 } & 32 & 11.0833 & 0.06873 & 10.946 & 11.221\end{array}$

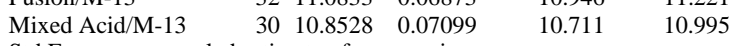

Std Error uses a pooled estimate of error variance

Tests that the Variances are Equal

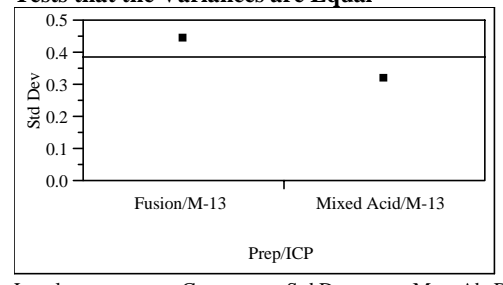

\begin{tabular}{|c|c|c|c|c|c|}
\hline Level & Count & Std Dev & & MeanAbsDif to Mean & $\begin{array}{r}\text { MeanAbsDif to } \\
\text { Median }\end{array}$ \\
\hline Fusion/M-13 & 32 & 0.4438665 & & 0.3608579 & 0.3602947 \\
\hline $\begin{array}{l}\text { Mixed Acid/M- } \\
13\end{array}$ & 30 & 0.3196135 & & 0.2556178 & 0.2540773 \\
\hline Test & $\begin{array}{r}F \\
\text { Ratio }\end{array}$ & DFNum I & DFDen & Prob $>$ F & \\
\hline O'Brien[.5] & 2.8416 & 1 & 60 & 0.0970 & \\
\hline Brown-Forsythe & 3.4523 & 1 & 60 & 0.0681 & \\
\hline Levene & 3.4965 & 1 & 60 & 0.0664 & \\
\hline Bartlett & 3.1013 & 1 & & 0.0782 & \\
\hline F Test 2-sided & 1.9287 & 31 & 29 & 0.0789 & \\
\hline \multicolumn{6}{|c|}{ Welch Anova testing Means Equal, allowing Std Devs Not Equal } \\
\hline F Ratio DFNuı & m DFDen & n Prob $>1$ & & & \\
\hline 5.5577 & 156.348 & $8 \quad 0.021$ & & & \\
\hline
\end{tabular}

Sample Type $=$ SME, Analyte $=\mathrm{Fe} / \mathrm{Ca}$, ICP $=\mathrm{M}-14$

(continued)
Oneway Analysis of Batch Average Value By Prep/ICP

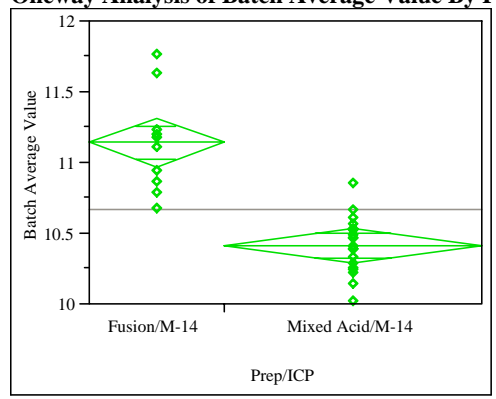

Oneway Anova

Summary of Fit

Rsquare

0.656566

Adj Rsquare

Root Mean Square Error $\quad 0.258696$

Mean of Response

Observations (or Sum Wgts) $\quad 29$

t Test

Fusion/M-14-Mixed Acid/M-14

Assuming equal variances

Difference 0.726125 t Ratio 7.184548

Std Err Dif $\quad 0.101068$ DF 27

Upper CL Dif 0.933498 Prob $>|\mathrm{t}|<.0001$

Lower CL Dif 0.518751 Prob $>t \quad<.0001$

$\begin{array}{lll}\text { Confidence } & 0.95 \text { Prob }<\mathrm{t} \quad 1.0000\end{array}$

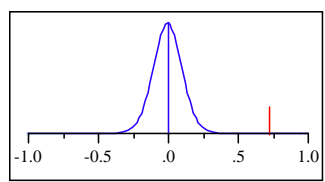

Analysis of Variance

Source DF Sum of Squares Mean Square F Ratio Prob $>$ F

$\begin{array}{lllllll}\text { Prep/ICP } & 1 & 3.4544427 & 3.45444 & 51.6177 & <.0001\end{array}$

$\begin{array}{llll}\text { Error } & 27 & 1.8069365 & 0.06692\end{array}$

C. Total $28 \quad 5.2613792$

Means for Oneway Anova

Level Number Mean Std Error Lower 95\% Upper 95\%

$\begin{array}{llllll}\text { Fusion/M-14 } & 10 & 11.1450 & 0.08181 & 10.977 & 11.313\end{array}$

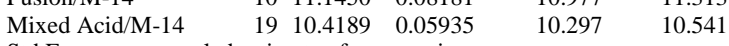

Std Error uses a pooled estimate of error variance

Tests that the Variances are Equal

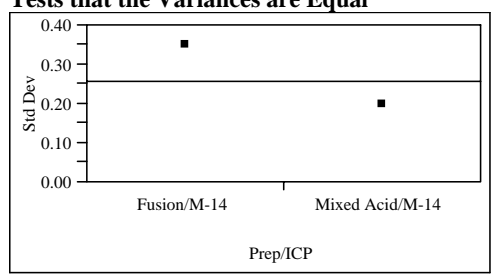

$\begin{array}{lrrrr}\text { Level } & \text { Count } & \text { Std Dev } & \text { MeanAbsDif to Mean } & \begin{array}{r}\text { MeanAbsDif to } \\ \text { Median }\end{array} \\ \text { Fusion/M-14 } & 10 & 0.3500611 & 0.2618308 & 0.2618308 \\ \text { Mixed Acid/M- } & 19 & 0.1977725 & 0.1521156 & 0.1531570\end{array}$

14

$\begin{array}{lrlll} & \text { Ratio } & & & \\ \text { O'Brien[.5] } & 4.2555 & 1 & 27 & 0.0489\end{array}$

Brown-Forsythe \begin{tabular}{rlll}
4.0899 & 1 & 27 & 0.0489 \\
\hline
\end{tabular}

$\begin{array}{lllll}\text { Levene } & 3.1235 & 1 & 27 & 0.0885\end{array}$

$\begin{array}{lrrrr}\text { Bartlett } & 4.0482 & 1 & . & 0.0442 \\ \text { F Test 2-sided } & 3.1330 & 9 & 18 & 0.0375\end{array}$

Welch Anova testing Means Equal, allowing Std Devs Not Equal

F Ratio DFNum DFDen Prob $>$ F

$\begin{array}{llll}36.8379 & 1 & 12.107 & <.0001\end{array}$

t Test

6.0694 
WSRC-STI-2006-00068

Revision 0

Exhibit A5. Prep Comparisons Using SME Batch Averages by Analyte for each ICP

Sample Type $=$ SME, Analyte $=\mathrm{Fe} / \mathrm{Li}$, ICP $=\mathrm{M}-13$

Oneway Analysis of Batch Average Value By Prep/ICP

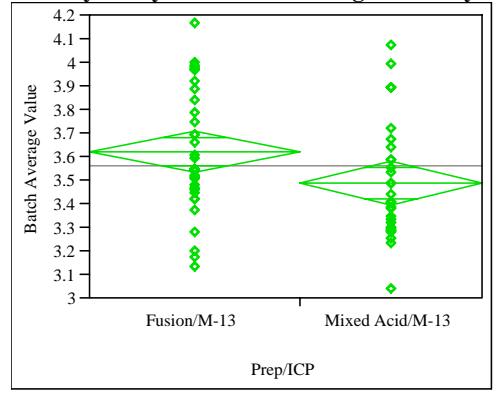

Oneway Anova

Summary of Fit

Rsquare

0.065865

Adj Rsquare

0.050551

Root Mean Square Error $\quad 0.25432$

Mean of Response 3.561458

Observations (or Sum Wgts) 63

t Test

Fusion/M-13-Mixed Acid/M-13

Assuming equal variances

Difference 0.133322 t Ratio 2.073894

Std Err Dif 0.064286 DF

61

Upper CL Dif 0.261869 Prob > |t 0.0423

Lower CL Dif 0.004775 Prob $>t \quad 0.0212$

Confidence $\quad 0.95$ Prob $<\mathrm{t} \quad 0.9788$

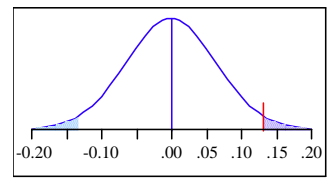

Analysis of Variance

Source DF Sum of Squares Mean Square F Ratio Prob $>$ F

$\begin{array}{llllll}\text { Prep/ICP } & 1 & 0.2781884 & 0.278188 & 4.3010 & 0.0423\end{array}$

$\begin{array}{llll}\text { Error } & 61 & 3.9454409 & 0.064679\end{array}$

C. Total $62 \quad 4.2236293$

Means for Oneway Anova

Level Number Mean Std Error Lower 95\% Upper 95\%

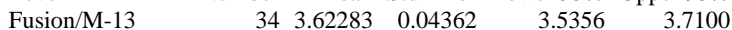

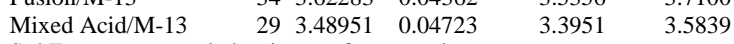

Std Error uses a pooled estimate of error variance

Tests that the Variances are Equal
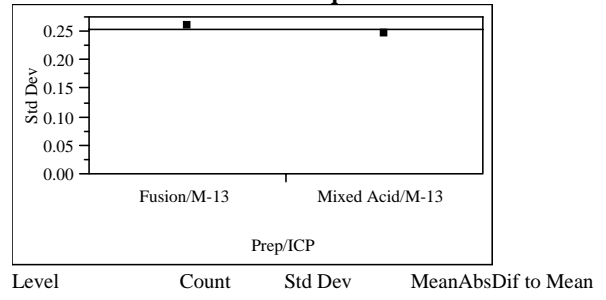

Fusion/M-13

Mixed Acid/M-

340.2609543

MeanAbsDif to Mean

13

Test

F DFNum DFDen

Prob $>$ F

O'Brien[.5]

Ratio

Brown-Forsythe 0.2074

Levene

Bartlett

0.2074

0.0995

1.1228

$\begin{array}{ll}1 & 61 \\ 1 & 61\end{array}$

$\begin{array}{ll}1 & 61 \\ 1 & 61\end{array}$

1
33

Welch Anova testing Means Equal, allowing Std Devs Not Equal

F Ratio DFNum DFDen Prob $>$ F

$\begin{array}{llll}4.3414 & 1 & 60.348 & 0.0414\end{array}$

t Test

2.0836
Sample Type $=\mathrm{SME}$, Analyte $=\mathrm{Fe} / \mathrm{Li}, \mathrm{ICP}=\mathrm{M}-14$

(continued)
Oneway Analysis of Batch Average Value By Prep/ICP

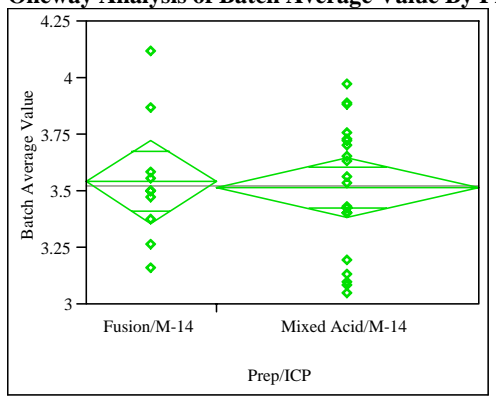

Oneway Anova

Summary of Fit

Rsquare

0.002043

Adj Rsquare

$-0.0336$

Root Mean Square Error $\quad 0.285182$

Mean of Response 3.52564

Observations (or Sum Wgts) 30

t Test

Fusion/M-14-Mixed Acid/M-14

Assuming equal variances

Difference $\quad 0.02644$ t Ratio 0.239402

Std Err Dif $\quad 0.11045$ DF 28

Upper CL Dif 0.25269 Prob $>|t| \quad 0.8125$

Lower CL Dif -0.19981 Prob $>\mathrm{t} \quad 0.4063$

$\begin{array}{lll}\text { Confidence } & 0.95 \text { Prob }<\mathrm{t} \quad 0.5937\end{array}$

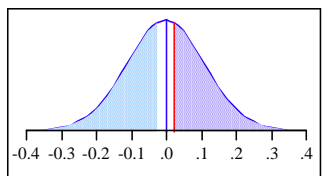

Analysis of Variance

Source DF Sum of Squares Mean Square F Ratio Prob > F

$\begin{array}{llllll}\text { Prep/ICP } & 1 & 0.0046612 & 0.004661 & 0.0573 & 0.8125\end{array}$

$\begin{array}{llll}\text { Error } & 28 & 2.2772026 & 0.081329\end{array}$

$\begin{array}{lll}\text { C. Total } 29 & 2.2818638\end{array}$

Means for Oneway Anova

Level Number Mean Std Error Lower 95\% Upper 95\%

$\begin{array}{llllrr}\text { Fusion/M-14 } & 10 & 3.54327 & 0.09018 & 3.3585 & 3.7280\end{array}$

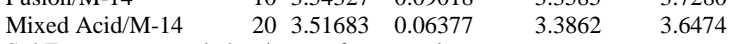

Std Error uses a pooled estimate of error variance

Tests that the Variances are Equal

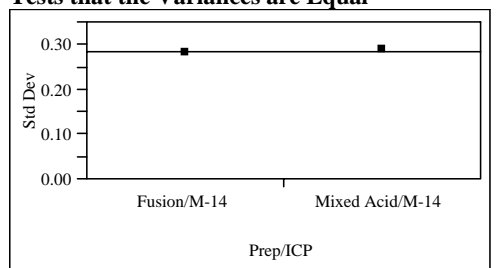

MeanAbsDif to

Median

0.2068247

0.1867964

Level

Prep/lC

$\begin{array}{lrrrr} & & & \text { MeanAbsDif to Mean } & \text { MeanAbsDif to } \\ \text { Median } \\ \text { Fusion/M-14 } & 10 & 0.2801446 & 0.1943889 & 0.1863862 \\ \text { Mixed Acid/M- } & 20 & 0.2875371 & 0.2397590 & 0.2375555\end{array}$

$\begin{array}{llll}\text { Test } & \text { F } & \text { DFNum DFDen } & \text { Prob }\end{array}$

$\begin{array}{lrrrr} & \text { Ratio } & & & \\ \text { O'Brien[.5] } & 0.0119 & 1 & 28 & 0.9139\end{array}$

Brown-Forsythe $\quad 0.5783 \quad 1128 \quad 0.4533$

$\begin{array}{lllll}\text { Levene } & 0.5126 & 1 & 28 & 0.4800\end{array}$

$\begin{array}{lrrrr}\text { Bartlett } & 0.0079 & 1 & - & 0.9292 \\ \text { F Test 2-sided } & 1.0535 & 19 & 9 & 0.9839\end{array}$

Welch Anova testing Means Equal, allowing Std Devs Not Equal

F Ratio DFNum DFDen Prob $>$ F

$\begin{array}{llll}0.0584 & 1 & 18.542 & 0.8118\end{array}$

t Test

0.2416 
WSRC-STI-2006-00068

Revision 0

Exhibit A5. Prep Comparisons Using SME Batch Averages by Analyte for each ICP

Sample Type $=$ SME, Analyte $=\mathrm{Fe} / \mathrm{Mg}, \mathrm{ICP}=\mathrm{M}-13$ Oneway Analysis of Batch Average Value By Prep/ICP

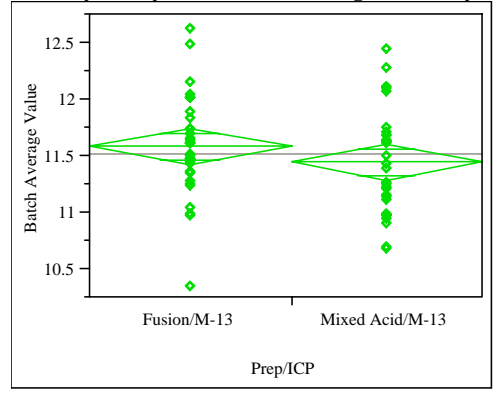

Oneway Anova

Summary of Fit

Rsquare

0.023647

Adj Rsquare

Root Mean Square

Mean of Response

0.452441

11.51645

Observations (or Sum Wgts) 62

t Test

Fusion/M-13-Mixed Acid/M-13

Assuming equal variances

Difference $\quad 0.13861$ t Ratio 1.205474

Std Err Dif $\quad 0.11498$ DF 60

Upper CL Dif 0.36860 Prob $>|t| \quad 0.2328$

Lower CL Dif -0.09139 Prob $>t \quad 0.1164$

Confidence $\quad 0.95$ Prob $<\mathrm{t} \quad 0.8836$

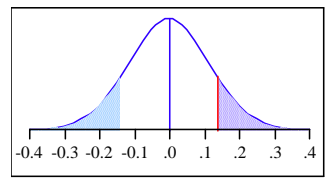

Analysis of Variance

Source DF Sum of Squares Mean Square F Ratio Prob $>$ F

$\begin{array}{llllll}\text { Prep/ICP } & 1 & 0.297468 & 0.297468 & 1.4532 & 0.2328\end{array}$

$\begin{array}{llll}\text { Error } & 60 & 12.282172 & 0.204703\end{array}$

C. Total $61 \quad 12.579640$

Means for Oneway Anova

Level Number Mean Std Error Lower 95\% Upper 95\%

$\begin{array}{lllllr}\text { Fusion/M-13 } & 32 & 11.5835 & 0.07998 & 11.424 & 11.744\end{array}$

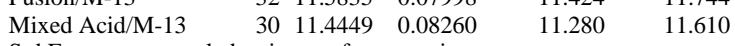

Std Error uses a pooled estimate of error variance

Tests that the Variances are Equal

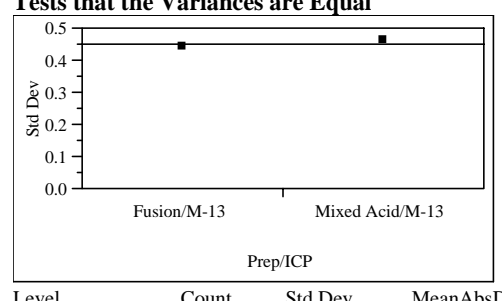

\begin{tabular}{|c|c|c|c|c|}
\hline Level & Count & Sta Dev & & MeanADsDir to Mean \\
\hline Fusion/M-13 & 32 & 0.4448137 & & 0.3207451 \\
\hline $\begin{array}{l}\text { Mixed Acid/M- } \\
13\end{array}$ & 30 & 0.4604547 & & 0.3780585 \\
\hline Test & $\begin{array}{r}F \\
\text { Ratio }\end{array}$ & DFNum & DFDen & Prob $>$ F \\
\hline O'Brien[.5] & 0.0309 & 1 & 60 & 0.8610 \\
\hline Brown-Forsythe & 0.6281 & 1 & 60 & 0.4312 \\
\hline Levene & 0.6490 & 1 & 60 & 0.4237 \\
\hline Bartlett & 0.0352 & 1 & & 0.8511 \\
\hline F Test 2-sided & 1.0716 & 29 & 31 & 0.8479 \\
\hline
\end{tabular}

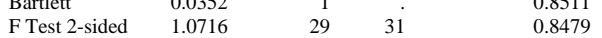

Welch Anova testing Means Equal, allowing Std Devs Not Equal

F Ratio DFNum DFDen Prob $>$ F

$\begin{array}{llll}1.4499 & 1 & 59.405 & 0.2333\end{array}$

t Test

1.2041
Sample Type $=$ SME, Analyte $=\mathrm{Fe} / \mathrm{Mg}$, ICP=M-14

(continued)
Oneway Analysis of Batch Average Value By Prep/ICP

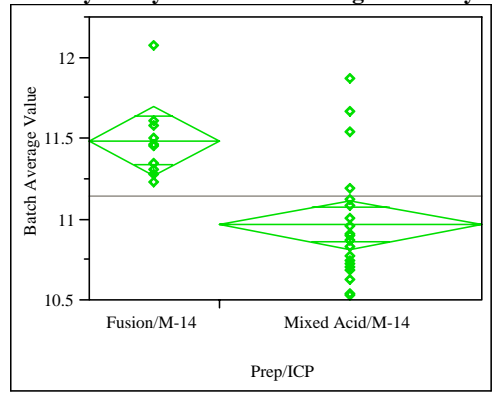

Oneway Anova

Summary of Fit

Rsquare

0.369356

Adj Rsquare

0.346833

Root Mean Square Error $\quad 0.331447$

Mean of Response $\quad 11.14224$

Observations (or Sum Wgts) 30

t Test

Fusion/M-14-Mixed Acid/M-14

Assuming equal variances

Difference $\quad 0.519840$ t Ratio $\quad 4.049575$

Std Err Dif $\quad 0.128369$ DF 28

Upper CL Dif 0.782792 Prob $>|t| 0.0004$

Lower CL Dif 0.256888 Prob $>$ t 0.0002

$\begin{array}{lll}\text { Confidence } & 0.95 \text { Prob }<\mathrm{t} \quad 0.9998\end{array}$

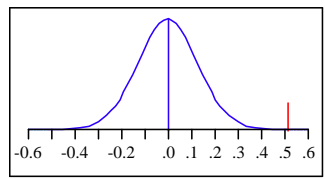

Analysis of Variance

Source DF Sum of Squares Mean Square F Ratio Prob $>$ F

$\begin{array}{lllllll}\text { Prep/ICP } & 1 & 1.8015581 & 1.80156 & 16.3991 & 0.0004\end{array}$

$\begin{array}{llll}\text { Error } & 28 & 3.0760077 & 0.10986\end{array}$

C. Total $29 \quad 4.8775658$

Means for Oneway Anova

Level Number Mean Std Error Lower 95\% Upper 95\%

$\begin{array}{lllllr}\text { Fusion/M-14 } & 10 & 11.4888 & 0.10481 & 11.274 & 11.703\end{array}$

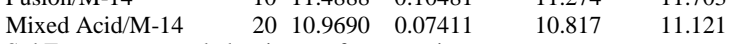

Std Error uses a pooled estimate of error variance

Tests that the Variances are Equal

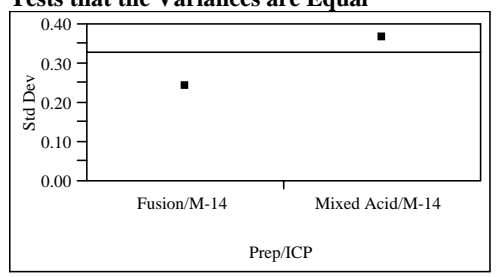

MeanAbsDif to

Median

0.3207451

0.3774143

$\begin{array}{llllr}\text { Fusion/M-14 } & 10 & 0.2418262 & 0.1645601 & \text { Median } \\ \text { Mixed Acid/M- } & 20 & 0.3663252 & 0.2733708 & 0.1604654\end{array}$

Test F DFNum DFDen Prob $>$ F

$\begin{array}{lrlll} & \text { Ratio } & & & \\ \text { O'Brien[.5] } & 0.9791 & 1 & 28 & 0.3309\end{array}$

Brown-Forsythe $1.2182 \quad 11 \quad 28 \quad 0.2791$

$\begin{array}{lllll}\text { Levene } & 1.6863 & 1 & 28 & 0.2047\end{array}$

$\begin{array}{lrrrr}\text { Bartlett } & 1.7959 & 1 & . & 0.1802 \\ \text { F Test 2-sided } & 2.2947 & 19 & 9 & 0.2024\end{array}$

Welch Anova testing Means Equal, allowing Std Devs Not Equal

F Ratio DFNum DFDen Prob $>$ F

$\begin{array}{llll}21.5194 & 1 & 25.561 & <.0001\end{array}$

t Test

4.6389 
WSRC-STI-2006-00068

Revision 0

Exhibit A5. Prep Comparisons Using SME Batch Averages by Analyte for each ICP

Sample Type $=$ SME, Analyte $=$ Fe $/$ Mn, ICP $=M-13$

Oneway Analysis of Batch Average Value By Prep/ICP

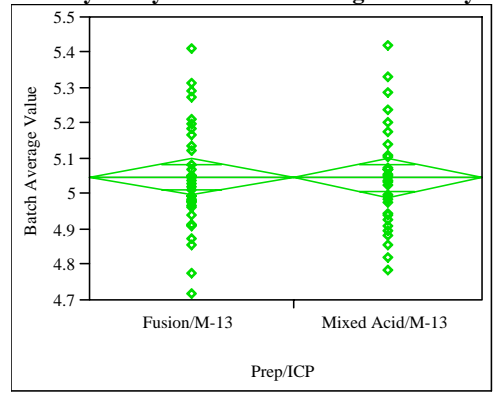

Oneway Anova

Summary of Fit

Rsquare

0.000062

Adj Rsquare

0.000062
-0.01581

Root Mean Square Erro

0.149067

Mean of Response

5.047899

Observations (or Sum Wgts) 65

t Test

Fusion/M-13-Mixed Acid/M-13

Assuming equal variances

Difference $\quad 0.00230$ t Ratio 0.062255

Std Err Dif $\quad 0.03702$ DF

Upper CL Dif 0.07628 Prob $>|\mathrm{t}| \quad 0.9506$

Lower CL Dif -0.07167 Prob $>t \quad 0.4753$

Confidence $\quad 0.95$ Prob $<\mathrm{t} \quad 0.5247$

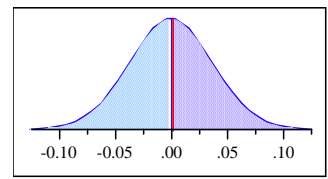

Analysis of Variance

Source DF Sum of Squares Mean Square F Ratio Prob $>$ F $\begin{array}{lllllll}\text { Prep/ICP } & 1 & 0.0000861 & 0.000086 & 0.0039 & 0.9506\end{array}$

$\begin{array}{llll}\text { Error } & 63 & 1.3999160 & 0.022221\end{array}$

C. Total $64 \quad 1.4000021$

Means for Oneway Anova

Level Number Mean Std Error Lower 95\% Upper 95\%

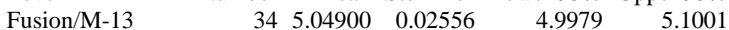

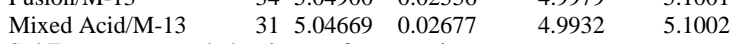

Std Error uses a pooled estimate of error variance

Tests that the Variances are Equal

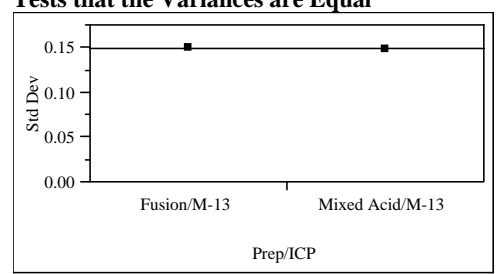

\begin{tabular}{lrrrr} 
Level & Count & Std Dev & \multicolumn{2}{r}{ MeanAbsDif to Mean } \\
Fusion/M-13 & 34 & 0.1503960 & \\
$\begin{array}{l}\text { Mixed Acid/M- } \\
13\end{array}$ & 31 & 0.1475907 & 0.1120515 \\
Test & F & DFNum & DFDen & Prob > F \\
& Ratio & & & \\
O'Brien[.5] & 0.0100 & 1 & 63 & 0.9207 \\
Brown-Forsythe & 0.0028 & 1 & 63 & 0.9577 \\
Levene & 0.0073 & 1 & 63 & 0.9321 \\
Bartlett & 0.0110 & 1 &. & 0.9166 \\
F Test 2-sided & 1.0384 & 33 & 30 & 0.9211
\end{tabular}

Welch Anova testing Means Equal, allowing Std Devs Not Equal

F Ratio DFNum DFDen Prob $>$ F

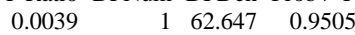

t Test

0.0623
Sample Type $=$ SME, Analyte $=$ Fe $/ M n$, ICP $=M-14$

(continued)
Oneway Analysis of Batch Average Value By Prep/ICP

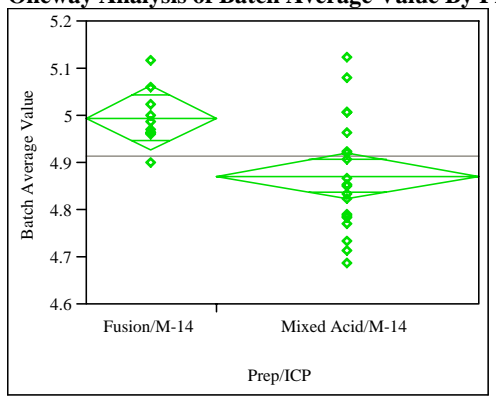

Oneway Anova

Summary of Fit

Rsquare

0.249505

Adj Rsquare

0.222701

Root Mean Square Error $\quad 0.104664$

Mean of Response $\quad 4.914152$

Observations (or Sum Wgts) 30

t Test

Fusion/M-14-Mixed Acid/M-14

Assuming equal variances

Difference $\quad 0.123677$ t Ratio $\quad 3.051016$

Std Err Dif $\quad 0.040536$ DF 28

Upper CL Dif 0.206711 Prob $>|t| 0.0049$

Lower CL Dif 0.040642 Prob $>$ t 0.0025

$\begin{array}{lll}\text { Confidence } & 0.95 \text { Prob }<\mathrm{t} \quad 0.9975\end{array}$

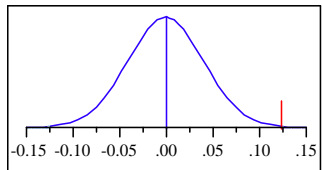

Analysis of Variance

Source DF Sum of Squares Mean Square F Ratio Prob > F

$\begin{array}{llllll}\text { Prep/ICP } & 1 & 0.10197271 & 0.101973 & 9.3087 & 0.0049\end{array}$

$\begin{array}{llll}\text { Error } & 28 & 0.30672772 & 0.010955\end{array}$

C. Total $29 \quad 0.40870043$

Means for Oneway Anova

Level Number Mean Std Error Lower 95\% Upper 95\%

$\begin{array}{llllll}\text { Fusion/M-14 } & 10 & 4.99660 & 0.03310 & 4.9288 & 5.0644\end{array}$

$\begin{array}{lllll}\text { Mixed Acid/M-14 } & 20 & 4.87293 & 0.02340 & 4.8250\end{array} 4.9209$

Std Error uses a pooled estimate of error variance

Tests that the Variances are Equal
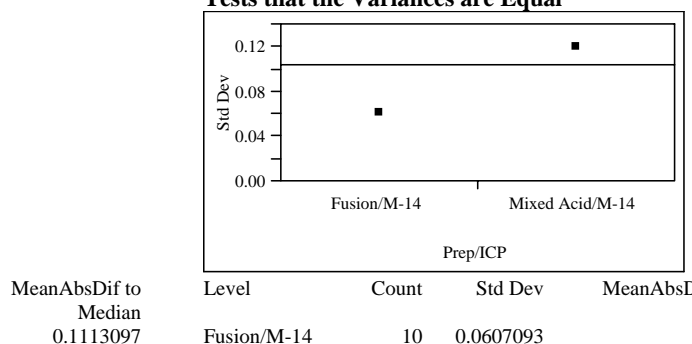

0.1113097

0.1100087

$\begin{array}{lrrrr}\text { Level } & \text { Count } & \text { Std Dev } & \text { MeanAbsDif to Mean } & \begin{array}{r}\text { MeanAbsDif to } \\ \text { Median }\end{array} \\ \text { Fusion/M-14 } & 10 & 0.0607093 & 0.0448562 & 0.0434392 \\ \text { Mixed Acid/M- } & 20 & 0.1199906 & 0.0964859 & 0.0943202\end{array}$

14

$\begin{array}{llll}\text { Test } & \text { F } & \text { DFNum DFDen } & \text { Prob }\end{array}$

$\begin{array}{lrrrr} & \text { Ratio } & & & \\ \text { O'Brien[.5] } & 3.2529 & 1 & 28 & 0.0821\end{array}$

Brown-Forsythe $\quad 4.0303 \quad 1128 \quad 0.0544$

$\begin{array}{lllll}\text { Levene } & 4.9552 & 1 & 28 & 0.0342\end{array}$

$\begin{array}{lrrrr}\text { Bartlett } & 4.4221 & 1 & . & 0.0355 \\ \text { F Test 2-sided } & 3.9065 & 19 & 9 & 0.0413\end{array}$

Welch Anova testing Means Equal, allowing Std Devs Not Equal

F Ratio DFNum DFDen Prob $>$ F

$\begin{array}{llll}14.0529 & 1 & 27.962 & 0.0008\end{array}$

t Test

3.7487 
WSRC-STI-2006-00068

Revision 0

Exhibit A5. Prep Comparisons Using SME Batch Averages by Analyte for each ICP

Sample Type $=$ SME, Analyte $=\mathrm{Fe} / \mathrm{Ni}$, ICP $=\mathbf{M}-13$

Oneway Analysis of Batch Average Value By Prep/ICP

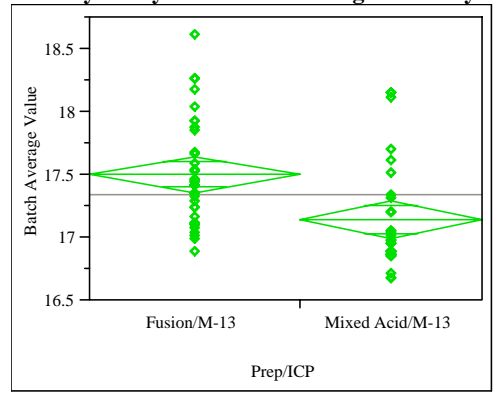

Oneway Anova

Summary of Fit

Rsquare

Adj Rsquare

0.155171

0.141761

0.424219

Mean of Response 17.33854

Observations (or Sum Wgts) 65

t Test

Fusion/M-13-Mixed Acid/M-13

Assuming equal variances

Difference $\quad 0.359040$ t Ratio 3.40166

Std Err Dif $\quad 0.105549$ DF

Upper CL Dif 0.569962 Prob $>|t| 0.0012$

Lower CL Dif 0.148118 Prob $>\mathrm{t} \quad 0.0006$

$\begin{array}{lll}\text { Confidence } & 0.95 \text { Prob }<\mathrm{t} \quad 0.9994\end{array}$

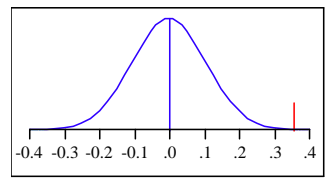

Analysis of Variance

Source DF Sum of Squares Mean Square F Ratio Prob $>$ F

$\begin{array}{llllll}\text { Prep/ICP } & 1 & 2.082390 & 2.08239 & 11.5713 & 0.0012\end{array}$

$\begin{array}{llll}\text { Error } & 63 & 11.337593 & 0.17996\end{array}$

C. Total $64 \quad 13.419983$

Means for Oneway Anova

Level Number Mean Std Error Lower 95\% Upper 95\%

$\begin{array}{lrrrrr}\text { Fusion/M-13 } & 35 & 17.5043 & 0.07171 & 17.361 & 17.648\end{array}$

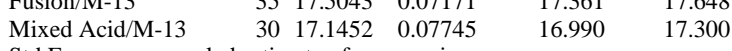

Std Error uses a pooled estimate of error variance

Tests that the Variances are Equal

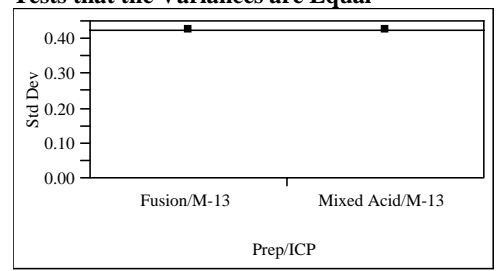

\begin{tabular}{lrrrr} 
Level & Count & Std Dev & \multicolumn{2}{r}{ MeanAbsDif to Mean } \\
Fusion/M-13 & 35 & 0.4248532 & \\
Mixed Acid/M- & 30 & 0.4234743 & 0.3393461 \\
13 & & & & 0.3272101 \\
Test & F & DFNum & DFDen & Prob > F \\
& Ratio & & & \\
O'Brien[.5] & 0.0003 & 1 & 63 & 0.9866 \\
Brown-Forsythe & 0.2690 & 1 & 63 & 0.6058 \\
Levene & 0.0366 & 1 & 63 & 0.8489 \\
Bartlett & 0.0003 & 1 &. & 0.9856 \\
F Test 2-sided & 1.0065 & 34 & 29 & 0.9932
\end{tabular}

Welch Anova testing Means Equal, allowing Std Devs Not Equal

F Ratio DFNum DFDen Prob $>$ F

$\begin{array}{lrrr}11.5772 & 1 & 61.549 & 0.0012\end{array}$

t Test

3.4025
Sample Type $=\mathrm{SME}$, Analyte $=\mathrm{Fe} / \mathrm{Ni}, \mathrm{ICP}=\mathrm{M}-14$

(continued)
Oneway Analysis of Batch Average Value By Prep/ICP

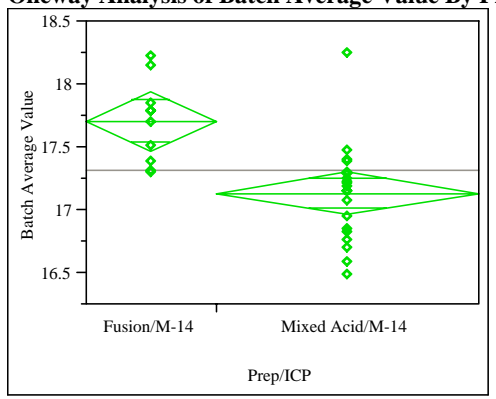

Oneway Anova

Summary of Fit

Rsquare

0.367201

Adj Rsquare

0.344601

Root Mean Square Error $\quad 0.367958$

Mean of Response $\quad 17.32412$

Observations (or Sum Wgts) $\quad 30$

t Test

Fusion/M-14-Mixed Acid/M-14

Assuming equal variances

Difference $\quad 0.574437$ t Ratio 4.03086

Std Err Dif $\quad 0.142510$ DF 28

Upper CL Dif 0.866354 Prob $>|\mathrm{t}| \quad 0.0004$

Lower CL Dif 0.282519 Prob $>\mathrm{t} \quad 0.0002$

$\begin{array}{lll}\text { Confidence } & 0.95 \text { Prob }<\mathrm{t} \quad 0.9998\end{array}$

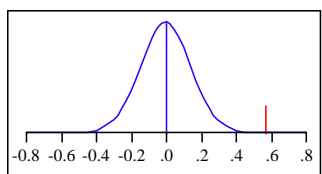

Analysis of Variance

Source DF Sum of Squares Mean Square F Ratio Prob $>$ F

$\begin{array}{lllllll}\text { Prep/ICP } & 1 & 2.1998488 & 2.19985 & 16.2478 & 0.0004\end{array}$

$\begin{array}{llll}\text { Error } & 28 & 3.7910141 & 0.13539\end{array}$

C. Total $29 \quad 5.9908628$

Means for Oneway Anova

Level Number Mean Std Error Lower 95\% Upper 95\%

$\begin{array}{llllrr}\text { Fusion/M-14 } & 10 & 17.7071 & 0.11636 & 17.469 & 17.945\end{array}$

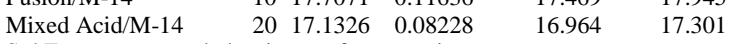

Std Error uses a pooled estimate of error variance

Tests that the Variances are Equal
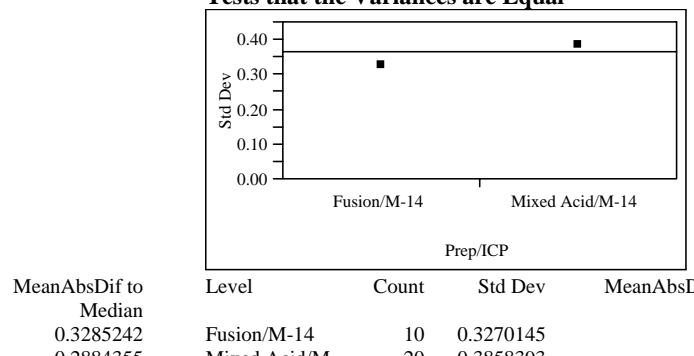

Median
0.3285242

0.2884355

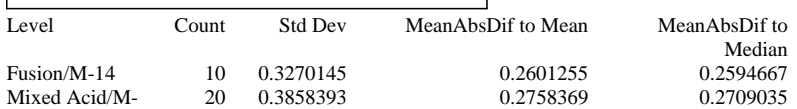

Test

$\begin{array}{cccc}\text { Test } & \text { F } & \text { DFNum DFDen } & \text { Prob }>\end{array}$

$\begin{array}{lrrrr}\text { O'Brien[.5] } & 0.1702 & 1 & 28 & 0.6831\end{array}$

Brown-Forsythe $\begin{array}{llll}0.0143 & 1 & 28 & 0.9831 \\ & 0.0289 & 1 & 28\end{array}$

$\begin{array}{lllll}\text { Levene } & 0.0289 & 1 & 28 & 0.8662\end{array}$

$\begin{array}{lrrrr}\text { Bartlett } & 0.3071 & 1 & . & 0.5795 \\ \text { F Test 2-sided } & 1.3921 & 19 & 9 & 0.6266\end{array}$

Welch Anova testing Means Equal, allowing Std Devs Not Equal

F Ratio DFNum DFDen Prob $>$ F

$\begin{array}{llll}18.1932 & 1 & 21.057 & 0.0003\end{array}$

t Test

4.2653 
WSRC-STI-2006-00068

Revision 0

Exhibit A5. Prep Comparisons Using SME Batch Averages by Analyte for each ICP

Sample Type $=\mathrm{SME}$, Analyte $=\mathrm{Fe} / \mathrm{U}$, ICP $=\mathrm{M}-13$

Oneway Analysis of Batch Average Value By Prep/ICP

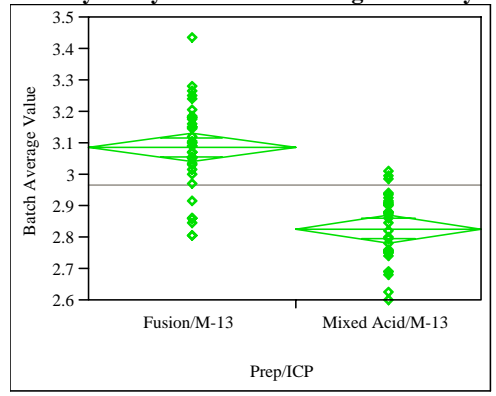

Oneway Anova

Summary of Fit

Rsquare

0.515413

Adj Rsquare

0.507841

Root Mean Square Error $\quad 0.127421$

Mean of Response 2.966048

Observations (or Sum Wgts) 66

t Test

Fusion/M-13-Mixed Acid/M-13

Assuming equal variances

Difference $\quad 0.259286$ t Ratio 8.25053

Std Err Dif $\quad 0.031427$ DF

Upper CL Dif 0.322068 Prob $>|t|<.0001$

Lower CL Dif 0.196505 Prob $>\mathrm{t} \quad<.0001$

Confidence $\quad 0.95$ Prob $<\mathrm{t} \quad 1.0000$

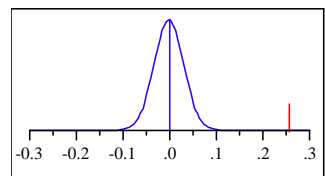

Analysis of Variance

Source DF Sum of Squares Mean Square F Ratio Prob $>$ F

$\begin{array}{lllllll}\text { Prep/ICP } & 1 & 1.1052115 & 1.10521 & 68.0712 & <.0001\end{array}$

$\begin{array}{llll}\text { Error } & 64 & 1.0391105 & 0.01624\end{array}$

C. Total $65 \quad 2.1443220$

Means for Oneway Anova

Level Number Mean Std Error Lower 95\% Upper 95\%

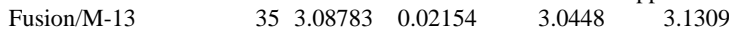

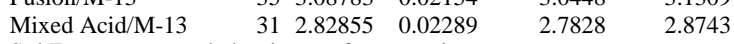

Std Error uses a pooled estimate of error variance

Tests that the Variances are Equal

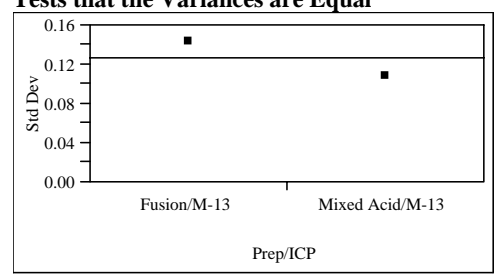

\begin{tabular}{lrrrr} 
Level & Count & Std Dev & \multicolumn{2}{r}{ MeanAbsDif to Mean } \\
Fusion/M-13 & 35 & 0.1426491 & & 0.1084380 \\
$\begin{array}{l}\text { Mixed Acid/M- } \\
13\end{array}$ & 31 & 0.1075876 & 0.0906651 \\
Test & F & DFNum & DFDen & Prob > F \\
& Ratio & & & \\
O'Brien[.5] & 2.2895 & 1 & 64 & 0.1352 \\
Brown-Forsythe & 0.7513 & 1 & 64 & 0.3893 \\
Levene & 0.8916 & 1 & 64 & 0.3486 \\
Bartlett & 2.4366 & 1 &. & 0.1185 \\
F Test 2-sided & 1.7580 & 34 & 30 & 0.1203
\end{tabular}

Welch Anova testing Means Equal, allowing Std Devs Not Equal

F Ratio DFNum DFDen Prob $>$ F

$\begin{array}{llll}70.4133 & 1 & 62.486 & <.0001\end{array}$

t Test

8.3913
Sample Type $=\mathrm{SME}$, Analyte $=\mathrm{Fe} / \mathrm{U}, \mathrm{ICP}=\mathrm{M}-14$

(continued)
Oneway Analysis of Batch Average Value By Prep/ICP

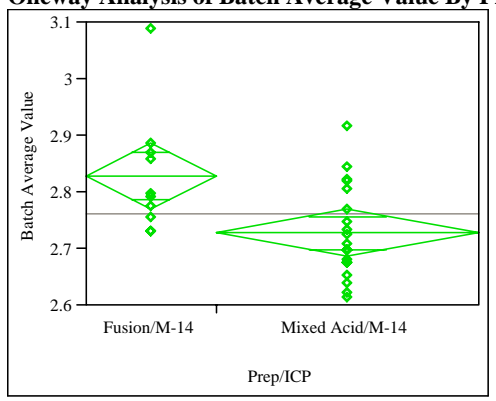

Oneway Anova

Summary of Fit

Rsquare

0.231846

Adj Rsquare

Root Mean Square Error $\quad 0.089922$

Mean of Response 2.762169

Observations (or Sum Wgts) $\quad 30$

t Test

Fusion/M-14-Mixed Acid/M-14

Assuming equal variances

Difference 0.101243 t Ratio 2.907066

Std Err Dif 0.034826 DF 28

Upper CL Dif 0.172582 Prob $>|t| \quad 0.0071$

Lower CL Dif 0.029904 Prob $>$ t 0.0035

$\begin{array}{lll}\text { Confidence } & 0.95 \text { Prob }<\mathrm{t} \quad 0.9965\end{array}$

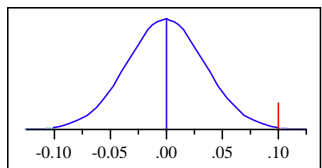

Analysis of Variance

Source DF Sum of Squares Mean Square F Ratio Prob $>$ F

$\begin{array}{lllllll}\text { Prep/ICP } & 1 & 0.06833421 & 0.068334 & 8.4510 & 0.0071\end{array}$

$\begin{array}{llll}\text { Error } & 28 & 0.22640519 & 0.008086\end{array}$

C. Total $29 \quad 0.29473940$

Means for Oneway Anova

Level Number Mean Std Error Lower 95\% Upper 95\%

$\begin{array}{lllllr}\text { Fusion/M-14 } & 10 & 2.82966 & 0.02844 & 2.7714 & 2.8879\end{array}$

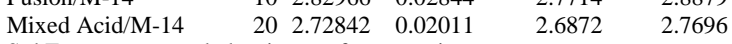

Std Error uses a pooled estimate of error variance

Tests that the Variances are Equal

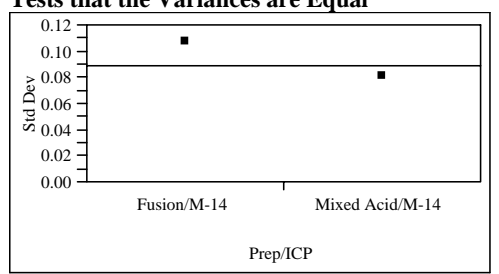

MeanAbsDif to Median 0.1074335 0.0906278

$\begin{array}{lrrrr}\text { Level } & \text { Count } & \text { Std Dev } & \text { MeanAbsDif to Mean } & \begin{array}{r}\text { MeanAbsDif to } \\ \text { Median }\end{array} \\ \text { Fusion/M-14 } & 10 & 0.1070507 & 0.0778166 & 0.0714630 \\ \text { Mixed Acid/M- } & 20 & 0.0805464 & 0.0639822 & 0.0619301\end{array}$

14

14

$\begin{array}{rrr}\text { Test } & \text { F } & \text { DFNum DFDen }\end{array}$

$\begin{array}{lrlll}\text { O'Brien[.5] } & 0.6813 & 1 & 28 & 0.4161\end{array}$

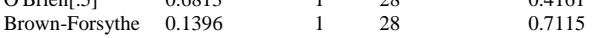

$\begin{array}{lllll}\text { Levene } & 0.4254 & 1 & 28 & 0.5196\end{array}$

$\begin{array}{llrrr}\text { Bartlett } & 1.0027 & 1 & . & 0.3167 \\ \text { F Test 2-sided } & 1.7664 & 9 & 19 & 0.2837\end{array}$

Welch Anova testing Means Equal, allowing Std Devs Not Equal

F Ratio DFNum DFDen Prob > F

$\begin{array}{llll}6.9711 & 1 & 14.274 & 0.0191\end{array}$

t Test

2.6403 
WSRC-STI-2006-00068

Revision 0

Exhibit A5. Prep Comparisons Using SME Batch Averages by Analyte for each ICP

Sample Type $=$ SME, Analyte $=K$, ICP $=$ M-13

Oneway Analysis of Batch Average Value By Prep/ICP

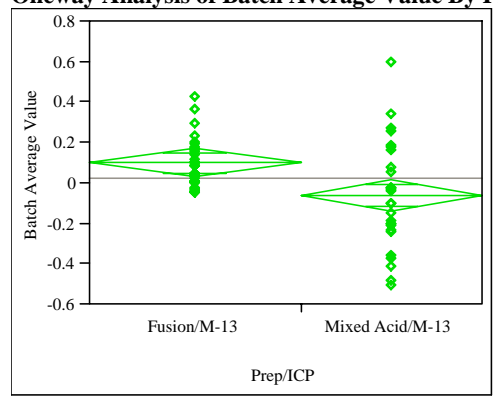

Oneway Anova

Summary of Fit

Rsquare

Adj Rsquare

0.145399

0.130406

0.200298

Mean of Response

0.027251

Observations (or Sum Wgts) 59

t Test

Fusion/M-13-Mixed Acid/M-13

Assuming equal variances

Difference $\quad 0.162998$ t Ratio 3.114124

Std Err Dif $\quad 0.052342$ DF

57

Upper CL Dif 0.267810 Prob $>|t| 0.0029$

Lower CL Dif 0.058186 Prob $>t \quad 0.0014$

Confidence $\quad 0.95$ Prob $<\mathrm{t} \quad 0.9986$

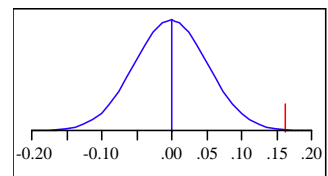

Analysis of Variance

Source DF Sum of Squares Mean Square F Ratio Prob $>$ F

$\begin{array}{llllll}\text { Prep/ICP } & 1 & 0.3890690 & 0.389069 & 9.6978 & 0.0029\end{array}$

$\begin{array}{llll}\text { Error } & 57 & 2.2868088 & 0.040119\end{array}$

C. Total $58 \quad 2.6758778$

Means for Oneway Anova

Level Number Mean Std Error Lower 95\% Upper 95\%

$\begin{array}{llllrr}\text { Fusion/M-13 } & 32 & 0.10184 & 0.03541 & 0.0309 & 0.17275\end{array}$

$\begin{array}{llllll}\text { Mixed Acid/M-13 } & 27 & -0.06115 & 0.03855 & -0.1383 & 0.01604\end{array}$

Std Error uses a pooled estimate of error variance

Tests that the Variances are Equal
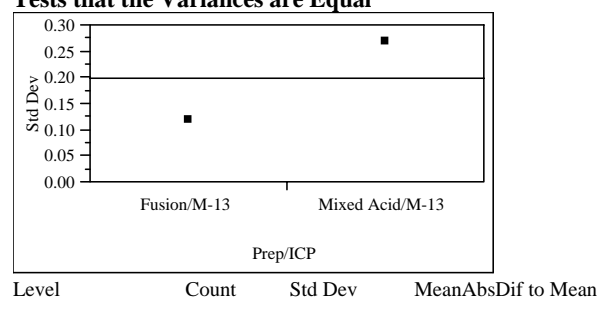

Fusion/M-13

Mixed Acid/M-

Mixed
Test

$$
\begin{array}{ll}
32 & 0.1172553 \\
27 & 0.2675096
\end{array}
$$

0.0909290

O'Brien[.5]

O'Brien[.5]

Levene

Bartlett

MeanAbsDif to Median 0.0896250 0.2107840
Sample Type=SME, Analyte $=K$, ICP $=M-14$

(continued)
Oneway Analysis of Batch Average Value By Prep/ICP

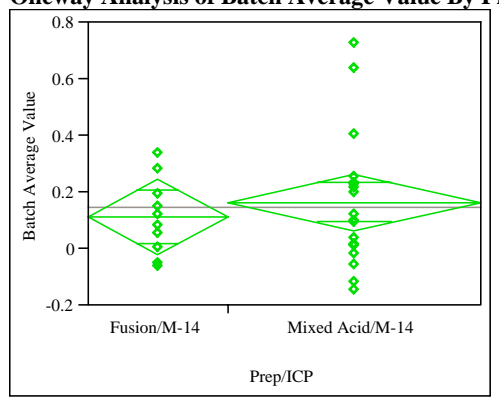

Oneway Anova

Summary of Fit

Rsquare

0.015066

Adj Rsquare

Root Mean Square Error $\quad 0.206064$

Mean of Response

Observations (or Sum Wgts) $\quad 28$

t Test

Fusion/M-14-Mixed Acid/M-14

Assuming equal variances

Difference $\quad-0.05125$ t Ratio $\quad-0.63064$

Std Err Dif $\quad 0.08127$ DF 26

Upper CL Dif 0.11581 Prob $>|t| \quad 0.5338$

Lower CL Dif -0.21831 Prob $>\mathrm{t} \quad 0.7331$

$\begin{array}{lrl}\text { Confidence } & 0.95 \text { Prob }<\mathrm{t} & 0.2669\end{array}$

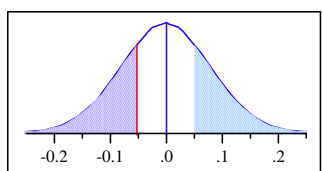

Analysis of Variance

Source DF Sum of Squares Mean Square F Ratio Prob $>$ F

$\begin{array}{lllllll}\text { Prep/ICP } & 1 & 0.0168875 & 0.016887 & 0.3977 & 0.5338\end{array}$

$\begin{array}{llll}\text { Error } & 26 & 1.1040243 & 0.042462\end{array}$

C. Total $27 \quad 1.1209118$

Means for Oneway Anova

Level Number Mean Std Error Lower 95\% Upper 95\%

$\begin{array}{lllllr}\text { Fusion/M-14 } & 10 & 0.115200 & 0.06516 & -0.0187 & 0.24914\end{array}$

$\begin{array}{llllll}\text { Mixed Acid/M-14 } & 18 & 0.166454 & 0.04857 & 0.0666 & 0.26629\end{array}$

Std Error uses a pooled estimate of error variance

Tests that the Variances are Equal

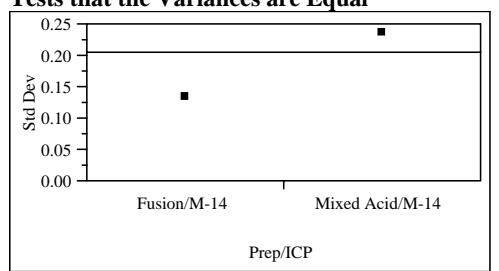

$\begin{array}{lrrrr}\text { Level } & \text { Count } & \text { Std Dev } & \text { MeanAbsDif to Mean } & \begin{array}{r}\text { MeanAbsDif to } \\ \text { Median }\end{array} \\ \text { Fusion/M-14 } & 10 & 0.1328890 & 0.1050000 & 0.1050000 \\ \text { Mixed Acid/M- } & 18 & 0.2357827 & 0.1763374 & 0.1716204\end{array}$

14 F DFNum DFDen

$\begin{array}{lrrrr} & \text { Ratio } & & & \\ \text { O'Brien[.5] } & 1.5826 & 1 & 26 & 0.2196\end{array}$

Brown-Forsythe $\begin{array}{llll}1.4400 & 1 & 26 & 0.2196 \\ & 1.9596 & 1 & 26\end{array}$

$\begin{array}{lllll}\text { Levene } & 1.9596 & 1 & 26 & 0.1734\end{array}$

$\begin{array}{lrrrr}\text { Bartlett } & 3.1764 & 1 & . & 0.0747\end{array}$

$\begin{array}{lllll}\text { F Test 2-sided } & 3.1481 & 17 & 9 & 0.0843\end{array}$

Welch Anova testing Means Equal, allowing Std Devs Not Equal

F Ratio DFNum DFDen Prob $>$ F

$\begin{array}{llll}0.5411 & 1 & 25.964 & 0.4686\end{array}$

t Test

0.7356

t Test

2.9370 
WSRC-STI-2006-00068

Revision 0

Exhibit A5. Prep Comparisons Using SME Batch Averages by Analyte for each ICP

Sample Type=SME, Analyte $=\mathrm{Li}, \mathrm{ICP}=\mathrm{M}-13$

Oneway Analysis of Batch Average Value By Prep/ICP

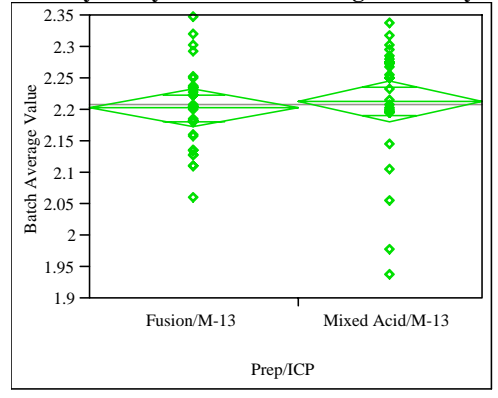

Oneway Anova

Summary of Fit

Rsquare

Adj Rsquare

Root Mean Square Error

Mean of Response

0.00449

$-0.01395$

0.082737

2.207985

Observations (or Sum Wgts) 56

t Test

Fusion/M-13-Mixed Acid/M-13

Assuming equal variances

Difference $\quad-0.01094$ t Ratio $\quad-0.49351$

Std Err Dif $\quad 0.02217$ DF

Upper CL Dif 0.03351 Prob $>|t| 0.6237$

Lower CL Dif -0.05539 Prob $>\mathrm{t} \quad 0.6882$

$\begin{array}{lll}\text { Confidence } & 0.95 \text { Prob }<\mathrm{t} \quad 0.3118\end{array}$

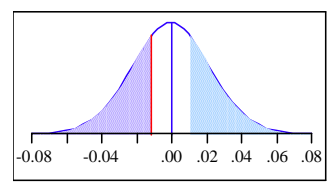

Analysis of Variance

Source DF Sum of Squares Mean Square F Ratio Prob $>$ F $\begin{array}{llllll}\text { Prep/ICP } & 1 & 0.00166720 & 0.001667 & 0.2435 & 0.6237\end{array}$

$\begin{array}{llll}\text { Error } & 54 & 0.36965531 & 0.006845\end{array}$

C. Total $55 \quad 0.37132252$

Means for Oneway Anova

Level Number Mean Std Error Lower 95\% Upper 95\%

$\begin{array}{llllll}\text { Fusion/M-13 } & 30 & 2.20291 & 0.01511 & 2.1726 & 2.2332\end{array}$

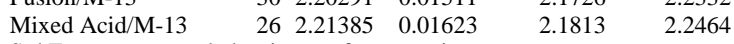

Std Error uses a pooled estimate of error variance

Tests that the Variances are Equal

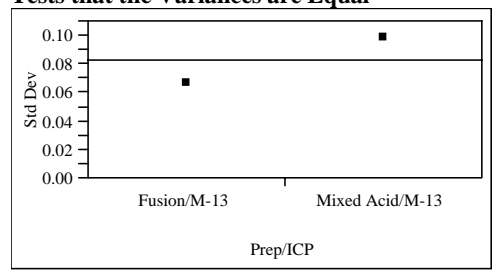

\begin{tabular}{|c|c|c|c|c|}
\hline Level & Count & Std De & & MeanAbsDif to Mean \\
\hline Fusion/M-13 & 30 & 0.066034 & & 0.0512007 \\
\hline $\begin{array}{l}\text { Mixed Acid/M- } \\
13\end{array}$ & 26 & 0.098630 & & 0.07076 \\
\hline Test & $\begin{array}{r}F \\
\text { Ratio }\end{array}$ & DFNum & DFDen & Prob $>$ \\
\hline O'Brien[.5] & 2.2007 & 1 & 54 & \\
\hline Brown-Forsythe & 1.2706 & 1 & 54 & 0.26 \\
\hline Levene & 1.7908 & 1 & 54 & \\
\hline Bartlett & 4.2147 & 1 & & \\
\hline F Test 2-sided & 2.2309 & 25 & 29 & 0.0 \\
\hline
\end{tabular}

Welch Anova testing Means Equal, allowing Std Devs Not Equal

F Ratio DFNum DFDen Prob $>$ F

$\begin{array}{llll}0.2304 & 1 & 42.648 & 0.6337\end{array}$

$\mathrm{t}$ Test

0.4800
Sample Type=SME, Analyte=Li, ICP=M-14

(continued)
Oneway Analysis of Batch Average Value By Prep/ICP

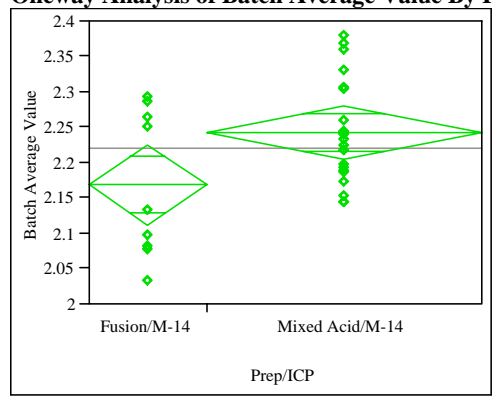

Oneway Anova

Summary of Fit

Rsquare

0.150795

Adj Rsquare

Root Mean Square Error $\quad 0.08317$

Mean of Response 2.221517

Observations (or Sum Wgts) 30

t Test

Fusion/M-14-Mixed Acid/M-14

Assuming equal variances

Difference $\quad-0.07389$ t Ratio $\quad-2.2298$

Std Err Dif $\quad 0.03314$ DF 28

Upper CL Dif -0.00601 Prob $>|\mathrm{t}| \quad 0.0340$

Lower CL Dif -0.14176 Prob $>$ t 0.9830

$\begin{array}{lll}\text { Confidence } & 0.95 \text { Prob }<\mathrm{t} \quad 0.0170\end{array}$

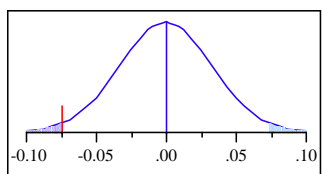

Analysis of Variance

Source DF Sum of Squares Mean Square F Ratio Prob > F

$\begin{array}{llllll}\text { Prep/ICP } & 1 & 0.03439281 & 0.034393 & 4.9720 & 0.0340\end{array}$

$\begin{array}{llll}\text { Error } & 28 & 0.19368393 & 0.006917\end{array}$

C. Total $29 \quad 0.22807674$

Means for Oneway Anova

Level Number Mean Std Error Lower 95\% Upper 95\%

$\begin{array}{lllllr}\text { Fusion/M-14 } & 9 & 2.16980 & 0.02772 & 2.1130 & 2.2266\end{array}$

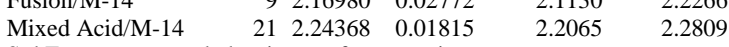

Std Error uses a pooled estimate of error variance

Tests that the Variances are Equal
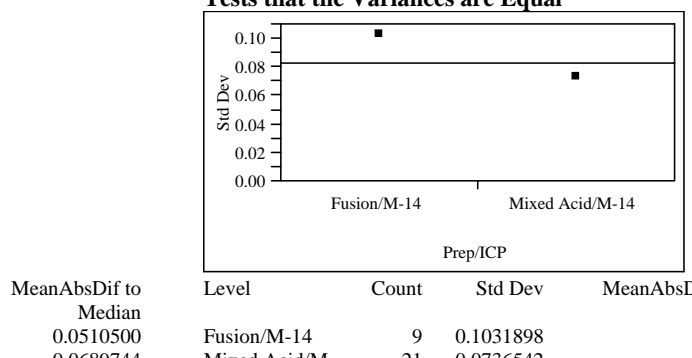

0.0689744

$\begin{array}{lrrrr}\text { Level } & \text { Count } & \text { Std Dev } & \text { MeanAbsDif to Mean } & \begin{array}{r}\text { MeanAbsDif to } \\ \text { Median }\end{array} \\ \text { Fusion/M-14 } & 9 & 0.1031898 & 0.0930700 & 0.0932037 \\ \text { Mixed Acid/M- } & 21 & 0.0736542 & 0.0585896 & 0.0583254\end{array}$

$\begin{array}{llll}14 & F & \text { DFNum DFDen } & \end{array}$

$\begin{array}{lrlll} & \text { Ratio } & & & \\ \text { O'Brien[.5] } & 4.5024 & 1 & 28 & 0.0428\end{array}$

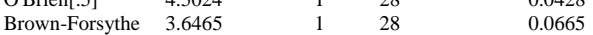

$\begin{array}{lllll}\text { Levene } & 4.8059 & 1 & 28 & 0.0368\end{array}$

$\begin{array}{llrrr}\text { Bartlett } & 1.3469 & 1 & . & 0.2458 \\ \text { F Test 2-sided } & 1.9628 & 8 & 20 & 0.2115\end{array}$

Welch Anova testing Means Equal, allowing Std Devs Not Equal

F Ratio DFNum DFDen Prob > F

$\begin{array}{llll}3.7873 & 1 & 11.653 & 0.0762\end{array}$

t Test

1.9461 
WSRC-STI-2006-00068

Revision 0

Exhibit A5. Prep Comparisons Using SME Batch Averages by Analyte for each ICP

Sample Type $=\mathrm{SME}$, Analyte $=\mathrm{Mg}, \mathrm{ICP}=\mathrm{M}-13$

Oneway Analysis of Batch Average Value By Prep/ICP

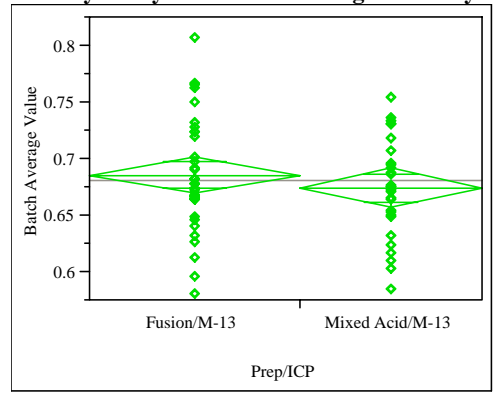

Oneway Anova

Summary of Fit

Rsquare

0.014633

Adj Rsquare

Root Mean Square Error

Mean of Response

0.680728

Observations (or Sum Wgts) 63

t Test

Fusion/M-13-Mixed Acid/M-13

Assuming equal variances

Difference $\quad 0.01138$ t Ratio 0.951774

Std Err Dif $\quad 0.01196$ DF

Upper CL Dif 0.03529 Prob $>|\mathrm{t}| \quad 0.3450$

Lower CL Dif -0.01253 Prob $>t \quad 0.1725$

Confidence $\quad 0.95$ Prob $<\mathrm{t} \quad 0.8275$

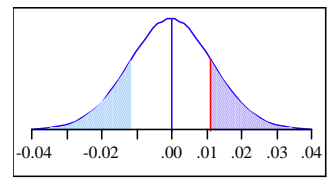

Analysis of Variance

Source DF Sum of Squares Mean Square F Ratio Prob > F

$\begin{array}{lllllll}\text { Prep/ICP } & 1 & 0.00202666 & 0.002027 & 0.9059 & 0.3450\end{array}$

$\begin{array}{llll}\text { Error } & 61 & 0.13647197 & 0.002237\end{array}$

C. Total $62 \quad 0.13849863$

Means for Oneway Anova

Level Number Mean Std Error Lower 95\% Upper 95\%

$\begin{array}{llllrr}\text { Fusion/M-13 } & 34 & 0.685966 & 0.00811 & 0.66975 & 0.70219\end{array}$

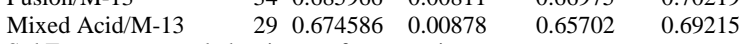

Std Error uses a pooled estimate of error variance

Tests that the Variances are Equal

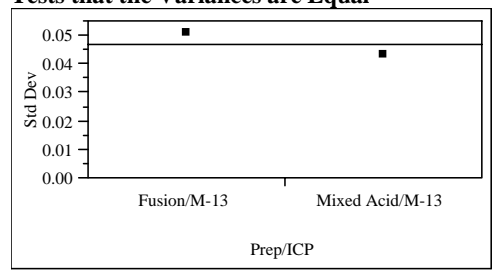

\begin{tabular}{|c|c|c|c|c|}
\hline Level & Count & Std De & & MeanAbsDif to Mean \\
\hline Fusion/M-13 & 34 & 0.050732 & & 0.03906 \\
\hline $\begin{array}{l}\text { Mixed Acid/M- } \\
13\end{array}$ & 29 & 0.042901 & & $0.0333 s$ \\
\hline Test & $\begin{array}{r}F \\
\text { Ratio }\end{array}$ & DFNum & DFDen & Prob > \\
\hline O'Brien[.5] & 0.8801 & 1 & 61 & \\
\hline Brown-Forsythe & 0.3940 & 1 & 61 & \\
\hline Levene & 0.5883 & 1 & 61 & \\
\hline Bartlett & 0.8263 & 1 & & \\
\hline F Test 2-sided & 1.3984 & 33 & 28 & 0.3 \\
\hline
\end{tabular}

Welch Anova testing Means Equal, allowing Std Devs Not Equal

F Ratio DFNum DFDen Prob $>$ F

$\begin{array}{llll}0.9305 & 1 & 60.998 & 0.3385\end{array}$

t Test

0.9646
Sample Type $=\mathrm{SME}$, Analyte $=\mathrm{Mg}$, ICP $=\mathrm{M}-14$

(continued)

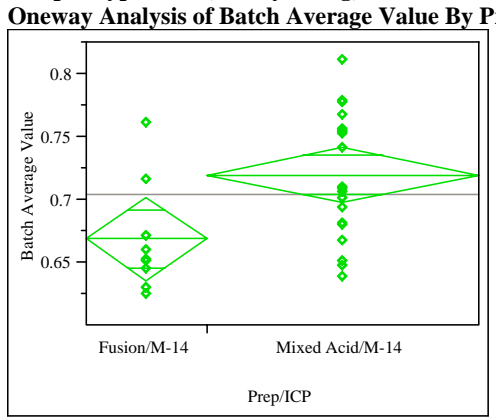

Oneway Anova

Summary of Fit

Rsquare

0.20609

Adj Rsquare

Root Mean Square Error $\quad 0.047852$

Mean of Response $\quad 0.703902$

Observations (or Sum Wgts) 29

t Test

Fusion/M-14-Mixed Acid/M-14

Assuming equal variances

Difference $\quad-0.05085$ t Ratio $\quad-2.64743$

Std Err Dif $\quad 0.01921$ DF 27

Upper CL Dif -0.01144 Prob $>|t| \quad 0.0134$

Lower CL Dif -0.09026 Prob $>t \quad 0.9933$

$\begin{array}{lll}\text { Confidence } \quad 0.95 \text { Prob }<\mathrm{t} \quad 0.0067 & \end{array}$

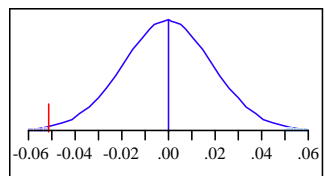

Analysis of Variance

Source DF Sum of Squares Mean Square F Ratio Prob > F

$\begin{array}{llllll}\text { Prep/ICP } & 1 & 0.01604931 & 0.016049 & 7.0089 & 0.0134\end{array}$

$\begin{array}{llll}\text { Error } & 27 & 0.06182588 & 0.002290\end{array}$

C. Total $28 \quad 0.07787520$

Means for Oneway Anova

Level Number Mean Std Error Lower 95\% Upper 95\%

$\begin{array}{lllllr}\text { Fusion/M-14 } & 9 & 0.668833 & 0.01595 & 0.63611 & 0.70156\end{array}$

$\begin{array}{lrllll}\text { Mixed Acid/M-14 } \quad 20 & 0.719683 & 0.01070 & 0.69773 & 0.74164\end{array}$

Std Error uses a pooled estimate of error variance

Tests that the Variances are Equal
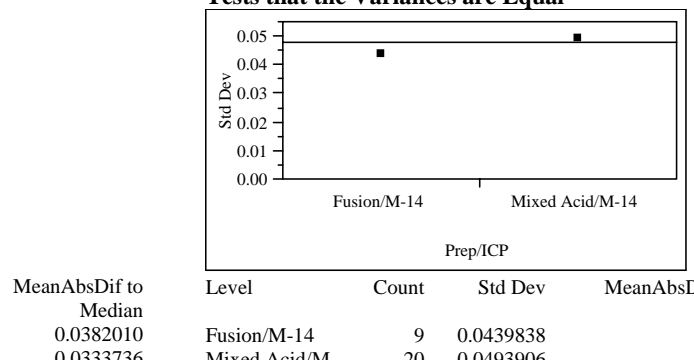

$\begin{array}{lrrrr}\text { Level } & \text { Count } & \text { Std Dev } & \text { MeanAbsDif to Mean } & \begin{array}{r}\text { MeanAbsDif to } \\ \text { Median }\end{array} \\ \text { Fusion/M-14 } & 9 & 0.0439838 & 0.0321481 & 0.0288333 \\ \text { Mixed Acid/M- } & 20 & 0.0493906 & 0.0422350 & 0.0413833\end{array}$

14
Test

O'Brien[.5] Ratio

Brown-Forsythe 1.1009

$\begin{array}{ll}\text { Levene } & 1.0120\end{array}$

Levene

F Ratio DFNum DFDen Prob $>$ F

$\begin{array}{llll}7.6745 & 1 & 17.308 & 0.0129\end{array}$

t Test

2.7703 
WSRC-STI-2006-00068

Revision 0

Exhibit A5. Prep Comparisons Using SME Batch Averages by Analyte for each ICP

Sample Type $=$ SME, Analyte $=M n, I C P=M-13$

Oneway Analysis of Batch Average Value By Prep/ICP

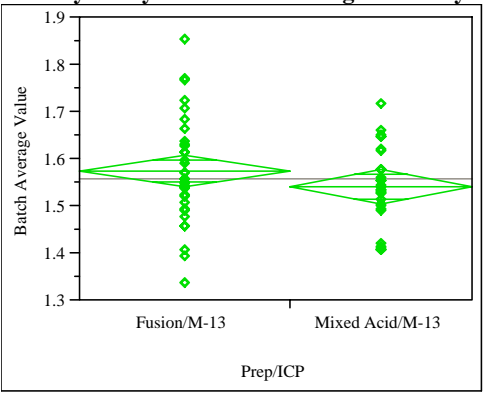

Oneway Anova

Summary of Fit

Rsquare

0.028205

Adj Rsquare

Root Mean Square Error $\quad 0.099082$

Mean of Response

1.55991

Observations (or Sum Wgts) 63

t Test

Fusion/M-13-Mixed Acid/M-13

Assuming equal variances

Difference $\quad 0.03332$ t Ratio $\quad 1.33057$

Std Err Dif $\quad 0.02505$ DF

61

Upper CL Dif 0.08341 Prob $>|t| \quad 0.1883$

Lower CL Dif -0.01676 Prob $>\mathrm{t} \quad 0.0941$

$\begin{array}{lll}\text { Confidence } & 0.95 \text { Prob }<\mathrm{t} \quad 0.9059\end{array}$

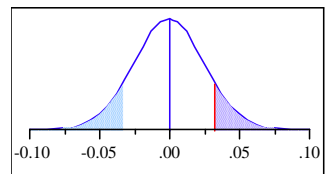

Analysis of Variance

Source DF Sum of Squares Mean Square F Ratio Prob $>$ F $\begin{array}{llllll}\text { Prep/ICP } & 1 & 0.01738078 & 0.017381 & 1.7704 & 0.1883\end{array}$

$\begin{array}{llll}\text { Error } & 61 & 0.59885732 & 0.009817\end{array}$

C. Total $62 \quad 0.61623810$

Means for Oneway Anova

Level Number Mean Std Error Lower 95\% Upper 95\%

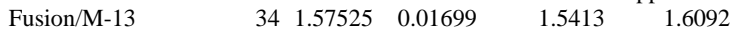

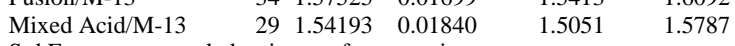

Std Error uses a pooled estimate of error variance

Tests that the Variances are Equal

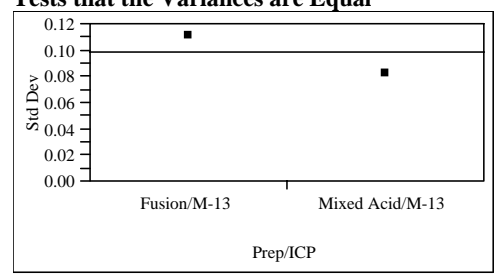

\begin{tabular}{|c|c|c|c|c|c|}
\hline Level & Count & Std Dev & & MeanAbsDif to Mean & $\begin{array}{r}\text { MeanAbsDif to } \\
\text { Median }\end{array}$ \\
\hline Fusion/M-13 & 34 & 0.1115083 & & 0.0847353 & 0.0833971 \\
\hline $\begin{array}{l}\text { Mixed Acid/M- } \\
13\end{array}$ & 29 & 0.0820566 & & 0.0618767 & 0.0617816 \\
\hline Test & $\begin{array}{r}F \\
\text { Ratio }\end{array}$ & DFNum D & DFDen & Prob $>$ F & \\
\hline O'Brien[.5] & 2.2431 & 1 & 61 & 0.1394 & \\
\hline Brown-Forsythe & 1.7031 & 1 & 61 & 0.1968 & \\
\hline Levene & 2.0469 & 1 & 61 & 0.1576 & \\
\hline Bartlett & 2.7158 & 1 & & 0.0994 & \\
\hline F Test 2-sided & 1.8467 & 33 & 28 & 0.1014 & \\
\hline \multicolumn{6}{|c|}{ Welch Anova testing Means Equal, allowing Std Devs Not Equal } \\
\hline F Ratio DFNu & m DFDen & Prob $>\mathrm{F}$ & & & \\
\hline 1.8574 & 159.797 & $7 \quad 0.1780$ & & & \\
\hline
\end{tabular}

Sample Type $=$ SME, Analyte $=$ Mn, ICP $=M-14$

(continued)
Oneway Analysis of Batch Average Value By Prep/ICP

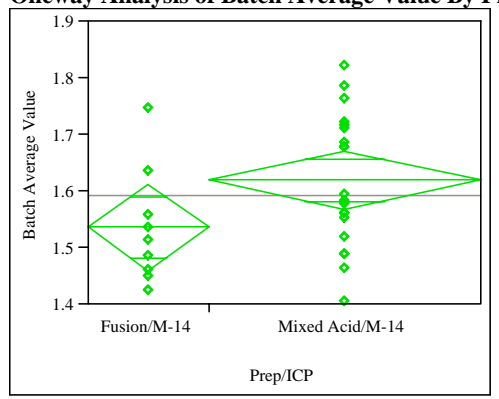

Oneway Anova

Summary of Fit

Rsquare $\quad 0.111662$

Adj Rsquare

0.07876
0.112757

Root Mean Square Error $\quad 0.11275$

Mean of Response 1.59372

Observations (or Sum Wgts) 29

t Test

Fusion/M-14-Mixed Acid/M-14

Assuming equal variances

Difference $\quad-0.08338$ t Ratio -1.84223

Std Err Dif $\quad 0.04526$ DF 27

Upper CL Dif 0.00949 Prob $>|t| \quad 0.0764$

Lower CL Dif -0.17624 Prob $>\mathrm{t} \quad 0.9618$

$\begin{array}{lll}\text { Confidence } & 0.95 \text { Prob }<\mathrm{t} \quad 0.0382\end{array}$

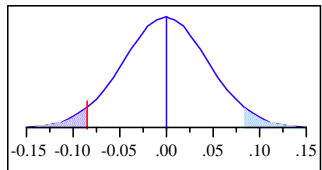

Analysis of Variance

Source DF Sum of Squares Mean Square F Ratio Prob $>$ F

$\begin{array}{llllll}\text { Prep/ICP } & 1 & 0.04314944 & 0.043149 & 3.3938 & 0.0764\end{array}$

Error $\quad 27 \quad 0.34328119 \quad 0.012714$

C. Total $28 \quad 0.38643063$

Means for Oneway Anova

Level Number Mean Std Error Lower 95\% Upper 95\%

$\begin{array}{llrrrr}\text { Fusion/M-14 } & 9 & 1.53622 & 0.03759 & 1.4591 & 1.6133\end{array}$

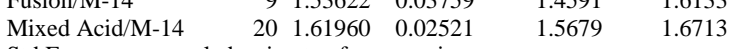

Std Error uses a pooled estimate of error variance

Tests that the Variances are Equal

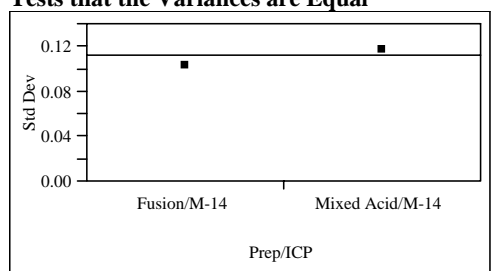

$\begin{array}{lrrrr}\text { Level } & \text { Count } & \text { Std Dev } & \text { MeanAbsDif to Mean } & \begin{array}{r}\text { MeanAbsDif to } \\ \text { Median }\end{array} \\ \text { Fusion/M-14 } & 9 & 0.1022824 & 0.0753580 & 0.0756111 \\ \text { Mixed Acid/M- } & 20 & 0.1168868 & 0.1002600 & 0.0977667\end{array}$

$\begin{array}{llll}14 & \text { F } & \text { DFNum DFDen } & \text { Prob }>\text { F }\end{array}$

$\begin{array}{lrlll} & \text { Ratio } & & & \text { Prob }> \\ \text { O'Brien[.5] } & 0.2760 & 1 & 27 & 0.6036\end{array}$

$\begin{array}{lllll}\text { Brown-Forsythe } & 0.6721 & 1 & 27 & 0.6036 \\ & 1.1404 & 1 & 27 & 0.4195\end{array}$

$\begin{array}{lllll}\text { Levene } & 1.1404 & 1 & 27 & 0.2950\end{array}$

$\begin{array}{lrrrr}\text { Bartlett } & 0.1844 & 1 & . & 0.6676 \\ \text { F Test 2-sided } & 1.3060 & 19 & 8 & 0.7272\end{array}$

Welch Anova testing Means Equal, allowing Std Devs Not Equal

F Ratio DFNum DFDen Prob $>$ F

$\begin{array}{llll}3.7669 & 1 & 17.606 & 0.0685\end{array}$

t Test

1.9408 
WSRC-STI-2006-00068

Revision 0

Exhibit A5. Prep Comparisons Using SME Batch Averages by Analyte for each ICP

Sample Type $=$ SME, Analyte $=\mathrm{Mn} / \mathrm{Mg}, \mathrm{ICP}=\mathrm{M}-13$ Oneway Analysis of Batch Average Value By Prep/ICP

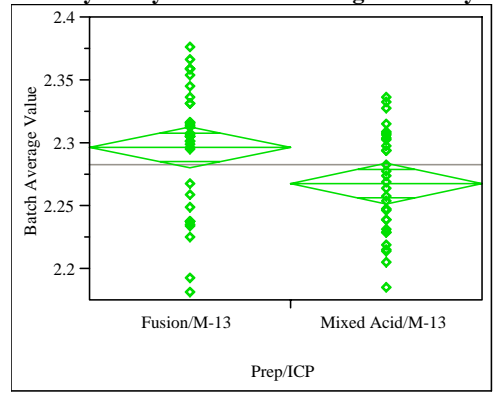

Oneway Anova

Summary of Fit

Rsquare

0.089477

Adj Rsquare

0.074791

Root Mean Square Error $\quad 0.045764$

Mean of Response 2.282918

Observations (or Sum Wgts) 64

t Test

Fusion/M-13-Mixed Acid/M-13

Assuming equal variances

Difference $\quad 0.028254$ t Ratio 2.468341

Std Err Dif $\quad 0.011447$ DF

Upper CL Dif 0.051136 Prob $>|t| \quad 0.0163$

Lower CL Dif 0.005373 Prob $>t \quad 0.0082$

$\begin{array}{lll}\text { Confidence } & 0.95 \text { Prob }<\mathrm{t} \quad 0.9918\end{array}$

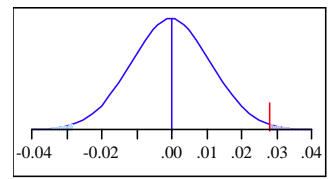

Analysis of Variance

Source DF Sum of Squares Mean Square F Ratio Prob $>$ F

$\begin{array}{llllll}\text { Prep/ICP } & 1 & 0.01276032 & 0.012760 & 6.0927 & 0.0163\end{array}$

$\begin{array}{llll}\text { Error } & 62 & 0.12985031 & 0.002094\end{array}$

C. Total $63 \quad 0.14261063$

Means for Oneway Anova

Level Number Mean Std Error Lower 95\% Upper 95\%

$\begin{array}{lllllr}\text { Fusion/M-13 } & 33 & 2.29660 & 0.00797 & 2.2807 & 2.3125\end{array}$

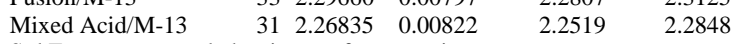

Std Error uses a pooled estimate of error variance

Tests that the Variances are Equal

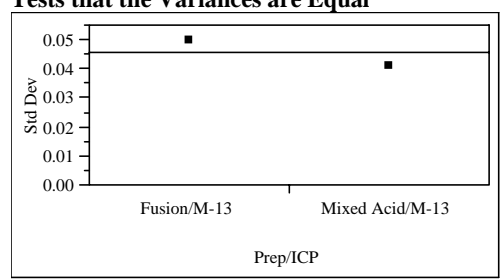

\begin{tabular}{lrrrr} 
Level & Count & Std Dev & \multicolumn{2}{r}{ MeanAbsDif to Mean } \\
Fusion/M-13 & 33 & 0.0497539 & & 0.0389877 \\
Mixed Acid/M- & 31 & 0.0410836 & 0.0350456 \\
13 & & & & \\
Test & F & DFNum & DFDen & Prob > F \\
& Ratio & & & \\
O'Brien[.5] & 1.4572 & 1 & 62 & 0.2320 \\
Brown-Forsythe & 0.0872 & 1 & 62 & 0.7688 \\
Levene & 0.3701 & 1 & 62 & 0.5452 \\
Bartlett & 1.1061 & 1 &. & 0.2929 \\
F Test 2-sided & 1.4666 & 32 & 30 & 0.2947
\end{tabular}

Welch Anova testing Means Equal, allowing Std Devs Not Equal

F Ratio DFNum DFDen Prob $>$ F

$\begin{array}{llll}6.1663 & 1 & 61.021 & 0.0158\end{array}$

t Test

2.4832
Sample Type $=$ SME, Analyte $=\mathrm{Mn} / \mathrm{Mg}, \mathrm{ICP}=\mathrm{M}-14$

(continued)
Oneway Analysis of Batch Average Value By Prep/ICP

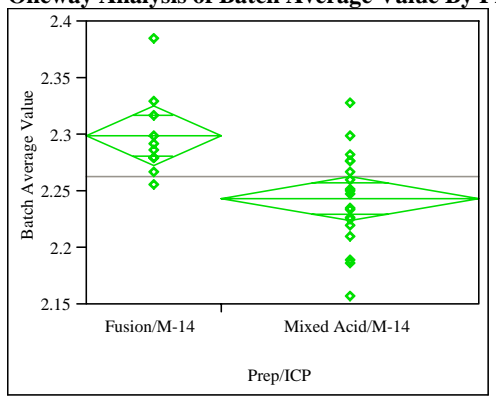

Oneway Anova

Summary of Fit

Rsquare $\quad 0.318805$

Adj

Root Mean Square Error $\quad 0.040197$

Mean of Response 2.26288

Observations (or Sum Wgts) 29

t Test

Fusion/M-14-Mixed Acid/M-14

Assuming equal variances

Difference 0.055824 t Ratio 3.554746

Std Err Dif $\quad 0.015704$ DF 27

Upper CL Dif 0.088047 Prob $>|\mathrm{t}| \quad 0.0014$

Lower CL Dif 0.023602 Prob $>\mathrm{t} \quad 0.0007$

$\begin{array}{lll}\text { Confidence } & 0.95 \text { Prob }<\mathrm{t} \quad 0.9993\end{array}$

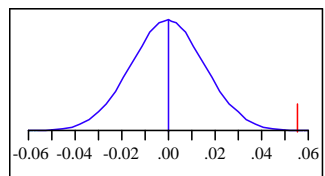

Analysis of Variance

Source DF Sum of Squares Mean Square F Ratio Prob $>$ F

$\begin{array}{llllll}\text { Prep/ICP } & 1 & 0.02041749 & 0.020417 & 12.6362 & 0.0014\end{array}$

$\begin{array}{llll}\text { Error } & 27 & 0.04362636 & 0.001616\end{array}$

C. Total $28 \quad 0.06404384$

Means for Oneway Anova

Level Number Mean Std Error Lower 95\% Upper 95\%

$\begin{array}{llllll}\text { Fusion/M-14 } & 10 & 2.29946 & 0.01271 & 2.2734 & 2.3255\end{array}$

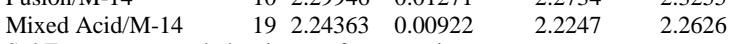

Std Error uses a pooled estimate of error variance

Tests that the Variances are Equal

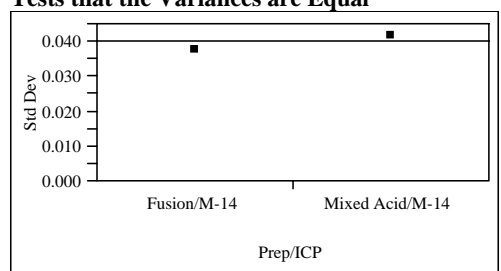

MeanAbsDif to Median

0.0372442

0.0351712

$\begin{array}{llllr}\text { Fusion/M-14 } & 10 & 0.0374779 & 0.0270839 & 0.0255771 \\ \text { Mixed Acid/M- } & 19 & 0.0414897 & 0.0322328 & 0.0322020\end{array}$

$\begin{array}{lrrrr} & \text { Ratio } & & & 0.7494\end{array}$

Brown-Forsythe $\begin{array}{llll}0.4177 & 1 & 27 & 0.7494 \\ & 0.2834 & 1 & 27\end{array}$

$\begin{array}{lllll}\text { Bevene } & 0.2834 & 1 & 27 & 0.5235 \\ \text { Lewn-Fyth } & 0.4177 & 1 & \end{array}$

$\begin{array}{lrrrr}\text { Bartlett } & 0.1161 & 1 & . & 0.7333 \\ \text { F Test 2-sided } & 1.2255 & 18 & 9 & 0.7821\end{array}$

Welch Anova testing Means Equal, allowing Std Devs Not Equal

F Ratio DFNum DFDen Prob $>$ F

$\begin{array}{llll}13.4873 & 1 & 20.161 & 0.0015\end{array}$

t Test

3.6725 
WSRC-STI-2006-00068

Revision 0

Exhibit A5. Prep Comparisons Using SME Batch Averages by Analyte for each ICP

Sample Type $=\mathrm{SME}$, Analyte $=\mathrm{Na}, \mathrm{ICP}=\mathrm{M}-13$

Oneway Analysis of Batch Average Value By Prep/ICP

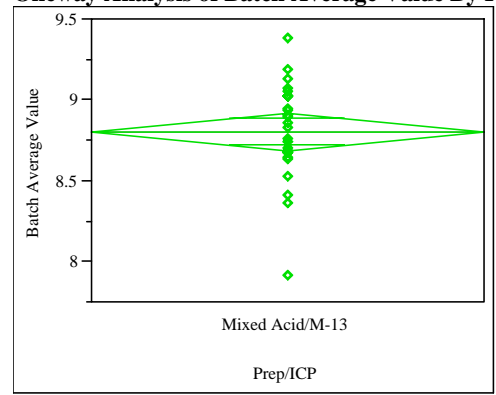

Missing Rows

350neway Anova

Summary of Fit

Rsquare

Adj Rsquare

Root Mean Square Error $\quad 0.296525$

Mean of Response 8.807543

Observations (or Sum Wgts)

Analysis of Variance

Source DF Sum of Squares Mean Square F Ratio Prob $>$ F

Prep/ICP 00.0000000

$\begin{array}{llll}\text { Error } & 26 & 2.2861069 & 0.087927\end{array}$

C. Total $26 \quad 2.2861069$

Means for Oneway Anova

Level Number Mean Std Error Lower 95\% Upper 95\%

$\begin{array}{llllll}\text { Mixed Acid/M-13 } & 27 & 8.80754 & 0.05707 & 8.6902 & 8.9248\end{array}$

Std Error uses a pooled estimate of error variance
Sample Type $=$ SME, Analyte $=\mathrm{Na}, \mathrm{ICP}=\mathrm{M}-14$

(continued)

Oneway Analysis of Batch Average Value By Prep/ICP

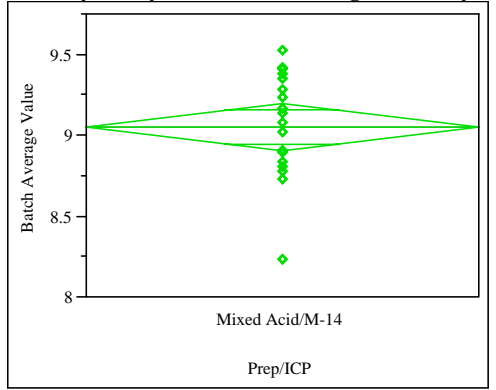

Missing Rows

10Oneway Anova

Summary of Fit

Rsquare

Adj Rsquare

$\begin{array}{ll}\text { Root Mean Square Error } & 0.311382 \\ \text { Mean of Response } & 9.053983\end{array}$

Observations (or Sum Wgts) 20

Analysis of Variance

Source DF Sum of Squares Mean Square F Ratio Prob > F

Prep/ICP $0 \quad 0.0000000$

$\begin{array}{llll}\text { Error } & 19 & 1.8422182 & 0.096959\end{array}$

C. Total $19 \quad 1.8422182$

Means for Oneway Anova

Level Number Mean Std Error Lower 95\% Upper 95\%

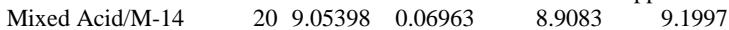

Std Error uses a pooled estimate of error variance 
WSRC-STI-2006-00068

Revision 0

Exhibit A5. Prep Comparisons Using SME Batch Averages by Analyte for each ICP

Sample Type $=$ SME, Analyte $=\mathrm{Ni}$, ICP $=\mathrm{M}-13$

Oneway Analysis of Batch Average Value By Prep/ICP

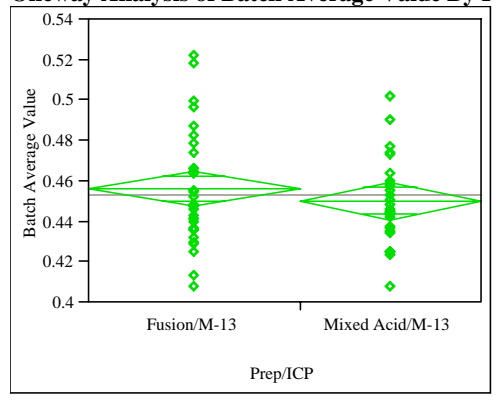

Oneway Anova

Summary of Fit

Rsquare

Adj Rsquare

0.015024

Root Mean Squar

Mean of Response

$-0.00167$

0.02457

0.453514

Observations (or Sum Wgts) 61

t Test

Fusion/M-13-Mixed Acid/M-13

Assuming equal variances

Difference 0.00599 t Ratio 0.948648

Std Err Dif $\quad 0.00631$ DF 59

Upper CL Dif 0.01862 Prob $>|t| 0.3467$

Lower CL Dif -0.00664 Prob $>\mathrm{t} \quad 0.1733$

$\begin{array}{lll}\text { Confidence } & 0.95 \text { Prob }<\mathrm{t} \quad 0.8267\end{array}$

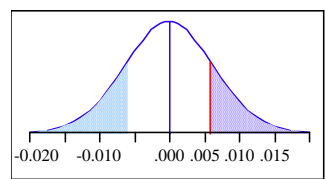

Analysis of Variance

Source DF Sum of Squares Mean Square F Ratio Prob $>$ F

$\begin{array}{llllll}\text { Prep/ICP } & 1 & 0.00054328 & 0.000543 & 0.8999 & 0.3467\end{array}$

$\begin{array}{llll}\text { Error } & 59 & 0.03561768 & 0.000604\end{array}$

C. Total $60 \quad 0.03616096$

Means for Oneway Anova

Level Number Mean Std Error Lower 95\% Upper 95\%

$\begin{array}{llllrr}\text { Fusion/M-13 } & 33 & 0.456263 & 0.00428 & 0.44770 & 0.46482\end{array}$

$\begin{array}{llllll}\text { Mixed Acid/M-13 } & 28 & 0.450274 & 0.00464 & 0.44098 & 0.45957\end{array}$

Std Error uses a pooled estimate of error variance

Tests that the Variances are Equal

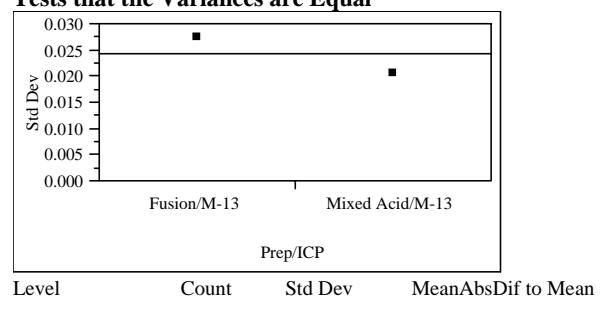

Fusion/M-13

Mixed Acid/M-

Count

Std Dev

0.0215810

$28 \quad 0.0205590$

0.0155153

13

Test

F DFNum DFDen

Prob $>$ F

O'Brien[.5]

Levene $\quad 2.4342$

Bartlett

1.7896

$1 \quad 59$

$\begin{array}{ll}1 & 59 \\ 1 & 59 \\ 1 & 59\end{array}$

$\begin{array}{rr}1 & 59 \\ 1 & . \\ 32 & 27\end{array}$

0.1730

0.1848

0.1241

0.1265

Welch Anova testing Means Equal, allowing Std Devs Not Equal

F Ratio DFNum DFDen Prob > F

$\begin{array}{lrrr}0.9434 & 1 & 58.141 & 0.3354\end{array}$

t Test

0.9713
Sample Type $=$ SME, Analyte $=\mathrm{Ni}$, ICP $=\mathrm{M}-14$

(continued)
Oneway Analysis of Batch Average Value By Prep/ICP

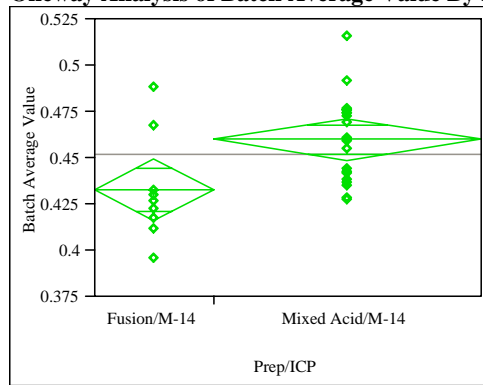

Oneway Anova

Summary of Fit

Rsquare

Adj Rsquare $\quad 0.185977$

Root Mean Square Error $\quad 0.02493$

Mean of Response $\quad 0.451695$

Observations (or Sum Wgts)

t Test

Fusion/M-14-Mixed Acid/M-14

Assuming equal variances

Difference $\quad-0.02722$ t Ratio $\quad-2.71976$

Std Err Dif $\quad 0.01001$ DF 27

Upper CL Dif -0.00668 Prob $>|\mathrm{t}| \quad 0.0113$

Lower CL Dif -0.04775 Prob $>\mathrm{t} \quad 0.9944$

Confidence $\quad 0.95$ Prob $<\mathrm{t} \quad 0.0056$

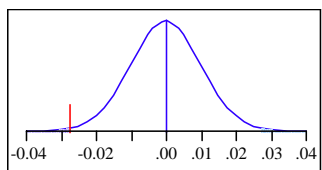

Analysis of Variance

Source DF Sum of Squares Mean Square F Ratio Prob > F

$\begin{array}{lrllll}\text { Prep/ICP } & 1 & 0.00459743 & 0.004597 & 7.3971 & 0.0113\end{array}$

$\begin{array}{llll}\text { Error } & 27 & 0.01678102 & 0.000622\end{array}$

C. Total $28 \quad 0.02137845$

Means for Oneway Anova

Level Number Mean Std Error Lower 95\% Upper 95\%

$\begin{array}{llllll}\text { Fusion/M-14 } & 9 & 0.432926 & 0.00831 & 0.41588 & 0.44998\end{array}$

$\begin{array}{llllll}\text { Mixed Acid/M-14 } & 20 & 0.460142 & 0.00557 & 0.44870 & 0.47158\end{array}$

Std Error uses a pooled estimate of error variance

Tests that the Variances are Equal

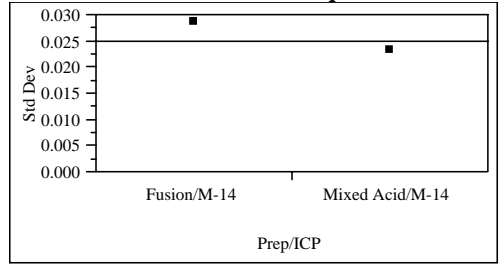

MeanAbsDif to Median 0.0210152 0.0151071

\begin{tabular}{|c|c|c|c|c|c|}
\hline Level & Count & Std Dev & & MeanAbsDif to Mean & $\begin{array}{r}\text { MeanAbsDif to } \\
\text { Median }\end{array}$ \\
\hline Fusion/M-14 & 9 & 0.0285609 & & 0.0202551 & 0.0193704 \\
\hline $\begin{array}{l}\text { Mixed Acid/M- } \\
14\end{array}$ & 20 & 0.0232325 & & 0.0190083 & 0.0190083 \\
\hline Test & $\begin{array}{r}F \\
\text { Ratio }\end{array}$ & DFNum & DFDen & Prob $>$ F & \\
\hline O'Brien[.5] & 0.5315 & 1 & 27 & 0.4723 & \\
\hline Brown-Forsythe & 0.0034 & 1 & 27 & 0.9542 & \\
\hline Levene & 0.0444 & 1 & 27 & 0.8346 & \\
\hline Bartlett & 0.4823 & 1 & & 0.4874 & \\
\hline F Test 2-sided & 1.5113 & 8 & 19 & 0.4365 & \\
\hline \multicolumn{6}{|c|}{ Welch Anova testing Means Equal, allowing Std Devs Not Equal } \\
\hline F Ratio DFNur & n DFDen & Prob $>$ & & & \\
\hline 6.2972 & 112.989 & 0.026 & & & \\
\hline
\end{tabular}


WSRC-STI-2006-00068

Revision 0

Exhibit A5. Prep Comparisons Using SME Batch Averages by Analyte for each ICP

Sample Type=SME, Analyte=Si, ICP=M-13

Oneway Analysis of Batch Average Value By Prep/ICP

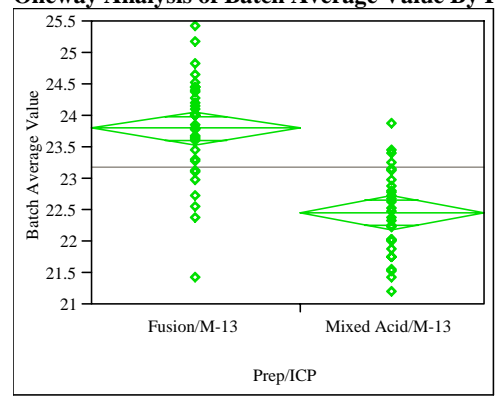

Oneway Anova

Summary of Fit

Rsquare

0.448846

Adj Rsquare

Root Mean Square Error $\quad 0.757817$

Mean of Response 23.17831

Observations (or Sum Wgts) 62

t Test

Fusion/M-13-Mixed Acid/M-13

Assuming equal variances

Difference $\quad 1.34832$ t Ratio 6.990176

Std Err Dif $\quad 0.19289$ DF

Upper CL Dif 1.73415 Prob $>|t|<.0001$

Lower CL Dif 0.96249 Prob $>\mathrm{t} \quad<.0001$

$\begin{array}{lll}\text { Confidence } & 0.95 \text { Prob }<\mathrm{t} \quad 1.0000\end{array}$

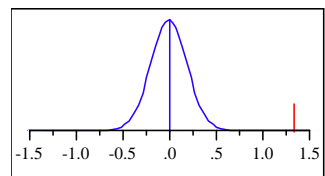

Analysis of Variance

Source DF Sum of Squares Mean Square F Ratio Prob $>$ F

$\begin{array}{llllll}\text { Prep/ICP } & 1 & 28.061151 & 28.0612 & 48.8626 & <.0001\end{array}$

$\begin{array}{llll}\text { Error } & 60 & 34.457238 & 0.5743\end{array}$

C. Total $61 \quad 62.518389$

Means for Oneway Anova

Level Number Mean Std Error Lower 95\% Upper 95\%

$\begin{array}{llrrrr}\text { Fusion/M-13 } & 33 & 23.8090 & 0.13192 & 23.545 & 24.073\end{array}$

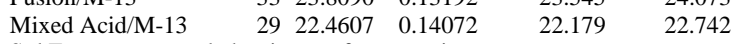

Std Error uses a pooled estimate of error variance

Tests that the Variances are Equal

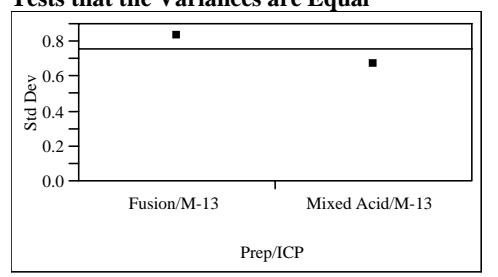

\begin{tabular}{lrrrr}
\hline Level & Count & Std Dev & \multicolumn{2}{c}{ MeanAbsDif to Mean } \\
& & & & 0.6262039 \\
Fusion/M-13 & 33 & 0.8280230 & & 0.5475232 \\
Mixed Acid/M- & 29 & 0.6686162 & \\
13 & & & & \\
Test & F & DFNum & DFDen & \\
& Ratio & & & \\
O'Brien[.5] & 1.0246 & 1 & 60 & 0.3155 \\
Brown-Forsythe & 0.4190 & 1 & 60 & 0.5199 \\
Levene & 0.4471 & 1 & 60 & 0.5063 \\
Bartlett & 1.3206 & 1 &. & 0.2505 \\
F Test 2-sided & 1.5337 & 32 & 28 & 0.2539
\end{tabular}

Welch Anova testing Means Equal, allowing Std Devs Not Equal

F Ratio DFNum DFDen Prob $>$ F

$\begin{array}{llll}50.2313 & 1 & 59.603<.0001\end{array}$

t Test

7.0874
Sample Type=SME, Analyte=Si, ICP=M-14

(continued)
Oneway Analysis of Batch Average Value By Prep/ICP

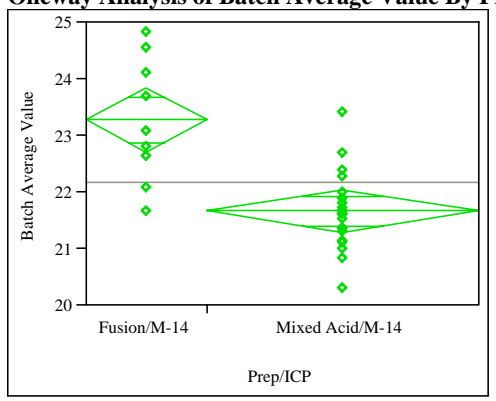

Oneway Anova

Summary of Fit

Rsquare

Adj Rsquare

$\quad 0.835618$

Mean of Response 22.17113

Observations (or Sum Wgts) 29

t Test

Fusion/M-14-Mixed Acid/M-14

Assuming equal variances

Difference $\quad 1.61917$ t Ratio $\quad 4.827502$

Std Err Dif $\quad 0.33541$ DF 27

Upper CL Dif 2.30737 Prob $>|t|<.0001$

Lower CL Dif 0.93098 Prob $>\mathrm{t} \quad<.0001$

$\begin{array}{lll}\text { Confidence } & 0.95 \text { Prob }<\mathrm{t} \quad 1.0000\end{array}$

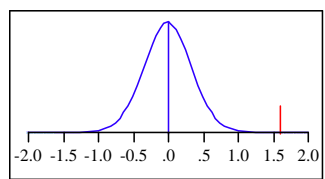

Analysis of Variance

Source DF Sum of Squares Mean Square F Ratio Prob $>$ F

$\begin{array}{lllllll}\text { Prep/ICP } & 1 & 16.272718 & 16.2727 & 23.3048 & <.0001\end{array}$

$\begin{array}{llll}\text { Error } & 27 & 18.852931 & 0.6983\end{array}$

C. Total $28 \quad 35.125649$

Means for Oneway Anova

Level Number Mean Std Error Lower 95\% Upper 95\%

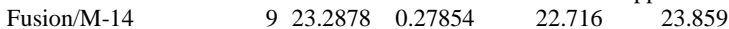

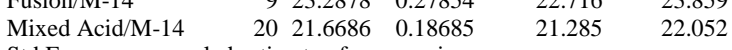

Std Error uses a pooled estimate of error variance

Tests that the Variances are Equal

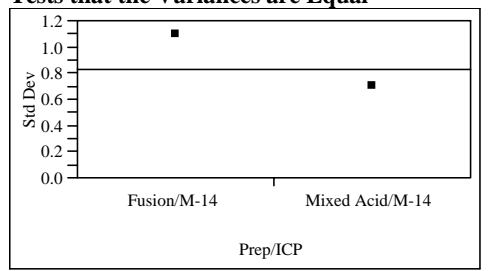
Median 0.6255354 0.5491264

$\begin{array}{lrrrr}\text { Level } & \text { Count } & \text { Std Dev } & \text { MeanAbsDif to Mean } & \begin{array}{r}\text { MeanAbsDif to } \\ \text { Median }\end{array} \\ \text { Fusion/M-14 } & 9 & 1.098223 & 0.9098848 & 0.9216111 \\ \text { Mixed Acid/M- } & 20 & 0.696010 & 0.5030208 & 0.4997750\end{array}$

14

Test F DFNum DFDen Prob $>$ F

$\begin{array}{lrrrr}\text { O'Brien[.5] } & 3.5179 & 1 & 27 & 0.0716\end{array}$

Brown-Forsythe \begin{tabular}{llll}
4.5097 & 1 & 27 & 0.0716 \\
\hline
\end{tabular}

$\begin{array}{lllll}\text { Levene } & 4.3748 & 1 & 27 & 0.0430 \\ & 2.4590 & 1 & & 0.0460\end{array}$

$\begin{array}{lllcl}\text { Bartlett } & 2.4590 & 1 & . & 0.1169\end{array}$

Welch Anova testing Means Equal, allowing Std Devs Not Equal

F Ratio DFNum DFDen Prob $>$ F

$\begin{array}{llll}16.5688 & 1 & 11.002 & 0.0018\end{array}$

t Test

4.0705 
WSRC-STI-2006-00068

Revision 0

Exhibit A5. Prep Comparisons Using SME Batch Averages by Analyte for each ICP

Sample Type $=$ SME, Analyte $=$ Sum of Oxides, ICP=M-13 Oneway Analysis of Batch Average Value By Prep/ICP

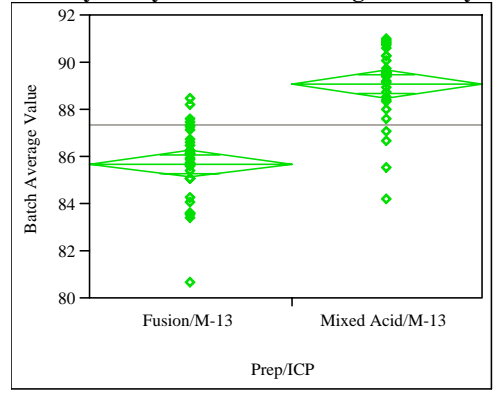

Oneway Anova

Summary of Fit

Rsquare

0.530855

Adj Rsquare

0.523036

1.609381

Mean of Response $\quad 87.3582$

Observations (or Sum Wgts) $\quad 62$

t Test

Fusion/M-13-Mixed Acid/M-13

Assuming equal variances

Difference $\quad-3.3700$ t Ratio $\quad-8.23968$

Std Err Dif 0.4090 DF

60

Upper CL Dif -2.5519 Prob $>|\mathrm{t}| \quad<.0001$

Lower CL Dif -4.1881 Prob $>$ t 1.0000

Confidence $\quad 0.95$ Prob $<\mathrm{t} \quad<.0001$

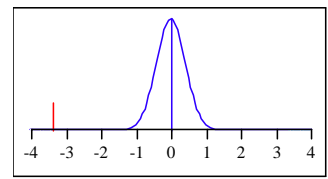

Analysis of Variance

Source DF Sum of Squares Mean Square F Ratio Prob $>$ F

$\begin{array}{lllllll}\text { Prep/ICP } & 1 & 175.84834 & 175.848 & 67.8923 & <.0001\end{array}$

$\begin{array}{llll}\text { Error } & 60 & 155.40636 & 2.590\end{array}$

C. Total $61 \quad 331.25470$

Means for Oneway Anova

Level Number Mean Std Error Lower 95\% Upper 95\%

$\begin{array}{llllll}\text { Fusion/M-13 } & 32 & 85.7276 & 0.28450 & 85.158 & 86.297\end{array}$

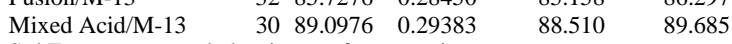

Std Error uses a pooled estimate of error variance

Tests that the Variances are Equal
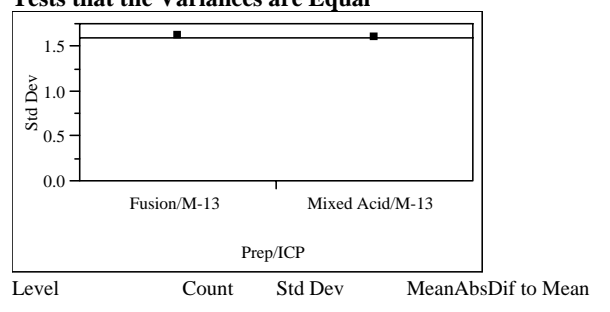

Fusion/M-13

Mixed Acid/M-

1.614402

if to Mean

13

Test

O'Brien[.5]

Brown-Forsythe

Levene

Bartlett

F Ratio DFNum DFDen Prob $>$ F

$\begin{array}{rrrr}67.9211 & 1 & 59.791<.0001\end{array}$

t Test

8.2414
Sample Type=SME, Analyte=Sum of Oxides, ICP=M-14

(continued)
Oneway Analysis of Batch Average Value By Prep/ICP

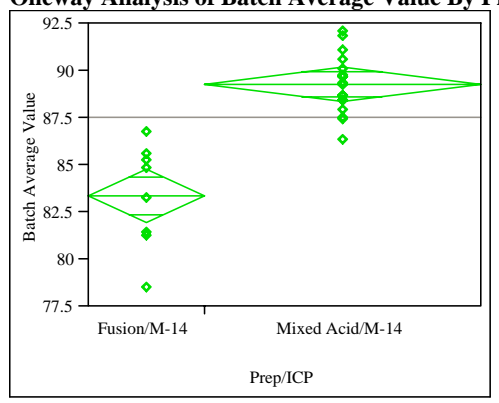

Oneway Anova

Summary of Fit

Rsquare

0.677267

Adj Rsquare

0.664358

Root Mean Square Error $\quad 1.932108$

Mean of Response $\quad 87.54829$

Observations (or Sum Wgts) 27

t Test

Fusion/M-14-Mixed Acid/M-14

Assuming equal variances

Difference $\quad-5.8982$ t Ratio $\quad-7.24317$

Std Err Dif $\quad 0.8143$ DF 25

Upper CL Dif -4.2211 Prob $>|t|<.0001$

Lower CL Dif -7.5753 Prob $>\mathrm{t} \quad 1.0000$

$\begin{array}{lll}\text { Confidence } & 0.95 \text { Prob }<\mathrm{t} \quad<.0001\end{array}$

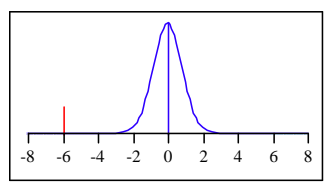

Analysis of Variance

Source DF Sum of Squares Mean Square F Ratio Prob $>$ F

$\begin{array}{lllllll}\text { Prep/ICP } & 1 & 195.84841 & 195.848 & 52.4635 & <.0001\end{array}$

$\begin{array}{llll}\text { Error } & 25 & 93.32605 & 3.733\end{array}$

C. Total $26 \quad 289.17445$

Means for Oneway Anova

Level Number Mean Std Error Lower 95\% Upper 95\%

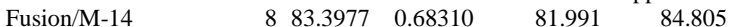

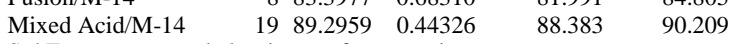

Std Error uses a pooled estimate of error variance

Tests that the Variances are Equal

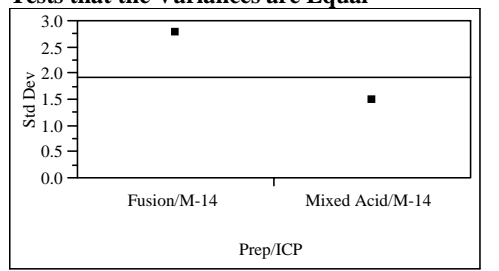

MeanAbsDif to

Median

1.158511

$\begin{array}{lrrrr}\text { Level } & \text { Count } & \text { Std Dev } & \text { MeanAbsDif to Mean } & \begin{array}{r}\text { MeanAbsDif to } \\ \text { Median }\end{array} \\ \text { Fusion/M-14 } & 8 & 2.765968 & 2.237687 & 2.237687 \\ \text { Mixed Acid/M- } & 19 & 1.486457 & 1.129869 & 1.125955 \\ 14 & & & & \end{array}$

14

Test F DFNum DFDen $\quad$ Prob $>$ F

$\begin{array}{lrrrr}\text { O'Brien[.5] } & \text { Ratio } & & & \\ & 5.4631 & 1 & 25 & 0.0277\end{array}$

Brown-Forsythe \begin{tabular}{rrrr}
5.4631 & 1 & 25 & 0.0277 \\
\hline .2841 & 1 & 25 & 0.0302
\end{tabular}

$\begin{array}{lllll}\text { Levene } & 5.9535 & 1 & 25 & 0.0302 \\ \text { Leversthe } & 5.2841 & 1 & 0.0221\end{array}$

$\begin{array}{lllll}\text { Bartlett } & 4.1953 & 1 & . & 0.0405\end{array}$

$\begin{array}{lllll}\text { F Test 2-sided } & 3.4625 & 7 & 18 & 0.0316\end{array}$

Welch Anova testing Means Equal, allowing Std Devs Not Equal

F Ratio DFNum DFDen Prob $>$ F

$\begin{array}{llll}32.4337 & 1 & 8.7556 & 0.0003\end{array}$

t Test

5.6951 
WSRC-STI-2006-00068

Revision 0

Exhibit A5. Prep Comparisons Using SME Batch Averages by Analyte for each ICP

Sample Type $=$ SME, Analyte $=$ Ti, ICP $=$ M-13

Oneway Analysis of Batch Average Value By Prep/ICP

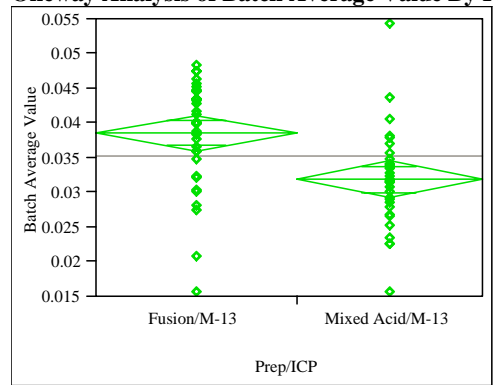

Oneway Anova

Summary of Fit

Rsquare $\quad 0.170303$

Adj Rsquare $\quad 0.157133$

Root Mean Square Error $\quad 0.007448$

Mean of Response 0.035431

Observations (or Sum Wgts) 65

t Test

Fusion/M-13-Mixed Acid/M-13

Assuming equal variances

Difference $\quad 0.006651$ t Ratio 3.596014

Std Err Dif $\quad 0.001850$ DF

Upper CL Dif 0.010348 Prob $>|t| \quad 0.0006$

Lower CL Dif 0.002955 Prob $>t \quad 0.0003$

Confidence $\quad 0.95$ Prob $<\mathrm{t} \quad 0.9997$

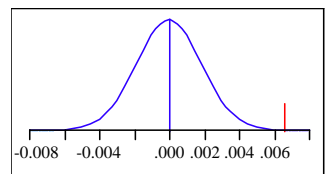

Analysis of Variance

Source DF Sum of Squares Mean Square F Ratio Prob $>$ F

$\begin{array}{llllll}\text { Prep/ICP } & 1 & 0.00071737 & 0.000717 & 12.9313 & 0.0006\end{array}$

Error $\quad 63 \quad 0.00349496$

C. Total $64 \quad 0.00421233$

Means for Oneway Anova

Level Number Mean Std Error Lower 95\% Upper 95\%

$\begin{array}{llllll}\text { Fusion/M-13 } & 34 & 0.038603 & 0.00128 & 0.03605 & 0.04116\end{array}$

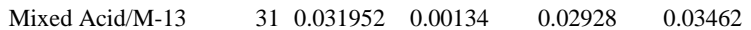

Std Error uses a pooled estimate of error variance

Tests that the Variances are Equal

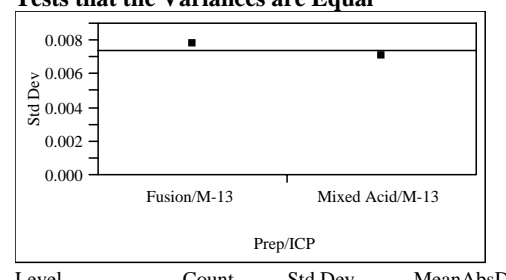

\begin{tabular}{|c|c|c|c|c|c|}
\hline Level & Count & Std Dev & & MeanAbsDif to Mean & $\begin{array}{r}\text { MeanAbsDif to } \\
\text { Median }\end{array}$ \\
\hline Fusion/M-13 & 34 & 0.0077496 & & 0.0060358 & 0.0058578 \\
\hline $\begin{array}{l}\text { Mixed Acid/M- } \\
13\end{array}$ & 31 & 0.0071019 & & 0.0049285 & 0.0049301 \\
\hline Test & $\begin{array}{r}F \\
\text { Ratio }\end{array}$ & DFNum I & DFDen & Prob $>$ F & \\
\hline O'Brien[.5] & 0.1350 & 1 & 63 & 0.7145 & \\
\hline Brown-Forsythe & 0.5330 & 1 & 63 & 0.4681 & \\
\hline Levene & 0.8331 & 1 & 63 & 0.3649 & \\
\hline Bartlett & 0.2347 & 1 & & 0.6281 & \\
\hline F Test 2-sided & 1.1907 & 33 & 30 & 0.6321 & \\
\hline \multicolumn{6}{|c|}{ Welch Anova testing Means Equal, allowing Std Devs Not Equal } \\
\hline F Ratio DFNu & m DFD & en Prob > & $>\mathrm{F}$ & & \\
\hline 13.0373 & 162.9 & $97 \quad 0.000$ & 06 & & \\
\hline
\end{tabular}

Sample Type=SME, Analyte=Ti, ICP=M-14

(continued)

Oneway Analysis of Batch Average Value By Prep/ICP

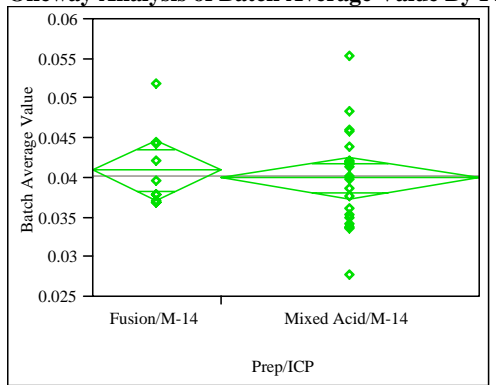

Oneway Anova

Summary of Fit

0.006457

Adj Rsquare $\quad-0.02903$

Root Mean Square Error $\quad 0.005851$

Mean of Response $\quad 0.040322$

Observations (or Sum Wgts)

30

t Test

Fusion/M-14-Mixed Acid/M-14

Assuming equal variances

Difference $\quad 0.00097$ t Ratio 0.426571

Std Err Dif $\quad 0.00227$ DF 28

Upper CL Dif 0.00561 Prob $>|t| \quad 0.6730$

Lower CL Dif -0.00368 Prob $>t \quad 0.3365$

Confidence $\quad 0.95$ Prob $<\mathrm{t} \quad 0.6635$

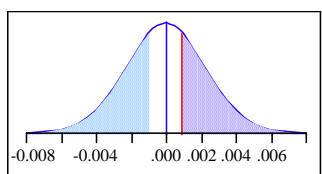

Analysis of Variance

Source DF Sum of Squares Mean Square F Ratio Prob $>$ F

$\begin{array}{lrrrrr}\text { Prep/ICP } & 1 & 0.00000623 & 0.000006 & 0.1820 & 0.6730\end{array}$

$\begin{array}{llll}\text { Error } & 28 & 0.00095860 & 0.000034\end{array}$

C. Total $29 \quad 0.00096483$

Means for Oneway Anova

Level Number Mean Std Error Lower 95\% Upper 95\%

$\begin{array}{llllll}\text { Fusion/M-14 } & 10 & 0.040967 & 0.00185 & 0.03718 & 0.04476\end{array}$

$\begin{array}{llllll}\text { Mixed Acid/M-14 } & 20 & 0.040000 & 0.00131 & 0.03732 & 0.04268\end{array}$

Std Error uses a pooled estimate of error variance

Tests that the Variances are Equal

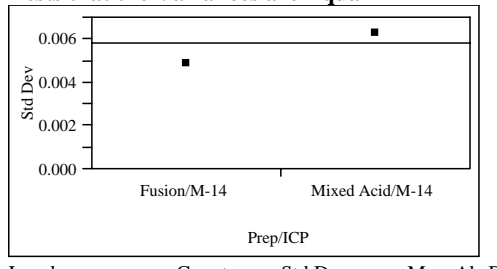

$\begin{array}{lrrrr}\text { Level } & \text { Count } & \text { Std Dev } & \text { MeanAbsDif to Mean } & \begin{array}{r}\text { MeanAbsDif to } \\ \text { Median }\end{array} \\ \text { Fusion/M-14 } & 10 & 0.0048673 & 0.0038267 & 0.0035667 \\ \text { Mixed Acid/M- } & 20 & 0.0062635 & 0.0047833 & 0.0047833 \\ 14 & & & & \end{array}$

14

Test F DFNum DFDen Prob $>$ F

$\begin{array}{lrlll}\text { O'Brien[.5] } & 0.4857 & 1 & 28 & 0.4916\end{array}$

$\begin{array}{lllll}\text { Brown-Forsythe } & 0.6588 & 1 & 28 & 0.4238\end{array}$

$\begin{array}{lllll}\text { Levene } & 0.4818 & 1 & 28 & 0.4933\end{array}$

$\begin{array}{lrrrr}\text { Bartlett } & 0.6964 & 1 & \dot{0} & 0.4040 \\ \text { F Test 2-sided } & 1.6560 & 19 & 9 & 0.4427\end{array}$

Welch Anova testing Means Equal, allowing Std Devs Not Equal

F Ratio DFNum DFDen Prob $>$ F

$\begin{array}{llll}0.2158 & 1 & 22.702 & 0.6467\end{array}$

t Test

0.4645 
WSRC-STI-2006-00068

Revision 0

Exhibit A5. Prep Comparisons Using SME Batch Averages by Analyte for each ICP

Sample Type $=$ SME, Analyte $=U$, ICP $=M-13$

Oneway Analysis of Batch Average Value By Prep/ICP

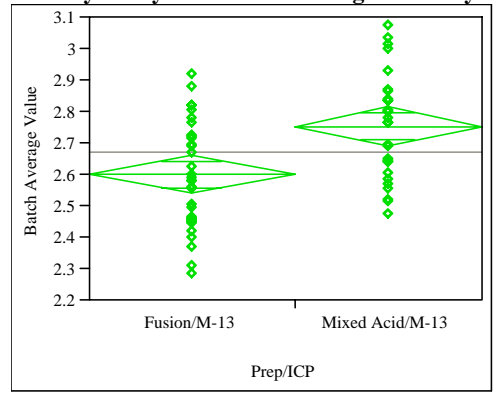

Oneway Anova

Summary of Fit

Rsquare

0.177983

Adj Rsquare

0.164051

Root Mean Square Error $\quad 0.167228$

Mean of Response 2.67418

Observations (or Sum Wgts) $\quad 61$

t Test

Fusion/M-13-Mixed Acid/M-13

Assuming equal variances

Difference $\quad-0.15324$ t Ratio $\quad-3.57417$

Std Err Dif $\quad 0.04287$ DF 59

Upper CL Dif -0.06745 Prob $>|t| 0.0007$

Lower CL Dif -0.23903 Prob $>\mathrm{t} \quad 0.9996$

$\begin{array}{lll}\text { Confidence } & 0.95 \text { Prob }<\mathrm{t} \quad 0.0004\end{array}$

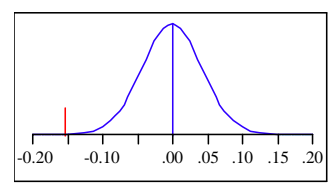

Analysis of Variance

Source DF Sum of Squares Mean Square F Ratio Prob $>$ F

$\begin{array}{lllllll}\text { Prep/ICP } & 1 & 0.3572458 & 0.357246 & 12.7747 & 0.0007\end{array}$

$\begin{array}{llll}\text { Error } & 59 & 1.6499432 & 0.027965\end{array}$

C. Total $60 \quad 2.0071890$

Means for Oneway Anova

Level Number Mean Std Error Lower 95\% Upper 95\%

$\begin{array}{lrrrrr}\text { Fusion/M-13 } & 32 & 2.60133 & 0.02956 & 2.5422 & 2.6605\end{array}$

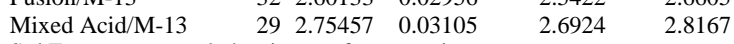

Std Error uses a pooled estimate of error variance

Tests that the Variances are Equal

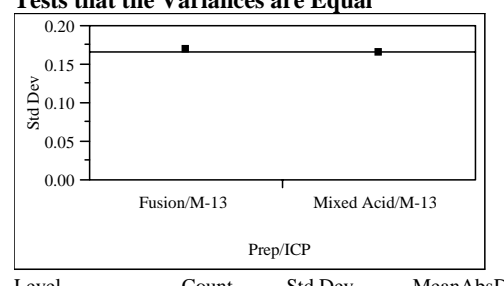

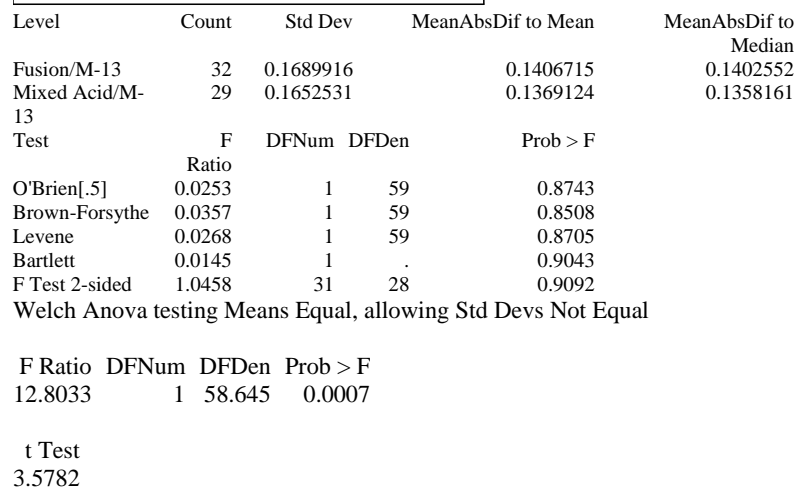

Sample Type $=$ SME, Analyte $=U$, ICP $=$ M-14

(continued)

Oneway Analysis of Batch Average Value By Prep/ICP

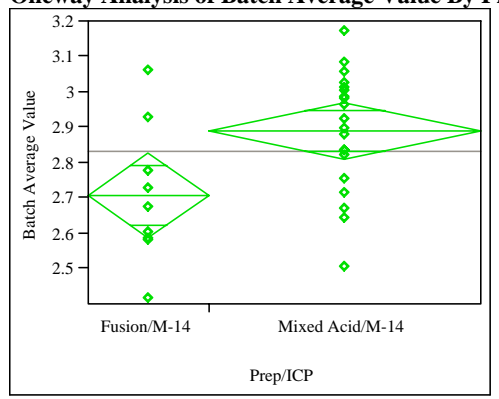

Oneway Anova

Summary of Fit

Rsquare

0.194922

Adj Rsquare

0.165104

Root Mean Square Error $\quad 0.176381$

Mean of Response

2.834799

Observations (or Sum Wgts) 29

t Test

Fusion/M-14-Mixed Acid/M-14

Assuming equal variances

Difference $\quad-0.18101$ t Ratio $\quad-2.55678$

Std Err Dif $\quad 0.07080$ DF 27

Upper CL Dif -0.03575 Prob $>|t| 0.0165$

Lower CL Dif -0.32628 Prob $>\mathrm{t} \quad 0.9917$

$\begin{array}{lll}\text { Confidence } & 0.95 \text { Prob }<\mathrm{t} \quad 0.0083\end{array}$

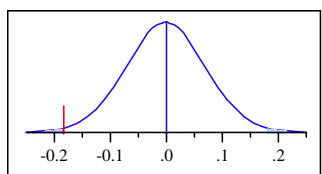

Analysis of Variance

Source DF Sum of Squares Mean Square F Ratio Prob > F

$\begin{array}{llllll}\text { Prep/ICP } & 1 & 0.2033712 & 0.203371 & 6.5371 & 0.0165\end{array}$

$\begin{array}{llll}\text { Error } & 27 & 0.8399769 & 0.031110\end{array}$

C. Total $28 \quad 1.0433481$

Means for Oneway Anova

Level Number Mean Std Error Lower 95\% Upper 95\%

$\begin{array}{llrrrr}\text { Fusion/M-14 } & 9 & 2.70996 & 0.05879 & 2.5893 & 2.8306\end{array}$

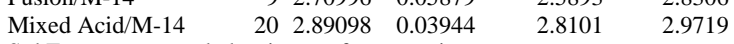

Std Error uses a pooled estimate of error variance

Tests that the Variances are Equal

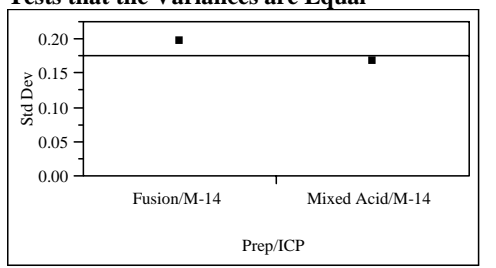

\begin{tabular}{lrrrr}
\hline Level & Count & Std Dev & MeanAbsDif to Mean & $\begin{array}{r}\text { MeanAbsDif to } \\
\text { Median }\end{array}$ \\
Fusion/M-14 & 9 & 0.1962503 & 0.1490700 & 0.1515370 \\
Mixed Acid/M- & 20 & 0.1673105 & 0.1335442 & 0.1326917
\end{tabular}

14

Test F DFNum DFDen Prob $>$ F

$\begin{array}{lrlll} & \text { Ratio } & & & \\ \text { O'Brien[.5] } & 0.3644 & 1 & 27 & 0.5511\end{array}$

$\begin{array}{lllll}\text { Brown-Forsythe } & 0.1964 & 1 & 27 & 0.6612\end{array}$

$\begin{array}{lllll}\text { Levene } & 0.1426 & 1 & 27 & 0.7087\end{array}$

$\begin{array}{lllll}\text { Bartlett } & 0.2849 & 1 & . & 0.5935\end{array}$

$\begin{array}{lcccc}\text { F Test 2-sided } & 1.3759 & 8 & 19 & 0.5372 \\ \text { Welch Anova testing Means Equal, allowing } & \text { Std Devs Not Equal }\end{array}$

F Ratio DFNum DFDen Prob $>$ F

$\begin{array}{rrrr}5.7696 & 1 & 13.482 & 0.0314\end{array}$

t Test

2.4020 
WSRC-STI-2006-00068

Revision 0

Exhibit A5. Prep Comparisons Using SME Batch Averages by Analyte for each ICP

Sample Type $=$ SME, Analyte $=\mathrm{U} / \mathrm{Ca}, \mathrm{ICP}=\mathrm{M}-13$

Oneway Analysis of Batch Average Value By Prep/ICP

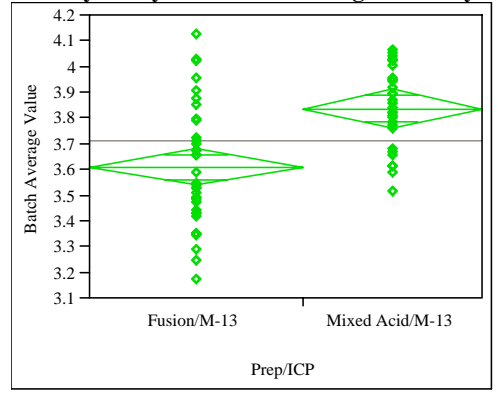

Oneway Anova

Summary of Fit

Rsquare

Adj Rsquare

0.241516

0.229282

Mean of Response 3.71468

Observations (or Sum Wgts) 64

t Test

Fusion/M-13-Mixed Acid/M-13

Assuming equal variances

Difference $\quad-0.22701$ t Ratio $\quad-4.4432$

Std Err Dif $\quad 0.05109$ DF

62

Upper CL Dif -0.12488 Prob $>|t|<.0001$

Lower CL Dif -0.32913 Prob $>$ t 1.0000

Confidence $\quad 0.95$ Prob $<\mathrm{t} \quad<.0001$

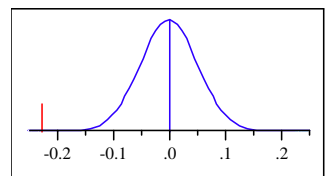

Analysis of Variance

Source DF Sum of Squares Mean Square F Ratio Prob $>$ F

$\begin{array}{lllllll}\text { Prep/ICP } & 1 & 0.8172607 & 0.817261 & 19.7420 & <.0001\end{array}$

$\begin{array}{llll}\text { Error } & 62 & 2.5666178 & 0.041397\end{array}$

C. Total $63 \quad 3.3838785$

Means for Oneway Anova

Level Number Mean Std Error Lower 95\% Upper 95\%

$\begin{array}{lrrrrr}\text { Fusion/M-13 } & 35 & 3.61182 & 0.03439 & 3.5431 & 3.6806\end{array}$

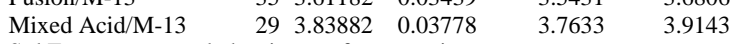

Std Error uses a pooled estimate of error variance

Tests that the Variances are Equal

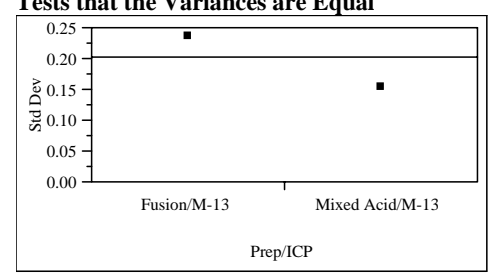

$\begin{array}{lrrrr}\text { Level } & \text { Count } & \text { Std Dev } & \text { MeanAbsDif to Mean } & \begin{array}{r}\text { MeanAbsDif to } \\ \text { Median }\end{array} \\ & & & & 0.1950319 \\ \text { Fusion/M-13 } & 35 & 0.2367872 & 0.1238851 & 0.1243072 \\ \text { Mixed Acid/M- } & 29 & 0.1535647 & \end{array}$

Mixed Acid/M-

Test F DFNum DFDen $\quad$ Prob $>\mathrm{F}$

$\begin{array}{lrrrr}\text { O'Brien[.5] } & 5.8176 & 1 & 62 & 0.0188\end{array}$

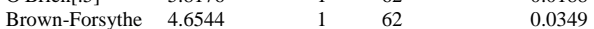

$\begin{array}{lllll}\text { Levene } & 6.2985 & 1 & 62 & 0.0147\end{array}$

Bartlett

5.3545

$1 \quad 62$

Welch Anova testing Means Equal, allowing Std Devs Not Equal

F Ratio DFNum DFDen Prob $>$ F

$\begin{array}{rrrr}21.3371 & 1 & 58.862<.0001\end{array}$

t Test

4.6192
Sample Type $=$ SME, Analyte $=$ U/Ca, ICP $=$ M-14

(continued)

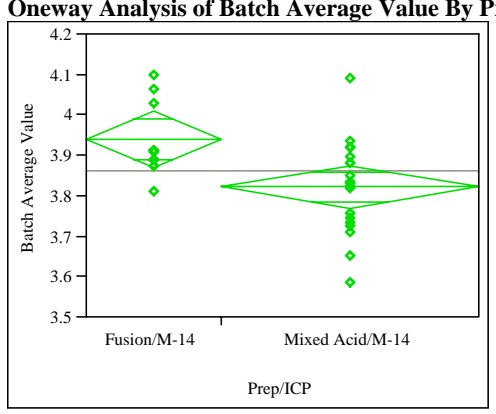

Oneway Anova

Summary of Fit

Rsquare

Adj Rsquare

0.221321

Root Mean Squar

Mean of Response

3.8637

Observations (or Sum Wgts) 29

t Test

Fusion/M-14-Mixed Acid/M-14

Assuming equal variances

Difference $\quad 0.118183$ t Ratio 2.770218

Std Err Dif $\quad 0.042662$ DF 27

Upper CL Dif 0.205719 Prob $>|t| \quad 0.0100$

Lower CL Dif 0.030648 Prob $>\mathrm{t} \quad 0.0050$

$\begin{array}{lll}\text { Confidence } & 0.95 \text { Prob }<\mathrm{t} \quad 0.9950\end{array}$

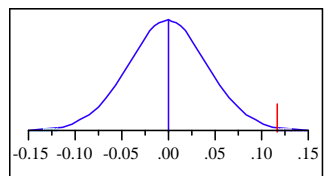

Analysis of Variance

Source DF Sum of Squares Mean Square F Ratio Prob > F

$\begin{array}{lllllll}\text { Prep/ICP } & 1 & 0.09150999 & 0.091510 & 7.6741 & 0.0100\end{array}$

$\begin{array}{llll}\text { Error } & 27 & 0.32196186 & 0.011925\end{array}$

C. Total $28 \quad 0.41347185$

Means for Oneway Anova

Level Number Mean Std Error Lower 95\% Upper 95\%

$\begin{array}{lllllr}\text { Fusion/M-14 } & 10 & 3.94113 & 0.03453 & 3.8703 & 4.0120\end{array}$

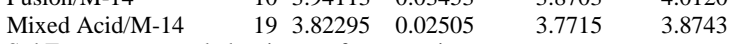

Std Error uses a pooled estimate of error variance

Tests that the Variances are Equal

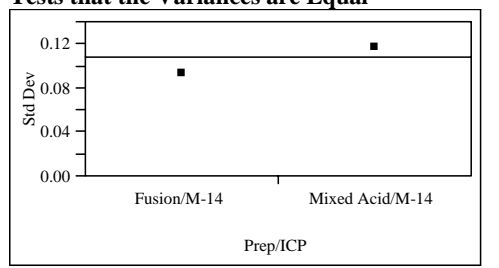

$\begin{array}{lrrrr}\text { Level } & \text { Count } & \text { Std Dev } & \text { MeanAbsDif to Mean } & \begin{array}{r}\text { MeanAbsDif to } \\ \text { Median }\end{array} \\ \text { Fusion/M-14 } & 10 & 0.0934078 & 0.0756119 & 0.0650832 \\ \text { Mixed Acid/M- } & 19 & 0.1162939 & 0.0882177 & 0.0874876\end{array}$

14

Test F DFNum DFDen Prob $>$ F

$\begin{array}{lrlll} & \text { Ratio } & & & \\ \text { O'Brien[.5] } & 0.4428 & 1 & 27 & 0.5114\end{array}$

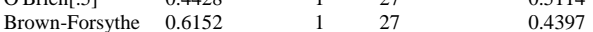

$\begin{array}{lllll}\text { Levene } & 0.2404 & 1 & 27 & 0.6279\end{array}$

$\begin{array}{lllll}\text { Bartlett } & 0.5230 & 1 & . & 0.4696\end{array}$

$\begin{array}{lcccc}\text { F Test } 2 \text {-sided } & 1.5501 & 18 & 9 & 0.5094 \\ \text { Welch Anova testing Means } & \text { Equal, allowing Std Devs Not Equal }\end{array}$

F Ratio DFNum DFDen Prob $>$ F

$\begin{array}{rrrr}8.8161 & 1 & 22.265 & 0.0070\end{array}$

t Test

2.9692 
WSRC-STI-2006-00068

Revision 0

Exhibit A5. Prep Comparisons Using SME Batch Averages by Analyte for each ICP

Sample Type $=$ SME, Analyte $=\mathrm{Zr}$, ICP $=\mathrm{M}-13$

Oneway Analysis of Batch Average Value By Prep/ICP

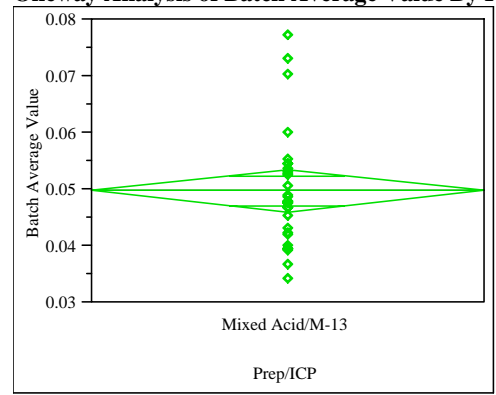

Missing Rows

350neway Anova

Summary of Fit

Rsquare

Adj Rsquare

Root Mean Square Error $\quad 0.010175$

Mean of Response

Observations (or Sum Wgts)

Analysis of Variance

Source DF Sum of Squares Mean Square F Ratio Prob $>$ F

Prep/ICP $0 \quad 0.00000000$

Error $\quad 29 \quad 0.00300268$

C. Total $29 \quad 0.00300268$

Means for Oneway Anova

Level $\quad$ Number $\quad$ Mean Std Error Lower 95\% Upper 95\%

$\begin{array}{llllll}\text { Mixed Acid/M-13 } & 30 & 0.049783 & 0.00186 & 0.04598 & 0.05358\end{array}$

Std Error uses a pooled estimate of error variance
Sample Type $=$ SME, Analyte $=\mathrm{Zr}$, ICP $=$ M-14

(continued)

Oneway Analysis of Batch Average Value By Prep/ICP

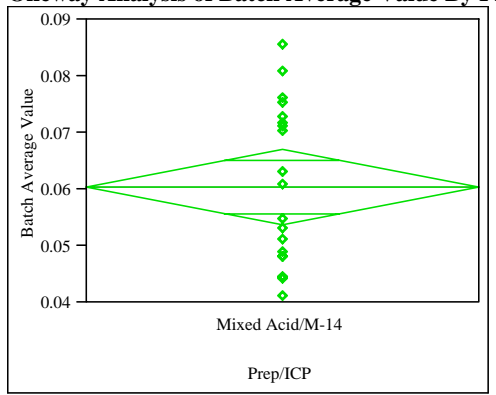

Missing Rows

10Oneway Anova

Summary of Fit

Rsquare

Adj Rsquare

$\begin{array}{ll}\text { Root Mean Square Error } & 0.014067 \\ \text { Mean of Response } & 0.060383\end{array}$

Observations (or Sum Wgts)

Analysis of Variance

Source DF Sum of Squares Mean Square F Ratio Prob $>$ F

Prep/ICP 00.00000000

$\begin{array}{llll}\text { Error } & 19 & 0.00375967 & 0.000198\end{array}$

C. Total $19 \quad 0.00375967$

Means for Oneway Anova

Level Number Mean Std Error Lower 95\% Upper 95\%

$\begin{array}{llllll}\text { Mixed Acid/M-14 } & 20 & 0.060383 & 0.00315 & 0.05380 & 0.06697\end{array}$

Std Error uses a pooled estimate of error variance 


\section{Exhibit A6. Prep/ICP Comparisons Using Process Batch Averages by Analyte}

Standard/Process=Process, Analyte $=$ Al/Ca

Oneway Analysis of Batch Average Value By Prep/ICP

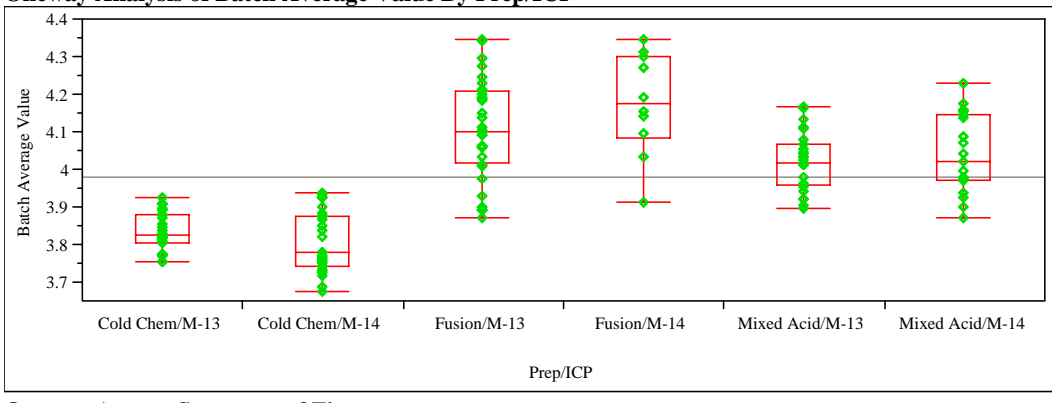

\section{Oneway Anova -Summary of Fit}

Rsquare $\quad 0.647368$

$\begin{array}{lr}\text { Adj Rsquare } & 0.63421 \\ \text { Root Mean Square Error } & 0.097878\end{array}$

$\begin{array}{ll}\text { Root Mean Square Error } & 0.097878 \\ \text { Mean of Response } & 3.981469\end{array}$

$\begin{array}{lr}\text { Mean of Response } & 3.981469 \\ \text { Observations (or Sum Wgts) } & 140\end{array}$

Analysis of Variance

Source DF Sum of Squares Mean Square F Ratio Prob > F

$\begin{array}{llllll}\text { Prep/ICP } & 5 & 2.3566792 & 0.471336 & 49.1999 & <.0001\end{array}$

$\begin{array}{llll}\text { Error } & 134 & 1.2837217 & 0.009580\end{array}$

C. Total $139 \quad 3.6404009$

Means for Oneway Anova

Level Number Mean Std Error Lower 95\% Upper 95\%

\begin{tabular}{lllllr} 
Cold Chem/M-13 & 25 & 3.83711 & 0.01958 & 3.7984 & 3.8758 \\
\hline
\end{tabular}

$\begin{array}{llllll}\text { Cold Chem/M-14 } & 27 & 3.80823 & 0.01884 & 3.7710 & 3.8455 \\ & 32 & 4.10978 & 0.01730 & 4.0756 & 4.1230\end{array}$

$\begin{array}{llllll}\text { Fusion/M-13 } & 32 & 4.10978 & 0.01730 & 4.0756 & 4.1440 \\ \text { Fusion/M-14 } & 10 & 4.17839 & 0.03095 & 4.1172 & 4.2396\end{array}$

$\begin{array}{llllll}\text { Fusion/M-14 } & 10 & 4.17839 & 0.03095 & 4.1172 & 4.2396 \\ \text { Mixed Acid/M-13 } & 27 & 4.02132 & 0.01884 & 3.9841 & 4.0586\end{array}$

$\begin{array}{llllll}\text { Mixed Acid/M-13 } & 27 & 4.02132 & 0.01884 & 3.9841 & 4.0586 \\ \text { Mixed Acid/M-14 } & 19 & 4.04122 & 0.02245 & 3.9968 & 4.0856\end{array}$

Std Error uses a pooled estimate of error variance

Means and Std Deviations

Level Number Mean Std Dev Std Err Mean Lower 95\% Upper 95\%

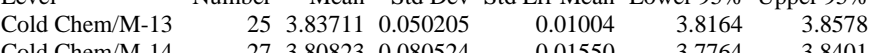

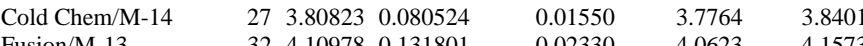

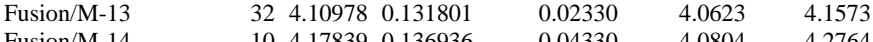

$\begin{array}{lllllll}\text { Fusion/M-14 } & 10 & 4.17839 & 0.136936 & 0.04330 & 4.0804 & 4.2764 \\ \text { Mixed Acid/M-13 } & 27 & 4.02132 & 0.076130 & 0.01465 & 3.9912 & 4.0514\end{array}$

$\begin{array}{lrrrrrr}\text { Mixed Acid/M-13 } & 27 & 4.02132 & 0.076130 & 0.01465 & 3.9912 & 4.0514 \\ \text { Mixed Acid/M-14 } & 19 & 4.04122 & 0.104528 & 0.02398 & 3.9908 & 4.0916\end{array}$

Means Comparisons -Comparisons for all pairs using Tukey-Kramer HSD

Level

Mean

Fusion/M-14 A $\quad 4.1783947$

Fusion/M-13 A B $\quad 4.1097784$

Mixed Acid/M-14 $\quad$ B C -4.0412206

$\begin{array}{lr}\text { Mixed Acid/M-13 } & \text { C } 4.0213233 \\ \text { Cold Chem/M-13 } & \text { D } 3.8371077\end{array}$

Cold Chem/M-13 $\quad$ D 3.8371077

Levels not connected by same letter are significantly different
Standard/Process=Process, Analyte $=\mathrm{Al} / \mathrm{Mg}$

Oneway Analysis of Batch Average Value By Prep/ICP

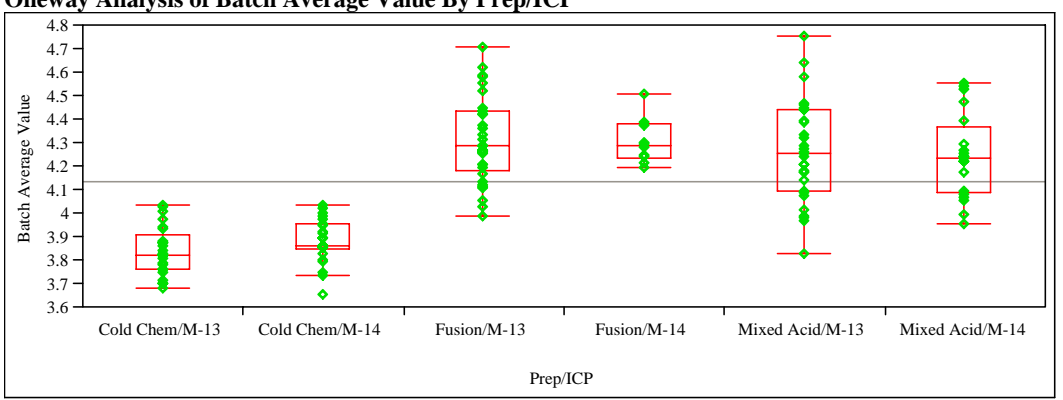

\section{Oneway Anova -Summary of Fit}

Rsquare

0.626737

Adj Rsquare

0.61331
0.159643

Root Mean Square 4.134868

Mean of Response

145

Analysis of Variance

Source DF Sum of Squares Mean Square F Ratio Prob > F

$\begin{array}{lllllll}\text { Prep/ICP } & 5 & 5.9482008 & 1.18964 & 46.6783 & <.0001\end{array}$

$\begin{array}{lll}\text { Error } & 139 & 3.5425457 \\ \text { C. Total } & 144 & 9.4907465\end{array}$

Means for Oneway Anova

Level Number Mean Std Error Lower 95\% Upper 95\%

$\begin{array}{llllll}\text { Cold Chem/M-13 } & 25 & 3.84187 & 0.03193 & 3.7787 & 3.9050\end{array}$

$\begin{array}{llllll}\text { Cold Chem/M-14 } & 26 & 3.88166 & 0.03131 & 3.8198 & 3.9436\end{array}$

$\begin{array}{llllll}\text { Fusion/M-13 } & 33 & 4.31493 & 0.02779 & 4.2600 & 4.3699\end{array}$

$\begin{array}{llllll}\text { Fusion/M-14 } & 10 & 4.30717 & 0.05048 & 4.2074 & 4.4070 \\ \text { Mixed Acid/M-13 } & 31 & 4.26423 & 0.02867 & 4.2075 & 4.3209\end{array}$

$\begin{array}{llllll}\text { Mixed Acid/M-13 } & 31 & 4.26423 & 0.02867 & 4.2075 & 4.3209 \\ \text { Mixed Acid/M-14 } & 20 & 4.24653 & 0.03570 & 4.1759 & 4.3171\end{array}$

Mixed Acid/M-14

Means and Std Deviation

Level Number Mean Std Dev Std Err Mean Lower 95\% Upper 95\%

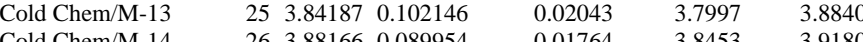

$\begin{array}{lllllll}\text { Cold Chem/M-14 } & 26 & 3.88166 & 0.089954 & 0.01764 & 3.8453 & 3.9180 \\ & 33 & 43193 & 0.181671 & 0.03162 & 4.2505 & 4.3793\end{array}$

\begin{tabular}{lllllll} 
Fusion/M-13 & 33 & 4.31493 & 0.181671 & 0.03162 & 4.2505 & 4.3793 \\
\hline & 10 & 430717 & 0.095209 & 0.03011 & 4.2391 & 43753
\end{tabular}

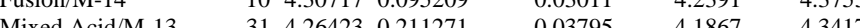

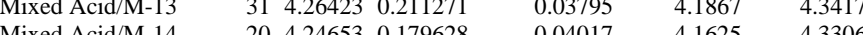

Means Comparisons- Comparisons for all pairs using Tukey-Kramer HSD

Level

$$
\text { Mean }
$$

Fusion/M-14 A 4.3149318

Mixed Acid/M-13 A 4.2642297

Mixed Acid/M-14 A 4.2465261

$\begin{array}{lll}\text { Cold Chem/M-14 } & \text { B } 3.8816567 \\ \text { Cold Chem/M-13 } & \text { B } 3.8418681\end{array}$

Levels not connected by same letter are significantly different 


\section{Exhibit A6. Prep/ICP Comparisons Using Process Batch Averages by Analyte}

(continued)

Standard/Process=Process, Analyte $=\mathrm{A} / \mathrm{M}$

Oneway Analysis of Batch Average Value By Prep/ICP

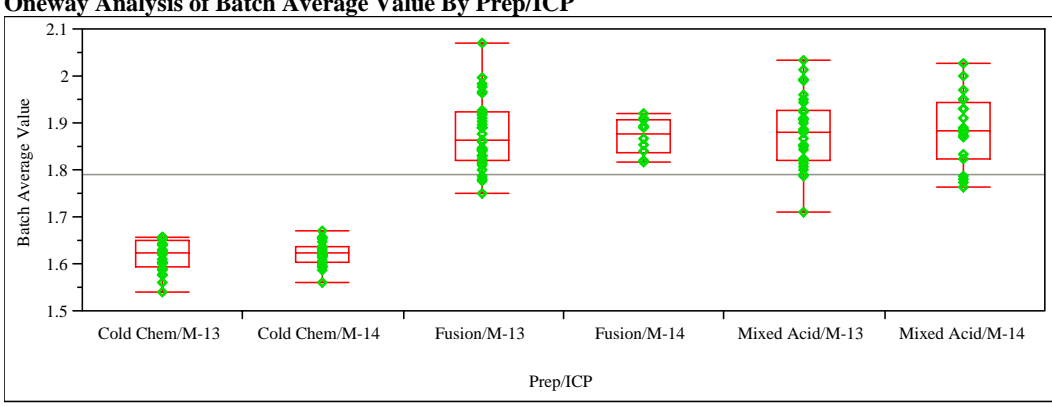

Oneway Anova -Summary of Fit

$\begin{array}{lr}\text { Rsquare } & 0.810463 \\ \text { Adj Rsquare } & 0.803546 \\ \text { Root Mean Square Error } & 0.060655 \\ \text { Mean of Response } & 1.791302 \\ \text { Observations (or Sum Wgts) } & 143\end{array}$

Mean of Response $\quad 1.791302$

Observations (or Sum Wgs)

143

A

$\begin{array}{llllll}\text { Prep/ICP } & 5 & 2.1552595 & 0.431052 & 117.1628 & <.0001\end{array}$

$\begin{array}{llll}\text { Error } & 137 & 0.5040346 & 0.003679\end{array}$

C. Total $142 \quad 2.659294$

Means for Oneway Anova

Number Mean Std Error Lower 95\% Upper 95\%

$\begin{array}{llllll}\text { Cold Chem/M-13 } & 24 & 1.61949 & 0.01238 & 1.5950 & 1.6440\end{array}$

$\begin{array}{llllll}\text { Cold Chem/M-14 } & 25 & 1.62309 & 0.01213 & 1.5991 & 1.6471\end{array}$

$\begin{array}{llllll}\text { Fusion/M-13 } & 33 & 1.87834 & 0.01056 & 1.8575 & 1.8992\end{array}$

\begin{tabular}{llllll} 
Fusion/M-14 & 10 & 1.87353 & 0.01918 & 1.8356 & 1.9115 \\
\hline
\end{tabular}

$\begin{array}{llllll}\text { Mixed Acid/M-13 } & 31 & 1.87914 & 0.01089 & 1.8576 & 1.9007\end{array}$

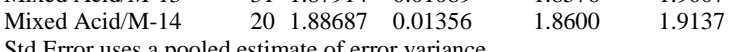

Std Error uses a pooled estimate of error variance

Means and Std Deviations

Level Number Mean Std Dev Std Err Mean Lower 95\% Upper 95\%

$\begin{array}{lllllll}\text { Cold Chem/M-13 } & 24 & 1.61949 & 0.033264 & 0.00679 & 1.6054 & 1.6335\end{array}$

$\begin{array}{lllllll}\text { Cold Chem/M-14 } & 25 & 1.62309 & 0.024970 & 0.00499 & 1.6128 & 1.6334\end{array}$

$\begin{array}{lllllll}\text { Fusion/M-13 } & 33 & 1.87834 & 0.073315 & 0.01276 & 1.8523 & 1.9043 \\ & 10 & 1.87353 & 0.037155 & 0.01175 & 1.8470 & 1.901\end{array}$

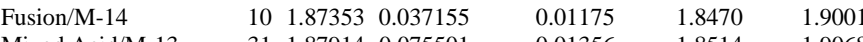

$\begin{array}{lllllll}\text { Mixed Acid/M-13 } & 31 & 1.87914 & 0.075501 & 0.01356 & 1.8514 & 1.9068 \\ \text { Mixed Acid/M-14 } & 20 & 1.88687 & 0.075457 & 0.01687 & 1.8516 & 1.9222\end{array}$

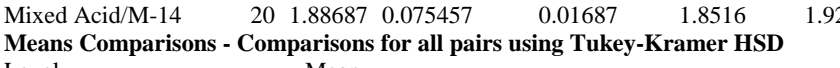

Level

Mixed Acid/M-14 A 1.8868651

Mixed Acid/M-13 A 1.8791437

Fusion/M-13 A 1.8783357

$\begin{array}{lrr}\text { Fusion/M-14 } & \text { A } & 1.8735308 \\ \text { Cold Chem/M-14 } & \text { B } 1.6230930\end{array}$

Cold Chem/M-13 $\quad$ B 1.6194894

Levels not connected by same letter are significantly different
Standard/Process $=$ Process, Analyte $=\mathbf{B} / \mathbf{L i}$

Oneway Analysis of Batch Average Value By Prep/ICP

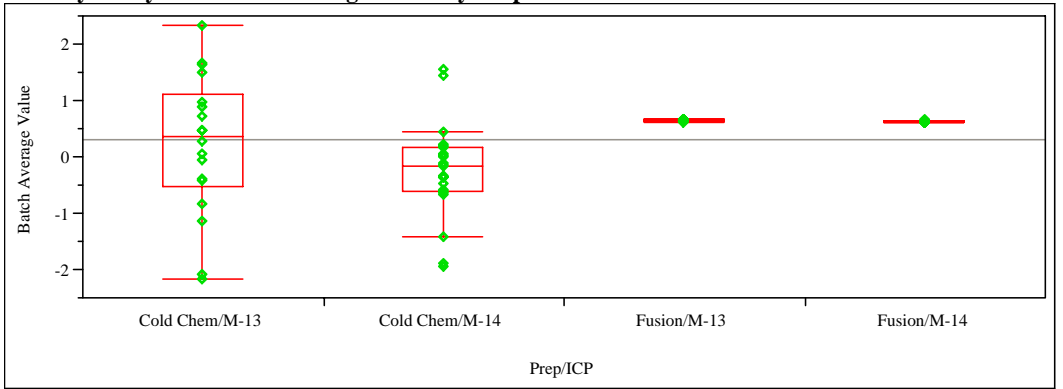

\section{Missing Rows 52}

Oneway Anova - Summary of Fit

Rsquare $\quad 0.224332$

Adj Rsquare $\quad 0.195603$

Root Mean Square Error $\quad 0.715619$

$\begin{array}{lr}\text { Mean of Response } & 0.325772 \\ \text { Observations (or Sum Wgts) } & 85\end{array}$

Observations (or Sum

Analysis of Variance

Source DF Sum of Squares Mean Square F Ratio Prob $>$ F

$\begin{array}{lllllll}\text { Prep/ICP } & 3 & 11.996723 & 3.99891 & 7.8087 & 0.0001\end{array}$

$\begin{array}{llll}\text { Error } & 81 & 41.480909 & 0.51211\end{array}$

C. Total $84 \quad 53.477632$

Means for Oneway Anova

Level Number Mean Std Error Lower 95\% Upper 95\%

$\begin{array}{llllll}\text { Cold Chem/M-13 } & 18 & 0.23250 & 0.16867 & -0.1031 & 0.5681\end{array}$

$\begin{array}{llllll}\text { Cold Chem/M-14 } \quad 23 & -0.22952 & 0.14922 & -0.5264 & 0.0674\end{array}$

$\begin{array}{llllll}\text { Fusion/M-13 } & 34 & 0.65809 & 0.12273 & 0.4139 & 0.9023\end{array}$

$\begin{array}{llllll}\text { Fusion/M-14 } & 10 & 0.64094 & 0.22630 & 0.1907 & 1.0912\end{array}$

Std Error uses a pooled estimate of error variance

Means and Std Deviation

Level Number Mean Std Dev Std Err Mean Lower 95\% Upper 95\%

$\begin{array}{lllllll}\text { Cold Chem/M-13 } & 18 & 0.23250 & 1.24484 & 0.29341 & -0.3865 & 0.85154\end{array}$

$\begin{array}{lllllll}\text { Cold Chem/M-14 } \quad 23 & -0.22952 & 0.82930 & 0.17292 & -0.5881 & 0.12910\end{array}$

$\begin{array}{lllllll}\text { Fusion/M-13 } & 34 & 0.65809 & 0.01294 & 0.00222 & 0.6536 & 0.66261\end{array}$

$\begin{array}{lllllll}\text { Fusion/M-14 } & 10 & 0.64094 & 0.01138 & 0.00360 & 0.6328 & 0.64908\end{array}$

Means Comparisons - Comparisons for all pairs using Tukey-Kramer HSD

Level

Fusion/M-13 A 0.6580946

Fusion/M-14 A 0.640935

Cold Chem/M-13 A B 0.2324978

Cold Chem/M-14 B $\quad-0.229516$

Levels not connected by same letter are significantly different 
Standard/Process=Process, Analyte $=$ Fe/Al

Oneway Analysis of Batch Average Value By Prep/ICP

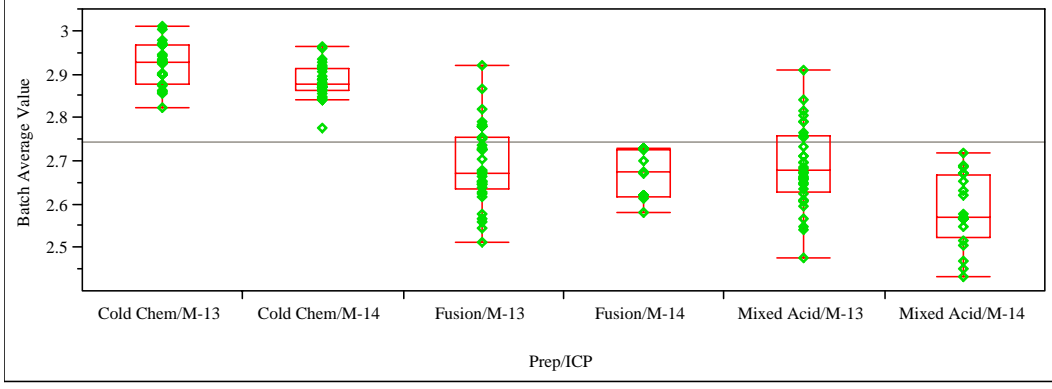

$\begin{array}{lr}\text { Oneway Anova - Summary of Fit } \\ \text { Rsquare } & 0.712609 \\ \text { Adj Rsquare } & 0.702272 \\ \text { Root Mean Square Error } & 0.076153 \\ \text { Mean of Response } & 2.746025 \\ \text { Observations (or Sum Wgts) } & 145\end{array}$

$\begin{array}{lr}\text { Wgts) } & 145\end{array}$

Analysis of Var

Source DF Sum of Squares Mean Square F Ratio Prob $>$ F

$\begin{array}{lllllll}\text { Prep/ICP } & 5 & 1.9988032 & 0.399761 & 68.9325 & <.0001\end{array}$

$\begin{array}{llll}\text { Error } & 139 & 0.8061036 & 0.005799\end{array}$

C. Total $144 \quad 2.8049067$

Means for Oneway Anova

Number Mean Std Error Lower 95\% Upper 95\%

$\begin{array}{llllll}\text { Cold Chem/M-13 } & 22 & 2.92328 & 0.01624 & 2.8912 & 2.9554\end{array}$

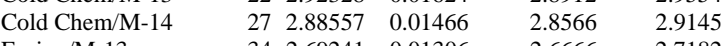

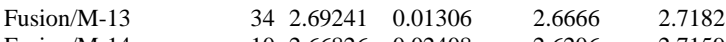

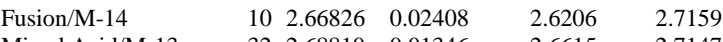

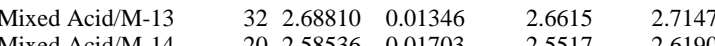

$\begin{array}{lllll}\text { Mixed Acid/M-14 } 20 & 2.58536 & 0.01703 & 2.5517 & 2.6190\end{array}$

Std Error uses a pooled estimate of error variance

Means and Std Deviations

Level Number Mean Std Dev Std Err Mean Lower 95\% Upper 95\%

$\begin{array}{lllllll}\text { Cold Chem/M-13 } & 22 & 2.92328 & 0.050257 & 0.01071 & 2.9010 & 2.9456\end{array}$

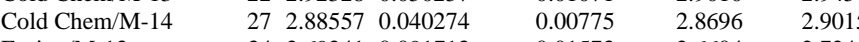

$\begin{array}{lllllll}\text { Fusion/M-13 } & 34 & 2.69241 & 0.091713 & 0.01573 & 2.6604 & 2.7244\end{array}$

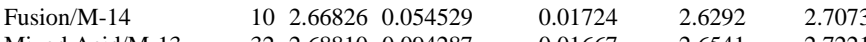

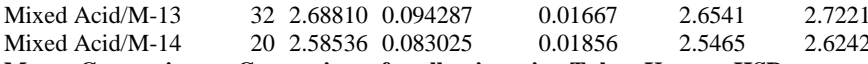

Means Comparisons - Comparisons for all pairs using Tukey-Kramer HSD

Level Mean

$\begin{array}{lll}\text { Cold Chem/M-13 } & \text { A } & 2.9232782 \\ \text { Cold Chem/M-14 } & \text { A } & 2.8855703 \\ \text { Fis } & & 2.6924118\end{array}$

$\begin{array}{lll}\text { Fusion/M-13 } & \text { B } & 2.6924118 \\ \text { Mixed Acid/M-13 } & \text { B } & 2.6881022\end{array}$

$\begin{array}{llr}\text { Mixed Acid/M-13 } & \text { B } 2.6881022 \\ \text { Fusion/M-14 } & \text { B C } 2.6682553\end{array}$

Mixed Acid/M-14 B C 2.6682553

Levels not connected by same letter are significantly different
Standard/Process=Process, Analyte=Fe/Ca

(continued) Oneway Analysis of Batch Average Value By Prep/ICP

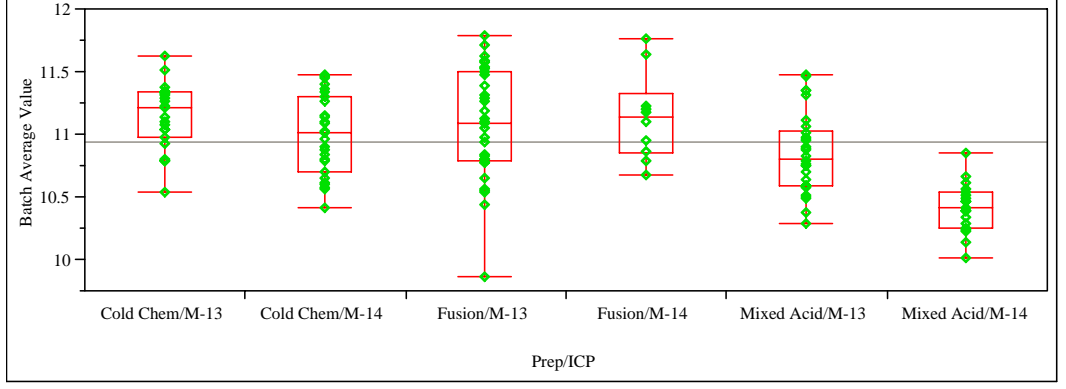

Oneway Anova - Summary of Fit

$\begin{array}{lr}\text { Rsquare } & 0.336092 \\ \text { Adj Rsquare } & 0.311503 \\ \text { Root Mean Square Error } & 0.333341 \\ \text { Mean of Response } & 10.9443 \\ \text { Observations (or Sum Wgts) } & 141\end{array}$

Analysis of Variance

Source DF Sum of Squares Mean Square F Ratio Prob $>$ F

$\begin{array}{llllll}\text { Prep/ICP } & 5 & 7.593844 & 1.51877 & 13.6683 & <.0001\end{array}$

$\begin{array}{llll}\text { Error } & 135 & 15.000700 & 0.11112\end{array}$

C. Total $140 \quad 22.594543$

Means for Oneway Anova

Level Number Mean Std Error Lower 95\% Upper 95\%

$\begin{array}{llllll}\text { Cold Chem/M-13 } & 23 & 11.1522 & 0.06951 & 11.015 & 11.290\end{array}$

$\begin{array}{llllll}\text { Cold Chem/M-14 } & 27 & 10.9995 & 0.06415 & 10.873 & 11.126\end{array}$

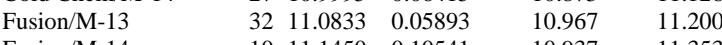

$\begin{array}{llllll}\text { Fusion/M-14 } & 10 & 11.1450 & 0.10541 & 10.937 & 11.353\end{array}$

$\begin{array}{llllll}\text { Mixed Acid/M-13 } & 30 & 10.8528 & 0.06086 & 10.732 & 10.973\end{array}$

$\begin{array}{llllll}\text { Mixed Acid/M-14 } & 19 & 10.4189 & 0.07647 & 10.268 & 10.570\end{array}$

Std Error uses a pooled estimate of error variance

Means and Std Deviation

Level Number Mean Std Dev Std Err Mean Lower 95\% Upper 95\%

$\begin{array}{lllllll}\text { Cold Chem/M-13 } & 23 & 11.1522 & 0.259899 & 0.05419 & 11.040 & 11.265\end{array}$

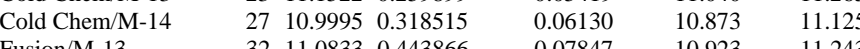

$\begin{array}{lllllll}\text { Fusion/M-13 } & 32 & 11.0833 & 0.443866 & 0.07847 & 10.923 & 11.243\end{array}$

$\begin{array}{lllllll}\text { Fusion/M-14 } & 10 & 11.1450 & 0.350061 & 0.11070 & 10.895 & 11.395 \\ & 30 & 10.8528 & 0.319613 & 0.05835 & 10.733 & 10.972\end{array}$

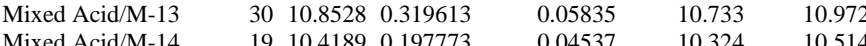

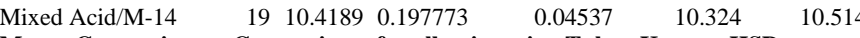

Means Comparisons - Comparisons for all pairs using Tukey-Kramer HSD

Level Mean

$\begin{array}{lll}\text { Fusion/M-14 } & \text { A B } & 11.145009\end{array}$

$\begin{array}{lll}\text { Fusion/M-13 } & \text { A B } & 11.083342\end{array}$

Cold Chem/M-14 A B 10.999479

$\begin{array}{lrr}\text { Mixed Acid/M-13 } & \text { B } \begin{array}{r}10.852817 \\ \text { Mixed Acid/M-14 }\end{array} \text { C } 10.418885\end{array}$

Levels not connected by same letter are significantly different 
Standard/Process=Process, Analyte $=\mathrm{Fe} / \mathrm{Li}$

Oneway Analysis of Batch Average Value By Prep/ICP

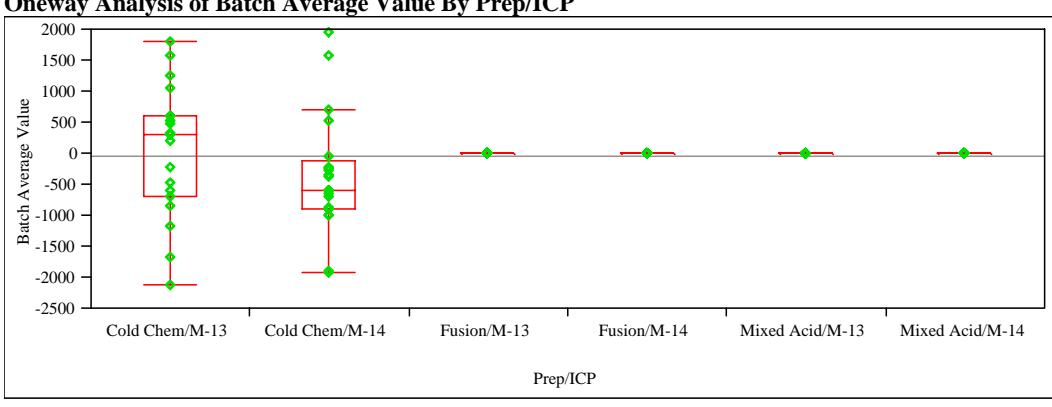

\section{Oneway Anova - Summary of Fit}

Rsquare $\quad 0.06193$

$\begin{array}{lr}\text { Adj Rsquare } & 0.024998 \\ \text { Root Mean Square Error } & 547.8332\end{array}$

$\begin{array}{lr}\text { Root Mean Square Error } & 547.8332 \\ \text { Mean of Response } & -45.8402\end{array}$

$\begin{array}{lr}\text { Mean of Response } & -45.8402 \\ \text { Observations (or Sum Wgts) } & 133\end{array}$

Analysis of Variance

Source DF Sum of Squares Mean Square F Ratio Prob $>$ F

$\begin{array}{lrrrrr}\text { Prep/ICP } & 5 & 2516308 & 503262 & 1.6769 & 0.1448\end{array}$

$\begin{array}{lll}\text { Error } & 127 & 38115395\end{array}$

$$
300121
$$

C. Total 132 (20)

Means for Oneway Anova

Level Number Mean Std Error Lower 95\% Upper 95\%

$\begin{array}{llllll}\text { Cold Chem/M-13 } & 19 & 59.98 & 125.68 & -188.7 & 308.7\end{array}$

$\begin{array}{llllll}\text { Cold Chem/M-14 } & 21 & -360.31 & 119.55 & -596.9 & -123.7\end{array}$

$\begin{array}{lrrrrr}\text { Fusion/M-13 } & 34 & 3.62 & 93.95 & -182.3 & 189.5 \\ \text { Fusion/M-14 } & 10 & 3.54 & 173.24 & -339.3 & 346.4\end{array}$

$\begin{array}{llllll}\text { Fusion/M-14 } & 10 & 3.54 & 173.24 & -339.3 & 346.4 \\ \text { Mixed Acid/M-13 } & 29 & 3.49 & 101.73 & -197.8 & 204.8\end{array}$

$\begin{array}{llllll}\text { Mixed Acid/M-13 } & 29 & 3.49 & 101.73 & -197.8 & 204.8 \\ \text { Mixed Acid/M-14 } & 20 & 3.52 & 122.50 & -238.9 & 245.9\end{array}$

Std Error uses a pooled estimate of error variance

245.9

Means and Std Deviations

Number Mean Std Dev Std Err Mean Lower 95\% Upper 95\%

$\begin{array}{lllllll}\text { Cold Chem/M-13 } & 19 & 59.98 & 1062.38 & 243.73 & -452.1 & 572.03\end{array}$

$\begin{array}{lrrrrrr}\text { Cold Chem/M-14 } & 21 & -360.31 & 943.39 & 205.87 & -789.7 & 69.12\end{array}$

$\begin{array}{lllllll}\text { Fusion/M-13 } & 34 & 3.62 & 0.26 & 0.04475 & 3.5 & 3.71 \\ \text { Fusion/M-14 } & 10 & 3.54 & 0.28 & 0.08859 & 3.3 & 3.74\end{array}$

$\begin{array}{lllllll}\text { Fusion/M-14 } & 10 & 3.54 & 0.28 & 0.08859 & 3.3 & 3.74 \\ \text { Mixed Acid/M-13 } & 29 & 3.49 & 0.25 & 0.04573 & 3.4 & 3.58\end{array}$

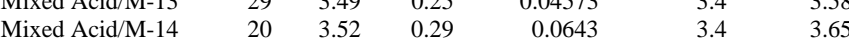

Means Comparisons - Comparisons for all pairs using Tukey-Kramer HSD

Level

Mean

Cold Chem/M-13 A 59.9779

Fusion/M-13 A 3.6228

Fusion/M-14 A 3.5433

Mixed Acid/M-14 A 3.5168

Cold Chen/M-14 A -360.3083

Levels not connected by same letter are significantly different
Standard/Process=Process, Analyte=Fe/Ms

Oneway Analysis of Batch Average Value By Prep/ICP

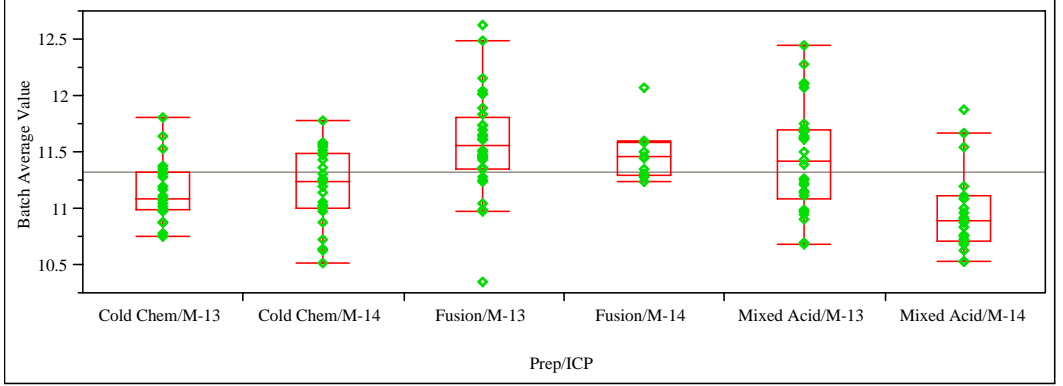

Oneway Anova - Summary of Fit

$\begin{array}{ll}\text { Rsquare } & 0.244268 \\ \text { Adj Rsquare } & 0.216687\end{array}$

Root Mean Square Error $\quad 0.379736$

Mean of Response 11.31998

Observations (or Sum Wgts) 143

Analysis of Variance

Source DF Sum of Squares Mean Square F Ratio Prob $>F$

$\begin{array}{lllllll}\text { Prep/ICP } & 5 & 6.385342 & 1.27707 & 8.8563 & <.0001\end{array}$

$\begin{array}{llll}\text { Error } & 137 & 19.755351 & 0.14420\end{array}$

C. Total $142 \quad 26.140693$

Means for Oneway Anova

Level Number Mean Std Error Lower 95\% Upper 95\%

$\begin{array}{llllll}\text { Cold Chem/M-13 } & 23 & 11.1610 & 0.07918 & 11.004 & 11.318\end{array}$

$\begin{array}{llllll}\text { Cold Chem/M-14 } & 28 & 11.2059 & 0.07176 & 11.064 & 11.348\end{array}$

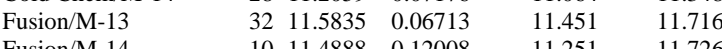

$\begin{array}{llllll}\text { Fusion/M-14 } & 10 & 11.4888 & 0.12008 & 11.251 & 11.726\end{array}$

$\begin{array}{llllll}\text { Mixed Acid/M-13 } & 30 & 11.4449 & 0.06933 & 11.308 & 11.582\end{array}$

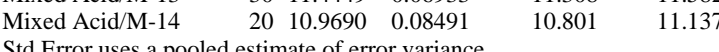

Std Error uses a pooled estimate of error variance

Means and Std Deviation

Level Number Mean Std Dev Std Err Mean Lower 95\% Upper 95\%

$\begin{array}{lllllll}\text { Cold Chem/M-13 } & 23 & 11.1610 & 0.265902 & 0.05544 & 11.046 & 11.276\end{array}$

$\begin{array}{lllllll}\text { Cold Chem/M-14 } & 28 & 11.2059 & 0.324419 & 0.06131 & 11.080 & 11.332 \\ & 32 & 11.583 & 0.444814 & 0.07863 & 11.423 & 11.744\end{array}$

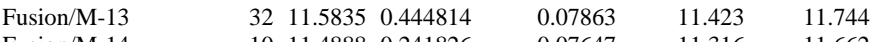

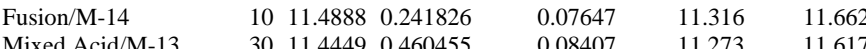

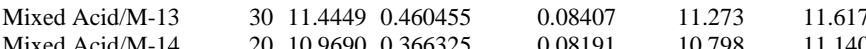

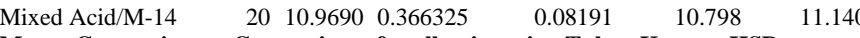

Means Comparisons - Comparisons for all pairs using Tukey-Kramer HSD

Level Mean

$\begin{array}{llr}\text { Fusion/M-13 } & \text { A } & 11.583522 \\ \text { Fusion/M-14 } & \text { A B } & 11.488800\end{array}$

$\begin{array}{llll}\text { Fusion/M-14 } & \text { A } & \text { B } & 11.488800 \\ \text { Mixed Acid/M-13 } & \text { A } & \text { B } & 11.444916\end{array}$

$\begin{array}{llll}\text { Mixed Acid/M-13 } & \text { A } & \text { B } & 11.444916 \\ \text { Cold Chem/M-14 } & \text { B C } 11.205928\end{array}$

Cold Chem/M-13 $\quad$ B C 11.16104

Mixed Acid/M-14 $\quad$ C 10.968960

Levels not connected by same letter are significantly different 
Standard/Process=Process, Analyte $=$ Fe/Mn

Oneway Analysis of Batch Average Value By Prep/ICP

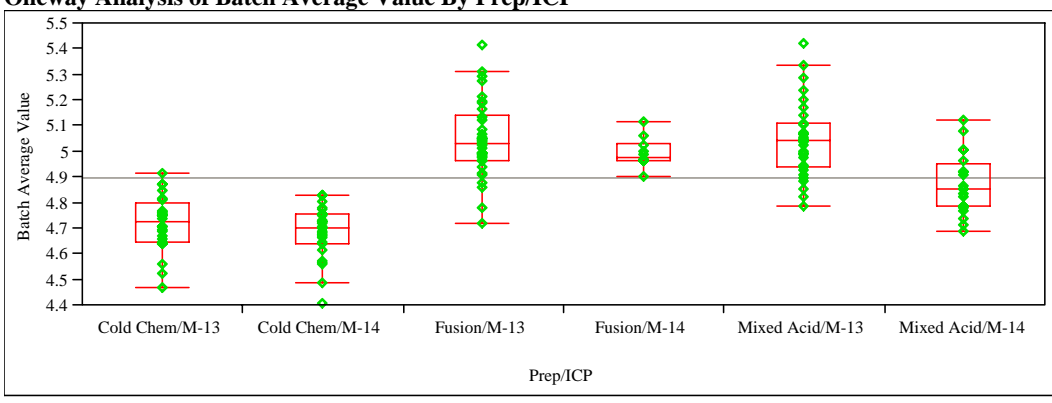

$\begin{array}{lr}\text { Oneway Anova - Summary of Fit } \\ \text { Rsquare } & 0.613965 \\ \text { Adj Rsquare } & 0.600276 \\ \text { Root Mean Square Error } & 0.126254 \\ \text { Mean of Response } & 4.898396 \\ \text { Observations (or Sum Wgts) } & 147\end{array}$

m Wgts) $\quad 147$

Analysis of Variance

Source DF Sum of Squares Mean Square F Ratio Prob $>$ F

$\begin{array}{lllllll}\text { Prep/ICP } & 5 & 3.5745806 & 0.714916 & 44.8504 & <.0001\end{array}$

Error $\begin{array}{lll}141 & 2.2475439 & 0.015940\end{array}$

C. Total $146 \quad 5.8221245$

Means for Oneway Anova

Number Mean Std Error Lower 95\% Upper 95\%

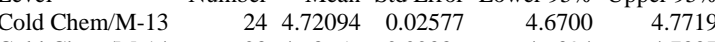

$\begin{array}{llllll}\text { Cold Chem/M-14 } & 28 & 4.68656 & 0.02386 & 4.6394 & 4.7337\end{array}$

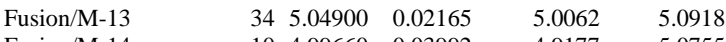

$\begin{array}{llllll}\text { Fusion/M-14 } & 10 & 4.99660 & 0.03992 & 4.9177 & 5.0755\end{array}$

$\begin{array}{lllll}\text { Mixed Acid/M-13 } & 315.04669 & 0.02268 & 5.0019 & 5.0915\end{array}$

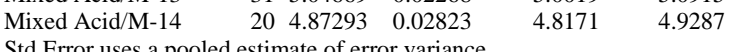

Std Error uses a pooled estimate of error variance

Means and Std Deviations

Level Number Mean Std Dev Std Err Mean Lower 95\% Upper 95\%

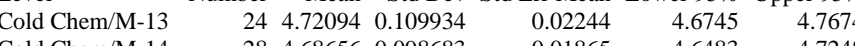

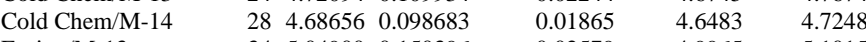

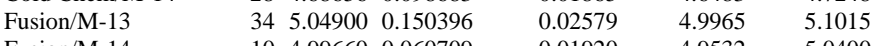

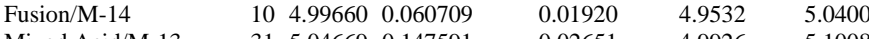

$\begin{array}{llllll}\text { Mixed Acid/M-13 } & 315.04669 & 0.147591 & 0.02651 & 4.9926 & 5.1008\end{array}$

$\begin{array}{lrrrrr}\text { Mixed Acid/M-14 } & 20 & 4.87293 & 0.119991 & 0.02683 & 4.8168\end{array} 4.929$

Means Comparisons - Comparisons for all pairs using Tukey-Kramer HSD

Level Mean

$\begin{array}{lrr}\text { Fusion/M-13 } & \text { A } & 5.0489976 \\ \text { Mixed Acid/M-13 } & \text { A } & 5.0466930\end{array}$

Mixed Acid/M-13 A $\quad 5.0466930$

Fusion/M-14 A B 4.9966027

Mixed Acid/M-14 B 4.8729261

Cold Chem/M-13 C 4.7209363

Cold Chem/M-14 C 4.6865628

Levels not connected by same letter are significantly different
Standard/Process=Process, Analyte=Fe/Ni

Oneway Analysis of Batch Average Value By Prep/ICP

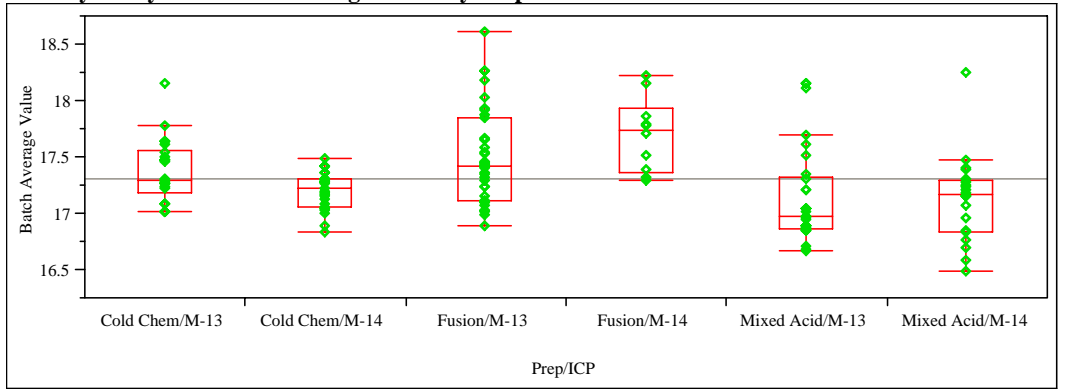

Oneway Anova - Summary of Fit

$\begin{array}{ll}\text { Rsquare } & 0.212214 \\ \text { Adj Rsquare } & 0.183671\end{array}$

Root Mean Square Error $\quad 0.356344$

Mean of Response $\quad 17.31878$

Observations (or Sum

Analysis of Variance
Source DF Sum of Squares Mean Square F Ratio Prob $>$ F

$\begin{array}{lrrrrr}\text { Prep/ICP } & 5 & 4.720452 & 0.944090 & 7.4349 & <.0001\end{array}$

$\begin{array}{llll}\text { Error } & 138 & 17.523351 & 0.12698\end{array}$

C. Total $143 \quad 22.243803$

Means for Oneway Anova

Number Mean Std Error Lower 95\% Upper 95\%

$\begin{array}{llllll}\text { Cold Chem/M-13 } & 22 & 17.3855 & 0.07597 & 17.235 & 17.536\end{array}$

$\begin{array}{llllll}\text { Cold Chem/M-14 } & 27 & 17.2109 & 0.06858 & 17.075 & 17.347\end{array}$

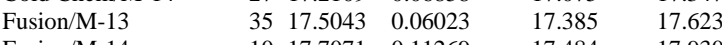

$\begin{array}{llllll}\text { Fusion/M-14 } & 10 & 17.7071 & 0.11269 & 17.484 & 17.930\end{array}$

Mixed Acid/M-13 $\quad 3017.1452 \quad 0.06506$

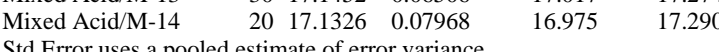

Std Error uses a pooled estimate of error variance

Means and Std Deviations

Level Number Mean Std Dev Std Err Mean Lower 95\% Upper 95\%

$\begin{array}{lllllll}\text { Cold Chem/M-13 } & 22 & 17.3855 & 0.282699 & 0.06027 & 17.260 & 17.511\end{array}$

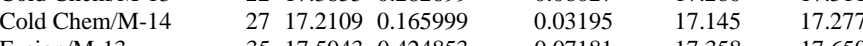

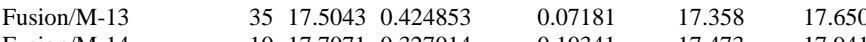

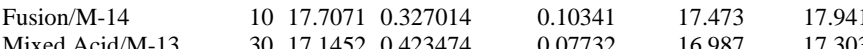

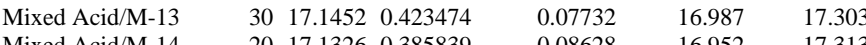

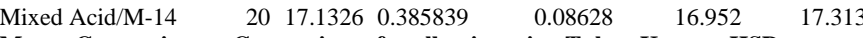

Means Comparisons - Comparisons for all pairs using Tukey-Kramer HSD

Level Mean

$\begin{array}{llr}\text { Fusion/M-14 } & \text { A } & 17.707078 \\ \text { Fusion/M-13 } & \text { A } & 17.504251\end{array}$

Cold Chem/M-13 A B 17.385469

Cold Chem/M-14 A 17.210916

Mixed Acid/M-13 $\quad$ B 17.145210

Mixed Acid/M-14 $\quad$ B 17.132642

Levels not connected by same letter are significantly different 


\section{Exhibit A6. Prep/ICP Comparisons Using Process Batch Averages by Analyte}

(continued)

Standard/Process=Process, Analyte=Fe/

Oneway Analysis of Batch Average Value By Prep/ICP

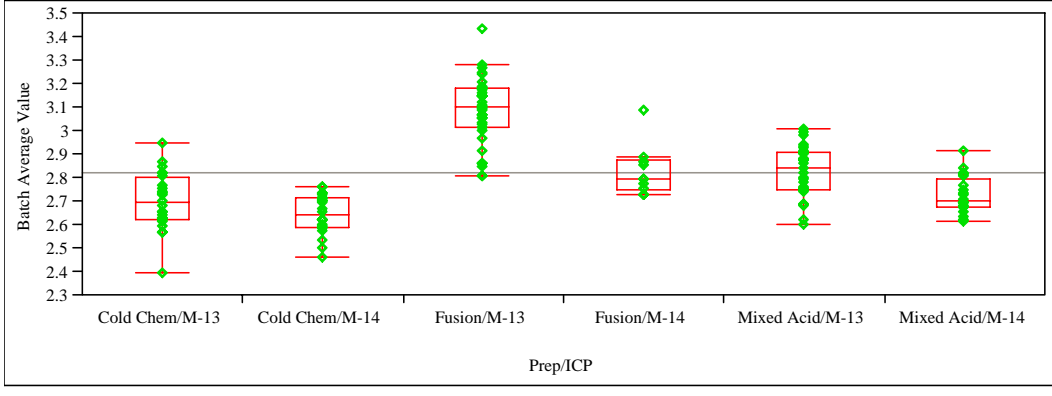

$\begin{array}{lr}\text { Oneway Anova - Summary of Fit } \\ \text { Rsquare } & 0.682009 \\ \text { Adj Rsquare } & 0.670652 \\ \text { Root Mean Square Error } & 0.112213 \\ \text { Mean of Response } & 2.824139 \\ \text { Observations (or Sum Wgts) } & 146\end{array}$

Mean of Response 2.824139

Observations (or Sum Wgs)

146

Source DF Sum of Squares Mean Square F Ratio Prob $>F$

$\begin{array}{lllllll}\text { Prep/ICP } & 5 & 3.7808343 & 0.756167 & 60.0527 & <.0001\end{array}$

$\begin{array}{llll}\text { Error } & 140 & 1.7628397 & 0.012592\end{array}$

C. Total $145 \quad 5.5436740$

Means for Oneway Anova

Number Mean Std Error Lower 95\% Upper 95\%

$\begin{array}{lllllr}\text { Cold Chem/M-13 } & 24 & 2.70189 & 0.02291 & 2.6566 & 2.7472\end{array}$

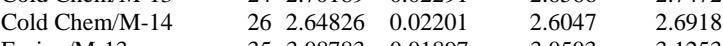

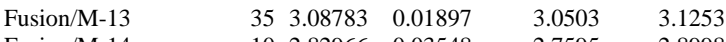

$\begin{array}{llllll}\text { Fusion/M-14 } & 10 & 2.82966 & 0.03548 & 2.7595 & 2.8998\end{array}$

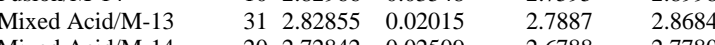

$\begin{array}{lllll}\text { Mixed Acid/M-14 } 20 & 2.72842 & 0.02509 & 2.6788 & 2.7780\end{array}$

Std Error uses a pooled estimate of error variance

Means and Std Deviations

Level Number Mean Std Dev Std Err Mean Lower 95\% Upper 95\%

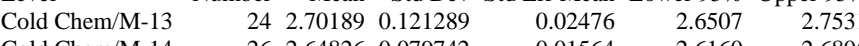

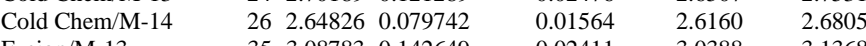

$\begin{array}{lllllll}\text { Fusion/M-13 } & 35 & 3.08783 & 0.142649 & 0.02411 & 3.0388 & 3.1368\end{array}$

$\begin{array}{lllllll}\text { Fusion/M-14 } & 10 & 2.82966 & 0.107051 & 0.03385 & 2.7531 & 2.9062\end{array}$

$\begin{array}{lllllll}\text { Mixed Acid/M-13 } & 31 & 2.82855 & 0.107588 & 0.01932 & 2.7891 & 2.8680 \\ \text { Mixed Acid/M-14 } & 20 & 2.72842 & 0.080546 & 0.01801 & 2.6907 & 2.7661\end{array}$

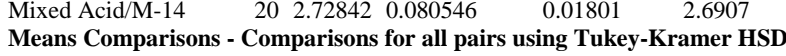

Level

Fusion/M-13 A 3.0878343

\begin{tabular}{lll} 
Fusion/M-14 & B C $\quad 2.8296644$ \\
\hline
\end{tabular}

Mixed Acid/M-13 $\quad$ B $\quad 2.8285478$

Mixed Acid/M-14 C D 2.7284214

Cold Chem/M-13 $\quad$ D 2.701894

Levels not connected by same letter are significantly differen
Standard $/$ Process $=$ Process, Analyte $=\mathrm{Mn} / \mathrm{Mg}$

Oneway Analysis of Batch Average Value By Prep/ICP

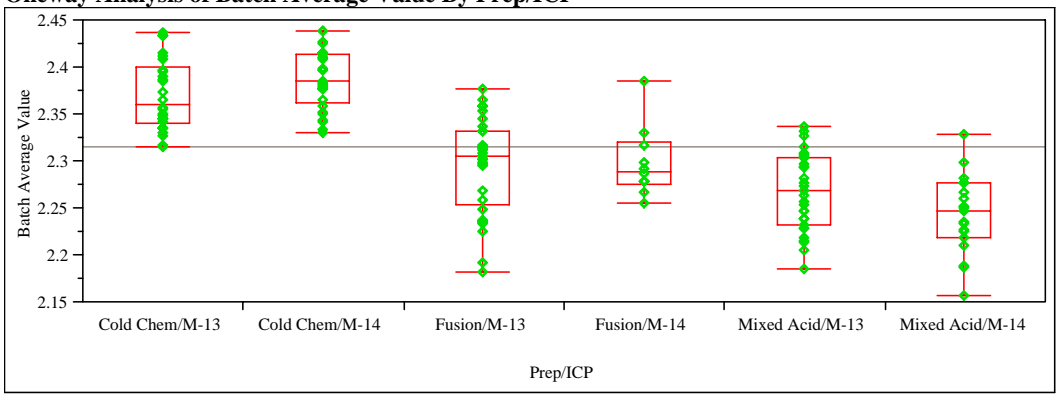

Oneway Anova - Summary of Fit

0.638645

Adj Rsquare $\quad 0.625921$

Root Mean Square Error $\quad 0.040758$

Mean of Response 2.315211

Observations (or Sum

Analysis of Variance

Source DF Sum of Squares Mean Square F Ratio Prob $>$ F

$\begin{array}{lllllll}\text { Prep/ICP } & 5 & 0.41691683 & 0.083383 & 50.1930 & <.000\end{array}$

$\begin{array}{llll}\text { Error } & 142 & 0.23589817 & 0.001661\end{array}$

C. Total $147 \quad 0.65281500$

Means for Oneway Anova

Level Number Mean Std Error Lower 95\% Upper 95\%

$\begin{array}{llllll}\text { Cold Chem/M-13 } & 26 & 2.37137 & 0.00799 & 2.3556 & 2.3872\end{array}$

$\begin{array}{llllll}\text { Cold Chem/M-14 } & 29 & 2.38846 & 0.00757 & 2.3735 & 2.4034\end{array}$

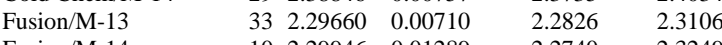

$\begin{array}{llllll}\text { Fusion/M-14 } & 10 & 2.29946 & 0.01289 & 2.2740 & 2.3249\end{array}$

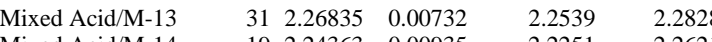

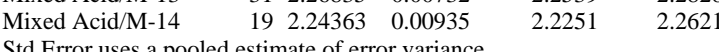

Std Error uses a pooled estimate of error variance

Means and Std Deviation

Level Number Mean Std Dev Std Err Mean Lower 95\% Upper 95\%

$\begin{array}{lllllll}\text { Cold Chem/M-13 } & 26 & 2.37137 & 0.037387 & 0.00733 & 2.3563 & 2.3865\end{array}$

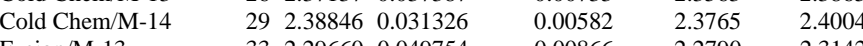

$\begin{array}{lllllll}\text { Fusion/M-13 } & 33 & 2.29660 & 0.049754 & 0.00866 & 2.2790 & 2.3142\end{array}$

$\begin{array}{lllllll}\text { Fusion/M-14 } & 10 & 2.29946 & 0.037478 & 0.01185 & 2.2726 & 2.3263 \\ & 31 & 2.26835 & 0.041084 & 0.00738 & 2.2533 & 2.2834\end{array}$

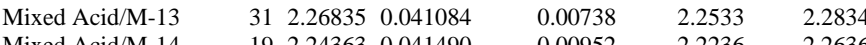

$\begin{array}{llllll}\text { Mixed Acid/M-14 } & 19 & 2.24363 & 0.041490 & 0.00952 & 2.2236\end{array} 2.2636$

Means Comparisons - Comparisons for all pairs using Tukey-Kramer HSD

Level Mean

Cold Chem/M-14 A 2.3884616

Cold Chem/M-13 A 2.3713659

$\begin{array}{lll}\text { Fusion/M-14 } & \text { B } & 2.2994587 \\ \text { Fusion/M-13 } & \text { B } & 2.2966034\end{array}$

$\begin{array}{llll}\text { Fusion/M-13 } & \text { B } & 2.2966034 \\ \text { Mixed Acid/M-13 } & \text { B C } & 2.2683492\end{array}$

Mixed Acid/M-14 $\quad$ C 2.2436343

Levels not connected by same letter are significantly different 
Standard/Process=Process, Analyte=U/Ca

Oneway Analysis of Batch Average Value By Prep/ICP

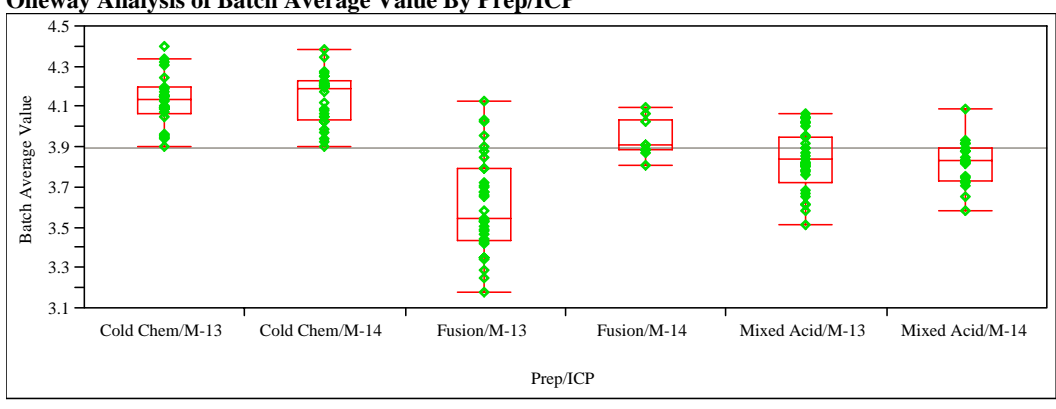

$\begin{array}{lr}\text { Oneway Anova - Summary of Fit } \\ \text { Rsquare } & 0.622559 \\ \text { Adj Rsquare } & 0.609175 \\ \text { Root Mean Square Error } & 0.162962 \\ \text { Mean of Response } & 3.899174 \\ \text { Observations (or Sum Wgts) } & 147\end{array}$

Observations (or Sum Wgts)

Preare F Ratio Prob $>$ F

$\begin{array}{lllllll}\text { Prep/ICP } & 5 & 6.1762188 & 1.23524 & 46.5137 & <.0001\end{array}$

$\begin{array}{llll}\text { Error } & 141 & 3.7444728 & 0.02656 \\ \text { C. Total } & 146 & 9.9206915 & \end{array}$

Means for Oneway Anova

Level Number Mean Std Error Lower 95\% Upper 95\%

$\begin{array}{lllllr}\text { Cold Chem/M-13 } & 26 & 4.13203 & 0.03196 & 4.0689 & 4.1952\end{array}$

$\begin{array}{llllll}\text { Cold Chem/M-14 } & 28 & 4.14139 & 0.03080 & 4.0805 & 4.2023\end{array}$

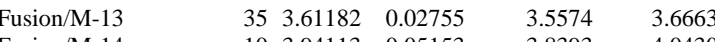

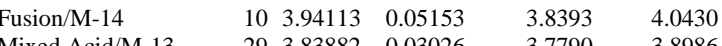

$\begin{array}{llllll}\text { Mixed Acid/M-13 } & 29 & 3.83882 & 0.03026 & 3.7790 & 3.8986\end{array}$

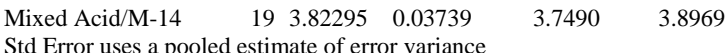

Std Error uses a pooled estimate of error variance

Means and Std Deviations

Level Number Mean Std Dev Std Err Mean Lower 95\% Upper 95\%

$\begin{array}{lllllll}\text { Cold Chem/M-13 } & 26 & 4.13203 & 0.126668 & 0.02484 & 4.0809 & 4.1832\end{array}$

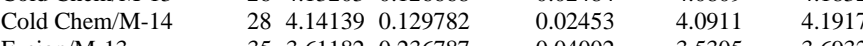

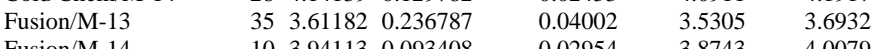

$\begin{array}{lllllll}\text { Fusion/M-14 } & 10 & 3.94113 & 0.093408 & 0.02954 & 3.8743 & 4.0079\end{array}$

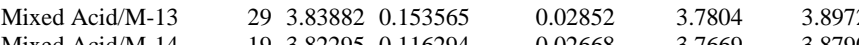

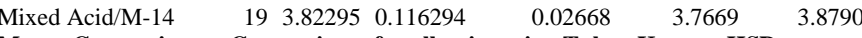

Means Comparisons - Comparisons for all pairs using Tukey-Kramer HSD

Level Mean

$\begin{array}{lll}\text { Cold Chem/M-14 } & \text { A } & 4.1413906 \\ \text { Cold Chem/M-13 } & \text { A } & 4.1320326\end{array}$

$\begin{array}{llll}\text { Cold Chem/M-13 } & \text { A } & & 4.1320326 \\ \text { Fusion/M-14 } & \text { B } & 3.9411301\end{array}$

\begin{tabular}{lll} 
Fusion/M-14 & B & 3.9411301 \\
Mixed Acid/M-13 & B & 3.8388243 \\
\hline
\end{tabular}

$\begin{array}{lll}\text { Mixed Acid/M-13 } & \text { B } & 3.8388243 \\ \text { Mixed Acid/M-14 } & \text { B } & 3.8229467\end{array}$

$\begin{array}{lrr}\text { Mixed Acid/M-14 } & \text { B } \begin{array}{r}3.8229467 \\ \text { Fusion/M-13 }\end{array} & \text { C } 3.6118184\end{array}$

Levels not connected by same letter are significantly different 
WSRC-STI-2006-00068

Revision 0

Exhibit A7. Analysis of Variance by Preparation Method, ICP, and Analyte

Sample Type=ARG-1, Prep=Cold Chem, ICP=M-13, Analyte=Al Response Measurement

Summary of Fit

RSquare Adj

Analysis of Variance

Source DF Sum of Squares Mean Square F Ratio

$\begin{array}{lllll}\text { Model } & 26 & 0.28122037 & 0.010816 & 2.0161\end{array}$

Error $27 \quad 0.14485150 \quad 0.005365$ Prob $>$ F

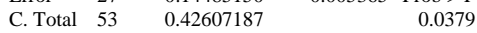

Expected Mean Squares

The Mean Square per row by the Variance Component per column

$\begin{array}{lrr}\text { EMS } & \text { Intercept } & \text { Batch\&Random } \\ \text { Intercept } & 0 & 0\end{array}$

$\begin{array}{lll}\text { Batch\&Random } & 0 & 2\end{array}$

plus 1.0 times Residual Error Variance

Variance Component Estimates

Component Var Comp Est Percent of Total

$\begin{array}{lll}\text { Batch\&Random } & 0.002726 & 33.689\end{array}$

$\begin{array}{lll}\text { Residual } & 0.005365 & 66.311\end{array}$

$\begin{array}{lll}\text { Total } & 0.0053651 & 66.311\end{array}$

These estimates based on equating Mean Squares to Expected Value.

Test Denominator Synthesis

Source MS Den DF Den Denom MS Synthesis

Batch\&Random $0.00536 \quad 27$ Residual

Tests wrt Random Effects

Source SS MS Num DF Num F Ratio Prob > F

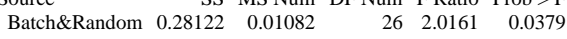

Sample Type=ARG-1, Prep=Cold Chem, ICP=M-13, Analyte=Al/Ca Response Measurement

Summary of Fi

RSquare $\quad 0.792196$

RSquare Adj $\quad 0.592385$

Root Mean Square Error $\quad 0.046937$

Mean of Response 2.417109

Observations (or Sum Wgts) 52

Analysis of Variance

Source DF Sum of Squares Mean Square F Ratio

$\begin{array}{lllll}\text { Model } & 25 & 0.21836806 & 0.008735 & 3.9647\end{array}$

$\begin{array}{lllll}\text { Error } & 26 & 0.05728082 & 0.002203 & \text { Prob }>\text { F }\end{array}$

$\begin{array}{llll}\text { C. Total } & 51 & 0.27564888 & 0.0004\end{array}$

Expected Mean Squares

The Mean Square per row by the Variance Component per column

$\begin{array}{lrr}\text { EMS } & \text { Intercept } & \text { Batch\&Random } \\ \text { Intercept } & 0 & 0\end{array}$

Batch\&Random $\quad 0 \quad 2$

plus 1.0 times Residual Error Variance

Variance Component Estimates

Component Var Comp Est Percent of Total

Batch\&Random $\quad 0.003266 \quad 59.71$

$\begin{array}{lrr}\text { Residual } & 0.002203 & 40.284 \\ \text { Total } & 0.005469 & 100.000\end{array}$

These estimates based on equating Mean Squares to Expected Value.

Test Denominator Synthesis

Source MS Den DF Den Denom MS Synthesis

Batch\&Random $\quad 0.0022 \quad 26$ Residual

Tests wrt Random Effect

Source SS MS Num DF Num F Ratio Prob > F

$\begin{array}{llllll}\text { Batch\&Random } & 0.21837 & 0.00873 & 25 & 3.9647 & 0.0004\end{array}$

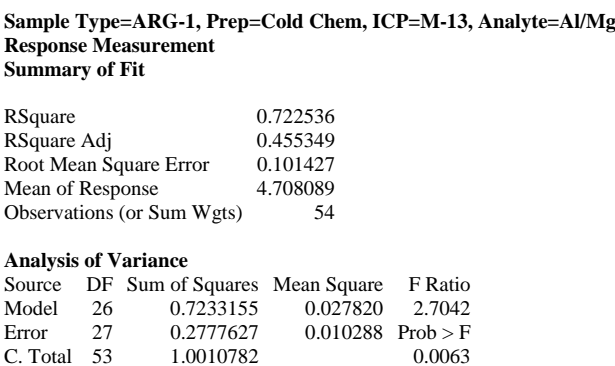

Expected Mean Squares

The Mean Square per row by the Variance Component per column

EMS

$\begin{array}{lrr}\text { Intercept } & \text { Intercept } & \text { Batch\&Random } \\ \text { Batch\&Random } & 0 & 0 \\ & 0 & 2\end{array}$

plus 1.0 times Residual Error Variance

\begin{tabular}{|c|c|c|c|c|}
\hline \multicolumn{5}{|c|}{ ariance Component Estimates } \\
\hline Component & \multicolumn{4}{|c|}{ Var Comp Est Percent of Total } \\
\hline Batch\&Random & \multicolumn{2}{|c|}{0.008766} & \multirow{2}{*}{\multicolumn{2}{|c|}{46.008}} \\
\hline Residual & \multicolumn{2}{|c|}{0.010288} & & \\
\hline Total & \multicolumn{2}{|c|}{0.019054} & $\begin{array}{r}53.992 \\
1000000\end{array}$ & .000 \\
\hline \multicolumn{5}{|c|}{ These estimates based on equating Mean Squares to } \\
\hline \multicolumn{5}{|c|}{ Test Denominator Synthesis } \\
\hline \multirow{2}{*}{$\begin{array}{l}\text { Source } \\
\text { Batch\&Random }\end{array}$} & r Synthesis & DF Den & \multirow{2}{*}{\multicolumn{2}{|c|}{$\begin{array}{l}\text { Denom N } \\
\text { Residual }\end{array}$}} \\
\hline & 0.01029 & 27 & & \\
\hline \multicolumn{5}{|c|}{ Tests wrt Random Effects } \\
\hline \multirow{2}{*}{$\begin{array}{l}\text { Source } \\
\text { Batch\&Random }\end{array}$} & & MS Num & \multirow{2}{*}{\multicolumn{2}{|c|}{$\begin{array}{rr}\text { DF Num } & \text { F Ra } \\
26 \quad 2.70\end{array}$}} \\
\hline & 0.72332 & 0.02782 & & \\
\hline \multicolumn{5}{|c|}{$\begin{array}{l}\text { Sample Type=ARG-1, Prep=Cold Chem, ICP=M-1 } \\
\text { Response Measurement } \\
\text { Summary of Fit }\end{array}$} \\
\hline \multicolumn{2}{|l|}{ RSquare } & \\
\hline \multicolumn{2}{|c|}{ RSquare Adj } & \multicolumn{2}{|c|}{$\begin{array}{r}0.52407 \\
0.065767\end{array}$} & \\
\hline \multicolumn{2}{|c|}{ Root Mean Square Error } & \multicolumn{3}{|c|}{0.049872} \\
\hline \multicolumn{2}{|c|}{ Mean of Response } & \multicolumn{3}{|c|}{1.651538} \\
\hline \multicolumn{2}{|c|}{ Observations (or Sum Wgts) } & \multicolumn{3}{|c|}{1.651538} \\
\hline \multicolumn{5}{|c|}{ Analysis of Variance } \\
\hline DF Sum & $\mathrm{n}$ of Squares & es Mean & Square & \\
\hline odel & 0.07394887 & & 002844 & \\
\hline $\begin{array}{ll}\text { irror } & 27 \\
& 53\end{array}$ & 0.06715607 & & $002487 \mathrm{~F}$ & Prob $>$ \\
\hline
\end{tabular}

Expected Mean Squares

The Mean Square per row by the Variance Component per column

$\begin{array}{lrr}\text { EMS } & \text { Intercept } & \text { Batch\&Random } \\ \text { Intercept } & 0 & 0\end{array}$

Batch\&Random $\quad 0$

plus 1.0 times Residual Error Variance

Variance Component Estimates

Component Var Comp Est Percent of Total

$\begin{array}{lll}\text { Batch\&Random } \quad 0.000178 & 6.695\end{array}$

$\begin{array}{lrr}\text { Residual } & 0.002487 & 93.305 \\ \text { Total } & 0.002666 & 100.000\end{array}$

These estimates based on equating Mean Squares to Expected Value.

Test Denominator Synthesis

Source MS Den DF Den Denom MS Synthesis

Batch\&Random $0.00249 \quad 27$ Residual

Tests wrt Random Effects

Source SS MS Num DF Num F Ratio Prob > F

$\begin{array}{llllll}\text { Batch\&Random } & 0.07395 & 0.00284 & 26 & 1.1435 & 0.3653\end{array}$ 
WSRC-STI-2006-00068

Revision 0

Exhibit A7. Analysis of Variance by Preparation Method, ICP, and Analyte (continued)

Sample Type=ARG-1, Prep=Cold Chem, ICP=M-13, Analyte=B Response Measurement

Summary of Fi

\begin{tabular}{|c|c|c|c|c|}
\hline \multicolumn{3}{|c|}{ RSquare } & 0.6505 & \\
\hline \multicolumn{3}{|c|}{ RSquare Adj } & 0.313944 & \\
\hline \multicolumn{3}{|c|}{ Root Mean Square Error } & 0.063481 & \\
\hline \multicolumn{3}{|c|}{ Mean of Response } & 2.612519 & \\
\hline \multicolumn{3}{|c|}{ Observations (or Sum Wgts) } & 54 & \\
\hline \multicolumn{5}{|c|}{ Analysis of Variance } \\
\hline Source & DF & Sum of Squares & Mean Square & F Ratio \\
\hline Model & 26 & 0.20251448 & $\quad 0.007789$ & 1.9328 \\
\hline Error & 27 & 0.10880700 & 0.004030 & Prob $>$ F \\
\hline C. Total & 53 & 0.31132148 & & 0.0474 \\
\hline
\end{tabular}

Expected Mean Squares

The Mean Square per row by the Variance Component per column

$\begin{array}{lrr}\text { EMS } & \text { Intercept } & \text { Batch\&Random } \\ \text { Intercept } & 0 & 0\end{array}$

Batch\&Random $\quad 0 \quad 2$

plus 1.0 times Residual Error Variance

Variance Component Estimates

Component Var Comp Est Percent of Total

$\begin{array}{lrl}\text { Batch\&Random } \quad 0.00188 & 31.806\end{array}$

$\begin{array}{lll}\text { Residual } & 0.00403 & 68.194\end{array}$

Total $\quad 0.005909 \quad 100.000$

These estimates based on equating Mean Squares to Expected Value.

Test Denominator Synthesi

Source MS Den DF Den Denom MS Synthesis

Batch\&Random $0.00403 \quad 27$ Residual

Tests wrt Random Effects
Source MS Num DF Num F Ratio Prob $>$ F

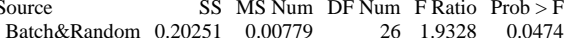

Sample Type=ARG-1, Prep=Cold Chem, ICP=M-13, Analyte $=$ B/Li Response Measurement

Summary of Fit

RSquare $\quad 0.698773$

RSquare Adj $\quad 0.408702$

Root Mean Square Error $\quad 0.053647$

Mean of Response 1.815821

Observations (or Sum Wgts) 54

Analysis of Variance

Source DF Sum of Squares Mean Square F Ratio

$\begin{array}{lllll}\text { Model } & 26 & 0.18025565 & 0.006933 & 2.4090\end{array}$

$\begin{array}{lllll}\text { Error } & 27 & 0.07770465 & 0.002878 \text { Prob }>\text { F }\end{array}$

$\begin{array}{llll}\text { C. Total } & 53 & 0.25796031 & 0.0134\end{array}$

Expected Mean Square

The Mean Square per row by the Variance Component per column

$\begin{array}{lrr}\text { EMS } & \text { Intercept } & \text { Batch\&Random } \\ \text { Intercept } & 0 & 0\end{array}$

$\begin{array}{lll}0 & 0 \\ \text { Batch\&Random } & 0 & 2\end{array}$

plus 1.0 times Residual Error Variance

Variance Component Estimates

Component Var Comp Est Percent of Total

Batch\&Random $\quad 0.002027 \quad 41.33$

$\begin{array}{lll}\text { Residual } & 0.002878 & 58.669\end{array}$

Total $\quad 0.004905 \quad 100.000$

These estimates based on equating Mean Squares to Expected Value.

Test Denominator Synthesis

Source MS Den DF Den Denom MS Synthesis

$\begin{array}{lrrr}\text { Batch\&Random } & 0.00288 & 27 & \text { Residual }\end{array}$

Tests wrt Random Effects

Source

SS MS Num DF Num F Ratio Prob $>$ F

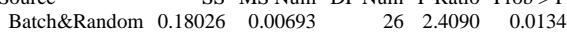

Sample Type=ARG-1, Prep=Cold Chem, ICP=M-13, Analyte=Ca Response Measurement

Summary of Fit

RSquare Adj $\quad 0.504523$

Root Mean Square Error $\quad 0.038372$

Mean of Response 0.967865

Observations (or Sum Wgts)

Analysis of Variance

Source DF Sum of Squares Mean Square F Ratio

$\begin{array}{lllll}\text { Model } & 25 & 0.11327356 & 0.004531 & 3.0772\end{array}$

$\begin{array}{lllll}\text { Error } & 26 & 0.03828250 & 0.001472 & \text { Prob }>\text { F }\end{array}$

$\begin{array}{lll}\text { C. Total } 51 & 0.15155606 & 0.0029\end{array}$

Expected Mean Squares

The Mean Square per row by the Variance Component per column

$\begin{array}{lrr}\text { EMS } & \text { Intercept } & \text { Batch\&Random } \\ \text { Intercept } & 0 & 0\end{array}$

Batch\&Random $\quad 0 \quad 2$

plus 1.0 times Residual Error Variance

Variance Component Estimates

$\begin{array}{rrr}\text { Component } & \text { Var Comp Est } & \text { Percent of Total } \\ \text { Batch\&Random } & 0.001529 & 50.947\end{array}$

$\begin{array}{ccc}\text { Batch\&Random } & 0.001529 & 50.947 \\ \text { Residual } & 0.001472 & 49.053\end{array}$

$\begin{array}{lrr}\text { Residual } & 0.001472 & 49.053 \\ \text { Total } & 0.003002 & 100.000\end{array}$

These estimates based on equating Mean Squares to Expected Value.

Test Denominator Synthesis

Source MS Den DF Den Denom MS Synthesis

Batch\&Random $0.00147 \quad 26$ Residual

Tests wrt Random Effects
Source

$\begin{array}{lrrrrr}\text { Source } & \text { SS } & \text { MS Num } & \text { DF Num } & \text { F Ratio } & \text { Prob > F } \\ \text { Batch\&Random } & 0.11327 & 0.00453 & 25 & 3.0772 & 0.0029\end{array}$

Sample Type=ARG-1, Prep=Cold Chem, ICP $=$ M-13, Analyte $=$ Cr Response Measurement

Summary of Fit

$\begin{array}{ll}0.846019 \\ \text { RSquare Adj } & 0.697741\end{array}$

Root Mean Square Error $\quad 0.69774$

0.003699

$\begin{array}{lr}\text { Mean of Response } & 0.065315 \\ \text { Observations (or Sum Wgts) } & 54\end{array}$

Analysis of Variance

Source DF Sum of Squares Mean Square F Ratio

$\begin{array}{lllll}\text { Model } & 26 & 0.00203015 & 0.000078 & 5.7056\end{array}$

$\begin{array}{lllll}\text { Error } & 27 & 0.00036950 & 0.000014 \quad \text { Prob }>\text { F }\end{array}$

$\begin{array}{llll}\text { C. Total } & 53 & 0.00239965 & <.0001\end{array}$

Expected Mean Squares

The Mean Square per row by the Variance Component per column

$\begin{array}{lrr}\text { EMS } & \text { Intercept } & \text { Batch\&Random } \\ \text { Intercept } & 0 & 0 \\ \text { Batch\&Random } & 0 & 2\end{array}$

plus 1.0 times Residual Error Variance

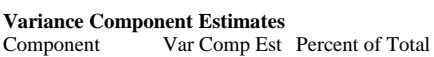

$\begin{array}{crr}\text { Component } & \text { Var Comp Est } & \text { Percent of Total } \\ \text { Batch\&Random } & 0.000032 & 70.174 \\ \text { Residual } & 0.000014 & 29.826\end{array}$

$\begin{array}{lrr}\text { Residual } & 0.000014 & 29.826 \\ \text { Total } & 0.000046 & 100.000\end{array}$

These estimates based on equating Mean Squares to Expected Value.

Test Denominator Synthesis

Source MS Den DF Den Denom MS Synthesis

$\begin{array}{lrrr}\text { Source } & \text { MS Den } & \text { DF Den } & \text { Denom MS } \\ \text { Batch\&Random } & 0.00001 & 27 & \text { Residual }\end{array}$

Tests wrt Random Effects

Source SS MS Num DF Num F Ratio Prob $>$ F

$\begin{array}{rrrrrr}\text { Batch\&Random } & 0.00203 & 0.00008 & 26 & 5.7056 & <.0001\end{array}$ 
WSRC-STI-2006-00068

Revision 0

Exhibit A7. Analysis of Variance by Preparation Method, ICP, and Analyte (continued)

Sample Type=ARG-1, Prep $=$ Cold Chem, ICP $=M-13$, Analyte $=C$ Response Measurement

Summary of Fit

\begin{tabular}{|c|c|c|c|c|}
\hline \multicolumn{3}{|c|}{ RSquare } & \multicolumn{2}{|l|}{0.400987} \\
\hline \multicolumn{3}{|c|}{ RSquare Adj } & \multicolumn{2}{|l|}{-0.17584} \\
\hline \multicolumn{3}{|c|}{ Root Mean Square Error } & \multicolumn{2}{|l|}{0.004794} \\
\hline \multicolumn{3}{|c|}{ Mean of Response } & \multicolumn{2}{|l|}{0.003759} \\
\hline \multicolumn{5}{|c|}{ Observations (or Sum Wgts) 54} \\
\hline \multicolumn{5}{|c|}{ Analysis of Variance } \\
\hline Source & DF & Sum of Squares & s Mean Square & F Ratio \\
\hline Model & 26 & 0.00041537 & $7 \quad 0.000016$ & 0.6952 \\
\hline Error & 27 & 0.00062050 & 0.000023 & Prob $>$ F \\
\hline C. Total & 53 & 0.00103587 & & 0.8215 \\
\hline
\end{tabular}

Expected Mean Squares

The Mean Square per row by the Variance Component per column

$\begin{array}{lrr}\text { EMS } & \text { Intercept } & \text { Batch\&Random } \\ \text { Intercept } & 0 & 0\end{array}$

Batch\&Random $\quad 0 \quad 2$

plus 1.0 times Residual Error Variance

Variance Component Estimates

Component Var Comp Est Percent of Total

Batch\&Random $\quad-3.5 \mathrm{e}-6 \quad 6 \quad-17.983$

Residual $\quad 0.000023 \quad 117.983$

Total $\quad 0.000019 \quad 100.000$

These estimates based on equating Mean Squares to Expected Value.

Test Denominator Synthesi

Source MS Den DF Den Denom MS Synthesis

Batch\&Random $0.00002 \quad 27$ Residual

Tests wrt Random Effects
Source MS Num DF Num F Ratio Prob > F

$\begin{array}{lrrrrr}\text { Source } & \text { SS } & \text { MS Num } & \text { DF Num } & \text { F Ratio } & \text { Prob > F } \\ \text { Batch\&Random } & 0.00042 & 0.00002 & 26 & 0.6952 & 0.8215\end{array}$

Sample Type=ARG-1, Prep=Cold Chem, ICP=M-13, Analyte=Fe Response Measurement

Summary of Fit

RSquare $\quad 0.642853$

RSquare Adj $\quad 0.298934$

Root Mean Square Error $\quad 0.240944$

Mean of Response 9.722981

Observations (or Sum Wgts) 54

Analysis of Variance

Source DF Sum of Squares Mean Square F Ratio

$\begin{array}{llllr}\text { Model } & 26 & 2.8213665 & 0.108514 & 1.8692\end{array}$

$\begin{array}{lllll}\text { Error } & 27 & 1.5674545 & 0.058054 \text { Prob }>\text { F }\end{array}$

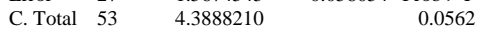

Expected Mean Square

The Mean Square per row by the Variance Component per column

$\begin{array}{lrr}\text { EMS } & \text { Intercept } & \text { Batch\&Random } \\ \text { Intercept } & 0 & 0\end{array}$

$\begin{array}{lll}0 & 0 \\ \text { Batch\&Random } & 0 & 2\end{array}$

plus 1.0 times Residual Error Variance

Variance Component Estimates

Component Var Comp Est Percent of Total

$\begin{array}{lrl}\text { Batch\&Random } \quad 0.02523 & 30.294\end{array}$

$\begin{array}{lll}\text { Residual } & 0.058054 & 69.706\end{array}$

Total $\quad 0.083284 \quad 100.000$

These estimates based on equating Mean Squares to Expected Value.

Test Denominator Synthesis

Source MS Den DF Den Denom MS Synthesis

$\begin{array}{lrrr}\text { Batch\&Random } & 0.05805 & 27 & \text { Residual }\end{array}$

Tests wrt Random Effects

Source

SS MS Num DF Num F Ratio Prob $>$ F

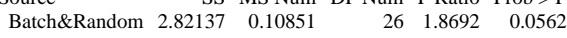

Sample Type=ARG-1, Prep=Cold Chem, ICP=M-13, Analyte=Fe/Al Response Measurement

Summary of Fit

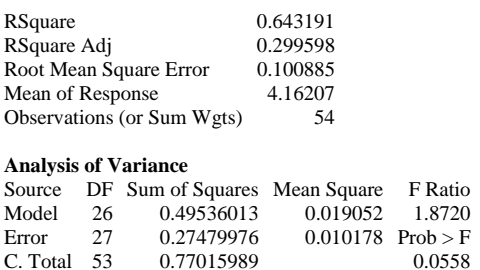

Expected Mean Squares

The Mean Square per row by the Variance Component per column

$\begin{array}{lrr}\text { EMS } & \text { Intercept } & \text { Batch\&Random } \\ \text { Intercept } & 0 & 0\end{array}$

Batch\&Random $\quad 0 \quad 2$

plus 1.0 times Residual Error Variance

Variance Component Estimates

$\begin{array}{rrr}\text { Component } & \text { Var Comp Est } & \text { Percent of Total } \\ \text { Batch\&Random } & 0.004437 & 30.361\end{array}$

$\begin{array}{ccc}\text { Batch\&Random } & 0.004437 & 30.361 \\ \text { Residual } & 0.010178 & 69.639\end{array}$

$\begin{array}{lrr}\text { Residual } & 0.010178 & 69.639 \\ \text { Total } & 0.014615 & 100.000\end{array}$

These estimates based on equating Mean Squares to Expected Value.

Test Denominator Synthesis

Source MS Den DF Den Denom MS Synthesis

Batch\&Random $0.01018 \quad 27$ Residual

Tests wrt Random Effects
$\begin{aligned} & \text { Source } \\ & \text { SS MS Num DF Num F Ratio Prob > F }\end{aligned}$

$\begin{array}{lrrrrr}\text { Source } & \text { SS } & \text { MS Num } & \text { DF Num } & \text { F Ratio } & \text { Prob }>\text { F } \\ \text { Batch\&Random } & 0.49536 & 0.01905 & 26 & 1.8720 & 0.0558\end{array}$

Sample Type=ARG-1, Prep=Cold Chem, ICP=M-13, Analyte=Fe/Ca Response Measurement

Summary of Fit

RSquare $\quad 0.551085$

RSquare Adj $\quad 0.120874$

Root Mean Square Error $\quad 0.369426$

Mean of Response 9.979773

Observations (or Sum Wgts) 48

Analysis of Variance

Source DF Sum of Squares Mean Square F Ratio

$\begin{array}{lllll}\text { Model } & 23 & 4.0208763 & 0.174821 & 1.2810\end{array}$

$\begin{array}{lllll}\text { Error } & 24 & 3.2754174 & 0.136476 & \text { Prob }>\text { F }\end{array}$

$\begin{array}{llrr}\text { C. Total } & 47 & 7.2962937 & 0.2755\end{array}$

Expected Mean Squares

The Mean Square per row by the Variance Component per column

$\begin{array}{lrr}\text { EMS } & \text { Intercept } & \text { Batch\&Random } \\ \text { Intercept } & 0 & 0 \\ \text { Batch\&Random } & 0 & 2\end{array}$

plus 1.0 times Residual Error Variance

Variance Component Estimates
Component Var Comp Est Percent of Total

$\begin{array}{lrr}\text { Component } & \text { Var Comp Est } & \text { Percent of Total } \\ \text { Batch\&Random } & 0.019172 & 12.318 \\ \text { Residual } & 0.136476 & 87.682\end{array}$

$\begin{array}{lrr}\text { Residual } & 0.136476 & 87.682 \\ \text { Total } & 0.155648 & 100.000\end{array}$

These estimates based on equating Mean Squares to Expected Value.

Test Denominator Synthesis

Source MS Den DF Den Denom MS Synthesis

$\begin{array}{rrrr}\text { Source } & \text { MS Den } & \text { DF Den } & \text { Denom } \\ \text { Batch\&Random } & 0.13648 & 24 & \text { Residual }\end{array}$

Tests wrt Random Effects

Source SS MS Num DF Num F Ratio Prob $>$ F

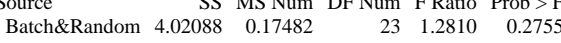


WSRC-STI-2006-00068

Revision 0

Exhibit A7. Analysis of Variance by Preparation Method, ICP, and Analyte (continued)

Sample Type=ARG-1, Prep=Cold Chem, ICP $=\mathrm{M}-13$, Analyte $=\mathrm{Fe} / \mathrm{L}$ Response Measurement

Summary of Fi

\begin{tabular}{|c|c|c|c|}
\hline RSquare & & 0.756 & \\
\hline RSquare & & 0.521037 & \\
\hline Root Me & in Square Error & 0.17547 & \\
\hline Mean of & Response & 6.757638 & \\
\hline Observat & ons (or Sum Wgts) & 54 & \\
\hline Analysis & of Variance & & \\
\hline Source & DF Sum of Squares & s Mean Square & F Ratio \\
\hline Model & $26 \quad 2.5757426$ & $\begin{array}{ll}6 & 0.099067\end{array}$ & 3.2175 \\
\hline Error & 0.8313251 & 0.030790 & Prob $>F$ \\
\hline C. Total & 3.4070677 & & 0.0018 \\
\hline
\end{tabular}

Expected Mean Squares

The Mean Square per row by the Variance Component per column

$\begin{array}{lrr}\text { EMS } & \text { Intercept } & \text { Batch\&Random } \\ \text { Intercept } & 0 & 0\end{array}$

Batch\&Random $\quad 0 \quad 2$

plus 1.0 times Residual Error Variance

Variance Component Estimates

Component Var Comp Est Percent of Total

Batch\&Random $\quad 0.034139 \quad 52.579$

$\begin{array}{lrr}\text { Residual } & 0.03079 & 47.421\end{array}$

Total $\quad 0.064928 \quad 100.000$

These estimates based on equating Mean Squares to Expected Value.

Test Denominator Synthesi

Source MS Den DF Den Denom MS Synthesis

Batch\&Random $0.03079 \quad 27$ Residual

Tests wrt Random Effects
Source

$\begin{array}{lrrrrr}\text { Source } & \text { SS } & \text { MS Num } & \text { DF Num } & \text { F Ratio } & \text { Prob }>\text { F } \\ \text { Batch\&Random } & 2.57574 & 0.09907 & 26 & 3.2175 & 0.0018\end{array}$

Sample Type=ARG-1, Prep=Cold Chem, ICP=M-13, Analyte=Fe/Mg Response Measurement

Summary of Fit

RSquare $\quad 0.782737$

RSquare Adj $\quad 0.574527$

Root Mean Square Error $\quad 0.315141$

Mean of Response 19.54323

Observations (or Sum Wgts) $\quad 48$

Analysis of Variance

Source DF Sum of Squares Mean Square F Ratio

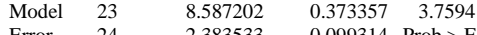

$\begin{array}{lllll}\text { Error } & 24 & 2.383533 & 0.099314 & \text { Prob }>\text { F }\end{array}$

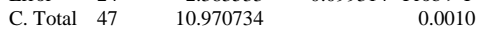

Expected Mean Squares

The Mean Square per row by the Variance Component per column

$\begin{array}{lrr}\text { EMS } & \text { Intercept } & \text { Batch\&Random } \\ \text { Intercept } & 0 & 0\end{array}$

Batch\&Random $\quad 0 \quad 2$

plus 1.0 times Residual Error Variance

Variance Component Estimates

Component Var Comp Est Percent of Total

Batch\&Random $\quad 0.137021 \quad 57.978$

$\begin{array}{lrr}\text { Residual } & 0.099314 & 42.022 \\ \text { Total } & 0.236335 & 100.000\end{array}$

These estimates based on equating Mean Squares to Expected Value.

Test Denominator Synthesis

Source MS Den DF Den Denom MS Synthesis

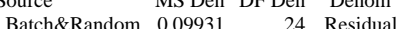

Tests wrt Random Effects

Source SS MS Num DF Num F Ratio Prob $>$ F

$\begin{array}{rrrrrr}\text { Batch\&Random } & 8.5872 & 0.37336 & 23 & 3.7594 & 0.0010\end{array}$
Sample Type=ARG-1, Prep=Cold Chem, ICP=M-13, Analyte=Fe $/$ Mn Response Measurement

Summary of Fit

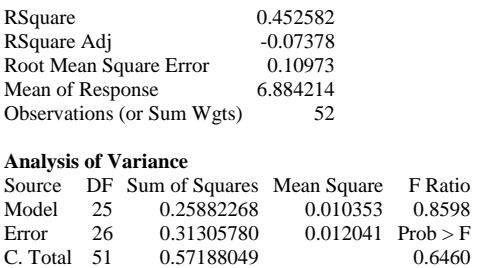

Expected Mean Squares

The Mean Square per row by the Variance Component per column

$\begin{array}{lrr}\text { EMS } & \text { Intercept } & \text { Batch\&Random } \\ \text { Intercept } & 0 & 0\end{array}$

Batch\&Random $\quad 0 \quad 2$

plus 1.0 times Residual Error Variance

Variance Component Estimates

$\begin{array}{crr}\text { Component } & \text { Var Comp Est } & \text { Percent of Total } \\ \text { Batch\&Random } & -0.00084 & -7.537 \\ \text { Residual } & 0.012041 & 107.537\end{array}$

$\begin{array}{lll}\text { Residual } & 0.012041 & 107.537 \\ \text { Total } & 0.011197 & 100.000\end{array}$

$\begin{array}{lcc}\text { Total } & 0.011197 & 100.000 \\ \text { These estimates based on equating Mean Squares to Expected Value. }\end{array}$

Test Denominator Synthesis

Source MS Den DF Den Denom MS Synthesis

Batch\&Random $0.01204 \quad 26$ Residual

Tests wrt Random Effects
Source SS MS Num DF Num F Ratio Prob $>$ F

$\begin{array}{lrrrrr}\text { Source } & \text { SS } & \text { MS Num } & \text { DF Num } & \text { F Ratio } & \text { Prob }>\text { F } \\ \text { Batch\&Random } & 0.25882 & 0.01035 & 25 & 0.8598 & 0.6460\end{array}$

Sample Type=ARG-1, Prep=Cold Chem, ICP=M-13, Analyte=Fe/Ni Response Measurement

Summary of Fit

0.185373

Mean of Response

Observations (or Sum Wgts) $\quad 52$

Analysis of Variance

Source DF Sum of Squares Mean Square F Ratio

$\begin{array}{lllll}\text { Model } & 25 & 1.7399690 & 0.069599 & 1.4642\end{array}$

$\begin{array}{lllll}\text { Error } & 26 & 1.2358644 & 0.047533 \text { Prob }>\text { F }\end{array}$

$\begin{array}{llll}\text { C. Total } & 51 & 2.9758334 & 0.1700\end{array}$

Expected Mean Squares

The Mean Square per row by the Variance Component per column

$\begin{array}{lrr}\text { EMS } & \text { Intercept } & \text { Batch\&Random } \\ \text { Intercept } & 0 & 0 \\ \text { Batch\&Random } & 0 & 2\end{array}$

plus 1.0 times Residual Error Variance

Variance Component Estimates
Component Var Comp Est Percent of Total

$\begin{array}{crr}\text { Component } & \text { Var Comp Est } & \text { Percent of Total } \\ \text { Batch\&Random } & 0.011033 & 18.838\end{array}$

$\begin{array}{lll}\text { Residual } & 0.047533 & 81.162\end{array}$

Total $\quad 0.058566 \quad 100.000$

These estimates based on equating Mean Squares to Expected Value.

Test Denominator Synthesis

Source MS Den DF Den Denom MS Synthesis

$\begin{array}{rrrr}\text { Source } & \text { MS Den } & \text { DF Den } & \text { Denom } \\ \text { Batch\&Random } & 0.04753 & 26 & \text { Residual }\end{array}$

Tests wrt Random Effects

Source SS MS Num DF Num F Ratio Prob $>$ F

$\begin{array}{lrrrrr} & \text { SS } & & & & \\ \text { Batch\&Random } & 1.73997 & 0.0696 & 25 & 1.4642 & 0.1700\end{array}$ 
WSRC-STI-2006-00068

Revision 0

Exhibit A7. Analysis of Variance by Preparation Method, ICP, and Analyte (continued)

Sample Type=ARG-1, Prep=Cold Chem, ICP $=\mathrm{M}-13$, Analyte $=\mathrm{Fe} / \mathrm{U}$ Response Measurement

Summary of Fi

\begin{tabular}{|c|c|c|c|c|}
\hline \multicolumn{3}{|c|}{ RSquare } & 0.42808 & \\
\hline \multicolumn{3}{|c|}{ RSquare Adj } & -0.11374 & \\
\hline \multicolumn{3}{|c|}{ Root Mean Square Error } & 221.8497 & \\
\hline \multicolumn{3}{|c|}{ Mean of Response } & -8.71399 & \\
\hline \multicolumn{3}{|c|}{ Observations (or Sum Wgts) } & 38 & \\
\hline \multicolumn{5}{|c|}{ Analysis of Variance } \\
\hline Source & DF & Sum of Squares & Mean Square & F Ratio \\
\hline Model & 18 & 699941.3 & 38885.6 & 0.7901 \\
\hline Error & 19 & 935128.5 & 49217.3 & Prob $>$ F \\
\hline C. Total & 37 & 1635069.7 & & 0.6895 \\
\hline
\end{tabular}

Expected Mean Squares

The Mean Square per row by the Variance Component per column

$\begin{array}{lrr}\text { EMS } & \text { Intercept } & \text { Batch\&Random } \\ \text { Intercept } & 0 & 0\end{array}$

Batch\&Random $\quad 0 \quad 2$

plus 1.0 times Residual Error Variance

Variance Component Estimates

Component Var Comp Est Percent of Total

$\begin{array}{lrr}\text { Batch\&Random } & -5165.83 & -11.727\end{array}$

Residual $\quad 49217.29 \quad 111.727$

Total $\quad 44051.46 \quad 100.000$

These estimates based on equating Mean Squares to Expected Value.

Test Denominator Synthesis

Source MS Den DF Den Denom MS Synthesis

Batch\&Random 49217.3 19 Residual

Tests wrt Random Effects
Source

$\begin{array}{lrrrrr}\text { Source } & \text { SS } & \text { MS Num } & \text { DF Num } & \text { F Ratio } & \text { Prob > F } \\ \text { Batch\&Random } & 699941 & 38885.6 & 18 & 0.7901 & 0.6895\end{array}$

Sample Type=ARG-1, Prep=Cold Chem, ICP $=$ M-13, Analyte=K Response Measurement

Summary of Fit

RSquare $\quad 0.56732$

RSquare Adj $\quad 0.150666$

Root Mean Square Error $\quad 0.203088$

Mean of Response 2.333074

Observations (or Sum Wgts) $\quad 54$

Analysis of Variance

Source DF Sum of Squares Mean Square F Ratio

$\begin{array}{lllll}\text { Model } & 26 & 1.4601367 & 0.056159 & 1.3616\end{array}$

$\begin{array}{lllll}\text { Error } & 27 & 1.1136070 & 0.041245 \text { Prob }>\text { F }\end{array}$

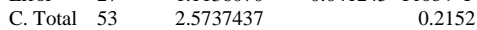

Expected Mean Squares

The Mean Square per row by the Variance Component per column

$\begin{array}{lrr}\text { EMS } & \text { Intercept } & \text { Batch\&Random } \\ \text { Intercept } & 0 & 0\end{array}$

Batch\&Random $\quad 0 \quad 2$

plus 1.0 times Residual Error Variance

Variance Component Estimates

Component Var Comp Est Percent of Total

$\begin{array}{lll}\text { Batch\&Random } \quad 0.007457 & 15.312\end{array}$

$\begin{array}{lll}\text { Residual } & 0.041245 & 84.688\end{array}$

Total $\quad 0.048702 \quad 100.000$

These estimates based on equating Mean Squares to Expected Value.

Test Denominator Synthesis

Source MS Den DF Den Denom MS Synthesis

$\begin{array}{lrrr}\text { Batch\&Random } & 0.04124 & 27 & \text { Residual }\end{array}$

Tests wrt Random Effects

Source

SS MS Num DF Num F Ratio Prob $>$ F

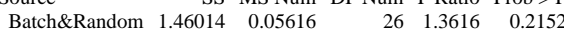

Sample Type=ARG-1, Prep=Cold Chem, ICP=M-13, Analyte $=\mathrm{Li}$ Response Measurement

Summary of Fit

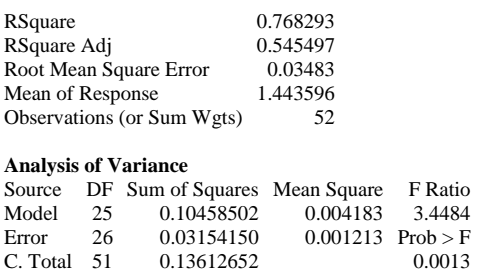

Expected Mean Squares

The Mean Square per row by the Variance Component per column

$\begin{array}{lrr}\text { EMS } & \text { Intercept } & \text { Batch\&Random } \\ \text { Intercept } & 0 & 0\end{array}$

Batch\&Random $\quad 0 \quad 2$

plus 1.0 times Residual Error Variance

Variance Component Estimates

\begin{tabular}{crr} 
Component & Var Comp Est & Percent of Total \\
Batch\&Random & 0.001485 & 55.040 \\
\hline & 0.001213 & 44.960
\end{tabular}

$\begin{array}{lll}\text { Batch\&Random } & 0.001485 & 55.040 \\ \text { Residual } & 0.001213 & 44.960\end{array}$

Total $\quad 0.002698 \quad 100.000$

These estimates based on equating Mean Squares to Expected Value.

Test Denominator Synthesis

Source MS Den DF Den Denom MS Synthesis

Batch\&Random $0.00121 \quad 26$ Residual

Tests wrt Random Effects
Source SS MS Num DF Num F Ratio Prob > F

$\begin{array}{lrrrrr}\text { Source } & \text { SS } & \text { MS Num } & \text { DF Num } & \text { F Ratio } & \text { Prob > F } \\ \text { Batch\&Random } & 0.10459 & 0.00418 & 25 & 3.4484 & 0.0013\end{array}$

Sample Type=ARG-1, Prep=Cold Chem, ICP=M-13, Analyte=Mg Response Measurement

Summary of Fit

0.841407

RSquare Adj $\quad 0.688688$

Root Mean Square Error $\quad 0.013647$

Mean of Response $\quad 0.496981$

Observations (or Sum Wgts) $\quad 54$

Analysis of Variance

Source DF Sum of Squares Mean Square F Ratio

$\begin{array}{lllll}\text { Model } & 26 & 0.02667848 & 0.001026 & 5.5095\end{array}$

$\begin{array}{lllll}\text { Error } & 27 & 0.00502850 & 0.000186 & \text { Prob }>\text { F }\end{array}$

$\begin{array}{llll}\text { C. Total } & 53 & 0.03170698 & <.0001\end{array}$

Expected Mean Squares

The Mean Square per row by the Variance Component per column

$\begin{array}{lrr}\text { EMS } & \text { Intercept } & \text { Batch\&Random } \\ \text { Intercept } & 0 & 0 \\ \text { Batch\&Random } & 0 & 2\end{array}$

plus 1.0 times Residual Error Variance

Variance Component Estimates
Component Var Comp Est Percent of Total

$\begin{array}{crr}\text { Component } & \text { Var Comp Est } & \text { Percent of Total } \\ \text { Batch\&Random } & 0.00042 & 69.276\end{array}$

$\begin{array}{llr}\text { Residual } & 0.000186 & 30.724\end{array}$

Total $\quad 0.000606 \quad 100.000$

These estimates based on equating Mean Squares to Expected Value.

Test Denominator Synthesis

Source MS Den DF Den Denom MS Synthesis

$\begin{array}{lrrr}\text { Source } & \text { MS Den } & \text { DF Den } & \text { Denom } \\ \text { Batch\&Random } & 0.00019 & 27 & \text { Residual }\end{array}$

Tests wrt Random Effects

Source SS MS Num DF Num F Ratio Prob $>$ F

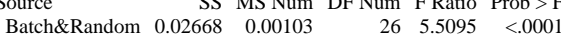


WSRC-STI-2006-00068

Revision 0

Exhibit A7. Analysis of Variance by Preparation Method, ICP, and Analyte (continued)

Sample Type=ARG-1, Prep=Cold Chem, ICP $=$ M-13, Analyte=Mn Response Measurement

Summary of Fit

\begin{tabular}{|c|c|c|c|c|}
\hline \multicolumn{3}{|c|}{ RSquare } & 0.533516 & \\
\hline \multicolumn{3}{|c|}{ RSquare Adj } & 0.084309 & \\
\hline \multicolumn{3}{|c|}{ Root Mean Square Error } & 0.0393 & \\
\hline \multicolumn{3}{|c|}{ Mean of Response } & 1.415741 & \\
\hline \multicolumn{3}{|c|}{ Observations (or Sum Wgts) } & 54 & \\
\hline \multicolumn{5}{|c|}{ Analysis of Variance } \\
\hline Source & DF & Sum of Squares & Mean Square & F Ratio \\
\hline Model & 26 & 0.04769437 & 0.001834 & 1.1877 \\
\hline Error & 27 & 0.04170200 & 0.001545 & Prob $>$ F \\
\hline C. Total & 53 & 0.08939637 & & 0.3296 \\
\hline
\end{tabular}

Expected Mean Squares

The Mean Square per row by the Variance Component per column

$\begin{array}{lrr}\text { EMS } & \text { Intercept } & \text { Batch\&Random } \\ \text { Intercept } & 0 & 0\end{array}$

Batch\&Random $\quad 0 \quad 2$

plus 1.0 times Residual Error Variance

Variance Component Estimates

Component Var Comp Est Percent of Total

$\begin{array}{rrr}\text { Component } & \text { Var Comp Est } & \text { Percent of Tota } \\ \text { Batch\&Random } & 0.000145 & 8.579\end{array}$

Residual $\quad 0.001545 \quad 91.421$

Total $\quad 0.001689 \quad 100.000$

These estimates based on equating Mean Squares to Expected Value.

Test Denominator Synthesi

Source MS Den DF Den Denom MS Synthesis

Batch\&Random $0.00154 \quad 27$ Residual

Tests wrt Random Effects
Source

$\begin{array}{lrrrrr}\text { Source } & \text { SS } & \text { MS Num } & \text { DF Num } & \text { F Ratio } & \text { Prob }>\text { F } \\ \text { Batch\&Random } & 0.04769 & 0.00183 & 26 & 1.1877 & 0.3296\end{array}$

Sample Type=ARG-1, Prep=Cold Chem, ICP $=M-13$, Analyte $=M n / M g$ Response Measurement

Summary of Fit

RSquare $\quad 0.829738$

RSquare Adj $\quad 0.666287$

Root Mean Square Error $\quad 0.053113$

Mean of Response 2.848788

Observations (or Sum Wgts) $\quad 50$

Analysis of Variance

Source DF Sum of Squares Mean Square F Ratio

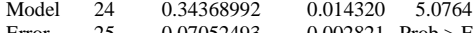

$\begin{array}{lllll}\text { Error } & 25 & 0.07052493 & 0.002821 & \text { Prob }>\text { F }\end{array}$

$\begin{array}{llll}\text { C. Total } & 49 & 0.41421485 & <.0001\end{array}$

Expected Mean Squares

The Mean Square per row by the Variance Component per column

$\begin{array}{lrr}\text { EMS } & \text { Intercept } & \text { Batch\&Random } \\ \text { Intercept } & 0 & 0\end{array}$

$\begin{array}{lll}0 & 0 \\ \text { Batch\&Random } & 0 & 2\end{array}$

plus 1.0 times Residual Error Variance

Variance Component Estimates

Component Var Comp Est Percent of Total

$\begin{array}{lrr}\text { Batch\&Random } \quad 0.00575 & 67.086\end{array}$

$\begin{array}{lll}\text { Residual } & 0.002821 & 32.914\end{array}$

Total $\quad 0.008571 \quad 100.000$

These estimates based on equating Mean Squares to Expected Value.

Test Denominator Synthesis

Source MS Den DF Den Denom MS Synthesis

Batch\&Random $0.00282 \quad 25$ Residual

Tests wrt Random Effects

Source

SS MS Num DF Num F Ratio Prob $>$ F

$\begin{array}{llllll}\text { Batch\&Random } & 0.34369 & 0.01432 & 24 & 5.0764 & <.0001\end{array}$
Sample Type=ARG-1, Prep=Cold Chem, ICP=M-13, Analyte=Na Response Measurement

Summary of Fit

RSquare Adj $\quad 0.25880$

Root Mean Square Error $\quad 0.127506$

Mean of Response $\quad 8.340146$

Observations (or Sum Wgts)

Analysis of Variance

Source DF Sum of Squares Mean Square F Ratio

$\begin{array}{lllll}\text { Model } & 23 & 0.6407365 & 0.027858 & 1.7135\end{array}$

$\begin{array}{lllll}\text { Error } & 24 & 0.3901895 & 0.016258 & \text { Prob }>\text { F }\end{array}$

$\begin{array}{llrr}\text { C. Total } 47 & 1.0309260 & 0.0987\end{array}$

Expected Mean Squares

The Mean Square per row by the Variance Component per column

$\begin{array}{lrr}\text { EMS } & \text { Intercept } & \text { Batch\&Random } \\ \text { Intercept } & 0 & 0\end{array}$

Batch\&Random $\quad 0 \quad 2$

plus 1.0 times Residual Error Variance

Variance Component Estimates

Component Var Comp Est Percent of Total

$\begin{array}{lrr}\text { Batch\&Random } & 0.0058 & 26.295 \\ \text { Residual } & 0.016258 & 73.705\end{array}$

$\begin{array}{lrr}\text { Residual } & 0.016258 & 73.705 \\ \text { Total } & 0.022058 & 100.000\end{array}$

These estimates based on equating Mean Squares to Expected Value.

Test Denominator Synthesis

Source MS Den DF Den Denom MS Synthesis

Batch\&Random $0.01626 \quad 24$ Residual

Tests wrt Random Effects
Source $\quad$ SS MS Num DF Num F Ratio Prob $>$ F

$\begin{array}{lrrrrr}\text { Source } & \text { SS } & \text { MS Num } & \text { DF Num } & \text { F Ratio } & \text { Prob > F } \\ \text { Batch\&Random } & 0.64074 & 0.02786 & 23 & 1.7135 & 0.0987\end{array}$

Sample Type=ARG-1, Prep=Cold Chem, ICP=M-13, Analyte=Ni Response Measurement

Summary of Fit

0.602188

RSquare Adj $\quad 0.219677$

Root Mean Square Error $\quad 0.015365$

Mean of Response $\quad 0.808288$

Observations (or Sum Wgts) 52

Analysis of Variance

Source DF Sum of Squares Mean Square F Ratio

$\begin{array}{lllll}\text { Model } & 25 & 0.00929217 & 0.000372 & 1.5743\end{array}$

$\begin{array}{lllll}\text { Error } & 26 & 0.00613850 & 0.000236 & \text { Prob }>\text { F }\end{array}$

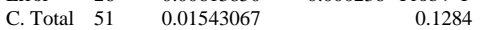

Expected Mean Squares

The Mean Square per row by the Variance Component per column

$\begin{array}{lrr}\text { EMS } & \text { Intercept } & \text { Batch\&Random } \\ \text { Intercept } & 0 & 0 \\ \text { Batch\&Random } & 0 & 2\end{array}$

plus 1.0 times Residual Error Variance

Variance Component Estimates
$\begin{array}{ll}\text { Component } & \text { Var Comp Est Percent of Total }\end{array}$

$\begin{array}{crr}\text { Component } & \text { Var Comp Est } & \text { Percent of Total } \\ \text { Batch\&Random } & 0.000068 & 22.309 \\ \text { Residual } & 0.000236 & 77.691 \\ \text { Tol } & 0.000304 & 100.000\end{array}$

$\begin{array}{lrr}\text { Residual } & 0.000236 & 77.691 \\ \text { Total } & 0.000304 & 100.000\end{array}$

These estimates based on equating Mean Squares to Expected Value.

Test Denominator Synthesis

Source MS Den DF Den Denom MS Synthesis

$\begin{array}{lrrr}\text { Source } & \text { MS Den } & \text { DF Den } & \text { Denom } \\ \text { Batch\&Random } & 0.00024 & 26 & \text { Residual }\end{array}$

Tests wrt Random Effects

Source SS MS Num DF Num F Ratio Prob $>$ F

$\begin{array}{rrrrrr}\text { Batch\&Random } & 0.00929 & 0.00037 & 25 & 1.5743 & 0.1284\end{array}$ 
WSRC-STI-2006-00068

Revision 0

Exhibit A7. Analysis of Variance by Preparation Method, ICP, and Analyte (continued)

Sample Type=ARG-1, Prep=Cold Chem, ICP=M-13, Analyte=Si Response Measurement

Summary of Fi

\begin{tabular}{|c|c|c|c|}
\hline \multicolumn{2}{|c|}{ RSquare } & 0.631191 & \\
\hline \multicolumn{2}{|c|}{ RSquare Adj } & 0.276567 & \\
\hline \multicolumn{2}{|c|}{ Root Mean Square Error } & 0.513755 & \\
\hline \multicolumn{2}{|c|}{ Mean of Response } & 21.85973 & \\
\hline \multicolumn{2}{|c|}{ Observations (or Sum Wgts) } & 52 & \\
\hline \multicolumn{4}{|c|}{ Analysis of Variance } \\
\hline Source & DF Sum of Squares & s Mean Square & F Ratio \\
\hline Model & $25 \quad 11.744780$ & $0 \quad 0.469791$ & 1.7799 \\
\hline Error & 6.862548 & 0.263944 & Prob $>$ F \\
\hline C. Total & 18.607328 & & 0.0754 \\
\hline
\end{tabular}

Expected Mean Squares

The Mean Square per row by the Variance Component per column

$\begin{array}{lrr}\text { EMS } & \text { Intercept } & \text { Batch\&Random } \\ \text { Intercept } & 0 & 0\end{array}$

Batch\&Random $\quad 0 \quad 2$

plus 1.0 times Residual Error Variance

Variance Component Estimates

Component Var Comp Est Percent of Total

Batch\&Random $\quad 0.102924 \quad 28.055$

$\begin{array}{lll}\text { Residual } & 0.263944 & 71.945\end{array}$

Total $\quad 0.366868 \quad 100.000$

These estimates based on equating Mean Squares to Expected Value.

Test Denominator Synthesi

Source MS Den DF Den Denom MS Synthesis

Batch\&Random $0.26394 \quad 26$ Residual

Tests wrt Random Effects
Source MS Num DF Num F Ratio Prob > F

$\begin{array}{lrrrrr}\text { Source } & \text { SS } & \text { MS Num } & \text { DF Num } & \text { F Ratio } & \text { Prob }>\text { F } \\ \text { Batch\&Random } & 11.7448 & 0.46979 & 25 & 1.7799 & 0.0754\end{array}$

Sample Type=ARG-1, Prep=Cold Chem, ICP=M-13, Analyte=Sum of Oxides Response Measurement

Summary of Fit

RSquare $\quad 0.624638$

RSquare Adj $\quad 0.263178$

Root Mean Square Error $\quad 2.8647$

Mean of Response 97.41286

Observations (or Sum Wgts) 54

Analysis of Variance

Source DF Sum of Squares Mean Square F Ratio

$\begin{array}{lllll}\text { Model } & 26 & 368.72301 & 14.1817 & 1.7281\end{array}$

Error $27 \quad 221.57563 \quad 8.2065$ Prob $>$ F

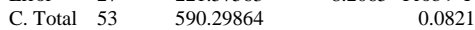

Expected Mean Squares

The Mean Square per row by the Variance Component per column

$\begin{array}{lrr}\text { EMS } & \text { Intercept } & \text { Batch\&Random } \\ \text { Intercept } & 0 & 0\end{array}$

$\begin{array}{lll}0 & 0 \\ \text { Batch\&Random } & 0 & 2\end{array}$

plus 1.0 times Residual Error Variance

Variance Component Estimates

Component Var Comp Est Percent of Total

Batch\&Random $\quad 2.987575 \quad 26.689$

Residual $\quad 8.206505 \quad 73.31$

Total $\quad 11.19408 \quad 100.000$

These estimates based on equating Mean Squares to Expected Value.

Test Denominator Synthesis

Source MS Den DF Den Denom MS Synthesis

$\begin{array}{rrrr}\text { Batch\&Random } & 8.2065 & 27 & \text { Residual }\end{array}$

Tests wrt Random Effects

Source

SS MS Num DF Num F Ratio Prob > F

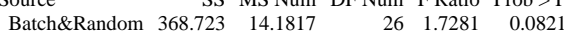

Sample Type=ARG-1, Prep=Cold Chem, ICP $=$ M-13, Analyte $=$ T Response Measurement

Summary of Fit

RSquare Adj $\quad 0.503797$

Root Mean Square Error $\quad 0.010688$

Mean of Response 0.672423

Observations (or Sum Wgts)

Analysis of Variance

Source DF Sum of Squares Mean Square F Ratio

$\begin{array}{lllll}\text { Model } & 25 & 0.00877069 & 0.000351 & 3.0712\end{array}$

$\begin{array}{lllll}\text { Error } & 26 & 0.00297000 & 0.000114 & \text { Prob }>\text { F }\end{array}$

$\begin{array}{llr}\text { C. Total } 51 & 0.01174069 & 0.0030\end{array}$

Expected Mean Squares

The Mean Square per row by the Variance Component per column

$\begin{array}{lrr}\text { EMS } & \text { Intercept } & \text { Batch\&Random } \\ \text { Intercept } & 0 & 0\end{array}$

Batch\&Random $\quad 0 \quad 2$

plus 1.0 times Residual Error Variance

Variance Component Estimates

Component Var Comp Est Percent of Total

$\begin{array}{lrr}\text { Component } & \text { Var Comp Est } & \text { Percent of Total } \\ \text { Batch\&Random } & 0.000118 & 50.875\end{array}$

$\begin{array}{lll}\text { Batch\&Random } & 0.000118 & 50.875 \\ \text { Residual } & 0.000114 & 49.125\end{array}$

$\begin{array}{lrr}\text { Residual } & 0.000114 & 49.125 \\ \text { Total } & 0.000233 & 100.000\end{array}$

These estimates based on equating Mean Squares to Expected Value.

Test Denominator Synthesis

Source MS Den DF Den Denom MS Synthesis

Batch\&Random $0.00011 \quad 26$ Residual

Tests wrt Random Effects
Source SS MS Num DF Num F Ratio Prob $>$ F

$\begin{array}{lrrrrr}\text { Source } & \text { SS } & \text { MS Num } & \text { DF Num } & \text { F Ratio } & \text { Prob }>\text { F } \\ \text { Batch\&Random } & 0.00877 & 0.00035 & 25 & 3.0712 & 0.0030\end{array}$

Sample Type=ARG-1, Prep=Cold Chem, ICP $=$ M-13, Analyte $=U$ Response Measurement

Summary of Fit

RSquare Adj $\quad-0.30226$

Root Mean Square Error $\quad 0.13254$

Mean of Response $\quad 0.093981$

Observations (or Sum Wgts) 54

Analysis of Variance

Source DF Sum of Squares Mean Square F Ratio

$\begin{array}{lllll}\text { Model } & 26 & 0.24064048 & 0.009255 & 0.5269\end{array}$

$\begin{array}{lllll}\text { Error } & 27 & 0.47430850 & 0.017567 & \text { Prob }>\text { F }\end{array}$

$\begin{array}{llll}\text { C. Total } & 53 & 0.71494898 & 0.9468\end{array}$

Expected Mean Squares

The Mean Square per row by the Variance Component per column

$\begin{array}{lrr}\text { EMS } & \text { Intercept } & \text { Batch\&Random } \\ \text { Intercept } & 0 & 0 \\ \text { Batch\&Random } & 0 & 2\end{array}$

plus 1.0 times Residual Error Variance

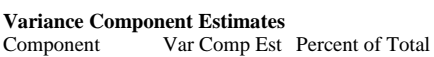

$\begin{array}{crr}\text { Component } & \text { Var Comp Est } & \text { Percent of Total } \\ \text { Batch\&Random } & -0.00416 & -30.987\end{array}$

$\begin{array}{ccc}\text { Batch\&Random } & -0.00416 & -30.987 \\ \text { Residual } & 0.017567 & 130.987\end{array}$

$\begin{array}{lll}\text { Total } & 0.013411 & 100.000\end{array}$

These estimates based on equating Mean Squares to Expected Value.

Test Denominator Synthesis

Source MS Den DF Den Denom MS Synthesis

$\begin{array}{lrrr}\text { Source } & \text { MS Den } & \text { DF Den } & \text { Denom MS } \\ \text { Batch\&Random } & 0.01757 & 27 & \text { Residual }\end{array}$

Tests wrt Random Effects

Source SS MS Num DF Num F Ratio Prob > F

$\begin{array}{rrrrrr}\text { Batch\&Random } & 0.24064 & 0.00926 & 26 & 0.5269 & 0.9468\end{array}$ 
WSRC-STI-2006-00068

Revision 0

Exhibit A7. Analysis of Variance by Preparation Method, ICP, and Analyte (continued)

Sample Type=ARG-1, Prep=Cold Chem, ICP $=$ M-13, Analyte=U/C Response Measurement

Summary of Fit

\begin{tabular}{|c|c|c|c|c|}
\hline \multicolumn{3}{|c|}{ RSquare } & 0.347568 & \\
\hline \multicolumn{3}{|c|}{ RSquare Adj } & -0.2807 & \\
\hline \multicolumn{3}{|c|}{ Root Mean Square Error } & 0.13376 & \\
\hline \multicolumn{3}{|c|}{ Mean of Response } & 0.096 & \\
\hline \multicolumn{3}{|c|}{ Observations (or Sum Wgts) } & 54 & \\
\hline \multicolumn{5}{|c|}{ Analysis of Variance } \\
\hline Source & DF & Sum of Squares & Mean Square & F Ratio \\
\hline Model & 26 & 0.25734678 & 0.009898 & 0.5532 \\
\hline Error & 27 & 0.48307402 & 0.017892 & Prob $>$ F \\
\hline C. Total & 53 & 0.74042080 & & 0.9323 \\
\hline
\end{tabular}

Expected Mean Squares

The Mean Square per row by the Variance Component per column

$\begin{array}{lrr}\text { EMS } & \text { Intercept } & \text { Batch\&Random } \\ \text { Intercept } & 0 & 0\end{array}$

Batch\&Random $\quad 0 \quad 2$

plus 1.0 times Residual Error Variance

Variance Component Estimates

Component Var Comp Est Percent of Total

$\begin{array}{rrr}\text { Batch\&Random } & -0.004 & -28.765\end{array}$

$\begin{array}{lrr}\text { Batch\&Random } & -0.004 & -28.765 \\ \text { Residual } & 0.017892 & 128.765\end{array}$

Total $\quad 0.013895 \quad 100.000$

These estimates based on equating Mean Squares to Expected Value.

Test Denominator Synthesi

Source MS Den DF Den Denom MS Synthesis

Batch\&Random $0.01789 \quad 27$ Residual

Tests wrt Random Effects
Source SS MS Num DF Num F Ratio Prob > F

$\begin{array}{lrrrrr}\text { Source } & \text { SS } & \text { MS Num } & \text { DF Num } & \text { F Ratio } & \text { Prob }>\text { F } \\ \text { Batch\&Random } & 0.25735 & 0.0099 & 26 & 0.5532 & 0.9323\end{array}$

Sample Type=ARG-1, Prep=Cold Chem, ICP $=M-13$, Analyte $=Z r$ Response Measurement

Summary of Fit

RSquare $\quad 0.845137$

RSquare Adj $\quad 0.69623$

Root Mean Square Error $\quad 0.003048$

Mean of Response $\quad 0.102173$

Observations (or Sum Wgts) 52

Analysis of Variance

Source DF Sum of Squares Mean Square F Ratio

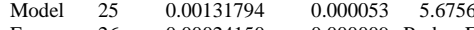

$\begin{array}{lllll}\text { Error } & 26 & 0.00024150 & 0.000009 & \text { Prob }>\text { F }\end{array}$

$\begin{array}{llll}\text { C. Total } & 51 & 0.00155944 & <.0001\end{array}$

Expected Mean Squares

The Mean Square per row by the Variance Component per column

$\begin{array}{lrr}\text { EMS } & \text { Intercept } & \text { Batch\&Random } \\ \text { Intercept } & 0 & 0\end{array}$

$\begin{array}{lll}0 & 0 \\ \text { Batch\&Random } & 0 & 2\end{array}$

plus 1.0 times Residual Error Variance

Variance Component Estimates

Component Var Comp Est Percent of Total

Batch\&Random $\quad 0.000022 \quad 70.040$

$\begin{array}{lll}\text { Residual } & 0.000009 & 29.960\end{array}$

Total $\quad 0.000031 \quad 100.000$

These estimates based on equating Mean Squares to Expected Value.

Test Denominator Synthesis

Source MS Den DF Den Denom MS Synthesis

Batch\&Random $\quad 9.29 \mathrm{e}-6 \quad 62$ Residual

Tests wrt Random Effects

Source

SS MS Num DF Num F Ratio Prob $>$ F

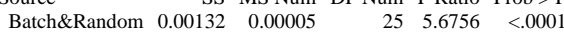

Sample Type=ARG-1, Prep=Cold Chem, ICP=M-14, Analyte=Al Response Measurement

Summary of Fit

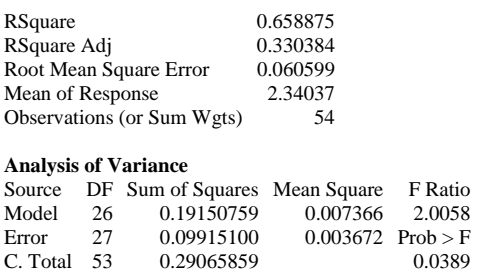

Expected Mean Squares

The Mean Square per row by the Variance Component per column

$\begin{array}{lrr}\text { EMS } & \text { Intercept } & \text { Batch\&Random } \\ \text { Intercept } & 0 & 0\end{array}$

Batch\&Random $\quad 0 \quad 2$

plus 1.0 times Residual Error Variance

Variance Component Estimates

$\begin{array}{crr}\text { Component } & \text { Var Comp Est } & \text { Percent of Total } \\ \text { Batch\&Random } & 0.001847 & 33.461 \\ \text { Residel } & 0.003672 & 66.539\end{array}$

$\begin{array}{lll}\text { Batch\&Random } & 0.001847 & 33.461 \\ \text { Residual } & 0.003672 & 66.539\end{array}$

Total $\quad 0.005519 \quad 100.000$

These estimates based on equating Mean Squares to Expected Value.

Test Denominator Synthesis

Source MS Den DF Den Denom MS Synthesis

Batch\&Random $0.00367 \quad 27$ Residual

Tests wrt Random Effects
Source SS MS Num DF Num F Ratio Prob > F

$\begin{array}{lrrrrr}\text { Source } & \text { SS } & \text { MS Num } & \text { DF Num } & \text { F Ratio } & \text { Prob }>\text { F } \\ \text { Batch\&Random } & 0.19151 & 0.00737 & 26 & 2.0058 & 0.0389\end{array}$

Sample Type=ARG-1, Prep=Cold Chem, ICP=M-14, Analyte=Al/Ca Response Measurement

Summary of Fit

RSquare $\quad 0.638688$

RSquare Adj $\quad 0.290279$

Root Mean Square Error $\quad 0.059692$

Mean of Response $\quad 2.406863$

Observations (or Sum Wgts) 56

Analysis of Variance

Source DF Sum of Squares Mean Square F Ratio

$\begin{array}{lllll}\text { Model } & 27 & 0.17636049 & 0.006532 & 1.8332\end{array}$

$\begin{array}{lllll}\text { Error } 28 & 0.09976896 & 0.003563 & \text { Prob }>\text { F }\end{array}$

$\begin{array}{llll}\text { C. Total } & 55 & 0.27612945 & 0.0585\end{array}$

Expected Mean Squares

The Mean Square per row by the Variance Component per column

$\begin{array}{lrr}\text { EMS } & \text { Intercept } & \text { Batch\&Random } \\ \text { Intercept } & 0 & 0 \\ \text { Batch\&Random } & 0 & 2\end{array}$

plus 1.0 times Residual Error Variance

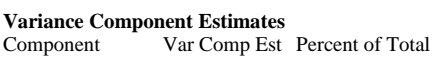

$\begin{array}{crr}\text { Component } & \text { Var Comp Est } & \text { Percent of Total } \\ \text { Batch\&Random } & 0.001484 & 29.407 \\ \text { Residual } & 0.003563 & 70.593\end{array}$

$\begin{array}{llr}\text { Residual } & 0.003563 & 70.593 \\ \text { Total } & 0.005048 & 100.000\end{array}$

These estimates based on equating Mean Squares to Expected Value.

Test Denominator Synthesis

Source MS Den DF Den Denom MS Synthesis

$\begin{array}{crrr}\text { Source } & \text { MS Den } & \text { DF Den } & \text { Denom MS } \\ \text { Batch\&Random } & 0.00356 & 28 & \text { Residual }\end{array}$

Tests wrt Random Effects

Source SS MS Num DF Num F Ratio Prob > F

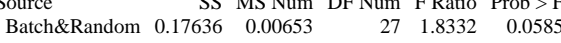


WSRC-STI-2006-00068

Revision 0

Exhibit A7. Analysis of Variance by Preparation Method, ICP, and Analyte (continued)

Sample Type=ARG-1, Prep=Cold Chem, ICP=M-14, Analyte=Al/Mg Response Measurement

Summary of Fit

\begin{tabular}{|c|c|c|c|}
\hline \multicolumn{2}{|c|}{ RSquare } & \multicolumn{2}{|l|}{0.769399} \\
\hline \multicolumn{2}{|c|}{ RSquare Adj } & 0.546485 & \\
\hline \multicolumn{2}{|c|}{ Root Mean Square Error } & 0.114859 & \\
\hline \multicolumn{2}{|c|}{ Mean of Response } & 4.838895 & \\
\hline \multicolumn{2}{|c|}{ Observations (or Sum Wgts) } & 60 & \\
\hline \multicolumn{4}{|c|}{ Analysis of Variance } \\
\hline Source & DF Sum of Squares & s Mean Square & F Ratio \\
\hline Model & $29 \quad 1.3205190$ & $0 \quad 0.045535$ & 3.4515 \\
\hline Error & 0.3957803 & 0.013193 & Prob $>$ F \\
\hline C. Total & 1.7162993 & & 0.0006 \\
\hline
\end{tabular}

Expected Mean Squares

The Mean Square per row by the Variance Component per column

$\begin{array}{lrr}\text { EMS } & \text { Intercept } & \text { Batch\&Random } \\ \text { Intercept } & 0 & 0\end{array}$

Batch\&Random $\quad 0 \quad 2$

plus 1.0 times Residual Error Variance

Variance Component Estimates

Component Var Comp Est Percent of Total

Batch\&Random $\quad 0.016171 \quad 55.072$

Residual $\quad 0.013193 \quad 44.928$

Total $\quad 0.029364 \quad 100.000$

These estimates based on equating Mean Squares to Expected Value.

Test Denominator Synthesi

Source MS Den DF Den Denom MS Synthesis

Batch\&Random $0.01319 \quad 30$ Residual

Tests wrt Random Effects
Source SS MS Num DF Num F Ratio Prob > F

$\begin{array}{lrrrrr}\text { Source } & \text { SS } & \text { MS Num } & \text { DF Num } & \text { F Ratio } & \text { Prob > F } \\ \text { Batch\&Random } & 1.32052 & 0.04554 & 29 & 3.4515 & 0.0006\end{array}$

Sample Type=ARG-1, Prep=Cold Chem, ICP=M-14, Analyte=Al/Mn Response Measurement

Summary of Fit

RSquare $\quad 0.758542$

RSquare Adj $\quad 0.525707$

Root Mean Square Error $\quad 0.032434$

Mean of Response $\quad 1.672907$

Observations (or Sum Wgts) 56

Analysis of Variance

Source DF Sum of Squares Mean Square F Ratio

$\begin{array}{lllll}\text { Model } & 27 & 0.09253537 & 0.003427 & 3.2579\end{array}$

$\begin{array}{lllll}\text { Error } & 28 & 0.02945577 & 0.001052 & \text { Prob }>\text { F }\end{array}$

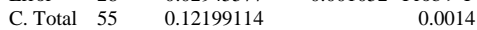

Expected Mean Squares

The Mean Square per row by the Variance Component per column

$\begin{array}{lrr}\text { EMS } & \text { Intercept } & \text { Batch\&Random } \\ \text { Intercept } & 0 & 0\end{array}$

$\begin{array}{lll}0 & 0 \\ \text { Batch\&Random } & 0 & 2\end{array}$

plus 1.0 times Residual Error Variance

Variance Component Estimates

Component Var Comp Est Percent of Total

Batch\&Random $\quad 0.001188 \quad 53.028$

$\begin{array}{lll}\text { Residual } & 0.001052 & 46.972\end{array}$

Total $\quad 0.00224 \quad 100.000$

These estimates based on equating Mean Squares to Expected Value.

Test Denominator Synthesis

Source MS Den DF Den Denom MS Synthesis

Batch\&Random $\quad 0.00105 \quad 28$ Residual

Tests wrt Random Effects

Source

SS MS Num DF Num F Ratio Prob $>$ F

$\begin{array}{llllll}\text { Batch\&Random } & 0.09254 & 0.00343 & 27 & 3.2579 & 0.0014\end{array}$
Sample Type=ARG-1, Prep=Cold Chem, ICP=M-14, Analyte=B Response Measurement

Summary of Fit

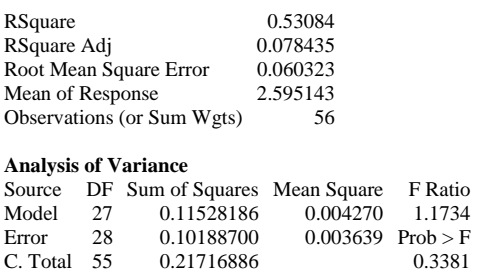

Expected Mean Squares

The Mean Square per row by the Variance Component per column

$\begin{array}{lrr}\text { EMS } & \text { Intercept } & \text { Batch\&Random } \\ \text { Intercept } & 0 & 0\end{array}$

Batch\&Random $\quad 0 \quad 2$

plus 1.0 times Residual Error Variance

Variance Component Estimates

$\begin{array}{crr}\text { Component } & \text { Var Comp Est } & \text { Percent of Total } \\ \text { Batch\&Random } & 0.000315 & 7.977 \\ \text { Residual } & 0.003639 & 92.023\end{array}$

$\begin{array}{lrr}\text { Batch\&Random } & 0.000315 & 7.977 \\ \text { Residual } & 0.003639 & 92.023 \\ \text { Total } & 0.003954 & 100.000\end{array}$

$\begin{array}{lcc}\text { Total } & 0.003954 & 100.000 \\ \text { These estimates based on equating Mean Squares to Expected Value. }\end{array}$

Test Denominator Synthesis

Source MS Den DF Den Denom MS Synthesis

Batch\&Random $0.00364 \quad 28$ Residual

Tests wrt Random Effects
Source $\quad$ SS MS Num DF Num F Ratio Prob > F

$\begin{array}{lrrrrr}\text { Batch\&Random } & 0.11528 & 0.00427 & 27 & 1.1734 & 0.3381\end{array}$

Sample Type=ARG-1, Prep=Cold Chem, ICP=M-14, Analyte $=B / L i$ Response Measurement

Summary of Fit

RSquare Adj $\quad 0.521248$

Root Mean Square Error $\quad 0.034897$

Mean of Response $\quad 1.785661$

Observations (or Sum Wgts)

60

Analysis of Variance

Source DF Sum of Squares Mean Square F Ratio

$\begin{array}{lllll}\text { Model } & 29 & 0.11354671 & 0.003915 & 3.2151\end{array}$

$\begin{array}{lllll}\text { Error } & 30 & 0.03653484 & 0.001218 & \text { Prob }>\text { F }\end{array}$

$\begin{array}{llll}\text { C. Total } & 59 & 0.15008155 & 0.0011\end{array}$

Expected Mean Squares

The Mean Square per row by the Variance Component per column

$\begin{array}{lrr}\text { EMS } & \text { Intercept } & \text { Batch\&Random } \\ \text { Intercept } & 0 & 0 \\ \text { Batch\&Random } & 0 & 2\end{array}$

plus 1.0 times Residual Error Variance

Variance Component Estimates

Component Var Comp Est Percent of Total

$\begin{array}{lll}\text { Batch\&Random } \quad 0.001349 & 52.551\end{array}$

$\begin{array}{lrr}\text { Residual } & 0.001218 & 47.449 \\ \text { Total } & 0.002567 & 100.000\end{array}$

These estimates based on equating Mean Squares to Expected Value.

Test Denominator Synthesis

Source MS Den DF Den Denom MS Synthesis

$\begin{array}{crrr}\text { Source } & \text { MS Den } & \text { DF Den } & \text { Denom } \\ \text { Batch\&Random } & 0.00122 & 30 & \text { Residual }\end{array}$

Tests wrt Random Effects

Source SS MS Num DF Num F Ratio Prob > F

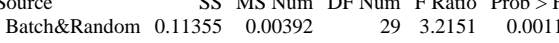


WSRC-STI-2006-00068

Revision 0

Exhibit A7. Analysis of Variance by Preparation Method, ICP, and Analyte (continued)

Sample Type=ARG-1, Prep $=$ Cold Chem, ICP $=M-14$, Analyte $=$ Ca Response Measurement

Summary of Fit

\begin{tabular}{|c|c|c|c|c|}
\hline \multicolumn{3}{|c|}{ RSquare } & 0.575738 & \\
\hline \multicolumn{3}{|c|}{ RSquare Adj } & 0.166106 & \\
\hline \multicolumn{3}{|c|}{ Root Mean Square Error } & 0.039324 & \\
\hline \multicolumn{3}{|c|}{ Mean of Response } & 0.970534 & \\
\hline \multicolumn{3}{|c|}{ Observations (or Sum Wgts) } & 58 & \\
\hline \multicolumn{5}{|c|}{ Analysis of Variance } \\
\hline Source & DF & Sum of Squares & Mean Square & F Ratio \\
\hline Model & 28 & 0.06085693 & 0.002173 & 1.4055 \\
\hline Error & 29 & 0.04484550 & 0.001546 & Prob $>$ F \\
\hline C. Total & 57 & 0.10570243 & & 0.1837 \\
\hline
\end{tabular}

Expected Mean Squares

The Mean Square per row by the Variance Component per column

$\begin{array}{lrr}\text { EMS } & \text { Intercept } & \text { Batch\&Random } \\ \text { Intercept } & 0 & 0\end{array}$

Batch\&Random $\quad 0 \quad 2$

plus 1.0 times Residual Error Variance

Variance Component Estimates

Component Var Comp Est Percent of Total

Batch\&Random $\quad 0.000314 \quad r .857$

Residual $\quad 0.001546 \quad 83.143$

Total $\quad 0.00186 \quad 100.000$

These estimates based on equating Mean Squares to Expected Value.

Test Denominator Synthesi

Source MS Den DF Den Denom MS Synthesis

Batch\&Random $0.00155 \quad 29$ Residual

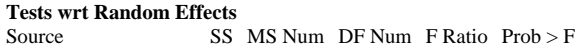

$\begin{array}{lrrrrr}\text { Source } & \text { SS } & \text { MS Num } & \text { DF Num } & \text { F Ratio } & \text { Prob }>\text { F } \\ \text { Batch\&Random } & 0.06086 & 0.00217 & 28 & 1.4055 & 0.1837\end{array}$

Sample Type $=$ ARG-1, Prep $=$ Cold Chem, ICP $=$ M-14, Analyte $=$ Cr Response Measurement

Summary of Fit

RSquare $\quad 0.862614$

RSquare Adj $\quad 0.729807$

Root Mean Square Error $\quad 0.003329$

Mean of Response $\quad 0.068383$

Observations (or Sum Wgts) $\quad 60$

Analysis of Variance

Source DF Sum of Squares Mean Square F Ratio

\begin{tabular}{lllll} 
Model & 29 & 0.00208768 & 0.000072 & 6.4953 \\
\hline
\end{tabular}

$\begin{array}{lllll}\text { Error } & 30 & 0.00033250 & 0.000011 & \text { Prob }>\text { F }\end{array}$

$\begin{array}{llll}\text { C. Total } & 59 & 0.00242018 & <.0001\end{array}$

Expected Mean Square

The Mean Square per row by the Variance Component per column

$\begin{array}{lrr}\text { EMS } & \text { Intercept } & \text { Batch\&Random } \\ \text { Intercept } & 0 & 0\end{array}$

$\begin{array}{lll}0 & 0 \\ \text { Batch\&Random } & 0 & 2\end{array}$

plus 1.0 times Residual Error Variance

Variance Component Estimates

Component Var Comp Est Percent of Total

Batch\&Random $\quad 0.00003 \quad 73.316$

$\begin{array}{lll}\text { Residual } & 0.000011 & 26.684\end{array}$

Total $\quad 0.000042 \quad 100.000$

These estimates based on equating Mean Squares to Expected Value.

Test Denominator Synthesis

Source MS Den DF Den Denom MS Synthesis

Batch\&Random $0.00001 \quad 30$ Residual

Tests wrt Random Effects

Source

SS MS Num DF Num F Ratio Prob $>$ F

Batch\&Random $0.00209 \quad 0.00007 \quad 29 \quad 6.4953<.0001$
Sample Type=ARG-1, Prep=Cold Chem, ICP=M-14, Analyte=Cu Response Measurement

Summary of Fit

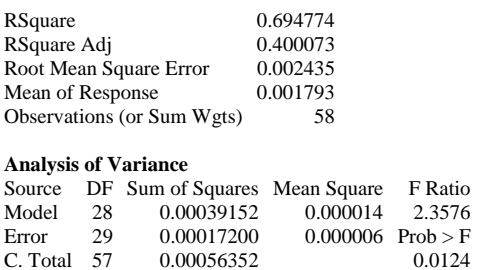

Expected Mean Squares

The Mean Square per row by the Variance Component per column

$\begin{array}{lrr}\text { EMS } & \text { Intercept } & \text { Batch\&Random } \\ \text { Intercept } & 0 & 0\end{array}$

Batch\&Random $\quad 0 \quad 2$

plus 1.0 times Residual Error Variance

Variance Component Estimates

$\begin{array}{lrr}\text { Component } & \text { Var Comp Est } & \text { Percent of Total } \\ \text { Batch\&Random } & 0.000004 & 40.433\end{array}$

$\begin{array}{ccc}\text { Batch\&Random } & 0.000004 & 40.433 \\ \text { Residual } & 0.000006 & 59.567\end{array}$

$\begin{array}{lrr}\text { Residual } & 0.000006 & 59.567 \\ \text { Total } & 0.00001 & 100.000\end{array}$

These estimates based on equating Mean Squares to Expected Value.

Test Denominator Synthesis

Source MS Den DF Den Denom MS Synthesis

Batch\&Random 5.93e-6 29 Residual

Tests wrt Random Effects
Source SS MS Num DF Num F Ratio Prob $>$ F

$\begin{array}{rrrrrr}\text { Source } & \text { SS } & \text { MS Num } & \text { DF Num } & \text { F Ratio } & \text { Prob }>\text { F } \\ \text { Batch\&Random } & 0.00039 & 0.00001 & 28 & 2.3576 & 0.0124\end{array}$

Sample Type=ARG-1, Prep=Cold Chem, ICP=M-14, Analyte=Fe Response Measurement

Summary of Fit

RSquare $\quad 0.80974$

RSquare Adj $\quad 0.626526$

Root Mean Square Error $\quad 0.127692$

Mean of Response $\quad 9.516833$

Observations (or Sum Wgts) 54

Analysis of Variance

Source DF Sum of Squares Mean Square F Ratio

$\begin{array}{lllll}\text { Model } & 26 & 1.8736550 & 0.072064 & 4.4197\end{array}$

$\begin{array}{lllll}\text { Error } & 27 & 0.4402425 & 0.016305 & \text { Prob }>\text { F }\end{array}$

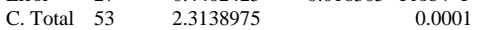

Expected Mean Squares

The Mean Square per row by the Variance Component per column

$\begin{array}{lrr}\text { EMS } & \text { Intercept } & \text { Batch\&Random } \\ \text { Intercept } & 0 & 0 \\ \text { Batch\&Random } & 0 & 2\end{array}$

plus 1.0 times Residual Error Variance

Variance Component Estimates
$\begin{array}{ll}\text { Component } & \text { Var Comp Est Percent of Total }\end{array}$

\begin{tabular}{crr} 
Component & Var Comp Est & Percent of Total \\
Batch\&Random & 0.027879 & 63.097 \\
Residual & 0.016305 & 36.903 \\
\hline
\end{tabular}

$\begin{array}{llr}\text { Residual } & 0.016305 & 36.903 \\ \text { Total } & 0.044184 & 100.000\end{array}$

These estimates based on equating Mean Squares to Expected Value.

Test Denominator Synthesis

Source MS Den DF Den Denom MS Synthesis

$\begin{array}{lrrr}\text { Source } & \text { MS Den } & \text { DF Den } & \text { Denom MS } \\ \text { Batch\&Random } & 0.01631 & 27 & \text { Residual }\end{array}$

Tests wrt Random Effects

Source SS MS Num DF Num F Ratio Prob > F

$\begin{array}{rrrrrr}\text { Batch\&Random } & 1.87365 & 0.07206 & 26 & 4.4197 & 0.0001\end{array}$ 
WSRC-STI-2006-00068

Revision 0

Exhibit A7. Analysis of Variance by Preparation Method, ICP, and Analyte (continued)

Sample Type=ARG-1, Prep=Cold Chem, ICP=M-14, Analyte=Fe/Al Response Measurement

Summary of Fit

\begin{tabular}{|c|c|c|c|c|}
\hline \multicolumn{3}{|c|}{ RSquare } & 0.871192 & \\
\hline \multicolumn{3}{|c|}{ RSquare Adj } & 0.746825 & \\
\hline \multicolumn{3}{|c|}{ Root Mean Square Error } & 0.066315 & \\
\hline \multicolumn{3}{|c|}{ Mean of Response } & 4.085312 & \\
\hline \multicolumn{3}{|c|}{ Observations (or Sum Wgts) } & 58 & \\
\hline \multicolumn{5}{|c|}{ Analysis of Variance } \\
\hline Source & DF & Sum of Squares & Mean Square & F Ratio \\
\hline Model & 28 & 0.86255704 & 0.030806 & 7.0050 \\
\hline Error & 29 & 0.12753153 & 0.004398 & Prob $>$ F \\
\hline C. Total & 57 & 0.99008856 & & $<.0001$ \\
\hline
\end{tabular}

Expected Mean Squares

The Mean Square per row by the Variance Component per column

$\begin{array}{lrr}\text { EMS } & \text { Intercept } & \text { Batch\&Random } \\ \text { Intercept } & 0 & 0\end{array}$

Batch\&Random $\quad 0 \quad 2$

plus 1.0 times Residual Error Variance

Variance Component Estimates

Component Var Comp Est Percent of Total

$\begin{array}{lrr}\text { Component } & \text { Var Comp Est } & \text { Percent of Tota } \\ \text { Batch\&Random } & 0.013204 & 75.016\end{array}$

$\begin{array}{lll}\text { Residual } & 0.004398 & 24.984\end{array}$

Total $\quad 0.017602 \quad 100.000$

These estimates based on equating Mean Squares to Expected Value.

Test Denominator Synthesi

Source MS Den DF Den Denom MS Synthesis

Batch\&Random $\quad 0.0044 \quad 29$ Residual

Tests wrt Random Effects
Source MS Num DF Num F Ratio Prob > F

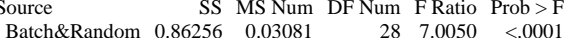

Sample Type=ARG-1, Prep=Cold Chem, ICP=M-14, Analyte=Fe/Ca Response Measurement

Summary of Fit

RSquare $\quad 0.616958$

RSquare Adj $\quad 0.247597$

Root Mean Square Error $\quad 0.317277$

Mean of Response 9.763857

Observations (or Sum Wgts) 56

Analysis of Variance

Source DF Sum of Squares Mean Square F Ratio

\begin{tabular}{lllll} 
Model & 27 & 4.5398908 & 0.168144 & 1.6703 \\
\hline
\end{tabular}

$\begin{array}{llll}\text { Error } & 28 & 2.8186123 & 0.100665 \text { Prob }>\text { F }\end{array}$

$\begin{array}{llll}\text { C. Total } & 55 & 7.3585031 & 0.0918\end{array}$

Expected Mean Squares

The Mean Square per row by the Variance Component per column

$\begin{array}{lrr}\text { EMS } & \text { Intercept } & \text { Batch\&Random } \\ \text { Intercept } & 0 & 0\end{array}$

$\begin{array}{lll}\text { Batch\&Random } & 0 & 0 \\ & 0 & 2\end{array}$

plus 1.0 times Residual Error Variance

Variance Component Estimates

Component Var Comp Est Percent of Total

$\begin{array}{lrl}\text { Batch\&Random } \quad 0.03374 & 25.103\end{array}$

$\begin{array}{lll}\text { Residual } & 0.100665 & 74.897\end{array}$

Total $\quad 0.134404 \quad 100.000$

These estimates based on equating Mean Squares to Expected Value.

Test Denominator Synthesis

Source MS Den DF Den Denom MS Synthesis

Batch\&Random $0.10066 \quad 28$ Residual

Tests wrt Random Effects

Source

SS MS Num DF Num F Ratio Prob $>$ F

$\begin{array}{llllll}\text { Batch\&Random } & 4.53989 & 0.16814 & 27 & 1.6703 & 0.0918\end{array}$
Sample Type=ARG-1, Prep=Cold Chem, ICP=M-14, Analyte=Fe/Li Response Measurement

Summary of Fit

\begin{tabular}{|c|c|c|c|c|}
\hline \multicolumn{3}{|c|}{ RSquare } & \multicolumn{2}{|l|}{0.73018} \\
\hline \multicolumn{3}{|c|}{ RSquare Adj } & \multicolumn{2}{|l|}{0.469355} \\
\hline \multicolumn{3}{|c|}{ Root Mean Square Error } & \multicolumn{2}{|l|}{0.127253} \\
\hline \multicolumn{3}{|c|}{ Mean of Response } & \multicolumn{2}{|l|}{6.547821} \\
\hline \multicolumn{5}{|c|}{ Observations (or Sum Wgts) $\quad 60$} \\
\hline \multicolumn{5}{|c|}{ Analysis of Variance } \\
\hline Source & $\mathrm{DF}$ & Sum of Squares & s Mean Square & F Ratio \\
\hline Model & 29 & 1.3146668 & 0.045333 & 2.7995 \\
\hline Error & 30 & 0.4858018 & 0.016193 & Prob $>\mathrm{F}$ \\
\hline C. Total & 59 & 1.8004686 & & 0.0032 \\
\hline
\end{tabular}

Expected Mean Squares

The Mean Square per row by the Variance Component per column

$\begin{array}{lrr}\text { EMS } & \text { Intercept } & \text { Batch\&Random } \\ \text { Intercept } & 0 & 0\end{array}$

Batch\&Random $\quad 0 \quad 2$

plus 1.0 times Residual Error Variance

Variance Component Estimates

$\begin{array}{rrr}\text { Component } & \text { Var Comp Est } & \text { Percent of Total } \\ \text { Batch\&Random } & 0.01457 & 47.361\end{array}$

$\begin{array}{lrr}\text { Batch\&Random } & 0.01457 & 47.361 \\ & 0.016193 & 52.639\end{array}$

$\begin{array}{lrr}\text { Residual } & 0.016193 & 52.639 \\ \text { Total } & 0.030763 & 100.000\end{array}$

$\begin{array}{lcc}\text { Total } & 0.030763 & 100.000 \\ \text { These estimates based on equating Mean Squares to Expected Value. }\end{array}$

Test Denominator Synthesis

Source MS Den DF Den Denom MS Synthesis

Batch\&Random $0.01619 \quad 30$ Residual

Tests wrt Random Effects
Source $\quad$ SS MS Num DF Num F Ratio Prob > F

$\begin{array}{lrrrrr}\text { Source } & \text { SS } & \text { MS Num } & \text { DF Num } & \text { F Ratio } & \text { Prob }>\text { F } \\ \text { Batch\&Random } & 1.31467 & 0.04533 & 29 & 2.7995 & 0.0032\end{array}$

Sample Type=ARG-1, Prep=Cold Chem, ICP=M-14, Analyte=Fe/Mg Response Measurement

Summary of Fit

RSquare Adj $\quad 0.665918$

Root Mean Square Error $\quad 0.263878$

Mean of Response $\quad 19.6221$

Observations (or Sum Wgts) 52

Analysis of Variance

Source DF Sum of Squares Mean Square F Ratio

$\begin{array}{lllll}\text { Model } & 25 & 8.819342 & 0.352774 & 5.0663\end{array}$

$\begin{array}{lllll}\text { Error } & 26 & 1.810422 & 0.069632 & \text { Prob }>\text { F }\end{array}$

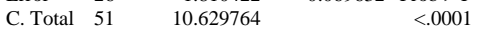

Expected Mean Squares

The Mean Square per row by the Variance Component per column

$\begin{array}{lrr}\text { EMS } & \text { Intercept } & \text { Batch\&Random } \\ \text { Intercept } & 0 & 0 \\ \text { Batch\&Random } & 0 & 2\end{array}$

plus 1.0 times Residual Error Variance

Variance Component Estimates
$\begin{array}{ll}\text { Component } & \text { Var Comp Est Percent of Total }\end{array}$

$\begin{array}{crr}\text { Component } & \text { Var Comp Est } & \text { Percent of Total } \\ \text { Batch\&Random } & 0.141571 & 67.031\end{array}$

$\begin{array}{lll}\text { Residual } & 0.069632 & 32.969\end{array}$

$\begin{array}{lll}\text { Total } & 0.211203 & 100.000\end{array}$

These estimates based on equating Mean Squares to Expected Value.

Test Denominator Synthesis

Source MS Den DF Den Denom MS Synthesis

$\begin{array}{lrrr}\text { Source } & \text { MS Den } & \text { DF Den } & \text { Denom } \\ \text { Batch\&Random } & 0.06963 & 26 & \text { Residual }\end{array}$

Tests wrt Random Effects

Source SS MS Num DF Num F Ratio Prob $>$ F

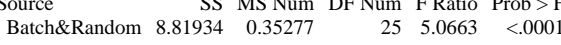


WSRC-STI-2006-00068

Revision 0

Exhibit A7. Analysis of Variance by Preparation Method, ICP, and Analyte (continued)

Sample Type=ARG-1, Prep=Cold Chem, ICP=M-14, Analyte=Fe/Mn Response Measurement

Summary of Fit

\begin{tabular}{|c|c|c|c|c|}
\hline \multicolumn{3}{|c|}{ RSquare } & 0.592807 & \\
\hline \multicolumn{3}{|c|}{ RSquare Adj } & 0.199188 & \\
\hline \multicolumn{3}{|c|}{ Root Mean Square Error } & 0.076922 & \\
\hline \multicolumn{3}{|c|}{ Mean of Response } & 6.8532 & \\
\hline \multicolumn{3}{|c|}{ Observations (or Sum Wgts) } & 60 & \\
\hline \multicolumn{5}{|c|}{ Analysis of Variance } \\
\hline Source & DF & Sum of Squares & Mean Square & F Ratio \\
\hline Model & 29 & 0.25842611 & 0.008911 & 1.5060 \\
\hline Error & 30 & 0.17750999 & 0.005917 & Prob $>$ F \\
\hline C. Total & 59 & 0.43593609 & & 0.1352 \\
\hline
\end{tabular}

Expected Mean Squares

The Mean Square per row by the Variance Component per column

$\begin{array}{lrr}\text { EMS } & \text { Intercept } & \text { Batch\&Random } \\ \text { Intercept } & 0 & 0\end{array}$

Batch\&Random $\quad 0 \quad 2$

plus 1.0 times Residual Error Variance

Variance Component Estimates

Component Var Comp Est Percent of Total

$\begin{array}{rrr}\text { Component } & \text { Var Comp Est } & \text { Percent of Tota } \\ \text { Batch\&Random } & 0.001497 & 20.193\end{array}$

$\begin{array}{lll}\text { Residual } & 0.005917 & 79.807\end{array}$

Total $\quad 0.007414 \quad 100.000$

These estimates based on equating Mean Squares to Expected Value.

Test Denominator Synthesi

Source MS Den DF Den Denom MS Synthesis

Batch\&Random $0.00592 \quad 30$ Residual

Tests wrt Random Effects

$\begin{array}{lrrrrr}\text { Source } & \text { SS } & \text { MS Num } & \text { DF Num } & \text { F Ratio } & \text { Prob }>\text { F } \\ \text { Batch\&Random } & 0.25843 & 0.00891 & 29 & 1.5060 & 0.1352\end{array}$

Sample Type=ARG-1, Prep=Cold Chem, ICP=M-14, Analyte=Fe/Ni Response Measurement

Summary of Fit

RSquare $\quad 0.661804$

RSquare Adj $\quad 0.33488$

Root Mean Square Error $\quad 0.168578$

Mean of Response $\quad 11.93734$

Observations (or Sum Wgts) $\quad 60$

Analysis of Variance

Source DF Sum of Squares Mean Square F Ratio

$\begin{array}{lllll}\text { Model } & 29 & 1.6683328 & 0.057529 & 2.0243\end{array}$

$\begin{array}{lllll}\text { Error } & 30 & 0.8525554 & 0.028419 \text { Prob }>\text { F }\end{array}$

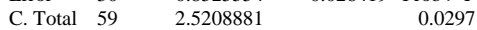

Expected Mean Squares

The Mean Square per row by the Variance Component per column

$\begin{array}{lrr}\text { EMS } & \text { Intercept } & \text { Batch\&Random } \\ \text { Intercept } & 0 & 0\end{array}$

$\begin{array}{lll}0 & 0 \\ \text { Batch\&Random } & 0 & 2\end{array}$

plus 1.0 times Residual Error Variance

Variance Component Estimates

Component Var Comp Est Percent of Total

Batch\&Random $\quad 0.014555 \quad 33.870$

$\begin{array}{lll}\text { Residual } & 0.028419 & 66.130\end{array}$

Total $\quad 0.042974 \quad 100.000$

These estimates based on equating Mean Squares to Expected Value.

Test Denominator Synthesis

Source MS Den DF Den Denom MS Synthesis

$\begin{array}{llll}\text { Batch\&Random } \quad 0.02842 \quad 30 & \text { Residual }\end{array}$

Tests wrt Random Effects

Source

SS MS Num DF Num F Ratio Prob $>$ F

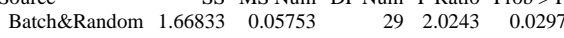

Sample Type=ARG-1, Prep=Cold Chem, ICP=M-14, Analyte=Fe/U Response Measurement

Summary of Fit

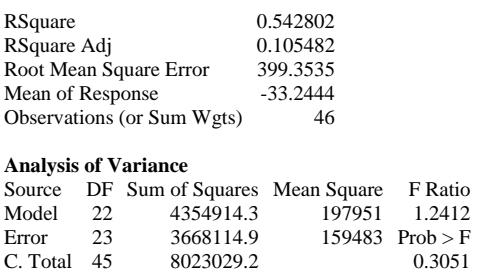

Expected Mean Squares

The Mean Square per row by the Variance Component per column

$\begin{array}{lrr}\text { EMS } & \text { Intercept } & \text { Batch\&Random } \\ \text { Intercept } & 0 & 0\end{array}$

Batch\&Random $\quad 0 \quad 2$

plus 1.0 times Residual Error Variance

Variance Component Estimates

\begin{tabular}{crr} 
Component & Var Comp Est & Percent of Total \\
Batch\&Random & 19233.7 & 10.762 \\
Residual & 159483.3 & 89.238 \\
\hline
\end{tabular}

$\begin{array}{lrr}\text { Residual } & 159483.3 & 89.238 \\ \text { Total } & 178717 & 100.000\end{array}$

$\begin{array}{lcc}\text { Total } & 178717 & 100.000 \\ \text { These estimates based on equating Mean Squares to Expected Value. }\end{array}$

Test Denominator Synthesis

Source MS Den DF Den Denom MS Synthesis

Batch\&Random $159483 \quad 23$ Residual

$\begin{array}{ll}\text { Tests wrt Random Effects } & \\ \text { Source } & \text { SS MS Num DF Num F Ratio Prob > F }\end{array}$

$\begin{array}{lrrrrr}\text { Source } & \text { SS } & \text { MS Num } & \text { DF Num } & \text { F Ratio } & \text { Prob }>\text { F } \\ \text { Batch\&Random } & 4354914 & 197951 & 22 & 1.2412 & 0.3051\end{array}$

Sample Type=ARG-1, Prep=Cold Chem, ICP=M-14, Analyte $=K$ Response Measurement

Summary of Fit

RSquare $\quad 0.471948$

RSquare Adj $\quad-0.0385$

Root Mean Square Error $\quad 0.13956$

Mean of Response $\quad 2.308267$

Observations (or Sum Wgts) 60

Analysis of Variance

Source DF Sum of Squares Mean Square F Ratio

$\begin{array}{lllll}\text { Model } & 29 & 0.5222287 & 0.018008 & 0.9246\end{array}$

$\begin{array}{lllll}\text { Error } & 30 & 0.5843090 & 0.019477 & \text { Prob }>\text { F }\end{array}$

$\begin{array}{llll}\text { C. Total } & 59 & 1.1065377 & 0.5828\end{array}$

Expected Mean Squares

The Mean Square per row by the Variance Component per column

$\begin{array}{lrr}\text { EMS } & \text { Intercept } & \text { Batch\&Random } \\ \text { Intercept } & 0 & 0 \\ \text { Batch\&Random } & 0 & 2\end{array}$

plus 1.0 times Residual Error Variance

Variance Component Estimates

\begin{tabular}{|c|c|c|}
\hline \\
\hline \multicolumn{3}{|c|}{ Var Comp Est Percent of Total } \\
\hline Batch\&Random & -0.00073 & -3.919 \\
\hline Residual & 0.019477 & 103.919 \\
\hline Total & 0.018742 & 100.000 \\
\hline \multicolumn{3}{|c|}{ These estimates based on equating Mean Squares to Expected Value. } \\
\hline \multicolumn{3}{|c|}{ Test Denominator Synthesis } \\
\hline Source & MS Den DF Den & Denom MS Synthesis \\
\hline Batch\&Random & $0.01948 \quad 30$ & Residual \\
\hline \multicolumn{3}{|c|}{ Tests wrt Random Effects } \\
\hline Source & SS MS Num & DF Num F Ratio Prob $>F$ \\
\hline Batch\&Random & $0.52223 \quad 0.01801$ & $\begin{array}{lll}29 & 0.9246 & 0.5828\end{array}$ \\
\hline
\end{tabular}


WSRC-STI-2006-00068

Revision 0

Exhibit A7. Analysis of Variance by Preparation Method, ICP, and Analyte (continued)

Sample Type=ARG-1, Prep=Cold Chem, ICP $=$ M-14, Analyte $=\mathrm{Li}$ Response Measurement

Summary of Fit

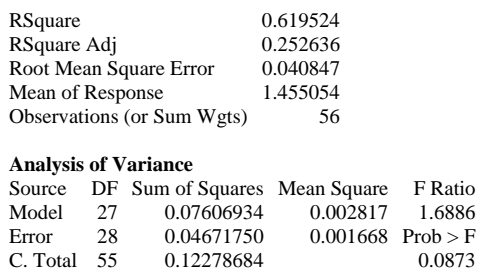

Expected Mean Squares

The Mean Square per row by the Variance Component per column

$\begin{array}{lrr}\text { EMS } & \text { Intercept } & \text { Batch\&Random } \\ \text { Intercept } & 0 & 0\end{array}$

Batch\&Random $\quad 0 \quad 2$

plus 1.0 times Residual Error Variance

Variance Component Estimates

Component Var Comp Est Percent of Total

Batch\&Random $\quad 0.000574 \quad 25.612$

$\begin{array}{lll}\text { Residual } & 0.001668 & 74.388\end{array}$

Total $\quad 0.002243 \quad 100.000$

These estimates based on equating Mean Squares to Expected Value.

Test Denominator Synthesis

Source MS Den DF Den Denom MS Synthesis

Batch\&Random $0.00167 \quad 28$ Residual

Tests wrt Random Effects
$\begin{aligned} & \text { Source } \\ & \text { SS MS Num DF Num F Ratio Prob > F }\end{aligned}$

$\begin{array}{lrrrrr}\text { Source } & \text { SS } & \text { MS Num } & \text { DF Num } & \text { F Ratio } & \text { Prob }>\text { F } \\ \text { Batch\&Random } & 0.07607 & 0.00282 & 27 & 1.6886 & 0.0873\end{array}$

Sample Type=ARG-1, Prep=Cold Chem, ICP=M-14, Analyte=Mg Response Measurement

Summary of Fit

RSquare $\quad 0.639143$

RSquare Adj $\quad 0.291651$

Root Mean Square Error $\quad 0.014841$

Mean of Response $\quad 0.483944$

Observations (or Sum Wgts) 54

Analysis of Variance

Source DF Sum of Squares Mean Square F Ratio

$\begin{array}{lllll}\text { Model } & 26 & 0.01053233 & 0.000405 & 1.8393\end{array}$

$\begin{array}{lllll}\text { Error } & 27 & 0.00594650 & 0.000220 & \text { Prob }>\text { F }\end{array}$

$\begin{array}{llll}\text { C. Total } & 53 & 0.01647883 & 0.0609\end{array}$

Expected Mean Squares

The Mean Square per row by the Variance Component per column

$\begin{array}{lrr}\text { EMS } & \text { Intercept } & \text { Batch\&Random } \\ \text { Intercept } & 0 & 0\end{array}$

Batch\&Random $\quad 0 \quad 2$

plus 1.0 times Residual Error Variance

Variance Component Estimates

Component Var Comp Est Percent of Total

Batch\&Random $\quad 0.000092 \quad 29.560$

$\begin{array}{lrr}\text { Residual } & 0.00022 & 70.440\end{array}$

$\begin{array}{lll}\text { Total } & 0.000313 & 100.000\end{array}$

These estimates based on equating Mean Squares to Expected Value.

Test Denominator Synthesis

Source MS Den DF Den Denom MS Synthesis

Batch\&Random $0.00022 \quad 27$ Residual

Tests wrt Random Effects

Source

SS MS Num DF Num F Ratio Prob > F

$\begin{array}{lrrrrr}\text { Batch\&Random } & 0.01053 & 0.00041 & 26 & 1.8393 & 0.0609\end{array}$
Sample Type=ARG-1, Prep $=$ Cold Chem, ICP=M-14, Analyte=Mn Response Measurement

Summary of Fit

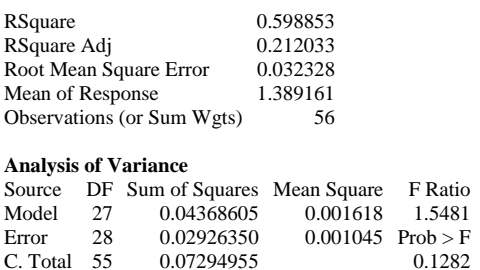

Expected Mean Squares

The Mean Square per row by the Variance Component per column

$\begin{array}{lrr}\text { EMS } & \text { Intercept } & \text { Batch\&Random } \\ \text { Intercept } & 0 & 0\end{array}$

Batch\&Random $\quad 0 \quad 2$

plus 1.0 times Residual Error Variance

Variance Component Estimates

$\begin{array}{rrr}\text { Component } & \text { Var Comp Est } & \text { Percent of Total } \\ \text { Batch\&Random } & 0.000286 & 21.511\end{array}$

$\begin{array}{ccc}\text { Batch\&Random } & 0.000286 & 21.511 \\ \text { Residual } & 0.001045 & 78.489\end{array}$

$\begin{array}{lrr}\text { Residual } & 0.001045 & 78.489 \\ \text { Total } & 0.001332 & 100.000\end{array}$

These estimates based on equating Mean Squares to Expected Value.

Test Denominator Synthesis

Source MS Den DF Den Denom MS Synthesis

Batch\&Random $0.00105 \quad 28$ Residual

Tests wrt Random Effects
Source $\quad$ SS MS Num DF Num F Ratio Prob $>$ F

$\begin{array}{rrrrrr}\text { Batch\&Random } & 0.04369 & 0.00162 & 27 & 1.5481 & 0.1282\end{array}$

Sample Type=ARG-1, Prep=Cold Chem, ICP=M-14, Analyte=Mn/Mg Response Measurement

Summary of Fit

RSquare Adj

0.754352

Root Mean Square Error $\quad 0.048439$

Mean of Response

Observations (or Sum Wgts) $\quad 54$

Analysis of Variance

Source DF Sum of Squares Mean Square F Ratio

$\begin{array}{lllll}\text { Model } & 26 & 0.19453939 & 0.007482 & 3.1890\end{array}$

$\begin{array}{lllll}\text { Error } & 27 & 0.06334990 & 0.002346 & \text { Prob }>\text { F }\end{array}$

$\begin{array}{llll}\text { C. Total } & 53 & 0.25788928 & 0.0019\end{array}$

Expected Mean Squares

The Mean Square per row by the Variance Component per column

$\begin{array}{lrr}\text { EMS } & \text { Intercept } & \text { Batch\&Random } \\ \text { Intercept } & 0 & 0 \\ \text { Batch\&Random } & 0 & 2\end{array}$

plus 1.0 times Residual Error Variance

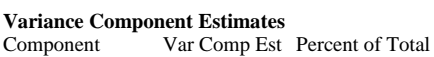

\begin{tabular}{crr} 
Component & Var Comp Est & Percent of Total \\
Batch\&Random & 0.002568 & 52.256 \\
Residual & 0.002346 & 47.744 \\
\hline
\end{tabular}

$\begin{array}{lrr}\text { Residual } & 0.002346 & 47.744 \\ \text { Total } & 0.004914 & 100.000\end{array}$

These estimates based on equating Mean Squares to Expected Value.

Test Denominator Synthesis

Source MS Den DF Den Denom MS Synthesis

$\begin{array}{lrrr}\text { Source } & \text { MS Den } & \text { DF Den } & \text { Denom MS } \\ \text { Batch\&Random } & 0.00235 & 27 & \text { Residual }\end{array}$

Tests wrt Random Effects

Source SS MS Num DF Num F Ratio Prob > F

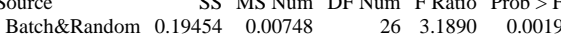


WSRC-STI-2006-00068

Revision 0

Exhibit A7. Analysis of Variance by Preparation Method, ICP, and Analyte (continued)

Sample Type=ARG-1, Prep=Cold Chem, ICP $=$ M-14, Analyte $=$ Na Response Measurement

Summary of Fit

\begin{tabular}{|c|c|c|c|}
\hline \multicolumn{2}{|c|}{ RSquare } & 0.63991 & \\
\hline \multicolumn{2}{|c|}{ RSquare Adj } & 0.293157 & \\
\hline \multicolumn{2}{|c|}{ Root Mean Square Error } & 0.149533 & \\
\hline \multicolumn{2}{|c|}{ Mean of Response } & 8.299648 & \\
\hline \multicolumn{2}{|c|}{ Observations (or Sum Wgts) } & 54 & \\
\hline \multicolumn{4}{|c|}{ Analysis of Variance } \\
\hline Source & DF Sum of Squares & s Mean Square & F Ratio \\
\hline Model & $26 \quad 1.0728698$ & $8 \quad 0.041264$ & 1.8454 \\
\hline Error & 0.6037245 & 0.022360 & Prob $>$ F \\
\hline C. Total & 1.6765943 & & 0.0599 \\
\hline
\end{tabular}

Expected Mean Squares

The Mean Square per row by the Variance Component per column

$\begin{array}{lrr}\text { EMS } & \text { Intercept } & \text { Batch\&Random } \\ \text { Intercept } & 0 & 0\end{array}$

Batch\&Random $\quad 0 \quad 2$

plus 1.0 times Residual Error Variance

Variance Component Estimates

Component Var Comp Est Percent of Total

Batch\&Random $\quad 0.009452 \quad 29.712$

$\begin{array}{lrl}\text { Residual } & 0.02236 & 70.288\end{array}$

Total $\quad 0.031812 \quad 100.000$

These estimates based on equating Mean Squares to Expected Value.

Test Denominator Synthesi

Source MS Den DF Den Denom MS Synthesis

Batch\&Random $0.02236 \quad 27$ Residual

Tests wrt Random Effects
Source

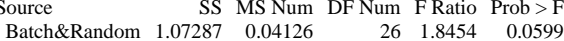

Sample Type=ARG-1, Prep=Cold Chem, ICP=M-14, Analyte=Ni Response Measurement

Summary of Fit

RSquare $\quad 0.659991$

RSquare Adj $\quad 0.332126$

Root Mean Square Error $\quad 0.018637$

Mean of Response $\quad 0.797821$

Observations (or Sum Wgts) $\quad 56$

Analysis of Variance

Source DF Sum of Squares Mean Square F Ratio

$\begin{array}{lllll}\text { Model } & 27 & 0.01887721 & 0.000699 & 2.0130\end{array}$

$\begin{array}{lllll}\text { Error } & 28 & 0.00972500 & 0.000347 & \text { Prob }>\text { F }\end{array}$

$\begin{array}{llll}\text { C. Total } & 55 & 0.02860221 & 0.0355\end{array}$

Expected Mean Square

The Mean Square per row by the Variance Component per column

$\begin{array}{lrr}\text { EMS } & \text { Intercept } & \text { Batch\&Random } \\ \text { Intercept } & 0 & 0\end{array}$

Batch\&Random $\quad 0 \quad 2$

plus 1.0 times Residual Error Variance

Variance Component Estimates

Component Var Comp Est Percent of Total

Batch\&Random $\quad 0.000176 \quad 33.62$

$\begin{array}{lll}\text { Residual } & 0.000347 & 66.379\end{array}$

Total $\quad 0.000523 \quad 100.000$

These estimates based on equating Mean Squares to Expected Value.

Test Denominator Synthesis

Source MS Den DF Den Denom MS Synthesis

Batch\&Random $\quad 0.00035 \quad 28$ Residual

Tests wrt Random Effects

Source

SS MS Num DF Num F Ratio Prob > F

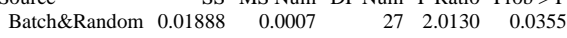

Sample Type=ARG-1, Prep=Cold Chem, ICP $=M-14$, Analyte $=S i$ Response Measurement

Summary of Fit

RSquare Adj

\begin{tabular}{ll}
0.119385 \\
\hline
\end{tabular}

Observations (or Sum Wgts) $\quad 54$

Analysis of Variance

Source DF Sum of Squares Mean Square F Ratio

$\begin{array}{lllll}\text { Model } & 26 & 10.404968 & 0.400191 & 1.2764\end{array}$

$\begin{array}{llrrr}\text { Error } & 27 & 8.465636 & 0.313542 & \text { Prob }>\text { F }\end{array}$

$\begin{array}{lrr}\text { C. Total } 53 & 18.870604 & 0.2662\end{array}$

Expected Mean Squares

The Mean Square per row by the Variance Component per column

$\begin{array}{lrr}\text { EMS } & \text { Intercept } & \text { Batch\&Random } \\ \text { Intercept } & 0 & 0\end{array}$

Batch\&Random $\quad 0 \quad 2$

plus 1.0 times Residual Error Variance

Variance Component Estimates

$\begin{array}{rrr}\text { Component } & \text { Var Comp Est } & \text { Percent of Total } \\ \text { Batch\&Random } & 0.043324 & 12.140\end{array}$

$\begin{array}{lll}\text { Batch\&Random } & 0.043324 & 12.140 \\ \text { Residual } & 0.313542 & 87.860\end{array}$

$\begin{array}{lrr}\text { Residual } & 0.313542 & 87.860 \\ \text { Total } & 0.356867 & 100.000\end{array}$

These estimates based on equating Mean Squares to Expected Value.

Test Denominator Synthesis

Source MS Den DF Den Denom MS Synthesis

Batch\&Random $0.31354 \quad 27$ Residual

Tests wrt Random Effect

Source SS MS Num DF Num F Ratio Prob > F

$\begin{array}{lrrrrr}\text { Batch\&Random } & 10.405 & 0.40019 & 26 & 1.2764 & 0.2662\end{array}$

Sample Type=ARG-1, Prep=Cold Chem, ICP=M-14, Analyte=Sum of Oxides Response Measurement

Summary of Fit

RSquare $\quad 0.482173$

RSquare Adj $\quad-0.0178$

Root Mean Square Error $\quad 3.789714$

Mean of Response $\quad 96.179$

Observations (or Sum Wgts) 58

Analysis of Variance

Source DF Sum of Squares Mean Square F Ratio

$\begin{array}{lllll}\text { Model } & 28 & 387.81917 & 13.8507 & 0.9644\end{array}$

$\begin{array}{lllll}\text { Error } & 29 & 416.49596 & 14.3619 \text { Prob }>\text { F }\end{array}$

$\begin{array}{llll}\text { C. Total } & 57 & 804.31514 & 0.5373\end{array}$

Expected Mean Squares

The Mean Square per row by the Variance Component per column

$\begin{array}{lrr}\text { EMS } & \text { Intercept } & \text { Batch\&Random } \\ \text { Intercept } & 0 & 0 \\ \text { Batch\&Random } & 0 & 2\end{array}$

plus 1.0 times Residual Error Variance

Variance Component Estimates

Component Var Comp Est Percent of Total

$\begin{array}{lll}\text { Batch\&Random } & -0.25562 & -1.812\end{array}$

$\begin{array}{lll}\text { Residual } & 14.36193 & 101.812\end{array}$

Total $\quad 14.10631 \quad 100.000$

These estimates based on equating Mean Squares to Expected Value.

Test Denominator Synthesis

Source MS Den DF Den Denom MS Synthesis

$\begin{array}{rrrr}\text { Source } & \text { MS Den } & \text { DF Den } & \text { Denomal } \\ \text { Batch\&Random } & 14.3619 & 29 & \text { Residual }\end{array}$

Tests wrt Random Effects

Source SS MS Num DF Num F Ratio Prob > F

$\begin{array}{rrrrrr}\text { Batch\&Random } & 387.819 & 13.8507 & 28 & 0.9644 & 0.5373\end{array}$ 
WSRC-STI-2006-00068

Revision 0

Exhibit A7. Analysis of Variance by Preparation Method, ICP, and Analyte (continued)

Sample Type=ARG-1, Prep=Cold Chem, ICP $=$ M-14, Analyte $=$ Ti Response Measurement

Summary of Fit

\begin{tabular}{|c|c|c|c|c|}
\hline \multicolumn{3}{|c|}{ RSquare } & \multicolumn{2}{|l|}{0.523964} \\
\hline \multicolumn{3}{|c|}{ RSquare Adj } & 0.066237 & \\
\hline \multicolumn{3}{|c|}{ Root Mean Square Error } & 0.01426 & \\
\hline \multicolumn{3}{|c|}{ Mean of Response } & 0.670615 & \\
\hline \multicolumn{3}{|c|}{ Observations (or Sum Wgts) } & 52 & \\
\hline \multicolumn{5}{|c|}{ Analysis of Variance } \\
\hline Source & DF & Sum of Squares & Mean Square & F Ratio \\
\hline Model & 25 & 0.00581931 & 0.000233 & 1.1447 \\
\hline Error & 26 & 0.00528700 & 0.000203 & Prob $>$ F \\
\hline C. Total & 51 & 0.01110631 & & 0.3668 \\
\hline
\end{tabular}

Expected Mean Squares

The Mean Square per row by the Variance Component per column

$\begin{array}{lrr}\text { EMS } & \text { Intercept } & \text { Batch\&Random } \\ \text { Intercept } & 0 & 0\end{array}$

Batch\&Random $\quad 0 \quad 2$

plus 1.0 times Residual Error Variance

Variance Component Estimates

Component Var Comp Est Percent of Total

$\begin{array}{lrr}\text { Component } & \text { Var Comp Est } & \text { Percent of Tota } \\ \text { Batch\&Random } & 0.000015 & 6.747\end{array}$

Residual $\quad 0.000203 \quad 93.253$

Total $\quad 0.000218 \quad 100.000$

These estimates based on equating Mean Squares to Expected Value.

Test Denominator Synthesis

Source MS Den DF Den Denom MS Synthesis

Batch\&Random $\quad 0.0002 \quad 26$ Residual

Tests wrt Random Effects

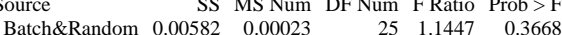

Sample Type=ARG-1, Prep=Cold Chem, ICP $=$ M-14, Analyte=U Response Measurement

Summary of Fit

RSquare $\quad 0.559232$

RSquare Adj $\quad 0.133662$

Root Mean Square Error $\quad 0.073536$

Mean of Response $\quad 0.029914$

Observations (or Sum Wgts) $\quad 58$

Analysis of Variance

Source DF Sum of Squares Mean Square F Ratio

$\begin{array}{lllll}\text { Model } & 28 & 0.19896707 & 0.007106 & 1.3141\end{array}$

$\begin{array}{lllll}\text { Error } & 29 & 0.15681950 & 0.005408 & \text { Prob }>\text { F }\end{array}$

$\begin{array}{llll}\text { C. Total } & 57 & 0.35578657 & 0.2345\end{array}$

Expected Mean Squares

The Mean Square per row by the Variance Component per column

$\begin{array}{lrr}\text { EMS } & \text { Intercept } & \text { Batch\&Random } \\ \text { Intercept } & 0 & 0\end{array}$

Batch\&Random $\quad 0 \quad 2$

plus 1.0 times Residual Error Variance

Variance Component Estimates

Component Var Comp Est Percent of Total

$\begin{array}{lll}\text { Batch\&Random } \quad 0.000849 & 13.572\end{array}$

$\begin{array}{lll}\text { Residual } & 0.005408 & 86.428\end{array}$

Total $\quad 0.006257 \quad 100.000$

These estimates based on equating Mean Squares to Expected Value.

Test Denominator Synthesis

Source MS Den DF Den Denom MS Synthesis

Batch\&Random $0.00541 \quad 29$ Residual

Tests wrt Random Effects

Source

SS MS Num DF Num F Ratio Prob $>$ F

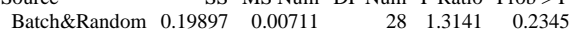

Sample Type=ARG-1, Prep=Cold Chem, ICP=M-14, Analyte=U/Ca Response Measurement

Summary of Fit

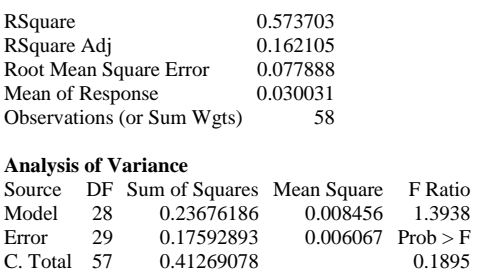

Expected Mean Squares

The Mean Square per row by the Variance Component per column

$\begin{array}{lrr}\text { EMS } & \text { Intercept } & \text { Batch\&Random } \\ \text { Intercept } & 0 & 0\end{array}$

Batch\&Random $\quad 0 \quad 2$

plus 1.0 times Residual Error Variance

Variance Component Estimates

$\begin{array}{crr}\text { Component } & \text { Var Comp Est } & \text { Percent of Total } \\ \text { Batch\&Random } & 0.001195 & 16.452 \\ \text { Residula } & 0.006067 & 83.548\end{array}$

$\begin{array}{lll}\text { Residual } & 0.006067 & 83.548\end{array}$

Total $\quad 0.007261 \quad 100.000$

These estimates based on equating Mean Squares to Expected Value.

Test Denominator Synthesis

Source MS Den DF Den Denom MS Synthesis

Batch\&Random $0.00607 \quad 29$ Residual

Tests wrt Random Effects
Source $\quad$ SS MS Num DF Num F Ratio Prob $>$ F

$\begin{array}{lrrrrr}\text { Source } & \text { SS } & \text { MS Num } & \text { DF Num } & \text { F Ratio } & \text { Prob }>\text { F } \\ \text { Batch\&Random } & 0.23676 & 0.00846 & 28 & 1.3938 & 0.1895\end{array}$

Sample Type=ARG-1, Prep=Cold Chem, ICP $=M-14$, Analyte $=\mathrm{Zr}$ Response Measurement

Summary of Fit

RSquare $\quad 0.772157$

RSquare Adj $\quad 0.552451$

Root Mean Square Error $\quad 0.004179$

Mean of Response $\quad 0.102679$

Observations (or Sum Wgts) 56

Analysis of Variance

Source DF Sum of Squares Mean Square F Ratio

$\begin{array}{lllll}\text { Model } & 27 & 0.00165721 & 0.000061 & 3.5145\end{array}$

$\begin{array}{lllll}\text { Error } & 28 & 0.00048900 & 0.000017 & \text { Prob }>\text { F }\end{array}$

$\begin{array}{llll}\text { C. Total } & 55 & 0.00214621 & 0.0007\end{array}$

Expected Mean Squares

The Mean Square per row by the Variance Component per column

$\begin{array}{lrr}\text { EMS } & \text { Intercept } & \text { Batch\&Random } \\ \text { Intercept } & 0 & 0 \\ \text { Batch\&Random } & 0 & 2\end{array}$

plus 1.0 times Residual Error Variance

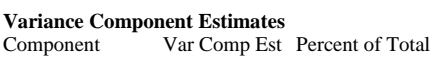

\begin{tabular}{crr} 
Component & Var Comp Est & Percent of Total \\
Batch\&Random & 0.000022 & 55.698 \\
Residual & 0.000017 & 44.302 \\
\hline
\end{tabular}

$\begin{array}{llr}\text { Residual } & 0.000017 & 44.302 \\ \text { Total } & 0.000039 & 100.000\end{array}$

These estimates based on equating Mean Squares to Expected Value.

Test Denominator Synthesis

Source MS Den DF Den Denom MS Synthesis

$\begin{array}{lrrr}\text { Source } & \text { MS Den } & \text { DF Den } & \text { Denom } \\ \text { Batch\&Random } & 0.00002 & 28 & \text { Residual }\end{array}$

Tests wrt Random Effects

Source SS MS Num DF Num F Ratio Prob $>$ F

$\begin{array}{rrrrrr}\text { Batch\&Random } & 0.00166 & 0.00006 & 27 & 3.5145 & 0.0007\end{array}$ 
WSRC-STI-2006-00068

Revision 0

Exhibit A7. Analysis of Variance by Preparation Method, ICP, and Analyte (continued)

Sample Type=ARG-1, Prep=Fusion, ICP=M-13, Analyte=Al Response Measurement

Summary of Fi

\begin{tabular}{|c|c|c|c|c|}
\hline \multicolumn{3}{|c|}{ RSquare } & \multicolumn{2}{|l|}{0.656329} \\
\hline \multicolumn{3}{|c|}{ RSquare Adj } & 0.32147 & \\
\hline \multicolumn{3}{|c|}{ Root Mean Square Error } & 0.077621 & \\
\hline \multicolumn{3}{|c|}{ Mean of Response } & 2.401051 & \\
\hline \multicolumn{3}{|c|}{ Observations (or Sum Wgts) } & 78 & \\
\hline \multicolumn{5}{|c|}{ Analysis of Variance } \\
\hline Source & DF & Sum of Squares & Mean Square & F Ratio \\
\hline Model & 38 & 0.44874379 & 0.011809 & 1.9600 \\
\hline Error & 39 & 0.23497400 & 0.006025 & Prob $>$ F \\
\hline C. Total & 77 & 0.68371779 & & 0.0197 \\
\hline
\end{tabular}

Expected Mean Square

The Mean Square per row by the Variance Component per column

$\begin{array}{lrr}\text { EMS } & \text { Intercept } & \text { Batch\&Random } \\ \text { Intercept } & 0 & 0\end{array}$

Batch\&Random $\quad 0 \quad 2$

plus 1.0 times Residual Error Variance

Variance Component Estimates

Component Var Comp Est Percent of Total

Batch\&Random $\quad 0.002892 \quad 32.433$

Residual $\quad 0.006025 \quad 67.567$

Total $\quad 0.008917 \quad 100.000$

These estimates based on equating Mean Squares to Expected Value.

Test Denominator Synthesis

Source MS Den DF Den Denom MS Synthesis

Batch\&Random $0.00602 \quad 39$ Residual

Tests wrt Random Effects

Batch\&Random $0.44874 \quad 0.01181 \quad 38 \quad 1.9600 \quad 0.0197$

Sample Type=ARG-1, Prep=Fusion, ICP=M-13, Analyte=Al/Ca Response Measurement

Summary of Fit

RSquare 0.758932

RSquare Adj $\quad 0.524208$

Root Mean Square Error $\quad 0.040017$

Mean of Response 2.438037

Observations (or Sum Wgts) $\quad 76$

Analysis of Variance

Source DF Sum of Squares Mean Square F Ratio

\begin{tabular}{lllll} 
Model & 37 & 0.19157794 & 0.005178 & 3.2333 \\
\hline
\end{tabular}

$\begin{array}{lllll}\text { Error } & 38 & 0.06085308 & 0.001601 & \text { Prob }>\text { F }\end{array}$

$\begin{array}{llll}\text { C. Total } & 75 & 0.25243101 & 0.0002\end{array}$

Expected Mean Square

The Mean Square per row by the Variance Component per column

$\begin{array}{lrr}\text { EMS } & \text { Intercept } & \text { Batch\&Random } \\ \text { Intercept } & 0 & 0\end{array}$

Batch\&Random $\quad 0 \quad 2$

plus 1.0 times Residual Error Variance

Variance Component Estimates

Component Var Comp Est Percent of Total

Batch\&Random $\quad 0.001788 \quad 52.755$

$\begin{array}{lll}\text { Residual } & 0.001601 & 47.245\end{array}$

Total $\quad 0.00339 \quad 100.000$

These estimates based on equating Mean Squares to Expected Value.

Test Denominator Synthesis

Source MS Den DF Den Denom MS Synthesis

Batch\&Random $0.0016 \quad 38$ Residual

Tests wrt Random Effects

ource

SS MS Num DF Num F Ratio Prob > F

$\begin{array}{lrrrrr}\text { Batch\&Random } & 0.19158 & 0.00518 & 37 & 3.2333 & 0.0002\end{array}$
Sample Type=ARG-1, Prep=Fusion, ICP=M-13, Analyte=AI/Mg Response Measurement

Summary of Fit

\begin{tabular}{|c|c|c|c|}
\hline \multicolumn{2}{|c|}{ RSquare } & \multicolumn{2}{|l|}{0.778937} \\
\hline \multicolumn{2}{|c|}{ RSquare Adj } & 0.563691 & \\
\hline \multicolumn{2}{|c|}{ Root Mean Square Error } & 0.082772 & \\
\hline \multicolumn{2}{|c|}{ Mean of Response } & 4.764103 & \\
\hline \multicolumn{2}{|c|}{ Observations (or Sum Wgts) } & 76 & \\
\hline \multicolumn{4}{|c|}{ Analysis of Variance } \\
\hline Source & DF Sum of Squares & s Mean Square & F Ratio \\
\hline Model & $37 \quad 0.9173570$ & $\quad 0.024793$ & 3.6188 \\
\hline Error & 0.2603470 & 0.006851 & Prob $>\mathrm{F}$ \\
\hline C. Total & 1.1777039 & & $<.0001$ \\
\hline
\end{tabular}

Expected Mean Squares

The Mean Square per row by the Variance Component per column

$\begin{array}{lrr}\text { EMS } & \text { Intercept } & \text { Batch\&Random } \\ \text { Intercept } & 0 & 0\end{array}$

Batch\&Random $\quad 0 \quad 2$

plus 1.0 times Residual Error Variance

Variance Component Estimates

$\begin{array}{crr}\text { Component } & \text { Var Comp Est } & \text { Percent of Total } \\ \text { Batch\&Random } & 0.008971 & 56.699 \\ \text { Residual } & 0.006851 & 43.301 \\ \text { Tol }\end{array}$

$\begin{array}{lcc}\text { Total } & 0.015822 & 100.000 \\ \text { These estimates based on equating Mean Squares to Expected Value. }\end{array}$

Test Denominator Synthesis

Source MS Den DF Den Denom MS Synthesis

Batch\&Random $0.00685 \quad 38$ Residual

Tests wrt Random Effects
Source SS MS Num DF Num F Ratio Prob $>$ F

$\begin{array}{lrrrrr}\text { Source } & \text { SS } & \text { MS Num } & \text { DF Num } & \text { F Ratio } & \text { Prob }>\text { F } \\ \text { Batch\&Random } & 0.91736 & 0.02479 & 37 & 3.6188 & <.0001\end{array}$

Sample Type=ARG-1, Prep=Fusion, ICP=M-13, Analyte=Al/Mn Response Measurement

Summary of Fit

RSquare Adj $\quad 0.492829$

Root Mean Square Error $\quad 0.028116$

Mean of Response $\quad 1.706018$

Observations (or Sum Wgts) $\quad 76$

Analysis of Variance

Source DF Sum of Squares Mean Square F Ratio

$\begin{array}{lllll}\text { Model } & 37 & 0.08686104 & 0.002348 & 2.9697\end{array}$

$\begin{array}{lllll}\text { Error } & 38 & 0.03003952 & 0.000791 \quad \text { Prob }>\text { F }\end{array}$

$\begin{array}{llll}\text { C. Total } & 75 & 0.11690056 & 0.0006\end{array}$

Expected Mean Squares

The Mean Square per row by the Variance Component per column

$\begin{array}{lrr}\text { EMS } & \text { Intercept } & \text { Batch\&Random } \\ \text { Intercept } & 0 & 0 \\ \text { Batch\&Random } & 0 & 2\end{array}$

plus 1.0 times Residual Error Variance

Variance Component Estimates
$\begin{array}{ll}\text { Component } & \text { Var Comp Est Percent of Total }\end{array}$

$\begin{array}{crr}\text { Component } & \text { Var Comp Est } & \text { Percent of Total } \\ \text { Batch\&Random } & 0.000779 & 49.618 \\ \text { Residual } & 0.000791 & 50.382\end{array}$

$\begin{array}{llr}\text { Residual } & 0.000791 & 50.382 \\ \text { Total } & 0.001569 & 100.000\end{array}$

These estimates based on equating Mean Squares to Expected Value.

Test Denominator Synthesis

Source MS Den DF Den Denom MS Synthesis

$\begin{array}{lrrr}\text { Source } & \text { MS Den } & \text { DF Den } & \text { Denom } \\ \text { Batch\&Random } & 0.00079 & 38 & \text { Residual }\end{array}$

Tests wrt Random Effects

Source SS MS Num DF Num F Ratio Prob $>$ F

$\begin{array}{rrrrrr}\text { Batch\&Random } & 0.08686 & 0.00235 & 37 & 2.9697 & 0.0006\end{array}$ 
WSRC-STI-2006-00068

Revision 0

Exhibit A7. Analysis of Variance by Preparation Method, ICP, and Analyte (continued)

Sample Type=ARG-1, Prep=Fusion, ICP=M-13, Analyte=B Response Measurement

Summary of Fi

\begin{tabular}{|c|c|c|c|c|}
\hline \multicolumn{3}{|c|}{ RSquare } & 0.61423 & \\
\hline \multicolumn{3}{|c|}{ RSquare Adj } & 0.238612 & \\
\hline \multicolumn{3}{|c|}{ Root Mean Square Error } & 0.077794 & \\
\hline \multicolumn{3}{|c|}{ Mean of Response } & 2.616763 & \\
\hline \multicolumn{3}{|c|}{ Observations (or Sum Wgts) } & 76 & \\
\hline \multicolumn{5}{|c|}{ Analysis of Variance } \\
\hline Source & DF & Sum of Squares & Mean Square & F Ratio \\
\hline Model & 37 & 0.36616574 & 0.009896 & 1.6353 \\
\hline Error & 38 & 0.22997200 & 0.006052 & Prob $>\mathrm{F}$ \\
\hline C. Total & 75 & 0.59613774 & & 0.0679 \\
\hline
\end{tabular}

Expected Mean Square

The Mean Square per row by the Variance Component per column

$\begin{array}{lrr}\text { EMS } & \text { Intercept } & \text { Batch\&Random } \\ \text { Intercept } & 0 & 0\end{array}$

Batch\&Random $\quad 0 \quad 2$

plus 1.0 times Residual Error Variance

Variance Component Estimates

Component Var Comp Est Percent of Total

$\begin{array}{lll}\text { Batch\&Random } \quad 0.001922 & 24.106\end{array}$

$\begin{array}{lll}\text { Residual } & 0.006052 & 75.894\end{array}$

Total $\quad 0.007974 \quad 100.000$

These estimates based on equating Mean Squares to Expected Value.

Test Denominator Synthesis

Source MS Den DF Den Denom MS Synthesis

Batch\&Random $0.00605 \quad 38$ Residual

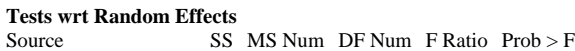

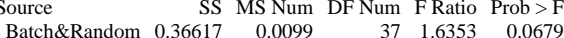

Sample Type=ARG-1, Prep=Fusion, ICP=M-13, Analyte $=\mathbf{B} / \mathrm{Li}$

Response Measurement

Summary of Fit

RSquare $\quad 0.564651$

RSquare Adj $\quad 0.140465$

Root Mean Square Error $\quad 0.044254$

Mean of Response $\quad 1.784125$

Observations (or Sum Wgts) 78

Analysis of Variance

Source DF Sum of Squares Mean Square F Ratio

$\begin{array}{lllll}\text { Model } & 38 & 0.09906250 & 0.002607 & 1.3311\end{array}$

$\begin{array}{lllll}\text { Error } & 39 & 0.07637777 & 0.001958 & \text { Prob }>\text { F }\end{array}$

$\begin{array}{llll}\text { C. Total } & 77 & 0.17544028 & 0.1889\end{array}$

Expected Mean Squares

The Mean Square per row by the Variance Component per column

$\begin{array}{lrr}\text { EMS } & \text { Intercept } & \text { Batch\&Random } \\ \text { Intercept } & 0 & 0\end{array}$

$\begin{array}{lll}0 & 0 \\ \text { Batch\&Random } & 0 & 2\end{array}$

plus 1.0 times Residual Error Variance

Variance Component Estimates

Component Var Comp Est Percent of Total

$\begin{array}{lll}\text { Batch\&Random } \quad 0.000324 & 14.205\end{array}$

$\begin{array}{lll}\text { Residual } & 0.001958 & 85.795\end{array}$

Total $\quad 0.002283 \quad 100.000$

These estimates based on equating Mean Squares to Expected Value.

Test Denominator Synthesis

Source MS Den DF Den Denom MS Synthesis

Batch\&Random $0.00196 \quad 39$ Residual

Tests wrt Random Effects

Source

SS MS Num DF Num F Ratio Prob $>$ F

$\begin{array}{lrrrrr}\text { Batch\&Random } & 0.09906 & 0.00261 & 38 & 1.3311 & 0.1889\end{array}$
Sample Type=ARG-1, Prep=Fusion, ICP $=$ M-13, Analyte $=$ Ca Response Measurement

Summary of Fit

RSquare Adj $\quad 0.691129$

$\begin{array}{ll}0.69129 & 0.390605 \\ \text { Root Mean Square Error } \quad 0.033645\end{array}$

Mean of Response

Observations (or Sum Wgts) $\quad 74$

Analysis of Variance

Source DF Sum of Squares Mean Square F Ratio

$\begin{array}{llllll}\text { Model } & 36 & 0.09371605 & 0.002603 & 2.2997\end{array}$

$\begin{array}{lllll}\text { Error } & 37 & 0.04188250 & 0.001132 & \text { Prob }>\text { F }\end{array}$

$\begin{array}{llll}\text { C. Total } & 73 & 0.13559855 & 0.0068\end{array}$

Expected Mean Squares

The Mean Square per row by the Variance Component per column

EMS Intercept Batch\&Random

$\begin{array}{lll}\text { Intercept } & 0 & 0 \\ \text { Batch\&Random } & 0 & 2\end{array}$

plus 1.0 times Residual Error Variance

Variance Component Estimates

$\begin{array}{rrr}\text { Component } & \text { Var Comp Est } & \text { Percent of Total } \\ \text { Batch\&Random } & 0.000736 & 39.389\end{array}$

$\begin{array}{ccc}\text { Batch\&Random } & 0.000736 & 39.389 \\ \text { Residual } & 0.001132 & 60.611\end{array}$

$\begin{array}{lrr}\text { Residual } & 0.001132 & 60.611 \\ \text { Total } & 0.001868 & 100.000\end{array}$

These estimates based on equating Mean Squares to Expected Value.

Test Denominator Synthesis

Source MS Den DF Den Denom MS Synthesis

Batch\&Random $0.00113 \quad 37$ Residual

Tests wrt Random Effects
Source $\quad$ SS MS Num DF Num F Ratio Prob > F

$\begin{array}{lrrrrr}\text { Source } & \text { SS } & \text { MS Num } & \text { DF Num } & \text { F Ratio } & \text { Prob > F } \\ \text { Batch\&Random } & 0.09372 & 0.0026 & 36 & 2.2997 & 0.0068\end{array}$

Sample Type=ARG-1, Prep=Fusion, ICP=M-13, Analyte $=$ Cr

Response Measurement

Summary of Fit

RSquare Adj

0.78767

Root Mean Square Error $\quad 0.08094$

Mean of Respons

Observations (or Sum Wgts) $\quad 76$

Analysis of Variance

Source DF Sum of Squares Mean Square F Ratio

$\begin{array}{llllr}\text { Model } & 37 & 0.00228338 & 0.000062 & 3.8101\end{array}$

$\begin{array}{lllll}\text { Error } & 38 & 0.00061550 & 0.000016 & \text { Prob }>\text { F }\end{array}$

$\begin{array}{llll}\text { C. Total } & 75 & 0.00289888 & <.0001\end{array}$

Expected Mean Squares

The Mean Square per row by the Variance Component per column

$\begin{array}{lrr}\text { EMS } & \text { Intercept } & \text { Batch\&Random } \\ \text { Intercept } & 0 & 0 \\ \text { Batch\&Random } & 0 & 2\end{array}$

plus 1.0 times Residual Error Variance

\begin{tabular}{|c|c|c|}
\hline \\
\hline \multicolumn{3}{|c|}{ 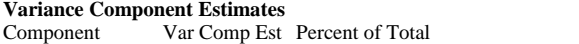 } \\
\hline Batch\&Random & 0.000023 & 58.421 \\
\hline Residual & 0.000016 & 41.579 \\
\hline Total & 0.000039 & 100.000 \\
\hline \multicolumn{3}{|c|}{ These estimates based on equating Mean Squares to Expected Value } \\
\hline \multicolumn{3}{|c|}{ Test Denominator Synthesis } \\
\hline Source & MS Den DF Den & Denom MS Synthesis \\
\hline Batch\&Random & $0.00002 \quad 38$ & Residual \\
\hline \multicolumn{3}{|c|}{ Tests wrt Random Effects } \\
\hline Source & SS MS Num & DF Num F Ratio Prob $>F$ \\
\hline Batch\&Random & $0.00228 \quad 0.00006$ & $\begin{array}{llll}37 & 3.8101 & <.0001\end{array}$ \\
\hline
\end{tabular}


WSRC-STI-2006-00068

Revision 0

Exhibit A7. Analysis of Variance by Preparation Method, ICP, and Analyte (continued)

Sample Type=ARG-1, Prep=Fusion, ICP $=$ M-13, Analyte $=$ Cu Response Measurement

Summary of Fit

\begin{tabular}{|c|c|c|c|c|}
\hline \multicolumn{3}{|c|}{ RSquare } & 0.795446 & \\
\hline \multicolumn{3}{|c|}{ RSquare Adj } & 0.596136 & \\
\hline \multicolumn{3}{|c|}{ Root Mean Square Error } & 0.002873 & \\
\hline \multicolumn{3}{|c|}{ Mean of Response } & 0.001846 & \\
\hline \multicolumn{3}{|c|}{ Observations (or Sum Wgts) } & 78 & \\
\hline \multicolumn{5}{|c|}{ Analysis of Variance } \\
\hline Source & DF & Sum of Squares & Mean Square & F Ratio \\
\hline Model & 38 & 0.00125215 & 0.000033 & 3.9910 \\
\hline Error & 39 & 0.00032200 & 0.000008 & Prob $>$ F \\
\hline C. Total & 77 & 0.00157415 & & $<.0001$ \\
\hline
\end{tabular}

Expected Mean Squares

The Mean Square per row by the Variance Component per column

$\begin{array}{lrr}\text { EMS } & \text { Intercept } & \text { Batch\&Random } \\ \text { Intercept } & 0 & 0\end{array}$

Batch\&Random $\quad 0 \quad 2$

plus 1.0 times Residual Error Variance

Variance Component Estimates

Component Var Comp Est Percent of Total

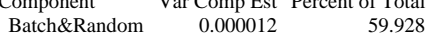

$\begin{array}{lll}\text { Residual } & 0.000008 & 40.072\end{array}$

Total $\quad 0.000021 \quad 100.000$

These estimates based on equating Mean Squares to Expected Value.

Test Denominator Synthesis

Source MS Den DF Den Denom MS Synthesis

Batch\&Random $\quad 8.26 e-6 \quad 39$ Residual

Tests wrt Random Effects

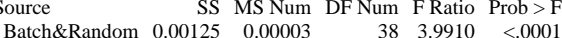

Sample Type=ARG-1, Prep=Fusion, ICP=M-13, Analyte=Fe

Response Measurement

Summary of Fit

RSquare $\quad 0.656536$

RSquare Adj $\quad 0.322355$

Root Mean Square Error $\quad 0.288246$

Mean of Response $\quad 9.708905$

Observations (or Sum Wgts) 74

Analysis of Variance

Source DF Sum of Squares Mean Square F Ratio

\begin{tabular}{llllr} 
Model & 36 & 5.8763208 & 0.163231 & 1.9646 \\
\hline
\end{tabular}

$\begin{array}{lllll}\text { Error } & 37 & 3.0741695 & 0.083086 & \text { Prob }>\text { F }\end{array}$

$\begin{array}{llll}\text { C. Total } & 73 & 8.9504903 & 0.0221\end{array}$

Expected Mean Squares

The Mean Square per row by the Variance Component per column

$\begin{array}{lrr}\text { EMS } & \text { Intercept } & \text { Batch\&Random } \\ \text { Intercept } & 0 & 0\end{array}$

Batch\&Random $\quad 0 \quad 2$

plus 1.0 times Residual Error Variance

Variance Component Estimates

Component Var Comp Est Percent of Total

Batch\&Random $\quad 0.040073 \quad 32.538$

$\begin{array}{lll}\text { Residual } & 0.083086 & 67.462\end{array}$

Total $\quad 0.123158 \quad 100.000$

These estimates based on equating Mean Squares to Expected Value.

Test Denominator Synthesis

Source MS Den DF Den Denom MS Synthesis

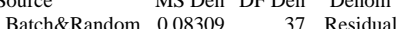

Tests wrt Random Effects

Source

SS MS Num DF Num F Ratio Prob $>$ F

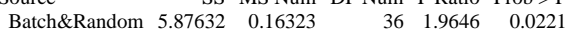

Sample Type=ARG-1, Prep=Fusion, ICP=M-13, Analyte=Fe/Al Response Measurement

Summary of Fit

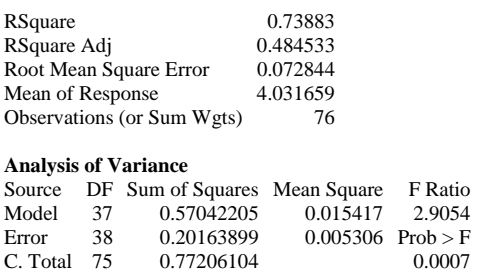

Expected Mean Squares

The Mean Square per row by the Variance Component per column

$\begin{array}{lrr}\text { EMS } & \text { Intercept } & \text { Batch\&Random } \\ \text { Intercept } & 0 & 0\end{array}$

Batch\&Random $\quad 0 \quad 2$

plus 1.0 times Residual Error Variance

Variance Component Estimates

$\begin{array}{lrr}\text { Component } & \text { Var Comp Est } & \text { Percent of Total } \\ \text { Batch\&Random } & 0.005055 & 48.789\end{array}$

$\begin{array}{lll}\text { Batch\&Random } & 0.005055 & 48.789 \\ \text { Residual } & 0.005306 & 51.211\end{array}$

$\begin{array}{lrr}\text { Residual } & 0.005306 & 51.211 \\ \text { Total } & 0.010362 & 100.000\end{array}$

$\begin{array}{lcc}\text { Total } & 0.010362 & 100.000 \\ \text { These estimates based on equating Mean Squares to Expected Value. }\end{array}$

Test Denominator Synthesis

Source MS Den DF Den Denom MS Synthesis

Batch\&Random $0.00531 \quad 38$ Residual

Tests wrt Random Effects
Source $\quad$ SS MS Num DF Num F Ratio Prob $>$ F

$\begin{array}{lrrrrr}\text { Source } & \text { SS } & \text { MS Num } & \text { DF Num } & \text { F Ratio } & \text { Prob > F } \\ \text { Batch\&Random } & 0.57042 & 0.01542 & 37 & 2.9054 & 0.0007\end{array}$

Sample Type=ARG-1, Prep=Fusion, ICP=M-13, Analyte=Fe/Ca Response Measurement

Summary of Fit

RSquare Adj $\quad 0.623213$

Root Mean Square Error $\quad 0.256342$

$\quad 0.265044$

$\begin{array}{lr}\text { Mean of Response } & 9.80705 \\ \text { Observations (or Sum Wgts) } & 76\end{array}$

Analysis of Variance

Source DF Sum of Squares Mean Square F Ratio

$\begin{array}{lllll}\text { Model } & 37 & 4.4153112 & 0.119333 & 1.6987\end{array}$

$\begin{array}{lllll}\text { Error } & 38 & 2.6694392 & 0.070248 & \text { Prob }>\text { F }\end{array}$

$\begin{array}{llll}\text { C. Total } & 75 & 7.0847504 & 0.0542\end{array}$

Expected Mean Squares

The Mean Square per row by the Variance Component per column

$\begin{array}{lrr}\text { EMS } & \text { Intercept } & \text { Batch\&Random } \\ \text { Intercept } & 0 & 0 \\ \text { Batch\&Random } & 0 & 2\end{array}$

plus 1.0 times Residual Error Variance

Variance Component Estimates
Component Var Comp Est Percent of Total

$\begin{array}{crr}\text { Component } & \text { Var Comp Est } & \text { Percent of Total } \\ \text { Batch\&Random } & 0.024542 & 25.891 \\ \text { Residual } & 0.070248 & 74.109 \\ \text { Told } & 0.094791 & 100.000\end{array}$

$\begin{array}{lrr}\text { Residual } & 0.070248 & 74.109 \\ \text { Total } & 0.094791 & 100.000\end{array}$

These estimates based on equating Mean Squares to Expected Value.

Test Denominator Synthesis

Source MS Den DF Den Denom MS Synthesis

$\begin{array}{rrrr}\text { Source } & \text { MS Den } & \text { DF Den } & \text { Denomal } \\ \text { Batch\&Random } & 0.07025 & 38 \text { Residual }\end{array}$

Tests wrt Random Effects

Source SS MS Num DF Num F Ratio Prob > F

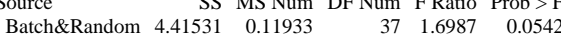


WSRC-STI-2006-00068

Revision 0

Exhibit A7. Analysis of Variance by Preparation Method, ICP, and Analyte (continued)

Sample Type=ARG-1, Prep=Fusion, ICP=M-13, Analyte=Fe/Li Response Measurement

Summary of Fi

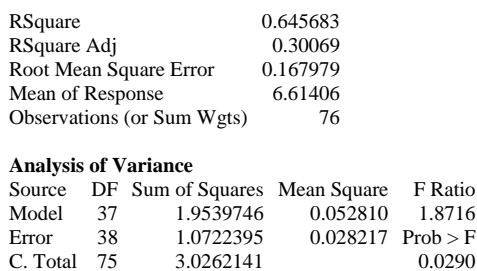

Expected Mean Squares

The Mean Square per row by the Variance Component per column

$\begin{array}{lrr}\text { EMS } & \text { Intercept } & \text { Batch\&Random } \\ \text { Intercept } & 0 & 0\end{array}$

Batch\&Random $\quad 0 \quad 2$

plus 1.0 times Residual Error Variance

Variance Component Estimates

Component Var Comp Est Percent of Total

Batch\&Random $\quad 0.012297 \quad 30.352$

$\begin{array}{lll}\text { Residual } & 0.028217 & 69.648\end{array}$

Total $\quad 0.040513 \quad 100.000$

These estimates based on equating Mean Squares to Expected Value.

Test Denominator Synthesis

Source MS Den DF Den Denom MS Synthesis

Batch\&Random $0.02822 \quad 38$ Residual

Tests wrt Random Effects
Source MS Num DF Num F Ratio Prob > F

$\begin{array}{lrrrrr}\text { Source } & \text { SS } & \text { MS Num } & \text { DF Num } & \text { F Ratio } & \text { Prob > F } \\ \text { Batch\&Random } & 1.95397 & 0.05281 & 37 & 1.8716 & 0.0290\end{array}$

Sample Type=ARG-1, Prep=Fusion, ICP=M-13, Analyte=Fe/Mg Response Measurement

Summary of Fit

RSquare $\quad 0.517585$

RSquare Adj $\quad 0.048209$

Root Mean Square Error $\quad 0.337358$

Mean of Response 19.16612

Observations (or Sum Wgts) 74

Analysis of Variance

Source DF Sum of Squares Mean Square F Ratio

$\begin{array}{lllll}\text { Model } & 36 & 4.5179883 & 0.125500 & 1.1027\end{array}$

$\begin{array}{lllll}\text { Error } & 37 & 4.2109856 & 0.113810 & \text { Prob }>\text { F }\end{array}$

$\begin{array}{llll}\text { C. Total } & 73 & 8.7289740 & 0.3841\end{array}$

Expected Mean Squares

The Mean Square per row by the Variance Component per column

$\begin{array}{lrr}\text { EMS } & \text { Intercept } & \text { Batch\&Random } \\ \text { Intercept } & 0 & 0\end{array}$

Batch\&Random $\quad 0 \quad 2$

plus 1.0 times Residual Error Variance

Variance Component Estimates

Component Var Comp Est Percent of Total

Batch\&Random $\quad 0.005845 \quad 4.885$

$\begin{array}{lrr}\text { Residual } & 0.11381 & 95.115\end{array}$

Total $\quad 0.119655 \quad 100.000$

These estimates based on equating Mean Squares to Expected Value.

Test Denominator Synthesis

Source MS Den DF Den Denom MS Synthesis

$\begin{array}{lrrr}\text { Batch\&Random } & 0.11381 & 37 & \text { Residual }\end{array}$

Tests wrt Random Effects

Source SS MS Num DF Num F Ratio Prob > F

$\begin{array}{llllll}\text { Batch\&Random } & 4.51799 & 0.1255 & 36 & 1.1027 & 0.3841\end{array}$
Sample Type=ARG-1, Prep=Fusion, ICP=M-13, Analyte=Fe $/$ Mn Response Measurement

Summary of Fit

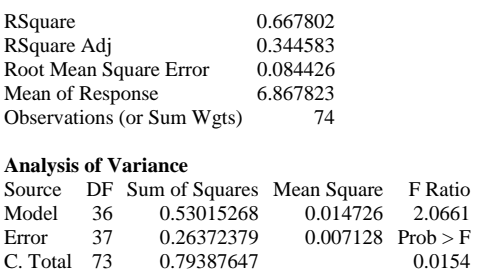

Expected Mean Squares

The Mean Square per row by the Variance Component per column

EMS

Intercept Batch\&Random

$\begin{array}{lll}\text { Batch\&Random } & 0 & 0 \\ & 0 & 2\end{array}$

plus 1.0 times Residual Error Variance

Variance Component Estimates

$\begin{array}{crr}\text { Component } & \text { Var Comp Est } & \text { Percent of Total } \\ \text { Batch\&Random } & 0.003799 & 34.771 \\ \text { Residual } & 0.007128 & 65.229\end{array}$

Total $\quad 0.010927 \quad 100.000$

These estimates based on equating Mean Squares to Expected Value.

Test Denominator Synthesis

Source MS Den DF Den Denom MS Synthesis

Batch\&Random $0.00713 \quad 37$ Residual

Tests wrt Random Effects
Source SS MS Num DF Num F Ratio Prob $>$ F Source $\quad$ SS MS Num DF Num F Ratio Prob > F

Sample Type=ARG-1, Prep=Fusion, ICP=M-13, Analyte=Fe/Ni Response Measurement

Summary of Fit

RSquare Adj $\quad-0.00657$

Root Mean Square Error $\quad 0.297587$

Mean of Response $\quad 12.05206$

Observations (or Sum Wgts) $\quad 76$

Analysis of Variance

Source DF Sum of Squares Mean Square F Ratio

$\begin{array}{lllll}\text { Model } & 37 & 3.2332756 & 0.087386 & 0.9868\end{array}$

$\begin{array}{lllll}\text { Error } & 38 & 3.3652131 & 0.088558 & \text { Prob }>\text { F }\end{array}$

$\begin{array}{llll}\text { C. Total } & 75 & 6.5984887 & 0.5156\end{array}$

Expected Mean Squares

The Mean Square per row by the Variance Component per column

$\begin{array}{lrr}\text { EMS } & \text { Intercept } & \text { Batch\&Random } \\ \text { Intercept } & 0 & 0 \\ \text { Batch\&Random } & 0 & 2\end{array}$

plus 1.0 times Residual Error Variance

\begin{tabular}{|c|c|c|}
\hline \multicolumn{3}{|c|}{ Variance Component Estimates } \\
\hline Component & Var Comp Est Per & cent of Total \\
\hline Batch\&Random & -0.00059 & -0.666 \\
\hline Residual & 0.088558 & 100.666 \\
\hline Total & 0.087972 & 100.000 \\
\hline These estimates b & ased on equating $\mathrm{M}$ & ean Squares to Expected Value \\
\hline Test Denominator & r Synthesis & \\
\hline Source & MS Den DF Den & Denom MS Synthesis \\
\hline Batch\&Random & $0.08856 \quad 38$ & Residual \\
\hline & II & \\
\hline Source & SS MS Num & DF Num F Ratio Prob $>F$ \\
\hline Batch\&Random & $3.23328 \quad 0.08739$ & $\begin{array}{lll}37 & 0.9868 & 0.5156\end{array}$ \\
\hline
\end{tabular}


WSRC-STI-2006-00068

Revision 0

Exhibit A7. Analysis of Variance by Preparation Method, ICP, and Analyte (continued)

Sample Type=ARG-1, Prep=Fusion, ICP=M-13, Analyte=Fe/U Response Measurement

Summary of Fi

\begin{tabular}{|c|c|c|c|}
\hline \multicolumn{2}{|c|}{ RSquare } & 0.607821 & \\
\hline \multicolumn{2}{|c|}{ RSquare Adj } & 0.228715 & \\
\hline \multicolumn{2}{|c|}{ Root Mean Square Error } & 339.2734 & \\
\hline \multicolumn{2}{|c|}{ Mean of Response } & 86.99412 & \\
\hline \multicolumn{2}{|c|}{ Observations (or Sum Wgts) } & 60 & \\
\hline \multicolumn{4}{|c|}{ Analysis of Variance } \\
\hline Source & DF Sum of Squares & s Mean Square & F Ratio \\
\hline Model & $29 \quad 5351956.5$ & $5 \quad 184550$ & 1.6033 \\
\hline Error & 3453193.6 & 115106 & Prob $>$ F \\
\hline C. Total & 8805150.1 & & 0.1022 \\
\hline
\end{tabular}

Expected Mean Squares

The Mean Square per row by the Variance Component per column

$\begin{array}{lrr}\text { EMS } & \text { Intercept } & \text { Batch\&Random } \\ \text { Intercept } & 0 & 0\end{array}$

Batch\&Random $\quad 0 \quad 2$

plus 1.0 times Residual Error Variance

Variance Component Estimates

Component Var Comp Est Percent of Total

Batch\&Random $\quad 34721.88 \quad 23.174$

$\begin{array}{lll}\text { Residual } & 34721.88 & 23.174 \\ & 115106.5 & 76.826\end{array}$

Total $\quad 149828.3 \quad 100.000$

These estimates based on equating Mean Squares to Expected Value.

Test Denominator Synthesis

Source MS Den DF Den Denom MS Synthesis

Batch\&Random $115106 \quad 30$ Residual

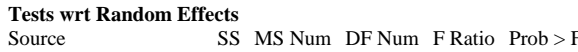

$\begin{array}{lrrrr}\text { Source } & \text { SS } & \text { MS Num DF Num F Ratio Prob > F } \\ \text { Batch\&Random } & 5351956 & 184550 & 29 & 1.6033\end{array}$

Sample Type $=$ ARG-1, Prep $=$ Fusion, ICP $=M-13$, Analyte $=K$

Response Measurement

Summary of Fit

RSquare $\quad 0.635748$

RSquare Adj $\quad 0.280836$

Root Mean Square Error $\quad 0.11278$

Mean of Response 2.197577

Observations (or Sum Wgts) $\quad 78$

Analysis of Variance

Source DF Sum of Squares Mean Square F Ratio

$\begin{array}{lllll}\text { Model } & 38 & 0.8657945 & 0.022784 & 1.7913 \\ \text { Error } & 39 & 0.4960565 & 0.012719 & 0.0369\end{array}$

$\begin{array}{lllll}\text { Error } & 39 & 0.4960565 & 0.012719 & \text { Prob }>\text { F }\end{array}$

$\begin{array}{llll}\text { C. Total } & 77 & 1.3618510 & 0.0369\end{array}$

Expected Mean Squares

The Mean Square per row by the Variance Component per column

$\begin{array}{lrr}\text { EMS } & \text { Intercept } & \text { Batch\&Random } \\ \text { Intercept } & 0 & 0\end{array}$

Batch\&Random $\quad 0 \quad 2$

plus 1.0 times Residual Error Variance

Variance Component Estimates

Component Var Comp Est Percent of Total

Batch\&Random $\quad 0.005032 \quad 28.348$

$\begin{array}{lll}\text { Residual } & 0.012719 & 71.652\end{array}$

Total $\quad 0.017752 \quad 100.000$

These estimates based on equating Mean Squares to Expected Value.

Test Denominator Synthesis

Source MS Den DF Den Denom MS Synthesis

Batch\&Random $0.01272 \quad 39$ Residual

Tests wrt Random Effects

Source

SS MS Num DF Num F Ratio Prob > F

$\begin{array}{llrrrr}\text { Batch\&Random } & 0.86579 & 0.02278 & 38 & 1.7913 & 0.0369\end{array}$
Sample Type=ARG-1, Prep=Fusion, ICP=M-13, Analyte=Li Response Measurement

Summary of Fit

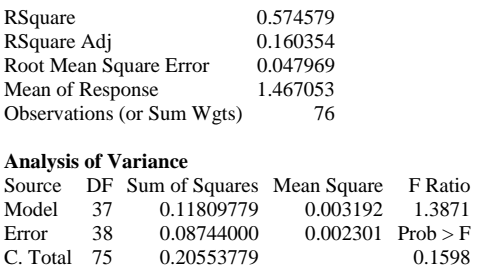

Expected Mean Squares

The Mean Square per row by the Variance Component per column

$\begin{array}{lrr}\text { EMS } & \text { Intercept } & \text { Batch\&Random } \\ \text { Intercept } & 0 & 0\end{array}$

Batch\&Random $\quad 0 \quad 2$

plus 1.0 times Residual Error Variance

Variance Component Estimates

$\begin{array}{rrr}\text { Component } & \text { Var Comp Est } & \text { Percent of Total } \\ \text { Batch\&Random } & 0.000445 & 16.217\end{array}$

$\begin{array}{lll}\text { Batch\&Random } & 0.000445 & 16.217 \\ \text { Residual } & 0.002301 & 83.783\end{array}$

$\begin{array}{lrr}\text { Residual } & 0.002301 & 83.783 \\ \text { Total } & 0.002746 & 100.000\end{array}$

These estimates based on equating Mean Squares to Expected Value.

Test Denominator Synthesis

Source MS Den DF Den Denom MS Synthesis

Batch\&Random $\quad 0.0023 \quad 38$ Residual

Tests wrt Random Effects

Source SS MS Num DF Num F Ratio Prob $>$ F

$\begin{array}{llllll}\text { Batch\&Random } & 0.1181 & 0.00319 & 37 & 1.3871 & 0.1598\end{array}$

Sample Type=ARG-1, Prep=Fusion, ICP=M-13, Analyte $=$ Mg Response Measurement

Summary of Fit

RSquare Adj $\quad 0.321897$

Root Mean Square Error $\quad 0.015993$

Mean of Response $\quad 0.506027$

Observations (or Sum Wgts) $\quad 74$

Analysis of Variance

Source DF Sum of Squares Mean Square F Ratio

$\begin{array}{lllll}\text { Model } & 36 & 0.01807195 & 0.000502 & 1.9626\end{array}$

$\begin{array}{lllll}\text { Error } & 37 & 0.00946400 & 0.000256 & \text { Prob }>\text { F }\end{array}$

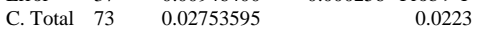

Expected Mean Squares

The Mean Square per row by the Variance Component per column

$\begin{array}{lrr}\text { EMS } & \text { Intercept } & \text { Batch\&Random } \\ \text { Intercept } & 0 & 0 \\ \text { Batch\&Random } & 0 & 2\end{array}$

plus 1.0 times Residual Error Variance

\begin{tabular}{|c|c|c|}
\hline \\
\hline \multicolumn{3}{|c|}{$\begin{array}{l}\text { Variance Component Estimates } \\
\text { Component } \\
\text { Var Comp Est }\end{array}$} \\
\hline Batch\&Random & 0.000123 & 32.491 \\
\hline Residual & 0.000256 & 67.509 \\
\hline Total & 0.000379 & 100.000 \\
\hline \multicolumn{3}{|c|}{ These estimates based on equating Mean Squares to Expected Value } \\
\hline \multicolumn{3}{|c|}{ Test Denominator Synthesis } \\
\hline Source & MS Den DF Den & Denom MS Synthesis \\
\hline Batch\&Random & $0.00026 \quad 37$ & Residual \\
\hline \multicolumn{3}{|c|}{ Tests wrt Random Effects } \\
\hline Source & SS MS Num & DF Num F Ratio Prob $>F$ \\
\hline Batch\&Random & 0.01807 & $\begin{array}{lll}36 & 1.9626 & 0.0223\end{array}$ \\
\hline
\end{tabular}


WSRC-STI-2006-00068

Revision 0

Exhibit A7. Analysis of Variance by Preparation Method, ICP, and Analyte (continued)

Sample Type=ARG-1, Prep=Fusion, ICP=M-13, Analyte $=$ Mn Response Measurement

Summary of Fit

\begin{tabular}{|c|c|c|c|c|}
\hline \multicolumn{3}{|c|}{ RSquare } & \multicolumn{2}{|l|}{0.616477} \\
\hline \multicolumn{3}{|c|}{ RSquare Adj } & 0.243046 & \\
\hline \multicolumn{3}{|c|}{ Root Mean Square Error } & 0.047961 & \\
\hline \multicolumn{3}{|c|}{ Mean of Response } & 1.414276 & \\
\hline \multicolumn{3}{|c|}{ Observations (or Sum Wgts) } & 76 & \\
\hline \multicolumn{5}{|c|}{ Analysis of Variance } \\
\hline Source & DF & Sum of Squares & Mean Square & F Ratio \\
\hline Model & 37 & 0.14050070 & 0.003797 & 1.6508 \\
\hline Error & 38 & 0.08740850 & 0.002300 & Prob $>$ F \\
\hline C. Total & 75 & 0.22790920 & & 0.0643 \\
\hline
\end{tabular}

Expected Mean Squares

The Mean Square per row by the Variance Component per column

$\begin{array}{lrr}\text { EMS } & \text { Intercept } & \text { Batch\&Random } \\ \text { Intercept } & 0 & 0\end{array}$

Batch\&Random $\quad 0 \quad 2$

plus 1.0 times Residual Error Variance

Variance Component Estimates

Component Var Comp Est Percent of Total

Batch\&Random $\quad 0.000749 \quad 24.552$

$\begin{array}{lrr}\text { Residual } & 0.0023 & 75.448\end{array}$

Total $\quad 0.003049 \quad 100.000$

These estimates based on equating Mean Squares to Expected Value.

Test Denominator Synthesis

Source MS Den DF Den Denom MS Synthesis

Batch\&Random $\quad 0.0023 \quad 38$ Residual

Tests wrt Random Effects
Source SS MS Num DF Num F Ratio Prob > F

$\begin{array}{lrrrrr}\text { Source } & \text { SS } & \text { MS Num } & \text { DF Num } & \text { F Ratio } & \text { Prob }>\text { F } \\ \text { Batch\&Random } & 0.1405 & 0.0038 & 37 & 1.6508 & 0.0643\end{array}$

Sample Type=ARG-1, Prep=Fusion, ICP=M-13, Analyte=Mn/Mg Response Measurement

Summary of Fit

RSquare $\quad 0.592187$

RSquare Adj $\quad 0.195105$

Root Mean Square Error $\quad 0.051871$

Mean of Response 2.792904

Observations (or Sum Wgts) $\quad 76$

Analysis of Variance

Source DF Sum of Squares Mean Square F Ratio

$\begin{array}{lllll}\text { Model } & 37 & 0.14846839 & 0.004013 & 1.4913\end{array}$

$\begin{array}{lllll}\text { Error } & 38 & 0.10224379 & 0.002691 & \text { Prob }>\text { F }\end{array}$

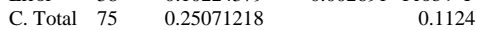

Expected Mean Square

The Mean Square per row by the Variance Component per column

$\begin{array}{lrr}\text { EMS } & \text { Intercept } & \text { Batch\&Random } \\ \text { Intercept } & 0 & 0\end{array}$

$\begin{array}{lll}0 & 0 \\ \text { Batch\&Random } & 0 & 2\end{array}$

plus 1.0 times Residual Error Variance

Variance Component Estimates

Component Var Comp Est Percent of Total

$\begin{array}{lll}\text { Batch\&Random } \quad 0.000661 & 19.722\end{array}$

Residual $\quad 0.002691 \quad 80.278$

Total $\quad 0.003352 \quad 100.000$

These estimates based on equating Mean Squares to Expected Value.

Test Denominator Synthesis

Source MS Den DF Den Denom MS Synthesis

Batch\&Random $0.00269 \quad 38$ Residual

Tests wrt Random Effects

Source SS MS Num DF Num F Ratio Prob $>$ F

$\begin{array}{llllll}\text { Batch\&Random } & 0.14847 & 0.00401 & 37 & 1.4913 & 0.1124\end{array}$

Sample Type=ARG-1, Prep=Fusion, ICP=M-13, Analyte=Na
Sample Type=ARG-1, Prep=Fusion, ICP=M-13, Analyte=Ni Response Measurement

Summary of Fit

\begin{tabular}{|c|c|c|c|c|}
\hline \multicolumn{3}{|c|}{ RSquare } & \multicolumn{2}{|l|}{0.710046} \\
\hline \multicolumn{3}{|c|}{ RSquare Adj } & 0.427722 & \\
\hline \multicolumn{3}{|c|}{ Root Mean Square Error } & 0.022985 & \\
\hline \multicolumn{3}{|c|}{ Mean of Response } & 0.802671 & \\
\hline \multicolumn{3}{|c|}{ Observations (or Sum Wgts) } & 76 & \\
\hline \multicolumn{5}{|c|}{ Analysis of Variance } \\
\hline Source & DF & Sum of Squares & S Mean Square & F Ratio \\
\hline Model & 37 & 0.04916128 & 0.001329 & 2.5150 \\
\hline Error & 38 & 0.02007550 & 0.000528 & Prob $>\mathrm{F}$ \\
\hline C. Total & 75 & 0.06923678 & & 0.0028 \\
\hline
\end{tabular}

Expected Mean Squares

The Mean Square per row by the Variance Component per column

$\begin{array}{lrr}\text { EMS } & \text { Intercept } & \text { Batch\&Random } \\ \text { Intercept } & 0 & 0\end{array}$

Batch\&Random $\quad 0 \quad 2$

plus 1.0 times Residual Error Variance

Variance Component Estimates

$\begin{array}{crr}\text { Component } & \text { Var Comp Est } & \text { Percent of Total } \\ \text { Batch\&Random } & 0.0004 & 43.101 \\ & 0.000528 & 56.899\end{array}$

$\begin{array}{lll}\text { Residual } & 0.000528 & 56.899\end{array}$

Total $\quad 0.000928 \quad 100.000$

These estimates based on equating Mean Squares to Expected Value.

Test Denominator Synthesis

Source MS Den DF Den Denom MS Synthesis

Batch\&Random $0.00053 \quad 38$ Residual

Tests wrt Random Effects
Source SS MS Num DF Num F Ratio Prob $>$ F

$\begin{array}{llllll}\text { Batch\&Random } & 0.04916 & 0.00133 & 37 & 25150 & 0.0028\end{array}$

Sample Type=ARG-1, Prep=Fusion, ICP=M-13, Analyte=S

Response Measurement

Summary of Fit

RSquare $\quad 0.662383$

RSquare Adj $\quad 0.333651$

Root Mean Square Error $\quad 0.648671$

Mean of Response $\quad 22.58568$

Observations (or Sum Wgts) $\quad 76$

Analysis of Variance

Source DF Sum of Squares Mean Square F Ratio

$\begin{array}{lllll}\text { Model } & 37 & 31.370196 & 0.847843 & 2.0150\end{array}$

$\begin{array}{lllll}\text { Error } & 38 & 15.989402 & 0.420774 \text { Prob }>\text { F }\end{array}$

$\begin{array}{llll}\text { C. Total } & 75 & 47.359598 & 0.0172\end{array}$

Expected Mean Squares

The Mean Square per row by the Variance Component per column

$\begin{array}{lrr}\text { EMS } & \text { Intercept } & \text { Batch\&Random } \\ \text { Intercept } & 0 & 0 \\ \text { Batch\&Random } & 0 & 2\end{array}$

plus 1.0 times Residual Error Variance

\begin{tabular}{|c|c|c|}
\hline \multicolumn{3}{|c|}{ Variance Component Estimates } \\
\hline Component & Var Comp Est Per & cent of Total \\
\hline Batch\&Random & 0.213535 & 33.664 \\
\hline Residual & 0.420774 & 66.336 \\
\hline Total & 0.634308 & 100.000 \\
\hline These estimates b & ased on equating $\mathrm{M}$ & ean Squares to Expected Value \\
\hline Test Denominator & r Synthesis & \\
\hline Source & MS Den DF Den & Denom MS Synthesis \\
\hline Batch\&Random & $0.42077 \quad 38$ & Residual \\
\hline & & \\
\hline Source & SS MS Num & DF Num F Ratio Prob $>F$ \\
\hline Batch\&Random & $31.3702 \quad 0.84784$ & $\begin{array}{lll}37 & 2.0150 & 0.0172\end{array}$ \\
\hline
\end{tabular}


WSRC-STI-2006-00068

Revision 0

Exhibit A7. Analysis of Variance by Preparation Method, ICP, and Analyte (continued)

Sample Type=ARG-1, Prep=Fusion, ICP=M-13, Analyte=Sum of Oxides Response Measurement

Summary of Fit

\begin{tabular}{|c|c|c|c|}
\hline \multicolumn{2}{|c|}{ RSquare } & \multicolumn{2}{|l|}{0.584057} \\
\hline \multicolumn{2}{|c|}{ RSquare Adj } & 0.178779 & \\
\hline \multicolumn{2}{|c|}{ Root Mean Square Error } & 3.026719 & \\
\hline \multicolumn{2}{|c|}{ Mean of Response } & 87.10261 & \\
\hline \multicolumn{2}{|c|}{ Observations (or Sum Wgts) } & 78 & \\
\hline \multicolumn{4}{|c|}{ Analysis of Variance } \\
\hline Source & DF Sum of Squares & s Mean Square & F Ratio \\
\hline Model & $38 \quad 501.68430$ & $0 \quad 13.2022$ & 1.4411 \\
\hline Error & 357.28012 & 9.1610 & Prob $>$ F \\
\hline C. Total & 858.96443 & & 0.1302 \\
\hline
\end{tabular}

Expected Mean Squares

The Mean Square per row by the Variance Component per column

$\begin{array}{lrr}\text { EMS } & \text { Intercept } & \text { Batch\&Random } \\ \text { Intercept } & 0 & 0\end{array}$

Batch\&Random $\quad 0 \quad 2$

plus 1.0 times Residual Error Variance

Variance Component Estimates

Component Var Comp Est Percent of Total

$\begin{array}{rrr}\text { Component } & \text { Var Comp Est } & \text { Percent of Total } \\ \text { Batch\&Random } & 2.020595 & 18.071\end{array}$

$\begin{array}{lll}\text { Residual } & 9.161029 & 81.929\end{array}$

Total $11.18162 \quad 100.000$

These estimates based on equating Mean Squares to Expected Value.

Test Denominator Synthesis

Source MS Den DF Den Denom MS Synthesis

Batch\&Random $9.16103 \quad 39$ Residual

Tests wrt Random Effects

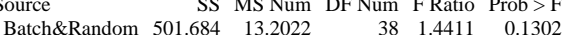

Sample Type=ARG-1, Prep=Fusion, ICP=M-13, Analyte=Ti

Response Measurement

Summary of Fit

RSquare $\quad 0.580661$

RSquare Adj $\quad 0.172074$

Root Mean Square Error $\quad 0.023355$

Mean of Response $\quad 0.670949$

Observations (or Sum Wgts) 78

Analysis of Variance

Source DF Sum of Squares Mean Square F Ratio

$\begin{array}{lllll}\text { Model } & 38 & 0.02945679 & 0.000775 & 1.4211\end{array}$

$\begin{array}{lllll}\text { Error } & 39 & 0.02127300 & 0.000545 \text { Prob }>\text { F }\end{array}$

$\begin{array}{llll}\text { C. Total } & 77 & 0.05072979 & 0.1395\end{array}$

Expected Mean Squares

The Mean Square per row by the Variance Component per column

$\begin{array}{lrr}\text { EMS } & \text { Intercept } & \text { Batch\&Random } \\ \text { Intercept } & 0 & 0\end{array}$

Batch\&Random $\quad 0 \quad 2$

plus 1.0 times Residual Error Variance

Variance Component Estimates

Component Var Comp Est Percent of Total

Batch\&Random $\quad 0.000115 \quad 17.394$

$\begin{array}{lrr}\text { Residual } & 0.000545 & 82.606\end{array}$

Total $\quad 0.00066 \quad 100.000$

These estimates based on equating Mean Squares to Expected Value.

Test Denominator Synthesis

Source MS Den DF Den Denom MS Synthesis

Batch\&Random $0.00055 \quad 39$ Residual

Tests wrt Random Effects

Source

SS MS Num DF Num F Ratio Prob $>$ F

$\begin{array}{lrrrrr}\text { Batch\&Random } & 0.02946 & 0.00078 & 38 & 1.4211 & 0.1395\end{array}$
Sample Type=ARG-1, Prep=Fusion, ICP=M-13, Analyte=U Response Measurement

Summary of Fit

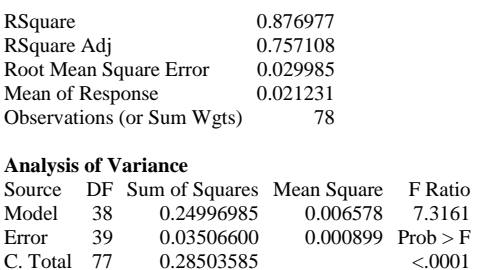

Expected Mean Squares

The Mean Square per row by the Variance Component per column

$\begin{array}{lrr}\text { EMS } & \text { Intercept } & \text { Batch\&Random } \\ \text { Intercept } & 0 & 0\end{array}$

Batch\&Random $\quad 0 \quad 2$

plus 1.0 times Residual Error Variance

Variance Component Estimates

\begin{tabular}{crr} 
Component & Var Comp Est & Percent of Total \\
Batch\&Random & 0.00284 & 75.950 \\
\hline & 0.000899 & 24.050
\end{tabular}

$\begin{array}{lll}\text { Residual } & 0.000899 & 24.050\end{array}$

Total $\quad 0.003739 \quad 100.000$

These estimates based on equating Mean Squares to Expected Value.

Test Denominator Synthesis

Source MS Den DF Den Denom MS Synthesis

Batch\&Random $0.0009 \quad 39$ Residual

Tests wrt Random Effects

Source SS MS Num DF Num F Ratio Prob $>$ F

Batch\&Random $0.24997 \quad 0.00658 \quad 387.3161<0001$

Sample Type=ARG-1, Prep=Fusion, ICP=M-13, Analyte=U/Ca Response Measurement

Summary of Fit

RSquare Adj $\quad 0.74941$

Root Mean Square Error $\quad 0.03141$

Mean of Response $\quad 0.022113$

Observations (or Sum Wgts) $\quad 78$

Analysis of Variance

Source DF Sum of Squares Mean Square F Ratio

$\begin{array}{lllll}\text { Model } & 38 & 0.26467117 & 0.006965 & 7.0599\end{array}$

$\begin{array}{lllll}\text { Error } & 39 & 0.03847616 & 0.000987 & \text { Prob }>\text { F }\end{array}$

$\begin{array}{llll}\text { C. Total } & 77 & 0.30314733 & <.0001\end{array}$

Expected Mean Squares

The Mean Square per row by the Variance Component per column

$\begin{array}{lrr}\text { EMS } & \text { Intercept } & \text { Batch\&Random } \\ \text { Intercept } & 0 & 0 \\ \text { Batch\&Random } & 0 & 2\end{array}$

plus 1.0 times Residual Error Variance

Variance Component Estimates
Component Var Comp Est Percent of Total

\begin{tabular}{crr} 
Component & Var Comp Est & Percent of Total \\
Batch\&Random & 0.002989 & 75.186 \\
Residual & 0.000987 & 24.814 \\
\hline
\end{tabular}

$\begin{array}{llr}\text { Residual } & 0.000987 & 24.814 \\ \text { Total } & 0.003976 & 100.000\end{array}$

These estimates based on equating Mean Squares to Expected Value.

Test Denominator Synthesis

Source MS Den DF Den Denom MS Synthesis

$\begin{array}{lrrr}\text { Source } & \text { MS Den } & \text { DF Den } & \text { Denom } \\ \text { Batch\&Random } & 0.00099 & 39 & \text { Residual }\end{array}$

Tests wrt Random Effects

Source SS MS Num DF Num F Ratio Prob $>$ F

$\begin{array}{rrrrrr} & \text { Source } & & & & \\ \text { Batch\&Random } & 0.26467 & 0.00697 & 38 & 7.0599 & <.0001\end{array}$ 
WSRC-STI-2006-00068

Revision 0

Exhibit A7. Analysis of Variance by Preparation Method, ICP, and Analyte (continued)

Sample Type=ARG-1, Prep=Fusion, ICP=M-13, Analyte $=\mathrm{Zr}$

Sample Type=ARG-1, Prep=Fusion, ICP=M-14, Analyte=Al Response Measurement

Summary of Fit

RSquare 0.596015

RSquare Adj 0.220886

Root Mean Square Error $\quad 0.066127$

Mean of Response 2.392286

Observations (or Sum Wgts) $\quad 28$

Analysis of Variance

Source DF Sum of Squares Mean Square F Ratio

$\begin{array}{lllll}\text { Model } & 13 & 0.09031871 & 0.006948 & 1.5888\end{array}$

$\begin{array}{lllll}\text { Error } & 14 & 0.06121900 & 0.004373 \text { Prob }>\text { F }\end{array}$

$\begin{array}{llrr}\text { C. Total } & 27 & 0.15153771 & 0.2005\end{array}$

Expected Mean Squares

The Mean Square per row by the Variance Component per column

EMS

$\begin{array}{lrr}\text { Intercept } & \text { Intercept } & \text { Batch\&Random } \\ \text { Batch\&Random } & 0 & 0 \\ & 0 & 2\end{array}$

plus 1.0 times Residual Error Variance

Variance Component Estimates

Component Var Comp Est Percent of Total

$\begin{array}{lr}\text { Batch\&Random } \quad 0.001287 & 22.745\end{array}$

$\begin{array}{lll}\text { Residual } & 0.004373 & 77.255\end{array}$

Total $\quad 0.00566 \quad 100.000$

These estimates based on equating Mean Squares to Expected Value.

Test Denominator Synthesis

Source MS Den DF Den Denom MS Synthesis

Batch\&Random $0.00437 \quad 14$ Residual

Tests wrt Random Effects

Source SS MS Num DF Num F Ratio Prob > F

$\begin{array}{llllll}\text { Batch\&Random } & 0.09032 & 0.00695 & 13 & 1.5888 & 0.2005\end{array}$

Sample Type=ARG-1, Prep=Fusion, ICP=M-14, Analyte=Al/Ca Response Measurement

Summary of Fit

RSquare

RSquare Adj

Root Mean Square Ertor

Mean of Response 2.475269

Observations (or Sum Wgts) $\quad 24$

Analysis of Variance

Source DF Sum of Squares Mean Square F Ratio

$\begin{array}{lllll}\text { Model } & 11 & 0.06024769 & 0.005477 & 2.9789\end{array}$

$\begin{array}{lllll}\text { Error } & 12 & 0.02206369 & 0.001839 & \text { Prob }>\text { F }\end{array}$

$\begin{array}{llrr}\text { C. Total } \quad 23 & 0.08231138 & 0.0367\end{array}$

Expected Mean Squares

The Mean Square per row by the Variance Component per column

EMS Intercept Batch\&Random

Batch\&Random $\quad 0 \quad 2$

plus 1.0 times Residual Error Variance

Variance Component Estimates

Component Var Comp Est Percent of Total

$\begin{array}{lll}\text { Batch\&Random } \quad 0.001819 & 49.734\end{array}$

$\begin{array}{llr}\text { Residual } & 0.001839 & 50.266\end{array}$

These estimates based on equating Mean Squares to Expected Value.

Test Denominator Synthesis

Source MS Den DF Den Denom MS Synthesis

Batch\&Random $0.00184 \quad 12$ Residual

Tests wrt Random Effects

Source SS MS Num DF Num F Ratio Prob > F
Sample Type=ARG-1, Prep=Fusion, ICP=M-14, Analyte=AI/Mg Response Measurement

Summary of Fit

RSquare Adj $\quad 0.039304$

Root Mean Square Error $\quad 0.087708$

Mean of Response 4.820871

Observations (or Sum Wgts) $\quad 28$

Analysis of Variance

Source DF Sum of Squares Mean Square F Ratio

$\begin{array}{lllll}\text { Model } & 13 & 0.10850295 & 0.008346 & 1.0850\end{array}$

$\begin{array}{lllll}\text { Error } & 14 & 0.10769820 & 0.007693 & \text { Prob }>\text { F }\end{array}$

$\begin{array}{llrr}\text { C. Total } & 27 & 0.21620115 & 0.4389\end{array}$

Expected Mean Squares

The Mean Square per row by the Variance Component per column

$\begin{array}{lrr}\text { EMS } & \text { Intercept } & \text { Batch\&Random } \\ \text { Intercept } & 0 & 0\end{array}$

$\begin{array}{lll}\text { Intercept } & 0 & 0 \\ \text { Batch\&Random } & 0 & 2\end{array}$

plus 1.0 times Residual Error Variance

Variance Component Estimates

$\begin{array}{crr}\text { Component } & \text { Var Comp Est } & \text { Percent of Total } \\ \text { Batch\&Random } & 0.000327 & 4.075 \\ \text { Residual } & 0.007693 & 95.925\end{array}$

Total $\quad 0.00802 \quad 100.000$

These estimates based on equating Mean Squares to Expected Value.

Test Denominator Synthesi

Source MS Den DF Den Denom MS Synthesis

Batch\&Random $0.00769 \quad 14$ Residual

Tests wrt Random Effects

Source SS MS Num DF Num F Ratio Prob > F

$\begin{array}{llrrrr}\text { Batch\&Random } & 0.1085 & 0.00835 & 13 & 1.0850 & 0.4389\end{array}$

Sample Type=ARG-1, Prep=Fusion, ICP=M-14, Analyte=AI/Mn Response Measurement

Summary of Fit

0.610742

0.249287

Root Mean Square Error $\quad 0.031091$

Mean of Respons Er 1.720974

Observations (or Sum Wgts) $\quad 28$

Analysis of Variance

Source DF Sum of Squares Mean Square F Ratio

$\begin{array}{lllll}\text { Model } & 13 & 0.02123358 & 0.001633 & 1.6897\end{array}$

$\begin{array}{lllll}\text { Error } & 14 & 0.01353330 & 0.000967 & \text { Prob }>\text { F }\end{array}$

$\begin{array}{llll}\text { C. Total } & 27 & 0.03476688 & 0.1711\end{array}$

Expected Mean Squares

The Mean Square per row by the Variance Component per column

$\begin{array}{lrr}\text { EMS } & \text { Intercept } & \text { Batch\&Random } \\ \text { Intercept } & 0 & 0 \\ \text { Batch\&Random } & 0 & 2\end{array}$

plus 1.0 times Residual Error Variance

Variance Component Estimates

Component Var Comp Est Percent of Total

Batch\&Random $\quad 0.000333 \quad 25.642$

$\begin{array}{lrr}\text { Residual } & 0.000967 & 74.358 \\ \text { Total } & 0.0013 & 100.000\end{array}$

These estimates based on equating Mean Squares to Expected Value.

Test Denominator Synthesis

Source MS Den DF Den Denom MS Synthesis

$\begin{array}{crrr}\text { Source } & \text { MS Den } & \text { DF Den } & \text { Denom MS } \\ \text { Batch\&Random } & 0.00097 & 14 & \text { Residual }\end{array}$

Tests wrt Random Effects

Source SS MS Num DF Num F Ratio Prob > F

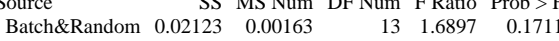


WSRC-STI-2006-00068

Revision 0

Exhibit A7. Analysis of Variance by Preparation Method, ICP, and Analyte (continued)

Sample Type=ARG-1, Prep=Fusion, ICP=M-14, Analyte=B Response Measurement

Summary of Fi

\begin{tabular}{|c|c|c|c|c|}
\hline \multicolumn{3}{|c|}{ RSquare } & 0.518082 & \\
\hline \multicolumn{3}{|c|}{ RSquare Adj } & 0.073234 & \\
\hline \multicolumn{3}{|c|}{ Root Mean Square Error } & 0.063766 & \\
\hline \multicolumn{3}{|c|}{ Mean of Response } & 2.555231 & \\
\hline \multicolumn{3}{|c|}{ Observations (or Sum Wgts) } & 26 & \\
\hline \multicolumn{5}{|c|}{ Analysis of Variance } \\
\hline Source & DF & Sum of Squares & Mean Square & F Ratio \\
\hline Model & 12 & 0.05682662 & 0.004736 & 1.1646 \\
\hline Error & 13 & 0.05286000 & 0.004066 & Prob $>$ F \\
\hline C. Total & 25 & 0.10968662 & & 0.3930 \\
\hline
\end{tabular}

Expected Mean Squares

The Mean Square per row by the Variance Component per column

$\begin{array}{lrr}\text { EMS } & \text { Intercept } & \text { Batch\&Random } \\ \text { Intercept } & 0 & 0\end{array}$

Batch\&Random $\quad 0 \quad 2$

plus 1.0 times Residual Error Variance

Variance Component Estimates

Component Var Comp Est Percent of Total

$\begin{array}{lr}\text { Batch\&Random } \quad 0.000335 & 7.605\end{array}$

Residual $\quad 0.004066 \quad 92.395$

Total $\quad 0.004401 \quad 100.000$

These estimates based on equating Mean Squares to Expected Value.

Test Denominator Synthesis

Source MS Den DF Den Denom MS Synthesis

Batch\&Random $0.00407 \quad 13$ Residual

Tests wrt Random Effects SS MS Num DF Num F Ratio Prob > F

SS MS Num DF Num F Ratio Prob > F
Batch\&Random 0.05683

Sample Type=ARG-1, Prep=Fusion, ICP=M-14, Analyte=B/Li

Response Measurement

Summary of Fit

RSquare $\quad 0.791643$

RSquare Adj $\quad 0.598169$

Root Mean Square Error $\quad 0.019674$

Mean of Response 1.744337

Observations (or Sum Wgts) $\quad 28$

Analysis of Variance

Source DF Sum of Squares Mean Square F Ratio

$\begin{array}{lllll}\text { Model } & 13 & 0.02058954 & 0.001584 & 4.0917\end{array}$

$\begin{array}{lllll}\text { Error } & 14 & 0.00541907 & 0.000387 & \text { Prob }>\text { F }\end{array}$

$\begin{array}{llll}\text { C. Total } & 27 & 0.02600861 & 0.0067\end{array}$

Expected Mean Squares

The Mean Square per row by the Variance Component per column

$\begin{array}{lrr}\text { EMS } & \text { Intercept } & \text { Batch\&Random } \\ \text { Intercept } & 0 & 0\end{array}$

Batch\&Random $\quad 0 \quad 2$

plus 1.0 times Residual Error Variance

Variance Component Estimates

Component Var Comp Est Percent of Total

$\begin{array}{lll}\text { Batch\&Random } \quad 0.000598 & 60.721\end{array}$

Residual $\quad 0.000387 \quad 39.279$

Total $\quad 0.000985 \quad 100.000$

These estimates based on equating Mean Squares to Expected Value.

Test Denominator Synthesis

Source MS Den DF Den Denom MS Synthesis

Batch\&Random $\quad 0.00039 \quad 14$ Residual

Tests wrt Random Effects

Source

SS MS Num DF Num F Ratio Prob $>$ F

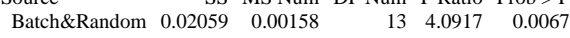

Sample Type=ARG-1, Prep=Fusion, ICP=M-14, Analyte=C Response Measurement

Summary of Fit

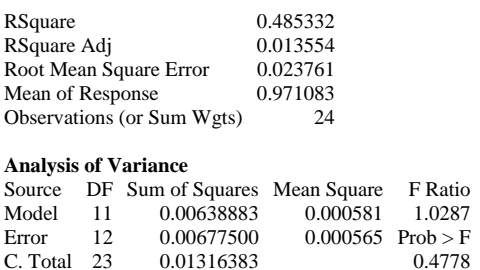

Expected Mean Squares

The Mean Square per row by the Variance Component per column

$\begin{array}{lrr}\text { EMS } & \text { Intercept } & \text { Batch\&Random } \\ \text { Intercept } & 0 & 0\end{array}$

Batch\&Random $\quad 0 \quad 2$

plus 1.0 times Residual Error Variance

Variance Component Estimates

$\begin{array}{crr}\text { Component } & \text { Var Comp Est } & \text { Percent of Total } \\ \text { Batch\&Random } & 0.000008 & 1.416 \\ \text { Residul } & 0.000565 & 98.584\end{array}$

$\begin{array}{lrr}\text { Batch\&Random } & 0.000008 & 1.416 \\ \text { Residual } & 0.000565 & 98.584\end{array}$

Total $\quad 0.000573 \quad 100.000$

These estimates based on equating Mean Squares to Expected Value.

Test Denominator Synthesis

Source MS Den DF Den Denom MS Synthesis

Batch\&Random $0.00056 \quad 12$ Residual

Tests wrt Random Effects
Source SS MS Num DF Num F Ratio Prob $>$ F

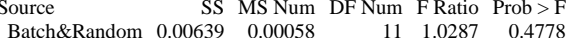

Sample Type=ARG-1, Prep=Fusion, ICP=M-14, Analyte $=$ Cr

Response Measurement

Summary of Fit

RSquare Adj $\quad 0.5228$

$\quad 0.0048$

Mean of Respons

0.066038

Observations (or Sum Wgts)

26

Analysis of Variance

Source DF Sum of Squares Mean Square F Ratio

$\begin{array}{lllll}\text { Model } & 12 & 0.00090746 & 0.000076 & 3.2824\end{array}$

$\begin{array}{lllll}\text { Error } & 13 & 0.00029950 & 0.000023 & \text { Prob }>\text { F }\end{array}$

$\begin{array}{llll}\text { C. Total } & 25 & 0.00120696 & 0.0214\end{array}$

Expected Mean Squares

The Mean Square per row by the Variance Component per column

$\begin{array}{lrr}\text { EMS } & \text { Intercept } & \text { Batch\&Random } \\ \text { Intercept } & 0 & 0 \\ \text { Batch\&Random } & 0 & 2\end{array}$

plus 1.0 times Residual Error Variance

\begin{tabular}{|c|c|c|}
\hline \multicolumn{3}{|c|}{ Variance Component Estimates } \\
\hline Component & Var Comp Est Per & cent of Total \\
\hline Batch\&Random & 0.000026 & 53.297 \\
\hline Residual & 0.000023 & 46.703 \\
\hline Total & 0.000049 & 100.000 \\
\hline \multicolumn{3}{|c|}{ These estimates based on equating Mean Squares to Expected Value } \\
\hline \multicolumn{3}{|c|}{ Test Denominator Synthesis } \\
\hline Source & MS Den DF Den & Denom MS Synthesis \\
\hline Batch\&Random & $0.00002 \quad 13$ & Residual \\
\hline \multicolumn{3}{|c|}{$\begin{array}{l}\text { Tests wrt Random Effects } \\
\text { Source }\end{array}$} \\
\hline Source & SS MS Num & DF Num F Ratio Prob $>F$ \\
\hline Batch\&Random & $0.00091 \quad 0.00008$ & $\begin{array}{lll}12 & 3.2824 & 0.0214\end{array}$ \\
\hline
\end{tabular}


WSRC-STI-2006-00068

Revision 0

Exhibit A7. Analysis of Variance by Preparation Method, ICP, and Analyte (continued)

Sample Type=ARG-1, Prep=Fusion, ICP=M-14, Analyte $=$ Cu Response Measurement

Summary of Fit

\begin{tabular}{|c|c|c|c|c|}
\hline \multicolumn{3}{|c|}{ RSquare } & 0.690819 & \\
\hline \multicolumn{3}{|c|}{ RSquare Adj } & 0.403722 & \\
\hline \multicolumn{3}{|c|}{ Root Mean Square Error } & 0.003566 & \\
\hline \multicolumn{3}{|c|}{ Mean of Response } & -0.00071 & \\
\hline \multicolumn{3}{|c|}{ Observations (or Sum Wgts) } & 28 & \\
\hline \multicolumn{5}{|c|}{ Analysis of Variance } \\
\hline Source & DF & Sum of Squares & Mean Square & F Ratio \\
\hline Model & 13 & 0.00039771 & 0.000031 & 2.4062 \\
\hline Error & 14 & 0.00017800 & 0.000013 & Prob $>$ F \\
\hline C. Total & 27 & 0.00057571 & & 0.0578 \\
\hline
\end{tabular}

Expected Mean Squares

The Mean Square per row by the Variance Component per column

$\begin{array}{lrr}\text { EMS } & \text { Intercept } & \text { Batch\&Random } \\ \text { Intercept } & 0 & 0\end{array}$

Batch\&Random $\quad 0 \quad 2$

plus 1.0 times Residual Error Variance

Variance Component Estimates

Component Var Comp Est Percent of Total

Batch\&Random $\quad 0.000009 \quad 41.284$

$\begin{array}{lll}\text { Residual } & 0.000013 & 58.716\end{array}$

Total $\quad 0.000022 \quad 100.000$

These estimates based on equating Mean Squares to Expected Value.

Test Denominator Synthesis

Source MS Den DF Den Denom MS Synthesis

Batch\&Random $0.00001 \quad 14$ Residual

Tests wrt Random Effects

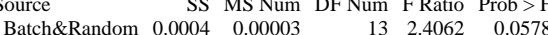

Sample Type=ARG-1, Prep=Fusion, ICP=M-14, Analyte=Fe

Response Measurement

Summary of Fit

RSquare $\quad 0.740332$

RSquare Adj $\quad 0.499212$

Root Mean Square Error $\quad 0.172285$

Mean of Response 9.549571

Observations (or Sum Wgts) $\quad 28$

Analysis of Variance

Source DF Sum of Squares Mean Square F Ratio

$\begin{array}{llllr}\text { Model } & 13 & 1.1847589 & 0.091135 & 3.0704 \\ & 14 & 0.4155480 & 0.029682 & \end{array}$

$\begin{array}{lllll}\text { Error } & 14 & 0.4155480 & 0.029682 & \text { Prob }>\text { F }\end{array}$

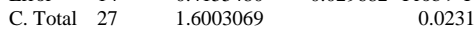

Expected Mean Squares

The Mean Square per row by the Variance Component per column

$\begin{array}{lrr}\text { EMS } & \text { Intercept } & \text { Batch\&Random } \\ \text { Intercept } & 0 & 0\end{array}$

Batch\&Random $\quad 0 \quad 2$

plus 1.0 times Residual Error Variance

Variance Component Estimates

Component Var Comp Est Percent of Total

Batch\&Random $\quad 0.030727 \quad 50.865$

$\begin{array}{lll}\text { Residual } & 0.029682 & 49.135\end{array}$

Total $\quad 0.060409 \quad 100.000$

These estimates based on equating Mean Squares to Expected Value.

Test Denominator Synthesis

Source MS Den DF Den Denom MS Synthesis

Batch\&Random $0.02968 \quad 14$ Residual

Tests wrt Random Effects

Source

SS MS Num DF Num F Ratio Prob $>$ F

$\begin{array}{lrrrrr}\text { Batch\&Random } & 1.18476 & 0.09114 & 13 & 3.0704 & 0.0231\end{array}$
Sample Type=ARG-1, Prep=Fusion, ICP=M-14, Analyte=Fe/Al Response Measurement

Summary of Fit

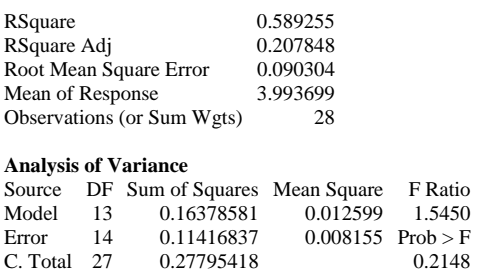

Expected Mean Squares

The Mean Square per row by the Variance Component per column

$\begin{array}{lrr}\text { EMS } & \text { Intercept } & \text { Batch\&Random } \\ \text { Intercept } & 0 & 0\end{array}$

Batch\&Random $\quad 0 \quad 2$

plus 1.0 times Residual Error Variance

Variance Component Estimates

$\begin{array}{rrr}\text { Component } & \text { Var Comp Est } & \text { Percent of Total } \\ \text { Batch\&Random } & 0.002222 & 21.413\end{array}$

$\begin{array}{ccc}\text { Batch\&Random } & 0.002222 & 21.413 \\ \text { Residual } & 0.008155 & 78.587\end{array}$

$\begin{array}{lrr}\text { Residual } & 0.008155 & 78.587 \\ \text { Total } & 0.010377 & 100.000\end{array}$

These estimates based on equating Mean Squares to Expected Value.

Test Denominator Synthesis

Source MS Den DF Den Denom MS Synthesis

Batch\&Random $0.00815 \quad 14$ Residual

Tests wrt Random Effects
Source SS MS Num DF Num F Ratio Prob $>$ F

$\begin{array}{lrrrrr}\text { Source } & \text { SS } & \text { MS Num } & \text { DF Num } & \text { F Ratio } & \text { Prob > F } \\ \text { Batch\&Random } & 0.16379 & 0.0126 & 13 & 1.5450 & 0.2148\end{array}$

Sample Type=ARG-1, Prep=Fusion, ICP=M-14, Analyte=Fe/Ca Response Measurement

Summary of Fit

RSquare $\quad 0.619454$

RSquare Adj $\quad 0.268182$

Root Mean Square Error $\quad 0.280918$

Mean of Response $\quad 9.882986$

Observations (or Sum Wgts) $\quad 26$

Analysis of Variance

Source DF Sum of Squares Mean Square F Ratio

$\begin{array}{lllll}\text { Model } & 12 & 1.6699543 & 0.139163 & 1.7635\end{array}$

$\begin{array}{lllll}\text { Error } & 13 & 1.0258926 & 0.078915 \text { Prob }>\text { F }\end{array}$

$\begin{array}{llll}\text { C. Total } & 25 & 2.6958469 & 0.1618\end{array}$

Expected Mean Squares

The Mean Square per row by the Variance Component per column

$\begin{array}{lrr}\text { EMS } & \text { Intercept } & \text { Batch\&Random } \\ \text { Intercept } & 0 & 0 \\ \text { Batch\&Random } & 0 & 2\end{array}$

plus 1.0 times Residual Error Variance

Variance Component Estimates

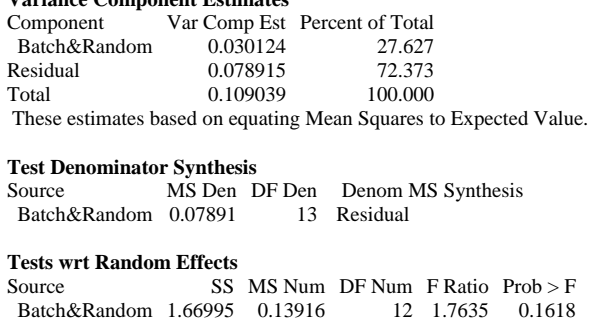


WSRC-STI-2006-00068

Revision 0

Exhibit A7. Analysis of Variance by Preparation Method, ICP, and Analyte (continued)

Sample Type=ARG-1, Prep=Fusion, ICP=M-14, Analyte=Fe/Li Response Measurement

Summary of Fit

\begin{tabular}{|c|c|c|c|c|}
\hline \multicolumn{3}{|c|}{ RSquare } & 0.742907 & \\
\hline \multicolumn{3}{|c|}{ RSquare Adj } & 0.504178 & \\
\hline \multicolumn{3}{|c|}{ Root Mean Square Error } & 0.099839 & \\
\hline \multicolumn{3}{|c|}{ Mean of Response } & 6.551828 & \\
\hline \multicolumn{3}{|c|}{ Observations (or Sum Wgts) } & 28 & \\
\hline \multicolumn{5}{|c|}{ Analysis of Variance } \\
\hline Source & DF & Sum of Squares & Mean Square & F Ratio \\
\hline Model & 13 & 0.40324659 & 0.031019 & 3.1119 \\
\hline Error & 14 & 0.13954887 & 0.009968 & Prob $>$ F \\
\hline C. Total & 27 & 0.54279546 & & 0.0219 \\
\hline
\end{tabular}

Expected Mean Squares

The Mean Square per row by the Variance Component per column

$\begin{array}{lrr}\text { EMS } & \text { Intercept } & \text { Batch\&Random } \\ \text { Intercept } & 0 & 0\end{array}$

Batch\&Random $\quad 0 \quad 2$

plus 1.0 times Residual Error Variance

Variance Component Estimates

Component Var Comp Est Percent of Total

Batch\&Random $\quad 0.010526 \quad 51.361$

Residual $\quad 0.009968 \quad 48.639$

Total $\quad 0.020493 \quad 100.000$

These estimates based on equating Mean Squares to Expected Value.

Test Denominator Synthesis

Source MS Den DF Den Denom MS Synthesis

Batch\&Random $0.00997 \quad 14$ Residual

Tests wrt Random Effects
Source MS Num DF Num F Ratio Prob > F

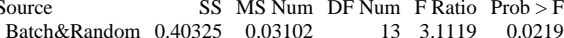

Sample Type=ARG-1, Prep=Fusion, ICP=M-14, Analyte=Fe/Mg Response Measurement

Summary of Fit

RSquare $\quad 0.726628$

RSquare Adj $\quad 0.474285$

Root Mean Square Error $\quad 0.159897$

Mean of Response $\quad 19.14317$

Observations (or Sum Wgts) 26

Analysis of Variance

Source DF Sum of Squares Mean Square F Ratio

\begin{tabular}{lllll} 
Model & 12 & 0.8834495 & 0.073621 & 2.8795 \\
\hline
\end{tabular}

$\begin{array}{lllll}\text { Error } & 13 & 0.3323710 & 0.025567 & \text { Prob }>\text { F }\end{array}$

$\begin{array}{lll}\text { C. Total } 25 & 1.2158205 & 0.0350\end{array}$

Expected Mean Squares

The Mean Square per row by the Variance Component per column

$\begin{array}{lrr}\text { EMS } & \text { Intercept } & \text { Batch\&Random } \\ \text { Intercept } & 0 & 0\end{array}$

Batch\&Random $\quad 0 \quad 2$

plus 1.0 times Residual Error Variance

Variance Component Estimates

Component Var Comp Est Percent of Total

Batch\&Random $\quad 0.024027 \quad 48.447$

$\begin{array}{lll}\text { Residual } & 0.025567 & 51.553\end{array}$

Total $\quad 0.049594 \quad 100.000$

These estimates based on equating Mean Squares to Expected Value.

Test Denominator Synthesis

Source MS Den DF Den Denom MS Synthesis

$\begin{array}{llll}\text { Batch\&Random } & 0.02557 & 13 & \text { Residual }\end{array}$

Tests wrt Random Effects

Source

SS MS Num DF Num F Ratio Prob $>$ F

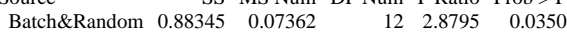

Sample Type=ARG-1, Prep=Fusion, ICP=M-14, Analyte=Fe $/$ Mn Response Measurement

Summary of Fit

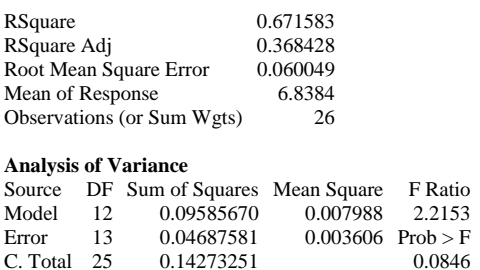

Expected Mean Squares

The Mean Square per row by the Variance Component per column

$\begin{array}{lrr}\text { EMS } & \text { Intercept } & \text { Batch\&Random } \\ \text { Intercept } & 0 & 0\end{array}$

Batch\&Random $\quad 0 \quad 2$

plus 1.0 times Residual Error Variance

Variance Component Estimates

\begin{tabular}{crr} 
Component & Var Comp Est & Percent of Total \\
Batch\&Random & 0.002191 & 37.798 \\
\hline & 0.003606 & 62.202
\end{tabular}

$\begin{array}{lll}\text { Batch\&Random } & 0.002191 & 37.798 \\ \text { Residual } & 0.003606 & 62.202\end{array}$

Total $\quad 0.005797 \quad 100.000$

These estimates based on equating Mean Squares to Expected Value.

Test Denominator Synthesis

Source MS Den DF Den Denom MS Synthesis

Batch\&Random $0.00361 \quad 13$ Residual

Tests wrt Random Effects
Source SS MS Num DF Num F Ratio Prob $>$ F

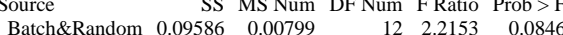

Sample Type=ARG-1, Prep=Fusion, ICP=M-14, Analyte=Fe/Ni Response Measurement

Summary of Fit

RSquare $\quad 0.666313$

RSquare Adj $\quad 0.356462$

Root Mean Square Error $\quad 0.217527$

Mean of Response $\quad 12.19136$

Observations (or Sum Wgts) $\quad 28$

Analysis of Variance

Source DF Sum of Squares Mean Square F Ratio

$\begin{array}{lllll}\text { Model } & 13 & 1.3228030 & 0.101754 & 2.1504\end{array}$

$\begin{array}{lllll}\text { Error } & 14 & 0.6624536 & 0.047318 & \text { Prob }>\text { F }\end{array}$

$\begin{array}{llrr}\text { C. Total } & 27 & 1.9852566 & 0.0843\end{array}$

Expected Mean Squares

The Mean Square per row by the Variance Component per column

$\begin{array}{lrr}\text { EMS } & \text { Intercept } & \text { Batch\&Random } \\ \text { Intercept } & 0 & 0 \\ \text { Batch\&Random } & 0 & 2\end{array}$

plus 1.0 times Residual Error Variance

$\begin{array}{ll}\text { Variance Component Estimates } \\ \text { Component } & \text { Var Comp Est Percent of Total }\end{array}$

$\begin{array}{crr}\text { Component } & \text { Var Comp Est } & \text { Percent of Total } \\ \text { Batch\&Random } & 0.027218 & 36.517 \\ \text { Residual } & 0.047318 & 63.483 \\ \text { Tor }\end{array}$

$\begin{array}{llr}\text { Residual } & 0.047318 & 63.483 \\ \text { Total } & 0.074536 & 100.000\end{array}$

These estimates based on equating Mean Squares to Expected Value.

Test Denominator Synthesis

Source MS Den DF Den Denom MS Synthesis

$\begin{array}{rrrr}\text { Source } & \text { MS Den } & \text { DF Den } & \text { Denom } \\ \text { Batch\&Random } & 0.04732 & 14 & \text { Residual }\end{array}$

Tests wrt Random Effects

Source SS MS Num DF Num F Ratio Prob > F

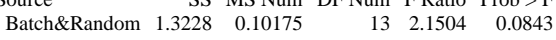


WSRC-STI-2006-00068

Revision 0

Exhibit A7. Analysis of Variance by Preparation Method, ICP, and Analyte (continued)

Sample Type=ARG-1, Prep=Fusion, ICP=M-14, Analyte=Fe/U Response Measurement

Summary of Fi

\begin{tabular}{|c|c|c|c|c|}
\hline \multicolumn{3}{|c|}{ RSquare } & \multicolumn{2}{|l|}{0.648233} \\
\hline \multicolumn{3}{|c|}{ RSquare Adj } & 0.323525 & \\
\hline \multicolumn{3}{|c|}{ Root Mean Square Error } & 202.3171 & \\
\hline \multicolumn{3}{|c|}{ Mean of Response } & 68.55243 & \\
\hline \multicolumn{3}{|c|}{ Observations (or Sum Wgts) } & 26 & \\
\hline \multicolumn{5}{|c|}{ Analysis of Variance } \\
\hline Source & DF & Sum of Squares & s Mean Square & F Ratio \\
\hline Model & 12 & 980582.7 & $7 \quad 81715.2$ & 1.9964 \\
\hline Error & 13 & 532118.8 & 40932.2 & Prob $>$ F \\
\hline C. Total & 25 & 1512701.5 & & 0.1154 \\
\hline
\end{tabular}

Expected Mean Squares

The Mean Square per row by the Variance Component per column

$\begin{array}{lrr}\text { EMS } & \text { Intercept } & \text { Batch\&Random } \\ \text { Intercept } & 0 & 0\end{array}$

Batch\&Random $\quad 0 \quad 2$

plus 1.0 times Residual Error Variance

Variance Component Estimates

Component Var Comp Est Percent of Total

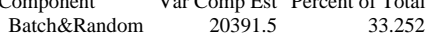

Residual $\quad 40932.22 \quad 66.748$

Total $\quad 61323.72 \quad 100.000$

These estimates based on equating Mean Squares to Expected Value.

Test Denominator Synthesis

Source MS Den DF Den Denom MS Synthesis

Batch\&Random $40932.2 \quad 13$ Residual

Tests wrt Random Effects

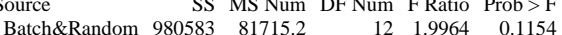

Sample Type=ARG-1, Prep=Fusion, ICP $=M-14$, Analyte $=K$

Response Measurement

Summary of Fit

RSquare $\quad 0.679696$

RSquare Adj $\quad 0.382271$

Root Mean Square Error $\quad 0.18012$

Mean of Response $\quad 2.165036$

Observations (or Sum Wgts) $\quad 28$

Analysis of Variance

Source DF Sum of Squares Mean Square F Ratio

$\begin{array}{lllll}\text { Model } & 13 & 0.9638425 & 0.074142 & 2.2853 \\ & 14 & 0.4542065 & 0.032443 & \end{array}$

$\begin{array}{lllll}\text { Error } & 14 & 0.4542065 & 0.032443 \text { Prob }>\text { F }\end{array}$

$\begin{array}{llll}\text { C. Total } & 27 & 1.4180490 & 0.0690\end{array}$

Expected Mean Square

The Mean Square per row by the Variance Component per column

$\begin{array}{lrr}\text { EMS } & \text { Intercept } & \text { Batch\&Random } \\ \text { Intercept } & 0 & 0\end{array}$

Batch\&Random $\quad 0 \quad 2$

plus 1.0 times Residual Error Variance

Variance Component Estimates

Component Var Comp Est Percent of Total

Batch\&Random $\quad 0.020849 \quad 39.122$

$\begin{array}{lll}\text { Residual } & 0.032443 & 60.878\end{array}$

Total $\quad 0.053293 \quad 100.000$

These estimates based on equating Mean Squares to Expected Value.

Test Denominator Synthesis

Source MS Den DF Den Denom MS Synthesis

Batch\&Random $0.03244 \quad 14$ Residual

Tests wrt Random Effects

Source

SS MS Num DF Num F Ratio Prob > F

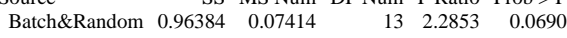

Sample Type=ARG-1, Prep=Fusion, ICP=M-14, Analyte=Li Response Measurement

Summary of Fit

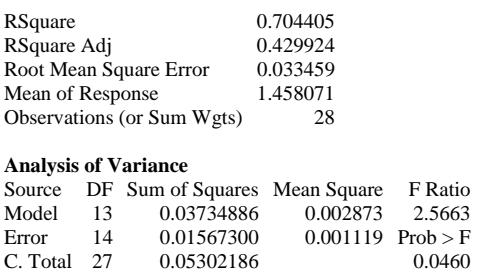

Expected Mean Squares

The Mean Square per row by the Variance Component per column

$\begin{array}{lrr}\text { EMS } & \text { Intercept } & \text { Batch\&Random } \\ \text { Intercept } & 0 & 0\end{array}$

Batch\&Random $\quad 0 \quad 2$

plus 1.0 times Residual Error Variance

Variance Component Estimates

$\begin{array}{crr}\text { Component } & \text { Var Comp Est } & \text { Percent of Total } \\ \text { Batch\&Random } & 0.000877 & 43.920 \\ \text { Residul } & 0.001119 & 56.080\end{array}$

$\begin{array}{lrr}\text { Batch\&Random } & 0.000877 & 43.920 \\ \text { Residual } & 0.001119 & 56.080 \\ \text { Total } & 0.001996 & 100.000\end{array}$

$\begin{array}{lcc}\text { Total } & 0.001996 & 100.000 \\ \text { These estimates based on equating Mean Squares to Expected Value. }\end{array}$

Test Denominator Synthesis

Source MS Den DF Den Denom MS Synthesis

Batch\&Random $0.00112 \quad 14$ Residual

Tests wrt Random Effects
Source SS MS Num DF Num F Ratio Prob $>$ F

$\begin{array}{lrrrrr}\text { Source } & \text { SS } & \text { MS Num } & \text { DF Num } & \text { F Ratio } & \text { Prob > F } \\ \text { Batch\&Random } & 0.03735 & 0.00287 & 13 & 2.5663 & 0.0460\end{array}$

Sample Type=ARG-1, Prep=Fusion, ICP=M-14, Analyte $=$ Mg Response Measurement

Summary of Fit

RSquare Adj $\quad 0.68721$

Root Mean Square Error $\quad 0.39677$

Mean of Response

$\begin{array}{lr}\text { Mean of Response } & 0.496357 \\ \text { Observations (or Sum Wgts) } & 28\end{array}$

Analysis of Variance

Source DF Sum of Squares Mean Square F Ratio

$\begin{array}{lllll}\text { Model } & 13 & 0.00514343 & 0.000396 & 2.3661\end{array}$

$\begin{array}{llllll}\text { Error } & 14 & 0.00234100 & 0.000167 & \text { Prob }>\text { F }\end{array}$

$\begin{array}{llll}\text { C. Total } & 27 & 0.00748443 & 0.0613\end{array}$

Expected Mean Squares

The Mean Square per row by the Variance Component per column

$\begin{array}{lrr}\text { EMS } & \text { Intercept } & \text { Batch\&Random } \\ \text { Intercept } & 0 & 0 \\ \text { Batch\&Random } & 0 & 2\end{array}$

plus 1.0 times Residual Error Variance

Variance Component Estimates
Component $\quad$ Var Comp Est Percent of Total

$\begin{array}{crr}\text { Component } & \text { Var Comp Est } & \text { Percent of Total } \\ \text { Batch\&Random } & 0.000114 & 40.584 \\ \text { Residual } & 0.000167 & 59.416\end{array}$

$\begin{array}{lrr}\text { Residual } & 0.000167 & 59.416 \\ \text { Total } & 0.000281 & 100.000\end{array}$

These estimates based on equating Mean Squares to Expected Value.

Test Denominator Synthesis

Source MS Den DF Den Denom MS Synthesis

$\begin{array}{lrrr}\text { Source } & \text { MS Den } & \text { DF Den } & \text { Denom } \\ \text { Batch\&Random } & 0.00017 & 14 & \text { Residual }\end{array}$

Tests wrt Random Effects

Source SS MS Num DF Num F Ratio Prob > F

$\begin{array}{rrrrrr}\text { Batch\&Random } & 0.00514 & 0.0004 & 13 & 2.3661 & 0.0613\end{array}$ 
WSRC-STI-2006-00068

Revision 0

Exhibit A7. Analysis of Variance by Preparation Method, ICP, and Analyte (continued)

Sample Type=ARG-1, Prep=Fusion, ICP=M-14, Analyte $=$ Mn Response Measurement

Summary of Fit

\begin{tabular}{|c|c|c|c|c|}
\hline \multicolumn{3}{|c|}{ RSquare } & 0.635363 & \\
\hline \multicolumn{3}{|c|}{ RSquare Adj } & 0.298775 & \\
\hline \multicolumn{3}{|c|}{ Root Mean Square Error } & 0.029966 & \\
\hline \multicolumn{3}{|c|}{ Mean of Response } & 1.397192 & \\
\hline \multicolumn{3}{|c|}{ Observations (or Sum Wgts) } & 26 & \\
\hline \multicolumn{5}{|c|}{ Analysis of Variance } \\
\hline Source & DF & Sum of Squares & Mean Square & F Ratio \\
\hline Model & 12 & 0.02034054 & 0.001695 & 1.8877 \\
\hline Error & 13 & 0.01167350 & 0.000898 & Prob $>F$ \\
\hline C. Total & 25 & 0.03201404 & & 0.1349 \\
\hline
\end{tabular}

Expected Mean Squares

The Mean Square per row by the Variance Component per column

$\begin{array}{lrr}\text { EMS } & \text { Intercept } & \text { Batch\&Random } \\ \text { Intercept } & 0 & 0\end{array}$

Batch\&Random $\quad 0 \quad 2$

plus 1.0 times Residual Error Variance

Variance Component Estimates

Component Var Comp Est Percent of Total

$\begin{array}{rrr}\text { Batch\&Random } & 0.000399 & 30.740\end{array}$

$\begin{array}{lll}\text { Residual } & 0.000898 & 69.260\end{array}$

Total $\quad 0.001297 \quad 100.000$

These estimates based on equating Mean Squares to Expected Value.

Test Denominator Synthesis

Source MS Den DF Den Denom MS Synthesis

Batch\&Random $0.0009 \quad 13$ Residual

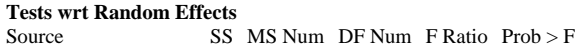

$\begin{array}{lrrrrr}\text { Source } & \text { SS } & \text { MS Num } & \text { DF Num } & \text { F Ratio } & \text { Prob }>\text { F } \\ \text { Batch\&Random } & 0.02034 & 0.0017 & 12 & 1.8877 & 0.1349\end{array}$

Sample Type=ARG-1, Prep=Fusion, ICP=M-14, Analyte $=\mathbf{M n} / \mathbf{M g}$ Response Measurement

Summary of Fit

RSquare $\quad 0.747367$

RSquare Adj $\quad 0.512779$

Root Mean Square Error $\quad 0.029015$

Mean of Response 2.80167

Observations (or Sum Wgts) $\quad 28$

Analysis of Variance

Source DF Sum of Squares Mean Square F Ratio

$\begin{array}{lllll}\text { Model } & 13 & 0.03486830 & 0.002682 & 3.1859\end{array}$

$\begin{array}{lllll}\text { Error } & 14 & 0.01178655 & 0.000842 & \text { Prob }>\text { F }\end{array}$

$\begin{array}{llll}\text { C. Total } & 27 & 0.04665485 & 0.0199\end{array}$

Expected Mean Squares

The Mean Square per row by the Variance Component per column

$\begin{array}{lrr}\text { EMS } & \text { Intercept } & \text { Batch\&Random } \\ \text { Intercept } & 0 & 0\end{array}$

$\begin{array}{lll}0 & 0 \\ \text { Batch\&Random } & 0 & 2\end{array}$

plus 1.0 times Residual Error Variance

Variance Component Estimates

Component Var Comp Est Percent of Total

Batch\&Random $\quad 0.00092 \quad 52.220$

$\begin{array}{lll}\text { Residual } & 0.000842 & 47.780\end{array}$

Total $\quad 0.001762 \quad 100.000$

These estimates based on equating Mean Squares to Expected Value.

Test Denominator Synthesis

Source MS Den DF Den Denom MS Synthesis

Batch\&Random $\quad 0.00084 \quad 14$ Residual

Tests wrt Random Effects

Source SS MS Num DF Num F Ratio Prob $>$ F

$\begin{array}{llllll}\text { Batch\&Random } & 0.03487 & 0.00268 & 13 & 3.1859 & 0.0199\end{array}$

Sample Type=ARG-1, Prep=Fusion, ICP=M-14, Analyte=Na
Sample Type=ARG-1, Prep=Fusion, ICP=M-14, Analyte=Ni Response Measurement

Summary of Fit

$\begin{array}{lr}0.4998 \\ \text { RSquare Adj } & 0.035328\end{array}$

Root Mean Square Error $\quad 0.023749$

Mean of Response $\quad 0.783607$

Observations (or Sum Wgts) $\quad 28$

Analysis of Variance

Source DF Sum of Squares Mean Square F Ratio

$\begin{array}{lllll}\text { Model } & 13 & 0.00789018 & 0.000607 & 1.076\end{array}$

$\begin{array}{lllll}\text { Error } 14 & 0.00789650 & 0.000564 & \text { Prob }>\text { F }\end{array}$

$\begin{array}{llll}\text { C. Total } 27 & 0.01578668 & 0.4447\end{array}$

Expected Mean Squares

The Mean Square per row by the Variance Component per column

$\begin{array}{lrr}\text { EMS } & \text { Intercept } & \text { Batch\&Random } \\ \text { Intercept } & 0 & 0\end{array}$

Batch\&Random $\quad 0 \quad 2$

plus 1.0 times Residual Error Variance

Variance Component Estimates

Component Var Comp Est Percent of Total

$\begin{array}{rrr}\text { Component } & \text { Var Comp Est } & \text { Percent of Total } \\ \text { Batch\&Random } & 0.000021 & 3.664\end{array}$

$\begin{array}{lrr}\text { Batch\&Random } & 0.000021 & 3.664 \\ \text { Residual } & 0.000564 & 96.336\end{array}$

$\begin{array}{lrr}\text { Total } & 0.000585 & 100.000\end{array}$

These estimates based on equating Mean Squares to Expected Value.

Test Denominator Synthesis

Source MS Den DF Den Denom MS Synthesis

Batch\&Random $0.00056 \quad 14$ Residual

Tests wrt Random Effects
Source SS MS Num DF Num F Ratio Prob $>$ F

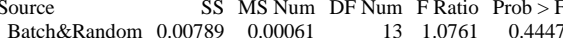

Sample Type=ARG-1, Prep=Fusion, ICP=M-14, Analyte=Si

Response Measurement

Summary of Fit

RSquare $\quad 0.603838$

RSquare Adj $\quad 0.235974$

Root Mean Square Error $\quad 0.513036$

Mean of Response 22.41382

Observations (or Sum Wgts) 28

Analysis of Variance

Source DF Sum of Squares Mean Square F Ratio

$\begin{array}{lllll}\text { Model } & 13 & 5.6165726 & 0.432044 & 1.6415\end{array}$

$\begin{array}{lllll}\text { Error } & 14 & 3.6848815 & 0.263206 & \text { Prob }>\text { F }\end{array}$

$\begin{array}{llrr}\text { C. Total } & 27 & 9.3014541 & 0.1845\end{array}$

Expected Mean Squares

The Mean Square per row by the Variance Component per column

$\begin{array}{lrr}\text { EMS } & \text { Intercept } & \text { Batch\&Random } \\ \text { Intercept } & 0 & 0 \\ \text { Batch\&Random } & 0 & 2\end{array}$

plus 1.0 times Residual Error Variance

Variance Component Estimates
Component Var Comp Est Percent of Total

$\begin{array}{crr}\text { Component } & \text { Var Comp Est } & \text { Percent of Total } \\ \text { Batch\&Random } & 0.084419 & 24.285 \\ \text { Residual } & 0.263206 & 75.715 \\ \text { Told } & 0.347625 & 150.000\end{array}$

$\begin{array}{lrr}\text { Residual } & 0.263206 & 75.715 \\ \text { Total } & 0.347625 & 100.000\end{array}$

These estimates based on equating Mean Squares to Expected Value.

Test Denominator Synthesis

Source MS Den DF Den Denom MS Synthesis

$\begin{array}{rrrr}\text { Source } & \text { MS Den } & \text { DF Den } & \text { Denom } \\ \text { Batch\&Random } & 0.26321 & 14 & \text { Residual }\end{array}$

Tests wrt Random Effects

Source SS MS Num DF Num F Ratio Prob $>$ F

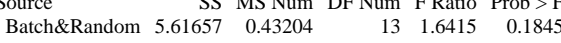


WSRC-STI-2006-00068

Revision 0

Exhibit A7. Analysis of Variance by Preparation Method, ICP, and Analyte (continued)

Sample Type=ARG-1, Prep=Fusion, ICP=M-14, Analyte=Sum of Oxides Response Measurement

Summary of Fit

\begin{tabular}{|c|c|c|c|}
\hline \multicolumn{2}{|c|}{ RSquare } & 0.578353 & \\
\hline \multicolumn{2}{|c|}{ RSquare Adj } & 0.186823 & \\
\hline \multicolumn{2}{|c|}{ Root Mean Square Error } & 1.808654 & \\
\hline \multicolumn{2}{|c|}{ Mean of Response } & 86.17594 & \\
\hline \multicolumn{2}{|c|}{ Observations (or Sum Wgts) } & 28 & \\
\hline \multicolumn{4}{|c|}{ Analysis of Variance } \\
\hline Source & DF Sum of Squares & s Mean Square & F Ratio \\
\hline Model & $13 \quad 62.81774$ & $4 \quad 4.83213$ & 1.4772 \\
\hline Error & 45.79722 & 3.27123 & Prob $>$ F \\
\hline C. Total & 108.61496 & & 0.2390 \\
\hline
\end{tabular}

Expected Mean Squares

The Mean Square per row by the Variance Component per column

$\begin{array}{lrr}\text { EMS } & \text { Intercept } & \text { Batch\&Random } \\ \text { Intercept } & 0 & 0\end{array}$

Batch\&Random $\quad 0 \quad 2$

plus 1.0 times Residual Error Variance

Variance Component Estimates

Component Var Comp Est Percent of Total

Batch\&Random $\quad 0.780452 \quad 19.262$

Residual $\quad 3.27123 \quad 80.738$

Total $\quad 4.051682 \quad 100.000$

These estimates based on equating Mean Squares to Expected Value.

Test Denominator Synthesi

Source MS Den DF Den Denom MS Synthesis

Batch\&Random $3.27123 \quad 14$ Residual

Tests wrt Random Effects
Source MS Num DF Num F Ratio Prob > F

$\begin{array}{lrrrrr}\text { Source } & \text { SS } & \text { MS Num } & \text { DF Num } & \text { F Ratio } & \text { Prob > F } \\ \text { Batch\&Random } & 62.8177 & 4.83213 & 13 & 1.4772 & 0.2390\end{array}$

Sample Type=ARG-1, Prep=Fusion, $\mathbf{I C P}=$ M-14, Analyte=Ti

Response Measurement

Summary of Fit

RSquare $\quad 0.615148$

RSquare Adj $\quad 0.259899$

Root Mean Square Error $\quad 0.013178$

Mean of Response $\quad 0.671654$

Observations (or Sum Wgts) $\quad 26$

Analysis of Variance

Source DF Sum of Squares Mean Square F Ratio

$\begin{array}{lllll}\text { Model } & 12 & 0.00360838 & 0.000301 & 1.7316\end{array}$

$\begin{array}{lllll}\text { Error } & 13 & 0.00225750 & 0.000174 & \text { Prob }>\text { F }\end{array}$

$\begin{array}{llll}\text { C. Total } & 25 & 0.00586588 & 0.1696\end{array}$

Expected Mean Square

The Mean Square per row by the Variance Component per column

$\begin{array}{lrr}\text { EMS } & \text { Intercept } & \text { Batch\&Random } \\ \text { Intercept } & 0 & 0\end{array}$

Batch\&Random $\quad 0 \quad 2$

plus 1.0 times Residual Error Variance

Variance Component Estimates

Component Var Comp Est Percent of Total

$\begin{array}{lll}\text { Batch\&Random } \quad 0.000064 & 26.783\end{array}$

$\begin{array}{lll}\text { Residual } & 0.000174 & 73.217\end{array}$

Total $\quad 0.000237 \quad 100.000$

These estimates based on equating Mean Squares to Expected Value.

Test Denominator Synthesis

Source MS Den DF Den Denom MS Synthesis

$\begin{array}{llll}\text { Batch\&Random } & 0.00017 & 13 & \text { Residual }\end{array}$

Tests wrt Random Effects

Source

SS MS Num DF Num F Ratio Prob $>$ F

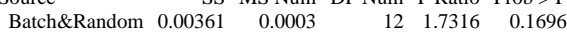

Sample Type=ARG-1, Prep=Fusion, ICP=M-14, Analyte=U Response Measurement

Summary of Fit

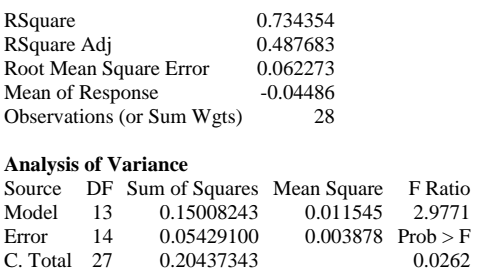

Expected Mean Squares

The Mean Square per row by the Variance Component per column

$\begin{array}{lrr}\text { EMS } & \text { Intercept } & \text { Batch\&Random } \\ \text { Intercept } & 0 & 0\end{array}$

Batch\&Random $\quad 0 \quad 2$

plus 1.0 times Residual Error Variance

Variance Component Estimates

$\begin{array}{crr}\text { Component } & \text { Var Comp Est } & \text { Percent of Total } \\ \text { Batch\&Random } & 0.003833 & 49.712 \\ \text { Residul } & 0.003878 & 50.288\end{array}$

$\begin{array}{lll}\text { Residual } & 0.003878 & 50.288\end{array}$

Total $\quad 0.007711 \quad 100.000$

These estimates based on equating Mean Squares to Expected Value.

Test Denominator Synthesis

Source MS Den DF Den Denom MS Synthesis

Batch\&Random $0.00388 \quad 14$ Residual

Tests wrt Random Effects
Source SS MS Num DF Num F Ratio Prob $>$ F Batch\&Random $0.15008 \quad 0.01154 \quad 13 \quad 297710.0262$

Sample Type=ARG-1, Prep=Fusion, ICP=M-14, Analyte=U/Ca Response Measurement

Summary of Fit

RSquare Adj $\quad 0.398169$

Root Mean Square Error $\quad 0.07285$

Mean of Response $\quad-0.049$

Observations (or Sum Wgts) 28

Analysis of Variance

Source DF Sum of Squares Mean Square F Ratio

$\begin{array}{lllll}\text { Model } & 13 & 0.16379532 & 0.012600 & 2.3741\end{array}$

$\begin{array}{lllll}\text { Error } & 14 & 0.07430022 & 0.005307 & \text { Prob }>\text { F }\end{array}$

$\begin{array}{llll}\text { C. Total } & 27 & 0.23809554 & 0.0606\end{array}$

Expected Mean Squares

The Mean Square per row by the Variance Component per column

$\begin{array}{lrr}\text { EMS } & \text { Intercept } & \text { Batch\&Random } \\ \text { Intercept } & 0 & 0 \\ \text { Batch\&Random } & 0 & 2\end{array}$

plus 1.0 times Residual Error Variance

Variance Component Estimates
Component $\quad$ Var Comp Est Percent of Total

$\begin{array}{lrr}\text { Component } & \text { Var Comp Est } & \text { Percent of Total } \\ \text { Batch\&Random } & 0.003646 & 40.725 \\ \text { Residual } & 0.005307 & 59.275 \\ \text { Told } & 0.008953 & 100.000\end{array}$

$\begin{array}{llr}\text { Residual } & 0.005307 & 59.275 \\ \text { Total } & 0.008953 & 100.000\end{array}$

These estimates based on equating Mean Squares to Expected Value.

Test Denominator Synthesis

Source MS Den DF Den Denom MS Synthesis

$\begin{array}{lrrr}\text { Source } & \text { MS Den } & \text { DF Den } & \text { Denom } \\ \text { Batch\&Random } & 0.00531 & 14 & \text { Residual }\end{array}$

Tests wrt Random Effects

Source SS MS Num DF Num F Ratio Prob > F

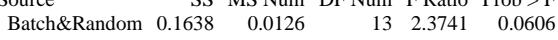

Sample Type=ARG-1, Prep=Fusion, ICP=M-14, Analyte=Zr 
WSRC-STI-2006-00068

Revision 0

Exhibit A7. Analysis of Variance by Preparation Method, ICP, and Analyte (continued)

Sample Type=ARG-1, Prep=Mixed Acid, ICP=M-13, Analyte=Al Response Measurement

Summary of Fi

\begin{tabular}{|c|c|c|c|c|}
\hline \multicolumn{3}{|c|}{ RSquare } & \multicolumn{2}{|l|}{0.666193} \\
\hline \multicolumn{3}{|c|}{ RSquare Adj } & 0.343513 & \\
\hline \multicolumn{3}{|c|}{ Root Mean Square Error } & 0.041992 & \\
\hline \multicolumn{3}{|c|}{ Mean of Response } & 2.298967 & \\
\hline \multicolumn{3}{|c|}{ Observations (or Sum Wgts) } & 60 & \\
\hline \multicolumn{5}{|c|}{ Analysis of Variance } \\
\hline Source & DF & Sum of Squares & Mean Square & F Ratio \\
\hline Model & 29 & 0.10557293 & 0.003640 & 2.0646 \\
\hline Error & 30 & 0.05289900 & 0.001763 & Prob $>$ F \\
\hline C. Total & 59 & 0.15847193 & & 0.0264 \\
\hline
\end{tabular}

Expected Mean Squares

The Mean Square per row by the Variance Component per column

$\begin{array}{lrr}\text { EMS } & \text { Intercept } & \text { Batch\&Random } \\ \text { Intercept } & 0 & 0\end{array}$

Batch\&Random $\quad 0 \quad 2$

plus 1.0 times Residual Error Variance

Variance Component Estimates

Component Var Comp Est Percent of Total

$\begin{array}{rrr}\text { Batch\&Random } & 0.000939 & 34.738\end{array}$

Residual $\quad 0.001763 \quad 65.262$

Total $\quad 0.002702 \quad 100.000$

These estimates based on equating Mean Squares to Expected Value.

Test Denominator Synthesis

Source MS Den DF Den Denom MS Synthesis

Batch\&Random $0.00176 \quad 30$ Residual

Tests wrt Random Effects
Source SS MS Num DF Num F Ratio Prob > F

$\begin{array}{lrrrrr}\text { Source } & \text { SS } & \text { MS Num } & \text { DF Num } & \text { F Ratio } & \text { Prob > F } \\ \text { Batch\&Random } & 0.10557 & 0.00364 & 29 & 2.0646 & 0.0264\end{array}$

Sample Type=ARG-1, Prep=Mixed Acid, ICP=M-13, Analyte=Al/Ca Response Measurement

Summary of Fit

RSquare

RSquare Adj $\quad 0.348113$

Root Mean Square Error $\quad 0.033412$

Mean of Response 2.312817

Observations (or Sum Wgts) 62

Analysis of Variance

Source DF Sum of Squares Mean Square F Ratio

$\begin{array}{lllll}\text { Model } & 30 & 0.06985549 & 0.002329 & 2.0858\end{array}$

$\begin{array}{lllll}\text { Error } & 31 & 0.03460710 & 0.001116 & \text { Prob }>\text { F }\end{array}$

$\begin{array}{llll}\text { C. Total } & 61 & 0.10446259 & 0.0229\end{array}$

Expected Mean Square

The Mean Square per row by the Variance Component per column

$\begin{array}{lrr}\text { EMS } & \text { Intercept } & \text { Batch\&Random } \\ \text { Intercept } & 0 & 0\end{array}$

Batch\&Random $\quad 0 \quad 2$

plus 1.0 times Residual Error Variance

Variance Component Estimates

Component Var Comp Est Percent of Total

Batch\&Random $\quad 0.000606 \quad 35.187$

$\begin{array}{lll}\text { Residual } & 0.001116 & 64.813\end{array}$

Total $\quad 0.001722 \quad 100.000$

These estimates based on equating Mean Squares to Expected Value.

Test Denominator Synthesis

Source MS Den DF Den Denom MS Synthesis

Batch\&Random $0.00112 \quad 31$ Residual

Tests wrt Random Effects

Source

SS MS Num DF Num F Ratio Prob $>$ F

$\begin{array}{lrrrrr}\text { Batch\&Random } & 0.06986 & 0.00233 & 30 & 2.0858 & 0.0229\end{array}$
Sample Type=ARG-1, Prep=Mixed Acid, ICP=M-13, Analyte=Al/Mg Response Measurement

Summary of Fit

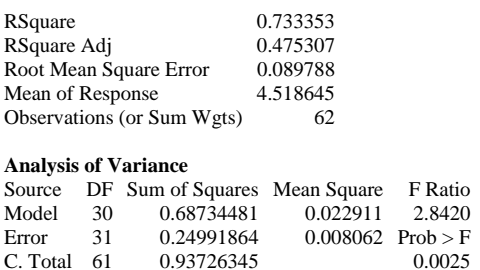

Expected Mean Squares

The Mean Square per row by the Variance Component per column

$\begin{array}{lrr}\text { EMS } & \text { Intercept } & \text { Batch\&Random } \\ \text { Intercept } & 0 & 0\end{array}$

Batch\&Random $\quad 0 \quad 2$

plus 1.0 times Residual Error Variance

Variance Component Estimates

$\begin{array}{crr}\text { Component } & \text { Var Comp Est } & \text { Percent of Total } \\ \text { Batch\&Random } & 0.007425 & 47.943 \\ \text { Residual } & 0.008062 & 52.057\end{array}$

Total $\quad 0.015487 \quad 100.000$

These estimates based on equating Mean Squares to Expected Value.

Test Denominator Synthesis

Source MS Den DF Den Denom MS Synthesis

Batch\&Random $0.00806 \quad 31$ Residual

Tests wrt Random Effects
$\begin{array}{lrrrrr}\text { Source } & \text { MS Num } & \text { DF Num } & \text { F Ratio } & \text { Prob }>\text { F } \\ \text { Batch\&Random } & 0.68734 & 0.02291 & 30 & 2.8420 & 0.0025\end{array}$

Sample Type=ARG-1, Prep=Mixed Acid, ICP=M-13, Analyte=Al/Mn Response Measurement

Summary of Fit

RSquare Adj $\quad 0.432312$

Root Mean Square Error $\quad 0.027375$

Mean of Response $\quad 1.654021$

Observations (or Sum Wgts) 62

Analysis of Variance

Source DF Sum of Squares Mean Square F Ratio

$\begin{array}{lllll}\text { Model } & 30 & 0.05729240 & 0.001910 & 2.5484\end{array}$

$\begin{array}{lllll}\text { Error } & 31 & 0.02323067 & 0.000749 & \text { Prob }>\text { F }\end{array}$

$\begin{array}{lllr}\text { C. Total } & 61 & 0.08052307 & 0.0058\end{array}$

Expected Mean Squares

The Mean Square per row by the Variance Component per column

$\begin{array}{lrr}\text { EMS } & \text { Intercept } & \text { Batch\&Random } \\ \text { Intercept } & 0 & 0 \\ \text { Batch\&Random } & 0 & 2\end{array}$

plus 1.0 times Residual Error Variance

Variance Component Estimates

$\begin{array}{lrr}\text { Component } & \text { Var Comp Est } & \text { Percent of Total } \\ \text { Batch\&Random } & 0.00058 & 43.637 \\ \text { Residual } & 0.000749 & 56.363\end{array}$

$\begin{array}{lrr}\text { Residual } & 0.000749 & 56.363 \\ \text { Total } & 0.00133 & 100.000\end{array}$

These estimates based on equating Mean Squares to Expected Value.

Test Denominator Synthesis

Source MS Den DF Den Denom MS Synthesis

$\begin{array}{crrr}\text { Source } & \text { MS Den } & \text { DF Den } & \text { Denom MS } \\ \text { Batch\&Random } & 0.00075 & 31 & \text { Residual }\end{array}$

Tests wrt Random Effects

Source SS MS Num DF Num F Ratio Prob > F

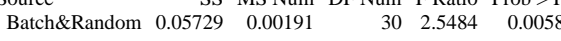

Sample Type=ARG-1, Prep=Mixed Acid, ICP=M-13, Analyte=B

Sample Type=ARG-1, Prep=Mixed Acid, ICP=M-13, Analyte=B/Li 
WSRC-STI-2006-00068

Revision 0

Exhibit A7. Analysis of Variance by Preparation Method, ICP, and Analyte (continued)

Sample Type=ARG-1, Prep=Mixed Acid, ICP=M-13, Analyte=C Response Measurement

Summary of Fit

\begin{tabular}{|c|c|c|c|c|}
\hline \multicolumn{3}{|c|}{ RSquare } & 0.717246 & \\
\hline \multicolumn{3}{|c|}{ RSquare Adj } & 0.443918 & \\
\hline \multicolumn{3}{|c|}{ Root Mean Square Error } & 0.016801 & \\
\hline \multicolumn{3}{|c|}{ Mean of Response } & 0.993833 & \\
\hline \multicolumn{3}{|c|}{ Observations (or Sum Wgts) } & 60 & \\
\hline \multicolumn{5}{|c|}{ Analysis of Variance } \\
\hline Source & DF & Sum of Squares & Mean Square & F Ratio \\
\hline Model & 29 & 0.02148033 & 0.000741 & 2.6241 \\
\hline Error & 30 & 0.00846800 & 0.000282 & Prob $>$ F \\
\hline C. Total & 59 & 0.02994833 & & 0.0053 \\
\hline
\end{tabular}

Expected Mean Squares

The Mean Square per row by the Variance Component per column

$\begin{array}{lrr}\text { EMS } & \text { Intercept } & \text { Batch\&Random } \\ \text { Intercept } & 0 & 0\end{array}$

Batch\&Random $\quad 0 \quad 2$

plus 1.0 times Residual Error Variance

Variance Component Estimates

Component Var Comp Est Percent of Total

Batch\&Random $\quad 0.000229 \quad 44.814$

Residual $\quad 0.000282 \quad 55.186$

Total $\quad 0.000511 \quad 100.000$

These estimates based on equating Mean Squares to Expected Value.

Test Denominator Synthesis

Source MS Den DF Den Denom MS Synthesis

Batch\&Random $0.00028 \quad 30$ Residual

Tests wrt Random Effects

$\begin{array}{lrrrrr}\text { Source } & \text { SS } & \text { MS Num } & \text { DF Num } & \text { F Ratio } & \text { Prob > F } \\ \text { Batch\&Random } & 0.02148 & 0.00074 & 29 & 2.6241 & 0.0053\end{array}$

Sample Type=ARG-1, Prep=Mixed Acid, ICP=M-13, Analyte=Cr Response Measurement

Summary of Fit

RSquare $\quad 0.799292$

RSquare Adj $\quad 0.605058$

Root Mean Square Error $\quad 0.005118$

Mean of Response $\quad 0.066806$

Observations (or Sum Wgts) $\quad 62$

Analysis of Variance

Source DF Sum of Squares Mean Square F Ratio

$\begin{array}{llllr}\text { Model } & 30 & 0.00323368 & 0.000108 & 4.1151 \\ \text { Error } & 31 & 0.00081200 & 0.00026 & \end{array}$

$\begin{array}{lllll}\text { Error } & 31 & 0.00081200 & 0.000026 & \text { Prob }>\text { F }\end{array}$

$\begin{array}{llll}\text { C. Total } & 61 & 0.00404568 & <.0001\end{array}$

Expected Mean Square

The Mean Square per row by the Variance Component per column

$\begin{array}{lrr}\text { EMS } & \text { Intercept } & \text { Batch\&Random } \\ \text { Intercept } & 0 & 0\end{array}$

Batch\&Random $\quad 0 \quad 2$

plus 1.0 times Residual Error Variance

Variance Component Estimates

Component Var Comp Est Percent of Total

$\begin{array}{lll}\text { Batch\&Random } \quad 0.000041 & 60.900\end{array}$

$\begin{array}{lll}\text { Residual } & 0.000026 & 39.100\end{array}$

Total $\quad 0.000067 \quad 100.000$

These estimates based on equating Mean Squares to Expected Value.

Test Denominator Synthesis

Source MS Den DF Den Denom MS Synthesis

Batch\&Random $0.00003 \quad 31$ Residual

Tests wrt Random Effects

Source

SS MS Num DF Num F Ratio Prob $>$ F

$\begin{array}{lrrrrr}\text { Batch\&Random } & 0.00323 & 0.00011 & 30 & 4.1151 & <.0001\end{array}$
Sample Type=ARG-1, Prep=Mixed Acid, ICP=M-13, Analyte $=$ Cu Response Measurement

Summary of Fit

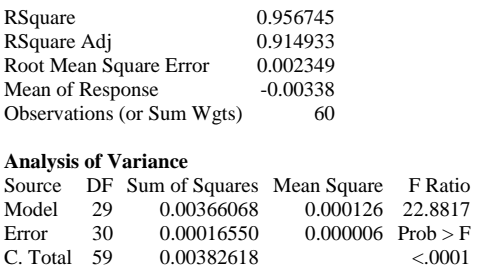

Expected Mean Squares

The Mean Square per row by the Variance Component per column

EMS Intercept Batch\&Random

$\begin{array}{lll}\text { Intercept } & 0 & 0 \\ \text { Batch\&Random } & 0 & 2\end{array}$

plus 1.0 times Residual Error Variance

Variance Component Estimates

Component Var Comp Est Percent of Total

$\begin{array}{lrr}\text { Component } & \text { Var Comp Est } & \text { Percent of Total } \\ \text { Batch\&Random } & 0.00006 & 91.625 \\ \text { Residual } & 0.000006 & 8.375\end{array}$

$\begin{array}{lrr}\text { Residual } & 0.000006 & 8.375 \\ \text { Total } & 0.000066 & 100.000\end{array}$

These estimates based on equating Mean Squares to Expected Value.

Test Denominator Synthesis

Source MS Den DF Den Denom MS Synthesis

Batch\&Random 5.52e-6 30 Residual

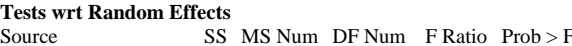

$\begin{array}{lrrrrr}\text { Bource } & \text { SS } & \text { MS Num } & \text { DF Num } & \text { F Ratio } & \text { Prob > F } \\ \text { Batch\&Random } & 0.00366 & 0.00013 & 29 & 22.8817 & <.0001\end{array}$

Sample Type=ARG-1, Prep=Mixed Acid, ICP=M-13, Analyte=Fe Response Measurement

Summary of Fit

0.515922

RSquare Adj $\quad 0.04798$

Root Mean Square Error $\quad 0.197928$

Mean of Response $\quad 9.523933$

Observations (or Sum Wgts)

60

Analysis of Variance

Source DF Sum of Squares Mean Square F Ratio

$\begin{array}{lllll}\text { Model } & 29 & 1.2525777 & 0.043192 & 1.1025\end{array}$

$\begin{array}{lllll}\text { Error } & 30 & 1.1752660 & 0.039176 & \text { Prob }>\text { F }\end{array}$

$\begin{array}{lllr}\text { C. Total } & 59 & 2.4278437 & 0.3955\end{array}$

Expected Mean Squares

The Mean Square per row by the Variance Component per column

$\begin{array}{lrr}\text { EMS } & \text { Intercept } & \text { Batch\&Random } \\ \text { Intercept } & 0 & 0 \\ \text { Batch\&Random } & 0 & 2\end{array}$

plus 1.0 times Residual Error Variance

Variance Component Estimates

\begin{tabular}{|c|c|c|}
\hline \\
\hline \multicolumn{3}{|c|}{ Var Comp Est Percent of Total } \\
\hline Batch\&Random & 0.002008 & 4.877 \\
\hline Residual & 0.039176 & 95.123 \\
\hline Total & 0.041184 & 100.000 \\
\hline \multicolumn{3}{|c|}{ These estimates based on equating Mean Squares to Expected Value. } \\
\hline \multicolumn{3}{|c|}{ Test Denominator Synthesis } \\
\hline Source & MS Den DF Den & Denom MS Synthesis \\
\hline Batch\&Random & $0.03918 \quad 30$ & Residual \\
\hline \multicolumn{3}{|c|}{ Tests wrt Random Effects } \\
\hline Source & SS MS Num & DF Num F Ratio Prob $>F$ \\
\hline Batch\&Random & $1.25258 \quad 0.04319$ & $\begin{array}{lll}29 & 1.1025 & 0.3955\end{array}$ \\
\hline
\end{tabular}


WSRC-STI-2006-00068

Revision 0

Exhibit A7. Analysis of Variance by Preparation Method, ICP, and Analyte (continued)

Sample Type=ARG-1, Prep=Mixed Acid, ICP=M-13, Analyte=Fe/Al Response Measurement

Summary of Fi

\begin{tabular}{|c|c|c|c|c|}
\hline \multicolumn{3}{|c|}{ RSquare } & \multicolumn{2}{|l|}{0.720126} \\
\hline \multicolumn{3}{|c|}{ RSquare Adj } & 0.44928 & \\
\hline \multicolumn{3}{|c|}{ Root Mean Square Error } & 0.079757 & \\
\hline \multicolumn{3}{|c|}{ Mean of Response } & 4.148937 & \\
\hline \multicolumn{3}{|c|}{ Observations (or Sum Wgts) } & 62 & \\
\hline \multicolumn{5}{|c|}{ Analysis of Variance } \\
\hline Source & DF & Sum of Squares & s Mean Square & F Ratio \\
\hline Model & 30 & 0.50739634 & $4 \quad 0.016913$ & \\
\hline Error & 31 & 0.19719757 & 0.006361 & Prob $>$ F \\
\hline C. Total & 61 & 0.70459391 & & 0.0042 \\
\hline
\end{tabular}

Expected Mean Squares

The Mean Square per row by the Variance Component per column

$\begin{array}{lrr}\text { EMS } & \text { Intercept } & \text { Batch\&Random } \\ \text { Intercept } & 0 & 0\end{array}$

Batch\&Random $\quad 0 \quad 2$

plus 1.0 times Residual Error Variance

Variance Component Estimates

Component Var Comp Est Percent of Total

$\begin{array}{rrr}\text { Component } & \text { Var Comp Est } & \text { Percent of Tota } \\ \text { Batch\&Random } & 0.005276 & 45.337\end{array}$

Residual $\quad 0.006361 \quad 54.663$

Total $\quad 0.011637 \quad 100.000$

These estimates based on equating Mean Squares to Expected Value.

Test Denominator Synthesis

Source MS Den DF Den Denom MS Synthesis

Batch\&Random $0.00636 \quad 31$ Residual

Tests wrt Random Effects
Source MS Num DF Num F Ratio Prob $>$ F

$\begin{array}{lrrrrr}\text { Source } & \text { SS } & \text { MS Num } & \text { DF Num } & \text { F Ratio } & \text { Prob }>\text { F } \\ \text { Batch\&Random } & 0.5074 & 0.01691 & 30 & 2.6588 & 0.0042\end{array}$

Sample Type=ARG-1, Prep=Mixed Acid, ICP=M-13, Analyte=Fe/Ca Response Measurement

Summary of Fit

RSquare $\quad 0.743525$

RSquare Adj $\quad 0.495324$

Root Mean Square Error $\quad 0.155039$

Mean of Response 9.593467

Observations (or Sum Wgts) 62

Analysis of Variance

Source DF Sum of Squares Mean Square F Ratio

\begin{tabular}{lllll} 
Model & 30 & 2.1602113 & 0.072007 & 2.9957 \\
\hline
\end{tabular}

$\begin{array}{lllll}\text { Error } & 31 & 0.7451522 & 0.024037 & \text { Prob }>\text { F }\end{array}$

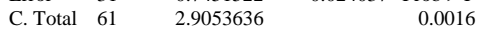

Expected Mean Squares

The Mean Square per row by the Variance Component per column

$\begin{array}{lrr}\text { EMS } & \text { Intercept } & \text { Batch\&Random } \\ \text { Intercept } & 0 & 0\end{array}$

Batch\&Random $\quad 0 \quad 2$

plus 1.0 times Residual Error Variance

Variance Component Estimates

Component Var Comp Est Percent of Total

Batch\&Random $\quad 0.023985 \quad 49.946$

$\begin{array}{lll}\text { Residual } & 0.024037 & 50.054\end{array}$

Total $\quad 0.048022 \quad 100.000$

These estimates based on equating Mean Squares to Expected Value.

Test Denominator Synthesis

Source MS Den DF Den Denom MS Synthesis

Batch\&Random $0.02404 \quad 31$ Residual

Tests wrt Random Effects

ource

SS MS Num DF Num F Ratio Prob $>$ F

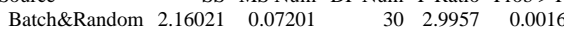

Sample Type=ARG-1, Prep=Mixed Acid, ICP=M-13, Analyte=Fe/Li Response Measurement

Summary of Fit

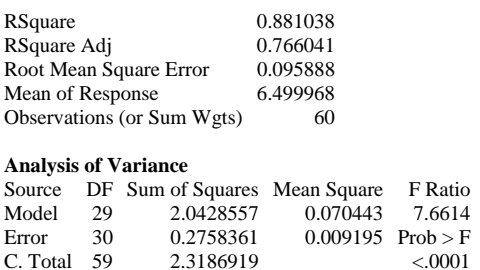

Expected Mean Squares

The Mean Square per row by the Variance Component per column

EMS Intercept Batch\&Random

$\begin{array}{lll}\text { Intercept } & 0 & 0 \\ \text { Batch\&Random } & 0 & 2\end{array}$

plus 1.0 times Residual Error Variance

Variance Component Estimates

$\begin{array}{rrr}\text { Component } & \text { Var Comp Est } & \text { Percent of Total } \\ \text { Batch\&Random } & 0.030624 & 76.909\end{array}$

$\begin{array}{lll}\text { Batch\&Random } & 0.030624 & 76.909 \\ \text { Residual } & 0.009195 & 23.091\end{array}$

$\begin{array}{lrr}\text { Residual } & 0.009195 & 23.091 \\ \text { Total } & 0.039819 & 100.000\end{array}$

These estimates based on equating Mean Squares to Expected Value.

Test Denominator Synthesis

Source MS Den DF Den Denom MS Synthesis

Batch\&Random $0.00919 \quad 30$ Residual

Tests wrt Random Effects
$\begin{aligned} & \text { Source } \\ & \text { SS MS Num DF Num F Ratio Prob > F }\end{aligned}$

$\begin{array}{lrrrrr}\text { Source } & \text { SS } & \text { MS Num } & \text { DF Num } & \text { F Ratio } & \text { Prob }>\text { F } \\ \text { Batch\&Random } & 2.04286 & 0.07044 & 29 & 7.6614 & <.0001\end{array}$

Sample Type=ARG-1, Prep=Mixed Acid, ICP=M-13, Analyte=Fe $/ \mathrm{Mg}$ Response Measurement

Summary of Fit

RSquare Adj

Root Mean Square Error $\quad 0.203208$

Mean of Response $\quad 18.73663$

Observations (or Sum Wgts)

62

Analysis of Variance

Source DF Sum of Squares Mean Square F Ratio

$\begin{array}{lllll}\text { Model } & 30 & 3.7013895 & 0.123380 & 2.9879\end{array}$

$\begin{array}{lllll}\text { Error } & 31 & 1.2801026 & 0.041294 \text { Prob }>\text { F }\end{array}$

$\begin{array}{llrr}\text { C. Total } & 61 & 4.9814921 & 0.0017\end{array}$

Expected Mean Squares

The Mean Square per row by the Variance Component per column

$\begin{array}{lrr}\text { EMS } & \text { Intercept } & \text { Batch\&Random } \\ \text { Intercept } & 0 & 0 \\ \text { Batch\&Random } & 0 & 2\end{array}$

plus 1.0 times Residual Error Variance

$\begin{array}{ll}\text { Variance Component Estimates } \\ \text { Component } & \text { Var Comp Est Percent of Total }\end{array}$

$\begin{array}{crr}\text { Component } & \text { Var Comp Est } & \text { Percent of Total } \\ \text { Batch\&Random } & 0.041043 & 49.848\end{array}$

$\begin{array}{lll}\text { Residual } & 0.041294 & 50.152\end{array}$

Total $\quad 0.082337 \quad 100.000$

These estimates based on equating Mean Squares to Expected Value.

Test Denominator Synthesis

Source MS Den DF Den Denom MS Synthesis

$\begin{array}{crrr}\text { Source } & \text { MS Den } & \text { DF Den } & \text { Denom } \\ \text { Batch\&Random } & 0.04129 & 31 & \text { Residual }\end{array}$

Tests wrt Random Effects

Source SS MS Num DF Num F Ratio Prob $>$ F

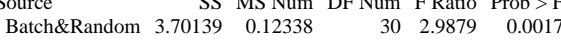


WSRC-STI-2006-00068

Revision 0

Exhibit A7. Analysis of Variance by Preparation Method, ICP, and Analyte (continued)

Sample Type=ARG-1, Prep=Mixed Acid, ICP=M-13, Analyte=Fe/Mn Response Measurement

Summary of Fi

\begin{tabular}{|c|c|c|c|c|}
\hline \multicolumn{3}{|c|}{ RSquare } & 0.72107 & \\
\hline \multicolumn{3}{|c|}{ RSquare Adj } & 0.451137 & \\
\hline \multicolumn{3}{|c|}{ Root Mean Square Error } & 0.075746 & \\
\hline \multicolumn{3}{|c|}{ Mean of Response } & 6.859287 & \\
\hline \multicolumn{3}{|c|}{ Observations (or Sum Wgts) } & 62 & \\
\hline \multicolumn{5}{|c|}{ Analysis of Variance } \\
\hline Source & DF & Sum of Squares & Mean Square & F Ratio \\
\hline Model & 30 & 0.45979275 & 0.015326 & 2.6713 \\
\hline Error & 31 & 0.17786111 & 0.005737 & Prob $>$ F \\
\hline C. Total & 61 & 0.63765385 & & 0.0040 \\
\hline
\end{tabular}

Expected Mean Squares

The Mean Square per row by the Variance Component per column

$\begin{array}{lrr}\text { EMS } & \text { Intercept } & \text { Batch\&Random } \\ \text { Intercept } & 0 & 0\end{array}$

Batch\&Random $\quad 0 \quad 2$

plus 1.0 times Residual Error Variance

Variance Component Estimates

Component Var Comp Est Percent of Total

$\begin{array}{rrr}\text { Batch\&Random } & 0.004794 & 45.523\end{array}$

Residual $\quad 0.005737 \quad 54.477$

Total $\quad 0.010532 \quad 100.000$

These estimates based on equating Mean Squares to Expected Value.

Test Denominator Synthesis

Source MS Den DF Den Denom MS Synthesis

Batch\&Random $0.00574 \quad 31$ Residual

Tests wrt Random Effects
Source MS Num DF Num F Ratio Prob > F

$\begin{array}{lrrrrr}\text { Source } & \text { SS } & \text { MS Num } & \text { DF Num } & \text { F Ratio } & \text { Prob > F } \\ \text { Batch\&Random } & 0.45979 & 0.01533 & 30 & 2.6713 & 0.0040\end{array}$

Sample Type=ARG-1, Prep=Mixed Acid, ICP=M-13, Analyte=Fe/Ni Response Measurement

Summary of Fit

0.377353

or $\quad 0.22444$

$\begin{array}{lr}\text { Mean of Response } & 11.8287 \\ \text { Observations (or Sum Wgts) } & 60\end{array}$

Analysis of Variance

Source DF Sum of Squares Mean Square F Ratio

$\begin{array}{lllll}\text { Model } & 29 & 3.2619994 & 0.112483 & 2.2330\end{array}$

$\begin{array}{lllll}\text { Error } & 30 & 1.5111932 & 0.050373 \text { Prob }>\text { F }\end{array}$

$\begin{array}{llrl}\text { C. Total } & 59 & 4.7731927 & 0.0161\end{array}$

Expected Mean Squares

The Mean Square per row by the Variance Component per column

$\begin{array}{lrr}\text { EMS } & \text { Intercept } & \text { Batch\&Random } \\ \text { Intercept } & 0 & 0\end{array}$

Batch\&Random $\quad 0 \quad 2$

plus 1.0 times Residual Error Variance

Variance Component Estimates

Component Var Comp Est Percent of Total

Batch\&Random $\quad 0.031055 \quad 38.138$

$\begin{array}{lll}\text { Residual } & 0.050373 & 61.862\end{array}$

Total $\quad 0.081428 \quad 100.000$

These estimates based on equating Mean Squares to Expected Value.

Test Denominator Synthesis

Source MS Den DF Den Denom MS Synthesis

Batch\&Random $\quad 0.05037 \quad 30$ Residual

Tests wrt Random Effects

Source SS MS Num DF Num F Ratio Prob > F

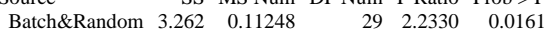

Sample Type=ARG-1, Prep=Mixed Acid, ICP=M-13, Analyte=Fe/U Response Measurement

Summary of Fit

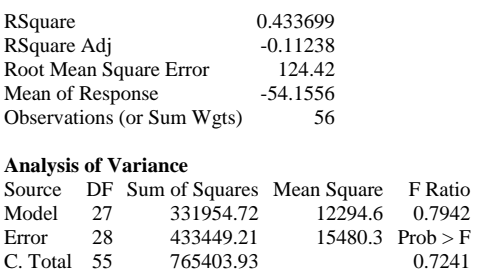

Expected Mean Squares

The Mean Square per row by the Variance Component per column

EMS Intercept Batch\&Random

$\begin{array}{lll}\text { Intercept } & 0 & 0 \\ \text { Batch\&Random } & 0 & 2\end{array}$

plus 1.0 times Residual Error Variance

Variance Component Estimates

$\begin{array}{crr}\text { Component } & \text { Var Comp Est } & \text { Percent of Total } \\ \text { Batch\&Random } & -1592.85 & -11.470 \\ \text { Residua } & 15480.33 & 111.470\end{array}$

$\begin{array}{lll}\text { Residual } & 15480.33 & 111.470 \\ \text { Total } & 13887.47 & 100.000\end{array}$

$\begin{array}{lcc}\text { Total } & 13887.47 & 100.000 \\ \text { These estimates based on equating Mean Squares to Expected Value. }\end{array}$

Test Denominator Synthesis

Source MS Den DF Den Denom MS Synthesis

$\begin{array}{llll}\text { Batch\&Random } \quad 15480.3 \quad 28 & \text { Residual }\end{array}$

Tests wrt Random Effects

Source SS MS Num DF Num F Ratio Prob > F

$\begin{array}{lrrrrr}\text { Batch\&Random } & 331955 & 12294.6 & 27 & 0.7942 & 0.7241\end{array}$

Sample Type=ARG-1, Prep=Mixed Acid, ICP=M-13, Analyte=K Response Measurement

Summary of Fit

0.816766

0.63964

$\quad 0.243545$

$\begin{array}{lr}\text { Mean of Response } & 2.0071 \\ \text { Observations (or Sum Wgts) } & 60\end{array}$

Analysis of Variance

Source DF Sum of Squares Mean Square F Ratio

$\begin{array}{lllll}\text { Model } & 29 & 7.9317684 & 0.273509 & 4.6112\end{array}$

$\begin{array}{lllll}\text { Error } & 30 & 1.7794190 \quad 0.059314 \quad \text { Prob }>\text { F }\end{array}$

$\begin{array}{llll}\text { C. Total } & 59 & 9.7111874 & <.0001\end{array}$

Expected Mean Squares

The Mean Square per row by the Variance Component per column

$\begin{array}{lrr}\text { EMS } & \text { Intercept } & \text { Batch\&Random } \\ \text { Intercept } & 0 & 0 \\ \text { Batch\&Random } & 0 & 2\end{array}$

plus 1.0 times Residual Error Variance

Variance Component Estimates
$\begin{array}{ll}\text { Component } & \text { Var Comp Est Percent of Total }\end{array}$

$\begin{array}{ccr}\text { Component } & \text { Var Comp Est } & \text { Percent of Total } \\ \text { Batch\&Random } & 0.107098 & 64.357\end{array}$

$\begin{array}{lll}\text { Residual } & 0.059314 & 35.643\end{array}$

$\begin{array}{llr}\text { Total } & 0.166412 & 35.643 \\ & & 100.000\end{array}$

These estimates based on equating Mean Squares to Expected Value.

Test Denominator Synthesis

Source MS Den DF Den Denom MS Synthesis

$\begin{array}{crrr}\text { Source } & \text { MS Den } & \text { DF Den } & \text { Denom MS } \\ \text { Batch\&Random } & 0.05931 & 30 & \text { Residual }\end{array}$

Tests wrt Random Effects

Source SS MS Num DF Num F Ratio Prob $>$ F

$\begin{array}{rrrrrr}\text { Batch\&Random } & 7.93177 & 0.27351 & 29 & 4.6112 & <.0001\end{array}$ 
WSRC-STI-2006-00068

Revision 0

Exhibit A7. Analysis of Variance by Preparation Method, ICP, and Analyte (continued)

Sample Type=ARG-1, Prep=Mixed Acid, ICP=M-13, Analyte $=\mathrm{Li}$ Response Measurement

Summary of Fi

\begin{tabular}{|c|c|c|c|c|}
\hline \multicolumn{3}{|c|}{ RSquare } & 0.858197 & \\
\hline \multicolumn{3}{|c|}{ RSquare Adj } & 0.721285 & \\
\hline \multicolumn{3}{|c|}{ Root Mean Square Error } & 0.025268 & \\
\hline \multicolumn{3}{|c|}{ Mean of Response } & 1.465466 & \\
\hline \multicolumn{3}{|c|}{ Observations (or Sum Wgts) } & 58 & \\
\hline \multicolumn{5}{|c|}{ Analysis of Variance } \\
\hline Source & DF & Sum of Squares & Mean Square & F Ratio \\
\hline Model & 28 & 0.11205693 & 0.004002 & 6.2682 \\
\hline Error & 29 & 0.01851550 & 0.000638 & Prob $>$ F \\
\hline C. Total & 57 & 0.13057243 & & $<.0001$ \\
\hline
\end{tabular}

Expected Mean Squares

The Mean Square per row by the Variance Component per column

$\begin{array}{lrr}\text { EMS } & \text { Intercept } & \text { Batch\&Random } \\ \text { Intercept } & 0 & 0\end{array}$

Batch\&Random $\quad 0 \quad 2$

plus 1.0 times Residual Error Variance

Variance Component Estimates

Component Var Comp Est Percent of Total

Batch\&Random $\quad 0.001682 \quad r .483$

Residual $\quad 0.000638 \quad 27.517$

Total $\quad 0.00232 \quad 100.000$

These estimates based on equating Mean Squares to Expected Value.

Test Denominator Synthesis

Source MS Den DF Den Denom MS Synthesis

Batch\&Random $0.00064 \quad 29$ Residual

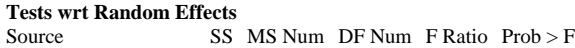

$\begin{array}{lrrrrr}\text { Source } & \text { SS } & \text { MS Num } & \text { DF Num } & \text { F Ratio } & \text { Prob > F } \\ \text { Batch\&Random } & 0.11206 & 0.004 & 28 & 6.2682 & <.0001\end{array}$

Sample Type=ARG-1, Prep=Mixed Acid, ICP=M-13, Analyte=Mg Response Measurement

Summary of Fit

RSquare $\quad 0.605266$

RSquare Adj $\quad 0.22369$

Root Mean Square Error $\quad 0.010778$

Mean of Response $\quad 0.508567$

Observations (or Sum Wgts) 60

Analysis of Variance

Source DF Sum of Squares Mean Square F Ratio

$\begin{array}{lllll}\text { Model } & 29 & 0.00534373 & 0.000184 & 1.5862\end{array}$

$\begin{array}{lllll}\text { Error } & 30 & 0.00348500 & 0.000116 & \text { Prob }>\text { F }\end{array}$

$\begin{array}{llll}\text { C. Total } & 59 & 0.00882873 & 0.1074\end{array}$

Expected Mean Squares

The Mean Square per row by the Variance Component per column

$\begin{array}{lrr}\text { EMS } & \text { Intercept } & \text { Batch\&Random } \\ \text { Intercept } & 0 & 0\end{array}$

$\begin{array}{lll}0 & 0 \\ \text { Batch\&Random } & 0 & 2\end{array}$

plus 1.0 times Residual Error Variance

Variance Component Estimates

Component Var Comp Est Percent of Total

$\begin{array}{lll}\text { Batch\&Random } \quad 0.000034 & 22.667\end{array}$

$\begin{array}{lll}\text { Residual } & 0.000116 & 77.333\end{array}$

Total $\quad 0.00015 \quad 100.000$

These estimates based on equating Mean Squares to Expected Value.

Test Denominator Synthesis

Source MS Den DF Den Denom MS Synthesis

Batch\&Random $0.00012 \quad 30$ Residual

Tests wrt Random Effects

Source

SS MS Num DF Num F Ratio Prob > F

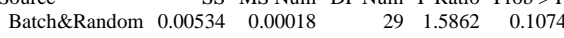

Sample Type=ARG-1, Prep=Mixed Acid, ICP=M-13, Analyte=Mn Response Measurement

Summary of Fit

RSquare Adj $\quad 0.052259$

Root Mean Square Error $\quad 0.027109$

Mean of Response $\quad 1.389017$

Observations (or Sum Wgts) $\quad 60$

Analysis of Variance

Source DF Sum of Squares Mean Square F Ratio

$\begin{array}{lllll}\text { Model } & 29 & 0.02370348 & 0.000817 & 1.1122\end{array}$

$\begin{array}{lllll}\text { Error } & 30 & 0.02204750 & 0.000735 \text { Prob }>\text { F }\end{array}$

$\begin{array}{llll}\text { C. Total } & 59 & 0.04575098 & 0.3865\end{array}$

Expected Mean Squares

The Mean Square per row by the Variance Component per column

$\begin{array}{lrr}\text { EMS } & \text { Intercept } & \text { Batch\&Random } \\ \text { Intercept } & 0 & 0\end{array}$

Batch\&Random $\quad 0 \quad 2$

plus 1.0 times Residual Error Variance

Variance Component Estimates

$\begin{array}{rrr}\text { Component } & \text { Var Comp Est } & \text { Percent of Total } \\ \text { Batch\&Random } & 0.000041 & 5.311\end{array}$

$\begin{array}{llr}\text { Batch\&Random } & 0.000041 & 5.311 \\ \text { Residual } & 0.000735 & 94.689\end{array}$

$\begin{array}{lrr}\text { Residual } & 0.000735 & 94.689 \\ \text { Total } & 0.000776 & 100.000\end{array}$

These estimates based on equating Mean Squares to Expected Value.

Test Denominator Synthesis

Source MS Den DF Den Denom MS Synthesis

Batch\&Random $0.00073 \quad 30$ Residual

Tests wrt Random Effects

Source SS MS Num DF Num F Ratio Prob $>$ F

$\begin{array}{llllll}\text { Batch\&Random } & 0.0237 & 0.00082 & 29 & 1.1122 & 0.3865\end{array}$

Sample Type=ARG-1, Prep=Mixed Acid, ICP=M-13, Analyte=Mn/Mg Response Measurement

Summary of Fit

RSquare Adj

Root Mean Square Error -0.03364

Mean of Response

Observations (or Sum Wgts) $\quad 62$

Analysis of Variance

Source DF Sum of Squares Mean Square F Ratio

$\begin{array}{lllll}\text { Model } & 30 & 0.11763773 & 0.003921 & 3.4632\end{array}$

$\begin{array}{lllll}\text { Error } & 31 & 0.03510053 & 0.001132 & \text { Prob }>\text { F }\end{array}$

$\begin{array}{lllr}\text { C. Total } & 61 & 0.15273826 & 0.0005\end{array}$

Expected Mean Squares

The Mean Square per row by the Variance Component per column

$\begin{array}{lrr}\text { EMS } & \text { Intercept } & \text { Batch\&Random } \\ \text { Intercept } & 0 & 0 \\ \text { Batch\&Random } & 0 & 2\end{array}$

plus 1.0 times Residual Error Variance

Variance Component Estimates
$\begin{array}{ll}\text { Component } & \text { Var Comp Est Percent of Total }\end{array}$

\begin{tabular}{crr} 
Component & Var Comp Est & Percent of Total \\
Batch\&Random & 0.001394 & 55.189 \\
Residual & 0.001132 & 44.811 \\
\hline
\end{tabular}

$\begin{array}{llr}\text { Residual } & 0.001132 & 44.811 \\ \text { Total } & 0.002527 & 100.000\end{array}$

These estimates based on equating Mean Squares to Expected Value.

Test Denominator Synthesis

Source MS Den DF Den Denom MS Synthesis

$\begin{array}{lrrr}\text { Source } & \text { MS Den } & \text { DF Den } & \text { Denom MS } \\ \text { Batch\&Random } & 0.00113 & 31 & \text { Residual }\end{array}$

Tests wrt Random Effects

Source SS MS Num DF Num F Ratio Prob $>$ F

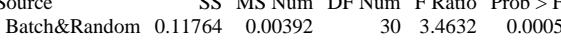


WSRC-STI-2006-00068

Revision 0

Exhibit A7. Analysis of Variance by Preparation Method, ICP, and Analyte (continued)

Sample Type=ARG-1, Prep=Mixed Acid, ICP=M-13, Analyte=Na Response Measurement

Summary of Fit

\begin{tabular}{|c|c|c|c|}
\hline \multicolumn{2}{|c|}{ RSquare } & 0.728344 & \\
\hline \multicolumn{2}{|c|}{ RSquare Adj } & 0.466056 & \\
\hline \multicolumn{2}{|c|}{ Root Mean Square Error } & 0.106444 & \\
\hline \multicolumn{2}{|c|}{ Mean of Response } & 8.340017 & \\
\hline \multicolumn{2}{|c|}{ Observations (or Sum Wgts) } & 58 & \\
\hline \multicolumn{4}{|c|}{ Analysis of Variance } \\
\hline Source & DF Sum of Squares & s Mean Square & F Ratio \\
\hline Model & $28 \quad 0.8809665$ & $5 \quad 0.031463$ & 2.7769 \\
\hline Error & 0.3285805 & 0.011330 & Prob $>$ F \\
\hline C. Total & 1.2095470 & & 0.0039 \\
\hline
\end{tabular}

Expected Mean Squares

The Mean Square per row by the Variance Component per column

$\begin{array}{lrr}\text { EMS } & \text { Intercept } & \text { Batch\&Random } \\ \text { Intercept } & 0 & 0\end{array}$

Batch\&Random $\quad 0 \quad 2$

plus 1.0 times Residual Error Variance

Variance Component Estimates

Component Var Comp Est Percent of Total

Batch\&Random $\quad 0.010066 \quad 47.046$

$\begin{array}{lrr}\text { Residual } & 0.01133 & 52.954\end{array}$

Total $\quad 0.021397 \quad 100.000$

These estimates based on equating Mean Squares to Expected Value.

Test Denominator Synthesis

Source MS Den DF Den Denom MS Synthesis

Batch\&Random $0.01133 \quad 29$ Residual

Tests wrt Random Effects
Source

$\begin{array}{lrrrrr}\text { Source } & \text { SS } & \text { MS Num } & \text { DF Num } & \text { F Ratio } & \text { Prob }>\text { F } \\ \text { Batch\&Random } & 0.88097 & 0.03146 & 28 & 2.7769 & 0.0039\end{array}$

Sample Type=ARG-1, Prep=Mixed Acid, ICP=M-13, Analyte=Ni Response Measurement

Summary of Fit

RSquare $\quad 0.726857$

RSquare Adj $\quad 0.462818$

Root Mean Square Error $\quad 0.018471$

Mean of Response $\quad 0.803683$

Observations (or Sum Wgts) $\quad 60$

Analysis of Variance

Source DF Sum of Squares Mean Square F Ratio

\begin{tabular}{llllr} 
Model & 29 & 0.02723748 & 0.000939 & 2.7528 \\
\hline
\end{tabular}

$\begin{array}{lllll}\text { Error } & 30 & 0.01023550 & 0.000341 & \text { Prob }>\text { F }\end{array}$

$\begin{array}{llll}\text { C. Total } & 59 & 0.03747298 & 0.0037\end{array}$

Expected Mean Square

The Mean Square per row by the Variance Component per column

$\begin{array}{lrr}\text { EMS } & \text { Intercept } & \text { Batch\&Random } \\ \text { Intercept } & 0 & 0\end{array}$

Batch\&Random $\quad 0 \quad 2$

plus 1.0 times Residual Error Variance

Variance Component Estimates

Component Var Comp Est Percent of Total

$\begin{array}{lll}\text { Batch\&Random } & 0.000299 & 46.707\end{array}$

$\begin{array}{lll}\text { Residual } & 0.000341 & 53.293\end{array}$

Total $\quad 0.00064 \quad 100.000$

These estimates based on equating Mean Squares to Expected Value.

Test Denominator Synthesis

Source MS Den DF Den Denom MS Synthesis

Batch\&Random $0.00034 \quad 30$ Residual

Tests wrt Random Effects

Source

SS MS Num DF Num F Ratio Prob $>$ F

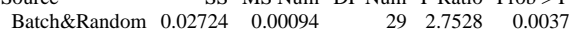

Sample Type=ARG-1, Prep=Mixed Acid, ICP=M-13, Analyte=S Response Measurement

Summary of Fit

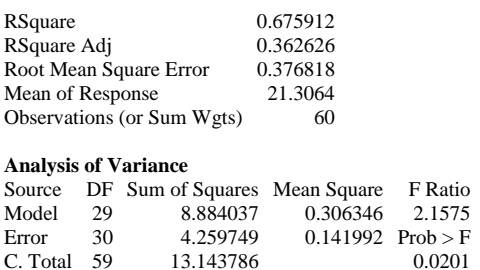

Expected Mean Squares

The Mean Square per row by the Variance Component per column

$\begin{array}{lrr}\text { EMS } & \text { Intercept } & \text { Batch\&Random } \\ \text { Intercept } & 0 & 0\end{array}$

Batch\&Random $\quad 0 \quad 2$

plus 1.0 times Residual Error Variance

Variance Component Estimates

$\begin{array}{crr}\text { Component } & \text { Var Comp Est } & \text { Percent of Total } \\ \text { Batch\&Random } & 0.082177 & 36.659 \\ \text { Residual } & 0.141992 & 63.341\end{array}$

Total $\quad 0.224169 \quad 100.000$

These estimates based on equating Mean Squares to Expected Value.

Test Denominator Synthesis

Source MS Den DF Den Denom MS Synthesis

Batch\&Random $0.14199 \quad 30$ Residual

Tests wrt Random Effects
Source $\quad$ SS MS Num DF Num F Ratio Prob $>$ F

$\begin{array}{lrrrrr}\text { Source } & \text { SS } & \text { MS Num } & \text { DF Num } & \text { F Ratio } & \text { Prob > F } \\ \text { Batch\&Random } & 8.88404 & 0.30635 & 29 & 2.1575 & 0.0201\end{array}$

Sample Type=ARG-1, Prep=Mixed Acid, ICP=M-13, Analyte=Sum of Oxides Response Measurement

Summary of Fit

0.627036

RSquare Adj $\quad 0.266505$

Root Mean Square Error $\quad 1.456726$

Mean of Response 86.57023

Observations (or Sum Wgts)

Analysis of Variance

Source DF Sum of Squares Mean Square F Ratio

$\begin{array}{lllll}\text { Model } & 29 & 107.02950 & 3.69067 & 1.7392\end{array}$

$\begin{array}{llrr}\text { Error } & 30 & 63.66156 & 2.12205 \text { Prob }>\text { F }\end{array}$

$\begin{array}{llll}\text { C. Total } & 59 & 170.69106 & 0.0688\end{array}$

Expected Mean Squares

The Mean Square per row by the Variance Component per column

$\begin{array}{lrr}\text { EMS } & \text { Intercept } & \text { Batch\&Random } \\ \text { Intercept } & 0 & 0 \\ \text { Batch\&Random } & 0 & 2\end{array}$

plus 1.0 times Residual Error Variance

Variance Component Estimates
Component Var Comp Est Percent of Total

\begin{tabular}{crr} 
Component & Var Comp Est & Percent of Total \\
Batch\&Random & 0.78431 & 26.986 \\
Residual & 2.122052 & 73.014 \\
\hline
\end{tabular}

$\begin{array}{lrr}\text { Residual } & 2.122052 & 73.014 \\ \text { Total } & 2.906362 & 100.000\end{array}$

These estimates based on equating Mean Squares to Expected Value.

Test Denominator Synthesis

Source MS Den DF Den Denom MS Synthesis

$\begin{array}{crrr}\text { Source } & \text { MS Den } & \text { DF Den } & \text { Denom MS } \\ \text { Batch\&Random } & 2.12205 & 30 & \text { Residual }\end{array}$

Tests wrt Random Effects

Source SS MS Num DF Num F Ratio Prob > F

$\begin{array}{rrrrrr}\text { Batch\&Random } & 107.029 & 3.69067 & 29 & 1.7392 & 0.0688\end{array}$ 
WSRC-STI-2006-00068

Revision 0

Exhibit A7. Analysis of Variance by Preparation Method, ICP, and Analyte (continued)

Sample Type=ARG-1, Prep=Mixed Acid, ICP $=$ M-13, Analyte $=$ Ti Response Measurement

Summary of Fit

\begin{tabular}{|c|c|c|c|c|}
\hline \multicolumn{3}{|c|}{ RSquare } & 0.73693 & \\
\hline \multicolumn{3}{|c|}{ RSquare Adj } & 0.482629 & \\
\hline \multicolumn{3}{|c|}{ Root Mean Square Error } & 0.013087 & \\
\hline \multicolumn{3}{|c|}{ Mean of Response } & 0.671467 & \\
\hline \multicolumn{3}{|c|}{ Observations (or Sum Wgts) } & 60 & \\
\hline \multicolumn{5}{|c|}{ Analysis of Variance } \\
\hline Source & DF & Sum of Squares & Mean Square & F Ratio \\
\hline Model & 29 & 0.01439293 & 0.000496 & 2.8979 \\
\hline Error & 30 & 0.00513800 & 0.000171 & Prob $>$ F \\
\hline C. Total & 59 & 0.01953093 & & 0.0025 \\
\hline
\end{tabular}

Expected Mean Squares

The Mean Square per row by the Variance Component per column

$\begin{array}{lrr}\text { EMS } & \text { Intercept } & \text { Batch\&Random } \\ \text { Intercept } & 0 & 0\end{array}$

Batch\&Random $\quad 0 \quad 2$

plus 1.0 times Residual Error Variance

Variance Component Estimates

Component Var Comp Est Percent of Total

$\begin{array}{lrl}\text { Batch\&Random } & 0.000163 & 48.690\end{array}$

Residual $\quad 0.000171 \quad 51.310$

Total $\quad 0.000334 \quad 100.000$

These estimates based on equating Mean Squares to Expected Value.

Test Denominator Synthesis

Source MS Den DF Den Denom MS Synthesis

Batch\&Random $0.00017 \quad 30$ Residual

Tests wrt Random Effects
$\begin{aligned} & \text { Source } \\ & \text { SS MS Num DF Num F Ratio Prob > F }\end{aligned}$

$\begin{array}{lrrrrr}\text { Source } & \text { SS } & \text { MS Num } & \text { DF Num } & \text { F Ratio } & \text { Prob }>\text { F } \\ \text { Batch\&Random } & 0.01439 & 0.0005 & 29 & 2.8979 & 0.0025\end{array}$

Sample Type=ARG-1, Prep=Mixed Acid, ICP=M-13, Analyte=U Response Measurement

Summary of Fit

RSquare $\quad 0.852579$

RSquare Adj $\quad 0.709914$

Root Mean Square Error $\quad 0.052496$

Mean of Response $\quad-0.12731$

Observations (or Sum Wgts) 62

Analysis of Variance

Source DF Sum of Squares Mean Square F Ratio

\begin{tabular}{llllr} 
Model & 30 & 0.49406568 & 0.016469 & 5.9761 \\
\hline
\end{tabular}

$\begin{array}{lllll}\text { Error } & 31 & 0.08542950 & 0.002756 \text { Prob }>\text { F }\end{array}$

$\begin{array}{llll}\text { C. Total } & 61 & 0.57949518 & <.0001\end{array}$

Expected Mean Square

The Mean Square per row by the Variance Component per column

$\begin{array}{lrr}\text { EMS } & \text { Intercept } & \text { Batch\&Random } \\ \text { Intercept } & 0 & 0\end{array}$

Batch\&Random $\quad 0 \quad 2$

plus 1.0 times Residual Error Variance

Variance Component Estimates

Component Var Comp Est Percent of Total

$\begin{array}{lll}\text { Batch\&Random } \quad 0.006857 & 71.331\end{array}$

$\begin{array}{lll}\text { Residual } & 0.002756 & 28.669\end{array}$

Total $\quad 0.009612 \quad 100.000$

These estimates based on equating Mean Squares to Expected Value.

Test Denominator Synthesis

Source MS Den DF Den Denom MS Synthesis

Batch\&Random $0.00276 \quad 31$ Residual

Tests wrt Random Effects

Source

SS MS Num DF Num F Ratio Prob $>$ F

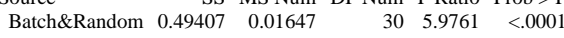

Sample Type=ARG-1, Prep=Mixed Acid, ICP=M-13, Analyte=U/Ca Response Measurement

Summary of Fit

RSquare Adj $\quad 0.689525$

Root Mean Square Error $\quad 0.051563$

Mean of Response $\quad-0.12214$

Observations (or Sum Wgts)

Analysis of Variance

Source DF Sum of Squares Mean Square F Ratio

$\begin{array}{lllll}\text { Model } & 29 & 0.42548008 & 0.014672 & 5.5183\end{array}$

$\begin{array}{lllll}\text { Error } & 30 & 0.07976187 & 0.002659 & \text { Prob }>\text { F }\end{array}$

$\begin{array}{llll}\text { C. Total } & 59 & 0.50524195 & <.0001\end{array}$

Expected Mean Squares

The Mean Square per row by the Variance Component per column

$\begin{array}{lrr}\text { EMS } & \text { Intercept } & \text { Batch\&Random } \\ \text { Intercept } & 0 & 0\end{array}$

Batch\&Random $\quad 0 \quad 2$

plus 1.0 times Residual Error Variance

Variance Component Estimates

$\begin{array}{rrr}\text { Component } & \text { Var Comp Est } & \text { Percent of Total } \\ \text { Batch\&Random } & 0.006006 & 69.317\end{array}$

$\begin{array}{ccc}\text { Batch\&Random } & 0.006006 & 69.317 \\ \text { Residual } & 0.002659 & 30.683\end{array}$

$\begin{array}{lrr}\text { Residual } & 0.002659 & 30.683 \\ \text { Total } & 0.008665 & 100.000\end{array}$

These estimates based on equating Mean Squares to Expected Value.

Test Denominator Synthesis

Source MS Den DF Den Denom MS Synthesis

Batch\&Random $0.00266 \quad 30$ Residual

Tests wrt Random Effects

Source SS MS Num DF Num F Ratio Prob > F

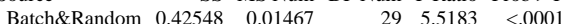

Sample Type=ARG-1, Prep=Mixed Acid, ICP=M-13, Analyte=Zr Response Measurement

Summary of Fit

RSquare Adj

0.89422

0.003362

Mean of Response

Observations (or Sum Wgts) $\quad 60$

Analysis of Variance

Source DF Sum of Squares Mean Square F Ratio

$\begin{array}{lllll}\text { Model } & 29 & 0.00286593 & 0.000099 & 8.7456\end{array}$

$\begin{array}{lllll}\text { Error } & 30 & 0.00033900 & 0.000011 & \text { Prob }>\text { F }\end{array}$

$\begin{array}{llll}\text { C. Total } & 59 & 0.00320493 & <.0001\end{array}$

Expected Mean Squares

The Mean Square per row by the Variance Component per column

$\begin{array}{lrr}\text { EMS } & \text { Intercept } & \text { Batch\&Random } \\ \text { Intercept } & 0 & 0 \\ \text { Batch\&Random } & 0 & 2\end{array}$

plus 1.0 times Residual Error Variance

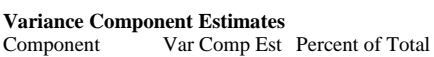

\begin{tabular}{crr} 
Component & Var Comp Est & Percent of Total \\
Batch\&Random & 0.000044 & 79.478 \\
Residual & 0.000011 & 20.522 \\
\hline
\end{tabular}

$\begin{array}{lrr}\text { Residual } & 0.000011 & 20.522 \\ \text { Total } & 0.000055 & 100.000\end{array}$

These estimates based on equating Mean Squares to Expected Value.

Test Denominator Synthesis

Source MS Den DF Den Denom MS Synthesis

$\begin{array}{lrrr}\text { Source } & \text { MS Den } & \text { DF Den } & \text { Denom } \\ \text { Batch\&Random } & 0.00001 & 30 & \text { Residual }\end{array}$

Tests wrt Random Effects

Source SS MS Num DF Num F Ratio Prob $>$ F

$\begin{array}{rrrrrr} & \text { SS } & \text { MS Num } & \text { DF Num } & \text { F Ratio } & \text { Prob }>\text { F } \\ \text { Batch\&Random } & 0.00287 & 0.0001 & 29 & 8.7456 & <.0001\end{array}$ 
WSRC-STI-2006-00068

Revision 0

Exhibit A7. Analysis of Variance by Preparation Method, ICP, and Analyte (continued)

Sample Type=ARG-1, Prep=Mixed Acid, ICP=M-14, Analyte=Al Response Measurement

Summary of Fi

\begin{tabular}{|c|c|c|c|c|}
\hline \multicolumn{3}{|c|}{ RSquare } & 0.62884 & \\
\hline \multicolumn{3}{|c|}{ RSquare Adj } & 0.274551 & \\
\hline \multicolumn{3}{|c|}{ Root Mean Square Error } & 0.042647 & \\
\hline \multicolumn{3}{|c|}{ Mean of Response } & 2.365818 & \\
\hline \multicolumn{3}{|c|}{ Observations (or Sum Wgts) } & 44 & \\
\hline \multicolumn{5}{|c|}{ Analysis of Variance } \\
\hline Source & DF & Sum of Squares & Mean Square & F Ratio \\
\hline Model & 21 & 0.06779055 & 0.003228 & 1.7749 \\
\hline Error & 22 & 0.04001200 & 0.001819 & Prob $>$ F \\
\hline C. Total & 43 & 0.10780255 & & 0.0948 \\
\hline
\end{tabular}

Expected Mean Squares

The Mean Square per row by the Variance Component per column

$\begin{array}{lrr}\text { EMS } & \text { Intercept } & \text { Batch\&Random } \\ \text { Intercept } & 0 & 0\end{array}$

Batch\&Random $\quad 0 \quad 2$

plus 1.0 times Residual Error Variance

Variance Component Estimates

Component Var Comp Est Percent of Total

Batch\&Random $\quad 0.000705 \quad 27.926$

Residual $\quad 0.001819 \quad 72.074$

Total $\quad 0.002523 \quad 100.000$

These estimates based on equating Mean Squares to Expected Value.

Test Denominator Synthesi

Source MS Den DF Den Denom MS Synthesis

Batch\&Random $0.00182 \quad 22$ Residual

Tests wrt Random Effects
Source

$\begin{array}{lrrrrr}\text { Source } & \text { SS } & \text { MS Num } & \text { DF Num } & \text { F Ratio } & \text { Prob }>\text { F } \\ \text { Batch\&Random } & 0.06779 & 0.00323 & 21 & 1.7749 & 0.0948\end{array}$

Sample Type=ARG-1, Prep=Mixed Acid, ICP=M-14, Analyte=Al/Ca Response Measurement

Summary of Fit

RSquare $\quad 0.620656$

RSquare Adj $\quad 0.258555$

Root Mean Square Error $\quad 0.029764$

Mean of Response $\quad 2.365209$

Observations (or Sum Wgts) $\quad 44$

Analysis of Variance

Source DF Sum of Squares Mean Square F Ratio

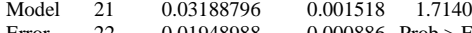

$\begin{array}{lllll}\text { Error } & 22 & 0.01948988 & 0.000886 & \text { Prob }>\text { F }\end{array}$

$\begin{array}{llll}\text { C. Total } & 43 & 0.05137784 & 0.1088\end{array}$

Expected Mean Square

The Mean Square per row by the Variance Component per column

$\begin{array}{lrr}\text { EMS } & \text { Intercept } & \text { Batch\&Random } \\ \text { Intercept } & 0 & 0\end{array}$

$\begin{array}{lll}0 & 0 \\ \text { Batch\&Random } & 0 & 2\end{array}$

plus 1.0 times Residual Error Variance

Variance Component Estimates

Component Var Comp Est Percent of Total

$\begin{array}{lll}\text { Batch\&Random } \quad 0.000316 & 26.309\end{array}$

Residual $\quad 0.000886 \quad 73.69$

Total $\quad 0.001202 \quad 100.000$

These estimates based on equating Mean Squares to Expected Value.

Test Denominator Synthesis

Source MS Den DF Den Denom MS Synthesis

Batch\&Random $0.00089 \quad 22$ Residual

Tests wrt Random Effects

Source

SS MS Num DF Num F Ratio Prob > F

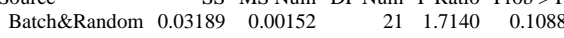

Sample Type=ARG-1, Prep=Mixed Acid, ICP=M-14, Analyte=Al/Mg Response Measurement

Summary of Fit

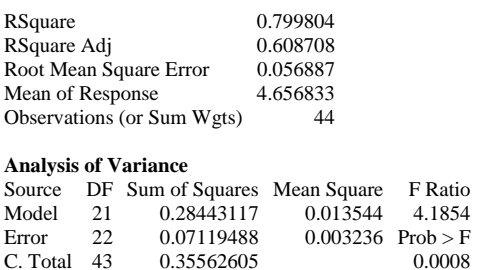

Expected Mean Squares

The Mean Square per row by the Variance Component per column

$\begin{array}{lrr}\text { EMS } & \text { Intercept } & \text { Batch\&Random } \\ \text { Intercept } & 0 & 0\end{array}$

Batch\&Random $\quad 0 \quad 2$

plus 1.0 times Residual Error Variance

Variance Component Estimates

$\begin{array}{rrr}\text { Component } & \text { Var Comp Est } & \text { Percent of Total } \\ \text { Batch\&Random } & 0.005154 & 61.430\end{array}$

$\begin{array}{lll}\text { Batch\&Random } & 0.005154 & 61.430 \\ \text { Residual } & 0.003236 & 38.570\end{array}$

$\begin{array}{lrr}\text { Residual } & 0.003236 & 38.570 \\ \text { Total } & 0.00839 & 100.000\end{array}$

These estimates based on equating Mean Squares to Expected Value.

Test Denominator Synthesis

Source MS Den DF Den Denom MS Synthesis

Batch\&Random $0.00324 \quad 22$ Residual

Tests wrt Random Effects
Source SS MS Num DF Num F Ratio Prob $>$ F

$\begin{array}{lrrrrr}\text { Source } & \text { SS } & \text { MS Num } & \text { DF Num } & \text { F Ratio } & \text { Prob }>\text { F } \\ \text { Batch\&Random } & 0.28443 & 0.01354 & 21 & 4.1854 & 0.0008\end{array}$

Sample Type=ARG-1, Prep=Mixed Acid, ICP=M-14, Analyte=Al/Mn Response Measurement

Summary of Fit

RSquare Adj $\quad 0.641923$

Root Mean Square Error $\quad 0.017924$

Mean of Response 1.691432

Observations (or Sum Wgts) 44

Analysis of Variance

Source DF Sum of Squares Mean Square F Ratio

$\begin{array}{lllll}\text { Model } & 21 & 0.03151064 & 0.001501 & 4.6708\end{array}$

$\begin{array}{lllll}\text { Error } 22 & 0.00706762 & 0.000321 & \text { Prob }>\text { F }\end{array}$

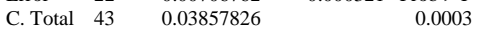

Expected Mean Squares

The Mean Square per row by the Variance Component per column

$\begin{array}{lrr}\text { EMS } & \text { Intercept } & \text { Batch\&Random } \\ \text { Intercept } & 0 & 0 \\ \text { Batch\&Random } & 0 & 2\end{array}$

plus 1.0 times Residual Error Variance

Variance Component Estimates

$\begin{array}{lrr}\text { Component } & \text { Var Comp Est } & \text { Percent of Total } \\ \text { Batch\&Random } & 0.00059 & 64.731 \\ \text { Residual } & 0.000321 & 35.269 \\ \text { Total } & 0.000911 & 100.000\end{array}$

These estimates based on equating Mean Squares to Expected Value.

Test Denominator Synthesis

Source MS Den DF Den Denom MS Synthesis

$\begin{array}{lrrr}\text { Source } & \text { MS Den } & \text { DF Den } & \text { Denom } \\ \text { Batch\&Random } & 0.00032 & 22 & \text { Residual }\end{array}$

Tests wrt Random Effects

Source SS MS Num DF Num F Ratio Prob > F

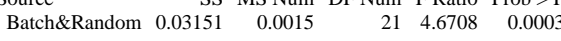

Sample Type=ARG-1, Prep=Mixed Acid, ICP=M-14, Analyte=B

Sample Type=ARG-1, Prep=Mixed Acid, ICP=M-14, Analyte=B/Li 
WSRC-STI-2006-00068

Revision 0

Exhibit A7. Analysis of Variance by Preparation Method, ICP, and Analyte (continued)

Sample Type=ARG-1, Prep=Mixed Acid, ICP=M-14, Analyte=C Response Measurement

Summary of Fit

\begin{tabular}{|c|c|c|c|c|}
\hline \multicolumn{3}{|c|}{ RSquare } & 0.571514 & \\
\hline \multicolumn{3}{|c|}{ RSquare Adj } & 0.162504 & \\
\hline \multicolumn{3}{|c|}{ Root Mean Square Error } & 0.020464 & \\
\hline \multicolumn{3}{|c|}{ Mean of Response } & 1.000386 & \\
\hline \multicolumn{3}{|c|}{ Observations (or Sum Wgts) } & 44 & \\
\hline \multicolumn{5}{|c|}{ Analysis of Variance } \\
\hline Source & DF & Sum of Squares & Mean Square & F Ratio \\
\hline Model & 21 & 0.01228893 & 0.000585 & 1.3973 \\
\hline Error & 22 & 0.00921350 & 0.000419 & Prob $>$ F \\
\hline C. Total & 43 & 0.02150243 & & 0.2209 \\
\hline
\end{tabular}

Expected Mean Squares

The Mean Square per row by the Variance Component per column

$\begin{array}{lrr}\text { EMS } & \text { Intercept } & \text { Batch\&Random } \\ \text { Intercept } & 0 & 0\end{array}$

Batch\&Random $\quad 0 \quad 2$

plus 1.0 times Residual Error Variance

Variance Component Estimates

Component Var Comp Est Percent of Total

Batch\&Random $\quad 0.000083 \quad r .573$

$\begin{array}{lll}\text { Residual } & 0.000419 & 83.427\end{array}$

Total $\quad 0.000502 \quad 100.000$

These estimates based on equating Mean Squares to Expected Value.

Test Denominator Synthesi

Source MS Den DF Den Denom MS Synthesis

Batch\&Random $0.00042 \quad 22$ Residual

Tests wrt Random Effects
Source

$\begin{array}{lrrrrr}\text { Source } & \text { SS } & \text { MS Num } & \text { DF Num } & \text { F Ratio } & \text { Prob > F } \\ \text { Batch\&Random } & 0.01229 & 0.00059 & 21 & 1.3973 & 0.2209\end{array}$

Sample Type=ARG-1, Prep=Mixed Acid, ICP=M-14, Analyte=Cr Response Measurement

Summary of Fit

RSquare $\quad 0.888281$

RSquare Adj $\quad 0.78164$

Root Mean Square Error $\quad 0.002426$

Mean of Response $\quad 0.059295$

Observations (or Sum Wgts) $\quad 44$

Analysis of Variance

Source DF Sum of Squares Mean Square F Ratio

$\begin{array}{lllll}\text { Model } & 21 & 0.00102966 & 0.000049 & 8.3297\end{array}$

$\begin{array}{lllll}\text { Error } & 22 & 0.00012950 & 0.000006 & \text { Prob }>\text { F }\end{array}$

$\begin{array}{llll}\text { C. Total } & 43 & 0.00115916 & <.0001\end{array}$

Expected Mean Squares

The Mean Square per row by the Variance Component per column

$\begin{array}{lrr}\text { EMS } & \text { Intercept } & \text { Batch\&Random } \\ \text { Intercept } & 0 & 0\end{array}$

$\begin{array}{lll}0 & 0 \\ \text { Batch\&Random } & 0 & 2\end{array}$

plus 1.0 times Residual Error Variance

Variance Component Estimates

Component Var Comp Est Percent of Total

Batch\&Random $\quad 0.000022 \quad 78.563$

$\begin{array}{lll}\text { Residual } & 0.000006 & 21.437\end{array}$

Total $\quad 0.000027 \quad 100.000$

These estimates based on equating Mean Squares to Expected Value.

Test Denominator Synthesis

y MS Den DF Den Denom MS Synthesis

Batch\&Random 5.89e-6 22 Residual

Tests wrt Random Effects

SS MS Num DF Num F Ratio Prob $>$ F

$\begin{array}{llllll}\text { Batch\&Random } & 0.00103 & 0.00005 & 21 & 8.3297 & <.0001\end{array}$
Sample Type=ARG-1, Prep=Mixed Acid, ICP=M-14, Analyte $=$ Cu Response Measurement

Summary of Fit

RSquare Adj $\quad 0.95972$

Root Mean Square Error $\quad 0.921274$

Mean of Response

Observations (or Sum Wgts) $\quad 44$

Analysis of Variance

Source DF Sum of Squares Mean Square F Ratio

$\begin{array}{lllll}\text { Model } & 21 & 0.00121518 & 0.000058 & 24.9617\end{array}$

$\begin{array}{lllll}\text { Error } 22 & 0.00005100 & 0.000002 & \text { Prob }>\text { F }\end{array}$

$\begin{array}{llll}\text { C. Total } & 43 & 0.00126618 & <.0001\end{array}$

Expected Mean Squares

The Mean Square per row by the Variance Component per column

$\begin{array}{lrr}\text { EMS } & \text { Intercept } & \text { Batch\&Random } \\ \text { Intercept } & 0 & 0\end{array}$

Batch\&Random $\quad 0 \quad 2$

plus 1.0 times Residual Error Variance

Variance Component Estimates

$\begin{array}{crr}\text { Component } & \text { Var Comp Est } & \text { Percent of Total } \\ \text { Batch\&Random } & 0.000028 & 92.296\end{array}$

$\begin{array}{lrr}\text { Residual } & 0.000002 & 7.704\end{array}$

Total $\quad 0.00003 \quad 100.000$

These estimates based on equating Mean Squares to Expected Value.

Test Denominator Synthesis

Source MS Den DF Den Denom MS Synthesis

Batch\&Random 2.32e-6 22 Residual

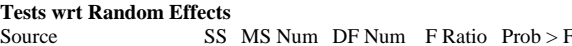

$\begin{array}{lrrrrr}\text { Source } & \text { SS } & \text { MS Num } & \text { DF Num } & \text { F Ratio } & \text { Prob > F } \\ \text { Batch\&Random } & 0.00122 & 0.00006 & 21 & 24.9617 & <.0001\end{array}$

Sample Type=ARG-1, Prep=Mixed Acid, ICP=M-14, Analyte=Fe Response Measurement

Summary of Fit

0.824371

RSquare Adj $\quad 0.656726$

Root Mean Square Error $\quad 0.13804$

Mean of Response 9.491727

Observations (or Sum Wgts) 44

Analysis of Variance

Source DF Sum of Squares Mean Square F Ratio

$\begin{array}{lllll}\text { Model } & 21 & 1.9677157 & 0.093701 & 4.9173\end{array}$

$\begin{array}{llll}\text { Error } & 22 & 0.4192130 & 0.019055 \text { Prob }>\text { F }\end{array}$

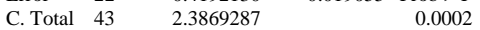

Expected Mean Squares

The Mean Square per row by the Variance Component per column

$\begin{array}{lrr}\text { EMS } & \text { Intercept } & \text { Batch\&Random } \\ \text { Intercept } & 0 & 0 \\ \text { Batch\&Random } & 0 & 2\end{array}$

plus 1.0 times Residual Error Variance

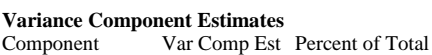

$\begin{array}{ccr}\text { Component } & \text { Var Comp Est } & \text { Percent of Total } \\ \text { Batch\&Random } & 0.037323 & 66.201\end{array}$

$\begin{array}{lll}\text { Residual } & 0.019055 & 33.799\end{array}$

Total $\quad 0.056378 \quad 100.000$

These estimates based on equating Mean Squares to Expected Value.

Test Denominator Synthesis

Source MS Den DF Den Denom MS Synthesis

$\begin{array}{lrrr}\text { Source } & \text { MS Den } & \text { DF Den } & \text { Denom } \\ \text { Batch\&Random } & 0.01906 & 22 & \text { Residual }\end{array}$

Tests wrt Random Effects

Source SS MS Num DF Num F Ratio Prob > F

$\begin{array}{rrrrrr} & \text { SS } & \text { MS Num } & \text { DF Num } & \text { F Ratio } & \text { Prob > F } \\ \text { Batch\&Random } & 1.96772 & 0.0937 & 21 & 4.9173 & 0.0002\end{array}$ 
WSRC-STI-2006-00068

Revision 0

Exhibit A7. Analysis of Variance by Preparation Method, ICP, and Analyte (continued)

Sample Type=ARG-1, Prep=Mixed Acid, ICP=M-14, Analyte=Fe/Al Response Measurement

Summary of Fit

\begin{tabular}{|c|c|c|c|c|}
\hline \multicolumn{3}{|c|}{ RSquare } & \multicolumn{2}{|l|}{0.805582} \\
\hline \multicolumn{3}{|c|}{ RSquare Adj } & 0.620001 & \\
\hline \multicolumn{3}{|c|}{ Root Mean Square Error } & 0.04842 & \\
\hline \multicolumn{3}{|c|}{ Mean of Response } & 4.012449 & \\
\hline \multicolumn{3}{|c|}{ Observations (or Sum Wgts) } & 44 & \\
\hline \multicolumn{5}{|c|}{ Analysis of Variance } \\
\hline Source & DF & Sum of Squares & Mean Square & F Ratio \\
\hline Model & 21 & 0.21371638 & $\quad 0.010177$ & 4.3409 \\
\hline Error & 22 & 0.05157810 & 0.002344 & Prob $>$ F \\
\hline C. Total & 43 & 0.26529448 & & 0.0006 \\
\hline
\end{tabular}

Expected Mean Squares

The Mean Square per row by the Variance Component per column

$\begin{array}{lrr}\text { EMS } & \text { Intercept } & \text { Batch\&Random } \\ \text { Intercept } & 0 & 0\end{array}$

Batch\&Random $\quad 0 \quad 2$

plus 1.0 times Residual Error Variance

Variance Component Estimates

Component Var Comp Est Percent of Total

$\begin{array}{rrr}\text { Component } & \text { Var Comp Est } & \text { Percent of Tota } \\ \text { Batch\&Random } & 0.003916 & 62.553\end{array}$

$\begin{array}{lll}\text { Residual } & 0.002344 & 37.447\end{array}$

Total $\quad 0.006261 \quad 100.000$

These estimates based on equating Mean Squares to Expected Value.

Test Denominator Synthesi

Source MS Den DF Den Denom MS Synthesis

Batch\&Random $0.00234 \quad 22$ Residual

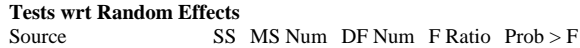

$\begin{array}{lrrrrr}\text { Source } & \text { SS } & \text { MS Num } & \text { DF Num } & \text { F Ratio } & \text { Prob }>\text { F } \\ \text { Batch\&Random } & 0.21372 & 0.01018 & 21 & 4.3409 & 0.0006\end{array}$

Sample Type=ARG-1, Prep=Mixed Acid, ICP=M-14, Analyte=Fe/Ca Response Measurement

Summary of Fit

RSquare $\quad 0.662295$

RSquare Adj $\quad 0.33994$

Root Mean Square Error $\quad 0.153169$

Mean of Response $\quad 9.489341$

Observations (or Sum Wgts) $\quad 44$

Analysis of Variance

Source DF Sum of Squares Mean Square F Ratio

$\begin{array}{lllll}\text { Model } & 21 & 1.0122211 & 0.048201 & 2.0546\end{array}$

$\begin{array}{llll}\text { Error } 22 & 0.5161331 & 0.023461 & \text { Prob }>\text { F }\end{array}$

$\begin{array}{llll}\text { C. Total } & 43 & 1.5283542 & 0.0505\end{array}$

Expected Mean Squares

The Mean Square per row by the Variance Component per column

$\begin{array}{lrr}\text { EMS } & \text { Intercept } & \text { Batch\&Random } \\ \text { Intercept } & 0 & 0\end{array}$

$\begin{array}{lll}\text { Batch\&Random } & 0 & 0 \\ & 0 & 2\end{array}$

plus 1.0 times Residual Error Variance

Variance Component Estimates

Component Var Comp Est Percent of Total

Batch\&Random $\quad 0.01237 \quad 34.524$

$\begin{array}{lll}\text { Residual } & 0.023461 & 65.476\end{array}$

Total $\quad 0.035831 \quad 100.000$

These estimates based on equating Mean Squares to Expected Value.

Test Denominator Synthesis

Source MS Den DF Den Denom MS Synthesis

$\begin{array}{lrrr}\text { Batch\&Random } & 0.02346 & 22 & \text { Residual }\end{array}$

Tests wrt Random Effects

Source

SS MS Num DF Num F Ratio Prob $>$ F

$\begin{array}{llllll}\text { Batch\&Random } & 1.01222 & 0.0482 & 21 & 2.0546 & 0.0505\end{array}$
Sample Type=ARG-1, Prep=Mixed Acid, ICP=M-14, Analyte=Fe/Li Response Measurement

Summary of Fit

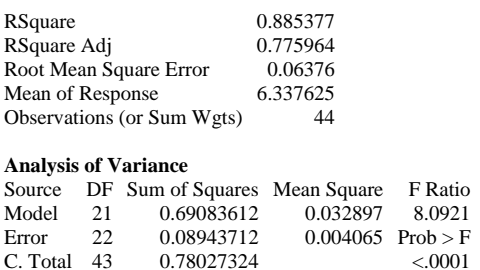

Expected Mean Squares

The Mean Square per row by the Variance Component per column

$\begin{array}{lrr}\text { EMS } & \text { Intercept } & \text { Batch\&Random } \\ \text { Intercept } & 0 & 0\end{array}$

Batch\&Random $\quad 0 \quad 2$

plus 1.0 times Residual Error Variance

Variance Component Estimates

$\begin{array}{rrr}\text { Component } & \text { Var Comp Est } & \text { Percent of Total } \\ \text { Batch\&Random } & 0.014416 & 78.003\end{array}$

$\begin{array}{lll}\text { Batch\&Random } & 0.014416 & 78.003 \\ & 0.004065 & 21.997\end{array}$

$\begin{array}{lrr}\text { Residual } & 0.004065 & 21.997 \\ \text { Total } & 0.018481 & 100.000\end{array}$

These estimates based on equating Mean Squares to Expected Value.

Test Denominator Synthesis

Source MS Den DF Den Denom MS Synthesis

Batch\&Random $0.00407 \quad 22$ Residual

Tests wrt Random Effects
Source SS MS Num DF Num F Ratio Prob $>$ F

$\begin{array}{lrrrrr}\text { Source } & \text { SS } & \text { MS Num } & \text { DF Num } & \text { F Ratio } & \text { Prob }>\text { F } \\ \text { Batch\&Random } & 0.69084 & 0.0329 & 21 & 8.0921 & <.0001\end{array}$

Sample Type=ARG-1, Prep=Mixed Acid, ICP=M-14, Analyte=Fe/Mg Response Measurement

Summary of Fit

0.841903

Root Mean Square Error $\quad 0.690993$

0.195758

$\begin{array}{lr}\text { Mean of Response } & 18.68157 \\ \text { Observations (or Sum Wgts) } & 44\end{array}$

Analysis of Variance

Source DF Sum of Squares Mean Square F Ratio

$\begin{array}{lllll}\text { Model } & 21 & 4.4895312 & 0.213787 & 5.5788\end{array}$

$\begin{array}{lllll}\text { Error } & 22 & 0.8430655 & 0.038321 & \text { Prob }>\text { F }\end{array}$

$\begin{array}{llll}\text { C. Total } & 43 & 5.3325967 & 0.038321 \\ \end{array}$

Expected Mean Squares

The Mean Square per row by the Variance Component per column

$\begin{array}{lrr}\text { EMS } & \text { Intercept } & \text { Batch\&Random } \\ \text { Intercept } & 0 & 0 \\ \text { Batch\&Random } & 0 & 2\end{array}$

plus 1.0 times Residual Error Variance

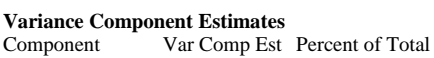

\begin{tabular}{crr} 
Component & Var Comp Est & Percent of Total \\
Batch\&Random & 0.087733 & 69.599 \\
Residual & 0.038321 & 30.401 \\
\hline
\end{tabular}

$\begin{array}{llr}\text { Residual } & 0.038321 & 30.401 \\ \text { Total } & 0.126054 & 100.000\end{array}$

These estimates based on equating Mean Squares to Expected Value.

Test Denominator Synthesis

Source MS Den DF Den Denom MS Synthesis

$\begin{array}{lrrr}\text { Source } & \text { MS Den } & \text { DF Den } & \text { Denom MS } \\ \text { Batch\&Random } & 0.03832 & 22 & \text { Residual }\end{array}$

Tests wrt Random Effects

Source SS MS Num DF Num F Ratio Prob $>$ F

$\begin{array}{rrrrrr}\text { Batch\&Random } & 4.48953 & 0.21379 & 21 & 5.5788 & <.0001\end{array}$ 
WSRC-STI-2006-00068

Revision 0

Exhibit A7. Analysis of Variance by Preparation Method, ICP, and Analyte (continued)

Sample Type=ARG-1, Prep=Mixed Acid, ICP=M-14, Analyte=Fe/Mn Response Measurement

Summary of Fi

\begin{tabular}{|c|c|c|c|c|}
\hline \multicolumn{3}{|c|}{ RSquare } & 0.825856 & \\
\hline \multicolumn{3}{|c|}{ RSquare Adj } & 0.660004 & \\
\hline \multicolumn{3}{|c|}{ Root Mean Square Error } & 0.068036 & \\
\hline \multicolumn{3}{|c|}{ Mean of Response } & 6.76655 & \\
\hline \multicolumn{3}{|c|}{ Observations (or Sum Wgts) } & 42 & \\
\hline \multicolumn{5}{|c|}{ Analysis of Variance } \\
\hline Source & DF & Sum of Squares & Mean Square & F Ratio \\
\hline Model & 20 & 0.46099663 & 0.023050 & 4.9795 \\
\hline Error & 21 & 0.09720815 & 0.004629 & Prob $>$ F \\
\hline C. Total & 41 & 0.55820478 & & 0.0003 \\
\hline
\end{tabular}

Expected Mean Squares

The Mean Square per row by the Variance Component per column

$\begin{array}{lrr}\text { EMS } & \text { Intercept } & \text { Batch\&Random } \\ \text { Intercept } & 0 & 0\end{array}$

Batch\&Random $\quad 0 \quad 2$

plus 1.0 times Residual Error Variance

Variance Component Estimates

Component Var Comp Est Percent of Total

$\begin{array}{rrr}\text { Component } & \text { Var Comp Est } & \text { Percent of Total } \\ \text { Batch\&Random } & 0.00921 & 66.552\end{array}$

$\begin{array}{lll}\text { Residual } & 0.004629 & 33.448\end{array}$

Total $\quad 0.013839 \quad 100.000$

These estimates based on equating Mean Squares to Expected Value.

Test Denominator Synthesis

Source MS Den DF Den Denom MS Synthesis

Batch\&Random $0.00463 \quad 21$ Residual

Tests wrt Random Effects

Source SS MS Num DF Num F Ratio Prob $>$ F

$\begin{array}{lrrrrr}\text { Batch\&Random } & 0.461 & 0.02305 & 20 & 4.9795 & 0.0003\end{array}$

Sample Type=ARG-1, Prep=Mixed Acid, ICP=M-14, Analyte=Fe/Ni Response Measurement

Summary of Fit

RSquare $\quad 0.705875$

RSquare Adj $\quad 0.425118$

Root Mean Square Error $\quad 0.189316$

Mean of Response 11.82032

Observations (or Sum Wgts) $\quad 44$

Analysis of Variance

Source DF Sum of Squares Mean Square F Ratio

\begin{tabular}{lllll} 
Model & 21 & 1.8923075 & 0.090110 & 2.5142 \\
\hline
\end{tabular}

$\begin{array}{lllll}\text { Error } & 22 & 0.7884910 & 0.035840 \text { Prob }>\text { F }\end{array}$

$\begin{array}{llll}\text { C. Total } & 43 & 2.6807985 & 0.0184\end{array}$

Expected Mean Squares

The Mean Square per row by the Variance Component per column

$\begin{array}{lrr}\text { EMS } & \text { Intercept } & \text { Batch\&Random } \\ \text { Intercept } & 0 & 0\end{array}$

Batch\&Random $\quad 0 \quad 2$

plus 1.0 times Residual Error Variance

Variance Component Estimates

Component Var Comp Est Percent of Total

$\begin{array}{lll}\text { Batch\&Random } \quad 0.027135 & 43.088\end{array}$

$\begin{array}{lrr}\text { Residual } & 0.03584 & 56.912\end{array}$

Total $\quad 0.062975 \quad 100.000$

These estimates based on equating Mean Squares to Expected Value.

Test Denominator Synthesis

Source MS Den DF Den Denom MS Synthesis

$\begin{array}{lrrr}\text { Batch\&Random } & 0.03584 & 22 & \text { Residual }\end{array}$

Tests wrt Random Effects

Source

SS MS Num DF Num F Ratio Prob $>$ F

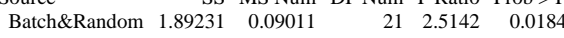

Sample Type=ARG-1, Prep=Mixed Acid, ICP=M-14, Analyte=Fe/U Response Measurement

Summary of Fit

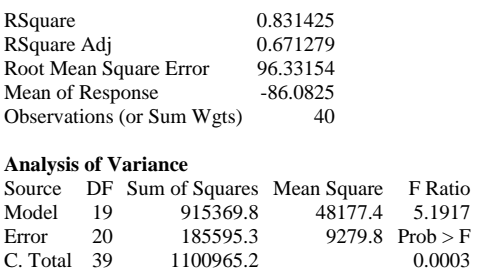

Expected Mean Squares

The Mean Square per row by the Variance Component per column

EMS Intercept Batch\&Random

$\begin{array}{lll}\text { Intercept } & 0 & 0 \\ \text { Batch\&Random } & 0 & 2\end{array}$

plus 1.0 times Residual Error Variance

Variance Component Estimates

$\begin{array}{rrr}\text { Component } & \text { Var Comp Est } & \text { Percent of Total } \\ \text { Batch\&Random } & 19448.8 & 67.698\end{array}$

$\begin{array}{lrr}\text { Batch\&Random } & 19448.8 & 67.698 \\ \text { Residual } & 9279.766 & 32.302\end{array}$

$\begin{array}{lrr}\text { Residual } & 9279.766 & 32.302 \\ \text { Total } & 28728.56 & 100.000\end{array}$

These estimates based on equating Mean Squares to Expected Value.

Test Denominator Synthesis

Source MS Den DF Den Denom MS Synthesis

Batch\&Random $9279.77 \quad 20$ Residual

Tests wrt Random Effects

Source SS MS Num DF Num F Ratio Prob > F

Batch\&Random $915370 \quad 48177.4 \quad 19 \quad 5.1917 \quad 0.0003$

Sample Type=ARG-1, Prep=Mixed Acid, ICP=M-14, Analyte=K Response Measurement

Summary of Fit

RSquare $\quad 0.638321$

RSquare Adj $\quad 0.293082$

Root Mean Square Error $\quad 0.134022$

Mean of Response 2.226818

Observations (or Sum Wgts) $\quad 4$

Analysis of Variance

Source DF Sum of Squares Mean Square F Ratio

$\begin{array}{lllll}\text { Model } & 21 & 0.6974095 & 0.033210 & 1.8489\end{array}$

$\begin{array}{lllll}\text { Error } & 22 & 0.3951590 & 0.017962 & \text { Prob }>\text { F }\end{array}$

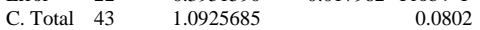

Expected Mean Squares

The Mean Square per row by the Variance Component per column

$\begin{array}{lrr}\text { EMS } & \text { Intercept } & \text { Batch\&Random } \\ \text { Intercept } & 0 & 0 \\ \text { Batch\&Random } & 0 & 2\end{array}$

plus 1.0 times Residual Error Variance

Variance Component Estimates
$\begin{array}{ll}\text { Component } & \text { Var Comp Est Percent of Total }\end{array}$

\begin{tabular}{crr} 
Component & Var Comp Est & Percent of Total \\
Batch\&Random & 0.007624 & 29.798 \\
Residual & 0.017962 & 70.202 \\
\hline
\end{tabular}

$\begin{array}{llr}\text { Residual } & 0.017962 & 70.202 \\ \text { Total } & 0.025586 & 100.000\end{array}$

These estimates based on equating Mean Squares to Expected Value.

Test Denominator Synthesis

Source MS Den DF Den Denom MS Synthesis

$\begin{array}{crrr}\text { Source } & \text { MS Den } & \text { DF Den } & \text { Denom MS } \\ \text { Batch\&Random } & 0.01796 & 22 & \text { Residual }\end{array}$

Tests wrt Random Effects

Source SS MS Num DF Num F Ratio Prob $>$ F

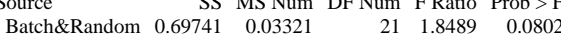


WSRC-STI-2006-00068

Revision 0

Exhibit A7. Analysis of Variance by Preparation Method, ICP, and Analyte (continued)

Sample Type=ARG-1, Prep=Mixed Acid, ICP=M-14, Analyte $=$ L Response Measurement

Summary of Fi

\begin{tabular}{|c|c|c|c|c|}
\hline \multicolumn{3}{|c|}{ RSquare } & 0.697446 & \\
\hline \multicolumn{3}{|c|}{ RSquare Adj } & 0.408645 & \\
\hline \multicolumn{3}{|c|}{ Root Mean Square Error } & 0.02374 & \\
\hline \multicolumn{3}{|c|}{ Mean of Response } & 1.497864 & \\
\hline \multicolumn{3}{|c|}{ Observations (or Sum Wgts) } & 44 & \\
\hline \multicolumn{5}{|c|}{ Analysis of Variance } \\
\hline Source & $\mathrm{DF}$ & Sum of Squares & Mean Square & F Ratio \\
\hline Model & 21 & 0.02858218 & 0.001361 & 2.4150 \\
\hline Error & 22 & 0.01239900 & 0.000564 & Prob $>$ F \\
\hline C. Total & 43 & 0.04098118 & & 0.0228 \\
\hline
\end{tabular}

Expected Mean Squares

The Mean Square per row by the Variance Component per column

$\begin{array}{lrr}\text { EMS } & \text { Intercept } & \text { Batch\&Random } \\ \text { Intercept } & 0 & 0\end{array}$

Batch\&Random $\quad 0 \quad 2$

plus 1.0 times Residual Error Variance

Variance Component Estimates

Component Var Comp Est Percent of Total

Batch\&Random $\quad 0.000399 \quad 41.434$

Residual $\quad 0.000564 \quad 58.566$

Total $\quad 0.000962 \quad 100.000$

These estimates based on equating Mean Squares to Expected Value.

Test Denominator Synthesis

Source MS Den DF Den Denom MS Synthesis

Batch\&Random $0.00056 \quad 22$ Residual

Tests wrt Random Effects
Source MS Num DF Num F Ratio Prob > F

$\begin{array}{lrrrrr}\text { Source } & \text { SS } & \text { MS Num } & \text { DF Num } & \text { F Ratio } & \text { Prob > F } \\ \text { Batch\&Random } & 0.02858 & 0.00136 & 21 & 2.4150 & 0.0228\end{array}$

Sample Type=ARG-1, Prep=Mixed Acid, ICP=M-14, Analyte=Mg Response Measurement

Summary of Fit

RSquare $\quad 0.762804$

RSquare Adj $\quad 0.536389$

Root Mean Square Error $\quad 0.008997$

Mean of Response $\quad 0.508182$

Observations (or Sum Wgts) $\quad 44$

Analysis of Variance

Source DF Sum of Squares Mean Square F Ratio

$\begin{array}{lllll}\text { Model } & 21 & 0.00572755 & 0.000273 & 3.3691\end{array}$

$\begin{array}{lllll}\text { Error } & 22 & 0.00178100 & 0.000081 & \text { Prob }>\text { F }\end{array}$

$\begin{array}{llll}\text { C. Total } & 43 & 0.00750855 & 0.0033\end{array}$

Expected Mean Square

The Mean Square per row by the Variance Component per column

$\begin{array}{lrr}\text { EMS } & \text { Intercept } & \text { Batch\&Random } \\ \text { Intercept } & 0 & 0\end{array}$

$\begin{array}{lll}0 & 0 \\ \text { Batch\&Random } & 0 & 2\end{array}$

plus 1.0 times Residual Error Variance

Variance Component Estimates

Component Var Comp Est Percent of Total

Batch\&Random $\quad 0.000096 \quad 54.224$

$\begin{array}{lll}\text { Residual } & 0.000081 & 45.776\end{array}$

Total $\quad 0.000177 \quad 100.000$

These estimates based on equating Mean Squares to Expected Value.

Test Denominator Synthesis

Source MS Den DF Den Denom MS Synthesis

Batch\&Random $0.00008 \quad 22$ Residual

Tests wrt Random Effects

Source

SS MS Num DF Num F Ratio Prob > F

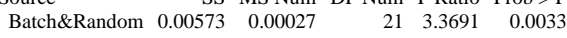

Sample Type=ARG-1, Prep=Mixed Acid, ICP=M-14, Analyte=Mn Response Measurement

Summary of Fit

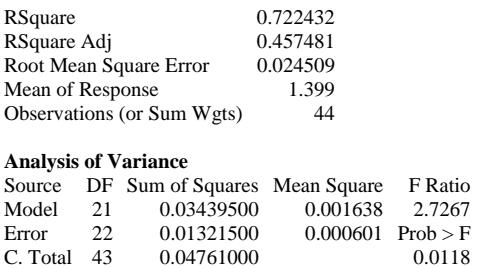

Expected Mean Squares

The Mean Square per row by the Variance Component per column

EMS Intercept Batch\&Random

$\begin{array}{lll}\text { Intercept } & 0 & 0 \\ \text { Batch\&Random } & 0 & 2\end{array}$

plus 1.0 times Residual Error Variance

Variance Component Estimates

$\begin{array}{crr}\text { Component } & \text { Var Comp Est } & \text { Percent of Total } \\ \text { Batch\&Random } & 0.000519 & 46.333 \\ \text { Residual } & 0.000601 & 53.667\end{array}$

Total $\quad 0.001119 \quad 100.000$

These estimates based on equating Mean Squares to Expected Value.

Test Denominator Synthesi

Source MS Den DF Den Denom MS Synthesis

Batch\&Random $0.0006 \quad 22$ Residual

Tests wrt Random Effects
Source SS MS Num DF Num F Ratio Prob > F

$\begin{array}{lrrrrr}\text { Batch\&Random } & 0.03439 & 0.00164 & 21 & 2.7267 & 0.0118\end{array}$

Sample Type=ARG-1, Prep=Mixed Acid, ICP=M-14, Analyte=Mn/Mg Response Measurement

Summary of Fit

0.785259

0.580279

0.029175

$\begin{array}{lr}\text { Mean of Response } & 2.753454 \\ \text { Observations (or Sum Wgts) } & 44\end{array}$

Analysis of Variance

Source DF Sum of Squares Mean Square F Ratio

$\begin{array}{lllll}\text { Model } & 21 & 0.06847782 & 0.003261 & 3.8309\end{array}$

$\begin{array}{lllll}\text { Error } 22 & 0.01872630 & 0.000851 \text { Prob }>\text { F }\end{array}$

$\begin{array}{llll}\text { C. Total } & 43 & 0.08720412 & 0.0014\end{array}$

Expected Mean Squares

The Mean Square per row by the Variance Component per column

$\begin{array}{lrr}\text { EMS } & \text { Intercept } & \text { Batch\&Random } \\ \text { Intercept } & 0 & 0 \\ \text { Batch\&Random } & 0 & 2\end{array}$

plus 1.0 times Residual Error Variance

Variance Component Estimates
Component Var Comp Est Percent of Total

$\begin{array}{crr}\text { Component } & \text { Var Comp Est } & \text { Percent of Total } \\ \text { Batch\&Random } & 0.001205 & 58.600\end{array}$

$\begin{array}{lll}\text { Residual } & 0.001205 & 58.600 \\ & 0.000851 & 41.400\end{array}$

Total $\quad 0.002056 \quad 100.000$

These estimates based on equating Mean Squares to Expected Value.

Test Denominator Synthesis

Source MS Den DF Den Denom MS Synthesis

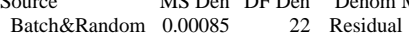

Tests wrt Random Effects

Source SS MS Num DF Num F Ratio Prob $>$ F

$\begin{array}{lrrrrr}\text { Batch\&Random } & 0.06848 & 0.00326 & 21 & 3.8309 & 0.0014\end{array}$ 
WSRC-STI-2006-00068

Revision 0

Exhibit A7. Analysis of Variance by Preparation Method, ICP, and Analyte (continued)

Sample Type=ARG-1, Prep=Mixed Acid, ICP=M-14, Analyte=Na Response Measurement

Summary of Fit

\begin{tabular}{|c|c|c|c|c|}
\hline \multicolumn{3}{|c|}{ RSquare } & 0.610283 & \\
\hline \multicolumn{3}{|c|}{ RSquare Adj } & 0.241078 & \\
\hline \multicolumn{3}{|c|}{ Root Mean Square Error } & 0.128408 & \\
\hline \multicolumn{3}{|c|}{ Mean of Response } & 8.400421 & \\
\hline \multicolumn{3}{|c|}{ Observations (or Sum Wgts) } & 38 & \\
\hline \multicolumn{5}{|c|}{ Analysis of Variance } \\
\hline Source & DF & Sum of Squares & Mean Square & F Ratio \\
\hline Model & 18 & 0.49059526 & 0.027255 & 1.6530 \\
\hline Error & 19 & 0.31328600 & 0.016489 & Prob $>$ F \\
\hline C. Total & 37 & 0.80388126 & & 0.1430 \\
\hline
\end{tabular}

Expected Mean Squares

The Mean Square per row by the Variance Component per column

$\begin{array}{lrr}\text { EMS } & \text { Intercept } & \text { Batch\&Random } \\ \text { Intercept } & 0 & 0\end{array}$

Batch\&Random $\quad 0 \quad 2$

plus 1.0 times Residual Error Variance

Variance Component Estimates

Component Var Comp Est Percent of Total

Batch\&Random $\quad 0.005383 \quad 24.613$

$\begin{array}{lll}\text { Residual } & 0.016489 & 75.387\end{array}$

Total $\quad 0.021872 \quad 100.000$

These estimates based on equating Mean Squares to Expected Value.

Test Denominator Synthesis

Source MS Den DF Den Denom MS Synthesis

Batch\&Random $0.01649 \quad 19$ Residual

Tests wrt Random Effects
Source MS Num DF Num F Ratio Prob $>$ F

$\begin{array}{lrrrrr}\text { Source } & \text { SS } & \text { MS Num } & \text { DF Num } & \text { F Ratio } & \text { Prob > F } \\ \text { Batch\&Random } & 0.4906 & 0.02726 & 18 & 1.6530 & 0.1430\end{array}$

Sample Type=ARG-1, Prep=Mixed Acid, ICP=M-14, Analyte=Ni Response Measurement

Summary of Fit

RSquare $\quad 0.589621$

RSquare Adj $\quad 0.197896$

Root Mean Square Error $\quad 0.015503$

Mean of Response $\quad 0.803114$

Observations (or Sum Wgts) $\quad 44$

Analysis of Variance

Source DF Sum of Squares Mean Square F Ratio

$\begin{array}{lllll}\text { Model } & 21 & 0.00759693 & 0.000362 & 1.5052\end{array}$

$\begin{array}{lllll}\text { Error } & 22 & 0.00528750 & 0.000240 & \text { Prob }>\text { F }\end{array}$

$\begin{array}{llll}\text { C. Total } & 43 & 0.01288443 & 0.1740\end{array}$

Expected Mean Squares

The Mean Square per row by the Variance Component per column

$\begin{array}{lrr}\text { EMS } & \text { Intercept } & \text { Batch\&Random } \\ \text { Intercept } & 0 & 0\end{array}$

Batch\&Random $\quad 0 \quad 2$

plus 1.0 times Residual Error Variance

Variance Component Estimates

Component Var Comp Est Percent of Total

Batch\&Random $\quad 0.000061 \quad 20.166$

$\begin{array}{lll}\text { Residual } & 0.00024 & 79.834\end{array}$

Total $\quad 0.000301 \quad 100.000$

These estimates based on equating Mean Squares to Expected Value.

Test Denominator Synthesis

Source MS Den DF Den Denom MS Synthesis

Batch\&Random $0.00024 \quad 22$ Residual

Tests wrt Random Effects

Source SS MS Num DF Num F Ratio Prob $>$ F

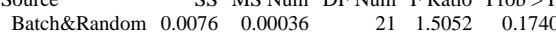

Sample Type=ARG-1, Prep=Mixed Acid, ICP=M-14, Analyte=S Response Measurement

Summary of Fit

\begin{tabular}{|c|c|c|c|c|}
\hline \multicolumn{3}{|c|}{ RSquare } & \multicolumn{2}{|l|}{0.699941} \\
\hline \multicolumn{3}{|c|}{ RSquare Adj } & 0.414884 & \\
\hline \multicolumn{3}{|c|}{ Root Mean Square Error } & 0.537641 & \\
\hline \multicolumn{3}{|c|}{ Mean of Response } & 20.98507 & \\
\hline \multicolumn{3}{|c|}{ Observations (or Sum Wgts) } & 40 & \\
\hline \multicolumn{5}{|c|}{ Analysis of Variance } \\
\hline Source & DF & Sum of Squares & S Mean Square & F Ratio \\
\hline Model & 19 & 13.485535 & $5 \quad 0.709765$ & 2.4554 \\
\hline Error & 20 & 5.781152 & 0.289058 & Prob $>$ F \\
\hline C. Total & 39 & 19.266687 & & 0.0263 \\
\hline
\end{tabular}

Expected Mean Squares

The Mean Square per row by the Variance Component per column

$\begin{array}{lrr}\text { EMS } & \text { Intercept } & \text { Batch\&Random } \\ \text { Intercept } & 0 & 0 \\ \text { Batch\&Random } & 0 & 2\end{array}$

plus 1.0 times Residual Error Variance

Variance Component Estimates

$\begin{array}{crr}\text { Component } & \text { Var Comp Est } & \text { Percent of Total } \\ \text { Batch\&Random } & 0.210354 & 42.120 \\ \text { Residul } & 0.289058 & 57.880\end{array}$

$\begin{array}{llr}\text { Residual } & 0.289058 & 57.880\end{array}$

Total $\quad 0.499411 \quad 100.000$

These estimates based on equating Mean Squares to Expected Value.

Test Denominator Synthesis

Source MS Den DF Den Denom MS Synthesis

Batch\&Random $0.28906 \quad 20$ Residual

Tests wrt Random Effects
$\begin{aligned} & \text { Source } \\ & \text { SS MS Num DF Num F Ratio Prob }>\text { F }\end{aligned}$

$\begin{array}{lrrrrr}\text { Source } & \text { SS } & \text { MS Num } & \text { DF Num } & \text { F Ratio } & \text { Prob > F } \\ \text { Batch\&Random } & 13.4855 & 0.70977 & 19 & 2.4554 & 0.0263\end{array}$

Sample Type=ARG-1, Prep=Mixed Acid, ICP=M-14, Analyte=Sum of Oxides Response Measurement

Summary of Fit

$\quad 0.660366$

RSquare Adj $\quad 0.33617$

$\quad 2.052126$

$\begin{array}{lr}\text { Mean of Response } & 85.97355 \\ \text { Observations (or Sum Wgts) } & 44\end{array}$

Analysis of Variance

Source DF Sum of Squares Mean Square F Ratio

$\begin{array}{lllll}\text { Model } & 21 & 180.13747 & 8.57797 & 2.0369\end{array}$

$\begin{array}{llrrr}\text { Error } & 22 & 92.64688 & 4.21122 & \text { Prob }>\text { F }\end{array}$

$\begin{array}{llll}\text { C. Total } & 43 & 272.78435 & 0.0525\end{array}$

Expected Mean Squares

The Mean Square per row by the Variance Component per column

$\begin{array}{lrr}\text { EMS } & \text { Intercept } & \text { Batch\&Random } \\ \text { Intercept } & 0 & 0 \\ \text { Batch\&Random } & 0 & 2\end{array}$

plus 1.0 times Residual Error Variance

Variance Component Estimates
Component Var Comp Est Percent of Total

$\begin{array}{crr}\text { Component } & \text { Var Comp Est } & \text { Percent of Total } \\ \text { Batch\&Random } & 2.183376 & 34.144\end{array}$

$\begin{array}{lll}\text { Residual } & 2.183376 & 34.144 \\ & 4.211222 & 65.856\end{array}$

Total $\quad 6.394598 \quad 100.000$

These estimates based on equating Mean Squares to Expected Value.

Test Denominator Synthesis

Source MS Den DF Den Denom MS Synthesis

$\begin{array}{rrrr}\text { Source } & \text { MS Den } & \text { DF Den } & \text { Denomal } \\ \text { Batch\&Random } & 4.21122 & 22 & \text { Residual }\end{array}$

Tests wrt Random Effects

Source SS MS Num DF Num F Ratio Prob $>$ F

$\begin{array}{rrrrrr}\text { Batch\&Random } & 180.137 & 8.57797 & 21 & 2.0369 & 0.0525\end{array}$ 
WSRC-STI-2006-00068

Revision 0

Exhibit A7. Analysis of Variance by Preparation Method, ICP, and Analyte (continued)

Sample Type=ARG-1, Prep=Mixed Acid, ICP=M-14, Analyte $=T$ Response Measurement

Summary of Fi

\begin{tabular}{|c|c|c|c|c|}
\hline \multicolumn{3}{|c|}{ RSquare } & \multicolumn{2}{|l|}{0.548033} \\
\hline \multicolumn{3}{|c|}{ RSquare Adj } & 0.116609 & \\
\hline \multicolumn{3}{|c|}{ Root Mean Square Error } & 0.013387 & \\
\hline \multicolumn{3}{|c|}{ Mean of Response } & 0.687977 & \\
\hline \multicolumn{3}{|c|}{ Observations (or Sum Wgts) } & 44 & \\
\hline \multicolumn{5}{|c|}{ Analysis of Variance } \\
\hline Source & $\mathrm{DF}$ & Sum of Squares & Mean Square & F Ratio \\
\hline Model & 21 & 0.00478048 & 0.000228 & 1.2703 \\
\hline Error & 22 & 0.00394250 & 0.000179 & Prob $>$ F \\
\hline C. Total & 43 & 0.00872298 & & 0.2907 \\
\hline
\end{tabular}

Expected Mean Squares

The Mean Square per row by the Variance Component per column

$\begin{array}{lrr}\text { EMS } & \text { Intercept } & \text { Batch\&Random } \\ \text { Intercept } & 0 & 0\end{array}$

Batch\&Random $\quad 0 \quad 2$

plus 1.0 times Residual Error Variance

Variance Component Estimates

Component Var Comp Est Percent of Total

Batch\&Random $\quad 0.000024 \quad 11.906$

$\begin{array}{lll}\text { Residual } & 0.000179 & 88.094\end{array}$

Total $\quad 0.000203 \quad 100.000$

These estimates based on equating Mean Squares to Expected Value.

Test Denominator Synthesi

Source MS Den DF Den Denom MS Synthesis

Batch\&Random $0.00018 \quad 22$ Residual

Tests wrt Random Effects
Source

$\begin{array}{lrrrrr}\text { Source } & \text { SS } & \text { MS Num } & \text { DF Num } & \text { F Ratio } & \text { Prob > F } \\ \text { Batch\&Random } & 0.00478 & 0.00023 & 21 & 1.2703 & 0.2907\end{array}$

Sample Type=ARG-1, Prep=Mixed Acid, ICP=M-14, Analyte=U Response Measurement

Summary of Fit

RSquare $\quad 0.837146$

RSquare Adj $\quad 0.681695$

Root Mean Square Error $\quad 0.043774$

Mean of Response $\quad-0.09157$

Observations (or Sum Wgts) 44

Analysis of Variance

Source DF Sum of Squares Mean Square F Ratio

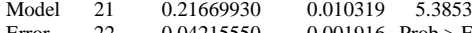

$\begin{array}{lllll}\text { Error } & 22 & 0.04215550 & 0.001916 & \text { Prob }>\text { F }\end{array}$

$\begin{array}{llll}\text { C. Total } & 43 & 0.25885480 & 0.0001\end{array}$

Expected Mean Square

The Mean Square per row by the Variance Component per column

$\begin{array}{lrr}\text { EMS } & \text { Intercept } & \text { Batch\&Random } \\ \text { Intercept } & 0 & 0\end{array}$

Batch\&Random $\quad 0 \quad 2$

plus 1.0 times Residual Error Variance

Variance Component Estimates

Component Var Comp Est Percent of Total

$\begin{array}{lll}\text { Batch\&Random } \quad 0.004201 & 68.678\end{array}$

$\begin{array}{lll}\text { Residual } & 0.001916 & 31.322\end{array}$

Total $\quad 0.006118 \quad 100.000$

These estimates based on equating Mean Squares to Expected Value.

Test Denominator Synthesis

Source MS Den DF Den Denom MS Synthesis

Batch\&Random $\quad 0.00192 \quad 22$ Residual

Tests wrt Random Effects

Source SS MS Num DF Num F Ratio Prob > F

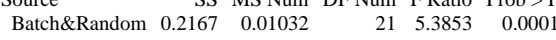

Sample Type=ARG-1, Prep=Mixed Acid, ICP=M-14, Analyte=U/Ca Response Measurement

Summary of Fit

\begin{tabular}{|c|c|c|c|c|}
\hline \multicolumn{3}{|c|}{ RSquare } & \multicolumn{2}{|l|}{0.826359} \\
\hline \multicolumn{3}{|c|}{ RSquare Adj } & 0.660611 & \\
\hline \multicolumn{3}{|c|}{ Root Mean Square Error } & 0.045751 & \\
\hline \multicolumn{3}{|c|}{ Mean of Response } & -0.09206 & \\
\hline \multicolumn{3}{|c|}{ Observations (or Sum Wgts) } & 44 & \\
\hline \multicolumn{5}{|c|}{ Analysis of Variance } \\
\hline Source & DF & Sum of Squares & s Mean Square & F Ratio \\
\hline Model & 21 & 0.21914848 & $3 \quad 0.010436$ & 4.9856 \\
\hline Error & 22 & 0.04604922 & 0.002093 & Prob $>F$ \\
\hline C. Total & 43 & 0.26519770 & & 0.0002 \\
\hline
\end{tabular}

Expected Mean Squares

The Mean Square per row by the Variance Component per column

$\begin{array}{lrr}\text { EMS } & \text { Intercept } & \text { Batch\&Random } \\ \text { Intercept } & 0 & 0\end{array}$

Batch\&Random $\quad 0 \quad 2$

plus 1.0 times Residual Error Variance

Variance Component Estimates

\begin{tabular}{crr} 
Component & Var Comp Est & Percent of Total \\
Batch\&Random & 0.004171 & 66.587 \\
\hline & 0.002093 & 33.413
\end{tabular}

$\begin{array}{lll}\text { Residual } & 0.002093 & 33.413\end{array}$

Total $\quad 0.006264 \quad 100.000$

These estimates based on equating Mean Squares to Expected Value.

Test Denominator Synthesis

Source MS Den DF Den Denom MS Synthesis

Batch\&Random $0.00209 \quad 22$ Residual

Tests wrt Random Effects
Source SS MS Num DF Num F Ratio Prob > F

$\begin{array}{lrrrrr}\text { Source } & \text { SS } & \text { MS Num } & \text { DF Num } & \text { F Ratio } & \text { Prob }>\text { F } \\ \text { Batch\&Random } & 0.21915 & 0.01044 & 21 & 4.9856 & 0.0002\end{array}$

Sample Type=ARG-1, Prep=Mixed Acid, ICP=M-14, Analyte=Zr Response Measurement

Summary of Fit

0.845019

RSquare Adj $\quad 0.697083$

Root Mean Square Error $\quad 0.002693$

Mean of Response 0.094205

Observations (or Sum Wgts) 44

Analysis of Variance

Source DF Sum of Squares Mean Square F Ratio

$\begin{array}{lllll}\text { Model } & 21 & 0.00086966 & 0.000041 & 5.7120\end{array}$

$\begin{array}{lllll}\text { Error } & 22 & 0.00015950 & 0.000007 & \text { Prob }>\text { F }\end{array}$

$\begin{array}{llll}\text { C. Total } & 43 & 0.00102916 & <.0001\end{array}$

Expected Mean Squares

The Mean Square per row by the Variance Component per column

$\begin{array}{lrr}\text { EMS } & \text { Intercept } & \text { Batch\&Random } \\ \text { Intercept } & 0 & 0 \\ \text { Batch\&Random } & 0 & 2\end{array}$

plus 1.0 times Residual Error Variance

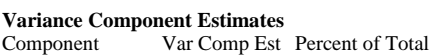

\begin{tabular}{crr} 
Component & Var Comp Est & Percent of Total \\
Batch\&Random & 0.000017 & 70.203 \\
Residual & 0.000007 & 29.797 \\
\hline
\end{tabular}

$\begin{array}{llr}\text { Residual } & 0.000007 & 29.797 \\ \text { Total } & 0.000024 & 100.000\end{array}$

These estimates based on equating Mean Squares to Expected Value.

Test Denominator Synthesis

Source MS Den DF Den Denom MS Synthesis

$\begin{array}{crrr}\text { Source } & \text { MS Den } & \text { DF Den } & \text { Denom } \\ \text { Batch\&Random } & 7.25 \mathrm{e}-6 & 22 & \text { Residual }\end{array}$

Tests wrt Random Effects

Source SS MS Num DF Num F Ratio Prob $>$ F

$\begin{array}{rrrrrr}\text { Batch\&Random } & 0.00087 & 0.00004 & 21 & 5.7120 & <.0001\end{array}$ 
WSRC-STI-2006-00068

Revision 0

Exhibit A7. Analysis of Variance by Preparation Method, ICP, and Analyte (continued)

Sample Type=SME, Prep=Fusion, ICP=M-13, Analyte=Al Response Measurement

Summary of Fit

\begin{tabular}{|c|c|c|c|c|}
\hline \multicolumn{3}{|l|}{ RSquare } & \multicolumn{2}{|l|}{0.74378} \\
\hline \multicolumn{3}{|c|}{ RSquare Adj } & 0.694089 & \\
\hline \multicolumn{3}{|c|}{ Root Mean Square Error } & 0.125284 & \\
\hline \multicolumn{3}{|c|}{ Mean of Response } & 2.956626 & \\
\hline \multicolumn{3}{|c|}{ Observations (or Sum Wgts) } & 198 & \\
\hline \multicolumn{5}{|c|}{ Analysis of Variance } \\
\hline Source & DF & Sum of Squares & s Mean Square & F Ratio \\
\hline Model & 32 & 7.518053 & $3 \quad 0.234939$ & 14.9680 \\
\hline Error & 165 & 2.589847 & 0.015696 & Prob $>F$ \\
\hline C. Total & 197 & 10.107900 & & $<.0001$ \\
\hline
\end{tabular}

Expected Mean Squares

The Mean Square per row by the Variance Component per column

$\begin{array}{lrr}\text { EMS } & \text { Intercept } & \text { Batch\&Random } \\ \text { Intercept } & 0 & 0\end{array}$

Batch\&Random $\quad 0 \quad 6$

plus 1.0 times Residual Error Variance

Variance Component Estimates

Component Var Comp Est Percent of Total

$\begin{array}{rrr}\text { Component } & \text { Var Comp Est } & \text { Percent of Tota } \\ \text { Batch\&Random } & 0.036541 & 69.952\end{array}$

$\begin{array}{lll}\text { Residual } & 0.015696 & 30.048\end{array}$

$\begin{array}{lrr}\text { Total } & 0.052237 & 100.000\end{array}$

These estimates based on equating Mean Squares to Expected Value.

Test Denominator Synthesis

Source MS Den DF Den Denom MS Synthesis

Batch\&Random $\quad 0.0157 \quad 165$ Residual

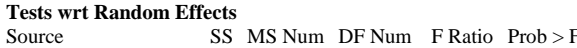

$\begin{array}{lrrrrr}\text { Source } & \text { SS } & \text { MS Num } & \text { DF Num } & \text { F Ratio } & \text { Prob }>\text { F } \\ \text { Batch\&Random } & 7.51805 & 0.23494 & 32 & 14.9680 & <0001\end{array}$

Sample Type=SME, Prep=Fusion, ICP $=$ M-13, Analyte=Al/Ca

Response Measurement

Summary of Fit

RSquare $\quad 0.539969$

RSquare Adj $\quad 0.450838$

Root Mean Square Error $\quad 0.131167$

Mean of Response 4.109778

Observations (or Sum Wgts) 192

Analysis of Variance

Source DF Sum of Squares Mean Square F Ratio

$\begin{array}{lrrrr}\text { Model } \quad 31 & 3.2311040 & 0.104229 & 6.0581\end{array}$

$\begin{array}{lllll}\text { Error } & 160 & 2.7527667 & 0.017205 & \text { Prob }>\text { F }\end{array}$

$\begin{array}{llll}\text { C. Total } 191 \quad 5.9838706 & <.0001\end{array}$

Expected Mean Squares

The Mean Square per row by the Variance Component per column

$\begin{array}{lrr}\text { EMS } & \text { Intercept } & \text { Batch\&Random } \\ \text { Intercept } & 0 & 0\end{array}$

$\begin{array}{lll}\text { Batch\&Random } & 0 & 0 \\ & 0 & 6\end{array}$

plus 1.0 times Residual Error Variance

Variance Component Estimates

Component Var Comp Est Percent of Total

$\begin{array}{lll}\text { Batch\&Random } & 0.014504 & 45.741\end{array}$

$\begin{array}{lll}\text { Residual } & 0.017205 & 54.259\end{array}$

Total $\quad 0.031709 \quad 100.000$

These estimates based on equating Mean Squares to Expected Value.

Test Denominator Synthesis

Source MS Den DF Den Denom MS Synthesis

Batch\&Random $\quad 0.0172 \quad 160$ Residual

Tests wrt Random Effects

Source SS MS Num DF Num F Ratio Prob $>$ F

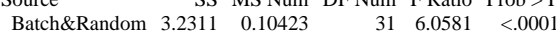

Sample Type=SME, Prep=Fusion, $\mathrm{ICP}=\mathrm{M}-13$, Analyte $=\mathrm{AI} / \mathrm{Mg}$ Response Measurement

Summary of Fit

\begin{tabular}{|c|c|c|c|c|}
\hline RSquare & & & 0.580288 & \\
\hline RSquare & Adj & & 0.49889 & \\
\hline Root Me & an Squ & uare Error & 0.166667 & \\
\hline Mean of & Respo & onse & 4.314932 & \\
\hline Observa & ions ( & (or Sum Wgts) & 198 & \\
\hline Analysis & of $\mathrm{Va}$ & ariance & & \\
\hline Source & DF & Sum of Squares & s Mean Square & F Ratio \\
\hline Model & 32 & 6.336846 & $6 \quad 0.198026$ & 7.1290 \\
\hline Error & 165 & 4.583325 & 0.027778 & Prob $>$ F \\
\hline C. Total & 197 & 10.920171 & & $<.0001$ \\
\hline
\end{tabular}

Expected Mean Squares

The Mean Square per row by the Variance Component per column

EMS Intercept Batch\&Random

$\begin{array}{crr}\text { Intercept } & 0 & 0 \\ \text { Batch\&Random } & 0 & 6\end{array}$

plus 1.0 times Residual Error Variance

Variance Component Estimates

$\begin{array}{crr}\text { Component } & \text { Var Comp Est } & \text { Percent of Total } \\ \text { Batch\&Random } & 0.028375 & 50.532 \\ \text { Residul } & 0.027778 & 49.468\end{array}$

$\begin{array}{lll}\text { Residual } & 0.027778 & 49.468\end{array}$

Total $\quad 0.056153 \quad 100.000$

These estimates based on equating Mean Squares to Expected Value.

Test Denominator Synthesis

Source MS Den DF Den Denom MS Synthesis

Batch\&Random $0.02778 \quad 165$ Residual

Tests wrt Random Effects
Source SS Num DF Num F Ratio Prob $>$ F Source $\quad$ SS MS Num DF Num F Ratio Prob $>$ F

Sample Type=SME, Prep=Fusion, ICP $=M-13$, Analyte $=A l / M n$ Response Measurement

Summary of Fit

RSquare Adj $\quad 0.688135$

Root Mean Square Error $\quad 0.627653$

0.05324

$\begin{array}{lr}\text { Mean of Response } & 1.878336 \\ \text { Observations (or Sum Wgts) } & 198\end{array}$

Analysis of Variance

Source DF Sum of Squares Mean Square F Ratio

$\begin{array}{lrrrr}\text { Model } & 32 & 1.0320209 & 0.032251 & 11.3774\end{array}$

$\begin{array}{lllll}\text { Error } & 165 & 0.4677145 & 0.002835 \text { Prob }>\text { F }\end{array}$

$\begin{array}{llll}\text { C. Total } 197 & 1.4997354 & <.0001\end{array}$

Expected Mean Squares

The Mean Square per row by the Variance Component per column

$\begin{array}{lrr}\text { EMS } & \text { Intercept } & \text { Batch\&Random } \\ \text { Intercept } & 0 & 0 \\ \text { Batch\&Random } & 0 & 6\end{array}$

plus 1.0 times Residual Error Variance

$\begin{array}{ll}\text { Variance Component Estimates } \\ \text { Component } & \text { Var Comp Est Percent of Total }\end{array}$

$\begin{array}{crr}\text { Component } & \text { Var Comp Est } & \text { Percent of Total } \\ \text { Batch\&Random } & 0.004903 & 63.364\end{array}$

$\begin{array}{lll}\text { Batch\&Random } & 0.004903 & 63.364 \\ \text { Residual } & 0.002835 & 36.636\end{array}$

Total $\quad 0.007737 \quad 100.000$

These estimates based on equating Mean Squares to Expected Value.

Test Denominator Synthesis

Source MS Den DF Den Denom MS Synthesis

$\begin{array}{rrrr}\text { Source } & \text { MS Den } & \text { DF Den } & \text { Denomal } \\ \text { Batch\&Random } & 0.00283 & 165 \text { Residual }\end{array}$

Tests wrt Random Effects

Source SS MS Num DF Num F Ratio Prob $>$ F

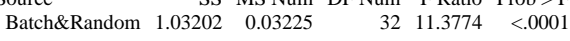


WSRC-STI-2006-00068

Revision 0

Exhibit A7. Analysis of Variance by Preparation Method, ICP, and Analyte (continued)

Sample Type=SME, Prep=Fusion, ICP=M-13, Analyte=B Response Measurement

Summary of Fi

\begin{tabular}{|c|c|c|c|c|}
\hline \multicolumn{3}{|c|}{ RSquare } & \multicolumn{2}{|l|}{0.543151} \\
\hline \multicolumn{3}{|c|}{ RSquare Adj } & 0.454827 & \\
\hline \multicolumn{3}{|c|}{ Root Mean Square Error } & 0.051433 & \\
\hline \multicolumn{3}{|c|}{ Mean of Response } & 1.448972 & \\
\hline \multicolumn{3}{|c|}{ Observations (or Sum Wgts) } & 180 & \\
\hline \multicolumn{5}{|c|}{ Analysis of Variance } \\
\hline Source & DF & Sum of Squares & s Mean Square & F Ratio \\
\hline Model & 29 & 0.47176603 & $\begin{array}{l}3 \\
0.016268\end{array}$ & 6.1495 \\
\hline Error & 150 & 0.39680683 & 0.002645 & Prob $>F$ \\
\hline C. Total & 179 & 0.86857286 & & $<.0001$ \\
\hline
\end{tabular}

Expected Mean Squares

The Mean Square per row by the Variance Component per column

$\begin{array}{lrr}\text { EMS } & \text { Intercept } & \text { Batch\&Random } \\ \text { Intercept } & 0 & 0\end{array}$

Batch\&Random

0

6

plus 1.0 times Residual Error Variance

Variance Component Estimates

Component Var Comp Est Percent of Total

$\begin{array}{rrr}\text { Component } & \text { Var Comp Est } & \text { Percent of Tota } \\ \text { Batch\&Random } & 0.00227 & 46.186\end{array}$

$\begin{array}{lrr}\text { Batch\&Random } & 0.00227 & 46.186 \\ \text { Residual } & 0.002645 & 53.814\end{array}$

$\begin{array}{lrr}\text { Total } & 0.002645 & 53.814 \\ \text { The } & 0.004916 & 100.000\end{array}$

These estimates based on equating Mean Squares to Expected Value.

Test Denominator Synthesis

Source MS Den DF Den Denom MS Synthesis

Batch\&Random $0.00265 \quad 150$ Residual

Tests wrt Random Effects
Source

$\begin{array}{lrrrrr}\text { Source } & \text { SS } & \text { MS Num } & \text { DF Num } & \text { F Ratio } & \text { Prob }>\text { F } \\ \text { Batch\&Random } & 0.47177 & 0.01627 & 29 & 6.1495 & <.0001\end{array}$

Sample Type=SME, Prep=Fusion, ICP=M-13, Analyte $=B / L i$

Response Measurement

Summary of Fit

RSquare $\quad 0.507462$

RSquare Adj $\quad 0.411852$

Root Mean Square Error $\quad 0.013754$

Mean of Response $\quad 0.658095$

Observations (or Sum Wgts) 204

Analysis of Variance

Source DF Sum of Squares Mean Square F Ratio

$\begin{array}{lrrrr}\text { Model } \quad 33 & 0.03313255 & 0.001004 & 5.3076\end{array}$

$\begin{array}{lllll}\text { Error } & 170 & 0.03215814 & 0.000189 & \text { Prob }>\text { F }\end{array}$

$\begin{array}{lll}\text { C. Total } 203 & 0.06529069 & <.0001\end{array}$

Expected Mean Squares

The Mean Square per row by the Variance Component per column

$\begin{array}{lrr}\text { EMS } & \text { Intercept } & \text { Batch\&Random } \\ \text { Intercept } & 0 & 0\end{array}$

Batch\&Random $\quad 0 \quad 6$

plus 1.0 times Residual Error Variance

Variance Component Estimates

Component Var Comp Est Percent of Total

$\begin{array}{lll}\text { Batch\&Random } & 0.000136 & 41.791\end{array}$

$\begin{array}{lll}\text { Residual } & 0.000189 & 58.209\end{array}$

Total $\quad 0.000325 \quad 100.000$

These estimates based on equating Mean Squares to Expected Value.

Test Denominator Synthesis

Source MS Den DF Den Denom MS Synthesis

$\begin{array}{lrrr}\text { Batch\&Random } & 0.00019 & 170 & \text { Residual }\end{array}$

Tests wrt Random Effects

Source

SS MS Num DF Num F Ratio Prob $>$ F

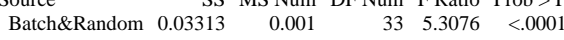

Sample Type=SME, Prep=Fusion, ICP $=M-13$, Analyte $=$ Ca Response Measurement

Summary of Fit

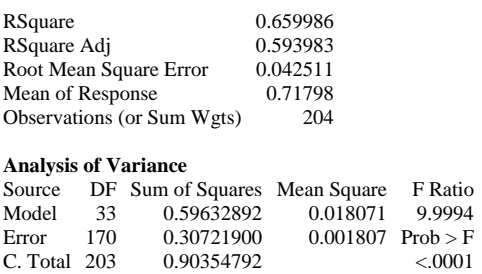

Expected Mean Squares

The Mean Square per row by the Variance Component per column

$\begin{array}{lrr}\text { EMS } & \text { Intercept } & \text { Batch\&Random } \\ \text { Intercept } & 0 & 0\end{array}$

Batch\&Random $\quad 0 \quad 6$

plus 1.0 times Residual Error Variance

Variance Component Estimates

\begin{tabular}{crr} 
Component & Var Comp Est & Percent of Total \\
Batch\&Random & 0.002711 & 59.998 \\
\hline & 0.001807 & 40.002
\end{tabular}

$\begin{array}{lll}\text { Batch\&Random } & 0.002711 & 59.998 \\ \text { Residual } & 0.001807 & 40.002\end{array}$

Total $\quad 0.004518 \quad 100.000$

These estimates based on equating Mean Squares to Expected Value.

Test Denominator Synthesis

Source MS Den DF Den Denom MS Synthesis

Batch\&Random $0.00181 \quad 170$ Residual

Tests wrt Random Effects

Source $\quad$ SS MS Num DF Num F Ratio Prob > F

Batch\&Random $0.59633 \quad 0.01807 \quad 33 \quad 9.9994<0001$

Sample Type=SME, Prep=Fusion, $\mathrm{ICP}=\mathrm{M}-13$, Analyte $=\mathrm{Cr}$

Response Measurement

Summary of Fit

RSquare Adj

0.772727

Root Mean Square Error $\quad 0.003723$

Mean of Response $\quad 0.055045$

$\begin{array}{lr}\text { Observations (or Sum Wgts) } & 198\end{array}$

Analysis of Variance

Source DF Sum of Squares Mean Square F Ratio

$\begin{array}{lrrrr}\text { Model } & 32 & 0.00777409 & 0.000243 & 17.5312\end{array}$

$\begin{array}{lllll}\text { Error } & 165 & 0.00228650 & 0.000014 & \text { Prob }>\text { F }\end{array}$

$\begin{array}{llll}\text { C. Total } 197 & 0.01006059 & <.0001\end{array}$

Expected Mean Squares

The Mean Square per row by the Variance Component per column

$\begin{array}{lrr}\text { EMS } & \text { Intercept } & \text { Batch\&Random } \\ \text { Intercept } & 0 & 0 \\ \text { Batch\&Random } & 0 & 6\end{array}$

plus 1.0 times Residual Error Variance

Variance Component Estimates

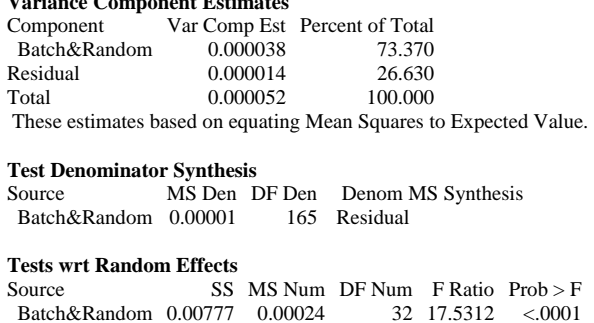


WSRC-STI-2006-00068

Revision 0

Exhibit A7. Analysis of Variance by Preparation Method, ICP, and Analyte (continued)

Sample Type=SME, Prep=Fusion, ICP=M-13, Analyte $=\mathrm{Cu}$ Response Measurement

Summary of Fit

\begin{tabular}{|c|c|c|c|c|}
\hline \multicolumn{3}{|c|}{ RSquare } & 0.937415 & \\
\hline \multicolumn{3}{|c|}{ RSquare Adj } & 0.925289 & \\
\hline \multicolumn{3}{|c|}{ Root Mean Square Error } & 0.001169 & \\
\hline \multicolumn{3}{|c|}{ Mean of Response } & 0.014146 & \\
\hline \multicolumn{3}{|c|}{ Observations (or Sum Wgts) } & 192 & \\
\hline \multicolumn{5}{|c|}{ Analysis of Variance } \\
\hline Source & DF & Sum of Squares & s Mean Square & F Ratio \\
\hline Model & 31 & 0.00327525 & $5 \quad 0.000106$ & 77.3072 \\
\hline Error & 160 & 0.00021867 & 0.000001 & Prob $>F$ \\
\hline C. Total & 191 & 0.00349392 & & $<.0001$ \\
\hline
\end{tabular}

Expected Mean Squares

The Mean Square per row by the Variance Component per column

$\begin{array}{lrr}\text { EMS } & \text { Intercept } & \text { Batch\&Random } \\ \text { Intercept } & 0 & 0\end{array}$

Batch\&Random

0

6

plus 1.0 times Residual Error Variance

Variance Component Estimates

Component Var Comp Est Percent of Total

$\begin{array}{lrr}\text { Component } & \text { Var Comp Est } & \text { Percent of Tota } \\ \text { Batch\&Random } & 0.000017 & 92.710\end{array}$

$\begin{array}{llr}\text { Residual } & 0.000001 & 7.290\end{array}$

Total $\quad 0.000019 \quad 100.000$

These estimates based on equating Mean Squares to Expected Value.

Test Denominator Synthesis

Source MS Den DF Den Denom MS Synthesis

Batch\&Random $\quad 1.37 \mathrm{e}-6 \quad 160$ Residual

Tests wrt Random Effects
Source MS Num DF Num F Ratio Prob $>$ F

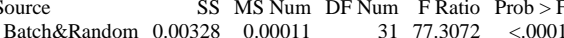

Sample Type=SME, Prep=Fusion, ICP=M-13, Analyte $=F e$

Response Measurement

Summary of Fit

RSquare $\quad 0.639357$

RSquare Adj $\quad 0.569414$

Root Mean Square Error $\quad 0.337043$

Mean of Response $\quad 7.96904$

Observations (or Sum Wgts) 198

Analysis of Variance

Source DF Sum of Squares Mean Square F Ratio

$\begin{array}{lrrrr}\text { Model } \quad 32 & 33.229186 & 1.03841 & 9.1411\end{array}$

$\begin{array}{lllll}\text { Error } & 165 & 18.743673 & 0.11360 & \text { Prob }>\text { F }\end{array}$

$\begin{array}{llll}\text { C. Total } 197 & 51.972860 & <.0001\end{array}$

Expected Mean Squares

The Mean Square per row by the Variance Component per column

$\begin{array}{lrr}\text { EMS } & \text { Intercept } & \text { Batch\&Random } \\ \text { Intercept } & 0 & 0\end{array}$

Batch\&Random $\quad 0 \quad 6$

plus 1.0 times Residual Error Variance

Variance Component Estimates

Component Var Comp Est Percent of Total

Batch\&Random $\quad 0.154136 \quad 57.571$

$\begin{array}{lrr}\text { Residual } & 0.113598 & 42.429 \\ \text { Total } & 0.267734 & 100.000\end{array}$

These estimates based on equating Mean Squares to Expected Value.

Test Denominator Synthesis

Source MS Den DF Den Denom MS Synthesis

Batch\&Random $\quad 0.1136 \quad 165$ Residual

Tests wrt Random Effects

Source

SS MS Num DF Num F Ratio Prob $>$ F

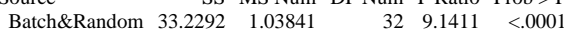

Sample Type=SME, Prep=Fusion, $\mathrm{ICP}=\mathrm{M}-13$, Analyte=Fe/Al Response Measurement

Summary of Fit

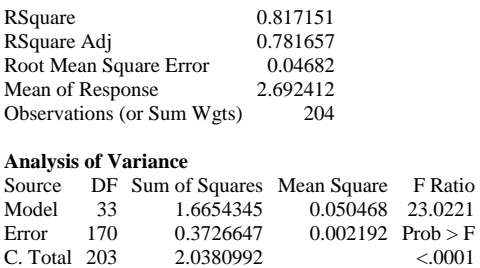

Expected Mean Squares

The Mean Square per row by the Variance Component per column

$\begin{array}{lrr}\text { EMS } & \text { Intercept } & \text { Batch\&Random } \\ \text { Intercept } & 0 & 0\end{array}$

Batch\&Random $\quad 0 \quad 6$

plus 1.0 times Residual Error Variance

Variance Component Estimates

$\begin{array}{rrr}\text { Component } & \text { Var Comp Est } & \text { Percent of Total } \\ \text { Batch\&Random } & 0.008046 & 78.588\end{array}$

$\begin{array}{lll}\text { Batch\&Random } & 0.008046 & 78.588 \\ \text { Residual } & 0.002192 & 21.412\end{array}$

$\begin{array}{lrr}\text { Residual } & 0.002192 & 21.412 \\ \text { Total } & 0.010238 & 100.000\end{array}$

These estimates based on equating Mean Squares to Expected Value.

Test Denominator Synthesis

Source MS Den DF Den Denom MS Synthesis

Batch\&Random $0.00219 \quad 170$ Residual

Tests wrt Random Effects

Source SS MS Num DF Num F Ratio Prob $>$ F

$\begin{array}{llllll}\text { Batch\&Random } & 1.66543 & 0.05047 & 33 & 23.0221 & <.0001\end{array}$

Sample Type=SME, Prep=Fusion, ICP=M-13, Analyte=Fe/Ca Response Measurement

Summary of Fit

$\begin{array}{ll}0.646798 \\ \text { RSquare Adj } & 0.578365\end{array}$

0.578365

0.353652

$\begin{array}{lr}\text { Mean of Response } & 11.08334 \\ \text { Observations (or Sum Wgts) } & 192\end{array}$

Analysis of Variance

Source DF Sum of Squares Mean Square F Ratio

$\begin{array}{lrrrr}\text { Model } \quad 31 & 36.645246 & 1.18210 & 9.4516\end{array}$

$\begin{array}{lllll}\text { Error } & 160 & 20.011178 & 0.12507 & \text { Prob }>\text { F }\end{array}$

$\begin{array}{llll}\text { C. Total } 191 & 56.656424 & <.12507 & \text { P. }\end{array}$

Expected Mean Squares

The Mean Square per row by the Variance Component per column

$\begin{array}{lrr}\text { EMS } & \text { Intercept } & \text { Batch\&Random } \\ \text { Intercept } & 0 & 0 \\ \text { Batch\&Random } & 0 & 6\end{array}$

plus 1.0 times Residual Error Variance

Variance Component Estimates

\begin{tabular}{|c|c|c|c|}
\hline \\
\hline \multicolumn{4}{|c|}{ Var Comp Est Percent of Total } \\
\hline Batch\&Random & 0.176172 & 58.48 & \\
\hline Residual & 0.12507 & 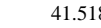 & \\
\hline Total & 0.301242 & 100.00 & \\
\hline \multicolumn{4}{|c|}{ These estimates based on equating Mean Squares to Expected Value. } \\
\hline \multicolumn{4}{|c|}{ Test Denominator Synthesis } \\
\hline Source & MS Den DF Den & Denom M & US Synthesis \\
\hline Batch\&Random & $0.12507 \quad 160$ & Residual & \\
\hline \multicolumn{4}{|c|}{ Tests wrt Random Effects } \\
\hline Source & SS MS Num & DF Num & F Ratio Prob $>F$ \\
\hline Batch\&Random & $36.6452 \quad 1.1821$ & 31 & $9.4516<.0001$ \\
\hline
\end{tabular}


WSRC-STI-2006-00068

Revision 0

Exhibit A7. Analysis of Variance by Preparation Method, ICP, and Analyte (continued)

Sample Type=SME, Prep=Fusion, $\mathrm{ICP}=\mathrm{M}-13$, Analyte $=\mathrm{Fe} / \mathrm{Li}$ Response Measurement

Summary of Fit

\begin{tabular}{|c|c|c|c|c|}
\hline \multicolumn{3}{|c|}{ RSquare } & \multicolumn{2}{|l|}{0.841853} \\
\hline \multicolumn{3}{|c|}{ RSquare Adj } & 0.811154 & \\
\hline \multicolumn{3}{|c|}{ Root Mean Square Error } & 0.122063 & \\
\hline \multicolumn{3}{|c|}{ Mean of Response } & 3.622828 & \\
\hline \multicolumn{3}{|c|}{ Observations (or Sum Wgts) } & 204 & \\
\hline \multicolumn{5}{|c|}{ Analysis of Variance } \\
\hline Source & $\mathrm{DF}$ & Sum of Squares & s Mean Square & F Ratio \\
\hline Model & 33 & 13.483237 & $7 \quad 0.408583$ & 27.4226 \\
\hline Error & 170 & 2.532911 & 0.014899 & Prob $>$ F \\
\hline C. Total & 203 & 16.016147 & & $<.0001$ \\
\hline
\end{tabular}

Expected Mean Squares

The Mean Square per row by the Variance Component per column

$\begin{array}{lrr}\text { EMS } & \text { Intercept } & \text { Batch\&Random } \\ \text { Intercept } & 0 & 0\end{array}$

Batch\&Random

0

0

plus 1.0 times Residual Error Variance

Variance Component Estimates

Component Var Comp Est Percent of Total

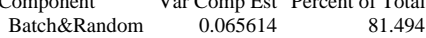

Residual $\quad 0.014899 \quad 18.506$

Total $\quad 0.080513 \quad 100.000$

These estimates based on equating Mean Squares to Expected Value.

Test Denominator Synthesis

Source MS Den DF Den Denom MS Synthesis

Batch\&Random $\quad 0.0149 \quad 170$ Residual

Tests wrt Random Effects
Source SS MS Num DF Num F Ratio Prob $>$ F

$\begin{array}{lrrrrr}\text { Source } & \text { SS } & \text { MS Num } & \text { DF Num } & \text { F Ratio } & \text { Prob }>\text { F } \\ \text { Batch\&Random } & 13.4832 & 0.40858 & 33 & 27.4226 & <0001\end{array}$

Sample Type=SME, Prep=Fusion, ICP=M-13, Analyte $=F e / M g$

Response Measurement

Summary of Fit

RSquare $\quad 0.677176$

RSquare Adj $\quad 0.614629$

Root Mean Square Error $\quad 0.331136$

Mean of Response 11.58352

Observations (or Sum Wgts) 192

Analysis of Variance

Source DF Sum of Squares Mean Square F Ratio

$\begin{array}{lrrrr}\text { Model } & 31 & 36.801809 & 1.18716 & 10.8267\end{array}$

Error $\begin{array}{llll}160 & 17.544179 & 0.10965 \text { Prob }>\text { F }\end{array}$

$\begin{array}{lll}\text { C. Total } 191 \quad 54.345988 & <.0001\end{array}$

Expected Mean Squares

The Mean Square per row by the Variance Component per column

$\begin{array}{lrr}\text { EMS } & \text { Intercept } & \text { Batch\&Random } \\ \text { Intercept } & 0 & 0\end{array}$

$\begin{array}{lll}\text { Batch\&Random } & 0 & 0 \\ & 0 & 6\end{array}$

plus 1.0 times Residual Error Variance

Variance Component Estimates

Component Var Comp Est Percent of Total

$\begin{array}{lll}\text { Batch\&Random } \quad 0.179584 & 62.089\end{array}$

Residual $\quad 0.109651 \quad 37.911$

Total $\quad 0.289235 \quad 100.000$

These estimates based on equating Mean Squares to Expected Value.

Test Denominator Synthesis

Source MS Den DF Den Denom MS Synthesis

Batch\&Random $0.10965 \quad 160$ Residual

Tests wrt Random Effects

Source

SS MS Num DF Num F Ratio Prob > F

Batch\&Random $36.8018 \quad 1.18716 \quad 31 \quad 10.8267 \quad<.0001$
Sample Type=SME, Prep=Fusion, ICP=M-13, Analyte=Fe/Mn Response Measurement

Summary of Fit

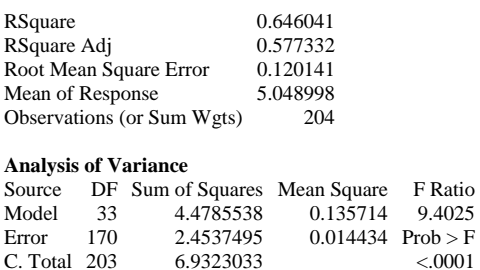

Expected Mean Squares

The Mean Square per row by the Variance Component per column

$\begin{array}{lrr}\text { EMS } & \text { Intercept } & \text { Batch\&Random } \\ \text { Intercept } & 0 & 0\end{array}$

Batch\&Random $\quad 0 \quad 6$

plus 1.0 times Residual Error Variance

Variance Component Estimates

$\begin{array}{crr}\text { Component } & \text { Var Comp Est } & \text { Percent of Total } \\ \text { Batch\&Random } & 0.020213 & 58.341 \\ \text { Residul } & 0.014434 & 41.659\end{array}$

$\begin{array}{ccc}\text { Batch\&Random } & 0.020213 & 58.341 \\ \text { Residual } & 0.014434 & 41.659\end{array}$

Total $\quad 0.034647 \quad 100.000$

These estimates based on equating Mean Squares to Expected Value.

Test Denominator Synthesis

Source MS Den DF Den Denom MS Synthesis

Batch\&Random $0.01443 \quad 170$ Residual

Tests wrt Random Effects

Source SS MS Num DF Num F Ratio Prob $>$ F

Batch\&Random $4.47855 \quad 0.13571 \quad 33 \quad 9.4025<.0001$

Sample Type=SME, Prep=Fusion, ICP=M-13, Analyte=Fe/Ni

Response Measurement

Summary of Fit

0.63813

RSquare Adj $\quad 0.567824$

Root Mean Square Error $\quad 0.345427$

Mean of Response $\quad 17.50425$

Observations (or Sum Wgts) $\quad 210$

Analysis of Variance

Source DF Sum of Squares Mean Square F Ratio

$\begin{array}{lrrrr}\text { Model } \quad 34 & 36.822052 & 1.08300 & 9.0765\end{array}$

$\begin{array}{lllll}\text { Error } & 175 & 20.880988 & 0.11932 \text { Prob }>\text { F }\end{array}$

$\begin{array}{llll}\text { C. Total } 209 & 57.703040 & <.11932 & \text { P.0001 }\end{array}$

Expected Mean Squares

The Mean Square per row by the Variance Component per column

$\begin{array}{lrr}\text { EMS } & \text { Intercept } & \text { Batch\&Random } \\ \text { Intercept } & 0 & 0 \\ \text { Batch\&Random } & 0 & 6\end{array}$

plus 1.0 times Residual Error Variance

Variance Component Estimates
$\begin{array}{ll}\text { Component } & \text { Var Comp Est Percent of Total }\end{array}$

$\begin{array}{lrr}\text { Component } & \text { Var Comp Est } & \text { Percent of Total } \\ \text { Batch\&Random } & 0.160614 & 57.376 \\ \text { Residual } & 0.11932 & 42.624\end{array}$

$\begin{array}{lrr}\text { Residual } & 0.11932 & 42.624 \\ \text { Total } & 0.279934 & 100.000\end{array}$

These estimates based on equating Mean Squares to Expected Value.

Test Denominator Synthesis

Source MS Den DF Den Denom MS Synthesis

$\begin{array}{lrrr}\text { Source } & \text { MS Den } & \text { DF Den } & \text { Denom } \\ \text { Batch\&Random } & 0.11932 & 175 & \text { Residual }\end{array}$

Tests wrt Random Effects

Source SS MS Num DF Num F Ratio Prob $>$ F

$\begin{array}{rrrrrr} & \text { SS } & \text { MS Num } & \text { DF Num } & \text { F Ratio } & \text { Prob > F } \\ \text { Batch\&Random } & 36.8221 & 1.083 & 34 & 9.0765 & <.0001\end{array}$ 
WSRC-STI-2006-00068

Revision 0

Exhibit A7. Analysis of Variance by Preparation Method, ICP, and Analyte (continued)

Sample Type=SME, Prep=Fusion, $\mathrm{ICP}=\mathrm{M}-13$, Analyte $=\mathrm{Fe} / \mathrm{U}$ Response Measurement

Summary of Fit

\begin{tabular}{|c|c|c|c|c|}
\hline \multicolumn{3}{|c|}{ RSquare } & \multicolumn{2}{|l|}{0.897711} \\
\hline \multicolumn{3}{|c|}{ RSquare Adj } & 0.877837 & \\
\hline \multicolumn{3}{|c|}{ Root Mean Square Error } & 0.051989 & \\
\hline \multicolumn{3}{|c|}{ Mean of Response } & 3.087834 & \\
\hline \multicolumn{3}{|c|}{ Observations (or Sum Wgts) } & 210 & \\
\hline \multicolumn{5}{|c|}{ Analysis of Variance } \\
\hline Source & $\mathrm{DF}$ & Sum of Squares & s Mean Square & F Ratio \\
\hline Model & 34 & 4.1511460 & 0.122093 & 45.1716 \\
\hline Error & 175 & 0.4730005 & 0.002703 & Prob $>$ F \\
\hline C. Total & 209 & 4.6241465 & & $<.0001$ \\
\hline
\end{tabular}

Expected Mean Squares

The Mean Square per row by the Variance Component per column

$\begin{array}{lrr}\text { EMS } & \text { Intercept } & \text { Batch\&Random } \\ \text { Intercept } & 0 & 0\end{array}$

Batch\&Random

0

0

plus 1.0 times Residual Error Variance

Variance Component Estimates

Component Var Comp Est Percent of Total

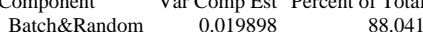

$\begin{array}{lll}\text { Residual } & 0.002703 & 11.959\end{array}$

Total $\quad 0.022601 \quad 100.000$

These estimates based on equating Mean Squares to Expected Value.

Test Denominator Synthesis

Source MS Den DF Den Denom MS Synthesis

Batch\&Random $\quad 0.0027 \quad 175$ Residual

Tests wrt Random Effects
$\begin{aligned} & \text { Source } \\ & \text { SS MS Num DF Num F Ratio Prob }>\text { F }\end{aligned}$

$\begin{array}{lrrrrr}\text { Source } & \text { SS } & \text { MS Num } & \text { DF Num } & \text { F Ratio } & \text { Prob }>\text { F } \\ \text { Batch\&Random } & 4.15115 & 0.12209 & 34 & 45.1716 & <0001\end{array}$

Sample Type=SME, Prep=Fusion, ICP=M-13, Analyte $=K$

Response Measurement

Summary of Fit

RSquare $\quad 0.578815$

RSquare Adj $\quad 0.49721$

Root Mean Square Error $\quad 0.107844$

Mean of Response $\quad 0.101844$

Observations (or Sum Wgts) 192

Analysis of Variance

Source DF Sum of Squares Mean Square F Ratio

$\begin{array}{lrrrr}\text { Model } & 31 & 2.5572770 & 0.082493 & 7.0929\end{array}$

$\begin{array}{lllll}\text { Error } & 160 & 1.8608483 & 0.011630 \quad \text { Prob }>\text { F }\end{array}$

$\begin{array}{llr}\text { C. Total } 191 & 4.4181253 & <.0001\end{array}$

Expected Mean Squares

The Mean Square per row by the Variance Component per column

$\begin{array}{lrr}\text { EMS } & \text { Intercept } & \text { Batch\&Random } \\ \text { Intercept } & 0 & 0\end{array}$

Batch\&Random $\quad 0 \quad 6$

plus 1.0 times Residual Error Variance

Variance Component Estimates

Component Var Comp Est Percent of Total

$\begin{array}{lrl}\text { Batch\&Random } & 0.01181 & 50.384\end{array}$

$\begin{array}{lll}\text { Residual } & 0.01163 & 49.616\end{array}$

Total $\quad 0.023441 \quad 100.000$

These estimates based on equating Mean Squares to Expected Value.

Test Denominator Synthesis

Source MS Den DF Den Denom MS Synthesis

$\begin{array}{llll}\text { Batch\&Random } & 0.01163 & 160 & \text { Residual }\end{array}$

Tests wrt Random Effects

Source

SS MS Num DF Num F Ratio Prob $>$ F

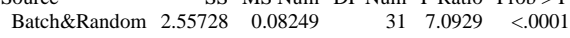

Sample Type=SME, Prep=Fusion, ICP=M-13, Analyte $=\mathrm{Li}$ Response Measurement

Summary of Fit

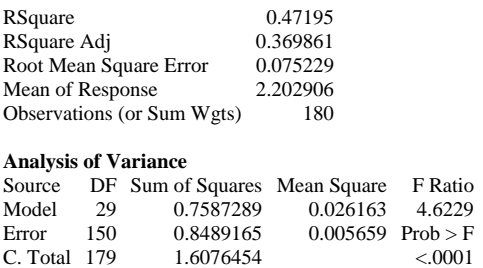

C. Total $179 \quad 1.6076454 \quad 0.005659$ Prob $>$ F

Expected Mean Squares

The Mean Square per row by the Variance Component per column

$\begin{array}{lrr}\text { EMS } & \text { Intercept } & \text { Batch\&Random } \\ \text { Intercept } & 0 & 0\end{array}$

Batch\&Random $\quad 0 \quad 6$

plus 1.0 times Residual Error Variance

Variance Component Estimates

$\begin{array}{crr}\text { Component } & \text { Var Comp Est } & \text { Percent of Total } \\ \text { Batch\&Random } & 0.003417 & 37.649 \\ \text { Residel } & 0.005659 & 62.351\end{array}$

$\begin{array}{lll}\text { Batch\&Random } & 0.003417 & 37.649 \\ \text { Residual } & 0.005659 & 62.351\end{array}$

Total $\quad 0.009077 \quad 100.000$

These estimates based on equating Mean Squares to Expected Value.

Test Denominator Synthesis

Source MS Den DF Den Denom MS Synthesis

Batch\&Random $0.00566 \quad 150$ Residual

Tests wrt Random Effects

Source SS MS Num DF Num F Ratio Prob > F

Batch\&Random $0.75873 \quad 0.02616 \quad 29 \quad 4.6229<.0001$

Sample Type=SME, Prep=Fusion, ICP $=M-13$, Analyte $=M g$

Response Measurement

Summary of Fit

RSquare Adj $\quad 0.672313$

Root Mean Square Error $\quad 0.608703$

Mean of Response $\quad 0.685966$

$\begin{array}{lr}\text { Observations (or Sum Wgts) } & 204\end{array}$

Analysis of Variance

Source DF Sum of Squares Mean Square F Ratio

$\begin{array}{lrrrr}\text { Model } & 33 & 0.50961526 & 0.015443 & 10.5693\end{array}$

$\begin{array}{lllll}\text { Error } & 170 & 0.24838750 & 0.001461 & \text { Prob }>\text { F }\end{array}$

$\begin{array}{llll}\text { C. Total } 203 & 0.75800276 & <.0001\end{array}$

Expected Mean Squares

The Mean Square per row by the Variance Component per column

$\begin{array}{lrr}\text { EMS } & \text { Intercept } & \text { Batch\&Random } \\ \text { Intercept } & 0 & 0 \\ \text { Batch\&Random } & 0 & 6\end{array}$

plus 1.0 times Residual Error Variance

Variance Component Estimates

\begin{tabular}{|c|c|c|c|c|c|}
\hline \\
\hline Component & Var Com & p Est Per & cent of Total & & \\
\hline Batch\&Random & & 0233 & 61.463 & & \\
\hline Residual & 0.00 & 1461 & 38.537 & & \\
\hline Total & 0.00 & 3791 & 100.000 & & \\
\hline These estimates ba & ased on eq & quating M & an Squares t & to Expecte & ed Value. \\
\hline Test Denominator & r Synthesi & & & & \\
\hline Source & MS Den & DF Den & Denom MS & S Synthesi & \\
\hline Batch\&Random & 0.00146 & 170 & Residual & & \\
\hline Pan & Effects & & & & \\
\hline Source & SS & MS Num & DF Num & F Ratio $\mathrm{P}$ & Prob $>$ F \\
\hline Batch\&Random & 0.50962 & 0.01544 & 331 & 10.5693 & $<.0001$ \\
\hline
\end{tabular}


WSRC-STI-2006-00068

Revision 0

Exhibit A7. Analysis of Variance by Preparation Method, ICP, and Analyte (continued)

Sample Type=SME, Prep=Fusion, ICP=M-13, Analyte $=$ Mn Response Measurement

Summary of Fi

\begin{tabular}{|c|c|c|c|c|}
\hline \multicolumn{3}{|c|}{ RSquare } & .694818 & \\
\hline \multicolumn{3}{|c|}{ RSquare Adj } & .635577 & \\
\hline \multicolumn{3}{|c|}{ Root Mean Square Error } & 0.079755 & \\
\hline \multicolumn{3}{|c|}{ Mean of Response } & 1.57525 & \\
\hline \multicolumn{3}{|c|}{ Observations (or Sum Wgts) } & 204 & \\
\hline \multicolumn{5}{|c|}{ Analysis of Variance } \\
\hline Source & $\mathrm{DF}$ & Sum of Squares & Mean Square & F Ratio \\
\hline Model & 33 & 2.4619514 & 0.074605 & 11.7286 \\
\hline Error & 170 & 1.0813508 & 0.006361 & Prob $>$ F \\
\hline C. Total & 203 & 3.5433023 & & $<.0001$ \\
\hline
\end{tabular}

Expected Mean Squares

The Mean Square per row by the Variance Component per column

$\begin{array}{lrr}\text { EMS } & \text { Intercept } & \text { Batch\&Random } \\ \text { Intercept } & 0 & 0\end{array}$

Batch\&Random

0

0

plus 1.0 times Residual Error Variance

Variance Component Estimates

Component Var Comp Est Percent of Total

$\begin{array}{rrr}\text { Component } & \text { Var Comp Est } & \text { Percent of Tota } \\ \text { Batch\&Random } & 0.011374 & 64.133\end{array}$

$\begin{array}{lll}\text { Residual } & 0.006361 & 35.867\end{array}$

$\begin{array}{lll}\text { Total } & 0.017735 & 100.000\end{array}$

These estimates based on equating Mean Squares to Expected Value.

Test Denominator Synthesis

Source MS Den DF Den Denom MS Synthesis

Batch\&Random $0.00636 \quad 170$ Residual

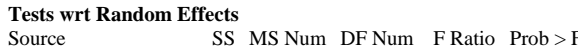

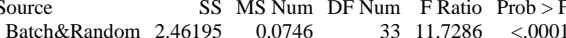

Sample Type=SME, Prep=Fusion, $\mathrm{ICP}=\mathrm{M}-13$, Analyte $=\mathrm{Mn} / \mathrm{Mg}$ Response Measurement

Summary of Fit

RSquare 0.623701

RSquare Adj $\quad 0.550722$

Root Mean Square Error $\quad 0.041688$

Mean of Response 2.296603

Observations (or Sum Wgts) 198

Analysis of Variance

Source DF Sum of Squares Mean Square F Ratio

$\begin{array}{lrrrr}\text { Model } \quad 32 & 0.47528649 & 0.014853 & 8.5463\end{array}$

$\begin{array}{lllll}\text { Error } & 165 & 0.28675547 & 0.001738 & \text { Prob }>\text { F }\end{array}$

$\begin{array}{llll}\text { C. Total } 197 & 0.76204196 & <.0001\end{array}$

Expected Mean Squares

The Mean Square per row by the Variance Component per column

$\begin{array}{lrr}\text { EMS } & \text { Intercept } & \text { Batch\&Random } \\ \text { Intercept } & 0 & 0\end{array}$

$\begin{array}{lll}\text { Batch\&Random } & 0 & 0 \\ & 0 & 6\end{array}$

plus 1.0 times Residual Error Variance

Variance Component Estimate

Component Var Comp Est Percent of Total

Batch\&Random $\quad 0.002186 \quad 55.707$

$\begin{array}{lll}\text { Residual } & 0.001738 & 44.293\end{array}$

Total $\quad 0.003924 \quad 100.000$

These estimates based on equating Mean Squares to Expected Value.

Test Denominator Synthesis

Source MS Den DF Den Denom MS Synthesis

$\begin{array}{lrrr}\text { Batch\&Random } & 0.00174 & 165 & \text { Residual }\end{array}$

Tests wrt Random Effects

Source SS MS Num DF Num F Ratio Prob $>$ F

$\begin{array}{llllll}\text { Batch\&Random } & 0.47529 & 0.01485 & 32 & 8.5463 & <.0001\end{array}$

Sample Type=SME, Prep=Fusion, ICP $=$ M-13, Analyte $=$ Na
Sample Type=SME, Prep=Fusion, $\mathrm{ICP}=\mathrm{M}-13$, Analyte $=\mathrm{Ni}$ Response Measurement

Summary of Fit

RSquare Adj $\quad 0.55073$

Root Mean Square Error $\quad 0.023044$

Mean of Response 0.456263

Observations (or Sum Wgts)

Analysis of Variance

Source DF Sum of Squares Mean Square F Ratio

$\begin{array}{lllll}\text { Model } & 32 & 0.14523334 & 0.004539 & 8.5466\end{array}$

$\begin{array}{lllll}\text { Error } & 165 & 0.08762100 & 0.000531 \text { Prob }>\text { F }\end{array}$

$\begin{array}{llll}\text { C. Total } 197 & 0.23285434 & <.0001\end{array}$

Expected Mean Squares

The Mean Square per row by the Variance Component per column

EMS Intercept Batch\&Random

$\begin{array}{lrr}\text { Intercept } & 0 & 0 \\ \text { Batch\&Random } & 0 & 6\end{array}$

plus 1.0 times Residual Error Variance

Variance Component Estimates

$\begin{array}{lr}\text { Component } & \text { Var Comp Est Percent of Total } \\ \text { Batchen } & 55.708\end{array}$

$\begin{array}{lll}\text { Batch\&Random } & 0.000668 & 55.708 \\ \text { Residual } & 0.000531 & 44.292\end{array}$

$\begin{array}{lrr}\text { Residual } & 0.000531 & 44.292 \\ \text { Total } & 0.001199 & 100.000\end{array}$

These estimates based on equating Mean Squares to Expected Value.

Test Denominator Synthesis

Source MS Den DF Den Denom MS Synthesis

Batch\&Random $0.00053 \quad 165$ Residual

Tests wrt Random Effects

Source SS MS Num DF Num F Ratio Prob $>$ F

Batch\&Random $0.14523 \quad 0.00454 \quad 32 \quad 8.5466<0001$

Sample Type=SME, Prep=Fusion, ICP $=M-13$, Analyte $=S i$

Response Measurement

Summary of Fit

0.38719

RSquare Adj $\quad 0.268342$

Root Mean Square Error $\quad 1.123704$

Mean of Response $\quad 23.80898$

Observations (or Sum Wgts) 198

Analysis of Variance

Source DF Sum of Squares Mean Square F Ratio

$\begin{array}{lrrrr}\text { Model } & 32 & 131.63943 & 4.11373 & 3.2579\end{array}$

$\begin{array}{lllll}\text { Error } & 165 & 208.34717 & 1.26271 \text { Prob }>\text { F }\end{array}$

$\begin{array}{llll}\text { C. Total } 197 & 339.98660 & 1.26271 & \text { P. } \\ \text { C.0001 }\end{array}$

Expected Mean Squares

The Mean Square per row by the Variance Component per column

$\begin{array}{lrr}\text { EMS } & \text { Intercept } & \text { Batch\&Random } \\ \text { Intercept } & 0 & 0 \\ \text { Batch\&Random } & 0 & 6\end{array}$

plus 1.0 times Residual Error Variance

Variance Component Estimates

Component Var Comp Est Percent of Total

Batch\&Random $\quad 0.47517 \quad 27.342$

$\begin{array}{lrr}\text { Residual } & 1.26271 & 72.658 \\ \text { Total } & 1.73788 & 100.000\end{array}$

These estimates based on equating Mean Squares to Expected Value.

Test Denominator Synthesis

Source MS Den DF Den Denom MS Synthesis

$\begin{array}{rrrr}\text { Source } & \text { MS Den } & \text { DF Den } & \text { Denomal } \\ \text { Batch\&Random } & 1.26271 & 165 \text { Residual }\end{array}$

Tests wrt Random Effects

Source SS MS Num DF Num F Ratio Prob $>$ F

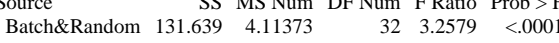


WSRC-STI-2006-00068

Revision 0

Exhibit A7. Analysis of Variance by Preparation Method, ICP, and Analyte (continued)

Sample Type=SME, Prep=Fusion, ICP=M-13, Analyte=Sum of Oxide Response Measurement

Summary of Fi

\begin{tabular}{|c|c|c|c|c|}
\hline \multicolumn{3}{|c|}{ RSquare } & \multicolumn{2}{|l|}{0.264641} \\
\hline \multicolumn{3}{|c|}{ RSquare Adj } & 0.122165 & \\
\hline \multicolumn{3}{|c|}{ Root Mean Square Error } & 2.901547 & \\
\hline \multicolumn{3}{|c|}{ Mean of Response } & 85.72756 & \\
\hline \multicolumn{3}{|c|}{ Observations (or Sum Wgts) } & 192 & \\
\hline \multicolumn{5}{|c|}{ Analysis of Variance } \\
\hline Source & $\mathrm{DF}$ & Sum of Squares & s Mean Square & F Ratio \\
\hline Model & 31 & 484.7706 & $6 \quad 15.6378$ & 1.8574 \\
\hline Error & 160 & 1347.0362 & 8.4190 & Prob $>$ F \\
\hline C. Total & 191 & 1831.8068 & & 0.0074 \\
\hline
\end{tabular}

Expected Mean Squares

The Mean Square per row by the Variance Component per column

$\begin{array}{lrr}\text { EMS } & \text { Intercept } & \text { Batch\&Random } \\ \text { Intercept } & 0 & 0\end{array}$

Batch\&Random

0

plus 1.0 times Residual Error Variance

Variance Component Estimates

Component Var Comp Est Percent of Total

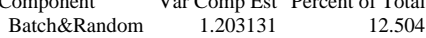

$\begin{array}{lll}\text { Residual } & 1.203131 & 12.504\end{array}$

Total $\quad 9.622107 \quad 100.000$

These estimates based on equating Mean Squares to Expected Value.

Test Denominator Synthesis

Source MS Den DF Den Denom MS Synthesis

Batch\&Random $8.41898 \quad 160$ Residual

Tests wrt Random Effects
Source MS Num DF Num F Ratio Prob > F

$\begin{array}{lrrrrr}\text { Source } & \text { SS } & \text { MS Num } & \text { DF Num } & \text { F Ratio } & \text { Prob > F } \\ \text { Batch\&Random } & 484.771 & 15.6378 & 31 & 1.8574 & 0.0074\end{array}$

Sample Type=SME, Prep=Fusion, ICP=M-13, Analyte $=$ Ti

Response Measurement

Summary of Fit

RSquare $\quad 0.951826$

RSquare Adj $\quad 0.942474$

Root Mean Square Error $\quad 0.001882$

Mean of Response $\quad 0.038603$

Observations (or Sum Wgts) 204

Analysis of Variance

Source DF Sum of Squares Mean Square F Ratio

$\begin{array}{llllll}\text { Model } & 33 & 0.01189100 & 0.000360 & 101.7835\end{array}$

$\begin{array}{lllll}\text { Error } & 170 & 0.00060183 & 0.000004 & \text { Prob }>\text { F }\end{array}$

$\begin{array}{llll}\text { C. Total } 203 & 0.01249284 & <.0001\end{array}$

Expected Mean Squares

The Mean Square per row by the Variance Component per column

$\begin{array}{lrr}\text { EMS } & \text { Intercept } & \text { Batch\&Random } \\ \text { Intercept } & 0 & 0\end{array}$

$\begin{array}{lll}\text { Batch\&Random } & 0 & 0 \\ \end{array}$

plus 1.0 times Residual Error Variance

Variance Component Estimates

Component Var Comp Est Percent of Total

$\begin{array}{lrr}\text { Batch\&Random } & 0.000059 & 94.381\end{array}$

$\begin{array}{llr}\text { Residual } & 0.000004 & 5.619\end{array}$

Total $\quad 0.000063 \quad 100.000$

These estimates based on equating Mean Squares to Expected Value.

Test Denominator Synthesis

Source MS Den DF Den Denom MS Synthesis

Batch\&Random $\quad 3.54 \mathrm{e}-6 \quad 6 \quad 170$ Residual

Tests wrt Random Effects

Source

SS MS Num DF Num F Ratio Prob $>$ F

$\begin{array}{lrrrrr}\text { Batch\&Random } & 0.01189 & 0.00036 & 33 & 101.7835 & <.0001\end{array}$
Sample Type=SME, Prep=Fusion, ICP=M-13, Analyte=U Response Measurement

Summary of Fit

\begin{tabular}{|c|c|c|c|c|}
\hline \multicolumn{3}{|c|}{ RSquare } & 0.754849 & \\
\hline \multicolumn{3}{|c|}{ RSquare Adj } & 0.707351 & \\
\hline \multicolumn{3}{|c|}{ Root Mean Square Error } & 0.103836 & \\
\hline \multicolumn{3}{|c|}{ Mean of Response } & 2.601328 & \\
\hline \multicolumn{3}{|c|}{ Observations (or Sum Wgts) } & 192 & \\
\hline \multicolumn{5}{|c|}{ Analysis of Variance } \\
\hline Source & $\mathrm{DF}$ & Sum of Squares & s Mean Square & F Ratio \\
\hline Model & 31 & 5.3118188 & $\begin{array}{ll}3 & 0.171349\end{array}$ & 15.8922 \\
\hline Error & 160 & 1.7251075 & 0.010782 & Prob $>F$ \\
\hline C. Total & 191 & 7.0369263 & & $<.0001$ \\
\hline
\end{tabular}

Expected Mean Squares

The Mean Square per row by the Variance Component per column

$\begin{array}{lrr}\text { EMS } & \text { Intercept } & \text { Batch\&Random } \\ \text { Intercept } & 0 & 0\end{array}$

Batch\&Random $\quad 0 \quad 6$

plus 1.0 times Residual Error Variance

Variance Component Estimates

\begin{tabular}{crr} 
Component & Var Comp Est & Percent of Total \\
Batch\&Random & 0.026761 & 71.281 \\
\hline & 0.010782 & 28.719
\end{tabular}

$\begin{array}{lll}\text { Residual } & 0.010782 & 28.719\end{array}$

Total $\quad 0.037543 \quad 100.000$

These estimates based on equating Mean Squares to Expected Value.

Test Denominator Synthesis

Source MS Den DF Den Denom MS Synthesis

Batch\&Random $0.01078 \quad 160$ Residual

Tests wrt Random Effects

Source SS MS Num DF Num F Ratio Prob $>$ F

$\begin{array}{lrrrrr}\text { Batch\&Random } & 5.31182 & 0.17135 & 31 & 15.8922 & <.0001\end{array}$

Sample Type=SME, Prep=Fusion, ICP=M-13, Analyte=U/Ca

Response Measurement

Summary of Fit

0.75331
Root Mean Square Error $\quad 0.13048$

Mean of Response

$\begin{array}{lr}\text { Observations (or Sum Wgts) } & 210\end{array}$

Analysis of Variance

Source DF Sum of Squares Mean Square F Ratio

$\begin{array}{lrrrr}\text { Model } & 34 & 11.437909 & 0.336409 & 19.7711\end{array}$

$\begin{array}{llll}\text { Error } & 175 & 2.977657 & 0.017015 \text { Prob }>\text { F }\end{array}$

$\begin{array}{lrr}\text { C. Total } 209 & 14.415566 & <.0001\end{array}$

Expected Mean Squares

The Mean Square per row by the Variance Component per column

$\begin{array}{lrr}\text { EMS } & \text { Intercept } & \text { Batch\&Random } \\ \text { Intercept } & 0 & 0 \\ \text { Batch\&Random } & 0 & 6\end{array}$

plus 1.0 times Residual Error Variance

$\begin{array}{ll}\text { Variance Component Estimates } \\ \text { Component } & \text { Var Comp Est Percent of Total }\end{array}$

\begin{tabular}{crr} 
Component & Var Comp Est & Percent of Total \\
Batch\&Random & 0.053232 & 75.778 \\
Residual & 0.017015 & 24.222 \\
\hline
\end{tabular}

$\begin{array}{lrr}\text { Residual } & 0.017015 & 24.222 \\ \text { Total } & 0.070248 & 100.000\end{array}$

These estimates based on equating Mean Squares to Expected Value.

Test Denominator Synthesis

Source MS Den DF Den Denom MS Synthesis

$\begin{array}{crrr}\text { Source } & \text { MS Den } & \text { DF Den } & \text { Denom MS } \\ \text { Batch\&Random } & 0.01702 & 175 & \text { Residual }\end{array}$

Tests wrt Random Effects

Source SS MS Num DF Num F Ratio Prob $>$ F

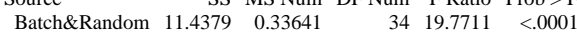

Sample Type=SME, Prep=Fusion, ICP=M-13, Analyte=Zr 
WSRC-STI-2006-00068

Revision 0

Exhibit A7. Analysis of Variance by Preparation Method, ICP, and Analyte (continued)

Sample Type=SME, Prep=Fusion, ICP=M-14, Analyte=Al Response Measurement

Summary of Fit

\begin{tabular}{|c|c|c|c|c|}
\hline \multicolumn{3}{|c|}{ RSquare } & \multicolumn{2}{|l|}{0.496826} \\
\hline \multicolumn{3}{|c|}{ RSquare Adj } & 0.407372 & \\
\hline \multicolumn{3}{|c|}{ Root Mean Square Error } & 0.184189 & \\
\hline \multicolumn{3}{|c|}{ Mean of Response } & 2.885389 & \\
\hline \multicolumn{3}{|c|}{ Observations (or Sum Wgts) } & 54 & \\
\hline \multicolumn{5}{|c|}{ Analysis of Variance } \\
\hline Source & DF & Sum of Squares & Mean Square & F Ratio \\
\hline Model & 8 & 1.5073903 & $\quad 0.188424$ & 5.5540 \\
\hline Error & 45 & 1.5266525 & 0.033926 & Prob $>$ F \\
\hline C. Total & 53 & 3.0340428 & & $<.0001$ \\
\hline
\end{tabular}

Expected Mean Squares

The Mean Square per row by the Variance Component per column

$\begin{array}{lrr}\text { EMS } & \text { Intercept } & \text { Batch\&Random } \\ \text { Intercept } & 0 & 0\end{array}$

Batch\&Random $\quad 0 \quad 6$

plus 1.0 times Residual Error Variance

Variance Component Estimates

Component Var Comp Est Percent of Total

$\begin{array}{rrr}\text { Batch\&Random } & 0.02575 & 43.150\end{array}$

Residual $\quad 0.033926 \quad 56.850$

Total $\quad 0.059675 \quad 100.000$

These estimates based on equating Mean Squares to Expected Value.

Test Denominator Synthesis

Source MS Den DF Den Denom MS Synthesis

Batch\&Random $0.03393 \quad 45$ Residual

Tests wrt Random Effects
$\begin{aligned} & \text { Source } \\ & \text { SS MS Num DF Num F Ratio Prob > F }\end{aligned}$

$\begin{array}{lrrrrr}\text { Source } & \text { SS } & \text { MS Num } & \text { DF Num } & \text { F Ratio } & \text { Prob }>\text { F } \\ \text { Batch\&Random } & 1.50739 & 0.18842 & 8 & 5.5540 & <.0001\end{array}$

Sample Type=SME, Prep=Fusion, $\mathrm{ICP}=\mathrm{M}-14$, Analyte=Al/Ca

Response Measurement

Summary of Fit

RSquare $\quad 0.597603$

RSquare Adj $\quad 0.525171$

Root Mean Square Error $\quad 0.116775$

Mean of Response 4.178395

Observations (or Sum Wgts) 60

Analysis of Variance

Source DF Sum of Squares Mean Square F Ratio

$\begin{array}{lrrrr}\text { Model } & 9 & 1.0125835 & 0.112509 & 8.2506\end{array}$

$\begin{array}{lllll}\text { Error } & 50 & 0.6818249 & 0.013636 & \text { Prob }>\text { F }\end{array}$

$\begin{array}{llll}\text { C. Total } & 59 & 1.6944084 & <.0001\end{array}$

Expected Mean Squares

The Mean Square per row by the Variance Component per column

$\begin{array}{lrr}\text { EMS } & \text { Intercept } & \text { Batch\&Random } \\ \text { Intercept } & 0 & 0\end{array}$

Batch\&Random $\quad 0 \quad 6$

plus 1.0 times Residual Error Variance

Variance Component Estimates

Component Var Comp Est Percent of Total

Batch\&Random $\quad 0.016479 \quad 54.719$

$\begin{array}{lll}\text { Residual } & 0.013636 & 45.28\end{array}$

Total $\quad 0.030115 \quad 100.000$

These estimates based on equating Mean Squares to Expected Value.

Test Denominator Synthesis

Source MS Den DF Den Denom MS Synthesis

Batch\&Random $0.01364 \quad 50$ Residual

Tests wrt Random Effects

Source

SS MS Num DF Num F Ratio Prob $>$ F

$\begin{array}{lrrrrr}\text { Batch\&Random } & 1.01258 & 0.11251 & 9 & 8.2506 & <.0001\end{array}$
Sample Type=SME, Prep=Fusion, ICP=M-14, Analyte=AI/Mg Response Measurement

Summary of Fit

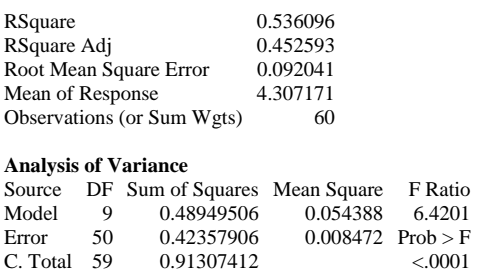

Expected Mean Squares

The Mean Square per row by the Variance Component per column

EMS Intercept Batch\&Random

$\begin{array}{crr}\text { Intercept } & 0 & 0 \\ \text { Batch\&Random } & 0 & 6\end{array}$

plus 1.0 times Residual Error Variance

Variance Component Estimates

$\begin{array}{crr}\text { Component } & \text { Var Comp Est } & \text { Percent of Total } \\ \text { Batch\&Random } & 0.007653 & 47.461\end{array}$

$\begin{array}{lll}\text { Batch\&Random } & 0.007653 & 47.461 \\ \text { Residual } & 0.008472 & 52.539\end{array}$

Total $\quad 0.016124 \quad 100.000$

These estimates based on equating Mean Squares to Expected Value.

Test Denominator Synthesis

Source MS Den DF Den Denom MS Synthesis

Batch\&Random $0.00847 \quad 50$ Residual

Tests wrt Random Effects

Source SS MS Num DF Num F Ratio Prob > F

Batch\&Random $0.4895 \quad 0.05439 \quad 9 \quad 6.4201<.0001$

Sample Type=SME, Prep=Fusion, ICP $=M-14$, Analyte $=A l / M n$ Response Measurement

Summary of Fit

0.480577

RSquare Adj $\quad 0.387081$

Root Mean Square Error $\quad 0.040142$

Mean of Response $\quad 1.873531$

Observations (or Sum Wgts)

60

Analysis of Variance

Source DF Sum of Squares Mean Square F Ratio

$\begin{array}{lrrrr}\text { Model } & 9 & 0.07454501 & 0.008283 & 5.1401\end{array}$

$\begin{array}{lllll}\text { Error } & 50 & 0.08057062 & 0.001611 & \text { Prob }>\text { F }\end{array}$

$\begin{array}{llll}\text { C. Total } & 59 & 0.15511563 & <.0001\end{array}$

Expected Mean Squares

The Mean Square per row by the Variance Component per column

$\begin{array}{lrr}\text { EMS } & \text { Intercept } & \text { Batch\&Random } \\ \text { Intercept } & 0 & 0 \\ \text { Batch\&Random } & 0 & 6\end{array}$

plus 1.0 times Residual Error Variance

Variance Component Estimates

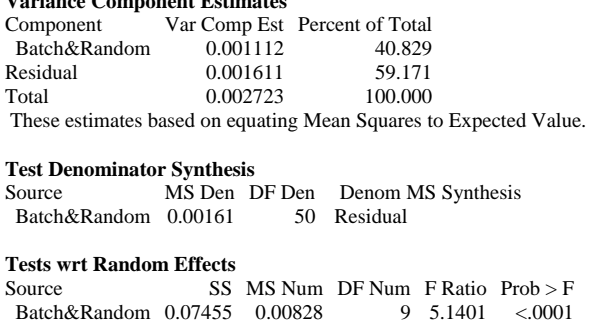


WSRC-STI-2006-00068

Revision 0

Exhibit A7. Analysis of Variance by Preparation Method, ICP, and Analyte (continued)

Sample Type=SME, Prep=Fusion, ICP=M-14, Analyte=B Response Measurement

Summary of Fi

\begin{tabular}{|c|c|c|c|c|}
\hline \multicolumn{3}{|c|}{ RSquare } & 0.44935 & \\
\hline \multicolumn{3}{|c|}{ RSquare Adj } & 0.351457 & \\
\hline \multicolumn{3}{|c|}{ Root Mean Square Error } & 0.08747 & \\
\hline \multicolumn{3}{|c|}{ Mean of Response } & 1.390241 & \\
\hline \multicolumn{3}{|c|}{ Observations (or Sum Wgts) } & 54 & \\
\hline \multicolumn{5}{|c|}{ Analysis of Variance } \\
\hline Source & DF & Sum of Squares & Mean Square & F Ratio \\
\hline Model & 8 & 0.28095904 & 0.035120 & 4.5902 \\
\hline Error & 45 & 0.34429683 & 0.007651 & Prob $>\mathrm{F}$ \\
\hline C. Total & 53 & 0.62525587 & & 0.0004 \\
\hline
\end{tabular}

Expected Mean Squares

The Mean Square per row by the Variance Component per column

$\begin{array}{lrr}\text { EMS } & \text { Intercept } & \text { Batch\&Random } \\ \text { Intercept } & 0 & 0\end{array}$

Batch\&Random

0

0

plus 1.0 times Residual Error Variance

Variance Component Estimates

Component Var Comp Est Percent of Total

$\begin{array}{rrr}\text { Batch\&Random } & 0.004578 & 37.436\end{array}$

$\begin{array}{lll}\text { Residual } & 0.007651 & 62.564\end{array}$

Total $\quad 0.012229 \quad 100.000$

These estimates based on equating Mean Squares to Expected Value.

Test Denominator Synthesis

Source MS Den DF Den Denom MS Synthesis

Batch\&Random $0.00765 \quad 45$ Residual

Tests wrt Random Effects
$\begin{aligned} & \text { Source } \\ & \text { SS MS Num DF Num F Ratio Prob > F }\end{aligned}$

$\begin{array}{lrrrrr}\text { Source } & \text { SS } & \text { MS Num } & \text { DF Num } & \text { F Ratio } & \text { Prob > F } \\ \text { Batch\&Random } & 0.28096 & 0.03512 & 8 & 4.5902 & 0.0004\end{array}$

Sample Type=SME, Prep=Fusion, ICP=M-14, Analyte=B/Li

Response Measurement

Summary of Fit

RSquare $\quad 0.609564$

RSquare Adj $\quad 0.539286$

Root Mean Square Error $\quad 0.009465$

Mean of Response $\quad 0.640935$

Observations (or Sum Wgts) $\quad 60$

Analysis of Variance

Source DF Sum of Squares Mean Square F Ratio

$\begin{array}{lrrrr}\text { Model } & 9 & 0.00699364 & 0.000777 & 8.6736 \\ & 5 & 0.00447954 & 0.000090 & \end{array}$

$\begin{array}{lllll}\text { Error } & 50 & 0.00447954 & 0.000090 & \text { Prob }>\text { F }\end{array}$

$\begin{array}{llll}\text { C. Total } & 59 & 0.01147318 & <.0001\end{array}$

Expected Mean Squares

The Mean Square per row by the Variance Component per column

$\begin{array}{lrr}\text { EMS } & \text { Intercept } & \text { Batch\&Random } \\ \text { Intercept } & 0 & 0\end{array}$

Batch\&Random $\quad 0 \quad 6$

plus 1.0 times Residual Error Variance

Variance Component Estimates

Component Var Comp Est Percent of Total

Batch\&Random $\quad 0.000115 \quad 56.120$

$\begin{array}{lll}\text { Residual } & 0.00009 & 43.880\end{array}$

Total $\quad 0.000204 \quad 100.000$

These estimates based on equating Mean Squares to Expected Value.

Test Denominator Synthesis

Source MS Den DF Den Denom MS Synthesis

Batch\&Random $0.00009 \quad 50$ Residual

Tests wrt Random Effects

Source

SS MS Num DF Num F Ratio Prob $>$ F

$\begin{array}{llllll}\text { Batch\&Random } & 0.00699 & 0.00078 & 9 & 8.6736 & <.0001\end{array}$
Sample Type=SME, Prep=Fusion, ICP $=M-14$, Analyte $=$ Ca Response Measurement

Summary of Fit

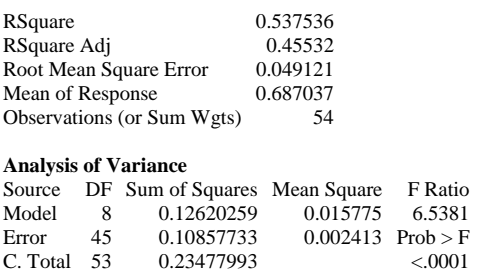

C. Total $53 \quad 0.23477993 \quad 0.002413 \quad$ Prob $>$ F

Expected Mean Squares

The Mean Square per row by the Variance Component per column

$\begin{array}{lrr}\text { EMS } & \text { Intercept } & \text { Batch\&Random } \\ \text { Intercept } & 0 & 0\end{array}$

Batch\&Random $\quad 0 \quad 6$

plus 1.0 times Residual Error Variance

Variance Component Estimates

$\begin{array}{rrr}\text { Component } & \text { Var Comp Est } & \text { Percent of Total } \\ \text { Batch\&Random } & 0.002227 & 47.998\end{array}$

$\begin{array}{ccc}\text { Batch\&Random } & 0.002227 & 47.998 \\ \text { Residual } & 0.002413 & 52.002\end{array}$

$\begin{array}{lrr}\text { Residual } & 0.002413 & 52.002 \\ \text { Total } & 0.00464 & 100.000\end{array}$

These estimates based on equating Mean Squares to Expected Value.

Test Denominator Synthesis

Source MS Den DF Den Denom MS Synthesis

Batch\&Random $0.00241 \quad 45$ Residual

Tests wrt Random Effects

Source SS MS Num DF Num F Ratio Prob $>$ F

$\begin{array}{rrrrrr}\text { Batch\&Random } & 0.1262 & 0.01578 & 8 & 6.5381 & <.0001\end{array}$

Sample Type=SME, Prep=Fusion, ICP=M-14, Analyte $=$ Cr

Response Measurement

Summary of Fit

0.633623
0.567675

Ropquar $\quad 0.567675$

0.00706

$\begin{array}{lr}\text { Mean of Response } & 0.051067 \\ \text { Observations (or Sum Wgts) } & 60\end{array}$

Analysis of Variance

Source DF Sum of Squares Mean Square F Ratio

$\begin{array}{lrrrr}\text { Model } & 9 & 0.00430973 & 0.000479 & 9.6079\end{array}$

$\begin{array}{lllll}\text { Error } & 50 & 0.00249200 & 0.000050 \quad \text { Prob }>\text { F }\end{array}$

$\begin{array}{llll}\text { C. Total } & 59 & 0.00680173 & <.0001\end{array}$

Expected Mean Squares

The Mean Square per row by the Variance Component per column

$\begin{array}{lrr}\text { EMS } & \text { Intercept } & \text { Batch\&Random } \\ \text { Intercept } & 0 & 0 \\ \text { Batch\&Random } & 0 & 6\end{array}$

plus 1.0 times Residual Error Variance

Variance Component Estimates
Component Var Comp Est Percent of Total

$\begin{array}{lrr}\text { Component } & \text { Var Comp Est } & \text { Percent of Total } \\ \text { Batch\&Random } & 0.000072 & 58.926 \\ \text { Residual } & 0.00005 & 41.074\end{array}$

$\begin{array}{lrr}\text { Residual } & 0.00005 & 41.074 \\ \text { Total } & 0.000121 & 100.000\end{array}$

These estimates based on equating Mean Squares to Expected Value.

Test Denominator Synthesis

Source MS Den DF Den Denom MS Synthesis

$\begin{array}{lrrr}\text { Source } & \text { MS Den } & \text { DF Den } & \text { Denom MS } \\ \text { Batch\&Random } & 0.00005 & 50 & \text { Residual }\end{array}$

Tests wrt Random Effects

Source SS MS Num DF Num F Ratio Prob $>$ F

$\begin{array}{rrrrrr} & \text { Source } & & & & \\ \text { Batch\&Random } & 0.00431 & 0.00048 & 9 & 9.6079 & <.0001\end{array}$ 
WSRC-STI-2006-00068

Revision 0

Exhibit A7. Analysis of Variance by Preparation Method, ICP, and Analyte (continued)

Sample Type=SME, Prep=Fusion, ICP=M-14, Analyte $=\mathrm{Cu}$ Response Measurement

Summary of Fit

\begin{tabular}{|c|c|c|c|c|}
\hline \multicolumn{3}{|c|}{ RSquare } & 0.792348 & \\
\hline \multicolumn{3}{|c|}{ RSquare Adj } & 0.755432 & \\
\hline \multicolumn{3}{|c|}{ Root Mean Square Error } & 0.002214 & \\
\hline \multicolumn{3}{|c|}{ Mean of Response } & 0.011241 & \\
\hline \multicolumn{3}{|c|}{ Observations (or Sum Wgts) } & 54 & \\
\hline \multicolumn{5}{|c|}{ Analysis of Variance } \\
\hline Source & $\mathrm{DF}$ & Sum of Squares & s Mean Square & F Ratio \\
\hline Model & 8 & 0.00084137 & $7 \quad 0.000105$ & 21.4635 \\
\hline Error & 45 & 0.00022050 & 0.000005 & Prob $>$ F \\
\hline C. Total & 53 & 0.00106187 & & $<.0001$ \\
\hline
\end{tabular}

Expected Mean Squares

The Mean Square per row by the Variance Component per column

$\begin{array}{lrr}\text { EMS } & \text { Intercept } & \text { Batch\&Random } \\ \text { Intercept } & 0 & 0\end{array}$

Batch\&Random

0

6

plus 1.0 times Residual Error Variance

Variance Component Estimates

Component Var Comp Est Percent of Total

$\begin{array}{rrr}\text { Batch\&Random } & 0.000017 & 77.327\end{array}$

$\begin{array}{lll}\text { Residual } & 0.000005 & 22.673\end{array}$

Total $\quad 0.000022 \quad 100.000$

These estimates based on equating Mean Squares to Expected Value.

Test Denominator Synthesis

Source MS Den DF Den Denom MS Synthesis

Batch\&Random 4.9e-6 45 Residual

Tests wrt Random Effects
Source MS Num DF Num F Ratio Prob $>$ F

SS MS Num DF Num F Ratio Prob > F

Sample Type=SME, Prep=Fusion, ICP=M-14, Analyte=Fe

Response Measurement

Summary of Fit

RSquare $\quad 0.448625$

RSquare Adj $\quad 0.350603$

Root Mean Square Error $\quad 0.526957$

Mean of Response $\quad 7.678778$

Observations (or Sum Wgts) $\quad 54$

Analysis of Variance

Source DF Sum of Squares Mean Square F Ratio

\begin{tabular}{lrrrr} 
Model & 8 & 10.167162 & 1.27090 & 4.5768 \\
\hline & 45 & 12.495777 & 0.27768 &
\end{tabular}

$\begin{array}{lllll}\text { Error } & 45 & 12.495777 & 0.27768 & \text { Prob }>\text { F }\end{array}$

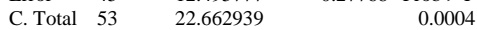

Expected Mean Squares

The Mean Square per row by the Variance Component per column

$\begin{array}{lrr}\text { EMS } & \text { Intercept } & \text { Batch\&Random } \\ \text { Intercept } & 0 & 0\end{array}$

Batch\&Random $\quad 0 \quad 6$

plus 1.0 times Residual Error Variance

Variance Component Estimates

Component Var Comp Est Percent of Total

$\begin{array}{lll}\text { Batch\&Random } \quad 0.165535 & 37.348\end{array}$

$\begin{array}{lll}\text { Residual } & 0.277684 & 62.652\end{array}$

Total $\quad 0.443219 \quad 100.000$

These estimates based on equating Mean Squares to Expected Value.

Test Denominator Synthesis

Source MS Den DF Den Denom MS Synthesis

$\begin{array}{lrrr}\text { Batch\&Random } & 0.27768 & 45 & \text { Residual }\end{array}$

Tests wrt Random Effects

Source SS MS Num DF Num F Ratio Prob $>$ F

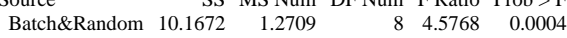

Sample Type=SME, Prep=Fusion, $\mathrm{ICP}=\mathrm{M}-14$, Analyte=Fe/Al Response Measurement

Summary of Fit

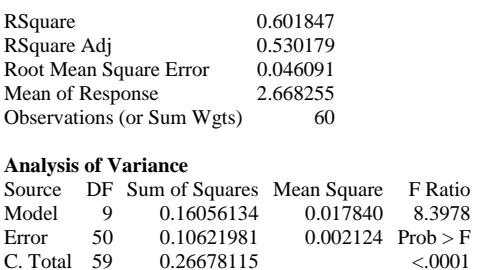

Expected Mean Squares

The Mean Square per row by the Variance Component per column

EMS Intercept Batch\&Random

$\begin{array}{crr}\text { Intercept } & 0 & 0 \\ \text { Batch\&Random } & 0 & 6\end{array}$

plus 1.0 times Residual Error Variance

Variance Component Estimates

$\begin{array}{crr}\text { Component } & \text { Var Comp Est } & \text { Percent of Total } \\ \text { Batch\&Random } & 0.002619 & 55.216 \\ \text { Residual } & 0.002124 & 44.784 \\ \text { Tol }\end{array}$

Total $\quad 0.004744 \quad 100.000$

These estimates based on equating Mean Squares to Expected Value.

Test Denominator Synthesis

Source MS Den DF Den Denom MS Synthesis

Batch\&Random $0.00212 \quad 50$ Residual

Tests wrt Random Effects
Source SS MS Num DF Num F Ratio Prob $>$ F

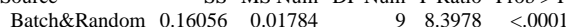

Sample Type=SME, Prep=Fusion, ICP=M-14, Analyte=Fe/Ca Response Measurement

Summary of Fit

0.58295
0.5078901

0.507889
Ret

0.307701

$\begin{array}{lr}\text { Mean of Response } & 11.14501 \\ \text { Observations (or Sum Wgts) } & 60\end{array}$

Analysis of Variance

Source DF Sum of Squares Mean Square F Ratio

$\begin{array}{lrlll}\text { Model } & 9 & 6.617311 & 0.735257 & 7.7657\end{array}$

$\begin{array}{lllll}\text { Error } & 50 & 4.733983 & 0.094680 & \text { Prob }>\text { F }\end{array}$

$\begin{array}{llll}\text { C. Total } & 59 & 11.351294 & <.0001\end{array}$

Expected Mean Squares

The Mean Square per row by the Variance Component per column

$\begin{array}{lrr}\text { EMS } & \text { Intercept } & \text { Batch\&Random } \\ \text { Intercept } & 0 & 0 \\ \text { Batch\&Random } & 0 & 6\end{array}$

plus 1.0 times Residual Error Variance

Variance Component Estimates

\begin{tabular}{|c|c|c|c|c|c|}
\hline \\
\hline \multicolumn{6}{|c|}{ Var Comp Est Percent of Total } \\
\hline Batch\&Random & 0.10 & 06763 & 52.999 & & \\
\hline Residual & & 99468 & 47.001 & & \\
\hline Total & 0.201 & 1443 & 100.000 & & \\
\hline \multicolumn{6}{|c|}{ These estimates based on equating Mean Squares to Expected Value. } \\
\hline \multicolumn{6}{|c|}{ Test Denominator Synthesis } \\
\hline Source & MS Den & DF Den & Denom MS & SS Synthes: & \\
\hline Batch\&Random & 0.09468 & 50 & Residual & & \\
\hline \multicolumn{6}{|c|}{ Tests wrt Random Effects } \\
\hline Source & SS & MS Num & DF Num $F$ & F Ratio & Prob > F \\
\hline Batch\&Random & 6.61731 & 0.73526 & & 7.7657 & $<.0001$ \\
\hline
\end{tabular}


WSRC-STI-2006-00068

Revision 0

Exhibit A7. Analysis of Variance by Preparation Method, ICP, and Analyte (continued)

Sample Type=SME, Prep=Fusion, $\mathrm{ICP}=\mathrm{M}-14$, Analyte $=\mathrm{Fe} / \mathrm{Li}$ Response Measurement

Summary of Fit

\begin{tabular}{lrrrr} 
RSquare & 0.885245 & \\
RSquare Adj & 0.864589 & \\
Root Mean Square Error & 0.104821 & \\
Mean of Response & 3.543268 & \\
Observations (or Sum Wgts) & 60 & \\
\multicolumn{5}{l}{} \\
\multicolumn{4}{l}{ Analysis of Variance } \\
Source & DF & Sum of Squares & Mean Square & F Ratio \\
Model & 9 & 4.2379731 & 0.470886 & 42.8567 \\
Error & 50 & 0.5493727 & 0.010987 & Prob > F \\
C. Total & 59 & 4.7873458 & & $<.0001$
\end{tabular}

Expected Mean Squares

The Mean Square per row by the Variance Component per column

$\begin{array}{lrr}\text { EMS } & \text { Intercept } & \text { Batch\&Random } \\ \text { Intercept } & 0 & 0\end{array}$

Batch\&Random

0

0

plus 1.0 times Residual Error Variance

Variance Component Estimates

Component Var Comp Est Percent of Total

$\begin{array}{rrr}\text { Component } & \text { Var Comp Est } & \text { Percent of Tota } \\ \text { Batch\&Random } & 0.07665 & 87.463\end{array}$

$\begin{array}{lrr}\text { Batch\&Random } & 0.07665 & 87.463 \\ \text { Residual } & 0.010987 & 12.537\end{array}$

Total $\quad 0.087637 \quad 100.000$

These estimates based on equating Mean Squares to Expected Value.

Test Denominator Synthesis

Source MS Den DF Den Denom MS Synthesis

Batch\&Random $0.01099 \quad 50$ Residual

Tests wrt Random Effects
Source SS MS Num DF Num F Ratio Prob > F

$\begin{array}{lrrrr}\text { Source } & \text { SS } & \text { MS Num DF Num } & \text { F Ratio } & \text { Prob }>\text { F } \\ \text { Batch\&Random } & 4.23797 & 0.47089 & 9 & 42.8567\end{array}$

Sample Type=SME, Prep=Fusion, ICP=M-14, Analyte $=F e / M g$

Response Measurement

Summary of Fit

RSquare $\quad 0.516502$

RSquare Adj $\quad 0.429473$

Root Mean Square Error $\quad 0.243151$

Mean of Response $\quad 11.4888$

Observations (or Sum Wgts) 60

Analysis of Variance

Source DF Sum of Squares Mean Square F Ratio

$\begin{array}{lrrrr}\text { Model } & 9 & 3.1579152 & 0.350879 & 5.9348\end{array}$

$\begin{array}{lllll}\text { Error } & 50 & 2.9561243 & 0.059122 & \text { Prob }>\text { F }\end{array}$

$\begin{array}{llll}\text { C. Total } & 59 & 6.1140395 & <.0001\end{array}$

Expected Mean Squares

The Mean Square per row by the Variance Component per column

$\begin{array}{lrr}\text { EMS } & \text { Intercept } & \text { Batch\&Random } \\ \text { Intercept } & 0 & 0\end{array}$

Batch\&Random $\quad 0 \quad 6$

plus 1.0 times Residual Error Variance

Variance Component Estimates

Component Var Comp Est Percent of Total

Batch\&Random $\quad 0.048626 \quad 45.129$

Residual $\quad 0.059122 \quad 54.87$

Total $\quad 0.107749 \quad 100.000$

These estimates based on equating Mean Squares to Expected Value.

Test Denominator Synthesis

Source MS Den DF Den Denom MS Synthesis

Batch\&Random $0.05912 \quad 50$ Residual

Tests wrt Random Effects

Source

SS MS Num DF Num F Ratio Prob $>$ F

$\begin{array}{lrrrrr}\text { Batch\&Random } & 3.15792 & 0.35088 & 9 & 5.9348 & <.0001\end{array}$
Sample Type=SME, Prep=Fusion, ICP=M-14, Analyte=Fe/Mn Response Measurement

Summary of Fit

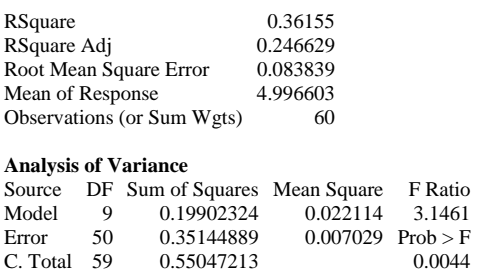

Expected Mean Squares

The Mean Square per row by the Variance Component per column

$\begin{array}{lrr}\text { EMS } & \text { Intercept } & \text { Batch\&Random } \\ \text { Intercept } & 0 & 0\end{array}$

$\begin{array}{lll}\text { Intercept } & 0 & 0 \\ \text { Batch\&Random } & 0 & 6\end{array}$

plus 1.0 times Residual Error Variance

Variance Component Estimates

Component Var Comp Est Percent of Total

$\begin{array}{rrr}\text { Component } & \text { Var Comp Est } & \text { Percent of Total } \\ \text { Batch\&Random } & 0.002514 & 26.345\end{array}$

$\begin{array}{lll}\text { Batch\&Random } & 0.002514 & 26.345 \\ \text { Residual } & 0.007029 & 73.655\end{array}$

Total $\quad 0.009543 \quad 100.000$

These estimates based on equating Mean Squares to Expected Value.

Test Denominator Synthesis

Source MS Den DF Den Denom MS Synthesis

Batch\&Random $0.00703 \quad 50$ Residual

Tests wrt Random Effects
Source SS MS Num DF Num F Ratio Prob $>$ F

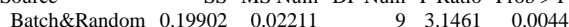

Sample Type=SME, Prep=Fusion, ICP=M-14, Analyte=Fe/Ni

Response Measurement

Summary of Fit

RSquare $\quad 0.482952$

RSquare Adj $\quad 0.389883$

Root Mean Square Error $\quad 0.351635$

Mean of Response $\quad 17.70708$

Observations (or Sum Wgts) 60

Analysis of Variance

Source DF Sum of Squares Mean Square F Ratio

$\begin{array}{lrrrr}\text { Model } & 9 & 5.774678 & 0.641631 & 5.1892\end{array}$

$\begin{array}{lllll}\text { Error } & 50 & 6.182363 & 0.123647 \quad \text { Prob }>\text { F }\end{array}$

$\begin{array}{llrr}\text { C. Total } & 59 & 11.957041 & <.0001\end{array}$

Expected Mean Squares

The Mean Square per row by the Variance Component per column

$\begin{array}{lrr}\text { EMS } & \text { Intercept } & \text { Batch\&Random } \\ \text { Intercept } & 0 & 0 \\ \text { Batch\&Random } & 0 & 6\end{array}$

plus 1.0 times Residual Error Variance

Variance Component Estimates
Component $\quad$ Var Comp Est Percent of Total

$\begin{array}{ccr}\text { Component } & \text { Var Comp Est } & \text { Percent of Total } \\ \text { Batch\&Random } & 0.086331 & 41.114 \\ \text { Residual } & 0.123647 & 58.886\end{array}$

$\begin{array}{lrr}\text { Residual } & 0.123647 & 58.886 \\ \text { Total } & 0.209978 & 100.000\end{array}$

These estimates based on equating Mean Squares to Expected Value.

Test Denominator Synthesis

Source MS Den DF Den Denom MS Synthesis

$\begin{array}{crrr}\text { Source } & \text { MS Den } & \text { DF Den } & \text { Denom MS } \\ \text { Batch\&Random } & 0.12365 & 50 & \text { Residual }\end{array}$

Tests wrt Random Effects

Source SS MS Num DF Num F Ratio Prob $>$ F

$\begin{array}{rrrrrr} & \text { SS } & \text { MS Num } & \text { DF Num } & \text { F Ratio } & \text { Prob }>\text { F } \\ \text { Batch\&Random } & 5.77468 & 0.64163 & 9 & 5.1892 & <.0001\end{array}$ 
WSRC-STI-2006-00068

Revision 0

Exhibit A7. Analysis of Variance by Preparation Method, ICP, and Analyte (continued)

Sample Type $=$ SME, Prep=Fusion, $\mathrm{ICP}=\mathrm{M}-14$, Analyte $=\mathrm{Fe} / \mathrm{U}$ Response Measurement

Summary of Fi

\begin{tabular}{|c|c|c|c|c|}
\hline \multicolumn{3}{|c|}{ RSquare } & 0.75144 & \\
\hline \multicolumn{3}{|c|}{ RSquare Adj } & 0.7067 & \\
\hline \multicolumn{3}{|c|}{ Root Mean Square Error } & 0.063984 & \\
\hline \multicolumn{3}{|c|}{ Mean of Response } & 2.829664 & \\
\hline \multicolumn{3}{|c|}{ Observations (or Sum Wgts) } & 60 & \\
\hline \multicolumn{5}{|c|}{ Analysis of Variance } \\
\hline Source & DF & Sum of Squares & Mean Square & F Ratio \\
\hline Model & 9 & 0.61883166 & 0.068759 & 16.7954 \\
\hline Error & 50 & 0.20469566 & 0.004094 & Prob $>$ F \\
\hline C. Total & 59 & 0.82352732 & & $<.0001$ \\
\hline
\end{tabular}

Expected Mean Squares

The Mean Square per row by the Variance Component per column

$\begin{array}{lrr}\text { EMS } & \text { Intercept } & \text { Batch\&Random } \\ \text { Intercept } & 0 & 0\end{array}$

Batch\&Random

0

6

plus 1.0 times Residual Error Variance

Variance Component Estimates

Component Var Comp Est Percent of Total

Batch\&Random $\quad 0.010778 \quad 72.471$

$\begin{array}{lll}\text { Residual } & 0.004094 & 27.529\end{array}$

Total $\quad 0.014871 \quad 100.000$

These estimates based on equating Mean Squares to Expected Value.

Test Denominator Synthesis

Source MS Den DF Den Denom MS Synthesis

Batch\&Random $0.00409 \quad 50$ Residual

Tests wrt Random Effects
Source SS MS Num DF Num F Ratio Prob $>$ F

$\begin{array}{lrrrrr}\text { Source } & \text { SS } & \text { MS Num } & \text { DF Num } & \text { F Ratio } & \text { Prob }>\text { F } \\ \text { Batch\&Random } & 0.61883 & 0.06876 & 9 & 16.7954 & <0001\end{array}$

Sample Type=SME, Prep=Fusion, ICP $=M-14$, Analyte $=K$

Response Measurement

Summary of Fit

RSquare $\quad 0.529689$

RSquare Adj $\quad 0.445033$

Root Mean Square Error $\quad 0.130132$

Mean of Response $\quad 0.1152$

Observations (or Sum Wgts) 60

Analysis of Variance

Source DF Sum of Squares Mean Square F Ratio

\begin{tabular}{lrrrr} 
Model & 9 & 0.9536119 & 0.105957 & 6.2570 \\
\hline
\end{tabular}

$\begin{array}{lllll}\text { Error } & 50 & 0.8467117 & 0.016934 & \text { Prob }>\text { F }\end{array}$

$\begin{array}{llll}\text { C. Total } & 59 & 1.8003236 & <.0001\end{array}$

Expected Mean Squares

The Mean Square per row by the Variance Component per column

$\begin{array}{lrr}\text { EMS } & \text { Intercept } & \text { Batch\&Random } \\ \text { Intercept } & 0 & 0\end{array}$

Batch\&Random $\quad 0 \quad 6$

plus 1.0 times Residual Error Variance

Variance Component Estimates

Component Var Comp Est Percent of Total

$\begin{array}{lll}\text { Batch\&Random } & 0.014837 & 46.700\end{array}$

$\begin{array}{lll}\text { Residual } & 0.016934 & 53.300\end{array}$

Total $\quad 0.031771 \quad 100.000$

These estimates based on equating Mean Squares to Expected Value.

Test Denominator Synthesis

Source MS Den DF Den Denom MS Synthesis

Batch\&Random $0.01693 \quad 50$ Residual

Tests wrt Random Effects

Source

SS MS Num DF Num F Ratio Prob $>$ F

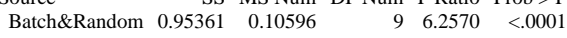

Sample Type=SME, Prep=Fusion, ICP=M-14, Analyte $=\mathrm{Li}$ Response Measurement

Summary of Fit

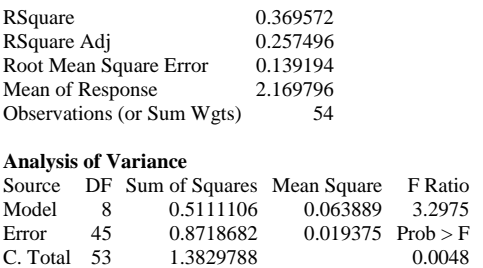

$\begin{array}{lllll}\text { C. Total } 53 & 1.3829788 & 0.019375 & \text { Prob }>\text { F }\end{array}$

Expected Mean Squares

The Mean Square per row by the Variance Component per column

$\begin{array}{lrr}\text { EMS } & \text { Intercept } & \text { Batch\&Random } \\ \text { Intercept } & 0 & 0\end{array}$

Batch\&Random $\quad 0 \quad 6$

plus 1.0 times Residual Error Variance

Variance Component Estimates

$\begin{array}{rrr}\text { Component } & \text { Var Comp Est } & \text { Percent of Total } \\ \text { Batch\&Random } & 0.007419 & 27.689\end{array}$

$\begin{array}{lll}\text { Batch\&Random } & 0.007419 & 27.689 \\ \text { Residual } & 0.019375 & 72.311\end{array}$

$\begin{array}{lrr}\text { Residual } & 0.019375 & 72.311 \\ \text { Total } & 0.026794 & 100.000\end{array}$

These estimates based on equating Mean Squares to Expected Value.

Test Denominator Synthesis

Source MS Den DF Den Denom MS Synthesis

Batch\&Random $0.01937 \quad 45$ Residual

Tests wrt Random Effects
Source SS MS Num DF Num F Ratio Prob $>$ F

$\begin{array}{lrrrrr}\text { Source } & \text { SS } & \text { MS Num } & \text { DF Num } & \text { F Ratio } & \text { Prob > F } \\ \text { Batch\&Random } & 0.51111 & 0.06389 & 8 & 3.2975 & 0.0048\end{array}$

Sample Type=SME, Prep=Fusion, ICP $=M-14$, Analyte $=M g$

Response Measurement

Summary of Fit

RSquare $\quad 0.522143$

RSquare Adj $\quad 0.43719$

Root Mean Square Error $\quad 0.043457$

Mean of Response $\quad 0.668833$

Observations (or Sum Wgts) 54

Analysis of Variance

Source DF Sum of Squares Mean Square F Ratio

$\begin{array}{lrrrr}\text { Model } & 8 & 0.09285967 & 0.011607 & 6.1463\end{array}$

$\begin{array}{lllll}\text { Error } & 45 & 0.08498383 & 0.001889 & \text { Prob }>\text { F }\end{array}$

$\begin{array}{llll}\text { C. Total } & 53 & 0.17784350 & <.0001\end{array}$

Expected Mean Squares

The Mean Square per row by the Variance Component per column

$\begin{array}{lrr}\text { EMS } & \text { Intercept } & \text { Batch\&Random } \\ \text { Intercept } & 0 & 0 \\ \text { Batch\&Random } & 0 & 6\end{array}$

plus 1.0 times Residual Error Variance

Variance Component Estimates
Component $\quad$ Var Comp Est Percent of Total

$\begin{array}{crr}\text { Component } & \text { Var Comp Est } & \text { Percent of Total } \\ \text { Batch\&Random } & 0.00162 & 46.170 \\ \text { Residual } & 0.001889 & 53.830 \\ \text { Tor } & 0.003508 & 100.000\end{array}$

$\begin{array}{lrr}\text { Residual } & 0.001889 & 53.830 \\ \text { Total } & 0.003508 & 100.000\end{array}$

These estimates based on equating Mean Squares to Expected Value.

Test Denominator Synthesis

Source MS Den DF Den Denom MS Synthesis

$\begin{array}{lrrr}\text { Source } & \text { MS Den } & \text { DF Den } & \text { Denom MS } \\ \text { Batch\&Random } & 0.00189 & 45 & \text { Residual }\end{array}$

Tests wrt Random Effects

Source SS MS Num DF Num F Ratio Prob $>$ F

$\begin{array}{rrrrrr}\text { Batch\&Random } & 0.09286 & 0.01161 & 8 & 6.1463 & <.0001\end{array}$ 
WSRC-STI-2006-00068

Revision 0

Exhibit A7. Analysis of Variance by Preparation Method, ICP, and Analyte (continued)

Sample Type=SME, Prep=Fusion, ICP=M-14, Analyte $=$ Mn Response Measurement

Summary of Fi

\begin{tabular}{|c|c|c|c|c|}
\hline \multicolumn{3}{|c|}{ RSquare } & 0.533125 & \\
\hline \multicolumn{3}{|c|}{ RSquare Adj } & 0.450125 & \\
\hline \multicolumn{3}{|c|}{ Root Mean Square Error } & 0.098856 & \\
\hline \multicolumn{3}{|c|}{ Mean of Response } & 1.536222 & \\
\hline \multicolumn{3}{|c|}{ Observations (or Sum Wgts) } & 54 & \\
\hline \multicolumn{5}{|c|}{ Analysis of Variance } \\
\hline Source & DF & Sum of Squares & Mean Square & F Ratio \\
\hline Model & 8 & 0.50216067 & 0.062770 & 6.4232 \\
\hline Error & 45 & 0.43975867 & 0.009772 & Prob $>$ F \\
\hline C. Total & 53 & 0.94191933 & & $<.0001$ \\
\hline
\end{tabular}

Expected Mean Squares

The Mean Square per row by the Variance Component per column

$\begin{array}{lrr}\text { EMS } & \text { Intercept } & \text { Batch\&Random } \\ \text { Intercept } & 0 & 0\end{array}$

Batch\&Random

0

0

plus 1.0 times Residual Error Variance

Variance Component Estimates

Component Var Comp Est Percent of Total

Batch\&Random $\quad 0.008833 \quad 47.475$

Residual $\quad 0.009772 \quad 52.525$

Total $\quad 0.018605 \quad 100.000$

These estimates based on equating Mean Squares to Expected Value.

Test Denominator Synthesis

Source MS Den DF Den Denom MS Synthesis

Batch\&Random $0.00977 \quad 45$ Residual

Tests wrt Random Effects
Source

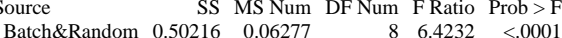

Sample Type=SME, Prep=Fusion, ICP $=M-14$, Analyte $=M n / M g$ Response Measurement

Summary of Fit

RSquare $\quad 0.466769$

RSquare Adj $\quad 0.370788$

Root Mean Square Error $\quad 0.041629$

Mean of Response 2.299459

Observations (or Sum Wgts) $\quad 60$

Analysis of Variance

Source DF Sum of Squares Mean Square F Ratio

\begin{tabular}{lrrrr} 
Model & 9 & 0.07584782 & 0.008428 & 4.8631 \\
\hline & 50 & 0.08664752 & 0.001733 & Prob $>$ F
\end{tabular}

$\begin{array}{lllll}\text { Error } & 50 & 0.08664752 & 0.001733 \text { Prob }>\text { F }\end{array}$

$\begin{array}{llll}\text { C. Total } & 59 & 0.16249534 & 0.0001\end{array}$

Expected Mean Squares

The Mean Square per row by the Variance Component per column

$\begin{array}{lrr}\text { EMS } & \text { Intercept } & \text { Batch\&Random } \\ \text { Intercept } & 0 & 0\end{array}$

Batch\&Random $\quad 0 \quad 6$

plus 1.0 times Residual Error Variance

Variance Component Estimates

Component Var Comp Est Percent of Total

$\begin{array}{lll}\text { Batch\&Random } \quad 0.001116 & 39.167\end{array}$

$\begin{array}{lll}\text { Residual } & 0.001733 & 60.833\end{array}$

Total $\quad 0.002849 \quad 100.000$

These estimates based on equating Mean Squares to Expected Value.

Test Denominator Synthesis

Source MS Den DF Den Denom MS Synthesis

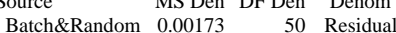

Tests wrt Random Effects

Source SS MS Num DF Num F Ratio Prob $>$ F

$\begin{array}{llllll}\text { Batch\&Random } & 0.07585 & 0.00843 & 9 & 4.8631 & 0.0001\end{array}$

Sample Type=SME, Prep=Fusion, ICP $=$ M-14, Analyte $=$ Na
Sample Type=SME, Prep=Fusion, $\mathrm{ICP}=\mathrm{M}-14$, Analyte=Ni Response Measurement

Summary of Fit

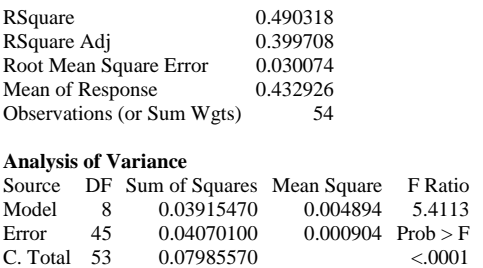

C. Total $53 \quad 0.07985570$

Expected Mean Squares

The Mean Square per row by the Variance Component per column

$\begin{array}{lrr}\text { EMS } & \text { Intercept } & \text { Batch\&Random } \\ \text { Intercept } & 0 & 0\end{array}$

Batch\&Random $\quad 0 \quad 6$

plus 1.0 times Residual Error Variance

Variance Component Estimates

$\begin{array}{rrr}\text { Component } & \text { Var Comp Est } & \text { Percent of Total } \\ \text { Batch\&Random } & 0.000665 & 42.370\end{array}$

$\begin{array}{lll}\text { Batch\&Random } & 0.000665 & 42.370 \\ \text { Residual } & 0.000904 & 57.630\end{array}$

$\begin{array}{llr}\text { Residual } & 0.000904 & 57.630 \\ \text { Total } & 0.001569 & 100.000\end{array}$

These estimates based on equating Mean Squares to Expected Value.

Test Denominator Synthesis

Source MS Den DF Den Denom MS Synthesis

Batch\&Random $0.0009 \quad 45$ Residual

Tests wrt Random Effects

Source SS MS Num DF Num F Ratio Prob $>$ F

Batch\&Random $0.03915 \quad 0.00489 \quad 8 \quad 5.4113<0001$

Sample Type=SME, Prep=Fusion, ICP $=M-14$, Analyte $=S i$

Response Measurement

Summary of Fit

RSquare $\quad 0.351167$

RSquare Adj $\quad 0.235819$

Root Mean Square Error $\quad 1.541752$

Mean of Response $\quad 23.2878$

Observations (or Sum Wgts) 54

Analysis of Variance

Source DF Sum of Squares Mean Square F Ratio

$\begin{array}{lrrrr}\text { Model } & 8 & 57.89251 & 7.23656 & 3.0444\end{array}$

$\begin{array}{lllll}\text { Error } & 45 & 106.96496 & 2.37700 \text { Prob }>\text { F }\end{array}$

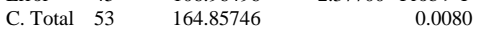

Expected Mean Squares

The Mean Square per row by the Variance Component per column

$\begin{array}{lrr}\text { EMS } & \text { Intercept } & \text { Batch\&Random } \\ \text { Intercept } & 0 & 0 \\ \text { Batch\&Random } & 0 & 6\end{array}$

plus 1.0 times Residual Error Variance

Variance Component Estimates
Component Var Comp Est Percent of Total

$\begin{array}{crr}\text { Component } & \text { Var Comp Est } & \text { Percent of Total } \\ \text { Batch\&Random } & 0.809927 & 25.414 \\ \text { Residual } & 2.376999 & 74.586 \\ \text { Tor }\end{array}$

$\begin{array}{lrr}\text { Residual } & 2.376999 & 74.586 \\ \text { Total } & 3.186926 & 100.000\end{array}$

These estimates based on equating Mean Squares to Expected Value.

Test Denominator Synthesis

Source MS Den DF Den Denom MS Synthesis

$\begin{array}{rrrr}\text { Source } & \text { MS Den } & \text { DF Den } & \text { Denom MS } \\ \text { Batch\&Random } & 2.377 & 45 & \text { Residual }\end{array}$

Tests wrt Random Effects

Source SS MS Num DF Num F Ratio Prob > F

$\begin{array}{rrrrrr}\text { Batch\&Random } & 57.8925 & 7.23656 & 8 & 3.0444 & 0.0080\end{array}$ 
WSRC-STI-2006-00068

Revision 0

Exhibit A7. Analysis of Variance by Preparation Method, ICP, and Analyte (continued)

Sample Type=SME, Prep=Fusion, ICP=M-14, Analyte=Sum of Oxide Response Measurement

Summary of Fi

\begin{tabular}{lrrrr} 
RSquare & 0.229986 & \\
RSquare Adj & 0.095234 & \\
Root Mean Square Error & 5.186094 & \\
Mean of Response & 83.3977 & \\
Observations (or Sum Wgts) & 48 & \\
\multicolumn{5}{l}{} \\
\multicolumn{7}{l}{ Analysis of Variance } \\
Source & DF & Sum of Squares & & \\
Model & 7 & 321.3243 & 45.9035 & F Ratio \\
Error & 40 & 1075.8230 & 26.8956 & Prob $>$ F \\
C. Total & 47 & 1397.1472 & & 0.1351
\end{tabular}

Expected Mean Squares

The Mean Square per row by the Variance Component per column

$\begin{array}{lrr}\text { EMS } & \text { Intercept } & \text { Batch\&Random } \\ \text { Intercept } & 0 & 0\end{array}$

Batch\&Random

0

plus 1.0 times Residual Error Variance

Variance Component Estimates

Component Var Comp Est Percent of Total

$\begin{array}{rrr}\text { Component } & \text { Var Comp Est } & \text { Percent of Total } \\ \text { Batch\&Random } & 3.167982 & 10.538\end{array}$

$\begin{array}{lll}\text { Residual } & 3.167982 & 10.538 \\ \text { Tota } & 26.89557 & 89.462\end{array}$

Total $\quad 30.06356 \quad 100.000$

These estimates based on equating Mean Squares to Expected Value.

Test Denominator Synthesis

Source MS Den DF Den Denom MS Synthesis

Batch\&Random $26.8956 \quad 40$ Residual

Tests wrt Random Effects

$\begin{array}{lrrrrr}\text { Source } & \text { SS } & \text { MS Num } & \text { DF Num } & \text { F Ratio } & \text { Prob > F } \\ \text { Batch\&Random } & 321.324 & 45.9035 & 7 & 1.7067 & 0.1351\end{array}$

Sample Type=SME, Prep=Fusion, ICP=M-14, Analyte=Ti

Response Measurement

Summary of Fit

RSquare $\quad 0.677602$

RSquare Adj $\quad 0.61957$

Root Mean Square Error $\quad 0.003489$

Mean of Response $\quad 0.040967$

Observations (or Sum Wgts) $\quad 60$

Analysis of Variance

Source DF Sum of Squares Mean Square F Ratio

\begin{tabular}{lrrrr} 
Model & 9 & 0.00127927 & 0.000142 & 11.6764 \\
\hline
\end{tabular}

$\begin{array}{lllll}\text { Error } & 50 & 0.00060867 & 0.000012 & \text { Prob }>\text { F }\end{array}$

$\begin{array}{lllll}\text { C. Total } & 59 & 0.00188793 & <.0001\end{array}$

Expected Mean Squares

The Mean Square per row by the Variance Component per column

$\begin{array}{lrr}\text { EMS } & \text { Intercept } & \text { Batch\&Random } \\ \text { Intercept } & 0 & 0\end{array}$

$\begin{array}{lll}\text { Batch\&Random } & 0 & 0 \\ \end{array}$

plus 1.0 times Residual Error Variance

Variance Component Estimates

Component Var Comp Est Percent of Total

Batch\&Random $\quad 0.000022 \quad 64.02$

$\begin{array}{lll}\text { Residual } & 0.000012 & 35.979\end{array}$

Total $\quad 0.000034 \quad 100.000$

These estimates based on equating Mean Squares to Expected Value.

Test Denominator Synthesis

Source MS Den DF Den Denom MS Synthesis

Batch\&Random $0.00001 \quad 50$ Residual

Tests wrt Random Effects

Source

SS MS Num DF Num F Ratio Prob > F

$\begin{array}{lrrrrr}\text { Batch\&Random } & 0.00128 & 0.00014 & 9 & 11.6764 & <.0001\end{array}$
Sample Type=SME, Prep=Fusion, ICP=M-14, Analyte=U Response Measurement

Summary of Fit

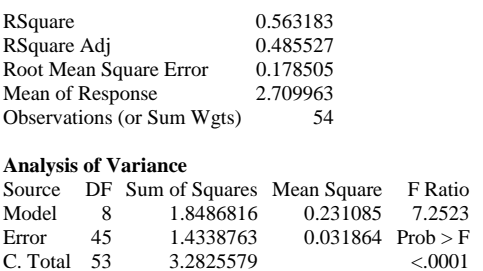

C. Total $53 \quad 3.2825579-0.031864 \quad$ Prob $>$ F

Expected Mean Squares

The Mean Square per row by the Variance Component per column

$\begin{array}{lrr}\text { EMS } & \text { Intercept } & \text { Batch\&Random } \\ \text { Intercept } & 0 & 0\end{array}$

Batch\&Random $\quad 0 \quad 6$

plus 1.0 times Residual Error Variance

Variance Component Estimates

$\begin{array}{crr}\text { Component } & \text { Var Comp Est } & \text { Percent of Total } \\ \text { Batch\&Random } & 0.033204 & 51.029 \\ \text { Residual } & 0.031864 & 48.971 \\ \text { Tol }\end{array}$

Total $\quad 0.065067 \quad 100.000$

These estimates based on equating Mean Squares to Expected Value.

Test Denominator Synthesis

Source MS Den DF Den Denom MS Synthesis

Batch\&Random $0.03186 \quad 45$ Residual

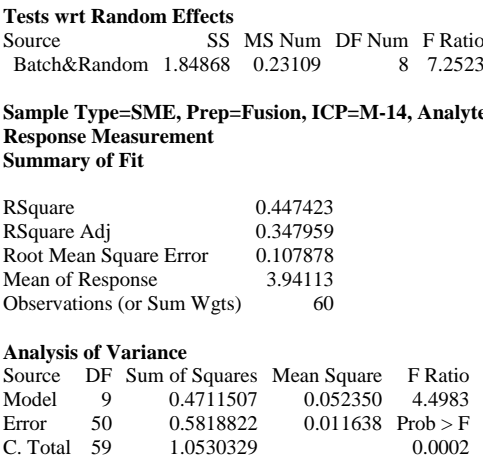

Expected Mean Squares

The Mean Square per row by the Variance Component per column

$\begin{array}{lrr}\text { EMS } & \text { Intercept } & \text { Batch\&Random } \\ \text { Intercept } & 0 & 0 \\ \text { Batch\&Random } & 0 & 6\end{array}$

plus 1.0 times Residual Error Variance

Variance Component Estimates
Component $\quad$ Var Comp Est Percent of Total

$\begin{array}{crr}\text { Component } & \text { Var Comp Est } & \text { Percent of Total } \\ \text { Batch\&Random } & 0.006785 & 36.831 \\ \text { Residual } & 0.011638 & 63.169 \\ \text { Tolul } & 0.018423 & 160.000\end{array}$

$\begin{array}{lrr}\text { Residual } & 0.011638 & 63.169 \\ \text { Total } & 0.018423 & 100.000\end{array}$

These estimates based on equating Mean Squares to Expected Value.

Test Denominator Synthesis

Source MS Den DF Den Denom MS Synthesis

$\begin{array}{lrrr}\text { Source } & \text { MS Den } & \text { DF Den } & \text { Denom MS } \\ \text { Batch\&Random } & 0.01164 & 50 & \text { Residual }\end{array}$

Tests wrt Random Effects

Source SS MS Num DF Num F Ratio Prob > F

$\begin{array}{rrrrrr}\text { Batch\&Random } & 0.47115 & 0.05235 & 9 & 4.4983 & 0.0002\end{array}$

Sample Type $=$ SME, Prep=Fusion, ICP $=M-14$, Analyte $=Z r$ 
WSRC-STI-2006-00068

Revision 0

Exhibit A7. Analysis of Variance by Preparation Method, ICP, and Analyte (continued)

Sample Type=SME, Prep=Mixed Acid, ICP=M-13, Analyte=Al Response Measurement

Summary of Fit

\begin{tabular}{|c|c|c|c|c|}
\hline \multicolumn{3}{|c|}{ RSquare } & \multicolumn{2}{|l|}{0.718986} \\
\hline \multicolumn{3}{|c|}{ RSquare Adj } & 0.664657 & \\
\hline \multicolumn{3}{|c|}{ Root Mean Square Error } & 0.11023 & \\
\hline \multicolumn{3}{|c|}{ Mean of Response } & 2.884844 & \\
\hline \multicolumn{3}{|c|}{ Observations (or Sum Wgts) } & 180 & \\
\hline \multicolumn{5}{|c|}{ Analysis of Variance } \\
\hline Source & $\mathrm{DF}$ & Sum of Squares & s Mean Square & F Ratio \\
\hline Model & 29 & 4.6631590 & $0 \quad 0.160799$ & 13.2338 \\
\hline Error & 150 & 1.8225847 & 0.012151 & Prob $>$ F \\
\hline C. Total & 179 & 6.4857436 & & $<.0001$ \\
\hline
\end{tabular}

Expected Mean Squares

The Mean Square per row by the Variance Component per column

$\begin{array}{lrr}\text { EMS } & \text { Intercept } & \text { Batch\&Random } \\ \text { Intercept } & 0 & 0\end{array}$

Batch\&Random

0

0

plus 1.0 times Residual Error Variance

Variance Component Estimates

Component Var Comp Est Percent of Total

$\begin{array}{rrr}\text { Batch\&Random } & 0.024775 & 67.094\end{array}$

Residual $\quad 0.012151 \quad 32.906$

Total $\quad 0.036925 \quad 100.000$

These estimates based on equating Mean Squares to Expected Value.

Test Denominator Synthesis

Source MS Den DF Den Denom MS Synthesis

Batch\&Random $0.01215 \quad 150$ Residual

Tests wrt Random Effects
$\begin{aligned} & \text { Source } \\ & \text { SS MS Num DF Num F Ratio Prob }>\text { F }\end{aligned}$

$\begin{array}{lrrrrr}\text { Source } & \text { SS } & \text { MS Num DF Num } & \text { F Ratio } & \text { Prob > F } \\ \text { Batch\&Random } & 4.66316 & 0.1608 & 29 & 13.2338 & <.0001\end{array}$

Sample Type=SME, Prep=Mixed Acid, ICP=M-13, Analyte=Al/Ca Response Measurement

Summary of Fit

RSquare $\quad 0.379827$

RSquare Adj $\quad 0.260387$

Root Mean Square Error $\quad 0.104571$

Mean of Response 4.021323

Observations (or Sum Wgts) 162

Analysis of Variance

Source DF Sum of Squares Mean Square F Ratio

$\begin{array}{lrrrr}\text { Model } & 26 & 0.9041311 & 0.034774 & 3.1800\end{array}$

$\begin{array}{lllll}\text { Error } & 135 & 1.4762436 & 0.010935 \text { Prob }>\text { F }\end{array}$

$\begin{array}{llll}\text { C. Total } 161 & 2.3803747 & <.0001\end{array}$

Expected Mean Square

The Mean Square per row by the Variance Component per column

$\begin{array}{lrr}\text { EMS } & \text { Intercept } & \text { Batch\&Random } \\ \text { Intercept } & 0 & 0\end{array}$

$\begin{array}{lll}\text { Batch\&Random } & 0 & 0 \\ \end{array}$

plus 1.0 times Residual Error Variance

Variance Component Estimates

Component Var Comp Est Percent of Total

$\begin{array}{lll}\text { Batch\&Random } \quad 0.003973 & 26.65\end{array}$

$\begin{array}{lll}\text { Residual } & 0.010935 & 73.349\end{array}$

Total $\quad 0.014908 \quad 100.000$

These estimates based on equating Mean Squares to Expected Value.

Test Denominator Synthesis

Source MS Den DF Den Denom MS Synthesis

Batch\&Random $0.01094 \quad 135$ Residual

Tests wrt Random Effects

Source

SS MS Num DF Num F Ratio Prob $>$ F

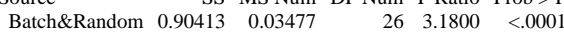

Sample Type=SME, Prep=Mixed Acid, ICP=M-13, Analyte=AI/Mg Response Measurement

Summary of Fit

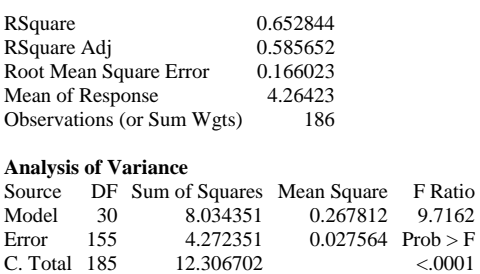

Expected Mean Squares

The Mean Square per row by the Variance Component per column

$\begin{array}{lrr}\text { EMS } & \text { Intercept } & \text { Batch\&Random } \\ \text { Intercept } & 0 & 0\end{array}$

Batch\&Random $\quad 0 \quad 6$

plus 1.0 times Residual Error Variance

Variance Component Estimates

$\begin{array}{crr}\text { Component } & \text { Var Comp Est } & \text { Percent of Total } \\ \text { Batch\&Random } & 0.040041 & 59.228\end{array}$

$\begin{array}{lll}\text { Batch\&Random } & 0.040041 & 59.228 \\ \text { Residual } & 0.027564 & 40.772\end{array}$

$\begin{array}{lrr}\text { Residual } & 0.027564 & 40.772 \\ \text { Total } & 0.067605 & 100.000\end{array}$

These estimates based on equating Mean Squares to Expected Value.

Test Denominator Synthesis

Source MS Den DF Den Denom MS Synthesis

Batch\&Random $0.02756 \quad 155$ Residual

Tests wrt Random Effects
Source SS MS Num DF Num F Ratio Prob $>$ F

$\begin{array}{lrrrrr}\text { Source } & \text { SS } & \text { MS Num } & \text { DF Num } & \text { F Ratio } & \text { Prob }>\text { F } \\ \text { Batch\&Random } & 8.03435 & 0.26781 & 30 & 9.7162 & <.0001\end{array}$

Sample Type=SME, Prep=Mixed Acid, ICP=M-13, Analyte=Al/Mn Response Measurement

Summary of Fit

RSquare Adj $\quad 0.703536$

Root Mean Square Error $\quad 0.052816$

Mean of Response $\quad 1.879144$

Observations (or Sum Wgts) 186

Analysis of Variance

Source DF Sum of Squares Mean Square F Ratio

$\begin{array}{lrrrr}\text { Model } \quad 30 & 1.0260732 & 0.034202 & 12.2610\end{array}$

$\begin{array}{lllll}\text { Error } & 155 & 0.4323774 & 0.002790 & \text { Prob }>\text { F }\end{array}$

$\begin{array}{llll}\text { C. Total } & 185 & 1.4584506 & <.0001\end{array}$

Expected Mean Squares

The Mean Square per row by the Variance Component per column

$\begin{array}{lrr}\text { EMS } & \text { Intercept } & \text { Batch\&Random } \\ \text { Intercept } & 0 & 0 \\ \text { Batch\&Random } & 0 & 6\end{array}$

plus 1.0 times Residual Error Variance

Variance Component Estimates
$\begin{array}{ll}\text { Component } & \text { Var Comp Est Percent of Total }\end{array}$

$\begin{array}{crr}\text { Component } & \text { Var Comp Est } & \text { Percent of Total } \\ \text { Batch\&Random } & 0.005235 & 65.240 \\ \text { Residual } & 0.00279 & 34.760\end{array}$

$\begin{array}{lrr}\text { Residual } & 0.00279 & 34.760 \\ \text { Total } & 0.008025 & 100.000\end{array}$

These estimates based on equating Mean Squares to Expected Value.

Test Denominator Synthesis

Source MS Den DF Den Denom MS Synthesis

$\begin{array}{lrrr}\text { Source } & \text { MS Den } & \text { DF Den } & \text { Denom } \\ \text { Batch\&Random } & 0.00279 & 155 & \text { Residual }\end{array}$

Tests wrt Random Effects

Source SS MS Num DF Num F Ratio Prob $>$ F

$\begin{array}{lrrrrr}\text { Batch\&Random } & 1.02607 & 0.0342 & 30 & 12.2610 & <.0001\end{array}$

Sample Type=SME, Prep=Mixed Acid, ICP=M-13, Analyte=B

Sample Type=SME, Prep=Mixed Acid, ICP=M-13, Analyte $=\mathbf{B} / \mathbf{L i}$ 
WSRC-STI-2006-00068

Revision 0

Exhibit A7. Analysis of Variance by Preparation Method, ICP, and Analyte (continued)

Sample Type=SME, Prep=Mixed Acid, ICP=M-13, Analyte=Ca Response Measurement

Summary of Fit

\begin{tabular}{|c|c|c|c|c|}
\hline \multicolumn{3}{|l|}{ RSquare } & \multicolumn{2}{|l|}{0.522824} \\
\hline \multicolumn{3}{|c|}{ RSquare Adj } & 0.430924 & \\
\hline \multicolumn{3}{|c|}{ Root Mean Square Error } & 0.033834 & \\
\hline \multicolumn{3}{|c|}{ Mean of Response } & 0.716852 & \\
\hline \multicolumn{3}{|c|}{ Observations (or Sum Wgts) } & 162 & \\
\hline \multicolumn{5}{|c|}{ Analysis of Variance } \\
\hline Source & $\mathrm{DF}$ & Sum of Squares & s Mean Square & F Ratio \\
\hline Model & 26 & 0.16932311 & $1 \quad 0.006512$ & 5.6890 \\
\hline Error & 135 & 0.15453933 & 0.001145 & Prob $>$ F \\
\hline C. Total & 161 & 0.32386244 & & $<.0001$ \\
\hline
\end{tabular}

Expected Mean Squares

The Mean Square per row by the Variance Component per column

$\begin{array}{lrr}\text { EMS } & \text { Intercept } & \text { Batch\&Random } \\ \text { Intercept } & 0 & 0\end{array}$

Batch\&Random

0

6

plus 1.0 times Residual Error Variance

Variance Component Estimates

Component Var Comp Est Percent of Total

$\begin{array}{rrr}\text { Component } & \text { Var Comp Est } & \text { Percent of Total } \\ \text { Batch\&Random } & 0.000895 & 43.868\end{array}$

$\begin{array}{lll}\text { Residual } & 0.001145 & 56.132\end{array}$

$\begin{array}{lrr}\text { Total } & 0.002039 & 56.132 \\ \text { The } & \end{array}$

These estimates based on equating Mean Squares to Expected Value.

Test Denominator Synthesis

Source MS Den DF Den Denom MS Synthesis

Batch\&Random $0.00114 \quad 135$ Residual

Tests wrt Random Effects
Source

$\begin{array}{lrrrrr}\text { Source } & \text { SS } & \text { MS Num } & \text { DF Num } & \text { F Ratio } & \text { Prob }>\text { F } \\ \text { Batch\&Random } & 0.16932 & 0.00651 & 26 & 5.6890 & <.0001\end{array}$

Sample Type=SME, Prep=Mixed Acid, ICP $=$ M-13, Analyte $=\mathrm{Cr}$ Response Measurement

Summary of Fit

RSquare $\quad 0.73292$

RSquare Adj $\quad 0.681174$

Root Mean Square Error $\quad 0.004451$

Mean of Response $\quad 0.054339$

Observations (or Sum Wgts) 192

Analysis of Variance

Source DF Sum of Squares Mean Square F Ratio

$\begin{array}{lrrrr}\text { Model } \quad 31 & 0.00870049 & 0.000281 & 14.1636\end{array}$

$\begin{array}{lllll}\text { Error } & 160 & 0.00317050 & 0.000020 & \text { Prob }>\text { F }\end{array}$

$\begin{array}{llll}\text { C. Total } 191 & 0.01187099 & <.0001\end{array}$

Expected Mean Squares

The Mean Square per row by the Variance Component per column

$\begin{array}{lrr}\text { EMS } & \text { Intercept } & \text { Batch\&Random } \\ \text { Intercept } & 0 & 0\end{array}$

$\begin{array}{lll}\text { Batch\&Random } & 0 & 0 \\ & 0 & 6\end{array}$

plus 1.0 times Residual Error Variance

Variance Component Estimates

Component Var Comp Est Percent of Total

$\begin{array}{lll}\text { Batch\&Random } & 0.000043 & 68.691\end{array}$

$\begin{array}{lrr}\text { Residual } & 0.00002 & 31.309\end{array}$

Total $\quad 0.000063 \quad 100.000$

These estimates based on equating Mean Squares to Expected Value.

Test Denominator Synthesis

Source MS Den DF Den Denom MS Synthesis

Batch\&Random $\quad 0.00002 \quad 160$ Residual

Tests wrt Random Effects

Source SS MS Num DF Num F Ratio Prob $>$ F

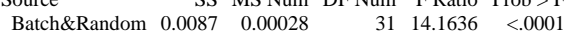

Sample Type=SME, Prep=Mixed Acid, ICP=M-13, Analyte $=\mathrm{Cu}$ Response Measurement Summary of Fit

RSquare

RSquare Adj

Root Mean Square Error

Mean of Response

Observations (or Sum Wgts)

0.901708

0.002403

Analysis of Variance

Source DF Sum of Squares Mean Square F Ratio

$\begin{array}{lllll}\text { Model } & 30 & 0.00997291 & 0.000332 & 57.5718\end{array}$

$\begin{array}{lllll}\text { Error } & 155 & 0.00089500 & 0.000006 & \text { Prob }>\text { F }\end{array}$

$\begin{array}{lll}\text { C. Total } 185 & 0.01086791 & <.0001\end{array}$

Expected Mean Squares

The Mean Square per row by the Variance Component per column

$\begin{array}{lrr}\text { EMS } & \text { Intercept } & \text { Batch\&Random } \\ \text { Intercept } & 0 & 0\end{array}$

Batch\&Random $\quad 0 \quad 6$

plus 1.0 times Residual Error Variance

Variance Component Estimates

$\begin{array}{crr}\text { Component } & \text { Var Comp Est } & \text { Percent of Total } \\ \text { Batch\&Random } & 0.000054 & 90.411 \\ \text { Residual } & 0.000006 & 9.589\end{array}$

$\begin{array}{lrr}\text { Batch\&Random } & 0.000054 & 90.411 \\ \text { Residual } & 0.000006 & 9.589 \\ \text { Total } & 0.00006 & 100.000\end{array}$

$\begin{array}{lcc}\text { Total } & 0.00006 & 100.000 \\ \text { These estimates based on equating Mean Squares to Expected Value. }\end{array}$

Test Denominator Synthesis

Source MS Den DF Den Denom MS Synthesis

Batch\&Random $\quad 5.77 \mathrm{e}-6 \quad 155$ Residual

Tests wrt Random Effects

Source SS MS Num DF Num F Ratio Prob $>$ F

Batch\&Random $0.00997 \quad 0.00033 \quad 30 \quad 57.5718<.0001$

Sample Type=SME, Prep=Mixed Acid, ICP=M-13, Analyte=Fe Response Measurement

Summary of Fit

$\begin{array}{ll}0.623674 \\ \text { RSquare Adj } & 0.551197\end{array}$

0.551197

$\quad 0.229852$

$\begin{array}{lr}\text { Mean of Response } & 7.782 \\ \text { Observations (or Sum Wgts) } & 162\end{array}$

Analysis of Variance

Source DF Sum of Squares Mean Square F Ratio

$\begin{array}{lrrrr}\text { Model } & 26 & 11.820243 & 0.454625 & 8.6051\end{array}$

$\begin{array}{lllll}\text { Error } & 135 & 7.132341 & 0.052832 & \text { Prob }>\text { F }\end{array}$

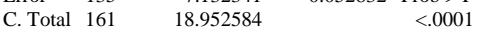

Expected Mean Squares

The Mean Square per row by the Variance Component per column

$\begin{array}{lrr}\text { EMS } & \text { Intercept } & \text { Batch\&Random } \\ \text { Intercept } & 0 & 0 \\ \text { Batch\&Random } & 0 & 6\end{array}$

plus 1.0 times Residual Error Variance

Variance Component Estimates
$\begin{array}{ll}\text { Component } & \text { Var Comp Est Percent of Total }\end{array}$

\begin{tabular}{crr} 
Component & Var Comp Est & Percent of Total \\
Batch\&Random & 0.066965 & 55.899 \\
Residual & 0.052832 & 44.101 \\
\hline
\end{tabular}

$\begin{array}{llr}\text { Residual } & 0.052832 & 44.101 \\ \text { Total } & 0.119798 & 100.000\end{array}$

These estimates based on equating Mean Squares to Expected Value.

Test Denominator Synthesis

Source MS Den DF Den Denom MS Synthesis

$\begin{array}{lrrr}\text { Source } & \text { MS Den } & \text { DF Den } & \text { Denom } \\ \text { Batch\&Random } & 0.05283 & 135 & \text { Residual }\end{array}$

Tests wrt Random Effects

Source SS MS Num DF Num F Ratio Prob $>$ F

Batch\&Random $11.8202 \quad 0.45462 \quad 26 \quad 8.6051<.0001$ 
WSRC-STI-2006-00068

Revision 0

Exhibit A7. Analysis of Variance by Preparation Method, ICP, and Analyte (continued)

Sample Type=SME, Prep=Mixed Acid, ICP=M-13, Analyte=Fe/Al Response Measurement

Summary of Fi

\begin{tabular}{|c|c|c|c|c|}
\hline \multicolumn{3}{|c|}{ RSquare } & \multicolumn{2}{|l|}{0.841267} \\
\hline \multicolumn{3}{|c|}{ RSquare Adj } & 0.810513 & \\
\hline \multicolumn{3}{|c|}{ Root Mean Square Error } & 0.044158 & \\
\hline \multicolumn{3}{|c|}{ Mean of Response } & 2.688102 & \\
\hline \multicolumn{3}{|c|}{ Observations (or Sum Wgts) } & 192 & \\
\hline \multicolumn{5}{|c|}{ Analysis of Variance } \\
\hline Source & $\mathrm{DF}$ & Sum of Squares & s Mean Square & F Ratio \\
\hline Model & 31 & 1.6535392 & $2 \quad 0.053340$ & 27.3543 \\
\hline Error & 160 & 0.3119946 & 0.001950 & Prob $>$ F \\
\hline C. Total & 191 & 1.9655338 & & $<.0001$ \\
\hline
\end{tabular}

Expected Mean Squares

The Mean Square per row by the Variance Component per column

$\begin{array}{lrr}\text { EMS } & \text { Intercept } & \text { Batch\&Random } \\ \text { Intercept } & 0 & 0\end{array}$

Batch\&Random $\quad 0 \quad 6$

plus 1.0 times Residual Error Variance

Variance Component Estimates

Component Var Comp Est Percent of Total

Batch\&Random $\quad 0.008565 \quad r 1.455$

$\begin{array}{lrr}\text { Residual } & 0.00195 & 18.545\end{array}$

Total $\quad 0.010515 \quad 100.000$

These estimates based on equating Mean Squares to Expected Value.

Test Denominator Synthesis

Source MS Den DF Den Denom MS Synthesis

Batch\&Random $0.00195 \quad 160$ Residual

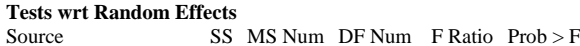

$\begin{array}{lrrrrr}\text { Source } & \text { SS } & \text { MS Num } & \text { DF Num } & \text { F Ratio } & \text { Prob }>\text { F } \\ \text { Batch\&Random } & 1.65354 & 0.05334 & 31 & 27.3543 & <.0001\end{array}$

Sample Type=SME, Prep=Mixed Acid, ICP=M-13, Analyte=Fe/Ca Response Measurement

Summary of Fit

RSquare $\quad 0.501832$

RSquare Adj $\quad 0.40552$

Root Mean Square Error $\quad 0.342975$

Mean of Response $\quad 10.85282$

Observations (or Sum Wgts) 180

Analysis of Variance

Source DF Sum of Squares Mean Square F Ratio

\begin{tabular}{lrrrr} 
Model & 29 & 17.774582 & 0.612917 & 5.2105 \\
\hline
\end{tabular}

$\begin{array}{lllll}\text { Error } & 150 & 17.644785 & 0.117632 & \text { Prob }>\text { F }\end{array}$

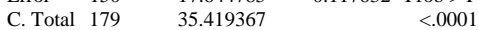

Expected Mean Squares

The Mean Square per row by the Variance Component per column

$\begin{array}{lrr}\text { EMS } & \text { Intercept } & \text { Batch\&Random } \\ \text { Intercept } & 0 & 0\end{array}$

$\begin{array}{lll}\text { Batch\&Random } & 0 & 0 \\ & 0 & 6\end{array}$

plus 1.0 times Residual Error Variance

Variance Component Estimates

Component Var Comp Est Percent of Total

Batch\&Random $\quad 0.082547 \quad 41.237$

Residual $\quad 0.117632 \quad 58.763$

Total $\quad 0.200179 \quad 100.000$

These estimates based on equating Mean Squares to Expected Value.

Test Denominator Synthesis

Source MS Den DF Den Denom MS Synthesis

$\begin{array}{llll}\text { Batch\&Random } & 0.11763 & 150 & \text { Residual }\end{array}$

Tests wrt Random Effects

Source

SS MS Num DF Num F Ratio Prob $>$ F

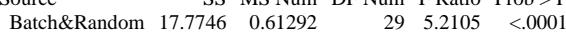

Sample Type=SME, Prep=Mixed Acid, ICP=M-13, Analyte=Fe/Li Response Measurement

Summary of Fit

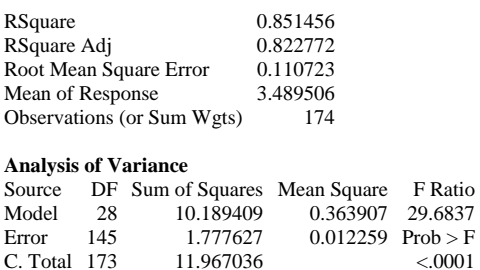

Expected Mean Squares

The Mean Square per row by the Variance Component per column

EMS Intercept Batch\&Random

$\begin{array}{lll}\text { Batch\&Random } & 0 & 0 \\ & 0 & 6\end{array}$

plus 1.0 times Residual Error Variance

Variance Component Estimates

$\begin{array}{crr}\text { Component } & \text { Var Comp Est } & \text { Percent of Total } \\ \text { Batch\&Random } & 0.058608 & 82.701 \\ \text { Residul } & 0.012259 & 17.299\end{array}$

$\begin{array}{lrr}\text { Batch\&Random } & 0.058608 & 82.701 \\ \text { Residual } & 0.012259 & 17.299 \\ \text { Total } & 0.070867 & 100.000\end{array}$

$\begin{array}{lcc}\text { Total } & 0.070867 & 100.000 \\ \text { These estimates based on equating Mean Squares to Expected Value. }\end{array}$

Test Denominator Synthesis

Source MS Den DF Den Denom MS Synthesis

Batch\&Random $0.01226 \quad 145$ Residual

Tests wrt Random Effects
$\begin{aligned} & \text { Source } \\ & \text { SS MS Num DF Num F Ratio Prob }>\text { F }\end{aligned}$

$\begin{array}{rrrrrr}\text { Batch\&Random } & 10.1894 & 0.36391 & 28 & 29.6837 & <.0001\end{array}$

Sample Type=SME, Prep=Mixed Acid, ICP=M-13, Analyte=Fe/Mg Response Measurement

Summary of Fit

0.639089

RSquare Adj $\quad 0.569313$

Root Mean Square Error $\quad 0.37268$

Mean of Response $\quad 11.44492$

Observations (or Sum Wgts) 180

Analysis of Variance

Source DF Sum of Squares Mean Square F Ratio

$\begin{array}{lrrrr}\text { Model } & 29 & 36.891226 & 1.27211 & 9.1591\end{array}$

$\begin{array}{lllll}\text { Error } & 150 & 20.833509 & 0.13889 \text { Prob }>\text { F }\end{array}$

$\begin{array}{llrl}\text { C. Total } 179 & 57.724735 & <.0001\end{array}$

Expected Mean Squares

The Mean Square per row by the Variance Component per column

$\begin{array}{lrr}\text { EMS } & \text { Intercept } & \text { Batch\&Random } \\ \text { Intercept } & 0 & 0 \\ \text { Batch\&Random } & 0 & 6\end{array}$

plus 1.0 times Residual Error Variance

Variance Component Estimates
Component $\quad$ Var Comp Est Percent of Total

$\begin{array}{crr}\text { Component } & \text { Var Comp Est } & \text { Percent of Total } \\ \text { Batch\&Random } & 0.18887 & 57.624\end{array}$

$\begin{array}{lll}\text { Batch\&Random } & 0.18887 & 57.624 \\ \text { Residual } & 0.13889 & 42.376\end{array}$

Total $\quad 0.32776 \quad 100.000$

These estimates based on equating Mean Squares to Expected Value.

Test Denominator Synthesis

Source MS Den DF Den Denom MS Synthesis

$\begin{array}{rrrr}\text { Source } & \text { MS Den } & \text { DF Den } & \text { Denomal } \\ \text { Batch\&Random } & 0.13889 & 150 & \text { Residual }\end{array}$

Tests wrt Random Effects

Source SS MS Num DF Num F Ratio Prob $>$ F

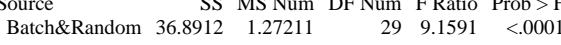


WSRC-STI-2006-00068

Revision 0

Exhibit A7. Analysis of Variance by Preparation Method, ICP, and Analyte (continued)

Sample Type=SME, Prep=Mixed Acid, ICP=M-13, Analyte=Fe/Mn Response Measurement

Summary of Fi

\begin{tabular}{|c|c|c|c|c|}
\hline \multicolumn{3}{|c|}{ RSquare } & \multicolumn{2}{|l|}{0.663526} \\
\hline \multicolumn{3}{|c|}{ RSquare Adj } & 0.598402 & \\
\hline \multicolumn{3}{|c|}{ Root Mean Square Error } & 0.11326 & \\
\hline \multicolumn{3}{|c|}{ Mean of Response } & 5.046693 & \\
\hline \multicolumn{3}{|c|}{ Observations (or Sum Wgts) } & 186 & \\
\hline \multicolumn{5}{|c|}{ Analysis of Variance } \\
\hline Source & $\mathrm{DF}$ & Sum of Squares & s Mean Square & F Ratio \\
\hline Model & 30 & 3.9209420 & ) $\quad 0.130698$ & 10.1886 \\
\hline Error & 155 & 1.9883107 & 0.012828 & Prob $>$ F \\
\hline C. Total & 185 & 5.9092527 & & $<.0001$ \\
\hline
\end{tabular}

Expected Mean Squares

The Mean Square per row by the Variance Component per column

$\begin{array}{lrr}\text { EMS } & \text { Intercept } & \text { Batch\&Random } \\ \text { Intercept } & 0 & 0\end{array}$

Batch\&Random

0

0

plus 1.0 times Residual Error Variance

Variance Component Estimates

Component Var Comp Est Percent of Total

$\begin{array}{rrr}\text { Component } & \text { Var Comp Est } & \text { Percent of Total } \\ \text { Batch\&Random } & 0.019645 & 60.497\end{array}$

$\begin{array}{lll}\text { Residual } & 0.012828 & 39.503\end{array}$

Total $\quad 0.032473 \quad 100.000$

These estimates based on equating Mean Squares to Expected Value.

Test Denominator Synthesis

Source MS Den DF Den Denom MS Synthesis

Batch\&Random $0.01283 \quad 155$ Residual

Tests wrt Random Effects
$\begin{array}{llll}\text { Source } & \text { SS MS Num DF Num F Ratio Prob }>\text { F }\end{array}$

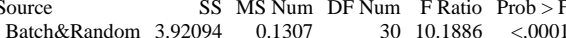

Sample Type=SME, Prep=Mixed Acid, ICP=M-13, Analyte=Fe/Ni Response Measurement

Summary of Fit

RSquare $\quad 0.626761$

RSquare Adj $\quad 0.554601$

Root Mean Square Error $\quad 0.351964$

Mean of Response $\quad 17.14521$

Observations (or Sum Wgts) 180

Analysis of Variance

Source DF Sum of Squares Mean Square F Ratio

$\begin{array}{lrrrr}\text { Model } & 29 & 31.203507 & 1.07598 & 8.6858\end{array}$

$\begin{array}{lllll}\text { Error } & 150 & 18.581837 & 0.12388 \text { Prob }>\text { F }\end{array}$

$\begin{array}{llrl}\text { C. Total } 179 & 49.785344 & <.0001\end{array}$

Expected Mean Squares

The Mean Square per row by the Variance Component per column

$\begin{array}{lrr}\text { EMS } & \text { Intercept } & \text { Batch\&Random } \\ \text { Intercept } & 0 & 0\end{array}$

$\begin{array}{lll}\text { Batch\&Random } & 0 & 0 \\ & 0 & 6\end{array}$

plus 1.0 times Residual Error Variance

Variance Component Estimates

Component Var Comp Est Percent of Total

Batch\&Random $\quad 0.158684 \quad 56.159$

$\begin{array}{lll}\text { Residual } & 0.123879 & 43.84\end{array}$

Total $\quad 0.282563 \quad 100.000$

These estimates based on equating Mean Squares to Expected Value.

Test Denominator Synthesis

Source MS Den DF Den Denom MS Synthesis

Batch\&Random $0.12388 \quad 150$ Residual

Tests wrt Random Effects

Source

SS MS Num DF Num F Ratio Prob $>$ F

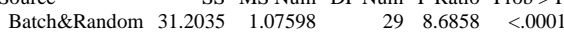

Sample Type=SME, Prep=Mixed Acid, ICP=M-13, Analyte=Fe $/ \mathrm{U}$ Response Measurement

Summary of Fit

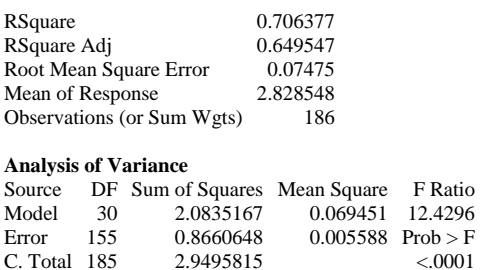

Expected Mean Squares

The Mean Square per row by the Variance Component per column

$\begin{array}{lrr}\text { EMS } & \text { Intercept } & \text { Batch\&Random } \\ \text { Intercept } & 0 & 0\end{array}$

Batch\&Random $\quad 0 \quad 6$

plus 1.0 times Residual Error Variance

Variance Component Estimates

$\begin{array}{rrr}\text { Component } & \text { Var Comp Est } & \text { Percent of Total } \\ \text { Batch\&Random } & 0.010644 & 65.576\end{array}$

$\begin{array}{ccc}\text { Batch\&Random } & 0.010644 & 65.576 \\ \text { Residual } & 0.005588 & 34.424\end{array}$

$\begin{array}{lrr}\text { Residual } & 0.005588 & 34.424 \\ \text { Total } & 0.016231 & 100.000\end{array}$

These estimates based on equating Mean Squares to Expected Value.

Test Denominator Synthesis

Source MS Den DF Den Denom MS Synthesis

Batch\&Random $0.00559 \quad 155$ Residual

Tests wrt Random Effects
Source

$\begin{array}{lrrrrr}\text { Source } & \text { SS } & \text { MS Num } & \text { DF Num } & \text { F Ratio } & \text { Prob > F } \\ \text { Batch\&Random } & 2.08352 & 0.06945 & 30 & 12.4296 & <.0001\end{array}$

Sample Type=SME, Prep=Mixed Acid, ICP $=M-13$, Analyte $=K$

Response Measurement

Summary of Fit

RSquare Adj $\quad 0.585187$

\begin{tabular}{ll}
0.505297 \\
\hline
\end{tabular}

Root Mean Squar $\quad 0.24211$

$\begin{array}{lr}\text { Mean of Response } & -0.06115 \\ \text { Observations (or Sum Wgts) } & 162\end{array}$

Analysis of Variance

Source DF Sum of Squares Mean Square F Ratio

$\begin{array}{lrrrr}\text { Model } & 26 & 11.163576 & 0.429368 & 7.3249\end{array}$

$\begin{array}{lllll}\text { Error } & 135 & 7.913372 & 0.058618 & \text { Prob }>\text { F }\end{array}$

$\begin{array}{llll}\text { C. Total } & 161 & 19.076947 & <.0001\end{array}$

Expected Mean Squares

The Mean Square per row by the Variance Component per column

$\begin{array}{lrr}\text { EMS } & \text { Intercept } & \text { Batch\&Random } \\ \text { Intercept } & 0 & 0 \\ \text { Batch\&Random } & 0 & 6\end{array}$

plus 1.0 times Residual Error Variance

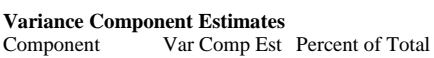

\begin{tabular}{crr} 
Component & Var Comp Est & Percent of Total \\
Batch\&Random & 0.061792 & 51.318 \\
Residual & 0.058618 & 48.682 \\
\hline
\end{tabular}

$\begin{array}{llr}\text { Residual } & 0.058618 & 48.682 \\ \text { Total } & 0.120409 & 100.000\end{array}$

These estimates based on equating Mean Squares to Expected Value.

Test Denominator Synthesis

Source MS Den DF Den Denom MS Synthesis

$\begin{array}{lrrr}\text { Source } & \text { MS Den } & \text { DF Den } & \text { Denom } \\ \text { Batch\&Random } & 0.05862 & 135 & \text { Residual }\end{array}$

Tests wrt Random Effects

Source SS MS Num DF Num F Ratio Prob $>$ F

$\begin{array}{rrrrrr}\text { Batch\&Random } & 11.1636 & 0.42937 & 26 & 7.3249 & <.0001\end{array}$ 
WSRC-STI-2006-00068

Revision 0

Exhibit A7. Analysis of Variance by Preparation Method, ICP, and Analyte (continued)

Sample Type=SME, Prep=Mixed Acid, ICP=M-13, Analyte $=$ L Response Measurement

Summary of Fit

\begin{tabular}{|c|c|c|c|c|}
\hline \multicolumn{3}{|c|}{ RSquare } & \multicolumn{2}{|l|}{0.790096} \\
\hline \multicolumn{3}{|c|}{ RSquare Adj } & 0.74973 & \\
\hline \multicolumn{3}{|c|}{ Root Mean Square Error } & 0.054608 & \\
\hline \multicolumn{3}{|c|}{ Mean of Response } & 2.213846 & \\
\hline \multicolumn{3}{|c|}{ Observations (or Sum Wgts) } & 156 & \\
\hline \multicolumn{5}{|c|}{ Analysis of Variance } \\
\hline Source & $\mathrm{DF}$ & Sum of Squares & s Mean Square & F Ratio \\
\hline Model & 25 & 1.4592030 & 0.058368 & 19.5732 \\
\hline Error & 130 & 0.3876653 & 0.002982 & Prob $>F$ \\
\hline C. Total & 155 & 1.8468683 & & $<.0001$ \\
\hline
\end{tabular}

Expected Mean Squares

The Mean Square per row by the Variance Component per column

$\begin{array}{lrr}\text { EMS } & \text { Intercept } & \text { Batch\&Random } \\ \text { Intercept } & 0 & 0\end{array}$

Batch\&Random

0

0

plus 1.0 times Residual Error Variance

Variance Component Estimates

Component Var Comp Est Percent of Total

Batch\&Random $\quad 0.009231 \quad 75.583$

$\begin{array}{lll}\text { Residual } & 0.002982 & 24.417\end{array}$

Total $\quad 0.012213 \quad 100.000$

These estimates based on equating Mean Squares to Expected Value.

Test Denominator Synthesis

Source MS Den DF Den Denom MS Synthesis

Batch\&Random $0.00298 \quad 130$ Residual

Tests wrt Random Effects

$\begin{array}{lrrrrr}\text { Source } & \text { SS } & \text { MS Num } & \text { DF Num } & \text { F Ratio } & \text { Prob }>\text { F } \\ \text { Batch\&Random } & 1.4592 & 0.05837 & 25 & 19.5732 & <.0001\end{array}$

Sample Type=SME, Prep=Mixed Acid, ICP $=M-13$, Analyte $=M g$ Response Measurement

Summary of Fit

RSquare $\quad 0.664547$

RSquare Adj $\quad 0.59977$

Root Mean Square Error $\quad 0.03281$

Mean of Response $\quad 0.674586$

Observations (or Sum Wgts) 174

Analysis of Variance

Source DF Sum of Squares Mean Square F Ratio

$\begin{array}{lrrrr}\text { Model } \quad 28 & 0.30921654 & 0.011043 & 10.2590\end{array}$

$\begin{array}{lllll}\text { Error } & 145 & 0.15608767 & 0.001076 & \text { Prob }>\text { F }\end{array}$

$\begin{array}{llll}\text { C. Total } 173 & 0.46530421 & <.0001\end{array}$

Expected Mean Squares

The Mean Square per row by the Variance Component per column

$\begin{array}{lrr}\text { EMS } & \text { Intercept } & \text { Batch\&Random } \\ \text { Intercept } & 0 & 0\end{array}$

$\begin{array}{lll}\text { Batch\&Random } & 0 & 0 \\ \end{array}$

plus 1.0 times Residual Error Variance

Variance Component Estimates

Component Var Comp Est Percent of Total

$\begin{array}{lll}\text { Batch\&Random } \quad 0.001661 & 60.679\end{array}$

$\begin{array}{lll}\text { Residual } & 0.001076 & 39.32\end{array}$

Total $\quad 0.002738 \quad 100.000$

These estimates based on equating Mean Squares to Expected Value.

Test Denominator Synthesis

Source MS Den DF Den Denom MS Synthesis

Batch\&Random $\quad 0.00108 \quad 145$ Residual

Tests wrt Random Effects

Source

SS MS Num DF Num F Ratio Prob > F

$\begin{array}{lrrrrr}\text { Batch\&Random } & 0.30922 & 0.01104 & 28 & 10.2590 & <.0001\end{array}$
Sample Type=SME, Prep=Mixed Acid, ICP=M-13, Analyte=Mn Response Measurement

Summary of Fit

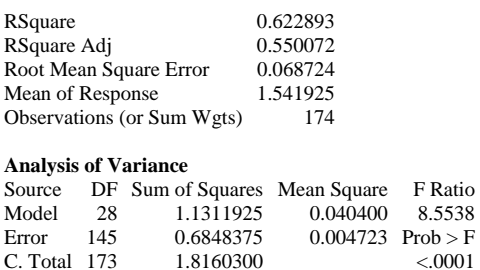

Expected Mean Squares

The Mean Square per row by the Variance Component per column

$\begin{array}{lrr}\text { EMS } & \text { Intercept } & \text { Batch\&Random } \\ \text { Intercept } & 0 & 0\end{array}$

$\begin{array}{lll}\text { Intercept } & 0 & 0 \\ \text { Batch\&Random } & 0 & 6\end{array}$

plus 1.0 times Residual Error Variance

Variance Component Estimates

Component Var Comp Est Percent of Total

$\begin{array}{rrr}\text { Component } & \text { Var Comp Est } & \text { Percent of Total } \\ \text { Batch\&Random } & 0.005946 & 55.732\end{array}$

$\begin{array}{lll}\text { Batch\&Random } & 0.005946 & 55.732 \\ \text { Residual } & 0.004723 & 44.268\end{array}$

Total $\quad 0.010669 \quad 100.000$

These estimates based on equating Mean Squares to Expected Value.

Test Denominator Synthesis

Source MS Den DF Den Denom MS Synthesis

Batch\&Random $0.00472 \quad 145$ Residual

Tests wrt Random Effects
Source

$\begin{array}{lrrrrr}\text { Source } & \text { SS } & \text { MS Num } & \text { DF Num } & \text { F Ratio } & \text { Prob }>\text { F } \\ \text { Batch\&Random } & 1.13119 & 0.0404 & 28 & 8.5538 & <.0001\end{array}$

Sample Type=SME, Prep=Mixed Acid, ICP $=M-13$, Analyte $=M n / M g$ Response Measurement

Summary of Fit

$\begin{array}{ll}0.512158 \\ \text { RSquare Adj } & 0.417737\end{array}$

Root Mean Square Error $\quad 0.417737$

0.043209

$\begin{array}{lr}\text { Mean of Response } & 2.268349 \\ \text { Observations (or Sum Wgts) } & 186\end{array}$

Analysis of Variance

Source DF Sum of Squares Mean Square F Ratio

$\begin{array}{lrrrr}\text { Model } & 30 & 0.30381537 & 0.010127 & 5.4242\end{array}$

$\begin{array}{lllll}\text { Error } & 155 & 0.28939074 & 0.001867 & \text { Prob }>\text { F }\end{array}$

$\begin{array}{llll}\text { C. Total } 185 & 0.59320611 & <.0001\end{array}$

Expected Mean Squares

The Mean Square per row by the Variance Component per column

$\begin{array}{lrr}\text { EMS } & \text { Intercept } & \text { Batch\&Random } \\ \text { Intercept } & 0 & 0 \\ \text { Batch\&Random } & 0 & 6\end{array}$

plus 1.0 times Residual Error Variance

Variance Component Estimates

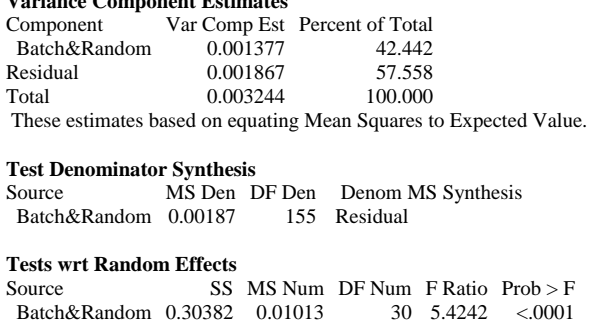


WSRC-STI-2006-00068

Revision 0

Exhibit A7. Analysis of Variance by Preparation Method, ICP, and Analyte (continued)

Sample Type=SME, Prep=Mixed Acid, ICP=M-13, Analyte=Na Response Measurement

Summary of Fit

\begin{tabular}{|c|c|c|c|c|}
\hline \multicolumn{3}{|c|}{ RSquare } & \multicolumn{2}{|l|}{0.542482} \\
\hline \multicolumn{3}{|c|}{ RSquare Adj } & 0.454367 & \\
\hline \multicolumn{3}{|c|}{ Root Mean Square Error } & 0.292731 & \\
\hline \multicolumn{3}{|c|}{ Mean of Response } & 8.807543 & \\
\hline \multicolumn{3}{|c|}{ Observations (or Sum Wgts) } & 162 & \\
\hline \multicolumn{5}{|c|}{ Analysis of Variance } \\
\hline Source & $\mathrm{DF}$ & Sum of Squares & s Mean Square & F Ratio \\
\hline Model & 26 & 13.716642 & $2 \quad 0.527563$ & 6.1566 \\
\hline Error & 135 & 11.568329 & 0.085691 & Prob $>$ F \\
\hline C. Tota & 161 & 25.284970 & & $<.0001$ \\
\hline
\end{tabular}

Expected Mean Squares

The Mean Square per row by the Variance Component per column

$\begin{array}{lrr}\text { EMS } & \text { Intercept } & \text { Batch\&Random } \\ \text { Intercept } & 0 & 0\end{array}$

Batch\&Random

0

0

plus 1.0 times Residual Error Variance

Variance Component Estimates

Component Var Comp Est Percent of Total

$\begin{array}{rrr}\text { Component } & \text { Var Comp Est } & \text { Percent of Tota } \\ \text { Batch\&Random } & 0.073645 & 46.220\end{array}$

$\begin{array}{lll}\text { Residual } & 0.085691 & 53.780\end{array}$

Total $\quad 0.159337 \quad 100.000$

These estimates based on equating Mean Squares to Expected Value.

Test Denominator Synthesis

Source MS Den DF Den Denom MS Synthesis

Batch\&Random $0.08569 \quad 135$ Residual

Tests wrt Random Effects
Source

$\begin{array}{lrrrrr}\text { Source } & \text { SS } & \text { MS Num } & \text { DF Num } & \text { F Ratio } & \text { Prob }>\text { F } \\ \text { Batch\&Random } & 13.7166 & 0.52756 & 26 & 6.1566 & <.0001\end{array}$

Sample Type=SME, Prep=Mixed Acid, ICP=M-13, Analyte=Ni Response Measurement

Summary of Fit

RSquare $\quad 0.588661$

RSquare Adj $\quad 0.509332$

Root Mean Square Error $\quad 0.018487$

Mean of Response $\quad 0.450274$

Observations (or Sum Wgts) 168

Analysis of Variance

Source DF Sum of Squares Mean Square F Ratio

$\begin{array}{lrrrr}\text { Model } \quad 27 & 0.06847274 & 0.002536 & 7.4205\end{array}$

$\begin{array}{lllll}\text { Error } & 140 & 0.04784667 & 0.000342 & \text { Prob }>\text { F }\end{array}$

$\begin{array}{llll}\text { C. Total } 167 & 0.11631940 & <.0001\end{array}$

Expected Mean Squares

The Mean Square per row by the Variance Component per column

$\begin{array}{lrr}\text { EMS } & \text { Intercept } & \text { Batch\&Random } \\ \text { Intercept } & 0 & 0\end{array}$

Batch\&Random $\quad 0 \quad 6$

plus 1.0 times Residual Error Variance

Variance Component Estimates

Component Var Comp Est Percent of Total

Batch\&Random $\quad 0.000366 \quad 51.693$

$\begin{array}{lll}\text { Residual } & 0.000342 & 48.307\end{array}$

Total $\quad 0.000707 \quad 100.000$

These estimates based on equating Mean Squares to Expected Value.

Test Denominator Synthesis

Source MS Den DF Den Denom MS Synthesis

Batch\&Random $0.00034 \quad 140$ Residual

Tests wrt Random Effects

Source

SS MS Num DF Num F Ratio Prob $>$ F

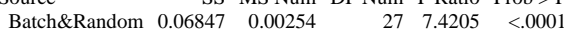

Sample Type=SME, Prep=Mixed Acid, ICP=M-13, Analyte=Si Response Measurement

Summary of Fit

\begin{tabular}{|c|c|c|c|c|}
\hline \multicolumn{3}{|c|}{ RSquare } & \multicolumn{2}{|l|}{0.503514} \\
\hline \multicolumn{3}{|c|}{ RSquare Adj } & 0.40764 & \\
\hline \multicolumn{3}{|c|}{ Root Mean Square Error } & 0.714654 & \\
\hline \multicolumn{3}{|c|}{ Mean of Response } & 22.46066 & \\
\hline \multicolumn{3}{|c|}{ Observations (or Sum Wgts) } & 174 & \\
\hline \multicolumn{5}{|c|}{ Analysis of Variance } \\
\hline Source & DF & Sum of Squares & s Mean Square & F Ratio \\
\hline Model & 28 & 75.10400 & $\begin{array}{l}\text { J } \\
\end{array}$ & 5.2519 \\
\hline Error & 145 & 74.05580 & 0.51073 & Prob $>$ F \\
\hline C. Total & 173 & 149.15980 & & $<.0001$ \\
\hline
\end{tabular}

Expected Mean Squares

The Mean Square per row by the Variance Component per column

$\begin{array}{lrr}\text { EMS } & \text { Intercept } & \text { Batch\&Random } \\ \text { Intercept } & 0 & 0\end{array}$

Batch\&Random $\quad 0 \quad 6$

plus 1.0 times Residual Error Variance

Variance Component Estimates

$\begin{array}{rrr}\text { Component } & \text { Var Comp Est } & \text { Percent of Total } \\ \text { Batch\&Random } & 0.361926 & 41.474\end{array}$

$\begin{array}{crr}\text { Batch\&Random } & 0.361926 & 41.474 \\ \text { Residual } & 0.51073 & 58.526\end{array}$

$\begin{array}{lrr}\text { Residual } & 0.51073 & 58.526 \\ \text { Total } & 0.872656 & 100.000\end{array}$

These estimates based on equating Mean Squares to Expected Value.

Test Denominator Synthesis

Source MS Den DF Den Denom MS Synthesis

Batch\&Random $0.51073 \quad 145$ Residual

Tests wrt Random Effects

Source SS MS Num DF Num F Ratio Prob $>$ F

$\begin{array}{llllll}\text { Batch\&Random } & 75.104 & 2.68229 & 28 & 5.2519 & <.0001\end{array}$

Sample Type=SME, Prep=Mixed Acid, ICP=M-13, Analyte=Sum of Oxides Response Measurement

Summary of Fit

0.378618

Root Mear Square Error $\quad 0.258485$

2.213148

$\begin{array}{lr}\text { Mean of Response } & 89.09756 \\ \text { Observations (or Sum Wgts) } & 180\end{array}$

Analysis of Variance

Source DF Sum of Squares Mean Square F Ratio

$\begin{array}{lrrrr}\text { Model } & 29 & 447.6676 & 15.4368 & 3.1516\end{array}$

$\begin{array}{lllll}\text { Error } & 150 & 734.7036 & 4.8980 & \text { Prob }>\text { F }\end{array}$

$\begin{array}{lrr}\text { C. Total } 179 & 1182.3712 & <.0001\end{array}$

Expected Mean Squares

The Mean Square per row by the Variance Component per column

$\begin{array}{lrr}\text { EMS } & \text { Intercept } & \text { Batch\&Random } \\ \text { Intercept } & 0 & 0 \\ \text { Batch\&Random } & 0 & 6\end{array}$

plus 1.0 times Residual Error Variance

Variance Component Estimates
Component Var Comp Est Percent of Total

$\begin{array}{crr}\text { Component } & \text { Var Comp Est } & \text { Percent of Total } \\ \text { Batch\&Random } & 1.756465 & 26.395 \\ \text { Residual } & 4.898024 & 73.605 \\ \text { Told } & 6.654489 & 100.000\end{array}$

$\begin{array}{lrr}\text { Residual } & 4.898024 & 73.605 \\ \text { Total } & 6.654489 & 100.000\end{array}$

These estimates based on equating Mean Squares to Expected Value.

Test Denominator Synthesis

Source MS Den DF Den Denom MS Synthesis

$\begin{array}{rrrr}\text { Source } & \text { MS Den } & \text { DF Den } & \text { Denomal } \\ \text { Batch\&Random } & 4.89802 & 150 & \text { Residual }\end{array}$

Tests wrt Random Effects

Source SS MS Num DF Num F Ratio Prob $>$ F

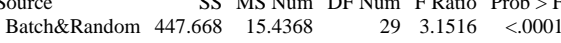


WSRC-STI-2006-00068

Revision 0

Exhibit A7. Analysis of Variance by Preparation Method, ICP, and Analyte (continued)

Sample Type=SME, Prep=Mixed Acid, ICP=M-13, Analyte=Ti Response Measurement

Summary of Fit

\begin{tabular}{|c|c|c|c|c|}
\hline \multicolumn{3}{|c|}{ RSquare } & 0.841983 & \\
\hline \multicolumn{3}{|c|}{ RSquare Adj } & 0.811399 & \\
\hline \multicolumn{3}{|c|}{ Root Mean Square Error } & 0.003315 & \\
\hline \multicolumn{3}{|c|}{ Mean of Response } & 0.031952 & \\
\hline \multicolumn{3}{|c|}{ Observations (or Sum Wgts) } & 186 & \\
\hline \multicolumn{5}{|c|}{ Analysis of Variance } \\
\hline Source & $\mathrm{DF}$ & Sum of Squares & s Mean Square & F Ratio \\
\hline Model & 30 & 0.00907873 & 30.000303 & 27.5301 \\
\hline Error & 155 & 0.00170383 & 0.000011 & Prob $>\mathrm{F}$ \\
\hline C. Total & 185 & 0.01078256 & & $<.0001$ \\
\hline
\end{tabular}

Expected Mean Squares

The Mean Square per row by the Variance Component per column

$\begin{array}{lrr}\text { EMS } & \text { Intercept } & \text { Batch\&Random } \\ \text { Intercept } & 0 & 0\end{array}$

Batch\&Random

0

0

plus 1.0 times Residual Error Variance

Variance Component Estimates

Component Var Comp Est Percent of Total

Batch\&Random $\quad 0.000049 \quad 81.556$

$\begin{array}{lll}\text { Residual } & 0.000011 & 18.444\end{array}$

Total $\quad 0.00006 \quad 100.000$

These estimates based on equating Mean Squares to Expected Value.

Test Denominator Synthesis

Source MS Den DF Den Denom MS Synthesis

Batch\&Random $0.00001 \quad 155$ Residual

Tests wrt Random Effects
Source SS MS Num DF Num F Ratio Prob $>$ F

$\begin{array}{lrrrrr}\text { Source } & \text { SS } & \text { MS Num } & \text { DF Num } & \text { F Ratio } & \text { Prob }>\text { F } \\ \text { Batch\&Random } & 0.00908 & 0.0003 & 30 & 27.5301 & <0001\end{array}$

Sample Type=SME, Prep=Mixed Acid, ICP=M-13, Analyte=U

Response Measurement

Summary of Fit

RSquare $\quad 0.673481$

RSquare Adj $\quad 0.610429$

Root Mean Square Error $\quad 0.123854$

Mean of Response 2.754569

Observations (or Sum Wgts) 174

Analysis of Variance

Source DF Sum of Squares Mean Square F Ratio

$\begin{array}{lrrrr}\text { Model } \quad 28 & 4.5878402 & 0.163851 & 10.6814\end{array}$

$\begin{array}{lllll}\text { Error } & 145 & 2.2242885 & 0.015340 \quad \text { Prob }>\text { F }\end{array}$

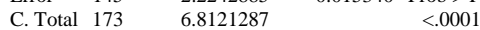

Expected Mean Squares

The Mean Square per row by the Variance Component per column

$\begin{array}{lrr}\text { EMS } & \text { Intercept } & \text { Batch\&Random } \\ \text { Intercept } & 0 & 0\end{array}$

Batch\&Random $\quad 0 \quad 6$

plus 1.0 times Residual Error Variance

Variance Component Estimates

Component Var Comp Est Percent of Total

$\begin{array}{lll}\text { Batch\&Random } \quad 0.024752 & 61.738\end{array}$

$\begin{array}{lll}\text { Residual } & 0.01534 & 38.262\end{array}$

Total $\quad 0.040092 \quad 100.000$

These estimates based on equating Mean Squares to Expected Value.

Test Denominator Synthesis

Source MS Den DF Den Denom MS Synthesis

Batch\&Random $0.01534 \quad 145$ Residual

Tests wrt Random Effects

Source

SS MS Num DF Num F Ratio Prob $>$ F

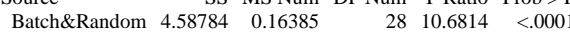

Sample Type=SME, Prep=Mixed Acid, ICP=M-13, Analyte=U/Ca Response Measurement

Summary of Fit

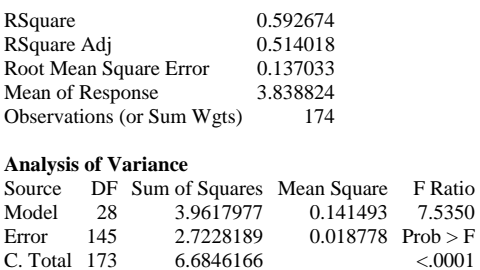

Expected Mean Squares

The Mean Square per row by the Variance Component per column

$\begin{array}{lrr}\text { EMS } & \text { Intercept } & \text { Batch\&Random } \\ \text { Intercept } & 0 & 0\end{array}$

Batch\&Random $\quad 0 \quad 6$

plus 1.0 times Residual Error Variance

Variance Component Estimates

$\begin{array}{crr}\text { Component } & \text { Var Comp Est } & \text { Percent of Total } \\ \text { Batch\&Random } & 0.020452 & 52.134\end{array}$

$\begin{array}{ccc}\text { Batch\&Random } & 0.020452 & 52.134 \\ \text { Residual } & 0.018778 & 47.866\end{array}$

$\begin{array}{lrr}\text { Residual } & 0.018778 & 47.866 \\ \text { Total } & 0.039231 & 100.000\end{array}$

These estimates based on equating Mean Squares to Expected Value.

Test Denominator Synthesis

Source MS Den DF Den Denom MS Synthesis

Batch\&Random $0.01878 \quad 145$ Residual

Tests wrt Random Effects

Source SS MS Num DF Num F Ratio Prob $>$ F

$\begin{array}{rrrrrr}\text { Batch\&Random } & 3.9618 & 0.14149 & 28 & 7.5350 & <.0001\end{array}$

Sample Type=SME, Prep=Mixed Acid, ICP=M-13, Analyte=Zr Response Measurement

Summary of Fit

0.917943
0.902077

0.902078
Ret

r $\quad 0.003277$

$\begin{array}{lr}\text { Mean of Response } & 0.049783 \\ \text { Observations (or Sum Wgts) } & 180\end{array}$

Analysis of Variance

Source DF Sum of Squares Mean Square F Ratio

$\begin{array}{lllll}\text { Model } & 29 & 0.01801605 & 0.000621 & 57.8618\end{array}$

$\begin{array}{lllll}\text { Error } & 150 & 0.00161050 & 0.000011 \quad \text { Prob }>\text { F }\end{array}$

$\begin{array}{llll}\text { C. Total } & 179 & 0.01962655 & <.0001\end{array}$

Expected Mean Squares

The Mean Square per row by the Variance Component per column

$\begin{array}{lrr}\text { EMS } & \text { Intercept } & \text { Batch\&Random } \\ \text { Intercept } & 0 & 0 \\ \text { Batch\&Random } & 0 & 6\end{array}$

plus 1.0 times Residual Error Variance

Variance Component Estimates

\begin{tabular}{|c|c|c|c|c|c|}
\hline \\
\hline Component & Var Com & p Est Perc & cent of Total & & \\
\hline Batch\&Random & 0.00 & 0102 & 90.455 & & \\
\hline Residual & 0.00 & 0011 & 9.545 & & \\
\hline Total & 0.00 & 0112 & 100.000 & & \\
\hline These estimates ba & ased on eq & quating $\mathrm{Me}$ & an Squares t & to Expecte & ed Value. \\
\hline Test Denominator & r Synthesi & & & & \\
\hline Source & MS Den & DF Den & Denom MS & S Synthesi & \\
\hline Batch\&Random & 0.00001 & 150 & Residual & & \\
\hline Tests & Effects & & & & \\
\hline Source & SS & MS Num & DF Num & F Ratio & Prob $>$ F \\
\hline Batch\&Random & 0.01802 & 0.00062 & 295 & 57.8618 & $<.0001$ \\
\hline
\end{tabular}


WSRC-STI-2006-00068

Revision 0

Exhibit A7. Analysis of Variance by Preparation Method, ICP, and Analyte (continued)

Sample Type=SME, Prep=Mixed Acid, ICP=M-14, Analyte=Al Response Measurement

Summary of Fi

\begin{tabular}{lrrrr} 
RSquare & 0.836762 & \\
RSquare Adj & 0.805747 & \\
Root Mean Square Error & 0.088055 & \\
Mean of Response & 3.050817 & \\
Observations (or Sum Wgts) & 120 & \\
\multicolumn{7}{l}{} \\
\multicolumn{7}{l}{$\begin{array}{l}\text { Analysis of Variance } \\
\text { Source }\end{array}$} & & & \\
Model & 19 & Sum of Squares & Mean Square & F Ratio \\
Error & 100 & 0.9745353 & 0.209186 & 26.9791 \\
C. Total & 119 & 4.743627 & 0.007754 & Prob > F \\
& & & & $<.0001$
\end{tabular}

Expected Mean Squares

The Mean Square per row by the Variance Component per column

$\begin{array}{lrr}\text { EMS } & \text { Intercept } & \text { Batch\&Random } \\ \text { Intercept } & 0 & 0\end{array}$

Batch\&Random

0

0

plus 1.0 times Residual Error Variance

Variance Component Estimates

Component Var Comp Est Percent of Total

$\begin{array}{rrr}\text { Batch\&Random } & 0.033572 & 81.238\end{array}$

Residual $\quad 0.007754 \quad 18.762$

Total $\quad 0.041326 \quad 100.000$

These estimates based on equating Mean Squares to Expected Value.

Test Denominator Synthesis

Source MS Den DF Den Denom MS Synthesis

Batch\&Random $0.00775 \quad 100$ Residual

Tests wrt Random Effects
Source SS MS Num DF Num F Ratio Prob $>$ F

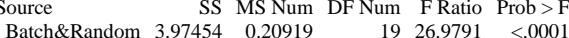

Sample Type=SME, Prep=Mixed Acid, ICP=M-14, Analyte=Al/Ca Response Measurement

Summary of Fit

RSquare $\quad 0.638343$

RSquare Adj $\quad 0.569818$

Root Mean Square Error $\quad 0.083889$

Mean of Response 4.041221

Observations (or Sum Wgts) 114

Analysis of Variance

Source DF Sum of Squares Mean Square F Ratio

\begin{tabular}{lllll} 
Model & 18 & 1.1800276 & 0.065557 & 9.3155 \\
\hline & 95 & 0.6685528 & 0.007037 &
\end{tabular}

$\begin{array}{llllll}\text { Error } & 95 & 0.6685528 & 0.007037 & \text { Prob }>\text { F }\end{array}$

$\begin{array}{llll}\text { C. Total } & 113 & 1.8485804 & <.0001\end{array}$

Expected Mean Square

The Mean Square per row by the Variance Component per column

$\begin{array}{lrr}\text { EMS } & \text { Intercept } & \text { Batch\&Random } \\ \text { Intercept } & 0 & 0\end{array}$

$\begin{array}{lll}\text { Batch\&Random } & 0 & 0 \\ \end{array}$

plus 1.0 times Residual Error Variance

Variance Component Estimates

Component Var Comp Est Percent of Total

Batch\&Random $\quad 0.009753 \quad 58.087$

$\begin{array}{lll}\text { Residual } & 0.007037 & 41.913\end{array}$

Total $\quad 0.016791 \quad 100.000$

These estimates based on equating Mean Squares to Expected Value.

Test Denominator Synthesis

Source MS Den DF Den Denom MS Synthesis

Batch\&Random $\quad 0.00704 \quad 95$ Residual

Tests wrt Random Effects

Source

SS MS Num DF Num F Ratio Prob $>$ F

$\begin{array}{rrrrrr}\text { Batch\&Random } & 1.18003 & 0.06556 & 18 & 9.3155 & <.0001\end{array}$
Sample Type=SME, Prep=Mixed Acid, ICP=M-14, Analyte=AI/Mg Response Measurement

Summary of Fit

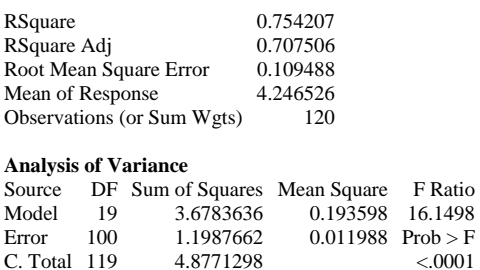

Expected Mean Squares

The Mean Square per row by the Variance Component per column

$\begin{array}{lrr}\text { EMS } & \text { Intercept } & \text { Batch\&Random } \\ \text { Intercept } & 0 & 0\end{array}$

Batch\&Random $\quad 0 \quad 6$

plus 1.0 times Residual Error Variance

Variance Component Estimates

\begin{tabular}{crr} 
Component & Var Comp Est & Percent of Total \\
Batch\&Random & 0.030268 & 71.631 \\
\hline
\end{tabular}

$\begin{array}{lll}\text { Residual } & 0.011988 & 28.369\end{array}$

Total $\quad 0.042256 \quad 100.000$

These estimates based on equating Mean Squares to Expected Value.

Test Denominator Synthesis

Source MS Den DF Den Denom MS Synthesis

Batch\&Random $0.01199 \quad 100$ Residual

Tests wrt Random Effects
Source $\quad$ SS MS Num DF Num F Ratio Prob $>$ F

$\begin{array}{lrrrrr}\text { Batch\&Random } & 3.67836 & 0.1936 & 19 & 16.1498 & <.0001\end{array}$

Sample Type=SME, Prep=Mixed Acid, ICP=M-14, Analyte=Al/Mn Response Measurement

Summary of Fit

0.780995
Root Mean Square Error $\quad 0.038262$

0.038262

$\begin{array}{lr}\text { Observations (or Sum Wgts) } & 120\end{array}$

Analysis of Variance

Source DF Sum of Squares Mean Square F Ratio

$\begin{array}{lrlll}\text { Model } & 19 & 0.64909084 & 0.034163 & 23.3351\end{array}$

$\begin{array}{lllll}\text { Error } & 100 & 0.14640040 & 0.001464 \quad \text { Prob }>\text { F }\end{array}$

$\begin{array}{llll}\text { C. Total } & 119 & 0.79549124 & <.0001\end{array}$

Expected Mean Squares

The Mean Square per row by the Variance Component per column

$\begin{array}{lrr}\text { EMS } & \text { Intercept } & \text { Batch\&Random } \\ \text { Intercept } & 0 & 0 \\ \text { Batch\&Random } & 0 & 6\end{array}$

plus 1.0 times Residual Error Variance

Variance Component Estimates

\begin{tabular}{crr} 
Component & Var Comp Est & Percent of Total \\
Batch\&Random & 0.00545 & 78.825 \\
\hline
\end{tabular}

$\begin{array}{lrr}\text { Residual } & 0.001464 & 21.175 \\ \text { Total } & 0.006914 & 100.000\end{array}$

These estimates based on equating Mean Squares to Expected Value.

Test Denominator Synthesis

Source MS Den DF Den Denom MS Synthesis

$\begin{array}{lrrr}\text { Source } & \text { MS Den } & \text { DF Den } & \text { Denomal } \\ \text { Batch\&Random } & 0.00146 & 100 & \text { Residual }\end{array}$

Tests wrt Random Effects

Source SS MS Num DF Num F Ratio Prob > F

$\begin{array}{lrrrrr}\text { Batch\&Random } & 0.64909 & 0.03416 & 19 & 23.3351 & <.0001\end{array}$

Sample Type=SME, Prep=Mixed Acid, ICP=M-14, Analyte=B

Sample Type=SME, Prep=Mixed Acid, ICP=M-14, Analyte $=\mathrm{B} / \mathrm{Li}$ 
WSRC-STI-2006-00068

Revision 0

Exhibit A7. Analysis of Variance by Preparation Method, ICP, and Analyte (continued)

Sample Type=SME, Prep=Mixed Acid, ICP=M-14, Analyte=Ca Response Measurement

Summary of Fit

\begin{tabular}{|c|c|c|c|c|}
\hline \multicolumn{3}{|c|}{ RSquare } & 0.750384 & \\
\hline \multicolumn{3}{|c|}{ RSquare Adj } & 0.703088 & \\
\hline \multicolumn{3}{|c|}{ Root Mean Square Error } & 0.026159 & \\
\hline \multicolumn{3}{|c|}{ Mean of Response } & 0.755316 & \\
\hline \multicolumn{3}{|c|}{ Observations (or Sum Wgts) } & 114 & \\
\hline \multicolumn{5}{|c|}{ Analysis of Variance } \\
\hline Source & $\mathrm{DF}$ & Sum of Squares & s Mean Square & F Ratio \\
\hline Model & 18 & 0.19541996 & $6 \quad 0.010857$ & 15.8658 \\
\hline Error & 95 & 0.06500667 & 0.000684 & Prob $>\mathrm{F}$ \\
\hline C. Total & 113 & 0.26042663 & & $<.0001$ \\
\hline
\end{tabular}

Expected Mean Squares

The Mean Square per row by the Variance Component per column

$\begin{array}{lrr}\text { EMS } & \text { Intercept } & \text { Batch\&Random } \\ \text { Intercept } & 0 & 0\end{array}$

Batch\&Random

0

0

plus 1.0 times Residual Error Variance

Variance Component Estimates

Component Var Comp Est Percent of Total

$\begin{array}{rrr}\text { Component } & \text { Var Comp Est } & \text { Percent of Tota } \\ \text { Batch\&Random } & 0.001695 & 71.245\end{array}$

Residual $\quad 0.000684 \quad 28.755$

$\begin{array}{lrr}\text { Total } & 0.00238 & 100.000\end{array}$

These estimates based on equating Mean Squares to Expected Value.

Test Denominator Synthesis

Source MS Den DF Den Denom MS Synthesis

Batch\&Random $0.00068 \quad 95$ Residual

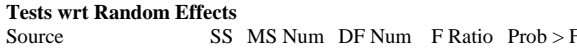

SS MS Num DF Num F Ratio Prob $>$ F

Sample Type=SME, Prep=Mixed Acid, ICP $=$ M-14, Analyte $=\mathbf{C r}$ Response Measurement

Summary of Fit

RSquare $\quad 0.748858$

RSquare Adj $\quad 0.701142$

Root Mean Square Error $\quad 0.003028$

Mean of Response $\quad 0.046758$

Observations (or Sum Wgts) 120

Analysis of Variance

Source DF Sum of Squares Mean Square F Ratio

$\begin{array}{lrrrr}\text { Model } \quad 19 & 0.00273483 & 0.000144 & 15.6938\end{array}$

$\begin{array}{lllll}\text { Error } & 100 & 0.00091717 & 0.000009 \text { Prob }>\end{array}$

Expected Mean Squares

The Mean Square per row by the Variance Component per column

$\begin{array}{lrr}\text { EMS } & \text { Intercept } & \text { Batch\&Random } \\ \text { Intercept } & 0 & 0\end{array}$

Batch\&Random $\quad 0 \quad 6$

plus 1.0 times Residual Error Variance

Variance Component Estimates

Component Var Comp Est Percent of Total

$\begin{array}{lll}\text { Batch\&Random } \quad 0.000022 & 71.006\end{array}$

$\begin{array}{lll}\text { Residual } & 0.000009 & 28.994\end{array}$

Total $\quad 0.000032 \quad 100.000$

These estimates based on equating Mean Squares to Expected Value.

Test Denominator Synthesis

Source MS Den DF Den Denom MS Synthesis

Batch\&Random $\quad 9.17 \mathrm{e}-6 \quad 60$ Residual

Tests wrt Random Effects

Source

SS MS Num DF Num F Ratio Prob > F

$\begin{array}{lrrrrr}\text { Batch\&Random } & 0.00273 & 0.00014 & 19 & 15.6938 & <.0001\end{array}$
Sample Type=SME, Prep=Mixed Acid, ICP=M-14, Analyte=Cu Response Measurement

Summary of Fit

$\begin{array}{ll}\text { RSquare Adj } & 0.826487 \\ \text { Root } & 0.002175\end{array}$

Mean of Response $\quad 0.007517$

Observations (or Sum Wgts)

Analysis of Variance

Source DF Sum of Squares Mean Square F Ratio

$\begin{array}{llllll}\text { Model } & 19 & 0.00277097 & 0.000146 & 30.8331\end{array}$

$\begin{array}{lllll}\text { Error } & 100 & 0.00047300 & 0.000005 & \text { Prob }>\text { F }\end{array}$

$\begin{array}{llll}\text { C. Total } 119 & 0.00324397 & <.0001\end{array}$

Expected Mean Squares

The Mean Square per row by the Variance Component per column

$\begin{array}{lrr}\text { EMS } & \text { Intercept } & \text { Batch\&Random } \\ \text { Intercept } & 0 & 0\end{array}$

$\begin{array}{ccc}\text { Intercept } & 0 & 0 \\ \text { Batch\&Random } & 0 & 6\end{array}$

plus 1.0 times Residual Error Variance

Variance Component Estimates

$\begin{array}{crr}\text { Component } & \text { Var Comp Est } & \text { Percent of Total } \\ \text { Batch\&Random } & 0.000024 & 83.256\end{array}$

$\begin{array}{lll}\text { Batch\&Random } & 0.000024 & 83.256 \\ \text { Residual } & 0.000005 & 16.744\end{array}$

$\begin{array}{lrr}\text { Residual } & 0.000005 & 16.744 \\ \text { Total } & 0.000028 & 100.000\end{array}$

These estimates based on equating Mean Squares to Expected Value.

Test Denominator Synthesis

Source MS Den DF Den Denom MS Synthesis

Batch\&Random $\quad$ 4.73e-6 100 Residual

Tests wrt Random Effects
Source SS MS Num DF Num F Ratio Prob $>$

$\begin{array}{lrrrrr}\text { Source } & \text { SS } & \text { MS Num } & \text { DF Num } & \text { F Ratio } & \text { Prob > F } \\ \text { Batch\&Random } & 0.00277 & 0.00015 & 19 & 30.8331 & <.0001\end{array}$

Sample Type=SME, Prep=Mixed Acid, ICP=M-14, Analyte $=$ Fe Response Measurement

Summary of Fit

RSquare $\quad 0.796133$

RSquare Adj $\quad 0.757398$

Root Mean Square Error $\quad 0.234398$

Mean of Response $\quad 7.880575$

Observations (or Sum Wgts) 120

Analysis of Variance

Source DF Sum of Squares Mean Square F Ratio

$\begin{array}{lrrrr}\text { Model } \quad 19 & 21.455891 & 1.12926 & 20.5535\end{array}$

$\begin{array}{lllll}\text { Error } & 100 & 5.494246 & 0.05494 \text { Prob }>\text { F }\end{array}$

$\begin{array}{llll}\text { C. Total } & 119 & 26.950137 & <.05494\end{array}$

Expected Mean Squares

The Mean Square per row by the Variance Component per column

$\begin{array}{lrr}\text { EMS } & \text { Intercept } & \text { Batch\&Random } \\ \text { Intercept } & 0 & 0 \\ \text { Batch\&Random } & 0 & 6\end{array}$

plus 1.0 times Residual Error Variance

Variance Component Estimates
$\begin{array}{ll}\text { Component } & \text { Var Comp Est Percent of Total }\end{array}$

$\begin{array}{crr}\text { Component } & \text { Var Comp Est } & \text { Percent of Total } \\ \text { Batch\&Random } & 0.179052 & 76.520 \\ \text { Residual } & 0.054942 & 23.480 \\ \text { Toridul } & 0.233955 & 130.000\end{array}$

$\begin{array}{lrr}\text { Residual } & 0.054942 & 23.480 \\ \text { Total } & 0.233995 & 100.000\end{array}$

These estimates based on equating Mean Squares to Expected Value.

Test Denominator Synthesis

Source MS Den DF Den Denom MS Synthesis

$\begin{array}{crrr}\text { Source } & \text { MS Den } & \text { DF Den } & \text { Denom MS } \\ \text { Batch\&Random } & 0.05494 & 100 & \text { Residual }\end{array}$

Tests wrt Random Effects

Source SS MS Num DF Num F Ratio Prob $>$ F

$\begin{array}{rrrrrr}\text { Batch\&Random } & 21.4559 & 1.12926 & 19 & 20.5535 & <.0001\end{array}$ 
WSRC-STI-2006-00068

Revision 0

Exhibit A7. Analysis of Variance by Preparation Method, ICP, and Analyte (continued)

Sample Type=SME, Prep=Mixed Acid, ICP=M-14, Analyte=Fe/AI Response Measurement

Summary of Fi

\begin{tabular}{|c|c|c|c|c|}
\hline \multicolumn{3}{|c|}{ RSquare } & 0.83586 & \\
\hline \multicolumn{3}{|c|}{ RSquare Adj } & 0.804674 & \\
\hline \multicolumn{3}{|c|}{ Root Mean Square Error } & 0.039282 & \\
\hline \multicolumn{3}{|c|}{ Mean of Response } & 2.585362 & \\
\hline \multicolumn{3}{|c|}{ Observations (or Sum Wgts) } & 120 & \\
\hline \multicolumn{5}{|c|}{ Analysis of Variance } \\
\hline Source & $\mathrm{DF}$ & Sum of Squares & s Mean Square & F Ratio \\
\hline Model & 19 & 0.78581079 & $9 \quad 0.041358$ & 26.8019 \\
\hline Error & 100 & 0.15431142 & 0.001543 & Prob $>$ F \\
\hline C. Total & 119 & 0.94012221 & & $<.0001$ \\
\hline
\end{tabular}

Expected Mean Squares

The Mean Square per row by the Variance Component per column

$\begin{array}{lrr}\text { EMS } & \text { Intercept } & \text { Batch\&Random } \\ \text { Intercept } & 0 & 0\end{array}$

Batch\&Random

0

plus 1.0 times Residual Error Variance

Variance Component Estimates

Component Var Comp Est Percent of Total

Batch\&Random $\quad 0.006636 \quad 81.133$

$\begin{array}{lll}\text { Residual } & 0.0061543 & 18.867\end{array}$

Total $\quad 0.008179 \quad 100.000$

These estimates based on equating Mean Squares to Expected Value.

Test Denominator Synthesis

Source MS Den DF Den Denom MS Synthesis

Batch\&Random $0.00154 \quad 100$ Residual

Tests wrt Random Effects
$\begin{aligned} & \text { Source } \\ & \text { SS MS Num DF Num F Ratio Prob }>\text { F }\end{aligned}$

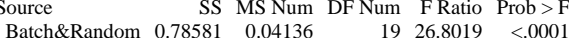

Sample Type=SME, Prep=Mixed Acid, ICP=M-14, Analyte=Fe/Ca Response Measurement

Summary of Fit

RSquare $\quad 0.452323$

RSquare Adj $\quad 0.348553$

Root Mean Square Error $\quad 0.232035$

Mean of Response $\quad 10.41888$

Observations (or Sum Wgts) 114

Analysis of Variance

Source DF Sum of Squares Mean Square F Ratio

\begin{tabular}{llllr} 
Model & 18 & 4.2243080 & 0.234684 & 4.3589 \\
\hline & 95 & 5.1148228 & 0.053840 &
\end{tabular}

$\begin{array}{lllll}\text { Error } & 95 & 5.1148228 & 0.053840 \quad \text { Prob }>\text { F }\end{array}$

$\begin{array}{llll}\text { C. Total } & 113 & 9.3391307 & <.0001\end{array}$

Expected Mean Square

The Mean Square per row by the Variance Component per column

$\begin{array}{lrr}\text { EMS } & \text { Intercept } & \text { Batch\&Random } \\ \text { Intercept } & 0 & 0\end{array}$

$\begin{array}{lll}\text { Batch\&Random } & 0 & 0 \\ & 0 & 6\end{array}$

plus 1.0 times Residual Error Variance

Variance Component Estimates

Component Var Comp Est Percent of Total

$\begin{array}{lll}\text { Batch\&Random } \quad 0.030141 & 35.890\end{array}$

$\begin{array}{lll}\text { Residual } & 0.05384 & 64.110\end{array}$

Total $\quad 0.083981 \quad 100.000$

These estimates based on equating Mean Squares to Expected Value.

Test Denominator Synthesis

Source MS Den DF Den Denom MS Synthesis

$\begin{array}{lrrr}\text { Batch\&Random } & 0.05384 & 95 & \text { Residual }\end{array}$

Tests wrt Random Effects

Source

SS MS Num DF Num F Ratio Prob $>$ F

$\begin{array}{lrrrrr}\text { Batch\&Random } & 4.22431 & 0.23468 & 18 & 4.3589 & <.0001\end{array}$
Sample Type=SME, Prep=Mixed Acid, ICP=M-14, Analyte=Fe/Li Response Measurement

Summary of Fit

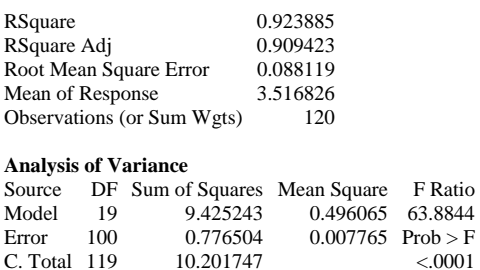

Expected Mean Squares

The Mean Square per row by the Variance Component per column

$\begin{array}{lrr}\text { EMS } & \text { Intercept } & \text { Batch\&Random } \\ \text { Intercept } & 0 & 0\end{array}$

Batch\&Random $\quad 0 \quad 6$

plus 1.0 times Residual Error Variance

Variance Component Estimates

\begin{tabular}{crr} 
Component & Var Comp Est & Percent of Total \\
Batch\&Random & 0.081383 & 91.290 \\
\hline & 0.007765 & 8710
\end{tabular}

$\begin{array}{lrr}\text { Batch\&Random } & 0.081383 & 91.290 \\ \text { Residual } & 0.007765 & 8.710\end{array}$

Total $\quad 0.089148 \quad 100.000$

These estimates based on equating Mean Squares to Expected Value.

Test Denominator Synthesis

Source MS Den DF Den Denom MS Synthesis

Batch\&Random $0.00777 \quad 100$ Residual

Tests wrt Random Effects

Source SS MS Num DF Num F Ratio Prob $>$ F

$\begin{array}{llllll}\text { Batch\&Random } & 9.42524 & 0.49607 & 19 & 63.8844 & <.0001\end{array}$

Sample Type=SME, Prep=Mixed Acid, ICP=M-14, Analyte=Fe/Mg Response Measurement

Summary of Fit

0.635052
0.565711

Re. 0.56571

0.296504

$\begin{array}{lr}\text { Mean of Response } & 10.96896 \\ \text { Observations (or Sum Wgts) } & 120\end{array}$

Analysis of Variance

Source DF Sum of Squares Mean Square F Ratio

$\begin{array}{lrrrr}\text { Model } \quad 19 & 15.298131 & 0.805165 & 9.1585\end{array}$

$\begin{array}{lllll}\text { Error } & 100 & 8.791457 & 0.087915 & \text { Prob }>\text { F }\end{array}$

$\begin{array}{llll}\text { C. Total } & 119 & 24.089588 & <.0001\end{array}$

Expected Mean Squares

The Mean Square per row by the Variance Component per column

$\begin{array}{lrr}\text { EMS } & \text { Intercept } & \text { Batch\&Random } \\ \text { Intercept } & 0 & 0 \\ \text { Batch\&Random } & 0 & 6\end{array}$

plus 1.0 times Residual Error Variance

Variance Component Estimates

Component Var Comp Est Percent of Total

Batch\&Random $\quad 0.119542 \quad 57.623$

Residual $\quad 0.087915 \quad 42.377$

Total $\quad 0.207456 \quad 100.000$

These estimates based on equating Mean Squares to Expected Value.

Test Denominator Synthesis

Source MS Den DF Den Denom MS Synthesis

$\begin{array}{rrrr}\text { Source } & \text { MS Den } & \text { DF Den } & \text { Denomal } \\ \text { Batch\&Random } & 0.08791 & 100 & \text { Residual }\end{array}$

Tests wrt Random Effects

Source SS MS Num DF Num F Ratio Prob $>$ F

$\begin{array}{lrrrrr}\text { Batch\&Random } & 15.2981 & 0.80516 & 19 & 9.1585 & <.0001\end{array}$ 
WSRC-STI-2006-00068

Revision 0

Exhibit A7. Analysis of Variance by Preparation Method, ICP, and Analyte (continued)

Sample Type=SME, Prep=Mixed Acid, ICP=M-14, Analyte=Fe/Mn Response Measurement

Summary of Fi

\begin{tabular}{|c|c|c|c|c|}
\hline \multicolumn{3}{|c|}{ RSquare } & 0.658059 & \\
\hline \multicolumn{3}{|c|}{ RSquare Adj } & 0.59309 & \\
\hline \multicolumn{3}{|c|}{ Root Mean Square Error } & 0.092351 & \\
\hline \multicolumn{3}{|c|}{ Mean of Response } & 4.872926 & \\
\hline \multicolumn{3}{|c|}{ Observations (or Sum Wgts) } & 120 & \\
\hline \multicolumn{5}{|c|}{ Analysis of Variance } \\
\hline Source & $\mathrm{DF}$ & Sum of Squares & Mean Square & F Ratio \\
\hline Model & 19 & 1.6413431 & 0.086386 & 10.1288 \\
\hline Error & 100 & 0.8528761 & 0.008529 & Prob $>F$ \\
\hline C. Total & 119 & 2.4942192 & & $<.0001$ \\
\hline
\end{tabular}

Expected Mean Squares

The Mean Square per row by the Variance Component per column

$\begin{array}{lrr}\text { EMS } & \text { Intercept } & \text { Batch\&Random } \\ \text { Intercept } & 0 & 0\end{array}$

Batch\&Random

0

0

plus 1.0 times Residual Error Variance

Variance Component Estimates

Component Var Comp Est Percent of Total

Batch\&Random $\quad 0.012976 \quad 60.341$

Residual $\quad 0.008529 \quad 39.659$

Total $\quad 0.021505 \quad 100.000$

These estimates based on equating Mean Squares to Expected Value.

Test Denominator Synthesis

Source MS Den DF Den Denom MS Synthesis

Batch\&Random $0.00853 \quad 100$ Residual

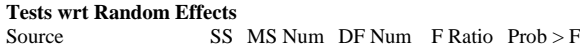

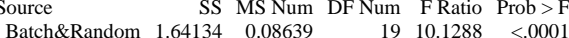

Sample Type=SME, Prep=Mixed Acid, ICP=M-14, Analyte=Fe/Ni Response Measurement

Summary of Fit

RSquare $\quad 0.55181$

RSquare Adj $\quad 0.466654$

Root Mean Square Error $\quad 0.371275$

Mean of Response $\quad 17.13264$

Observations (or Sum Wgts) 120

Analysis of Variance

Source DF Sum of Squares Mean Square F Ratio

$\begin{array}{lrrrr}\text { Model } \quad 19 & 16.971406 & 0.893232 & 6.4800\end{array}$

\begin{tabular}{lllll} 
Error 100 & 13.784497 & 0.137845 Prob $>$ \\
\hline
\end{tabular}

Expected Mean Squares

The Mean Square per row by the Variance Component per column

$\begin{array}{lrr}\text { EMS } & \text { Intercept } & \text { Batch\&Random } \\ \text { Intercept } & 0 & 0\end{array}$

$\begin{array}{lll}\text { Batch\&Random } & 0 & 0 \\ \end{array}$

plus 1.0 times Residual Error Variance

Variance Component Estimates

Component Var Comp Est Percent of Total

$\begin{array}{lrr}\text { Batch\&Random } \quad 0.125898 & 47.735\end{array}$

Residual $\quad 0.137845 \quad 52.265$

Total $\quad 0.263743 \quad 100.000$

These estimates based on equating Mean Squares to Expected Value.

Test Denominator Synthesis

Source MS Den DF Den Denom MS Synthesis

Batch\&Random $0.13784 \quad 100$ Residual

Tests wrt Random Effects

Source

SS MS Num DF Num F Ratio Prob $>$ F

$\begin{array}{lrrrrr}\text { Batch\&Random } & 16.9714 & 0.89323 & 19 & 6.4800 & <.0001\end{array}$
Sample Type=SME, Prep=Mixed Acid, ICP=M-14, Analyte=Fe $/ \mathrm{U}$ Response Measurement

Summary of Fit

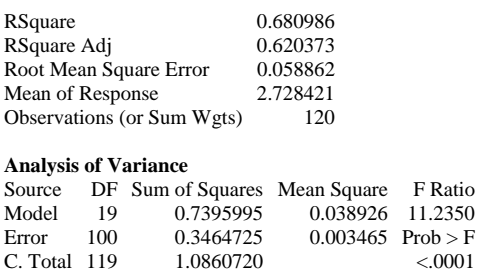

Expected Mean Squares

The Mean Square per row by the Variance Component per column

EMS Intercept Batch\&Random

$\begin{array}{lll}\text { Batch\&Random } & 0 & 0 \\ & 0 & 6\end{array}$

plus 1.0 times Residual Error Variance

Variance Component Estimates

\begin{tabular}{crr} 
Component & Var Comp Est & Percent of Total \\
Batch\&Random & 0.00591 & 63.043 \\
\hline & 0.003465 & 36.957
\end{tabular}

$\begin{array}{lll}\text { Residual } & 0.003465 & 36.957\end{array}$

Total $\quad 0.009375 \quad 100.000$

These estimates based on equating Mean Squares to Expected Value.

Test Denominator Synthesis

Source MS Den DF Den Denom MS Synthesis

Batch\&Random $0.00346 \quad 100$ Residual

Tests wrt Random Effects

Source SS MS Num DF Num F Ratio Prob $>$ F

$\begin{array}{llllll}\text { Batch\&Random } & 0.7396 & 0.03893 & 19 & 11.2350 & <0001\end{array}$

Sample Type=SME, Prep=Mixed Acid, ICP $=M-14$, Analyte $=K$

Response Measurement

Summary of Fit

0.778168

RSquare Adj $\quad 0.736266$

Root Mean Square Error $\quad 0.134019$

Mean of Response $\quad 0.166454$

Observations (or Sum Wgts) 108

Analysis of Variance

Source DF Sum of Squares Mean Square F Ratio

$\begin{array}{lllll}\text { Model } & 17 & 5.6705339 & 0.333561 & 18.5713\end{array}$

$\begin{array}{lrrr}\text { Error } \quad 90 & 1.6164968 \quad 0.017961 \text { Prob > F }\end{array}$

$\begin{array}{llll}\text { C. Total } 107 & 7.2870308 & <.0001\end{array}$

Expected Mean Squares

The Mean Square per row by the Variance Component per column

$\begin{array}{lrr}\text { EMS } & \text { Intercept } & \text { Batch\&Random } \\ \text { Intercept } & 0 & 0 \\ \text { Batch\&Random } & 0 & 6\end{array}$

plus 1.0 times Residual Error Variance

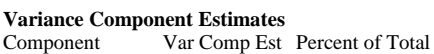

$\begin{array}{lrr}\text { Component } & \text { Var Comp Est } & \text { Percent of Total } \\ \text { Batch\&Random } & 0.0526 & 74.545 \\ \text { Residual } & 0.017961 & 25.455\end{array}$

$\begin{array}{lrr}\text { Residual } & 0.017961 & 25.455 \\ \text { Total } & 0.070561 & 100.000\end{array}$

These estimates based on equating Mean Squares to Expected Value.

Test Denominator Synthesis

Source MS Den DF Den Denom MS Synthesis

$\begin{array}{lrrr}\text { Source } & \text { MS Den } & \text { DF Den } & \text { Denom } \\ \text { Batch\&Random } & 0.01796 & 90 & \text { Residual }\end{array}$

Tests wrt Random Effects

Source SS MS Num DF Num F Ratio Prob $>$ F

$\begin{array}{rrrrrr}\text { Batch\&Random } & 5.67053 & 0.33356 & 17 & 18.5713 & <.0001\end{array}$ 
WSRC-STI-2006-00068

Revision 0

Exhibit A7. Analysis of Variance by Preparation Method, ICP, and Analyte (continued)

Sample Type=SME, Prep=Mixed Acid, ICP=M-14, Analyte=Li Response Measurement

Summary of Fit

\begin{tabular}{|c|c|c|c|c|}
\hline \multicolumn{3}{|l|}{ RSquare } & 0.679799 & \\
\hline \multicolumn{3}{|c|}{ RSquare Adj } & 0.618809 & \\
\hline \multicolumn{3}{|c|}{ Root Mean Square Error } & 0.05404 & \\
\hline \multicolumn{3}{|c|}{ Mean of Response } & 2.243683 & \\
\hline \multicolumn{3}{|c|}{ Observations (or Sum Wgts) } & 126 & \\
\hline \multicolumn{5}{|c|}{ Analysis of Variance } \\
\hline Source & $\mathrm{DF}$ & Sum of Squares & s Mean Square & F Ratio \\
\hline Model & 20 & 0.65099297 & $7 \quad 0.032550$ & 11.1460 \\
\hline Error & 105 & 0.30663233 & 0.002920 & Prob $>$ F \\
\hline C. Total & 125 & 0.95762530 & & $<.0001$ \\
\hline
\end{tabular}

Expected Mean Squares

The Mean Square per row by the Variance Component per column

$\begin{array}{lrr}\text { EMS } & \text { Intercept } & \text { Batch\&Random } \\ \text { Intercept } & 0 & 0\end{array}$

Batch\&Random

0

0

plus 1.0 times Residual Error Variance

Variance Component Estimates

Component Var Comp Est Percent of Total

Batch\&Random $\quad 0.004938 \quad r .839$

$\begin{array}{lrr}\text { Residual } & 0.00292 & 37.161\end{array}$

Total $\quad 0.007859 \quad 100.000$

These estimates based on equating Mean Squares to Expected Value.

Test Denominator Synthesis

Source MS Den DF Den Denom MS Synthesis

Batch\&Random $0.00292 \quad 105$ Residual

Tests wrt Random Effects
Source SS MS Num DF Num F Ratio Prob $>$ F

$\begin{array}{lrrr}\text { SS MS Num DF Num } & \text { F Ratio Prob }>\text { F } \\ \text { Batce } & 20 & 11.1460 & <0001\end{array}$

Sample Type=SME, Prep=Mixed Acid, ICP $=M-14$, Analyte $=\mathbf{M g}$ Response Measurement

Summary of Fit

RSquare $\quad 0.822223$

RSquare Adj $\quad 0.788446$

Root Mean Square Error $\quad 0.024521$

Mean of Response $\quad 0.719683$

Observations (or Sum Wgts) 120

Analysis of Variance

Source DF Sum of Squares Mean Square F Ratio

$\begin{array}{lrrrr}\text { Model } & 19 & 0.27809563 & 0.014637 & 24.3423\end{array}$

$\begin{array}{lllll}\text { Error } & 100 & 0.06012833 & 0.000601 & \text { Prob }>\end{array}$

Expected Mean Squares

The Mean Square per row by the Variance Component per column

$\begin{array}{lrr}\text { EMS } & \text { Intercept } & \text { Batch\&Random } \\ \text { Intercept } & 0 & 0\end{array}$

Batch\&Random $\quad 0 \quad 6$

plus 1.0 times Residual Error Variance

Variance Component Estimates

Component Var Comp Est Percent of Total

$\begin{array}{lll}\text { Batch\&Random } & 0.002339 & 79.552\end{array}$

$\begin{array}{lll}\text { Residual } & 0.000601 & 20.448\end{array}$

Total $\quad 0.002941 \quad 100.000$

These estimates based on equating Mean Squares to Expected Value.

Test Denominator Synthesis

Source MS Den DF Den Denom MS Synthesis

Batch\&Random $\quad 0.0006 \quad 100$ Residual

Tests wrt Random Effects

Source SS MS Num DF Num F Ratio Prob $>$ F

$\begin{array}{lrrrrr}\text { Batch\&Random } & 0.2781 & 0.01464 & 19 & 24.3423 & <.0001\end{array}$
Sample Type=SME, Prep=Mixed Acid, ICP=M-14, Analyte=Mn Response Measurement

Summary of Fit

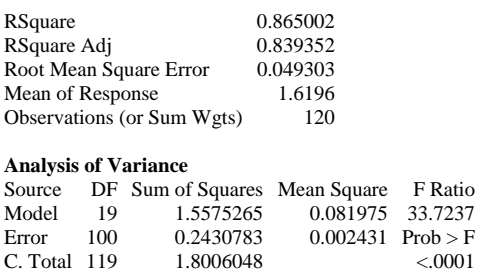

Expected Mean Squares

The Mean Square per row by the Variance Component per column

EMS

Intercept Batch\&Random

$\begin{array}{lll}\text { Batch\&Random } & 0 & 0 \\ & 0 & 6\end{array}$

plus 1.0 times Residual Error Variance

Variance Component Estimates

$\begin{array}{crr}\text { Component } & \text { Var Comp Est } & \text { Percent of Total } \\ \text { Batch\&Random } & 0.013257 & 84.506 \\ \text { Residual } & 0.002431 & 15.494\end{array}$

$\begin{array}{lrr}\text { Residual } & 0.002431 & 15.494 \\ \text { Total } & 0.015688 & 100.000\end{array}$

$\begin{array}{lcc}\text { Total } & 0.015688 & 100.000 \\ \text { These estimates based on equating Mean Squares to Expected Value. }\end{array}$

Test Denominator Synthesis

Source MS Den DF Den Denom MS Synthesis

Batch\&Random $0.00243 \quad 100$ Residual

Tests wrt Random Effects
Source $\quad$ SS MS Num DF Num F Ratio Prob $>$ F

$\begin{array}{lrrrrr}\text { Source } & \text { SS } & \text { MS Num } & \text { DF Num } & \text { F Ratio } & \text { Prob > F } \\ \text { Batch\&Random } & 1.55753 & 0.08198 & 19 & 33.7237 & <.0001\end{array}$

Sample Type=SME, Prep=Mixed Acid, ICP $=M-14$, Analyte $=M n / M g$ Response Measurement

Summary of Fit

0.663488
RSquare

RSquare Adj 0.59972

0.031505

$\begin{array}{lr}\text { Mean of Response } & 2.243634 \\ \text { Observations (or Sum Wgts) } & 114\end{array}$

Analysis of Variance

Source DF Sum of Squares Mean Square F Ratio

$\begin{array}{lllll}\text { Model } & 18 & 0.18591032 & 0.010328 & 10.4060\end{array}$

$\begin{array}{lllll}\text { Error } & 95 & 0.09429130 & 0.000993 \quad \text { Prob }>\text { F }\end{array}$

$\begin{array}{llll}\text { C. Total } 113 & 0.28020162 & <.0001\end{array}$

Expected Mean Squares

The Mean Square per row by the Variance Component per column

$\begin{array}{lrr}\text { EMS } & \text { Intercept } & \text { Batch\&Random } \\ \text { Intercept } & 0 & 0 \\ \text { Batch\&Random } & 0 & 6\end{array}$

plus 1.0 times Residual Error Variance

Variance Component Estimates

Component Var Comp Est Percent of Total

Batch\&Random $\quad 0.001556 \quad 61.054$

$\begin{array}{lll}\text { Residual } & 0.000993 & 38.946\end{array}$

Total $\quad 0.002549 \quad 100.000$

These estimates based on equating Mean Squares to Expected Value.

Test Denominator Synthesis

Source MS Den DF Den Denom MS Synthesis

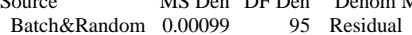

Tests wrt Random Effects

Source SS MS Num DF Num F Ratio Prob $>$ F

$\begin{array}{lrrrrr}\text { Batch\&Random } & 0.18591 & 0.01033 & 18 & 10.4060 & <.0001\end{array}$ 
WSRC-STI-2006-00068

Revision 0

Exhibit A7. Analysis of Variance by Preparation Method, ICP, and Analyte (continued)

Sample Type=SME, Prep=Mixed Acid, ICP=M-14, Analyte=Na Response Measurement

Summary of Fi

\begin{tabular}{|c|c|c|c|c|}
\hline \multicolumn{3}{|c|}{ RSquare } & 0.658216 & \\
\hline \multicolumn{3}{|c|}{ RSquare Adj } & 0.593278 & \\
\hline \multicolumn{3}{|c|}{ Root Mean Square Error } & 0.239573 & \\
\hline \multicolumn{3}{|c|}{ Mean of Response } & 9.053983 & \\
\hline \multicolumn{3}{|c|}{ Observations (or Sum Wgts) } & 120 & \\
\hline \multicolumn{5}{|c|}{ Analysis of Variance } \\
\hline Source & $\mathrm{DF}$ & Sum of Squares & Mean Square & F Ratio \\
\hline Model & 19 & 11.053309 & 0.581753 & 10.1359 \\
\hline Error & 100 & 5.739509 & 0.057395 & Prob $>$ F \\
\hline C. Total & 119 & 16.792818 & & $<.0001$ \\
\hline
\end{tabular}

Expected Mean Squares

The Mean Square per row by the Variance Component per column

$\begin{array}{lrr}\text { EMS } & \text { Intercept } & \text { Batch\&Random } \\ \text { Intercept } & 0 & 0\end{array}$

Batch\&Random

0

0

plus 1.0 times Residual Error Variance

Variance Component Estimates

Component Var Comp Est Percent of Total

$\begin{array}{rrr}\text { Component } & \text { Var Comp Est } & \text { Percent of Total } \\ \text { Batch\&Random } & 0.087393 & 60.359\end{array}$

$\begin{array}{lll}\text { Batch\&Random } & 0.087393 & 60.359 \\ \text { Residual } & 0.057395 & 39.641\end{array}$

$\begin{array}{llr}\text { Total } & 0.144788 & 100.000\end{array}$

These estimates based on equating Mean Squares to Expected Value.

Test Denominator Synthesis

Source MS Den DF Den Denom MS Synthesis

Batch\&Random $\quad 0.0574 \quad 100$ Residual

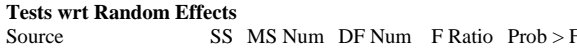

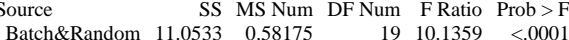

Sample Type=SME, Prep=Mixed Acid, ICP=M-14, Analyte=Ni

Response Measurement

Summary of Fit

RSquare $\quad 0.680804$

RSquare Adj $\quad 0.620156$

Root Mean Square Error $\quad 0.016985$

Mean of Response $\quad 0.460142$

Observations (or Sum Wgts) 120

Analysis of Variance

Source DF Sum of Squares Mean Square F Ratio

$\begin{array}{lrrrr}\text { Model } \quad 19 & 0.06153143 & 0.003238 & 11.2256\end{array}$

$\begin{array}{lllll}\text { Error } & 100 & 0.02884917 & 0.000288 & \text { Prob }>\text { F }\end{array}$

$\begin{array}{lll}\text { C. Total } 119 & 0.09038059 & <.0001\end{array}$

Expected Mean Squares

The Mean Square per row by the Variance Component per column

$\begin{array}{lrr}\text { EMS } & \text { Intercept } & \text { Batch\&Random } \\ \text { Intercept } & 0 & 0\end{array}$

Batch\&Random $\quad 0 \quad 6$

plus 1.0 times Residual Error Variance

Variance Component Estimates

Component Var Comp Est Percent of Total

$\begin{array}{lll}\text { Batch\&Random } \quad 0.000492 & 63.021\end{array}$

$\begin{array}{lll}\text { Residual } & 0.000288 & 36.979\end{array}$

Total $\quad 0.00078 \quad 100.000$

These estimates based on equating Mean Squares to Expected Value.

Test Denominator Synthesis

Source MS Den DF Den Denom MS Synthesis

Batch\&Random $\quad 0.00029 \quad 100$ Residual

Tests wrt Random Effects

Source

SS MS Num DF Num F Ratio Prob > F

$\begin{array}{lrrrrr}\text { Batch\&Random } & 0.06153 & 0.00324 & 19 & 11.2256 & <.0001\end{array}$
Sample Type=SME, Prep=Mixed Acid, ICP=M-14, Analyte=Si Response Measurement

Summary of Fit

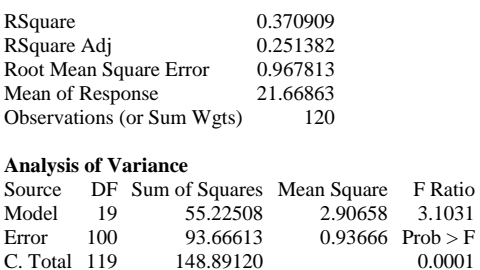

Expected Mean Squares

The Mean Square per row by the Variance Component per column

$\begin{array}{lrr}\text { EMS } & \text { Intercept } & \text { Batch\&Random } \\ \text { Intercept } & 0 & 0\end{array}$

Batch\&Random $\quad 0 \quad 6$

plus 1.0 times Residual Error Variance

Variance Component Estimates

$\begin{array}{crr}\text { Component } & \text { Var Comp Est } & \text { Percent of Total } \\ \text { Batch\&Random } & 0.32832 & 25.955 \\ \text { Residual } & 0.936661 & 74.045 \\ \text { Tot }\end{array}$

Total $\quad 1.264982 \quad 100.000$

These estimates based on equating Mean Squares to Expected Value.

Test Denominator Synthesis

Source MS Den DF Den Denom MS Synthesis

Batch\&Random $0.93666 \quad 100$ Residual

Tests wrt Random Effects
Source SS MS Num DF Num F Ratio Prob > F

$\begin{array}{lrrrrr}\text { Source } & \text { SS } & \text { MS Num } & \text { DF Num } & \text { F Ratio } & \text { Prob }>\text { F } \\ \text { Batch\&Random } & 55.2251 & 2.90658 & 19 & 3.1031 & 0.0001\end{array}$

Sample Type=SME, Prep=Mixed Acid, ICP=M-14, Analyte=Sum of Oxides Response Measurement

Summary of Fit

RSquare $\quad 0.356252$

RSquare Adj $\quad 0.234278$

Root Mean Square Error $\quad 2.130502$

Mean of Response $\quad 89.2959$

Observations (or Sum Wgts) 114

Analysis of Variance

Source DF Sum of Squares Mean Square F Ratio

$\begin{array}{lllll}\text { Model } & 18 & 238.63201 & 13.2573 & 2.9207\end{array}$

$\begin{array}{llll}\text { Error } & 95 & 431.20886 & 4.5390 \quad \text { Prob }>\text { F }\end{array}$

$\begin{array}{lll}\text { C. Total } 113 & 669.84088 & 0.0004\end{array}$

Expected Mean Squares

The Mean Square per row by the Variance Component per column

$\begin{array}{lrr}\text { EMS } & \text { Intercept } & \text { Batch\&Random } \\ \text { Intercept } & 0 & 0 \\ \text { Batch\&Random } & 0 & 6\end{array}$

plus 1.0 times Residual Error Variance

Variance Component Estimates

Component Var Comp Est Percent of Total

$\begin{array}{lll}\text { Batch\&Random } & 1.453049 & 24.249\end{array}$

$\begin{array}{lll}\text { Residual } & 4.539041 & 75.751\end{array}$

Total $\quad 5.99209 \quad 100.000$

These estimates based on equating Mean Squares to Expected Value.

Test Denominator Synthesis

Source MS Den DF Den Denom MS Synthesis

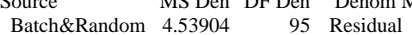

Tests wrt Random Effects

Source SS MS Num DF Num F Ratio Prob $>$ F

$\begin{array}{rrrrrr}\text { Batch\&Random } & 238.632 & 13.2573 & 18 & 2.9207 & 0.0004\end{array}$ 
WSRC-STI-2006-00068

Revision 0

Exhibit A7. Analysis of Variance by Preparation Method, ICP, and Analyte (continued)

Sample Type=SME, Prep=Mixed Acid, ICP=M-14, Analyte=Ti Response Measurement

Summary of Fi

\begin{tabular}{|c|c|c|c|c|}
\hline \multicolumn{3}{|c|}{ RSquare } & 0.894109 & \\
\hline \multicolumn{3}{|c|}{ RSquare Adj } & 0.87399 & \\
\hline \multicolumn{3}{|c|}{ Root Mean Square Error } & 0.002301 & \\
\hline \multicolumn{3}{|c|}{ Mean of Response } & 0.04 & \\
\hline \multicolumn{3}{|c|}{ Observations (or Sum Wgts) } & 120 & \\
\hline \multicolumn{5}{|c|}{ Analysis of Variance } \\
\hline Source & $\mathrm{DF}$ & Sum of Squares & Mean Square & F Ratio \\
\hline Model & 19 & 0.00447233 & 0.000235 & 44.4404 \\
\hline Error & 100 & 0.00052967 & 0.000005 & Prob $>\mathrm{F}$ \\
\hline C. Total & 119 & 0.00500200 & & $<.0001$ \\
\hline
\end{tabular}

Expected Mean Squares

The Mean Square per row by the Variance Component per column

$\begin{array}{lrr}\text { EMS } & \text { Intercept } & \text { Batch\&Random } \\ \text { Intercept } & 0 & 0\end{array}$

Batch\&Random

0

0

plus 1.0 times Residual Error Variance

Variance Component Estimates

Component Var Comp Est Percent of Total

Batch\&Random $\quad 0.000038 \quad r .864$

$\begin{array}{lll}\text { Residual } & 0.000005 & 12.136\end{array}$

Total $\quad 0.000044 \quad 100.000$

These estimates based on equating Mean Squares to Expected Value.

Test Denominator Synthesis

Source MS Den DF Den Denom MS Synthesis

Batch\&Random $\quad$ 5.3e-6 100 Residual

Tests wrt Random Effects

Source SS MS Num DF Num F Ratio Prob > F

$\begin{array}{llllll}\text { Batch\&Random } & 0.00447 & 0.00024 & 19 & 44.4404 & <0001\end{array}$

Sample Type=SME, Prep=Mixed Acid, ICP=M-14, Analyte=U

Response Measurement

Summary of Fit

RSquare $\quad 0.761621$

RSquare Adj $\quad 0.716329$

Root Mean Square Error $\quad 0.09994$

Mean of Response 2.890975

Observations (or Sum Wgts) 120

Analysis of Variance

Source DF Sum of Squares Mean Square F Ratio

$\begin{array}{lrrrrr}\text { Model } & 19 & 3.1911798 & 0.167957 & 16.8158\end{array}$

$\begin{array}{lllll}\text { Error } & 100 & 0.9988032 & 0.009988 \text { Prob }>\text { F }\end{array}$

$\begin{array}{llr}\text { C. Total } 119 & 4.1899829 & <.0001\end{array}$

Expected Mean Square

The Mean Square per row by the Variance Component per column

$\begin{array}{lrr}\text { EMS } & \text { Intercept } & \text { Batch\&Random } \\ \text { Intercept } & 0 & 0\end{array}$

$\begin{array}{lll}\text { Batch\&Random } & 0 & 0 \\ \end{array}$

plus 1.0 times Residual Error Variance

Variance Component Estimates

Component Var Comp Est Percent of Total

$\begin{array}{lll}\text { Batch\&Random } & 0.026328 & 72.497\end{array}$

$\begin{array}{lll}\text { Residual } & 0.009988 & 27.503\end{array}$

Total $\quad 0.036316 \quad 100.000$

These estimates based on equating Mean Squares to Expected Value.

Test Denominator Synthesis

Source MS Den DF Den Denom MS Synthesis

Batch\&Random $0.00999 \quad 100$ Residual

Tests wrt Random Effects

Source

SS MS Num DF Num F Ratio Prob > F

$\begin{array}{lrrrrr}\text { Batch\&Random } & 3.19118 & 0.16796 & 19 & 16.8158 & <.0001\end{array}$
Sample Type=SME, Prep=Mixed Acid, ICP=M-14, Analyte=U/Ca Response Measurement

Summary of Fit

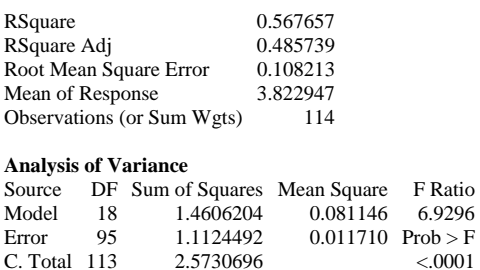

Expected Mean Squares

The Mean Square per row by the Variance Component per column

$\begin{array}{lrr}\text { EMS } & \text { Intercept } & \text { Batch\&Random } \\ \text { Intercept } & 0 & 0\end{array}$

Batch\&Random $\quad 0 \quad 6$

plus 1.0 times Residual Error Variance

Variance Component Estimates

Component Var Comp Est Percent of Total

$\begin{array}{lrr}\text { Batch\&Random } & 0.011573 & 49.705 \\ \text { Residual } & 0.01171 & 50.295\end{array}$

$\begin{array}{lrr}\text { Residual } & 0.01171 & 50.295 \\ \text { Total } & 0.023283 & 100.000\end{array}$

These estimates based on equating Mean Squares to Expected Value.

Test Denominator Synthesis

Source MS Den DF Den Denom MS Synthesis

Batch\&Random $0.01171 \quad 95$ Residual

Tests wrt Random Effects
Source SS MS Num DF Num F Ratio Prob $>$ F

$\begin{array}{lrrrrr}\text { Source } & \text { SS } & \text { MS Num } & \text { DF Num } & \text { F Ratio } & \text { Prob }>\text { F } \\ \text { Batch\&Random } & 1.46062 & 0.08115 & 18 & 6.9296 & <.0001\end{array}$

Sample Type=SME, Prep=Mixed Acid, ICP=M-14, Analyte $=\mathbf{Z r}$ Response Measurement

Summary of Fit

0.984879

0.982006

r $\quad 0.001861$

$\begin{array}{lr}\text { Mean of Response } & 0.060383 \\ \text { Observations (or Sum Wgts) } & 120\end{array}$

Analysis of Variance

Source DF Sum of Squares Mean Square F Ratio

$\begin{array}{llllll}\text { Model } & 19 & 0.02255803 & 0.001187 & 342.8099\end{array}$

$\begin{array}{lllll}\text { Error } & 100 & 0.00034633 & 0.000003 & \text { Prob }>\text { F }\end{array}$

$\begin{array}{llll}\text { C. Total } 119 & 0.02290437 & <.0001\end{array}$

Expected Mean Squares

The Mean Square per row by the Variance Component per column

$\begin{array}{lrr}\text { EMS } & \text { Intercept } & \text { Batch\&Random } \\ \text { Intercept } & 0 & 0 \\ \text { Batch\&Random } & 0 & 6\end{array}$

plus 1.0 times Residual Error Variance

Variance Component Estimates

\begin{tabular}{|c|c|c|c|c|c|}
\hline Component & Var Com & p Est Per & rcent of Total & & \\
\hline Batch\&Random & 0.00 & 0197 & 98.275 & & \\
\hline Residual & 0.00 & 0003 & 1.725 & & \\
\hline Total & 0.00 & 0201 & 100.000 & & \\
\hline These estimates b & ased on ec & quating Me & ean Squares to & to Expecte & ed Value. \\
\hline Test Denominato & or Synthes & & & & \\
\hline Source & MS Den & DF Den & Denom MS & 5 Synthesis & \\
\hline Batch\&Random & $3.46 \mathrm{e}-6$ & 100 & Residual & & \\
\hline & teces & & & & \\
\hline Source & SS & MS Num & DF Num & F Ratio & Prob $>$ F \\
\hline
\end{tabular}


WSRC-STI-2006-00068

Revision 0

Exhibit A7. Analysis of Variance by Preparation Method, ICP, and Analyte (continued)

Sample Type=SRAT, Prep=Cold Chem, ICP=M-13, Analyte=Al Response Measurement

Summary of Fi

\begin{tabular}{|c|c|c|c|c|}
\hline \multicolumn{3}{|l|}{ RSquare } & \multicolumn{2}{|l|}{0.441535} \\
\hline \multicolumn{3}{|c|}{ RSquare Adj } & 0.33572 & \\
\hline \multicolumn{3}{|c|}{ Root Mean Square Error } & 0.193305 & \\
\hline \multicolumn{3}{|c|}{ Mean of Response } & 5.142316 & \\
\hline \multicolumn{3}{|c|}{ Observations (or Sum Wgts) } & 114 & \\
\hline \multicolumn{5}{|c|}{ Analysis of Variance } \\
\hline Source & DF & Sum of Squares & Mean Square & F Ratio \\
\hline Model & 18 & 2.8065800 & 0.155921 & 4.1727 \\
\hline Error & 95 & 3.5498387 & 0.037367 & Prob $>F$ \\
\hline C. Total & 113 & 6.3564186 & & $<.0001$ \\
\hline
\end{tabular}

Expected Mean Squares

The Mean Square per row by the Variance Component per column

$\begin{array}{lrr}\text { EMS } & \text { Intercept } & \text { Batch\&Random } \\ \text { Intercept } & 0 & 0\end{array}$

Batch\&Random

0

0

plus 1.0 times Residual Error Variance

Variance Component Estimates

Component Var Comp Est Percent of Total

$\begin{array}{rrr}\text { Batch\&Random } & 0.019759 & 34.589\end{array}$

Residual $\quad 0.037367 \quad 65.411$

Total $\quad 0.057126 \quad 100.000$

These estimates based on equating Mean Squares to Expected Value.

Test Denominator Synthesi

Source MS Den DF Den Denom MS Synthesis

Batch\&Random $0.03737 \quad 95$ Residual

Tests wrt Random Effects
SS MS Num DF Num F Ratio Prob > F

$\begin{array}{lrrrrr}\text { Source } & \text { SS } & \text { MS Num } & \text { DF Num } & \text { F Ratio } & \text { Prob > F } \\ \text { Batch\&Random } & 2.80658 & 0.15592 & 18 & 4.1727 & <.0001\end{array}$

Sample Type=SRAT, Prep=Cold Chem, ICP $=$ M-13, Analyte=Al/Ca Response Measurement

Summary of Fit

RSquare $\quad 0.364563$

RSquare Adj $\quad 0.242559$

Root Mean Square Error $\quad 0.071141$

Mean of Response 3.837108

Observations (or Sum Wgts) 150

Analysis of Variance

Source DF Sum of Squares Mean Square F Ratio

$\begin{array}{lrrrr}\text { Model } & 24 & 0.36295529 & 0.015123 & 2.9881\end{array}$

$\begin{array}{lllll}\text { Error } & 125 & 0.63263485 & 0.005061 & \text { Prob }>\text { F }\end{array}$

$\begin{array}{llll}\text { C. Total } 149 & 0.99559013 & <.0001\end{array}$

Expected Mean Squares

The Mean Square per row by the Variance Component per column

$\begin{array}{lrr}\text { EMS } & \text { Intercept } & \text { Batch\&Random } \\ \text { Intercept } & 0 & 0\end{array}$

$\begin{array}{lll}\text { Batch\&Random } & 0 & 0 \\ \end{array}$

plus 1.0 times Residual Error Variance

Variance Component Estimates

Component Var Comp Est Percent of Total

$\begin{array}{lll}\text { Batch\&Random } & 0.001677 & 24.889\end{array}$

$\begin{array}{lll}\text { Residual } & 0.005061 & 75.11\end{array}$

Total $\quad 0.006738 \quad 100.000$

These estimates based on equating Mean Squares to Expected Value.

Test Denominator Synthesis

Source MS Den DF Den Denom MS Synthesis

Batch\&Random $0.00506 \quad 125$ Residual

Tests wrt Random Effects

Source

SS MS Num DF Num F Ratio Prob $>$ F

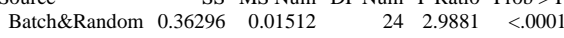

Sample Type=SRAT, Prep=Cold Chem, ICP=M-13, Analyte=Al/Mg Response Measurement

Summary of Fit

RSquare Adj $\quad 0.477933$

Root Mean Square Error $\quad 0.096782$

Mean of Response 3.841868

Observations (or Sum Wgts) $\quad 150$

Analysis of Variance

Source DF Sum of Squares Mean Square F Ratio

$\begin{array}{lllll}\text { Model } & 24 & 1.5024686 & 0.062603 & 6.6835\end{array}$

$\begin{array}{llllll}\text { Error } & 125 & 1.1708490 & 0.009367 & \text { Prob }>\text { F }\end{array}$

$\begin{array}{llll}\text { C. Total } 149 & 2.6733176 & <.0001\end{array}$

Expected Mean Squares

The Mean Square per row by the Variance Component per column

EMS

$\begin{array}{lrr}\text { Intercept } & \text { Intercept } & \text { Batch\&Random } \\ \text { Bar } & 0 & 0\end{array}$

Batch\&Random $\quad 0 \quad 6$

plus 1.0 times Residual Error Variance

Variance Component Estimates

$\begin{array}{rrr}\text { Component } & \text { Var Comp Est } & \text { Percent of Total } \\ \text { Batch\&Random } & 0.008873 & 48.645\end{array}$

$\begin{array}{lll}\text { Batch\&Random } & 0.008873 & 48.645 \\ \text { Residual } & 0.009367 & 51.355\end{array}$

$\begin{array}{lrr}\text { Residual } & 0.009367 & 51.355 \\ \text { Total } & 0.018239 & 100.000\end{array}$

These estimates based on equating Mean Squares to Expected Value.

Test Denominator Synthesis

Source MS Den DF Den Denom MS Synthesis

Batch\&Random $0.00937 \quad 125$ Residual

$\begin{array}{lrrrrr}\text { Tests wrt Random Effects } & & & & \\ \text { Source } & \text { SS } & \text { MS Num } & \text { DF Num } & \text { F Ratio } & \text { Prob > F } \\ \text { Batch\&Random } & 1.50247 & 0.0626 & 24 & 6.6835 & <.0001\end{array}$

Bample Type=SRAT, Prep=Cold Chem, ICP=M-13, Analyte=Al/M Response Measurement

Summary of Fit

RSquare Adj $\quad 0.665952$

0.601926
Reot

$\quad 0.02526$

$\begin{array}{lr}\text { Mean of Response } & 1.619489 \\ \text { Observations (or Sum Wgts) } & 144\end{array}$

Analysis of Variance

Source DF Sum of Squares Mean Square F Ratio

$\begin{array}{llllll}\text { Model } & 23 & 0.15269487 & 0.006639 & 10.4013\end{array}$

$\begin{array}{lllll}\text { Error } & 120 & 0.07659321 & 0.000638 & \text { Prob }>\text { F }\end{array}$

$\begin{array}{llll}\text { C. Total } & 143 & 0.22928808 & <.0001\end{array}$

Expected Mean Squares

The Mean Square per row by the Variance Component per column

$\begin{array}{lrr}\text { EMS } & \text { Intercept } & \text { Batch\&Random } \\ \text { Intercept } & 0 & 0 \\ \text { Batch\&Random } & 0 & 6\end{array}$

plus 1.0 times Residual Error Variance

Variance Component Estimates
$\begin{array}{ll}\text { Component } & \text { Var Comp Est Percent of Total }\end{array}$

$\begin{array}{crr}\text { Component } & \text { Var Comp Est } & \text { Percent of Total } \\ \text { Batch\&Random } & 0.001 & 61.042 \\ \text { Residual } & 0.000638 & 38.958\end{array}$

$\begin{array}{lrr}\text { Residual } & 0.000638 & 38.958 \\ \text { Total } & 0.001638 & 100.000\end{array}$

These estimates based on equating Mean Squares to Expected Value.

Test Denominator Synthesis

Source MS Den DF Den Denom MS Synthesis

$\begin{array}{crrr}\text { Source } & \text { MS Den } & \text { DF Den } & \text { Denom MS } \\ \text { Batch\&Random } & 0.00064 & 120 & \text { Residual }\end{array}$

Tests wrt Random Effects

Source SS MS Num DF Num F Ratio Prob $>$ F

$\begin{array}{rrrrrr} & \text { SS } & \text { MS Num } & \text { DF Num } & \text { F Ratio } & \text { Prob > F } \\ \text { Batch\&Random } & 0.15269 & 0.00664 & 23 & 10.4013 & <.0001\end{array}$ 
WSRC-STI-2006-00068

Revision 0

Exhibit A7. Analysis of Variance by Preparation Method, ICP, and Analyte (continued)

Sample Type=SRAT, Prep=Cold Chem, ICP $=$ M-13, Analyte $=B$ Response Measurement

Summary of Fit

\begin{tabular}{|c|c|c|c|c|}
\hline \multicolumn{3}{|c|}{ RSquare } & 0.954818 & \\
\hline \multicolumn{3}{|c|}{ RSquare Adj } & 0.946129 & \\
\hline \multicolumn{3}{|c|}{ Root Mean Square Error } & 0.005691 & \\
\hline \multicolumn{3}{|c|}{ Mean of Response } & 0.011891 & \\
\hline \multicolumn{3}{|c|}{ Observations (or Sum Wgts) } & 156 & \\
\hline \multicolumn{5}{|c|}{ Analysis of Variance } \\
\hline Source & $\mathrm{DF}$ & Sum of Squares & s Mean Square & F Ratio \\
\hline Model & 25 & 0.08897865 & $5 \quad 0.003559$ & 109.8893 \\
\hline Error & 130 & 0.00421050 & 0.000032 & Prob $>$ F \\
\hline C. Total & 155 & 0.09318915 & & $<.0001$ \\
\hline
\end{tabular}

Expected Mean Square

The Mean Square per row by the Variance Component per column

$\begin{array}{lrr}\text { EMS } & \text { Intercept } & \text { Batch\&Random } \\ \text { Intercept } & 0 & 0\end{array}$

Batch\&Random $\quad 0 \quad 6$

plus 1.0 times Residual Error Variance

Variance Component Estimates

Component Var Comp Est Percent of Total

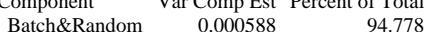

Residual $\quad 0.000032 \quad 5.222$

Total $\quad 0.00062 \quad 100.000$

These estimates based on equating Mean Squares to Expected Value.

Test Denominator Synthesis

Source MS Den DF Den Denom MS Synthesis

Batch\&Random $0.00003 \quad 130$ Residual

Tests wrt Random Effects
Source MS Num DF Num F Ratio Prob $>$ F

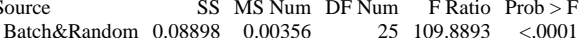

Sample Type=SRAT, Prep $=$ Cold Chem, ICP $=M-13$, Analyte $=B / L i$ Response Measurement

Summary of Fit

RSquare $\quad 0.673132$

RSquare Adj $\quad 0.610696$

Root Mean Square Error $\quad 0.912914$

Mean of Response $\quad 0.253943$

Observations (or Sum Wgts) 107

Analysis of Variance

Source DF Sum of Squares Mean Square F Ratio

$\begin{array}{lllll}\text { Model } & 17 & 152.74842 & 8.98520 & 10.7812\end{array}$

$\begin{array}{lllll}\text { Error } & 89 & 74.17366 & 0.83341 \quad \text { Prob }>\text { F }\end{array}$

$\begin{array}{lrrr}\text { C. Total } 106 & 226.92208 & <.0001\end{array}$

Expected Mean Squares

The Mean Square per row by the Variance Component per column

$\begin{array}{lrr}\text { EMS } & \text { Intercept } & \text { Batch\&Random } \\ \text { Intercept } & 0 & 0\end{array}$

Batch\&Random $\quad 0 \quad 5.94393$

plus 1.0 times Residual Error Variance

Variance Component Estimates

Component Var Comp Est Percent of Total

$\begin{array}{lll}\text { Batch\&Random } & 1.371449 & 62.201\end{array}$

$\begin{array}{lll}\text { Residual } & 0.833412 & 37.799\end{array}$

Total $\quad 2.204861 \quad 100.000$

These estimates based on equating Mean Squares to Expected Value.

Test Denominator Synthesis

Source MS Den DF Den Denom MS Synthesis

Batch\&Random $\quad 0.83341 \quad 89$ Residual

Tests wrt Random Effects

Source SS MS Num DF Num F Ratio Prob $>$ F

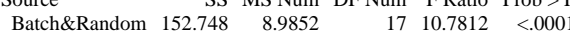

Sample Type=SRAT, Prep=Cold Chem, ICP $=M-13$, Analyte $=C$ Response Measurement

Summary of Fit

RSquare Adj $\quad 0.585505$

Root Mean Square Error $\quad 0.034304$

Mean of Response $\quad 1.342026$

Observations (or Sum Wgts) 114

Analysis of Variance

Source DF Sum of Squares Mean Square F Ratio

$\begin{array}{lllll}\text { Model } & 18 & 0.20901942 & 0.011612 & 9.8678\end{array}$

$\begin{array}{llllll}\text { Error } & 95 & 0.11179350 & 0.001177 & \text { Prob }>\text { F }\end{array}$

$\begin{array}{llll}\text { C. Total } 113 & 0.32081292 & <.0001\end{array}$

Expected Mean Squares

The Mean Square per row by the Variance Component per column

$\begin{array}{lrr}\text { EMS } & \text { Intercept } & \text { Batch\&Random } \\ \text { Intercept } & 0 & 0\end{array}$

$\begin{array}{ccc}\text { Intercept } & 0 & 0 \\ \text { Batch\&Random } & 0 & 6\end{array}$

plus 1.0 times Residual Error Variance

Variance Component Estimates

$\begin{array}{rrr}\text { Component } & \text { Var Comp Est } & \text { Percent of Total } \\ \text { Batch\&Random } & 0.001739 & 59.644\end{array}$

$\begin{array}{ccc}\text { Batch\&Random } & 0.001739 & 59.644 \\ \text { Residual } & 0.001177 & 40.356\end{array}$

$\begin{array}{lrr}\text { Residual } & 0.001177 & 40.356 \\ \text { Total } & 0.002916 & 100.000\end{array}$

These estimates based on equating Mean Squares to Expected Value.

Test Denominator Synthesis

Source MS Den DF Den Denom MS Synthesis

Batch\&Random $0.00118 \quad 95$ Residual

Tests wrt Random Effects
Source $\quad$ SS MS Num DF Num F Ratio Prob $>$ F

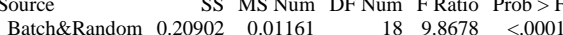

Sample Type $=$ SRAT, Prep $=$ Cold $\mathrm{Chem}, \mathrm{ICP}=\mathrm{M}-13$, Analyte $=\mathrm{Cr}$ Response Measurement

Summary of Fit

0.611409
0.53707

Root Mean Square Error $\quad 0.00546$

Mean of Response $\quad 0.084246$

$\begin{array}{lr}\text { Observations (or Sum Wgts) } & 138\end{array}$

Analysis of Variance

Source DF Sum of Squares Mean Square F Ratio

$\begin{array}{lrrrr}\text { Model } 22 & 0.00539362 & 0.000245 & 8.2246\end{array}$

$\begin{array}{lllll}\text { Error } & 115 & 0.00342800 & 0.000030 & \text { Prob }>\text { F }\end{array}$

$\begin{array}{llll}\text { C. Total } 137 & 0.00882162 & <.0001\end{array}$

Expected Mean Squares

The Mean Square per row by the Variance Component per column

$\begin{array}{lrr}\text { EMS } & \text { Intercept } & \text { Batch\&Random } \\ \text { Intercept } & 0 & 0 \\ \text { Batch\&Random } & 0 & 6\end{array}$

plus 1.0 times Residual Error Variance

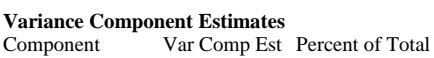

\begin{tabular}{lrr} 
Component & Var Comp Est & Percent of Total \\
Batch\&Random & 0.000036 & 54.630 \\
Residual & 0.00003 & 45.370 \\
\hline
\end{tabular}

$\begin{array}{lrr}\text { Residual } & 0.00003 & 45.370 \\ \text { Total } & 0.000066 & 100.000\end{array}$

These estimates based on equating Mean Squares to Expected Value.

Test Denominator Synthesis

Source MS Den DF Den Denom MS Synthesis

$\begin{array}{crrr}\text { Source } & \text { MS Den } & \text { DF Den } & \text { Denom } \\ \text { Batch\&Random } & 0.00003 & 115 & \text { Residual }\end{array}$

Tests wrt Random Effects

Source SS MS Num DF Num F Ratio Prob $>$ F

$\begin{array}{rrrrrr}\text { Batch\&Random } & 0.00539 & 0.00025 & 22 & 8.2246 & <.0001\end{array}$ 
WSRC-STI-2006-00068

Revision 0

Exhibit A7. Analysis of Variance by Preparation Method, ICP, and Analyte (continued)

Sample Type=SRAT, Prep=Cold $\mathrm{Chem}, \mathrm{ICP}=\mathrm{M}-13$, Analyte $=\mathrm{Cu}$ Response Measurement

Summary of Fi

\begin{tabular}{|c|c|c|c|c|}
\hline \multicolumn{3}{|c|}{ RSquare } & 0.598064 & \\
\hline \multicolumn{3}{|c|}{ RSquare Adj } & 0.521027 & \\
\hline \multicolumn{3}{|c|}{ Root Mean Square Error } & 0.002778 & \\
\hline \multicolumn{3}{|c|}{ Mean of Response } & 0.032562 & \\
\hline \multicolumn{3}{|c|}{ Observations (or Sum Wgts) } & 144 & \\
\hline \multicolumn{5}{|c|}{ Analysis of Variance } \\
\hline Source & $\mathrm{DF}$ & Sum of Squares & s Mean Square & F Ratio \\
\hline Model & 23 & 0.00137760 & $0 \quad 0.000060$ & 7.7633 \\
\hline Error & 120 & 0.00092583 & 0.000008 & Prob $>F$ \\
\hline C. Total & 143 & 0.00230344 & & $<.0001$ \\
\hline
\end{tabular}

Expected Mean Squares

The Mean Square per row by the Variance Component per column

$\begin{array}{lrr}\text { EMS } & \text { Intercept } & \text { Batch\&Random } \\ \text { Intercept } & 0 & 0\end{array}$

Batch\&Random

0

0

plus 1.0 times Residual Error Variance

Variance Component Estimates

Component Var Comp Est Percent of Total

$\begin{array}{rrr}\text { Batch\&Random } & 0.000009 & 52.990\end{array}$

$\begin{array}{lll}\text { Residual } & 0.000008 & 47.010\end{array}$

$\begin{array}{lll}\text { Total } & 0.000016 & 100.000\end{array}$

These estimates based on equating Mean Squares to Expected Value.

Test Denominator Synthesis

Source MS Den DF Den Denom MS Synthesis

Batch\&Random $\quad 7.72 \mathrm{e}-6 \quad 120$ Residual

Tests wrt Random Effects
Source MS Num DF Num F Ratio Prob > F

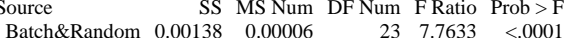

Sample Type=SRAT, Prep=Cold Chem, ICP $=$ M-13, Analyte $=F e$ Response Measurement

Summary of Fit

RSquare $\quad 0.465745$

RSquare Adj $\quad 0.363982$

Root Mean Square Error $\quad 0.768055$

Mean of Response $\quad 15.06258$

Observations (or Sum Wgts) 126

Analysis of Variance

Source DF Sum of Squares Mean Square F Ratio

\begin{tabular}{lrrrr} 
Model & 20 & 53.99740 & 2.69987 & 4.5768 \\
\hline
\end{tabular}

$\begin{array}{lllll}\text { Error } & 105 & 61.94036 & 0.58991 \quad \text { Prob }>\text { F }\end{array}$

$\begin{array}{lrr}\text { C. Total } 125 & 115.93776 & <.0001\end{array}$

Expected Mean Squares

The Mean Square per row by the Variance Component per column

$\begin{array}{lrr}\text { EMS } & \text { Intercept } & \text { Batch\&Random } \\ \text { Intercept } & 0 & 0\end{array}$

Batch\&Random $\quad 0 \quad 6$

plus 1.0 times Residual Error Variance

Variance Component Estimates

Component Var Comp Est Percent of Total

$\begin{array}{lrr}\text { Batch\&Random } \quad 0.35166 & 37.348\end{array}$

$\begin{array}{lll}\text { Residual } & 0.589908 & 62.652\end{array}$

Total $\quad 0.941569 \quad 100.000$

These estimates based on equating Mean Squares to Expected Value.

Test Denominator Synthesis

Source MS Den DF Den Denom MS Synthesis

Batch\&Random $\quad 0.58991 \quad 105$ Residual

Tests wrt Random Effects

Source

SS MS Num DF Num F Ratio Prob $>$ F

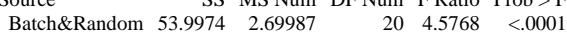

Sample Type=SRAT, Prep=Cold Chem, ICP=M-13, Analyte=Fe $/$ A Response Measurement

Summary of Fit

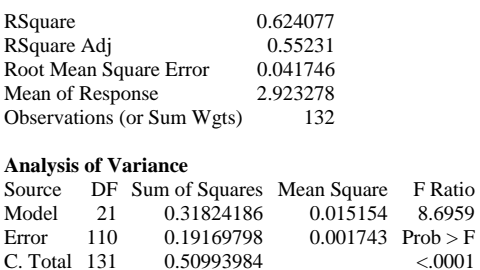

Expected Mean Squares

The Mean Square per row by the Variance Component per column

EMS Intercept Batch\&Random

$\begin{array}{lll}\text { Bntercept } & 0 & 0 \\ \text { Batch\&Random } & 0 & 6\end{array}$

plus 1.0 times Residual Error Variance

Variance Component Estimates

$\begin{array}{rrr}\text { Component } & \text { Var Comp Est } & \text { Percent of Total } \\ \text { Batch\&Random } & 0.002235 & 56.191\end{array}$

$\begin{array}{ccc}\text { Batch\&Random } & 0.002235 & 56.191 \\ \text { Residual } & 0.001743 & 43.809\end{array}$

$\begin{array}{lrr}\text { Residual } & 0.001743 & 43.809 \\ \text { Total } & 0.003978 & 100.000\end{array}$

These estimates based on equating Mean Squares to Expected Value.

Test Denominator Synthesis

Source MS Den DF Den Denom MS Synthesis

Batch\&Random $0.00174 \quad 110$ Residual

Tests wrt Random Effects

Source SS MS Num DF Num F Ratio Prob $>$ F

$\begin{array}{lrrrrr}\text { Batch\&Random } & 0.31824 & 0.01515 & 21 & 8.6959 & <.0001\end{array}$

Sample Type=SRAT, Prep=Cold Chem, ICP=M-13, Analyte $=\mathrm{Fe} / \mathrm{Ca}$ Response Measurement

Summary of Fit

0.570995

Root Mean Square Error $\quad 0.488925$

0.241356

$\begin{array}{lr}\text { Mean of Response } & 11.15218 \\ \text { Observations (or Sum Wgts) } & 138\end{array}$

Analysis of Variance

Source DF Sum of Squares Mean Square F Ratio

$\begin{array}{lrrrr}\text { Model } & 22 & 8.916263 & 0.405285 & 6.9574\end{array}$

$\begin{array}{lllll}\text { Error } & 115 & 6.699045 & 0.058253 & \text { Prob }>\text { F }\end{array}$

$\begin{array}{lrrr}\text { C. Total } 137 & 15.615308 & <.058253 & \text { P. }\end{array}$

Expected Mean Squares

The Mean Square per row by the Variance Component per column

$\begin{array}{lrr}\text { EMS } & \text { Intercept } & \text { Batch\&Random } \\ \text { Intercept } & 0 & 0 \\ \text { Batch\&Random } & 0 & 6\end{array}$

plus 1.0 times Residual Error Variance

Variance Component Estimates
Component $\quad$ Var Comp Est Percent of Total

$\begin{array}{crr}\text { Component } & \text { Var Comp Est } & \text { Percent of Total } \\ \text { Batch\&Random } & 0.057839 & 49.822 \\ \text { Residual } & 0.058253 & 50.178\end{array}$

$\begin{array}{llr}\text { Residual } & 0.058253 & 50.178 \\ \text { Total } & 0.116091 & 100.000\end{array}$

These estimates based on equating Mean Squares to Expected Value.

Test Denominator Synthesis

Source MS Den DF Den Denom MS Synthesis

$\begin{array}{rrrr}\text { Source } & \text { MS Den } & \text { DF Den } & \text { Denomal } \\ \text { Batch\&Random } & 0.05825 & 115 & \text { Residual }\end{array}$

Tests wrt Random Effects

Source SS MS Num DF Num F Ratio Prob $>$ F

$\begin{array}{rrrrrr}\text { Batch\&Random } & 8.91626 & 0.40528 & 22 & 6.9574 & <.0001\end{array}$ 
WSRC-STI-2006-00068

Revision 0

Exhibit A7. Analysis of Variance by Preparation Method, ICP, and Analyte (continued)

Sample Type=SRAT, Prep=Cold Chem, ICP $=M-13$, Analyte $=F e / L$ Response Measurement

Summary of Fi

\begin{tabular}{|c|c|c|c|c|}
\hline \multicolumn{3}{|c|}{ RSquare } & 0.706741 & \\
\hline \multicolumn{3}{|c|}{ RSquare Adj } & 0.650585 & \\
\hline \multicolumn{3}{|c|}{ Root Mean Square Error } & 719.1431 & \\
\hline \multicolumn{3}{|c|}{ Mean of Response } & 79.15296 & \\
\hline \multicolumn{3}{|c|}{ Observations (or Sum Wgts) } & 113 & \\
\hline \multicolumn{5}{|c|}{ Analysis of Variance } \\
\hline Source & $\mathrm{DF}$ & Sum of Squares & s Mean Square & F Ratio \\
\hline Model & 18 & 117156842 & $2 \quad 6508713$ & 12.5853 \\
\hline Error & 94 & 48613682 & 517167 & Prob $>F$ \\
\hline C. Total & 112 & 165770524 & & $<.0001$ \\
\hline
\end{tabular}

Expected Mean Squares

The Mean Square per row by the Variance Component per column

$\begin{array}{lrr}\text { EMS } & \text { Intercept } & \text { Batch\&Random } \\ \text { Intercept } & 0 & 0\end{array}$

Batch\&Random $\quad 0 \quad 5.9469$

plus 1.0 times Residual Error Variance

Variance Component Estimates

Component Var Comp Est Percent of Total

$\begin{array}{rrr} & \text { Vomponent } & \text { Var } \\ \text { Batch\&Random } & 1007507 & 66.080\end{array}$

$\begin{array}{rrr}\text { Batch\&Random } & 1007507 & 66.080 \\ \text { Residual } & 517166.8 & 33.920\end{array}$

Total $\quad 1524674 \quad 100.000$

These estimates based on equating Mean Squares to Expected Value.

Test Denominator Synthesis

Source MS Den DF Den Denom MS Synthesis

Batch\&Random $517167 \quad 94$ Residual

Tests wrt Random Effects
Source

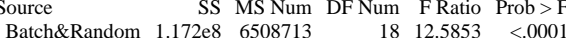

Sample Type=SRAT, Prep=Cold Chem, ICP=M-13, Analyte=Fe/Mg Response Measurement

Summary of Fit

RSquare $\quad 0.528148$

RSquare Adj $\quad 0.43788$

Root Mean Square Error $\quad 0.269268$

Mean of Response $\quad 11.16104$

$\begin{array}{lr}\text { Observations (or Sum Wgts) } & 138\end{array}$

Analysis of Variance

Source DF Sum of Squares Mean Square F Ratio

$\begin{array}{lrrrr}\text { Model } & 22 & 9.332889 & 0.424222 & 5.8509\end{array}$

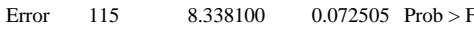

$\begin{array}{lrrr}\text { C. Total } 137 & 17.670988 & <.0001\end{array}$

Expected Mean Squares

The Mean Square per row by the Variance Component per column

$\begin{array}{lrr}\text { EMS } & \text { Intercept } & \text { Batch\&Random } \\ \text { Intercept } & 0 & 0\end{array}$

$\begin{array}{lll}\text { Batch\&Random } & 0 & 0 \\ & 0 & 6\end{array}$

plus 1.0 times Residual Error Variance

Variance Component Estimates

Component Var Comp Est Percent of Total

$\begin{array}{lll}\text { Batch\&Random } \quad 0.058619 & 44.705\end{array}$

Residual $\quad 0.072505 \quad 55.295$

Total $\quad 0.131125 \quad 100.000$

These estimates based on equating Mean Squares to Expected Value.

Test Denominator Synthesis

Source MS Den DF Den Denom MS Synthesis

$\begin{array}{lrrr}\text { Batch\&Random } & 0.07251 & 115 & \text { Residual }\end{array}$

Tests wrt Random Effects

Source

SS MS Num DF Num F Ratio Prob $>$ F

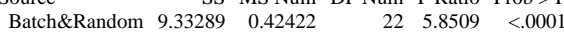

Sample Type $=$ SRAT, Prep $=$ Cold Chem, ICP $=M-13$, Analyte $=\mathrm{Fe} / \mathrm{Mn}$ Response Measurement

Summary of Fit

RSquare Adj $\quad 0.553462$

Root Mean Square Error $\quad 0.091263$

Mean of Response 4.720936

Observations (or Sum Wgts)

Analysis of Variance

Source DF Sum of Squares Mean Square F Ratio

$\begin{array}{lllll}\text { Model } & 23 & 1.6677900 & 0.072513 & 8.7062\end{array}$

$\begin{array}{lllll}\text { Error } & 120 & 0.9994662 & 0.008329 & \text { Prob }>\text { F }\end{array}$

$\begin{array}{lll}\text { C. Total } 143 \quad 2.6672562 & <.0001\end{array}$

Expected Mean Squares

The Mean Square per row by the Variance Component per column

$\begin{array}{lrr}\text { EMS } & \text { Intercept } & \text { Batch\&Random } \\ \text { Intercept } & 0 & 0\end{array}$

Batch\&Random $\quad 0 \quad 6$

plus 1.0 times Residual Error Variance

Variance Component Estimates

$\begin{array}{rrr}\text { Component } & \text { Var Comp Est } & \text { Percent of Total } \\ \text { Batch\&Random } & 0.010697 & 56.224\end{array}$

$\begin{array}{cll}\text { Batch\&Random } & 0.010697 & 56.224 \\ \text { Residual } & 0.008329 & 43.776\end{array}$

$\begin{array}{lrr}\text { Residual } & 0.008329 & 43.776 \\ \text { Total } & 0.019026 & 100.000\end{array}$

These estimates based on equating Mean Squares to Expected Value.

Test Denominator Synthesis

Source MS Den DF Den Denom MS Synthesis

Batch\&Random $0.00833 \quad 120$ Residual

Tests wrt Random Effects

Source SS MS Num DF Num F Ratio Prob $>$ F

$\begin{array}{lrrrrr}\text { Batch\&Random } & 1.66779 & 0.07251 & 23 & 8.7062 & <.0001\end{array}$

Sample Type=SRAT, Prep=Cold Chem, ICP $=M-13$, Analyte $=$ Fe $/ \mathrm{Ni}$ Response Measurement

Summary of Fit

0.652006
0.58557

\begin{tabular}{ll}
0.58557 \\
\hline
\end{tabular}

0.221042

$\begin{array}{lr}\text { Mean of Response } & 17.38547 \\ \text { Observations (or Sum Wgts) } & 132\end{array}$

Analysis of Variance

Source DF Sum of Squares Mean Square F Ratio

$\begin{array}{lrrrr}\text { Model } & 21 & 10.069775 & 0.479513 & 9.8141\end{array}$

$\begin{array}{lrrrr}\text { Error } & 110 & 5.374532 & 0.048859 \text { Prob }>\text { F }\end{array}$

$\begin{array}{lrrr}\text { C. Total } 131 & 15.444307 & <.0001\end{array}$

Expected Mean Squares

The Mean Square per row by the Variance Component per column

$\begin{array}{lrr}\text { EMS } & \text { Intercept } & \text { Batch\&Random } \\ \text { Intercept } & 0 & 0 \\ \text { Batch\&Random } & 0 & 6\end{array}$

plus 1.0 times Residual Error Variance

Variance Component Estimates
$\begin{array}{ll}\text { Component } & \text { Var Comp Est Percent of Total }\end{array}$

\begin{tabular}{crr} 
Component & Var Comp Est & Percent of Total \\
Batch\&Random & 0.071776 & 59.498 \\
Residual & 0.048859 & 40.502 \\
\hline
\end{tabular}

$\begin{array}{lrr}\text { Residual } & 0.048859 & 40.502 \\ \text { Total } & 0.120635 & 100.000\end{array}$

These estimates based on equating Mean Squares to Expected Value.

Test Denominator Synthesis

Source MS Den DF Den Denom MS Synthesis

$\begin{array}{crrr}\text { Source } & \text { MS Den } & \text { DF Den } & \text { Denom MS } \\ \text { Batch\&Random } & 0.04886 & 110 & \text { Residual }\end{array}$

Tests wrt Random Effects

Source SS MS Num DF Num F Ratio Prob $>$ F

$\begin{array}{rrrrrr}\text { Batch\&Random } & 10.0698 & 0.47951 & 21 & 9.8141 & <.0001\end{array}$ 
WSRC-STI-2006-00068

Revision 0

Exhibit A7. Analysis of Variance by Preparation Method, ICP, and Analyte (continued)

Sample Type $=$ SRAT, Prep $=$ Cold Chem, ICP $=M-13$, Analyte $=F e / U$ Response Measurement

Summary of Fi

\begin{tabular}{|c|c|c|c|c|}
\hline \multicolumn{3}{|c|}{ RSquare } & 0.78862 & \\
\hline \multicolumn{3}{|c|}{ RSquare Adj } & 0.748105 & \\
\hline \multicolumn{3}{|c|}{ Root Mean Square Error } & 0.067339 & \\
\hline \multicolumn{3}{|c|}{ Mean of Response } & 2.701894 & \\
\hline \multicolumn{3}{|c|}{ Observations (or Sum Wgts) } & 144 & \\
\hline \multicolumn{5}{|c|}{ Analysis of Variance } \\
\hline Source & $\mathrm{DF}$ & Sum of Squares & s Mean Square & F Ratio \\
\hline Model & 23 & 2.0301209 & $9 \quad 0.088266$ & 19.4651 \\
\hline Error & 120 & 0.5441502 & 0.004535 & Prob $>\mathrm{F}$ \\
\hline C. Total & 143 & 2.5742711 & & $<.0001$ \\
\hline
\end{tabular}

Expected Mean Squares

The Mean Square per row by the Variance Component per column

$\begin{array}{lrr}\text { EMS } & \text { Intercept } & \text { Batch\&Random } \\ \text { Intercept } & 0 & 0\end{array}$

Batch\&Random $\quad 0 \quad 6$

plus 1.0 times Residual Error Variance

Variance Component Estimates

Component Var Comp Est Percent of Total

$\begin{array}{rrr}\text { Batch\&Random } & \text { Var Comp Est } & \text { Percent of Tota } \\ \text { Bats955 } & 75.475\end{array}$

Residual $\quad 0.004535 \quad 24.525$

Total $\quad 0.01849 \quad 100.000$

These estimates based on equating Mean Squares to Expected Value.

Test Denominator Synthesis

Source MS Den DF Den Denom MS Synthesis

Batch\&Random $0.00453 \quad 120$ Residual

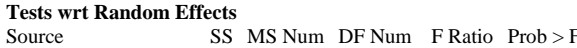

$\begin{array}{lrrrrr}\text { Source } & \text { SS } & \text { MS Num } & \text { DF Num } & \text { F Ratio } & \text { Prob }>\text { F } \\ \text { Batch\&Random } & 2.03012 & 0.08827 & 23 & 19.4651 & <.0001\end{array}$

Sample Type=SRAT, Prep=Cold Chem, ICP=M-13, Analyte $=K$

Response Measurement

Summary of Fit

RSquare $\quad 0.777052$

RSquare Adj $\quad 0.734178$

Root Mean Square Error $\quad 0.10697$

Mean of Response $\quad 0.251314$

Observations (or Sum Wgts) 156

Analysis of Variance

Source DF Sum of Squares Mean Square F Ratio

$\begin{array}{lrrrr}\text { Model } \quad 25 & 5.1846108 & 0.207384 & 18.1239\end{array}$

$\begin{array}{lllll}\text { Error } & 130 & 1.4875408 & 0.011443 \quad \text { Prob }>\text { F }\end{array}$

$\begin{array}{llr}\text { C. Total } 155 & 6.6721516 & <.011443\end{array}$

Expected Mean Squares

The Mean Square per row by the Variance Component per column

$\begin{array}{lrr}\text { EMS } & \text { Intercept } & \text { Batch\&Random } \\ \text { Intercept } & 0 & 0\end{array}$

$\begin{array}{lll}\text { Batch\&Random } & 0 & 0 \\ & 0 & 6\end{array}$

plus 1.0 times Residual Error Variance

Variance Component Estimates

Component Var Comp Est Percent of Total

Batch\&Random $\quad 0.032657 \quad 74.053$

$\begin{array}{lrr}\text { Residual } & 0.011443 & 25.947\end{array}$

Total $\quad 0.0441 \quad 100.000$

These estimates based on equating Mean Squares to Expected Value.

Test Denominator Synthesis

Source MS Den DF Den Denom MS Synthesis

Batch\&Random $0.01144 \quad 130$ Residual

Tests wrt Random Effects

Source SS MS Num DF Num F Ratio Prob >

$\begin{array}{rrrrrr}\text { Batch\&Random } & 5.18461 & 0.20738 & 25 & 18.1239 & <.0001\end{array}$
Sample Type=SRAT, Prep=Cold Chem, ICP=M-13, Analyte $=$ Li Response Measurement

Summary of Fit

RSquare Adj $\quad 0.948119$

Root Mean Square Error $\quad 0.005814$

Mean of Response $\quad 0.007727$

Observations (or Sum Wgts)

Analysis of Variance

Source DF Sum of Squares Mean Square F Ratio

Model $\quad 24 \quad 0.09285063 \quad 0.003869 \quad 114.4563$

$\begin{array}{lllll}\text { Error } & 125 & 0.00422517 & 0.000034 & \text { Prob }>\text { F }\end{array}$

$\begin{array}{llll}\text { C. Total } & 149 & 0.09707579 & <.0001\end{array}$

Expected Mean Squares

The Mean Square per row by the Variance Component per column

$\begin{array}{lrr}\text { EMS } & \text { Intercept } & \text { Batch\&Random } \\ \text { Intercept } & 0 & 0\end{array}$

$\begin{array}{ccc}\text { Intercept } & 0 & 0 \\ \text { Batch\&Random } & 0 & 6\end{array}$

plus 1.0 times Residual Error Variance

Variance Component Estimates

Component Var Comp Est Percent of Total

$\begin{array}{rrr}\text { Component } & \text { Var Comp Est } & \text { Percent of Total } \\ \text { Batch\&Random } & 0.000639 & 94.977\end{array}$

$\begin{array}{lrr}\text { Residual } & 0.000034 & 5.023\end{array}$

Total $\quad 0.000673 \quad 100.000$

These estimates based on equating Mean Squares to Expected Value.

Test Denominator Synthesis

Source MS Den DF Den Denom MS Synthesis

Batch\&Random $0.00003 \quad 125$ Residual

Tests wrt Random Effects
Source $\quad$ SS MS Num DF Num F Ratio Prob $>$ F Batch\&Random $0.09285 \quad 0.00387 \quad 24 \quad 114.4563<0001$

Sample Type=SRAT, Prep=Cold Chem, ICP $=M-13$, Analyte $=$ Mg Response Measurement

Summary of Fit

0.541983

RSquare Adj $\quad 0.454742$

Root Mean Square Error $\quad 0.052505$

Mean of Response $\quad 1.340317$

Observations (or Sum Wgts) 126

Analysis of Variance

Source DF Sum of Squares Mean Square F Ratio

$\begin{array}{lrrrr}\text { Model } & 20 & 0.34252197 & 0.017126 & 6.2125\end{array}$

$\begin{array}{lllll}\text { Error } & 105 & 0.28945733 & 0.002757 & \text { Prob > F }\end{array}$

$\begin{array}{llll}\text { C. Total } & 125 & 0.63197930 & <.0001\end{array}$

Expected Mean Squares

The Mean Square per row by the Variance Component per column

$\begin{array}{lrr}\text { EMS } & \text { Intercept } & \text { Batch\&Random } \\ \text { Intercept } & 0 & 0 \\ \text { Batch\&Random } & 0 & 6\end{array}$

plus 1.0 times Residual Error Variance

Variance Component Estimates

Component Var Comp Est Percent of Total

$\begin{array}{lll}\text { Batch\&Random } \quad 0.002395 & 46.488\end{array}$

$\begin{array}{lll}\text { Residual } & 0.002757 & 53.512\end{array}$

Total $\quad 0.005152 \quad 100.000$

These estimates based on equating Mean Squares to Expected Value.

Test Denominator Synthesis

Source MS Den DF Den Denom MS Synthesis

$\begin{array}{lrrr}\text { Source } & \text { MS Den } & \text { DF Den } & \text { Denomal } \\ \text { Batch\&Random } & 0.00276 & 105 & \text { Residual }\end{array}$

Tests wrt Random Effects

Source SS MS Num DF Num F Ratio Prob $>$ F

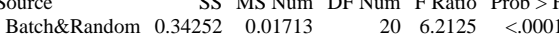


WSRC-STI-2006-00068

Revision 0

Exhibit A7. Analysis of Variance by Preparation Method, ICP, and Analyte (continued)

Sample Type $=$ SRAT, Prep $=$ Cold Chem, ICP $=M-13$, Analyte $=M n$ Response Measurement

Summary of Fi

\begin{tabular}{|c|c|c|c|c|}
\hline \multicolumn{3}{|c|}{ RSquare } & \multicolumn{2}{|l|}{0.623402} \\
\hline \multicolumn{3}{|c|}{ RSquare Adj } & 0.551849 & \\
\hline \multicolumn{3}{|c|}{ Root Mean Square Error } & 0.107885 & \\
\hline \multicolumn{3}{|c|}{ Mean of Response } & 3.184317 & \\
\hline \multicolumn{3}{|c|}{ Observations (or Sum Wgts) } & 120 & \\
\hline \multicolumn{5}{|c|}{ Analysis of Variance } \\
\hline Source & $\mathrm{DF}$ & Sum of Squares & s Mean Square & F Ratio \\
\hline Model & 19 & 1.9267073 & $3 \quad 0.101406$ & 8.7124 \\
\hline Error & 100 & 1.1639247 & 0.011639 & Prob $>$ F \\
\hline C. Total & 119 & 3.0906320 & & $<.0001$ \\
\hline
\end{tabular}

Expected Mean Squares

The Mean Square per row by the Variance Component per column

$\begin{array}{lrr}\text { EMS } & \text { Intercept } & \text { Batch\&Random } \\ \text { Intercept } & 0 & 0\end{array}$

Batch\&Random

0

0

plus 1.0 times Residual Error Variance

Variance Component Estimates

Component Var Comp Est Percent of Total

Batch\&Random $\quad 0.014961 \quad 56.244$

$\begin{array}{lrr}\text { Residual } & 0.011639 & 43.756\end{array}$

$\begin{array}{lrr}\text { Total } & 0.0266 & 100.000\end{array}$

These estimates based on equating Mean Squares to Expected Value.

Test Denominator Synthesis

Source MS Den DF Den Denom MS Synthesis

Batch\&Random $0.01164 \quad 100$ Residual

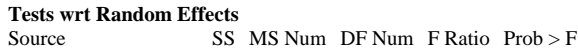

$\begin{array}{lrrrrr}\text { Source } & \text { SS } & \text { MS Num } & \text { DF Num } & \text { F Ratio } & \text { Prob > F } \\ \text { Batch\&Random } & 1.92671 & 0.10141 & 19 & 8.7124 & <.0001\end{array}$

Sample Type=SRAT, Prep=Cold Chem, ICP $=M-13$, Analyte $=M n / M g$ Response Measurement

Summary of Fit

RSquare $\quad 0.436277$

RSquare Adj $\quad 0.327868$

Root Mean Square Error $\quad 0.04565$

Mean of Response 2.371366

Observations (or Sum Wgts) $\quad 156$

Analysis of Variance

Source DF Sum of Squares Mean Square F Ratio

$\begin{array}{lrrrr}\text { Model } & 25 & 0.20966623 & 0.008387 & 4.0244\end{array}$

$\begin{array}{lllll}\text { Error } & 130 & 0.27091461 & 0.002084 & \text { Prob }>\text { F }\end{array}$

$\begin{array}{llll}\text { C. Total } 155 & 0.48058084 & <.0001\end{array}$

Expected Mean Squares

The Mean Square per row by the Variance Component per column

$\begin{array}{lrr}\text { EMS } & \text { Intercept } & \text { Batch\&Random } \\ \text { Intercept } & 0 & 0\end{array}$

$\begin{array}{lll}\text { Batch\&Random } & 0 & 0 \\ & 0 & 6\end{array}$

plus 1.0 times Residual Error Variance

Variance Component Estimates

Component Var Comp Est Percent of Total

Batch\&Random $\quad 0.00105 \quad 33.513$

$\begin{array}{lll}\text { Residual } & 0.002084 & 66.487\end{array}$

Total $\quad 0.003134 \quad 100.000$

These estimates based on equating Mean Squares to Expected Value.

Test Denominator Synthesis

Source MS Den DF Den Denom MS Synthesis

Batch\&Random $0.00208 \quad 130$ Residual

Tests wrt Random Effects

Source

SS MS Num DF Num F Ratio Prob > F

$\begin{array}{llllll}\text { Batch\&Random } & 0.20967 & 0.00839 & 25 & 4.0244 & <.0001\end{array}$
Sample Type=SRAT, Prep $=$ Cold Chem, ICP $=$ M-13, Analyte $=$ Na Response Measurement

Summary of Fit

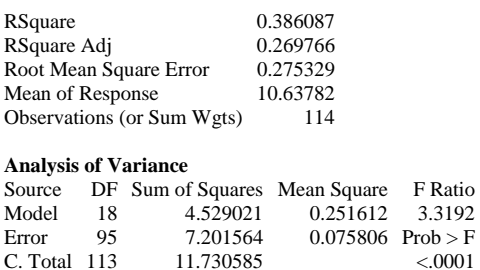

Expected Mean Squares

The Mean Square per row by the Variance Component per column

EMS Intercept Batch\&Random

$\begin{array}{lll}\text { Bntercept } & 0 & 0 \\ \text { Batch\&Random } & 0 & 6\end{array}$

plus 1.0 times Residual Error Variance

Variance Component Estimates

Component Var Comp Est Percent of Total

$\begin{array}{rrr}\text { Component } & \text { Var Comp Est } & \text { Percent of Total } \\ \text { Batch\&Random } & 0.029301 & 27.877\end{array}$

$\begin{array}{ccc}\text { Batch\&Random } & 0.029301 & 27.877 \\ \text { Residual } & 0.075806 & 72.123\end{array}$

Total $\quad 0.105107 \quad 100.000$

These estimates based on equating Mean Squares to Expected Value.

Test Denominator Synthesis

Source MS Den DF Den Denom MS Synthesis

Batch\&Random $0.07581 \quad 95$ Residual

Tests wrt Random Effects
Source $\quad$ SS MS Num DF Num F Ratio Prob $>$ F

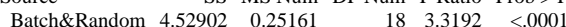

Sample Type=SRAT, Prep=Cold Chem, ICP $=M-13$, Analyte $=\mathrm{Ni}$ Response Measurement

Summary of Fit

RSquare Adj $\quad 0.443155$

Root Mean Square Error $\quad 0.035733$

Mean of Response 0.866895

Observations (or Sum Wgts) 114

Analysis of Variance

Source DF Sum of Squares Mean Square F Ratio

$\begin{array}{lllll}\text { Model } & 18 & 0.13780640 & 0.007656 & 5.9961\end{array}$

$\begin{array}{lrrrr}\text { Error } & 95 & 0.12129833 & 0.001277 & \text { Prob }>\text { F }\end{array}$

$\begin{array}{lrrr}\text { C. Total } 113 & 0.25910474 & <.0001\end{array}$

Expected Mean Squares

The Mean Square per row by the Variance Component per column

$\begin{array}{lrr}\text { EMS } & \text { Intercept } & \text { Batch\&Random } \\ \text { Intercept } & 0 & 0 \\ \text { Batch\&Random } & 0 & 6\end{array}$

plus 1.0 times Residual Error Variance

Variance Component Estimates
Component $\quad$ Var Comp Est Percent of Total

$\begin{array}{crr}\text { Component } & \text { Var Comp Est } & \text { Percent of Total } \\ \text { Batch\&Random } & 0.001063 & 45.435\end{array}$

$\begin{array}{lll}\text { Residual } & 0.001277 & 54.565\end{array}$

Total $\quad 0.00234 \quad 100.000$

These estimates based on equating Mean Squares to Expected Value.

Test Denominator Synthesis

Source MS Den DF Den Denom MS Synthesis

$\begin{array}{lrrr}\text { Source } & \text { MS Den } & \text { DF Den } & \text { Denom MS } \\ \text { Batch\&Random } & 0.00128 & 95 & \text { Residual }\end{array}$

Tests wrt Random Effects

Source SS MS Num DF Num F Ratio Prob $>$ F

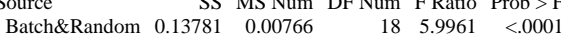


WSRC-STI-2006-00068

Revision 0

Exhibit A7. Analysis of Variance by Preparation Method, ICP, and Analyte (continued)

Sample Type=SRAT, Prep=Cold Chem, ICP=M-13, Analyte $=S i$ Response Measurement

Summary of Fi

\begin{tabular}{|c|c|c|c|c|}
\hline \multicolumn{3}{|c|}{ RSquare } & \multicolumn{2}{|l|}{0.75095} \\
\hline \multicolumn{3}{|c|}{ RSquare Adj } & 0.703306 & \\
\hline \multicolumn{3}{|c|}{ Root Mean Square Error } & 0.071728 & \\
\hline \multicolumn{3}{|c|}{ Mean of Response } & 1.162522 & \\
\hline \multicolumn{3}{|c|}{ Observations (or Sum Wgts) } & 138 & \\
\hline \multicolumn{5}{|c|}{ Analysis of Variance } \\
\hline Source & $\mathrm{DF}$ & Sum of Squares & s Mean Square & F Ratio \\
\hline Model & 22 & 1.7839998 & $8 \quad 0.081091$ & 15.7616 \\
\hline Error & 115 & 0.5916567 & 0.005145 & Prob $>$ F \\
\hline C. Total & 137 & 2.3756564 & & $<.0001$ \\
\hline
\end{tabular}

Expected Mean Squares

The Mean Square per row by the Variance Component per column

$\begin{array}{lrr}\text { EMS } & \text { Intercept } & \text { Batch\&Random } \\ \text { Intercept } & 0 & 0\end{array}$

Batch\&Random $\quad 0 \quad 6$

plus 1.0 times Residual Error Variance

Variance Component Estimates

Component Var Comp Est Percent of Total

Batch\&Random $\quad 0.012658 \quad 71.100$

Residual $\quad 0.005145 \quad 28.900$

Total $\quad 0.017803 \quad 100.000$

These estimates based on equating Mean Squares to Expected Value.

Test Denominator Synthesis

Source MS Den DF Den Denom MS Synthesis

Batch\&Random $0.00514 \quad 115$ Residual

Tests wrt Random Effects

Source SS MS Num DF Num F Ratio Prob $>$ F

$\begin{array}{llllll}\text { Batch\&Random } & 1.784 & 0.08109 & 22 & 15.7616 & <.0001\end{array}$

Sample Type=SRAT, Prep=Cold Chem, ICP=M-13, Analyte $=$ Sum of Oxides Response Measurement

Summary of Fit

RSquare $\quad 0.579482$

RSquare Adj $\quad 0.499805$

Root Mean Square Error $\quad 1.916708$

Mean of Response $\quad 64.68359$

Observations (or Sum Wgts) 114

Analysis of Variance

Source DF Sum of Squares Mean Square F Ratio

$\begin{array}{lllrr}\text { Model } & 18 & 480.94049 & 26.7189 & 7.2729\end{array}$

$\begin{array}{lllll}\text { Error } & 95 & 349.00822 & 3.6738 \text { Prob }>\text { F }\end{array}$

$\begin{array}{lrrr}\text { C. Total } 113 & 829.94871 & <.0001\end{array}$

Expected Mean Squares

The Mean Square per row by the Variance Component per column

$\begin{array}{lrr}\text { EMS } & \text { Intercept } & \text { Batch\&Random } \\ \text { Intercept } & 0 & 0\end{array}$

$\begin{array}{lll}\text { Batch\&Random } & 0 & 0 \\ \end{array}$

plus 1.0 times Residual Error Variance

Variance Component Estimates

Component Var Comp Est Percent of Total

$\begin{array}{lll}\text { Batch\&Random } & 3.840858 & 51.112 \\ \text { Residual } & 3.673771 & 48.888\end{array}$

Total $\quad 7.514628 \quad 100.000$

These estimates based on equating Mean Squares to Expected Value.

Test Denominator Synthesis

Source MS Den DF Den Denom MS Synthesis

$\begin{array}{lrrr}\text { Batch\&Random } & 3.67377 & 95 & \text { Residual }\end{array}$

Tests wrt Random Effects

Source SS MS Num DF Num F Ratio Prob $>$ F

$\begin{array}{rrrrrr}\text { Batch\&Random } & 480.94 & 26.7189 & 18 & 7.2729 & <.0001\end{array}$
Sample Type=SRAT, Prep=Cold Chem, ICP=M-13, Analyte $=$ Ti Response Measurement

Summary of Fit

$\begin{array}{ll}\text { RSquare Adj } & 0.790065 \\ \text { Root Mean Square Error } & 0.001684\end{array}$

Mean of Response $\quad 0.014567$

Observations (or Sum Wgts)

Analysis of Variance

Source DF Sum of Squares Mean Square F Ratio

$\begin{array}{lllll}\text { Model } & 24 & 0.00165833 & 0.000069 & 24.3643\end{array}$

$\begin{array}{lllll}\text { Error } & 125 & 0.00035450 & 0.000003 & \text { Prob }>\text { F }\end{array}$

$\begin{array}{llll}\text { C. Total } 149 & 0.00201283 & <.0001\end{array}$

Expected Mean Squares

The Mean Square per row by the Variance Component per column

$\begin{array}{lrr}\text { EMS } & \text { Intercept } & \text { Batch\&Random } \\ \text { Intercept } & 0 & 0\end{array}$

$\begin{array}{ccc}\text { Intercept } & 0 & 0 \\ \text { Batch\&Random } & 0 & 6\end{array}$

plus 1.0 times Residual Error Variance

Variance Component Estimates

$\begin{array}{crr}\text { Component } & \text { Var Comp Est } & \text { Percent of Total } \\ \text { Batch\&Random } & 0.000011 & 79.567\end{array}$

$\begin{array}{lll}\text { Batch\&Random } & 0.000011 & 79.567 \\ \text { Residual } & 0.000003 & 20.433\end{array}$

$\begin{array}{lrr}\text { Residual } & 0.000003 & 20.433 \\ \text { Total } & 0.000014 & 100.000\end{array}$

These estimates based on equating Mean Squares to Expected Value.

Test Denominator Synthesis

Source MS Den DF Den Denom MS Synthesis

Batch\&Random 2.84e-6 125 Residual

Tests wrt Random Effects

Source SS MS Num DF Num F Ratio Prob $>$ F

$\begin{array}{rrrrrr}\text { Batch\&Random } & 0.00166 & 0.00007 & 24 & 24.3643 & <.0001\end{array}$

Sample Type=SRAT, Prep=Cold Chem, ICP $=M-13$, Analyte $=U$

Response Measurement

Summary of Fit

RSquare $\quad 0.644112$

RSquare Adj $\quad 0.576681$

Root Mean Square Error $\quad 0.172466$

Mean of Response $\quad 5.57614$

Observations (or Sum Wgts) 114

Analysis of Variance

Source DF Sum of Squares Mean Square F Ratio

$\begin{array}{lllll}\text { Model } & 18 & 5.1142218 & 0.284123 & 9.5521\end{array}$

$\begin{array}{lrrr}\text { Error } & 95 & 2.8257300 & 0.029745 \text { Prob }>\text { F }\end{array}$

$\begin{array}{llll}\text { C. Total } 113 & 7.9399518 & <.029745 & \text { P.ob }>\text { F }\end{array}$

Expected Mean Squares

The Mean Square per row by the Variance Component per column

$\begin{array}{lrr}\text { EMS } & \text { Intercept } & \text { Batch\&Random } \\ \text { Intercept } & 0 & 0 \\ \text { Batch\&Random } & 0 & 6\end{array}$

plus 1.0 times Residual Error Variance

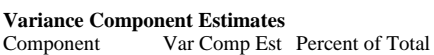

$\begin{array}{crr}\text { Component } & \text { Var Comp Est } & \text { Percent of Total } \\ \text { Batch\&Random } & 0.042396 & 58.769 \\ \text { Residual } & 0.029745 & 41.231 \\ \text { Told } & 0.072141 & 100.000\end{array}$

$\begin{array}{lrr}\text { Residual } & 0.029745 & 41.231 \\ \text { Total } & 0.072141 & 100.000\end{array}$

These estimates based on equating Mean Squares to Expected Value.

Test Denominator Synthesis

Source MS Den DF Den Denom MS Synthesis

$\begin{array}{lrrr}\text { Source } & \text { MS Den } & \text { DF Den } & \text { Denom } \\ \text { Batch\&Random } & 0.02974 & 95 & \text { Residual }\end{array}$

Tests wrt Random Effects

Source SS MS Num DF Num F Ratio Prob $>$ F

$\begin{array}{rrrrrr} & \text { SS } & \text { MS Num } & \text { DF Num } & \text { F Ratio } & \text { Prob > F } \\ \text { Batch\&Random } & 5.11422 & 0.28412 & 18 & 9.5521 & <.0001\end{array}$ 
WSRC-STI-2006-00068

Revision 0

Exhibit A7. Analysis of Variance by Preparation Method, ICP, and Analyte (continued)

Sample Type $=$ SRAT, Prep $=$ Cold Chem, ICP $=$ M-13, Analyte $=$ U $/$ Ca Response Measurement

Summary of Fi

\begin{tabular}{|c|c|c|c|c|}
\hline \multicolumn{3}{|c|}{ RSquare } & \multicolumn{2}{|l|}{0.827155} \\
\hline \multicolumn{3}{|c|}{ RSquare Adj } & 0.793915 & \\
\hline \multicolumn{3}{|c|}{ Root Mean Square Error } & 0.062198 & \\
\hline \multicolumn{3}{|c|}{ Mean of Response } & 4.132033 & \\
\hline \multicolumn{3}{|c|}{ Observations (or Sum Wgts) } & 156 & \\
\hline \multicolumn{5}{|c|}{ Analysis of Variance } \\
\hline Source & DF & Sum of Squares & s Mean Square & F Rat \\
\hline Model & 25 & 2.4067243 & $3 \quad 0.096269$ & 24.8847 \\
\hline Error & 130 & 0.5029184 & 0.003869 & Prob $>F$ \\
\hline C. Total & 155 & 2.9096427 & & $<.0001$ \\
\hline
\end{tabular}

Expected Mean Squares

The Mean Square per row by the Variance Component per column

$\begin{array}{lrr}\text { EMS } & \text { Intercept } & \text { Batch\&Random } \\ \text { Intercept } & 0 & 0\end{array}$

Batch\&Random $\quad 0 \quad 6$

plus 1.0 times Residual Error Variance

Variance Component Estimates

Component Var Comp Est Percent of Total

$\begin{array}{rrr}\text { Component } & \text { Var Comp Est } & \text { Percent of Tota } \\ \text { Batch\&Random } & 0.0154 & 79.923\end{array}$

Residual $\quad 0.003869 \quad 20.077$

Total $\quad 0.019269 \quad 100.000$

These estimates based on equating Mean Squares to Expected Value.

Test Denominator Synthesis

Source MS Den DF Den Denom MS Synthesis

Batch\&Random $0.00387 \quad 130$ Residual

Tests wrt Random Effects
Source SS MS Num DF Num F Ratio Prob $>$ F

$\begin{array}{lrrrrr}\text { Source } & \text { SS } & \text { MS Num } & \text { DF Num } & \text { F Ratio } & \text { Prob > F } \\ \text { Batch\&Random } & 2.40672 & 0.09627 & 25 & 24.8847 & <0001\end{array}$

Sample Type=SRAT, Prep=Cold Chem, ICP $=$ M-13, Analyte $=\mathrm{Zr}$ Response Measurement

Summary of Fit

RSquare $\quad 0.643136$

RSquare Adj $\quad 0.574738$

Root Mean Square Error $\quad 0.005135$

Mean of Response $\quad 0.077667$

Observations (or Sum Wgts) 144

Analysis of Variance

Source DF Sum of Squares Mean Square F Ratio

$\begin{array}{lrrrr}\text { Model } & 23 & 0.00570333 & 0.000248 & 9.4027\end{array}$

$\begin{array}{lllll}\text { Error } & 120 & 0.00316467 & 0.000026 & \text { Prob }>\text { F }\end{array}$

$\begin{array}{llll}\text { C. Total } 143 & 0.00886800 & <.0001\end{array}$

Expected Mean Squares

The Mean Square per row by the Variance Component per column

$\begin{array}{lrr}\text { EMS } & \text { Intercept } & \text { Batch\&Random } \\ \text { Intercept } & 0 & 0\end{array}$

$\begin{array}{lll}\text { Batch\&Random } & 0 & 0 \\ & 0 & 6\end{array}$

plus 1.0 times Residual Error Variance

Variance Component Estimates

Component Var Comp Est Percent of Total

Batch\&Random $\quad 0.000037 \quad 58.34$

Residual $\quad 0.000026 \quad 41.659$

Total $\quad 0.000063 \quad 100.000$

These estimates based on equating Mean Squares to Expected Value.

Test Denominator Synthesis

Source MS Den DF Den Denom MS Synthesis

Batch\&Random $\quad 0.00003 \quad 120$ Residual

Tests wrt Random Effects

Source SS MS Num DF Num F Ratio Prob $>$ F

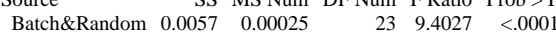

Sample Type=SRAT, Prep=Cold Chem, ICP=M-14, Analyte=Al Response Measurement

Summary of Fit

\begin{tabular}{|c|c|c|c|c|}
\hline \multicolumn{3}{|c|}{ RSquare } & \multicolumn{2}{|l|}{0.457857} \\
\hline \multicolumn{3}{|c|}{ RSquare Adj } & 0.353301 & \\
\hline \multicolumn{3}{|c|}{ Root Mean Square Error } & 0.266954 & \\
\hline \multicolumn{3}{|c|}{ Mean of Response } & 5.092173 & \\
\hline \multicolumn{3}{|c|}{ Observations (or Sum Wgts) } & 168 & \\
\hline \multicolumn{5}{|c|}{ Analysis of Variance } \\
\hline Source & DF & Sum of Squares & s Mean Square & F Ratio \\
\hline Model & 27 & 8.425928 & $\begin{array}{ll}3 & 0.312071\end{array}$ & 4.3791 \\
\hline Error & 140 & 9.977038 & 0.071265 & Prob $>$ F \\
\hline C. Total & 167 & 18.402966 & & $<.0001$ \\
\hline
\end{tabular}

Expected Mean Squares

The Mean Square per row by the Variance Component per column

$\begin{array}{lrr}\text { EMS } & \text { Intercept } & \text { Batch\&Random } \\ \text { Intercept } & 0 & 0\end{array}$

Batch\&Random $\quad 0 \quad 6$

plus 1.0 times Residual Error Variance

Variance Component Estimates

$\begin{array}{rrr}\text { Component } & \text { Var Comp Est } & \text { Percent of Total } \\ \text { Batch\&Random } & 0.040134 & 36.028\end{array}$

$\begin{array}{cll}\text { Batch\&Random } & 0.040134 & 36.028 \\ \text { Residual } & 0.071265 & 63.972\end{array}$

$\begin{array}{lrr}\text { Residual } & 0.071265 & 63.972 \\ \text { Total } & 0.111399 & 100.000\end{array}$

These estimates based on equating Mean Squares to Expected Value.

Test Denominator Synthesis

Source MS Den DF Den Denom MS Synthesis

Batch\&Random $0.07126 \quad 140$ Residual

Tests wrt Random Effects
Source SS MS Num DF Num F Ratio Prob > F

$\begin{array}{rrrrrr}\text { Batch\&Random } & 8.42593 & 0.31207 & 27 & 4.3791 & <.0001\end{array}$

Sample Type=SRAT, Prep=Cold Chem, ICP $=$ M-14, Analyte $=$ Al/Ca Response Measurement

Summary of Fit

RSquare $\quad 0.439896$

RSquare Adj $\quad 0.332024$

Root Mean Square Error $\quad 0.097675$

Mean of Response 3.808229

Observations (or Sum Wgts) $\quad 162$

Analysis of Variance

Source DF Sum of Squares Mean Square F Ratio

$\begin{array}{lrrrr}\text { Model } & 26 & 1.0115288 & 0.038905 & 4.0779\end{array}$

$\begin{array}{llll}\text { Error } & 135 & 1.2879445 & 0.009540 \text { Prob }>\text { F }\end{array}$

$\begin{array}{llll}\text { C. Total } & 161 & 2.2994734 & <.0001\end{array}$

Expected Mean Squares

The Mean Square per row by the Variance Component per column

$\begin{array}{lrr}\text { EMS } & \text { Intercept } & \text { Batch\&Random } \\ \text { Intercept } & 0 & 0 \\ \text { Batch\&Random } & 0 & 6\end{array}$

plus 1.0 times Residual Error Variance

Variance Component Estimates
$\begin{array}{ll}\text { Component } & \text { Var Comp Est Percent of Total }\end{array}$

\begin{tabular}{lrr} 
Component & Var Comp Est & Percent of Total \\
Batch\&Random & 0.004894 & 33.906 \\
Residual & 0.00954 & 66.094 \\
\hline
\end{tabular}

$\begin{array}{lrr}\text { Residual } & 0.00954 & 66.094 \\ \text { Total } & 0.014434 & 100.000\end{array}$

These estimates based on equating Mean Squares to Expected Value.

Test Denominator Synthesis

Source MS Den DF Den Denom MS Synthesis

$\begin{array}{lrrr}\text { Source } & \text { MS Den } & \text { DF Den } & \text { Denom } \\ \text { Batch\&Random } & 0.00954 & 135 & \text { Residual }\end{array}$

Tests wrt Random Effects

Source SS MS Num DF Num F Ratio Prob $>$ F

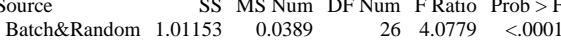


WSRC-STI-2006-00068

Revision 0

Exhibit A7. Analysis of Variance by Preparation Method, ICP, and Analyte (continued)

Sample Type=SRAT, Prep=Cold Chem, ICP $=$ M-14, Analyte=AI/Mg Response Measurement

Summary of Fi

\begin{tabular}{lrrrr} 
RSquare & 0.34661 & \\
RSquare Adj & 0.220958 & \\
Root Mean Square Error & 0.132666 & \\
Mean of Response & 3.881657 \\
Observations (or Sum Wgts) & 156 & \\
\multicolumn{5}{l}{} \\
\multicolumn{5}{l}{ Analysis of Variance } \\
Source & DF & Sum of Squares & Mean Square & F Ratio \\
Model & 25 & 1.2137498 & 0.048550 & 2.7585 \\
Error & 130 & 2.2880279 & 0.017600 & Prob > F \\
C. Total & 155 & 3.5017777 & & 0.0001
\end{tabular}

Expected Mean Squares

The Mean Square per row by the Variance Component per column

$\begin{array}{lrr}\text { EMS } & \text { Intercept } & \text { Batch\&Random } \\ \text { Intercept } & 0 & 0\end{array}$

Batch\&Random $\quad 0 \quad 6$

plus 1.0 times Residual Error Variance

Variance Component Estimates

Component Var Comp Est Percent of Total

Batch\&Random $\quad 0.005158 \quad 22.665$

$\begin{array}{lrr}\text { Residual } & 0.0176 & 77.335\end{array}$

Total $\quad 0.022759 \quad 100.000$

These estimates based on equating Mean Squares to Expected Value.

Test Denominator Synthesis

Source MS Den DF Den Denom MS Synthesis

Batch\&Random $\quad 0.0176 \quad 130$ Residual

Tests wrt Random Effects
Source SS MS Num DF Num F Ratio Prob > F

$\begin{array}{lrrrrr}\text { Source } & \text { SS } & \text { MS Num } & \text { DF Num } & \text { F Ratio } & \text { Prob }>\text { F } \\ \text { Batch\&Random } & 1.21375 & 0.04855 & 25 & 2.7585 & 0.0001\end{array}$

Sample Type $=$ SRAT, Prep $=$ Cold Chem, ICP $=M-14$, Analyte $=$ Al/Mn Response Measurement

Summary of Fit

RSquare $\quad 0.427243$

RSquare Adj $\quad 0.317274$

Root Mean Square Error $\quad 0.031031$

Mean of Response 1.623093

Observations (or Sum Wgts) 150

Analysis of Variance

Source DF Sum of Squares Mean Square F Ratio

$\begin{array}{lrrrr}\text { Model } \quad 24 & 0.08978287 & 0.003741 & 3.8851\end{array}$

$\begin{array}{lllll}\text { Error } & 125 & 0.12036179 & 0.000963 \quad \text { Prob }>\text { F }\end{array}$

$\begin{array}{llrl}\text { C. Total } 149 & 0.21014467 & <.0001\end{array}$

Expected Mean Squares

The Mean Square per row by the Variance Component per column

$\begin{array}{lrr}\text { EMS } & \text { Intercept } & \text { Batch\&Random } \\ \text { Intercept } & 0 & 0\end{array}$

$\begin{array}{lll}\text { Batch\&Random } & 0 & 0 \\ & 0 & 6\end{array}$

plus 1.0 times Residual Error Variance

Variance Component Estimates

Component Var Comp Est Percent of Total

$\begin{array}{lll}\text { Batch\&Random } \quad 0.000463 & 32.471\end{array}$

Residual $\quad 0.000963 \quad 67.529$

Total $\quad 0.001426 \quad 100.000$

These estimates based on equating Mean Squares to Expected Value.

Test Denominator Synthesis

Source MS Den DF Den Denom MS Synthesis

Batch\&Random $0.00096 \quad 125$ Residual

Tests wrt Random Effects

Source

SS MS Num DF Num F Ratio Prob $>$ F

$\begin{array}{llllll}\text { Batch\&Random } & 0.08978 & 0.00374 & 24 & 3.8851 & <.0001\end{array}$
Sample Type=SRAT, Prep=Cold Chem, ICP=M-14, Analyte=B Response Measurement

Summary of Fit

RSquare Adj $\quad 0.940544$

Root Mean Square Error $\quad 0.003899$

Mean of Response $\quad 0.007577$

Observations (or Sum Wgts)

Analysis of Variance

Source DF Sum of Squares Mean Square F Ratio

$\begin{array}{lllll}\text { Model } & 27 & 0.04056883 & 0.001503 & 98.8442\end{array}$

$\begin{array}{lllll}\text { Error } & 140 & 0.00212817 & 0.000015 & \text { Prob }>\text { F }\end{array}$

$\begin{array}{llr}\text { C. Total } 167 & 0.04269699 & <.000015\end{array}$

Expected Mean Squares

The Mean Square per row by the Variance Component per column

$\begin{array}{lrr}\text { EMS } & \text { Intercept } & \text { Batch\&Random } \\ \text { Intercept } & 0 & 0\end{array}$

$\begin{array}{lll}\text { Intercept } & 0 & 0 \\ \text { Batch\&Random } & 0 & 6\end{array}$

plus 1.0 times Residual Error Variance

Variance Component Estimates

Component Var Comp Est Percent of Total

$\begin{array}{crr}\text { Component } & \text { Var Comp Est } & \text { Percent of Total } \\ \text { Batch\&Random } & 0.000248 & 94.222 \\ \text { Residual } & 0.000015 & 5.778\end{array}$

$\begin{array}{lrr}\text { Residual } & 0.000015 & 5.778 \\ \text { Total } & 0.000263 & 100.000\end{array}$

These estimates based on equating Mean Squares to Expected Value.

Test Denominator Synthesis

Source MS Den DF Den Denom MS Synthesis

Batch\&Random $0.00002 \quad 140$ Residual

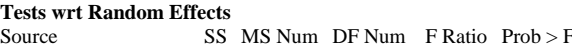

$\begin{array}{crrrrr}\text { Source } & \text { SS } & \text { MS Num } & \text { DF Num } & \text { F Ratio } & \text { Prob > F } \\ \text { Batch\&Random } & 0.04057 & 0.0015 & 27 & 98.8442 & <.0001\end{array}$

Sample Type=SRAT, Prep=Cold Chem, ICP $=M-14$, Analyte $=B / L i$ Response Measurement

Summary of Fit

RSquare Adj $\quad 0.737013$

0.68535
Rot Mean Square Error $\quad 0.533267$

or $\quad 0.533267$

$\begin{array}{lr}\text { Mean of Response } & -0.22092 \\ \text { Observations (or Sum Wgts) } & 135\end{array}$

Analysis of Variance

Source DF Sum of Squares Mean Square F Ratio

$\begin{array}{lrrrr}\text { Model } & 22 & 89.25817 & 4.05719 & 14.2671\end{array}$

$\begin{array}{lllll}\text { Error } & 112 & 31.84982 & 0.28437 & \text { Prob }>\text { F }\end{array}$

$\begin{array}{llll}\text { C. Total } 134 & 121.10798 & <.28437 & \text { P.0001 }\end{array}$

Expected Mean Squares

The Mean Square per row by the Variance Component per column

$\begin{array}{lrr}\text { EMS } & \text { Intercept } & \text { Batch\&Random } \\ \text { Intercept } & 0 & 0 \\ \text { Batch\&Random } & 0 & 5.86869\end{array}$

plus 1.0 times Residual Error Variance

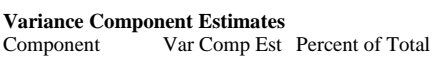

\begin{tabular}{crr} 
Component & Var Comp Est & Percent of Total \\
Batch\&Random & 0.642872 & 69.331 \\
Residual & 0.284373 & 30.669 \\
\hline
\end{tabular}

$\begin{array}{lrr}\text { Residual } & 0.284373 & 30.669 \\ \text { Total } & 0.927246 & 100.000\end{array}$

These estimates based on equating Mean Squares to Expected Value.

Test Denominator Synthesis

Source MS Den DF Den Denom MS Synthesis

$\begin{array}{crrr}\text { Source } & \text { MS Den } & \text { DF Den } & \text { Denom } \\ \text { Batch\&Random } & 0.28437 & 112 & \text { Residual }\end{array}$

Tests wrt Random Effects

Source SS MS Num DF Num F Ratio Prob $>$ F

$\begin{array}{rrrrrr}\text { Batch\&Random } & 89.2582 & 4.05719 & 22 & 14.2671 & <.0001\end{array}$ 
WSRC-STI-2006-00068

Revision 0

Exhibit A7. Analysis of Variance by Preparation Method, ICP, and Analyte (continued)

Sample Type=SRAT, Prep=Cold Chem, ICP=M-14, Analyte $=$ Ca Response Measurement

Summary of Fi

\begin{tabular}{|c|c|c|c|c|}
\hline \multicolumn{3}{|c|}{ RSquare } & 0.523064 & \\
\hline \multicolumn{3}{|c|}{ RSquare Adj } & 0.431652 & \\
\hline \multicolumn{3}{|c|}{ Root Mean Square Error } & 0.041737 & \\
\hline \multicolumn{3}{|c|}{ Mean of Response } & 1.336208 & \\
\hline \multicolumn{3}{|c|}{ Observations (or Sum Wgts) } & 144 & \\
\hline \multicolumn{5}{|c|}{ Analysis of Variance } \\
\hline Source & DF & Sum of Squares & s Mean Square & F Rat \\
\hline Model & 23 & 0.22925275 & $5 \quad 0.009968$ & 5.7220 \\
\hline Error & 120 & 0.20903500 & 0.001742 & Prob $>F$ \\
\hline C. Total & 143 & 0.43828775 & & $<.0001$ \\
\hline
\end{tabular}

Expected Mean Squares

The Mean Square per row by the Variance Component per column

$\begin{array}{lrr}\text { EMS } & \text { Intercept } & \text { Batch\&Random } \\ \text { Intercept } & 0 & 0\end{array}$

Batch\&Random

0

0

plus 1.0 times Residual Error Variance

Variance Component Estimates

Component Var Comp Est Percent of Total

Batch\&Random $\quad 0.001371 \quad r 4.040$

Residual $\quad 0.001742 \quad 55.960$

Total $\quad 0.003113 \quad 100.000$

These estimates based on equating Mean Squares to Expected Value.

Test Denominator Synthesis

Source MS Den DF Den Denom MS Synthesis

Batch\&Random $0.00174 \quad 120$ Residual

Tests wrt Random Effects
Source MS Num DF Num F Ratio Prob > F

$\begin{array}{lrrrrr}\text { Source } & \text { SS } & \text { MS Num } & \text { DF Num } & \text { F Ratio } & \text { Prob }>\text { F } \\ \text { Batch\&Random } & 0.22925 & 0.00997 & 23 & 5.7220 & <.0001\end{array}$

Sample Type=SRAT, Prep $=$ Cold Chem, ICP $=$ M-14, Analyte $=\mathrm{Cr}$ Response Measurement

Summary of Fit

RSquare $\quad 0.669013$

RSquare Adj $\quad 0.605179$

Root Mean Square Error $\quad 0.005372$

Mean of Response $\quad 0.08831$

Observations (or Sum Wgts) 168

Analysis of Variance

Source DF Sum of Squares Mean Square F Ratio

$\begin{array}{lrrrr}\text { Model } & 27 & 0.00816590 & 0.000302 & 10.4806\end{array}$

$\begin{array}{lllll}\text { Error } & 140 & 0.00404000 & 0.000029 & \text { Prob }>\text { F }\end{array}$

$\begin{array}{llll}\text { C. Total } 167 & 0.01220590 & <.0001\end{array}$

Expected Mean Squares

The Mean Square per row by the Variance Component per column

$\begin{array}{lrr}\text { EMS } & \text { Intercept } & \text { Batch\&Random } \\ \text { Intercept } & 0 & 0\end{array}$

$\begin{array}{lll}\text { Batch\&Random } & 0 & 0 \\ & 0 & 6\end{array}$

plus 1.0 times Residual Error Variance

Variance Component Estimates

Component Var Comp Est Percent of Total

Batch\&Random $\quad 0.000046 \quad 61.242$

$\begin{array}{lll}\text { Residual } & 0.000029 & 38.758\end{array}$

Total $\quad 0.000074 \quad 100.000$

These estimates based on equating Mean Squares to Expected Value.

Test Denominator Synthesis

Source MS Den DF Den Denom MS Synthesis

Batch\&Random $0.00003 \quad 140$ Residual

Tests wrt Random Effects

Source SS MS Num DF Num F Ratio Prob $>$ F

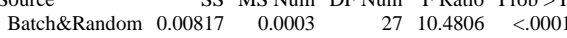

Sample Type=SRAT, Prep=Cold Chem, ICP $=M-14$, Analyte $=C$ Response Measurement

Summary of Fit

$\begin{array}{ll}\text { RSquare Adj } & 0.666572 \\ \text { Root Mean Square Error } & 0.002298\end{array}$

Mean of Response $\quad 0.028247$

Observations (or Sum Wgts)

Analysis of Variance

Source DF Sum of Squares Mean Square F Ratio

$\begin{array}{lllll}\text { Model } & 28 & 0.00197454 & 0.000071 & 13.3519\end{array}$

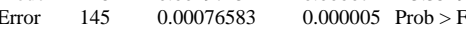

$\begin{array}{llll}\text { C. Total } 173 & 0.00274037 & <.0001\end{array}$

Expected Mean Squares

The Mean Square per row by the Variance Component per column

$\begin{array}{lrr}\text { EMS } & \text { Intercept } & \text { Batch\&Random } \\ \text { Intercept } & 0 & 0\end{array}$

$\begin{array}{ccc}\text { Intercept } & 0 & 0 \\ \text { Batch\&Random } & 0 & 6\end{array}$

plus 1.0 times Residual Error Variance

Variance Component Estimates

$\begin{array}{crr}\text { Component } & \text { Var Comp Est } & \text { Percent of Total } \\ \text { Batch\&Random } & 0.000011 & 67.306\end{array}$

$\begin{array}{ccc}\text { Batch\&Random } & 0.000011 & 67.306 \\ \text { Residual } & 0.000005 & 32.694\end{array}$

$\begin{array}{llr}\text { Total } & 0.000016 & 100.000\end{array}$

These estimates based on equating Mean Squares to Expected Value.

Test Denominator Synthesis

Source MS Den DF Den Denom MS Synthesis

Batch\&Random 5.28e-6 145 Residual

Tests wrt Random Effects
Source SS MS Num DF Num F Ratio Prob $>$

$\begin{array}{lrrrrr}\text { Source } & \text { SS } & \text { MS Num } & \text { DF Num } & \text { F Ratio } & \text { Prob }>\text { F } \\ \text { Batch\&Random } & 0.00197 & 0.00007 & 28 & 13.3519 & <.0001\end{array}$

Sample Type=SRAT, Prep=Cold Chem, ICP=M-14, Analyte=Fe Response Measurement

Summary of Fit

0.523388

RSquare Adj $\quad 0.431596$

Root Mean Square Error $\quad 0.772514$

Mean of Response 14.66683

Observations (or Sum Wgts) 162

Analysis of Variance

Source DF Sum of Squares Mean Square F Ratio

$\begin{array}{lrrrrr}\text { Model } & 26 & 88.47191 & 3.40277 & 5.7019\end{array}$

$\begin{array}{lllll}\text { Error } & 135 & 80.56507 & 0.59678 \text { Prob > F }\end{array}$

$\begin{array}{llll}\text { C. Total } & 161 & 169.03698 & <.59601\end{array}$

Expected Mean Squares

The Mean Square per row by the Variance Component per column

$\begin{array}{lrr}\text { EMS } & \text { Intercept } & \text { Batch\&Random } \\ \text { Intercept } & 0 & 0 \\ \text { Batch\&Random } & 0 & 6\end{array}$

plus 1.0 times Residual Error Variance

$\begin{array}{ll}\text { Variance Component Estimates } \\ \text { Component } & \text { Var Comp Est Percent of Total }\end{array}$

$\begin{array}{crr}\text { Component } & \text { Var Comp Est } & \text { Percent of Total } \\ \text { Batch\&Random } & 0.467665 & 43.935\end{array}$

$\begin{array}{ccc}\text { Batch\&Random } & 0.467665 & 43.935 \\ \text { Residual } & 0.596778 & 56.065\end{array}$

Total $1.064443 \quad 100.000$

These estimates based on equating Mean Squares to Expected Value.

Test Denominator Synthesis

Source MS Den DF Den Denom MS Synthesis

$\begin{array}{rrrr}\text { Source } & \text { MS Den } & \text { DF Den } & \text { Denomal } \\ \text { Batch\&Random } & 0.59678 & 135 \text { Residual }\end{array}$

Tests wrt Random Effects

Source SS MS Num DF Num F Ratio Prob $>$ F

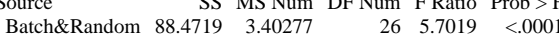


WSRC-STI-2006-00068

Revision 0

Exhibit A7. Analysis of Variance by Preparation Method, ICP, and Analyte (continued)

Sample Type=SRAT, Prep=Cold Chem, ICP=M-14, Analyte=Fe/Al Response Measurement

Summary of Fi

\begin{tabular}{|c|c|c|c|c|}
\hline \multicolumn{3}{|c|}{ RSquare } & 0.473363 & \\
\hline \multicolumn{3}{|c|}{ RSquare Adj } & 0.371937 & \\
\hline \multicolumn{3}{|c|}{ Root Mean Square Error } & 0.045665 & \\
\hline \multicolumn{3}{|c|}{ Mean of Response } & 2.88557 & \\
\hline \multicolumn{3}{|c|}{ Observations (or Sum Wgts) } & 162 & \\
\hline \multicolumn{5}{|c|}{ Analysis of Variance } \\
\hline Source & $\mathrm{DF}$ & Sum of Squares & Mean Square & F Ratio \\
\hline Model & 26 & 0.25303360 & 0.009732 & 4.6671 \\
\hline Error & 135 & 0.28151077 & 0.002085 & Prob $>\mathrm{F}$ \\
\hline C. Total & 161 & 0.53454437 & & $<.0001$ \\
\hline
\end{tabular}

Expected Mean Squares

The Mean Square per row by the Variance Component per column

$\begin{array}{lrr}\text { EMS } & \text { Intercept } & \text { Batch\&Random } \\ \text { Intercept } & 0 & 0\end{array}$

Batch\&Random

0

0

plus 1.0 times Residual Error Variance

Variance Component Estimates

Component Var Comp Est Percent of Total

$\begin{array}{lrr}\text { Component } & \text { Var Comp Est } & \text { Percent of Tota } \\ \text { Batch\&Random } & 0.001274 & 37.934\end{array}$

Residual $\quad 0.002085 \quad 62.066$

Total $\quad 0.00336 \quad 100.000$

These estimates based on equating Mean Squares to Expected Value.

Test Denominator Synthesis

Source MS Den DF Den Denom MS Synthesis

Batch\&Random $0.00209 \quad 135$ Residual

Tests wrt Random Effects
Source SS MS Num DF Num F Ratio Prob > F

$\begin{array}{lrrrrr}\text { Source } & \text { SS } & \text { MS Num } & \text { DF Num } & \text { F Ratio } & \text { Prob }>\text { F } \\ \text { Batch\&Random } & 0.25303 & 0.00973 & 26 & 4.6671 & <.0001\end{array}$

Sample Type=SRAT, Prep=Cold Chem, ICP $=\mathrm{M}-14$, Analyte $=\mathrm{Fe} / \mathrm{Ca}$ Response Measurement

Summary of Fit

RSquare $\quad 0.539372$

RSquare Adj $\quad 0.450658$

Root Mean Square Error $\quad 0.316415$

Mean of Response 10.99948

Observations (or Sum Wgts) 162

Analysis of Variance

Source DF Sum of Squares Mean Square F Ratio

$\begin{array}{lrrrrr}\text { Model } & 26 & 15.826487 & 0.608711 & 6.0799\end{array}$

$\begin{array}{lllll}\text { Error } & 135 & 13.515951 & 0.100118 \text { Prob }>\text { F }\end{array}$

$\begin{array}{llll}\text { C. Total } 161 & 29.342438 & <.0001\end{array}$

Expected Mean Squares

The Mean Square per row by the Variance Component per column

$\begin{array}{lrr}\text { EMS } & \text { Intercept } & \text { Batch\&Random } \\ \text { Intercept } & 0 & 0\end{array}$

$\begin{array}{lll}\text { Batch\&Random } & 0 & 0 \\ & 0 & 6\end{array}$

plus 1.0 times Residual Error Variance

Variance Component Estimates

Component Var Comp Est Percent of Total

Batch\&Random $\quad 0.084765 \quad 45.848$

$\begin{array}{lll}\text { Residual } & 0.100118 & 54.152\end{array}$

Total $\quad 0.184884 \quad 100.000$

These estimates based on equating Mean Squares to Expected Value.

Test Denominator Synthesis

Source MS Den DF Den Denom MS Synthesis

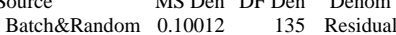

Tests wrt Random Effects

Source

SS MS Num DF Num F Ratio Prob $>$ F

Batch\&Random $15.8265 \quad 0.60871 \quad 26 \quad 6.0799<.0001$
Sample Type=SRAT, Prep=Cold Chem, ICP=M-14, Analyte=Fe/Li Response Measurement

Summary of Fit

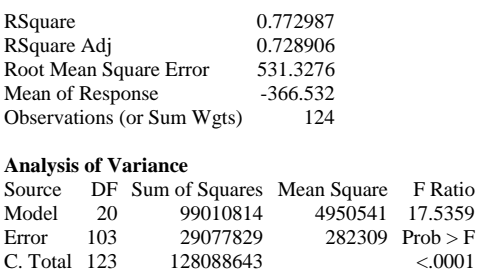

Expected Mean Squares

The Mean Square per row by the Variance Component per column

$\begin{array}{lrr}\text { EMS } & \text { Intercept } & \text { Batch\&Random } \\ \text { Intercept } & 0 & 0\end{array}$

$\begin{array}{llr}\text { Intercept } & 0 & 0 \\ \text { Batch\&Random } & 0 & 5.90403\end{array}$

plus 1.0 times Residual Error Variance

Variance Component Estimates

$\begin{array}{lrr}\text { Component } & \text { Var Comp Est } & \text { Percent of Total } \\ \text { Batch\&Random } & 790685.3 & 73.690 \\ \text { Residual } & 282309 & 26.310 \\ \text { Total } & 1072994 & 100.000\end{array}$

$\begin{array}{lcc}\text { Total } & 1072994 & 100.000 \\ \text { These estimates based on equating Mean Squares to Expected Value. }\end{array}$

Test Denominator Synthesis

Source MS Den DF Den Denom MS Synthesis

Batch\&Random $282309 \quad 103$ Residual

Tests wrt Random Effects
$\begin{aligned} & \text { Source } \\ & \text { SS MS Num DF Num F Ratio Prob }>\text { F }\end{aligned}$

$\begin{array}{lrrrrr}\text { Source } & \text { SS } & \text { MS Num } & \text { DF Num } & \text { F Ratio } & \text { Prob }>\text { F } \\ \text { Batch\&Random } & 9.901 \mathrm{e} 7 & 4950541 & 20 & 17.5359 & <.0001\end{array}$

Sample Type=SRAT, Prep=Cold Chem, ICP=M-14, Analyte=Fe $/ \mathrm{Mg}$ Response Measurement

Summary of Fit

RSquare $\quad 0.486046$

RSquare Adj $\quad 0.386927$

Root Mean Square Error $\quad 0.358858$

Mean of Response 11.20593

Observations (or Sum Wgts) 168

Analysis of Variance

Source DF Sum of Squares Mean Square F Ratio

$\begin{array}{lrrrr}\text { Model } & 27 & 17.050138 & 0.631487 & 4.9036\end{array}$

$\begin{array}{lllll}\text { Error } \quad 140 & 18.029095 & 0.128779 & \text { Prob }>\text { F }\end{array}$

$\begin{array}{llrl}\text { C. Total } 167 & 35.079233 & <.0001\end{array}$

Expected Mean Squares

The Mean Square per row by the Variance Component per column

$\begin{array}{lrr}\text { EMS } & \text { Intercept } & \text { Batch\&Random } \\ \text { Intercept } & 0 & 0 \\ \text { Batch\&Random } & 0 & 6\end{array}$

plus 1.0 times Residual Error Variance

$\begin{array}{ll}\text { Variance Component Estimates } \\ \text { Component } & \text { Var Comp Est Percent of Total }\end{array}$

$\begin{array}{crr}\text { Component } & \text { Var Comp Est } & \text { Percent of Total } \\ \text { Batch\&Random } & 0.083785 & 39.416\end{array}$

$\begin{array}{ccc}\text { Batch\&Random } & 0.083785 & 39.416 \\ \text { Residual } & 0.128779 & 60.584\end{array}$

$\begin{array}{llr}\text { Total } & 0.212564 & 100.000\end{array}$

These estimates based on equating Mean Squares to Expected Value.

Test Denominator Synthesis

Source MS Den DF Den Denom MS Synthesis

$\begin{array}{rrrr}\text { Source } & \text { MS Den } & \text { DF Den } & \text { Denomal } \\ \text { Batch\&Random } & 0.12878 & 140 & \text { Residual }\end{array}$

Tests wrt Random Effects

Source SS MS Num DF Num F Ratio Prob $>$ F

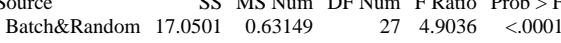


WSRC-STI-2006-00068

Revision 0

Exhibit A7. Analysis of Variance by Preparation Method, ICP, and Analyte (continued)

Sample Type=SRAT, Prep=Cold Chem, ICP=M-14, Analyte=Fe/Mn Response Measurement

Summary of Fi

\begin{tabular}{lrrrr} 
RSquare & 0.628361 & \\
RSquare Adj & 0.556688 & \\
Root Mean Square Error & 0.081638 & \\
Mean of Response & 4.686563 & \\
Observations (or Sum Wgts) & 168 & \\
\multicolumn{5}{l}{} \\
\multicolumn{7}{l}{ Analysis of Variance } \\
Source & DF & Sum of Squares & Mean Square & F Ratio \\
Model & 27 & 1.5776110 & 0.058430 & 8.7670 \\
Error & 140 & 0.9330640 & 0.006665 & Prob > F \\
C. Total & 167 & 2.5106751 & & $<.0001$
\end{tabular}

Expected Mean Squares

The Mean Square per row by the Variance Component per column

$\begin{array}{lrr}\text { EMS } & \text { Intercept } & \text { Batch\&Random } \\ \text { Intercept } & 0 & 0\end{array}$

Batch\&Random $\quad 0 \quad 6$

plus 1.0 times Residual Error Variance

Variance Component Estimates

Component Var Comp Est Percent of Total

Batch\&Random $\quad 0.008628 \quad 56.418$

$\begin{array}{lll}\text { Residual } & 0.008628 & 56.418 \\ \text { Totom } & 0.006665 & 43.582\end{array}$

Total $\quad 0.015292 \quad 100.000$

These estimates based on equating Mean Squares to Expected Value.

Test Denominator Synthesi

MS De

Batch\&Random $\quad 0.00666$

Tests wrt Random Effects
Source

$\begin{array}{lrrrrr}\text { Source } & \text { SS } & \text { MS Num } & \text { DF Num } & \text { F Ratio } & \text { Prob > F } \\ \text { Batch\&Random } & 1.57761 & 0.05843 & 27 & 8.7670 & <.0001\end{array}$

Sample Type=SRAT, Prep=Cold Chem, ICP=M-14, Analyte=Fe/Ni Response Measurement

Summary of Fit

RSquare $\quad 0.335887$

RSquare Adj $\quad 0.207984$

Root Mean Square Error $\quad 0.250914$

Mean of Response $\quad 17.21092$

Observations (or Sum Wgts) 162

Analysis of Variance

Source DF Sum of Squares Mean Square F Ratio

$\begin{array}{lrrrr}\text { Model } \quad 26 & 4.298690 & 0.165334 & 2.6261\end{array}$

$\begin{array}{lllll}\text { Error } & 135 & 8.499322 & 0.062958 \text { Prob }>\text { F }\end{array}$

$\begin{array}{lrr}\text { C. Total } 161 & 12.798012 & 0.0002\end{array}$

Expected Mean Squares

The Mean Square per row by the Variance Component per column

$\begin{array}{lrr}\text { EMS } & \text { Intercept } & \text { Batch\&Random } \\ \text { Intercept } & 0 & 0\end{array}$

$\begin{array}{lll}\text { Batch\&Random } & 0 & 0 \\ & 0 & 6\end{array}$

plus 1.0 times Residual Error Variance

Variance Component Estimates

Component Var Comp Est Percent of Total

$\begin{array}{ccc}\text { Batch\&Random } & 0.017063 & 21.323 \\ \text { Residual } & 0.062958 & 78.677\end{array}$

Total $\quad 0.080021 \quad 100.000$

These estimates based on equating Mean Squares to Expected Value.

Test Denominator Synthesis

Source MS Den DF Den Denom MS Synthesis

Batch\&Random $0.06296 \quad 135$ Residual

Tests wrt Random Effects

Source

SS MS Num DF Num F Ratio Prob $>$ F

$\begin{array}{rrrrrr}\text { Batch\&Random } & 4.29869 & 0.16533 & 26 & 2.6261 & 0.0002\end{array}$
Sample Type=SRAT, Prep=Cold Chem, ICP=M-14, Analyte=Fe/U Response Measurement

Summary of Fit

RSquare Adj $\quad 0.532245$

Root Mean Square Error $\quad 0.0803$

Mean of Response 2.648256

Observations (or Sum Wgts) $\quad 156$

Analysis of Variance

Source DF Sum of Squares Mean Square F Ratio

$\begin{array}{lllll}\text { Model } & 25 & 0.9538236 & 0.038153 & 5.9169\end{array}$

$\begin{array}{lllll}\text { Error } & 130 & 0.8382517 & 0.006448 & \text { Prob }>\text { F }\end{array}$

$\begin{array}{llr}\text { C. Total } 155 & 1.7920753 & <.0001\end{array}$

Expected Mean Squares

The Mean Square per row by the Variance Component per column

EMS Intercept Batch\&Random

$\begin{array}{crr}\text { Intercept } & 0 & 0 \\ \text { Batch\&Random } & 0 & 6\end{array}$

plus 1.0 times Residual Error Variance

Variance Component Estimates

Component Var Comp Est Percent of Total

$\begin{array}{rrr}\text { Component } & \text { Var } \\ \text { Batch \&andom } & 0.005284 & 45.040\end{array}$

$\begin{array}{lll}\text { Batch\&Random } & 0.005284 & 45.040 \\ \text { Residual } & 0.006448 & 54.960\end{array}$

$\begin{array}{lrr}\text { Residual } & 0.006448 & 54.960 \\ \text { Total } & 0.011732 & 100.000\end{array}$

These estimates based on equating Mean Squares to Expected Value.

Test Denominator Synthesis

DF Den Denom MS Synthesisource MS Den DF Den Denom MS Synthesis

140 Residual Batch\&Random $0.00645 \quad 130$ Residual

Tests wrt Random Effects

Source SS MS Num DF Num F Ratio Prob $>$ F

Batch\&Random $0.95382 \quad 0.03815 \quad 25 \quad 5.9169<0001$

Sample Type=SRAT, Prep=Cold Chem, ICP=M-14, Analyte $=K$ Response Measurement

Summary of Fit

0.704586

RSquare Adj $\quad 0.647473$

Root Mean Square Error $\quad 0.072786$

Mean of Response $\quad 0.159494$

Observations (or Sum Wgts) 180

Analysis of Variance

Source DF Sum of Squares Mean Square F Ratio

$\begin{array}{lrrrr}\text { Model } & 29 & 1.8953768 & 0.065358 & 12.3366\end{array}$

$\begin{array}{lllll}\text { Error } & 150 & 0.7946802 & 0.005298 & \text { Prob }>\text { F }\end{array}$

$\begin{array}{llll}\text { C. Total } & 179 & 2.6900570 & <.0001\end{array}$

Expected Mean Squares

The Mean Square per row by the Variance Component per column

$\begin{array}{lrr}\text { EMS } & \text { Intercept } & \text { Batch\&Random } \\ \text { Intercept } & 0 & 0 \\ \text { Batch\&Random } & 0 & 6\end{array}$

plus 1.0 times Residual Error Variance

Variance Component Estimates

Component Var Comp Est Percent of Total

$\begin{array}{lrr}\text { Batch\&Random } \quad 0.01001 & 65.391\end{array}$

$\begin{array}{lll}\text { Residual } & 0.005298 & 34.609\end{array}$

Total $\quad 0.015308 \quad 100.000$

These estimates based on equating Mean Squares to Expected Value.

Test Denominator Synthesis

Source MS Den DF Den Denom MS Synthesis

$\begin{array}{rrrr}\text { Source } & \text { MS Den } & \text { DF Den } & \text { Denomal } \\ \text { Batch\&Random } & 0.0053 & 150 & \text { Residual }\end{array}$

Tests wrt Random Effects

Source SS MS Num DF Num F Ratio Prob $>$ F

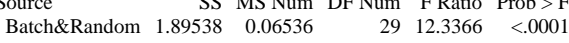


WSRC-STI-2006-00068

Revision 0

Exhibit A7. Analysis of Variance by Preparation Method, ICP, and Analyte (continued)

Sample Type=SRAT, Prep=Cold Chem, ICP=M-14, Analyte $=$ Li Response Measurement

Summary of Fi

\begin{tabular}{|c|c|c|c|c|}
\hline \multicolumn{3}{|c|}{ RSquare } & 0.88956 & \\
\hline \multicolumn{3}{|c|}{ RSquare Adj } & 0.86829 & \\
\hline \multicolumn{3}{|c|}{ Root Mean Square Error } & 0.00765 & \\
\hline \multicolumn{3}{|c|}{ Mean of Response } & -0.01106 & \\
\hline \multicolumn{3}{|c|}{ Observations (or Sum Wgts) } & 162 & \\
\hline \multicolumn{5}{|c|}{ Analysis of Variance } \\
\hline Source & DF & Sum of Squares & s Mean Square & F Ratio \\
\hline Model & 26 & 0.06363600 & $0 \quad 0.002448$ & 41.8224 \\
\hline Error & 135 & 0.00790050 & 0.000059 & Prob $>F$ \\
\hline C. Total & 161 & 0.07153650 & & $<.0001$ \\
\hline
\end{tabular}

Expected Mean Squares

The Mean Square per row by the Variance Component per column

$\begin{array}{lrr}\text { EMS } & \text { Intercept } & \text { Batch\&Random } \\ \text { Intercept } & 0 & 0\end{array}$

Batch\&Random

0

6

plus 1.0 times Residual Error Variance

Variance Component Estimates

Component Var Comp Est Percent of Total

$\begin{array}{rrr}\text { Batch\&Random } & 0.000398 & 87.186\end{array}$

$\begin{array}{lll}\text { Residual } & 0.000059 & 12.814\end{array}$

Total $\quad 0.000457 \quad 100.000$

These estimates based on equating Mean Squares to Expected Value.

Test Denominator Synthesis

Source MS Den DF Den Denom MS Synthesis

Batch\&Random $0.00006 \quad 135$ Residual

Tests wrt Random Effects
Source SS MS Num DF Num F Ratio Prob $>$ F

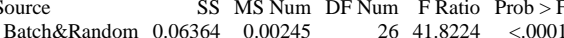

Sample Type=SRAT, Prep=Cold Chem, ICP=M-14, Analyte=Mg Response Measurement

Summary of Fit

RSquare $\quad 0.614052$

RSquare Adj $\quad 0.540218$

Root Mean Square Error $\quad 0.038519$

Mean of Response 1.316891

Observations (or Sum Wgts) 138

Analysis of Variance

Source DF Sum of Squares Mean Square F Ratio

$\begin{array}{llll}\text { Model } \quad 22 & 0.27147320 & 0.012340 & 8.3167\end{array}$

$\begin{array}{lllll}\text { Error } & 115 & 0.17062817 & 0.001484 \text { Prob }>\text { F }\end{array}$

$\begin{array}{llrl}\text { C. Total } & 137 & 0.44210137 & <.0001\end{array}$

Expected Mean Squares

The Mean Square per row by the Variance Component per column

$\begin{array}{lrr}\text { EMS } & \text { Intercept } & \text { Batch\&Random } \\ \text { Intercept } & 0 & 0\end{array}$

Batch\&Random $\quad 0 \quad 6$

plus 1.0 times Residual Error Variance

Variance Component Estimates

Component Var Comp Est Percent of Total

Batch\&Random $\quad 0.001809 \quad 54.944$

$\begin{array}{lll}\text { Residual } & 0.001484 & 45.056\end{array}$

Total $\quad 0.003293 \quad 100.000$

These estimates based on equating Mean Squares to Expected Value.

Test Denominator Synthesis

Source MS Den DF Den Denom MS Synthesis

Batch\&Random $0.00148 \quad 115$ Residual

Tests wrt Random Effects

Source

SS MS Num DF Num F Ratio Prob $>$ F

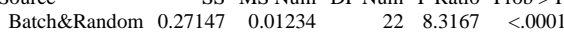

Sample Type=SRAT, Prep $=$ Cold Chem, ICP $=M-14$, Analyte $=M n$ Response Measurement

Summary of Fit

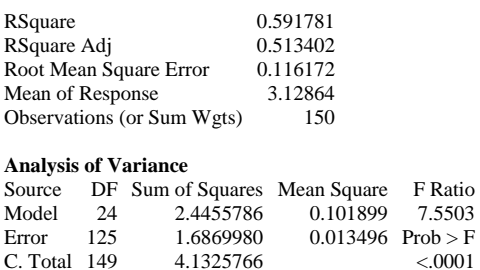

Expected Mean Squares

The Mean Square per row by the Variance Component per column

EMS Intercept Batch\&Random

$\begin{array}{lll}\text { Batch\&Random } & 0 & 0 \\ & 0 & 6\end{array}$

plus 1.0 times Residual Error Variance

Variance Component Estimates

$\begin{array}{crr}\text { Component } & \text { Var Comp Est } & \text { Percent of Total } \\ \text { Batch\&Random } & 0.014734 & 52.192 \\ \text { Residual } & 0.013496 & 47.808\end{array}$

Total $\quad 0.02823 \quad 100.000$

These estimates based on equating Mean Squares to Expected Value.

Test Denominator Synthesis

Source MS Den DF Den Denom MS Synthesis

Batch\&Random $0.0135 \quad 125$ Residual

Tests wrt Random Effects
SS MS Num DF Num F Ratio Prob > F

$\begin{array}{llllll}\text { Batch\&Random } 2.44558 & 0.1019 & 24 & 7.5503 & <.0001\end{array}$

Sample Type=SRAT, Prep=Cold Chem, ICP $=M-14$, Analyte $=M n / M g$ Response Measurement

Summary of Fit

RSquare $\quad 0.296519$

RSquare Adj $\quad 0.160674$

Root Mean Square Error $\quad 0.051937$

Mean of Response 2.388462

Observations (or Sum Wgts) $\quad 174$

Analysis of Variance

Source DF Sum of Squares Mean Square F Ratio

$\begin{array}{lrrrr}\text { Model } & 28 & 0.16486281 & 0.005888 & 2.1828\end{array}$

$\begin{array}{lllll}\text { Error } & 145 & 0.39113155 & 0.002697 & \text { Prob > F }\end{array}$

$\begin{array}{lll}\text { C. Total } 173 & 0.55599436 & 0.0015\end{array}$

Expected Mean Squares

The Mean Square per row by the Variance Component per column

$\begin{array}{lrr}\text { EMS } & \text { Intercept } & \text { Batch\&Random } \\ \text { Intercept } & 0 & 0 \\ \text { Batch\&Random } & 0 & 6\end{array}$

plus 1.0 times Residual Error Variance

Variance Component Estimates

Component Var Comp Est Percent of Total

$\begin{array}{lll}\text { Batch\&Random } \quad 0.000532 & 16.467\end{array}$

$\begin{array}{lll}\text { Residual } & 0.002697 & 83.533\end{array}$

Total $\quad 0.003229 \quad 100.000$

These estimates based on equating Mean Squares to Expected Value.

Test Denominator Synthesis

Source MS Den DF Den Denom MS Synthesis

$\begin{array}{rrrr}\text { Source } & \text { MS Den } & \text { DF Den } & \text { Denom MS } \\ \text { Batch\&Random } & 0.0027 & 145 & \text { Residual }\end{array}$

Tests wrt Random Effects

Source SS MS Num DF Num F Ratio Prob $>$ F

$\begin{array}{rrrrrr} & 0.16486 & 0.00589 & 28 & 2.1828 & 0.0015\end{array}$ 
WSRC-STI-2006-00068

Revision 0

Exhibit A7. Analysis of Variance by Preparation Method, ICP, and Analyte (continued)

Sample Type=SRAT, Prep=Cold Chem, ICP=M-14, Analyte=Na Response Measurement

Summary of Fi

\begin{tabular}{|c|c|c|c|}
\hline \multicolumn{2}{|c|}{ RSquare } & 0.7194 & \\
\hline \multicolumn{2}{|c|}{ RSquare Adj } & 0.665831 & \\
\hline \multicolumn{2}{|c|}{ Root Mean Square Error } & 0.243501 & \\
\hline \multicolumn{2}{|c|}{ Mean of Response } & 10.48891 & \\
\hline \multicolumn{2}{|c|}{ Observations (or Sum Wgts) } & 132 & \\
\hline \multicolumn{4}{|c|}{ Analysis of Variance } \\
\hline Source & DF Sum of Squares & es Mean Square & F Ratio \\
\hline Model & $21 \quad 16.721592$ & $2 \quad 0.796266$ & \\
\hline Error & 6.522213 & 0.059293 & Prob $>$ F \\
\hline C. Total & 23.24380 & & $<.0001$ \\
\hline
\end{tabular}

Expected Mean Squares

The Mean Square per row by the Variance Component per column

$\begin{array}{lrr}\text { EMS } & \text { Intercept } & \text { Batch\&Random } \\ \text { Intercept } & 0 & 0\end{array}$

Batch\&Random

0

0

plus 1.0 times Residual Error Variance

Variance Component Estimates

Component Var Comp Est Percent of Total

Batch\&Random $\quad 0.122829 \quad 67.443$

$\begin{array}{lll}\text { Residual } & 0.059293 & 32.557\end{array}$

Total $\quad 0.182122 \quad 100.000$

These estimates based on equating Mean Squares to Expected Value.

Test Denominator Synthesis

Source MS Den DF Den Denom MS Synthesis

Batch\&Random $0.05929 \quad 110$ Residual

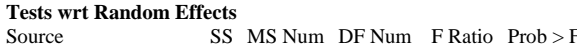

$\begin{array}{lrrrrr}\text { Source } & \text { SS } & \text { MS Num } & \text { DF Num } & \text { F Ratio } & \text { Prob }>\text { F } \\ \text { Batch\&Random } & 16.7216 & 0.79627 & 21 & 13.4294 & <0001\end{array}$

Sample Type=SRAT, Prep=Cold Chem, ICP $=M-14$, Analyte $=\mathrm{Ni}$

Response Measurement

Summary of Fit

RSquare $\quad 0.621063$

RSquare Adj $\quad 0.548433$

Root Mean Square Error $\quad 0.036561$

Mean of Response $\quad 0.852729$

Observations (or Sum Wgts) 144

Analysis of Variance

Source DF Sum of Squares Mean Square F Ratio

$\begin{array}{lrrrr}\text { Model } \quad 23 & 0.26289727 & 0.011430 & 8.5511\end{array}$

$\begin{array}{lllll}\text { Error } & 120 & 0.16040517 & 0.001337 & \text { Prob }>\text { F }\end{array}$

$\begin{array}{lllll}\text { C. Total } 143 & 0.42330244 & <.0001\end{array}$

Expected Mean Squares

The Mean Square per row by the Variance Component per column

$\begin{array}{lrr}\text { EMS } & \text { Intercept } & \text { Batch\&Random } \\ \text { Intercept } & 0 & 0\end{array}$

$\begin{array}{lll}\text { Batch\&Random } & 0 & 0 \\ \end{array}$

plus 1.0 times Residual Error Variance

Variance Component Estimates

Component Var Comp Est Percent of Total

$\begin{array}{lll}\text { Batch\&Random } & 0.001682 & 55.723 \\ \text { Residual } & 0.001337 & 44.277\end{array}$

$\begin{array}{llr}\text { Residual } & 0.001337 & 44.277 \\ \text { Total } & 0.003019 & 100.000\end{array}$

These estimates based on equating Mean Squares to Expected Value.

Test Denominator Synthesis

Source MS Den DF Den Denom MS Synthesis

Batch\&Random $0.00134 \quad 120$ Residual

Tests wrt Random Effects

Source SS MS Num DF Num F Ratio Prob $>$ F

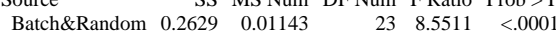

Sample Type=SRAT, Prep=Cold Chem, ICP=M-14, Analyte $=$ S Response Measurement

Summary of Fit

RSquare Adj $\quad 0.900854$

Root Mean Square Error $\quad 0.060247$

Mean of Response $\quad 1.078161$

Observations (or Sum Wgts) $\quad 174$

Analysis of Variance

Source DF Sum of Squares Mean Square F Ratio

$\begin{array}{lllll}\text { Model } & 28 & 5.8071805 & 0.207399 & 57.1390\end{array}$

$\begin{array}{llll}\text { Error } & 145 & 0.5263110 & 0.003630 \text { Prob }>\text { F }\end{array}$

$\begin{array}{lll}\text { C. Total } 173 \quad 6.3334915 & <.0001\end{array}$

Expected Mean Squares

The Mean Square per row by the Variance Component per column

$\begin{array}{lrr}\text { EMS } & \text { Intercept } & \text { Batch\&Random } \\ \text { Intercept } & 0 & 0\end{array}$

Batch\&Random $\quad 0 \quad 6$

plus 1.0 times Residual Error Variance

Variance Component Estimates

Component Var Comp Est Percent of Total

$\begin{array}{crr}\text { Component } & \text { Var Comp Est } & \text { Percent of Total } \\ \text { Batch\&Random } & 0.033962 & 90.344 \\ \text { Residual } & 0.00363 & 9.656\end{array}$

$\begin{array}{lrr}\text { Residual } & 0.00363 & 9.656 \\ \text { Total } & 0.037591 & 100.000\end{array}$

These estimates based on equating Mean Squares to Expected Value.

Test Denominator Synthesis

Source MS Den DF Den Denom MS Synthesis

Batch\&Random $0.00363 \quad 145$ Residual

$\begin{array}{lrrrrr}\text { Tests wrt Random Effects } & & & & \\ \text { Source } & \text { SS } & \text { MS Num } & \text { DF Num } & \text { F Ratio } & \text { Prob > F } \\ \text { Batch\&Random } & 5.80718 & 0.2074 & 28 & 57.1390 & <.0001\end{array}$

Sample Type=SRAT, Prep=Cold Chem, ICP=M-14, Analyte=Sum of Oxides Response Measurement

Summary of Fit

RSquare $\quad 0.470796$

RSquare Adj $\quad 0.369189$

Root Mean Square Error $\quad 2.457654$

Mean of Response 62.99344

Observations (or Sum Wgts) 150

Analysis of Variance

Source DF Sum of Squares Mean Square F Ratio

$\begin{array}{lrrrr}\text { Model } & 24 & 671.6789 & 27.9866 & 4.6335\end{array}$

$\begin{array}{lllll}\text { Error } & 125 & 755.0080 & 6.0401 \text { Prob }>\text { F }\end{array}$

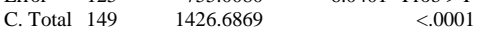

Expected Mean Squares

The Mean Square per row by the Variance Component per column

$\begin{array}{lrr}\text { EMS } & \text { Intercept } & \text { Batch\&Random } \\ \text { Intercept } & 0 & 0 \\ \text { Batch\&Random } & 0 & 6\end{array}$

plus 1.0 times Residual Error Variance

Variance Component Estimates

Component Var Comp Est Percent of Total

$\begin{array}{lll}\text { Batch\&Random } \quad 3.657759 & 37.717\end{array}$

Residual $\quad 6.040064 \quad 62.283$

Total $\quad 9.697823 \quad 100.000$

These estimates based on equating Mean Squares to Expected Value.

Test Denominator Synthesis

Source MS Den DF Den Denom MS Synthesis

$\begin{array}{lrr}\text { Source } & \text { MS Den } & \text { DF Den } \\ \text { Batch\&Random } & 6.04006 & 125 \text { Residual }\end{array}$

Tests wrt Random Effects

Source SS MS Num DF Num F Ratio Prob $>$ F

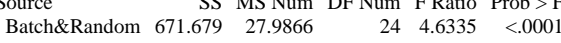


WSRC-STI-2006-00068

Revision 0

Exhibit A7. Analysis of Variance by Preparation Method, ICP, and Analyte (continued)

Sample Type=SRAT, Prep=Cold Chem, ICP=M-14, Analyte $=$ Ti Response Measurement

Summary of Fi

\begin{tabular}{|c|c|c|c|c|}
\hline \multicolumn{3}{|l|}{ RSquare } & \multicolumn{2}{|l|}{0.900313} \\
\hline \multicolumn{3}{|c|}{ RSquare Adj } & 0.881087 & \\
\hline \multicolumn{3}{|c|}{ Root Mean Square Error } & 0.001284 & \\
\hline \multicolumn{3}{|c|}{ Mean of Response } & 0.016476 & \\
\hline \multicolumn{3}{|c|}{ Observations (or Sum Wgts) } & 168 & \\
\hline \multicolumn{5}{|c|}{ Analysis of Variance } \\
\hline Source & $\mathrm{DF}$ & Sum of Squares & s Mean Square & F Ratio \\
\hline Model & 27 & 0.00208324 & $\begin{array}{ll}4 & 0.000077\end{array}$ & 46.8294 \\
\hline Error & 140 & 0.00023067 & 0.000002 & Prob $>$ F \\
\hline C. Total & 167 & 0.00231390 & & $<.0001$ \\
\hline
\end{tabular}

Expected Mean Squares

The Mean Square per row by the Variance Component per column

$\begin{array}{lrr}\text { EMS } & \text { Intercept } & \text { Batch\&Random } \\ \text { Intercept } & 0 & 0\end{array}$

Batch\&Random $\quad 0 \quad 6$

plus 1.0 times Residual Error Variance

Variance Component Estimates

Component Var Comp Est Percent of Total

Batch\&Random $\quad 0.000013 \quad 88.424$

Residual $\quad 0.000002 \quad 11.576$

$\begin{array}{lll}\text { Total } & 0.000014 & 100.000\end{array}$

These estimates based on equating Mean Squares to Expected Value.

Test Denominator Synthesis

Source MS Den DF Den Denom MS Synthesis

Batch\&Random $\quad 1.65 e-6 \quad 140$ Residual

Tests wrt Random Effects
Source MS Num DF Num F Ratio Prob $>$ F

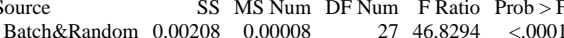

Sample Type=SRAT, Prep=Cold Chem, ICP $=$ M-14, Analyte $=U$

Response Measurement

Summary of Fit

RSquare $\quad 0.518183$

RSquare Adj $\quad 0.425526$

Root Mean Square Error $\quad 0.220675$

Mean of Response $\quad 5.506865$

Observations (or Sum Wgts) 156

Analysis of Variance

Source DF Sum of Squares Mean Square F Ratio

\begin{tabular}{lrrrr} 
Model & 25 & 6.808463 & 0.272339 & 5.5925 \\
\hline
\end{tabular}

$\begin{array}{lllll}\text { Error } & 130 & 6.330653 & 0.048697 \quad \text { Prob }>\text { F }\end{array}$

$\begin{array}{lrr}\text { C. Total } 155 & 13.139116 & <.0001\end{array}$

Expected Mean Squares

The Mean Square per row by the Variance Component per column

$\begin{array}{lrr}\text { EMS } & \text { Intercept } & \text { Batch\&Random } \\ \text { Intercept } & 0 & 0\end{array}$

Batch\&Random $\quad 0 \quad 6$

plus 1.0 times Residual Error Variance

Variance Component Estimates

Component Var Comp Est Percent of Total

Batch\&Random $\quad 0.037274 \quad 43.356$

Residual $\quad 0.048697 \quad 56.644$

Total $\quad 0.085971 \quad 100.000$

These estimates based on equating Mean Squares to Expected Value.

Test Denominator Synthesis

Source MS Den DF Den Denom MS Synthesis

Batch\&Random $\begin{array}{rrr}0.0487 & 130 \text { Residual }\end{array}$

Tests wrt Random Effects

Source

SS MS Num DF Num F Ratio Prob $>$ F

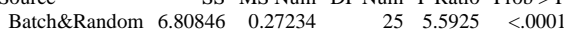

Sample Type=SRAT, Prep=Cold Chem, ICP=M-14, Analyte=U/Ca Response Measurement

Summary of Fit

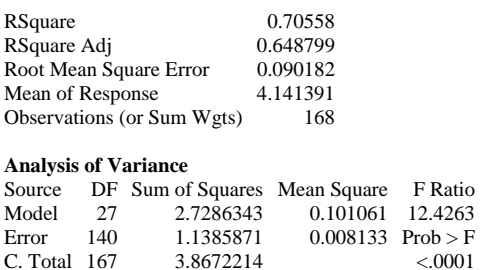

Expected Mean Squares

The Mean Square per row by the Variance Component per column

EMS Intercept Batch\&Random

$\begin{array}{lll}\text { Batch\&Random } & 0 & 0 \\ & 0 & 6\end{array}$

plus 1.0 times Residual Error Variance

Variance Component Estimates

\begin{tabular}{crr} 
Component & Var Comp Est & Percent of Total \\
Batch\&Random & 0.015488 & 65.569 \\
\hline
\end{tabular}

$\begin{array}{lll}\text { Residual } & 0.008133 & 34.431\end{array}$

Total $\quad 0.023621 \quad 100.000$

These estimates based on equating Mean Squares to Expected Value.

Test Denominator Synthesis

Source MS Den DF Den Denom MS Synthesis

Batch\&Random $0.00813 \quad 140$ Residual

Tests wrt Random Effects
Source

$\begin{array}{rrrrrr}\text { Batch\&Random } & 2.72863 & 0.10106 & 27 & 12.4263 & <.0001\end{array}$

Sample Type=SRAT, Prep=Cold Chem, ICP $=$ M-14, Analyte $=Z \mathbf{Z r}$ Response Measurement

Summary of Fit

RSquare Adj $\quad 0.634318$

Root Mean Square Error $\quad 0.004327$

Mean of Response $\quad 0.07804$

Observations (or Sum Wgts) 174

Analysis of Variance

Source DF Sum of Squares Mean Square F Ratio

$\begin{array}{llllll}\text { Model } & 28 & 0.00614355 & 0.000219 & 11.7174\end{array}$

$\begin{array}{lllll}\text { Error } & 145 & 0.00271517 & 0.000019 & \text { Prob }>\text { F }\end{array}$

$\begin{array}{llll}\text { C. Total } & 173 & 0.00885872 & <.0001\end{array}$

Expected Mean Squares

The Mean Square per row by the Variance Component per column

$\begin{array}{lrr}\text { EMS } & \text { Intercept } & \text { Batch\&Random } \\ \text { Intercept } & 0 & 0 \\ \text { Batch\&Random } & 0 & 6\end{array}$

plus 1.0 times Residual Error Variance

Variance Component Estimates
Component Var Comp Est Percent of Total

$\begin{array}{crr}\text { Component } & \text { Var Comp Est } & \text { Percent of Total } \\ \text { Batch\&Random } & 0.000033 & 64.109 \\ \text { Residual } & 0.000019 & 35.891\end{array}$

$\begin{array}{llr}\text { Residual } & 0.000019 & 35.891 \\ \text { Total } & 0.000052 & 100.000\end{array}$

These estimates based on equating Mean Squares to Expected Value.

Test Denominator Synthesis

Source MS Den DF Den Denom MS Synthesis

$\begin{array}{lrrr}\text { Source } & \text { MS Den } & \text { DF Den } & \text { Denom } \\ \text { Batch\&Random } & 0.00002 & 145 & \text { Residual }\end{array}$

Tests wrt Random Effects

Source SS MS Num DF Num F Ratio Prob $>$ F

$\begin{array}{rrrrrr} & \text { SS } & \text { MS Num } & \text { DF Num } & \text { F Ratio } & \text { Prob > F } \\ \text { Batch\&Random } & 0.00614 & 0.00022 & 28 & 11.7174 & <.0001\end{array}$ 
WSRC-STI-2006-00068

Revision 0

Exhibit A8. JMP Formulas Used to Conduct Sensitivity Study for Targeting WL at Blending

Formula for Targeted WL Using Uncertainties of M-13 ICP

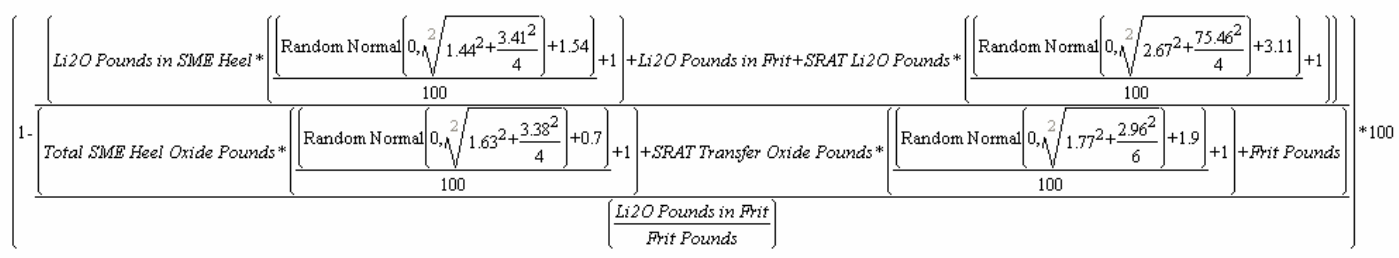

Formula for Targeted WL Using Uncertainties of M-14 ICP

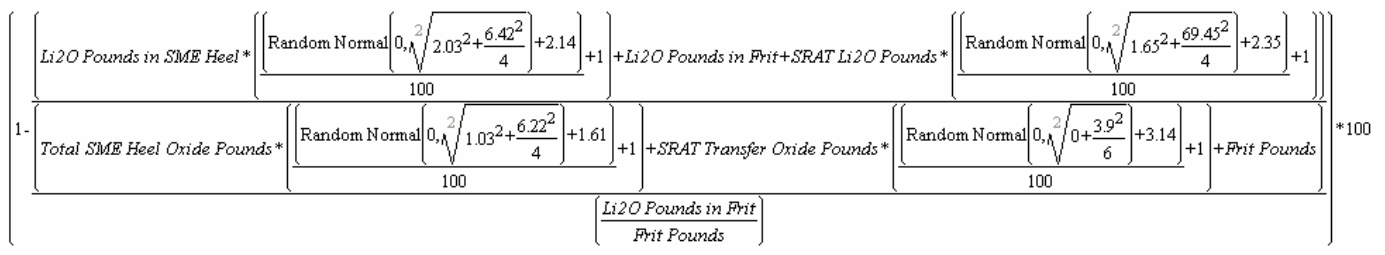


WSRC-STI-2006-00068

Revision 0

Exhibit A9. Sensitivity of Blending Target WLs to the Uncertainties of This Report

Batch $=300$

Blending $\mathrm{WL}=36.47$

WL Calc $=36.51$

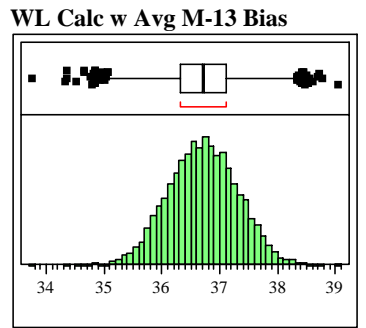

Quantiles

$100.0 \%$ maximum 39.053

$99.5 \% \quad 38.241$

$97.5 \% \quad 37.855$

$90.0 \% \quad 37.482$

$75.0 \%$ quartile $\quad 37.116$

$50.0 \%$ median 36.715

$25.0 \%$ quartile $\quad 36.307$

$10.0 \%$

$2.5 \% \quad 35.544$

$0.5 \% \quad 35.180$

$0.0 \%$ minimum 33.775

Moments

Mean $\quad 36.711588$

Std Dev $\quad 0.5977405$

Std Err Mean $\quad 0.0059774$

upper 95\% Mean 36.723305

lower 95\% Mean 36.699871

$\mathrm{N}$

10000

WL Calc w Avg M-14 Bias

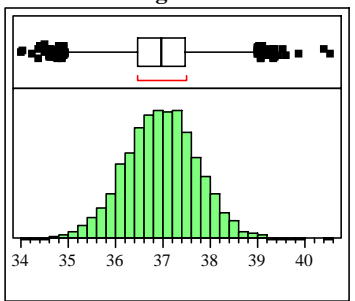

Quantiles

$100.0 \%$ maximum 40.536

$99.5 \% \quad 38.954$

$97.5 \% \quad 38.446$

$90.0 \% \quad 37.926$

$75.0 \%$ quartile 37.477

$50.0 \%$ median 36.973

$25.0 \%$ quartile 36.462

$10.0 \% \quad 36.009$

$2.5 \% \quad 35.452$

$0.5 \% \quad 34.957$

$0.0 \%$ minimum 34.022

Moments

Mean 36.965906

Std Dev $\quad 0.758823$

Std Err Mean $\quad 0.0075882$

upper 95\% Mean 36.980781

lower 95\% Mean 36.951032

$\mathrm{N}$
Batch $=301$

Blending WL = 35.31

WL Calc $=35.35$

WL Calc w Avg M-13 Bias

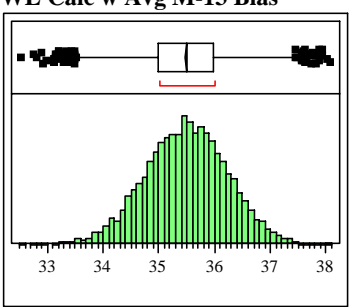

Quantiles

$100.0 \%$ maximum 38.091

$99.5 \% \quad 37.338$

$97.5 \% \quad 36.894$

$90.0 \% \quad 36.413$

$75.0 \%$ quartile 35.983

$50.0 \%$ median 35.498

$25.0 \%$ quartile 35.001

$10.0 \% \quad 34.547$

$2.5 \% \quad 34.038$

$0.5 \% \quad 33.512$

$0.0 \%$ minimum 32.542

Moments

Mean $\quad 35.489434$

Std Dev $\quad 0.7312574$

Std Err Mean $\quad 0.0073126$

upper 95\% Mean 35.503768

lower 95\% Mean 35.4751

$\mathrm{N} \quad 10000$

WL Calc w Avg M-14 Bias

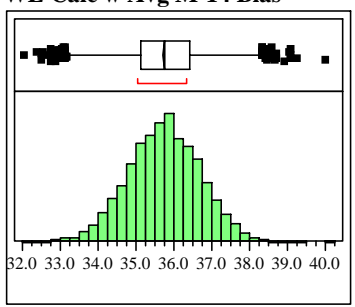

Quantiles

$100.0 \%$ maximum 40.028

$99.5 \% \quad 38.184$

$\begin{array}{ll}97.5 \% & 37.599\end{array}$

$90.0 \% \quad 36.949$

$75.0 \%$ quartile 36.398

$50.0 \%$ median 35.759

$25.0 \%$ quartile 35.108

$10.0 \% \quad 34.511$

$2.5 \% \quad 33.856$

$0.5 \% \quad 33.196$

$0.0 \%$ minimum 32.054

Moments

Mean $\quad 35.744969$

Std Dev $\quad 0.9509611$

Std Err Mean 0.0095096

upper 95\% Mean 35.76361

lower 95\% Mean 35.726328
Batch $=302$

Blending $W L=37.57$

WL Calc $=37.61$

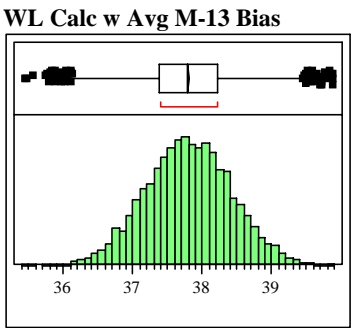

Quantiles

$100.0 \%$ maximum 39.897

$\begin{array}{ll}99.5 \% & 39.355 \\ 97.5 \% & 39.010\end{array}$

$97.5 \% \quad 39.010$

$90.0 \% \quad 38.583$

$75.0 \%$ quartile 38.213

$50.0 \%$ median 37.795

$25.0 \%$ quartile $\quad 37.379$

$10.0 \% \quad 37.008$

$2.5 \% \quad 36.593$

$0.5 \% \quad 36.203$

$0.0 \%$ minimum 35.468

Moments

Mean $\quad 37.796737$

Std Dev $\quad 0.6158182$

Std Err Mean $\quad 0.0061582$

upper 95\% Mean 37.808808$$
\mathrm{N}
$$

WL Calc w Avg M-14 Bias

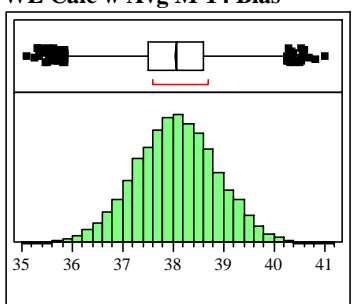

Quantiles

$100.0 \%$ maximum 41.028

$99.5 \%$

$\begin{array}{ll}97.5 \% & 39.628\end{array}$

$90.0 \% \quad 39.108$

$75.0 \%$ quartile 38.605

$50.0 \%$ median 38.056

$25.0 \%$ quartile 37.509

$10.0 \% \quad 37.021$

$2.5 \% \quad 36.456$

$0.5 \% \quad 35.980$

$0.0 \%$ minimum 35.119

Moments

Mean $\quad 38.058718$

Std Dev $\quad 0.80861$

Std Err Mean $\quad 0.0080861$

upper 95\% Mean 38.074568

lower 95\% Mean 38.042867

$\mathrm{N}$
Batch $=303$

Blending WL $=35.70$

WL Calc $=35.74$

WL Calc w Avg M-13 Bias

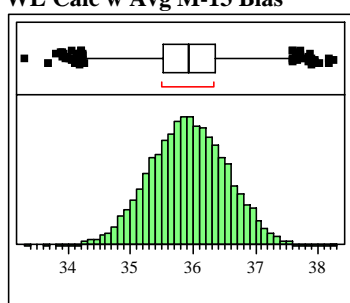

Quantiles

$100.0 \%$ maximum 38.266

$99.5 \% \quad 37.477$

$97.5 \% \quad 37.109$

$90.0 \% \quad 36.711$

$75.0 \%$ quartile 36.343

$50.0 \%$ median 35.923

$25.0 \%$ quartile 35.511

$10.0 \% \quad 35.148$

$2.5 \% \quad 34.736$

$0.5 \% \quad 34.333$

$0.0 \%$ minimum 33.323

Moments

Mean $\quad 35.926397$

Std Dev $\quad 0.6104064$

Std Err Mean $\quad 0.0061041$

upper 95\% Mean 35.938362

lower 95\% Mean 35.914431

N 10000

WL Calc w Avg M-14 Bias

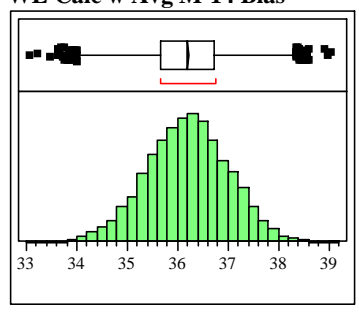

Quantiles

$100.0 \%$ maximum 39.067

$99.5 \% \quad 38.263$

$97.5 \% \quad 37.751$

$90.0 \% \quad 37.241$

$75.0 \%$ quartile 36.737

$50.0 \%$ median 36.208

$25.0 \%$ quartile 35.655

$10.0 \% \quad 35.168$

$2.5 \% \quad 34.548$

$0.5 \% \quad 34.084$

$0.0 \%$ minimum 33.077

Moments

Mean $\quad 36.196299$

Std Dev $\quad 0.8091581$

Std Err Mean $\quad 0.0080916$

upper 95\% Mean 36.21216

lower 95\% Mean 36.180438

$\mathrm{N} \quad 10000$ 
WSRC-STI-2006-00068

Revision 0

Exhibit A9. Sensitivity of Blending Target WLs to the Uncertainties of This Report (continued)

\section{Batch $=304$}

Blending $\mathrm{WL}=34.73$

WL Calc $=34.78$

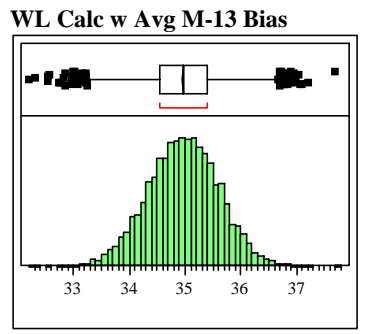

Quantiles

$100.0 \%$ maximum 37.714

$99.5 \% \quad 36.586$

$97.5 \% \quad 36.178$

$90.0 \% \quad 35.755$

$75.0 \%$ quartile 35.397

$50.0 \%$ median 34.973

$25.0 \%$ quartile 34.543

$10.0 \% \quad 34.155$

$2.5 \% \quad 33.712$

$0.5 \% \quad 33.319$

$0.0 \% \quad$ minimum 32.209

Moments

Mean $\quad 34.966868$

Std Dev

0.6320947

Std Err Mean $\quad 0.0063209$

upper 95\% Mean 34.979258

lower 95\% Mean 34.954478

$\mathrm{N}$

10000

WL Calc w Avg M-14 Bias

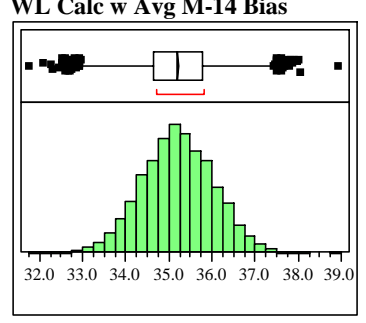

Quantiles

$100.0 \%$ maximum 38.932

$99.5 \% \quad 37.271$

$97.5 \% \quad 36.811$

$90.0 \% \quad 36.275$

$75.0 \%$ quartile $\quad 35.771$

$50.0 \%$ median 35.196

$25.0 \%$ quartile 34.650

$10.0 \% \quad 34.141$

$2.5 \% \quad 33.583$

$0.5 \% \quad 33.052$

$0.0 \%$ minimum 31.759

Moments

Mean $\quad 35.202991$

Std Dev $\quad 0.8264575$

Std Err Mean $\quad 0.0082646$

upper 95\% Mean 35.219191

lower 95\% Mean 35.186791

$\mathrm{N}$

10000
Batch $=305$

Blending $\mathrm{WL}=\mathbf{3 6 . 0 0}$

WL Calc $=36.05$

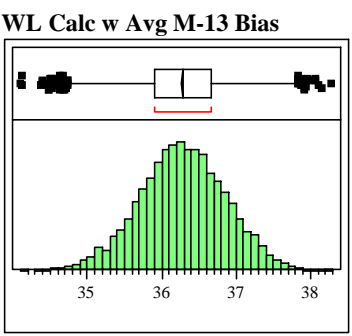

Quantiles

$100.0 \%$ maximum 38.283

$\begin{array}{ll}97.5 \% & 37.384\end{array}$

$90.0 \% \quad 37.018$

$75.0 \%$ quartile 36.671

$50.0 \%$ median 36.276

$25.0 \%$ quartile 35.902

$10.0 \% \quad 35.550$

$2.5 \% \quad 35.127$

$0.5 \% \quad 34.761$

$0.0 \%$ minimum 34.116

Moments

Mean $\quad 36.280693$

Std Dev $\quad 0.5737744$

Std Err Mean $\quad 0.0057377$

upper 95\% Mean 36.291941

lower 95\% Mean 36.269446

$\mathrm{N}$

10000

WL Calc w Avg M-14 Bias

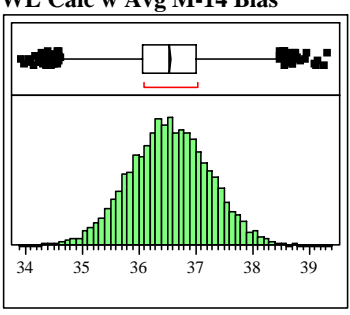

Quantiles

Batch $=306$

Blending WL $=35.76$

WL Calc $=35.81$

WL Calc w Avg M-13 Bias

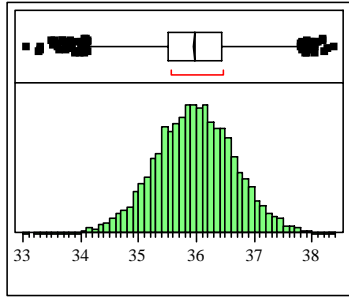

Quantiles

$100.0 \%$ maximum 38.386

$99.5 \% \quad 37.737$

$\begin{array}{ll}97.5 \% & 37.326\end{array}$

$90.0 \% \quad 36.841$

$75.0 \%$ quartile 36.433

$50.0 \%$ median 35.975

$25.0 \%$ quartile 35.512

$10.0 \% \quad 35.110$

$2.5 \% \quad 34.616$

$0.5 \% \quad 34.165$

$0.0 \%$ minimum 33.065

Moments

Mean

Std Dev $\quad 0.6813711$

Std Err Mean $\quad 0.0068137$

upper 95\% Mean 35.985559

lower 95\% Mean 35.958846

$\mathrm{N}$

10000

WL Calc w Avg M-14 Bias

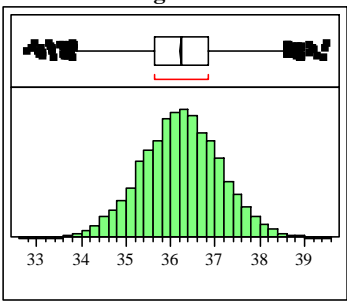

Quantiles

$100.0 \%$ maximum 39.329

$99.5 \% \quad 38.382$

$97.5 \% \quad 37.918$

$90.0 \% \quad 37.446$

$75.0 \%$ quartile 37.021

$50.0 \%$ median 36.540

$25.0 \%$ quartile 36.064

$10.0 \% \quad 35.637$

$2.5 \% \quad 35.149$

$0.5 \% \quad 34.647$

$0.0 \%$ minimum 33.932

Moments

Mean $\quad 36.542283$

Std Dev $\quad 0.7114382$

Std Err Mean $\quad 0.007114$

upper 95\% Mean 36.556229

lower 95\% Mean 36.528338

$\mathrm{N}$

10000

$100.0 \%$ maximum 39.527

$99.5 \% \quad 38.559$

$97.5 \% \quad 37.964$

$90.0 \% \quad 37.359$

$75.0 \%$ quartile 36.830

$50.0 \%$ median 36.236

$25.0 \%$ quartile 35.642

$10.0 \% \quad 35.101$

$2.5 \% \quad 34.461$

$0.5 \% \quad 33.884$

$0.0 \%$ minimum 32.792

Moments

Mean $\quad 36.232027$

Std Dev $\quad 0.8897052$

Std Err Mean $\quad 0.0088971$

upper 95\% Mean 36.249467

lower 95\% Mean 36.214587

$\mathrm{N}$

10000
Batch $=307$

Blending $\mathrm{WL}=\mathbf{3 5 . 8 4}$

WL Calc $=35.90$

WL Calc w Avg M-13 Bias

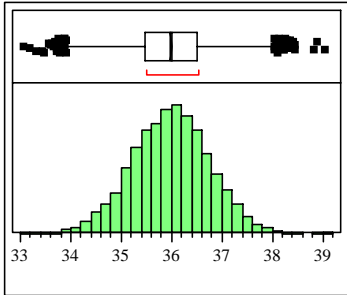

Quantiles

$100.0 \%$ maximum 39.074

$99.5 \% \quad 37.922$

$97.5 \% \quad 37.432$

$90.0 \% \quad 36.935$

$75.0 \%$ quartile 36.494

$50.0 \%$ median 35.991

$25.0 \%$ quartile 35.467

$10.0 \% \quad 35.020$

$2.5 \% \quad 34.464$

$0.5 \% \quad 33.996$

$0.0 \%$ minimum 33.078

Moments

Mean $\quad 35.980431$

Std Dev $\quad 0.756274$

Std Err Mean $\quad 0.0075627$

upper 95\% Mean 35.995256

lower 95\% Mean 35.965607

WL Calc w Avg M-14 Bias

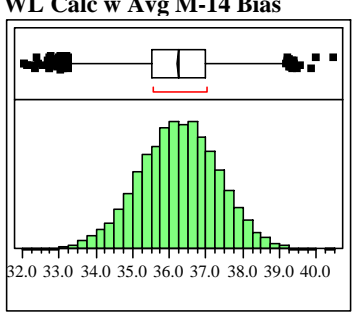

Quantiles
$100.0 \%$ maximum 40.494

$99.5 \% \quad 38.958$

$97.5 \% \quad 38.296$

$90.0 \% \quad 37.610$

$75.0 \%$ quartile 36.985

$50.0 \%$ median 36.260

$25.0 \%$ quartile 35.518

$10.0 \% \quad 34.858$

$2.5 \% \quad 34.065$

$0.5 \% \quad 33.357$

$0.0 \%$ minimum 32.047

Moments

Mean

Std Dev $\quad 36.243$

Std Err Mean $\quad 0.010802$

upper 95\% Mean 36.264527

lower 95\% Mean 36.222179

$\mathrm{N}$

10000 
WSRC-STI-2006-00068

Revision 0

Exhibit A9. Sensitivity of Blending Target WLs to the Uncertainties of This Report (continued)

Batch $=308$

Blending WL = 34.92

WL Calc $=34.98$

WL Calc w Avg M-13 Bias

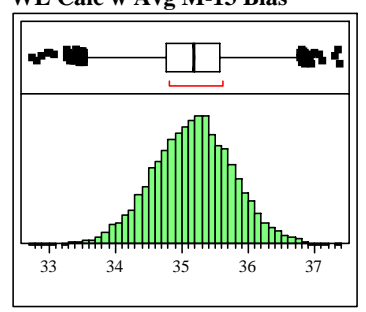

Quantiles

$100.0 \%$ maximum 37.389

$99.5 \% \quad 36.716$

$97.5 \% \quad 36.359$

$90.0 \% \quad 35.928$

$75.0 \%$ quartile 35.578

$50.0 \%$ median 35.181

$25.0 \%$ quartile 34.767

$10.0 \% \quad 34.399$

$2.5 \% \quad 33.974$

$0.5 \% \quad 33.596$

$0.0 \%$ minimum 32.768

Moments

Mean $\quad 35.171119$

Std Dev

0.5989475

Std Err Mean $\quad 0.0059895$

upper 95\% Mean 35.182859

lower 95\% Mean 35.159378

$\mathrm{N}$

10000

WL Calc w Avg M-14 Bias

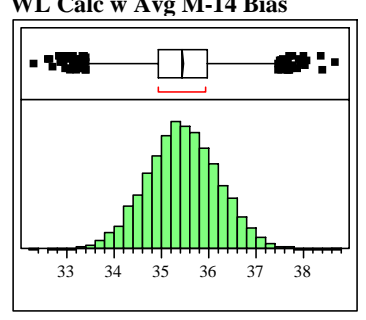

Quantiles

$100.0 \%$ maximum 38.699

$99.5 \% \quad 37.397$

$97.5 \% \quad 36.922$

$90.0 \% \quad 36.429$

$75.0 \%$ quartile 35.958

$50.0 \%$ median 35.441

$25.0 \%$ quartile 34.947

$10.0 \% \quad 34.482$

$2.5 \% \quad 33.964$

$0.5 \% \quad 33.459$

$0.0 \%$ minimum 32.305

Moments

Mean $\quad 35.448336$

$\begin{array}{ll}\text { Std Dev } & 0.7564367\end{array}$

Std Err Mean $\quad 0.0075644$

upper 95\% Mean 35.463164

lower 95\% Mean 35.433508

$\mathrm{N}$

10000
Batch $=309$

Blending WL $=36.26$

WL Calc $=36.32$

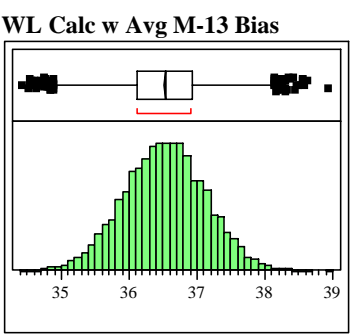

Quantiles

$100.0 \%$ maximum 38.937

$99.5 \%$

$97.5 \% \quad 37.690$

$90.0 \% \quad 37.304$

$75.0 \%$ quartile 36.926

$50.0 \%$ median

$25.0 \%$ quartile 36.117

$10.0 \% \quad 35.759$

$2.5 \% \quad 35.348$

$0.5 \% \quad 34.962$

$0.0 \%$ minimum 34.442

Moments

Mean $\quad 36.527967$

Std Dev $\quad 0.5999852$

Std Err Mean $\quad 0.0059999$

upper 95\% Mean 36.539728

lower 95\% Mean 36.516206

$\mathrm{N}$

10000

WL Calc w Avg M-14 Bias

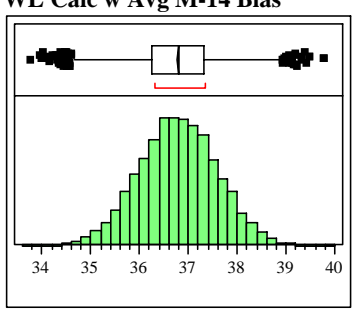

Quantiles

$100.0 \%$ maximum 39.800

$99.5 \% \quad 38.796$

$97.5 \% \quad 38.339$

$90.0 \% \quad 37.820$

$75.0 \%$ quartile 37.328

$50.0 \%$ median 36.785

$25.0 \%$ quartile 36.251

$10.0 \% \quad 35.746$

$2.5 \% \quad 35.196$

$0.5 \% \quad 34.708$

$0.0 \%$ minimum 33.769

Moments

Mean $\quad 36.784099$

Std Dev $\quad 0.8007519$

Std Err Mean $\quad 0.0080075$

upper 95\% Mean 36.799796

lower 95\% Mean 36.768403

$\mathrm{N}$

10000
Batch $=310$

Blending WL = 34.89

WL Calc $=34.94$

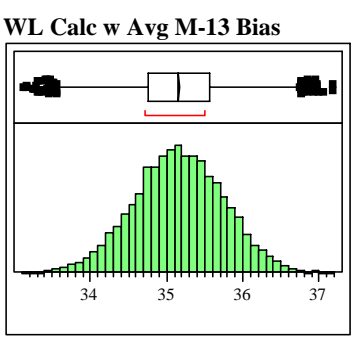

Quantiles

$\begin{array}{lll}100.0 \% & \text { maximum } & 37.195 \\ 99.5 \% & & 36.624 \\ 97.5 \% & & 36.292 \\ 90.0 \% & & 35.907 \\ 75.0 \% & \text { quartile } & 35.562 \\ 50.0 \% & \text { median } & 35.160 \\ 25.0 \% & \text { quartile } & 34.766 \\ 10.0 \% & & 34.403 \\ 2.5 \% & & 33.989 \\ 0.5 \% & & 33.635 \\ 0.0 \% \text { minimum } & 33.141 \\ \text { Moments } & \end{array}$

Mean $\quad 35.157705$

Std Dev $\quad 0.5850875$

Std Err Mean $\quad 0.0058509$

upper 95\% Mean 35.169174

lower 95\% Mean 35.146236

$\mathrm{N}$

10000

WL Calc w Avg M-14 Bias

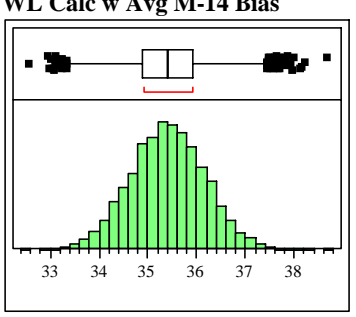

Quantiles

$100.0 \%$ maximum 38.698

$99.5 \% \quad 37.360$

$97.5 \% \quad 36.917$

$90.0 \% \quad 36.371$

$75.0 \%$ quartile 35.917

$50.0 \%$ median 35.406

$25.0 \%$ quartile 34.897

$10.0 \% \quad 34.425$

$2.5 \% \quad 33.928$

$0.5 \% \quad 33.487$

$0.0 \%$ minimum 32.574

Moments

Mean $\quad 35.407026$

Std Dev $\quad 0.7577035$

Std Err Mean $\quad 0.007577$

upper 95\% Mean 35.421879

lower 95\% Mean 35.392174

$\mathrm{N}$

10000
Batch=311

Blending $\mathrm{WL}=\mathbf{3 7 . 0 0}$

WL Calc $=37.04$

WL Calc w Avg M-13 Bias

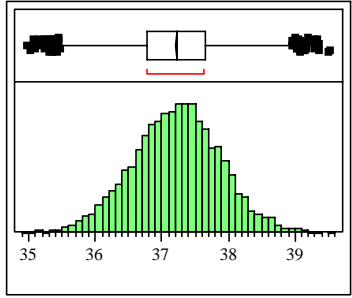

Quantiles

$100.0 \%$ maximum 39.538

$99.5 \% \quad 38.903$

$97.5 \% \quad 38.503$

$90.0 \% \quad 38.025$

$75.0 \%$ quartile 37.652

$50.0 \%$ median 37.232

$25.0 \%$ quartile 36.784

$10.0 \% \quad 36.374$

$2.5 \% \quad 35.907$

$0.5 \% \quad 35.551$

$0.0 \%$ minimum 34.992

Moments

Mean $\quad 37.215757$

Std Dev $\quad 0.6505755$

Std Err Mean $\quad 0.0065058$

upper 95\% Mean 37.228509

lower 95\% Mean 37.203004

$\mathrm{N}$

WL Calc w Avg M-14 Bias

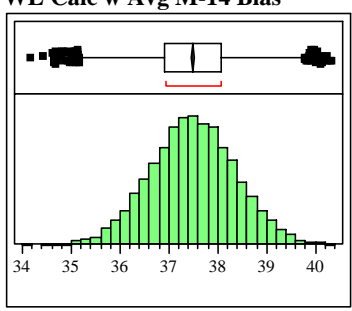

Quantiles

$100.0 \%$ maximum 40.363

$99.5 \% \quad 39.707$

$97.5 \% \quad 39.192$

$90.0 \% \quad 38.600$

$75.0 \%$ quartile 38.071

$50.0 \%$ median 37.492

$25.0 \%$ quartile 36.913

$10.0 \% \quad 36.376$

$2.5 \% \quad 35.793$

$0.5 \% \quad 35.204$

$0.0 \%$ minimum 34.168

Moments

Mean $\quad 37.490398$

Std Dev $\quad 0.8647074$

Std Err Mean $\quad 0.0086471$

upper 95\% Mean 37.507348

lower 95\% Mean 37.473448

$\mathrm{N}$

10000 
WSRC-STI-2006-00068

Revision 0

Exhibit A9. Sensitivity of Blending Target WLs to the Uncertainties of This Report (continued)

\section{Batch=312}

Blending WL $=35.24$

WL Calc $=35.28$

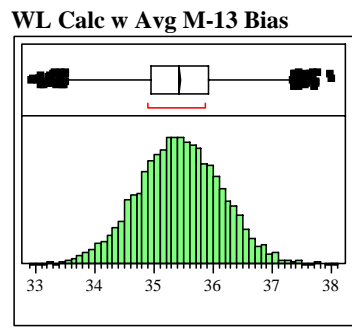

Quantiles

$100.0 \%$ maximum 38.002

$99.5 \%$

$97.5 \% \quad 36.816$

$90.0 \% \quad 36.339$

$75.0 \%$ quartile 35.913

$50.0 \%$ median 35.432

$25.0 \%$ quartile $\quad 34.958$

$10.0 \% \quad 34.539$

$2.5 \% \quad 34.045$

$0.5 \% \quad 33.616$

$0.0 \%$ minimum 32.942

Moments

Mean $\quad 35.433703$

Std Dev $\quad 0.7044119$

Std Err Mean $\quad 0.0070441$

upper 95\% Mean 35.447511

lower 95\% Mean 35.419895

$\mathrm{N}$

10000

WL Calc w Avg M-14 Bias

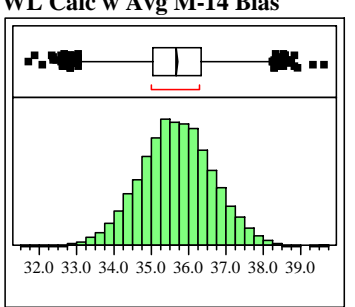

Quantiles

$100.0 \%$ maximum 39.654

$99.5 \% \quad 38.154$

$97.5 \% \quad 37.602$

$90.0 \% \quad 36.926$

$75.0 \%$ quartile 36.322

$50.0 \%$ median 35.673

$25.0 \%$ quartile 35.021

$10.0 \% \quad 34.426$

$\begin{array}{ll}2.5 \% & 33.751\end{array}$

$0.5 \% \quad 33.083$

$0.0 \%$ minimum 31.730

Moments

Mean 35.673155

Std Dev $\quad 0.9763361$

Std Err Mean $\quad 0.0097634$

upper 95\% Mean 35.692293

lower 95\% Mean 35.654017

$\mathrm{N}$

10000
Batch=313

Blending WL $=35.63$

WL Calc $=35.67$

WL Calc w Avg M-13 Bias

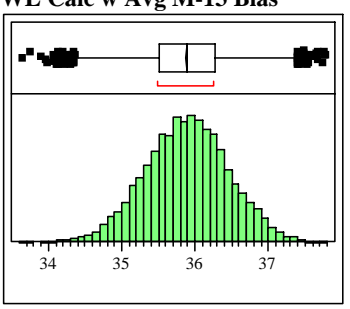

Quantiles

$100.0 \%$ maximum 37.799

$99.5 \% \quad 37.350$

$97.5 \%$

$90.0 \% \quad 36.621$

$75.0 \%$ quartile 36.268

$50.0 \%$ median 35.895

$25.0 \%$ quartile 35.508

$10.0 \% \quad 35.162$

$2.5 \% \quad 34.770$

$0.5 \% \quad 34.404$

$0.0 \%$ minimum 33.649

Moments

Mean $\quad 35.888287$

Std Dev $\quad 0.5667491$

Std Err Mean $\quad 0.0056675$

upper 95\% Mean 35.899396

lower 95\% Mean 35.877177

$\mathrm{N}$

10000

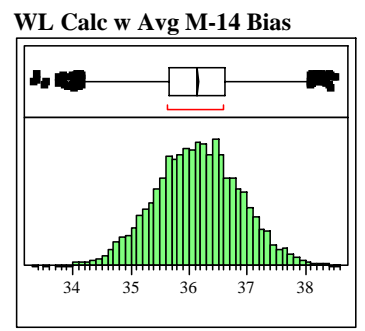

Quantiles

$100.0 \%$ maximum 38.546

$99.5 \% \quad 38.009$

$97.5 \% \quad 37.579$

$90.0 \% \quad 37.068$

$75.0 \%$ quartile 36.631

$50.0 \%$ median 36.146

$25.0 \%$ quartile 35.653

$10.0 \% \quad 35.199$

$2.5 \% \quad 34.710$

$0.5 \% \quad 34.234$

$0.0 \%$ minimum 33.328

Moments

Mean 36.142442

Std Dev $\quad 0.7300782$

Std Err Mean $\quad 0.0073008$

upper 95\% Mean 36.156753

lower 95\% Mean 36.128131

$\mathrm{N}$

10000
Batch=314

Blending WL $=35.06$

WL Calc $=35.11$

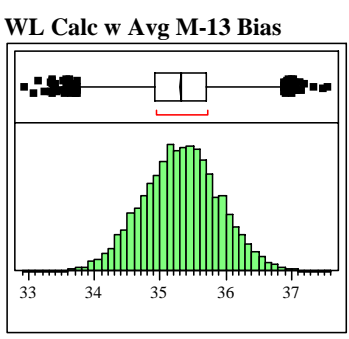

Quantiles

$100.0 \%$ maximum 37.554

$99.5 \% \quad 36.841$

$97.5 \% \quad 36.477$

$90.0 \% \quad 36.070$

$75.0 \%$ quartile $\quad 35.710$

$50.0 \%$ median 35.32

$25.0 \%$ quartile 34.925

$\begin{array}{ll}25.0 \% & 34.557\end{array}$

$2.5 \%-34.170$

$0.5 \% \quad 33.803$

$0.0 \%$ minimum 32.940

Moments

Mean

Std Dev $\quad 0.5885449$

Std Err Mean $\quad 0.0058854$

upper 95\% Mean 35.332178

lower 95\% Mean 35.309104

$\mathrm{N}$

WL Calc w Avg M-14 Bias

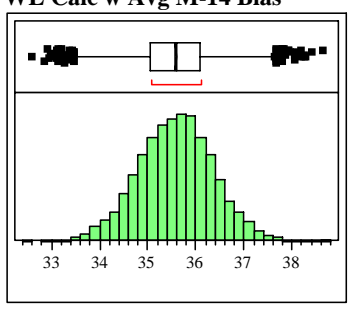

Quantiles

$100.0 \%$ maximum 38.648

$99.5 \% \quad 37.558$

$\begin{array}{ll}97.5 \% & 37.090\end{array}$

$90.0 \% \quad 36.550$

$75.0 \%$ quartile 36.097

$50.0 \%$ median 35.596

$25.0 \%$ quartile 35.061

$10.0 \% \quad 34.599$

$2.5 \% \quad 34.036$

$0.5 \% \quad 33.589$

$0.0 \%$ minimum 32.596

Moments

Mean $\quad 35.581796$

Std Dev $\quad 0.7695542$

Std Err Mean $\quad 0.0076955$

upper 95\% Mean 35.596881

lower 95\% Mean 35.566711

$\mathrm{N}$

10000
Batch=315

Blending $W L=34.83$

WL Calc $=\mathbf{3 4 . 8 5}$

WL Calc w Avg M-13 Bias

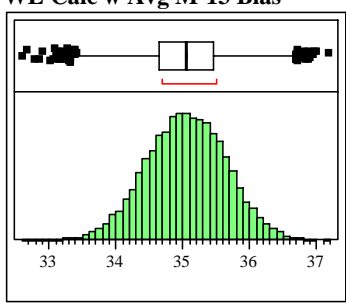

Quantiles

$100.0 \%$ maximum 37.191

$99.5 \% \quad 36.504$

$97.5 \% \quad 36.183$

$90.0 \% \quad 35.792$

$75.0 \%$ quartile 35.464

$50.0 \%$ median 35.054

$25.0 \%$ quartile 34.649

$10.0 \% \quad 34.295$

$2.5 \% \quad 33.885$

$0.5 \% \quad 33.519$

$0.0 \% \quad$ minimum 32.611

Moments

Mean

$\begin{array}{ll}\text { Std Dev } & 0.5901808 \\ \text { Std Err Mean } & 0.0059018\end{array}$

upper 95\% Mean 35.060429

lower 95\% Mean 35.037292

$\mathrm{N}$

10000

WL Calc w Avg M-14 Bias

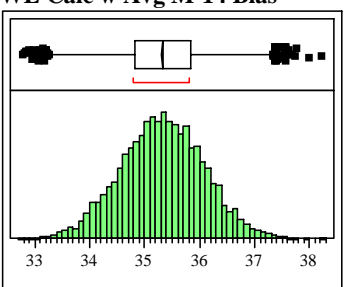

Quantiles

$100.0 \%$ maximum 38.218

$99.5 \% \quad 37.248$

$97.5 \% \quad 36.776$

$90.0 \% \quad 36.275$

$75.0 \%$ quartile 35.829

$50.0 \%$ median 35.322

$25.0 \%$ quartile 34.810

$10.0 \% \quad 34.339$

$\begin{array}{ll}10.0 \% & 33.845\end{array}$

$0.5 \% \quad 33.404$

$0.0 \%$ minimum 32.792

Moments

Mean

Std Dev $\quad 0.7516734$

Std Err Mean $\quad 0.0075167$

upper 95\% Mean 35.331235

lower 95\% Mean 35.301767

$\mathrm{N}$

10000 
WSRC-STI-2006-00068

Revision 0

Exhibit A9. Sensitivity of Blending Target WLs to the Uncertainties of This Report (continued)

\section{Batch=316}

Blending $\mathrm{WL}=34.53$

WL Calc $=34.57$

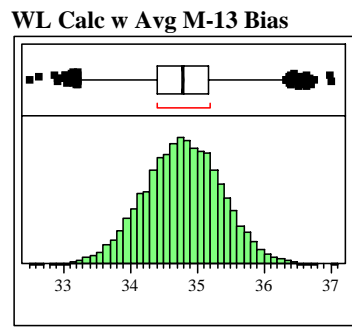

Quantiles

$100.0 \%$ maximum 37.010

$99.5 \% \quad 36.292$

$97.5 \% \quad 35.906$

$90.0 \%$

$75.0 \%$ quartile 35.179

$50.0 \%$ median

$25.0 \%$ quartile $\quad 34.400$

$10.0 \% \quad 34.046$

$2.5 \% \quad 33.645$

$0.5 \% \quad 33.318$

$0.0 \%$ minimum 32.502

Moments

Mean $\quad 34.788381$

Std Dev $\quad 0.5765944$

Std Err Mean $\quad 0.0057659$

upper 95\% Mean 34.799683

lower 95\% Mean 34.777078

$\mathrm{N}$

10000

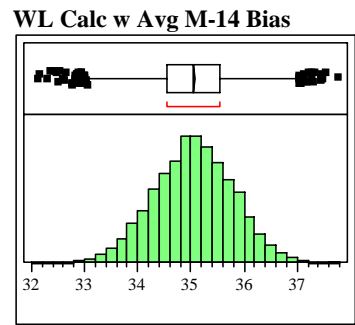

Quantiles

$100.0 \%$ maximum 37.792

$99.5 \% \quad 36.898$

$97.5 \% \quad 36.472$

$90.0 \% \quad 35.989$

$75.0 \%$ quartile 35.549

$50.0 \%$ median 35.058

$25.0 \%$ quartile 34.554

$10.0 \% \quad 34.086$

$2.5 \% \quad 33.565$

$0.5 \% \quad 33.062$

$0.0 \%$ minimum 32.121

Moments

Mean $\quad 35.047785$

Std Dev $\quad 0.7415025$

Std Err Mean $\quad 0.007415$

upper 95\% Mean 35.06232

lower 95\% Mean 35.033251

$\mathrm{N}$

10000
Batch $=317$

Blending WL = 35.75

WL Calc $=35.79$

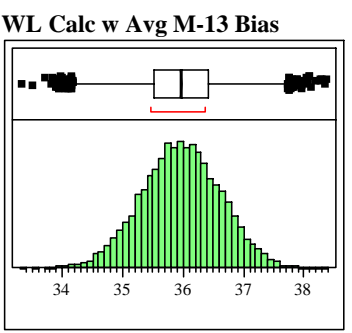

Quantiles

37.583

37.241

$90.0 \% \quad 36.799$

$75.0 \%$ quartile 36.407

$50.0 \%$ median 35.967

$25.0 \%$ quartile 35.526

$10.0 \% \quad 35.123$

$2.5 \% \quad 34.659$

$0.5 \% \quad 34.239$

$0.0 \%$ minimum 33.340

Moments

Mean $\quad 35.963065$

Std Dev $\quad 0.654566$

Std Err Mean $\quad 0.0065457$

upper 95\% Mean 35.975896

lower 95\% Mean 35.950234

$\mathrm{N}$

10000

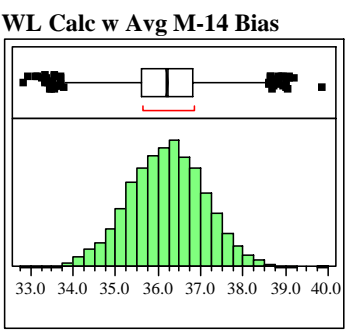

Quantiles

$100.0 \%$ maximum 39.872

$99.5 \% \quad 38.461$

$97.5 \% \quad 37.918$

$90.0 \% \quad 37.330$

$75.0 \%$ quartile 36.811

$50.0 \%$ median 36.220

$25.0 \%$ quartile 35.601

$10.0 \% \quad 35.075$

$2.5 \% \quad 34.431$

$0.5 \% \quad 33.952$

$0.0 \%$ minimum 32.851

Moments

Mean $\quad 36.207791$

Std Dev $\quad 0.8862807$

Std Err Mean $\quad 0.0088628$

upper 95\% Mean 36.225163

lower 95\% Mean 36.190418

$\mathrm{N}$

10000
Batch $=318$

Blending WL $=35.03$

WL Calc $=35.07$

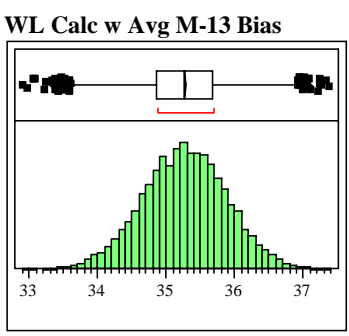

Quantiles

$100.0 \%$ maximum 37.381

$99.5 \% \quad 36.818$

$97.5 \% \quad 36.466$

$90.0 \% \quad 36.047$

$75.0 \%$ quartile 35.682

$50.0 \%$ median 35.27

$25.0 \%$ quartile 34.853

$10.0 \% \quad 34.481$

$2.5 \%-34.029$

$0.5 \% \quad 33.650$

$0.0 \%$ minimum 32.911

Moments

Mean

Std Dev

35.266595

0.6130712

upper 95\% Mean 35.278612

lower 95\% Mean 35.254577

$\mathrm{N}$

10000

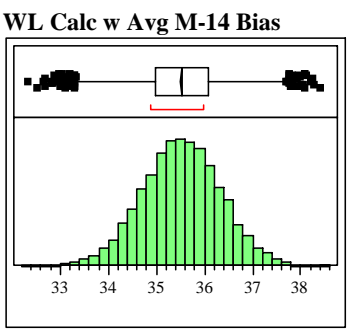

Quantiles

$100.0 \%$ maximum 38.423

$99.5 \% \quad 37.590$

$97.5 \% \quad 37.112$

$90.0 \% \quad 36.552$

$75.0 \%$ quartile 36.075

$50.0 \%$ median 35.522

$25.0 \%$ quartile 34.979

$10.0 \% \quad 34.469$

$2.5 \% \quad 33.895$

$0.5 \% \quad 33.382$

$0.0 \%$ minimum 32.358

Moments

Mean $\quad 35.519981$

Std Dev $\quad 0.8123312$

Std Err Mean $\quad 0.0081233$

upper 95\% Mean 35.535904

lower 95\% Mean 35.504057

$\mathrm{N}$

10000
Batch=319

Blending $\mathrm{WL}=35.21$

WL Calc $=35.26$

WL Calc w Avg M-13 Bias

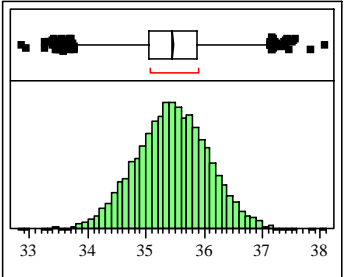

Quantiles

$100.0 \%$ maximum 38.098

$99.5 \% \quad 37.037$

$97.5 \% \quad 36.677$

$90.0 \% \quad 36.247$

$75.0 \%$ quartile $\quad 35.880$

$50.0 \%$ median 35.455

$25.0 \%$ quartile $\quad 35.039$

$10.0 \% \quad 34.643$

$2.5 \% \quad 34.229$

$0.5 \% \quad 33.839$

$0.0 \%$ minimum 32.876

Moments

Mean

Std Dev $\quad 0.6258832$

0.0062588

upper 95\% Mean 35.46605

lower 95\% Mean 35.441512

$\mathrm{N}$

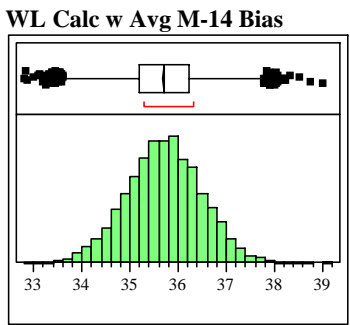

Quantiles

$100.0 \%$ maximum 39.019

$99.5 \% \quad 37.712$

$97.5 \% \quad 37.213$

$90.0 \% \quad 36.712$

$75.0 \%$ quartile 36.230

$50.0 \%$ median 35.715

$25.0 \%$ quartile 35.191

$10.0 \% \quad 34.702$

$\begin{array}{ll}10.0 \% & 34.154\end{array}$

$0.5 \% \quad 33.639$

$0.0 \%$ minimum 32.804

Moments

Mean $\quad 35.705944$

Std Dev $\quad 0.7812591$

Std Err Mean $\quad 0.0078126$

upper 95\% Mean 35.721258

lower 95\% Mean 35.69063

$\mathrm{N}$

10000 
WSRC-STI-2006-00068

Revision 0

Exhibit A9. Sensitivity of Blending Target WLs to the Uncertainties of This Report (continued)

Batch $=320$

Blending WL = 34.96

WL Calc $=35.01$

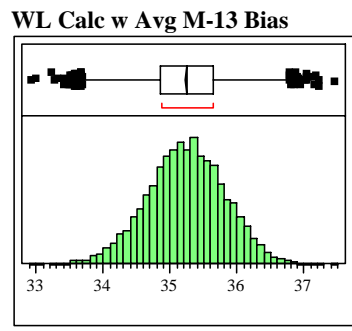

Quantiles

$100.0 \%$ maximum 37.463

$99.5 \%$

$97.5 \% \quad 36.338$

$90.0 \% \quad 35.981$

$75.0 \%$ quartile 35.630

$50.0 \%$ median 35.245

$25.0 \%$ quartile $\quad 34.859$

$10.0 \% \quad 34.489$

$2.5 \% \quad 34.078$

$0.5 \% \quad 33.686$

$0.0 \%$ minimum 32.934

Moments

Mean $\quad 35.238056$

Std Dev $\quad 0.5775652$

Std Err Mean $\quad 0.0057757$

upper 95\% Mean 35.249377

lower 95\% Mean 35.226735

$\mathrm{N}$

10000

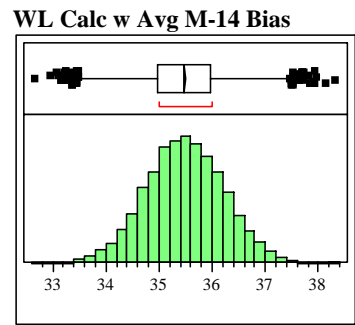

Quantiles

$100.0 \%$ maximum 38.325

$99.5 \% \quad 37.353$

$97.5 \% \quad 36.936$

$90.0 \% \quad 36.425$

$75.0 \%$ quartile 35.981

$50.0 \%$ median 35.479

$25.0 \%$ quartile 34.987

$10.0 \% \quad 34.553$

$\begin{array}{ll}2.5 \% & 34.028\end{array}$

$0.5 \% \quad 33.558$

$0.0 \%$ minimum 32.676

Moments

Mean $\quad 35.48289$

Std Dev $\quad 0.7351337$

Std Err Mean $\quad 0.0073513$

upper 95\% Mean 35.4973

lower 95\% Mean 35.46848

$\mathrm{N}$

10000
Batch $=321$

Blending WL $=33.93$

WL Calc $=33.98$

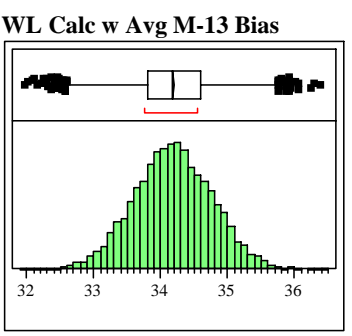

Quantiles

35.652

35.330

$90.0 \% \quad 34.934$

$75.0 \%$ quartile 34.584

$50.0 \%$ median 34.182

$25.0 \%$ quartile 33.796

$10.0 \% \quad 33.429$

$2.5 \% \quad 33.039$

$0.5 \% \quad 32.655$

$0.0 \%$ minimum 31.982

Moments

Mean $\quad 34.183913$

Std Dev $\quad 0.582328$

Std Err Mean $\quad 0.0058233$

upper 95\% Mean 34.195328

lower 95\% Mean 34.172498

$\mathrm{N}$

10000

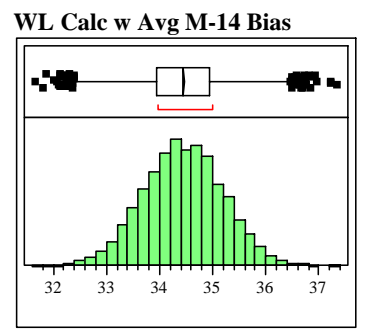

Quantiles

$100.0 \%$ maximum 37.350

$99.5 \% \quad 36.388$

$97.5 \% \quad 35.906$

$90.0 \% \quad 35.399$

$75.0 \%$ quartile 34.950

$50.0 \%$ median 34.438

$25.0 \%$ quartile 33.931

$10.0 \% \quad 33.476$

$\begin{array}{ll}10.5 \% & 32.970\end{array}$

$0.5 \% \quad 32.497$

$0.0 \%$ minimum 31.672

Moments

Mean $\quad 34.442822$

Std Dev $\quad 0.7506428$

Std Err Mean $\quad 0.0075064$

upper 95\% Mean 34.457536

lower 95\% Mean 34.428108

$\mathrm{N}$

10000
Batch $=322$

Blending WL $=\mathbf{3 4 . 4 7}$

WL Calc $=34.52$

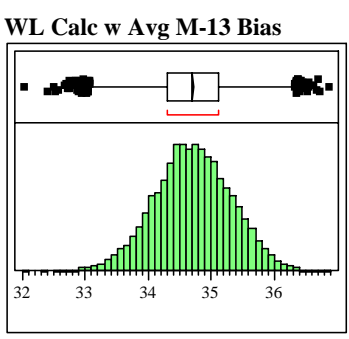

Quantiles

Batch $=323$

Blending $W L=35.30$

WL Calc $=35.35$

WL Calc w Avg M-13 Bias

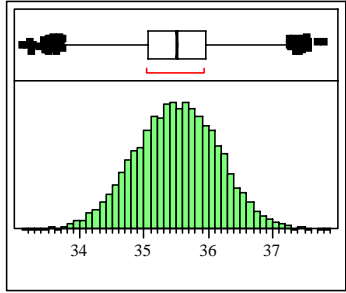

Quantiles

$100.0 \%$ maximum 36.884

$99.5 \% \quad 36.248$

$97.5 \% \quad 35.886$

$90.0 \% \quad 35.499$

$75.0 \%$ quartile 35.123

$50.0 \%$ median 34.705

$25.0 \%$ quartile 34.304

$10.0 \% \quad 33.931$

$2.5 \% \quad 33.489$

$0.5 \% \quad 33.073$

$0.0 \%$ minimum 32.048

Moments

Mean $\quad 34.708521$

Std Dev $\quad 0.6128189$

Std Err Mean $\quad 0.0061282$

upper 95\% Mean 34.720534

lower 95\% Mean 34.696509

$\mathrm{N}$

10000

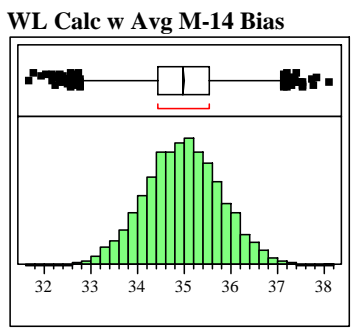

Quantiles

$100.0 \%$ maximum 38.112

$99.5 \% \quad 37.045$

$97.5 \% \quad 36.570$

$90.0 \% \quad 36.020$

$75.0 \%$ quartile 35.519

$50.0 \%$ median 34.972

$25.0 \%$ quartile $\quad 34.427$

$10.0 \% \quad 33.925$

$\begin{array}{ll}10.5 \% & 33.365\end{array}$

$0.5 \% \quad 32.850$

$0.0 \%$ minimum 31.686

Moments

Mean 34.970667

Std Dev $\quad 0.8138692$

Std Err Mean $\quad 0.0081387$

upper 95\% Mean 34.98662

lower 95\% Mean 34.954714

$\mathrm{N}$

10000
$100.0 \%$ maximum 37.813

$99.5 \% \quad 37.150$

$97.5 \% \quad 36.751$

$90.0 \% \quad 36.324$

$75.0 \%$ quartile 35.955

$50.0 \%$ median 35.513

$25.0 \%$ quartile 35.069

$2.5 \% \quad 34.225$

$0.5 \% \quad 33.868$

$0.0 \%$ minimum 33.124

Moments

$\begin{array}{ll}\text { Std Dev } & 0.6482447 \\ \text { Std Err Mean } & 0.0064824\end{array}$

upper 95\% Mean 35.519697

lower 95\% Mean 35.494283

$\mathrm{N}$

10000

WL Calc w Avg M-14 Bias

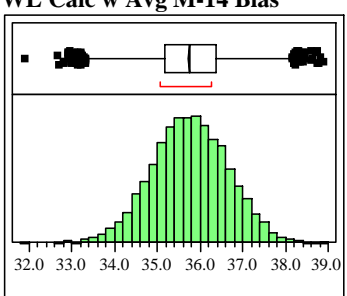

Quantiles

$100.0 \%$ maximum 38.913

$99.5 \% \quad 38.041$

$97.5 \% \quad 37.474$

$90.0 \% \quad 36.897$

$75.0 \%$ quartile 36.370

$50.0 \%$ median 35.759

$25.0 \%$ quartile 35.165

$\begin{array}{ll}10.0 \% & 33.997\end{array}$

$0.5 \% \quad 33.367$

$0.0 \%$ minimum 31.931

Moments

Mean

Std Dev $\quad 0.8879478$

Std Err Mean $\quad 0.0088795$

upper 95\% Mean 35.778334

lower 95\% Mean 35.743523

$\mathrm{N}$
$10.0 \% \quad 34.665$

$10.0 \% \quad 34.631$ 
WSRC-STI-2006-00068

Revision 0

Exhibit A9. Sensitivity of Blending Target WLs to the Uncertainties of This Report (continued)

\section{Batch $=324$}

Blending WL $=34.95$

WL Calc $=35.00$

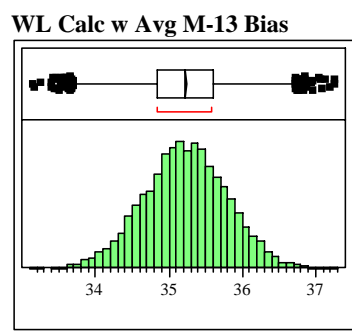

Quantiles

$100.0 \%$ maximum 37.272

$99.5 \%$

$97.5 \% \quad 36.315$

$90.0 \% \quad 35.945$

$75.0 \%$ quartile 35.603

$50.0 \%$ median 35.225

$25.0 \%$ quartile $\quad 34.849$

$\begin{array}{ll}10.0 \% & 34.495\end{array}$

$2.5 \% \quad 34.097$

$0.5 \% \quad 33.763$

$0.0 \%$ minimum 33.148

Moments

Mean $\quad 35.223016$

Std Dev $\quad 0.5637165$

Std Err Mean $\quad 0.0056372$

upper 95\% Mean 35.234066

lower 95\% Mean 35.211966

$\mathrm{N}$

10000

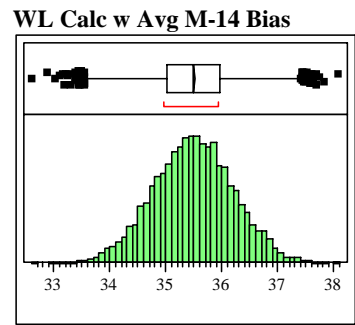

Quantiles

$100.0 \%$ maximum 38.091

$99.5 \% \quad 37.296$

$97.5 \% \quad 36.866$

$90.0 \% \quad 36.400$

$75.0 \%$ quartile 35.969

$50.0 \%$ median 35.490

$25.0 \%$ quartile 35.008

$10.0 \% \quad 34.582$

$2.5 \% \quad 34.092$

$0.5 \% \quad 33.702$

$0.0 \%$ minimum 32.616

Moments

Mean $\quad 35.489628$

Std Dev $\quad 0.7065612$

Std Err Mean $\quad 0.0070656$

upper 95\% Mean 35.503478

lower 95\% Mean 35.475778

$\mathrm{N}$

10000
Batch $=325$

Blending WL $=\mathbf{3 4 . 0 1}$

WL Calc $=34.06$

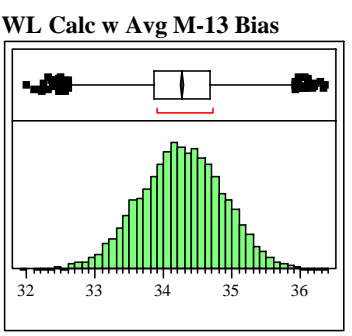

Quantiles

$100.0 \%$ maximum 36.357

35.802

35.434

$90.0 \% \quad 35.041$

$75.0 \%$ quartile 34.679

$50.0 \%$ median 34.267

$25.0 \%$ quartile 33.855

$10.0 \% \quad 33.474$

$2.5 \% \quad 33.077$

$0.5 \% \quad 32.664$

$0.0 \%$ minimum 31.996

Moments

Mean $\quad 34.263573$

Std Dev $\quad 0.6066981$

Std Err Mean $\quad 0.006067$

upper 95\% Mean 34.275465

lower 95\% Mean 34.25168

$\mathrm{N}$

10000

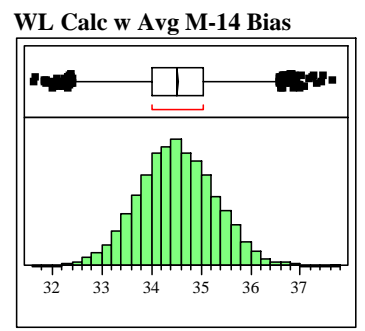

Quantiles

$100.0 \%$ maximum 37.666

$99.5 \% \quad 36.606$

$97.5 \% \quad 36.043$

$90.0 \% \quad 35.524$

$75.0 \%$ quartile 35.030

$50.0 \%$ median 34.503

$25.0 \%$ quartile 33.996

$10.0 \% \quad 33.533$

$\begin{array}{ll}10.5 \% & 33.000\end{array}$

$0.5 \% \quad 32.540$

$0.0 \%$ minimum 31.639

Moments

Mean $\quad 34.514609$

Std Dev $\quad 0.7757651$

Std Err Mean $\quad 0.0077577$

upper 95\% Mean 34.529816

lower 95\% Mean 34.499402

$\mathrm{N}$

10000
Batch $=326$

Blending WL $=34.49$

WL Calc $=34.54$

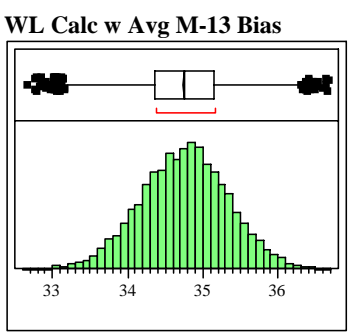

Quantiles

Batch $=327$

Blending WL $=34.13$

WL Calc $=34.19$

WL Calc w Avg M-13 Bias

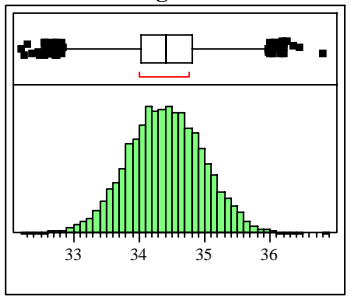

Quantiles

$100.0 \%$ maximum 36.680

$99.5 \% \quad 36.216$

$97.5 \% \quad 35.878$

$90.0 \% \quad 35.486$

$75.0 \%$ quartile 35.144

$50.0 \%$ median 34.760

$25.0 \%$ quartile 34.360

$\begin{array}{ll}25.0 \% & 34.006\end{array}$

$2.5 \% \quad 33.599$

$0.5 \% \quad 33.200$

$0.0 \%$ minimum 32.671

Moments

Mean $\quad 34.750432$

Std Dev $\quad 0.5799365$

Std Err Mean 0.0057994

upper 95\% Mean 34.7618

lower 95\% Mean 34.739064

$\mathrm{N}$

10000

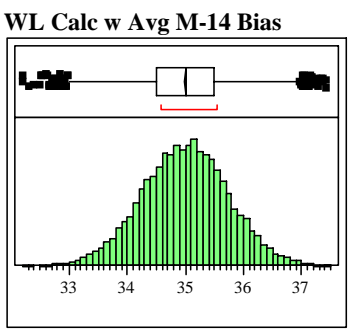

Quantiles

$100.0 \%$ maximum 37.445

$99.5 \% \quad 36.902$

$97.5 \% \quad 36.447$

$90.0 \% \quad 35.946$

$75.0 \%$ quartile 35.495

$50.0 \%$ median 35.007

$25.0 \%$ quartile 34.500

$10.0 \% \quad 34.055$

$2.5 \% \quad 33.517$

$0.5 \% \quad 33.051$

$0.0 \%$ minimum 32.209

Moments

Mean $\quad 34.998293$

Std Dev $\quad 0.7415456$

Std Err Mean $\quad 0.0074155$

upper 95\% Mean 35.012829

lower 95\% Mean 34.983758

$\mathrm{N}$

10000
$100.0 \%$ maximum 36.829

99.5\% $\quad 35.890$

$97.5 \% \quad 35.522$

$90.0 \% \quad 35.144$

$75.0 \%$ quartile 34.801

$50.0 \%$ median 34.405

$25.0 \%$ quartile 34.018

$10.0 \% \quad 33.679$

$2.5 \% \quad 33.290$

$0.5 \% \quad 32.896$

$0.0 \%$ minimum 32.210

Moments

Mean

Std Dev $\quad 0.5744645$

Std Err Mean 0.0057446

upper 95\% Mean 34.418925

lower 95\% Mean 34.396403

$\mathrm{N}$

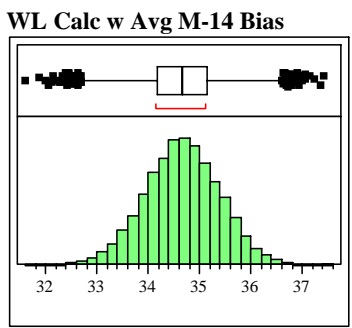

Quantiles

$100.0 \%$ maximum 37.420

$99.5 \% \quad 36.556$

$97.5 \% \quad 36.071$

$90.0 \% \quad 35.589$

$75.0 \%$ quartile 35.155

$50.0 \%$ median 34.663

$25.0 \%$ quartile $\quad 34.177$

$10.0 \% \quad 33.736$

$\begin{array}{ll}10.0 \% & 33.205\end{array}$

$0.5 \% \quad 32.731$

$0.0 \%$ minimum 31.614

Moments

Mean $\quad 34.660994$

Std Err Mean $\quad 0.0072878$

upper 95\% Mean 34.675279

lower 95\% Mean 34.646708

$\mathrm{N}$

10000
Std Dev $\quad 0.728775$ 
WSRC-STI-2006-00068

Revision 0

Exhibit A9. Sensitivity of Blending Target WLs to the Uncertainties of This Report (continued)

Batch=328

Blending WL $=34.42$

WL Calc $=34.47$

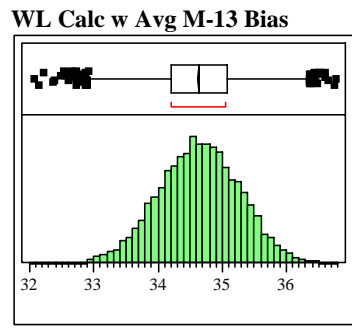

Quantiles

$100.0 \%$ maximum 36.785

$99.5 \%$

$97.5 \% \quad 35.841$

$90.0 \% \quad 35.445$

$75.0 \%$ quartile 35.069

$50.0 \%$ median 34.645

$25.0 \%$ quartile 34.211

$10.0 \% \quad 33.832$

$2.5 \% \quad 33.392$

$0.5 \% \quad 33.031$

$0.0 \%$ minimum 32.076

Moments

Mean $\quad 34.638822$

Std Dev $\quad 0.6289779$

Std Err Mean $\quad 0.0062898$

upper 95\% Mean 34.651151

lower 95\% Mean 34.626492

$\mathrm{N}$

10000

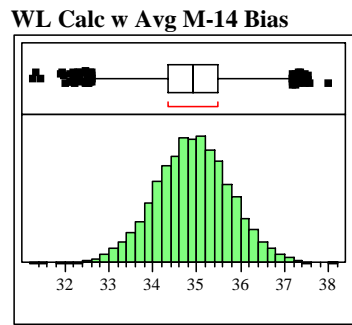

Quantiles

$100.0 \%$ maximum 38.020

$99.5 \% \quad 37.074$

$97.5 \% \quad 36.583$

$90.0 \% \quad 35.989$

$75.0 \%$ quartile 35.478

$50.0 \%$ median 34.917

$25.0 \%$ quartile 34.343

$10.0 \% \quad 33.831$

$\begin{array}{ll}2.5 \% & 33.217\end{array}$

$0.5 \% \quad 32.730$

$0.0 \%$ minimum 31.284

Moments

Mean $\quad 34.911755$

Std Dev $\quad 0.8488435$

Std Err Mean $\quad 0.0084884$

upper 95\% Mean 34.928394

lower 95\% Mean 34.895116

$\mathrm{N}$

10000
Batch=329

Blending $W L=34.36$

WL Calc $=34.41$

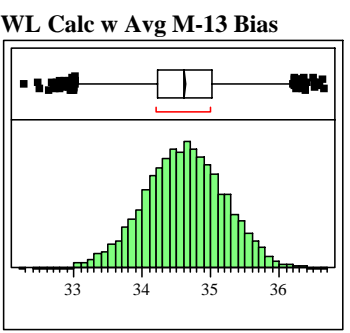

Quantiles

$99.5 \%$

$97.5 \% \quad 35.743$

$90.0 \% \quad 35.369$

$75.0 \%$ quartile 35.012

$50.0 \%$ median

$25.0 \%$ quartile 34.221

$10.0 \% \quad 33.868$

$2.5 \% \quad 33.442$

$0.5 \% \quad 33.074$

$0.0 \%$ minimum 32.285

Moments

Mean $\quad 34.614745$

Std Dev $\quad 0.5843498$

Std Err Mean $\quad 0.0058435$

upper 95\% Mean 34.6262

lower 95\% Mean 34.603291

$\mathrm{N}$

10000

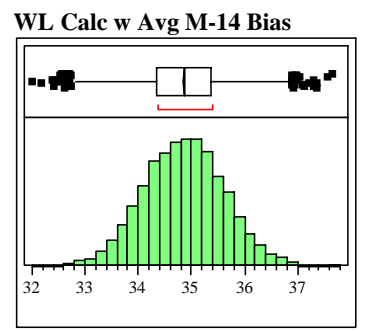

Quantiles

$100.0 \%$ maximum 37.676

$99.5 \% \quad 36.771$

$97.5 \% \quad 36.326$

$90.0 \% \quad 35.817$

$75.0 \%$ quartile 35.368

$50.0 \%$ median 34.871

$25.0 \%$ quartile 34.344

$10.0 \% \quad 33.903$

$\begin{array}{ll}10.5 \% & 33.417\end{array}$

$0.5 \% \quad 32.900$

$0.0 \%$ minimum 32.023

Moments

Mean $\quad 34.86294$

Std Dev $\quad 0.7496004$

Std Err Mean $\quad 0.007496$

upper 95\% Mean 34.877634

lower 95\% Mean 34.848247

$\mathrm{N}$

10000
Batch $=330$

Blending $W L=35.18$

WL Calc $=35.23$

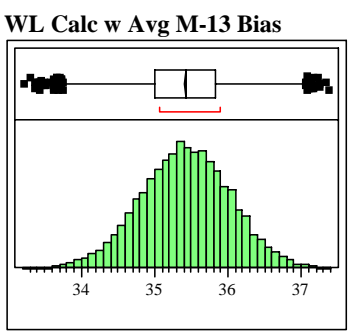

Quantiles

Batch $=331$

Blending $W L=34.65$

WL Calc $=34.70$

WL Calc w Avg M-13 Bias

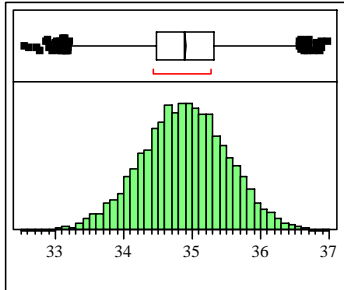

Quantiles

$100.0 \%$ maximum 37.386

$99.5 \% \quad 36.940$

$97.5 \% \quad 36.601$

$90.0 \% \quad 36.192$

$75.0 \%$ quartile 35.835

$50.0 \%$ median 35.421

$25.0 \%$ quartile 35.008

$10.0 \% \quad 34.633$

$2.5 \% \quad 34.197$

$0.5 \% \quad 33.814$

$0.0 \%$ minimum 33.228

Moments

Mean

Std Dev $\quad 0.6084637$

Std Err Mean $\quad 0.0060846$

upper 95\% Mean 35.429174

lower 95\% Mean 35.40532

$\mathrm{N}$

10000

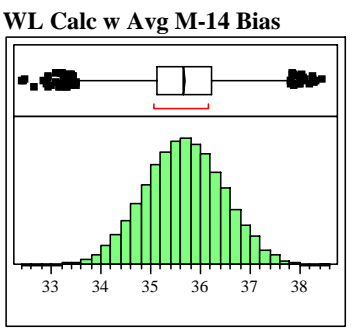

Quantiles

$100.0 \%$ maximum 38.455

$99.5 \% \quad 37.649$

$97.5 \% \quad 37.212$

$90.0 \% \quad 36.701$

$75.0 \%$ quartile 36.211

$50.0 \%$ median 35.668

$25.0 \%$ quartile $\quad 35.133$

$10.0 \% \quad 34.642$

$2.5 \% \quad 34.12$

$0.5 \% \quad 33.588$

$0.0 \%$ minimum 32.411

Moments

Mean $\quad 35.670001$

Std Dev $\quad 0.796059$

Std Err Mean $\quad 0.0079606$

upper 95\% Mean 35.685606

lower 95\% Mean 35.654397

$\mathrm{N}$

10000
$100.0 \%$ maximum 36.997

$99.5 \% \quad 36.470$

$97.5 \% \quad 36.108$

$90.0 \% \quad 35.694$

$75.0 \%$ quartile 35.315

$50.0 \%$ median 34.893

$25.0 \%$ quartile 34.472

$\begin{array}{ll}10.0 \% & 34.085\end{array}$

$2.5 \% \quad 33.649$

$0.5 \% \quad 33.273$

$0.0 \%$ minimum 32.553

Moments

Mean

Std Err Mean $\quad 0.0062439$

upper 95\% Mean 34.903204

lower 95\% Mean 34.878726

$\mathrm{N}$

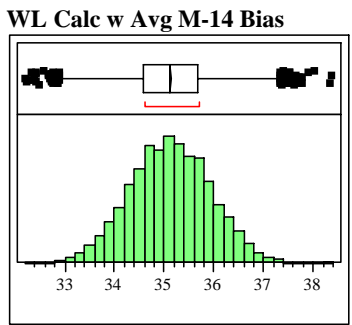

Quantiles

100.0\% maximum 38.393

$99.5 \% \quad 37.231$

$97.5 \% \quad 36.695$

$90.0 \% \quad 36.166$

$75.0 \%$ quartile 35.680

$50.0 \%$ median 35.123

$25.0 \%$ quartile $\quad 34.570$

$10.0 \% \quad 34.081$

$\begin{array}{ll}10.0 \% & 33.516\end{array}$

$0.5 \% \quad 33.033$

$0.0 \%$ minimum 32.220

Moments

Mean

Std Dev $\quad 0.8135559$

Std Err Mean $\quad 0.0081356$

upper 95\% Mean 35.136167

lower 95\% Mean 35.104272

$\mathrm{N}$ 
WSRC-STI-2006-00068

Revision 0

Exhibit A9. Sensitivity of Blending Target WLs to the Uncertainties of This Report (continued)

\section{Batch=332}

Blending WL $=35.58$

WL Calc $=35.63$

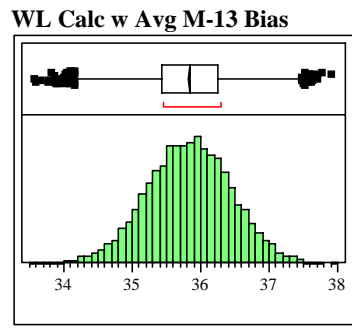

Quantiles

$100.0 \%$ maximum 37.925

$99.5 \% \quad 37.358$

$97.5 \% \quad 37.023$

$90.0 \% \quad 36.617$

$75.0 \%$ quartile 36.247

$50.0 \%$ median

$25.0 \%$ quartile $\quad 35.421$

$10.0 \% \quad 35.055$

$2.5 \% \quad 34.622$

$0.5 \% \quad 34.230$

$0.0 \%$ minimum 33.586

Moments

Mean $\quad 35.83223$

$\begin{array}{ll}\text { Std Dev } & 0.6083728 \\ \text { Std Err Mean } & 0.0060837\end{array}$

upper 95\% Mean 35.844155

lower 95\% Mean 35.820304

$\mathrm{N}$

10000

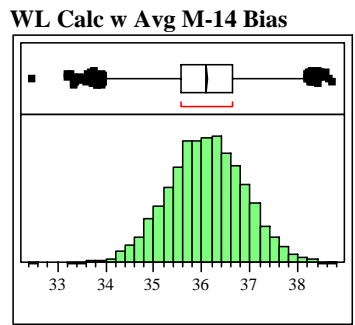

Quantiles

$100.0 \%$ maximum 38.715

99.5\% 38.135

$97.5 \% \quad 37.616$

$90.0 \% \quad 37.094$

$75.0 \%$ quartile 36.623

$50.0 \%$ median 36.091

$25.0 \%$ quartile 35.566

$10.0 \% \quad 35.074$

$2.5 \% \quad 34.529$

$0.5 \% \quad 34.019$

$0.0 \%$ minimum 32.466

Moments

Mean $\quad 36.087406$

Std Dev $\quad 0.7881357$

Std Err Mean $\quad 0.0078814$

upper 95\% Mean 36.102855

lower 95\% Mean 36.071957

$\mathrm{N}$

10000
Batch=333

Blending WL = 36.31

WL Calc $=36.36$

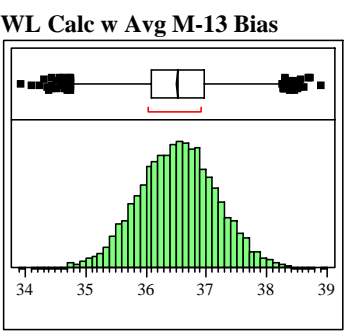

Quantiles

$100.0 \%$ maximum 38.909

$99.5 \%$

$97.5 \% \quad 37.800$

$90.0 \% \quad 37.355$

$75.0 \%$ quartile 36.958

$50.0 \%$ median

$25.0 \%$ quartile 36.086

$10.0 \% \quad 35.703$

$2.5 \% \quad 35.263$

$0.5 \% \quad 34.818$

$0.0 \%$ minimum 33.929

Moments

Mean $\quad 36.526689$

Std Dev $\quad 0.6436873$

Std Err Mean $\quad 0.0064369$

upper 95\% Mean 36.539306

lower 95\% Mean 36.514071

$\mathrm{N}$

10000

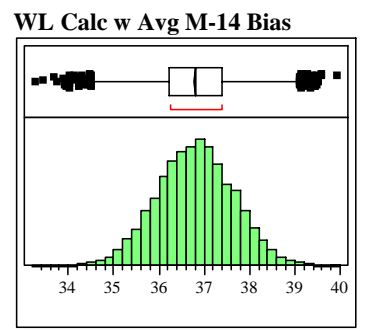

Quantiles

$100.0 \%$ maximum 39.936

$99.5 \% \quad 39.016$

$97.5 \% \quad 38.468$

$90.0 \% \quad 37.896$

$75.0 \%$ quartile 37.376

$50.0 \%$ median 36.809

$25.0 \%$ quartile 36.236

$10.0 \% \quad 35.725$

$\begin{array}{ll}10.0 \% & 35.157\end{array}$

$0.5 \% \quad 34.567$

$0.0 \%$ minimum 33.277

Moments

Mean $\quad 36.804888$

Std Dev $\quad 0.8476697$

Std Err Mean $\quad 0.0084767$

upper 95\% Mean 36.821504

lower 95\% Mean 36.788272

$\mathrm{N}$

10000
Batch $=334$

Blending WL $=35.07$

WL Calc $=35.12$

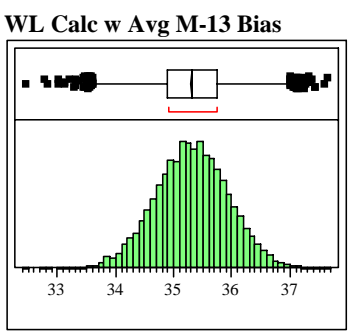

Quantiles

Batch=335

Blending $W L=37.19$

WL Calc $=37.24$

WL Calc w Avg M-13 Bias

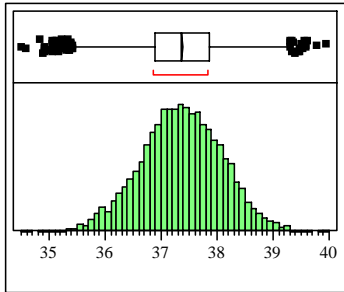

Quantiles

$100.0 \%$ maximum 37.659

$99.5 \% \quad 36.918$

$97.5 \% \quad 36.515$

$90.0 \% \quad 36.113$

$75.0 \%$ quartile 35.739

$50.0 \%$ median 35.313

$25.0 \%$ quartile 34.896

$10.0 \% \quad 34.513$

$2.5 \% \quad 34.080$

$0.5 \% \quad 33.707$

$0.0 \%$ minimum 32.473

Moments

Mean $\quad 35.313305$

Std Dev $\quad 0.6257863$

Std Err Mean $\quad 0.0062579$

upper 95\% Mean 35.325572

lower 95\% Mean 35.301038

$\mathrm{N}$

10000

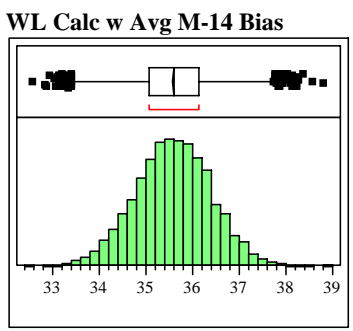

Quantiles

$100.0 \%$ maximum 38.808

$99.5 \% \quad 37.707$

$97.5 \% \quad 37.151$

$90.0 \% \quad 36.613$

$75.0 \%$ quartile 36.132

$50.0 \%$ median 35.590

$25.0 \%$ quartile $\quad 35.051$

$10.0 \% \quad 34.550$

$\begin{array}{ll}10.5 \% & 33.996\end{array}$

$0.5 \% \quad 33.490$

$0.0 \%$ minimum 32.590

Moments

Mean 35.587147

Std Dev $\quad 0.805937$

Std Err Mean $\quad 0.0080594$

upper 95\% Mean 35.602945

lower 95\% Mean 35.571349

$\mathrm{N}$

10000
$100.0 \%$ maximum 39.945

$99.5 \% \quad 39.152$

$97.5 \% \quad 38.736$

$90.0 \% \quad 38.268$

$75.0 \%$ quartile 37.856

$50.0 \%$ median 37.365

$25.0 \%$ quartile 36.891

$10.0 \% \quad 36.436$

$2.5 \% \quad 35.919$

$0.5 \% \quad 35.494$

$0.0 \%$ minimum 34.506

Moments

Mean

Std Dev $\quad 0.7144185$

Std Err Mean $\quad 0.0071442$

upper 95\% Mean 37.375862

lower 95\% Mean 37.347854

$\mathrm{N}$

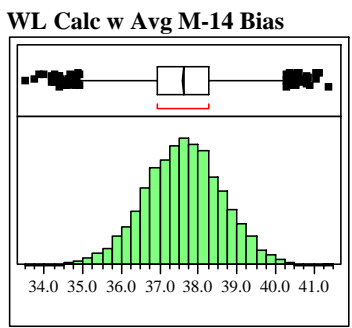

Quantiles

$100.0 \%$ maximum 41.417

$97.5 \% \quad 39.551$

$90.0 \% \quad 38.902$

$75.0 \%$ quartile 38.280

$50.0 \%$ median 37.614

$25.0 \%$ quartile 36.941

$10.0 \% \quad 36.325$

$\begin{array}{ll}10.0 \% & 35.593\end{array}$

$0.5 \% \quad 34.979$

$0.0 \%$ minimum 33.523

Moments

Mean

Std Dev $\quad 1.0080843$

Std Err Mean $\quad 0.0100808$

upper 95\% Mean 37.630981

lower 95\% Mean 37.59146

$\mathrm{N}$
$99.5 \% \quad 40.176$ 
WSRC-STI-2006-00068

Revision 0

Exhibit A9. Sensitivity of Blending Target WLs to the Uncertainties of This Report (continued)

Batch=336

Blending WL = 37.52

WL Calc $=37.57$

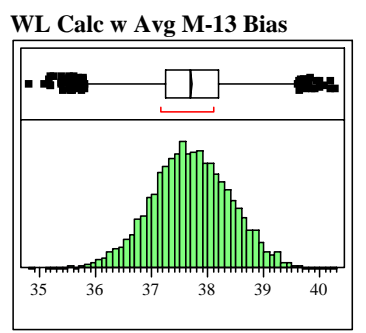

Quantiles

$100.0 \%$ maximum 40.296

$99.5 \% \quad 39.484$

$97.5 \% \quad 39.082$

$90.0 \% \quad 38.614$

$75.0 \%$ quartile 38.184

$50.0 \%$ median

$25.0 \%$ quartile $\quad 37.233$

$10.0 \% \quad 36.814$

$2.5 \% \quad 36.298$

$0.5 \% \quad 35.833$

$0.0 \%$ minimum 34.825

Moments

Mean $\quad 37.701507$

Std Dev $\quad 0.7048085$

Std Err Mean $\quad 0.0070481$

upper 95\% Mean 37.715323

lower 95\% Mean 37.687692

$\mathrm{N}$

10000

WL Calc w Avg M-14 Bias

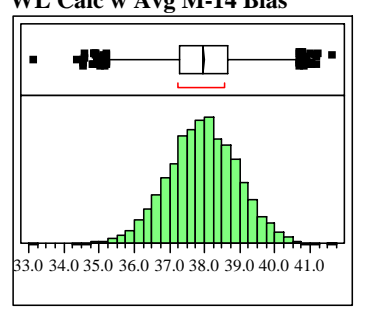

Quantiles

$100.0 \%$ maximum 41.618

$99.5 \% \quad 40.455$

$97.5 \% \quad 39.892$

$90.0 \% \quad 39.225$

$75.0 \%$ quartile 38.646

$50.0 \%$ median 37.964

$25.0 \%$ quartile $\quad 37.295$

$10.0 \% \quad 36.678$

$\begin{array}{ll}2.5 \% & 35.991\end{array}$

$0.5 \% \quad 35.342$

$0.0 \%$ minimum 33.148

Moments

Mean $\quad 37.957142$

Std Dev $\quad 0.9959028$

Std Err Mean $\quad 0.009959$

upper 95\% Mean 37.976664

lower 95\% Mean 37.93762

$\mathrm{N}$

10000
Batch $=337$

Blending WL $=36.94$

WL Calc $=37.00$

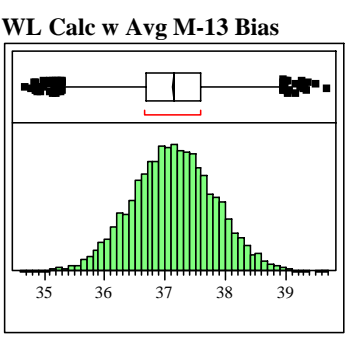

Quantiles

Batch $=338$

Blending WL = 37.13

WL Calc $=37.19$

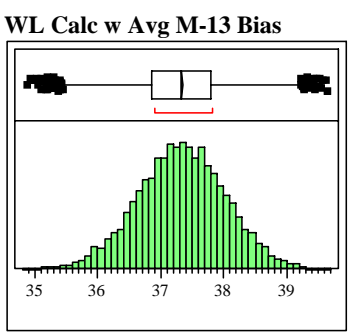

Quantiles

$100.0 \%$ maximum 39.691

$99.5 \% \quad 38.837$

$97.5 \% \quad 38.465$

$90.0 \% \quad 37.999$

$75.0 \%$ quartile 37.594

$50.0 \%$ median 37.14

$25.0 \%$ quartile 36.685

$10.0 \% \quad 36.273$

$2.5 \% \quad 35.826$

$0.5 \% \quad 35.394$

$0.0 \%$ minimum 34.700

Moments

Mean $\quad 37.140182$

Std Dev $\quad 0.6718426$

Std Err Mean $\quad 0.0067184$

upper 95\% Mean 37.153352

lower 95\% Mean 37.127013

$\mathrm{N}$

10000

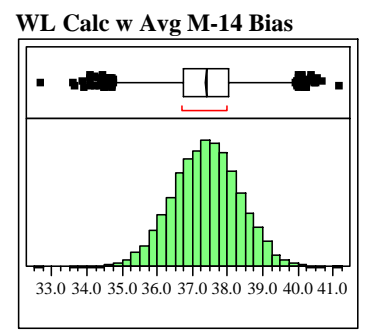

Quantiles

$100.0 \%$ maximum 41.178

$99.5 \% \quad 39.811$

$97.5 \% \quad 39.206$

$90.0 \% \quad 38.610$

$75.0 \%$ quartile 38.031

$50.0 \%$ median 37.398

$25.0 \%$ quartile 36.750

$10.0 \% \quad 36.186$

$\begin{array}{ll}10.5 \% & 35.531\end{array}$

$0.5 \% \quad 34.940$

$0.0 \%$ minimum 32.702

Moments

Mean 37.391795

Std Dev $\quad 0.943669$

Std Err Mean $\quad 0.0094367$

upper 95\% Mean 37.410293

lower 95\% Mean 37.373297

$\mathrm{N}$

10000 $\begin{array}{lll}100.0 \% & \text { maximum } & 39.666 \\ 99.5 \% & & 39.099 \\ 97.5 \% & & 38.669 \\ 90.0 \% & & 38.215 \\ 75.0 \% & \text { quartile } & 37.800 \\ 50.0 \% & \text { median } & 37.331 \\ 25.0 \% & \text { quartile } & 36.859 \\ 10.0 \% & & 36.442 \\ 2.5 \% & & 35.943 \\ 0.5 \% & & 35.487 \\ 0.0 \% & \text { minimum } & 34.880\end{array}$

Moments

Mean $\quad 37.327356$

Std Dev $\quad 0.6956868$

Std Err Mean $\quad 0.0069569$

upper 95\% Mean 37.340993

lower 95\% Mean 37.313719

$\mathrm{N}$

10000

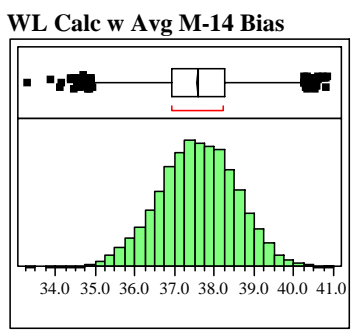

Quantiles

$100.0 \%$ maximum 40.843

$99.5 \% \quad 40.098$

$97.5 \% \quad 39.455$

$90.0 \% \quad 38.828$

$75.0 \%$ quartile 38.257

$50.0 \%$ median 37.598

$25.0 \%$ quartile 36.942

$10.0 \% \quad 36.331$

$\begin{array}{ll}2.5 \% & 35.642\end{array}$

$0.5 \% \quad 35.088$

$0.0 \%$ minimum 33.325

Moments

Mean 37.58998

Std Dev $\quad 0.9754458$

Std Err Mean $\quad 0.0097545$

upper 95\% Mean 37.609101

lower 95\% Mean 37.570859

$\mathrm{N}$

10000
Batch=339

Blending WL $=37.63$

WL Calc $=37.66$

WL Calc w Avg M-13 Bias

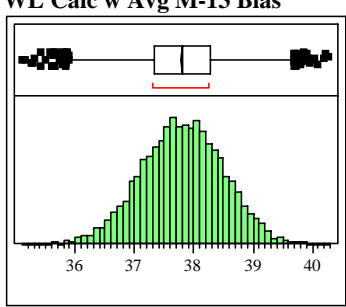

Quantiles

$100.0 \%$ maximum 40.277

$99.5 \% \quad 39.557$

$97.5 \% \quad 39.121$

$90.0 \% \quad 38.683$

$75.0 \%$ quartile 38.276

$50.0 \%$ median 37.806

$25.0 \%$ quartile 37.332

$10.0 \% \quad 36.921$

$2.5 \% \quad 36.418$

$0.5 \% \quad 35.985$

$0.0 \%$ minimum 35.103

Moments

Mean

Std Err Mean $\quad 0.6916879$

upper 95\% Mean 37.814062

lower 95\% Mean 37.786945

$\mathrm{N}$

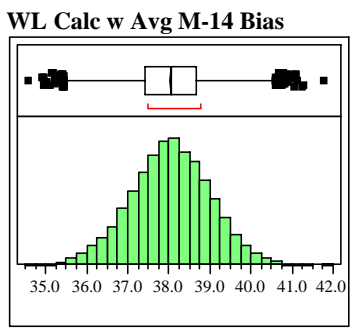

Quantiles

$100.0 \%$ maximum 41.800

$99.5 \% \quad 40.500$

$97.5 \% \quad 39.928$

$90.0 \% \quad 39.264$

$75.0 \%$ quartile 38.685

$50.0 \%$ median 38.051

$25.0 \%$ quartile 37.407

$10.0 \% \quad 36.801$

$\begin{array}{ll}10.0 \% & 36.109\end{array}$

$0.5 \% \quad 35.536$

$0.0 \%$ minimum 34.587

Moments

Mean

Std Dev $\quad 0.9634812$

Std Err Mean $\quad 0.0096348$

upper 95\% Mean 38.061222

lower 95\% Mean 38.023449

$\mathrm{N}$ 
WSRC-STI-2006-00068

Revision 0

Exhibit A9. Sensitivity of Blending Target WLs to the Uncertainties of This Report (continued)

Batch=340

Blending WL = 37.32

WL Calc $=37.35$

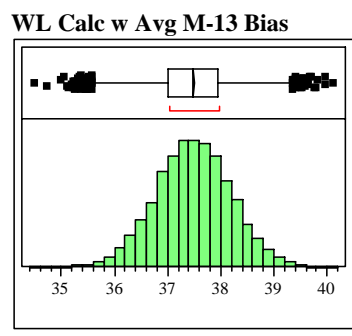

Quantiles

$100.0 \%$ maximum 40.141

$99.5 \% \quad 39.311$

$97.5 \% \quad 38.875$

$90.0 \% \quad 38.380$

$75.0 \%$ quartile $\quad 37.956$

$50.0 \%$ median 37.486

$25.0 \%$ quartile $\quad 37.014$

$10.0 \% \quad 36.591$

$2.5 \% \quad 36.102$

$0.5 \% \quad 35.607$

$0.0 \%$ minimum 34.501

Moments

Mean $\quad 37.485803$

Std Dev $\quad 0.7066824$

Std Err Mean $\quad 0.0070668$

upper 95\% Mean 37.499655

lower 95\% Mean 37.47195

$\mathrm{N}$

10000

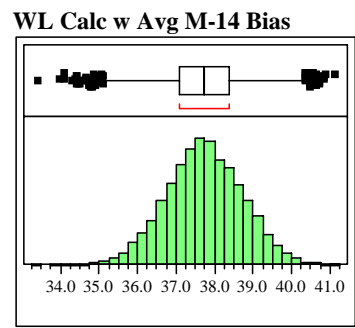

Quantiles

$100.0 \%$ maximum 41.147

$99.5 \% \quad 40.206$

$97.5 \% \quad 39.648$

$90.0 \% \quad 39.005$

$75.0 \%$ quartile 38.397

$50.0 \%$ median 37.730

$25.0 \%$ quartile 37.087

$10.0 \% \quad 36.483$

$\begin{array}{ll}10.0 \% & 35.792\end{array}$

$0.5 \% \quad 35.126$

$0.0 \%$ minimum 33.419

Moments

Mean $\quad 37.734291$

Std Dev $\quad 0.9854045$

Std Err Mean $\quad 0.009854$

upper 95\% Mean 37.753607

lower 95\% Mean 37.714975

$\mathrm{N}$

10000
Batch $=341$

Blending WL = 37.37

WL Calc $=\mathbf{3 7 . 4 0}$

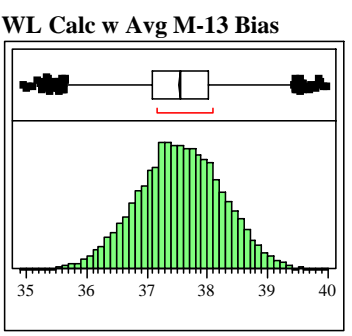

Quantiles

Batch $=342$

Blending WL = 38.31

WL Calc $=38.34$

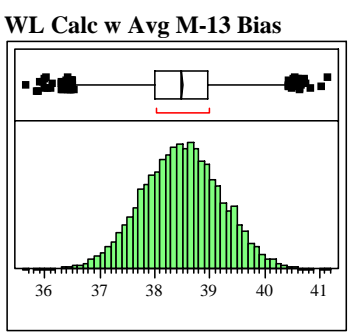

Quantiles

$100.0 \%$ maximum 39.988

$99.5 \% \quad 39.260$

$97.5 \% \quad 38.885$

$90.0 \% \quad 38.447$

$75.0 \%$ quartile 38.029

$50.0 \%$ median 37.549

$25.0 \%$ quartile 37.078

$10.0 \% \quad 36.643$

$2.5 \% \quad 36.149$

$0.5 \% \quad 35.712$

$0.0 \%$ minimum 34.959

Moments

Mean $\quad 37.547454$

Std Dev $\quad 0.6983935$

Std Err Mean $\quad 0.0069839$

upper 95\% Mean 37.561144

lower 95\% Mean 37.533764

$\mathrm{N}$

10000

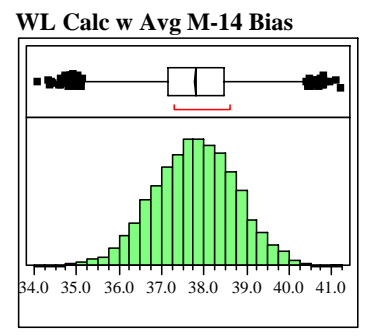

Quantiles

$100.0 \%$ maximum 41.230

$99.5 \% \quad 40.154$

$97.5 \% \quad 39.659$

$90.0 \% \quad 38.998$

$75.0 \%$ quartile 38.455

$50.0 \%$ median 37.810

$25.0 \%$ quartile 37.137

$10.0 \% \quad 36.554$

$\begin{array}{ll}10.5 \% & 35.895\end{array}$

$0.5 \% \quad 35.236$

$0.0 \%$ minimum 34.099

Moments

Mean $\quad 37.792132$

Std Dev $\quad 0.9612397$

Std Err Mean $\quad 0.0096124$

upper 95\% Mean 37.810974

lower 95\% Mean 37.77329

$\mathrm{N}$

10000
$100.0 \%$ maximum 41.163

$99.5 \% \quad 40.292$

$97.5 \% \quad 39.874$

$90.0 \% \quad 39.430$

$75.0 \%$ quartile 38.977

$50.0 \%$ median 38.497

$25.0 \%$ quartile 38.002

$10.0 \% \quad 37.572$

$2.5 \% \quad 37.090$

$0.5 \% \quad 36.621$

$0.0 \%$ minimum 35.679

Moments

Mean

Std Dev $\quad 0.7169546$

Std Err Mean $\quad 0.0071695$

upper 95\% Mean 38.507792

lower 95\% Mean 38.479685

$\mathrm{N}$

10000

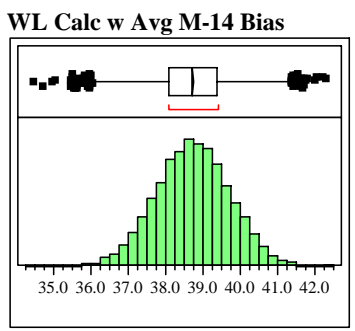

Quantiles

$100.0 \%$ maximum 42.318

$99.5 \% \quad 41.211$

$97.5 \% \quad 40.612$

$90.0 \% \quad 39.998$

$75.0 \%$ quartile 39.394

$50.0 \%$ median 38.728

$25.0 \%$ quartile 38.067

$10.0 \% \quad 37.471$

$\begin{array}{ll}10.0 \% & 36.812\end{array}$

$0.5 \% \quad 36.147$

$0.0 \%$ minimum 34.483

Moments

Mean $\quad 38.727618$

Std Err Mean $\quad 0.0098001$

upper 95\% Mean 38.746828

lower 95\% Mean 38.708408

$\mathrm{N}$

10000
Std Dev $\quad 0.9800105$
Batch $=343$

Blending $\mathrm{WL}=\mathbf{3 7 . 1 1}$

WL Calc $=37.17$

WL Calc w Avg M-13 Bias

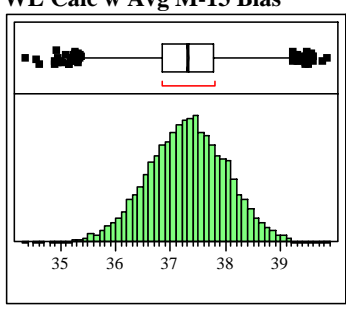

Quantiles

$100.0 \%$ maximum 39.866

$99.5 \% \quad 39.072$

$97.5 \% \quad 38.673$

$90.0 \% \quad 38.204$

$75.0 \%$ quartile 37.791

$50.0 \%$ median 37.317

$25.0 \%$ quartile 36.833

$10.0 \% \quad 36.392$

$2.5 \% \quad 35.894$

$0.5 \% \quad 35.485$

$0.0 \%$ minimum 34.383

Moments

Mean

Std Dev $\quad 0.7073936$

Std Err Mean $\quad 0.0070739$

upper 95\% Mean 37.321485

lower 95\% Mean 37.293752

$\mathrm{N}$

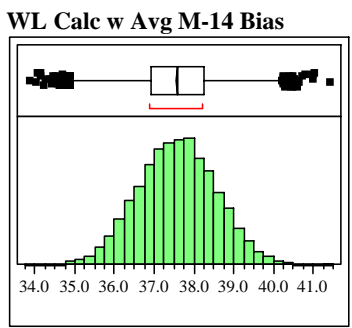

Quantiles

$100.0 \%$ maximum 41.433

$99.5 \% \quad 40.030$

$97.5 \% \quad 39.454$

$90.0 \% \quad 38.824$

$75.0 \%$ quartile 38.245

$50.0 \%$ median 37.584

$25.0 \%$ quartile 36.919

$10.0 \% \quad 36.320$

$\begin{array}{ll}10.5 \% & 35.686\end{array}$

$0.5 \% \quad 35.009$

$0.0 \%$ minimum 33.897

Moments

Mean

Std Dev $\quad 0.9748945$

Std Err Mean $\quad 0.0097489$

upper 95\% Mean 37.594048

lower 95\% Mean 37.555829

$\mathrm{N}$ 
WSRC-STI-2006-00068

Revision 0

Exhibit A9. Sensitivity of Blending Target WLs to the Uncertainties of This Report (continued)

\section{Batch $=344$}

Blending $\mathrm{WL}=\mathbf{3 7 . 2 9}$

WL Calc $=37.35$

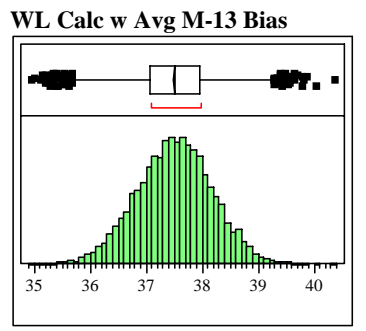

Quantiles

$100.0 \%$ maximum 40.383

$99.5 \% \quad 39.231$

$97.5 \% \quad 38.799$

$90.0 \%$

$75.0 \%$ quartile 37.954

$50.0 \%$ median 37.516

$25.0 \%$ quartile $\quad 37.055$

$10.0 \% \quad 36.633$

$2.5 \% \quad 36.163$

$0.5 \% \quad 35.683$

$0.0 \% \quad$ minimum 34.957

Moments

Mean $\quad 37.502828$

Std Dev

0.67373

Std Err Mean $\quad 0.0067373$

upper 95\% Mean 37.516035

lower 95\% Mean 37.489622

$\mathrm{N}$

10000

WL Calc w Avg M-14 Bias

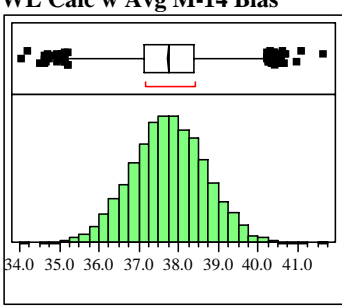

Quantiles

$100.0 \%$ maximum 41.638

$99.5 \% \quad 40.151$

$97.5 \% \quad 39.553$

$90.0 \% \quad 38.928$

$75.0 \%$ quartile 38.376

$50.0 \%$ median 37.752

$25.0 \%$ quartile 37.129

$10.0 \% \quad 36.559$

$2.5 \% \quad 35.963$

$0.5 \% \quad 35.392$

$0.0 \%$ minimum 34.049

Moments

Mean $\quad 37.750636$

Std Dev $\quad 0.9217905$

Std Err Mean $\quad 0.0092179$

upper 95\% Mean 37.768705

lower 95\% Mean 37.732567

$\mathrm{N}$

10000
Batch $=345$

Blending $W L=37.26$

WL Calc $=37.32$

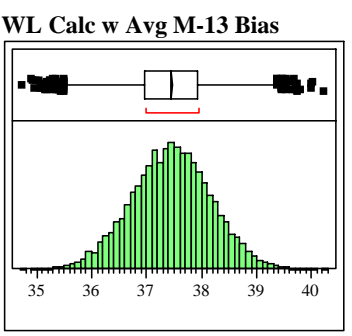

Quantiles

$100.0 \%$ maximum 40.234

$99.5 \%$

$97.5 \% \quad 38.847$

$90.0 \% \quad 38.375$

$75.0 \%$ quartile 37.930

$50.0 \%$ median 37.452

$25.0 \%$ quartile 36.965

$10.0 \% \quad 36.512$

$2.5 \% \quad 36.008$

$0.5 \% \quad 35.537$

$0.0 \%$ minimum 34.753

Moments

Mean $\quad 37.446664$

Std Dev $\quad 0.7228752$

Std Err Mean $\quad 0.0072288$

upper 95\% Mean 37.460834

lower 95\% Mean 37.432494

$\mathrm{N}$

10000

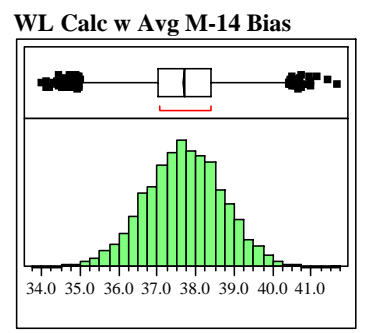

Quantiles

$100.0 \%$ maximum 41.676

$99.5 \% \quad 40.269$

$97.5 \% \quad 39.671$

$90.0 \% \quad 38.986$

$75.0 \%$ quartile 38.381

$50.0 \%$ median $\quad 37.706$

$25.0 \%$ quartile 37.034

$10.0 \% \quad 36.406$

$\begin{array}{ll}10.5 \% & 35.703\end{array}$

$0.5 \% \quad 35.04$

$0.0 \%$ minimum 33.998

Moments

Mean $\quad 37.70126$

Std Dev $\quad 1.0057604$

Std Err Mean $\quad 0.0100576$

upper 95\% Mean 37.720975

lower 95\% Mean 37.681545

$\mathrm{N}$

10000

0.6432744

$0.5 \% \quad 35.650$
Batch=346

Blending WL = 37.37

WL Calc $=37.43$

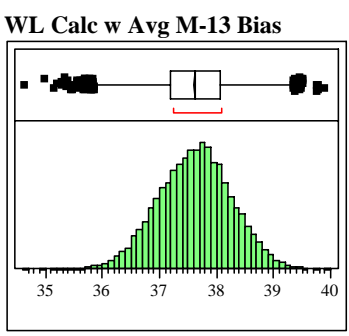

Quantiles

Batch $=347$

Blending $W L=37.30$

WL Calc $=37.36$

WL Calc w Avg M-13 Bias

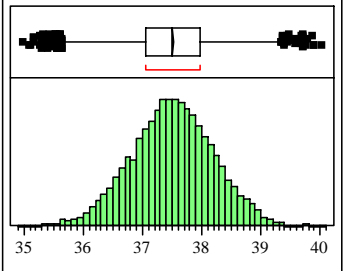

Quantiles

$100.0 \%$ maximum 39.910

$99.5 \% \quad 39.231$

$97.5 \% \quad 38.861$

$90.0 \% \quad 38.442$

$75.0 \%$ quartile 38.055

$50.0 \%$ median 37.635

$25.0 \%$ quartile 37.186

$10.0 \% \quad 36.792$

$2.5 \% \quad 36.345$

$0.5 \% \quad 35.872$

$0.0 \%$ minimum 34.651

Moments

Mean

Std Dev

37.620042

upper 95\% Mean 37.632651

lower 95\% Mean 37.607432

$\mathrm{N}$

10000

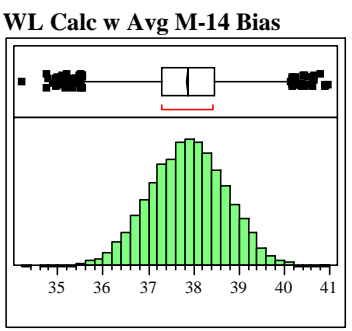

Quantiles

$100.0 \%$ maximum 40.999

$99.5 \% \quad 40.047$

$97.5 \% \quad 39.471$

$90.0 \% \quad 38.949$

$75.0 \%$ quartile 38.447

$50.0 \%$ median 37.883

$25.0 \%$ quartile $\quad 37.297$

$10.0 \% \quad 36.780$

$\begin{array}{ll}2.5 \% & 36.220\end{array}$

$0.0 \%$ minimum 34.229

Moments

Mean $\quad 37.871106$

Std Dev $\quad 0.843855$

Std Err Mean $\quad 0.0084385$

upper 95\% Mean 37.887648

lower 95\% Mean 37.854565

$\mathrm{N}$

10000
$100.0 \%$ maximum 40.044

$99.5 \% \quad 39.304$

$97.5 \% \quad 38.855$

$90.0 \% \quad 38.395$

$75.0 \%$ quartile $\quad 37.970$

$50.0 \%$ median 37.509

$25.0 \%$ quartile 37.045

$10.0 \% \quad 36.600$

$2.5 \% \quad 36.122$

$0.5 \% \quad 35.643$

$0.0 \%$ minimum 34.984

Moments

Mean

Std Dev

37.505217

0.6992
Std Err Mean $\quad 0.006992$

upper 95\% Mean 37.518923

lower 95\% Mean 37.491511

$\mathrm{N}$

10000

WL Calc w Avg M-14 Bias

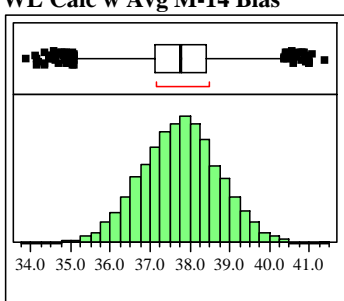

Quantiles

$100.0 \%$ maximum 41.395

$97.5 \% \quad 39.649$

$90.0 \% \quad 39.012$

$75.0 \%$ quartile 38.408

$50.0 \%$ median 37.772

$25.0 \%$ quartile 37.102

$10.0 \% \quad 36.497$

$\begin{array}{ll}10.0 \% & 35.851\end{array}$

$0.5 \% \quad 35.198$

$0.0 \%$ minimum 33.889

Moments

Mean $\quad 37.757063$

Std Dev $\quad 0.9800465$

Std Err Mean $\quad 0.0098005$

upper 95\% Mean 37.776274

lower 95\% Mean 37.737852

$\mathrm{N}$

10000
$99.5 \% \quad 40.277$ 
WSRC-STI-2006-00068

Revision 0

Exhibit A9. Sensitivity of Blending Target WLs to the Uncertainties of This Report (continued)

Batch=348

Blending WL $=38.32$

WL Calc $=38.38$

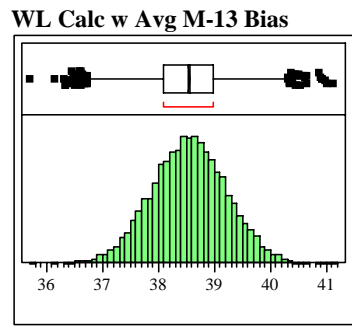

Quantiles

$100.0 \%$ maximum 41.127

$99.5 \% \quad 40.198$

$97.5 \% \quad 39.831$

$90.0 \% \quad 39.391$

$75.0 \%$ quartile 38.988

$50.0 \%$ median

$25.0 \%$ quartile 38.098

$10.0 \% \quad 37.686$

$2.5 \% \quad 37.241$

$0.5 \% \quad 36.809$

$0.0 \%$ minimum 35.720

Moments

Mean $\quad 38.543872$

Std Dev $\quad 0.6629853$

Std Err Mean $\quad 0.0066299$

upper 95\% Mean 38.556868

lower 95\% Mean 38.530877

$\mathrm{N}$

10000

WL Calc w Avg M-14 Bias

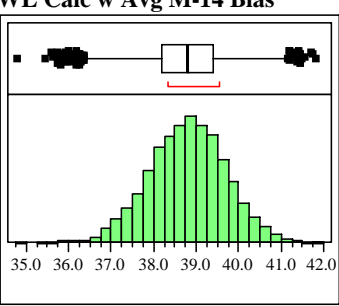

Quantiles

$100.0 \%$ maximum 41.843

$99.5 \% \quad 41.058$

$97.5 \% \quad 40.527$

$90.0 \% \quad 39.926$

$75.0 \%$ quartile 39.393

$50.0 \%$ median 38.809

$25.0 \%$ quartile 38.193

$10.0 \% \quad 37.638$

$\begin{array}{ll}2.5 \% & 37.005\end{array}$

$0.5 \% \quad 36.343$

$0.0 \%$ minimum 34.806

Moments

Mean 38.79365

Std Dev $\quad 0.8939885$

Std Err Mean $\quad 0.0089399$

upper 95\% Mean 38.811174

lower 95\% Mean 38.776126

$\mathrm{N}$

10000
Batch=349

Blending WL $=38.46$

WL Calc $=38.52$

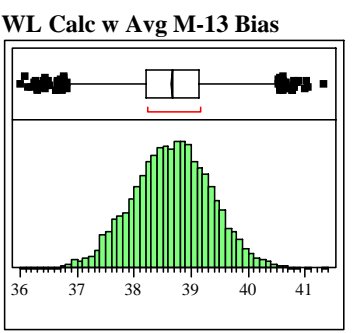

Quantiles

$100.0 \%$ maximum 41.344

$99.5 \% \quad 40.412$

$97.5 \% \quad 39.994$

$90.0 \% \quad 39.526$

$75.0 \%$ quartile 39.134

$50.0 \%$ median 38.679

$25.0 \%$ quartile 38.209

$\begin{array}{ll}25.0 \% & 37.766\end{array}$

$2.5 \% \quad 37.324$

$0.5 \% \quad 36.872$

$0.0 \%$ minimum 36.021

Moments

Mean $\quad 38.665304$

Std Dev $\quad 0.686103$

Std Err Mean $\quad 0.006861$

upper 95\% Mean 38.678753

lower 95\% Mean 38.651855

$\mathrm{N}$

10000

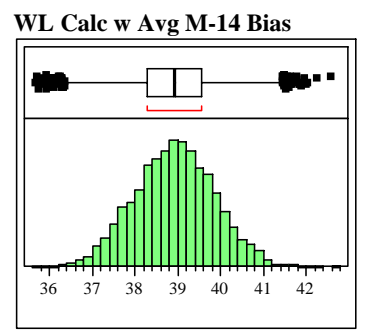

Quantiles

$100.0 \%$ maximum 42.607

$99.5 \% \quad 41.315$

$97.5 \% \quad 40.778$

$90.0 \% \quad 40.114$

$75.0 \%$ quartile 39.554

$50.0 \%$ median 38.930

$25.0 \%$ quartile 38.286

$10.0 \% \quad 37.691$

$2.5 \% \quad 37.104$

$0.5 \% \quad 36.450$

$0.0 \%$ minimum 35.690

Moments

Mean $\quad 38.918496$

Std Dev $\quad 0.9423808$

Std Err Mean 0.0094238

upper 95\% Mean 38.936968

lower 95\% Mean 38.900023

$\mathrm{N}$

10000
Batch $=350$

Blending WL $=38.12$

WL Calc $=38.17$

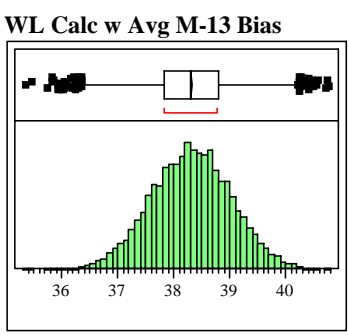

Quantiles

Batch $=351$

Blending WL $=\mathbf{3 7 . 6 7}$

WL Calc $=37.73$

WL Calc w Avg M-13 Bias

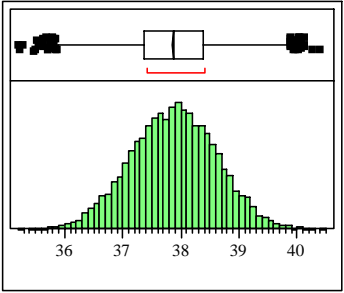

Quantiles

$100.0 \%$ maximum 40.775

$99.5 \% \quad 40.097$

$97.5 \% \quad 39.668$

$90.0 \% \quad 39.214$

$75.0 \%$ quartile 38.789

$50.0 \%$ median 38.312

$25.0 \%$ quartile 37.828

$\begin{array}{ll}25.0 \% & 37.401\end{array}$

$2.5 \% \quad 36.919$

$0.5 \% \quad 36.507$

$0.0 \%$ minimum 35.366

Moments

Mean $\quad 38.309033$

Std Dev $\quad 0.7057071$

Std Err Mean $\quad 0.0070571$

upper 95\% Mean 38.322866

lower 95\% Mean 38.2952

$\mathrm{N}$

10000

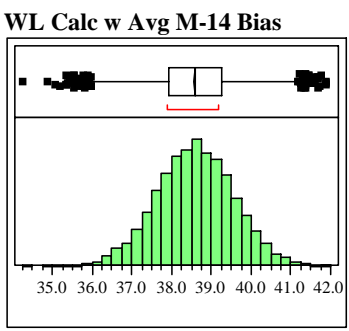

Quantiles

$100.0 \%$ maximum 41.912

$99.5 \% \quad 41.064$

$97.5 \% \quad 40.471$

$90.0 \%$

$75.0 \%$ quartile 39.243

$50.0 \%$ median 38.593

$25.0 \%$ quartile 37.944

$10.0 \% \quad 37.348$

$\begin{array}{ll}2.5 \% & 36.671\end{array}$

$0.5 \% \quad 36.091$

$0.0 \%$ minimum 34.287

Moments

Mean 38.591852

Std Dev $\quad 0.9638818$

Std Err Mean $\quad 0.0096388$

upper 95\% Mean 38.610746

lower 95\% Mean 38.572958

$\mathrm{N}$

10000
$100.0 \%$ maximum 40.407

$99.5 \% \quad 39.693$

$97.5 \% \quad 39.264$

$90.0 \% \quad 38.807$

$75.0 \%$ quartile $\quad 38.379$

$50.0 \%$ median 37.885

$25.0 \%$ quartile $\quad 37.378$

$10.0 \% \quad 36.933$

$2.5 \% \quad 36.446$

$0.5 \% \quad 36.011$

$0.0 \%$ minimum 35.200

Moments

Mean

Std Err Mean $\quad 0.729286$

upper 95\% Mean 37.889667

lower 95\% Mean 37.861076

$\mathrm{N}$

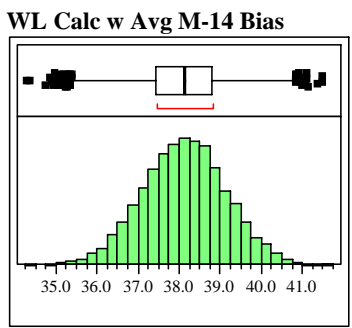

Quantiles

$100.0 \%$ maximum 41.505

$99.5 \% \quad 40.616$

$97.5 \% \quad 40.098$

$90.0 \% \quad 39.420$

$75.0 \%$ quartile 38.794

$50.0 \%$ median 38.136

$25.0 \%$ quartile 37.439

$10.0 \% \quad 36.812$

$\begin{array}{ll}10.0 \% & 36.129\end{array}$

$0.5 \% \quad 35.468$

$0.0 \%$ minimum 34.296

Moments

Mean

Std Dev $\quad 1.0092789$

Std Err Mean $\quad 0.0100928$

upper 95\% Mean 38.140442

lower 95\% Mean 38.100874

$\mathrm{N}$ 
WSRC-STI-2006-00068

Revision 0

Exhibit A9. Sensitivity of Blending Target WLs to the Uncertainties of This Report (continued)

Batch $=352$

Blending WL $=37.00$

WL Calc $=37.06$

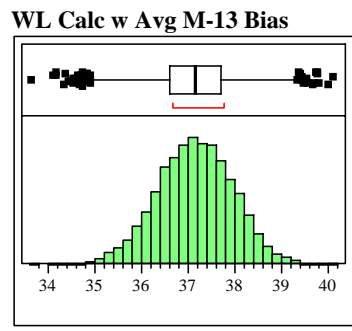

Quantiles

$100.0 \%$ maximum 40.114

$99.5 \%$

$97.5 \% \quad 38.687$

$90.0 \%$

$75.0 \%$ quartile 37.703

$50.0 \%$ median

$25.0 \%$ quartile 36.602

$10.0 \% \quad 36.121$

$2.5 \% \quad 35.528$

$0.5 \% \quad 35.097$

$0.0 \%$ minimum 33.641

Moments

Mean $\quad 37.149665$

Std Dev $\quad 0.8051325$

Std Err Mean $\quad 0.0080513$

upper 95\% Mean 37.165448

lower 95\% Mean 37.133883

$\mathrm{N}$

10000

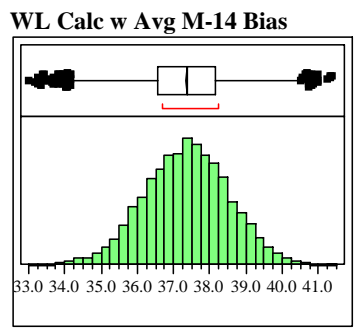

Quantiles

$100.0 \%$ maximum 41.405

$99.5 \% \quad 40.257$

$97.5 \% \quad 39.600$

$90.0 \% \quad 38.847$

$75.0 \%$ quartile 38.159

$50.0 \%$ median 37.382

$25.0 \%$ quartile 36.573

$10.0 \% \quad 35.868$

$\begin{array}{ll}2.5 \% & 35.051\end{array}$

$0.5 \% \quad 34.245$

$0.0 \%$ minimum 33.017

Moments

Mean $\quad 37.361936$

Std Dev $\quad 1.1613708$

Std Err Mean $\quad 0.0116137$

upper 95\% Mean 37.384701

lower 95\% Mean 37.339171

$\mathrm{N}$

10000
Batch $=353$

Blending $W L=37.44$

WL Calc $=\mathbf{3 7 . 5 0}$

WL Calc w Avg M-13 Bias

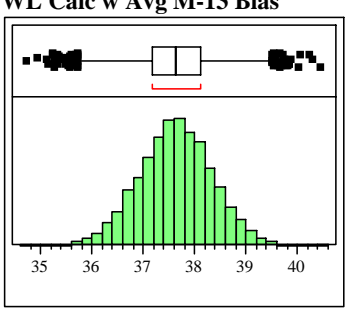

Quantiles

Batch $=354$

Blending WL $=39.25$

WL Calc $=39.30$

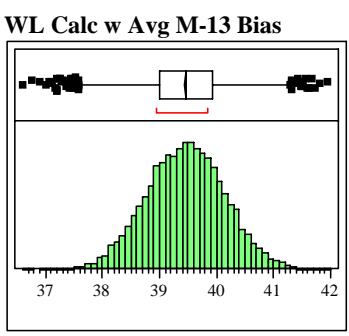

Quantiles

$100.0 \%$ maximum 40.458

$99.5 \% \quad 39.431$

$97.5 \% \quad 39.006$

$90.0 \% \quad 38.539$

$75.0 \%$ quartile 38.108

$50.0 \%$ median 37.635

$25.0 \%$ quartile 37.165

$10.0 \% \quad 36.701$

$2.5 \% \quad 36.234$

$0.5 \% \quad 35.769$

$0.0 \%$ minimum 34.750

Moments

Mean $\quad 37.629678$

Std Dev $\quad 0.7088292$

Std Err Mean $\quad 0.0070883$

upper 95\% Mean 37.643572

lower 95\% Mean 37.615783

$\mathrm{N}$

10000

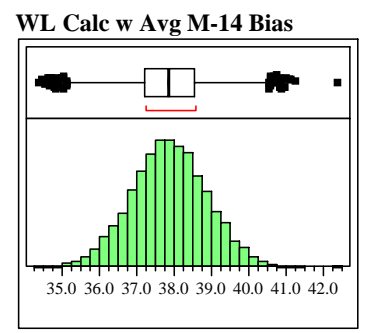

Quantiles

$100.0 \%$ maximum 42.393

$99.5 \% \quad 40.333$

$97.5 \% \quad 39.821$

$90.0 \% \quad 39.153$

$75.0 \%$ quartile 38.533

$50.0 \%$ median 37.854

$25.0 \%$ quartile $\quad 37.191$

$10.0 \% \quad 36.570$

$\begin{array}{ll}10.5 \% & 35.901\end{array}$

$0.5 \% \quad 35.297$

$0.0 \%$ minimum 34.397

Moments

Mean $\quad 37.863049$

Std Dev $\quad 0.9972616$

Std Err Mean $\quad 0.0099726$

upper 95\% Mean 37.882598

lower 95\% Mean 37.843501

$\mathrm{N}$

10000
$100.0 \%$ maximum 41.958

$99.5 \% \quad 41.156$

$97.5 \% \quad 40.777$

$90.0 \% \quad 40.322$

$75.0 \%$ quartile 39.919

$50.0 \%$ median 39.462

$25.0 \%$ quartile 38.992

$10.0 \% \quad 38.577$

$2.5 \% \quad 38.141$

$0.5 \% \quad 37.716$

$0.0 \%$ minimum 36.625

Moments

Mea

Std Dev $\quad 0.6781991$

Std Err Mean $\quad 0.006782$

upper 95\% Mean 39.469771

lower 95\% Mean 39.443183

$\mathrm{N}$

10000

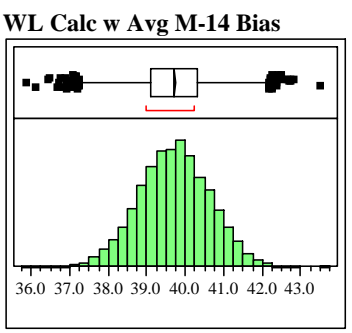

Quantiles

$100.0 \%$ maximum 43.508

$99.5 \% \quad 42.004$

$97.5 \% \quad 41.455$

$90.0 \% \quad 40.896$

$75.0 \%$ quartile 40.332

$50.0 \%$ median 39.727

$25.0 \%$ quartile $\quad 39.102$

$10.0 \% \quad 38.546$

$2.5 \% \quad 37.889$

$0.5 \% \quad 37.358$

$0.0 \%$ minimum 35.911

Moments

Mean 39.71459

Std Dev $\quad 0.9097609$

Std Err Mean $\quad 0.0090976$

upper 95\% Mean 39.732423

lower 95\% Mean 39.696757

$\mathrm{N}$

10000
Batch=355

Blending WL = 34.45

WL Calc $=34.50$

WL Calc w Avg M-13 Bias

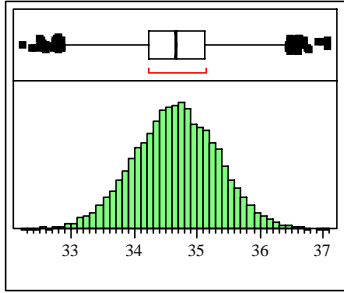

Quantiles

$100.0 \%$ maximum 37.096

$99.5 \% \quad 36.373$

$97.5 \% \quad 35.939$

$90.0 \% \quad 35.499$

$75.0 \%$ quartile 35.116

$50.0 \%$ median 34.672

$25.0 \%$ quartile 34.217

$10.0 \% \quad 33.808$

$2.5 \% \quad 33.354$

$0.5 \% \quad 32.982$

$0.0 \%$ minimum 32.232

Moments

Mean

Std Dev

34.662102

Std Err Mean $\quad 0.0065988$

upper 95\% Mean 34.675037

lower 95\% Mean 34.649167

$\mathrm{N}$

10000

WL Calc w Avg M-14 Bias

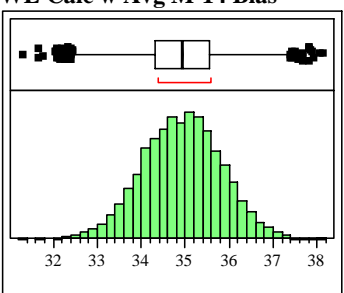

Quantiles

$100.0 \%$ maximum 38.146

$99.5 \% \quad 37.164$

$97.5 \% \quad 36.675$

$90.0 \% \quad 36.067$

$75.0 \%$ quartile 35.537

$50.0 \%$ median 34.939

$25.0 \%$ quartile 34.306

$10.0 \% \quad 33.777$

$2.5 \% \quad 33.131$

$0.5 \% \quad 32.567$

$0.0 \%$ minimum 31.322

Moments

Mean $\quad 34.92513$

Std Dev $\quad 0.897837$

Std Err Mean $\quad 0.0089784$

upper 95\% Mean 34.94273

lower 95\% Mean 34.907531

$\mathrm{N}$

10000 
WSRC-STI-2006-00068

Revision 0

Exhibit A9. Sensitivity of Blending Target WLs to the Uncertainties of This Report (continued)

Batch $=356$

Blending WL = 35.57

WL Calc $=35.63$

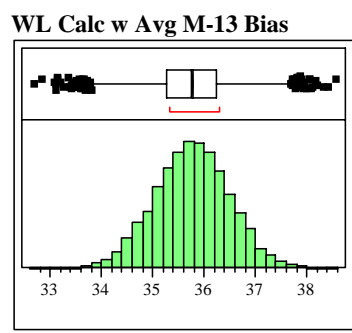

Quantiles

$100.0 \%$ maximum 38.586

$99.5 \% \quad 37.618$

$97.5 \%$

$90.0 \% \quad 36.689$

$75.0 \%$ quartile 36.247

$50.0 \%$ median 35.771

$25.0 \%$ quartile $\quad 35.275$

$10.0 \% \quad 34.809$

$2.5 \% \quad 34.330$

$0.5 \% \quad 33.869$

$0.0 \%$ minimum 32.719

Moments

Mean $\quad 35.758188$

Std Dev $\quad 0.7241482$

Std Err Mean $\quad 0.0072415$

upper 95\% Mean 35.772383

lower 95\% Mean 35.743993

N

WL Calc w Avg M-14 Bias

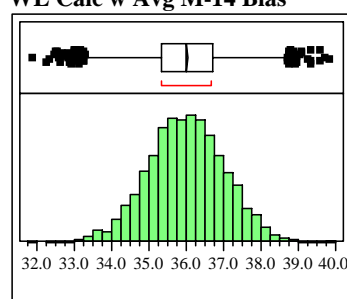

Quantiles

$100.0 \%$ maximum 39.839

$99.5 \% \quad 38.561$

$97.5 \% \quad 37.969$

$90.0 \% \quad 37.312$

$75.0 \%$ quartile 36.697

$50.0 \%$ median 36.007

$25.0 \%$ quartile 35.337

$10.0 \% \quad 34.718$

$\begin{array}{ll}2.5 \% & 34.017 \\ 0.5 \% & 33.356\end{array}$

$0.5 \%$

$0.0 \%$ minimum 31.882

Moments

Mean 36.008355

Std Dev $\quad 1.0125709$

Std Err Mean $\quad 0.0101257$

upper 95\% Mean 36.028203

lower 95\% Mean 35.988506

$\mathrm{N}$

10000 
Exhibit A10. JMP Formulas Used to Conduct Sensitivity Study for Estimating WL at the SME

Formula for Estimating WL Using Uncertainties of M-13 ICP

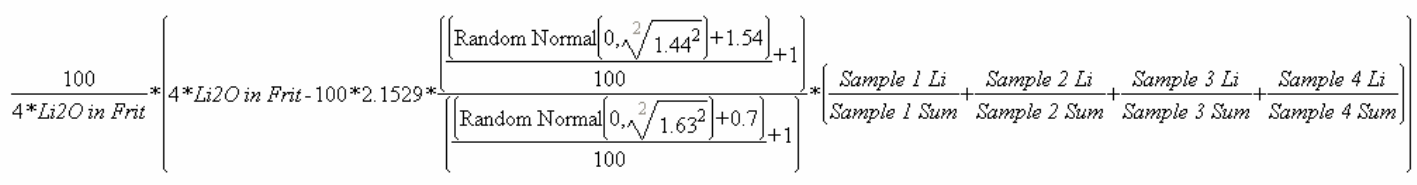

Formula for Estimating WL Using Uncertainties of M-14 ICP

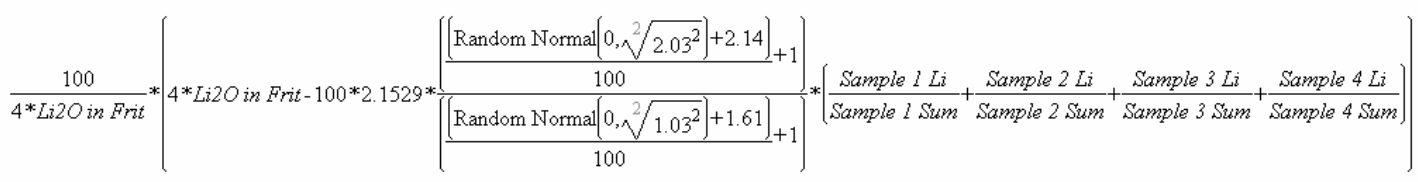


WSRC-STI-2006-00068

Revision 0

Exhibit A11. Sensitivity of SME WL Estimations to the Uncertainties of This Report

Batch $=300$

SME Estimated WL $=37.54$

WL Re-Calc $=\mathbf{3 7 . 5 0}$

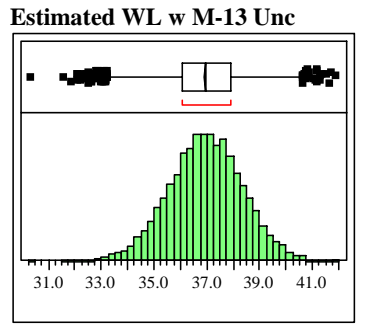

Quantiles

$100.0 \%$ maximum 41.940

$99.5 \% \quad 40.497$

$97.5 \% \quad 39.661$

$90.0 \% \quad 38.720$

$75.0 \%$ quartile 37.892

$50.0 \%$ median 36.967

$25.0 \%$ quartile 36.043

$10.0 \% \quad 35.184$

$\begin{array}{ll}2.5 \% & 34.137\end{array}$

$0.5 \% \quad 33.249$

$0.0 \%$ minimum 30.352

Moments

Mean 36.951464

Std Dev $\quad 1.3905389$

Std Err Mean $\quad 0.0139054$

upper 95\% Mean 36.978721

lower 95\% Mean 36.924207

$\mathrm{N}$

10000

Estimated WL w M-14 Unc

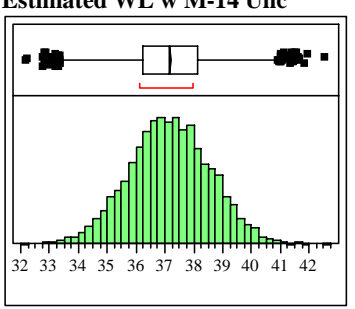

Quantiles

$100.0 \%$ maximum 42.538

$99.5 \% \quad 40.755$

$97.5 \% \quad 39.911$

$90.0 \% \quad 38.972$

$75.0 \%$ quartile 38.121

$50.0 \%$ median 37.162

$25.0 \%$ quartile 36.241

$10.0 \% \quad 35.349$

$2.5 \% \quad 34.422$

$0.5 \% \quad 33.546$

$0.0 \%$ minimum 32.164

Moments

Mean $\quad 37.170269$

Std Dev $\quad 1.4019099$

Std Err Mean $\quad 0.0140191$

upper 95\% Mean 37.197749

lower 95\% Mean 37.142789

N

10000
Batch $=301$

SME Estimated WL $=\mathbf{4 2 . 5 4}$ WL Re-Calc $=42.53$

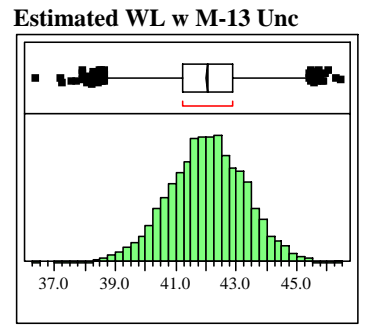

Quantiles

$\begin{array}{lll}100.0 \% & \text { maximum } & 46.495 \\ 99.5 \% & & 45.190 \\ 97.5 \% & & 44.482 \\ 90.0 \% & & 43.627 \\ 75.0 \% & \text { quartile } & 42.895 \\ 50.0 \% & \text { median } & 42.047 \\ 25.0 \% & \text { quartile } & 41.206 \\ 10.0 \% & & 40.417 \\ 2.5 \% & & 39.491 \\ 0.5 \% & 38.703 \\ 0.0 \% \text { minimum } & 36.371 \\ \text { Moments } & \end{array}$

Mean $\quad 42.035008$

Std Dev $\quad 1.2539394$

Std Err Mean $\quad 0.0125394$

upper 95\% Mean 42.059588

lower 95\% Mean 42.010429

$\mathrm{N}$

10000

Estimated WL w M-14 Unc

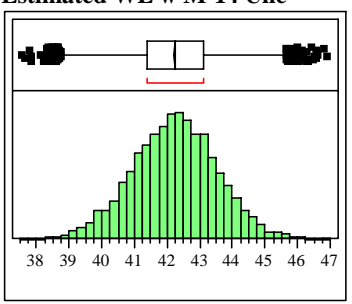

Quantiles

$100.0 \%$ maximum 46.919

$99.5 \% \quad 45.606$

$97.5 \% \quad 44.727$

$90.0 \% \quad 43.862$

$75.0 \%$ quartile 43.098

$50.0 \%$ median 42.249

$25.0 \%$ quartile 41.369

$10.0 \% \quad 40.579$

$2.5 \% \quad 39.668$

$0.5 \% \quad 38.932$

$0.0 \%$ minimum 37.594

Moments

Mean 42.230713

Std Dev $\quad 1.2893342$

Std Err Mean $\quad 0.0128933$

upper 95\% Mean 42.255986

lower 95\% Mean 42.205439

$\mathrm{N}$
Batch $=302$

SME Estimated WL $=37.66$

WL Re-Calc $=37.65$

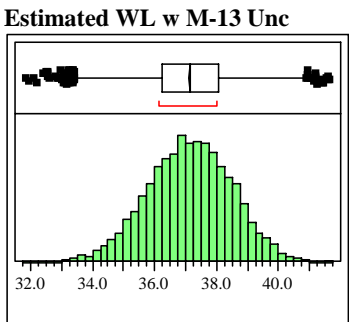

Quantiles

$100.0 \%$ maximum 41.660

$99.5 \% \quad 40.525$

$97.5 \% \quad 39.733$

$90.0 \% \quad 38.852$

$75.0 \%$ quartile 38.079

$50.0 \%$ median 37.164

$25.0 \%$ quartile $\quad 36.225$

$10.0 \% \quad 35.378$

$2.5 \% \quad 34.384$

$0.5 \% \quad 33.506$

$0.0 \%$ minimum 31.881

Moments

Mean $\quad 37.136433$

Std Dev $\quad 1.3594666$

Std Err Mean $\quad 0.0135947$

upper 95\% Mean 37.163081

$\mathrm{N} \quad 10000$

Estimated WL w M-14 Unc

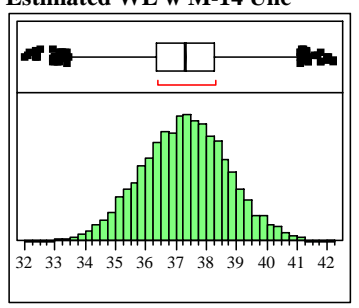

Quantiles

$100.0 \%$ maximum 42.215

$99.5 \% \quad 40.928$

$97.5 \% \quad 40.092$

$90.0 \% \quad 39.080$

$75.0 \%$ quartile 38.260

$50.0 \%$ median 37.318

$25.0 \%$ quartile 36.339

$10.0 \% \quad 35.449$

$2.5 \% \quad 34.509$

$0.5 \% \quad 33.616$

$0.0 \%$ minimum 32.002

Moments

Mean $\quad 37.294863$

Std Dev $\quad 1.4161349$

Std Err Mean $\quad 0.0141613$

upper 95\% Mean 37.322622

lower 95\% Mean 37.267104

$\mathrm{N}$
Batch $=303$

SME Estimated WL $=38.12$ WL Re-Calc $=38.11$

Estimated WL w M-13 Unc

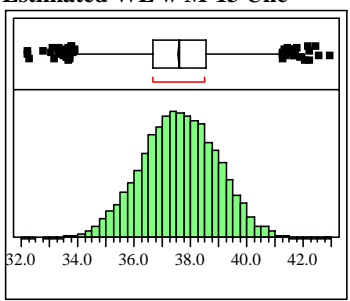

Quantiles

$\begin{array}{lll}100.0 \% & \text { maximum } & 42.952 \\ 99.5 \% & & 40.937 \\ 97.5 \% & & 40.159 \\ 90.0 \% & & 39.328 \\ 75.0 \% & \text { quartile } & 38.538 \\ 50.0 \% & \text { median } & 37.600 \\ 25.0 \% & \text { quartile } & 36.694 \\ 10.0 \% & & 35.854 \\ 2.5 \% & & 34.947 \\ 0.5 \% & & 34.144 \\ 0.0 \% & \text { minimum } & 32.245\end{array}$

Moments

Mean $\quad 37.602201$

Std Dev $\quad 1.3462434$

Std Err Mean $\quad 0.0134624$

upper 95\% Mean 37.62859

lower 95\% Mean 37.575812

$\mathrm{N}$

Estimated WL w M-14 Unc

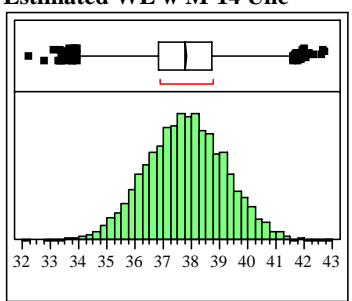

Quantiles

$100.0 \%$ maximum 42.756

$99.5 \% \quad 41.268$

$97.5 \% \quad 40.498$

$90.0 \% \quad 39.571$

$75.0 \%$ quartile 38.735

$50.0 \%$ median 37.791

$25.0 \%$ quartile 36.840

$10.0 \% \quad 35.997$

$2.5 \% \quad 35.042$

$0.5 \% \quad 34.178$

$0.0 \%$ minimum 32.247

Moments

Mean $\quad 37.784194$

Std Dev $\quad 1.3928957$

Std Err Mean $\quad 0.013929$

upper 95\% Mean 37.811497

lower 95\% Mean 37.75689

$\mathrm{N}$ 
WSRC-STI-2006-00068

Revision 0

Exhibit A11. Sensitivity of SME WL Estimations to the Uncertainties of This Report (continued)

Batch=304

SME Estimated WL $=37.95$

WL Re-Calc $=37.94$

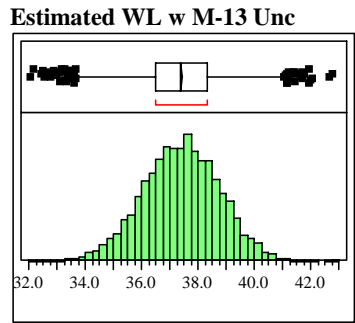

Quantiles

$100.0 \%$ maximum 42.779

$99.5 \% \quad 40.722$

$97.5 \% \quad 40.015$

$90.0 \%$

$75.0 \%$ quartile 38.328

$50.0 \%$ median 37.411

$25.0 \%$ quartile $\quad 36.487$

$10.0 \% \quad 35.657$

$\begin{array}{ll}10.5 \% & 34.689\end{array}$

$0.5 \% \quad 33.875$

$0.0 \%$ minimum 32.106

Moments

Mean $\quad 37.394614$

Std Dev $\quad 1.353142$

Std Err Mean $\quad 0.0135314$

upper 95\% Mean 37.421138

lower 95\% Mean 37.36809

$\mathrm{N} \quad 10000$

Estimated WL w M-14 Unc

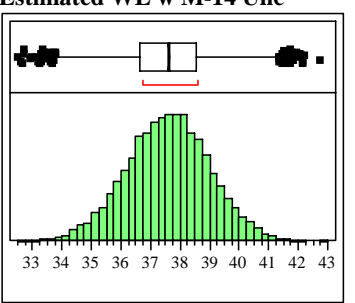

Quantiles

$100.0 \%$ maximum 42.752

$99.5 \% \quad 41.204$

$97.5 \% \quad 40.345$

$90.0 \% \quad 39.391$

$75.0 \%$ quartile 38.542

$50.0 \%$ median 37.624

$25.0 \%$ quartile 36.657

$10.0 \% \quad 35.784$

$2.5 \% \quad 34.774$

$0.5 \% \quad 33.993$

$0.0 \%$ minimum 32.523

Moments

Mean $\quad 37.596502$

Std Dev $\quad 1.4038819$

Std Err Mean $\quad 0.0140388$

upper 95\% Mean 37.624021

lower 95\% Mean 37.568983

$\mathrm{N}$
Batch $=305$

SME Estimated WL $=38.85$

WL Re-Calc $=38.84$

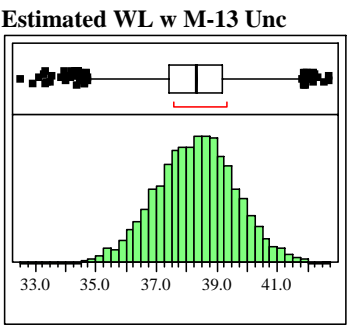

Quantiles

$100.0 \%$ maximum 42.730

$99.5 \% \quad 41.571$

$97.5 \% \quad 40.854$

$90.0 \% \quad 39.961$

$75.0 \%$ quartile 39.200

$50.0 \%$ median 38.335

$25.0 \%$ quartile $\quad 37.428$

$10.0 \% \quad 36.606$

$2.5 \% \quad 35.693$

$0.5 \% \quad 34.898$

$0.0 \%$ minimum 32.527

Moments

Mean $\quad 38.304485$

Std Dev $\quad 1.311878$

Std Err Mean $\quad 0.0131188$

upper 95\% Mean 38.3302

lower 95\% Mean 38.278769$$
\mathrm{N}
$$

10000

Estimated WL w M-14 Unc

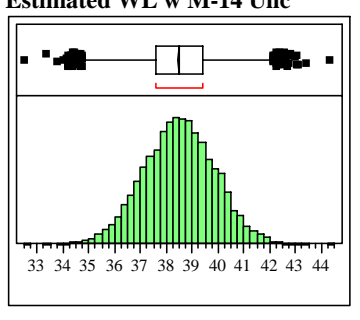

Quantiles

$100.0 \%$ maximum 44.331

42.041

$97.5 \% \quad 41.166$

$90.0 \% \quad 40.239$

$75.0 \%$ quartile 39.414

$50.0 \%$ median 38.497

$25.0 \%$ quartile 37.574

$10.0 \% \quad 36.731$

$2.5 \% \quad 35.785$

$0.5 \% \quad 34.928$

$0.0 \%$ minimum 32.540

Moments

Mean $\quad 38.495289$

Std Dev 1.3743208

Std Err Mean $\quad 0.0137432$

upper 95\% Mean 38.522229

lower 95\% Mean 38.46835

$\mathrm{N}$
Batch=306

SME Estimated WL = 37.96

WL Re-Calc $=37.95$

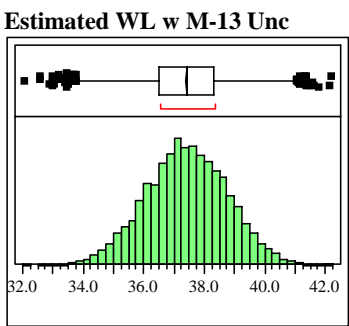

Quantiles

$100.0 \%$ maximum 42.217

$99.5 \% \quad 40.689$

$97.5 \% \quad 39.994$

$90.0 \% \quad 39.121$

$75.0 \%$ quartile 38.341

$50.0 \%$ median 37.413

$25.0 \%$ quartile $\quad 36.528$

$10.0 \% \quad 35.700$

$\begin{array}{ll}10.5 \% & 34.777\end{array}$

$0.5 \% \quad 33.987$

$0.0 \%$ minimum 32.100

Moments

Mean $\quad 37.414021$

Std Dev $\quad 1.3335459$

Std Err Mean $\quad 0.0133355$

upper 95\% Mean 37.440161

lower 95\% Mean 37.387881

10000

Estimated WL w M-14 Unc

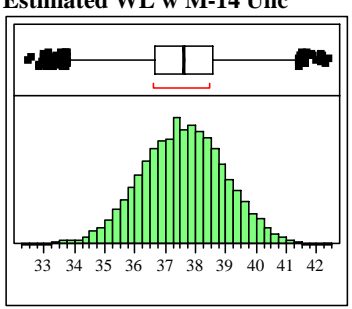

Quantiles

$100.0 \%$ maximum 42.403

$99.5 \% \quad 41.102$

$\begin{array}{ll}97.5 \% & 40.295\end{array}$

$90.0 \% \quad 39.373$

$75.0 \%$ quartile 38.543

$50.0 \%$ median 37.609

$25.0 \%$ quartile 36.658

$10.0 \% \quad 35.829$

$2.5 \% \quad 34.890$

$0.5 \% \quad 33.862$

$0.0 \%$ minimum 32.462

Moments

Mean $\quad 37.600109$

Std Dev $\quad 1.3865897$

Std Err Mean $\quad 0.0138659$

upper 95\% Mean 37.627289

lower 95\% Mean 37.572929

$\mathrm{N} \quad 10000$
Batch $=307$

SME Estimated WL $=\mathbf{4 0 . 4 4}$

WL Re-Calc $=40.43$

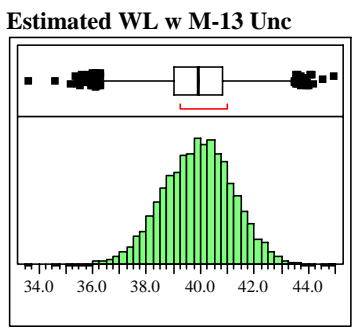

Quantiles

$100.0 \%$ maximum 44.999

$99.5 \% \quad 43.166$

$97.5 \% \quad 42.396$

$90.0 \% \quad 41.548$

$75.0 \%$ quartile 40.804

$50.0 \%$ median 39.953

$25.0 \%$ quartile $\quad 39.027$

$10.0 \% \quad 38.233$

$2.5 \% \quad 37.298$

$0.5 \% \quad 36.424$

$0.0 \%$ minimum 33.637

Moments

Mean 39.915059

Std Dev $\quad 1.299532$

Std Err Mean $\quad 0.0129953$

upper 95\% Mean 39.940533

lower 95\% Mean 39.889586

$\mathrm{N}$

Estimated WL w M-14 Unc

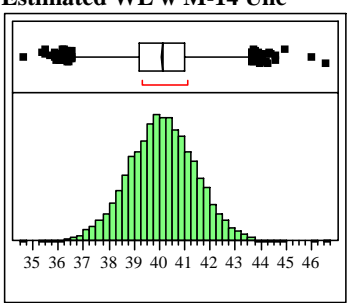

Quantiles

$100.0 \%$ maximum 46.594

$99.5 \% \quad 43.484$

$97.5 \% \quad 42.715$

$90.0 \% \quad 41.812$

$75.0 \%$ quartile 40.999

$50.0 \%$ median 40.107

$25.0 \%$ quartile 39.226

$10.0 \% \quad 38.440$

$2.5 \% \quad 37.502$

$0.5 \% \quad 36.691$

$0.0 \%$ minimum 34.666

Moments

Mean $\quad 40.115134$

Std Dev $\quad 1.3214571$

Std Err Mean 0.0132146

upper 95\% Mean 40.141037

lower 95\% Mean 40.08923

$\mathrm{N}$ 
WSRC-STI-2006-00068

Revision 0

Exhibit A11. Sensitivity of SME WL Estimations to the Uncertainties of This Report (continued)

Batch $=308$

SME Estimated WL $=37.89$

WL Re-Calc $=37.88$

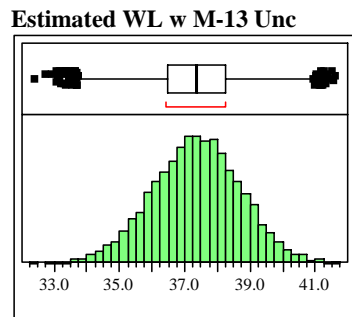

Quantiles

$100.0 \%$ maximum 41.635

$99.5 \% \quad 40.735$

$97.5 \% \quad 39.939$

$90.0 \% \quad 39.058$

$75.0 \%$ quartile $\quad 38.264$

$50.0 \%$ median 37.364

$25.0 \%$ quartile 36.460

$10.0 \% \quad 35.623$

$\begin{array}{ll}2.5 \% & 34.682\end{array}$

$0.5 \% \quad 33.793$

$0.0 \%$ minimum 32.431

Moments

Mean $\quad 37.357202$

Std Dev $\quad 1.3392101$

Std Err Mean $\quad 0.0133921$

upper 95\% Mean 37.383453

lower 95\% Mean 37.33095

$\mathrm{N} \quad 10000$

Estimated WL w M-14 Unc

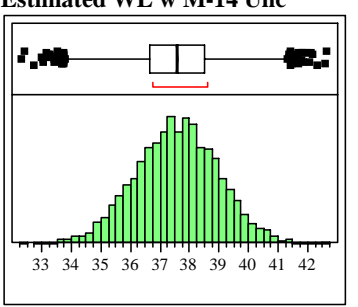

Quantiles

$100.0 \%$ maximum 42.646

$99.5 \% \quad 41.127$

$97.5 \% \quad 40.273$

$90.0 \% \quad 39.319$

$75.0 \%$ quartile 38.524

$50.0 \%$ median 37.596

$25.0 \%$ quartile 36.635

$10.0 \% \quad 35.759$

$2.5 \% \quad 34.839$

$0.5 \% \quad 33.950$

$0.0 \%$ minimum 32.311

Moments

Mean $\quad 37.571247$

Std Dev $\quad 1.3862602$

Std Err Mean $\quad 0.0138626$

upper 95\% Mean 37.59842

lower 95\% Mean 37.544073

$\mathrm{N}$
Batch=309

SME Estimated WL $=37.75$

WL Re-Calc $=37.74$

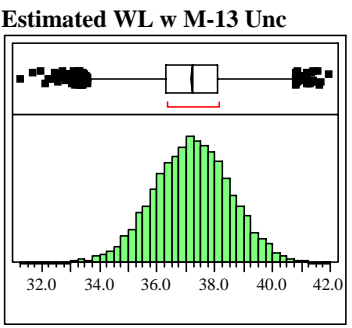

Quantiles

$100.0 \%$ maximum 41.965

$99.5 \%$

$90.0 \%$

$\begin{array}{ll}75.0 \% & \text { quartile } \\ 38.112\end{array}$

$50.0 \%$ median 37.221

$25.0 \%$ quartile 36.318

$10.0 \% \quad 35.481$

$2.5 \% \quad 34.515$

$0.5 \% \quad 33.446$

$0.0 \%$ minimum 31.262

Moments

Mean $\quad 37.210615$

Std Dev $\quad 1.3498274$

Std Err Mean $\quad 0.0134983$

upper 95\% Mean 37.237074

lower 95\% Mean 37.184156

$\mathrm{N}$

10000

Estimated WL w M-14 Unc

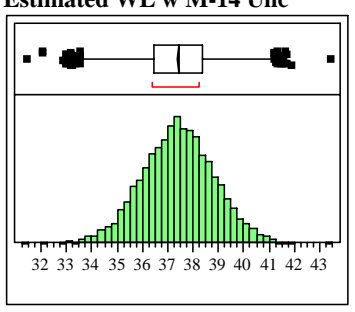

Quantiles

$100.0 \%$ maximum 43.464

$\begin{array}{ll}99.5 \% & 40.895 \\ 97.5 \% & 40.184\end{array}$

$90.0 \% \quad 39.217$

$75.0 \%$ quartile 38.363

$50.0 \%$ median 37.418

$25.0 \%$ quartile 36.466

$10.0 \% \quad 35.607$

$2.5 \% \quad 34.604$

$0.5 \% \quad 33.758$

$0.0 \%$ minimum 31.463

Moments

Mean $\quad 37.411252$

Std Dev $\quad 1.4035765$

Std Err Mean $\quad 0.0140358$

upper 95\% Mean 37.438765

lower 95\% Mean 37.38374

$\mathrm{N}$
Batch=310

SME Estimated WL $=38.41$

WL Re-Calc $=38.40$

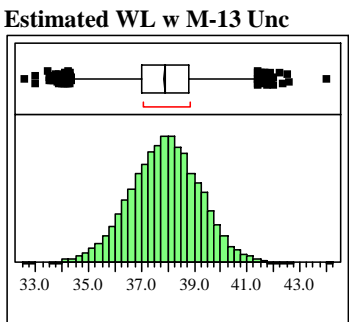

Quantiles

$100.0 \%$ maximum 44.063

$99.5 \% \quad 41.280$

$97.5 \% \quad 40.476$

$90.0 \% \quad 39.562$

$75.0 \%$ quartile 38.771

$50.0 \%$ median $\quad 37.913$

$25.0 \%$ quartile 37.010

$10.0 \% \quad 36.195$

$2.5 \% \quad 35.222$

$0.5 \% \quad 34.317$

$0.0 \%$ minimum 32.581

Moments

Mean $\quad 37.889748$

Std Dev $\quad 1.3240635$

Std Err Mean $\quad 0.0132406$

upper 95\% Mean 37.915702

lower 95\% Mean 37.863794

10000

Estimated WL w M-14 Unc

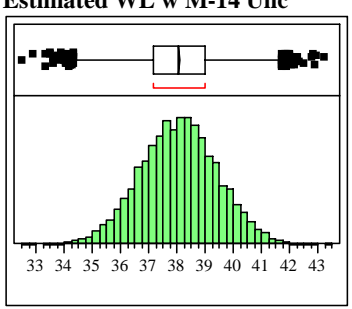

Quantiles

$100.0 \%$ maximum 43.265

$99.5 \% \quad 41.579$

$97.5 \% \quad 40.753$

$90.0 \% \quad 39.837$

$75.0 \%$ quartile 38.976

$50.0 \%$ median 38.081

$25.0 \%$ quartile 37.140

$10.0 \% \quad 36.310$

$2.5 \% \quad 35.354$

$0.5 \% \quad 34.446$

$0.0 \%$ minimum 32.519

Moments

Mean $\quad 38.064339$

Std Dev 1.3730231

Std Err Mean $\quad 0.0137302$

upper 95\% Mean 38.091253

lower 95\% Mean 38.037425

$\mathrm{N} \quad 10000$
Batch $=311$

SME Estimated WL $=35.19$

WL Re-Calc $=35.18$

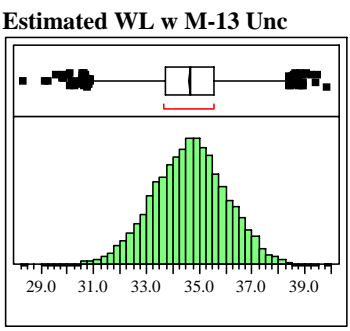

Quantiles

$100.0 \%$ maximum 39.839

$99.5 \% \quad 38.130$

$97.5 \% \quad 37.325$

$90.0 \% \quad 36.451$

$75.0 \%$ quartile 35.566

$50.0 \%$ median 34.664

$25.0 \%$ quartile 33.691

$10.0 \% \quad 32.835$

$2.5 \% \quad 31.823$

$0.5 \% \quad 30.878$

$0.0 \%$ minimum 28.336

Moments

Mean 34.63441

Std Dev $\quad 1.4065654$

Std Err Mean $\quad 0.0140657$

upper 95\% Mean 34.661982

lower 95\% Mean 34.606839

$\mathrm{N}$

Estimated WL w M-14 Unc

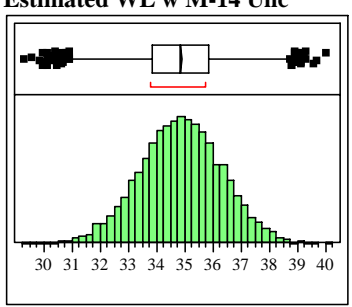

Quantiles

$100.0 \%$ maximum 40.068

$99.5 \% \quad 38.478$

$\begin{array}{ll}97.5 \% & 37.697\end{array}$

$90.0 \% \quad 36.707$

$75.0 \%$ quartile 35.847

$50.0 \%$ median 34.862

$25.0 \%$ quartile 33.889

$10.0 \% \quad 33.022$

$2.5 \% \quad 31.970$

$0.5 \% \quad 31.085$

$0.0 \%$ minimum 29.321

Moments

Mean $\quad 34.861684$

Std Dev $\quad 1.4440609$

Std Err Mean $\quad 0.0144406$

upper 95\% Mean 34.88999

lower 95\% Mean 34.833377

$\mathrm{N} \quad 10000$ 
WSRC-STI-2006-00068

Revision 0

Exhibit A11. Sensitivity of SME WL Estimations to the Uncertainties of This Report (continued)

Batch=312

SME Estimated WL $=39.68$

WL Re-Calc $=39.67$

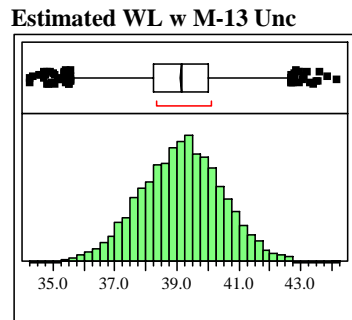

Quantiles

$100.0 \%$ maximum 44.187

$99.5 \% \quad 42.494$

$97.5 \% \quad 41.702$

$90.0 \% \quad 40.821$

$75.0 \%$ quartile 40.032

$50.0 \%$ median 39.170

$25.0 \%$ quartile $\quad 38.265$

$10.0 \% \quad 37.436$

$\begin{array}{ll}2.5 \% & 36.529\end{array}$

$0.5 \% \quad 35.707$

$0.0 \%$ minimum 34.259

Moments

Mean $\quad 39.143758$

Std Dev $\quad 1.3196433$

Std Err Mean $\quad 0.0131964$

upper 95\% Mean 39.169626

lower 95\% Mean 39.117891

$\mathrm{N} \quad 10000$

Estimated WL w M-14 Unc

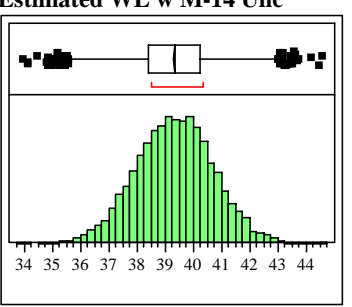

Quantiles

$100.0 \%$ maximum 44.639

$99.5 \% \quad 42.797$

$97.5 \% \quad 41.970$

$90.0 \% \quad 41.070$

$75.0 \%$ quartile $\quad 40.256$

$50.0 \%$ median 39.340

$25.0 \%$ quartile 38.408

$10.0 \% \quad 37.574$

$2.5 \% \quad 36.654$

$0.5 \% \quad 35.857$

$0.0 \%$ minimum 33.975

Moments

Mean $\quad 39.337947$

Std Dev $\quad 1.3625463$

Std Err Mean 0.0136255

upper 95\% Mean 39.364655

lower 95\% Mean 39.311238

$\mathrm{N}$
Batch $=313$

SME Estimated WL $=37.40$

WL Re-Calc $=37.39$

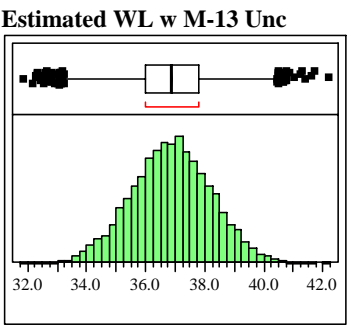

Quantiles

$100.0 \%$ maximum 42.244

$99.5 \% \quad 40.278$

$97.5 \% \quad 39.490$

$90.0 \% \quad 38.600$

$75.0 \%$ quartile 37.776

$50.0 \%$ median 36.879

$25.0 \%$ quartile $\quad 35.973$

$10.0 \% \quad 35.141$

$2.5 \% \quad 34.167$

$0.5 \% \quad 33.418$

$0.0 \%$ minimum 31.894

Moments

Mean 36.86741

Std Dev $\quad 1.3476589$

Std Err Mean $\quad 0.0134766$

upper 95\% Mean 36.893827

lower 95\% Mean 36.840993

10000

Estimated WL w M-14 Unc

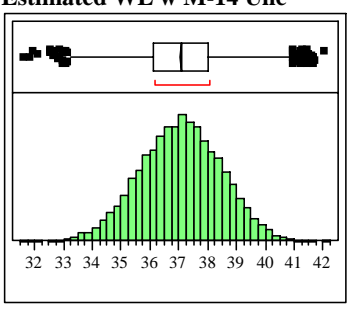

Quantiles

$100.0 \%$ maximum 42.083

$\begin{array}{ll}99.5 \% & 40.640 \\ 97.5 \% & 39.784\end{array}$

$90.0 \% \quad 38.870$

$75.0 \%$ quartile 38.035

$50.0 \%$ median 37.089

$25.0 \%$ quartile 36.107

$10.0 \% \quad 35.254$

$2.5 \% \quad 34.294$

$0.5 \% \quad 33.475$

$0.0 \%$ minimum 31.654

Moments

Mean $\quad 37.071328$

Std Dev $\quad 1.4087612$

Std Err Mean $\quad 0.0140876$

upper 95\% Mean 37.098943

lower 95\% Mean 37.043714

$\mathrm{N}$

10000
Batch $=314$

SME Estimated WL = 38.19

WL Re-Calc $=38.18$

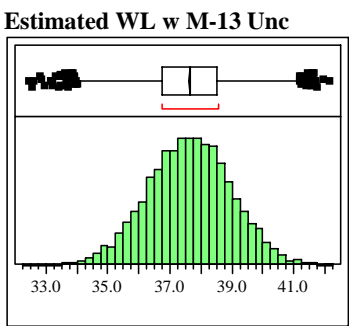

Quantiles

$100.0 \%$ maximum 42.169

$99.5 \% \quad 41.067$

$97.5 \% \quad 40.215$

$90.0 \% \quad 39.330$

$75.0 \%$ quartile 38.527

$50.0 \%$ median 37.641

$25.0 \%$ quartile $\quad 36.729$

$10.0 \% \quad 35.914$

$\begin{array}{ll}10.5 \% & 34.945\end{array}$

$0.5 \% \quad 34.189$

$0.0 \%$ minimum 32.465

Moments

Mean $\quad 37.629142$

Std Dev 1.3329946

Std Err Mean $\quad 0.0133299$

upper 95\% Mean 37.655272

lower 95\% Mean 37.603013

$\mathrm{N}$

10000

Estimated WL w M-14 Unc

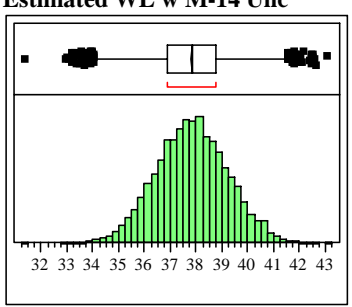

Quantiles

$100.0 \%$ maximum 43.073

$99.5 \% \quad 41.380$

$97.5 \% \quad 40.587$

$90.0 \% \quad 39.617$

$75.0 \%$ quartile 38.764

$50.0 \%$ median 37.834

$25.0 \%$ quartile 36.885

$10.0 \% \quad 36.068$

$2.5 \% \quad 35.130$

$0.5 \% \quad 34.171$

$0.0 \%$ minimum 31.376

Moments

Mean $\quad 37.832113$

Std Dev $\quad 1.3916569$

Std Err Mean 0.0139166

upper 95\% Mean 37.859393

lower 95\% Mean 37.804834

$\mathrm{N} \quad 10000$
Batch=315

SME Estimated WL $=39.11$

WL Re-Calc $=39.10$

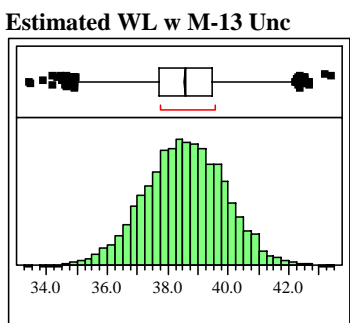

Quantiles

$100.0 \%$ maximum 43.441

$99.5 \% \quad 41.960$

$97.5 \% \quad 41.066$

$90.0 \% \quad 40.230$

$75.0 \%$ quartile 39.483

$50.0 \%$ median 38.577

$25.0 \%$ quartile 37.682

$10.0 \% \quad 36.869$

$2.5 \% \quad 35.901$

$0.5 \% \quad 35.079$

$0.0 \%$ minimum 33.408

Moments

Mean $\quad 38.560447$

Std Dev $\quad 1.3196455$

Std Err Mean $\quad 0.0131965$

upper 95\% Mean 38.586314

lower 95\% Mean 38.534579

$\mathrm{N}$

Estimated WL w M-14 Unc

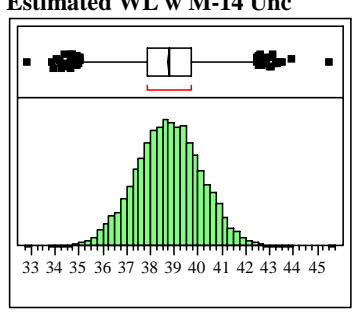

Quantiles

$100.0 \%$ maximum 45.532

$99.5 \% \quad 42.250$

$97.5 \% \quad 41.418$

$90.0 \% \quad 40.525$

$75.0 \%$ quartile 39.686

$50.0 \%$ median 38.761

$25.0 \%$ quartile 37.839

$10.0 \% \quad 36.999$

$2.5 \% \quad 36.032$

$0.5 \% \quad 35.229$

$0.0 \%$ minimum 32.841

Moments

Mean $\quad 38.757848$

Std Dev $\quad 1.3709395$

Std Err Mean $\quad 0.0137094$

upper 95\% Mean 38.784721

lower 95\% Mean 38.730975

$\mathrm{N}$ 
WSRC-STI-2006-00068

Revision 0

Exhibit A11. Sensitivity of SME WL Estimations to the Uncertainties of This Report (continued)

Batch=316

SME Estimated WL $=36.66$

WL Re-Calc $=36.65$

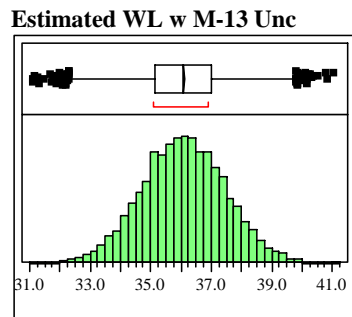

Quantiles

$100.0 \%$ maximum 41.069

$99.5 \% \quad 39.639$

$97.5 \% \quad 38.809$

$90.0 \% \quad 37.856$

$75.0 \%$ quartile $\quad 37.020$

$50.0 \%$ median 36.089

$25.0 \%$ quartile $\quad 35.153$

$10.0 \% \quad 34.336$

$\begin{array}{ll}2.5 \% & 33.413\end{array}$

$0.5 \% \quad 32.494$

$0.0 \%$ minimum 31.121

Moments

Mean $\quad 36.090261$

Std Dev $\quad 1.3756626$

Std Err Mean $\quad 0.0137566$

upper 95\% Mean 36.117227

lower 95\% Mean 36.063295

$\mathrm{N}$

10000

Estimated WL w M-14 Unc

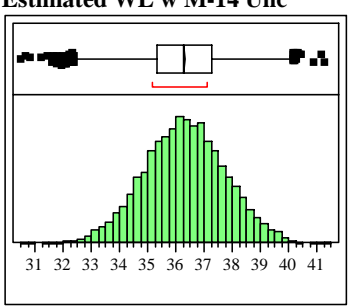

Quantiles

$100.0 \%$ maximum 41.296

$99.5 \% \quad 39.755$

$97.5 \% \quad 39.116$

$90.0 \% \quad 38.148$

$75.0 \%$ quartile 37.265

$50.0 \%$ median 36.296

$25.0 \%$ quartile 35.326

$10.0 \% \quad 34.463$

$2.5 \% \quad 33.459$

$0.5 \% \quad 32.651$

$0.0 \%$ minimum 30.541

Moments

Mean $\quad 36.297665$

Std Dev $\quad 1.4279314$

Std Err Mean 0.0142793

upper 95\% Mean 36.325655

lower 95\% Mean 36.269675

$\mathrm{N}$
Batch $=317$

SME Estimated WL $=38.14$

WL Re-Calc $=38.12$

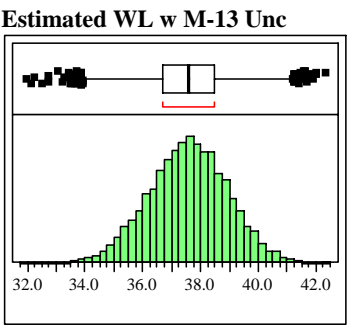

Quantiles

$100.0 \%$ maximum 42.379

$99.5 \% \quad 40.990$

$97.5 \% \quad 40.189$

$90.0 \% \quad 39.290$

$75.0 \%$ quartile 38.498

$50.0 \%$ median 37.613

$25.0 \%$ quartile 36.685

$10.0 \% \quad 35.809$

$2.5 \% \quad 34.906$

$0.5 \% \quad 34.02$

$0.0 \%$ minimum 31.978

Moments

Mean $\quad 37.58321$

Std Dev $\quad 1.353587$

Std Err Mean $\quad 0.0135359$

upper 95\% Mean 37.609743

lower 95\% Mean 37.556677

10000

Estimated WL w M-14 Unc

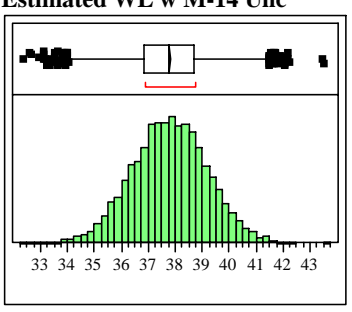

Quantiles

$100.0 \%$ maximum 43.538

$\begin{array}{ll}99.5 \% & 41.350 \\ 97.5 \% & 40.490\end{array}$

$90.0 \% \quad 39.541$

$75.0 \%$ quartile 38.720

$50.0 \%$ median 37.795

$25.0 \%$ quartile 36.864

$10.0 \% \quad 36.011$

$2.5 \% \quad 35.098$

$0.5 \% \quad 34.171$

$0.0 \%$ minimum 32.378

Moments

Mean $\quad 37.789871$

Std Dev $\quad 1.3854777$

Std Err Mean $\quad 0.0138548$

upper 95\% Mean 37.817029

lower 95\% Mean 37.762713

N 10000
Batch $=318$

SME Estimated WL $=\mathbf{4 1 . 6 4}$

WL Re-Calc $=41.63$

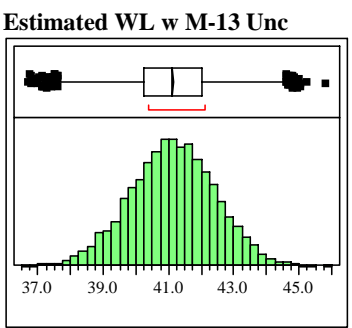

Quantiles

$100.0 \%$ maximum 45.820

$99.5 \% \quad 44.289$

$97.5 \% \quad 43.585$

$90.0 \% \quad 42.773$

$75.0 \%$ quartile 42.002

$50.0 \%$ median 41.129

$25.0 \%$ quartile 40.26

$10.0 \% \quad 39.457$

$\begin{array}{ll}10.5 \% & 38.549\end{array}$

$0.5 \% \quad 37.818$

$0.0 \%$ minimum 36.708

Moments

Mean $\quad 41.12148$

Std Dev $\quad 1.287708$

Std Err Mean $\quad 0.0128771$

upper 95\% Mean 41.146721

$\mathrm{N} \quad 10000$

Estimated WL w M-14 Unc

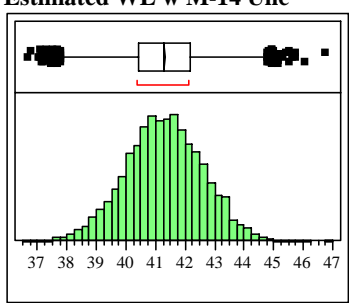

Quantiles

$100.0 \%$ maximum 46.777

$99.5 \% \quad 44.615$

$97.5 \% \quad 43.819$

$90.0 \% \quad 42.966$

$75.0 \%$ quartile $\quad 42.175$

$50.0 \%$ median 41.292

$25.0 \%$ quartile 40.435

$10.0 \% \quad 39.633$

$2.5 \% \quad 38.721$

$0.5 \% \quad 37.862$

$0.0 \%$ minimum 36.711

Moments

Mean $\quad 41.292436$

Std Dev $\quad 1.2985365$

Std Err Mean $\quad 0.0129854$

upper 95\% Mean 41.317889

lower 95\% Mean 41.266982

$\mathrm{N} \quad 10000$
Batch $=319$

SME Estimated WL $=39.53$

WL Re-Calc $=39.52$

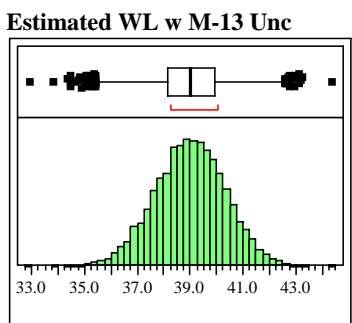

Quantiles

$100.0 \%$ maximum 44.400

$99.5 \% \quad 42.288$

$97.5 \% \quad 41.511$

$90.0 \% \quad 40.675$

$75.0 \%$ quartile 39.901

$50.0 \%$ median 39.016

$25.0 \%$ quartile 38.123

$10.0 \% \quad 37.306$

$2.5 \% \quad 36.368$

$0.5 \% \quad 35.521$

$0.0 \%$ minimum 32.932

Moments

Mean $\quad 39.000303$

Std Dev $\quad 1.3153234$

Std Err Mean $\quad 0.0131532$

upper 95\% Mean 39.026086

lower 95\% Mean 38.97452

$\mathrm{N}$

Estimated WL w M-14 Unc

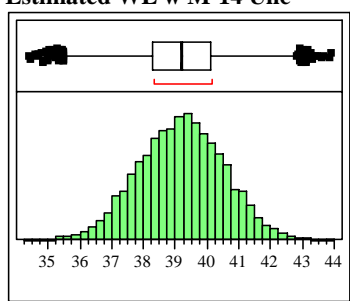

Quantiles

$100.0 \%$ maximum 43.907

$99.5 \% \quad 42.591$

$97.5 \% \quad 41.783$

$90.0 \% \quad 40.916$

$75.0 \%$ quartile $\quad 40.103$

$50.0 \%$ median 39.210

$25.0 \%$ quartile 38.276

$10.0 \% \quad 37.448$

$2.5 \% \quad 36.550$

$0.5 \% \quad 35.589$

$0.0 \%$ minimum 34.411

Moments

Mean $\quad 39.186375$

Std Dev 1.3469502

Std Err Mean 0.0134695

upper 95\% Mean 39.212778

lower 95\% Mean 39.159972

$\mathrm{N} \quad 10000$ 
WSRC-STI-2006-00068

Revision 0

Exhibit A11. Sensitivity of SME WL Estimations to the Uncertainties of This Report (continued)

Batch=320

SME Estimated WL $=\mathbf{4 0 . 2 6}$

WL Re-Calc $=40.25$

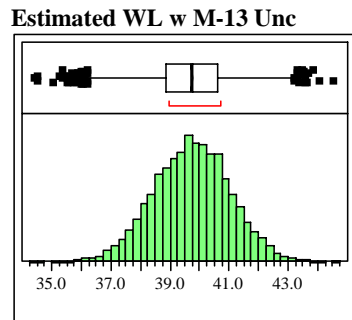

Quantiles

$100.0 \%$ maximum 44.573

$99.5 \% \quad 42.984$

$97.5 \% \quad 42.223$

$90.0 \% \quad 41.372$

$75.0 \%$ quartile 40.618

$50.0 \%$ median 39.755

$25.0 \%$ quartile 38.865

$10.0 \% \quad 38.066$

$\begin{array}{ll}2.5 \% & 37.177\end{array}$

$0.5 \% \quad 36.237$

$0.0 \%$ minimum 34.460

Moments

Mean 39.736706

Std Dev $\quad 1.293499$

Std Err Mean $\quad 0.012935$

upper 95\% Mean 39.762061

lower 95\% Mean 39.711351

$\mathrm{N}$

10000

Estimated WL w M-14 Unc

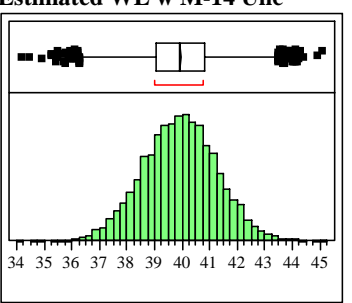

Quantiles

$100.0 \%$ maximum 45.088

$99.5 \% \quad 43.457$

$97.5 \% \quad 42.550$

$90.0 \% \quad 41.623$

$75.0 \%$ quartile 40.810

$50.0 \%$ median 39.935

$25.0 \%$ quartile 39.031

$10.0 \% \quad 38.212$

$2.5 \% \quad 37.285$

$0.5 \% \quad 36.471$

$0.0 \%$ minimum 34.175

Moments

Mean $\quad 39.924359$

Std Dev $\quad 1.3415177$

Std Err Mean $\quad 0.0134152$

upper 95\% Mean 39.950656

lower 95\% Mean 39.898063

$\mathrm{N}$
Batch=321

SME Estimated WL $=36.44$

WL Re-Calc $=36.43$

Estimated WL w M-13 Unc

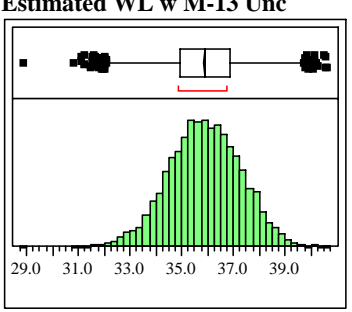

Quantiles

$100.0 \%$ maximum 40.666

$99.5 \%$

$90.0 \%$

$\begin{array}{lll}75.0 \% & \text { quartile } \quad 37.689 \\ 50.847\end{array}$

$50.0 \%$ median 35.896

$25.0 \%$ quartile 34.958

$10.0 \% \quad 34.123$

$2.5 \% \quad 33.110$

$0.5 \% \quad 32.180$

$0.0 \%$ minimum 28.889

Moments

Mean 35.895942

Std Dev $\quad 1.3888317$

Std Err Mean $\quad 0.0138883$

upper 95\% Mean 35.923166

lower 95\% Mean 35.868718

$\mathrm{N}$

10000

Estimated WL w M-14 Unc

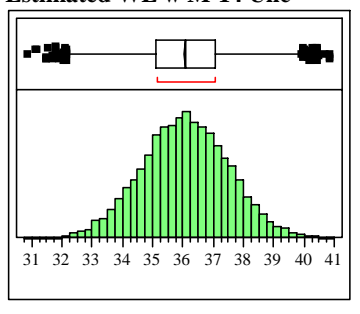

Quantiles

$100.0 \%$ maximum 40.894

$99.5 \% \quad 39.697$

$97.5 \% \quad 38.831$

$90.0 \% \quad 37.893$

$75.0 \%$ quartile 37.045

$50.0 \%$ median 36.065

$25.0 \%$ quartile 35.114

$10.0 \%$ q 34.233

$2.5 \% \quad 33.271$

$0.5 \% \quad 32.452$

$0.0 \%$ minimum 30.883

Moments

Mean $\quad 36.070001$

Std Dev $\quad 1.4186111$

Std Err Mean $\quad 0.0141861$

upper 95\% Mean 36.097809

lower 95\% Mean 36.042193

$\mathrm{N}$
Batch $=322$

SME Estimated WL $=\mathbf{4 0 . 9 7}$

WL Re-Calc $=40.96$

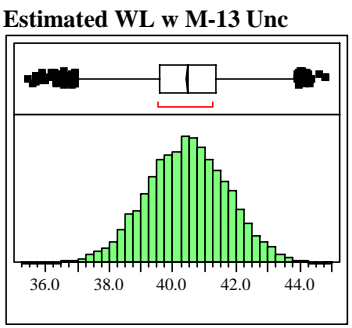

Quantiles

$100.0 \%$ maximum 44.824

$99.5 \% \quad 43.658$

$97.5 \% \quad 42.954$

$90.0 \% \quad 42.077$

$75.0 \%$ quartile 41.334

$50.0 \%$ median 40.462

$25.0 \%$ quartile $\quad 39.590$

$10.0 \% \quad 38.796$

$\begin{array}{ll}10.5 \% & 37.888\end{array}$

$0.5 \% \quad 36.997$

$0.0 \%$ minimum 35.481

Moments

Mean $\quad 40.450431$

Std Dev $\quad 1.2843562$

Std Err Mean $\quad 0.0128436$

upper 95\% Mean 40.475607

lower 95\% Mean 40.425255

$\mathrm{N}$

10000

Estimated WL w M-14 Unc

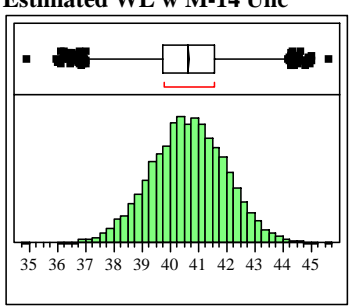

Quantiles

$100.0 \%$ maximum 45.680

$99.5 \% \quad 44.144$

$97.5 \% \quad 43.246$

$90.0 \% \quad 42.344$

$75.0 \%$ quartile 41.556

$50.0 \%$ median 40.651

$25.0 \%$ quartile 39.762

$10.0 \% \quad 38.944$

$2.5 \% \quad 38.001$

$0.5 \% \quad 37.165$

$0.0 \%$ minimum 34.938

Moments

Mean

1.3364622

Std Err Mean $\quad 0.0133646$

upper 95\% Mean 40.676196

lower 95\% Mean 40.623801

$\mathrm{N}$

10000
Batch $=323$

SME Estimated WL $=43.18$

WL Re-Calc $=43.17$

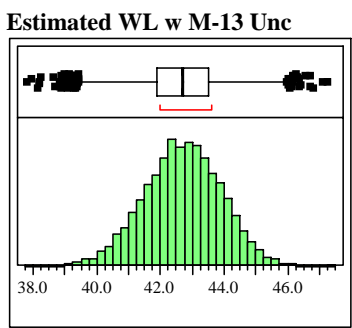

Quantiles

$100.0 \%$ maximum 47.257

$99.5 \% \quad 45.727$

$97.5 \% \quad 45.013$

$90.0 \% \quad 44.239$

$75.0 \%$ quartile 43.531

$50.0 \%$ median 42.718

$25.0 \%$ quartile 41.896

$10.0 \% \quad 41.115$

$2.5 \% \quad 40.267$

$0.5 \% \quad 39.430$

$0.0 \%$ minimum 37.809

Moments

Mean 42.69832

Std Dev $\quad 1.2157632$

Std Err Mean $\quad 0.0121576$

upper 95\% Mean 42.722152

lower 95\% Mean 42.674489

$\mathrm{N}$

Estimated WL w M-14 Unc

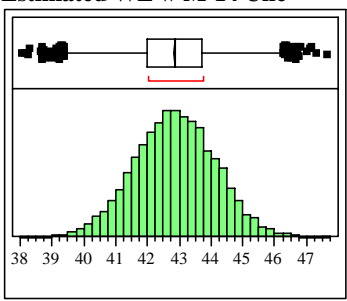

Quantiles

$100.0 \%$ maximum 47.662

$99.5 \% \quad 46.116$

$97.5 \% \quad 45.350$

$90.0 \% \quad 44.480$

$75.0 \%$ quartile 43.723

$50.0 \%$ median 42.864

$25.0 \%$ quartile 42.001

$10.0 \% \quad 41.233$

$2.5 \% \quad 40.342$

$0.5 \% \quad 39.519$

$0.0 \%$ minimum 38.068

Moments

Mean $\quad 42.859422$

Std Dev $\quad 1.2738397$

Std Err Mean $\quad 0.0127384$

upper 95\% Mean 42.884392

lower 95\% Mean 42.834452

$\mathrm{N} \quad 10000$ 
WSRC-STI-2006-00068

Revision 0

Exhibit A11. Sensitivity of SME WL Estimations to the Uncertainties of This Report (continued)

Batch=324

SME Estimated WL $=36.82$

WL Re-Calc $=36.80$

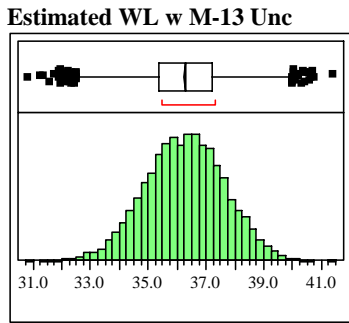

Quantiles

$100.0 \%$ maximum 41.405

$99.5 \% \quad 39.565$

$97.5 \% \quad 38.883$

$90.0 \%$

$75.0 \%$ quartile $\quad 37.203$

$50.0 \%$ median 36.283

$25.0 \%$ quartile $\quad 35.341$

$10.0 \% \quad 34.502$

$2.5 \% \quad 33.599$

$0.5 \% \quad 32.701$

$0.0 \%$ minimum 30.822

Moments

Mean 36.265971

Std Dev $\quad 1.3682013$

Std Err Mean $\quad 0.013682$

upper 95\% Mean 36.29279

lower 95\% Mean 36.239151

N 10000

Estimated WL w M-14 Unc

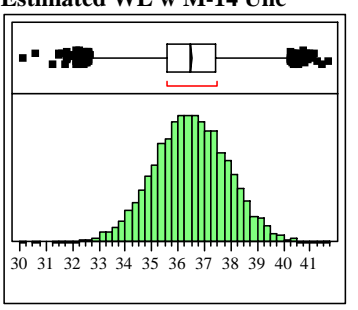

Quantiles

$100.0 \%$ maximum 41.748

$99.5 \% \quad 40.064$

$97.5 \% \quad 39.219$

$90.0 \% \quad 38.271$

$75.0 \%$ quartile 37.441

$50.0 \%$ median 36.479

$25.0 \%$ quartile 35.549

$10.0 \% \quad 34.693$

$2.5 \% \quad 33.714$

$0.5 \% \quad 32.823$

$0.0 \%$ minimum 30.156

Moments

Mean $\quad 36.485249$

Std Dev $\quad 1.4027897$

Std Err Mean $\quad 0.0140279$

upper 95\% Mean 36.512746

lower 95\% Mean 36.457751

$\mathrm{N}$
Batch $=325$

SME Estimated WL $=\mathbf{3 6 . 9 1}$

WL Re-Calc $=36.90$

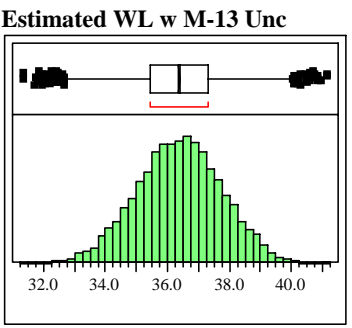

Quantiles

$100.0 \%$ maximum 41.175

$99.5 \% \quad 39.867$

$97.5 \% \quad 38.996$

38.139
$75.0 \%$

$75.0 \%$ quartile $\quad 37.290$

$50.0 \%$ median 36.387

$25.0 \%$ quartile 35.467

$10.0 \% \quad 34.607$

$2.5 \% \quad 33.652$

$0.5 \% \quad 32.784$

$0.0 \%$ minimum 31.380

Moments

Mean $\quad 36.371246$

Std Dev $\quad 1.3757693$

Std Err Mean $\quad 0.0137577$

upper 95\% Mean 36.398214

lower 95\% Mean 36.344278

10000

Estimated WL w M-14 Unc

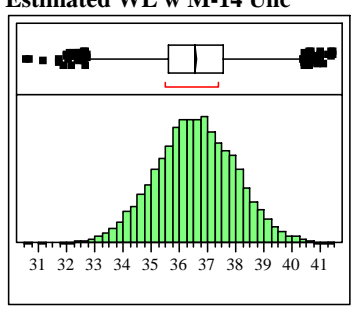

Quantiles

$100.0 \%$ maximum 41.485

$99.5 \% \quad 40.253$

$97.5 \% \quad 39.310$

$90.0 \% \quad 38.362$

$75.0 \%$ quartile 37.538

$50.0 \%$ median 36.570

$25.0 \%$ quartile 35.627

$10.0 \% \quad 34.743$

$2.5 \% \quad 33.777$

$0.5 \% \quad 32.886$

$0.0 \%$ minimum 30.566

Moments

Mean $\quad 36.566826$

Std Dev $\quad 1.415802$

Std Err Mean $\quad 0.014158$

upper 95\% Mean 36.594579

lower 95\% Mean 36.539073

N 10000
Batch $=326$

SME Estimated WL = 36.15

WL Re-Calc $=36.13$

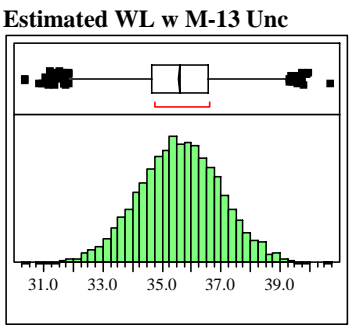

Quantiles

$100.0 \%$ maximum 40.746

$99.5 \% \quad 39.010$

$97.5 \% \quad 38.315$

$90.0 \% \quad 37.372$

$75.0 \%$ quartile 36.550

$50.0 \%$ median 35.610

$25.0 \%$ quartile 34.677

$10.0 \% \quad 33.817$

$\begin{array}{ll}10.5 \% & 32.873\end{array}$

$0.5 \% \quad 31.968$

$0.0 \%$ minimum 30.377

Moments

Mean $\quad 35.603994$

Std Dev $\quad 1.3783281$

Std Err Mean $\quad 0.0137833$

upper 95\% Mean 35.631012

10000

Estimated WL w M-14 Unc

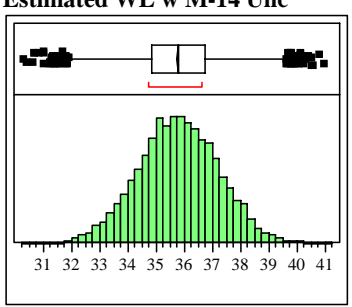

Quantiles

$100.0 \%$ maximum 41.018

$99.5 \% \quad 39.509$

$97.5 \% \quad 38.556$

$90.0 \% \quad 37.631$

$75.0 \%$ quartile $\quad 36.767$

$50.0 \%$ median 35.787

$25.0 \%$ quartile 34.837

$10.0 \% \quad 33.958$

$2.5 \% \quad 32.938$

$0.5 \% \quad 32.100$

$0.0 \%$ minimum 30.313

Moments

Mean $\quad 35.789996$

Std Dev $\quad 1.4306256$

Std Err Mean 0.0143063

upper 95\% Mean 35.818039

lower 95\% Mean 35.761953

$\mathrm{N} \quad 10000$
Batch $=327$

SME Estimated WL $=38.92$

WL Re-Calc $=38.91$

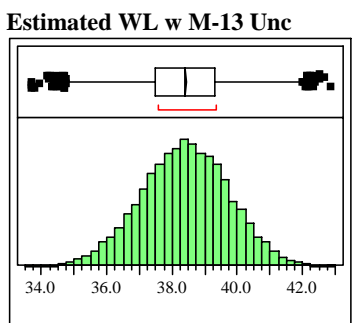

Quantiles

$100.0 \%$ maximum 42.879

$99.5 \% \quad 41.718$

$97.5 \% \quad 40.941$

$90.0 \% \quad 40.095$

$75.0 \%$ quartile 39.308

$50.0 \%$ median 38.405

$25.0 \%$ quartile 37.502

$10.0 \% \quad 36.670$

$2.5 \% \quad 35.774$

$0.5 \% \quad 34.987$

$0.0 \%$ minimum 33.718

Moments

Mean $\quad 38.397045$

Std Dev $\quad 1.325846$

Std Err Mean $\quad 0.0132585$

upper 95\% Mean 38.423034

lower 95\% Mean 38.371055

$\mathrm{N}$

Estimated WL w M-14 Unc

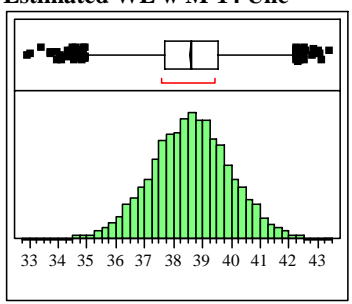

Quantiles

$100.0 \%$ maximum 43.402

$99.5 \% \quad 42.091$

$97.5 \% \quad 41.322$

$90.0 \% \quad 40.367$

$75.0 \%$ quartile 39.514

$50.0 \%$ median 38.611

$25.0 \%$ quartile 37.694

$10.0 \% \quad 36.839$

$2.5 \% \quad 35.884$

$0.5 \% \quad 34.946$

$0.0 \%$ minimum 32.923

Moments

Mean $\quad 38.604571$

Std Dev $\quad 1.370711$

Std Err Mean $\quad 0.0137071$

upper 95\% Mean 38.63144

lower 95\% Mean 38.577702

$\mathrm{N}$

10000 
WSRC-STI-2006-00068

Revision 0

Exhibit A11. Sensitivity of SME WL Estimations to the Uncertainties of This Report (continued)

Batch $=328$

SME Estimated WL $=37.58$

WL Re-Calc $=37.57$

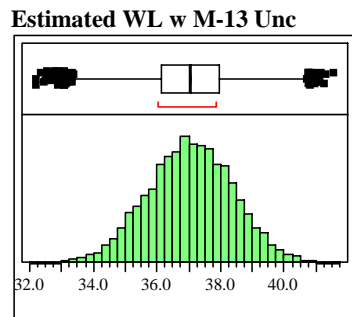

Quantiles

$100.0 \%$ maximum 41.562

$99.5 \% \quad 40.446$

$97.5 \% \quad 39.657$

$90.0 \% \quad 38.765$

$75.0 \%$ quartile $\quad 37.979$

$50.0 \%$ median 37.049

$25.0 \%$ quartile 36.146

$10.0 \% \quad 35.260$

$\begin{array}{ll}2.5 \% & 34.359\end{array}$

$0.5 \% \quad 33.466$

$0.0 \%$ minimum 32.231

Moments

Mean $\quad 37.041449$

Std Dev $\quad 1.3566958$

Std Err Mean $\quad 0.013567$

upper 95\% Mean 37.068043

lower 95\% Mean 37.014855

$\mathrm{N}$

10000

Estimated WL w M-14 Unc

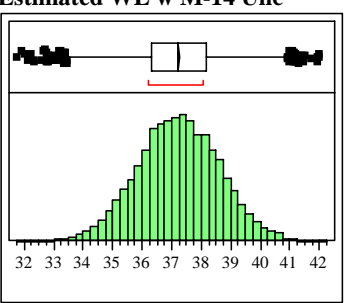

Quantiles

$100.0 \%$ maximum 42.032

$99.5 \% \quad 40.717$

$97.5 \% \quad 39.936$

$90.0 \% \quad 38.984$

$75.0 \%$ quartile 38.171

$50.0 \%$ median 37.229

$25.0 \%$ quartile 36.303

$10.0 \% \quad 35.455$

$2.5 \% \quad 34.482$

$0.5 \% \quad 33.602$

$0.0 \%$ minimum 31.785

Moments

Mean $\quad 37.225888$

Std Dev $\quad 1.383576$

Std Err Mean $\quad 0.0138358$

upper 95\% Mean 37.253009

lower 95\% Mean 37.198767

$\mathrm{N}$
Batch=329

SME Estimated WL $=38.62$

WL Re-Calc $=38.61$

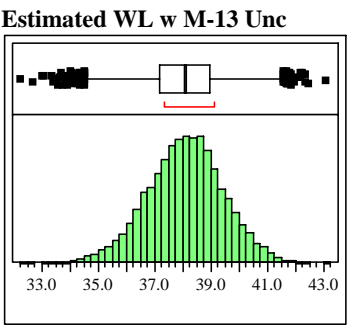

Quantiles

$100.0 \%$ maximum 43.126

$99.5 \% \quad 41.360$

$97.5 \% \quad 40.682$

$90.0 \% \quad 39.784$

$75.0 \%$ quartile 38.962

$50.0 \%$ median 38.116

$25.0 \%$ quartile $\quad 37.210$

$10.0 \% \quad 36.361$

$2.5 \% \quad 35.326$

$0.5 \% \quad 34.463$

$0.0 \%$ minimum 32.277

Moments

Mean $\quad 38.083757$

Std Dev $\quad 1.3395347$

Std Err Mean $\quad 0.0133953$

upper 95\% Mean 38.110015

ower 95\% Mean

$\mathrm{N} \quad 10000$

Estimated WL w M-14 Unc

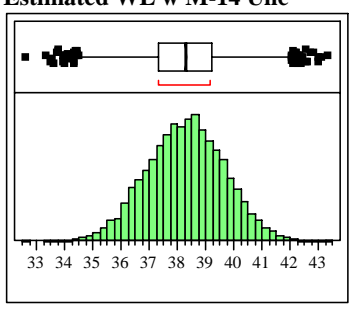

Quantiles

$100.0 \%$ maximum 43.346

$\begin{array}{ll}99.5 \% & 41.766 \\ 97.5 \% & 40.943\end{array}$

$90.0 \% \quad 40.034$

$75.0 \%$ quartile 39.227

$50.0 \%$ median 38.310

$25.0 \%$ quartile 37.351

$10.0 \% \quad 36.487$

$2.5 \% \quad 35.553$

$0.5 \% \quad 34.721$

$0.0 \%$ minimum 32.646

Moments

Mean $\quad 38.281371$

Std Dev $\quad 1.3779735$

Std Err Mean $\quad 0.0137797$

upper 95\% Mean 38.308382

lower 95\% Mean 38.25436

$\mathrm{N}$
Batch $=330$

SME Estimated WL = 37.96

WL Re-Calc $=37.94$

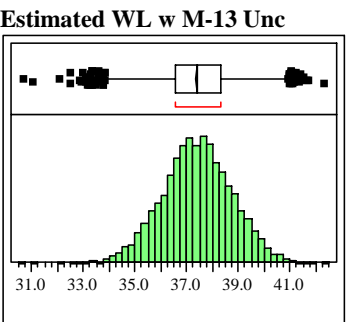

Quantiles

$100.0 \%$ maximum 42.357

$99.5 \% \quad 40.736$

$97.5 \% \quad 39.988$

$90.0 \% \quad 39.134$

$75.0 \%$ quartile 38.303

$50.0 \%$ median 37.411

$25.0 \%$ quartile $\quad 36.536$

$10.0 \% \quad 35.663$

$\begin{array}{ll}10.5 \% & 34.727\end{array}$

$0.5 \% \quad 33.949$

$0.0 \%$ minimum 30.720

Moments

Mean $\quad 37.403451$

Std Dev 1.3390252

Std Err Mean $\quad 0.0133903$

upper 95\% Mean 37.429699

lower 95\% Mean 37.377204

$\mathrm{N}$

10000

Estimated WL w M-14 Unc

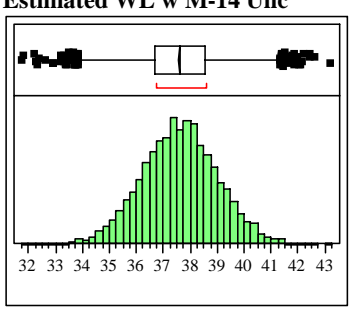

Quantiles

$100.0 \%$ maximum 43.242

$99.5 \% \quad 41.262$

$97.5 \% \quad 40.357$

$90.0 \% \quad 39.424$

$75.0 \%$ quartile 38.540

$50.0 \%$ median 37.613

$25.0 \%$ quartile 36.680

$10.0 \% \quad 35.810$

$2.5 \% \quad 34.855$

$0.5 \% \quad 33.862$

$0.0 \%$ minimum 31.805

Moments

Mean $\quad 37.614431$

Std Dev $\quad 1.4020567$

Std Err Mean $\quad 0.0140206$

upper 95\% Mean 37.641914

lower 95\% Mean 37.586948

$\mathrm{N}$

10000
Batch $=331$

SME Estimated WL $=37.01$

WL Re-Calc $=37.00$

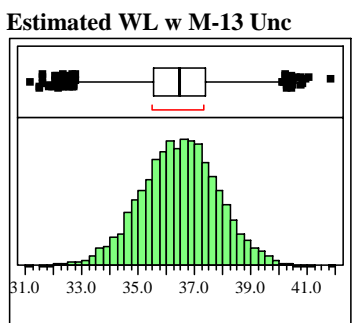

Quantiles

$100.0 \%$ maximum 41.853

$99.5 \% \quad 39.874$

$97.5 \% \quad 39.112$

$90.0 \% \quad 38.166$

$75.0 \%$ quartile 37.387

$50.0 \%$ median 36.493

$25.0 \%$ quartile 35.563

$10.0 \% \quad 34.722$

$2.5 \% \quad 33.705$

$0.5 \% \quad 32.687$

$0.0 \%$ minimum 31.189

Moments

Mean 36.462992

Std Dev $\quad 1.362866$

Std Err Mean $\quad 0.0136287$

upper 95\% Mean 36.489707

lower 95\% Mean 36.436277

$\mathrm{N}$

Estimated WL w M-14 Unc

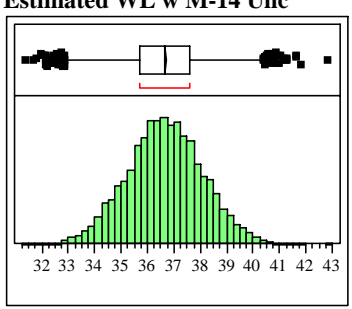

Quantiles

100.0\% maximum 42.862

$99.5 \% \quad 40.227$

$97.5 \% \quad 39.473$

$90.0 \% \quad 38.492$

$75.0 \%$ quartile 37.598

$50.0 \%$ median 36.649

$25.0 \%$ quartile 35.714

$10.0 \% \quad 34.803$

$2.5 \% \quad 33.825$

$0.5 \% \quad 32.947$

$0.0 \%$ minimum 31.394

Moments

Mean $\quad 36.653935$

Std Dev $\quad 1.4286004$

Std Err Mean $\quad 0.014286$

upper 95\% Mean 36.681938

lower 95\% Mean 36.625931

$\mathrm{N} \quad 10000$ 
WSRC-STI-2006-00068

Revision 0

Exhibit A11. Sensitivity of SME WL Estimations to the Uncertainties of This Report (continued)

Batch=332

SME Estimated WL $=38.56$

WL Re-Calc $=38.54$

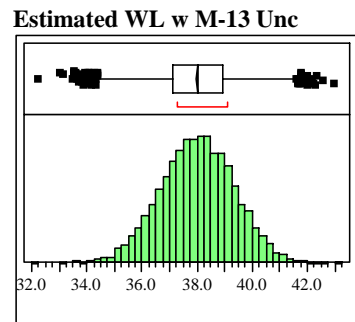

Quantiles

$100.0 \%$ maximum 43.005

$99.5 \% \quad 41.378$

$97.5 \% \quad 40.575$

$90.0 \%$

$75.0 \%$ quartile 38.923

$50.0 \%$ median 38.025

$25.0 \%$ quartile $\quad 37.112$

$10.0 \% \quad 36.284$

$\begin{array}{ll}2.5 \% & 35.329\end{array}$

$0.5 \% \quad 34.405$

$0.0 \%$ minimum 32.246

Moments

Mean $\quad 38.004291$

Std Dev $\quad 1.3386673$

Std Err Mean $\quad 0.0133867$

upper 95\% Mean 38.030531

lower 95\% Mean 37.97805

$\mathrm{N} \quad 10000$

Estimated WL w M-14 Unc

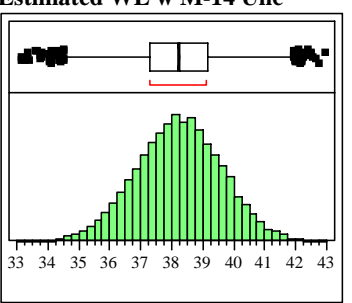

Quantiles

$100.0 \%$ maximum 42.967

$99.5 \% \quad 41.723$

$97.5 \% \quad 40.902$

$90.0 \% \quad 39.973$

$75.0 \%$ quartile 39.151

$50.0 \%$ median 38.234

$25.0 \%$ quartile 37.311

$10.0 \% \quad 36.436$

$2.5 \% \quad 35.465$

$0.5 \% \quad 34.609$

$0.0 \%$ minimum 33.175

Moments

Mean $\quad 38.224194$

Std Dev $\quad 1.3828483$

Std Err Mean $\quad 0.0138285$

upper 95\% Mean 38.251301

lower 95\% Mean 38.197088

$\mathrm{N}$
Batch=333

SME Estimated WL $=36.25$

WL Re-Calc $=36.24$

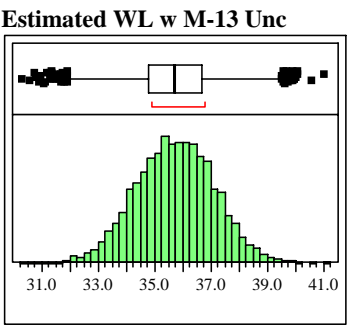

Quantiles

$100.0 \%$ maximum 41.083

$99.5 \% \quad 39.209$

$97.5 \% \quad 38.361$

$90.0 \% \quad 37.452$

$75.0 \%$ quartile 36.682

$50.0 \%$ median 35.735

$25.0 \%$ quartile 34.785

$10.0 \% \quad 33.960$

$2.5 \% \quad 33.026$

$0.5 \% \quad 32.077$

$0.0 \%$ minimum 30.332

Moments

Mean $\quad 35.72104$

Std Dev $\quad 1.3762476$

Std Err Mean $\quad 0.0137625$

upper 95\% Mean 35.748017

lower 95\% Mean 35.694063

10000

Estimated WL w M-14 Unc

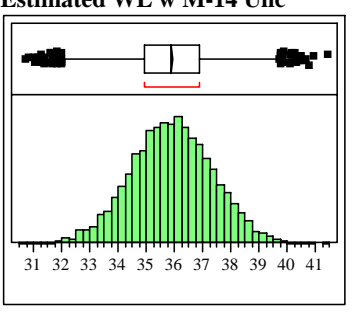

Quantiles

$100.0 \%$ maximum 41.500

$99.5 \% \quad 39.535$

$97.5 \% \quad 38.666$

$90.0 \% \quad 37.759$

$75.0 \%$ quartile 36.870

$50.0 \%$ median 35.890

$25.0 \%$ quartile 34.938

$10.0 \% \quad 34.067$

$2.5 \% \quad 33.068$

$0.5 \% \quad 32.183$

$0.0 \%$ minimum 30.744

Moments

Mean $\quad 35.899514$

Std Dev 1.4312406

Std Err Mean $\quad 0.0143124$

upper 95\% Mean 35.927569

lower 95\% Mean 35.871459

N 10000
Batch $=334$

SME Estimated WL $=40.56$

WL Re-Calc $=\mathbf{4 0 . 5 5}$

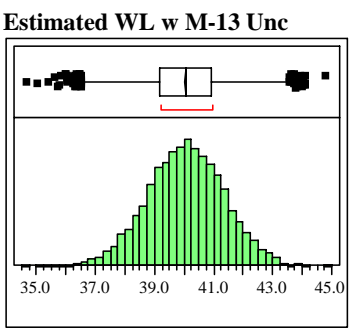

Quantiles

$100.0 \%$ maximum 44.800

$99.5 \% \quad 43.203$

$97.5 \% \quad 42.558$

$90.0 \% \quad 41.703$

$75.0 \%$ quartile 40.940

$50.0 \%$ median 40.064

$25.0 \%$ quartile $\quad 39.193$

$10.0 \% \quad 38.423$

$\begin{array}{ll}10.5 \% & 37.500\end{array}$

$0.5 \% \quad 36.657$

$0.0 \%$ minimum 34.697

Moments

Mean 40.06149

Std Dev $\quad 1.2863239$

Std Err Mean $\quad 0.0128632$

upper 95\% Mean 40.086705

$\mathrm{N}$

10000

Estimated WL w M-14 Unc

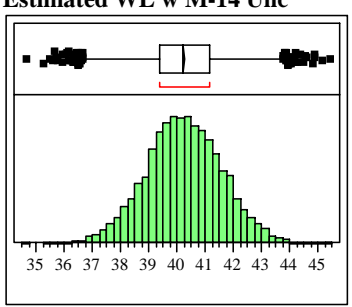

Quantiles

$100.0 \%$ maximum 45.465

$\begin{array}{ll}99.5 \% & 43.717 \\ 97.5 \% & 42.874\end{array}$

$90.0 \% \quad 41.943$

$75.0 \%$ quartile $\quad 41.151$

$50.0 \%$ median 40.229

$25.0 \%$ quartile 39.368

$10.0 \%$

$2.5 \% \quad 37.617$

$0.5 \% \quad 36.764$

$0.0 \%$ minimum 34.696

Moments

Mean $\quad 40.243954$

Std Dev 1.336991

Std Err Mean $\quad 0.0133699$

upper 95\% Mean 40.270162

lower 95\% Mean 40.217746

$\mathrm{N} \quad 10000$
Batch $=335$

SME Estimated WL $=41.73$

WL Re-Calc $=41.72$

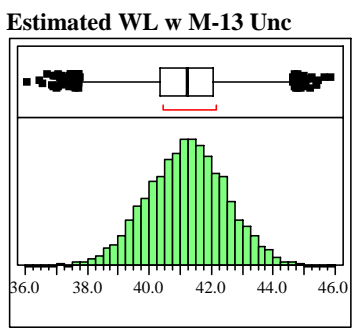

Quantiles

$100.0 \%$ maximum 45.875

$99.5 \% \quad 44.582$

$97.5 \% \quad 43.746$

$90.0 \% \quad 42.834$

$75.0 \%$ quartile 42.077

$50.0 \%$ median 41.240

$25.0 \%$ quartile 40.358

$10.0 \% \quad 39.562$

$2.5 \% \quad 38.669$

$0.5 \% \quad 37.764$

$0.0 \%$ minimum 36.052

Moments

Mean $\quad 41.215031$

Std Dev $\quad 1.2838864$

Std Err Mean $\quad 0.0128389$

upper 95\% Mean 41.240198

lower 95\% Mean 41.189864

$\mathrm{N}$

Estimated WL w M-14 Unc

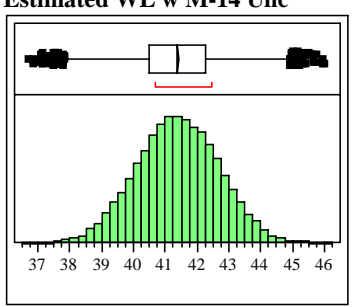

Quantiles

$100.0 \%$ maximum 46.028

$99.5 \% \quad 44.799$

$97.5 \% \quad 43.922$

$90.0 \% \quad 43.060$

$75.0 \%$ quartile $\quad 42.281$

$50.0 \%$ median 41.393

$25.0 \%$ quartile 40.510

$10.0 \% \quad 39.695$

$2.5 \% \quad 38.811$

$0.5 \% \quad 37.874$

$0.0 \%$ minimum 36.720

Moments

Mean $\quad 41.385617$

Std Dev $\quad 1.3123099$

Std Err Mean $\quad 0.0131231$

upper 95\% Mean 41.411341

lower 95\% Mean 41.359893

$\mathrm{N} \quad 10000$ 
WSRC-STI-2006-00068

Revision 0

Exhibit A11. Sensitivity of SME WL Estimations to the Uncertainties of This Report (continued)

Batch=336

SME Estimated WL $=42.11$

WL Re-Calc $=42.10$

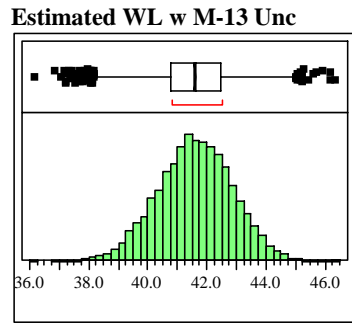

Quantiles

$100.0 \%$ maximum 46.347

$99.5 \% \quad 44.656$

$97.5 \% \quad 43.964$

$90.0 \% \quad 43.200$

$75.0 \%$ quartile 42.467

$50.0 \%$ median 41.604

$25.0 \%$ quartile $\quad 40.759$

$10.0 \% \quad 39.969$

$\begin{array}{ll}2.5 \% & 39.088\end{array}$

$0.5 \% \quad 38.181$

$0.0 \%$ minimum 36.178

Moments

Mean 41.594316

Std Dev $\quad 1.2617997$

Std Err Mean $\quad 0.012618$

upper 95\% Mean 41.61905

lower 95\% Mean 41.569582

$\mathrm{N} \quad 10000$

Estimated WL w M-14 Unc

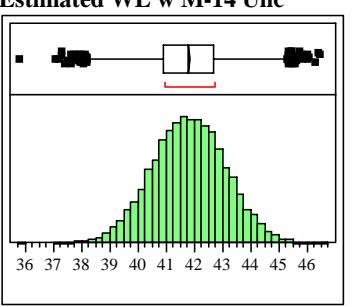

Quantiles

$100.0 \%$ maximum 46.506

$99.5 \% \quad 45.079$

$97.5 \% \quad 44.333$

$90.0 \% \quad 43.456$

$75.0 \%$ quartile 42.692

$50.0 \%$ median 41.812

$25.0 \%$ quartile 40.921

$10.0 \% \quad 40.141$

$2.5 \% \quad 39.256$

$\begin{array}{ll}0.5 \% & 38.469\end{array}$

$0.0 \%$ minimum 35.857

Moments

Mean $\quad 41.808405$

Std Dev $\quad 1.2996823$

Std Err Mean 0.0129968

upper 95\% Mean 41.833881

lower 95\% Mean 41.782928

$\mathrm{N}$
Batch $=337$

SME Estimated WL $=39.53$

WL Re-Calc $=39.52$

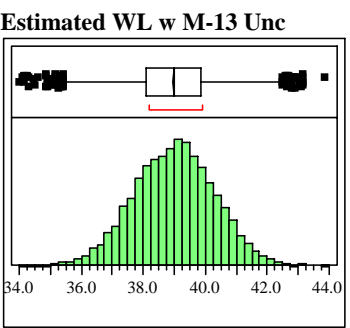

Quantiles

$100.0 \%$ maximum 43.891

$99.5 \% \quad 42.321$

$97.5 \% \quad 41.515$

$90.0 \% \quad 40.653$

$75.0 \%$ quartile 39.872

$50.0 \%$ median 39.019

$25.0 \%$ quartile 38.107

$10.0 \% \quad 37.337$

$\begin{array}{ll}2.5 \% & 36.414\end{array}$

$0.5 \% \quad 35.444$

$0.0 \%$ minimum 34.047

Moments

Mean 38.992986

Std Dev $\quad 1.3030834$

Std Err Mean $\quad 0.0130308$

upper 95\% Mean 39.018529

lower 95\% Mean 38.967443

$\mathrm{N}$

10000

Estimated WL w M-14 Unc

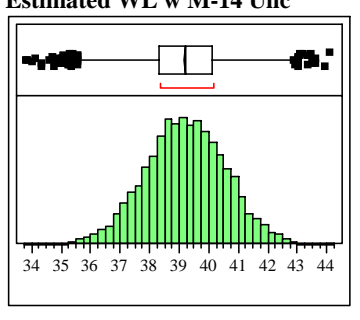

Quantiles

$100.0 \%$ maximum 44.136

$\begin{array}{ll}99.5 \% & 42.551 \\ 97.5 \% & 41.858\end{array}$

$\begin{array}{ll}97.5 \% & 41.858 \\ 90.0 \% & 40.923\end{array}$

$75.0 \%$ quartile $\quad 40.138$

$50.0 \%$ median 39.204

$25.0 \%$ quartile 38.314

$10.0 \% \quad 37.456$

$2.5 \% \quad 36.507$

$0.5 \% \quad 35.696$

$0.0 \%$ minimum 33.805

Moments

Mean $\quad 39.204436$

Std Dev $\quad 1.3554619$

Std Err Mean $\quad 0.0135546$

upper 95\% Mean 39.231006

lower 95\% Mean 39.177867

N 10000
Batch $=338$

SME Estimated WL $=38.92$

WL Re-Calc $=38.91$

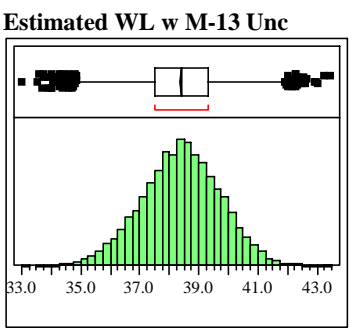

Quantiles

$100.0 \%$ maximum 43.482

$99.5 \% \quad 41.772$

$97.5 \% \quad 40.948$

$90.0 \% \quad 40.080$

$75.0 \%$ quartile 39.288

$50.0 \%$ median 38.409

$25.0 \%$ quartile 37.530

$10.0 \% \quad 36.649$

$2.5 \% \quad 35.679$

$0.5 \% \quad 34.780$

$0.0 \%$ minimum 33.045

Moments

Mean $\quad 38.392877$

Std Dev $\quad 1.3332897$

Std Err Mean $\quad 0.0133329$

upper 95\% Mean 38.419012

ower $95 \%$

10000

Estimated WL w M-14 Unc

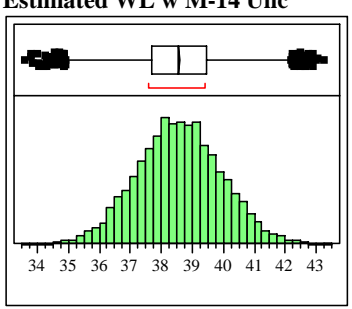

Quantiles

$100.0 \%$ maximum 43.266

$99.5 \% \quad 42.167$

$97.5 \% \quad 41.251$

$90.0 \% \quad 40.347$

$75.0 \%$ quartile $\quad 39.484$

$50.0 \%$ median 38.568

$25.0 \%$ quartile 37.668

$10.0 \% \quad 36.813$

$2.5 \% \quad 35.878$

$0.5 \% \quad 34.971$

$0.0 \%$ minimum 33.65

Moments

Mean $\quad 38.574156$

Std Dev $\quad 1.3702144$

Std Err Mean $\quad 0.0137021$

upper 95\% Mean 38.601015

lower 95\% Mean 38.547297

$\mathrm{N} \quad 10000$
Batch $=339$

SME Estimated WL $=\mathbf{4 0 . 5 5}$

WL Re-Calc $=40.53$

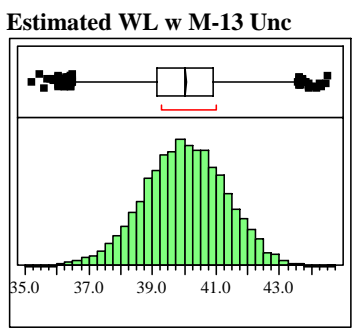

Quantiles

$100.0 \%$ maximum 44.553

$99.5 \% \quad 43.234$

$97.5 \% \quad 42.468$

$90.0 \% \quad 41.693$

$75.0 \%$ quartile 40.921

$50.0 \%$ median 40.032

$25.0 \%$ quartile 39.157

$10.0 \% \quad 38.370$

$2.5 \% \quad 37.432$

$0.5 \% \quad 36.574$

$0.0 \%$ minimum 35.204

Moments

Mean $\quad 40.024368$

Std Dev $\quad 1.2926916$

Std Err Mean $\quad 0.0129269$

upper 95\% Mean 40.049707

lower 95\% Mean 39.999029

$\mathrm{N}$

Estimated WL w M-14 Unc

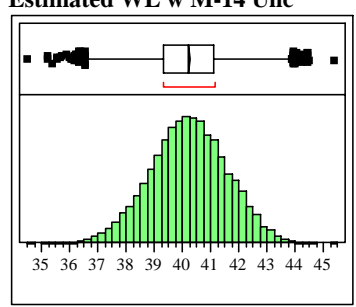

Quantiles

$100.0 \%$ maximum 45.410

$99.5 \% \quad 43.566$

$97.5 \% \quad 42.798$

$90.0 \% \quad 41.975$

$75.0 \%$ quartile $\quad 41.134$

$50.0 \%$ median 40.223

$25.0 \%$ quartile 39.329

$10.0 \% \quad 38.487$

$2.5 \% \quad 37.556$

$0.5 \% \quad 36.776$

$0.0 \%$ minimum 34.544

Moments

Mean $\quad 40.224528$

Std Dev $\quad 1.3444281$

Std Err Mean 0.0134443

upper 95\% Mean 40.250881

lower 95\% Mean 40.198174

$\mathrm{N} \quad 10000$ 
WSRC-STI-2006-00068

Revision 0

Exhibit A11. Sensitivity of SME WL Estimations to the Uncertainties of This Report (continued)

Batch=340

SME Estimated WL $=\mathbf{4 0 . 2 8}$

WL Re-Calc $=40.27$

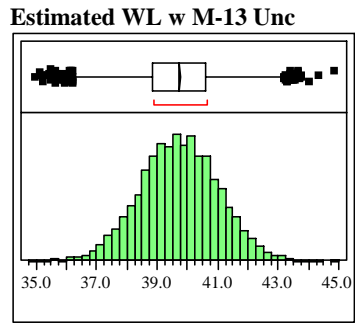

Quantiles

$100.0 \%$ maximum 44.886

$99.5 \% \quad 43.079$

$97.5 \% \quad 42.239$

$90.0 \% \quad 41.376$

$75.0 \%$ quartile 40.608

$50.0 \%$ median 39.727

$25.0 \%$ quartile $\quad 38.865$

$10.0 \% \quad 38.102$

$\begin{array}{ll}10.5 \% & 37.205\end{array}$

$0.5 \% \quad 36.287$

$0.0 \%$ minimum 34.988

Moments

Mean $\quad 39.732825$

Std Dev $\quad 1.2871393$

Std Err Mean $\quad 0.0128714$

upper 95\% Mean 39.758055

lower 95\% Mean 39.707594

$\mathrm{N}$

10000

Estimated WL w M-14 Unc

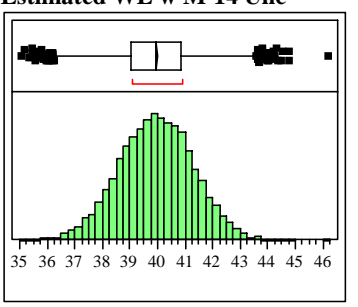

Quantiles

$100.0 \%$ maximum 46.243

$99.5 \% \quad 43.392$

$97.5 \% \quad 42.559$

$90.0 \% \quad 41.667$

$75.0 \%$ quartile 40.865

$50.0 \%$ median 39.960

$25.0 \%$ quartile 39.034

$10.0 \% \quad 38.224$

$2.5 \% \quad 37.309$

$0.5 \% \quad 36.490$

$0.0 \%$ minimum 35.088

Moments

Mean $\quad 39.948903$

Std Dev $\quad 1.3431169$

Std Err Mean $\quad 0.0134312$

upper 95\% Mean 39.97523

lower 95\% Mean 39.922575

$\mathrm{N}$
Batch=341

SME Estimated WL $=39.86$

WL Re-Calc $=39.85$

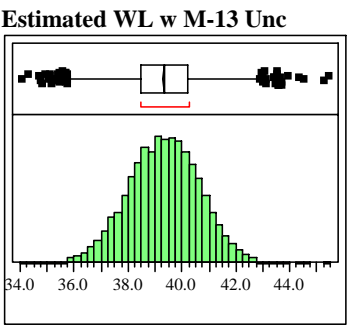

Quantiles

$100.0 \%$ maximum 45.448

$99.5 \% \quad 42.609$

$97.5 \% \quad 41.855$

$90.0 \% \quad 40.995$

$75.0 \%$ quartile 40.238

$50.0 \%$ median 39.354

$25.0 \%$ quartile 38.453

$10.0 \% \quad 37.637$

$\begin{array}{ll}2.5 \% & 36.721\end{array}$

$0.5 \% \quad 35.928$

$0.0 \%$ minimum 34.083

Moments

Mean 39.33531

Std Dev $\quad 1.3143443$

Std Err Mean $\quad 0.0131434$

upper 95\% Mean 39.361073

lower 95\% Mean 39.309546$$
\mathrm{N}
$$

10000

Estimated WL w M-14 Unc

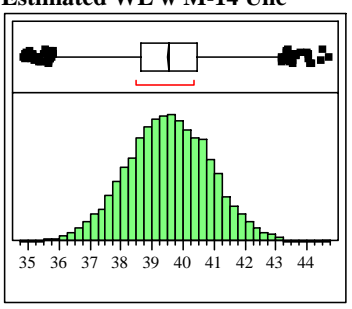

Quantiles

$100.0 \%$ maximum 44.707

$99.5 \% \quad 43.018$

$97.5 \% \quad 42.176$

$90.0 \% \quad 41.224$

$75.0 \%$ quartile 40.463

$50.0 \%$ median 39.529

$25.0 \%$ quartile 38.631

$10.0 \% \quad 37.803$

$2.5 \% \quad 36.890$

$\begin{array}{ll}0.5 \% & 36.890 \\ 0.0 \% & 36.864\end{array}$

$0.0 \%$ minimum 34.864

Moments

Mean $\quad 39.534948$

Std Dev 1.3456378

Std Err Mean $\quad 0.0134564$

upper 95\% Mean 39.561325

lower 95\% Mean 39.508571

$\mathrm{N}$

10000
Batch $=342$

SME Estimated WL $=\mathbf{4 1 . 2 4}$

WL Re-Calc $=41.23$

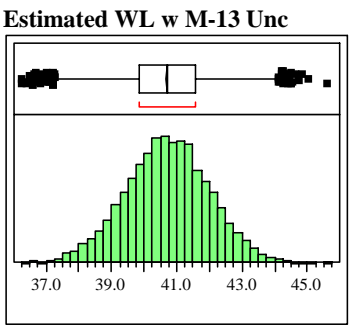

Quantiles

$100.0 \%$ maximum 45.643

$99.5 \% \quad 43.957$

$97.5 \% \quad 43.190$

$90.0 \% \quad 42.355$

$75.0 \%$ quartile 41.560

$50.0 \%$ median 40.722

$25.0 \%$ quartile 39.859

$10.0 \% \quad 39.045$

$\begin{array}{ll}2.5 \% & 38.099\end{array}$

$0.5 \% \quad 37.324$

$0.0 \%$ minimum 36.288

Moments

Mean $\quad 40.705986$

Std Dev $\quad 1.2900784$

Std Err Mean $\quad 0.0129008$

upper 95\% Mean 40.731275

lower $95 \%$

$\mathrm{N}$

10000

Estimated WL w M-14 Unc

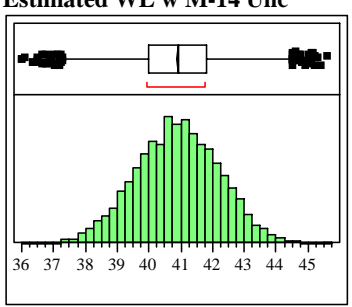

Quantiles

$100.0 \%$ maximum 45.616

$99.5 \% \quad 44.330$

$97.5 \% \quad 43.479$

$90.0 \% \quad 42.605$

$75.0 \%$ quartile 41.812

$50.0 \%$ median 40.905

$25.0 \%$ quartile 40.004

$10.0 \% \quad 39.191$

$2.5 \% \quad 38.272$

$0.5 \% \quad 37.477$

$0.0 \%$ minimum 36.013

Moments

Mean $\quad 40.902757$

Std Dev 1.3254158

Std Err Mean $\quad 0.0132542$

upper $95 \%$ Mean 40.928737

lower 95\% Mean 40.876776

$\mathrm{N} \quad 10000$
Batch $=343$

SME Estimated WL $=38.04$

WL Re-Calc $=38.03$

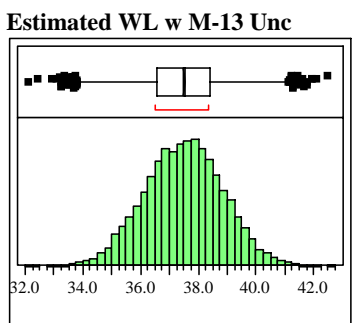

Quantiles

$100.0 \%$ maximum 42509

$99.5 \% \quad 40.904$

$97.5 \% \quad 40.084$

$90.0 \% \quad 39.222$

$75.0 \%$ quartile 38.414

$50.0 \%$ median 37.521

$25.0 \%$ quartile 36.586

$10.0 \% \quad 35.746$

$2.5 \% \quad 34.875$

$0.5 \% \quad 34.000$

$0.0 \%$ minimum 32.162

Moments

Mean $\quad 37.498542$

Std Dev $\quad 1.3461819$

Std Err Mean $\quad 0.0134618$

upper 95\% Mean 37.52493

lower 95\% Mean 37.472155

$\mathrm{N}$

Estimated WL w M-14 Unc

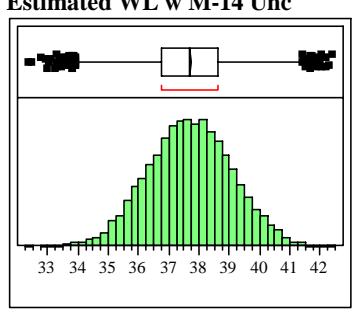

Quantiles

$100.0 \%$ maximum 42.402

$99.5 \% \quad 41.133$

$97.5 \% \quad 40.381$

$90.0 \% \quad 39.476$

$75.0 \%$ quartile 38.630

$50.0 \%$ median 37.697

$25.0 \%$ quartile 36.762

$10.0 \% \quad 35.914$

$2.5 \% \quad 35.042$

$0.5 \% \quad 34.035$

$0.0 \%$ minimum 32.405

Moments

Mean $\quad 37.697049$

Std Dev $\quad 1.3806992$

Std Err Mean $\quad 0.013807$

upper 95\% Mean 37.724114

lower 95\% Mean 37.669985

$\mathrm{N}$ 
WSRC-STI-2006-00068

Revision 0

Exhibit A11. Sensitivity of SME WL Estimations to the Uncertainties of This Report (continued)

Batch=344

SME Estimated WL $=38.79$

WL Re-Calc $=38.78$

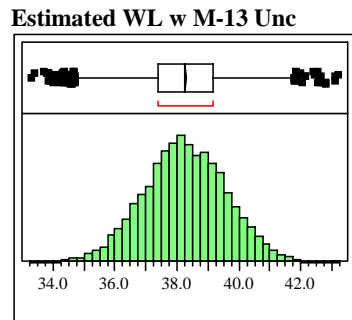

Quantiles

$100.0 \%$ maximum 43.218

$99.5 \% \quad 41.588$

$97.5 \% \quad 40.839$

$90.0 \% \quad 39.930$

$75.0 \%$ quartile 39.155

$50.0 \%$ median 38.240

$25.0 \%$ quartile $\quad 37.387$

$10.0 \% \quad 36.551$

$\begin{array}{ll}2.5 \% & 35.668\end{array}$

$0.5 \% \quad 34.716$

$0.0 \%$ minimum 33.302

Moments

Mean 38.251403

Std Dev $\quad 1.3231393$

Std Err Mean $\quad 0.0132314$

upper 95\% Mean 38.277339

lower 95\% Mean 38.225466

$\mathrm{N}$

10000

Estimated WL w M-14 Unc

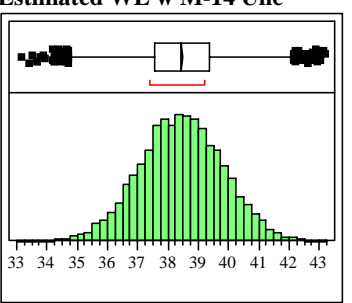

Quantiles

$100.0 \%$ maximum 43.203

$99.5 \% \quad 42.051$

$97.5 \% \quad 41.127$

$90.0 \% \quad 40.205$

$75.0 \%$ quartile 39.386

$50.0 \%$ median 38.439

$25.0 \%$ quartile 37.536

$10.0 \% \quad 36.690$

$2.5 \% \quad 35.724$

$0.5 \% \quad 34.870$

$0.0 \%$ minimum 33.196

Moments

Mean $\quad 38.446137$

Std Dev $\quad 1.3747659$

Std Err Mean $\quad 0.0137477$

upper 95\% Mean 38.473086

lower 95\% Mean 38.419189

$\mathrm{N}$
Batch=345

SME Estimated WL $=40.50$

WL Re-Calc $=40.48$

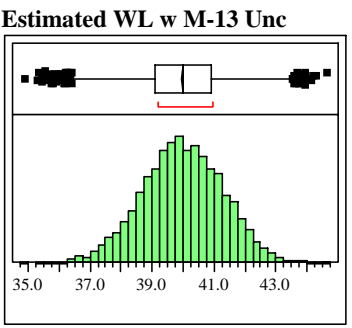

Quantiles

$100.0 \%$ maximum 44.650

$99.5 \% \quad 43.220$

$97.5 \% \quad 42.486$

$90.0 \% \quad 41.646$

$75.0 \%$ quartile 40.887

$50.0 \%$ median 39.978

$25.0 \%$ quartile 39.115

$10.0 \% \quad 38.308$

$\begin{array}{ll}2.5 \% & 37.367\end{array}$

$0.5 \% \quad 36.544$

$0.0 \%$ minimum 34.951

Moments

Mean 39.982432

Std Dev $\quad 1.3052784$

Std Err Mean $\quad 0.0130528$

upper 95\% Mean 40.008018

lower 95\% Mean 39.956846

10000

Estimated WL w M-14 Unc

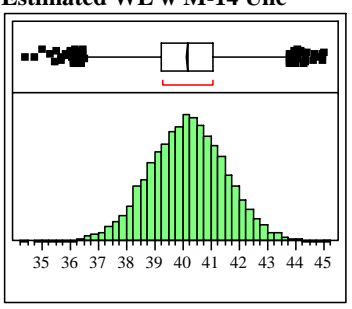

Quantiles

$100.0 \%$ maximum 45.034

$\begin{array}{ll}99.5 \% & 43.604 \\ 97.5 \% & 42.785\end{array}$

$90.0 \% \quad 41.878$

$75.0 \%$ quartile 41.079

$50.0 \%$ median 40.181

$25.0 \%$ quartile 39.268

$10.0 \% \quad 38.450$

$2.5 \% \quad 37.502$

$0.5 \% \quad 36.680$

$0.0 \%$ minimum 34.457

Moments

Mean $\quad 40.168676$

Std Dev $\quad 1.3411464$

Std Err Mean $\quad 0.0134115$

upper 95\% Mean 40.194965

lower 95\% Mean 40.142387

N 10000
Batch $=346$

SME Estimated WL = 36.96

WL Re-Calc $=36.95$

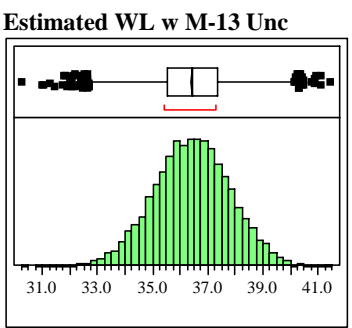

Quantiles

$100.0 \%$ maximum 41.460

$99.5 \% \quad 39.766$

$97.5 \% \quad 39.085$

$90.0 \% \quad 38.201$

$75.0 \%$ quartile 37.361

$50.0 \%$ median 36.446

$25.0 \%$ quartile 35.507

$10.0 \% \quad 34.652$

$\begin{array}{ll}10.5 \% & 33.668\end{array}$

$0.5 \% \quad 32.784$

$0.0 \%$ minimum 30.276

Moments

Mean $\quad 36.419605$

Std Dev $\quad 1.3766034$

Std Err Mean $\quad 0.013766$

upper 95\% Mean 36.446589

lower $95 \%$

$\mathrm{N} \quad 10000$

Estimated WL w M-14 Unc

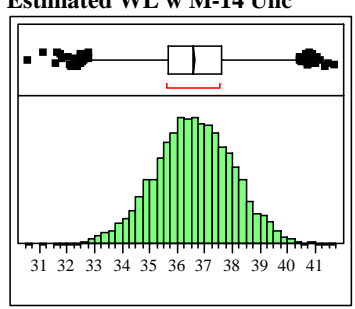

Quantiles

$100.0 \%$ maximum 41.741

$99.5 \% \quad 40.142$

$97.5 \% \quad 39.332$

$90.0 \% \quad 38.393$

$75.0 \%$ quartile 37.576

$50.0 \%$ median 36.604

$25.0 \%$ quartile 35.661

$10.0 \% \quad 34.791$

$2.5 \% \quad 33.790$

$0.5 \% \quad 32.981$

$0.0 \%$ minimum 30.558

Moments

Mean

1.4083675

Std Err Mean $\quad 0.0140837$

upper 95\% Mean 36.633427

lower 95\% Mean 36.578213

$\mathrm{N} \quad 10000$
Batch $=347$

SME Estimated WL $=40.35$

WL Re-Calc $=40.34$

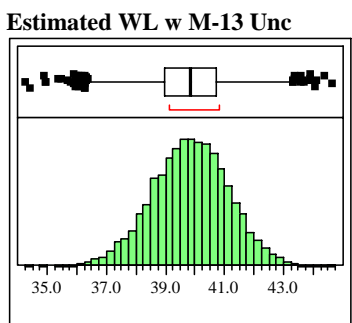

Quantiles

$100.0 \%$ maximum 44.677

$99.5 \% \quad 42.996$

$97.5 \% \quad 42.323$

$90.0 \% \quad 41.471$

$75.0 \%$ quartile 40.722

$50.0 \%$ median 39.860

$25.0 \%$ quartile 38.987

$10.0 \% \quad 38.197$

$2.5 \% \quad 37.277$

$0.5 \% \quad 36.477$

$0.0 \%$ minimum 34.277

Moments

Mean $\quad 39.842721$

Std Dev $\quad 1.2802691$

Std Err Mean $\quad 0.0128027$

upper 95\% Mean 39.867817

lower 95\% Mean 39.817625

$\mathrm{N}$

Estimated WL w M-14 Unc

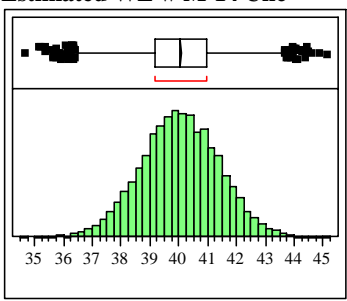

Quantiles

$100.0 \%$ maximum 45.146

$99.5 \% \quad 43.559$

$97.5 \% \quad 42.681$

$90.0 \% \quad 41.765$

$75.0 \%$ quartile 40.953

$50.0 \%$ median 40.039

$25.0 \%$ quartile 39.143

$10.0 \% \quad 38.300$

$2.5 \% \quad 37.348$

$0.5 \% \quad 36.531$

$0.0 \%$ minimum 34.707

Moments

Mean $\quad 40.044351$

Std Dev $\quad 1.349572$

Std Err Mean $\quad 0.0134957$

upper 95\% Mean 40.070806

lower 95\% Mean 40.017897

$\mathrm{N} \quad 10000$ 
WSRC-STI-2006-00068

Revision 0

Exhibit A11. Sensitivity of SME WL Estimations to the Uncertainties of This Report (continued)

Batch=348

SME Estimated WL $=41.02$

WL Re-Calc $=41.01$

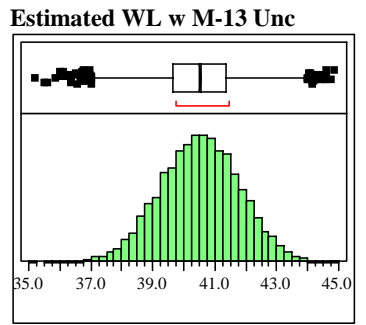

Quantiles

$100.0 \%$ maximum 44.852

$99.5 \% \quad 43.733$

$97.5 \% \quad 42.986$

$90.0 \% \quad 42.148$

$75.0 \%$ quartile 41.386

$50.0 \%$ median 40.531

$25.0 \%$ quartile $\quad 39.659$

$10.0 \% \quad 38.867$

$2.5 \% \quad 38.004$

$0.5 \% \quad 37.162$

$0.0 \%$ minimum 35.216

Moments

Mean $\quad 40.5205$

Std Dev $\quad 1.2764725$

Std Err Mean $\quad 0.0127647$

upper 95\% Mean 40.545522

lower 95\% Mean 40.495479

$\mathrm{N}$

10000

Estimated WL w M-14 Unc

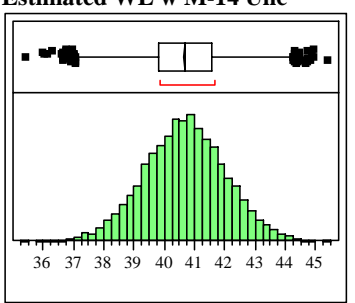

Quantiles

$100.0 \%$ maximum 45.407

$99.5 \% \quad 44.068$

$97.5 \% \quad 43.301$

$90.0 \% \quad 42.403$

$75.0 \%$ quartile 41.574

$50.0 \%$ median 40.694

$25.0 \%$ quartile 39.781

$10.0 \% \quad 38.967$

$2.5 \% \quad 38.052$

$0.5 \% \quad 37.255$

$0.0 \%$ minimum 35.434

Moments

Mean $\quad 40.681689$

Std Dev $\quad 1.3289177$

Std Err Mean 0.0132892 upper 95\% Mean 40.707738 lower 95\% Mean 40.655639

$\mathrm{N}$
Batch=349

SME Estimated WL $=39.43$

WL Re-Calc $=39.41$

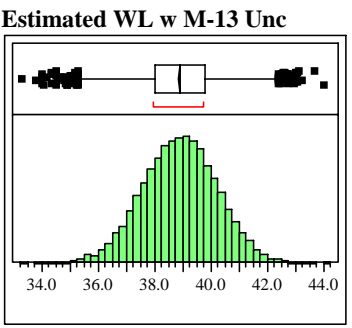

Quantiles

$100.0 \%$ maximum 44.060

$99.5 \%$

$97.5 \%$

$75.0 \%$ quartile 39.783

$50.0 \%$ median 38.915

$25.0 \%$ quartile 38.008

$10.0 \% \quad 37.210$

$2.5 \% \quad 36.315$

$0.5 \% \quad 35.408$

$0.0 \%$ minimum 33.348

Moments

Mean $\quad 38.892635$

Std Dev $\quad 1.3149853$

Std Err Mean $\quad 0.0131499$

upper 95\% Mean 38.918412

lower 95\% Mean 38.866859

10000

Estimated WL w M-14 Unc

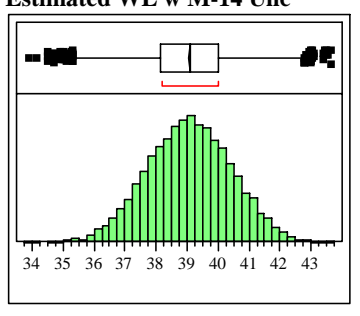

Quantiles

$100.0 \%$ maximum 43.679

$\begin{array}{ll}99.5 \% & 42.476 \\ 97.5 \% & 41.711\end{array}$

$90.0 \% \quad 40.834$

$75.0 \%$ quartile 40.006

$50.0 \%$ median 39.078

$25.0 \%$ quartile 38.149

$10.0 \% \quad 37.355$

$2.5 \% \quad 36.403$

$0.5 \% \quad 35.515$

$0.0 \%$ minimum 33.903

Moments

Mean $\quad 39.081219$

Std Dev $\quad 1.3570407$

Std Err Mean $\quad 0.0135704$

upper 95\% Mean 39.10782

lower 95\% Mean 39.054618

$\mathrm{N}$
Batch $=350$

SME Estimated WL $=34.55$

WL Re-Calc $=34.53$

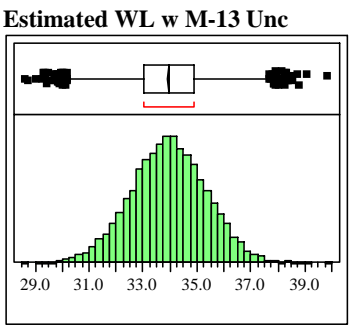

Quantiles

$100.0 \%$ maximum 39.871

$99.5 \% \quad 37.567$

$97.5 \% \quad 36.650$

$90.0 \% \quad 35.747$

$75.0 \%$ quartile 34.888

$50.0 \%$ median 33.949

$25.0 \%$ quartile 33.017

$10.0 \% \quad 32.163$

$\begin{array}{ll}10.5 \% & 31.158\end{array}$

$0.5 \% \quad 30.235$

$0.0 \%$ minimum 28.665

Moments

Mean 33.947793

Std Dev $\quad 1.4006253$

Std Err Mean $\quad 0.0140063$

upper 95\% Mean 33.975248

lower 95\% Mean 33.920338

$\mathrm{N}$

10000

Estimated WL w M-14 Unc

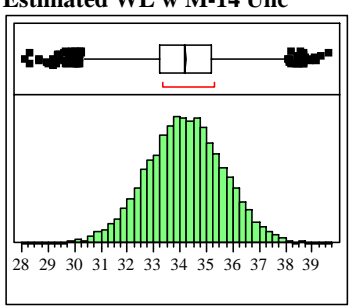

Quantiles

$100.0 \%$ maximum 39.647

$\begin{array}{ll}99.5 \% & 37.841 \\ 97.5 \% & 37.067\end{array}$

$90.0 \% \quad 36.067$

$75.0 \%$ quartile 35.185

$50.0 \%$ median 34.198

$25.0 \%$ quartile 33.228

$10.0 \%$

$2.5 \% \quad 31.266$

$0.5 \% \quad 30.252$

$0.0 \%$ minimum 28.120

Moments

Mean $\quad 34.195258$

Std Dev $\quad 1.4666471$

Std Err Mean 0.0146665

upper 95\% Mean 34.224007

lower 95\% Mean 34.166509

$\mathrm{N} \quad 10000$
Batch $=351$

SME Estimated WL $=41.51$

WL Re-Calc $=41.50$

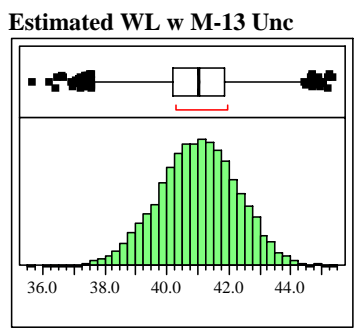

Quantiles

$100.0 \%$ maximum 45.363

$99.5 \% \quad 44.17$

$97.5 \% \quad 43.425$

$90.0 \% \quad 42.638$

$75.0 \%$ quartile 41.889

$50.0 \%$ median 41.040

$25.0 \%$ quartile $\quad 40.179$

$10.0 \% \quad 39.363$

$2.5 \% \quad 38.485$

$0.5 \% \quad 37.709$

$0.0 \%$ minimum 35.687

Moments

Mean $\quad 41.019467$

Std Dev $\quad 1.2658359$

Std Err Mean $\quad 0.0126584$

upper 95\% Mean 41.04428

lower 95\% Mean 40.994654

$\mathrm{N}$

Estimated WL w M-14 Unc

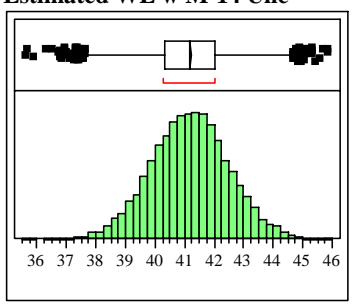

Quantiles

$100.0 \%$ maximum 45.863

$99.5 \% \quad 44.545$

$97.5 \% \quad 43.776$

$90.0 \% \quad 42.857$

$75.0 \%$ quartile $\quad 42.047$

$50.0 \%$ median 41.185

$25.0 \%$ quartile 40.303

$10.0 \% \quad 39.511$

$2.5 \% \quad 38.560$

$0.5 \% \quad 37.747$

$0.0 \%$ minimum 35.653

Moments

Mean $\quad 41.175532$

Std Dev $\quad 1.3125268$

Std Err Mean $\quad 0.0131253$

upper 95\% Mean 41.20126

lower 95\% Mean 41.149804

$\mathrm{N} \quad 10000$ 
WSRC-STI-2006-00068

Revision 0

Exhibit A11. Sensitivity of SME WL Estimations to the Uncertainties of This Report (continued)

Batch=352

SME Estimated WL $=39.99$

WL Re-Calc $=39.98$

Estimated WL w M-13 Unc

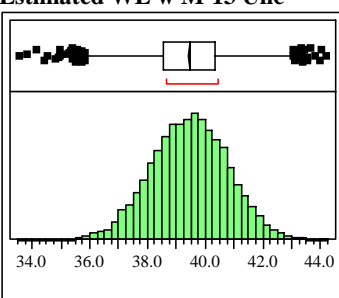

Quantiles

$100.0 \%$ maximum 44.218

$99.5 \% \quad 42.756$

$97.5 \% \quad 41.983$

$90.0 \%$

$75.0 \%$ quartile 40.365

$50.0 \%$ median 39.472

$25.0 \%$ quartile $\quad 38.562$

$10.0 \% \quad 37.753$

$\begin{array}{ll}10.5 \% & 36.849\end{array}$

$0.5 \% \quad 35.946$

$0.0 \%$ minimum 33.584

Moments

Mean $\quad 39.450994$

Std Dev $\quad 1.3216104$

Std Err Mean $\quad 0.0132161$

upper 95\% Mean 39.476901

lower 95\% Mean 39.425088

$\mathrm{N}$

10000

Estimated WL w M-14 Unc

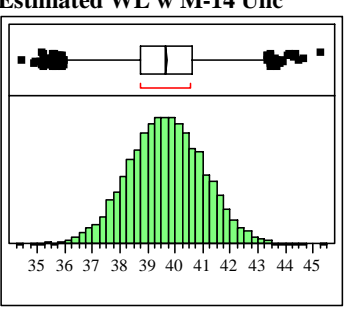

Quantiles

$100.0 \%$ maximum 45.324

$99.5 \% \quad 43.099$

$97.5 \% \quad 42.305$

$90.0 \% \quad 41.420$

$75.0 \%$ quartile 40.601

$50.0 \%$ median 39.648

$25.0 \%$ quartile 38.758

$10.0 \% \quad 37.932$

$2.5 \% \quad 36.964$

$0.5 \% \quad 36.119$

$0.0 \%$ minimum 34.461

Moments

Mean $\quad 39.666925$

Std Dev $\quad 1.3588557$

Std Err Mean 0.0135886

upper 95\% Mean 39.693561

lower 95\% Mean 39.640288

$\mathrm{N}$
Batch $=353$

SME Estimated WL $=42.76$

WL Re-Calc $=42.75$

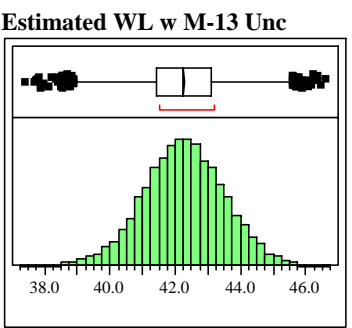

Quantiles

$100.0 \%$ maximum 46.640

$99.5 \% \quad 45.448$

$97.5 \% \quad 44.683$

$90.0 \% \quad 43.852$

$75.0 \%$ quartile 43.097

$50.0 \%$ median 42.262

$25.0 \%$ quartile $\quad 41.428$

$10.0 \% \quad 40.688$

$\begin{array}{ll}2.5 \% & 39.737\end{array}$

$0.5 \% \quad 38.826$

$0.0 \%$ minimum 37.395

Moments

Mean $\quad 42.25785$

Std Dev $\quad 1.2520271$

Std Err Mean $\quad 0.0125203$

upper 95\% Mean 42.282392

lower 95\% Mean 42.233308

10000

Estimated WL w M-14 Unc

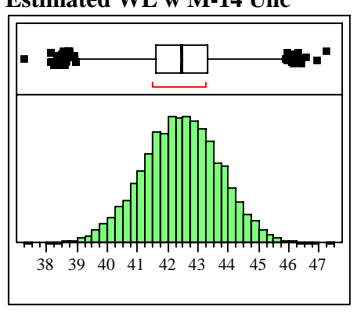

Quantiles

$100.0 \%$ maximum 47.266

$\begin{array}{ll}99.5 \% & 45.639 \\ 97.5 \% & 44.908\end{array}$

$90.0 \% \quad 44.071$

$75.0 \%$ quartile 43.316

$50.0 \%$ median 42.455

$25.0 \%$ quartile 41.580

$10.0 \% \quad 40.790$

$2.5 \% \quad 39.847$

$0.5 \% \quad 39.111$

$0.0 \%$ minimum 37.284

Moments

Mean $\quad 42.441143$

Std Dev $\quad 1.2820422$

Std Err Mean $\quad 0.0128204$

upper 95\% Mean 42.466273

lower 95\% Mean 42.416012

$\mathrm{N} \quad 10000$
Batch $=354$

SME Estimated WL $=40.62$

WL Re-Calc $=\mathbf{4 0 . 6 1}$

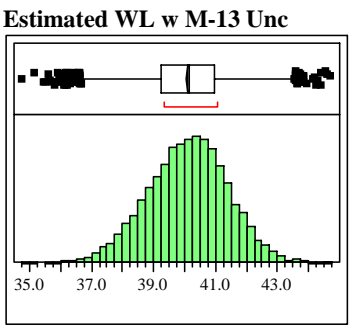

Quantiles

$100.0 \%$ maximum 44.702

$99.5 \% \quad 43.341$

$97.5 \% \quad 42.567$

$90.0 \% \quad 41.722$

$75.0 \%$ quartile 40.972

$50.0 \%$ median 40.144

$25.0 \%$ quartile 39.257

$10.0 \% \quad 38.428$

$\begin{array}{ll}10.5 \% & 37.484\end{array}$

$0.5 \% \quad 36.648$

$0.0 \%$ minimum 34.754

Moments

Mean $\quad 40.101928$

Std Dev $\quad 1.2871999$

Std Err Mean $\quad 0.012872$

upper 95\% Mean 40.12716

ower 95\% Mean 40.076696

$\mathrm{N}$

10000

Estimated WL w M-14 Unc

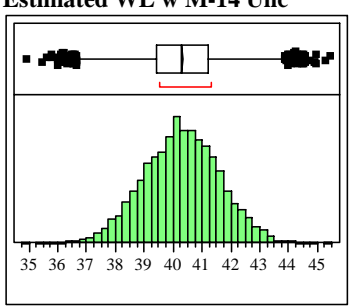

Quantiles

$100.0 \%$ maximum 45.480

$\begin{array}{ll}99.5 \% & 43.759 \\ 97.5 \% & 42.884\end{array}$

$90.0 \% \quad 41.967$

$75.0 \%$ quartile $\quad 41.187$

$50.0 \%$ median 40.298

$25.0 \%$ quartile 39.398

$10.0 \% \quad 38.589$

$2.5 \% \quad 37.718$

$0.5 \% \quad 36.787$

$0.0 \%$ minimum 34.916

Moments

Mean

1.3206315

$\quad 0.0132063$

upper 95\% Mean 40.320767

lower 95\% Mean 40.268992

$\mathrm{N}$

10000
Batch $=355$

SME Estimated WL $=35.47$

WL Re-Calc $=35.46$

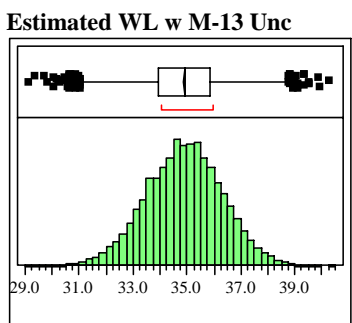

Quantiles

$100.0 \%$ maximum 40.277

$99.5 \% \quad 38.483$

$97.5 \% \quad 37.668$

$90.0 \% \quad 36.717$

$75.0 \%$ quartile 35.852

$50.0 \%$ median 34.922

$25.0 \%$ quartile 33.939

$10.0 \% \quad 33.089$

$2.5 \% \quad 32.110$

$0.5 \% \quad 31.230$

$0.0 \%$ minimum 29.174

Moments

Mean $\quad 34.905662$

Std Dev $\quad 1.4154448$

Std Err Mean $\quad 0.0141544$

upper 95\% Mean 34.933407

lower 95\% Mean 34.877916

$\mathrm{N}$

Estimated WL w M-14 Unc

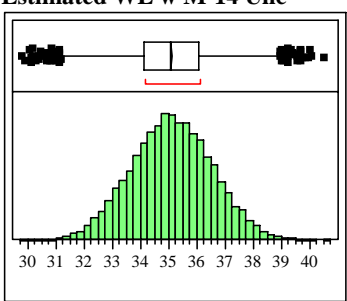

Quantiles

$100.0 \%$ maximum 40.528

$99.5 \% \quad 38.828$

$97.5 \% \quad 37.918$

$90.0 \% \quad 36.945$

$75.0 \%$ quartile 36.076

$50.0 \%$ median 35.104

$25.0 \%$ quartile 34.133

$10.0 \% \quad 33.230$

$2.5 \% \quad 32.312$

$0.5 \% \quad 31.467$

$0.0 \%$ minimum 29.810

Moments

Mean $\quad 35.105589$

Std Dev 1.4408918

Std Err Mean $\quad 0.0144089$

upper 95\% Mean 35.133834

lower 95\% Mean 35.077345

$\mathrm{N} \quad 10000$ 
WSRC-STI-2006-00068

Revision 0

Exhibit A11. Sensitivity of SME WL Estimations to the Uncertainties of This Report (continued)

Batch=356

SME Estimated WL $=38.05$

WL Re-Calc $=38.04$

Estimated WL w M-13 Unc

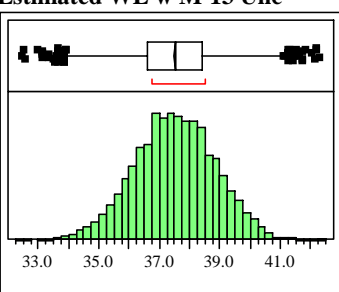

Quantiles

$100.0 \%$ maximum 42.338

$99.5 \% \quad 40.823$

$97.5 \% \quad 40.077$

$90.0 \%$

$75.0 \%$ quartile 38.418

$50.0 \%$ median 37.512

$25.0 \%$ quartile 36.618

$10.0 \% \quad 35.798$

$2.5 \% \quad 34.848$

$0.5 \% \quad 34.005$

$0.0 \%$ minimum 32.457

Moments

Mean $\quad 37.511667$

Std Dev $\quad 1.33572$

Std Err Mean $\quad 0.0133572$

upper 95\% Mean 37.53785

lower 95\% Mean 37.485484

$\mathrm{N}$

10000

Estimated WL w M-14 Unc

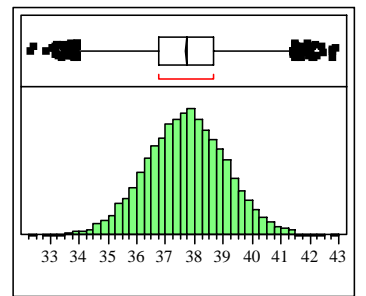

Quantiles

$100.0 \%$ maximum 42.909

$99.5 \% \quad 41.320$

$97.5 \% \quad 40.477$

$90.0 \% \quad 39.476$

$75.0 \%$ quartile 38.640

$50.0 \%$ median 37.720

$25.0 \%$ quartile 36.778

$10.0 \% \quad 35.934$

$2.5 \% \quad 34.946$

$0.5 \% \quad 33.945$

$0.0 \%$ minimum 32.340

Moments

Mean $\quad 37.711754$

Std Dev $\quad 1.3955528$

Std Err Mean $\quad 0.0139555$

upper 95\% Mean 37.73911

lower 95\% Mean 37.684399

$\mathrm{N}$

10000 
WSRC-STI-2006-00068

Revision 0

Exhibit A12. Relationships between Analytes and WLs by Preparation Method, ICP, and Analyte

Prep=Fusion, Sample Type=SME, ICP=M-13, Analyte $=$ Al Bivariate Fit of Avg Measurement By Blending WL

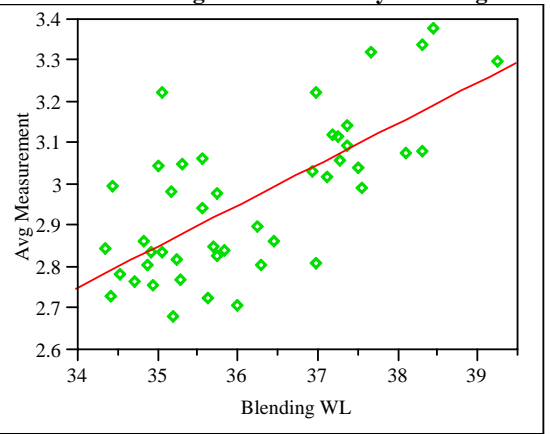

Linear Fit

Avg Measurement $=-0.619798+0.099138$ Blending WL Summary of Fit

RSquare $\quad 0.48735$

RSquare Adj $\quad 0.475428$

Root Mean Square Error $\quad 0.132834$

Mean of Response 2.967059

Observations (or Sum Wgts) $\quad 45$

Analysis of Variance

Source DF Sum of Squares Mean Square F Ratio

$\begin{array}{lllll}\text { Model } & 1 & 0.7212865 & 0.721286 & 40.8778\end{array}$

$\begin{array}{llll}\text { Error } & 43 & 0.7587320 & 0.017645 \text { Prob }>\text { F }\end{array}$

$\begin{array}{llll}\text { C. Total } 44 & 1.4800185 & <.0001\end{array}$

Bivariate Fit of Avg Measurement By SME Avg WL

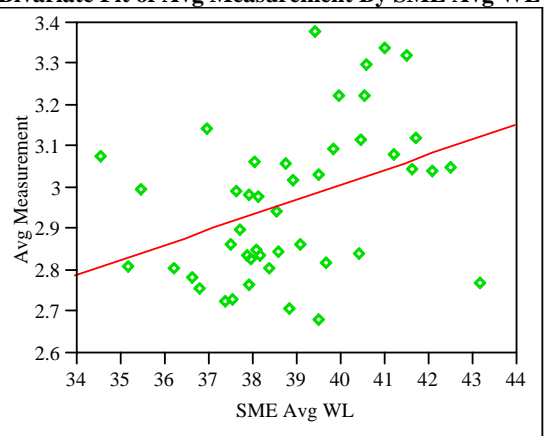

Linear Fit

Avg Measurement $=1.5478012+0.0364864$ SME Avg WL Summary of Fit

RSquare $\quad 0.151545$

RSquare Adj $\quad 0.131814$

Root Mean Square Error $\quad 0.170889$

Mean of Respons

Observations (or Sum Wgts) $\quad 45$

Analysis of Variance

Source DF Sum of Squares Mean Square F Ratio

$\begin{array}{lllll}\text { Model } & 1 & 0.2242900 & 0.224290 & 7.6804\end{array}$

$\begin{array}{llll}\text { Error } & 43 & 1.2557285 & 0.029203 \text { Prob }>\text { F }\end{array}$

$\begin{array}{llll}\text { C. Total } 44 \quad 1.4800185 & 0.0082\end{array}$
Prep=Fusion, Sample Type=SME, ICP $=$ M-13, Analyte $=$ Al $/$ Ca Bivariate Fit of Avg Measurement By Blending WL

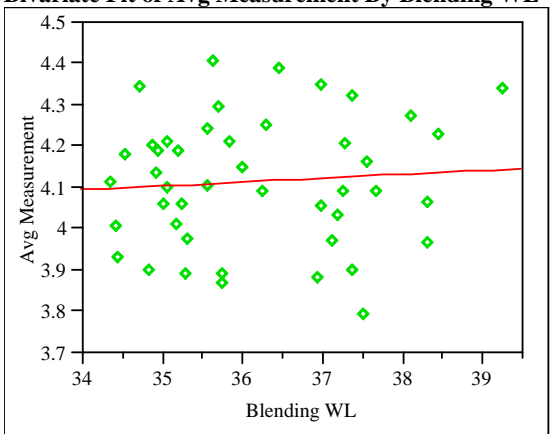

Linear Fit

Avg Measurement $=3.7743621+0.0094478$ Blending WL Summary of Fit

$\begin{array}{lr}\text { RSquare } & 0.006098 \\ \text { RSquare Adj } & -0.01702 \\ \text { Root Mean Square Error } & 0.157577 \\ \text { Mean of Response } & 4.116189 \\ \text { Observations (or Sum Wgts) } & 45\end{array}$

Analysis of Variance

Source DF Sum of Squares Mean Square F Ratio $\begin{array}{lllll}\text { Model } & 1 & 0.0065508 & 0.006551 & 0.2638\end{array}$ $\begin{array}{llll}\text { Error } 43 & 1.0677109 & 0.024830 \text { Prob }>\text { F }\end{array}$

$\begin{array}{lll}\text { C. Total } 44 & 1.0742617 & 0.6101\end{array}$

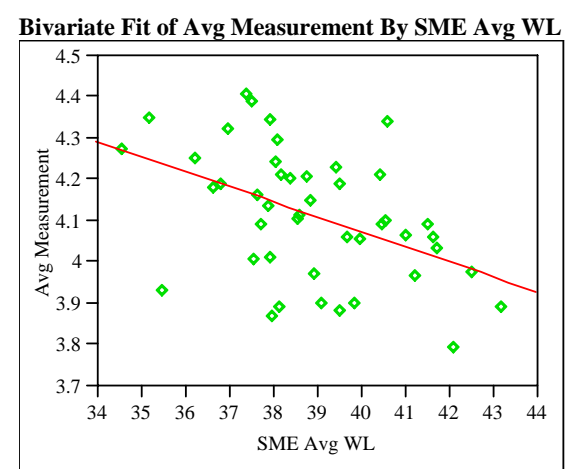

Linear Fit

Avg Measurement $=5.53256-0.0364122$ SME Avg WL Summary of Fit

RSquare

0.207937

RSquare Adj

0.189517

Root Mean Square Error $\quad 0.14067$

Mean of Response

4.116189

Observations (or Sum Wgts)

45

Analysis of Variance

Source DF Sum of Squares Mean Square F Ratio

$\begin{array}{lllll}\text { Model } & 1 & 0.2233786 & 0.223379 & 11.2886\end{array}$

$\begin{array}{lllll}\text { Error } & 43 & 0.8508831 & 0.019788 \text { Prob }>\text { F }\end{array}$

$\begin{array}{llll}\text { C. Total } \quad 44 & 1.0742617 & 0.0016\end{array}$ 
WSRC-STI-2006-00068

Revision 0

Exhibit A12. Relationships between Analytes and WLs by Preparation Method, ICP, and Analyte (continued)

Prep=Fusion, Sample Type=SME, ICP=M-13, Analyte=Al/Mg Bivariate Fit of Avg Measurement By Blending WI

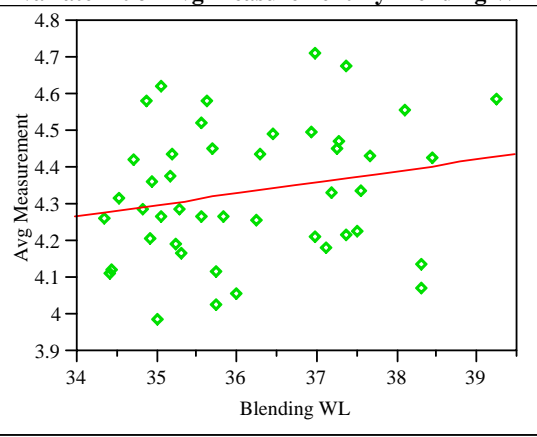

Linear Fit

Avg Measurement $=3.223925+0.0306901$ Blending $\mathrm{WL}$ Summary of Fit

$\begin{array}{lr}\text { RSquare } & 0.047329 \\ \text { RSquare Adj } & 0.025173 \\ \text { Root Mean Square Error } & 0.179882 \\ \text { Mean of Response } & 4.334306 \\ \text { Observations (or Sum Wgts) } & 45\end{array}$

Analysis of Variance

Source DF Sum of Squares Mean Square F Ratio

$\begin{array}{lllll}\text { Model } & 1 & 0.0691232 & 0.069123 & 2.1362\end{array}$

$\begin{array}{llll}\text { Error } & 43 & 1.3913715 & 0.032357 \text { Prob }>\text { F }\end{array}$

$\begin{array}{lll}\text { C. Total } 44 & 1.4604947 & 0.1511\end{array}$

Bivariate Fit of Avg Measurement By SME Avg WL

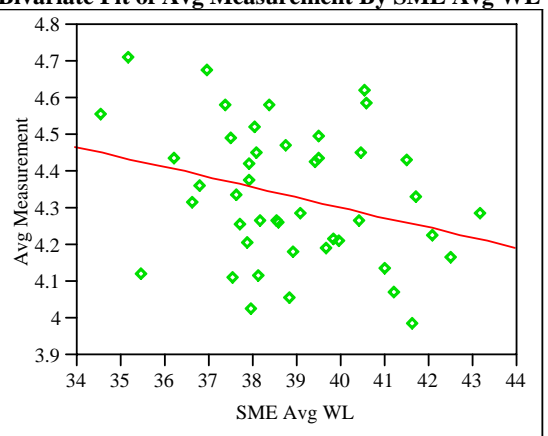

Linear Fit

Avg Measurement $=5.4069199-0.0275748$ SME Avg WL

Summary of Fit

$\begin{array}{lr}\text { RSquare } & 0.087715 \\ \text { RSquare Adj } & 0.066499 \\ \text { Root Mean Square Error } & 0.176028 \\ \text { Mean of Response } & 4.334306 \\ \text { Observations (or Sum Wgts) } & 45\end{array}$

Observations (or Sum Wgts)

Analysis of Variance

Source DF Sum of Squares Mean Square F Ratio

$\begin{array}{lllll}\text { Model } & 1 & 0.1281072 & 0.128107 & 4.1344\end{array}$

$\begin{array}{llll}\text { Error } & 43 & 1.3323874 & 0.030986 \text { Prob }>\text { F }\end{array}$

$\begin{array}{lll}\text { C. Total } 44 & 1.4604947 & 0.0482\end{array}$
Prep=Fusion, Sample Type=SME, ICP=M-13, Analyte=AI/Mn Bivariate Fit of Avg Measurement By Blending WL

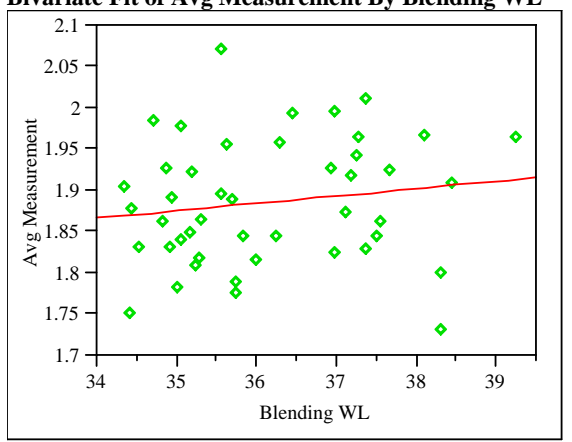

Linear Fit

Avg Measurement $=1.5664396+0.0088446$ Blending WL Summary of Fit

$\begin{array}{lr}\text { RSquare } & 0.022824 \\ \text { RSquare Adj } & 0.000099 \\ \text { Root Mean Square Error } & 0.075604 \\ \text { Mean of Response } & 1.88644 \\ \text { Observations (or Sum Wgts) } & 45\end{array}$

Analysis of Variance

Source DF Sum of Squares Mean Square F Ratio

$\begin{array}{lllll}\text { Model } & 1 & 0.00574091 & 0.005741 & 1.0044\end{array}$

$\begin{array}{lllll}\text { Error } & 43 & 0.24578791 & 0.005716 \text { Prob }>\text { F }\end{array}$

$\begin{array}{lllr}\text { C. Total } & 44 & 0.25152881 & 0.3219\end{array}$

Bivariate Fit of Avg Measurement By SME Avg WL

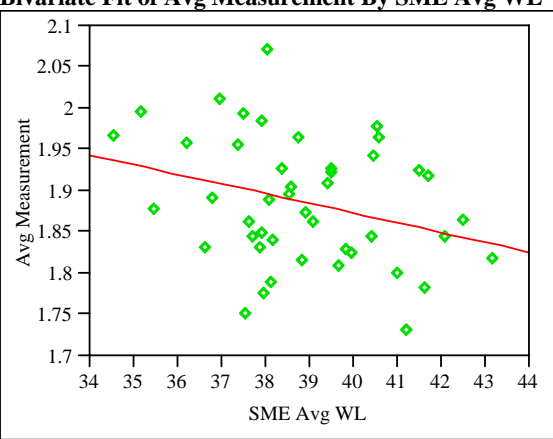

Linear Fit

Avg Measurement $=2.3464365-0.0118256$ SME Avg WL Summary of Fit

RSquare

0.093672

RSquare Adj

0.072594

Root Mean Square Error $\quad 0.072812$

Mean of Response $\quad 1.88644$

Observations (or Sum Wgts)

45

Analysis of Variance

Source DF Sum of Squares Mean Square F Ratio

$\begin{array}{lllll}\text { Model } & 1 & 0.02356113 & 0.023561 & 4.4442\end{array}$

$\begin{array}{lllll}\text { Error } & 43 & 0.22796768 & 0.005302 & \text { Prob }>\text { F }\end{array}$

$\begin{array}{llrr}\text { C. Total } & 44 & 0.25152881 & 0.0409\end{array}$ 
WSRC-STI-2006-00068

Revision 0

Exhibit A12. Relationships between Analytes and WLs by Preparation Method, ICP, and Analyte (continued)

Prep $=$ Fusion, Sample Type $=$ SME, ICP $=$ M-13, Analyte $=B$ Bivariate Fit of Avg Measurement By Blending WL

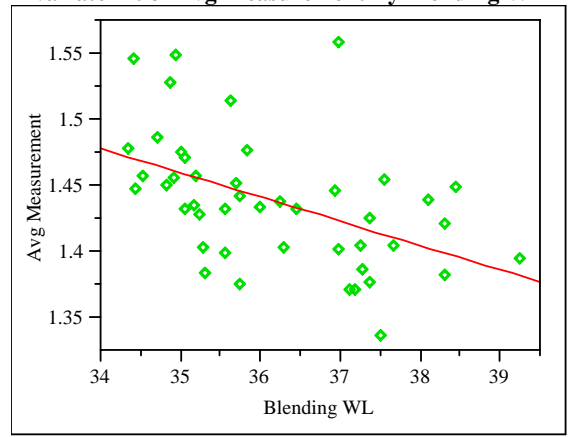

Linear Fit

Avg Measurement $=2.1047036-0.0184191$ Blending WL Summary of Fit

$\begin{array}{lr}\text { RSquare } & 0.230363 \\ \text { RSquare Adj } & 0.212465 \\ \text { Root Mean Square Error } & 0.043983 \\ \text { Mean of Response } & 1.438293 \\ \text { Observations (or Sum Wgts) } & 45\end{array}$

Analysis of Variance

Source DF Sum of Squares Mean Square F Ratio

$\begin{array}{lllll}\text { Model } & 1 & 0.02489793 & 0.024898 & 12.8705\end{array}$

Error $43 \quad 0.083183310 .001934$ Prob $>$ F

C. Total $44 \quad 0.10808124 \quad 0.0008$

Bivariate Fit of Avg Measurement By SME Avg WL

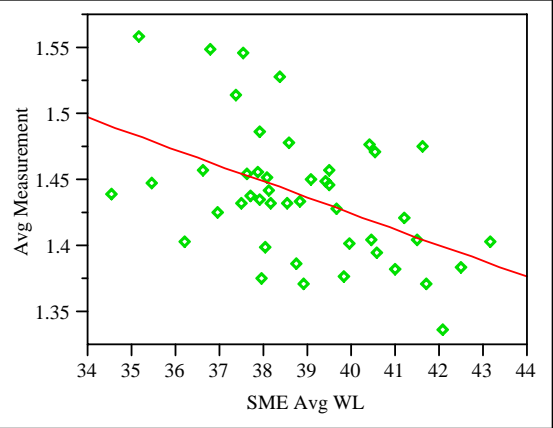

Linear Fit

Avg Measurement $=1.9083612-0.0120846$ SME Avg WL

Summary of Fit

$\begin{array}{lr}\text { RSquare } & 0.227645 \\ \text { RSquare Adj } & 0.209683 \\ \text { Root Mean Square Error } & 0.04406 \\ \text { Mean of Response } & 1.438293 \\ \text { Observations (or Sum Wgts) } & 45\end{array}$

Analysis of Variance

Source DF Sum of Squares Mean Square F Ratio

$\begin{array}{lllll}\text { Model } & 1 & 0.02460418 & 0.024604 & 12.6739\end{array}$

$\begin{array}{llll}\text { Error } 43 & 0.08347707 & 0.001941 \text { Prob }>\text { F }\end{array}$

$\begin{array}{llr}\text { C. Total } 44 & 0.10808124 & 0.0009\end{array}$
Prep $=$ Fusion, Sample Type $=$ SME, ICP $=$ M-13, Analyte $=B / L i$ Bivariate Fit of Avg Measurement By Blending WL

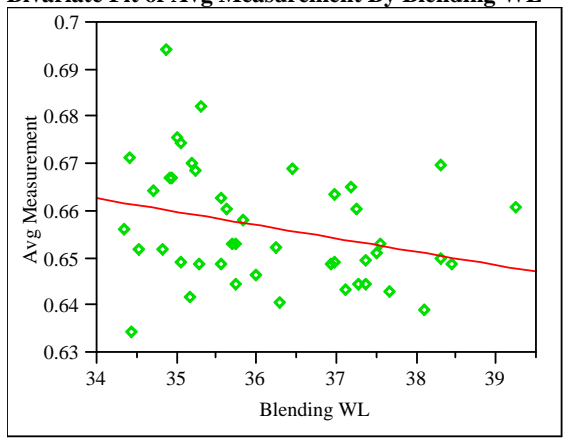

Linear Fit

Avg Measurement $=0.7588217-0.0028257$ Blending WL Summary of Fit

$\begin{array}{lr}\text { RSquare } & 0.085629 \\ \text { RSquare Adj } & 0.064365 \\ \text { Root Mean Square Error } & 0.012063 \\ \text { Mean of Response } & 0.656588 \\ \text { Observations (or Sum Wgts) } & 45\end{array}$

Analysis of Variance

Source DF Sum of Squares Mean Square F Ratio

$\begin{array}{lllll}\text { Model } & 1 & 0.00058596 & 0.000586 & 4.0269\end{array}$

$\begin{array}{llll}\text { Error } 43 & 0.00625703 & 0.000146 \text { Prob }>\text { F }\end{array}$

$\begin{array}{llr}\text { C. Total } 44 & 0.00684299 & 0.0511\end{array}$

Bivariate Fit of Avg Measurement By SME Avg WL

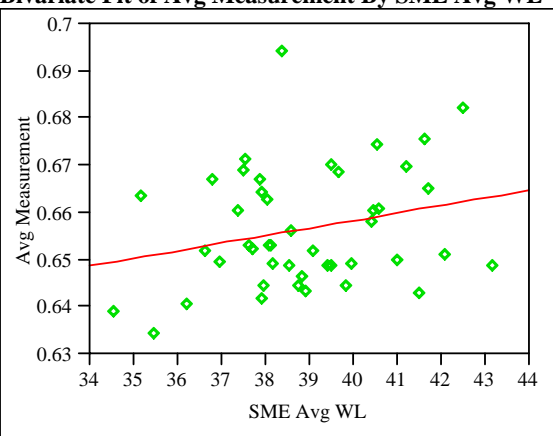

Linear Fit

Avg Measurement $=0.5945972+0.0015937$ SME Avg WL Summary of Fit

RSquare

0.062531

RSquare Adj

0.040729

Root Mean Square Error $\quad 0.012214$

Mean of Response $\quad 0.656588$

Observations (or Sum Wgts) 45

Analysis of Variance

Source DF Sum of Squares Mean Square F Ratio

$\begin{array}{lllll}\text { Model } & 1 & 0.00042790 & 0.000428 & 2.8682\end{array}$

$\begin{array}{lllll}\text { Error } & 43 & 0.00641509 & 0.000149 \text { Prob }>\text { F }\end{array}$

$\begin{array}{llr}\text { C. Total } 44 & 0.00684299 & 0.0976\end{array}$ 
WSRC-STI-2006-00068

Revision 0

Exhibit A12. Relationships between Analytes and WLs by Preparation Method, ICP, and Analyte (continued)

Prep $=$ Fusion, Sample Type $=$ SME, ICP $=$ M-13, Analyte $=$ Ca Bivariate Fit of Avg Measurement By Blending WL

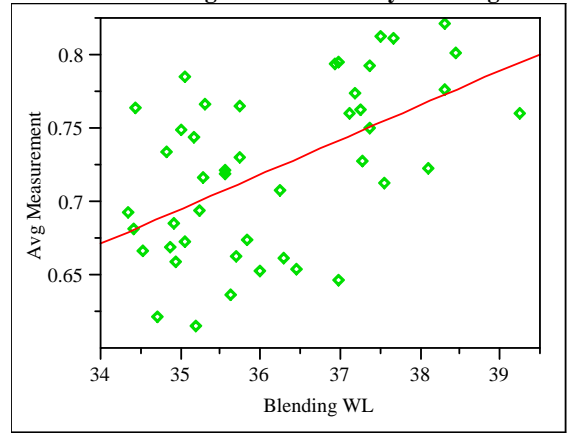

Linear Fit

Avg Measurement $=-0.127574+0.0235141$ Blending WL Summary of Fit

$\begin{array}{lr}\text { RSquare } & 0.287989 \\ \text { RSquare Adj } & 0.271431 \\ \text { Root Mean Square Error } & 0.048302 \\ \text { Mean of Response } & 0.723177 \\ \text { Observations (or Sum Wgts) } & 45\end{array}$

Analysis of Variance

Source DF Sum of Squares Mean Square F Ratio

$\begin{array}{lllll}\text { Model } & 1 & 0.04057734 & 0.040577 & 17.3923\end{array}$

Error $43 \quad 0.10032159 \quad 0.002333$ Prob $>$ F

C. Total $44 \quad 0.14089893 \quad 0.0001$

Bivariate Fit of Avg Measurement By SME Avg WL

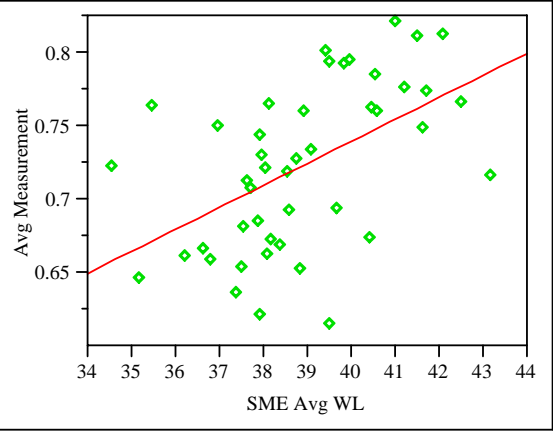

Linear Fit

Avg Measurement $=0.1408496+0.0149705$ SME Avg WL

Summary of Fit

$\begin{array}{lr}\text { RSquare } & 0.267987 \\ \text { RSquare Adj } & 0.250963 \\ \text { Root Mean Square Error } & 0.048976 \\ \text { Mean of Response } & 0.723177 \\ \text { Observations (or Sum Wgts) } & 45\end{array}$

Analysis of Variance

Source DF Sum of Squares Mean Square F Ratio

$\begin{array}{lllll}\text { Model } & 1 & 0.03775905 & 0.037759 & 15.7421\end{array}$

$\begin{array}{llll}\text { Error } & 43 & 0.10313988 & 0.002399 \text { Prob }>\text { F }\end{array}$

C. Total $44 \quad 0.14089893 \quad 0.0003$
Prep=Fusion, Sample Type $=$ SME, ICP $=$ M-13, Analyte $=C r$ Bivariate Fit of Avg Measurement By Blending WL

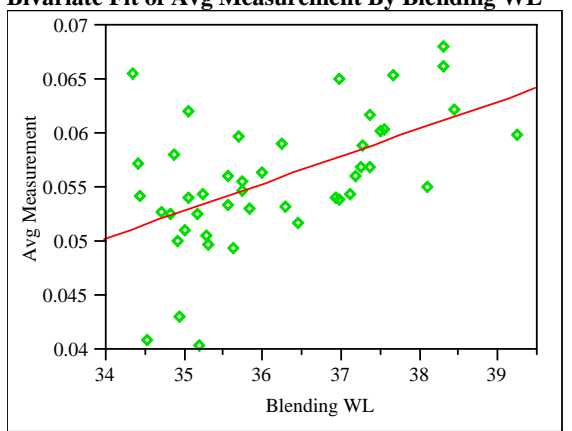

Linear Fit

Avg Measurement $=-0.035616+0.0025265$ Blending WL Summary of Fit

\begin{tabular}{ll} 
RSquare & 0.290283 \\
RSquare Adj & 0.273778 \\
Root Mean Square Error & 0.005161 \\
Mean of Response & 0.055794 \\
\hline
\end{tabular}

Observations (or Sum Wgts) $\quad 45$

Analysis of Variance

Source DF Sum of Squares Mean Square F Ratio

$\begin{array}{lllll}\text { Model } & 1 & 0.00046845 & 0.000468 & 17.5875\end{array}$

$\begin{array}{lllll}\text { Error } & 43 & 0.00114532 & 0.000027 & \text { Prob }>\text { F }\end{array}$

$\begin{array}{lll}\text { C. Total } 44 & 0.00161376 & 0.0001\end{array}$

Bivariate Fit of Avg Measurement By SME Avg WL

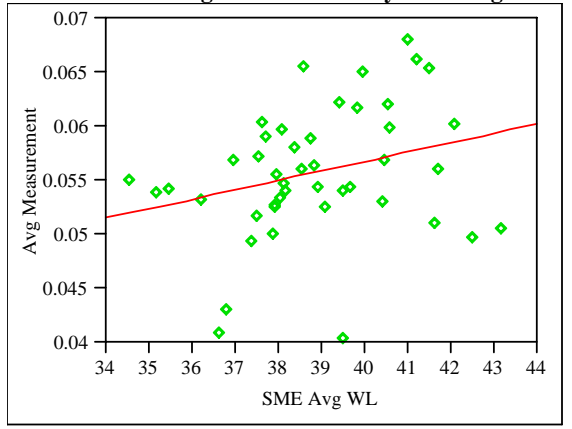

Linear Fit

Avg Measurement $=0.0218908+0.0008716$ SME Avg WL Summary of Fit

RSquare

RSquare Adj

0.079309

Mean of Response $\quad 0.055794$

Observations (or Sum Wgts)

45

Analysis of Variance

Source DF Sum of Squares Mean Square F Ratio

$\begin{array}{lllll}\text { Model } & 1 & 0.00012799 & 0.000128 & 3.7041\end{array}$

$\begin{array}{llll}\text { Error } & 43 & 0.00148578 & 0.000035 \text { Prob }>\text { F }\end{array}$

$\begin{array}{llll}\text { C. Total } 44 & 0.00161376 & 0.0609\end{array}$ 
WSRC-STI-2006-00068

Revision 0

Exhibit A12. Relationships between Analytes and WLs by Preparation Method, ICP, and Analyte (continued)

Prep $=$ Fusion, Sample Type $=$ SME, ICP $=$ M-13, Analyte $=\mathrm{Cu}$ Bivariate Fit of Avg Measurement By Blending WL

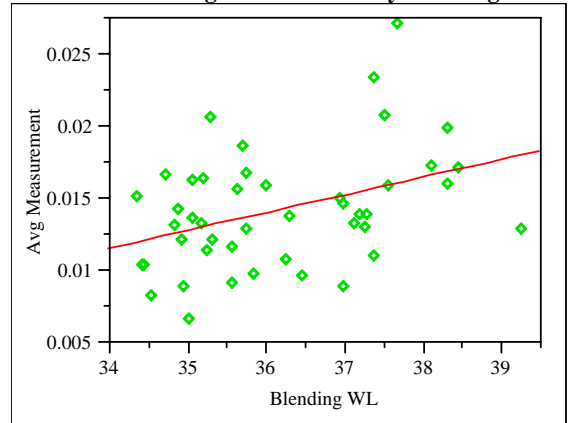

Linear Fit

Avg Measurement $=-0.030247+0.0012298$ Blending WL Summary of Fit

$\begin{array}{lr}\text { RSquare } & 0.150607 \\ \text { RSquare Adj } & 0.130854 \\ \text { Root Mean Square Error } & 0.003815 \\ \text { Mean of Response } & 0.014247 \\ \text { Observations (or Sum Wgts) } & 45\end{array}$

Observations (or Sum Wgts) 45

Analysis of Variance

Source DF Sum of Squares Mean Square F Ratio

$\begin{array}{lllll}\text { Model } & 1 & 0.00011099 & 0.000111 & 7.6244\end{array}$

$\begin{array}{llll}\text { Error } & 43 & 0.00062595 & 0.000015 \text { Prob }>\text { F }\end{array}$

$\begin{array}{lll}\text { C. Total } 44 & 0.00073694 & 0.0084\end{array}$

Bivariate Fit of Avg Measurement By SME Avg WL

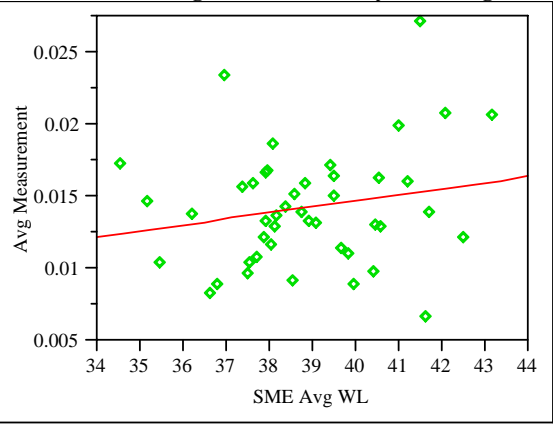

Linear Fit

Avg Measurement $=-0.002042+0.0004188$ SME Avg WL Summary of Fit

RSquare $\quad 0.040089$

RSquare Adj $\quad 0.017766$

Root Mean Square Error $\quad 0.004056$

Mean of Response $\quad 0.014247$

Observations (or Sum Wgts) 45

Analysis of Variance

Source DF Sum of Squares Mean Square F Ratio

$\begin{array}{lllll}\text { Model } & 1 & 0.00002954 & 0.000030 & 1.7958\end{array}$

$\begin{array}{llll}\text { Error } 43 & 0.00070740 & 0.000016 \text { Prob }>\text { F }\end{array}$

C. Total $44 \quad 0.00073694 \quad 0.1873$
Prep=Fusion, Sample Type $=$ SME, ICP $=$ M-13, Analyte $=$ Fe Bivariate Fit of Avg Measurement By Blending WL

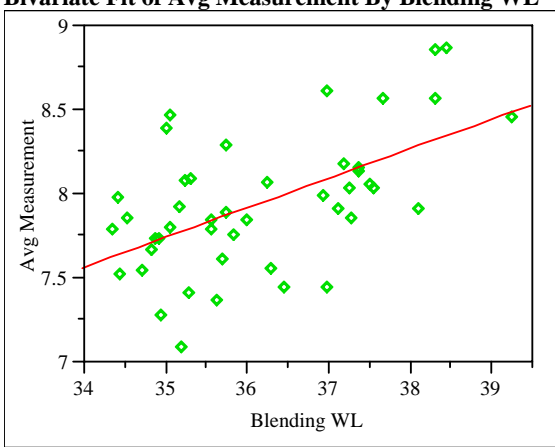

Linear Fit

Avg Measurement $=1.6024992+0.1753911$ Blending $\mathrm{WL}$ Summary of Fit

$\begin{array}{lr}\text { RSquare } & 0.313804 \\ \text { RSquare Adj } & 0.297846 \\ \text { Root Mean Square Error } & 0.33883 \\ \text { Mean of Response } & 7.948228 \\ \text { Observations (or Sum Wgts) } & 45\end{array}$

Analysis of Variance

Source DF Sum of Squares Mean Square F Ratio $\begin{array}{lllll}\text { Model } & 1 & 2.2575772 & 2.25758 & 19.6643\end{array}$ $\begin{array}{llll}\text { Error } & 43 & 4.9366480 & 0.11481 \text { Prob }>\text { F }\end{array}$

$\begin{array}{llll}\text { C. Total } 44 & 7.1942252 & <.0001\end{array}$

Bivariate Fit of Avg Measurement By SME Avg WL

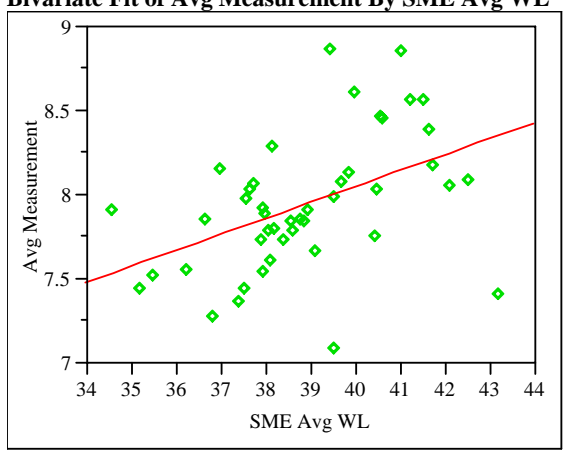

Linear Fit

Avg Measurement $=4.2572473+0.0948881$ SME Avg WL Summary of Fit

$\begin{array}{lr}\text { RSquare } & 0.210856 \\ \text { RSquare Adj } & 0.192504 \\ \text { Root Mean Square Error } & 0.363359 \\ \text { Mean of Response } & 7.948228 \\ \text { Observations (or Sum Wgts) } & 45\end{array}$

Analysis of Variance

Source DF Sum of Squares Mean Square F Ratio

$\begin{array}{lllll}\text { Model } & 1 & 1.5169484 & 1.51695 & 11.4894\end{array}$

$\begin{array}{llll}\text { Error } & 43 & 5.6772768 & 0.13203 \text { Prob }>\text { F }\end{array}$

$\begin{array}{llr}\text { C. Total } 44 & 7.1942252 & 0.0015\end{array}$ 
WSRC-STI-2006-00068

Revision 0

Exhibit A12. Relationships between Analytes and WLs by Preparation Method, ICP, and Analyte (continued)

Prep $=$ Fusion, Sample Type $=$ SME, ICP $=$ M-13, Analyte $=$ Fe $/ \mathrm{A}$ Bivariate Fit of Avg Measurement By Blending WL

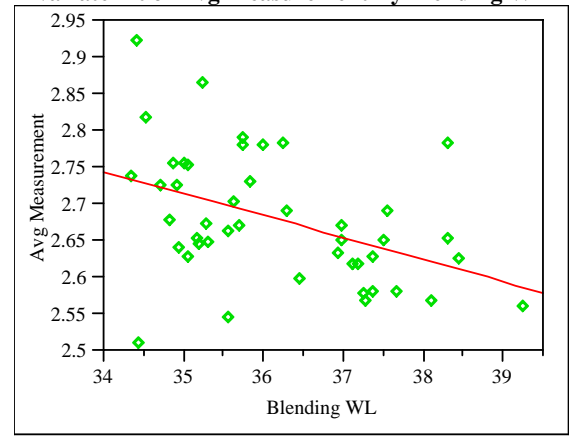

Linear Fit

Avg Measurement $=3.7669182-0.03006$ Blending WL Summary of Fit

$\begin{array}{lr}\text { RSquare } & 0.193989 \\ \text { RSquare Adj } & 0.175245 \\ \text { Root Mean Square Error } & 0.080048 \\ \text { Mean of Response } & 2.679332 \\ \text { Observations (or Sum Wgts) } & 45\end{array}$

Analysis of Variance

Source DF Sum of Squares Mean Square F Ratio

$\begin{array}{lllll}\text { Model } & 1 & 0.06631420 & 0.066314 & 10.3492\end{array}$

$\begin{array}{llll}\text { Error } & 43 & 0.27553056 & 0.006408 \text { Prob }>\text { F }\end{array}$

$\begin{array}{lll}\text { C. Total } 44 & 0.34184476 & 0.0025\end{array}$

Bivariate Fit of Avg Measurement By SME Avg WL

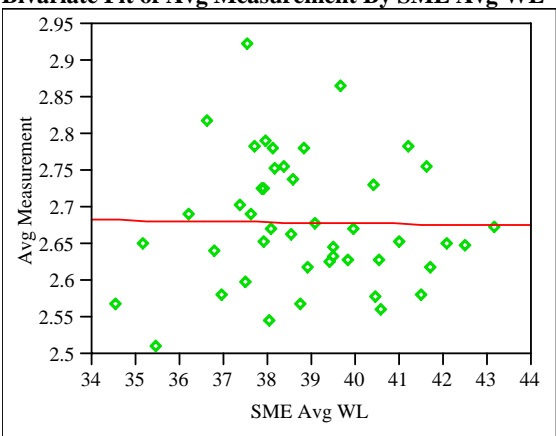

Linear Fit

Avg Measurement $=2.7108928-0.0008114$ SME Avg WL

Summary of Fit

RSquare

RSquare Adj

0.000324

Root Mean Square Error $\quad 0.089148$

$-0.02292$

Mean of Response 2.679332

Observations (or Sum Wgts)

45

Analysis of Variance

Source DF Sum of Squares Mean Square F Ratio

$\begin{array}{lllll}\text { Model } & 1 & 0.00011091 & 0.000111 & 0.0140\end{array}$

$\begin{array}{lllll}\text { Error } & 43 & 0.34173385 & 0.007947 \text { Prob }>\text { F }\end{array}$

$\begin{array}{llr}\text { C. Total } 44 & 0.34184476 & 0.9065\end{array}$
Prep $=$ Fusion, Sample Type $=$ SME, ICP $=M-13$, Analyte $=$ Fe $/ \mathrm{Ca}$ Bivariate Fit of Avg Measurement By Blending WL

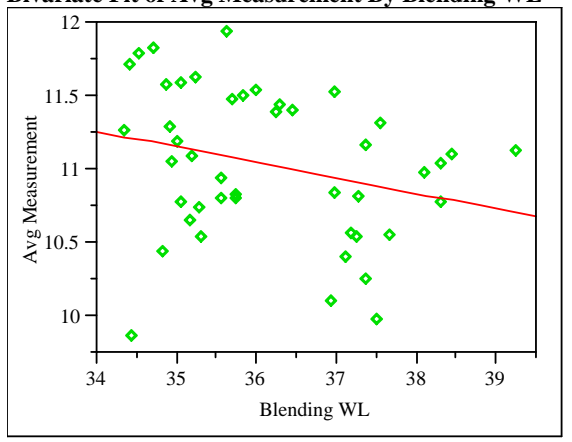

Linear Fit

Avg Measurement = $14.852943-0.1056533$ Blending WL Summary of Fit

$\begin{array}{lr}\text { RSquare } & 0.072473 \\ \text { RSquare Adj } & 0.050903 \\ \text { Root Mean Square Error } & 0.493785 \\ \text { Mean of Response } & 11.03036 \\ \text { Observations (or Sum Wgts) } & 45\end{array}$

Observations (or Sum Wgts) $\quad 45$

\section{Analysis of Variance}

Source DF Sum of Squares Mean Square F Ratio

$\begin{array}{lllll}\text { Model } & 1 & 0.819207 & 0.819207 & 3.3598\end{array}$

$\begin{array}{llll}\text { Error } 43 & 10.484408 & 0.243823 \text { Prob }>\text { F }\end{array}$

$\begin{array}{llrr}\text { C. Total } & 44 & 11.303615 & 0.0737\end{array}$

Bivariate Fit of Avg Measurement By SME Avg WL

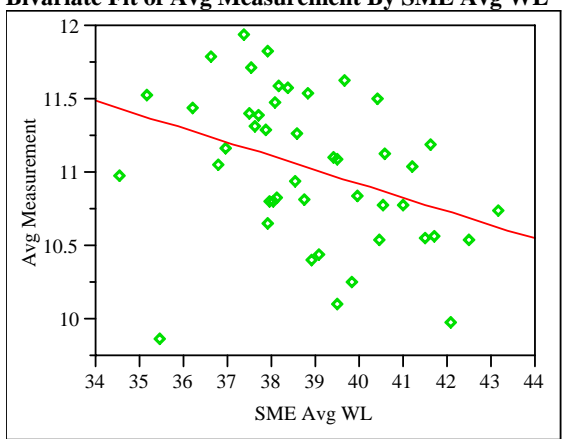

Linear Fit

Avg Measurement $=14.692184-0.0941385$ SME Avg WL Summary of Fit

RSquare

0.132089

RSquare Adj

0.111905

Root Mean Square Error $\quad 0.477653$

Mean of Response $\quad 11.03036$

Observations (or Sum Wgts)

45

Analysis of Variance

Source DF Sum of Squares Mean Square F Ratio

$\begin{array}{lllll}\text { Model } & 1 & 1.493078 & 1.49308 & 6.5442\end{array}$

$\begin{array}{llll}\text { Error } & 43 & 9.810537 & 0.22815 \text { Prob }>\text { F }\end{array}$

$\begin{array}{lll}\text { C. Total } 44 & 11.303615 & 0.0141\end{array}$ 
WSRC-STI-2006-00068

Revision 0

Exhibit A12. Relationships between Analytes and WLs by Preparation Method, ICP, and Analyte (continued)

Prep=Fusion, Sample Type $=\mathrm{SME}, \mathrm{ICP}=\mathrm{M}-13$, Analyte $=\mathrm{Fe} / \mathrm{Li}$ Bivariate Fit of Avg Measurement By Blending WL

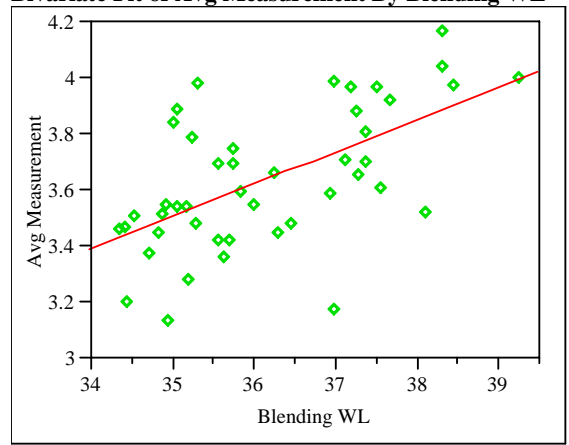

Linear Fit

Avg Measurement $=-0.505118+0.1145928$ Blending WL Summary of Fit

RSquare $\quad 0.348549$

RSquare Adj $\quad 0.333399$

Root Mean Square Error $\quad 0.204666$

Mean of Response 3.640902

Observations (or Sum Wgts) $\quad 45$

Analysis of Variance

Source DF Sum of Squares Mean Square F Ratio

$\begin{array}{lllll}\text { Model } & 1 & 0.9637011 & 0.963701 & 23.0065\end{array}$

Error $43 \quad 1.8011940 \quad 0.041888$ Prob $>$ F

C. Total $44 \quad 2.7648952<.0001$

Bivariate Fit of Avg Measurement By SME Avg WL

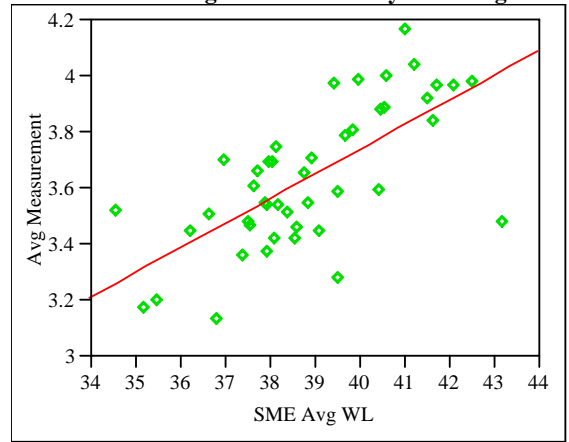

Linear Fit

Avg Measurement $=0.2197905+0.0879502$ SME Avg WL Summary of Fit

\begin{tabular}{lr} 
RSquare & 0.471349 \\
RSquare Adj & 0.459055 \\
Root Mean Square Error & 0.18437 \\
Mean of Response & 3.640902 \\
\hline
\end{tabular}

Mean of Response 3.640902

Observations (or Sum Wgts) $\quad 45$

Analysis of Variance

Source DF Sum of Squares Mean Square F Ratio

$\begin{array}{lllll}\text { Model } & 1 & 1.3032318 & 1.30323 & 38.3392\end{array}$

$\begin{array}{llll}\text { Error } & 43 & 1.4616633 & 0.03399 \text { Prob }>\text { F }\end{array}$

$\begin{array}{llr}\text { C. Total } 44 & 2.7648952 & <.0001\end{array}$
Prep=Fusion, Sample Type=SME, ICP=M-13, Analyte=Fe/Mg Bivariate Fit of Avg Measurement By Blending WL

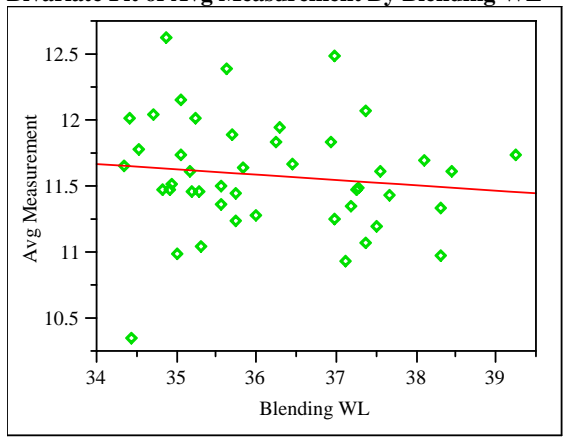

Linear Fit

Avg Measurement $=13.009-0.0393189$ Blending WL

Summary of Fit

RSquare

0.013854

RSquare Adj

$-0.00908$

Root Mean Square Error $\quad 0.433382$

Mean of Response $\quad 11.58642$

Observations (or Sum Wgts)

45

Analysis of Variance

Source DF Sum of Squares Mean Square F Ratio

$\begin{array}{lllll}\text { Model } & 1 & 0.1134569 & 0.113457 & 0.6041\end{array}$

$\begin{array}{lllll}\text { Error } & 43 & 8.0762689 & 0.187820 & \text { Prob > F }\end{array}$

$\begin{array}{llll}\text { C. Total } & 44 & 8.1897257 & 0.4413\end{array}$

Bivariate Fit of Avg Measurement By SME Avg WL

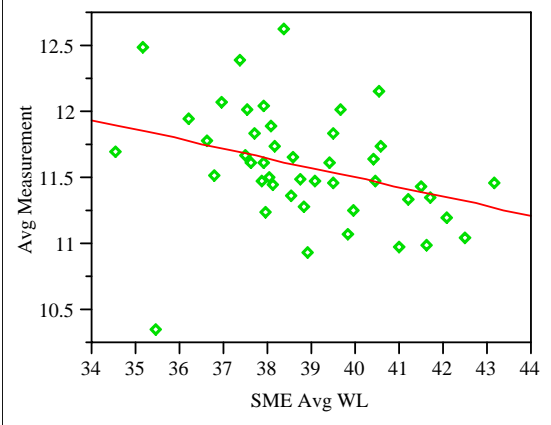

Linear Fit

Avg Measurement $=14.413721-0.0726844$ SME Avg WL Summary of Fit

RSquare

0.108683

RSquare Adj

0.087955

Root Mean Square Error $\quad 0.412018$

Mean of Response $\quad 11.58642$

Observations (or Sum Wgts)

45

Analysis of Variance

Source DF Sum of Squares Mean Square F Ratio

$\begin{array}{lllll}\text { Model } & 1 & 0.8900826 & 0.890083 & 5.2432\end{array}$

$\begin{array}{lllll}\text { Error } & 43 & 7.2996432 & 0.169759 \text { Prob }>\text { F }\end{array}$

$\begin{array}{llrr}\text { C. Total } 44 & 8.1897257 & 0.0270\end{array}$ 
WSRC-STI-2006-00068

Revision 0

Exhibit A12. Relationships between Analytes and WLs by Preparation Method, ICP, and Analyte (continued)

Prep=Fusion, Sample Type=SME, ICP=M-13, Analyte=Fe/Mn Bivariate Fit of Avg Measurement By Blending WL

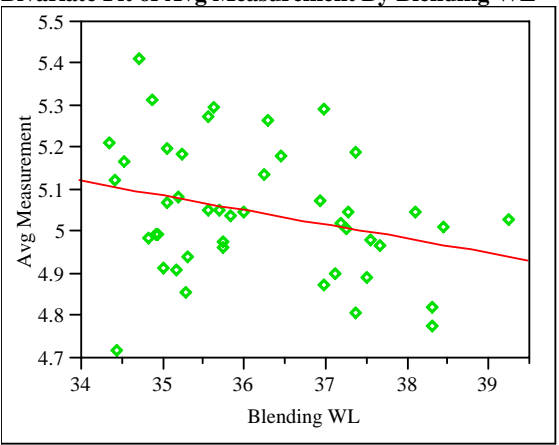

Linear Fit

Avg Measurement $=6.2802096-0.034052$ Blending WL Summary of Fit

RSquare $\quad 0.08105$

RSquare Adj $\quad 0.059679$

Root Mean Square Error $\quad 0.149793$

Mean of Response

Observations (or Sum Wgts) 45

Analysis of Variance

Source DF Sum of Squares Mean Square F Ratio

$\begin{array}{lllll}\text { Model } & 1 & 0.0850965 & 0.085096 & 3.7925\end{array}$

$\begin{array}{llll}\text { Error } 43 & 0.9648323 & 0.022438 \text { Prob }>\text { F }\end{array}$

$\begin{array}{llll}\text { C. Total } 44 & 1.0499287 & 0.0580\end{array}$

Bivariate Fit of Avg Measurement By SME Avg WL

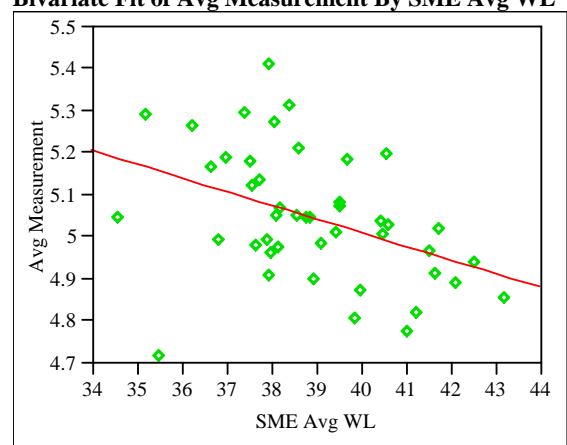

Linear Fit

Avg Measurement $=6.3135279-0.0325293$ SME Avg WL

Summary of Fit

\begin{tabular}{lr} 
RSquare & 0.1698 \\
RSquare Adj & 0.150493 \\
Root Mean Square Error & 0.142376 \\
Mean of Response & 5.048195 \\
\hline
\end{tabular}

Mean of Response 5.048195

Observations (or Sum Wgts) 45

Analysis of Variance

Source DF Sum of Squares Mean Square F Ratio

$\begin{array}{lllll}\text { Model } & 1 & 0.1782777 & 0.178278 & 8.7947\end{array}$

$\begin{array}{llll}\text { Error } 43 & 43716510 & 0.020271 \text { Prob }>\text { F }\end{array}$

$\begin{array}{llrr}\text { C. Total } 44 & 1.0499287 & 0.0049\end{array}$
Prep=Fusion, Sample Type $=$ SME, ICP $=$ M-13, Analyte $=$ Fe $/ \mathrm{Ni}$ Bivariate Fit of Avg Measurement By Blending WL

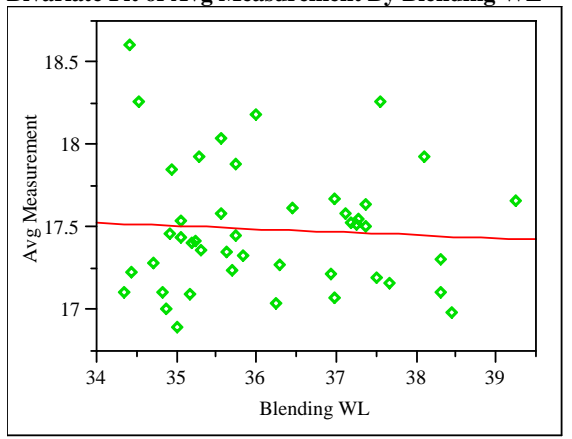

Linear Fit

Avg Measurement $=18.147833-0.0181432$ Blending WL Summary of Fit

$\begin{array}{lr}\text { RSquare } & 0.003753 \\ \text { RSquare Adj } & -0.01942 \\ \text { Root Mean Square Error } & 0.386177 \\ \text { Mean of Response } & 17.4914 \\ \text { Observations (or Sum Wgts) } & 45\end{array}$

Analysis of Variance

Source DF Sum of Squares Mean Square F Ratio

$\begin{array}{lllll}\text { Model } & 1 & 0.0241577 & 0.024158 & 0.1620\end{array}$

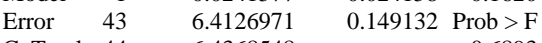

$\begin{array}{llrr}\text { C. Total } & 44 & 6.4368548 & 0.6893\end{array}$

Bivariate Fit of Avg Measurement By SME Avg WL

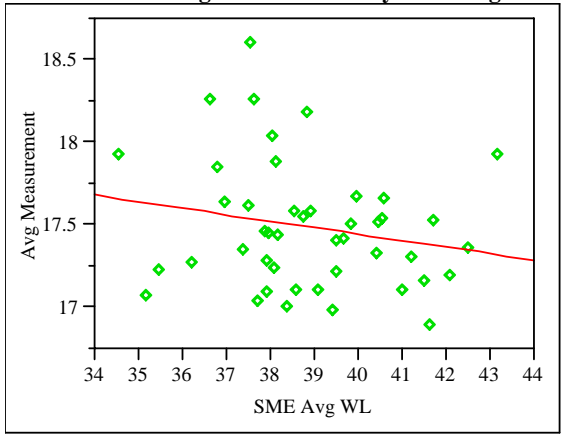

Linear Fit

Avg Measurement $=19.01807-0.0392477$ SME Avg WL Summary of Fit

RSquare 0.040318

RSquare Adj

0.018

Root Mean Square Error $\quad 0.379024$

Mean of Response $\quad 17.4914$

Observations (or Sum Wgts)

45

Analysis of Variance

Source DF Sum of Squares Mean Square F Ratio

$\begin{array}{lllll}\text { Model } & 1 & 0.2595225 & 0.259522 & 1.8065\end{array}$

$\begin{array}{lllll}\text { Error } & 43 & 6.1773323 & 0.143659 \text { Prob }>\text { F }\end{array}$

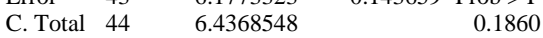


WSRC-STI-2006-00068

Revision 0

Exhibit A12. Relationships between Analytes and WLs by Preparation Method, ICP, and Analyte (continued)

Prep $=$ Fusion, Sample Type $=$ SME, ICP $=$ M-13, Analyte $=F e / U$ Bivariate Fit of Avg Measurement By Blending WL

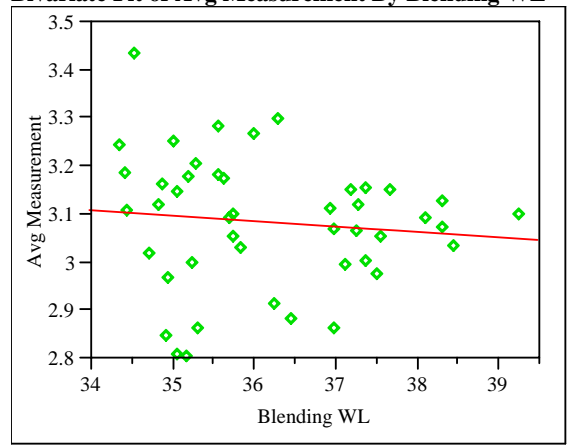

Linear Fit

Avg Measurement $=3.5000042-0.011474$ Blending WL Summary of Fit

RSquare $\quad 0.011873$

RSquare Adj $\quad-0.0111$

Root Mean Square Error $\quad 0.136746$

Mean of Response 3.084871

Observations (or Sum Wgts) $\quad 45$

Analysis of Variance

Source DF Sum of Squares Mean Square F Ratio

$\begin{array}{lllll}\text { Model } & 1 & 0.00966173 & 0.009662 & 0.5167\end{array}$

$\begin{array}{llll}\text { Error } & 43 & 0.80407308 & 0.018699 \text { Prob }>\text { F }\end{array}$

C. Total $44 \quad 0.81373481 \quad 0.4761$

Bivariate Fit of Avg Measurement By SME Avg WL

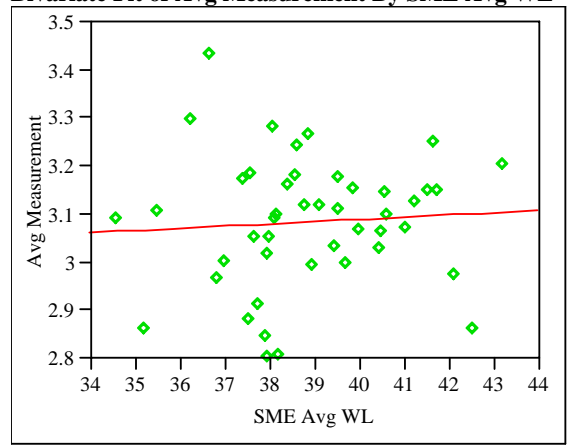

Linear Fit

Avg Measurement $=2.9006635+0.0047356$ SME Avg WL

Summary of Fit

\begin{tabular}{lr} 
RSquare & 0.004643 \\
RSquare Adj & -0.0185 \\
Root Mean Square Error & 0.137245 \\
Mean of Response & 3.084871 \\
\hline
\end{tabular}

Mean of Response 3.084871

Observations (or Sum Wgts) $\quad 45$

Analysis of Variance

Source DF Sum of Squares Mean Square F Ratio

$\begin{array}{lllll}\text { Model } & 1 & 0.00377834 & 0.003778 & 0.2006\end{array}$

$\begin{array}{llll}\text { Error } & 43 & 0.80995647 & 0.018836 \text { Prob }>\text { F }\end{array}$

$\begin{array}{llr}\text { C. Total } 44 & 0.81373481 & 0.6565\end{array}$
Prep $=$ Fusion, Sample Type $=$ SME, ICP $=M-13$, Analyte $=K$ Bivariate Fit of Avg Measurement By Blending WL

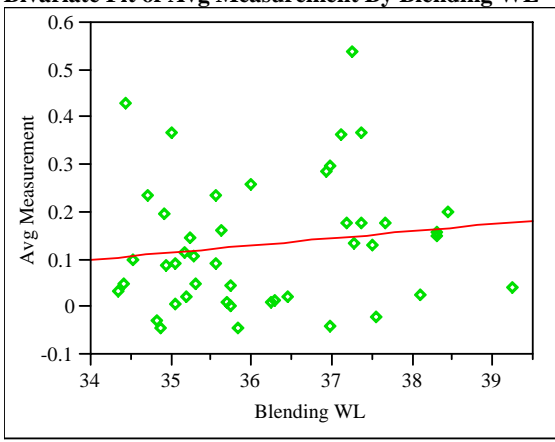

Linear Fit

Avg Measurement $=-0.412548+0.0150687$ Blending $\mathrm{WL}$ Summary of Fit

$\begin{array}{lr}\text { RSquare } & 0.020247 \\ \text { RSquare Adj } & -0.00254 \\ \text { Root Mean Square Error } & 0.13694 \\ \text { Mean of Response } & 0.132644 \\ \text { Observations (or Sum Wgts) } & 45\end{array}$

Analysis of Variance

Source DF Sum of Squares Mean Square F Ratio

$\begin{array}{lllll}\text { Model } & 1 & 0.01666398 & 0.016664 & 0.8886\end{array}$

$\begin{array}{lllll}\text { Error } & 43 & 0.80635478 & 0.018752 \text { Prob }>\text { F }\end{array}$

$\begin{array}{llll}\text { C. Total } 44 & 0.82301876 & 0.3511\end{array}$

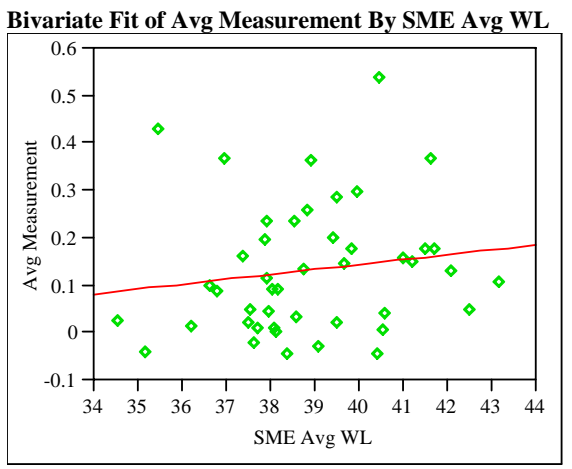

Linear Fit

Avg Measurement $=-0.271244+0.0103832$ SME Avg WL Summary of Fit

RSquare 0.02207

RSquare Adj

$-0.00067$

Root Mean Squar

Mean of Response

0.136812

Observations (or Sum Wgts)

0.132644
45

Analysis of Variance

Source DF Sum of Squares Mean Square F Ratio

$\begin{array}{lllll}\text { Model } & 1 & 0.01816394 & 0.018164 & 0.9704\end{array}$

$\begin{array}{lllll}\text { Error } & 43 & 0.80485481 & 0.018718 \text { Prob }>\text { F }\end{array}$

$\begin{array}{llll}\text { C. Total } & 44 & 0.82301876 & 0.3301\end{array}$ 
WSRC-STI-2006-00068

Revision 0

Exhibit A12. Relationships between Analytes and WLs by Preparation Method, ICP, and Analyte (continued)

Prep=Fusion, Sample Type $=$ SME, ICP=M-13, Analyte $=\mathrm{Li}$ Bivariate Fit of Avg Measurement By Blending WL

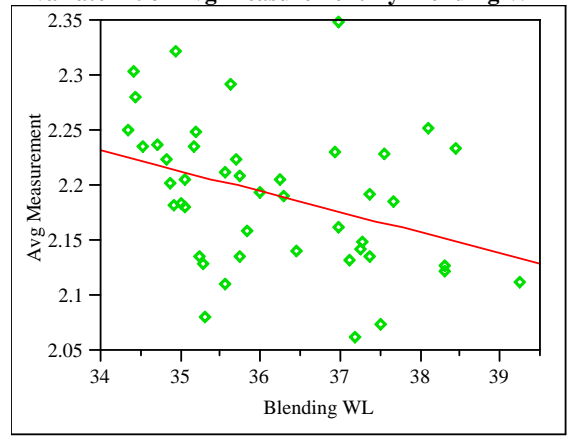

Linear Fit

Avg Measurement $=2.8630616-0.0185598$ Blending WL Summary of Fit

$\begin{array}{lr}\text { RSquare } & 0.134904 \\ \text { RSquare Adj } & 0.114785 \\ \text { Root Mean Square Error } & 0.061401 \\ \text { Mean of Response } & 2.191558 \\ \text { Observations (or Sum Wgts) } & 45\end{array}$

Analysis of Variance

Source DF Sum of Squares Mean Square F Ratio

$\begin{array}{lllll}\text { Model } & 1 & 0.02527993 & 0.025280 & 6.7055\end{array}$

Error $43 \quad 0.16211242 \quad 0.003770$ Prob $>$ F

$\begin{array}{lll}\text { C. Total } 44 & 0.18739236 & 0.0131\end{array}$

Bivariate Fit of Avg Measurement By SME Avg WL

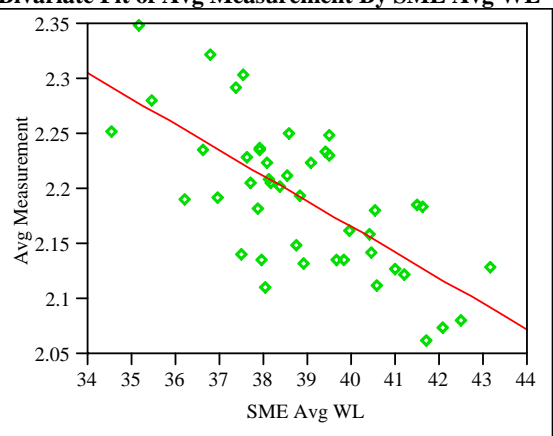

Linear Fit

Avg Measurement $=3.0955876-0.0232409$ SME Avg WL

Summary of Fit

$\begin{array}{lr}\text { RSquare } & 0.485624 \\ \text { RSquare Adj } & 0.473662 \\ \text { Root Mean Square Error } & 0.047346 \\ \text { Mean of Response } & 2.191558 \\ \text { Observations (or Sum Wgts) } & 45\end{array}$

Analysis of Variance

Source DF Sum of Squares Mean Square F Ratio

$\begin{array}{lllll}\text { Model } & 1 & 0.09100227 & 0.091002 & 40.5965\end{array}$

$\begin{array}{llll}\text { Error } & 43 & 0.09639009 & 0.002242 \text { Prob }>\text { F }\end{array}$

$\begin{array}{llr}\text { C. Total } 44 & 0.18739236 & <.0001\end{array}$
Prep $=$ Fusion, Sample Type $=$ SME, ICP $=M-13$, Analyte $=M g$ Bivariate Fit of Avg Measurement By Blending WL

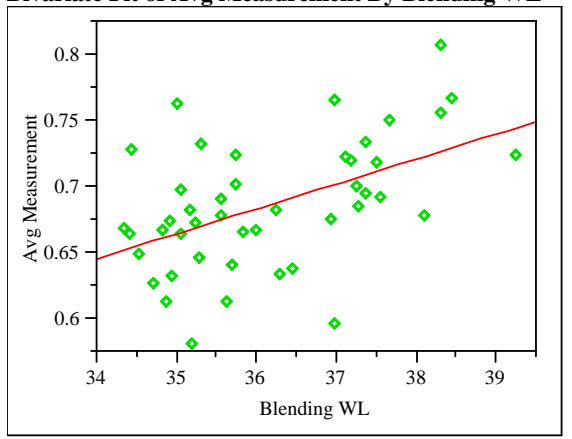

Linear Fit

Avg Measurement $=0.0018135+0.0189274$ Blending WL Summary of Fit

$\begin{array}{lr}\text { RSquare } & 0.249392 \\ \text { RSquare Adj } & 0.231936 \\ \text { Root Mean Square Error } & 0.042898 \\ \text { Mean of Response } & 0.686616 \\ \text { Observations (or Sum Wgts) } & 45\end{array}$

Analysis of Variance

Source DF Sum of Squares Mean Square F Ratio

$\begin{array}{lllll}\text { Model } & 1 & 0.02629121 & 0.026291 & 14.2869\end{array}$

$\begin{array}{lllll}\text { Error } 43 & 0.07913003 & 0.001840 \text { Prob }>\text { F }\end{array}$

$\begin{array}{llr}\text { C. Total } 44 & 0.10542124 & 0.0005\end{array}$

Bivariate Fit of Avg Measurement By SME Avg WL

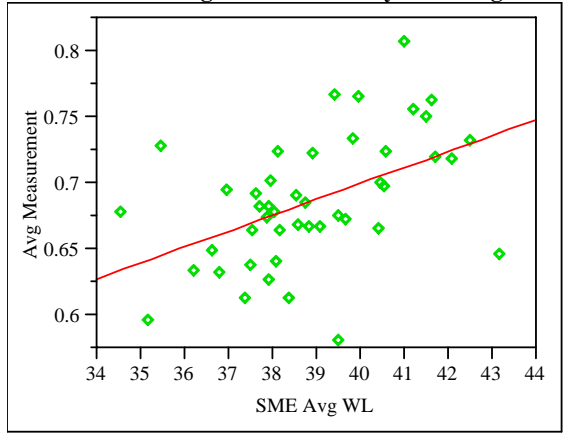

Linear Fit

Avg Measurement $=0.216652+0.0120819$ SME Avg WL Summary of Fit

RSquare 0.233286

RSquare Adj

0.215456

Root Mean Square Error $\quad 0.043356$

Mean of Response $\quad 0.686616$

Observations (or Sum Wgts)

45

Analysis of Variance

Source DF Sum of Squares Mean Square F Ratio

$\begin{array}{lllll}\text { Model } & 1 & 0.02459331 & 0.024593 & 13.0835\end{array}$

$\begin{array}{lllll}\text { Error } 43 & 0.08082793 & 0.001880 \text { Prob }>\text { F }\end{array}$

$\begin{array}{lll}\text { C. Total } 44 & 0.10542124 & 0.0008\end{array}$ 
WSRC-STI-2006-00068

Revision 0

Exhibit A12. Relationships between Analytes and WLs by Preparation Method, ICP, and Analyte (continued)

Prep $=$ Fusion, Sample Type $=$ SME, ICP $=$ M-13, Analyte $=M n$ Bivariate Fit of Avg Measurement By Blending WL

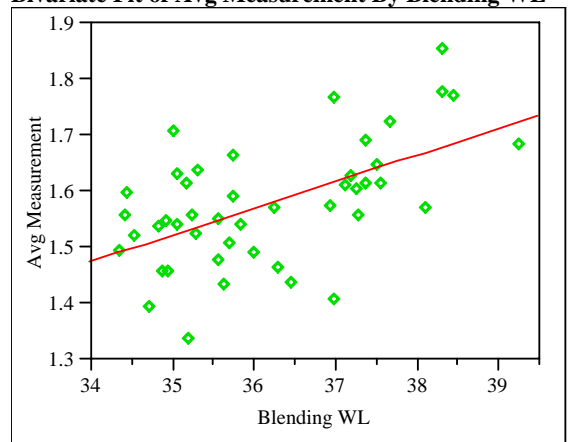

Linear Fit

Avg Measurement $=-0.142173+0.0475279$ Blending WL Summary of Fit

RSquare $\quad 0.316029$

RSquare Adj $\quad 0.300122$

Root Mean Square Error $\quad 0.091345$

Mean of Response 1.577408

Observations (or Sum Wgts) $\quad 45$

Analysis of Variance

Source DF Sum of Squares Mean Square F Ratio

$\begin{array}{lllll}\text { Model } & 1 & 0.16577723 & 0.165777 & 19.8681\end{array}$

$\begin{array}{llll}\text { Error } 43 & 0.35878656 & 0.008344 \text { Prob }>\text { F }\end{array}$

$\begin{array}{llll}\text { C. Total } 44 & 0.52456379 & <.0001\end{array}$

Bivariate Fit of Avg Measurement By SME Avg WL

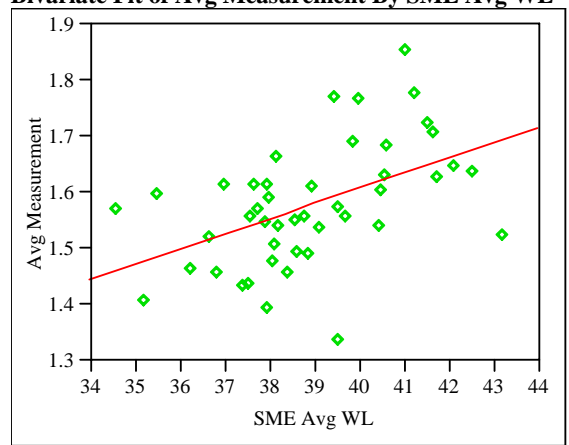

Linear Fit

Avg Measurement $=0.5170451+0.0272599$ SME Avg WL

Summary of Fit

\begin{tabular}{lr} 
RSquare & 0.23867 \\
RSquare Adj & 0.220965 \\
Root Mean Square Error & 0.096372 \\
Mean of Response & 1.577408 \\
\hline
\end{tabular}

Observations (or Sum Wgts) $\quad 45$

Analysis of Variance

Source DF Sum of Squares Mean Square F Ratio

$\begin{array}{lllll}\text { Model } & 1 & 0.12519773 & 0.125198 & 13.4801\end{array}$

$\begin{array}{llll}\text { Error } & 43 & 0.39936607 & 0.009288 \text { Prob }>\text { F }\end{array}$

$\begin{array}{llr}\text { C. Total } 44 & 0.52456379 & 0.0007\end{array}$
Prep=Fusion, Sample Type=SME, ICP=M-13, Analyte $=M n / M g$ Bivariate Fit of Avg Measurement By Blending WL

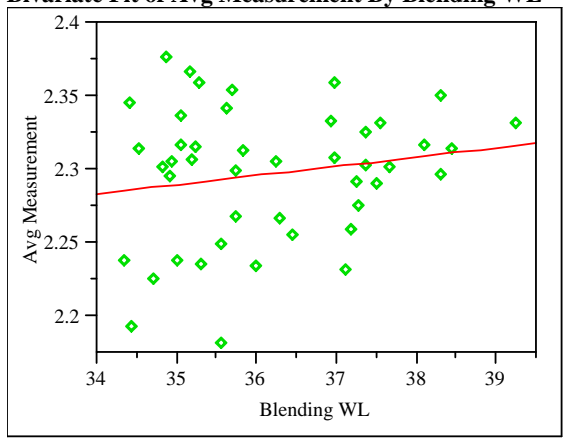

Linear Fit

Avg Measurement $=2.0704698+0.0062635$ Blending WL Summary of Fit

$\begin{array}{lr}\text { RSquare } & 0.030657 \\ \text { RSquare Adj } & 0.008114 \\ \text { Root Mean Square Error } & 0.046012 \\ \text { Mean of Response } & 2.297085 \\ \text { Observations (or Sum Wgts) } & 45\end{array}$

Observations (or Sum Wgts) 45

\section{Analysis of Variance}

Source DF Sum of Squares Mean Square F Ratio

$\begin{array}{lllll}\text { Model } & 1 & 0.00287912 & 0.002879 & 1.3599\end{array}$

$\begin{array}{llll}\text { Error } 43 & 0.09103473 & 0.002117 \text { Prob }>\text { F }\end{array}$

$\begin{array}{llr}\text { C. Total } 44 & 0.09391385 & 0.2500\end{array}$

Bivariate Fit of Avg Measurement By SME Avg WL

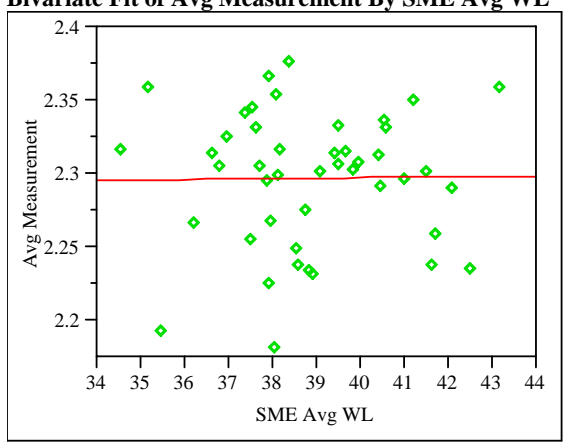

Linear Fit

Avg Measurement $=2.2850337+0.0003098$ SME Avg WL Summary of Fit

RSquare

0.000172

RSquare Adj

$-0.02308$

Root Mean Square Error $\quad 0.04673$

Mean of Response 2.297085

Observations (or Sum Wgts)

45

Analysis of Variance

Source DF Sum of Squares Mean Square F Ratio

$\begin{array}{lllll}\text { Model } & 1 & 0.00001617 & 0.000016 & 0.0074\end{array}$

$\begin{array}{llll}\text { Error } 43 \quad 0.09389767 & 0.002184 \text { Prob }>\text { F }\end{array}$

$\begin{array}{llr}\text { C. Total } 44 & 0.09391385 & 0.9318\end{array}$ 
WSRC-STI-2006-00068

Revision 0

Exhibit A12. Relationships between Analytes and WLs by Preparation Method, ICP, and Analyte (continued)

Prep $=$ Fusion, Sample Type $=$ SME, ICP $=$ M-13, Analyte $=$ Na Bivariate Fit of Avg Measurement By Blending WL

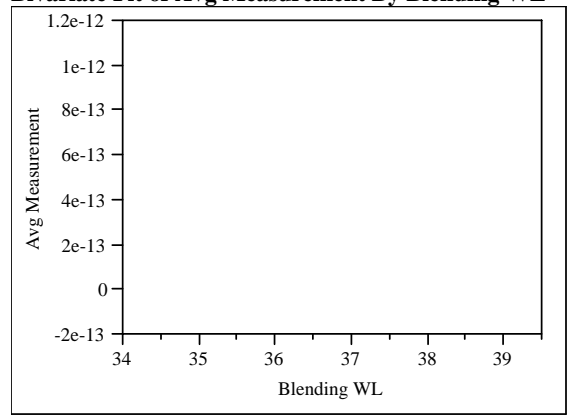

Bivariate Fit of Avg Measurement By SME Avg WL

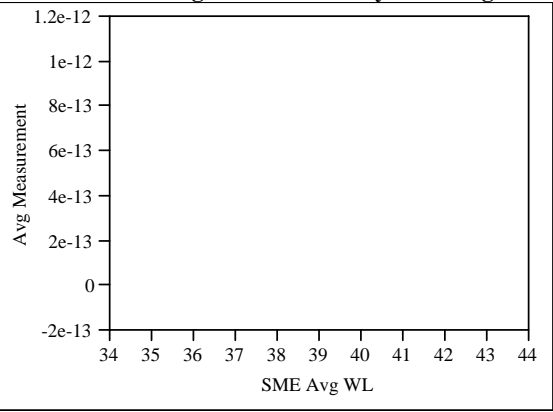

Prep=Fusion, Sample Type $=$ SME, ICP $=M-13$, Analyte $=$ Ni Bivariate Fit of Avg Measurement By Blending WL

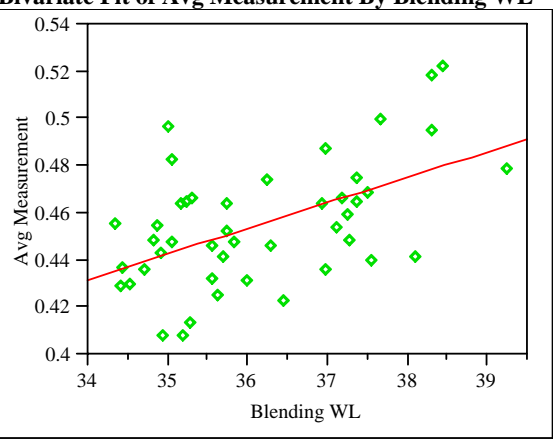

Linear Fit

Avg Measurement $=0.0632886+0.0108395$ Blending WL Summary of Fit

RSquare $\quad 0.281539$

RSquare Adj $\quad 0.264831$

Root Mean Square Error $\quad 0.022622$

Mean of Response $\quad 0.455468$

Observations (or Sum Wgts) $\quad 45$

Analysis of Variance

Source DF Sum of Squares Mean Square F Ratio

$\begin{array}{lllll}\text { Model } & 1 & 0.00862283 & 0.008623 & 16.8502\end{array}$

$\begin{array}{llll}\text { Error } & 43 & 0.02200465 & 0.000512 \text { Prob }>\text { F }\end{array}$

$\begin{array}{llll}\text { C. Total } 44 & 0.03062748 & 0.0002\end{array}$

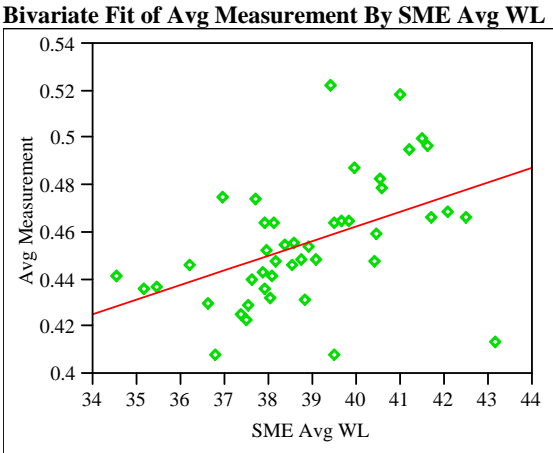

Linear Fit

Avg Measurement $=0.2126764+0.0062417$ SME Avg WL Summary of Fit

$\begin{array}{lr}\text { RSquare } & 0.214311 \\ \text { RSquare Adj } & 0.196039 \\ \text { Root Mean Square Error } & 0.023656 \\ \text { Mean of Response } & 0.455468 \\ \text { Observations (or Sum Wgts) } & 45\end{array}$

Analysis of Variance

Source DF Sum of Squares Mean Square F Ratio $\begin{array}{lllll}\text { Model } & 1 & 0.00656380 & 0.006564 & 11.7290\end{array}$

$\begin{array}{llll}\text { Error } & 43 & 0.02406368 & 0.000560 \text { Prob }>\text { F }\end{array}$

$\begin{array}{lll}\text { C. Total } 44 & 0.03062748 & 0.0014\end{array}$

Prep=Fusion, Sample Type=SME, ICP $=$ M-13, Analyte $=S i$ Bivariate Fit of Avg Measurement By Blending WL

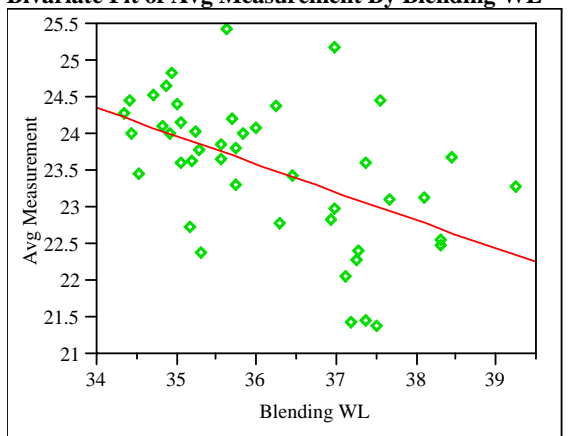

Linear Fit

Avg Measurement $=37.404384-0.3836321$ Blending WL Summary of Fit

$\begin{array}{lr}\text { RSquare } & 0.263977 \\ \text { RSquare Adj } & 0.24686 \\ \text { Root Mean Square Error } & 0.836868 \\ \text { Mean of Response } & 23.5244 \\ \text { Observations (or Sum Wgts) } & 45\end{array}$

Analysis of Variance

Source DF Sum of Squares Mean Square F Ratio $\begin{array}{lllll}\text { Model } & 1 & 10.800835 & 10.8008 & 15.4221\end{array}$ $\begin{array}{lllll}\text { Error } & 43 & 30.114945 & 0.7003 \text { Prob }>\text { F }\end{array}$ $\begin{array}{llrr}\text { C. Total } & 44 & 40.915780 & 0.0003\end{array}$ 
WSRC-STI-2006-00068

Revision 0

Exhibit A12. Relationships between Analytes and WLs by Preparation Method, ICP, and Analyte (continued)

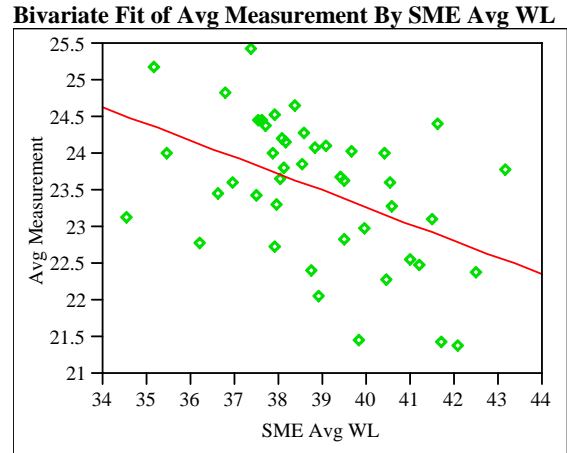

Linear Fit

Avg Measurement $=32.382738-0.2277309$ SME Avg WL

Summary of Fit

$\begin{array}{lr}\text { RSquare } & 0.21355 \\ \text { RSquare Adj } & 0.195261 \\ \text { Root Mean Square Error } & 0.865061 \\ \text { Mean of Response } & 23.5244 \\ \text { Observations (or Sum Wgts) } & 45\end{array}$

Observations (or Sum Wgts) $\quad 45$

Analysis of Variance

Source DF Sum of Squares Mean Square F Ratio

$\begin{array}{lllll}\text { Model } & 1 & 8.737585 & 8.73759 & 11.6761\end{array}$

$\begin{array}{llll}\text { Error } & 43 & 32.178195 & 0.74833 \text { Prob }>\text { F }\end{array}$

$\begin{array}{llr}\text { C. Total } 44 & 40.915780 & 0.0014\end{array}$

Prep=Fusion, Sample Type=SME, ICP=M-13, Analyte=Sum of Oxides Bivariate Fit of Avg Measurement By Blending WL

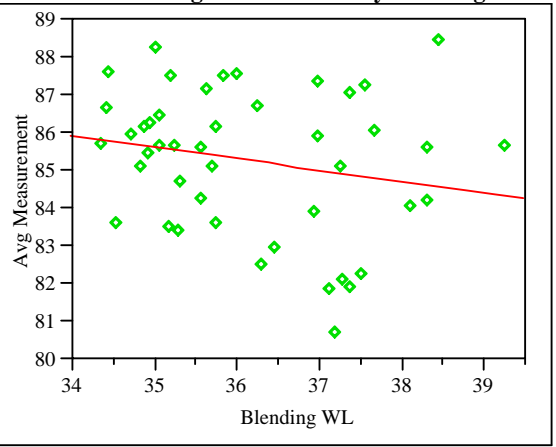

Linear Fit

Avg Measurement $=96.107982-0.2995983$ Blending WL Summary of Fit

RSquare $\quad 0.041504$

RSquare Adj $\quad 0.019213$

Root Mean Square Error $\quad 1.880919$

Mean of Response 85.26838

Observations (or Sum Wgts) $\quad 45$

Analysis of Variance

Source DF Sum of Squares Mean Square F Ratio

$\begin{array}{lrrrr}\text { Model } & 1 & 6.58728 & 6.58728 & 1.8619\end{array}$

$\begin{array}{llll}\text { Error } & 43 & 152.12787 & 3.53786 \text { Prob }>\text { F }\end{array}$

$\begin{array}{llll}\text { C. Total } 44 & 158.71515 & 0.1795\end{array}$

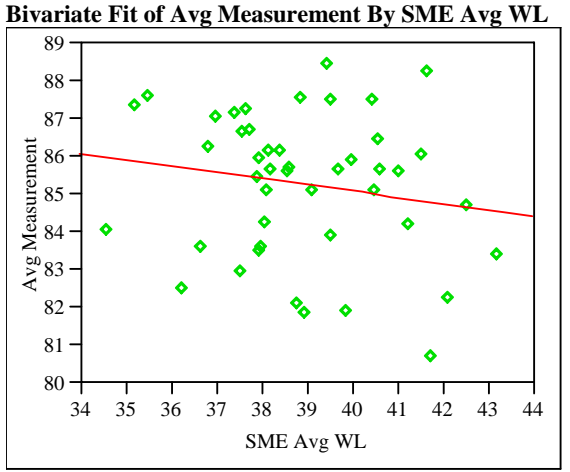

Linear Fit

Avg Measurement $=91.540499-0.1612441$ SME Avg WL Summary of Fit

RSquare

Root Mean Square Error $\quad 1.894513$

Mean of Response $\quad 85.26838$

Observations (or Sum Wgts) $\quad 45$

Analysis of Variance

Source DF Sum of Squares Mean Square F Ratio

$\begin{array}{lllll}\text { Model } & 1 & 4.38042 & 4.38042 & 1.2205\end{array}$

$\begin{array}{lllll}\text { Error } & 43 & 154.33474 & 3.58918 \text { Prob }>\text { F }\end{array}$

$\begin{array}{lll}\text { C. Total } 44 & 158.71515 & 0.2754\end{array}$

Prep=Fusion, Sample Type=SME, ICP=M-13, Analyte=Ti Bivariate Fit of Avg Measurement By Blending WL

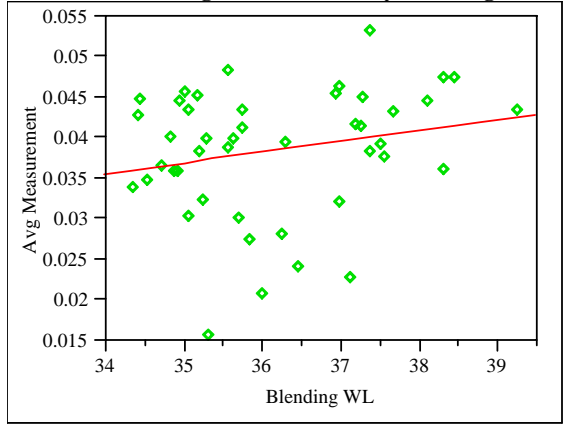

Linear Fit

Avg Measurement $=-0.008981+0.0013126$ Blending $\mathrm{WL}$ Summary of Fit

RSquare

0.045475

RSquare Adj

0.023277

Root Mean Square Error $\quad 0.007856$

Mean of Response 0.038508

Observations (or Sum Wgts) $\quad 45$

Analysis of Variance

Source DF Sum of Squares Mean Square F Ratio

$\begin{array}{lllll}\text { Model } & 1 & 0.00012644 & 0.000126 & 2.0486\end{array}$

$\begin{array}{llll}\text { Error } & 43 & 0.00265393 & 0.000062 \text { Prob }>\text { F }\end{array}$

$\begin{array}{lll}\text { C. Total } 44 & 0.00278037 & 0.1596\end{array}$ 
WSRC-STI-2006-00068

Revision 0

Exhibit A12. Relationships between Analytes and WLs by Preparation Method, ICP, and Analyte (continued)

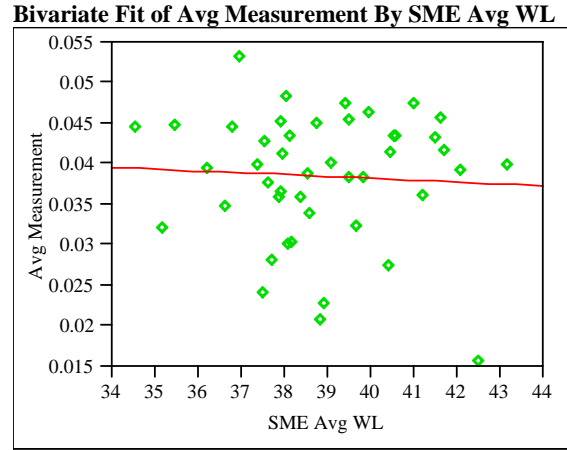

Linear Fit

Avg Measurement $=0.0476551-0.0002351$ SME Avg WL Summary of Fit

RSquare $\quad 0.003351$

RSquare Adj $\quad-0.01983$

Root Mean Square Error $\quad 0.008028$

Mean of Response 0.038508

Observations (or Sum Wgts) $\quad 45$

Analysis of Variance

Source DF Sum of Squares Mean Square F Ratio $\begin{array}{lllll}\text { Model } & 1 & 0.00000932 & 0.000009 & 0.1446\end{array}$

$\begin{array}{llll}\text { Error } 43 & 0.00277105 & 0.000064 \text { Prob }>\text { F }\end{array}$

$\begin{array}{llll}\text { C. Total } 44 & 0.00278037 & 0.7057\end{array}$

Prep $=$ Fusion, Sample Type $=$ SME, ICP $=M-13$, Analyte $=U$ Bivariate Fit of Avg Measurement By Blending WL

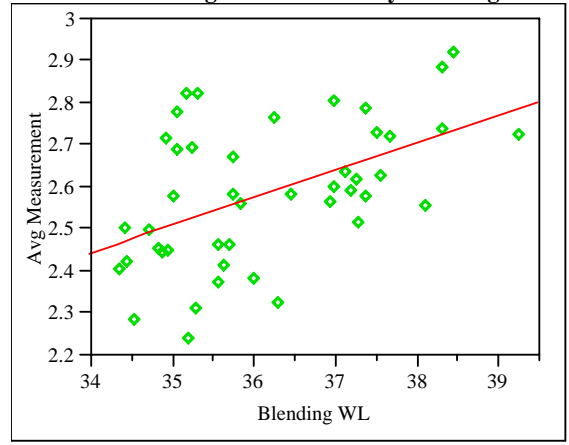

Linear Fit

Avg Measurement $=0.2259216+0.0652411$ Blending WL Summary of Fit

$\begin{array}{lr}\text { RSquare } & 0.250812 \\ \text { RSquare Adj } & 0.233389 \\ \text { Root Mean Square Error } & 0.147306 \\ \text { Mean of Response } & 2.586374 \\ \text { Observations (or Sum Wgts) } & 45\end{array}$

Analysis of Variance

Source DF Sum of Squares Mean Square F Ratio

$\begin{array}{lllll}\text { Model } & 1 & 0.3123706 & 0.312371 & 14.3955\end{array}$

$\begin{array}{lllll}\text { Error } & 43 & 0.9330653 & 0.021699 \text { Prob }>\text { F }\end{array}$

$\begin{array}{lll}\text { C. Total } 44 & 1.2454359 & 0.0005\end{array}$

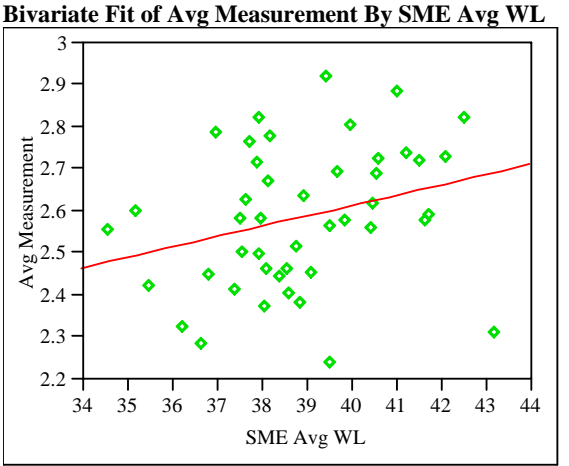

Linear Fit

Avg Measurement $=1.6346347+0.0244674$ SME Avg WL Summary of Fit

$\begin{array}{lr}\text { RSquare } & 0.080985 \\ \text { RSquare Adj } & 0.059612 \\ \text { Root Mean Square Error } & 0.16315 \\ \text { Mean of Response } & 2.586374 \\ \text { Observations (or Sum Wgts) } & 45\end{array}$

Analysis of Variance

Source DF Sum of Squares Mean Square F Ratio

$\begin{array}{lllll}\text { Model } & 1 & 0.1008610 & 0.100861 & 3.7892\end{array}$

$\begin{array}{lllll}\text { Error } & 43 & 1.1445749 & 0.026618 \text { Prob }>\text { F }\end{array}$

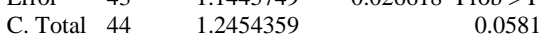

Prep $=$ Fusion, Sample Type $=$ SME, ICP $=M-13$, Analyte $=$ U/Ca Bivariate Fit of Avg Measurement By Blending WL

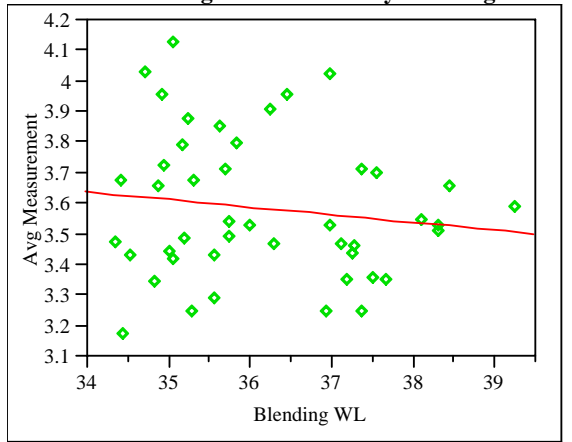

Linear Fit

Avg Measurement $=4.4798248-0.0247299$ Blending WL Summary of Fit

$\begin{array}{lr}\text { RSquare } & 0.018487 \\ \text { RSquare Adj } & -0.00434 \\ \text { Root Mean Square Error } & 0.235404 \\ \text { Mean of Response } & 3.585086 \\ \text { Observations (or Sum Wgts) } & 45\end{array}$

Analysis of Variance

Source DF Sum of Squares Mean Square F Ratio $\begin{array}{lllll}\text { Model } & 1 & 0.0448820 & 0.044882 & 0.8099\end{array}$

$\begin{array}{llll}\text { Error } 43 & 43828399 & 0.055415 \text { Prob }>\text { F }\end{array}$

$\begin{array}{llrr}\text { C. Total } & 44 & 2.4277219 & 0.3732\end{array}$ 
WSRC-STI-2006-00068

Revision 0

Exhibit A12. Relationships between Analytes and WLs by Preparation Method, ICP, and Analyte (continued)

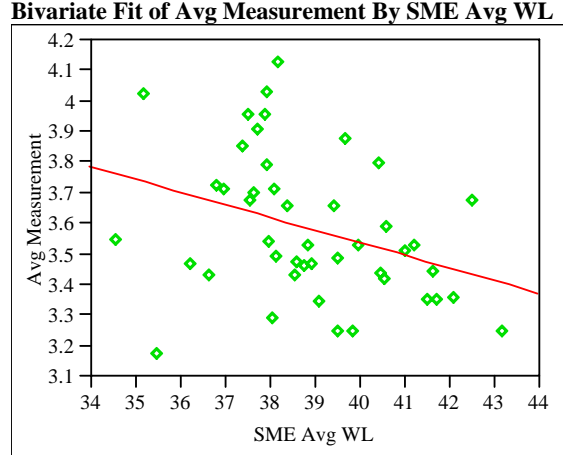

Linear Fit

Avg Measurement $=5.1909832-0.0412846$ SME Avg WL Summary of Fit

$\begin{array}{lr}\text { RSquare } & 0.118283 \\ \text { RSquare Adj } & 0.097778 \\ \text { Root Mean Square Error } & 0.223116 \\ \text { Mean of Response } & 3.585086 \\ \text { Observations (or Sum Wgts) } & 45\end{array}$

Analysis of Variance

Source DF Sum of Squares Mean Square F Ratio

$\begin{array}{lllll}\text { Model } & 1 & 0.2871593 & 0.287159 & 5.7685\end{array}$

$\begin{array}{llll}\text { Error } & 43 & 2.1405627 & 0.049781 \text { Prob }>\text { F }\end{array}$

$\begin{array}{llr}\text { C. Total } 44 & 2.4277219 & 0.0207\end{array}$

Prep=Fusion, Sample Type $=$ SME, ICP $=$ M-13, Analyte $=\mathrm{Zr}$ Bivariate Fit of Avg Measurement By Blending WL

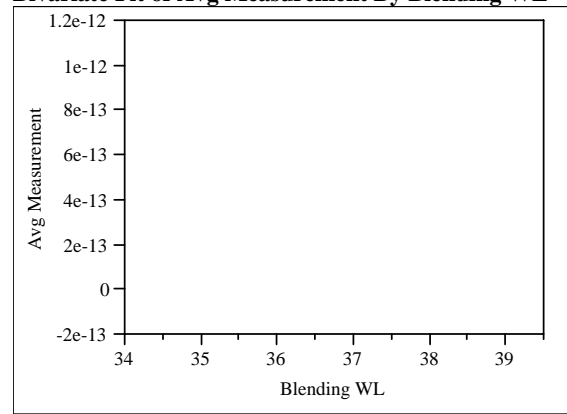

Bivariate Fit of Avg Measurement By SME Avg WL

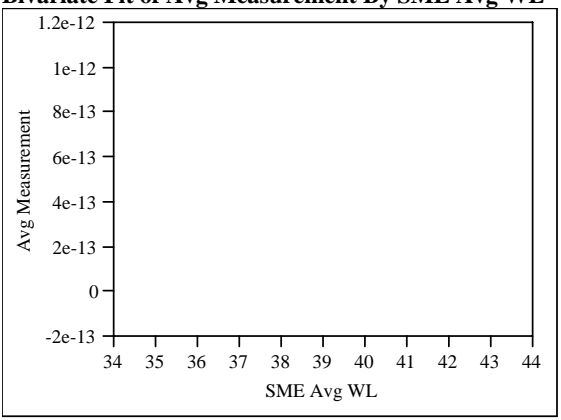

Prep=Fusion, Sample Type $=$ SME, ICP $=$ M-14, Analyte $=$ Al Bivariate Fit of Avg Measurement By Blending WL

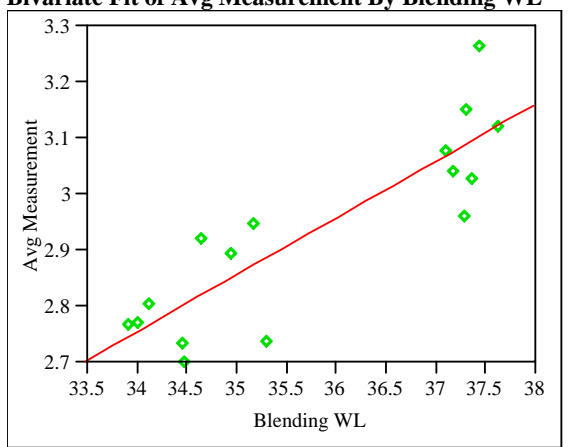

Linear Fit

Avg Measurement $=-0.689576+0.1012661$ Blending $\mathrm{WL}$ Summary of Fit

$\begin{array}{lr}\text { RSquare } & 0.752813 \\ \text { RSquare Adj } & 0.735156 \\ \text { Root Mean Square Error } & 0.088198 \\ \text { Mean of Response } & 2.933726 \\ \text { Observations (or Sum Wgts) } & 16\end{array}$

Analysis of Variance

Source DF Sum of Squares Mean Square F Ratio $\begin{array}{lllll}\text { Model } & 1 & 0.33167185 & 0.331672 & 42.6372\end{array}$ $\begin{array}{lllll}\text { Error } & 14 & 0.10890499 & 0.007779 \text { Prob }>\text { F }\end{array}$ C. Total $15 \quad 0.44057684<.0001$

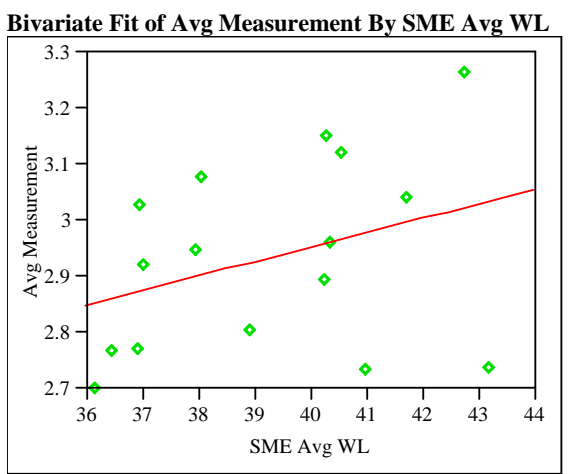

Linear Fit

Avg Measurement $=1.9281314+0.0256017$ SME Avg WL Summary of Fit

\begin{tabular}{|c|c|c|c|c|}
\hline \multicolumn{3}{|c|}{ RSquare } & \multicolumn{2}{|l|}{0.11658} \\
\hline \multicolumn{3}{|c|}{ RSquare Adj } & 0.053478 & \\
\hline \multicolumn{3}{|c|}{ Root Mean Square Error } & 0.166736 & \\
\hline \multicolumn{3}{|c|}{ Mean of Response } & 2.933726 & \\
\hline \multicolumn{3}{|c|}{ Observations (or Sum Wgts) } & 16 & \\
\hline \multicolumn{5}{|c|}{ Analysis of Variance } \\
\hline Source & DF & Sum of Squares & Mean Square & F Ratio \\
\hline Model & 1 & 0.05136231 & 0.051362 & 1.8475 \\
\hline Error & 14 & 0.38921453 & 0.027801 & Prob $>$ F \\
\hline C. Total & 15 & 0.44057684 & & 0.1956 \\
\hline
\end{tabular}


WSRC-STI-2006-00068

Revision 0

Exhibit A12. Relationships between Analytes and WLs by Preparation Method, ICP, and Analyte (continued)

Prep $=$ Fusion, Sample Type $=$ SME, ICP $=$ M-14, Analyte $=$ Al $/$ Ca Bivariate Fit of Avg Measurement By Blending WL

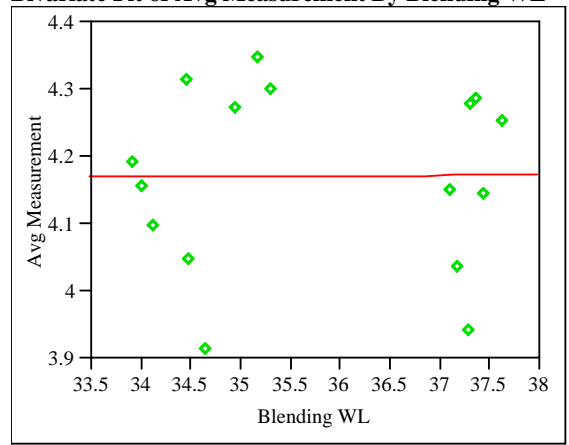

Linear Fit

Avg Measurement $=4.160622+0.0003129$ Blending $\mathrm{WL}$ Summary of Fit

RSquare $\quad 0.000012$

RSquare Adj $\quad-0.07142$

Root Mean Square Error $\quad 0.13854$

Mean of Response $\quad 4.171817$

Observations (or Sum Wgts) 16

Analysis of Variance

Source DF Sum of Squares Mean Square F Ratio

$\begin{array}{lllll}\text { Model } & 1 & 0.00000317 & 0.000003 & 0.0002\end{array}$

$\begin{array}{llll}\text { Error } & 14 & 0.26870850 & 0.019193 \text { Prob }>\text { F }\end{array}$

C. Total $15 \quad 0.26871167 \quad 0.9899$

Bivariate Fit of Avg Measurement By SME Avg WL

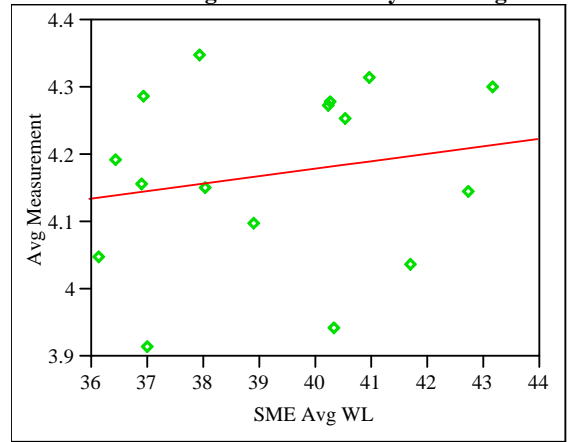

Linear Fit

Avg Measurement $=3.7318262+0.0112019$ SME Avg WL Summary of Fit

$\begin{array}{ll}\text { RSquare } & 0.036593 \\ \text { RSquare Adj } & -0.03222 \\ \text { Root Mean Square Error } & 0.135983 \\ \text { Mean of Response } & 4.171817\end{array}$

Mean of Response 4.171817

Observations (or Sum Wgts) $\quad 16$

Analysis of Variance

Source DF Sum of Squares Mean Square F Ratio

$\begin{array}{lllll}\text { Model } & 1 & 0.00983301 & 0.009833 & 0.5318\end{array}$

$\begin{array}{llll}\text { Error } & 14 & 0.25887866 & 0.018491 \text { Prob }>\text { F }\end{array}$

$\begin{array}{lllr}\text { C. Total } 15 & 0.26871167 & 0.4779\end{array}$
Prep $=$ Fusion, Sample Type $=$ SME, ICP $=$ M-14, Analyte $=$ Al $/ \mathbf{M g}$ Bivariate Fit of Avg Measurement By Blending WL

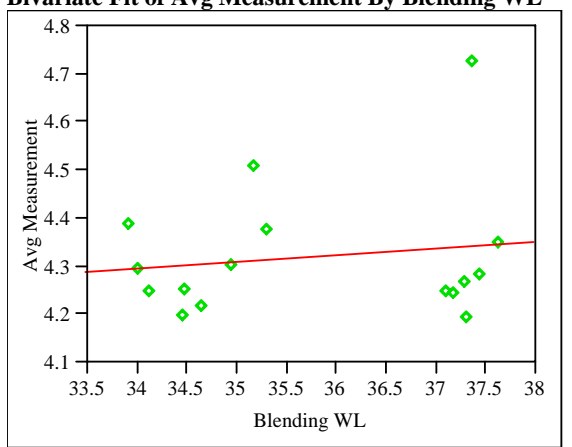

Linear Fit

Avg Measurement $=3.8347221+0.0135529$ Blending $\mathrm{WL}$ Summary of Fit

RSquare

0.021429

RSquare Adj

$-0.04847$

Root Mean Square Error $\quad 0.139206$

Mean of Response

4.319645

Observations (or Sum Wgts) 16

Analysis of Variance

Source DF Sum of Squares Mean Square F Ratio $\begin{array}{lllll}\text { Model } & 1 & 0.00594079 & 0.005941 & 0.3066\end{array}$ $\begin{array}{lllll}\text { Error } & 14 & 0.27129675 & 0.019378 \text { Prob }>\text { F }\end{array}$

$\begin{array}{llll}\text { C. Total } 15 & 0.27723755 & 0.5885\end{array}$

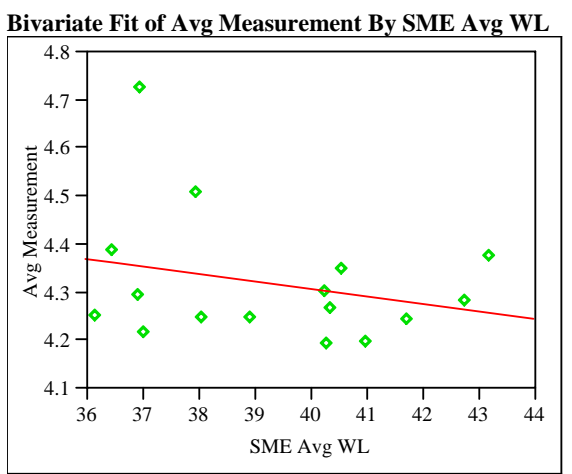

Linear Fit

Avg Measurement $=4.933046-0.0156168$ SME Avg WL Summary of Fit

$\begin{array}{lr}\text { RSquare } & 0.068934 \\ \text { RSquare Adj } & 0.00243 \\ \text { Root Mean Square Error } & 0.135785 \\ \text { Mean of Response } & 4.319645 \\ \text { Observations (or Sum Wgts) } & 16\end{array}$

Analysis of Variance

Source DF Sum of Squares Mean Square F Ratio

$\begin{array}{lllll}\text { Model } & 1 & 0.01911123 & 0.019111 & 1.0365\end{array}$

$\begin{array}{lllll}\text { Error } & 14 & 0.25812632 & 0.018438 \text { Prob }>\text { F }\end{array}$

$\begin{array}{llrr}\text { C. Total } & 15 & 0.27723755 & 0.3259\end{array}$ 
WSRC-STI-2006-00068

Revision 0

Exhibit A12. Relationships between Analytes and WLs by Preparation Method, ICP, and Analyte (continued)

Prep=Fusion, Sample Type=SME, ICP=M-14, Analyte=Al/Mn Bivariate Fit of Avg Measurement By Blending WL

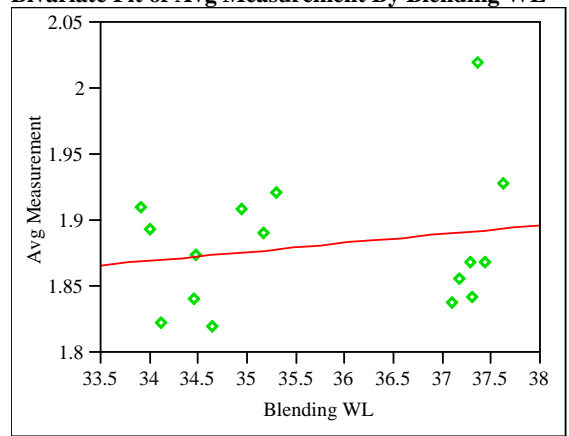

Linear Fit

Avg Measurement $=1.6422375+0.0066926$ Blending WL Summary of Fit

$\begin{array}{lr}\text { RSquare } & 0.037872 \\ \text { RSquare Adj } & -0.03085 \\ \text { Root Mean Square Error } & 0.051272 \\ \text { Mean of Response } & 1.881698 \\ \text { Observations (or Sum Wgts) } & 16\end{array}$

Observations (or Sum Wgts) 16

Analysis of Variance

Source DF Sum of Squares Mean Square F Ratio

$\begin{array}{lllll}\text { Model } & 1 & 0.00144866 & 0.001449 & 0.5511\end{array}$

$\begin{array}{llll}\text { Error } & 14 & 0.03680337 & 0.002629 \text { Prob }>\text { F }\end{array}$

C. Total $15 \quad 0.03825203 \quad 0.4702$

Bivariate Fit of Avg Measurement By SME Avg WL

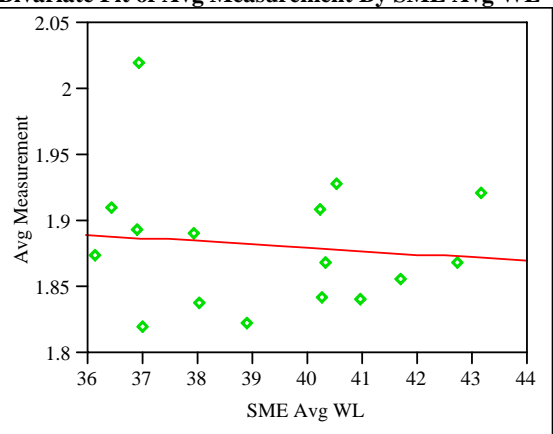

Linear Fit

Avg Measurement $=1.9800429-0.0025038$ SME Avg WL

Summary of Fit

RSquare $\quad 0.012842$

RSquare Adj

Root Mean Square Error $\quad 0.051935$

Mean of Response $\quad 1.881698$

Observations (or Sum Wgts) 16

Analysis of Variance

Source DF Sum of Squares Mean Square F Ratio

$\begin{array}{lllll}\text { Model } & 1 & 0.00049125 & 0.000491 & 0.1821\end{array}$

$\begin{array}{lllll}\text { Error } & 14 & 0.03776078 & 0.002697 \text { Prob }>\text { F }\end{array}$

C. Total $15 \quad 0.03825203 \quad 0.6760$
Prep $=$ Fusion, Sample Type $=$ SME, ICP $=$ M-14, Analyte $=B$ Bivariate Fit of Avg Measurement By Blending WL

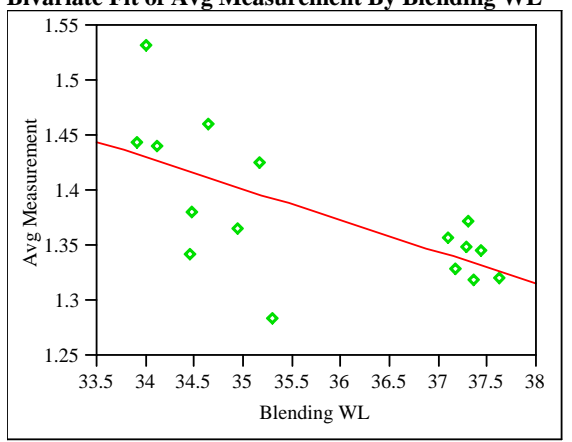

Linear Fit

Avg Measurement $=2.4042945-0.0286402$ Blending WL Summary of Fit

$\begin{array}{lr}\text { RSquare } & 0.420417 \\ \text { RSquare Adj } & 0.379018 \\ \text { Root Mean Square Error } & 0.051112 \\ \text { Mean of Response } & 1.379548 \\ \text { Observations (or Sum Wgts) } & 16\end{array}$

16

\section{Analysis of Variance}

Source DF Sum of Squares Mean Square F Ratio

$\begin{array}{lllll}\text { Model } & 1 & 0.02652972 & 0.026530 & 10.1553\end{array}$

$\begin{array}{llll}\text { Error } & 14 & 0.03657363 & 0.002612 \text { Prob }>\text { F }\end{array}$

$\begin{array}{llrr}\text { C. Total } & 15 & 0.06310335 & 0.0066\end{array}$

Bivariate Fit of Avg Measurement By SME Avg WL

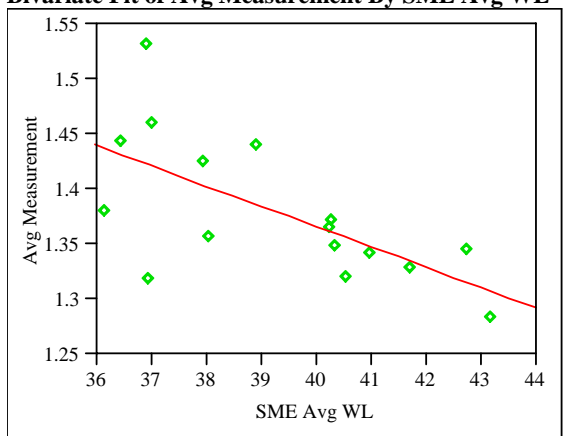

Linear Fit

Avg Measurement $=2.1071075-0.0185232$ SME Avg WL Summary of Fit

RSquare

0.426073

RSquare Adj

0.385078

Root Mean Square Error $\quad 0.050862$

Mean of Response $\quad 1.379548$

Observations (or Sum Wgts)

16

Analysis of Variance

Source DF Sum of Squares Mean Square F Ratio

$\begin{array}{lllll}\text { Model } & 1 & 0.02688663 & 0.026887 & 10.3933\end{array}$

$\begin{array}{lllll}\text { Error } & 14 & 0.03621672 & 0.002587 & \text { Prob }>\text { F }\end{array}$

$\begin{array}{llrr}\text { C. Total } & 15 & 0.06310335 & 0.0061\end{array}$ 
WSRC-STI-2006-00068

Revision 0

Exhibit A12. Relationships between Analytes and WLs by Preparation Method, ICP, and Analyte (continued)

Prep=Fusion, Sample Type $=$ SME, ICP=M-14, Analyte=B/L Bivariate Fit of Avg Measurement By Blending WL

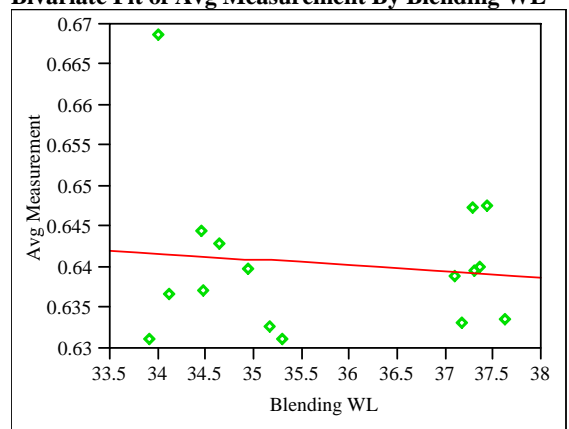

Linear Fit

Avg Measurement $=0.6684974-0.0007846$ Blending WL Summary of Fit

$\begin{array}{lr}\text { RSquare } & 0.015612 \\ \text { RSquare Adj } & -0.0547 \\ \text { Root Mean Square Error } & 0.009469 \\ \text { Mean of Response } & 0.640425\end{array}$

$\begin{array}{lr}\text { Mean of Response } & 0.640425 \\ \text { Observations (or Sum Wgts) } & 16\end{array}$

Analysis of Variance

Source DF Sum of Squares Mean Square F Ratio

$\begin{array}{lllll}\text { Model } & 1 & 0.00001991 & 0.000020 & 0.2220\end{array}$

$\begin{array}{lllll}\text { Error } & 14 & 0.00125534 & 0.000090 \text { Prob }>\text { F }\end{array}$

$\begin{array}{lll}\text { C. Total } 15 & 0.00127525 & 0.6448\end{array}$

Bivariate Fit of Avg Measurement By SME Avg WL

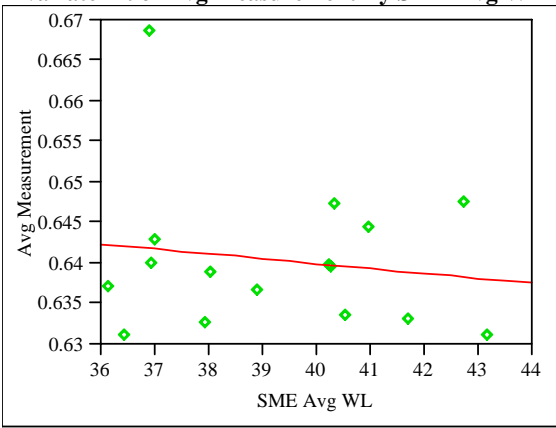

Linear Fit

Avg Measurement $=0.6642841-0.0006074$ SME Avg WL Summary of Fit

RSquare $\quad 0.022672$

RSquare Adj $\quad-0.04714$

Root Mean Square Error $\quad 0.009435$

Mean of Response $\quad 0.640425$

Observations (or Sum Wgts) 16

Analysis of Variance

Source DF Sum of Squares Mean Square F Ratio

$\begin{array}{lllll}\text { Model } & 1 & 0.00002891 & 0.000029 & 0.3248\end{array}$

$\begin{array}{lllll}\text { Error } & 14 & 0.00124634 & 0.000089 \text { Prob }>\text { F }\end{array}$

$\begin{array}{llll}\text { C. Total } & 15 & 0.00127525 & 0.5778\end{array}$
Prep=Fusion, Sample Type=SME, ICP=M-14, Analyte $=$ Ca Bivariate Fit of Avg Measurement By Blending WL

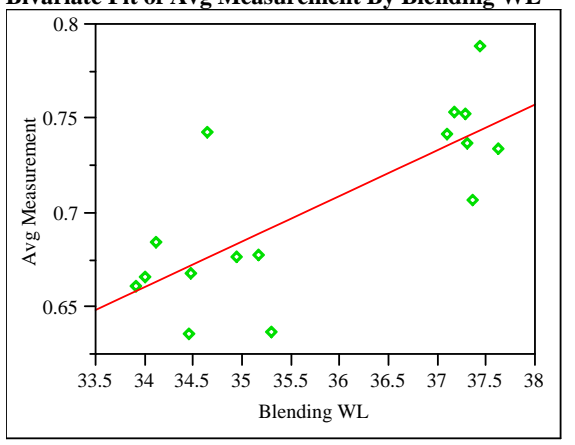

Linear Fit

Avg Measurement $=-0.162343+0.0242213$ Blending WL Summary of Fit

$\begin{array}{lr}\text { RSquare } & 0.587344 \\ \text { RSquare Adj } & 0.557868 \\ \text { Root Mean Square Error } & 0.030858 \\ \text { Mean of Response } & 0.704293 \\ \text { Observations (or Sum Wgts) } & 16\end{array}$

Observations (or Sum Wgts) 16

Analysis of Variance

Source DF Sum of Squares Mean Square F Ratio

$\begin{array}{lllll}\text { Model } & 1 & 0.01897464 & 0.018975 & 19.9265\end{array}$

$\begin{array}{llll}\text { Error } & 14 & 0.01333122 & 0.000952 \text { Prob }>\text { F }\end{array}$

$\begin{array}{llr}\text { C. Total } 15 & 0.03230586 & 0.0005\end{array}$

Bivariate Fit of Avg Measurement By SME Avg WL

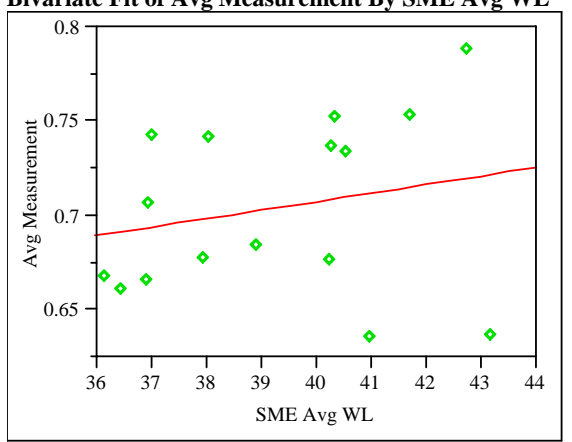

Linear Fit

Avg Measurement $=0.5257809+0.0045448$ SME Avg WL Summary of Fit

RSquare

0.050102

RSquare Adj

$-0.01775$

Root Mean Square Error $\quad 0.046818$

Mean of Response $\quad 0.704293$

Observations (or Sum Wgts)

16

Analysis of Variance

Source DF Sum of Squares Mean Square F Ratio

$\begin{array}{lllll}\text { Model } & 1 & 0.00161858 & 0.001619 & 0.7384\end{array}$

$\begin{array}{llll}\text { Error } & 14 & 0.03068728 & 0.002192 \text { Prob }>\text { F }\end{array}$

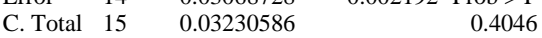


WSRC-STI-2006-00068

Revision 0

Exhibit A12. Relationships between Analytes and WLs by Preparation Method, ICP, and Analyte (continued)

Prep $=$ Fusion, Sample Type $=$ SME, ICP $=$ M-14, Analyte $=\mathrm{Cr}$ Bivariate Fit of Avg Measurement By Blending WL

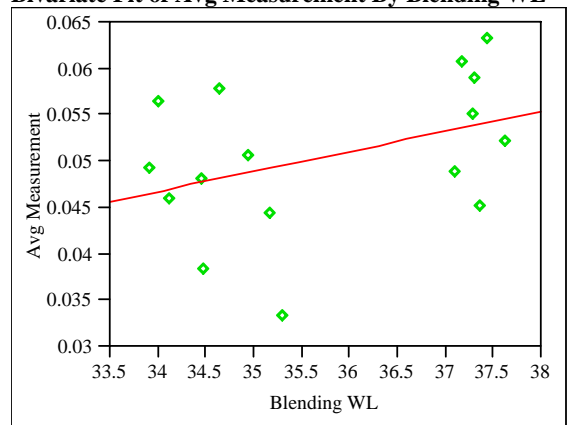

Linear Fit

Avg Measurement $=-0.026666+0.0021601$ Blending WL Summary of Fit

\begin{tabular}{lr} 
RSquare & 0.151871 \\
RSquare Adj & 0.09129 \\
Root Mean Square Error & 0.007759 \\
Mean of Response & 0.050621 \\
\hline
\end{tabular}

Observations (or Sum Wgts) $\quad 16$

Analysis of Variance

Source DF Sum of Squares Mean Square F Ratio

$\begin{array}{lllll}\text { Model } & 1 & 0.00015091 & 0.000151 & 2.5069\end{array}$

$\begin{array}{lllll}\text { Error } & 14 & 0.00084276 & 0.000060 \text { Prob }>\text { F }\end{array}$

$\begin{array}{lll}\text { C. Total } 15 & 0.00099367 & 0.1357\end{array}$

Bivariate Fit of Avg Measurement By SME Avg WL

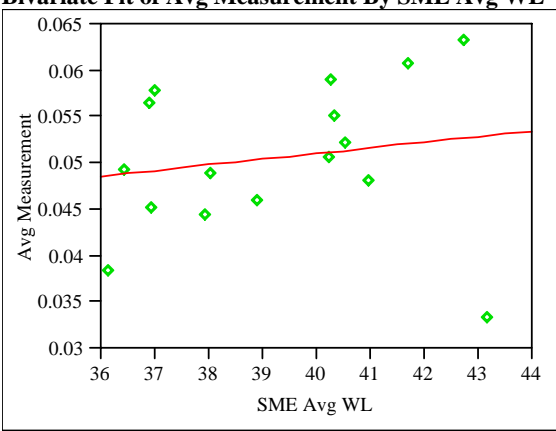

Linear Fit

Avg Measurement $=0.0264463+0.0006155$ SME Avg WL Summary of Fit

RSquare $\quad 0.029874$

RSquare Adj $\quad-0.03942$

Root Mean Square Error $\quad 0.008298$

Mean of Response $\quad 0.050621$

Observations (or Sum Wgts) 16

Analysis of Variance

Source DF Sum of Squares Mean Square F Ratio

$\begin{array}{lrrrr}\text { Model } & 1 & 0.00002968 & 0.000030 & 0.4311\end{array}$

$\begin{array}{llll}\text { Error } & 14 & 0.00096398 & 0.000069 \text { Prob }>\text { F }\end{array}$

C. Total $15 \quad 0.00099367$

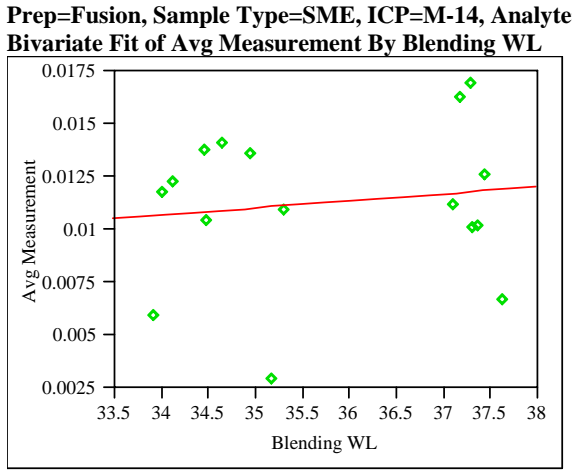

Linear Fit

Avg Measurement $=-0.000666+0.000334$ Blending $\mathrm{WL}$ Summary of Fit

$\begin{array}{lr}\text { RSquare } & 0.017832 \\ \text { RSquare Adj } & -0.05232 \\ \text { Root Mean Square Error } & 0.003768 \\ \text { Mean of Response } & 0.011285 \\ \text { Observations (or Sum Wgts) } & 16\end{array}$

Analysis of Variance

Source DF Sum of Squares Mean Square F Ratio $\begin{array}{lllll}\text { Model } & 1 & 0.00000361 & 0.000004 & 0.2542\end{array}$

$\begin{array}{lrrr}\text { Error } & 14 & 0.00019877 & 0.000014 \text { Prob }>\text { F }\end{array}$

$\begin{array}{llll}\text { C. Total } & 15 & 0.00020238 & 0.6220\end{array}$

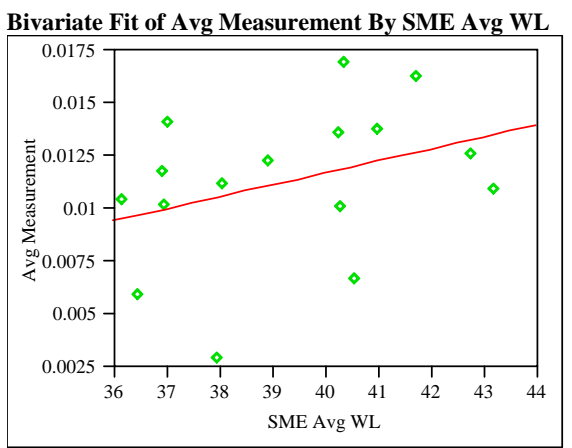

Linear Fit

Avg Measurement $=-0.010976+0.0005668$ SME Avg WL Summary of Fit

RSquare

0.124372

RSquare Adj

0.061827

Root Mean Square Error $\quad 0.003558$

Mean of Response $\quad 0.011285$

Observations (or Sum Wgts) 16

Analysis of Variance

Source DF Sum of Squares Mean Square F Ratio

$\begin{array}{lllll}\text { Model } & 1 & 0.00002517 & 0.000025 & 1.9885\end{array}$

$\begin{array}{llll}\text { Error } & 14 & 0.00017721 & 0.000013 \text { Prob }>\text { F }\end{array}$

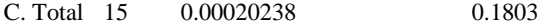


WSRC-STI-2006-00068

Revision 0

Exhibit A12. Relationships between Analytes and WLs by Preparation Method, ICP, and Analyte (continued)

Prep=Fusion, Sample Type=SME, ICP=M-14, Analyte=Fe Bivariate Fit of Avg Measurement By Blending WL

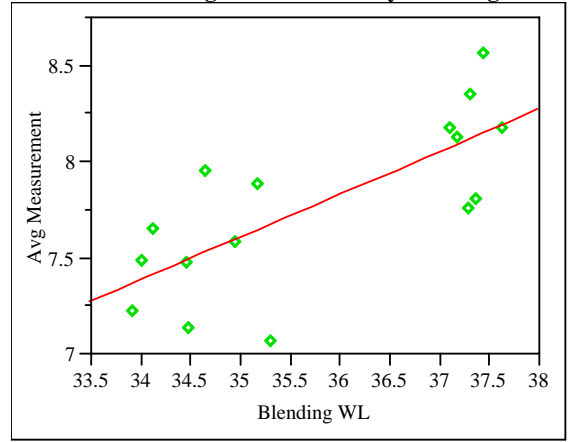

Linear Fit

Avg Measurement $=-0.162233+0.2220148$ Blending WL Summary of Fit

RSquare $\quad 0.552725$

RSquare Adj $\quad 0.520777$

Root Mean Square Error $\quad 0.303557$

Mean of Response 7.781455

Observations (or Sum Wgts) $\quad 16$

Analysis of Variance

Source DF Sum of Squares Mean Square F Ratio

$\begin{array}{lllll}\text { Model } & 1 & 1.5942043 & 1.59420 & 17.3007\end{array}$

$\begin{array}{llll}\text { Error } & 14 & 1.2900565 & 0.09215 \text { Prob }>\text { F }\end{array}$

$\begin{array}{lll}\text { C. Total } 15 & 2.8842608 & 0.0010\end{array}$

Bivariate Fit of Avg Measurement By SME Avg WL

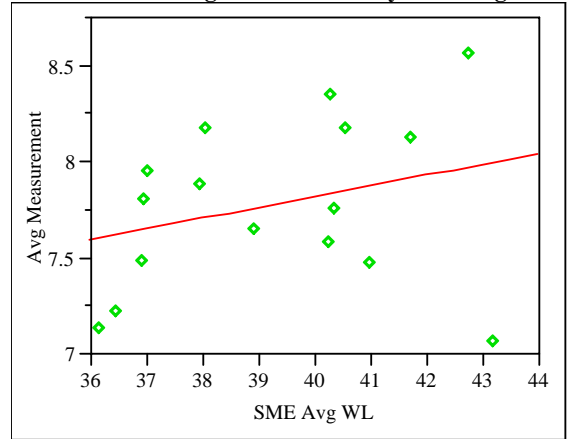

Linear Fit

Avg Measurement $=5.5807942+0.0560272$ SME Avg WL

Summary of Fit

$\begin{array}{ll}\text { RSquare } & 0.085285 \\ \text { RSquare Adj } & 0.019948 \\ \text { Root Mean Square Error } & 0.434106 \\ \text { Mean of Response } & 7.781455\end{array}$

$\begin{array}{lr}\text { Mean of Response } & 7.781455 \\ \text { Observations (or Sum Wgts) } & 16\end{array}$

Analysis of Variance

Source DF Sum of Squares Mean Square F Ratio

$\begin{array}{lllll}\text { Model } & 1 & 0.2459831 & 0.245983 & 1.3053\end{array}$

$\begin{array}{llll}\text { Error } & 14 & 2.6382777 & 0.188448 \text { Prob }>\text { F }\end{array}$

$\begin{array}{llrr}\text { C. Total } 15 & 2.8842608 & 0.2724\end{array}$
Prep=Fusion, Sample Type $=$ SME, ICP $=$ M-14, Analyte $=$ Fe $/$ A Bivariate Fit of Avg Measurement By Blending WL

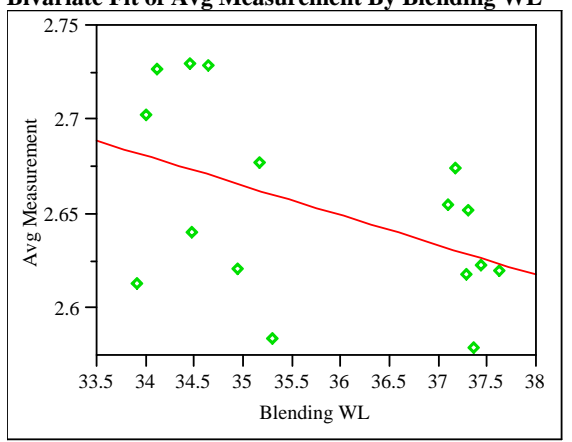

Linear Fit

Avg Measurement $=3.2205383-0.0158602$ Blending WL Summary of Fit

$\begin{array}{lr}\text { RSquare } & 0.220268 \\ \text { RSquare Adj } & 0.164573 \\ \text { Root Mean Square Error } & 0.045356 \\ \text { Mean of Response } & 2.65306 \\ \text { Observations (or Sum Wgts) } & 16\end{array}$

Observations (or Sum Wgts) 16

\section{Analysis of Variance}

Source DF Sum of Squares Mean Square F Ratio

$\begin{array}{lllll}\text { Model } & 1 & 0.00813575 & 0.008136 & 3.9549\end{array}$

$\begin{array}{lrlll}\text { Error } & 14 & 0.02880000 & 0.002057 \text { Prob }>\text { F }\end{array}$

$\begin{array}{llrr}\text { C. Total } & 15 & 0.03693576 & 0.002057 \\ \end{array}$

Bivariate Fit of Avg Measurement By SME Avg WL

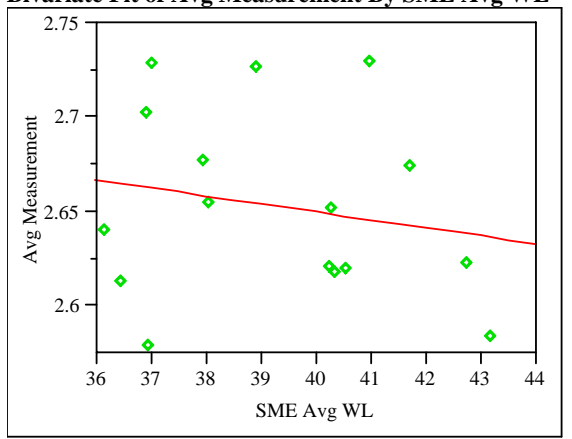

Linear Fit

Avg Measurement $=2.8200855-0.0042523$ SME Avg WL Summary of Fit

RSquare

0.038363

RSquare Adj

$-0.03033$

Root Mean Square Error $\quad 0.050369$

Mean of Response 2.65306

Observations (or Sum Wgts)

16

Analysis of Variance

Source DF Sum of Squares Mean Square F Ratio

$\begin{array}{lllll}\text { Model } & 1 & 0.00141698 & 0.001417 & 0.5585\end{array}$

$\begin{array}{lllll}\text { Error } & 14 & 0.03551878 & 0.002537 & \text { Prob }>\text { F }\end{array}$

$\begin{array}{llr}\text { C. Total } 15 & 0.03693576 & 0.4672\end{array}$ 
WSRC-STI-2006-00068

Revision 0

Exhibit A12. Relationships between Analytes and WLs by Preparation Method, ICP, and Analyte (continued)

Prep=Fusion, Sample Type $=$ SME, ICP $=M-14$, Analyte $=$ Fe $/ C$ Bivariate Fit of Avg Measurement By Blending WL

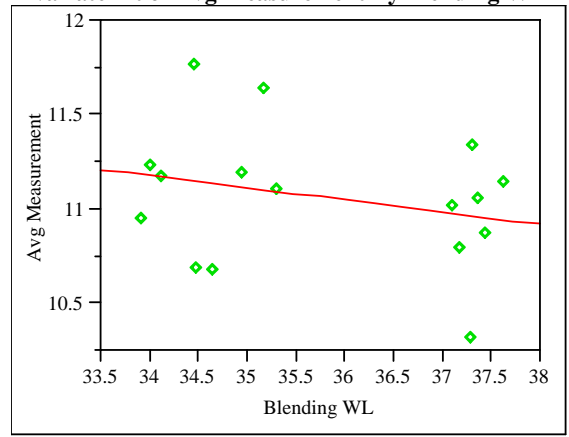

Linear Fit

Avg Measurement $=13.366637-0.0643301$ Blending WL Summary of Fit

$\begin{array}{lr}\text { RSquare } & 0.068662 \\ \text { RSquare Adj } & 0.002138 \\ \text { Root Mean Square Error } & 0.36011 \\ \text { Mean of Response } & 11.06491 \\ \text { Observations (or Sum Wgts) } & 16\end{array}$

Analysis of Variance

Source DF Sum of Squares Mean Square F Ratio

$\begin{array}{lllll}\text { Model } & 1 & 0.1338471 & 0.133847 & 1.0321\end{array}$

$\begin{array}{llll}\text { Error } & 14 & 1.8155116 & 0.129679 \text { Prob }>\text { F }\end{array}$

$\begin{array}{llr}\text { C. Total } 15 & 1.9493588 & 0.3269\end{array}$

Bivariate Fit of Avg Measurement By SME Avg WL

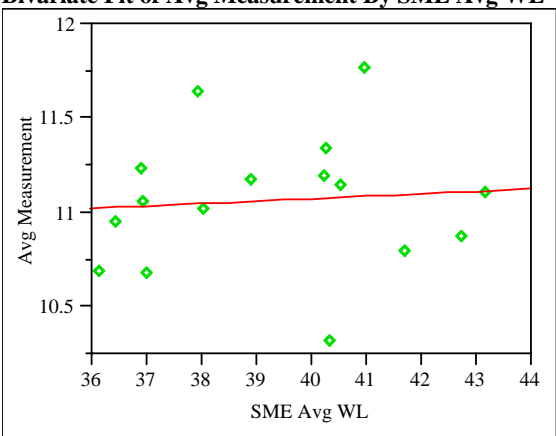

Linear Fit

Avg Measurement $=10.560725+0.0128361$ SME Avg WL

Summary of Fit

RSquare

RSquare Adj

0.006623

Root Mean Square Error $\quad 0.371911$

$-0.06433$

Mean of Response 11.06491

Observations (or Sum Wgts)

16

Analysis of Variance

Source DF Sum of Squares Mean Square F Ratio

$\begin{array}{lllll}\text { Model } & 1 & 0.0129114 & 0.012911 & 0.0933\end{array}$

$\begin{array}{llll}\text { Error } & 14 & 1.9364474 & 0.138318 \text { Prob }>\text { F }\end{array}$

$\begin{array}{llr}\text { C. Total } 15 & 1.9493588 & 0.7645\end{array}$
Prep $=$ Fusion, Sample Type $=\mathrm{SME}, \mathrm{ICP}=\mathrm{M}-14$, Analyte $=\mathrm{Fe} / \mathrm{Li}$ Bivariate Fit of Avg Measurement By Blending WL

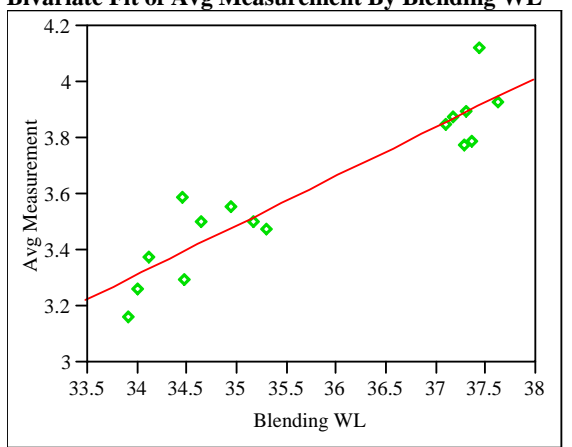

Linear Fit

Avg Measurement $=-2.646282+0.1752249$ Blending $\mathrm{WL}$ Summary of Fit

$\begin{array}{lr}\text { RSquare } & 0.863585 \\ \text { RSquare Adj } & 0.853841 \\ \text { Root Mean Square Error } & 0.105852 \\ \text { Mean of Response } & 3.623266 \\ \text { Observations (or Sum Wgts) } & 16\end{array}$

Analysis of Variance

Source DF Sum of Squares Mean Square F Ratio $\begin{array}{llllll}\text { Model } & 1 & 0.9930521 & 0.993052 & 88.6283\end{array}$ $\begin{array}{llll}\text { Error } & 14 & 0.1568656 & 0.011205 \text { Prob }>\text { F }\end{array}$

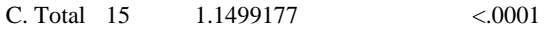

Bivariate Fit of Avg Measurement By SME Avg WL

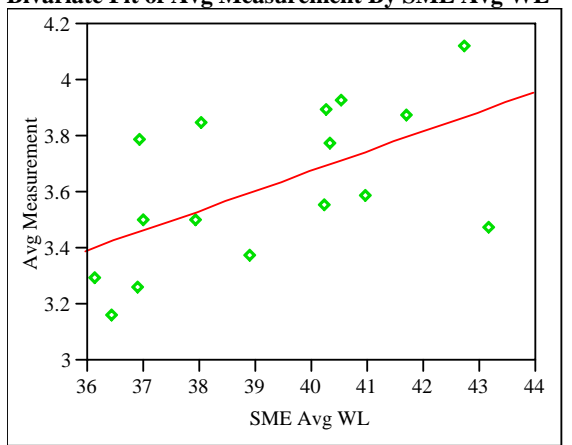

Linear Fit

Avg Measurement $=0.8516798+0.0705626$ SME Avg WL Summary of Fit

$\begin{array}{lr}\text { RSquare } & 0.339304 \\ \text { RSquare Adj } & 0.292112 \\ \text { Root Mean Square Error } & 0.232954 \\ \text { Mean of Response } & 3.623266 \\ \text { Observations (or Sum Wgts) } & 16\end{array}$

Analysis of Variance

Source DF Sum of Squares Mean Square F Ratio $\begin{array}{lllll}\text { Model } & 1 & 0.3901718 & 0.390172 & 7.1898\end{array}$

$\begin{array}{lllll}\text { Error } & 14 & 0.7597459 & 0.054268 \text { Prob }>\text { F }\end{array}$

$\begin{array}{llr}\text { C. Total } 15 & 1.1499177 & 0.0179\end{array}$ 
WSRC-STI-2006-00068

Revision 0

Exhibit A12. Relationships between Analytes and WLs by Preparation Method, ICP, and Analyte (continued)

Prep=Fusion, Sample Type=SME, ICP=M-14, Analyte=Fe/Mg Bivariate Fit of Avg Measurement By Blending WL

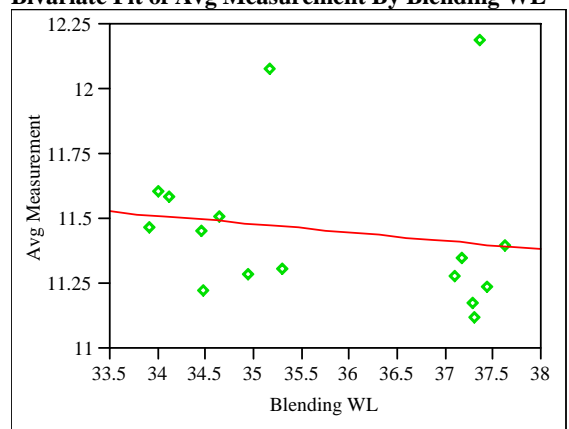

Linear Fit

Avg Measurement $=12.628491-0.032791$ Blending WL Summary of Fit

$\begin{array}{ll}\text { RSquare } & 0.025737 \\ \text { RSquare Adj } & -0.04385 \\ \text { Root Mean Square Error } & 0.306651 \\ \text { Mean of Response } & 11.45523\end{array}$

$\begin{array}{lr}\text { Mean of Response } & 11.45523 \\ \text { Observations (or Sum Wgts) } & 16\end{array}$

Analysis of Variance

Source DF Sum of Squares Mean Square F Ratio

$\begin{array}{lllll}\text { Model } & 1 & 0.0347769 & 0.034777 & 0.3698\end{array}$

$\begin{array}{llll}\text { Error } & 14 & 1.3164879 & 0.094035 \text { Prob }>\text { F }\end{array}$

$\begin{array}{lll}\text { C. Total } 15 & 1.3512648 & 0.5528\end{array}$

Bivariate Fit of Avg Measurement By SME Avg WL

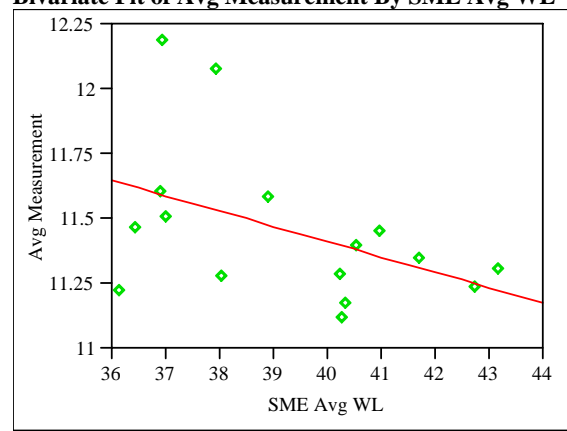

Linear Fit

Avg Measurement $=13.769062-0.0589086$ SME Avg WL Summary of Fit

$\begin{array}{lr}\text { RSquare } & 0.201244 \\ \text { RSquare Adj } & 0.14419 \\ \text { Root Mean Square Error } & 0.27766 \\ \text { Mean of Response } & 11.45523 \\ \text { Observations (or Sum Wgts) } & 16\end{array}$

Analysis of Variance

Source DF Sum of Squares Mean Square F Ratio

$\begin{array}{lllll}\text { Model } & 1 & 0.2719340 & 0.271934 & 3.5273\end{array}$

$\begin{array}{llll}\text { Error } & 14 & 1.0793308 & 0.077095 \text { Prob }>\text { F }\end{array}$

$\begin{array}{llll}\text { C. Total } & 15 & 1.3512648 & 0.0814\end{array}$
Prep=Fusion, Sample Type $=$ SME, ICP $=M-14$, Analyte $=$ Fe $/ M n$ Bivariate Fit of Avg Measurement By Blending WL

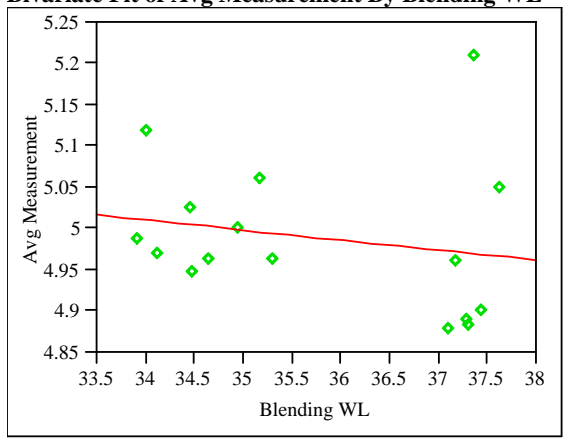

Linear Fit

Avg Measurement $=5.4217809-0.0120816$ Blending WL Summary of Fit

$\begin{array}{lr}\text { RSquare } & 0.038932 \\ \text { RSquare Adj } & -0.02972 \\ \text { Root Mean Square Error } & 0.091238 \\ \text { Mean of Response } & 4.9895 \\ \text { Observations (or Sum Wgts) } & 16\end{array}$

Observations (or Sum Wgts) 16

\section{Analysis of Variance}

Source DF Sum of Squares Mean Square F Ratio

$\begin{array}{lllll}\text { Model } & 1 & 0.00472097 & 0.004721 & 0.5671\end{array}$

$\begin{array}{lrlll}\text { Error } & 14 & 0.11654246 & 0.008324 & \text { Prob }>\text { F }\end{array}$

$\begin{array}{llr}\text { C. Total } 15 & 0.12126343 & 0.4639\end{array}$

Bivariate Fit of Avg Measurement By SME Avg WL

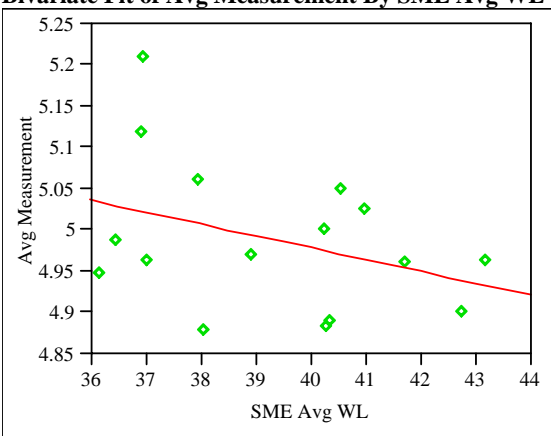

Linear Fit

Avg Measurement $=5.554662-0.0143886$ SME Avg WL Summary of Fit

0.071915

Root Mean Square Error $\quad 0.086619$

Mean of Response 4.9895

Observations (or Sum Wgts) 16

Analysis of Variance

Source DF Sum of Squares Mean Square F Ratio

$\begin{array}{lllll}\text { Model } & 1 & 0.01622350 & 0.016224 & 2.1623\end{array}$

$\begin{array}{llll}\text { Error } & 14 & 0.10503993 & 0.007503 \text { Prob }>\text { F }\end{array}$

$\begin{array}{llr}\text { C. Total } 15 & 0.12126343 & 0.1635\end{array}$ 
WSRC-STI-2006-00068

Revision 0

Exhibit A12. Relationships between Analytes and WLs by Preparation Method, ICP, and Analyte (continued)

Prep $=$ Fusion, Sample Type $=\mathrm{SME}$, ICP $=\mathrm{M}-14$, Analyte $=\mathrm{Fe} / \mathrm{Ni}$ Bivariate Fit of Avg Measurement By Blending WL

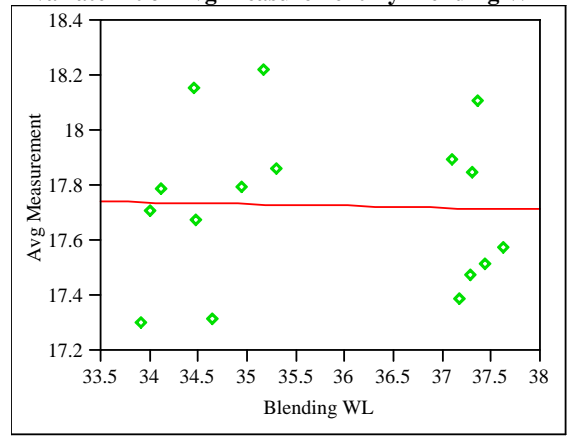

Linear Fit

Avg Measurement $=17.962607-0.0065424$ Blending WL Summary of Fit

$\begin{array}{lr}\text { RSquare } & 0.001115 \\ \text { RSquare Adj } & -0.07023 \\ \text { Root Mean Square Error } & 0.297585 \\ \text { Mean of Response } & 17.72852 \\ \text { Observations (or Sum Wgts) } & 16\end{array}$

Analysis of Variance

Source DF Sum of Squares Mean Square F Ratio

$\begin{array}{lllll}\text { Model } & 1 & 0.0013844 & 0.001384 & 0.0156\end{array}$

$\begin{array}{llll}\text { Error } & 14 & 1.2397919 & 0.088557 \text { Prob }>\text { F }\end{array}$

$\begin{array}{llr}\text { C. Total } 15 & 1.2411763 & 0.9023\end{array}$

Bivariate Fit of Avg Measurement By SME Avg WL

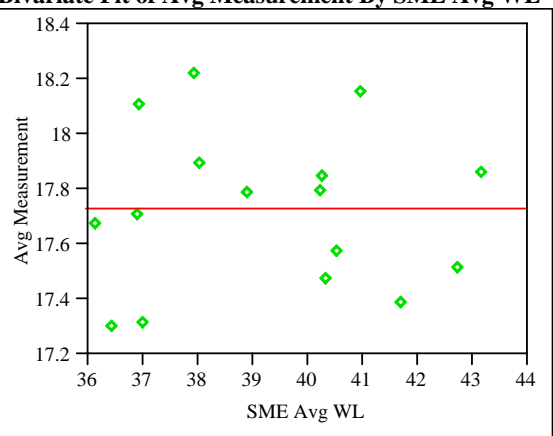

Linear Fit

Avg Measurement $=17.734975-0.0001644$ SME Avg WL

Summary of Fit

$\begin{array}{lr}\text { RSquare } & 0.000002 \\ \text { RSquare Adj } & -0.07143 \\ \text { Root Mean Square Error } & 0.29775 \\ \text { Mean of Response } & 17.72852 \\ \text { Observations (or Sum Wgts) } & 16\end{array}$

Analysis of Variance

Source DF Sum of Squares Mean Square F Ratio

$\begin{array}{lllll}\text { Model } & 1 & 0.0000021 & 0.000002 & 0.0000\end{array}$

$\begin{array}{llll}\text { Error } & 14 & 1.2411742 & 0.088655 \text { Prob }>\text { F }\end{array}$

$\begin{array}{llrr}\text { C. Total } 15 & 1.2411763 & 0.9962\end{array}$
Prep $=$ Fusion, Sample Type $=$ SME, ICP $=M-14$, Analyte $=F e / U$ Bivariate Fit of Avg Measurement By Blending WL

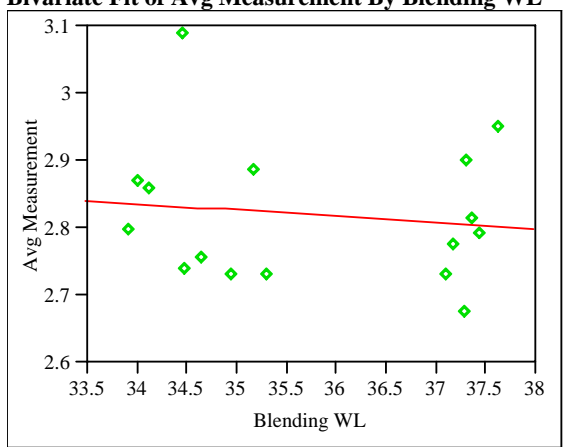

Linear Fit

Avg Measurement $=3.1539075-0.0093416$ Blending WL Summary of Fit

RSquare

0.017453

RSquare Adj

$-0.05273$

Root Mean Square Error $\quad 0.106534$

Mean of Response

2.819664

Observations (or Sum Wgts) 16

Analysis of Variance

Source DF Sum of Squares Mean Square F Ratio $\begin{array}{lrrrr}\text { Model } & 1 & 0.00282244 & 0.002822 & 0.2487\end{array}$ $\begin{array}{lllll}\text { Error } & 14 & 0.15889369 & 0.011350 \text { Prob }>\text { F }\end{array}$

$\begin{array}{llll}\text { C. Total } 15 & 0.16171613 & 0.6257\end{array}$

Bivariate Fit of Avg Measurement By SME Avg WL

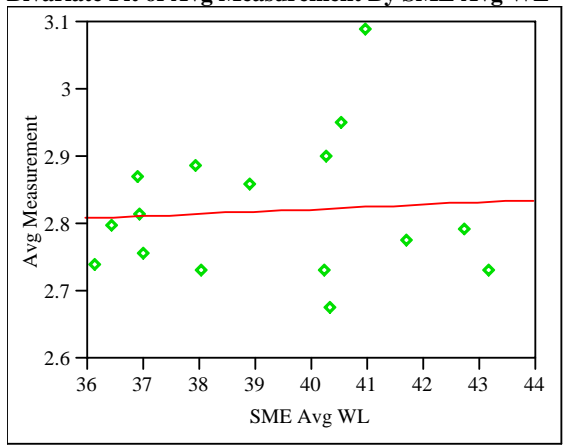

Linear Fit

Avg Measurement $=2.6853252+0.0034202$ SME Avg WL Summary of Fit

$\begin{array}{lr}\text { RSquare } & 0.005668 \\ \text { RSquare Adj } & -0.06536 \\ \text { Root Mean Square Error } & 0.107171 \\ \text { Mean of Response } & 2.819664 \\ \text { Observations (or Sum Wgts) } & 16\end{array}$

Analysis of Variance

Source DF Sum of Squares Mean Square F Ratio $\begin{array}{lllll}\text { Model } & 1 & 0.00091665 & 0.000917 & 0.0798\end{array}$

$\begin{array}{lllll}\text { Error } & 14 & 0.16079948 & 0.011486 \text { Prob }>\text { F }\end{array}$

$\begin{array}{llr}\text { C. Total } 15 & 0.16171613 & 0.7817\end{array}$ 
WSRC-STI-2006-00068

Revision 0

Exhibit A12. Relationships between Analytes and WLs by Preparation Method, ICP, and Analyte (continued)

Prep $=$ Fusion, Sample Type $=$ SME, ICP $=M-14$, Analyte $=K$ Bivariate Fit of Avg Measurement By Blending WL

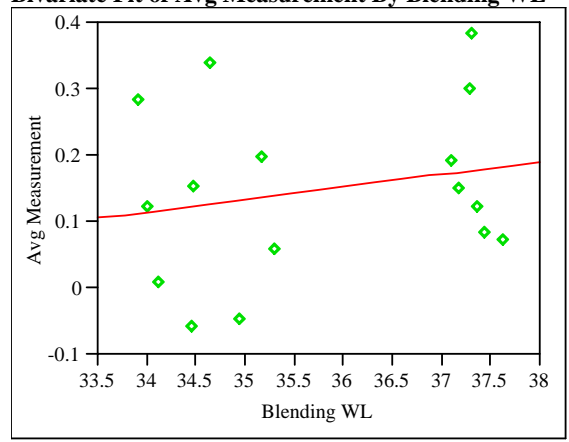

Linear Fit

Avg Measurement $=-0.526583+0.0188764$ Blending WL Summary of Fit

$\begin{array}{lr}\text { RSquare } & 0.044768 \\ \text { RSquare Adj } & -0.02346 \\ \text { Root Mean Square Error } & 0.132531 \\ \text { Mean of Response } & 0.148815 \\ \text { Observations (or Sum Wgts) } & 16\end{array}$

Analysis of Variance

Source DF Sum of Squares Mean Square F Ratio

$\begin{array}{lllll}\text { Model } & 1 & 0.01152440 & 0.011524 & 0.6561\end{array}$

$\begin{array}{llll}\text { Error } & 14 & 0.24590219 & 0.017564 \text { Prob }>\text { F }\end{array}$

$\begin{array}{lll}\text { C. Total } 15 & 0.25742660 & 0.4315\end{array}$

Bivariate Fit of Avg Measurement By SME Avg WL

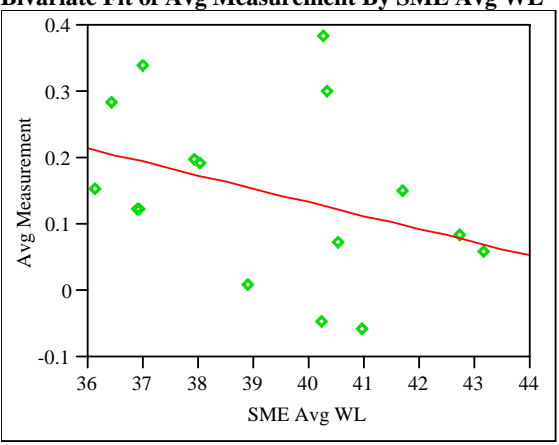

Linear Fit

Avg Measurement $=0.9460523-0.0202971$ SME Avg WL Summary of Fit

$\begin{array}{lr}\text { RSquare } & 0.125407 \\ \text { RSquare Adj } & 0.062936 \\ \text { Root Mean Square Error } & 0.126814 \\ \text { Mean of Response } & 0.148815 \\ \text { Observations (or Sum Wgts) } & 16\end{array}$

Analysis of Variance

Source DF Sum of Squares Mean Square F Ratio

$\begin{array}{lllll}\text { Model } & 1 & 0.03228306 & 0.032283 & 2.0074\end{array}$

$\begin{array}{llll}\text { Error } & 14 & 0.22514353 & 0.016082 \text { Prob }>\text { F }\end{array}$

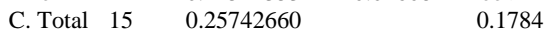

Prep=Fusion, Sample Type $=$ SME, ICP $=$ M-14, Analyte $=$ Li Bivariate Fit of Avg Measurement By Blending WL

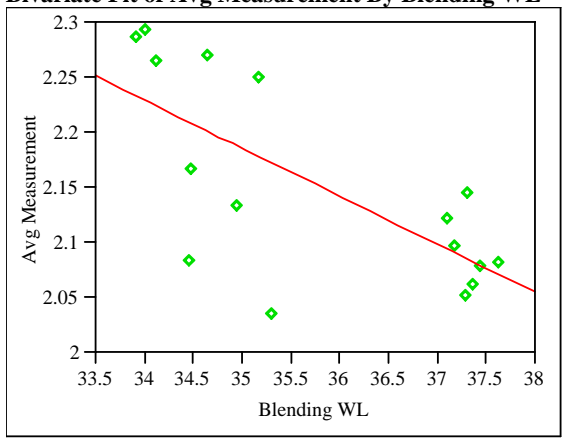

Linear Fit

Avg Measurement = $3.7162919-0.043718$ Blending WL Summary of Fit

$\begin{array}{lr}\text { RSquare } & 0.488857 \\ \text { RSquare Adj } & 0.452347 \\ \text { Root Mean Square Error } & 0.067946 \\ \text { Mean of Response } & 2.152063 \\ \text { Observations (or Sum Wgts) } & 16\end{array}$

16

\section{Analysis of Variance}

Source DF Sum of Squares Mean Square F Ratio

$\begin{array}{lllll}\text { Model } & 1 & 0.06181591 & 0.061816 & 13.3896\end{array}$

$\begin{array}{lllll}\text { Error } & 14 & 0.06463402 & 0.004617 & \text { Prob }>\text { F }\end{array}$

$\begin{array}{llrr}\text { C. Total } & 15 & 0.12644993 & 0.0026\end{array}$

Bivariate Fit of Avg Measurement By SME Avg WL

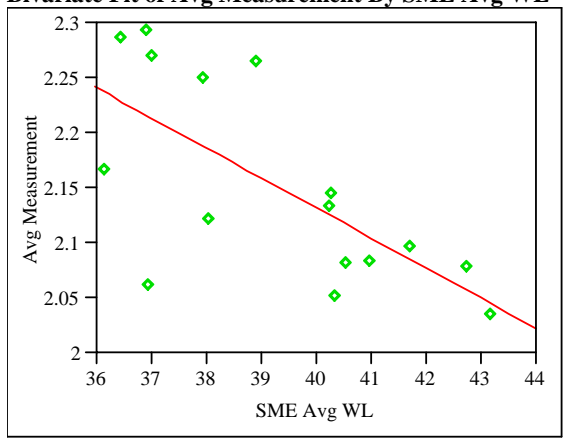

Linear Fit

Avg Measurement = $3.2278736-0.0273894$ SME Avg WL Summary of Fit

RSquare

0.464892

RSquare Adj

0.42667

Root Mean Square Error $\quad 0.069521$

Mean of Response 2.152063

Observations (or Sum Wgts)

16

Analysis of Variance

Source DF Sum of Squares Mean Square F Ratio

$\begin{array}{lllll}\text { Model } & 1 & 0.05878557 & 0.058786 & 12.1629\end{array}$

$\begin{array}{llll}\text { Error } & 14 & 0.06766436 & 0.004833 \text { Prob }>\text { F }\end{array}$

$\begin{array}{llr}\text { C. Total } 15 & 0.12644993 & 0.0036\end{array}$ 
WSRC-STI-2006-00068

Revision 0

Exhibit A12. Relationships between Analytes and WLs by Preparation Method, ICP, and Analyte (continued)

Prep $=$ Fusion, Sample Type $=$ SME, ICP $=M-14$, Analyte $=M g$ Bivariate Fit of Avg Measurement By Blending WL

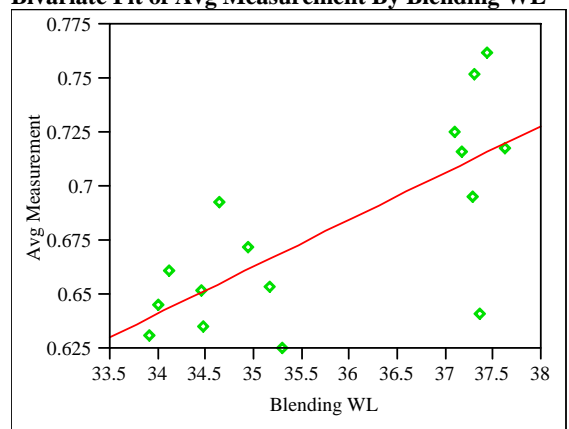

Linear Fit

Avg Measurement $=-0.097374+0.0217266$ Blending WL Summary of Fit

$\begin{array}{ll}\text { RSquare } & 0.522235 \\ \text { RSquare Adj } & 0.488109 \\ \text { Root Mean Square Error } & 0.031586 \\ \text { Mean of Response } & 0.680003\end{array}$

Observations (or Sum Wgts) $\quad 16$

Analysis of Variance

Source DF Sum of Squares Mean Square F Ratio

$\begin{array}{lllll}\text { Model } & 1 & 0.01526730 & 0.015267 & 15.3031\end{array}$

$\begin{array}{lllll}\text { Error } & 14 & 0.01396726 & 0.000998 \text { Prob }>\text { F }\end{array}$

$\begin{array}{lll}\text { C. Total } 15 & 0.02923456 & 0.0016\end{array}$

Bivariate Fit of Avg Measurement By SME Avg WL

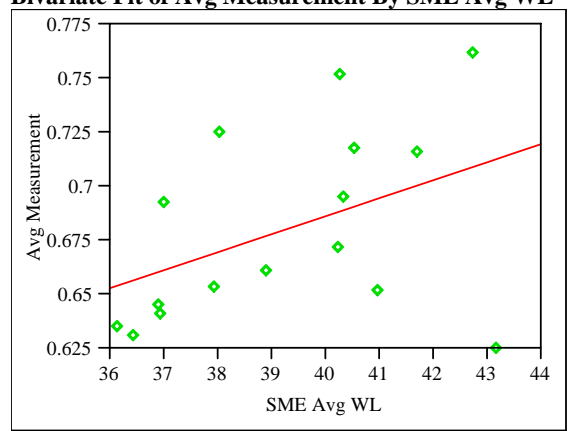

Linear Fit

Avg Measurement $=0.353199+0.0083202$ SME Avg WL Summary of Fit

RSquare $\quad 0.185557$

RSquare Adj $\quad 0.127382$

Root Mean Square Error $\quad 0.04124$

Mean of Response 0.680003

Observations (or Sum Wgts) 16

Analysis of Variance

Source DF Sum of Squares Mean Square F Ratio

$\begin{array}{lllll}\text { Model } & 1 & 0.00542466 & 0.005425 & 3.1897\end{array}$

$\begin{array}{llll}\text { Error } & 14 & 0.02380989 & 0.001701 \text { Prob }>\text { F }\end{array}$

$\begin{array}{llll}\text { C. Total } & 15 & 0.02923456 & 0.0958\end{array}$
Prep=Fusion, Sample Type $=$ SME, ICP $=$ M-14, Analyte $=M n$ Bivariate Fit of Avg Measurement By Blending WL

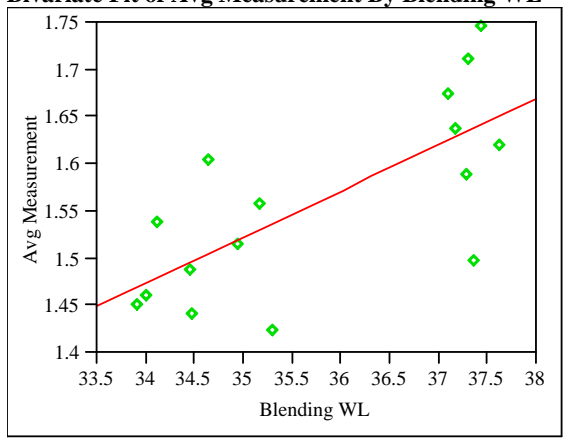

Linear Fit

Avg Measurement $=-0.189245+0.0489085$ Blending WL Summary of Fit

$\begin{array}{lr}\text { RSquare } & 0.515592 \\ \text { RSquare Adj } & 0.480992 \\ \text { Root Mean Square Error } & 0.072055 \\ \text { Mean of Response } & 1.5607 \\ \text { Observations (or Sum Wgts) } & 16\end{array}$

Analysis of Variance

Source DF Sum of Squares Mean Square F Ratio

$\begin{array}{lllll}\text { Model } & 1 & 0.07736568 & 0.077366 & 14.9013\end{array}$

$\begin{array}{llll}\text { Error } & 14 & 0.07268635 & 0.005192 \text { Prob }>\text { F }\end{array}$

$\begin{array}{llr}\text { C. Total } 15 & 0.15005203 & 0.0017\end{array}$

Bivariate Fit of Avg Measurement By SME Avg WL

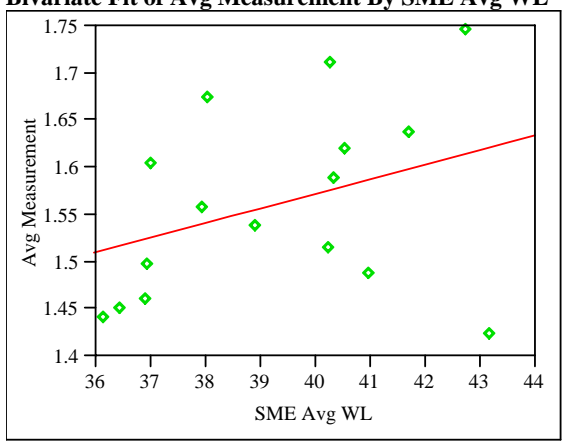

Linear Fit

Avg Measurement $=0.9423548+0.0157426$ SME Avg WL Summary of Fit

RSquare

0.129425

RSquare Adj

0.067241

Root Mean Square Error $\quad 0.096596$

Mean of Response $\quad 1.5607$

Observations (or Sum Wgts)

16

Analysis of Variance

Source DF Sum of Squares Mean Square F Ratio

$\begin{array}{lllll}\text { Model } & 1 & 0.01942053 & 0.019421 & 2.0813\end{array}$

$\begin{array}{lllll}\text { Error } & 14 & 0.13063150 & 0.009331 \text { Prob }>\text { F }\end{array}$

$\begin{array}{llrr}\text { C. Total } & 15 & 0.15005203 & 0.1711\end{array}$ 
WSRC-STI-2006-00068

Revision 0

Exhibit A12. Relationships between Analytes and WLs by Preparation Method, ICP, and Analyte (continued)

Prep=Fusion, Sample Type $=$ SME, ICP $=M-14$, Analyte $=M n / M g$ Bivariate Fit of Avg Measurement By Blending WL

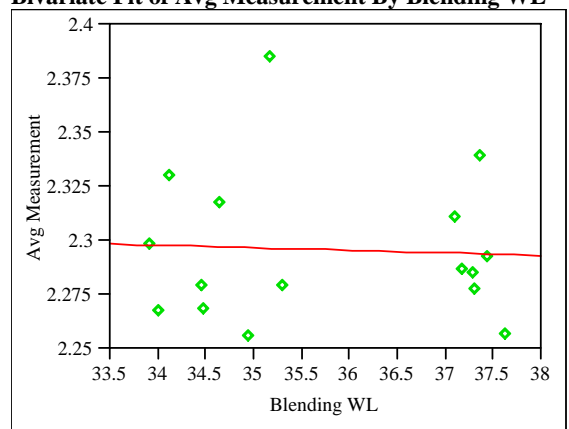

Linear Fit

Avg Measurement $=2.3383308-0.0011875$ Blending WL Summary of Fit

$\begin{array}{ll}\text { RSquare } & 0.002592 \\ \text { RSquare Adj } & -0.06865 \\ \text { Root Mean Square Error } & 0.035408 \\ \text { Mean of Response } & 2.295843\end{array}$

$\begin{array}{lr}\text { Mean of Response } & 2.295843 \\ \text { Observations (or Sum Wgts) } & 16\end{array}$

Analysis of Variance

Source DF Sum of Squares Mean Square F Ratio

$\begin{array}{lllll}\text { Model } & 1 & 0.00004561 & 0.000046 & 0.0364\end{array}$

$\begin{array}{llll}\text { Error } & 14 & 0.01755247 & 0.001254 \text { Prob }>\text { F }\end{array}$

$\begin{array}{lll}\text { C. Total } 15 & 0.01759808 & 0.8515\end{array}$

Bivariate Fit of Avg Measurement By SME Avg WL

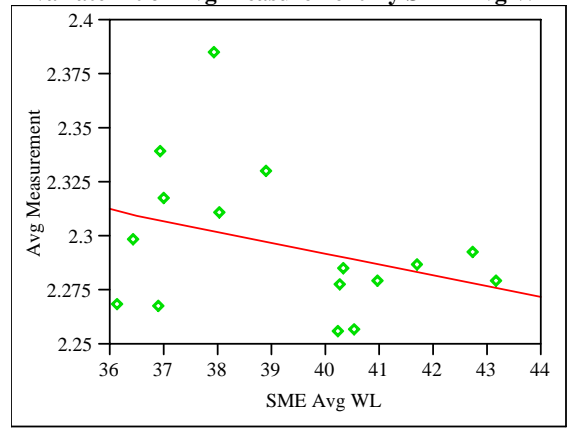

Linear Fit

Avg Measurement $=2.495876-0.0050927$ SME Avg WL Summary of Fit

RSquare $\quad 0.115488$

RSquare Adj $\quad 0.052308$

Root Mean Square Error $\quad 0.033344$

Mean of Response 2.295843

Observations (or Sum Wgts) 16

Analysis of Variance

Source DF Sum of Squares Mean Square F Ratio

$\begin{array}{lllll}\text { Model } & 1 & 0.00203236 & 0.002032 & 1.8279\end{array}$

$\begin{array}{lllll}\text { Error } & 14 & 0.01556572 & 0.001112 \text { Prob }>\text { F }\end{array}$

$\begin{array}{llll}\text { C. Total } 15 & 0.01759808 & 0.1978\end{array}$
Prep $=$ Fusion, Sample Type $=$ SME, ICP $=M-14$, Analyte $=N$ Bivariate Fit of Avg Measurement By Blending WL

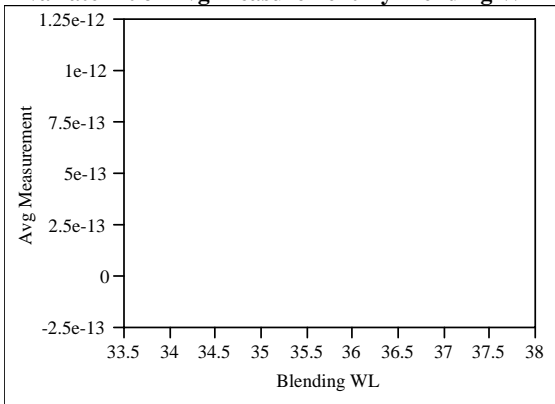

Bivariate Fit of Avg Measurement By SME Avg WL

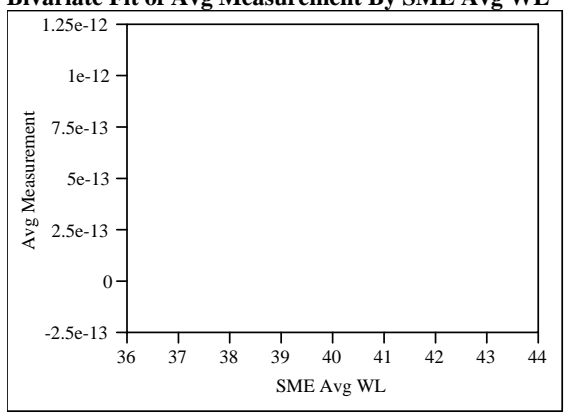

Prep=Fusion, Sample Type=SME, ICP $=$ M-14, Analyte $=\mathrm{Ni}$ Bivariate Fit of Avg Measurement By Blending WL

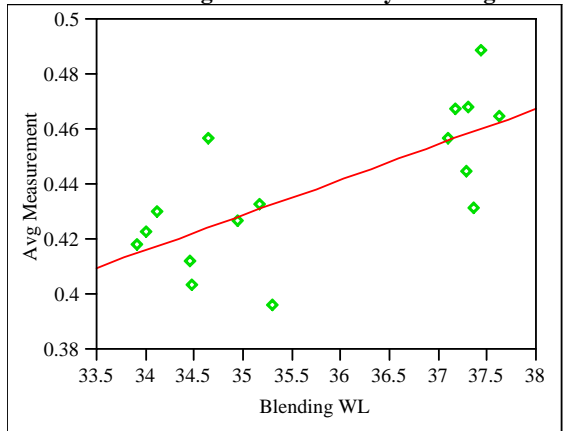

Linear Fit

Avg Measurement $=-0.020493+0.0128429$ Blending WL Summary of Fit

RSquare 0.512239

RSquare Adj 0.477399

Root Mean Square Error $\quad 0.019048$

Mean of Response $\quad 0.439025$

Observations (or Sum Wgts) $\quad 16$

Analysis of Variance

Source DF Sum of Squares Mean Square F Ratio $\begin{array}{lrrrr}\text { Model } & 1 & 0.00533464 & 0.005335 & 14.7026\end{array}$

$\begin{array}{llll}\text { Error } & 14 & 0.00507973 & 0.000363 \text { Prob }>\text { F }\end{array}$

$\begin{array}{lll}\text { C. Total } 15 & 0.01041437 & 0.0018\end{array}$ 
WSRC-STI-2006-00068

Revision 0

Exhibit A12. Relationships between Analytes and WLs by Preparation Method, ICP, and Analyte (continued)

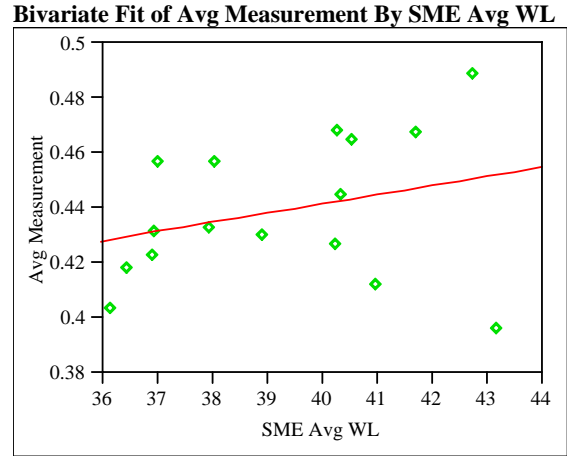

Linear Fit

Avg Measurement $=0.3069319+0.003363$ SME Avg WL Summary of Fit

$\begin{array}{lr}\text { RSquare } & 0.085099 \\ \text { RSquare Adj } & 0.019749 \\ \text { Root Mean Square Error } & 0.026088 \\ \text { Mean of Response } & 0.439025 \\ \text { Observations (or Sum Wgts) } & 16\end{array}$

Observations (or Sum Wgts) $\quad 16$

Analysis of Variance

Source DF Sum of Squares Mean Square F Ratio

$\begin{array}{lllll}\text { Model } & 1 & 0.00088626 & 0.000886 & 1.3022\end{array}$

$\begin{array}{llll}\text { Error } & 14 & 0.00952811 & 0.000681 \text { Prob }>\text { F }\end{array}$

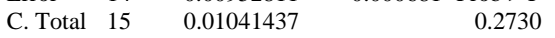

Prep $=$ Fusion, Sample Type $=$ SME, ICP $=$ M-14, Analyte $=S i$ Bivariate Fit of Avg Measurement By Blending WL

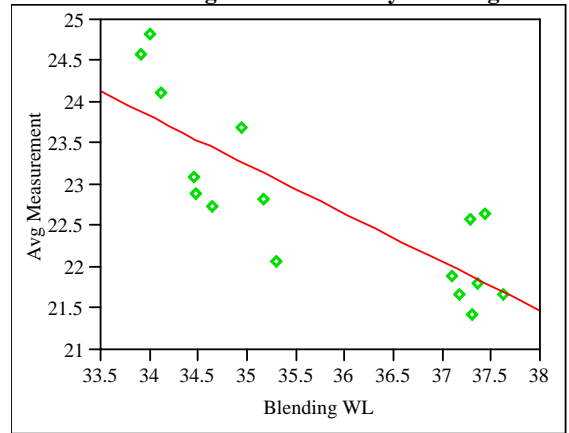

Linear Fit

Avg Measurement $=43.872177-0.5892038$ Blending WL

Summary of Fit

$\begin{array}{lr}\text { RSquare } & 0.670244 \\ \text { RSquare Adj } & 0.64669 \\ \text { Root Mean Square Error } & 0.628162 \\ \text { Mean of Response } & 22.79046 \\ \text { Observations (or Sum Wgts) } & 16\end{array}$

Analysis of Variance

Source DF Sum of Squares Mean Square F Ratio

$\begin{array}{lllll}\text { Model } & 1 & 11.228233 & 11.2282 & 28.4556\end{array}$

$\begin{array}{llrr}\text { Error } & 14 & 5.524232 & 0.3946 \text { Prob }>\text { F }\end{array}$

$\begin{array}{lrr}\text { C. Total } 15 & 16.752465 & 0.0001\end{array}$

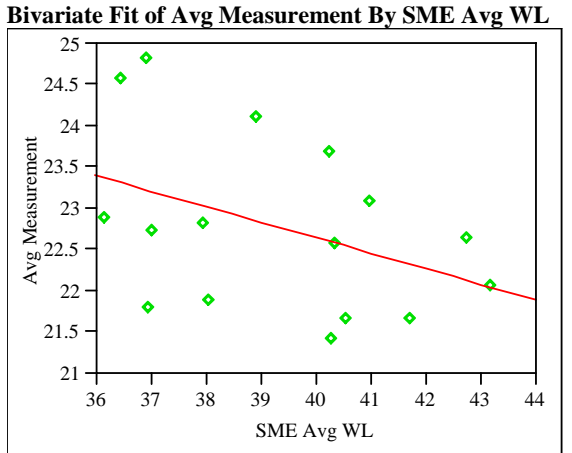

Linear Fit

Avg Measurement $=30.217246-0.1890806$ SME Avg WL Summary of Fit

$\begin{array}{lr}\text { RSquare } & 0.167233 \\ \text { RSquare Adj } & 0.10775 \\ \text { Root Mean Square Error } & 0.998245 \\ \text { Mean of Response } & 22.79046 \\ \text { Observations (or Sum Wgts) } & 16\end{array}$

Analysis of Variance

Source DF Sum of Squares Mean Square F Ratio $\begin{array}{lllll}\text { Model } & 1 & 2.801563 & 2.80156 & 2.8114\end{array}$

$\begin{array}{llll}\text { Error } & 14 & 13.950902 & 0.99649 \text { Prob > F }\end{array}$

$\begin{array}{llr}\text { C. Total } 15 & 16.752465 & 0.1158\end{array}$

Prep=Fusion, Sample Type=SME, ICP=M-14, Analyte=Sum of Oxides Bivariate Fit of Avg Measurement By Blending WL

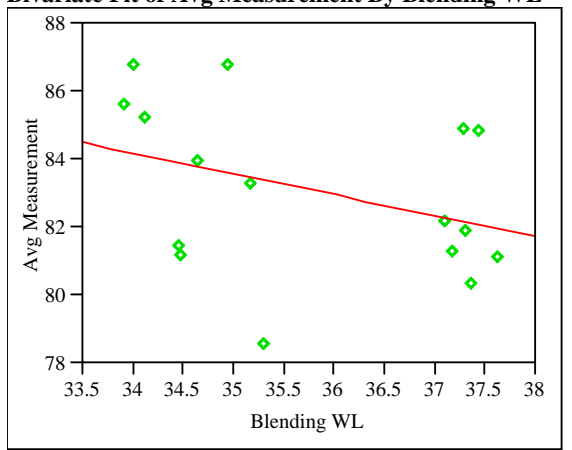

Linear Fit

Avg Measurement $=105.15588-0.6164041$ Blending WL Summary of Fit

RSquare

0.137712

RSquare Ad

0.07612

Root Mean Square Error $\quad 2.344403$

Mean of Response 83.10095

Observations (or Sum Wgts) 16

Analysis of Variance

Source DF Sum of Squares Mean Square F Ratio

$\begin{array}{lrrrr}\text { Model } & 1 & 12.288853 & 12.2889 & 2.2359\end{array}$

$\begin{array}{lllll}\text { Error } & 14 & 76.947186 & 5.4962 \text { Prob }>\text { F }\end{array}$

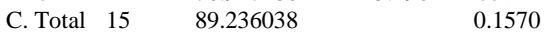


WSRC-STI-2006-00068

Revision 0

Exhibit A12. Relationships between Analytes and WLs by Preparation Method, ICP, and Analyte (continued)

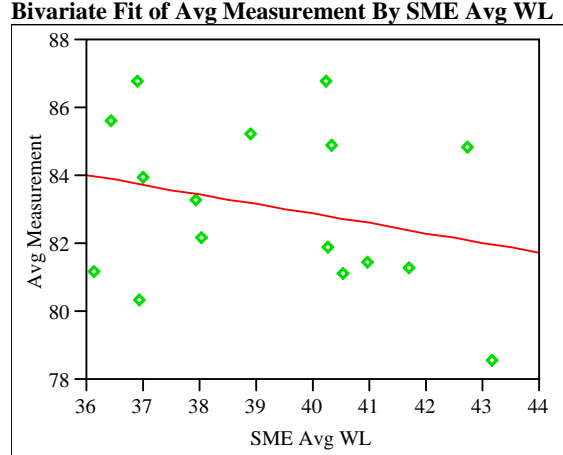

Linear Fit

Avg Measurement $=94.266249-0.2842607$ SME Avg WL Summary of Fit

RSquare $\quad 0.070958$

RSquare Adj $\quad 0.004598$

Root Mean Square Error $\quad 2.433458$

Mean of Response 83.10095

Observations (or Sum Wgts) 16

Analysis of Variance

Source DF Sum of Squares Mean Square F Ratio

$\begin{array}{lrrrr}\text { Model } & 1 & 6.331990 & 6.33199 & 1.0693\end{array}$

Error $14 \quad 82.904049 \quad 5.92172$ Prob $>$ F

C. Total $15 \quad 89.236038 \quad 0.3186$

Prep=Fusion, Sample Type=SME, ICP=M-14, Analyte $=$ Ti Bivariate Fit of Avg Measurement By Blending WL

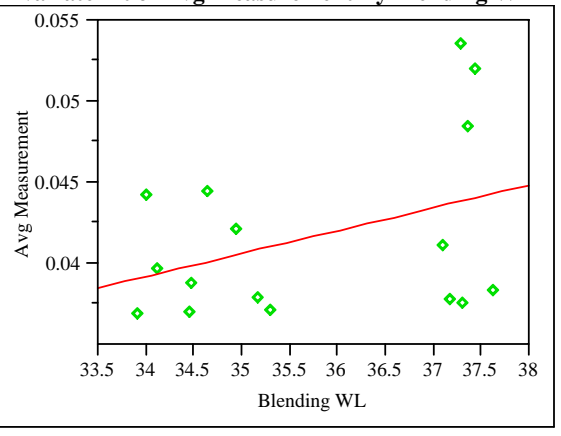

Linear Fit

Avg Measurement $=-0.008594+0.0014066$ Blending WL Summary of Fit

RSquare $\quad 0.144364$

RSquare Adj $\quad 0.083247$

Root Mean Square Error $\quad 0.005205$

Mean of Response 0.041734

Observations (or Sum Wgts)

Analysis of Variance

Source DF Sum of Squares Mean Square F Ratio

$\begin{array}{lllll}\text { Model } & 1 & 0.00006399 & 0.000064 & 2.3621\end{array}$

$\begin{array}{llllll}\text { Error } & 14 & 0.00037927 & 0.000027 & \text { Prob }>\text { F }\end{array}$

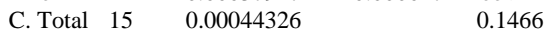

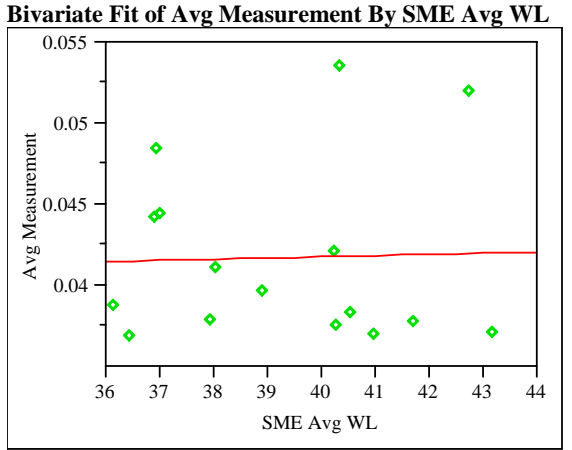

Linear Fit

Avg Measurement $=0.0387434+0.0000761$ SME Avg WL Summary of Fit

RSquare

0.001025

RSquare Adj

$-0.07033$

Root Mean Square Error $\quad 0.005624$

Mean of Response

0.041734

Observations (or Sum Wgts)

16

Analysis of Variance

Source DF Sum of Squares Mean Square F Ratio $\begin{array}{lllll}\text { Model } & 1 & 0.00000045 & 4.544 \mathrm{e}-7 & 0.0144\end{array}$ $\begin{array}{lllll}\text { Error } & 14 & 0.00044281 & 0.000032 & \text { Prob }>\text { F }\end{array}$

$\begin{array}{llll}\text { C. Total } & 15 & 0.00044326 & 0.9063\end{array}$

Prep $=$ Fusion, Sample Type $=$ SME, ICP $=M-14$, Analyte $=U$ Bivariate Fit of Avg Measurement By Blending WL

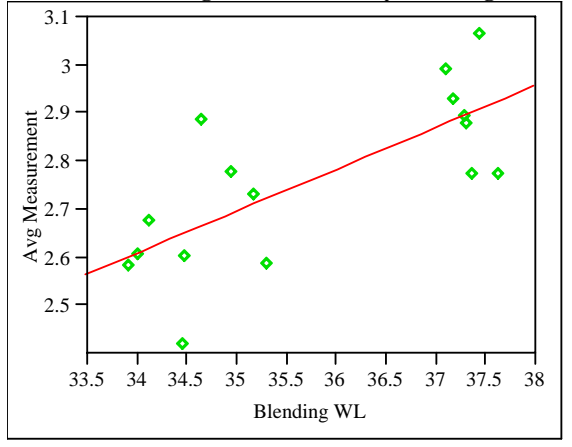

Linear Fit

Avg Measurement $=-0.364293+0.0874023$ Blending WL Summary of Fit

$\begin{array}{lr}\text { RSquare } & 0.536759 \\ \text { RSquare Adj } & 0.503671 \\ \text { Root Mean Square Error } & 0.123414 \\ \text { Mean of Response } & 2.762962 \\ \text { Observations (or Sum Wgts) } & 16\end{array}$

Observations (or Sum Wgts) $\quad 16$

Analysis of Variance

Source DF Sum of Squares Mean Square F Ratio

$\begin{array}{lllll}\text { Model } & 1 & 0.24707364 & 0.247074 & 16.2219\end{array}$

$\begin{array}{lllll}\text { Error } & 14 & 0.21323258 & 0.015231 \text { Prob }>\text { F }\end{array}$

$\begin{array}{llr}\text { C. Total } 15 & 0.46030622 & 0.0012\end{array}$ 
WSRC-STI-2006-00068

Revision 0

Exhibit A12. Relationships between Analytes and WLs by Preparation Method, ICP, and Analyte (continued)

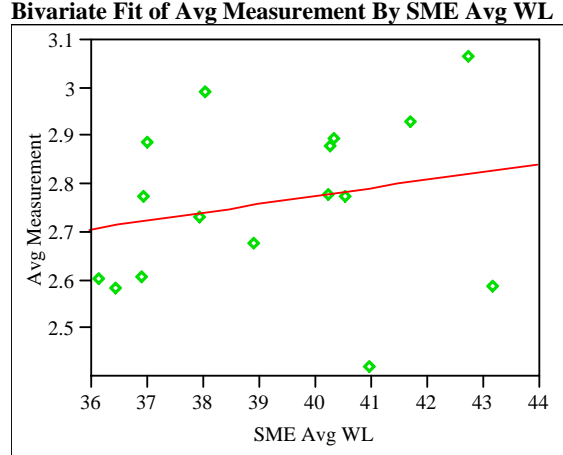

Linear Fit

Avg Measurement $=2.0944563+0.0170197$ SME Avg WL Summary of Fit

$\begin{array}{lr}\text { RSquare } & 0.049313 \\ \text { RSquare Adj } & -0.01859 \\ \text { Root Mean Square Error } & 0.176798 \\ \text { Mean of Response } & 2.762962 \\ \text { Observations (or Sum Wgts) } & 16\end{array}$

Analysis of Variance

Source DF Sum of Squares Mean Square F Ratio

$\begin{array}{lllll}\text { Model } & 1 & 0.02269917 & 0.022699 & 0.7262\end{array}$

$\begin{array}{llll}\text { Error } & 14 & 0.43760704 & 0.031258 \text { Prob }>\text { F }\end{array}$

$\begin{array}{llr}\text { C. Total } 15 & 0.46030622 & 0.4085\end{array}$

Prep $=$ Fusion, Sample Type $=$ SME, ICP $=M-14$, Analyte $=$ U/Ca Bivariate Fit of Avg Measurement By Blending WL

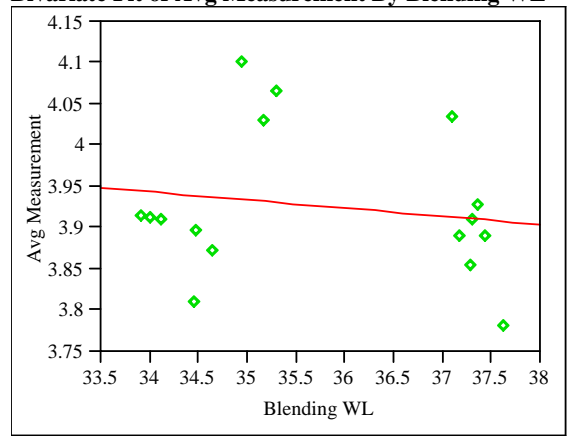

Linear Fit

Avg Measurement $=4.280371-0.0098893$ Blending WL Summary of Fit

RSquare $\quad 0.026457$

RSquare Adj $\quad-0.04308$

Root Mean Square Error $\quad 0.091179$

Mean of Response 3.926534

Observations (or Sum Wgts) 16

Analysis of Variance

Source DF Sum of Squares Mean Square F Ratio

$\begin{array}{lrrrr}\text { Model } & 1 & 0.00316306 & 0.003163 & 0.3805\end{array}$

$\begin{array}{llll}\text { Error } & 14 & 0.11639021 & 0.008314 \text { Prob }>\text { F }\end{array}$

C. Total $15 \quad 0.11955327 \quad 0.5473$

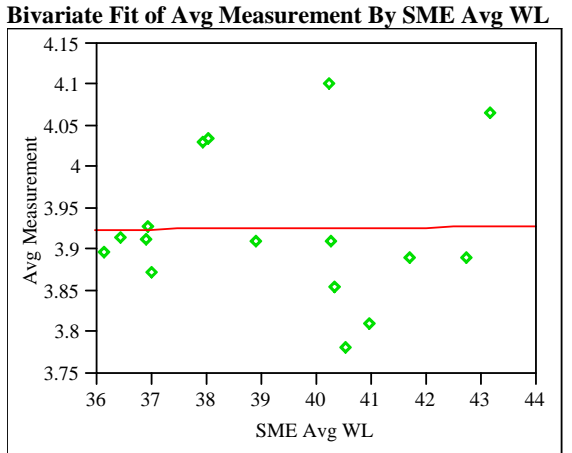

Linear Fit

Avg Measurement $=3.9092162+0.0004409$ SME Avg WL Summary of Fit

$\begin{array}{lr}\text { RSquare } & 0.000127 \\ \text { RSquare Adj } & -0.07129 \\ \text { Root Mean Square Error } & 0.092404 \\ \text { Mean of Response } & 3.926534 \\ \text { Observations (or Sum Wgts) } & 16\end{array}$

Analysis of Variance

Source DF Sum of Squares Mean Square F Ratio $\begin{array}{lllll}\text { Model } & 1 & 0.00001523 & 0.000015 & 0.0018\end{array}$

$\begin{array}{llll}\text { Error } & 14 & 0.11953804 & 0.008538 \text { Prob }>\text { F }\end{array}$

$\begin{array}{llr}\text { C. Total } 15 & 0.11955327 & 0.9669\end{array}$

Prep $=$ Fusion, Sample Type $=$ SME, ICP $=M-14$, Analyte $=Z r$ Bivariate Fit of Avg Measurement By Blending WL

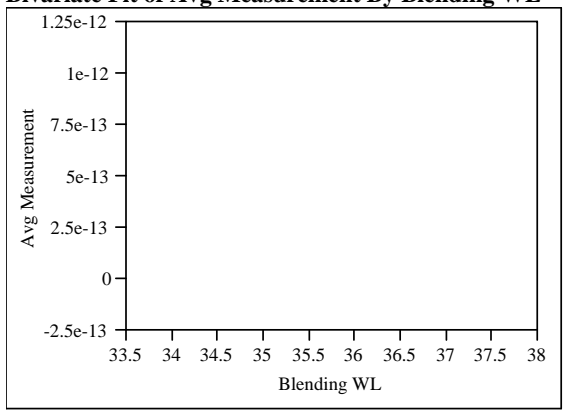

Bivariate Fit of Avg Measurement By SME Avg WL

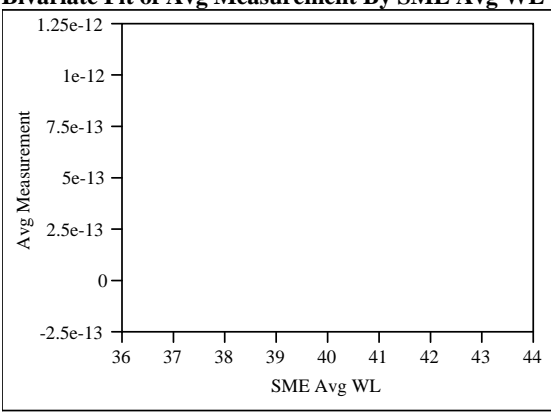


WSRC-STI-2006-00068

Revision 0

Exhibit A12. Relationships between Analytes and WLs by Preparation Method, ICP, and Analyte (continued)

Prep=Mixed Acid, Sample Type=SME, ICP=M-13, Analyte $=A \mathrm{I}$ Bivariate Fit of Avg Measurement By Blending WL

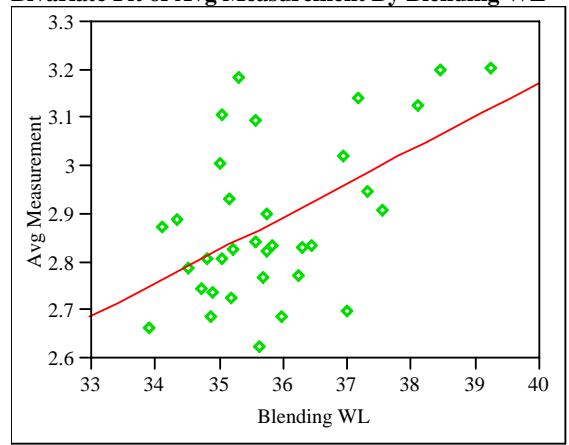

Linear Fit

Avg Measurement $=0.3945079+0.0694351$ Blending WL Summary of Fit

RSquare $\quad 0.277006$

RSquare Adj $\quad 0.254413$

Root Mean Square Error $\quad 0.143123$

Mean of Response

Observations (or Sum Wgts) $\quad 34$

Analysis of Variance

Source DF Sum of Squares Mean Square F Ratio

$\begin{array}{lllll}\text { Model } & 1 & 0.25114552 & 0.251146 & 12.2604\end{array}$

$\begin{array}{llll}\text { Error } & 32 & 0.65549685 & 0.020484 \text { Prob }>\text { F }\end{array}$

$\begin{array}{llll}\text { C. Total } 33 & 0.90664238 & 0.0014\end{array}$

Bivariate Fit of Avg Measurement By SME Avg WL

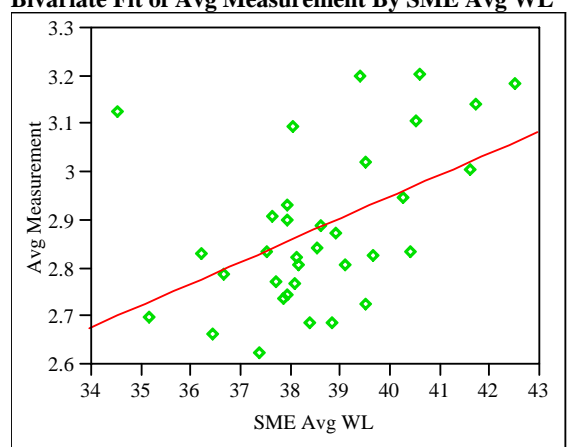

Linear Fit

Avg Measurement $=1.1364873+0.0452884$ SME Avg WL

Summary of Fit

$\begin{array}{ll}\text { RSquare } & 0.229685 \\ \text { RSquare Adj } & 0.205612 \\ \text { Root Mean Square Error } & 0.147733 \\ \text { Mean of Response } & 2.884248\end{array}$

Mean of Response 2.884248

Observations (or Sum Wgts) 34

Analysis of Variance

Source DF Sum of Squares Mean Square F Ratio

$\begin{array}{lllll}\text { Model } & 1 & 0.20824191 & 0.208242 & 9.5414\end{array}$

$\begin{array}{llll}\text { Error } & 32 & 0.69840047 & 0.021825 \text { Prob }>\text { F }\end{array}$

$\begin{array}{llr}\text { C. Total } 33 & 0.90664238 & 0.0041\end{array}$
Prep=Mixed Acid, Sample Type $=$ SME, ICP $=$ M-13, Analyte $=$ Al $/$ Ca Bivariate Fit of Avg Measurement By Blending WL

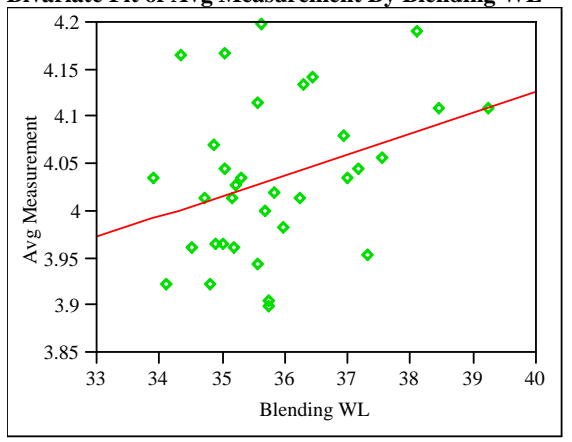

Linear Fit

Avg Measurement $=3.2413268+0.0221586$ Blending WL Summary of Fit

$\begin{array}{lr}\text { RSquare } & 0.111295 \\ \text { RSquare Adj } & 0.083523 \\ \text { Root Mean Square Error } & 0.07989 \\ \text { Mean of Response } & 4.035869 \\ \text { Observations (or Sum Wgts) } & 34\end{array}$

Analysis of Variance

Source DF Sum of Squares Mean Square F Ratio $\begin{array}{lllll}\text { Model } & 1 & 0.02557709 & 0.025577 & 4.0075\end{array}$ $\begin{array}{llll}\text { Error } & 32 & 0.20423584 & 0.006382 \text { Prob }>\text { F }\end{array}$

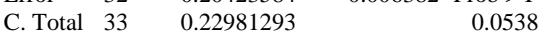

Bivariate Fit of Avg Measurement By SME Avg WL

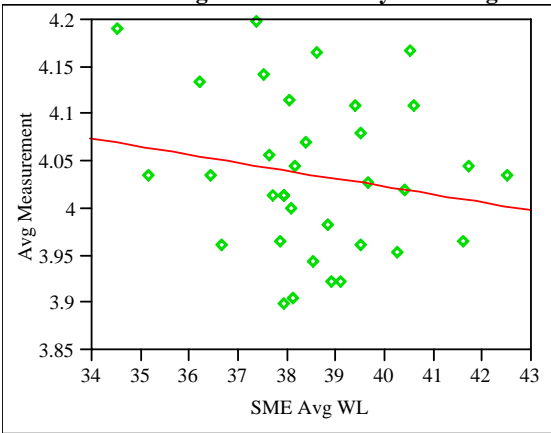

Linear Fit

Avg Measurement $=4.362395-0.008461$ SME Avg WL Summary of Fit

RSquare 0.031628

RSquare Adj

0.001366

Root Mean Square Error $\quad 0.083394$

Mean of Response 4.035869

Observations (or Sum Wgts)

34

Analysis of Variance

Source DF Sum of Squares Mean Square F Ratio

$\begin{array}{lllll}\text { Model } & 1 & 0.00726844 & 0.007268 & 1.0451\end{array}$

$\begin{array}{llll}\text { Error } & 32 & 0.22254449 & 0.006955 \text { Prob }>\text { F }\end{array}$

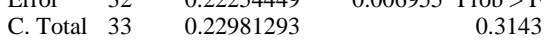


WSRC-STI-2006-00068

Revision 0

Exhibit A12. Relationships between Analytes and WLs by Preparation Method, ICP, and Analyte (continued)

Prep=Mixed Acid, Sample Type=SME, ICP=M-13, Analyte=Al $/$ Mg Bivariate Fit of Avg Measurement By Blending WL

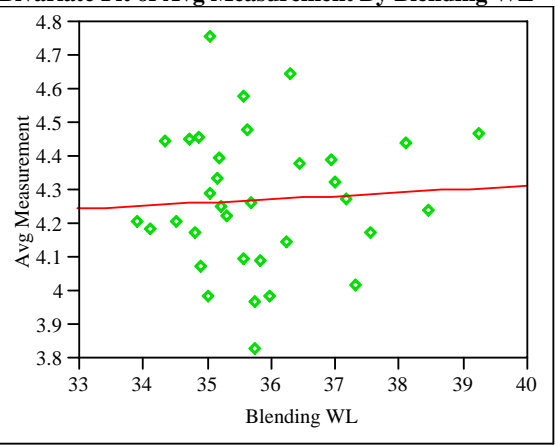

Linear Fit

Avg Measurement $=3.9221995+0.0097754$ Blending WL Summary of Fit

RSquare $\quad 0.003561$

RSquare Adj $\quad-0.02758$

Root Mean Square Error $\quad 0.208619$

Mean of Response $\quad 4.272718$

Observations (or Sum Wgts) $\quad 34$

Analysis of Variance

Source DF Sum of Squares Mean Square F Ratio

$\begin{array}{lllll}\text { Model } & 1 & 0.0049778 & 0.004978 & 0.1144\end{array}$

$\begin{array}{llll}\text { Error } & 32 & 1.3926999 & 0.043522 \text { Prob }>\text { F }\end{array}$

$\begin{array}{llll}\text { C. Total } 33 & 1.3976777 & 0.7374\end{array}$

Bivariate Fit of Avg Measurement By SME Avg WL

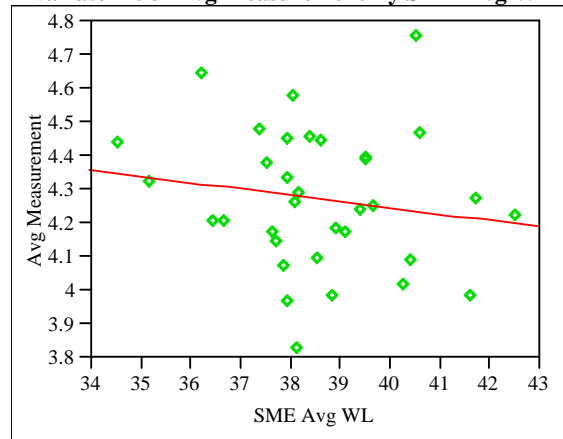

Linear Fit

Linear Fit

Avg Measurement $=4.9902462-0.0185928$ SME Avg WL

Summary of Fit

RSquare $\quad 0.025112$

RSquare Adj $\quad-0.00535$

Root Mean Square Error $\quad 0.206351$

Mean of Response 4.272718

Observations (or Sum Wgts) $\quad 34$

Analysis of Variance

Source DF Sum of Squares Mean Square F Ratio

$\begin{array}{lrrrr}\text { Model } & 1 & 0.0350980 & 0.035098 & 0.8243\end{array}$

$\begin{array}{lllll}\text { Error } & 32 & 1.3625797 & 0.042581 \text { Prob }>\text { F }\end{array}$

$\begin{array}{llll}\text { C. Total } 33 & 1.3976777 & 0.3707\end{array}$
Prep=Mixed Acid, Sample Type=SME, ICP=M-13, Analyte $=$ Al $/ M n$ Bivariate Fit of Avg Measurement By Blending WL

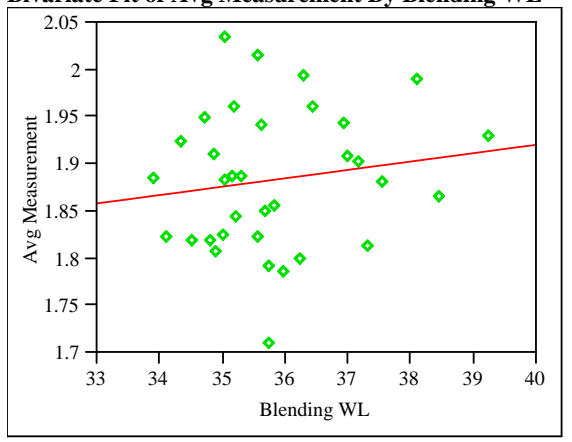

Linear Fit

Avg Measurement $=1.5565088+0.0091235$ Blending WL Summary of Fit

RSquare 0.02393

RSquare Adj

$-0.00657$

Root Mean Square Error $\quad 0.074342$

Mean of Response 1.883652

Observations (or Sum Wgts)

34

Analysis of Variance

Source DF Sum of Squares Mean Square F Ratio

$\begin{array}{lllll}\text { Model } & 1 & 0.00433605 & 0.004336 & 0.7846\end{array}$

$\begin{array}{lllll}\text { Error } & 32 & 0.17685730 & 0.005527 & \text { Prob }>\text { F }\end{array}$

$\begin{array}{llr}\text { C. Total } 33 & 0.18119335 & 0.3824\end{array}$

Bivariate Fit of Avg Measurement By SME Avg WL

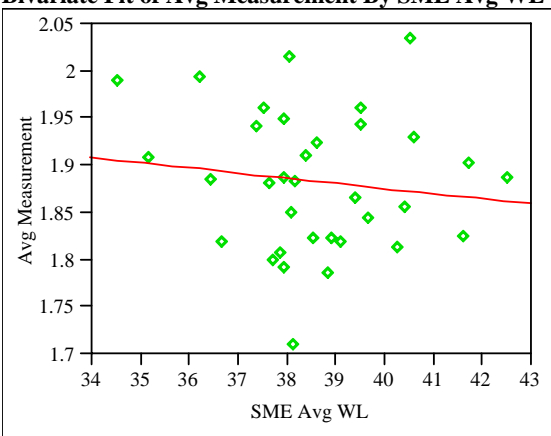

Linear Fit

Avg Measurement $=2.0936611-0.0054418$ SME Avg WL Summary of Fit

RSquare

0.016593

RSquare Adj

$-0.01414$

Root Mean Square Error $\quad 0.074621$

Mean of Response $\quad 1.883652$

Observations (or Sum Wgts) 34

Analysis of Variance

Source DF Sum of Squares Mean Square F Ratio

$\begin{array}{lllll}\text { Model } & 1 & 0.00300663 & 0.003007 & 0.5400\end{array}$

$\begin{array}{lllll}\text { Error } & 32 & 0.17818672 & 0.005568 \text { Prob }>\text { F }\end{array}$

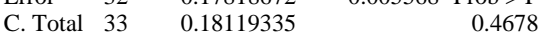


WSRC-STI-2006-00068

Revision 0

Exhibit A12. Relationships between Analytes and WLs by Preparation Method, ICP, and Analyte (continued)

Prep=Mixed Acid, Sample Type $=$ SME, ICP $=M-13$, Analyte $=B$ Bivariate Fit of Avg Measurement By Blending WL

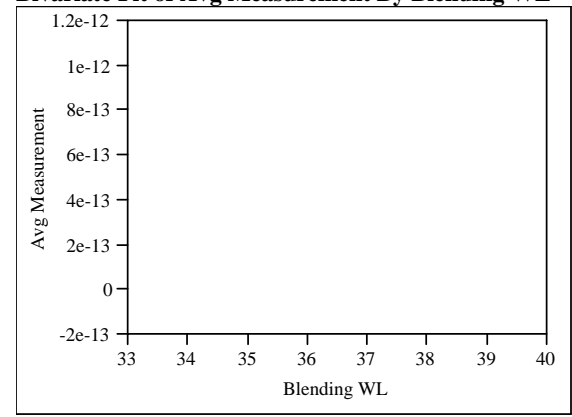

Bivariate Fit of Avg Measurement By SME Avg WL

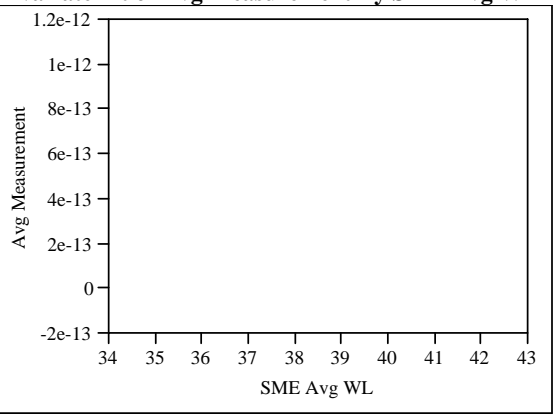

Prep=Mixed Acid, Sample Type=SME, ICP=M-13, Analyte $=\mathrm{B} / \mathrm{Li}$ Bivariate Fit of Avg Measurement By Blending WL

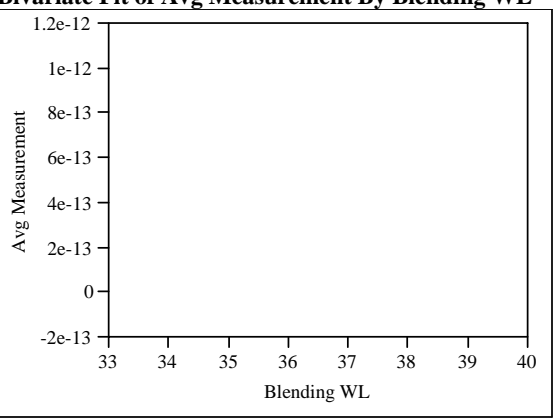

Bivariate Fit of Avg Measurement By SME Avg WL

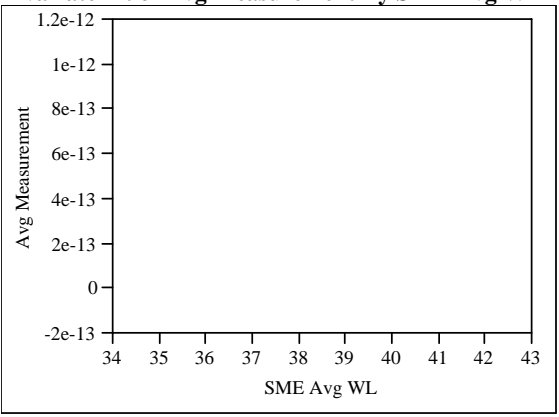

Prep $=$ Mixed Acid, Sample Type $=$ SME, ICP $=$ M-13, Analyte $=$ Ca Bivariate Fit of Avg Measurement By Blending WL

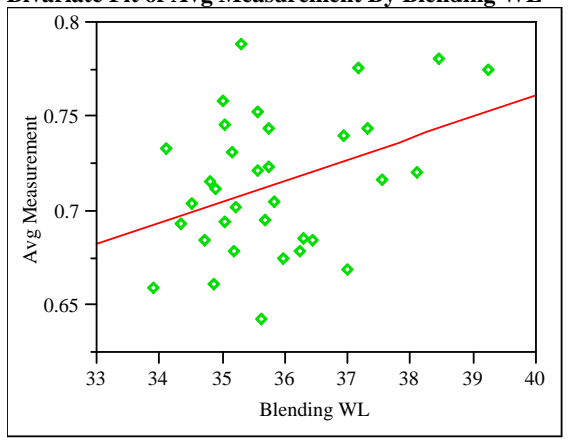

Linear Fit

Avg Measurement $=0.3104975+0.011273$ Blending WL Summary of Fit

$\begin{array}{lr}\text { RSquare } & 0.142532 \\ \text { RSquare Adj } & 0.115736 \\ \text { Root Mean Square Error } & 0.035278 \\ \text { Mean of Response } & 0.714714 \\ \text { Observations (or Sum Wgts) } & 34\end{array}$

Analysis of Variance

Source DF Sum of Squares Mean Square F Ratio

$\begin{array}{lllll}\text { Model } & 1 & 0.00661980 & 0.006620 & 5.3192\end{array}$

$\begin{array}{llll}\text { Error } & 32 & 0.03982448 & 0.001245 \text { Prob }>\text { F }\end{array}$

$\begin{array}{llll}\text { C. Total } & 33 & 0.04644429 & 0.0277\end{array}$

Bivariate Fit of Avg Measurement By SME Avg WL

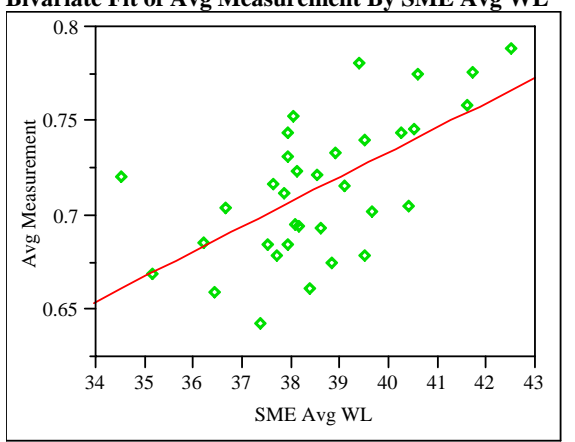

Linear Fit

Avg Measurement $=0.2054602+0.0131959$ SME Avg WL Summary of Fit

RSquare

0.380663

RSquare Adj

0.361308

Root Mean Square Error $\quad 0.029982$

Mean of Response $\quad 0.714714$

Observations (or Sum Wgts) 34

Analysis of Variance

Source DF Sum of Squares Mean Square F Ratio

$\begin{array}{lllll}\text { Model } & 1 & 0.01767960 & 0.017680 & 19.6681\end{array}$

$\begin{array}{lllll}\text { Error } & 32 & 0.02876468 & 0.000899 & \text { Prob }>\text { F }\end{array}$

$\begin{array}{llr}\text { C. Total } 33 & 0.04644429 & 0.0001\end{array}$ 
WSRC-STI-2006-00068

Revision 0

Exhibit A12. Relationships between Analytes and WLs by Preparation Method, ICP, and Analyte (continued)

Prep=Mixed Acid, Sample Type $=$ SME, ICP $=M-13$, Analyte $=\mathrm{Cr}$ Bivariate Fit of Avg Measurement By Blending WL

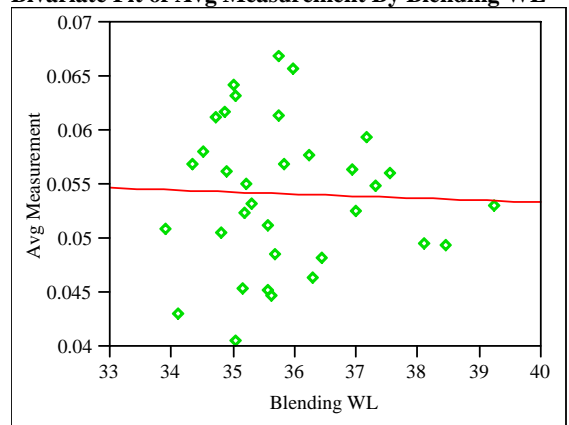

Linear Fit

Avg Measurement $=0.0608811-0.0001883$ Blending WL Summary of Fit

\begin{tabular}{lr} 
RSquare & 0.001243 \\
RSquare Adj & -0.02997 \\
Root Mean Square Error & 0.00681 \\
Mean of Response & 0.05413 \\
\hline
\end{tabular}

Observations (or Sum Wgts) $\quad 34$

Analysis of Variance

Source DF Sum of Squares Mean Square F Ratio

$\begin{array}{lllll}\text { Model } & 1 & 0.00000185 & 0.000002 & 0.0398\end{array}$

$\begin{array}{llll}\text { Error } & 32 & 0.00148400 & 0.000046 \text { Prob }>\text { F }\end{array}$

$\begin{array}{lll}\text { C. Total } 33 & 0.00148585 & 0.8431\end{array}$

Bivariate Fit of Avg Measurement By SME Avg WL

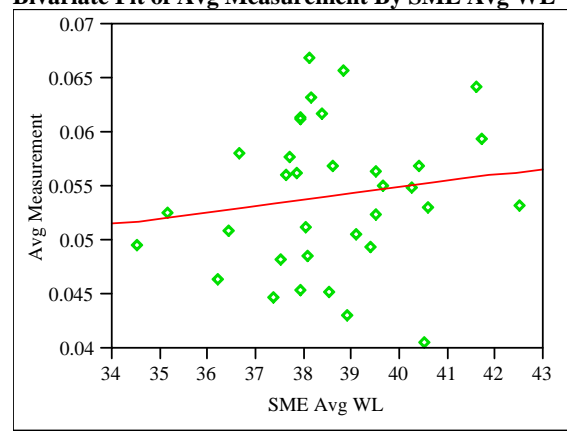

Linear Fit

Avg Measurement $=0.0320829+0.0005713$ SME Avg WL Summary of Fit

RSquare $\quad 0.022301$

RSquare Adj $\quad-0.00825$

Root Mean Square Error $\quad 0.006738$

Mean of Response 0.05413

Observations (or Sum Wgts) 34

Analysis of Variance

Source DF Sum of Squares Mean Square F Ratio

$\begin{array}{lllll}\text { Model } & 1 & 0.00003314 & 0.000033 & 0.7299\end{array}$

$\begin{array}{llll}\text { Error } & 32 & 0.00145271 & 0.000045 \text { Prob }>\text { F }\end{array}$

C. Total $33 \quad 0.00148585 \quad 0.3993$
Prep $=$ Mixed Acid, Sample Type $=$ SME, ICP $=$ M-13, Analyte $=\mathrm{Cu}$ Bivariate Fit of Avg Measurement By Blending WL

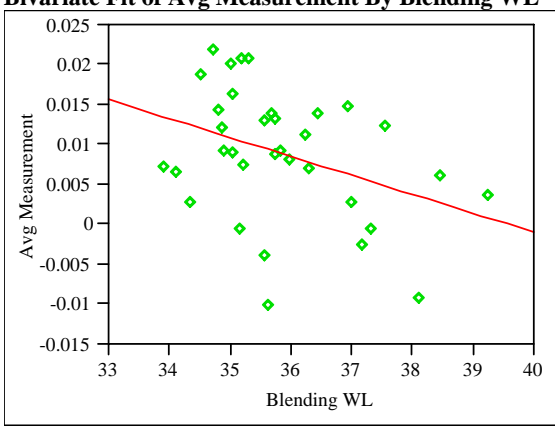

Linear Fit

Avg Measurement $=0.0939614-0.0023717$ Blending WL Summary of Fit

RSquare

0.133728

RSquare Adj

0.106657

Root Mean Square Error $\quad 0.007702$

Mean of Response

0.008919

Observations (or Sum Wgts) $\quad 34$

Analysis of Variance

Source DF Sum of Squares Mean Square F Ratio $\begin{array}{lllll}\text { Model } & 1 & 0.00029301 & 0.000293 & 4.9399\end{array}$ $\begin{array}{llll}\text { Error } & 32 & 0.00189810 & 0.000059 \text { Prob }>\text { F }\end{array}$

$\begin{array}{lll}\text { C. Total } 33 & 0.00219112 & 0.0334\end{array}$

Bivariate Fit of Avg Measurement By SME Avg WL

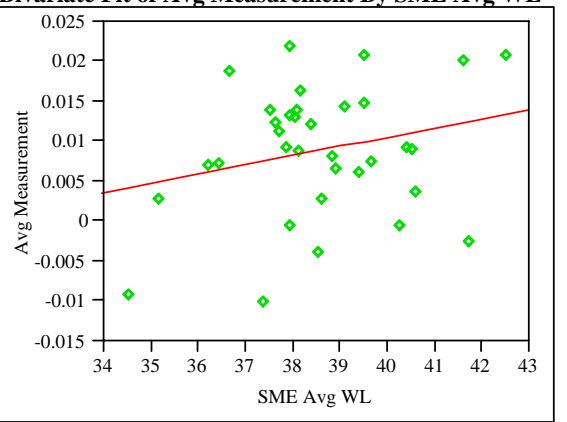

Linear Fit

Avg Measurement $=-0.035578+0.001153$ SME Avg WL Summary of Fit

RSquare

RSquare Adj

0.061603

Root Mean Squar

Mean of Response

0.008919

Analysis of Variance

Source DF Sum of Squares Mean Square F Ratio

$\begin{array}{lllll}\text { Model } & 1 & 0.00013498 & 0.000135 & 2.1007\end{array}$

$\begin{array}{llll}\text { Error } & 32 & 0.00205614 & 0.000064 \text { Prob }>\text { F }\end{array}$

$\begin{array}{llr}\text { C. Total } 33 & 0.00219112 & 0.1570\end{array}$ 
WSRC-STI-2006-00068

Revision 0

Exhibit A12. Relationships between Analytes and WLs by Preparation Method, ICP, and Analyte (continued)

Prep=Mixed Acid, Sample Type=SME, ICP=M-13, Analyte $=F e$ Bivariate Fit of Avg Measurement By Blending WL

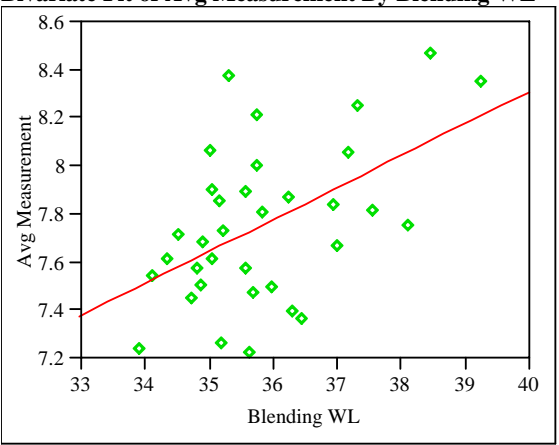

Linear Fit

Avg Measurement $=2.975339+0.1333343$ Blending WL Summary of Fit

RSquare $\quad 0.260064$

RSquare Adj $\quad 0.236941$

Root Mean Square Error $\quad 0.286951$

Mean of Response $\quad 7.756314$

Observations (or Sum Wgts) $\quad 34$

Analysis of Variance

Source DF Sum of Squares Mean Square F Ratio

$\begin{array}{lllll}\text { Model } & 1 & 0.9260844 & 0.926084 & 11.2470\end{array}$

$\begin{array}{llll}\text { Error } & 32 & 2.6349071 & 0.082341 \text { Prob }>\text { F }\end{array}$

C. Total $33 \quad 3.5609915 \quad 0.0021$

Bivariate Fit of Avg Measurement By SME Avg WL

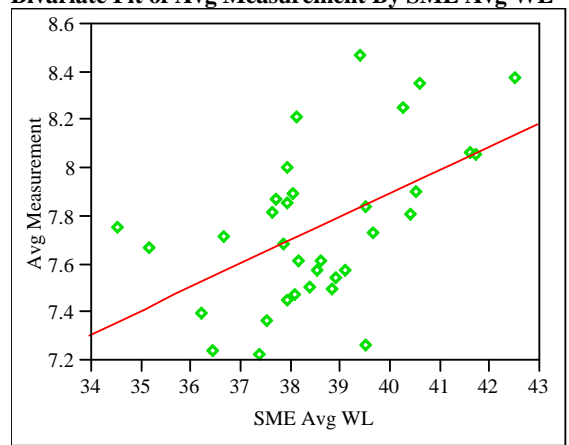

Linear Fit

Avg Measurement $=3.9822876+0.0977935$ SME Avg WL

Summary of Fit

$\begin{array}{lr}\text { RSquare } & 0.272674 \\ \text { RSquare Adj } & 0.249945 \\ \text { Root Mean Square Error } & 0.284495 \\ \text { Mean of Response } & 7.756314 \\ \text { Observations (or Sum Wgts) } & 34\end{array}$

Analysis of Variance

Source DF Sum of Squares Mean Square F Ratio

$\begin{array}{lllll}\text { Model } & 1 & 0.9709890 & 0.970989 & 11.9968\end{array}$

$\begin{array}{llll}\text { Error } & 32 & 2.5900025 & 0.080938 \text { Prob }>\text { F }\end{array}$

$\begin{array}{llr}\text { C. Total } 33 & 3.5609915 & 0.0015\end{array}$
Prep=Mixed Acid, Sample Type $=$ SME, ICP $=$ M-13, Analyte $=F e / A I$ Bivariate Fit of Avg Measurement By Blending WL

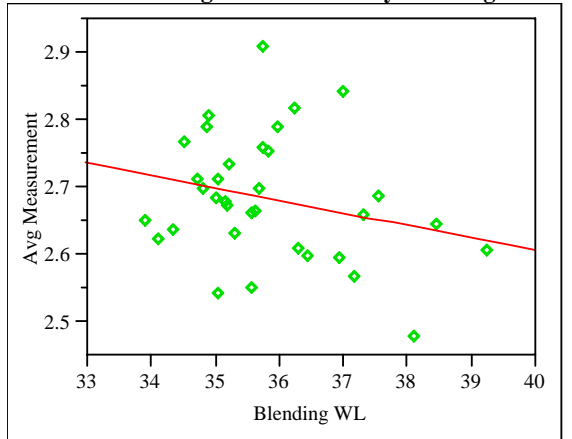

Linear Fit

Avg Measurement $=3.3502897-0.0185883$ Blending WL Summary of Fit

RSquare

0.062857

RSquare Adj

0.033571

Root Mean Square Error $\quad 0.091574$

Mean of Response

2.683768

Observations (or Sum Wgts)

34

Analysis of Variance

Source DF Sum of Squares Mean Square F Ratio

$\begin{array}{lllll}\text { Model } & 1 & 0.01799890 & 0.017999 & 2.1463\end{array}$

$\begin{array}{lllll}\text { Error } & 32 & 0.26834717 & 0.008386 & \text { Prob }>\text { F }\end{array}$

C. Total $33 \quad 0.28634607 \quad 0.1527$

Bivariate Fit of Avg Measurement By SME Avg WL

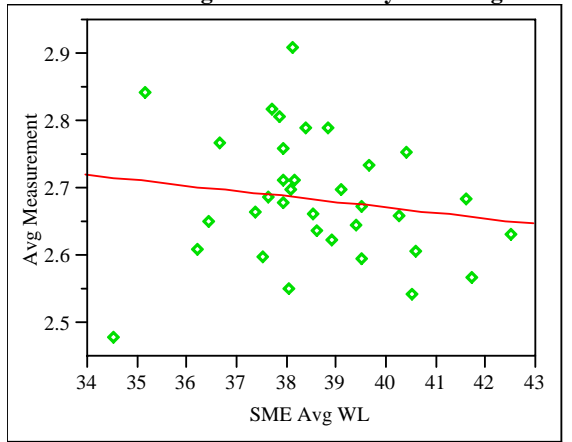

Linear Fit

Avg Measurement $=2.996464-0.0081026$ SME Avg WL Summary of Fit

$\begin{array}{lr}\text { RSquare } & 0.023279 \\ \text { RSquare Adj } & -0.00724 \\ \text { Root Mean Square Error } & 0.093488 \\ \text { Mean of Response } & 2.683768 \\ \text { Observations (or Sum Wgts) } & 34\end{array}$

Analysis of Variance

Source DF Sum of Squares Mean Square F Ratio

$\begin{array}{lllll}\text { Model } & 1 & 0.00666574 & 0.006666 & 0.7627\end{array}$

$\begin{array}{lllll}\text { Error } & 32 & 0.27968033 & 0.008740 \text { Prob }>\text { F }\end{array}$

$\begin{array}{llr}\text { C. Total } 33 & 0.28634607 & 0.3890\end{array}$ 
WSRC-STI-2006-00068

Revision 0

Exhibit A12. Relationships between Analytes and WLs by Preparation Method, ICP, and Analyte (continued)

Prep=Mixed Acid, Sample Type=SME, ICP=M-13, Analyte=Fe $/ \mathrm{Ca}$ Bivariate Fit of Avg Measurement By Blending WL

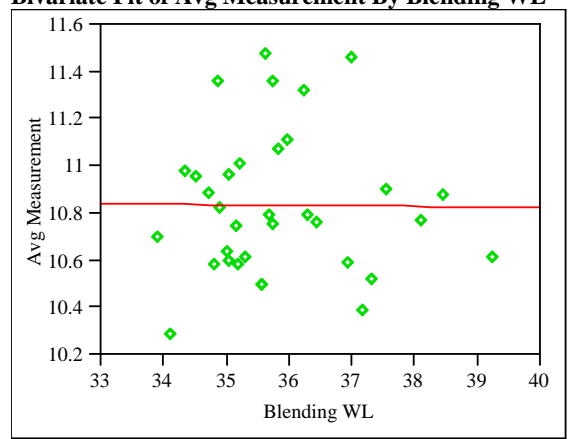

Linear Fit

Avg Measurement $=10.91126-0.0021397$ Blending WL Summary of Fit

$\begin{array}{lr}\text { RSquare } & 0.000078 \\ \text { RSquare Adj } & -0.03117 \\ \text { Root Mean Square Error } & 0.309929 \\ \text { Mean of Response } & 10.83454 \\ \text { Observations (or Sum Wgts) } & 34\end{array}$

Analysis of Variance

Source DF Sum of Squares Mean Square F Ratio

$\begin{array}{lllll}\text { Model } & 1 & 0.0002385 & 0.000238 & 0.0025\end{array}$

$\begin{array}{llll}\text { Error } & 32 & 3.0737917 & 0.096056 \text { Prob }>\text { F }\end{array}$

C. Total $33 \quad 3.0740302 \quad 0.9606$

Bivariate Fit of Avg Measurement By SME Avg WL

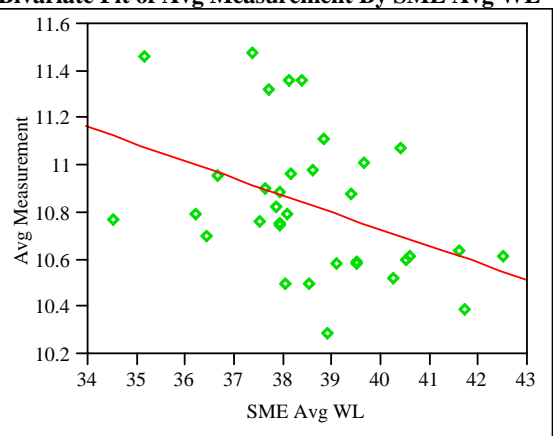

Linear Fit

Avg Measurement $=13.630497-0.0724496$ SME Avg WL

Summary of Fit

$\begin{array}{lr}\text { RSquare } & 0.173364 \\ \text { RSquare Adj } & 0.147531 \\ \text { Root Mean Square Error } & 0.281797 \\ \text { Mean of Response } & 10.83454 \\ \text { Observations (or Sum Wgts) } & 34\end{array}$

Analysis of Variance

Source DF Sum of Squares Mean Square F Ratio

$\begin{array}{lllll}\text { Model } & 1 & 0.5329253 & 0.532925 & 6.7111\end{array}$

$\begin{array}{llll}\text { Error } & 32 & 2.5411049 & 0.079410 \text { Prob }>\text { F }\end{array}$

$\begin{array}{lll}\text { C. Total } 33 & 3.0740302 & 0.0143\end{array}$
Prep=Mixed Acid, Sample Type $=$ SME, ICP $=$ M-13, Analyte $=\mathrm{Fe} / \mathrm{Li}$ Bivariate Fit of Avg Measurement By Blending WL

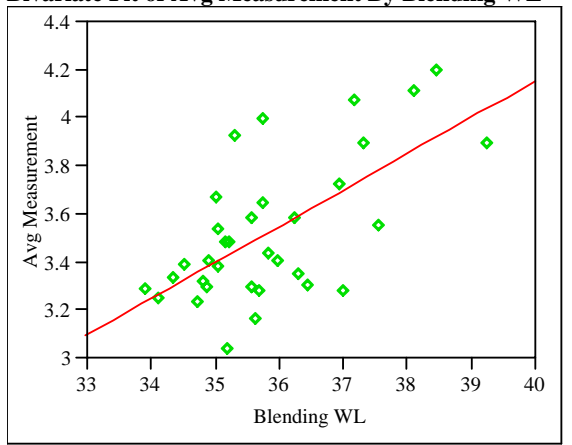

Linear Fit

Avg Measurement $=-1.904023+0.1514666$ Blending $\mathrm{WL}$ Summary of Fit

RSquare

0.414337

RSquare Adj

0.396035

Root Mean Square Error $\quad 0.229759$

Mean of Response

3.527124

Observations (or Sum Wgts) $\quad 34$

Analysis of Variance

Source DF Sum of Squares Mean Square F Ratio

$\begin{array}{lllll}\text { Model } & 1 & 1.1950904 & 1.19509 & 22.6390\end{array}$

$\begin{array}{llll}\text { Error } & 32 & 1.6892507 & 0.05279 \text { Prob }>\text { F }\end{array}$

C. Total $33 \quad 2.8843411<.0001$

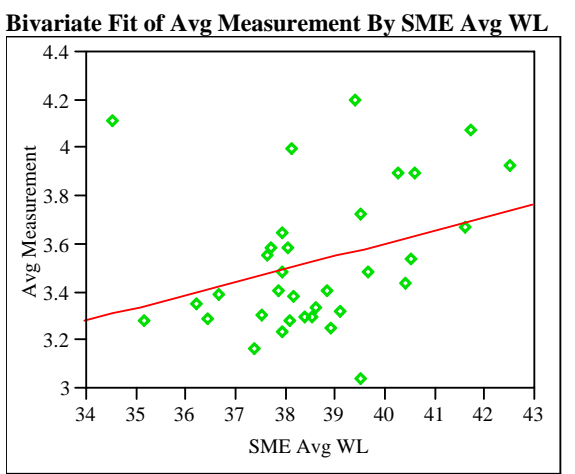

Linear Fit

Avg Measurement $=1.4602954+0.0535562$ SME Avg WL

Summary of Fit

$\begin{array}{lr}\text { RSquare } & 0.100964 \\ \text { RSquare Adj } & 0.072869 \\ \text { Root Mean Square Error } & 0.284667 \\ \text { Mean of Response } & 3.527124 \\ \text { Observations (or Sum Wgts) } & 34\end{array}$

Analysis of Variance

Source DF Sum of Squares Mean Square F Ratio

$\begin{array}{lllll}\text { Model } & 1 & 0.2912149 & 0.291215 & 3.5937\end{array}$

$\begin{array}{llll}\text { Error } & 32 & 2.5931262 & 0.081035 \text { Prob }>\text { F }\end{array}$

$\begin{array}{llr}\text { C. Total } 33 & 2.8843411 & 0.0671\end{array}$ 
WSRC-STI-2006-00068

Revision 0

Exhibit A12. Relationships between Analytes and WLs by Preparation Method, ICP, and Analyte (continued)

Prep=Mixed Acid, Sample Type=SME, ICP=M-13, Analyte=Fe/Mg Bivariate Fit of Avg Measurement By Blending WL

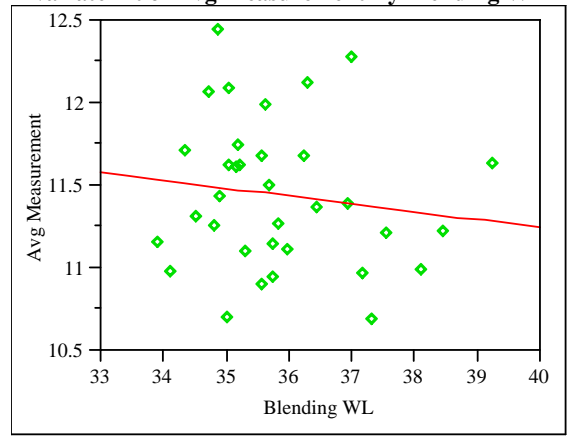

Linear Fit

Avg Measurement = $13.154403-0.0476611$ Blending WL Summary of Fit

$\begin{array}{lr}\text { RSquare } & 0.017971 \\ \text { RSquare Adj } & -0.01272 \\ \text { Root Mean Square Error } & 0.44952 \\ \text { Mean of Response } & 11.44542 \\ \text { Observations (or Sum Wgts) } & 34\end{array}$

Analysis of Variance

Source DF Sum of Squares Mean Square F Ratio

$\begin{array}{lllll}\text { Model } & 1 & 0.1183299 & 0.118330 & 0.5856\end{array}$

$\begin{array}{llll}\text { Error } & 32 & 6.4661741 \quad 0.202068 \text { Prob }>\text { F }\end{array}$

$\begin{array}{llr}\text { C. Total } 33 & 6.5845040 & 0.4497\end{array}$

Bivariate Fit of Avg Measurement By SME Avg WL

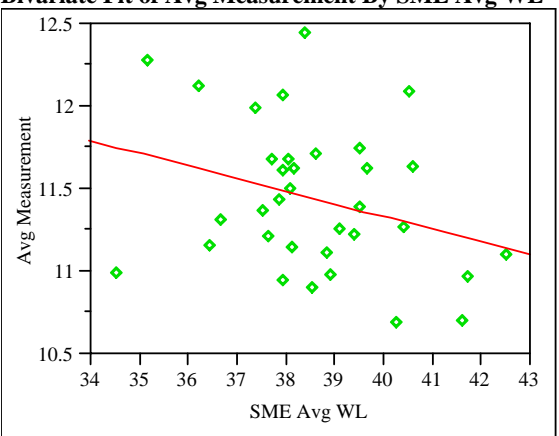

Linear Fit

Avg Measurement $=14.411276-0.076852$ SME Avg WL

Summary of Fit

RSquare

RSquare Adj

0.091071

Root Mean Square Error $\quad 0.432465$

Mean of Response $\quad 11.44542$

Observations (or Sum Wgts)

34

Analysis of Variance

Source DF Sum of Squares Mean Square F Ratio

Model $\quad \begin{array}{llll}1 & 0.5996604 & 0.599660 & 3.2063\end{array}$

$\begin{array}{llll}\text { Error } & 32 & 5.9848435 & 0.187026 \text { Prob }>\text { F }\end{array}$

$\begin{array}{llr}\text { C. Total } 33 & 6.5845040 & 0.0828\end{array}$
Prep=Mixed Acid, Sample Type=SME, ICP=M-13, Analyte $=\mathrm{Fe} / \mathrm{Mn}$ Bivariate Fit of Avg Measurement By Blending WL

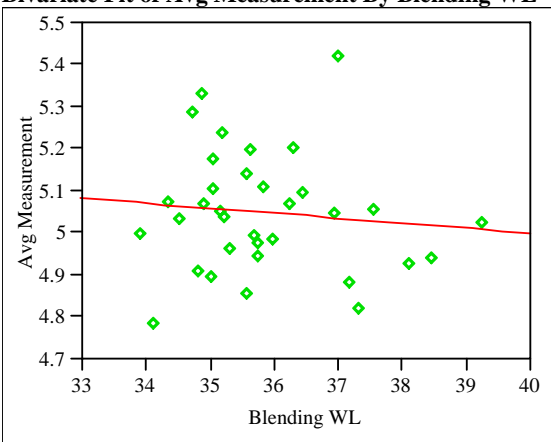

Linear Fit

Avg Measurement $=5.4723457-0.011771$ Blending WL Summary of Fit

RSquare

0.010515

RSquare Adj

$-0.02041$

Root Mean Square Error $\quad 0.145687$

Mean of Response

5.050272

Observations (or Sum Wgts) $\quad 34$

Analysis of Variance

Source DF Sum of Squares Mean Square F Ratio

$\begin{array}{lllll}\text { Model } & 1 & 0.00721763 & 0.007218 & 0.3401\end{array}$

$\begin{array}{llll}\text { Error } & 32 & 0.67919509 & 0.021225 \text { Prob }>\text { F }\end{array}$

$\begin{array}{llll}\text { C. Total } 33 & 0.68641272 & 0.5639\end{array}$

Bivariate Fit of Avg Measurement By SME Avg WL

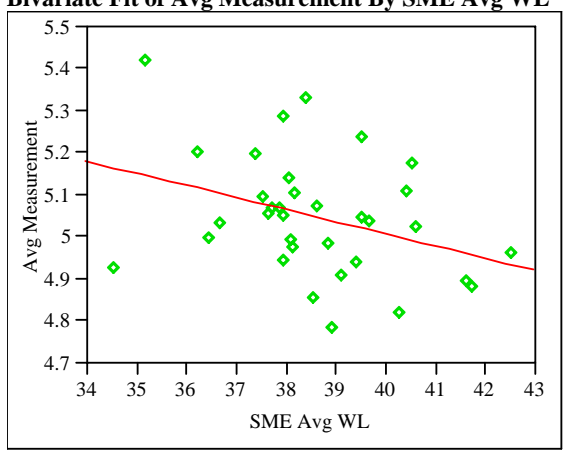

Linear Fit

Avg Measurement $=6.1646163-0.0288752$ SME Avg WL

Summary of Fit

$\begin{array}{lr}\text { RSquare } & 0.123327 \\ \text { RSquare Adj } & 0.095931 \\ \text { Root Mean Square Error } & 0.137131 \\ \text { Mean of Response } & 5.050272 \\ \text { Observations (or Sum Wgts) } & 34\end{array}$

Analysis of Variance

Source DF Sum of Squares Mean Square F Ratio

$\begin{array}{lllll}\text { Model } & 1 & 0.08465319 & 0.084653 & 4.5016\end{array}$

$\begin{array}{llll}\text { Error } & 32 & 0.60175953 & 0.018805 \text { Prob }>\text { F }\end{array}$

$\begin{array}{llr}\text { C. Total } 33 & 0.68641272 & 0.0417\end{array}$ 
WSRC-STI-2006-00068

Revision 0

Exhibit A12. Relationships between Analytes and WLs by Preparation Method, ICP, and Analyte (continued)

Prep=Mixed Acid, Sample Type=SME, ICP=M-13, Analyte=Fe $/ \mathrm{Ni}$ Bivariate Fit of Avg Measurement By Blending WL

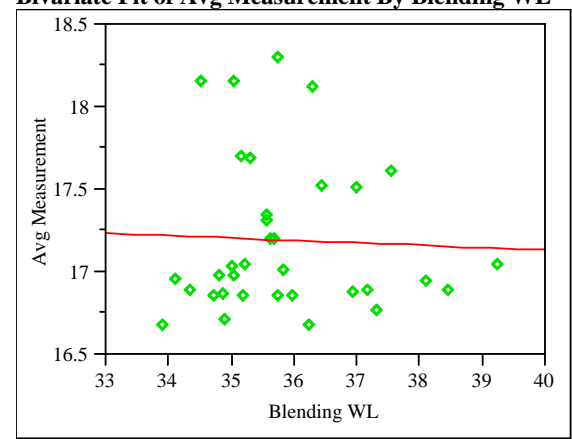

Linear Fit

Avg Measurement $=17.710825-0.0143635$ Blending WL Summary of Fit

$\begin{array}{lr}\text { RSquare } & 0.001523 \\ \text { RSquare Adj } & -0.02968 \\ \text { Root Mean Square Error } & 0.469196 \\ \text { Mean of Response } & 17.19579 \\ \text { Observations (or Sum Wgts) } & 34\end{array}$

Analysis of Variance

Source DF Sum of Squares Mean Square F Ratio

$\begin{array}{lllll}\text { Model } & 1 & 0.0107470 & 0.010747 & 0.0488\end{array}$

$\begin{array}{llll}\text { Error } & 32 & 7.0446373 \quad 0.220145 \text { Prob }>\text { F }\end{array}$

C. Total $33 \quad 7.0553844 \quad 0.8265$

Bivariate Fit of Avg Measurement By SME Avg WL

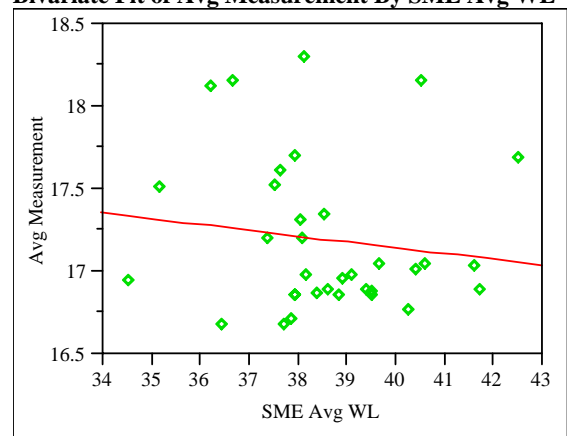

Linear Fit

Avg Measurement $=18.553323-0.0351767$ SME Avg WL

Summary of Fit

$\begin{array}{lr}\text { RSquare } & 0.017807 \\ \text { RSquare Adj } & -0.01289 \\ \text { Root Mean Square Error } & 0.465354 \\ \text { Mean of Response } & 17.19579 \\ \text { Observations (or Sum Wgts) } & 34\end{array}$

Analysis of Variance

Source DF Sum of Squares Mean Square F Ratio

$\begin{array}{lllll}\text { Model } & 1 & 0.1256333 & 0.125633 & 0.5801\end{array}$

$\begin{array}{llll}\text { Error } & 32 & 6.9297511 & 0.216555 \text { Prob }>\text { F }\end{array}$

$\begin{array}{llr}\text { C. Total } 33 & 7.0553844 & 0.4518\end{array}$
Prep=Mixed Acid, Sample Type $=$ SME, ICP $=M-13$, Analyte $=F e / U$ Bivariate Fit of Avg Measurement By Blending WL

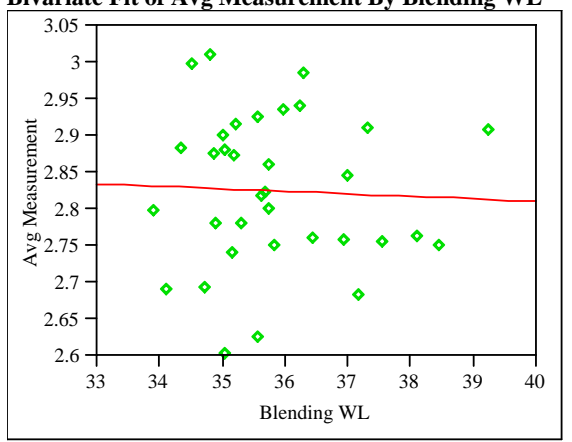

Linear Fit

Avg Measurement $=2.9490163-0.0034607$ Blending WL Summary of Fit

$\begin{array}{lr}\text { RSquare } & 0.001764 \\ \text { RSquare Adj } & -0.02943 \\ \text { Root Mean Square Error } & 0.105022 \\ \text { Mean of Response } & 2.824926 \\ \text { Observations (or Sum Wgts) } & 34\end{array}$

34

\section{Analysis of Variance}

Source DF Sum of Squares Mean Square F Ratio

$\begin{array}{lllll}\text { Model } & 1 & 0.00062387 & 0.000624 & 0.0566\end{array}$

$\begin{array}{llll}\text { Error } & 32 & 0.35294478 & 0.011030 \text { Prob }>\text { F }\end{array}$

$\begin{array}{llrr}\text { C. Total } & 33 & 0.35356865 & 0.011030 \\ \end{array}$

Bivariate Fit of Avg Measurement By SME Avg WL

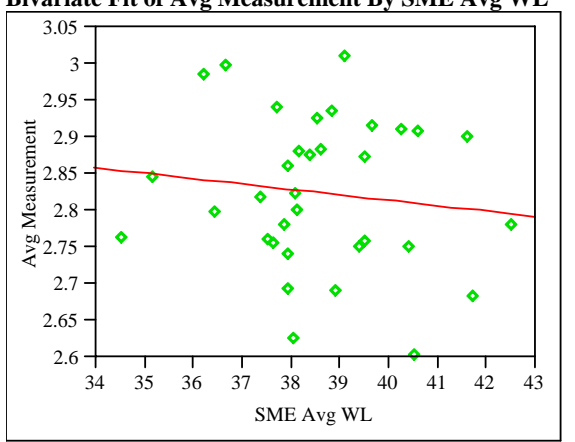

Linear Fit

Avg Measurement $=3.1088318-0.0073566$ SME Avg WL Summary of Fit

RSquare

0.015541

RSquare Adj

$-0.01522$

Root Mean Square Error $\quad 0.104294$

Mean of Response 2.824926

Observations (or Sum Wgts)

34

Analysis of Variance

Source DF Sum of Squares Mean Square F Ratio

$\begin{array}{lllll}\text { Model } & 1 & 0.00549481 & 0.005495 & 0.5052\end{array}$

$\begin{array}{lllll}\text { Error } & 32 & 0.34807384 & 0.010877 \text { Prob }>\text { F }\end{array}$

$\begin{array}{llll}\text { C. Total } & 33 & 0.35356865 & 0.4824\end{array}$ 
WSRC-STI-2006-00068

Revision 0

Exhibit A12. Relationships between Analytes and WLs by Preparation Method, ICP, and Analyte (continued)

Prep=Mixed Acid, Sample Type=SME, ICP=M-13, Analyte $=K$ Bivariate Fit of Avg Measurement By Blending WL

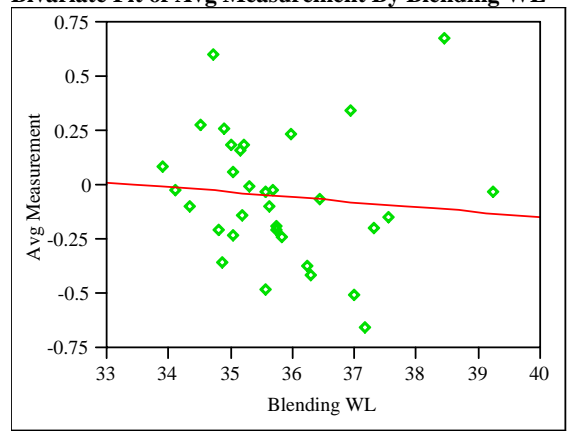

Linear Fit

Avg Measurement $=0.7836713-0.0232519$ Blending WL

Summary of Fit

$\begin{array}{lr}\text { RSquare } & 0.008876 \\ \text { RSquare Adj } & -0.0231 \\ \text { Root Mean Square Error } & 0.301948 \\ \text { Mean of Response } & -0.04848\end{array}$

Observations (or Sum Wgts) $\quad 33$

Analysis of Variance

Source DF Sum of Squares Mean Square F Ratio

$\begin{array}{lllll}\text { Model } & 1 & 0.0253108 & 0.025311 & 0.2776\end{array}$

$\begin{array}{llll}\text { Error } & 31 & 2.8263592 & 0.091173 \text { Prob }>\text { F }\end{array}$

$\begin{array}{llr}\text { C. Total } 32 & 2.8516700 & 0.6020\end{array}$

Bivariate Fit of Avg Measurement By SME Avg WL

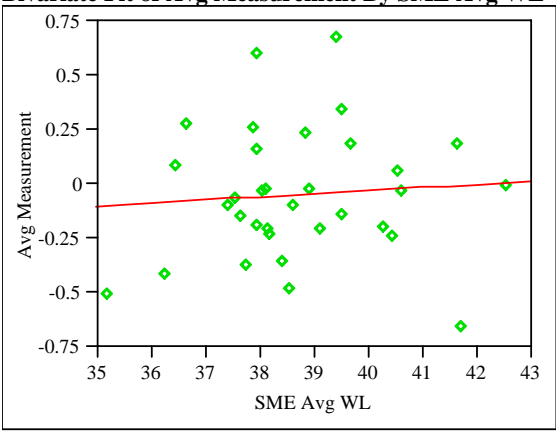

Linear Fit

Avg Measurement $=-0.588173+0.0139404$ SME Avg WL

Summary of Fit

RSquare $\quad 0.005769$

RSquare Adj $\quad-0.0263$

Root Mean Square Error $\quad 0.302421$

Mean of Response $\quad-0.04848$

Observations (or Sum Wgts) $\quad 33$

Analysis of Variance

Source DF Sum of Squares Mean Square F Ratio

$\begin{array}{lllll}\text { Model } & 1 & 0.0164513 & 0.016451 & 0.1799\end{array}$

$\begin{array}{llll}\text { Error } & 31 & 2.8352187 & 0.091459 \text { Prob }>\text { F }\end{array}$

C. Total $32 \quad 2.8516700 \quad 0.6744$
Prep=Mixed Acid, Sample Type=SME, ICP=M-13, Analyte $=\mathrm{Li}$ Bivariate Fit of Avg Measurement By Blending WL

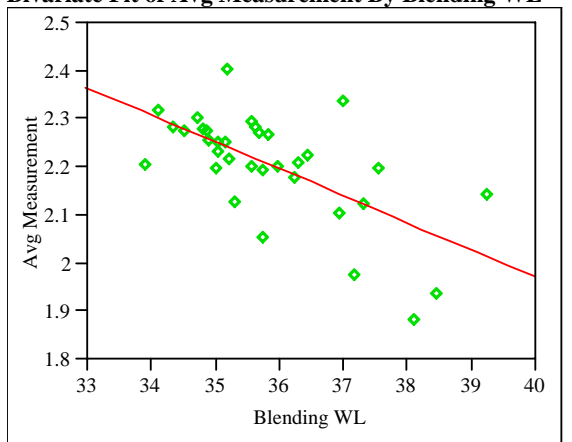

Linear Fit

Avg Measurement $=4.2214671-0.0562135$ Blending WL Summary of Fit

RSquare

RSquare Adj $\quad 0.385519$

Root Mean Square Error $\quad 0.087087$

Mean of Response $\quad 2.205817$

Observations (or Sum Wgts) $\quad 34$

Analysis of Variance

Source DF Sum of Squares Mean Square F Ratio

$\begin{array}{llllll}\text { Model } & 1 & 0.16460689 & 0.164607 & 21.7039\end{array}$

$\begin{array}{llll}\text { Error } & 32 & 0.24269488 & 0.007584 \text { Prob }>\text { F }\end{array}$

$\begin{array}{llll}\text { C. Total } 33 & 0.40730177<.0001\end{array}$

Bivariate Fit of Avg Measurement By SME Avg WL

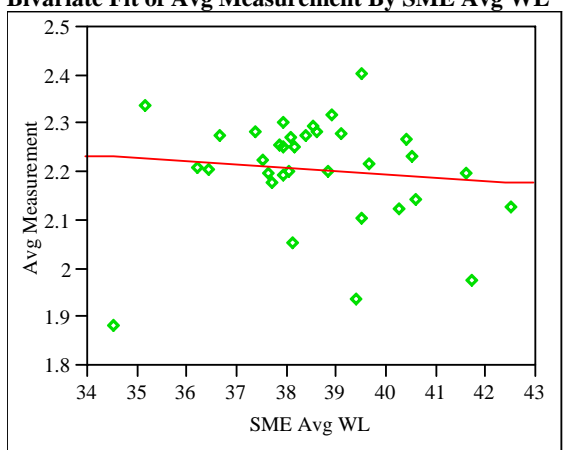

Linear Fit

Avg Measurement $=2.4545556-0.0064454$ SME Avg WL

Summary of Fit

\begin{tabular}{|c|c|c|c|c|}
\hline \multicolumn{3}{|c|}{ RSquare } & \multicolumn{2}{|l|}{0.010356} \\
\hline \multicolumn{3}{|c|}{ RSquare Adj } & -0.02057 & \\
\hline \multicolumn{3}{|c|}{ Root Mean Square Error } & 0.112234 & \\
\hline \multicolumn{3}{|c|}{ Mean of Response } & 2.205817 & \\
\hline \multicolumn{3}{|c|}{ Observations (or Sum Wgts) } & 34 & \\
\hline \multicolumn{5}{|c|}{ Analysis of Variance } \\
\hline Source & $\mathrm{DF} S$ & Sum of Squares & Mean Square & F Ratio \\
\hline Model & 1 & 0.00421786 & 0.004218 & 0.3348 \\
\hline Error & 32 & 0.40308391 & 0.012596 & Prob $>$ F \\
\hline C. Total & 33 & 0.40730177 & & 0.5669 \\
\hline
\end{tabular}


WSRC-STI-2006-00068

Revision 0

Exhibit A12. Relationships between Analytes and WLs by Preparation Method, ICP, and Analyte (continued)

Prep=Mixed Acid, Sample Type $=$ SME, ICP=M-13, Analyte $=M g$ Bivariate Fit of Avg Measurement By Blending WL

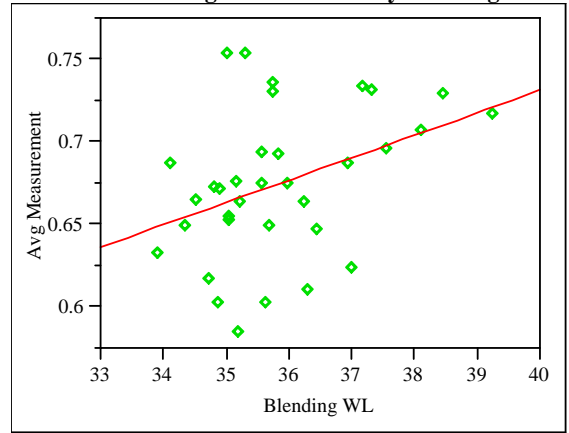

Linear Fit

Avg Measurement $=0.1879206+0.0135943$ Blending WL Summary of Fit

$\begin{array}{lr}\text { RSquare } & 0.144182 \\ \text { RSquare Adj } & 0.117438 \\ \text { Root Mean Square Error } & 0.042257 \\ \text { Mean of Response } & 0.675371 \\ \text { Observations (or Sum Wgts) } & 34\end{array}$

Analysis of Variance

Source DF Sum of Squares Mean Square F Ratio

$\begin{array}{lllll}\text { Model } & 1 & 0.00962673 & 0.009627 & 5.3911\end{array}$

$\begin{array}{llll}\text { Error } & 32 & 0.05714109 & 0.001786 \text { Prob }>\text { F }\end{array}$

$\begin{array}{lll}\text { C. Total } 33 & 0.06676781 & 0.0268\end{array}$

Bivariate Fit of Avg Measurement By SME Avg WL

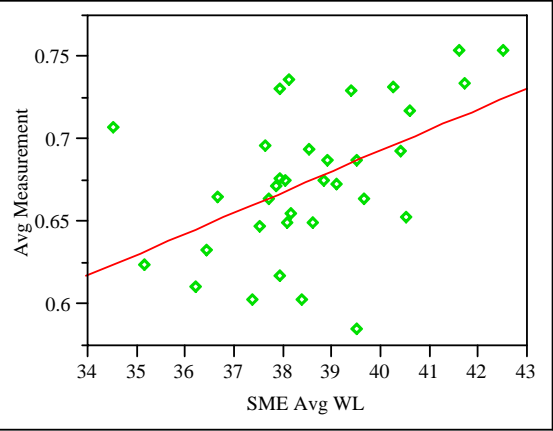

Linear Fit

Avg Measurement $=0.1872001+0.0126496$ SME Avg WL

Summary of Fit

$\begin{array}{lr}\text { RSquare } & 0.243322 \\ \text { RSquare Adj } & 0.219676 \\ \text { Root Mean Square Error } & 0.039734 \\ \text { Mean of Response } & 0.675371 \\ \text { Observations (or Sum Wgts) } & 34\end{array}$

Analysis of Variance

Source DF Sum of Squares Mean Square F Ratio

$\begin{array}{lllll}\text { Model } & 1 & 0.01624607 & 0.016246 & 10.2901\end{array}$

$\begin{array}{llll}\text { Error } & 32 & 0.05052174 & 0.001579 \text { Prob }>\text { F }\end{array}$

$\begin{array}{lll}\text { C. Total } 33 & 0.06676781 & 0.0030\end{array}$

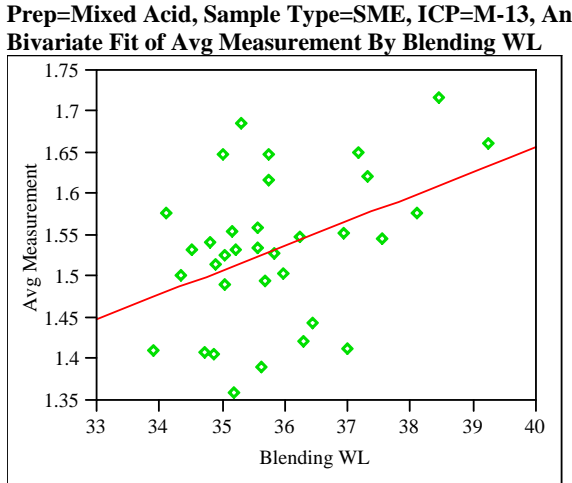

Linear Fit

Avg Measurement $=0.4662863+0.0297718$ Blending WL Summary of Fit

$\begin{array}{lr}\text { RSquare } & 0.169232 \\ \text { RSquare Adj } & 0.143271 \\ \text { Root Mean Square Error } & 0.084161 \\ \text { Mean of Response } & 1.533814 \\ \text { Observations (or Sum Wgts) } & 34\end{array}$

Analysis of Variance

Source DF Sum of Squares Mean Square F Ratio

$\begin{array}{lllll}\text { Model } & 1 & 0.04617168 & 0.046172 & 6.5186\end{array}$

$\begin{array}{lllll}\text { Error } & 32 & 0.22665864 & 0.007083 \text { Prob }>\text { F }\end{array}$

$\begin{array}{llr}\text { C. Total } 33 & 0.27283032 & 0.0156\end{array}$

Bivariate Fit of Avg Measurement By SME Avg WL

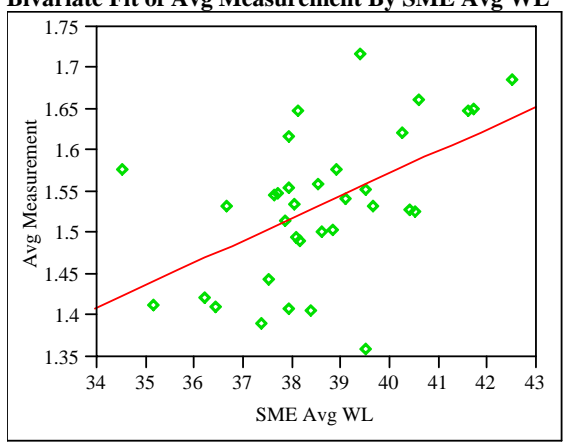

Linear Fit

Avg Measurement $=0.4869847+0.0271257$ SME Avg WL

Summary of Fit

RSquare

0.273819

RSquare Adj

0.251126

Root Mean Square Error $\quad 0.078685$

Mean of Response $\quad 1.533814$

Observations (or Sum Wgts)

34

Analysis of Variance

Source DF Sum of Squares Mean Square F Ratio

$\begin{array}{lllll}\text { Model } & 1 & 0.07470608 & 0.074706 & 12.0661\end{array}$

$\begin{array}{llll}\text { Error } & 32 & 0.19812424 & 0.006191 \text { Prob }>\text { F }\end{array}$

$\begin{array}{llr}\text { C. Total } 33 & 0.27283032 & 0.0015\end{array}$ 
WSRC-STI-2006-00068

Revision 0

Exhibit A12. Relationships between Analytes and WLs by Preparation Method, ICP, and Analyte (continued)

Prep=Mixed Acid, Sample Type $=$ SME, ICP $=M-13$, Analyte $=M n / M g$ Bivariate Fit of Avg Measurement By Blending WL

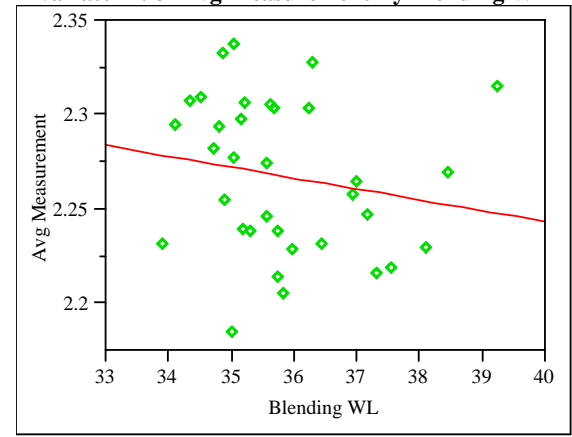

Linear Fit

Avg Measurement $=2.4750801-0.0057894$ Blending WL Summary of Fit

$\begin{array}{lr}\text { RSquare } & 0.032193 \\ \text { RSquare Adj } & 0.001949 \\ \text { Root Mean Square Error } & 0.0405 \\ \text { Mean of Response } & 2.267491 \\ \text { Observations (or Sum Wgts) } & 34\end{array}$

Analysis of Variance

Source DF Sum of Squares Mean Square F Ratio

$\begin{array}{lllll}\text { Model } & 1 & 0.00174593 & 0.001746 & 1.0644\end{array}$

$\begin{array}{llll}\text { Error } & 32 & 0.05248789 & 0.001640 \text { Prob }>\text { F }\end{array}$

C. Total $33 \quad 0.05423382 \quad 0.3099$

Bivariate Fit of Avg Measurement By SME Avg WL

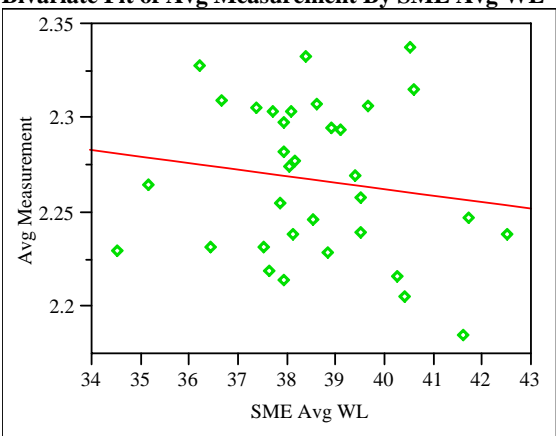

Linear Fit

Avg Measurement $=2.4028027-0.0035062$ SME Avg WL

Summary of Fit

$\begin{array}{lr}\text { RSquare } & 0.023015 \\ \text { RSquare Adj } & -0.00752 \\ \text { Root Mean Square Error } & 0.040692 \\ \text { Mean of Response } & 2.267491 \\ \text { Observations (or Sum Wgts) } & 34\end{array}$

Analysis of Variance

Source DF Sum of Squares Mean Square F Ratio

$\begin{array}{lllll}\text { Model } & 1 & 0.00124818 & 0.001248 & 0.7538\end{array}$

$\begin{array}{llll}\text { Error } & 32 & 0.05298564 & 0.001656 \text { Prob }>\text { F }\end{array}$

$\begin{array}{lll}\text { C. Total } 33 & 0.05423382 & 0.3917\end{array}$
Prep=Mixed Acid, Sample Type=SME, ICP $=$ M-13, Analyte $=\mathrm{Na}$ Bivariate Fit of Avg Measurement By Blending WL

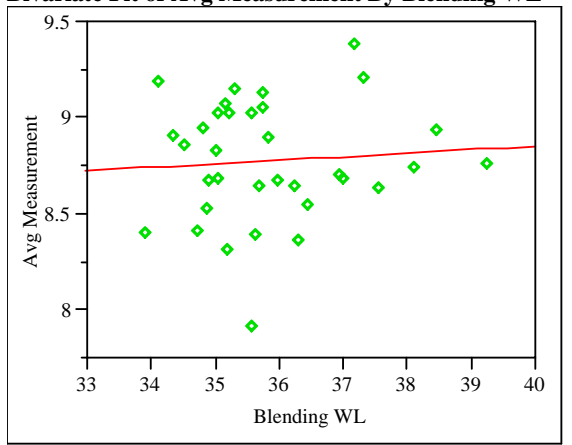

Linear Fit

Avg Measurement $=8.1167453+0.0184658$ Blending $\mathrm{WL}$ Summary of Fit

RSquare

0.005544

RSquare Adj

$-0.02553$

Root Mean Square Error $\quad 0.315547$

Mean of Response

8.778875

Observations (or Sum Wgts) $\quad 34$

Analysis of Variance

Source DF Sum of Squares Mean Square F Ratio

$\begin{array}{lllll}\text { Model } & 1 & 0.0177625 & 0.017763 & 0.1784\end{array}$

$\begin{array}{llll}\text { Error } & 32 & 3.1862464 & 0.099570 \text { Prob }>\text { F }\end{array}$

$\begin{array}{lll}\text { C. Total } 33 & 3.2040089 & 0.6756\end{array}$

Bivariate Fit of Avg Measurement By SME Avg WL

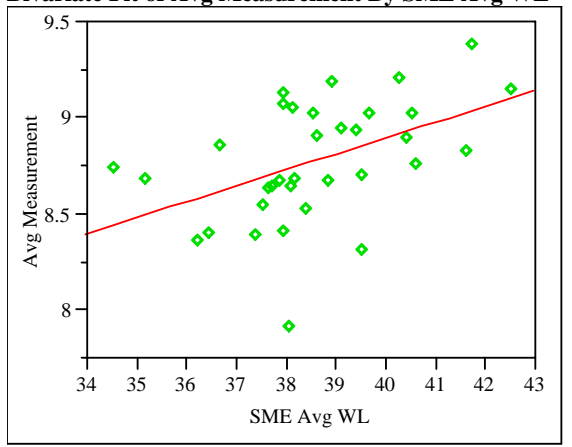

Linear Fit

Avg Measurement $=5.5834856+0.0827997$ SME Avg WL Summary of Fit

$\begin{array}{lr}\text { RSquare } & 0.217249 \\ \text { RSquare Adj } & 0.192788 \\ \text { Root Mean Square Error } & 0.279952 \\ \text { Mean of Response } & 8.778875 \\ \text { Observations (or Sum Wgts) } & 34\end{array}$

Analysis of Variance

Source DF Sum of Squares Mean Square F Ratio

$\begin{array}{lllll}\text { Model } & 1 & 0.6960687 & 0.696069 & 8.8815\end{array}$

$\begin{array}{llll}\text { Error } & 32 & 2.5079402 & 0.078373 \text { Prob }>\text { F }\end{array}$

$\begin{array}{llr}\text { C. Total } 33 & 3.2040089 & 0.0055\end{array}$ 
WSRC-STI-2006-00068

Revision 0

Exhibit A12. Relationships between Analytes and WLs by Preparation Method, ICP, and Analyte (continued)

Prep=Mixed Acid, Sample Type=SME, ICP=M-13, Analyte=Ni Bivariate Fit of Avg Measurement By Blending WL

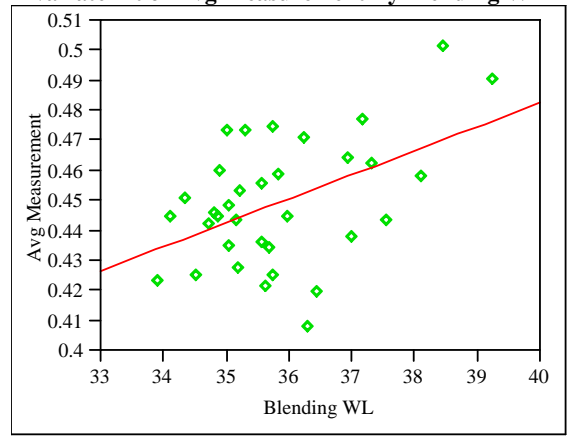

Linear Fit

Avg Measurement $=0.1638342+0.0079687$ Blending WL Summary of Fit

$\begin{array}{lr}\text { RSquare } & 0.224229 \\ \text { RSquare Adj } & 0.199986 \\ \text { Root Mean Square Error } & 0.018911 \\ \text { Mean of Response } & 0.44957 \\ \text { Observations (or Sum Wgts) } & 34\end{array}$

Analysis of Variance

Source DF Sum of Squares Mean Square F Ratio

$\begin{array}{lllll}\text { Model } & 1 & 0.00330786 & 0.003308 & 9.2493\end{array}$

$\begin{array}{llll}\text { Error } & 32 & 0.01144429 & 0.000358 \text { Prob }>\text { F }\end{array}$

$\begin{array}{lll}\text { C. Total } 33 & 0.01475215 & 0.0047\end{array}$

Bivariate Fit of Avg Measurement By SME Avg WL

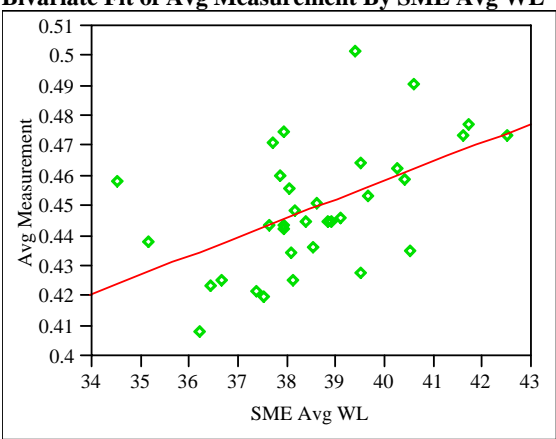

Linear Fit

Avg Measurement $=0.2050873+0.0063351$ SME Avg WL

Summary of Fit

$\begin{array}{lr}\text { RSquare } & 0.276214 \\ \text { RSquare Adj } & 0.253596 \\ \text { Root Mean Square Error } & 0.018267 \\ \text { Mean of Response } & 0.44957 \\ \text { Observations (or Sum Wgts) } & 34\end{array}$

Analysis of Variance

Source DF Sum of Squares Mean Square F Ratio

$\begin{array}{lllll}\text { Model } & 1 & 0.00407475 & 0.004075 & 12.2120\end{array}$

$\begin{array}{llll}\text { Error } & 32 & 0.01067740 & 0.000334 \text { Prob }>\text { F }\end{array}$

$\begin{array}{lll}\text { C. Total } 33 & 0.01475215 & 0.0014\end{array}$
Prep=Mixed Acid, Sample Type=SME, ICP=M-13, Analyte $=S i$ Bivariate Fit of Avg Measurement By Blending WL

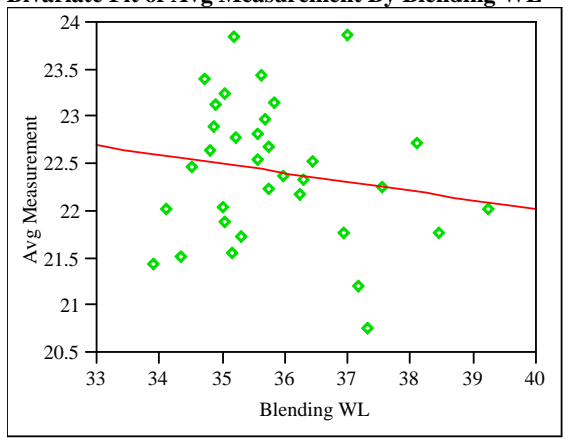

Linear Fit

Avg Measurement $=25.875602-0.0962555$ Blending WL Summary of Fit

$\begin{array}{lr}\text { RSquare } & 0.026914 \\ \text { RSquare Adj } & -0.0035 \\ \text { Root Mean Square Error } & 0.738454 \\ \text { Mean of Response } & 22.42416 \\ \text { Observations (or Sum Wgts) } & 34\end{array}$

Analysis of Variance

Source DF Sum of Squares Mean Square F Ratio

$\begin{array}{lllll}\text { Model } & 1 & 0.482634 & 0.482634 & 0.8851\end{array}$

$\begin{array}{llll}\text { Error } & 32 & 17.450047 & 0.545314 \text { Prob }>\text { F }\end{array}$

$\begin{array}{llrr}\text { C. Total } & 33 & 17.932681 & 0.3539\end{array}$

Bivariate Fit of Avg Measurement By SME Avg WL

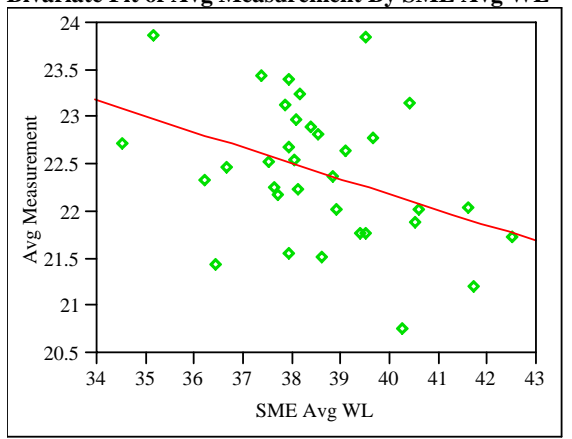

Linear Fit

Avg Measurement $=28.844378-0.1663622$ SME Avg WL Summary of Fit

Root Mean Square Error $\quad 0.687448$

Mean of Response $\quad 22.42416$

Observations (or Sum Wgts) 34

Analysis of Variance

Source DF Sum of Squares Mean Square F Ratio

$\begin{array}{lllll}\text { Model } & 1 & 2.809983 & 2.80998 & 5.9460\end{array}$

$\begin{array}{llll}\text { Error } & 32 & 15.122698 & 0.47258 \text { Prob }>\text { F }\end{array}$

$\begin{array}{lrr}\text { C. Total } 33 & 17.932681 & 0.0205\end{array}$ 
WSRC-STI-2006-00068

Revision 0

Exhibit A12. Relationships between Analytes and WLs by Preparation Method, ICP, and Analyte (continued)

Prep=Mixed Acid, Sample Type=SME, ICP=M-13, Analyte=Sum of Oxides

Bivariate Fit of Avg Measurement By Blending WL

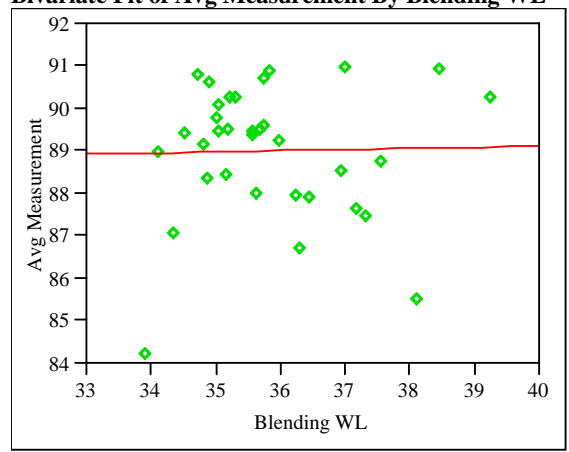

Linear Fit

Avg Measurement $=88.041736+0.0272333$ Blending WL

Summary of Fit

$\begin{array}{lr}\text { RSquare } & 0.000477 \\ \text { RSquare Adj } & -0.03076 \\ \text { Root Mean Square Error } & 1.591241 \\ \text { Mean of Response } & 89.01824 \\ \text { Observations (or Sum Wgts) } & 34\end{array}$

Analysis of Variance

Source DF Sum of Squares Mean Square F Ratio

$\begin{array}{lllll}\text { Model } & 1 & 0.038634 & 0.03863 & 0.0153\end{array}$

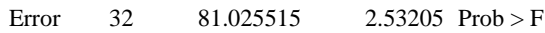

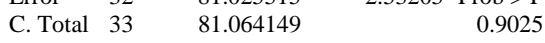

Bivariate Fit of Avg Measurement By SME Avg WL

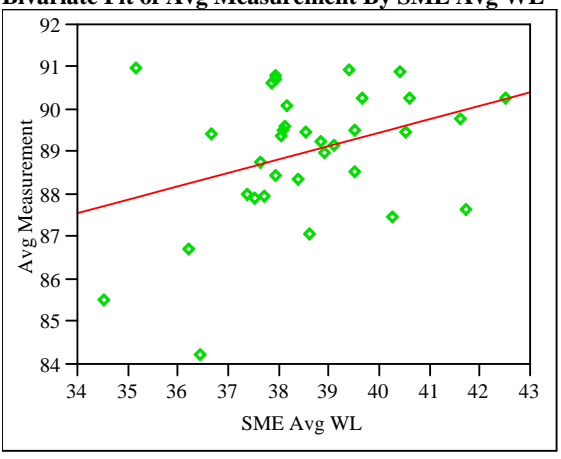

Linear Fit

Avg Measurement $=76.8489+0.3153349$ SME Avg WL Summary of Fit

RSquare

RSquare Adj

0.12454

Root Mean Square Error $\quad 1.489215$

Mean of Response

89.01824

Observations (or Sum Wgts) $\quad 34$

Analysis of Variance

Source DF Sum of Squares Mean Square F Ratio

$\begin{array}{lrrrr}\text { Model } & 1 & 10.095749 & 10.0957 & 4.5522\end{array}$

$\begin{array}{llll}\text { Error } & 32 & 70.968400 & 2.2178 \text { Prob }>\text { F }\end{array}$

$\begin{array}{lll}\text { C. Total } 33 \quad 81.064149 & 0.0406\end{array}$
Prep=Mixed Acid, Sample Type $=$ SME, ICP=M-13, Analyte $=T i$ Bivariate Fit of Avg Measurement By Blending WL

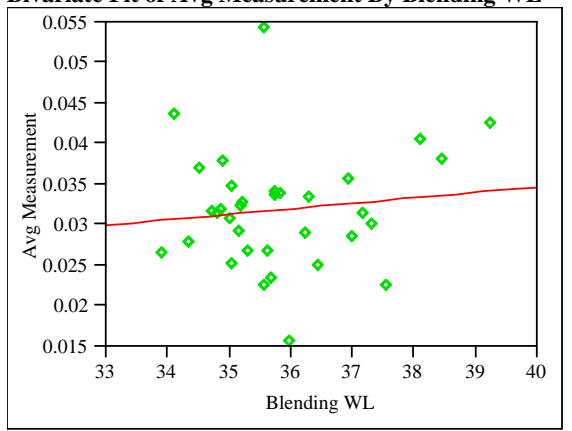

Linear Fit

Avg Measurement $=0.0074717+0.0006817$ Blending WL Summary of Fit

RSquare Adj

0.014257

Root Mean Square Error $\quad 0.007233$

Mean of Response $\quad 0.031917$

Observations (or Sum Wgts) 34

Analysis of Variance

Source DF Sum of Squares Mean Square F Ratio

$\begin{array}{lrrrr}\text { Model } & 1 & 0.00002421 & 0.000024 & 0.4628\end{array}$

$\begin{array}{lllll}\text { Error } & 32 & 0.00167395 & 0.000052 & \text { Prob }>\text { F }\end{array}$

$\begin{array}{lll}\text { C. Total } 33 & 0.00169816 & 0.5012\end{array}$

Bivariate Fit of Avg Measurement By SME Avg WL

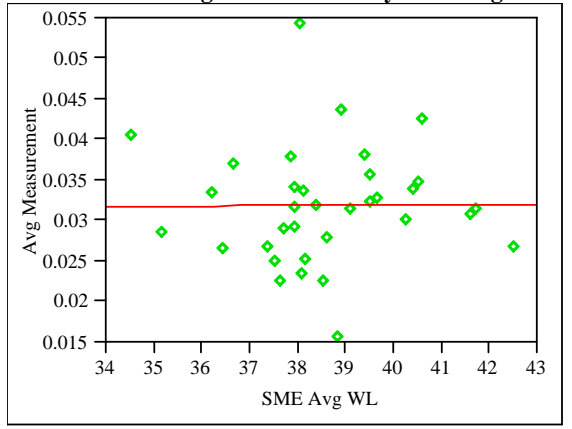

Linear Fit

Avg Measurement $=0.0313452+0.0000148$ SME Avg WL Summary of Fit

RSquare

RSquare Adj

0.000013

Mean of Response $\quad 0.031917$

Observations (or Sum Wgts) $\quad 34$

Analysis of Variance

Source DF Sum of Squares Mean Square F Ratio

$\begin{array}{lllll}\text { Model } & 1 & 2.22988 \mathrm{e}-8 & 2.23 \mathrm{e}-8 & 0.0004\end{array}$

$\begin{array}{llll}\text { Error } & 32 & 0.00169814 & 0.000053 \text { Prob }>\text { F }\end{array}$

$\begin{array}{llr}\text { C. Total } 33 & 0.00169816 & 0.9838\end{array}$ 
WSRC-STI-2006-00068

Revision 0

Exhibit A12. Relationships between Analytes and WLs by Preparation Method, ICP, and Analyte (continued)

Prep=Mixed Acid, Sample Type $=$ SME, ICP $=M-13$, Analyte $=\mathrm{U}$ Bivariate Fit of Avg Measurement By Blending WL

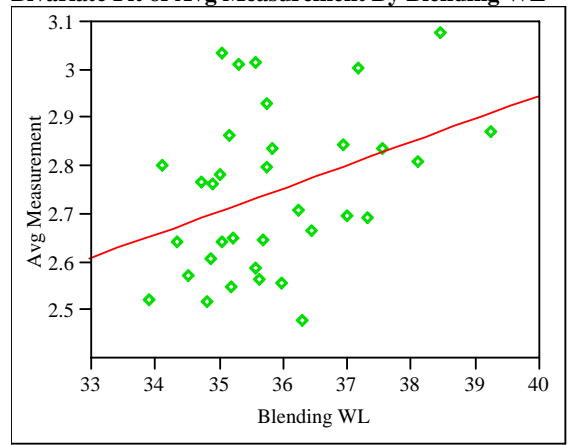

Linear Fit

Avg Measurement $=1.0135258+0.0483372$ Blending WL Summary of Fit

RSquare $\quad 0.132991$

RSquare Adj $\quad 0.105897$

Root Mean Square Error $\quad 0.157467$

Mean of Response 2.746754

Observations (or Sum Wgts) 34

Analysis of Variance

Source DF Sum of Squares Mean Square F Ratio

$\begin{array}{lllll}\text { Model } & 1 & 0.12171078 & 0.121711 & 4.9085\end{array}$

$\begin{array}{llll}\text { Error } & 32 & 0.79346860 & 0.024796 \text { Prob }>\text { F }\end{array}$

$\begin{array}{llll}\text { C. Total } 33 & 0.91517938 & 0.0340\end{array}$

Bivariate Fit of Avg Measurement By SME Avg WL

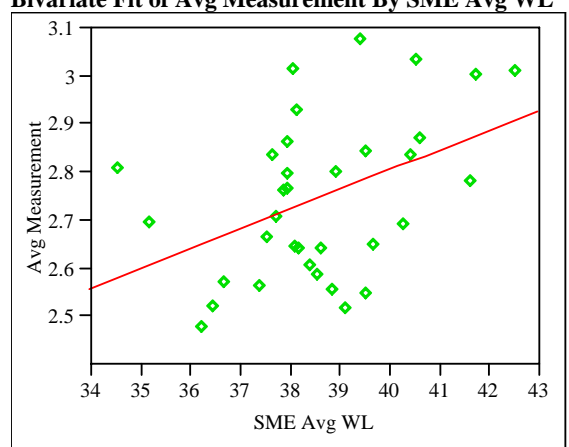

Linear Fit

Avg Measurement $=1.1630939+0.0410362$ SME Avg WL

Summary of Fit

$\begin{array}{ll}\text { RSquare } & 0.186819 \\ \text { RSquare Adj } & 0.161408 \\ \text { Root Mean Square Error } & 0.152501 \\ \text { Mean of Response } & 2.746754\end{array}$

Mean of Response 2.746754

Observations (or Sum Wgts) $\quad 34$

Analysis of Variance

Source DF Sum of Squares Mean Square F Ratio

$\begin{array}{lllll}\text { Model } & 1 & 0.17097332 & 0.170973 & 7.3517\end{array}$

$\begin{array}{llll}\text { Error } & 32 & 0.74420605 & 0.023256 \text { Prob }>\text { F }\end{array}$

$\begin{array}{llr}\text { C. Total } 33 & 0.91517938 & 0.0107\end{array}$
Prep=Mixed Acid, Sample Type $=$ SME, ICP $=$ M-13, Analyte $=U /$ Ca Bivariate Fit of Avg Measurement By Blending WL

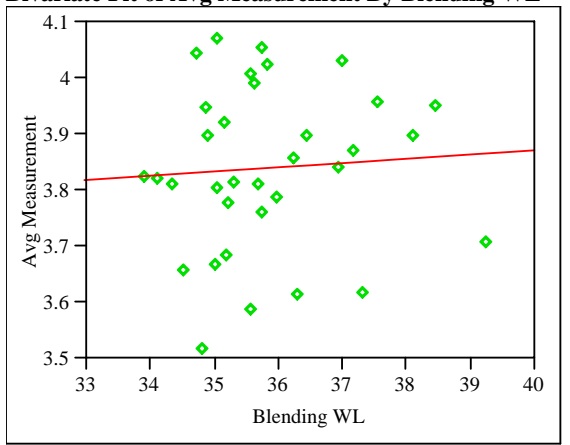

Linear Fit

Avg Measurement $=3.5742002+0.0074052$ Blending $\mathrm{WL}$ Summary of Fit

RSquare

RSquare Adj

0.00405

Root Mean Squar

$-0.02707$

Mean of Response

0.148158

Observations (or Sum Wgts)

34

Analysis of Variance

Source DF Sum of Squares Mean Square F Ratio $\begin{array}{lllll}\text { Model } & 1 & 0.00285655 & 0.002857 & 0.1301\end{array}$ $\begin{array}{llll}\text { Error } & 32 & 0.70242203 & 0.021951 \text { Prob }>\text { F }\end{array}$

$\begin{array}{llll}\text { C. Total } 33 & 0.70527858 & 0.7207\end{array}$

Bivariate Fit of Avg Measurement By SME Avg WL

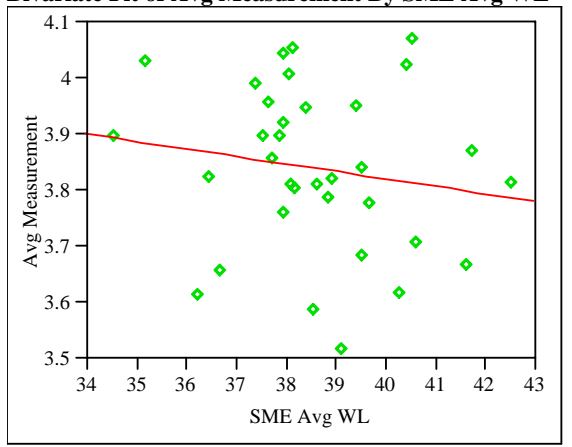

Linear Fit

Avg Measurement $=4.3537383-0.0133191$ SME Avg WL Summary of Fit

$\begin{array}{lr}\text { RSquare } & 0.025538 \\ \text { RSquare Adj } & -0.00491 \\ \text { Root Mean Square Error } & 0.146551 \\ \text { Mean of Response } & 3.839729 \\ \text { Observations (or Sum Wgts) } & 34\end{array}$

Analysis of Variance

Source DF Sum of Squares Mean Square F Ratio

$\begin{array}{lllll}\text { Model } & 1 & 0.01801133 & 0.018011 & 0.8386\end{array}$

$\begin{array}{lllll}\text { Error } & 32 & 0.68726725 & 0.021477 \text { Prob }>\text { F }\end{array}$

$\begin{array}{llr}\text { C. Total } 33 & 0.70527858 & 0.3666\end{array}$ 
WSRC-STI-2006-00068

Revision 0

Exhibit A12. Relationships between Analytes and WLs by Preparation Method, ICP, and Analyte (continued)

Prep=Mixed Acid, Sample Type=SME, ICP=M-13, Analyte=Zr Bivariate Fit of Avg Measurement By Blending WL

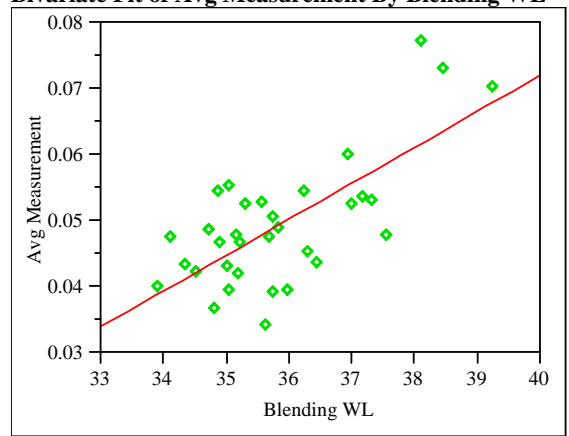

Linear Fit

Avg Measurement $=-0.145599+0.0054398$ Blending WL Summary of Fit

$\begin{array}{lr}\text { RSquare } & 0.499085 \\ \text { RSquare Adj } & 0.482926 \\ \text { Root Mean Square Error } & 0.007059 \\ \text { Mean of Response } & 0.049503 \\ \text { Observations (or Sum Wgts) } & 33\end{array}$

Analysis of Variance

Source DF Sum of Squares Mean Square F Ratio

$\begin{array}{lllll}\text { Model } & 1 & 0.00153894 & 0.001539 & 30.8867\end{array}$

$\begin{array}{llll}\text { Error } & 31 & 0.00154458 & 0.000050 \text { Prob }>\text { F }\end{array}$

$\begin{array}{llr}\text { C. Total } 32 & 0.00308352 & <.0001\end{array}$

Bivariate Fit of Avg Measurement By SME Avg WL

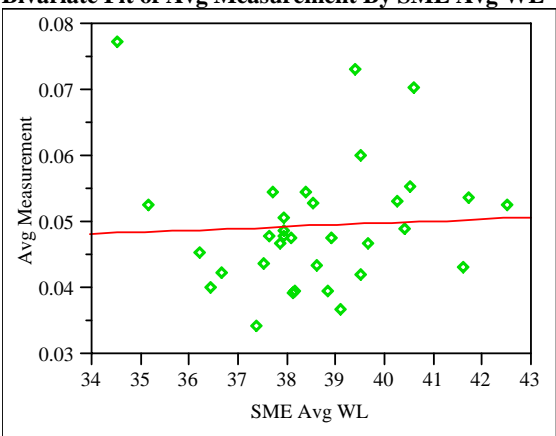

Linear Fit

Avg Measurement $=0.0387591+0.0002783$ SME Avg WL

Summary of Fit

$\begin{array}{lr}\text { RSquare } & 0.002542 \\ \text { RSquare Adj } & -0.02963 \\ \text { Root Mean Square Error } & 0.009961 \\ \text { Mean of Response } & 0.049503 \\ \text { Observations (or Sum Wgts) } & 33\end{array}$

Analysis of Variance

Source DF Sum of Squares Mean Square F Ratio

$\begin{array}{lllll}\text { Model } & 1 & 0.00000784 & 0.000008 & 0.0790\end{array}$

$\begin{array}{llll}\text { Error } & 31 & 0.00307568 & 0.000099 \text { Prob }>\text { F }\end{array}$

$\begin{array}{llr}\text { C. Total } 32 & 0.00308352 & 0.7805\end{array}$
Prep=Mixed Acid, Sample Type=SME, ICP=M-14, Analyte=A Bivariate Fit of Avg Measurement By Blending WL

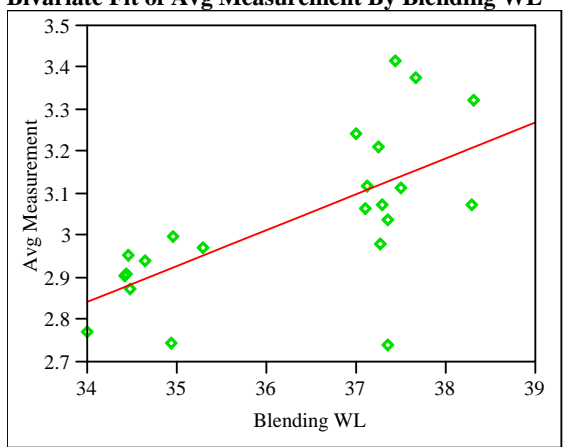

Linear Fit

Avg Measurement $=-0.062793+0.0854541$ Blending WL Summary of Fit

$\begin{array}{lr}\text { RSquare } & 0.442704 \\ \text { RSquare Adj } & 0.414839 \\ \text { Root Mean Square Error } & 0.14537 \\ \text { Mean of Response } & 3.03993 \\ \text { Observations (or Sum Wgts) } & 22\end{array}$

Analysis of Variance

Source DF Sum of Squares Mean Square F Ratio $\begin{array}{lllll}\text { Model } & 1 & 0.33574173 & 0.335742 & 15.8876\end{array}$

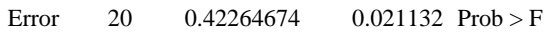

$\begin{array}{llll}\text { C. Total } 21 & 0.75838846 & 0.0007\end{array}$

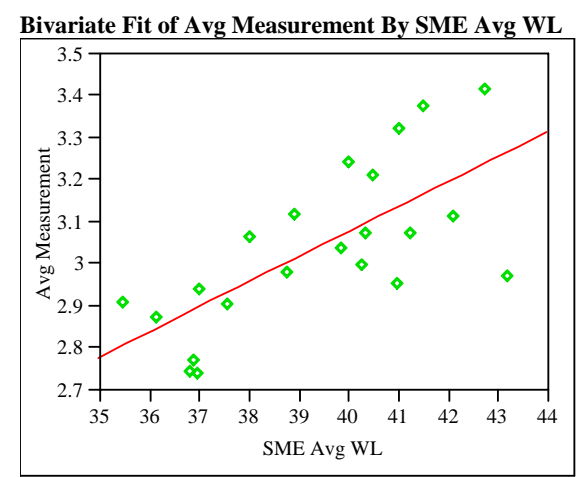

Linear Fit

Avg Measurement $=0.7021435+0.0593638$ SME Avg WL Summary of Fit

$\begin{array}{lr}\text { RSquare } & 0.490573 \\ \text { RSquare Adj } & 0.465101 \\ \text { Root Mean Square Error } & 0.138986 \\ \text { Mean of Response } & 3.03993 \\ \text { Observations (or Sum Wgts) } & 22\end{array}$

Analysis of Variance

Source DF Sum of Squares Mean Square F Ratio $\begin{array}{lllll}\text { Model } & 1 & 0.37204453 & 0.372045 & 19.2598\end{array}$

$\begin{array}{lllll}\text { Error } & 20 & 0.38634394 & 0.019317 \text { Prob }>\text { F }\end{array}$

$\begin{array}{llr}\text { C. Total } 21 & 0.75838846 & 0.0003\end{array}$ 
WSRC-STI-2006-00068

Revision 0

Exhibit A12. Relationships between Analytes and WLs by Preparation Method, ICP, and Analyte (continued)

Prep=Mixed Acid, Sample Type=SME, ICP $=$ M-14, Analyte $=$ Al $/$ Ca Bivariate Fit of Avg Measurement By Blending WL

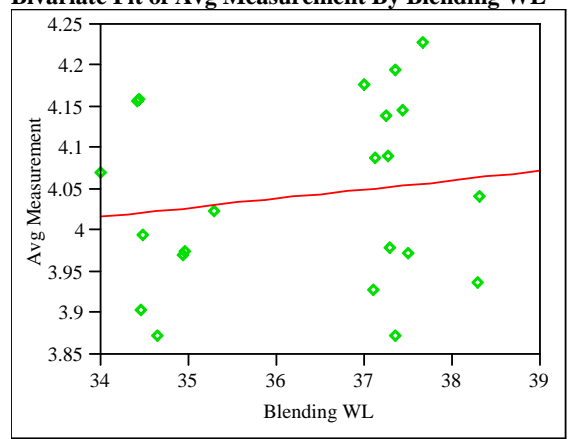

Linear Fit

Avg Measurement $=3.6411903+0.0110611$ Blending WL Summary of Fit

$\begin{array}{lr}\text { RSquare } & 0.022444 \\ \text { RSquare Adj } & -0.02643 \\ \text { Root Mean Square Error } & 0.11068 \\ \text { Mean of Response } & 4.042804 \\ \text { Observations (or Sum Wgts) } & 22\end{array}$

Analysis of Variance

Source DF Sum of Squares Mean Square F Ratio

$\begin{array}{lllll}\text { Model } & 1 & 0.00562519 & 0.005625 & 0.4592\end{array}$

$\begin{array}{llll}\text { Error } & 20 & 0.24500251 & 0.012250 \text { Prob }>\text { F }\end{array}$

$\begin{array}{llr}\text { C. Total } 21 & 0.25062771 & 0.5058\end{array}$

Bivariate Fit of Avg Measurement By SME Avg WL

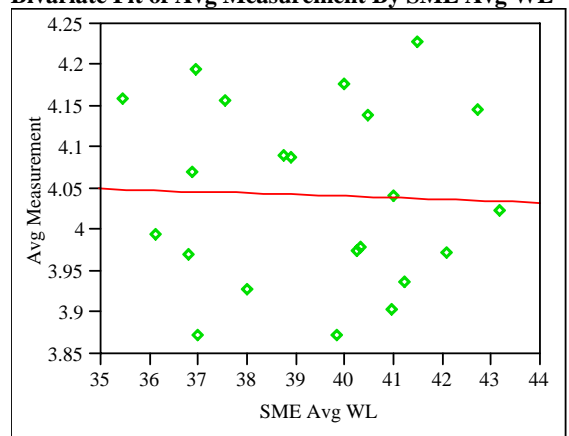

Linear Fit

Avg Measurement $=4.114579-0.0018226$ SME Avg WL

Summary of Fit

RSquare

RSquare Adj

0.001399

Root Mean Square Error $\quad 0.111865$

$-0.04853$

Mean of Response 4.042804

Observations (or Sum Wgts)

22

Analysis of Variance

Source DF Sum of Squares Mean Square F Ratio

$\begin{array}{lllll}\text { Model } & 1 & 0.00035069 & 0.000351 & 0.0280\end{array}$

$\begin{array}{llll}\text { Error } & 20 & 0.25027701 & 0.012514 \text { Prob }>\text { F }\end{array}$

$\begin{array}{lll}\text { C. Total } 21 & 0.25062771 & 0.8687\end{array}$
Prep=Mixed Acid, Sample Type=SME, ICP=M-14, Analyte=Al/Mg Bivariate Fit of Avg Measurement By Blending WL

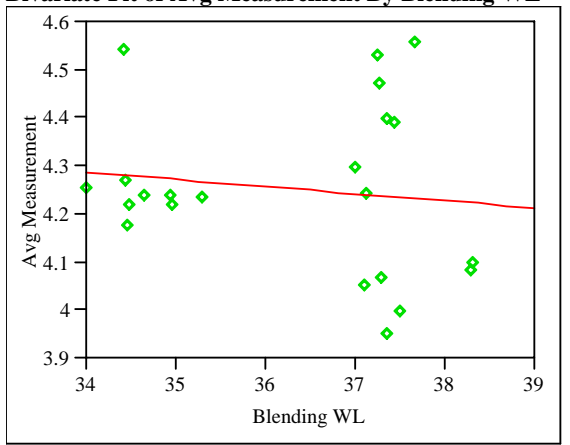

Linear Fit

Avg Measurement $=4.7876662-0.014718$ Blending WL Summary of Fit

RSquare

0.015678

RSquare Adj

$-0.03354$

Root Mean Square

0.176821

an of Response

4.253276

Observations (or Sum Wgts)

Analysis of Variance

Source DF Sum of Squares Mean Square F Ratio

$\begin{array}{lrrrr}\text { Model } & 1 & 0.00995947 & 0.009959 & 0.3185\end{array}$

$\begin{array}{llll}\text { Error } & 20 & 0.62531123 & 0.031266 \text { Prob }>\text { F }\end{array}$

$\begin{array}{llll}\text { C. Total } 21 & 0.63527070 & 0.5788\end{array}$

Bivariate Fit of Avg Measurement By SME Avg WL

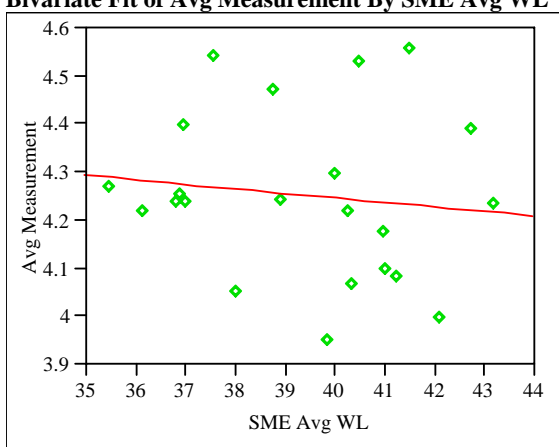

Linear Fit

Avg Measurement $=4.6237392-0.0094072$ SME Avg WL

Summary of Fit

$\begin{array}{lr}\text { RSquare } & 0.014707 \\ \text { RSquare Adj } & -0.03456 \\ \text { Root Mean Square Error } & 0.176908 \\ \text { Mean of Response } & 4.253276 \\ \text { Observations (or Sum Wgts) } & 22\end{array}$

Analysis of Variance

Source DF Sum of Squares Mean Square F Ratio

$\begin{array}{lllll}\text { Model } & 1 & 0.00934275 & 0.009343 & 0.2985\end{array}$

$\begin{array}{llll}\text { Error } & 20 & 0.62592795 & 0.031296 \text { Prob }>\text { F }\end{array}$

$\begin{array}{llr}\text { C. Total } 21 & 0.63527070 & 0.5909\end{array}$ 
WSRC-STI-2006-00068

Revision 0

Exhibit A12. Relationships between Analytes and WLs by Preparation Method, ICP, and Analyte (continued)

Prep=Mixed Acid, Sample Type=SME, ICP=M-14, Analyte=Al/Mn Bivariate Fit of Avg Measurement By Blending WL

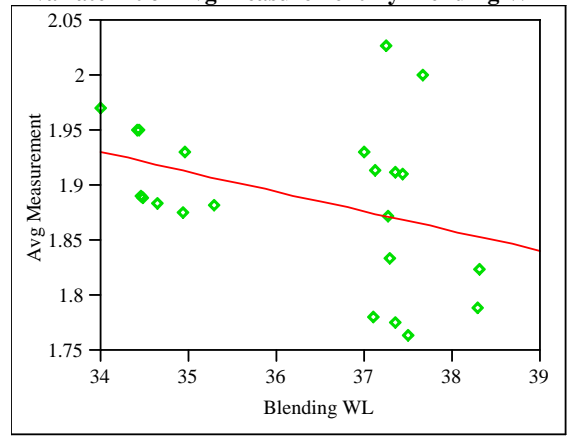

Linear Fit

Avg Measurement $=2.5394798-0.0179066$ Blending WL Summary of Fit

$\begin{array}{lr}\text { RSquare } & 0.134631 \\ \text { RSquare Adj } & 0.091362 \\ \text { Root Mean Square Error } & 0.068833 \\ \text { Mean of Response } & 1.889314 \\ \text { Observations (or Sum Wgts) } & 22\end{array}$

Analysis of Variance

Source DF Sum of Squares Mean Square F Ratio

$\begin{array}{lllll}\text { Model } & 1 & 0.01474237 & 0.014742 & 3.1115\end{array}$

$\begin{array}{llll}\text { Error } & 20 & 0.09476002 & 0.004738 \text { Prob }>\text { F }\end{array}$

$\begin{array}{lll}\text { C. Total } 21 & 0.10950238 & 0.0930\end{array}$

Bivariate Fit of Avg Measurement By SME Avg WL

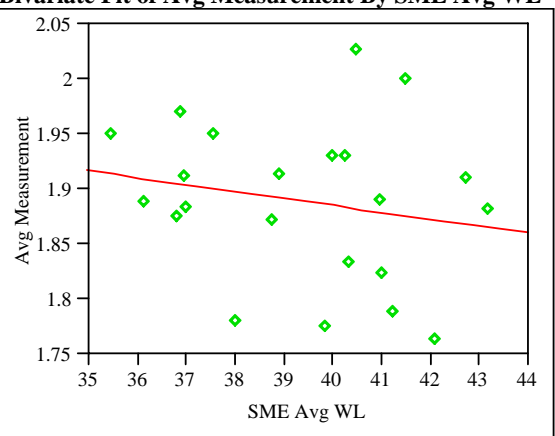

Linear Fit

Avg Measurement $=2.1382725-0.0063218$ SME Avg WL

Summary of Fit

RSquare

0.038531

Root Mean Square Error $\quad 0.072555$

Mean of Response $\quad 1.889314$

Observations (or Sum Wgts) 22

Analysis of Variance

Source DF Sum of Squares Mean Square F Ratio

$\begin{array}{lllll}\text { Model } & 1 & 0.00421927 & 0.004219 & 0.8015\end{array}$

$\begin{array}{llll}\text { Error } & 20 & 0.10528311 & 0.005264 \text { Prob }>\text { F }\end{array}$

C. Total $21 \quad 0.10950238 \quad 0.3813$
Prep=Mixed Acid, Sample Type $=$ SME, ICP $=$ M-14, Analyte $=B$ Bivariate Fit of Avg Measurement By Blending WL

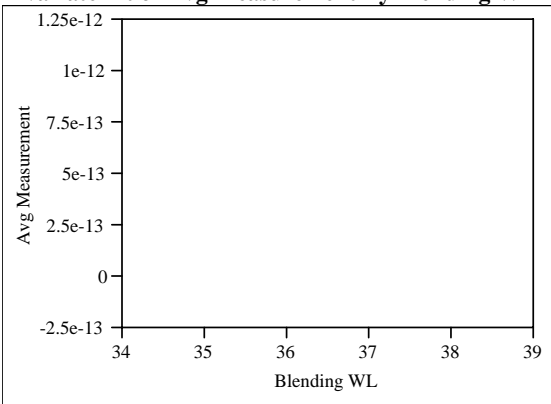

Bivariate Fit of Avg Measurement By SME Avg WL

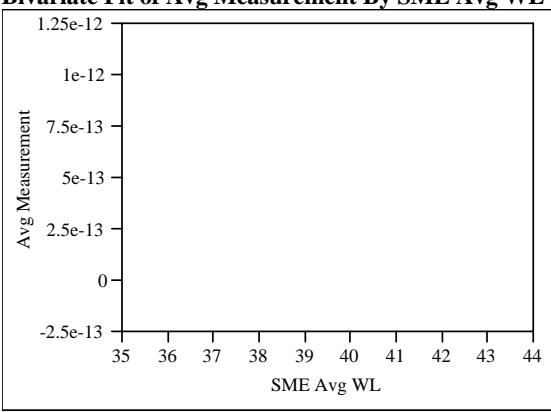

Prep=Mixed Acid, Sample Type=SME, ICP=M-14, Analyte=B/L Bivariate Fit of Avg Measurement By Blending WL

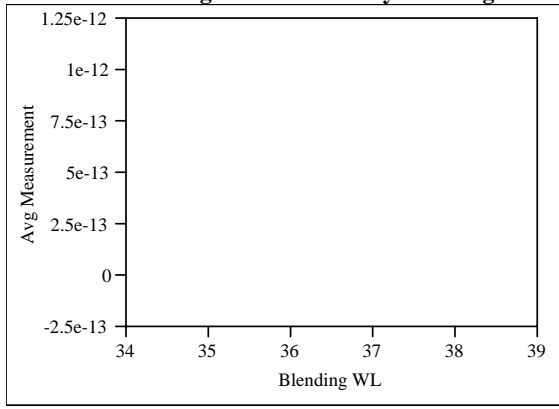

Bivariate Fit of Avg Measurement By SME Avg WL

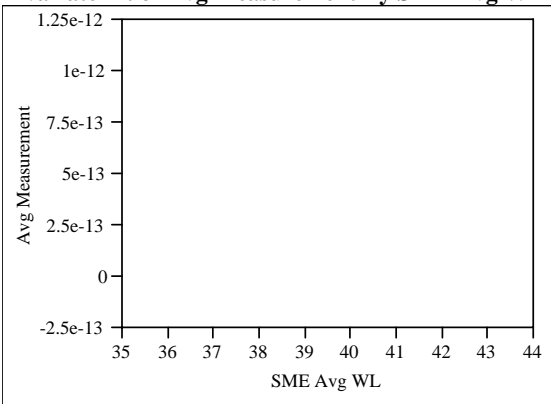


WSRC-STI-2006-00068

Revision 0

Exhibit A12. Relationships between Analytes and WLs by Preparation Method, ICP, and Analyte (continued)

Prep=Mixed Acid, Sample Type $=$ SME, ICP $=M-14$, Analyte $=$ Ca Bivariate Fit of Avg Measurement By Blending WL

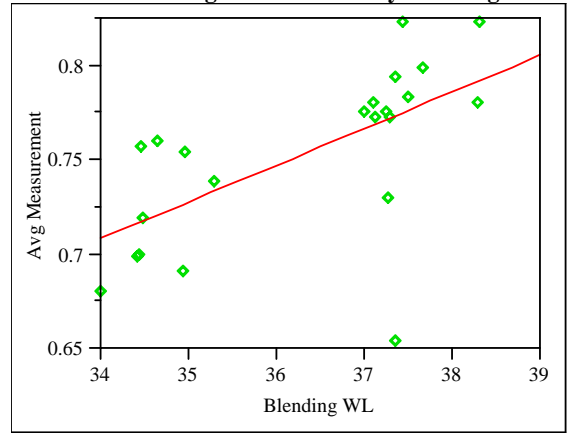

Linear Fit

Avg Measurement $=0.0473403+0.0194439$ Blending WL Summary of Fit

$\begin{array}{lr}\text { RSquare } & 0.390072 \\ \text { RSquare Adj } & 0.359576 \\ \text { Root Mean Square Error } & 0.036864 \\ \text { Mean of Response } & 0.753323 \\ \text { Observations (or Sum Wgts) } & 22\end{array}$

Analysis of Variance

Source DF Sum of Squares Mean Square F Ratio

$\begin{array}{lllll}\text { Model } & 1 & 0.01738230 & 0.017382 & 12.7908\end{array}$

Error $20 \quad 0.02717948 \quad 0.001359$ Prob $>$ F

C. Total $21 \quad 0.04456178 \quad 0.0019$

Bivariate Fit of Avg Measurement By SME Avg WL

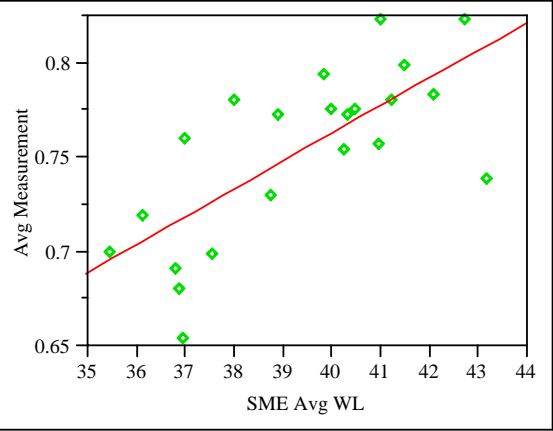

Linear Fit

Avg Measurement $=0.1716744+0.0147699$ SME Avg WL

Summary of Fit

$\begin{array}{lr}\text { RSquare } & 0.516825 \\ \text { RSquare Adj } & 0.492666 \\ \text { Root Mean Square Error } & 0.032811 \\ \text { Mean of Response } & 0.753323 \\ \text { Observations (or Sum Wgts) } & 22\end{array}$

Analysis of Variance

Source DF Sum of Squares Mean Square F Ratio

$\begin{array}{lllll}\text { Model } & 1 & 0.02303065 & 0.023031 & 21.3929\end{array}$

$\begin{array}{lllll}\text { Error } 20 & 0.02153113 & 0.001077 \text { Prob }>\text { F }\end{array}$

$\begin{array}{lll}\text { C. Total } 21 & 0.04456178 & 0.0002\end{array}$
Prep=Mixed Acid, Sample Type $=$ SME, ICP $=M-14$, Analyte $=C r$ Bivariate Fit of Avg Measurement By Blending WL

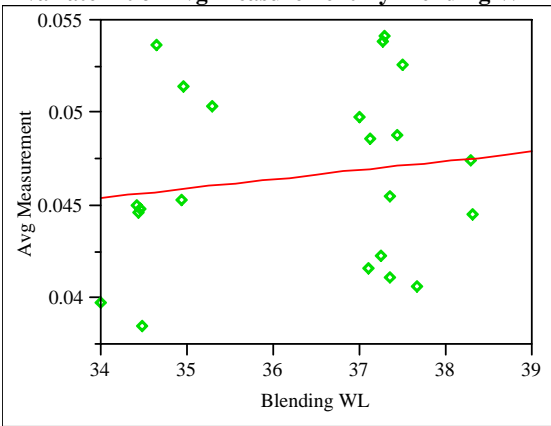

Linear Fit

Avg Measurement $=0.0286689+0.0004935$ Blending $\mathrm{WL}$ Summary of Fit

$\begin{array}{ll}\text { RSquare } & 0.022831 \\ \text { RSquare Adj } & -0.02603 \\ \text { Root Mean Square Error } & 0.004896 \\ \text { Mean of Response } & 0.046589\end{array}$

$\begin{array}{lr}\text { Mean of Response } & 0.046589 \\ \text { Observations (or Sum Wgts) } & 22\end{array}$

Analysis of Variance

Source DF Sum of Squares Mean Square F Ratio

$\begin{array}{lllll}\text { Model } & 1 & 0.00001120 & 0.000011 & 0.4673\end{array}$

$\begin{array}{lllll}\text { Error } & 20 & 0.00047935 & 0.000024 \text { Prob }>\text { F }\end{array}$

$\begin{array}{lll}\text { C. Total } 21 & 0.00049055 & 0.5021\end{array}$

Bivariate Fit of Avg Measurement By SME Avg WL

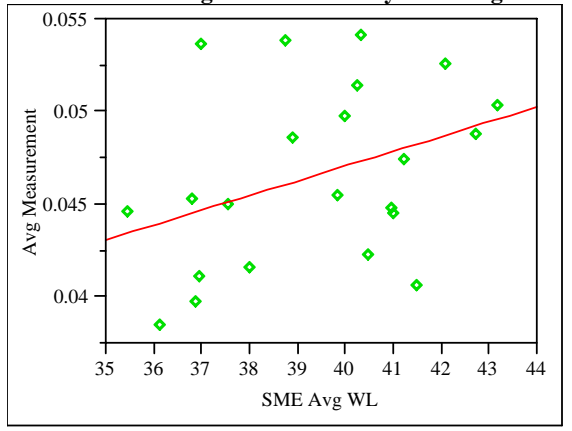

Linear Fit

Avg Measurement $=0.0152995+0.0007945$ SME Avg WL Summary of Fit

RSquare

RSquare Adj $\quad 0.092656$

Root Mean Square Error $\quad 0.004604$

Mean of Response $\quad 0.046589$

Observations (or Sum Wgts) 22

Analysis of Variance

Source DF Sum of Squares Mean Square F Ratio

$\begin{array}{lllll}\text { Model } & 1 & 0.00006665 & 0.000067 & 3.1445\end{array}$

$\begin{array}{llll}\text { Error } & 20 & 0.00042390 & 0.000021 \text { Prob }>\text { F }\end{array}$

$\begin{array}{lll}\text { C. Total } 21 & 0.00049055 & 0.0914\end{array}$ 
WSRC-STI-2006-00068

Revision 0

Exhibit A12. Relationships between Analytes and WLs by Preparation Method, ICP, and Analyte (continued)

Prep=Mixed Acid, Sample Type $=$ SME, ICP $=M-14$, Analyte $=C u$ Bivariate Fit of Avg Measurement By Blending WL

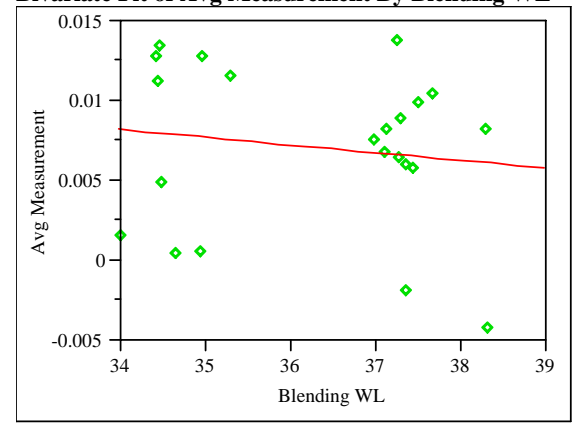

Linear Fit

Avg Measurement $=0.0246236-0.000482$ Blending WL Summary of Fit

RSquare

0.019521

RSquare Adj

Root Mean Square Error $\quad 0.005179$

Mean of Response

Observations (or Sum Wgts) 22

Analysis of Variance

Source DF Sum of Squares Mean Square F Ratio

$\begin{array}{lllll}\text { Model } & 1 & 0.00001068 & 0.000011 & 0.3982\end{array}$

$\begin{array}{lllll}\text { Error } & 20 & 0.00053648 & 0.000027 & \text { Prob }>\text { F }\end{array}$

C. Total $21 \quad 0.00054716 \quad 0.5352$

Bivariate Fit of Avg Measurement By SME Avg WL

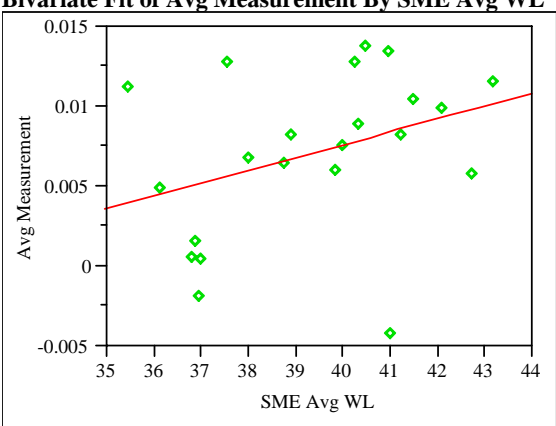

Linear Fit

Avg Measurement $=-0.024134+0.0007937$ SME Avg WL Summary of Fit

RSquare

RSquare Adj $\quad 0.077631$

Root Mean Square Error $\quad 0.004902$

Mean of Response $\quad 0.007123$

Observations (or Sum Wgts) 22

Analysis of Variance

Source DF Sum of Squares Mean Square F Ratio

$\begin{array}{lllll}\text { Model } & 1 & 0.00006651 & 0.000067 & 2.7675\end{array}$

$\begin{array}{llll}\text { Error } & 20 & 0.00048065 & 0.000024 \text { Prob }>\text { F }\end{array}$

$\begin{array}{lll}\text { C. Total } 21 & 0.00054716 & 0.1118\end{array}$
Prep=Mixed Acid, Sample Type $=$ SME, ICP $=$ M-14, Analyte $=F e$ Bivariate Fit of Avg Measurement By Blending WL

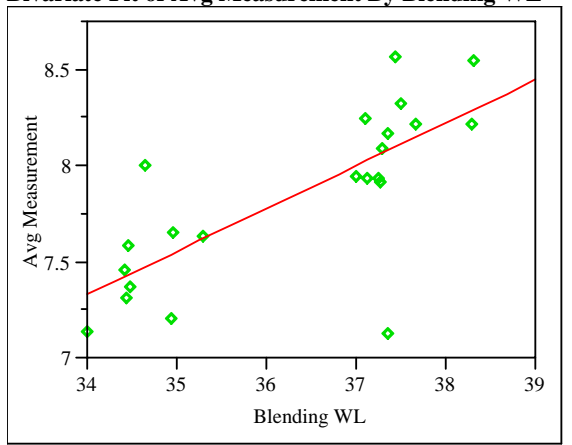

Linear Fit

Avg Measurement $=-0.236114+0.2226881$ Blending WL Summary of Fit

$\begin{array}{lr}\text { RSquare } & 0.553551 \\ \text { RSquare Adj } & 0.531229 \\ \text { Root Mean Square Error } & 0.30322 \\ \text { Mean of Response } & 7.849386 \\ \text { Observations (or Sum Wgts) } & 22\end{array}$

Analysis of Variance

Source DF Sum of Squares Mean Square F Ratio $\begin{array}{lllll}\text { Model } & 1 & 2.2799915 & 2.27999 & 24.7980\end{array}$ $\begin{array}{llll}\text { Error } & 20 & 1.8388517 & 0.09194 \text { Prob }>\text { F }\end{array}$

C. Total $21 \quad 4.1188432<.0001$

Bivariate Fit of Avg Measurement By SME Avg WL

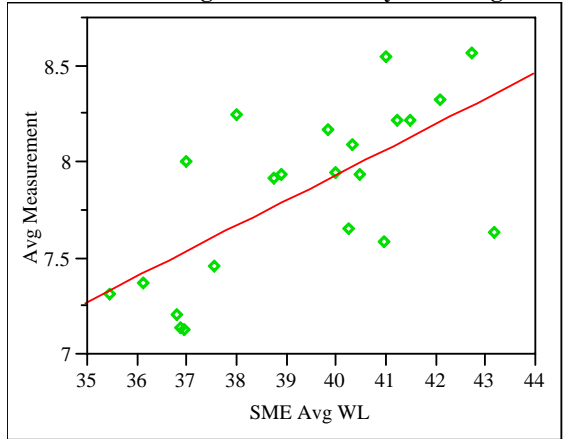

Linear Fit

Avg Measurement $=2.6500565+0.1320274$ SME Avg WL Summary of Fit

$\begin{array}{lr}\text { RSquare } & 0.446791 \\ \text { RSquare Adj } & 0.419131 \\ \text { Root Mean Square Error } & 0.337534 \\ \text { Mean of Response } & 7.849386 \\ \text { Observations (or Sum Wgts) } & 22\end{array}$

Analysis of Variance

Source DF Sum of Squares Mean Square F Ratio $\begin{array}{lllll}\text { Model } & 1 & 1.8402635 & 1.84026 & 16.1527\end{array}$

$\begin{array}{lllll}\text { Error } & 20 & 2.2785797 & 0.11393 \text { Prob > F }\end{array}$

$\begin{array}{llrr}\text { C. Total } & 21 & 4.1188432 & 0.0007\end{array}$ 
WSRC-STI-2006-00068

Revision 0

Exhibit A12. Relationships between Analytes and WLs by Preparation Method, ICP, and Analyte (continued)

Prep=Mixed Acid, Sample Type=SME, ICP=M-14, Analyte=Fe/A Bivariate Fit of Avg Measurement By Blending WL

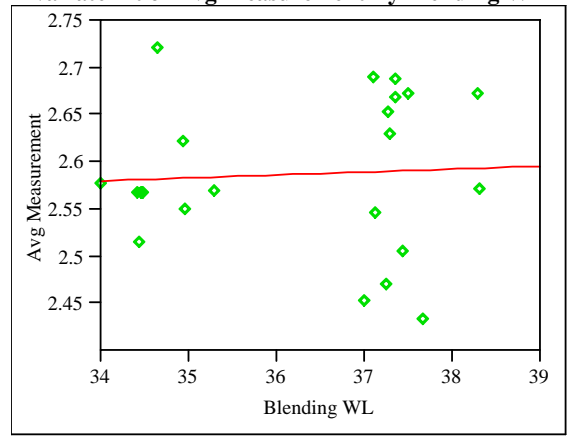

Linear Fit

Avg Measurement $=2.4685166+0.0032766$ Blending WL Summary of Fit

RSquare

0.00354

RSquare Adj

$-0.04628$

Root Mean Square Error $\quad 0.083349$

Mean of Response 2.587484

Observations (or Sum Wgts)

22

Analysis of Variance

Source DF Sum of Squares Mean Square F Ratio

$\begin{array}{lllll}\text { Model } & 1 & 0.00049360 & 0.000494 & 0.0711\end{array}$

$\begin{array}{lllll}\text { Error } & 20 & 0.13893996 & 0.006947 & \text { Prob }>\text { F }\end{array}$

$\begin{array}{lll}\text { C. Total } 21 & 0.13943356 & 0.7925\end{array}$

Bivariate Fit of Avg Measurement By SME Avg WL

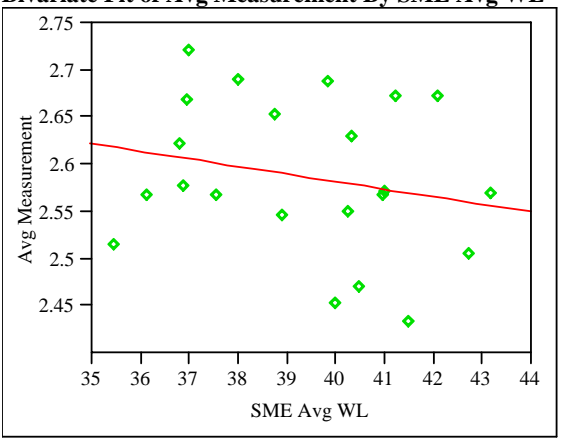

Linear Fit

Avg Measurement $=2.9048967-0.0080601$ SME Avg WL

Summary of Fit

$\begin{array}{lr}\text { RSquare } & 0.049189 \\ \text { RSquare Adj } & 0.001648 \\ \text { Root Mean Square Error } & 0.081417 \\ \text { Mean of Response } & 2.587484 \\ \text { Observations (or Sum Wgts) } & 22\end{array}$

Analysis of Variance

Source DF Sum of Squares Mean Square F Ratio

$\begin{array}{lllll}\text { Model } & 1 & 0.00685858 & 0.006859 & 1.0347\end{array}$

$\begin{array}{llll}\text { Error } 20 & 0.13257498 & 0.006629 \text { Prob }>\text { F }\end{array}$

$\begin{array}{lll}\text { C. Total } 21 & 0.13943356 & 0.3212\end{array}$
Prep=Mixed Acid, Sample Type=SME, ICP $=$ M-14, Analyte $=\mathrm{Fe} / \mathrm{Ca}$ Bivariate Fit of Avg Measurement By Blending WL

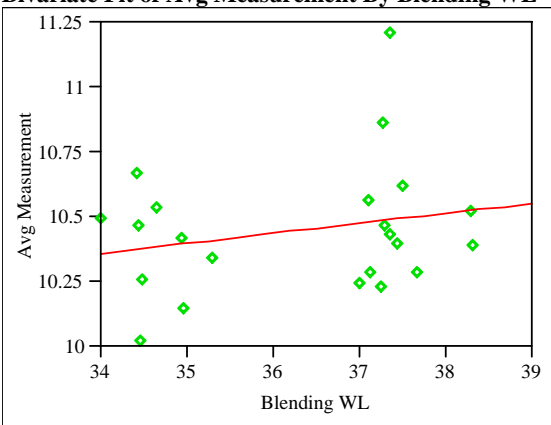

Linear Fit

Avg Measurement $=9.0451751+0.0386806$ Blending WL Summary of Fit

$\begin{array}{ll}\text { RSquare } & 0.051945 \\ \text { RSquare Adj } & 0.004542 \\ \text { Root Mean Square Error } & 0.250549 \\ \text { Mean of Response } & 10.44961\end{array}$

$\begin{array}{lr}\text { Mean of Response } & 10.44961 \\ \text { Observations (or Sum Wgts) } & 22\end{array}$

Analysis of Variance

Source DF Sum of Squares Mean Square F Ratio

$\begin{array}{lrrrr}\text { Model } & 1 & 0.0687899 & 0.068790 & 1.0958\end{array}$

$\begin{array}{llll}\text { Error } & 20 & 1.2554969 & 0.062775 \text { Prob }>\text { F }\end{array}$

$\begin{array}{lll}\text { C. Total } 21 & 1.3242868 & 0.3077\end{array}$

Bivariate Fit of Avg Measurement By SME Avg WL

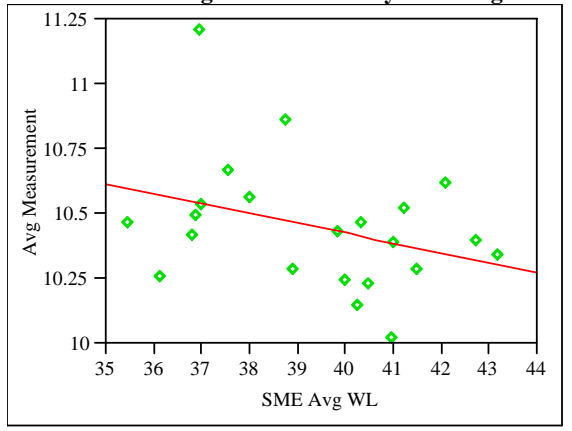

Linear Fit

Avg Measurement $=11.933993-0.0376931$ SME Avg WL Summary of Fit

RSquare

RSquare Adj

0.113264

Mean of Response 10.44961

Observations (or Sum Wgts) 22

Analysis of Variance

Source DF Sum of Squares Mean Square F Ratio

$\begin{array}{lllll}\text { Model } & 1 & 0.1499945 & 0.149994 & 2.5546\end{array}$

$\begin{array}{llll}\text { Error } & 20 & 1.1742923 & 0.058715 \text { Prob }>\text { F }\end{array}$

$\begin{array}{llll}\text { C. Total } 21 & 1.3242868 & 0.1257\end{array}$ 
WSRC-STI-2006-00068

Revision 0

Exhibit A12. Relationships between Analytes and WLs by Preparation Method, ICP, and Analyte (continued)

Prep=Mixed Acid, Sample Type=SME, ICP=M-14, Analyte $=F e / L i$ Bivariate Fit of Avg Measurement By Blending WL

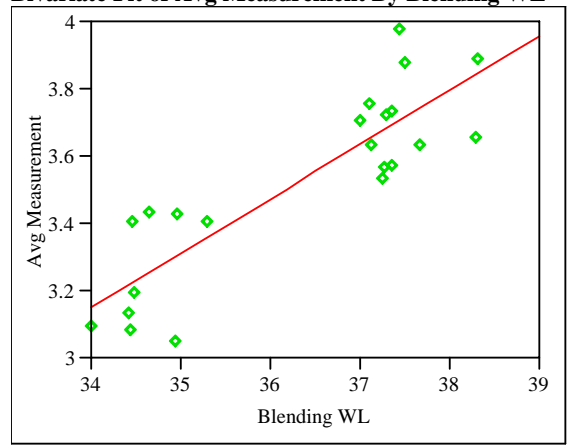

Linear Fit

Avg Measurement $=-2.33049+0.1612656$ Blending WL Summary of Fit

RSquare $\quad 0.753566$

RSquare Adj $\quad 0.741244$

Root Mean Square Error $\quad 0.139825$

Mean of Response 3.524845

Observations (or Sum Wgts) 22

Analysis of Variance

Source DF Sum of Squares Mean Square F Ratio

$\begin{array}{lllll}\text { Model } & 1 & 1.1957019 & 1.19570 & 61.1576\end{array}$

$\begin{array}{llll}\text { Error } & 20 & 0.3910231 & 0.01955 \text { Prob }>\text { F }\end{array}$

C. Total $21<1.5867250<.0001$

Bivariate Fit of Avg Measurement By SME Avg WL

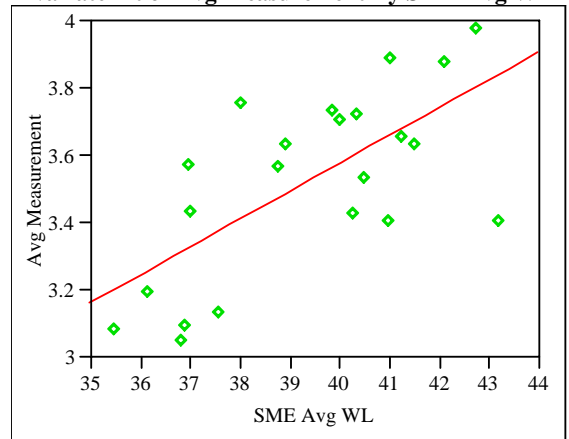

Linear Fit

Avg Measurement $=0.2667658+0.0827329$ SME Avg WL

Summary of Fit

$\begin{array}{ll}\text { RSquare } & 0.455414 \\ \text { RSquare Adj } & 0.428185 \\ \text { Root Mean Square Error } & 0.207859 \\ \text { Mean of Response } & 3.524845\end{array}$

Mean of Response 3.524845

Observations (or Sum Wgts) 22

Analysis of Variance

Source DF Sum of Squares Mean Square F Ratio

$\begin{array}{lllll}\text { Model } & 1 & 0.7226174 & 0.722617 & 16.7252\end{array}$

Error $20 \quad 0.8641076 \quad 0.043205$ Prob $>$ F

$\begin{array}{lrr}\text { C. Total } 21 & 1.5867250 & 0.0006\end{array}$
Prep=Mixed Acid, Sample Type=SME, ICP=M-14, Analyte $=$ Fe $/$ Mg Bivariate Fit of Avg Measurement By Blending WL

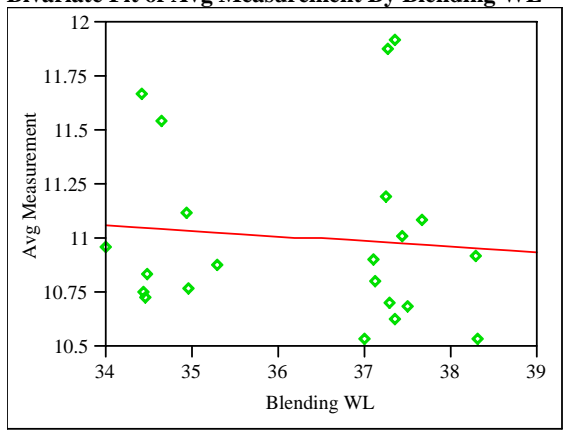

Linear Fit

Avg Measurement $=11.885157-0.0242472$ Blending WL Summary of Fit

$\begin{array}{lr}\text { RSquare } & 0.007814 \\ \text { RSquare Adj } & -0.0418 \\ \text { Root Mean Square Error } & 0.414258 \\ \text { Mean of Response } & 11.00478 \\ \text { Observations (or Sum Wgts) } & 22\end{array}$

Analysis of Variance

Source DF Sum of Squares Mean Square F Ratio $\begin{array}{lrrrr}\text { Model } & 1 & 0.0270309 & 0.027031 & 0.1575\end{array}$

$\begin{array}{lllll}\text { Error } & 20 & 3.4321945 & 0.171610 \text { Prob }>\text { F }\end{array}$

$\begin{array}{lll}\text { C. Total } 21 & 3.4592254 & 0.6957\end{array}$

Bivariate Fit of Avg Measurement By SME Avg WL

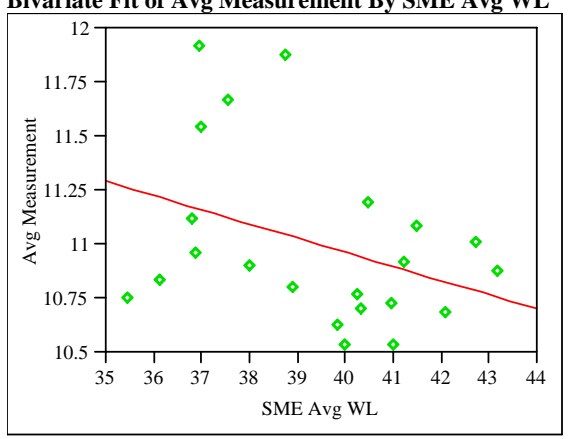

Linear Fit

Avg Measurement $=13.585102-0.0655226$ SME Avg WL Summary of Fit

RSquare

RSquare Adj

0.131025

11.00478

Observations (or Sum Wgts) 22

Analysis of Variance

Source DF Sum of Squares Mean Square F Ratio

$\begin{array}{lllll}\text { Model } & 1 & 0.4532463 & 0.453246 & 3.0156\end{array}$

$\begin{array}{llll}\text { Error } & 20 & 3.0059791 & 0.150299 \text { Prob }>\text { F }\end{array}$

$\begin{array}{llr}\text { C. Total } 21 & 3.4592254 & 0.0978\end{array}$ 
WSRC-STI-2006-00068

Revision 0

Exhibit A12. Relationships between Analytes and WLs by Preparation Method, ICP, and Analyte (continued)

Prep=Mixed Acid, Sample Type=SME, ICP=M-14, Analyte=Fe/Mn Bivariate Fit of Avg Measurement By Blending WL

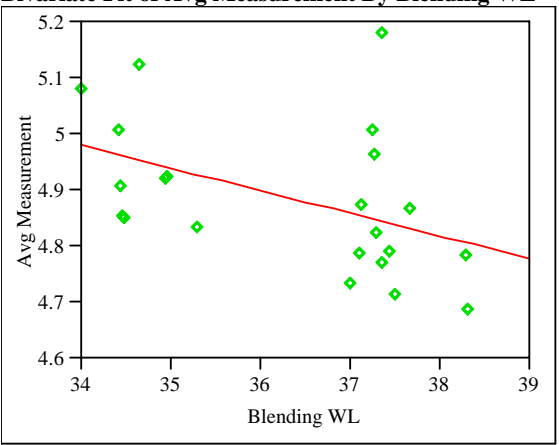

Linear Fit

Avg Measurement $=6.3507637-0.0403115$ Blending WL Summary of Fit

RSquare $\quad 0.204461$

RSquare Adj $\quad 0.164684$

Root Mean Square Error $\quad 0.120562$

Mean of Response 4.887108

Observations (or Sum Wgts) 22

Analysis of Variance

Source DF Sum of Squares Mean Square F Ratio

$\begin{array}{lllll}\text { Model } & 1 & 0.07471318 & 0.074713 & 5.1402\end{array}$

$\begin{array}{llll}\text { Error } & 20 & 0.29070232 & 0.014535 \text { Prob }>\text { F }\end{array}$

C. Total $21 \quad 0.36541551 \quad 0.0346$

Bivariate Fit of Avg Measurement By SME Avg WL

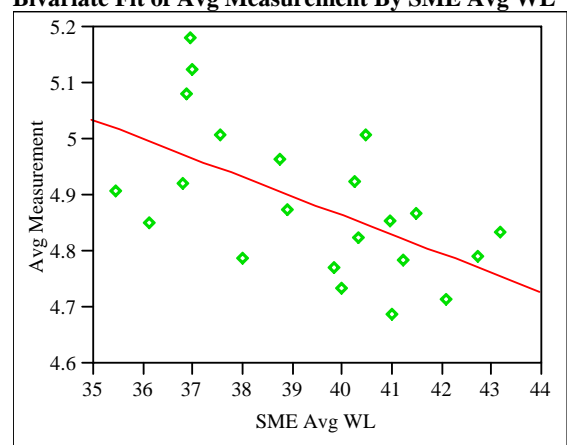

Linear Fit

Avg Measurement $=6.2296836-0.0340922$ SME Avg WL

Summary of Fit

$\begin{array}{ll}\text { RSquare } & 0.335796 \\ \text { RSquare Adj } & 0.302586 \\ \text { Root Mean Square Error } & 0.110161 \\ \text { Mean of Response } & 4.887108\end{array}$

Mean of Response 4.887108

Observations (or Sum Wgts) 22

Analysis of Variance

Source DF Sum of Squares Mean Square F Ratio

$\begin{array}{lllll}\text { Model } & 1 & 0.12270514 & 0.122705 & 10.1112\end{array}$

$\begin{array}{llll}\text { Error } & 20 & 0.24271037 & 0.012136 \text { Prob }>\text { F }\end{array}$

$\begin{array}{llr}\text { C. Total } 21 & 0.36541551 & 0.0047\end{array}$
Prep=Mixed Acid, Sample Type $=$ SME, ICP $=M-14$, Analyte $=\mathrm{Fe} / \mathrm{Ni}$ Bivariate Fit of Avg Measurement By Blending WL

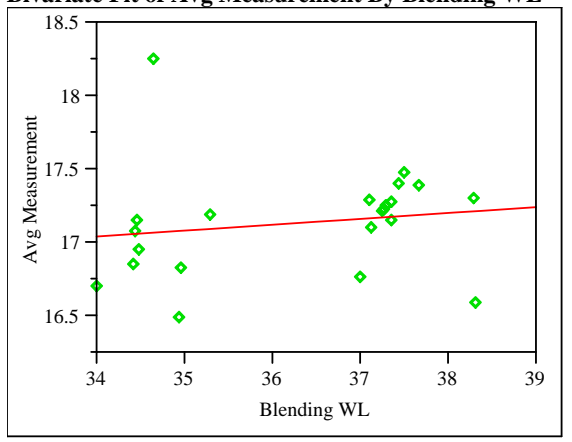

Linear Fit

Avg Measurement $=15.639392+0.0412738$ Blending WL Summary of Fit

$\begin{array}{lr}\text { RSquare } & 0.027485 \\ \text { RSquare Adj } & -0.02114 \\ \text { Root Mean Square Error } & 0.372244 \\ \text { Mean of Response } & 17.13799 \\ \text { Observations (or Sum Wgts) } & 22\end{array}$

Analysis of Variance

Source DF Sum of Squares Mean Square F Ratio

$\begin{array}{lllll}\text { Model } & 1 & 0.0783229 & 0.078323 & 0.5652\end{array}$

$\begin{array}{llll}\text { Error } & 20 & 2.7713173 & 0.138566 \text { Prob }>\text { F }\end{array}$

$\begin{array}{llrr}\text { C. Total } & 21 & 2.8496402 & 0.4609\end{array}$

Bivariate Fit of Avg Measurement By SME Avg WL

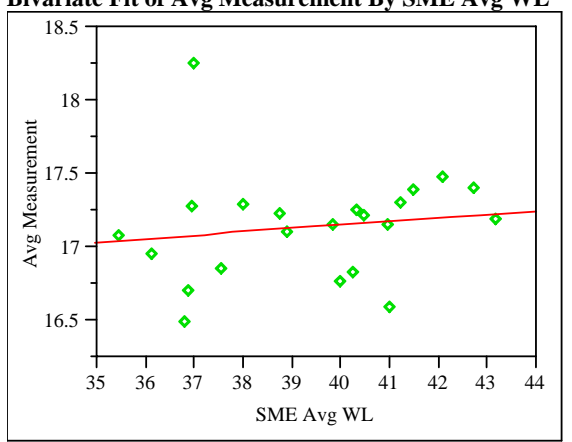

Linear Fit

Avg Measurement $=16.188577+0.0241085$ SME Avg WL

Summary of Fit

RSquare

0.021533

RSquare Adj

$-0.02739$

Root Mean Square Error $\quad 0.373382$

Mean of Response $\quad 17.13799$

Observations (or Sum Wgts)

22

Analysis of Variance

Source DF Sum of Squares Mean Square F Ratio

$\begin{array}{lllll}\text { Model } & 1 & 0.0613611 & 0.061361 & 0.4401\end{array}$

$\begin{array}{llll}\text { Error } & 20 & 2.7882791 & 0.139414 \text { Prob }>\text { F }\end{array}$

$\begin{array}{llrr}\text { C. Total } & 21 & 2.8496402 & 0.5146\end{array}$ 
WSRC-STI-2006-00068

Revision 0

Exhibit A12. Relationships between Analytes and WLs by Preparation Method, ICP, and Analyte (continued)

Prep=Mixed Acid, Sample Type=SME, ICP=M-14, Analyte $=F e / U$ Bivariate Fit of Avg Measurement By Blending WL

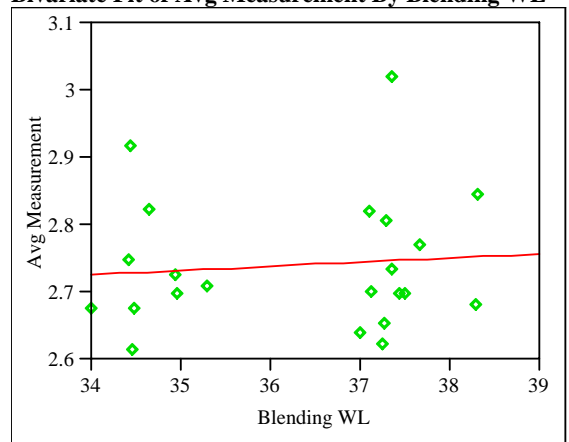

Linear Fit

Avg Measurement $=2.5173917+0.0061455$ Blending WL Summary of Fit

RSquare $\quad 0.008384$

RSquare Adj $\quad-0.0412$

Root Mean Square Error $\quad 0.101334$

Mean of Response

Observations (or Sum Wgts) 22

Analysis of Variance

Source DF Sum of Squares Mean Square F Ratio

$\begin{array}{lllll}\text { Model } & 1 & 0.00173640 & 0.001736 & 0.1691\end{array}$

$\begin{array}{llll}\text { Error } & 20 & 0.20537147 & 0.010269 \text { Prob }>\text { F }\end{array}$

C. Total $21 \quad 0.20710787 \quad 0.6853$

Bivariate Fit of Avg Measurement By SME Avg WL

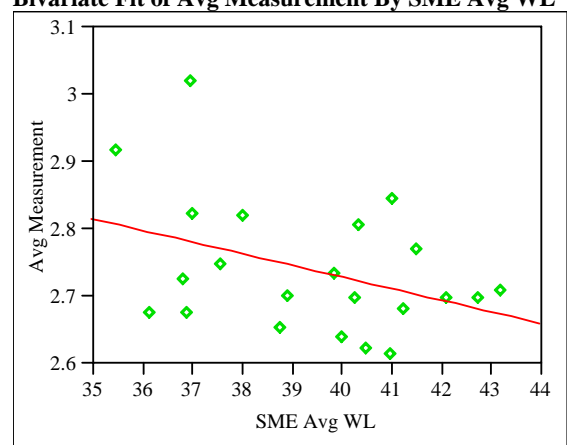

Linear Fit

Avg Measurement $=3.4217008-0.0172972$ SME Avg WL

Summary of Fit

$\begin{array}{ll}\text { RSquare } & 0.152513 \\ \text { RSquare Adj } & 0.110139 \\ \text { Root Mean Square Error } & 0.093681 \\ \text { Mean of Response } & 2.740525\end{array}$

Mean of Response 2.740525

Observations (or Sum Wgts) 22

Analysis of Variance

Source DF Sum of Squares Mean Square F Ratio

$\begin{array}{lllll}\text { Model } & 1 & 0.03158663 & 0.031587 & 3.5992\end{array}$

$\begin{array}{llll}\text { Error } & 20 & 0.17552124 & 0.008776 \text { Prob }>\text { F }\end{array}$

$\begin{array}{llr}\text { C. Total } 21 & 0.20710787 & 0.0723\end{array}$
Prep=Mixed Acid, Sample Type $=$ SME, ICP $=$ M-14, Analyte $=K$ Bivariate Fit of Avg Measurement By Blending WL

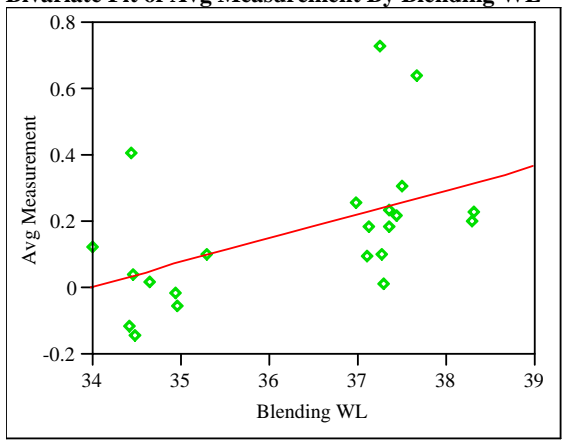

Linear Fit

Avg Measurement $=-2.46183+0.072535$ Blending WL Summary of Fit

$\begin{array}{lr}\text { RSquare } & 0.249674 \\ \text { RSquare Adj } & 0.212157 \\ \text { Root Mean Square Error } & 0.190652 \\ \text { Mean of Response } & 0.171818 \\ \text { Observations (or Sum Wgts) } & 22\end{array}$

Analysis of Variance

Source DF Sum of Squares Mean Square F Ratio

$\begin{array}{lllll}\text { Model } & 1 & 0.24189936 & 0.241899 & 6.6551\end{array}$

$\begin{array}{lllll}\text { Error } & 20 & 0.72696325 & 0.036348 \text { Prob }>\text { F }\end{array}$

$\begin{array}{llll}\text { C. Total } 21 & 0.96886261 & 0.0179\end{array}$

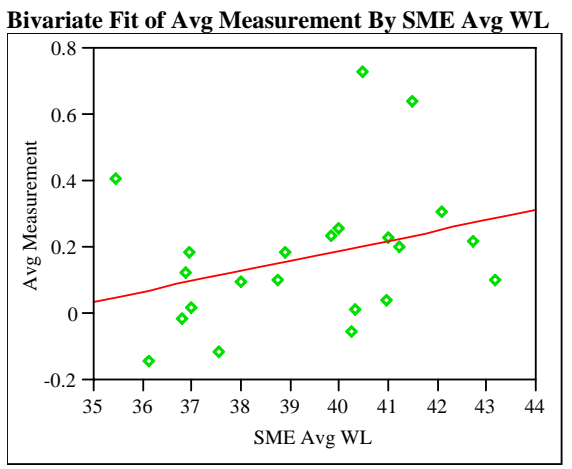

Linear Fit

Avg Measurement $=-1.033166+0.0305983$ SME Avg WL Summary of Fit

RSquare

0.10202

RSquare Adj

0.057121

Root Mean Square Error $\quad 0.208569$

Mean of Response $\quad 0.171818$

Observations (or Sum Wgts)

22

Analysis of Variance

Source DF Sum of Squares Mean Square F Ratio

$\begin{array}{lllll}\text { Model } & 1 & 0.09884333 & 0.098843 & 2.2722\end{array}$

$\begin{array}{lllll}\text { Error } & 20 & 0.87001927 & 0.043501 & \text { Prob }>\text { F }\end{array}$

$\begin{array}{llll}\text { C. Total } & 21 & 0.96886261 & 0.1473\end{array}$ 
WSRC-STI-2006-00068

Revision 0

Exhibit A12. Relationships between Analytes and WLs by Preparation Method, ICP, and Analyte (continued)

Prep=Mixed Acid, Sample Type=SME, ICP=M-14, Analyte $=\mathrm{Li}$ Bivariate Fit of Avg Measurement By Blending WL

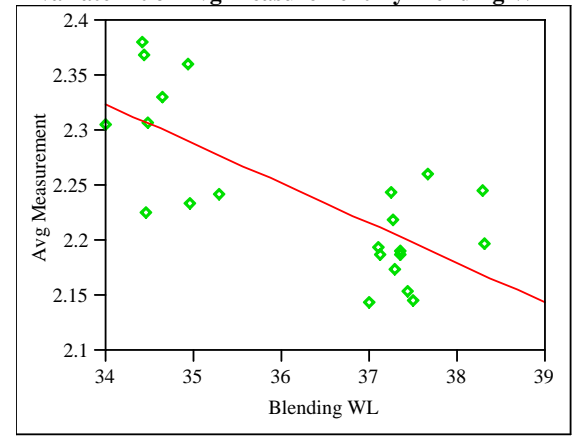

Linear Fit

Avg Measurement $=3.5510166-0.0360755$ Blending WL Summary of Fit

$\begin{array}{lr}\text { RSquare } & 0.536977 \\ \text { RSquare Adj } & 0.513825 \\ \text { Root Mean Square Error } & 0.050792 \\ \text { Mean of Response } & 2.241163 \\ \text { Observations (or Sum Wgts) } & 22\end{array}$

Analysis of Variance

Source DF Sum of Squares Mean Square F Ratio

$\begin{array}{lllll}\text { Model } & 1 & 0.05983634 & 0.059836 & 23.1944\end{array}$

$\begin{array}{llll}\text { Error } & 20 & 0.05159558 & 0.002580 \text { Prob }>\text { F }\end{array}$

C. Total $21 \quad 0.11143192 \quad 0.0001$

Bivariate Fit of Avg Measurement By SME Avg WL

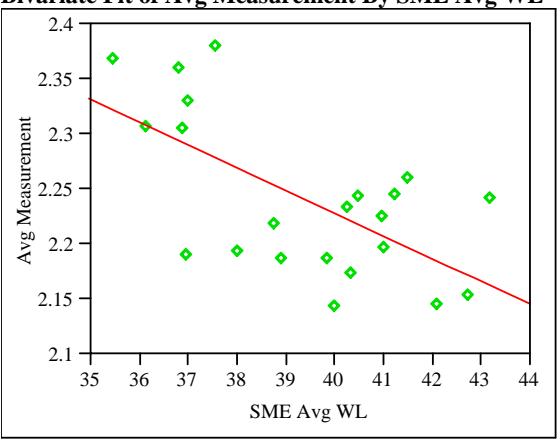

Linear Fit

Avg Measurement $=3.0553297-0.0206743$ SME Avg WL

Summary of Fit

$\begin{array}{lr}\text { RSquare } & 0.404951 \\ \text { RSquare Adj } & 0.375199 \\ \text { Root Mean Square Error } & 0.057579 \\ \text { Mean of Response } & 2.241163 \\ \text { Observations (or Sum Wgts) } & 22\end{array}$

Analysis of Variance

Source DF Sum of Squares Mean Square F Ratio

$\begin{array}{lllll}\text { Model } & 1 & 0.04512447 & 0.045124 & 13.6107\end{array}$

$\begin{array}{llll}\text { Error } 20 & 0.06630746 & 0.003315 \text { Prob }>\text { F }\end{array}$

$\begin{array}{llr}\text { C. Total } 21 & 0.11143192 & 0.0015\end{array}$
Prep=Mixed Acid, Sample Type $=$ SME, ICP $=M-14$, Analyte $=M g$ Bivariate Fit of Avg Measurement By Blending WL

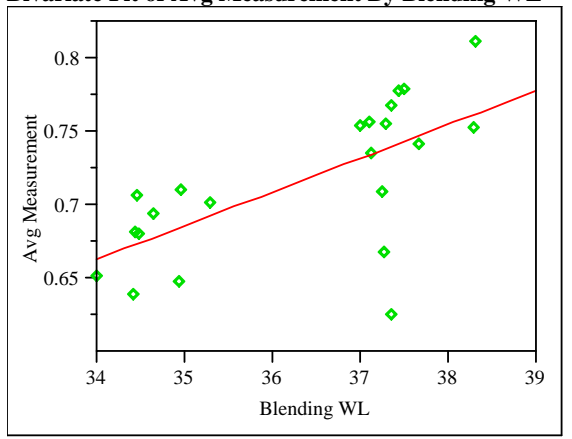

Linear Fit

Avg Measurement $=-0.117496+0.0229596$ Blending WL Summary of Fit

$\begin{array}{lr}\text { RSquare } & 0.438596 \\ \text { RSquare Adj } & 0.410526 \\ \text { Root Mean Square Error } & 0.039384 \\ \text { Mean of Response } & 0.716136 \\ \text { Observations (or Sum Wgts) } & 22\end{array}$

Analysis of Variance

Source DF Sum of Squares Mean Square F Ratio

$\begin{array}{lllll}\text { Model } & 1 & 0.02423641 & 0.024236 & 15.6250\end{array}$

$\begin{array}{llll}\text { Error } & 20 & 0.03102269 & 0.001551 \text { Prob }>\text { F }\end{array}$

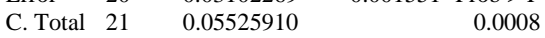

Bivariate Fit of Avg Measurement By SME Avg WL

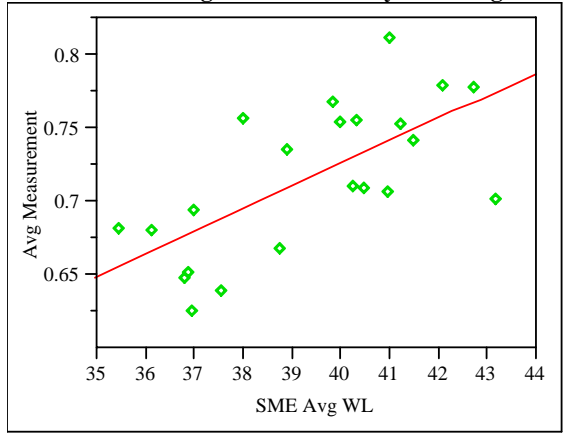

Linear Fit

Avg Measurement $=0.1099223+0.0153937$ SME Avg WL

Summary of Fit

RSquare

0.452724

RSquare Adj

0.42536

Root Mean Square Error $\quad 0.038886$

Mean of Response $\quad 0.716136$

Observations (or Sum Wgts)

22

Analysis of Variance

Source DF Sum of Squares Mean Square F Ratio

$\begin{array}{lllll}\text { Model } & 1 & 0.02501712 & 0.025017 & 16.5446\end{array}$

$\begin{array}{llll}\text { Error } & 20 & 0.03024199 & 0.001512 \text { Prob }>\text { F }\end{array}$

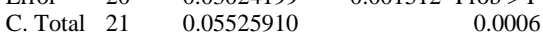


WSRC-STI-2006-00068

Revision 0

Exhibit A12. Relationships between Analytes and WLs by Preparation Method, ICP, and Analyte (continued)

Prep=Mixed Acid, Sample Type $=$ SME, ICP=M-14, Analyte $=$ Mn Bivariate Fit of Avg Measurement By Blending WL

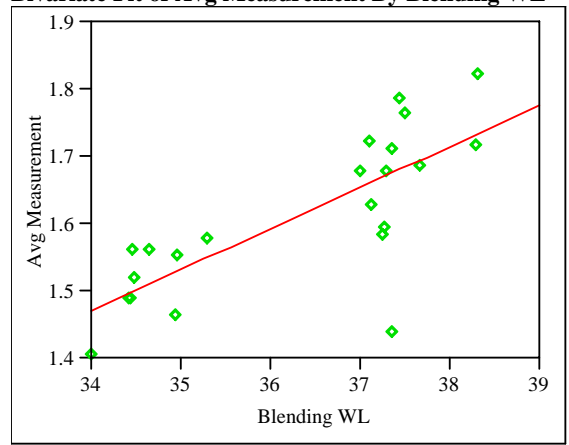

Linear Fit

Avg Measurement $=-0.603128+0.0610061$ Blending WL Summary of Fit

RSquare $\quad 0.588615$

RSquare Adj $\quad 0.568046$

Root Mean Square Error $\quad 0.077328$

Mean of Response 1.611919

Observations (or Sum Wgts) 22

Analysis of Variance

Source DF Sum of Squares Mean Square F Ratio

$\begin{array}{lllll}\text { Model } & 1 & 0.17111385 & 0.171114 & 28.6163\end{array}$

Error $20 \quad 0.11959208 \quad 0.005980$ Prob $>$ F

C. Total $21 \quad 0.29070593 \quad<.0001$

Bivariate Fit of Avg Measurement By SME Avg WL

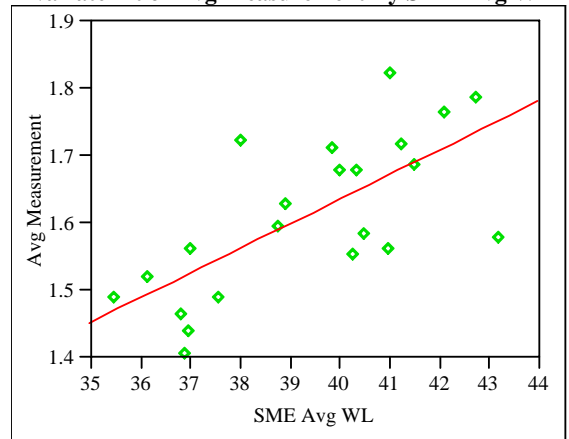

Linear Fit

Avg Measurement $=0.1731839+0.036534$ SME Avg WL

Summary of Fit

$\begin{array}{ll}\text { RSquare } & 0.484722 \\ \text { RSquare Adj } & 0.458958 \\ \text { Root Mean Square Error } & 0.086543 \\ \text { Mean of Response } & 1.611919\end{array}$

Mean of Response 1.611919

Observations (or Sum Wgts) 22

Analysis of Variance

Source DF Sum of Squares Mean Square F Ratio

$\begin{array}{lllll}\text { Model } & 1 & 0.14091158 & 0.140912 & 18.8140\end{array}$

$\begin{array}{llll}\text { Error } & 20 & 0.14979434 & 0.007490 \text { Prob }>\text { F }\end{array}$

$\begin{array}{llr}\text { C. Total } 21 & 0.29070593 & 0.0003\end{array}$
Prep=Mixed Acid, Sample Type $=$ SME, ICP $=M-14$, Analyte $=M n / M g$ Bivariate Fit of Avg Measurement By Blending WL

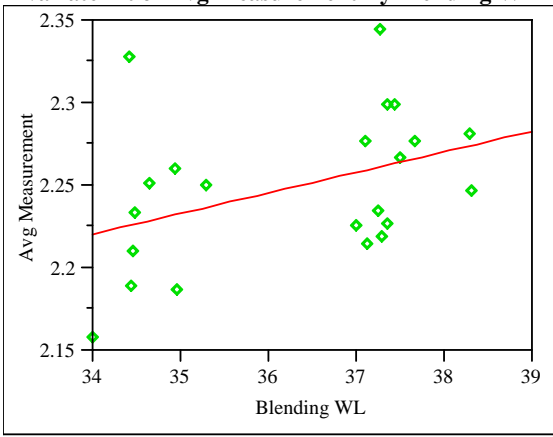

Linear Fit

Avg Measurement $=1.7968736+0.012467$ Blending WL Summary of Fit

$\begin{array}{lr}\text { RSquare } & 0.160481 \\ \text { RSquare Adj } & 0.118505 \\ \text { Root Mean Square Error } & 0.043234 \\ \text { Mean of Response } & 2.249535 \\ \text { Observations (or Sum Wgts) } & 22\end{array}$

Analysis of Variance

Source DF Sum of Squares Mean Square F Ratio

$\begin{array}{lllll}\text { Model } & 1 & 0.00714604 & 0.007146 & 3.8232\end{array}$

$\begin{array}{llll}\text { Error } 20 & 0.03738283 & 0.001869 \text { Prob }>\text { F }\end{array}$

$\begin{array}{llrr}\text { C. Total } & 21 & 0.04452887 & 0.0647\end{array}$

Bivariate Fit of Avg Measurement By SME Avg WL

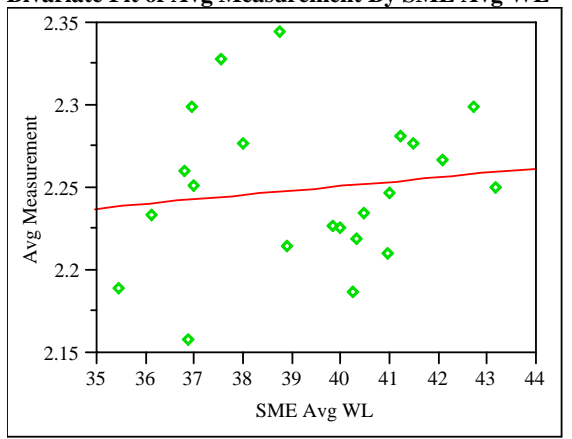

Linear Fit

Avg Measurement $=2.1430769+0.0027033$ SME Avg WL

Summary of Fit

RSquare

0.017326

RSquare Adj

$-0.03181$

Root Mean Square Error $\quad 0.046775$

Mean of Response 2.249535

Observations (or Sum Wgts)

22

Analysis of Variance

Source DF Sum of Squares Mean Square F Ratio

$\begin{array}{lllll}\text { Model } & 1 & 0.00077151 & 0.000772 & 0.3526\end{array}$

$\begin{array}{lllll}\text { Error } & 20 & 0.04375737 & 0.002188 \text { Prob }>\text { F }\end{array}$

$\begin{array}{llrr}\text { C. Total } & 21 & 0.04452887 & 0.002188 \\ \end{array}$ 
WSRC-STI-2006-00068

Revision 0

Exhibit A12. Relationships between Analytes and WLs by Preparation Method, ICP, and Analyte (continued)

Prep=Mixed Acid, Sample Type=SME, ICP $=M-14$, Analyte $=\mathrm{Na}$ Bivariate Fit of Avg Measurement By Blending WL

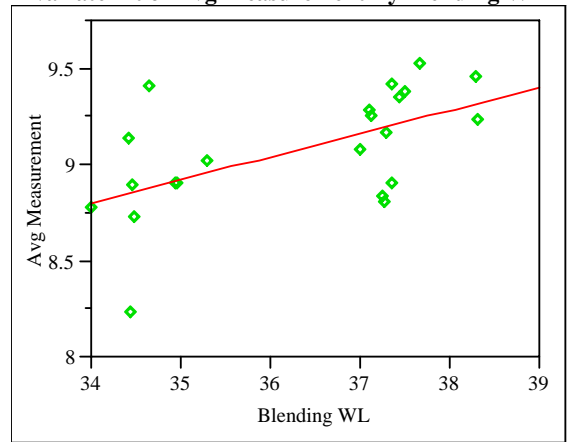

Linear Fit

Avg Measurement $=4.7277024+0.1199129$ Blending WL Summary of Fit

RSquare $\quad 0.325496$

RSquare Adj $\quad 0.291771$

Root Mean Square Error $\quad 0.261722$

Mean of Response 9.081578

Observations (or Sum Wgts) 22

Analysis of Variance

Source DF Sum of Squares Mean Square F Ratio

$\begin{array}{lllll}\text { Model } & 1 & 0.6611065 & 0.661107 & 9.6514\end{array}$

$\begin{array}{llll}\text { Error } & 20 & 1.3699659 & 0.068498 \text { Prob }>\text { F }\end{array}$

C. Total $21 \quad 2.0310724 \quad 0.0056$

Bivariate Fit of Avg Measurement By SME Avg WL

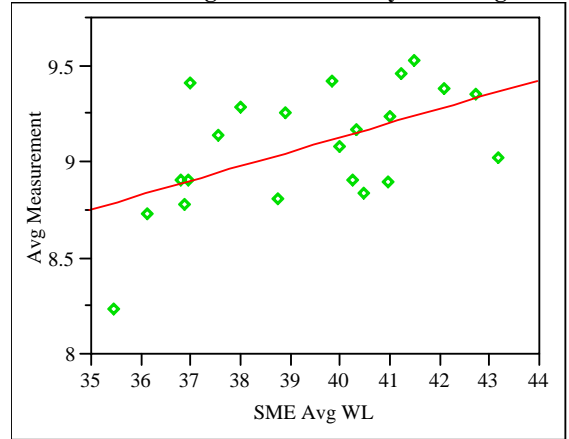

Linear Fit

Avg Measurement $=6.1304846+0.0749376$ SME Avg WL Summary of Fit

$\begin{array}{ll}\text { RSquare } & 0.291894 \\ \text { RSquare Adj } & 0.256489 \\ \text { Root Mean Square Error } & 0.268162 \\ \text { Mean of Response } & 9.081578\end{array}$

Mean of Response 9.081578

Observations (or Sum Wgts) 22

Analysis of Variance

Source DF Sum of Squares Mean Square F Ratio

$\begin{array}{lllll}\text { Model } & 1 & 0.5928587 & 0.592859 & 8.2444\end{array}$

$\begin{array}{llll}\text { Error } & 20 & 1.4382138 & 0.071911 \text { Prob }>\text { F }\end{array}$

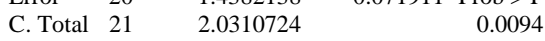

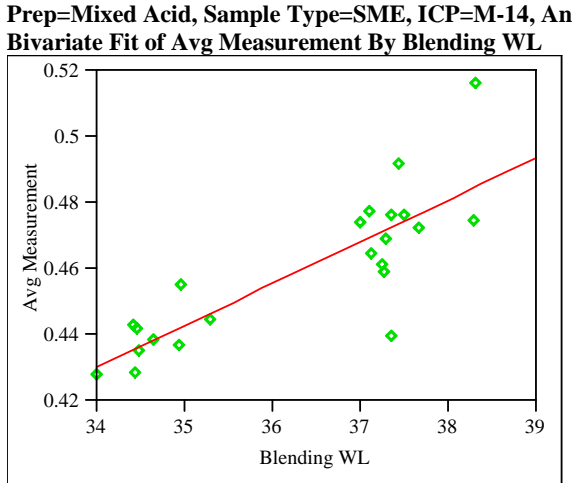

Linear Fit

Avg Measurement $=-0.000263+0.0126604$ Blending WL Summary of Fit

$\begin{array}{lr}\text { RSquare } & 0.690199 \\ \text { RSquare Adj } & 0.674709 \\ \text { Root Mean Square Error } & 0.01286 \\ \text { Mean of Response } & 0.459419 \\ \text { Observations (or Sum Wgts) } & 22\end{array}$

Analysis of Variance

Source DF Sum of Squares Mean Square F Ratio

$\begin{array}{lllll}\text { Model } & 1 & 0.00736944 & 0.007369 & 44.5577\end{array}$

$\begin{array}{llll}\text { Error } 20 & 0.00330782 & 0.000165 \text { Prob }>\text { F }\end{array}$

$\begin{array}{llr}\text { C. Total } 21 & 0.01067726 & <.0001\end{array}$

Bivariate Fit of Avg Measurement By SME Avg WL

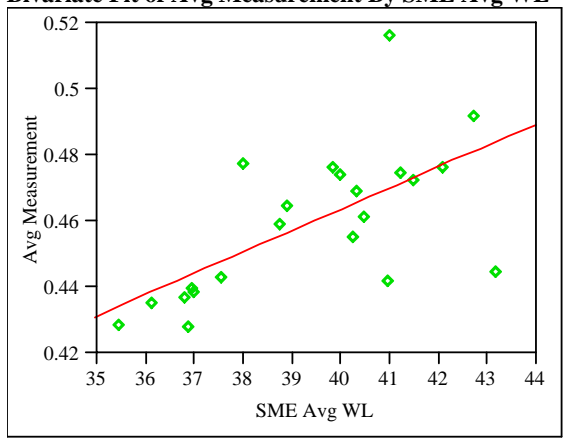

Linear Fit

Avg Measurement $=0.2046941+0.0064683$ SME Avg WL Summary of Fit

RSquare 0.413683

RSquare Adj

0.384368

Root Mean Square Error $\quad 0.017692$

Mean of Response $\quad 0.459419$

Observations (or Sum Wgts) 22

Analysis of Variance

Source DF Sum of Squares Mean Square F Ratio

$\begin{array}{lllll}\text { Model } & 1 & 0.00441701 & 0.004417 & 14.1113\end{array}$

$\begin{array}{llll}\text { Error } & 20 & 0.00626025 & 0.000313 \text { Prob }>\text { F }\end{array}$

$\begin{array}{llr}\text { C. Total } 21 & 0.01067726 & 0.0012\end{array}$ 
WSRC-STI-2006-00068

Revision 0

Exhibit A12. Relationships between Analytes and WLs by Preparation Method, ICP, and Analyte (continued)

Prep=Mixed Acid, Sample Type=SME, ICP=M-14, Analyte=Si Bivariate Fit of Avg Measurement By Blending WL

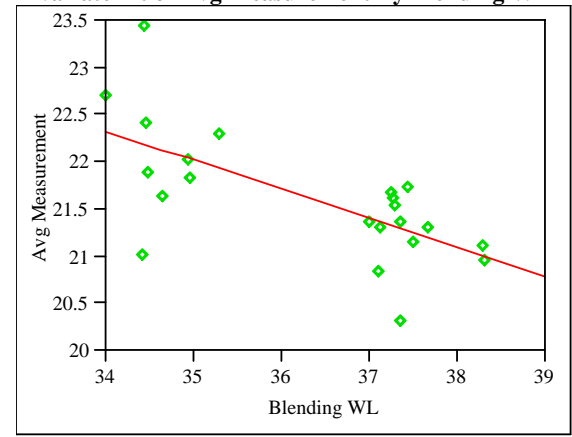

Linear Fit

Avg Measurement $=32.797441-0.3078431$ Blending WL Summary of Fit

$\begin{array}{lr}\text { RSquare } & 0.445449 \\ \text { RSquare Adj } & 0.417721 \\ \text { Root Mean Square Error } & 0.520782 \\ \text { Mean of Response } & 21.62008 \\ \text { Observations (or Sum Wgts) } & 22\end{array}$

Analysis of Variance

Source DF Sum of Squares Mean Square F Ratio

Model $\quad 1 \quad 4.3571049 \quad 4.35710 \quad 16.0652$

Error $20 \quad 5.4242789 \quad 0.27121$ Prob $>$ F

$\begin{array}{lll}\text { C. Total } 21 & 9.7813839 & 0.0007\end{array}$

Bivariate Fit of Avg Measurement By SME Avg WL

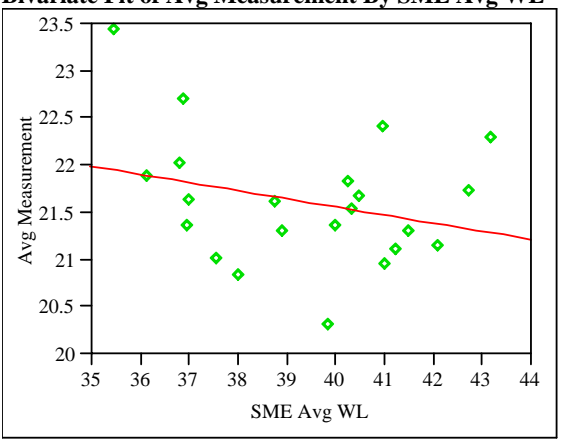

Linear Fit

Avg Measurement $=25.033222-0.0866705$ SME Avg WL

Summary of Fit

$\begin{array}{lr}\text { RSquare } & 0.081076 \\ \text { RSquare Adj } & 0.03513 \\ \text { Root Mean Square Error } & 0.670386 \\ \text { Mean of Response } & 21.62008 \\ \text { Observations (or Sum Wgts) } & 22\end{array}$

Analysis of Variance

Source DF Sum of Squares Mean Square F Ratio

$\begin{array}{lllll}\text { Model } & 1 & 0.7930383 & 0.793038 & 1.7646\end{array}$

$\begin{array}{lllll}\text { Error } & 20 & 8.9883456 & 0.449417 \text { Prob }>\text { F }\end{array}$

$\begin{array}{lll}\text { C. Total } 21 & 9.7813839 & 0.1990\end{array}$
Prep=Mixed Acid, Sample Type=SME, ICP=M-14, Analyte=Sum of Oxides

Bivariate Fit of Avg Measurement By Blending WL

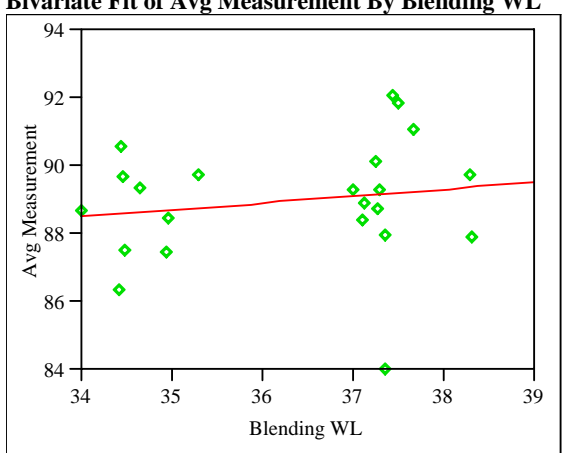

Linear Fit

Avg Measurement $=81.705889+0.2002185$ Blending $\mathrm{WL}$

Summary of Fit

$\begin{array}{lr}\text { RSquare } & 0.027322 \\ \text { RSquare Adj } & -0.02131 \\ \text { Root Mean Square Error } & 1.811289 \\ \text { Mean of Response } & 88.97555 \\ \text { Observations (or Sum Wgts) } & 22\end{array}$

Observations (or Sum Wgts) 22

Analysis of Variance

Source DF Sum of Squares Mean Square F Ratio

$\begin{array}{lllll}\text { Model } & 1 & 1.843094 & 1.84309 & 0.5618\end{array}$

$\begin{array}{lllll}\text { Error } & 20 & 65.615382 & 3.28077 \text { Prob > F }\end{array}$

$\begin{array}{llrr}\text { C. Total } & 21 & 67.458477 & 3.28077 \\ \end{array}$

Bivariate Fit of Avg Measurement By SME Avg WL

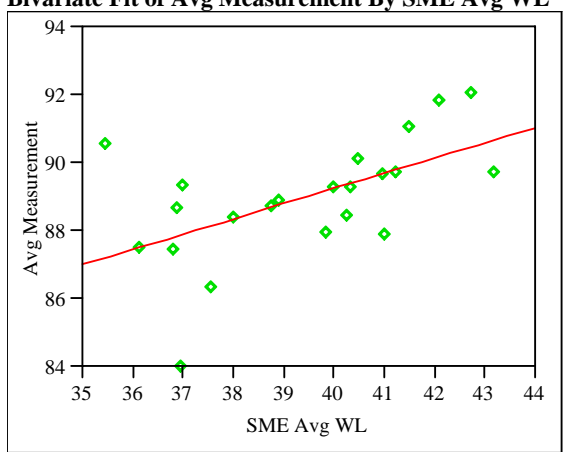

Linear Fit

Avg Measurement $=71.422669+0.4457232$ SME Avg WL Summary of Fit

RSquare

0.310918

RSquare Adj

0.276464

Root Mean Square Error $\quad 1.52454$

Mean of Response

Observations (or Sum Wgts) 22

Analysis of Variance

Source DF Sum of Squares Mean Square F Ratio

$\begin{array}{lrrrr}\text { Model } & 1 & 20.974034 & 20.9740 & 9.0241\end{array}$

$\begin{array}{llll}\text { Error } & 20 & 46.484443 & 2.3242 \text { Prob }>\text { F }\end{array}$

$\begin{array}{llll}\text { C. Total } 21 & 67.458477 & 0.0070\end{array}$ 
WSRC-STI-2006-00068

Revision 0

Exhibit A12. Relationships between Analytes and WLs by Preparation Method, ICP, and Analyte (continued)

Prep=Mixed Acid, Sample Type=SME, ICP=M-14, Analyte=Ti Bivariate Fit of Avg Measurement By Blending WL

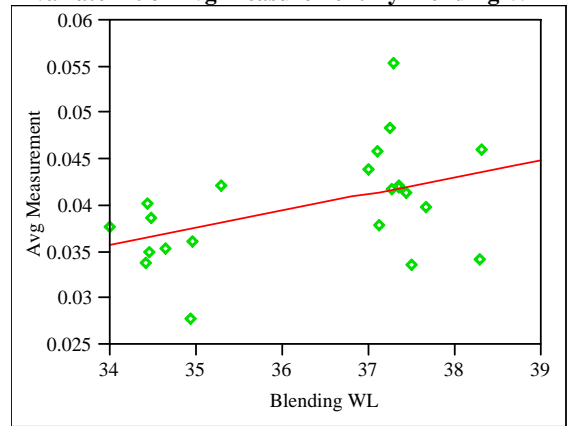

Linear Fit

Avg Measurement $=-0.027348+0.0018552$ Blending WL Summary of Fit

\begin{tabular}{lr} 
RSquare & 0.20974 \\
RSquare Adj & 0.170227 \\
Root Mean Square Error & 0.00546 \\
Mean of Response & 0.040011 \\
\hline
\end{tabular}

Observations (or Sum Wgts) 22

Analysis of Variance

Source DF Sum of Squares Mean Square F Ratio

$\begin{array}{lllll}\text { Model } & 1 & 0.00015824 & 0.000158 & 5.3081\end{array}$

$\begin{array}{llll}\text { Error } & 20 & 0.00059621 & 0.000030 \text { Prob }>\text { F }\end{array}$

$\begin{array}{lll}\text { C. Total } 21 & 0.00075445 & 0.0321\end{array}$

Bivariate Fit of Avg Measurement By SME Avg WL

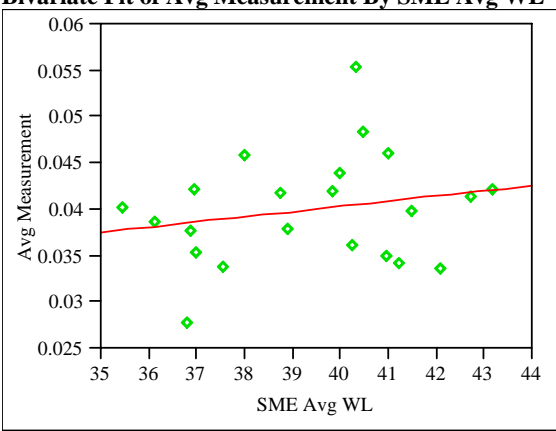

Linear Fit

Avg Measurement $=0.0178212+0.0005635$ SME Avg WL Summary of Fit

RSquare

RSquare Adj
Root Mean Sc

0.04443

$-0.00335$

Observations (or Sum Wgts)

Analysis of Variance

Source DF Sum of Squares Mean Square F Ratio

$\begin{array}{lllll}\text { Model } & 1 & 0.00003352 & 0.000034 & 0.9299\end{array}$

$\begin{array}{llll}\text { Error } & 20 & 0.00072093 & 0.000036 \text { Prob > F }\end{array}$

$\begin{array}{lll}\text { C. Total } 21 & 0.00075445 & 0.3464\end{array}$
Prep=Mixed Acid, Sample Type=SME, ICP=M-14, Analyte $=U$ Bivariate Fit of Avg Measurement By Blending WL

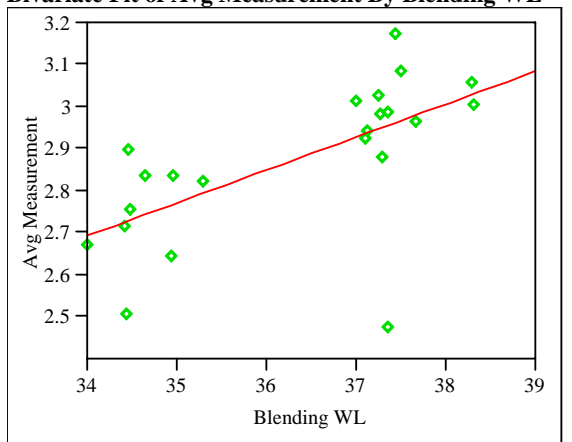

Linear Fit

Avg Measurement $=0.0343925+0.0782201$ Blending $\mathrm{WL}$ Summary of Fit

RSquare

0.401311

RSquare Ad

0.371377

Root Mean Square Error $\quad 0.144855$

Mean of Response

2.874458

Observations (or Sum Wgts) 22

Analysis of Variance

Source DF Sum of Squares Mean Square F Ratio

$\begin{array}{lllll}\text { Model } & 1 & 0.28130422 & 0.281304 & 13.4063\end{array}$

$\begin{array}{llll}\text { Error } & 20 & 0.41965855 & 0.020983 \text { Prob }>\text { F }\end{array}$

$\begin{array}{lll}\text { C. Total } 21 & 0.70096277 & 0.0016\end{array}$

Bivariate Fit of Avg Measurement By SME Avg WL

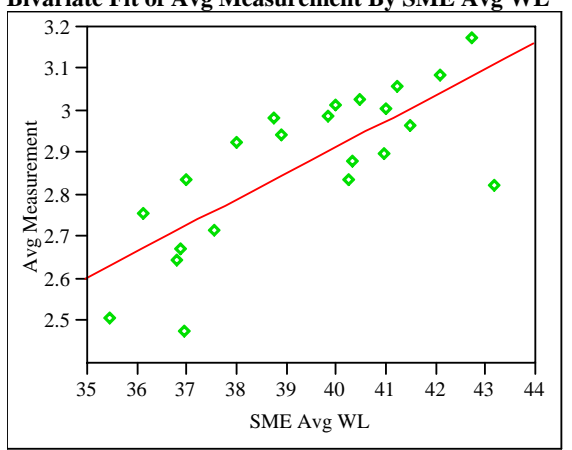

Linear Fit

Avg Measurement $=0.4375512+0.0618808$ SME Avg WL Summary of Fit

$\begin{array}{lr}\text { RSquare } & 0.576724 \\ \text { RSquare Adj } & 0.555561 \\ \text { Root Mean Square Error } & 0.121799 \\ \text { Mean of Response } & 2.874458 \\ \text { Observations (or Sum Wgts) } & 22\end{array}$

Analysis of Variance

Source DF Sum of Squares Mean Square F Ratio

$\begin{array}{lllll}\text { Model } & 1 & 0.40426229 & 0.404262 & 27.2505\end{array}$

$\begin{array}{llll}\text { Error } & 20 & 0.29670049 & 0.014835 \text { Prob }>\text { F }\end{array}$

$\begin{array}{llll}\text { C. Total } 21 & 0.70096277 & <.0001\end{array}$ 
WSRC-STI-2006-00068

Revision 0

Exhibit A12. Relationships between Analytes and WLs by Preparation Method, ICP, and Analyte (continued)

Prep=Mixed Acid, Sample Type=SME, ICP=M-14, Analyte $=$ U $/$ Ca Bivariate Fit of Avg Measurement By Blending WL

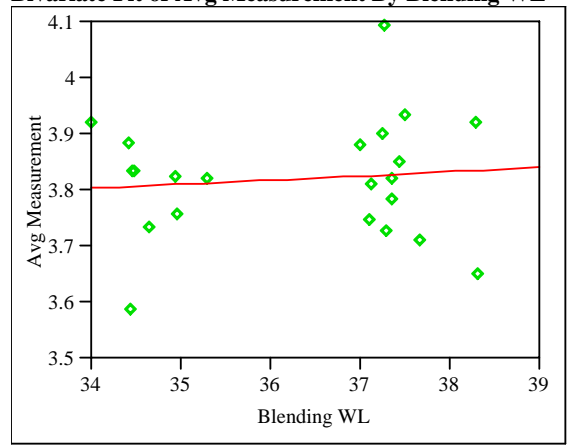

Linear Fit

Avg Measurement $=3.553866+0.0073476$ Blending WL Summary of Fit

RSquare $\quad 0.010134$

RSquare Adj $\quad-0.03936$

Root Mean Square Error $\quad 0.110101$

Mean of Response 3.820646

Observations (or Sum Wgts) 22

Analysis of Variance

Source DF Sum of Squares Mean Square F Ratio $\begin{array}{lllll}\text { Model } & 1 & 0.00248214 & 0.002482 & 0.2048\end{array}$

$\begin{array}{llll}\text { Error } & 20 & 0.24244308 & 0.012122 \text { Prob }>\text { F }\end{array}$

$\begin{array}{llll}\text { C. Total } 21 & 0.24492521 & 0.6558\end{array}$

Bivariate Fit of Avg Measurement By SME Avg WL

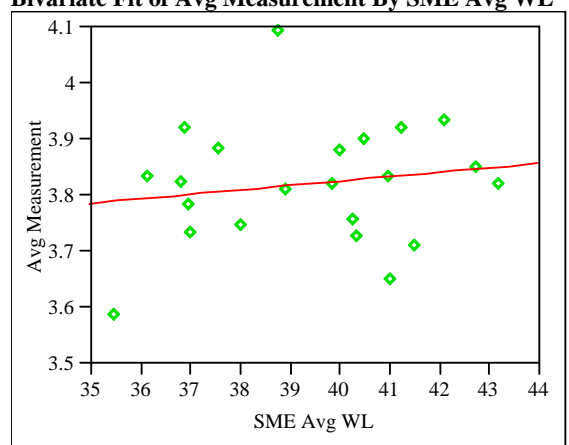

Linear Fit

Avg Measurement $=3.512458+0.0078259$ SME Avg WL

Summary of Fit

$\begin{array}{ll}\text { RSquare } & 0.026399 \\ \text { RSquare Adj } & -0.02228 \\ \text { Root Mean Square Error } & 0.109192 \\ \text { Mean of Response } & 3.820646\end{array}$

Mean of Response 3.820646

Observations (or Sum Wgts) 22

Analysis of Variance

Source DF Sum of Squares Mean Square F Ratio

$\begin{array}{lllll}\text { Model } & 1 & 0.00646572 & 0.006466 & 0.5423\end{array}$

$\begin{array}{llll}\text { Error } & 20 & 0.23845950 & 0.011923 \text { Prob }>\text { F }\end{array}$

$\begin{array}{llrr}\text { C. Total } 21 & 0.24492521 & 0.4700\end{array}$

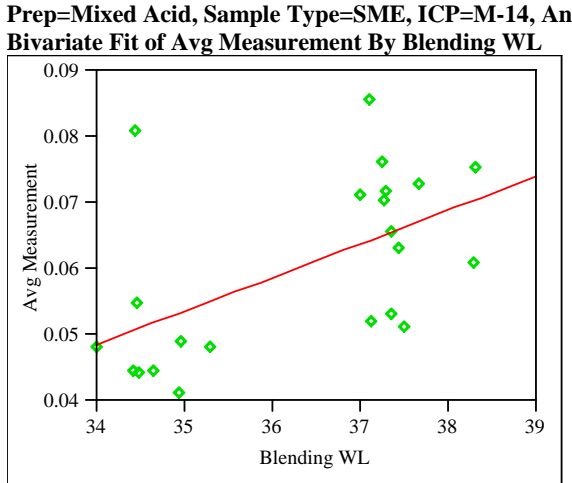

Linear Fit

Avg Measurement $=-0.124672+0.005093$ Blending WL Summary of Fit

$\begin{array}{lr}\text { RSquare } & 0.309418 \\ \text { RSquare Adj } & 0.274889 \\ \text { Root Mean Square Error } & 0.011536 \\ \text { Mean of Response } & 0.060248 \\ \text { Observations (or Sum Wgts) } & 22\end{array}$

Analysis of Variance

Source DF Sum of Squares Mean Square F Ratio

$\begin{array}{lllll}\text { Model } & 1 & 0.00119258 & 0.001193 & 8.9611\end{array}$

$\begin{array}{llll}\text { Error } 20 & 0.00266168 & 0.000133 \text { Prob }>\text { F }\end{array}$

$\begin{array}{llrr}\text { C. Total } & 21 & 0.00385426 & 0.0072\end{array}$

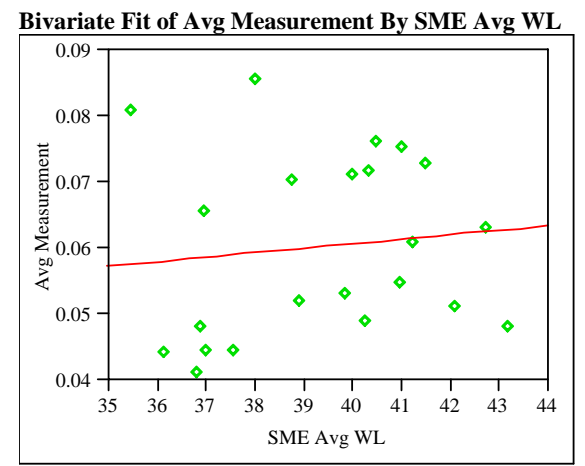

Linear Fit

Avg Measurement $=0.0334881+0.0006795$ SME Avg WL Summary of Fit

RSquare 0.012648

RSquare Adj

$-0.03672$

Root Mean Square Error $\quad 0.013794$

Mean of Response $\quad 0.060248$

Observations (or Sum Wgts) 22

Analysis of Variance

Source DF Sum of Squares Mean Square F Ratio

$\begin{array}{lllll}\text { Model } & 1 & 0.00004875 & 0.000049 & 0.2562\end{array}$

$\begin{array}{lllll}\text { Error } & 20 & 0.00380551 & 0.000190 \text { Prob }>\text { F }\end{array}$

$\begin{array}{llr}\text { C. Total } 21 & 0.00385426 & 0.6183\end{array}$ 
Distribution:

C.J. Bannochie, 773-42A

M.J. Barnes, SRNL

N.E. Bibler, SRNL

D.R. Best, 786-1A

D.B. Burns, 786-5A

T.B. Calloway, 999-W

L.M. Chandler, SRNL

D.R. Click, SRNL

C.J. Coleman, SRNL

A.J. Cross, 704-71S

D.A. Crowley, SRNL

B.H. Culbertson, 704-27S

B.A. Davis, 704-27S

R.E. Edwards, SRNL

T.B. Edwards, 773-42A

M.T. Feller, 704-28S

T.L. Fellinger, 704-27S
S.P. Harris, 773-42A

C.C. Herman, 773-42A

C.M. Jantzen, SRNL

R.N. Mahannah, 704-28S

J.E. Marra, SRNL

W.L. Melton III, 704-28S

M. S. Miller, 704-S

J.E. Occhipinti, 704-S

P.M. Patel, 704-27S

F.M. Pennebaker, SRNL

D.K. Peeler, 999-W

J.W. Ray, 704-S

M.E. Smith, 773-42A

M.E. Stone, 999-W

R.C. Tuckfield, 773-42A

J.P. Vaughan, 773-41A

S.W. Wilkerson, 704-S 